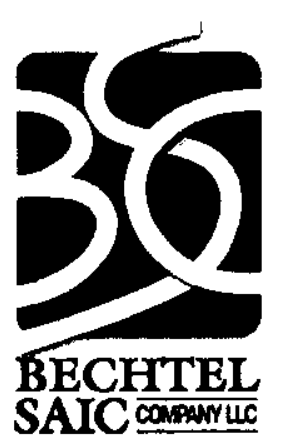

QA: QA

ANL-EBS-MD-000027 REV 03

September 2004

NOTICE OF OPEN CHANGED DOCUMENTS - THIS DOCUMENT IS IMPACTED BY THE LISTED CHANGE DOCUMENT AND CANNOT BE USED WITHOUT IT.

1) ACN-001, DATED 04/18/2005

\title{
Drift Degradation Analysis
}

Prepared for:

U.S. Department of Energy

Office of Civilian Radioactive Waste Management

Office of Repository Development

1551 Hillshire Drive

Las Vegas, Nevada 89134-6321

Prepared by:

Bechtel SAIC Company, LLC

1180 Town Center Drive

Las Vegas, Nevada 89144

Under Contract Number

DE-AC28-01RW12101 


\section{DISCLAIMER}

This report was prepared as an account of work sponsored by an agency of the United States Government. Neither the United States Government nor any agency thereof, nor any of their employees, nor any of their contractors, subcontractors or their employees, makes any warranty, express or implied, or assumes any legal liability or responsibility for the accuracy, completeness, or any third party's use or the results of such use of any information, apparatus, product, or process disclosed, or represents that its use would not infringe privately owned rights. Reference herein to any specific commercial product, process, or service by trade name, trademark, manufacturer, or otherwise, does not necessarily constitute or imply its endorsement, recommendation, or favoring by the United States Government or any agency thereof or its contractors or subcontractors. The views and opinions of authors expressed herein do not necessarily state or reflect those of the United States Government or any agency thereof. 
QA: QA

\section{Drift Degradation Analysis \\ ANL-EBS-MD-000027 REV 03}

September 2004 


\section{OCRWM}

\section{Model Signature Page/Change History}

Page iii

1. Total Pages: 976

2. Type of Mathematical Model

$\bigotimes$ Process Model

Abstraction Model

System Model

Describe Intended Use of Model

The models and associated analyses documented in this report provide drift degradation input, including rockfall data, for various calculations, models, and analyses. The users of the output data provided in this document include the Specialty Analyses \& Waste Package Design Department, the Total System Performance Assessment Department, the Disruptive Events Department, the Ambient and Thermal Drift Seepage Department, the Subsurface Department, and the Preclosure Safety Analysis Department.

\section{Title}

Drift Degradation Analysis

4. DI (including Rev. No., if applicable):

ANL-EBS-MD-000027 REV 03

\begin{tabular}{|l|l}
\hline 5. Total Appendices & 6. No. of Pages in Each Appendix \\
& A-14, B-10, C-30, D-28, E-58, F-18, G-6, H- \\
25 & $\begin{array}{l}8, \mathrm{I}-10, \mathrm{~J}-8, \mathrm{~K}-14, \mathrm{~L}-4, \mathrm{M}-8, \mathrm{~N}-26, \mathrm{O}-46, \mathrm{P}- \\
34, \mathrm{Q}-16, \mathrm{R}-22, \mathrm{~S}-64, \mathrm{~T}-16, \mathrm{U}-8, \mathrm{~V}-10, \mathrm{~W}-8, \\
\mathrm{X}-10, \mathrm{Y}-18\end{array}$
\end{tabular}

\begin{tabular}{|c|c|c|c|}
\hline & Printed Name & Signature & Date \\
\hline 7. Originator & Dwayne C. Kicker (lead) & -ille & $9 / 16 / 04$ \\
\hline $\begin{array}{l}\text { 8. Independent Technical } \\
\text { Reviewer }\end{array}$ & Robert L. Howard & $\Phi$ & 16 sep ox \\
\hline 9. Checker & Junghun Leem (lead) & & $9 / 16 / 14$ \\
\hline 10. QER & Judith E. Gebhart & & 9116104 \\
\hline 11. Responsible Manager/Lead & Mark P. Board & Mank Brase & $9 / 16 / 04$ \\
\hline 12. Responsible Manager & Mark P. Board & Mal israne & $9 / 16 / 09$ \\
\hline
\end{tabular}

13. Remarks

The preparer and checker for each section in this report are identified as follows:

\begin{tabular}{lll}
\multicolumn{1}{c}{ Section or Appendix } & \multicolumn{1}{c}{ Preparer } & \multicolumn{1}{c}{ Checker } \\
1 & Dwayne Kicker, Mark Board & Junghun Leem \\
$2,3,5,6.1$ & Dwayne Kicker & Junghun Leem \\
$4,9, \mathrm{O}$ & Dwayne Kicker & David Tang \\
$6.2, \mathrm{C}, \mathrm{M}, \mathrm{Q}$ & Junghun Leem & Ming Lin \\
$6.3,6.4$ & Ming Lin & Junghun Leem \\
6.5 through $6.8,8, \mathrm{~B}, \mathrm{~F}, \mathrm{O}, \mathrm{S}, \mathrm{T}$ & Dwayne Kicker & Junghun Leem \\
7 & Mark Board & Junghun Leem \\
$\mathrm{A}$ & Dwayne Kicker, Ming Lin & Junghun Leem \\
$\mathrm{E}$ & Dwayne Kicker, Mark Board & David Tang \\
$\mathrm{D}, \mathrm{G}, \mathrm{H}, \mathrm{I}, \mathrm{J}, \mathrm{K}, \mathrm{L}, \mathrm{N}, \mathrm{P}, \mathrm{R}, \mathrm{U}, \mathrm{V}, \mathrm{W}, \mathrm{Y}$ & Ming Lin & Junghun Leem \\
$\mathrm{X}$ & Ming Lin & David Tang
\end{tabular}

Robert Lung (USBR) and Michael Fahy (USGS) provided technical support in the development of Section 6.1 and Appendix B.

David Buesch (USGS) provided technical support in the development of Section 6.1, Appendices O and T.

(Continued on next page) 


\begin{tabular}{|c|c|l|}
\hline \multirow{2}{*}{ OCRWM } & Model Signature Page/Change HiStory & Page iv \\
\cline { 3 - 3 } & (CONTINUED) & 1. Total Pages: 976 \\
\hline
\end{tabular}

13. Remarks

(Continued from previous page)

Branko Damjanac (Itasca) provided technical support in the development of Sections 6.3, 6.4, 7, Appendices S, U, V, W, and Y. Carlos Carranza-Torres (Itasca) provided technical support in the development of Section 6.2 and Appendix C.

David Potyondy (Itasca) provided technical support in the development of Section 7.6 and Appendix S.

John Kemeny (Univ. of Arizona) provided technical support in the development of Appendix D.

\begin{tabular}{|c|c|}
\hline \multicolumn{2}{|r|}{ Change History } \\
\hline 14. Revision No. & 15. Description of Change \\
\hline REV 00 & Initial issue. \\
\hline REV 00 ICN 1 & $\begin{array}{l}\text { The technical product cover sheet was changed to indicate that this document reports the } \\
\text { development and use of a model. Section } 6.5 \text { on model validation was added. The report was } \\
\text { changed to include results for } 75^{\circ} \text {-azimuth emplacement drifts and to provide additional results } \\
\text { for emplacement drifts with no backfill. The Document Input Reference System (DIRS) } \\
\text { information was removed from document and made part of the records package. The } \\
\text { numbering of the attachments has been changed to reflect removal of the DIRS information. } \\
\text { Attachment VI is now Attachment I. Table } 2 \text { was modified. The description of the use of } \\
\text { software routines in Section } 3 \text { was changed. The data in Tables } 14,15,20,21,23,24 \text {, and } \\
\text { Figure } 17 \text { were corrected. Additional attachments were added to document the field } \\
\text { observation of key blocks in the Cross-Drift, and to document natural analogues for the seismic } \\
\text { effect on rock fall. }\end{array}$ \\
\hline REV 01 & $\begin{array}{l}\text { The Tptpln fracture geometry inputs to DRKBA were revised to be consistent with the } \\
\text { developed fracture geometry data in ANL-EBS-GE-000006. Output information for the Tptpln } \\
\text { was revised throughout the report. The data and information presented in the supporting } \\
\text { calculation, CAL-EBS-MD-000010 REV 00, has been updated and merged with this report. } \\
\text { Therefore, this revision supersedes calculation CAL-EBS-MD-000010 REV 00. Additional } \\
\text { seismic analyses have been included in Attachment V. Information supporting the analysis of } \\
\text { drift degradation features, events, and processes (FEPS) has been added in Section } 6.6 \text {. } \\
\text { Information supporting the resolution of applicable Nuclear Regulatory Commission (NRC) } \\
\text { key technical issues has been added in Section 6.7. A brief discussion of the impacts of the } \\
\text { small-trace length fracture data on drift degradation has been added in Section 7.2. } \\
\text { Attachments VIII through XI were added to include the information that was previously } \\
\text { provided in calculation CAL-EBS-MD-000010 REV } 00 \text { (note that data for the Tptpln unit has } \\
\text { been updated in these attachments). Drift profile figures were moved from Section } 6.4 .3 \text { to } \\
\text { Attachment XII. The calculation of mean input data based on source DTNs identified in } \\
\text { Section } 4.1 \text { was added as documented in Attachment XIII. An assessment of the joint plane } \\
\text { representation in the DRKBA rock fall model was added in Attachment XIV to provide } \\
\text { additional bases for Assumption 5.1. }\end{array}$ \\
\hline
\end{tabular}

Assumption 5.6 has been revised resulting in the removal of TBV-4408 from the input status of DTN: MO0003SEPSDARS.002, which provides the basis for ground motion parameters.

Section 7.3 of the previous version of this document has been omitted, and Section 7.4 has been renumbered as Section 7.3 in this document. Additional documentation of the use of exempt software has been provided in response to Deficiency Report LVMO-00-D-039

REV 01 ICN 1 (DR 39), as described in a stand alone DR 39 package (Kicker 2001). This documentation includes minor changes to Section 3.2 and Attachments I, II, and XI (note: the information on the CDs included with Attachment II has not changed). Also, Attachments XV through XVIII were added to provide additional information on the use of commercial software consistent with the requirements of AP3.10Q, Attachment I, and Section 3.

(Continued on next page) 


\begin{tabular}{|c|c|c|}
\hline \multirow[b]{2}{*}{ OCRWM } & \multirow{2}{*}{$\begin{array}{l}\text { MODEL SignatuRE PAGE/CHANGE HISTORY } \\
\text { (CONTINUED) }\end{array}$} & Page v \\
\hline & & 1. Total Pages: 976 \\
\hline \multicolumn{3}{|c|}{ Change History } \\
\hline 14. Revision No. & \multicolumn{2}{|l|}{ 15. Description of Change } \\
\hline REV 01 ICN 1 & \multicolumn{2}{|c|}{$\begin{array}{l}\text { Attachment VIII of this technical product contains documentation of a single-use software } \\
\text { macro (Volume_cal V1.1) that was qualified under procedure AP-SI.1Q, Software } \\
\text { Management, prior to the release of Revision } 3 \text { of said procedure. This macro has not changed } \\
\text { with the development of this ICN, nor has the macro been used to develop additional quality } \\
\text { affecting information. However, an error in the listing of the macro source code } \\
\text { (Figure VIII-1) was corrected in this ICN. } \\
\text { The changes in this ICN are indicated by change bars in the right margin. }\end{array}$} \\
\hline REV 02 & \multicolumn{2}{|c|}{$\begin{array}{l}\text { This document has been completely revised to include additional approaches for analyzing } \\
\text { seismic, thermal, and time-dependent effects on drift degradation. Since this revision is an } \\
\text { extensive modification to the model and analysis documentation, the specific changes have not } \\
\text { been tracked. The primary changes include the following: } \\
\text { 1. A nonlithophysal rockfall model was developed using the three-dimensional discontinuum } \\
\text { code, 3DEC. } \\
\text { 2. A lithophysal rockfall model was developed using the two-dimensional discontinuum } \\
\text { code, UDEC. } \\
\text { 3. Site-specific ground motion time histories appropriate for both the preclosure and } \\
\text { postclosure time periods have been included in the rockfall models. } \\
\text { 4. Thermal stresses have been calculated and included in the rockfall models. } \\
\text { 5. Model validation activities have been added for validating the mechanical material models } \\
\text { for both lithophysal and nonlithophysal rocks, and for validating the implementation of } \\
\text { these material models in general numerical modeling schemes. } \\
\text { The changes included in this revision correct the errors identified in Technical Error Report } \\
\text { TER-02-0036. }\end{array}$} \\
\hline REV 03 & \multicolumn{2}{|c|}{$\begin{array}{l}\text { This document has been completely revised to include additional details for FracMan fracture } \\
\text { modeling and new seismic ground motion data. Time-dependent strength analyses have also } \\
\text { been included based on static-fatigue test data for tuff. Since this revision is an extensive } \\
\text { modification to the model and analysis documentation, the specific changes have not been } \\
\text { tracked. The primary changes include the following: } \\
\text { 1. Updated format, including renumbered pages, figures, and tables; and changing } \\
\text { Attachments to Appendices. } \\
\text { 2. Minor editorial corrections. } \\
\text { 3. Updated superseded DTNs and references. } \\
\text { 4. Updated impact analyses on thermal properties in response to superseded DTN } \\
\text { (Appendix Q). } \\
\text { 6. Updated FracMan fracture modeling in Section } 6.1 .6 \text {. } \\
\text { probabilities of exceedance (Sections } 6.3 \text { and } 6.4) \text {. } \\
\text { 7. Added time-dependent strength analyses in Section } 6.4 .2 \text { and Appendix S. } \\
\text { (Continued on next page) }\end{array}$} \\
\hline
\end{tabular}




\begin{tabular}{|c|c|c|}
\hline \multirow{2}{*}{ OCRWM } & \multirow{2}{*}{$\begin{array}{l}\text { MODEL SignATURE PAGE/CHANGE HiSTORY } \\
\text { (CONTINUED) }\end{array}$} & Page vi \\
\hline & & 1. Total Pages: 976 \\
\hline \multicolumn{3}{|c|}{ Change History } \\
\hline 14. Revision No. & \multicolumn{2}{|l|}{ 15. Description of Change } \\
\hline REV 03 & $\begin{array}{l}\text { 8. Added rockfall modeling with a consideration of spatial var } \\
\text { throughout the model region (Appendix S, Section S4). } \\
\text { 9. Added discussion of limitations and uncertainties of the sta } \\
\text { strength data used in the predictions of time-dependent beh } \\
\text { excavations in Section } 6.5 \text {. } \\
\text { 10. Added an assessment of the sufficiency of the number of 3I } \\
\text { the rockfall characteristics (Appendix K). } \\
\text { 11. Added an assessment of spatial variation of lithophysal por } \\
\text { 12. Added a discussion of the methodology and verification of } \\
\text { the NUFT thermal calculation to the UDEC rockfall model } \\
\text { 13. Added details for the calculation of bulking of broken rock } \\
\text { arching in the broken rock above the drip shield (Appendix } \\
\text { 14. Added details for boundary conditions in the thermal-mech } \\
\text { 15. Added a listing of site-specific ground motion parameters ( } \\
\text { 16. Added validation of the UDEC drip shield model (Appendi } \\
\text { This revision corrects the errors identified in REV } 02 \text { Errata } 001\end{array}$ & $\begin{array}{l}\text { nued from previous page) } \\
\text { of rock mass strength } \\
\text { igue and long-term } \\
\text { of emplacement drift } \\
\text { imulations to represent } \\
\text { n Appendix T. } \\
\text { terchange of output from } \\
\text { endix U). } \\
\text { ee impact of stress } \\
\text { model (Appendix W). } \\
\text { idix X). }\end{array}$ \\
\hline
\end{tabular}




\section{EXECUTIVE SUMMARY}

Degradation of underground openings as a function of time is a natural and expected occurrence for any subsurface excavation. Over time, changes occur to both the stress condition and the strength of the rock mass due to several interacting factors. Once the factors contributing to degradation are characterized, the effects of drift degradation can typically be mitigated through appropriate design and maintenance of the ground support system. However, for the emplacement drifts of the geologic repository at Yucca Mountain, it is necessary to characterize drift degradation over a 10,000-year period, which is well beyond the functional period of the ground support system. This document provides an analysis of the amount of drift degradation anticipated in repository emplacement drifts for discrete events and time increments extending throughout the 10,000-year regulatory period for postclosure performance. This revision of the drift degradation analysis was developed to support the license application and fulfill specific agreement items between the U.S. Nuclear Regulatory Commission (NRC) and the U.S. Department of Energy (DOE).

The earlier versions of Drift Degradation Analysis (BSC 2001 [DIRS 156304]) relied primarily on the DRKBA numerical code, which provides for a probabilistic key-block assessment based on realistic fracture patterns determined from field mapping in the Exploratory Studies Facility (ESF) at Yucca Mountain. A key block is defined as a critical block in the surrounding rock mass of an excavation, which is removable and oriented in an unsafe manner such that it is likely to move into an opening unless support is provided. However, the use of the DRKBA code to determine potential rockfall data at the repository horizon during the postclosure period has several limitations:

- The DRKBA code cannot explicitly apply dynamic loads due to seismic ground motion.

- The DRKBA code cannot explicitly apply loads due to thermal stress.

- The DRKBA code, which determines structurally controlled key-block failure, is not applicable for stress-controlled failure in the lithophysal units.

To address these limitations, additional numerical codes have been included that can explicitly apply seismic and thermal loads, providing significant improvements to the analysis of drift degradation and extending the validity of drift degradation models.

\section{KEY COMPONENTS OF REPOSITORY ROCKFALL MODELING}

Rock Mass Characterization-The repository horizon is located in both lithophysal (lower lithophysal [Tptpll] and upper lithophysal [Tptpul] zones) and nonlithophysal (middle nonlithophysal [Tptpmn] and lower nonlithophysal [Tptpln] zones) rock units in the Topopah Spring Tuff. These two rock types are expected to have fundamentally different modes of failure under static and dynamic loading, and require different analysis methods. The nonlithophysal rocks, which comprise roughly 15 percent of the emplacement area, are hard, strong; jointed rock masses; whereas the lithophysal rocks, which comprise approximately 85 percent of the emplacement area, are relatively more deformable with lower compressive strength. 
The geologic structure and rock strength defines the failure mode in the Tptpmn. The failure mode in the Tptpmn is due to gravity drop of rock blocks resulting from stress-induced yield in either the intact rock or the joint surfaces. The analysis of the failure mechanism is complicated somewhat by the fact that the jointing in the Tptpmn is of relatively short continuous trace length and is discontinuous in nature, thus forming fewer kinematically removable blocks. This type of jointing results in an inherently stronger rock mass as opposed to typical "blocky" rock masses where the block structure is well defined by multiple, continuous joint sets.

The Tptpll is characterized by about 10 to 30 percent lithophysal cavities by volume. This unit has abundant small-scale fractures between lithophysae that result in the relatively weaker nature of the material. Rock mass failure in the Tptpll is controlled by the transient ground motion induced stress concentrations that occur around the excavation. The mode of failure is primarily via tension from rarefaction of vertically traveling compression waves.

Seismic Ground Motion-Site-specific ground motions have been determined based on results from a probabilistic seismic hazard analysis. For a suite of ground motion measures, the probabilistic seismic hazard analysis determined the annual probability that various levels of ground motion would be exceeded. For an annual probability of exceedance of interest, a site response model modifies the ground motion from the probabilistic seismic hazard analysis by taking into account the effect of local site materials. Peak ground velocity determined from the site response model is used to develop seismic time histories (typically fifteen three-component sets) for postclosure rockfall analysis. The time histories are developed such that observed randomness among time histories, for a given peak ground velocity, is maintained. The time histories thus appropriately reflect variability in ground motion estimation for Yucca Mountain.

Thermal Stress-Once the waste packages are placed within the emplacement drifts, heat will be released as a part of the process of the radioactive materials in the waste packages becoming less radioactive over time. This heat will transfer to the rock mass and thermally induced stresses will be generated by thermal expansion of the rock mass. Thermal stresses at any location depend on the proximity and timing of waste emplacement, the amount of heat generated, the age of the waste, packaging and emplacement configuration, ventilation of the emplacement drifts, and the thermal-mechanical properties of the rock mass. Thermal stresses are time-dependent and are calculated over the 10,000-year regulatory period for postclosure performance.

Time-Dependent Degradation of Rock Strength-The rock mass surrounding the emplacement drifts may undergo over-stressing from thermal heating or time-dependent damage associated with static fatigue resulting from stress corrosion mechanisms. This damaged material may result in a slow unraveling (lithophysal rock) or block fallout (nonlithophysal rock). In the nonlithophysal rocks, static fatigue failure of roughness along fracture surfaces is possible and could result in gravitationally induced block failures. Static fatigue of hard rocks typically is associated with stress levels on the order of 80 percent or greater of the uniaxial compressive strength. This means that fatigue failure would presumably initiate along asperities on fracture surfaces, reducing their effective friction angle. In the case of the lithophysal rocks, the compressive stress concentrations along the immediate rib springline of the emplacement drifts will be near the uniaxial compressive strength so static fatigue failure is a distinct possibility. 


\section{ROCKFALL MODELING OF NONLITHOPHYSAL TUFF}

A nonlithophysal rockfall model was developed using the three-dimensional discontinuum code, 3DEC. This model includes the development of fracture patterns generated from multiple sampling from a synthetic rock mass volume that contains a realistic fracture population based on field mapping data. Site-specific ground motion time histories appropriate for both the preclosure and postclosure time periods, are included in the model.

Degradation in the nonlithophysal units is primarily controlled by geologic structure. Preclosure ground motion results in minor drift damage due to rockfall. It should be noted that the results presented in this report are based on unsupported drift openings. The rockfall estimate during the preclosure period should be conservative, because the rockfall models do not consider ground support, while ground support will in fact be included to prevent rockfall. Postclosure ground motion results in varying extent of drift damage due to rockfall, with localized areas of rock failure sufficient to cover the drip shield.

Thermal-mechanical analyses were conducted using both a base case set of thermal properties and a sensitivity case considering the values for thermal conductivity and specific heat one standard deviation smaller than the mean. The transient temperature field around the repository was calculated using 90- and 70-percent ventilation heat removal efficiencies. There was minimal rockfall predicted at any time for the thermal only scenario (i.e., no seismic loading) for the cases analyzed. When thermal stresses were considered in combination with the stresses resulting from postclosure seismic ground motion, it is clearly shown that thermal loading significantly reduces the amount of rockfall.

Drift stability due to the effect of time-dependent rock joint degradation is assessed based on a reduction of joint cohesion and friction angle. The reduced joint strength parameters are estimated to be in the range of the residual state with joint cohesion reduced to zero and the joint friction angle reduced to 30 degrees. Dilation angle is also reduced to zero considering that the asperities on fracture surfaces had been sheared off. The degraded joint strength and dilational properties were applied for several selected cases, including the worst cases (cases with the most rockfall), the typical case, and the no rockfall case observed with postclosure seismic ground motion. While a slight increase in rockfall is predicted for the degradated state, joint strength degradation has a minor impact on drift stability.

\section{ROCKFALL MODELING OF LITHOPHYSAL TUFF}

A lithophysal rockfall model was developed using the two-dimensional discontinuum code, UDEC. In this model, the rock mass is represented as an assembly of polygonal, elastic blocks in which the bond strength of the blocks is calibrated such that the overall mechanical behavior of the mass is consistent with the material model developed for the lithophysal rock. The lithophysal rockfall model allows for the formation of fractures between blocks (i.e., the formation of internal fracturing), separation, and instability (under action of gravity) of the rock mass around the drift. Site-specific ground motion time histories appropriate for both the preclosure and postclosure periods, are included in the model. Thermal-mechanical analyses were conducted using both a base case set of thermal properties and a sensitivity case considering the values for thermal conductivity and specific heat one standard deviation smaller 
than the mean. The transient temperature field around the repository was calculated using 90and 70-percent ventilation heat removal efficiencies. The analysis was done for five categories of rock mass qualities, which represents the variability in lithophysal rock mechanical properties expected on the repository level. The lowest quality categories ( 1 and 2$)$ represent the rock mass with 20 percent or greater lithophysal porosity, and make up less than about 10 percent of the repository host rock. Category 1, which represents the lowest quality/highest porosity rock, makes up less than 5 percent of the rock mass and thus represents localized conditions of high porosity rock found primarily near the top of the Tptpll. Categories 3, 4, and 5, which are representative of the rock mass with approximately 10 to 20 percent lithophysal porosity, are of higher geomechanical quality. Category 3, which represents rock with lithophysal porosity of approximately 15 to 20 percent, represents a typical rock quality condition.

Preclosure degradation in the lithophysal units is primarily controlled by stress conditions. The analyses show that the drifts are stable after excavation with fracturing extending to a maximum depth of less than $0.5 \mathrm{~m}$ in the drift walls for the poorest quality rock. No significant rockfall is predicted, due to heating, for any of the five rock mass categories irrespective of the considered ventilation efficiency ( 70 or 90 percent) and the selection of rock mass thermal properties. There is also no significant rockfall due to preclosure ground motion for rock mass Categories 1 through 5. A relatively minor amount of rockfall is predicted for preclosure seismic loading for the lowest quality, Category 1 rock mass. Little or no rockfall is predicted for other rock qualities for preclosure ground motions. Again, it should be noted that the modeled rockfall in the Tptpll is based on unsupported drift openings. The absence of ground support in the lithophysal rockfall model leads to a conservative rockfall estimate during the preclosure period, because the preclosure ground support will be designed to prevent rockfall.

The analyses of the available static fatigue data indicate that an approximate 40 percent reduction in cohesive strength occurs over a 20,000-year period. The nominal case for drift degradation (i.e., considering thermal and time-dependent effects, but excluding seismic effects) results in only partial collapse of the emplacement drifts at 20,000 years. The lower bound rock mass quality is represented as rock mass Category 2, which is considered to be less than 10 percent of the rock mass. A combination of the thermally induced stresses with time-dependent strength degradation results in time-dependent fracturing and a deterioration of the emplacement drift walls for Category 2, however, the drip shield is not expected to be covered during the postclosure period. As rock mass quality increases to categories 3 to 5, rockfall becomes less in volume with little change in drift profile. Coupling preclosure seismic ground motion with both time-dependent strength degradation and thermal load causes additional, but not significant, rockfall as a result of shaking down already loose, broken ground. Thus, the nominal scenario considers negligible drift degradation occurs over the postclosure period.

Postclosure ground motions cause drift collapse irrespective of rock mass quality or particular case of ground motion. The extreme conditions of drift deterioration due to rock mass strength degradation were analyzed. Cohesive strength (cohesion and tensile strength) was gradually reduced to zero and resulting rockfall was monitored. The model was set to achieve conservative conditions of bulking of the caved rock mass (i.e., such that larger vertical pressures are imposed). The resulting average vertical pressures of the rock on the drip shield are, with few exceptions, in the range between $150 \mathrm{kN} / \mathrm{m}^{2}$ and $200 \mathrm{kN} / \mathrm{m}^{2}$. The vertical and lateral pressures 
associated with complete collapse of the emplacement drifts are conservatively used as input loading parameters for the design of the drip shield.

\section{RESOLUTION OF KEY TECHNICAL ISSUES REGARDING ROCKFALL}

The drift degradation models and analyses documented in this report address the requirements of NRC/DOE agreement items regarding rockfall and related issues to support the resolution of NRC's key technical issue (KTI) on Repository Design and Thermal-Mechanical Effects. 


\section{INTENTIONALLY LEFT BLANK}




\section{CONTENTS}

Page

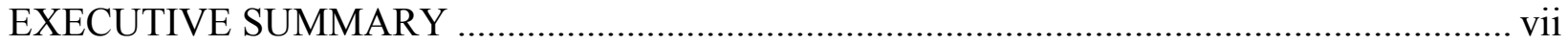
ACRONYMS AND ABBREVIATIONS ……….............................................................. lii

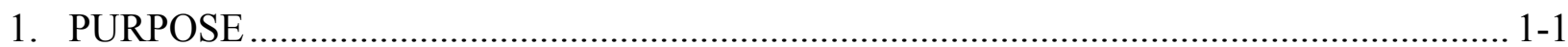

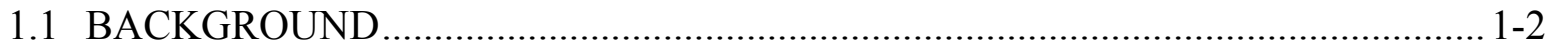

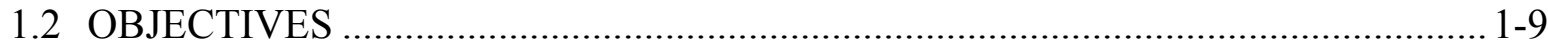

1.3 SCOPE OF MODEL DOCUMENTATION ………………………………….... 1-10

1.4 ANALYSIS/MODEL APPLICABILITY AND LIMITATIONS..............................1-10

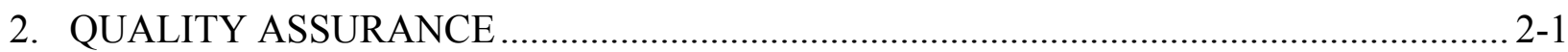

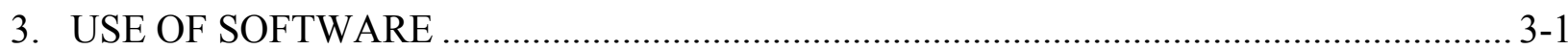

3.1 QUALIFIED COMPUTER SOFTWARE …………............................................ 3-1

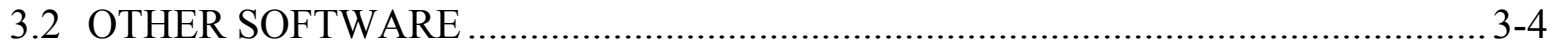

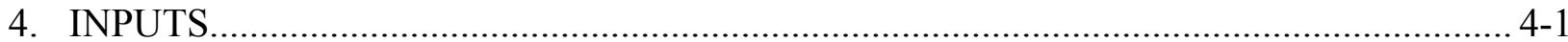

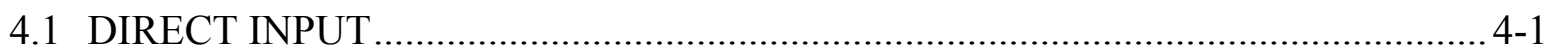

4.1.1 Fracture Geometry Data........................................................................ 4-1

4.1.2 Fracture Mechanical Properties Data............................................................. 4-10

4.1.3 Intact Rock Physical and Mechanical Properties Data ……........................... 4-10

4.1.4 Rock Mass Properties Data....................................................................... 4-11

4.1.4.1 Strength of Lithophysal Rock....................................................... 4-11

4.1.4.2 Rock Mass Elastic Properties for Thermal-Mechanical Units ....... 4-11

4.1.4.3 Rock Mass Properties for the Heated Drift in the ESF …………... 4-12

4.1.4.4 Block Strength of Nonlithophysal Rock ....................................... 4-12

4.1.5 Seismic Ground Motion Data ............................................................ 4-12

4.1.6 Rock Thermal Properties Data...................................................................... 4-13

4.1.7 Repository Layout Information .................................................................. 4-13

4.1.8 Matrix and Fracture Hydrologic Properties Data .......................................... 4-13

4.1.9 In Situ Stress Data............................................................................ 4-13

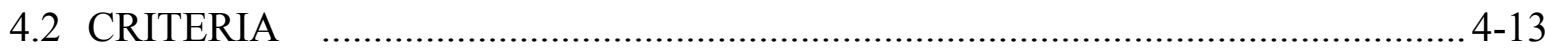

4.3 CODES, STANDARDS, AND REGULATIONS ............................................ 4 -14

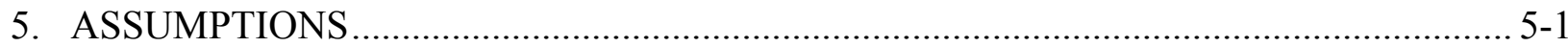

5.1 THERMAL-MECHANICAL CALCULATION ………………………………...... 5-1

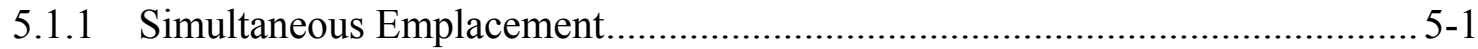

5.1.2 Ventilation Heat Removal Ratio................................................................ 5-1

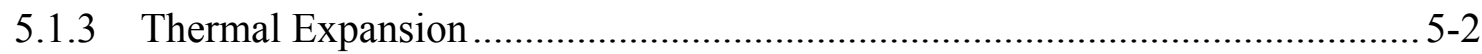

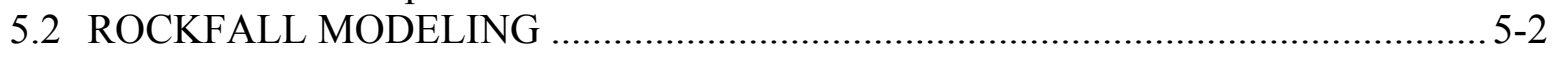

5.2.1 Joint Position Parameter in DRKBA ………….......................................... 5-2

5.2.2 Block Size Distribution for Potential Rockfall in Lithophysal Units ............... 5-2

6. MODEL DISCUSSION AND ANALYSIS RESULTS ………………............................ 6-1

6.1 ROCK MASS CHARACTERISTICS OF REPOSITORY HOST HORIZON ........... 6-4 


\section{CONTENTS (Continued)}

Page

6.1.1 Regional Geology 6-4

6.1.2 Lithostratigraphy at the Repository Horizon ................................................ 6-6

6.1.3 Geotechnical Characterization .......................................................................

6.1.4 Discussion of Engineering Characteristics of Rock Mass Important

to Geomechanical Performance ..................................................................... 6-10

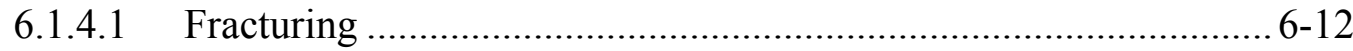

6.1.4.2 Lithophysae ..................................................................... 6-17

6.1.5 Field Observation of Key Blocks ........................................................ 6-21

6.1.6 Generation of Representative Rock Volumes Using FracMan...................... 6-24

6.1.6.1 Background ........................................................................... 6-24

6.1.6.2 FracMan Program Approach to Fracture Geometry Analysis........ 6-25

6.1.6.3 Fracture Studies in the ESF and ECRB Cross-Drift...................... 6-27

6.1.6.3.1 Data Sources

6.1.6.3.2 Representativeness of ESF and ECRB Cross-Drift

Data of the Tptpmn Across the Repository

Emplacement Area.....

6.1.6.4 Construction Techniques used in Generating the FracMan Simulations

6.1.6.4.1 Hierarchy of Fracture Formation in the Topopah Spring Tuff.

6.1.6.4.2 Hierarchical Construction of Fractures in the FracMan Model ........................................................ 6-30

6.1.6.4.3 Fracture Trace Length .......................................... 6-32

6.1.6.4.4 Fracture Geometry ............................................ 6-33

6.1.6.4.5 Fracture Intensity ............................................ 6-39

6.1.6.4.6 Comparison of FracMan Synthetic Fracture Geometry and Field Data ........................................ 6-41

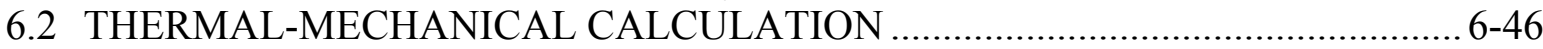

6.3 ROCKFALL IN THE NONLITHOPHYSAL UNITS ......................................... 6-56

6.3.1 Three-Dimensional Discontinuum Analysis of Jointed Rock Mass for

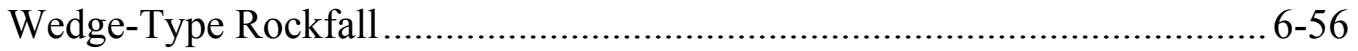

6.3.1.1 3DEC Model Set Up............................................................. 6-57

6.3.1.2 Seismic Consideration in Nonlithophysal Units ......................... 6-59

6.3.1.2.1 Site Specific Ground Motions .................................... 6-59

6.3.1.2.2 Combinations of Ground Motion and Fracture

Pattern ................................................................... 6-64

6.3.1.2.3 Results for Seismic Analysis Subjected to $1 \times 10^{-5}$

Annual Probability of Exceedance Ground Motions .....

6.3.1.2.4 Results for Seismic Analysis Subjected to $1 \times 10^{-6}$ Annual Probability of Exceedance Ground Motions 


\section{CONTENTS (Continued)}

Page

6.3.1.2.5 Results for Seismic Analysis Subjected to $1 \times 10^{-7}$ Annual Probability of Exceedance Ground Motions ………............................................. 6-87

6.3.1.2.6 Results for Seismic Analysis Subjected to Preclosure Ground Motion.

6.3.1.3 Thermal Consideration in Nonlithophysal Units.......................... 6-101

6.3.1.4 Combined Seismic and Thermal Effects in Nonlithophysal Units ................................................................ 6-103

6.3.1.5 Rock Joint Degradation in Nonlithophysal Units......................... 6-107

6.3.1.6 Sensitivity Study of the Parameters............................................. 6-111

6.3.1.6.1 Ground Motion Parameters........................................ 6-111

6.3.1.6.2 Joint Mechanical Properties ........................................ 6-115

6.3.1.6.3 Rock Bridge Strength Parameters ............................. 6-117

6.3.1.6.4 Intact Block Failure Response Under Low-Probability Ground Motions.............................. 6-119

6.3.1.6.5 Model Dimension..................................................... 6-126

6.3.1.6.6 Block Deletion ...................................................... 6-128

6.3.2 Consideration of Intensely Fractured Zone …………................................ 6-130

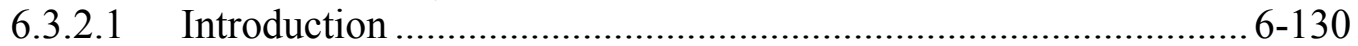

6.3.2.2 Numerical Modeling................................................................... 6-132

6.3.3 Impact of Small-Scale Fractures on Rockfall in Nonlithophysal Units........ 6-137

6.3.3.1 DRKBA Comparative Analysis ............................................... 6-138

6.3.3.2 Comparison of Analysis Results ................................................. 6-140

6.3.4 Drift Profile and Block Geometry Prediction in Nonlithophysal Units........ 6-142

6.4 ROCKFALL IN THE LITHOPHYSAL UNITS …………………................... 6-150

6.4.1 Problem Approach ............................................................................... 6-150

6.4.1.1 Estimate of Block Size ………………………......................... 6-150

6.4.1.2 Approach to Modeling of Lithophysal Rock-Homogeneity and Bounding Rock Mass Properties Estimates ................................... 6-150

6.4.2 UDEC Discontinuum Analysis of the Lithophysal Rock Mass..................... 6-153

6.4.2.1 Model Development .................................................................. 6-153

6.4.2.2 Seismic Consideration in Lithophysal Units ................................ 6-155

6.4.2.2.1 Analysis of Drift Response to Preclosure Ground Motion.......................................................... 6-160

6.4.2.2.2 Analysis of Drift Response to Postclosure Ground Motions 6-163

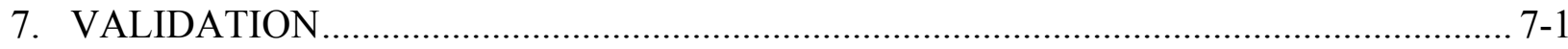

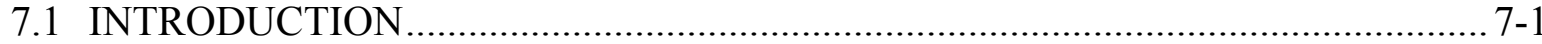

7.2 MODEL VALIDATION LEVEL AND CRITERIA FOR VALIDATION

BASED ON INTENDED USE................................................................................. 7-4

7.2.1 Confidence Building During Model Development to Establish

Scientific Basis and Accuracy for Intended Use 7-4 


\section{CONTENTS (Continued)}

Page

7.2.2 Confidence Building After Model Development to Support the Scientific Basis of the Model.................................................................. 7-7

7.2.3 Validation Criteria .................................................................................... $7-7$

7.3 DEVELOPMENT OF A MECHANICAL MATERIAL MODEL FOR LITHOPHYSAL ROCKS AND SELECTION OF INPUT PARAMETERS ............. 7-8

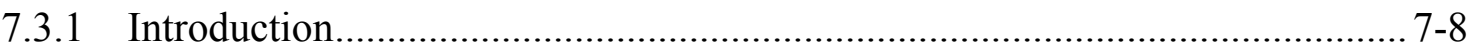

7.3.2 Description of the Lithophysal Rocks ......................................................... 7-8

7.3.3 Model Requirements for Drift Degradation Prediction ............................... 7-11

7.3.4 Laboratory and Field Database for Constitutive Model Development........... 7-12

7.4 STRATEGY FOR DEVELOPMENT OF A MECHANICAL MATERIAL MODEL FOR LITHOPHYSAL ROCKS (CONFIDENCE BUILDING

DURING MODEL DEVELOPMENT).

7.4.1 Continuum-Based Approach to Representing Rock Masses ......................... 7-12

7.4.2 Discontinuum Approach to Representing Rock Masses................................ 7-13

7.4.3 Strategy for Discontinuum Material Model Development ............................ 7-14

7.5 VALIDATION OF THE PFC-A MICROMECHANICAL MODEL REPRESENTATION OF THE MECHANICAL BEHAVIOR OF

LITHOPHYSAL ROCK

7.5.1 The PFC Model (Confidence Building During Model Development) ........... 7-15

7.5.2 Validation Exercises for the PFC Model ........................................................ 7-19

7.5.2.1 PFC Post-development Validation Exercise 1 - Simulation of the Stress-Strain Behavior of Nonlithophysal and Lithophysal Rock in Compression and Tension ............................................ 7-20

7.5.2.2 PFC Post-Development Validation Exercise 2 - Comparison of PFC Stress Corrosion Model Ability to Reproduce Typical Primary, Secondary and Tertiary Creep Response of the Tptpmn .............................................................................

7.5.2.3 PFC Post-Development Validation Exercise 3 - Model Validation by Technical Review ................................................. 7-31

7.5.2.4 Conclusion from Particle Flow Code (PFC) Model Validation - Comparison to Criteria............................................ 7-32

7.6 DEVELOPMENT AND VALIDATION OF A DRIFT-SCALE MODELING METHOD FOR LITHOPHYSAL ROCK USING THE UDEC PROGRAM .......... 7-33

7.6.1 Qualification of the UDEC Program (Confidence Building During Model

Development) 7-33

7.6.2 Justification for a Two-Dimensional Isotropic Model of the Lithophysal

Rock (Confidence Building During Model Development) ......................... 7-33

7.6.3 Rock Mass Properties for Model Calibration ............................................. 7-34

7.6.4 Model Calibration (Confidence Building During Model Development)........ 7-34

7.6.5 Post-Development Validation Strategy $7-41$

7.6.5.1 UDEC Post-Development Validation Exercise 1 - Comparison of Predicted Failure Modes to Laboratory Observations (Corroboration with Relevant Observations) 


\section{CONTENTS (Continued)}

Page

7.6.5.2 UDEC Post-Development Validation Exercise 2 - Comparison of Model Predictions to Observations in the ECRB Cross-Drift (Corroboration with Field Observations)..................... 7-43

7.6.5.3 UDEC Post-Development Validation Exercise 3 - Comparison of Model to Drift Scale Experiment in the Tptpmn (Corroboration with Field Experiments)

7.6.5.4 UDEC Post-Development Validation Exercise 4 - Comparison of UDEC Voronoi Block Model with Continuum Constitutive Models (Corroboration of Results with Alternative Mathematical Models)

7.6.5.5 UDEC Post-Development Validation Exercise 5 Comparison of the Mathematical Model Implemented in the UDEC Program to other Numerical Approaches in Solving Dynamic Tunnel Stability Problems in Fractured Rock (Corroboration with Information Published in the Literature) ....... 7-70

7.6.6 Conclusions from UDEC Lithophysal Rockfall Model

Validation - Comparison to Criteria........................................................... 7-78

7.6.7 UDEC Lithophysal Rockfall Model Limitations............................................ 7-79

7.6.7.1 Impact of Block Discretization Level ........................................... 7-79

7.6.7.2 Impact of Inertial Forces in Quasi-Static Loading ......................... 7-82

7.6.7.3 Consideration of Homogenous and Isotropic Response of the Lithophysal Rock Mass ............................................................... 7-82

7.6.7.4 Lack of Confined Compression Tests in the Lithophysal Rock..... 7-82

7.7 MODEL VALIDATION FOR REPRESENTATION OF

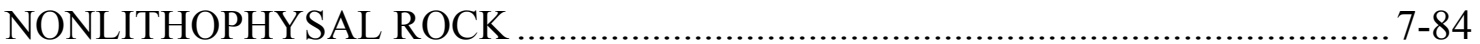

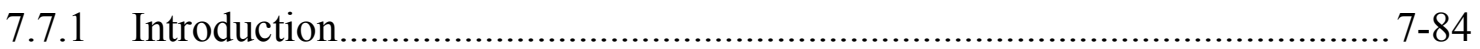

7.7.2 Verification of Initial Conditions and Dynamic Boundary Conditions (Confidence Building During Model Development)

7.7.3 3DEC Post-Development Validation Exercise 1 - Validation of the Fracture Mechanical Representation - Comparison to Laboratory Direct Shear Testing (Corroboration with Laboratory Data)..................................... 7-85

7.7.3.1 Introduction ............................................................................ 7-85

7.7.3.2 Direct Shear Data …………………………............................. 7-85

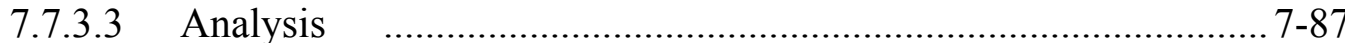

7.7.4 3DEC Post-Development Validation Exercise 2 - Validation of the Nonlithophysal Rockfall Model Implemented in 3DEC by Comparison to an Explosively Loaded, Scaled Tunnel Stability Experiment in Jointed Rock (Corroboration with Information Published in the Literature)............... 7-92

7.7.4.1 Rock Properties Data................................................................ 7-93

7.7.4.2 Constitutive Models .................................................................. 7-94

7.7.5 3DEC Post-Development Validation Exercise 3 - Nonlithophysal

Rockfall Model Validation by Corroboration with Alternative Numerical Model $7-102$ 


\section{CONTENTS (Continued)}

7.7.6 3DEC Post-Development Validation Exercise 4 - Model Validation by Expert Technical Review

7.7.7 Conclusions and Comparison to Validation Criteria ..................................... 7-103

7.8 VALIDATION SUMMARY ………………................................................. 7-104

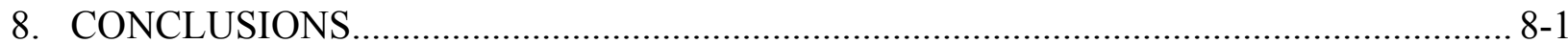

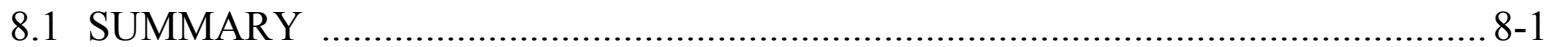

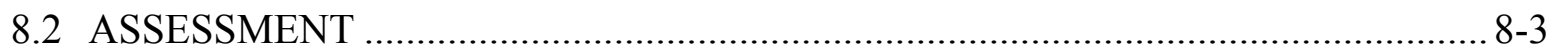

8.3 RECOMMENDATIONS ..............................................................................

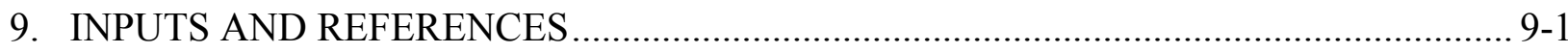

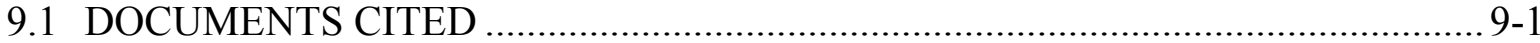

9.2 CODES, STANDARDS, REGULATIONS, AND PROCEDURES ……............... 9-17

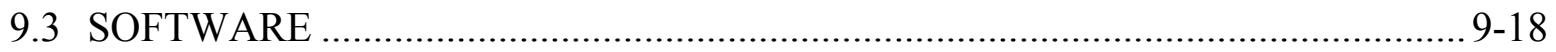

9.4 SOURCE DATA, LISTED BY DATA TRACKING NUMBER ……………........... 9-18

9.5 DEVELOPED DATA, LISTED BY DATA TRACKING NUMBER …………........9-27

APPENDICES

APPENDIX A - DRIFT DEGRADATION ANALYSIS COMPUTER FILES ............... A-1

APPENDIX B - DEVELOPMENT OF JOINT DATA FOR THE TPTPLL ZONE ...... B-1

APPENDIX C - REGIONAL AND LOCAL SCALE THERMAL MECHANICAL ANALYSIS OF THE ROCK MASS SURROUNDING WASTE EMPLACEMENT DRIFTS AT YUCCA MOUNTAIN ………............ C-1

APPENDIX D - DRKBA ANALYSIS OF NONLITHOPHYSAL ROCK...................... D-1

APPENDIX E - CALCULATION OF ROCK PROPERTIES ……………………........

APPENDIX F - FIELD OBSERVATION OF KEY BLOCKS IN THE ECRB CROSS-DRIFT .........................................................................

APPENDIX G - NATURAL ANALOGUES OF THE EFFECT OF SEISMIC EVENTS ON THE DEGRADATION OF UNDERGROUND STRUCTURES

APPENDIX H - 3DEC PROGRAM MODIFICATION AND MODEL OPTIMIZATION FOR ROCKFALL ANALYSIS ............................. $\mathrm{H}-1$

APPENDIX I - BLOCK SIZE GEOMETRY …………..........................................

APPENDIX J - RANDOM SELECTION OF 3DEC MODELING REGION IN A 100-M CUBE FRACTURE NETWORK GENERATED BY FRACMAN

APPENDIX K - SUFFICENCY OF THE NUMBER OF 3DEC SIMULATIONS TO REPRESENT THE ROCKFALL CHARACTERISTICS ..................... K-1

APPENDIX L - CONVERSION OF FRACMAN FRACTURE OUTPUT TO 3 DEC INPUT

APPENDIX M - GFM2000 INPUT AND OUTPUT FILES FOR STRATIGRAPHIC UNIT THICKNESS DATA AND CROSS-SECTIONS 


\section{CONTENTS (Continued)}

Page

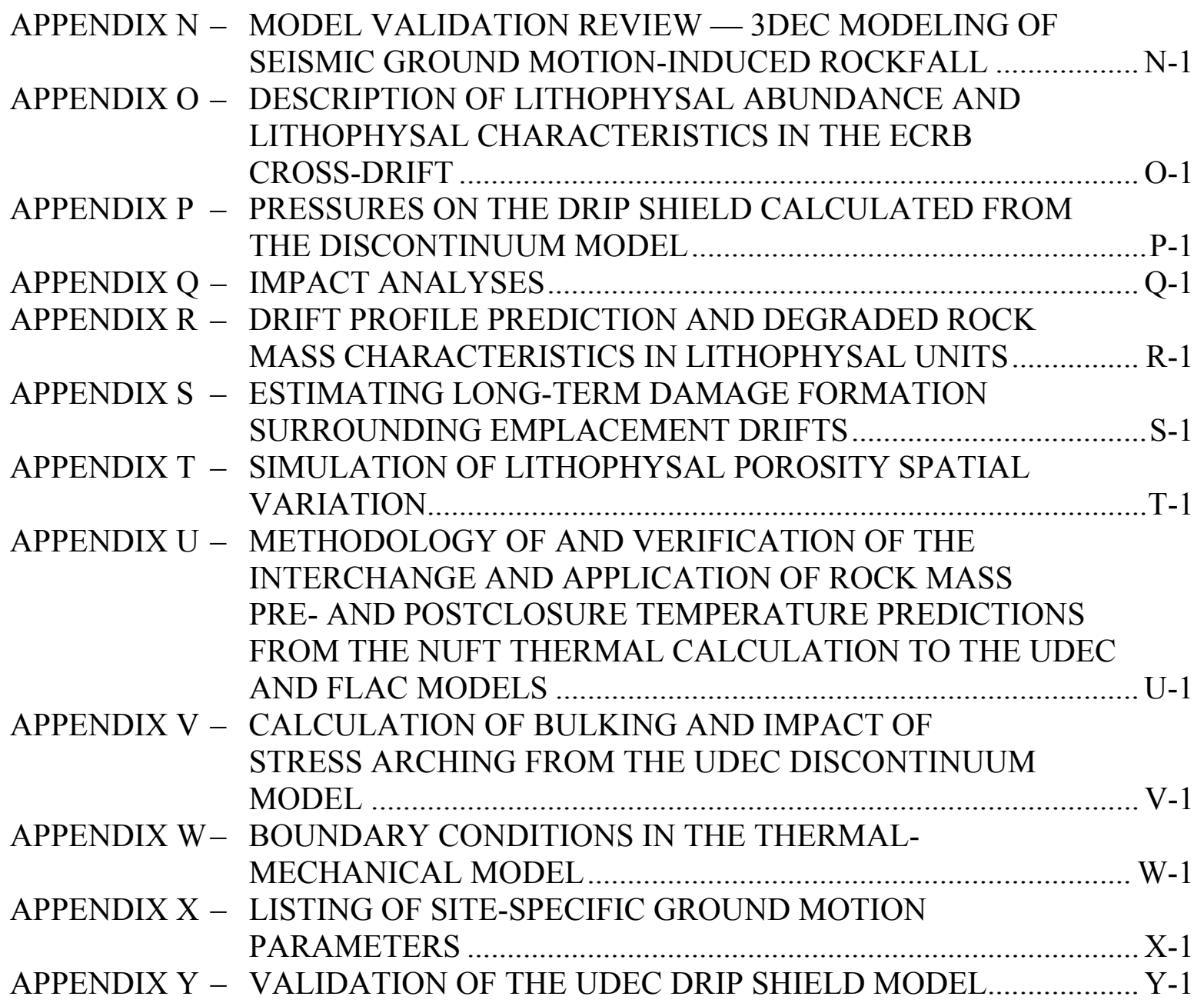




\section{INTENTIONALLY LEFT BLANK}




\section{FIGURES}

Page

1-1. Drift Degradation Analysis ........................................................................................ 1-3

1-2. Proposed Repository Layout in Plan View Showing Intersections of Geologic Sub-units With Emplacement Drifts............................................................................. 1-4

1-3. Potential Postclosure Performance Impacts of Rockfall on Engineered Barriers, In-Drift Environment, and Groundwater Seepage into Drifts ........................................ 1-6

1-4. General Approach to Resolution of the Repository Design and Thermal-Mechanical Effects KTIs

6-1. Simplified Lithostratigraphic Column of Paintbrush Group and the Rock Units that Form the Repository Host Horizon................................................................................. 6-5

6-2. Geology of the Central Block at Yucca Mountain and Location of the ESF, Including the ECRB Cross-Drift

6-3. Lithostratigraphic Features Related to Lithophysae and Fractures.................................. 6-7

6-4. Schematic Illustration of the Structure of the Topopah Spring Tuff ............................. 6-11

6-5. Fractures and Lithophysal Abundance in the ECRB Cross-Drift from Stations $0+00$ to $27+00$

6-6. Fracture Trace Length from Detailed Line Surveys as a Function of Stationing Along the ECRB Cross-Drift

6-7. Illustrative Example of a Full Periphery Geologic Map from the ESF, Tptpmn........... 6-14

6-8. Fractures in Wall of the ECRB Cross-Drift in the Tptpmn ......................................... 6-15

6-9. Low-Angle Vapor-Phase Partings in Nonlithophysal Units in the ESF ....................... 6-16

6-10. Comparison of Lithophysae and Fracturing in the Tptpul and Tptpll .......................... 6-17

6-11. Lithophysae, Spots, and Clasts of Tptpll in Panel Map 1493 Located on the Right Rib from Stations $14+93$ to $14+96$

6-12. Calculated Porosity of Lithophysal Cavities, Rims, Spots, Matrix-Groundmass, and the Total Porosity in the Tptpll Exposed Along the ECRB Cross-Drift.

6-13. Illustration of a Typical Key Block and Associated Fracture Planes

6-14. Evidence of Key-Block Occurrence in the ECRB Cross-Drift, Station 11+55 ... 6-23

6-15. Opening Profile at ESF Main Loop Station 60+24.70 (Steel Set \#1272, Tptpmn Lithostratigraphic Unit) Based on Field Survey Data.

6-16. Trace Length Distribution of the Tptpmn Fractures with Dips $>20^{\circ}$ 6-31

6-17. Pole Plot of Tptpmn Detailed Line Survey Data from the ESF Main Loop and ECRB Cross-Drift 6-32

6-18. FracMan Input Sheet for the Tptpmn. 6-34

6-19. Comparison of the Observed Tptpmn Fracture Poles to the FracMan Fracture Poles $6-38$

6-20. Cumulative Number of Fractures Versus Stationing for Detailed Line Surveys Along the ESF

6-21. Comparison of (a) Full Periphery Geologic Maps from the Tptpmn in the ESF

(b) with Simulated Full Periphery Geologic Maps from the FracMan Cube $6-43$

6-22. Distribution Comparisons of Inter-Fracture Distance. 6-44

6-23. Comparison of Sampled Fracture Trace Lengths from the FracMan Cube and Full Periphery Geologic Maps from the ESF for the Tptpmn. $6-45$ 


\section{FIGURES (Continued)}

6-24. Heat Decay Curves for Thermal Calculations

6-25. Temperature History at the Drift Crown Due to the Linear Heat Load Presented in Figure 6-24

6-26. Comparison of Temperature Histories at Tunnel Crown for Case 1 Calculated Using NUFT and FLAC3D.

6-27. Comparison of Stresses Around the Drift Between the NUFT-FLAC and FLAC3D

Predictions After 10 Years of Heating...

6-28. Comparison of Stresses Around the Drift Between the FLAC and FLAC3D

Predictions After 100 Years of Heating.

6-29. Comparison of Stresses Around the Drift Between the NUFT-FLAC and FLAC3D Predictions After 1,000 Years of Heating.

6-30. Comparison of Temperature Histories at Tunnel Crown for Case 1 Calculated Using NUFT (at the Center of the Repository) and FLAC3D (for the Edge of the Repository)

6-31. Comparison of Stresses Around the Drift Between the NUFT-FLAC and FLAC3D

Calculations for Edge of the Repository After 10 Years of Heating .... 6-54

6-32. Comparison of Stresses Around the Drift Between the NUFT-FLAC and FLAC3D

Calculations for Edge of the Repository After 100 Years of Heating

6-33. Comparison of Stresses Around the Drift Between the NUFT-FLAC and FLAC3D Calculations for Edge of the Repository After 1,000 Years of Heating

6-34. 3DEC Model Geometry and Cross-Sections

6-35. Illustration of Free-Field Boundaries in 3DEC Model ...

6-36. Examples of Ground Velocity Time Histories (H1) with Truncated Duration for Analysis

6-37. Comparison of Input Seismic Wave and Recorded Velocities in 3DEC Model (Ground Motion Set 4, H1).

6-38. Illustration of the Simulation of Rockfall Impact to the Drip Shield 3DEC

Simulation \#44, $1 \times 10^{-5}$ Ground Motion \# 9, at $\mathrm{t}=3.6 \mathrm{sec}$

6-39. Time Histories for Normal and Shear Stress at Selected Fracture Subcontacts for $1 \times 10^{5}$ Annual Probability of Exceedance Hazard (Simulation 16, Ground Motion Set 11)

6-40. Information for the Selected Fracture Subcontacts

6-41. Normal and Shear Stress Path at Selected Fracture Subcontacts for $1 \times 10^{-5}$ Annual

Probability of Exceedance Hazard (Simulation 16, Ground Motion Set 11)

6-42. Definition of Impact Angle and Drip Shield Block Local Coordinate System ............ 6-77

6-43. Histogram for Block Mass $\left(1 \times 10^{-5}\right.$ Annual Probability of Exceedance Hazard) .......... 6-78

6-44. Histogram for Relative Impact Velocity $\left(1 \times 10^{-5}\right.$ Annual Probability of Exceedance Hazard)

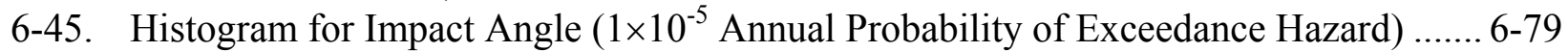

6-46. Histogram for Impact Momentum $\left(1 \times 10^{-5}\right.$ Annual Probability of

Exceedance Hazard)

6-47. Histogram for Impact Energy $\left(1 \times 10^{-5}\right.$ Annual Probability of Exceedance Hazard)...... 6-80 


\section{FIGURES (Continued)}

Page

6-48. Comparison of Input Seismic Wave and Recorded Velocities in 3DEC Model for $1 \times 10^{-6}$ Annual Probability of Exceedance Ground Motion (Ground Motion Set $6, \mathrm{H} 2$ )

6-49. Illustration of the Simulation of Rockfall Impact to the Drip Shield (3DEC Simulation \# 22, $1 \times 10^{-6}$ Ground Motion \# 5, at $\mathrm{t}=5.24 \mathrm{sec}$ ) (Simulation 16, Ground Motion Set 11).

6-50. Time Histories for Normal and Shear Stress at Selected Fracture Subcontacts for $1 \times 10^{-6}$ Annual Probability of Exceedance Hazard

6-51. Normal and Shear Stress Path at Selected Fracture Subcontacts for $1 \times 10^{-6}$ Annual Probability of Exceedance Hazard (Simulation 16, Ground Motion Set 11)

6-52. Histogram for Block Mass ( $1 \times 10^{-6}$ Annual Probability of Exceedance Hazard) .......... 6-85

6-53. Histogram for Relative Impact Velocity $\left(1 \times 10^{-6}\right.$ Annual Probability of Exceedance Hazard)............................................................................................. 6-85

6-54. Histogram for Impact Angle $\left(1 \times 10^{-6}\right.$ Annual Probability of Exceedance Hazard $)$....... 6-86

6-55. Histogram for Impact Momentum $\left(1 \times 10^{-6}\right.$ Annual Probability of

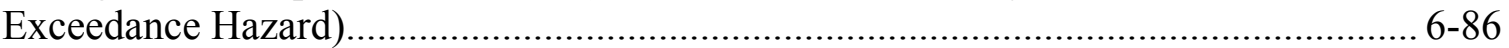

6-56. Histogram for Impact Energy $\left(1 \times 10^{-6}\right.$ Annual Probability of Exceedance Hazard $)$...... 6-87

6-57. Comparison of Input Seismic Wave and Recorded Velocities in 3DEC Model for $1 \times 10^{-7}$ Annual Probability of Exceedance Ground Motion (Ground Motion Set 3, Vertical Motion)

6-58. Illustration of the Simulation of Rockfall Impact to the Drip Shield (3DEC Simulation \# 64, $1 \times 10^{-7}$ Ground Motion \# 14, at $\mathrm{t}=7.37 \mathrm{sec}$ ).

6-59. Time Histories for Normal and Shear Stress at Selected Fracture Subcontacts for $1 \times 10^{-7}$ Annual Probability of Exceedance Hazard (Simulation 16, Ground Motion Set 11)

6-60. Normal and Shear Stress Path at Selected Fracture Subcontacts for $1 \times 10^{-7}$ Annual Probability of Exceedance Hazard (Simulation 16, Ground Motion Set 11)

6-61. Histogram for Block Mass ( $1 \times 10^{-7}$ Annual Probability of Exceedance Hazard) .......... 6-91

6-62. Histogram for Relative Impact Velocity $\left(1 \times 10^{-7}\right.$ Annual Probability of Exceedance Hazard)

6-63. Histogram for Impact Angle $\left(1 \times 10^{-7}\right.$ Annual Probability of Exceedance Hazard) ....... 6-92

6-64. Histogram for Impact Momentum $\left(1 \times 10^{-7}\right.$ Annual Probability of Exceedance Hazard).

6-65. Histogram for Impact Energy ( $1 \times 10^{-7}$ Annual Probability of Exceedance Hazard)...... 6-93

6-66. Comparison of Input Seismic Wave and Recorded Velocities in 3DEC Model for $1 \times 10^{-4}$ Annual Probability of Exceedance Ground Motion (H1)

6-67. Illustration of the Simulation of Rockfall Impact to the Drip Shield (3DEC Simulation for $1 \times 10^{-4}$ Preclosure Run 21, at $\mathrm{t}=32.5 \mathrm{sec}$ )

6-68. Time Histories for Normal and Shear Stress at Selected Fracture Subcontact for $1 \times 10^{-4}$ Annual Probability of Exceedance Hazard (Simulation 16).

6-69. Normal and Shear Stress Path at Selected Fracture Subcontact for $1 \times 10^{-4}$ Annual Probability of Exceedance Hazard (Simulation 16)..

6-70. Histogram for Block Mass ( $1 \times 10^{-4}$ Annual Probability of Exceedance Hazard) 6-98 


\section{FIGURES (Continued)}

Page

6-71. Histogram for Impact Velocity $\left(1 \times 10^{-4}\right.$ Annual Probability of Exceedance Hazard) ... 6-99

6-72. Histogram for Impact Angle $\left(1 \times 10^{-4}\right.$ Annual Probability of Exceedance Hazard $)$....... 6-99

6-73. Histogram for Impact Momentum $\left(1 \times 10^{-4}\right.$ Annual Probability of Exceedance Hazard)

6-74. Histogram for Impact Energy $\left(1 \times 10^{-4}\right.$ Annual Probability of Exceedance Hazard $)$.... 6-100

6-75. Stress Paths at Selected Fractures in the Drift Wall: Case 63 with

Fracture Pattern 96

6-76. Stress Paths at Selected Fractures in the Drift Roof: Case 63 with

Fracture Pattern 96

6-77. Stress Paths in the Drift Wall: Elastic Model

6-78. Stress Paths in the Drift Roof: Elastic Model 6-104

6-79. Stress Paths at Selected Fractures in the Drift Wall: Case 63 with Fracture Pattern 96, Thermal Sensitivity Case.

6-80. Stress Paths at Selected Fractures in the Drift Roof: Case 63 with Fracture Pattern 96, Thermal Sensitivity Case.

6-81. Comparison of Histograms of Block Mass from Preclosure and Postclosure Ground Motions

6-82. Comparison of Block Size Distribution from Preclosure and Postclosure Ground Motions

6-83. Rockfall Volume vs. Peak Ground Velocity........................................................ 6-114

6-84. Rockfall Volume vs. Arias Intensity......

6-85. Comparison of Block Size Distribution for Variation of Joint Mechanical Properties (Case 38)

6-86. Correlation of Rock Bridge Damage Percentage and Peak Ground Velocity .....

6-87. Probability Density Functions for the Bound to Horizontal Peak Ground Velocity at the Waste Emplacement Level

6-88. $1 \times 10^{-6}$ (a) and the $1 \times 10^{-7}$ (b) Ground Motion Time Histories in Terms of Peak Ground Velocity for Median Rockfall Condition, Case 45

6-89. Three-dimensional Visualization of Rockfall for the Median Rockfall Condition

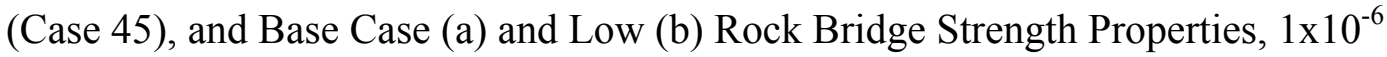
Ground Motion

6-90. Three-dimensional Visualization of Rockfall for the Median Rockfall Condition

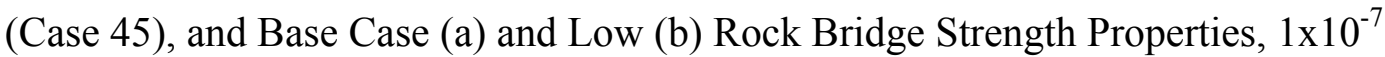
Ground Motion

6-91. Cross Section of the Four Model Dimensions Selected for Sensitivity Study, Case 45

6-92. Blocks Accumulated Above the Drip Shield Without Implementing Block Deletion Algorithm, Case 64, Fracture Pattern 49, $1 \times 10^{-7}$ Ground Motion Set \#14

6-93. Blocks Accumulated Above the Drip Shield Without Implementing Block Deletion Algorithm, Case 40, Fracture Pattern 99, $1 \times 10^{-7}$ Ground Motion Set \#6

6-94. Photo Showing the Intensely Fractured Zone in ESF Main Drift.

6-95. Fracture Analysis for the Intensely Fractured Zone 6-131

6-96. FLAC3D Model Mesh and Fracture Orientation. $6-132$

6-97. Yield State Prediction $-5 \times 10^{-4}$ Preclosure Ground Motion at 29 Seconds 6-133 


\section{FIGURES (Continued)}

6-98. In-Plane Shear Stress Contours $-5 \times 10^{-4}$ Preclosure Ground Motion at 29 Seconds... 6-134

6-99. Principal Stress Tensor $-5 \times 10^{-4}$ Preclosure Ground Motion at 29 Seconds

6-100. Yield State Prediction - Postclosure Ground Motion at Two Seconds

6-101. In-Plane Shear Stress Contours - Postclosure Ground Motion at Two Seconds $6-135$

6-102. Principal Stress Tensor - Postclosure Ground Motion at Two Seconds $6-136$

6-103. Stress Path at Roof Under Preclosure Seismic Motion. 6-136

6-104. Stress Path at Roof Under Postclosure Seismic Motion 6-137

6-105. Histogram Fracture Traces in Panels $11+15$ and $11+30$

6-106. Pole Plots for the Filtered Small-Scale Fractures $6-140$

6-107. Block Size Distribution Predicted from DRKBA Analyses 6-141

6-108. Drift Profile for $1 \times 10^{-7}$ Hazard Level, Case with Greatest Amount of Rockfall......... 6-143

6-109. Drift Profile for $1 \times 10^{-7}$ Hazard Level, Median Rockfall Case

6-110. Drift Profile for $1 \times 10^{-6}$ Hazard Level, Case with Greatest Amount of Rockfall. 6-145

6-111. Drift Profile for $1 \times 10^{-6}$ Hazard Level, Median Rockfall Case 6-146

6-112. Drift Profile for $1 \times 10^{-5}$ Hazard Level, Case with Greatest Amount of Rockfall. 6-147

6-113. Drift Profile for $1 \times 10^{-5}$ Hazard Level, Median Rockfall Case 6-148

6-114. Drift Profile for $1 \times 10^{-4}$ Hazard Level, Case with Greatest Amount of Rockfall.......... 6-149

6-115. Histogram of the Percentage of Lithophysal Porosity as Determined from Field Measurements in the ECRB Cross-Drift Taken on 5-m Intervals.

6-116. Geometry and Initial Conditions of the UDEC Lithophysal Rockfall Model 6-156

6-117. Dynamic Model, Initial and Boundary Conditions: Initial Quasi-Static Simulation

6-118. Model Boundary Conditions for Dynamic Simulation. 6-159

6-119. Horizontal Velocity, Component 1 for Ground Motion 4 of $1 \times 10^{-6}$ Probability

6-120. Geometry of the Model after Simulation for Preclosure Ground Motions: Rock Mass Category 1

6-121. Elastic Stress Paths in the Drift Wall Due to $1 \times 10^{-4}$ Preclosure Ground Motion: Category 1

6-122. Elastic Stress Paths in the Drift Roof Due to $1 \times 10^{-4}$ Preclosure Ground Motion: Category 1

6-123. Elastic Stress Paths in the Drift Wall Due to $1 \times 10^{-4}$ Preclosure Ground Motion: Category 5

6-124. Elastic Stress Paths in the Drift Roof Due to $1 \times 10^{-4}$ Preclosure Ground Motion: Category 5

6-125. Example of Comparison of Damage Levels for Lower End of PGV $(104 \mathrm{~cm} / \mathrm{sec})$ for $1 \times 10^{-5}$ Annual Exceedance Level.

6-126. Example of Comparison of Damage Levels for PGV of $152 \mathrm{~cm} / \mathrm{sec}$ for $1 \times 10^{-5}$ Annual Exceedance Level.

6-127. Example of Comparison of Damage Levels for Upper End of PGV $(333 \mathrm{~cm} / \mathrm{sec})$ for $1 \times 10^{-5} \mathrm{~m} / \mathrm{sec}$

6-128. Estimate $1 \times 10^{-5}$ Damage Level, Expressed as $\mathrm{m}^{2} / \mathrm{m}$ of Emplacement Drift Length for Rock Strength Categories 1, 3, and 5 for the 15 Ground Motion Time Histories 


\section{FIGURES (Continued)}

Page

6-129. Rockfall Damage as a Function of the Energy Associated With the Vertical Velocity Time History

6-130. Representation of the Drip Shield as a Deformable Structure With Actual Geometries and Footings That are Either Free to Slide or to Slide and Separate From the Invert

6-131. Example of Dynamic Impact Loading with $1 \times 10^{-5}$ Ground Motions to the Right Wall (top) and Roof (bottom) of Deformable Drip Shield With Arched Roof ..

6-132. Geometry of the Model After Simulations for Postclosure Ground Motions (Probability $1 \times 10^{-6}$ ): Realizations 1 Through 6 from Table 6-44

6-133. Elastic Stress Paths in the Drift Wall Due to Postclosure Ground Motion No. 1: Category 1

6-134. Elastic Stress Paths in the Drift Roof Due to Postclosure Ground Motion No. 1: Category 1

6-135. Elastic Stress Paths in the Drift Wall Due to Postclosure Ground Motion No. 1: Category 5 6-176

6-136. Elastic Stress Paths in the Drift Roof Due to Postclosure Ground Motion No. 1: Category 5 $6-176$

6-137. Drift Damage for Category 5 Lower Bound Strength Subject to $1 \times 10^{-5}$ Ground Motions

6-138. Contours of Lithophysal Porosity Contoured on the UDEC Spatial Variability Model

6-139. Thermal-Mechanical Model Initial and Boundary Conditions 6-181

6-140. Thermally Induced Rockfall and Stresses After 80 and 10,000 years of Heating in Rock Mass Category 1

6-141. Elastic Stress Paths in the Drift Wall Due to Temperature History: Category 1 1........ 6-184

6-142. Elastic Stress Paths in the Drift Roof Due to Temperature History: Category 1........ 6-184

6-143. Elastic Stress Paths in the Drift Wall Due to Temperature History: Category 5 ........ 6-185

6-144. Elastic Stress Paths in the Drift Roof Due to Temperature History: Category 5........ 6-185

6-145. Rockfall and Fractures Induced Around a Drift by $1 \times 10^{-4}$ Preclosure Ground Motion After the Peak Thermal Condition Occurring at 80 Years of Heating (30 Years after Closure) in Rock Mass Categories 1 and 5.

6-146. Rockfall and Fractures Induced Around a Drift by $1 \times 10^{-5}$ Earthquake Set 10 (peak ground velocity $=104.6 \mathrm{~cm} / \mathrm{sec}$ ) After 80 Years of Heating in Rock Mass Categories 1 and 5

6-147. Rockfall and Fractures Induced Around a Drift by $1 \times 10^{-5}$ Earthquake Set 6 (peak ground velocity $=173.88 \mathrm{~cm} / \mathrm{sec}$ ) After 80 Years of Heating in Rock Mass Categories 1 and 5

6-148. Rockfall and Fractures Induced Around a Drift by $1 \times 10^{-5}$ Earthquake Set 13 (peak ground velocity $=318.01 \mathrm{~cm} / \mathrm{sec}$ ) After 80 Years of Heating in Rock Mass Categories 1 and 5

6-149. Excavation Dimensions Required for Caving Gained from Field Experience in Block and Panel Caving Mines

6-150. Excavation for Nevada Canyon Wall Outlet Works (Top) Showing Construction Adit in 1933 and (Bottom) in 2004 


\section{FIGURES (Continued)}

Page

6-151. 2004 Photographs of Unsupported Construction Adit at Hoover Dam, Excavated in 1931

6-152. Example of Creep Strain Plotted as a Function of Time for a Static Fatigue Test Conducted on a Sample of Topopah Spring Tuff at a Constant Differential Stress of 132.8 MPa, a Confining Pressure of 5.0 MPa, a Pore Pressure of $1 \mathrm{MPa}$, and a Temperature of $150^{\circ} \mathrm{C}$.

6-153. Crack Length as a Function of Time for an Axial Crack Growth Experiment in Single Crystal Quartz....

6-154. Triaxial Static Fatigue Experimental Setup and Posttest Sample for Heated, Saturated, $50.8 \mathrm{~mm}$ Diameter Samples of Tptpmn

6-155. Static-Fatigue Data for Unconfined and Triaxial Compression of Heated, Saturated Welded Tuff and Lac du Bonnet Granite.

6-156. Example of Simulated Creep Curve and Brittle Rupture Calibration for Nonlithophysal Tuff, (in This Case, Providing a Lower-Bound Estimate by Using Lac du Bonnet Granite Time-to-Failure Curve) Static-Fatigue Test at Driving-Stress Ratio (Ratio of Applied Stress to Unconfined Compression Strength) of 0.8

6-157. Example Particle Flow Code Specimens with Void Porosities of 0.107 and 0.204 (a) and Effect of Void Porosity on Time-to-Failure Response for Lithophysal Tuff Material, in This Case, Providing a Lower Bound Estimate by Using Lac du Bonnet Granite Time-to-Failure Curve ( $0 \%$ to $20 \%$ Void Porosity, $\mathrm{n}_{\mathrm{v}}$ ) (b)

6-158. Time Evolution of Damage Due to Strength Degradation Coefficient for Nonlithophysal Tuff Material During Static-Fatigue Tests at Driving-Stress Ratios Ranging from 0.2 to 0.8 (a) and Idealized Damage Coefficient as a Function of Time for a Range of Applied Stress Conditions (b) .....

6-159. Effect of $10^{-4}$ Ground Motion After 80 Years of Heating in Category 2: Blocks Colored by Contours of Displacement Magnitude

6-160. Effect of $10^{-4}$ Ground Motion After 80 Years of Heating in Category 5: Blocks Colored by Contours of Displacement Magnitude

6-161. Effect of $10^{-4}$ Ground Motion After 10,000 Years of Heating in Category 2: Blocks Colored by Contours of Displacement Magnitude

6-162. Effect of $10^{-4}$ Ground Motion After 10,000 Years of Heating in Category 5: Blocks Colored by Contours of Displacement Magnitude

6-163. Thermal-Hydrologic Variables for the "Hottest" Waste Package (21-PWR Absorber Plate Waste Package) at the P2WR5C10 Location in the Tptpll (tsw35) Unit for the Mean Infiltration Flux Case

6-164. "Piping" Type of Caving Mechanism 6-218

6-165. Terzaghi Type of Caving Mechanism 6-218

6-166. Cave Height as a Function of Bulking Factor: Analytical Solution

6-167. Vertical Load on the Drip Shield as a Function of Bulking Factor: Analytical Solutions

6-168. Failure Mechanism of a Deep Tunnel in Cohesionless, Mohr-Coulomb Material as Predicted by the FLAC Continuum Model

6-222 


\section{FIGURES (Continued)}

6-169. Piping Failure Mechanism Represented in the in the FLAC Continuum Model: Bulking Factor $B=0.2$

6-170. Terzaghi Failure Mechanism Represented in the FLAC Continuum Model: Bulking Factor $B=0.1$

6-171. Evolution of the Cave as a Function of the Cohesive Strength, Category 1 Rock Mass Strength

6-172. Realization 1 for Quasi-static Drift Degradation, Rock Mass Category 1, $0.2 \mathrm{~m}$ Block Size: Equilibrium State for Deformable Drip Shield

6-173. Quasi-static Drift Degradation, Rock Mass Category 1, $0.2 \mathrm{~m}$ Block Size: Contours of Displacement (m) Magnitude for Deformable Drip Shield Showing Approximate Collapse Height of $7 \mathrm{~m}$ (about $6 \mathrm{~m}$ above top of drip shield crown) .... 6-227

6-174. Quasi-static Pressure on Drip Shield Segments for Six Realizations for Random, $0.2 \mathrm{~m}$ Block Geometries

6-175. Drip Shield Pressures for Base Case and for Consideration of Increase in the Density of the Rubble

6-176. Contours of Displacement Magnitudes (M) for Previously Collapsed Drift After Subsequent Shaking by Ground Motions With $1 \times 10^{-4}$ Probability Of Annual Recurrence

6-177. Stress Arching (stress tensor field colored by the magnitudes of the major principal stress) Before and After Shaking, Showing Somewhat Greater Stress Transfer to the Drip Shield

6-178. Pressures on the Rigid, Rectangular Drip Shield After Shaking by the Seismic Event With $1 \times 10^{-4}$ Probability of Annual Recurrence.

6-179. Summary of Vertical Load on the Drip Shield as a Function of Bulking Factor 6-233

6-180. Cross Section of a Typical Simulated Lithophysal Rock Mass in 3DEC

7-1. (a) Matrix Fracturing in the Tptpll in 12-in-Diameter Core and (b) Lack of Fracturing in Matrix of Tptpul as Seen in the Wall of Alcove 8 off the ECRB Cross-Drift $7-10$

7-2. Variation in Lithophysal Cavities in the Tptpll in the ECRB Cross-Drift from Top (Left) to Bottom of the Sub-Unit as Estimated by Tape and Angular Measurement Collected at 5-m Intervals

7-3. Schematic Illustration of Continuum (Left) and Discontinuum (Right) Approaches to Modeling Drift Stability....

7-4. General Approach to Validation of Mechanical Material Model for Lithophysal Rocks

7-5. The Basic Mechanics of the PFC Program 7-18

7-6. Relative Distributions of the Three Components of Lithophysal Tuff for (a) Real Material (Price et al. 1985 [DIRS 106602]) and (b) PFC Materials

7-7. PFC2D Unconfined Compressive Strength Test Specimens

7-8. PFC3D Unconfined Compressive Strength Test Specimens

7-9. PFC2D Simulation of Confined Compression of 2:1 L:D (Length:Diameter) Samples of Nonlithophysal Material $(\mathrm{nv}=0)$ Composed of Several Thousand Bonded Particles 


\section{FIGURES (Continued)}

Page

7-10. PFC2D Simulation of Confined Compression of 2:1 L:D (Length:Diameter) Samples of Lithophysal Material $\left(n_{v}=0.10\right)$ Composed of Several Thousand Bonded Particles

7-11. PFC2D Simulation of Confined Compression of 2:1 L:D (Length:Diameter) Samples of Lithophysal Material $\left(n_{v}=0.20\right)$ Composed of Several Thousand Bonded Particles

7-12. Young's Modulus Versus Void Porosity for Lithophysal Tuff and PFC Materials ...... 7-26

7-13. Unconfined Compressive Strength Versus Void Porosity for Lithophysal Tuff and PFC Materials

7-14. Unconfined Compressive Strength Versus Young's Modulus for Lithophysal Tuff and PFC Materials

7-15. Examples of Particle Flow Code Compression Tests Using Simulated Rock Specimens Developed by "Stenciling" Field Panel Maps in the Enhanced Characterization of the Repository Block

7-16. Unconfined Compressive Strength Versus Young's Modulus Showing Large Core Data and Results from PFC Panel Map Lithophysae Shape Study

7-17. Simulated Creep Curve and Brittle Rupture Calibration for Nonlithophysal Tuff, Static-Fatigue Test at Driving-Stress Ratio (Ratio of Applied Stress to Unconfined Compression Strength) of 0.8

7-18. UDEC Lithophysal Rock Specimen Composed of Many Irregular Blocks with Roughly Equi-Dimensional Side Lengths $7-35$

7-19. Micro Properties of the UDEC Voronoi Model.......................................................... 7-37

7-20. Numerical Experiment, Category 1: Stress-Strain Curves and Modes of Failure for Different Confinements and Loading Conditions

7-21. Numerical Experiment, Category 1: Failure Envelope 7-39

7-22. Numerical Experiment, Category 1: Volumetric Strain Versus Axial Strain for Different Confinements and Loading Conditions $7-40$

7-23. UDEC Discontinuum Model of Failure of Lithophysal Tuff Specimen Under Uniaxial Compression. $7-42$

7-24. Predicted Failure Mode of UDEC Sample in Direct Tension Test. $7-43$

7-25. Observed Rock Mass Conditions at the Tunnel Springline in Lithophysal Rock in the ESF

7-26. Estimate of Rock Mass Fracturing and Stress State Under In Situ Loading Only, Depth of $300 \mathrm{~m}$, Tptpll, Strength Category 1 (Low-Strength Characteristics) and 5 (High-Strength Characteristics)

7-27. Estimate of Stress-Induced Rock Mass Fracturing (seen as red block contacts) as a Function of Overburden Between $250 \mathrm{~m}$ and $350 \mathrm{~m}$, Tptpll, Strength Category 1 (Low-Strength Characteristics)

7-28. Perspective View of Heated Drift Scale Test Showing Wing Heaters .......................... 7-48

7-29. Minor Superficial Slabbing in the Center of the Roof Span Observed During Thermal Overstressing of the Heated Drift Scale Test.

7-30. UDEC Sample Calibration to Size-Effect Strength Data for an Approximate 1-m

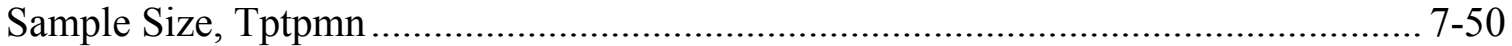

7-31. Results from Heated Drift Analysis with 1997 Temperature Conditions...................... 7-52 


\section{FIGURES (Continued)}

7-32. Results from Heated Drift Analysis with 1998 Temperature Conditions $7-53$

7-33. Results from Heated Drift Analysis with 1999 Temperature Conditions $7-54$

7-34. Results from Heated Drift Analysis with 2000 Temperature Conditions

7-35. Results from Heated Drift Analysis with 2001 Temperature Conditions $7-56$

7-36. Results from Heated Drift Analysis with 2002 Temperature Conditions $7-57$

7-37. Elastic Models of Drift Excavation: Vertical Normal Stress Along the Horizontal Profile Through the Center of Tunnel (Distance is measured from the tunnel center)

7-38. Elastic Models of Drift Excavation: Horizontal Normal Stress Along the Horizontal Profile Through the Center of Tunnel (Distance is measured from the tunnel center)

7-39. Elastic Models of Drift Excavation: Horizontal Displacement Along the Horizontal Profile Through the Center of Tunnel (Distance is measured from the tunnel center)

7-40. Elastic Models of Drift Excavation: Horizontal Normal Stress Along the Vertical Profile Through the Center of Tunnel (Distance is measured from the tunnel center)

7-41. Elastic Models of Drift Excavation: Vertical Normal Stress Along the Vertical Profile Through the Center of Tunnel (Distance is measured from the tunnel center)

7-42. Elastic Models of Drift Excavation: Vertical Displacement Along the Vertical Profile Through the Center of Tunnel (Distance is measured from the tunnel center)

7-43. Damage Around the Emplacement Drifts Predicted Using Different Inelastic Models

7-44. Inelastic Models of Drift Excavation: Vertical Normal Stress Along the Horizontal Profile Through the Center of Tunnel (Distance is measured from the tunnel center)

7-45. Inelastic Models of Drift Excavation: Horizontal Normal Stress Along the Horizontal Profile Through the Center of Tunnel (Distance is measured from the tunnel center)

7-46. Inelastic Models of Drift Excavation: Horizontal Displacement Along the Horizontal Profile Through the Center of Tunnel (Distance is measured from the tunnel center)

7-47. Inelastic Models of Drift Excavation: Horizontal Normal Stress Along the Vertical Profile Through the Center of Tunnel (Distance is measured from the tunnel center)

7-48. Inelastic Models of Drift Excavation: Vertical Normal Stress Along the Vertical Profile Through the Center of Tunnel (Distance is measured from the tunnel center)

7-49. Inelastic Models of Drift Excavation: Vertical Displacement Along the Vertical Profile Through the Center of Tunnel (Distance is measured from the tunnel center) 


\section{FIGURES (Continued)}

Page

7-50. Inelastic Models After 80 Years of Heating: Vertical Normal Stress Along the Horizontal Profile Through the Center of Tunnel (Distance is measured from the tunnel center)

7-51. Inelastic Models After 80 Years of Heating: Horizontal Normal Stress Along the Horizontal Profile Through the Center of Tunnel (Distance is measured from the tunnel center)

7-52. Inelastic Models After 80 Years of Heating: Horizontal Displacement Along the Horizontal Profile Through the Center of Tunnel (Distance is measured from the tunnel center)

7-53. Inelastic Models After 80 Years of Heating: Horizontal Normal Stress Along the Vertical Profile Through the Center of Tunnel (Distance is measured from the tunnel center)

7-54. Inelastic Models After 80 Years of Heating: Vertical Normal Stress Along the Vertical Profile Through the Center of Tunnel (Distance is measured from the tunnel center)

7-55. Inelastic Models After 80 Years of Heating: Vertical Displacement Along the Vertical Profile Through the Center of Tunnel (Distance is measured from the tunnel center)

7-56. Problem Geometry of the Mechanical Response of a 5-m Diameter Tunnel in Jointed Rock Subjected to a Spherically Expanding Blasting Source.

7-57. Radial Stress (Top) and Radial Velocity (Bottom) at the Centroid of the Future Tunnel Location in Problem 4 $7-74$

7-58. Comparison of Predicted Tunnel Invert-Crown (Top) and Springline (Bottom) Closure for Problem 5. $7-75$

7-59. Comparison of Radial Stress Along Radial Lines at Peak Free Field Stress Arrival Time, Problem 5

7-60. Comparisons of Exaggerated Tunnel Shapes $(\times 10)$ at Equilibrium, Problem 5............ 7-77

7-61. Block Size Effect: Behavior of the Rock Mass (Rock Mass Category 1, 300-m Overburden) Under Vertical and Horizontal Stress at Ratio of 2:1

7-62. Effect of Voronoi Block Realization: Behavior of the Rock Mass (Rock Mass Category 1, 350-m Overburden) Under Vertical and Horizontal Stress at Ratio of 2:1

7-63. Sample UDEC Simulation of Triaxial Response for $23.8 \%$ Lithophysal Porosity (top) and Hoek-Brown Failure Criteria Fits for Lithophysal Rocks Determined from UDEC Lithophysal Rockfall model Triaxial Numerical Test Analysis................ 7-83

7-64. Direct Shear Test Results for a Rough, Sub-Horizontal Vapor-Phase Parting.............. 7-86

7-65. Direct Shear Test Results for a Smooth, Sub-Vertical Cooling Joint............................ 7-87

7-66. Perspective View of 3DEC Model of Direct Shear Test of Joint …………….............. 7-88

7-67. Cross-Sectional View Through Model Showing Relative Shear Displacement of

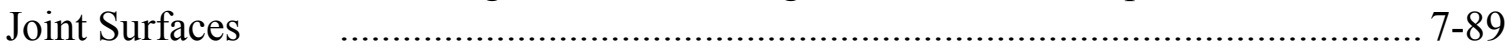

7-68. Comparison of 3DEC Mohr-Coulomb Joint Constitutive Model to Laboratory Direct Shear Testing for Sample 643, Hole ERCB-GTEC-CS1250-13 $7-90$

7-69. Comparison of 3DEC Simulation of Direction Shear Testing of a Vapor-Phase Parting (see Figure 7-64) 


\section{FIGURES (Continued)}

Page

7-70. Geometry of the 2.1-m Square (2.4 m Long) Joint Rock Experiment Showing Internal Tunnel and Instrument Locations.

7-71. Stress Strain Curves for Salem Limestone: (a) Unconfined Compression and (b) Triaxial Compression

7-72. Comparison of Extension and Compression Strength Envelopes for Salem Limestone

7-73. Compressibility and Strength in Salem Limestone: (a) Normal-Load Compressibility and (b) Shear Strength Envelope.

7-74. 3DEC Half-Symmetry Model Used in the Simulation Showing Boundary Conditions

7-75. Predicted (3DEC) and Measured Final Deformation (Exp) of the Crown-Invert and Springline Tunnel Diameters at Three Locations Along the Tunnel Length.

7-76. Predicted Stresses in Block Adjacent to Measured Stresses (Gauges FP24 and FP27) Above the Tunnel Crown

7-77. Predicted and Measured Stresses Adjacent to the Tunnel Springline. $7-101$

7-78. Measured and Predicted Shape of the Deformed Aluminum Liner (Displacements

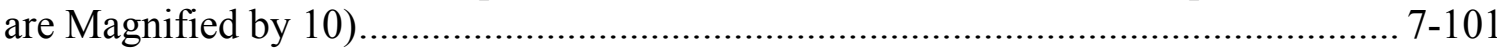

7-79. Comparison of Rockfall Results from 3DEC and DRKBA...................................... 7-104

B-1. Tptpll Pole Plot Showing Great Circles for the Tptpll Fractures........................................

B-2. Trace Length Distribution of the Tptpll Fractures $\left(>45^{\circ}\right)$..............................................

B-3. FracMan Input Sheet for the Tptpll ........................................................................

B-4. Comparison of Full Periphery Geologic Maps ……………………..............................

B-5. Comparison of the Observed Tptpll Fracture Poles to the FracMan Fracture Poles ........B-6

B-6. Comparison of the Observed Trace Length Distribution (Scaled by Two Thirds) to the FracMan Radii Distribution for Tptpll ....................................................................

B-7. Evaluation of Constant Intensity for Tptpll .............................................................

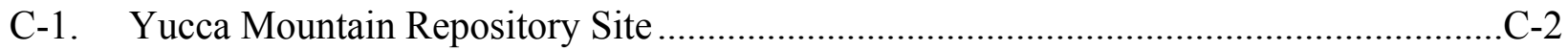

C-2. Local (Large) Scale Calculation in the Central Part of the Repository .............................-3

C-3. Topographical Plan View of the Yucca Mountain Site and Main Elements Considered in the Regional Scale Calculation..................................................................

C-4. Cross-Sections Showing the Four Thermal-Mechanical Units and Faults at the Locations Indicated as S3, S7, and S10 in Figure C-3 .................................................

C-5. E-W Cross-Sections S3 and S10 of Figures C-3 and C-4 and N-S Cross-Section Through the FLAC3D Calculation ..........................................................................

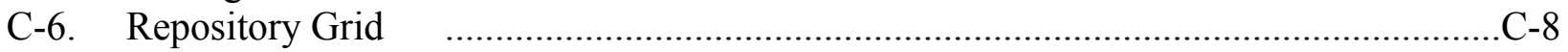

C-7. Contours of the In Situ Vertical Stress $\sigma_{2}=\sigma_{1}$ and Direction of the Horizontal

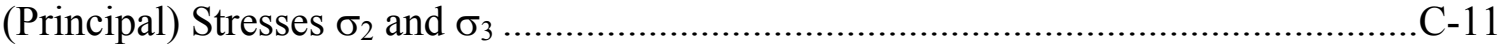

C-8. Heat Source Correction Functions for a) Radioactive Decay and b) Ventilation...........C-12

C-9. Plan View of the Repository Area Showing Boundaries of Uniformly Distributed

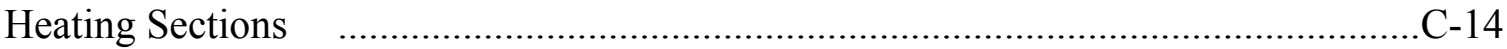

C-10. Evolution of Temperature Increase as a Function ...................................................... -15

C-11. Contours of Mean Temperature Change ( $\leq 100$ Years) ……….....................................16 


\section{FIGURES (Continued)}

C-12. Contours of Mean Temperature Change ( $\geq 1,000$ Years). C-17

C-13. Contours of Magnitude of Induced Displacements $(\geq 100$ Years) .................................. 18

C-14. Geographical Location of the Local Scale Calculation ...................................................19

C-15. Isometric and Plan View, and Cross-Sections of the Local Scale Center Calculation

C-16. Evolution of (Induced) Temperatures at Different Locations Around the Central Drift in the Local Scale Center Calculation.

C-17. Contours of Induced Temperatures in the Local Scale Center Calculation on Heating

C-18. Contours of Induced Vertical Stress $\sigma_{\mathrm{z}}$ for the Local Scale Center Calculation on Heating

C-19. Evolution of (Induced) Temperatures at Different Locations Around the Drift in the Local Scale Edge Calculation

C-20. Contours of Induced Temperatures in the Local Scale Edge Calculation on Heating

C-21. Contours of Induced Vertical Stress $\sigma_{z}$ for the Local Scale Edge Calculation on Heating

D-1. Determination of Primary Joint Sets, Tptpmn .............................................................. D-3

D-2. Illustrative Example of Derivation of Equation D-1 ……………………............... D-7

D-3. Illustrative Examples for the Alternative Method to Account for Seismic Effect.......... D-8

D-4. Parameters Used for Calculation of Mode II Stress Intensity Factor ............................ D-9

D-5. Function of the Additional Shear Stress Due to Thermal Loading............................. D-11

D-6. Degradation of Joint Cohesion with Respect to Time ................................................ D-12

D-7. Cumulative Key-block Size Distribution for Seismic Consideration in the Tptpmn Unit, $75^{\circ}$-Azimuth

D-8. Block Size Distributions for the Test Runs, Tptpmn Unit.......................................... D-19

D-9. Predicted Number of Key Blocks Per 10 Monte Carlo Simulations, Tptpmn Unit...... D-19

D-10. Predicted Number of Maximum Block Size, Tptpmn Unit ........................................ D-20

D-11. Top View of a Circular Fracture Disc Intersecting an Opening ................................. D-2

D-12. Opening Representation - No Backfill................................................................. D-23

E-1. Plot of Shear Strength Test Data from the TSw2 Thermal Mechanical Unit ..................E-4

E-2. Uniaxial and Triaxial Test Data from Borehole Samples Near the ESF for the Tptpmn Lithostratigraphic Unit E-16

E-3. Intact Uniaxial Compressive Strength and Young's Modulus for Topopah Spring Subunits as a Function of Effective Porosity for $50.8 \mathrm{~mm}$ Diameter Samples. E-18

E-4. Plan View of the ESF Main Loop and ECRB Cross-Drift Showing the Topopah Spring Rock Units and Location of 11.5-in Core Samples Taken in the Tptpul and Tptpll

E-5. Photographs of Large Lithophysal Core Samples (290-mm/11.5-in. Diameter)............E-20

E-6. Variation in Diameter Cores from the Tptpul and Tptpll ..............................................2-24

E-7. Histograms of Diameter Core Samples of Lithophysal Tuff ........................................E-25

E-8. Relationship of Unconfined Compressive Strength to Young's Modulus for RoomDry and Saturated 10.5-in. and 11.5-in. Core Samples from the Tptpul and Tptp11......E-27 


\section{FIGURES (Continued)}

Page

E-9. Examples of Approximate Rock Strength Category Levels Taken from 1x3-m Panel Maps

E-10. Distribution of Lithophysal Porosity Abundance (Frequency) for the Tptpll in the Enhanced Characterization of the Repository Block Cross-Drift

E-11. Examples of Particle Flow Code Compression Tests Using Simulated Rock Specimens Developed by "Stenciling" Field Panel Maps in the Enhanced Characterization of the Repository Block.

E-12. Plots Showing Data from Large Core Compression Testing of Tptpul and Tptpll Compared to Particle Flow Code Simulations Using Circular and Triangular Shaped Lithophysae as Well as Actual "Stenciled" Shapes from Enhanced Characterization of the Repository Block Panel Maps ....

E-13. Unconfined Compressive Strength Versus Young's Modulus Showing Large Core Data and Results from PFC Panel Map Lithophysae Shape Study

E-14. Emplacement Drift Stability Analysis Under In Situ Loading for Combinations of UCS and Young's Modulus Along the Lower Bound Properties Line

E-15. Schematic Illustration of the Process of Sampling and Modeling Spatial Variability Using Lithophysal Porosity Simulation Model

E-16. Spatial Variability in Lithophysal Porosity in Each of 30 Samples Taken.....................E-40

E-17. Example of Unconfined Compression Test Results on $10 \mathrm{~m} \times 5 \mathrm{~m}$ Rock Mass Sample Containing Spatially Variable Lithophysal Porosity

E-18. Relationship of UCS to Young's Modulus Showing the Results of Modeling Estimates of Properties for Spatially-Variable Lithophysal Rock Mass

E-19. Development of Rectangular Specimens for Matrix Size Effect and Anisotropy Study E-43

E-20. Results of Size Effect Study Showing Variation in Sample Uniaxial Compressive Strength as a Function of Sample Volume E-44

E-21. Anisotropy in Young's Modulus of Nonlithophysal Tptpll Matrix for Three Mutually Perpendicular Coring Directions....

E-22. Sample Size Effect on Compressive Strength Based on Laboratory Test Data for Nonlithophysal Rock E-54

F-1. Explanation of Symbols on Full Periphery Geologic Maps …………………….........F-2

F-2. Key-Block Location, Tptpul Unit, ECRB Cross-Drift Stations $8+60$ to $9+00$ ……...........F-3

F-3. Key-Block Location, Tptpul Unit, ECRB Cross-Drift Stations 9+00 to 9+30.................F-4

F-4. Key-Block Location, Tptpul Unit, ECRB Cross-Drift Stations 9+64 to 10+00...............F-5

F-5. Key-Block Location, Tptpmn Unit, ECRB Cross-Drift Stations $10+30$ to $10+60 \ldots \ldots \ldots . .$. F-6

F-6. Key-Block Location, Tptpmn Unit, ECRB Cross-Drift Stations $10+60$ to $11+00 \ldots \ldots \ldots . .$. F-7

F-7. Key-Block Location, Tptpmn Unit, ECRB Cross-Drift Stations $11+00$ to $11+30 \ldots \ldots \ldots . .$. F-8

F-8. Key-Block Location, Tptpmn Unit, ECRB Cross-Drift Stations $11+30$ to $11+60 \ldots \ldots \ldots . .$. F-9

F-9. Key-Block Location, Tptpmn Unit, ECRB Cross-Drift Stations 11+60 to 12+00 .........F-10

F-10. Key-Block Location, Tptpmn Unit, ECRB Cross-Drift Stations $12+00$ to $12+30 \ldots \ldots . .$. F-11

F-11. Key-Block Location, Tptpmn Unit, ECRB Cross-Drift Stations $13+00$ to $13+30 \ldots \ldots . .$. F-12

F-12. Key-Block Location, Tptpmn Unit, ECRB Cross-Drift Stations $13+60$ to $14+00 \ldots \ldots . .$. F-13

F-13. Key-Block Location, Tptpmn Unit, ECRB Cross-Drift Stations 14+00 to 14+30.........F-14 


\section{FIGURES (Continued)}

F-14. Key-Block Location, Tptpln Unit, ECRB Cross-Drift Stations $23+65$ to $24+00$ F-15

G-1. Epicenter of the 1964 Alaskan Earthquake G-2

H-1. Block Forming with Finite Trace Length Fractures and Rock Bridges in 3DEC........... H-2

H-2. Flow Chart for Treating the Small Edge Length Block ................................................. H-5

I-1. Block Geometry Information for Block \#1 …...........................................................

I-2. Block Geometry Information for Block \#2 ……........................................................

I-3. Block Geometry Information for Block \#3 ……...........................................................

I-4. Block Geometry Information for Block \#4 …….......................................................

I-5. Block Geometry Information for Block \#5 .............................................................

I-6. Block Geometry Information for Block \#6 ................................................................

I-7. Block Geometry Information for Block \#7 ……..........................................................

J-1. Microsoft Excel Inputs for Random Number Generation...................................................-1

J-2. Centroid Locations Projected to X-Y Plane....................................................................

J-3. Centroid Locations Projected to X-Z Plane ...................................................................

J-4. Centroid Locations Projected to Y-Z Plane ............................................................................

K-1. Summary Statistics of Block Size (metric ton) for $1 \times 10^{-4}$ Preclosure Ground Motion.......................................................................................................... K-2

K-2. Summary Statistics of Impact Velocity $(\mathrm{m} / \mathrm{sec})$ for $1 \times 10^{-4}$ Preclosure Ground

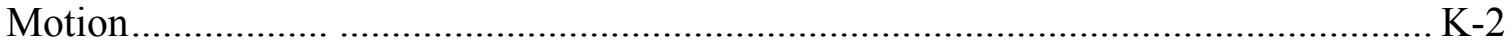

K-3. Summary Statistics of Impact Energy (J) for $1 \times 10^{-4}$ Preclosure Ground Motion ............ K-3

K-4. Block Size Distribution for $1 \times 10^{-4}$ Preclosure Ground Motion ………………............ K-3

K-5. Summary Statistics of Block Size (metric ton) for $1 \times 10^{-5}$ Ground Motion.................... K-5

K-6. Summary Statistics of Impact Velocity $(\mathrm{m} / \mathrm{sec})$ for $1 \times 10^{-5}$ Ground Motion.................... K-5

K-7. Summary Statistics of Impact Energy (J) for $1 \times 10^{-5}$ Ground Motion............................ K-6

K-8. Block Size Distribution for $1 \times 10^{-5}$ Ground Motion .................................................. K-6

K-9. Summary Statistics of Block Size (metric ton) for $1 \times 10^{-6}$ Ground Motion..................... K-8

K-10. Summary Statistics of Impact Velocity $(\mathrm{m} / \mathrm{sec})$ for $1 \times 10^{-6}$ Ground Motion................... K-8

K-11. Summary Statistics of Impact Energy (J) for $1 \times 10^{-6}$ Ground Motion............................. K-9

K-12. Block Size Distribution for $1 \times 10^{-6}$ Ground Motion ...................................................... K-9

K-13. Summary Statistics of Block Size (metric ton) for $1 \times 10^{-7}$ Ground Motion.................. K-11

K-14. Summary Statistics of Impact Velocity $(\mathrm{m} / \mathrm{sec})$ for $1 \times 10^{-7}$ Ground Motion.................. K-11

K-15. Summary Statistics of Impact Energy (J) for $1 \times 10^{-7}$ Ground Motion ........................... K-12

K-16. Block Size Distribution for $1 \times 10^{-7}$ Ground Motion...................................................... K-12

L-1. Coordinate System Adopted in FracMan and 3DEC .......................................................

M-1. Cross-Section Extracted at the Location of S3 (NS 231637 m), Using the EarthVision Software. 


\section{FIGURES (Continued)}

M-2. Cross-Section Extracted at the Location of S7 (NS 234075 m), Using the EarthVision Software.

M-3. Cross-Section Extracted at the Location of S10 (NS $235904 \mathrm{~m}$ ), Using the EarthVision Software M-4

O-1. Geometric Relations of Tape and Angular Traverse Data from the Tptpll $\mathrm{O}-2$

O-2. Abundance of Lithophysal Cavities from Angular Traverse data and Tape Traverse Data Collected at $5 \mathrm{~m}$ Intervals from the Tptpll in the ECRB Cross-Drift with $10 \mathrm{~m}$ and $20 \mathrm{~m}$ Moving Averages.

O-3. Lithophysae, Spots, and Clasts of Tptpll in Panel Map 1493 Located on the Right Rib from Station $14+93$ to $14+96$

O-4. Lithophysae, Spots, and Clasts of Tptpll in Panel Map 1641 Located on the Left rib from Station $16+41$ to $16+44$

O-5. Lithophysae, Spots, and Clasts of Tptpll in Panel Map 1641 Located on the Right Rib from Station 16+41 to $16+44$

O-6. Lithophysae, Spots, and Clasts of Tptpll in Panel Map 1726 Located on the Left Rib from Station $17+26$ to $17+29$

O-7. Lithophysae, Spots, and Clasts of Tptpll in Panel Map 2124 Located on the Left

Rib from Station $21+24$ to $21+27$

O-8. Lithophysae, Spots, and Clasts of Tptpll in Panel Map 2232 Located on the Left Rib from Station $22+32$ to $22+35$

O-9. Abundance of Lithophysal Cavities from Panel Maps (Cp) and Angular and Tape Traverses ( $\mathrm{Ca}$ and $\mathrm{Ct}$, Respectively)

O-10. Abundance of Rims From Panel Maps (Rp) and Angular (Ra) and the Combined Rim and Spot Values from Tape Traverses (Rt)

O-11. Abundance of Rims and Spots from Panel Maps (Rp and Sp), Angular (Ra and $\mathrm{Sa}$ ), and the Original Estimated Combined Rim and Spot Values from Tape Traverses (RSt)

O-12. Abundance (Number of Large Lithophysae) per $5 \mathrm{~m}$ Intervals, Locations, Areas, and Long and Short Axes of Large Lithophysae in the Tptpll and Tptpln from ECRB Cross-Drift Station $14+50$ to $25+00$

O-13. Frequency and Cumulative Frequency of the Long Axes and Areas of Large Lithophysae in the Tptpll in the Cross-Drift

O-14. Abundance Curves of Lithophysal Cavities, Rims, and Spots (Determined by Combining Panel Map and Tape and Angular Traverse Data), Large-Lithophysae Based on $5 \mathrm{~m}$ Segments of the Tunnel, and Estimates of Lithophysae and Spots

O-15. Calculated Porosity of Lithophysal Cavities, Rims, Spots, Matrix-Groundmass, and the Total Porosity in the Tptpll Exposed Along the ECRB Cross-Drift.

O-16. Calculated Porosity of Lithophysal Cavities (Including Large Lithophysae), the Combination of Rims and Spots, Matrix-Groundmass (MGM), and the Total Porosity in the Tptpll Exposed in the ECRB Cross-Drift from Station 14+44 to $23+30$

O-17. Frequency (Number) and Cumulative Frequency of the Abundance (Percent) Lithophysal Cavities from Tape Traverses in the Tptpll of the ECRB Cross-Drift from $14+05$ to $23+35$ (All) and $14+60$ to $22+00$ (Truncated Data). 


\section{FIGURES (Continued)}

Page

O-18. Frequency (Number) and Cumulative Frequency of the Abundance (Percent) of Individual Lithophysal Cavities from Tape Traverses in the Tptpll in the CrossDrift from $14+05$ to $23+35$ (All) and $14+60$ to $22+00$ (Truncated Data)

O-19. Frequency (Number) and Cumulative Frequency of the Lengths ( $\mathrm{mm}$ ) of Individual Lithophysal Cavities from Tape Traverses in the Tptpll of the ECRB Cross-Drift from $14+05$ to $23+35$ (All) and 14+60 to 22+00 (Truncated Data).

O-20. Sample Variance in the Summed Length of Lithophysal Cavities Based on $5 \mathrm{~m}$ Data and $10 \mathrm{~m}$ to $30 \mathrm{~m}$ Moving Average Data from Tape Traverses in the Tptpll of the ECRB Cross-Drift from $14+05$ to $23+35$

O-21. Differences in Sample Variance in the Summed Length of Lithophysal Cavities with Pairs of Various Moving Average Data from Tape Traverses in the Tptpll of the ECRB Cross-Drift from $14+05$ to $23+35$.

O-22. Geometric Relations of Three-Dimensional Ellipsoid with Two-Dimensional Cross Sections and One-Dimensional Transects

P-1. Ground motion $10^{-5}$, Case 11: Equilibrium State for Rigid, Rectangular Drip Shield

P-2. Ground Motion $10^{-5}$, Case 11: Equilibrium State for Deformable Drip Shield With Arched Top, Pinned Bottom, No Invert

P-3. Ground motion $10^{-5}$, Case 11: Loads On the Drip Shield For Cases Without the Invert

P-4. Ground Motion $10^{-5}$, Case 11: Equilibrium State for Rigid Drip Shield With Arched Top, Bottom Fixed to the Invert................................................................. P-5

P-5. Ground Motion $10^{-5}$, Case 11: Equilibrium State for Deformable Drip Shield With Arched Top, Bottom Slides On the Invert ................................................................. P-6

P-6. Ground Motion $10^{-5}$, Case 11: Equilibrium State for Deformable Drip Shield With Arched Top, Bottom Rests On the Invert .................................................................. P-6

P-7. Ground Motion 10 $0^{-5}$, Case 11: Loads On The Drip Shield for Cases With the Invert

P-8. Ground Motion $10^{-5}$, Case 11: Dynamic Loads On the Right Side for Deformable Drip Shield With Arched Top, Bottom Rests On the Invert.

P-9. Ground Motion 10 $0^{-5}$, Case 11: Dynamic Loads On The Top for Deformable Drip Shield With Arched Top, Bottom Rests On the Invert

P-10. Ground Motion $10^{-5}$, Case 11: Dynamic Loads On the Left Side for Deformable Drip Shield With Arched Top, Bottom Rests On the Invert.

P-11. Quasi-Static Drift Degradation, $0.3 \mathrm{~m}$ Block Size: Equilibrium State for Rigid, Rectangular Drip Shield.

P-12. Quasi-Static Drift Degradation, 0.3-m Block Size: Equilibrium State for Deformable Drip Shield With Arched Top, Pinned Bottom, No Invert..... P-10

P-13. Quasi-Static Drift Degradation, 0.3 m Block Size: Loads On the Drip Shield for Cases Without Invert.

P-14. Quasi-Static Drift Degradation, $0.3 \mathrm{~m}$ Block Size: Equilibrium State for Rigid Drip Shield With Arched Top, Bottom Fixed To the Invert. P-12

P-15. Quasi-static Drift Degradation, $0.3 \mathrm{~m}$ Block Size: Equilibrium State for Deformable Drip Shield With Arched Top, Bottom Rests On the Invert $\mathrm{P}-12$ 


\section{FIGURES (Continued)}

Page

P-16. Quasi-Static Drift Degradation, $0.3 \mathrm{~m}$ Block Size: Loads On the Drip Shield for

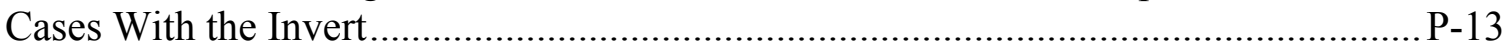

P-17. Quasi-Static Drift Degradation, 0.2-m Block Size: Equilibrium State for Rigid, Rectangular Drip Shield $\mathrm{P}-14$

P-18. Quasi-Static Drift Degradation, $0.2 \mathrm{~m}$ Block Size: Equilibrium State for Deformable Drip Shield With Arched Top, Pinned Bottom, No Invert

P-19. Quasi-Static Drift Degradation, $0.2 \mathrm{~m}$ Block Size: Contours of Displacement (m) Magnitude for Deformable Drip Shield With Arched Top, Pinned Bottom, No Invert

P-20. Quasi-Static Drift Degradation, $0.2 \mathrm{~m}$ block size: Stress Tensor Field (Pa) for Deformable Drip Shield With Arched Top, Pinned Bottom, No Invert

P-21. Quasi-Static Drift Degradation, $0.2 \mathrm{~m}$ Block Size: Loads on the Drip Shield for Cases Without the Invert. P-16

P-22. Quasi-Static Drift Degradation, 0.2 m Block Size: Equilibrium State for Rigid Drip Shield With Arched Top, Bottom Fixed to the Invert $\mathrm{P}-17$

P-23. Quasi-Static Drift Degradation, $0.2 \mathrm{~m}$ Block Size: Contours of Displacement (m) Magnitude for Rigid Drip Shield With Arched Top, Bottom Fixed to the Invert ..........P-18

P-24. Quasi-Static Drift Degradation, $0.2 \mathrm{~m}$ Block Size: Equilibrium State for Deformable Drip Shield With Arched Top, Bottom Rests On the Invert P-18

P-25. Quasi-Static Drift Degradation, $0.2 \mathrm{~m}$ Block Size: Contours of Displacement (m) Magnitude for Deformable Drip Shield With Arched Top, Bottom Rests On the Invert

P-26. Quasi-static Drift Degradation, $0.2 \mathrm{~m}$ Block Size: Loads On the Drip Shield for Cases With the Invert.....

P-27. Ground Motion $10^{-6}$ Number 3: Model Configuration After $2.75 \mathrm{~s}$ of Shaking P-21

P-28. Ground Motion $10^{-6}$ Number 3: Model Configuration in the Equilibrium State After Shaking

P-29. Ground Motion $10^{-6}$ Number 3: Dynamic Loads On the Right Side.

P-30. Ground Motion $10^{-6}$ Number 3: Dynamic Loads On the Top $\mathrm{P}-22$

P-31. Ground Motion $10^{-6}$ Number 3: Dynamic Loads On the Left Side P-23

P-32. Static Loads On The Drip Shield After Shaking With Four Different $10^{-6}$ Ground Motions

P-33. Ground Motion $10^{-7}$ Number 3: Model Configuration in the Equilibrium State After Shaking

P-34. Ground Motion $10^{-7}$ Number 3: Dynamic Loads On the Right Side .............................P-25

P-35. Ground Motion $10^{-7}$ Number 3: Dynamic Loads On the Top …………………….......

P-36. Ground Motion $10^{-7}$ Number 3: Dynamic Loads On the Left Side ................................2-26

P-37. Static Loads On the Drip Shield After Shaking With Four Different $10^{-7}$ Ground Motions

P-38. Static Loads On The Drip Shield After Quasi-Static Drift Degradation For Six Realizations Of Voronoi Block Geometry.... P-28

P-39. Already Collapsed Drift, Ground Motion $10^{-4}$ : Dynamic Loads On the Right Side

P-40. Already Collapsed Drift, Ground Motion $10^{-4}$ : Dynamic Loads On the Top P-29 


\section{FIGURES (Continued)}

P-41. Already Collapsed Drift, Ground Motion $10^{-4}$ : Dynamic Loads On the Left Side........P-30

P-42. Already Collapsed Drift, Ground Motion $10^{-6}$ Number 1: Dynamic Loads On the Right Side

P-43. Already Collapsed Drift, Ground Motion $10^{-6}$ Number 1: Dynamic Loads On the Top

P-44. Already Collapsed Drift, Ground Motion $10^{-6}$ Number 1: Dynamic Loads On The Left Side

P-45. Effect Of Seismic Shaking After Quasi-Static Collapse On Drip Shield Loads $\mathrm{P}-32$

Q-1. Temperature History at the Drift Crown up to 10000 Years ......................................... Q-3

Q-2. Temperature History at the Drift Crown up to 80 Years ............................................. Q-5

Q-3. Evolution of Damage Due to Strength Degradation and with Revised Thermal Load for Category 2 - Tuff Best-fit Static-Fatigue Curve................................................... Q-6

Q-4. Evolution of Damage Due to Strength Degradation and with Revised Thermal Load for Category 5 - Tuff Best-fit Static-Fatigue Curve.

Q-5. Strain Energy Stored During the Static Fatigue Simulations....................................... Q-10

Q-6. $\quad$ Log Files from PFC2D.................................................................................... Q-11

Q-7. Axial (wsyy) and Confining Stresses (wsxx and wszz) During the Biaxial Simulations

R-1. Drift Profile for Scenario 1: Seismic with $5 \times 10^{-4}$ Probability of Exceedance Ground Motion, Rock Mass Category 1, Voronoi Block Size $0.3 \mathrm{~m}$

R-2. Drift Profile for Scenario 2: Seismic with $1 \times 10^{-6}$ Probability of Exceedance Ground Motion, Rock Mass Category 1, Ground Motion \#12, Voronoi Block Size 0.3 m .........R-5

R-3. Drift Profile for Scenario 3: Seismic with $1 \times 10^{-6}$ Probability of Exceedance Ground Motion, Rock Mass Category 1, Ground Motion \#8, Voronoi Block Size 0.3 m ...........R-5

R-4. Drift Profile for Scenario 4: Seismic with $1 \times 10^{-6}$ Probability of Exceedance Ground Motion, Rock Mass Category 1, Ground Motion \#9, Voronoi Block Size 0.3 m ...........R-6

R-5. Drift Profile for Scenario 5: Seismic with $1 \times 10^{-6}$ Probability of Exceedance Ground Motion, Rock Mass Category 1, Ground Motion \#1, Voronoi Block Size 0.3 m ............R-6

R-6. Drift Profile for Scenario 6: Thermal at 10,000 Years, Rock Mass Category 1, Voronoi Block Size $0.3 \mathrm{~m}$.

R-7. Drift Profile for Scenario 7: Degradation Consideration, 0\% Cohesion Reduction, Voronoi Block Size $0.3 \mathrm{~m}$, and Random Block Generation Seed \#1

R-8. Drift Profile for Scenario 8: Degradation Consideration, 20\% Cohesion Reduction, Voronoi Block Size $0.3 \mathrm{~m}$, and Random Block Generation Seed \#1

R-9. Drift Profile for Scenario 9: Degradation Consideration, 40\% Cohesion Reduction, Voronoi Block Size $0.3 \mathrm{~m}$, and Random Block Generation Seed \#1

R-10. Drift Profile for Scenario 10: Degradation Consideration, 60\% Cohesion Reduction, Voronoi Block Size 0.3 m, and Random Block Generation Seed \#1 .............R-9

R-11. Drift Profile for Scenario 11: Degradation Consideration, $80 \%$ Cohesion Reduction, Voronoi Block Size 0.3 m, and Random Block Generation Seed \#1 


\section{FIGURES (Continued)}

Page

R-12. Drift Profile for Scenario 12: Degradation Consideration, $100 \%$ Cohesion Reduction, Voronoi Block Size 0.3 m, and Random Block Generation Seed \#1 ..........R-10

R-13. Drift Profile for Scenario 13: Degradation Consideration, $0 \%$ Cohesion Reduction, Voronoi Block Size 0.3 m, and Random Block Generation Seed \#2 ...........R-10

R-14. Drift Profile for Scenario 14: Degradation Consideration, 20\% Cohesion Reduction, Voronoi Block Size 0.3 m, and Random Block Generation Seed \#2..........R-11

R-15. Drift Profile for Scenario 15: Degradation Consideration, $40 \%$ Cohesion Reduction, Voronoi Block Size 0.3 m, and Random Block Generation Seed \#2..........R-11

R-16. Drift Profile for Scenario 16: Degradation Consideration, 60\% Cohesion Reduction, Voronoi Block Size 0.3 m, and Random Block Generation Seed \#2 ..........R-12

R-17. Drift Profile for Scenario 17: Degradation Consideration, $80 \%$ Cohesion Reduction, Voronoi Block Size 0.3 m, and Random Block Generation Seed \#2 ..........R-12

R-18. Drift Profile for Scenario 18: Degradation Consideration, 100\% Cohesion Reduction, Voronoi Block Size 0.3 m, and Random Block Generation Seed \#2..........R-13

R-19. Drift Profile for Scenario 19: Degradation Consideration, $0 \%$ Cohesion Reduction, Voronoi Block Size 0.2 m, and Random Block Generation Seed \#1 ..........R-13

R-20. Drift Profile for Scenario 20: Degradation Consideration, 20\% Cohesion Reduction, Voronoi Block Size 0.2 m, and Random Block Generation Seed \#1 ..........R-14

R-21. Drift Profile for Scenario 21: Degradation Consideration, $40 \%$ Cohesion Reduction, Voronoi Block Size 0.2 m, and Random Block Generation Seed \#1 ...........R-14

R-22. Drift Profile for Scenario 22: Degradation Consideration, 60\% Cohesion Reduction, Voronoi Block Size 0.2 m, and Random Block Generation Seed \#1 ..........R-15

R-23. Drift Profile for Scenario 23: Degradation Consideration, $80 \%$ Cohesion Reduction, Voronoi Block Size 0.2 m, and Random Block Generation Seed \#1 ...........R-15

R-24. Drift Profile for Scenario 24: Degradation Consideration, 100\% Cohesion Reduction, Voronoi Block Size 0.2 m, and Random Block Generation Seed \#1 ...........R-16

R-25. Drift Profile for Scenario 25: Degradation Consideration, $0 \%$ Cohesion Reduction, Voronoi Block Size 0.2 m, and Random Block Generation Seed \#2 ...........R-16

R-26. Drift Profile for Scenario 26: Degradation Consideration, 20\% Cohesion Reduction, Voronoi Block Size 0.2 m, and Random Block Generation Seed \#2..........R-17

R-27. Drift Profile for Scenario 27: Degradation Consideration, $40 \%$ Cohesion Reduction, Voronoi Block Size 0.2 m, and Random Block Generation Seed \#2 ..........R-17

R-28. Drift Profile for Scenario 28: Degradation Consideration, 60\% Cohesion Reduction, Voronoi Block Size 0.2 m, and Random Block Generation Seed \#2 2..........R-18

R-29. Drift Profile for Scenario 29: Degradation Consideration, 80\% Cohesion Reduction, Voronoi Block Size 0.2 m, and Random Block Generation Seed \#2 2.........R-18

R-30. Drift Profile for Scenario 30: Degradation Consideration, 100\% Cohesion Reduction, Voronoi Block Size 0.2 m, and Random Block Generation Seed \#2 ..........R-19

S-1. Static-Fatigue Data for Lac du Bonnet Granite (Confinements of 0, 5, and $10 \mathrm{MPa}$ ) $\mathrm{S}-2$

S-2. Static-Fatigue Data for Welded Tuff and Lac du Bonnet Granite ................................ S-6

S-3. Young's Modulus Versus Void Porosity for Lithophysal Tuff and PFC2D Models of Randomly Distributed Circular Voids 


\section{FIGURES (Continued)}

Page

S-4. Unconfined Compressive Strength Versus Void Porosity for Lithophysal Tuff and PFC2D Models of Randomly Distributed Circular Voids

S-5. Young's Modulus Versus Unconfined Compressive Strength for Lithophysal Tuff and PFC2D Models of Randomly Distributed Circular Voids ........................................ S-8

S-6. PFC2D Specimens of mS50 Material ........................................................................

S-7. Number of Cracks Versus Time for Different Equilibrium Ratio Limits...................... S-11

S-8. Normalized Time-to-Failure Versus Subinterval Factor for mS50 Material for Numerical Static-Fatigue Tests (0.1 MPa Confinement)............................................ S-12

S-9. Effect of Subinterval Factor on Creep Curves for mS50 Material for Numerical Static-Fatigue Tests (0.1 MPa Confinement).

S-10. Static-Fatigue Curve (0.1 MPa Confinement) for mS50 Material for Numerical Static-Fatigue Tests Compared with the Data and Curve for Lac du Bonnet Granite

S-11. Static-Fatigue Curve (0.1 MPa Confinement) for mS50 Material for Numerical Static-Fatigue Tests Compared with the Data and Curve for Lac du Bonnet Granite - Expanded Scales

$\mathrm{S}$-12. Creep Curves for mS50 Material for Numerical Static-Fatigue Tests (0.1 MPa Confinement)

S-13. Creep Curve and Damage in mS50 Material for Static-Fatigue Test (0.1 MPa Confinement)

S-14. Effect of Void Porosity on Static-Fatigue Curves (0.1 MPa Confinement) for mS50 Material

S-15. Effect of Void Porosity on Static-Fatigue Curves (0.1 MPa Confinement) for mS50 Material - Expanded Scales.

S-16. Effect of Void Porosity on Static-Fatigue Curves (0.1-MPa Confinement) for mS50 Material (Straight-Line Fit)..................................................................... S-17

S-17. Effect of Void Porosity on Static-Fatigue Curves (0.1 MPa Confinement) for mS50 Material (Straight-Line Fit) — Expanded Scales

S-18. Effect of Confinement on Static-Fatigue Curves for mS50 Material ............................ S-19

S-19. Effect of Confinement on Static-Fatigue Curves for mS50 Material - Expanded Scales.

S-20. Effect of Void Porosity on Static-Fatigue Curves (5 MPa Confinement) for mS50 Material

S-21. Effect of Void Porosity on Static-Fatigue Curves (5-MPa Confinement) for mS50 Material - Expanded Scales.

S-22. Time Evolution of Damage Coefficient for mS50 Material During Numerical Static-Fatigue Tests ( $0.1 \mathrm{MPa}$ Confinement)

S-23. Stress-Strain Curves for mS50 Material at Different Times During Static-Fatigue Test (0.1 MPa Confinement).

S-24. Stress-Strain Curves for mS50 Material at Different Times During Static-Fatigue Test $(0.1 \mathrm{MPa}$ Confinement).....

S-25. Stress-Strain Curves for mS50 Material at Different Times During Static-Fatigue

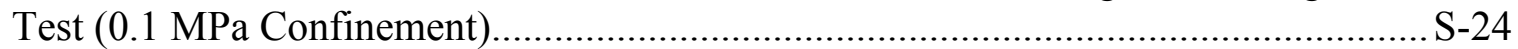

S-26. Static-Fatigue Data for Welded Tuff and Best-Fit Lines............................................. S-26 


\section{FIGURES (Continued)}

S-27. Static-Fatigue Curves Used as Input to the UDEC Analyses S-26

S-28. Damage Curves Used as Input to the UDEC LdB Analyses $\mathrm{S}-27$

S-29. Damage Curves Used as Input to the UDEC Tuff Best-fit Analyses

S-30. Damage Curves for Sensitivity Analysis of Damage Rate ..... S-29

S-31. The Effect of the Damage Rate on Rockfall Predictions Due to Time-Dependent Strength Degradation After 100 Years and 10,000 Years

S-32. Model State for Tuff, Category 2 After 500 Years S-33

S-33. Evolution of Damage Due to Strength Degradation for Category 1 - Lac du Bonnet Granite Static-Fatigue Curve

S-34. Evolution of Damage Due to Strength Degradation for Category 2 - Lac du Bonnet Granite Static-Fatigue Curve

S-35. Evolution of Damage Due to Strength Degradation for Category 5 - Lac du Bonnet Granite Static-Fatigue Curve

S-36. Evolution of Damage Due to Strength Degradation for Category 2 - Tuff Best-Fit Static-Fatigue Curve (Reduced Time Increment)

S-37. Evolution of Damage Due to Strength Degradation for Category 1 - Tuff Best-Fit Static-Fatigue Curve .....

S-38. Evolution of Damage Due to Strength Degradation for Category 2 - Tuff Best-Fit Static-Fatigue Curve

S-39. Evolution of Damage Due to Strength Degradation for Category 3 - Tuff Best-Fit Static-Fatigue Curve

S-40. Evolution of Damage Due to Strength Degradation for Category 5 - Tuff Best-Fit Static-Fatigue Curve

S-41. Damage Due to Strength Degradation for Categories 1, 2, 3, and 5 - Tuff Best-Fit Static-Fatigue Curve at Year 20,000.....

S-42. Evolution of Damage Due to Strength Degradation and Thermal Load for Category 2 - Tuff Best-Fit Static-Fatigue Curve

S-43. Evolution of Damage Due to Strength Degradation and Thermal Load for Category 3 - Tuff Best-Fit Static-Fatigue Curve

S-44. Evolution of Damage Due to Strength Degradation and Thermal Load for Category 5 - Tuff Best-Fit Static-Fatigue Curve

S-45. Effect of $1 \times 10^{-4}$ Ground Motion After 80 Years of Heating in Category 2 Contours of Displacement Magnitude (m)

S-46. Effect of $1 \times 10^{-4}$ Ground Motion After 80 Years of Heating in Category 5: Contours of Displacement Magnitude (m)

S-47. Effect of $1 \times 10^{-4}$ Ground Motion After 10,000 Years of Heating in Category 2:

Contours of Displacement Magnitude $(\mathrm{m})$

S-48. Effect of $1 \times 10^{-4}$ Ground Motion After 10,000 Years of Heating in Category 5: Contours of Displacement Magnitude (m)

S-49. Effect of Two Successive $1 \times 10^{-4}$ Ground Motions in Category 2: Contours of Displacement Magnitude (m)

S-50. Distribution of Lithophysal Porosity in the ECRB Cross-Drift................................... S-52

S-51. Porosity Contours in Cross-Sections Through the 3D Simulated Porosity Field ........... S-53 


\section{FIGURES (Continued)}

S-52. Distribution of Block Bulk Modulus for Section 1

S-53. Evolution of Damage Due to Strength Degradation and Thermal Load for Spatially Variable Properties, Section 1 - Tuff Best-Fit Static-Fatigue Curve

T-1. Simplified Steps for Projecting and Distributing Lithophysal Cavity Porosity Values in a Tunnel Into a Two-Dimensional Cross Section.

T-2. Geometric Relations of Strike and Dip and the Apparent Dips in Cross Sections Parallel and Perpendicular to the ECRB Cross-Drift.....................................................T-4

T-3. Variation in Lithophysal Cavity Porosity Along the ECRB Cross-Drift and the Geometric Relations of Calculation Components.

T-4. Lithophysal Cavity Porosity in the Lower Lithophysal Zone of the ECRB CrossDrift with the Centerline of the Simulated Cross Section at $1756 \mathrm{~m}$

T-5. Two $50 \times 200 \mathrm{~m}$ Simulated Cross Sections of Lithophysal Cavity Porosity at Stations $17+56$ and $20+14$

U-1. Portion of the Excel Spreadsheet With the NUFT Output

U-2. Example of ASCII File With Temperature Field for 50.8 Years After Waste Emplacement

U-3. Interpolation of UDEC Temperatures from the NUFT Grid ........................................ U-4

U-4. Comparison of Temperature Contours 50.8 Years after Waste Emplacement Obtained from the NUFT Results and the Data Transferred into UDEC

U-5. Comparison of Temperature Profiles Along the Horizontal Section Through the Center of the Drift 50.8 Years After Waste Emplacement Obtained from the NUFT Results and the Data Transferred into UDEC

V-1. Contours of Displacement Magnitudes (m): Case 4 of the Drift Degradation Analysis

V-2. Printout of Information for the Blocks with Average Displacement Larger than $0.12 \mathrm{~m}$ V-3

V-3. Outline of the Caved Rock Mass and Its Dimensions Used for Manual Integration $\mathrm{V}-3$

V-4. Quasi-static Drift Degradation, 0.2-m Block Size: Equilibrium State for Rigid Drip Shield with Arched Top, Bottom Fixed to the Invert. . . V-6

V-5. Quasi-static Drift Degradation, 0.2-m Block Size: Contours of Displacement (m) Magnitude for Rigid Drip Shield with Arched Top, Bottom Fixed to the Invert ........... V-6

V-6. Quasi-static Drift Degradation, $0.2 \mathrm{~m}$ Block Size: Equilibrium State for Deformable Drip Shield with Arched Top, Bottom Rests on the Invert $\mathrm{V}-7$

V-7. Quasi-static Drift Degradation, $0.2 \mathrm{~m}$ Block Size: Contours of Displacement (m) Magnitude for Deformable Drip Shield with Arched Top, Bottom Rests on the Invert

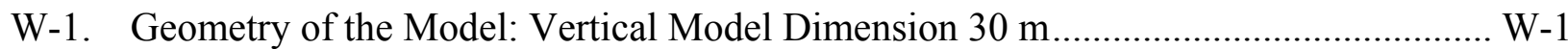

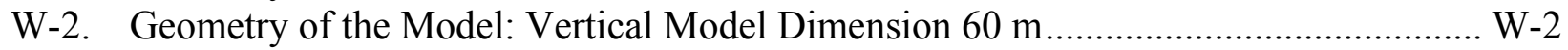

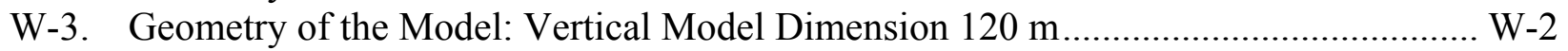

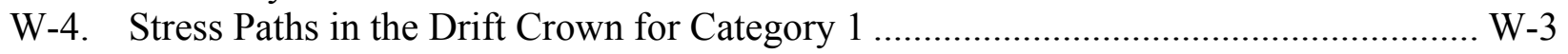




\section{FIGURES (Continued)}

W-5. Stress Paths in the Drift Wall for Category 1 $\mathrm{W}-4$

W-6. Stress Paths in the Drift Crown for Category 5 $\mathrm{W}-4$

W-7. Stress Paths in the Drift Wall for Category 5 W-5

Y-1. Geometry of the Drip Shield: Cross-Section …………………………………........... Y-3

Y-2. Geometry of the Drip Shield: Side View ………................................................... Y-3

Y-3. Geometry of the Drip Shield: Plane View ………………………........................... Y-4

Y-4. Section A-A through the Roof of the Drip Shield Indicated in Figure Y-1 ................... Y-5

Y-5. Horizontal Section Through the Wall of the Drip Shield …………………………....... Y-5

Y-6. Geometry of the Drip Shield as Idealized in the UDEC Model .................................... Y-6

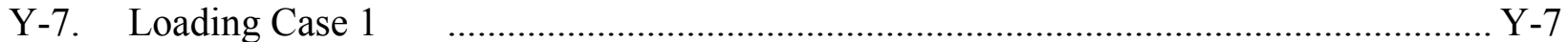

Y-8. Deformation (m) of the Drip Shield for Loading Case 1 …........................................ Y-8

Y-9. Original and Deformed Configuration of the Drip Shield for Loading Case 1 .............. Y-8

Y-10. History of Vertical Displacement (m) of a Point on the Drip Shield Where Vertical Concentrated Force is Applied for Loading Case 1 ....................................... Y-9

Y-11. Deformation of FLAC Structure Elements for Loading Case 1 ................................... Y-9

Y-12. History of Vertical Displacement (m) of a Point on the Drip Shield Where Vertical Concentrated Force is Applied for Loading Case 1 Calculated Using FLAC Structural Elements................................................................................. Y-10

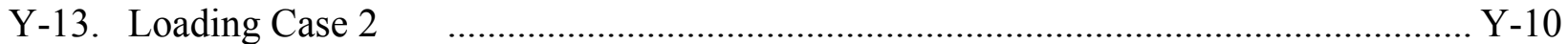

Y-14. Deformation (m) of the Drip Shield for Loading Case 2............................................ Y-11

Y-15. Original and Deformed Configuration of the Drip Shield for Loading Case 2 ............ Y-11

Y-16. History of Vertical Displacement (m) of a Point on the Drip Shield Where Vertical Concentrated Force is Applied for Loading Case 2 ....................................... Y-12

Y-17. Deformation of FLAC Structure Elements for Loading Case 2 ………….................. Y-12

Y-18. History of Vertical Displacement (m) of a Point on the Drip Shield Where Vertical Concentrated Force is Applied for Loading Case 2 Calculated Using FLAC Structural Elements.................................................................................... Y-13

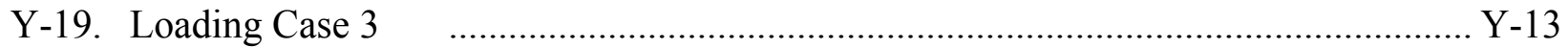

Y-20. Deformation (m) of the Drip Shield for Loading Case 3 ………............................... Y-14

Y-21. Original and Deformed Configuration of the Drip Shield for Loading Case 3 ............ Y-14

Y-22. History of Vertical Displacement (m) of a Point on the Drip Shield Where Vertical Concentrated Force is Applied for Loading Case 3 


\section{TABLES}

Page

3-1. List of Qualified Software Supporting the Drift Degradation Analysis .......................... 3-1

4-1. Input Data and Parameters for the Drift Degradation Analysis ..................................... 4-2

6-1. General Characteristics of Fracture Sets in the Middle Nonlithophysal Unit ............... 6-13

6-2. Comparison of Data from Underground Mapping and FracMan for the Tptpmn ......... 6-39

6-3. Base Case Material Properties for 3DEC Analysis.................................................... 6-61

6-4. Boundary Conditions for 3DEC Analysis.............................................................. 6-61

6-5. Peak Ground Motion Parameters ............................................................................. 6-64

6-6. Arias Intensity $(\mathrm{m} / \mathrm{sec})$ for Each Ground Motion Set .............................................. 6-68

6-7. Seismic Analysis Duration and Complete Time History Duration................................ 6-69

6-8. Combinations of Ground Motion and Fracture Modeling Region of 3DEC

Analyses

6-9. Summary of Joint Slip/Separation and Bridge Damage for $1 \times 10^{-5}$ Ground Motions

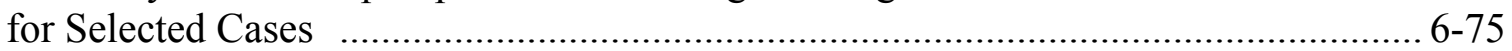

6-10. Summary of 3DEC Rockfall Prediction for $1 \times 10^{-5}$ Annual Probability of

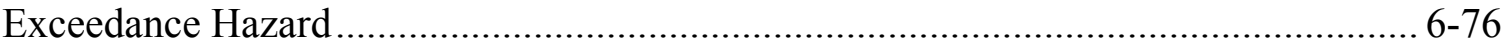

6-11. Statistic Summary of the Rockfall Impact Parameters, $1 \times 10^{-5}$ Annual Probability of

Exceedance Hazard .......................................................................................... 6-76

6-12. Summary of Joint Slip/Separation and Bridge Damage for $1 \times 10^{-6}$ Ground Motions for Selected Cases

6-13. Summary of 3DEC Rockfall Prediction for $1 \times 10^{-6}$ Annual Probability of

Exceedance Hazard.

6-14. Statistic Summary of the Rockfall Impact Parameters, $1 \times 10^{-6}$ Annual Probability of Exceedance Hazard....

6-15. Summary of Joint Slip/Separation and Bridge Damage for $1 \times 10^{-7}$ Ground Motions

for Selected Cases

6-16. Summary of 3DEC Rockfall Prediction for $1 \times 10^{-7}$ Annual Probability of

Exceedance Hazard.

6-17. Statistic Summary of the Rockfall Impact Parameters, $1 \times 10^{-7}$ Annual Probability of

Exceedance Hazard.

6-18. Summary of Joint Slip/Separation and Bridge Damage for $1 \times 10^{-4}$ Ground Motions for Selected Cases

6-19. Summary of 3DEC Rockfall Prediction for 1×10-4 Annual Probability of Exceedance Hazard

6-20. Statistical Summary of the Rockfall Impact Parameters, $1 \times 10^{-4}$ Annual Probability of Exceedance Hazard.

6-21. Rockfall in Nonlithophysal Rock Due to Heating, Base Case of Thermal Properties

6-22. Rockfall in Nonlithophysal Rock Due to Heating, Sensitivity Case of

Thermal Properties 


\section{TABLES (Continued)}

Page

6-23. Rockfall in Nonlithophysal Rock Due to $10^{-5}$ Ground Motion Combined with Thermal-Mechanical Effects, Base Case of Thermal Properties

6-24. Rockfall in Nonlithophysal Rock Due to $10^{-5}$ Ground Motion Combined with Thermal-Mechanical Effects, Sensitivity Case of Thermal Properties

6-25. Predicted Rockfall for Degraded Joints with Comparison to the Base Case Results 6-110

6-26. Comparison of Rockfall Statistics for Preclosure and Postclosure Events 6-112

6-27. Statistic Summary of the Block Size (metric ton) for Preclosure and Postclosure Events

6-28. Rockfall in Nonlithophysal Rock Due to $10^{-5}$ Ground Motion Combined with Thermal-Mechanical Effects, Base Case of Thermal Properties

6-29. Three Categories of Joint Properties Used in the Sensitivity Study 6-116

6-30. Sensitivity of Joint Properties for Rockfall Prediction 6-116

6-31. Three Categories of Rock Bridge Strength Parameters Used in the Sensitivity Study

6-32. Sensitivity of Rock Bridge Strength Parameters for Rockfall Prediction

6-33. Sensitivity of Rock Bridge Strength Parameters for Case 45 with $1 \times 10^{-6}$ and $1 \times 10^{-7}$ Ground Motions

6-34. Various Model Dimension for Sensitivity Study $6-126$

6-35. Predicted Rockfall for Various Model Dimensions $6-128$

6-36. Predicted Rockfall With and Without Block Deletion After Impact. $6-128$

6-37. Range of Fracture Traces in Panels $11+15$ and 13+00 6-138

6-38. Block Volume (in cubic meter) Corresponding to Various Levels of Predicted Cumulative Frequency of Occurrence.

6-39. Summary of Results for DRKBA Comparative Analysis. 6-141

6-40. Predicted Number of Rockfall and Volume for the Presented Drift Profile $6-150$

6-41. Categories of the Lithophysal Rock Mass Selected for Analysis 6-152

6-42. Calibrated Properties of the Bonded Fractures and Intact Blocks in the Model with $0.2 \mathrm{~m}$ Block Size.

6-43. Calibrated Properties of the Bonded Fractures and Intact Blocks in the Model with $0.3 \mathrm{~m}$ Block Size

6-44. Simulated Combinations of $10^{-6}$ Ground Motions and Rock Mass Categories.

6-45. Summary of $10^{-5}$ Ground Motion Characteristics

6-46. Thermal Conductivity of Rubble 6-214

6-47. Summary of Pressures on the Drip Shield Calculated from the Continuum Model .... 6-224

6-48. Effect of Seismic Shaking on Load of Caved Rock on the Rigid, Rectangular Drip Shield

6-49. Summary of 3DEC Rockfall Prediction for Lithophysal Units $6-234$

6-50. Included FEPs Addressed by This Model Report.

6-51. Excluded FEPs Addressed by This Model Report.

6-52. Alternative Conceptual Models Considered

6-53. Repository Design and Thermal-Mechanical Effects KTI Agreement Items Addressed in This Model Report 


\section{TABLES (Continued)}

7-1. Code-to-Code Comparison Problems

$7-71$

7-2. Programs and Modeling Participants in the Benchmark Study

7-3. Estimated Lithophysal Rock Mass Properties as Estimated from UDEC Triaxial Test Simulations

7-4. Properties of the Limestone Rock Mass and Aluminum Liner.

8-1. Mapping of Yucca Mountain Review Plan Acceptance Criteria and Drift Degradation Analysis.....

A-1. List of Drift Degradation Calculation Files .................................................................. A-3

B-1. Summary Statistics of the Tptpll Detailed Line Survey Data..........................................

B-2. Relative Proportions of Fractures from the Detailed Line Survey Versus FracMan Output for the Tptpll ..................................................................................................

C-1. Spatial Location of the Tectonic Faults Considered in the Analysis C-5

C-2. Spatial Location of the Stratigraphic Units Contracts Considered in the Calculation

C-3. Mechanical Properties Considered for the Rock Mass in the Regional and Local Scale Calculations

C-4. Thermal Properties Considered for the Rock Mass in the Regional and Local Scale Calculations

D-1. Joint Set Orientation Data and Concentration Factors................................................. D-4

D-2. Beta Distribution Parameters for Tptpmn Unit...................................................... D-4

D-3. Reduced Joint Strength Parameters to Account for Seismic Effect................................ D-6

D-4. Block Volume Corresponding to Various Levels of Predicted Cumulative Frequency of Occurrence, $75^{\circ}$-Azimuth Emplacement Drift in Tptpmn Unit, with Seismic Consideration

D-5. Predicted Number of Key Blocks per Unit Length (km) Along $75^{\circ}$-Azimuth

Emplacement Drift, with Seismic Consideration

D-6. Calculation of the a, b, p, and q Parameters for Joint Spacing, Radii, and Positioning

D-7. Calculation of the Components for the Orientation Matrix ……………………....... D-16

D-8. Calculation of the Concentration Factor k for Joint Orientation ............................... D-18

D-9. Probability of $\mathrm{R}>\mathrm{M} \times \mathrm{T}$ for Various Multipliers ........................................................ D-2

D-10. Structure of Spreadsheet Files for Key-Block Size Distribution ................................. D-24

E-1. Density Data for Various Thermal Mechanical Units and Associated Lithostratigraphic Units

E-2. Density Data from the Tptpln Unit ……………......................................................

E-3. Data from Shear Stress Experiments on Natural Fractures from the Nonlithophysal Units of the Repository Horizon 


\section{TABLES (Continued)}

E-4. Normal and Shear Stiffness Data from Shear Stress Experiments on Natural Fractures from the Nonlithophysal Units of the Repository Horizon...............................E-6

E-5. Summary Statistics of Direct Joint Shear Test Results.....................................................

E-6. Elastic Properties Data from the Nonlithophysal Units of the Repository Horizon

E-7. Tensile Strength Data from the TSw2 Thermal Mechanical Unit .................................E-10

E-8. Uniaxial and Triaxial Test Data from the Tptpmn Lithostratigraphic Unit..................... E-14

E-9. Mechanical Properties of Lithophysal Tuff from Large-Diameter Samples ..................E-22

E-10. Suggested Range of Mechanical Properties Developed from 11.5-in. Core Testing, Selected for Base-Case Design and Performance Analyses

E-11. Base Case and Lower Bound Strength Values for Rock Categories Used in UDEC Analyses of Spatial Variability

E-12. Impact of Moisture Conditions on Uniaxial Compressive Strength of Nonlithophysal Tptpll Samples

E-13. Q System Rock Mass Classification Data from the Heated Drift..................................-47

E-14. Intact Compressive Strength Data for the Tptpmn Unit ................................................

E-15. Calculated Rock Mass Properties for the Heated Drift..................................................

E-16. Rock Mass Poisson's Ratio and Modulus of Deformation Values for Thermal Mechanical Units

E-17. Size-Effect Laboratory Compression Test Data for Nonlithophysal Rock E-52

E-18. Thermal Conductivity for Various Thermal Mechanical Units and Associated Lithostratigraphic Units

E-19. Specific Heat for Various Thermal Mechanical Units and Associated Lithostratigraphic Units

E-20. Thermal Expansion for Various Thermal Mechanical Units ...........................................

F-1. Number of Key Blocks Observed in the ECRB Cross-Drift ...........................................F-1

J-1. Listing of Fracture Model Region Centroid Coordinates ......................................................

K-1. Summary Statistics of Block Size (metric ton) for $1 \times 10^{-4}$ Preclosure Ground Motion $\mathrm{K}-1$

K-2. Summary Statistics of Impact Velocity $(\mathrm{m} / \mathrm{sec})$ for $1 \times 10^{-4}$ Preclosure Ground Motion $\mathrm{K}-1$

K-3. Summary Statistics of Impact Energy (J) for $1 \times 10^{-4}$ Preclosure Ground Motion ............. K-1

K-4. Summary Statistics of Block Size (metric ton) for $1 \times 10^{-5}$ Ground Motion ..................... K-4

K-5. Summary Statistics of Impact Velocity $(\mathrm{m} / \mathrm{sec})$ for $1 \times 10^{-5}$ Ground Motion.................... K-4

K-6. Summary Statistics of Impact Energy (J) for $1 \times 10^{-5}$ Preclosure Ground Motion ........... K-4

K-7. Summary Statistics of Block Size (metric ton) for $1 \times 10^{-6}$ Ground Motion ...................... K-7

K-8. Summary Statistics of Impact Velocity $(\mathrm{m} / \mathrm{sec})$ for $1 \times 10^{-6}$ Ground Motion.................... K-7

K-9. Summary Statistics of Impact Energy (J) for $1 \times 10^{-6}$ Ground Motion............................ K-7

K-10. Summary Statistics of Block Size (metric ton) for $1 \times 10^{-7}$ Ground Motion ................... K-10

K-11. Summary Statistics of Impact Velocity $(\mathrm{m} / \mathrm{sec})$ for $1 \times 10^{-7}$ Ground Motion................. K-10 


\section{TABLES (Continued)}

K-12. Summary Statistics of Impact Energy (J) for $1 \times 10^{-7}$ Ground Motion.......................... K-10

M-1. Overburden Load at the Depth of the In Situ Test.............................................................

O-1. Methods Used to Document the Distribution of Lithostratigraphic Features in the Lower Lithophysal Zone of the Topopah Spring Tuff in the ECRB Cross-Drift........... O-1

O-2. Summary of Traverse Lengths and Abundance (Percentage) of Lithophysal Cavities, Rims, Spots, Lithic Clasts and Matrix-Groundmass Based on Angular Traverses from Stations $14+60$ to $22+00$ in the ECRB Cross-Drift

O-3. Summary of Abundance (Percentage) of Lithophysal Cavities, Rims, Spots, and Matrix-Groundmass Based on Panel Maps in the ECRB CROSS-DRIFT from Stations $14+93$ to $22+94$

O-4. Descriptive Statistics for the Abundance of Lithophysal Cavities in Individual Tape Traverses for Various Lengths of Tunnel in the Tptpll in the Cross-Drift

O-5. Descriptive Statistics for the Abundance of Individual Lithophysal Cavities in Individual Tape Traverses for Various Lengths of Tunnel in the Tptpll in the Cross-Drift

O-6. Descriptive Statistics for the Lengths ( $\mathrm{mm}$ ) of Individual Lithophysal Cavities in Individual Tape Traverses for Various Lengths of Tunnel in the Tptpll zone in the Cross-Drift

O-7. Descriptive Statistics for the Abundance of Lithophysal Cavities in Tape Traverses Calculated with $10 \mathrm{~m}, 15 \mathrm{~m}, 20 \mathrm{~m}, 25 \mathrm{~m}$, and $30 \mathrm{~m}$ "moving averages" for the Total Tptpll in the ECRB Cross-Drift

O-8. Descriptive Statistics for the Abundance of "Rims Plus Spots" in Individual Tape Traverses for Various Lengths of Tunnel in the Tptpll of the ECRB Cross-Drift ....... O-25

O-9. Descriptive Statistics for Abundance of Lithophysal Cavities, Rims, and Spots in Panel Maps, Angular Traverses, and Corrected Tape Traverses in the Tptpll Exposed in the ECRB Cross-Drift from Stations $14+60$ to $23+20$ and $14+60$ to $22+00$

O-10. Descriptive Statistics for Porosity of Lithophysal Cavities, Rims, and Spots in Panel Maps, Angular Traverses and Corrected Tape Traverses in the Tptpll Exposed in the ECRB Cross-Drift from Stations 14+60 to 23+20 (without Large Lithophysae)

O-11. Descriptive Statistics for Porosity of Lithophysal Cavities, Rims, and Spots in Panel Maps, Angular Traverses and Corrected Tape Traverses and the Large Lithophysae Inventory in the Tptpll Exposed in the ECRB Cross-Drift from Stations $14+60$ to $23+20$

O-12. Descriptive Statistics for "Median" and "Maximum" Abundance (Percent) of Lithophysal Cavities and Spots in the Tptpll Exposed in the ECRB Cross-Drift from Stations $14+44$ to $23+26$ O-36

O-13. Mean Porosity of Lithophysal Cavities, Large-Lithophysal Cavities, Rims, Spots, Matrix-groundmass, and Total Porosity in the Tptpll Exposed in the ECRB Cross-Drift from Stations $14+60$ to $23+20$ Using Three Methods 


\section{TABLES (Continued)}

O-14. Comparative Values from the Original Position of the Panel Map and Four Alternative-Position Maps

P-1. Ground motion 10-5, Case 11: Average Loads On the Drip Shield For Cases Without the Invert P-4

P-2. Ground Motion $10^{-5}$, Case 11: Average Loads On the Drip Shield for Cases With Invert

P-3. Quasi-Static Drift Degradation, 0.3 m Block Size: Average Loads On the Drip Shield For Cases Without the Invert

P-4 Quasi-Static Drift Degradation, $0.3 \mathrm{~m}$ Block Size: Average Loads On the Drip Shield For Cases With Invert

P-5. Quasi-Static Drift Degradation, 0.2 m Block Size: Average Loads On the Drip Shield For Cases Without the Invert

P-6. Quasi-Static Drift Degradation, 0.2 m Block Size: Average Loads On the Drip Shield For Cases With Invert.....

P-7. Four Different $10^{-6}$ Ground Motions: Average Loads On the Drip Shield.....................P-24

P-8. Four Different $10^{-7}$ Ground Motions: Average Loads On the Drip Shield......................

P-9. Quasi-Static Drift Degradation, $0.2 \mathrm{~m}$ Block Size, Multiple Realizations of Voronoi Block Geometry: Average Loads On the Drip Shield

P-10. Effect of Seismic Shaking After Quasi-Static Collapse: Average Loads On the Drip Shield

Q-1. Preclosure Ventilation Heat Removal Ratio at $600 \mathrm{~m}$ from Inlet................................... Q-2

Q-2. Maximum Increase of Thermal Stress during the Postclosure ....................................... Q-3

Q-3. Specific Heat Considered for the Rock Mass in the Regional and Local Scale Thermal-Mechanical Calculations (Appendix C) ....................................................... Q-8

R-1. Considered Scenarios for Drift Profile and Degraded Rock Mass Characteristics .........R-3

S-1. Static-Fatigue Data for Busted Butte Specimens ........................................................ S-3

S-2. PFC2D Material for Lithophysal Tuff (Microproperties and Void Geometry) ................ S-7

S-3. PFC Resolutions for Lithophysal Tuff Specimens .................................................. S-9

S-4. PFC2D Material for Lithophysal Tuff (Short- and Long-Term Microproperties and Void Geometry)

S-5. PFC2D Resolutions for Current Lithophysal Tuff Specimens ................................... S-10

T-1. Windows Containing Unique Variations of Lithophysal Cavity Porosity Values ..........T-6

T-2. Display of Part of the $50 \times 200$ Cell Table with Descriptive Statistics for Calculation of Lithophysal Cavity Porosity in a 50×200 m Simulated Cross Section with the Centerline Station $17+56$ T-8

T-3. Display of Part of the $20 \times 80$ Cell Table with Descriptive Statistics for Calculation of Lithophysal Cavity Porosity in a $50 \times 200 \mathrm{~m}$ Simulated Cross Section with the Centerline at Station $17+56$ 


\section{TABLES (Continued)}

Page

T-4. Comparison of Descriptive Statistics for the Total Tptpll Zone in the ECRB Cross-Drift, Individual Windows from the Input Data, and Selective Statistics for $5 \mathrm{~m}$ Tall Horizons in a $50 \times 200 \mathrm{~m}$ Simulated Cross Section with $1 \times 1 \mathrm{~m}$ and $2.5 \times 2.5 \mathrm{~m}$ Grids

T-5. Comparison of Descriptive Statistics for the Total Windows from ECRB Cross-Drift (Input) Data and the Total 50×200 m Simulated Cross Section with $1 \times 1 \mathrm{~m}$ and $2.5 \times 2.5 \mathrm{~m}$ Grids

V-1. Quasi-static Drift Degradation, $0.2 \mathrm{~m}$ Block Size: Average Loads on the Drip Shield for Cases with Invert. V-8

X-1. Peak Ground Velocity $(\mathrm{cm} / \mathrm{sec})$ for Preclosure Ground Motions ..................................... X-1

X-2. Peak Ground Velocity $(\mathrm{cm} / \mathrm{sec})$ for $1 \times 10^{-5}$ Ground Motions......................................... X-2

X-3. Peak Ground Velocity $(\mathrm{cm} / \mathrm{sec})$ for $1 \times 10^{-6}$ Ground Motions (Revised Set) ................... X-2

X-4. Peak Ground Velocity $(\mathrm{cm} / \mathrm{sec})$ for $1 \times 10^{-6}$ Ground Motions (Original Set)................... X-3

X-5. Peak Ground Velocity $(\mathrm{cm} / \mathrm{sec})$ for $1 \times 10^{-7}$ Ground Motions....................................... X-3

X-6. Arias Intensity $(\mathrm{m} / \mathrm{sec})$ for Preclosure Ground Motions …………............................... X-4

X-7. Arias Intensity $(\mathrm{m} / \mathrm{sec})$ for $1 \times 10^{-5}$ Ground Motions................................................... X-4

X-8. Arias Intensity $(\mathrm{m} / \mathrm{sec})$ for $1 \times 10^{-6}$ Ground Motions (Revised Set) ............................. X-4

$\mathrm{X}-9$. Arias Intensity $(\mathrm{m} / \mathrm{sec})$ for $1 \times 10^{-6}$ Ground Motions (Original Set) .............................. X-5

$\mathrm{X}-10$. Arias Intensity $(\mathrm{m} / \mathrm{sec})$ for $1 \times 10^{-7}$ Ground Motions................................................ X-5

$\mathrm{X}-11$. Power Spectral Density $\left(\mathrm{m}^{2} / \mathrm{sec}\right)$ for Preclosure Ground Motions................................. X-6

$\mathrm{X}-12$. Power Spectral Density $\left(\mathrm{m}^{2} / \mathrm{sec}\right)$ for $1 \times 10^{-5}$ Ground Motions ..................................... X-6

$\mathrm{X}-13$. Power Spectral Density $\left(\mathrm{m}^{2} / \mathrm{sec}\right)$ for $1 \times 10^{-6}$ Ground Motions (Revised Set) .................. X-6

$\mathrm{X}-14$. Power Spectral Density $\left(\mathrm{m}^{2} / \mathrm{sec}\right)$ for $1 \times 10^{-6}$ Ground Motions (Original Set) .................. X-7

$\mathrm{X}-15$. Power Spectral Density $\left(\mathrm{m}^{2} / \mathrm{sec}\right)$ for $1 \times 10^{-7}$ Ground Motions ...................................... X-7

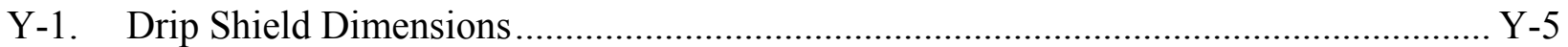

Y-2. Geometrical Characteristic of Cross-Sections ....................................................... Y-5 


\section{INTENTIONALLY LEFT BLANK}




\section{ACRONYMS}

\section{ACRONYMS AND ABBREVIATIONS}

\begin{tabular}{|c|c|}
\hline $\mathrm{BSC}$ & Bechtel SAIC Company, LLC \\
\hline DOE & U.S. Department of Energy \\
\hline DRKBA & Discrete Region Key Block Analysis \\
\hline DTN & data tracking number \\
\hline EBS & engineered barrier system \\
\hline ECRB & Enhanced Characterization of the Repository Block \\
\hline ESF & Exploratory Studies Facility \\
\hline FEPs & features, events, and processes \\
\hline GSI & geological strength index \\
\hline $\mathrm{ICN}$ & Interim Change Notice \\
\hline KTI & key technical issue \\
\hline $\mathrm{LdB}$ & Lac du Bonnet granite \\
\hline LDTH & line-averaged heat source, drift scale, thermohydrologic \\
\hline $\mathrm{NRC}$ & U.S. Nuclear Regulatory Commission \\
\hline $\begin{array}{l}\text { PFC } \\
\text { PGV }\end{array}$ & $\begin{array}{l}\text { Particle Flow Code } \\
\text { peak ground velocity }\end{array}$ \\
\hline RMR & rock mass rating \\
\hline RQD & rock quality designation \\
\hline TSPA-LA & Total System Performance Assessment for the License Application \\
\hline UCS & unconfined compressive strength \\
\hline YMP & Yucca Mountain Project \\
\hline
\end{tabular}

\section{ABBREVIATIONS}

CHn1 Calico Hills and Lower Paintbrush non-welded

CHn2 Calico Hills and Lower Paintbrush non-welded

TCw Tiva Canyon welded

Tptpll Topopah Spring Tuff crystal poor lower lithophysal

Tptpln Topopah Spring Tuff crystal poor lower nonlithophysal

Tptpmn Topopah Spring Tuff crystal poor middle nonlithophysal 


\section{ACRONYMS AND ABBREVIATIONS (Continued)}

Tptpul Topopah Spring Tuff crystal poor upper lithophysal

TSw1 Topopah Spring welded, lithophysal-rich

TSw2 Topopah Spring welded, lithophysal-poor

TSw3 Topopah Spring welded, vitrophyre 


\section{PURPOSE}

The purpose of this report is to document the scientific analysis and modeling of the behavior of the rock mass surrounding the emplacement drifts of the geologic repository at Yucca Mountain. Drift degradation has the potential to affect drip shield integrity, waste package integrity, and thermal-hydrologic environments within drifts. The results of this modeling and analysis activity provide:

- Data on rockfall (size distribution, velocity, impact energy and impact location) in response to the combined effects of in situ, thermal and seismic loading to support structural analyses of the ground support system, the drip shield, and waste package.

- Transient change in drift profile (size and shape) due to combined in situ, thermal and seismic loading and due to nominal time-dependent change in rock mechanical properties, which supports analyses of groundwater seepage into the emplacement drift during the period of compliance for postclosure performance.

- Quasi-static load distribution to the drip shield from accumulated rubble for structural analysis of drip shield stability.

- Support for the assessment of in-drift temperature and humidity resulting from the presence of rubble within the emplacement drift.

Figure 1-1 is a schematic that depicts the required inputs supporting the drift degradation analysis along with the primary users of the results of this study. In addition to acquired data from field mapping (i.e., fracture geometry) and laboratory testing (i.e., rock strength properties), the following analysis and modeling reports provide developed data inputs for this report:

- Geologic Framework Model (GFM2000) (BSC 2004 [DIRS 170029])

- Development of Earthquake Ground Motion Input for Preclosure Seismic Design and Postclosure Performance Assessment of a Geologic Repository at Yucca Mountain, NV (BSC 2004 [DIRS 170027])

- Multiscale Thermohydrologic Model (BSC 2004 [DIRS 169565])

- Thermal Conductivity of the Potential Repository Horizon (BSC 2004 [DIRS 169854])

- Thermal Conductivity of Non-Repository Lithostratigraphic Layers (BSC 2004 [DIRS 170033])

- Heat Capacity and Thermal Expansion Coefficients Analysis Report (BSC 2003 [DIRS 164670])

- Sampling of Stochastic Input Parameters for Rockfall Calculations and for Structural Response Calculations Under Vibratory Ground Motion (BSC 2004 [DIRS 169999]). 
The outputs from the drift degradation analysis support scientific analyses, models, and design calculations, including the following:

- Abstraction of Drift Seepage

- Seismic Consequence Abstraction

- Structural Stability of a Drip Shield Under Quasi-Static Pressure

- Drip Shield Structural Response to Rock Fall.

This report has been developed in accordance with Technical Work Plan for: Regulatory Integration Modeling of Drift Degradation, Waste Package and Drip Shield Vibratory Motion and Seismic Consequences (BSC 2004 [DIRS 171520]). The drift degradation analysis includes the development and validation of rockfall models that approximate phenomenon associated with various components of rock mass behavior anticipated within the repository horizon. Two drift degradation rockfall models have been developed: the rockfall model for nonlithophysal rock and the rockfall model for lithophysal rock. These models reflect the two distinct types of tuffaceous rock at Yucca Mountain. The output of this modeling and analysis activity documents the expected drift deterioration for drifts constructed in accordance with the repository layout configuration (BSC 2004 [DIRS 164519]).

\subsection{BACKGROUND}

Information on the Geologic Setting and Repository Subsurface Design-The repository site at Yucca Mountain is located approximately $300 \mathrm{~m}$ below ground surface within the Topopah Spring formation - a densely welded, laterally-expansive tuff unit comprised of a number of subunits that dip gently from west to east (BSC 2004 [DIRS 170029], Section 6.5.1.4). These subunits can be divided into two broad physical and mechanical categories: nonlithophysal and lithophysal ${ }^{1}$ welded tuffs. The basic matrix material of these two subunits is similar in most respects (mineralogical, textural, mechanical properties). However, due to varying cooling histories and as a result of position within the flow, they are, structurally (and therefore thermomechanically), significantly different in character. The nonlithophysal rocks (the middle and lower nonlithophysal units) are hard, strong, fine-grained and fractured volcanic rocks whose mechanical behavior is strongly controlled by the geometry and surface characteristics of its fracturing. The lithophysal rocks (the upper and lower lithophysal units) are composed of the same strong, hard matrix material, but have porosity in the form of lithophysal cavities ranging from about 10 percent to 30 percent by volume. The presence of these cavities results in significantly different mechanical behavior (i.e., in the deformability and strength) of the rock mass.

${ }^{1}$ Lithophysae-A hollow, bubble like cavity in a volcanic rock that is surrounded by a porous rim formed by fine-grained alkali feldspar, quartz, and other minerals. Lithophysae are typically a few centimeters to a few decimeters in diameter; however, they can be as small as $1 \mathrm{~mm}$ in diameter or less to as large as $1 \mathrm{~m}$ or more in diameter (BSC 2003 [DIRS 166660]). 


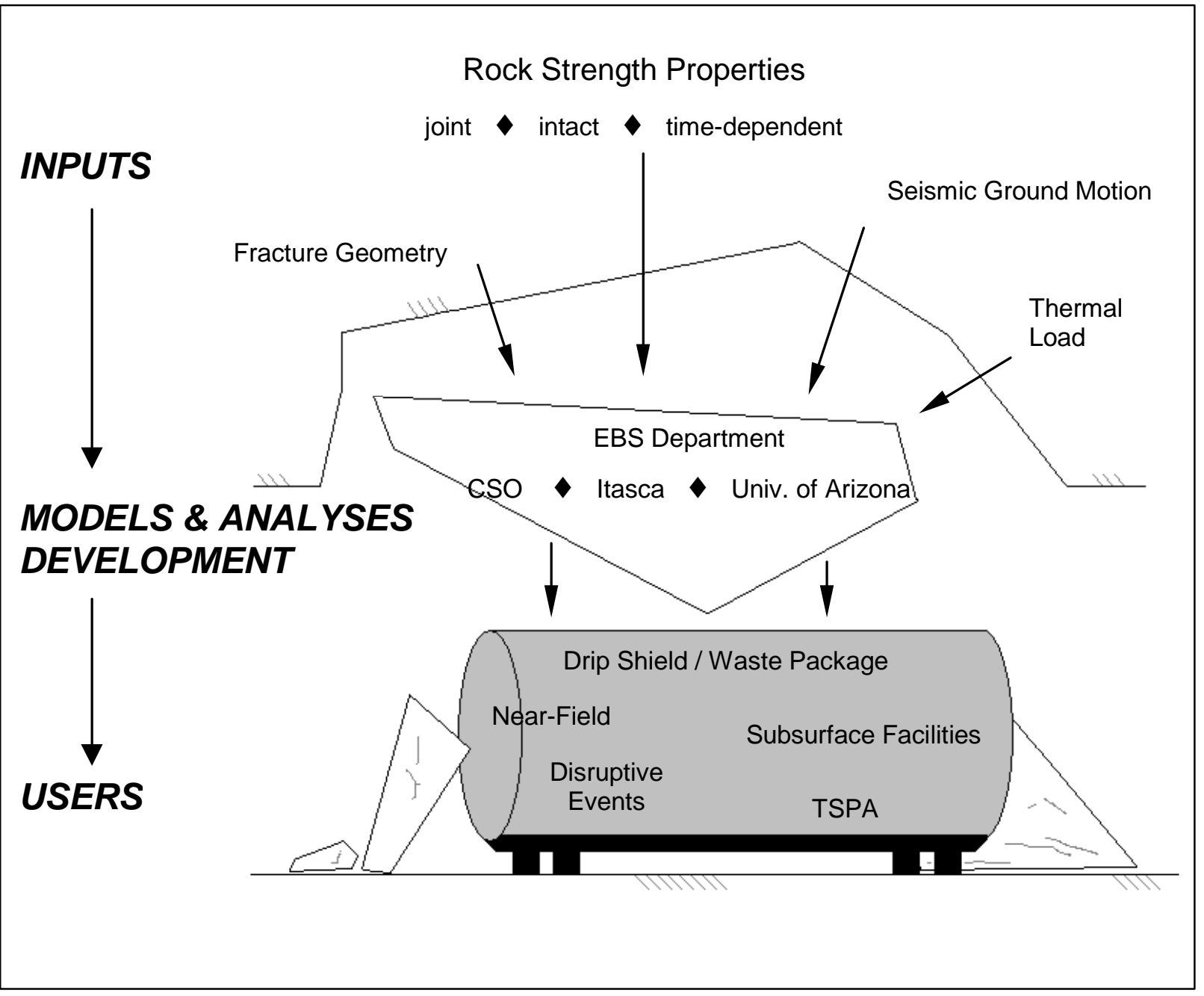

Figure 1-1. Drift Degradation Analysis

The proposed repository layout and the Topopah Spring Tuff subunits within which the excavations are located are shown in Figure 1-2. The repository consists of a series of emplacement panels that are accessed via ramps and access mains from the ground surface. The emplacement drifts are circular in the cross-section with a diameter of $5.5 \mathrm{~m}$ (BSC 2003 [DIRS 165572], Table 8), and driven at 81-m spacing (Williams 2002 [DIRS 159916]). This layout results in approximately 85 percent of the emplacement area to be within the lithophysal rocks, and about 15 percent within the nonlithophysal units (BSC 2003 [DIRS 165572], Table II-2).

Waste packages will be delivered to the emplacement drift from the surface facilities on steel pallets. The waste package assembly will be placed, using remote handling equipment, on a steel framework and crushed tuff drift invert at a nominal $10 \mathrm{~cm}$ end-to-end spacing. The nominal waste package heat output and spacing result in a maximum thermal loading density of $1.45 \mathrm{~kW} / \mathrm{m}$ of drift length (BSC 2004 [DIRS 167369]). The waste packages will be ventilated for a minimum of 50 years using forced ventilation air at a nominal delivery rate of $15 \mathrm{~m}^{3} / \mathrm{sec}$ per emplacement drift (BSC 2004 [DIRS 169862], Section 4.1.10). This ventilation air removes 
approximately 80 to 90 percent of the heat generated by the waste packages along the typical 600-m nominal emplacement drift length (BSC 2004 [DIRS 169862], Section 6.6, Figure 6-7) during the ventilation period, with resulting drift wall temperatures being approximately $80^{\circ} \mathrm{C}$ (BSC 2004 [DIRS 169862], Section 6.6, Figure 6-5). Closure of the repository is considered to occur within 100 years after emplacement of the first waste package. Closure involves placing drip shields in a continuous covering over the waste packages, backfilling of the access drifts, and cessation of forced ventilation. Drift wall temperatures will rapidly rise, reaching a maximum at approximately $160^{\circ} \mathrm{C}$ about 20 years after closure, followed by a slow decay over time. The drift wall temperature will remain above $100^{\circ} \mathrm{C}$ for approximately 1,000 years (see Section 6.2, Figure 6-25).

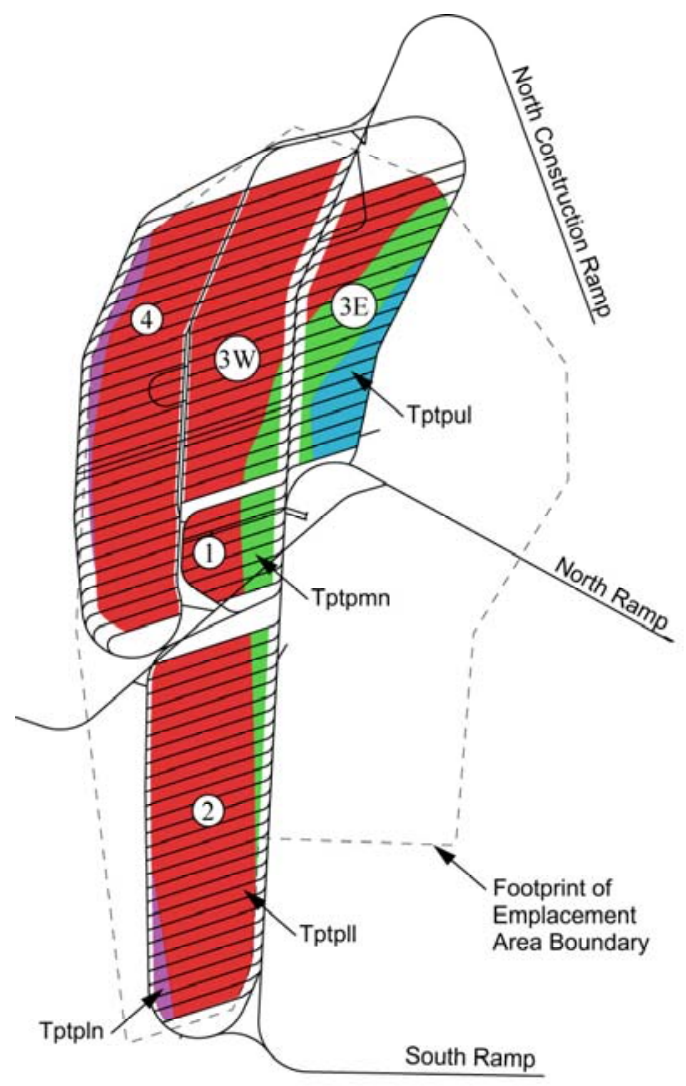

00387DC_003a.ai

Source: Underground Layout Configuration (BSC 2003 [DIRS 165572], Figure II-2).

NOTE: Numbered labels refer to emplacement panel numbers (BSC 2003 [DIRS 165572], Section 8.1).

Figure 1-2. Proposed Repository Layout in Plan View Showing Intersections of Geologic Sub-units With Emplacement Drifts

Preclosure and Postclosure Periods and Objectives of Mechanical Degradation AnalysesGround support will be functional and maintained during the preclosure period. After closure, the ground support will corrode and lose its function over the period of perhaps tens to hundreds of additional years. Thus, the emplacement drifts will essentially be unsupported through a greater part of the postclosure period. 
During the postclosure period, the emplacement drifts will be subjected to the following loading conditions (Figure 1-3):

- In situ gravitational stress state

- Transient thermally induced stresses due to expansion of the rock mass ${ }^{2}$

- Seismic stresses due to potential earthquake shaking.

In addition, the rock mass strength, particularly in lithophysal rock, will exhibit a degree of time-dependency as a result of typical stress corrosion mechanisms ${ }^{3}$. The impact of these in situ and induced stress components is the potential for rock mass yield in the immediate region around the tunnels and some degree of rockfall. The rockfall has potential performance impacts on the following systems:

- Mechanical degradation effects on engineered barriers

- Effects include possible rock particle impacts and dynamic loading of the drip shield, either under gravitational or earthquake-induced accelerations. The dynamic loading from rock impact derived from this document provides input to Drip Shield Structural Response to Rock Fall, which is a calculation providing a structural damage assessment due to rockfall impacts.

- Quasi-static loading and contact from rock particles resting on the drip shield following rockfall. The quasi-static loading from rubble derived from a degraded emplacement drift presented in this document provides input to Structural Stability of a Drip Shield Under Quasi-Static Pressure, which is a calculation providing a structural stability assessment of the drip shield under rubble loading.

- Mechanical degradation effects on in-drift environment

- Rockfall of sufficient volume could result in an "insulating" blanket surrounding the drip shield (and waste package), impairing heat transfer to the rock mass, and increasing waste package temperatures. The importance of this effect on heat transfer is dependent on the timing of the rockfall. For example, if significant amounts of rockfall occur relatively early in the postclosure period when the waste package is still outputting significant heat energy, then there will be a greater impact on waste package temperature. Conversely, if significant rockfall occurs in later periods of the postclosure period when the waste package has lost most of its energy, then there will be a less significant impact on temperature distributions. Additionally, rock particles within the drift can potentially alter the in-drift humidity environment and, therefore, need to be accounted for in drip shield and waste package corrosion. The impact of a complete collapse of an emplacement drift at various times in the postclosure period

\footnotetext{
${ }^{2}$ A large portion of the thermally induced strains and stress are recoverable as the rock mass cools over time.

3 "Stress Corrosion" is a term used for time-dependent, sub-critical crack growth that occurs when existing material flaws in the rock are subjected to stresses that are near the failure state of the material. This process, which occurs at a more rapid rate in the presence of moisture, may result in damage and yield at applied stresses that are less than the short-term strength. Corrosion here does not refer to corrosion of metals.
} 
on in-drift temperature and humidity is analyzed in Multiscale Thermohydrologic Model (BSC 2004 [DIRS 169565]).

- Mechanical degradation effects on seepage of groundwater into the drift

- Drift degradation could result in temporal changes to the size and shape of the emplacement drifts, as well as impact to the capillary flow barrier provided by the drift itself. These effects could alter the seepage flow to the drift. Impacts of seepage are accounted for in the seismic scenario class and are described in Seismic Consequence Abstraction and in Abstraction of Drift Seepage.

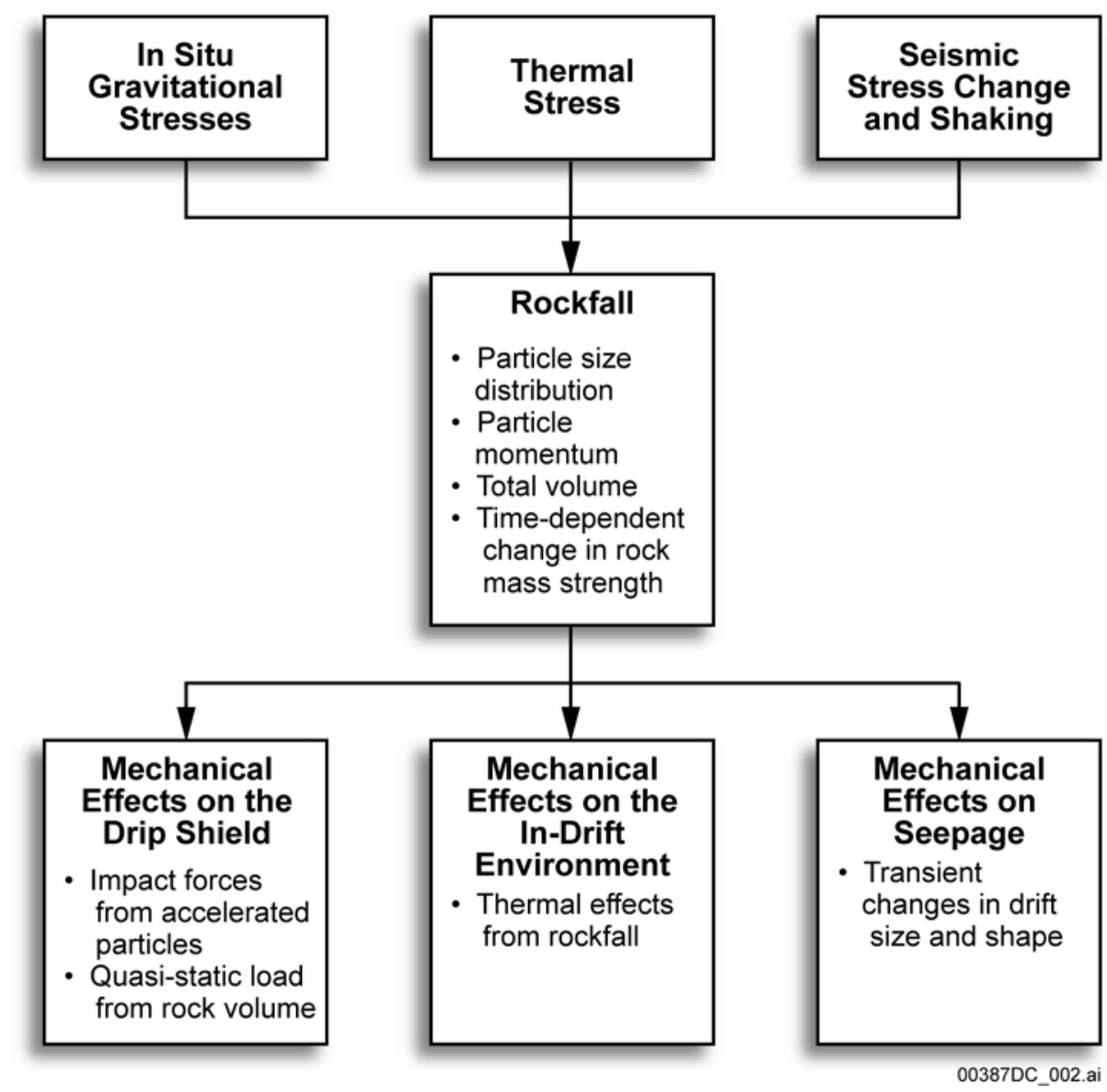

Figure 1-3. Potential Postclosure Performance Impacts of Rockfall on Engineered Barriers, In-Drift Environment, and Groundwater Seepage into Drifts

The primary objectives of the drift degradation analyses discussed in this analysis and model report are to provide postclosure estimates of the temporal development of both rockfall and drift dimension changes, which are input to the seismic consequences and drift seepage abstractions for eventual inclusion into the total system performance assessment (TSPA) modeling.

Summary of Approach to Addressing Mechanical Degradation Issues-The approach to addressing the mechanical degradation issues described above was presented in Resolution 
Strategy for Geomechanically-Related Repository Design and Thermal-Mechanical Effects (RDTME) (Board 2003 [DIRS 165036]). A basic factor in the approach described in that report is that the repository host rock mass may be subdivided into two general thermomechanical units: lithophysal and nonlithophysal rocks, as was described previously. This subdivision is made as the mechanical properties and behavior of these units are distinctly different, and, thus, the response requires different testing and modeling strategies. In the case of the nonlithophysal subunit, the rock mass response is largely controlled by the fracturing; whereas, in the lithophysal rock, the mechanical response is highly dependent on the lithophysal porosity and its variability. It is recognized that, due to the impact of the geologic structure on the rock mass performance, detailed geotechnical characterization is required as a basic building block in formulating the rock mass properties, applicable modeling techniques, and analysis procedures.

The approach (Figure 1-4), which forms the basis of the analyses presented in this report, involves the progressive development of a knowledge of the mechanical behavior of lithophysal and nonlithophysal rock through:

- Detailed geotechnical characterization of the rock structure, laboratory, and field testing and estimation of rock mass properties

- Development and validation of numerical modeling tools for estimation of mechanical degradation processes

- Performance analyses of mechanical degradation in response to in situ, thermal, and seismic loading.

This report presents data and analyses in these three broad areas:

- Geological characterization of the lithophysal and nonlithophysal rock mass and development of rock mass properties and their variability

- Description and analysis of the variability of rock mass fracturing and lithophysae characteristics obtained from field mapping in the ESF and Enhanced Characterization of the Repository Block (ECRB) Cross-Drift (Sections 6.1 and Appendix B describe fracture characteristics, and Sections 7.3 and Appendix O describe lithophysal characteristics)

- Laboratory and in situ testing database of thermal-mechanical and time-dependent material properties for the intact rock matrix, lithophysal rock, and fractures (Section 4 and Appendix E describe the rock properties database)

- Estimation of the effect of geologic structure (fractures and lithophysae) and its variability on rock mass properties (Section 7.3 and Appendix E) 


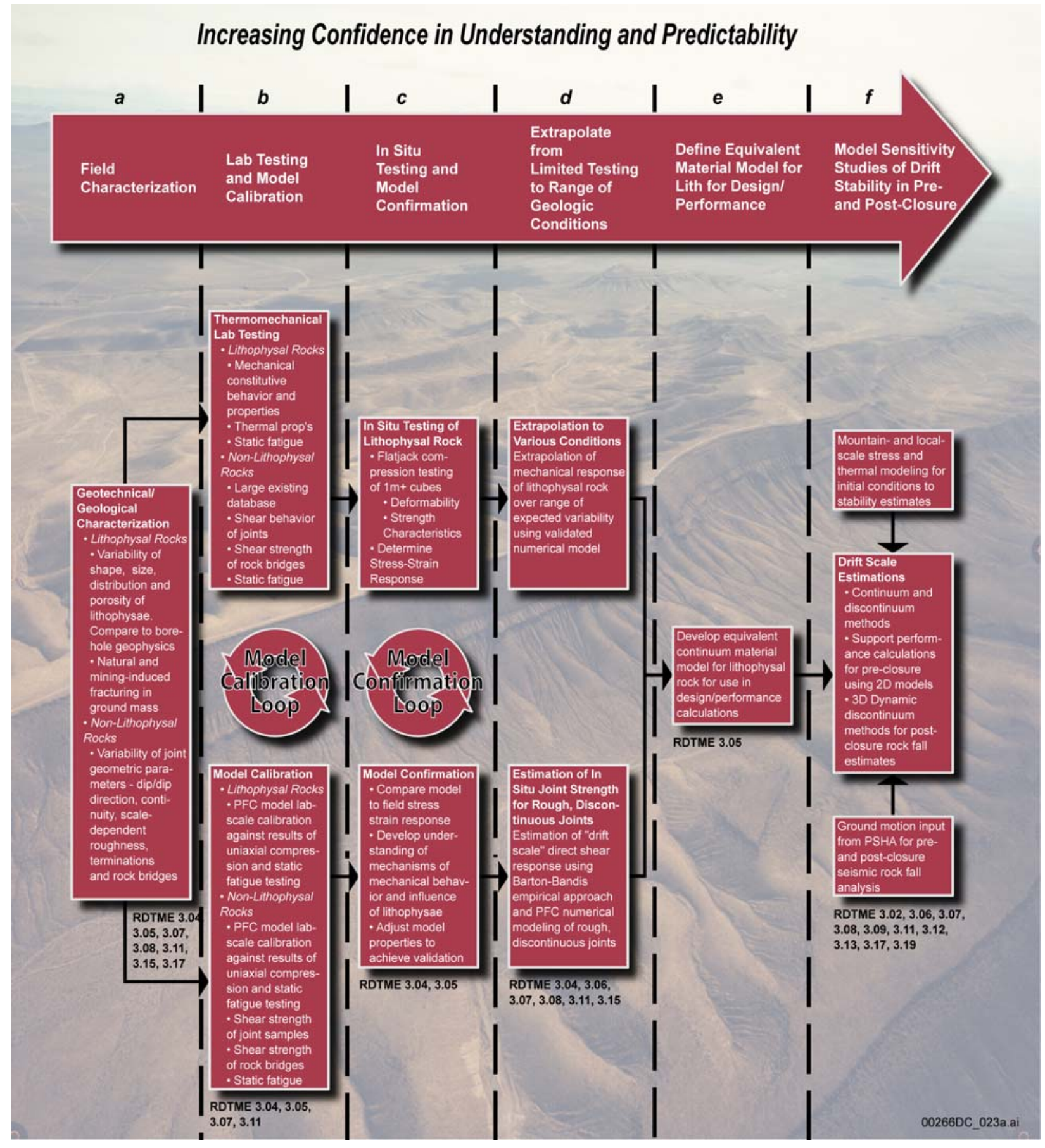

NOTE: Process starts with compilation and analysis of basic geotechnical mapping, followed by laboratory and field testing and model validation to develop rock mass property estimates for design and performance sensitivity studies.

Figure 1-4. General Approach to Resolution of the Repository Design and Thermal-Mechanical Effects KTIS 
- Development and validation of numerical modeling tools

- Determination or development of appropriate models for sensitivity studies of excavation stability and rockfall under gravitational, thermal, and seismic loading as well as time-dependent strength changes (Sections 6.3, 6.4, 7, and Appendices S, T, $\mathrm{U}, \mathrm{W}$, and Y). Specific issues related to selection of appropriate modeling techniques addressed in these sections of the report include:

-- Continuum versus discontinuum modeling

-- Two versus three-dimensional models

-- Appropriate initial and boundary conditions

-- Inclusion of time-dependency in the models

- Mechanical degradation performance analyses and feeds of model output to engineered barrier system and drift seepage abstractions to the TSPA model

- Stability analysis and rockfall estimates for nonlithophysal and lithophysal subunits under the action of in situ, thermal, and seismic loading (Section 6)

- Assessment of long-term stability and rockfall in tunnels subject to time-dependent rock mass strength degradation and in situ, thermal, and seismic loading (Appendix S).

\subsection{OBJECTIVES}

The specific objectives of the drift degradation analysis are to:

- Provide validated modeling methods that adequately represent:

- The mechanical response of the rock mass structure (fractures and lithophysae) surrounding the emplacement drift

- The applied in situ, thermal, and seismic loading conditions and time-dependent rock strength degradation mechanisms.

- Provide a statistical description of block sizes and rockfall volume resulting from stress-induced rockfall around the emplacement drifts for the lithologic units of the repository host horizon.

- Provide dynamic and static load distributions to the drip shield resulting from rockfall and rubble accumulation in the emplacement drifts

- Estimate transient changes in emplacement drift profiles resulting from in situ, thermal, and seismic stressing and time-dependent rock strength degradation. 


\subsection{SCOPE OF MODEL DOCUMENTATION}

Activities documented in this report involve developing models, using analytical methods, and performing calculations and statistical analyses to determine the expected quantities, locations, size distributions, and frequencies of rockfall, based on the repository layout configuration (BSC 2004 [DIRS 164519]). Drift profiles, including the predicted deterioration as a result of rockfall, have been determined. This analysis has examined unsupported drifts with no backfill, and applied static, thermal, and seismic loading conditions.

The scope of model documentation required for analyzing the degradation anticipated in the repository emplacement drifts includes the following activities:

- Conduct a thermal-mechanical assessment of the repository block at Yucca Mountain to determine thermal stress inputs to the drift degradation models.

- Conduct a fracture degradation assessment to account for long-term strength degradation. This assessment provides strength degradation inputs to the drift degradation models.

- Develop a drift degradation structural model for nonlithophysal rock that includes thermal and seismic loading.

- Develop a drift degradation lithophysal model that includes thermal and seismic loading.

Revision 1 ICN 1 of this analysis (BSC 2001 [DIRS 156304]) considered various emplacement drift orientations, with the drift azimuth varied in appropriate increments to examine the effect of orientation on key block size and frequency. The results from this drift orientation study have not been included in this revision, and only the current emplacement drift orientation (BSC 2004 [DIRS 164519]) has been considered in this report.

\subsection{ANALYSIS/MODEL APPLICABILITY AND LIMITATIONS}

The drift degradation results with seismic and thermal consideration, including the drift profiles, are applicable for 5.5-m-diameter emplacement drifts oriented at an azimuth of $72^{\circ}$ in accordance with the repository underground layout configuration (BSC 2004 [DIRS 164519]; BSC 2004 [DIRS 168489]; BSC 2003 [DIRS 165572]). The model results presented in this report are applicable to the lithophysal and nonlithophysal rock units of the repository host horizon. Uncertainties associated with the data available for model development are described in Section 6.5. The rockfall models presented in this report are valid for conditions anticipated within the repository over the 10,000-year regulatory period for both preclosure and postclosure performance, including increased loads due to seismic ground motion and thermal stress, and decreased rock strength due to time-dependent strength degradation. 


\section{QUALITY ASSURANCE}

This analysis and modeling report and the supporting modeling activities are subject to the Office of Civilian Radioactive Waste Management quality assurance program, as indicated in Technical Work Plan for: Regulatory Integration Modeling of Drift Degradation, Waste Package and Drip Shield Vibratory Motion and Seismic Consequences (BSC 2004 [DIRS 171520], Section 8). Approved QA procedures identified in the technical work plan (BSC 2004 [DIRS 171520], Section 4) have been used to conduct and document the activities described in this analysis and model report. The technical work plan also identifies the methods used to control the electronic management of data (BSC 2004 [DIRS 171520], Section 8) during modeling and documentation activities.

To ensure accuracy and completeness of the information generated by this report, access to the information on the personal computer used to develop this report is controlled with password protection. The personal computer files are stored on a network drive that is backed up daily per Yucca Mountain Project (YMP) standards. Upon completion of this work, the files are transferred to a suitable media, appropriately labeled, and verified by examining the file listing. Visual checks are conducted on printouts. The electronic files generated by this report are transmitted to Document Control for transfer to the Records Processing Center. During the checking process, accuracy and completeness of the data retrieved and reported in this document is verified against the information placed in the Records Processing Center and YMP information databases, as applicable.

This model report examines the properties of natural or engineered barriers that are classified in the Q-List (BSC 2004 [DIRS 168361]) as "Safety Category" because they are important to waste isolation, as defined in AP-2.22Q, Classification Analyses and Maintenance of the Q-List. It contributes to the analysis and modeling data used to support performance assessment. The conclusions of this model report do not affect the proposed repository design or engineered features important to safety, as defined in AP-2.22Q. 


\section{INTENTIONALLY LEFT BLANK}




\section{USE OF SOFTWARE}

\subsection{QUALIFIED COMPUTER SOFTWARE}

All controlled and baselined software used in the development of the drift degradation analysis is identified in Table 3-1, including the software tracking number, version, operating environment, and range of use. Table 3-1 also includes a discussion of why the software was selected and describes any limitations on outputs from the software. The software documented in this section is appropriate for the applications used in this drift degradation analysis, and is consistent with its intended use. Each software item was obtained from Software Configuration Management in accordance with LP-SI.11Q-BSC. All software was used only within the range of its validation as specified in the software qualification documentation, in accordance with LP-SI.11Q-BSC. The input and output files for each software item used in this analysis have been submitted to the Technical Data Management System as noted in Appendix A.

Table 3-1. List of Qualified Software Supporting the Drift Degradation Analysis

\begin{tabular}{|c|c|c|c|}
\hline $\begin{array}{c}\text { Software } \\
\text { Title/Version }\end{array}$ & $\begin{array}{l}\text { Software } \\
\text { Tracking } \\
\text { Number }\end{array}$ & $\begin{array}{c}\text { Operating Environment } \\
\text { (Platform/Operating } \\
\text { System) }\end{array}$ & $\begin{array}{c}\text { Brief Description of Software } \\
\text { (Range of Use/Selection/Limitations) }\end{array}$ \\
\hline $\begin{array}{l}\text { UDEC V3.1 } \\
\text { (BSC } 2002 \\
\text { [DIRS 161949]) }\end{array}$ & 10173-3.1-00 & PC/Windows 2000 & $\begin{array}{l}\text { UDEC was used to analyze the seismic and } \\
\text { thermal effects on block movement in the } \\
\text { lithophysal rock units (Section 6.4). UDEC was } \\
\text { selected for its capability of modeling block slip } \\
\text { and block separation in plane strain condition. } \\
\text { Also, it is capable of thermal and dynamic } \\
\text { simulation. There are no known limitations on } \\
\text { outputs. }\end{array}$ \\
\hline $\begin{array}{l}\text { 3DEC V2.01 } \\
\text { (BSC } 2002 \\
\text { [DIRS 161930]) }\end{array}$ & $10025-2.01-00$ & PC/Windows 2000 & $\begin{array}{l}\text { 3DEC was used to analyze the seismic and } \\
\text { thermal effects on block movement in the } \\
\text { nonlithophysal rock units (Section 6.3). 3DEC } \\
\text { was selected for its capability of modeling of } \\
\text { wedge type of rockfall with consideration of } \\
\text { block slip and block separation in three- } \\
\text { dimensional space. Also, it is capable of } \\
\text { thermal and dynamic simulation. There are no } \\
\text { known limitations on outputs. }\end{array}$ \\
\hline $\begin{array}{l}\text { FLAC V4.0 } \\
\text { (BSC } 2002 \\
\text { [DIRS 161953]) }\end{array}$ & $10167-4.0-00$ & PC/Windows 2000 & $\begin{array}{l}\text { FLAC was used in the thermal-mechanical } \\
\text { calculation to define the distribution of stresses } \\
\text { around the drifts due to the progressive } \\
\text { heating of the repository area (Section } 6.2 \text { ). } \\
\text { FLAC was selected as an efficient code to run } \\
\text { thermal-mechanical analysis. There are no } \\
\text { known limitations on outputs. }\end{array}$ \\
\hline $\begin{array}{l}\text { FLAC3D V2.1 } \\
\text { (BSC } 2002 \\
\text { [DIRS 161947]) }\end{array}$ & $10502-2.1-00$ & PC/Windows 2000 & $\begin{array}{l}\text { FLAC3D was used in the thermal-mechanical } \\
\text { calculation to define the distribution of stresses } \\
\text { around the drifts due to the progressive } \\
\text { heating of the repository area (Appendix C). } \\
\text { FLAC3D was selected as an efficient code to } \\
\text { run thermal-mechanical analysis for the } \\
\text { regional scale and drift scale. There are no } \\
\text { known limitations on outputs. }\end{array}$ \\
\hline
\end{tabular}


Table 3-1. List of Qualified Software Supporting the Drift Degradation Analysis (Continued)

\begin{tabular}{|c|c|c|c|}
\hline $\begin{array}{c}\text { Software } \\
\text { Title/Version }\end{array}$ & $\begin{array}{l}\text { Software } \\
\text { Tracking } \\
\text { Number }\end{array}$ & $\begin{array}{c}\text { Operating Environment } \\
\text { (Platform/Operating } \\
\text { System) }\end{array}$ & $\begin{array}{c}\text { Brief Description of Software } \\
\text { (Range of Use/Selection/Limitations) }\end{array}$ \\
\hline $\begin{array}{l}\text { PFC2D V2.0 } \\
\text { (BSC } 2002 \\
\text { [DIRS 161950]) }\end{array}$ & $10828-2.0-00$ & PC/Windows 2000 & $\begin{array}{l}\text { PFC2D was used to characterize rock mass } \\
\text { behavior, including the analysis of long-term } \\
\text { strength degradation (Section } 7 \text { and } \\
\text { Appendix S). PFC2D was selected for its } \\
\text { capability of modeling behaviors of a rock } \\
\text { material by combining behaviors of individual } \\
\text { grain particles to simulate complicated non- } \\
\text { linear deformation of a rock material including } \\
\text { long-term mechanical strength degradation } \\
\text { and rock mass deformation with voids. There } \\
\text { are no known limitations on outputs from } \\
\text { PFC2D. }\end{array}$ \\
\hline $\begin{array}{l}\text { PFC2D V2.0 } \\
\text { (BSC 2004 } \\
\text { [DIRS 169930]) }\end{array}$ & 10828-2.0-01 & PC/Windows 2000 & $\begin{array}{l}\text { This version of PFC2D was used to run impact } \\
\text { analyses to confirm the initial PFC2D results } \\
\text { (using software tracking number } \\
\text { 10828-2.0-00), as documented in Appendix Q. } \\
\text { The initial PFC2D software qualification did not } \\
\text { specifically identify the library of support } \\
\text { functions (known as Fish functions) that are } \\
\text { used within the code. This new version } \\
\text { (software tracking number 10828-2.0-01) } \\
\text { specifically qualifies FishTank 041b, which is } \\
\text { the library of Fish functions included within the } \\
\text { code. The impact assessments in Appendix Q } \\
\text { confirm that the results are identical using } \\
\text { either the initial or new version of PFC2D. }\end{array}$ \\
\hline $\begin{array}{l}\text { PFC3D V2.0 } \\
\text { (BSC 2002 } \\
\text { [DIRS 160612]) }\end{array}$ & $10830-2.0-00$ & PC/Windows 2000 & $\begin{array}{l}\text { PFC3D was used to characterize rock mass } \\
\text { behavior, including the analysis of long-term } \\
\text { strength degradation (Section } 7 \text { and } \\
\text { Appendix S). PFC3D was selected for its } \\
\text { capability of modeling behaviors of a rock } \\
\text { material by combining behaviors of individual } \\
\text { grain particles to simulate complicated non- } \\
\text { linear deformation of a rock material including } \\
\text { long-term mechanical strength degradation } \\
\text { and rock mass deformation with voids. There } \\
\text { are no known limitations on outputs from } \\
\text { PFC3D. }\end{array}$ \\
\hline $\begin{array}{l}\text { PFC3D V2.0 } \\
\text { (BSC 2004 } \\
\text { [DIRS 169931]) }\end{array}$ & $10830-2.0-01$ & PC/Windows 2000 & $\begin{array}{l}\text { This version of PFC3D was used to run impact } \\
\text { analyses to confirm the initial PFC3D results } \\
\text { (using software tracking number } \\
\text { 10830-2.0-00), as documented in Appendix Q. } \\
\text { The initial PFC3D software qualification did not } \\
\text { specifically identify the library of support } \\
\text { functions (known as Fish functions) that are } \\
\text { used within the code. This new version } \\
\text { (software tracking number 10830-2.0-01) } \\
\text { specifically qualifies FishTank 041b, which is } \\
\text { the library of Fish functions included within the } \\
\text { code. The impact assessments in Appendix Q } \\
\text { confirm that the results are identical using } \\
\text { either the initial or new version of PFC3D. }\end{array}$ \\
\hline
\end{tabular}


Table 3-1. List of Qualified Software Supporting the Drift Degradation Analysis (Continued)

\begin{tabular}{|c|c|c|c|}
\hline $\begin{array}{c}\text { Software } \\
\text { Title/Version }\end{array}$ & $\begin{array}{l}\text { Software } \\
\text { Tracking } \\
\text { Number }\end{array}$ & $\begin{array}{c}\text { Operating Environment } \\
\text { (Platform/Operating } \\
\text { System) }\end{array}$ & $\begin{array}{c}\text { Brief Description of Software } \\
\text { (Range of Use/Selection/Limitations) }\end{array}$ \\
\hline $\begin{array}{l}\text { DRKBA Version } \\
3.31 \text { (BSC 2002 } \\
\text { [DIRS 161946]) }\end{array}$ & $10071-3.31-00$ & PC/Windows 2000 & $\begin{array}{l}\text { DRKBA was used to analyze block } \\
\text { development and failure in the nonlithophysal } \\
\text { rock units (Appendix D). DRKBA was selected } \\
\text { to assess the impact of small-scale fractures } \\
\text { on rockfall because it has an efficient } \\
\text { key-block simulation algorithm. DRKBA was } \\
\text { also selected as an alternative numerical code } \\
\text { to verify the results from 3DEC. DRKBA does } \\
\text { not directly apply seismic and thermal loads, } \\
\text { and therefore was not selected as the primary } \\
\text { code for rockfall analyses. }\end{array}$ \\
\hline $\begin{array}{l}\text { FracMan V2.512 } \\
\text { (USGS } 1999 \\
\text { [DIRS 160577]) }\end{array}$ & $\begin{array}{l}10114-2.511- \\
00\end{array}$ & PC/Windows NT & $\begin{array}{l}\text { FracMan was used to replicate the fracture } \\
\text { geometry observed in the ESF to develop a } \\
\text { representative volume of jointed rock mass } \\
\text { (Section 6.1.6). FracMan was selected for its } \\
\text { capability of discrete fracture data analysis, } \\
\text { geologic fracture network construction, spatial } \\
\text { analysis, and visualization. There are no } \\
\text { known limitations on outputs. }\end{array}$ \\
\hline $\begin{array}{l}\text { NUFT V3.0s } \\
\text { (LLNL } 2002 \\
\text { [DIRS 157280]) }\end{array}$ & 10088-3.0s-01 & SUN/SUN O.S. 5.7 & $\begin{array}{l}\text { NUFT was used to simulate heat transfer } \\
\text { around the emplacement drift (Section 6.2). } \\
\text { NUFT was selected for its capability of } \\
\text { modeling thermal-hydrology of an unsaturated } \\
\text { zone including subsurface heat and fluid flow. } \\
\text { There are no known limitations on outputs } \\
\text { from NUFT. }\end{array}$ \\
\hline $\begin{array}{l}\text { EarthVision V.5.1 } \\
\text { (Dynamic } \\
\text { Graphics 2000 } \\
\text { [DIRS 167994]) }\end{array}$ & $10174-5.1-00$ & SGI/IRIX 6.5 & $\begin{array}{l}\text { EarthVision was used to extract stratigraphic } \\
\text { unit thickness and cross-sections from the } \\
\text { Geological Framework Model (GFM2000) } \\
\text { (Appendix M). EarthVision was selected for its } \\
\text { capability of extracting specific data from } \\
\text { GFM2000 and presenting the data in a } \\
\text { common graphical format. EarthVision was } \\
\text { not used to perform data manipulation in this } \\
\text { report. There are no known limitations on } \\
\text { outputs based on the range of use in this } \\
\text { report. }\end{array}$ \\
\hline $\begin{array}{l}\text { UNWEDGE V2.3 } \\
\text { (CRWMS M\&O } \\
1998 \\
\text { [DIRS 145366]) }\end{array}$ & 30053 V2.3 & PC/DOS Emulation & $\begin{array}{l}\text { UNWEDGE was used as a reference-only } \\
\text { example of a deterministic method for } \\
\text { key-block analysis (Appendix D). UNWEDGE } \\
\text { was selected for its common usage on static } \\
\text { block analysis for the geotechnical and mining } \\
\text { industries. There are no known limitations on } \\
\text { outputs. }\end{array}$ \\
\hline $\begin{array}{l}\text { Clustran V.1.1 } \\
\text { (BSC 2004 } \\
\text { [DIRS 169203]) }\end{array}$ & $11162-1.1-00$ & PC/Windows 2000 & $\begin{array}{l}\text { Clustran was used to analyze fracture data in } \\
\text { Section 6.1.6. Clustran was selected for its } \\
\text { common usage on fracture orientation analysis } \\
\text { for the geotechnical and mining industries. } \\
\text { There are no known limitations on outputs. }\end{array}$ \\
\hline
\end{tabular}


Table 3-1. List of Qualified Software Supporting the Drift Degradation Analysis (Continued)

\begin{tabular}{|c|c|c|c|}
\hline $\begin{array}{c}\text { Software } \\
\text { Title/Version }\end{array}$ & $\begin{array}{l}\text { Software } \\
\text { Tracking } \\
\text { Number }\end{array}$ & $\begin{array}{c}\text { Operating Environment } \\
\text { (Platform/Operating } \\
\text { System) }\end{array}$ & $\begin{array}{c}\text { Brief Description of Software } \\
\text { (Range of Use/Selection/Limitations) }\end{array}$ \\
\hline $\begin{array}{l}\text { Read DXF V.1.0 } \\
\text { (BSC 2004 } \\
\text { [DIRS 169204]) }\end{array}$ & $11159-1.0-00$ & PC/Windows 2000 & $\begin{array}{l}\text { Read DXF was used to read fracture data files } \\
\text { in DXF format and extract polyline data with } \\
\text { associated strike/dip tags for input into } \\
\text { FracMan (Section 6.1.6). Read DXF was } \\
\text { specifically developed to extract fracture data } \\
\text { from full periphery geologic maps to facilitate } \\
\text { the comparison of field fracture data to } \\
\text { synthetic FracMan fracture data. There are no } \\
\text { known limitations on outputs. }\end{array}$ \\
\hline
\end{tabular}

\subsection{OTHER SOFTWARE}

In addition to the above listed items, the standard functions of commercial off-the-shelf software, including both Microsoft Excel 97 SR-2 and Mathcad 2001i Professional, were used. These software items were used to perform support calculation activities as described in Section 6.3, Section 6.4, and associated Appendices. Appendix A provides a listing of the calculation files (Table A-1), including the location in this report where specific details of the calculation can be found. Microsoft Excel was used to calculate joint cohesion degradation, excavation orientation inputs, joint description input, and mean rock property values. Additionally, Microsoft Excel was used to process and summarize rockfall data and to provide graphical presentation of the block size distribution data. Mathcad was used to calculate joint cohesion degradation, joint description input parameters, and rock property values. Microsoft Excel 97 SR-2 and Mathcad 2001i Professional are exempted software applications in accordance with LP-SI.11Q-BSC, Section 2.1.

Appendices D, E, I, J, K, L, O, and T have been provided with this report to document the use of standard functions of commercial off-the-shelf software in sufficient detail to allow independent repetition of the software in accordance with AP-SIII.10Q, Attachment 2. Specifically, these Appendices provide:

- The formula or algorithm used

- A listing of the inputs to the formula or algorithm

- A listing of the outputs from the formula or algorithm

- Narrative to describe the calculation(s).

These Appendices document the following calculations:

- Calculation of joint parameter inputs to DRKBA (Appendix D)

- Calculation of joint cohesion reduction for thermal and time-dependent effects in DRKBA analyses (Appendix D)

- Calculation of the plane equations to describe the excavation opening as input to DRKBA (Appendix D) 
- Calculation of rock property values (Appendix E)

- Random selection of 3DEC modeling region (Appendix J)

- Study of the sufficiency of the number of 3DEC simulations to represent the rockfall characteristics (Appendix K)

- Conversion of FracMan fracture output to 3DEC input (Appendix L)

- Calculation of descriptive statistics of lithophysal abundance and characteristics (Appendix O)

- Projection of lithophysal cavity porosity to a vertical cross section (Appendix T)

- Calculation of Power Spectral Density and summary of ground motion parameters (Appendix X)

DIPS Version 4.03 (CRWMS M\&O 1997 [DIRS 149839]) was used solely for graphical presentation of fracture data in Sections 6.1, 6.3, and Appendix B, and is an exempted software application in accordance with LP-SI.11Q-BSC, Section 2.1. 


\section{INTENTIONALLY LEFT BLANK}




\section{INPUTS}

\subsection{DIRECT INPUT}

The geotechnical parameters used as direct input for drift degradation analyses include data and information collected either by field mapping or by laboratory testing. Input data include

- Joint geometry

- Joint mechanical properties

- Intact rock physical and mechanical properties

- Rock mass mechanical properties

- Seismic ground motion

- Rock thermal properties

- Repository layout information.

These data and parameters are summarized in Table 4-1 and described below. Uncertainties in input data and parameters are discussed in Section 6.5.

\subsubsection{Fracture Geometry Data}

The development of fracture geometry parameters is based on mapping data collected from the ESF, including the main loop (which is composed of the North Ramp, Main Drift, South Ramp) and the ECRB Cross-Drift. Qualified joint mapping data in the ESF were collected from the following lithologic units: the Topopah Spring Tuff crystal poor upper lithophysal zone (Tptpul), the Topopah Spring Tuff crystal poor middle nonlithophysal zone (Tptpmn), the Topopah Spring Tuff crystal poor lower lithophysal zone (Tptpll), and the Topopah Spring Tuff crystal poor lower nonlithophysal zone (Tptpln).

Mapping data from the ESF being used in the analysis include both U.S. Geological Survey/U.S. Bureau of Reclamation full periphery geologic maps and the detailed line survey. Source data tracking numbers (DTNs) for the full periphery geologic maps and the detailed line survey data are listed in Table 4-1. 


\begin{tabular}{|c|c|c|c|c|c|}
\hline \multicolumn{2}{|r|}{ Parameter } & Value & Range & Source/Supporting Information ${ }^{a}$ & Application \\
\hline \multirow[t]{2}{*}{$\begin{array}{l}\text { Fracture } \\
\text { geometry }\end{array}$} & $\begin{array}{l}\text { Fracture type - from detailed } \\
\text { line survey } \\
\text { (Location, Strike, Dip, Length) }\end{array}$ & $\begin{array}{l}\text { See files Tptpmn } \\
\text { DLS pole plot.xls } \\
\text { and Tptpll cu\# \& } \\
\text { rad dist plots.xls in } \\
\text { FracMan Inputs \& } \\
\text { Outputs (Appendix } \\
\text { A) } \\
\text { Data summary } \\
\text { provided by } \\
\text { Table 6-2 } \\
\text { (Tptpmn); } \\
\text { Appendix B, } \\
\text { Table B-1 (Tptpll) }\end{array}$ & $\begin{array}{l}\text { See files Tptpmn } \\
\text { DLS pole plot.xls } \\
\text { and Tptpll cu\# \& } \\
\text { rad dist plots.xls in } \\
\text { FracMan Inputs \& } \\
\text { Outputs (Appendix } \\
\text { A) } \\
\text { Data summary } \\
\text { provided by } \\
\text { Table 6-2 } \\
\text { (Tptpmn); } \\
\text { Appendix B, } \\
\text { Table B-1 (Tptpll) }\end{array}$ & $\begin{array}{l}\text { GS971108314224.025 DIRS 106025] } \\
\text { GS960708314224.008 DIRS 105617] } \\
\text { GS000608314224.004 [DIRS 152573] } \\
\text { GS960708314224.010 [DIRS 106031] } \\
\text { GS960908314224.014 [DIRS 106033] } \\
\text { GS970208314224.003 [DIRS 106048] } \\
\text { GS970808314224.010 [DIRS 106050] } \\
\text { GS971108314224.028 [DIRS 106047] } \\
\text { GS990408314224.001 [DIRS 108396] } \\
\text { GS990408314224.002 [DIRS 105625] }\end{array}$ & $\begin{array}{l}\text { Rockfall Model for } \\
\text { Nonlithophysal Rock } \\
\text { (Sections 6.1.6, } \\
\text { 6.3.1.2.2, } \\
\text { Appendix D) }\end{array}$ \\
\hline & $\begin{array}{l}\text { Fracture type - from full } \\
\text { periphery geologic map }\end{array}$ & $\begin{array}{l}\text { Full periphery } \\
\text { geologic maps } \\
\text { provided by the } \\
\text { source DTNs } \\
\text { Data summary } \\
\text { provided by } \\
\text { Table 6-2 } \\
\text { (Tptpmn); } \\
\text { Appendix B, } \\
\text { Table B-1 (Tptpll) }\end{array}$ & $\begin{array}{l}\text { Full periphery } \\
\text { geologic maps } \\
\text { provided by the } \\
\text { source DTNs } \\
\text { Data summary } \\
\text { provided by } \\
\text { Table 6-2 } \\
\text { (Tptpmn); } \\
\text { Appendix B, } \\
\text { Table B-1 (Tptpll) }\end{array}$ & $\begin{array}{l}\text { GS960908314224.020 [DIRS 106059] } \\
\text { GS000608314224.006 [DIRS 152572] } \\
\text { GS960908314224.015 [DIRS 108372] } \\
\text { GS960908314224.016 [DIRS 107373] } \\
\text { GS960908314224.017 [DIRS 108376] } \\
\text { GS970108314224.002 [DIRS 107490] } \\
\text { GS990408314224.004 [DIRS 108405] } \\
\text { GS990408314224.005 [DIRS 108408] } \\
\text { GS990408314224.006 [DIRS 108409] }\end{array}$ & $\begin{array}{l}\text { Rockfall Model for } \\
\text { Lithophysal Rock } \\
\text { (Section 6.4.3, } \\
\text { Appendix B) }\end{array}$ \\
\hline $\begin{array}{l}\text { Small-scale } \\
\text { fracture } \\
\text { geometry }\end{array}$ & $\begin{array}{l}\text { Fracture type - from detailed } \\
\text { line survey } \\
\text { (Location, Strike, Dip, Length) }\end{array}$ & $\begin{array}{l}\text { See Appendix A, } \\
\text { calculation file, } \\
\text { small trace } \\
\text { filtering.xls } \\
\text { Data summary } \\
\text { provided by } \\
\text { Table 6-37 and } \\
\text { Figure 6-105 }\end{array}$ & $\begin{array}{l}\text { See Appendix A, } \\
\text { calculation file, } \\
\text { small trace } \\
\text { filtering.xls } \\
\text { Data summary } \\
\text { provided by } \\
\text { Table 6-37 and } \\
\text { Figure 6-105 }\end{array}$ & GS040108314224.001 [DIRS 169591] & $\begin{array}{l}\text { Rockfall Model for } \\
\text { Nonlithophysal Rock } \\
\text { (Sections 6.1.4.1, } \\
6.3 .3 \text { ) }\end{array}$ \\
\hline
\end{tabular}


Table 4-1. Input Data and Parameters for the Drift Degradation Analysis (Continued)

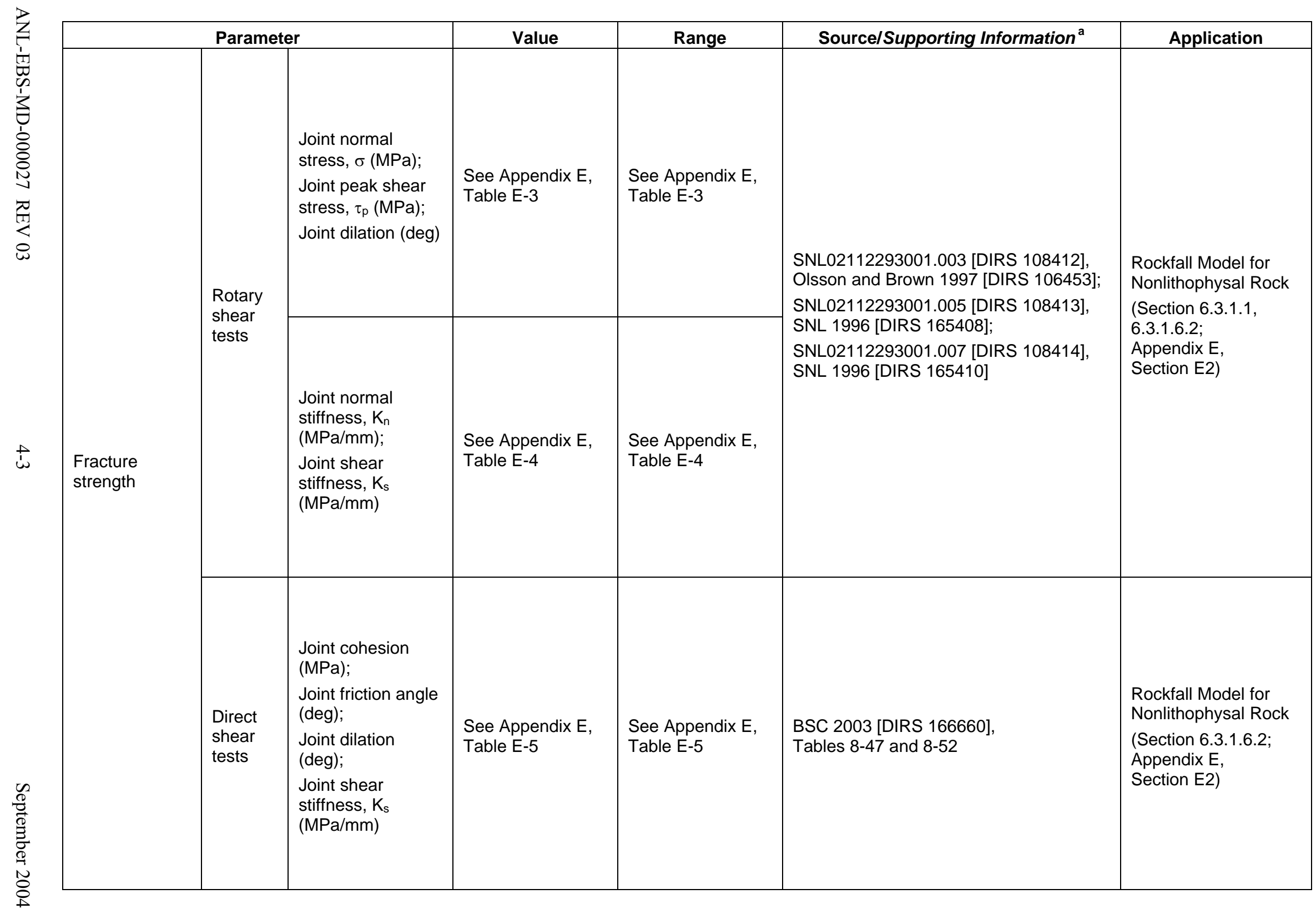


Table 4-1. Input Data and Parameters for the Drift Degradation Analysis (Continued)

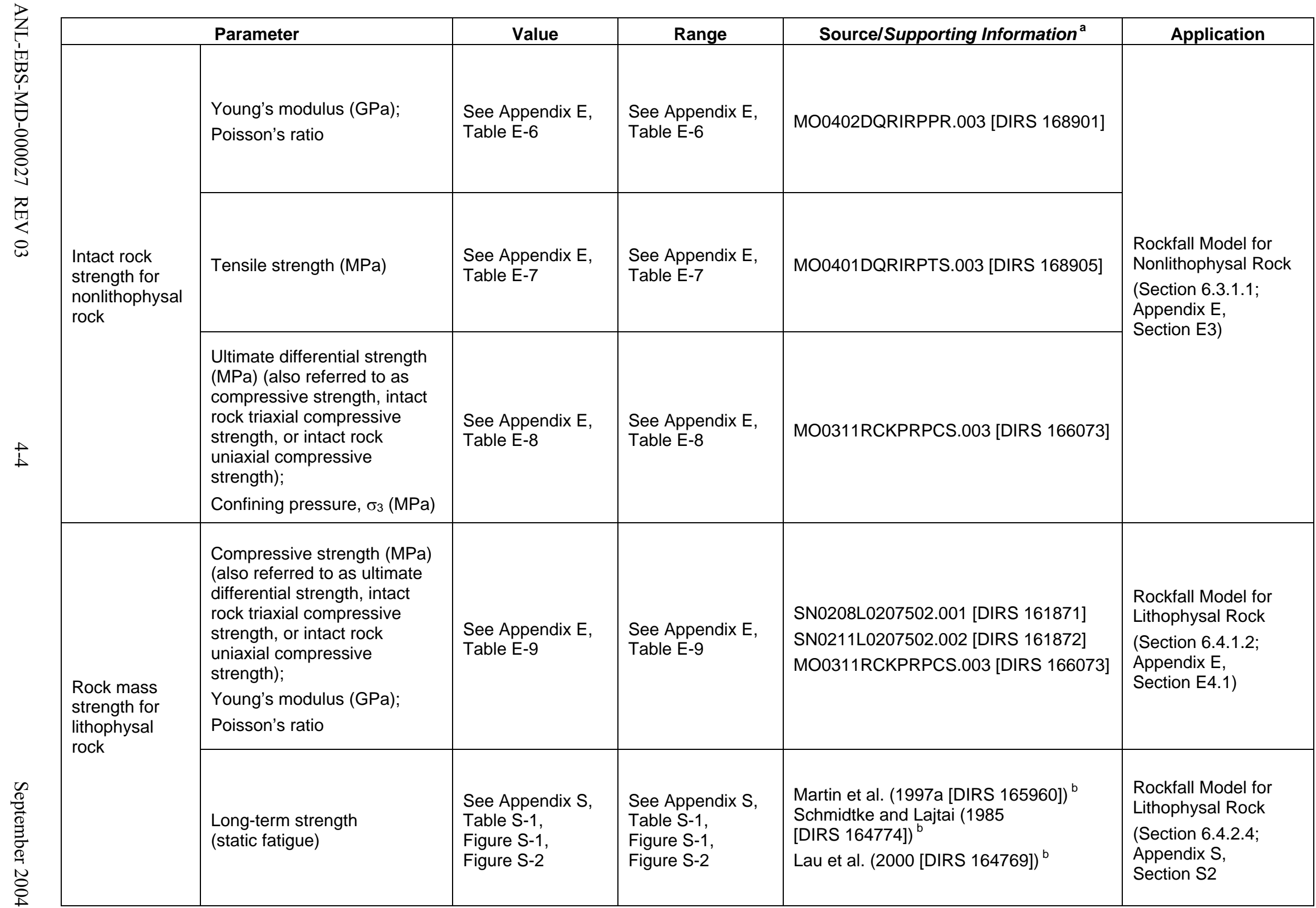


Table 4-1. Input Data and Parameters for the Drift Degradation Analysis (Continued)

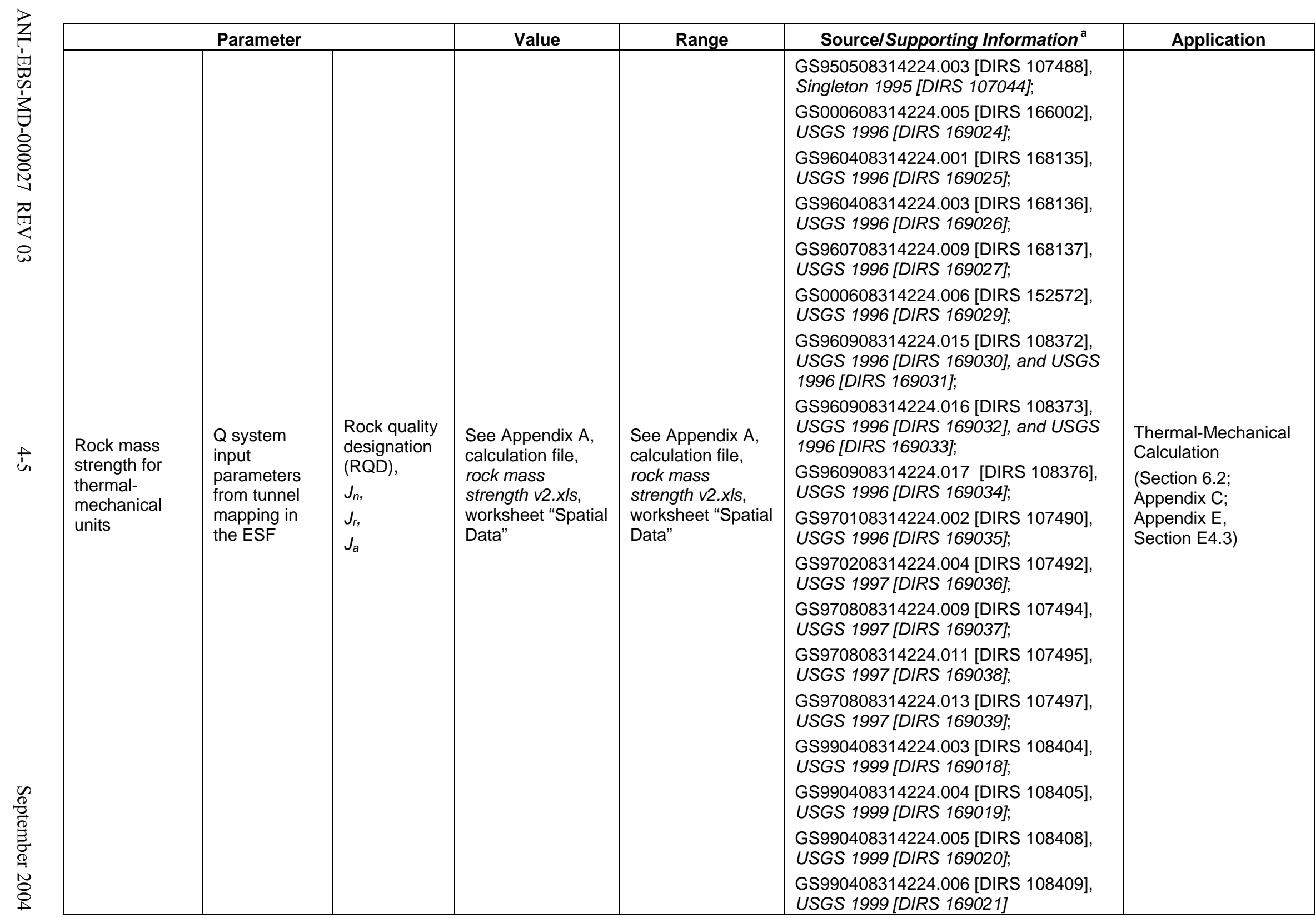


Table 4-1. Input Data and Parameters for the Drift Degradation Analysis (Continued)

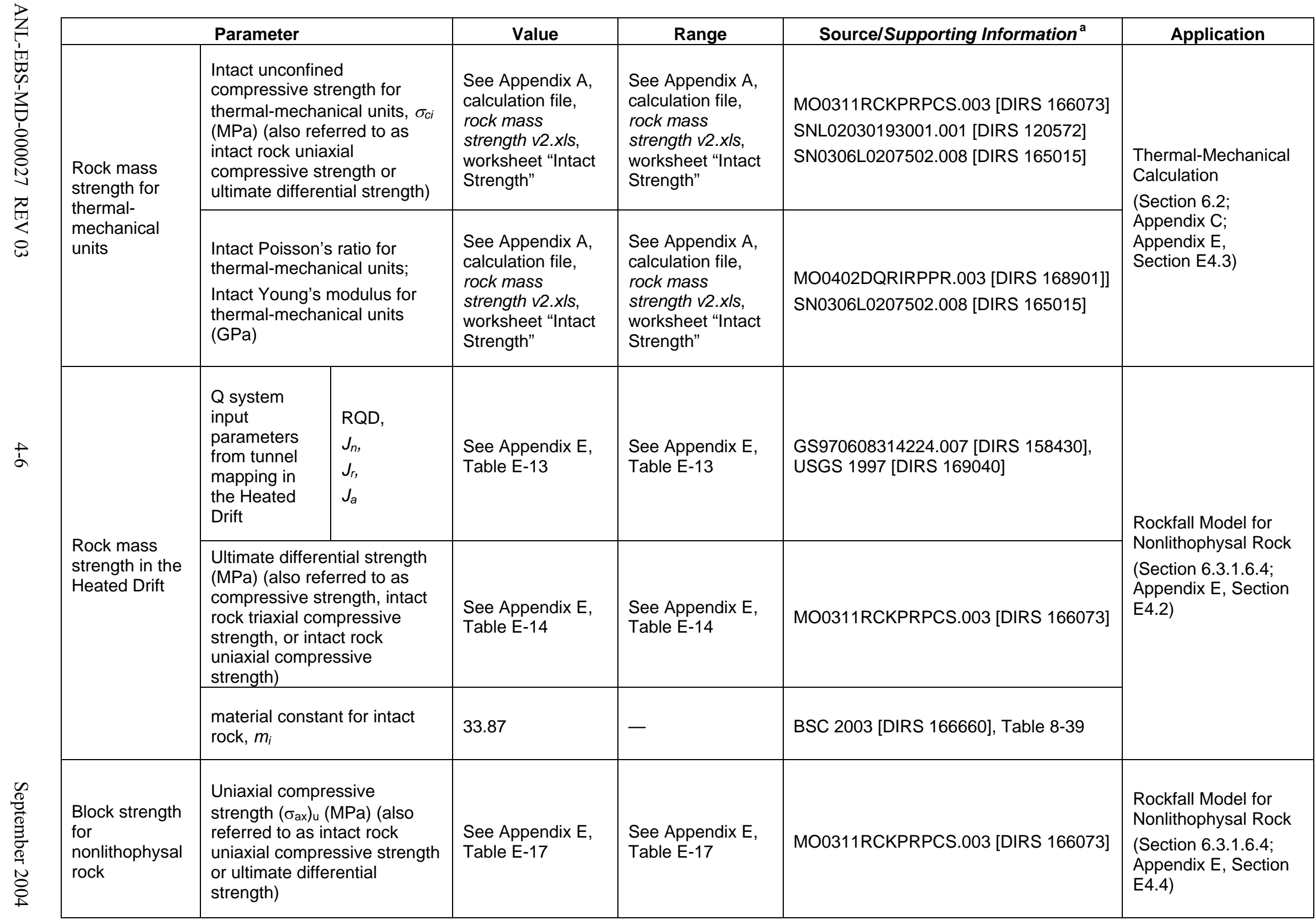


Table 4-1. Input Data and Parameters for the Drift Degradation Analysis (Continued)

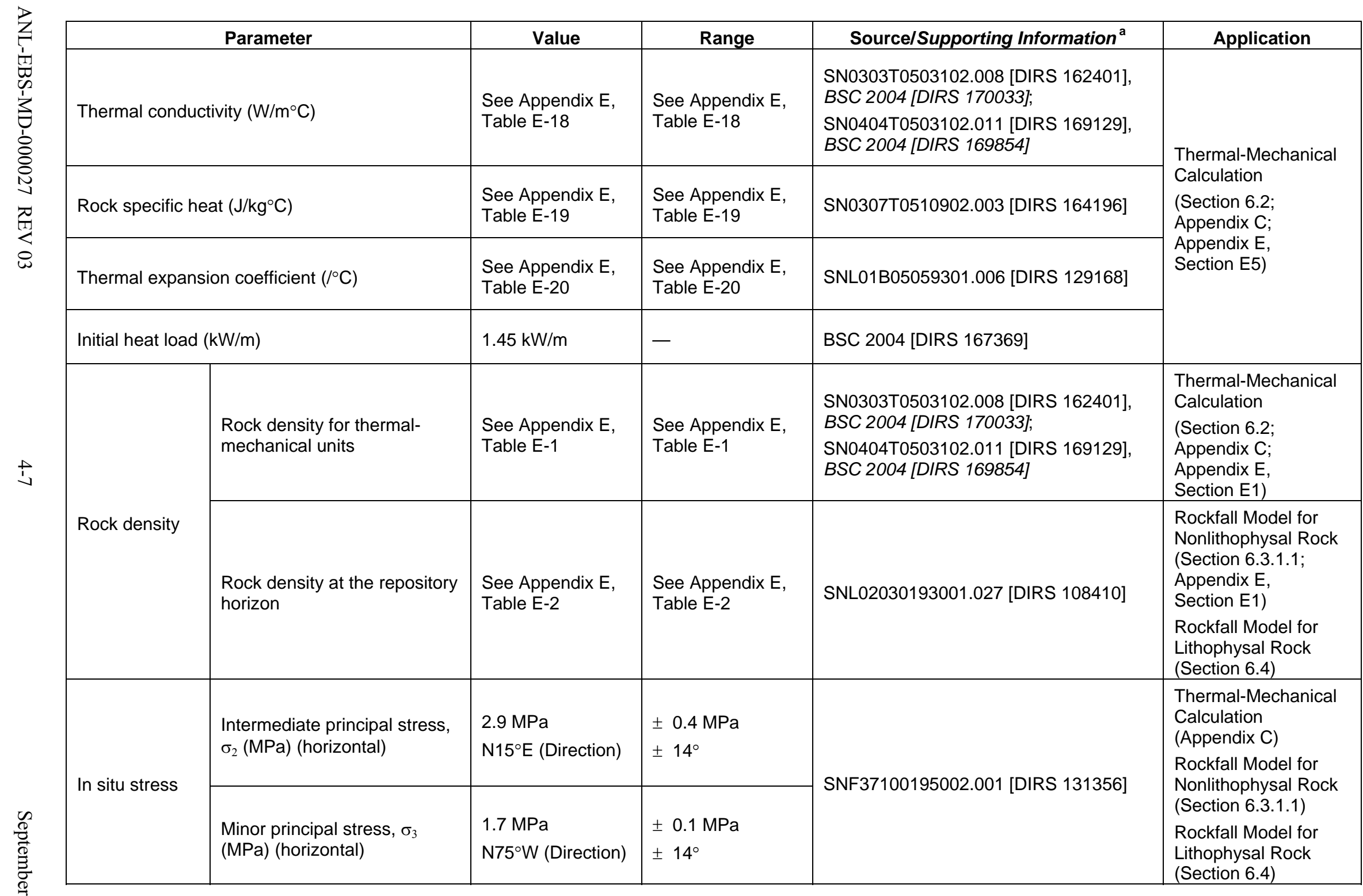


Table 4-1. Input Data and Parameters for the Drift Degradation Analysis (Continued)

\begin{tabular}{|c|c|c|c|c|c|}
\hline & Parameter & Value & Range & Source/Supporting Information ${ }^{a}$ & Application \\
\hline \multicolumn{2}{|c|}{ Repository layout } & $\begin{array}{l}\text { See Appendix C, } \\
\text { Sections C2 and } \\
\text { C3 }\end{array}$ & $\begin{array}{l}\text { See Appendix C, } \\
\text { Sections C2 and } \\
\text { C3 }\end{array}$ & $\begin{array}{l}\text { BSC } 2004 \text { [DIRS 164519], } \\
\text { BSC } 2003 \text { [DIRS 165572] }\end{array}$ & $\begin{array}{l}\text { Thermal-Mechanical } \\
\text { Calculation } \\
\text { (Appendix C) }\end{array}$ \\
\hline \multicolumn{2}{|c|}{ Emplacement drift orientation } & $72^{\circ}$ drift azimuth & - & $\begin{array}{l}\text { BSC } 2004 \text { [DIRS 164519], } \\
\text { BSC } 2003 \text { [DIRS 165572] }\end{array}$ & \multirow{2}{*}{$\begin{array}{l}\text { Rockfall Model for } \\
\text { Nonlithophysal Rock } \\
\text { (Section 6.3.1.1) } \\
\text { Rockfall Model for } \\
\text { Lithophysal Rock } \\
\text { (Section 6.4.2.2, } \\
\text { Appendix Y) }\end{array}$} \\
\hline \multicolumn{2}{|c|}{ Emplacement drift diameter (m) } & $5.5 \mathrm{~m}$ & - & BSC 2004 [DIRS 168489] & \\
\hline \multirow{4}{*}{$\begin{array}{l}\text { Seismic } \\
\text { ground motion }\end{array}$} & $5 \times 10^{-4}$ per year & \multirow{4}{*}{$\begin{array}{l}\text { See Section } \\
\text { 6.3.1.2.1 } \\
\text { (Tables 6-5, 6-6, } \\
\text { 6-7; Figure 6-36), } \\
\text { Appendix X }\end{array}$} & \multirow{4}{*}{$\begin{array}{l}\text { See Section } \\
\text { 6.3.1.2.1 } \\
\text { (Tables 6-5, 6-6, } \\
\text { 6-7; Figure 6-36), } \\
\text { Appendix X }\end{array}$} & MO0407TMHIS104.003 [DIRS 170599] & \multirow{4}{*}{$\begin{array}{l}\text { Rockfall Model for } \\
\text { Nonlithophysal Rock } \\
\text { (Section 6.3.1.2, } \\
\text { Appendix X) } \\
\text { Rockfall Model for } \\
\text { Lithophysal Rock } \\
\text { (Section 6.4.2.2) }\end{array}$} \\
\hline & $1 \times 10^{-4}$ per year & & & MO0306SDSAVDTH.000 [DIRS 164033] & \\
\hline & $1 \times 10^{-5}$ per year & & & MO0402AVDTM105.001 [DIRS 168890] & \\
\hline & $1 \times 10^{-6}$ per year $^{c}$ & & & $\begin{array}{l}\text { MO0403AVDSC106.001 [DIRS 168891] } \\
\text { MO0301TMHIS106.001 [DIRS 161868]; }\end{array}$ & \\
\hline
\end{tabular}


Table 4-1. Input Data and Parameters for the Drift Degradation Analysis (Continued)

\begin{tabular}{|c|c|c|c|c|}
\hline Parameter & Value & Range & Source/Supporting Information ${ }^{a}$ & Application \\
\hline Sampling of Stochastic Input Parameters & $\begin{array}{l}\text { See Section } \\
6.3 .1 .2 .2 \\
\text { (Table 6-8) and } \\
\text { Section 6.4.2.2 } \\
\text { (Table 6-44) }\end{array}$ & $\begin{array}{l}\text { See Section } \\
6.3 .1 .2 .2 \\
\text { (Table 6-8) and } \\
\text { Section 6.4.2.2 } \\
\text { (Table 6-44) }\end{array}$ & MO0301SPASIP27.004 [DIRS 161869] & $\begin{array}{l}\text { Rockfall Model for } \\
\text { Nonlithophysal Rock } \\
\text { (Section 6.3.1.2) } \\
\text { Rockfall Model for } \\
\text { Lithophysal Rock } \\
\text { (Section 6.4.2.2) }\end{array}$ \\
\hline Lithophysal abundance & See Appendix O & See Appendix O & $\begin{array}{l}\text { GS021008314224.002 [DIRS 161910] } \\
\text { GS040608314224.001 [DIRS 171367] }\end{array}$ & $\begin{array}{l}\text { Rockfall Model for } \\
\text { Lithophysal Rock } \\
\text { (Section 6.4) }\end{array}$ \\
\hline
\end{tabular}

${ }^{a}$ The italicized supplemental references listed along with the source DTNs provide either summary or supporting information that is linked to the source DTN, and provide direct input for this analysis and model report.

${ }^{b}$ Long-term strength data are provided by outside sources and qualified for use in this report (Appendix S, Section S2.1.2) in accordance with the requirements of AP-SIII.10Q, Section 5.2 .

${ }^{c}$ Note that two sets of $1 \times 10^{-6}$ time histories are provided. The difference in these sets is described in DTN: MO0403AVDSC106.001 [DIRS 168891], file 10-6 TH memo.doc. The original set (i.e., DTN: MO0301TMHIS106.001 [DIRS 161868]) is used in Section 6.4.2.2. Since this ground motion results in complete drift collapse for lithophysal rock, it was not necessary to repeat the analyses using the revised set (i.e., DTN: MO0403AVDSC106.001 [DIRS 168891]. 
DRKBA Fracture Geometry Inputs-Studies by the U.S. Geological Survey/U.S. Bureau of Reclamation have generated data on "small-scale" fractures with trace lengths less than $1 \mathrm{~m}$ (DTN: GS040108314224.001 [DIRS 169591]). These data were collected at six locations in the Tptpmn (2 locations), Tptpll (3 locations), and Tptpln (1 location). These data are used in this analysis to provide an assessment of the impact of the small trace length fracture data on rockfall development (Section 6.3.3).

3DEC Fracture Geometry Inputs-The 3DEC software uses source fracture geometry inputs provided in Table 4-1. These inputs are then developed to produce a 100-m x 100-m x 100-m rock mass volume that contains a three-dimensional generation of fracture data derived from the field mapping data using a Poisson process (Section 6.1.6). Fractures are generated within this volume as circular disks with their size, dip, and dip direction determined based on field data. The location of each fracture plane within the three dimensional space is also provided. Details for sampling within this rock mass volume to select fracture patterns for 3DEC modeling are provided in Section 6.3.1.2.2.

\subsubsection{Fracture Mechanical Properties Data}

Fracture strength is characterized by cohesion, friction angle, dilation, and stiffness. Joint cohesion $\left(C_{\mathrm{j}}\right)$ and friction angle $\left(\phi_{\mathrm{j}}\right)$ values were developed in Appendix E based on laboratory shear strength test data from core specimens (see Appendix E, Table E-3). Mean value and standard deviation are required as the inputs for the DRKBA and 3DEC structural analyses. The calculation of mean values in Appendix E (Section E2) is consistent with Yucca Mountain Site Geotechnical Report (CRWMS M\&O 1997 [DIRS 103564], p. 5-143). Joint stiffness values $\left(K_{\mathrm{n}}\right.$ and $K_{\mathrm{s}}$ ) are required as inputs for 3DEC, and are documented in Appendix E (Table E-4) based on laboratory shear strength test data from core specimens. Joint dilation data are provided based on the laboratory shear strength test data from core specimens (see Appendix E, Table E-3). Note that for 3DEC analyses, dilation was conservatively selected to be zero, resulting in a higher estimation of rockfall (see Section 6.3.1.1).

\subsubsection{Intact Rock Physical and Mechanical Properties Data}

The mean rock density value used in rockfall modeling (Sections 6.3 and 6.4) was calculated based on data from laboratory tests performed on rock cores from the North Ramp geotechnical and the systematic drilling boreholes (see Appendix E, Table E-2). The saturated bulk density $(\rho)$ of $2.41 \mathrm{~g} / \mathrm{cc}$ (see Appendix E, Table E-2) for the Tptpln unit was used in each of the rockfall models in this analysis. This value is in agreement with the mean Tptpln saturated bulk density reported in the Yucca Mountain Site Geotechnical Report (CRWMS M\&O 1997 [DIRS 103564], p. 5-26). That document also indicates that the mean density for the Tptpln unit is the highest mean value compared to other units of the repository horizon (i.e., the Tptpul, Tptpmn, Tptpll, and Tptpln) (CRWMS M\&O 1997 [DIRS 103564], pp. 5-25 and 5-26). The use of the mean density for the Tptpln unit to represent the density of the rock units in this analysis results in a larger mass of rock blocks, and is, therefore, conservative. The thermal-mechanical calculation (Section 6.2) uses density inputs grouped according to thermal-mechanical units. The calculation of mean density values for each thermal-mechanical unit is also documented in Appendix E (Table E-1). 
Mean elastic rock properties from the TSw2 thermal-mechanical unit, including a Young's modulus $(E)$ of $33.6 \mathrm{GPa}$ and a Poisson's ratio $(v)$ of 0.20 , were used in this analysis for modeling nonlithophysal rock as calculated in Appendix E (Table E-6). Elastic rock properties were determined from laboratory tests performed on rock cores from the North Ramp geotechnical and the systematic drilling boreholes. The calculation of mean values in Appendix $\mathrm{E}$ is consistent with Yucca Mountain Site Geotechnical Report (CRWMS M\&O 1997 [DIRS 103564], pp. 5-88 and 5-96). Intact bulk modulus $(K)$ and intact shear modulus $(G)$ for nonlithophysal rock were calculated based on the mean values of $E$ and $v$ using Equations E-2 and E-3, respectively, as documented in Appendix E (Section E3).

Tensile strength data for the TSw2 thermal-mechanical unit were obtained from indirect tensile strength tests performed by the Brazilian Test method using core specimens (Appendix E, Table E-7). The mean tensile strength from this data is $8.9 \mathrm{MPa}$.

Triaxial strength data (see Appendix E, Table E-8) are used to calculate intact cohesion and friction angle of the nonlithophysal rocks. The calculation of cohesion and friction angle is documented in Appendix E, resulting in a cohesion of $36 \mathrm{MPa}$ and a friction angle of 50 degrees.

\subsubsection{Rock Mass Properties Data}

\subsubsection{Strength of Lithophysal Rock}

Mechanical properties for lithophysal rock were determined based on available laboratory testing data on large rock cores from drilling in the ECRB Cross-Drift and Busted Butte (Appendix E, Section E4.1.3 and Table E-9). Values of cohesion $(C)$, bulk modulus $(K)$, and shear modulus $(G)$ for lithophysal rock were calculated based on values of unconfined compressive strength $\left(\sigma_{\mathrm{c}}\right)$, Young's modulus $(E)$, and Poisson's ratio $(v)$ as documented in Appendix E (Section E4.1).

\subsubsection{Rock Mass Elastic Properties for Thermal-Mechanical Units}

The rock mass properties data used in this report include modulus of deformation and Poisson's ratio for each of the thermal-mechanical units (see Appendix E, Table E-16). The rock mass properties data were calculated based on the intact rock data from laboratory testing and the Q system input parameters from tunnel mapping in the ESF identified in Table 4-1. Note that Q system parameters $J_{n}, J_{r}$, and $J_{a}$ are provided by the supplemental sources cited in Table 4-1 (see italicized references in Table 4-1). Since the verified source DTNs providing the Q values have been calculated using the parameters $J_{n}, J_{r}$, and $J_{a}$, the supplemental sources providing the $Q$ system data are also qualified and verified.

The rock mass modulus of deformation data is provided for five rock mass categories representing the range of rock mass conditions encountered in ESF tunnels. The five rock mass categories correspond to 5 percent, 20 percent, 40 percent, 70 percent, and 90 percent probabilities of occurrence, and are provided to be consistent with geotechnical design analyses (BSC 2004 [DIRS 170292], Section 3.1.4). Mid-range values corresponding to a 40 percent probability of occurrence were used in this analysis, which provides an approximate estimate of the mean value. This data is appropriate for its use in the thermal-mechanical calculation (Section 6.2), which provides an assessment of the regional stresses anticipated within the rock 
mass. Poisson's ratio for the rock mass was determined to be equal to the Poisson's ratio from intact laboratory tests based on recent field testing (see Appendix E, Table E-16).

\subsubsection{Rock Mass Properties for the Heated Drift in the ESF}

Rock mass properties for the Heated Drift are calculated using the Hoek-Brown failure criterion (Hoek et al. 2002 [DIRS 162204]) as documented in Appendix E (Section E4.2). The inputs needed include rock mass classification data using the $\mathrm{Q}$ system as provided in Appendix $\mathrm{E}$ (Table E-13). Additionally, intact unconfined compressive strength $\left(\sigma_{c i}\right)$ is required input for the Hoek-Brown method (Table E-14). The calculated rock mass properties using these data are provided in Appendix E (Table E-15).

\subsubsection{Block Strength of Nonlithophysal Rock}

The strength of large-scale intact rock block material (i.e., between joints) for nonlithophysal rock is calculated based on available size-effect laboratory compression test data from Price (1986 [DIRS 106589]). The size-effect data are presented in Appendix E (Table E-17). The approach for extrapolating this data to the block scale is documented in Appendix E (Section E4.4).

\subsubsection{Seismic Ground Motion Data}

Seismic ground motion time history data were provided for the following hazard levels: $5 \times 10^{-4}$ per year, $1 \times 10^{-4}$ per year, $1 \times 10^{-6}$ per year, and $1 \times 10^{-7}$ per year. DTNs for each of these ground motion levels are listed in Table 4-1. The ground motion data for the postclosure ground motion levels (i.e., $1 \times 10^{-6}$ and $1 \times 10^{-7}$ ) each include 15 sets (three components) of time histories at the repository horizon. The sets were developed by scaling recorded motions such that their integrated peak particle velocities match expected point repository horizon particle velocities for the hazard level under consideration. Additionally, a desirable feature of the 15 sets is a magnitude distribution reflective of the horizontal component peak particle velocity deaggregation. This ensures a reasonable and defensible distribution of spectral shapes and time history durations. Conditioning on expected peak particle velocity alone was considered desirable as damage to underground structures is most strongly correlated with this point measurement, recognizing that underground (at-depth) spectral shapes are generally not identical to surficial or outcrop spectral shapes due to the effects of down going wave fields (BSC 2004 [DIRS 170027], Section 6.3.2).

The ground motion data for preclosure annual exceedance probabilities (i.e., $5 \times 10^{-4}$ and $1 \times 10^{-4}$ ) consist of a single three-component set of time histories. These sets were developed such that the response spectra of the time histories match the design response spectra for the hazard level at the repository horizon. 


\subsubsection{Rock Thermal Properties Data}

A regional thermal-mechanical calculation has been developed as part of this drift degradation analysis (Section 6.2), and uses the following thermal properties data (see Table 4-1 and Appendix E, Section E5 for parameter values and source DTNs):

- Thermal conductivity $\left(\mathrm{W} / \mathrm{m}^{\circ} \mathrm{K}\right)$

- Rock specific heat $\left(\mathrm{J} / \mathrm{kg}^{\circ} \mathrm{K}\right)$

- Thermal expansion $\left(/{ }^{\circ} \mathrm{C}\right)$

- Heat decay curve.

\subsubsection{Repository Layout Information}

Repository layout information (Table 4-1), including emplacement drift diameter and azimuth, is provided by repository design and performance assessment information exchange drawings (BSC 2004 [DIRS 164519]; BSC 2004 [DIRS 168489]) and Underground Layout Configuration (BSC 2003 [DIRS 165572], Sections 5.1.4 and 8.7).

\subsubsection{Matrix and Fracture Hydrologic Properties Data}

A temperature-history calculation has been developed as part of this analysis (Section 6.2) based on a two-dimensional drift scale thermohydrologic model from Multiscale Thermohydrologic Model (BSC 2004 [DIRS 169565]) and DTN: LL030808623122.036 [DIRS 165790]. Matrix and fracture hydrologic properties data used in the calculation are provided in DTN: LL030808623122.036 [DIRS 165790] as a part of the NUFT input files (i.e., file $d k m-a f c-1 D d s-m c-m i-04)$. Summaries of the matrix and fracture hydrologic properties data are also available in DTN: LB0205REVUZPRP.001 [DIRS 159525] and DTN: LB0208UZDSCPMI.002 [DIRS 161243].

\subsubsection{In Situ Stress Data}

In situ stress data were determined by hydraulic fracturing in a borehole located in the Tptpmn unit in the Thermal Test Facility in the ESF (DTN: SNF37100195002.001 [DIRS 131356]; CRWMS M\&O 1997 [DIRS 147458], pp. 15, 19, and 20). The in situ stress measurements included a series of five hydraulic fracturing tests, resulting in an estimate of the state of stress in the ESF as shown in Table 4-1. The vertical stress shown in Table 4-1 was calculated based on the depth of cover in the Thermal Test Facility at the test borehole location. The in situ stress for each emplacement drift will vary depending on the cover depth on top of the drift. The approximated values assigned for the in situ stress for the rockfall modeling activities in Sections 6.3 and 6.4 are adequate and insensitive to the results judging the magnitude of the induced seismic and thermal stress.

\subsection{CRITERIA}

This model report addresses acceptance criteria from Sections 2.2.1.3.1.3 and 2.2.1.3.2.3 of Yucca Mountain Review Plan, Final Report (NRC 2003 [DIRS 163274]) regarding the degradation of engineered barriers and the mechanical disruption of engineered barriers. 
Acceptance criteria from the Yucca Mountain Review Plan include the following:

- AC1: System description and model integration are adequate

- AC2: Data are sufficient for model justification

- AC3: Data uncertainty is characterized and propagated through the model abstraction

- AC4: Model uncertainty is characterized and propagated through the model abstraction

- AC5: Model abstraction output is supported by objective comparison.

The Yucca Mountain Review Plan criteria are based on meeting the requirements of 10 CFR 63.114(a)-(c) and (e)-(g), relating to the degradation and mechanical disruption of engineered barriers model abstractions. A mapping between the Acceptance Criteria and subcriteria and where they are addressed in this document is provided in Section 8.2 (see Table 8-1).

Similarly, the Project Requirements Document (Canori and Leitner 2003 [DIRS 166275], Table 2-3) expresses these requirements as follows:

- PRD-002/T-014 "Performance Objectives for the Geologic Repository After Permanent Closure" (traceable to 10 CFR 63.113)

- PRD-002/T-015 "Requirements for Performance Assessment" (traceable to 10 CFR 63.114)

This report was therefore prepared to comply with subparts of the NRC high-level waste rule, 10 CFR Part 63. Relevant requirements for performance assessment from Section 114 of that document are:

Any performance assessment used to demonstrate compliance with Sec. 63.113 must: (a) Include data related to the geology, hydrology, and geochemistry ... used to define parameters and conceptual models used in the assessment. (b) Account for uncertainties and variabilities in parameter values and provide for the technical basis for parameter ranges, probability distributions, or bounding values used in the performance assessment. ... (g) Provide the technical basis for models used in the performance assessment such as comparisons made with outputs of detailed process-level models and/or empirical observations (e.g., laboratory testing, field investigations, and natural analogs).

\subsection{CODES, STANDARDS, AND REGULATIONS}

There are no codes and standards applicable to this drift degradation analysis. The regulation that is applicable to the development of this document is 10 CFR Part 63 [DIRS 156605], specifically 10 CFR 63.113 and 10 CFR 63.114. 


\section{ASSUMPTIONS}

The following assumptions have been used in this drift degradation analysis.

\subsection{THERMAL-MECHANICAL CALCULATION}

\subsubsection{Simultaneous Emplacement}

Assumption: The thermal-mechanical calculation in this report assumes that generation of heat from the waste packages occurs simultaneously throughout the repository. The entire repository begins heating at the same time because sequential emplacement of waste packages has not been considered.

Basis: This assumption is necessary because design information is available only for the emplacement drift layout (BSC 2004 [DIRS 164519]), and not for the emplacement schedule.

Confirmation Status: This assumption does not require further confirmation, because results from the thermal-mechanical calculation should be the most conservative based on this assumption (i.e., the assumption produces increased heat and greater stresses in the rock mass). Sequential emplacement may cause an additional internal stress between the emplacement drifts and the remaining drifts. This internal stress will be insignificant during the preclosure period, because the majority of the heat load will be removed from the emplacement drifts due to ventilation (Section 5.1.2). The effects of the internal stress are expected to be minor during the postclosure period, because the waste packages will cool down significantly during the preclosure period, and the repository temperature is expected to be homogenized due to heat conduction between the drifts during the preclosure period. A range of temperatures has been considered in the rockfall analyses presented in this report (Sections 6.3.1.3 and 6.4.2.3), and the rockfall results are relatively insensitive to the temperature changes evaluated.

Use in the Analysis/Model: This assumption is used in the thermal-mechanical calculation of regional (repository-scale) and local (drift scale) temperature and thermal stress (Sections 6.2, 6.3.1, and 6.4.2; Appendix C).

\subsubsection{Ventilation Heat Removal Ratio}

Assumption: During the ventilated preclosure period, 90 percent of the decay heat output is removed from the emplacement drift system.

Basis: The basis of this assumption is provided from the ventilation model supporting a license application (BSC 2004 [DIRS 169862]), which has integrated heat removal ratios (averaged spatially and temporally) of 88 percent and 90 percent for the 50 -year preclosure ventilation period and 600-m long drifts (MO0306MWDASLCV.001 [DIRS 165695] and MO0306MWDALAFV.000 [DIRS 163961], respectively).

Confirmation Status: No further confirmation is needed for this assumption because sensitivity calculation regarding the heat removal ratio was conducted covering the heat removal ratio down to 70 percent (Section 6.2). The calculation showed that the results of rockfall analyses are not sensitive to heat removal ratio over this range. Heat removal ratio that is a function of time and 
distance from the drift inlet was considered in an impact analyses (Appendix Q). The impact analyses also showed that the results of rockfall analyses are not sensitive to the heat removal ratio.

Use in the Analysis/Model: This assumption is used in the preclosure thermal-mechanical calculations except the ventilation sensitivity calculation (Sections 6.2, 6.3.1, and 6.4.2; Appendix $\mathrm{C}$ ). Because of this assumption it is accurate to model the preclosure period by simply reducing the decay heat output to 10 percent of its non-ventilated rate.

\subsubsection{Thermal Expansion}

Assumption: Thermal expansion values used in the underlying layers ( $\mathrm{CHn} 1$ and $\mathrm{CHn} 2)$ under the repository units (TSw2) are assumed to be equal to those for the repository layers.

Basis: This assumption is necessary because the test data from core samples are limited.

Confirmation Status: This assumption does not require further confirmation because temperature increase in the underlying layers is insignificant and thermally induced stresses are negligible.

Use in the Analysis/Model: This assumption is used in the thermal-mechanical calculations throughout the report (Sections 6.3.1 and 6.4.2; Appendix C).

\subsection{ROCKFALL MODELING}

\subsubsection{Joint Position Parameter in DRKBA}

Assumption: The positioning parameter required as joint parameter input is assumed to be the offset measured from the center of the trace length to the scan line of the detailed line survey.

Basis: This is the best available way to represent the positioning parameter because the determination of the true positioning parameter requires the three dimensional information of the joint plane that is not available.

Confirmation Status: This assumption does not require further confirmation. This approach is considered conservative because the offset measured from the one-dimensional scan line is smaller than the true offset in three-dimensional space (the probability of forming a key block is higher with a smaller offset value). The DRKBA rockfall results are used for confirmation only. This assumption does not impact the rockfall output documented in this report.

Use in the Analysis/Model: This assumption is used in Section 6.3.3 and Appendix D.

\subsubsection{Block Size Distribution for Potential Rockfall in Lithophysal Units}

Assumption: Block size distribution is assumed as a function of inter-lithophysal fracture density and lithophysae spacing.

Basis: This assumption is needed because the size of rock particles that are created from the lithophysal rocks is estimated from geologic and empirical evidence. 
Confirmation Status: This assumption does not require further confirmation. The relatively abundant uniformly distributed lithophysae combined with fracturing fabric provide natural breaking surfaces. Observation in the ECRB Cross-Drift for block sizes on the order of a few inches in diameter supports this assumption (Appendix $\mathrm{O}$ ).

Use in the Analysis/Model: This assumption is used in Section 6.4. 


\section{INTENTIONALLY LEFT BLANK}




\section{MODEL DISCUSSION AND ANALYSIS RESULTS}

This section documents the models and analyses conducted to predict the postclosure drift degradation resulting from thermally induced stresses, seismically induced rockfall, and possible time-dependent static fatigue mechanisms.

The potential exists for rockfall to occur as a result of shaking induced by earthquakes. The models and analyses described in this section quantify possible seismically induced rockfall over the 10,000-year regulatory postclosure period. Geologic mapping is used to define a "synthetic" or representative rock mass that is sampled randomly to create possible rock masses in which the tunnel is simulated. Numerical models (two- or three-dimensional, depending on the lithology in question), with input geometry and properties based on the geologic variability, are used to make rockfall estimates for ground motion levels whose amplitude is based on the probability of occurrence in terms of annual exceedance frequency. For each annual exceedance frequency, a number of probabilistically based, site-specific ground motions have been developed and used to provide the transient boundary conditions to the models. The resulting rockfall, in terms of the tonnage of the maximum size rock particle, total tonnage for a given simulated length of tunnel, and the velocity of rock particles, has been determined.

The rock mass surrounding the excavations may undergo damage from thermally induced stresses or time-dependent damage associated with static fatigue resulting from stress corrosion mechanisms. This damaged material may result in a slow unraveling (Tptpll) or block fallout (Tptpmn) mode of failure with some extent of drift filling. The effect of thermal stress on rock failure extent has been examined using the numerical techniques discussed in the subsequent sections.

Time-dependent degradation (i.e., rockfall from a tunnel or other unsupported excavation over long time periods) is not currently well understood, particularly in hard, strong rocks. It is expected that time-related rockfall will be more prominent in heavily fractured rocks such as the Tptpll, and will be related to the ratio of induced stress to rock mass strength. The analyses presented in this section provide a reasonable estimate of the propensity for yield and rockfall as a function of the induced stress levels and time.

Ground support is not considered in the rockfall models presented in this report. The rock blocks predicted in this model report are, therefore, blocks that fail in an unsupported opening. This modeling approach leads to a conservative prediction of blocks for the preclosure period (i.e., more blocks will be predicted to fail in the model than would otherwise be supported and remain stable with ground support). During the postclosure period, ground support will degrade and eventually fail. Not including ground support in the rockfall models is realistic for the postclosure period.

All direct inputs used to develop the rockfall models are listed in Table 4-1. Corroborating/ supporting data, models, and product output that are used to develop the rockfall models include the following:

- Rock mass characteristics of the repository horizon (Section 6.1)

- Albin et al. 1997 [DIRS 101367] 
- Barton et al. 1974 [DIRS 101541]

- Bieniawski 1989 [DIRS 101715]

- Broxton et al. 1993 [DIRS 107386]

- Buesch 2003 [DIRS 162271]

- Buesch 2003 [DIRS 163729]

- Buesch and Spengler 1998 [DIRS 101433]

- Buesch et al. 1996 [DIRS 100106]

- Byers et al. 1976 [DIRS 104639]

- Christiansen et al. 1977 [DIRS 157236]

- CRWMS M\&O 1999 [DIRS 108441]

- Day et al. 1998 [DIRS 100027]

- Dershowitz and Herda (1992 [DIRS 104893]

- Flint 1998 [DIRS 100033]

- Gibson et al. 1990 [DIRS 157245]

- Goodman and Shi 1985 [DIRS 150094]

- Hoek 2000 [DIRS 160705]

- Lipman et al. 1966 [DIRS 100773]

- Mongano et al. 1999 [DIRS 149850]

- Munsell Color Company 1994 [DIRS 106399]

- Ortiz et al. 1985 [DIRS 101280]

- Peterman and Cloke 2002 [DIRS 162576]

- Sawyer et al. 1994 [DIRS 100075]

- Schuraytz et al. 1989 [DIRS 107248]

- Scott 1990 [DIRS 106751]

- Scott and Bonk 1984 [DIRS 104181]

- Terzaghi 1966 [DIRS 105805]

- Thermal-mechanical calculation (Section 6.2)

- BSC 2003 [DIRS 164670]

- BSC 2004 [DIRS 169565]

- Itasca Consulting Group 2002 [DIRS 160331]

- Rockfall in the nonlithophysal units (Section 6.3)

- Albin et al. 1997 [DIRS 101367]

- BSC 2003 [DIRS 166183]

- BSC 2003 DIRS [166660]

- Buesch and Lung 2003 [DIRS 170297]

- Carlos et al. 1995 [DIRS 101326]

- CRWMS M\&O 1998 [DIRS 102679]

- Duan 2003 [DIRS 163586]

- Goodman 1980 [DIRS 101966]

- Itasca Consulting Group 2002 [DIRS 160331] 
- Rockfall in the lithophysal units (Section 6.4)

- Bauer et al. 1991 [DIRS 161775]

- Bieniawski 1989 [DIRS 101715]

- Brace et al. 1966 [DIRS 101990]

- Brekke et al. 1999 [DIRS 119404]

- Brown 2003 [DIRS 169527]

- BSC 2003 [DIRS 166660]

- BSC 2004 [DIRS 169131]

- BSC 2004 [DIRS 169183]

- BSC 2004 [DIRS 168993]

- BSC 2004 [DIRS 169999]

- BSC 2004 [DIRS 169565]

- Byrne et al. 1990 [DIRS 168921]

- Charles 1959 [DIRS 170308]

- Duncan et al. 1980 [DIRS 161776]

- Fruchtbaum 1988 [DIRS 161774]

- Goodman 1980 [DIRS 101966]

- Hoek 2000 [DIRS 160705]

- Hoek and Brown 1982 [DIRS 120981]

- Itasca Consulting Group 2002 [DIRS 160331]

- Lefebvre et al. 1976 [DIRS 168919]

- Martin 1972 [DIRS 169721]

- Martin and Durham 1975 [DIRS 170301]

- MRD 1995 [DIRS 169719]

- Newmark 1965 [DIRS 169515]

- Potyondy and Cundall 2001 [DIRS 156895]

- Scholz 1972 [DIRS 169724]

- SN0406L0212303.002 [DIRS 170289]

- Terzaghi 1943 [DIRS 162180]

- Wiederhorn 1968 [DIRS 170309]

- Uncertainties and Limitations (Section 6.5)

- Potyondy 2003 [DIRS 165550]

- Drift Degradation FEPs (Section 6.6)

- Freeze et al. 2001 [DIRS 154365]

- MO0407SEPFEPLA.000 [DIRS 170760]

- Documentation of Alternative Conceptual Models (Section 6.7)

- Chen 1987 [DIRS 101800]

- CRWMS M\&O 1998 [DIRS 102723]

- Hudson and Priest 1979 DIRS 104915] 
- Resolution of key technical issues (Section 6.8)

- BSC 2003 [DIRS 166660]

- NRC 2002 [DIRS 159538]

- Reamer and Williams 2001 [DIRS 154348]

\subsection{ROCK MASS CHARACTERISTICS OF REPOSITORY HOST HORIZON}

The purpose of this section is to provide a background discussion of rock mass characteristics that are important in understanding fundamental rock mass behavior. Specific rock mass parameters that are input to the rockfall models developed in this report are identified in Sections 6.3 and 6.4. Two systems of stratigraphic nomenclature are used in this report: thermal-mechanical (Ortiz et al. 1985 [DIRS 101280]) and lithostratigraphic (Buesch et al. 1996 [DIRS 100106]). Correlation between these two systems is provided in Figure 6-1.

\subsubsection{Regional Geology}

Yucca Mountain lies in southern Nevada, in the Great Basin, which is part of the Basin and Range structural/physiographic province. In the Yucca Mountain area, pre-Tertiary rocks (consisting of a thick sequence of Proterozoic and Paleozoic sedimentary rocks) underlie approximately 1,000 to 3,000 m of Miocene volcanic rocks (Gibson et al. 1990 [DIRS 157245]).

The Miocene volcanic sequence exposed at Yucca Mountain includes units of the Paintbrush and Timber Mountain Groups (Sawyer et al. 1994 [DIRS 100075]) and the entire section dips 5 to 10 degrees east (Day et al. 1998 [DIRS 100027]). The Paintbrush Group consists of pyroclastic rocks and lavas that originate from the Claim Canyon caldera (approximately $6 \mathrm{~km}$ north of the study area) and are from 12.7 to 12.8 million years old (Byers et al. 1976 [DIRS 104639]; Sawyer et al. 1994 [DIRS 100075]). The Paintbrush Group includes a sequence of four formations: the Tiva Canyon, Yucca Mountain, Pah Canyon, and Topopah Spring Tuffs, each of which consist primarily of large-volume, pyroclastic-flow deposits with minor amounts of pyroclastic-fall deposits (Byers et al. 1976 [DIRS 104639]; Christiansen et al. 1977 [DIRS 157236]; Broxton et al. 1993 [DIRS 107386]; Buesch et al. 1996 [DIRS 100106]) (Figure 6-1). At Yucca Mountain, two of these formations, the Topopah Spring and Tiva Canyon Tuffs, are voluminous, mostly densely welded, compositionally zoned, outflow sheet, pyroclastic-flow deposits (also referred to as ignimbrites) that grade upward from rhyolite composition to quartz latite composition (Lipman et al. 1966 [DIRS 100773]; Byers et al. 1976 [DIRS 104639]; Schuraytz et al. 1989 [DIRS 107248]). The formations of the Paintbrush Group are interbedded with bedded tuffs, which consist of thinner pyroclastic-flow and pyroclastic-fall deposits, and, locally, a few lava flows (Byers et al. 1976 [DIRS 104639]; Christiansen et al. 1977 [DIRS 157236]; Broxton et al. 1993 [DIRS 107386]; Buesch et al. 1996 [DIRS 100106]; Day et al. 1998 [DIRS 100027]). The 11.45 to 11.6 million year old rocks of the Timber Mountain Group were erupted from Timber Mountain caldera complex and consist of the Ammonia Tanks and Rainer Mesa Tuffs (Sawyer et al. 1994 [DIRS 100075]) and interbedded tuffaceous rocks and lava flows. 


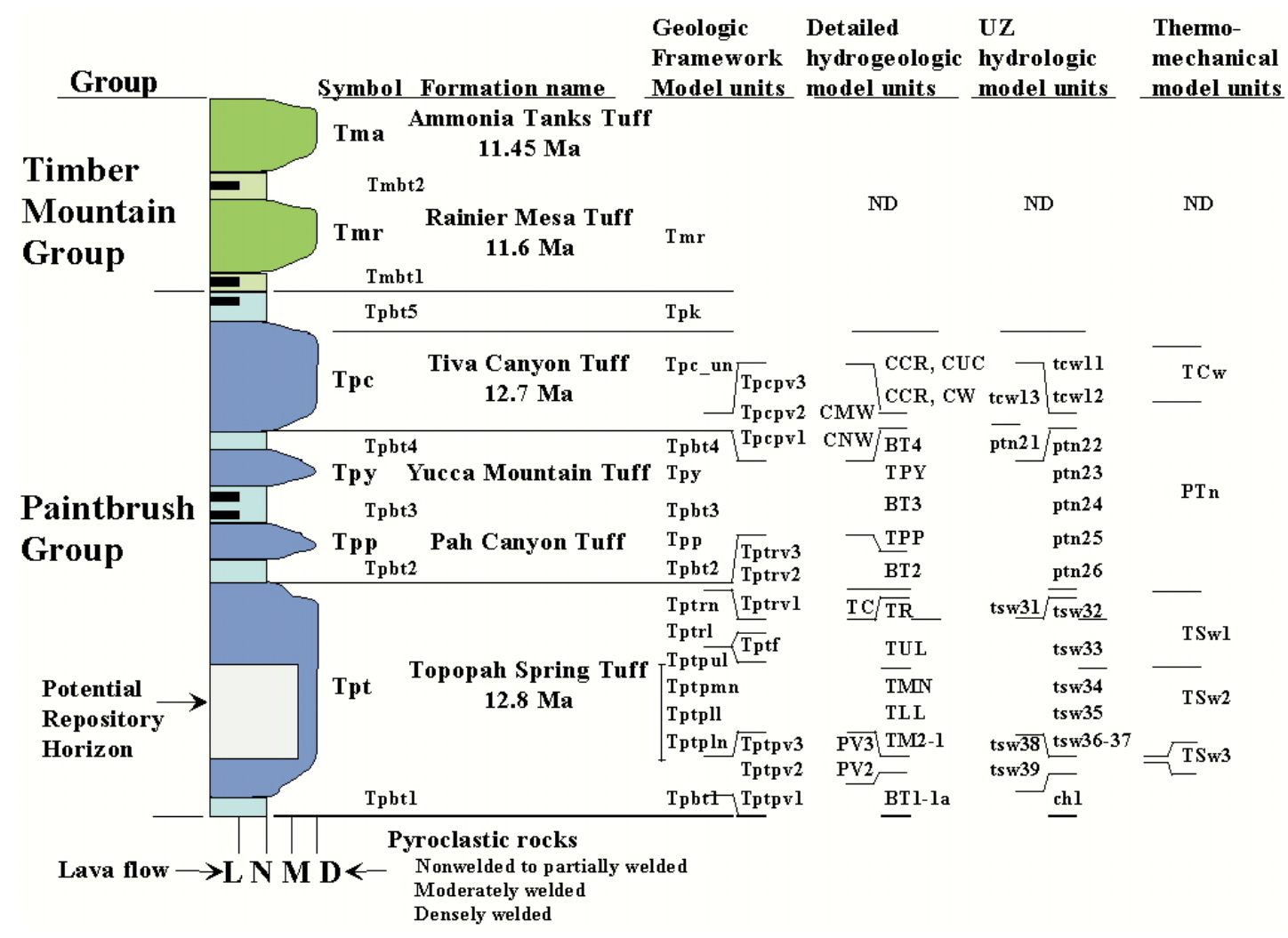

Figure 6-1. Simplified Lithostratigraphic Column of Paintbrush Group and the Rock Units that Form the Repository Host Horizon

The central block of Yucca Mountain is bounded by the Yucca Wash to the north, by the Solitario Canyon fault to the west, and the Bow Ridge fault to the east (Figure 6-2). Alluvium-filled structural valleys, consisting mostly of alluvial fan deposits (fluvial and colluvial sediments) and some thin eolian deposits, lie adjacent to the Bow Ridge and Solitario Canyon faults on the east and west sides, respectively. The Yucca Mountain area is cut by steeply dipping, north-south-striking normal faults, which separate the Tertiary volcanic rocks into blocks one to four km wide (Scott 1990 [DIRS 106751]; Day et al. 1998 [DIRS 100027]). The Solitario Canyon and Ghost Dance faults dip steeply toward the west, and displacement, amount of brecciation, and number of associated splays vary considerably along their trace (Scott and Bonk 1984 [DIRS 104181]; Day et al. 1998 [DIRS 100027]). The Solitario Canyon fault has normal down-to-the-west displacement of about $260 \mathrm{~m}$ in the vicinity of the repository block (Mongano et al. 1999 [DIRS 149850], p. 60). The Ghost Dance fault is in the central part the repository block and is a generally north-striking normal fault zone, with down to the west displacement. The Sundance fault is located in the north-central portion of the repository block. It is a northwest-striking, east-dipping normal fault with a maximum cumulative down-to-the-northeast displacement of 6 to $11 \mathrm{~m}$ (Day et al. 1998 [DIRS 100027]). Numerous smaller faults and fault zones are present throughout the repository block, generally north-trending with offsets less than $5 \mathrm{~m}$ (Mongano et al. 1999 [DIRS 149850]). 


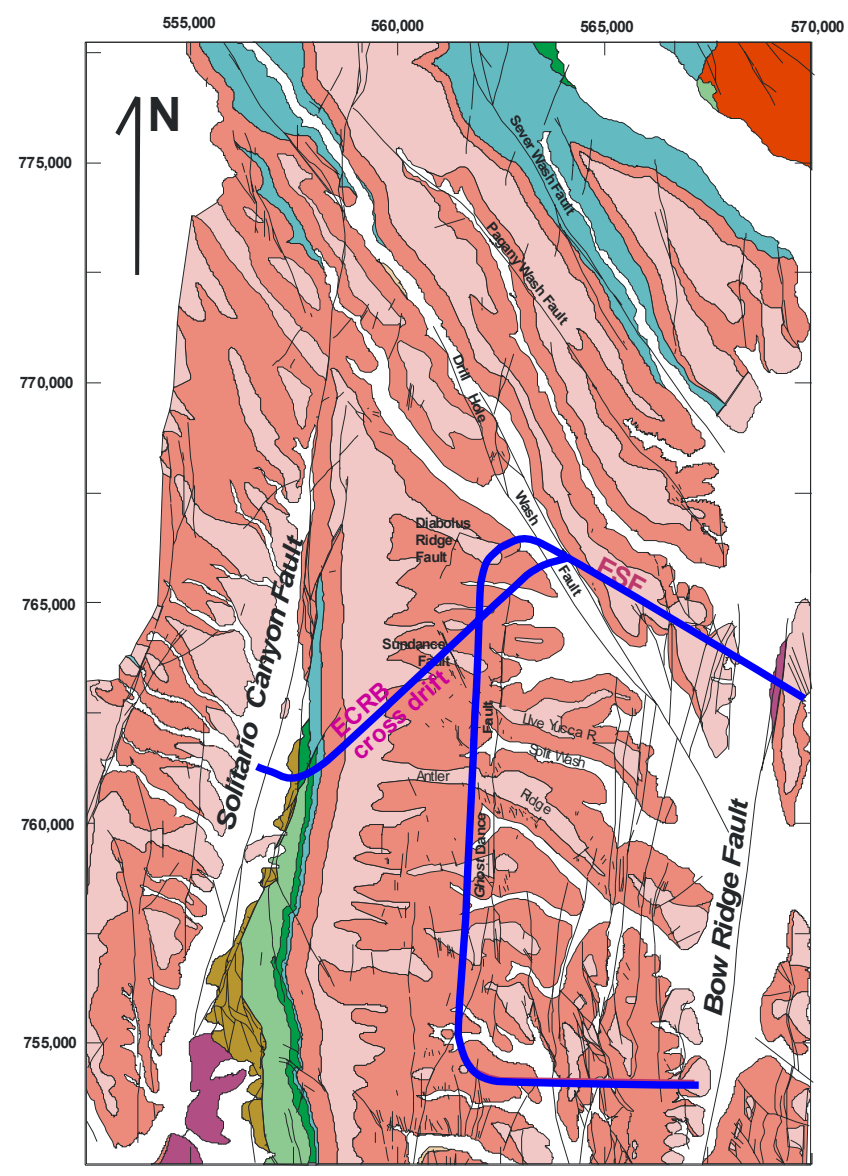

\section{Bedrock Geologic Map of the Central Block Area, Yucca Mountain, Nevada (simplified from Day et al., 1998) \\ Explanation}

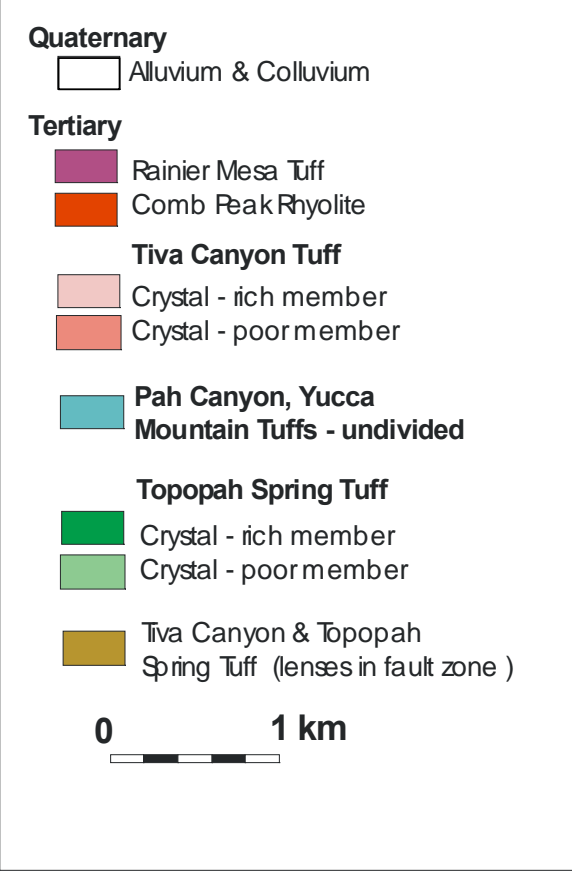

Source: Day et al. 1998 [DIRS 100027].

Figure 6-2. Geology of the Central Block at Yucca Mountain and Location of the ESF, Including the ECRB Cross-Drift

\subsubsection{Lithostratigraphy at the Repository Horizon}

All of the rocks of the repository host horizon lie within the Topopah Spring Tuff-specifically within the crystal-poor member-and geochemically these rocks have a very uniform composition of rhyolite (Peterman and Cloke 2002 [DIRS 162576]). The repository host horizon includes rocks from the lower part of the upper lithophysal zone (Tptpul) of the TSw1 thermal-mechanical unit and the TSw2 thermal-mechanical unit, including the middle nonlithophysal zone (Tptpmn), the lower lithophysal zone (Tptpll), and the lower nonlithophysal zone (Tptpln) (Figure 6-1). These lithostratigraphic units are described in this section and are based on Mongano et al. (1999 [DIRS 149850]) unless otherwise indicated.

In the densely welded and crystallized rocks of the Topopah Spring Tuff, the zones and many of the subzones are identified on the basis of the abundance, size, and distribution (or lack thereof) of lithophysae, which are cavities in the rock formed during welding from the accumulation of the vapor phase. Lithophysae, spots (which are similar to the rims on lithophysae, but there is no cavity), and many fractures have similar characteristics, such as rims, borders, and possibly vapor-phase mineral coatings (Figure 6-3). 


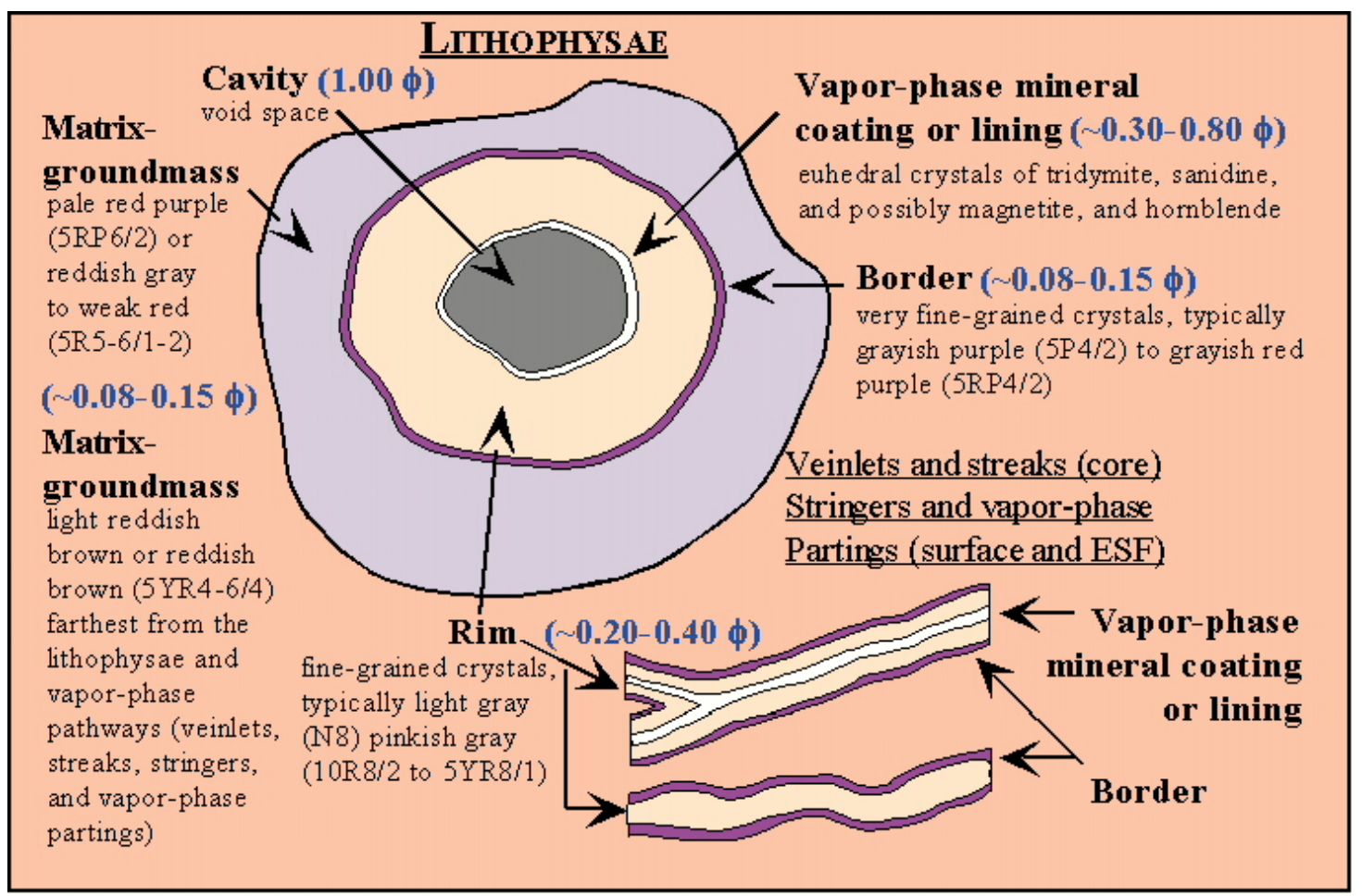

NOTE: Porosity values for the matrix-groundmass are by Flint (1998 [DIRS 100033]), and the values for rims, borders, and vapor-phase mineral coatings are estimates by Buesch (2003 [DIRS 162271]). The nomenclature for color (e.g., pale red purple is 5RP6/2), is based on soil color charts (Munsell Color Company 1994 [DIRS 106399]).

Figure 6-3. Lithostratigraphic Features Related to Lithophysae and Fractures

Tptpul-The Tptpul is exposed in both the ESF main loop and ECRB Cross-Drift. In the ESF main loop, the upper lithophysal zone is exposed from Stations $17+97$ to $27+20,63+08$ to $64+55,67+91$ to $68+47$, and $71+68$ to $73+02$. The ECRB Cross-Drift begins in the upper central portion of the zone and it exposes rocks of the middle and lower portions of the zone from Stations $0+00$ to $10+15$. The upper portion of the upper lithophysal zone is also exposed in the hanging wall of the eastern strand of the Solitario Canyon fault zone from Stations 25+90 to 26+57.5. The unit is densely welded, crystallized, lithophysal, and has various amounts of vapor-phase corrosion and mineralization. The rock contains 1 to 5 percent crystal fragments, 0 to 5 percent lithic fragments, 0 to 15 percent pumice fragments, 3 to 60 percent lithophysae, and 40 to 92 percent matrix-groundmass. The matrix-groundmass is a variable mix of pale to grayish red-purple (5RP5-7/1-2 to 5RP4/2), light brown (5YR6/3-4) to pale reddish brown (10R5/4), and pale red (5-10R6/2) crystallized material. The matrix-groundmass contains 3 to 50 percent white to very light gray (N-9 to N6) to grayish pink (5-10R8/2-1) spots, veinlets, streaks, rims on fractures, stringers, and vapor-phase partings of crystallized materials.

Tptpmn-The Tptpmn is exposed in both the ESF main loop and ECRB Cross-Drift. The ESF main loop is excavated in the middle nonlithophysal zone from Stations $27+21$ to $57+29,58+78$ to $63+08$, and from $70+58$ to $71+68$. The middle nonlithophysal zone contains an intensely fractured zone exposed in the ESF main loop from Stations 42+00 to 51+50 (Albin et al. 1997 [DIRS 101367]). This intensely fractured zone has been treated separately in the analyses 
presented in this report. The ECRB Cross-Drift exposes the middle nonlithophysal zone from Stations $10+15$ to $14+44$. In general, the rocks are densely welded, crystallized, and have various amounts of vapor-phase corrosion and mineralization. The rock contains 1 to 2 percent crystal fragments, 1 to 5 percent lithic fragments, 1 to 15 percent pumice fragments, 0 to 3 percent lithophysae, and 76 to 97 percent matrix-groundmass. The matrix-groundmass has two main colors that appear to result from variations in the types of crystallization, but locally there are gradations between these two types that form a heterogeneous mix of colors and crystallization products. One type of rock is a mix of grayish orange-pink (5YR7/2), grayish red (5R4/2), and grayish red-purple (5RP4-5/2) that locally has small veinlets and stringers. The other type of rock is pale brown (5YR6/2), light brown (5YR6/3-4), and moderate brown (5YR4/3), grayish brown (5YR6/1), or pale red (5-10R6/2). The matrix-groundmass contains 0 to 25 percent, white (N9), very light gray (N8), and light gray (N7) to grayish pink (5R8/2) spots, veinlets, streaks, rims on fractures, stringers, and vapor-phase partings of crystallized materials. Smooth, high-angle fractures are typical of the zone, but it also contains some lowangle, continuous shears and cooling joints. Another feature characteristic of the Tptpmn is the presence of concentrations of vapor-phase minerals along vapor-phase partings and these features appear as low-angle continuous partings subparallel to the dip of the unit. The lithophysae-bearing subzone (Tptpmn2) described by Buesch et al. (1996 [DIRS 100106]) occurs in the ECRB Cross-Drift and has 1 to 3 percent lithophysae (Mongano et al. 1999 [DIRS 149850]), but this subzone does not occur in the Main Drift of the ESF (Mongano et al. 1999; Buesch and Spengler 1998 [DIRS 101433]).

Tptpll-The Tptpll is exposed in both the ESF main loop and ECRB Cross-Drift. The ESF main loop exposes the uppermost few meters of the lower lithophysal zone from Stations 57+29 to 58+78. The lower lithophysal zone is exposed along the ECRB Cross-Drift from Stations $14+44$ to $23+26$. The rocks are densely welded, crystallized, lithophysal, and have various amounts of vapor-phase corrosion and mineralization. The rocks are composed of 1 to 2 percent crystal fragments, 1 to 5 percent lithic fragments (locally 12 to 15 percent), 0 to 7 percent pumice fragments (locally 10 to 35 percent), 5 to 30 percent lithophysae (locally 1 to 5 percent), and 56 to 93 percent matrix-groundmass. The matrix-groundmass is a mottled mix of pale red (5R6/2, 5R5/2, 10R6/2-3) and pale to light brown (5YR6/2; 5YR6/3; 5YR6/4), and moderate brown (5YR4-5/4) with variable amounts of pale to grayish red-purple (5RP5-7/1-2 to 5RP4/2), and locally it is dusky yellowish brown (10YR3/2). The matrixgroundmass contains 3 to 20 percent (locally 15 to 40 percent) grayish orange-pink (5YR7/2) or pinkish gray (5R8/2; 10R8/2) to light or very light gray (N7; N8) spots, veinlets, streaks, rims on fractures, stringers, and vapor-phase partings of crystallized materials. Lithophysae vary in size from a few centimeters to greater than $1 \mathrm{~m}$ in diameter.

Tptpln-The Tptpln is not exposed in the ESF main loop, but is exposed in the ECRB Cross-Drift from Stations $23+26$ to $25+85$. The rocks are densely welded, crystallized pyroclastic-flow material and typically are composed of 1 to 2 percent crystal fragments, 3 to 7 percent lithic fragments, 3 to 20 percent pumice fragments, 0 to 5 percent lithophysae, and 66 to 93 percent matrix-groundmass. Rocks of the lower nonlithophysal zone vary from a heterogeneous mix of grayish red and grayish orange pink (5YR7/2) matrix-groundmass to comparatively homogeneous pale red, light brown, pale brown, or grayish brown (5YR6/4) matrix-groundmass. Veinlets, streaks, and stringers form a minor component of the rock in some portions of the unit. In proximity to the Solitario Canyon fault zone, the unit is brecciated and 
altered. In this area, the breccia matrix varies from moderate reddish brown to grayish orange pink. Some breccia clasts adjacent to the fault plane are very light gray.

\subsubsection{Geotechnical Characterization}

Geotechnical data were collected based on two empirical rock mass classification systems: the Norwegian Geotechnical Institute rock quality system (Q system) (Barton et al. 1974 [DIRS 101541]) and the Geomechanics Rock Mass Rating (RMR) system (Bieniawski 1989 [DIRS 101715]). Ratings are assigned to a 5-m length of tunnel using both rock classification systems. The use of this relatively short rating length may have the disadvantage of introducing variations in some evaluated parameters, which may be expected to be stable, yet it has the advantage of capturing expected variations in more unstable parameters. For example, using the Q system, the number of joint sets could be considered constant over a long reach of tunnel. Using a 5-m rating length permits evaluation of the actual occurrence of a particular joint set; therefore, the rating value for the number of joint sets may vary within a 10-m reach of tunnel. On the other hand, the 5-m rating length permits a description of the changes in fracture frequency represented by the rock quality designation (RQD). Overall, the 5-m rating length emphasizes changes in rock quality from one length to the next. When longer reaches of the tunnel or various stratigraphic units are compared, differences in the trends of the 5-m ratings and differences in the average ratings are meaningful. The geotechnical characterization of lithostratigraphic units is described in this section and is based on Mongano et al. (1999 [DIRS 149850]). It must be recognized that application of geotechnical characterization methods and determination of rock "quality" is problematic in lithophysal rocks since these classification systems are based on the presence of fractures as the primary structural features and have no provision for lithophysal cavities. Therefore, it was considered that the RQD rating accounts for the presence of lithophysal cavities. The difficulty inherent in correspondence of RQD based on cross-cutting fractures and RQD based on isolated cavities in a solid rock matrix tends to downplay the utility of rock mass classifications in lithophysal rock.

Tptpul-The Tptpul (Stations $0+00$ to $10+15$ and Stations 23+26 to 25+85), the longest reach of the ECRB Cross-Drift, has the lowest RQD rating (36 [poor]), yet the highest Q system rating (14 good). The Tptpul RMR value (57 fair) equals the RMR value of the Tptpll and its lithophysae content ranges from 10 to 40 percent by volume. These cavities average $10 \mathrm{~cm}$ in diameter. Fractures are difficult to distinguish, with an average of only one joint set. No key blocks are expected to form within this unit; however, there are occasionally some horizontal cooling joints. It has 11 faults, 1 fault zone, and 25 shears or shear zones.

Tptpmn-The Tptpmn (Stations 10+15 to 14+44) has a mean horizontal RQD rating of 60 (fair) including lithophysae, and 62 (fair) excluding lithophysae. The tunnel-calculated Q rating is 12.7 (good). The RMR system rates the Tptpmn and the Tptpln as the highest, with a rating of 60 (fair). The unit is generally characterized by less than 3 percent lithophysae by volume. The Tptpmn has $430 \mathrm{~m}$ of exposure in the ECRB Cross-Drift and has the least amount of fault/shear activity with a total of 1 fault zone, 6 faults, and 13 shears. It has an average of three to three+ random joint sets. The horizontal joint sets, or vapor-phase partings, cause the formation of key blocks at Stations $10+80$ to $11+55$ and Stations $13+10$ to $13+15$. 
Tptpll-The Tptpll (Stations $14+44$ to 23+26) has a horizontal RQD rating of 42 (poor). Its tunnel-calculated Q rating is 7.9 (fair), the lowest in the ECRB Cross-Drift. The RMR system estimates this unit at 57 (fair). The Tptpll is generally characterized by lithophysae of 5 to 30 percent by volume and that range in size from 5 to $130 \mathrm{~cm}$. The larger lithophysal cavities tend to be irregular or ellipsoidal features that exhibit prismatic fracturing. The unit has an average of two+ random joint sets; however, no key-block problems are apparent. The Tptpll has 4 faults and 30 shears exposed in $882 \mathrm{~m}$ of rated tunnel.

Tptpln-The Tptpln (Stations 23+26 to 25+85) has the best horizontal RQD ratings: 62 (fair) including lithophysae, and 67 (fair) excluding the lithophysal cavities. Its tunnel-calculated $\mathrm{Q}$ rating is 12.3 (good). The RMR system rates this unit at 60 (fair). This unit is characterized by generally less than 3 percent lithophysal cavities by volume. The Tptpln has an average of three joint sets, with no significant key-block occurrences, and has 6 faults and 36 shear or shear zones.

\subsubsection{Discussion of Engineering Characteristics of Rock Mass Important to Geomechanical Performance}

The structure of the rock mass plays an important role in defining the structural response of the repository to thermal and mechanical loading. In particular, the fracture geometry and properties and the amount of lithophysal porosity are the primary geologic structures of importance. Extensive geotechnical mapping of fractures has been performed in the entire ESF main loop and the ECRB Cross-Drift (CRWMS M\&O 1998 [DIRS 102679]; Mongano et al. 1999 [DIRS 149850]). Figure 6-4 shows a schematic of the Topopah Spring Tuff illustrating the general occurrence of fracturing and lithophysae in the various zones of the formation. The occurrence of fractures and lithophysae are roughly inversely proportional. This is illustrated schematically in Figure 6-4 and demonstrated quantitatively in Figure 6-5, where the fracture density (fractures with trace length greater than $1 \mathrm{~m}$ ), determined from detailed line mapping (i.e., the detailed line survey), and the approximate percentage of lithophysal porosity in the ECRB Cross-Drift are shown. The density of fractures with trace length greater than $1 \mathrm{~m}$ is significantly larger in the Tptpmn and Tptpln (20-35 fractures/10 m), as compared to five fractures/10 $\mathrm{m}$ or less in the Tptpul and Tptpll. 


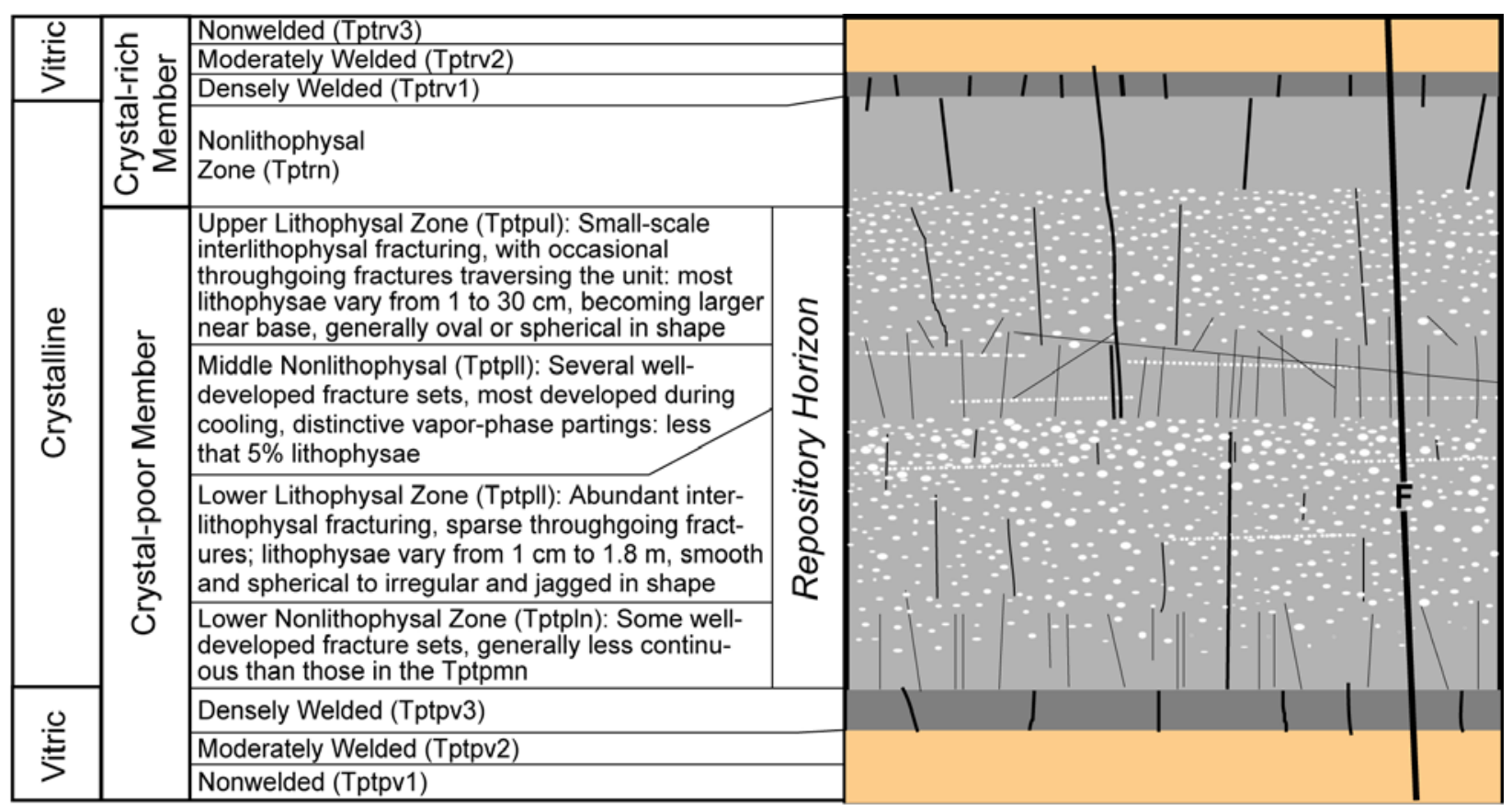

Diagrammatic Cross Section of the Topopah Spring Tuff Illustrating Relative Discontinuity Densities and Orientations: This figure indicates how fractures, faults, and lithophysae are typically distributed through the ignimbrite.

Legend
Densely welded, crystalline rocks; white dashed lines indicate
vapor-phase partings; white circles and ellipses indicate lithophysae;
black lines indicate fractures.
Densely welded, vitric rock; black lines indicate fractures.
Nonwelded to moderately welded, vitric rocks;
black lines with "F" designation indicate faults.

Source: Buesch et al. 1996 [DIRS 100106], Appendix 2; Mongano et al. 1999 [DIRS 149850], pp. 12 to 43.

Figure 6-4. Schematic Illustration of the Structure of the Topopah Spring Tuff 


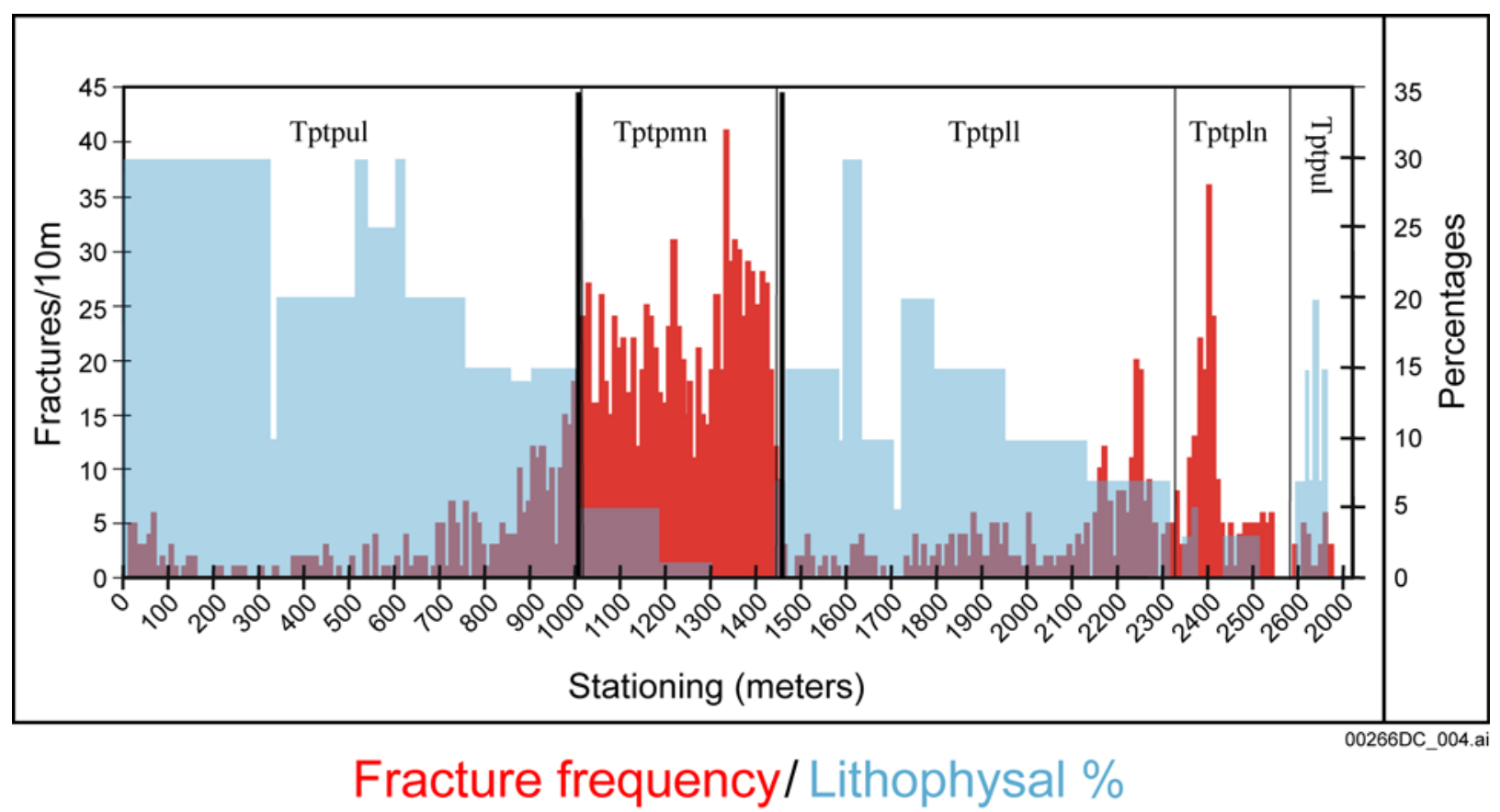

Source: Mongano et al. 1999 [DIRS 149850], Figure 13.

Figure 6-5. Fractures and Lithophysal Abundance in the ECRB Cross-Drift from Stations $0+00$ to $27+00$

\subsubsection{Fracturing}

The discussion of fracturing presented in this section is based on Mongano et al. (1999 [DIRS 149850]). Full periphery geologic mapping and detailed line surveys (consisting of a description of orientation, trace length, small and large scale roughness, and end terminations for fractures with trace lengths of greater than or equal to $1 \mathrm{~m}$ ) were performed in the drifts. The database consists of over 35,000 entries and is recorded on CAD drawings as well as spreadsheets. There are, in general, four sets of fractures in the Tptpmn with the characteristics identified in Table 6-1.

The fractures have relatively short continuous trace lengths (Figure 6-6), with ends often terminating either against other fractures or in solid rock, leaving a solid rock "bridge" between joint tracks. Full periphery geologic maps that logged the fracture traces with lengths greater than $1 \mathrm{~m}$ were created behind the tunnel boring machine as the ESF main loop and the ECRB Cross-Drift were driven. A typical full periphery geologic fracture map is shown in Figure 6-7. Figure 6-8 provides a photograph typical of the wall of the ECRB Cross-Drift within the Tptpmn, and shows the discontinuous nature of the fractures in each joint set. The fracture traces were painted during the detailed line mapping (Figure 6-8). Each fracture termination was logged as being against another fracture, within solid rock, or continuous. The photo shows the common occurrence of fractures that terminate in solid rock (T-junctions) as opposed to continuous structures (arrowheads). The sub-vertical fractures, in particular, often have curved surfaces with large-amplitude (dozens of centimeters) asperities and wavelength of meters. Fractures sometimes terminate in solid rock with discontinuous interconnection to adjacent joint tracks (i.e., a rock "bridge”) or terminate against other joints. 
Table 6-1. General Characteristics of Fracture Sets in the Middle Nonlithophysal Unit

\begin{tabular}{|c|l|c|c|l|}
\hline Set & $\begin{array}{c}\text { Mean } \\
\text { Azimuth/Dip }\end{array}$ & $\begin{array}{c}\text { Median } \\
\text { Spacing }(\mathbf{m})\end{array}$ & $\begin{array}{c}\text { Median Trace } \\
\text { Length }(\mathbf{m})\end{array}$ & \multicolumn{1}{c|}{ Comment } \\
\hline 1 & $120 / 84$ & 0.48 & 3.3 & Rough to smooth, planar \\
\hline 2 & $215 / 88$ & 1.08 & 2.8 & Smooth but curved \\
\hline 3 & $302 / 38$ & 3.40 & 3.7 & Random fractures with generally flat to moderate dip \\
\hline 4 & $329 / 14$ & 2.46 & 3.5 & $\begin{array}{l}\text { Vapor-phase partings, rough, cohesive with coating } \\
\text { minerals, planar }\end{array}$ \\
\hline
\end{tabular}

Source: Median spacing and trace length are from tunnel mapping data (see Table 6-2).

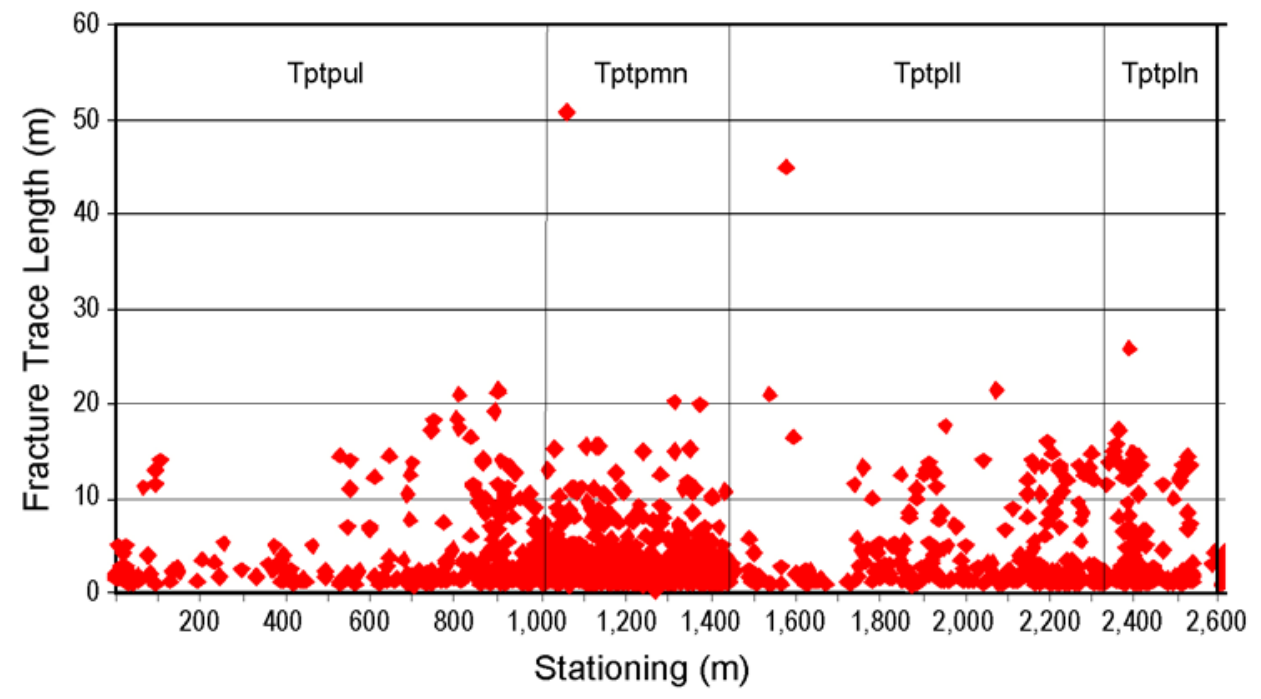

Source: Mongano et al. 1999 [DIRS 149850], Figure 14.

Figure 6-6. Fracture Trace Length from Detailed Line Surveys as a Function of Stationing Along the ECRB Cross-Drift 


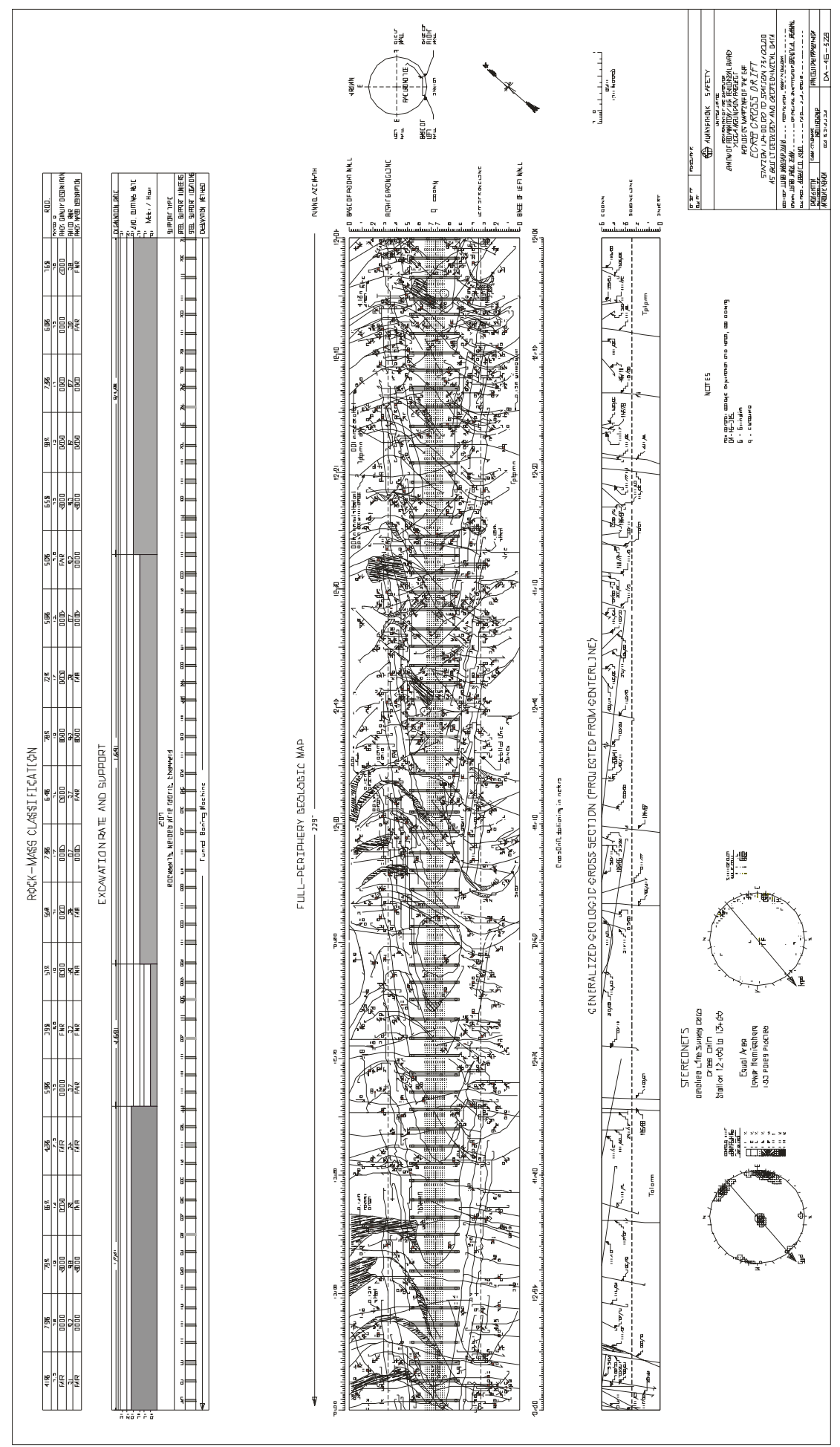

Source: DTN: GS990408314224.004 [DIRS 108405].

NOTE: The purpose of this figure is to illustrate the geologic structure contained on a full periphery geologic map. The annotated information on this figure is not intended to be legible. An enlarged, legible map is available through the source DTN.

Figure 6-7. Illustrative Example of a Full Periphery Geologic Map from the ESF, Tptpmn 


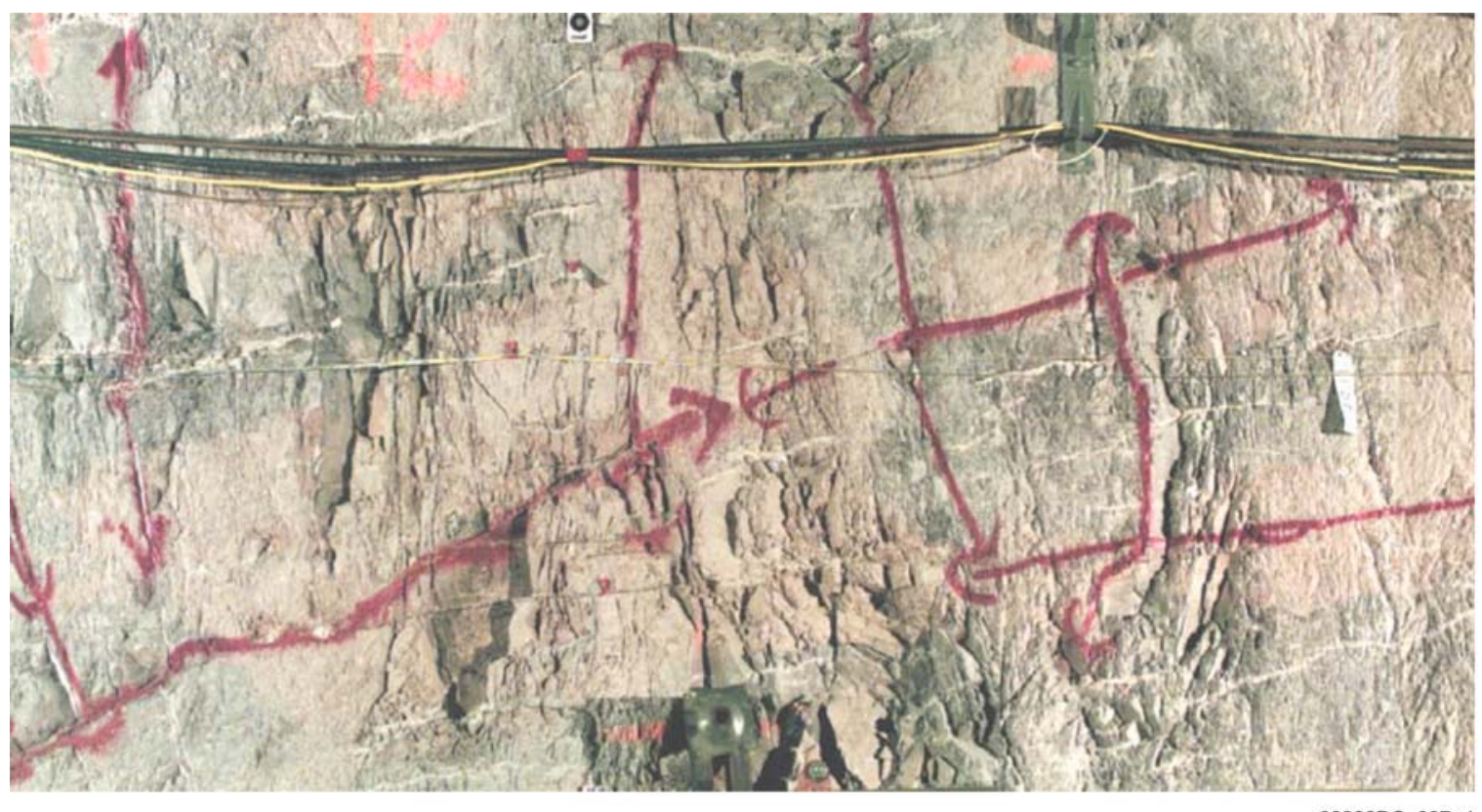

NOTE: T-junctions on fractures indicate terminations; arrowheads show continuous features.

Figure 6-8. Fractures in Wall of the ECRB Cross-Drift in the Tptpmn

The sub-horizontal vapor-phase partings (Figure 6-9) are relatively continuous structures seen throughout the Tptpmn. These continuous, but anastomosing fractures are sub-parallel to the dip of the rock unit, and are filled with concentrations of vapor-phase minerals (primarily tridymite and cristobalite). The surfaces are rough on a small scale and, as a result of the mineral filling, they have cohesion (unlike the sub-vertical fractures).

The nature of the fracture geometry is extremely important to estimates of the stability of the rock mass, particularly under seismic shaking, as well as to estimates of the support function and level of required ground support. Most rock mass classification schemes are based on experience of rock masses with continuous joint sets that create regular, blocky masses (e.g., Hoek 2000 [DIRS 160705]). In the Tptpmn, the relatively short trace lengths and non-persistent joints create relatively few kinematically removable blocks. This sparseness is evidenced by the fact that only a very small number of rock blocks have actually been removed in the ECRB Cross-Drift. Those blocks removed actually occurred under the action of the tunnel boring machine or were scaled out of the back and walls.

Short-length fractures (less than 1-m trace length), coupled with the lithophysae, are the most important features that govern stability in the Tptpll because they impact the rock mass strength as described in Appendix E (Section E4). Whereas the Tptpul tends to have some small-scale fractures in the matrix-groundmass between lithophysae, and a few that intersect lithophysae (Figure 6-10a), the Tptpll has abundant fractures. Figure 6-10b, from the upper portion of the Tptpll, shows the intensive fracturing of the matrix-groundmass between lithophysae, several "circum-lithophysal" fractures (fractures that formed around or parallel to the margins of lithophysae), and very few fractures that actually intersect the lithophysae. The fractures, which exist throughout the Tptpll, have a primary vertical orientation, and have lateral spacing of a few centimeters. 
Small-scale fracture traverses in the Tptpll confirm the close spacing and short trace lengths of fractures in this zone. The intensity and short trace lengths of fractures in this zone create a texture that severely limits the potential block size in this zone. By comparing the detailed line survey (fracture greater than $1 \mathrm{~m}$ ) and the small-scale surveys, this intensity is clearly due to small-scale fractures (less than $1 \mathrm{~m}$ trace length). The detailed line survey sampled almost $880 \mathrm{~m}$ of tunnel in the ECRB Cross-Drift. There are 300 fractures recorded over this run of tunnel that have a trace length greater than $1 \mathrm{~m}$. The small-scale survey in the Tptpll can be combined into $18 \mathrm{~m}$ of horizontal sampling. There are 376 fractures recorded over this $18 \mathrm{~m}$ of sampling.

In some cases, it is difficult to distinguish whether these fractures have been disturbed by mining or induced by in situ stresses, or whether they are newly created by mining along a weakness fabric in the rock. However, it is clear that the middle portion of the Tptpll has a ubiquitous fracture fabric that is most evident when large diameter core is removed from boreholes (see Figure 7-1a). The core, although competent, has numerous fractured surfaces that break into small blocks when stressed. Lithophysae and occasional horizontal fractures tend to create blocks with dimensions on the order of about $10 \mathrm{~cm}$ or less on a side. Thin section analyses of the fracturing in the Tptpll and the Tptpmn show rims on many of the fracture surfaces within the rock mass away from the tunnel wall, indicating there are numerous natural fractures (i.e., not mining-induced) and were formed during the cooling process (Buesch 2003 [DIRS 163729]).

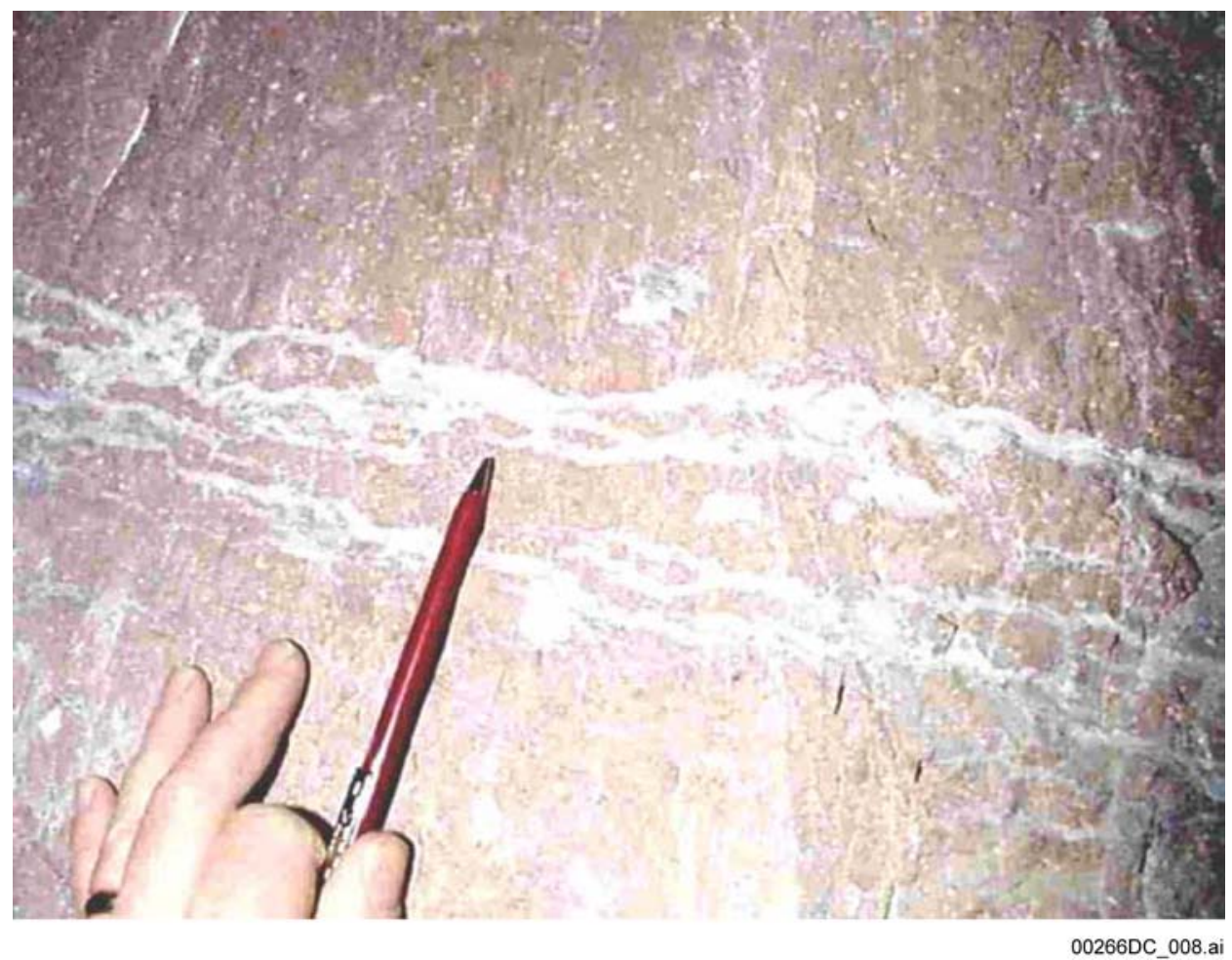

Figure 6-9. Low-Angle Vapor-Phase Partings in Nonlithophysal Units in the ESF 
(a)

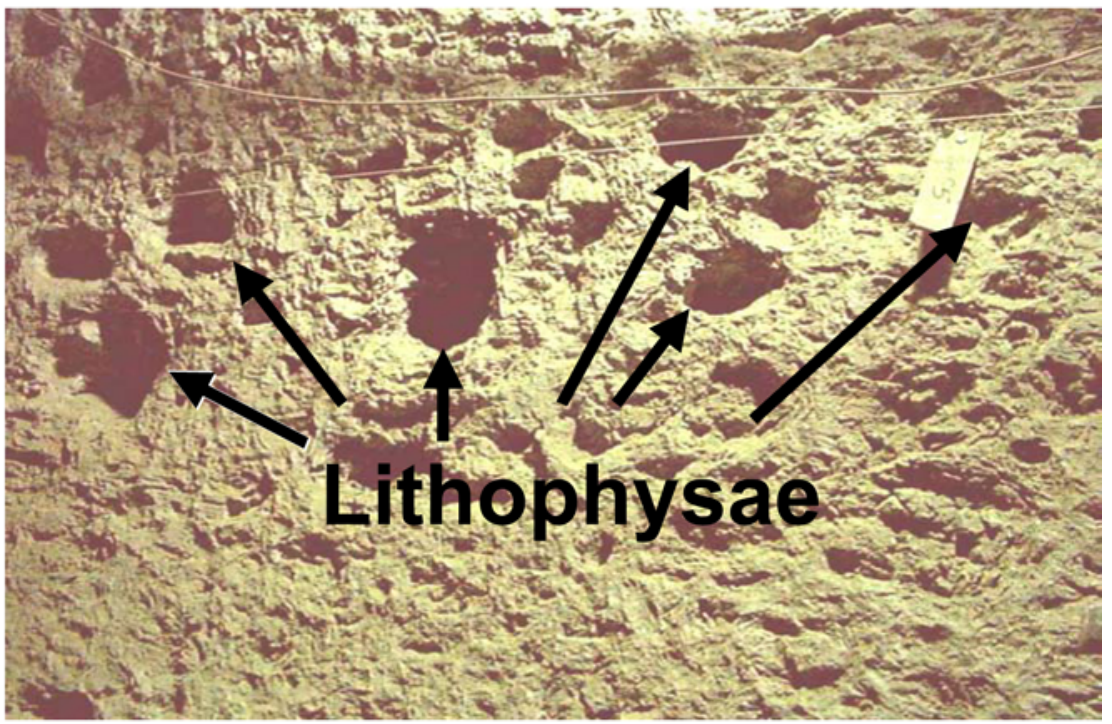

(b)

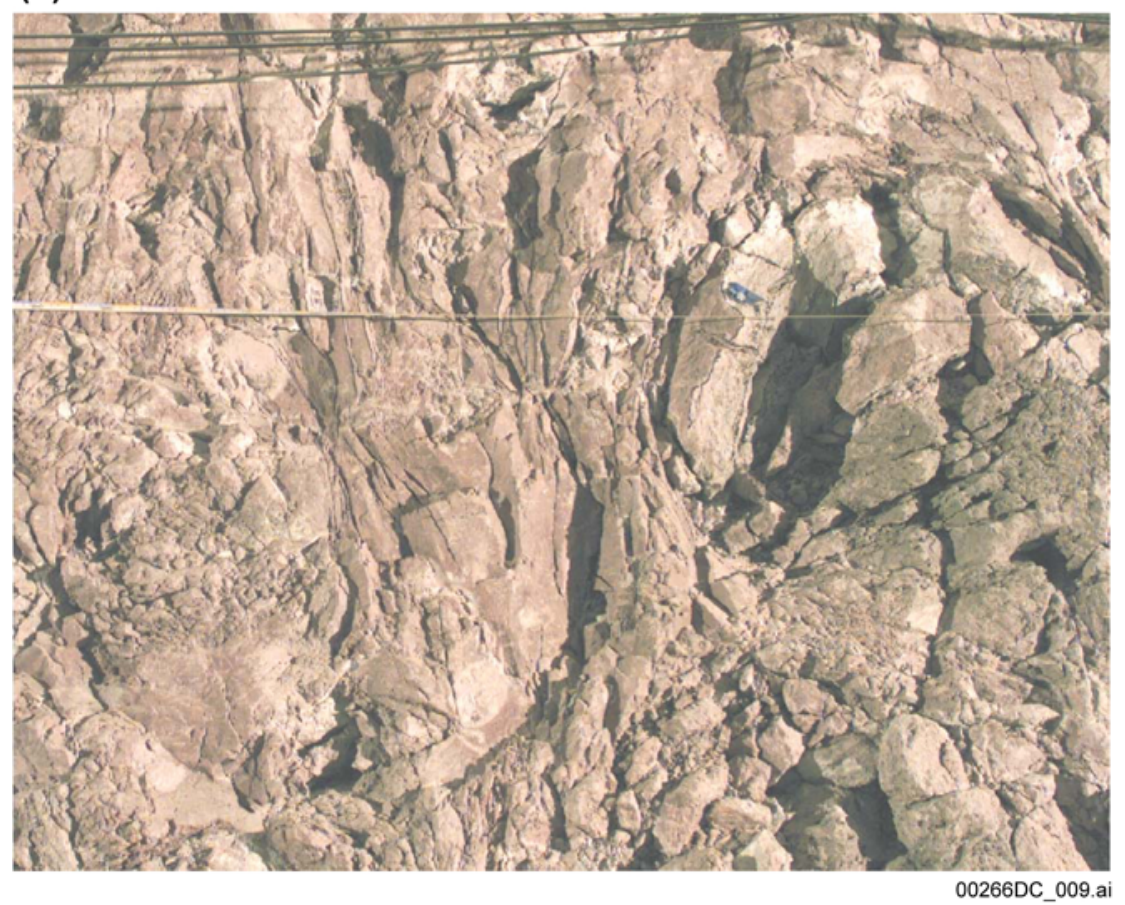

NOTE: The Tptpul (a) is characterized by a relatively few fractures in the matrix-groundmass between lithophysae whereas the Tptpll (b) has abundant, natural, short-length fractures in the matrix-groundmass, some of which intersect or connect lithophysae. Spacing of the fractures in the Tptpll is generally less than $5 \mathrm{~cm}$.

Figure 6-10. Comparison of Lithophysae and Fracturing in the Tptpul and Tptpll

\subsubsection{Lithophysae}

Although the character of the lithophysae varies between the Tptpul and Tptpll as shown in Figure 6-10, the mineralogy of the matrix material within both of these units is generally the 
same as in the nonlithophysal units, based on the rock unit descriptions provided by Mongano et al. (1999 [DIRS 149850]).

Compositionally and mineralogically the rocks in lithophysal and nonlithophysal zones are similar, but there can be variations in the amounts of quartz, cristobalite, and tridymite; however, the main difference is in the abundance of lithophysae and features formed by crystallization in the presence of the vapor phase (rims, spots, etc.). The upper and lower lithophysal zones share many characteristics, but there are also numerous distinctions (Mongano et al. 1999 [DIRS 149850]), and these general characteristics are as follows.

The lithophysae in the Tptpul:

- Tend to be smaller (roughly 1 to $10 \mathrm{~cm}$ in diameter) compared to the Tptpll

- Are more uniform in size and distribution within the unit compared to the Tptpll

- Vary in infilling and rim thicknesses

- Have a volume percentage that varies consistently with stratigraphic position

- Are stratigraphically predictable.

The lithophysae in the Tptpll:

- Are highly variable in size, from less than $1 \mathrm{~cm}$ to $1.8 \mathrm{~m}$ in size

- Have shapes that are highly variable and are described as simple (elliptical cross-sections and spherical to ellipsoidal shapes), irregular, cuspate, merged (two or more lithophysae joined into one large one), and extension-crack lithophysae

- Have infilling and rim thickness that vary greatly with vertical and horizontal spacing

- Have volume percentages that vary consistently with stratigraphic position

- Are stratigraphically predictable.

With the large amount of the repository located in the lower lithophysal zone, a detailed study of the lithostratigraphic features in the lower lithophysal zone exposed in the ECRB Cross-Drift has been completed (DTNs: GS021008314224.002 [DIRS 161910] and GS040608314224.001 [DIRS 171367]). The data package documents the distributions of size, shape, and abundance of lithophysal cavities, rims, spots, and lithic clasts, and these data can be displayed and analyzed as local variations, along the tunnel (a critical type of variation), and as values for the total zone. A detailed description of lithophysal abundance and lithophysal characteristics is provided in Appendix $\mathrm{O}$.

In addition to the along-the-tunnel variation in the abundance of features such as lithophysae, there are variations in the sizes, shapes, and distances between features. These types of variations are most easily observed with panel map data (Figure 6-11). Locations of the panel maps were positioned to capture representative variations in the rocks along the tunnel. Additional details on the development of these panel maps are provided in Appendix $\mathrm{O}$. 

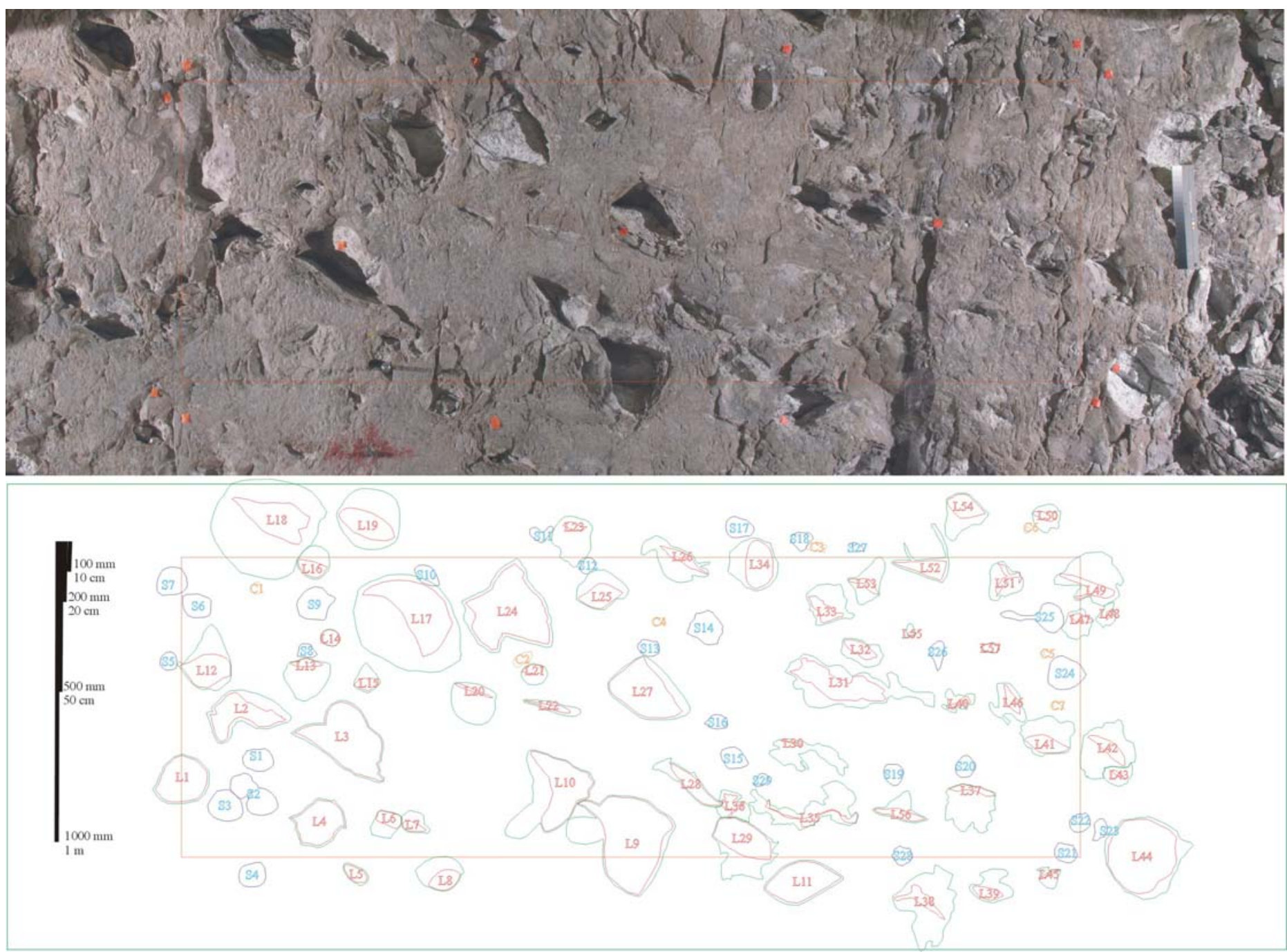

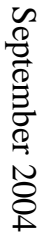

NOTE: Lithophysae have red "L" identifiers with cavities outlined in red and rims in green. Spots have blue "S" identifiers with cyan outlines. Lithic clasts have orange " $\mathrm{C}$ " identifiers with gold outlines.

Figure 6-11. Lithophysae, Spots, and Clasts of Tptpll in Panel Map 1493 Located on the Right Rib from Stations 14+93 to 14+96 
Using the approach described in Appendix O, the total porosity of the component features of the lithophysal rock mass (i.e., the porosity of the lithophysal cavities, rims, and spots) has been calculated. The porosity variation along the ECRB Cross-Drift is shown in Figure 6-12, with total porosity typically ranging from 20 to 35 percent.

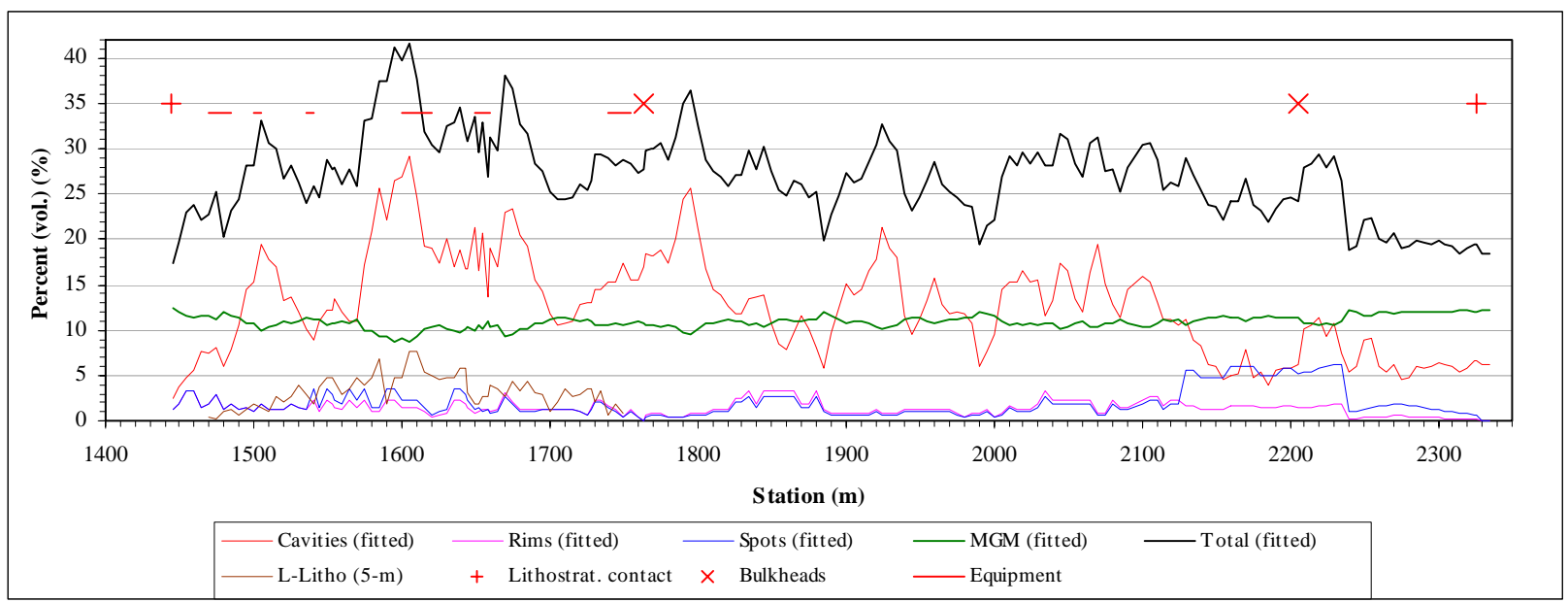

a. Porosity Along the Tunnel Displayed in Five Components (Excluding the 5-m Averaged Large-Lithophysae).

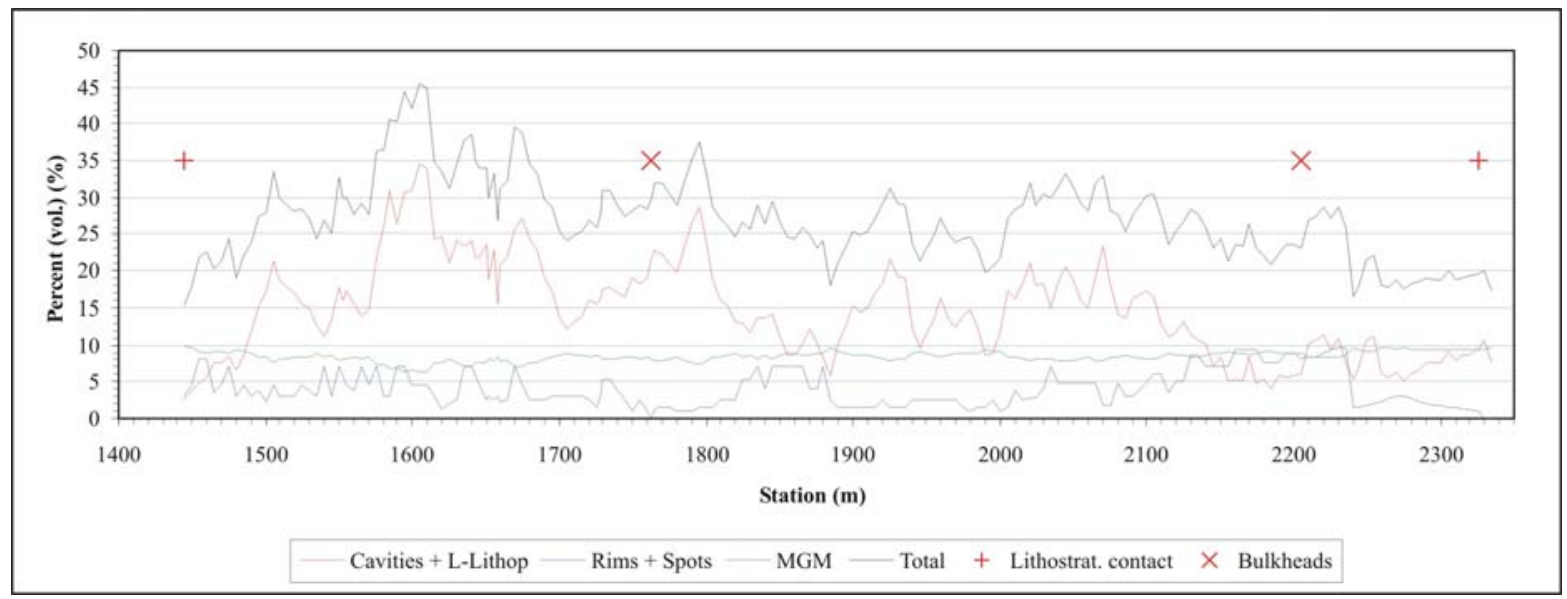

b. Porosity Along the Tunnel Displayed in Three Components (Lithophysal Cavities and Large-Lithophysae Inventory are Combined, and Rims and Spots are Combined).

NOTE: Source file provided in DTN: MO0408MWDDDMIO.002, file Drift Deg AMR AF T-A-P Fit V1.xIs.

Figure 6-12. Calculated Porosity of Lithophysal Cavities, Rims, Spots, Matrix-Groundmass, and the Total Porosity in the Tptpll Exposed Along the ECRB Cross-Drift 


\subsubsection{Field Observation of Key Blocks}

Key blocks are critical blocks in the surrounding rock mass of an excavation which are kinematically removable and oriented in an unsafe manner so that they are likely to move into an opening unless support is provided (Goodman and Shi 1985 [DIRS 150094], pp. 98 and 99). The failure of a key block opens up the excavation surface for further potential failures by subsequent blocks. Key blocks are formed by the intersection of three or more planes of structural discontinuities as shown in Figure 6-13. Key blocks in the 5-m diameter ECRB Cross-Drift are first evident in the crown at about Station 10+50 in the Tptpmn unit (note that metric stationing is used throughout the ESF; i.e., Station 10+50 is located $1050 \mathrm{~m}$ from the start of the tunnel). Most of the key blocks in this region are of minor size and typically fall immediately after excavation prior to ground support installation. Key blocks are possible in this area because of the increased presence of the plane of weakness (i.e., a vapor-phase parting) in the near horizontal orientation that intersects with two opposing near-vertical joint planes. Fallout from these key blocks during excavation is typical of the rock in the middle nonlithophysal zone (Tptpmn) of the TSw2 thermal-mechanical unit. The largest resultant void is possibly 0.5 cubic meters at approximately Station $11+55$ as shown in Figure 6-14. No unstable key blocks were observed in the field. Documentation of key blocks observed in the ECRB Cross-Drift is provided in Appendix F. 
Stereographic Projection of Key-Block-Forming Fracture Planes

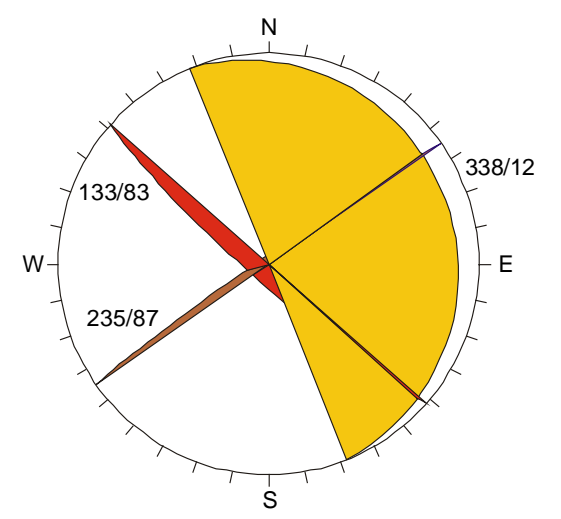

Key Block Formed by the Intersection of an Excavation with Three Fracture Planes

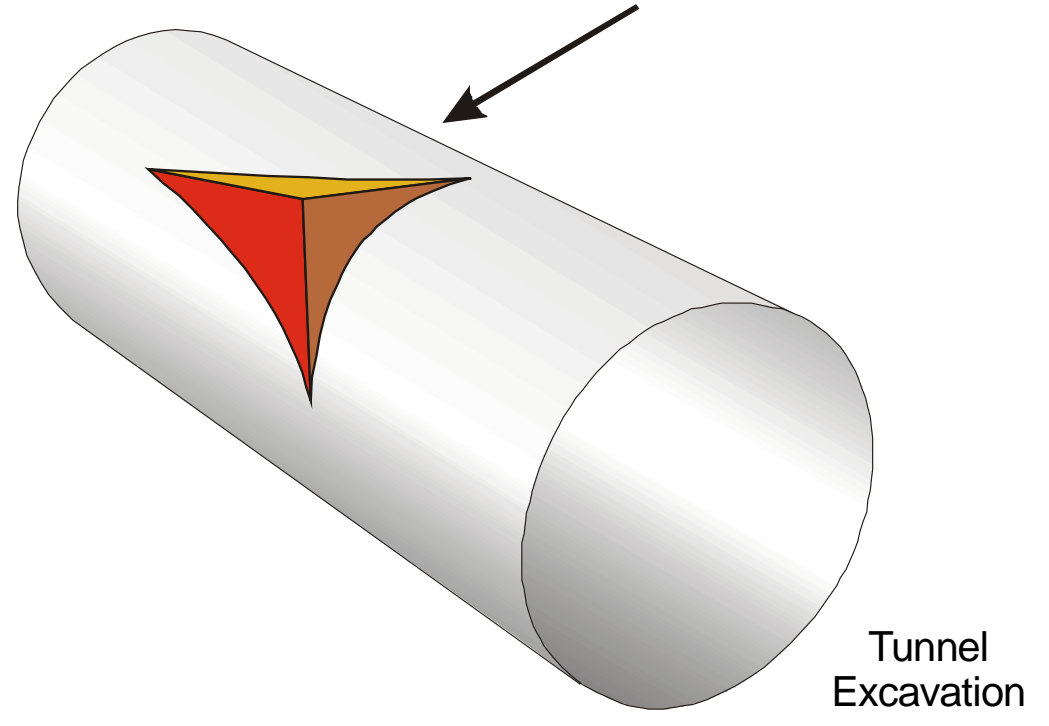




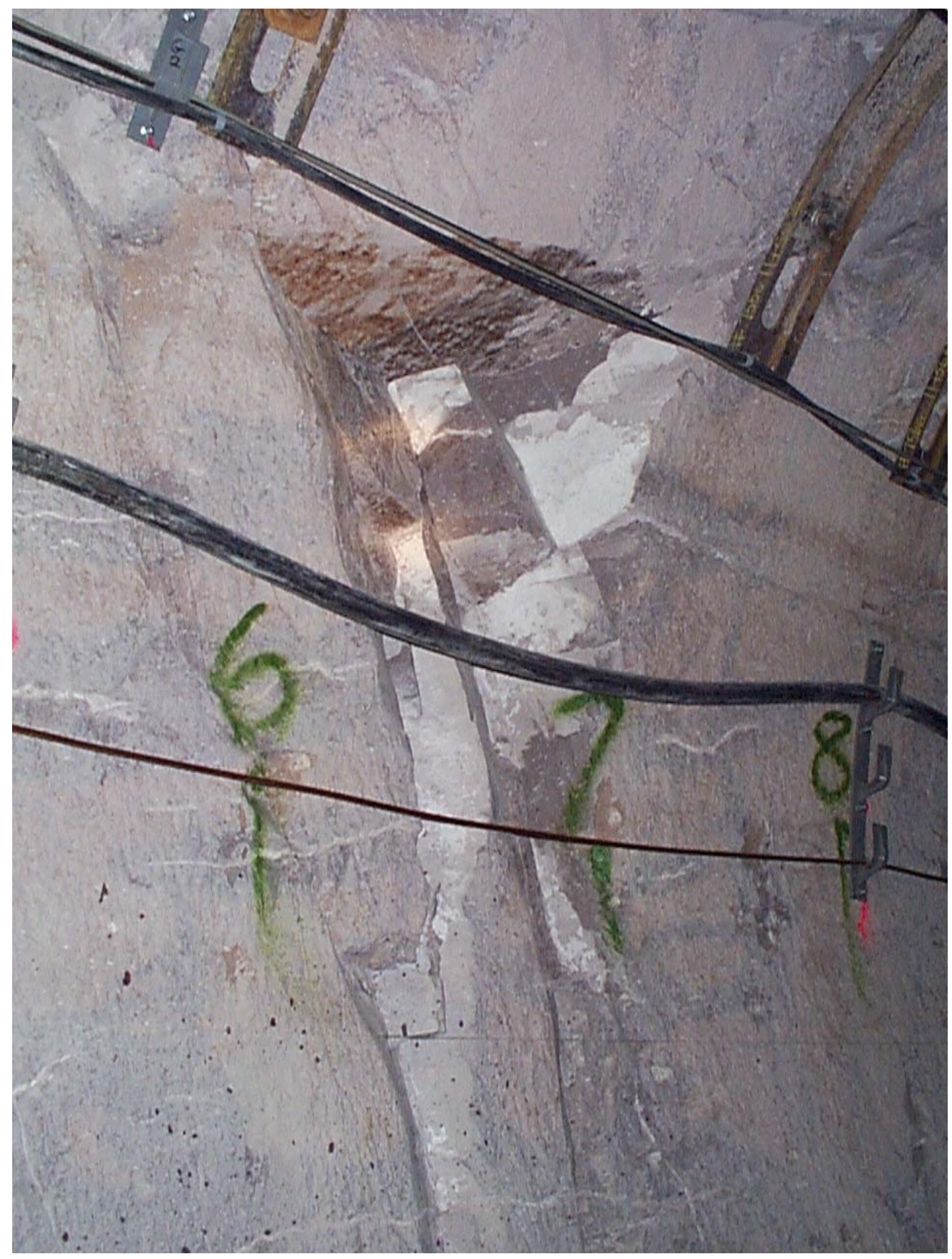

Figure 6-14. Evidence of Key-Block Occurrence in the ECRB Cross-Drift, Station 11+55

While ground support monitoring in the ESF main loop has provided long-term evidence indicating stable rock support performance, there are several sections in the ESF where raveling and block fallout have occurred. These typically corresponded to the $3.01 \mathrm{X}$ areas, and most often occurred in fault zones and in the TCw and TSw2 thermal-mechanical units. The 3.01X areas refer to sections of the ESF main loop that were constructed under Section 3.01X of the subsurface general construction specification (BSC 2002 [DIRS 161707], p. 17). The specification indicates that special actions may be necessary to continue excavation in the event 
that adverse ground conditions prevent normal tunnel boring machine operations. The location of 3.01X areas is provided by South Ramp 3.01.X Area Ground Support Analysis (CRWMS M\&O 1999 [DIRS 108441], Section 1). A typical opening profile in a 3.01X area is shown in Figure 6-15. This profile is indicative of the worst case ground conditions in the Tptpmn lithologic unit of the ESF main loop.

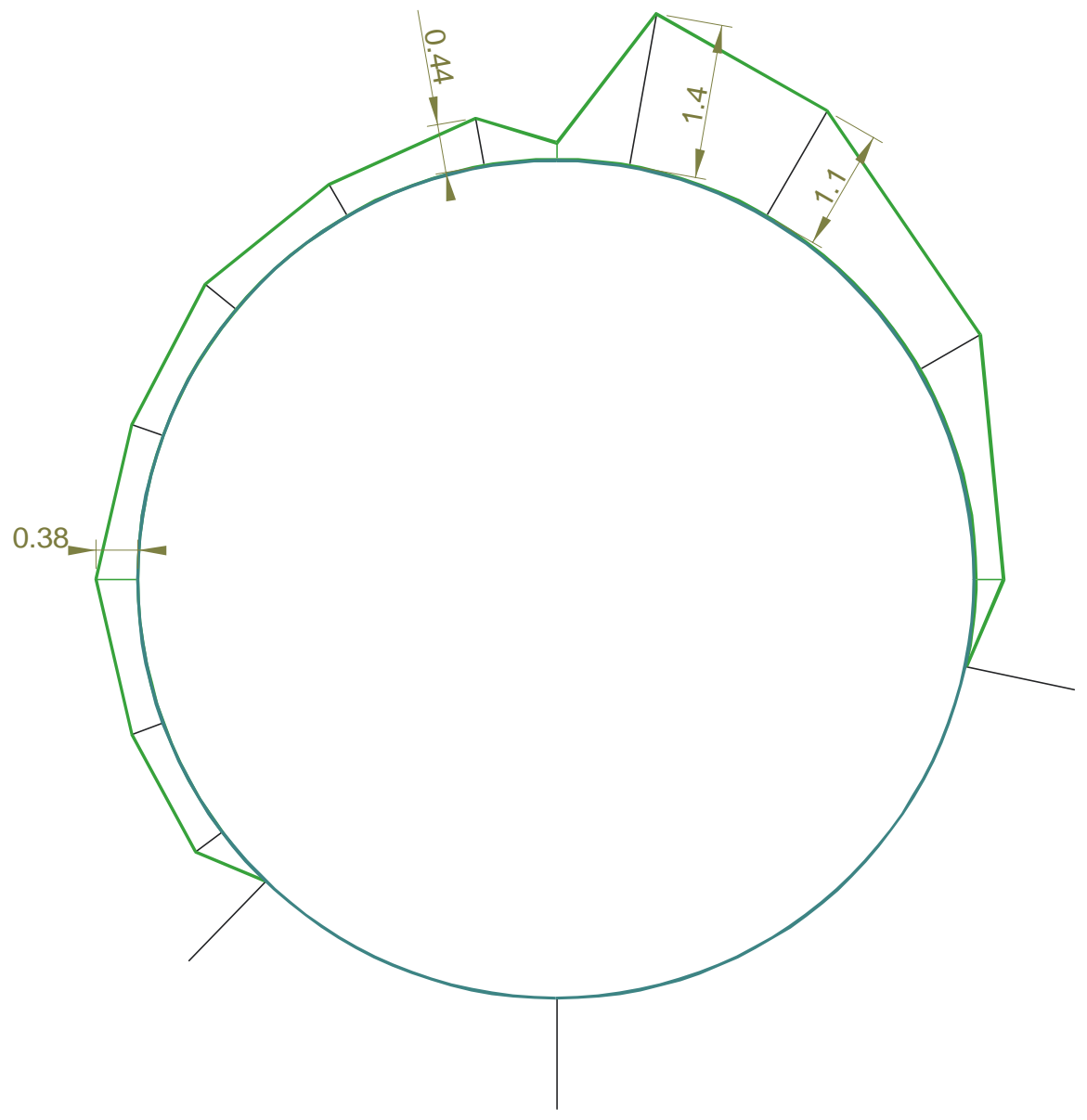

Source: CRWMS M\&O 1999 [DIRS 108441], p. 29.

NOTE: Dimensions are in meters.

Figure 6-15. Opening Profile at ESF Main Loop Station 60+24.70 (Steel Set \#1272, Tptpmn Lithostratigraphic Unit) Based on Field Survey Data

\subsubsection{Generation of Representative Rock Volumes Using FracMan}

\subsubsection{Background}

Analysis of seismic response and rockfall in emplacement drifts in fractured, nonlithophysal rock is, in general, a three-dimensional problem requiring the rock mass to be represented as an explicitly fractured assemblage. To achieve this objective, the 3DEC three-dimensional discontinuum program (see Section 6.3.1) is used to model the mechanical response of a rock block assemblage subjected to in situ, thermal, and seismic loads. The 3DEC program allows direct input of the fracture geometry in creation of a "synthetic" rock mass composed of an 
assemblage of blocks within which emplacement drifts may be simulated. The details of the 3DEC model are described in Section 6.3.1.1.

The blocks of nonlithophysal rock are significantly stronger than the in situ and thermally induced stresses, and thus the problem of modeling this material is essentially one of elastic blocks separated by fracture surfaces. Therefore, in modeling of the stability of the tunnels and the rockfall that may occur from the applied load, the fracture geometry and surface properties become of primary importance. A methodology for defining statistically representative fractures is therefore required as an input to the 3DEC program for development of the rock block structure. In particular, the input fracture geometry must provide an adequate representation of the orientation, length (area), spacing and continuity of fractures and their variability, as this controls the size and number of kinematically removable blocks that surround the tunnel. Additionally, the surface characteristics, including roughness, planarity, and alteration/infilling define the shearing and tensile resistance of the fractures under load. In the following section, the generation of a statistically representative network of fractures for describing the repository host horizon subunits is described. In particular, the fracturing within the Tptpmn unit is given since this unit represents the largest emplacement area of nonlithophysal rock.

\subsubsection{FracMan Program Approach to Fracture Geometry Analysis}

The development of a stochastically defined fracture system, representative of the host horizon rock mass is accomplished using the FracMan program (USGS 1999 [DIRS 160577]). FracMan is a special-purpose fracture-analysis tool that was developed for the creation of synthetic fracture representations for use in hydrologic modeling, reservoir engineering, and rock mechanics applications. It has been used for preliminary hydrologic modeling of Yucca Mountain (Anna 1998 [DIRS 144421] and Anna 1998 [DIRS 138501]) for estimation of rock mass permeability.

The existing fracture mapping database (see fracture geometry data in Table 4-1) provides the basic input to the FracMan program, which develops sets of planar, circular fractures whose geometric parameters conform to the statistical variability of the geometric characteristics of the input data. Statistical models are fitted to the various geometric characteristics of each fracture set in the database, followed by generation of representative fracture sets. These representative fractures are then back-checked against the statistical variability and geologic realism of the original sets (i.e., field data) to achieve an acceptable facsimile. The FracMan simulations are not intended to replicate actual field conditions but to create a reasonable facsimile of these conditions based on the observed data.

The use of the FracMan program for providing a calibrated set of fractures representative of the repository host horizon is considered to be a scientific analysis governed by procedure AP-SIII.9Q. The definition of a scientific analysis in this procedure is (pg. 6):

A documented study that 1) defines, calculates, or investigates scientific phenomena or parameters; 2) evaluates performance of components or aspects of the overall geologic repository; or 3) solves a mathematical problem by formula, algorithm, or other numerical method. A scientific analysis may involve numerical manipulations that are not part of a previously developed and 
validated mathematical model (per AP-SIII.10Q,, Models) if the choice of method is evident from standard scientific practice, approach, or method.

Use of FracMan as a scientific analysis is justified based on the following considerations:

- FracMan is used to investigate and evaluate the stochastic variability of fracture geometry only. FracMan is not used to model a physical process (e.g., rockfall) that involves prediction or extrapolation of physical response.

- FracMan is used only to provide a reasonable facsimile of the occurrence and variability of fracturing in the Tptpmn and Tptpll units. To provide this facsimile, the model is calibrated against the existing field data in such a way that the statistical variability of the dip, dip direction, spacing (intensity) and trace length can be verified to be quantitatively similar.

- The FracMan analysis is not used for extrapolation purposes, but only to provide a calibrated representation of the fracture geometry represented by the database from which it is derived. This database is obtained from detailed line survey and full periphery geologic mapping in the ESF and ECRB Cross-Drift. The ESF provides a North-South sampling over a substantial length of the Tptpmn along the eastern boundary of panels 1 and 2 of the proposed repository, and the ECRB Cross-Drift cuts across all repository host horizon units on a NE-SE azimuth through the center of the repository (see Figure 1-2). It is considered that this total sampling reasonably represents the range of fracture geometries with trace lengths of $1 \mathrm{~m}$ or longer, to be expected within the repository and the Tptpmn in particular. Therefore, the FracMan representation, calibrated to the complete fracture database provides a similar representation of the fracture variability in the Tptpmn in particular. In this manner, FracMan is not used to extrapolate fracture geometry to new regions since it is implicit in this approach that the fracture database provides a reasonable representation of the fracture variability throughout the repository host horizon.

- FracMan is a fracture geometry simulation program that is commonly used in industrial and scientific practice.

Based on these considerations, model validation, as described in procedure AP-SIII.10Q, Models, is not required for the fracture simulation analysis described in this section.

The FracMan simulations consist of development of cubical regions of fractures, 100-meter on-a-side, representing the Tptpmn and Tptpll lithostratigraphic zones of the repository horizon. The regions are populated with simulated fracture networks to represent the rock mass of the respective zones. Data from the detailed line survey and full periphery geologic mapping are used as a basis for constructing the representative fracture networks in these regions. As previously discussed, these data consist of fractures with trace lengths of one meter or greater. Each fracture is described by its centroid coordinate, dip, dip direction, and radius. These geometric properties are used as input to the 3DEC program for development of a block geometry within which emplacement drifts can be randomly excavated. Development of the Tptpmn FracMan cube is described in this section to represent the modeling approach used for 
nonlithophysal rock. Details for the analysis of the Tptpll long-fracture network, which represents the lithophysal rock within the repository, are provided in Appendix B.

\subsubsection{Fracture Studies in the ESF and ECRB Cross-Drift}

\subsection{Data Sources}

There are two primary data sources for subsurface fractures within the repository horizon at Yucca Mountain: the detailed line survey and the full-periphery geologic mapping (Beason et al. 1996 [DIRS 101191]; Barr et al. 1996 [DIRS 100029]; Albin et al. 1997 [DIRS 101367]; Eatman et al. 1997 [DIRS 101219], Mongano et al. 1999 [DIRS 149850]). The detailed line survey presents a detailed inventory of fractures and fracture attributes as measured in the ESF and ECRB Cross-Drift. The survey was conducted using a traverse located $0.9 \mathrm{~m}$ below the right-rib springline in the ESF (Albin et al. 1997 [DIRS 101367], p. 10; Eatman et al. 1997 [DIRS 101219], p. 8) and at the left-rib springline in the ECRB Cross-Drift (Mongano et al. 1999 [DIRS 149850], p. 9). Data collected by the detailed line survey included information on fracture location (i.e., station), orientation, trace length, width, roughness, among others. The full periphery geologic mapping presents a "rolled-out" record of geologic conditions encountered during tunnel excavation activities. The maps are hinged at the crownline and unrolled to produce flat maps of the tunnel periphery at 100-m intervals. The maps record lithostratigraphic contacts and structural discontinuities (i.e., fractures, faults, and shears) with trace lengths longer than $1 \mathrm{~m}$, as well as engineered features (e.g., rock bolts, steel sets, and installed lagging).

As previously discussed, both the detailed line survey and the full periphery geologic map methods exhibit an inherent sampling bias in that fractures approaching the orientation of the survey line will be underrepresented. Various methods exist for evaluating this bias. The Terzaghi correction (Terzaghi 1966) is a commonly used method to evaluate this directional bias in these types of linear surveys. However, the need for bias correction is avoided in the FracMan model, because the simulations are constructed to reproduce the statistical variability of the field data. As a result the output from a FracMan detailed line survey, similarly oriented to a comparable ESF detailed line survey, will automatically recreate the same bias as exists in the field data, confirming the accurate reproduction of field conditions in the FracMan simulations. In other words the same bias encountered in collecting the observed data is sampled in the synthetic data allowing a valid comparison without necessitating bias correction for the observed fractures. For this reason there is no requirement to apply corrections to evaluate bias. Comparisons of simulated detailed line surveys to the actual field surveys are presented in Section 6.1.6.4.

\subsection{Representativeness of ESF and ECRB Cross-Drift Data of the Tptpmn Across the Repository Emplacement Area}

Fracture data from the existing ESF and ECRB Cross-Drift excavations has been used for developing the FracMan analysis. Although the excavations traverse a large portion of the subsurface area being considered for the repository, they do not extend to the limits of the proposed repository area (Figure 1-2). To investigate changes in the geometry and character of fractures outside the existing excavations, studies of fractures were implemented in surface exposures of Topopah Spring Tuff at various locations around Yucca Mountain. These studies 
examined the significant outcrops of the repository host horizon in the vicinity of the site. These areas included Solitario Canyon (west of the proposed repository area), WT-11 wash (south of the site), Windy Wash (northwest of the site), and Yucca Wash (north of the site).

In each of these areas, the purpose of the data collection was to determine how fracture orientation might vary with distance from the repository area. Orientation data was collected, along with some fracture characteristics and notes, from the four zones in the repository host horizon (i.e., the Tptpul, Tptpmn, Tptpll, and Tptpln). The bulk of the data was collected in the Tptpmn, as this unit is the most erosion resistant. Comparing the fracturing in the Tptpmn from around the periphery of the site allows a relatively easy evaluation of the changes in fracture orientation. Useable outcrops of the other zones - Tptpul, Tptpll, and Tptpln - are sparse in the Yucca Mountain area.

Note that fracture orientation data is only a portion of the fracture data used to develop fracture sets in the FracMan analysis. The analysis has used a hierarchical approach to develop the fracture geometry in FracMan. This approach starts with fracture length, based on the consideration that the long fractures formed first, shorter fractures thereafter. An orientational analysis was then done of the different length fractures to determine the orientation of the fracture sets. Fracture length however, is not easily collected on a systematic basis at outcrop, so a comparison of orientations has been used here for simplicity.

Data from the various Tptpmn outcrops around the Yucca Mountain area show remarkable consistency in fracture orientation. Measurements from the Tptpmn in Solitario Canyon, even far south of the repository area show essentially identical fracture orientations to those observed in the ESF and ECRB Cross-Drift (DTN: GS020908314224.001 [DIRS 171038]). Data from the far southern outcrops in WT-11 Wash show a slight rotation of fractures in that area in comparison with those farther north (along Solitario Canyon). Fractures along the Solitario Canyon fault show similar orientations to those collected in the ESF and ECRB Cross-Drift. Fractures in Windy Wash (DTN: GS040308314224.002 [DIRS 171039]), northwest of the proposed repository, also show similar orientations to those in the underground. These data from widely dispersed locales indicate that fracturing in the Tptpmn is similar across the repository site, and that variations observed underground (such as the intensely fractured zone) generally bound the variations observed in outcrop.

It has been long understood that the fractures at Yucca Mountain and in particular the fractures in the repository host horizon are stratabound (Mongano et al. 1999 [DIRS 149850]). Data from the ECRB Cross-Drift show that fracture orientation in the nonlithophysal Tptpmn and Tptpln are similar in orientation (Mongano et al. 1999 [DIRS 149850]). While not identical, the orientation, frequency, and infilling were found to be quite similar in the two nonlithophysal units. Using the relative frequency and orientation differences seen between the lithophysal and nonlithophysal zones in the ESF Main Drift, South Ramp, and ECRB Cross-Drift, a general understanding can be developed of the density and character of fractures in the lithophysal units as compared to the over- and underlying nonlithophysal zones. Outcrops in Windy Wash, Solitario Canyon, and WT-11 Wash (near Iron Ridge) display similar relationships between lithophysal and nonlithophysal zones. Fracture densities and orientations in Tptpmn outcrops at all locations (except at Prow Pass and Yucca Wash) display 3 to 4 closely spaced sets of fractures, a significant percentage of which are cooling joints. Where the contacts with the 
adjacent lithophysal units are exposed, the fracture characteristics change. This change across lithostratigraphic boundaries has been observed at the locations where the rock is exposed. The most dramatic of these exposures are underground such as the Tptpmn/Tptpll contact at station 14+44 in the ECRB Cross-Drift (Mongano et al. 1999 [DIRS 149850]) and the same contact at the southern end of the Main Drift at station 57+29 (Eatman et al. 1997 [DIRS 101219]). At both these locations, the fracture sets that are clearly exposed in the base of the Tptpmn terminate within 1 to $2 \mathrm{~m}$ of penetrating into the underlying lithophysal rock of the Tptpll. Similar changes are observed at the Tptpul/Tptpmn and the Tptpll/Tptpln contacts. In each case, the transition from lithophysal to nonlithophysal rock results in a significant increase in long, recognizable fractures. This same relationship is also clearly exposed in surface outcrops. Wherever the contact is visible between lithophysal and nonlithophysal zones, fracture attributes display consistent differences at such contacts (see Figure 6-4).

Fractures in the Yucca Wash area are the only exception to the uniformity of fractures around Yucca Mountain. The area where most of the fractures were measured was west of where the Solitario Canyon fault enters the Yucca Wash drainage. The lithostratigraphic zones of the Topopah Spring Tuff in this area differ considerably in thickness and characteristics from the rest of the mountain (DTN: MO0012MWDGFM02.002 [DIRS 153777]). This change in lithostratigraphy may result from thickness increases in the underlying Calico Hills, specifically the presence of lava flows that extend to the southeast. The rocks in the repository host horizon at this locale differ from the rest of the mountain such that Day et al. (1998 [DIRS 100027]) mapped this area breaking out only the crystal-rich/crystal-poor members, rather than the zones recognized elsewhere. This change causes the fractures in this region to have significantly different orientations and characteristics from those observed elsewhere at Yucca Mountain, and represents the boundary of where present fracture analyses can be used with confidence.

\subsubsection{Construction Techniques used in Generating the FracMan Simulations}

\subsection{Hierarchy of Fracture Formation in the Topopah Spring Tuff}

Fractures in the densely welded and crystallized tuffs at Yucca Mountain, for example the lithophysal and nonlithophysal zones of the Topopah Spring Tuff, can be divided into two petrogenetic groups: those associated with cooling processes, and those associated with tectonic processes. Because the timing of fracture formation determines the geometry of the fracture network (i.e., trace length and truncations), and thus the size and position of potential rock blocks, it is important to understand the general sequence of fracture formation based on these processes.

All fractures have been described on the basis of geometric relations (strike, dip, trace length, planarity, truncations, etc.) and features such as tubular structures, rims (the light gray crystallized area along the edge of the fracture that is similar to what surrounds lithophysal cavities), and mineral or material filling of the fractures. Tubular structures, rims, and vapor-phase mineralization are indicative of features that formed very early in the cooling history of the deposit (possibly during the first 100 years), and are characteristic of cooling joints (Buesch and Spengler 1998 [DIRS 101433]; Buesch et al. 1999 [DIRS 165483]). Early-formed and even late-formed cooling fractures (referred to as Type 1 and Type 2 fractures in Buesch et al. 1999 [DIRS 165483]) typically have long trace lengths, are the fractures into which shorter 
trace-length fractures typically truncate, and form the initial geometric framework for the fracture network. Included in these cooling fractures are (1) vapor-phase partings, which are characteristically long, anastomosing to planar, low-angle discontinuities (i.e., dips less than $20^{\circ}$ ), and (2) typically long, smooth (i.e., planar), high-angle (i.e., steeply dipping) fractures. As cooling progressed, shorter trace-length fractures formed, which typically truncate into the earlier formed and longer fractures. These smaller fractures can have any orientation (shallowly, moderately, or steeply dipping), but typically have similar orientations as the longer fractures, and may or may not have rims or vapor-phase mineralization. After the rocks had cooled, and in the 12.8 million years since the time of cooling, some fractures, shears (discontinuities with less than $0.1 \mathrm{~m}$ of separation), and faults formed as a result of structural tilting and faulting of the mountain. These post-cooling fractures typically have shorter trace lengths and are not as smooth (i.e., are rougher) as cooling fractures. Many shears appear to be reactivated cooling joints or an integration of cooling joints, although some might have formed in conjunction with development of the fracture itself. Some faults can be fairly simple and somewhat planar discontinuities, but many are an integration of short-trace-length fractures to form irregular and rough discontinuities, and some are complex zones of deformation (Mongano et al. 1999 [DIRS 149850]). Many faults and shears, especially those with separations of less than four meters, have similar strikes and dips to the fractures (Mongano et al. 1999 [DIRS 149850]).

\subsection{Hierarchical Construction of Fractures in the FracMan Model}

Construction of the FracMan network starts with the low-angle vapor phase features. Because these features form first in the cooling process their truncation by other features is minimal. The truncation probability value (i.e., the probability that a fracture that intersects another fracture will be terminated against that fracture) for these features used in FracMan is set to 0 percent as qualitatively estimated from fracture terminations from the full periphery geologic maps. To continue the construction of the FracMan network, the remaining fractures, having a dip greater than 20 degrees are separated into two classes. The first class includes those fractures that formed about the same time as the vapor-phase partings. These fractures are referred to as cooling joints and have long trace lengths with some truncation occurring against the vapor-phase partings and themselves. A truncated power law distribution is used for these features. A large max/min fracture length is used along with a termination probability value of 15 percent, again based on qualitative examination of the terminations in the full periphery geologic maps. The second class includes the fractures that have a shorter trace length. The length distribution can be separated into two populations; those with trace length below 7 to 8 meters ("short" trace length) and those with trace length greater than 7 to $8 \mathrm{~m}$ ("long" trace length fractures). This separation is based on a break in slope of the trace length frequency as shown in Figure 6-16. These fractures are considered to be later cooling and tectonic fractures. These fractures are generated into a network comprised of vapor-phase partings and long high-angle cooling fractures and are truncated more severely than the earlier fractures. A shorter $\max / \mathrm{min}$ fracture length is used along with a termination probability value of 10 percent (as qualitatively estimated from full periphery geologic maps). 


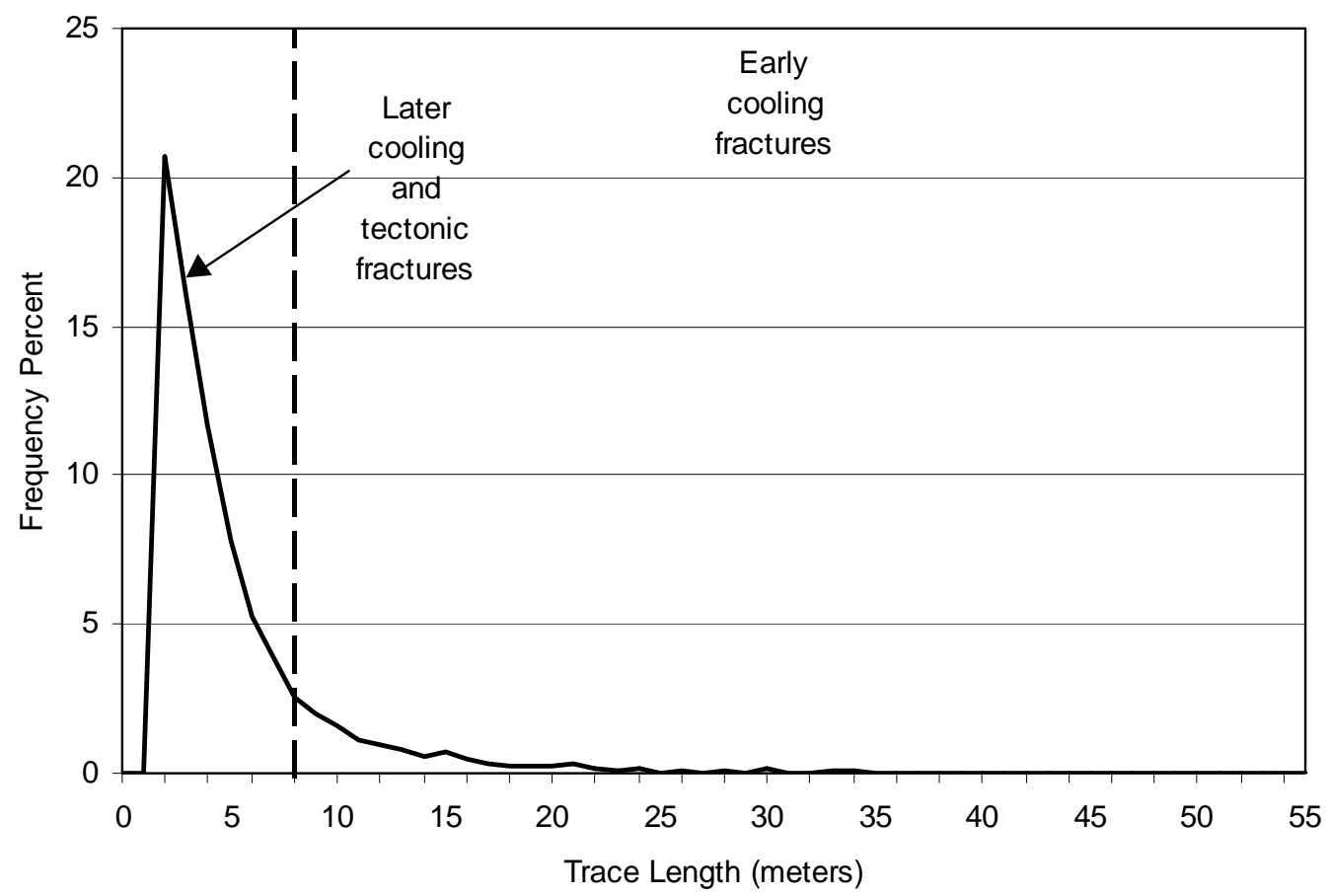

Figure 6-16. Trace Length Distribution of the Tptpmn Fractures with Dips $>20^{\circ}$

Based on the observed data, four fracture sets are defined in the Tptpmn. The great circles for these sets are displayed in Figure 6-17. The fracture analysis of the Tptpmn begins with defining the first forming discontinuities. Based on a hierarchical distribution of discontinuities, the first forming features are the low angle (less than 20 degrees) vapor-phase partings and the long high-angle fractures.

The hierarchical or sequential method of construction is significantly different from a construction with sets solely identified on the basis of orientation. Observations of mineralization and truncation relations (Mongano et al. 1999 [DIRS 149850]) suggest that the current sequential construction is more appropriate to generate a representative rock volume since short fractures truncate against longer fractures. This construction does not create a replicate of the actual fracture geometries observed in the limited sampling afforded by the detailed line surveys and the full periphery geologic maps. The objective is to provide a generalized, representative fracture network for evaluation of the Tptpmn rock mass as a whole. The output from FracMan is a fracture network whose geometry is conditioned from evaluation of the detailed line survey and full periphery geologic map data. Special geologic features are not represented in this effort. For example, in a given segment of tunnel mapping there may be a small section that shows an increased amount of fractures from a given set. The developer may decide to represent this zone by developing a specific distribution for this occurrence ${ }^{1}$. However,

\footnotetext{
${ }^{1} \mathrm{~A}$ zone within the Tptpmn that was given specific treatment and not included in the general fracture characteristics for FracMan development is the "intensely fractured zone". The intensely fractured zone, a 1000-m zone with anomalously high Set 1 fracture frequency (i.e., the mean and median joint spacing for the predominant Set 1 fractures were calculated to be $0.24 \mathrm{~m}$ and $0.12 \mathrm{~m}$, respectively), is not modeled with FracMan, but is treated as an anomalous zone of ubiquitous fracturing with the Set 1 orientation as described in Section 6.3.2.
} 
for this report an average geometry is used to describe the simulation because the fracture network developed does not represent a specific section of the mapped area, but is representative of the general condition of the rock mass. Zones that display anomalous geometries in each lithostratigraphic unit are averaged into the simulation when the decision is made that adding this input helps represent the rock mass correctly (in an overall sense) with the data that is available. Because this output is not a replicate, a single constant fracture intensity is imposed for each set in each lithostratigraphic unit.

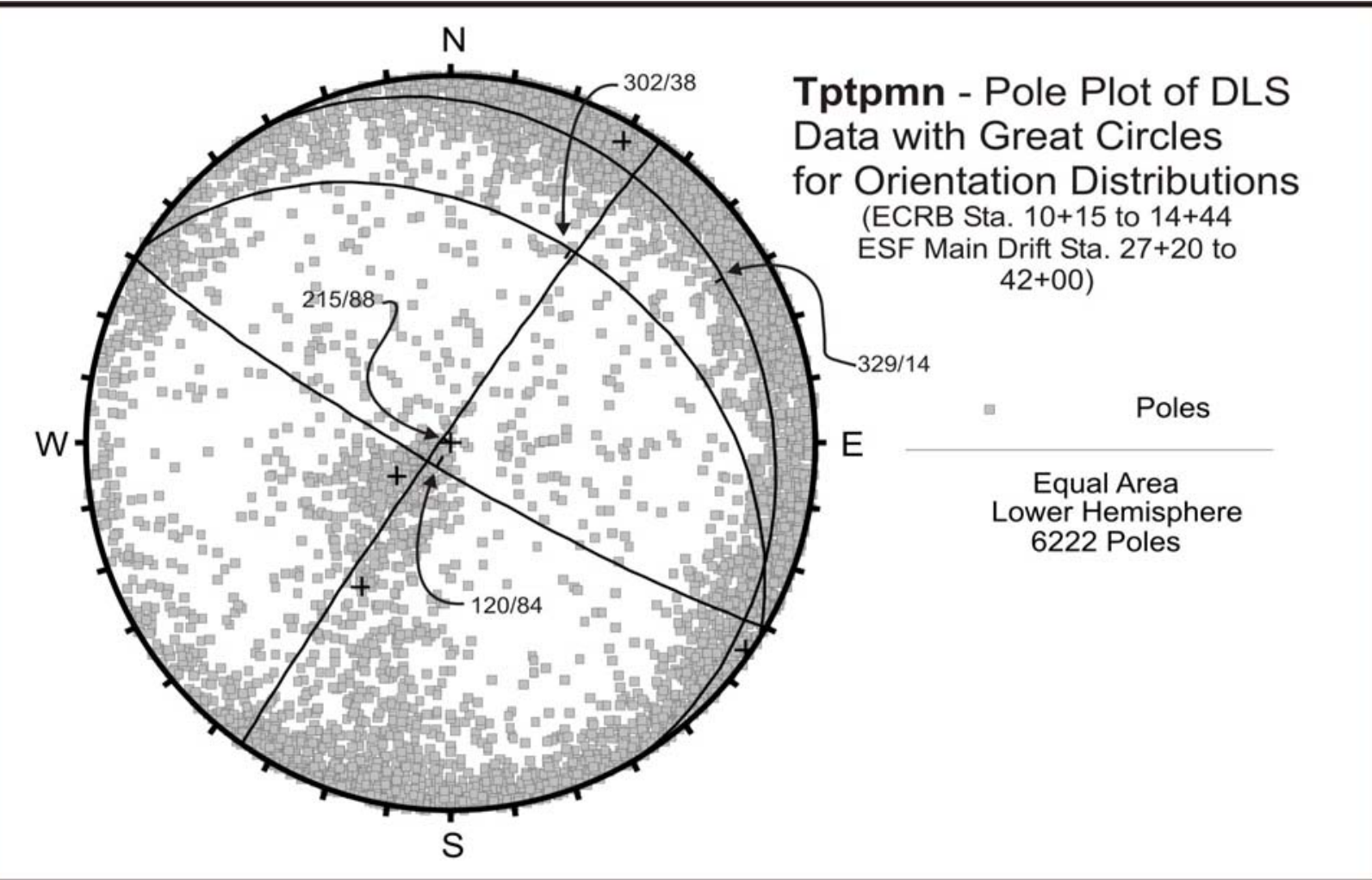

Source: DTN: GS971108314224.025 [DIRS 106025]; GS000608314224.004 [DIRS 152573] GS960708314224.008 [DIRS 105617]; GS960708314224.010 [DIRS 106031]; GS990408314224.001 [DIRS 108396].

NOTE: Data from the intensely fractured zone are not included in this pole plot. Orientations are given in strike and dip of mean poles.

Figure 6-17. Pole Plot of Tptpmn Detailed Line Survey Data from the ESF Main Loop and ECRB Cross-Drift

\subsection{Fracture Trace Length}

Correct fracture size (trace length and area) is critical to the construction of a representative network. Unfortunately, the radius of a fracture cannot be measured from sampling of the fracture network along the surface of a tunnel. If the fractures are considered circular disks, the centers of those disks do not have to coincide with the sampling surface. The observed trace length is then typically not the disk diameter because the centers of the fracture disks do not coincide with the sample surface. In a tunnel surface sampling, observed trace length could be longer or shorter depending on the position of the center of the fracture. 
To get an intuitive feel for the radius distribution and how it relates to the observed trace length distribution consider a single fracture of radius $\mathrm{R}$ oriented perpendicular to the sampling plane. If the fracture intersects the plane, the observed trace length can vary from 0.0 to 2.0R.

The trace length, $\mathrm{T}$, is a function of the distance from the sampling plane, $\mathrm{z}$, and the fracture radius, $\mathrm{R}$, and is defined based on standard geometric relationships (see Figure D-11):

$$
\mathrm{T}=2\left(\mathrm{R}^{2}-\mathrm{z}^{2}\right)^{0.5}
$$

The mean observed trace length $\mathrm{T}_{\mathrm{m}}$ is then

$$
\begin{gathered}
\mathrm{T}_{\mathrm{m}}=\frac{1}{\mathrm{R}} \int_{0}^{\mathrm{R}} 2\left(\mathrm{R}^{2}-\mathrm{z}^{2}\right)^{0.5} \mathrm{dz} \\
\mathrm{T}_{\mathrm{m}}=\pi \mathrm{R} / 2 \text { or } \mathrm{R}=\mathrm{T}_{\mathrm{m}} 2 / \pi
\end{gathered}
$$

indicating that the mean fracture radius is about $2 / 3$ of the mean trace length observed.

This means that the expected distribution of trace lengths is equal to the distribution of the intersecting fractures times a constant factor $\pi / 2$. In a log-log plot, multiplication of a power law by a constant does not change the slope, so that the scaling exponent of trace lengths is the same as the scaling exponent of the radius distribution of intersecting fractures.

The radii distributions are compared to a distribution formed from the trace lengths observed multiplied by two-thirds to adjust the trace lengths to approximate radii. This is not a perfect adjustment because the dip of the fractures as well as their persistence will influence the number "two-thirds." The trace lengths are observed with a sampling surface or detailed line survey. Additional effects may be present when comparing the radii in the 100-m cube synthetic fracture region generated by FracMan with the surface or line sampling. Individual plots of these distributions are included in each of the following sections for the lithostratigraphic units. Overall, the fits are good to excellent.

After the sequence of formation is defined and the length distribution selected, orientation is evaluated to further subdivide the fractures into sets based on analysis of stereonet pole plots. Fractures with a dip greater than 20 degrees are used for this analysis because the orientations of the longer fractures and the shorter fractures are coincident. Once this is accomplished, the actual inputs for FracMan are developed.

\subsection{Fracture Geometry}

The following is a brief description of the inputs required to begin the generation of simulated fracture geometries. The fracture geometry data for each lithostratigraphic unit are converted to the parameters needed for FracMan. The input values for the FracMan model of each lithostratigraphic unit are derived from the detailed line survey data and used to develop an input data form. The FracMan input sheet for the Tptpmn is shown in Figure 6-18. Sets are based on 


\begin{tabular}{|c|c|c|c|c|c|c|c|c|c|c|c|c|c|}
\hline \multicolumn{14}{|c|}{ FracMan/FracWorks } \\
\hline \multirow{3}{*}{$\begin{array}{l}\text { Project } \\
\text { Seed \#: } \\
\text { Direction }\end{array}$} & \multicolumn{2}{|c|}{ Tptpmn } & Task & \multicolumn{2}{|c|}{ Drift Degradation } & Date & \multicolumn{2}{|l|}{$03 / 04$} & Modeler _ & \multicolumn{4}{|l|}{ Lung-Fahy } \\
\hline & \multicolumn{2}{|r|}{ Frac } & eter Unit: & 50 & \multicolumn{2}{|c|}{ runcation mode Region } & & & View Center & \multicolumn{2}{|l|}{$0,0,0$} & \\
\hline & & Scale & & $\% d$ & played & 0 & Orientatio & $=$ Pole $\mathrm{c}$ & Dip & Pole & rac sides & 6 & \\
\hline $\begin{array}{l}\text { Frac. } \\
\text { Set }\end{array}$ & $\begin{array}{l}\text { Model } \\
\text { Type }\end{array}$ & $\begin{array}{c}\text { Generation } \\
\text { Region \& } \\
\text { Dimension }\end{array}$ & $\begin{array}{l}\text { Orientation } \\
\text { Trend, Plunge }\end{array}$ & $\begin{array}{l}\text { Dist. } \\
\text { Type }\end{array}$ & $\begin{array}{c}\mathrm{K} \text { or } \\
\mathrm{K} 1 / \mathrm{K} 2 \\
\text { dispersion }\end{array}$ & $\begin{array}{c}\text { Size } \\
\text { Eqv. } \\
\text { Radius }\end{array}$ & $\begin{array}{l}\text { Dist. } \\
\text { Type }\end{array}$ & $\frac{\text { Mean }}{\text { SD }}$ & $\frac{\text { Max. }}{\text { Min. }}$ & Elongation & $\begin{array}{c}\text { Aspect } \\
\text { Ratio }\end{array}$ & $\begin{array}{c}\text { Termin. } \\
\%\end{array}$ & Intensity \\
\hline S1s & BART & $100 \times 100 \times 100$ & $035 / 06$ & BiBing & $-39.5 /-4.5$ & 1.00 & $\begin{array}{l}\text { TPow } \\
(3.5)\end{array}$ & & $8 / 1$ & NA & NA & 10 & 0.40 \\
\hline S2s & BART & $100 \times 100 \times 100$ & $124 / 04$ & BiBing & $-11.8 /-6.2$ & 1.00 & $\begin{array}{l}\text { TPow } \\
(3.5) \\
\end{array}$ & & $8 / 1$ & NA & NA & 10 & 0.30 \\
\hline S3s & BART & $100 \times 100 \times 100$ & $209 / 47$ & BiBing & $-72.6 /-8.8$ & 1.00 & $\begin{array}{l}\text { TPow } \\
\text { (3.5) }\end{array}$ & & $8 / 1$ & NA & NA & 10 & 0.10 \\
\hline VPP & Baecher & $100 \times 100 \times 100$ & $237 / 82$ & Fisher & 05 & 1.00 & $\begin{array}{c}\text { Power } \\
(3.5)\end{array}$ & & NA & NA & NA & 0 & 0.16 \\
\hline S1l & BART & $100 \times 100 \times 100$ & $035 / 06$ & BiBing & $-39.5 /-4.5$ & 1.00 & $\begin{array}{l}\text { TPow } \\
\text { (3.5) }\end{array}$ & & $50 / 4$ & NA & NA & 15 & 0.2 \\
\hline S2l & BART & $100 \times 100 \times 100$ & $124 / 04$ & BiBing & $-11.8 /-6.2$ & 1.00 & $\begin{array}{l}\text { TPow } \\
(3.5) \\
\end{array}$ & & $50 / 4$ & NA & NA & 15 & 0.2 \\
\hline S3l & BART & $100 \times 100 \times 100$ & 209/47 & BiBing & $-72.6 /-8.8$ & 1.00 & $\begin{array}{l}\text { TPow } \\
(3.5)\end{array}$ & & $50 / 4$ & NA & NA & 15 & 0.15 \\
\hline & & & & & & & & & & & & & \\
\hline
\end{tabular}

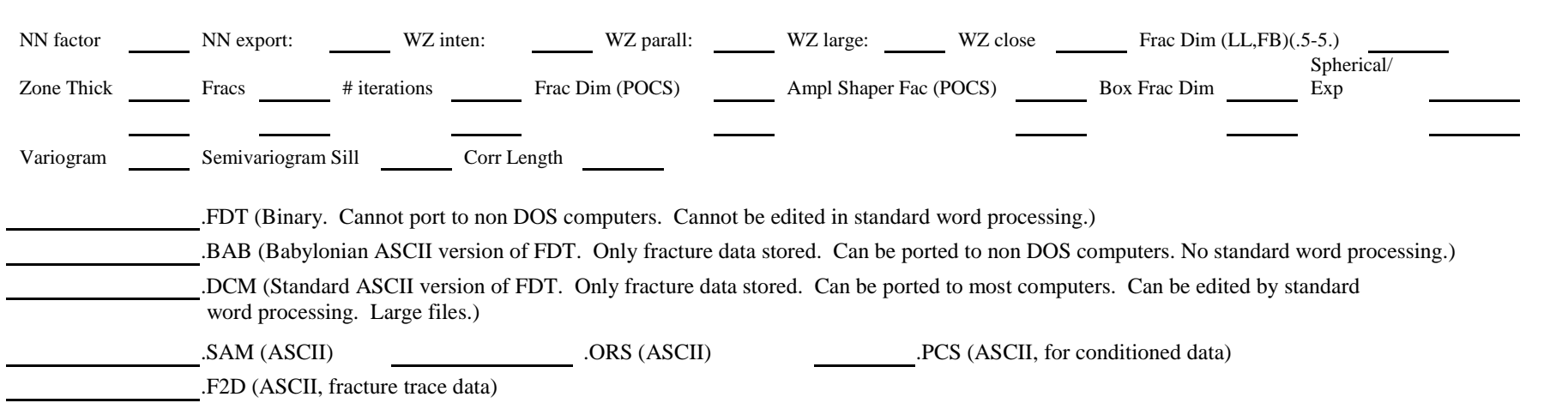

NOTE: See Figure 6-17 for detailed line survey source DTNs. The parameter, "K or K1/K2 dispersion" is determined using CLUSTRAN (with the exception of VPP, or vapor-phase parting, which is determined visually by comparing simulated stereonets to observed stereonets). The parameter, "Size Eqv. Radius" is the mean radius $(\mathrm{m})$. The power law distribution is used for the parameter, "Dist. Type." The power law is selected because the fracture process generally follows power law physics, such that the number of fractures greater than a given length $(x)$ is proportional to $1 / x$ raised to the power law exponent. The parameter, "Intensity" is selected to maintain the proportion of fractures in each set.

Figure 6-18. FracMan Input Sheet for the Tptpmn 
length in a hierarchical model. A truncated power law is used because the short and long fractures are defined for a given window of trace length (Figure 6-16). Vapor-phase partings are not subjected to a truncated power law distribution, because they are first-occurring features with a long trace length. The other sets are developed using "Baecher Revised Terminations" model type in order to simulate the truncation probability.

Based on the long fractures, the trend and plunge of the poles are used to set the mean orientations for each of the sets. CLUSTRAN (Shanley and Mahtab 1974 [DIRS 169199]), a structural geology statistical software application, is used to determine both mean pole values and dispersion of fractures around the mean. CLUSTRAN is a computer program that analyzes fracture data using stereographic projection techniques. Stereographic projection involves the projection of points from a spherical surface (typically the lower hemisphere of the surface) to a planar surface (the stereographic plot surface). The purpose of the CLUSTRAN program is to plot and analyze the orientations of fracture directional data sets for the purpose of identification and analysis of clusters of poles from which sets and their dispersion can be identified. Conventional identification of fracture sets involves plotting of the fracture poles onto a stereographic net, followed by contouring of the poles and use of the concentrations of data to identify clusters that indicate numbers of sets and directional trends. The use of CLUSTRAN eliminates the conventional visual interpretation of data, presenting a more objective interpretation through evaluation of set clusters and dispersion directly using statistical evaluation techniques.

CLUSTRAN statistically analyzes the identified longer fractures for non-randomness. The program locates clustered subsets of the data by using an algorithm described by Shanley and Mahtab 1974 [DIRS 169199]). This algorithm uses an iterative process to identify the statistically optimal data clusters. In the algorithm, dense points (those data points that have at least $n$ neighbors within a cluster radius $R$ ) are first identified. The remaining non-dense points are then allocated to the nearest dense point. Finally, the dense points are grouped into clusters by chaining them together by segments of length $R$ or less. In the original algorithm developed by Shanley and Mahtab (1974 [DIRS 169199], p. 2), both variables $R$ and $n$ had to be selected by the user. In CLUSTRAN, the integer $n$ is calculated from a Poisson statistical model such that the probability of $n$ points occurring within the radius $R$ by chance alone is no more than 5 percent. Because a data set can be clustered many different ways depending on the cluster radius, Shanley and Mahtab (1974 [DIRS 169199], p. 3) developed an objective function, $F(P)$, as a tool for selecting the best clustering of the data set. This function is the sum of the within-cluster distances squared with the between-cluster distances squared. The best partition, and best value of $R$, occurs where the $F(P)$ is minimum. This condition means that the distances have been minimized by trading off within-cluster distances with between-cluster distances. Thus, the CLUSTRAN cluster analysis process is iterative. The user selects a trial value for the cluster radius, $R$. CLUSTRAN identifies the clusters based on this $R$ and evaluates for the objective function, $F(P)$. Other values of $R$ are tried over a broad range until the lowest objective function value is found. CLUSTRAN will evaluate the iterative runs and select the correct $R$ to use based on the lowest $F(P)$ value.

Once clusters have been identified from the data set, CLUSTRAN carries out statistical analysis on each cluster. First, moment-of-inertia analysis is carried out. This analysis treats each data point as a point of mass on a unit hemisphere. The maximum moment-of-inertia goes through 
the center of the cluster, the intermediate moment parallels the long axis, and the minimum moment is perpendicular to the long axis. The Bingham probability distribution is applicable to moment-of-inertia analysis (DOE 2004 [DIRS 170474]). It provides two concentration parameters, $K 1$ and $K 2$, that describe the shape and concentration of the data set. Then, using the output from the Bingham distribution, the test for circular symmetry is performed to yield bipolar and girdle test statistics.

If the distribution is symmetric according to these previous tests, then additional tests are performed. The Dimroth-Watson distribution (the circularly symmetric form of the Bingham distribution) yields a concentration parameter to describe the data cluster (DOE 2004 [DIRS 170474]). If the concentration parameter is near zero the distribution is random, whereas if the concentration parameter is large, the points are concentrated. Further, if the parameter is less than zero the distribution is symmetric bipolar, and if the parameter is greater than zero the distribution is a symmetric girdle.

If the cluster is symmetric and bipolar, the vector mean and associated Fisher statistics are also calculated. The Fisher distribution (equivalent to a normal distribution in univariate statistics) does not apply to moment-of-inertia analyses, but to vector analyses (DOE 2004 [DIRS 170474]). It is also strictly applicable to the polar distribution, but bipolar distribution may be treated by using the axis ends nearest each other. The Fisher mean is the vector sum of the directions, where each fracture pole direction is treated as a unit vector. These parameters, mean orientation and dispersion, are "inputs" into the FracMan code. Just as one would set the variance of a univariate parameter, distributions of structural geology vectors are described by a mean orientation and a dispersion about the mean direction.

Several comparisons are made to confirm that the results of the FracMan output are producing a simulated fracture geometry that resembles the actual rock mass. Comparison is made between the detailed line survey data pole plots and the FracMan data pole plots. Correct selection of the mean orientation as well as the correct dispersion, $K$, is key to obtaining an acceptable distribution of poles on the stereonet. The results of this comparison are presented in the following section for the Tptpmn. Stereonets generated by the FracMan realization and stereonets from the observed detailed line survey data show reasonable comparisons for both the mean orientation and dispersion about the mean (Figure 6-19). There are several methodologies to modeling the dispersion of real fracture data. One is to completely encompass the full range of observed data. When fitting the dispersion in this style the dispersion factor is small, typically less than 20 for a Fisher $K$ value. However the range of variability is large. An alternative method focuses on a tighter description of the observed data, considering that the extent of the observed data is below the level of significance for data on the stereonet. For example, with 100 data points, a 1 percent count circle needs to have encompassed approximately four data points in order for the level of significance to be distinguishable from a random data set. There are no random sets in nature so we wish to depict sets that meet the nonrandomness criteria. A larger $K$ value will accomplish this. Larger $K$ values depict a smaller dispersion about the mean orientation. This is the style of fit used for these analyses.

Comparison of the observed to synthetic fracture geometry for each set is given qualitatively in the stereonet plots of poles given in Figure 6-19 and quantitatively in Table 6-2. The criteria for adequate agreement of the fracture geometry from observed to synthetic models are: 1) that the 
mean orientation is adequately estimated, and 2) that a large portion of the observed data dispersion is encompassed but not every pole. Analysis of data on the stereonet requires that sets are identified from data that are significantly different from a uniform distribution on the stereonet. The outer portions of a distribution are similar to the tail of a univariate distribution. The goal was to simulate the main portion of the distribution and not the tail of the distribution. Therefore, the synthetic data pole plots are more tightly clustered than the observed pole plots for this reason (Figure 6-19).

The goal of the orientation comparison is, therefore, to represent the major sets with reasonable conformance to the observed mean orientations and the observed spread or dispersion about the mean. Not every fracture observed will be represented in the FracMan realizations since the synthetic model represents a reasonable facsimile of the rock mass, but not a replicate.

More fractures will be displayed in the 100-m on a side FracMan cube than are observed in the detailed line survey data. The detailed line survey data samples a small surface area compared to full periphery geologic mapping and considerably fewer fractures are observed than are present in the 100-m cube. The primary comparison to make between the rock mass geometry and the FracMan geometry is to compare full periphery geologic maps. The FracMan geometry allows for the same kind of sampling as the original data. For each of the following sections a direct comparison is presented to confirm that the FracMan geometry resembles the observed geometry. Intensity controls the number of fractures and the check for intensities relies on the comparison of FracMan full periphery geologic maps to the observed full periphery geologic maps for validation. If the intensity from the FracMan full periphery geologic maps and the observed full periphery geologic maps are similar and trace length comparisons are good, the validation is considered satisfactory. 


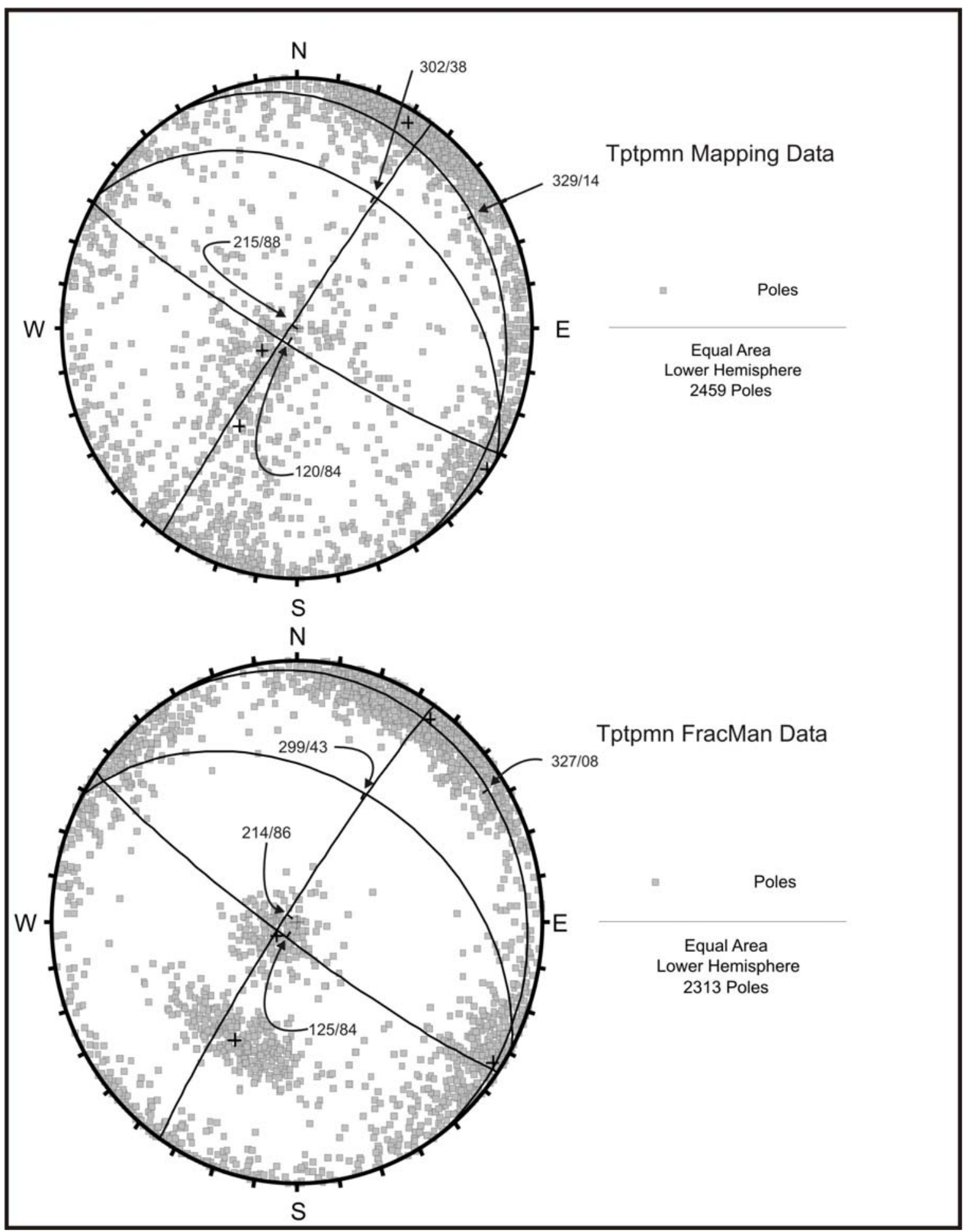

NOTE: The Tptpmn FracMan data include 15 samples, or "excavations", extracted from the FracMan cube at random locations resulting in 2313 fractures. The Tptpmn mapping data was selected by sampling the full periphery geologic maps until a similar number of fractures could be compared to the FracMan data. The source DTNs for the full periphery geologic map are: GS960908314224.020, GS000608314224.006, GS960908314224.015, GS960908314224.016.

Figure 6-19. Comparison of the Observed Tptpmn Fracture Poles to the FracMan Fracture Poles 
Table 6-2. Comparison of Data from Underground Mapping and FracMan for the Tptpmn

\begin{tabular}{|c|c|c|c|c|c|c|}
\hline \multirow{2}{*}{$\begin{array}{c}\text { Set } \\
\text { Number }\end{array}$} & \multirow{2}{*}{$\begin{array}{c}\text { Observed } \\
\text { Orientation } \\
\text { Strike/Dip } \\
\text { (Trend/Plunge) }\end{array}$} & \multirow{2}{*}{$\begin{array}{l}\text { FracMan } \\
\text { Orientation } \\
\text { (Strike/Dip) }\end{array}$} & \multicolumn{2}{|c|}{$\begin{array}{l}\text { Inter-Fracture Median } \\
\text { Distance }(\mathrm{m})\end{array}$} & \multirow{2}{*}{$\begin{array}{c}\text { Trace Length } \\
\text { Median from Full } \\
\text { Periphery Geologic } \\
\text { Maps }(\mathrm{m})\end{array}$} & \multirow{2}{*}{$\begin{array}{l}\text { Trace Length } \\
\text { Median from } \\
\text { FracMan (m) }\end{array}$} \\
\hline & & & Observed & FracMan & & \\
\hline Set 1 & $120 / 84(030 / 06)$ & $125 / 84$ & 0.48 & 0.79 & 3.3 & 2.8 \\
\hline Set 2 & $215 / 88(125 / 02)$ & $214 / 86$ & 1.08 & 1.29 & 2.8 & 3.1 \\
\hline Set 3 & $302 / 38(212 / 52)$ & $299 / 43$ & 3.40 & 3.16 & 3.7 & 3.6 \\
\hline $\begin{array}{l}\text { Vapor- } \\
\text { Phase } \\
\text { Parting }\end{array}$ & $329 / 14(239 / 76)$ & $327 / 08$ & 2.46 & 1.48 & 3.5 & 3.4 \\
\hline Source: & \multicolumn{6}{|c|}{$\begin{array}{l}\text { DTNs for tunnel mapping include: GS960908314224.020 [DIRS 106059]; GS000608314224.006 } \\
\text { [DIRS 152572]; GS960908314224.015 [DIRS 108372]; GS960908314224.016 [DIRS 108373]; } \\
\text { GS971108314224.025 [DIRS 106025]; GS960708314224.008 [DIRS 105617]; GS000608314224.004 } \\
\text { [DIRS 152573]; GS960708314224.010 [DIRS 106031]; GS960908314224.014 [DIRS 106033]; } \\
\text { GS970208314224.003 [DIRS 106048]; GS970808314224.010 [DIRS 106050]; and } \\
\text { GS971108314224.028 [DIRS 106047]. }\end{array}$} \\
\hline
\end{tabular}

NOTE: Trace length medians are taken from a compilation of tunnel mapping and synthetic tunnel samples from FracMan (see Figure 6-23 for the trace-length distribution).

\subsection{Fracture Intensity}

A number of fracture intensity (e.g., the relationship of fracture spacing, orientation and areal extent within a rock mass) measures are typically used for quantification of field measurements. These include (Dershowitz and Herda 1992 [DIRS 104893]):

- $\mathrm{P}_{10}{ }^{2}$ - the number of fractures/length of a scanline

- $\mathrm{P}_{21}$ - the length of fracture traces/area of exposure from a full periphery map

- $\mathrm{P}_{32}$ - area of fractures/volume of the rock mass

Thus, $\mathrm{P}_{10}$ represents a linear measurement of fracture intensity, $\mathrm{P}_{21}$ an areal measurement and $\mathrm{P}_{32}$ is a volumetric measure. The first two measures of intensity can be made from available detailed line surveys and full periphery geologic maps. The $\mathrm{P}_{32}$ measure is the most accurate measure of fracture intensity, but must be estimated since it is impossible in practice to provide a volumetric measurement since sampling is via a line or tunnel surface mapping.

The general relationship between the fracture intensity $\mathrm{P}_{32}$ and the mean fracture spacing, $\mathrm{S}$, along a line is given by Dershowitz and Herda (1992):

$$
\mathrm{P}_{32}=\mathrm{C} / \mathrm{S}=\mathrm{C} \mathrm{P}_{10}
$$

where $\mathrm{C}$ is a constant that depends on the orientation distribution of the fractures. Dershowitz and Herda (1992, p. 763) suggested a range of expected values for C between 1.0 and 3.0 and a value of 2.0 for a uniform distribution of orientations.

\footnotetext{
2 The term P stands for persistence.
} 
Equation 6-4 has been derived for the simplified case where the orientation distribution is constant. For different orientation distributions, the equation becomes inaccurate for large variations about the mean pole orientation. In the general case, the $\mathrm{P}_{32}$ value can be expressed as:

$$
P_{32}=\frac{C}{d \cdot\left(\frac{1}{\int_{0}^{\pi} \sin (\theta) f(\theta) d \theta}\right)}
$$

where $d$ is the inter-fracture distance along a line, and $f(\theta)$ is the orientation probability density function.

In this report, the FracMan model uses a constant $\mathrm{P}_{32}$ for each set of fractures, which is based on the consideration that there is no spatial heterogeneity in intensity. There are a few discrete changes in intensity observed in the detailed line survey and full periphery geologic map data, but for the most part, the "average" intensity is constant as depicted by a linear cumulative fracture number versus stationing plot for each of the lithostratigraphic units. As shown in Figure 6-20, a plot of the cumulative number of fractures versus distance along the ESF for the Tptpmn is given based on detailed line survey data. This data shows that a roughly linear relationship exists between fracture frequency and distance for the Tptpmn within the ESF at a slope of approximately 2 fractures per meter. A distinct break in slope occurs over a 1000-m section termed the "intensely fractured zone" in which the fracture frequency roughly doubles. This zone is considered to be anomalous as it is not observed in any other locations in the underground excavations, and is excluded from FracMan. Modeling studies (see Section 6.3.2.1) examine stability of the intensely fractured zone using continuum-based modeling methods. The linear character of the cumulative fracture frequency plot demonstrates that little spatial heterogeneity of the fracture intensity exists in the Tptpmn overall. 


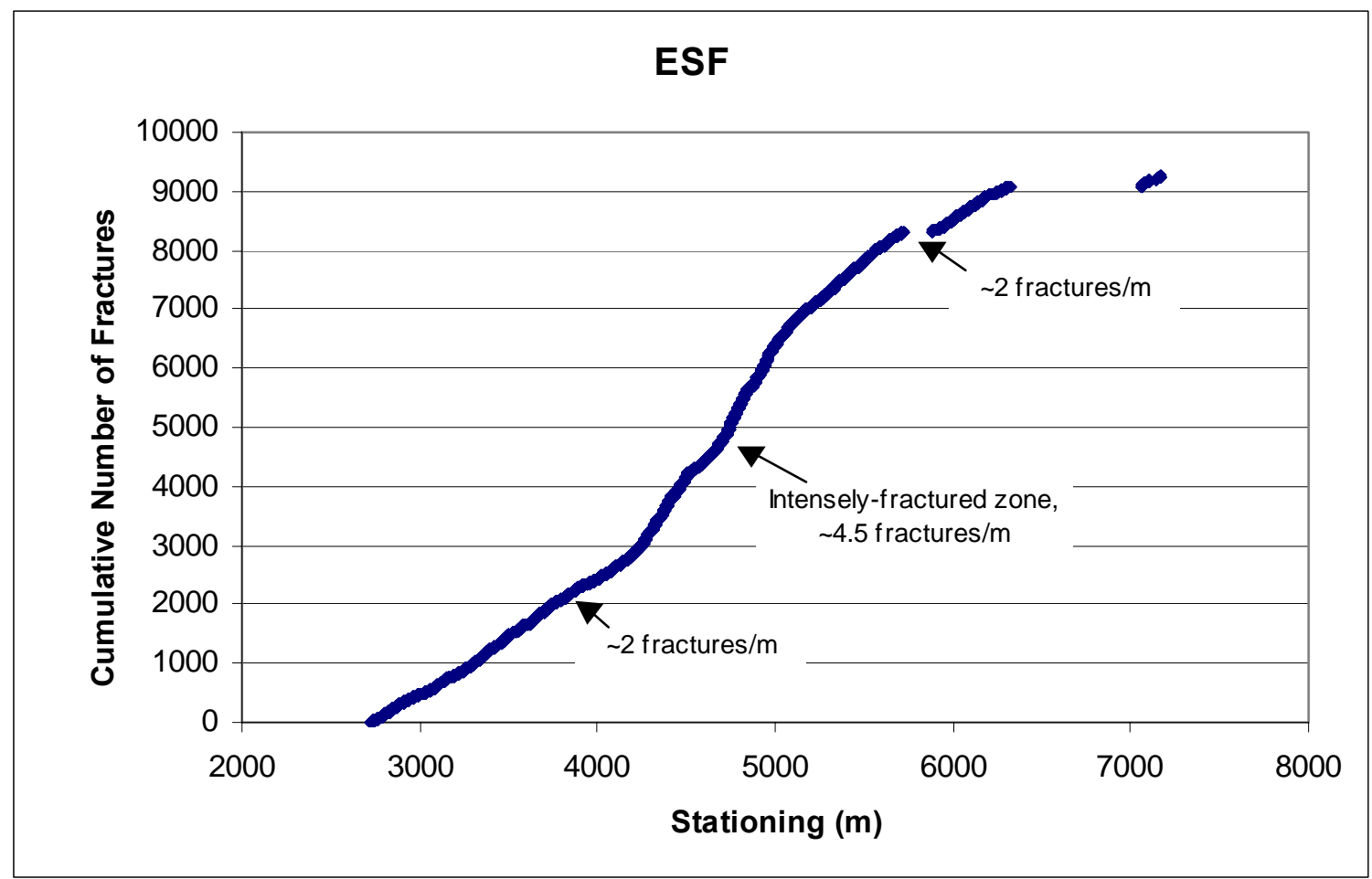

NOTE: The fracture frequency shows a break in slope from approximately 2 fractures per meter to over 4 fractures per meter over an approximately 1000-m section of the ESF. This region is termed the "intensely fractured zone" and is not observed in the ECRB Cross-Drift.

Figure 6-20. Cumulative Number of Fractures Versus Stationing for Detailed Line Surveys Along the ESF

\subsection{Comparison of FracMan Synthetic Fracture Geometry and Field Data}

Comparison of the FracMan-generated synthetic fracture geometry to the field fracture data is performed both qualitatively and quantitatively. From a qualitative standpoint, the FracMan program is used to create equivalent full periphery geologic maps by creation of virtual tunnels parallel to the ESF within the FracMan synthetic rock mass. Visual comparison is made between the FracMan and field full periphery maps are performed to ensure that the model produces the primary structural features evident in the field data. Quantitative comparisons of fracture trace length, spacing and orientation are made by comparison of the statistical distributions.

Qualitative Comparison-To insure that the synthetic fracture network is not only statistically representative, a qualitative comparison of random full periphery geologic maps from the ESF and FracMan synthetic full periphery geologic maps created at the same orientation are visually compared (Figure 6-21). This is a direct comparison between actual full periphery geologic maps from the ESF to synthetic full periphery geologic maps from FracMan. The comparison is made to evaluate the general fracture intensity and length with the same biases inherent in the field full periphery geologic mapping. Based on the professional expertise and experience of project geologists, the FracMan full periphery geologic maps are acceptably conditioned to be visually similar to observed full periphery geologic mapping. 
Quantitative Comparison-The detailed line survey data and full periphery geologic maps are used to condition FracMan to develop representative fracture trace lengths and inter-fracture distance. The same comparisons of the mapping data and FracMan output apply to this realization. Table 6-2 provides a quantitative comparison of the orientation of the sets and trace lengths from the full periphery geologic maps and samples from FracMan. Intensity (inter-fracture distance) from FracMan and inter-fracture distance from the detailed line surveys is also compared. Because no line surveys were conducted on the full periphery geologic maps, detailed line survey data were used for generating inter-fracture distance data, which was compared to $1 \mathrm{~m}$ diameter (synthetic) boreholes randomly drilled in the same orientation in the FracMan rock mass. By sampling the FracMan rock mass in the same orientation as the detailed line survey data, the need for a correction to either data set is eliminated. Distribution comparisons of inter-fracture distance from both FracMan and detailed line survey data are shown in Figure 6-22, show a reasonable comparison, both in the univariate statistical mean as well as the general shape of the distributions.

The comparison in Figure 6-23 confirms that a reasonable conformance exists between the trace length distribution from FracMan and the observed trace length distribution. To develop a true comparison of trace length between the observed and the synthetic data, length data from observed and synthetic full periphery geologic maps are compared. As with the inter-fracture distance comparisons, the full periphery geologic maps from FracMan are sampled on the same orientation as the observed data to eliminated the need to correct either data set. The orientation comparison was previously presented in Figure 6-19.

In summary, a FracMan fracture region was constructed which is calibrated to the observed data for orientation and its dispersion, size and its distribution, and intensity (as measured by interfracture distance) and its distribution on a set by set basis. In addition, any biases due to sampling were effectively removed by using the same sampling style as the observed data collection when comparing the synthetic and the observed data sets. 
(a)
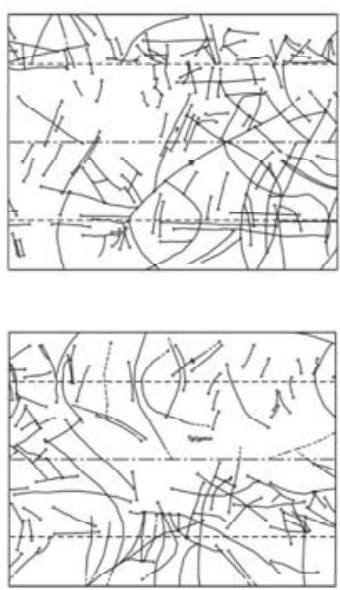

(b)
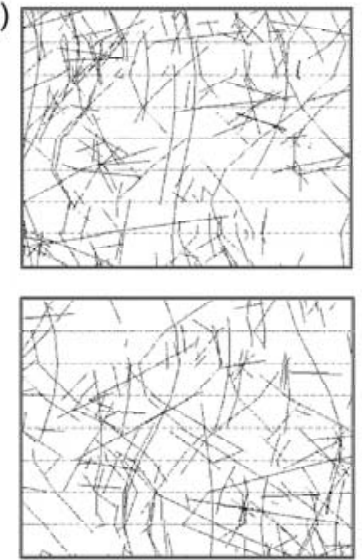
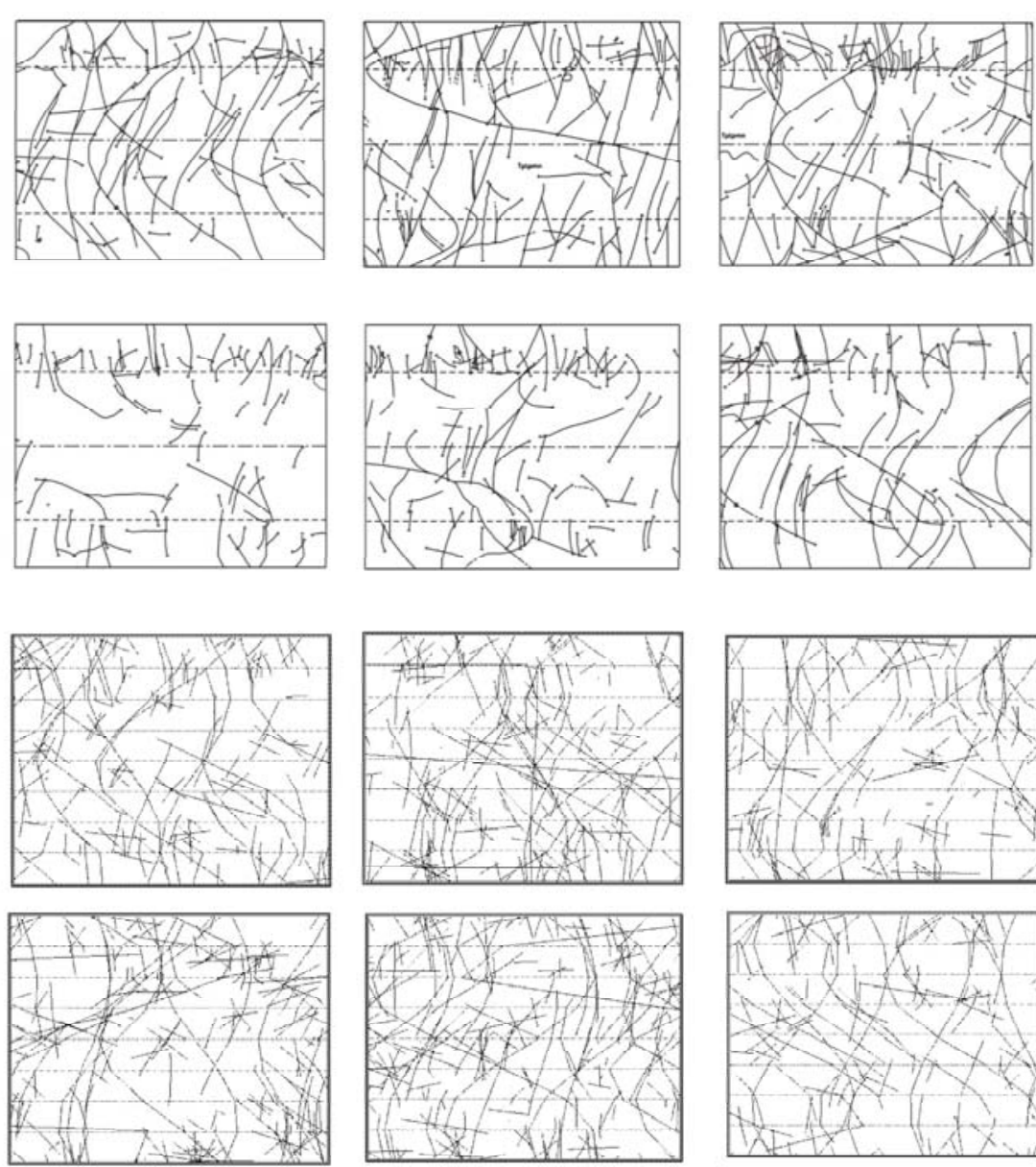
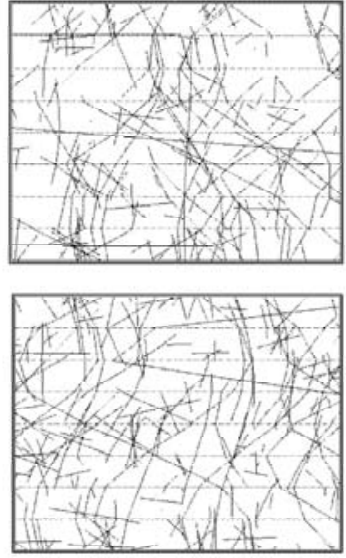

Source: DTNs: GS990408314224.004 [DIRS 108405]; GS000608314224.006 [DIRS 152572]; GS960908314224.015 [DIRS 108372]; GS960908314224.016 [DIRS 108373]; GS960908314224.017 [DIRS 108376]; GS970108314224.002 [DIRS 107490].

NOTE: The purpose of this figure is to illustrate the geologic structure contained on a full periphery geologic map. The annotated information on this figure is not intended to be legible.

Figure 6-21. Comparison of (a) Full Periphery Geologic Maps from the Tptpmn in the ESF (b) with Simulated Full Periphery Geologic Maps from the FracMan Cube 

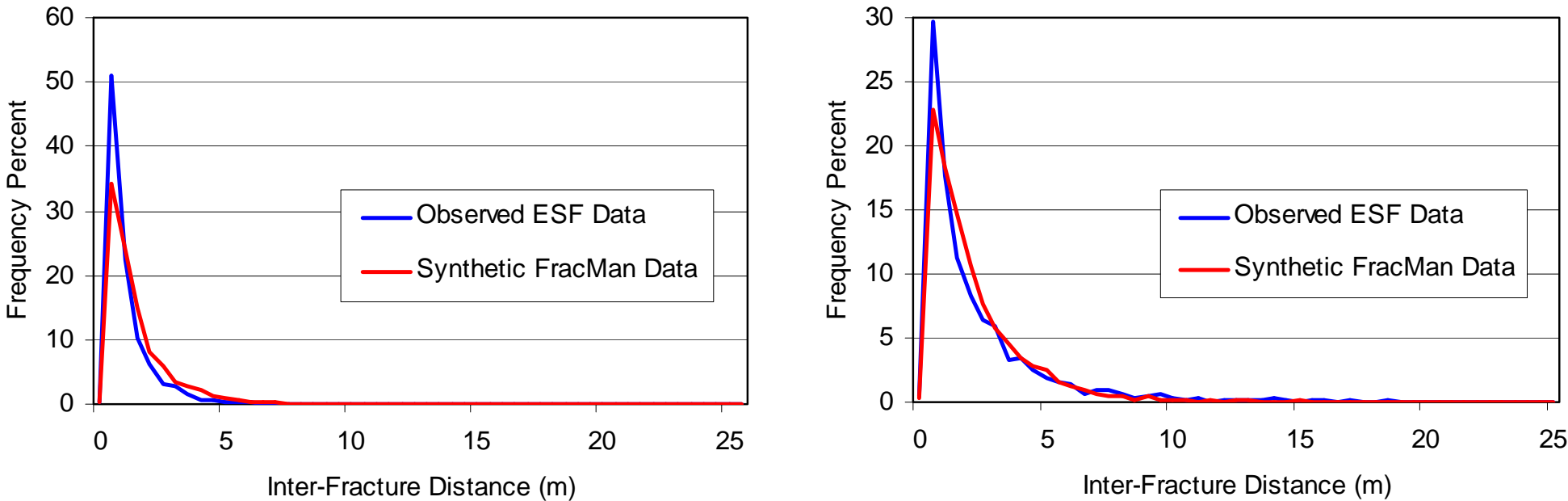

\section{a. Set 1}

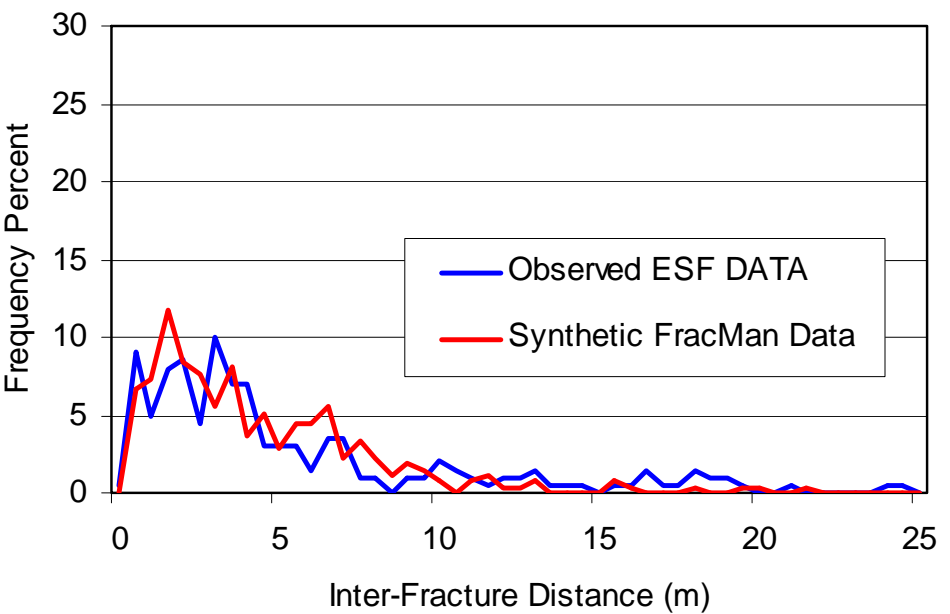

c. Set 3 b. Set 2

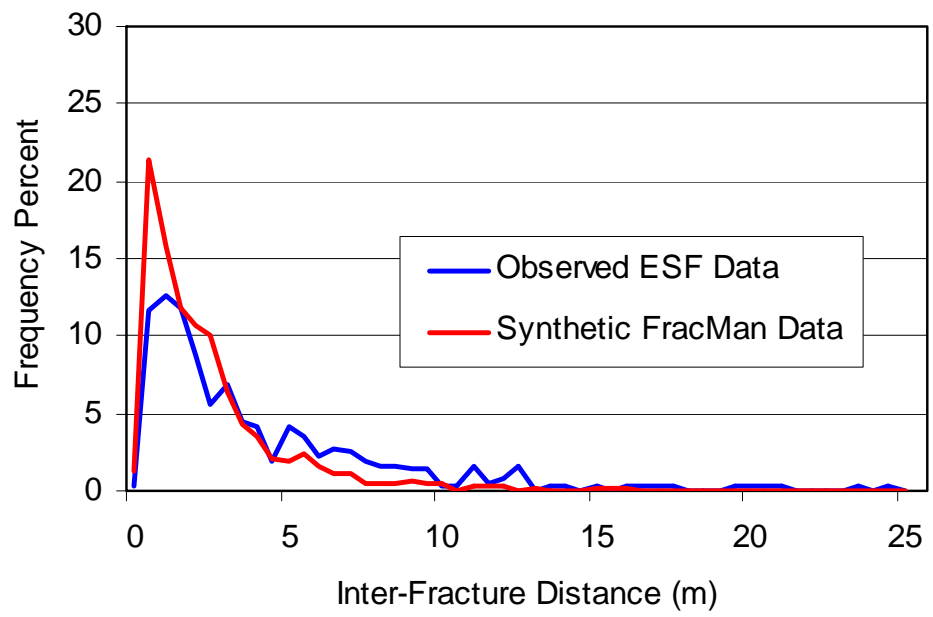

d. Vapor-Phase Parting

Source: DTNs for the detailed line survey data include GS971108314224.025 [DIRS 106025]; GS960708314224.008 [DIRS 105617]; GS000608314224.004 [DIRS 152573]; GS960708314224.010 [DIRS 106031]; GS960908314224.014 [DIRS 106033]; GS970208314224.003 [DIRS 106048]; GS970808314224.010 [DIRS 106050]; GS971108314224.028 [DIRS 106047].

Figure 6-22. Distribution Comparisons of Inter-Fracture Distance 

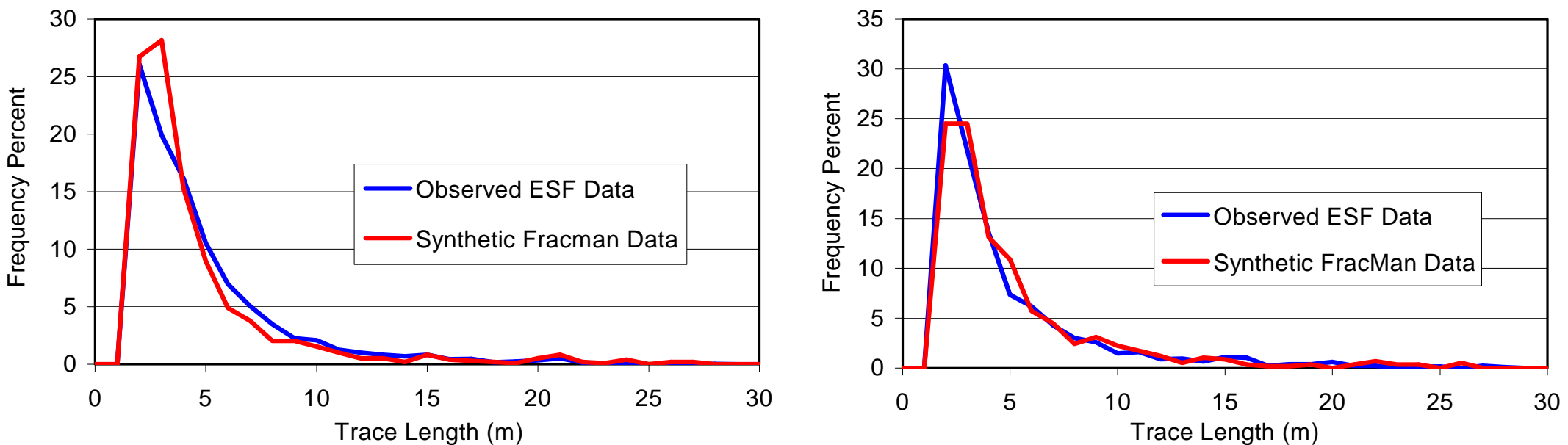

\section{a. Set 1}

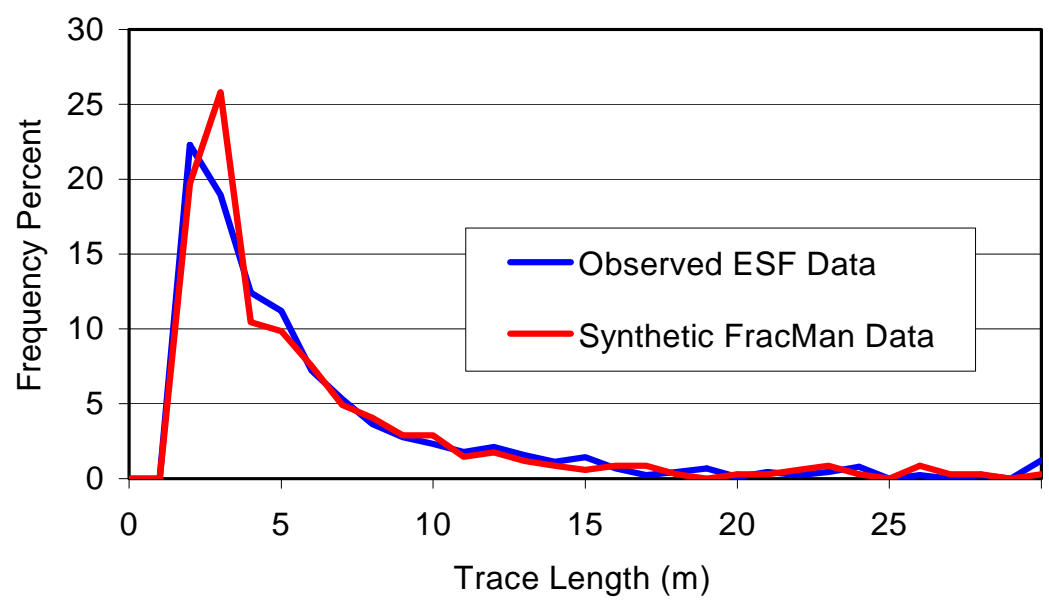

c. Set 3

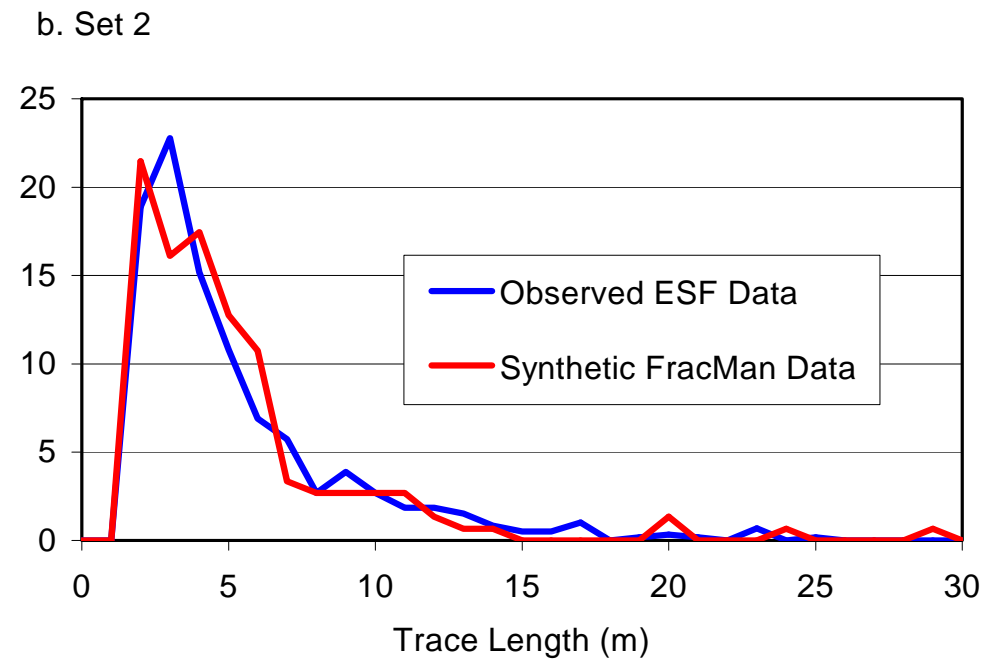

d. Vapor-Phase Parting

Source: The source DTNs for the full periphery geologic map are: GS960908314224.020, GS000608314224.006, GS960908314224.015, GS960908314224.016.

Figure 6-23. Comparison of Sampled Fracture Trace Lengths from the FracMan Cube and Full Periphery Geologic Maps from the ESF for the Tptpmn 


\subsection{THERMAL-MECHANICAL CALCULATION}

Coupled thermal-mechanical processes in the rock mass surrounding the geologic repository at Yucca Mountain are examined in this section. This thermal-mechanical calculation investigates the temperature history throughout the preclosure and postclosure periods of the repository, and stress changes, $\Delta \sigma_{i j}$, due to temperature change, according to the following relation (Itasca Consulting Group 2002 [DIRS 160331], Manuals/3DEC/Optional Features/Section 1: Thermal Option, Section 1.2.3):

$$
\Delta \sigma_{i j}=\delta_{i j} 3 K \alpha \Delta T
$$

where $\delta_{i j}$ is the Kronecker $\delta$ (unit matrix), $\alpha$ is the coefficient of thermal expansion $\left({ }^{\circ} \mathrm{C}^{-1}\right), K$ is the bulk modulus $(\mathrm{Pa})$, and $\Delta T$ is the change in temperature $\left({ }^{\circ} \mathrm{C}\right)$. The coupled thermal-mechanical calculation was conducted by two sets of calculations: the drift scale (described in this section) and the coupled regional and drift scale calculations (described in Appendix C).

The drift scale thermal-mechanical calculation consists of the temperature history (thermal) calculation and the thermal stress (mechanical) calculation. The thermal part of the drift scale calculation was performed by the NUFT thermohydrology software simulating two-dimensional drift scale thermal-hydrologic behavior. The temperature history results from the NUFT code were imported to the UDEC discrete-element software and the FLAC finite-difference software to calculate the thermal stress around the emplacement drift (see Appendix U). UDEC and 3DEC (the three-dimensional equivalent of UDEC) were used to model the effects of the thermal stress and to conduct a rockfall analysis associated with the previous thermal stress calculation. Details of the thermal stress calculation and the rockfall analysis for nonlithophysal and lithophysal units are presented in Sections 6.3.1.3 and 6.4.1.2, respectively.

The drift scale calculations (both thermal and mechanical) consider an infinite extent (perpendicular and in the direction of the drifts) of the repository; consequently, they are two-dimensional (a single drift included in the calculation), with a symmetry boundary condition on a plane halfway between the emplacement drifts ${ }^{3}$. The coupled regional and drift scale thermal-mechanical calculation (Appendix C) was planned and conducted to support this drift scale calculation by assessing repository-scale effects, including edge effects and the effects of finite repository size and depth on predicted temperatures and stresses. These calculations are three-dimensional, and analysis was carried out in two steps. First, the regional scale thermal-mechanical calculation was used to determine temperature and stress changes on the scale of the entire mountain. In the next step, the drift scale thermal-mechanical analysis was performed such that boundary conditions for temperature and stress fields (functions of time) were determined from the regional scale calculation. Thus, this calculation did not use any simplifying assumptions (e.g., infinite extent of the repository) for the boundary conditions. Both components of the regional and drift scale thermal-mechanical calculations were performed using FLAC3D. Because the goal of the calculation was to support the drift scale calculation, details of the calculation and results are presented in Appendix C. A comparison of temperatures

\footnotetext{
${ }^{3}$ The symmetry boundary condition results in zero displacements perpendicular to the boundary and zero heat flux across the boundary.
} 
and stresses as calculated by the drift scale and the coupled regional and drift scale calculations is presented at the end of this section.

The thermal part of the drift scale calculation was performed by the NUFT thermohydrology software, applying a two-dimensional line-averaged heat source, drift scale, thermohydrologic (LDTH) sub-model, which is described in Multiscale Thermohydrologic Model (BSC 2004 [DIRS 169565]). The LDTH sub-model is a part of the multiscale thermohydrologic model that is created by the NUFT software. The LDTH sub-model accounts for hydrologic effects in the rock mass, and conductive and radioactive heat transfer mechanisms around the drift. Effects of the preclosure forced ventilation are accounted for by removing a percentage of the heat given off by the waste package (Section 5.1.2). A non-backfilled and mean infiltration version of the LDTH sub-model L2C3 (coordinates: E170731, N234973) was selected and extracted among the 31 LDTH sub-models. The L2C3 LDTH sub-model is used to compute temperature history of the emplacement drift and surrounding areas throughout the preclosure and postclosure periods.

The L2C3 LDTH sub-model location selected has the following characteristics of interest:

- Approximately the geometric center of the license application reference repository layout (BSC 2004 [DIRS 164519]).

- The repository horizon is located approximately $281 \mathrm{~m}$ below the ground surface and $327 \mathrm{~m}$ above the water table. This elevation puts the repository horizon at approximately $1057 \mathrm{~m}$ above sea level.

- The repository horizon is located in the Tptpll with approximately $34 \mathrm{~m}$ of Tptpll above the repository horizon and $68 \mathrm{~m}$ of Tptpll below the repository horizon.

- The mean infiltration conditions have surface infiltration rates of $12.0 \mathrm{~mm} / \mathrm{year}$ during the first 600 years of emplacement (present day climate), $40.8 \mathrm{~mm} /$ year from 600 years to 2000 years (monsoonal climate), and $63.2 \mathrm{~mm} /$ year from 2,000 years on (glacial transition climate).

- The ground surface temperature is fixed at $16.9^{\circ} \mathrm{C}$, and the water table temperature is fixed at $29.2^{\circ} \mathrm{C}$.

In addition to the LDTH sub-model, updated thermal and hydrologic properties were used for the repository and non-repository rock units. The thermal and hydrologic properties are presented in Section 4.1.6 and 4.1.8, respectively. Details of the data preparation for input files of the LDTH sub-model are described in Multiscale Thermohydrologic Model (BSC 2004 [DIRS 169565]).

Three major cases of the drift scale thermal calculation were carried out, including:

- Case 1: Base case calculation with $1.45 \mathrm{~kW} / \mathrm{m}$ initial heat load and 50 years preclosure ventilation (90 percent heat removal ratio, Section 5.1).

- Case 2: Sensitivity calculation for thermal properties of repository rock material (Tptpll) with $1.45 \mathrm{~kW} / \mathrm{m}$ initial heat load, 50 years preclosure ventilation, and 90 percent 
heat removal ratio. Values of thermal conductivity and specific heat one standard deviation less than the mean values were used:

- Thermal Conductivity (DTN: SN0404T0503102.011 [DIRS 169129]): $1.64 \mathrm{~W} / \mathrm{m}-\mathrm{K}$ $(=1.89 \mathrm{~W} / \mathrm{m}-\mathrm{K}-$ one standard deviation $[0.25 \mathrm{~W} / \mathrm{m}-\mathrm{K}])$ for wet conditions and 1.03 $\mathrm{W} / \mathrm{m}-\mathrm{K}(=1.28 \mathrm{~W} / \mathrm{m}-\mathrm{K}$ - one standard deviation $[0.25 \mathrm{~W} / \mathrm{m}-\mathrm{K}])$ for dry conditions.

- Heat Capacity: 811 J/kg-K (= 954 J/kg-K - one standard deviation [143 J/kg-K]).

- Case 3: Sensitivity calculation for heat removal ratio. 70 percent heat removal ratio was used for the preclosure ventilation (Section 5.1).

The LDTH sub-model that was used in the thermal-mechanical analysis presented in this document has been superseded by a new LDTH sub-model (DTN: LL030808623122.036 [DIRS 165790]). The new LDTH sub-model updated several input parameters including rock mass thermal property data and preclosure ventilation efficiency data. The heat capacity data used in the thermal analyses were preliminary and have been superseded by Heat Capacity and Thermal Expansion Coefficients Analysis Report (BSC 2003 [DIRS 164670], Table 6-5) and DTN: SN0307T0510902.003 [DIRS 164196] (see Appendix E, Table E-16). In this document, heat capacity values for the range of $\mathrm{T} \leq 95^{\circ} \mathrm{C}$ only were utilized for the thermal calculations using the LDTH sub-model (Table E-16). Because consideration of latent heat effects above the boiling point is built into the NUFT code, the high heat capacity value at the temperature range of 95 to $114^{\circ} \mathrm{C}$ (Table E-16) were not used in the thermal calculations in this document. The new LDTH sub-model uses a drift location-dependent and time-dependent heat removal ratio (DTN: MO0306MWDALAFV.000 [DIRS 163961]) instead of a constant heat removal ratio (Section 5.1.2) as was assumed in the rock mass temperature calculations performed in this document. This new logic considers that ventilation air will have a varying heat removal capacity as it travels from the entrance to the exit of an emplacement drift. The heat removal capacity will also vary as a function of time as both the waste package power output and rock mass temperature change (BSC 2004 [DIRS 169862]). These changes could potentially cause a significant difference in drift wall temperature during the preclosure period. Further details of the new LDTH sub-model can be found in Multiscale Thermohydrologic Model (BSC 2004 [DIRS 169565]).

Impact analyses were conducted regarding the new LDTH sub-model and are presented in Appendix Q (Section Q2). The impact analyses show that the use of the new LDTH sub-model primarily impacts preclosure temperature. The impact on the prediction of rock mass stress and drift degradation is insignificant.

Decay curves of the linear heat load used in the calculation cases are presented in Figure 6-24. The original linear heat decay curve (no ventilation) was obtained from $D \& E / P A / C I E D$ Subsurface Facilities (BSC 2004 [DIRS 167369]). Ninety percent of the constant ventilation heat removal ratio (Section 5.1) was applied for Cases 1 and 2, while 70 percent of constant heat removal ratio (Section 5.1) was used in Case 3. 
Temperature histories at the drift crown for the cases of the drift scale thermal calculations are presented in Figure 6-25. The results exhibited the temperature increase from base case (Case 1) to sensitivity calculations (Cases 2 and 3). In particular, Case 3 showed a significant temperature increase at the preclosure period. The peak temperate for Case 1 was $138^{\circ} \mathrm{C}$ at around 75 years, while Cases 2 and 3 were $161^{\circ} \mathrm{C}$ and $153^{\circ} \mathrm{C}$ at around 75 years, respectively.

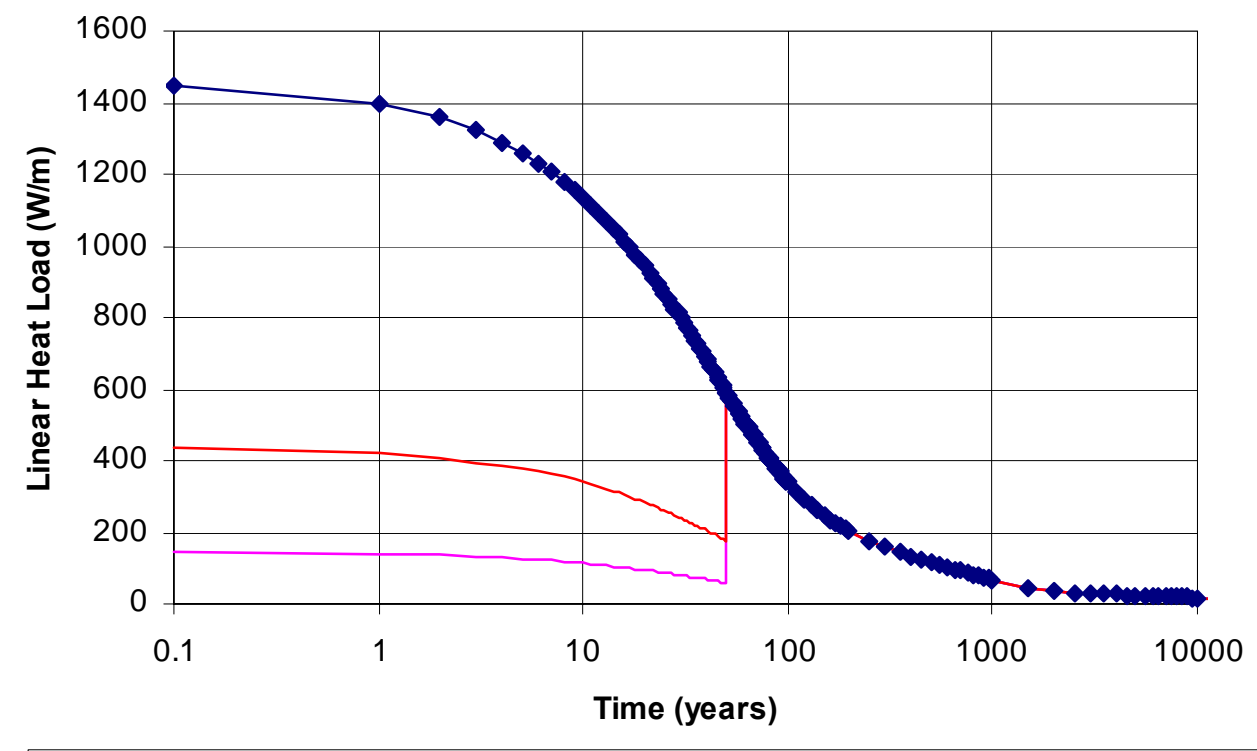

$\longrightarrow$ no ventilation $\_$Cases $1 \& 2$ (90\% heat removal) Case 3 (70 \% heat removal)

Source File: DTN: MO0408MWDDDMIO.002, file Heat_Decay_Cal_LA1450.xls.

NOTE: The no ventilation curve is from BSC 2004 [DIRS 167369]. Cases 1 and 2 use the 90 percent heat removal curve while Case 3 uses the 70 percent heat removal curve.

Figure 6-24. Heat Decay Curves for Thermal Calculations 
Temperature-History at Drift Crown

$1.45 \mathrm{~kW} / \mathrm{m}$ linear heat load, 50 years pre-closure ventilation

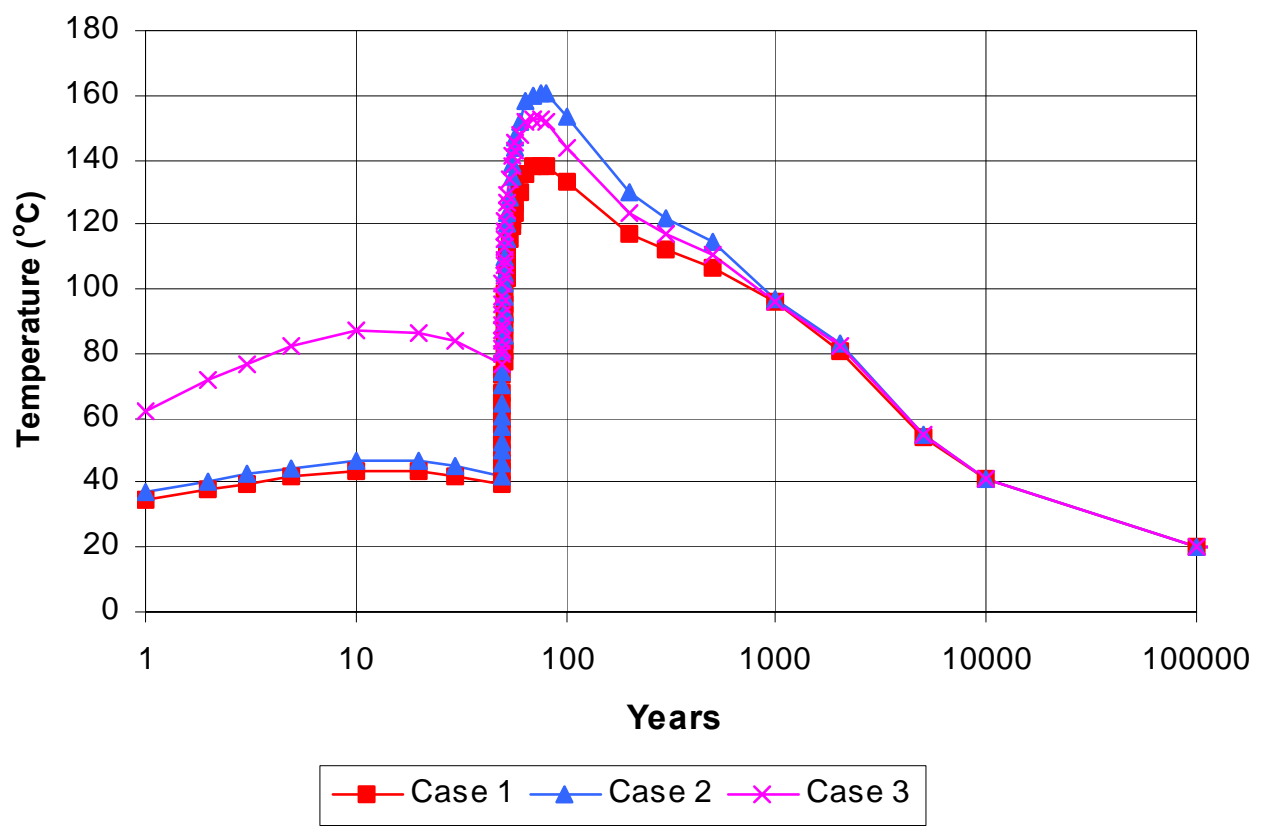

Source File: DTN: MO0408MWDDDMIO.002, file LA1450_NUFT_Temp_crss-sctn3.xIs.

Figure 6-25. Temperature History at the Drift Crown Due to the Linear Heat Load Presented in Figure 6-24

A comparison of temperature histories in the drift crown for Case 1, as determined in the drift scale calculation (NUFT) and the coupled regional and drift scale calculations (FLAC3D) for the conditions in the middle of the repository, is shown in Figure 6-26. The agreement between histories is quite good. With the exception of the state at 10,000 years after waste emplacement, the temperature differences between the two calculations are less than $10^{\circ} \mathrm{C}$. 


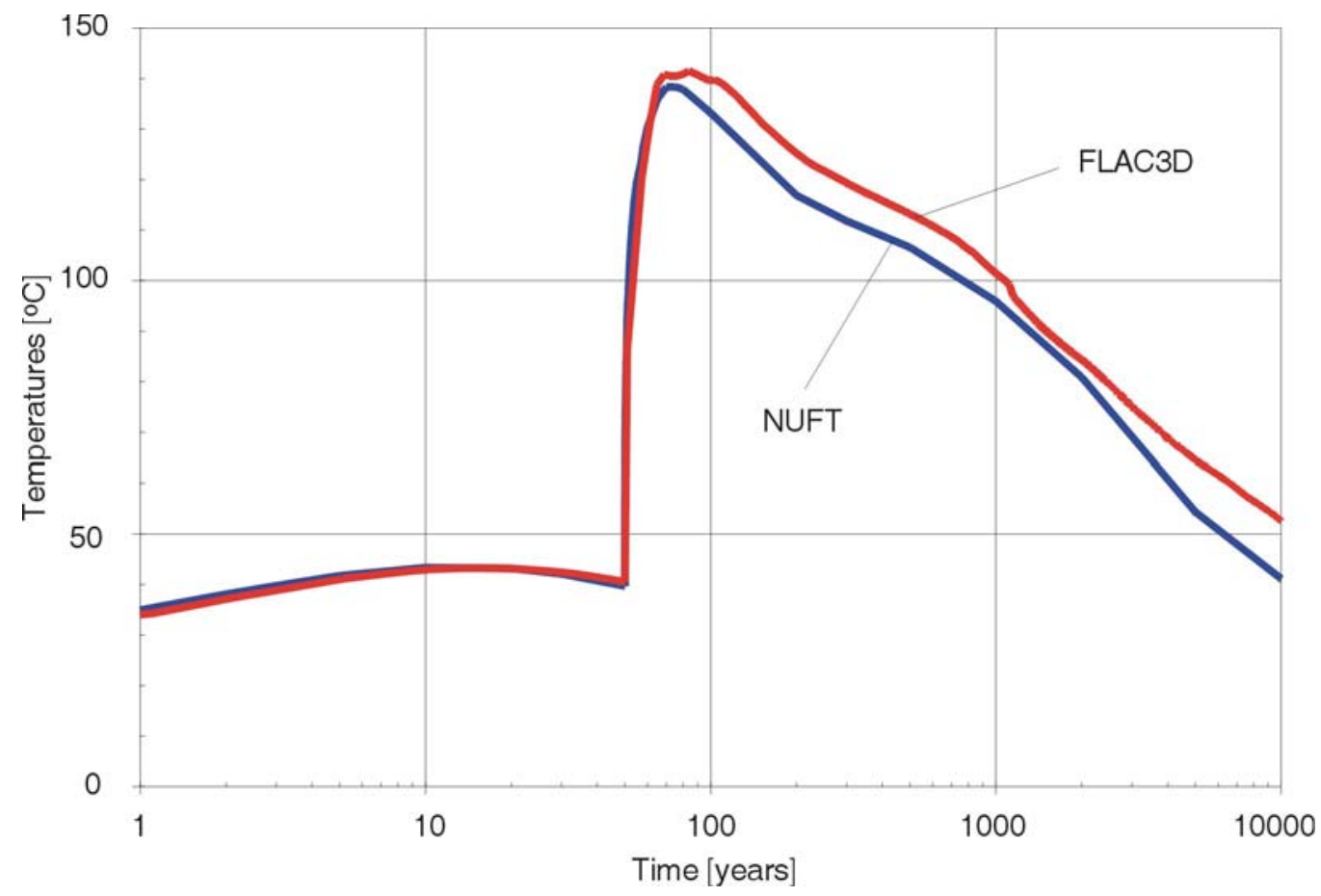

Source File: DTN: MO0408MWDDDMIO.002, FLAC 3D Inputs \& OutputsITM model.

Figure 6-26. Comparison of Temperature Histories at Tunnel Crown for Case 1 Calculated Using NUFT and FLAC3D

Stresses in the drift wall and crown for conditions in the middle of the repository, as predicted by two calculations (drift scale [NUFT-FLAC] and coupled regional and drift scale [FLAC3D]), are shown for 10 years, 100 years, and 1,000 years after waste emplacement in Figures 6-27, 28, and 29 , respectively. NUFT-FLAC results are presented from the calculation for lithophysal rock mass Category 4 (discussed in Section 6.4), which has the same Young's modulus as the value used in the coupled regional and drift scale calculation. Agreement of the tangential stresses in the crown is excellent at the three times presented. As expected, the two-dimensional calculation (NUFT-FLAC) predicts a slightly higher tangential stress in the crown after 1,000 years of heating. The most significant difference between the two calculations is the vertical stress after 100 and 1,000 years. The coupled regional and drift scale calculations (FLAC3D) show an increase in the vertical stress (in the wall after 100 years and 1,000 years, but also throughout the repository horizon after 1,000 years) because of the effect of the finite repository size and elastic restoring stresses caused by the heat-induced deformation. This effect could not be accounted for in the drift scale calculation in which the average vertical stress is determined by the weight of the overburden. The drift scale calculation stress predictions are justified for use in the analysis of drift degradation, because the increase in the vertical stress in the wall (not accounted for in the two-dimensional calculation) is not significant. 


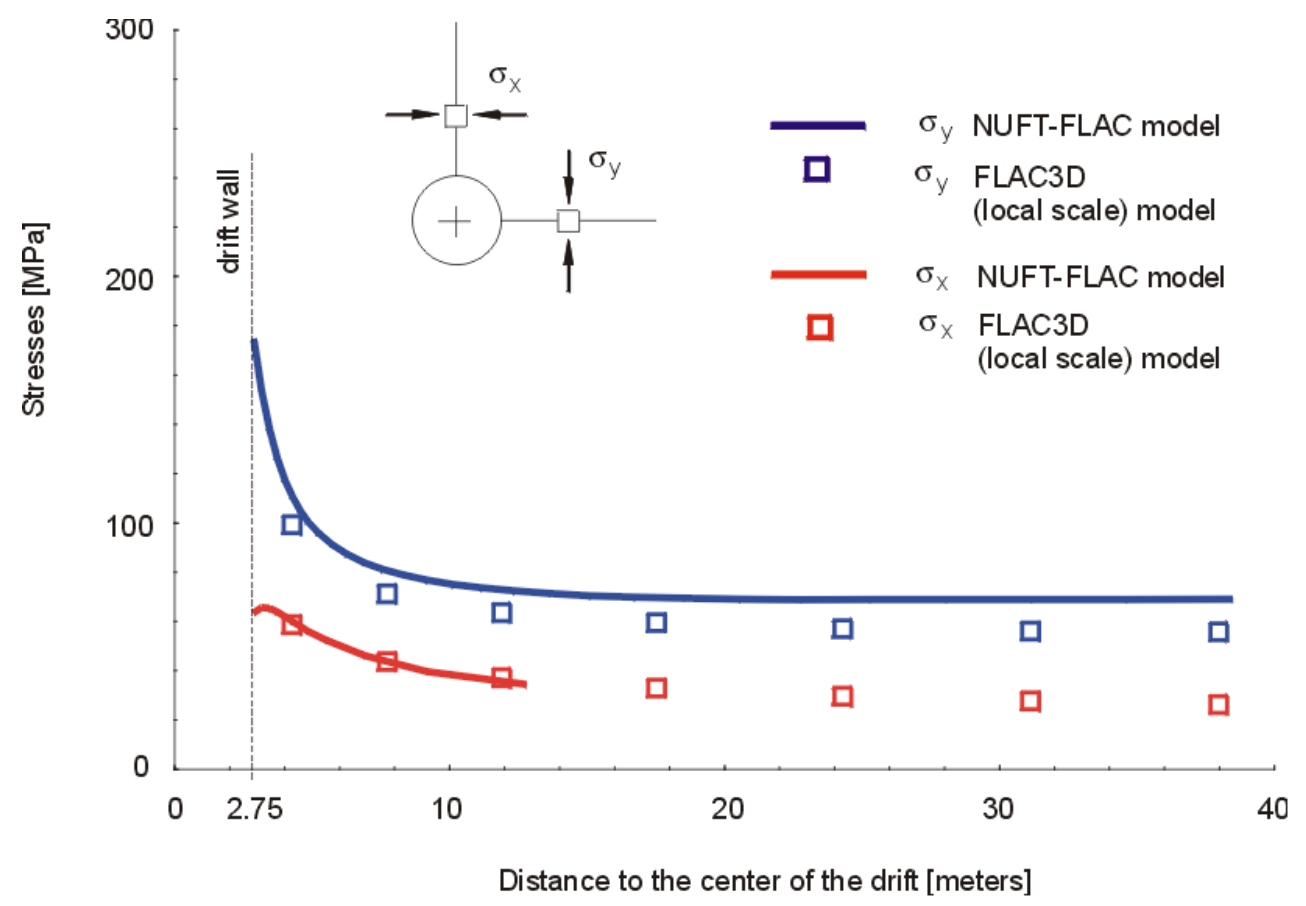

Source File: DTN: MO0408MWDDDMIO.002, FLAC 3D Inputs \& OutputsITM model.

Figure 6-27. Comparison of Stresses Around the Drift Between the NUFT-FLAC and FLAC3D Predictions After 10 Years of Heating

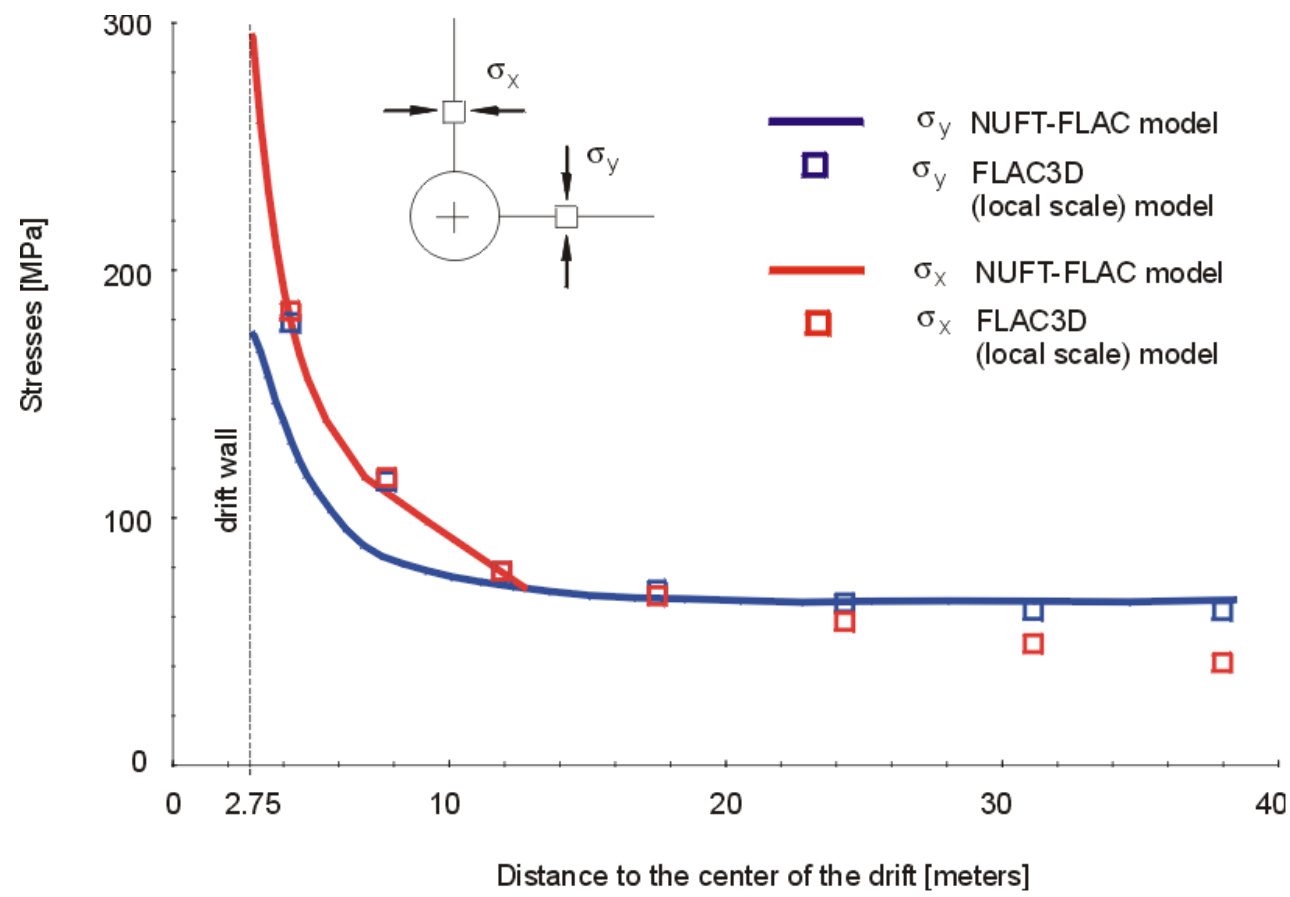

Source File: DTN: MO0408MWDDDMIO.002, FLAC 3D Inputs \& OutputsITM model.

Figure 6-28. Comparison of Stresses Around the Drift Between the FLAC and FLAC3D Predictions After 100 Years of Heating 


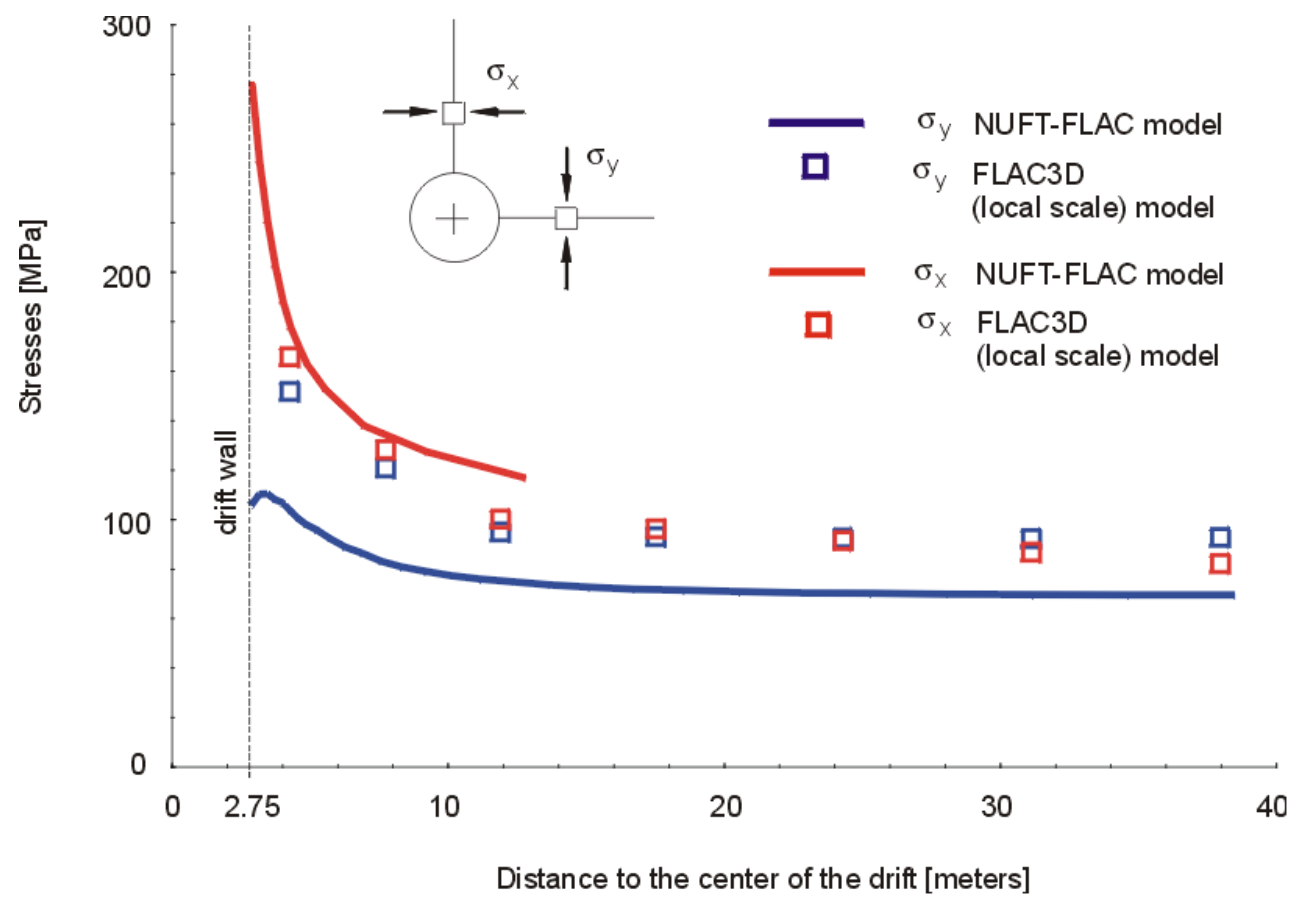

Source File: DTN: MO0408MWDDDMIO.002, FLAC 3D Inputs \& OutputsITM model.

Figure 6-29. Comparison of Stresses Around the Drift Between the NUFT-FLAC and FLAC3D Predictions After 1,000 Years of Heating

The drift stability analysis presented in this report was carried out for temperature and stress conditions in the middle of the repository. However, the temperatures and stresses for the conditions at the edge of the repository are investigated using the coupled regional and drift scale (FLAC3D) calculations (the actual location considered and other details are described in Appendix C). The temperature history from the coupled calculations for the edge of the repository, compared with the NUFT results for the center of the repository, are shown in Figure 6-30. As expected, the temperatures at the edge of the repository will be smaller than temperatures in the middle of the repository.

The stress profiles around the emplacement drift located at the edge of the repository-10, 100 and 1,000 years after waste emplacement-are shown in Figures 6-31 through 6-33. Stresses at the edge of the repository are, in general, smaller than in the middle of the repository. Smaller vertical stress at the repository edge is due to smaller overburden. However, the most significant difference between stress conditions at the edge and in the middle is in the horizontal stress 1,000 years after waste emplacement. The horizontal stress is approximately $5 \mathrm{MPa}$ smaller at the edge compared to the middle of the repository (Figure 6-32). After a heating time when the drifts start to thermally interact with each other, conditions of almost complete confinement (idealized in two-dimensional models by symmetry conditions on the plane half-way between the drifts) exist in the middle of the repository, leading to increased horizontal stresses. The confinement and temperatures at the edge are smaller (than in the middle of the repository) resulting in smaller horizontal stresses. It appears from these results that limiting the drift degradation analysis to thermally induced stresses in the middle of the repository is justified. 


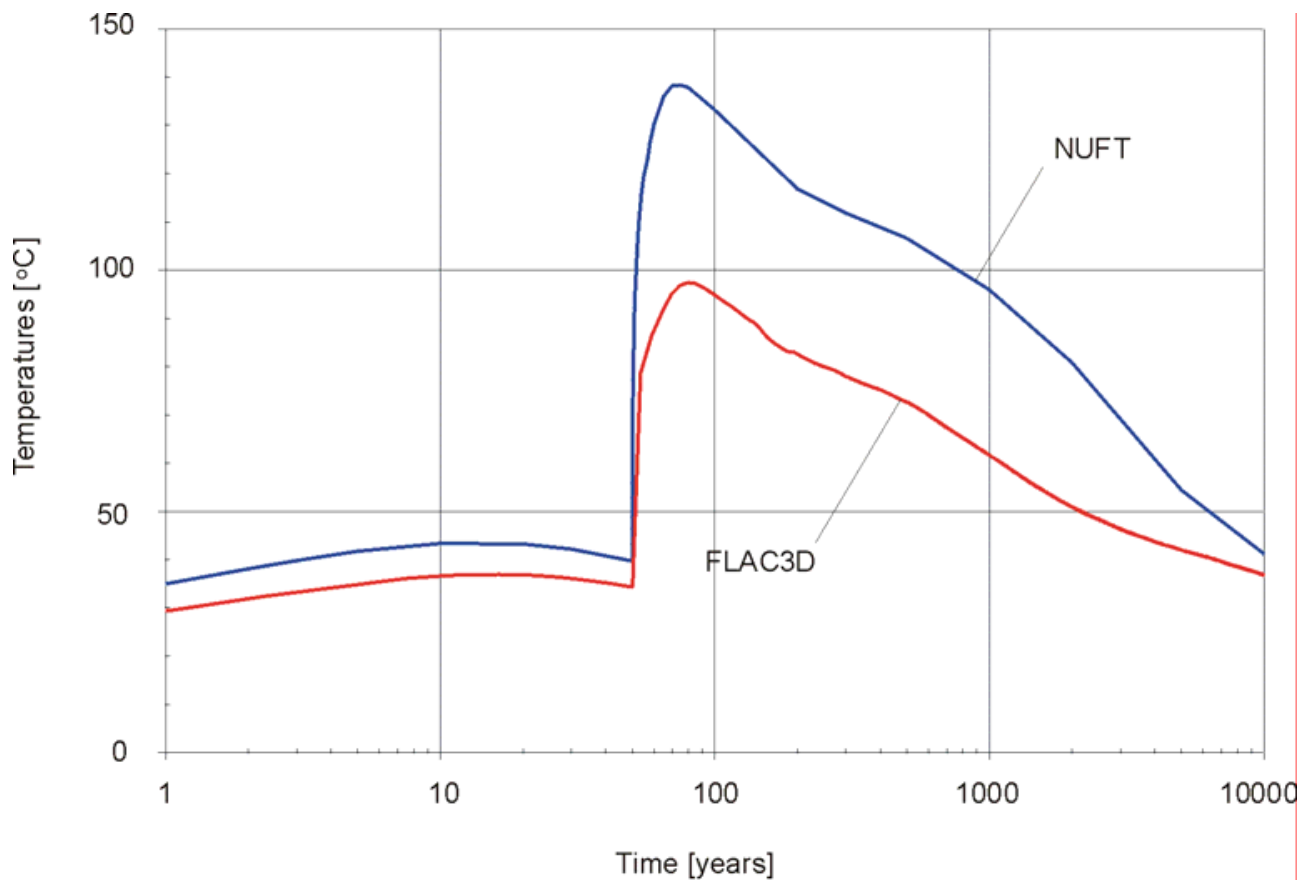

Source File: DTN: MO0408MWDDDMIO.002, FLAC 3D Inputs \& OutputsITM model.

Figure 6-30. Comparison of Temperature Histories at Tunnel Crown for Case 1 Calculated Using NUFT (at the Center of the Repository) and FLAC3D (for the Edge of the Repository)

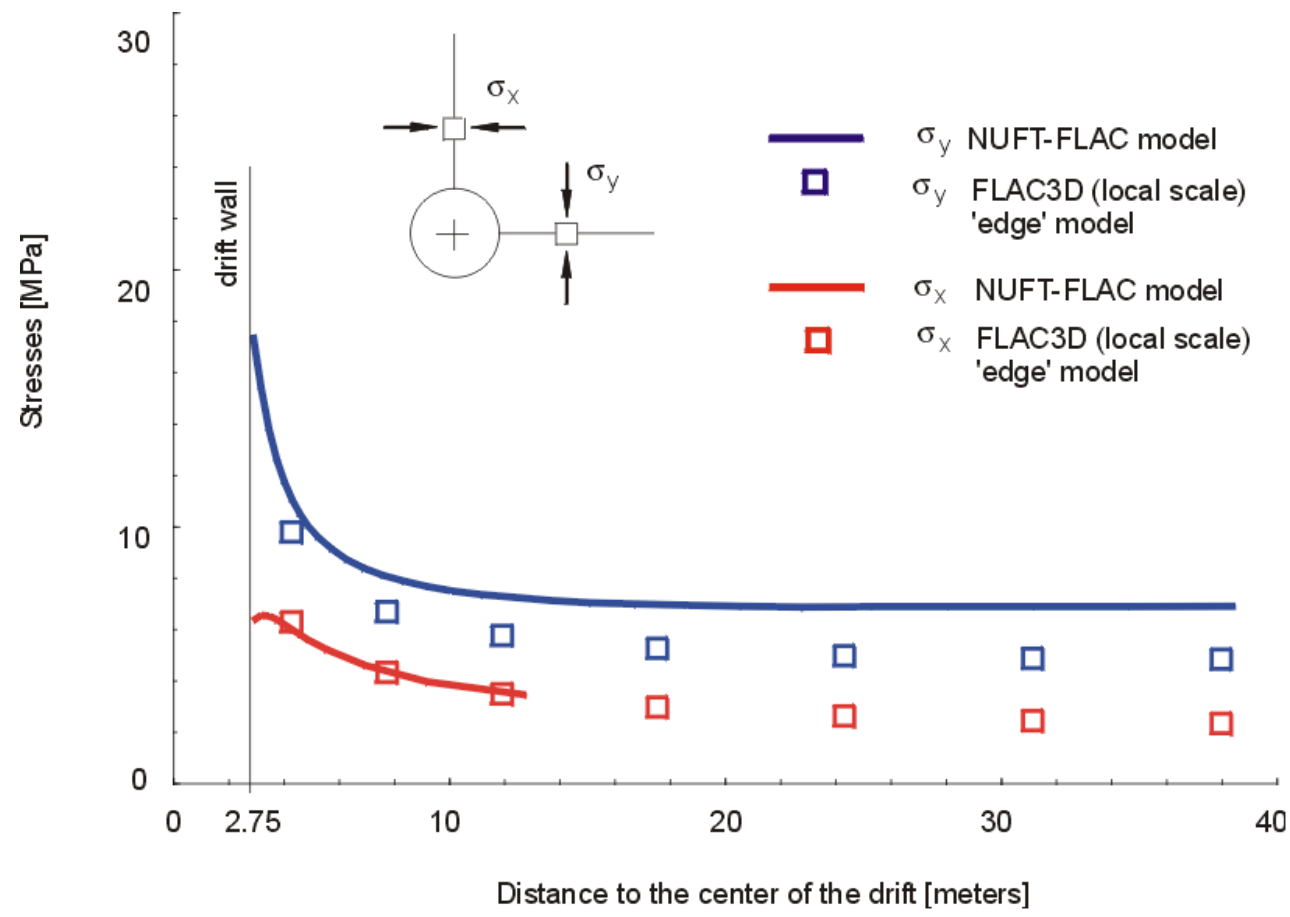

Source File: DTN: MO0408MWDDDMIO.002, FLAC 3D Inputs \& OutputsITM model.

Figure 6-31. Comparison of Stresses Around the Drift Between the NUFT-FLAC and FLAC3D Calculations for Edge of the Repository After 10 Years of Heating 


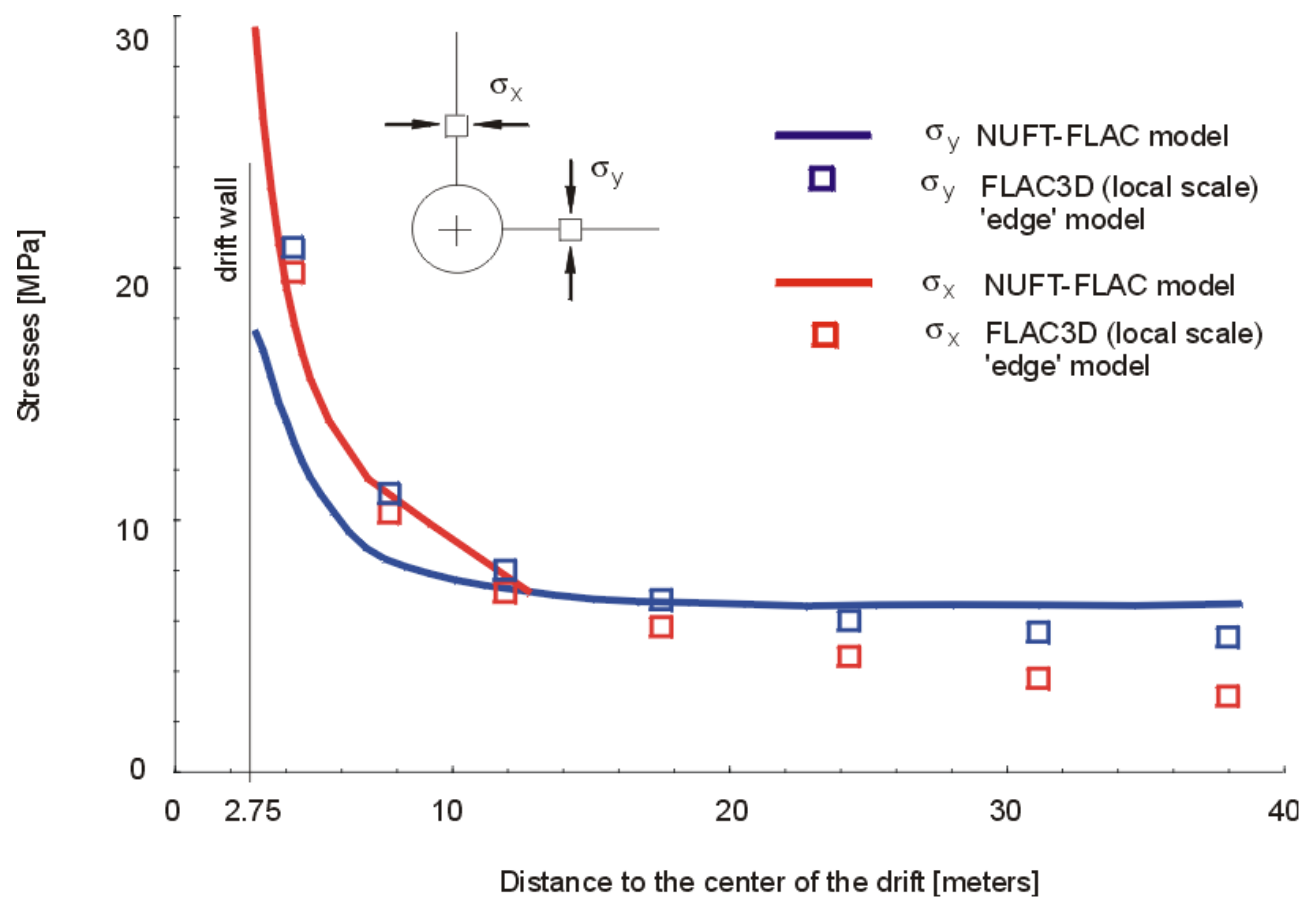

Source File: DTN: MO0408MWDDDMIO.002, FLAC 3D Inputs \& OutputsITM model.

Figure 6-32. Comparison of Stresses Around the Drift Between the NUFT-FLAC and FLAC3D Calculations for Edge of the Repository After 100 Years of Heating

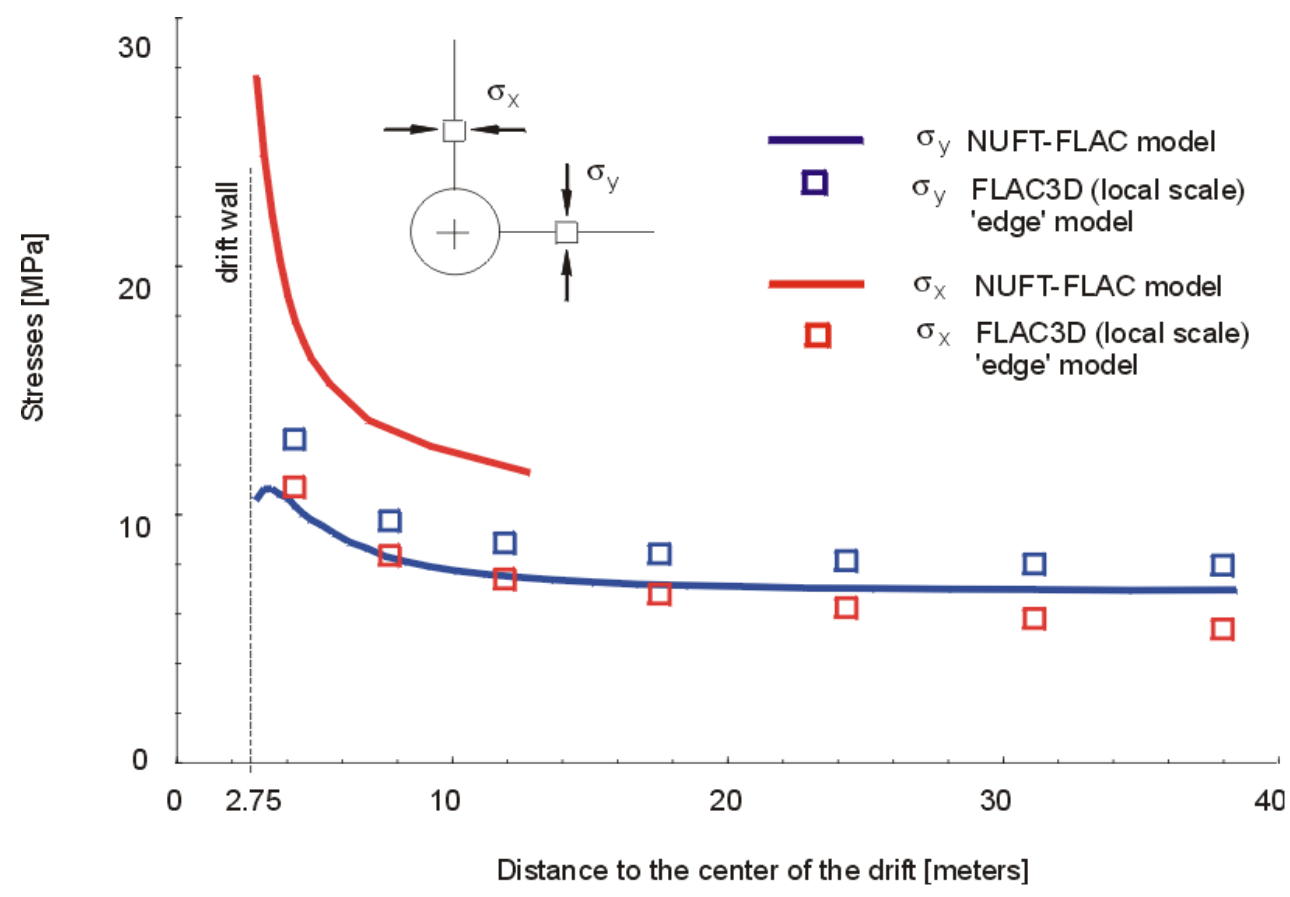

Source File: DTN: MO0408MWDDDMIO.002, FLAC 3D Inputs \& OutputsITM model.

Figure 6-33. Comparison of Stresses Around the Drift Between the NUFT-FLAC and FLAC3D Calculations for Edge of the Repository After 1,000 Years of Heating 


\subsection{ROCKFALL IN THE NONLITHOPHYSAL UNITS}

The assessment of rockfall in the nonlithophysal units is primarily based on a three-dimensional discontinuum analysis (3DEC analysis). This analysis is adequate for the wedge-type failure in a jointed rock mass, which has been validated in Section 7.7. A description of this set of analyses and a presentation of the results are provided in Section 6.3.1. An intensely fractured zone was observed in the ESF main loop between Stations 42+00 and 51+50 (Albin et al. 1997 [DIRS 101367], p. 58). A 3DEC analysis is not suited for such highly fractured rock. Therefore, a three-dimensional continuum analysis with a ubiquitous joint model (FLAC3D analysis) was adopted to account for the effect of the highly fractured and anisotropic behavior of the rock mass in this limited zone as described in Section 6.3.2. The aforementioned analyses consider only fractures with trace lengths greater than $1 \mathrm{~m}$. The impact of small-scale fractures (less than 1-m trace length) for block forming is assessed using the key-block code DRKBA. A comparison of the results for including and excluding the small-scale fractures is provided in Section 6.3.3. The drift profile predictions considering wedge-type failure are provided in Section 6.3.4.

It should be noted that in previous versions of this document (BSC 2001 [DIRS 156304]), rockfall in the nonlithophysal units was based on a Discrete Region Key Block Analysis (DRKBA). In this report, DRKBA analyses primarily provide a confirmatory role in the assessment of drift degradation. DRKBA analyses are documented in Appendix D.

\subsubsection{Three-Dimensional Discontinuum Analysis of Jointed Rock Mass for Wedge-Type Rockfall}

The three-dimensional discontinuum analysis is used for simulation of the mechanical behavior of the jointed rock mass in the nonlithophysal units for loading conditions with which stability response will be controlled by the fractures. 3DEC was selected for its capability of simulating fractured rock masses under both thermal and seismic loadings. The fractured rock mass is represented as a number of intact rock blocks that are separated by interface planes whose mechanical behavior is represented by a standard Coulomb slip criterion. The intact blocks are subdivided into tetrahedral finite difference zones and can be assigned suitable mechanical constitutive law (Itasca Consulting Group 2002 [DIRS 160331]). Due to the high intact rock strength in the nonlithophysal units, rock blocks are considered to behave elastically.

It is important in the 3DEC analysis to include field fracture geometric data for modeling the nonlithophysal units. Because the fractures within the Tptpmn may be non-persistent in nature (with median trace lengths of approximately $3 \mathrm{~m}$ [see Table 6-2], which is smaller than the diameter of the tunnel), many fractures are of insufficient length to form a regular block. The fracture geometries used as input to 3DEC are derived from FracMan simulations as discussed in Section 6.1.6. Modifications to the 3DEC program have been made to accommodate the FracMan output; namely, the discontinuous nature of the fractures. In versions of the 3DEC program developed prior to the use described here, fractures are modeled as continuous in nature and thus it was impossible to have a fracture that ends in solid rock. The program was modified to provide the capability to allow contact points along a fracture trace to be assigned a particular material property. In other words, portions of a fracture plane could be assigned a standard Coulomb slip behavior, whereas others could be bonded to the opposing surface with the 
strength of the adjacent rock blocks, thereby creating fractures that have rock "bridges" along their surface. In this case, the rock bridge acts as a strong location along the fracture surface, but can still fail in shear or tension if the stresses so dictate. In this manner, it is possible to represent a discontinuous fracture system, but one in which breakage of solid rock can occur.

Other enhancements added to 3DEC for rockfall modeling include:

- Implementation of the "free field" boundary to provide a "quiet" or "non-reflecting" boundary for dynamic analysis with superposition of the P and S wave motions

- Partial density scaling for dynamic analysis.

Descriptions for these enhancements are provided in Appendix H.

For each simulated fracture, the FracMan program provides the centroid, radius (fractures are considered to be circular), dip and dip direction for input to 3DEC which then generates the fracture by cutting the block(s) in which the fracture lies. The coordinate systems adopted in FracMan and 3DEC are different; requiring a conversion of the outputs from FracMan to inputs in 3DEC (Appendix L). To account for the stochastic nature of the jointed medium, a total of 50 fracture geometries were selected by generating random tunnel centroid locations within the 100-m-cube simulated FracMan rock mass. A representative tunnel volume, approximately two tunnel diameters around the tunnel centroid and $25 \mathrm{~m}$ in length, is created at each of these locations to contain fractures generated in FracMan. This volume is considered sufficient to contain the limits of damaged rock, and of sufficient length (approximately five times the tunnel diameter and about 10 times the median trace lengths) to provide a representative volume of rockfall (see Figure 6-34 for 3DEC model region).

The combination of computer runs considering fracture geometry, seismic ground motion, material properties variation, and thermal loading scenario are immense. In order to complete the task in a timely fashion, several techniques were used to speed up the calculation. These techniques are described in Appendix $\mathrm{H}$.

\subsubsection{3DEC Model Set Up}

Figure 6-34 shows the base case 3DEC model geometry with fracture modeling region \#38. The model is slightly larger than a $25-\mathrm{m} \times 25-\mathrm{m} \times 25-\mathrm{m}$ cube with the $5.5-\mathrm{m}$ diameter tunnel oriented at 75 degrees azimuth ${ }^{4}$. The region with detailed fractures imported from FracMan is one tunnel diameter at the side of the tunnel and two diameters on top of the tunnel. Three cross-section views are included in Figure 6-34 to illustrate the fractures and blocks around the excavation. That portion of the rock mass that does not form blocks is shown with a green color, while distinct blocks are identified as areas with different colors. Some of the fractures shown in the cross-section views are artificial, i.e., they were generated during the block cutting process or to facilitate mesh generation. A detailed description of mesh generation with artificial fractures is

\footnotetext{
${ }^{4}$ The emplacement drift azimuth of $72^{\circ}$ (see Table 4-1) was modeled in this document with drifts trending $75^{\circ}$. This 3-degree difference between the modeled and actual drift alignment is acceptable given the variability of joint set orientations captured in the model (see Section 6.1.6). The 3-degree difference does not significantly effect the results from this analysis.
} 
provided in the 3DEC manual (Itasca Consulting Group 2002 [DIRS 160331]). The dimension of the model is selected to optimize the time required for analysis and the ability of the model to predict rockfall accurately. Sensitivity of the model dimension to the outcome of rockfall prediction is provided in Section 6.3.1.6. The drip shield is represented as a stiff, rectangular block fixed to the invert of the drift, based on a simplified drip shield geometry (BSC 2004 [DIRS 169220]). The drip shield block is placed to collect information on the locations and relative velocities of the rockfall impact.

Input properties for the distinct block 3DEC model involve both the fracture and block (intact) properties. Table 6-3 lists the base case properties used in 3DEC. The selected input properties were derived as the best estimates at the time of analysis. These values may have slight deviation from the statistics mean or median presented in Appendix E. Sensitivity analyses on these input parameters to the outcome of rockfall prediction were conducted and the results are presented in Section 6.3.1.6.

A linear elastic model is used for the block material, whereas Coulomb slip criterion is used to present joint mechanical behavior. A linear elastic model is used as the intact block constitutive model for the 3DEC analysis. This approach is used to obtain a conservative (i.e., increased) estimate of the block volume. Breaking and spalling of the rock inside the blocks are expected considering the large amplitude of seismic waves for postclosure ground motions. This mechanism is addressed in Section 6.3.1.6 with a two-dimensional discontinuum model representing the rock mass (UDEC analysis). Although the shallow-dipping vapor-phase parting consists of higher cohesive material, a single set of joint mechanical properties are used for the joint sets for conservatism (i.e., more rockfall will be produced). Coulomb slip criterion is also used for the intact bridges between adjacent fractures, as the intact cohesion and friction is assigned for the bridge strength. Sensitivity analyses of the joint strength properties, dilation angle, and joint stiffness were conducted to evaluate their impact to rockfall, the range of properties, and their impacts to the analysis results are presented in Section 6.3.1.6.

The initial state of stress was included at the model consolidation stage. From the in situ stress measurement using the hydraulic fracturing technique (DTN: SNF37100195002.001 [DIRS 131356]), the horizontal components of in situ stress are provided: maximum 2.9 MPa acting $\mathrm{N} 15^{\circ} \mathrm{E}$ and minimum $1.7 \mathrm{MPa}$ acting $\mathrm{N} 105^{\circ} \mathrm{E}$ (Table 4-1). The vertical component of in situ stress was calculated based on the weight of the overburden at the depth of the test from the surface. First, the coordinates of borehole ESF-AOD-HDRFR\#1 (i.e., the hydraulic fracturing test borehole) were estimated based on the layout of the ESF and the Thermal Test Facility, starting from known coordinates at Main Drift Station 28+04 (BSC 2003 [DIRS 165572], Figure 3; CRWMS M\&O 1997 [DIRS 147458], MOL.19970717.0008, Appendix 6). The estimated coordinates of the borehole ESF-AOD-HDRFR\#1 are NS 234025 and WE 171440. Next, the overburden stratigraphic unit thickness at the borehole location was extracted from DTN: MO0012MWDGFM02.002 [DIRS 153777] using EarthVison (see Appendix M for input/output details and Table M-1 for the overburden unit thickness). The overburden unit thickness and the mean unit densities in Table E-1 are used to calculate an overburden load of 4.7 MPa at the depth of the test (Table M-1). The calculated vertical stress is in agreement with the initially estimated vertical stress at the location of the hydraulic fracturing test (CRWMS M\&O 1997 [DIRS 147458], MOL.19970717.0008, Table 4). Therefore, the direction of the intermediate principal stress is $\mathrm{N} 15^{\circ} \mathrm{E}$ with a ratio to major principal stress 
of 0.617 (= $2.9 \mathrm{MPa} \div 4.7 \mathrm{MPa})$, whereas the direction of the minor principal stress is $\mathrm{N} 105^{\circ} \mathrm{E}$ with a ratio to major principal stress of $0.361(=1.7 \mathrm{MPa} \div 4.7 \mathrm{MPa})$.

The vertical component of in situ stress (the major principal stress) is approximated as $7 \mathrm{MPa}$ considering an overburden depth of $300 \mathrm{~m}$ (BSC 2003 [DIRS 166183], Section 4.2.1) and an overburden density of $2.41 \quad \mathrm{~g} / \mathrm{cc} \quad$ (Section 4.1.3) (i.e., vertical stress $=300 \mathrm{~m} \times 9.81 \mathrm{~m} / \mathrm{sec}^{2} \times 2.41 \mathrm{~g} / \mathrm{cc} \approx 7 \mathrm{MPa}$ ). The horizontal components of in situ stress (the minor and intermediate principal stresses) are simplified to be $3.5 \mathrm{MPa}$ based on an average horizontal-to-vertical stress ratio of 0.5 (i.e., the average of 0.617 and 0.361 as described above). The in situ stress for each emplacement drift will vary depending on the cover depth on top of the drift. The approximated values assigned for the in situ stress are adequate and insensitive to the results judging the magnitude of the induced seismic and thermal stress.

The boundary conditions for various stages of the analysis are presented in Table 6-4. At the initial consolidation stage and the later thermal loading period, fixed velocity boundaries were used to ensure the boundary effect does not affect the stress distribution around the opening. For the seismic analysis, non-reflecting boundaries are used for both the top and bottom of the model, whereas free-field boundaries are imposed at the perimeter of the model as shown in Figure 6-35. The free-field boundaries ensure that plane waves propagating upward suffer no distortion at the boundary. A description of the free-field boundary is provided in Appendix $\mathrm{H}$. Dynamic loading was applied at the bottom of the model as a prescribed stress boundary, and propagated vertically upwards. The conversion of the ground motion velocity to input seismic stress is discussed in Section 6.4.2.2 (Equation 6-7).

\subsubsection{Seismic Consideration in Nonlithophysal Units}

\subsection{Site Specific Ground Motions}

Site-specific ground motions for five levels of annual probability of exceedance, $5 \times 10^{-4}, 1 \times 10^{-4}$, $1 \times 10^{-5}, 1 \times 10^{-6}$, and $1 \times 10^{-7}$, are included in this study (see Table 4-1 for source DTNs). Development of the ground motion time histories following use of a probabilistic seismic hazard analysis and Yucca Mountain site response model can be found in BSC 2004 [DIRS 170027]. The $5 \times 10^{-4}$ and $1 \times 10^{-4}$ ground motions are for preclosure consideration, while the $1 \times 10^{-5}, 1 \times 10^{-6}$ and $1 \times 10^{-7}$ ground motions are for postclosure. The preclosure ground motion levels are provided in this section for comparison to the postclosure levels. For higher-frequency spectral accelerations (5 to $10 \mathrm{~Hz}$ ) and an annual exceedance probability of $5 \times 10^{-4}$, results of the probabilistic seismic hazard analysis for Yucca Mountain indicate the ground motion hazard derives primarily from earthquakes in the magnitude range of 5.0 to 6.5 occurring at distances less than $15 \mathrm{~km}$ from the site. For lower-frequency spectral accelerations (1 to $2 \mathrm{~Hz}$ ) at the same annual exceedance probability, the hazard shows, in addition to nearby sources, a significant contribution from earthquakes in the magnitude range of 7.0 to 8.0 occurring at an epicentral distance of about $50 \mathrm{~km}$. For annual exceedance probabilities of $1 \times 10^{-6}$ and $1 \times 10^{-7}$, nearby earthquakes in the magnitude range 5.5 to 7.0 are the dominant sources contributing to ground motion hazard at both higher and lower spectral acceleration frequency ranges. 

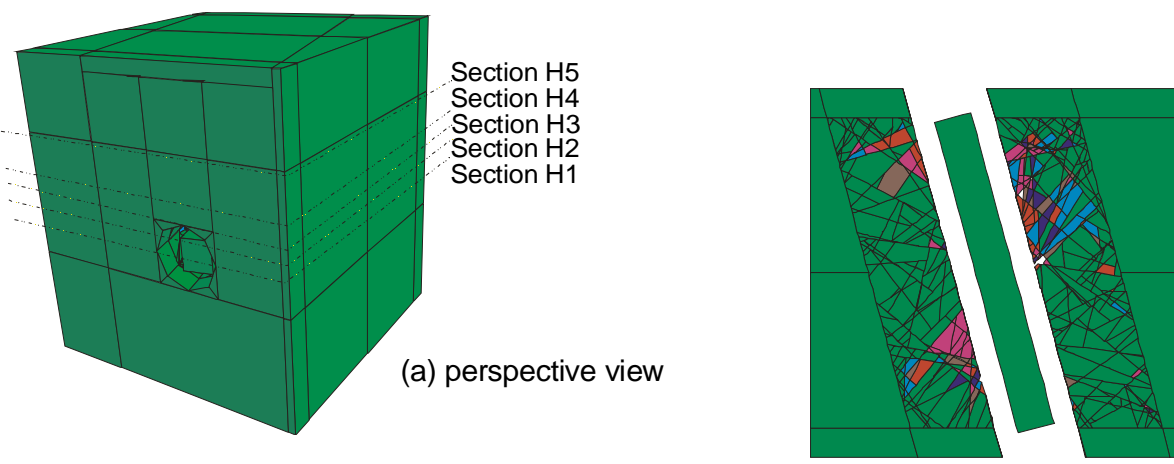

(f) Section $\mathrm{H} 1$

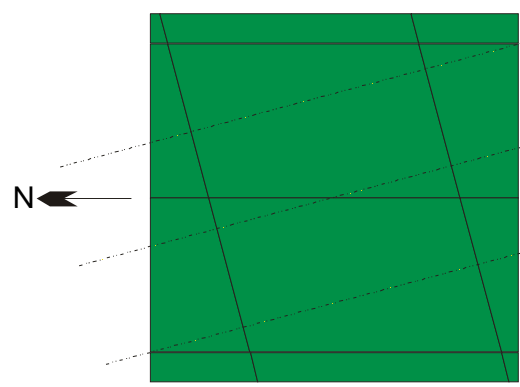

Section V1

Section V2

Section V3

(b) top view

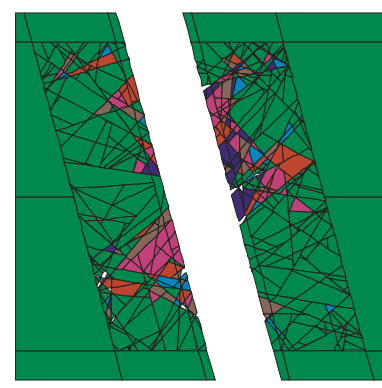

(g) Section H2

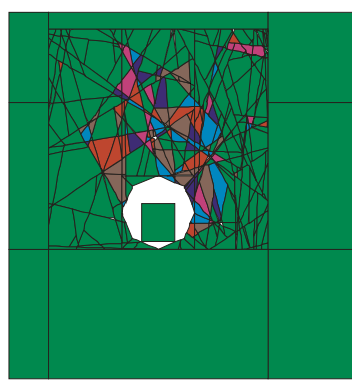

(c) Section V1

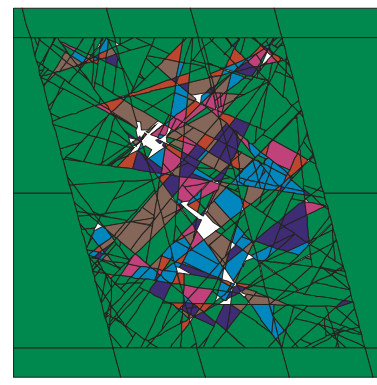

(h) Section $\mathrm{H} 3$

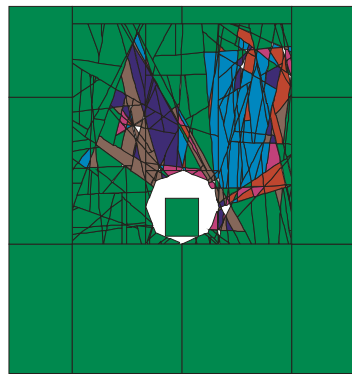

(d) Section V2

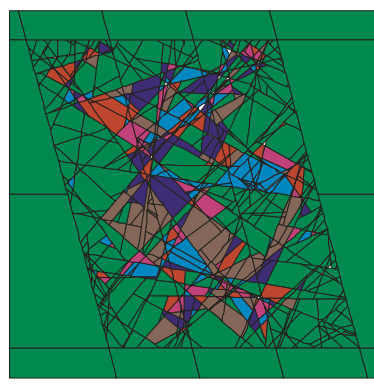

(i) Section $\mathrm{H} 4$

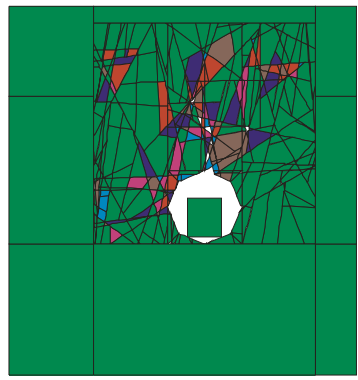

(e) Section V3

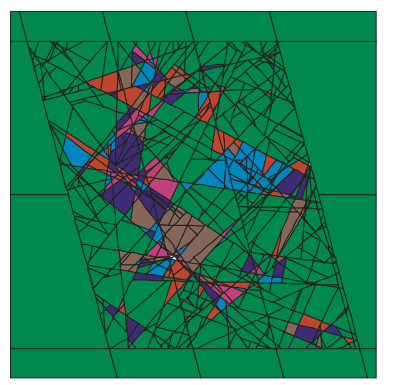

(j) Section $\mathrm{H} 5$

Figure 6-34. 3DEC Model Geometry and Cross-Sections 
Table 6-3. Base Case Material Properties for 3DEC Analysis

\begin{tabular}{|c|c|c|}
\hline \multicolumn{2}{|c|}{ Parameter } & \multirow{2}{*}{$\begin{array}{c}\text { Value } \\
0.1\end{array}$} \\
\hline \multirow{5}{*}{ Joint strength properties } & Joint cohesion (MPa) & \\
\hline & Joint friction (deg) & 41 \\
\hline & Joint dilation (deg) & 0 \\
\hline & Joint normal stiffness, $\mathrm{K}_{\mathrm{n}}(\mathrm{MPa} / \mathrm{m})$ & $5.0 \mathrm{E}+04$ \\
\hline & Joint shear stiffness, $\mathrm{K}_{\mathrm{s}}(\mathrm{MPa} / \mathrm{m})$ & $5.0 \mathrm{E}+04$ \\
\hline \multirow{4}{*}{ Intact rock deformation properties } & Young's Modulus (GPa) & 33.03 \\
\hline & Poisson's ratio & 0.21 \\
\hline & Bulk modulus (GPa) & 19.2 \\
\hline & Shear modulus (GPa) & 13.6 \\
\hline \multirow{3}{*}{ Intact bridge strength properties } & Cohesion (MPa) & 47.2 \\
\hline & Friction angle (deg) & 42 \\
\hline & Tensile strength (MPa) & 11.56 \\
\hline
\end{tabular}

NOTE: The selected input properties were derived as the best estimates at the time of analysis. These values may have slight deviation from the statistics mean or median presented in Appendix E. Sensitivity analyses on these input parameters to the outcome of rockfall prediction were conducted and the results are presented in Section 6.3.1.6.

Table 6-4. Boundary Conditions for 3DEC Analysis

\begin{tabular}{|l|l|l|l|}
\hline \multicolumn{1}{|c|}{ Boundary } & \multicolumn{1}{c|}{$\begin{array}{c}\text { Initial Consolidation and } \\
\text { Excavation Stage }\end{array}$} & \multicolumn{1}{c|}{ Thermal Analysis Stage } & \multicolumn{1}{c|}{ Dynamic Analysis Stage } \\
\hline Lateral & $\begin{array}{l}\text { Fixed at the direction normal } \\
\text { to the face }\end{array}$ & $\begin{array}{l}\text { Fixed at the direction normal } \\
\text { to the face }\end{array}$ & Free-Field boundary \\
\hline Bottom & Fixed at the vertical direction & Fixed at the vertical direction & Non-reflecting boundary \\
\hline Top & Fixed at the vertical direction & Fixed at the vertical direction & Non-reflecting boundary \\
\hline
\end{tabular}




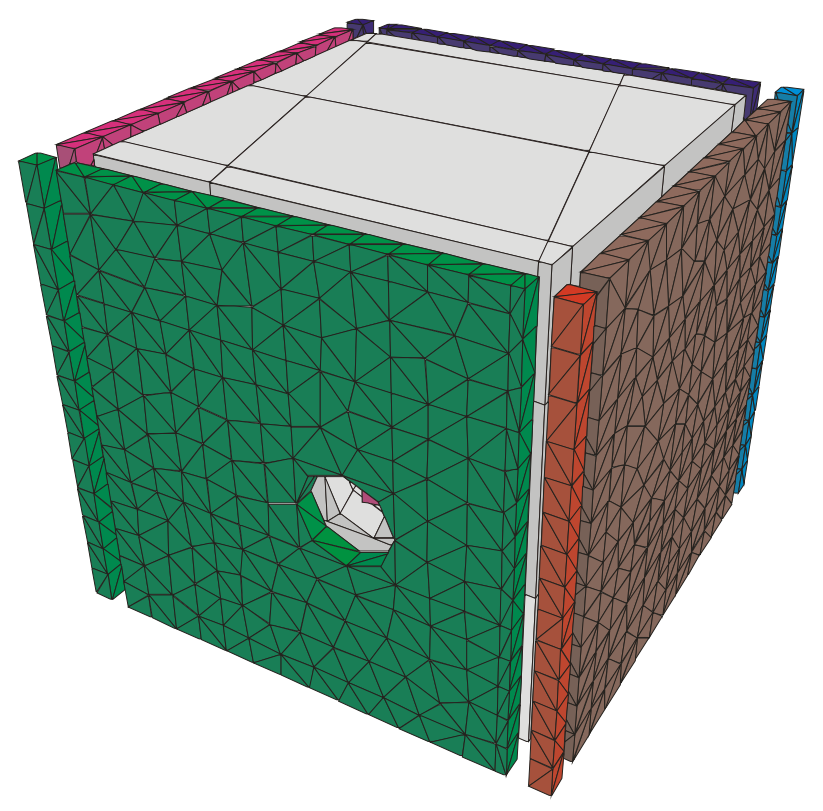

(a) Free-Field Boundaries (Perspective View)

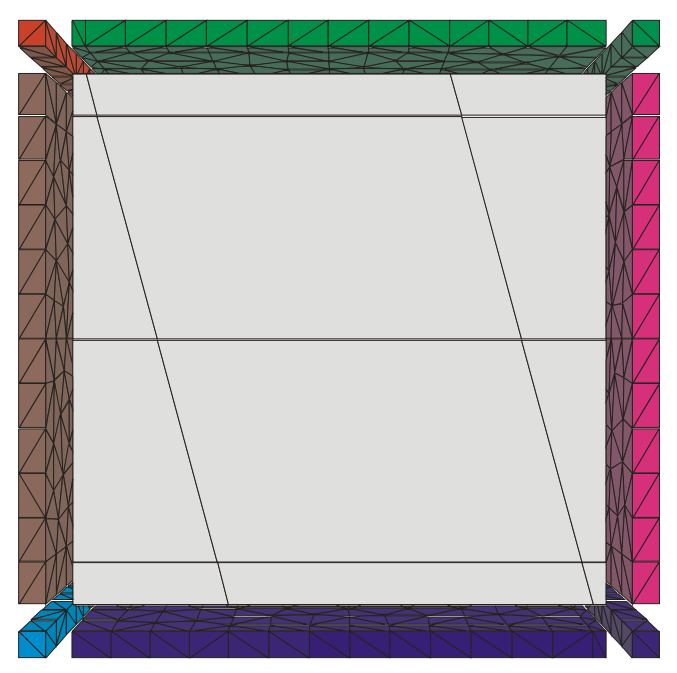

(b) Free-Field Boundaries (Top View)

Figure 6-35. Illustration of Free-Field Boundaries in 3DEC Model

A total of 15 sets of Point B ground motions (i.e., ground motions developed at repository horizon) were selected for each annual postclosure hazard level. The multiple sets ensure a reasonable distribution of spectral shapes and time history durations. For each set of ground motions, two horizontal components ( $\mathrm{H} 1$ and $\mathrm{H} 2$ ) and one vertical component (V) of acceleration, velocity, and displacement are supplied. Figure 6-36 shows the H1 velocity time history for four annual hazard levels. Only one ground motion was provided for the preclosure hazard levels because of the deterministic-based approach for preclosure consideration. The 
amplitude of the peak ground acceleration, velocity, and displacement, and the seismic induced far field stress for one of the ground motion sets from each hazard level, are provided in Table 6-5. The induced stresses are calculated based on the intact material properties for nonlithophysal rock. This table is used to demonstrate the typical ground motion parameters for the three hazard levels considered. It is apparent that the preclosure ground motions have lower amplitude vibrations and, hence, lower induced stresses compared with the postclosure ground motions.

The peak values for each ground motion set provided for postclosure hazard level varies significantly and can be highly conservative, particularly for the $1 \times 10^{-6}$ and $1 \times 10^{-7}$ probability levels as summarized in Table 6-5 (see Appendix X for a complete listing of ground motion parameters). Arias intensity (an estimate of energy delivered to structures) for each set of ground motions is listed in Table 6-6. A large variation of energy within the same hazard level is observed. The 15 sets of ground motions were combined with fracture patterns for probabilistic analysis. The combining of ground motion and fracture patterns is described in Section 6.3.1.2.2.

Although not taken into account in the base-case calculations provided in this document, a study addressing the conservative, and potential physically-unrealizable peak ground velocities associated with these low hazard levels has been developed (BSC 2004 [DIRS 170137]). Geologic evidence gained from panel mapping of lithophysae and fractures in the Tptpll (Appendix O) has shown that the rock mass has not been subjected to shear strain levels sufficient to result in fracture between lithophysal cavities since the rock mass was deposited and cooled (the existing fractures can be shown to have occurred as a result of cooling). As shown by the large-core laboratory testing (Appendix E), this strain level is approximately 0.1 to 0.35 percent. Therefore, in the approximately 12.8 million years since the Topopah Spring Tuff was deposited, an earthquake sufficient to produce a peak shear strain of this level has not occurred. Since peak ground velocity (PGV) can be directly related to strain, these observations can provide an indication of the maximum PGV that has occurred in this time period. The peak ground velocity study (BSC 2004 [DIRS 170137]) has subsequently been used to develop a conservative estimate that the horizontal PGV varies as a uniform distribution with lower and upper limits of 1.5 and $5 \mathrm{~m} / \mathrm{sec}$ which, in turn, has been used to develop a modified hazard curve (the relationship between PGV and annual exceedance probability).

The base-case modeling performed in this document does not limit the highly conservative PGV values generated from the site response model, and thus the estimates of rockfall and drift damage generated by the postclosure ground motions (e.g., $1 \times 10^{-5}, 1 \times 10^{-6}$ and $1 \times 10^{-7}$ ) are correspondingly conservative. However, the abstraction of damage to Engineered Barrier System components for the seismic scenario, presented in the Seismic Consequence Abstraction (BSC 2004 [DIRS 169183]), is based on relating damage (e.g., area of stress corrosion cracking on drip shield or waste package) to PGV, and, in turn, to probability based on the hazard curve. The seismic consequence abstraction uses the hazard curve, modified by bounding PGV limits, to define damage. 
Table 6-5. Peak Ground Motion Parameters

\begin{tabular}{|c|c|c|c|c|c|}
\hline $\begin{array}{c}\text { Annual } \\
\text { Hazard Level }\end{array}$ & $\begin{array}{c}\text { Ground Motion } \\
\text { Component }\end{array}$ & $\begin{array}{c}\text { Peak } \\
\text { Acceleration (g) } \\
\end{array}$ & $\begin{array}{c}\text { Peak Velocity } \\
\text { (cm/sec) }\end{array}$ & $\begin{array}{c}\text { Peak } \\
\begin{array}{c}\text { Displacement } \\
(\mathbf{c m})\end{array} \\
\end{array}$ & $\begin{array}{c}\text { Seismic Induced Stress } \\
\text { Corresponding to Peak } \\
\text { Velocity (MPa) }\end{array}$ \\
\hline \multirow{3}{*}{$5 \times 10^{-4}$} & $\mathrm{H} 1$ & 0.19 & 19.00 & 12.86 & 1.09 \\
\hline & $\mathrm{H} 2$ & 0.18 & 17.72 & 12.37 & 1.02 \\
\hline & $\mathrm{V}$ & 0.22 & 17.73 & 11.34 & 1.68 \\
\hline \multirow{3}{*}{$1 \times 10^{-4}$} & $\mathrm{H} 1$ & 0.39 & 38.38 & 44.44 & 2.20 \\
\hline & $\mathrm{H} 2$ & 0.37 & 43.78 & 45.30 & 2.51 \\
\hline & $\mathrm{V}$ & 0.47 & 47.51 & 31.73 & 4.50 \\
\hline \multirow{3}{*}{$\begin{array}{l}1 \times 10^{-5} \text { Ground } \\
\text { Motion Set } 1\end{array}$} & $\mathrm{H} 1$ & 2.77 & 104.58 & 20.06 & 6.00 \\
\hline & $\mathrm{H} 2$ & 2.50 & 83.31 & 14.37 & 4.78 \\
\hline & $\mathrm{V}$ & 2.63 & 70.88 & 13.00 & 6.71 \\
\hline \multirow{3}{*}{$\begin{array}{l}1 \times 10^{-6} \text { Ground } \\
\text { Motion Set } 1\end{array}$} & $\mathrm{H} 1$ & 7.42 & 244.14 & 16.76 & 14.009 \\
\hline & $\mathrm{H} 2$ & 6.74 & 195.41 & 26.78 & 11.21 \\
\hline & V & 4.90 & 111.29 & 13.75 & 10.54 \\
\hline \multirow{3}{*}{$\begin{array}{l}1 \times 10^{-7} \text { Ground } \\
\text { Motion Set } 1\end{array}$} & $\mathrm{H} 1$ & 16.28 & 535.26 & 58.68 & 30.0 \\
\hline & $\mathrm{H} 2$ & 14.79 & 428.42 & 58.72 & 24.57 \\
\hline & V & 13.15 & 298.44 & 36.86 & 28.25 \\
\hline
\end{tabular}

Source: DTNs: MO0407TMHIS104.003 [DIRS 170599]; MO0306SDSAVDTH.000 [DIRS 164033]; MO0402AVDTM105.001 [DIRS 168890]; MO0403AVDSC106.001 [DIRS 168891]; MO0403AVTMH107.003 [DIRS 168892].

NOTES: Native data files (available as ASCII text files) containing the acceleration, velocity, and displacement time-history data can be downloaded from the source DTNs.

Seismic induced stress (column six) is calculated based on elastic wave equations (Itasca Consulting Group 2002 [DIRS 160331], Manuals/3DEC/Optional Features/Section 2: Dynamic Analysis, Section 2.5).

Peak ground motion parameters for the ground motion sets are provided in Appendix X.

In running the 3DEC seismic simulation, the duration of the seismic time histories was truncated to that portion of the records displaying the majority of the energy. Initially, records were truncated to a duration bracketed by the 5 percent and 95 percent points in the energy buildup as measured by the Arias Intensity. For each three-component set of ground motions, these points were determined for each component $(\mathrm{H} 1, \mathrm{H} 2$, and $\mathrm{V})$ and then the earliest 5 percent point and the latest 95 percent point were used to define the duration for that set of ground motions. Because preliminary analyses showed that rockfall continued in some cases beyond the 95 percent energy buildup point, additional time was added for analyses to ensure that the simulated duration covered the rockfall. Table 6-7 presents the total duration of each set of time histories and the 5 percent and 95 percent points. The sensitivity of rockfall to the duration of seismic ground motion is examined in Section 6.3.1.6.

\subsection{Combinations of Ground Motion and Fracture Pattern}

Rockfall is part of the seismic scenario calculations in support of the Total System Performance Assessment for the License Application. The analysis results provide inputs to the drip shield structural response calculation for assessment of the structural integrity of drip shields. To ensure that the ultimate performance measure of interest (i.e., damaged surface area of the drip shield) can be tracked to the underlying uncertain inputs in a consistent fashion, a sampling 
strategy was developed to include a consistent set of pointers for the sampled parameters (i.e., ground motions and fracture modeling regions in rockfall analysis). A detailed description of the sampling strategy is provided in DTN: MO0301SPASIP27.004 [DIRS 161869].

As described in Section 6.1, a 100-m cube was constructed for providing the fracture network required in 3DEC analysis. A random selection of 105 centroid locations was conducted. These 105 centroid locations combined with the 15 sets of ground motions served as the pointers for sampling. The process of random generation and the coordinate of the centroid locations in the 100-m cube are provided in Appendix J. A simple Latin Hypercube sampling scheme was used for the paring of ground motion and fracture modeling region (DTN: MO0301SPASIP27.004 [DIRS 161869]). Table 6-8 lists the 50 sets of analyses conducted for seismic consideration. The adequacy of 50 sets of 3DEC analyses representing the rockfall characteristics for the non-lithophysal rock is presented in Appendix K.

\subsection{Results for Seismic Analysis Subjected to $1 \times 10^{-5}$ Annual Probability of Exceedance Ground Motions}

The results for a complete set of 3DEC analyses, as tabulated in Table 6-8, subjected to the postclosure hazard level of $1 \times 10^{-5}$ annual probability of exceedance ground motions are presented in this section. Figure 6-37 compares the input ground motion for the first horizontal component (H1, Ground Motion Set 10) with the recorded velocities at the base of the model and at the center of the model. The results confirm the correct wave inputs and proper wave propagation in the 3DEC model. As described in Section 6.3.1.1, a drip shield block anchored at the invert is included in the model to record the information of the locations and relative velocities for the rockfall impact. Figure 6-38 shows a typical block impacting the drip shield in the 3DEC dynamic simulation. Note that fallen blocks are subsequently deleted after impacting the drip shield. The deletion is to facilitate the recording of all possible rockfall on the drip shield. If the blocks are not deleted for the heavy rockfall cases, the drip shield will be covered with fallen rocks so that some of the rockfall at the later part of seismic shaking will not impact the drip shield. The simulation without deletion of the rock block after the impact is presented in Section 6.3.1.6. The results indicate less rockfall impact without the deletion scheme. For certain conditions, the algorithm for accounting and deletion of the blocks may lead to deleting stable blocks with corner and/or edge in the near vicinity of the drift shield at the floor. Blocks are not accounted as rockfall for these conditions.

Time histories of normal and shear stresses for joints close to the opening were recorded during the seismic shaking in the 3DEC model. Figure 6-39 shows normal and shear stress time histories at selected fracture subcontacts taken from 3DEC simulation \#16 with ground motion set \#11. Peak seismic loading appears to occur at the time of 4 to 6 seconds, consistent with the input ground motion. Information of the subcontacts is provided in Figure 6-40. Subcontact $a$ represents the true fracture while subcontacts $b$ and $c$ are for the rock bridge in between the fracture segments. The stress paths of the fracture subcontacts are plotted against the fracture Coulomb slip criterion and rock bridge shear or tensile strength criterion, as shown in Figure 6-41. The in situ normal and shear stress state along the fracture is also included as the orange square for each subcontact in the figure. The in situ stress state at subcontact $a$ is very close to the Coulomb slip criterion. The fracture containing this subcontact has apparently undergone yielding during seismic motions. The stress paths for rock bridges containing 
subcontacts $b$ and $c$ are well under the rock shear or tensile strength criterion and representative of most of the rock mass.

The percentages of the area of joint slip/separation versus the total area of joint planes for the selected cases were calculated as a stability indicator for the fracture system around the opening. A total of 8 cases are presented in Table 6-9. Total joint and bridge areas contained in the model were first calculated. The bridge area is around 20 percent of the total joint area for the selected cases. A large portion of fractures (greater than 70 percent) has undergone shear slip or tensile separation when subjected to $1 \times 10^{-5}$ ground motions. The percentage of shear and tensile failure is transient during the seismic shaking. Tensile mode can dominate for one instance and then change to shear mode for the next instance. However, shear failure becomes the dominant mode when approaching to the end of shaking. In addition to joint slip/separation, bridge damage percentage was also calculated. The results are presented in Table 6-9. In general, less than 1 percent bridge area is predicted to be damaged by shaking. However, for certain large ground motions (e.g., ground motion \#3 for Case 38), higher damage percentage is predicted. Correlation of the bridge damage percentage versus peak ground velocity shows a strong relationship between the two. A detailed discussion on the bridge damage is provided in Section 6.3.1.6.3.

The results of the 50 3DEC simulations are summarized in Table 6-10. Approximately two thirds of the simulations predicted rockfall under seismic shaking. A total of 1,767 blocks have been identified from the analyses. The associated impact parameters for these blocks from the analyses include the following:

- Rock block volume falling on the drip shields (unit in $\mathrm{m}^{3}$ )

- Relative impact velocity of rock block to the drip shields (unit in $\mathrm{m} / \mathrm{sec}$ )

- Impact location. 

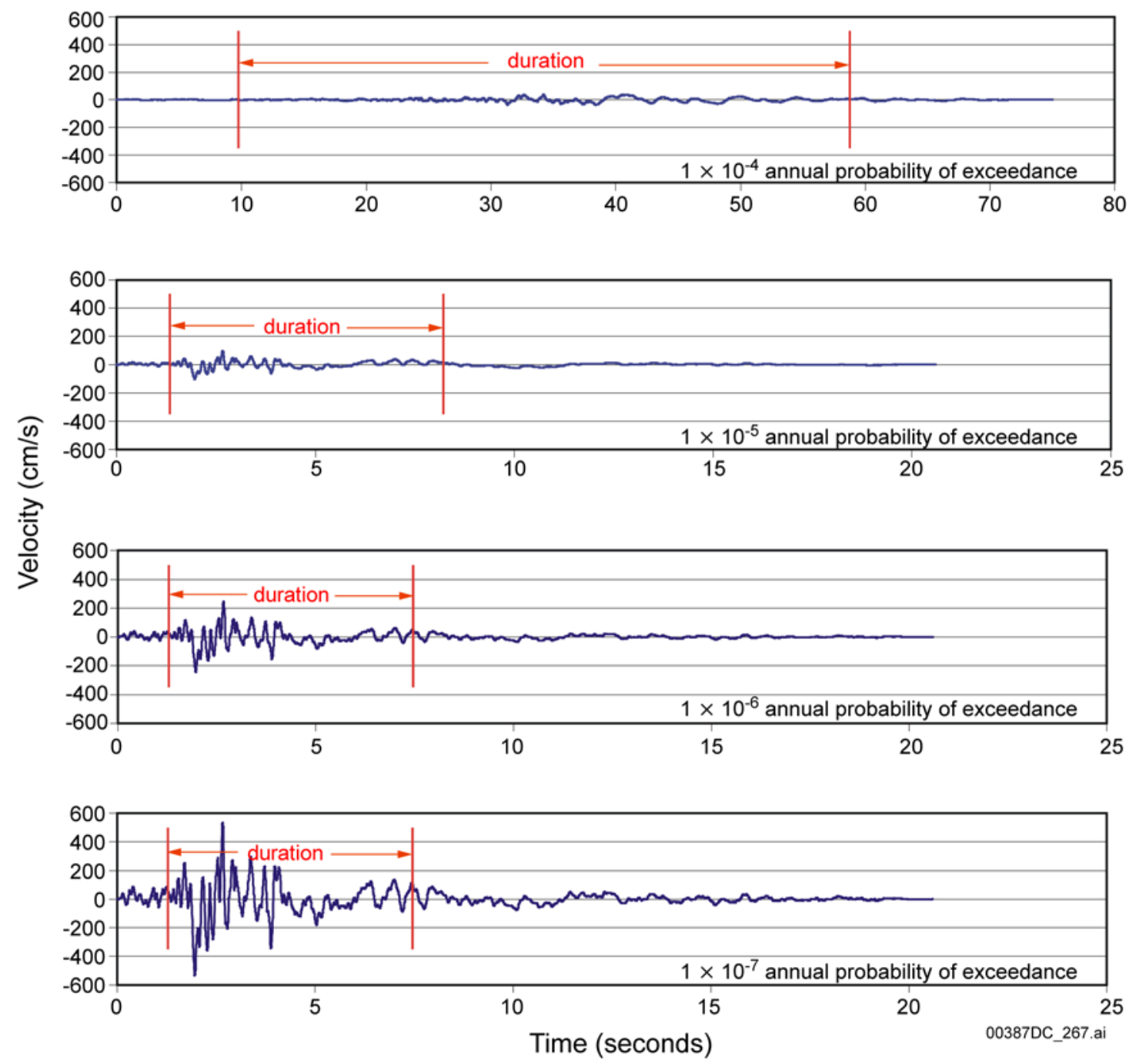

Sources: DTNs: MO0306SDSAVDTH.000 [DIRS 164033]; MO0402AVDTM105.001 [DIRS 168890]; MO0403AVDSC106.001 [DIRS 168891]; and MO0403AVTMH107.003 [DIRS 168892].

NOTES: The $5 \times 10^{-4}$ time history is not presented due to its small magnitude. Native data files (available as ASCII text files) containing the velocity time-history data can be downloaded from the source DTN.

Figure 6-36. Examples of Ground Velocity Time Histories (H1) with Truncated Duration for Analysis 
Table 6-6. Arias Intensity $(\mathrm{m} / \mathrm{sec})$ for Each Ground Motion Set

\begin{tabular}{|c|c|c|c|c|c|}
\hline Annual Hazard Level & Ground Motion Set & H1 & $\mathrm{H} 2$ & $\mathbf{V}$ & Total Sum \\
\hline \multirow{15}{*}{ 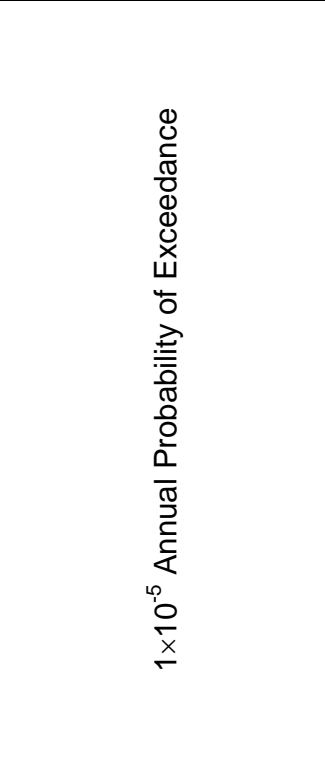 } & 1 & 33 & 34 & 36 & 103 \\
\hline & 2 & 31 & 38 & 123 & 192 \\
\hline & 3 & 34 & 48 & 48 & 130 \\
\hline & 4 & 12 & 15 & 20 & 48 \\
\hline & 5 & 16 & 11 & 13 & 41 \\
\hline & 6 & 7 & 5 & 18 & 30 \\
\hline & 7 & 4 & 4 & 49 & 57 \\
\hline & 8 & 8 & 13 & 16 & 37 \\
\hline & 9 & 22 & 52 & 139 & 213 \\
\hline & 10 & 9 & 4 & 14 & 26 \\
\hline & 11 & 8 & 7 & 15 & 30 \\
\hline & 12 & 4 & 4 & 7 & 15 \\
\hline & 13 & 9 & 16 & 26 & 51 \\
\hline & 14 & 3 & 2 & 7 & 12 \\
\hline & 16 & 3 & 2 & 7 & 11 \\
\hline & 1 & 235 & 253 & 114 & 602 \\
\hline & 2 & 206 & 250 & 413 & 869 \\
\hline$\stackrel{Ð}{0}$ & 3 & 120 & 153 & 135 & 408 \\
\hline$\frac{\pi}{2}$ & 4 & 178 & 219 & 141 & 538 \\
\hline ्ֻّ & 5 & 78 & 52 & 29 & 159 \\
\hline யँ & 6 & 69 & 56 & 79 & 204 \\
\hline$\stackrel{\vec{E}}{=}$ & 7 & 63 & 61 & 467 & 590 \\
\hline 可 & 8 & 71 & 109 & 61 & 241 \\
\hline 흠 & 9 & 169 & 352 & 465 & 986 \\
\hline$\overline{\bar{\sigma}}$ & 10 & 59 & 26 & 57 & 141 \\
\hline 产 & 11 & 57 & 45 & 45 & 146 \\
\hline 0 & 12 & 58 & 59 & 46 & 163 \\
\hline$\stackrel{\vec{x}}{\rightarrow}$ & 13 & 98 & 170 & 123 & 390 \\
\hline & 14 & 63 & 73 & 119 & 255 \\
\hline & 16 & 23 & 15 & 34 & 72 \\
\hline & 1 & 1128 & 1215 & 820 & 3163 \\
\hline ¿ & 2 & 989 & 1202 & 2972 & 5163 \\
\hline$\stackrel{\overparen{Z}}{\overline{\bar{n}}}$ & 3 & 577 & 735 & 971 & 2283 \\
\hline శ్ వి & 4 & 856 & 1052 & 1013 & 2921 \\
\hline 음 $\frac{5}{0}$ & 5 & 373 & 252 & 205 & 830 \\
\hline 즐 导 & 6 & 331 & 271 & 566 & 1168 \\
\hline 言希 & 7 & 303 & 291 & 3357 & 3951 \\
\hline 서어 & 8 & 343 & 524 & 437 & 1304 \\
\hline$\stackrel{x}{\stackrel{x}{*}}$ & 9 & 813 & 1691 & 3340 & 5844 \\
\hline & 10 & 282 & 125 & 409 & 816 \\
\hline
\end{tabular}


Table 6-6. Arias Intensity (m/sec) for Each Ground Motion Set (Continued)

\begin{tabular}{|c|c|c|c|c|c|}
\hline Annual Hazard Level & Ground Motion Set & H1 & $\mathrm{H} 2$ & $\mathbf{V}$ & Total Sum \\
\hline \multirow{5}{*}{ 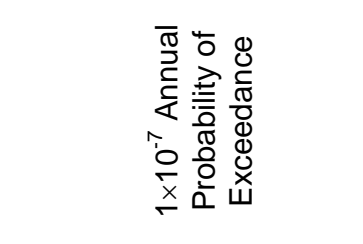 } & 11 & 272 & 214 & 321 & 808 \\
\hline & 12 & 277 & 284 & 332 & 893 \\
\hline & 13 & 469 & 815 & 881 & 2165 \\
\hline & 14 & 302 & 351 & 854 & 1507 \\
\hline & 16 & 112 & 72 & 244 & 428 \\
\hline \multicolumn{2}{|c|}{$5 \times 10^{-4}$ Annual Probability of Exceedance } & 0.59 & 0.67 & 0.46 & 1.72 \\
\hline \multicolumn{2}{|c|}{$1 \times 10^{-4}$ Annual Probability of Exceedance } & 4.21 & 4.51 & 8.97 & 17.69 \\
\hline
\end{tabular}

Sources: DTNs: MO0407TMHIS104.003 [DIRS 170599]; MO0306SDSAVDTH.000 [DIRS 164033]; MO0402AVDTM105.001 [DIRS 168890]; MO0403AVDSC106.001 [DIRS 168891]; MO0403AVTMH107.003 [DIRS 168892].

NOTES: A total of 17 sets of ground motions was developed for each postclosure level. Ground motion sets \#15 and \#17 were not used. The selection of ground motion sets is documented in Sampling of Stochastic Input Parameters for Rockfall Calculations and for Structural Response Calculations Under Vibratory Ground Motion (BSC 2004 [DIRS 169999]). Native data files (available as ASCII text files) containing the Arias intensity data can be downloaded from the source DTNs (see file Dur.zip). Arias intensity is the total energy $(\mathrm{m} / \mathrm{sec})$ over the full duration (0 to 100 percent energy).

Table 6-7. Seismic Analysis Duration and Complete Time History Duration

\begin{tabular}{|c|c|c|c|c|}
\hline $\begin{array}{c}\text { Annual Hazard } \\
\text { Level }\end{array}$ & $\begin{array}{c}\text { Ground } \\
\text { Motion Set }\end{array}$ & $\begin{array}{c}\text { Duration of Time } \\
\text { History (sec) }\end{array}$ & $5 \%$ Time (sec) & $95 \%$ Time (sec) \\
\hline \multirow{15}{*}{ 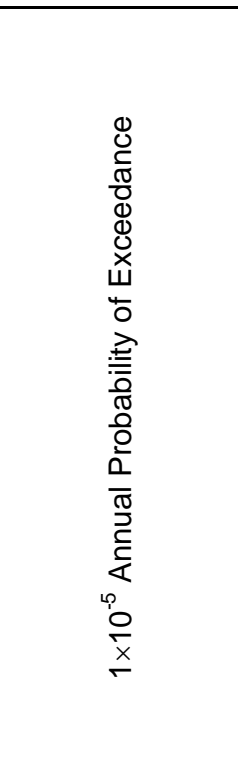 } & Set 1 & 20.60 & 1.34 & 8.22 \\
\hline & Set 2 & 20.60 & 0.80 & 8.58 \\
\hline & Set 3 & 20.01 & 1.76 & 4.62 \\
\hline & Set 4 & 26.13 & 1.57 & 17.90 \\
\hline & Set 5 & 20.01 & 1.70 & 10.27 \\
\hline & Set 6 & 20.01 & 2.62 & 10.73 \\
\hline & Set 7 & 16.27 & 3.76 & 12.17 \\
\hline & Set 8 & 20.60 & 1.21 & 7.48 \\
\hline & Set 9 & 29.98 & 0.75 & 8.83 \\
\hline & Set 10 & 20.02 & 1.68 & 10.26 \\
\hline & Set 11 & 20.60 & 2.07 & 10.93 \\
\hline & Set 12 & 40.02 & 2.27 & 17.53 \\
\hline & Set 13 & 39.96 & 2.05 & 20.33 \\
\hline & Set 14 & 40.00 & 5.49 & 24.85 \\
\hline & Set 16 & 32.01 & 3.80 & 11.63 \\
\hline \multirow{8}{*}{ 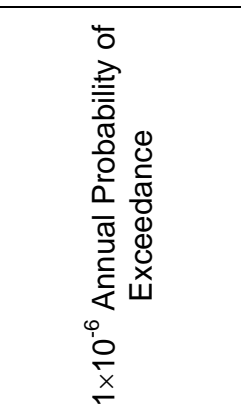 } & Set 1 & 20.60 & 1.28 & 7.47 \\
\hline & Set 2 & 20.60 & 0.80 & 7.40 \\
\hline & Set 3 & 20.01 & 1.75 & 4.73 \\
\hline & Set 4 & 26.13 & 1.48 & 17.29 \\
\hline & Set 5 & 20.01 & 1.69 & 8.78 \\
\hline & Set 6 & 20.01 & 2.44 & 10.57 \\
\hline & Set 7 & 16.27 & 3.55 & 12.23 \\
\hline & Set 8 & 20.60 & 1.21 & 6.48 \\
\hline
\end{tabular}


Table 6-7. Seismic Analysis Duration and Complete Time History Duration (Continued)

\begin{tabular}{|c|c|c|c|c|}
\hline $\begin{array}{c}\text { Annual Hazard } \\
\text { Level }\end{array}$ & $\begin{array}{c}\text { Ground } \\
\text { Motion Set }\end{array}$ & $\begin{array}{c}\text { Duration of Time } \\
\text { History (sec) }\end{array}$ & $5 \%$ Time (sec) & $95 \%$ Time (sec) \\
\hline \multirow{7}{*}{ 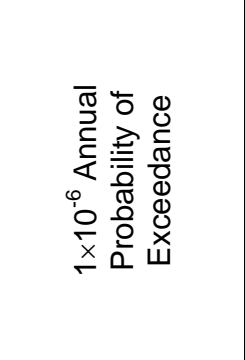 } & Set 9 & 29.98 & 0.76 & 8.00 \\
\hline & Set 10 & 20.02 & 1.67 & 9.58 \\
\hline & Set 11 & 20.60 & 2.08 & 10.30 \\
\hline & Set 12 & 40.02 & 2.17 & 15.66 \\
\hline & Set 13 & 39.96 & 1.90 & 19.53 \\
\hline & Set 14 & 40.00 & 5.37 & 23.94 \\
\hline & Set 16 & 32.01 & 3.43 & 10.43 \\
\hline \multirow{15}{*}{ 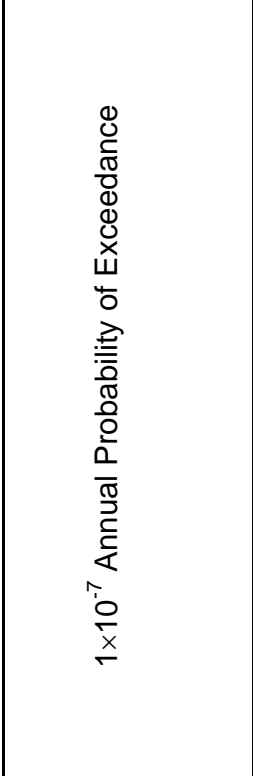 } & Set 1 & 20.60 & 1.28 & 7.47 \\
\hline & Set 2 & 20.60 & 0.80 & 7.40 \\
\hline & Set 3 & 20.01 & 1.75 & 4.73 \\
\hline & Set 4 & 26.13 & 1.48 & 17.29 \\
\hline & Set 5 & 20.01 & 1.69 & 8.78 \\
\hline & Set 6 & 20.01 & 2.44 & 10.57 \\
\hline & Set 7 & 16.27 & 3.55 & 12.23 \\
\hline & Set 8 & 20.60 & 1.21 & 6.48 \\
\hline & Set 9 & 29.98 & 0.76 & 8.00 \\
\hline & Set 10 & 20.02 & 1.67 & 9.58 \\
\hline & Set 11 & 20.60 & 2.08 & 10.30 \\
\hline & Set 12 & 40.02 & 2.17 & 15.66 \\
\hline & Set 13 & 39.96 & 1.90 & 19.53 \\
\hline & Set 14 & 40.00 & 5.37 & 23.94 \\
\hline & Set 16 & 32.01 & 3.43 & 10.43 \\
\hline \multicolumn{2}{|c|}{$5 \times 10^{-4}$ Annual Probability of Exceedance } & 40.96 & 3.46 & 28.67 \\
\hline \multicolumn{2}{|c|}{$1 \times 10^{-4}$ Annual Probability of Exceedance } & 75.00 & 9.78 & 58.79 \\
\hline
\end{tabular}

Sources: DTNs: MO0407TMHIS104.003 [DIRS 170599]; MO0306SDSAVDTH.000 [DIRS 164033]; MO0402AVDTM105.001 [DIRS 168890]; MO0403AVDSC106.001 [DIRS 168891]; MO0403AVTMH107.003 [DIRS 168892].

NOTES: A total of 17 sets of ground motions was developed for each postclosure level. Ground motion sets \#15 and \#17 were not used. The selection of ground motion sets is documented in Sampling of Stochastic Input Parameters for Rockfall Calculations and for Structural Response Calculations Under Vibratory Ground Motion (BSC 2004 [DIRS 169999]). Native data files (available as ASCII text files) containing time-history duration can be downloaded from the source DTNs (see file Dur.zip). Data are extracted from the 5 to 95 percent energy range. The earliest 5 percent point and the latest 95 percent point for each component $(\mathrm{H} 1, \mathrm{H} 2$, and $\mathrm{V})$ are used to define the duration of each ground motion set. 
Drift Degradation Analysis

Table 6-8. Combinations of Ground Motion and Fracture Modeling Region of 3DEC Analyses

\begin{tabular}{|c|c|c|}
\hline $\begin{array}{c}\text { 3DEC Simulation } \\
\text { Number }\end{array}$ & $\begin{array}{c}\text { Ground Motion Time History } \\
\text { Number }\end{array}$ & Fracture Pattern \\
\hline 14 & 7 & 22 \\
\hline 15 & 11 & 21 \\
\hline 16 & 11 & 30 \\
\hline 17 & 16 & 27 \\
\hline 18 & 14 & 26 \\
\hline 19 & 13 & 10 \\
\hline 20 & 5 & 19 \\
\hline 21 & 10 & 9 \\
\hline 22 & 5 & 23 \\
\hline 23 & 12 & 5 \\
\hline 24 & 3 & 6 \\
\hline 25 & 3 & 17 \\
\hline 27 & 6 & 14 \\
\hline 28 & 7 & 25 \\
\hline 29 & 13 & 3 \\
\hline 31 & 16 & 79 \\
\hline 32 & 12 & 7 \\
\hline 33 & 1 & 102 \\
\hline 34 & 16 & 75 \\
\hline 35 & 11 & 33 \\
\hline 36 & 5 & 78 \\
\hline 38 & 3 & 29 \\
\hline 39 & 5 & 37 \\
\hline 40 & 6 & 99 \\
\hline 41 & 16 & 42 \\
\hline 42 & 6 & 24 \\
\hline 43 & 4 & 59 \\
\hline 44 & 9 & 65 \\
\hline 45 & 10 & 39 \\
\hline 46 & 6 & 50 \\
\hline 48 & 16 & 35 \\
\hline 49 & 5 & 57 \\
\hline 50 & 9 & 67 \\
\hline 51 & 10 & 63 \\
\hline 52 & 9 & 82 \\
\hline 53 & 12 & 4 \\
\hline 54 & 1 & 83 \\
\hline 55 & 12 & 16 \\
\hline 56 & 3 & 98 \\
\hline 57 & 14 & 28 \\
\hline
\end{tabular}


Table 6-8. Combinations of Ground Motion and Fracture Modeling Region of 3DEC Analyses (Continued)

\begin{tabular}{|c|c|c|}
\hline $\begin{array}{c}\text { 3DEC Simulation } \\
\text { Number }\end{array}$ & $\begin{array}{c}\text { Ground Motion Time History } \\
\text { Number }\end{array}$ & Fracture Pattern \\
\hline 58 & 4 & 8 \\
\hline 59 & 2 & 74 \\
\hline 60 & 11 & 80 \\
\hline 61 & 12 & 81 \\
\hline 62 & 12 & 71 \\
\hline 63 & 11 & 96 \\
\hline 64 & 14 & 49 \\
\hline 65 & 7 & 20 \\
\hline 66 & 3 & 62 \\
\hline 67 & 9 & 41 \\
\hline
\end{tabular}

Source: DTN: MO0301SPASIP27.004 [DIRS 161869].

NOTES: 3DEC simulation numbers 14 through 29 are from the corresponding realization numbers from the first sampling in the nonlithophysal zone provided by the source DTN.

3DEC simulation numbers 31 through 67 are from the second sampling (realization numbers 1 through 60 ) in the nonlithophysal zone provided by the source DTN.

Duplicate fracture modeling regions (i.e., synthetic fracture pattern numbers) occurring in both the first and second samplings were not used as part of the base case for rockfall modeling.

Simulation Number 26, 37, and 47 were not used due to numerical difficulties for 3DEC block generation.

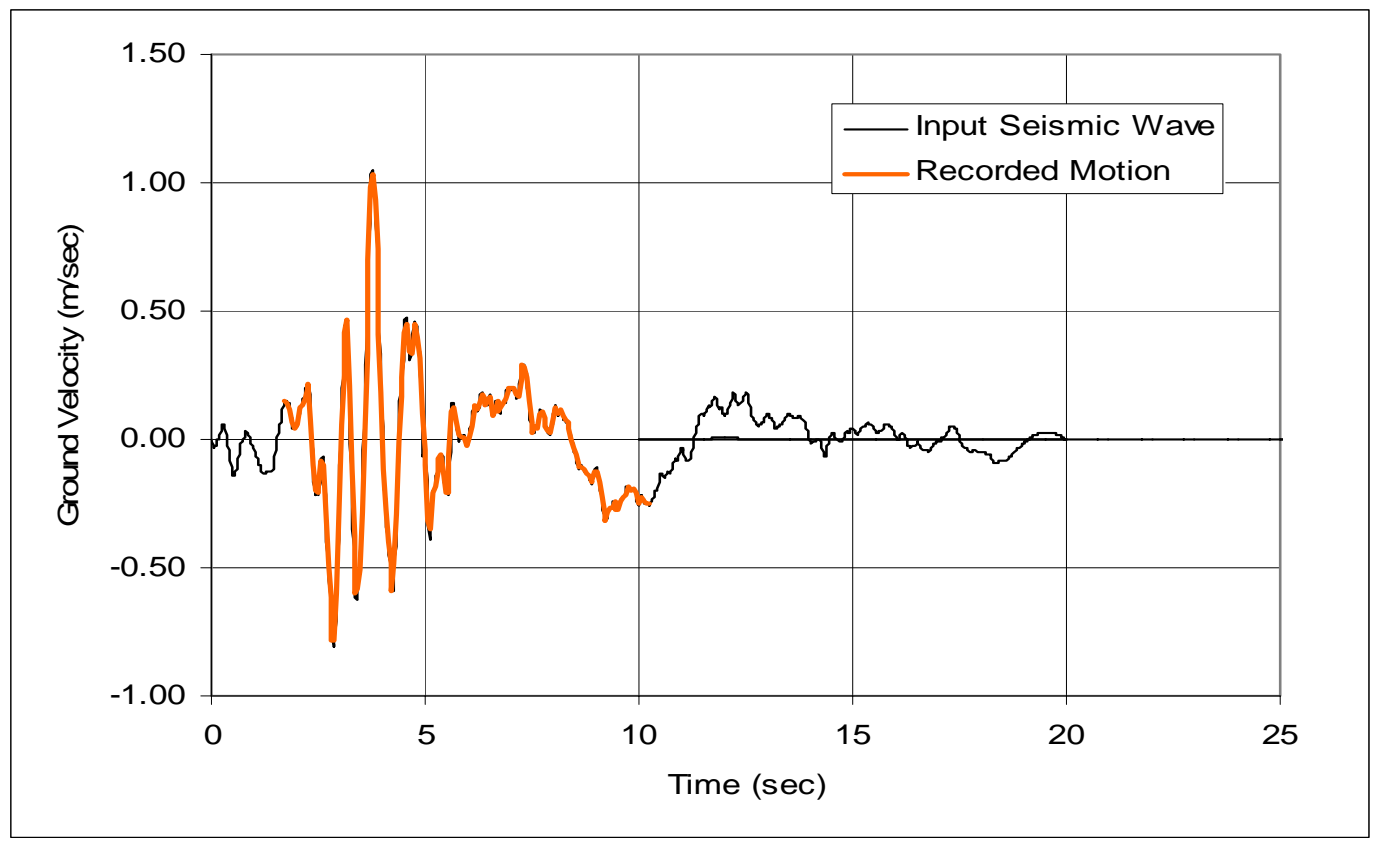

NOTE: The ground motion was recorded at the drip shield block during 3DEC simulation.

Figure 6-37. Comparison of Input Seismic Wave and Recorded Velocities in 3DEC Model (Ground Motion Set 4, H1) 


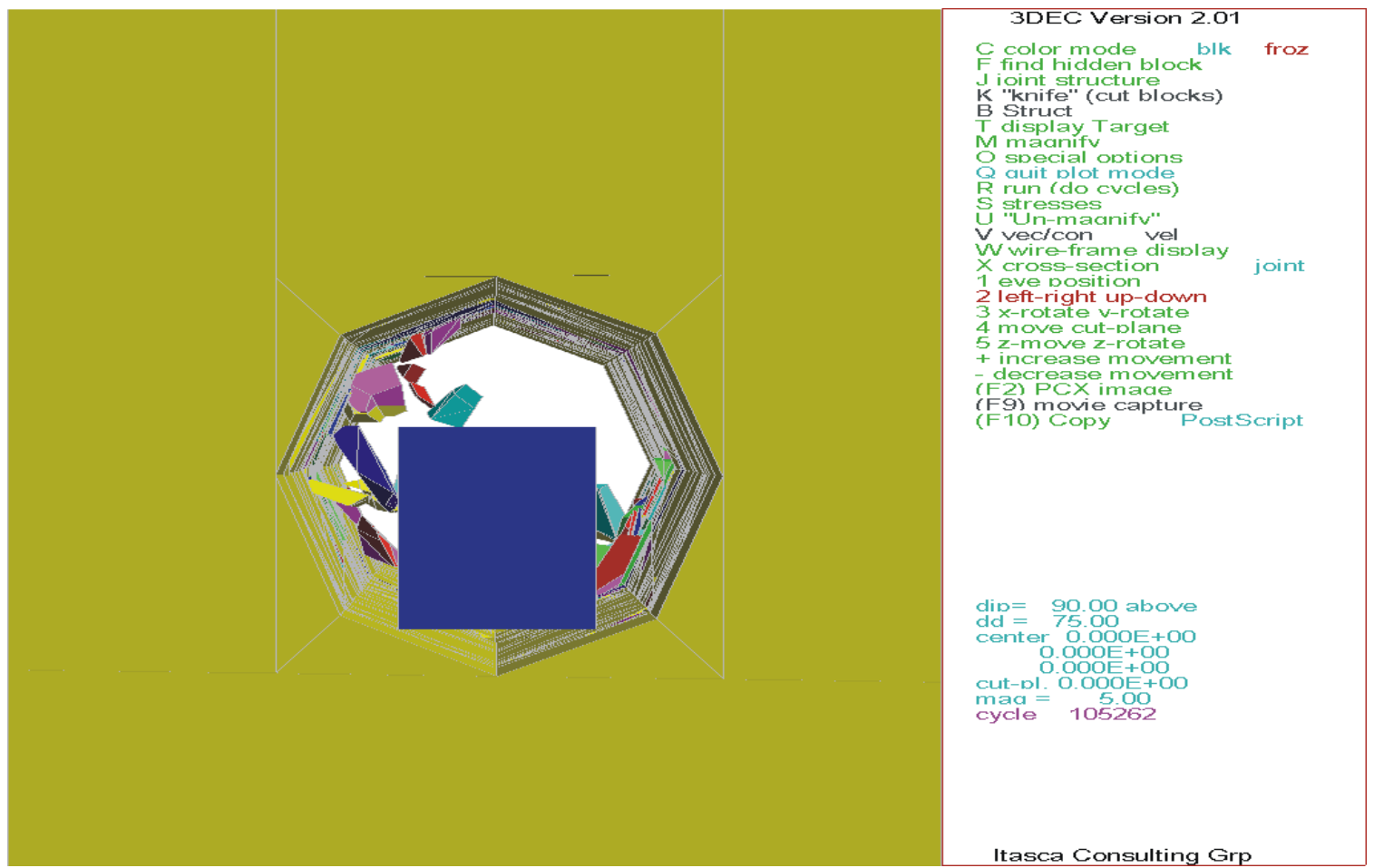

Figure 6-38. Illustration of the Simulation of Rockfall Impact to the Drip Shield 3DEC Simulation \#44, $1 \times 10^{-5}$ Ground Motion \# 9, at $\mathrm{t}=3.6 \mathrm{sec}$

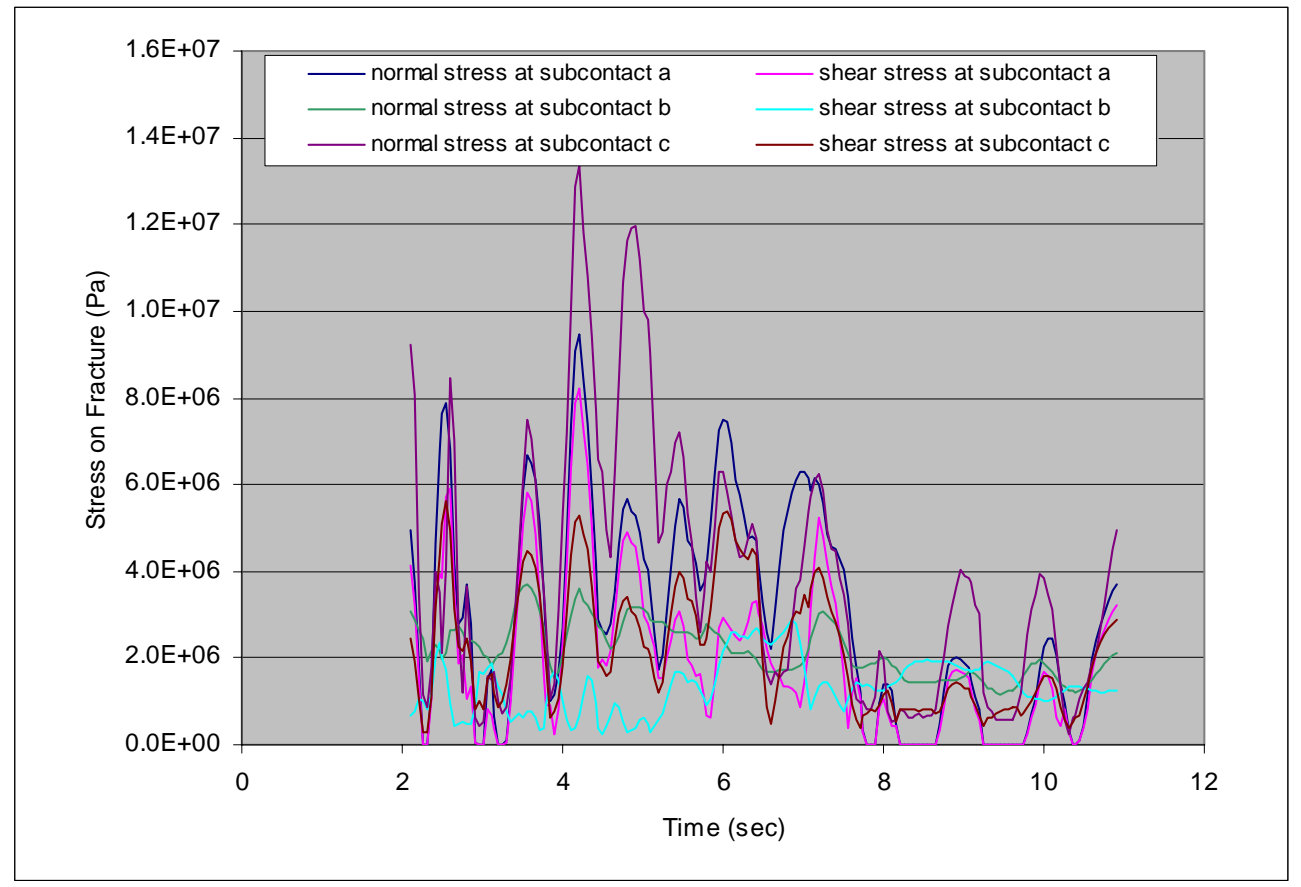

Figure 6-39. Time Histories for Normal and Shear Stress at Selected Fracture Subcontacts for $1 \times 10^{-5}$ Annual Probability of Exceedance Hazard (Simulation 16, Ground Motion Set 11) 


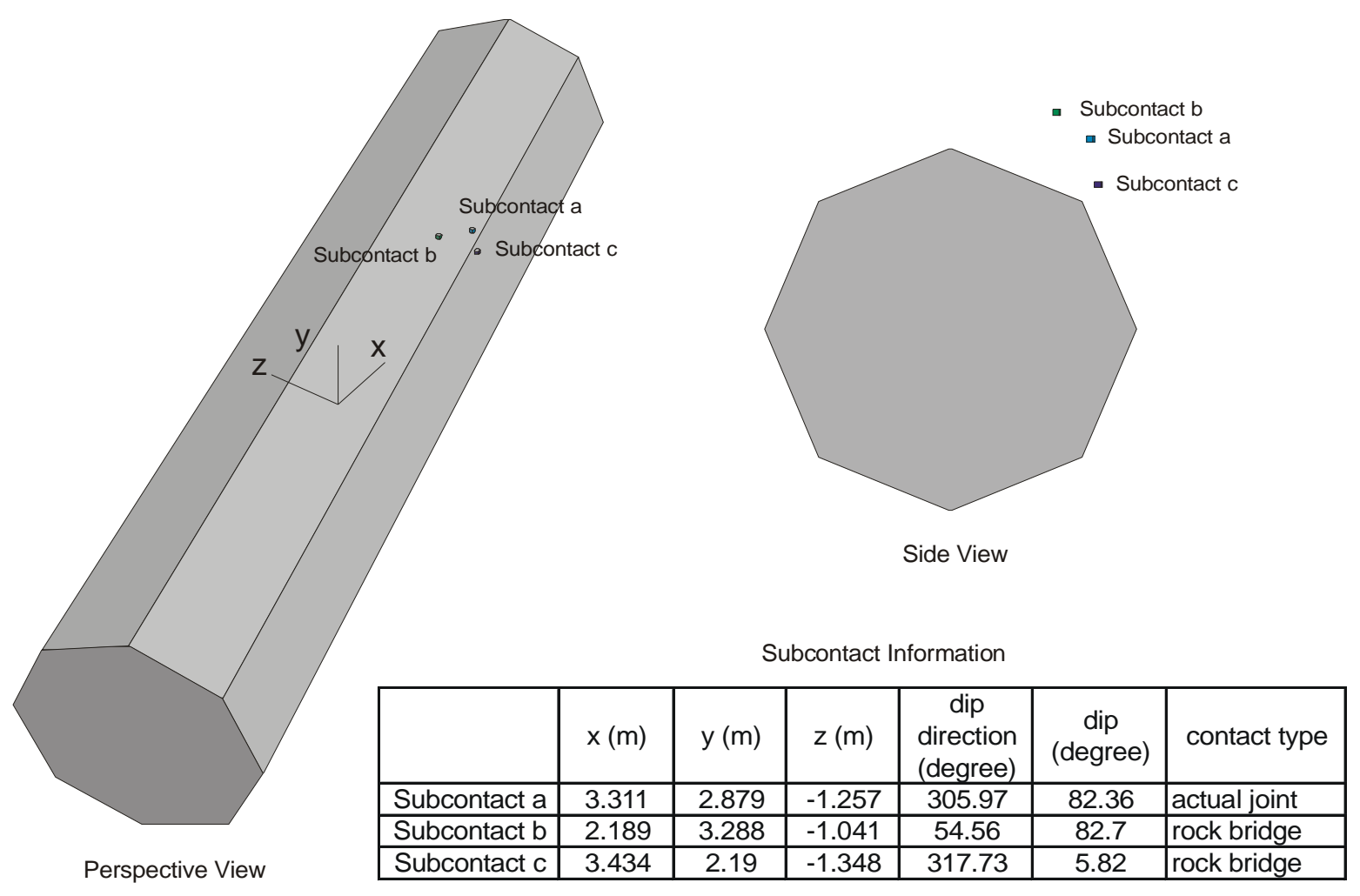

Figure 6-40. Information for the Selected Fracture Subcontacts 


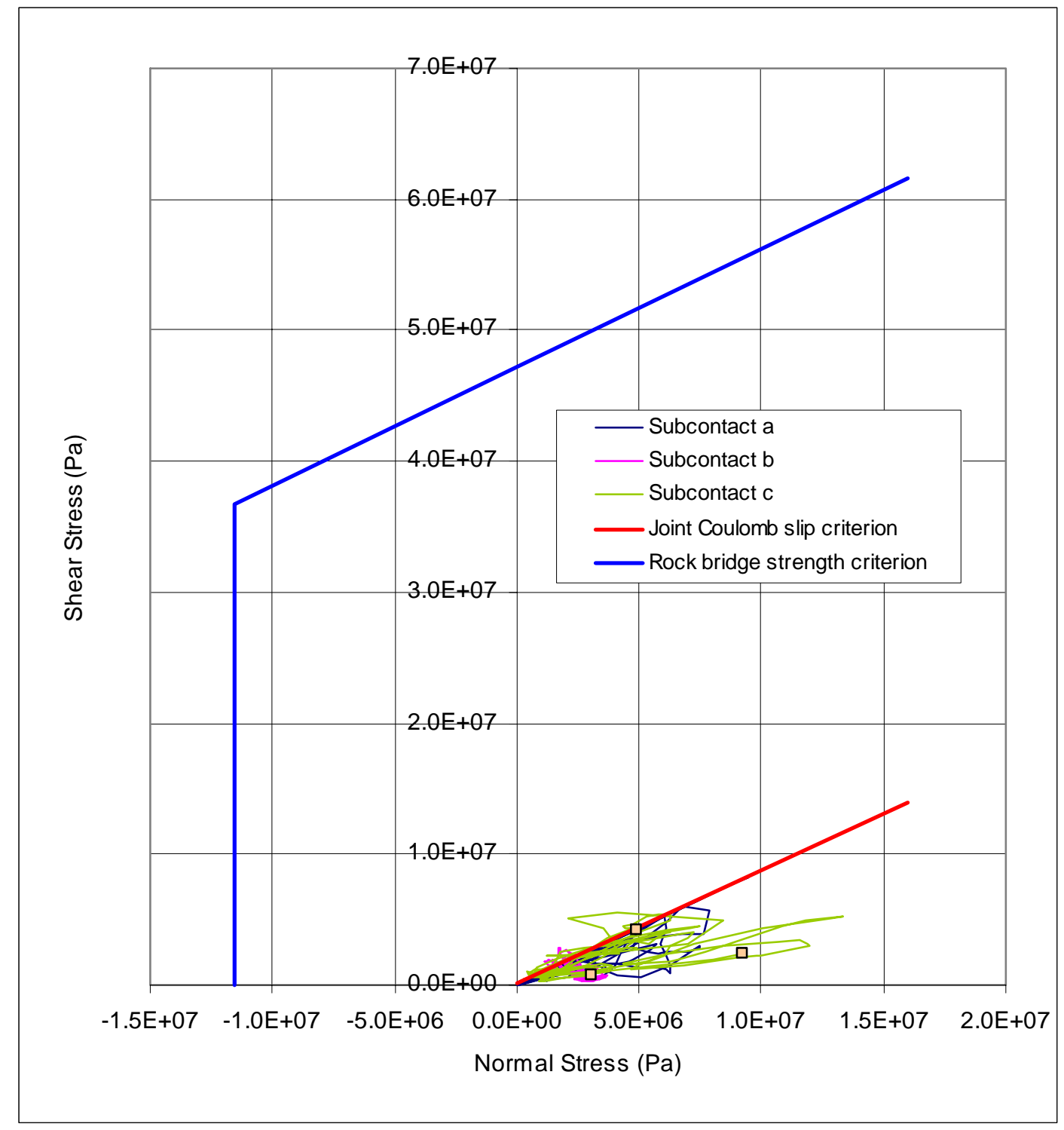

Figure 6-41. Normal and Shear Stress Path at Selected Fracture Subcontacts for $1 \times 10^{-5}$ Annual Probability of Exceedance Hazard (Simulation 16, Ground Motion Set 11)

Table 6-9. Summary of Joint Slip/Separation and Bridge Damage for $1 \times 10^{-5}$ Ground Motions for Selected Cases

\begin{tabular}{|l|c|c|c|c|c|c|c|c|}
\hline \multicolumn{1}{|c|}{ Parameter } & Case 38 & Case 40 & Case 66 & Case 23 & Case 48 & Case 45 & Case 63 & Case 31 \\
\hline Total Joint Area $\left(\mathrm{m}^{2}\right)$ & 4319 & 4251 & 2583 & 3026 & 4260 & 4737 & 1911 & 3400 \\
\hline Total Bridge Area $\left(\mathrm{m}^{2}\right)$ & 862 & 885 & 592 & 550 & 923 & 1054 & 425 & 720 \\
\hline $\begin{array}{l}\text { Percentage of Joint } \\
\text { Slip/Separation }\end{array}$ & $94.98 \%$ & $90.94 \%$ & $96.24 \%$ & $77.07 \%$ & $82.09 \%$ & $70.80 \%$ & $79.33 \%$ & $73.59 \%$ \\
\hline $\begin{array}{l}\text { Percentage of Bridge } \\
\text { Damaged }\end{array}$ & $14.62 \%$ & $1.00 \%$ & $10.14 \%$ & $0.24 \%$ & $0.06 \%$ & $0.00 \%$ & $0.47 \%$ & $0.06 \%$ \\
\hline
\end{tabular}


Table 6-10. Summary of 3DEC Rockfall Prediction for $1 \times 10^{-5}$ Annual Probability of Exceedance Hazard

\begin{tabular}{|l|c|}
\hline \multicolumn{1}{|c|}{ Parameter } & Value \\
\hline Simulations Completed & 50 \\
\hline Number of Simulations Predicting No Rockfall & 1 \\
\hline Total Number of Rockfall & 1767 \\
\hline Total Volume of Rockfall $\left(\mathrm{m}^{3}\right)$ & 255.4 \\
\hline Total Length of Drift Simulated $(\mathrm{m})$ & 1250 \\
\hline Number of Blocks per $\mathrm{km}$ & 1414 \\
\hline Volume of Rockfall per $\mathrm{km}\left(\mathrm{m}^{3}\right)$ & 204.3 \\
\hline
\end{tabular}

A detailed listing of the impact information for each recorded block is provided in an output DTN of this document (DTN: MO0408MWDDDMIO.002, file nonlith rockfall characteristics in emplacement drifts with 1e-5 gm.xls). The impact locations are provided as the coordinates based on the drip shield local coordinate system (Figure 6-42). The distribution of the data for each parameter (i.e., block mass, relative impact velocity, impact angle, impact momentum, and impact energy) is presented using histograms (Figures 6-43 to 6-47). Also included in each histogram plot is the cumulative frequency of occurrence. Due to the gravity effect, most of the rockfall will occur in the range of 48 degrees to 132 degrees as confirmed in Figure 6-45. The impact momentum and impact energy, both functions of block mass and impact velocity, were calculated as the required outputs for drip shield structural response calculation. Summary statistics for these parameters are provided in Table 6-11. The maximum rockfall block mass predicted is 19.07 metric tons with median block size of 0.12 metric tons. The predicted results (Table 6-11) show large variance and high skewness with the exception of impact velocity, as confirmed by the shape of the histograms (Figures 6-43 to 6-47). The block mass, impact angle, impact momentum, and impact energy show the trend of exponential distribution with most of the data concentrated on the low end of the data range. The impact velocity shows a typical bell shape for the normal distribution. The distribution centers around $3 \mathrm{~m} / \mathrm{sec}$ with a standard deviation of approximately $1.5 \mathrm{~m} / \mathrm{sec}$. The relative low impact velocities indicate that block fall-out is mainly due to free fall. Differential acceleration or energy trapping to induce high ejection velocity is not observed.

Table 6-11. Statistic Summary of the Rockfall Impact Parameters, $1 \times 10^{-5}$ Annual Probability of Exceedance Hazard

\begin{tabular}{|l|c|c|c|c|c|}
\hline \multicolumn{1}{|c|}{ Parameter } & $\begin{array}{c}\text { Block Mass } \\
\text { (tonnes) }\end{array}$ & $\begin{array}{c}\text { Relative Impact } \\
\text { Velocity (m/sec) }\end{array}$ & $\begin{array}{c}\text { Impact Angle } \\
\text { (degree) }\end{array}$ & $\begin{array}{c}\text { Impact Momentum } \\
\text { (kg*m/sec) }\end{array}$ & $\begin{array}{c}\text { Impact Energy } \\
\text { (Joules) }\end{array}$ \\
\hline Mean & 0.35 & 2.69 & 144.74 & 964 & 1814 \\
\hline Median & 0.12 & 2.57 & 127.13 & 276 & 357 \\
\hline Standard Deviation & 0.93 & 1.48 & 99.69 & 3789 & 11430 \\
\hline Skewness & 10.03 & 0.74 & 0.75 & 24 & 32 \\
\hline Range & 19.04 & 9.38 & 359.74 & 128809 & 435077 \\
\hline Minimum & 0.02 & 0.04 & 0.18 & 3 & 0 \\
\hline Maximum & 19.07 & 9.42 & 359.92 & 128812 & 435077 \\
\hline Sum & 615.97 & NA & NA & 1703088 & 3205138 \\
\hline
\end{tabular}

NA = Not Applicable 

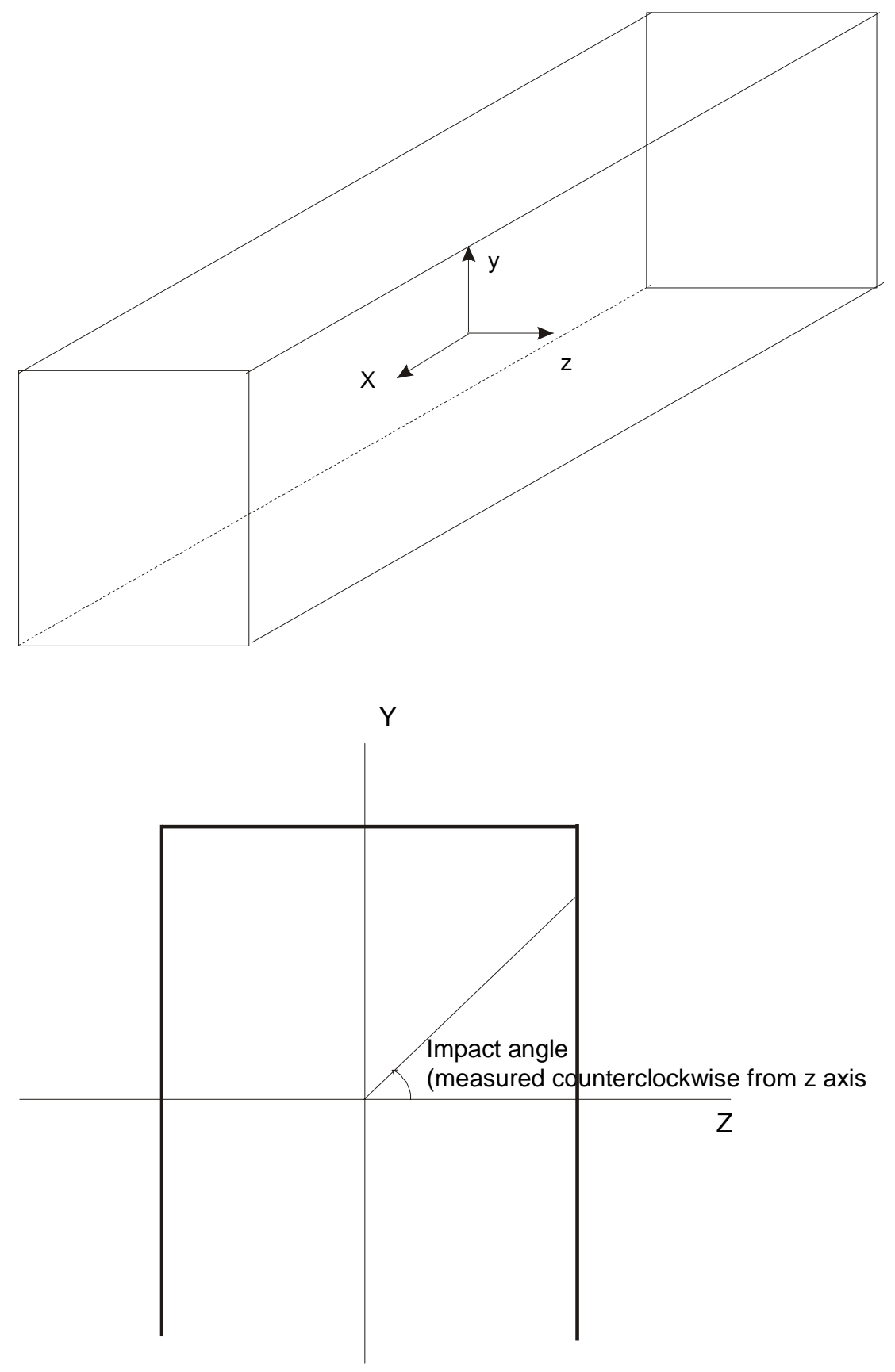

Figure 6-42. Definition of Impact Angle and Drip Shield Block Local Coordinate System 


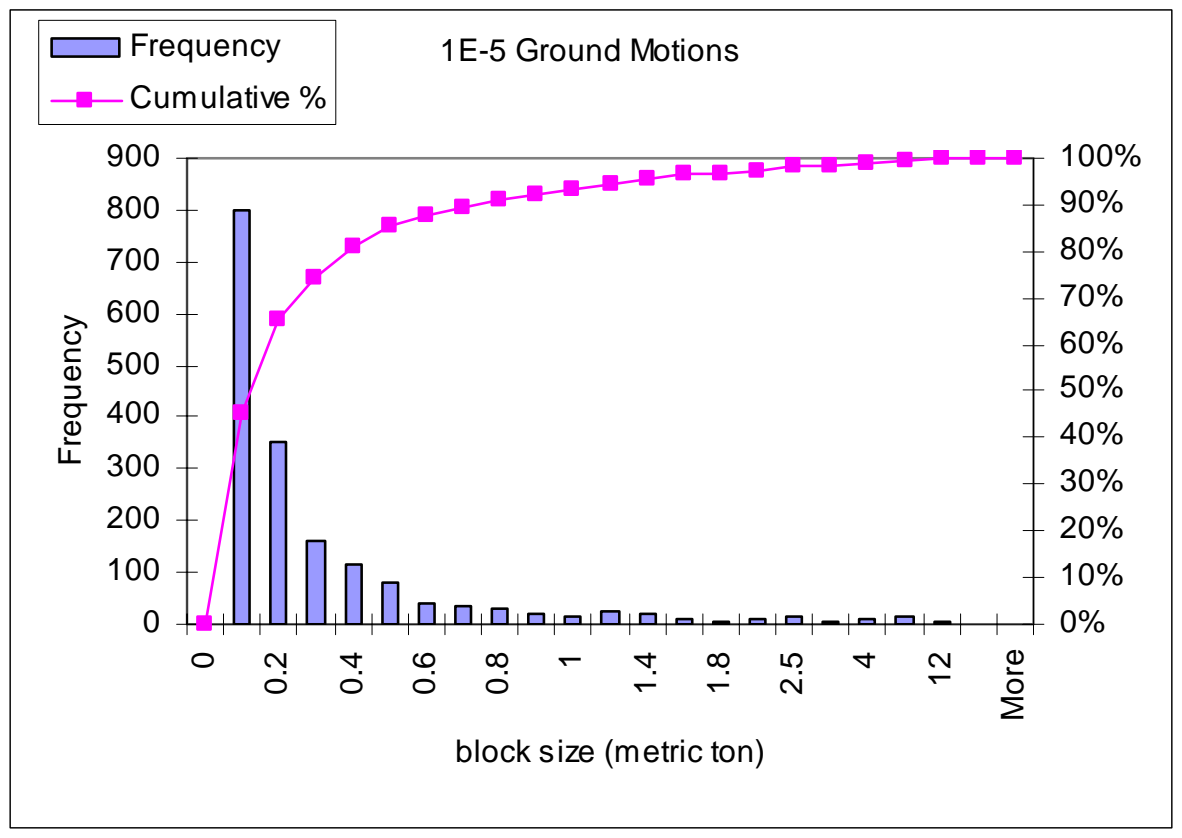

Figure 6-43. Histogram for Block Mass $\left(1 \times 10^{-5}\right.$ Annual Probability of Exceedance Hazard)

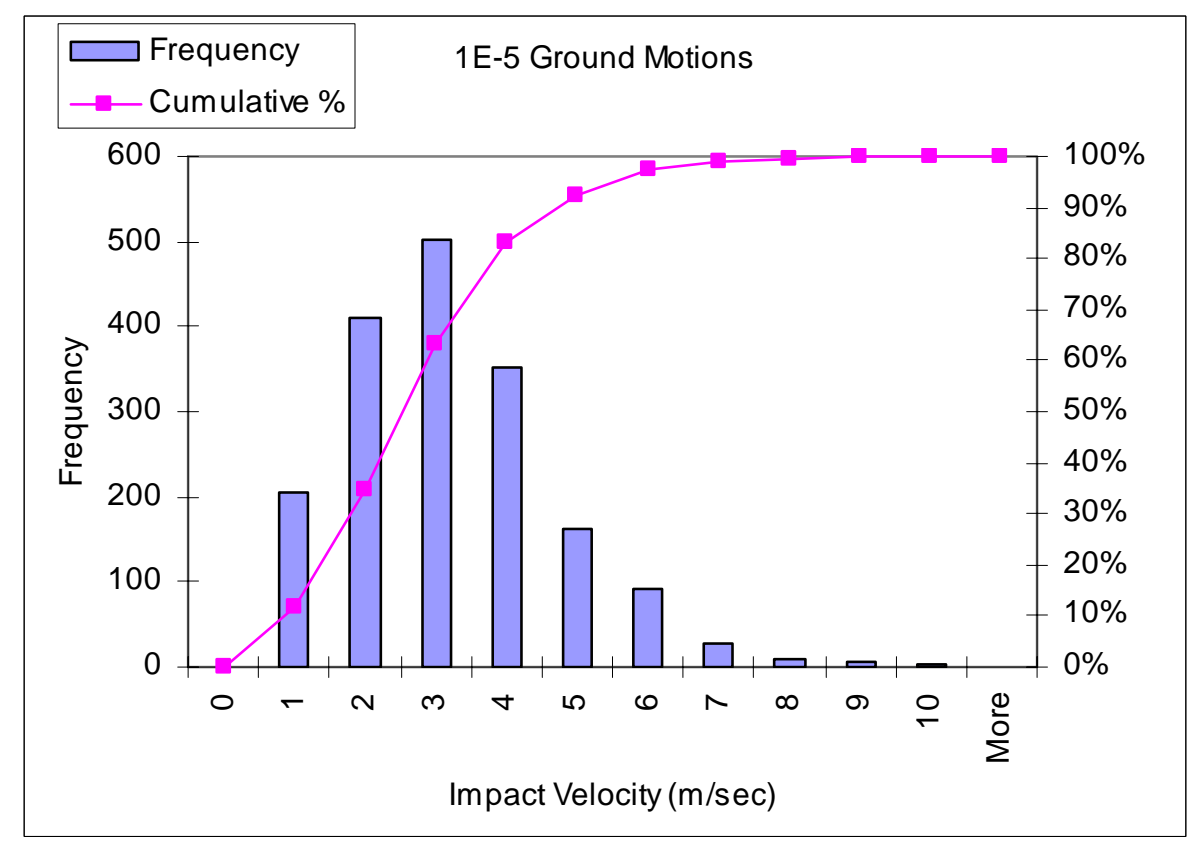

Figure 6-44. Histogram for Relative Impact Velocity $\left(1 \times 10^{-5}\right.$ Annual Probability of Exceedance Hazard) 


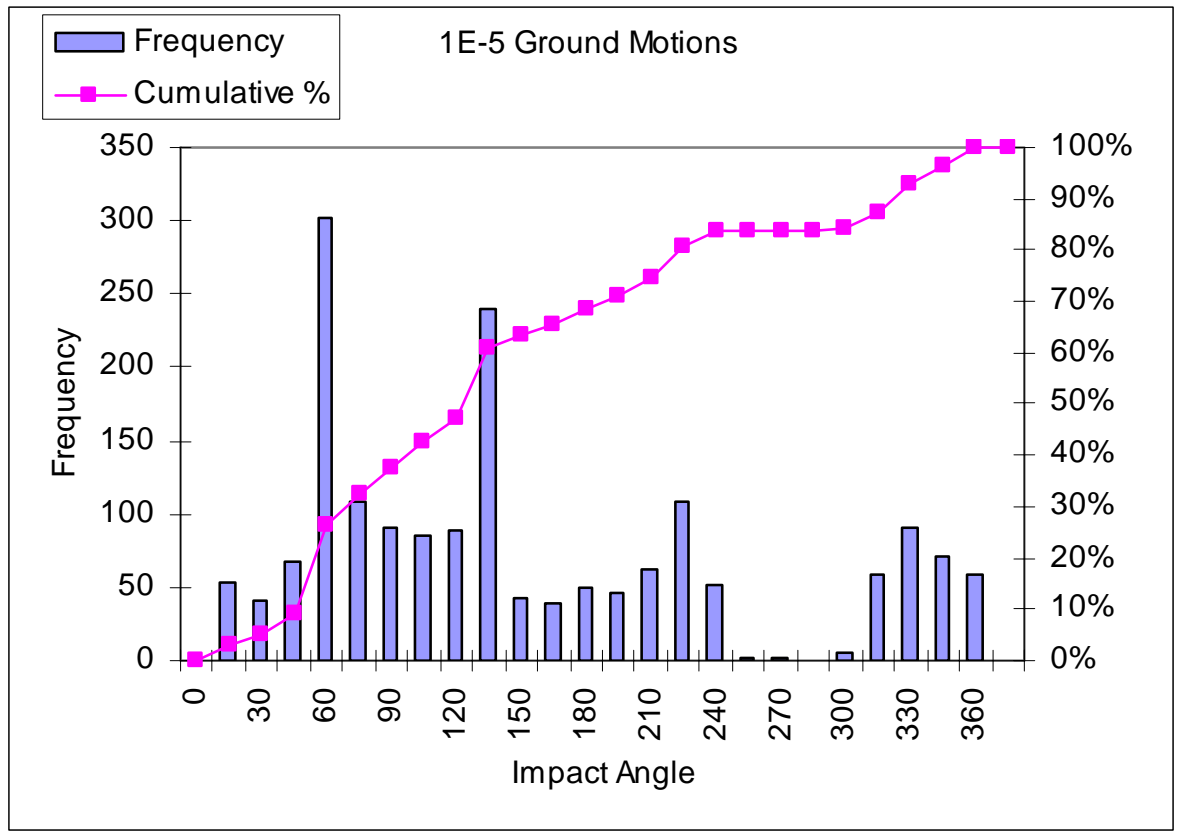

Figure 6-45. Histogram for Impact Angle ( $1 \times 10^{-5}$ Annual Probability of Exceedance Hazard)

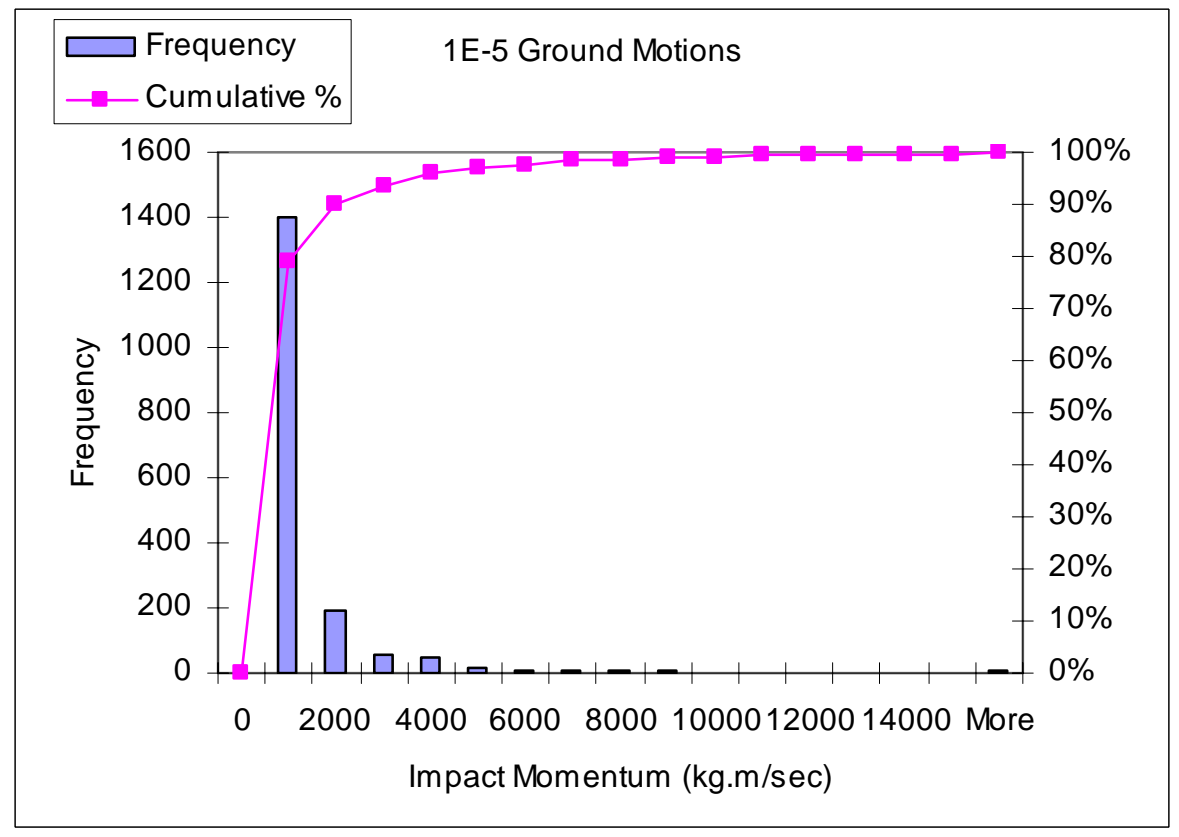

Figure 6-46. Histogram for Impact Momentum ( $1 \times 10^{-5}$ Annual Probability of Exceedance Hazard) 


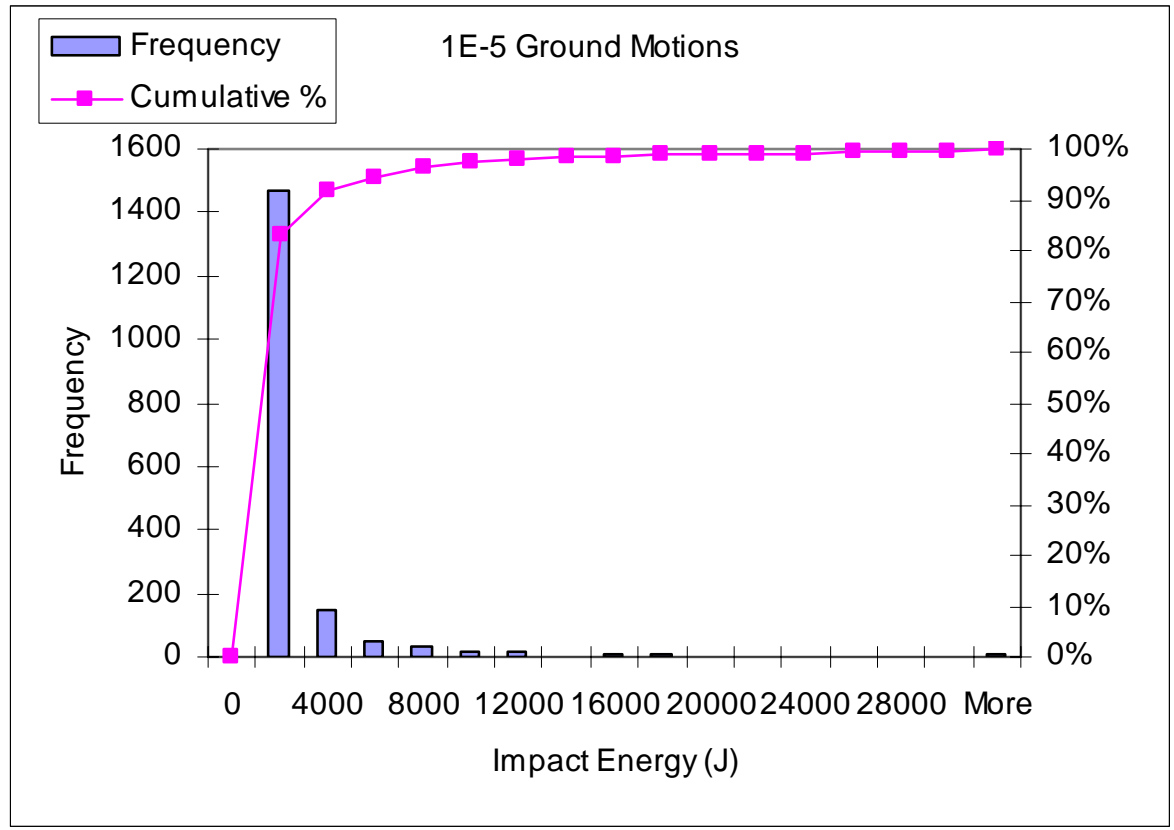

Figure 6-47. Histogram for Impact Energy $\left(1 \times 10^{-5}\right.$ Annual Probability of Exceedance Hazard)

\subsection{Results for Seismic Analysis Subjected to $1 \times 10^{-6}$ Annual Probability of Exceedance Ground Motions}

The results for a complete set of 3DEC analyses subjected to the postclosure hazard level of $1 \times 10^{-6}$ annual probability of exceedance ground motions are presented in this section. Figure 6-48 compares the input ground motion for the second horizontal component (H2, Ground Motion Set 6) with the recorded velocities at the center of the model. As for the case of $1 \times 10^{-6}$ annual probability of exceedance hazard, the results confirm the correct wave inputs and proper wave propagation in the 3DEC model.

Figure 6-49 shows a perspective view of blocks impacting drip shield in 3DEC dynamic simulation. Time histories of normal and shear stresses for fractures and rock bridges close to the opening were recorded during the seismic shaking in the 3DEC model. Figure 6-50 shows normal and shear stress time histories at the same selected fracture subcontacts as presented for the $1 \times 10^{-5}$ annual probability of exceedance ground motions (3DEC simulation \#16 with ground motion set \#11). Peak normal stress at subcontact $c$ reaches approximately $20 \mathrm{MPa}$ at around 4 seconds. Information of the subcontacts is provided in Figure 6-40. The stress paths of the fracture subcontacts are plotted against the fracture Coulomb slip criterion and rock bridge strength criterion, as shown in Figure 6-51. The in situ normal and shear stress state along the fracture is also included as the orange square for each subcontact in the figure. As in the $1 \times 10^{-5}$ ground motion case, the fracture containing subcontact $a$ yielded during seismic motions. The stress paths for rock bridges containing subcontacts $b$ and $c$ are still under the rock strength criterion when subjected to $1 \times 10^{-6}$ ground motion.

The percentages of the area of joint slip/separation versus the total area of joint planes for the selected cases were calculated and presented in Table 6-12. The majority of fractures (greater 
than 95 percent for most cases) have undergone shear slip or tensile separation when subjected to $1 \times 10^{-6}$ ground motions. Bridge damage percentages are also presented in Table 6-12. It is predicted that, for the majority of cases, around 5 percent bridge area would be damaged by shaking of $1 \times 10^{-6}$ ground motions. However, for certain large ground motions (e.g., ground motion \#3 for Case 38), higher damage percentage is predicted. Correlation of the bridge damage percentage versus peak ground velocity shows a strong relationship between the two. A detailed discussion on the bridge damage is provided in Section 6.3.1.6.3.

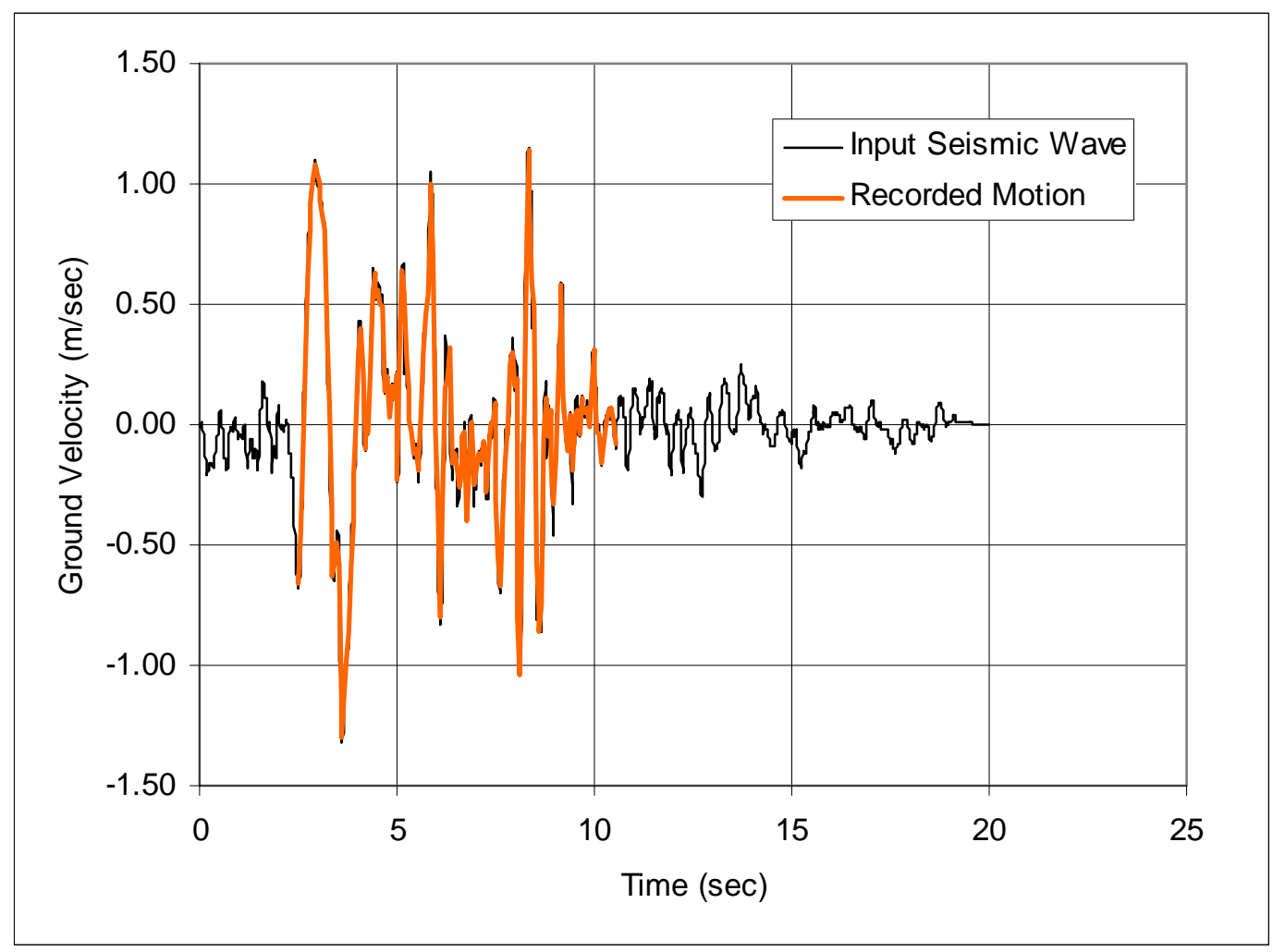

NOTE: The ground motion was recorded at the drip shield block during 3DEC simulation.

Figure 6-48. Comparison of Input Seismic Wave and Recorded Velocities in 3DEC Model for $1 \times 10^{-6}$ Annual Probability of Exceedance Ground Motion (Ground Motion Set 6, H2) 


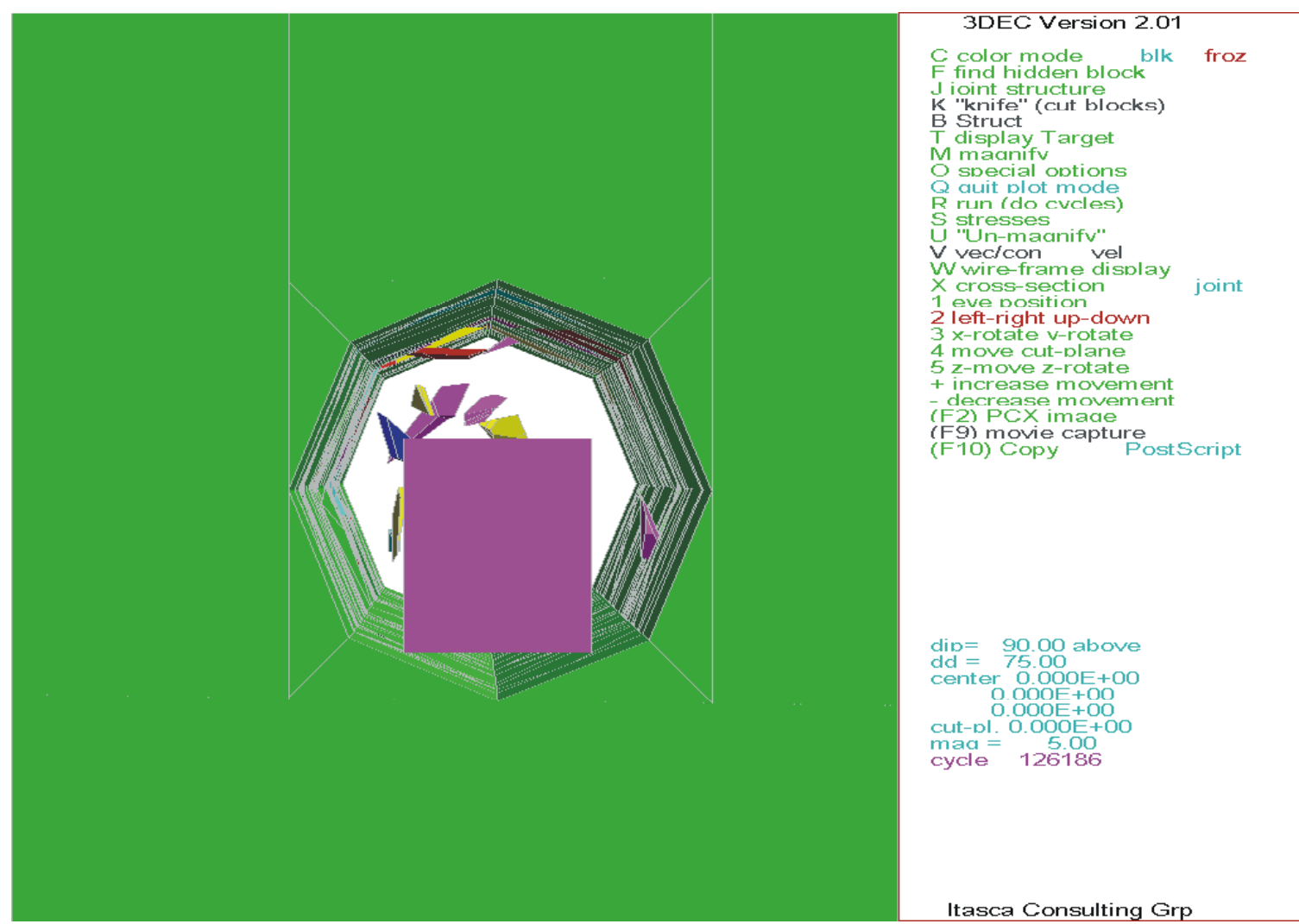

Figure 6-49. Illustration of the Simulation of Rockfall Impact to the Drip Shield (3DEC Simulation \# 22, $1 \times 10^{-6}$ Ground Motion \# 5, at $t=5.24 \mathrm{sec}$ ) (Simulation 16, Ground Motion Set 11)

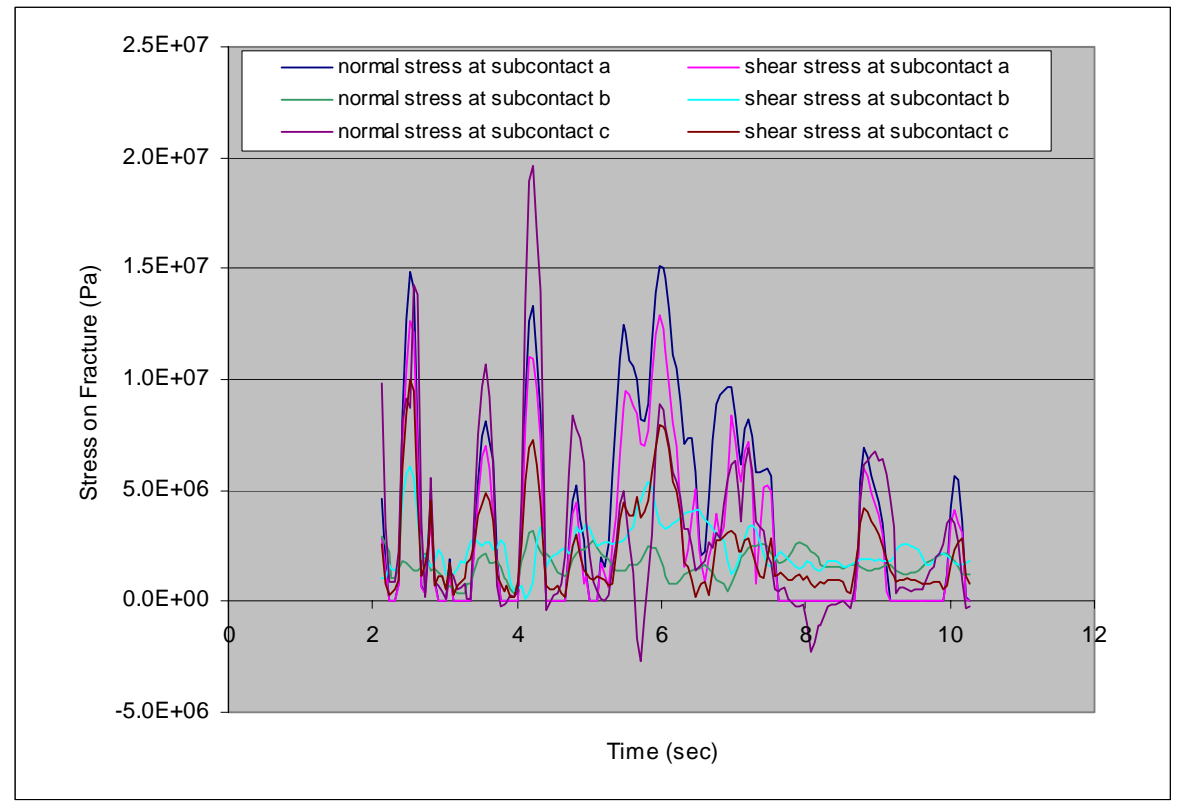

NOTE: Information for the subcontacts is presented in Figure 6-40.

Figure 6-50. Time Histories for Normal and Shear Stress at Selected Fracture Subcontacts for $1 \times 10^{-6}$ Annual Probability of Exceedance Hazard 


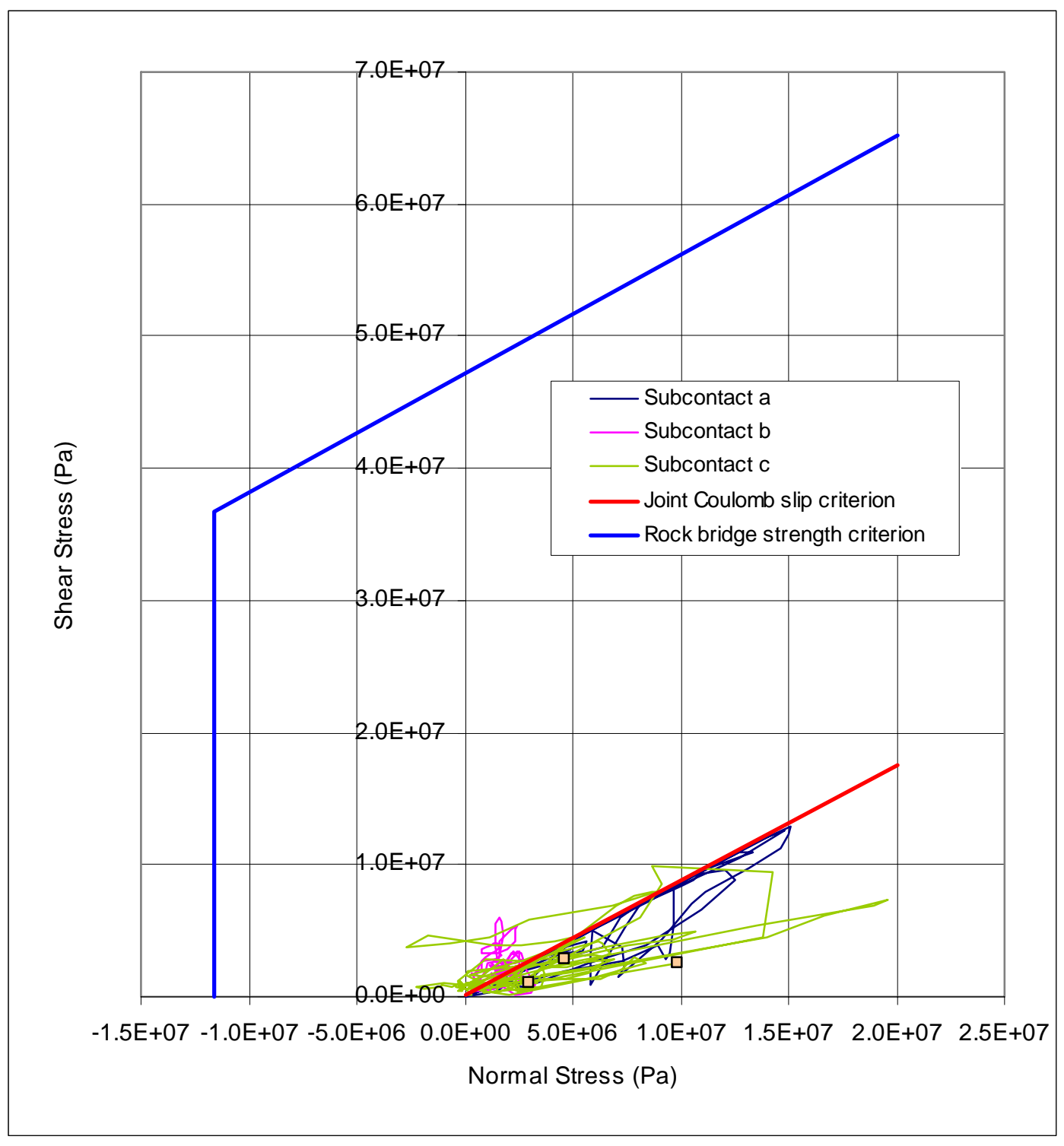

NOTE: Information for the subcontacts is presented in Figure 6-40.

Figure 6-51. Normal and Shear Stress Path at Selected Fracture Subcontacts for $1 \times 10^{-6}$ Annual Probability of Exceedance Hazard (Simulation 16, Ground Motion Set 11)

The results of the 50 3DEC simulations are summarized in Table 6-13. A total of 2,797 blocks have been identified from the analyses. A detailed listing of the impact information for each recorded block is included in an output DTN of this document (DTN: MO0408MWDDDMIO.002, file nonlith rockfall characteristics in emplacement drifts with 1e-6 gm.xls). Summary statistics for these parameters are provided in Table 6-14. The maximum rockfall block mass predicted is 28.22 metric tons. The median block size is 0.13 metric tons, very similar to the value predicted for the $1 \times 10^{-5}$ annual probability of exceedance hazard. Figures 6-52 to 6-56 present the histograms and the cumulative frequency of occurrence for the five impact parameters. The distribution of each parameter is similar to that for the $1 \times 10^{-5}$ annual probability of exceedance hazard. 
Table 6-12. Summary of Joint Slip/Separation and Bridge Damage for $1 \times 10^{-6}$ Ground Motions for Selected Cases

\begin{tabular}{|l|c|c|c|c|c|c|c|c|}
\hline \multicolumn{1}{|c|}{ Parameter } & Case 38 & Case 40 & Case 66 & Case 23 & Case 48 & Case 45 & Case 63 & Case 31 \\
\hline Total Joint Area $\left(\mathrm{m}^{2}\right)$ & 4319 & 4251 & 2583 & 3026 & 4260 & 4737 & 1911 & 3400 \\
\hline Total Bridge Area $\left(\mathrm{m}^{2}\right)$ & 862 & 885 & 592 & 550 & 923 & 1054 & 425 & 720 \\
\hline $\begin{array}{l}\text { Percentage of Joint } \\
\text { Slip/Separation }\end{array}$ & $93.70 \%$ & $97.13 \%$ & $96.36 \%$ & $97.06 \%$ & $96.74 \%$ & $95.33 \%$ & $95.40 \%$ & $96.50 \%$ \\
\hline $\begin{array}{l}\text { Percentage of Bridge } \\
\text { Damaged }\end{array}$ & $32.60 \%$ & $6.07 \%$ & $28.89 \%$ & $4.28 \%$ & $4.14 \%$ & $2.66 \%$ & $2.82 \%$ & $2.31 \%$ \\
\hline
\end{tabular}

Table 6-13. Summary of 3DEC Rockfall Prediction for $1 \times 10^{-6}$ Annual Probability of Exceedance Hazard

\begin{tabular}{|l|l|}
\hline \multicolumn{1}{|c|}{ Parameter } & \multicolumn{1}{c|}{ Value } \\
\hline Simulations Completed & 50 \\
\hline Total Number of Rockfall & 2797 \\
\hline Total Volume of Rockfall $\left(\mathrm{m}^{3}\right)$ & 497.7 \\
\hline Total Length of Drift Simulated $(\mathrm{m})$ & 1250 \\
\hline Number of Blocks per $\mathrm{km}$ & 2238 \\
\hline Volume of Rockfall per $\mathrm{km}\left(\mathrm{m}^{3}\right)$ & 398.2 \\
\hline
\end{tabular}

Table 6-14. Statistic Summary of the Rockfall Impact Parameters, $1 \times 10^{-6}$ Annual Probability of Exceedance Hazard

\begin{tabular}{|l|l|l|l|l|l|}
\hline \multicolumn{1}{|c|}{ Parameter } & $\begin{array}{c}\text { Block Mass } \\
\text { (tonnes) }\end{array}$ & $\begin{array}{c}\text { Relative Impact } \\
\text { Velocity (m/sec) }\end{array}$ & $\begin{array}{c}\text { Impact Angle } \\
\text { (degree) }\end{array}$ & $\begin{array}{c}\text { Impact } \\
\text { Momentum } \\
\text { (kg*m/sec) }\end{array}$ & $\begin{array}{c}\text { Impact Energy } \\
\text { (Joules) }\end{array}$ \\
\hline Mean & 0.43 & 3.23 & 136 & 1217 & 2350 \\
\hline Median & 0.13 & 2.97 & 124 & 377 & 576 \\
\hline Standard Deviation & 1.30 & 1.74 & 93 & 3464 & 7704 \\
\hline Skewness & 11.61 & 1.06 & 0.87 & 11 & 12 \\
\hline Range & 28.19 & 12.03 & 359 & 79001 & 163657 \\
\hline Minimum & 0.02 & 0.07 & 0 & 2 & 0 \\
\hline Maximum & 28.22 & 12.10 & 360 & 79003 & 163657 \\
\hline Sum & 1200.43 & NA* & NA* & 3403555 & 6573633 \\
\hline
\end{tabular}

* Not Applicable 


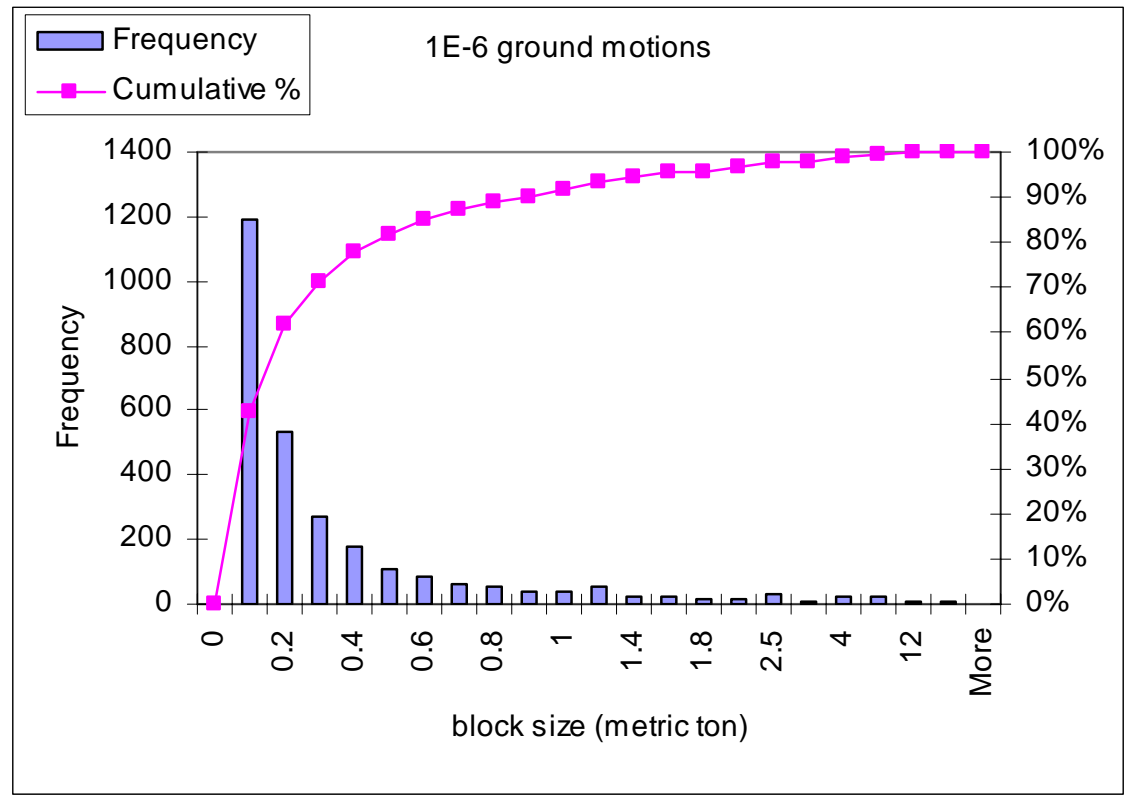

Figure 6-52. Histogram for Block Mass $\left(1 \times 10^{-6}\right.$ Annual Probability of Exceedance Hazard)

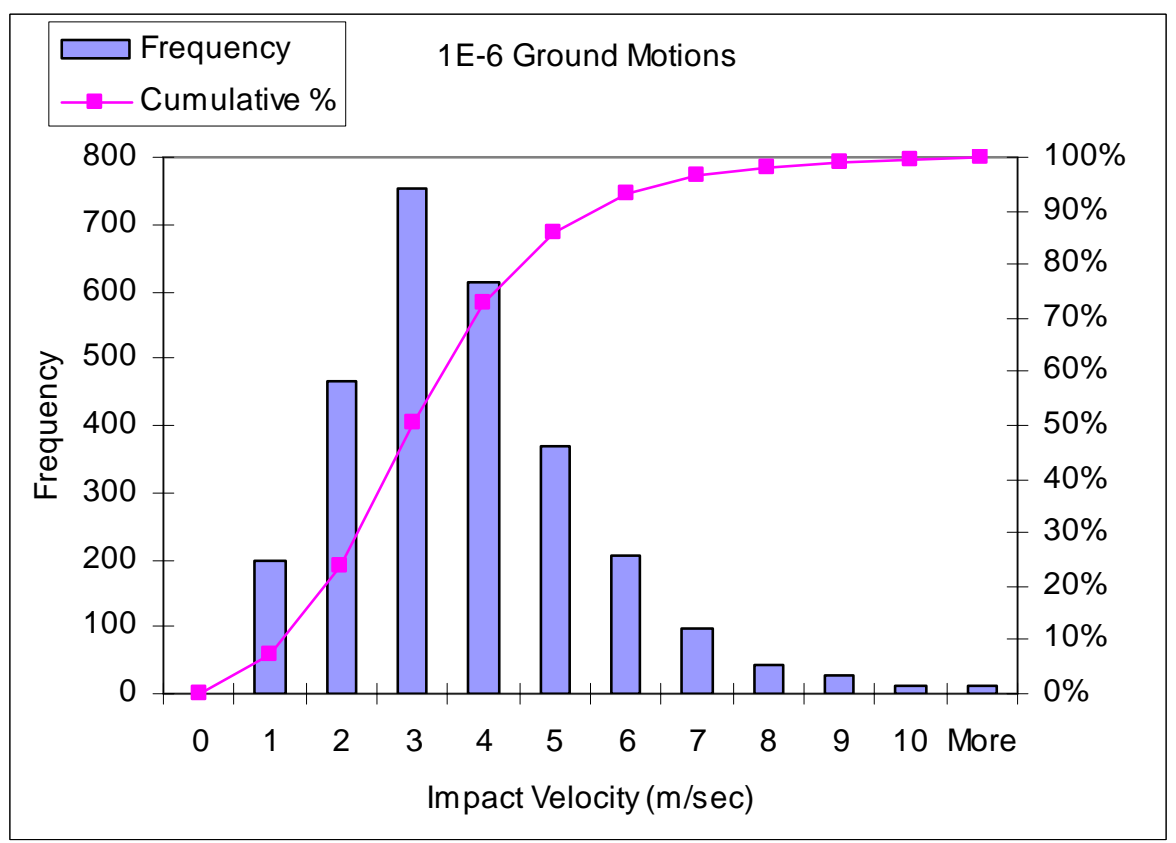

Figure 6-53. Histogram for Relative Impact Velocity $\left(1 \times 10^{-6}\right.$ Annual Probability of Exceedance Hazard) 


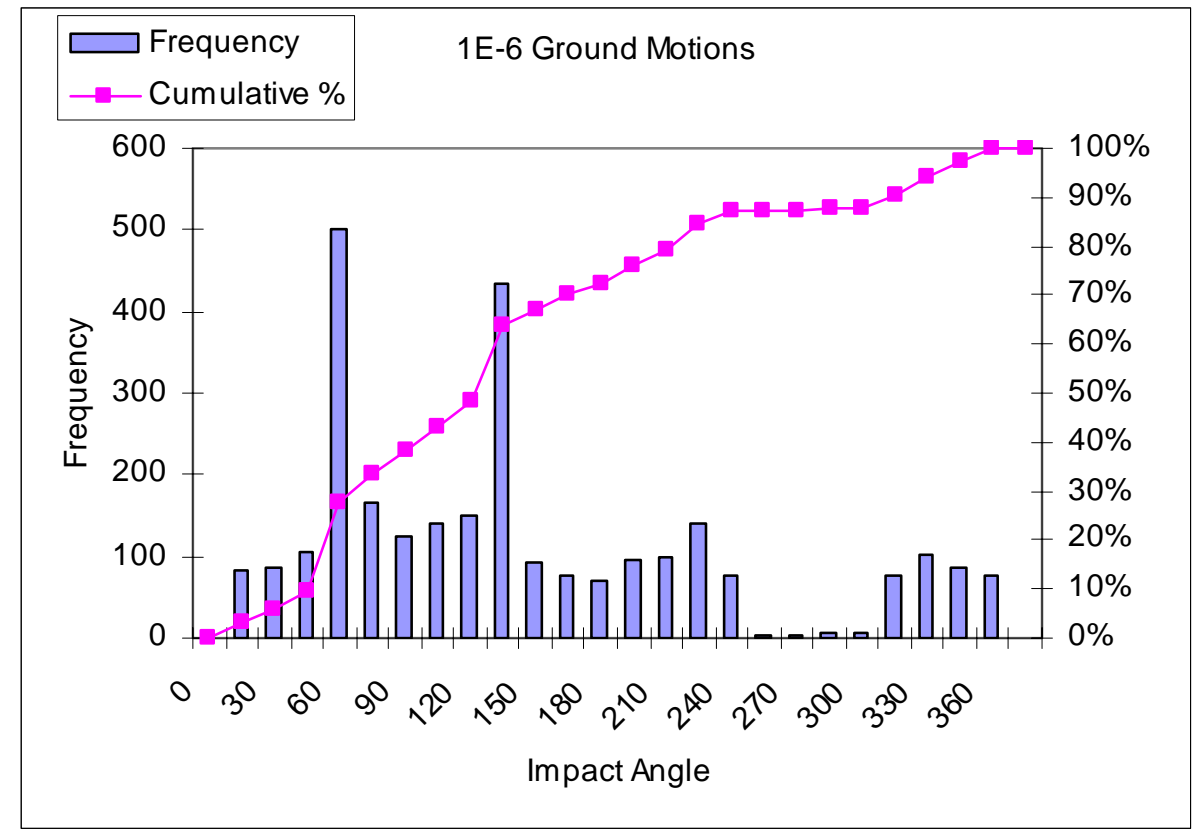

Figure 6-54. Histogram for Impact Angle ( $1 \times 10^{-6}$ Annual Probability of Exceedance Hazard)

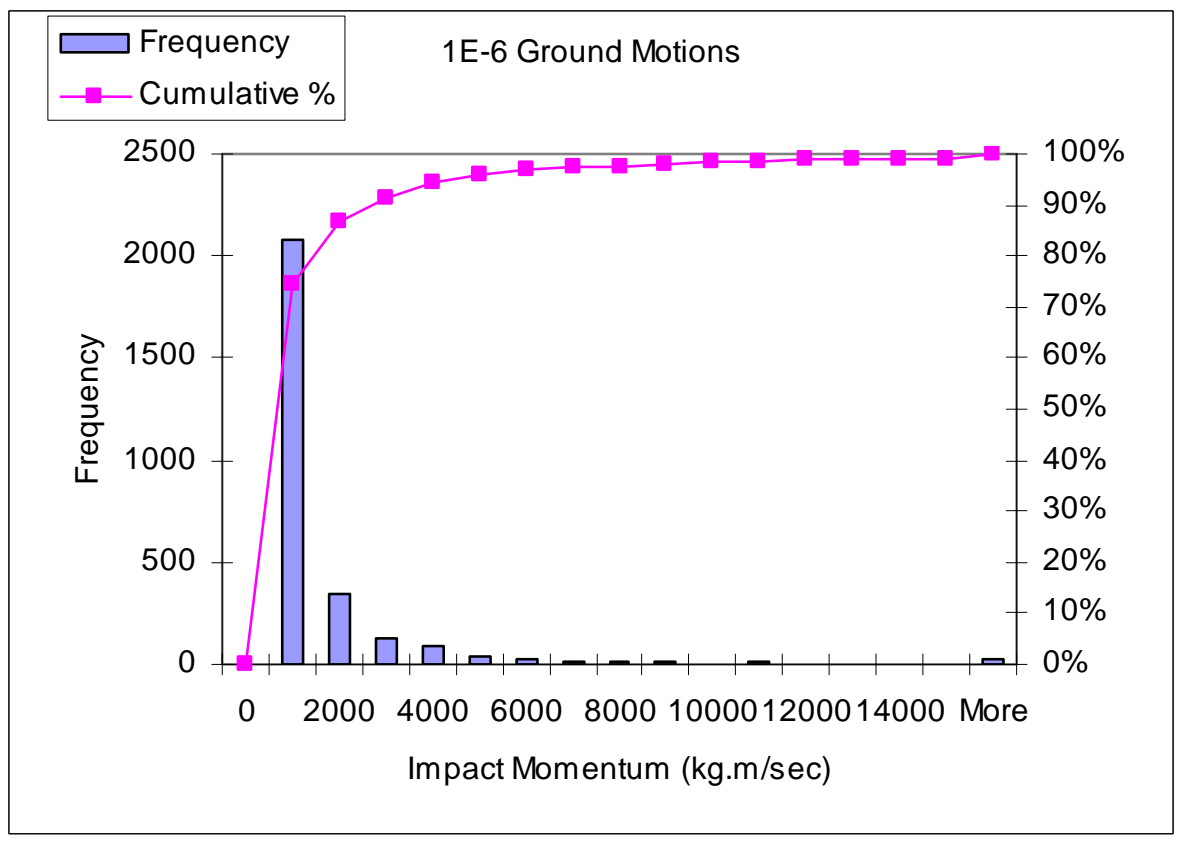

Figure 6-55. Histogram for Impact Momentum ( $1 \times 10^{-6}$ Annual Probability of Exceedance Hazard) 


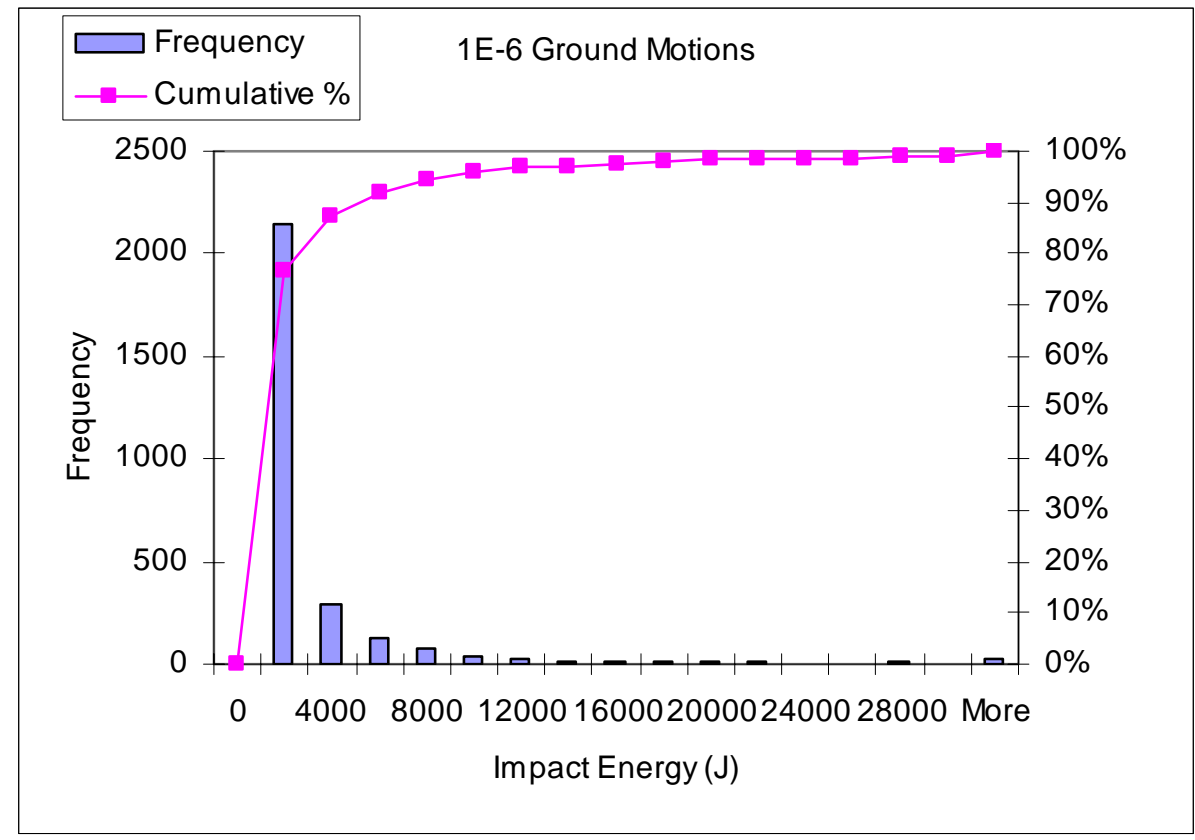

Figure 6-56. Histogram for Impact Energy $\left(1 \times 10^{-6}\right.$ Annual Probability of Exceedance Hazard)

\subsection{Results for Seismic Analysis Subjected to $1 \times 10^{-7}$ Annual Probability of Exceedance Ground Motions}

The results for a complete set of 3DEC analyses subjected to the postclosure hazard level of $1 \times 10^{-7}$ annual probability of exceedance ground motions are presented in this section. Figure 6-57 compares the input ground motion for the vertical component (V, Ground Motion Set 3) with the recorded velocities at the center of the model. The results confirm the correct wave inputs and proper wave propagation in the 3DEC model.

Figure 6-58 shows a perspective view of blocks impacting the drip shield in the 3DEC dynamic simulation. Extensive rockfall is observed for many simulations for this level of ground motion. Numerical difficulties were encountered for several simulations due to the extremely large inertial force applied to the discontinuum. A total of 44 simulations were completed for this level of ground motion (Simulations 19, 24, 25, 28, 38, and 52 were not completed due to numerical difficulties). The sufficiency of 44 simulations to capture the rockfall characteristics for this level of ground motion is documented in Appendix K.

Time histories of normal and shear stresses for fractures and rock bridges close to the opening were recorded during the seismic shaking in the 3DEC model. Figure 6-59 shows normal and shear stress time histories at the same selected fracture subcontacts as presented for the $1 \times 10^{-5}$ annual probability of exceedance ground motions (3DEC simulation \#16 with ground motion set \#11). Peak normal stress at subcontacts $a$ and $c$ reaches approximately $25 \mathrm{MPa}$ and $30 \mathrm{MPa}$ respectively, while the peak shear stress reaches to $25 \mathrm{MPa}$ (information of the subcontacts is provided in Figure 6-40). The stress paths of the fracture subcontacts are plotted against the fracture Coulomb slip criterion and rock bridge strength criterion, as shown in Figure 6-60. The in situ normal and shear stress state along the fracture is identified as the orange square for each 
subcontact in the figure. As with other postclosure level ground motions, the fracture containing subcontact $a$ yielded during seismic motions. However, the stress paths for rock bridges containing subcontacts $b$ and $c$ are under the rock strength criterion when subjected to $1 \times 10^{-7}$ ground motion.

The percentages of the area of fracture slip/separation versus the total area of joint planes for the selected cases were calculated and presented in Table 6-15. Most of the fractures (greater than 95 percent for most cases) have undergone shear slip or tensile separation when subjected to $1 \times 10^{-7}$ ground motions. Bridge damage percentages are also presented in Table 6-15. It is predicted that, for the majority of the cases, around 20 percent bridge area would be damaged by shaking of $1 \times 10^{-7}$ ground motions. However, for certain large ground motions (e.g., ground motion \#3 for Case 38), damage percentage goes up to approximately 60 percent. Correlation of the bridge damage percentage versus peak ground velocity shows a strong relationship between the two. A detailed discussion on the bridge damage is provided in Section 6.3.1.6.3.

The results of the 44 3DEC simulations are summarized in Table 6-16. A total of 3,387 blocks have been identified from the analyses. A detailed listing of the impact information for each recorded block is included in an output DTN of this document (DTN: MO0408MWDDDMIO.002, file nonlith rockfall characteristics in emplacement drifts with 1 e-7 gm.xls). Summary statistics for these parameters are provided in Table 6-17. The maximum rockfall block mass predicted is 28.29 metric tons, which is similar to the prediction for the $1 \times 10^{-6}$ annual probability of exceedance ground motions. The median block size is 0.15 metric tons, similar to the value predicted for the $1 \times 10^{-5}$ and $1 \times 10^{-6}$ annual probability of exceedance hazards. Figures 6-61 to 6-65 present the histograms and the cumulative frequency of occurrence for the five impact parameters.

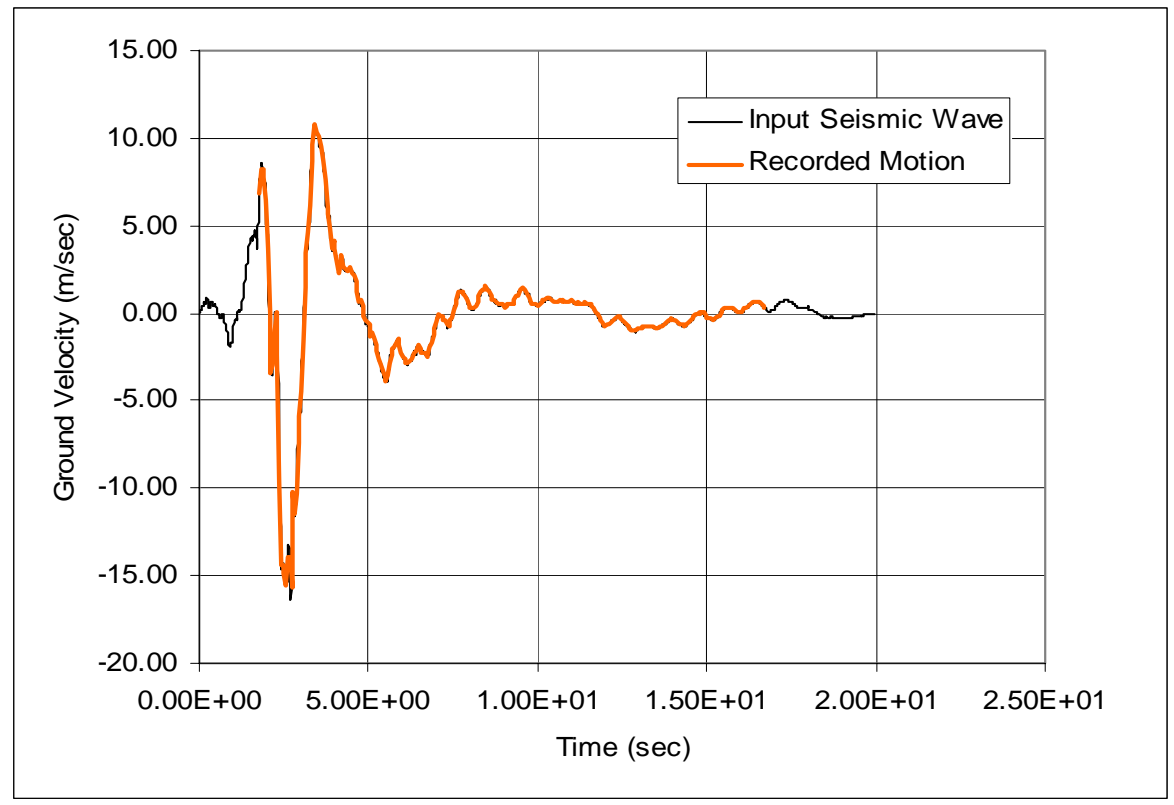

NOTE: The ground motion was recorded at the drip shield block during 3DEC simulation.

Figure 6-57. Comparison of Input Seismic Wave and Recorded Velocities in 3DEC Model for $1 \times 10^{-7}$ Annual Probability of Exceedance Ground Motion (Ground Motion Set 3, Vertical Motion) 


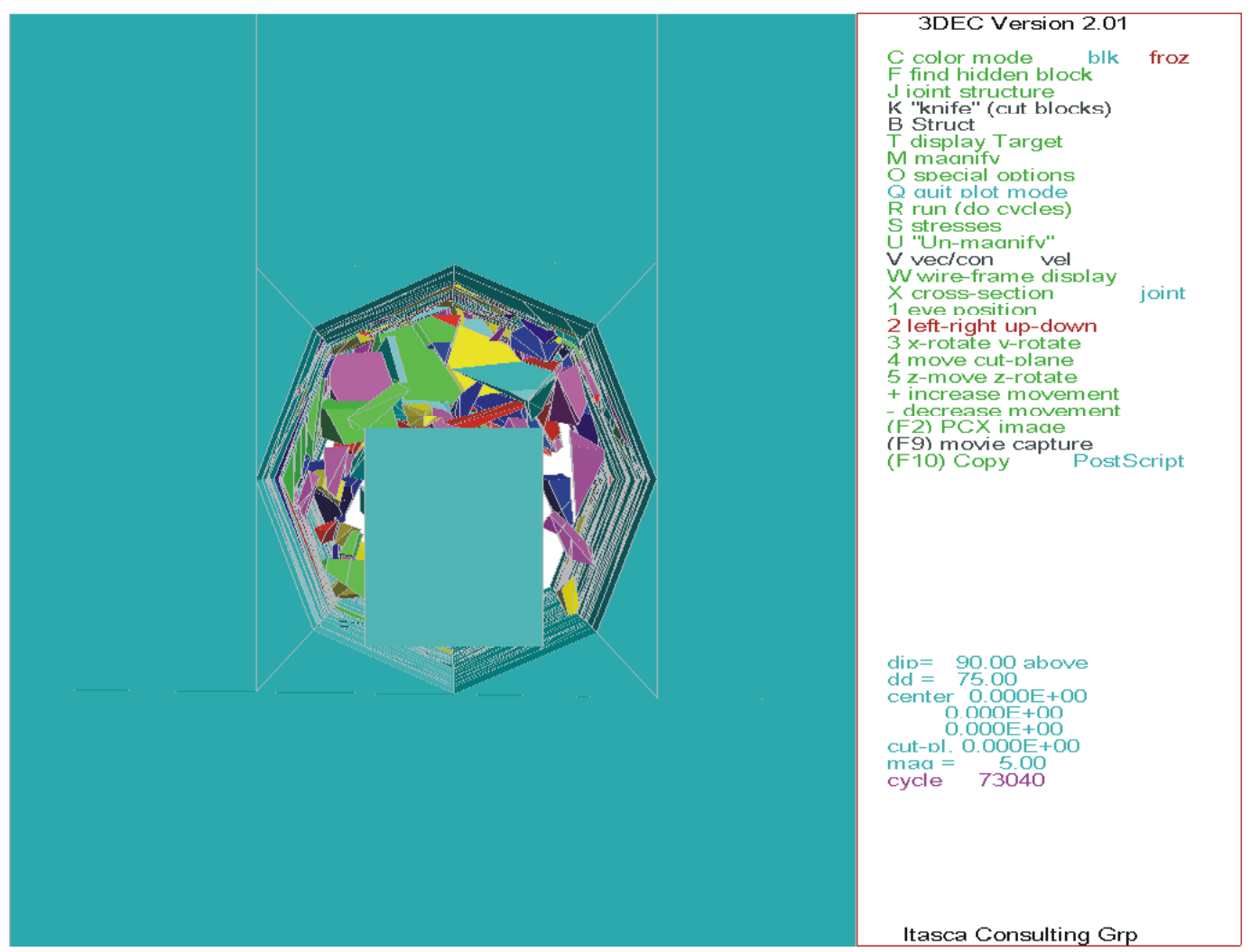

Figure 6-58. Illustration of the Simulation of Rockfall Impact to the Drip Shield (3DEC Simulation \# 64, $1 \times 10^{-7}$ Ground Motion \# 14, at $t=7.37 \mathrm{sec}$ )

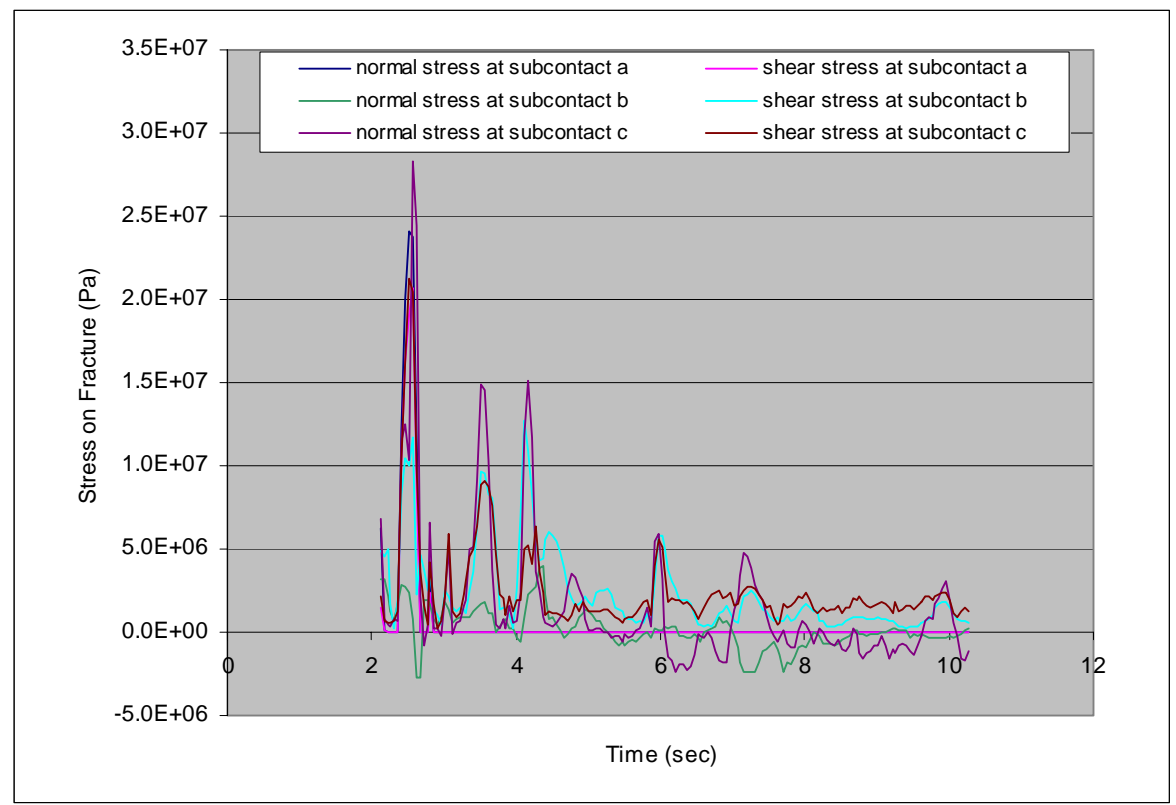

NOTE: Information for the Subcontacts is presented in Figure 6-40.

Figure 6-59. Time Histories for Normal and Shear Stress at Selected Fracture Subcontacts for $1 \times 10^{-7}$ Annual Probability of Exceedance Hazard (Simulation 16, Ground Motion Set 11) 


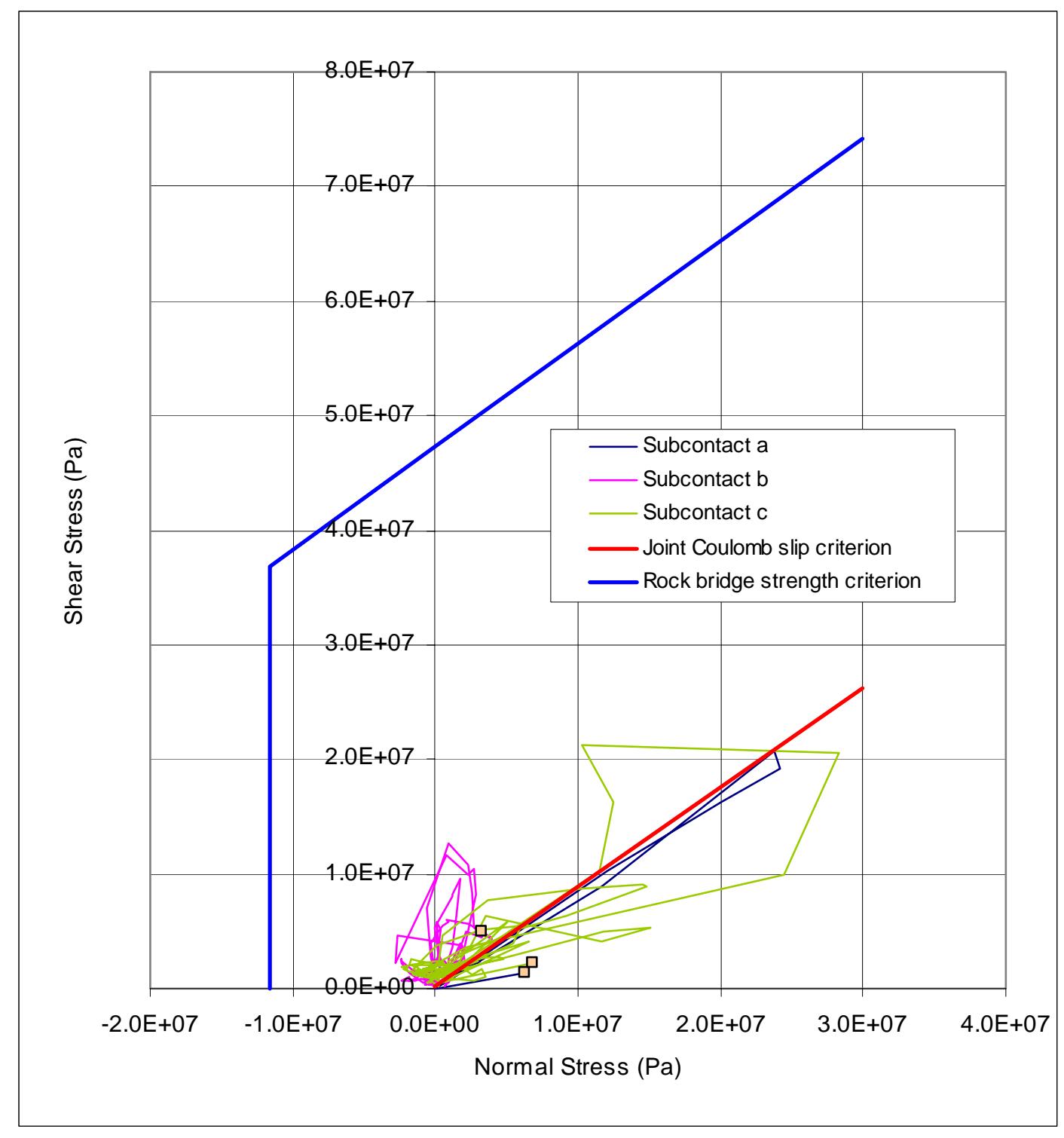

NOTE: Information for the Subcontacts is presented in Figure 6-40.

Figure 6-60. Normal and Shear Stress Path at Selected Fracture Subcontacts for $1 \times 10^{-7}$ Annual Probability of Exceedance Hazard (Simulation 16, Ground Motion Set 11)

Table 6-15. Summary of Joint Slip/Separation and Bridge Damage for $1 \times 10^{-7}$ Ground Motions for Selected Cases

\begin{tabular}{|l|c|c|c|c|c|c|c|}
\hline \multicolumn{1}{|c|}{ Parameter } & Case 40 & Case 66 & Case 23 & Case 48 & Case 45 & Case 63 & Case 31 \\
\hline Total Joint Area $\left(\mathrm{m}^{2}\right)$ & 4251 & 2583 & 3026 & 4260 & 4737 & 1911 & 3400 \\
\hline Total Bridge Area $\left(\mathrm{m}^{2}\right)$ & 885 & 592 & 550 & 923 & 1054 & 425 & 720 \\
\hline $\begin{array}{l}\text { Percentage of Joint } \\
\text { Slip/Separation }\end{array}$ & $97.18 \%$ & $92.26 \%$ & $97.88 \%$ & $97.11 \%$ & $97.91 \%$ & $98.53 \%$ & $98.32 \%$ \\
\hline $\begin{array}{l}\text { Percentage of Bridge } \\
\text { Damaged }\end{array}$ & $27.78 \%$ & $61.99 \%$ & $29.07 \%$ & $21.99 \%$ & $18.22 \%$ & $20.47 \%$ & $16.92 \%$ \\
\hline
\end{tabular}


Table 6-16. Summary of 3DEC Rockfall Prediction for $1 \times 10^{-7}$ Annual Probability of Exceedance Hazard

\begin{tabular}{|l|c|}
\hline \multicolumn{1}{|c|}{ Parameter } & Value \\
\hline Simulations Completed & 44 \\
\hline Total Number of Rockfall & 3387 \\
\hline Total Volume of Rockfall $\left(\mathrm{m}^{3}\right)$ & 705.2 \\
\hline Total Length of Drift Simulated $(\mathrm{m})$ & 1100 \\
\hline Number of Blocks per km & 3079 \\
\hline Volume of Rockfall per ${\mathrm{km}\left(\mathrm{m}^{3}\right)}^{3}$ & 641.1 \\
\hline
\end{tabular}

Table 6-17. Statistic Summary of the Rockfall Impact Parameters, $1 \times 10^{-7}$ Annual Probability of Exceedance Hazard

\begin{tabular}{|l|c|c|c|c|c|}
\hline \multicolumn{1}{|c|}{ Parameter } & $\begin{array}{c}\text { Block Mass } \\
\text { (tonnes) }\end{array}$ & $\begin{array}{c}\text { Relative Impact } \\
\text { Velocity (m/sec) }\end{array}$ & $\begin{array}{c}\text { Impact } \\
\text { Impact Angle } \\
\text { (degree) }\end{array}$ & $\begin{array}{c}\text { Momentum } \\
\text { (kg*m/sec) }\end{array}$ & $\begin{array}{c}\text { Impact Energy } \\
\text { (Joules) }\end{array}$ \\
\hline Mean & 0.50 & 4.17 & 135 & 1676 & 4146 \\
\hline Median & 0.15 & 3.78 & 124 & 528 & 1022 \\
\hline Standard Deviation & 1.43 & 2.47 & 92 & 5293 & 16749 \\
\hline Skewness & 8.81 & 1.21 & 0.94 & 20 & 26 \\
\hline Range & 28.26 & 20.90 & 359 & 199976 & 706914 \\
\hline Minimum & 0.02 & 0.04 & 0 & 3 & 0 \\
\hline Maximum & 28.29 & 20.94 & 359 & 199979 & 706914 \\
\hline Sum & 1699.57 & NA & NA & 5677385 & 14044153 \\
\hline
\end{tabular}

NA = Not Applicable

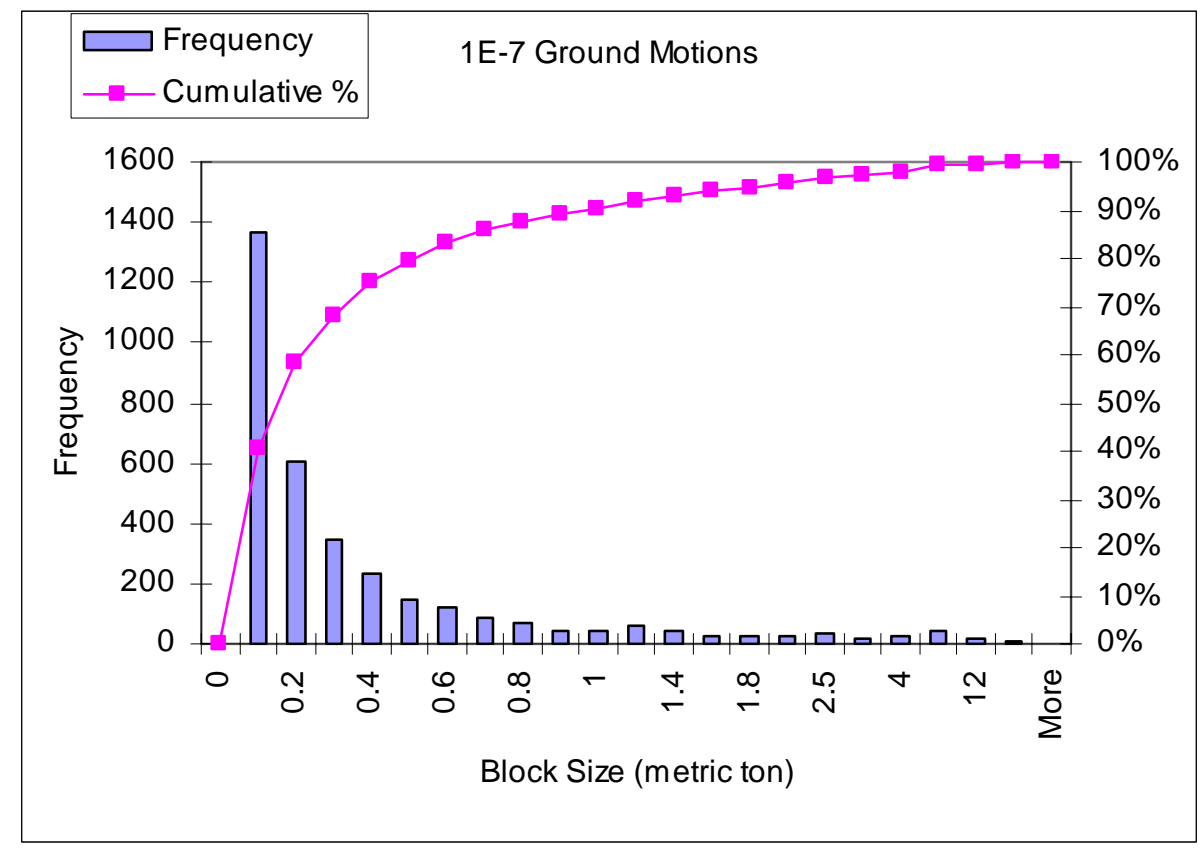

Figure 6-61. Histogram for Block Mass $\left(1 \times 10^{-7}\right.$ Annual Probability of Exceedance Hazard) 


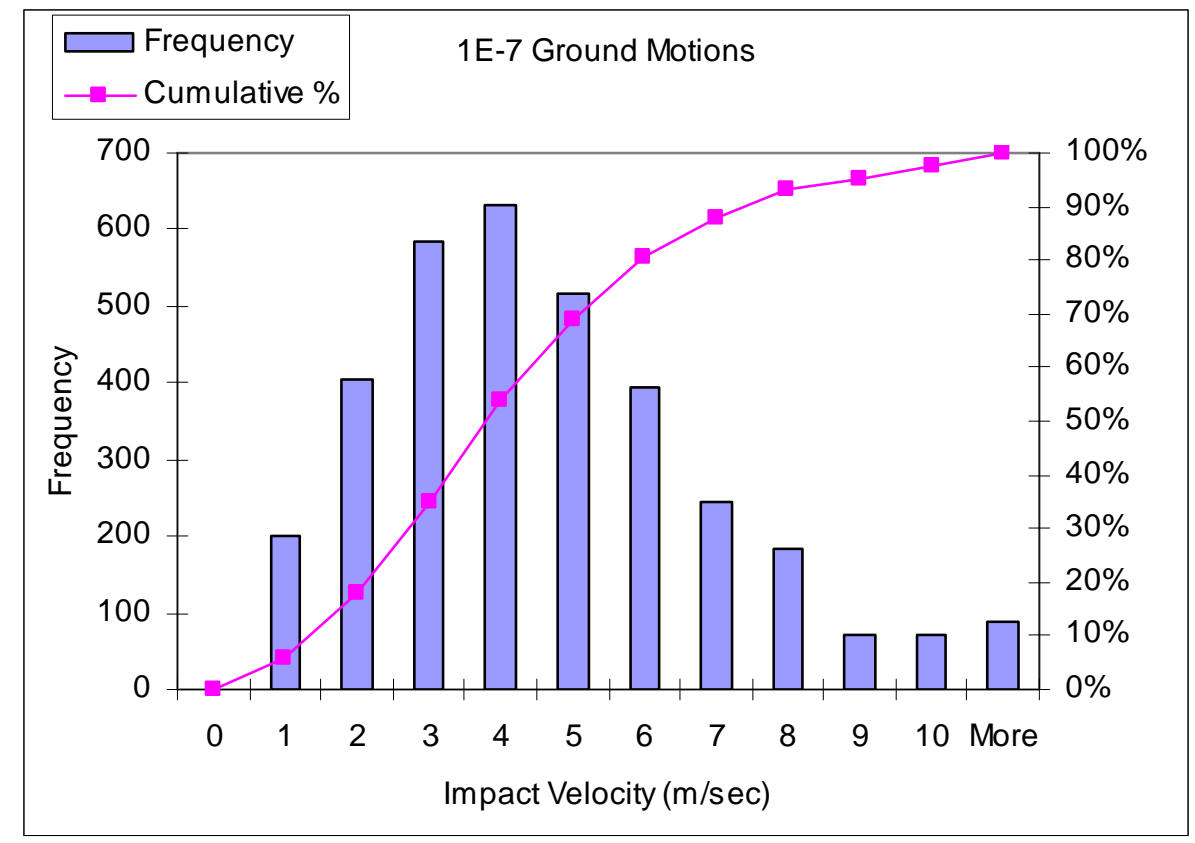

Figure 6-62. Histogram for Relative Impact Velocity $\left(1 \times 10^{-7}\right.$ Annual Probability of Exceedance Hazard)

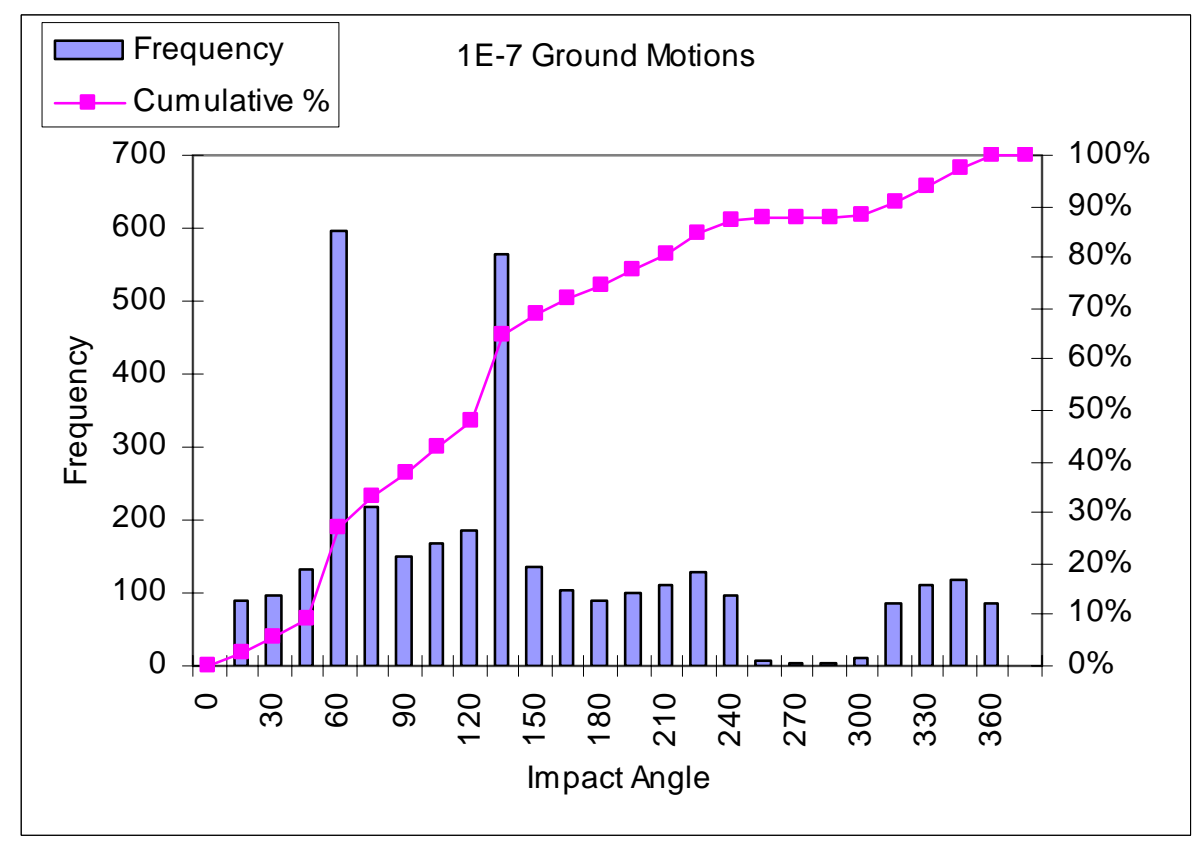

Figure 6-63. Histogram for Impact Angle $\left(1 \times 10^{-7}\right.$ Annual Probability of Exceedance Hazard) 


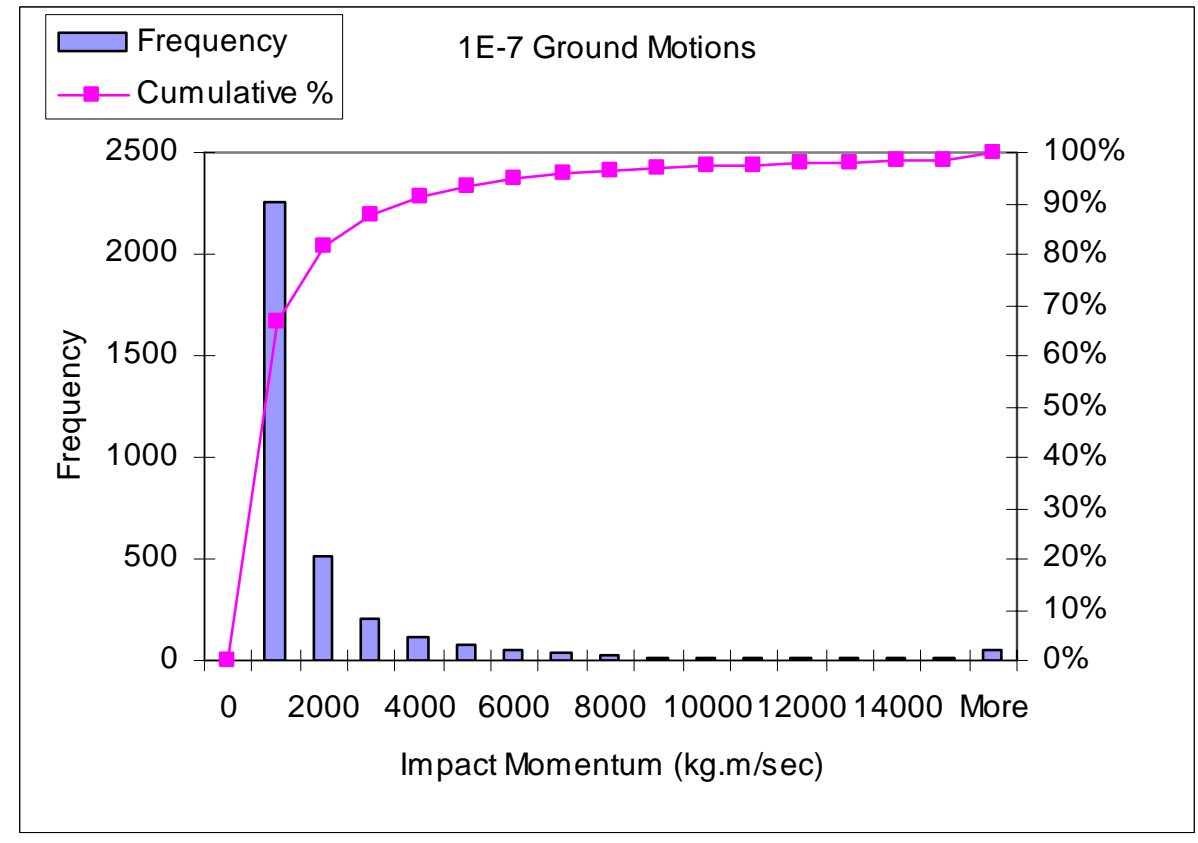

Figure 6-64. Histogram for Impact Momentum ( $1 \times 10^{-7}$ Annual Probability of Exceedance Hazard)

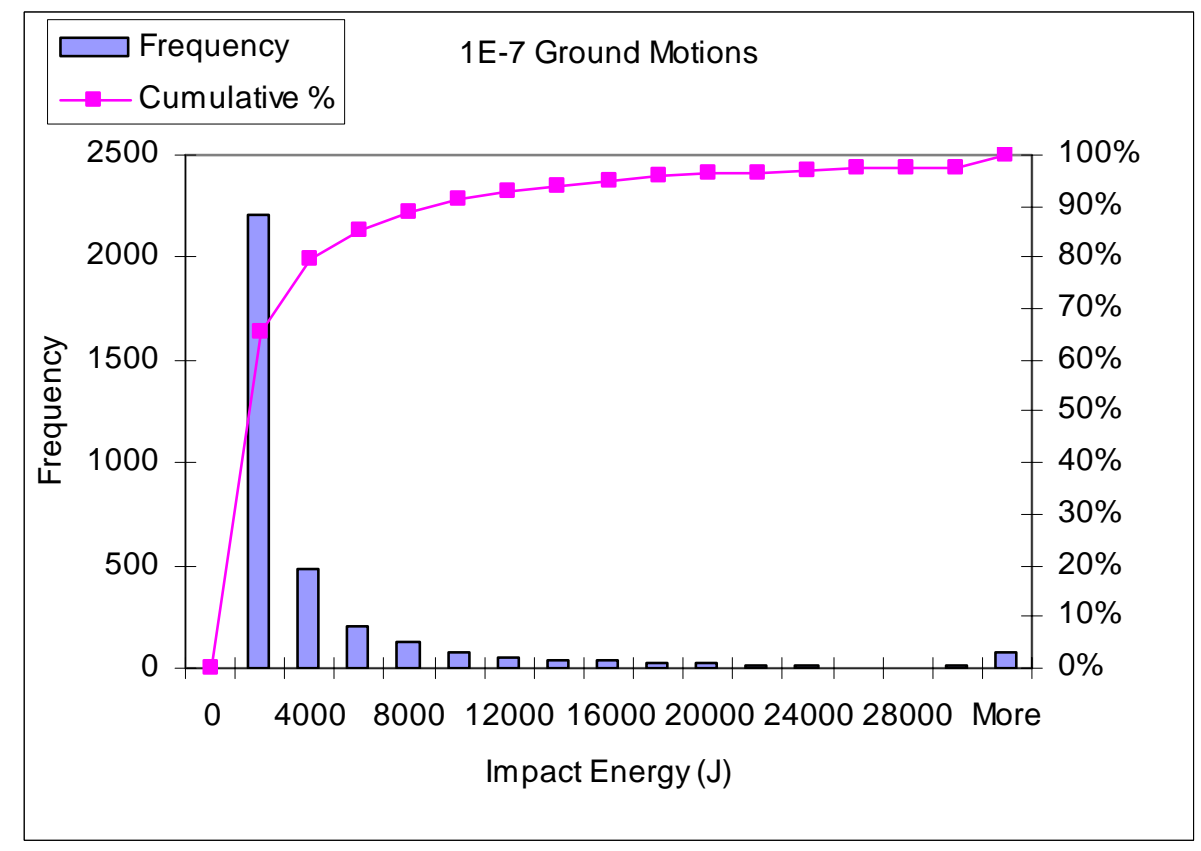

Figure 6-65. Histogram for Impact Energy $\left(1 \times 10^{-7}\right.$ Annual Probability of Exceedance Hazard) 


\subsection{Results for Seismic Analysis Subjected to Preclosure Ground Motion}

The results for the preclosure hazard level of $1 \times 10^{-4}$ annual probability of exceedance ground motion are presented in this section. The $5 \times 10^{-4}$ annual probability of exceedance ground motion was not included due to the relatively small amount of rockfall predicted for the $1 \times 10^{-4}$ motion. As described in Section 6.3.1.2.1, only a single set of ground motion is considered in the rockfall analysis for preclosure seismic level for the deterministic design approach. Due to the much lower amplitude of ground motion considered for the preclosure hazard level and, hence, much less rockfall hazard anticipated, only 32 simulations were conducted for preclosure cases compared to 50 cases for postclosure. The sufficiency of 32 simulations to capture the rockfall characteristics for the preclosure ground motion is documented in Appendix K.

Figure 6-66 compares the input ground motion for the first horizontal component (H1) with the recorded velocities at the center of the model. The results confirm that the correct wave inputs were used and proper wave propagation occurs in the 3DEC preclosure seismic analyses. Figure 6-67 shows rockfall impacting a drip shield in the 3DEC dynamic simulation. Blocks are small and sporadic in most of the simulations.

Time histories of normal and shear stresses for fractures and rock bridges close to the opening were recorded during the seismic shaking in the 3DEC model. Figure 6-68 shows normal and shear stress time histories at the same selected fracture subcontacts as presented in Figure 6-40. The stress paths of the fracture subcontacts are plotted against the fracture Coulomb slip criterion and rock bridge strength criterion, as shown in Figure 6-69. The in situ normal and shear stress states along the fracture are identified as the orange squares for each subcontact in the figure. As with the postclosure level ground motions, the fracture containing subcontact $a$ yielded during seismic motions. However, the stress paths for rock bridges containing subcontacts $b$ and $c$ are under both the Coulomb slip criterion and the rock strength criterion when subjected to $1 \times 10^{-4}$ ground motion.

The percentages of the area of fracture slip/separation versus the total area of fracture planes under $1 \times 10^{-4}$ ground motion for the selected cases were calculated and presented in Table 6-18. Contrary to the postclosure earthquake results, only around 20 percent of total fractures have undergone shear slip or tensile separation when subjected to $1 \times 10^{-4}$ ground motions. Limited rock bridge damage is observed for this level of ground motion, as presented in Table 6-18.

The results of the 32 3DEC preclosure simulations are summarized in Table 6-19. Approximately half of the simulations predicted rockfall under seismic shaking. A total of 428 blocks were identified from the analyses.

The associated impact parameters due to rockfall on the drip shield are included in an output DTN of this document (DTN: MO0408MWDDDMIO.002, file nonlith rockfall characteristics in emplacement drifts with 1 e-4 gm.xls). Summary statistics for these parameters are provided in Table 6-20. The maximum rockfall block mass predicted for preclosure case is 2.72 metric tons with a median block size of 0.10 metric ton. Most of the estimated parameters are considerably smaller than predicted for postclosure cases. Figures 6-70 to 6-74 present the histograms and the cumulative frequency of occurrence for the five parameters. The relatively low impact 
velocities, as shown in Figure 6-71, indicate that block fall-out is mainly due to free fall. Differential acceleration or energy trapping to induce high ejection velocity is not observed.

The bounding impact velocity for preclosure rockfall is required for characterization of credible rockfalls of the preclosure period (BSC 2004 [DIRS 168508]). Calculation of the bounding velocity is based on the drop height of the fallen rock at one drift diameter above the drift crown. The approach is based on the observation of drift profiles at areas with rockfall in 3DEC simulations. Detailed description of the bounding calculation is provided in file, impact velocity bounding calculation for preclosure rockfall revl.mcd, listed in Appendix A (Table A-1). The bounding impact velocity is calculated to be $14 \mathrm{~m} / \mathrm{sec}$, which is approximately two times the maximum impact velocity listed in Table 6-20.

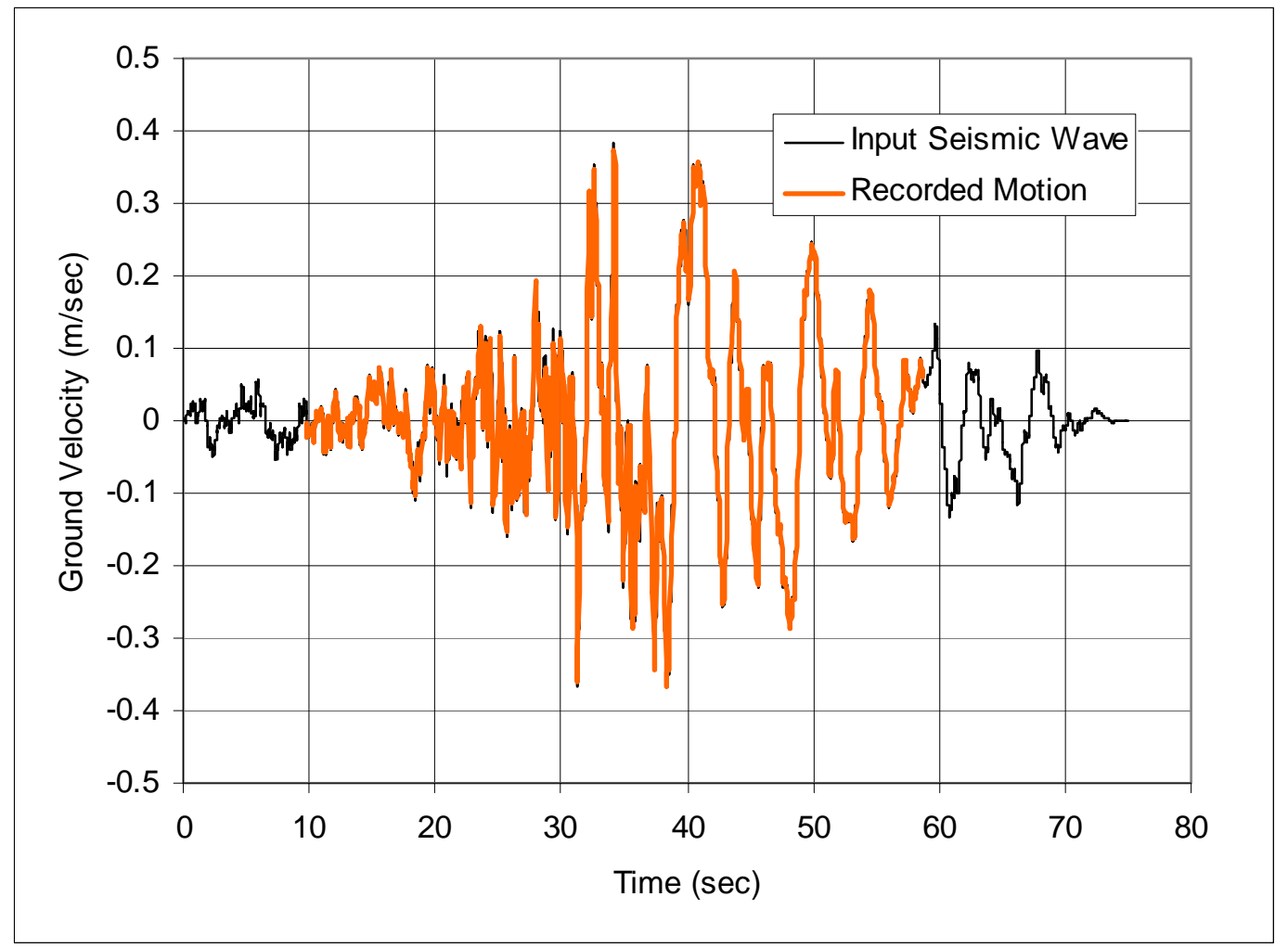

Figure 6-66. Comparison of Input Seismic Wave and Recorded Velocities in 3DEC Model for $1 \times 10^{-4}$ Annual Probability of Exceedance Ground Motion (H1) 


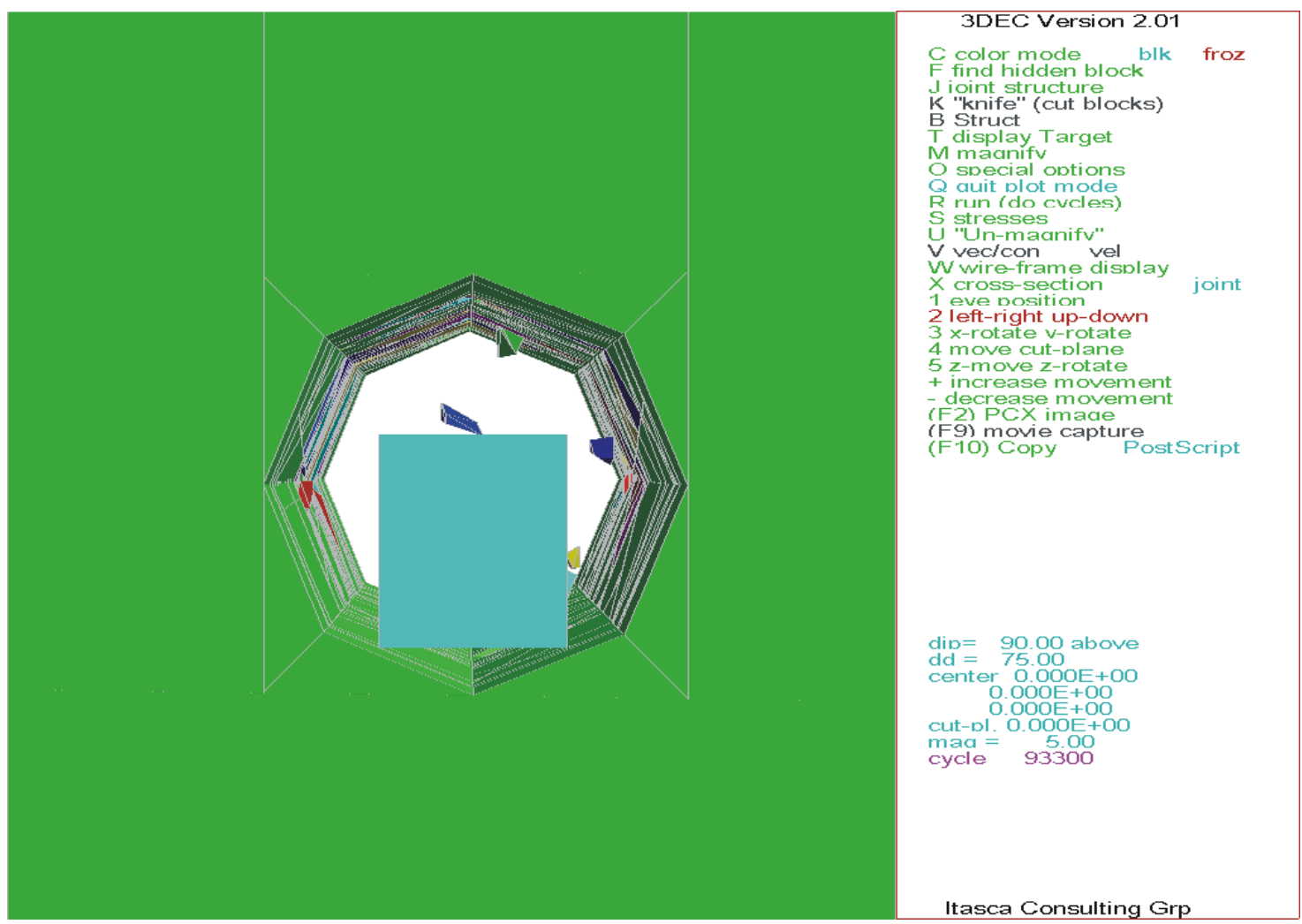

NOTE: The ground motion was recorded at the drip shield block during 3DEC simulation.

Figure 6-67. Illustration of the Simulation of Rockfall Impact to the Drip Shield (3DEC Simulation for $1 \times 10^{-4}$ Preclosure Run 21 , at $\mathrm{t}=32.5 \mathrm{sec}$ )

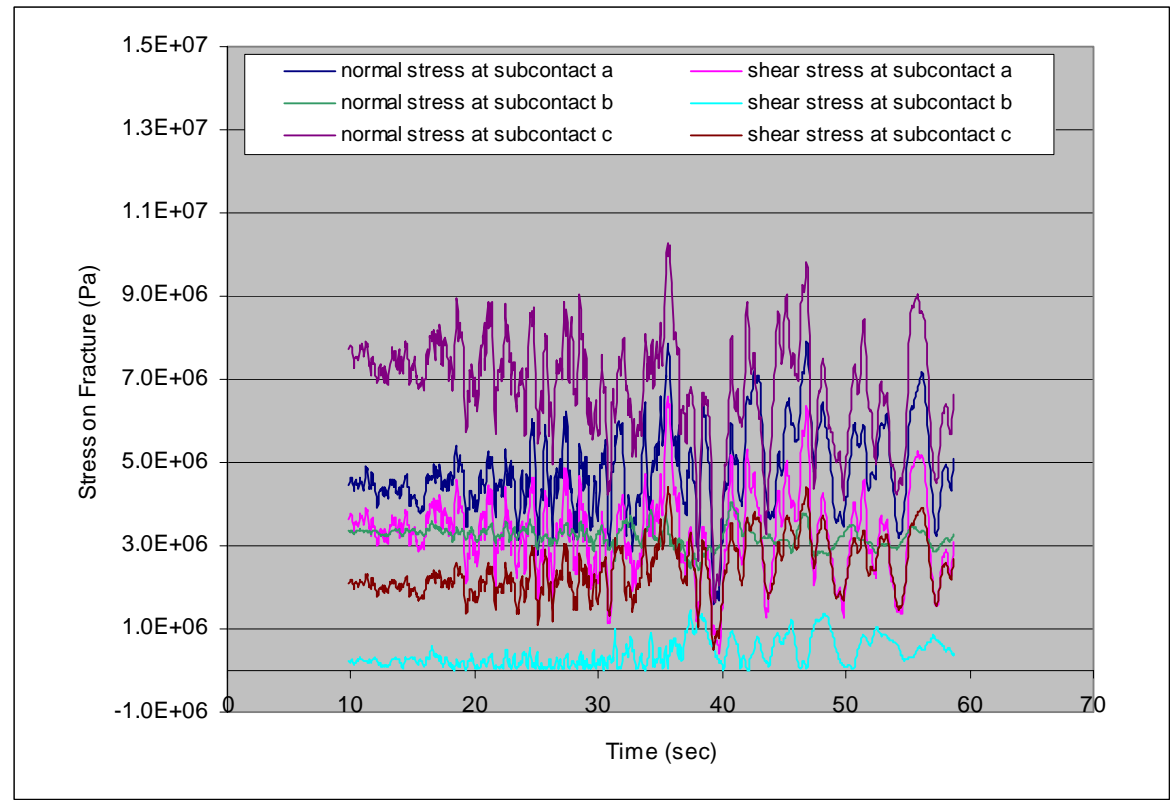

NOTE: Subcontact Information is presented in Figure 6-40.

Figure 6-68. Time Histories for Normal and Shear Stress at Selected Fracture Subcontact for $1 \times 10^{-4}$ Annual Probability of Exceedance Hazard (Simulation 16) 


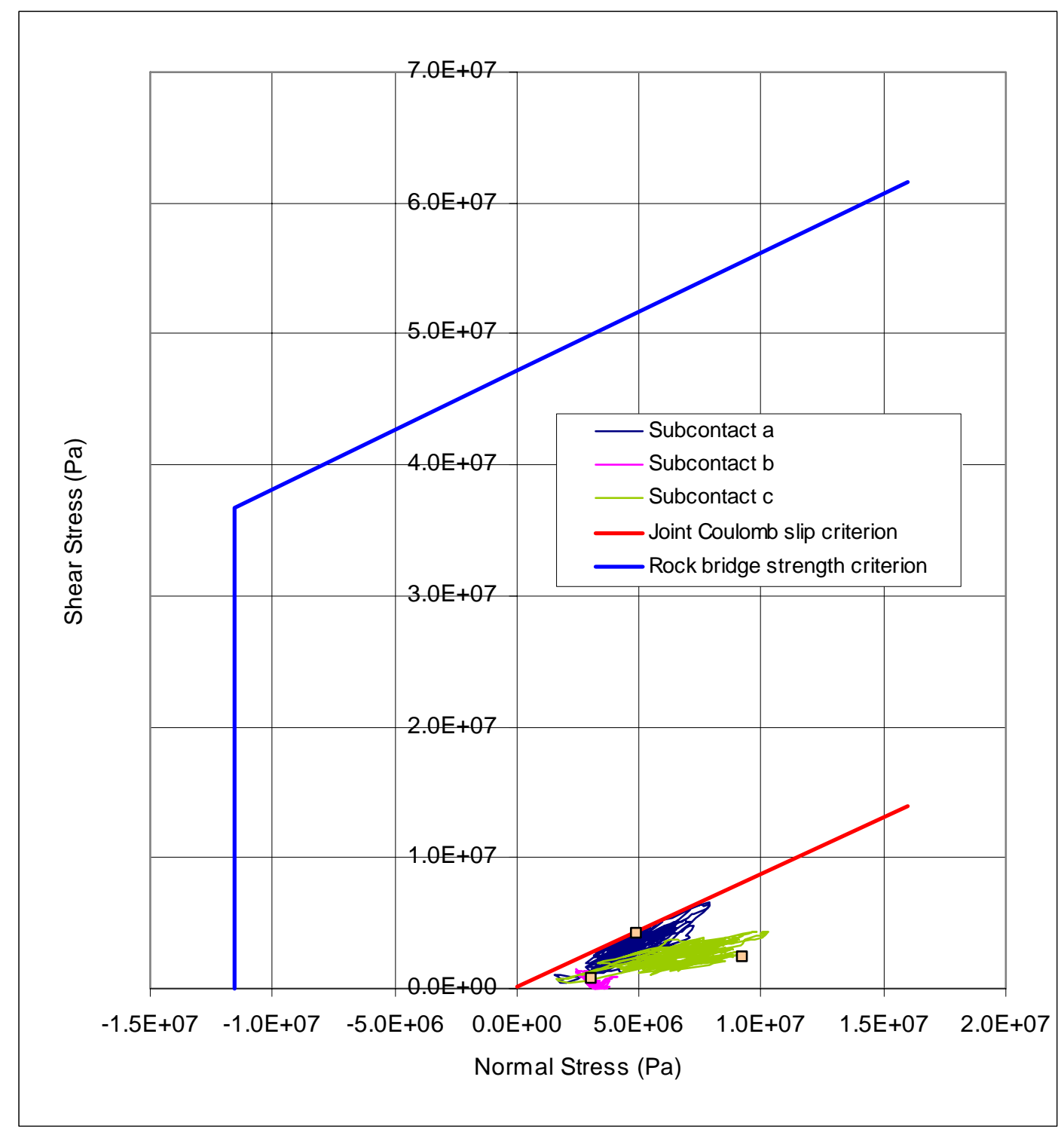

NOTE: Subcontact Information is presented in Figure 6-40.

Figure 6-69. Normal and Shear Stress Path at Selected Fracture Subcontact for $1 \times 10^{-4}$ Annual Probability of Exceedance Hazard (Simulation 16)

Table 6-18. Summary of Joint Slip/Separation and Bridge Damage for $1 \times 10^{-4}$ Ground Motions for Selected Cases

\begin{tabular}{|l|c|c|c|c|}
\hline \multicolumn{1}{|c|}{ Parameter } & Case 40 & Case 23 & Case 45 & Case 31 \\
\hline Total Joint Area $\left(\mathrm{m}^{2}\right)$ & 4251 & 3026 & 4737 & 3400 \\
\hline Total Bridge Area $\left(\mathrm{m}^{2}\right)$ & 885 & 550 & 1054 & 720 \\
\hline Percentage of Joint Slip/Separation & $26.68 \%$ & $17.68 \%$ & $26.73 \%$ & $14.35 \%$ \\
\hline Percentage of Bridge Damaged & $0.00 \%$ & $0.19 \%$ & $0.00 \%$ & $0.02 \%$ \\
\hline
\end{tabular}


Table 6-19. Summary of 3DEC Rockfall Prediction for $1 \times 10-4$ Annual Probability of Exceedance Hazard

\begin{tabular}{|c|c|}
\hline Parameter & Value \\
\hline Simulations Completed & 32 \\
\hline Total Number of Rockfall & 428 \\
\hline Total Volume of Rockfall $\left(\mathrm{m}^{3}\right)$ & 39.4 \\
\hline Total Length of Drift Simulated $(\mathrm{m})$ & 800 \\
\hline Number of Blocks per $\mathrm{km}$ & 535 \\
\hline Volume of Rockfall per $\mathrm{km}\left(\mathrm{m}^{3}\right)$ & 49.3 \\
\hline
\end{tabular}

Table 6-20. Statistical Summary of the Rockfall Impact Parameters, $1 \times 10^{-4}$ Annual Probability of Exceedance Hazard

\begin{tabular}{|l|c|c|c|c|c|}
\hline & $\begin{array}{c}\text { Block Mass } \\
\text { (tonnes) }\end{array}$ & $\begin{array}{c}\text { Relative Impact } \\
\text { Velocity (m/sec) }\end{array}$ & $\begin{array}{c}\text { Impact Angle } \\
\text { (degree) }\end{array}$ & $\begin{array}{c}\text { Impact Momentum } \\
\text { (kg·m/sec) }\end{array}$ & $\begin{array}{c}\text { Impact Energy } \\
\text { (Joules) }\end{array}$ \\
\hline Mean & 0.22 & 2.43 & 169.15 & 601 & 1022 \\
\hline Median & 0.10 & 2.25 & 141.29 & 213 & 232 \\
\hline Standard Deviation & 0.33 & 1.38 & 108.31 & 1092 & 2224 \\
\hline Skewness & 3.47 & 0.54 & 0.36 & 4 & 5 \\
\hline Range & 2.69 & 7.17 & 357.12 & 9273 & 20358 \\
\hline Minimum & 0.02 & 0.03 & 2.70 & 1 & 0 \\
\hline Maximum & 2.72 & 7.20 & 359.82 & 9274 & 20358 \\
\hline Sum & 95.00 & NA & NA & 257069 & 437350 \\
\hline
\end{tabular}

NA = Not Applicable

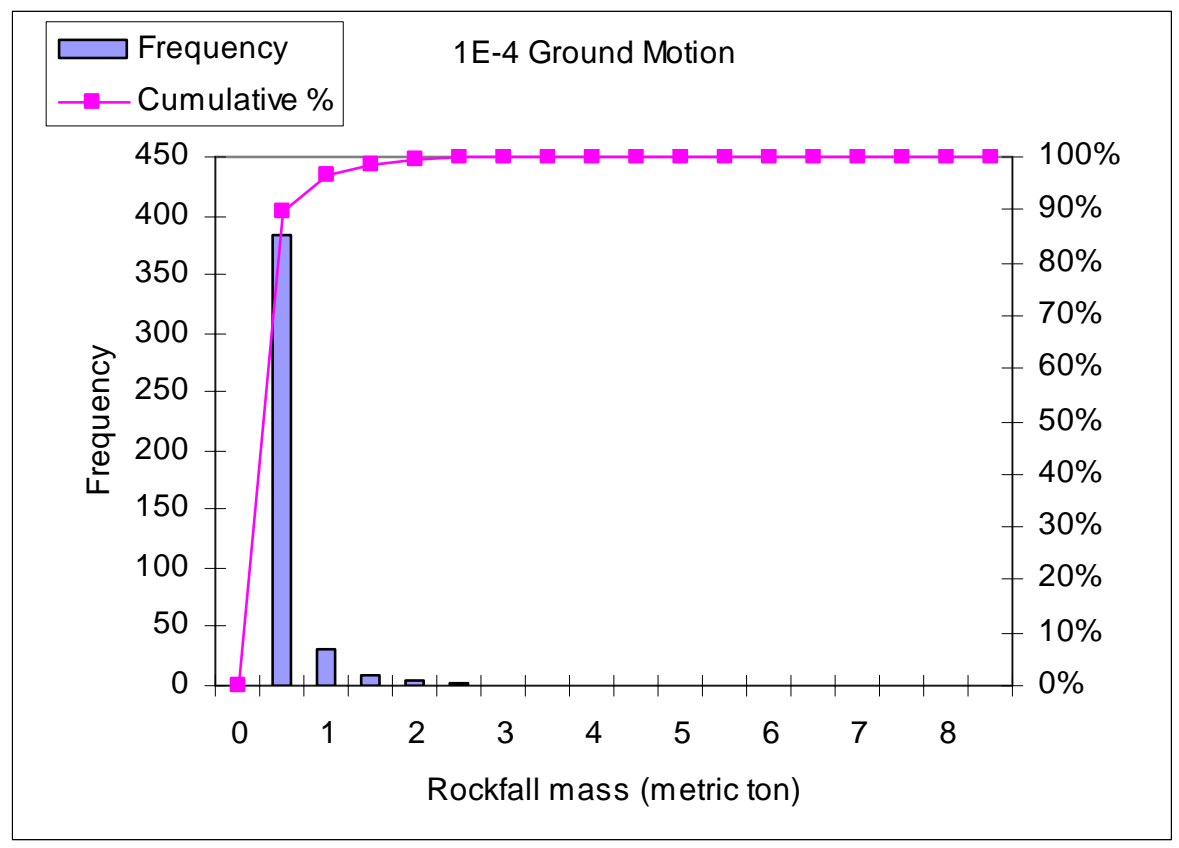

Figure 6-70. Histogram for Block Mass ( $1 \times 10^{-4}$ Annual Probability of Exceedance Hazard) 


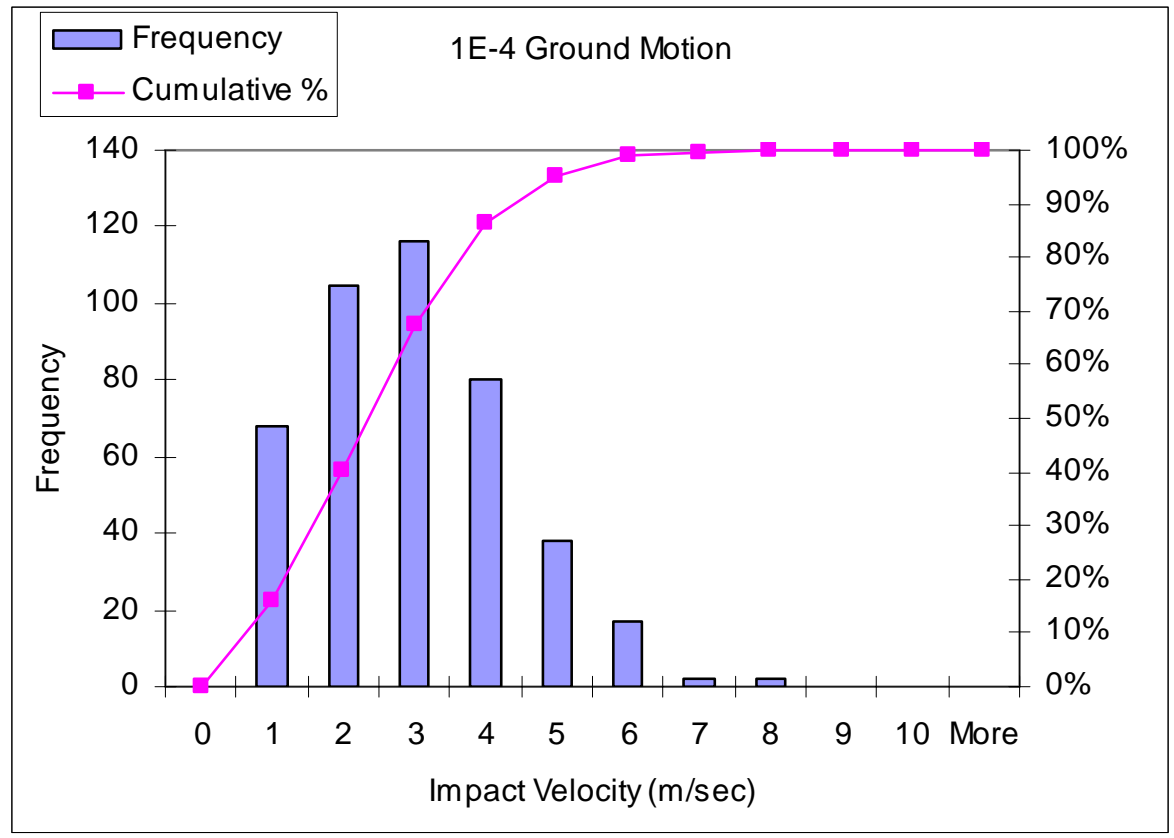

Figure 6-71. Histogram for Impact Velocity $\left(1 \times 10^{-4}\right.$ Annual Probability of Exceedance Hazard)

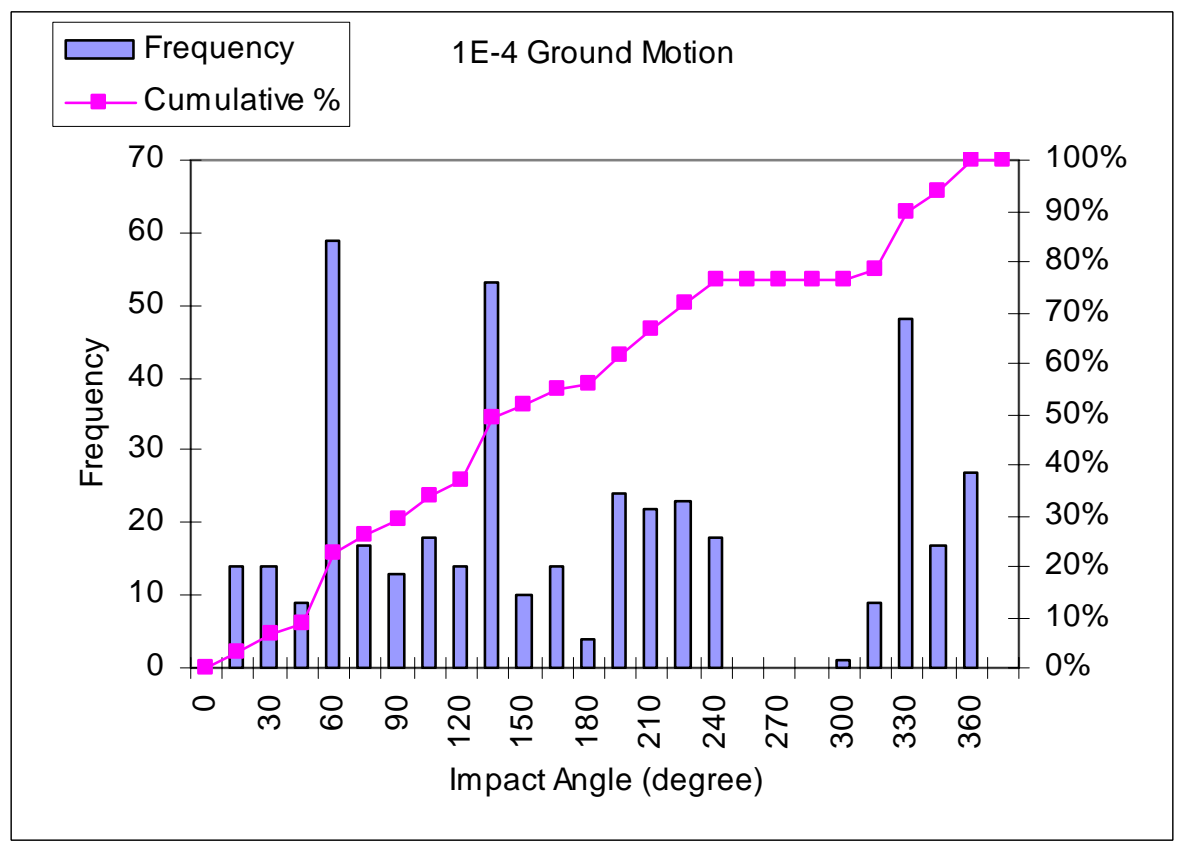

Figure 6-72. Histogram for Impact Angle ( $1 \times 10^{-4}$ Annual Probability of Exceedance Hazard) 


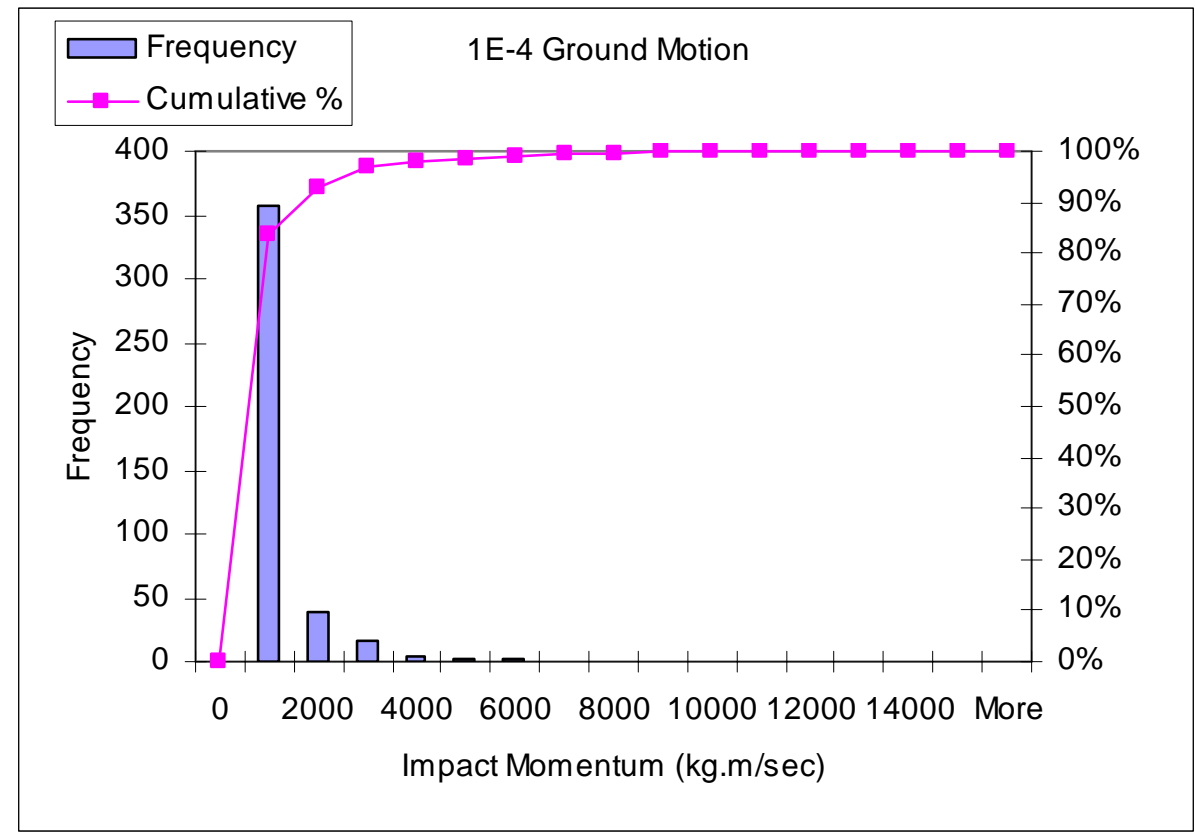

Figure 6-73. Histogram for Impact Momentum ( $1 \times 10^{-4}$ Annual Probability of Exceedance Hazard)

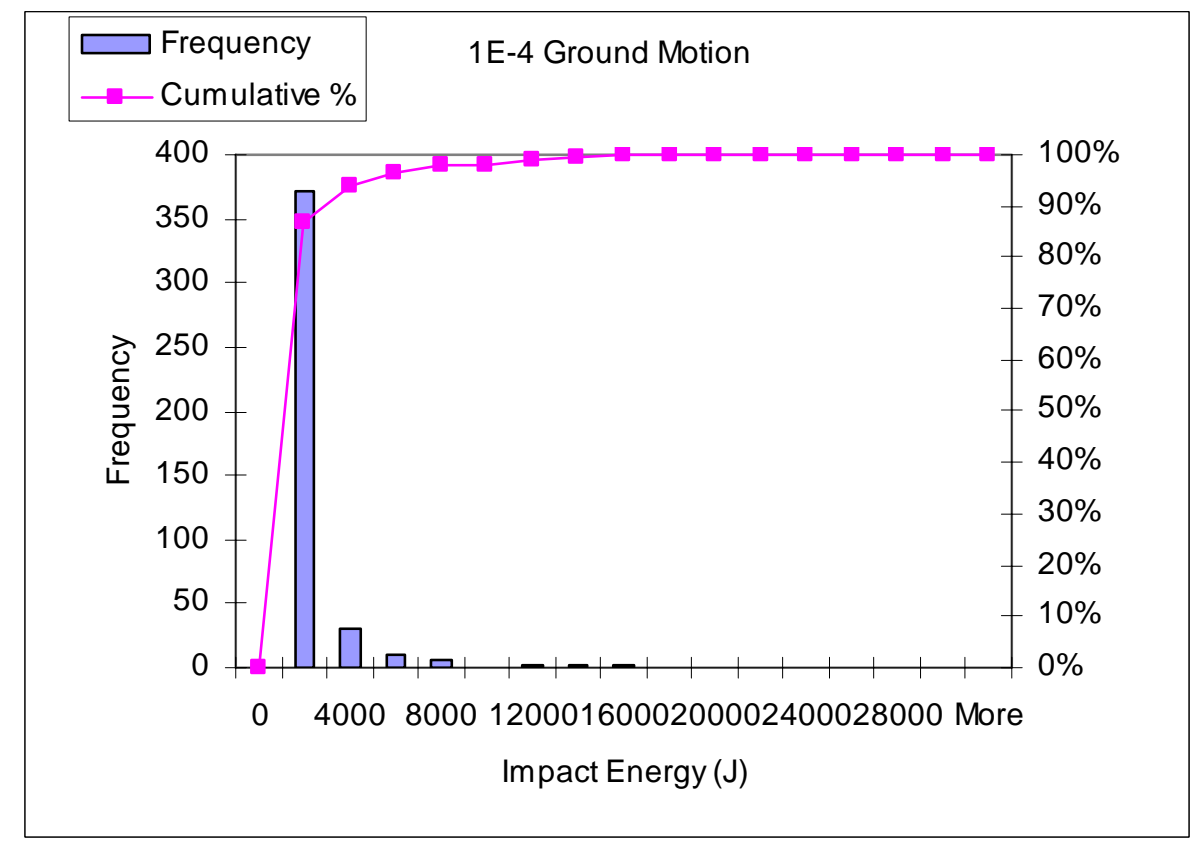

Figure 6-74. Histogram for Impact Energy $\left(1 \times 10^{-4}\right.$ Annual Probability of Exceedance Hazard) 


\subsubsection{Thermal Consideration in Nonlithophysal Units}

The extensive analysis of drift stability in nonlithophysal units discussed in Section 6.3.1.2 has been conducted considering an in situ stress state perturbed by the excavation of the emplacement drifts only. The effects of the thermally generated stresses in the rock mass surrounding the repository were not taken into account. This section provides the results for the analyses including thermal consideration.

3DEC was not used for the thermal-mechanical analysis of the drift in the nonlithophysal units because it has a simplistic model of heat conduction based on analytic solutions. The analytic solutions deal with complicated boundaries in an approximate way. Instead, the analysis for the nonlithophysal units was done as a three-step process. Variation of temperatures throughout the rock mass due to heating was calculated using NUFT (Section 6.2), which generated temperature fields for a number of times after waste emplacement. This implies that the mechanical models that use those temperature fields will be subjected to discrete temperature and, consequently, stress changes when moving from one temperature state to another. In reality, those changes are continuous. Because the mechanical models of drift stability are non-linear, their results are path-dependent. To ensure that the model results are not affected by discrete stress changes, the temperature increment was limited to around $5^{\circ} \mathrm{C}$. It was difficult to perform thermal stress calculations in the 3DEC model because it is limited to a certain region around the drift. Also, the model axes are oblique relative to the drift axis, making it very difficult to extend the model to the plane of symmetry between the drifts, which is necessary for stress calculation due to heating. Therefore, the stress changes due to the temperature changes, as calculated by NUFT and described in Section 6.2, were calculated using the continuum code FLAC. In the next step, elastic stress states are imported from FLAC into 3DEC in a sequential manner. For each elastic stress change due to temperature change, 3DEC is first run elastically to equilibrium (all joints were elastic). Subsequently, the finite strength was assigned to the joints, and the new equilibrium was determined.

Thermal-mechanical analysis was conducted for two sets of thermal rock mass properties (discussed in Section 6.2):

- Base case, using the mean values of thermal conductivity and specific heat

- Thermal sensitivity case, using the values for thermal conductivity and specific heat one standard deviation smaller than the mean.

The values for the sensitivity case thermal properties are provided in Section 6.2.

The fracture patterns included for thermal-mechanical analysis were selected based on the rockfall results from seismic analyses of $1 \times 10^{-5}$ annual probability of exceedance. Three fracture patterns, corresponding to the cases with most rockfall (Case 38 with Fracture Pattern 29), the median rockfall (Case 45 with Fracture Pattern 39), and the least rockfall (Case 63 with Fracture Pattern 96), were selected. The results for these fracture patterns with other levels of ground motion also indicate the selected patterns are adequate to represent the range of rockfall. 
Rockfall induced by thermal loading are found to be minor. Tables 6-21 and 6-22 present the rockfall predictions considering only thermal loading for the thermal base case and sensitivity case respectively. The results are presented for the beginning of heating ( 1 year), at the peak of temperature (80 years), and at the end of the regulatory period (10,000 years). The block size for rockfall induced by thermal effect is small with a mean size less than 0.2 metric ton. The impact of thermal properties on rockfall is insignificant considering the close amount of rockfall predicted for the base case and sensitivity case. The stress paths (shear stress versus normal stress) on the fractures around the drift (in the wall and the roof) for Case 63 with Fracture Pattern 96 considering the base case thermal properties, are shown in Figures 6-75 and 6-76. Stress paths at similar locations for other cases considered in the thermal-mechanical analyses have also been generated and reviewed. For most of the points (particularly in the wall), the stress paths move away from the slip surface, indicating increasing block stability. The analysis is carried out considering the blocks to be elastic. To demonstrate that heating will not induce stress levels inside the blocks sufficient to cause damage, stress paths from the linearly elastic model (for nonlithophysal rock stiffness) are shown in Figures 6-77 and 6-78 relative to the Mohr-Coulomb yield surface (using an unconfined compressive strength of $70 \mathrm{MPa}$ and a $40^{\circ}$ friction angle). The unconfined compressive strength of $70 \mathrm{MPa}$ is the recommended rock mass strength value presented in Figure E-22. The friction angle of $40^{\circ}$ is a conservative estimate based on the range of rock mass friction angle reported in Subsurface Geotechnical Report (BSC 2003 DIRS [166660], Table 8-41). In both the wall and the roof, thermally induced stress variations are well within the elastic region. The approach of linear block behavior during thermal loading is justified. Stress paths for Case 63 considering the thermal properties one standard deviation smaller than the mean, are presented in Figures 6-79 and 6-80. The paths are similar to the base case results presented in Figures 6-75 and 6-76 with normal and shear stresses slightly magnified. The effect of seismic shaking, in addition to thermal loading, is discussed in Section 6.3.1.4.

Table 6-21. Rockfall in Nonlithophysal Rock Due to Heating, Base Case of Thermal Properties

\begin{tabular}{|c|c|c|c|c|c|c|}
\hline \multirow{2}{*}{ Case } & \multicolumn{2}{|c|}{$\mathbf{y r}$} & \multicolumn{2}{c|}{$\mathbf{8 0} \mathbf{y r}$} & \multicolumn{2}{c|}{$\mathbf{1 0 , 0 0 0}$ yr } \\
\cline { 2 - 7 } & $\begin{array}{c}\text { Number of } \\
\text { Rockfall }\end{array}$ & $\begin{array}{c}\text { Rockfall } \\
\text { Volume }\left(\mathbf{m}^{\mathbf{3}}\right)\end{array}$ & $\begin{array}{c}\text { Number of } \\
\text { Rockfall }\end{array}$ & $\begin{array}{c}\text { Rockfall } \\
\text { Volume }\left(\mathbf{m}^{\mathbf{3}}\right)\end{array}$ & $\begin{array}{c}\text { Number of } \\
\text { Rockfall }\end{array}$ & $\begin{array}{c}\text { Rockfall } \\
\text { Volume }\left(\mathbf{m}^{3}\right)\end{array}$ \\
\hline 38 & 15 & 0.50 & 28 & 0.88 & 28 & 0.88 \\
\hline 45 & 0 & 0.00 & 20 & 0.79 & 25 & 0.80 \\
\hline 63 & 1 & 0.09 & 1 & 0.09 & 3 & 0.13 \\
\hline
\end{tabular}

Table 6-22. Rockfall in Nonlithophysal Rock Due to Heating, Sensitivity Case of Thermal Properties

\begin{tabular}{|c|c|c|c|c|c|c|}
\hline \multirow{2}{*}{ Case } & \multicolumn{2}{|c|}{$\mathbf{~ y r}$} & \multicolumn{2}{c|}{$\mathbf{8 0} \mathbf{~ r r}$} & \multicolumn{2}{c|}{$\mathbf{1 0 , 0 0 0} \mathbf{~ y r}$} \\
\cline { 2 - 7 } & $\begin{array}{c}\text { Number of } \\
\text { Rockfall }\end{array}$ & $\begin{array}{c}\text { Rockfall } \\
\text { Volume }\left(\mathbf{m}^{\mathbf{3}}\right)\end{array}$ & $\begin{array}{c}\text { Number of } \\
\text { Rockfall }\end{array}$ & $\begin{array}{c}\text { Rockfall } \\
\text { Volume }\left(\mathbf{m}^{\mathbf{3}}\right)\end{array}$ & $\begin{array}{c}\text { Number of } \\
\text { Rockfall }\end{array}$ & $\begin{array}{c}\text { Rockfall } \\
\text { Volume }\left(\mathbf{m}^{3}\right)\end{array}$ \\
\hline 38 & 11 & 0.40 & 34 & 2.49 & 35 & 2.50 \\
\hline 45 & 0 & 0.00 & 18 & 0.60 & 20 & 0.62 \\
\hline 63 & 2 & 0.10 & 2 & 0.10 & 3 & 0.13 \\
\hline
\end{tabular}




\subsubsection{Combined Seismic and Thermal Effects in Nonlithophysal Units}

The effect of the thermal stresses on seismic drift stability depends on how the stress state, throughout the rock mass and on the pre-existing fractures, changes in the stress space relative to the failure surface. If the stress state (particularly in the vicinity of the drifts) predominantly moves away from the failure surface due to stress changes caused by heating, the rock mass becomes more stable and resistant to ground shaking. However, if the stress state predominantly moves toward, or reaches, the yield surface (i.e., rock mass yields during the heating), there will be more rockfall caused by ground motion. It is difficult to determine a single index or condition that characterizes this effect in an integrated way for the entire rock mass.

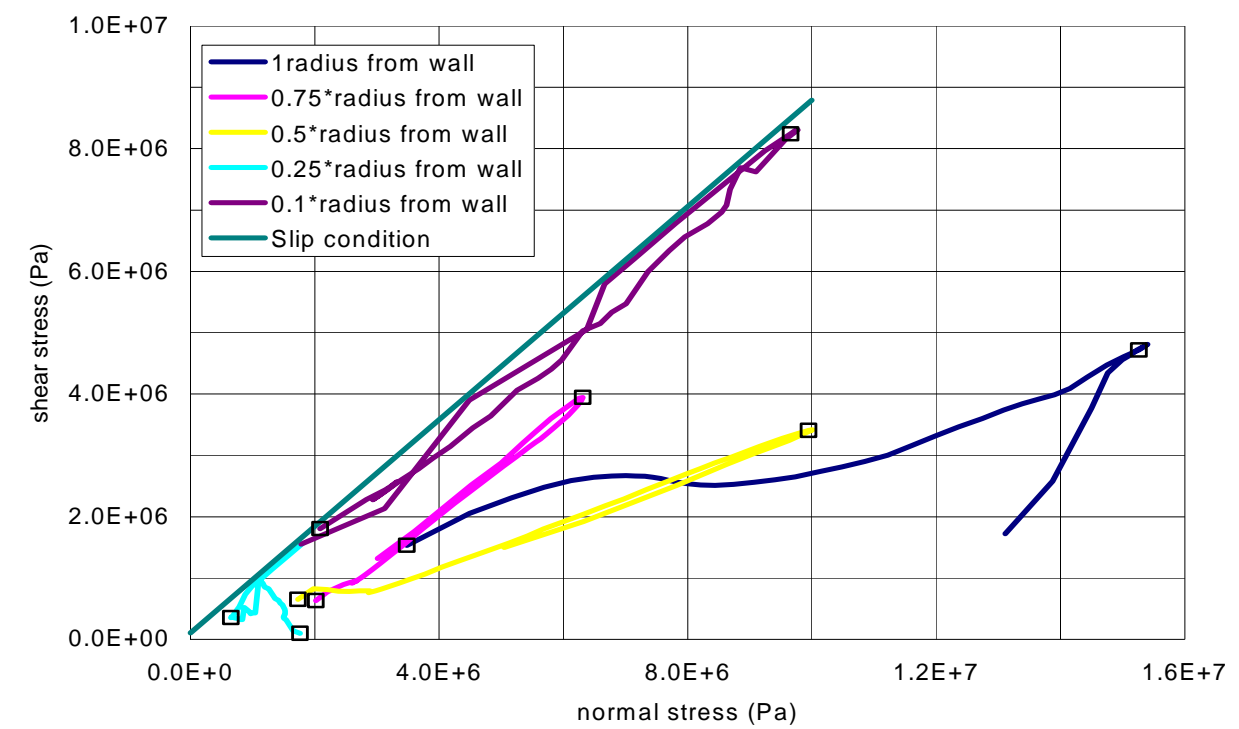

Figure 6-75. Stress Paths at Selected Fractures in the Drift Wall: Case 63 with Fracture Pattern 96

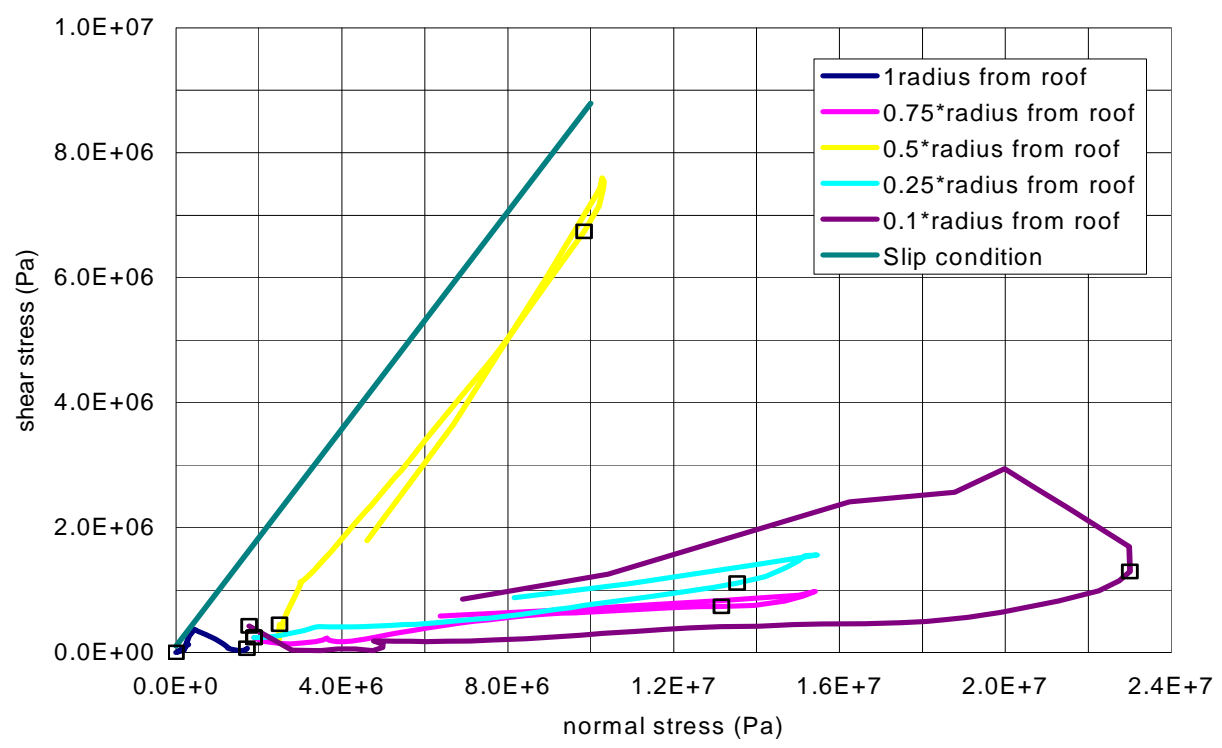

Figure 6-76. Stress Paths at Selected Fractures in the Drift Roof: Case 63 with Fracture Pattern 96 


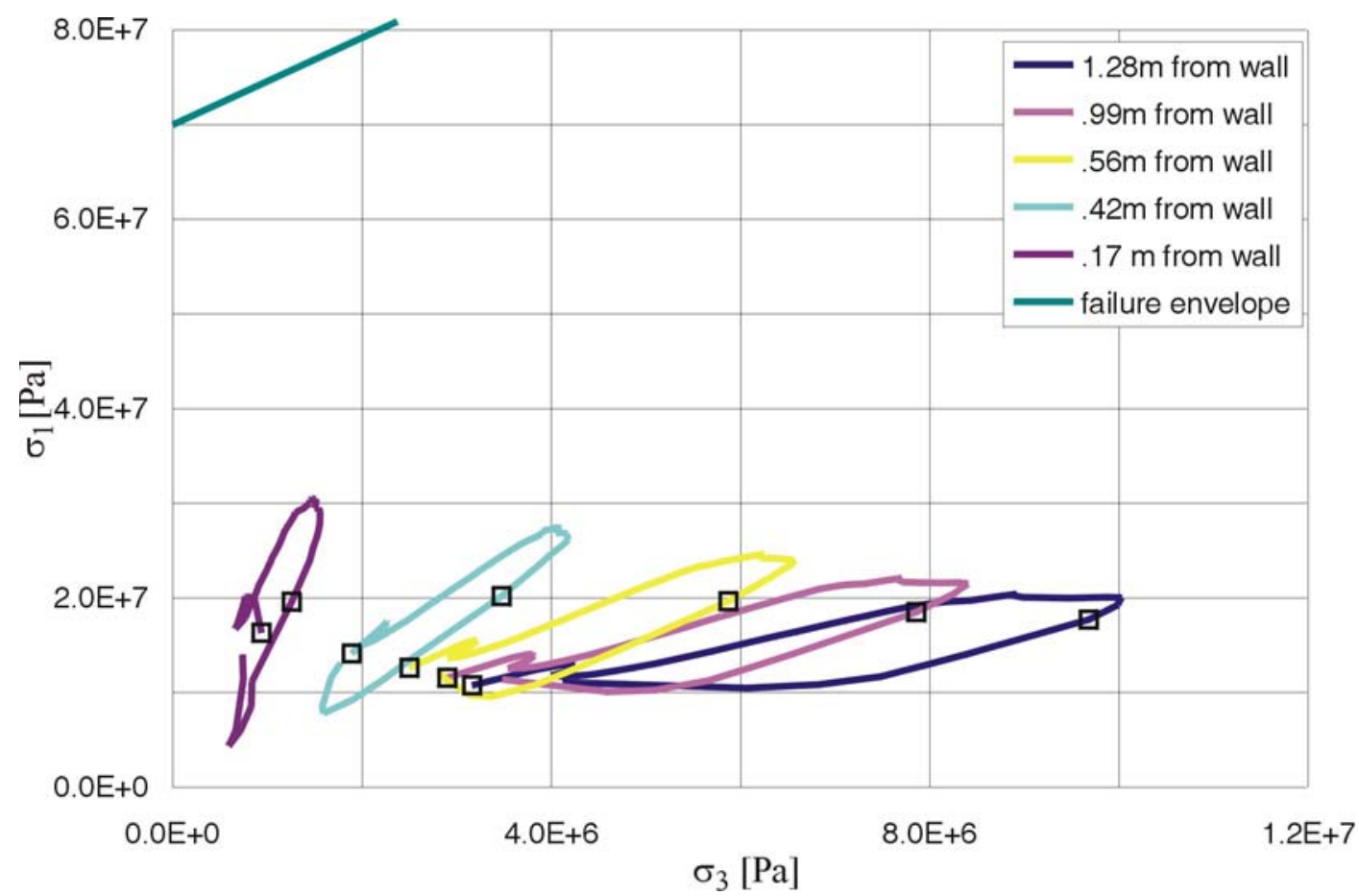

Figure 6-77. Stress Paths in the Drift Wall: Elastic Model

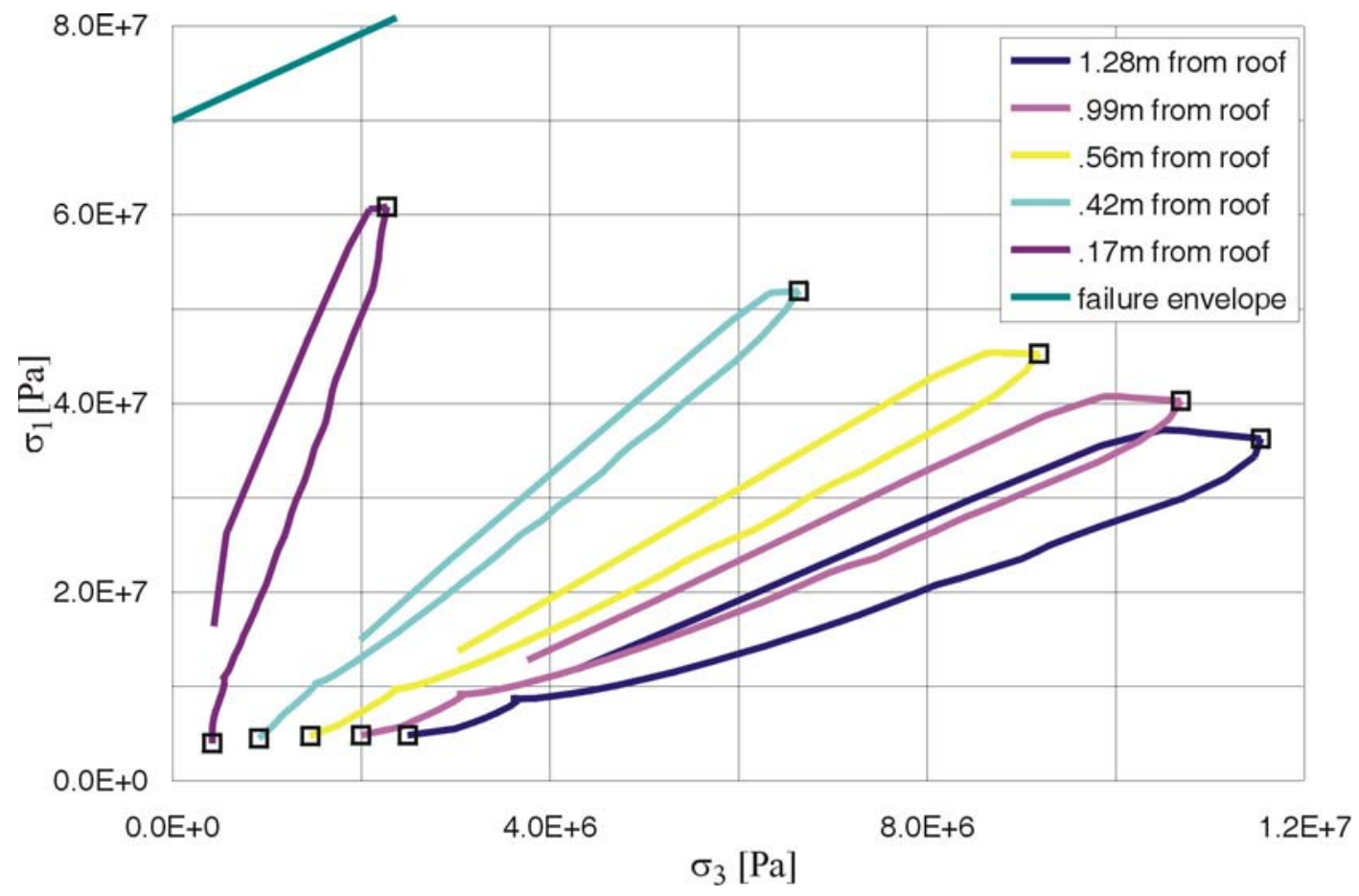

Figure 6-78. Stress Paths in the Drift Roof: Elastic Model 
Temperatures around the emplacement drift will increase for a certain period of time after emplacement of the waste; however, as a result of decay of the released heat, the temperatures will also decrease. Consequently, the stress state around the repository during the regulatory period will be transient. A simplified approach was adopted in which rockfall caused by ground shaking was estimated for the "most critical" stress state during the regulatory period. Stress paths at a number of locations on the joints surrounding the drift were recorded during the temperature changes. The critical state (or time after waste emplacement) was determined by qualitative inspection of those stress paths. The model in the most critical state during the regulatory period was then subjected to a ground motion corresponding to $1 \times 10^{-5}$ probability of annual occurrence.

The effect of seismic shaking combined with thermal-mechanical effects was considered for the three cases presented in Section 6.3.1.3. Stress paths at five points on fractures in the wall and the roof of the drift (shown in Figures 6-75 and 6-76) move away, in general, from the yield. The critical state seems to be the in situ stress state (marked with a square at the beginning of each curve) for which extensive seismic stability analysis had been conducted. Another state of interest was the other extreme point on the stress path curves (also marked with a square), which, for Case 63 represented in Figures 6-75 and 6-76, corresponds to 80 years after waste emplacement. Comparison of rockfall with seismic shaking at the in situ stress state and at 80 years after waste emplacement is provided in Table 6-23. It is apparent that heating significantly reduces the amount of rockfall.

Comparison of rockfall with seismic shaking at the in situ stress state and at 80 years after waste emplacement for the thermal sensitivity case is provided in Table 6-24. These results are consistent with the base case prediction presented in Table 6-23.

The results of rockfall thermal-mechanical and seismic analyses indicate that the condition with seismic shaking at in situ state (the cases considered in Section 6.3.1.2) is conservative since a higher number of unstable blocks and a larger amount of rockfall are predicted for the in situ state. Temperatures throughout the regulatory period will be higher than in situ temperatures.

Table 6-23. Rockfall in Nonlithophysal Rock Due to $10^{-5}$ Ground Motion Combined with ThermalMechanical Effects, Base Case of Thermal Properties

\begin{tabular}{|c|c|c|c|c|c|}
\hline \multirow{2}{*}{ Case } & \multirow{2}{*}{$\begin{array}{c}\text { Ground } \\
\text { Motion }\end{array}$} & \multicolumn{2}{|c|}{ Time of Earthquake at $\mathbf{0} \mathbf{~ y r}$} & \multicolumn{2}{c|}{ Time of Earthquake at $\mathbf{8 0}$ yr } \\
\cline { 3 - 6 } & Number of Rockfall & $\begin{array}{c}\text { Rockfall Volume } \\
\left(\mathbf{m}^{\mathbf{3}}\right)\end{array}$ & $\begin{array}{c}\text { Rumber of Rockfall } \\
\left(\mathbf{m}^{\mathbf{3}}\right)\end{array}$ \\
\hline 38 & 3 & 173 & 42.03 & 56 & 13.59 \\
\hline 45 & 10 & 14 & 2.49 & 5 & 1.07 \\
\hline 63 & 11 & 0 & 0.00 & 2 & 5.93 \\
\hline
\end{tabular}


Table 6-24. Rockfall in Nonlithophysal Rock Due to $10^{-5}$ Ground Motion Combined with ThermalMechanical Effects, Sensitivity Case of Thermal Properties

\begin{tabular}{|c|c|c|c|c|c|}
\hline \multirow{2}{*}{ Case } & \multirow{2}{*}{$\begin{array}{c}\text { Ground } \\
\text { Motion }\end{array}$} & \multicolumn{2}{|c|}{ Time of Earthquake at $\mathbf{0} \mathbf{~ y r}$} & \multicolumn{2}{c|}{ Time of Earthquake at $8 \mathbf{~ y r}$} \\
\cline { 3 - 6 } & Number of Rockfall & $\begin{array}{c}\text { Rockfall Volume } \\
\left(\mathbf{m}^{\mathbf{3}}\right)\end{array}$ & Number of Rockfall & $\begin{array}{c}\text { Rockfall Volume } \\
\left(\mathbf{m}^{\mathbf{3}}\right)\end{array}$ \\
\hline 38 & 3 & 173 & 42.03 & 43 & 11.41 \\
\hline 45 & 10 & 14 & 2.49 & 6 & 1.63 \\
\hline 63 & 11 & 0 & 0.00 & 3 & 7.93 \\
\hline
\end{tabular}

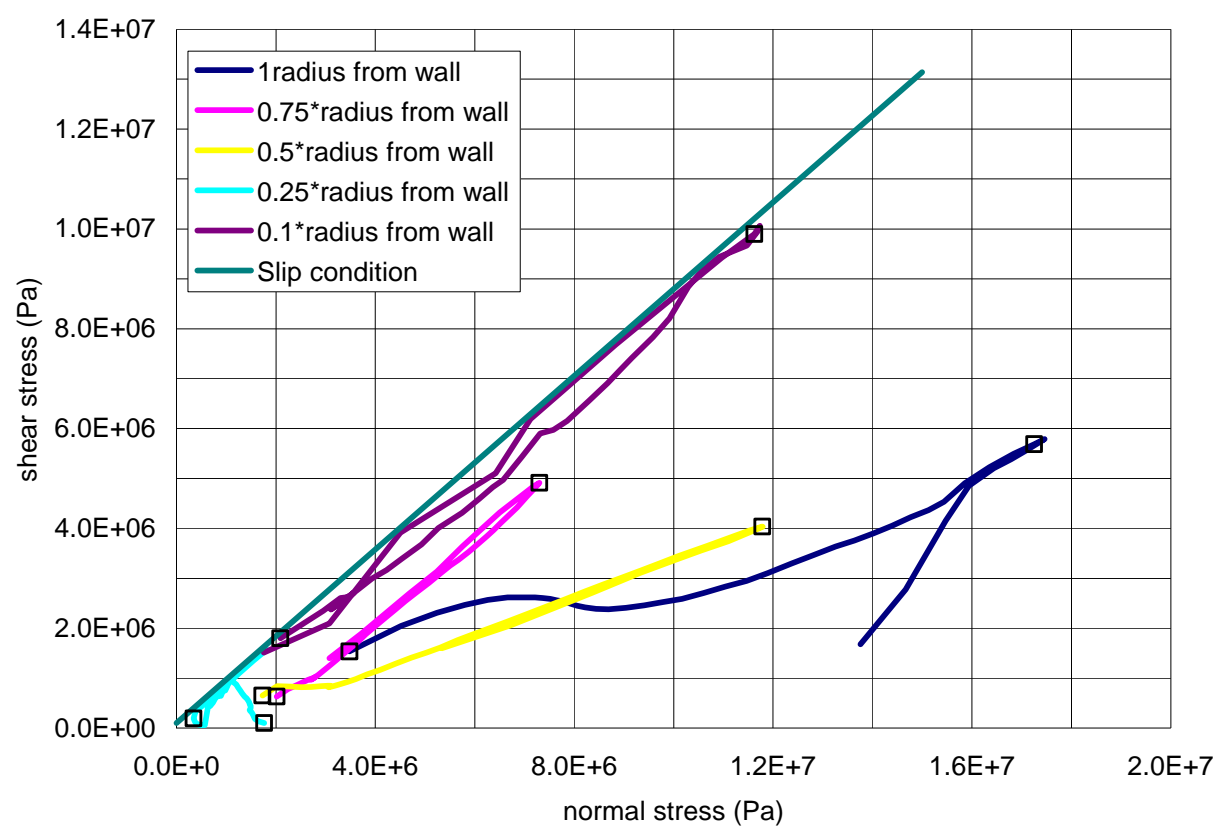

Figure 6-79. Stress Paths at Selected Fractures in the Drift Wall: Case 63 with Fracture Pattern 96, Thermal Sensitivity Case 


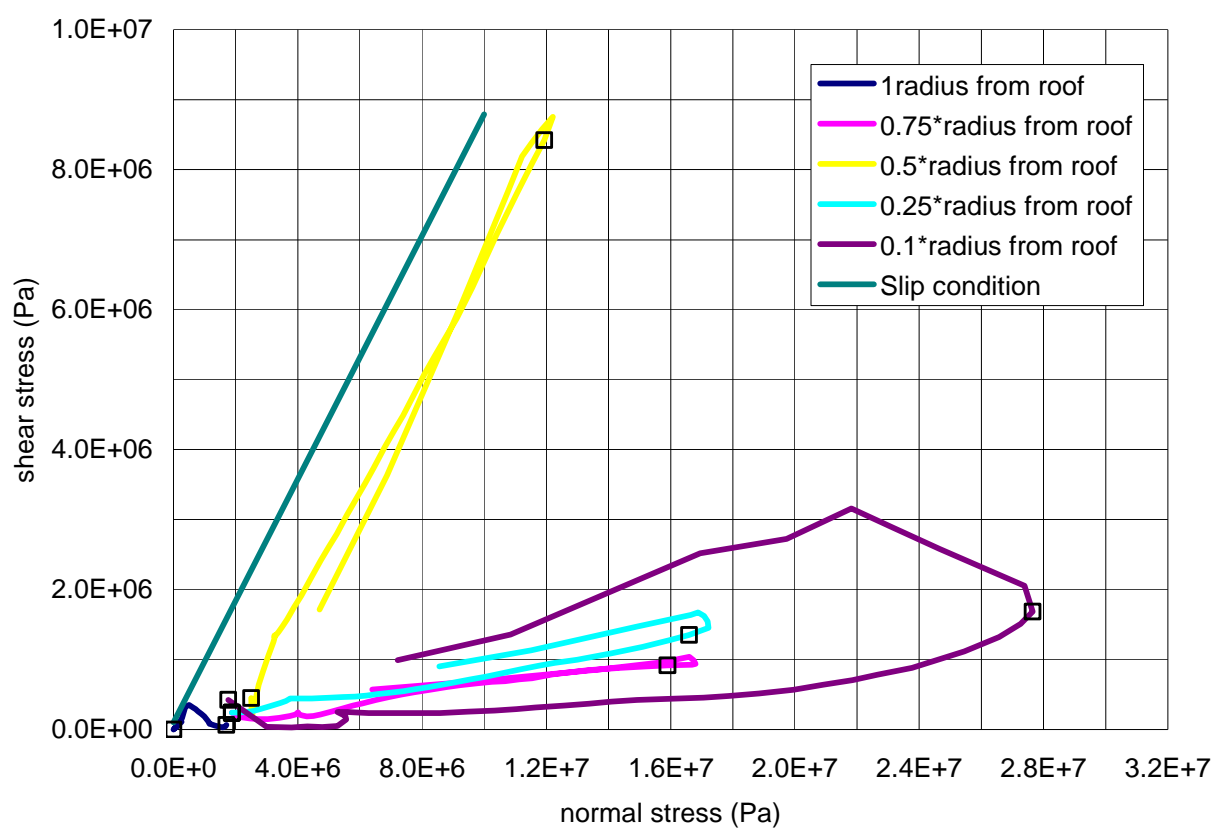

Figure 6-80. Stress Paths at Selected Fractures in the Drift Roof: Case 63 with Fracture Pattern 96, Thermal Sensitivity Case

\subsubsection{Rock Joint Degradation in Nonlithophysal Units}

Degradation Due to Time-Dependent Alteration of Rock Matrix or Joint Filling Materials from Postclosure Thermal and Moisture Conditions-The rock mass surrounding the excavations may undergo over-stressing from thermal heating and/or time-dependent damage associated with static fatigue resulting from stress corrosion mechanisms. Another likely long-term effect includes the increasing amounts of moisture/air induced weathering along the joints close to the tunnels. This damaged and/or weathered material may result in block fallout in the nonlithophysal units.

The time-to-failure for intact nonlithophysal rock blocks shows significantly less time dependency than for the lithophysal rock described in Appendix S (see Figure S-17). Therefore, insignificant time-related fracture growth is expected in the intact rock blocks. However, the potential exists for time-dependent yield of roughness (asperities) on fracture surfaces subjected to long-term shear stress. Time-related degradation of tunnels due to wetting and drying cycles is an important factor for drift stability in some rock types. These rock types are typically those in which highly-altered rock, or rock with significant swelling clay along fracture planes occurs. In the case of the host repository horizon at Yucca Mountain, these issues are not particularly important. Clay is not a common mineral in the crystallized rocks of the repository host horizon, nor are clay minerals a volumetrically significant fracture-coating material. Data to support this observation are described below.

A number of detailed geological studies have been conducted at the Yucca Mountain site to define the basic mineralogy of the rocks, and the petrologic and geochemical processes that 
occurred during the formation of the Topopah Spring Tuff, and have continued from that time. These studies have included a detailed description of the mineralogy of the repository host horizon from samples and observations developed from surface-based core holes through the repository block, as well as from the ESF and ECRB Cross-Drift. From the standpoint of mechanical degradation of the rock mass, these studies show:

- The Topopah Spring Tuff is largely composed of fine-grained feldspars and silicate-based rocks that formed during the cooling of the rock mass shortly after deposition. Clay-forming minerals were typically not formed during the petrogenesis of the repository host horizon.

- Clays typically do not form significant fracture-fill materials in the crystallized rocks of the Topopah Spring Tuff.

- $\quad$ There are limitations on the environmental conditions needed to form clays and indicate the minimum likelihood that clays might form along fractures in the near field of a repository. Therefore, mineral alteration during the postclosure is considered negligible.

The following discussion summarizes the data obtained from a number of studies that support the above points.

1. Mineralization in the Repository Host Horizon-The Topopah Spring Tuff is a compositionally zoned pyroclastic flow deposit. High-silica rhyolite forms approximately the lower two-thirds of the section and trachyte (or quartz latite) in the upper one-third of the section. The crystallized rocks that formed during the cooling of the deposit consist primarily of very fine-grained intergrowths of feldspar and silica polymorphs of quartz and cristobalite. These minerals typically crystallized from volcanic glass at temperatures of approximately $800^{\circ} \mathrm{C}$. X-ray diffraction analyses of 444 core samples from 13 boreholes that penetrate $3.5 \mathrm{~km}$ of the crystallized Topopah Springs Tuff indicate that there are different ratios of feldspar and silica polymorphs in the crystal-rich rocks (DTNs LADB831321AN98.002 [DIRS 109003], LADV831321AQ97.001 [DIRS 107142], LADV831321AQ99.001 [DIRS 109044], LA000000000086.002 [DIRS 107144]). In the crystal-rich member, 93 samples have mean percentages of feldspar (69.1percent), quartz (2.4 percent), cristobalite (13.3 percent), and tridymite (11.2 per cent), and in the crystal-poor member, 351 samples have mean percentages of feldspar (55.7 per cent), quartz (15.8 per cent), cristobalite (19.3 percent), and tridymite (5.1 percent). The total of the percentages cited for these two members do not sum to 100 percent because there are minor amounts of other minerals in many of these rocks. Smectite values vary from trace amounts to 15 percent with a mean value of 3.1 percent. These compositions of rocks form the walls of fractures where the minerals are very fine-grained and form various textures; however, the minerals are relatively uniformly distributed at scales of millimeters to centimeters. These data indicate that concentrations of smectite minerals along fractures do not occur as a result of crystallization during cooling.

2. Clay Infillings Are Rarely Observed Along Fractures in the ESF and ECRB Cross-Drift-Detailed line survey data collected in the ECRB Cross-Drift indicate that 
of the 1,816 fractures in the 2.66-km long tunnel, only 10 (or 0.4 per cent) of the discontinuities such as fractures, shears, and faults have some amount of clay (DTNs GS990408314224.001 [DIRS 108396], GS990408314224.002 [DIRS 105625]). These 10 discontinuities are filled (or partially filled) with clay and "broken or crushed rock or sand". Detailed studies of the clast textures, structures, and architectures of the "broken or crushed rock or sand" fill materials have not been completed, but general observations indicate many of these features do not show evidence of mechanical degradation and shear. Buesch and Lung (2003 [DIRS 170297]) describe volcaniclastic tuffaceous sandstone and claystone as fracture-fill material in the crystallized rocks of the Tiva Canyon and Topopah Spring Tuff. They proposed that volcanic glass particles settled by gravity along open fractures from the superjacent nonwelded bedded tuffs, and the clay formed in place (possibly millions of years later) by water seeping along the fractures and reacting with the glass. This mechanism is entirely consistent with occurrences of clays in the ECRB Cross-Drift detailed line survey data. Detailed line survey data from the crystallized Topopah Spring Tuff in the ESF Main Drift indicate that only 4 per cent of the fractures recorded have clay as filling material.

The Integrated Issue Resolution Status Report of NRC (NRC 2002 [DIRS 159538], Section 2.1.7.3.3.2, pp. 2.1.7-19 and 2.1.7-20) specifically discussed the work by Carlos et al. (1995 [DIRS 101326]) in regard to fracture fillings. Carlos et al. (1995 DIRS 101326]) described the qualitative amount of materials in the fractures only, but typically they did not describe the amount or thickness of the mineral coatings. For example, if a mineral such as clay (smectite) is listed as "major abundance", then this means that greater than 20 percent of the minerals in the fractures, but the mineral coating might be less than 1-mm thick. Only for mordenite in the crystallized Topopah Spring Tuff did Carlos et al. (1995 DIRS 101326]) describe about 1 percent of the fractures with this mineral and the amount increased with depth to more than 20 percent (and more than 50 percent in some boreholes). The relevant point for this discussion is that selective fractures were sampled and the intention was not to quantify the relative proportion of fractures with specific minerals, nor to quantify the thickness or continuity of the mineral coatings. However, there is one detailed study of mineral coatings on fracture walls in core with descriptions of the percentages of the amount of mineral coatings and thickness of the coatings (DTN: LA9912SL831151.001 [DIRS 146447]). Borehole ESF-HD-TEMP-2 is a $60 \mathrm{~m}$ (200-ft) long, horizontal borehole in the Heated Drift Test, and the rocks are in the middle nonlithophysal (Tptpmn) zone of the Topopah Spring Tuff. Only fractures in two $1.3 \mathrm{~m}$ (4.3-ft) long segments of core were described [7.6 to $8.9 \mathrm{~m}$ (25.0 to $29.3 \mathrm{ft}$ ) and 18.9 to $20.3 \mathrm{~m}$ (62.15 to $66.45 \mathrm{ft}$ )]. Clay forms localized deposits on the fracture surfaces that typically are less than 5 percent of the fracture surface area with thickness typically about $0.1 \mathrm{~mm}$ and a few deposits as much as $0.5-\mathrm{mm}$ thick. These descriptions demonstrate that clay does not form continuous coatings on fracture walls and that the coats are very thin.

3. Alteration of Repository Host Rocks is Not Expected in the Repository Environment-Conditions such as temperature, chemistry of water, and amount of water needed for the alteration of feldspars in the crystallized host rock to form clay 
and other sheet silicate minerals (sericite) are not considered to have been present within the Topopah Spring Tuff since its formation. Sericite is a general term for very fine-grained sheet silicates (illites) that form with other alteration products in hydrothermal systems at temperatures near or above $400^{\circ} \mathrm{C}$, typically in acidic aqueous solutions (Jackson 1997 [DIRS 109119]). As pointed out by the predicted temperature conditions expected in the repository environment (e.g., Figure 6-25), these conditions are not anticipated in the near-field environment of the repository. Even in samples from the Drift Scale Test boreholes, the clays on fractures appeared to have been there prior to the test and were not affected by the experimental conditions.

In summary, these petrologic and empirical relations indicate that clays typically do not form significant fracture-fill materials in the crystallized rocks of the Topopah Spring Tuff. They also indicate that the expected repository environmental conditions are not conducive to formation of clays during the postclosure period. Therefore, the impact of geochemical alteration within the postclosure environment is expected to have a negligible impact on drift degradation processes.

3DEC Analysis for Time-Dependent Joint Degradation-Drift stability due to the effect of time-dependent rock joint strength degradation is assessed based on a conservative estimate of the reduction of joint cohesion and friction angle. The reduced joint strength parameters are estimated to be represented by the residual state (after joint shear) with joint cohesion reduced to 0 and the joint friction angle reduced to $30^{\circ}$. The reduced friction angle is a typical value for a smooth joint reported by Goodman (1980 [DIRS 101966], p. 158) and is consistent with the observation of the cooling joints from direct shear test results (Table E-5). Dilation angle is also conservatively presumed to be zero considering the asperities on fracture surfaces had been sheared off, resulting in greater rockfall. The degradated joint strength and dilatational properties were applied in $1 \times 10^{-5}$ seismic motion Cases 38, 45, and 63. These three cases cover the range of rockfall condition from the most rockfall to the least rockfall. The predicted number of rockfall and the total rockfall volume are presented in Table 6-25 with a comparison to the results of the base case. Approximately 30 to 40 percent rockfall increase is observed for the high rockfall case (Case 38), while the results were very similar for the median rockfall case (Case 45). The maximum block sizes are the same for the base case and the degraded joint case. As for the least rockfall case, limited rockfall is also observed even with degraded joints. In all, the degraded joint state results in higher rockfall prediction, but the amount of rockfall stays within the same order of magnitude as the base case.

Table 6-25. Predicted Rockfall for Degraded Joints with Comparison to the Base Case Results

\begin{tabular}{|c|c|c|c|c|c|c|}
\hline \multirow[b]{2}{*}{ Case } & \multicolumn{3}{|c|}{$\begin{array}{c}\text { Degradated State } \\
\left(\text { cohesion }=0, \text { friction angle }=30^{\circ}, \text { dilation }\right. \\
\left.\text { angle }=0^{\circ}\right)\end{array}$} & \multicolumn{3}{|c|}{ 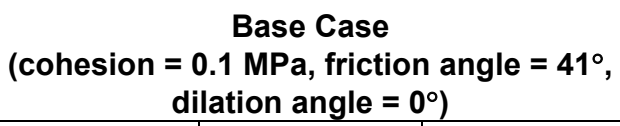 } \\
\hline & $\begin{array}{c}\text { Number of } \\
\text { Blocks }\end{array}$ & $\begin{array}{l}\text { Maximum } \\
\text { Block }\left(\mathrm{m}^{3}\right)\end{array}$ & $\begin{array}{c}\text { Rockfall } \\
\text { Volume }\left(\mathrm{m}^{3}\right)\end{array}$ & $\begin{array}{l}\text { Number of } \\
\text { Blocks }\end{array}$ & $\begin{array}{l}\text { Maximum } \\
\text { Block }\left(\mathrm{m}^{3}\right)\end{array}$ & $\begin{array}{c}\text { Rockfall } \\
\text { Volume }\left(\mathrm{m}^{3}\right)\end{array}$ \\
\hline 38 & 233 & 3.53 & 59.23 & 173 & 3.53 & 42.03 \\
\hline 45 & 16 & 0.84 & 2.21 & 14 & 0.84 & 2.49 \\
\hline 63 & 7 & 0.13 & 0.39 & 0 & 0 & 0.00 \\
\hline
\end{tabular}




\subsubsection{Sensitivity Study of the Parameters}

There are four major variable sets included in the three-dimensional discontinuum analysis: ground motion, joint geometrical properties, joint and intact mechanical properties, and thermal stress history. For the ground motion parameters, four levels of annual probability of exceedance $\left(1 \times 10^{-4}, 1 \times 10^{-5}, 1 \times 10^{-6}\right.$, and $\left.1 \times 10^{-7}\right)$ are included, and 15 sets of ground motions were used for each hazard level in the postclosure consideration. The description of the ground motions used is provided in Section 6.3.1 and Appendix X. Results for the sensitivity study on the probability level, peak ground velocities, energy contents, and orientation of horizontal motions in the 3DEC model to the rockfall prediction are presented in Section 6.3.1.6.1.

The variability of joint geometrical properties is incorporated into the application of FracMan to generate a $100-\mathrm{m}$ cube fracture network. A total of 50 drift locations were selected from the 100-m cube fractured rock mass for the 3DEC analyses. Results from the analyses of 50 drift locations (or fracture patterns) cover the variability of joint geometrical properties as verified in Appendix K.

The results presented in previous sections are based on the base case material properties presented in Table 6-3. The impact of the variability of joint properties to rockfall prediction is described in Section 6.3.1.6.2. Variation of the rock bridge strength is considered in Section 6.3.1.6.3. A linear elastic material is used as the intact block material for the base case. The likelihood of breaking and spalling of the intact rock subject to vibratory ground motions is discussed in Section 6.3.1.6.4. Other sensitivity and uncertainty studies include model dimension and block deletion after impacting the drip shield. These are addressed in Sections 6.3.1.6.5 and 6.3.1.6.6, respectively.

Sensitivity analyses were conducted using the representative cases with $1 \times 10^{-5}$ annual probability of exceedance ground motions except for the consideration of block deletion in Section 6.3.1.6.6. Similar to the thermal-mechanical analyses, three cases corresponding to the case with most rockfall (Case 38 with Fracture Pattern 29 and Ground Motion 3), the case with the median rockfall (Case 45 with Fracture Pattern 39 and Ground Motion 10), and the case with least rockfall (Case 63 with Fracture Pattern 96 and Ground Motion 11), were selected.

\subsection{Ground Motion Parameters}

The ground motion time histories were truncated at 5 percent and 95 percent energy content to shorten the time required to conduct the dynamic analyses. The analyses show that the majority of the rockfall occurs coincident with the arrival of the strong motion, which is typically within the first 15 seconds of shaking. The truncating of the ground motion appears to have minor impact on the amount of rockfall.

Four levels of annual probability of exceedance $\left(1 \times 10^{-4}, 1 \times 10^{-5}, 1 \times 10^{-6}\right.$, and $\left.1 \times 10^{-7}\right)$ plus 15 sets of ground motions for each postclosure level were included in the drift degradation study to ensure a reasonable distribution of spectral shapes and time history durations. Results for the sensitivity study on the probability level, peak ground velocities, energy contents, and orientation of horizontal motions in the 3DEC model to the rockfall prediction are presented in this section. 
Probability Levels-The predicted rockfall results for each level of ground motions are presented in the subsections of Section 6.3.1.2. The results are summarized and compared in this section to observe the trend of rockfall versus ground motions with various annual probability of exceedance. Figure 6-81 shows the comparison of histograms of block mass for the ground motions considered. The rockfall number increases as the frequency of occurrence of ground motion gets lower. Figure 6-82 presents the cumulative percentage of block size distribution with block mass in a logarithmic scale. Essentially, the results show that the motions result in the same general negative exponential distribution of block sizes. As expected, a higher portion of large blocks is predicted for lower frequency ground motions.

A comparison of the rockfall statistics is provided in Tables 6-26 and 6-27. The number and volume of blocks per $\mathrm{km}$ increase substantially in going from the preclosure motion to postclosure motions. The predicted rockfall volume per $\mathrm{km}$ for $1 \times 10^{-7}$ ground motions is approximately 12 times of that for $1 \times 10^{-4}$ ground motions. The predicted mean, median, and maximum block size also show a large increase from the preclosure motion to postclosure motions. However, the differences of the block size statistics in between the postclosure motions are relatively minor, especially for the results of $1 \times 10^{-6}$ and $1 \times 10^{-7}$ ground motions.

Table 6-26. Comparison of Rockfall Statistics for Preclosure and Postclosure Events

\begin{tabular}{|l|c|c|c|c|}
\hline \multirow{2}{*}{ Statistic } & \multicolumn{4}{c|}{ Ground Motion } \\
\cline { 2 - 5 } & $\mathbf{1 0}^{\mathbf{- 4}}$ & $\mathbf{1 0}^{-\mathbf{5}}$ & $\mathbf{1 0}^{-\mathbf{6}}$ & $\mathbf{1 0}^{\mathbf{- 7}}$ \\
\hline Runs Completed & 32 & 50 & 50 & 44 \\
\hline Total Number of Rockfall & 428 & 1764 & 2797 & 3387 \\
\hline Total Volume of Rockfall $\left(\mathrm{m}^{3}\right)$ & 39.4 & 255.4 & 497.7 & 705.2 \\
\hline Total Length of Drift Simulated $(\mathrm{m})$ & 800 & 1250 & 1250 & 1100 \\
\hline Number of Blocks per km & 535 & 1414 & 2238 & 3079 \\
\hline Volume of Rockfall per $\mathrm{km}\left(\mathrm{m}^{3} / \mathrm{km}\right)$ & 49.3 & 204.3 & 398.2 & 641.1 \\
\hline
\end{tabular}

Table 6-27. Statistic Summary of the Block Size (metric ton) for Preclosure and Postclosure Events

\begin{tabular}{|l|c|c|c|c|}
\hline \multirow{2}{*}{\multicolumn{1}{c|}{ Statistic }} & \multicolumn{4}{c|}{ Ground Motion } \\
\cline { 2 - 5 } & $\mathbf{1 0}^{-\mathbf{4}}$ & $\mathbf{1 0}^{-\mathbf{5}}$ & $\mathbf{1 0}^{\mathbf{- 6}}$ & $\mathbf{1 0}^{\mathbf{- 7}}$ \\
\hline Mean & 0.22 & 0.35 & 0.43 & 0.50 \\
\hline Median & 0.10 & 0.12 & 0.13 & 0.15 \\
\hline Standard Deviation & 0.33 & 0.93 & 1.30 & 1.43 \\
\hline Skewness & 3.47 & 10.03 & 11.61 & 8.81 \\
\hline Range & 2.69 & 19.04 & 28.19 & 28.26 \\
\hline Minimum & 0.02 & 0.02 & 0.02 & 0.02 \\
\hline Maximum & 2.72 & 19.07 & 28.22 & 28.29 \\
\hline Sum & 95.00 & 615.97 & 1200.43 & 1699.57 \\
\hline
\end{tabular}




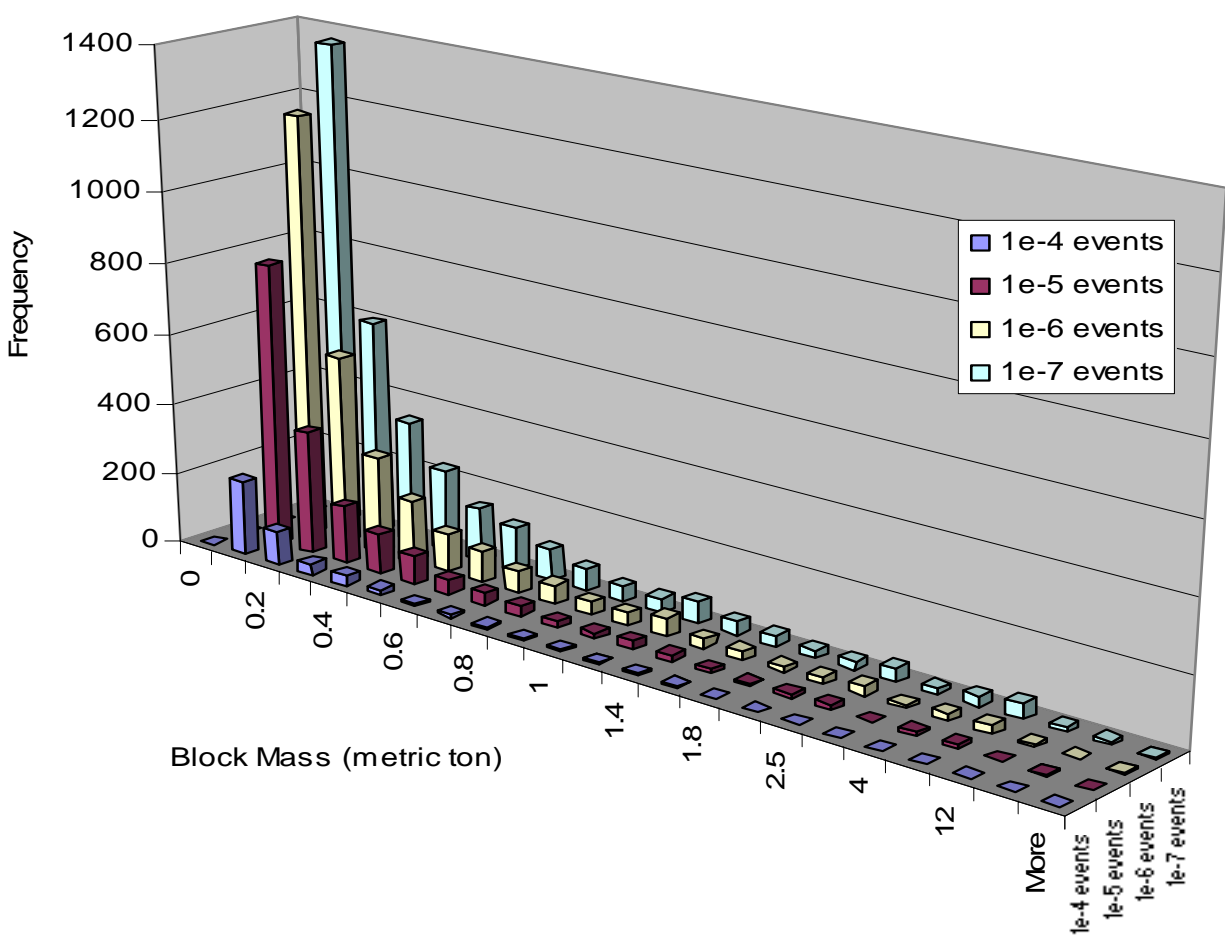

Figure 6-81. Comparison of Histograms of Block Mass from Preclosure and Postclosure Ground Motions

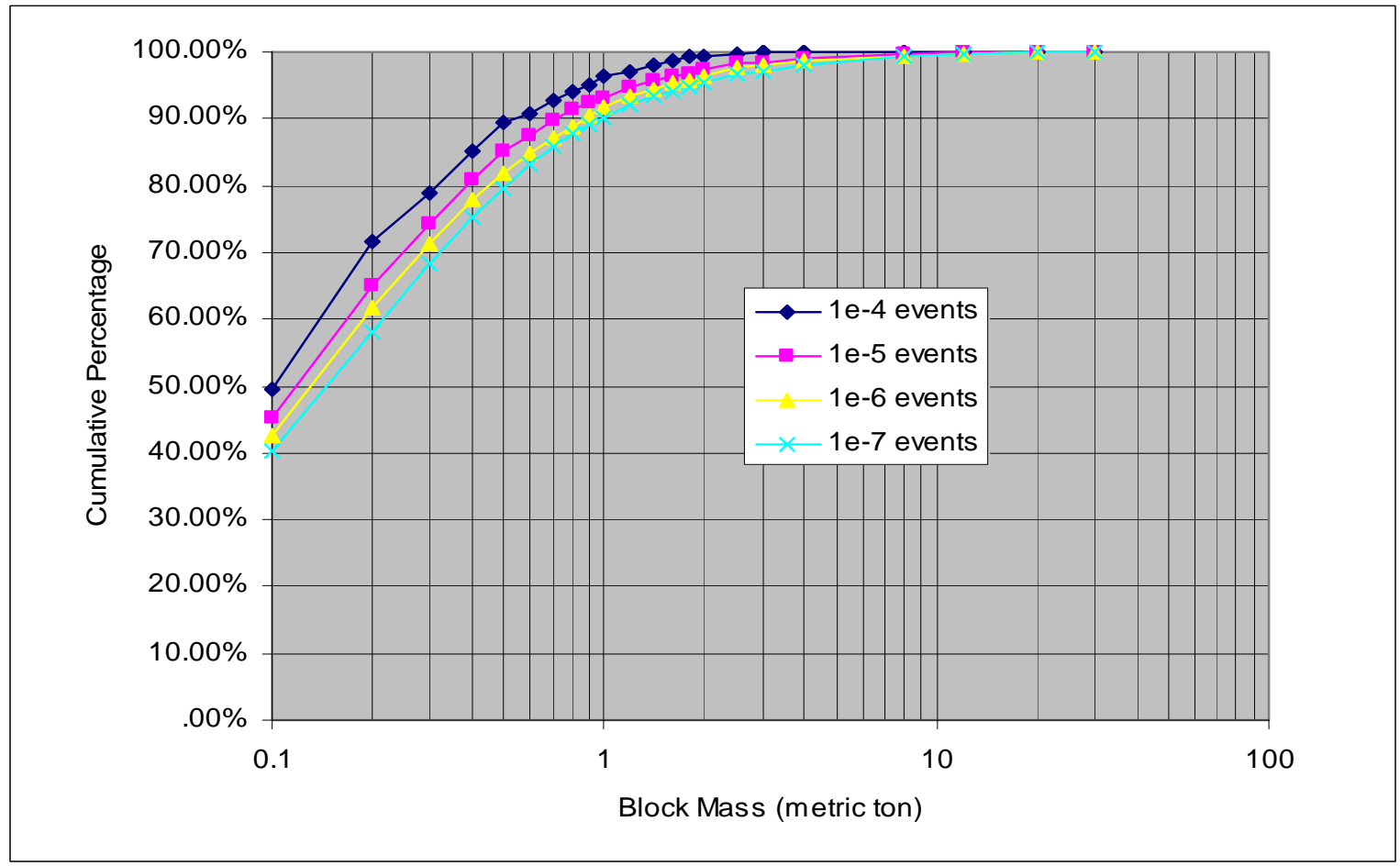

Figure 6-82. Comparison of Block Size Distribution from Preclosure and Postclosure Ground Motions 
Peak Ground Velocities and Energy Contents-Correlation of the rockfall volume per 3DEC simulation with the peak ground velocity and energy content in terms of Arias Intensity is presented in Figures 6-83 and 6-84. The three levels of postclosure ground motions are included. At any given level of PGV, the variability in rockfall based on the variability in fracture pattern and ground motion frequency characteristics results in a fairly wide distribution in response. Although no strong relationship is observed between rockfall volume and PGV, a roughly linear relationship exists between the upper bound to rockfall volume and PGV on this semi-log plot. It appears that the predominant mechanism for variability in rockfall at a given level of PGV is the fracture pattern.

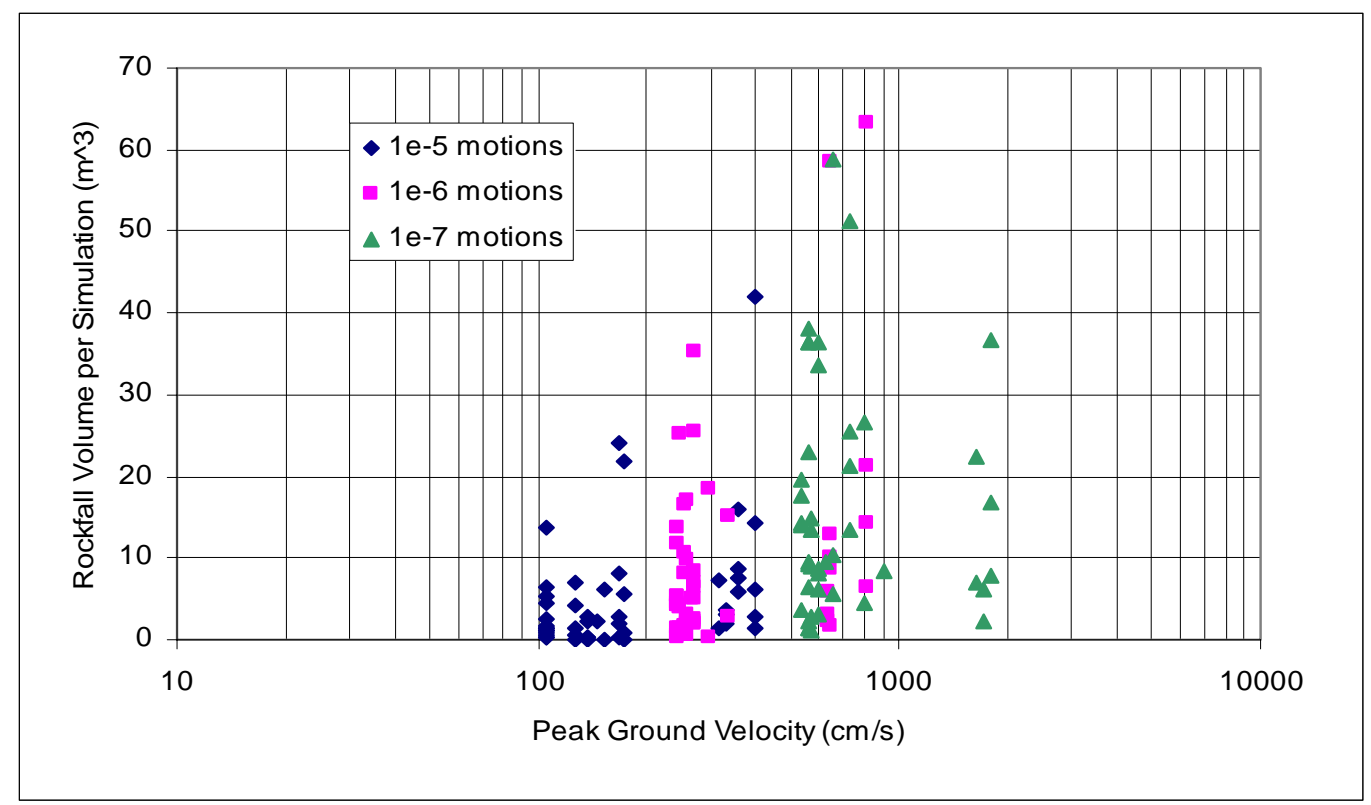

Figure 6-83. Rockfall Volume vs. Peak Ground Velocity

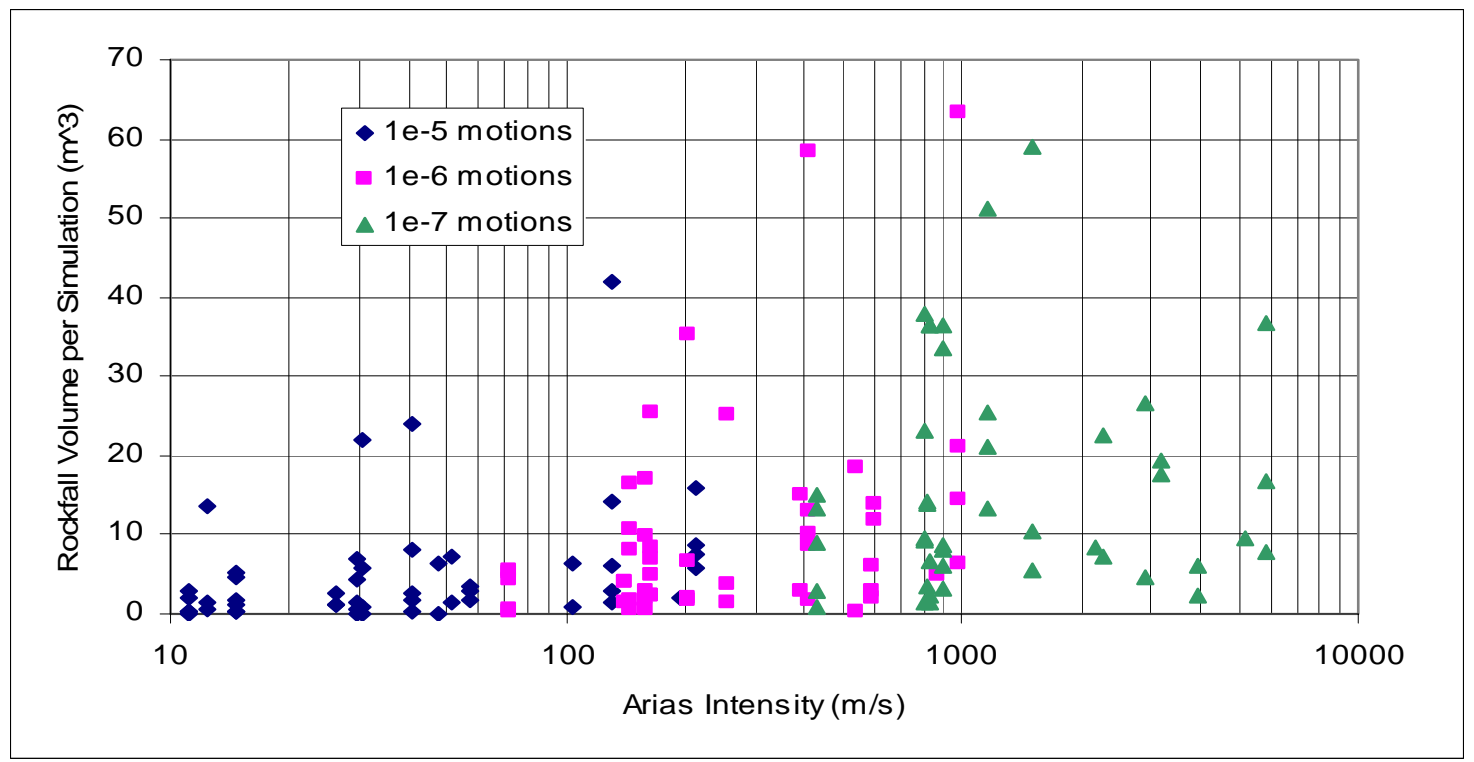

Figure 6-84. Rockfall Volume vs. Arias Intensity 
Orientation of Horizontal Motions-The orientation of horizontal motions is conveniently specified as $\mathrm{H} 1$ parallel to the $\mathrm{x}$-axis and $\mathrm{H} 2$ parallel to the $\mathrm{z}$-axis (the North direction) in the 3DEC model (3DEC coordinate system is shown in Figure L-1). An alternative approach with $\mathrm{H} 1$ parallel to the z-axis (North) and $\mathrm{H} 2$ parallel to the $\mathrm{x}$-axis was used to check the sensitivity of the orientation. Table 6-28 presents the comparison of the predicted rockfall with the two approaches. In general the difference is minor because the amplitudes of the peak motions are similar for the two horizontal components of the ground motion.

Table 6-28. Rockfall in Nonlithophysal Rock Due to $10^{-5}$ Ground Motion Combined with ThermalMechanical Effects, Base Case of Thermal Properties

\begin{tabular}{|c|c|c|c|c|c|}
\hline \multirow{2}{*}{ Case } & \multirow{2}{*}{$\begin{array}{c}\text { Ground } \\
\text { Motion }\end{array}$} & \multicolumn{2}{|c|}{ Original Approach $(\mathbf{H 2}$ in North) } & \multicolumn{2}{c|}{ Alternative Approach (H1 in North) } \\
\cline { 3 - 6 } & 3 & 173 & $\begin{array}{c}\text { Rockfall Volume } \\
\left(\mathbf{m}^{\mathbf{3}}\right)\end{array}$ & $\begin{array}{c}\text { Number of Rockfall } \\
\begin{array}{c}\text { Rockfall Volume } \\
\left(\mathbf{m}^{\mathbf{3}}\right)\end{array}\end{array}$ \\
\hline 38 & 10 & 42.03 & 170 & 39.04 \\
\hline 45 & 14 & 2.49 & 18 & 2.92 \\
\hline 63 & 11 & 0 & 0.00 & 0 & 0.00 \\
\hline
\end{tabular}

\subsection{Joint Mechanical Properties}

Joint mechanical properties in 3DEC modeling consist of cohesion, friction angle, dilation angle, normal stiffness, and shear stiffness. The base case joint mechanical properties, listed in Table 6-3, were based on the rotary shear tests of the cored specimen as derived in Appendix E. With limited joint test results available and the fact that the use of rotary shear devices in rock mechanics is limited, some of the parameters in the base case, such as cohesion and dilation angle, were scaled down from the testing results for conservatism, to allow for potential over-prediction of rockfall.

The direct shear test results (Table E-5) are used to provide the range of variation in the sensitivity study. A range of joint mechanical properties, as shown in Table 6-29, was selected for the sensitivity study. Three categories were included to cover the possible range of variation. Category 1 represents the weakest fractures observed, whereas Category 3 represents the strongest fractures. The values of friction angle were established based on the residual friction angle of $30^{\circ}$ (see Section 6.3.1.5) and three tiers of dilation angles. The dilation angles were selected based on the empirical estimate of peak dilation angle for the Yucca Mountain joint set (Duan 2003 [DIRS 163586], p.41). The ranges of the peak friction and dilation angle are selected to be consistent with the reported direct shear test results presented in Appendix E (Table E-5). A conservative estimate of cohesion of $0.1 \mathrm{MPa}$ remained the same as the base case.

The joint stiffness values were taken from both the rotary shear test and direct shear test results. The mean and standard deviation of the shear stiffness values for the cooling joint from the direct shear tests (Table E-5) were used to estimate the values presented in Table 6-29. Shear stiffness for Category 2 joint is set to be equivalent to the mean value, whereas the shear stiffness values for Category 1 and 3 joints is estimated to be the mean value minus one standard deviation and the mean value plus one standard deviation respectively. Because the normal stiffness is not reported from the direct shear tests, the mean and standard deviation of the normal stiffness value 
from rotary shear tests (Table E-4) were used to estimate the values used for the three categories. The same approach is adopted for normal stiffness as for shear stiffness with the mean value assigned for Category 2 joints and the standard deviation as the range of variation.

The results for the sensitivity of joint properties to the rockfall prediction are presented in Table 6-30. Results for the three categories are quite similar irrespective of the variation of the mechanical properties used for each category. In general, the results are also similar to those for the base case. The exception is Case 38 with approximately 50 percent more rockfall for the sensitivity cases compared to the base case. It was observed that the blocks jammed at the roof preventing additional rockfall, was due to the large amount of rockfall that occurred in a short time for this case. Jamming appears to occur at earlier time for the base case than other sensitivity cases, this contributes to less rockfall for the base case. Comparison of the size distribution of the base case and sensitivity cases for Case 38 are shown in Figure 6-85. The distributions are similar, with the distributions for the base case and joint Categories 2 and 3 nearly identical. The results show that the mechanical properties variation for rockfall is a secondary effect compared to the variation of fracture pattern.

Table 6-29. Three Categories of Joint Properties Used in the Sensitivity Study

\begin{tabular}{|c|c|c|c|c|c|}
\hline Joint Category & $\begin{array}{c}\text { Joint Cohesion } \\
\mathbf{( P a )}\end{array}$ & $\begin{array}{c}\text { Joint } \\
\text { Dilation Angle }\end{array}$ & $\begin{array}{c}\text { Peak Friction } \\
\text { Angle }\end{array}$ & $\begin{array}{c}\text { Joint Normal } \\
\text { Stiffness } \mathbf{( P a} / \mathbf{m})\end{array}$ & $\begin{array}{c}\text { Joint Shear Stiffness } \\
\mathbf{( P a / m})\end{array}$ \\
\hline 1 & $1.0 \mathrm{E}+5$ & 1.4 & 31.4 & $7.20 \mathrm{E}+10$ & $5.30 \mathrm{E}+09$ \\
\hline 2 & $1.0 \mathrm{E}+5$ & 4.4 & 34.4 & $9.40 \mathrm{E}+10$ & $1.10 \mathrm{E}+10$ \\
\hline 3 & $1.0 \mathrm{E}+5$ & 11 & 41 & $1.16 \mathrm{E}+11$ & $1.67 \mathrm{E}+10$ \\
\hline
\end{tabular}

Table 6-30. Sensitivity of Joint Properties for Rockfall Prediction

\begin{tabular}{|c|c|c|c|c|c|c|c|c|}
\hline & \multicolumn{2}{|c|}{ Base Case } & \multicolumn{2}{c|}{ Joint Category 1 } & \multicolumn{2}{c|}{ Joint Category 2 } & \multicolumn{2}{c|}{ Joint Category 3 } \\
\cline { 2 - 9 } Case & $\begin{array}{c}\text { Number of } \\
\text { Rockfall }\end{array}$ & $\begin{array}{c}\text { Rockfall } \\
\left.\text { Volume } \mathbf{( m}^{\mathbf{3}}\right)\end{array}$ & $\begin{array}{c}\text { Number of } \\
\text { Rockfall }\end{array}$ & $\begin{array}{c}\text { Rockfall } \\
\left.\text { Volume } \mathbf{( m}^{\mathbf{3}}\right)\end{array}$ & $\begin{array}{c}\text { Number of } \\
\text { Rockfall }\end{array}$ & $\begin{array}{c}\text { Rockfall } \\
\left.\text { Volume } \mathbf{( m}^{\mathbf{3}}\right)\end{array}$ & $\begin{array}{c}\text { Number of } \\
\text { Rockfall }\end{array}$ & $\begin{array}{c}\text { Rockfall } \\
\text { Volume }\left(\mathbf{m}^{\mathbf{3}}\right)\end{array}$ \\
\hline 38 & 173 & 42.03 & 237 & 78.95 & 257 & 66.48 & 251 & 65.45 \\
\hline 45 & 14 & 2.49 & 16 & 2.21 & 12 & 2.07 & 16 & 2.37 \\
\hline 63 & 0 & 0 & 3 & 0.12 & 6 & 0.35 & 3 & 0.19 \\
\hline
\end{tabular}




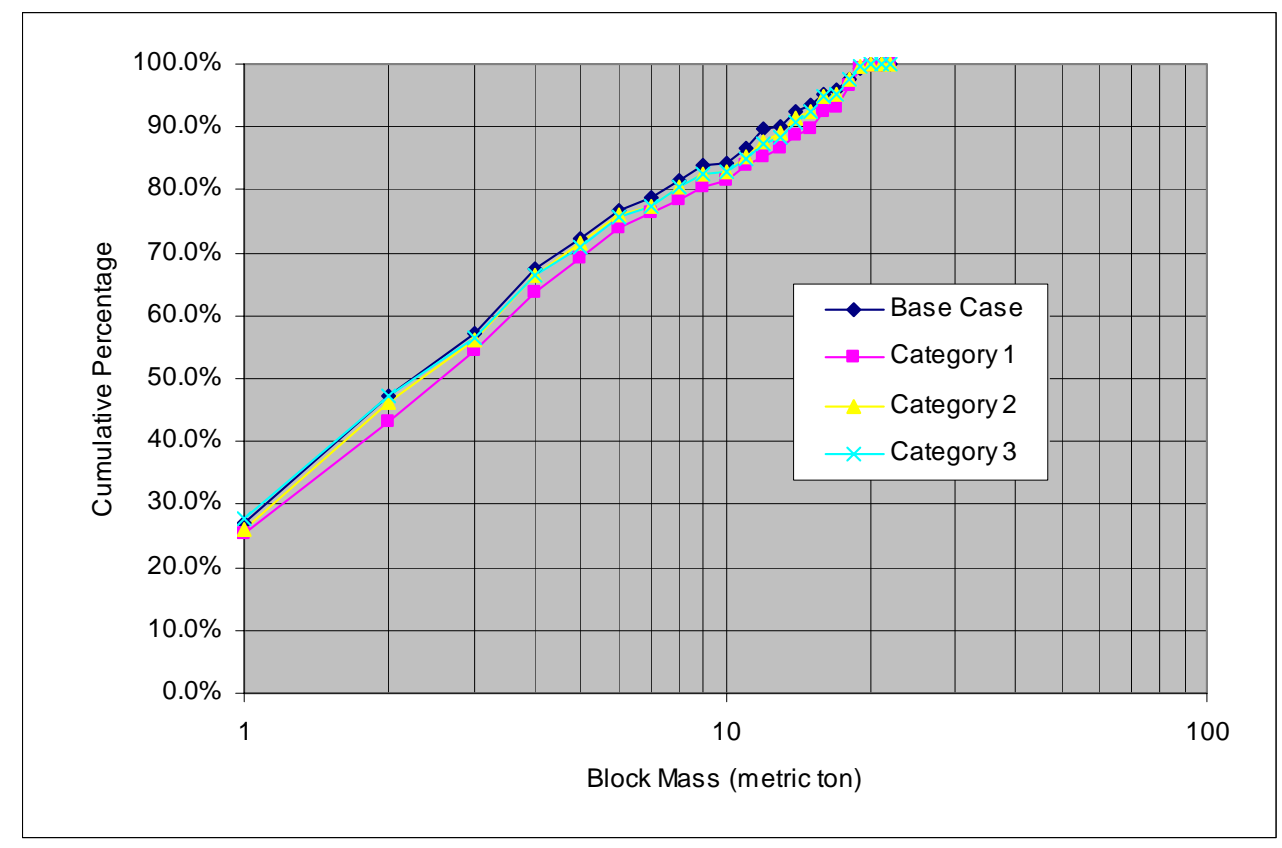

Figure 6-85. Comparison of Block Size Distribution for Variation of Joint Mechanical Properties (Case 38)

\subsection{Rock Bridge Strength Parameters}

Rock bridges were generated as the extension of finite trace length fractures to form the distinct blocks in the 3DEC model (see Figure H-1 in Appendix H). The strength parameters of the rock bridges used for the base case (listed in Table 6-3) are the best estimate of the intact rock strength. Rock bridge damage appears to have a strong relationship with peak ground velocity. In general, less than 1 percent of the bridge area is damaged when subjected to $1 \times 10^{-5}$ ground motions, with about 5 percent bridge damage for $1 \times 10^{-6}$ ground motions, reaching to 20 percent bridge damage for $1 \times 10^{-7}$ ground motions. However, for certain large ground motions (such as ground motion \#3), much higher damage percentage is expected. Figure 6-86 shows the correlation between the damage percentage and the peak ground velocity. As shown in the figure, the coefficient of determination $\left(\mathrm{R}^{2}\right)$ is estimated to be around 0.95 , indicating a strong relationship. Note that over 60 percent of the bridge area could be damaged with the extremely conservative $16 \mathrm{~m} / \mathrm{sec}$ peak ground velocity seismic shaking.

A range of bridge strength parameters, in terms of cohesion, friction angle, and tensile strength, as shown in Table 6-31, was selected for the sensitivity study. Three categories were included to cover the possible range of variation. The base case joint strength parameters are used for Category 1 to represent the extreme case where the bridges are sheared off to become fractures. The extreme case could be interpreted as a simulation where the jointed rock mass has been previously subjected to a ground motion greater than $16 \mathrm{~m} / \mathrm{sec}$. The mean values of the intact strength parameters listed in Table E-7 (tensile strength for TSw2) and Figure E-2 (cohesion and friction angle) are used for Category 2. The mean plus one standard deviation values are assigned as the strength parameters for Category 3 representing the upper bound for the rock bridge strength. 


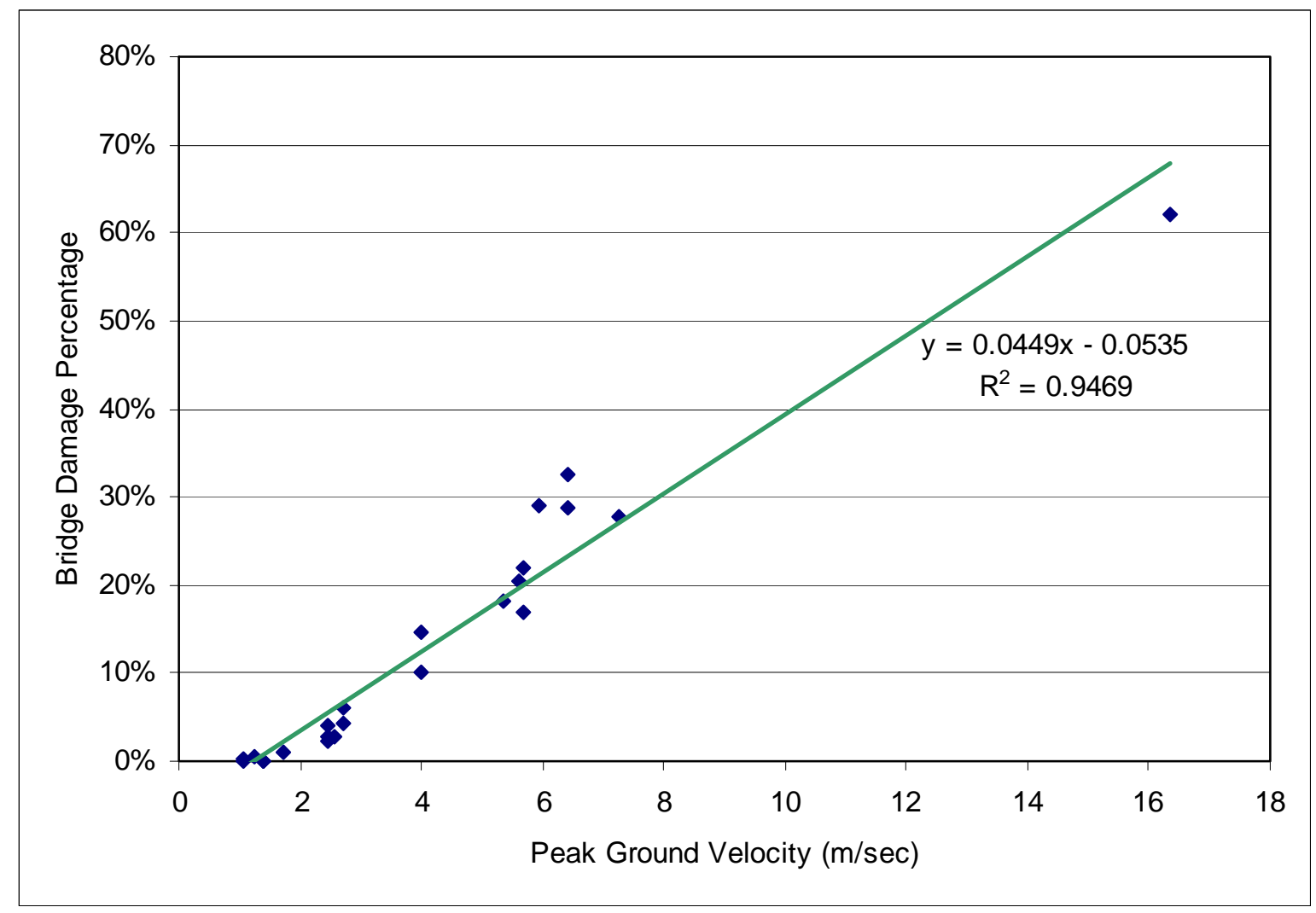

Figure 6-86. Correlation of Rock Bridge Damage Percentage and Peak Ground Velocity

Table 6-31. Three Categories of Rock Bridge Strength Parameters Used in the Sensitivity Study

\begin{tabular}{|c|c|c|c|}
\hline Rock Bridge Category & Cohesion $(\mathbf{P a})$ & Friction Angle & Tensile Strength $\mathbf{( P a )}$ \\
\hline 1 & $1.00 \mathrm{E}+5$ & 41 & 0 \\
\hline 2 & $3.60 \mathrm{E}+7$ & 50 & $8.90 \mathrm{E}+6$ \\
\hline 3 & $4.00 \mathrm{E}+7$ & 56 & $1.22 \mathrm{E}+7$ \\
\hline
\end{tabular}

The results for the sensitivity of rock bridge strength parameters to the rockfall prediction when subjected to $1 \times 10^{-5}$ ground motions are presented in Table 6-32. Increase of rockfall is predicted for Category 1, representing the extreme case with the bridges sheared off. Significant increase is observed for the median rockfall case (Case 45) and minor increase is detected for the most (Case 38) and least (Case 63) rockfall cases. Results for Categories 2 and 3 are similar to the base case. The results show that within the range of variation for the intact strength parameters (Categories 2 and 3), rock bridge strength parameters have an insignificant impact on rockfall prediction. However, if the rock bridges are sheared off as represented by Category 1, a significant increase of rockfall is likely.

Since the damage percentage varies with different levels of ground motions, additional analyses for the median rock fall case (Case 45) subjected to $1 \times 10^{-6}$ and $1 \times 10^{-7}$ ground motions were also 
conducted. Table 6-33 presents the results with lower probability ground motions. In general, the trend for rockfall is similar to the results for $1 \times 10^{-5}$ ground motions.

Table 6-32. Sensitivity of Rock Bridge Strength Parameters for Rockfall Prediction

\begin{tabular}{|c|c|c|c|c|c|c|c|c|}
\hline & \multicolumn{2}{|c|}{ Base Case } & \multicolumn{2}{c|}{ Rock Bridge Category 1 } & \multicolumn{2}{c|}{ Rock Bridge Category 2 } & \multicolumn{2}{c|}{ Rock Bridge Category 3 } \\
\cline { 2 - 9 } Case & $\begin{array}{c}\text { Number of } \\
\text { Rockfall }\end{array}$ & $\begin{array}{c}\text { Rockfall } \\
\text { Volume }\left(\mathbf{m}^{3}\right)\end{array}$ & $\begin{array}{c}\text { Number of } \\
\text { Rockfall }\end{array}$ & $\begin{array}{c}\text { Rockfall } \\
\text { Volume }\left(\mathbf{m}^{3}\right)\end{array}$ & $\begin{array}{c}\text { Number of } \\
\text { Rockfall }\end{array}$ & $\begin{array}{c}\text { Rockfall } \\
\text { Volume }\left(\mathbf{m}^{3}\right)\end{array}$ & $\begin{array}{c}\text { Number of } \\
\text { Rockfall }\end{array}$ & $\begin{array}{c}\text { Rockfall } \\
\text { Volume }\left(\mathbf{m}^{3}\right)\end{array}$ \\
\hline 38 & 173 & 42.03 & 221 & 61.08 & 184 & 45.97 & 201 & 56.99 \\
\hline 45 & 14 & 2.49 & 47 & 8.92 & 14 & 2.49 & 13 & 2.34 \\
\hline 63 & 0 & 0 & 6 & 0.27 & 1 & 0.09 & 0 & 0 \\
\hline
\end{tabular}

Table 6-33. Sensitivity of Rock Bridge Strength Parameters for Case 45 with $1 \times 10^{-6}$ and $1 \times 10^{-7}$ Ground Motions

\begin{tabular}{|c|c|c|c|c|c|c|c|c|}
\hline \multirow{2}{*}{$\begin{array}{c}\text { Ground } \\
\text { Motion } \\
\text { Level }\end{array}$} & $\begin{array}{c}\text { Base Case } \\
\text { Number of } \\
\text { Rockfall }\end{array}$ & $\begin{array}{c}\text { Rockfall } \\
\text { Volume }\left(\mathbf{m}^{3}\right)\end{array}$ & $\begin{array}{c}\text { Number of } \\
\text { Rockfall }\end{array}$ & $\begin{array}{c}\text { Rockfall } \\
\text { Volume }\left(\mathbf{m}^{3}\right)\end{array}$ & $\begin{array}{c}\text { Number of } \\
\text { Rockfall }\end{array}$ & $\begin{array}{c}\text { Rockfall } \\
\text { Volume }\left(\mathbf{m}^{\mathbf{3}}\right)\end{array}$ & $\begin{array}{c}\text { Number of } \\
\text { Rockfall }\end{array}$ & $\begin{array}{c}\text { Rockfall } \\
\text { Volume }\left(\mathbf{m}^{3}\right)\end{array}$ \\
\hline $1 \times 10^{-6}$ & 29 & 4.19 & 97 & 19.75 & 34 & 5.52 & 23 & 3.29 \\
\hline $1 \times 10^{-7}$ & 86 & 14.27 & 219 & 47.64 & 94 & 15.49 & 97 & 16.01 \\
\hline
\end{tabular}

\subsection{Intact Block Failure Response Under Low-Probability Ground Motions}

\subsection{Introduction}

At the lower probability levels, the ground motions show extreme peak ground velocities levels, ranging from $2.44 \mathrm{~m} / \mathrm{sec}$ at the $1 \times 10^{-6}$ to $5.35 \mathrm{~m} / \mathrm{sec}$ at the $1 \times 10^{-7}$ annual exceedance probabilities. The previous calculations and estimates of dislodged block masses and volumes assumed that the rock blocks were, in general, elastic. The only block failure that was allowed was breakage of solid rock "bridges" that occur along the extension of fracture planes, between the end of the fracture and its possible termination against adjacent fractures. Thus, in the current model, it is possible for a block to split into several smaller blocks if the seismic stresses are sufficient to fail the rock bridge in shear or in tension. The following discussion provides a simplified analysis of a more general failure mechanism of intact blocks in shear or in tension. The average principal stresses in blocks surrounding the emplacement drift are examined for the $1 \times 10^{-6}$ and $1 \times 10^{-7}$ cases to determine if widespread block failure is possible at these hazard levels. If so, then either the amount of rockfall or the size of dislodged rock masses derived from the previous calculations could be in error. Initially, a discussion is given on analyses aimed at providing a physical bound to peak ground velocities experienced at the Yucca Mountain site. Although no bounds on the PGV of time histories have been used in the damage assessments made from analyses presented in this document, an estimate of the maximum PGV is useful here to determine whether the modeling approach needs to include intact block failure mechanisms. An analysis of the peak stress conditions in blocks surrounding the emplacement drift is then conducted to determine the extent of potential shear or tensile failure mechanisms. 


\subsection{Bounding of the Peak Ground Velocity}

The ground motion hazard determined in the Probabilistic Seismic Hazard Assessment expert elicitation is unbounded. Because the ground motion experts characterized aleatory variability in ground motion using unbounded lognormal distributions, as the Probabilistic Seismic Hazard Assessment calculations are extended to lower and lower annual probabilities of exceedence, the mean ground motions increase without bound, eventually reaching levels that are not credible. These levels of ground motion are not credible in that they eventually result in seismic strains that would cause the rock mass (in absence of any excavation) to fail through formation of fractures, an effect that is not observed at Yucca Mountain. As stated in 10 CFR 63.102(J) [DIRS 156605] with respect to events that are to be included in the TSPA, "the event class for seismicity includes the range of credible earthquakes for the Yucca Mountain site.” Therefore, to ensure the ground motions considered in the Seismic Consequence Abstraction (BSC 2004 [DIRS 169183]) and TSPA are credible, an analysis was conducted to determine a bound to PGV at the repository level. This analysis, presented in Peak Ground Velocities for Seismic Events at Yucca Mountain, Nevada (BSC 2004 [DIRS 170137], estimates an upper bound to the ground motions at the Yucca Mountain site based on the shear strain increments (relative to the in situ stress state) required to damage (fracture) the Tptpll ${ }^{5}$. The analysis presented argues that, since seismic induced fracturing is not observed in subsurface exposures of the Tptpll, ground motions equal to or greater than that which would produce shear strains equal to the fracturing limit have not occurred since the Topopah Spring unit was erupted and cooled, some 12.8 million years ago. The shear strain limits are defined from the large core lithophysal rock compression testing and from numerical extrapolation using the PFC and UDEC programs similar to that described in Appendix E, Section E4. Even though bounding peak ground velocities have been estimated, they have not been used explicitly in the calculations of seismic damage presented in this document. In other words, damage has been assessed for time histories with PGVs in excess of the bounding values defined in Peak Ground Velocities for Seismic Events at Yucca Mountain, Nevada (BSC 2004 [DIRS 170137]). Instead, the damage to EBS components is bounded within the Seismic Consequence Abstraction (BSC 2004 [DIRS 169183], Section 6.4.4); i.e., damage associated with PGVs in excess of $5 \mathrm{~m} / \mathrm{sec}$ is bounded at the $5 \mathrm{~m} / \mathrm{sec}$ level.

The details of the derivation of the bounding PGVs based on shear strain limits of the Tptpll can be found in the PGV study (BSC 2004 [DIRS 170137]). The result of the analyses presented there are two potential bounding distributions of horizontal PGV at the repository level - one based on the assumption of a uniform distribution and one based on a triangular distribution (Figure 6-87). The lower and upper limits for the distributions are assessed at 150 and $500 \mathrm{~cm} / \mathrm{s}$, respectively, based on the range of shear-strain increments at yield derived from the combined laboratory testing and numerical simulations and the corresponding horizontal PGV values that produce these shear strain increments. To translate the shear-strain threshold probability distribution into a distribution for horizontal PGV at the waste emplacement level, the results of the ground-motion site-response modeling were used. The average horizontal PGV values

\footnotetext{
${ }^{5}$ Tensile strains may also be induced by the vertically propagating wave associated with the seismic event. A number of the ground motion time histories at the $1 \times 10^{-5}, 1 \times 10^{-6}$ and $1 \times 10^{-7}$ annual exceedance probabilities are characterized by a vertical component that is larger than the horizontal component. The tensile strain limit of the rock is less than the shear strain limit, which is used to derive the bounded horizontal PGV. Therefore, using shear strain limit will result in larger bounded ground motions than use of both shear and tensile strain limits. The bounded PGVs based on a shear strain limit alone are thus conservative in nature.
} 
associated with the average shear-strain values from the site-response results are used to transpose the shear-strain threshold probability distribution. The average horizontal PGV values calculated, assuming PGV values are normally distributed, yield higher PGVs than those calculated for a lognormal distribution. The resulting distribution for horizontal PGV departs slightly from a triangular shape because the relation between shear-strain threshold and horizontal PGV is not linear. This distribution ranges from a minimum value of $151 \mathrm{~cm} / \mathrm{s}$ to a maximum value of $451 \mathrm{~cm} / \mathrm{s}$ and has a mode of $236 \mathrm{~cm} / \mathrm{s}$. The uniform distribution of bounding PGVs is used in the Seismic Consequence Abstraction (BSC 2004 [DIRS 169183]) to bound mechanical damage to EBS components since it produces a more conservative approach with an upper bound of $5 \mathrm{~m} / \mathrm{sec}$ to the horizontal PGV at the repository level.

In summary, the PGV at the repository level has been shown, based on physical strain limitations of the lithophysal rock mass, to be, at most, $5 \mathrm{~m} / \mathrm{sec}$. Depending of the distribution assumed, the maximum could also be as low as approximately $4.5 \mathrm{~m} / \mathrm{sec}$ with a mode of $2.36 \mathrm{~m} / \mathrm{sec}$.

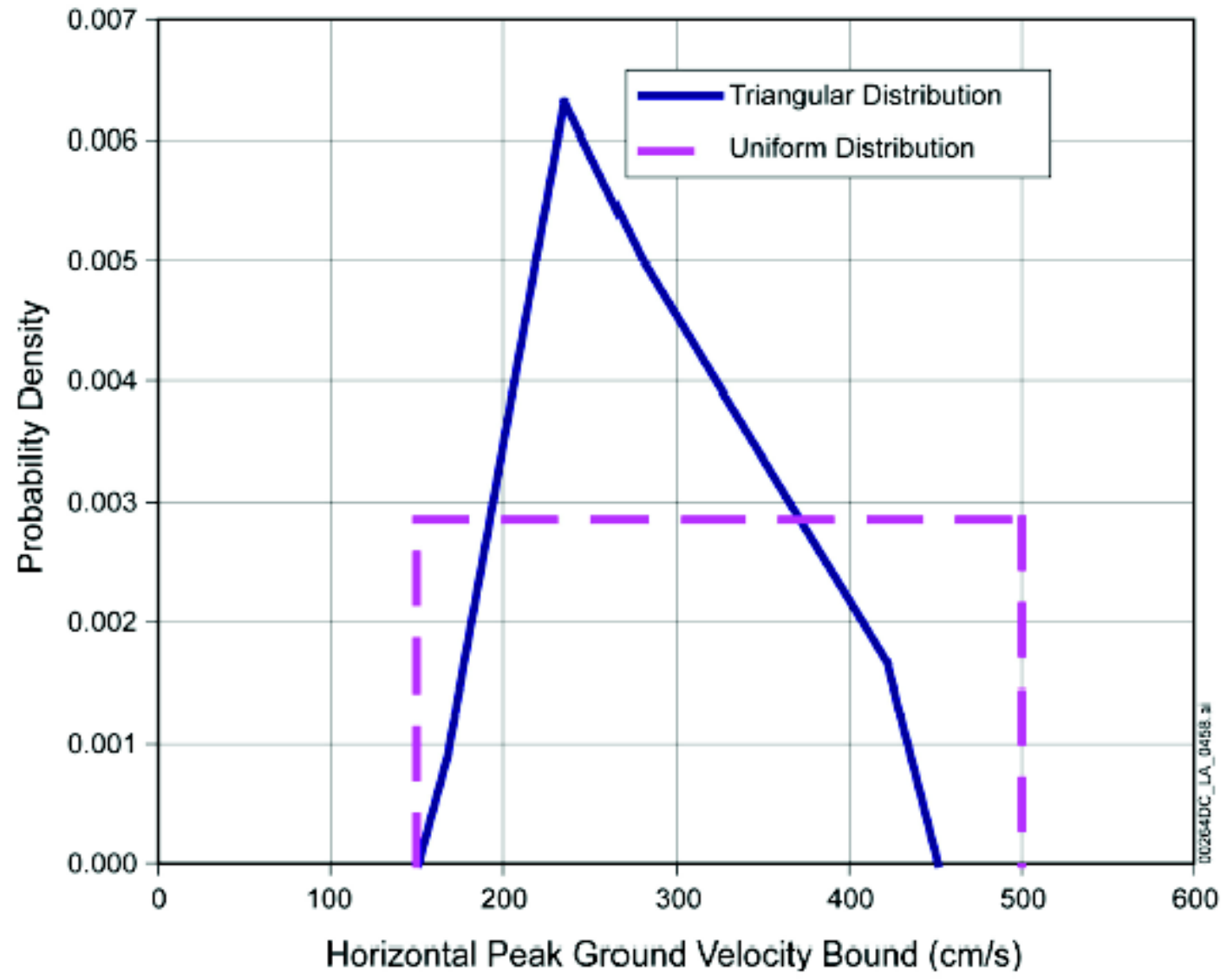

Source: BSC 2004 [DIRS 170137].

Figure 6-87. Probability Density Functions for the Bound to Horizontal Peak Ground Velocity at the Waste Emplacement Level 


\subsection{Analysis of Intact Block Failure Mechanism}

Tensile stresses in the rock mass are induced by both the shear (horizontal component) and during the reversal of the compression (vertical component). The tensile strength of the rock mass is a consequence of the tensile strength of the solid rock bridges that occur between discontinuous fracture traces. Therefore, as the rock mass is loaded in a transient tensile fashion by the combined effect of the shear and compression waves, the intact blocks could be split into a number of smaller blocks through tensile (or shear) failure of the rock bridges. These smaller blocks can then become unstable under the successive shaking of the ground motion, with subsequent collapse into the drift.

To examine the potential for intact block breakage, the analyses conducted to examine the impact of rock bridge failure are reviewed here. The base case $1 \times 10^{-6}$ and $1 \times 10^{-7}$ nonlithophysal 3DEC model, described in Section 6.3.1 are based on fracture geometries (i.e., the orientation, radius and spacing distribution) obtained from a synthetic fracture representation developed from field mapping. A general result of this fracture representation is a distinct block system that is formed by solid rock bridges and finite trace fractures as shown in Appendix H (Figure H-1). In the base case analyses, the strength of the solid rock bridges, which is represented as bonded "patches" along fracture planes, is governed by the shear and tensile strength of the solid Tptpmn, as given in Table 6-3 (cohesion of 47.2 MPa, friction angle of $42^{\circ}$ and tensile strength of $11.56 \mathrm{MPa}$ ). During a simulation, the stress conditions acting on these solid rock bridges are monitored, and failure in shear or tension can occur. If failure occurs, the cohesive and tensile strength of the bridge is reduced to zero, and the bonded "patch" is fractured. Thus, the block within which the bridge is located can be fractured into multiple blocks. As described in Section 6.3.1.6.3, less than 1 percent of the rock bridges are damaged during the $1 \times 10^{-5}$ ground motions, about 5 percent during the $1 \times 10^{-6}$ ground motions, and about 20 percent for the $1 \times 10^{-7}$ ground motions. Figure 6-86 presented the rock bridge damage percentage estimated from the 3DEC modeling as a function of the PGV of the ground motion. As seen in this figure, the damage to rock bridges is approximately 20 percent or less (for PGVs less than $5 \mathrm{~m} / \mathrm{s}$ ) in terms of total rockfall, with the results presented in Tables 6-9, 6-12 and 6-15 for the $1 \times 10^{-5}, 1 \times 10^{-6}$, and $1 \times 10^{-7}$ cases, respectively.

A sensitivity study of rock bridge strength, presented in Section 6.3.1.6.3 provides a conservative assessment of the case in which the tensile strength of the rock bridges is assumed to be zero. This case effectively represents the condition in which the tensile strength of the rock mass is conservatively assumed to be zero as no rock bridges exist. These analyses indicate that the rockfall volume (for the median rockfall case 45 ) increases between 3 to 5 times for the $1 \times 10^{-6}$ and the $1 \times 10^{-7}$ cases (summarized in Table 6-33). The ground motion time histories for the median rockfall condition (Case 45) for the $1 \times 10^{-6}$ and the $1 \times 10^{-7}$ annual exceedance probabilities are shown in Figure 6-88. The rockfall for Case 45, for the base case rock bridge strength and the case in which the rock bridge tensile strength is set to zero are shown in Figures 6-89 to 6-90 for the $1 \times 10^{-6}$ and the $1 \times 10^{-7}$ ground motions. As seen in these figures, the rockfall increases significantly with the assumption of zero rock bridge tensile strength, but total collapse is not evident. 


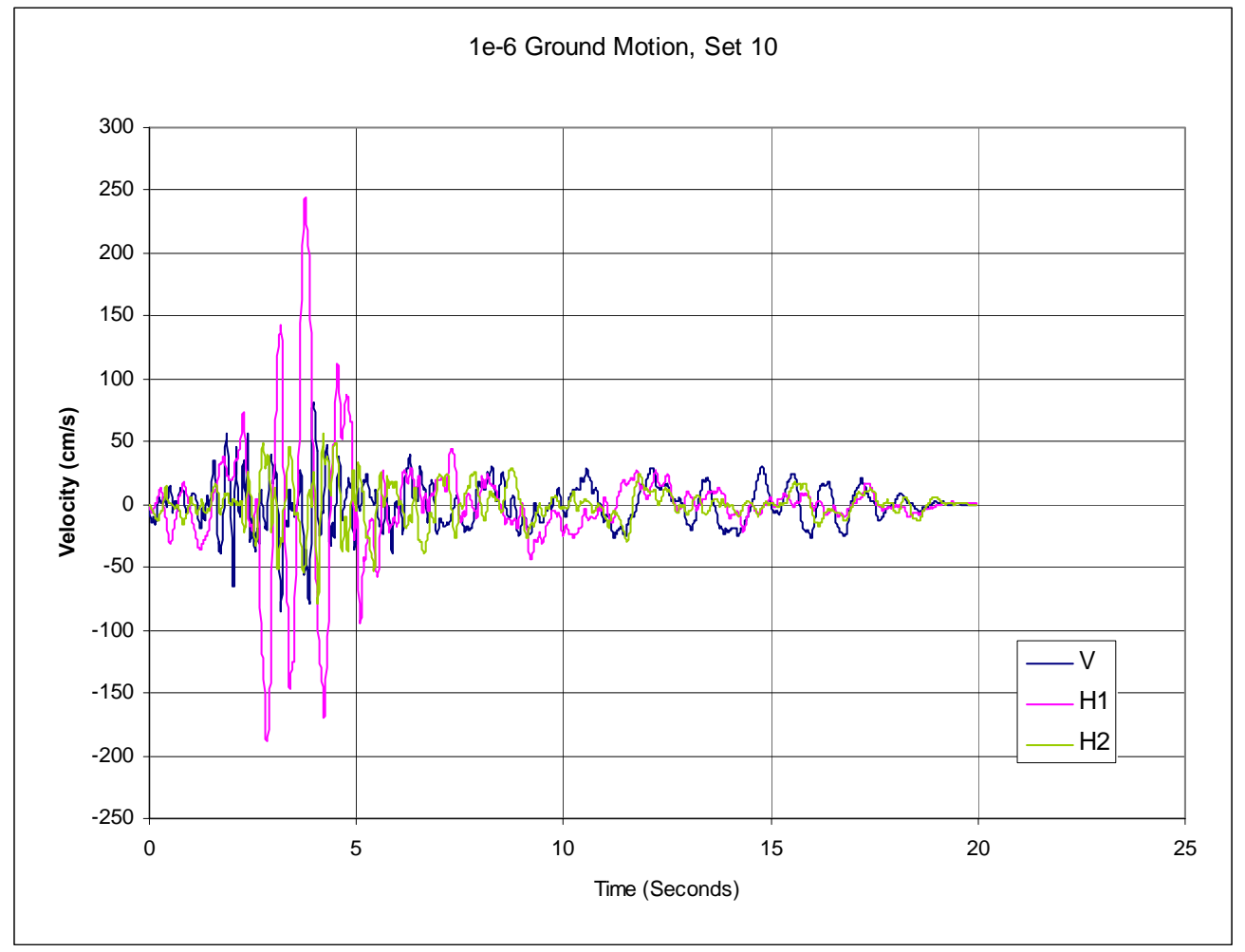

a)

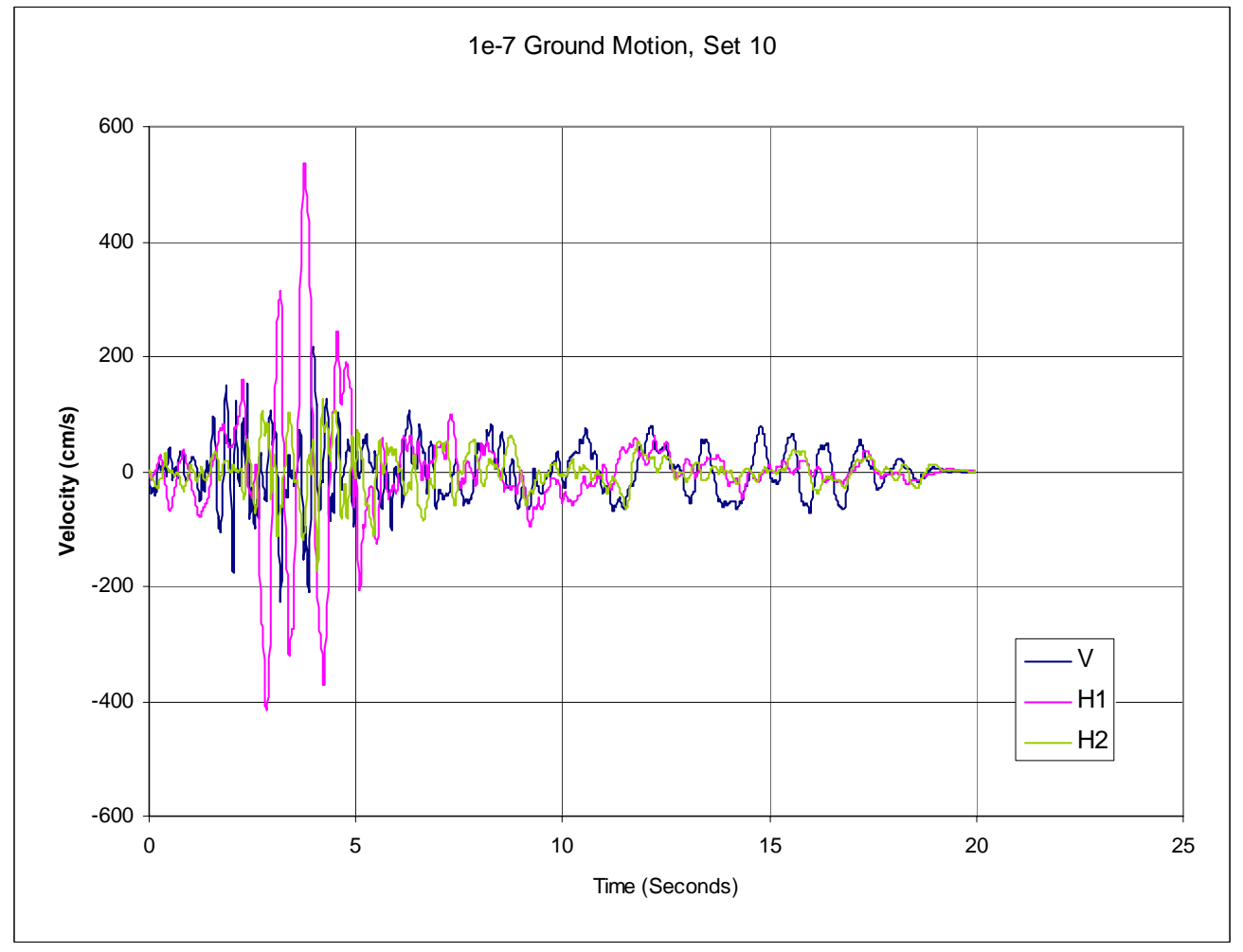

b)

Figure 6-88. $1 \times 10^{-6}$ (a) and the $1 \times 10^{-7}$ (b) Ground Motion Time Histories in Terms of Peak Ground Velocity for Median Rockfall Condition, Case 45 


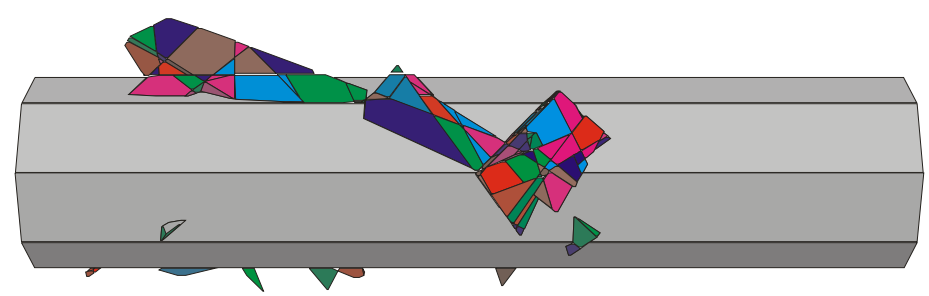

Top View

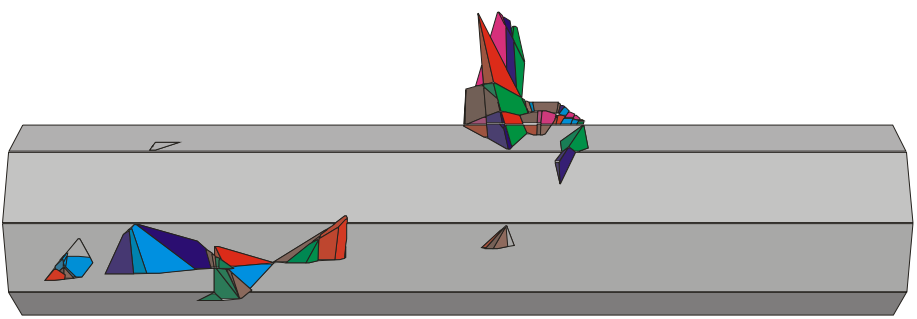

Side View

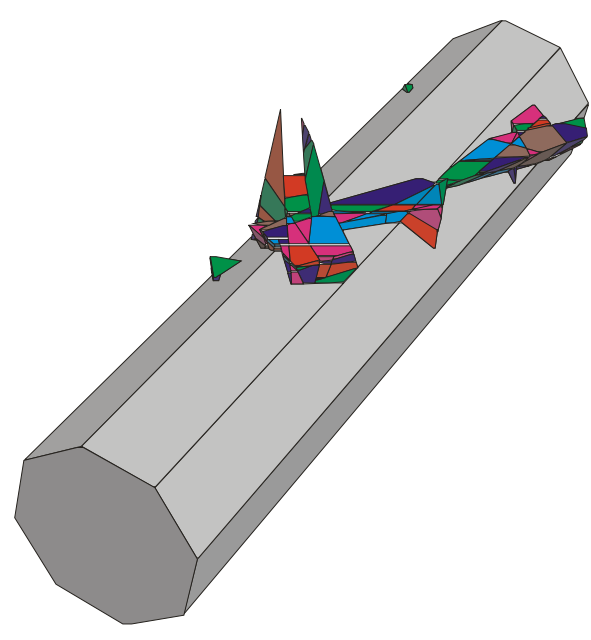

Perspective View

a)

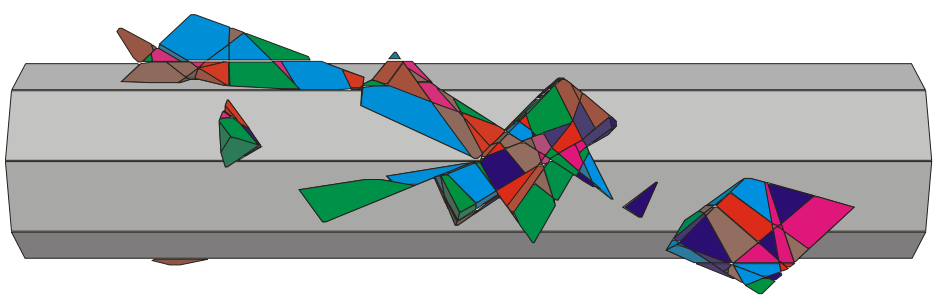

Top View

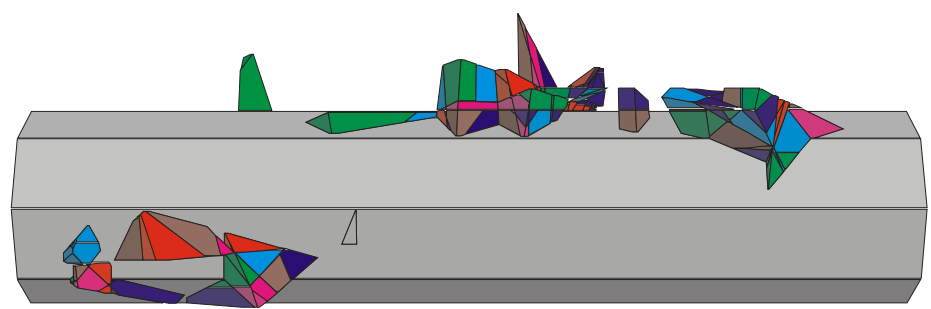

Side View

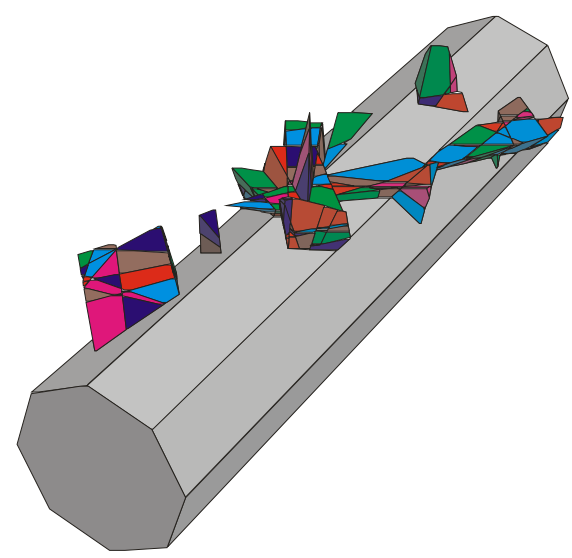

Perspective View

b)

NOTE: Base case rock bridge strength properties given by cohesion of $47.2 \mathrm{MPa}$, friction angle of $42^{\circ}$ and tensile strength of $11.56 \mathrm{MPa}$. Low rock bridge strength properties given by by cohesion of $0.1 \mathrm{MPa}$, friction angle of $41^{\circ}$ and tensile strength of 0 .

Figure 6-89. Three-dimensional Visualization of Rockfall for the Median Rockfall Condition (Case 45), and Base Case (a) and Low (b) Rock Bridge Strength Properties, $1 \times 10^{-6}$ Ground Motion 

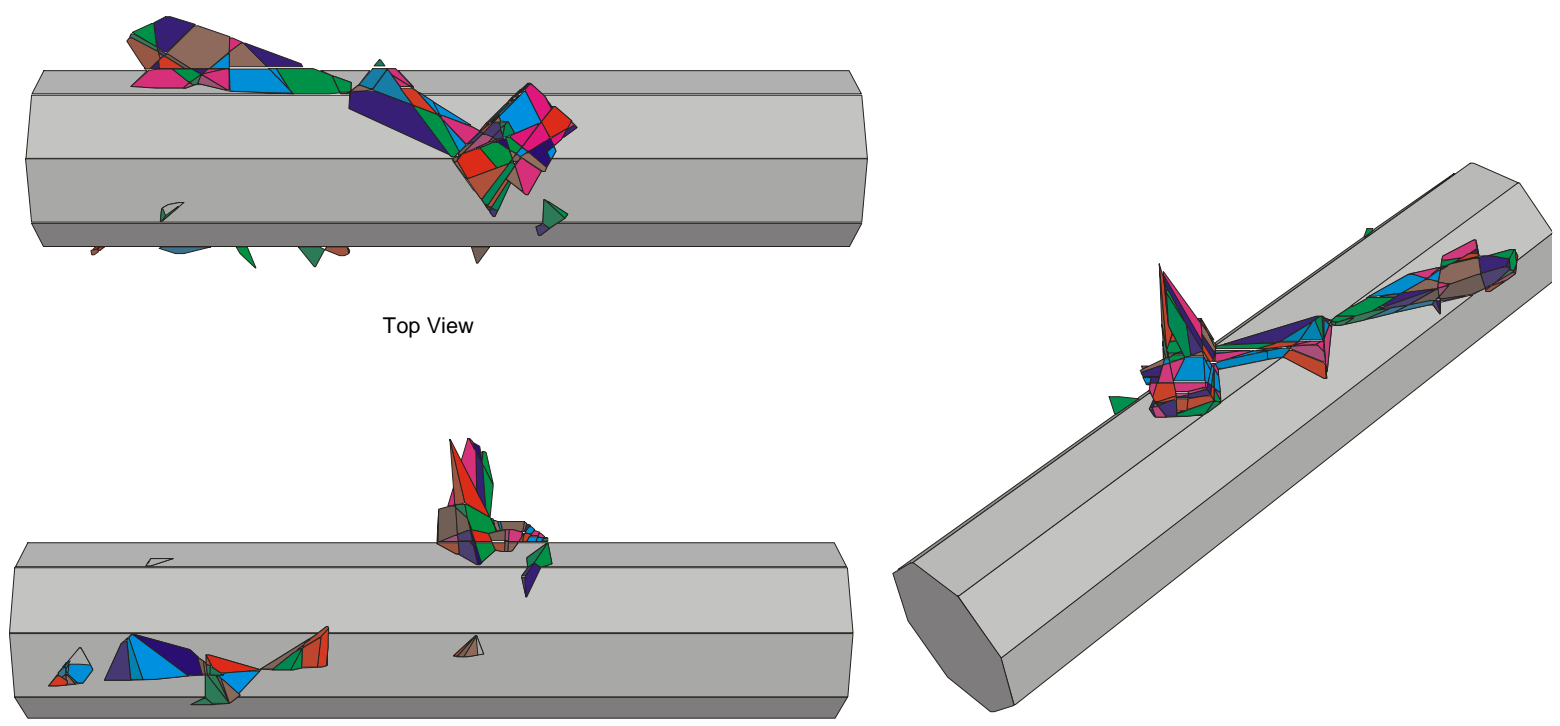

Side View

Perspective View

a)
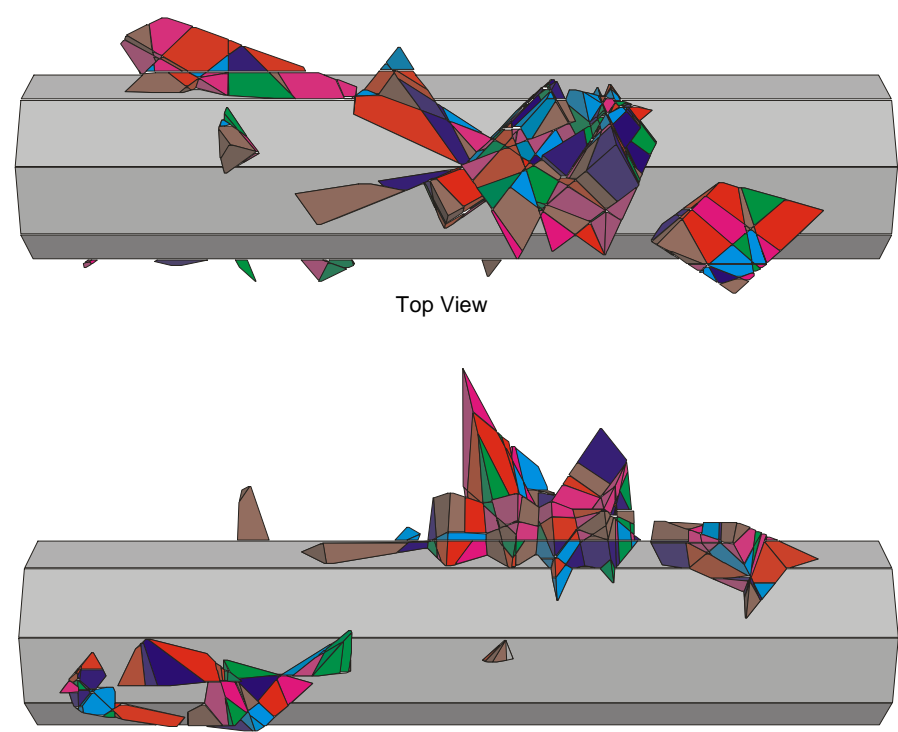

Side View

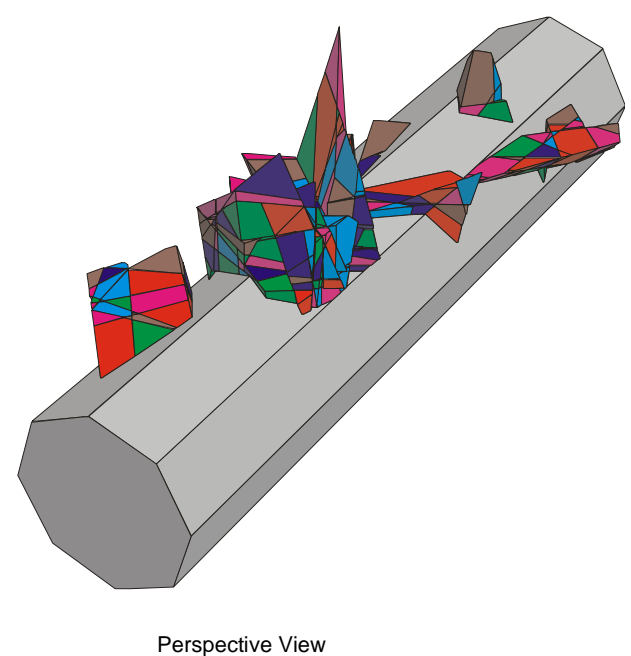

b)

NOTE: Base case rock bridge strength properties given by cohesion of $47.2 \mathrm{MPa}$, friction angle of $42^{\circ}$ and tensile strength of $11.56 \mathrm{MPa}$. Low rock bridge strength properties given by cohesion of $0.1 \mathrm{MPa}$, friction angle of $41^{\circ}$ and tensile strength of 0 .

Figure 6-90. Three-dimensional Visualization of Rockfall for the Median Rockfall Condition (Case 45), and Base Case (a) and Low (b) Rock Bridge Strength Properties, $1 \times 10^{-7}$ Ground Motion

In summary, the rock mass tensile strength is a function of the strength of the solid rock bridges occurring along pre-existing fractures, as well as the geometry of the fractures themselves. The impact of fracture of the solid rock blocks as a potential mechanism in the nonlithophysal rocks was examined via a sensitivity study of the shear and tensile strength of the solid rock bridges. This sensitivity study showed that the damage to rock bridges is an approximate linear function 
of the PGV of the ground motion (Figure 6-86), with a maximum damage for base case rock bridge properties of about 20 percent. The impact of assumption of a conservative rock mass tensile strength was examined by assuming the rock bridges had zero tensile strength. Significantly more rockfall occurs for this case, but total drift collapse in the nonlithophysal rock is still not indicated for any of the ground motions examined.

\subsection{Model Dimension}

As described in Section 6.3.1.1, the 3DEC base case model is slightly larger than a 25-m cube (the actual size is $25 \mathrm{~m} \times 27.5 \mathrm{~m} \times 25 \mathrm{~m}$ ) with the tunnel oriented at 75 degrees azimuth. The region with detail fractures imported from FracMan is one diameter at the side of the tunnel (dimension s) and two diameters on top of the tunnel for the base case (dimension t). Additional analyses with various modeling dimensions were conducted to investigate the sensitivity of model dimension to rockfall prediction. Table 6-34 lists the additional three model dimensions used for the sensitivity runs. The length along the $\mathrm{X}$-axis (15 degrees clockwise from the drift axis) remains constant at $25 \mathrm{~m}$ for all cases (3DEC coordinate system is shown in Figure L-1).

Table 6-34. Various Model Dimension for Sensitivity Study

\begin{tabular}{|l|l|l|l|}
\hline \multicolumn{1}{|c|}{ Model Size } & \multicolumn{1}{c|}{ Model Dimension $(\mathbf{m})$} & \multicolumn{1}{c|}{$\mathbf{~}(\mathbf{m})$} & \multicolumn{1}{c|}{$\mathbf{t}(\mathbf{m})$} \\
\hline Small & $25 \times 25 \times 25$ & 2.75 & 5.5 \\
\hline base case & $25 \times 27.5 \times 25$ & 5.5 & 11 \\
\hline large 1 & $25 \times 33.75 \times 30$ & 8 & 16.5 \\
\hline large 2 & $25 \times 38.75 \times 37.5$ & 11 & 22 \\
\hline
\end{tabular}

$\mathrm{s}=$ horizontal distance away from the side wall; $\mathrm{t}=$ vertical distance away from the roof

Cases 38, 45, and 63 with $1 \times 10^{-5}$ ground motions were selected for the sensitivity study to cover the range of rockfall prediction. Figure 6-91 shows the cross-sectional views of Case 45 (the median rockfall case) for the four various dimensions. The predicted rockfall for the four model dimensions are presented in Table 6-35. In general, the four models predict a similar amount of rockfall. The exception is the small model for Case 38 that predicts approximately 40 percent less rockfall than the base case. In all, the base case appears to be adequate to provide a reasonable estimate for rockfall. 


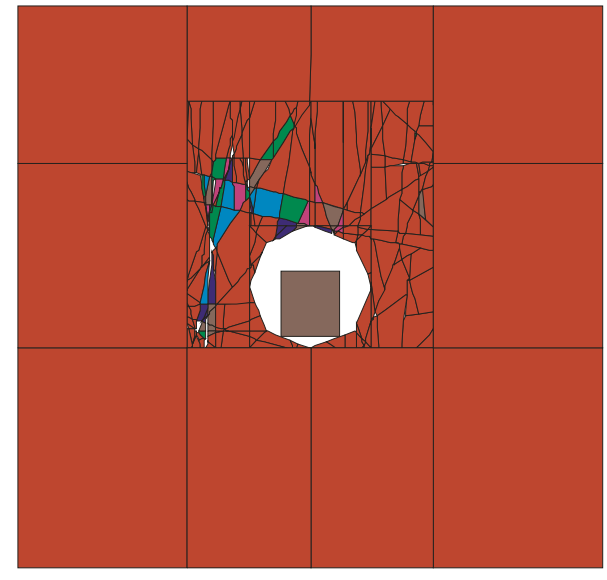

Small $(25 \times 25 \times 25)$

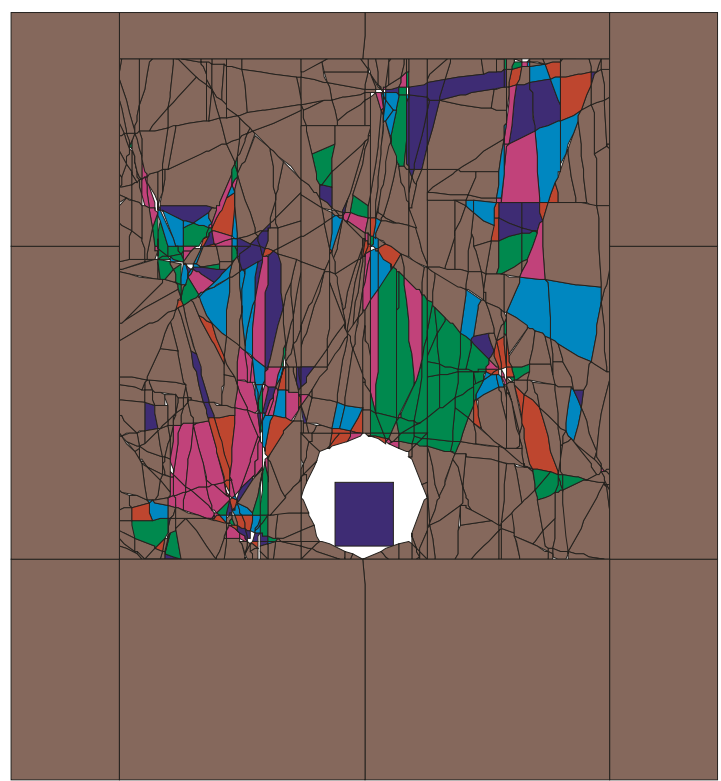

Large $1(25 \times 33.75 \times 30)$

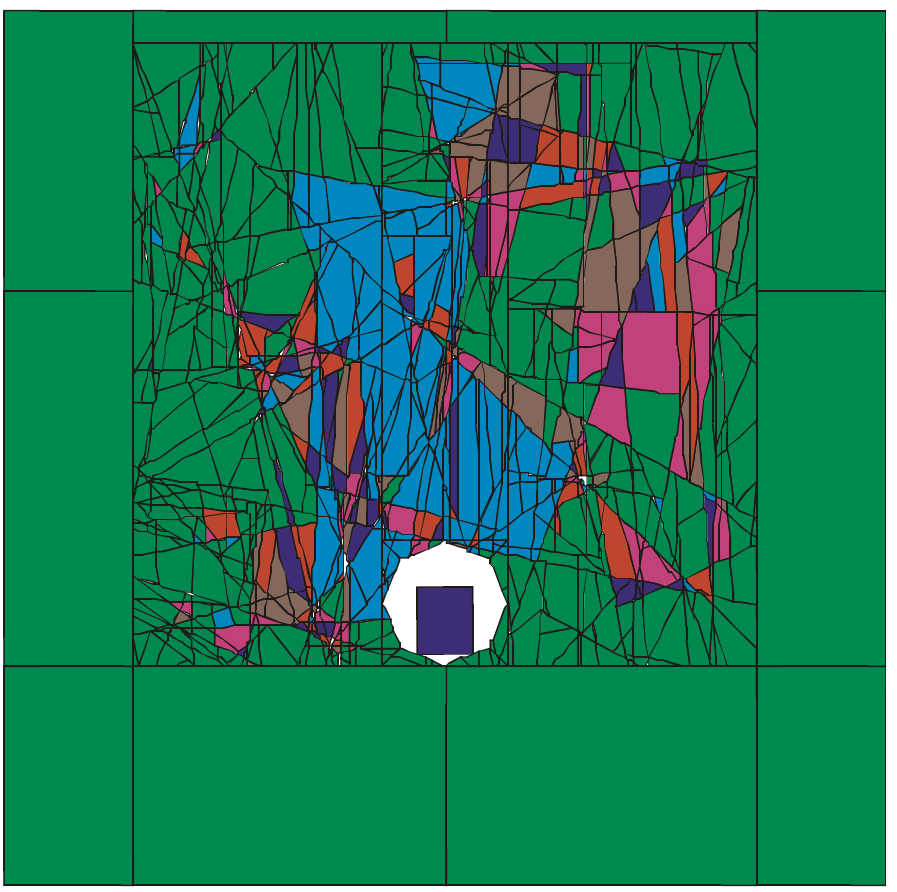

Large $2(25 \times 38.75 \times 37.5)$

Base Case (25x27.5x25)

Figure 6-91. Cross Section of the Four Model Dimensions Selected for Sensitivity Study, Case 45 
Table 6-35. Predicted Rockfall for Various Model Dimensions

\begin{tabular}{|l|l|c|c|c|c|c|c|}
\hline \multirow{2}{*}{$\begin{array}{c}\text { Model } \\
\text { Size }\end{array}$} & $\begin{array}{c}\text { Model } \\
\text { Dimension }\end{array}$ & $\begin{array}{c}\text { Number of } \\
\text { Blocks }\end{array}$ & $\begin{array}{c}\text { Rockfall } \\
\left.\text { Volume } \mathbf{( m}^{\mathbf{3}}\right)\end{array}$ & $\begin{array}{c}\text { Number of } \\
\text { Blocks }\end{array}$ & $\begin{array}{c}\text { Rockfall } \\
\text { Volume }\left(\mathbf{m}^{\mathbf{3}}\right)\end{array}$ & $\begin{array}{c}\text { Number of } \\
\text { Blocks }\end{array}$ & $\begin{array}{c}\text { Rockfall } \\
\text { Volume }\left(\mathbf{m}^{\mathbf{3}}\right)\end{array}$ \\
\hline small & $25 \times 25 \times 25$ & 157 & 27.33 & 13 & 2.29 & 0 & 0 \\
\hline base case & $25 \times 27.5 \times 25$ & 173 & 42.03 & 14 & 2.49 & 0 & 0 \\
\hline large 1 & $25 \times 33.75 \times 30$ & 179 & 54.61 & 15 & 2.51 & 6 & 0.68 \\
\hline large 2 & $25 \times 38.75 \times 37.5$ & 154 & 34.29 & 14 & 2.38 & 3 & 0.41 \\
\hline
\end{tabular}

\subsection{Block Deletion}

As described in Section 6.3.1.1, a drip shield block anchored at the invert is included in the model to record the information of the locations and relative velocities for the rockfall impact. An algorithm was developed to delete the fallen block after the impact. The deletion is to facilitate the recording of all possible rockfall on the drip shield. If the blocks are not deleted for the heavy rockfall cases, the drip shield will be covered with fallen rocks so that some of the rockfall at the later part of seismic shaking will not directly impact the drip shield. The two cases with the most rockfall subjected to $1 \times 10^{-7}$ ground motions (Case 64 [Fracture Pattern 49 and Ground Motion 14] and Case 40 [Fracture Pattern 99 and Ground Motion 6]) are selected to assess the impact of no deletion to rockfall prediction.

Figures 6-92 and 6-93 show the two selected cases in which the block deletion algorithm is not included. As expected, with the fallen blocks piled on the drip shield, the blocks on top do not directly impact the drip shield. Table 6-36 compares the results for rockfall prediction with and without the block deletion algorithm. Rockfall volume for the cases without block deletion is approximately half of the amount for the cases with block deletion. The effect of blocks not directly impacting the drip shield will be the dead load added onto the drip shield. The accumulation of dead load on top of the drip shield for the fallen rock is addressed in Section 6.4.2.5.

Table 6-36. Predicted Rockfall With and Without Block Deletion After Impact

\begin{tabular}{|c|c|c|c|c|}
\hline \multirow{2}{*}{ Case } & \multicolumn{2}{|c|}{ With Block Deletion } & \multicolumn{2}{c|}{ Without Block Deletion } \\
\cline { 2 - 5 } & Number of Blocks & $\begin{array}{c}\text { Rockfall Volume } \\
\left(\mathbf{m}^{3}\right)\end{array}$ & Number of Blocks & $\begin{array}{c}\text { Rockfall Volume } \\
\left(\mathbf{m}^{3}\right)\end{array}$ \\
\hline 64 & 269 & 58.93 & 186 & 28.69 \\
\hline 40 & 120 & 51.29 & 69 & 20.49 \\
\hline
\end{tabular}




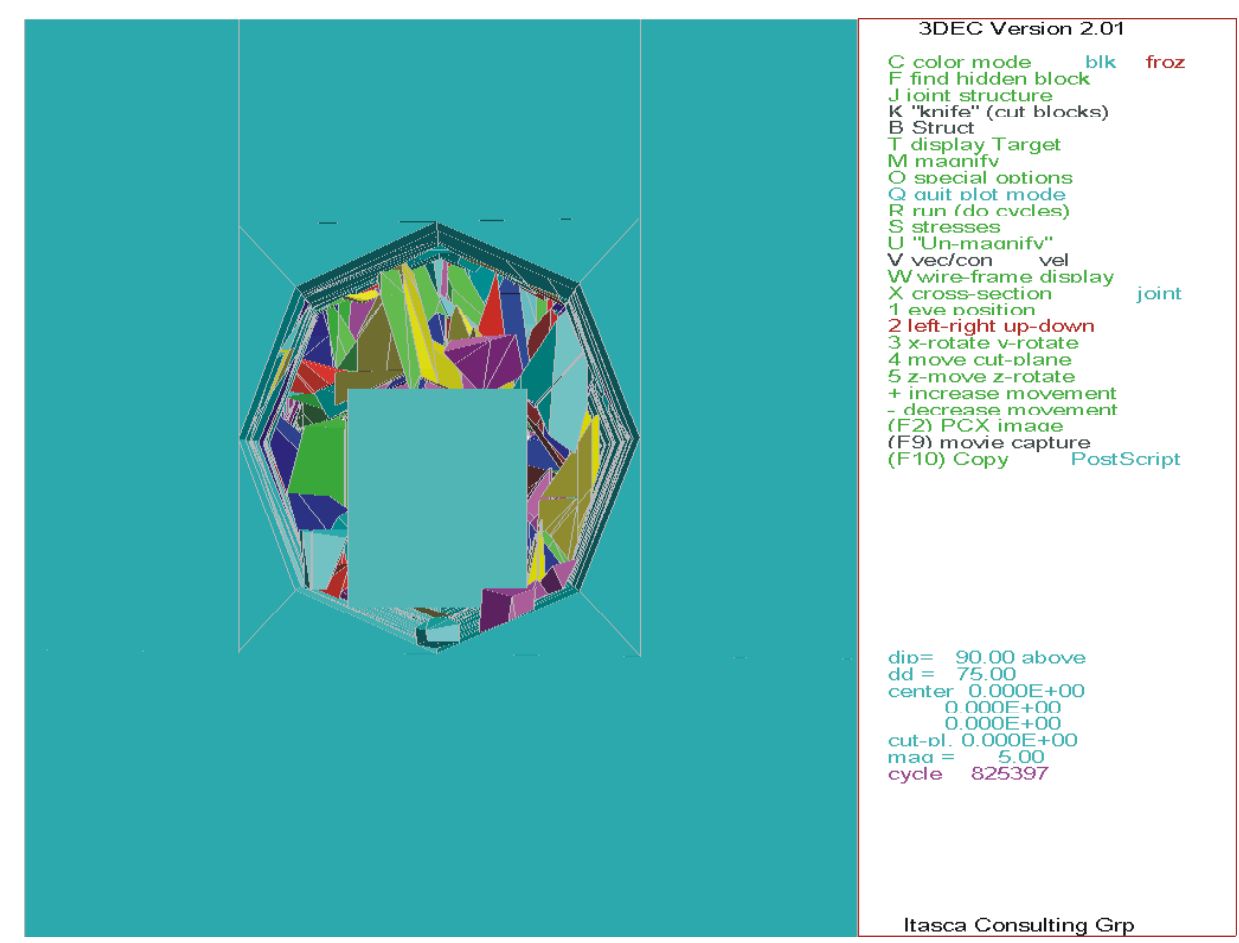

Figure 6-92. Blocks Accumulated Above the Drip Shield Without Implementing Block Deletion Algorithm, Case 64, Fracture Pattern 49, $1 \times 10^{-7}$ Ground Motion Set \#14

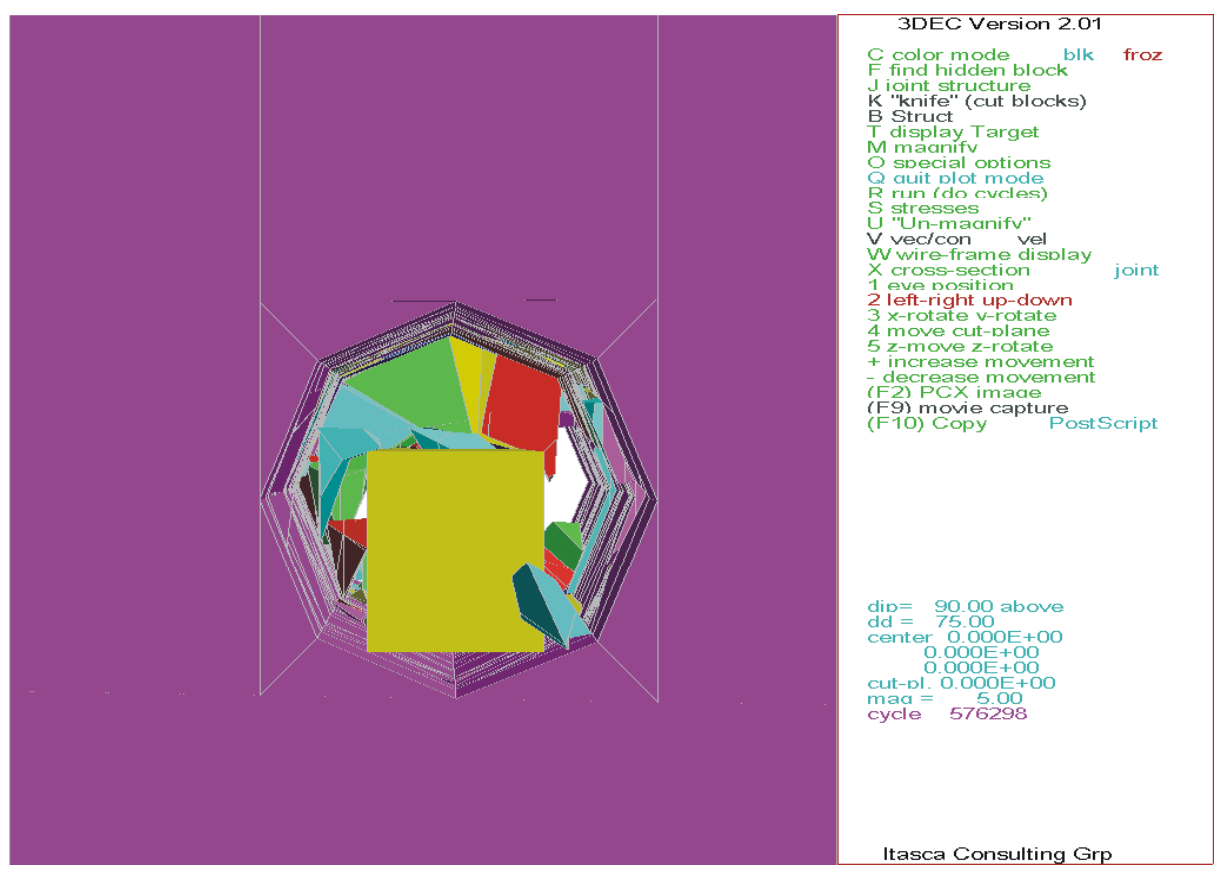

Figure 6-93. Blocks Accumulated Above the Drip Shield Without Implementing Block Deletion Algorithm, Case 40, Fracture Pattern 99, $1 \times 10^{-7}$ Ground Motion Set \#6 


\subsubsection{Consideration of Intensely Fractured Zone}

\subsubsection{Introduction}

An intensely fractured zone is observed at ESF main loop Stations $42+00$ to $51+50$ with an approximate 1000-m length. A description of this fracture zone is provided in Geology of the Main Drift - Station 28+00 to 55+00, Exploratory Studies Facility, Yucca Mountain Project, Yucca Mountain, Nevada (Albin et al. 1997 [DIRS 101367], p. 58):

The fracture zone between Sta. $42+00$ and $51+50$ is a zone of intense Set 1 fracturing. This zone appears to be strata bound within the Tptpmn. The zone does not crop out on the surface. Down-hole video from drill hole SD-12, located $39.4 \mathrm{~m}$ west of tunnel Sta. 46+49, shows a similar zone of intensely fractured rock only within the Tptpmn. The Main Drift in the area of the fracture zone is parallel to the Ghost Dance Fault and is approximately $100 \mathrm{~m}$ west of and in the hanging wall of the fault. It is not known whether the fracture zone is continuous across the Ghost Dance fault as only limited information exists east of the Main Drift.

According to Albin et al. (1997 [DIRS 101367]), the two likely hypotheses for the origin of this zone are tectonic and/or cooling of the ash-flow sheet. Figures 6-94 and 6-95 show the intensely fractured rock mass with a predominant joint set of 134/83 (strike/dip). Set 2 and Set 3 fractures are sparse compared to Set 1 fractures. The mean and median joint spacing for the predominant Set 1 fractures were calculated to be $0.24 \mathrm{~m}$ and $0.12 \mathrm{~m}$, respectively.

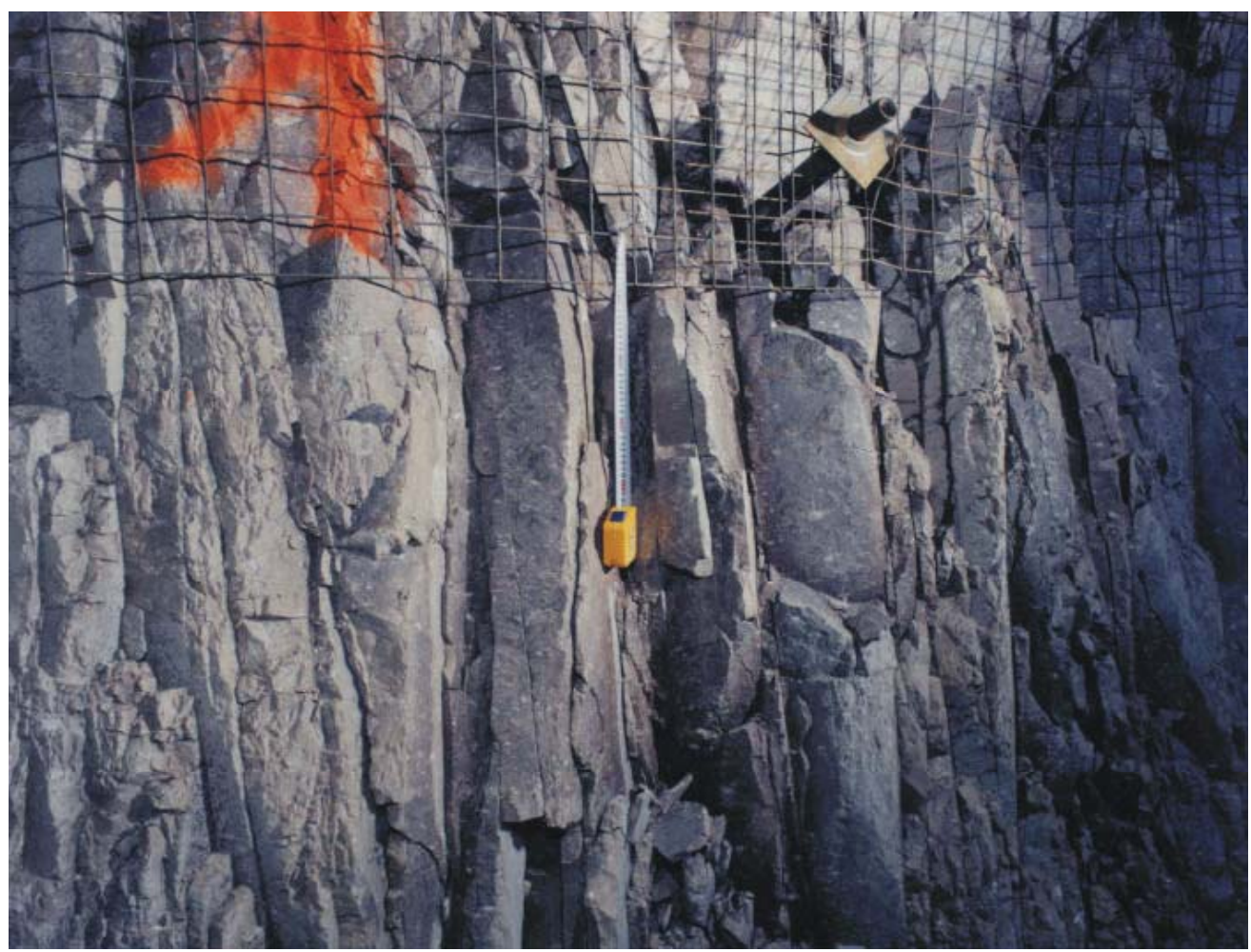

Figure 6-94. Photo Showing the Intensely Fractured Zone in ESF Main Drift 

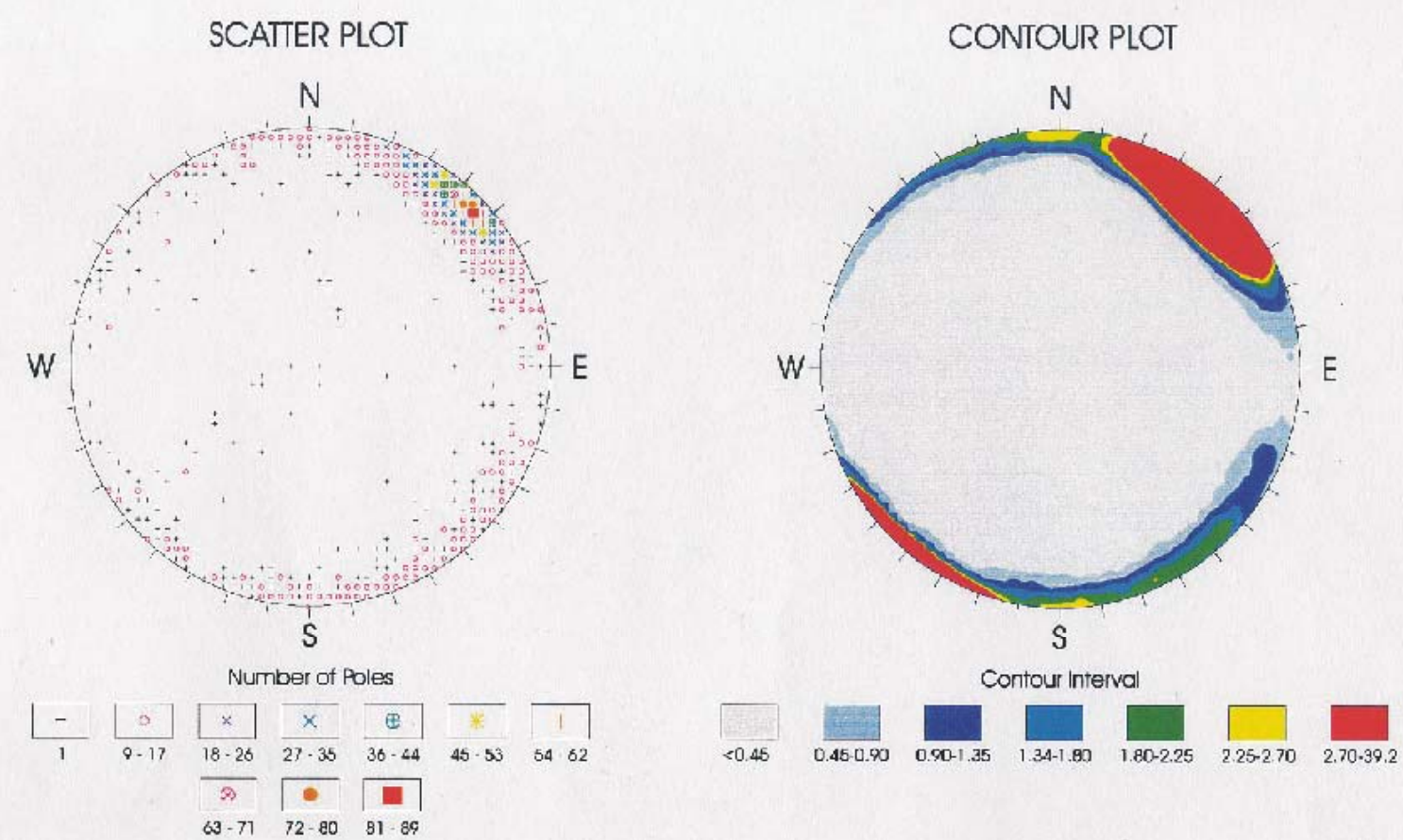

STRIKE ROSE PLOT
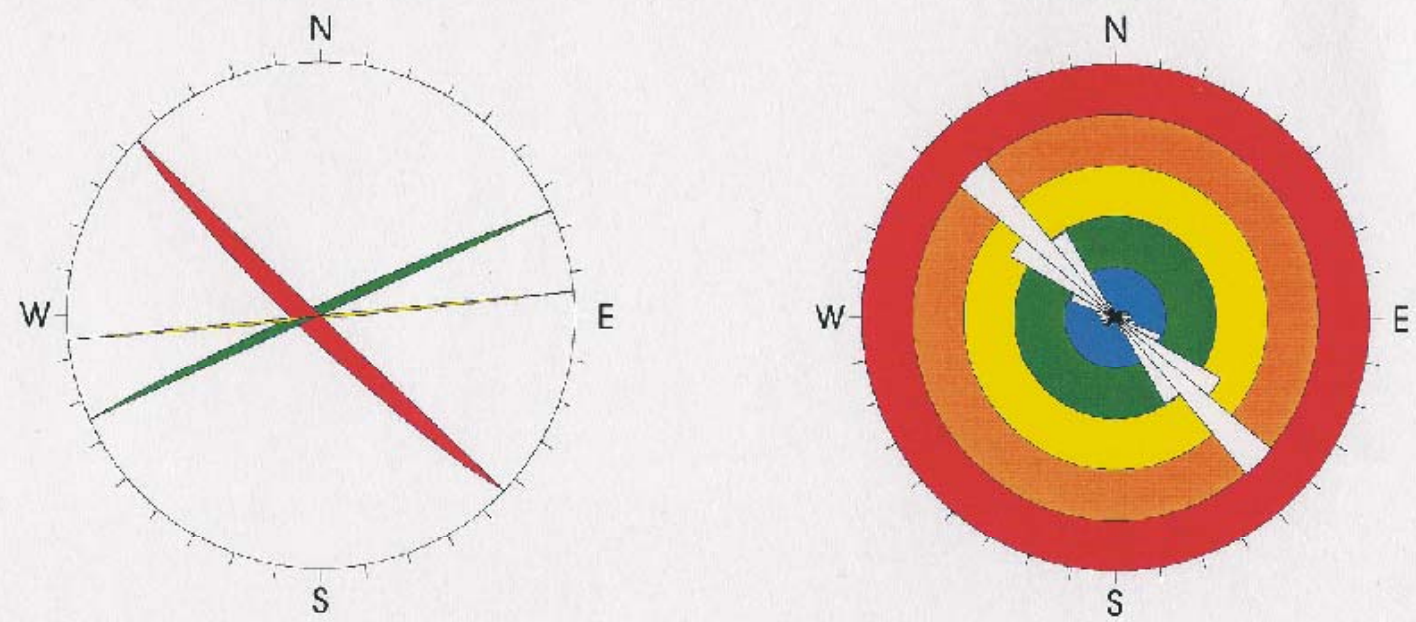

Plane Orientation

Number of Poles
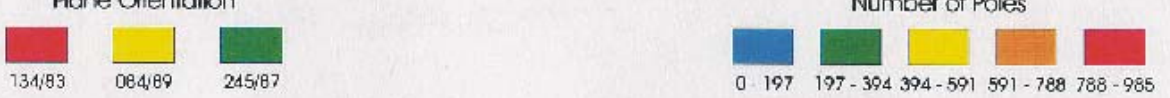

Source: CRWMS M\&O 1998 [DIRS 102679], p. II-66.

Figure 6-95. Fracture Analysis for the Intensely Fractured Zone 


\subsubsection{Numerical Modeling}

A 3DEC analysis, which is used for rockfall modeling of the nonlithophysal jointed rock mass, is not suitable for such highly fractured rock. A three-dimensional continuum analysis with ubiquitous joint model (FLAC3D analysis) was adopted to account for the highly fractured and anisotropic nature of the rock mass in this zone. The ubiquitous joint model is ideal for conditions with one predominant fracture set in the rock mass.

Figure 6-96 shows a 25-m cube FLAC3D model constructed for the analysis. To simplify the model, the tunnel axis was oriented parallel to the y-axis and the input fracture orientation was adjusted based on the coordinate system shown in Figure 6-96. The intact rock deformation properties and joint strength properties used in the model are identical to the 3DEC base case model presented in Table 6-3. A typical modeling sequence was simulated with initial consolidation and tunnel excavation. The lateral and bottom boundaries were fixed at the direction normal to the boundary surface, whereas the in situ static pressure was applied to the top boundary for the consolidation and excavation stages. Both the preclosure seismic motion $\left(5 \times 10^{-4}\right.$ seismic ground motion) and the postclosure seismic motion $\left(1 \times 10^{-6}\right.$ seismic ground motion Set 1 (DTN MO0301TMHIS106.001, see Appendix X)) were applied to the model with free-field boundary condition imposed. These analyses do not include thermal loading.
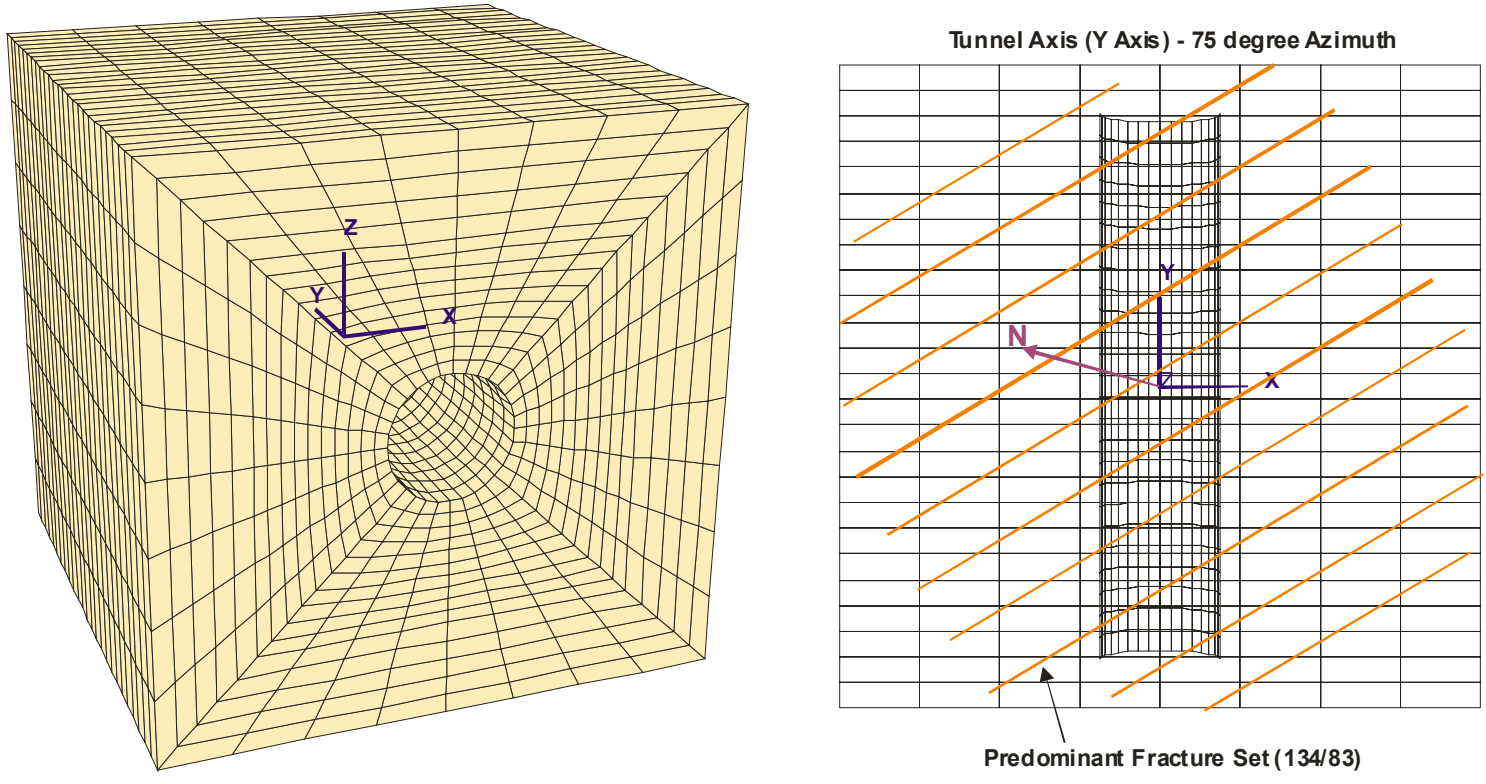

Figure 6-96. FLAC3D Model Mesh and Fracture Orientation 
Figures 6-97 to 6-99 show the yield state, in-plane shear stress contours, and principal stress tensor for the $5 \times 10^{-4}$ preclosure seismic analysis after approximately 29 seconds of ground motion. The same set of figures for the postclosure seismic analysis is presented in Figures 6-100 to 6-102. Yielding is confined within an element around the opening for the $5 \times 10^{-4}$ preclosure analysis as shown in Figure 6-97. The drift appears to be stable for the entire duration of seismic shaking in this case. However, extensive yielding is observed in the model region for both the $1 \times 10^{-4}$ preclosure and postclosure seismic analyses. The extensile stresses imposed by the large amplitude of seismic motion exceed the in situ compressive stress on the ubiquitous joint planes, tensile and shear failure is observed at these planes. The stress path of shear and normal stresses at the roof projected onto the predominant joint plane are presented in Figures 6-103 and 6-104 for the preclosure $\left(5 \times 10^{-4}\right.$ seismic ground motion) and postclosure $\left(1 \times 10^{-6}\right.$ seismic ground motion set 1$)$ analyses, respectively. Perturbation of stresses is minor in the preclosure case, whereas large stress variation is observed in the postclosure case. The stress states at the predominant joint plane reach the Mohr-Coulomb failure envelope under the postclosure seismic motion as shown in Figure 6-104.

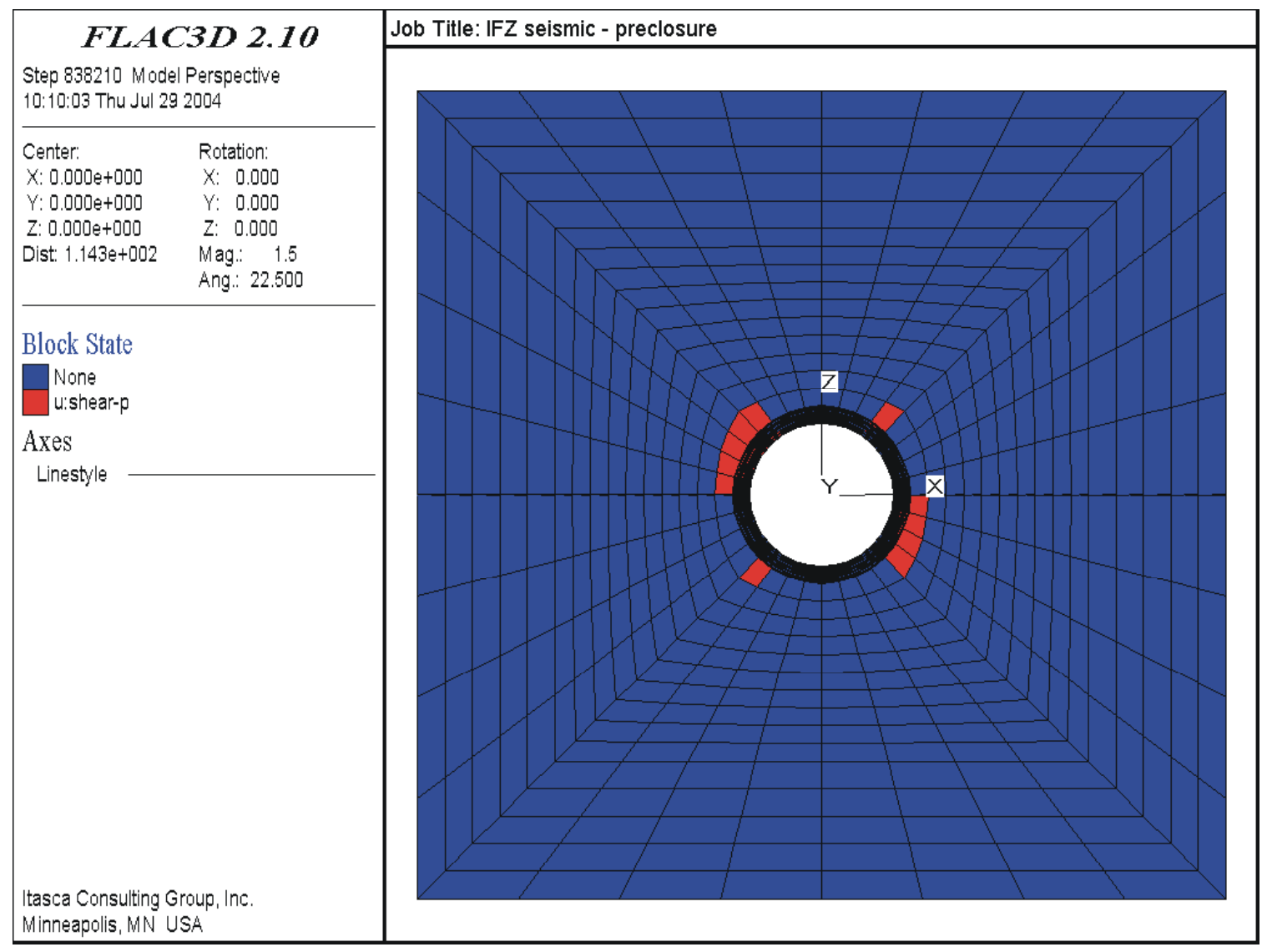

Figure 6-97. Yield State Prediction $-5 \times 10^{-4}$ Preclosure Ground Motion at 29 Seconds 


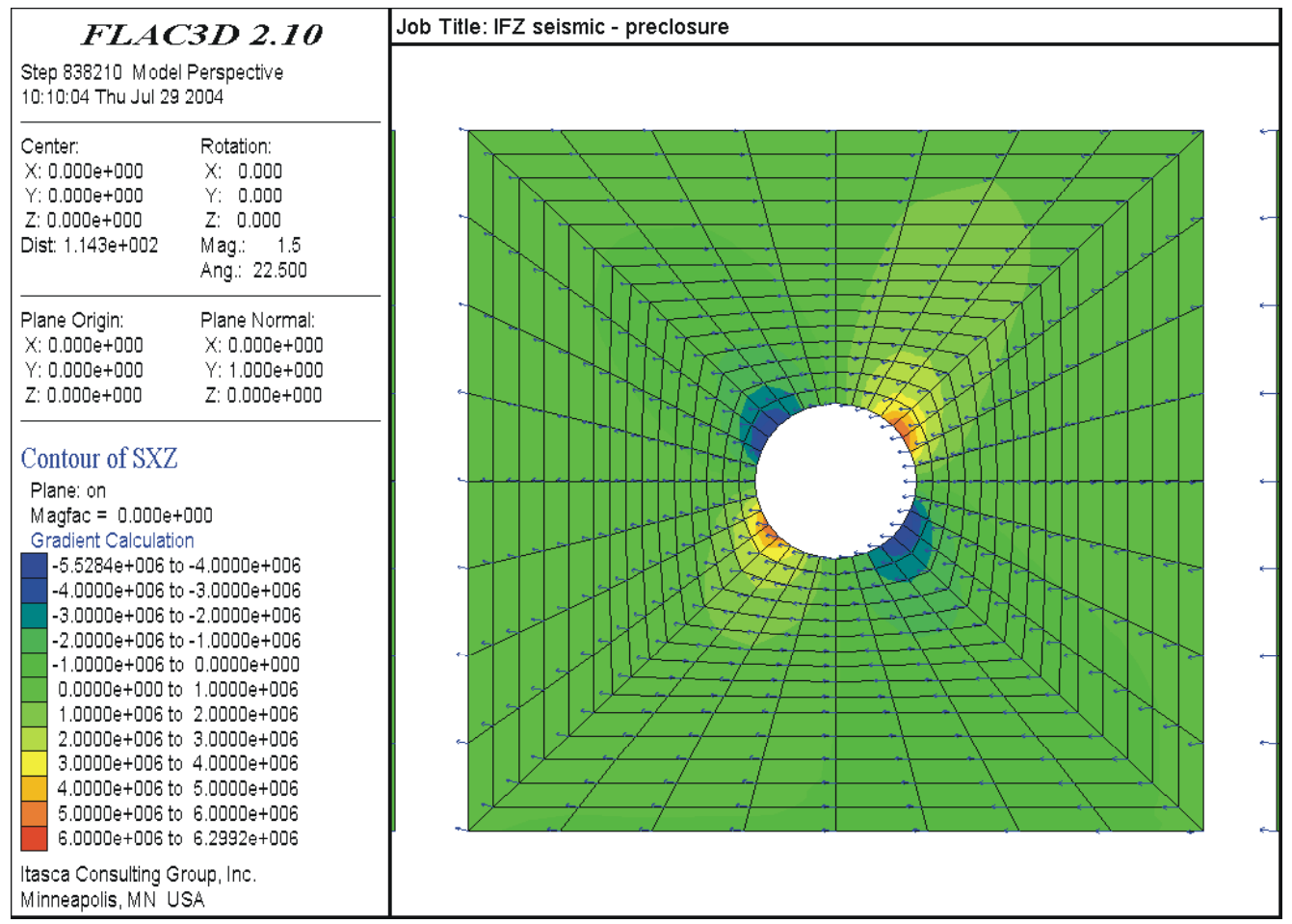

Figure 6-98. In-Plane Shear Stress Contours $-5 \times 10^{-4}$ Preclosure Ground Motion at 29 Seconds

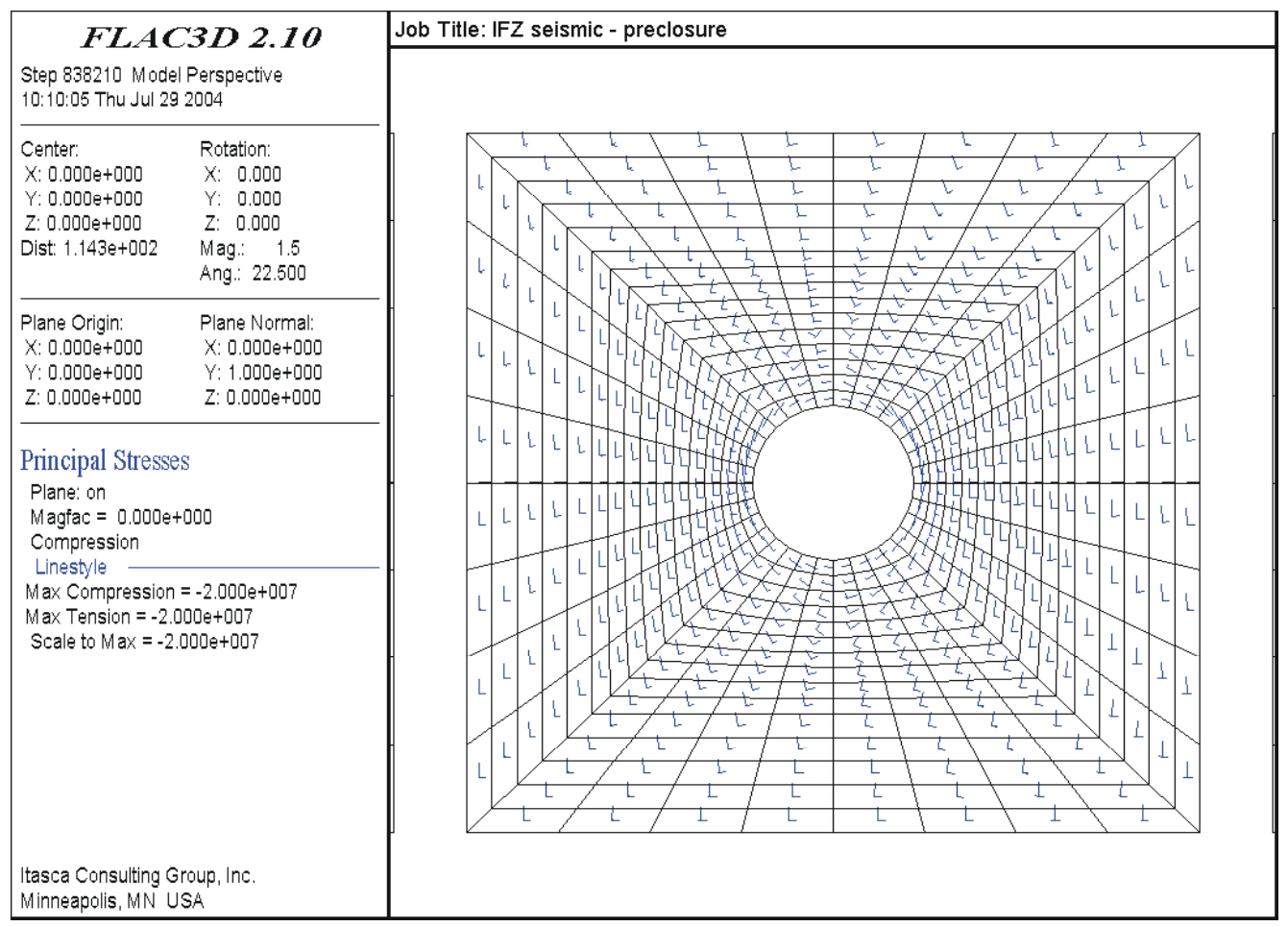

Figure 6-99. Principal Stress Tensor $-5 \times 10^{-4}$ Preclosure Ground Motion at 29 Seconds 


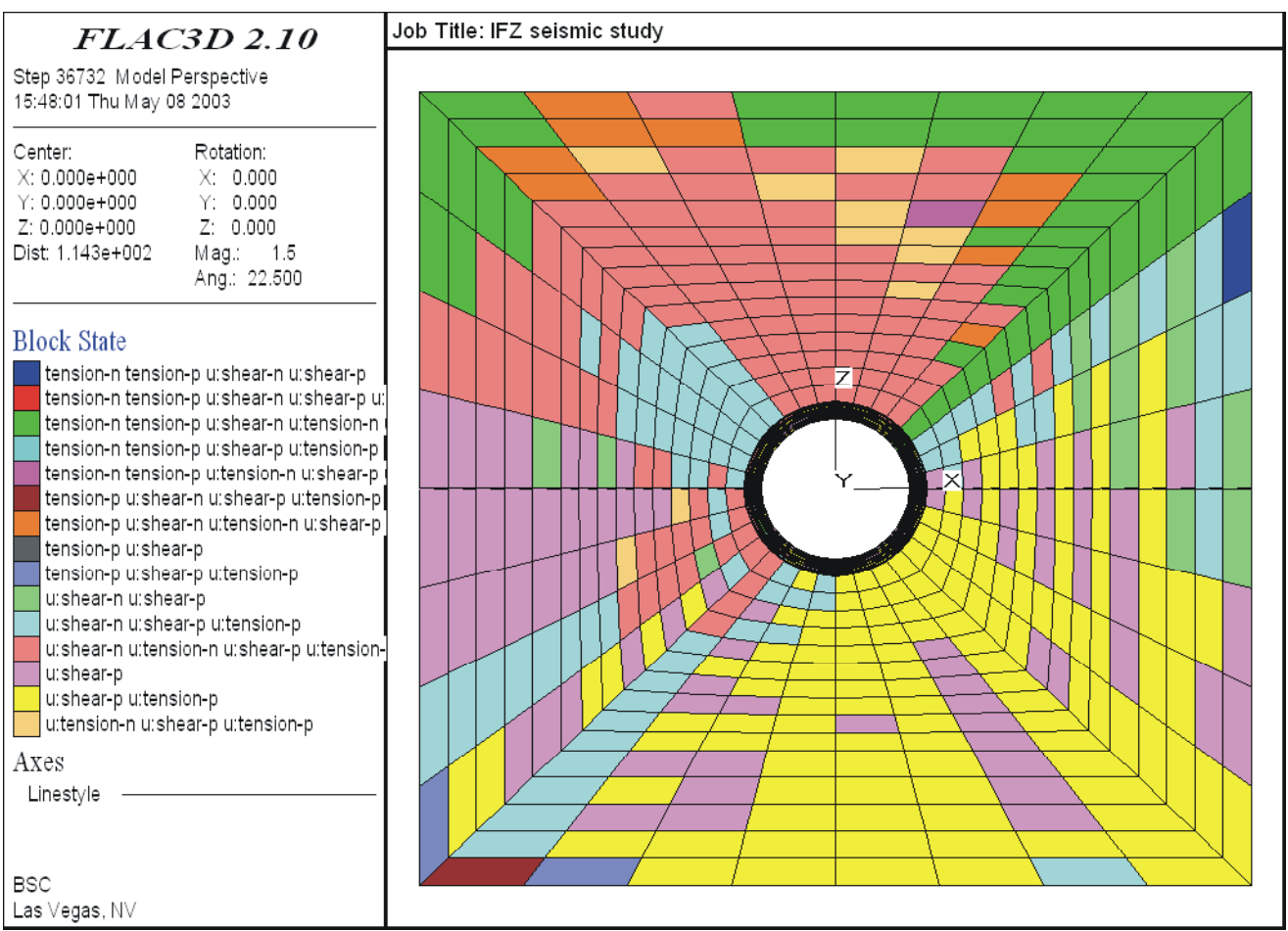

Figure 6-100. Yield State Prediction - Postclosure Ground Motion at Two Seconds

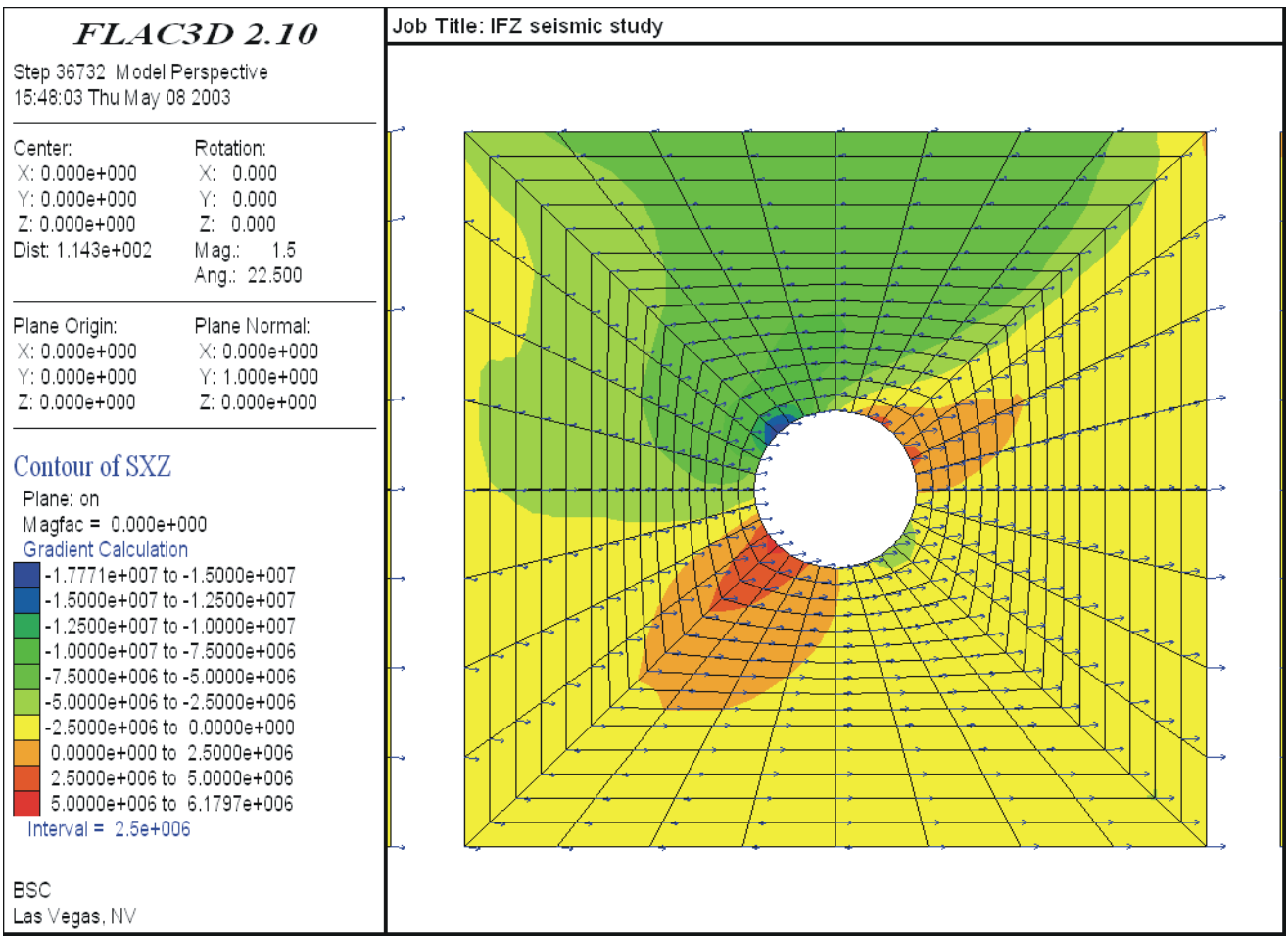

Figure 6-101. In-Plane Shear Stress Contours - Postclosure Ground Motion at Two Seconds 


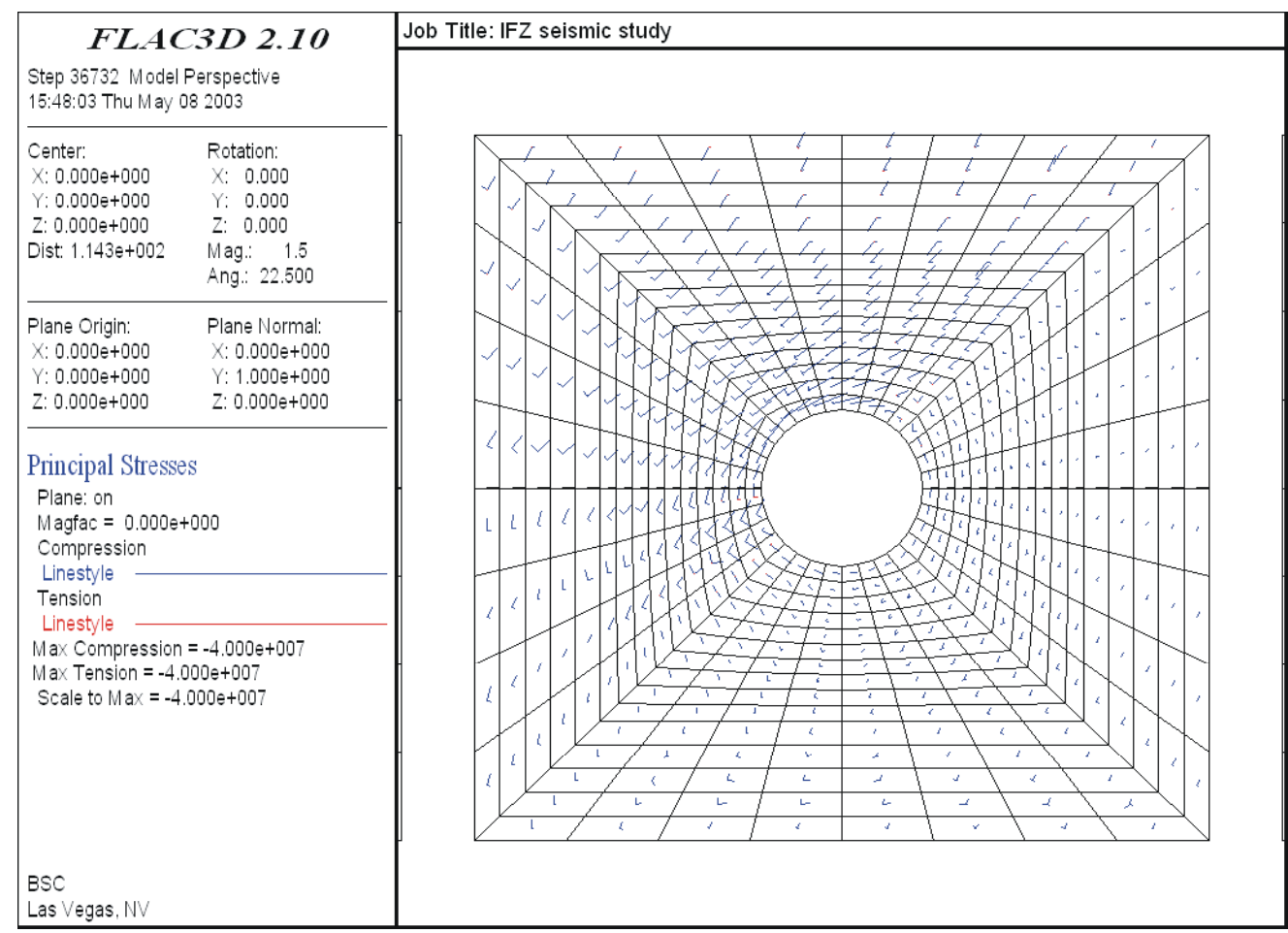

Figure 6-102. Principal Stress Tensor - Postclosure Ground Motion at Two Seconds

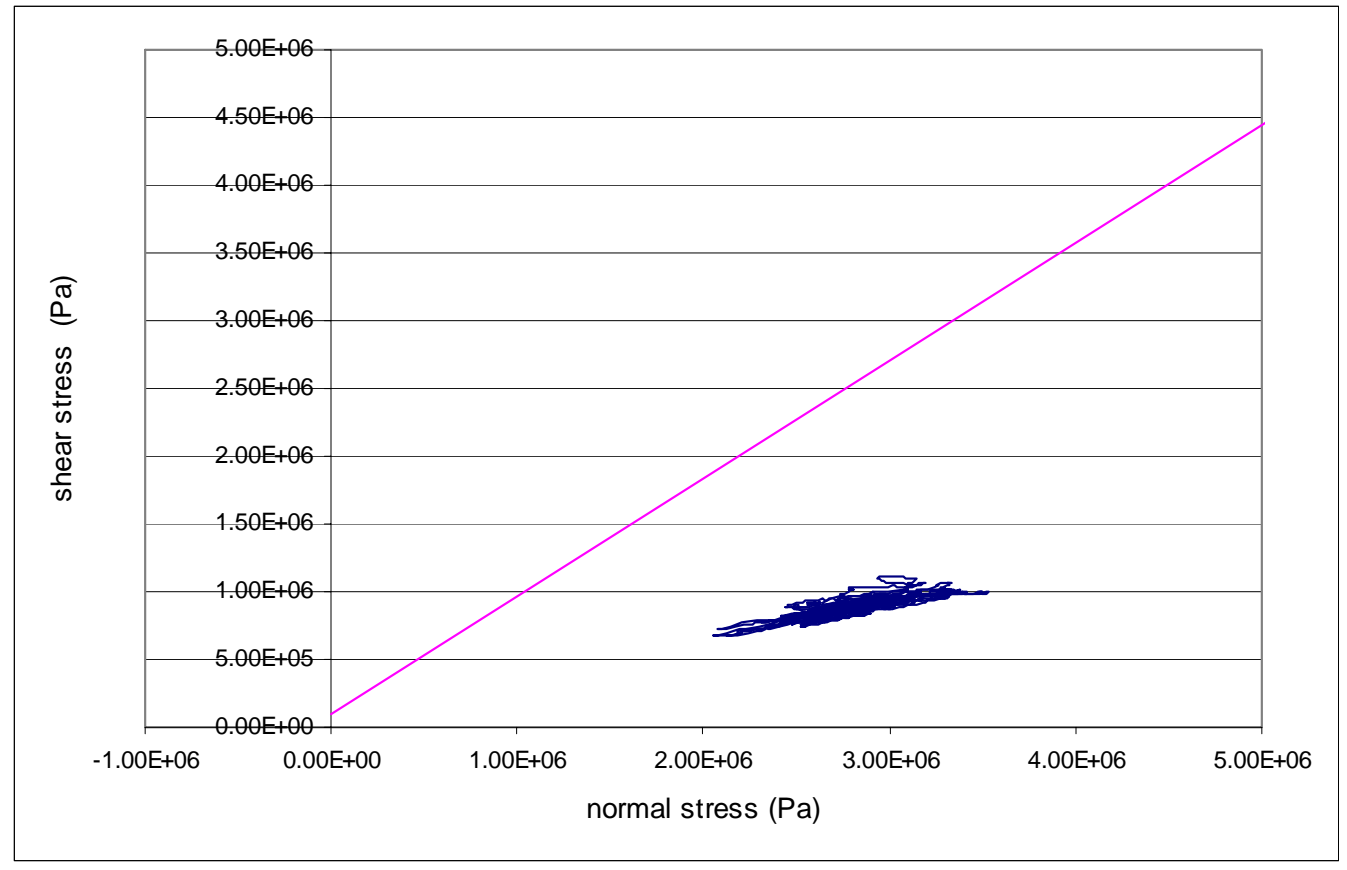

Figure 6-103. Stress Path at Roof Under Preclosure Seismic Motion 


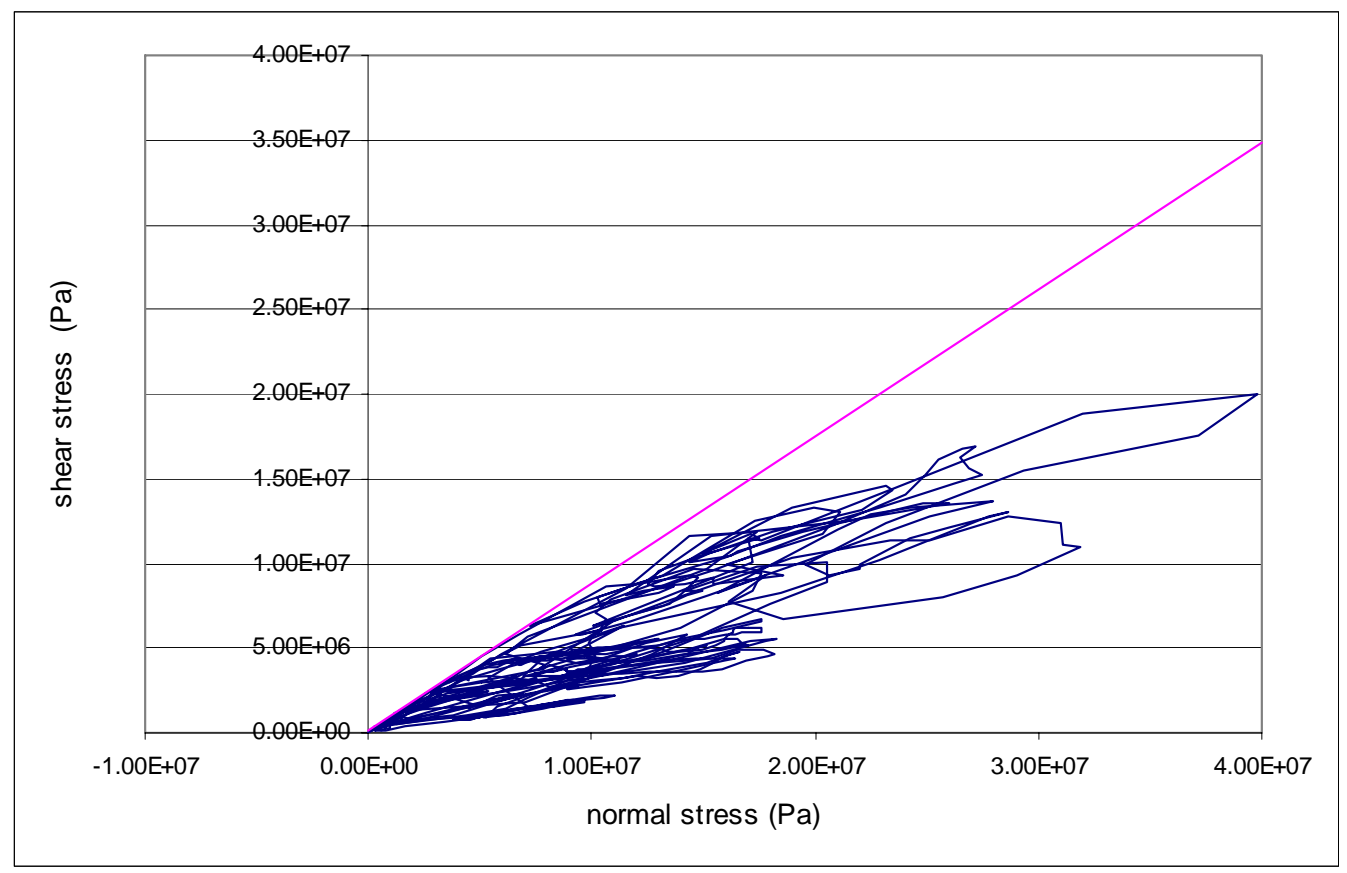

Figure 6-104. Stress Path at Roof Under Postclosure Seismic Motion

The ubiquitous joint model used in the analysis considers through-going joints in the model region. However, rock bridges do exist and will provide additional strength to resist the extensile and shear strains induced by the seismic motions. The prediction of yielding in the model region for the postclosure ground motion is therefore conservative. Based on the FLAC3D analysis results presented in this section, and the spalling type of failure predicted in Section 6.3.1.6, extensive failure around the drift opening is likely.

\subsubsection{Impact of Small-Scale Fractures on Rockfall in Nonlithophysal Units}

Small-scale fractures were mapped in six 6-m panels (DTN: GS040108314224.001 [DIRS 169591]) as described in Section 6.1.4.1. Two of the six panels are located in the Tptpmn unit (Stations 11+15 and 13+00). The small-scale fracture data in these two panels are used in this study to determine their impact to block formation. The ranges of fracture traces mapped in these two panels are tabulated in Table 6-37 and presented in Figure 6-105. As shown in Figure $6-105$, the fracture trace length distributions are the typical negative exponential nature with the concentration in the range of $10 \mathrm{~cm}$ to $20 \mathrm{~cm}$. The fractures with trace lengths longer than $1 \mathrm{~m}$ account for less than 20 percent of the fractures mapped in these two panels.

Due to the extraordinary computational effort, it is not practical to incorporate the small trace length fractures into a distinct block code, such as 3DEC used in the seismic and thermal analysis presented in Section 6.3.1. The probabilistic key-block code DRKBA, with an efficient key-block simulation algorithm, is therefore selected to assess the impact of small-scale fractures to rockfall. The assessment is based on a static condition with comparison of the results of two cases: including the small-scale fractures and excluding the small-scale fractures. 
Table 6-37. Range of Fracture Traces in Panels $11+15$ and 13+00

\begin{tabular}{|c|c|c|}
\hline Trace Length Bin(m) & Frequency & Cumulative \% \\
\hline 0 & 0 & $.00 \%$ \\
\hline 0.1 & 87 & $22.25 \%$ \\
\hline 0.2 & 112 & $50.90 \%$ \\
\hline 0.3 & 53 & $64.45 \%$ \\
\hline 0.4 & 31 & $72.38 \%$ \\
\hline 0.5 & 12 & $75.45 \%$ \\
\hline 0.6 & 9 & $77.75 \%$ \\
\hline 0.7 & 5 & $79.03 \%$ \\
\hline 0.8 & 3 & $79.80 \%$ \\
\hline 0.9 & 7 & $81.59 \%$ \\
\hline 1 & 8 & $83.63 \%$ \\
\hline 1.1 & 10 & $86.19 \%$ \\
\hline 1.2 & 2 & $86.70 \%$ \\
\hline 1.3 & 6 & $88.24 \%$ \\
\hline 1.4 & 0 & $88.24 \%$ \\
\hline 1.5 & 4 & $89.26 \%$ \\
\hline 2 & 12 & $92.33 \%$ \\
\hline 2.5 & 9 & $94.63 \%$ \\
\hline 3 & 7 & $96.42 \%$ \\
\hline More & 14 & $100.00 \%$ \\
\hline
\end{tabular}

NOTE: See small scale filtering.xls file in Appendix A.

Because the fractures with trace lengths greater than $1 \mathrm{~m}$ have already been accounted for in the existing joint data for DRKBA analysis, the fractures included in the 6-m panels were first filtered out. Additionally, fractures with trace lengths less than $15 \mathrm{~cm}$ are filtered out to reduce the computational effort for key-block analysis. This criterion is reasonable because the block volume formed by small traces less than $15 \mathrm{~cm}$ would be too small to be considered relevant to the damage of waste package or drip shield. The orientation of the remaining small-scale fractures is presented in the fracture pole plot as shown in Figure 6-106.

\subsubsection{DRKBA Comparative Analysis}

For the comparative analysis, the primary excavation is a horizontal 3-m diameter drift trending 75 degrees. The region around the excavation has been modeled with a grid consisting of 2,744,000 nodes. The nodes are spaced $15 \mathrm{~cm}(0.5 \mathrm{ft})$ apart, with each node representing 0.0035 cubic meters ( 0.125 cubic foot) of the rock mass. The smaller size tunnel is used because of the excessive computer memory required for the mesh compatible to 5.5-m diameter drift. Because of the comparative nature of the analysis, and the focus of small-scale fractures in this analysis, the smaller size tunnel is justified. 


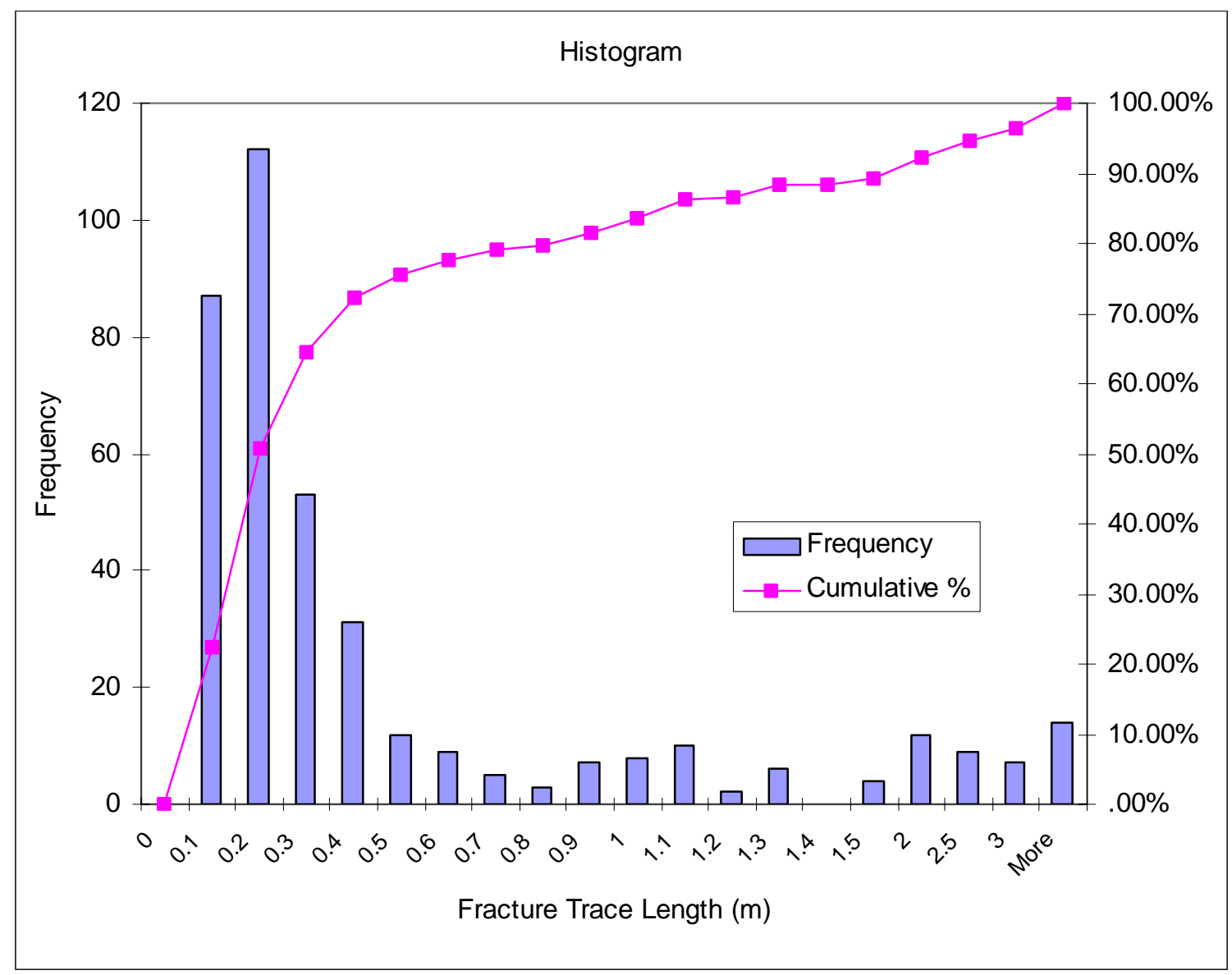

NOTE: See small scale filtering.xls file in Appendix A.

Figure 6-105. Histogram Fracture Traces in Panels 11+15 and 11+30

For each Monte Carlo simulation, an 18.3-m long (60-ft) tunnel has been modeled in three-dimensional space. Eighteen plane equations were used to describe the circumference of the circular tunnel. In addition, two plane equations were used to describe each end of the tunnel. Random joint patterns are generated with joint centers positioned in three-dimensional space, considering each joint set in sequence for each Monte Carlo simulation. The forming of key blocks is therefore different in each Monte Carlo simulation. Four hundred Monte Carlo simulations were used in this analysis.

In addition to the four joint sets identified based on the mapped fractures data with trace length greater than $1 \mathrm{~m}$ (Section 6.1), a random set representing the small-scale fractures is included in the DRKBA analysis for the case considering the small-scale fractures. The required input parameters for each individual joint set and its derivation are provided in Appendix D. Cohesion and friction angle of the joints are simulated with the bivariate normal distribution. Mean and standard deviation for the cohesion and friction angle are provided in Appendix E. Cohesion values were conservatively reduced, providing increased rockfall (Appendix D, Section D2). 


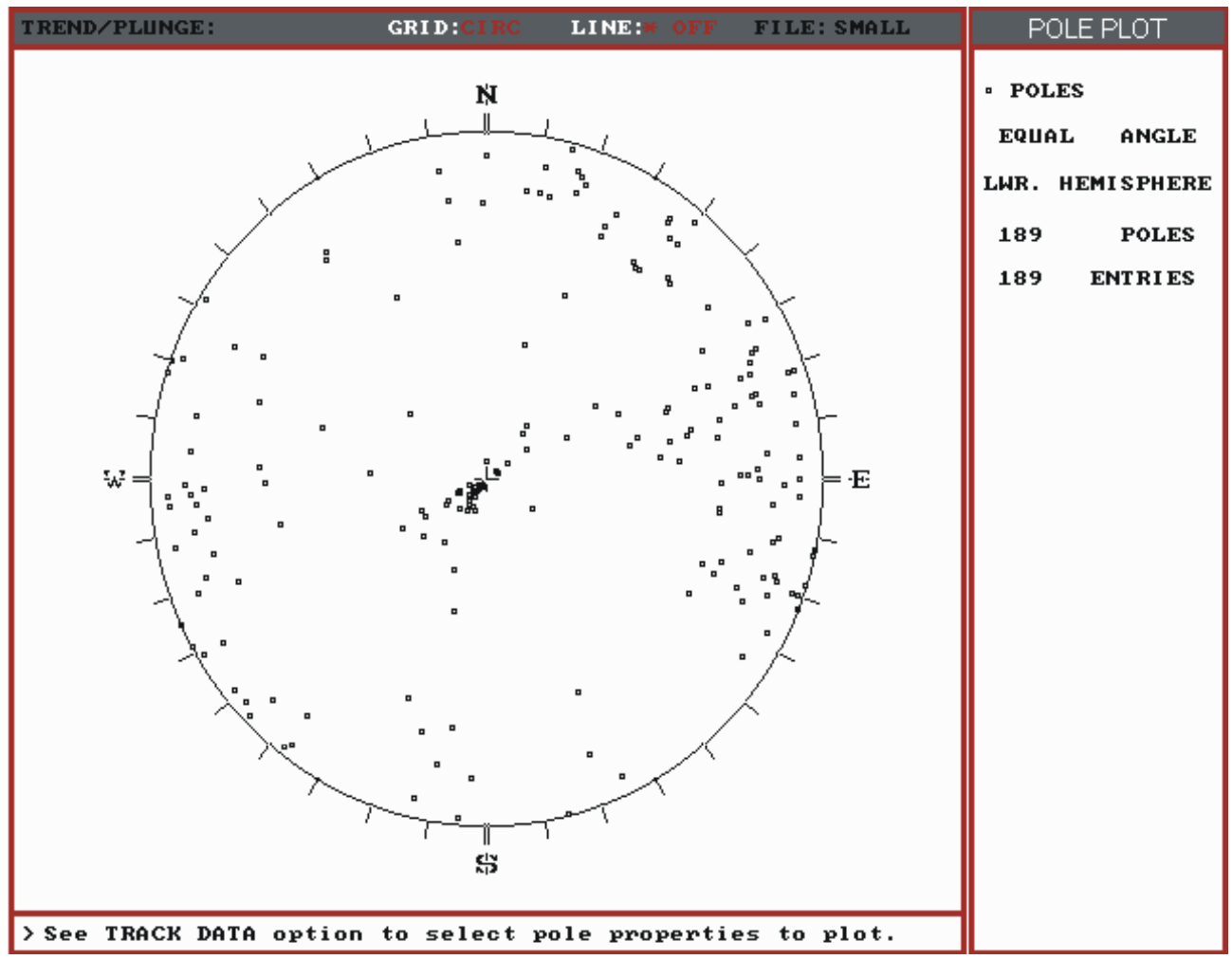

Figure 6-106. Pole Plots for the Filtered Small-Scale Fractures

\subsubsection{Comparison of Analysis Results}

Figure 6-107 presents the key-block analysis results in the format of cumulative frequency of occurrence for both cases. The cumulative frequencies of occurrence corresponding to 50-, 75-, 90-, 95-, and 98-percentile block volume for each unit are listed in Table 6-38. The maximum block sizes predicted from the analyses are also presented in this table. In general, the block size predicted considering the small-scale fractures is smaller than the case without including the small-scale fractures as shown in Table 6-38. The maximum block predicted is 7.4 cubic meters for the case without small-scale fractures compared with 3.25 cubic meters for the case including the small-scale fractures. The results also show that by considering the small-scale fractures, more blocks would form. Three hundred and forty-seven blocks were generated in the case with inclusion of the small-scale fractures, compared to 325 blocks predicted in the case without the small-scale fractures. The results are summarized in Table 6-39. Approximately 10 percent more blocks are predicted when considering the small-scale fractures. It is therefore concluded that small-scale fractures have a minor impact on key-block development in the nonlithophysal units. 
Impact of Small Scale Fractures to the Block Size Distribution

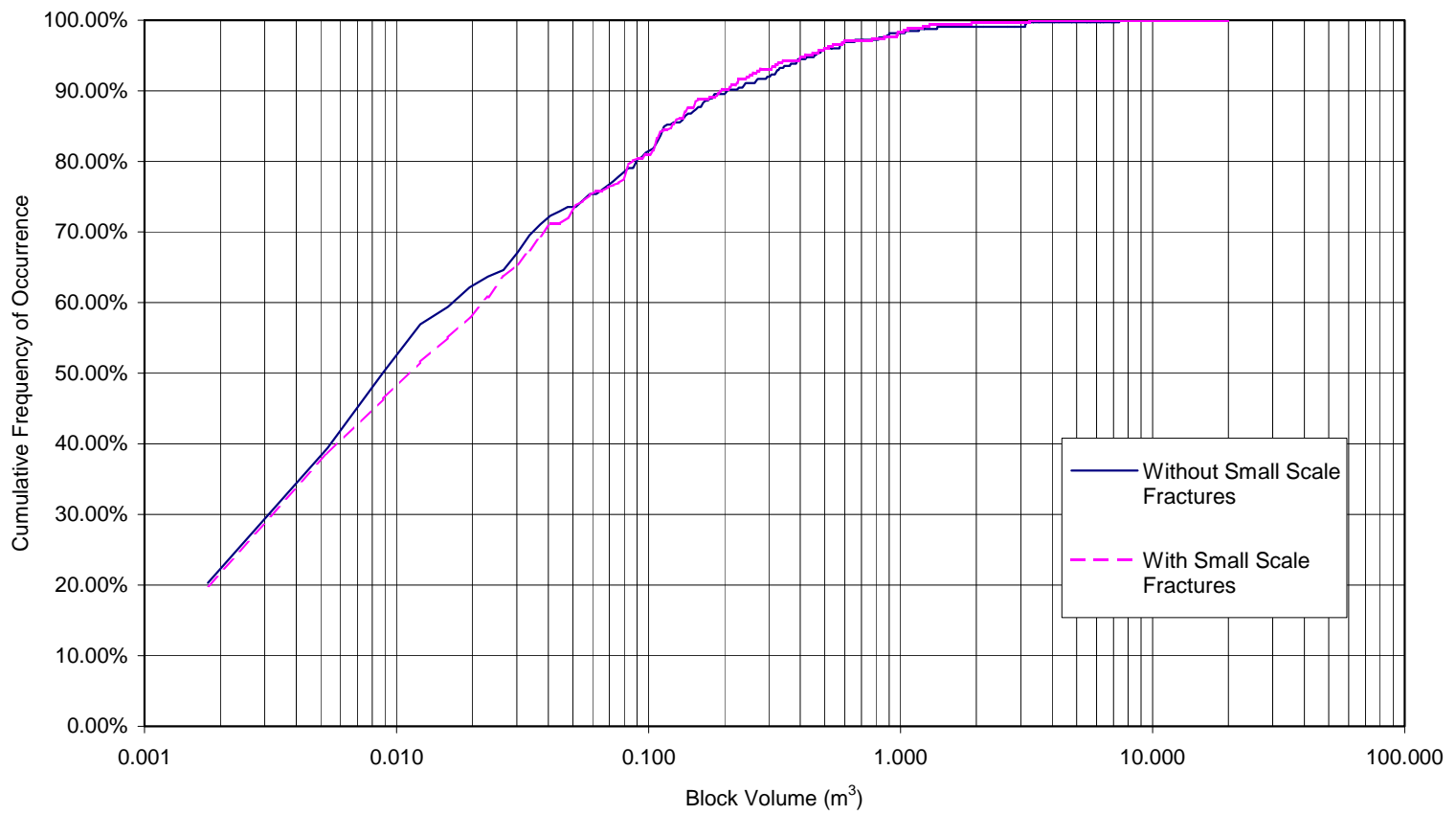

Figure 6-107. Block Size Distribution Predicted from DRKBA Analyses

Table 6-38. Block Volume (in cubic meter) Corresponding to Various Levels of Predicted Cumulative Frequency of Occurrence

\begin{tabular}{|c|c|c|}
\hline $\begin{array}{c}\text { Cumulative Frequency of } \\
\text { Occurrence }\end{array}$ & Without Small-Scale Fractures & With Small-Scale Fractures \\
\hline $50 \%$ & 0.01 & 0.01 \\
\hline $75 \%$ & 0.05 & 0.05 \\
\hline $90 \%$ & 0.20 & 0.19 \\
\hline $95 \%$ & 0.45 & 0.42 \\
\hline $98 \%$ & 0.90 & 0.97 \\
\hline $100 \%$ & 7.36 & 3.25 \\
\hline
\end{tabular}

NOTE: Calculation of block volumes documented in Appendix D (Section D11).

Table 6-39. Summary of Results for DRKBA Comparative Analysis

\begin{tabular}{|l|c|c|}
\hline & Without Small-Scale Fractures & With Small-Scale Fractures \\
\hline Total Number of Blocks & 325 & 347 \\
\hline Number of Blocks per km & 44 & 47 \\
\hline Total Volume of Blocks $\left(\mathrm{m}^{3}\right)$ & 38.0 & 32.0 \\
\hline Volume of Blocks per $\mathrm{km}\left(\mathrm{m}^{3} / \mathrm{km}\right)$ & 5.2 & 4.4 \\
\hline
\end{tabular}

NOTE: Calculation of block information is documented in Appendix D, Section D11; and Appendix A (small scale fracture results.xIs). 


\subsubsection{Drift Profile and Block Geometry Prediction in Nonlithophysal Units}

The distinct block approach applied in this analysis has provided an assessment of existing fracture data to determine probable occurrences of rock blocks that would fall onto the drip shield in the absence of ground support. The 3DEC approach considers progressive block failure, such that when an initial rock block fails and is removed, an additional failure surface may open up allowing other blocks to fall. Progressive block failure continues until the crown becomes geometrically and mechanically stable, and no additional blocks can fall. The final progressive failure surface provides the basis for the drift profile predictions presented in this section.

The deteriorated drift profiles from selected simulations are shown in Figures 6-108 to 6-114. These profiles were the outcome of the 3DEC analysis with the rock mass and opening subject to in situ and seismic loadings. In general, the drifts are more stable under the thermal loading as shown in Sections 6.3.1.3 and 6.3.1.4; the drift profiles for the cases considering thermal loading are not included.

The selected drift profiles include the profiles with the greatest and median rockfall cases for the $1 \times 10^{-5}, 1 \times 10^{-6}$, and $1 \times 10^{-7}$ hazard levels (Figures 6-108 and 6-111). In addition, the greatest rockfall profile for the preclosure consideration $\left(1 \times 10^{-4}\right.$ hazard level) is shown in Figure 6-114. The median case profile is selected as the 50 percentile among the simulations predicting rockfall for the given hazard level. The median case profile ranking was based on the total rockfall volume within the simulation. Due to the limited amount of rockfall predicted for the $1 \times 10^{-4}$ seismic hazard, only the greatest rockfall profile is presented. The total rockfall volume and the number of blocks predicted for each simulation presented are listed in Table 6-40. The profile for each simulation includes the side view and perspective view of the drift with predicted fallen blocks. Also included are selected cross sections at the locations indicated in the side view figure. Failure of intact rock bridges may occur for the postclosure level of ground motions as described in Section 6.3.1.6. Additional break up of rock around the opening is likely when subject to postclosure level of ground motions.

The drift profile for the intensely fractured zone cannot be directly obtained from the FLAC3D ubiquitous joint model (described in Section 6.3.2) because the model is a continuum. Considering the small yield zone shown in Figure 6-97 for the preclosure ground shaking, minor spalling is expected along the sidewall for the preclosure period. However, severe spalling is likely for the seismic shaking due to postclosure ground motions with an extensive yield zone shown in Figure 6-100. It is estimated that the likely profile for the intensely fractured zone with the postclosure consideration will be similar to Figure 6-90.

There are many different sizes and shapes of rock blocks predicted to impact the drip shield. Because block geometry information is mainly used for drip shield impact calculations, the geometry of large blocks is provided in this section. A total of 7 blocks simulated were selected, each with a volume greater than 6 metric tons. The block geometric information for each individual block is presented in Appendix I (Figures I-1 to I-7). 


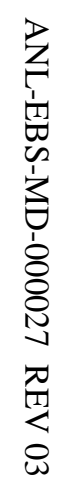
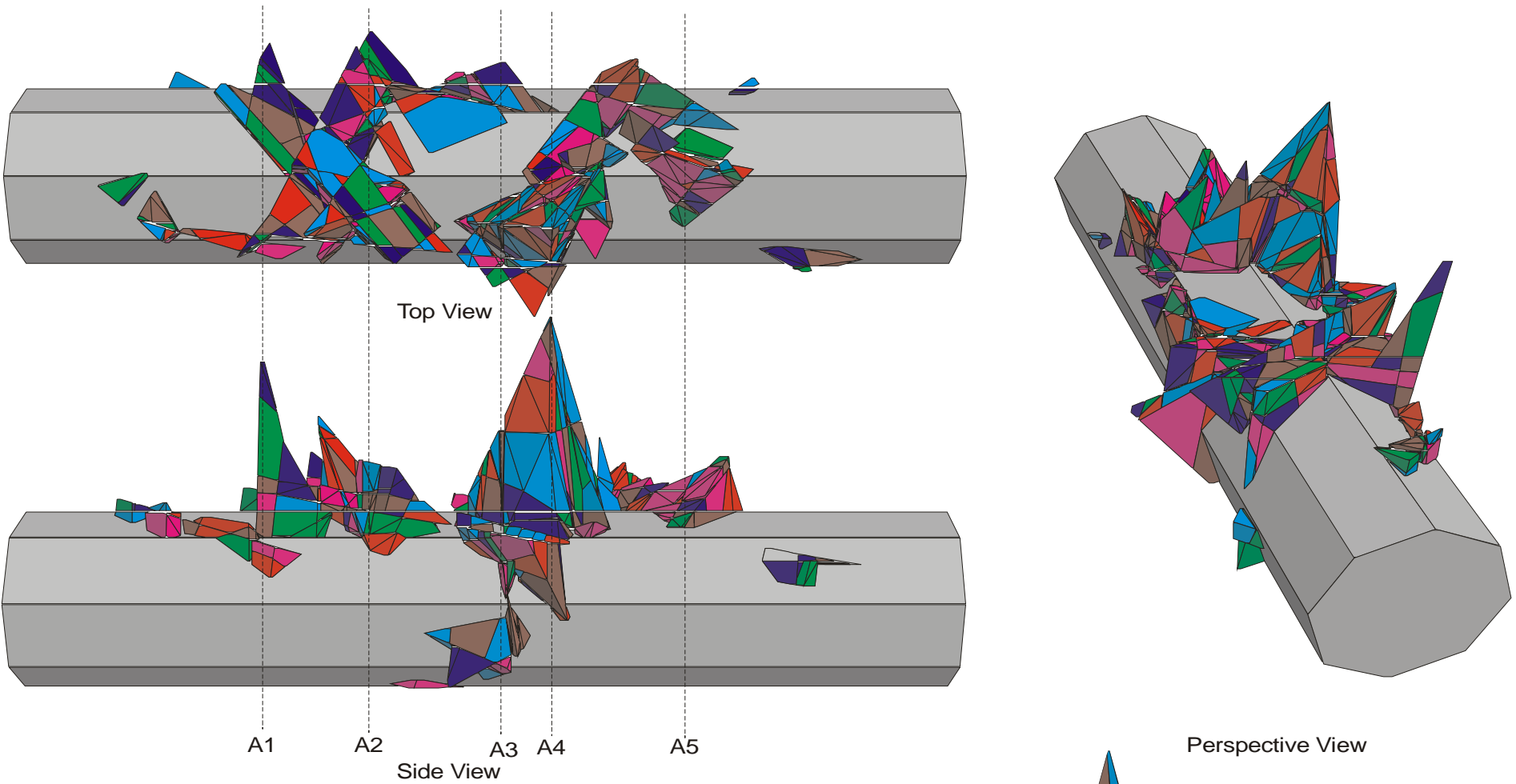

悹
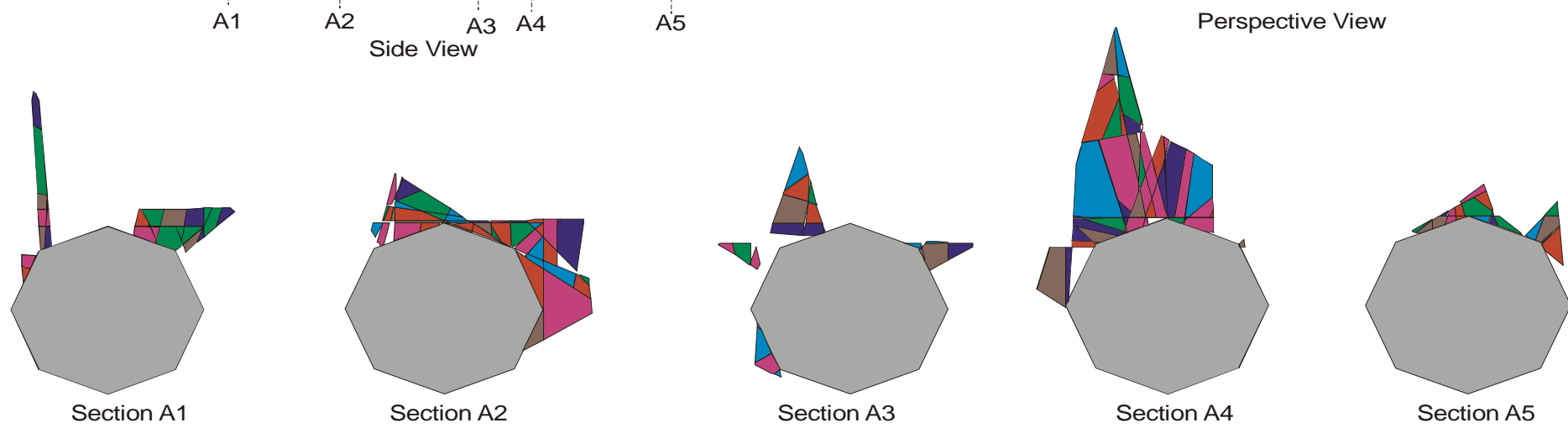

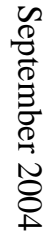

Figure 6-108. Drift Profile for $1 \times 10^{-7}$ Hazard Level, Case with Greatest Amount of Rockfall 

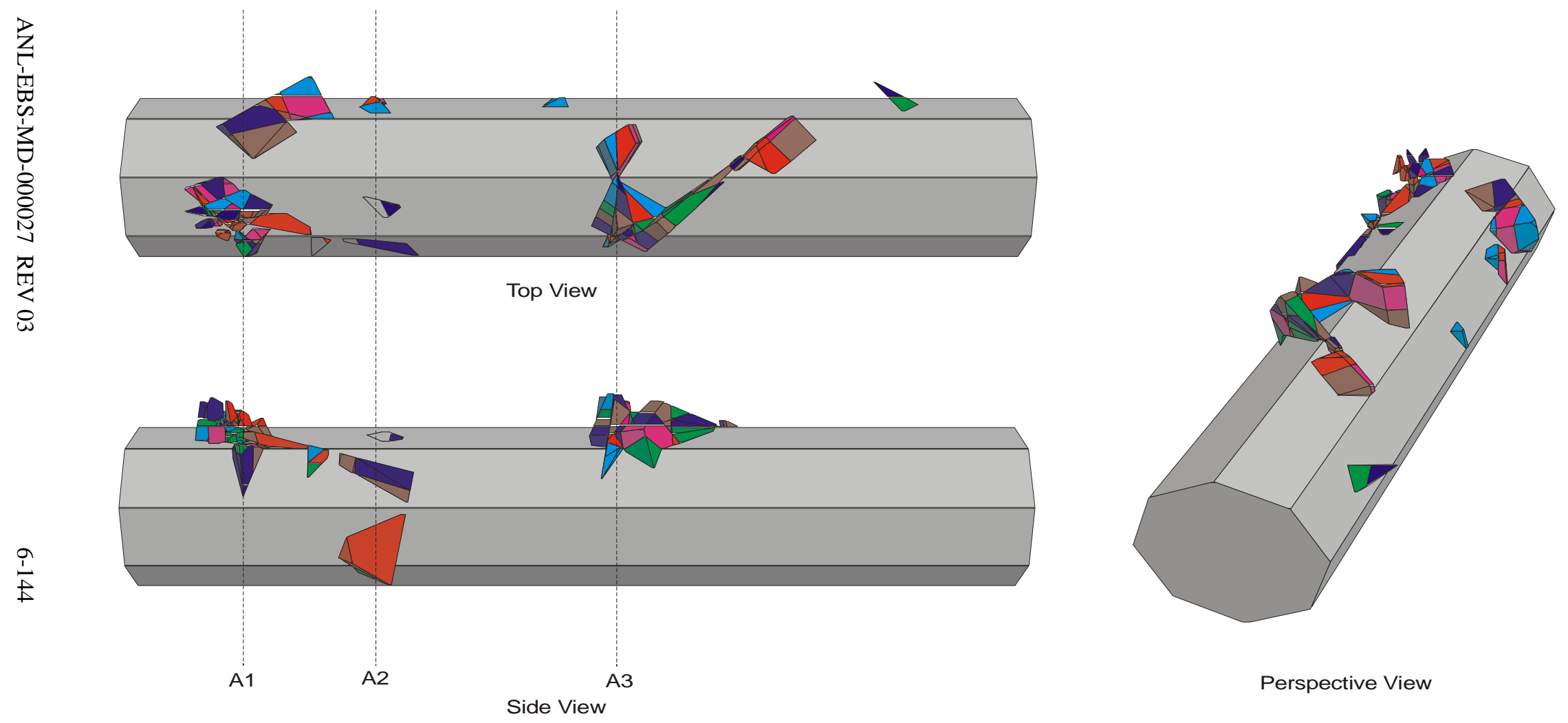

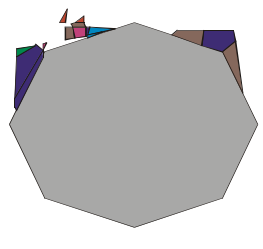

Section A1

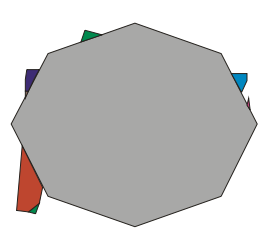

Section A2

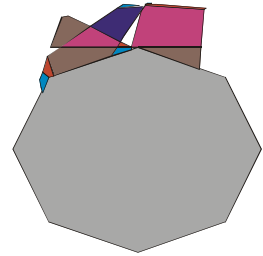

Section A3

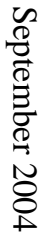

Figure 6-109. Drift Profile for $1 \times 10^{-7}$ Hazard Level, Median Rockfall Case 

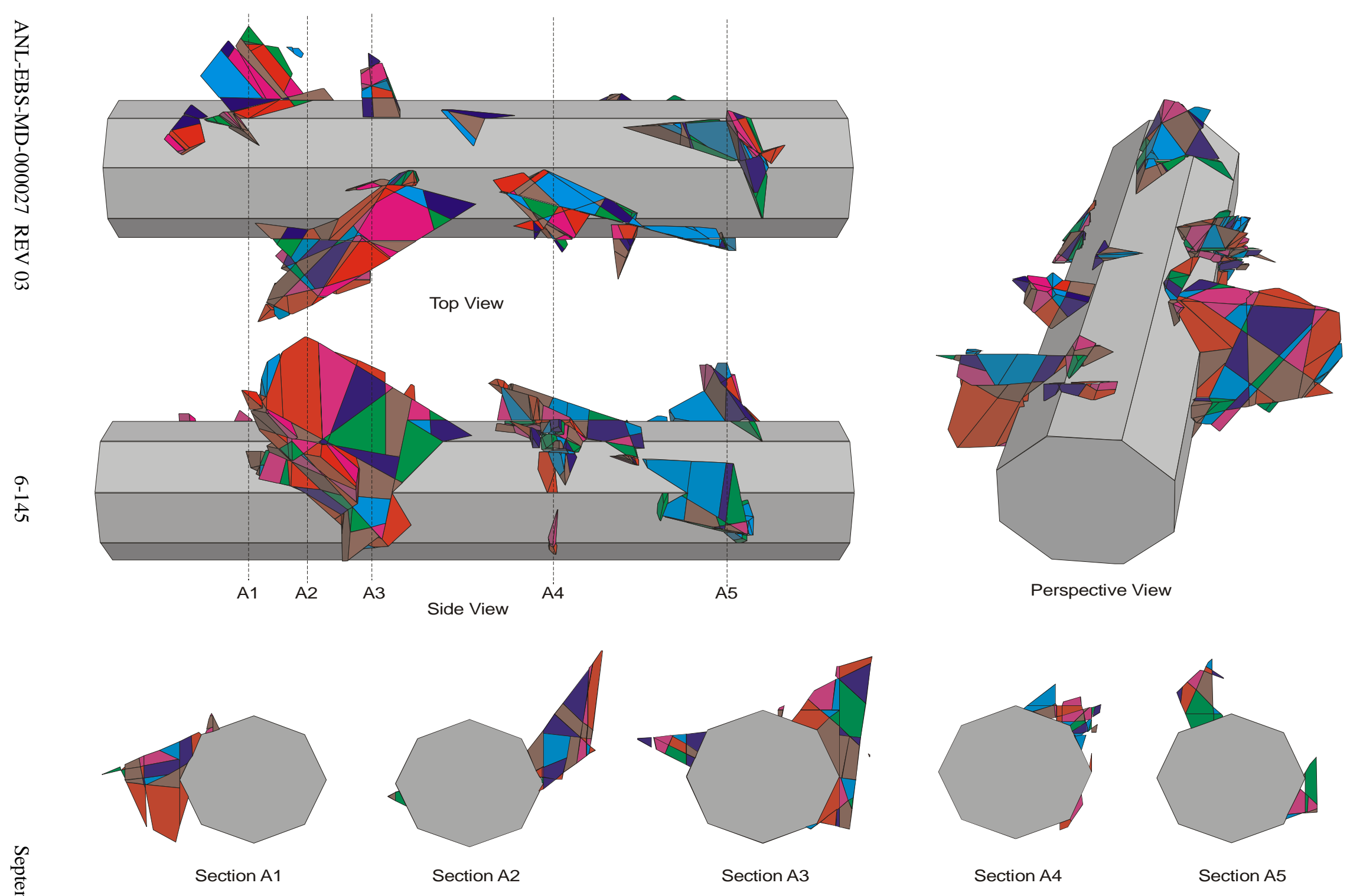

Figure 6-110. Drift Profile for $1 \times 10^{-6}$ Hazard Level, Case with Greatest Amount of Rockfall 

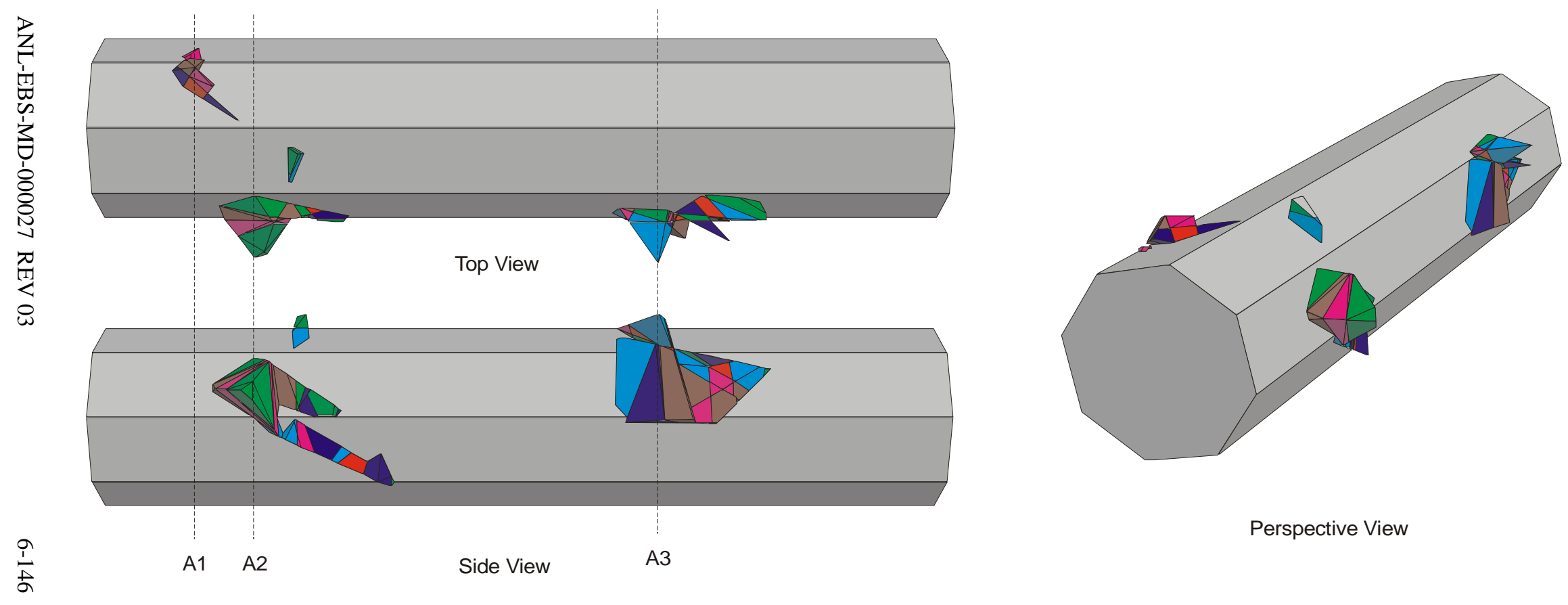

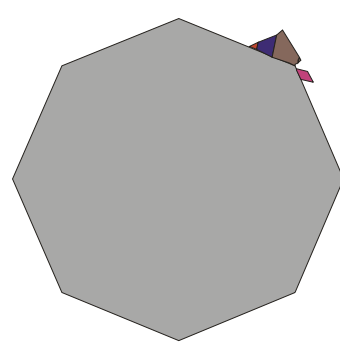

Section A1

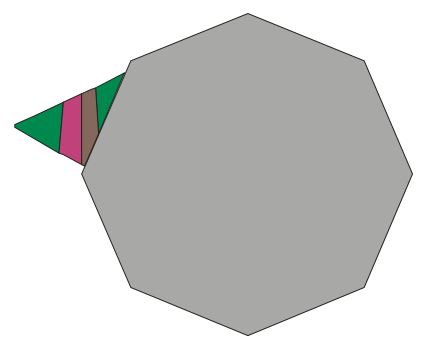

Section A2

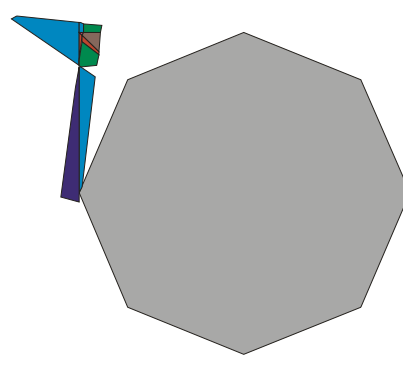

Section A3

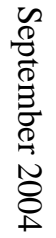

Figure 6-111. Drift Profile for $1 \times 10^{-6}$ Hazard Level, Median Rockfall Case 


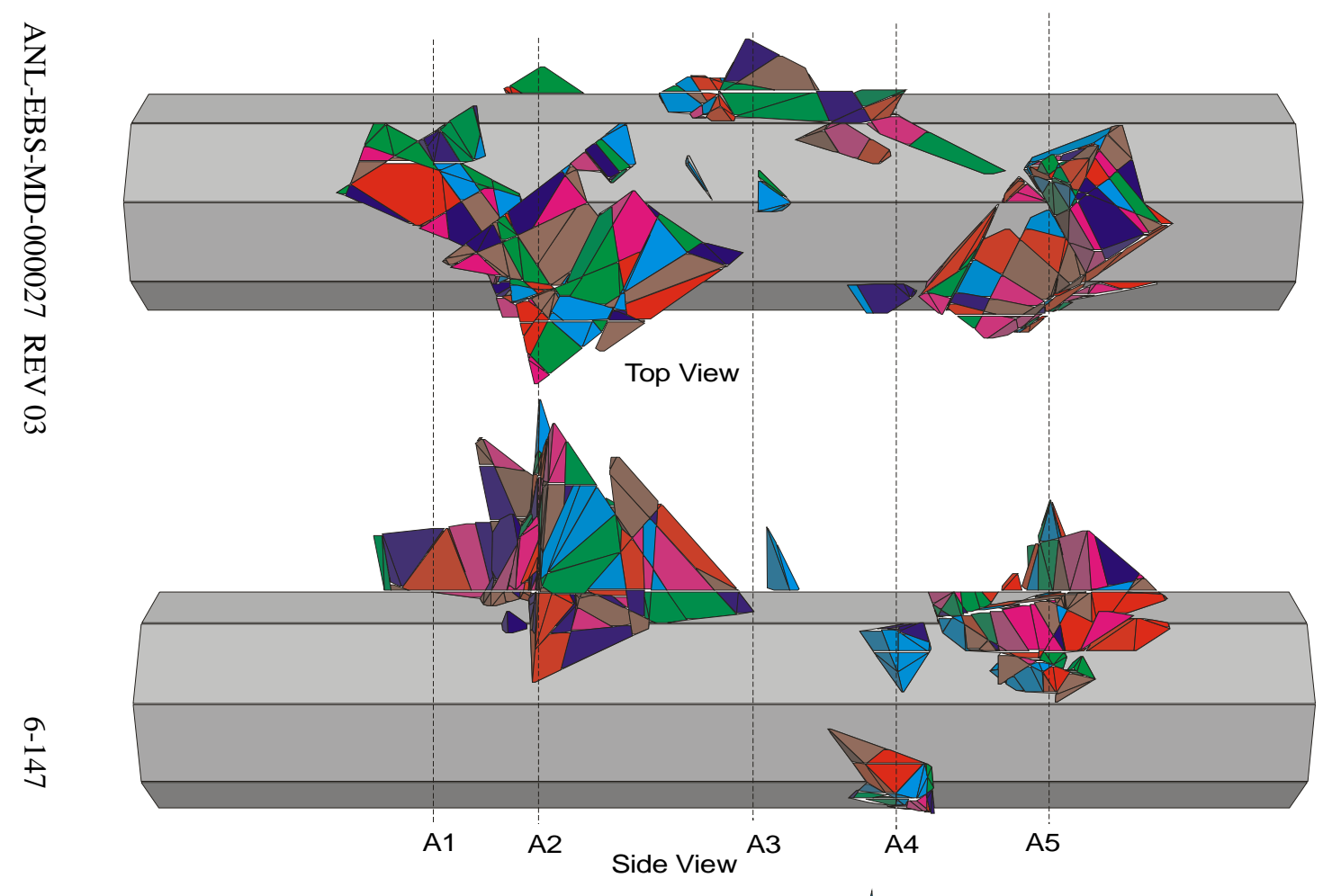

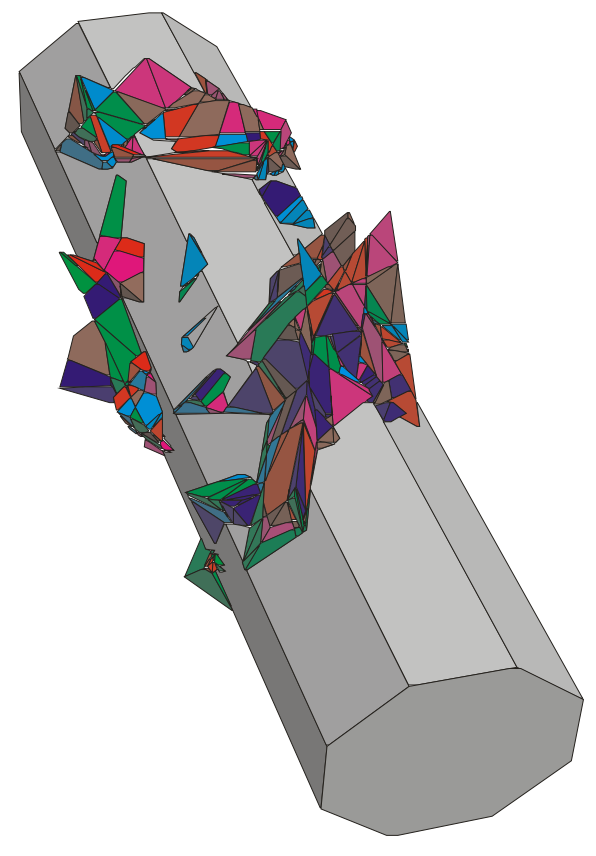

Perspective View

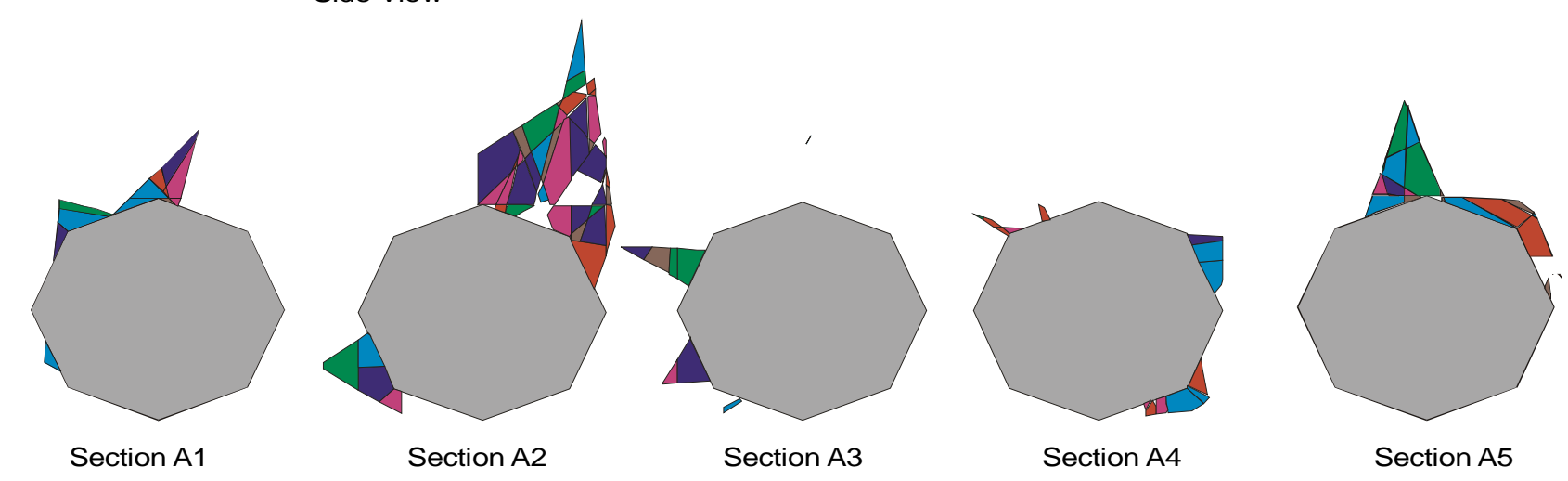

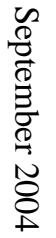

Figure 6-112. Drift Profile for $1 \times 10^{-5}$ Hazard Level, Case with Greatest Amount of Rockfall 


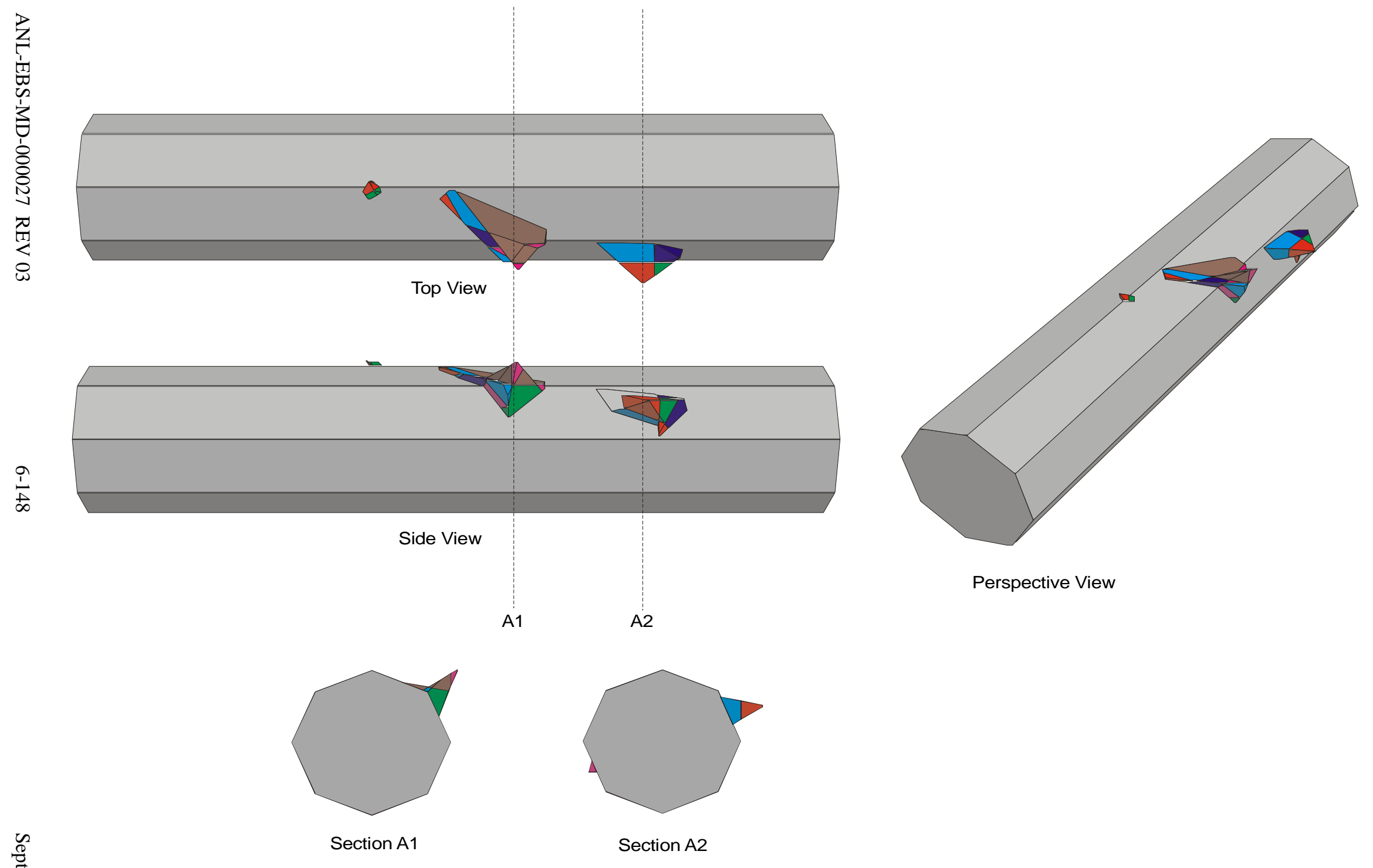

Figure 6-113. Drift Profile for $1 \times 10^{-5}$ Hazard Level, Median Rockfall Case 

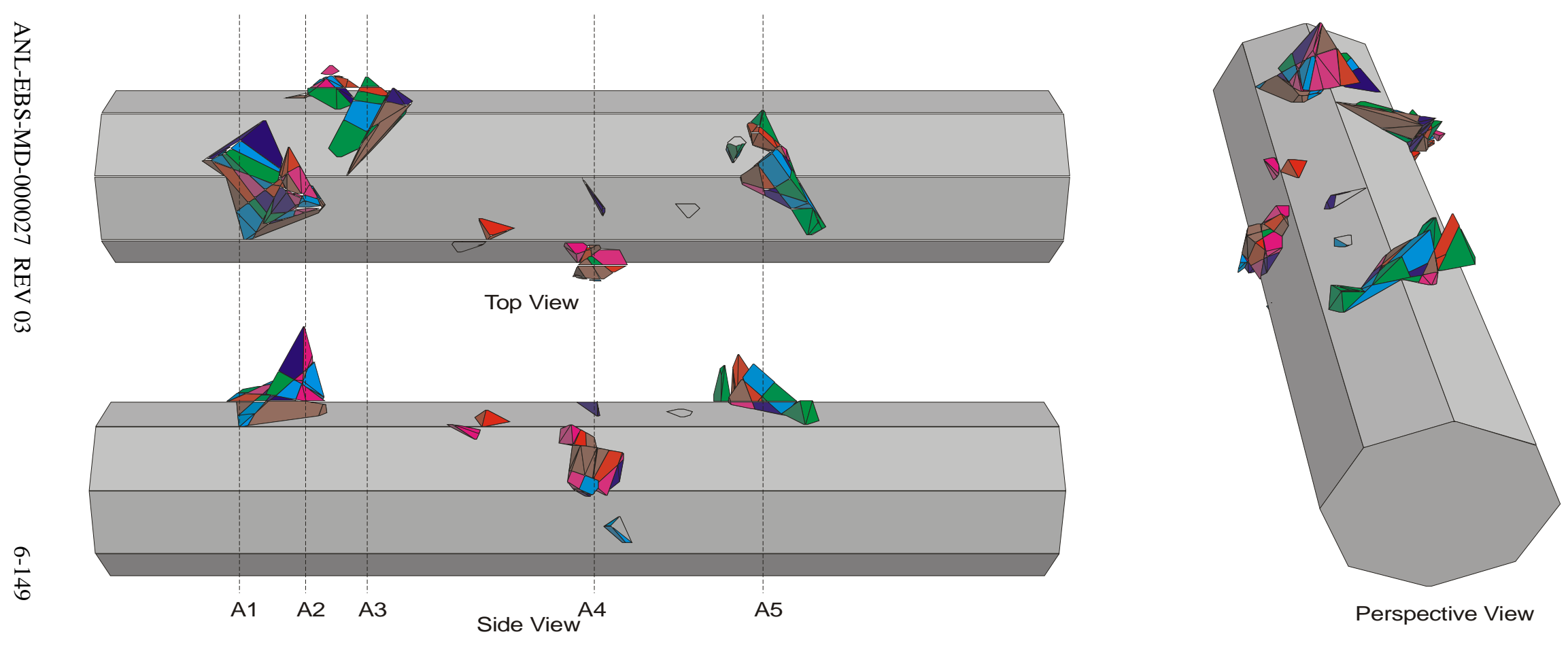

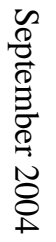
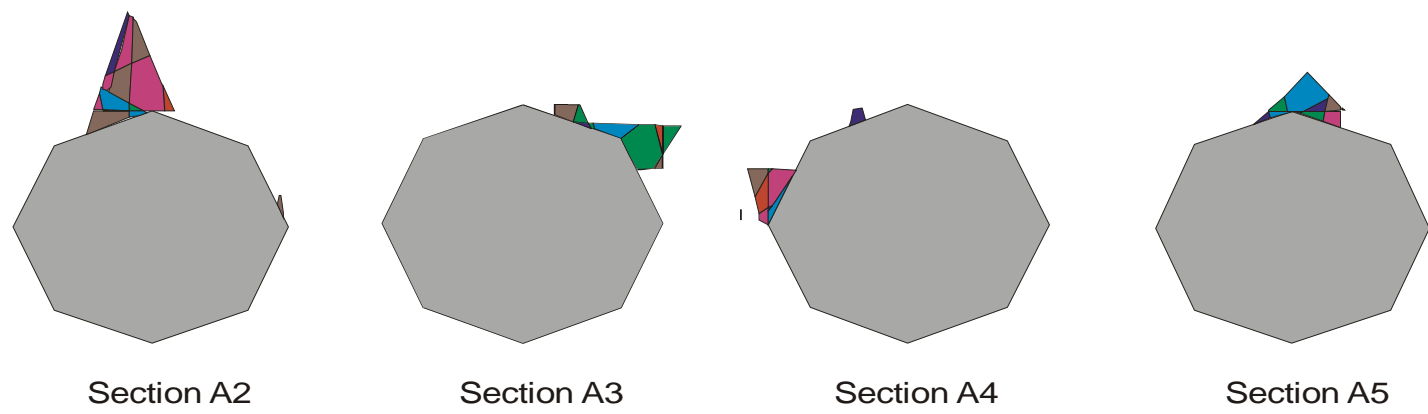

Figure 6-114. Drift Profile for $1 \times 10^{-4}$ Hazard Level, Case with Greatest Amount of Rockfall 
Table 6-40. Predicted Number of Rockfall and Volume for the Presented Drift Profile

\begin{tabular}{|l|c|c|}
\hline \multicolumn{1}{|c|}{ Simulation } & Number of Blocks & Total Volume $\mathbf{~}^{\mathbf{3}} \mathbf{)}$ \\
\hline $1 \times 10^{-7}$ hazard, worst case profile & 269 & 58.93 \\
\hline $1 \times 10^{-7}$ hazard, median case profile & 77 & 10.43 \\
\hline $1 \times 10^{-6}$ hazard, worst case profile & 167 & 63.33 \\
\hline $1 \times 10^{-6}$ hazard, median case profile & 36 & 5.19 \\
\hline $1 \times 10^{-4}$ hazard, worst case profile & 62 & 7.17 \\
\hline
\end{tabular}

\subsection{ROCKFALL IN THE LITHOPHYSAL UNITS}

\subsubsection{Problem Approach}

\subsubsection{Estimate of Block Size}

Analysis of rockfall in the lithophysal units presents a significantly different problem than that given in the previous section with regard to nonlithophysal rocks. In general, the nonlithophysal rocks are composed of strong, intact blocks of welded tuff that are separated by fracture planes. The fracture surfaces provide the primary weaknesses in the system and control the failure mode and resulting rock block dimensions. For this reason, it is necessary that the fracture planes be explicitly represented within the model to allow estimation of block dimensions, masses, and velocities.

Lithophysal units, particularly the Tptpll, are characterized by lithophysal voids interconnected by intense fracturing. Fracture sets are not as clearly defined as in the Tptpmn. Average fracture spacing is less than $1 \mathrm{~m}$ and, at certain locations, this spacing is much smaller, on the order of 0.1 to $0.3 \mathrm{~m}$ (as discussed in Section 6.1.4.1). In addition to fracturing on different scales, the lithophysal rock mass is characterized by the presence of almost uniformly distributed holes (lithophysae) of varying size (from less than 1-cm to greater than 1-m in diameter). The lithophysae account for up to about 30 percent of the rock mass volume (see Section 6.1.4.2 for a detailed discussion on lithophysae). It is assumed in the following analyses that, when stressed beyond its strength limits, the lithophysal rock mass will break into relatively small block sizes controlled by the spacing of natural fractures (Section 5.2.2). Therefore, as opposed to the 3DEC modeling of the Tptpmn, the modeling of the lithophysal rock does not attempt to calculate the block sizes resulting from yield but considers them to be on the order of 0.1 to $0.3 \mathrm{~m}$ (or smaller) in dimension. The models developed here are discontinuum models in which the rock mass is discretize into random block sizes with dimensions on the order of 0.1 to $0.2 \mathrm{~m}$.

\subsubsection{Approach to Modeling of Lithophysal Rock-Homogeneity and Bounding Rock Mass Properties Estimates}

Lithophysal Porosity and Consideration of a Homogeneous Rock Mass-The size of the internal lithophysae structure and fracture spacing is much smaller than the drift size (i.e., 5.5-m diameter). There is no preferred direction in the fracture or lithophysae orientation that would justify introduction of anisotropy into drift scale modeling. As discussed in Appendices E, O, and $\mathrm{T}$, lithophysal porosity varies in a bedded or stratiform fashion with layering orientation 
coincident with the dip of the Tptpll. For example, the areas of highest lithophysal porosity (i.e., greater than about 20 percent) lie in a thin band in the upper portion of the Tptpll unit, just below the contact with the Tptpmn. Here, the largest lithophysae are also found. The lowest levels of lithophysal porosity are found near the bottom of the Tptpll where it grades into the nonlithophysal Tptpln. Figure 6-115 is a histogram that shows the variability in lithophysal porosity for the entire Tptpll as obtained from angular traverse measurements in the ECRB Cross-Drift.

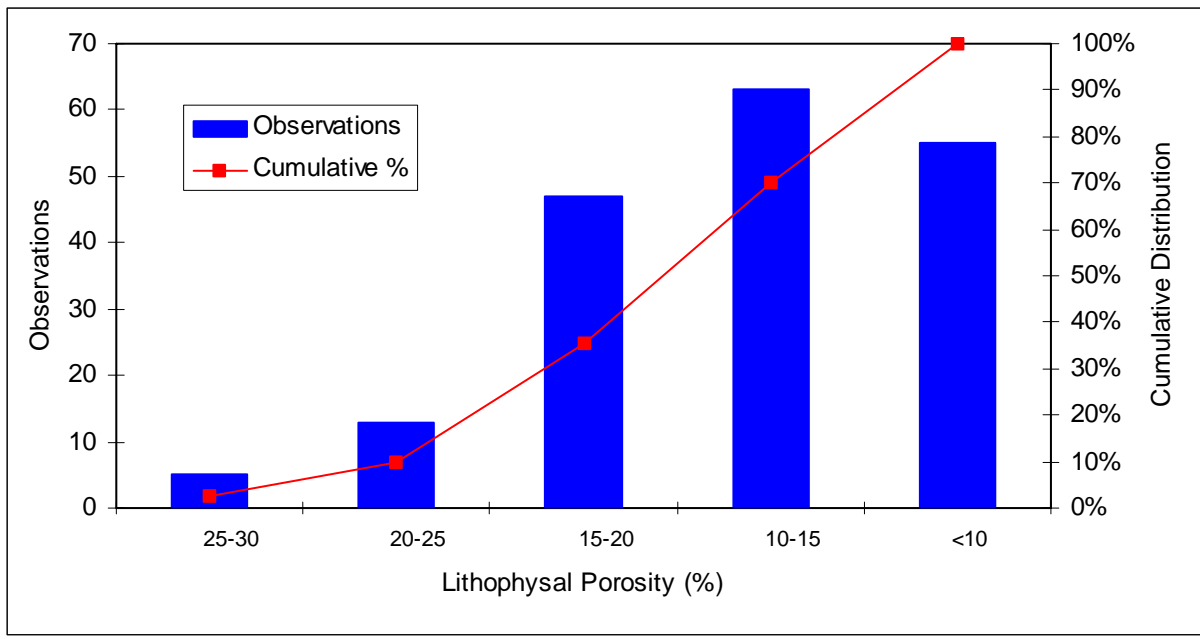

NOTE: $\quad$ Lithophysal porosity data are from ECRB Cross-Drift station 14+44 to 23+26 (Appendix O, Section O6.6; see Microsoft Excel file, Drift Deg AMR AF T-A-P Fit.xIs, worksheet "Volume Percent - Stats", which can be accessed through the Technical Data Management System using DTN: MO0408MWDDDMIO.002).

Figure 6-115. Histogram of the Percentage of Lithophysal Porosity as Determined from Field Measurements in the ECRB Cross-Drift Taken on 5-m Intervals

This figure shows that about 10 percent of the Tptpll is composed of a rock mass with lithophysal porosity levels greater than 20 percent. These levels tend to be concentrated near the top of the unit. Approximately 25 percent of the Tptpll has lithophysal porosity between 15 and 20 percent, approximately 35 percent with lithophysal porosity between 10 and 15 percent, and approximately 30 percent with lithophysal porosities less than 10 percent.

As discussed in Appendix E, the lithophysal rock mass strength and Young's modulus are dependent on the percentage of lithophysal porosity. The initial base case approach taken to modeling of this rock mass, is to subdivide the rock mass strength and modulus into a series of "categories" based on lithophysal porosity percentage. The rock mass strength and modulus are determined from large-diameter core testing of lithophysal rocks as well as numerical extrapolations using the Particle Flow Code program (PFC). The process of estimation of rock mass properties is given in detail in Appendix E.

Parameter studies are then conducted to examine the mechanical response of emplacement drifts to in situ, thermal, and seismic stressing considering homogeneous rock mass properties (i.e., constant lithophysal porosity) for a given drift cross section. Since the modeling is conducted for the complete range of properties represented by the "categories," the full range of response is examined. To examine the conservatism inherent in this approach (i.e., the use of parametric 
studies based on the consideration of a homogeneous rock mass and a range of rock mass properties) additional analyses are conducted in which the spatial variability of the rock mass lithophysal porosity is taken into account. Appendix $\mathrm{T}$ describes a model of the spatial variability of lithophysal porosity within the Tptpll, based on field mapping studies. This three-dimensional geometric model of the Tptpll lithophysal porosity is sampled to create two-dimensional cross section representations that can be used for investigation of spatial variability on both rock mass properties and drift stability. As discussed in Appendix E, these representations are used for investigation of the impact of spatial variability of porosity on the ultimate strength and modulus of the rock mass. The discussion in Appendix E compares the laboratory test data to these spatial variability examinations. It is confirmed that the lowest ranges of strength categories based on lithophysal porosities greater than 20 percent, do yield conservative estimates of rock mass strength. Full drift scale modeling presented in Section 6.4.2.2, again using two dimensional cross sections taken from the geometrical spatial variability representations, is used for comparison of conservatism to the base case models that consider homogeneous rock property ranges.

Base Case Rock Mass Properties-As discussed above, the assessment of rock mass properties for lithophysal rock is documented in Appendix E (Section E4.1). Large diameter room-dry and saturated laboratory testing is supplemented by numerical model extrapolations to examine the impact of in situ lithophysal porosities, shapes, sizes, and distributions on the rock mass mechanical properties. This information is used to define a set of base case mechanical properties and estimates of ranges of these properties for parameter analysis. Five base case categories were developed to represent the range of rock mass properties as summarized in Table 6-41. The validity of this approach to represent the lithophysal rock mass is discussed in Section 7.3. Categories 1 through 5 represent variability of rock mass quality throughout the repository emplacement level. These categories can be related approximately to levels of lithophysal porosity in the Tptpll (see Table 6-41).

Table 6-41. Categories of the Lithophysal Rock Mass Selected for Analysis

\begin{tabular}{|c|c|c|c|c|c|c|c|}
\hline \multirow[b]{2}{*}{ Category } & \multicolumn{4}{|c|}{ Base Case Properties } & \multicolumn{2}{|c|}{$\begin{array}{l}\text { Bounding Unconfined } \\
\text { Compressive Strength }\end{array}$} & \multirow[b]{2}{*}{$\begin{array}{c}\text { Estimated } \\
\text { Lithophysal } \\
\text { Porosity }\end{array}$} \\
\hline & $\begin{array}{c}\text { Unconfined } \\
\text { Compressive } \\
\text { Strength } \\
\text { (MPa) }\end{array}$ & $\begin{array}{c}\text { Young's } \\
\text { Modulus, E } \\
\text { (GPa) }\end{array}$ & $\begin{array}{c}\text { Bulk } \\
\text { Modulus, } \mathrm{K} \\
\text { (GPa) }\end{array}$ & $\begin{array}{c}\text { Shear } \\
\text { Modulus, } \\
\text { G (GPa) }\end{array}$ & $\begin{array}{l}\text { Lower } \\
\text { Bound } \\
\text { (MPa) }\end{array}$ & $\begin{array}{l}\text { Upper } \\
\text { Bound } \\
\text { (MPa) }\end{array}$ & \\
\hline 1 & 10 & 1.9 & 1.07 & 0.80 & 10 & 11 & 35 \\
\hline 2 & 15 & 6.4 & 3.54 & 2.65 & 10 & 23 & 28 \\
\hline 3 & 20 & 10.8 & 6.01 & 4.51 & 10 & 32 & 21 \\
\hline 4 & 25 & 15.3 & 8.48 & 6.36 & 13 & 40 & 13 \\
\hline 5 & 30 & 19.7 & 10.95 & 8.21 & 16 & 47 & 7 \\
\hline
\end{tabular}

NOTE: The calculation of rock strength properties is documented in Appendix E (Section E4.1). 


\subsubsection{UDEC Discontinuum Analysis of the Lithophysal Rock Mass}

\subsubsection{Model Development}

The objective of the analysis presented in this section is to predict the amount of rockfall in the emplacement drifts due to:

- Drift excavation

- Stresses induced by the heat released from the waste packages

- Seismic ground motions with varying probabilities of occurrence

- Time-dependent strength degradation.

The standard approach in geotechnical engineering for solving problems of stability of underground excavations is through the use of models based on continuum mechanics. Such an approach is quite effective if the main interest is estimating stress redistribution around an opening or solving for tunnel wall displacements. However, difficulties are encountered if a continuum model is used for prediction of instability. Continuum approaches use constitutive models to describe the mechanical behavior of a material. A linearly elastic-perfectly plastic Mohr-Coulomb constitutive model is often used to represent mechanical behavior of a rock mass (i.e., see Hoek 2000 [DIRS 160705]). The material strength of a perfectly plastic Mohr-Coulomb model does not decrease as a function of plastic (i.e., post-yield) deformation. This, combined with the use of a continuum-based modeling approach, ${ }^{6}$ means that the model of a drift may show indications of material yielding (i.e., plastic deformation) in different portions of the model, but will never actually predict rockfall. It was decided, based on these considerations, to use UDEC, a two-dimensional discontinuum program (Section 3.1) for drift stability analysis in lithophysal rock. In the UDEC lithophysal rockfall model, the rock mass is represented as an assembly of polygonal elastic blocks. As described in Section 7.6 of this report, the objective of the UDEC lithophysal rock mass model is to provide a model in which the rock mass has the proper deformability and strength characteristics of the rock mass, and will respond elastically for stresses up to its peak strength. However, after the peak strength is reached, the model must be capable of representing the failure process, including fracturing and dislodging of blocks under quasi-static and dynamic loading. This can be accomplished by subdivision of the rock mass into many blocks of approximately the same size as those that may ultimately be formed during yielding, due to the inherent ubiquitous fracturing within the Tptpll. These fractures can be bonded by the strength and stiffness values that allow correct representation of the rock mass strength and modulus given by the strength categories in Table 6-41. Prior to yielding, the fractures in the rock mass are essentially "invisible" or "incipient" and the rock mass will behave in an elastic, isotropic fashion during loading and unloading. However, once the shear or tension strength of the incipient fractures is reached, the rock mass can realistically fail through propagation of fractures and form unstable rock blocks that are free to dislodge and fall into the excavation as the forces dictate. An important aspect of

\footnotetext{
${ }^{6}$ A continuum model is one in which the elements used to discretize the rock mass are intimately connected at their nodal points. These elements can represent yielding in an indirect way via the use of non-linear constitutive models that relate stress to strain, but cannot fracture apart or separate as may occur in reality. Thus, partial or total collapse of a tunnel and the specific volume or mass of rockfall occurring during a simulation cannot be estimated with reliability.
} 
this approach is that the fracture properties must be calibrated to reproduce the desired overall rock mass strength and modulus for each of the rock strength categories in Table 6-41.

The entire rock mass domain is discretized into blocks using a technique referred to as Voronoi tessellations $^{7}$ (Itasca Consulting Group 2002 [DIRS 160331]), to achieve randomly-shaped blocks of roughly uniform size. The initially-bonded fractures between blocks represent the approximate spacing and ubiquitous and random nature of the existing fracturing within the Tptpll (see Section 5.2.2), and are considered to be linearly elastic-brittle. The elastic behavior of fractures (and thus the rock mass deformability) is controlled by their normal and shear stiffnesses (fracture stiffness is constant). The initially-bonded fractures can sustain a finite tensile stress as prescribed by their tensile strength. The Coulomb slip condition governs the onset of shear failure as a function of fracture cohesion and friction angle. If a bonded fracture fails, either in tension or shear, its tensile strength, friction coefficient, and cohesion are reset to residual values. This model allows for the formation of broken fractures between blocks, and possible subsequent separation and instability (under action of gravity) of portions of rock mass around a drift. No ground support was considered in the analyses as it was considered to be non-functional in the postclosure period. The cases of thermal and seismic loading considered in this section were also analyzed using a continuum, linearly elastic approximation. The analyses were done using the finite difference code FLAC (Section 3.1) to provide both a check against the UDEC lithophysal rockfall model, and to provide an elastic-based reference for gaining insight into interpretation of the results from the complex UDEC lithophysal rockfall model.

Additional details for the justification and calibration of the lithophysal rockfall model are provided in Section 7.6. The calibration process of the UDEC block model requires calibration of the mechanical properties of the initially-bonded fractures so they reproduce the desired rock mass properties of the lithophysal rock. As stated previously, the rock mass properties are subdivided into five rock strength and modulus categories that span the range of expected lithophysal rock mass porosity. It is therefore necessary that the bonded fractures of the lithophysal rock mass be calibrated to each of these five rock mass categories. In addition, two average block sizes are examined for representation of the Tptpll fractures- $0.2 \mathrm{~m}$ and $0.3 \mathrm{~m}$. Because the rock mass properties are a function of the fracture spacing, it is necessary to calibrate the bonded fracture properties for each of these representations. The calibrated properties of the bonded fractures are listed in Tables 6-42 and 6-43 for UDEC lithophysal rockfall models with average block sizes of $0.2 \mathrm{~m}$ and $0.3 \mathrm{~m}$, respectively. Note that, if not indicated otherwise, the analysis was done using a block size of $0.3 \mathrm{~m}$.

The geometry of the UDEC lithophysal rockfall model is shown in Figure 6-116. As indicated, only the region around the drift where inelastic deformation is expected is discretized into Voronoi blocks. The rest of the model is composed of a few large, elastic blocks that act to transmit forces from the boundaries to the inner portions of the model. Verification of the proper extent of the thermo-mechanical boundary conditions of the model can be found in Appendix U. The overall stiffness of the discretized portion of the model (i.e., stiffness of blocks and joints together) is the same as the stiffness of the large elastic blocks, which represent far-field behavior. This provides mechanical compatibility of the inner and outer portions of the model.

\footnotetext{
${ }^{7}$ The Voronoi tessellation is simply a block discretization method available within the UDEC program that allows a rock mass to be subdivided into a number of randomly-shaped blocks that have a specified average dimension.
} 
Table 6-42. Calibrated Properties of the Bonded Fractures and Intact Blocks in the Model with $0.2 \mathrm{~m}$ Block Size

\begin{tabular}{|c|c|c|c|c|c|c|c|c|}
\hline Category & $\begin{array}{c}\text { Friction } \\
\text { Angle } \\
\text { (deg) }\end{array}$ & $\begin{array}{c}\text { Residual } \\
\text { Friction } \\
\text { Angle } \\
\text { (deg) }\end{array}$ & $\begin{array}{c}\text { Cohesion } \\
\text { (MPa) }\end{array}$ & $\begin{array}{c}\text { Tension } \\
\text { (MPa) }\end{array}$ & $\begin{array}{c}\text { Normal } \\
\text { Stiffnes } \\
(\mathbf{G P a} / \mathbf{m})\end{array}$ & $\begin{array}{c}\text { Shear } \\
\text { Stiffness } \\
(\mathbf{G P a} / \mathbf{m})\end{array}$ & $\begin{array}{c}\text { Block Bulk } \\
\text { Modulus } \\
\text { (GPa) }\end{array}$ & $\begin{array}{c}\text { Block Shear } \\
\text { Modulus } \\
\text { (GPa) }\end{array}$ \\
\hline 1 & 35 & 15 & 3.91 & 1.56 & 13.40 & 6.69 & 13.00 & 9.75 \\
\hline 2 & 35 & 15 & 5.86 & 2.34 & 45.10 & 22.50 & 43.60 & 32.80 \\
\hline 3 & 35 & 15 & 7.82 & 3.12 & 76.20 & 38.00 & 73.60 & 55.40 \\
\hline 4 & 35 & 15 & 9.77 & 3.90 & 108.00 & 53.90 & 104.00 & 78.50 \\
\hline 5 & 35 & 15 & 11.70 & 4.68 & 139.00 & 69.40 & 134.00 & 101.00 \\
\hline
\end{tabular}

NOTE: Residual cohesion and tensile strength are zero. See Section 7.6 for calibration methodology.

Table 6-43. Calibrated Properties of the Bonded Fractures and Intact Blocks in the Model with $0.3 \mathrm{~m}$ Block Size

\begin{tabular}{|c|c|c|c|c|c|c|c|c|}
\hline Category & $\begin{array}{c}\text { Friction } \\
\text { Angle } \\
(\mathbf{d e g})\end{array}$ & $\begin{array}{c}\text { Residual } \\
\text { Friction } \\
\text { Angle } \\
(\mathbf{d e g})\end{array}$ & $\begin{array}{c}\text { Cohesion } \\
(\mathbf{M P a})\end{array}$ & $\begin{array}{c}\text { Tension } \\
(\mathbf{M P a})\end{array}$ & $\begin{array}{c}\text { Normal } \\
\text { Stiffness } \\
(\mathbf{G P a} / \mathbf{m})\end{array}$ & $\begin{array}{c}\text { Shear } \\
\text { Stiffness } \\
(\mathbf{G P a} / \mathbf{m})\end{array}$ & $\begin{array}{c}\text { Block Bulk } \\
\text { Modulus } \\
(\mathbf{G P a})\end{array}$ & $\begin{array}{c}\text { Block Shear } \\
\text { Modulus } \\
(\mathbf{G P a})\end{array}$ \\
\hline 1 & 35 & 15 & 3.83 & 1.53 & 9.34 & 4.67 & 9.03 & 6.80 \\
\hline 2 & 35 & 15 & 5.85 & 2.34 & 31.48 & 15.72 & 30.44 & 22.88 \\
\hline 3 & 35 & 15 & 7.94 & 3.18 & 53.08 & 26.57 & 51.37 & 38.60 \\
\hline 4 & 35 & 15 & 10.09 & 4.03 & 74.90 & 37.60 & 72.80 & 54.70 \\
\hline 5 & 35 & 15 & 12.30 & 4.92 & 97.00 & 48.40 & 93.60 & 70.50 \\
\hline
\end{tabular}

NOTE: Residual cohesion and tensile strength are zero. See Section 7.6 for calibration methodology.

\subsubsection{Seismic Consideration in Lithophysal Units}

Ground Motions-Drift stability was analyzed for different conditions of ground motion:

- Ground motion with $5 \times 10^{-4}$ probability of annual occurrence (preclosure earthquake, DTN: MO0407TMHIS104.003 [DIRS 170599])

- Ground motion with $1 \times 10^{-4}$ probability of annual occurrence (preclosure earthquake, DTN: MO0306SDSAVDTH.000 [DIRS 164033])

- Ground motion with $1 \times 10^{-5}$ probability of annual occurrence (postclosure earthquake, DTN: MO0402AVDTM105.001 [DIRS 168890])

- Ground motion with $1 \times 10^{-6}$ probability of annual occurrence (postclosure earthquake, DTN: MO0301TMHIS106.001 [DIRS 161868]). 


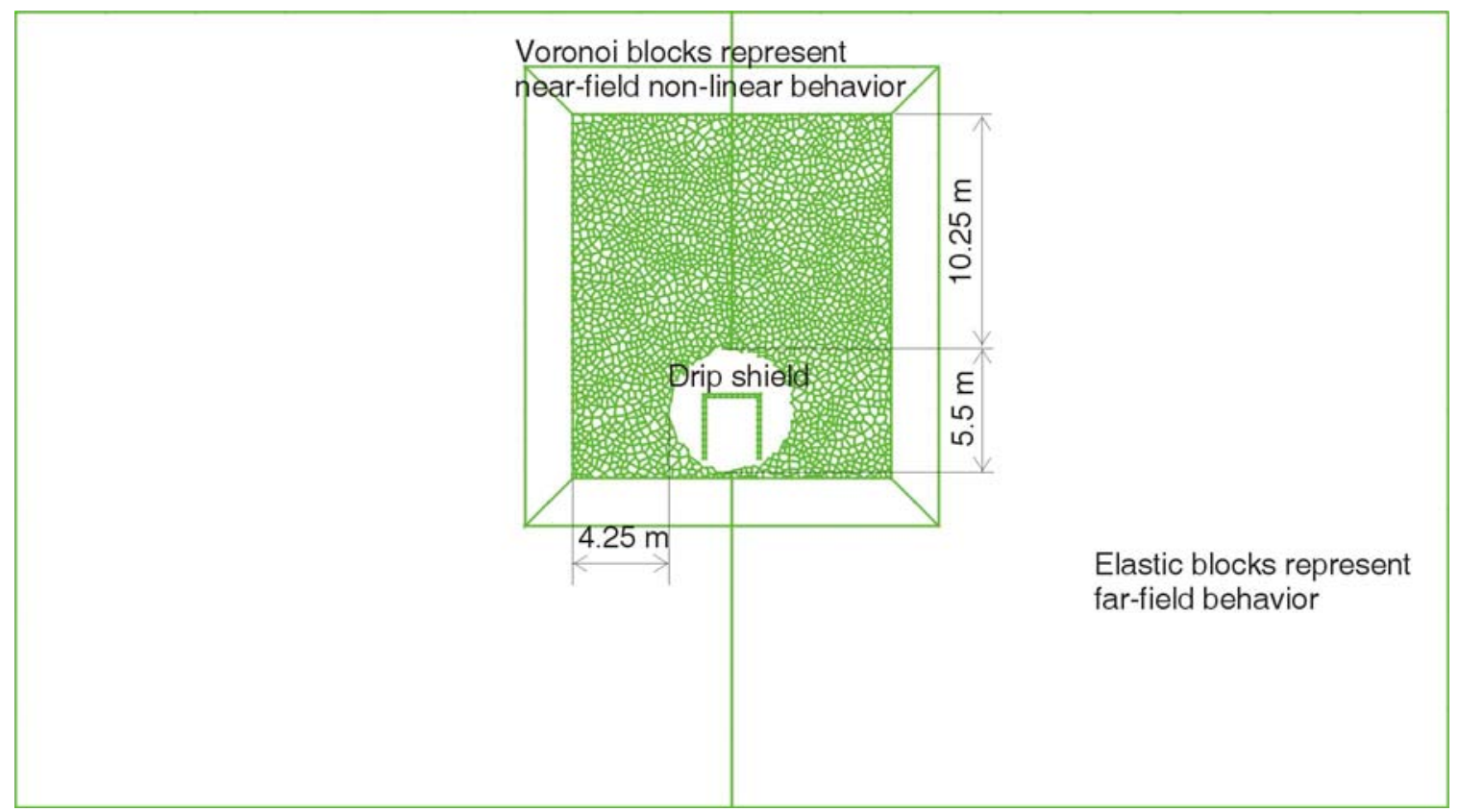

NOTE: Simplified drip shield geometry is based on BSC 2004 [DIRS 169220].

Figure 6-116. Geometry and Initial Conditions of the UDEC Lithophysal Rockfall Model

The ground motions are discussed in detail in Section 6.3.1.2.1. Fifteen ground motions (two horizontal and one vertical component of motion) were considered in the analysis for $1 \times 10^{-5}$ and $1 \times 10^{-6}$ probabilities of annual occurrence. Only one ground motion was considered for each preclosure level (i.e., $5 \times 10^{-4}$ and $1 \times 10^{-4}$ probabilities of annual occurrence). Because there is just one ground motion case for each preclosure level, the $5 \times 10^{-4}$ and $1 \times 10^{-4}$ probabilities of annual occurrence ground motions were analyzed for the five rock mass categories.

For the $1 \times 10^{-5}$ ground motion, three rock strength categories that span the range of lithophysal porosities were chosen (Categories 1, 3, and 5). For each of these categories, the 15 ground motion sets were analyzed. Because the $1 \times 10^{-5}$ analyses show a large range in damage level depending on the rock strength and ground motion set, more extensive examination was made. Analyses were conducted for each of the three categories lower bound values (Table 6-41) in addition to the base case values. Analyses using a model with simulated spatial variability in lithophysal porosity (and thus spatial variability in mechanical properties) were also conducted as a check against the base case models that consider constant properties.

Instead of simulating all possible combinations of the 15 cases of ground motion for $1 \times 10^{-6}$ probability with five rock mass categories, only 15 realizations shown in Table 6-44 were simulated (note that 15 ground motions are numbered 1 through 14 in sequence, and 16). Based on Latin Hypercube sampling (see Sampling of Stochastic Input Parameters for Rockfall Calculations and for Structural Response Calculations Under Vibratory Ground Motion (BSC 2004 [DIRS 169999]) and DTN: MO0301SPASIP27.004 [DIRS 161869]), realizations from Table 6-44 are selected as representative of the possible realizations. Combinations in Table 6-44 include rock mass Categories 1 through 5, as representative of the variability of lithophysal rock mass quality on the repository level. It was planned to conduct simulations of 
drift stability for ground motions with $1 \times 10^{-7}$ probability of annual occurrence. However, the results of analyses for $1 \times 10^{-6}$ probability of annual occurrence (complete collapse of the emplacement drifts) determined such an analysis unnecessary.

Table 6-44. Simulated Combinations of $10^{-6}$ Ground Motions and Rock Mass Categories

\begin{tabular}{|c|c|c|}
\hline Realization Number & $\begin{array}{c}\text { Ground Motion Time } \\
\text { History Number }\end{array}$ & $\begin{array}{c}\text { Rock Mass Category } \\
\text { Number }\end{array}$ \\
\hline 1 & 4 & 3 \\
\hline 2 & 8 & 5 \\
\hline 3 & 16 & 4 \\
\hline 4 & 12 & 1 \\
\hline 5 & 2 & 3 \\
\hline 6 & 8 & 1 \\
\hline 7 & 14 & 2 \\
\hline 8 & 4 & 4 \\
\hline 9 & 10 & 2 \\
\hline 10 & 6 & 3 \\
\hline 11 & 9 & 1 \\
\hline 12 & 1 & 1 \\
\hline 13 & 1 & 3 \\
\hline 14 & 7 & 4 \\
\hline 15 & 11 & 4 \\
\hline
\end{tabular}

Source: DTN: MO0301SPASIP27.004 [DIRS 161869].

NOTE: Realization numbers 1 through 15 are from the sampling in the lithophysal zone provided by the source DTN.

Model Initial and Boundary Conditions-An in situ (before excavation) stress state, defined by $7 \mathrm{MPa}$ vertical and 3.5 MPa horizontal stresses, is used throughout the simulations, which is consistent with the 3DEC modeling in Section 6.3. The vertical stress represents the stress state at a depth of $300 \mathrm{~m}$, and the lateral stress represents the horizontal component projected in the plane perpendicular to the emplacement drifts, whose azimuth is oriented at 72 degrees east of north. The equilibrium state of the model after excavation of a drift represents the initial condition for the dynamic analysis. This equilibrium state is achieved by performing a quasi-static simulation (because the mathematical formulation of UDEC is fully dynamic in nature) in which the in situ stresses are applied to the model that is allowed to equilibrate. The geometry and the boundary and initial conditions used in the initial quasi-static simulation preceding the dynamic simulation are illustrated in Figure 6-117. 


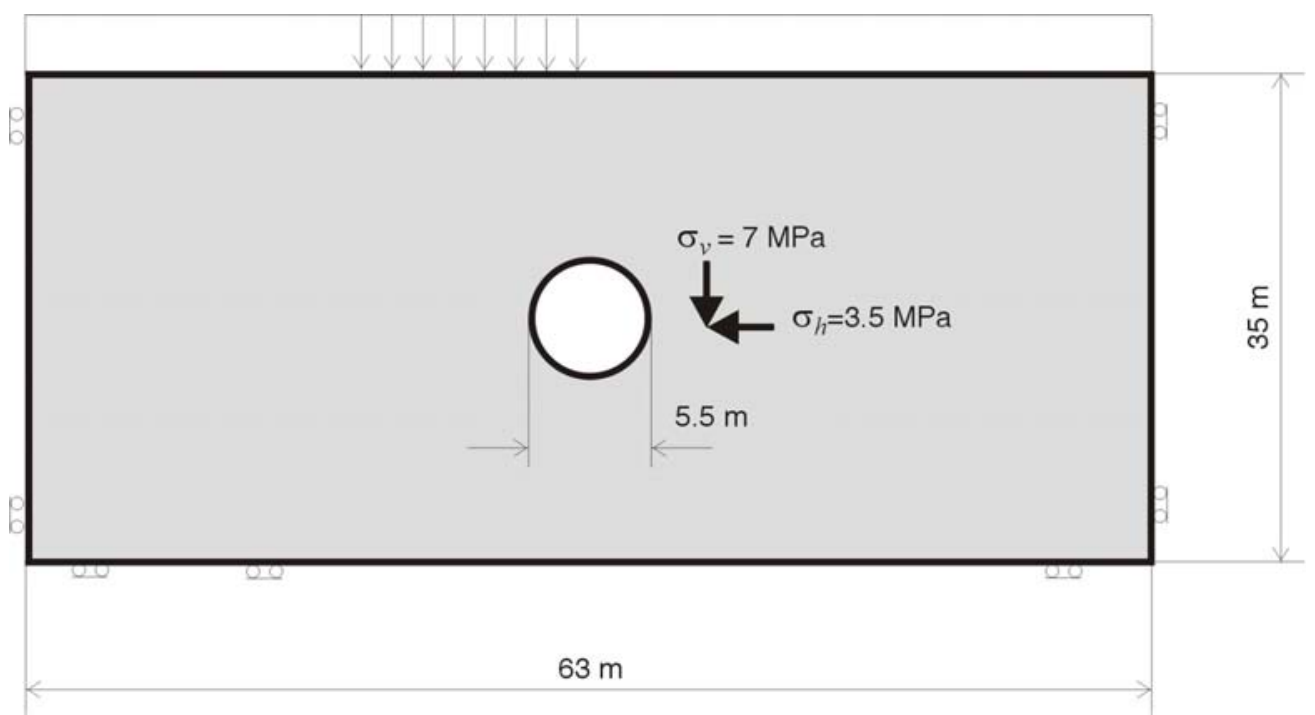

Figure 6-117. Dynamic Model, Initial and Boundary Conditions: Initial Quasi-Static Simulation

The boundary conditions as used in the dynamic analysis are illustrated in Figure 6-118. Quiet boundaries (indicated in Figure 6-118 as viscous boundaries) were used on the outside boundaries of the models. These boundaries prevent reflection of outgoing seismic waves back into the model. Quiet boundaries were combined with free-field boundaries on the vertical outside boundaries. The free-field boundaries perform a one-dimensional simulation of vertically-propagating plane waves representing motion of a truncated, semi-infinite medium, thereby preventing distortion of vertically-propagating plane waves along the quiet boundaries. Dynamic loading was applied at the bottom of the model to provide vertically propagating shear and compression waves. Although the dynamic loading was specified as velocity time-histories, it was applied at the bottom model boundary as a time-varying stress boundary condition. This is possible because there is a direct correspondence between velocity and induced stress for plane waves in elastodynamics, and, therefore, time-varying velocity or stress boundary conditions are equivalent. The relationships used are given as follows (Itasca Consulting Group 2002 [DIRS 160331], Manuals/3DEC/Optional Features/Section 2: Dynamic Analysis, Section 2.6):

$$
\begin{aligned}
& \sigma_{y}=2 \rho C_{p} v_{v} \\
& \sigma_{x y}=2 \rho C_{s} v_{h}
\end{aligned}
$$

where $\rho$ is rock density; $C_{p}$ and $C_{s}$ are $\mathrm{P}$ and S wave velocities, respectively; and $v_{v}$ and $v_{h}$ are vertical and horizontal velocity components. The factor 2 in Equation 6-7 is due to correction for the quiet boundaries. Figure 6-119 shows specified component 1 of the horizontal velocity history for ground motion 4 of $1 \times 10^{-6}$ probability. Velocity histories at the bottom and the top of the model (shown in Figure 6-119), recorded during the simulation, confirm that the applied stress boundary condition results in ground motion velocity time histories that are the same as the specified velocity boundary condition. Comparison of the velocities at the top and bottom of the model (identical histories slightly offset in time) confirms that the free-field boundaries operate correctly in elimination of boundary effects. 


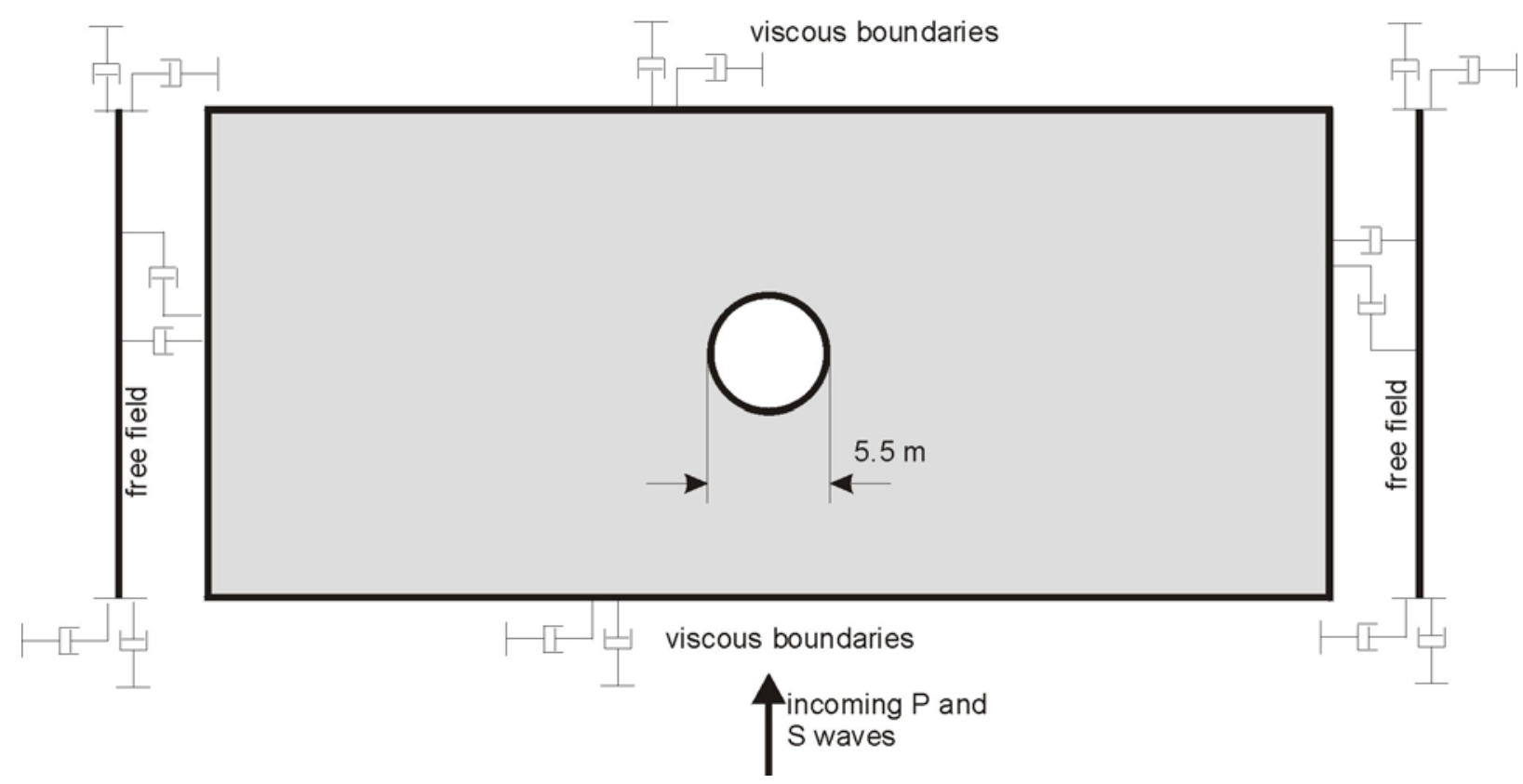

Figure 6-118. Model Boundary Conditions for Dynamic Simulation

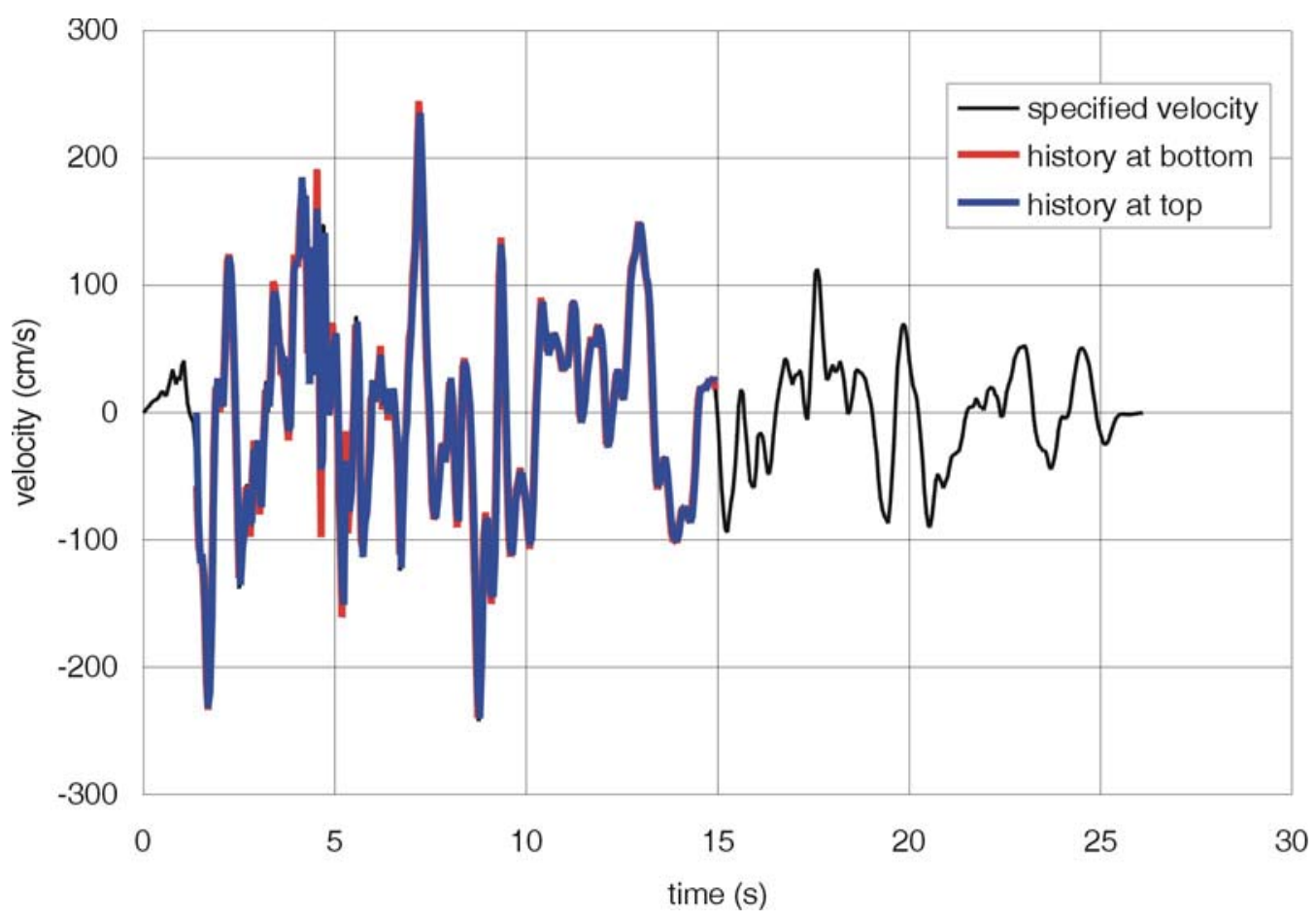

Source: DTN: MO0301TMHIS106.001 [DIRS 161868] provides the specified horizontal velocity.

NOTE: The horizontal velocities recorded at the top and at the bottom of the model coincide with the specified velocity.

Figure 6-119. Horizontal Velocity, Component 1 for Ground Motion 4 of $1 \times 10^{-6}$ Probability 


\subsection{Analysis of Drift Response to Preclosure Ground Motion}

The analyses indicate that preclosure ground motion levels (i.e., with probabilities of annual occurrence of $5 \times 10^{-4}$ and $1 \times 10^{-4}$ ) will not induce any rockfall for rock mass strength Categories 2 through 5. A relatively small amount of rockfall from the drift walls (shown in Figure 6-120) is expected for unsupported excavations in Category 1, which represents less than 5 percent of the Tptpll (see Figure 6-115 and Appendix E). The elastic stress paths from the $1 \times 10^{-4}$ preclosure ground motion simulation for the Category 1 rock mass (shown in Figures 6-121 and 6-122 in the wall and roof, respectively), and the Category 5 rock mass (shown in Figures 6-123 and 6-124 in the wall and roof, respectively), indicate that this level of ground motion causes small oscillations of the stress state relative to the initial equilibrium. With the exception of the monitoring location at the drift wall for the Category 1 rock mass, the stress states are within the elastic region throughout the duration of the $1 \times 10^{-4}$ preclosure ground motion. The observed rockfall is a consequence of regions that are above the yield limit after excavation of the drift (i.e., the wall in the Category 1 rock mass) being shaken down in the absence of ground support.

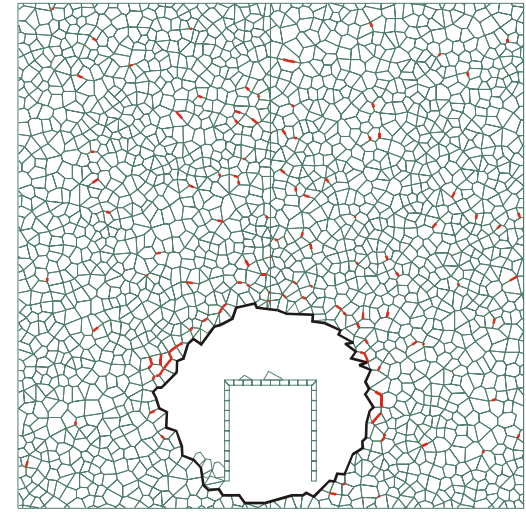

a) $5 \times 10^{-4}$ ground motion

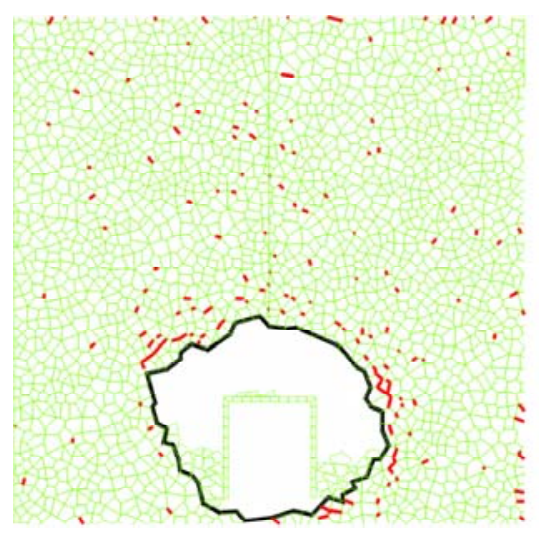

b) $1 \times 10^{-4}$ ground motion
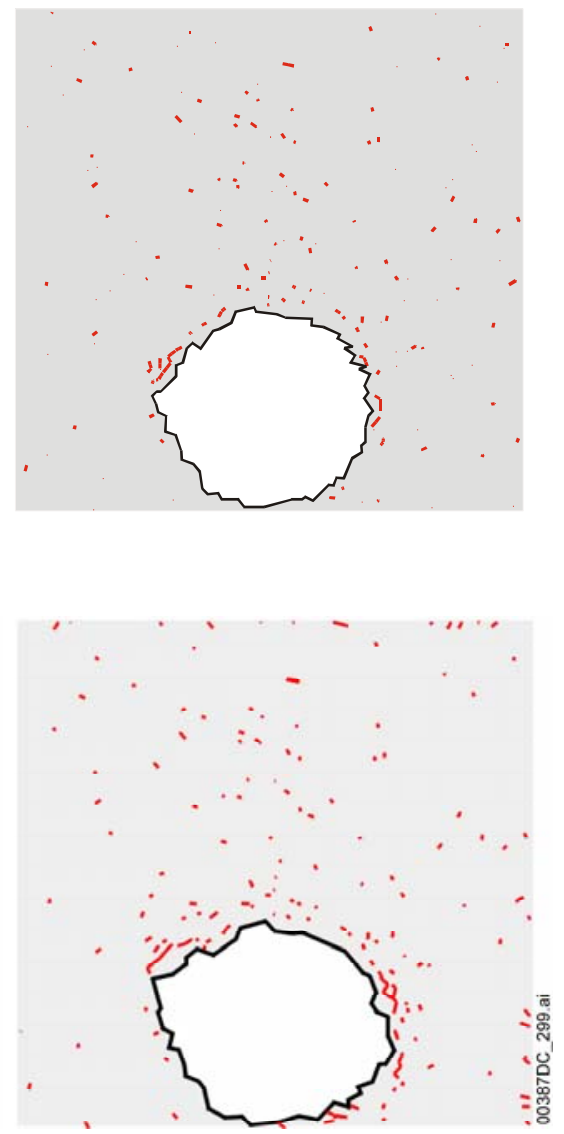

NOTE: Rock mass Categories 2 to 5 show no damage. Red lines indicate block bonds that have failed in shear or tension.

Figure 6-120. Geometry of the Model after Simulation for Preclosure Ground Motions: Rock Mass Category 1 


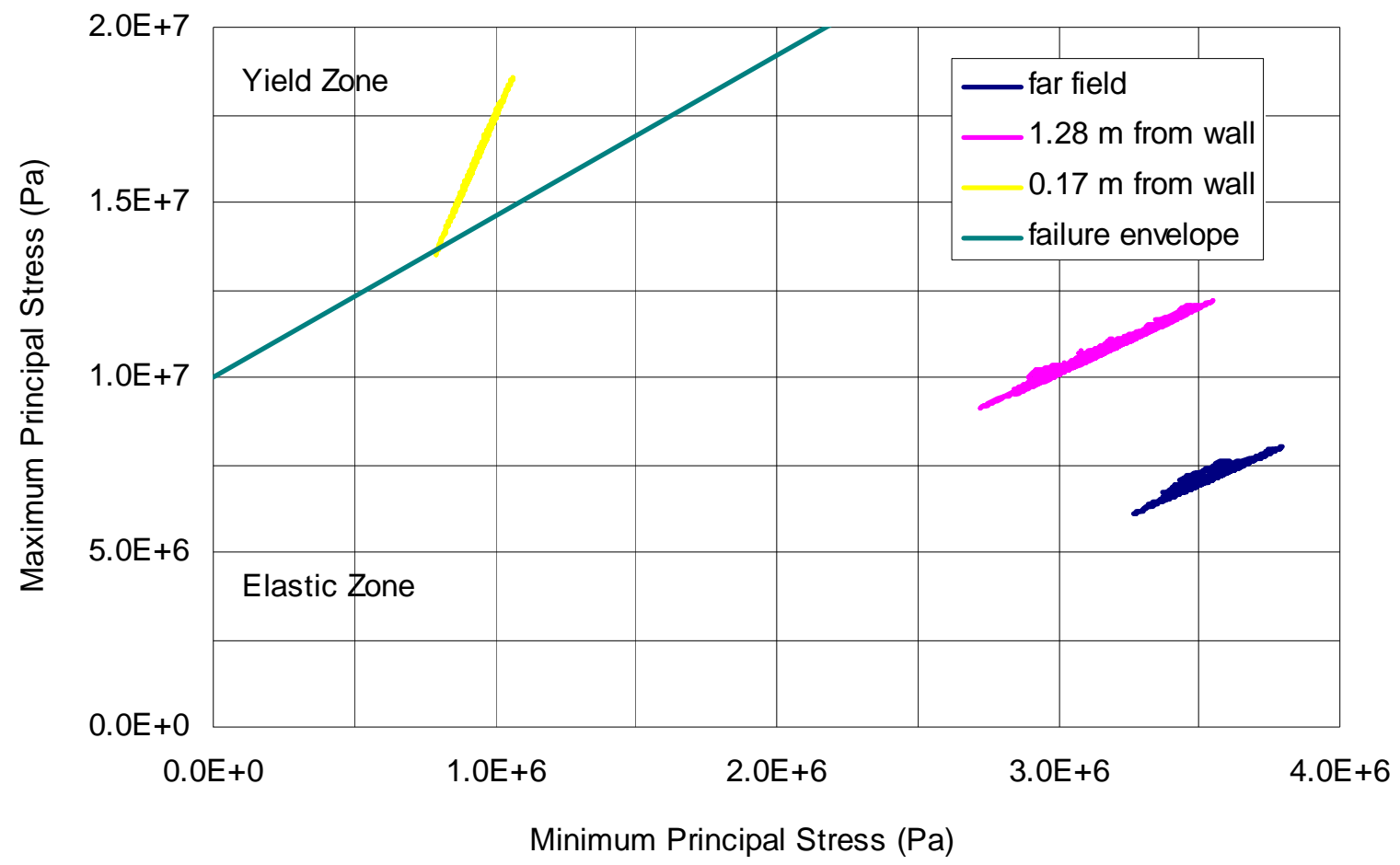

Figure 6-121. Elastic Stress Paths in the Drift Wall Due to $1 \times 10^{-4}$ Preclosure Ground Motion: Category 1

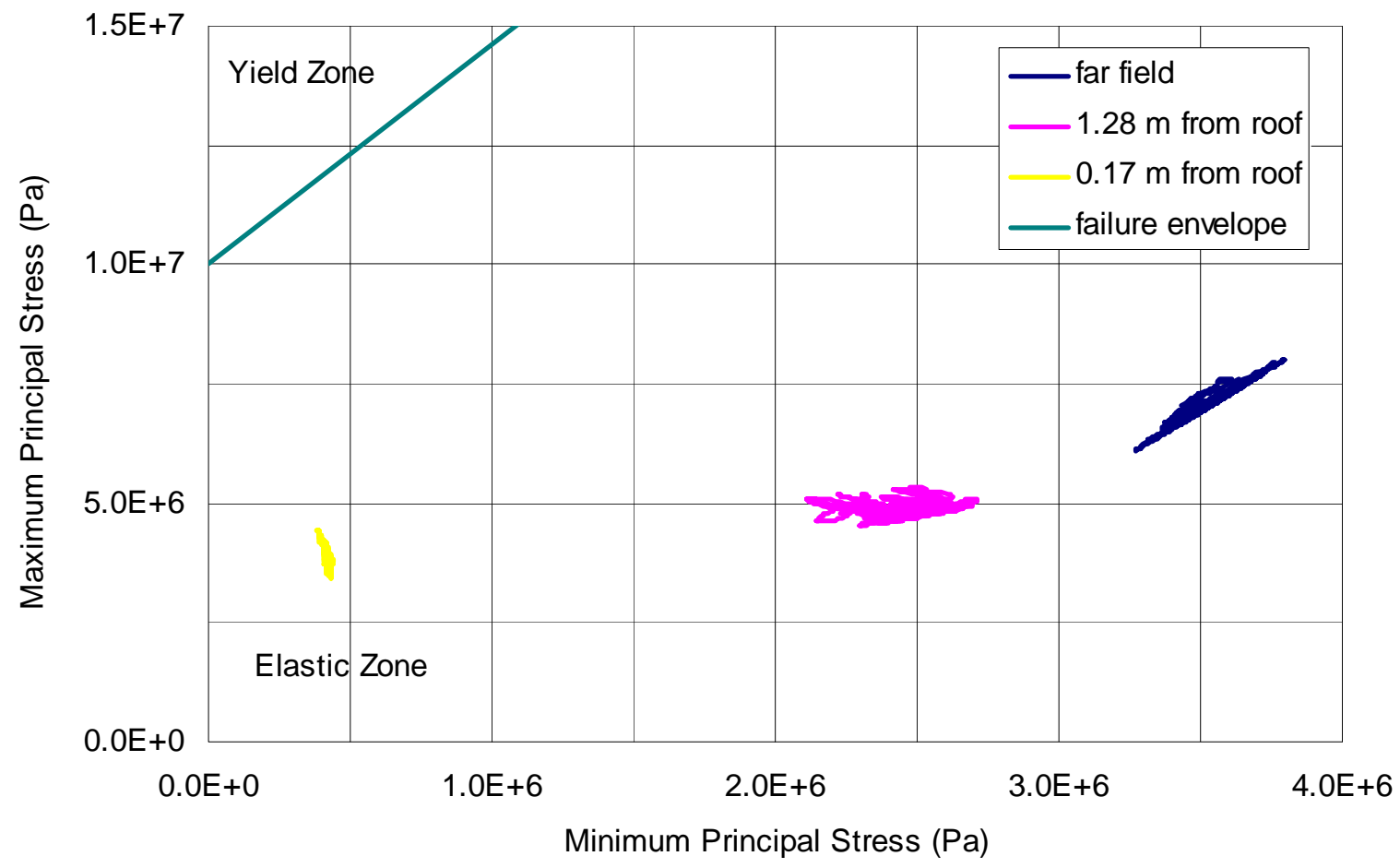

Figure 6-122. Elastic Stress Paths in the Drift Roof Due to $1 \times 10^{-4}$ Preclosure Ground Motion: Category 1 


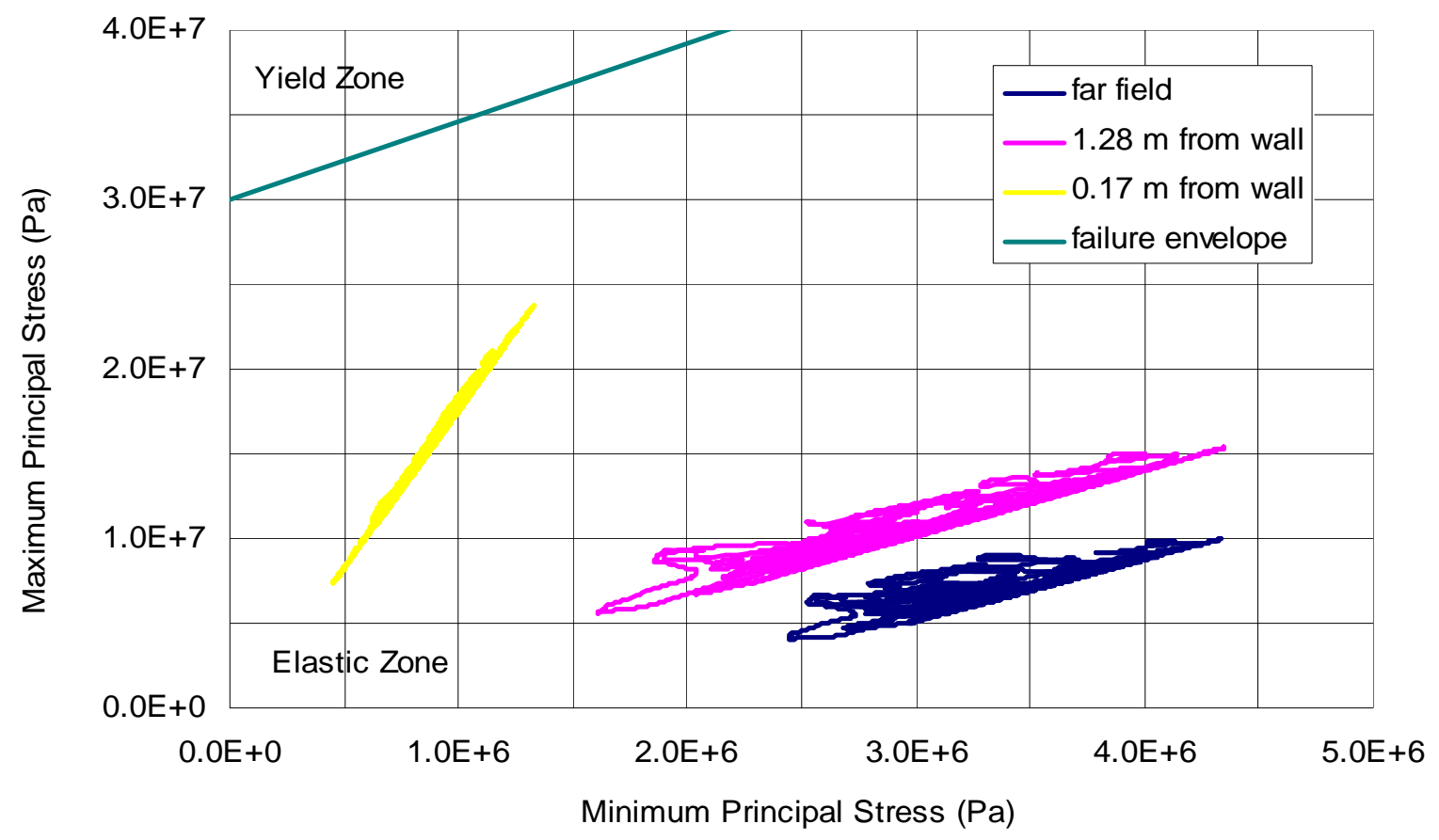

Figure 6-123. Elastic Stress Paths in the Drift Wall Due to $1 \times 10^{-4}$ Preclosure Ground Motion: Category 5

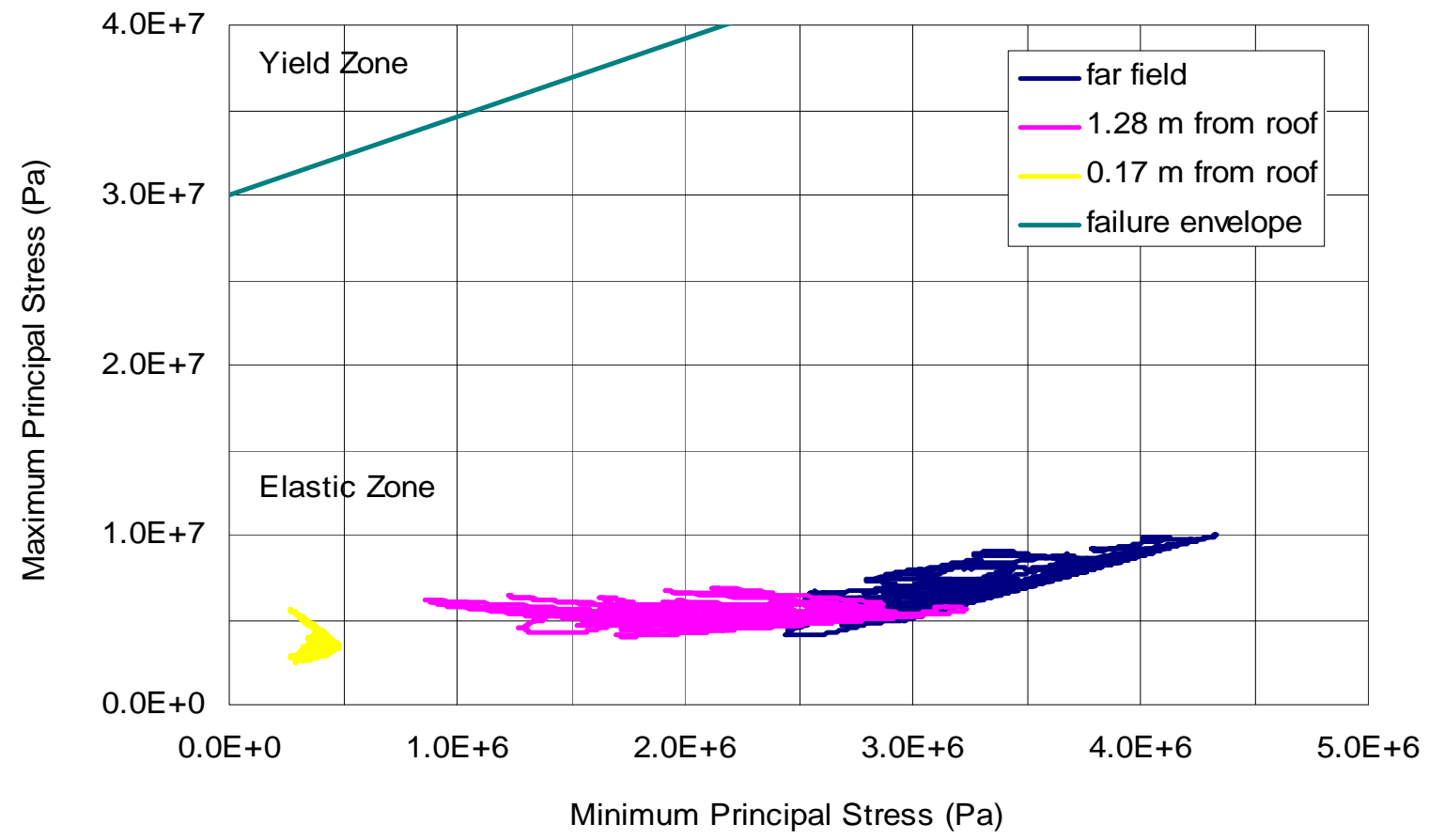

Figure 6-124. Elastic Stress Paths in the Drift Roof Due to $1 \times 10^{-4}$ Preclosure Ground Motion: Category 5 


\subsection{Analysis of Drift Response to Postclosure Ground Motions}

\subsection{Analysis of $1 \times 10^{-5}$ Ground Motions}

The $1 \times 10^{-5}$ annual exceedance frequency is described by 15 sets of three ground motions-one vertical and two horizontal. These ground motions were developed by scaling horizontal component 1 to a repository level target peak ground velocity (PGV), and scaling other components to maintain inter-component variability. For a detailed discussion of the development of the ground motion time histories see Development of Earthquake Ground Motion Input for Preclosure Seismic Design and Postclosure Performance Assessment of a Geologic Repository at Yucca Mountain, NV (BSC 2004 [DIRS 170027]). Table 6-45 summarizes the peak ground velocities for each of the motions.

Table 6-45. Summary of $10^{-5}$ Ground Motion Characteristics

\begin{tabular}{|c|c|c|c|}
\hline Ground Motion & $\begin{array}{c}\text { Horizontal } \\
\text { Component 1 } \\
\text { PGV (cm/sec) }\end{array}$ & $\begin{array}{c}\text { Horizontal } \\
\text { Component 2 } \\
\text { PGV (cm/sec) }\end{array}$ & $\begin{array}{c}\text { Vertical } \\
\text { Component PGV } \\
\text { (cm/sec) }\end{array}$ \\
\hline Set 1 & 104.58 & 83.31 & 70.88 \\
\hline Set 2 & 104.58 & 125.02 & 145.25 \\
\hline Set 3 & 104.58 & 262.05 & 398.11 \\
\hline Set 4 & 104.59 & 100.41 & 152.27 \\
\hline Set 5 & 104.58 & 166.71 & 106.52 \\
\hline Set 6 & 104.54 & 45.61 & 173.88 \\
\hline Set 7 & 104.51 & 89.33 & 333.16 \\
\hline Set 8 & 104.56 & 152.20 & 98.16 \\
\hline Set 9 & 104.59 & 357.76 & 281.76 \\
\hline Set 10 & 104.60 & 31.81 & 50.16 \\
\hline Set 11 & 104.60 & 126.04 & 120.31 \\
\hline Set 12 & 104.54 & 70.34 & 100.60 \\
\hline Set 13 & 104.58 & 103.75 & 318.01 \\
\hline Set 14 & 104.62 & 40.87 & 92.78 \\
\hline Set 15 & 104.56 & 67.43 & 137.53 \\
\hline
\end{tabular}

Source: DTN: MO0402AVDTM105.001 [DIRS 168890].

The vertical (V) and horizontal component 1 (H1) are applied at the base of the cross-sectional UDEC lithophysal rockfall model for consistency with three-dimensional waste package vibratory motion models in which the $\mathrm{H} 1$ component acts in the drift cross-sectional plane and $\mathrm{H} 2$ acts along the axis of the tunnel (BSC 2004 [DIRS 167083]). As seen in Table 6-45, approximately 25 percent (4 of 15) of the ground motion sets have a largest associated PGV in excess of $300 \mathrm{~cm} / \mathrm{sec}$, approximately 60 percent ( 9 of 15) with largest associated PGV of 100 to approximately $150 \mathrm{~cm} / \mathrm{sec}$, and approximately 15 percent (2 of 15) with largest associated PGV between 150 and $175 \mathrm{~cm} / \mathrm{sec}$. In a significant number of the ground motion sets, the vertical component has the largest associated PGV.

Parametric Analyses-All 15 motion sets were applied to base case rock mass strength Categories 1, 3, and 5 to cover the range of rock qualities. As discussed previously, Category 1 (and Category 2) is viewed as a condition of localized, high porosity (possibly 
large lithophysae) and represents less than 10 percent of the Tptpll. Category 3 (and Category 4) is viewed as a typical condition encountered in the Tptpll, representing approximately 60 percent of the Tptpll, and Category 5 viewed as the higher rock mass quality areas in the Tptpll, representing approximately 30 percent of the Tptpll. The sequencing of modeling initially involved application of in situ stresses to the rock mass and the unsupported emplacement drift, and allowed the system to equilibrate with any associated rockfall. Each ground motion is applied to the base of the model in the form of the time-varying vertical and horizontal motions, which are allowed to run through to the cutoff time of 95 percent of total energy.

Results-The level of damage induced by the ground motion is quantified here by the area (volume) of the rock that is detached from the surrounding rock mass and falls into the tunnel. Because the model is two dimensional, it essentially represents a 1-m thick slice of material parallel to the axis of the drift. The damage is thus given in terms of volume/m of emplacement drift, or $\mathrm{m}^{3} / \mathrm{m}$. This could be converted to metric tons by multiplying by the density, which, for the lithophysal rock, is approximately 2 tons $/ \mathrm{m}^{3}$ (the matrix density is approximately 2.5 tons $/ \mathrm{m}^{3}$ ).

Figures 6-125 to 6-127 show representative examples of the mechanism and level of damage induced for rock strength Categories 1, 3, and 5 for ground motions 12 (104 cm/sec PGV), $4(152 \mathrm{~cm} / \mathrm{sec} \mathrm{PGV})$, and $7(333 \mathrm{~cm} / \mathrm{sec} \mathrm{PGV})$. These ground motions cover the approximate range of PGVs for the 15 motions. The damage levels are further plotted for each rock mass strength category as a function of PGV in Figure 6-128. The analyses show that the damage appears to be primarily related to the magnitude of PGV, but is highly variable, particularly at large PGV, presumably due to the variability in the time histories and their impact on the energy (or power) contained in the waveform. An approximate linear upper bound to the damage can be seen in this plot in a fashion similar to that shown in Figure 6-83 for rockfall as a function of PGV in nonlithophysal rock. The variability in the response is a function of the properties of the ground motion time histories, not the rock properties, since constant modulus and strength are considered for a given category.

To investigate further the correlation to energy content of the ground motion, the vertical time history for each ground motion was run through a Fast Fourier Transform. The Fast Fourier Transform performs an integration of the square of the velocity over the duration of the time history, thus producing a power spectral density for velocity. This term is proportional to the integrated kinetic energy [kinetic energy $=1 / 2\left(m v^{2}\right)$ ] of the time history. The damage as a function of the velocity power spectral density for the vertical ground motion for each of the 45 analyses is plotted in Figure 6-129. This plot shows that the damage is linearly related to the energy associated with the velocity time history. Therefore, although PGV appears to be reasonably associated with the damage level and provides a means of bounding the response, the energy in the time history is a better indicator of the potential damage. 

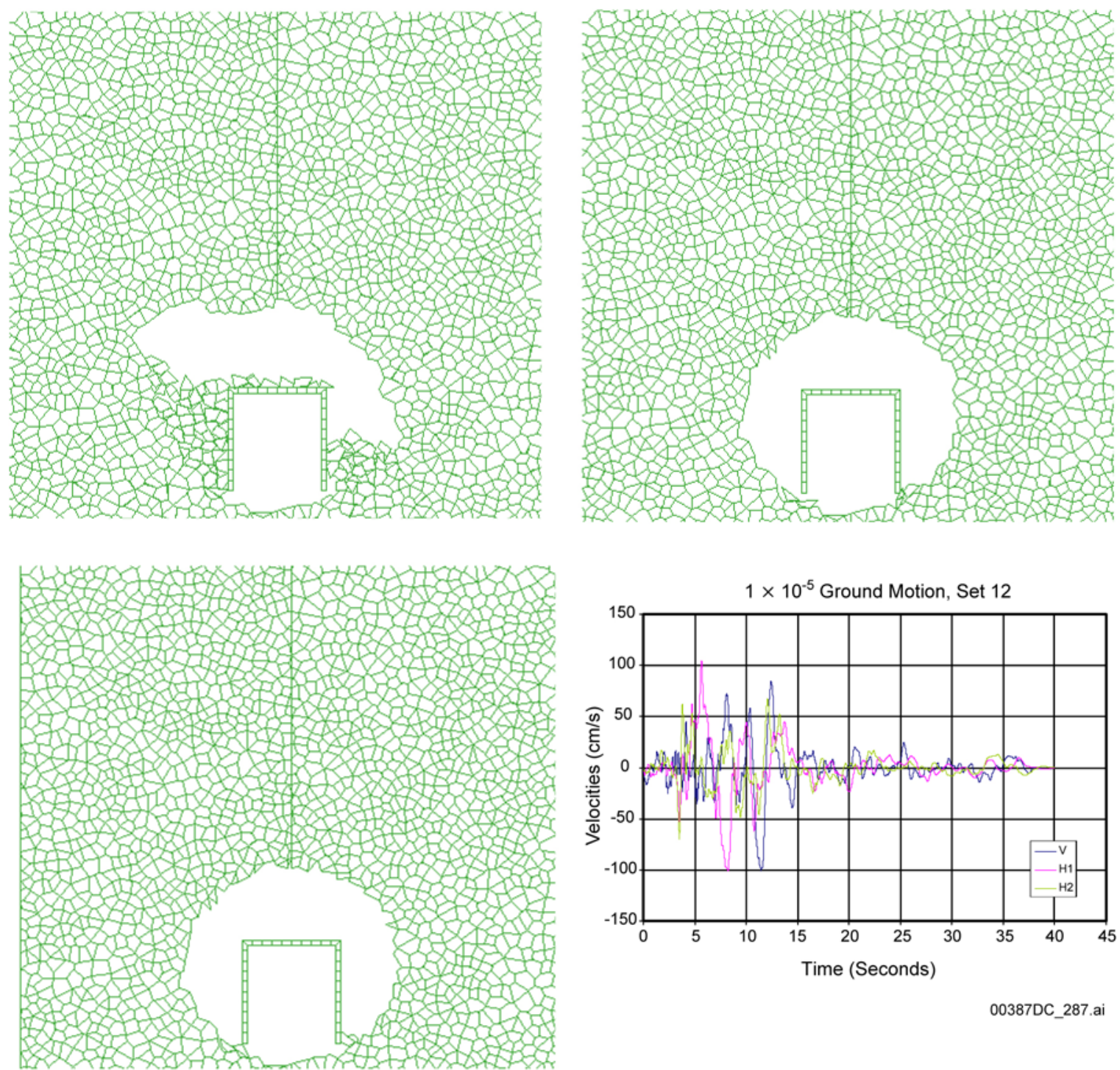

00387DC_287.ai

NOTE: (upper left) Rock Strength Category $1\left(5.6 \mathrm{~m}^{2} / \mathrm{m}\right.$ drift length), (upper right) Category $3\left(0.02 \mathrm{~m}^{2} / \mathrm{m}\right)$, (lower left) Category $5\left(0.1 \mathrm{~m}^{2} / \mathrm{m}\right)$, and (lower right) Ground Motion History 12, PGV=104 cm/sec.

Figure 6-125. Example of Comparison of Damage Levels for Lower End of PGV $(104 \mathrm{~cm} / \mathrm{sec})$ for $1 \times 10^{-5}$ Annual Exceedance Level 

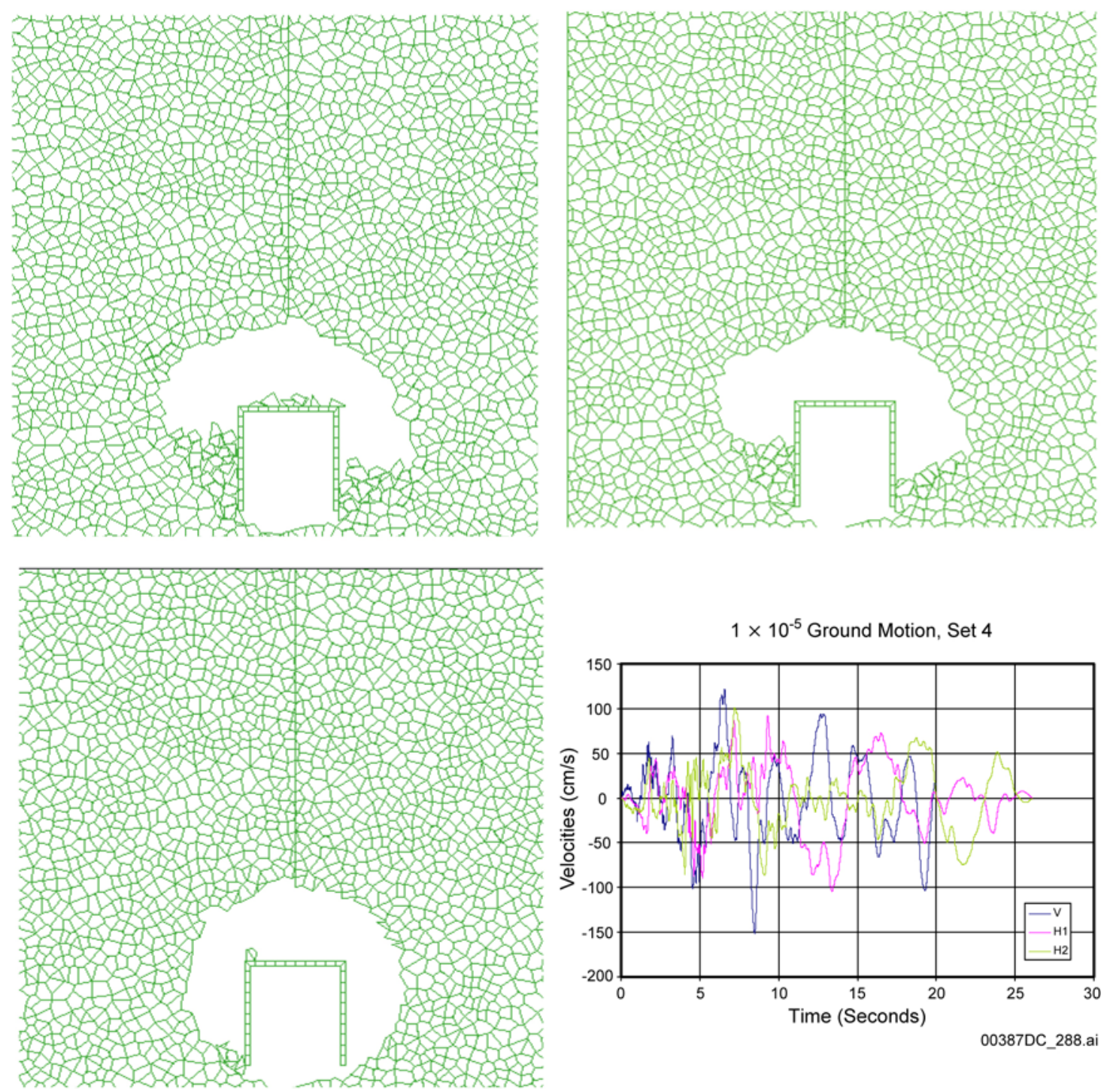

NOTE: (upper left) Rock Strength Category $1\left(3.3 \mathrm{~m}^{2} / \mathrm{m}\right.$ drift length), (upper right) Category $3(2.2 \mathrm{~m} / \mathrm{m})$, (lower left) Category $5\left(0.3 \mathrm{~m}^{2} / \mathrm{m}\right)$, and (lower right) Ground Motion History 4, PGV=152 cm/sec.

Figure 6-126. Example of Comparison of Damage Levels for PGV of $152 \mathrm{~cm} / \mathrm{sec}$ for $1 \times 10^{-5}$ Annual Exceedance Level 

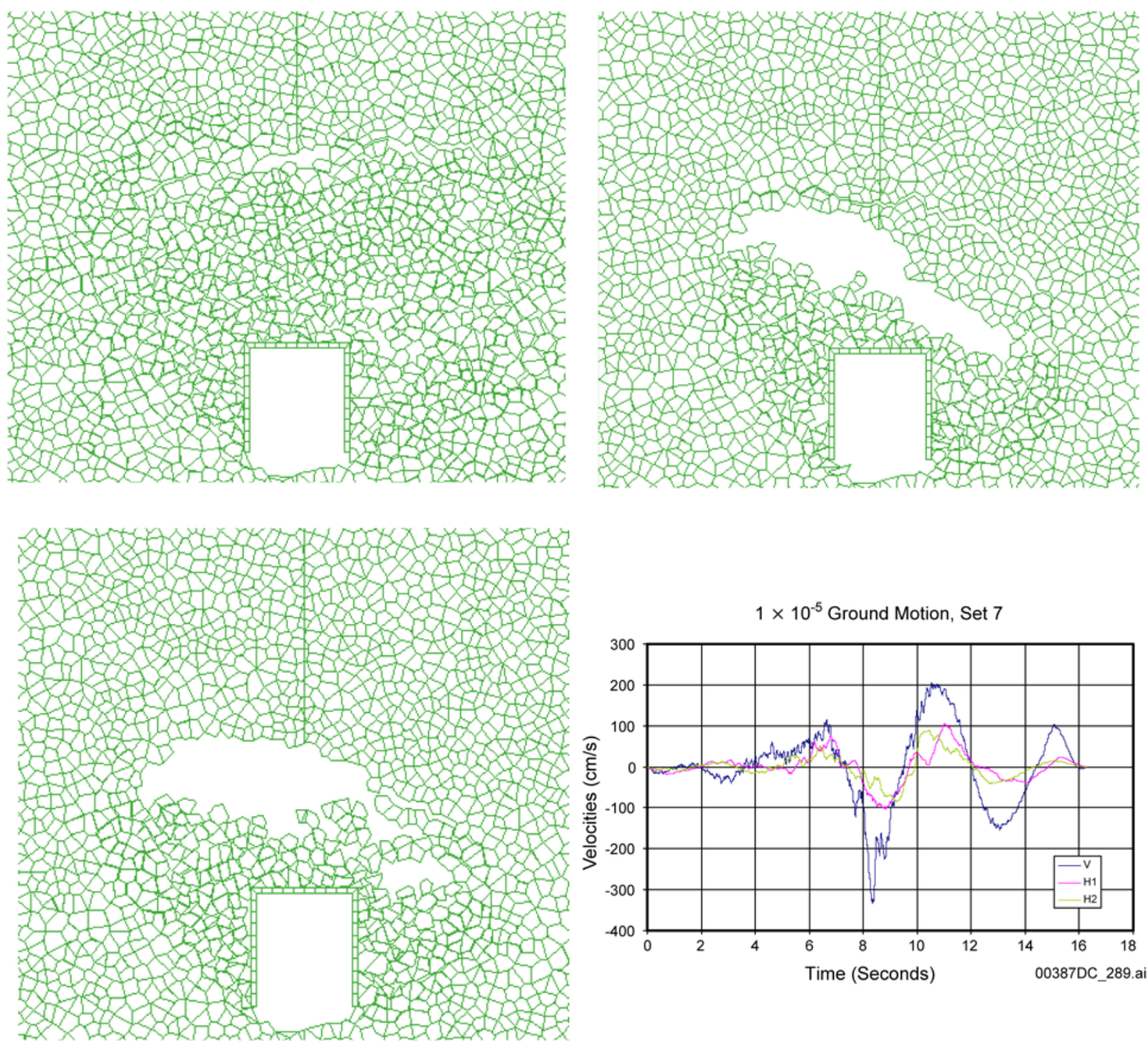

NOTE: (upper left) Rock Strength Category $1\left(40.6 \mathrm{~m}^{2} / \mathrm{m}\right.$ drift length), (upper right) Category $5\left(19.7 \mathrm{~m}^{2} / \mathrm{m}\right)$, (lower left) Category $3\left(15.4 \mathrm{~m}^{2} / \mathrm{m}\right)$, and (lower right) Ground Motion History 7, PGV $=333 \mathrm{~cm} / \mathrm{sec}$.

Figure 6-127. Example of Comparison of Damage Levels for Upper End of PGV $(333 \mathrm{~cm} / \mathrm{sec})$ for $1 \times 10^{-5} \mathrm{~m} / \mathrm{sec}$ 


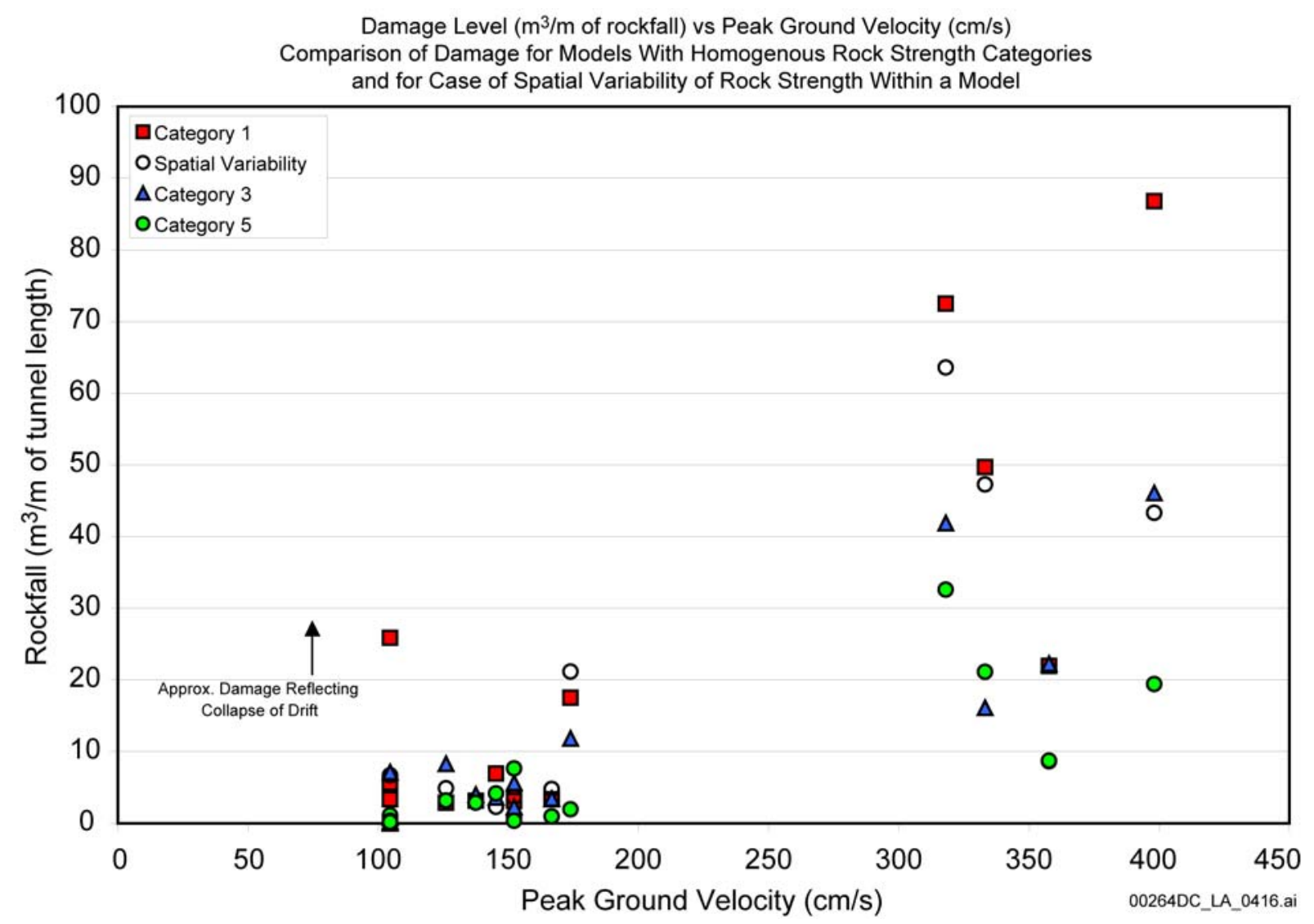

NOTE: Damage levels for the 15 ground motions are given. Results for spatially variable lithophysal porosity are also given for comparison.

Figure 6-128. Estimate $1 \times 10^{-5}$ Damage Level, Expressed as $\mathrm{m}^{2} / \mathrm{m}$ of Emplacement Drift Length for Rock Strength Categories 1, 3, and 5 for the 15 Ground Motion Time Histories 
Damage Level ( $\mathrm{m}^{2}$ of rockfall) in Lithophysal Rock

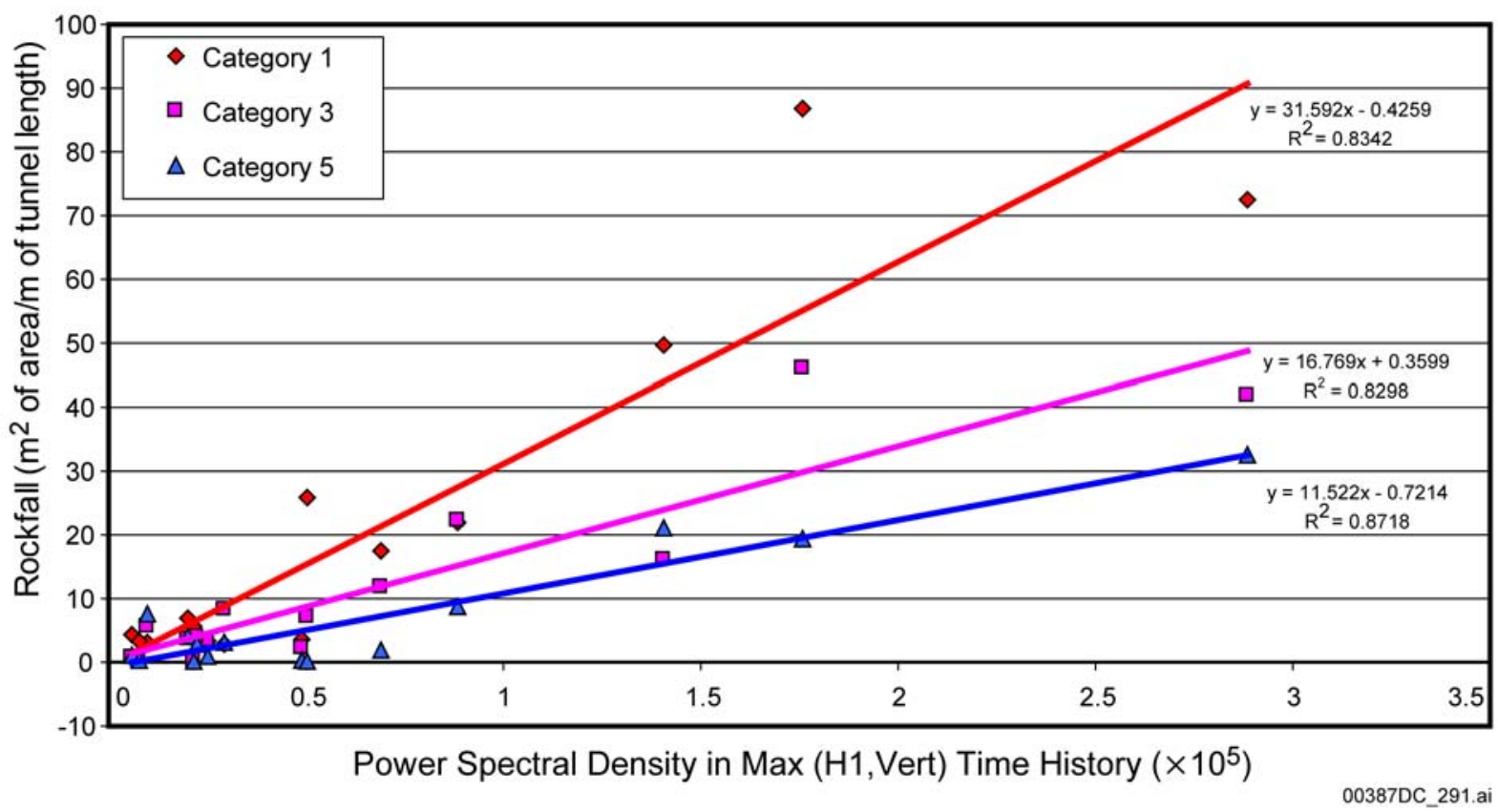

NOTE: The power spectral density is obtained by integrating the square of the velocity time history, producing a value proportional to the kinetic energy.

Figure 6-129. Rockfall Damage as a Function of the Energy Associated With the Vertical Velocity Time History

Discussion-The drift damage mechanism consists primarily of shear failure at the springlines of the tunnel coinciding with passage of the compressive stress increase associated with PGV peaks in the time history. The in situ stress field has major vertical and secondary horizontal stress components. The vertical compression or horizontal shear wave essentially results in a free field dynamic stress increase as shown in Equation 6-7 (note that the correction factor of 2 in Equation 6-7 is for boundary conditions only, and therefore is not required). These dynamic components are superimposed on the existing in situ stress field to cause additional stressing or relaxation of the rock mass surrounding the drift. The end-result of this superposition is that the stress tensor rotates about the general vertical axis as the ground velocities oscillate over the duration of the strong ground motion. If the addition of dynamic plus in situ stress is large enough, shear failure occurs primarily at the springlines, resulting in development of an elliptic shape of the opening as the rock mass yields and rockfall occurs and falls along the sides of the drip shield. The extent of shear failure and rockfall around the circumference of the tunnel, up and down from the springline, is due to both the general ratio of rock mass strength to stress, but also to the ratio of the vertical to horizontal PGV. The greater the horizontal component, the greater the rotation of the stress tensor, which results in greater inclination of the major principal stress. Generally, this shear failure mechanism occurs with the arrival of the PGV peaks. Compressive stresses also appear responsible for some cases in which roof slabbing is observed where the rock mass strength and stiffness are larger (i.e., Category 5). A second failure mechanism observed includes tensile failure of the rock mass resulting from the reversal of the ground motion and inducement of dynamic tensile straining in the rock mass. 
In general, it appears that the rock mass failure and the rockfall occur simultaneously with the arrival of velocity peaks in the time histories. In a similar fashion, the peak ground velocity has been recognized by many authors as the primary contributing factor to dynamic rock mass failure in mine tunnels, slopes, and dams (e.g., MRD 1995 [DIRS 169719], Volume 2, Section 6.2.3; Newmark 1965 [DIRS 169515]). In the present case, the shear or tensile failure mechanism results in a predicted creation of blocks resulting from fracture of the rock mass along the ubiquitous fracture network of the material. The blocks that contact the drip shield are relatively small in size, and governed by the inherent fracture network and lithophysae spacing. The UDEC lithophysal rockfall model studies have primarily used a 0.3-m average fracture spacing in developing the block structure, although simulations with 0.2-m spacing have also been conducted. In each case, the transient dynamic stress changes, in addition to pre-existing in situ stresses, result in breakage of the bonds between the blocks in the rockfall zone around the tunnel. In other words, the stressing does not create large blocks that impact the drip shield, but small component blocks defined by the inherent fracturing of the Tptpll.

Although the damage levels appear to correlate somewhat better to the energy content of the time history, correlation to PGV provides a simpler method for interpretation of the results. Correlation to PGV is also consistent with that used in waste package and drip shield vibratory motion damage abstractions (Seismic Consequence Abstraction, BSC 2004 [DIRS 169183]). An approximate relationship of damage level to PGV in terms of both $\mathrm{m}^{3} / \mathrm{m}$ of drift length and physical interpretation can be roughly approximated as follows:

- Peak ground velocities below about $1 \mathrm{~m} / \mathrm{sec}$ result in relatively minor damage to unsupported drifts.

- Peak ground velocities below about $1.5 \mathrm{~m} / \mathrm{sec}$ result in an approximate damage level below $5 \mathrm{~m}^{3} / \mathrm{m}$. This damage level is characterized by a range from minor spalling to damage characterized by rock particles filling the invert along the sides of the drip shield (see Figure 6-125).

- Peak ground velocities from approximately 1.5 to $2 \mathrm{~m} / \mathrm{sec}$ result in damage levels from 5 to $15 \mathrm{~m}^{3} / \mathrm{m}$. This damage level is characterized by rock particles covering the sides of the drip shield to, approximately, the height of the drip shield, and may cover the top of the drip shield (see Figure 6-126).

- Peak ground velocities in excess of about $2 \mathrm{~m} / \mathrm{sec}$ result in damage levels above $15 \mathrm{~m}^{3} / \mathrm{m}$. This damage level is characterized by complete collapse of the tunnel (see Figure 6-127).

Dynamic Drip Shield Loading From $1 \times 10^{-5}$ Ground Motions-Collapse of a tunnel in lithophysal rock results in loading applied to the drip shield. The rock loads fall under three primary categories:

- Dynamic loading from the rock particles striking the drip shield 
- Quasi-static loading of the drip shield due to the dead weight of the fallen rock at rest on the drip shield

- Dynamic loading of the drip shield due to rockfall induced by drift collapse.

In this section, the dynamic loading of the drip shield due to rockfall induced by drift collapse from the $1 \times 10^{-5}$ ground motion, is examined. The quasi-static load on the drip shield once the seismic shaking stops and the system comes to force equilibrium, is discussed in Section 6.4.2.5. In these analyses, the drip shield is considered deformable, with the geometry consistent with Seismic Consequence Abstraction (BSC 2004 [DIRS 169183]; and see Figure 6-130). The drip shield is idealized as a two-dimensional model of the actual geometry and deformability of the drip shield using the standard UDEC element structure. The drip shield is subdivided into 30 total segments of equal length. The elements are considered to be elastic, and, thus, no potential yield response is modeled. The purpose of these analyses is to provide estimates of both dynamic and quasi-static structural loading to the detailed dynamic analysis of drip shield structural response using the LS-DYNA three-dimensional finite element model (Drip Shield Structural Response to Rock Fall, BSC 2004 [DIRS 168993]). Because the UDEC lithophysal rockfall model is two-dimensional and does not attempt to model the detailed structure of the drip shield, the stiffness of the elements must be adjusted to provide an equivalent overall deformability to the actual three-dimensional structure. The stiffness of the UDEC elements has been calibrated against the three-dimensional LS-DYNA model to reproduce the deformability of the actual drip shield design (see Appendix Y). The dynamic loading from detached rock particles during the seismic shaking (includes the effect of relative velocity of between the drip shield and the falling rock) is examined here.

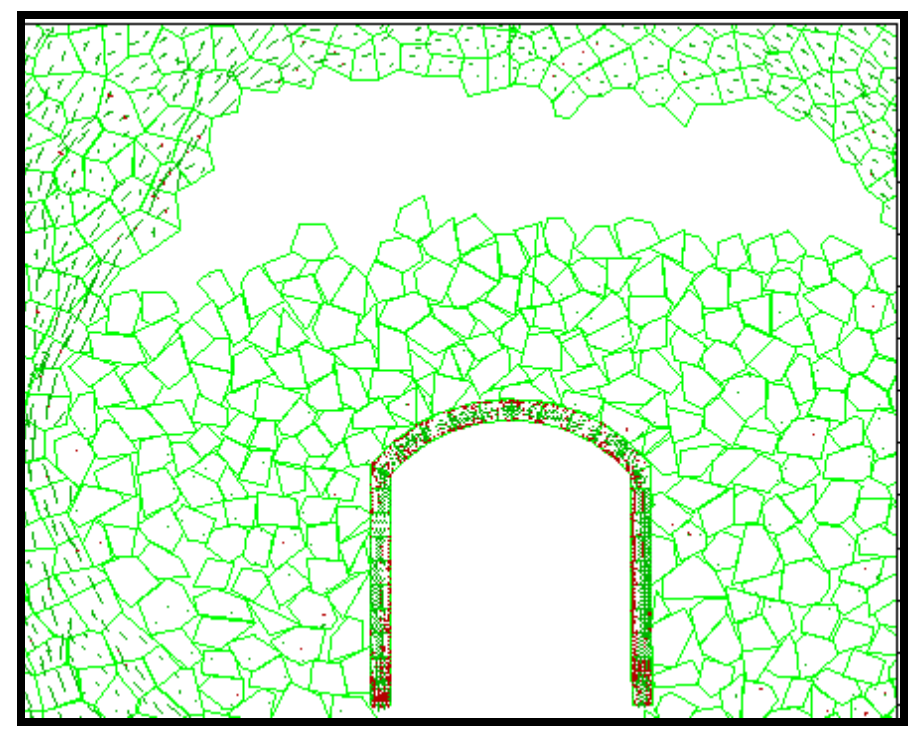

NOTE: Case with drift collapse for Rock Mass Category 1 and Ground Motion Set 9 with PGV of $2.82 \mathrm{~m} / \mathrm{sec}$.

Figure 6-130. Representation of the Drip Shield as a Deformable Structure With Actual Geometries and Footings That are Either Free to Slide or to Slide and Separate From the Invert 
An example of the dynamic impact loading from side and top impacts to the deformable drip shield resulting from the $1 \times 10^{-5}$ ground motion ( $\mathrm{PGV}=3.33 \mathrm{~m} / \mathrm{sec}$ case) are given in Figure 6-131. ${ }^{8}$ In this figure, the average pressure across an element (in Pa) is given as a function of time (in seconds). In general, the transient stress at any given element is approximately one order of magnitude greater than the eventual dead weight load of bulked rock for the case of a completely-collapsed tunnel at equilibrium (see Section 6.4.2.5). However, due to the relatively small size of the rock particles developed in the lithophysal rock (in comparison to the much larger blocks in the nonlithophysal material), the nonlithophysal dynamic impact loading to the drip shield provides a more conservative, bounding case. Therefore, the nonlithophysal rockfall case provides the primary input for dynamic impact loading for the damage analysis and design of the drip shield. Dead weight quasi-static loading of the drip shield as described in Section 6.4.2.5 is felt to be a more important loading mechanism in the lithophysal rock mass.

\subsection{Analysis of $1 \times 10^{-6}$ Ground Motions}

Drift Failure Response - Ground motions with a probability of an annual occurrence of $1 \times 10^{-6}$ cause complete collapse of the emplacement drifts irrespective of the rock mass category and ground motion case. The model geometries after simulations of realization numbers 1 through 6 from Table 6-44 are shown in Figure 6-132. Elastic stress paths (for ground motion case 1) shown in Figures 6-133 and 6-134, for the Category 1 rock mass, and Figures 6-135 and 6-136, for the Category 5 rock mass, demonstrate different mechanisms of drift collapse depending on the rock mass quality. In poor quality rock masses (e.g., Category 1), far-field stress (unaffected by the drift) is mostly elastic during the history of the ground shaking. However, stress amplifications and concentrations around the drift cause intense yielding in tension and shear, which eventually causes the drift to collapse. In the case of better rock mass quality (e.g., Category 5), the rock mass fails in tension even for far-field conditions (away from the drift), and tensile fractures propagate throughout the rock mass. The drift creates an open space into which the loose blocks collapse.

Dynamic Drip Shield Loading From $1 \times 10^{-6}$ Ground Motions-Collapse of a tunnel in lithophysal rock results in loading applied to the drip shield. The dynamic loading of the drip shield due to rockfall induced by drift collapse from the $1 \times 10^{-6}$ ground motion is examined and presented in Appendix P (Figures P-29 to P-31). The quasi-static load on the drip shield once the seismic shaking stops and the system comes to force equilibrium, is discussed in Section 6.4.2.5.

\footnotetext{
8 The dynamic loading of the drip shield by small rock blocks from the Tptpll determined from $1 \times 10^{-5}$ ground motions is considered to be reasonable for the ground motions that cause complete collapse since the rock blocks fall from the same height under gravity.
} 

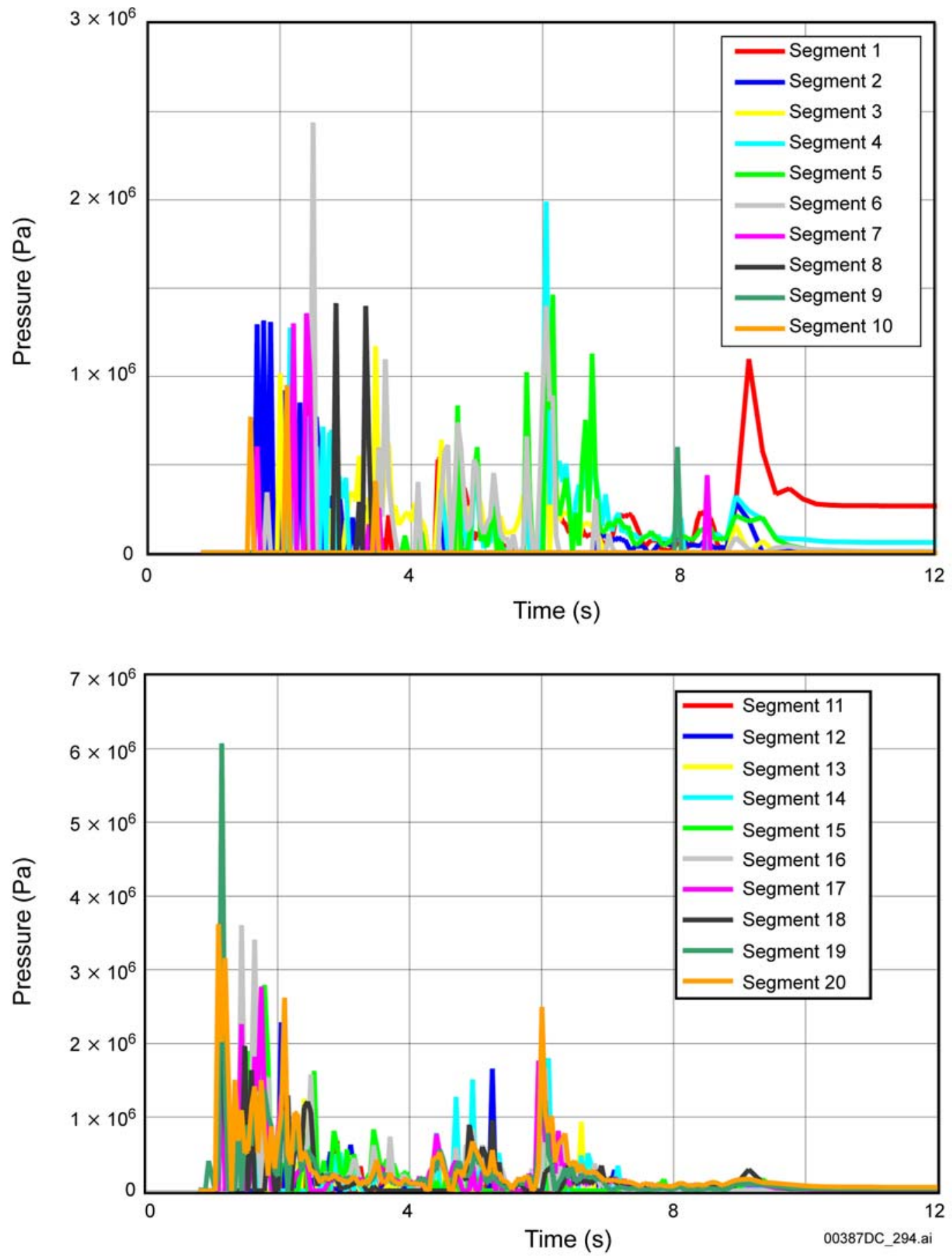

NOTE: Segments 1-10 are found along the wall, starting at the footing.

Figure 6-131. Example of Dynamic Impact Loading with $1 \times 10^{-5}$ Ground Motions to the Right Wall (top) and Roof (bottom) of Deformable Drip Shield With Arched Roof 


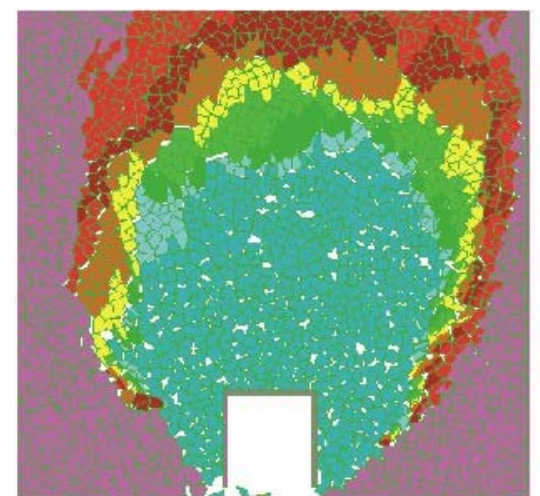

a) realization 1

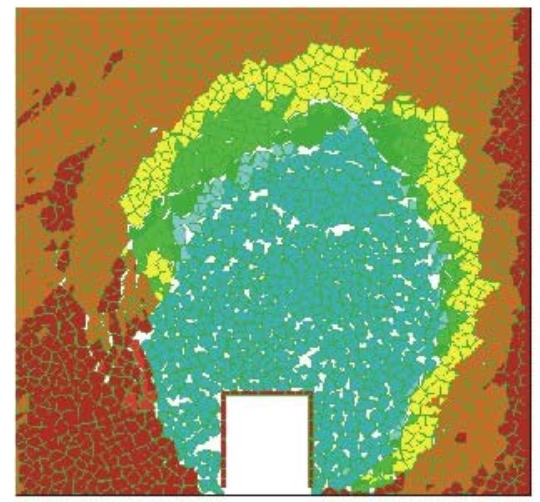

c) realization 3

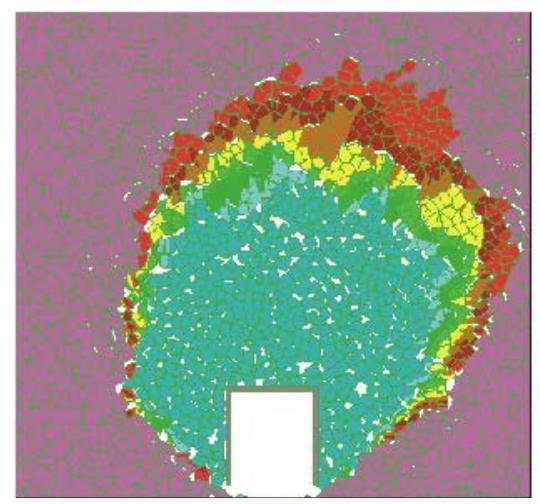

e) realization 5

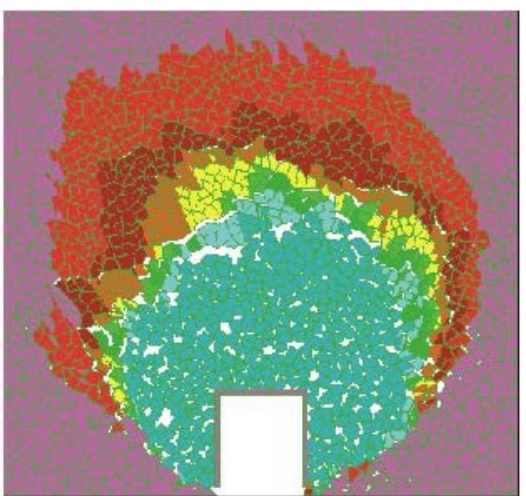

b) realization 2

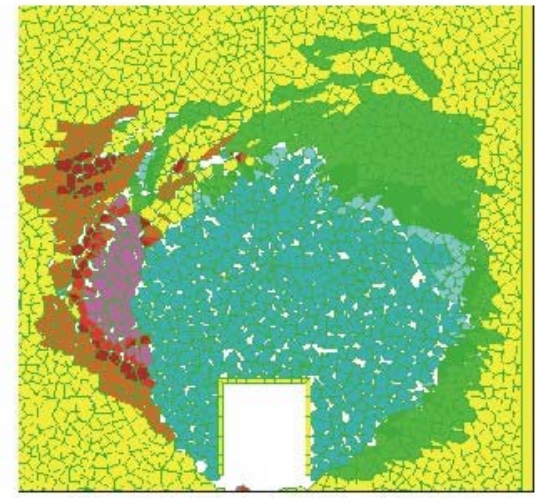

d) realization 4

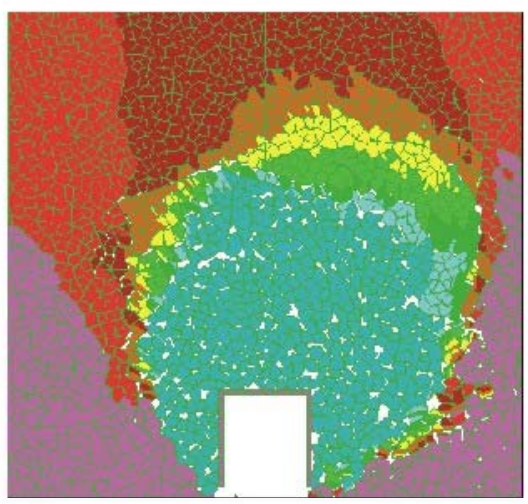

f) realization 6
$1.500 \mathrm{E}-01$

$2.000 \mathrm{E}-01$

$2.500 \mathrm{E}-01$

$3.000 \mathrm{E}-01$

$3.500 \mathrm{E}-01$

$4.000 \mathrm{E}-01$

$4.500 \mathrm{E}-01$

5.000E-01

NOTE: Blocks are colored by magnitude of displacement $(m)$.

Figure 6-132. Geometry of the Model After Simulations for Postclosure Ground Motions (Probability $\left.1 \times 10^{-6}\right)$ : Realizations 1 Through 6 from Table 6-44 


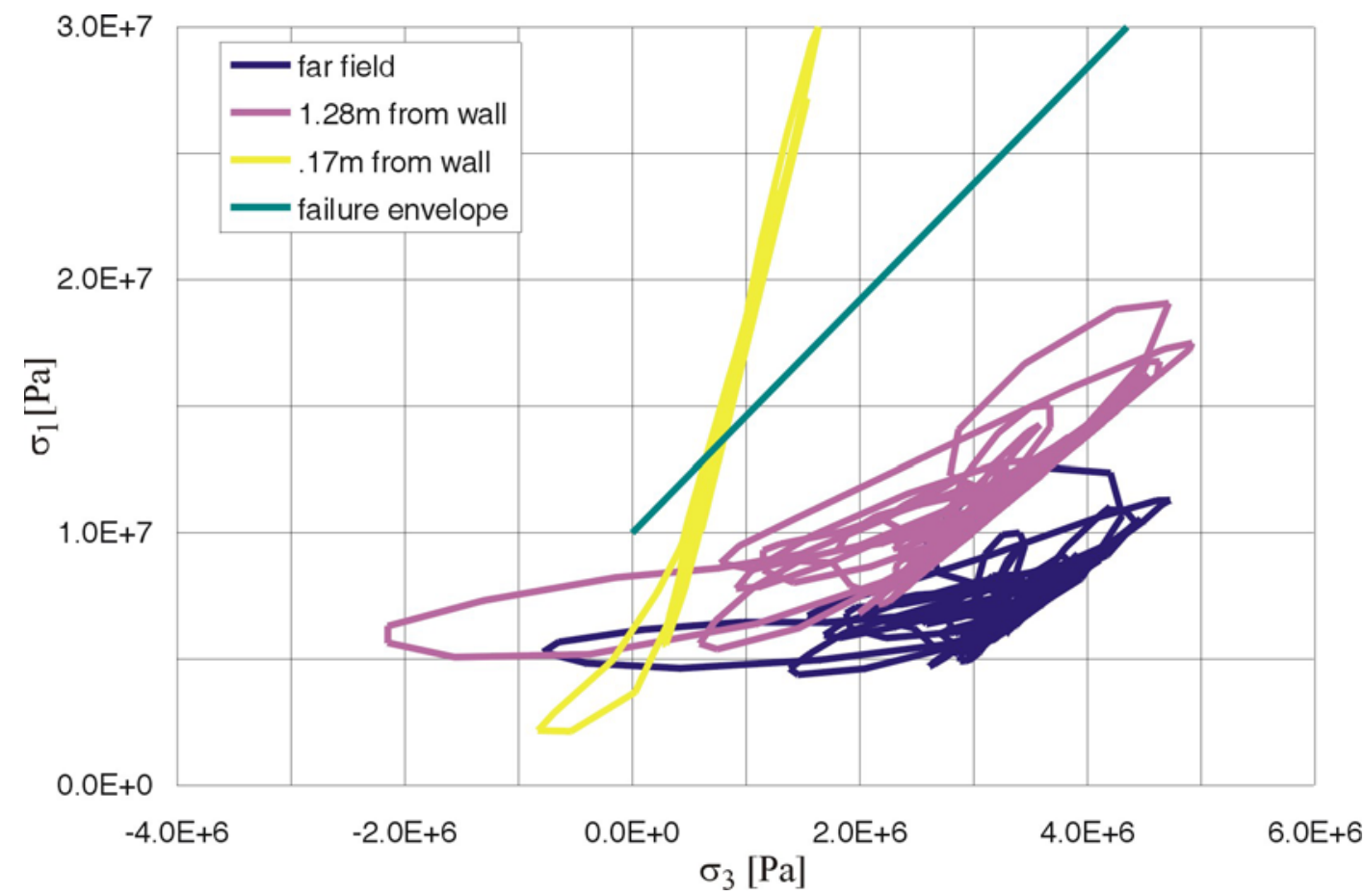

Figure 6-133. Elastic Stress Paths in the Drift Wall Due to Postclosure Ground Motion No. 1: Category 1

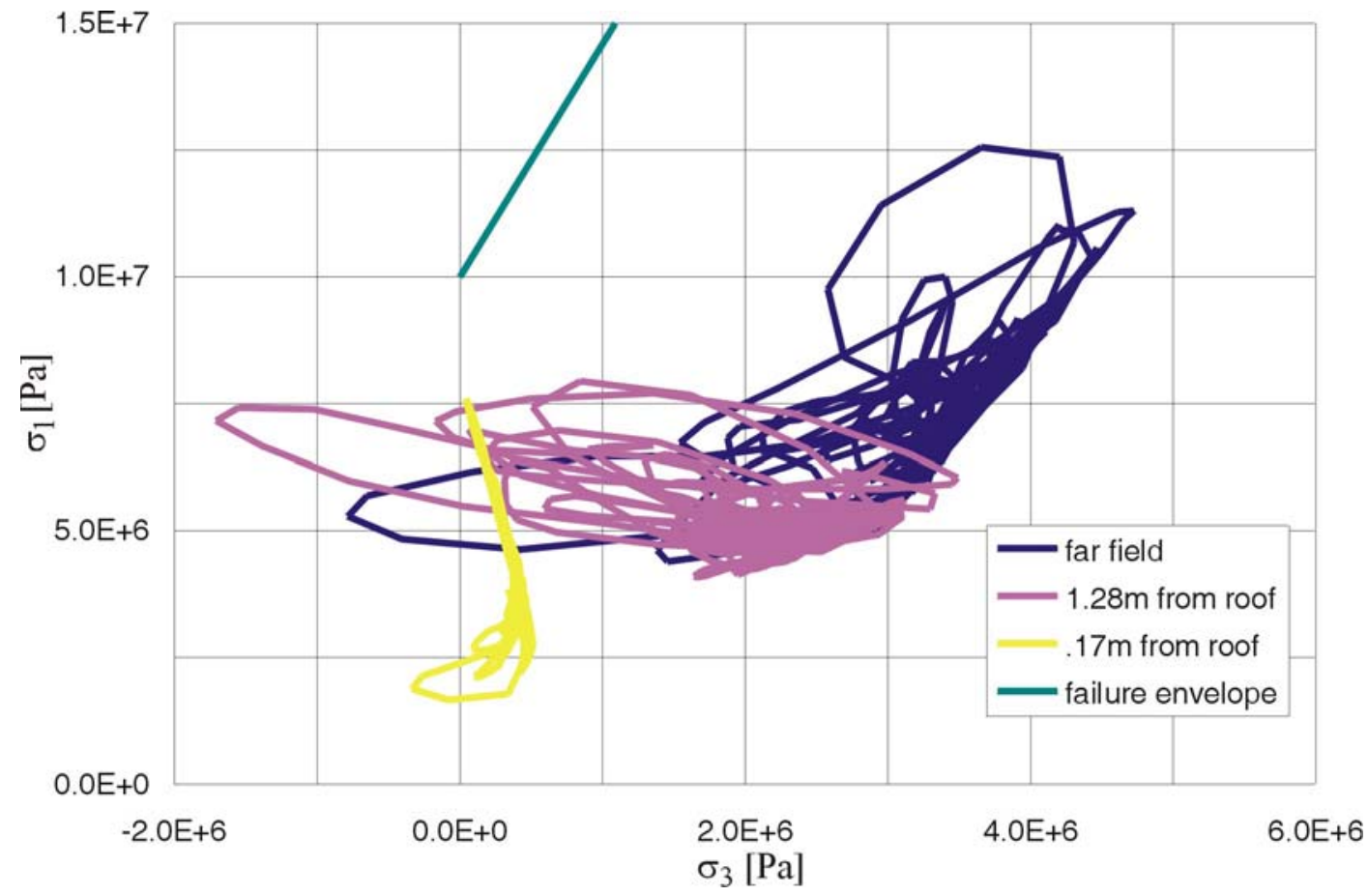

Figure 6-134. Elastic Stress Paths in the Drift Roof Due to Postclosure Ground Motion No. 1: Category 1 


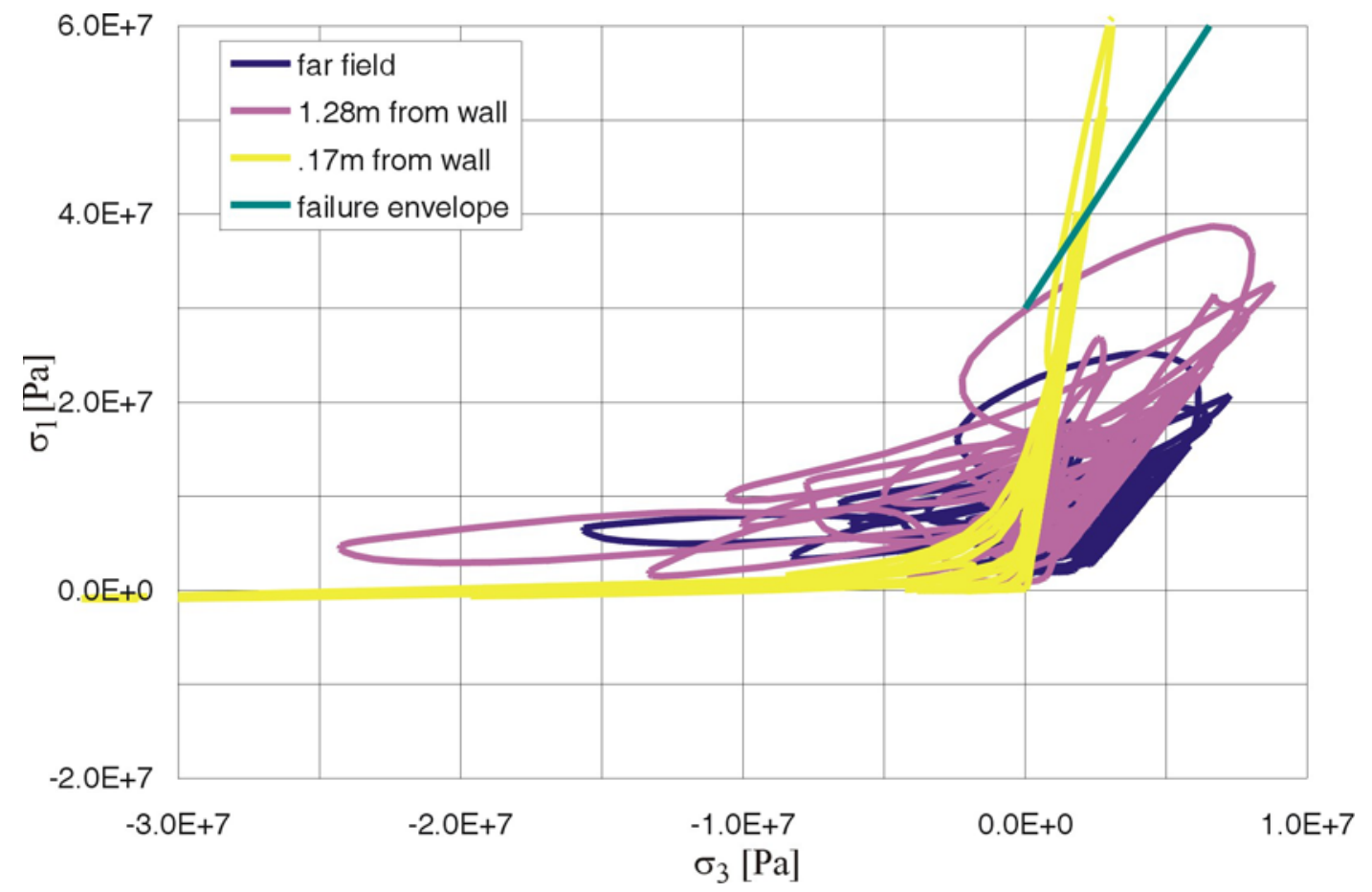

Figure 6-135. Elastic Stress Paths in the Drift Wall Due to Postclosure Ground Motion No. 1: Category 5

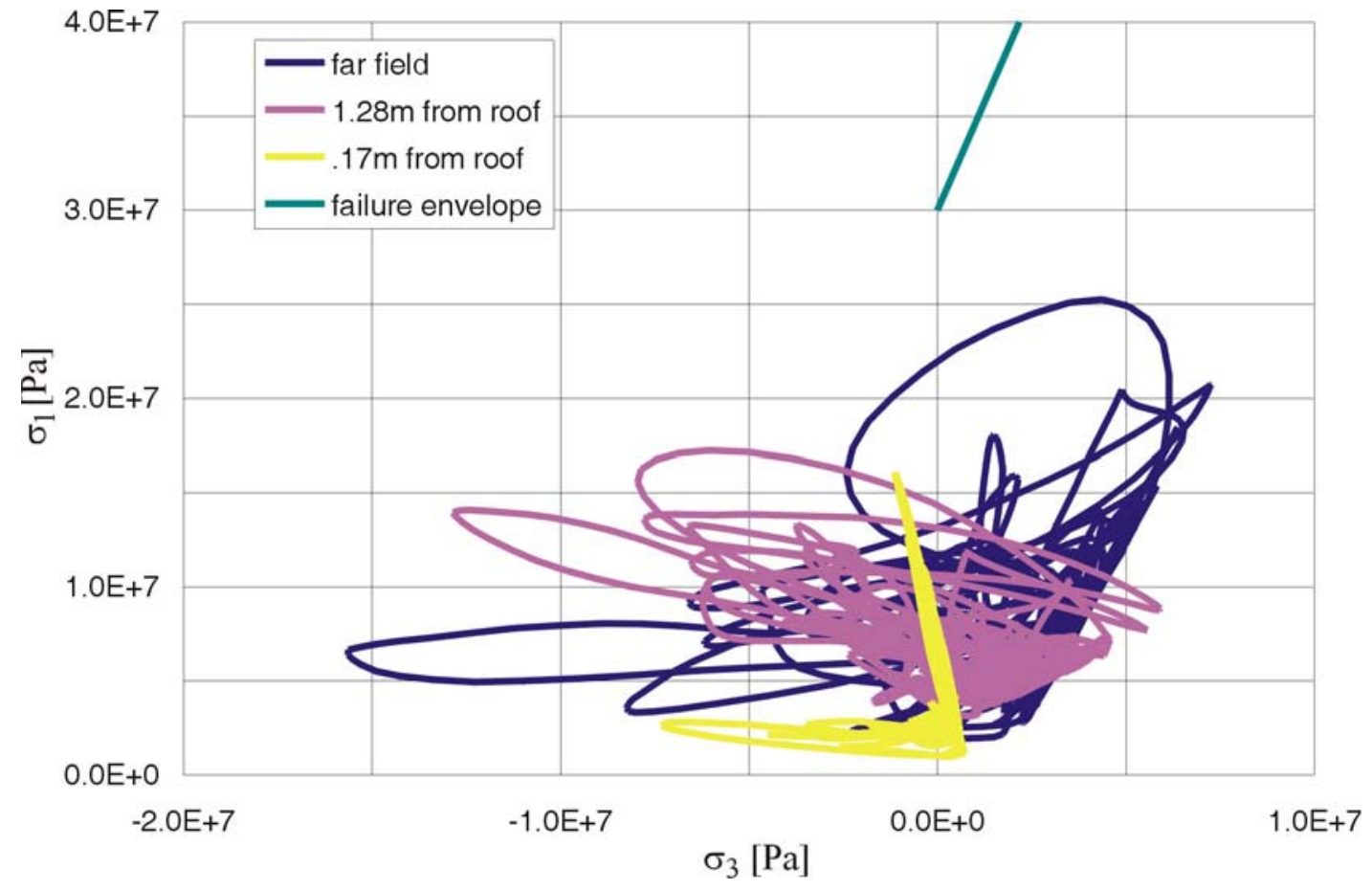

Figure 6-136. Elastic Stress Paths in the Drift Roof Due to Postclosure Ground Motion No. 1: Category 5 


\subsection{Sensitivity of Mechanical Properties to Rockfall Prediction}

The base case and bounding case rock mechanical properties are presented in Table 6-41. Uncertainties for the range of rock properties are considered in the previous sections with 5 categories of rock mass properties which cover the strength range of 10 to $30 \mathrm{MPa}$. Consideration was also given to the likely scatterness of the strength within the same category (the lower and upper bounds column in Table 6-41). This section presents the results for the analyses based on lower bound strength properties. The upper bound with higher strength will yield more stable drift conditions compared with the base case and hence is not considered in the sensitivity study. The region of analyses is simplified as homogeneous material for the base case and lower bound case. Sensitivity of spatial variation within the model region is also considered.

\subsection{Consideration of Lower Bound Strength}

Based on the assessment of rock mass properties documented in Appendix E (Section E4.1), the lower bound strength ranges from $10 \mathrm{MPa}$ to $16 \mathrm{MPa}$ for the 5 categories compared with the range of $10 \mathrm{MPa}$ to $30 \mathrm{MPa}$ for the base case. In fact, $10 \mathrm{MPa}$ lower bound strength was assigned to categories 1 to 3 (Table 6-41). Categories 3 and 5 were selected for the seismic analysis sensitivity consideration. Since rockfall results presented in the previous sections indicate that minor spalling or no damage is predicted for the preclosure ground motion and drift collapse predicted for the $1 \times 10^{-6}$ ground motions, the sensitivity case only considers $1 \times 10^{-5}$ ground motions. The 15 ground motions were applied to categories 3 and 5 rock. Collapse of the drift is observed for most of the cases even with category 5 rock. Figure 6-137 shows the results for category 5 rock subject to ground motion set $12(\mathrm{PGV}=104 \mathrm{~cm} / \mathrm{sec})$, set $4(\mathrm{PGV}=152 \mathrm{~cm} / \mathrm{sec})$, and set $7(\mathrm{PGV}=333 \mathrm{~cm} / \mathrm{sec})$, the same selection as presented in Figures 6-125 to 6-127. The results represent a very conservative for the nominal case with the consideration in that the surrounding rock is homogeneous and entirely biased to the low-strength end of the distribution within its category. Since the lower bound is estimated based on the saturated samples as shown in Figure E-18, the results indicate that the saturated drift environment is likely to collapse when subject to $1 \times 10^{-5}$ ground motions. But for nominal case with relatively dry condition, spatial variation of rock around the drift is most realistic and should be considered. This is described in the following subsection. 


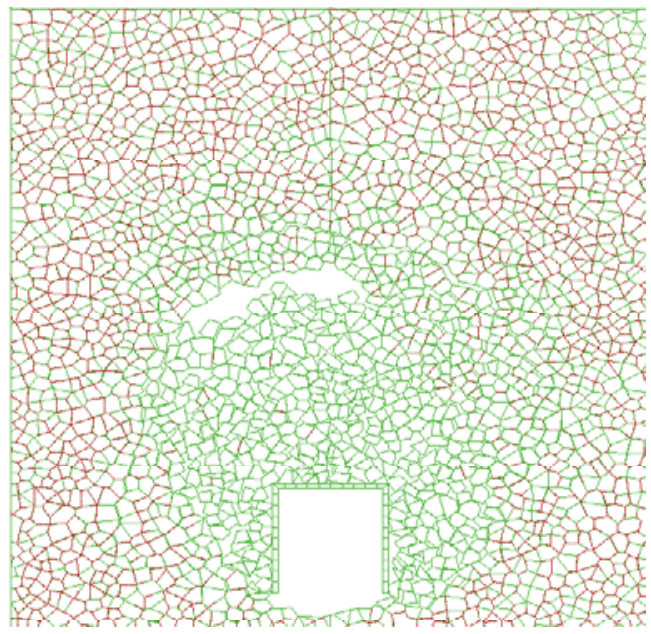

a) ground motion set 12 , peak ground motion $=104 \mathrm{~cm} / \mathrm{sec}$

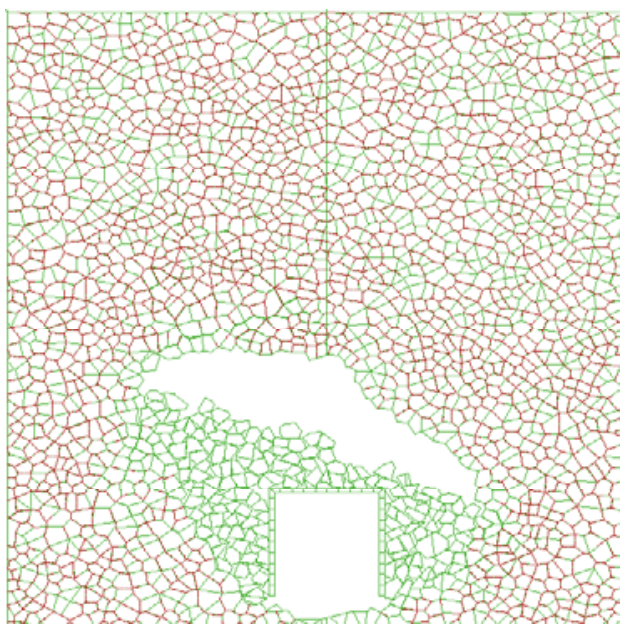

b) ground motion set 4, peak ground motion $=152 \mathrm{~cm} / \mathrm{sec}$

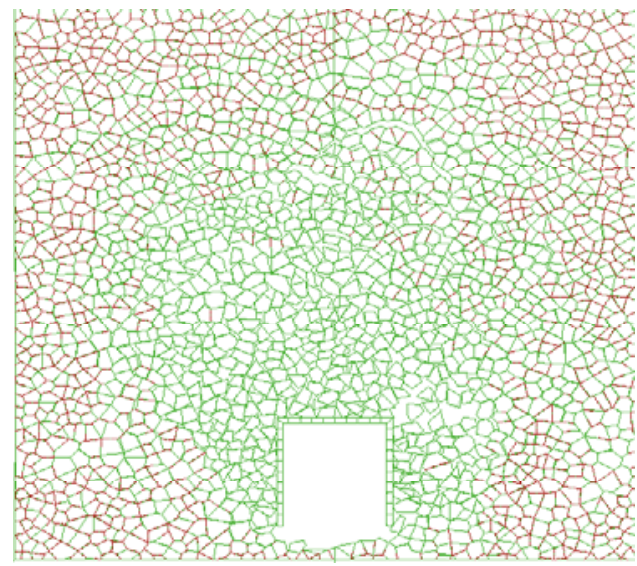

c) ground motion set 7 , peak ground motion $=333 \mathrm{~cm} / \mathrm{sec}$

Figure 6-137. Drift Damage for Category 5 Lower Bound Strength Subject to $1 \times 10^{-5}$ Ground Motions 


\subsection{Impact of Spatial Variability on Drift Stability}

In the previous analyses, the rock mass properties were considered homogeneous for a given drift cross-section. Here, the impact of considering actual spatial variability of lithophysal porosity on damage from $1 \times 10^{-5}$ ground motions is examined. A representative section of the Tptpll was extracted from the upper portion of the lithophysal porosity model as described in Appendix T. This model contains a wide range of lithophysal porosity averaging approximately 15 percent, but ranging from greater than 20 percent to less than 10 percent. The resulting UDEC lithophysal rockfall model showing spatially variable porosity is given in Figure 6-138.

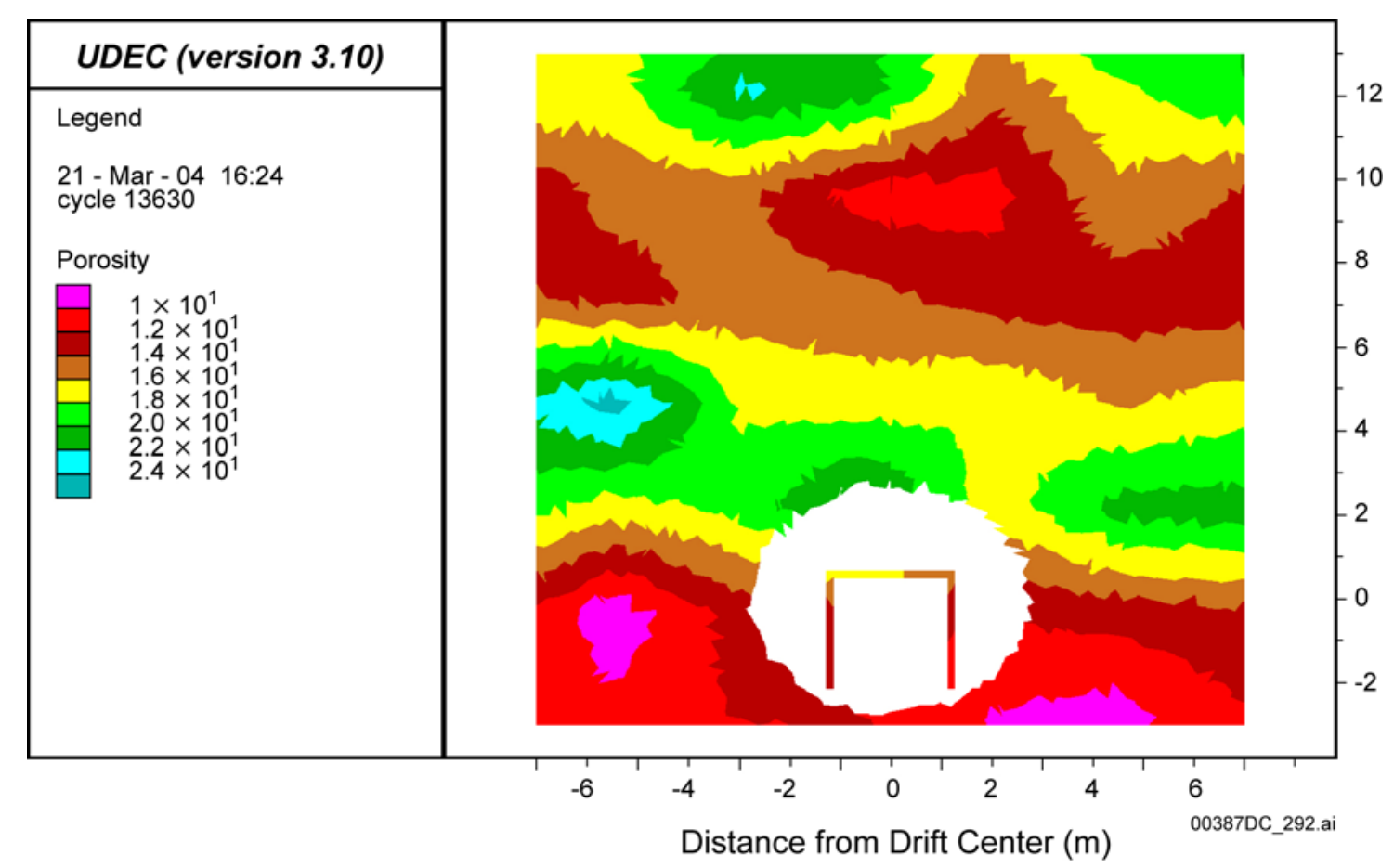

NOTE: Lithophysal porosity variability derived from Appendix T, Figure T-5.

Figure 6-138. Contours of Lithophysal Porosity Contoured on the UDEC Spatial Variability Model

Rock mass strength properties for Categories 1 to 5 were assigned to regions within the model based on the lithophysal porosity levels (Table E-10), achieving spatial variability in strength and moduli. This model was subjected to the $151 \times 10^{-5}$ ground motions, and damage levels were determined. The results of the dynamic simulations, in terms of damage versus PGV, are shown in Figure 6-128. The damage levels are approximately within the range of that predicted for Category 3 rock mass, as expected, because the mean lithophysal porosity of the model falls within the range of the Category 3 levels. This analysis indicates that the use of homogenous rock properties that span the range of strength categories does span the range of expected response, including conservative damage for the low strength categories. 


\subsection{Estimation of Drift Profile for Feeds to the Abstraction of Drift Seepage}

The analyses presented here have provided an estimate of the extent of drift degradation due seismic shaking as a function of annual probability of exceedance. A summary of the resulting drift profiles extracted from the UDEC lithophysal rockfall modeling is provided in output DTN: MO0306MWDDPPDR.000 [DIRS 164736] for the worst case for preclosure and postclosure damage from seismic loading. The drift profile exhibiting the greatest breakout resulting from preclosure ground motion is shown in Figure 6-120. The drift profile exhibiting the greatest breakout resulting from $1 \times 10^{-6}$ postclosure ground motion is shown in Figure 6-132, which shows complete collapse of the drift opening. The $1 \times 10^{-7}$ postclosure ground motion also results in complete drift collapse.

Among other factors, the seepage flux depends on both the size and geometry of the drift and the capillary strength of the fractured rock surrounding the drift opening (BSC 2004 [DIRS 169131], Section 6.4.2.4). In partially or fully collapsed drifts, the larger size and potentially different crown shape after collapse will reduce the potential for flow diversion compared to the initial drift geometry; furthermore, the larger footprint of the collapsed drift leads to an increase in the total amount of percolation flux arriving at the drifts, which, in turn, can affect the total amount of seepage. In addition, the capillary-barrier behavior at the drift wall can be affected by the rubble rock particles filling the opening, as the capillary strength inside the opening will be different from the zero capillarity condition in the initially-open drift. Thus, the geometry of the degraded drift and the capillary strength of the rubble material inside the drift are of importance in the abstraction of drift seepage.

Appendix R includes the drift profiles for strength Category 1 rock with consideration of seismic loading, thermal loading (discussed in Section 6.4.2.3), and strength degradation (discussed in Sections 6.4.2.4 and 6.4.2.5). Thirty scenarios are provided. Appendix R also provides information for degraded rock mass characteristics around the opening that may be of potential importance from a seepage or capillary strength standpoint. The information consists of the stress tensor for UDEC zones, aperture change along the joints, and averaged volumetric strain.

\subsubsection{Thermal Consideration in Lithophysal Units}

\subsection{Thermal Loading}

Geometry and boundary conditions used in the model for predictions of thermally induced rockfall are shown in Figure 6-139. A detailed discussion of the boundary conditions for the thermal-mechanical model is provided in Appendix W. The model does not perform complete thermal-mechanical simulations. Instead, temperature fields calculated with the code NUFT, for $1.45 \mathrm{~kW} / \mathrm{m}$ and 50 years of forced ventilation, are imported into UDEC (thermal calculation described in Section 6.2, see Appendix $U$ for methodology for importing temperatures). Two cases of ventilation efficiency were considered: 90 and 70 percent. Stresses are calculated for each new temperature state based on the temperature increment (from the previous temperature state) and the coefficient of thermal expansion. For the considered cases, the same coefficient of thermal expansion as a function of temperature, was used. To have gradual evolution of stresses during the simulated time, 45 temperature fields (corresponding to different 
times after waste emplacements) were imported from NUFT to UDEC. For each new temperature field, a simulation was conducted in two steps:

- The model was run to equilibrium elastically (i.e., the unbroken bonds were made infinitely strong)

- After the model had reached equilibrium, the actual strength was assigned to the unbroken bonds and the model was run again to the equilibrium.

The reason for the two-step approach was to reduce the impact of non-gradual stress changes due to incremental changes of the temperature state. The entire analysis was conducted considering that rock mass strength does not degrade with time. Any observed damage and rockfall are consequences of the thermally induced stresses only. The three cases of thermal calculation (described in Section 6.2) were considered for the drift stability analysis in lithophysal rock mass:

- Base case (average thermal properties and 90 percent ventilation efficiency)

- Case 2, sensitivity calculation for thermal properties (thermal properties one standard deviation smaller than the average properties)

- Case 3, sensitivity calculation for the heat removal ratio (average thermal properties and 70 percent ventilation efficiency).

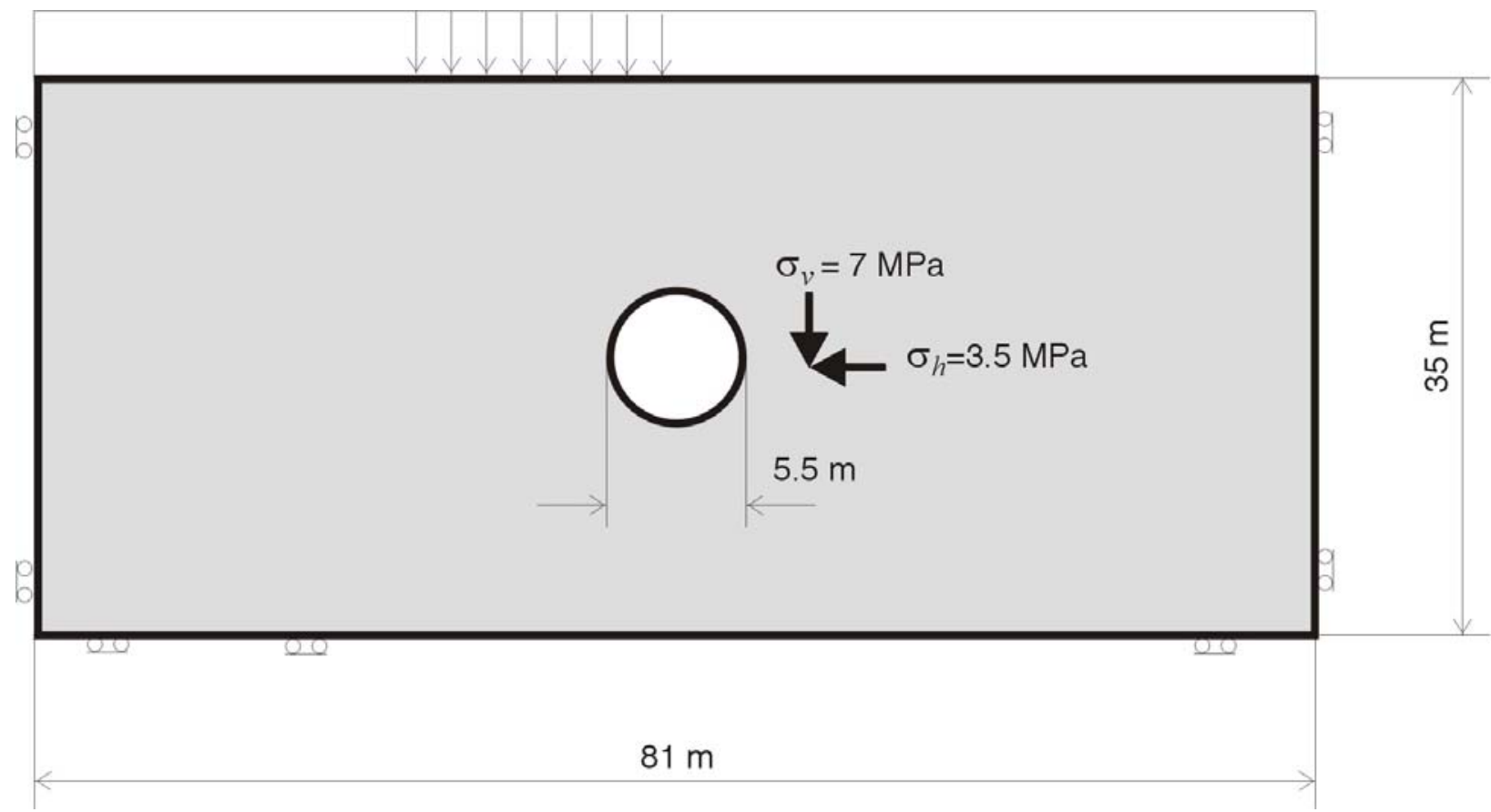

Figure 6-139. Thermal-Mechanical Model Initial and Boundary Conditions 
The simulation was conducted for the five mechanical properties categories of the rock mass. It is observed that the amount of thermally induced rockfall is generally small. The temperature and stress fields for rock mass Category 1 with the base case thermal properties and 90 percent ventilation efficiency are shown in Figure 6-140. The figure shows the model state after 80 and 10,000 years of heating for the consideration of no time-dependent change in rock strength. There is no significant rockfall or damage induced by heating. Conditions are similar for other rock mass categories. Elastic stress paths during 10,000 years of temperature variation are shown in Figures 6-141 and 6-142, for rock mass Category 1 in the wall and roof, respectively; and in Figures 6-143 and 6-144, for rock mass Category 5 in the wall and roof, respectively. The elastic stress paths confirm the results of the UDEC lithophysal rockfall model. The drift wall in the Category 1 rock mass is in the yielding state after drift excavation. Heating does not increase damage significantly (Figure 6-141). The stress state in the drift roof in Category 1 (shown in Figure 6-142) moves closer to the yield surface during heating, but it remains elastic. The thermal stress increase in the drift roof in the Category 5 rock mass (Young's modulus of 19.7 $\mathrm{MPa}$ ) moves the stress state barely above the yield surface (Figure 6-144) during the relatively short period when the temperature reaches the maximum, around 80 years after waste emplacement. This is consistent with observation of minor rockfall from the drift roof in rock mass Category 5.

The rockfall simulations using temperatures from Cases 2 and 3 of the thermal calculation do not show any increase in rockfall compared to the base case.

\subsection{Combined Seismic and Thermal Effect in Lithophysal Units}

Stability of the emplacement drifts located in the lithophysal rock units was investigated for both thermal and seismic loading conditions independently for both seismic and thermal loading conditions in Sections 6.4.2.2 and 6.4.2.3.1, respectively. The initial condition for the seismic analysis discussed in Section 6.4.2.2 was in situ stress state perturbed by excavation of the drifts only. An additional analysis, presented in this section, was done to assess the effect of changing thermal stress in the rock mass around the repository after waste emplacement as an initial condition for seismic ground shaking. Using a similar approach as for the nonlithophysal rock (Section 6.3.1.4), stress paths during the regulatory period of 10,000 years were recorded at a number of locations around the drift. Temperatures from the thermal calculations for the base case and the sensitivity calculation for the heat removal ratio (case 3 in Section 6.2) were considered. The critical state was qualitatively determined from those paths, based on locations of stress states along that path relative to the yield surface. The critical state was used as an initial condition for the seismic analysis. Because the ground motion with $1 \times 10^{-6}$ probability of annual occurrence results in complete drift collapse, it was not of particular interest to investigate the effect of that level of ground motion combined with thermally induced initial stresses. Instead, ground motions with $1 \times 10^{-4}$ and $1 \times 10^{-5}$ probability of annual occurrence were considered. Since the predicted temperatures are similar for the base case and the sensitivity case 2 at preclosure period, the sensitivity case 2 is not considered for the evaluation of the combined seismic and thermal effect. Rock mass categories 1 and 5 were considered in this analysis.

Stress paths (transient change in principal stresses) at 14 different locations around the drifts in rock mass category 5 during the regulatory period of 10,000 years are shown in Figures 6-141, 
6-142, and 6-143. A yield condition corresponding to $30 \mathrm{MPa}$ uniaxial compressive strength, and a friction angle of $40^{\circ}$ is also indicated in the figures. The stress state at a point close to the drift springline (shown in Figure 6-141), is above the yield surface, indicating yielding. Because those stresses are at the points inside the elastic blocks (inelastic behavior of this model is due to inelastic deformation of joints only), it is possible that they lie outside the yielding surface. The initial stress state and the state after 80 years of heating, selected as critical on the stress path, are marked on the plots with the squares.

(a) Temperatures

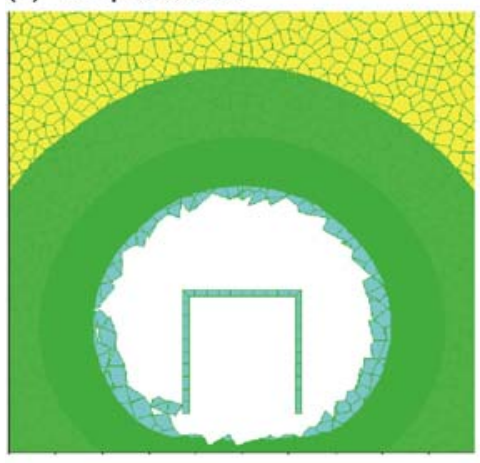

(b) Major principal stress

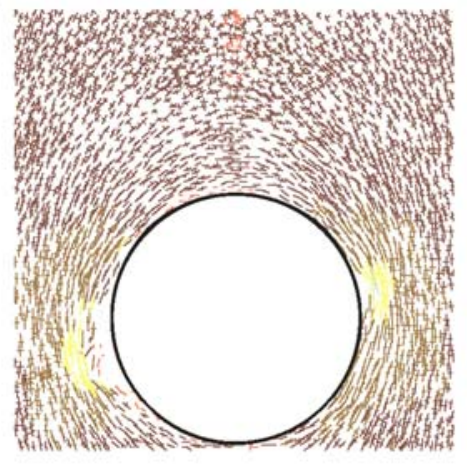

(c) Minor principal stress

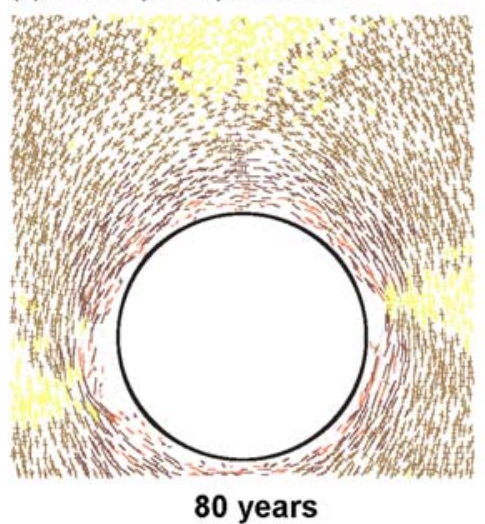

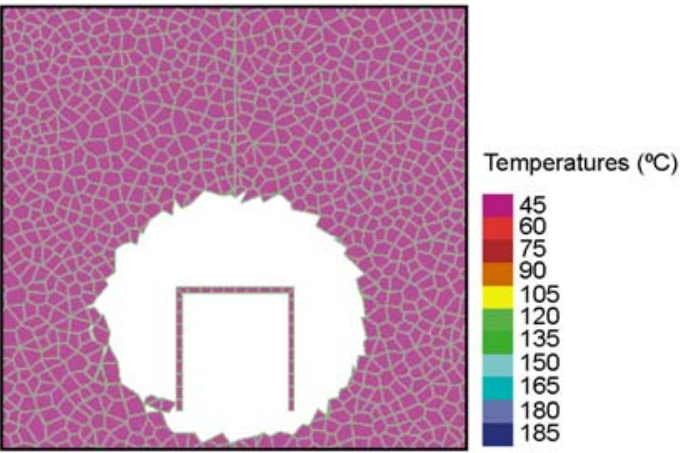
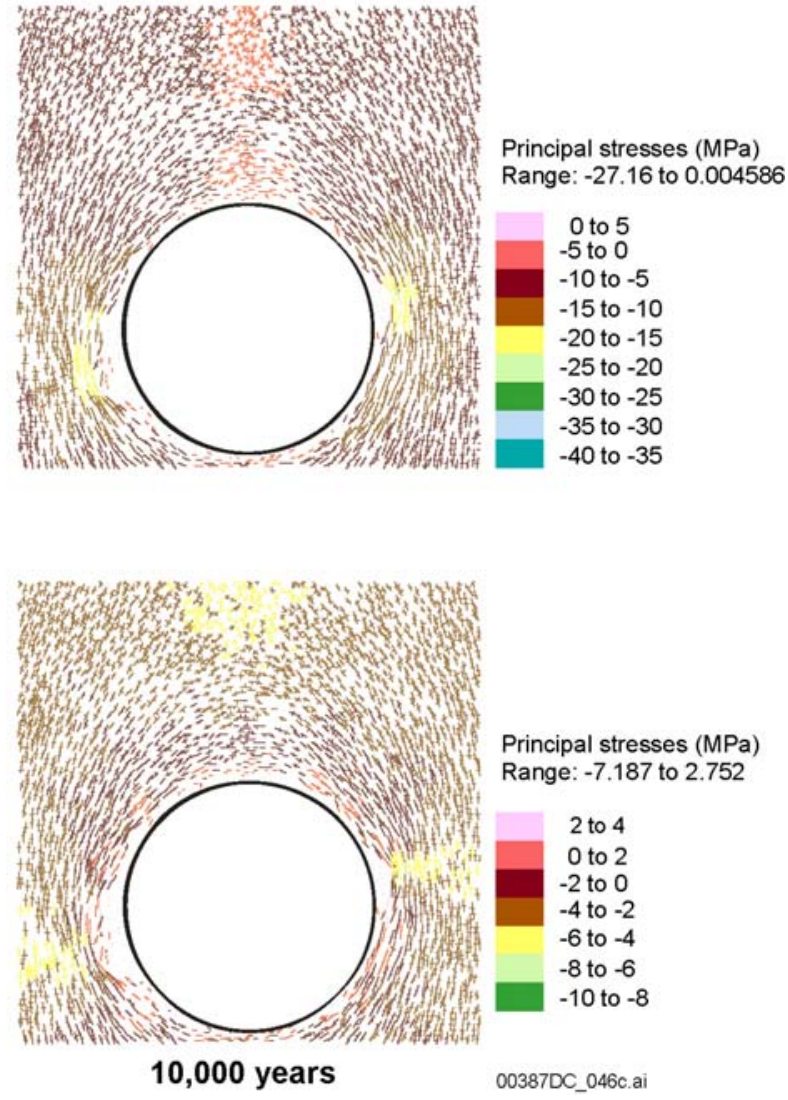

Figure 6-140. Thermally Induced Rockfall and Stresses After 80 and 10,000 years of Heating in Rock Mass Category 1 


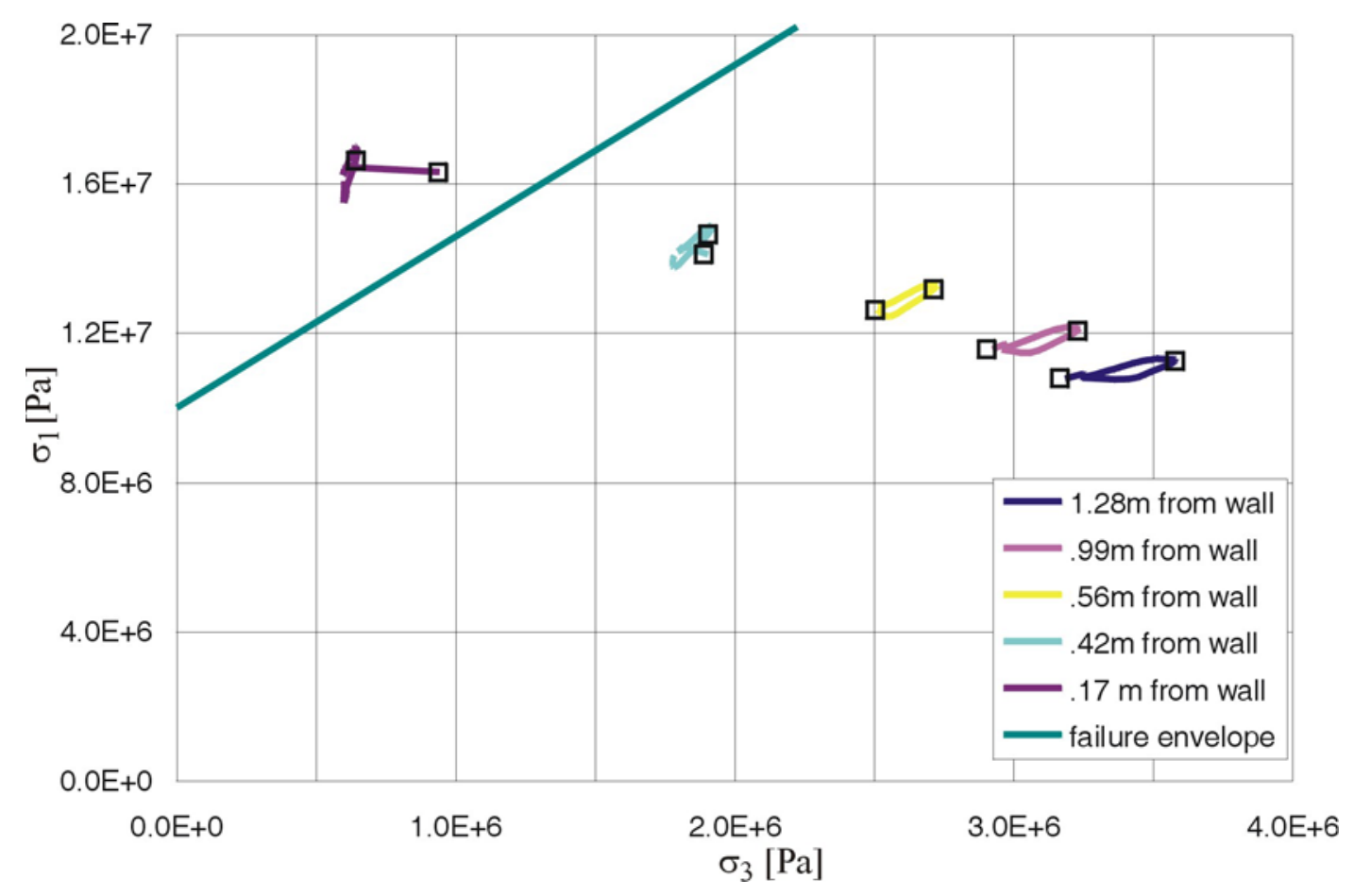

Figure 6-141. Elastic Stress Paths in the Drift Wall Due to Temperature History: Category 1

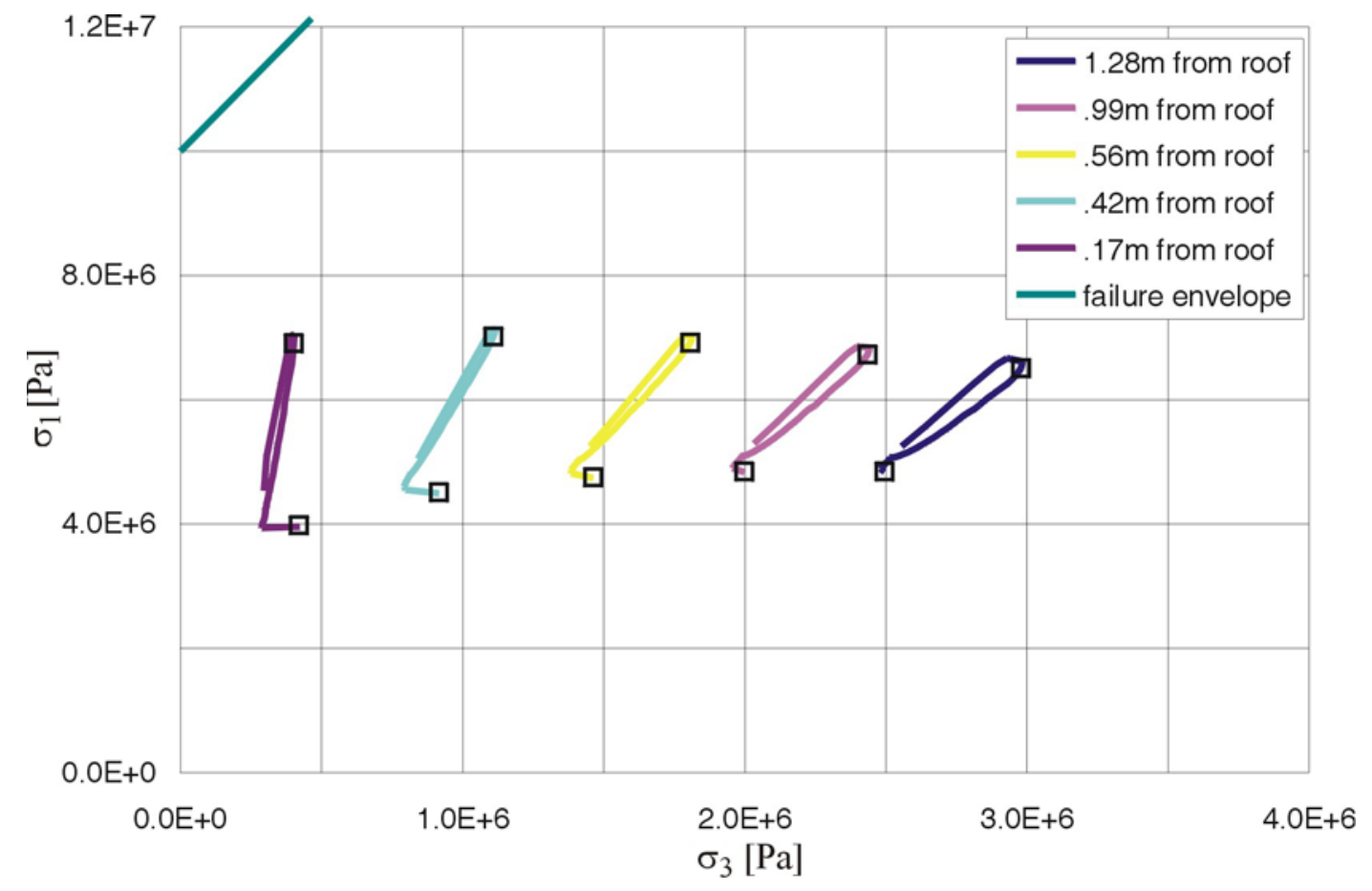

Figure 6-142. Elastic Stress Paths in the Drift Roof Due to Temperature History: Category 1 


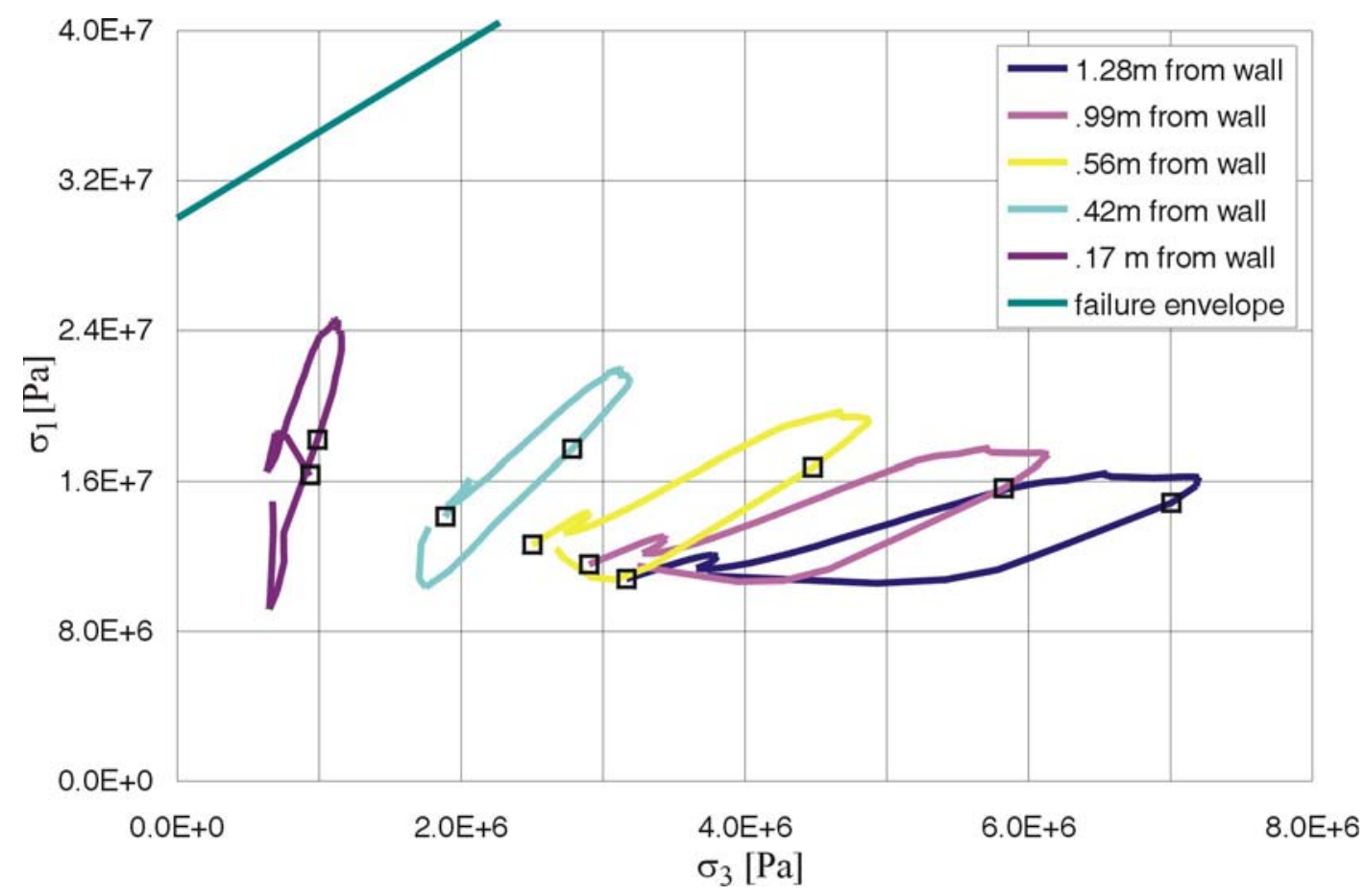

Figure 6-143. Elastic Stress Paths in the Drift Wall Due to Temperature History: Category 5

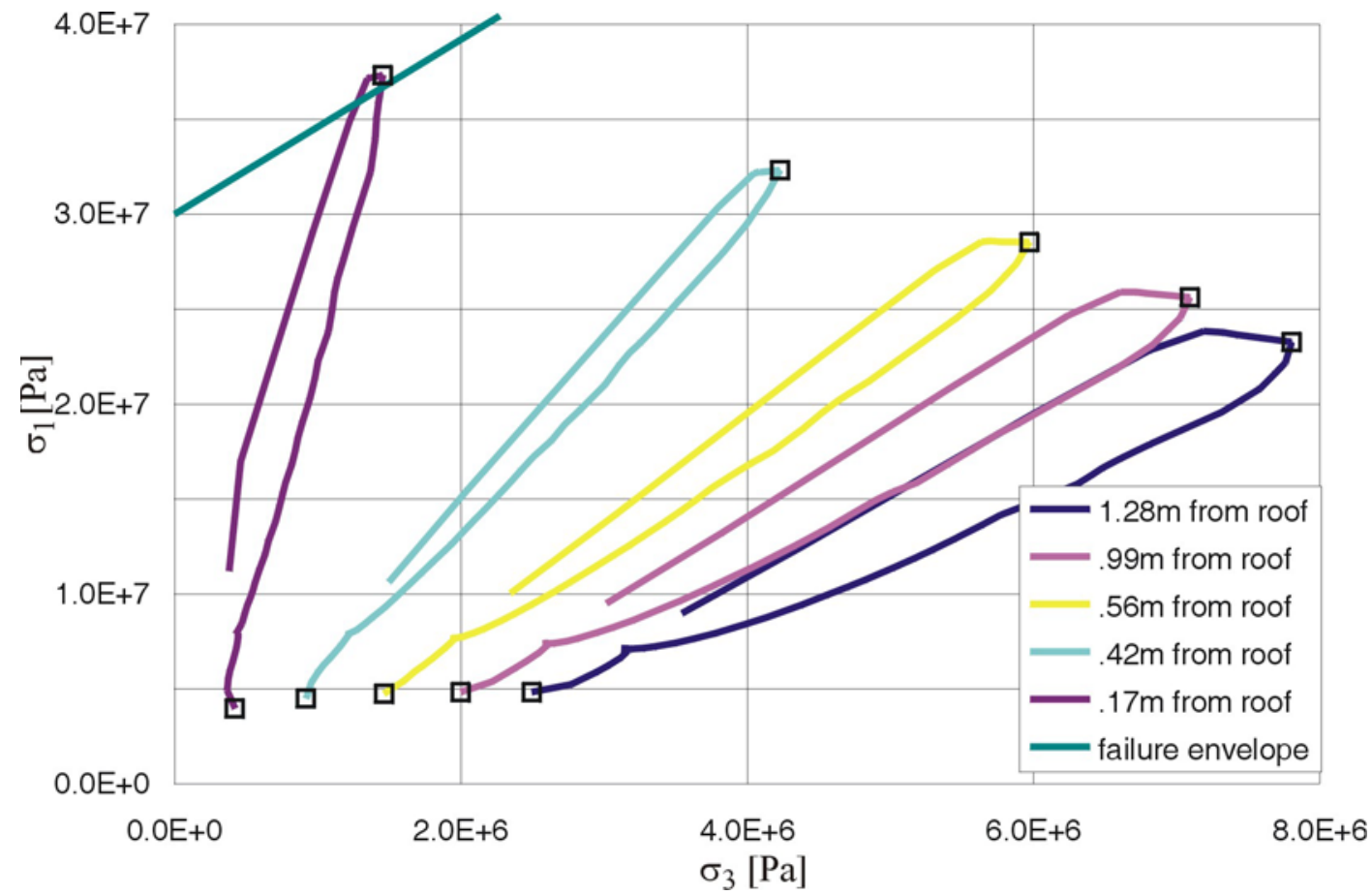

Figure 6-144. Elastic Stress Paths in the Drift Roof Due to Temperature History: Category 5 
Seismic analysis after 80 years of heating for rock mass category 1 resulted in an increased rockfall compared to rockfall from the seismic shaking of the rock mass at an in situ stress state (see Figure 6-145 for results with $1 \times 10^{-4}$ ground motion). Very little rockfall is induced in rock mass category 5 in the case of 70 percent ventilation efficiency. For the cases with 80 years heating and $1 \times 10^{-5}$ ground motions shaking, 3 sets of ground motions were considered: (a) set 10 with peak ground velocity $=104.6 \mathrm{~cm} / \mathrm{sec}$, (b) set 6 with peak ground velocity $=173.88 \mathrm{~cm} / \mathrm{sec}$, and (c) set 13 with peak ground velocity $=318.01 \mathrm{~cm} / \mathrm{sec}$. The results are presented in Figures 6-146 to 6-148. Rockfall with set 10 ground motion are similar to the results for preclosure ground motions. However, more extensive rockfall is observed for ground motion sets 6 and 13. The results show increase of rockfall for category 5 rock mass when comparing with seismic only scenario with large ground motions as shown in Figure 6-127.

The result of an increase in rockfall for lithophysal rock mass category 1 with thermal loading is in an apparent contradiction with the results of the same analysis for the nonlithophysal units. Thermal stresses in the case of nonlithophysal rock resulted in reduced rockfall. However, the mechanism of rockfall is completely different for these two cases. In the case of the nonlithophysal rock mass, rockfall is due to sliding of blocks along the pre-existing joints, and an increase in the initial stress increases confinement on the joints, thereby increasing their resistance to sliding. In the case of the lithophysal rock mass, ground motion with $1 \times 10^{-4}$ probability of annual occurrence causes rockfall by shaking down already damaged rock mass around the drift. Therefore, the heating induces additional damage (compared to damage caused by drift excavation), which does not necessarily result in a rockfall under static loading conditions, but is shaken down by the $1 \times 10^{-4}$ ground motion.
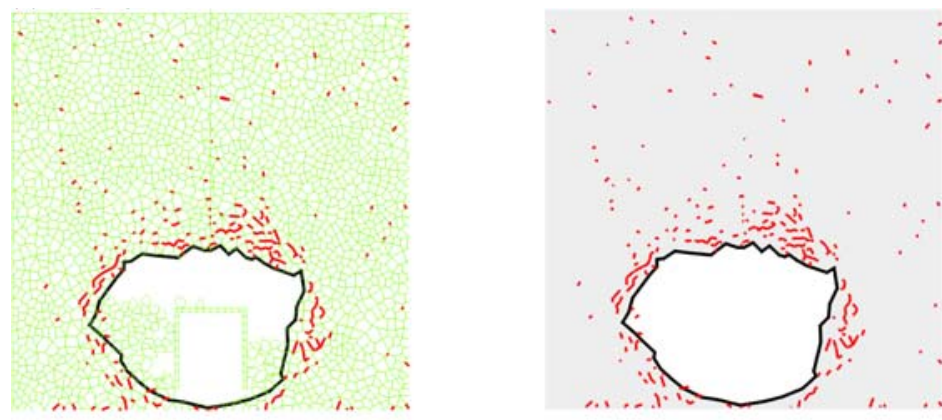

a) category 1

b) category 5
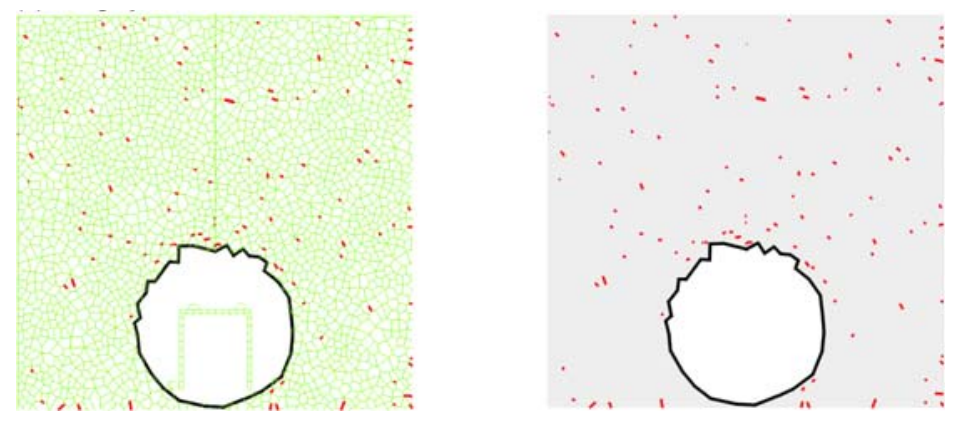

Figure 6-145. Rockfall and Fractures Induced Around a Drift by $1 \times 10^{-4}$ Preclosure Ground Motion After the Peak Thermal Condition Occurring at 80 Years of Heating (30 Years after Closure) in Rock Mass Categories 1 and 5 


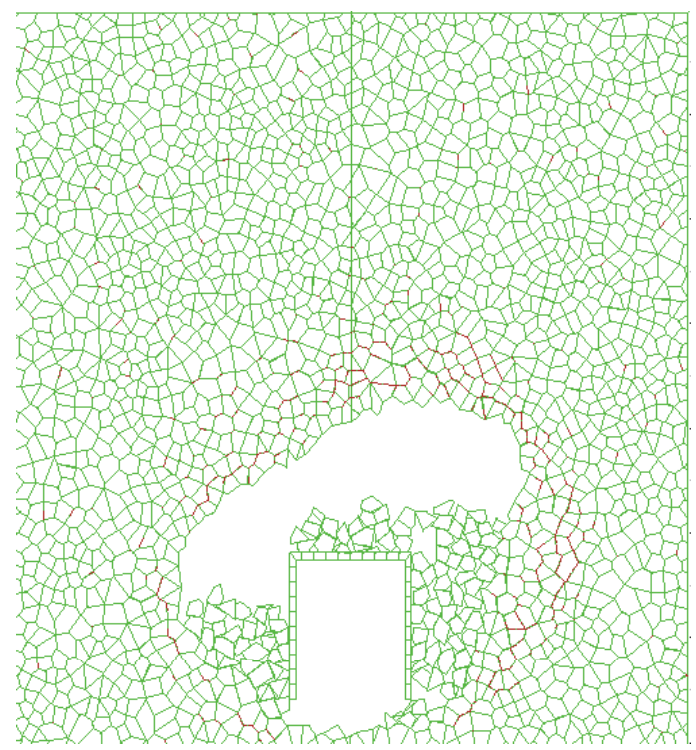

a) Category 1

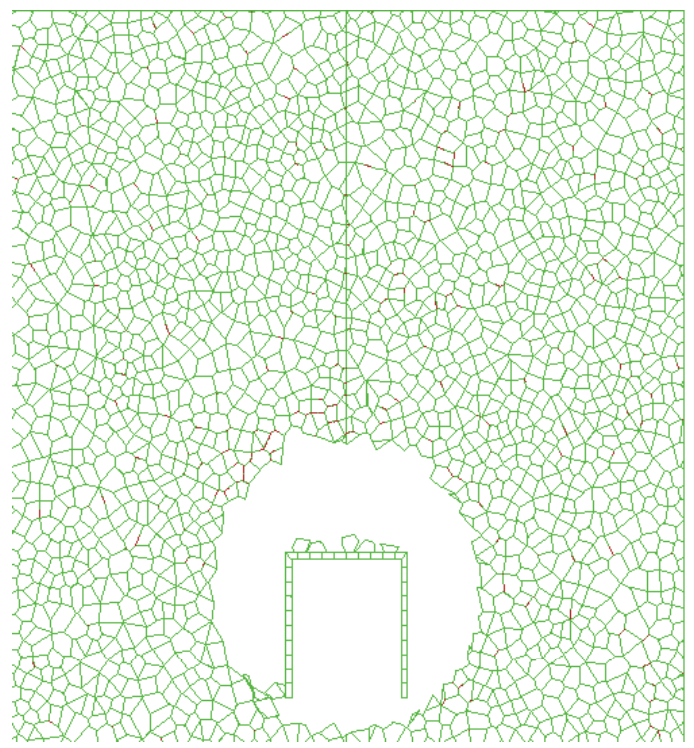

b) Category 5

Figure 6-146. Rockfall and Fractures Induced Around a Drift by $1 \times 10^{-5}$ Earthquake Set 10 (peak ground velocity $=104.6 \mathrm{~cm} / \mathrm{sec}$ ) After 80 Years of Heating in Rock Mass Categories 1 and 5 


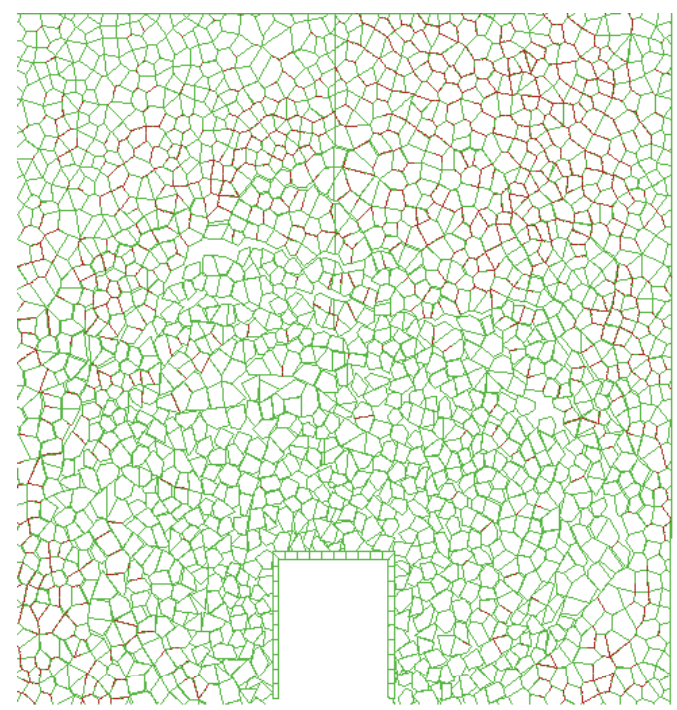

a) Category 1

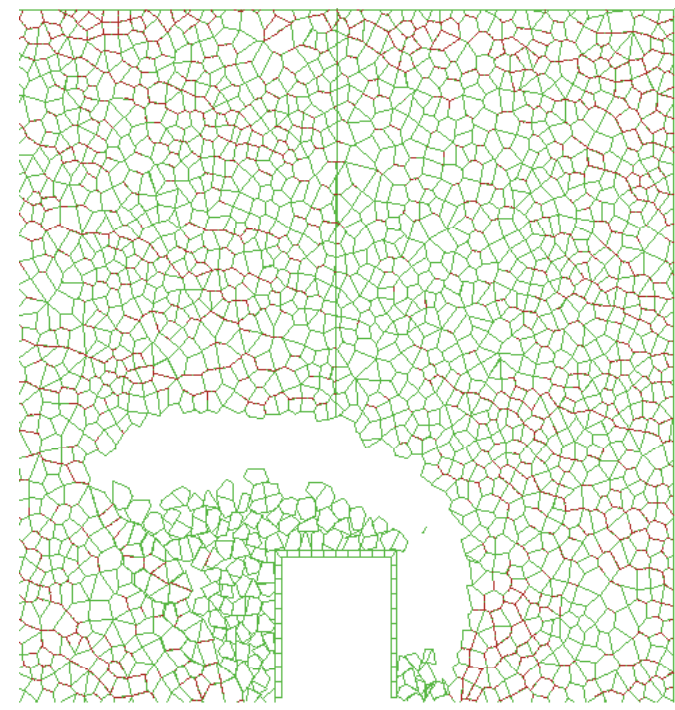

b) Category 5

Figure 6-147. Rockfall and Fractures Induced Around a Drift by $1 \times 10^{-5}$ Earthquake Set 6 (peak ground velocity $=173.88 \mathrm{~cm} / \mathrm{sec}$ ) After 80 Years of Heating in Rock Mass Categories 1 and 5 


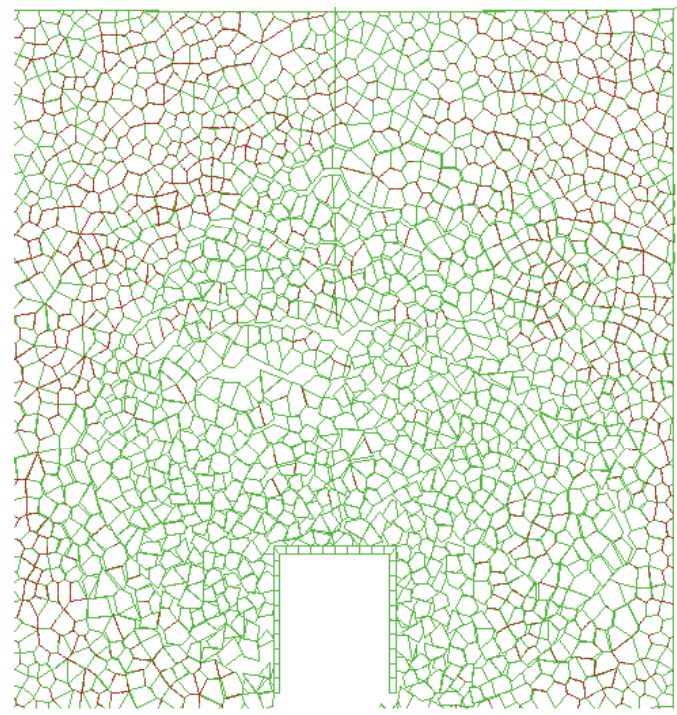

a) Category 1

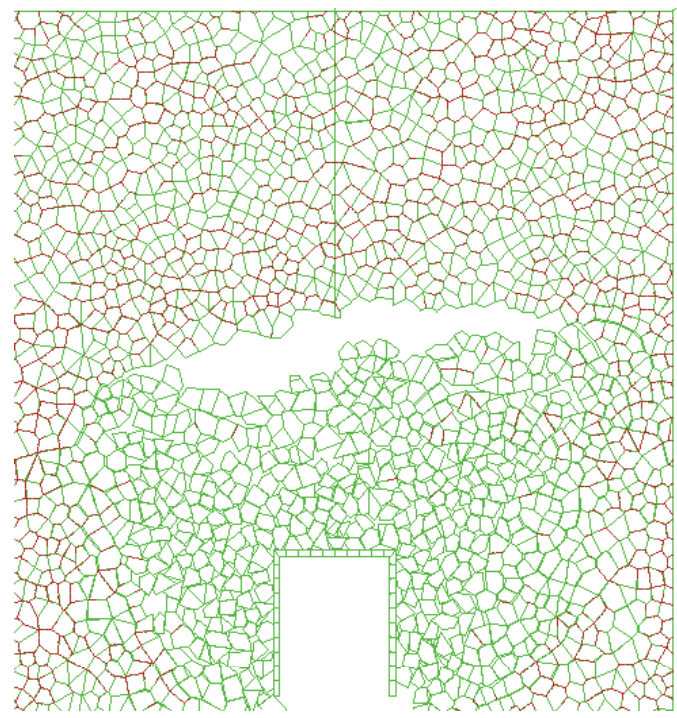

b) Category 5

Figure 6-148. Rockfall and Fractures Induced Around a Drift by $1 \times 10^{-5}$ Earthquake Set 13 (peak ground velocity $=318.01 \mathrm{~cm} / \mathrm{sec}$ ) After 80 Years of Heating in Rock Mass Categories 1 and 5

\subsubsection{Time-Dependent Consideration in Lithophysal Units}

Underground and surface excavations, which are designed to be stable after excavation, degrade with time, and some eventually collapse completely. The degradation of excavations in hard rocks has not been studied extensively, because most underground excavations have service lives of 100 years or less and are maintained as required. However, there are many examples of stable, unsupported excavations associated with mining, and civil construction or 
naturally-occurring caves in numerous rock types that are stable, or have suffered only minor instability for hundreds or even thousands of years. Thus, there is no certainty that collapse of unsupported excavations, particularly those subjected to low stress, relatively dry conditions, is inevitable.

The primary reason for eventual yield and collapse is that a hard rock mass, exposed to humidity and temperature of the open atmosphere, may undergo strength decay with time when it is loaded to stress levels higher than about 50 to 60 percent of its short-term strength. The rate of strength decay depends on, among other parameters, rock type (particularly the mineralogy and grain structure), stress state, relative humidity, and temperature. Stress corrosion is considered the primary mechanism causing strength degradation of hard rocks (Potyondy and Cundall 2001 [DIRS 156895], Section 3).

The emplacement drifts at Yucca Mountain will be stable under existing conditions (in situ stresses and rock mass strength) with ground support as demonstrated by the ESF and ECRB Cross-Drift observations. However, it is expected that the ground support will completely lose its integrity during the 10,000-year regulatory period, and drift degradation, to some extent, will occur due to strength decay of the rock mass. Drift degradation is an important issue for repository design and performance because drifts must remain stable during the preclosure operational period and, eventually, rubble resulting from degradation could impact in-drift environmental conditions, seepage, and the integrity and performance of the drip shields. Estimation of the rate of drift degradation for the duration of the 10,000-year regulatory period is, therefore, required.

\subsection{Empirical Observations of Degradation and Collapse of Excavations}

\subsection{Unsupported Excavation Spans and Stand-Up Time}

There is currently no accepted methodology for estimating the time-dependent degradation behavior of tunnels in hard rocks. However, a number of empirical correlations have been developed for providing a means of estimating maximum stable spans of unsupported excavations and the length of time that an unsupported excavation may remain open and still provide a safe working environment (termed stand-up time) (Bieniawski 1989 [DIRS 101715]). Because these correlations are often used in estimating the time of instability of excavations, this appendix discusses their applicability to the postclosure stability of emplacement drifts at Yucca Mountain.

Emplacement drifts for the repository are $5.5 \mathrm{~m}$ in diameter, are separated from one another by a center-to-center distance of $81 \mathrm{~m}$, and are located at a nominal depth of $300 \mathrm{~m}$ below ground surface. The large ratio of drift diameter to spacing and diameter to depth means that each emplacement drift is mechanically isolated from one another and from the effects of the ground surface. Eventually there is thermal interaction between tunnels, but the local mechanical effects related to isolated tunnels is of greatest importance to short-term and long-term stability. Comparison of the maximum unsupported span from mining practice to the span of the proposed emplacement drifts is a reasonable means of estimating collapse potential. 
As the span of an excavation is made larger, there eventually becomes a point when instability and unsafe working conditions result. Empirical correlations (e.g., Hoek and Brown 1982 [DIRS 120981], p. 287) of the maximum safe unsupported span and the time that this span may remain unsupported have been developed to assist tunneling engineers in planning excavations that are safe for tunnel construction workers. These correlations, which are typically based on some measure of rock mass quality, are inherently conservative in nature due to their purpose: to ensure personnel safety. The correlations are not based on case histories of actual collapse. For example, stand-up time is typically projected to be on the order of hours or days, even for good quality rock masses and may be only on the order of years (e.g., Hoek and Brown 1982 [DIRS 120981], Figure 6). Examples of the existing tunnels at the Yucca Mountain site and Hoover Dam indicate that stand-up time is a worker-safety-related indicator and is not relevant to predictions of degradation or collapse time. These remarks indicate that construction-related span and stand-up time correlations have only limited application to postclosure predictions of drift degradation at the Yucca Mountain site.

Stand-up time curves provide an estimate for potential of rockfall as a function of span, rock-mass quality, and time after excavation. The stress state around an excavation (e.g., depth of the excavation) is not a parameter that affects the stand-up time estimate. The stress state in the rock mass around the excavation, scaled to the short-term strength of the rock mass, is one of the most important factors controlling stability of the rock mass and evolution of stability as a function of time. Stand-up time curves were developed based on empirical evidence of instability of excavations in particular stress conditions (e.g., deep South African mines), and their application to completely different conditions is not relevant.

\subsection{Evidence of Maximum Unsupported Span from Mining Case Examples}

The mining industry, on the other hand, routinely drives unsupported excavations to large spans with the express purpose of inducing collapse for caving of ore bodies. Therefore, empirical evidence of maximum unsupported spans from mining case examples is more relevant to the estimation of the actual spans of excavations that induce degradation and ultimate collapse. The span of an excavation required to induce caving and collapse has been the topic of extensive study in the mining industry because certain types of mining methods (e.g., block and panel caving) are predicated to induce caving when a rock mass is undercut. Brown (2003 [DIRS 169527]) provides a summary of worldwide caving operations and the spans of excavations necessary to induce collapse as a function of the rock mass quality (i.e., strength). Figure 6-149 provides a summary of worldwide experience in excavation span and collapse potential for cave mining. The plot provides a correlation between rock mass quality rating (in terms of rock mass rating) and the hydraulic radius (plan view area/perimeter) of excavations that produce: (1) stable spans, (2) transitional excavations in which instability may begin but caving is not yet occurring, and (3) caving. As the rock mass quality rating decreases, the spans at which collapse occurs also decrease. To apply these data to emplacement tunnels at Yucca Mountain, an estimate of the rock mass quality is required. The case of lithophysal rock is presented here because it is the weakest of the host horizon units. As described in Subsurface Geotechnical Parameters Report (BSC 2003 [DIRS 166660], Section 9.2.5), the estimated rock mass quality rating in terms of Geologic Strength Index or Rock Mass Rating (GSI or RMR) for the lithophysal rocks at Yucca Mountain is in the range of approximately 50 to 60 . For this range of RMR, the hydraulic radius of a flat-roofed excavation required for caving is in the range 
of approximately 25 to $35 \mathrm{~m}$ (Figure 6-149). A transitional zone between stable excavations and caving for the lithophysal rock RMR range occurs for hydraulic radii of 15 to $20 \mathrm{~m}$. For the proposed 5.5-m diameter emplacement drifts, the hydraulic radius is simply equal to the radius $(2.75 \mathrm{~m})$. Therefore, field practice indicates that the stable to transitional caving-stable state is characterized by a hydraulic radius for lithophysal tuff in the range of 15 to $20 \mathrm{~m}$. The boundary between transitional stable/caving to a caving state is characterized by a hydraulic radius in the range of approximately 25 to $35 \mathrm{~m}$. Note that the typical mining undercut has a flat roof, which promotes instability, while the shape of the emplacement drifts is circular, which promotes stability. The emplacement drift hydraulic radius is, therefore, approximately 5 to 7 times below what would be considered to be a transitional state between stable and caving conditions. Based on field experience in caving, the hydraulic radius of the emplacement drifts is well below the level of the hydraulic radius estimated to be in a transitional state of collapse and even further below the level for assurance of complete collapse. Therefore, it is not surprising that the existing ESF and ECRB Cross-Drift (7.62- and 5-m diameter, respectively) are stable and show no evidence of degradation nearly a decade after excavation, even though the ground support is minimal.

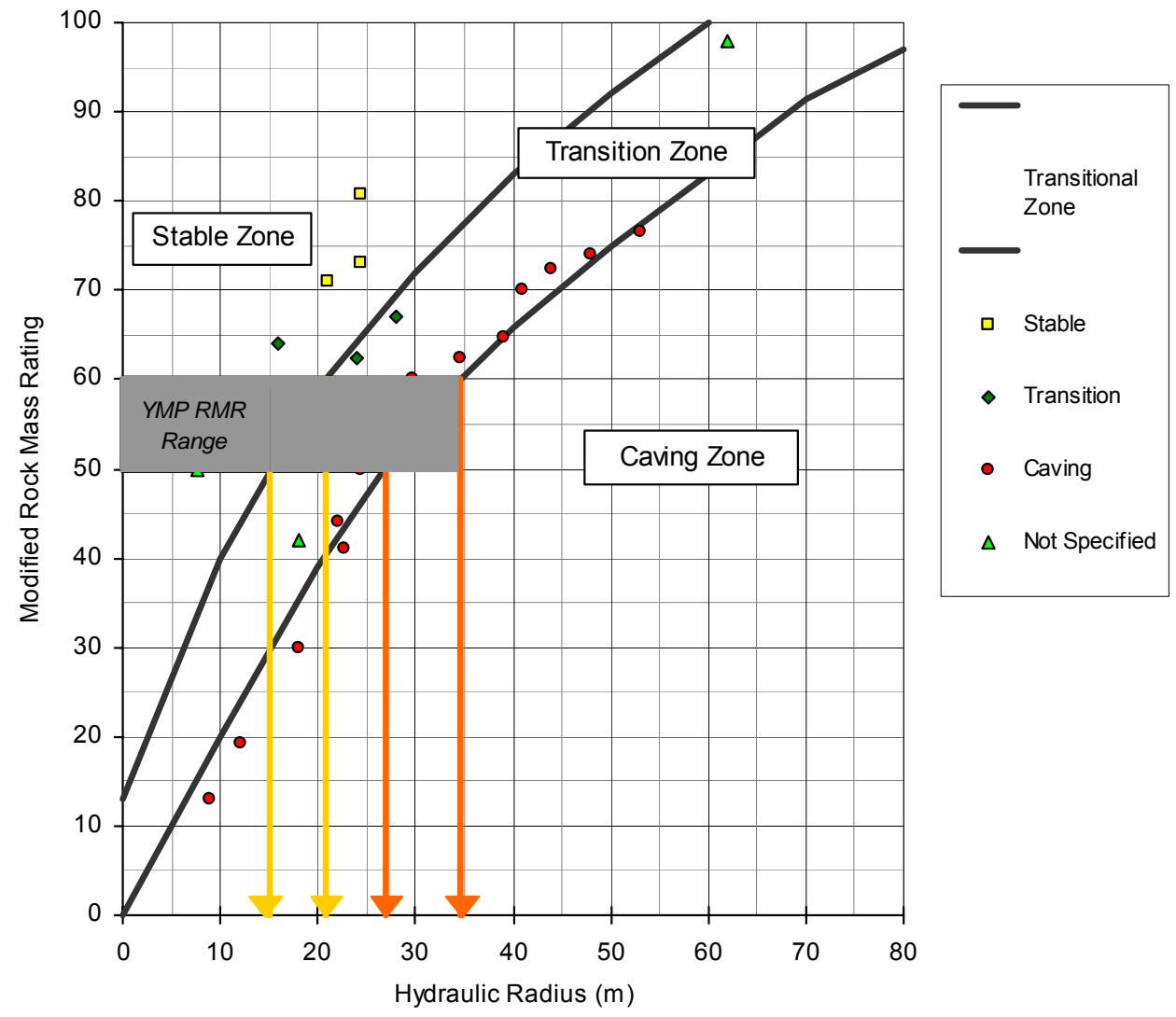

Source: Brown 2003 [DIRS 169527], Figure 3.1.

NOTE: Caving potential is expressed in terms of the modified rock mass rating and hydraulic radius. Modified rock mass rating is equivalent to rock mass rating in case of Yucca Mountain excavations. Stable and caving regions are separated by a transition zone.

Figure 6-149. Excavation Dimensions Required for Caving Gained from Field Experience in Block and Panel Caving Mines 


\subsection{Observations of Yucca Mountain Tunnels and Excavations at Hoover Dam}

Unsupported or lightly supported tunnels (although perhaps not considered safe from a personnel standpoint) can stand in a stable condition for long time periods, particularly in good quality rock masses. For example, the ESF (7.62 m diameter) and ECRB Cross-Drift ( $5 \mathrm{~m}$ diameter) tunnels at the Yucca Mountain site were constructed in 1995 to 1997 and in 1998, respectively. Although the ESF main loop is located largely in the Tptpmn, the ECRB Cross-Drift cuts through and exposes all of the repository host horizon units. The tunnels are, in general, lightly supported with friction rock bolts and light wire mesh in the tunnel roof, with occasional friction bolts in the tunnel walls. There is no evidence of significant deterioration or degradation of the rock mass, and no significant episodes of rockfall have occurred.

An external review panel convened to examine Yucca Mountain drift stability (Brekke et al. 1999 [DIRS 119404]) found that excavations of the North Ramp through the upper lithophysal zone and the ECRB Cross-Drift through the lower lithophysal zone show that both zones have properties that are favorable for stability with minimum ground support. The panel also found that rock conditions in the lower lithophysal zone in the ECRB Cross-Drift were similar to those observed in the upper lithophysal zone in the North Ramp; that continuous joints were not apparent, and there was almost no overbreak or loosening of the slabs or blocks; and that zones with more frequent short fractures were present and could be described as fracture zones, but even in these areas, overbreak and block loosening were largely absent. Tunnel deformation measurements have been regularly monitored since excavation, showing stable conditions. The conclusion is that the tunnels in both the lithophysal and nonlithophysal rock masses are in a stable and self-supporting mode with no obvious deterioration in 5 to 8 years. Additionally, the Drift Scale Test involved heating a representative repository-scale tunnel in the nonlithophysal rock mass, first, to postclosure temperature distributions, followed by a thermal overdrive experiment to test rock strength limits. The experiment, now well into its cool-down phase, showed stable and predictable conditions at expected repository peak temperature conditions. Overdrive to approximately $200^{\circ} \mathrm{C}$ drift-wall temperatures showed predictable, minor spalling of a small portion of the center of the crown of the drift (Section 7.6.5.3). Cool-down has showed no observable loosening or instability of the tunnel. This experiment confirmed modeling estimates of stable drift conditions for expected repository temperature and combined in situ and thermal stress conditions.

The Hoover Dam, with abutments excavated in Tertiary pyroclastic flows, was completed by the Bureau of Reclamation in 1936. Along with the construction of the dam itself are a series of tunnels and adits (Figure 6-150) that were excavated to accommodate the various penstocks, valves, access ways, spillways, and river bypasses. With the exception of the visitor center elevator shaft (completed in the 1990s), the excavations were completed with simple drill and blast methods ("simple" meaning here that no smooth-wall blasting techniques were used). Some of the larger openings, generally those more than $6 \mathrm{~m}(20 \mathrm{ft}) \mathrm{high}$, were excavated using heading-and-bench methods to develop the full size of the openings. Many of the tunnels and adits were excavated to greater than $12 \mathrm{~m}(40 \mathrm{ft})$ in diameter. While some of the penstock and spillway tunnels were lined with concrete, many of the adits and access ways remain unlined. 


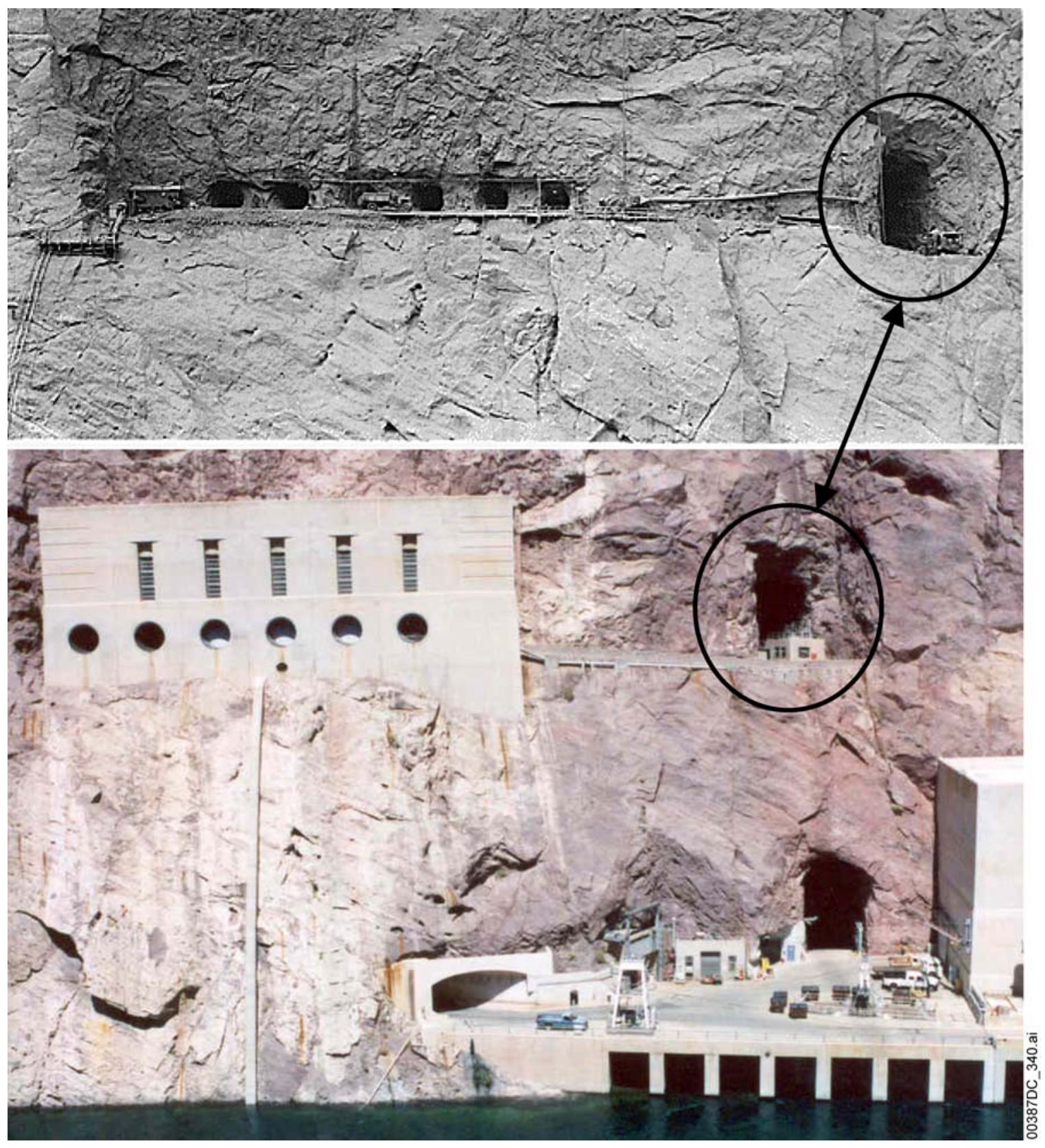

NOTE: Construction adit, shown at right, is approximately $40 \mathrm{ft}$ high.

Figure 6-150. Excavation for Nevada Canyon Wall Outlet Works (Top) Showing Construction Adit in 1933 and (Bottom) in 2004 
The rock at the site is the tuff of Hoover Dam, a fairly localized unit composed of andesitic to dacitic pyroclastic flows and breccias. At the dam, the volcanics are slightly to densely welded, and slightly weathered to unweathered. At the penstock adits, the rock is moderately hard to hard and contains abundant lithic fragments and occasional corroded pumice fragments. The rock is slightly to moderately fractured, with most fractures devoid of fracture filling. Many of the discontinuities exposed in the adits are frequently shears and small faults displaying distinct slickensides. Where the adits extend below the phreatic surface, occasional calcium carbonate precipitate is present adjacent to active or old seeps.

The adits were excavated downstream of the power plant to allow insertion of large, steel penstock sections into tunnels that paralleled the canyon walls. The adits are in still in use, housing the sewage treatment system and other support utilities necessary to the function of the dam. The adits are approximately $40 \mathrm{ft}(12 \mathrm{~m})$ high by $35 \mathrm{ft}(10.7 \mathrm{~m})$ wide (Figure 6-151) becoming slightly taller with depth. After the drill and blast excavation, the adits were left unlined and unsupported, and continue to be unsupported to the present time. Rock fall in the adits has been limited to very occasional centimeter-size fragments, even without ground support.

Additionally, there are numerous access ways throughout the lower canyon walls in and around the Hoover Dam power plant. These smaller tunnels, 6 to $15 \mathrm{ft}$ (1.8 to $4.6 \mathrm{~m})$ in diameter, allow access by personnel and tourists to various areas of the power plant and penstocks. Few of these tunnels are supported either by rock bolts or mesh. No steel supports are visible in the Hoover excavations. As with the adits, rock in the access ways and tunnels has been limited to rare centimeter-size fragments that are removed by the janitorial staff. 

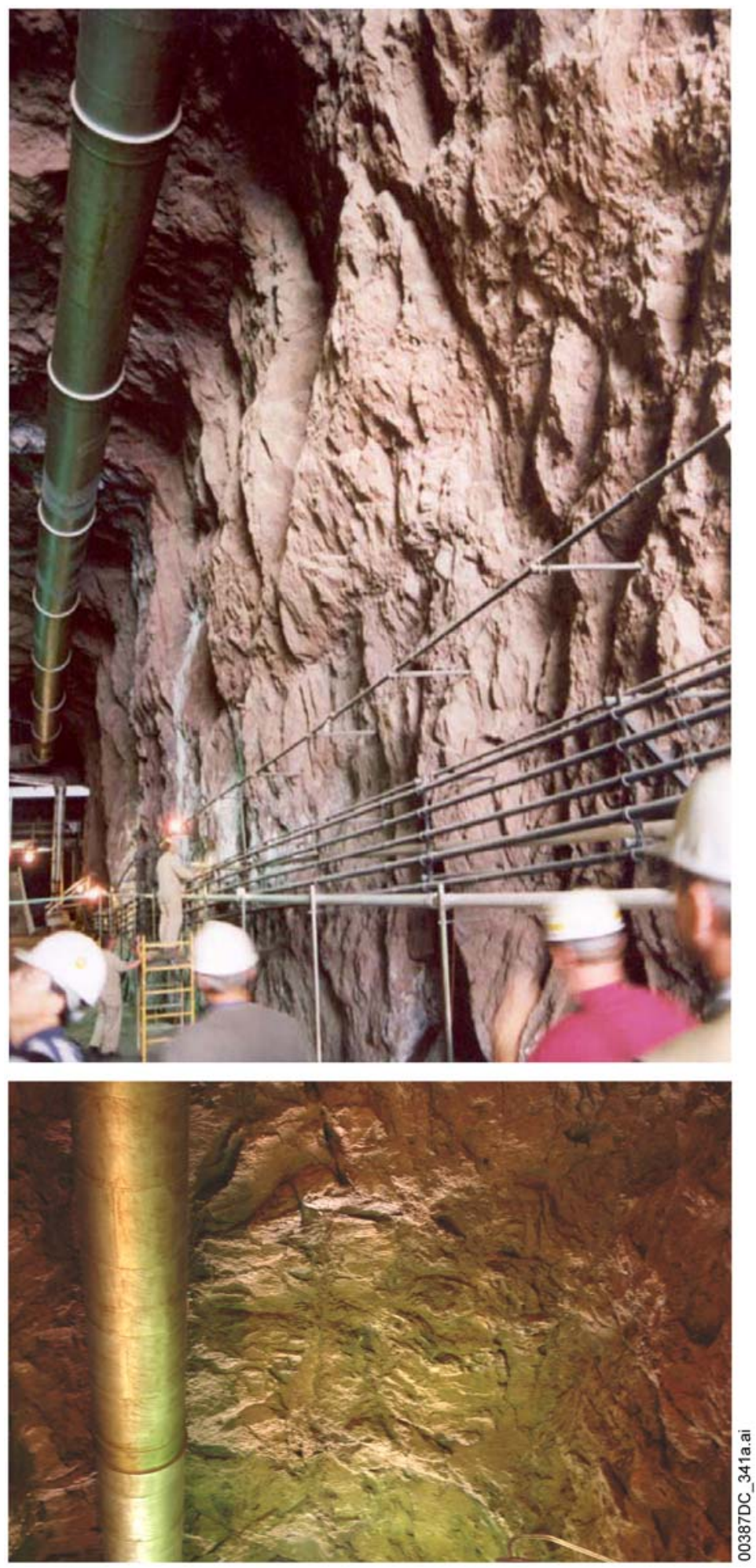

NOTE: Irregular tunnel walls resulting from drill-and-blast excavations (top) and close-up view of the tunnel crown showing evidence of drill half-barrels (bottom).

Figure 6-151. 2004 Photographs of Unsupported Construction Adit at Hoover Dam, Excavated in 1931 


\subsection{Mechanics-Based Approach to Analysis of Time-Dependent Degradation of Repository Excavations}

\subsection{Background on Time Dependent Characteristics of Brittle Rocks}

One of the most striking characteristics of brittle rocks is that at temperatures well below the melting point, a rock subjected to a constant load exhibits a continuous increase in strain with time. This time-dependent deformation is termed creep. Studies on creep indicate that the observed strain depends upon the applied stress, the temperature, the partial pressure of water, and the confining pressure (e.g., Martin 1972 [DIRS 169721]). Moreover, the same mechanism responsible for the strain of brittle rocks in constant strain-rate tests is also operative in creep. That is, cracking, both along grain boundaries and through individual grains, produces the observed strain (e.g., Brace et al. 1966 [DIRS 101990]). Above approximately one half to two-thirds of the compressive strength, the dominant mode of deformation for brittle rocks is the opening and growth of cracks parallel to the major principal stress direction or axial orientation in unconfined compression. It is typically considered that the strain rate of hard rocks in creep is related to the time-dependent growth of these cracks.

Verification of the relationship between time-dependent crack growth and creep strain rate in brittle rock is performed through laboratory testing. Experimental results indicate that stable time-dependent crack growth at a constant compressive load or at a constant stress intensity factor occurs in quartz and glass in the presence of water vapor. Moreover, the rate of crack growth depends on the applied stress, the temperature, and the partial pressure of water in the atmosphere surrounding the crack. The relative weakening of quartz or silicate glass, reflected by an increase in the rate of crack growth with an increase in any of the three variables, is consistent with the general theory of stress corrosion in silicates proposed by Charles (1959 [DIRS 170308]). He postulated that the velocity of a slowly propagating crack with a high tensile stress at the crack tip is proportional to the rate of the hydration reaction at the crack tip. The following equation (Martin 1972 [DIRS 169721]) quantifies the general relationship for environment-sensitive crack growth.

$$
v=v_{0} \beta P^{n} \exp \left(\frac{\Delta F-V^{*} \sigma}{R T}+\frac{\gamma V_{m}}{\rho R T}\right)
$$

where $v$ is the rate of crack growth, $v_{0}$ is the initial flaw size, $P$ is the partial pressure of water, $\Delta F$ is the activation energy for the process, $T$ is temperature, $R$ is the universal gas constant, $V^{*}$ is the activation volume, $\sigma$ is stress, $\gamma$ is the surface energy of the solid, $V_{m}$ is the molar volume of the solid, $\rho$ is the radius of curvature of the crack tip, and $\beta$ and $n$ are constants.

If the partial pressure of water, the temperature, and the applied stress are constant, a constant crack propagation velocity will be observed. When any one of the thermodynamic variables is increased, the crack velocity increases. This expression has been verified with experimental studies (Wiederhorn 1968 [DIRS 170309]; Martin 1972 [DIRS 169721]; Scholz 1972 [DIRS 169724]).

The validation of Equation 6-8 is extremely important. First, it establishes a rate-dependent process for the propagation of cracks in quartz and silicate glass. If the same behavior is 
observed in rocks then it implies that time can be scaled from very short times to extremely long times in the absence of other competing mechanisms. Specifically, if moisture-assisted stable crack growth is the primary mechanism of creep in brittle rocks, measurements made at laboratory scales of up to $10^{6}$ seconds can be extrapolated to much longer scales on the order of $10^{11}$ to $10^{14}$ seconds. Presently there are no other independent data that suggest other competing mechanisms for time dependent deformation in brittle rocks at temperatures below $300^{\circ} \mathrm{C}$. Based on these results and verifications by other experimenters, there is confidence that Equation 6-8 accurately represents the behavior of the rate of crack growth at the crack tip for brittle silicate materials at temperatures below $300^{\circ} \mathrm{C}$.

Next, the behavior of brittle rocks can be examined during creep and compared to the observations of stable, time-dependent crack growth gained from tests on quartz and glass. A creep test is conducted by rapid application of uniaxial or triaxial load to a rock sample to a given differential stress, followed by holding the load constant while monitoring the longitudinal and lateral strains. Typically, creep is reported in terms of three distinct phases: (1) primary or transient creep, (2) secondary or steady-state creep, and (3) tertiary or accelerating creep (Figure 6-152).

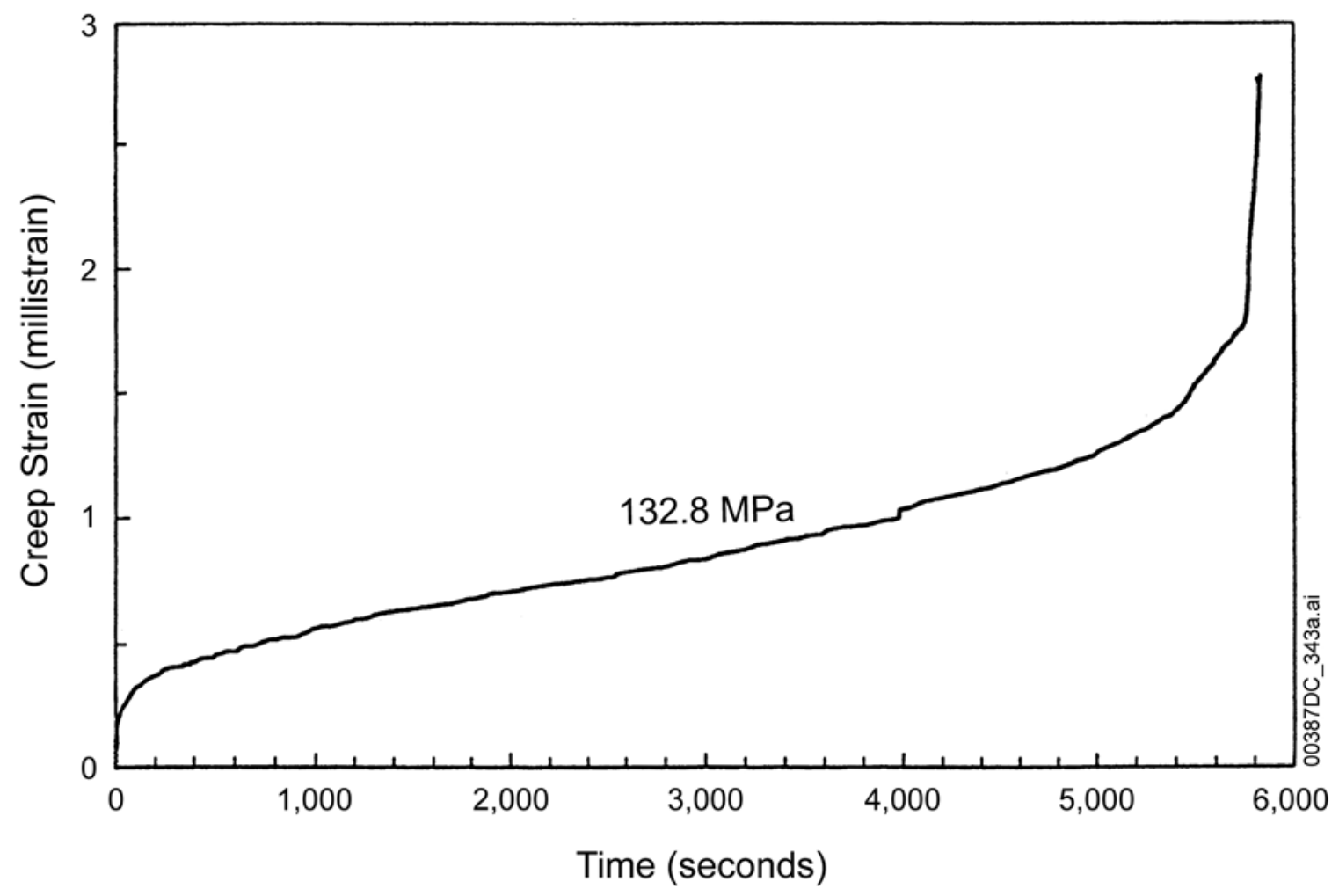

Source: Martin et al. 1997 [DIRS 165960], Figure 4.

NOTE: Specimen failed at tertiary creep phase.

Figure 6-152. Example of Creep Strain Plotted as a Function of Time for a Static Fatigue Test Conducted on a Sample of Topopah Spring Tuff at a Constant Differential Stress of 132.8 $\mathrm{MPa}$, a Confining Pressure of 5.0 MPa, a Pore Pressure of $1 \mathrm{MPa}$, and a Temperature of $150^{\circ} \mathrm{C}$. 
Transient creep has been reported for a variety of rock types over a wide range of temperatures and pressures. The strain in this region decelerates rapidly and is often reported as proportional to the logarithm of time. Moreover, both the lateral and the longitudinal strains exhibit this logarithmic time dependence.

At low stresses, transient creep may account for the observed strain. However, at high stresses, secondary creep is often observed. Generally, in secondary creep, often called steady-state creep, the strain is proportional to time. The total strain caused by both primary and secondary creep is often represented by an equation of the form

$$
\varepsilon=A+B \log t+C t
$$

where $\varepsilon$ is strain, $t$ is time, and $A, B$, and $C$ are constants.

If secondary creep is allowed to continue, eventually the strain rate increases (tertiary creep) and the rock fails. The three stages of creep have been observed in granite, quartzite, and tuff (Martin 1972 [DIRS 169721]; Martin et al. 1997 [DIRS 165960]). A typical creep curve for a specimen of welded tuff from the middle nonlithophysal unit of the Topopah Spring (Tptpmn) is shown in Figure 6-152. The three stages of creep are clearly evident.

Stable crack growth in quartz reported by Martin (1972 [DIRS 169721]) and Martin and Durham (1975 [DIRS 170301]), illustrated specific characteristics that are related to creep deformation. In these studies, the specimens were loaded to a fixed compressive stress and the growth of a crack parallel to the applied load was observed. Each specimen was tested in a controlled environment and the change in crack length was noted as a function of time. A typical data set obtained on a single specimen of quartz tested at a temperature of $241^{\circ} \mathrm{C}$ and a partial pressure of water of $4.5 \times 10^{-2} \mathrm{kPa}$ is shown in Figure 6-153. The test specimen geometry is shown in the upper left portion of the graph. At a stress of $66 \mathrm{MPa}$, the change in crack length with time is very similar to that observed in the creep of brittle crystalline rocks. The crack exhibits an initial period of rapidly decelerating growth followed by a quasi-linear or secondary segment. After $6.3 \times 10^{4}$ seconds, the stress was increased to $74 \mathrm{MPa}$. Immediately, the rate of crack growth increased. The same characteristics observed at the lower stress were exhibited for the $74 \mathrm{MPa}$ segment. There was a strong transient followed by a secondary or quasi-linear crack growth segment. At approximately $8 \times 10^{4}$ seconds, the stress was increased to $83 \mathrm{MPa}$. The rate of crack growth increased dramatically; and the experiment was terminated when the crack length reached $3.7 \mathrm{~mm}$. These data are consistent with Equation 6-8; that is, the rate of crack growth increased with increasing stress and nearly vanishes at low stresses. Additional experiments showed that increasing either the partial pressure of water surrounding the crack or the temperature also results in an increase in the rate of crack growth. 


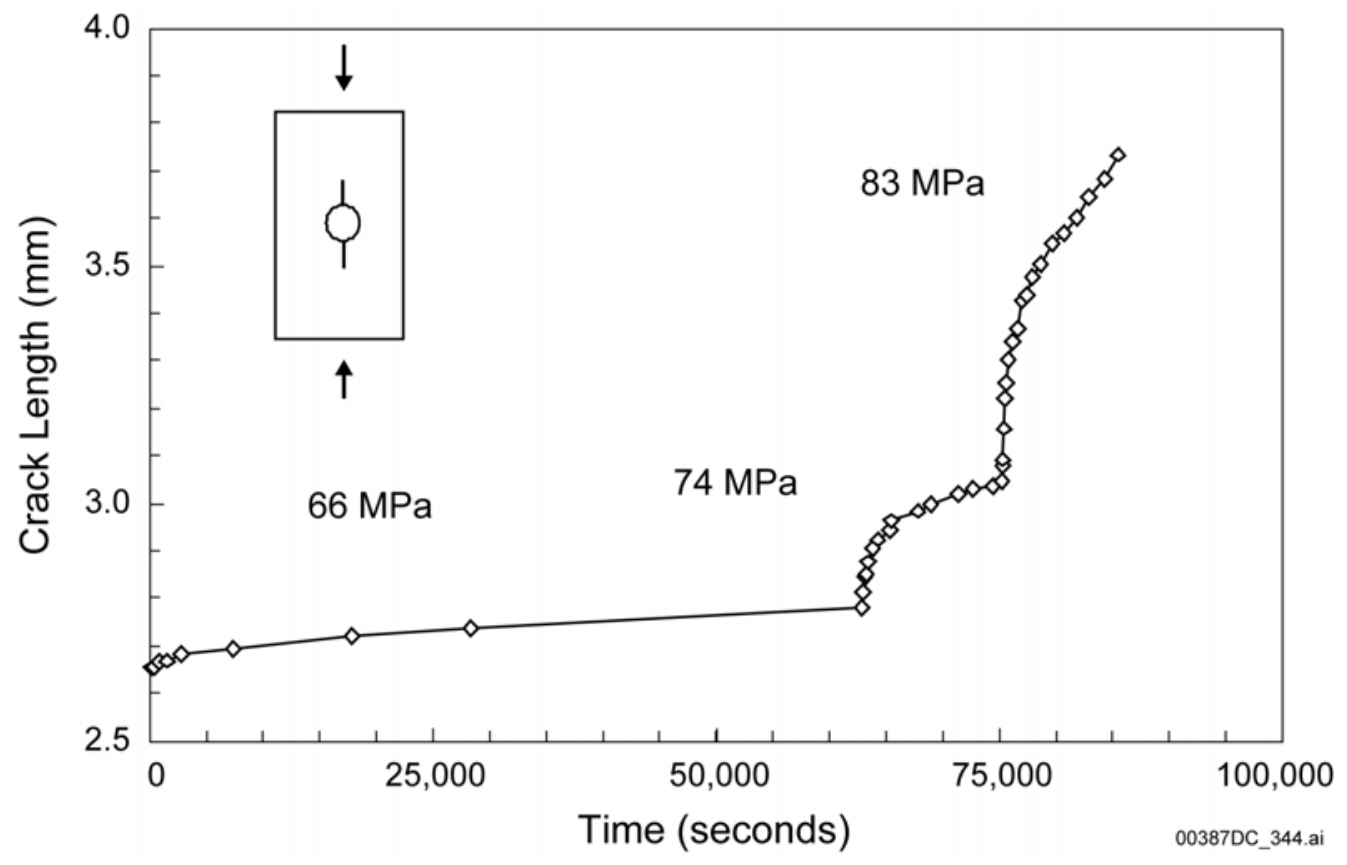

Source: Martin 1972 [DIRS 169721].

NOTE: The experiment was conducted at $241^{\circ} \mathrm{C}$ and a partial pressure of water of $4.05 \times 10^{-2} \mathrm{kPa}$.

Figure 6-153. Crack Length as a Function of Time for an Axial Crack Growth Experiment in Single Crystal Quartz

The above discussion points out that creep experiments with complex, silicate rocks display the same basic time-dependent response as demonstrated by crack-growth studies in single crystals of quartz and glass. From a practical standpoint, it is advantageous to define the ultimate time-to-failure in terms of the stress, temperature and partial pressure of water, rather than in terms of crack growth. Time-to-failure is typically defined using the creep test to determine the static fatigue of a material. Static fatigue refers to the failure time of a rock or single crystal at constant stress, temperature, confining pressure, and partial pressure of water without regard to the strain history. Scholz (1972 [DIRS 169724]) conducted a series of static fatigue tests in compression on single crystal quartz. He observed that the mean time to failure, $\langle t\rangle$, depended on the partial pressure of water $(P)$, stress $(\sigma)$, activation energy $(\Delta F)$, and temperature $(T)$ according to:

$$
\langle t\rangle=t_{0} P^{-a} \exp \left(\frac{\Delta F}{R T}-K^{\prime \sigma}\right)
$$

where $a$ and $K^{\prime}$ are constants. 
The foregoing discussion demonstrates that:

- The strength of brittle silicate rocks such as tuff is not a single-valued function of any parameter, but is a complex continuum that depends on the state of stress, the saturation (pore pressure), the temperature, and the time (including strain rate).

- Studies of the basic growth of single fractures and the creep strain resulting from microcrack growth in complex silicate rocks demonstrate that the same basic stress corrosion mechanism is responsible for time-dependent crack growth and the ultimate time-to-failure of the material.

- The stress corrosion mechanism gives rise to a logarithmic relationship of time-to-failure as a function of the state of stress, the temperature, and the pore pressure.

- As a result of the basic understanding of the static fatigue mechanism in brittle rocks, it is possible to extrapolate long-term failure response from relatively short-term static fatigue experiments in the laboratory.

Since the effects of time-dependent fracture development on weakening of tuff and its impact on drift degradation may be important in the postclosure repository environment, creep experiments on tuff samples have been conducted to determine its static fatigue response under appropriate environmental conditions.

\subsection{Static Fatigue Testing to Define Time-Dependent Behavior of Welded Tuff}

The typical way to define the time-dependent strength of rock is to establish the time required for failure of heated, saturated rock samples that are subjected to an applied constant axial stress. Creep test experiments are conducted to determine the static fatigue strength of the rock associated with tertiary creep rupture. These tests, typically conducted in uniaxial or triaxial compression, involve rapidly increasing the applied axial stress to a given percentage of the estimated compressive strength of the same size rock samples. The stress is then held constant until the sample spontaneously fails due to time-dependent rupture. A plot of the logarithm of the time-to-failure versus the ratio of the applied stress to the unconfined compressive strength is developed. The plot is typically linear, reflecting the basic mechanisms of stress corrosion as described above. Rock samples subjected to stress levels that are small in comparison to the compressive strength (i.e., below about 50 to 60 percent) result in excessively long times to failure and cannot be tested practically in the lab due to the long test duration. However, these loading conditions are not of interest for drift stability in the postclosure time frame of hundreds to thousands of years. The loading conditions of interest to time-dependent degradation at Yucca Mountain are those in which the applied stresses from in situ and thermal loading in the drift wall periphery are a high percentage of the rock strength (e.g., greater than approximately 60 to 70 percent). Here, the time to failure may result in significant degradation in hundreds to thousands of years. In this case, relatively short-term laboratory experiments (on the order of days to weeks) can supply time constants capable of describing the stress corrosion process. 
A series of triaxial static fatigue experiments were conducted on heated and saturated nonlithophysal cores from the Tptpmn in 1997 (Martin et al. 1997 [DIRS 169721]) and in 2004 (DTN: SN0406L0212303.002 [DIRS 170289]). Triaxial experiments on $50.8 \mathrm{~mm}$ diameter cores with a confining pressure of $5 \mathrm{MPa}$ and pore water pressure of $4.5 \mathrm{MPa}$ were conducted so that pore water of the saturated samples would remain in a liquid state as the temperatures were increased over boiling $\left(125^{\circ} \mathrm{C}\right.$ and $\left.150^{\circ} \mathrm{C}\right)$. The resulting effective stress (the confining pressure minus the pore water pressure) was approximately $0.5 \mathrm{MPa}$, or essentially a state of uniaxial compression. This procedure was used to ensure a conservative state in which saturated samples were maintained at postclosure rock temperatures. Figure 6-154 shows a typical specimen ready for testing.

The results of the testing on nonlithophysal cores of Tptpmn, as well as those from similar testing of Lac du Bonnet granite performed for the Canadian high-level radioactive waste program (Schmidtke and Lajtai 1985 [DIRS 164774]; Lau et al. 2000 [DIRS 164769]) are given in Figure 6-155. Granite results are included as a means of comparing the effects of rock type and for demonstrating the similarity in the general nature of the time-to-failure data for different rock types. Scatter in the data is due to sample inhomogeneity, as well as the fact that the driving stress ratio (the horizontal axis) uses an estimated value for the unconfined compressive strength (adjusted for sample porosity) for normalizing the applied stress level.

Since there is significant variability in the unconfined compressive strength of each sample, there will be a scatter in the resulting plot of time-to-failure versus driving stress ratio. As seen in Figure 6-155, the welded tuff has a significantly slower time static fatigue failure than granite, as evidenced by the steeper slope of the linear fit to the data. This slower time-to-failure is presumably a result of the relatively homogeneous, fine-grained, high silica content nature of the tuff, as opposed to the heterogeneous nature of the grain structure of granite.
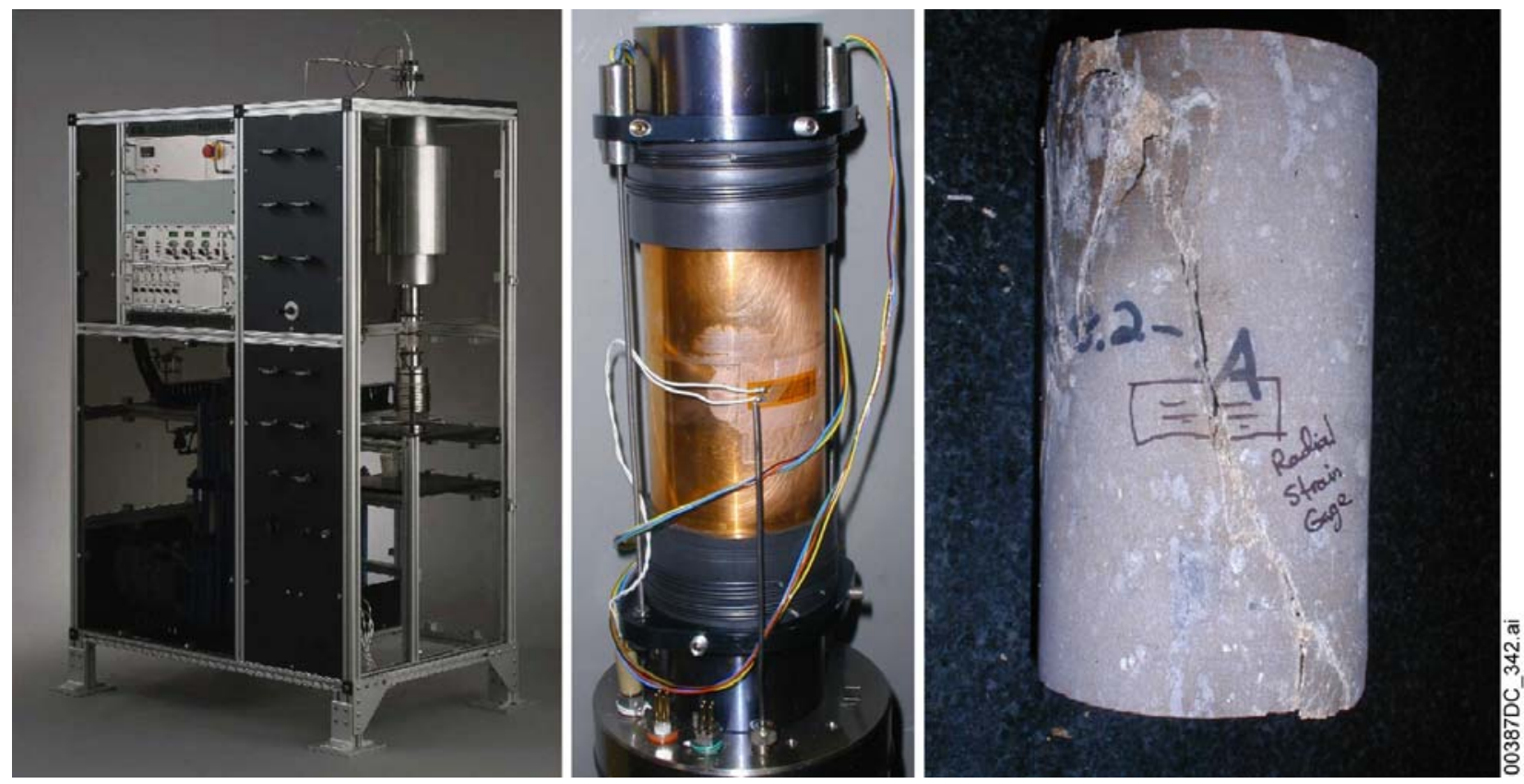

Figure 6-154. Triaxial Static Fatigue Experimental Setup and Posttest Sample for Heated, Saturated, $50.8 \mathrm{~mm}$ Diameter Samples of Tptpmn 


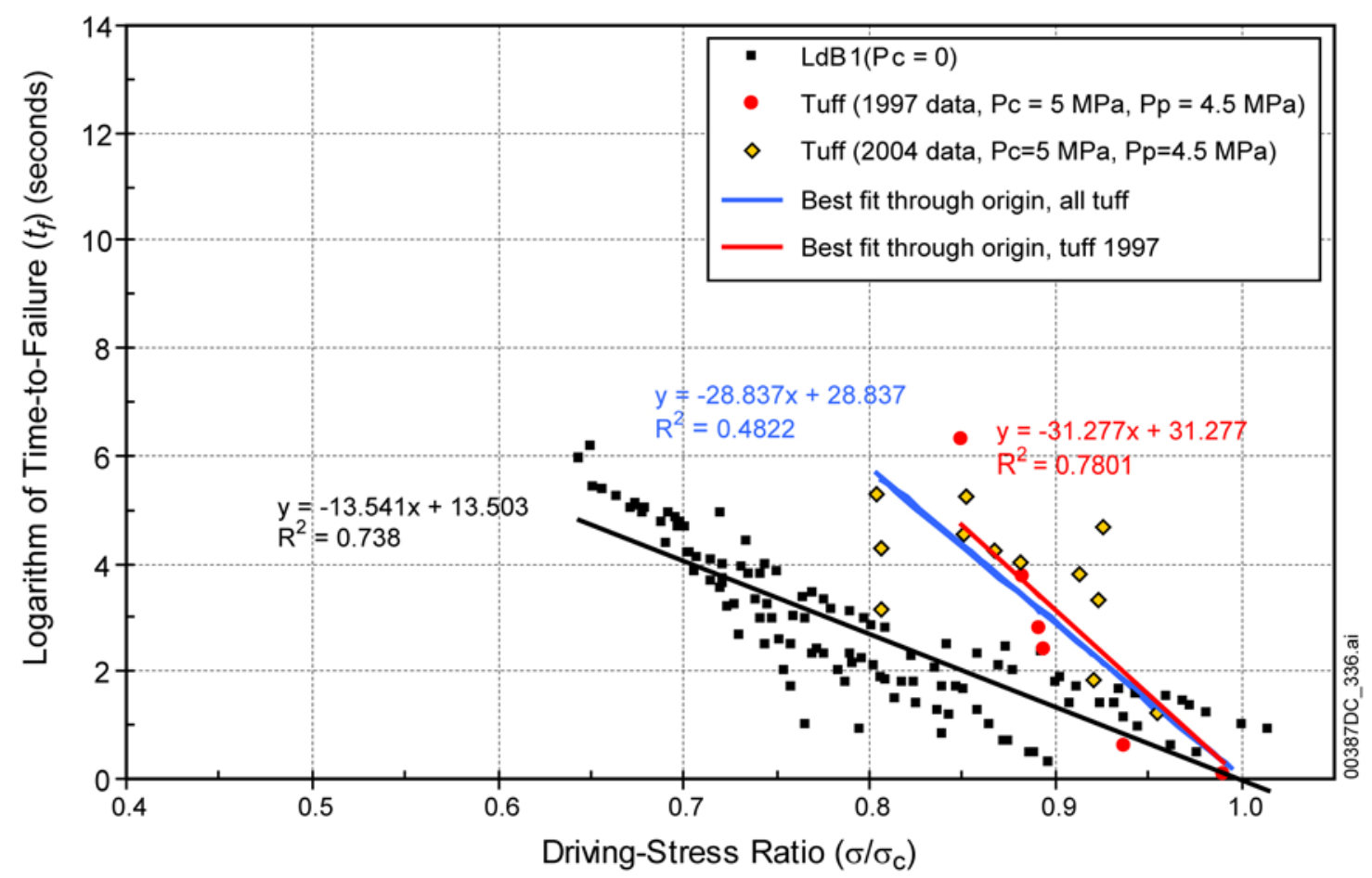

Source: Schmidtke and Lajtai 1985 [DIRS 164774] (Lac du Bonnet data); Martin et al. 1997 [DIRS 165960] (tuff 1997 data); DTN: SN0406L0212303.002 [DIRS 170289] (tuff 2004 data).

NOTE: Tests of Lac du Bonnet granite were conducted at $25^{\circ} \mathrm{C}$. The driving stress ratio is defined as the ratio of applied constant test stress to the estimated unconfined compressive strength. 1997 tuff tests were conducted at $150^{\circ} \mathrm{C}, 2004$ tuff tests were conducted at $125^{\circ} \mathrm{C}$. LdB $=\mathrm{Lac}$ du Bonnet. Linear fits to 1997 Lac du Bonnet only and 1997 and 2004 tuff tests are shown. Samples that did not fail are also shown but not used in developing linear fits to data.

Figure 6-155. Static-Fatigue Data for Unconfined and Triaxial Compression of Heated, Saturated Welded Tuff and Lac du Bonnet Granite

Linear fits to the unconfined compression data of Lac du Bonnet granite and to the tuff 1997 data only and to the welded tuff data (including both 1997 and 2004 data) are given. The fits to both sets of welded tuff data are given because the analysis of drift degradation presented in the following section was conducted based on fits to only the 1997 data. After these analyses were completed, the additional 2004 data were collected. The linear fits to the data sets show the general consistency of the overall slope of the fits, although there is considerably more scatter in the 2004 test results. Due to data uncertainty, a lower bound for the slope of the time-to-failure curve based on the Lac du Bonnet data, was also used in numerical modeling estimates. The static fatigue testing was performed on saturated tuff cores at elevated temperature, ensuring that the impact of water on time-dependent yielding was accounted for in the estimation of time-dependent effects on drift stability. 


\subsection{Development of a Mechanical Model for Simulating Time-Dependency in Nonlithophysal and Lithophysal Rock}

After an estimate of the relationship of stress level to time-to-failure for nonlithophysal tuff has been defined through testing, it is necessary to establish the impact of lithophysal porosity on the time dependence and to generalize the results into a time-dependent strength model that can be used to estimate drift stability. The methodology for development of a mechanical model for representing time-dependent degradation effects in welded tuff is described below.

The particle flow code PFC2D (BSC 2002 [DIRS 161950]) and PFC3D (BSC 2002 [DIRS 160612]) discontinuum numerical modeling tools were used for understanding the impact of lithophysal porosity on time-to-failure as a function of applied stress. A modification to the basic particle flow code program was developed for simulation of time-dependent, stress corrosion cracking of rock. This model, termed the particle flow code stress corrosion model, was used for simulating time-dependent tunnel fracturing of Lac du Bonnet granite for the Canadian waste disposal research program. In this model, time-dependent intergranular bond fracture strength was developed based on the general concept of a stress corrosion mechanism. The long-term behavior is controlled by three particle flow code stress corrosion model parameters, $\beta_{1}, \beta_{2}$, and $\sigma_{a}$. The terms $\beta_{1}$ and $\beta_{2}$ (rate constants) and $\sigma_{a}$ (microactivation stress) do not affect short-term material properties. These material parameters are derived from calibration against the time-to-failure data supplied by static fatigue testing (e.g., Figure 6-155). The particle flow code stress corrosion model has been extensively documented and calibrated against static fatigue testing of Lac du Bonnet granite and validated against time-dependent tunnel breakout observed at the Underground Research Laboratory in Manitoba, Canada (Potyondy and Cundall 2001 [DIRS 156895]). Details of the stress corrosion model in particle flow code and its calibration are presented in Appendix S.

Prior to representing time dependency, it was necessary to demonstrate that the particle flow code model can reproduce the basic, non-time-dependent mechanical behavior of nonlithophysal and lithophysal tuff. The calibration of the model against laboratory compression data from small cores of nonlithophysal tuff and from large cores of lithophysal tuff from the Tptpul and Tptpll was described in Section 7.5. The same basic particle flow code model, incorporating a time-dependent particle bonding strength, was then calibrated to reproduce the time-to-failure dependent response of nonlithophysal tuff determined from the static fatigue testing. The calibration of the model is carried out by conducting simulated creep tests on nonlithophysal samples in exactly the same way they are performed in the laboratory. Figure 6-156 presents a typical simulated creep test in which axial load is applied to the particle flow code sample and held constant at 80 percent of its unconfined compressive strength. Tensile fractures (cracks) develop spontaneously in the model as a function of time based on the time-dependent bond strength of the constituent grains. The plot shows the development of a network of tensile stress corrosion cracks that accumulate and propagate within the sample until a macroscopic shear failure mechanism develops with resulting brittle rupture during the tertiary creep stage. The simulated creep test shows the three stages of creep: transient, secondary and tertiary, and reproduces the typical response of creep experiments in tuff (e.g., Figure 6-152). 


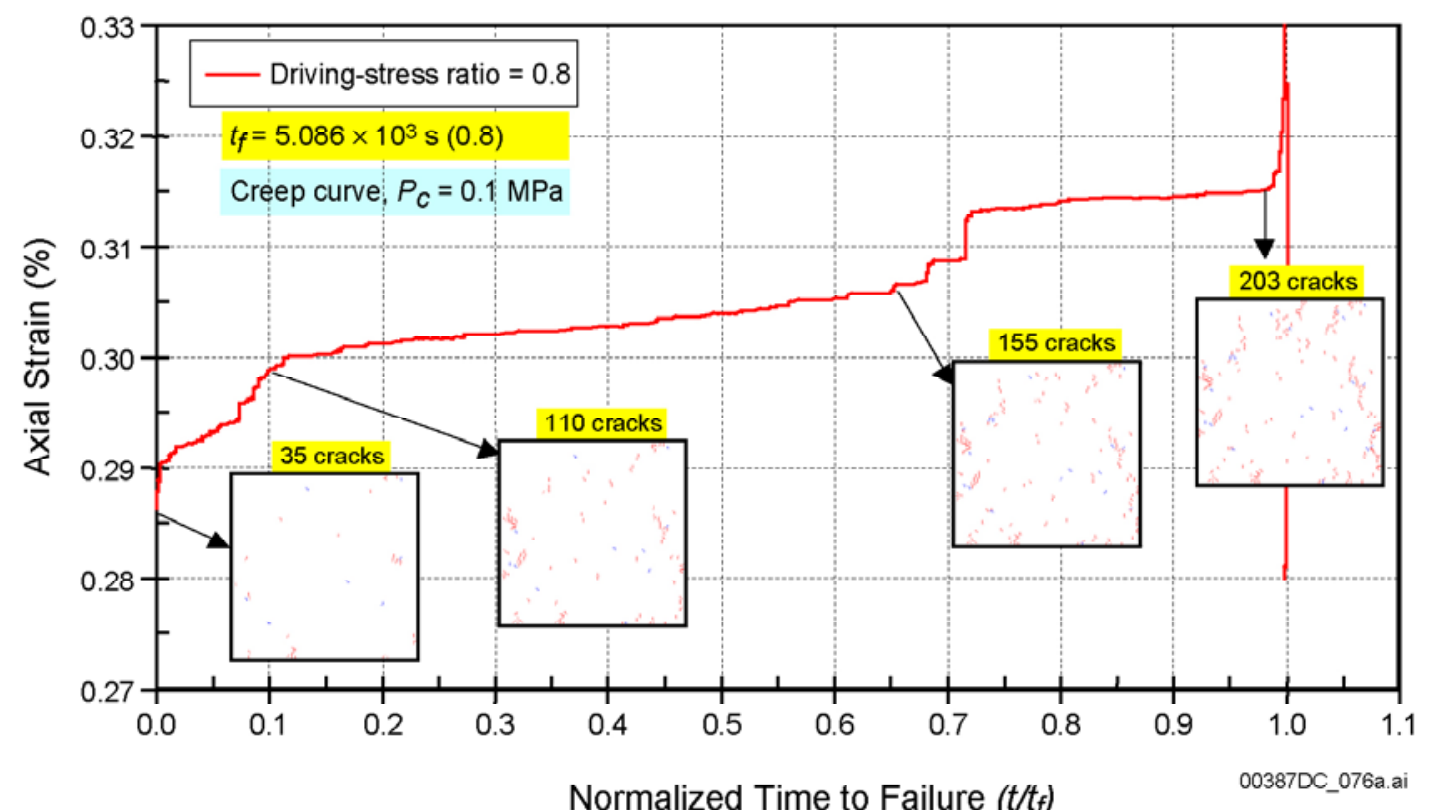

NOTE: Numerical simulation of creep test run by holding applied axial stress constant at 0.8 times the unconfined compressive strength. The damage, in terms of new crack growth, is displayed at various times along the creep curve. Brittle failure of the sample occurs when sufficient time-dependent crack growth results in failure mechanism.

Figure 6-156. Example of Simulated Creep Curve and Brittle Rupture Calibration for Nonlithophysal Tuff, (in This Case, Providing a Lower-Bound Estimate by Using Lac du Bonnet Granite Time-to-Failure Curve) Static-Fatigue Test at Driving-Stress Ratio (Ratio of Applied Stress to Unconfined Compression Strength) of 0.8

A large number of particle flow code simulations of static fatigue tests of nonlithophysal rock was run at a wide range of driving stress ratios, and two particle flow code stress corrosion parameters were calibrated, so that the model was able to reproduce the basic time-to-failure fits shown in Figure 6-155 for tuff and granite. The third stress corrosion parameter, the activation stress, was conservatively considered to be 0 . The consequence of this consideration is that the long-term strength of the particle flow code synthetic material is 0 . It is well known that real rocks have long-term (true) strength that is on the order of 50 percent of the short-term strength. In other words, if the load is less than long-term strength, the rock will never fail, irrespective of duration of the load. The model was then used to investigate the impact of lithophysal porosity on the rate of time dependence. It is considered that time-dependent behavior of the matrix is the same for both lithophysal and nonlithophysal rocks. A series of simulated creep experiments for lithophysal porosities of 11 percent and 20 percent were conducted, resulting in the generation of a set of time-to-failure versus driving stress ratio plots for various levels of lithophysal porosity (Figure 6-157). 
(a)

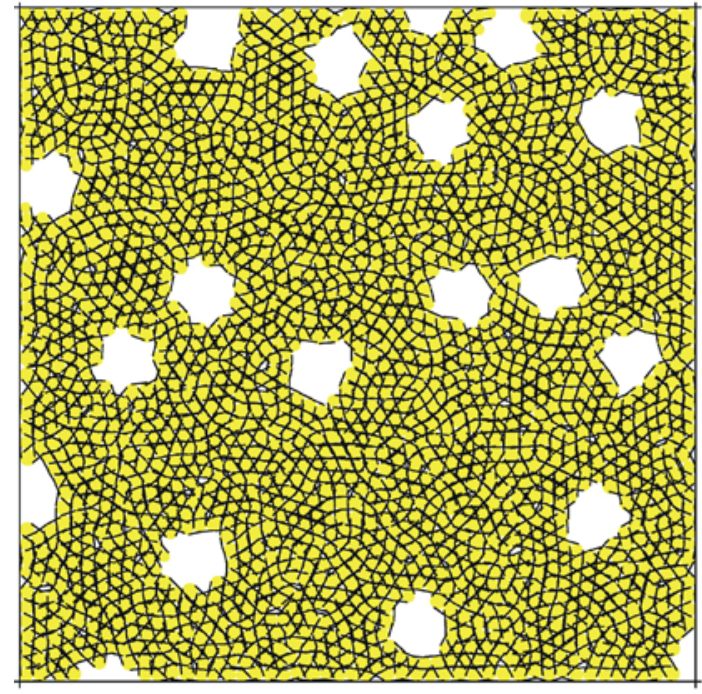

0.107 Void Porosity

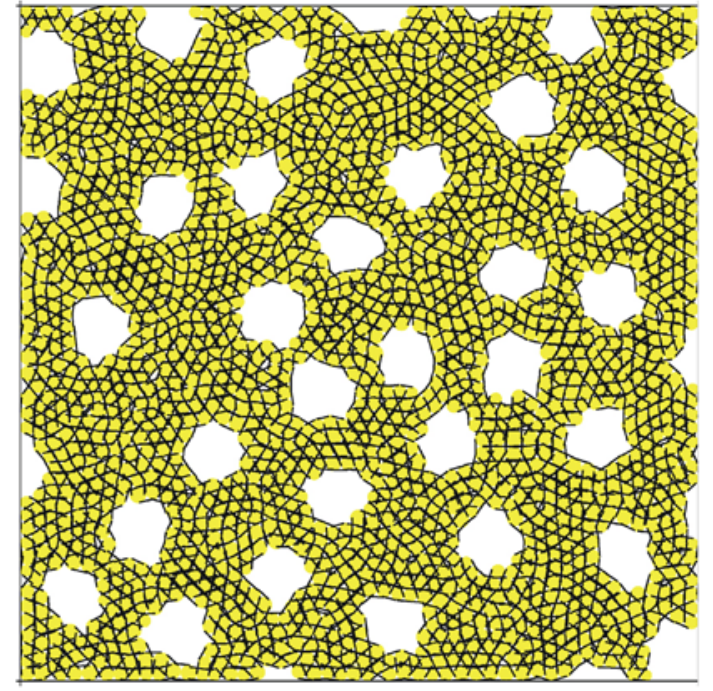

0.204 Void Porosity

(b)

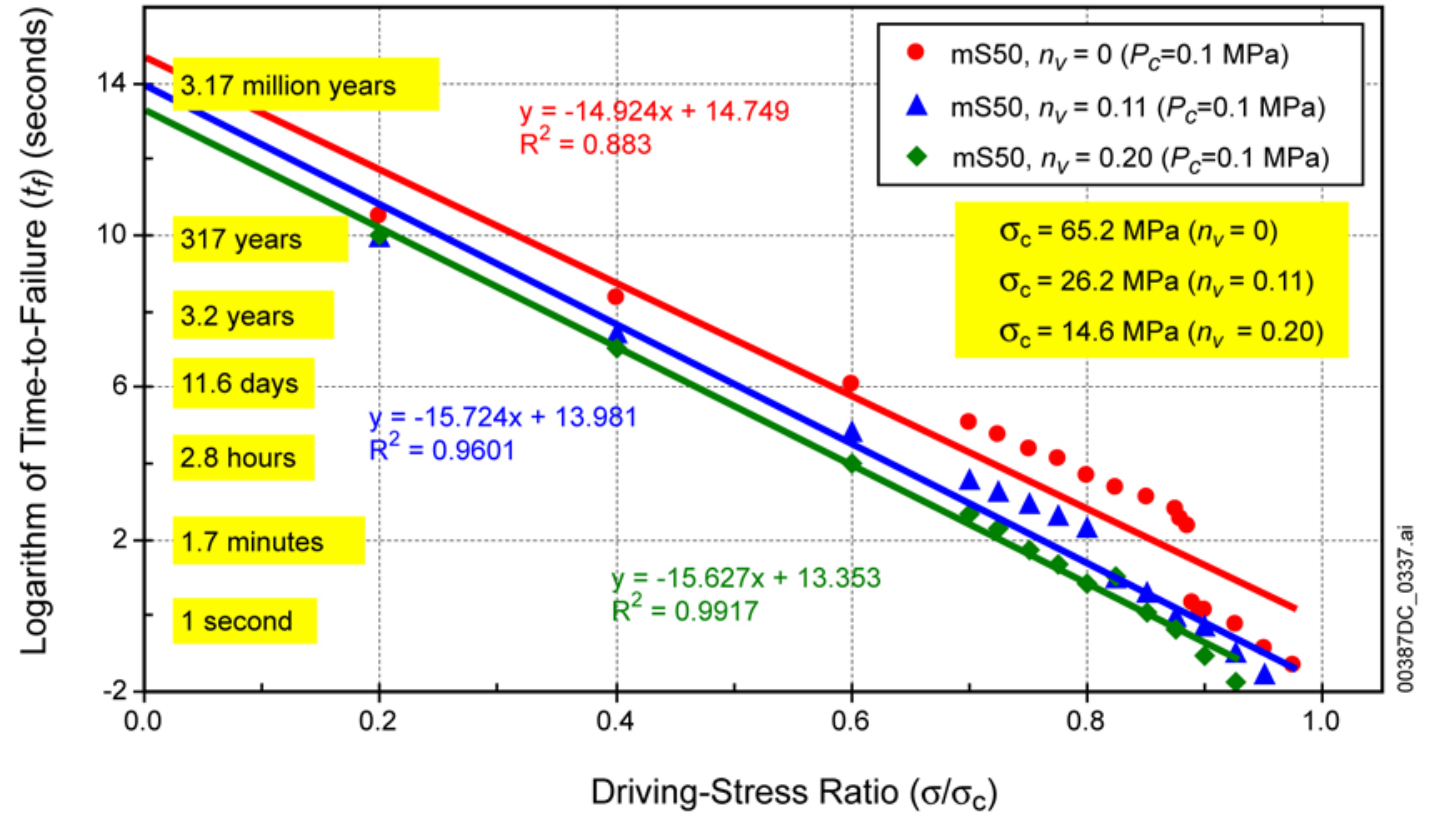

NOTE: The time dependency has approximately the same slope for the void porosities for the straight-line fit. Lithophysae are simulated as circles with a diameter of $90 \mathrm{~mm}$. mS50 is the designation for the material properties of the matrix derived from nonlithophysal calibrations.

Figure 6-157. Example Particle Flow Code Specimens with Void Porosities of 0.107 and 0.204 (a) and Effect of Void Porosity on Time-to-Failure Response for Lithophysal Tuff Material, in This Case, Providing a Lower Bound Estimate by Using Lac du Bonnet Granite Time-to-Failure Curve ( $0 \%$ to $20 \%$ Void Porosity, $\left.n_{v}\right)(b)$ 


\subsection{Drift-Scale Model for Simulation of Time-Degradation of Emplacement Drifts}

The particle flow code model for time dependency of lithophysal rock, shown in Figure 6-157, is computationally very large and is difficult to apply on the scale of a complete emplacement drift. To overcome these computational limitations, a drift-scale model using the UDEC discontinuum program was developed for investigation of non-time-dependent drift degradation analyses in lithophysal rocks as presented in the previous sections. The same model is used for time-dependent drift-scale analyses with the exception that the strength properties of the model are adjusted as a function of time. The relationships for time-to-failure as a function of lithophysal porosity developed from the laboratory testing and particle flow code extrapolations are used to define time-dependent strength properties for the drift-scale UDEC model. The approach to definition of time-dependent effects on strength in UDEC is simplistic in that it relates rock mass damage resulting from stress corrosion cracking directly to a loss of cohesion and tensile strength of the rock mass. The degree of strength loss was determined by (1) conducting a series of particle flow code numerical creep tests at different values of driving stress ratio and (2) interrupting the particle flow code creep test simulations at various times during a simulated test and conducting numerical compression and tensile strength tests on the damaged sample. For example, Figure 6-156 shows four "snapshots" of the crack-damaged state of a simulated rock sample at various times along the creep curve. The strength properties of these damaged states were determined, and the resulting cohesion and tensile strength defined as a function of time for a given driving stress ratio. The strength loss was generalized into a damage coefficient that varies from 0 to 1 ( 0 indicates no strength loss, while 1 is complete strength loss). The cohesion and tensile strength of the rock is multiplied by this coefficient to derive the strength properties of the rock mass as a function of time. Essentially, this approach relates the reduction in strength properties (shear and tensile strength) to the increase in fracture density or damage to the rock mass. Figure 6-158a shows the form of the damage coefficient as a function of time for various driving stress ratios as derived from the particle flow code stress corrosion model for a nonlithophysal simulation. As seen in this plot, damage occurs in a brittle fashion with abrupt failure near the peak strength. The amount of damage accumulated prior to the abrupt failure (as shown by the damage coefficient) is less than 10 percent for high driving stress ratios (e.g., $>0.6$ ), whereas damage accumulation is significantly larger for low driving stress ratios (e.g., <0.6). A simplified representation of the damage coefficient evolution in terms of time is shown in Figure 6-158b.

The UDEC drift-scale model is composed of many small elastic blocks that are bonded across incipient, ubiquitous fractures with shear and tensile strength components. While the non-time-dependent UDEC drift-scale model considers constant strength properties for the incipient fractures, the time-dependent damage model is transient in nature and assigns cohesion and tensile strength based on the damage coefficient as a function of time after excavation (i.e., Figure 6-158b). 
(a)

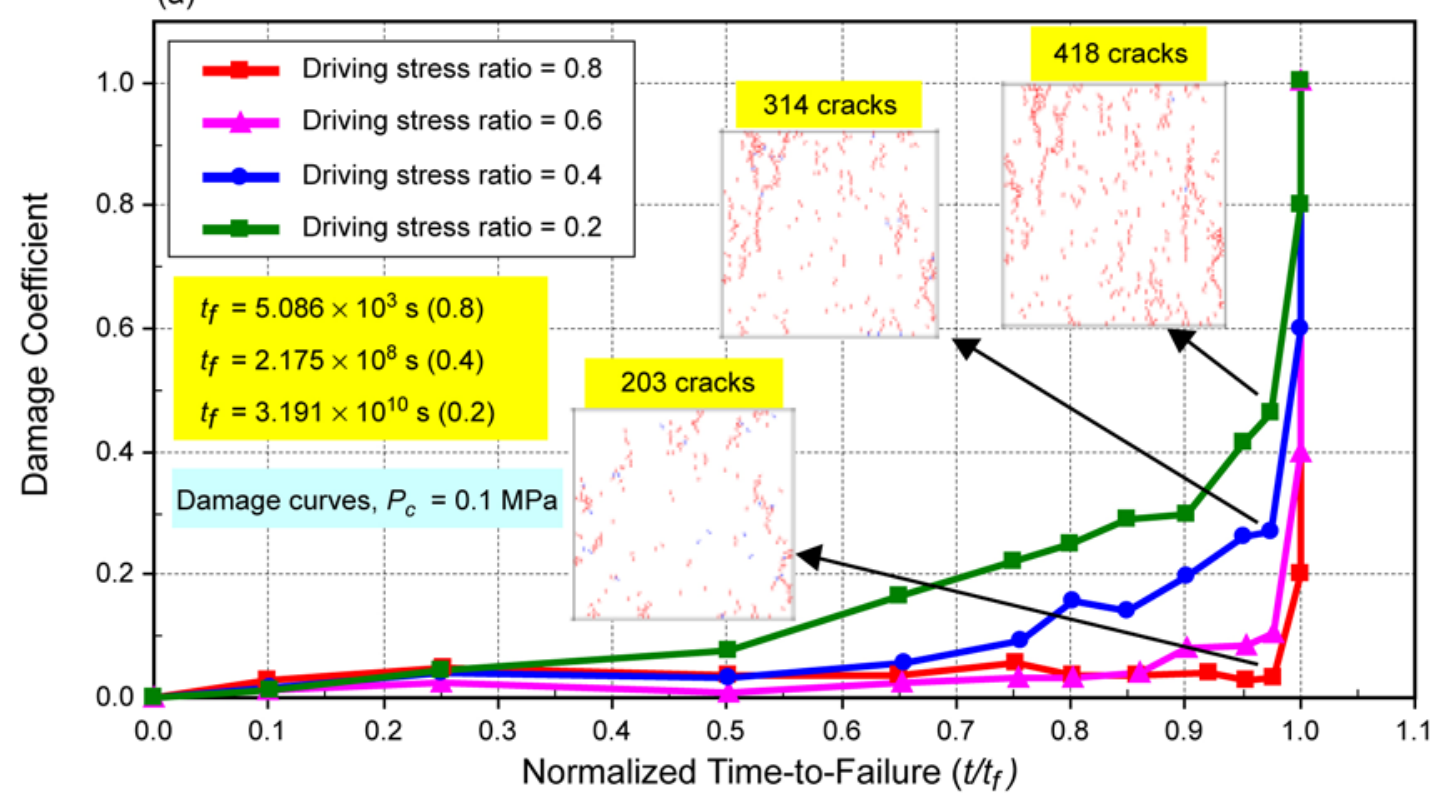

(b)
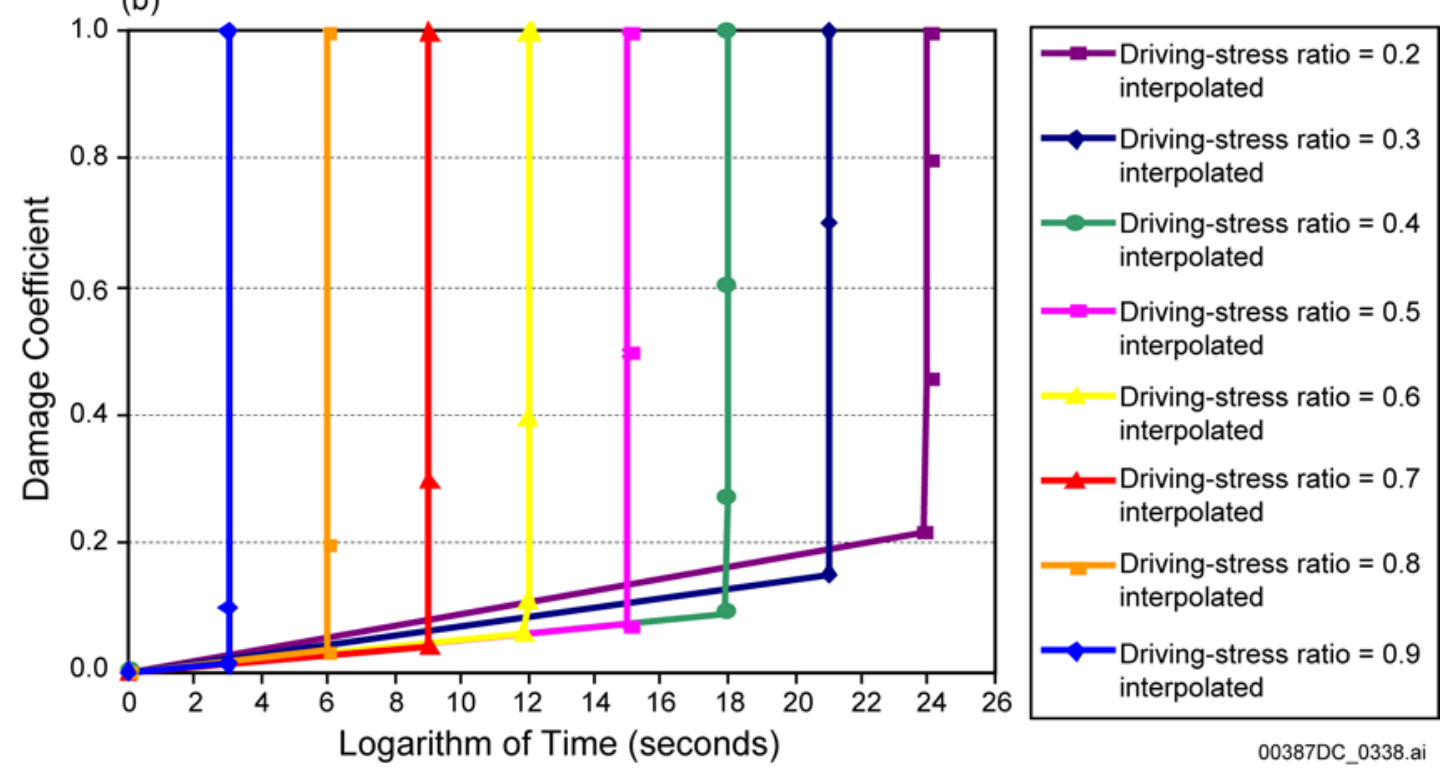

NOTE: Each curve has a vertical asymptote at a time-to-failure for a given driving-stress ratio, which is provided by the best fit to tuff (1997 data) given in Figure S-27 (Appendix S). Plot (a) was developed by using the Lac du Bonnet granite time-to-failure curve.

Figure 6-158. Time Evolution of Damage Due to Strength Degradation Coefficient for Nonlithophysal Tuff Material During Static-Fatigue Tests at Driving-Stress Ratios Ranging from 0.2 to 0.8 (a) and Idealized Damage Coefficient as a Function of Time for a Range of Applied Stress Conditions (b) 


\subsection{Time-Dependent Drift Degradation Analyses for In Situ Stress Only}

A series of parametric drift degradation simulations were conducted for the range of potential lithophysal rock mass strength categories in the Tptpll. Time-dependent drift degradation analyses for the postclosure time frame were conducted for each of these strength categories. When performing a time-dependent drift degradation analysis, the cohesion and tensile strength at each incipient fracture location is adjusted as a function of time, with yield considered to occur in a brittle fashion when the time-to-failure is reached (Figure 6-158). Thus, as the drift is excavated and as transient thermal stresses develop, time-dependent yield and fracture can occur around the excavation, resulting in redistribution of stress and possible propagation of drift breakout, collapse, and rockfall.

The model was run by first excavating the emplacement drift under in situ stresses only, followed by application of the transient rock mass temperature conditions. The time-dependent fracture state and drift stability was examined at 1, 5, 10, 100, 1,000, and 10,000 years during the heating and cooling phases of the postclosure period. Additional analyses were conducted to examine the effect of seismic loading with the application of the $10^{-4}$ annual exceedance level ground motion time histories (approx. $0.5 \mathrm{~m} / \mathrm{s}$ peak ground velocity). This ground motion was applied to the time-degraded model at the time of peak thermal stress (approximately 30 years after closure), at 1,000 years, and at 10,000 years. The $10^{-4}$ event was chosen to determine if the added seismic stress and shaking would be sufficient to dislodge time-degraded, fractured, and loosened rock that may still be in place on tunnel walls.

The resulting time-dependent drift degradation estimates for mechanical property categories $1,2,3$, and 5 for loading by in situ stresses only for 1 to 10,000 years are presented in Figures S-37 to S-40 in Appendix S. The results for the lowest rock qualities (categories 1 and 2) show significant deterioration of the drifts would be expected soon after excavation as a result of in situ stress loading only. Observations in the ECRB Cross-Drift and the ESF, which have been excavated for 6 or more years, show no progressive raveling or overbreak (e.g., Brekke et al. 1999 [DIRS 119404], p. 2-5). This observation holds even in those areas of high lithophysal porosity found near the top of the Tptpll. Categories 3 and 5 show little time-dependent effect from in situ stressing only. These results point out that the best estimate of tuff time dependence, coupled with the considerations of brittle rock failure and constant, homogeneous properties within a given model cross section produces conservative damage estimates. Category 3 is considered to represent an average condition of lithophysal porosity for the Tptpll and shows little overbreak with time. Analyses presented in Section 6.4.2.2.3 examine the impact of spatially variable rock properties within a given model section based on the mapped variability of lithophysal porosity in the ECRB Cross-Drift. The spatially variable model has a range of rock categories distributed throughout the cross section, and results of analyses show time-dependent drift degradation response similar to that shown for category 3 mechanical properties. An important conclusion from these initial in-situ-stress-only analyses is that best estimate time-dependent fracture growth within the tuff matrix is not expected to lead to collapse modes and significant drift degradation. 


\subsection{Time-Dependent Drift Degradation Analyses for Combined Thermal and Time-Dependent Effects}

Throughout the regulatory period of 10,000 years, the emplacement drifts and surrounding rock mass will be subject to a heating cycle. Time-dependent strength degradation will happen concurrently with transient, thermally induced stress changes. Increased stresses around the excavation will accelerate the process of strength degradation. The results of numerical simulation of drift degradation as a result of these two processes are shown in Figures S-42 to S-44 in Appendix S. Time-dependent strength degradation is assessed using the tuff best-fit static-fatigue line. As expected, most rockfall occurs in category 2 rock mass, as shown in Figure S-42. Initially, most of the rockfall comes from the walls, which are loaded almost to a yielding state for this rock mass category under in situ stress conditions only. Strength degradation combined with a temperature increase, which at early times increases the hoop stress in the walls (not only in the roof), results in some rockfall from the wall at 5 and 10 years after emplacement of the waste. The large increase in the temperature and, consequently, in the stresses after the forced ventilation stops causes additional rockfall (at 80 years). At this stage, stress increase is predominantly in the roof. Therefore, some rockfall comes from the roof. It is counterintuitive that more rockfall is predicted in category 5 (Figure S-44) than in category 3 (Figure S-43). However, a large stiffness of category 5 lithophysal rock mass causes a large (larger than in category 3 ) increase in the hoop stress and yielding in the roof, even considering the short-term yield strength of the rock mass.

It should be noted that static-fatigue curves are temperature dependent. This dependence is not explicitly included in the analysis. However, the tuff data are obtained from tests conducted at $150^{\circ} \mathrm{C}$, which is larger than the maximum temperature of the rock mass anticipated throughout the repository for postclosure. Consequently, the results obtained in this analysis, although for isothermal static-fatigue curves, are conservative.

\subsection{Time-Dependent Drift Degradation Analyses for Combined Seismic, Thermal and Time-Dependent Effects}

The $10^{-4}$ ground motion was applied to category 2 and 5 rock mechanical property cases at two time periods: (1) at the time peak thermal stress state (nominally at 80 years after emplacement, or 30 years after cessation of 50 years of forced ventilation) and (2) at 10,000 years at the completion of the postclosure heating and cooling cycle. Figures 6-159 and 6-162 show the resulting predicted degraded drift states for these cases. Essentially, the application of the $10^{-4}$ ground motion (peak ground velocity of approximately $0.5 \mathrm{~m} / \mathrm{s}$ ) dislodges any fractured and loosened rock created by the thermal stress and time dependency. As seen in these figures, the impact of time dependency of strength properties is to widen the diameter of the emplacement drifts in the lower quality (category 2 ) rock due to progressive shear failure at the sidewalls. In the highest quality (category 5) rock, additional progressive yield of the roof is evident. Roof yield in higher quality rock is due to the higher modulus of the rock mass and, thus, higher roof-parallel thermally induced stresses during the heating cycle. This is similar to the roof crown spalling effect observed in the Drift Scale Test. 


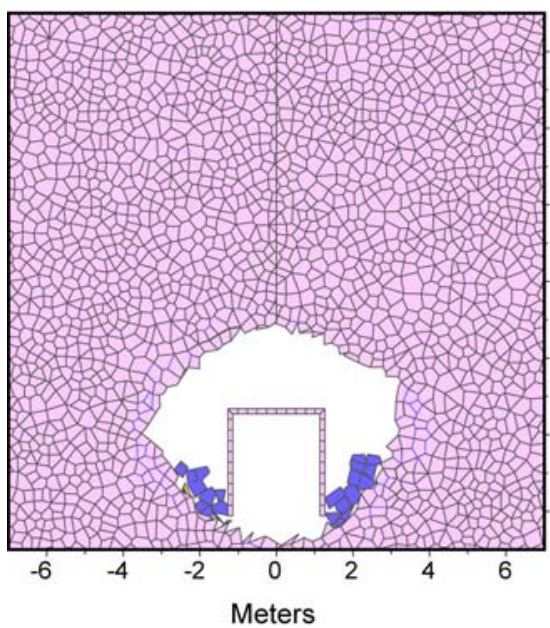

(a) before earthquake

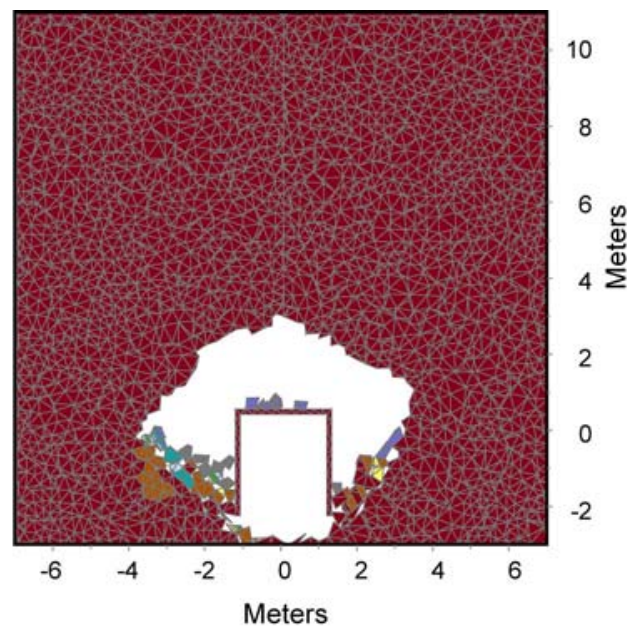

00387DC_088d.ai

(b) after earthquake

Figure 6-159. Effect of $10^{-4}$ Ground Motion After 80 Years of Heating in Category 2: Blocks Colored by Contours of Displacement Magnitude

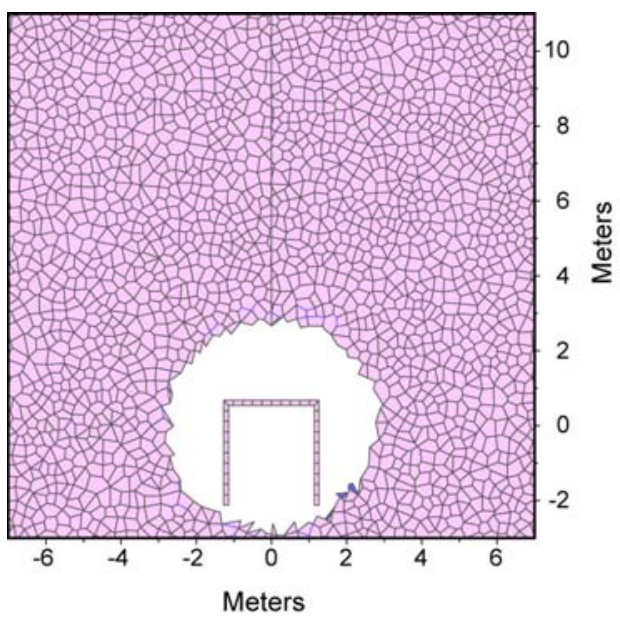

(a) before earthquake

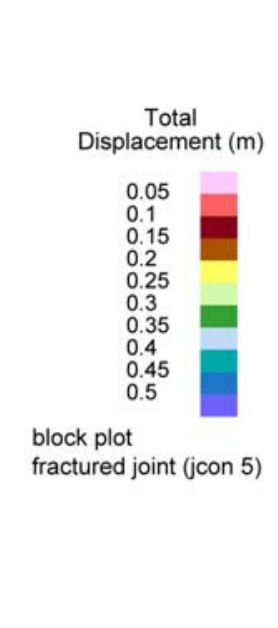

Figure 6-160. Effect of $10^{-4}$ Ground Motion After 80 Years of Heating in Category 5: Blocks Colored by

Figure 6-160. Effect of $10^{-4}$ Ground Motion After 80
Contours of Displacement Magnitude

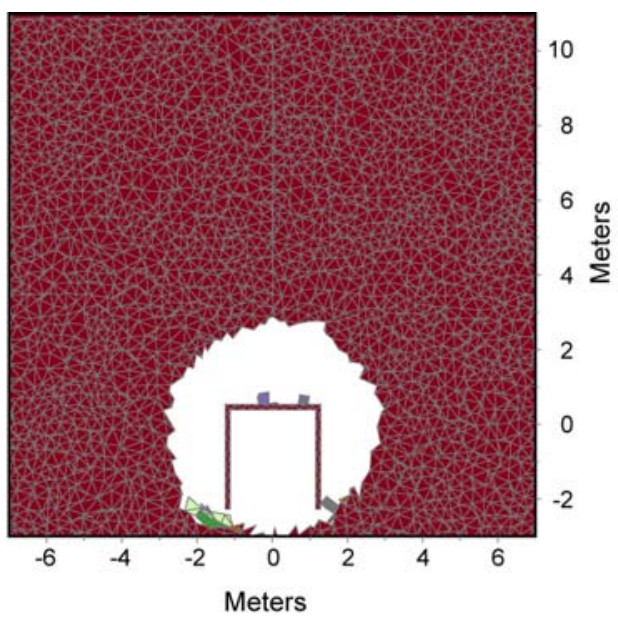

00387DC_089d.ai

(b) after earthquake 


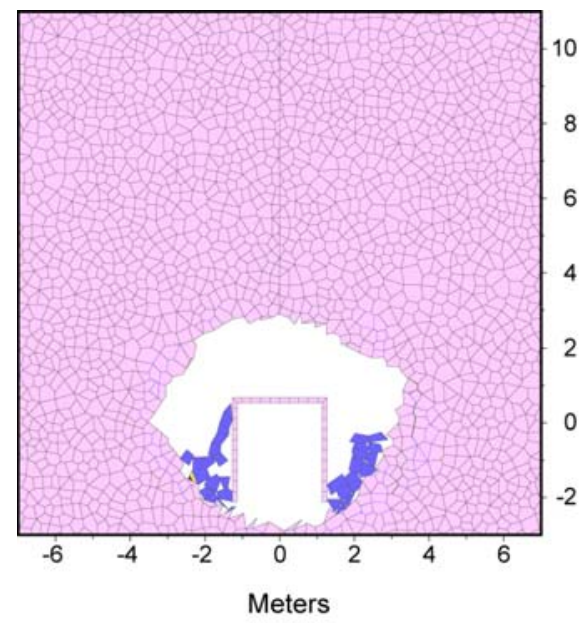

(a) before earthquake

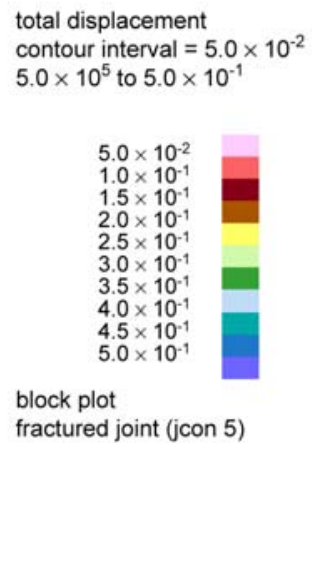

contour interval $=5.0 \times 10^{-2}$

$5.0 \times 10^{5}$ to $5.0 \times 10^{-1}$

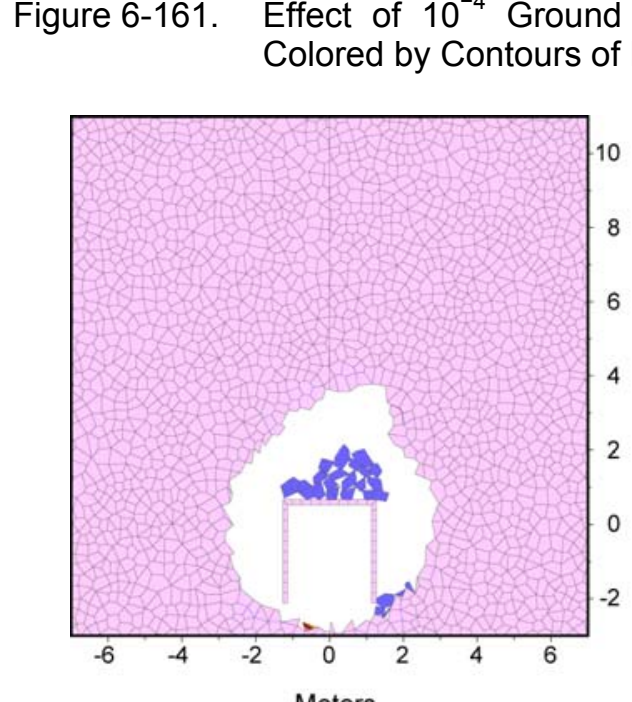
Colored by Contours of Displacement Magnitude

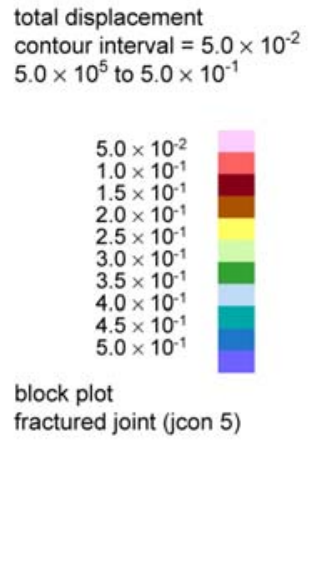

(a) before earthquake

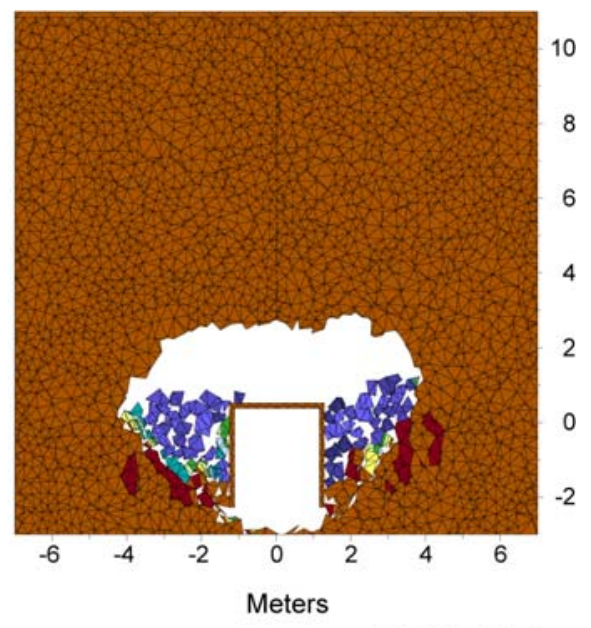

00387DC_090b.ai

(b) after earthquake

Figure 6-161. Effect of $10^{-4}$ Ground Motion After 10,000 Years of Heating in Category 2: Blocks

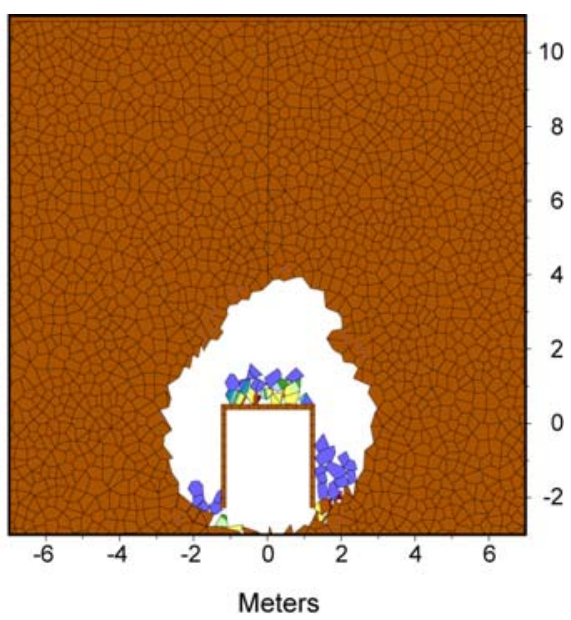

00387DC_091b.ai

(b) after earthquake

Figure 6-162. Effect of $10^{-4}$ Ground Motion After 10,000 Years of Heating in Category 5: Blocks Colored by Contours of Displacement Magnitude 


\subsection{Summary of Time-Dependent Consideration}

\subsection{Summary of Empirical Observations}

The safety-related empirical correlations for maximum unsupported span and stand-up time of excavations developed for the tunneling industry are not relevant for prediction of long-term response of repository excavations. The span of the emplacement drifts is significantly less than that required to initiate collapse, as indicated by practice in the mining industry. The excavations will be developed using nonblasting methods (i.e., using a tunnel boring machine) and with a circular shape that minimizes overbreak and promotes stability. Observations of existing tunnels in the repository host horizon at the Yucca Mountain site as well as in similar rock at Hoover Dam show stable conditions with minimal or no ground support.

\subsection{Effect of Drift Collapse on the In-Drift Environment}

Estimates of the coupled thermal-hydrologic behavior of the rock mass in the near vicinity of the drifts is examined in Multiscale Thermohydrologic Model (BSC 2004 [DIRS 169565]). Numerical parameter analyses of the impact of waste heating on fluid pressures on fractures and infiltration into the emplacement drifts were conducted using the multiscale thermal-hydrologic model. For the range of hydrologic properties of the four host-rock units, the fracture permeability is sufficiently large and fractures are sufficiently well connected to allow gravity-driven drainage of water to occur in an unrestricted fashion. Thus, percolation flux, not fracture permeability, is the rate-limiting quantity governing the magnitude of gravity-driven liquid-phase flow to the boiling-dryout zone. Additionally, the analyses show that potential pressure buildup along fractures due to vapor pressure from boiling of water is also negligible due to the free-draining nature of the fractured rock mass. From a mechanical stability standpoint, this means that fluid pressure on fractures during the drying and rewetting phases of the postclosure period has a negligible effect on drift stability. These predictions are borne out by the Drift Scale Test in which no mechanical drift instabilities occurred for thermal conditions representative of repository postclosure conditions.

A parameter study was conducted to examine the impact of drift collapse on in-drift thermal-hydrologic parameters (BSC 2004 [DIRS 169565]). The multiscale thermal-hydrologic model was used to examine the effect of a rubble-filled drift on waste package and invert temperature and relative humidity at the waste package and invert. The drift was considered to collapse (instantaneously) to twice the initial diameter (i.e., $11 \mathrm{~m}$ collapsed diameter) and is filled with rubble with a bulking factor of 0.231 . The thermal conductivity of the rubble $\left(K_{t h}\right)$ is defined as the intact rock thermal conductivity of the Tptpll multiplied by the factor $(1 /(1+$ bulking factor $))$. Two thermal conductivity values (a high case calculated as defined above for a bulking factor of 0.231 , and a low case, which is taken to be one-half the high case value) of the dry and wet rubble thermal conductivity were used in the analyses, as shown in Table 6-46. 
Table 6-46. Thermal Conductivity of Rubble

\begin{tabular}{|c|c|c|c|}
\hline Property & $\begin{array}{c}\text { Intact Host-Rock } \\
\text { Property Value }\end{array}$ & Host-Rock Rubble Property Value & $\begin{array}{c}\text { Basis for Rubble Property } \\
\text { Value }\end{array}$ \\
\hline $\begin{array}{c}\text { Bulk dry thermal } \\
\text { conductivity }\end{array}$ & $1.28 \mathrm{~W} / \mathrm{m} \cdot \mathrm{K}$ & $1 \mathrm{~W} / \mathrm{m} \cdot \mathrm{K}\left(\text { High- } K_{\text {th }} \text { case) }\right)^{\mathrm{a}}$ & $\begin{array}{c}\text { Intact Value } \times 1 /(1+\mathrm{BF}) \\
\left(\text { High- } K_{\text {th }} \text { rubble value }\right) / 2\end{array}$ \\
\hline $\begin{array}{c}\text { Bulk wet thermal } \\
\text { conductivity }\end{array}$ & $1.89 \mathrm{~W} / \mathrm{m} \cdot \mathrm{K}$ & $1.515 \mathrm{~W} / \mathrm{m} \cdot \mathrm{K}\left(\text { High- } K_{\text {th }} \text { case }\right)^{\mathrm{b}}$ & $\begin{array}{c}\text { Intact Value } \times 1 /(1+\mathrm{BF}) \\
\left.\text { (High- } K_{\text {th }} \text { rubble value }\right) / 2\end{array}$ \\
\hline
\end{tabular}

Source: BSC 2004 [DIRS 169565], Table 6.2-3.

a This value is rounded down slightly.

${ }^{b}$ Value is close to, but slightly less than, the value obtained from the Intact Value $\times 1 /(1+B F)$, in order to be consistent with the slight reduction made to the dry $K_{\text {th }}$ value, which was rounded down.

Figure 6-163 shows the in-drift thermal-hydrologic parameters as functions of time from repository closure for the case of the hottest waste package, which is the 21-PWR Absorber Plate waste package. These plots show three cases: (1) an open, noncollapsed drift, (2) a collapsed, rubble-filled drift with high $K_{t h}$ for the rubble, and (3) a collapsed, rubble-filled drift with low $K_{t h}$. The temperature (or any of the other environmental parameters plotted) will follow the intact drift curve until the time of collapse. At that point, the temperature (or other parameters) will translate vertically to one of the other curves, depending on the thermal conductivity of the rubble.

Examination of the waste package temperature curve (Figure 6-163a) shows that significant impact to peak waste package temperature results only if drift collapse occurs within the first 100 to 200 years after closure. After that time, the waste package temperature will always be below the peak temperature for the intact drift case, which occurs within about 20 to 30 years after closure. The total time at which the waste package surface remains above boiling for the hottest waste package case is approximately 1,000 years for the intact drift, 1,500 years for the high $K_{t h}$ case, and 2,000 years for the low $K_{t h}$ case. The relative humidity at the waste package decreases significantly for collapsed cases. 

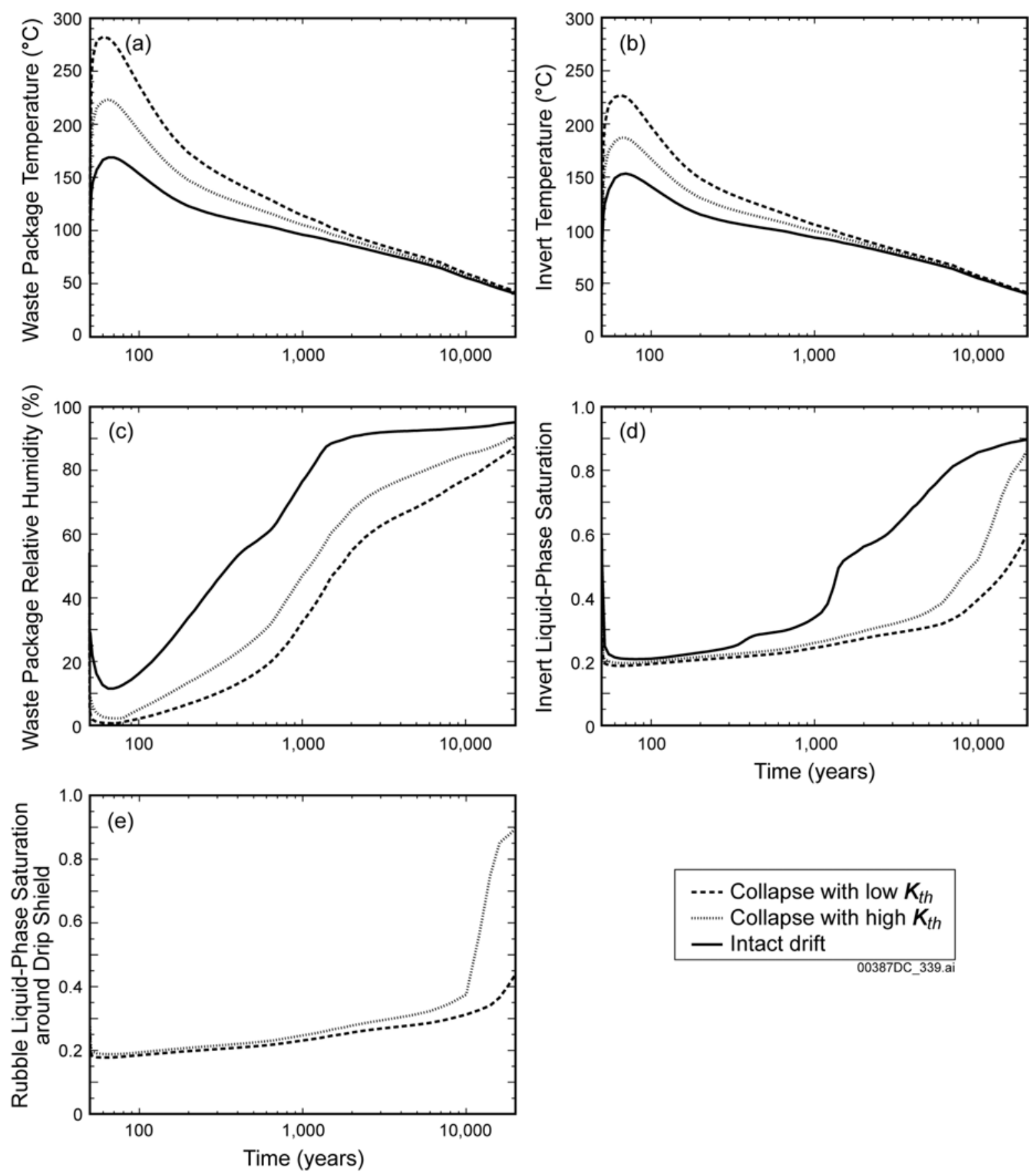

Source: BSC 2004 [DIRS 169565], Figure 6.3-56.

NOTE: The cases are: (1) intact-drift (nominal) case, (2) low-probability-seismic collapsed drift with high-Kth hostrock rubble, and (3) low-probability-seismic collapsed drift with low- $K_{\text {th }}$ rubble. The plotted variables are (a) waste package temperature, (b) invert temperature, (c) waste package relative humidity, (d) invert liquidphase saturation, and (e) matrix liquid-phase saturation of the rubble surrounding the drip shield.

Figure 6-163. Thermal-Hydrologic Variables for the "Hottest" Waste Package (21-PWR Absorber Plate Waste Package) at the P2WR5C10 Location in the Tptpll (tsw35) Unit for the Mean Infiltration Flux Case 


\subsubsection{Quasi-Static Drip Shield Loading from Rockfall}

\subsection{Introduction}

Two types of drip shield loading cases are examined:

- Dynamic impact loading due to rockfall resulting from the seismic event or simple gravity fall

- Quasi-static loading of the drip shield once rockfall has come to rest and the weight of the rock lies on the crown and sides of the drip shield.

Loading in the dynamic case is discussed in Section 6.4.2.2 for the case of lithophysal rock, and in Section 6.3.1.2 for nonlithophysal rock. Since the rock block size estimated in the nonlithophysal rock is substantially larger than that projected for the lithophysal units, it is considered that the estimates of impact energy from those calculations will provide an upper bound to the dynamic loading in lithophysal rocks. In lithophysal rocks, a potentially more important drip shield loading mechanism is from quasi-static load developed from the accumulated weight of rubble on the drip shield. Although the discussion here centers on the lithophysal units, the rock blocks resulting from failure in nonlithophysal rocks are expected to result in similar ultimate dead weight loading.

As the lithophysal rock mass fails, pre-existing and new fractures will break, forming block sizes of relatively small volume (estimated to be on the order of $\mathrm{cm}$ on a side). The falling rock blocks will come to rest on the invert of the tunnel and the drip shield. Because the fallen blocks do not perfectly fit together as they did in the in situ rock mass, there will be an overall increase in volume (termed "bulking"). Eventually, if the failure process continues, the tunnel will completely fill with bulked rock and will choke off further failure because the backpressure provided by the rubble will stabilize further yield.

To determine the ultimate load on the drip shield, it is necessary to estimate the amount of bulking that will take place, and the shape of the resulting failed excavation profile. These two factors define the height and density of the rock load that lies on the drip shield. The vertical weight of the accumulated rubble will rest on the drip shield roof, with load transferred to the invert via its vertical supports. Lateral loading, developed from the vertical weight of the rubble, as well as from passive loading in response to drip shield deformation, will also act on the sidewalls of the drip shield structure. The most conservative consideration of loading is that rock rubble acts as a fluid with the density of the bulked rock, and that the overlying height simply rests downward on the drip shield. The rubble is, in fact, a coarse, frictional and dilatant material that has shear strength, and is able to carry load itself. Therefore, realistic estimates of load need to account for the interaction of the rubble and the deformability of the drip shield itself. As the drip shield deforms during loading, an equilibrium state will be reached in which the rubble itself and the drip shield will share in load bearing. The load carried by the rubble and transmitted to the solid rock invert of the tunnel is termed "arching." Measurements of strain in cut-and-cover tunnels with thin-conduit arched liners have verified the significant effect of arching and the conservatism inherent in assumptions of full-column height, dead weight loading (e.g., Lefebvre et. al. 1976 [DIRS 168919]; Byrne et. al. 1990 [DIRS 168921]). 
In the following discussion the bulking of rock is discussed and a review of analytical and numerical methods for estimating the drip shield loading are described and compared. The preferred methodology for estimating the drip shield load is to use the same UDEC discontinuum numerical modeling method used previously to simulate the process of rock mass failure, rubble bulking, and interaction of the rubble and the deformable drip shield. In this fashion, the process is modeled naturally and assumptions regarding ultimate failed height and shape of the excavation are unnecessary, as they are when using analytical approaches. The purpose of this section is to provide estimates of the rock rubble loading to the drip shield. Calculations of the structural response of the drip shield to this loading is addressed in Structural Stability of a Drip Shield Under Quasi-Static Pressure.

\subsection{Bulking of the Rubble}

When the rock mass above underground openings collapses, it increases volume (i.e., it bulks). During the collapse, either sudden or gradual, rock mass disintegrates in a number of pieces (blocks), which fall separately rotating along the way. When blocks equilibrate after caving, they do not fit together, resulting in increased porosity and overall volume. Rock mass of volume $V$ in the in situ conditions has volume $V_{B}$ after caving, where:

$$
V_{B}=(1+B) V
$$

where $B$ is the bulking factor.

Amount of bulking (i.e., the bulking factor, $B$ ) depends on, among other things, the lithology, pre-existing internal structure (jointing, bedding), and the mechanism of collapse. For example, density of crushed limestone is in the range between $1360 \mathrm{~kg} / \mathrm{m}^{3}$ and $1440 \mathrm{~kg} / \mathrm{m}^{3}$, while density of the crushed dolomite is in the range between $1280 \mathrm{~kg} / \mathrm{m}^{3}$ and $1600 \mathrm{~kg} / \mathrm{m}^{3}$ (Fruchtbaum 1988 [DIRS 161774], Section 14). Considering that the specific gravity of limestones and dolomites is approximately 2.6 (Bauer et al. 1991 [DIRS 161775], Tables 10 and 11), and using an in situ porosity of 20 percent (Goodman 1980 [DIRS 101966], Section 2.3), the in situ density of limestones and dolomites is approximately $2200 \mathrm{~kg} / \mathrm{m}^{3}$. Consequently, bulking of these rocks from in situ state to a crushed state is between 37.5 and 72 percent. Duncan et al. (1980 [DIRS 161776], Table 5) reported that porosity of the rock fill for dams is between 23 and 36 percent. The rock fill used for dams is crushed to satisfy certain size requirements and is compacted during construction, which leads to reduction of its porosity. It appears from this discussion that bulking factor for the caved rock can be conservatively selected to be in the range between 0.2 and 0.4 .

Caving of the underground excavations is a self-limiting process in many situations. At a certain stage of caving, due to bulking, the volume of the caved rock completely fills the volume of the original excavation and the volume occupied by the collapsed rock before onset of collapse. When the cave is completely filled, the broken rock provides the backpressure, which prevents further collapse of the rock mass. 


\subsection{Estimation of Collapse Dimensions and Drift Profile}

Analytical Models of Collapse Height-Analytical methods consider that the cave above the emplacement drift grows until it becomes filled with the broken rock. The extent of the caved rock is calculated as a function of the bulking factor, $B$, considering that the cave stabilizes only when it is completely filled with the broken rock. In addition to the bulking factor, the shape of the cave must also be considered. In these analyses, neither the in situ stress conditions, nor the rock mass mechanical properties enter into the solution - the results are governed simply by the modeling considerations and kinematic solutions. Two extreme conditions illustrated in Figures 6-164 and 6-165 and were considered.

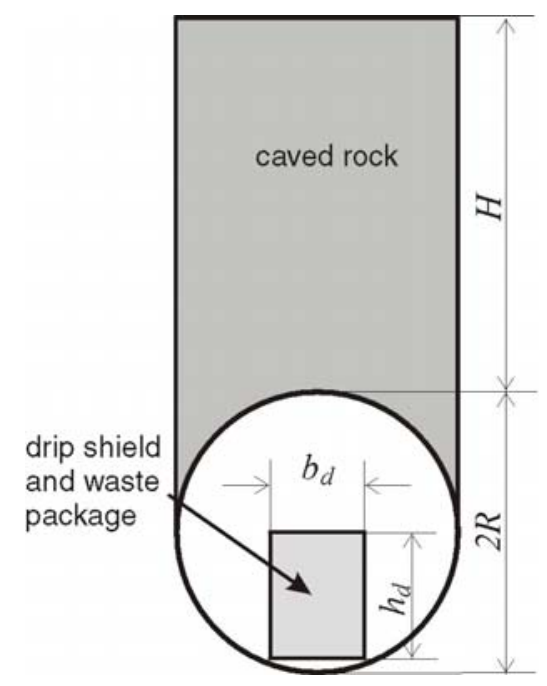

Figure 6-164. "Piping" Type of Caving Mechanism

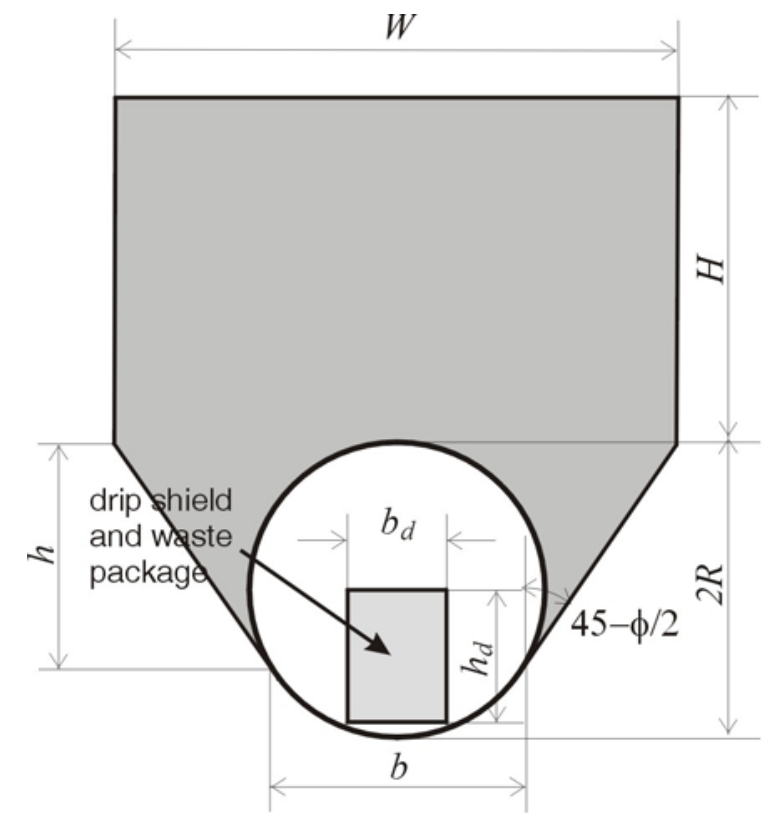

Figure 6-165. Terzaghi Type of Caving Mechanism 
The "piping" mode of roof collapse (shown in Figure 6-164) is typical for conditions when the rock mass is bedded and there is a relatively large ratio of the span of the excavation to its depth. This type of roof collapse is typical for coal mines (with bedded sediments as overburden) using the longwall mining method, and almost always occurs suddenly. Roof piping collapse is highly unlikely as a potential mode of drift collapse at the Yucca Mountain site for the following reasons:

- None of the rock mass units are layered

- Drifts are deep below the ground surface (i.e., the depth is $>>$ the diameter of the tunnels)

- Drift collapse due to strength decay will evolve gradually over a long period of time, rather than form as a sudden mechanism.

The piping mechanism is considered here as an unlikely and conservative extreme condition and is a mechanism that results in the largest vertical extent of the cave, $H$.

The other extreme condition of the rock mass collapse around the underground opening (shown in Figure 6-165) corresponds to the limit equilibrium conditions around a shallow tunnel, which Terzaghi (1943 [DIRS 162180]) used as a basis for calculation of the load on tunnel supports. Slip lines, related to plastic yield in the rock, extend from the drift walls at an angle of 45 degrees $-\phi / 2$ from the vertical direction, where $\phi$ is the friction angle.

The cave height, $H$, is calculated for both of these cases as a function of the bulking factor, $B$. The vertical pressure of the collapsed rock exerted on the drip shield is calculated considering that the rock filling the cave acts on the drip shield as a dead weight. Expressions for the height of the cave are shown in Equations 6-12 and 6-13 for the piping and Terzaghi failure mechanisms, respectively, which have been derived based on the consideration of the geometries shown in Figures 6-164 and 6-165:

$$
\begin{aligned}
\frac{H}{2 R} & =\frac{1}{2}\left[\frac{\pi}{2 B}-\frac{b_{d} h_{d}}{2 B R^{2}}-\left(1-\frac{\pi}{4}\right)\right] \\
\frac{H}{2 R} & =\frac{\frac{\pi}{B}-\frac{b_{d} h_{d}}{B R^{2}}-\frac{b+W}{2 R^{2}} h+\frac{V_{s}}{R^{2}}}{\frac{2 W}{R}}
\end{aligned}
$$

where

$$
\begin{aligned}
& \frac{b}{R}=2 \cos \left(\frac{\pi}{4}-\frac{\phi}{2}\right) \\
& \frac{h}{R}=1+\sin \left(\frac{\pi}{4}-\frac{\phi}{2}\right)
\end{aligned}
$$




$$
\begin{gathered}
\frac{W}{R}=2\left\{\cos \left(\frac{\pi}{4}-\frac{\phi}{2}\right)+\left[1+\sin \left(\frac{\pi}{4}-\frac{\phi}{2}\right)\right] \tan \left(\frac{\pi}{4}-\frac{\phi}{2}\right)\right\} \\
\frac{V_{s}}{R^{2}}=\frac{3 \pi}{4}-\frac{\phi}{2}+2 \cos \left(\frac{\pi}{4}-\frac{\phi}{2}\right) \sin \left(\frac{\pi}{4}-\frac{\phi}{2}\right)
\end{gathered}
$$

The predictions of the ultimate cave height are shown in Figure 6-166 for the range of bulking factors between 0.2 and 0.4. As expected, the cave height is larger in the case of the piping mechanism than in the case of the Terzaghi failure mechanism. The cave height varies (for the two cases considered and for the bulking factor in the range between 0.2 and 0.4 ) between approximately 1 and $2.5 \mathrm{drift}$ diameters.

The vertical pressure of the broken rock on the drip shield is calculated from the following equation, also derived based on the consideration of the geometries shown in Figures 6-164 and 6-165:

$$
p=(H+R-t) \frac{\rho g}{1+B}
$$

where $t$ is the height of the upper surface of the drip shield above the drift centerline. Calculated vertical pressure on the drip shield as a function of the bulking factor is shown in Figure 6-167.

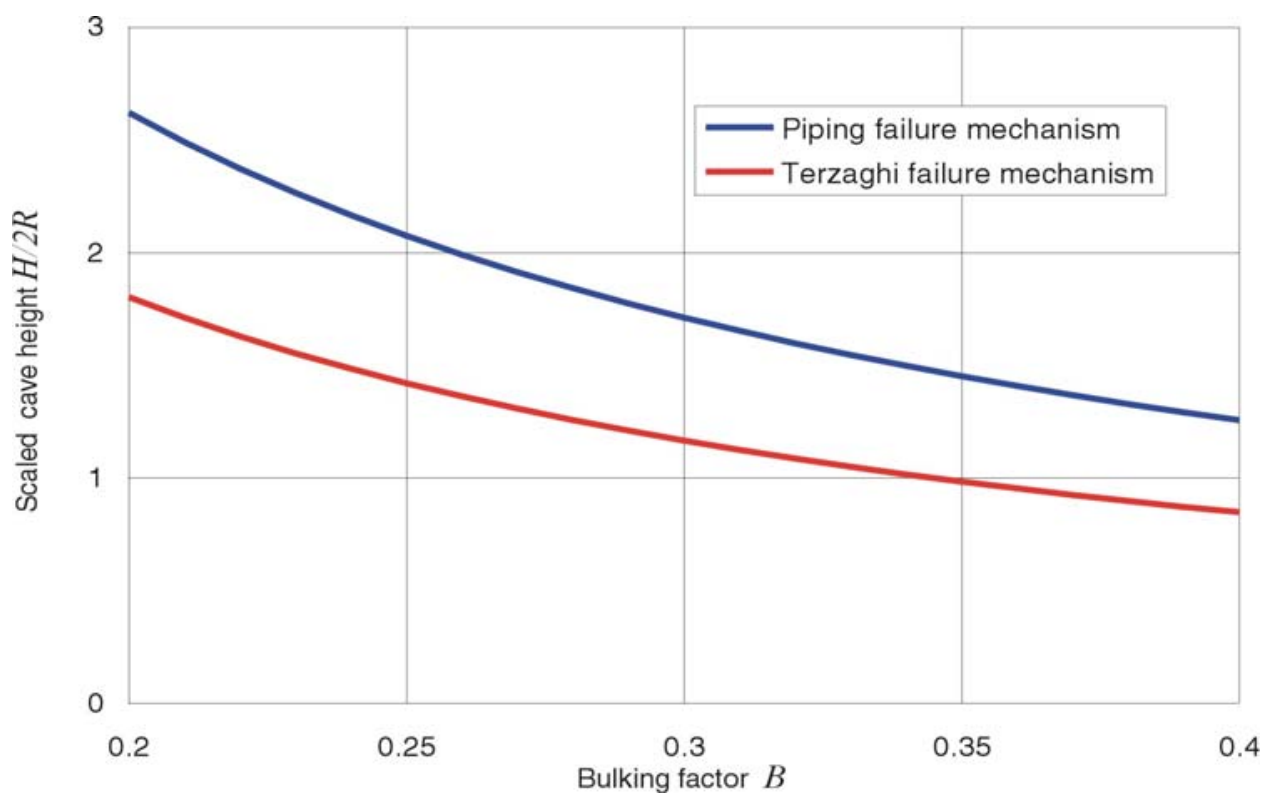

Figure 6-166. Cave Height as a Function of Bulking Factor: Analytical Solution 


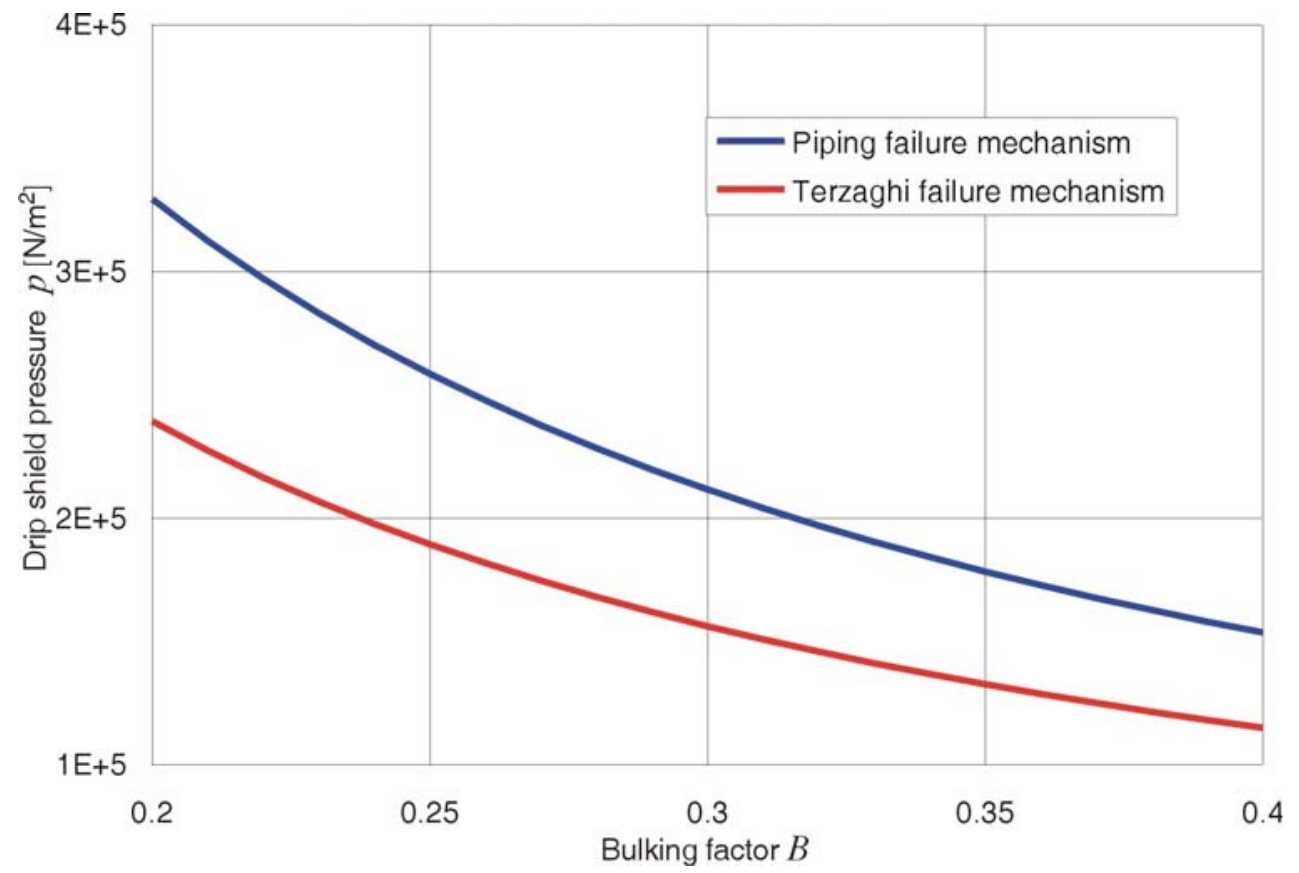

Figure 6-167. Vertical Load on the Drip Shield as a Function of Bulking Factor: Analytical Solutions

Numerical Continuum Approach-The analytical methods described previously in this section require an estimation of both the bulking factor and the ultimate shape of the collapsed zone that forms. A continuum-based numerical assessment of caving provides the next level of sophistication of analysis beyond analytical methods in that they take into account the rock mass strength properties and stress state while automatically estimating the ultimate cave shape. The bulking factor and friction angle of the caved rock must still be considered in this analysis, although the potential effect of stress arching within the broken rock is accounted for in determination of the ultimate load of the broken rock resting on the drip shield. A simplistic methodology was used in implementing caving into the numerical model. A model of the drift in a Mohr-Coulomb rock mass was developed using the FLAC continuum numerical code. "Roller" boundary conditions were used on the vertical and the bottom model boundaries. A stress boundary condition was applied on the top model boundary. The model uses symmetry conditions along the vertical plane through the drift center. The model width was set equal to 10 drift radii. The total model height is either 16 or 25 drift radii, depending on vertical extent of the zone of the caved rock mass. The model bottom boundary is 4.8 radii below the drift center.

The estimated strength of the lithophysal rock mass was used initially for solution of the equilibrium state under in situ stress conditions (strength properties are from Table E-10, Category 1, with a friction angle of 40 degrees). After initial equilibrium, the cohesion and tensile strength of the rock mass were reduced gradually, in steps, to induce collapse and formation of the caved zone. In this case, the bulking factor is estimated, but the model is allowed to achieve the cave shape and dimension dictated by the rock mass properties and stress conditions. At each stage of strength reduction, the model was run until either equilibrium was achieved, or there was clear indication that equilibrium could not be achieved (i.e., the rock mass around the drift was collapsing as evidenced by continued deformation). 
The onset of collapse was detected by monitoring the deformations of the excavation (an example is shown in Figure 6-168). When collapse is detected, the model simulation is interrupted, and the cave height calculated based on the estimated bulking factor and the volume of the rock mass within the destabilized region. The accumulation of rubble is represented by filling the previously empty drift and the caved region with elements with the estimated properties of caved rock. The properties of the caved rock were selected to have no cohesion or tensile strength, and its density accounting for the bulking factor. The simulation is then continued, allowing excavation collapse to progress. Equilibrium will eventually be achieved when the caved rock elements provide a back-pressure to the excavation surface sufficient to prevent further yielding. The ultimate vertical pressures induced by the caved rock can be extracted from the model at the drip shield location. As was the case with the analytical solutions, the numerical model can be used to examine loads from two limiting mechanisms:

- A piping mechanism (shown in Figure 6-169, where the caved region is assigned zero cohesion), in which the cave width was limited to the drift width

- A Terzaghi mechanism (shown in Figure 6-170), in which cave width coincides with the width of the destabilized region of the rock mass.

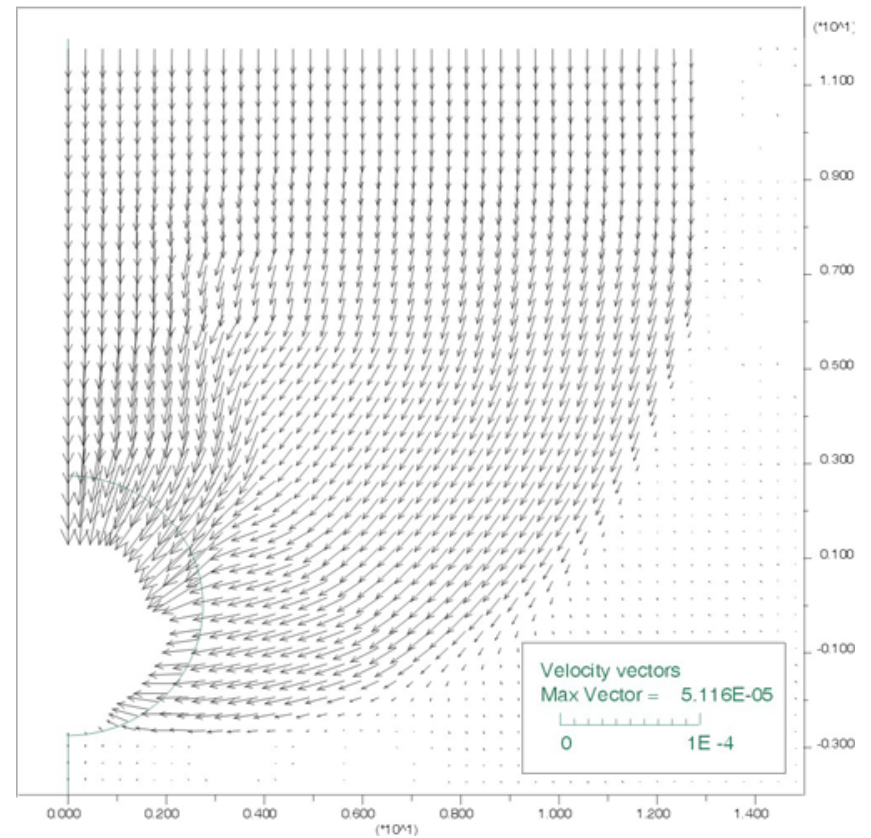

Figure 6-168. Failure Mechanism of a Deep Tunnel in Cohesionless, Mohr-Coulomb Material as Predicted by the FLAC Continuum Model 


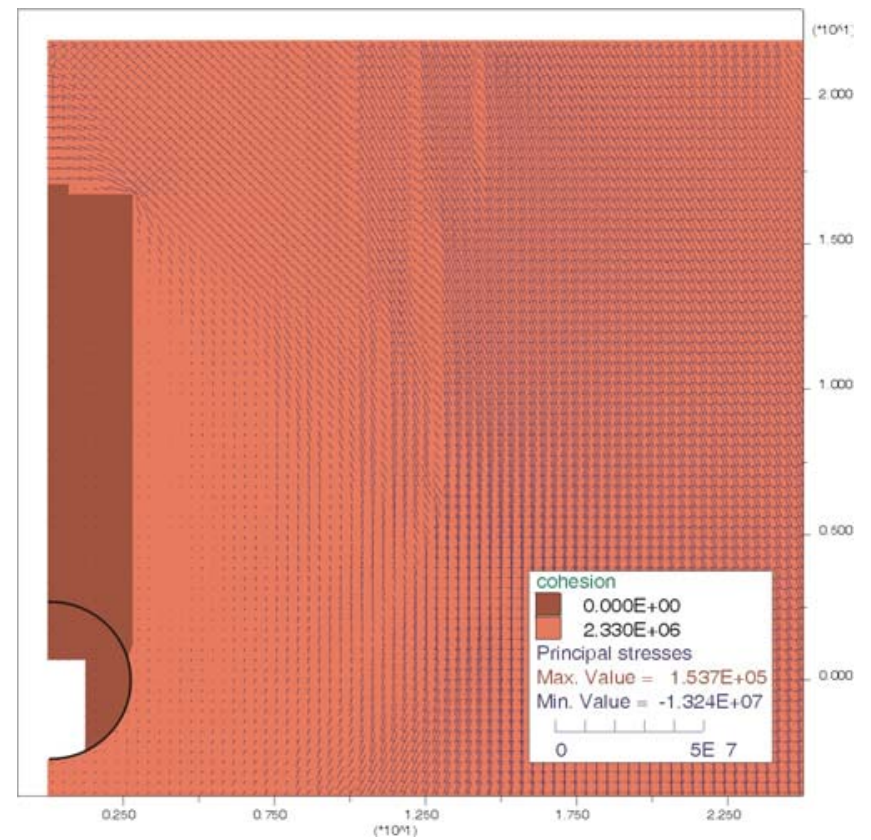

Figure 6-169. Piping Failure Mechanism Represented in the in the FLAC Continuum Model: Bulking Factor $B=0.2$

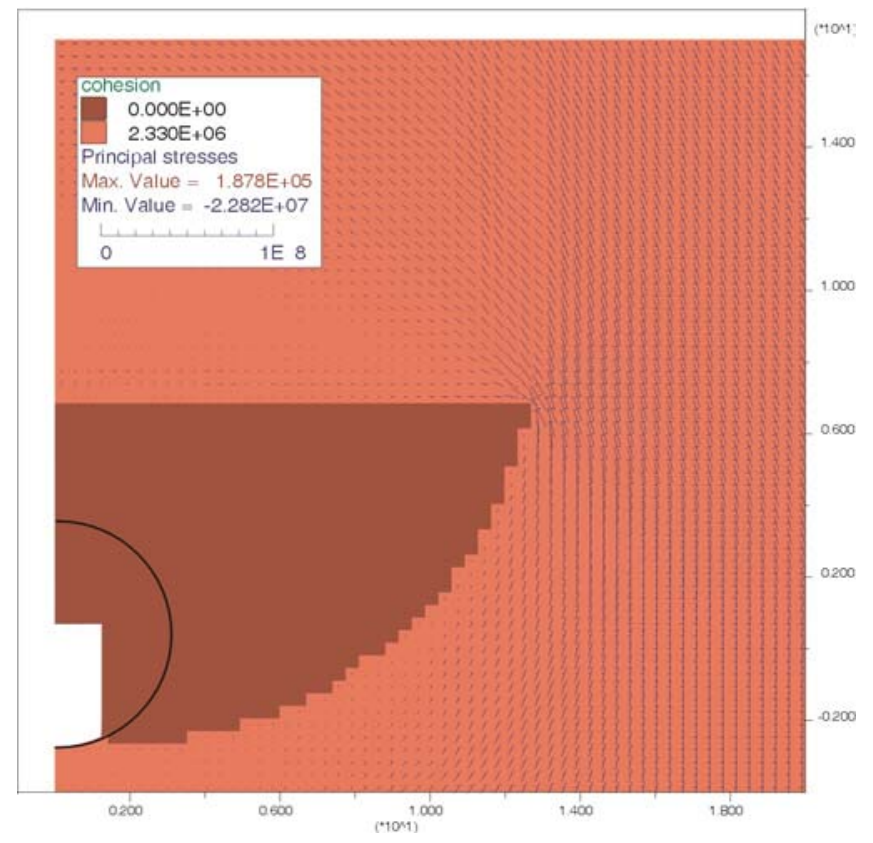

Figure 6-170. Terzaghi Failure Mechanism Represented in the FLAC Continuum Model: Bulking Factor $B=0.1$ 
Subsequently, the drift and the caved region were filled with zones (caved rock selected to have no cohesion or tensile strength, and density accounting for the bulking), and the model was run to the equilibrium to determine the load on the drip shield.

Clearly, the failure mechanism shown in Figure 6-168 is not a realistic mechanism of the drift collapse at Yucca Mountain. This mechanism is more typical for the shallow tunnels in a soil-like media where shearing is the predominant mechanism of inelastic deformation. For emplacement drifts, collapse of the rock mass from the roof will occur much before the deep-seated shear failure in the walls can be mobilized.

Results of the continuum analysis of rock pressure on the drip shield as a function of the bulking factor and different failure mechanism types are summarized in Table 6-47.

Table 6-47. Summary of Pressures on the Drip Shield Calculated from the Continuum Model

\begin{tabular}{|c|c|c|c|c|c|}
\hline \multirow[b]{2}{*}{ Case } & \multirow{2}{*}{$\begin{array}{l}\text { Property } \\
\text { Category }\end{array}$} & \multirow[b]{2}{*}{ Failure Type } & \multirow[b]{2}{*}{ Bulking } & \multicolumn{2}{|c|}{ Pressure $\left(\mathrm{kN} / \mathrm{m}^{2}\right)$} \\
\hline & & & & Top of Drip Shield & Side of Drip Shield \\
\hline 1 & 1 & Terzaghi & 0.1 & 269.2 & 47.1 \\
\hline 2 & 1 & pipe & 0.1 & 403.3 & 39.6 \\
\hline 3 & 1 & Terzaghi & 0.2 & 203.6 & 27.3 \\
\hline 4 & 1 & pipe & 0.2 & 295.6 & 28.3 \\
\hline 5 & 1 & Terzaghi & 0.4 & 117.9 & 20.1 \\
\hline 6 & 1 & pipe & 0.4 & 161.6 & 17.8 \\
\hline
\end{tabular}

Source: DTN: MO0408MWDDDMIO.002, file FLAC drip shield pressures.xls.

Numerical Discontinuum Approach-The analytical and continuum modeling representations of the collapse zone and drip shield loading discussed previously are considered to be overly conservative in the predictions of the resulting cavity size and transfer of the load through the caved rock. Consequently, predicted loads on the drip shield are quite large. The conservatism arises due to the considerations inherent in these methods. To attempt to achieve more realistic rubble loading of the drip shield, the problem was solved using the UDEC two-dimensional discontinuum numerical code. As in Section 6.4.1, the rock mass was represented as an assembly of polygonal blocks of random shape, but with a defined average dimension. The size and the shape of the blocks were the same as used in the previous stability analyses, and were chosen to be approximately the size expected to form during yielding of the Tptpll-within the range of approximately 0.2 to $0.3 \mathrm{~m}$. The blocks are much smaller than the diameter of the drift, and therefore do not affect the collapse mode of the drift or its ultimate shape. The same rock mass material model as used in Section 6.4.1, which was calibrated to strength categories 1 to 5 of the rock mass (associated micro properties are shown in Tables 6-42 and 6-43), is used in these analyses of drift collapse.

The simulations are initiated at the in situ stress equilibrium state for a given rock mass strength value. Since the goal of these studies is to understand the maximum ultimate shape of the cavity and associated rubble load, the tunnel is forced to collapse in the numerical model. To force collapse of the tunnel, shear (cohesion) and tensile strength of the rock mass were subsequently reduced in a series of five increments, each equal to 20 percent of the initial strength. For each step of strength reduction, the model was run to equilibrium, allowing development of shear or tensile fractures in the rock mass and subsequent loosening, detachment, and gravity-fall of 
blocks. At the end of the simulation, when cohesion and tensile strength were completely reduced to zero, the model provides an estimate of the maximum extent of the collapsed rock mass, the maximum pressures on the drip shield, and the ultimate shape of the collapse drift. An example of the evolution of rockfall and the cave size for as a function of strength degradation is shown in Figure 6-171. The model shows that in this case (lithophysal rock mass Category 1 and rectangular, rigid, drip shield) the emplacement drift begins significant degradation after about 50 percent reduction in the cohesive strength of the rock mass. ${ }^{1}$ The drift is completely filled with caved rock after 80 percent degradation of the cohesive rock strength for the poorest rock quality case shown here (Figure 6-171). In the analyses shown here, complete collapse of the drifts was forced. The amount of strength degradation required to produce collapse (e.g., 80 percent) depends on the initial strength level. For example, in the case of rock mass Category 5 (not shown), which has an unconfined compressive strength of $30 \mathrm{MPa}$ (or three times more than the uniaxial compressive strength for Category 1), there will be some rockfall from the walls, but the drifts will generally remain open even after 80 percent strength degradation.

This modeling approach differs from the analytical and continuum-based methods in that the bulking of the caved rock is not a model parameter but is a result of the modeling. The bulking in reality depends on the size and the shape of the falling blocks, which are predetermined by the size and the shape of the randomly shaped blocks in the model. An average block dimension of $0.2 \mathrm{~m}$ was selected for two reasons:

- This dimension is consistent with the spacing of fractures in the Tptpll, and represents a reasonable estimate of the expected block dimensions on failure

- The use of $0.2 \mathrm{~m}$ blocks results in bulking factors of approximately 16 to 17 percent which is on the low end of observed field bulking factors in rock and is therefore considered to yield a conservative result of both cave height and drip shield load.

Six realizations of different random block geometries with average dimension of $0.2 \mathrm{~m}$ were run to achieve complete collapse. In each case, a deformable drip shield was considered in which the contacts of the footings to the invert were free to slide (frictional) or to separate from the invert as the forces dictate (for details of the drip shield formulation and verification, see Appendix Y). The drip shield is considered to be elastic with stiffness calibrated to be equivalent to the deformability of the three-dimensional frame structure as derived from the LS-DYNA finite element model ${ }^{2}$ (Appendix V). The drip shield is represented by 30 elements starting at element number 1 at the right hand footing, and numbered counterclockwise to the left side footing. Figure 6-172 shows an example of the final collapsed shape of the tunnel and the rubble lying on

\footnotetext{
${ }^{1}$ This agrees, in general, with the predictions of little time-dependent collapse in the previous section. The static fatigue data does not indicate that a reduction in strength of the rock mass of 50 percent occurs in the regulatory period.

${ }^{2}$ The purpose of the two-dimensional UDEC analyses is to determine rubble loading to the drip shield, but not to perform a structural analysis of the drip shield itself. The loads are fed to a detailed three-dimensional structural analysis of the drip shield described in a separate calculation. However, it is important to account for the deformability of the drip shield in determination of the interaction of the rubble and the structure and the subsequent loads that develop. Therefore, the two-dimensional UDEC model of the drip shield was calibrated to provide the proper equivalent stiffness and deformability through comparison to a series of simple loading problems from LS-DYNA as described in Appendix Y.
} 
the drip shield. Figure 6-173 provides contours of displacement of the rock mass and rubble to illustrate the ultimate collapse height of the tunnel. As seen, the height of collapse is approximately $6 \mathrm{~m}$ or slightly more than 1 diameter above the roof of the drip shield. The bulking factor of the rubble is approximately 19 percent in this case (see Appendix $\mathrm{V}$ for discussion of calculation of bulking factors from model results). The resultant pressure on each element at quasi-static equilibrium for each element for the six realizations, along with the average for the realizations, is given in Figure 6-174. As seen in this plot the average loads on the right- and left-hand sides are approximately the same, while the average pressure on the top of the drip shield is about 50 percent higher.

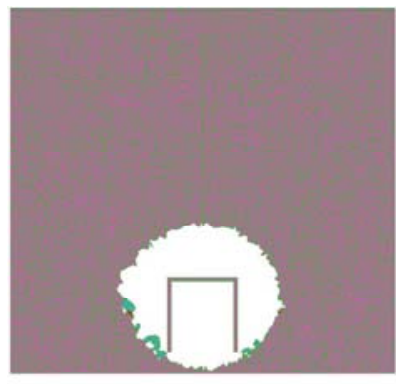

a) $100 \%$ cohesive strength

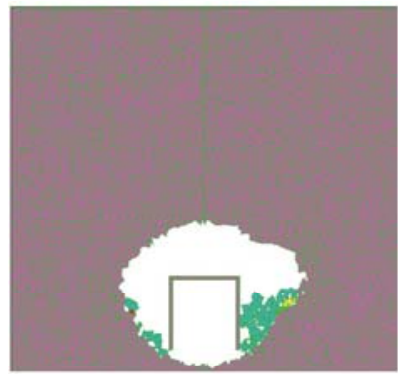

b) $80 \%$ cohesive strength

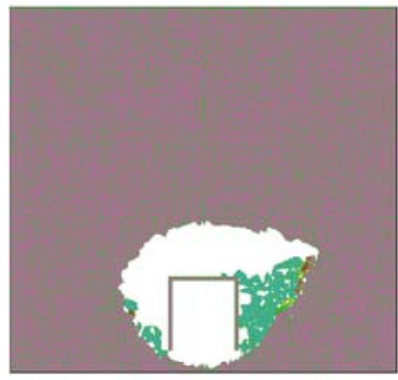

c) $60 \%$ cohesive strength

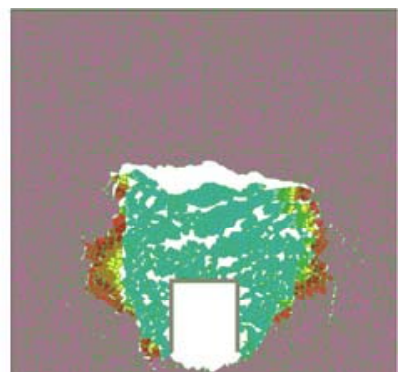

d) $40 \%$ cohesive strength

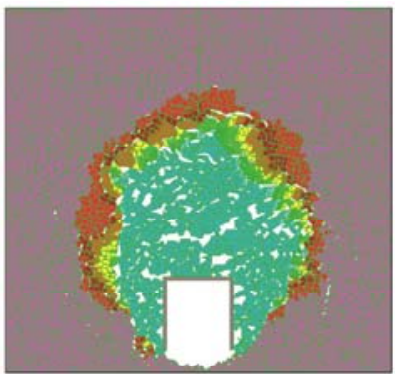

e) $20 \%$ cohesive strength

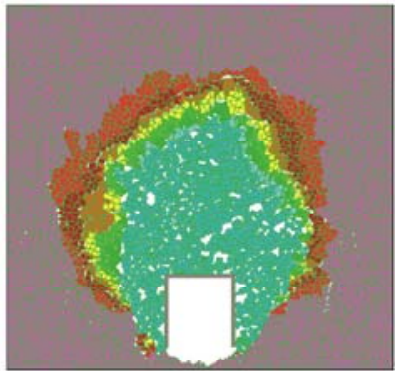

f) $0 \%$ cohesive strength

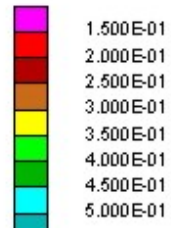

NOTE: Displacement contours are given to assist in visualizing the collapsed area vs. the surrounding undisturbed rock mass. Displacement scale is in meters. Other strength categories will require larger percent strength reduction to produce similar profiles, although the ultimate caved profile will be similar.

Figure 6-171. Evolution of the Cave as a Function of the Cohesive Strength, Category 1 Rock Mass Strength 


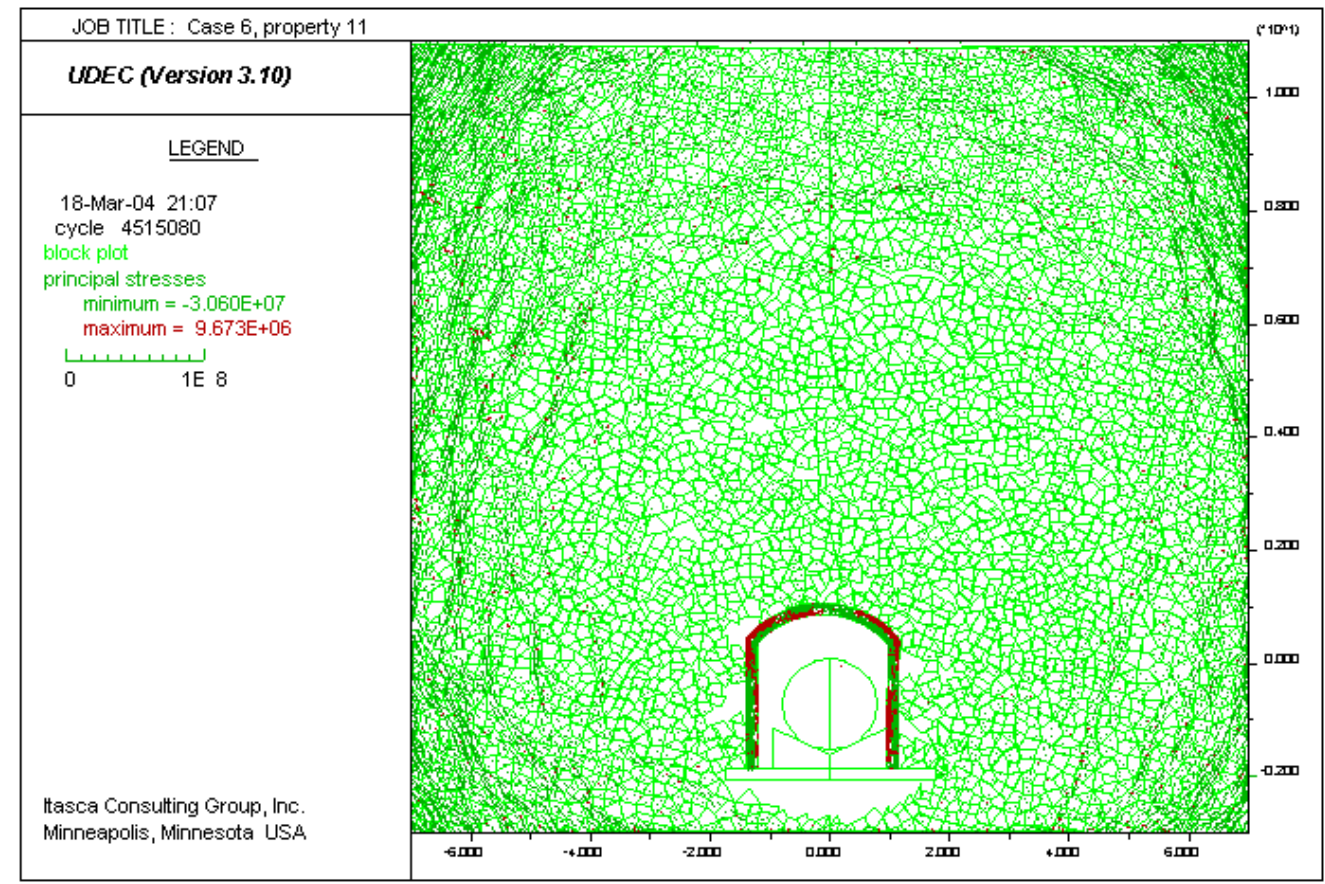

Figure 6-172. Realization 1 for Quasi-static Drift Degradation, Rock Mass Category 1, 0.2 m Block Size: Equilibrium State for Deformable Drip Shield

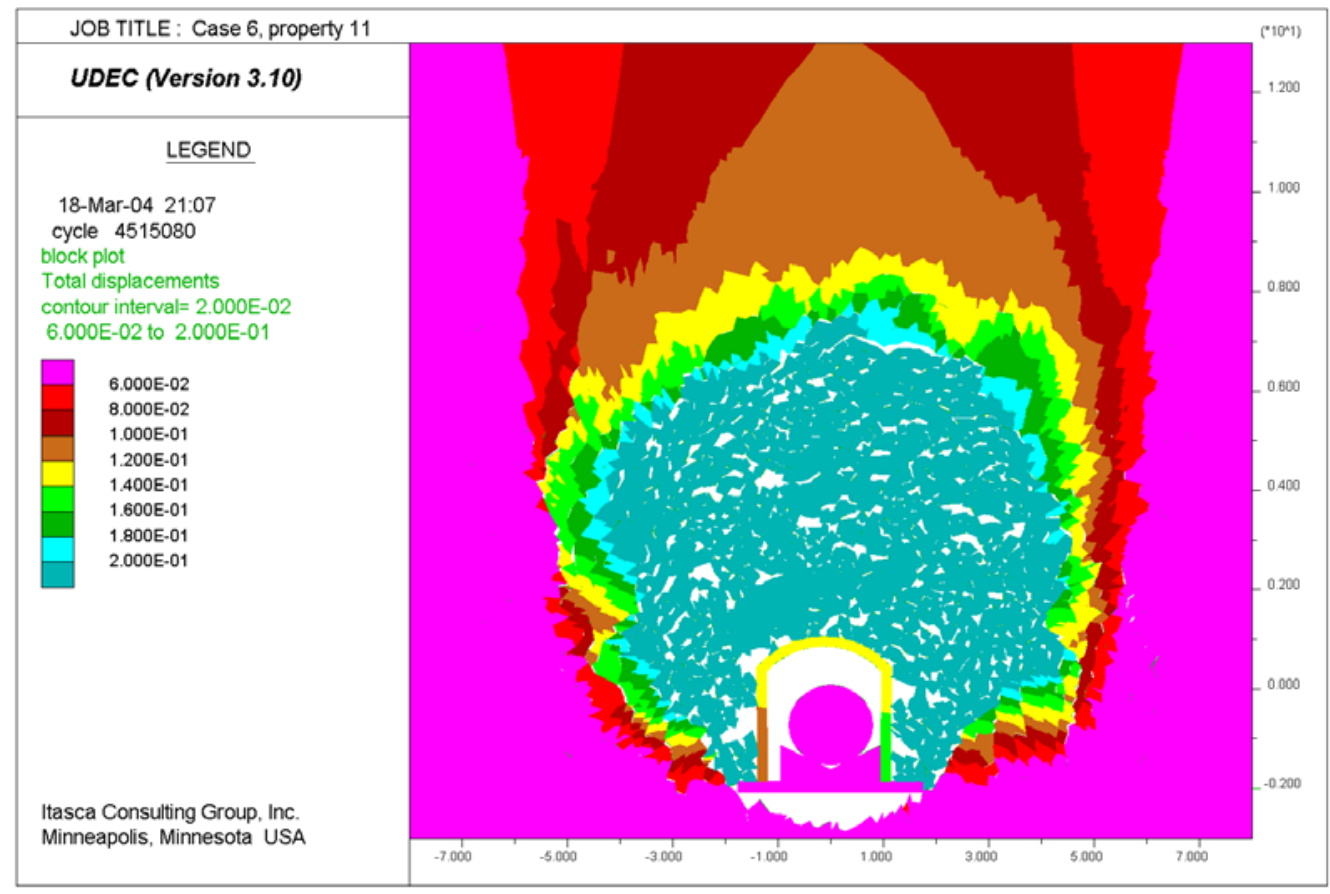

Figure 6-173. Quasi-static Drift Degradation, Rock Mass Category 1, $0.2 \mathrm{~m}$ Block Size: Contours of Displacement $(m)$ Magnitude for Deformable Drip Shield Showing Approximate Collapse Height of $7 \mathrm{~m}$ (about $6 \mathrm{~m}$ above top of drip shield crown) 


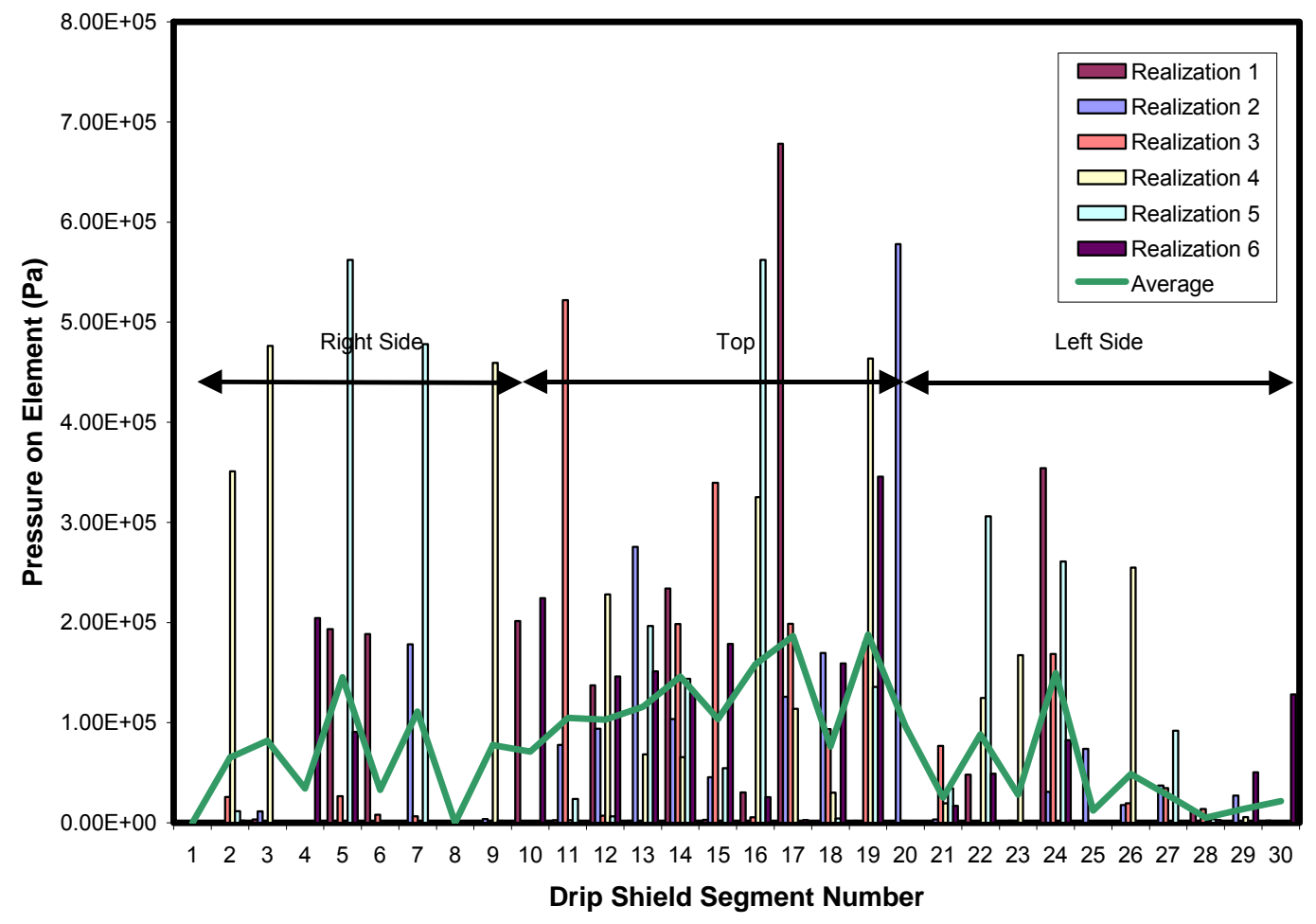

NOTE: Average pressure on each segment is shown for the six realizations plus average for the six realizations combined. Segment numbering starts at 1 at right side footing and continues counterclockwise to the left footing. Those elements on the right, top, and left sides of the drip shield are shown in the figure. This data provided in output DTN: MO0407MWDDSLCR.000 (file final drip shield quasi-static pressures.xIs).

Figure 6-174. Quasi-static Pressure on Drip Shield Segments for Six Realizations for Random, $0.2 \mathrm{~m}$ Block Geometries

The effect of point-loads on the drip shield by rock blocks can be seen in Figure 6-174. Occasional, isolated point loads (as well as locations where the segment is not in contact with rock blocks) occur that may be several times larger than neighboring segments. The average pressure on the crown of the drip shield is approximately $0.15 \mathrm{MPa}$, with a peak pressure on the crown at about 0.7 MPa. The pressure distributions given in Figure 6-174 are used as direct feeds to a sensitivity analysis of quasi-static structural analysis of the drip shield as described in Structural Stability of a Drip Shield Under Quasi-Static Pressure. These analyses are considered to be base case conditions for drip shield load.

An examination of the ultimate load-bearing capacity of the drip shield is provided in Structural Stability of a Drip Shield Under Quasi-Static Pressure. That analysis requires that increased levels of load be applied to the drip shield until a failure mechanism develops. The UDEC model was used to define increasing rubble pressures applied to the drip shield as input to this analysis. Larger gravitational rubble pressures were simulated in the model by increasing the density of the rock particles that comprise the rubble, and allowing the model to come to equilibrium while the increased rubble pressures on the drip shield are monitored. This method allows simulation of the effect of increased vertical pressure on the drip shield (due to larger heights of the caved zone) while also estimating the associated effect of increased vertical 
pressure on the lateral loads. The result of these calculations, considering rock rubble density increases of 1.5, 2, 2.5, 3 and 4 times is shown in Figure 6-175. This plot shows the pressure distribution around the drip shield, as averaged from six realizations at each level of density, along with the base case given in Figure 6-174. The increase in average vertical pressure across the top of the drip shield can be roughly related to an equivalent height of failed rock.

Drip Shield Loading for Base Case Loading and for Increased Density of Rubble

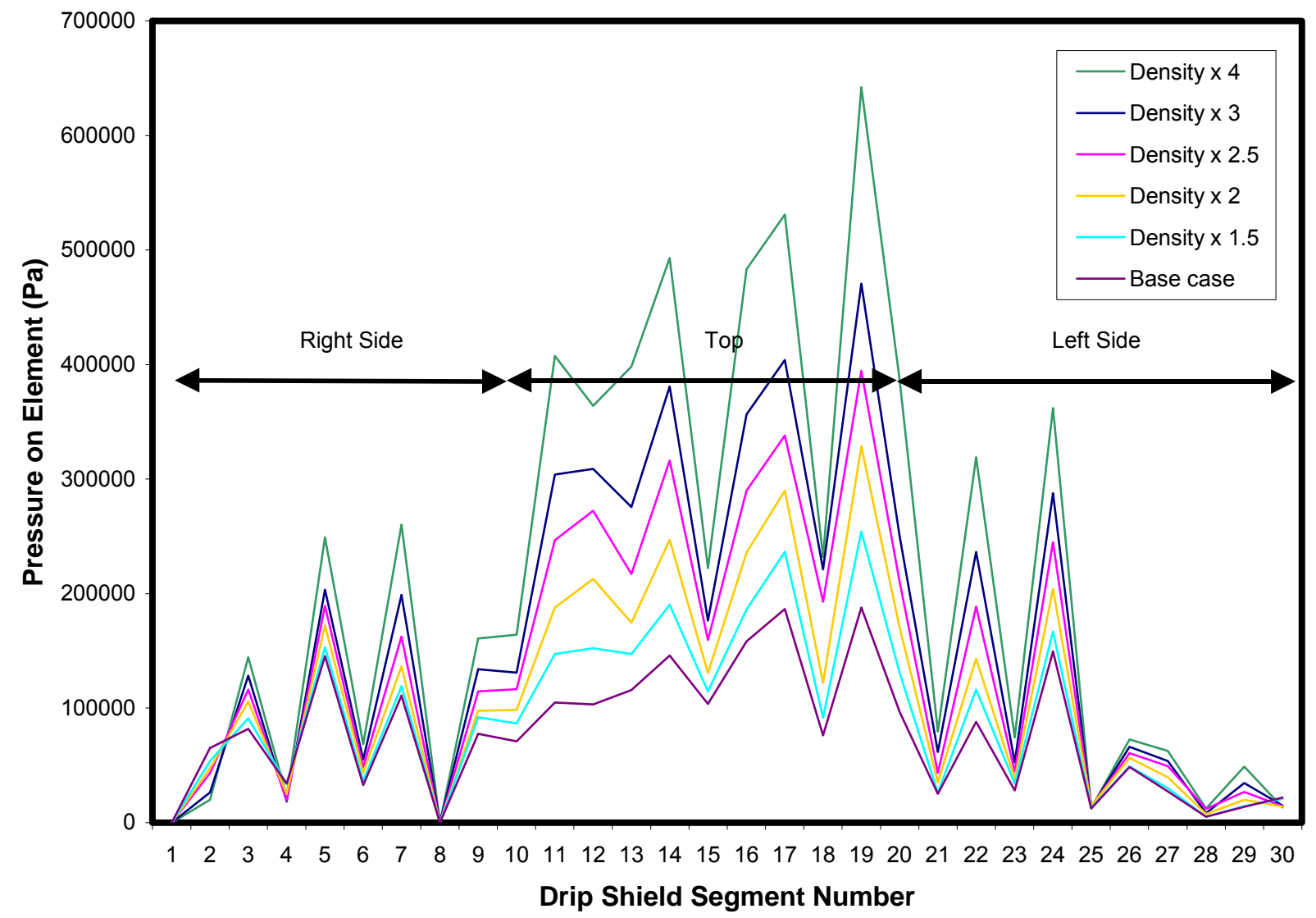

NOTE: Each curve represents the averaging of 6 realizations of rubble distribution. This data provided in output DTN: MO0407MWDDSLCR.000 (file drip shield quasi-static pressures fs 4.xIs).

Figure 6-175. Drip Shield Pressures for Base Case and for Consideration of Increase in the Density of the Rubble

Effect of Seismic Ground Shaking on Bulking Factor and Stress Arching in Rubble from Previously-Collapsed Drift-Vibratory shaking may cause settlement (irreversible deformation) of granular materials due to packing of grains. This phenomenon is the primary reason for liquefaction of water saturated granular media during seismic shaking. Seismic events occurring after potential collapse of the emplacement drifts may cause additional compaction of the caved rock inside the drift and, consequently, could reduce the positive arching effect within the rubble and increase the load of the caved rock mass on the drip shield. To investigate this effect, the state of the model of the emplacement drift degradation after total collapse of the drift (with rigid, rectangular drip shield) is subjected to shaking by the ground motion with $1 \times 10^{-4}$ 
probability of annual recurrence (10,000 year ground motion). ${ }^{3}$ A rigid drip shield was considered in this simulation as it will conservatively overestimate stress transfer to the drip shield when additional compaction of the fill occurs.

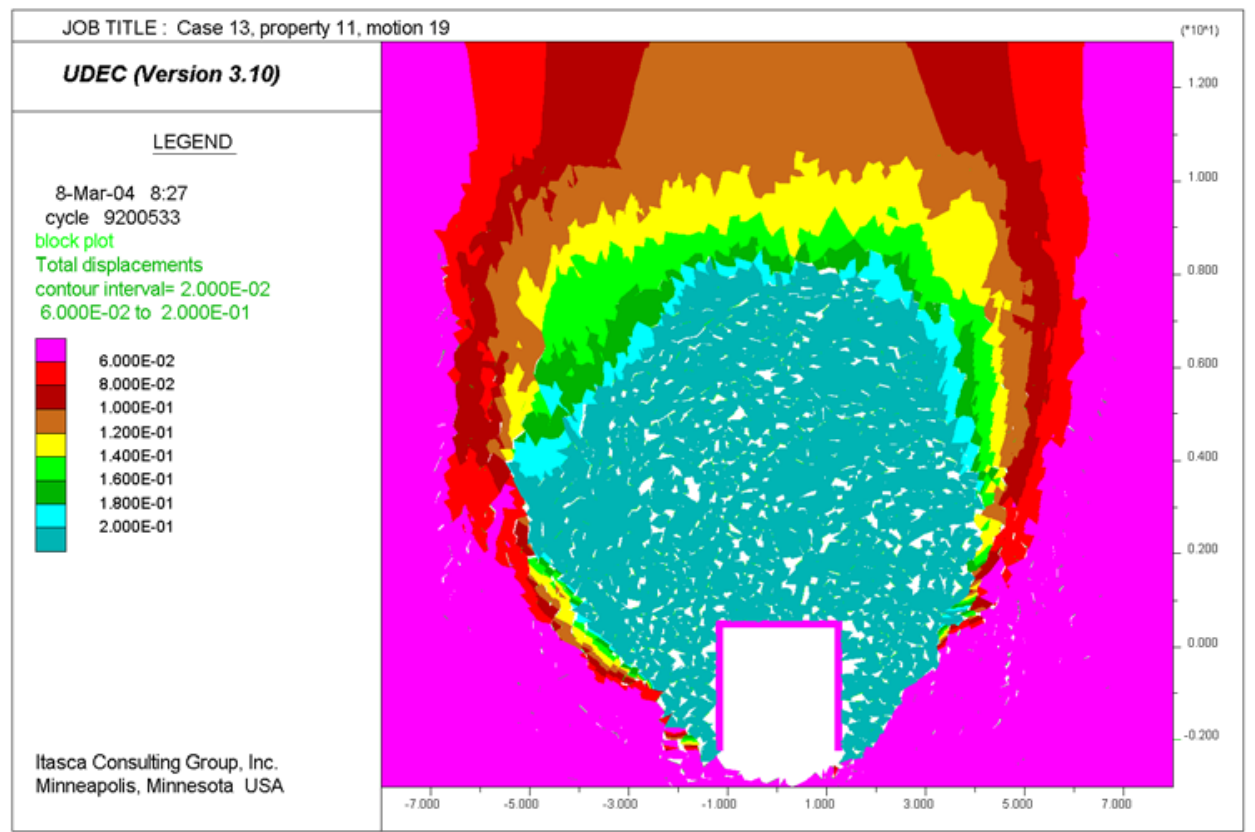

Figure 6-176. Contours of Displacement Magnitudes (M) for Previously Collapsed Drift After Subsequent Shaking by Ground Motions With $1 \times 10^{-4}$ Probability Of Annual Recurrence

The state of the model and the load of the caved rock mass on the drip shield before and after ground shaking are compared. The contours of displacement magnitudes (relative to the displacement of the model base, which is not zero at the end of the simulation) after the shaking of the model are shown in Figure 6-176. It can be concluded, comparing Figures 6-171f and 6-176, that the size and the shape of the region of the caved rock do not change significantly after dynamic load. Such a result is expected since the 10,000-year ground motion does not cause significant damage of an open drift, and the rubble provides a stabilizing support to the interior of the cave. Therefore, little additional rock mass damage takes place when the drift is already filled with broken rock. The plot of the stress tensor field in the caved blocks around the drip shield before and after ground shaking shows the stress arching formed within the caved rock and the effect of shaking on the stress transmission in the rubble (Figure 6-177). The model indicates that this level of ground shaking does affect arching to some extent.

Observations from the plot of stress arching in the caved rock mass are confirmed in Figure 6-178 and Table 6-48. There is significant increase in the load on the right side of the drip shield as rock blocks come into point contact with the drip shield. In this case, since the drip shield is rigid and footings rigidly attached to the invert, no sliding occurs to more equally distribute loads on opposing sides of the drip shield. However, the increase in the load on the top of the drip shield is relatively small-less than 10 percent. There is practically no change in the bulking factor, because shaking does not create any additional collapse.

\footnotetext{
${ }^{3}$ Only one ground motion was supplied for the $1 \times 10^{-4}$ annual recurrence level.
} 


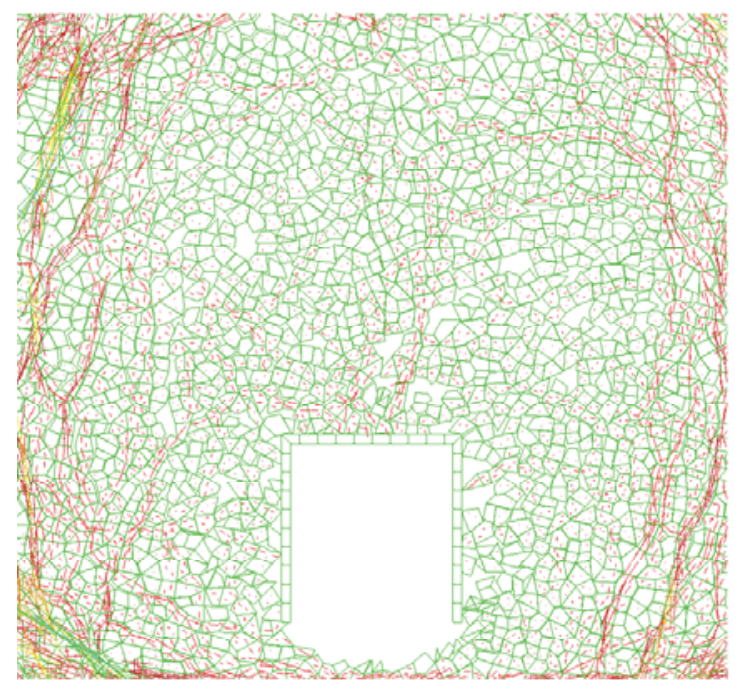

a) before shaking
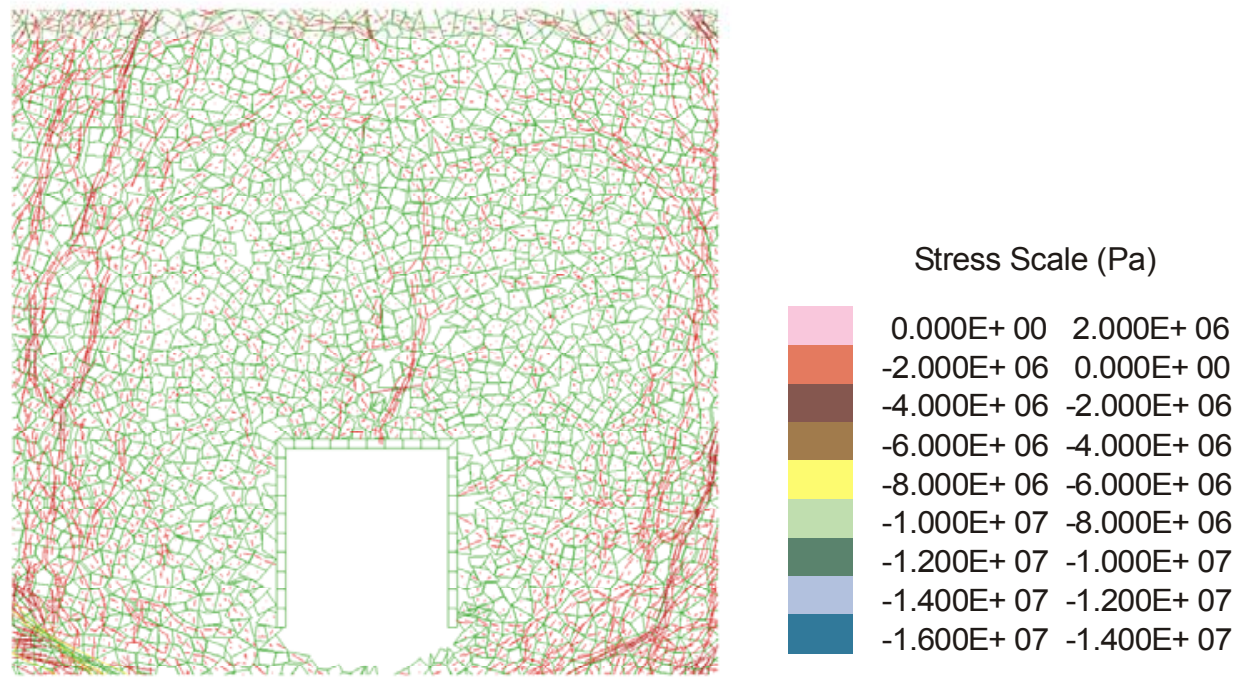

b) after shaking

NOTE: Stress arching is shown by the stress tensor field colored by the magnitudes of the major principal stress. Somewhat greater stress transfer to the drip shield is shown after shaking.

Figure 6-177. Stress Arching (stress tensor field colored by the magnitudes of the major principal stress) Before and After Shaking, Showing Somewhat Greater Stress Transfer to the Drip Shield 


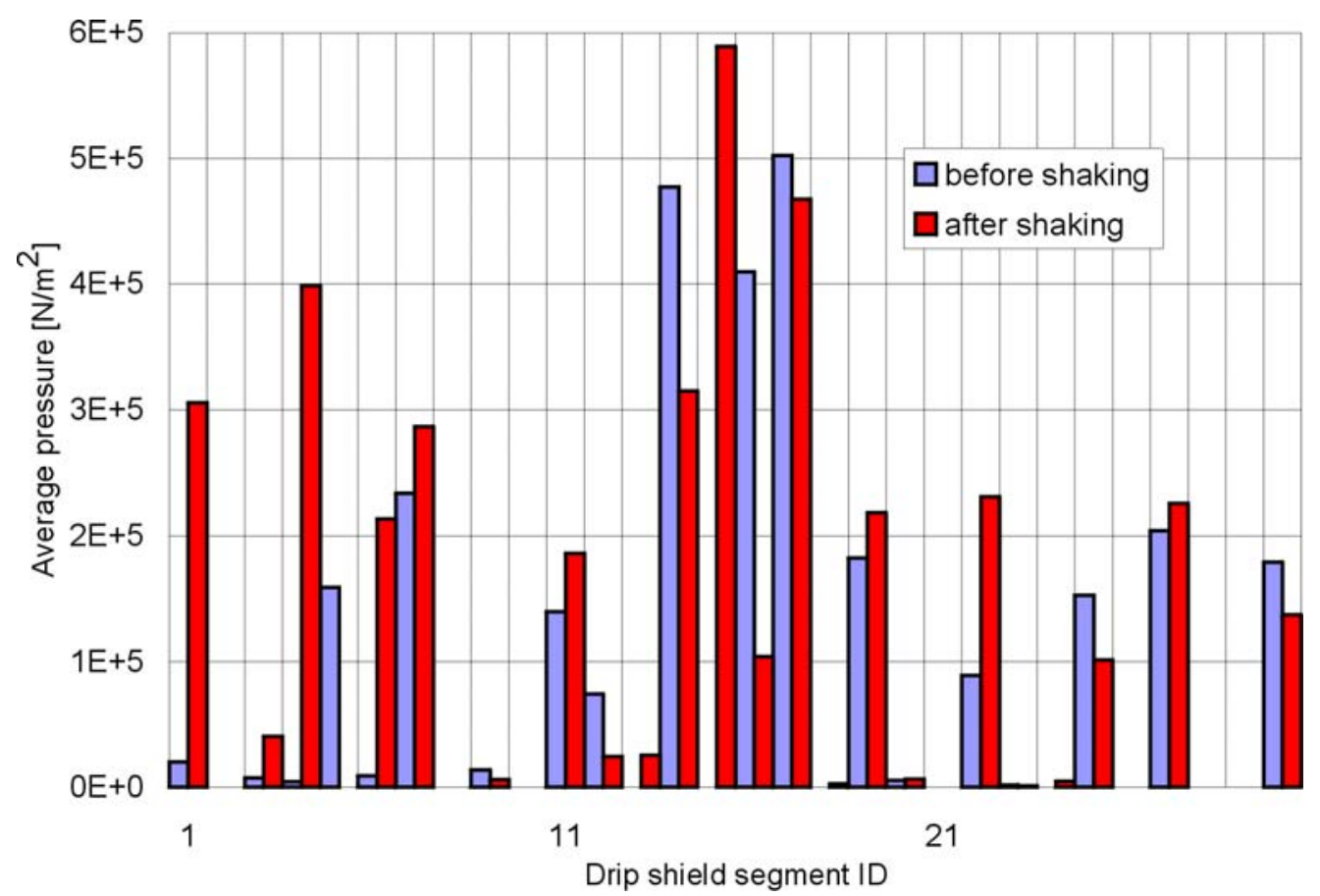

NOTE: Outside outline of the drip shield is divided into 30 segments (10 per height and 10 per width), which are numbered from 1 to 30 starting from lower right end in the counter-clockwise direction.

Figure 6-178. Pressures on the Rigid, Rectangular Drip Shield After Shaking by the Seismic Event With $1 \times 10^{-4}$ Probability of Annual Recurrence

Table 6-48. Effect of Seismic Shaking on Load of Caved Rock on the Rigid, Rectangular Drip Shield

\begin{tabular}{|c|c|c|c|c|}
\hline \multirow{2}{*}{$\begin{array}{l}\text { Loading } \\
\text { Condition }\end{array}$} & \multicolumn{3}{|c|}{ Pressure $\left(\mathrm{kN} / \mathrm{m}^{2}\right)$} & \multirow[b]{2}{*}{ Bulking Factor } \\
\hline & Left Side & Top & Right Side & \\
\hline before shaking & 62.6 & 179.2 & 44.8 & 0.19 \\
\hline after shaking & 70.2 & 193.9 & 125.1 & 0.21 \\
\hline
\end{tabular}

Summary of Quasi-static Loading of the Drip Shield-The predictions of the average vertical pressure of the caved rock on the drip shield by the three modeling approaches are summarized in Figure 6-179. As expected, the analytical models yield the largest loads due to the conservative considerations of dead weight on the drip shield and no stress arching in the rubble. The continuum numerical model accounts more accurately for transfer of load by friction from the caved rock to the surrounding stable rock mass. Consequently, predicted loads for small bulking factors and large cavity size are much smaller than analytical predictions. When the bulking factor is large, the height of the cave becomes small. Stress arching cannot be realized within the small column of the caved rock and, consequently, prediction between analytical and continuum models are identical. The most accurate approach, using the discontinuum model, does not use an imposed condition about the shape of the caved region or the bulking factor of the rubble. It also correctly accounts for load transfer through the caved rock. The predictions of the pressures on the drip shield using this approach are smaller than the predictions of the analytical and continuum models for the values of the bulking factor. The non-uniform and averaged quasi-static drip shield pressure distribution, illustrated in Figure 6-174, as well as the 
increased pressures for estimation of the ultimate load bearing capacity of the drip shield are used as a direct feed to the structural analysis of the drip shield as provided in Structural Stability of a Drip Shield Under Quasi-Static Pressure. Further compaction of the rubble during subsequent seismic events may result in re-adjustment of point loads to the lining, but does not appear to result in reduction in bulking factor of the rubble material.

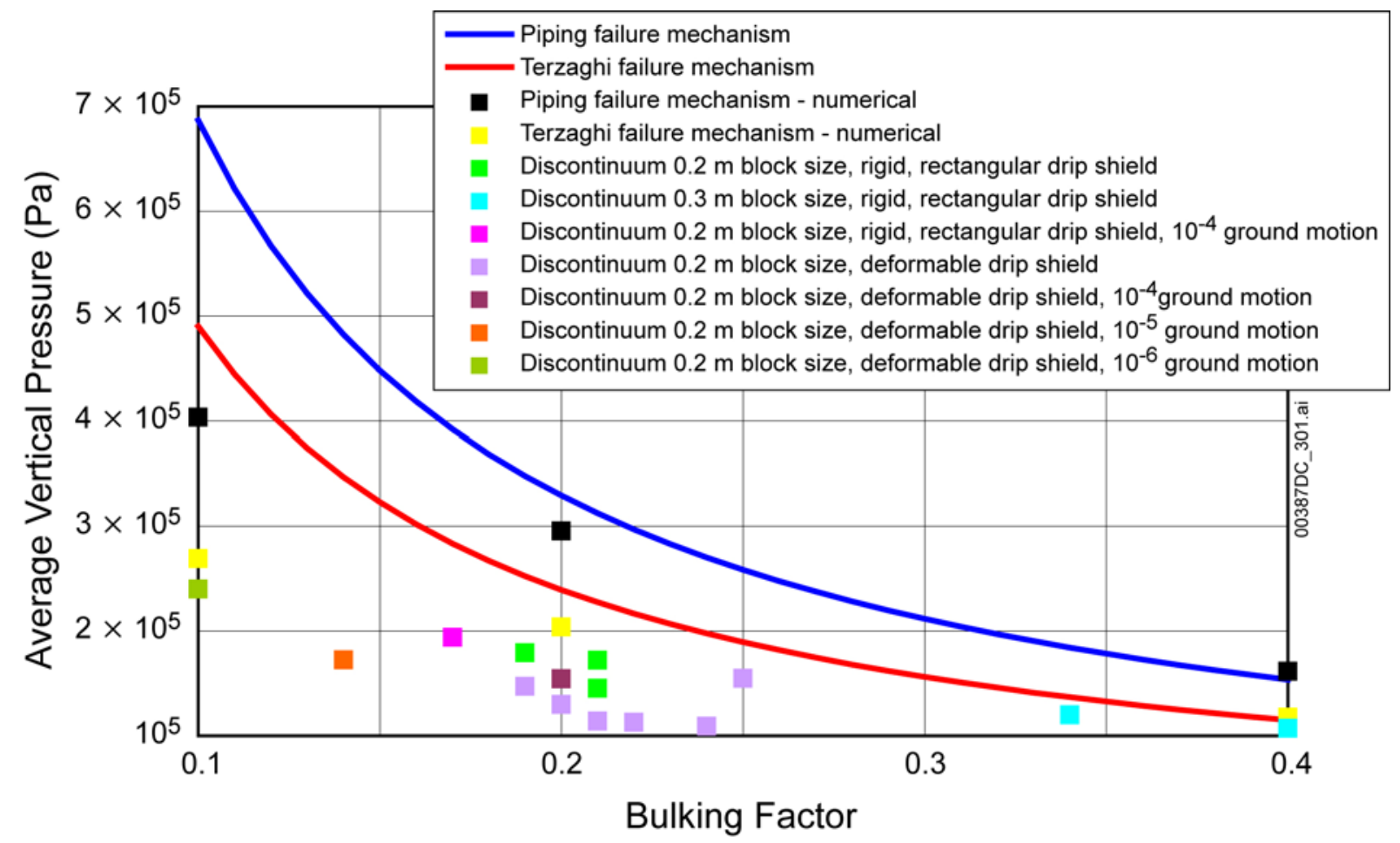

NOTE: Two different sizes of the randomly shaped blocks used in the discontinuum analyses were used to produce a range of bulking factors.

Figure 6-179. Summary of Vertical Load on the Drip Shield as a Function of Bulking Factor

\subsubsection{Investigation of Potential Key Blocks in Lithophysal Units}

The stability analyses of the lithophysal rock mass presented thus far consider that the ubiquitous fracture fabric in this unit will control failure mode, resulting in raveling of small rock particles. However, a set of widely spaced, longer trace length cooling fractures exists that are not truncated by the small-scale fractures. It is possible that, in addition to the raveling mode of failure, that larger rock blocks (key blocks) are formed by these longer fractures. This section describes the probability of key-block existence, or the possibility that wedge-type failure may occur in the lithophysal units. The general approach used for analyses of wedge-type failure in the nonlithophysal units, as described in Section 6.3.1, is also applied in this study. The three-dimensional discontinuum code 3DEC is used for the mechanical analysis of the jointed rock mass simulated by FracMan. Since small-scale fractures have minor effect on wedge formation as confirmed in Section 6.3.3, only the fractures with trace lengths greater than or equal to $1 \mathrm{~m}$ long are included here. 
In a similar manner as that used for examination of the nonlithophysal base case, a total of 50 fracture modeling regions were selected from the 100-m cube simulated FracMan fractured rock mass for the Tptpll unit (Appendix B). Because the coordinates of the 50 fracture modeling regions selected for the nonlithophysal units were randomly generated, they were also used in the lithophysal units. For conservatism and efficiency, fracture strength parameters (cohesion and friction angle) were reduced to small values to evaluate the probability of key-block existence. With strength parameter values assigned as 0 , the predicted rockfall is equivalent to the blocks that are kinematically admissible to fall regardless of the frictional resistance of fracture surfaces.

The summary of the analyses is presented in Table 6-49. Twenty-one distinct rock blocks are formed by the longer fractures in the 50 simulations. Notice that the distinct blocks are all of the blocks that exist in the rock mass regardless of whether the blocks are kinematically or mechanically suitable to fall. A typical cross section of the analysis with prediction of the distinct block is provided in Figure 6-180. Only two blocks were predicted to fall into the drift with block volume of $0.16 \mathrm{~m}^{3}$ and $0.08 \mathrm{~m}^{3}$. With only two blocks predicted for $1.25 \mathrm{~km}$ of drift simulated while using extremely conservative (i.e., low) fracture strength properties, the probability of key-block occurrence in lithophysal units is very low and not considered further. This analysis confirms that raveling of small blocks is expected to be the dominant potential failure mode of drifts in lithophysal rocks.

Table 6-49. Summary of 3DEC Rockfall Prediction for Lithophysal Units

\begin{tabular}{|l|c|}
\hline \multicolumn{1}{|c|}{ Parameter } & Value \\
\hline Simulations Completed & 50 \\
\hline Number of Simulations Predicting No Rockfall & 48 \\
\hline Number of Simulations Predicting No Distinct Block & 37 \\
\hline Total Number of Rockfall & 2 \\
\hline Total Volume of Rockfall $\left(\mathrm{m}^{3}\right)$ & 0.24 \\
\hline Total Length of Drift Simulated $(\mathrm{m})$ & 1250 \\
\hline Number of Blocks per $\mathrm{km}$ & 1.6 \\
\hline Volume of Rockfall per $\mathrm{km}\left(\mathrm{m}^{3} / \mathrm{km}\right)$ & 0.19 \\
\hline
\end{tabular}




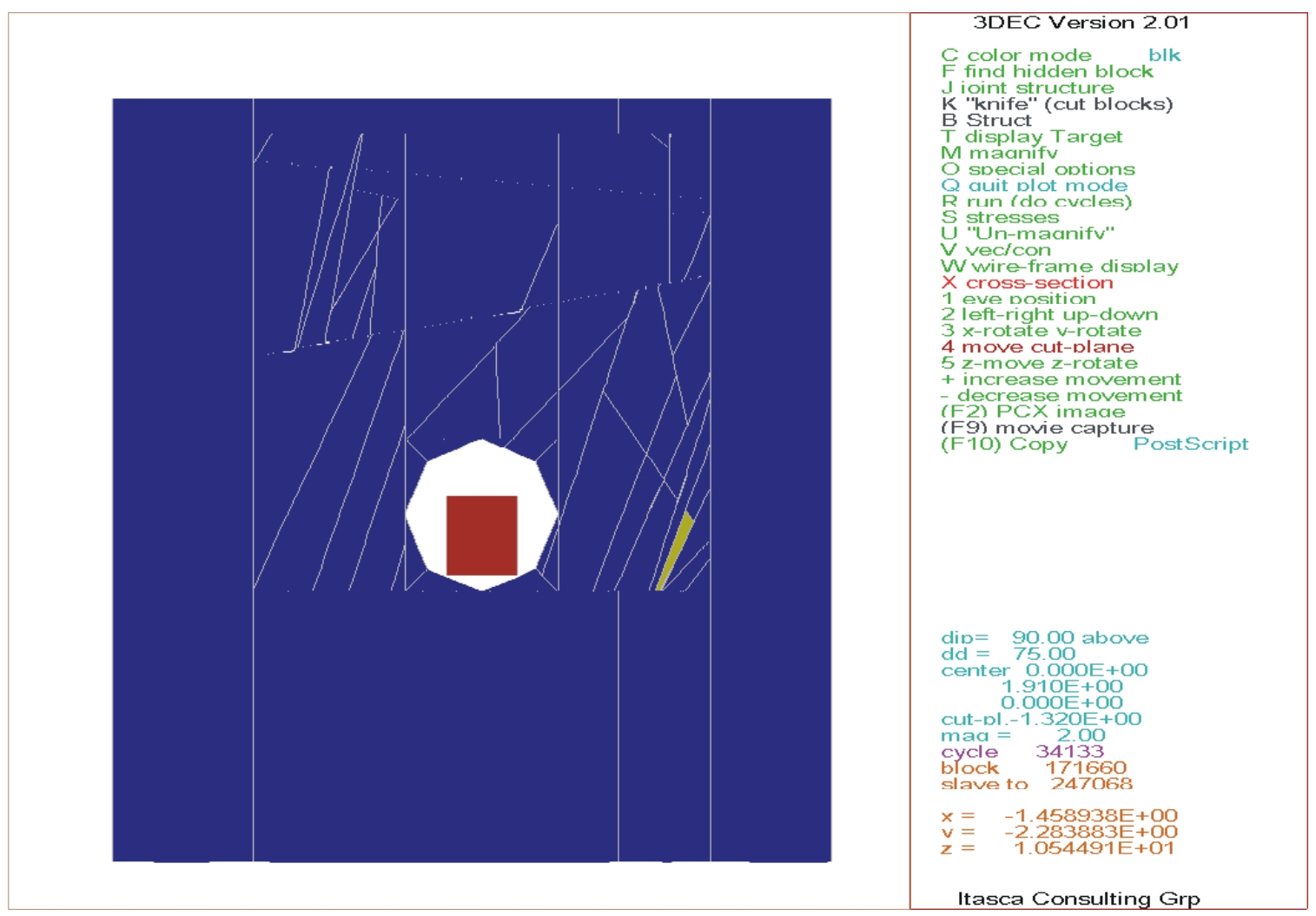

NOTE: The fracture traces shown in this cross section do not necessarily form a coherent block in three-dimensions. The only distinct block formed in this cross section is shown in yellow, and is obviously not "removable".

Figure 6-180. Cross Section of a Typical Simulated Lithophysal Rock Mass in 3DEC

\subsection{UNCERTAINTIES AND LIMITATIONS}

The task of predicting and characterizing drift degradation anticipated within repository emplacement drifts throughout the 10,000-year period of compliance for postclosure performance has several inherent uncertainties and limitations. These uncertainties are associated with both the modeling methods and the model inputs. To provide a meaningful assessment of drift degradation, the uncertainties must be identified and adequately represented within the model. The uncertainties associated with modeling methods are addressed with model validation (Section 7). Additionally, a discussion of alternative conceptual models has been provided (Section 6.7), which provides justification for use of the modeling methods employed in this document, thereby demonstrating that the drift degradation models presented in this report are adequate to account for the uncertainties and limitations.

This section provides a discussion of uncertainties associated with model inputs. The discussion below has been rank-ordered according to importance in control of drift degradation under in situ, thermal, and seismic loading. That is, the parameters and their associated uncertainty that have the most significant impact on model results are discussed first. In general, those uncertainties associated with drift degradation in lithophysal rocks are considered to be most significant due to the relatively larger amount of emplacement area located in them. The rock 
mass properties for lithophysal rock and fracture geometry in nonlithophysal rock have the greatest impact on drift degradation. The seismic ground motions, particularly those at low annual probability levels, have a large impact on stability of both nonlithophysal and lithophysal rock masses.

Rock Mass Mechanical Properties Data-Rock mass mechanical properties data for nonlithophysal rock are calculated using rock mass classification data collected from field mapping within the ESF and intact rock properties data collected from laboratory testing. The uncertainties associated with the intact rock properties data are described above. The uncertainties associated with the rock mass classification data are epistemic, and are assessed to be low because an abundance of data has been collected based on established, industry-accepted methods. There is a moderate degree of epistemic uncertainty associated with the calculation approach for assessing rock mass properties, since they are based on empirical methods and have an inherent characteristic of imprecision. This uncertainty has been accounted for by using two separate empirical calculation methods and demonstrating that the results are similar. The rock mass properties data are primarily used in the thermal-mechanical calculation to determine stresses within the model as described in Section 6.2, and are a relatively insensitive parameter to the stress calculations.

Rock mass mechanical properties data for lithophysal rock are based on large-diameter uniaxial compression test data and in situ slot test data (Appendix E, Section E4.1). The epistemic uncertainty associated with this rock mass data for lithophysal rock is assessed to be high. To account for this uncertainty in the rockfall model for lithophysal rock, five categories of rock properties were included in the model to assess the impact of the ranges in rock mass properties data. Additionally, the PFC numerical model was calibrated to reproduce the large-core laboratory mechanical properties data and its dependency on lithophysal porosity as well as the observed failure mechanisms. The model was then used to build confidence in the understanding of the bounding ranges of lithophysal rock mass properties through numerical extrapolations to examine the effect of lithophysal cavity porosity, size, shape and distribution variability as defined by field mapping. This work is described in detail in Appendix E, Section E4.1. The impact of use of the range of rock properties on drift degradation and rockfall was explored through use of sensitivity studies in Section 6.4.

Seismic Ground Motion Data-The seismic time histories used to evaluate rockfall reflect a number of variabilities, including epistemic uncertainty and randomness (aleatoric uncertainty). Epistemic uncertainties (due to incomplete knowledge) in the characterization of seismic sources and median ground motion attenuation, along with randomness in seismic ground motion, were explicitly incorporated into the probabilistic seismic hazard analysis. The mean results of that analysis form the basis for the site-specific ground motions used in this report. At annual probabilities of exceedance lower than about $1 \times 10^{-6}$, the mean hazard exceeds the 85 th percentile of the hazard uncertainty distribution.

Development of site-specific ground motions incorporates additional epistemic uncertainty in the velocity and dynamic properties of site materials. Observed randomness of site materials is also addressed. Finally, randomness in the spectral content and duration of time histories that produce the same peak ground motion is accommodated in the drift degradation analyses through the use of 15 sets of time histories for each of the two postclosure hazard levels considered. The 
earthquake magnitudes and epicentral distances of the recorded strong motion data that form an input to these time histories, reflect the range of magnitudes and distances contributing most strongly to seismic hazard at the site for the given annual probabilities of ground motion exceedance.

While the seismic ground motion inputs developed in this manner fully account for the underlying uncertainties and randomness, the result is that for annual exceedance probabilities of about $1 \times 10^{-6}$ and lower, some realizations of ground motion are larger than the largest ground motions observed and may not be physically realizable. Nonetheless, these ground motions are consistent with and demonstrate fully the current state of uncertainty and randomness in deriving ground motion inputs for very low annual probabilities of exceedance. Lacking a technical basis to limit such ground motions to smaller values, these inputs are used in the analyses supporting TSPA-license application (LA) ${ }^{4}$.

Static Fatigue and Long-Term Strength Data-The long-term strength predictions (Section 6.4.2.4 and Appendix S) are based on very limited static-fatigue test data, which provide time-dependent strength behavior of the lithophysal rock. A static-fatigue (creep) test involves applying a constant compressive stress to a specimen, and recording the time to failure (Potyondy 2003 [DIRS 165550], Section 1.4). One of the main limitations of the predictions of time-dependent behavior of excavations in a rock mass for a period of 10 years or longer after excavation, is that existing static-fatigue testing (for any rock) is typically performed for no more than a few months. Predictions for longer time frames are based on extrapolation of existing testing data, and involve a significant level of uncertainty. The static-fatigue curve is usually considered to be a straight line in a logarithm plot of time-to-failure versus driving-stress ratio, which is fitted to experimental data. However, it appears from available data for Lac du Bonnet granite (see Appendix S, Figure S-27) that the fitted static-fatigue curve underestimates time-to-failure compared to experimental data in the range of driving-stress ratios between 0.65 and 0.70 (which corresponds to the longest measured times-to-failure). It seems that a curved line (instead of straight line) would be a better fit for long times-to-failure. Consequently, predictions obtained using the straight line are conservative, because the straight line appears to under-predict time-to-failure for low values of the driving stress.

Failure times and the evolution of the damage of the rock are provided by standard creep (i.e., strain versus time) plots derived from the laboratory static-fatigue test. The PFC stress corrosion model was calibrated to reproduce the time-evolution of damage response as determined from these laboratory tests. The sensitivity of the PFC stress corrosion predictions to damage rate has been investigated to determine how damage rates affect the final result of the model (i.e., the rockfall induced by time-dependent strength degradation). Damage curves were generated for tuff best fit static-fatigue (see Appendix S, Figure S-29), where the damage rates for the driving stress levels are considered to be the same, equal to the maximum rate predicted by the PFC

\footnotetext{
${ }^{4}$ An analysis to provide an estimate of the bounding peak ground velocity for the Yucca Mountain site has been developed (BSC 2004, [DIRS 170137]). This estimate is based on examination of the maximum shear strain that the lithophysal rock can withstand, and relating this to the peak ground velocity that will produce this strain. Since no seismic-related shear damage can be observed in the field in the lithophysal rocks, it is argued that no seismic event has occurred with peak ground velocity exceeding this failure limit in the approximately 12.8 million years since the Topopah Spring tuff has been deposited and cooled. However, non-bounded ground motion time histories were used in the analyses presented in this document.
} 
stress corrosion model. The rockfall predictions due to time-dependent strength reduction using a range of damage curves have been compared, and it is clear that the considered variation of damage rates has no practical effect on predicted rockfall (see Appendix S, Figure S-31). The time-to-failure is the main factor controlling evolution of the rockfall due to time-dependent strength reduction. Consequently, UDEC predictions are not very sensitive to the damage rate input from the PFC stress corrosion model.

Further investigation of uncertainty in the time-dependent UDEC modeling of drift degradation was performed by using the time-dependent strength degradation obtained from extensive Lac du Bonnet granite as a lower bound to the time-dependent strength loss of Topopah Spring tuff. Although the extent of drift degradation is greater when using these lower bound considerations, the overall conclusions regarding extent of collapse and timing of collapse are not significantly different (Appendix S).

Fracture Geometry Data for Nonlithophysal Rock-The natural variability of fractures within a rock mass represents epistemic uncertainty (i.e., uncertainty due to incomplete knowledge) in the design of structures in rock. The large amount of fracture data collected at the YMP provides a very good representation of the range of fracture geometry anticipated at the emplacement drift horizon. The range of fracture geometry variability from tunnel mapping has been captured in the rockfall model for nonlithophysal rock through multiple simulations of the rock mass. Section 6.1.6 describes the generation of representative rock volumes using FracMan with the consideration of the natural variability of fracture geometry. The representativeness of the FracMan-generated rock volume is verified in Section 6.1.6 through comparison of the FracMan synthetic fracture network to the statistical variability of the fractures as measured by field mapping. Section 6.3.1.2.2 documents the random selection of the fracture-modeling region in the rockfall analyses to cover the uncertainties associated with fracture orientation, intensity and length. The fracture geometry is concluded to be the dominant factor for wedge-type rockfall in nonlithophysal rock. The uncertainty associated with joint geometry data in the rockfall models is assessed to be low.

Intact Rock Physical and Mechanical Properties Data-A sufficient amount of intact rock physical and mechanical properties data has been collected for the nonlithophysal rock units. The epistemic uncertainty associated with this intact data for nonlithophysal rock is assessed to be low. Conversely, the amount of intact rock physical and mechanical properties data for the lithophysal units is limited. The epistemic uncertainty associated with this intact data for lithophysal rock is assessed to be high. To account for this uncertainty in the rockfall model for lithophysal rock, five categories of rock properties were included in the model to assess the impact of the ranges in intact properties data. The difference of rockfall prediction for the range of properties considered is provided in Section 6.4.

Fracture Mechanical Properties Data-The amount of fracture mechanical properties data for both the nonlithophysal and lithophysal rock units is limited; therefore, the uncertainty associated with this data is epistemic, and is relatively high. To account for this uncertainty in the rockfall models, sensitivity analyses for the possible range of fracture strength parameters, dilation angle, and fracture stiffness were conducted and the results are presented in Section 6.3.1.6. Fracture mechanical properties are judged to have a secondary effect on rockfall compared with fracture geometry data. 
Rock Thermal Properties Data-A sufficient amount of rock thermal properties data has been collected for the nonlithophysal rock units. The epistemic uncertainty associated with this thermal properties data for nonlithophysal rock is assessed to be low. Conversely, the amount of rock thermal properties data for the lithophysal units is limited. Therefore, the epistemic uncertainty associated with this thermal properties data for lithophysal rock is assessed to be high. Uncertainty assessments are provided in the data source documentation identified in Table 4-1 and in Appendix E (Section E5). Sensitivity calculations for thermal properties were conducted with one standard deviation less values used for thermal conductivity and specific heat as described in Section 6.2, Section 6.3.1.3, and Section 6.4.2.3. The sensitivity case results in approximately $23^{\circ} \mathrm{C}$ higher peak temperature comparing with the base case but with minor impact to the rockfall prediction.

Repository Layout Information-The repository layout data are based on design information, which is currently in the preliminary design stage. This design information is subject to change before being finalized. The model results documented in this report are applicable for the emplacement drift diameter and emplacement drift alignment provided by repository design and performance assessment information exchange drawings (BSC 2004 [DIRS 164519]; BSC 2004 [DIRS 168489]) and Section 5.1.4 and 8.7 of Underground Layout Configuration (BSC 2003 [DIRS 165572]). The rockfall models are sensitive to both emplacement drift diameter and alignment. While no changes are expected to the emplacement drift diameter and alignment, and any change to this design information would require reevaluation.

\subsection{DRIFT DEGRADATION FEPS}

The development of a comprehensive list of features, events, and processes (FEPs) potentially relevant to postclosure of the repository is an ongoing, iterative process based on site-specific information, design, and regulations. The approach for developing an initial list of FEPs was documented by The Development of Information Catalogued in REV00 of the YMP FEP Database (Freeze et al. 2001 [DIRS 154365]). To support TSPA-LA, the FEP list was re-evaluated and is provided by DTN: MO0407SEPFEPLA.000 [DIRS 170760]. Table 6-50 provides a list of FEPs addressed in this model document that have been included in TSPA-LA (based on MO0407SEPFEPLA.000 [DIRS 170760]), and provides specific references to sections within this document. Additionally, Table 6-51 provides a list of FEPs addressed in this model document that have been excluded in TSPA-LA (based on MO0407SEPFEPLA.000 [DIRS 170760]). 
Table 6-50. Included FEPs Addressed by This Model Report

\begin{tabular}{|c|c|c|}
\hline FEP No. & FEP Name & Section Where the FEP is Discussed \\
\hline 1.2.03.02.0A & $\begin{array}{l}\text { Seismic ground } \\
\text { motion } \\
\text { damages EBS } \\
\text { components }\end{array}$ & $\begin{array}{l}\text { This report provides rockfall models that are based on site characterization data, including joint geometry and rock } \\
\text { strength data, coupled with anticipated thermal stresses and seismic ground motion. Based on the analyses presented in } \\
\text { this report (Section } 6.3 \text { and } 6.4 \text { ), postclosure ground motion levels are sufficient to produce collapse of drifts in the } \\
\text { lithophysal rock units (which represent approximately } 85 \text { percent of the emplacement drifts). Minor to moderate } \\
\text { degradation or collapse of drift is anticipated in the nonlithophysal rock units throughout the regulatory period for } \\
\text { postclosure performance. }\end{array}$ \\
\hline 1.2.03.02.0B & $\begin{array}{l}\text { Seismic- } \\
\text { induced rockfall } \\
\text { damages EBS } \\
\text { components }\end{array}$ & $\begin{array}{l}\text { This report provides rockfall models that are based on site characterization data. Probabilistic descriptions of rock size } \\
\text { and rockfall frequency are provided for use in engineering design analyses (Sections } 6.3 \text { and } 6.4 \text { ). The block size } \\
\text { distributions presented in this report are similar to the block size distributions developed using the approach in the previous } \\
\text { version of this document (Section 7.7.5). However, the frequency of blocks has increased with the larger ground motions } \\
\text { used in this report compared to the previous approach (Section 7.7.5). }\end{array}$ \\
\hline 1.2.03.02.0C & $\begin{array}{l}\text { Seismic induced } \\
\text { drift collapse } \\
\text { damages EBS } \\
\text { components }\end{array}$ & $\begin{array}{l}\text { This report provides rockfall models that are based on site characterization data, including joint geometry and rock } \\
\text { strength data, coupled with anticipated thermal stresses and seismic ground motion. Based on the analyses presented in } \\
\text { this report (Section } 6.3 \text { and 6.4), minor degradation or collapse of drift is anticipated for the static (i.e., no seismic) case } \\
\text { and during the preclosure period. The mechanical degradation or collapse of drift predicted for the static case and during } \\
\text { the preclosure period is similar to the results from the previous approach using DRKBA (Section } 7.7 .5 \text { ). Based on the } \\
\text { analyses presented in this report (Section } 6.3 \text { and } 6.4 \text { ), postclosure ground motion levels are sufficient to produce collapse } \\
\text { of drifts in the lithophysal rock units (which represent approximately } 85 \text { percent of the emplacement drifts). Minor to } \\
\text { moderate degradation or collapse of drift is anticipated in the nonlithophysal rock units throughout the regulatory period for } \\
\text { postclosure performance. }\end{array}$ \\
\hline 1.2.03.02.0D & $\begin{array}{l}\text { Seismic induced } \\
\text { drift collapse } \\
\text { alters in-drift } \\
\text { thermo- } \\
\text { hydrology }\end{array}$ & $\begin{array}{l}\text { This report provides rockfall models that are based on site characterization data, including joint geometry and rock } \\
\text { strength data, coupled with anticipated thermal stresses and seismic ground motion. Based on the analyses presented in } \\
\text { this report (Section } 6.3 \text { and 6.4), minor degradation or collapse of drift is anticipated for the static (i.e., no seismic) case } \\
\text { and during the preclosure period. The mechanical degradation or collapse of drift predicted for the static case and during } \\
\text { the preclosure period is similar to the results from the previous approach using DRKBA (Section } 7.7 .5 \text { ). Based on the } \\
\text { analyses presented in this report (Section } 6.3 \text { and 6.4), postclosure ground motion levels are sufficient to produce collapse } \\
\text { of drifts in the lithophysal rock units (which represent approximately } 85 \text { percent of the emplacement drifts). Minor to } \\
\text { moderate degradation or collapse of drift is anticipated in the nonlithophysal rock units throughout the regulatory period for } \\
\text { postclosure performance. }\end{array}$ \\
\hline
\end{tabular}

NOTE: The screening decision to determine the include/exclude status of the FEP is documented in MO0407SEPFEPLA.000 [DIRS 170760]. 


\begin{tabular}{|l|l|l|l|} 
2.1.06.02.0A & $\begin{array}{l}\text { Mechanical } \\
\text { effects of rock } \\
\text { reinforcement } \\
\text { materials in } \\
\text { EBS }\end{array}$ & $\begin{array}{l}\text { In this model report, no credit is taken for ground support in rockfall models (Section 6.0). Therefore, the consideration of } \\
\text { the mechanical effects of rock reinforcement is implicit in the modeling approaches discussed in Sections 6.3 and 6.4. The } \\
\text { rockfall models presented in this report (Sections 6.3 and 6.4) provide a bounding scenario in the analysis of the effects of } \\
\text { rock reinforcement on drift degradation. }\end{array}$ \\
\hline 2.1.07.01.0A & Rockfall & $\begin{array}{l}\text { This report provides rockfall models that are based on site characterization data. Probabilistic descriptions of rock size } \\
\text { and rockfall frequency are provided for use in engineering design analyses (Sections } 6.3 \text { and 6.4). The block size } \\
\text { distributions and frequency of blocks presented in this report for static (i.e., no seismic) and preclosure ground motion are } \\
\text { similar to the block size data developed using the approach in the previous version of this document (Section 7.7.5). }\end{array}$ \\
\hline 2.1.07.02.0A & $\begin{array}{l}\text { Drift collapse } \\
\text { This report provides rockfall models that are based on site characterization data. Based on the analyses presented in this } \\
\text { report (Section 6.3 and 6.4), minor degradation or collapse of drift is anticipated for the static (i.e., no seismic) case and } \\
\text { during the preclosure period. The mechanical degradation or collapse of drift predicted for the static case and during the } \\
\text { preclosure period is similar to the results from the previous approach using DRKBA (Section 7.7.5). }\end{array}$ \\
\hline 2.1.11.07.0A & $\begin{array}{l}\text { Thermal } \\
\text { expansion/ } \\
\text { stress of in-drift } \\
\text { EBS } \\
\text { components }\end{array}$ & $\begin{array}{l}\text { This report provides rockfall models that include the potential impact of thermally induced stress changes in the rock mass } \\
\text { (Section 6.2). The effects of thermally induced stress changes on drift degradation are documented in Sections 6.3.1.3 } \\
\text { (nonlithophysal rock) and 6.4.2.3 (lithophysal rock). }\end{array}$ \\
\hline
\end{tabular}

NOTE: The screening decision to determine the include/exclude status of the FEP is documented in MO0407SEPFEPLA.000 [DIRS 170760]. 


\subsection{DOCUMENTATION OF ALTERNATIVE CONCEPTUAL MODELS}

Alternative conceptual models are based on assumptions and simplifications that are different from those employed in the base case models (i.e., the rockfall model for nonlithophysal rock (Section 6.3) and the rockfall model for lithophysal rock (Section 6.4)). An important reason for considering alternative conceptual models is to help build confidence that changes in modeling assumptions or simplifications will not change conclusions regarding subsystem and total system performance. Conceptual model uncertainty results from sparse observational data and a lack of available information to corroborate or refute plausible alternative interpretations of the subsystem and the processes occurring within the subsystem.

The alternative conceptual models considered in this analysis of drift degradation are summarized in Table 6-52.

Table 6-52. Alternative Conceptual Models Considered

\begin{tabular}{|c|c|c|}
\hline $\begin{array}{c}\text { Alternative } \\
\text { Conceptual Model } \\
\end{array}$ & Key Assumptions & $\begin{array}{c}\text { Screening Assessment } \\
\text { and Basis }\end{array}$ \\
\hline $\begin{array}{l}\text { Continuum model of } \\
\text { lithophysal rock }\end{array}$ & $\begin{array}{l}\text { Lithophysae and fractures } \\
\text { are smeared into the } \\
\text { elements in the equivalent } \\
\text { continuum representation of } \\
\text { the rock mass. Rock } \\
\text { damage is expressed as } \\
\text { element yielding following } \\
\text { the selected failure criterion. }\end{array}$ & $\begin{array}{l}\text { The continuum model, such as FLAC or FLAC3D, is capable } \\
\text { of modeling the material yielding behavior with elasto-plastic } \\
\text { constitutive model. Yielding occurs when the stress state } \\
\text { within the element reach the strength criterion specified by } \\
\text { the constitutive law, the yielding of elements in the } \\
\text { continuum, however, is not equivalent to rockfall. To } \\
\text { estimate the extent of rockfall based on the depth of yielding } \\
\text { is not realistic. Therefore, this alternative conceptual model } \\
\text { is excluded from further evaluation. }\end{array}$ \\
\hline $\begin{array}{l}\text { Continuum model of } \\
\text { nonlithophysal rock }\end{array}$ & $\begin{array}{l}\text { Fractures are smeared into } \\
\text { the elements in the } \\
\text { equivalent continuum } \\
\text { representation of the rock } \\
\text { mass. Element contains the } \\
\text { weak plane information for } \\
\text { potential shear slipping. }\end{array}$ & $\begin{array}{l}\text { The compliant joint model (Chen } 1987 \text { [DIRS } 101800] \text { ) is } \\
\text { capable of analyzing jointed media behavior with fractures } \\
\text { smeared into the elements. The model includes a } \\
\text { continuum approximation based on average discontinuous } \\
\text { displacements across joint planes within a representative } \\
\text { elementary volume. The model also includes a material } \\
\text { constitutive description based on linear elastic matrix } \\
\text { material behavior and nonlinear normal and shear joint } \\
\text { behavior between joint planes. The continuum model } \\
\text { provides global rock mass response with predominant weak } \\
\text { plane orientation, but cannot predict wedge-type failure. } \\
\text { Therefore, this alternative conceptual model is excluded } \\
\text { from further evaluation. }\end{array}$ \\
\hline $\begin{array}{l}\text { Hudson and Priest } \\
\text { (1979 DIRS 104915]) } \\
\text { model of } \\
\text { nonlithophysal rock } \\
\text { for estimating block } \\
\text { size distribution }\end{array}$ & $\begin{array}{l}\text { All joint planes are assumed } \\
\text { to be perfectly planar, } \\
\text { persistent, and extend } \\
\text { throughout the rock volume } \\
\text { of interest. The distribution } \\
\text { of joint spacing values along } \\
\text { a line is assumed to be of } \\
\text { negative exponential form. }\end{array}$ & $\begin{array}{l}\text { The approach to determine block size distribution using the } \\
\text { Hudson and Priest approach has been documented by } \\
\text { Preliminary Block Size Calculation (CRWMS M\&O } 1998 \\
\text { [DIRS 102723], Section 5.3). This approach provides a } \\
\text { generalized statistical representation of the joint geometry. } \\
\text { In particular, the assumption of continuous joints is not } \\
\text { consistent with the discontinuous joints observed in the } \\
\text { ESF. Since joint geometry is a primary factor in the } \\
\text { assessment of block development, the generalized } \\
\text { approach by Hudson and Priest does not provide the level of } \\
\text { detail required to accurately model drift degradation. } \\
\text { Therefore, this alternative conceptual model is excluded } \\
\text { from further evaluation. }\end{array}$ \\
\hline
\end{tabular}




\subsection{RESOLUTION OF KEY TECHNICAL ISSUES}

The NRC is conducting an ongoing review of the information provided by the YMP to allow early identification and resolution of potential licensing issues. The NRC has identified several key technical issues (KTIs) and associated sub-issues, along with acceptance criteria for resolution of the issue. The drift degradation analysis provides information that is directly related to the KTI on Repository Design and Thermal-Mechanical Effects (NRC 2002 [DIRS 159538]). To provide a clear understanding of the technical issues, a NRC/DOE Technical Exchange and Management Meeting on Repository Design and Thermal-Mechanical Effects was held in February of 2001. As a result of this meeting, a number of agreements between the NRC and DOE were formally adopted (Reamer and Williams 2001 [DIRS 154348]), outlining the plan for resolution of the technical issues. The agreement items addressed in this report are presented verbatim as follows:

- RDTME 3.04-Provide in the Design Parameter Analysis Report (or some other document) site-specific properties of the host rock, as a minimum those included in the NRC handout, together with the spatial and temporal variations and uncertainties in such properties, as an update to the information contained in the March 1997 Yucca Mountain Site Geotechnical Report. The DOE will: (1) evaluate the adequacy of the currently available measured and derived data to support the potential repository licensing case and identify areas where available data may warrant additional field measurements or testing to reduce uncertainty. DOE will provide a design parameters analysis report (or other document) that will include the results of these evaluations, expected to be available to NRC in FY 2002; and (2) acquire data and/or perform additional analyses as necessary to respond to the needs identified in 1 above. The DOE will provide these results prior to any potential license application.

- RDTME 3.05-Provide the Rock Mass Classification Analysis (or some other document) including the technical basis for accounting for the effects of lithophysae. The DOE will provide a rock mass classification analysis (or other document), including the technical basis for accounting for the effects of lithophysae, expected to be available to NRC in FY 2002.

- RDTME 3.07- The DOE should account for the effect of sustained loading on intact rock strength or provide justification for not accounting for it. The DOE will assess the effects of sustained loading on intact rock strength. The DOE will provide the results of this assessment in a design parameters analysis report (or other document), expected to be available to NRC in FY 2002.

- RDTME 3.10-Provide technical basis for the assessment that two-dimensional modeling for emplacement drifts is considered to be adequate, considering the fact that neither the in-situ stress field nor the principle fracture orientation are parallel or perpendicular to emplacement drift orientation. The DOE will provide the technical bases for the modeling methods used in ground control analysis in a revision to the Ground Control for Emplacement Drifts for site recommendation, ANL-EBS-GE-000002 (or other document) supporting any potential license application. This is expected to be available to NRC in FY 2003. 
- RDTME 3.15-Provide field data and analysis of rock bridges between rock joints that are treated as cohesion in DRKBA modeling together with a technical basis for how a reduction in cohesion adequately accounts for thermal effects. The DOE will provide clarification of the approach and technical basis for how reduction in cohesion adequately accounts for thermal effects, including any additional applicable supporting data and analyses. Additionally, the adequacy of the cohesion reduction approach will be verified according to the approach described in Subissue 3, Agreement 22 [RDTME 3.19], of the Repository Design and Thermal-Mechanical Effects Technical Exchange. This will be documented in a revision to the Drift Degradation Analysis, ANL-EBS-MD-000027, expected to be available to NRC in FY 2003.

- RDTME 3.16-Provide a technical basis for the DOE position that the method used to model joint planes as circular discs does not under-represent the smaller trace-length fractures. The DOE will analyze the available small trace-length fracture data from the Exploratory Studies Facility and Enhanced Characterization of the Repository Block, including their effect on block development. This will be documented in a revision to the Drift Degradation Analysis, ANL-EBS-MD-000027, expected to be available to NRC in FY 2003.

- RDTME 3.17-Provide the technical basis for effective maximum rock size including consideration of the effect of variation of the joint dip angle. The DOE will provide the technical basis for effective maximum rock size including consideration of the effect of variation of the joint dip angle. This will be documented in revisions to the Drift Degradation Analysis, ANL-EBS-MD-000027, and the Rockfall on Drip Shield, CAL-EBS-ME-000001, expected to be available to NRC in FY 2003.

- RDTME 3.19-The acceptability of the process models that determine whether rockfall can be screened out from performance assessment abstractions needs to be substantiated by the DOE by doing the following: (1) provide revised DRKBA analyses using appropriate range of strength properties for rock joints from the Design Analysis Parameters Report, accounting for their long-term degradation; (2) provide an analysis of block sizes based on the full distribution of joint trace length data from the Fracture Geometry Analysis Report for the Stratigraphic Units of the Repository Host Horizon, including small joints trace lengths; (3) verify the results of the revised DRKBA analyses using: (a) appropriate boundary conditions for thermal and seismic loading; (b) critical fracture patterns from the DRKBA Monte Carlo simulations (at least two patterns for each rock unit); (c) thermal and mechanical properties for rock blocks and joints from the Design Analysis Parameters Report; (d) long-term degradation of rock block and joint strength parameters; and (e) site-specific ground motion time histories appropriate for post-closure period; provide a detailed documentation of the analyses results; and (4) in view of the uncertainties related to the rockfall analyses and the importance of the outcome of the analyses to the performance of the repository, evaluate the impacts of rockfall in performance assessment calculations. DOE believes that the Drift Degradation Analysis is consistent with current understanding of the Yucca Mountain site and the level of detail of the design to date. As understanding of the site and the design evolve, DOE will: (1) provide revised DRKBA analyses using appropriate range of strength properties for rock joints from a design parameters analysis 
report (or other document), accounting for their long-term degradation; (2) provide an analysis of block sizes based on the full distribution of joint trace length data from the Fracture Geometry Analysis for the Stratigraphic Units of the Repository Host Horizon, ANL-EBS-GE-000006, supplemented by available small joint trace length data; (3) verify the results of the revised DRKBA analyses using: (a) appropriate boundary conditions for thermal and seismic loading; (b) critical fracture patterns from the DRKBA Monte Carlo simulations (at least two patterns for each rock unit); (c) thermal and mechanical properties for rock blocks and joints from a design parameters analysis report (or other document); (d) long-term degradation of joint strength parameters; and (e) site-specific ground motion time histories appropriate for post-closure period. This will be documented in a revision to the Drift Degradation Analysis, ANL-EBS-MD-000027, expected to be available to NRC in FY 2003. Based on the results of the analyses above and subsequent drip shield calculation revisions, DOE will reconsider the screening decision for inclusion or exclusion of rockfall in performance assessment analysis. Any changes to screening decisions will be documented in analyses prior to any potential license application

The contribution toward fulfillment of these agreement items provided by this model report is identified in Table 6-53. 
Table 6-53. Repository Design and Thermal-Mechanical Effects KTI Agreement Items Addressed in This Model Report

\begin{tabular}{|c|c|c|}
\hline $\begin{array}{l}\text { Agreement } \\
\text { Item }\end{array}$ & Approach and Section Reference & Status of Agreement \\
\hline RDTME 3.04 & $\begin{array}{l}\text { Geotechnical data to support the drift degradation analyses documented in this report are identified in } \\
\text { Section } 4 \text {, Section } 7 \text {, and Appendix E. Discussions of data adequacy are provided throughout Sections } 6,7 \text {, } \\
\text { and } 8 \text {. Newly acquired data from lithophysal rocks have been used to develop the lithophysal rockfall model, } \\
\text { including data from laboratory compression testing on large-diameter cores. Note that the primary document } \\
\text { addressing this agreement item is Subsurface Geotechnical Parameters Report (BSC } 2003 \text { [DIRS 166660]). }\end{array}$ & $\begin{array}{l}\text { The data and information } \\
\text { provided in this model report } \\
\text { contributes to the closure of } \\
\text { this agreement. }\end{array}$ \\
\hline RDTME 3.05 & $\begin{array}{l}\text { The technical basis for accounting for the effects of lithophysae is presented in Section } 6.4 \text {. The validity of } \\
\text { this approach is discussed in Sections } 7.3 \text { and } 7.4 \text {. Note that the primary document addressing this } \\
\text { agreement item is Subsurface Geotechnical Parameters Report (BSC } 2003 \text { [DIRS 166660]). }\end{array}$ & $\begin{array}{l}\text { The data and information } \\
\text { provided in this model report } \\
\text { contributes to the closure of } \\
\text { this agreement. }\end{array}$ \\
\hline RDTME 3.07 & $\begin{array}{l}\text { The technical basis for accounting for the effects of time-dependent degradation is presented in } \\
\text { Sections } 6.3 .1 .5,6.4 .2 .4 \text {, and Appendix } S \text {. }\end{array}$ & $\begin{array}{l}\text { The data and information } \\
\text { provided in this model report } \\
\text { are intended to fully address } \\
\text { the requirements of this } \\
\text { agreement. }\end{array}$ \\
\hline RDTME 3.10 & $\begin{array}{l}\text { The assessment of an appropriate approach to model the rock mass is a function of the specific repository } \\
\text { host rock type: lithophysal or nonlithophysal rock (Section 7.1). } \\
\text { For nonlithophysal rock, jointing controls the mechanical response, which is generally anisotropic in nature. } \\
\text { Therefore, two-dimensional modeling of nonlithophysal rock is not realistic for rockfall modeling, and a three- } \\
\text { dimensional modeling approach must be used. } \\
\text { Conversely, lithophysal rock is characterized by the presence of more-or-less uniformly distributed voids } \\
\text { (lithophysae) of varying size. Additionally, in the Tptpll, short trace length interlithophysae fracturing exists. } \\
\text { Under these conditions, the representation of lithophysal rock as a homogeneous, isotropic rock mass is } \\
\text { appropriate. Therefore, in models of drift stability, the use of a two-dimensional model in the plane } \\
\text { perpendicular to the axis is adequate. }\end{array}$ & $\begin{array}{l}\text { The data and information } \\
\text { provided in this model report } \\
\text { are intended to fully address } \\
\text { the requirements of this } \\
\text { agreement. }\end{array}$ \\
\hline RDTME 3.15 & $\begin{array}{l}\text { Additional clarification of the approach and technical basis for how reduction in cohesion adequately } \\
\text { accounts for thermal effects in the DRKBA analyses is provided in Appendix D. However, the DRKBA } \\
\text { analyses now provide a confirmatory role in the assessment of drift degradation. The drift degradation } \\
\text { analyses are primarily conducted using UDEC and 3DEC, in which thermal loads have been explicitly } \\
\text { modeled (Sections } 6.3 \text { and } 6.4 \text { ). The adequacy of the methods to account for thermal effects on drift } \\
\text { degradation is validated in Section } 7.8 \text {. }\end{array}$ & $\begin{array}{l}\text { The data and information } \\
\text { provided in this model report } \\
\text { are intended to fully address } \\
\text { the requirements of this } \\
\text { agreement. }\end{array}$ \\
\hline RDTME 3.16 & $\begin{array}{l}\text { The available small trace-length fracture data have been analyzed and included in this report, documenting } \\
\text { their effect on block development (Section 6.3.3). }\end{array}$ & $\begin{array}{l}\text { The data and information } \\
\text { provided in this model report } \\
\text { are intended to fully address } \\
\text { the requirements of this } \\
\text { agreement. }\end{array}$ \\
\hline
\end{tabular}


Table 6-53. Repository Design and Thermal-Mechanical Effects KTI Agreement Items Addressed in This Model Report (Continued)

\begin{tabular}{|c|c|c|}
\hline $\begin{array}{l}\text { Agreement } \\
\text { Item }\end{array}$ & Approach and Section Reference & Status of Agreement \\
\hline RDTME 3.17 & $\begin{array}{l}\text { The approach for determining the effective maximum rock size has been revised in this model report. The } \\
\text { approach of varying the joint geometry input to UNWEDGE is no longer applied. The maximum rock size } \\
\text { and shape is taken directly from the 3DEC output, which includes the variation in joint strike, dip, spacing, } \\
\text { and persistence. The variation of joint geometry parameters is based on field mapping data from the ESF, } \\
\text { which has been input into the rockfall model (Sections } 6.1 .6 \text { and 6.3). }\end{array}$ & $\begin{array}{l}\text { The data and information } \\
\text { provided in this model report } \\
\text { are intended to fully address } \\
\text { the requirements of this } \\
\text { agreement. }\end{array}$ \\
\hline RDTME 3.19 & $\begin{array}{l}\text { (1) In this revision of this model report, the DRKBA analyses provide a confirmatory role in the assessment of } \\
\text { drift degradation. The primary analysis for degradation of nonlithophysal rock is provided using 3DEC } \\
\text { (Section 6.3), while lithophysal rock is analyzed using UDEC (Section 6.4). An appropriate range of joint } \\
\text { strength properties has been applied as documented in Section 6.3.1.6. Long-term degradation has been } \\
\text { accounted for as documented in Section 6.3.1.5. } \\
\text { (2) An analysis of block sizes based on the full distribution of joint trace length data has been included in this } \\
\text { report (Sections } 6.1 .4 \text { and 6.1.6), including the available small joint trace length data (Section 6.3.3). } \\
\text { (3) As indicated above, the DRKBA results now provide a confirmatory role in the assessment of drift } \\
\text { degradation. 3DEC has replaced DRKBA as the primary code for analyzing structural block development in } \\
\text { the nonlithophysal rock units. The 3DEC and DRKBA results are in good agreement (Section 7.7.5). } \\
\text { (a) Appropriate boundary conditions for thermal and seismic loading have been included in 3DEC as } \\
\text { documented in Section 6.3.1.1. } \\
\text { (b) A total of } 50 \text { fracture patterns have been analyzed, which were drawn from the same fracture population } \\
\text { used in the DRKBA analyses (Section 6.3.1.1). } \\
\text { (c) Thermal and mechanical properties for rock blocks and joints are available in the Technical Data } \\
\text { Management System as documented in Section 4.1. } \\
\text { (d) Long-term degradation of joint strength has been included as documented in Section 6.3.1.5. } \\
\text { (e) Site-specific ground motion time histories appropriate for postclosure period have been modeled as } \\
\text { documented in Sections } 6.3 .1 .2 \text { and 6.4.2.2. }\end{array}$ & $\begin{array}{l}\text { The data and information } \\
\text { provided in this model report } \\
\text { are intended to fully address } \\
\text { the requirements of this } \\
\text { agreement. }\end{array}$ \\
\hline
\end{tabular}




\section{INTENTIONALLY LEFT BLANK}




\section{VALIDATION}

\subsection{INTRODUCTION}

This section contains a discussion of the activities that were conducted to validate the mechanical material models and their implementation within qualified discontinuum numerical programs for mechanical representation of the repository host rocks. It is noted that the term "model" here refers first to the development and validation of the mechanical material models or representations for the two specific repository host rock types: lithophysal and nonlithophysal rocks. Secondly, validation refers to the examination of the implementation of these material models in a general numerical modeling scheme. In the case of the lithophysal rock, it is necessary to first discuss the existing laboratory database as a precursor to discussion of the implementation of this data in a numerical scheme. Validation of this implementation is addressed through comparison examples of the models to field and laboratory data.

Corroborating/supporting data, models, and information that are used to complete the model validation activities include the following:

- Confidence Building During Model Development to Establish Scientific Basis and Accuracy for Intended Use (Section 7.2.1)

- Cundall and Strack 1979 [DIRS 162194]

- Itasca Consulting Group 2002 [DIRS 160331]

- Konietzky 2003 [DIRS 162198]

- Confidence Building During Development of a Mechanical Material Model for Lithophysal Rocks and Selection of Input Parameters (Sections 7.3 and 7.4)

- Hoek 2000 [DIRS 160705]

- Itasca Consulting Group 2002 [DIRS 160331]

- Potyondy and Cundall 2001 [DIRS 156895]

- Price et al. 1985 [DIRS 106602]

- Confidence Building During PFC Model Development (Section 7.5.1)

- Itasca Consulting Group 2002 [DIRS 160331]

- Price 1986 [DIRS 106589]

- Price et al. 1985 [DIRS 106602]

- Post-Development Validation for the PFC Model (Section 7.5.2)

- Potyondy 2003 [DIRS 165550]

- Potyondy and Cundall 2001 [DIRS 156895]

- Confidence Building During Development of the Lithophysal Rockfall Model (Sections 7.6.1 and 7.6.4)

- Itasca Consulting Group 2002 [DIRS 160331] 
- Post-Development Validation for Lithophysal Rock (Section 7.6.5)

- Hoek 2000 [DIRS 160705]

- MO0001SEPDSTPC.000 [DIRS 153836]

- MO0002ABBLSLDS.000 [DIRS 147304]

- MO0007SEPDSTPC.001 [DIRS 153707]

- MO0107SEPDSTPC.003 [DIRS 158321]

- MO0202SEPDSTTV.001 [DIRS 158320]

- MO9807DSTSET01.000 [DIRS 113644]

- MO9906DSTSET03.000 [DIRS 113673]

- Price 1986 [DIRS 106589]

- Price et al. 1985 [DIRS 106602]

- Senseny 1993 [DIRS 162017]

- Williams 2001 [DIRS 159516]

- Post-Development Validation for Nonlithophysal Rock (Section 7.7)

- Itasca Consulting Group 2002 [DIRS 160331]

- GS030283114222.001 [DIRS 161913]

- Senseny and Pucik 1999 [DIRS 168479]

The scope of the validation and the order of presentation are as follows:

\section{- Lithophysal rocks}

- Mechanical Material Behavior-A discussion of the mechanical behavior of the lithophysal rocks is presented as the basis for development of the mechanical material model. The properties of this rock are controlled by the degree of lithophysal porosity as well as the interlithophysal fracturing. The lithophysae vary in size, shape, and in porosity vertically within the flow, but are distributed relatively uniformly locally within each unit. Since the diameter of the lithophysae are generally much less than the tunnel diameter, and, further, because they are uniformly distributed, a two-dimensional, isotropic equivalent mechanical material model can be used to describe their response to gravitational, thermal, and seismic loading. The mechanical material properties of the upper (Tptpul) and lower (Tptpll) lithophysal units of the Topopah Spring formation have been determined from laboratory compression testing on large (11.5-in and 10.5-in diameter) cores, and from in situ flatjack (slot) compression testing in the ESF main loop and ECRB Cross-Drift.

- Particle Flow Model of Rock Mass Behavior-The purpose of the PFC program is primarily as a simulation tool for developing a detailed understanding of the effects of lithophysal porosity on rock mass behavior. The program is used to supplement limited field testing by providing a means for examining the effects of lithophysae variability on rock mass properties (i.e., as a supplement to laboratory and field testing). A mechanical material model for representing the elasticity and yield of these rocks is developed from the basic laboratory data using a "micromechanical" numerical model (i.e., PFC). The PFC model predictions are compared to laboratory measured rock properties as a means of validation. The drift degradation analyses 
include time-dependent rock mass behavior modeled using the PFC model that incorporates a stress corrosion cracking representation. The PFC stress corrosion modeling approach provides a representation of subcritical crack growth in rocks that embraces both the microscopic processes of reactions and thermal activation at crack tips and the more mesoscopic processes of microcrack-microstructure-macrocrack interaction.

- Lithophysal Rockfall Mechanical Model Component Validation-Although the PFC program could theoretically be used to model tunnel-scale stability issues, the simulation times are too long for existing computer resources. Therefore, it is necessary to develop a simpler, engineering-based approach to represent the potential yielding and fracturing behavior of lithophysal rock. This is done by creating an equivalent lithophysal mechanical model, which is implemented in the UDEC discontinuum program. The equivalent model is first calibrated such that it reproduces the basic laboratory mechanical response (as well as the PFC model response). Post-development model validation is accomplished via comparison to laboratory data, field observation of ECRB Cross-Drift tunnel mechanical response, and field thermal testing and brittle yield observed in the Drift Scale Thermal Test in the ESF. A continuum approach using different constitutive models is included to validate the UDEC Voronoi block model of lithophysal rock. Additionally, a comparison of the mathematical model implemented in the UDEC program to a number of other dynamic jointed rock models for modeling of blast-related, lined tunnel stability conducted for the Defense Nuclear Agency is also given as a confidence-building exercise. These blasting simulations provide a difficult challenge for the models. The UDEC code itself is commercial software that is widely used internationally for design and research in rock engineering. The program has been extensively validated against analytic solutions and design problems that are documented in the User's Manual (Itasca Consulting Group 2002 [DIRS 160331]). This validation provides a comparison of UDEC to several discontinuum and continuum-based programs for solution of tunnels subjected to dynamic loading.

\section{- Nonlithophysal rocks}

- Nonlithophysal Rockfall Model Validation-The 3DEC discontinuum program is used to model the mechanical response of the fracture-rock block system in three dimensions. Fracture mechanical property data, in the form of shear strength and stiffness properties, are derived from rotary and direct shear test measurements as well as empirical correlations derived from underground mapping. Validation of the ability of the nonlithophysal rockfall model implemented in the 3DEC program to represent this direct shear response for fractures as derived from laboratory direct shear testing of large cores is presented. Validation of the dynamic stability of a jointed rock mass through comparison of 3DEC to instrumented field tests is also provided. Specific, well-documented field examples of tunnels subjected to earthquake loading that would be suitable as validation examples were not identified. Therefore, the validation of the mathematical model for nonlithophysal rock implemented in the 3DEC program is performed through corroboration with an alternative numerical model (i.e., the key-block software, DRKBA) to validate the 
model results on block size distribution and rockfall frequency, and through use of an external technical review to validate the overall modeling approach. The 3DEC code itself is commercial software that has been used in international rock engineering practice for nearly 20 years.

\subsection{MODEL VALIDATION LEVEL AND CRITERIA FOR VALIDATION BASED ON INTENDED USE}

The drift degradation analysis provides input to the Seismic Consequence Abstraction which, in turn, supplies input to the Seismic Scenario Class in the TSPA. The input to the Seismic Consequence Abstraction falls into two general areas:

1. Rockfall - Damage to emplacement drifts as a function of peak ground velocity. The damage takes the form dynamic impact of rock blocks to the drip shield, and static load of the accumulated rubble on the drip shield following partial or complete collapse of the drift.

2. Drift Profile Change - Breakout and enlargement of the emplacement drifts as a function of peak ground velocity for lithophysal and nonlithophysal units.

Rockfall masses, velocities and drip shield impact locations, output from the drift degradation analyses, are used for structural stability and damage estimates of the drip shield. The Seismic Consequence Abstraction conservatively assumes that complete collapse of drifts in the lithophysal rocks occurs coincident with the $1 \times 10^{-4}$ (approximate PGV of $0.5 \mathrm{~m} / \mathrm{sec}$ ) event. Static load from accumulated rubble was determined for the assumption of complete collapse of the emplacement drifts. The load distributions at 30 elements around the drip shield from six different complete collapse simulations (using the UDEC program) are used as input to structural analysis of the drip shield.

The drift profile changes estimated from collapse of the drifts are used in the Abstraction of Drift Seepage to estimate changes in seepage flux to emplacement drifts in the event of a seismic event. Again, since complete collapse is assumed for the $1 \times 10^{-4}$ level, then drift profile changes to two times the original diameter.

Based on the intended use described above, the Technical Work Plan for: Regulatory Integration Modeling of Drift Degradation, Waste Package and Drip Shield Vibratory Motion and Seismic Consequences (BSC 2004 [DIRS 171520], Section 2.2.1) requires Level III Validation.

\subsubsection{Confidence Building During Model Development to Establish Scientific Basis and Accuracy for Intended Use}

Section 2.2.1.4 of the Technical Work Plan for: Regulatory Integration Modeling of Drift Degradation, Waste Package and Drip Shield Vibratory Motion and Seismic Consequences (BSC 2004 [DIRS 171520], Section 2.2.2) specifies criteria for confidence building during model development. Additionally, the development of the model should be documented in accordance with the requirements of Section 5.3.2(b) of AP-SIII.10Q. The development of the drift degradation models for lithophysal and nonlithophysal rock types have been conducted according to these criteria, as follows: 
1. Selection of input parameters and/or input data, and a discussion of how the selection process builds confidence in the model. [AP-SIII.10 Q 5.3.2(b) (1) and AP-2.27Q Attachment 3 Level I (a)]

The types and quality of the data selected as input builds confidence in the model. The geotechnical parameters and information that are inputs to the drift degradation analyses are site specific and have been collected by either field mapping or laboratory testing. The site specific geotechnical information includes:
a. Fracture geometry
b. Fracture mechanical properties
c. Intact rock physical and mechanical properties
d. Rock mass mechanical properties
e. Seismic ground motion
f. Rock thermal properties
g. Repository layout information.

Section 4.1 provides a discussion of the inputs and Table 4-1 identifies the data and design parameters used. A detailed discussion of the mineralogy, texture, fracturing, and porosity are given in Section 6.1.4 and in Appendix O. Further justification for the bases of selection of input parameters for the mechanical model for lithophysal rocks is covered in Section 7.3.2. Discussions of parameter ranges and uncertainties are covered in Section 6.5. Model assumptions have been described in Section 5. Thus, this requirement can be considered satisfied.

2. Description of calibration activities, and/or initial boundary condition runs, and/or run convergences, simulation conditions set up to span the range of intended use and avoid inconsistent outputs, and a discussion of how the activity or activities build confidence in the model. Inclusion of a discussion of impacts of any non-convergence runs. [(AP-SIII.10Q 5.3.2(b)(2) and AP-2.27Q Attachment 3 Level I (e)]

A general discussion of the overall model domain, rock mass characteristics, and generation of representative rock volumes are described in Section 6.1. Additional discussions are provided in section 7.4, 7.5, 7.6, and 7.7. The set-up of the thermal-mechanical simulations is described in Section 6.2 and Appendix C. The set-up of the three-dimensional simulations of drift degradation in the nonlithophysal units is described in Section 6.3 and Appendix C. The set-up of the simulations for drift degradation in the lithophysal units is discussed in Section 6.4. Calibration activities for the models are described in Sections 7.5.1 and 7.6.4. The input and output files for the simulations (all simulations completed and therefore converged) are listed in Appendix A. The simulation conditions accounted for the rock types encountered at the repository horizon (lithophysal and nonlithophysal units), account for the effects of thermal-mechanical coupling, and addressed the seismic loading using site-specific ground motions for the preclosure and postclosure periods. Therefore, the drift degradation analyses have addressed the conditions that span the range of its intended use. This requirement can be considered satisfied. 
3. Discussion of the impacts of uncertainties to the model results including how the model results represent the range of possible outcomes consistent with important uncertainties. [(AP-SIII.10 Q 5.3.2(b)(3) and AP-2.27Q Attachment 3 Level 1 (d) and (f)].

Treatment of uncertainty is discussed in Section 6.5. Uncertainties associated with model inputs are listed in the order of their impact on model results as follows:

a. Rock mass mechanical properties data

b. Seismic ground motion data

c. Static fatigue and long-term strength data

d. Fracture geometry data

e. Intact rock physical and mechanical properties data

f. Fracture mechanical properties data

g. Rock thermal properties data

Sensitivity studies that represent the range of possible outcomes of these parameters can be found in Sections 6.3.1 and Sections 6.4.2. An evaluation of alternative conceptual models can be found in Section 6.7. These criteria can be considered satisfied.

4. Formulation of defensible assumptions and simplifications. [AP-2.27Q Attachment 3 Level I (b)].

Discussions of assumptions are provided in Section 5. Simplifications required for the set-up of the three-dimensional analyses of the nonlithophysal units are discussed in Section 6.3.1. Discussions of the simplifications necessary for the two-dimensional analyses of lithophysal units are provided in Sections 6.4.1 and 7.6.2.

5. Consistency with physical principles, such as conservation of mass, energy, and momentum. [AP-2.27Q Attachment 3 Level I (c)]

Consistency with physical principles, such as conservation of mass, energy, and momentum is maintained through the selection and use of the appropriate geotechnical codes identified in Section 3. The numerical models discussed are commercially available software codes that have been extensively and rigorously tested. The programs have extensive User's Manuals that provide detailed derivation of the implementation of the governing equations, the mathematical description of the constitutive models, and verification of the accuracy and limitations of the programs through comparison of results to analytical solutions and example problems. These derivations and verification of ability to satisfy equilibrium and energy conservation are provided in the software User's Manual (Itasca Consulting Group 2002 [DIRS 160331]). Additional discussion can also be found in Section 7.6.7.2 regarding the use of UDEC and accounting for thermally induced expansion and stresses.

The UDEC and 3DEC programs have been commercially marketed for approximately 20 years, and are used extensively in the civil construction, mining, waste disposal, and geotechnical industries. The UDEC program, originally developed under contract to the U.S. Army Corps of Engineers' Waterways Experiment Station in the mid-1970s, was initially used as a publicly available research tool in geomechanics. The predecessor of 
UDEC, the Rigid Block Model, was developed in the early 1970's (Itasca Consulting Group 2002 [DIRS 160331]). Both UDEC and 3DEC have been used for design studies and analysis of field experiments on nuclear waste repository projects in the United States, Canada, Sweden, United Kingdom, France, and Finland. The PFC program has been available commercially for approximately eight years, although its initial development as a program for research in soil and granular materials mechanics dates to the late 1970's (Cundall and Strack 1979 [DIRS 162194]). Currently, PFC is being used extensively as a research and design tool in geomechanics, powder compaction, structural geology and tectonics, oil production, etc. A recent symposium dedicated to use of PFC (Konietzky 2003 [DIRS 162198]) provides a description of the extent of application of this approach.

\subsubsection{Confidence Building After Model Development to Support the Scientific Basis of the Model}

Post-development model validation is to be performed using two or more methods as described in Section 5.3.2c of AP-SIII.10Q, Models, consistent with Level III model validation expectations. Validation of drift degradation models is accomplished by the following methods:

- Corroboration with laboratory measurements or relevant observations not previously used to develop or calibrate the model

- Corroboration with results of alternative mathematical models developed independently

- Corroboration with data published in refereed journals or literature

- Technical review by reviewers independent of the development, checking, and interdisciplinary review of the model documentation.

The model validation activities discussed in this report follow the Level III validation requirements given in AP-SIII.10Q, at a minimum, while exceeding these requirements in some instances. No further activities are needed to complete this model validation for its intended use.

\subsubsection{Validation Criteria}

The prediction of rockfall requires that the models be able to represent:

- The geologic structure that creates rock blocks surrounding the tunnels needs to be developed from field geologic mapping and represented in a realistic fashion in the numerical rockfall model.

- The rock mass transient stresses induced by heating or ground motions

- The interaction of the stresses and geologic structure, including, in the lithophysal rock, the potential for intact rock mass failure, fracturing, and formation of rock blocks that can detach themselves from the surrounding rock mass. 
With these points in mind, the criteria for a Level III validation of the drift degradation models, which address both adequacy of the scientific basis and accuracy of the model, are as follows:

\section{For mechanical models of nonlithophysal rock:}

- The geometry and variability of geologic structure need to be represented in the rockfall (3DEC) model in a qualitatively reasonable fashion. The "synthetic" fracture geometries and their variability developed by FracMan and used as input to 3DEC needs to be quantitatively calibrated against field-measured geometry data from detailed line surveys and full periphery geologic maps. This calibration, presented in Section 6.1.6 ensures that the resulting block geometries will reflect in situ block structure.

- The mechanical constitutive model of the fractures in 3DEC needs to be validated against the laboratory direct shear testing data.

- The ability of the numerical model to accurately represent seismic boundary conditions and wave transmission through the rock mass needs to be verified.

- The overall ability of the model to adequately represent the dynamic stressing effects of the ground motion on tunnel stability needs to be validated.

\section{For mechanical models of lithophysal rock:}

- The material model and analyses must account for the variability of rock mass properties resulting from variability of porosity in the lithophysal rock.

- The material model and its numerical implementation must provide the ability to represent, in a realistic fashion, the yielding response of lithophysal rock in laboratory specimens and around tunnels, and the associated fracturing into blocks that can detach themselves from the surrounding rock.

- The model must account for dynamic boundary conditions properly, and the subsequent interaction of dynamic stresses with rock mass yielding.

\subsection{DEVELOPMENT OF A MECHANICAL MATERIAL MODEL FOR LITHOPHYSAL ROCKS AND SELECTION OF INPUT PARAMETERS}

\subsubsection{Introduction}

Prior to presentation of validation exercises for the lithophysal rockfall model, a description of the development of the model is given. This is done so that the basic considerations inherent in the model development that impact validation methods can be understood.

\subsubsection{Description of the Lithophysal Rocks}

The Tptpul and Tptpll comprise roughly 85 percent of the repository emplacement area. A detailed description of the mineralogy, texture, fracturing, and porosity are given in Section 6.1.4 and in Appendix O. A review of the aspects of the geology important to the mechanical behavior 
is provided in this section. From a mechanical standpoint, the lithophysal rocks are composed of two distinct components: the matrix groundmass (including fracturing) and the porosity. The matrix groundmass is mineralogically, similar to the matrix of the nonlithophysal rocks. The primary difference in the groundmass of the Tptpll and Tptpul is in the type and extent of fractures. The Tptpll is intensely fractured with short-length, rough, and interlocking inter-lithophysal fractures which have a predominant vertical orientation with spacing on the order of centimeters. Figure 7-1a is a photograph of a 12-in. diameter core sample removed from the Tptpll showing the intensely fractured nature of this unit, creating intact block sizes a centimeters on a side. The rough and interlocking nature of the fractures is an important feature in that the periphery of excavations are stable under in situ conditions without failure along fracture boundaries. This is contrasted by Figure 7-1b showing the wall of an alcove in the Tptpul, off the ECRB Cross-Drift, showing the typical unfractured matrix groundmass in this unit.

The rock mass porosity in the lithophysal units has been shown to be the primary physical factor that governs elastic and strength properties (Price et al. 1985 [DIRS 106602]). The porosity is found in three basic components: the matrix grain to grain porosity, which averages around 10 percent in the Topopah Spring sub-units (Price et al. 1985 [DIRS 106602]); the lithophysal void porosity; and the porosity of alteration, which includes lithophysal rims and spots. Figure 7-2 shows the variation in lithophysal cavity percentage within the Tptpll in the ECRB Cross-Drift as determined by direct tape and angular measurement (Appendix O). This plot shows that the lithophysal cavity porosity varies from approximately 10 to 30 percent with variability on a scale of 5 to $10 \mathrm{~m}$.

The lithophysal cavities vary in size and shape, with characteristics that are somewhat different in the Tptpul and Tptpll.

The lithophysae in the Tptpul:

- Tend to be smaller (roughly 1 to $10 \mathrm{~cm}$ in diameter)

- Are more uniform in size and distribution within the unit

- Vary in infilling and rim thicknesses

- Have a volume percentage that varies consistently with stratigraphic position

- Are stratigraphically predictable.

In contrast, the lithophysae in the Tptpll:

- Tend to be highly variable in size, from roughly $1 \mathrm{~cm}$ to $1.8 \mathrm{~m}$ in size

- Have shapes that are highly variable from smooth and spherical to irregular and sharp boundaries

- Have infilling and rim thickness that vary widely with vertical and horizontal spacing

- Have volume percentages that vary consistently with stratigraphic position

- Are stratigraphically predictable. 


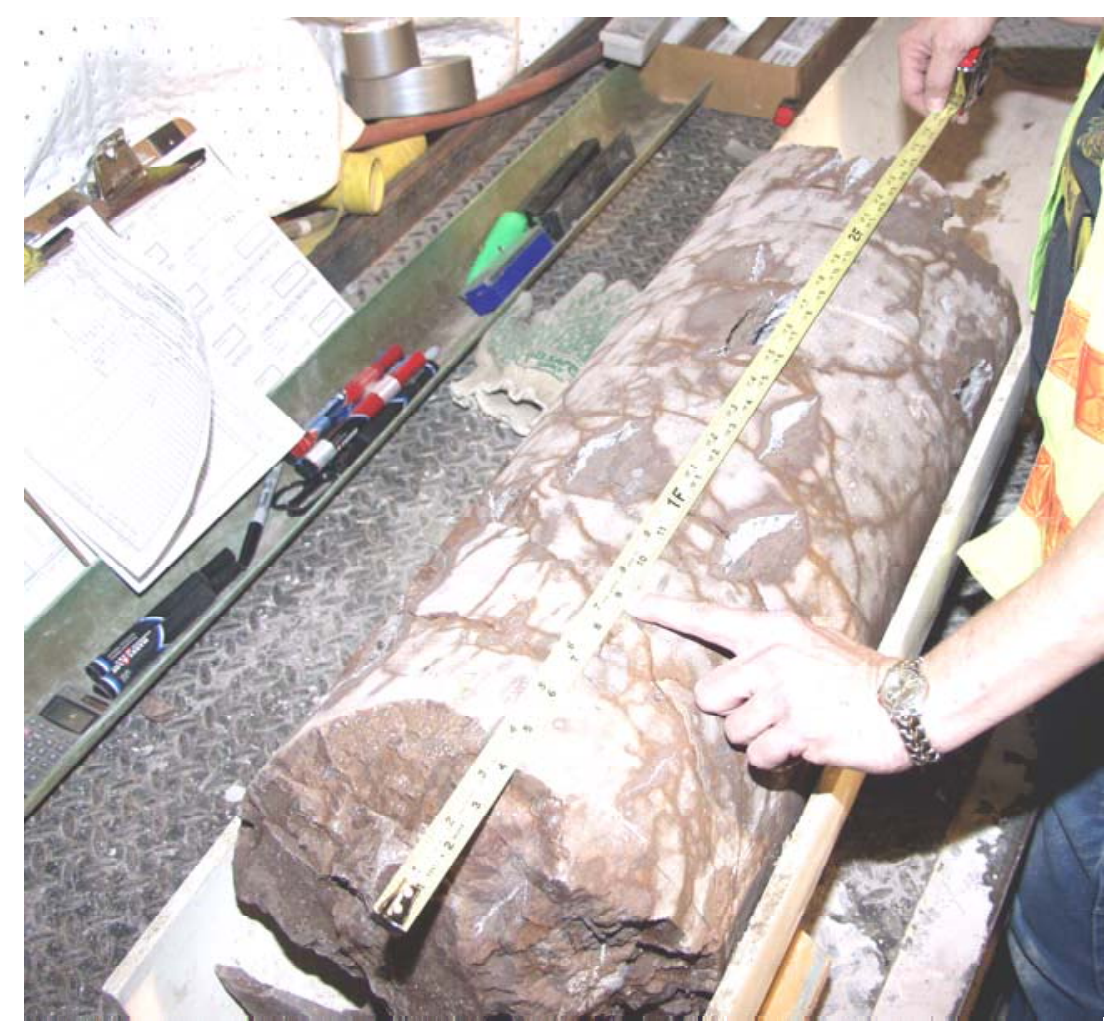

a)

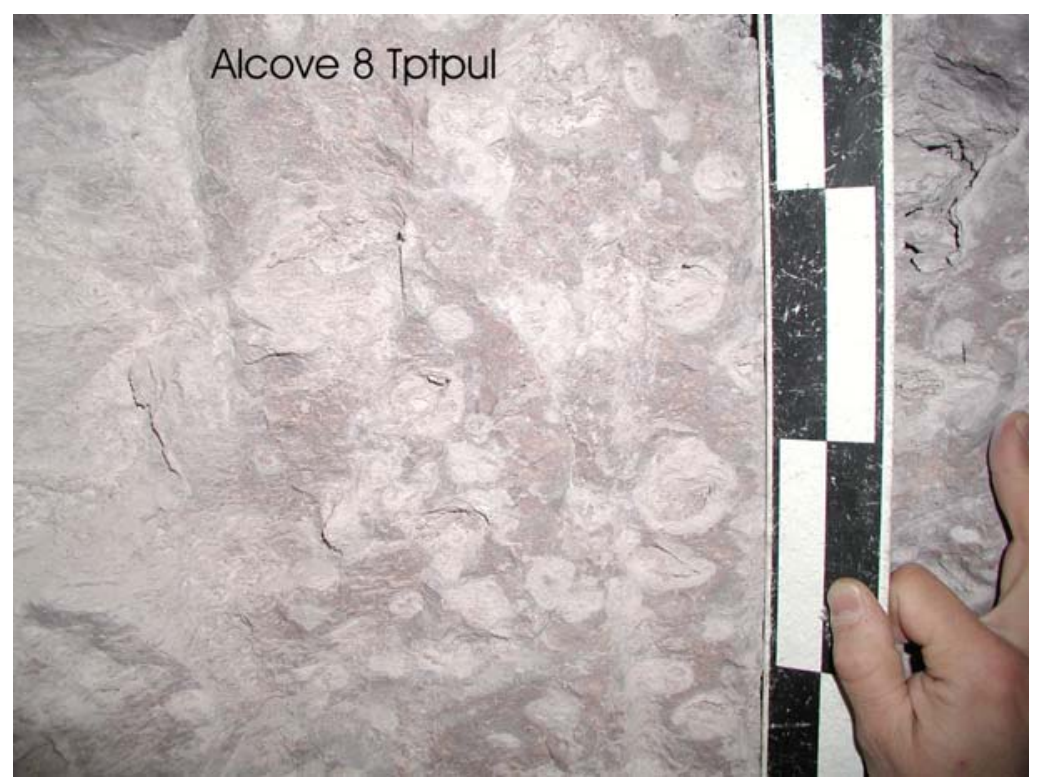

b)

NOTE: The core (top photo) was drilled with water and the porous rims and fractures (many of which have rims) retain water and appear dark, whereas the matrix-groundmass, which has minimal porosity, dries in a relatively short amount of time.

Figure 7-1. (a) Matrix Fracturing in the Tptpll in 12-in-Diameter Core and (b) Lack of Fracturing in Matrix of Tptpul as Seen in the Wall of Alcove 8 off the ECRB Cross-Drift 
In general, the lithophysae diameter is much less than the diameter of the emplacement drifts $(5.5 \mathrm{~m})$. As shown in Figure 7-2, the variability of the porosity along the ECRB Cross-Drift is on the order of $5 \mathrm{~m}$ (additional data analysis is provided in Appendix $\mathrm{O}$ ). In representing the mechanical response of the lithophysal rocks, it is judged to be adequate to use a two dimensional, cross-sectional modeling approach in which the rock mass is considered to be of constant porosity, homogeneous and isotropic within that section.

\subsubsection{Model Requirements for Drift Degradation Prediction}

To represent drift degradation mechanisms and rockfall, the mechanical model and the numerical method in which it is embedded must have the following capabilities:

- The model must provide a general capability of modeling in situ stress and thermal and seismic loading of the rock mass.

- The model must represent the effects of porosity and matrix pre-existing fracturing on the elastic and strength properties of the material.

The model must allow internal fracturing and detachment of the rock mass (i.e., rockfall) to occur in response to gravity, thermal effects, and seismic shaking.

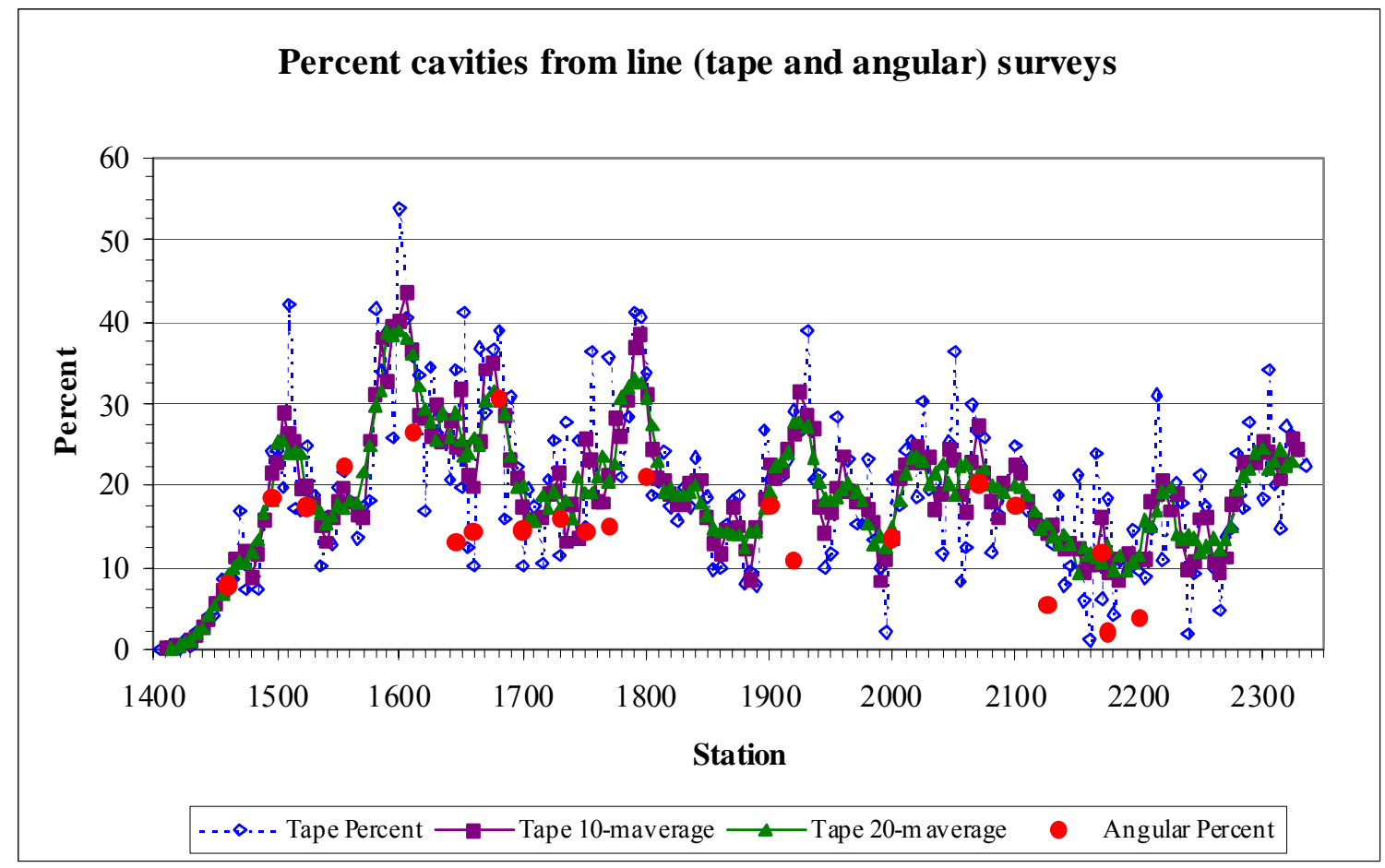

Source: Tape percent and Angular percent from DTN: GS021008314224.002 [DIRS 161910]; Tape 10-m average and Tape 20-m average from DTN: MO0408MWDDDMIO.002, file Drift Deg AMR AC T-Trav.xIs.

Figure 7-2. Variation in Lithophysal Cavities in the Tptpll in the ECRB Cross-Drift from Top (Left) to Bottom of the Sub-Unit as Estimated by Tape and Angular Measurement Collected at 5-m Intervals 
The above model requirements imply the necessity of use of a discontinuum approach to representation of the rock mass, as described in Sections 6.3.1 and 6.4.2.

\subsubsection{Laboratory and Field Database for Constitutive Model Development}

The development of the laboratory and field database of material properties for lithophysal rocks is presented in detail in Appendix E, Section E.4. This section describes large core laboratory testing program that has been used to define the relationship of compressive strength and Young's modulus to lithophysal porosity content. The use of the PFC model (described later) to extrapolate the impact of lithophysae size, shape and distribution on the mechanical properties is also presented, and the proposed bounding ranges determined. The rock mass mechanical properties ranges are subdivided into five equally divided categories for subsequent sensitivity studies as described in Section 6.4. These properties provide the basis for the model development described in Section 7.4.

\subsection{STRATEGY FOR DEVELOPMENT OF A MECHANICAL MATERIAL MODEL FOR LITHOPHYSAL ROCKS (CONFIDENCE BUILDING DURING MODEL DEVELOPMENT)}

\subsubsection{Continuum-Based Approach to Representing Rock Masses}

The objective of the drift degradation analyses presented in this report is to predict the amount and particle size distribution of rockfall in the repository drifts due to stresses induced by the heat released by the emplaced waste, due to seismically related ground motions, and due to time-dependent strength loss of the rock mass. A standard approach for solving excavation stability problems in geotechnical engineering is the use of numerical models based on continuum mechanics (Figure 7-3). This alternative conceptual model is discussed in Section 6.7. Such an approach is quite effective if the rock mass, in response to stressing, eventually arrives at a state of mechanical stability and where the primary purpose of the modeling is the computation of stress redistribution around an opening or determination of the final displacement profiles. However, difficulties are encountered if a continuum model is used for prediction of a mechanical system (i.e., a tunnel) that does not arrive at stable condition. Continuum models use constitutive relations to describe the mechanical behavior of a material. In rock, the mechanical effects of fractures and other features are "lumped" into the constitutive model, often using empirically based methods that take into account the spacing and continuity of the fractures, the roughness and alteration of the fracture surfaces, and the laboratory-determined properties of the intact rock blocks (e.g., Hoek 2000 [DIRS 160705]). 


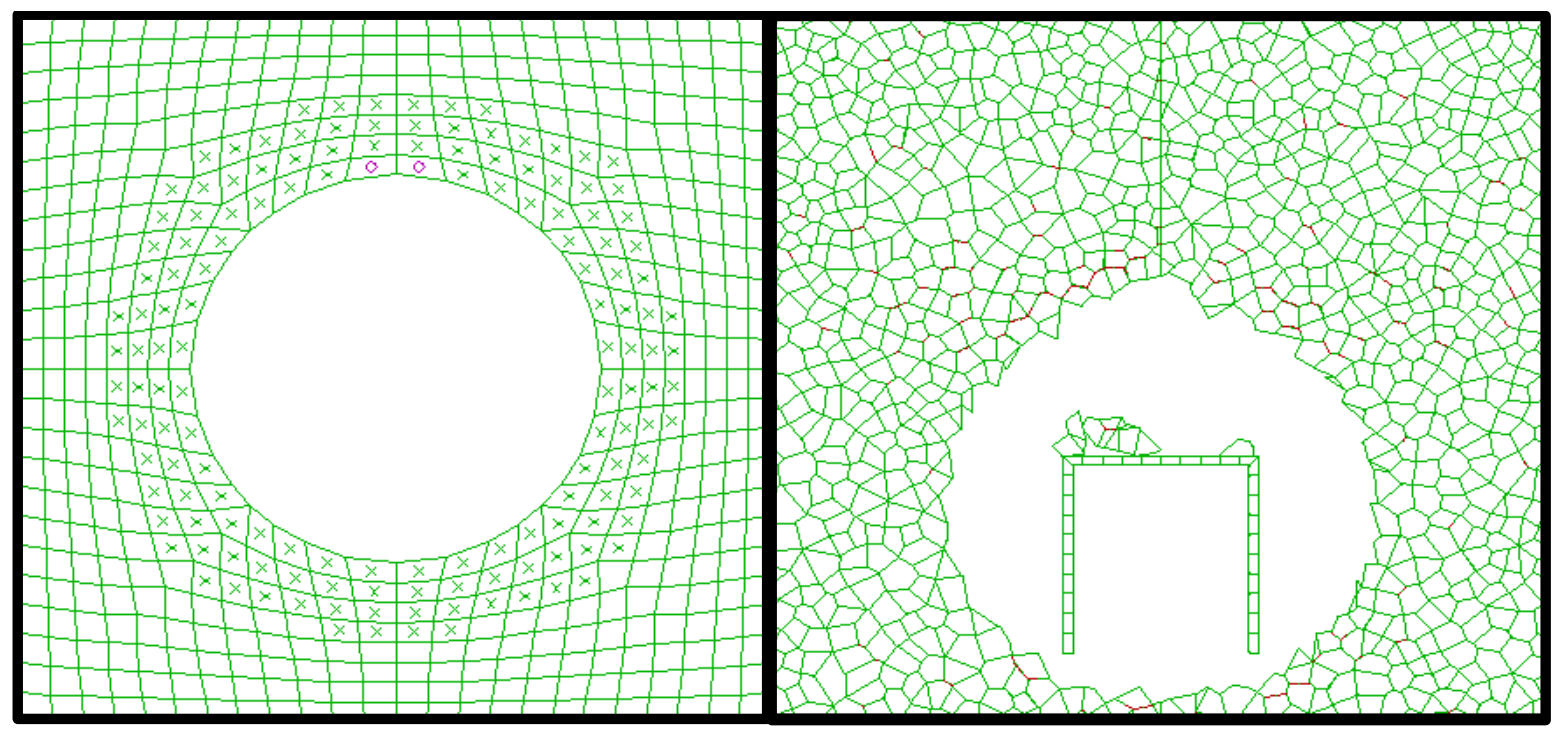

NOTE: The continuum approach models yield of the rock through use of a material model that enforces plasticity relations (note marked elements). Rock breakage and separation is not possible in this approach. The discontinuum approach also represents the rock mass using similar material models, but provides the capability for the rock mass to fracture and break apart on potential fracture surfaces.

Figure 7-3. Schematic Illustration of Continuum (Left) and Discontinuum (Right) Approaches to Modeling Drift Stability

A linearly elastic-perfectly plastic material model with Mohr-Coulomb yield criteria is a constitutive model often used to represent mechanical behavior of a rock mass. Because the material strength of a perfectly plastic, Mohr-Coulomb model does not decrease as a function of plastic deformation, this model will show indications of material yielding (i.e., plastic deformation) in different portions of the model, but will never actually predict the instability or rockfall. To be able to predict rockfall, it is necessary to use some kind of strain-softening constitutive model, in which strength degrades as a function of deformation after the peak-strength of material has been reached. However, the strain-softening model, within the framework of continuum mechanics, is the subject of much research and debate, and not applicable with any degree of certainty to estimates of physical fracture and rockfall as required here. For this reason, continuum modeling methods are not used to represent rockfall.

\subsubsection{Discontinuum Approach to Representing Rock Masses}

The estimation of rockfall requires that the modeling technique and mechanical material model be capable of representing physical fracture of the rock mass and separation of the intact rock mass into blocks of material. In particular, an estimate of the size distribution of particles is desired. This requires the use of a discontinuum numerical method (i.e., a method in which slip and separation of contacting rock blocks can be estimated [Figure 7-3]). The following strategy is based on use of discontinuum methods for development of a material model for lithophysal rocks. 


\subsubsection{Strategy for Discontinuum Material Model Development}

Typically, development of a mechanical material model for a rock mass is based on extensive laboratory testing of rock core, determination of strength and moduli reduction factors via in situ mapping of rock quality, followed by validation against field measurement. Such an approach to development of a material model for the lithophysal rocks presents a number of challenges. As discussed in the previous section, it is problematic to conduct an extensive mechanical properties testing program on lithophysal rocks due to the need to obtain and test large cores or to create large in situ samples from sawing or drilling. Additionally, direct determination of the true triaxial stress behavior of samples is difficult since pressure vessels to provide confinement to large core samples are not available. It is also not possible to conduct testing on a wide range of lithophysae shapes and size distributions. Finally, geotechnical classification systems are not particularly applicable to the lithophysal rocks due to a lack of contemporary experience in construction and testing in this type of rock mass.

As described previously, the database available for model development includes: 1) uniaxial and triaxial compression and direct pull tensile testing of nonlithophysal rock; and, 2) uniaxial compression testing of large scale cores and in situ blocks of lithophysal tuff. To overcome these sampling and testing limitations, an alternative strategy is used here, as illustrated in Figure 7-4. In this section, an approach is described in which a physics-based "micromechanical," discontinuum numerical modeling program - the PFC program (Itasca Consulting Group 2002 [DIRS 160331]; Potyondy and Cundall 2001 [DIRS 156895]) —is used as a numerical "laboratory" to simulate and test the basic deformation and failure response mechanisms of lithophysal tuff. The PFC program was chosen due to its ability to simulate the physics of deformation and fracture of a bonded granular matrix that contains void space of varying shape, size and porosity. The program is first validated against the existing laboratory compression data. Specifically, it is demonstrated that a detailed understanding of the basic physical mechanisms of the rock mass behavior can be obtained without resorting to empiricism or complex constitutive modeling. The model is then used to extend the laboratory data by conducting numerical experiments on simulated samples of lithophysal tuffs at various physical conditions of porosity, lithophysae shape and distribution, as well as various levels of confinement and applied stress. From this modeling, it is possible to understand the size-scaling and variability issues introduced by lithophysae shape and distribution, and their impact on rock mass properties and failure criteria. 


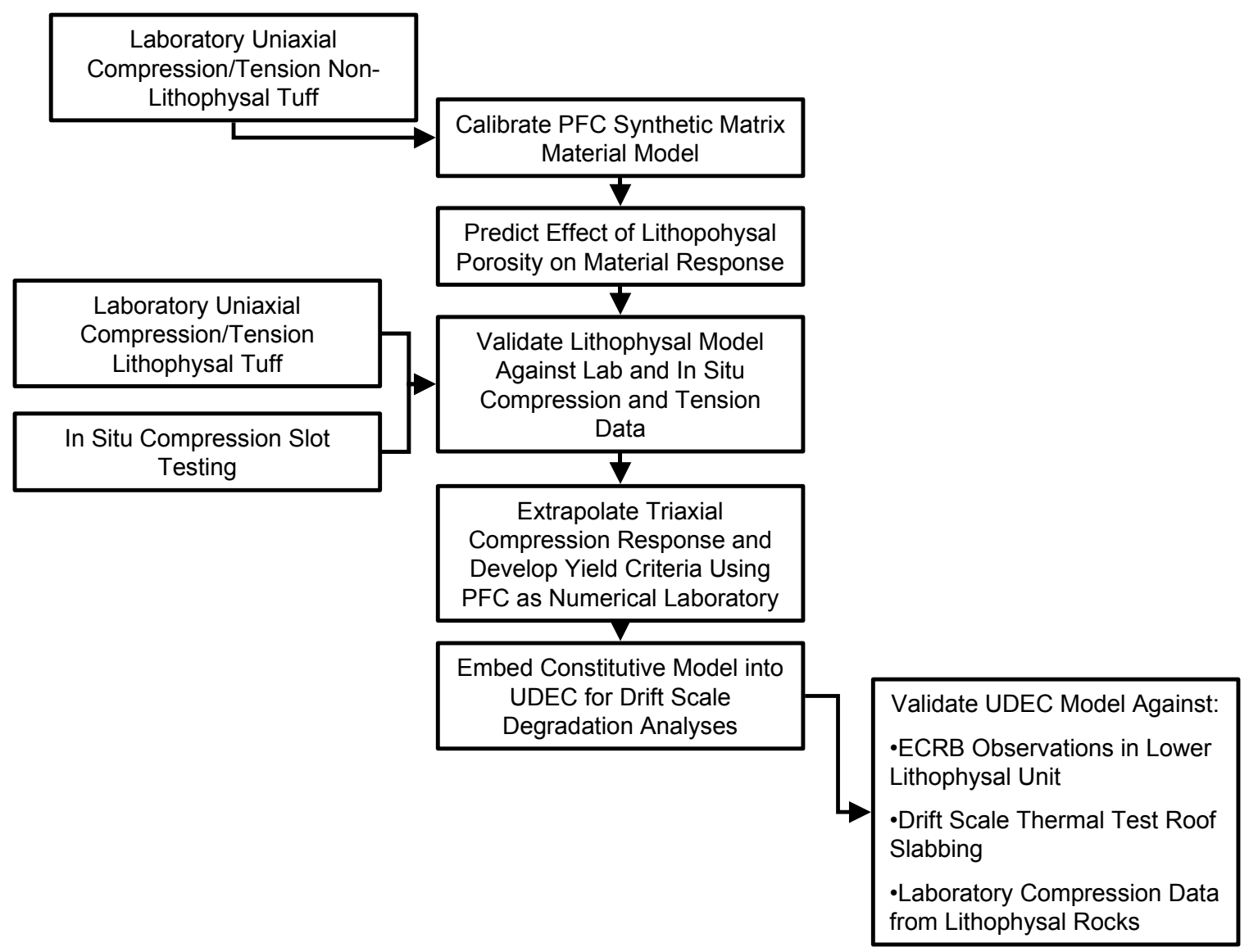

Figure 7-4. General Approach to Validation of Mechanical Material Model for Lithophysal Rocks

Although possible, it is impractical to use the PFC program as a general modeling tool to investigate drift degradation due to the extensive computing demands that result from large-scale problems. Instead, the material model developed from the testing and PFC extrapolation is embedded in the UDEC discontinuum program, which has been used efficiently to examine tunnel-scale seismic, heating and time-degradation issues (see Section 6.4.2).

\subsection{VALIDATION OF THE PFC-A MICROMECHANICAL MODEL REPRESENTATION OF THE MECHANICAL BEHAVIOR OF LITHOPHYSAL ROCK}

\subsubsection{The PFC Model (Confidence Building During Model Development)}

The Particle Flow Code has been qualified for use as indicated in Section 3. The PFC approach (Figure 7-5) represents rock as a number of small, rigid, spherical grains that are bonded together at their contacts with a shear and tensile strength, as well as a grain to grain friction angle after the "contact bond" has been broken. If cementing exists between grains, it can be represented with a "parallel bond" that provides a rotational resistance as well. Details on the mechanics of the PFC program are provided in Itasca Software-Cutting Edge Tools for Computational Mechanics (Itasca Consulting Group 2002 [DIRS 160331]). The deformability of the contacts between particles is represented by a normal and shear stiffness at the contact point. Porosity is 
developed naturally in the model by control of the shape and size of void space between chains of bonded grains. The contact properties and porosity distribution are referred to as "microstructural" properties. Thus, the input conditions necessary for the model are very simple, only contact strength and stiffness. However, as shown below, extremely rich constitutive behavior may develop naturally based on porosity and the few straightforward input properties and their variability throughout the rock.

When load is applied to the grain assembly, forces are transmitted across contacts. If the shear or tensile strength of the contact is reached, failure will occur, and the adjacent particles are free to slide past one another, or to separate. In either case, a fracture is formed and the forces must reorient in some fashion, thus redistributing loads. Realistic failure mechanisms may then develop which can be compared to those observed in the laboratory. Calibration of the model against laboratory testing is necessary via sensitivity studies in which the contact strength and stiffness values are varied and the macroscopic stress-strain response is compared to that monitored.

A discussion of the PFC calibration and extrapolations is provided in this section, including a summary of the approach and results. The PFC program in both two- and three-dimensions was "calibrated" first against laboratory strength tests of nonlithophysal rocks. Since it is considered that the matrix or groundmass material of the Tptpul, Tptpmn, and Tptpll is essentially the same, both mineralogically and mechanically, it is necessary to first make certain the PFC model can represent the mechanical response of the material without lithophysal voids. Once the matrix material response is identified, then representation of the mechanical behavior of the lithophysal material is possible with the simple addition of void space (assuming the consideration of similar matrix is correct).

The tuff can be divided into lithophysal and nonlithophysal types. These two rock types differ significantly in their microstructural and mechanical properties. In the lithophysal tuff, the vast majority of the porosity is concentrated in lithophysae and surrounding vapor-phase altered material, whereas in the nonlithophysal tuffs porosity is more evenly distributed throughout the material. The nonlithophysal tuffs have effective porosities that range from approximately 0.1 to 0.4 (Price et al. 1985 [DIRS 106602], Figure 15). The high-porosity nonlithophysal tuffs have large effective porosities because of the voids between grains, whereas similar effective porosities in lithophysal tuffs arise from the presence of lithophysae and vapor-phase altered material (Price et al. 1985 [DIRS 106602], pp. 25-28). The matrix fabric of the lithophysal tuff is microscopically identical to that of moderately to densely welded nonlithophysal tuff. Price et. al. (1985 [DIRS 106602]) divide the lithophysal tuff into the following three components: a fine-grained matrix $(M)$, large lithophysae $(L)$, and vapor-phase altered material $(A)$ surrounding the lithophysae. Based on the approach described by Price et al. (1985 [DIRS 106602]) for determining bulk properties of lithophysal tuff, the porosity of component-i is denoted by

$$
\phi_{i}=\frac{\left(V_{v}\right)_{i}}{V_{i}}, \quad i=\{M, A, L\}
$$


and the volume fraction of component-i by

$$
P_{i}=\frac{V_{i}}{V,} \quad i=\{M, A, L\}
$$

where $\left(V_{v}\right)_{i}$ is the void volume of component-i, $V_{i}$ is the solid volume of component-i and $V$ is the total volume. The total porosity can be expressed as

$$
\phi=\frac{\left(V_{v}\right)_{M}+\left(V_{v}\right)_{A}+\left(V_{v}\right)_{L}}{V}=\phi_{M} P_{M}+\phi_{A} P_{A}+\phi_{L} P_{L}
$$

The PFC material models lithophysal tuff as a base material with discrete voids. The base material represents both the matrix $(M)$ and the vapor-phase altered material $(A)$ in a smeared fashion, and the discrete voids represent the lithophysae $(L)$. The void porosity, $n_{v}$, defined by Equation 7-1, of the PFC model corresponds with the volume fraction, $P_{i}$, of the lithophysal tuff. The relative distributions of these components for the lithophysal tuff and the PFC model are shown in Figure 7-6. Note that the PFC base material has an inherent porosity (approximately 0.17 and 0.36 , for PFC2D and PFC3D, respectively) that does not correspond with that of the tuff; the tuff microstructure at this small-scale is not reproduced by the PFC material. Only the void porosity of the PFC material can be compared with the lithophysal volume fraction. Also note that $P_{A}$ as a function of $P_{L}$ is not known, but $P_{A}$ must approach zero as $P_{L}$ approaches zero. The microproperties of the PFC material are kept constant for the values of $n_{v}=P_{i}$, and thus, the PFC materials with low void porosity are overestimating the weakening effect of the vapor-phase altered material. One approach to incorporate this effect in the PFC models would be to modify the PFC microproperties as a function of $n_{v}$ such that they match the laboratory data for the lithophysal tuff in the non-zero range of $n_{v}$ and match the nonlithophysal tuff when $n_{v}=0$. This approach has not been adopted here.

The void-filled PFC material can be calibrated by matching the variation of modulus and strength with volume fraction of lithophysal tuff. The laboratory data used for calibration is that shown in Appendix E (Table E-9). The nonlithophysal tuff exhibits a size effect such that larger specimens are weaker with unconfined compressive strength values ranging from approximately 190 to $90 \mathrm{MPa}$ as specimen diameter ranges from 25 to $230 \mathrm{~mm}$ (Price 1986 [DIRS 106589]). The form of a size effect for lithophysal tuff has not been identified, but is considered to be similar to that of the nonlithophysal tuff. The effect of specimen size is not investigated for the PFC models; instead, the PFC models are either 1:1 or 2:1 aspect ratio specimens of one-meter diameter, and microproperties are chosen to match the laboratory data. 


\section{Physics of PFC Model for Rock}

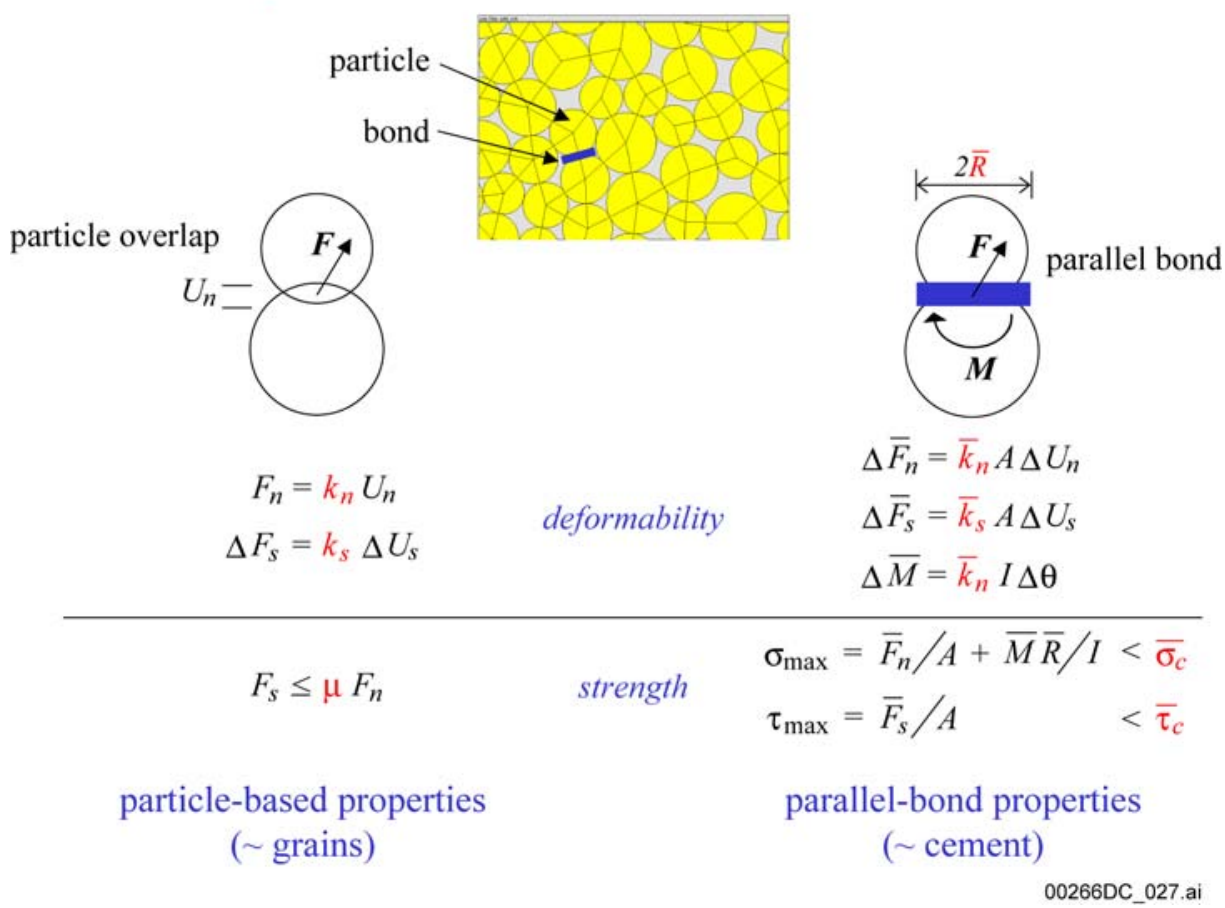

NOTE: Mechanical response in the PFC program is governed by the strength and deformability relationships of the bonds between rigid particles. Two bond types are provided: a simple contact bond (left), and a parallel bond (right), which simulates cement between particles that resists moments as well as shear and normal loads.

$F_{n}=\quad$ normal contact force

$k_{n}=$ normal stiffness

$U_{n}=\quad$ relative normal displacement

$\Delta F_{s}=$ shear contact force increment

$k_{s}=\quad$ shear stiffness

$\Delta U_{s}=$ relative shear displacement increment

$\Delta \bar{F}_{n}=$ axial-directed force increment for bond

$\bar{k}_{n}=$ bond normal stiffness

$A=\quad$ area of bond cross-section

$\Delta U_{n}=$ relative normal displacement increment

$\Delta \bar{F}_{s}=$ shear-directed force increment for bond

$\bar{k}_{s}=$ bond shear stiffness
$\Delta U_{s}=$ relative shear displacement increment

$\Delta \bar{M}=$ bending moment increment for bond

$I=\quad$ moment of inertia of the bond cross-section

$\Delta \theta=\quad$ increment of rotational angle

$F_{s}=\quad$ shear contact force

$\mu=\quad$ contact friction coefficient

$\sigma_{\max }=$ maximum tensile stress acting on the bond periphery

$\tau_{\max }=$ maximum shear stress acting on the bond periphery

$\bar{R}=$ particle radius

$\bar{F}_{n}=$ axial-directed force for bond

$\bar{F}_{s}=$ shear-directed force for bond

Figure 7-5. The Basic Mechanics of the PFC Program 


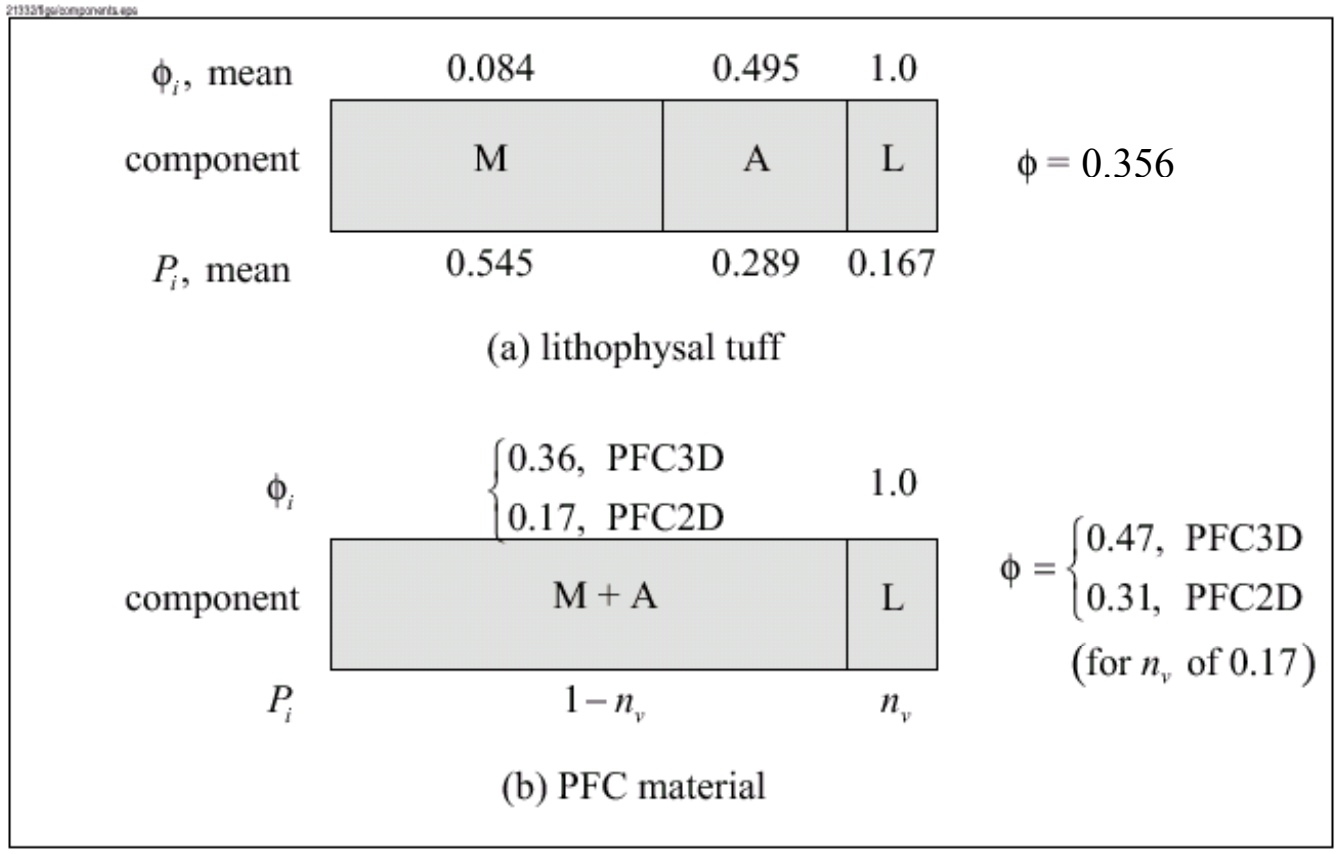

Figure 7-6. Relative Distributions of the Three Components of Lithophysal Tuff for (a) Real Material (Price et al. 1985 [DIRS 106602]) and (b) PFC Materials

\subsubsection{Validation Exercises for the PFC Model}

The PFC model of lithophysal rock is used to extrapolate both quasi-static and time-dependent compression data from existing laboratory test data to examine the impacts of variable size, shape and distribution of lithophysae. This extrapolated information is used to assist in defining the bounding ranges of in situ properties of lithophysal rocks. These ranges are, in turn, used as input to drift-scale calculations of emplacement drift stability resulting from in situ, thermal and seismic loading as well as time-dependent strength loss. Since the PFC model provides input to drift degradation studies, it is considered to require a Level III validation, which requires at least two post-development validation exercises. The following section provides three post-development exercises. The first example tests the ability of the PFC model to provide a reasonable reproduction of the mechanical response of lithophysal rock as determined from large core laboratory testing. The second validation example tests the ability of the PFC model to reproduce the basic creep response of the nonlithophysal matrix material through comparison of the model output to the primary, secondary and tertiary creep response as observed from laboratory creep experiments. The third validation exercise presented is an external technical review of the PFC model for representation of the time-dependent response of Topopah Spring tuff. 


\subsubsection{PFC Post-development Validation Exercise 1 - Simulation of the Stress-Strain Behavior of Nonlithophysal and Lithophysal Rock in Compression and Tension}

The PFC2D and 3D models were first calibrated against laboratory strength and modulus data from large diameter core testing at an approximate mean lithophysal porosity of 15 percent using an idealized model that represented lithophysae as circular voids that are uniformly distributed through the samples. The purpose of the calibration is to set an approximate value for the particle bond strength and stiffness. This calibration was followed by validation through prediction and comparison of the model to the entire large-core compression testing from cores obtained from the Tptpll and Tptpll in the ECRB Cross-Drift and from the Busted Butte site (see Section E.4). Additionally, the mode of failure of rock samples in compression must be similar to that observed in the laboratory.

A sensitivity analysis of the PFC model is then conducted using model samples developed from field "panel" maps created in the Tptpll in the ECRB Cross-Drift. These panel maps (see Appendix O) are used to create PFC samples by "stenciling" the irregular shapes and distributions from 18 panel maps to create realistic lithophysae geometries for the PFC test samples. These samples are then used to conduct simulated uniaxial compression tests to examine the impact of realistic lithophysae geometries on variability in mechanical properties.

Figures 7-7 and 7-8 show PFC2D and PFC3D models of several lithophysal rock "samples" at increasing void ratios that are used to conduct numerical laboratory experiments. Particles are removed to create circular or spherical voids with random location.

Examples of the predicted stress-strain behavior and post-test fracturing response of simulated uniaxial compression simulations for nonlithophysal and lithophysal samples with circular voids and void porosities of 0,10 and 20 percent are shown in Figures 7-9 to 7-11. The models show numerous physical features that correspond well to those observed in laboratory response. The nonlithophysal samples fail through formation of conjugate shear fractures composed of coalescing tensile bond breakages. The response is highly elastic to the point of brittle failure (i.e., there is little observable hysteresis on load-unload cycles directly up to the yield limit). This behavior is a function of the uniform grain structure and welding of the matrix material. The addition of lithophysal voids results in significant decreases in both the strength and modulus. The failure mechanism in this case is a function of tensile splitting between adjacent lithophysal voids due to induced tensile stresses in the thin webbing between voids. The PFC model shows that the failure strength is simply governed by the ratio of void span to webbing thickness. With voids randomly distributed, the thinnest of webbing will fail first, shunting load to other solid webs, resulting in progressive failure of the weakest "link." The resulting stress-strain behavior becomes less brittle in nature due to this progressive failure mode. 

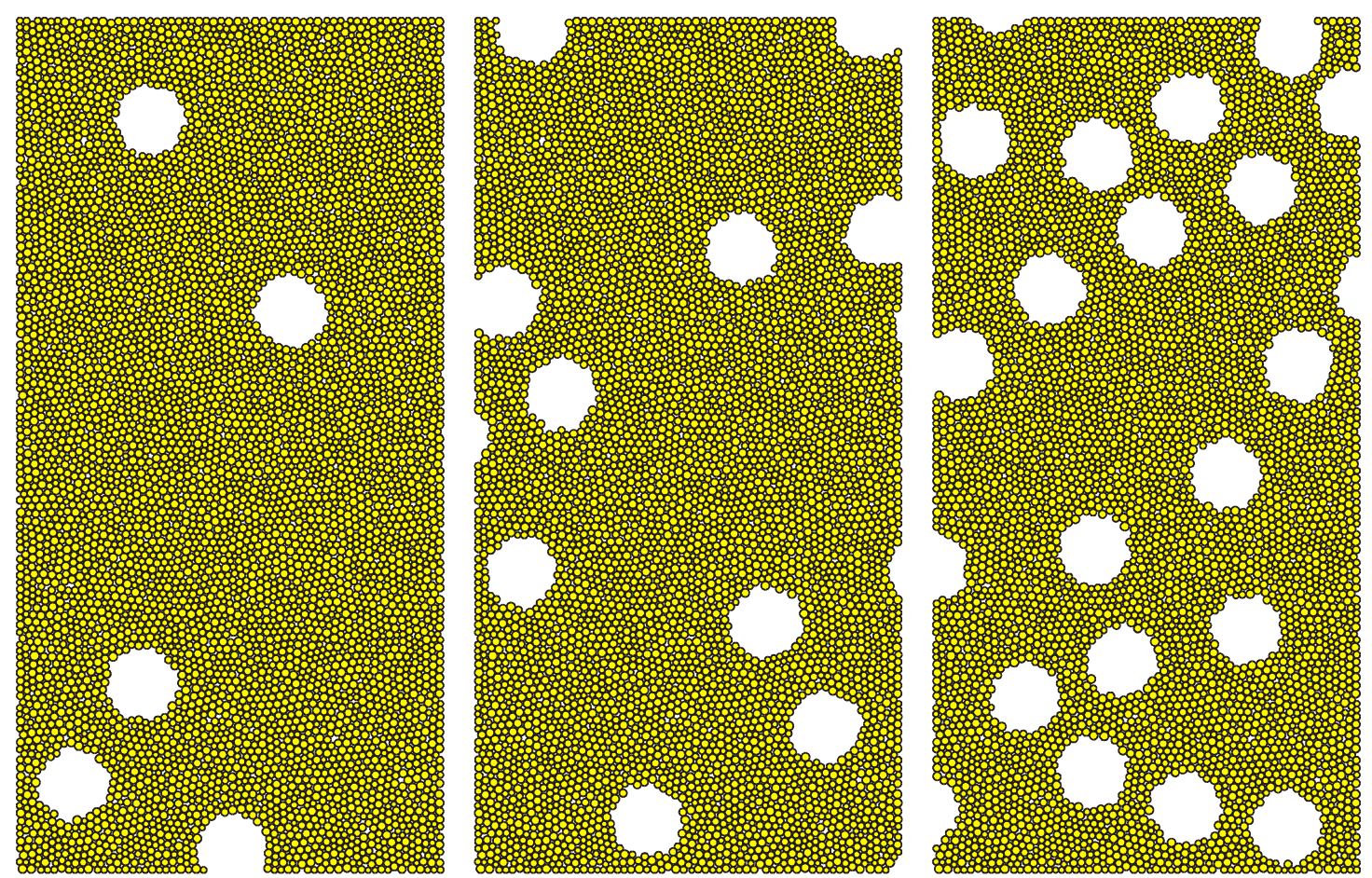

NOTE: Circular Voids; Radius $=83 \mathrm{~mm} ; \mathrm{nv}=0.05,0.10$, and 0.20 .

Figure 7-7. PFC2D Unconfined Compressive Strength Test Specimens
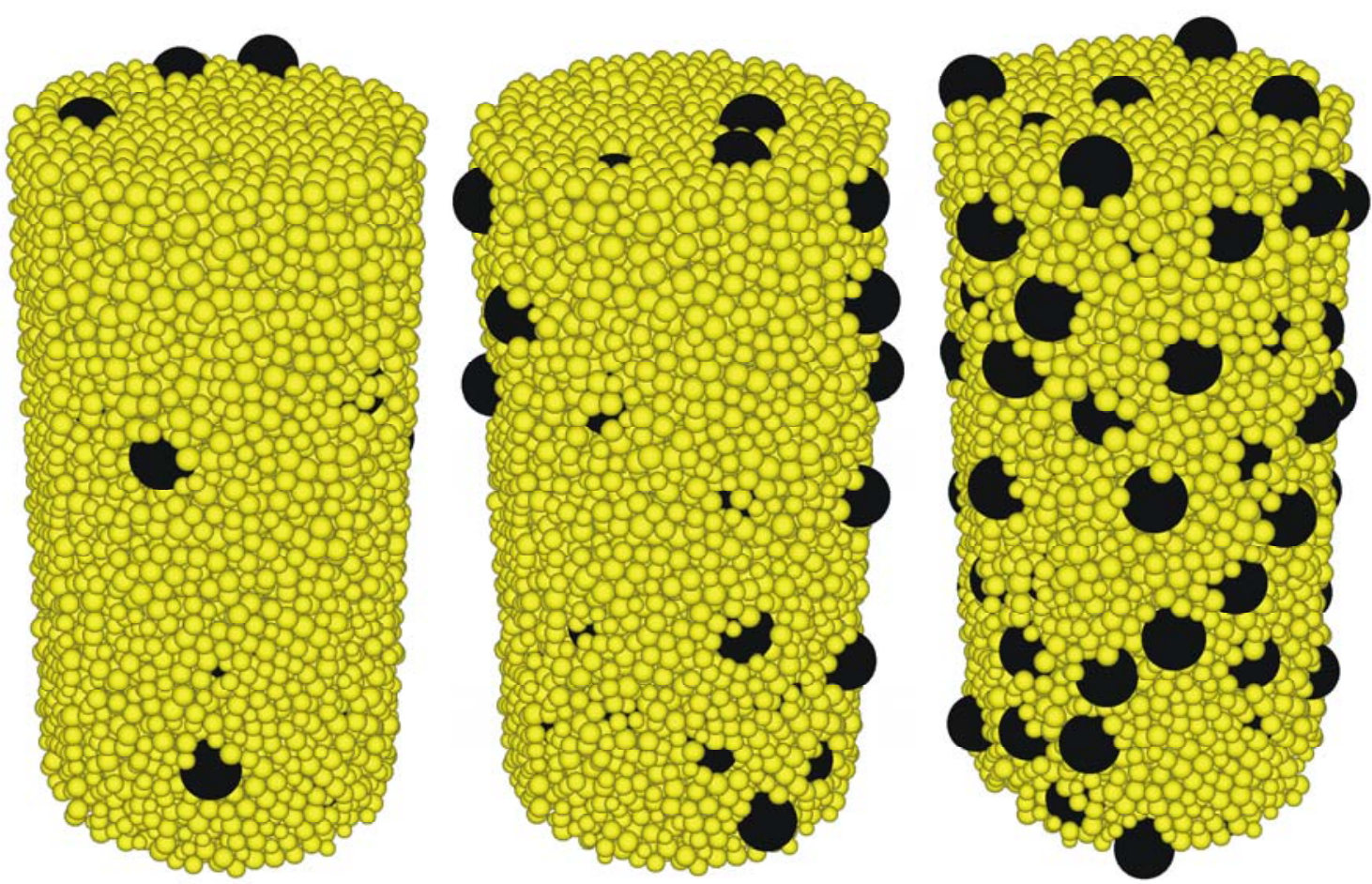

NOTE: Spherical voids; Radius $=83 \mathrm{~mm} ; n_{v}=0.05,0.10$, and 0.20 .

Figure 7-8. PFC3D Unconfined Compressive Strength Test Specimens 


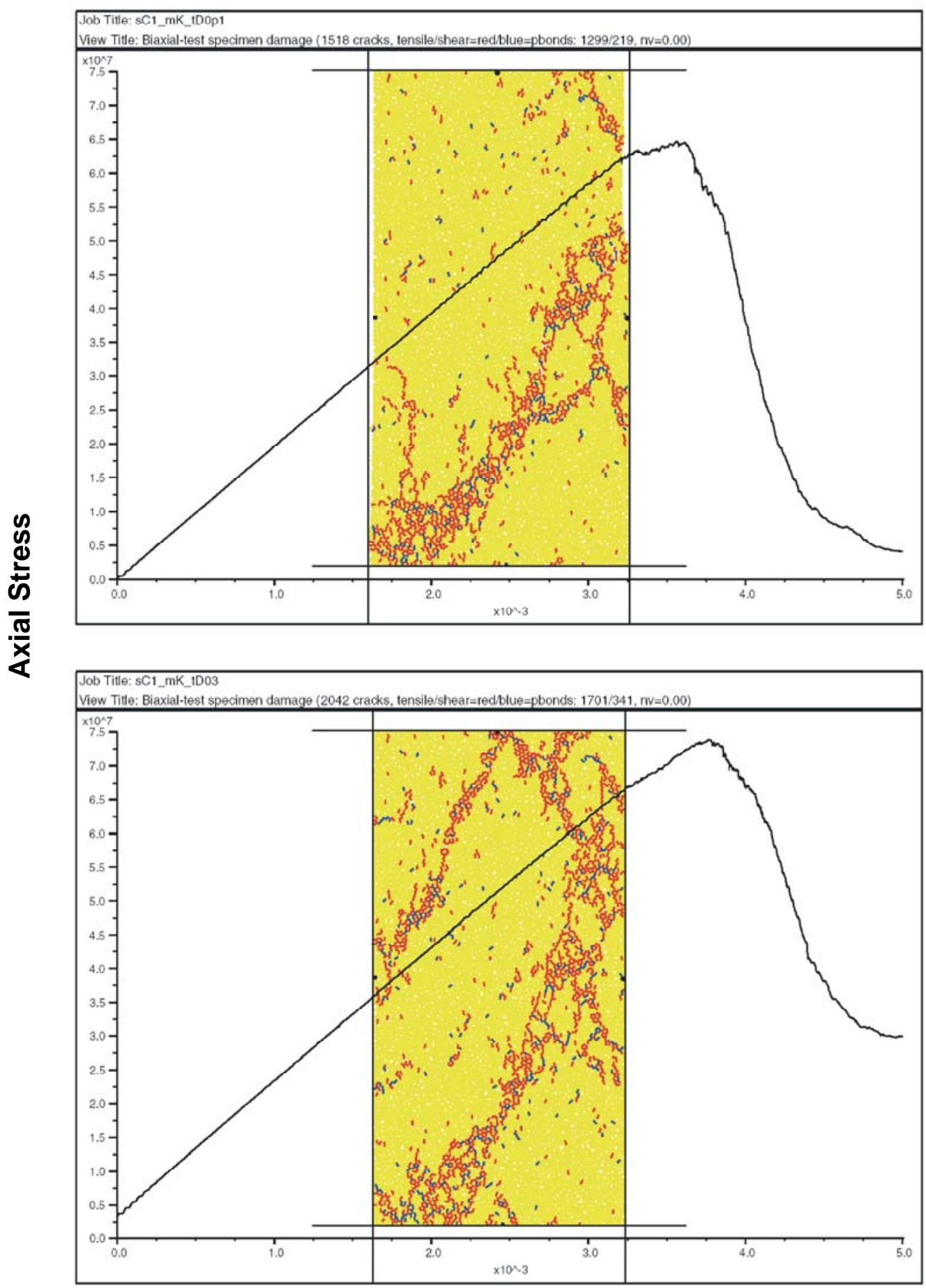

Axial

NOTE: Final sample damage state is plotted with bond failures in tension (red) and shear (blue). Samples fail with typical conjugate shear fractures. Two confining pressures are shown: $0.1 \mathrm{MPa}$ (top) and $3 \mathrm{MPa}$ (bottom). The primary impact of confinement is slightly increased peak and residual strength.

Figure 7-9. PFC2D Simulation of Confined Compression of 2:1 L:D (Length:Diameter) Samples of Nonlithophysal Material $(n v=0)$ Composed of Several Thousand Bonded Particles 


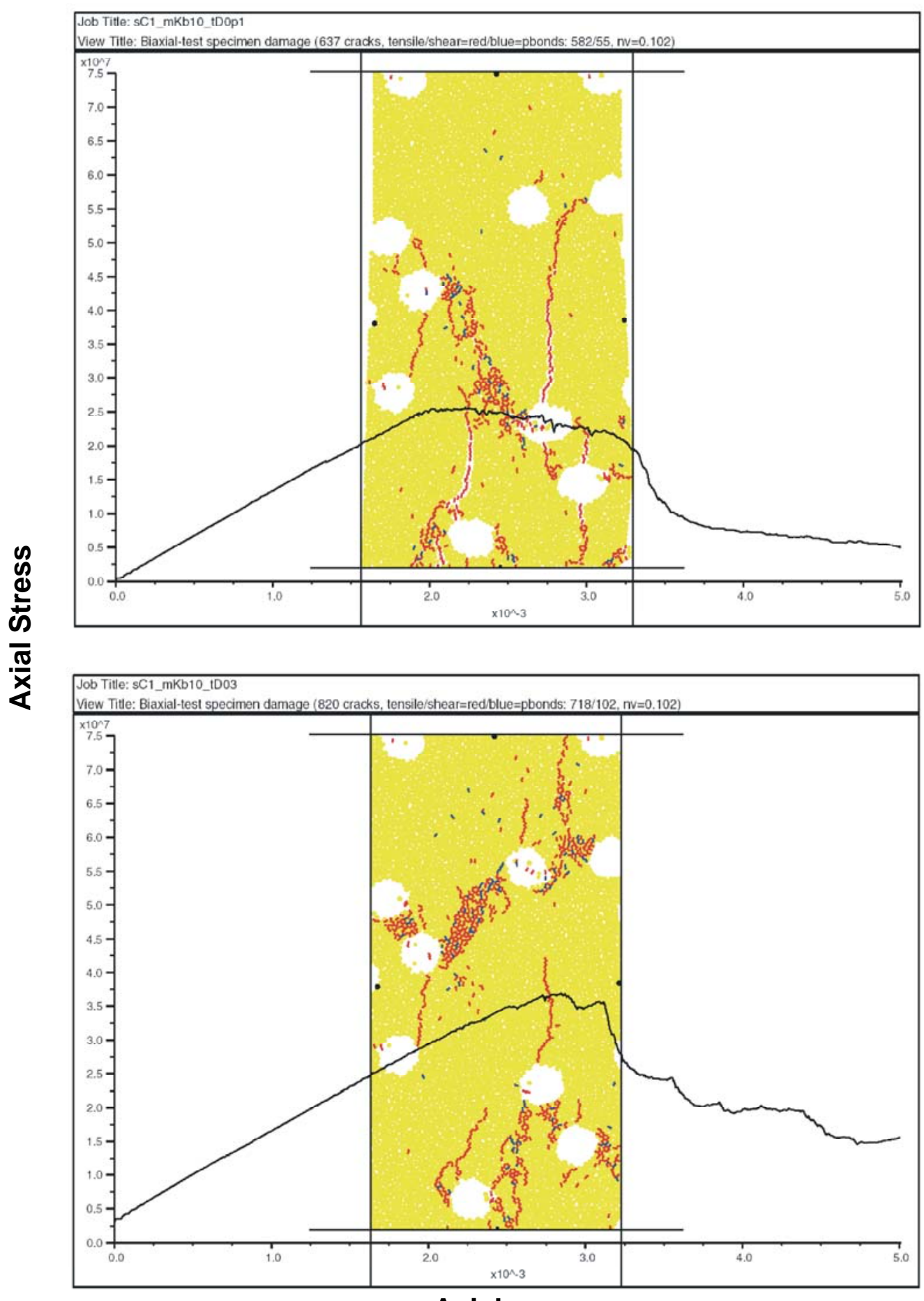

Axial

NOTE: Final sample damage state is plotted with bond failures in tension (red) and shear (blue). Two confining pressures are shown: $0.1 \mathrm{MPa}$ (top) and $3 \mathrm{MPa}$ (bottom). Samples fail in an axial splitting mode which is most pronounced in the low confinement model at left. Note that confinement increases peak strength with increased residual strength.

Figure 7-10. PFC2D Simulation of Confined Compression of 2:1 L:D (Length:Diameter) Samples of Lithophysal Material $\left(n_{v}=0.10\right)$ Composed of Several Thousand Bonded Particles 

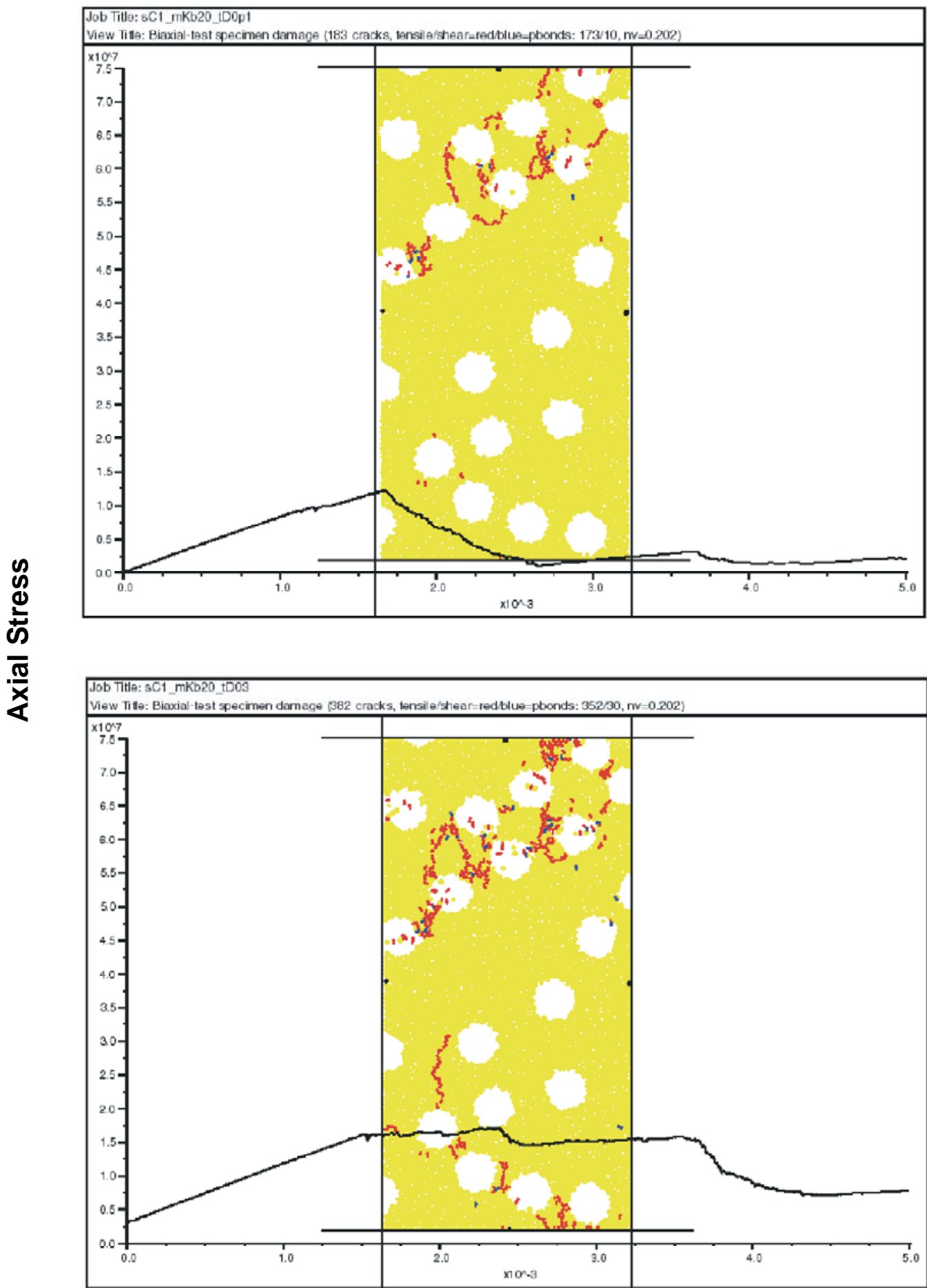

Axial

NOTE: Final sample damage state is plotted with bond failures in tension (red) and shear (blue). Two confining pressures are shown: $0.1 \mathrm{MPa}$ (top) and $3 \mathrm{MPa}$ (bottom). Samples fail due to tensile splitting between adjacent voids in the low confinement model at left. Note that confinement results in a slight increase in peak strength with increased residual strength at high values of void porosity.

Figure 7-11. PFC2D Simulation of Confined Compression of 2:1 L:D (Length:Diameter) Samples of Lithophysal Material $\left(n_{v}=0.20\right)$ Composed of Several Thousand Bonded Particles 
The impact of lithophysae on direct tension strength follows the same general mechanism: the voids result in less area of solid rock for any given cross-section . For a constant applied force, the stress in the remaining solid will be higher, thus reducing the overall averaged tensile strength of the sample. Particles are removed to create circular or spherical voids with random location subject to the constraint that no two voids are closer than one-half of the void radius (17.1 $\mathrm{mm}$ mean void diameter and $41.5 \mathrm{~mm}$ minimum bridge length).

The properties of the lithophysal tuff samples (i.e., Young's modulus and unconfined compressive strength) from the ESF main loop and ECRB Cross-Drift (Appendix E, Table E-9) are plotted along with those of the circular-void PFC model in Figures 7-12 and 7-13, as a function of lithophysal porosity. Figure 7-14 presents the same laboratory and numerical test results in the form of unconfined compressive strength versus Young's modulus. Both PFC models provide reasonable correspondence to the large core laboratory data. The PFC models show the same general decrease in both strength and modulus with lithophysal porosity. The PFC models are performed for circular, constant diameter lithophysal voids. As described in Appendix E, Section E4.1.4.1, the scatter in the laboratory data is a result of the variability in size, shape and distribution of the lithophysal voids. The PFC model was used to simulate compression testing of in situ variability of lithophysal voids on actual field-mapped sections of the Tptpll in the ECRB Cross-Drift. Figure 7-15 shows PFC test samples stenciled from field panel maps, and the corresponding stress-strain curves obtained from test simulations. The impact of actual lithophysal shape, size and distribution on the variability of uniaxial compression strength and modulus results in the same general trend of strength and modulus decrease with lithophysal porosity, but introduces a considerable scatter in the range of results. This scatter is primarily due to the distribution of the voids within a test sample, and, in particular, the non-uniformity of the voids. The distribution of thickness of the solid rock "bridge" between voids weakens the samples as the bridge size decreases. Figure 7-16 shows a comparison of the laboratory test data against the PFC modeling of test samples from field panel maps. It is seen here that, when the variability of the actual lithophysae structure and distribution are taken into account, the scatter in PFC model results fall within the range of the large core laboratory test results. Bounding ranges, as described in Section E.4, can then be assigned for the complete range of expected lithophysal mechanical response.

This validation exercise shows that:

- The PFC model can reproduce the general failure mechanism observed in the laboratory - i.e., tensile splitting between adjacent lithophysae

- The PFC model can reproduce the general trend of strength and modulus as functions of the lithophysal porosity as seen in the test data

- The PFC model successfully provides an explanation for the observed scatter in the strength and modulus as functions of the lithophysal porosity. The model shows that the variability is a result of the shape and distribution of the lithophysae within a sample volume. 


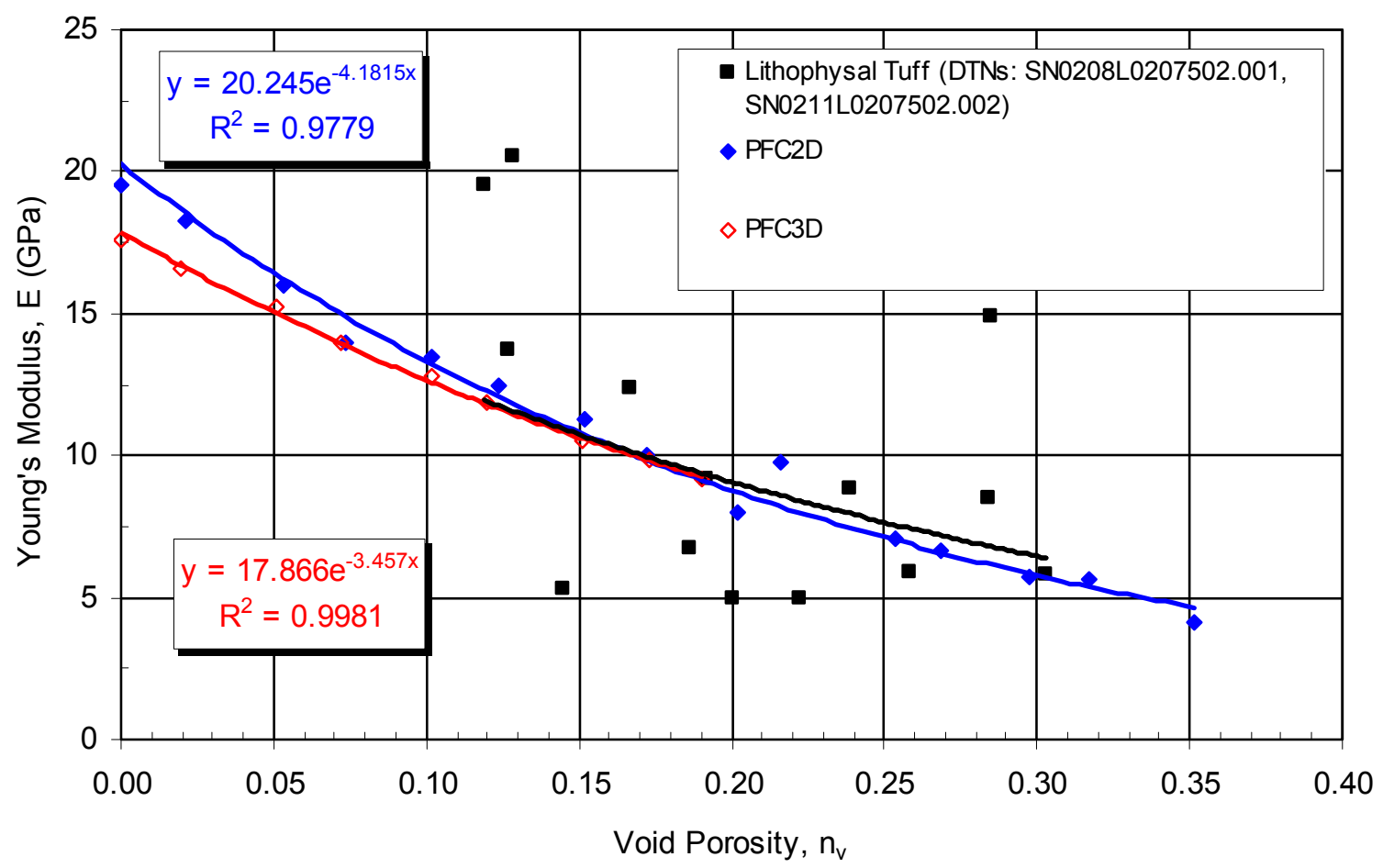

Figure 7-12. Young's Modulus Versus Void Porosity for Lithophysal Tuff and PFC Materials

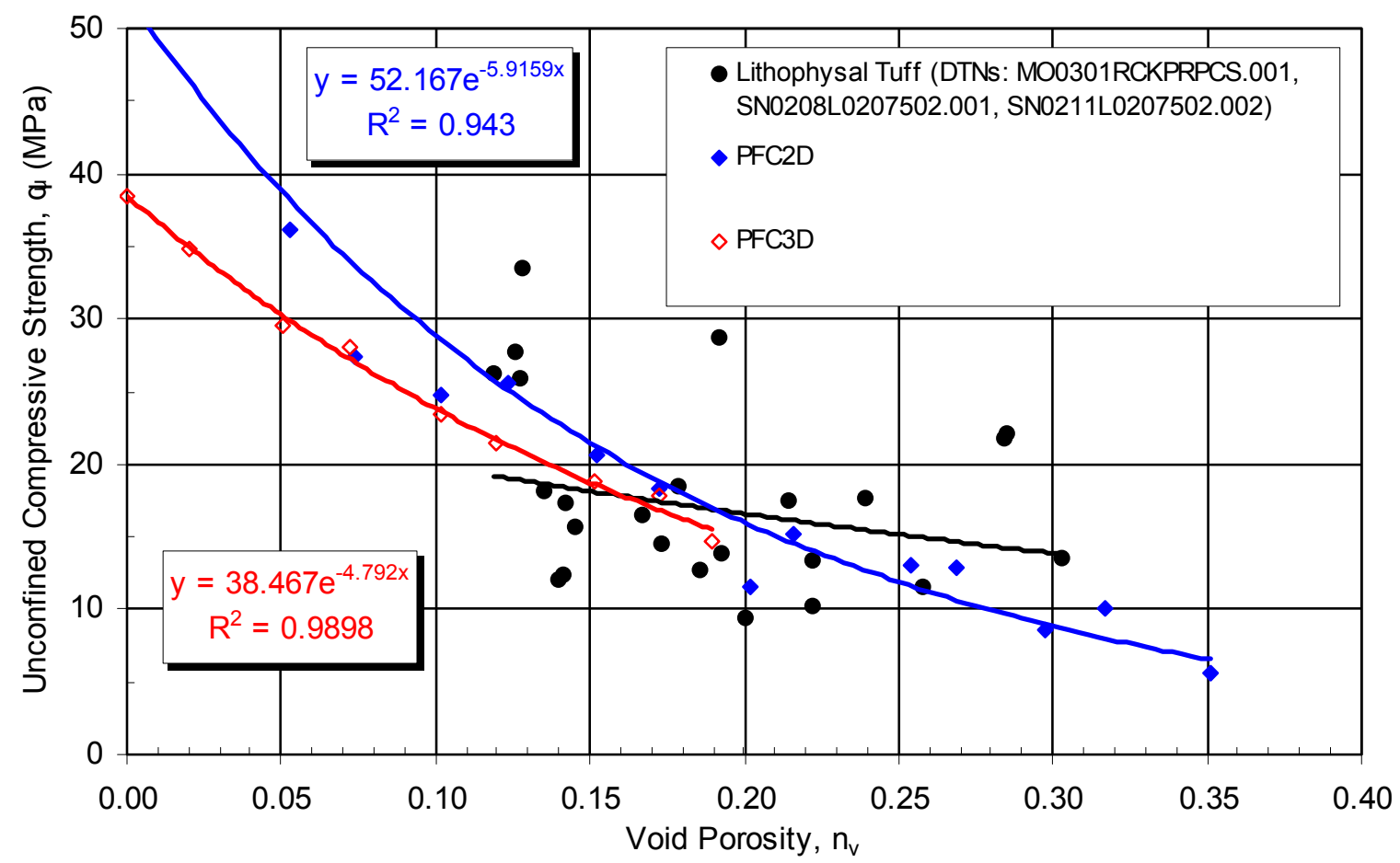

Figure 7-13. Unconfined Compressive Strength Versus Void Porosity for Lithophysal Tuff and PFC Materials 


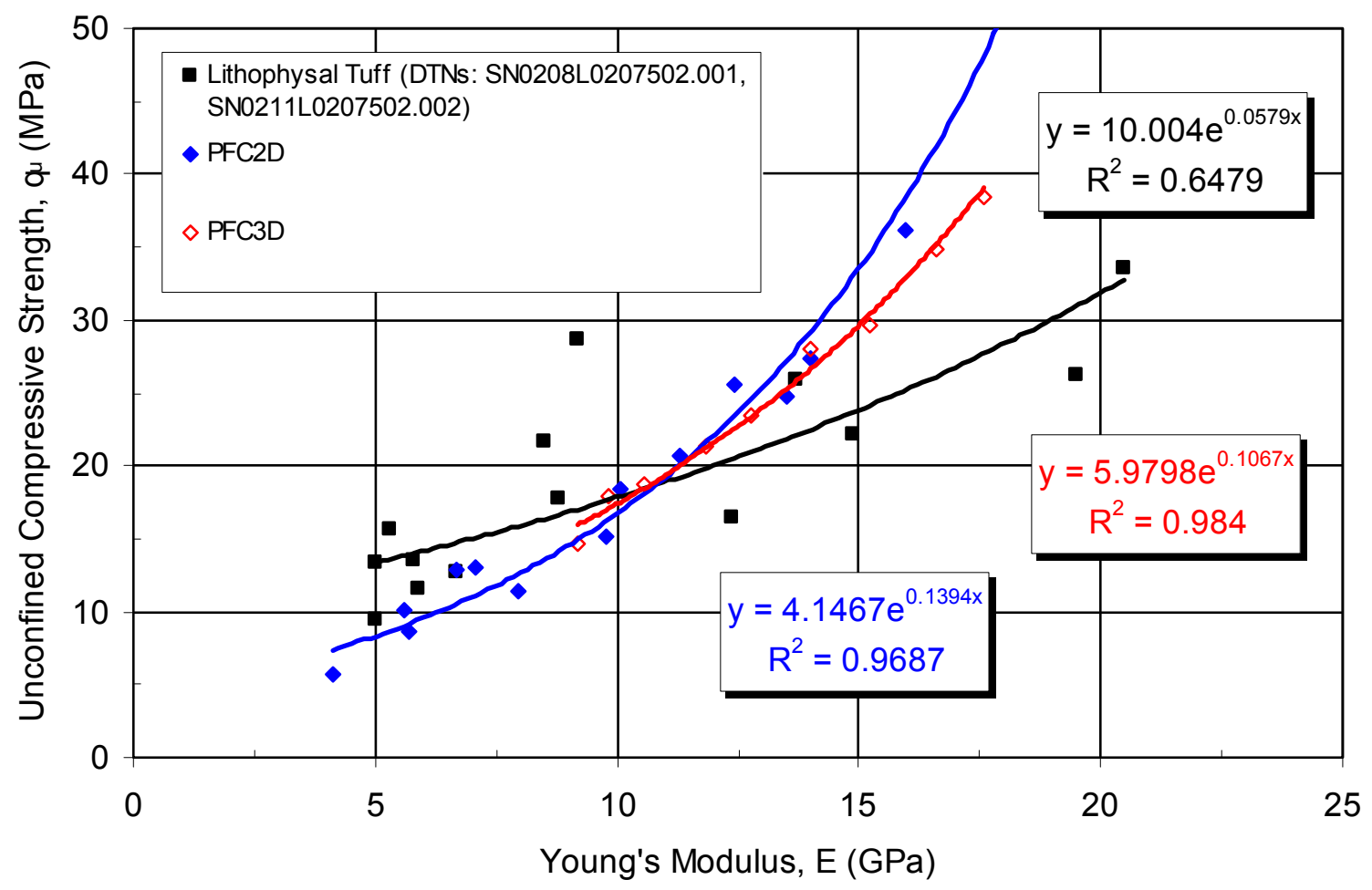

Figure 7-14. Unconfined Compressive Strength Versus Young's Modulus for Lithophysal Tuff and PFC Materials 

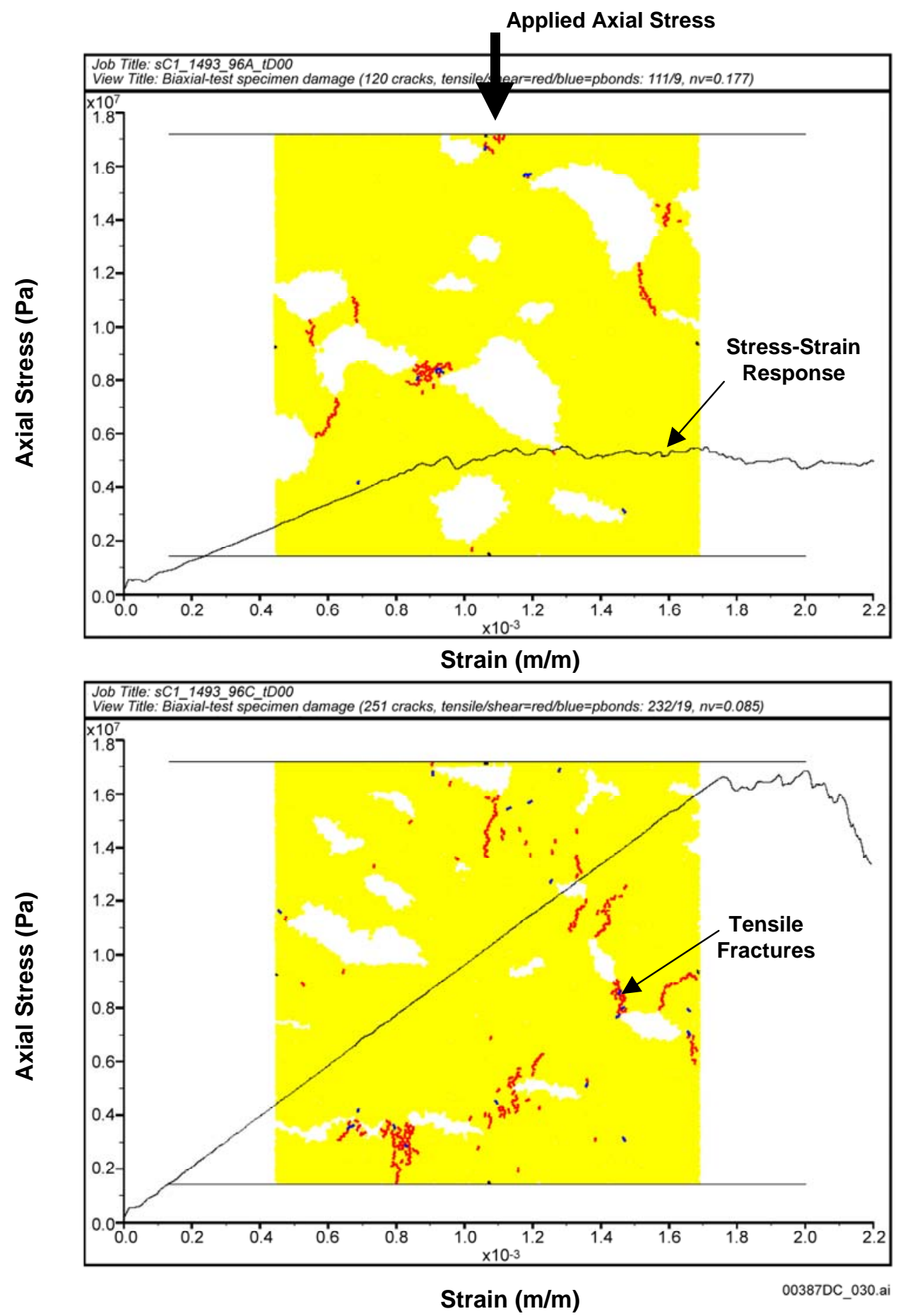

NOTE: Specimen is composed of several thousand bonded particles. Red lines are tensile fractures that have propagated between lithophysae to ultimately form a failure mechanism. Superimposed stress-strain curve illustrates impact of lithophysae distribution on strength, modulus and post-peak failure mechanism. Vertical axis is axial stress in $\mathrm{Pa}$; horizontal axis is strain in $\mathrm{m} / \mathrm{m}$.

Figure 7-15. Examples of Particle Flow Code Compression Tests Using Simulated Rock Specimens Developed by "Stenciling" Field Panel Maps in the Enhanced Characterization of the Repository Block 


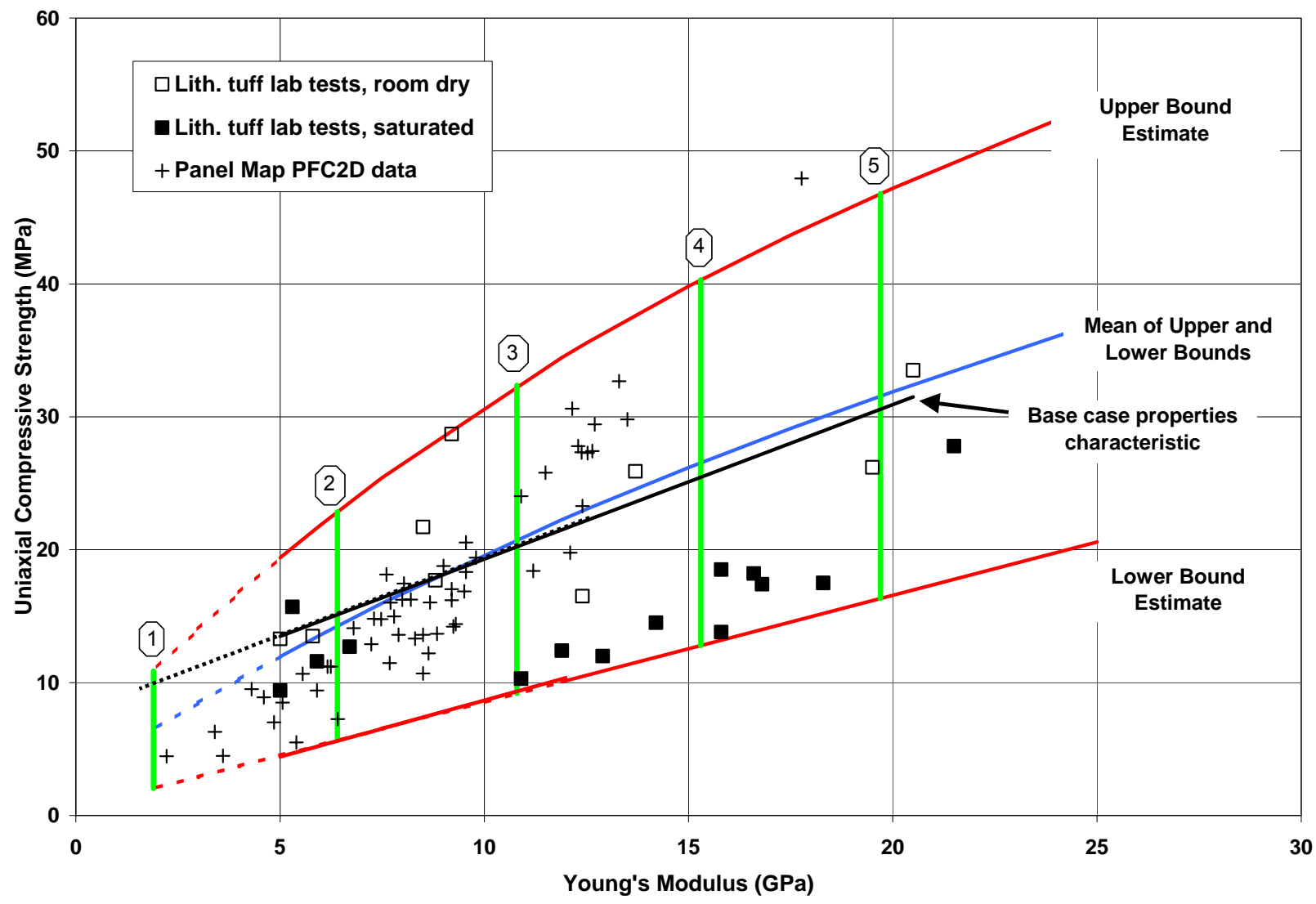

NOTE: Approximate upper and lower bounds are shown.

Figure 7-16. Unconfined Compressive Strength Versus Young's Modulus Showing Large Core Data and Results from PFC Panel Map Lithophysae Shape Study

\subsubsection{PFC Post-Development Validation Exercise 2 - Comparison of PFC Stress Corrosion Model Ability to Reproduce Typical Primary, Secondary and Tertiary Creep Response of the Tptpmn}

The drift degradation analyses include time-dependent rock mass behavior modeled using the PFC model that incorporates a stress corrosion cracking representation. The PFC stress corrosion modeling approach provides a representation of subcritical crack growth in rocks that embraces both the microscopic processes of reactions and thermal activation at crack tips and the more mesoscopic processes of microcrack-microstructure-macrocrack interaction. The PFC stress corrosion model is described in detail by Potyondy (2003 [DIRS 165550]) and reviewed in Appendix S. The PFC stress corrosion model is calibrated by adjusting the particle bond strength and radius as a function of time to provide a match to the time-to-failure curve produced by performing a series of laboratory static fatigue tests (Appendix S, Figure S-27). The PFC stress corrosion model bypasses the need to idealize the rock in the classical Linear Elastic Fracture Mechanics sense, yet can itself reproduce the Linear Elastic Fracture Mechanics behavior. That is, to model static-fatigue behavior, there is no need to begin with a Linear Elastic Fracture Mechanics material, which is an elastic body with classical sharp cracks. Such discrete cracks form naturally in the PFC material as the result of bond breakages. The PFC 
material is comprised of complex grain-scale discontinuities, which induce the micro-tensions that drive the stress-corrosion process, and these discontinuities are not necessarily the same as the discontinuities in an elastic body with classical sharp cracks. This suggests that the PFC stress corrosion model may be more appropriate for use in modeling the physical behavior mechanisms of rock than a more idealized Linear Elastic Fracture Mechanics material.

Much of the development of the PFC stress corrosion model was funded by Atomic Energy of Canada Limited and Ontario Power Generation during the years 1995-2001 as part of a joint thermal-mechanical stability study (Potyondy and Cundall 2001 [DIRS 156895]). One aim of this model development was to improve the fundamental understanding of short- and long-term rock-mass behavior around underground openings at ambient and elevated temperatures. The study was conducted in tunnels constructed in the Lac du Bonnet granites (Manitoba, Canada) as part of the joint Atomic Energy of Canada Limited and Ontario Power Generation Underground Research Laboratory project.

The result of this work was the development and verification of the Bonded-Particle Model for Rock - a mechanistically based numerical model used for predicting excavation-induced rock-mass damage and long-term strength (by incorporating a damage process based on a stress-corrosion mechanism) in Lac du Bonnet granite (Potyondy and Cundall 2001 [DIRS 156895]).

A validation of the PFC stress corrosion model is to compare the general nature of time-dependency of the strain of rock samples when subjected to constant axial load. This test is typically termed a "creep" test, and involves rapid application of axial load to a rock sample to a specific load level that is typically greater than 80 or 90 percent of the considered strength of the material. This load is held constant while axial and lateral strain in the sample is monitored as a function of time. The sample will typically undergo three stages of creep that can easily be discerned from the strain versus time curve. These are the initial primary or transient creep stage that exhibits rapidly-decelerating strain, followed by the secondary or steady-state creep stage in which strain occurs at a constant rate for extended time periods. The steady state creep stage is characterized by slow growth of microcracks either along or through grain boundaries. Finally, as the sample reaches its static fatigue limit, brittle materials will enter another stage of rapid strain rate increase leading to brittle failure. During this stage of deformation, the microcracks form major through-going fractures, which results in formation of a macroscopic failure mechanism. An example of a typical creep test for the Tptpmn is given in Section 6.4.2.4 (see Figure 6-152). Each creep stage can clearly be seen from this curve.

The PFC stress corrosion model adjusts the particle bond strength properties and radius to represent the basic time-dependent weakening effects resulting from stress corrosion. The bonding properties are calibrated to reproduce the slope of the time-to-failure plots derived from static fatigue experiments. However, the model should also reproduce the general time-dependent creep response of the Tptpmn, and should be able to show equivalent transient, steady-state and tertiary creep phases. Figure 7-17 shows a typical PFC-generated creep curve from a simulated constant load (at 80 percent of the uniaxial compressive strength) creep experiment. The time-to-failure (i.e., the point of tertiary creep rupture at $t / t_{f}$ ) is set via calibration to static fatigue experiments, thus establishing a match of the specific time of creep rupture. Tensile fractures (cracks) develop spontaneously in the model as a function of time 
based on the time-dependent bond strength of the constituent grains. The plot shows the development of a network of tensile stress corrosion cracks that accumulate and propagate within the sample until a macroscopic shear failure mechanism develops with resulting brittle rupture during the tertiary creep stage. The simulated creep test shows the three stages of creep: transient, secondary and tertiary, and reproduces the typical response of creep experiments in tuff (e.g., Figure 6-152).

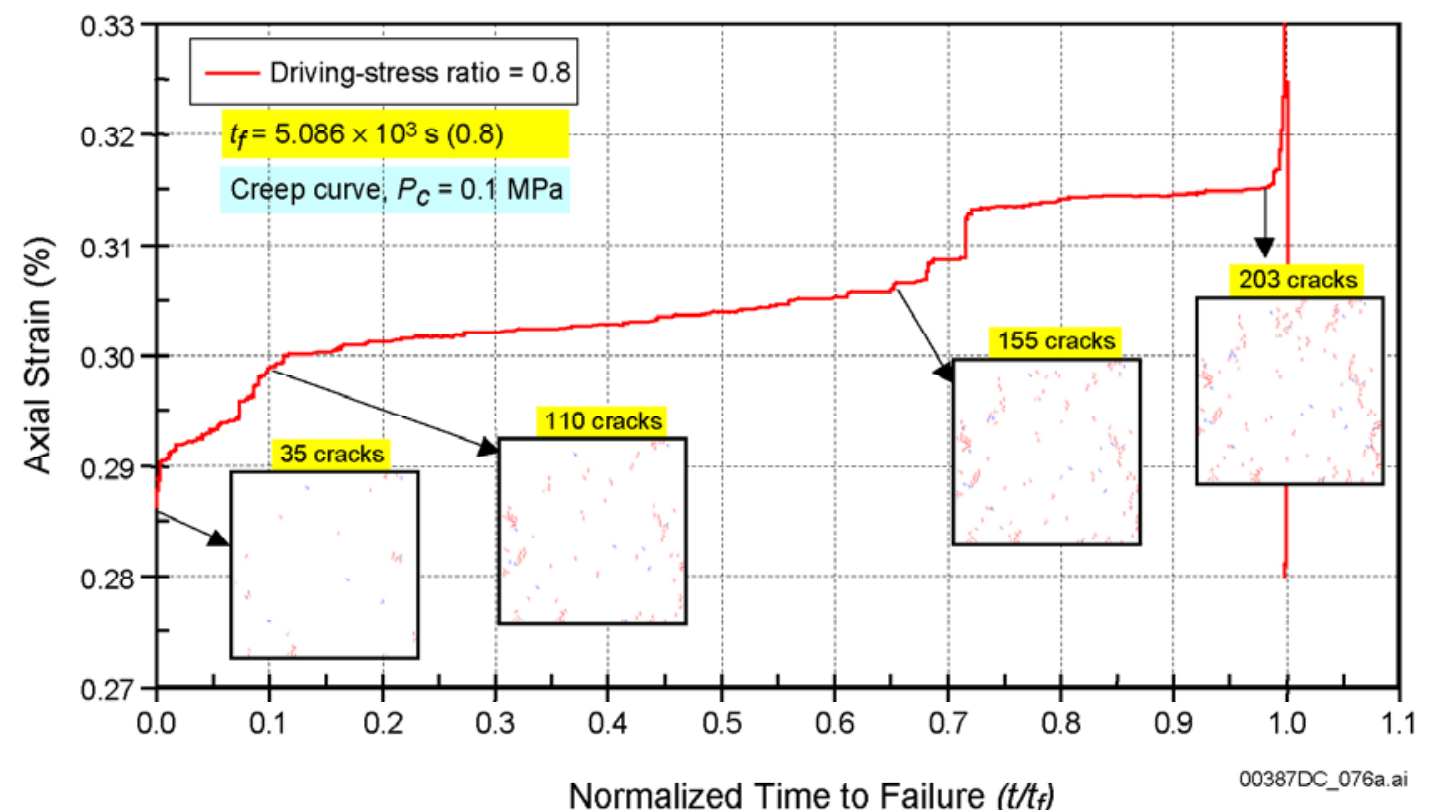

Source: Appendix S, Figure S-13.

NOTE: Numerical simulation of creep test run by holding applied axial stress constant at 0.8 times the unconfined compressive strength. The damage, in terms of new crack growth, is displayed at various times along the creep curve. Brittle failure of the sample occurs when sufficient time-dependent crack growth results in failure mechanism.

Figure 7-17. Simulated Creep Curve and Brittle Rupture Calibration for Nonlithophysal Tuff, Static-Fatigue Test at Driving-Stress Ratio (Ratio of Applied Stress to Unconfined Compression Strength) of 0.8

In conclusion, the PFC stress corrosion model is shown to spontaneously reproduce the observed primary, secondary and tertiary stages of creep observed in laboratory. The approximate evolution of each stage and the proportionate length of each stage is reasonably similar to that observed in the laboratory.

\subsubsection{PFC Post-Development Validation Exercise 3 - Model Validation by Technical Review}

Two outside expert technical reviews were conducted as a means of validation, as discussed in procedure AP-SIII.10Q, Models. The first independent technical review is provided by Dr. Jaak Daemen, Professor of Mining Engineering and Department Chair at the University of Nevada, Reno. Dr. Daemen received his Ph.D. in Geological Engineering from the University of Minnesota where his research involved development of the analytical and numerical solutions for 
ground support - rock mass interaction. His current research involves time-dependent testing of joints and intact tuff from the Yucca Mountain nuclear waste disposal site.

The second independent technical review is provided by Mr. Ronald Price and Dr. Randolph Martin. Mr. Price is a Senior Member of Technical Staff at Sandia National Laboratories in Albuquerque, New Mexico. He has a M.S. in Geology from the Center for Tectonophysics at Texas A\&M University. Since his arrival at Sandia in 1980, Mr. Price has planned, carried out and published results from laboratory studies on many different rock types and for many applications, with special emphasis on Yucca Mountain tuffs, for over 22 years. Dr. Martin is the President of and Principal Scientist at New England Research, Inc. in White River Junction, Vermont. He has a Ph.D. from MIT and has a wide range of experience managing and performing both field and laboratory rock mechanics projects, specifically including time-dependent crack growth and creep of rocks. Dr. Martin's seminal work in the area of static fatigue, coupled with Mr. Price's depth of knowledge of tuff rheological properties, makes them particularly valuable in the review of this material.

The technical review reports are provided in Appendix S (Section S5). In general, the technical reviews find the PFC stress corrosion approach to be adequate for the simulation of long-term drift degradation. The model approach, data selection and ranges were found to be adequate. The model boundary conditions and methodology for application of the static-fatigue test data were also felt to be proper. The reviewers noted that limited test data to build confidence in the model is the model's primary limitation. Since the technical reviews have been completed, additional time-dependent testing data has been provided and is included in the analysis of time-dependent drift degradation (Section 6.4.2.4.2).

\subsubsection{Conclusion from Particle Flow Code (PFC) Model Validation - Comparison to Criteria}

Consistent with the stated level of confidence required for the model, the above PFC studies have shown the following:

- The PFC model is able to reproduce the basic failure mechanisms observed in the laboratory for nonlithophysal and lithophysal rocks (lithophysal rock validation criteria, Section 7.2.3).

- The model provides information that allows understanding of the detailed mechanism of failure in lithophysal rocks and accounts for the strength and moduli reduction mechanism with increasing lithophysal void percentage. The presence of voids in a sample under compression creates stress concentrations around the voids, promoting tensile splitting phenomena between voids. The result is a weakening effect that increases as a function of increasing void volume, and decreasing web thickness between voids (lithophysal rock validation criteria, Section 7.2.3).

- The strength and modulus reduction with void porosity predicted by the model compares reasonably well with that observed in the laboratory. Thus, the PFC model is able to capture the impact of lithophysal porosity variability on strength and deformability properties (lithophysal rock validation criteria, Section 7.2.3). 
- The PFC model is able to spontaneously reproduce the basic time-dependency behavior of the tuff as determined from creep testing. The model is able to reasonably reproduce the primary, secondary and tertiary phases of creep, and provides an understanding of the underlying mechanism of stress corrosion-based microcrack propagation.

\subsection{DEVELOPMENT AND VALIDATION OF A DRIFT-SCALE MODELING METHOD FOR LITHOPHYSAL ROCK USING THE UDEC PROGRAM}

As was noted in Section 7.1, the PFC program is computationally intensive and, therefore, not particularly practical for use as a modeling tool for drift-scale analyses as required. The method used here is to calibrate a similar modeling approach based on the UDEC (Section 3.1) discontinuum program to the laboratory data and then validate this approach against:

- Observations of failure mechanism in the laboratory

- Field observations of tunnel response in the ECRB Cross-Drift

- Thermally induced fracture development in the Drift Scale Test within the Tptpmn unit

- Literature data from related field experiments in which blast-induced yield of a jointed rock mass and large deformations of a scaled, lined tunnel are induced.

- Comparison of the output predictions of rock mass stress and yield around emplacement drifts using the UDEC discontinuum model of lithophysal rock model to alternative continuum-based representations of the mechanical response of lithophysal rock.

Figure 7-4 provides a flow chart illustrating the calibration and validation strategy for UDEC. The following section describes the validation of the UDEC lithophysal rockfall model and exploration of its limitations.

\subsubsection{Qualification of the UDEC Program (Confidence Building During Model Development)}

The UDEC program has been qualified as documented in Section 3. The software documentation contained in the UDEC user's manuals (Itasca Consulting Group 2002 [DIRS 160331]) provides details of the analytical development of the program and the mechanical basis for the material constitutive models that it uses. Extensive documentation (Itasca Consulting Group 2002) is dedicated to verification of the ability of the model to solve analytical solutions that test the various aspects of the model (e.g., mechanical, thermal, porous media flow, dynamics).

\subsubsection{Justification for a Two-Dimensional Isotropic Model of the Lithophysal Rock (Confidence Building During Model Development)}

As was discussed in Section 7.3, the lithophysal units, particularly lower lithophysal zone (Tptpll), are characterized by the presence of more-or-less uniformly distributed voids (lithophysae) of varying size (from centimeter size to over $1 \mathrm{~m}$ in diameter). The lithophysae account for up to about 30 percent of the rock mass. Additionally, in the Tptpll, intense, short 
trace length interlithophysae fracturing exists. Average joint spacing is on the order of $\mathrm{cm}$ to $\mathrm{dm}$, creating block dimensions on the order of the fracture spacings, or $\mathrm{cm}$ to $\mathrm{dm}$ in dimension.

Under such conditions, representation of lithophysal rock units, in the models of drift stability, as a homogeneous, isotropic rock mass is appropriate. The size of the internal structure and spacing is much smaller than the drift size (i.e., $5.5-\mathrm{m}$ diameter). There is no preferred direction in the orientation that would justify introduction of anisotropy. Heterogeneity was considered on the scale of the repository. The analysis was conducted using different properties of the rock mass to investigate the effect of varying quality of rock mass on drift stability. However, properties inside each model were considered homogeneous. Under such conditions, when there is no internal structure in the model, and properties are isotropic and homogeneous, the drift stability analysis was conducted using a two-dimensional model in the plane perpendicular to the drift axis. The model results of rockfall prediction (in a cross-section characterized by particular rock mass properties) are then used for estimating overall rockfall in the entire repository based on estimated distribution of different rock mass qualities throughout the repository.

\subsubsection{Rock Mass Properties for Model Calibration}

The rock mass properties for lithophysal rock mass were determined based on:

- Laboratory testing on 10.5-in diameter cores of Tptpll from Busted Butte

- Laboratory testing on 11.5-in diameter cores of Tptpll and Tptpul from ESF main loop and ECRB Cross-Drift

- PFC and UDEC extrapolations of mechanical response under triaxial stress conditions.

The division of rock mass properties into five categories based on the lithophysal porosity and size effect is described in Appendix E, Section E.4 and is shown graphically in Figure 7-16.

\subsubsection{Model Calibration (Confidence Building During Model Development)}

The two-dimensional distinct element code, UDEC (Section 3.1), is used here for drift stability analysis. The rock mass is represented as an assembly of polygonal, elastic blocks (Figure 7-18) that are bonded together across their boundaries to form a coherent solid. The goal is to provide a rock mass in which the overall mechanical behavior of the mass is consistent with the material model developed for the lithophysal rock, yet allow internal fracturing to form and blocks to loosen and detach as the evolving stress state dictates. In other words, the fractures are "invisible" to the model until yielding begins. 


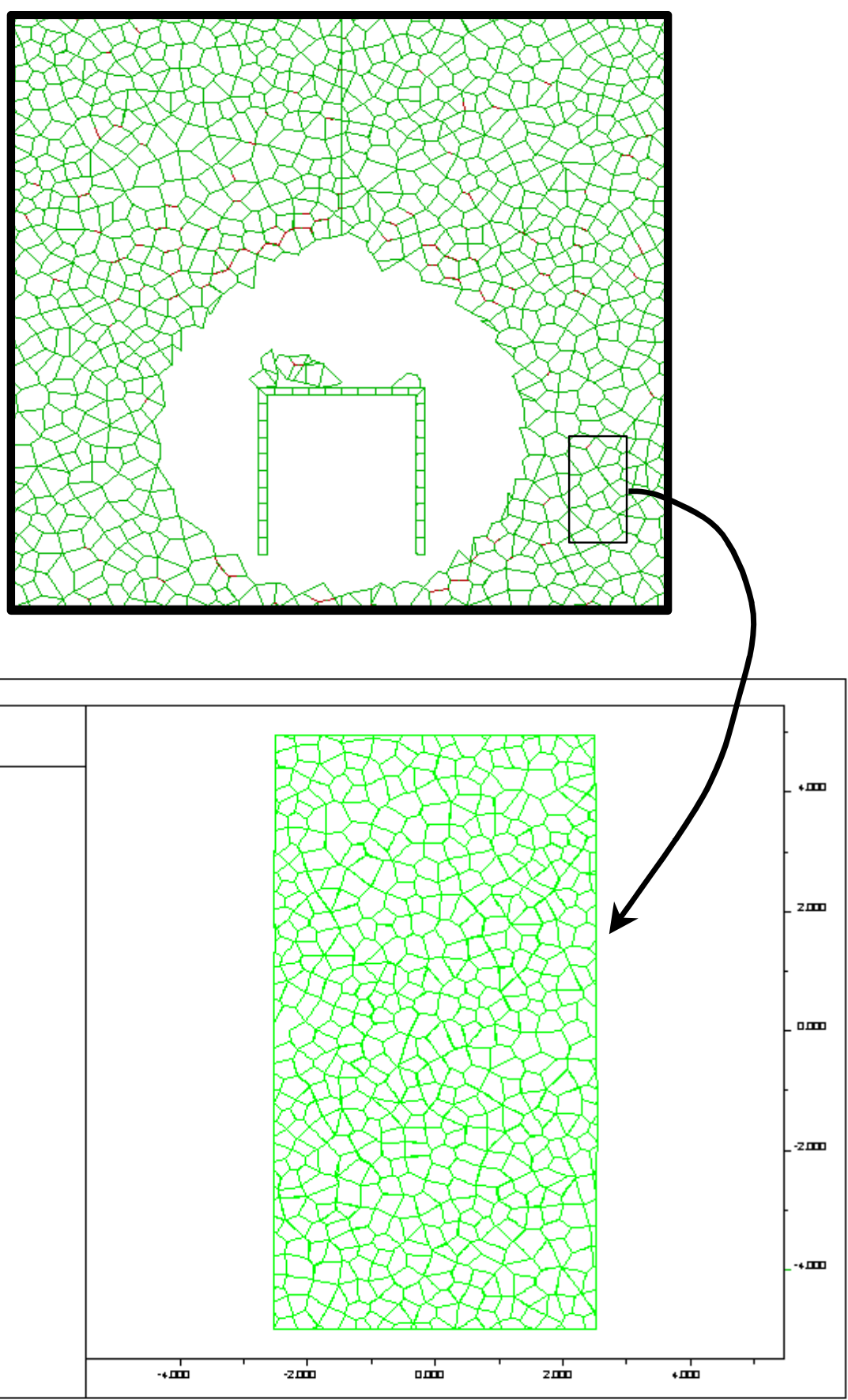

NOTE: Blocks are bonded at their contacts with a cohesion and tensile strength. When these break, the contacts become purely frictional. Specimen is "sampled" from equivalent rock mass representing the Tptpll.

Figure 7-18. UDEC Lithophysal Rock Specimen Composed of Many Irregular Blocks with Roughly Equi-Dimensional Side Lengths 
Since the block boundaries can fail in tension and shear, they act as "potential or incipient fracture" locations should the stresses dictate that fracture is possible. It is important that the block assemblage contain blocks that are sufficiently small such that the model does not dictate where and how fractures can form and propagate. The entire tunnel domain is discretized into small blocks (using Voronoi tessellations, see Itasca Consulting Group 2002 [DIRS 160331]) that are roughly consistent with the maximum block size expected from core fracture spacings. The potential fractures between blocks are considered to behave mechanically according to a linearly elastic-perfectly plastic model. The elastic behavior of potential fractures is controlled by constant normal and shear stiffness, and are consistent with the Young's modulus of the intact rock blocks. The possible failure modes of the rock mass are controlled by the strength of the fractures. The fractures can sustain a finite tensile stress, whereas a Coulomb slip condition governs the onset of slip, as a function of joint cohesion and friction angle. If a potential fracture fails, either in tension or shear, tensile strength and cohesion are set to zero, whereas the friction angle is set to the residual value. This model allows for the formation of fractures between blocks, separation and instability (under action of gravity) of portions of the rock mass around a drift.

The blocks used in the UDEC lithophysal rockfall model do not represent the actual internal structure of the lithophysal rock mass. They are a tool in the numerical model used to simulate damage and fracturing of the rock mass (i.e., the potential fractures in this model do not correspond to actual features). Therefore, it is not possible to directly obtain the potential fracture properties in the UDEC lithophysal rockfall model to results of laboratory or field testing on samples of lithophysal rock. To assure that an assembly of Voronoi blocks behaves as a lithophysal rock mass, it has to be calibrated. Calibration is done by numerical simulation of tests (e.g., unconfined compressive strength tests), which are actually conducted in the laboratory or the field, and for which the test results are available. During the numerical experiment (calibration), the model parameters (i.e., potential fracture properties) are varied until macro-properties of the rock mass important for the drift stability analysis (e.g., Young's modulus and unconfined compressive strength) are matched with measurements from the actual tests. When the calibration is completed it is possible to say that the synthetic material (i.e., the assembly of Voronoi blocks) behaves (on the scale of a drift) equivalently to the lithophysal rock mass. Following calibration, the model can be used to conduct additional simulations under biaxial compression and tension to produce the yield criteria for the material. These yield criteria can be compared to typical empirically derived yield criteria for other rock types as a means of verification of the model.

The following parameters characterize the mechanical behavior of the UDEC Voronoi model:

- The block size scaled to the model size, or a number of blocks in the model.

- Elastic properties of blocks $\left(E^{m}, v^{m}\right)$.

- Properties of joints, both elastic (normal stiffness, $k_{n}$, and shear stiffness, $k_{s}$ ) and plastic (tensile strength, $t^{m}$, cohesion, $c^{m}$, and friction, $\phi^{m}$ ). Note that plastic joint parameters are functions of shear and tensile plastic strains. In the simulations presented in this report, it is considered that cohesion and tensile strength soften to zero at the onset of yield. 
The micro properties are illustrated in Figure 7-19. Because of the geometrical complexity of the model, a direct functional correlation between micro- and macro-properties (model response on a large scale) does not exist. Therefore, to match model macro-behavior, it is necessary to calibrate the model. During the calibration, which is done during simulation of simple uniaxial and biaxial experiments, the micro-properties are adjusted until the desired macro-behavior is matched. The calibration uses a trial-and-error approach, but some understanding of the model mechanics and previous experience can expedite convergence of the iterative process.

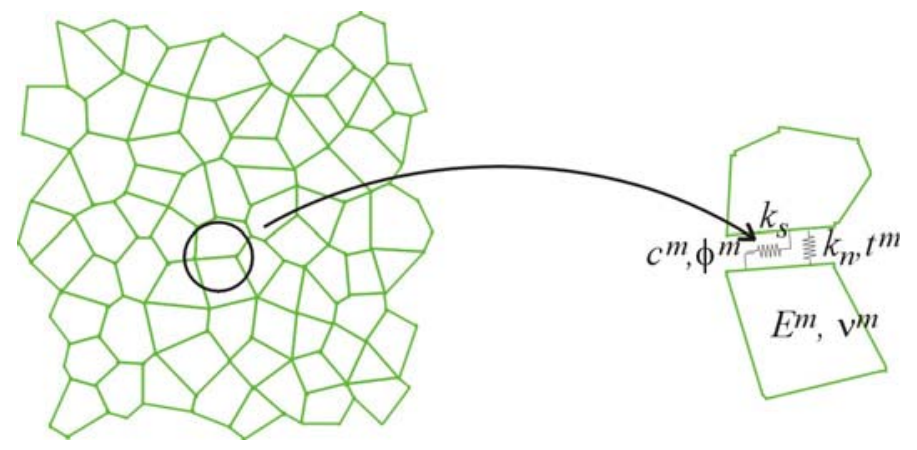

Figure 7-19. Micro Properties of the UDEC Voronoi Model

Elastic and strength properties can be decoupled during the iteration process (i.e., model deformability and strength can be calibrated separately). It is common to calibrate model elastic parameters first. Clearly, calibration of the elastic properties is a problem with a non-unique solution. The two elastic macro-properties ( $E$ and $v$ ) are functions of block size and four micro properties $\left(k_{n}, k_{s}, E^{m}\right.$, and $\left.v^{m}\right)$. The block size is determined based on observed fracture spacing and the condition that the ratio between the drift radius and the block size is sufficiently large $(>15)$. The Poisson's ratio of the blocks is selected to be equal to the macro Poisson's ratio, such that $v^{m}=v$. The additional requirement needed to match the macro Poisson's ratio is that the ratio between normal and shear joint stiffnesses is larger than 1 . Simulations confirm that a Poisson's ratio of 0.2 is matched when $k_{n} / k_{s} \approx 2$. It is reasonable that the contribution of joints to model deformability is larger than the contribution of blocks, but it is desirable, from the perspective of convergence of the numerical model, that stiffnesses of blocks and joints are of the same order of magnitude. Therefore, based on guidance in the UDEC User's Manual (Itasca Consulting Group 2002 [DIRS 160331], Manuals/UDEC/User's Guide/Section 3: Problem Solving, Section 3.2.3), it was selected that

$$
5<\frac{K^{m}+\frac{4}{3} G^{m}}{b k_{n}}<10
$$

where $b$ is the average block size, and $K^{m}$ and $G^{m}$ are the bulk and shear moduli of the blocks, respectively. With these considerations, there is a single independent elastic micro-parameter (e.g., $k_{n}$ ). The proper macro deformability of the model is than matched by rescaling of the elastic micro-properties $\left(k_{n}, k_{s}, K^{m}\right.$, and $\left.G^{m}\right)$. 
Calibration of strength micro properties involves matching macro failure envelope and post-peak behavior by adjusting strength micro-properties. Note that model plastic deformation appears to be a function of the size and shape of blocks. The failure envelope, which, in general, is a surface in the principal stress space, reduces to a line if it is considered that the failure envelope is not a function of the intermediate principal stress. Test runs have proven that the micro friction angle, which is initially equal to $35^{\circ}$ and softens in a brittle fashion to $15^{\circ}$, results in the desired post-peak behavior and strength increase as a function of confinement. In order to match the observed mode of failure of non-lithophysal tuff under unconfined loading conditions (i.e., axial splitting), the micro tensile strength is assigned to be less than 50 percent of the micro cohesion. After these relations are established, the proper peak strength is matched by rescaling micro cohesion and tensile strength.

Stress-strain curves obtained from numerical experiments with different conditions of confinement (unconfined, 1-MPa confinement, and 3-MPa confinement) and loading (tension and compression) are shown in Figure 7-20. The mode of failure is also illustrated for each case by a plot of displacement vectors at the final state of the model. The model matches unconfined compressive strength of $10 \mathrm{MPa}$ and Young's modulus of $1.9 \mathrm{GPa}$ for Category 1 (Table E-10). Laboratory testing data on the post-peak behavior of lithophysal rock is inconclusive. However, the model exhibits qualitatively reasonable post-peak behavior. The response for low confinement is brittle (see unconfined compressive strength curve in Figure 7-20). As confinement increases the response becomes more ductile, almost perfectly plastic for 3-MPa confinements (Figure 7-20). The mode of sample failure in the case of unconfined compressive strength is axial splitting, similarly to observations from laboratory experiments. The mode of failure for confined cases becomes more of the "shear band" type.

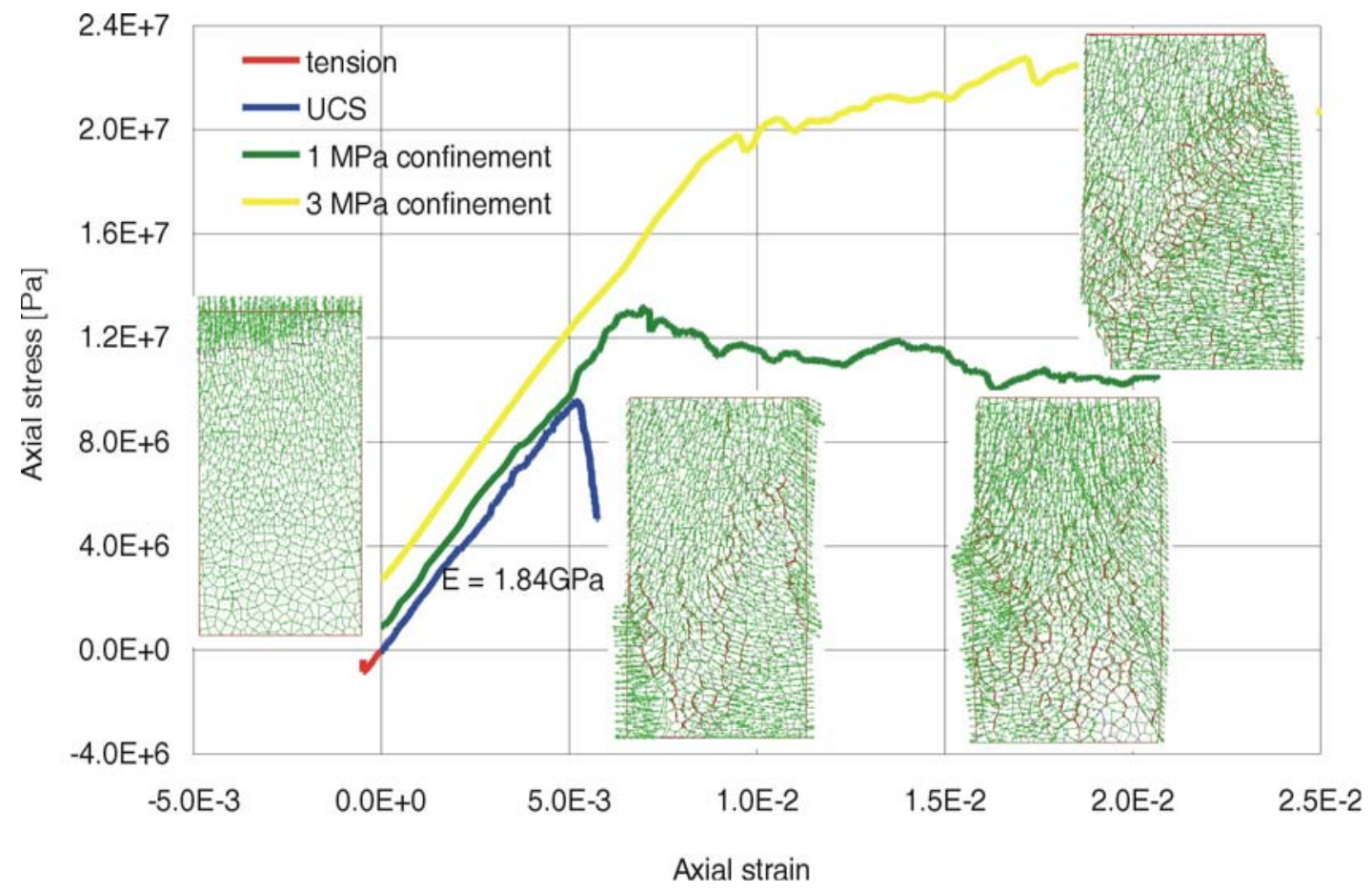

Figure 7-20. Numerical Experiment, Category 1: Stress-Strain Curves and Modes of Failure for Different Confinements and Loading Conditions 
The failure envelope in the principal stress space, constructed based on numerical tests at different confinement levels, is shown in Figure 7-21. The failure envelope is curvilinear, as expected for a rock mass (similar to Hoek-Brown failure criterion). The initial friction angle (in the range of confining stress, $\sigma_{3}$, between 0 and $1 \mathrm{MPa}$ ) is $33^{\circ}$, but it decreases for larger confinement. The ratio between uniaxial compressive and tensile strengths is larger than 10 .

The volumetric deformation of the model during the experiments is illustrated in Figure 7-22, which shows curves of volumetric strain versus axial strain. In general, these curves are bilinear. Initially, while the sample behaves elastically, its volume reduces due to the Poisson's effect. The initial slope of the curves is a function of the Poisson's ratio. Thus, the Poisson's ratio, $v$, of the synthetic material can be calculated from the initial slope of the curve, $s_{e}$, according to the following formula derived from elasticity theory:

$$
v=\frac{1-s_{e}}{2-s_{e}}
$$

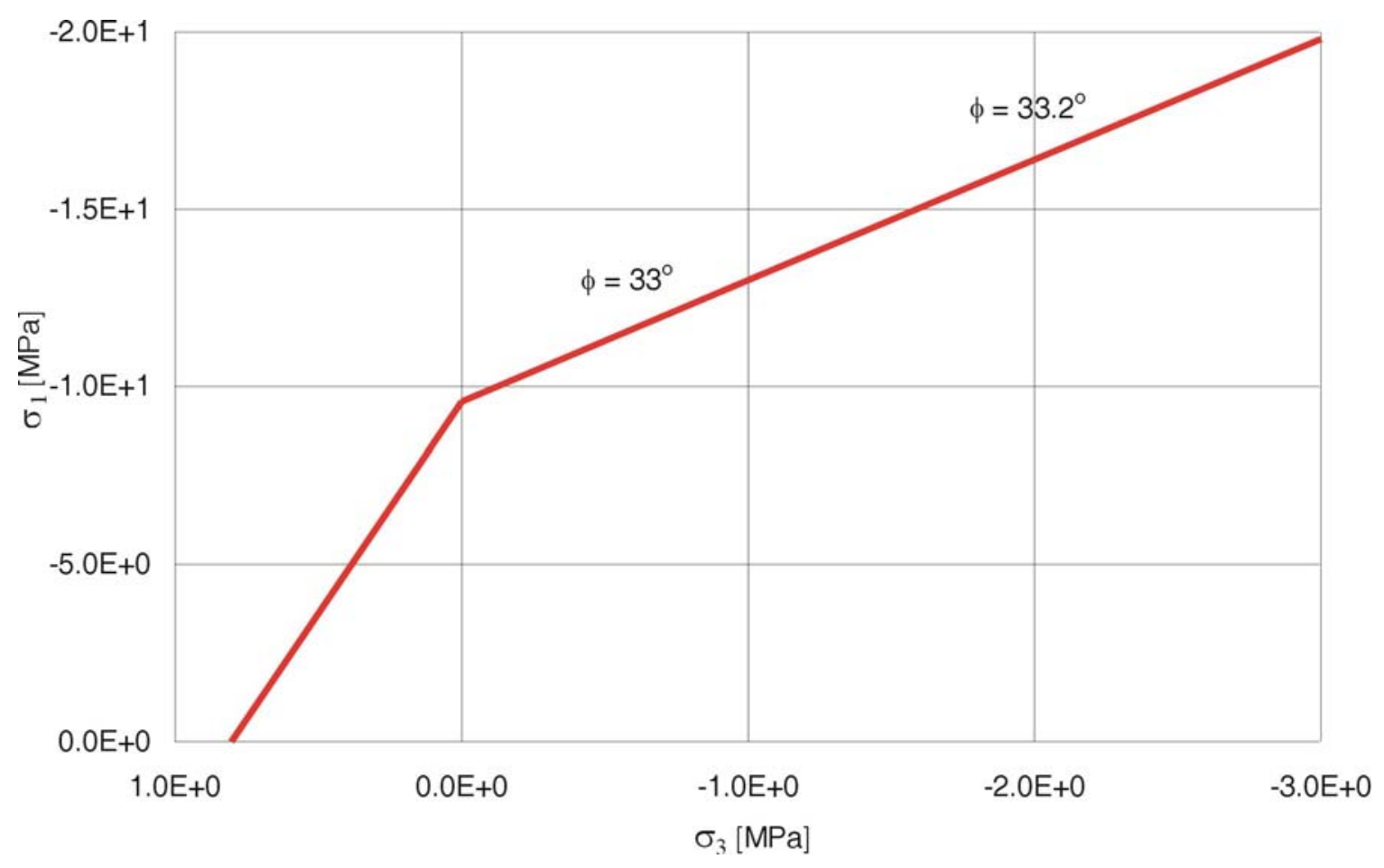

Figure 7-21. Numerical Experiment, Category 1: Failure Envelope 


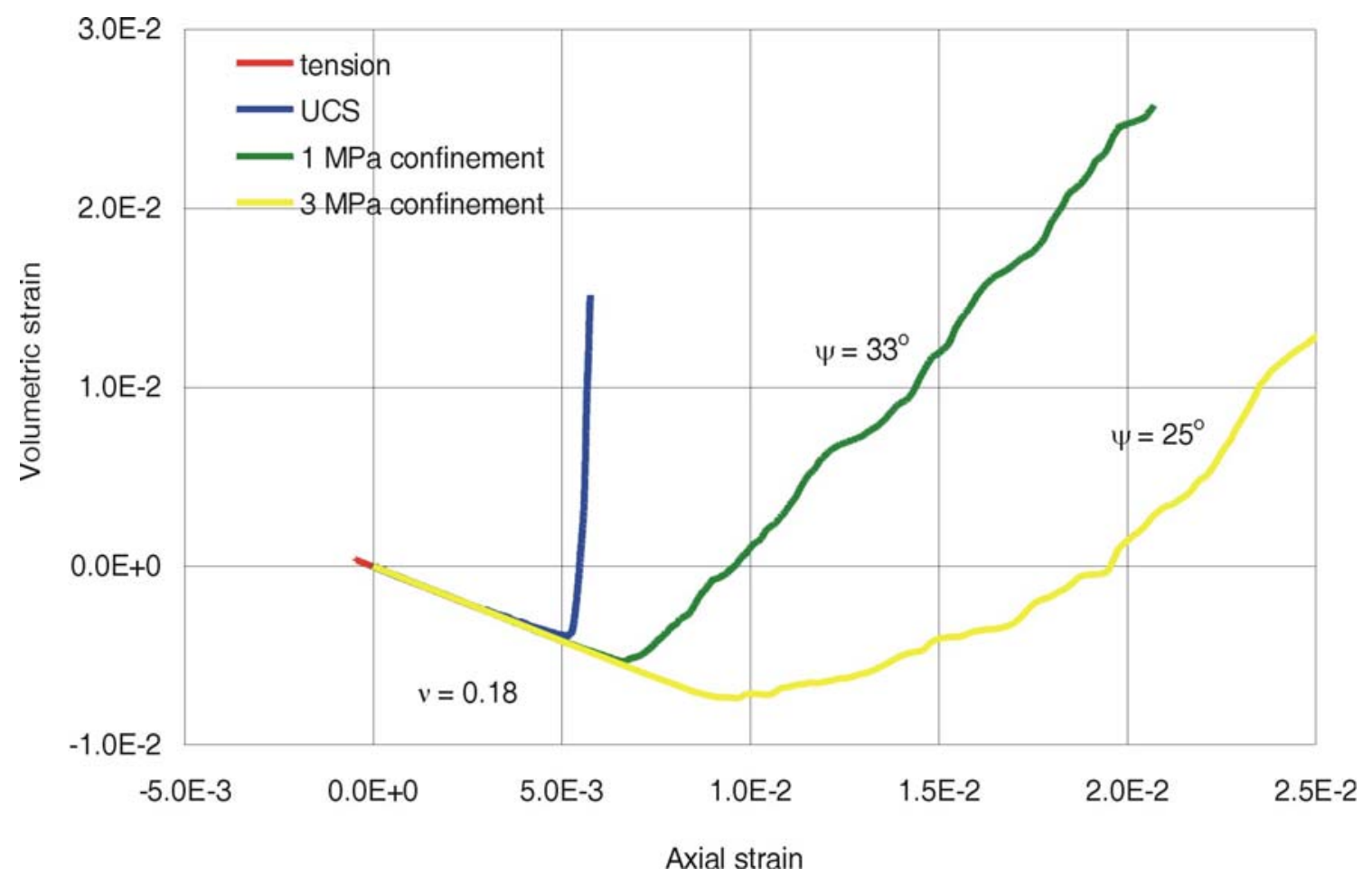

Figure 7-22. Numerical Experiment, Category 1: Volumetric Strain Versus Axial Strain for Different Confinements and Loading Conditions

As the material yields and starts plastic deformation, it usually dilates (increases volume). Consequently the curves in Figure 7-22 change the slope. Initially negative slopes, indicating contraction, become positive, indicating dilation. The slope of the curves during plastic deformation is a function of the dilation angle, which is the parameter used to characterize plastic volumetric deformation. The dilation angle, $\psi$, of the synthetic material can be calculated from the post-peak slope of the curve, $s_{p}$, according to the following formula, which was derived from Mohr-Coulomb plastic flow equations in Itasca Software-Cutting Edge Tools for Computational Mechanics (Itasca Consulting Group 2002 [DIRS 160331]):

$$
\psi=\arcsin \left(\frac{s_{p}}{s_{p}+2}\right)
$$

The synthetic material clearly exhibits a very large dilation angle for unconfined compressive strength. Such behavior is expected because micro damage of the material during unconfined compressive strength testing is predominantly tensile fracturing, which results in extremely large dilation. 


\subsubsection{Post-Development Validation Strategy}

Once calibrated, the UDEC lithophysal rockfall model and properties require validation against field observations and testing. The model is also validated against laboratory failure mechanisms and drift scale response by:

- Comparison of lithophysal sample failure mechanisms in the laboratory

- Comparison of the prediction of drift scale fracturing in the Tptpll at ECRB Cross-Drift depth to observations of tunnel sidewall fracturing in the ECRB Cross-Drift

- Comparison of roof spalling in the Drift Scale Heater Test in the Tptpmn during thermal overdrive experiments to UDEC lithophysal rockfall model predictions

- Comparison of several different numerical modeling techniques to UDEC for a field simulation of steel tube-reinforced tunnel to dynamic loading from a blast

- Additionally, the capabilities of the UDEC program for representing dynamic response of jointed or fractured media is demonstrated by code-to-code comparisons conducted through past dynamic tunnel stability analysis for the Defense Nuclear Agency.

\subsubsection{UDEC Post-Development Validation Exercise 1 - Comparison of Predicted Failure Modes to Laboratory Observations (Corroboration with Relevant Observations)}

The UDEC "potential fracture" model is formulated to allow fractures to form as the stresses dictate. An initial and simple validation is to compare the predictions of the model to observations and common knowledge from laboratory testing. In uniaxial compression, with 2:1 length-to-diameter specimens, the failure mode is typically in the form of axial splitting, or coalescence of axially oriented fractures observable on the surface of the sample. Figure 7-23 presents a typical UDEC plot of predicted fracturing (red tensile cracks) that forms axial to the sample axis. The block structure of the sample was previously shown in Figure 7-18, but is not shown in Figure 7-23 so that the formed cracks are clearly seen. The typical laboratory failure response is shown in the associated photograph of a large core sample from the Tptpul after testing. The axial fractures are clearly visible in this photo. The UDEC lithophysal rockfall model further is able to produce typical tensile fracture orientation from a simulated direct tension test (Figure 7-24). The model will seek out a unique fracture path composed of coalescing "potential fractures" to form a distinct separation plane. 


\section{Applied Axial Load}
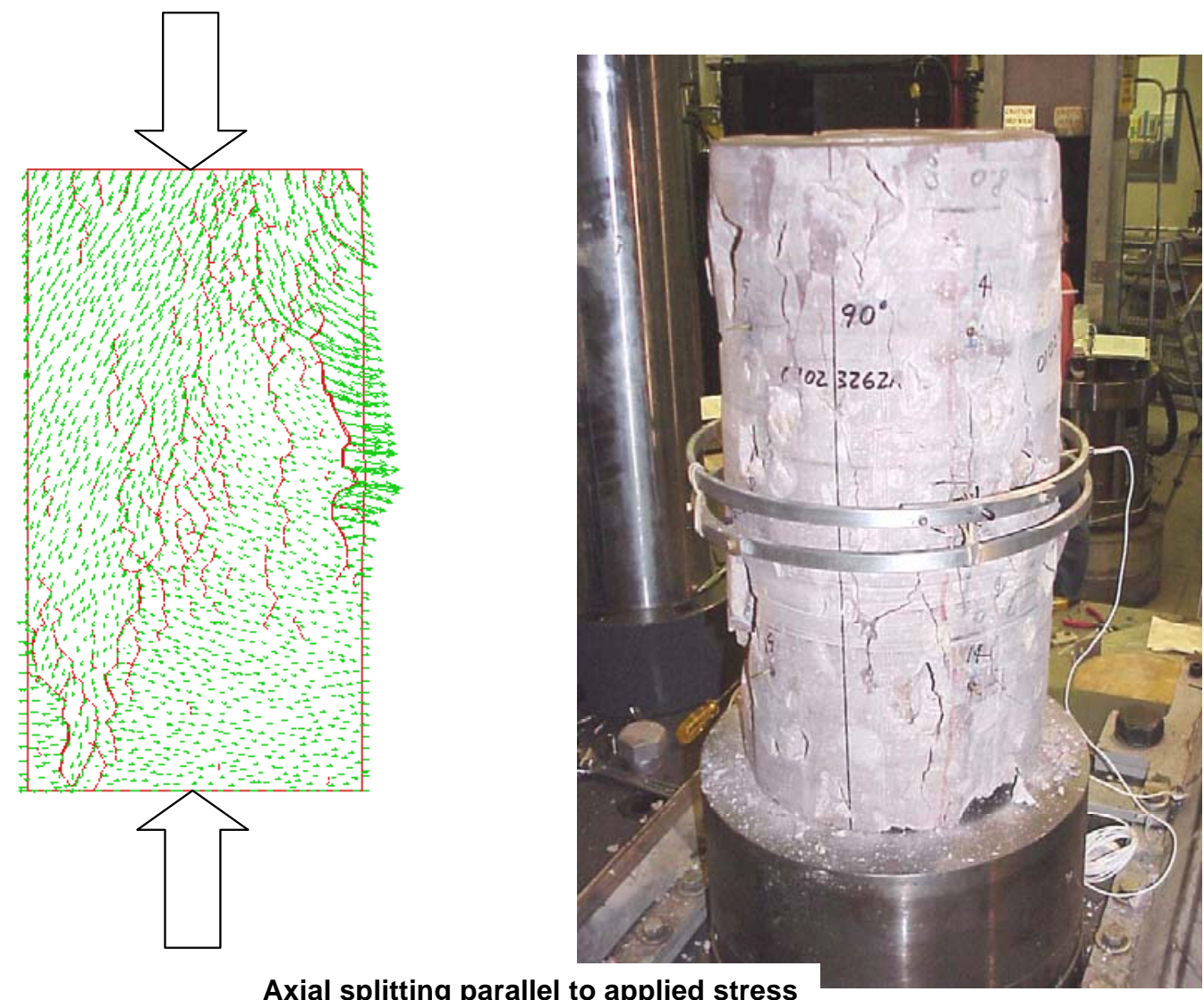

Axial splitting parallel to applied stress

NOTE: The model predicts axial splitting when no confinement is applied as seen by the red tensile block boundary breakages (fractures) formed and by the velocity vectors that show the sidewall spalling. Core photo shows similar axial splitting phenomena.

Figure 7-23. UDEC Discontinuum Model of Failure of Lithophysal Tuff Specimen Under Uniaxial Compression 


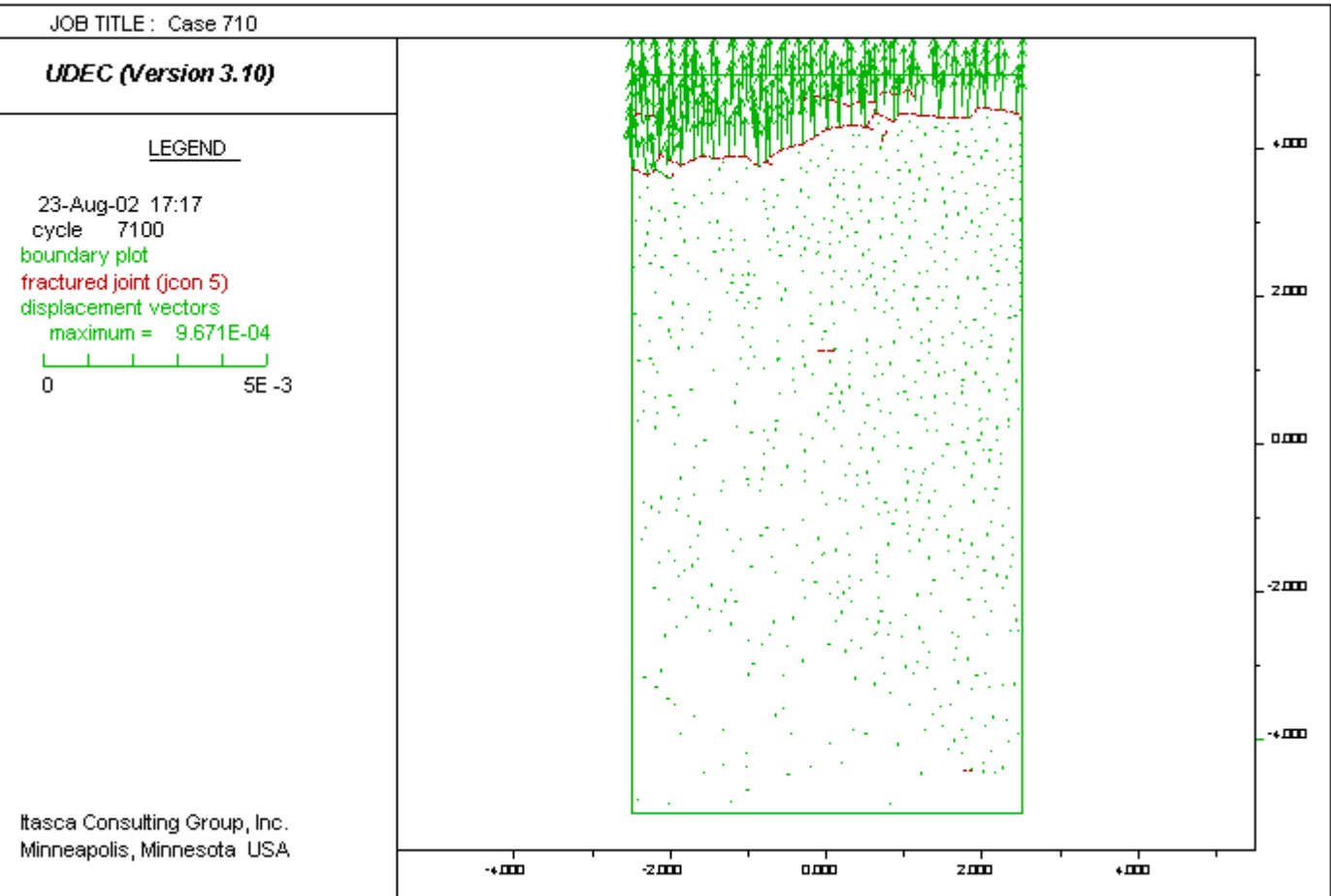

NOTE: A distinct tensile fracture formed from coalescence of individual breakages.

Figure 7-24. Predicted Failure Mode of UDEC Sample in Direct Tension Test

\subsubsection{UDEC Post-Development Validation Exercise 2 - Comparison of Model Predictions to Observations in the ECRB Cross-Drift (Corroboration with Field Observations)}

The proposed modeling approach was verified by comparison of predicted in situ stress-induced damage to the minor damage observed in sidewalls of ESF main loop and ECRB Cross-Drift in the lowest quality Tptpll. Additionally, no sidewall damage is observed in drifts in higher quality Tptpul at shallower depth. Tunnels in all rock units are stable after excavation, regardless of depth or rock quality. However, some damage, in the form of wall parallel fractures (opening of existing fracture fabric) at the springline (the point of highest shearing stress), can be observed in the sidewalls of the tunnels at greater depth in the Tptpll. Figure 7-25 shows formation/opening of wall-parallel fractures observed in 12-in. diameter boreholes drilled for geomechanical sampling in the sidewalls of the ESF main loop and ECRB Cross-Drift at the tunnel springline. The wall-parallel fractures are typical of stress-induced yield in tunnels. The boreholes drilled in the relatively low quality Tptpll at depths of 300 to $350 \mathrm{~m}$ show sidewall fracturing to depths of approximately 0.5 to $0.6 \mathrm{~m}$. Holes drilled into relatively high quality Tptpul at depths of approximately 200 to $250 \mathrm{~m}$ show no fracturing. 

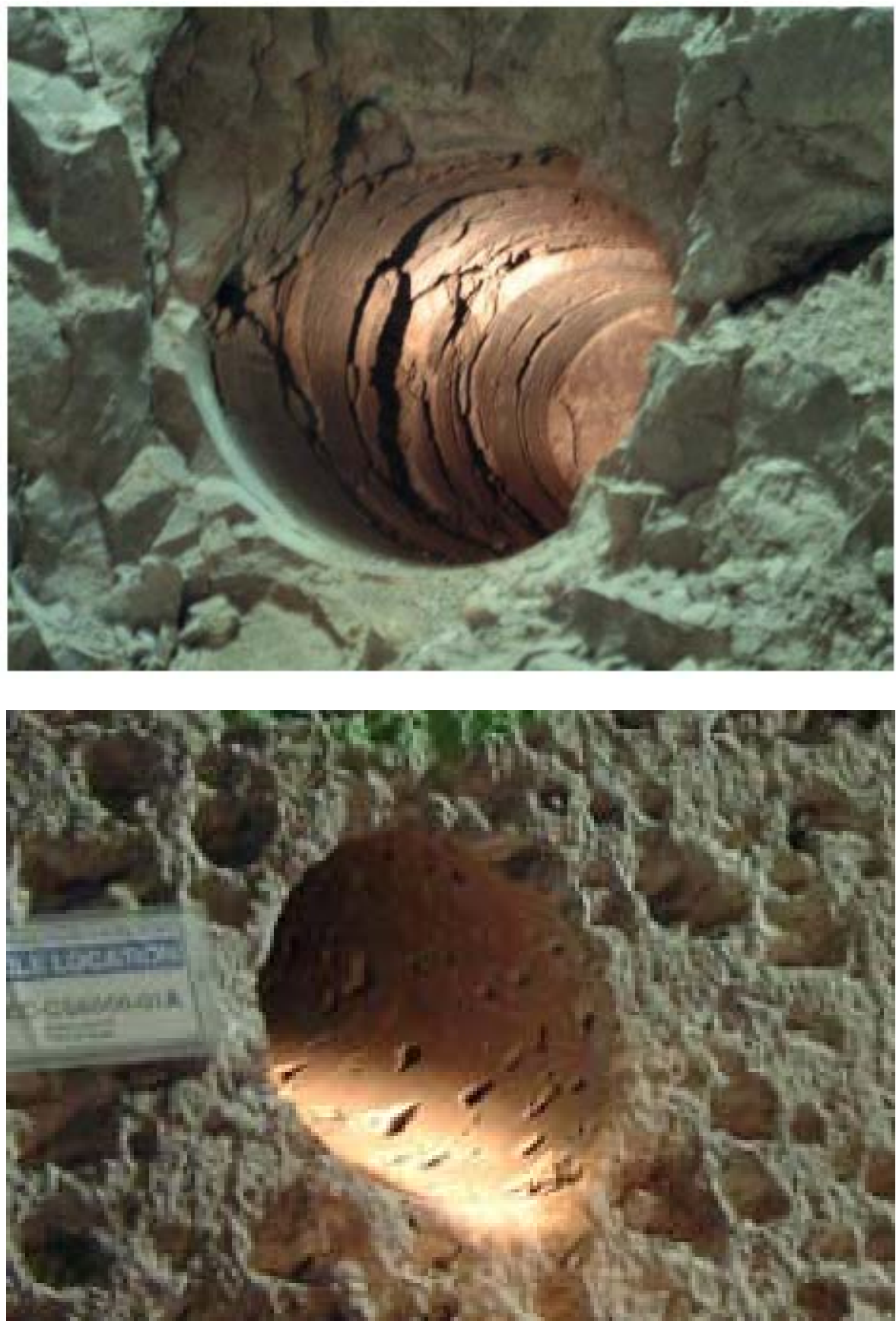

NOTE: Top photo shows sidewall fracturing/opening of preexisting wall-parallel fractures in a 12" diameter horizontal borehole drilled in the springline of the ESF in low quality Tptpll (approximately Category 1). Overburden depth is approximately $325 \mathrm{~m}$. Depth of fracturing is approximately 1.5 to $2 \mathrm{ft}(0.46$ to $0.61 \mathrm{~m})$. The bottom photo shows a horizontal, 12-in diameter borehole drilled in the springline in good quality Tptpul (approximately Category 5) in ESF near site of slot test 2 showing no sidewall damage. The depth of overburden is approximately $250 \mathrm{~m}$.

Figure 7-25. Observed Rock Mass Conditions at the Tunnel Springline in Lithophysal Rock in the ESF 
The presence of these fractures and their depth into the drift wall, observed in large hole drilling, is a convenient feature from which an estimate of the rock mass strength properties and validation of the model can be made. A parametric study of drift stability and rock yield depth was conducted using the UDEC lithophysal model for the five strength categories (Appendix E, Section E.4) and imposed overburden depths of 250, 300, and $350 \mathrm{~m}$, corresponding to the Tptpll and Tptpul. As seen in Figures 7-26 and 7-27, the model reproduces the approximate depth and orientation of drift wall-parallel fractures observed underground for strength Category 1. The failure of the rock is contained to the immediate springline due to the stress concentration resulting from the vertical maximum stress (vertical stress in $\mathrm{MPa}=0.024 \times$ depth $(\mathrm{m})$, horizontal/vertical stress $=0.36$ to 0.62 (SNF37100195002.001 [DIRS 131356])). The model results indicate that the rock adjacent to the drift wall yields in a state of uniaxial compression since the minimum stress at or near the drift wall is zero or small since the radial stress component is zero. The depth of fracturing is clearly visible in these models as the zone where stress relaxation has occurred. The models also show that, for the range of potential lithophysal rock properties, there is no drift wall yield at the depth of the Tptpul from strength Category 1.

In conclusion, this validation exercise shows that:

- The model is able to represent the observed wall fracturing at the Tptpll depth for a range of rock strengths that agree with laboratory measurements of uniaxial compressive strength (i.e., the observed yield is consistent with laboratory measured values).

- The model shows that reduction of depth to that of the Tptpul results in no yield of the drift wall, and thus no fracturing as observed.

\subsubsection{UDEC Post-Development Validation Exercise 3 - Comparison of Model to Drift Scale Experiment in the Tptpmn (Corroboration with Field Experiments)}

The Drift Scale Heater Test was conducted in the Tptpmn unit, primarily as a fluid migration experiment (Williams 2001 [DIRS 159516]). This test involved driving a 5-m $\times 5-\mathrm{m}$ drift, 50-m in length completely within the Tptpmn. The drift was heated using simulated electrically heated canisters within the drift itself, as well as horizontally placed borehole heaters in the springline of the tunnel to additionally raise the ambient rock mass temperature (Figure 7-28). Heating was started in 1997 and lasted for four years until 2001. The experiment is currently in the cool-down phase. After three years of heating (from 1997 to 2000), the heater power was raised to provide a thermal overstressing condition. The rock temperature level was driven to approximately $200^{\circ} \mathrm{C}$, or a maximum $180^{\circ} \mathrm{C}$ temperature rise. Spalling of rock was first observed in late 1999 as small chips of rock on the tunnel invert, however there was no observation of obvious larger rock fragments or bulking in the welded wire fabric. Therefore, it is unknown if these small particles are related to thermal stress effects. In April 2001, obvious loose rock was observed at several locations in the crown of the tunnel, contained behind the wire mesh (Figure 7-29). At least four zones of loosened rock were observed along the tunnel crown, using the rail mounted remote camera. It is not clear that these are all of the zones of spalling due to the difficulty in observation using this camera technique, however, it is clear that they are largely congregated along the tunnel crown. The rock plates held within the welded wire fabric from about 5 to $20 \mathrm{~cm}$. This type of "slabbing" is typical of hard, brittle rock masses subjected to horizontal stresses in the crown that exceed their uniaxial compressive strength. 

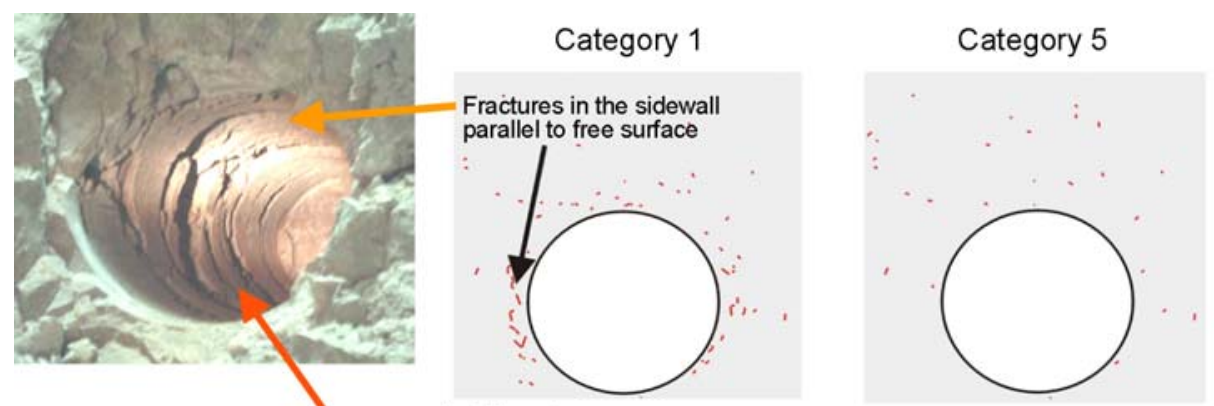

(a) Fractures
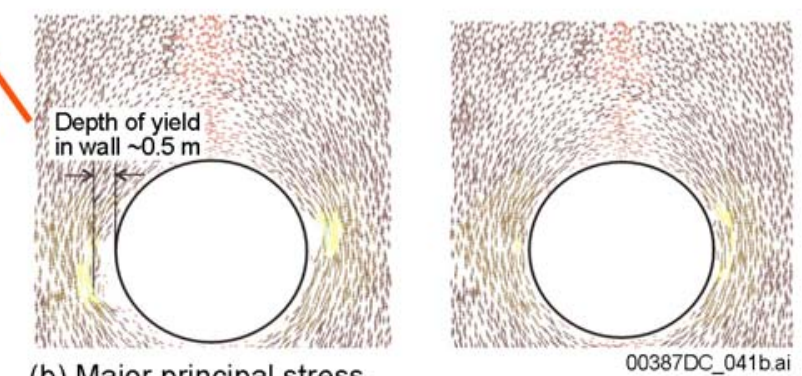

Principal stresses $(\mathrm{MPa})$ (color code - $\mathrm{s} 1$ magnitude)

(b) Major principal stress

NOTE: Upper figure for Category 1 shows predicted fracturing to a depth of approximately $0.5 \mathrm{~m}$ in the sidewall of ECRB Cross-Drift. Lower picture shows stress vectors (in $\mathrm{Pa}$ ) colored by the magnitude of the stress component. Depth of yield for Category 1 is limited to about $0.5 \mathrm{~m}$ in the immediate springline area. The model for Category 5 shows elastic rock mass response (i.e., no yield). Stress vectors in lower figure also shows elastic stress distributions with no readjustment due to yielding.

Figure 7-26. Estimate of Rock Mass Fracturing and Stress State Under In Situ Loading Only, Depth of $300 \mathrm{~m}$, Tptpll, Strength Category 1 (Low-Strength Characteristics) and 5 (High-Strength Characteristics) 


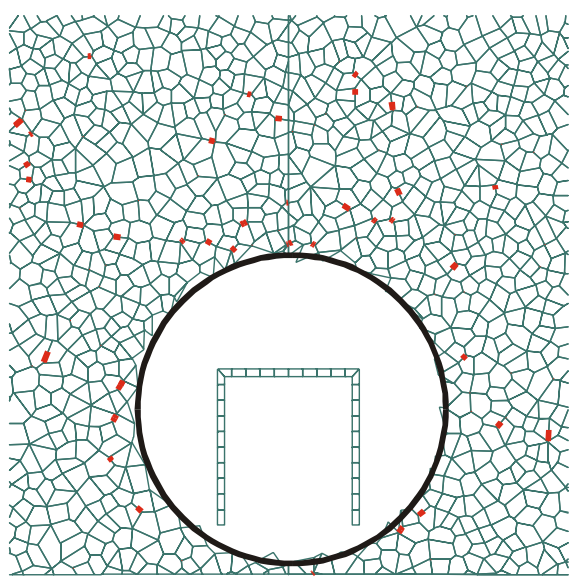

(a) Overburden at $250 \mathrm{~m}$

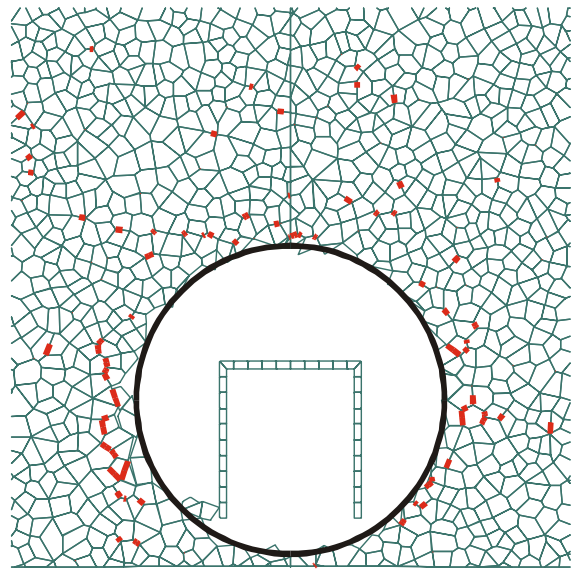

(b) Overburden at $300 \mathrm{~m}$

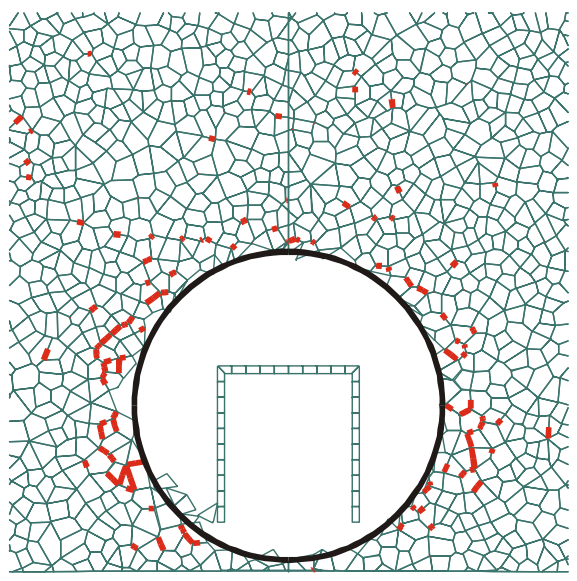

(c) Overburden at $350 \mathrm{~m}$

Figure 7-27. Estimate of Stress-Induced Rock Mass Fracturing (seen as red block contacts) as a Function of Overburden Between $250 \mathrm{~m}$ and $350 \mathrm{~m}$, Tptpll, Strength Category 1 (Low-Strength Characteristics) 


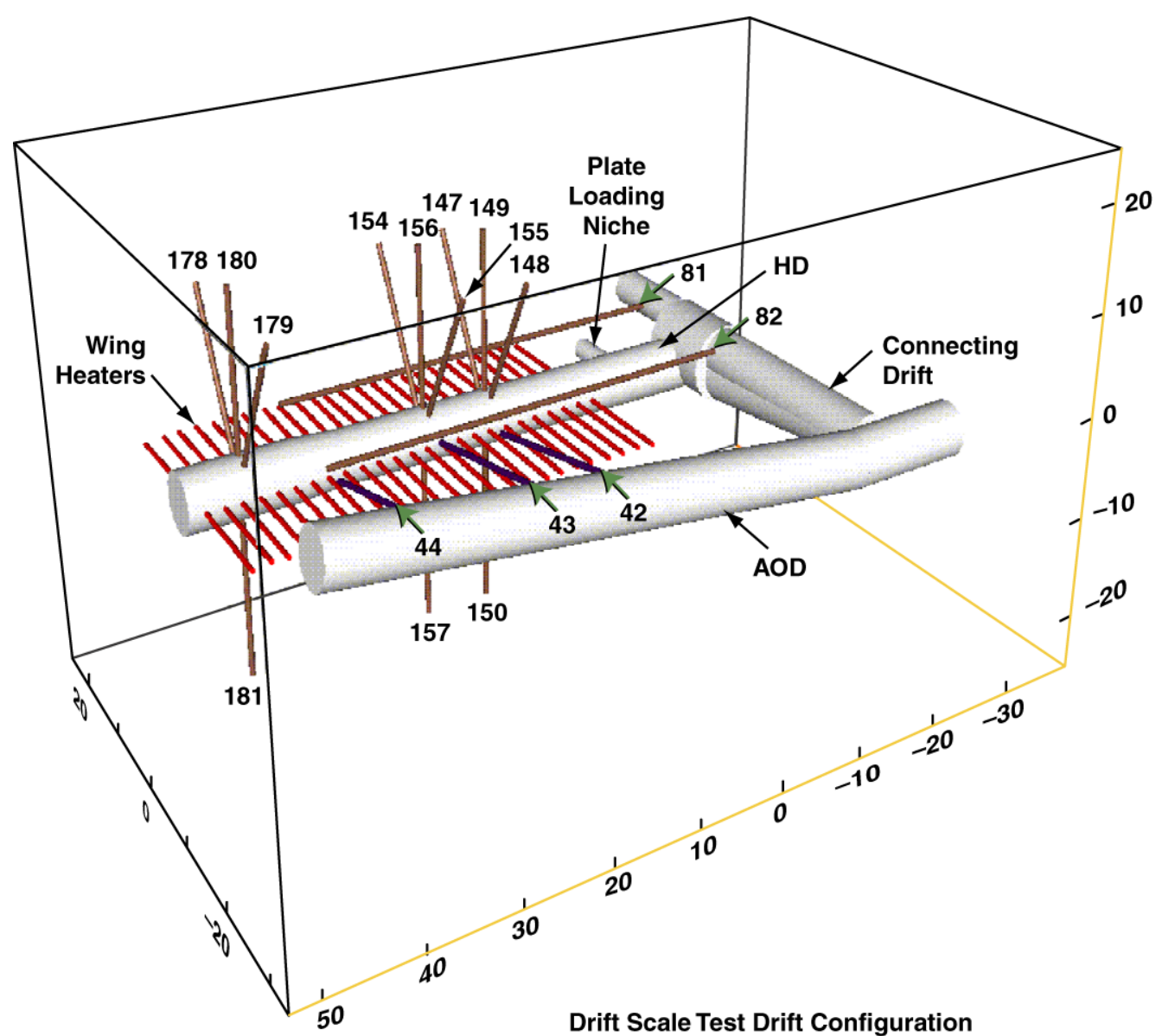

$\mathrm{HD}=$ Heated Drift; $\mathrm{AOD}=$ Access $/$ Observation Drift

NOTE: Numbered boreholes contain rock mass monitoring instrumentation. Canister heaters are placed in the Heated Drift.

Figure 7-28. Perspective View of Heated Drift Scale Test Showing Wing Heaters

It is the goal of this validation exercise to demonstrate that the UDEC lithophysal rockfall model with random block subdivision is capable of reproducing thermal fracturing response at the proper approximate temperature and thermally induced stress levels as observed in the Drift Scale Heater Test. The first step in the validation is to calibrate the UDEC "potential" fracture properties against laboratory compression data. A compilation of the results of uniaxial compression strength test data for a range of sample sizes as described by Price (1986 [DIRS 106589]) is provided in Appendix E (Figure E-22). The sample sizes vary from $25 \mathrm{~mm}$ to approximately $230 \mathrm{~mm}$, resulting in a curve that describes compressive strength as a function of sample size. Since the Drift Scale Heater Test represents in situ sample size, the UDEC lithophysal rockfall model is calibrated to the predicted field scale, represented by a sample size scale of approximately $1-\mathrm{m}$ size, or 70 to $75 \mathrm{MPa}$, or about 50 percent of the strength of a standard 50-mm diameter sample (Figure E-22). This size-strength relationship compares quite favorably with suggestions for other rock types as used in common practice for rock engineering design purposes. Hoek (2000 [DIRS 160705]) suggests that the rock mass strength for a 1-m sample size approaches an approximate value of about 50 to 60 percent of the uniaxial compressive strength of 50-mm cores samples. 

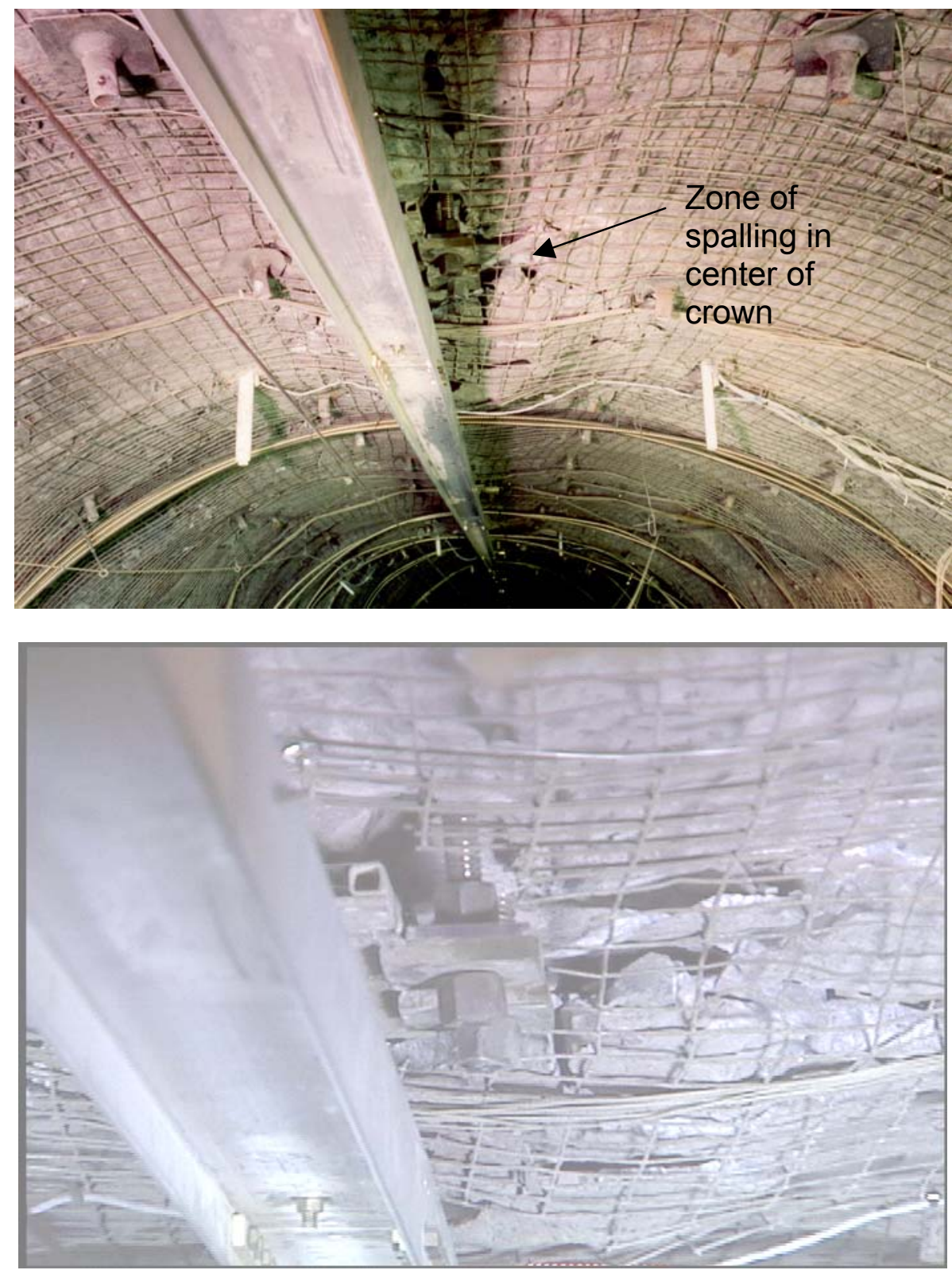

NOTE: Rock spalling is contained by 3 -in $\times 3$-in wire mesh and Swellex bolts. Top view shows general spalled region. Bottom view is a close up along the camera rail showing slabbing into small, flat pieces.

Figure 7-29. Minor Superficial Slabbing in the Center of the Roof Span Observed During Thermal Overstressing of the Heated Drift Scale Test 
The UDEC lithophysal rockfall model was calibrated based on a sample uniaxial compressive strength of approximately 50 to $70 \mathrm{MPa}$, using an average Young's modulus of $30 \mathrm{GPa}$. The mean measured Young's modulus for Tptpmn data is $33.6 \mathrm{GPa} \pm 6.5 \mathrm{GPa}$ from laboratory data (see Appendix E, Table E-6). Figure 7-30 shows the representative calibration of the UDEC equivalent Tptpmn material showing linear elastic behavior to peak strength, followed by a brittle post-peak failure mode. The term representative is used since the calibration is performed for a specific value of strength and modulus, whereas the data span a wide range of possible values. The rock mass surrounding the Drift Scale Heater Test drift was formed using randomly shaped, roughly spherical blocks using the Voronoi generation technique described in Section 6.4.2.1. The in situ stress state was selected to be $7 \mathrm{MPa}$ vertical stress and $3.5 \mathrm{MPa}$ lateral stress.

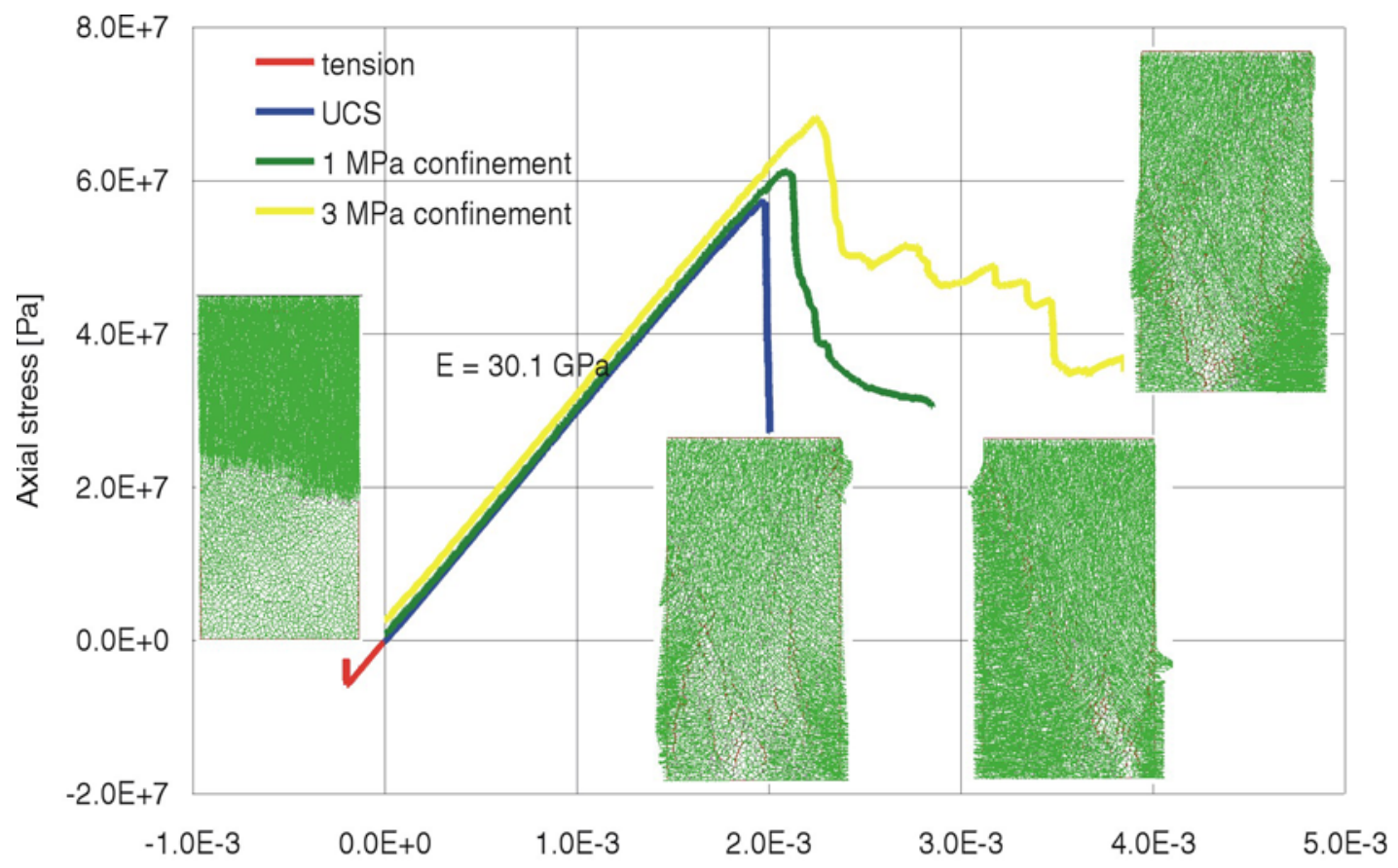

Axial strain

Figure 7-30. UDEC Sample Calibration to Size-Effect Strength Data for an Approximate 1-m Sample Size, Tptpmn

The model in situ stresses are applied and allowed to equilibrate prior to drift excavation. After excavation, the measured temperatures at thermocouple locations (DTNs: MO9807DSTSET01.000 [DIRS 113644]; MO9906DSTSET03.000 [DIRS 113673]; MO0001SEPDSTPC.000 [DIRS 153836]; MO0007SEPDSTPC.001 [DIRS 153707]; MO0107SEPDSTPC.003 [DIRS 158321]; MO0202SEPDSTTV.001 [DIRS 158320]; and MO0002ABBLSLDS.000 [DIRS 147304]) for a representative tunnel cross-section are used to linearly interpolate temperatures at UDEC lithophysal rockfall model gridpoints at successive one-year intervals. At each of these intervals, the model is allowed to equilibrate, developing thermally induced stresses that are added to the mining-induced stress conditions. The rock mass is free to fracture and deform under the influence of the stresses. 
Figures 7-31 to 7-36 show the temperatures, major and minor principal stresses and predicted fracturing for the time period of 1997 to 2002. Initially, under mining-induced stresses only (1997), no fracturing of the rock mass has occurred. As early as 1998, the temperature rise in the rock mass exceeds $130^{\circ} \mathrm{C}$ around the drift periphery, and approximately $150^{\circ} \mathrm{C}$ along the wall heater holes. The vertically symmetric temperature field induces a significant tangential compression to the crown of the tunnel, which is approximately equal to the projected uniaxial compressive strength of the rock mass. A very small amount of non-coherent fracturing is predicted in the crown at this stage. At the year 2000, the rock mass temperature in the immediate crown reaches approximately $190^{\circ} \mathrm{C}$, and slabbing occurs (as seen in the upper right hand portion of figure as red fractured contact planes between blocks). The roof-parallel slabbing (or spalling) occurs largely in the crown over a span of perhaps 2 meters, and rapidly equilibrates and dies out into the roof where the confinement is sufficient to suppress this response. A seen in these figures, a number of particles detach themselves and fall onto the invert. The spalling phenomenon appears to occur in much the same fashion as axial splitting of samples in uniaxial compression in the laboratory. The rock adjacent to the free surface is subjected to the tangential compression and radial tension which results in the fracturing parallel to the minimum principal stress.

The model response can be compared to field observations:

- With the selected strength parameters, the model shows no spalling behavior due to in situ mining-induced stresses only. No spalling is observed in the field.

- Small-scale fracture development can be observed early on in both the model and field. Small particles were observed on the drift floor as early as 1999 in the field while non-coherent fractures develop in the model in the crown as early as 1998.

- Large-scale spalling in the model is observed when the heater power is raised in the year 2000, thus creating a large change in thermally induced tangential compression and radial tension in the roof (Figure 7-34). A change in roof spalling and rock plates lying on the floor of the drift are observed in the Drift Scale Heater Test in early 2001. Depth of the spalling in the field is unknown at present as it is held in place by the rock support. However, the general location (restricted to the immediate crown) and lateral extent (a meter or two) of the simulated spalling (Figure 7-34) is consistent with field observation.

- The model spalling occurs when the rock stresses roughly equal the proposed uniaxial compressive strength of the rock mass, confirming the selection and calibration of the rock strength and its relationship to in situ modulus.

Obviously, the strength and moduli of the Tptpmn rock mass varies in situ. This validation exercise shows that, for rock mass properties within the ranges defined by Price et al. (1985 [DIRS 106602]), the model is able to produce thermally induced fracturing response similar in nature and extent to that observed at the proper temperature and thus thermally induced stress levels. 


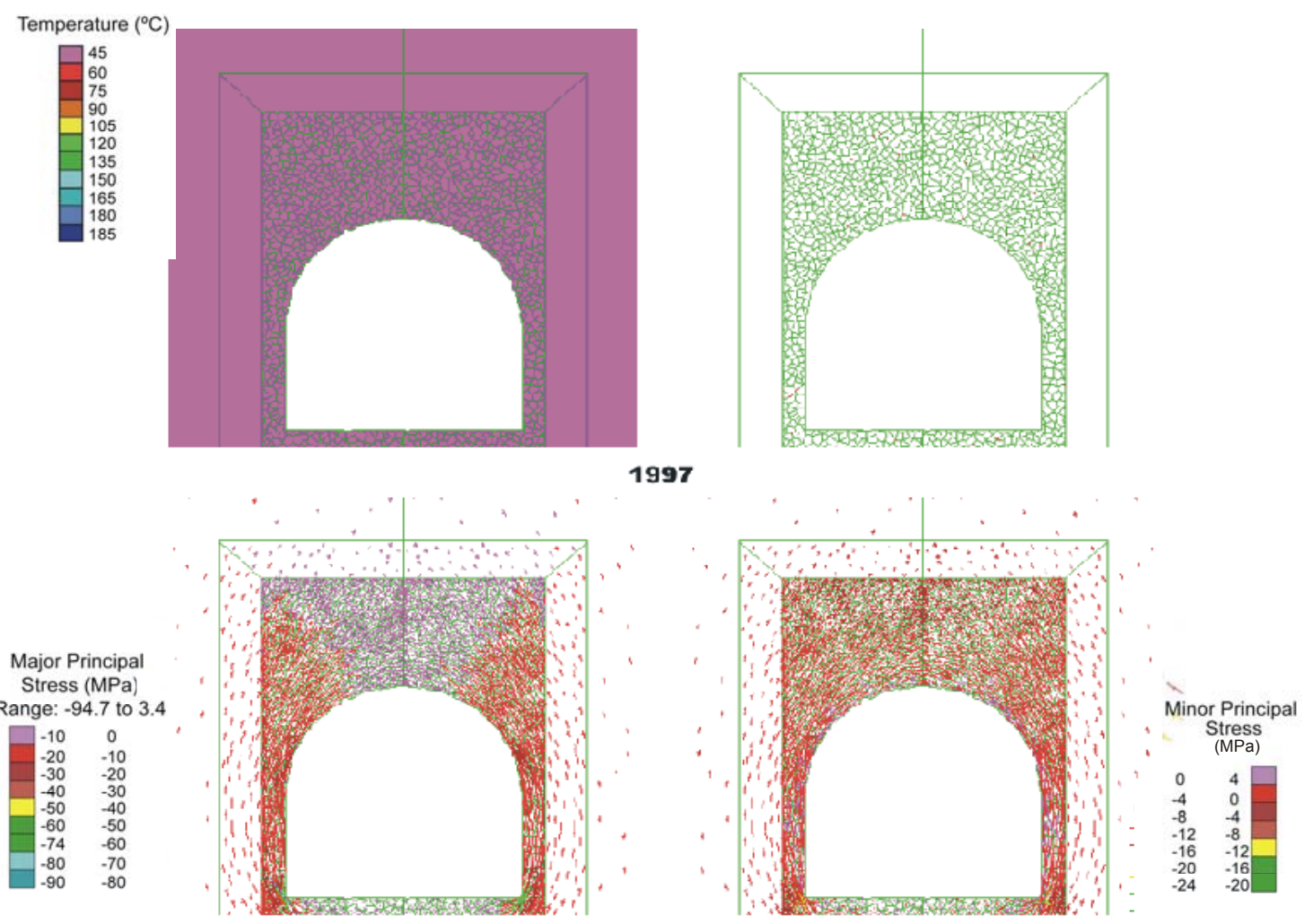

Source: DTNs: MO9807DSTSET01.000 [DIRS 113644]; MO9906DSTSET03.000 [DIRS 113673]; MO0001SEPDSTPC.000 [DIRS 153836]; MO0007SEPDSTPC.001 [DIRS 153707]; MO0107SEPDSTPC.003 [DIRS 158321]; MO0202SEPDSTTV.001 [DIRS 158320], MO0002ABBLSLDS.000 [DIRS 147304].

NOTE: Clockwise from upper left: temperatures, fractures, minimum principal stress, and maximum principal stress. Temperatures obtained from field thermal measurements; fracture and stress levels predicted from UDEC lithophysal rockfall model.

Figure 7-31. Results from Heated Drift Analysis with 1997 Temperature Conditions 


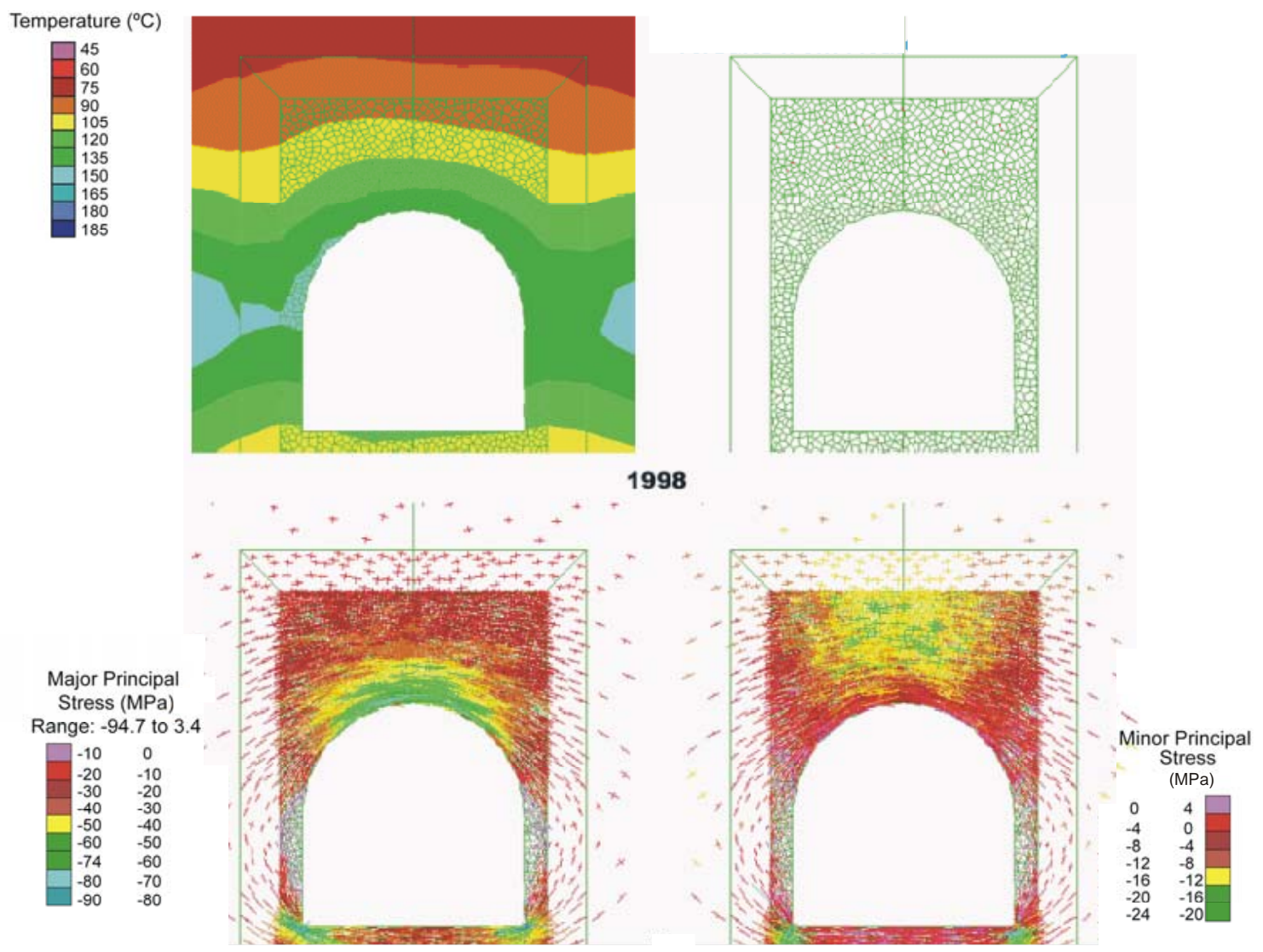

Source: DTNS: MO9807DSTSET01.000 [DIRS 113644]; MO9906DSTSET03.000 [DIRS 113673];

MO0001SEPDSTPC.000 [DIRS 153836]; MO0007SEPDSTPC.001 [DIRS 153707]; MO0107SEPDSTPC.003 [DIRS 158321]; MO0202SEPDSTTV.001 [DIRS 158320]; MO0002ABBLSLDS.000 [DIRS 147304].

NOTE: Clockwise from upper left: temperatures, fractures, minimum principal stress, and maximum principal stress. Temperatures obtained from field thermal measurements; fracture and stress levels predicted from UDEC lithophysal rockfall model. Conditions represent 1 year of heating in the Heated Drift.

Figure 7-32. Results from Heated Drift Analysis with 1998 Temperature Conditions 


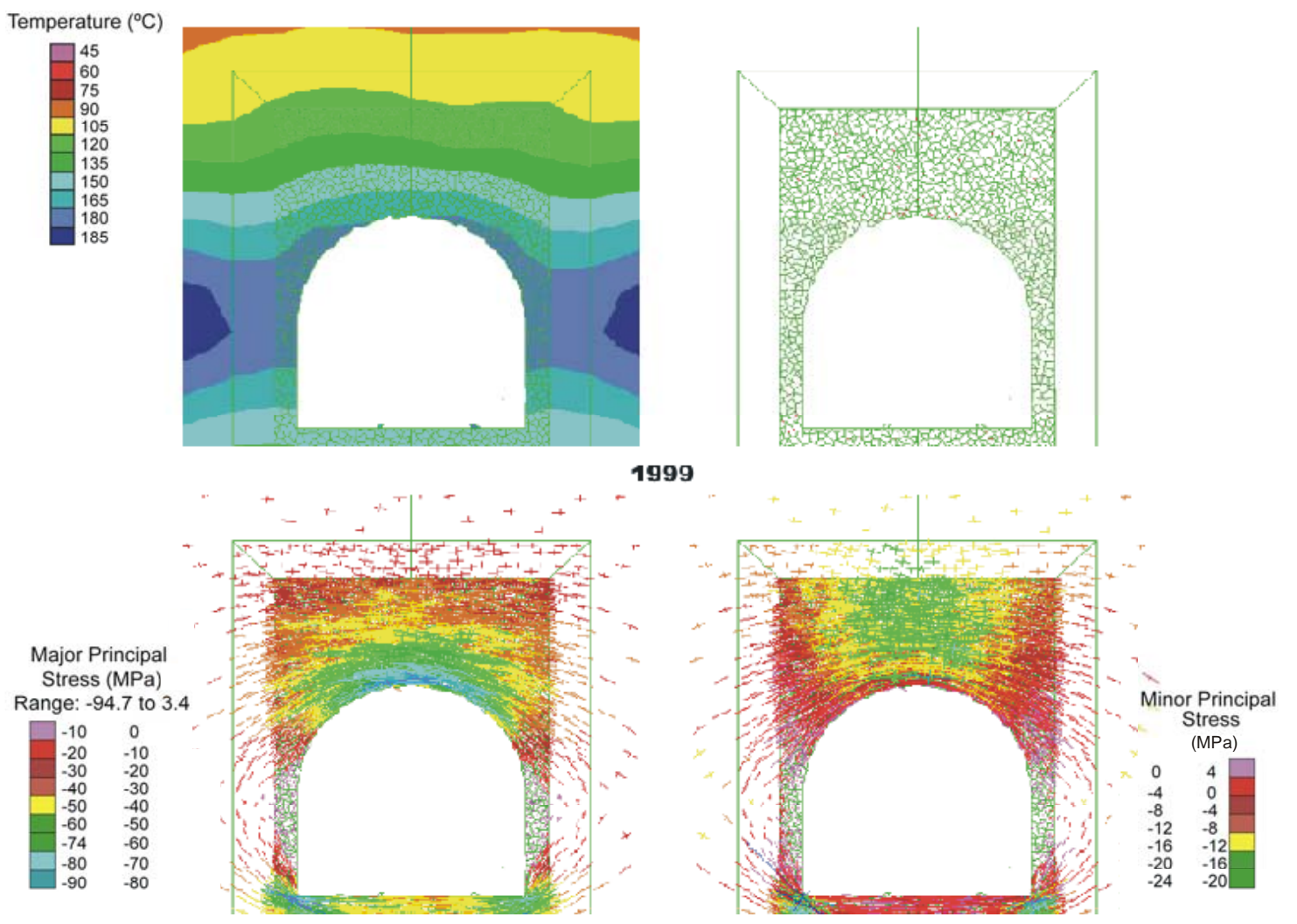

Source: DTNS: MO9807DSTSET01.000 [DIRS 113644]; MO9906DSTSET03.000 [DIRS 113673]; MO0001SEPDSTPC.000 [DIRS 153836]; MO0007SEPDSTPC.001 [DIRS 153707]; MO0107SEPDSTPC.003 [DIRS 158321]; MO0202SEPDSTTV.001 [DIRS 159320]; MO0002ABBLSLDS.000 [DIRS 147304].

NOTE: Clockwise from upper left: temperatures, fractures, minimum principal stress, and maximum principal stress. Temperatures obtained from field thermal measurements; fracture and stress levels predicted from UDEC lithophysal rockfall model. Conditions represent 2 years of heating in the Heated Drift.

Figure 7-33. Results from Heated Drift Analysis with 1999 Temperature Conditions 

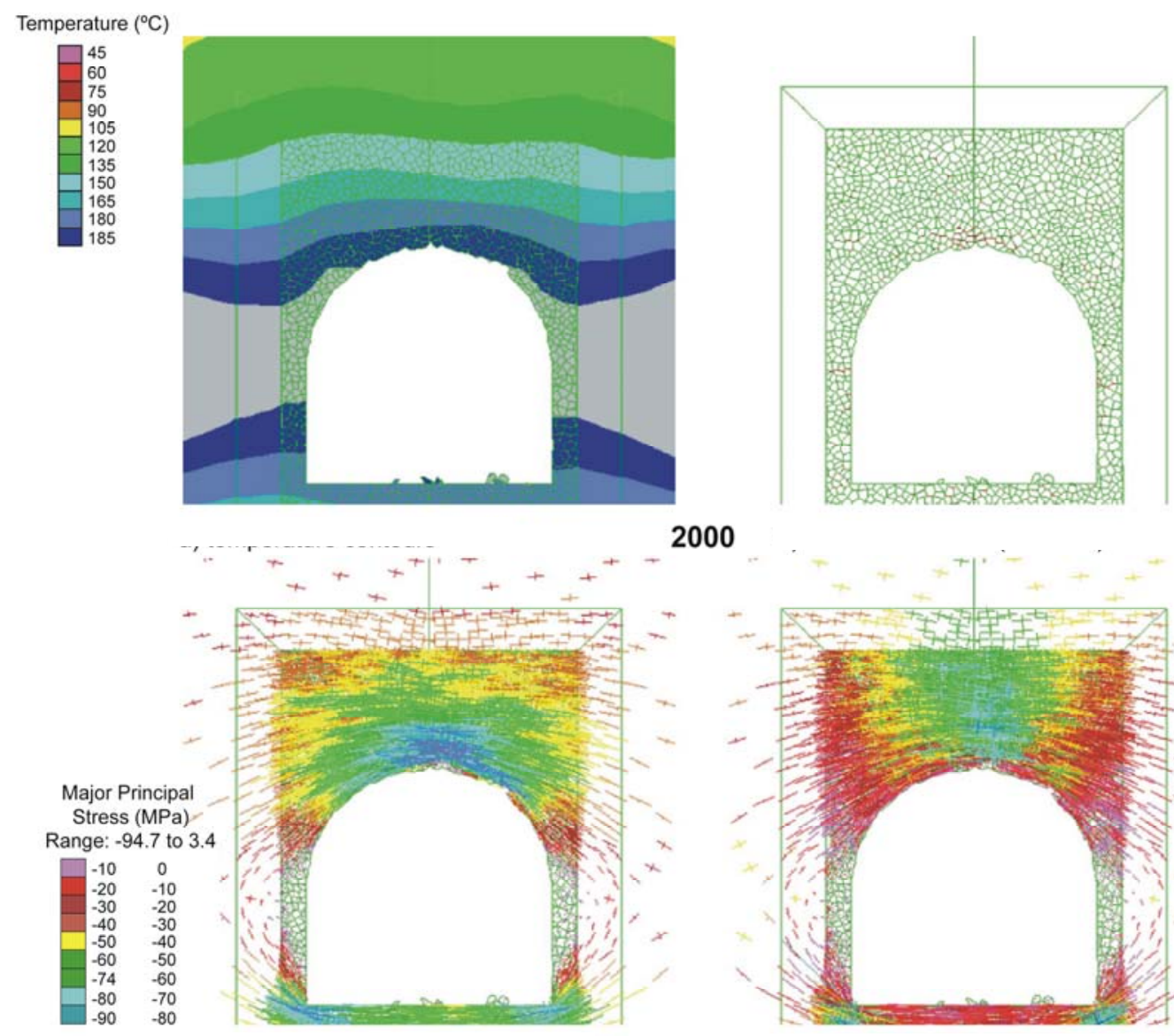

2000

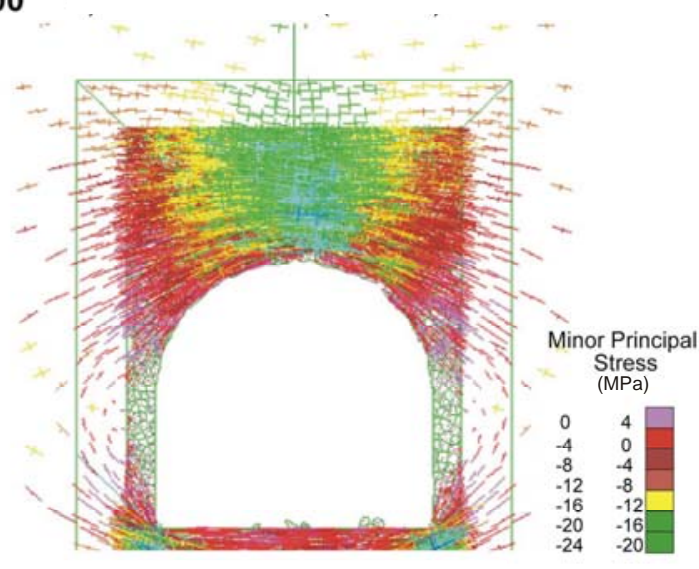

00387DC_042C.ai

Source: DTNS: MO9807DSTSET01.000 [DIRS 113644]; MO9906DSTSET03.000 [DIRS 113673];

MO0001SEPDSTPC.000 [DIRS 153836]; MO0007SEPDSTPC.001 [DIRS 153707];

MO0107SEPDSTPC.003 [DIRS 158321]; MO0202SEPDSTTV.001 [DIRS 159320]; MO0002ABBLSLDS.000 [DIRS 147304].

NOTE: Clockwise from upper left: temperatures, fractures, minimum principal stress, and maximum principal stress. Temperatures obtained from field thermal measurements; fracture and stress levels predicted from UDEC lithophysal rockfall model. Conditions represent 3 years of heating in the Heated Drift.

Figure 7-34. Results from Heated Drift Analysis with 2000 Temperature Conditions 


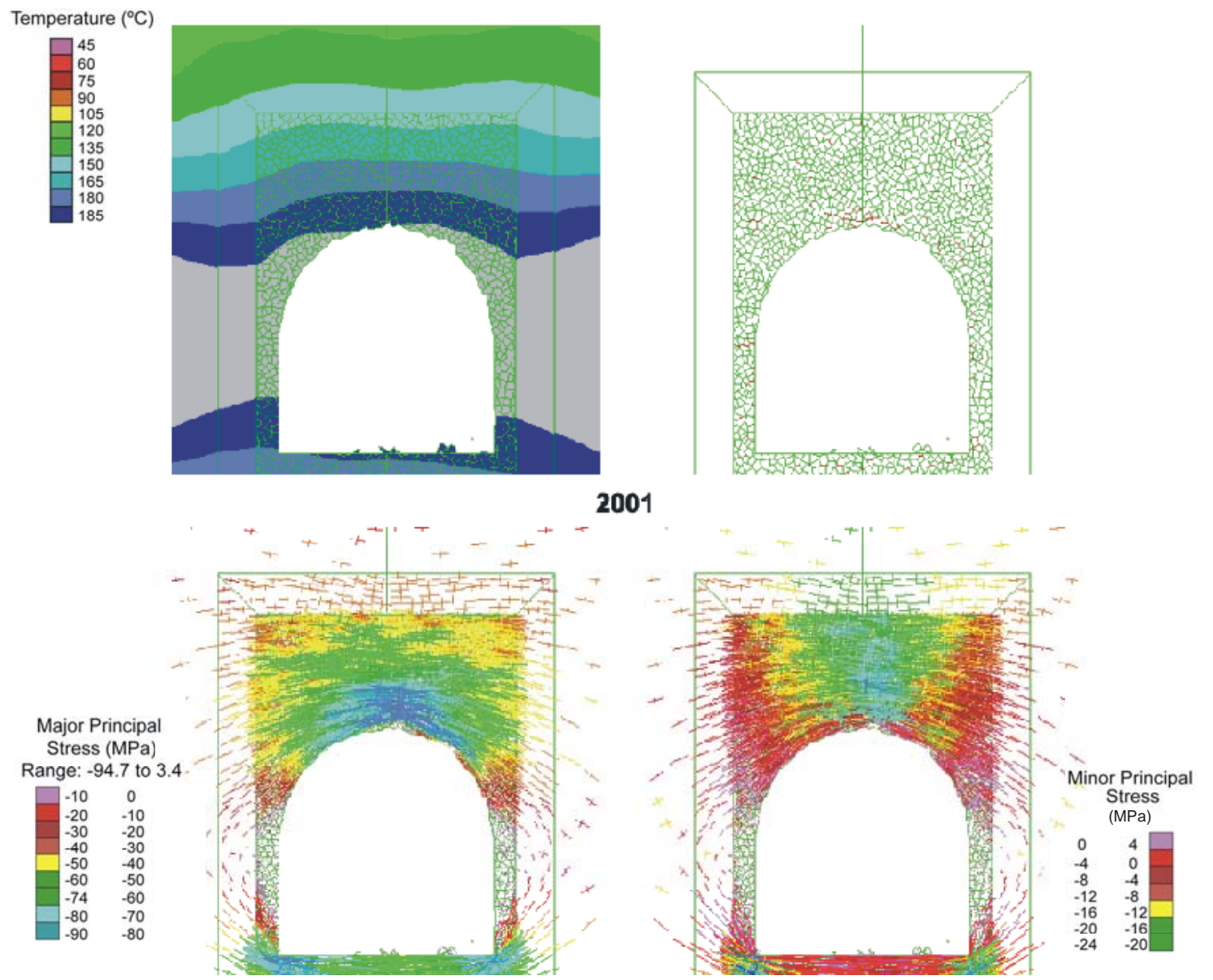

Source: DTNS: MO9807DSTSET01.000 [DIRS 113644]; MO9906DSTSET03.000 [DIRS 113673]; MO0001SEPDSTPC.000 [DIRS 153836]; MO0007SEPDSTPC.001 [DIRS 153707]; MO0107SEPDSTPC.003 [DIRS 158321]; MO0202SEPDSTTV.001 [DIRS 159320]; MO0002ABBLSLDS.000 [DIRS 147304].

NOTE: Clockwise from upper left: temperatures, fractures, minimum principal stress, and maximum principal stress. Temperatures obtained from field thermal measurements; fracture and stress levels predicted from UDEC lithophysal rockfall model. Conditions represent 4 years of heating in the Heated Drift.

Figure 7-35. Results from Heated Drift Analysis with 2001 Temperature Conditions 


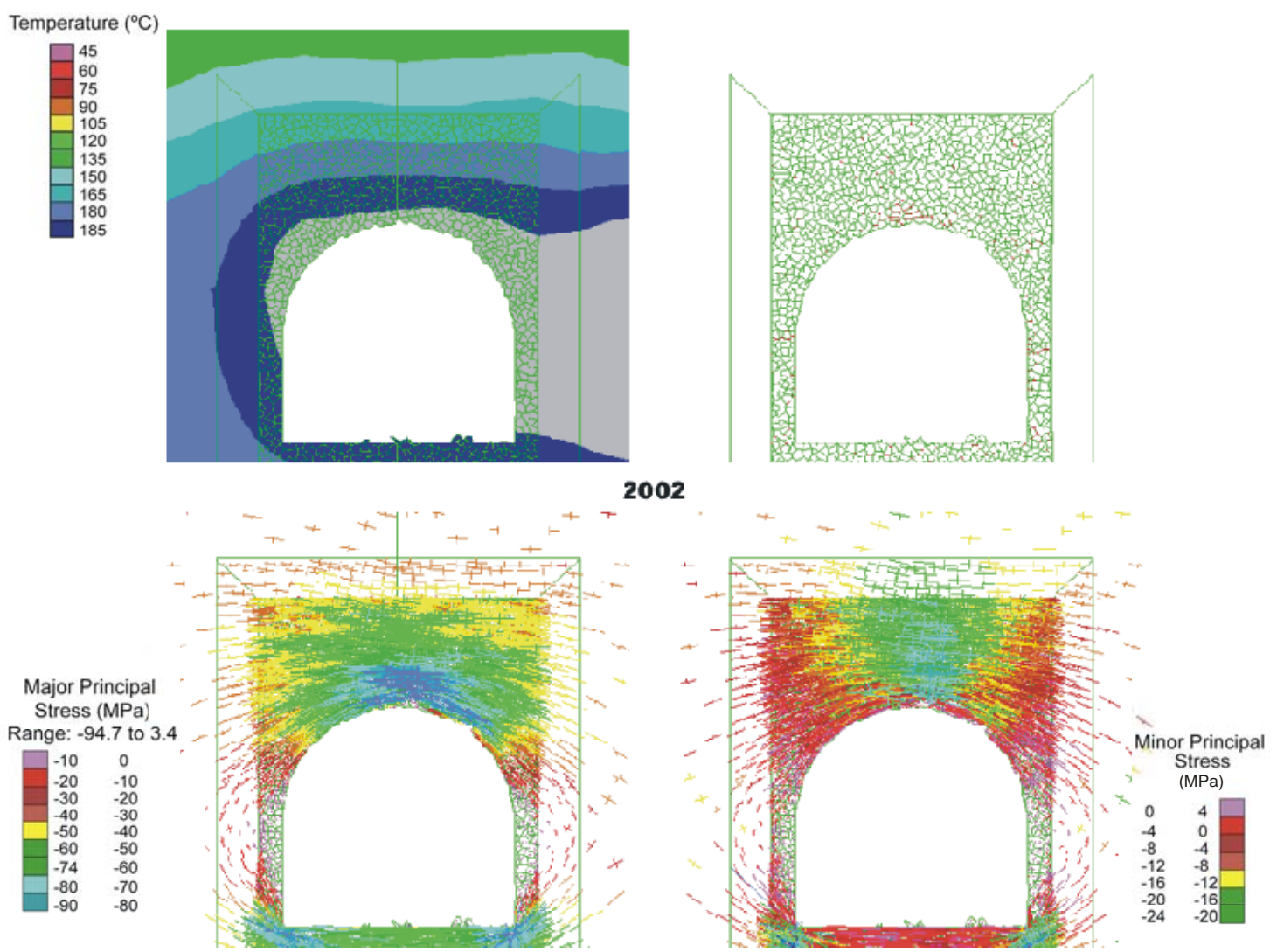

Source: DTNS: MO9807DSTSET01.000 [DIRS 113644]; MO9906DSTSET03.000 [DIRS 113673]; MO0001SEPDSTPC.000 [DIRS 153836]; MO0007SEPDSTPC.001 [DIRS 153707]; MO0107SEPDSTPC.003 [DIRS 158321]; MO0202SEPDSTTV.001 [DIRS 159320]; MO0002ABBLSLDS.000 [DIRS 147304].

NOTE: Clockwise from upper left: temperatures, fractures, minimum principal stress, and maximum principal stress. Temperatures obtained from field thermal measurements; fracture and stress levels predicted from UDEC lithophysal rockfall model. Conditions represent the cool-down period in the Heated Drift.

Figure 7-36. Results from Heated Drift Analysis with 2002 Temperature Conditions

\subsubsection{UDEC Post-Development Validation Exercise 4 - Comparison of UDEC Voronoi Block Model with Continuum Constitutive Models (Corroboration of Results with Alternative Mathematical Models)}

A UDEC model in which the rock mass is represented as an assembly of polygonal blocks is used to analyze the stability of the emplacement drifts located in the lithophysal rock. The main reason for using this approach, which is uncommon in engineering practice, was the requirement for the analysis to predict the rockfall. The Voronoi block model has an advantage over the continuum models in that fracturing of the rock mass, formation of loose blocks, and their rockfall can be simulated in a straightforward manner within the same model. However, the Voronoi block model must be calibrated in order to ensure that it behaves mechanically equivalent to the simulated rock mass. Another way of validating the UDEC Voronoi block model of lithophysal rock is to compare its results with those of the continuum approach using different constitutive models. The comparison is presented in this section. 
Elastic Models of Drift Excavation-The Voronoi block model behaves as a linearly elastic model before fracturing occurs. Stress redistribution and deformation around the emplacement drift for the in situ stress state, in which the vertical stress is $7 \mathrm{MPa}$ and the horizontal stress is 3.5 MPa, are analyzed using continuum, linearly elastic constitutive models in FLAC and the UDEC Voronoi block model. In order to ensure linearly elastic behavior of the UDEC Voronoi block model, the strength of the contact bonds between the blocks was considered to be infinitely large. The problem was solved using two different geometries of the Voronoi block model, with average block sizes of $0.2 \mathrm{~m}$ and $0.3 \mathrm{~m}$. Comparison of stresses and displacements calculated using the different methods is presented in Figures 7-37 to 7-42. Stress profiles calculated in UDEC show more scatter because of the discontinuous nature of the model. However, the agreement, in general, is rather good. The systematic difference in the horizontal and vertical displacements shown in Figures 7-39 and 7-42 is due to the different outer boundary sizes of the UDEC and FLAC models. The smaller FLAC model results in larger vertical displacements, because a stress boundary condition was used on the top model boundary.

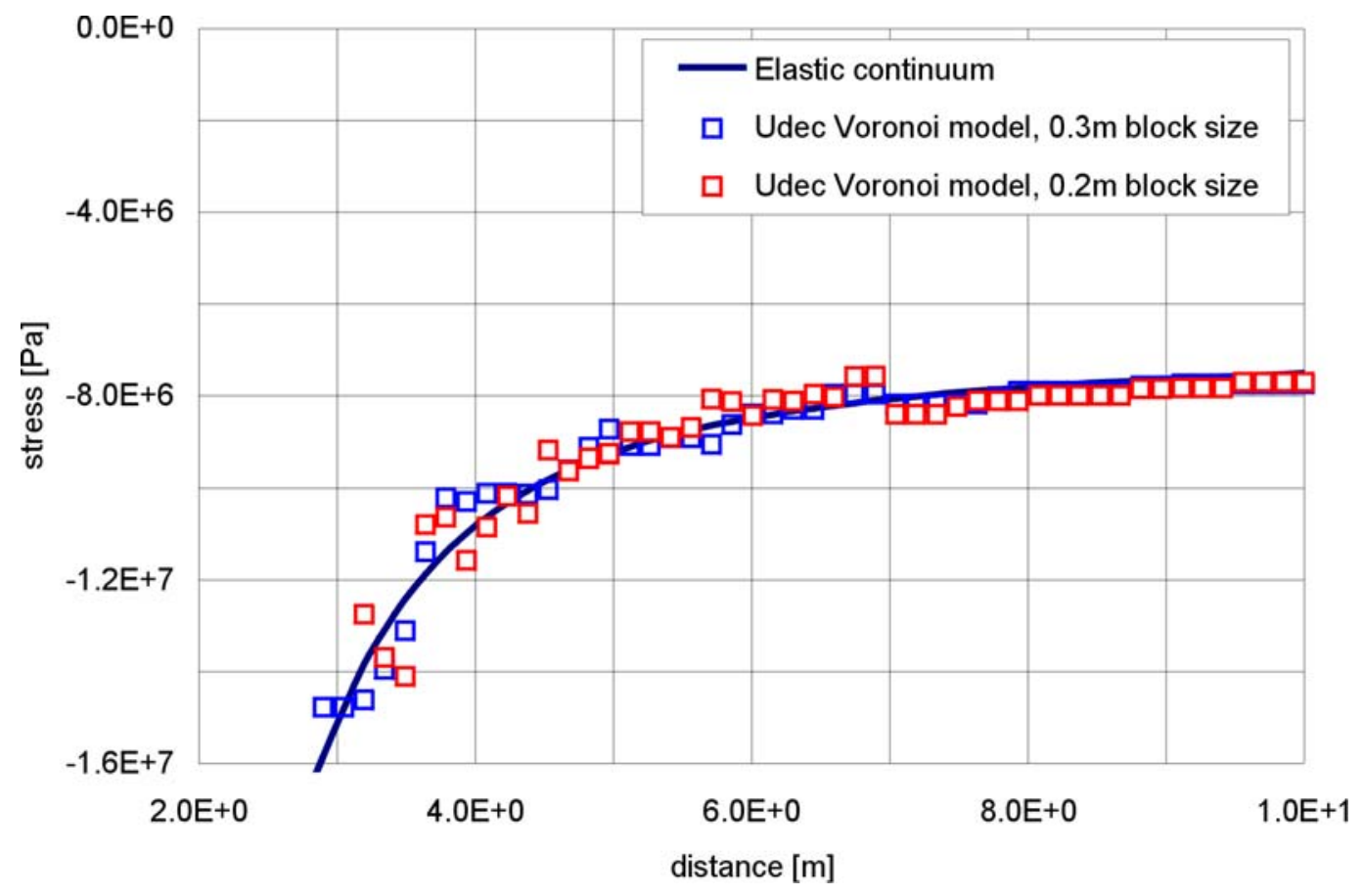

Figure 7-37. Elastic Models of Drift Excavation: Vertical Normal Stress Along the Horizontal Profile Through the Center of Tunnel (Distance is measured from the tunnel center) 


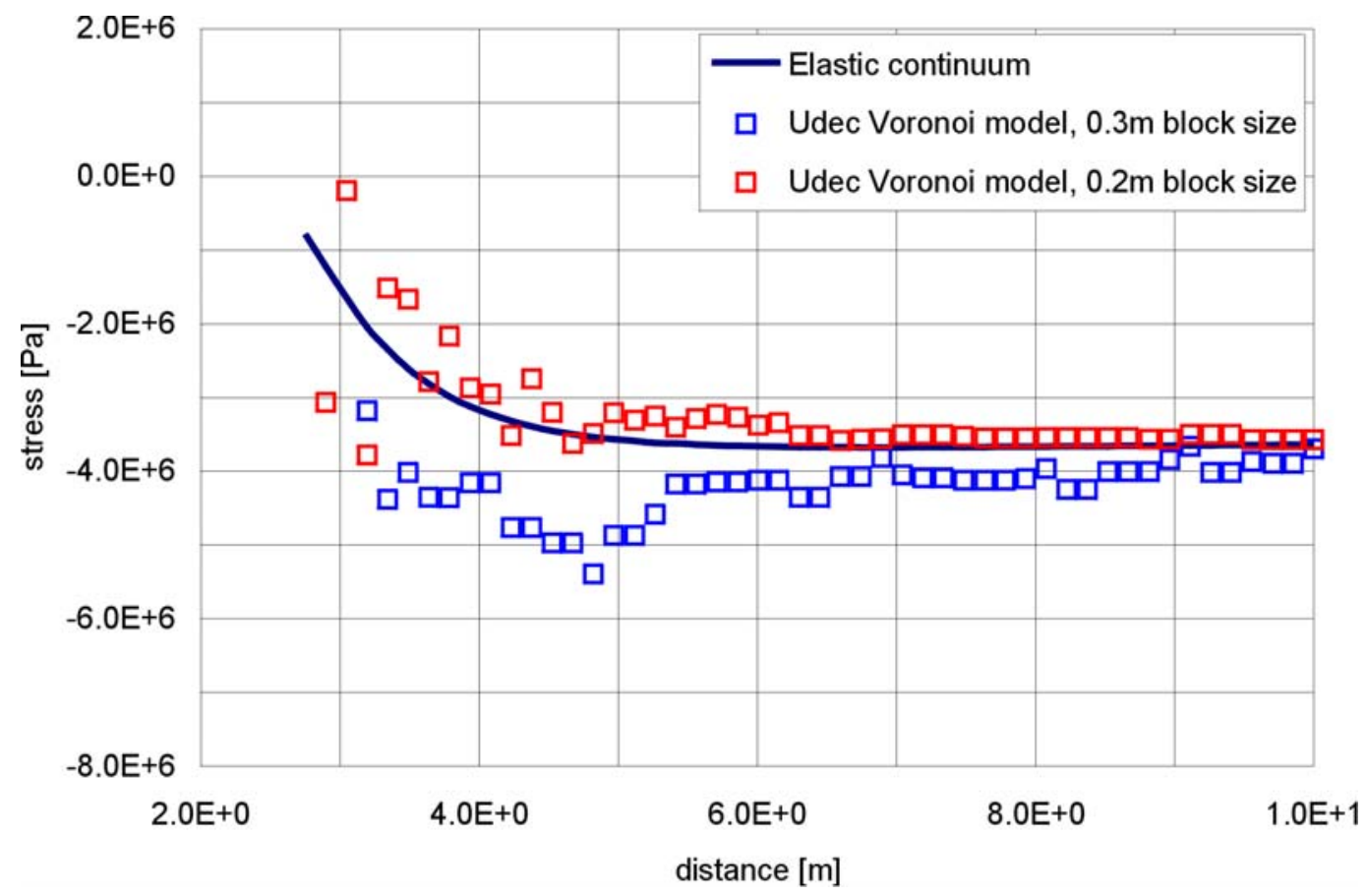

Figure 7-38. Elastic Models of Drift Excavation: Horizontal Normal Stress Along the Horizontal Profile Through the Center of Tunnel (Distance is measured from the tunnel center)

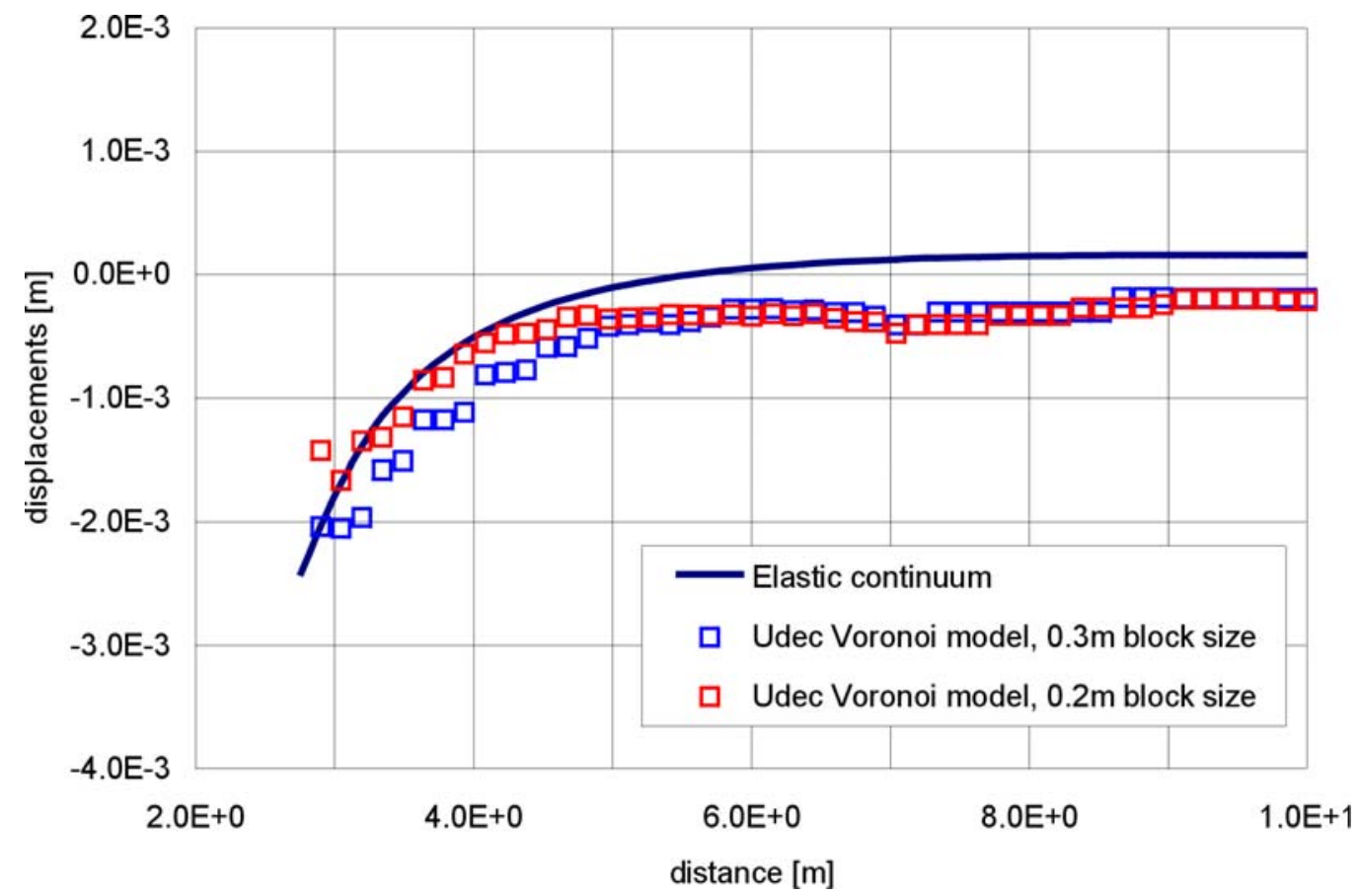

Figure 7-39. Elastic Models of Drift Excavation: Horizontal Displacement Along the Horizontal Profile Through the Center of Tunnel (Distance is measured from the tunnel center) 


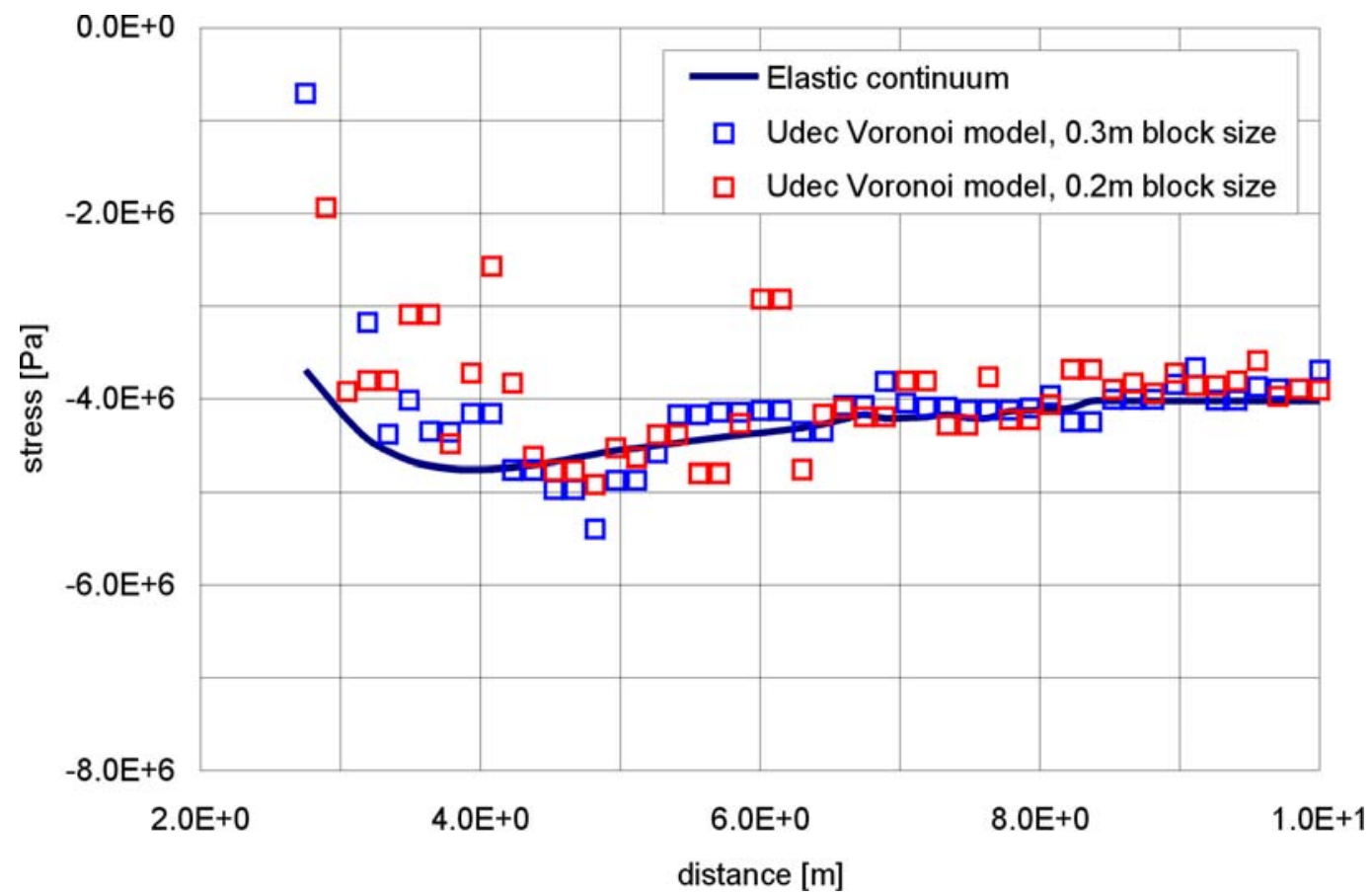

Figure 7-40. Elastic Models of Drift Excavation: Horizontal Normal Stress Along the Vertical Profile Through the Center of Tunnel (Distance is measured from the tunnel center)

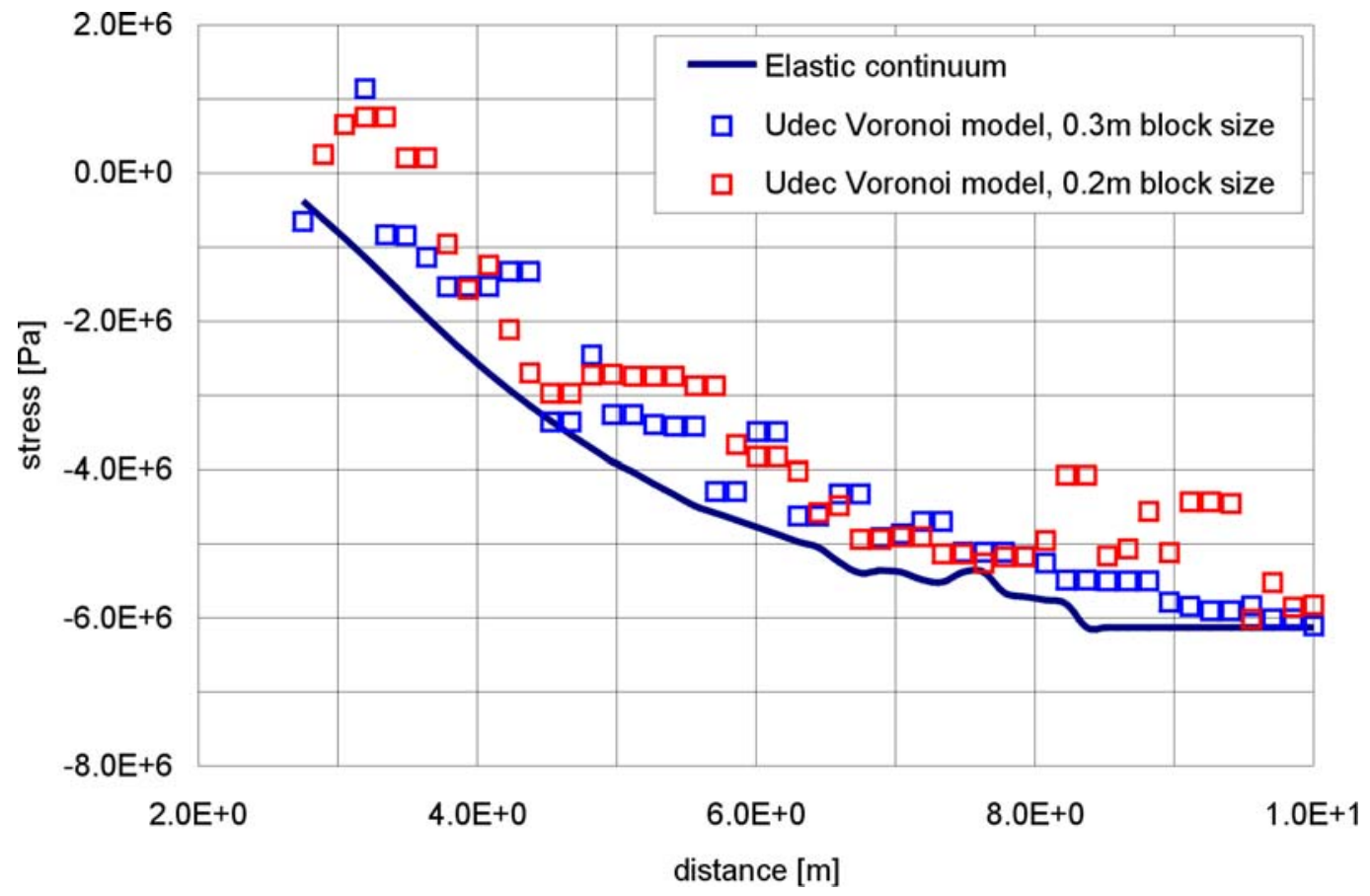

Figure 7-41. Elastic Models of Drift Excavation: Vertical Normal Stress Along the Vertical Profile Through the Center of Tunnel (Distance is measured from the tunnel center) 


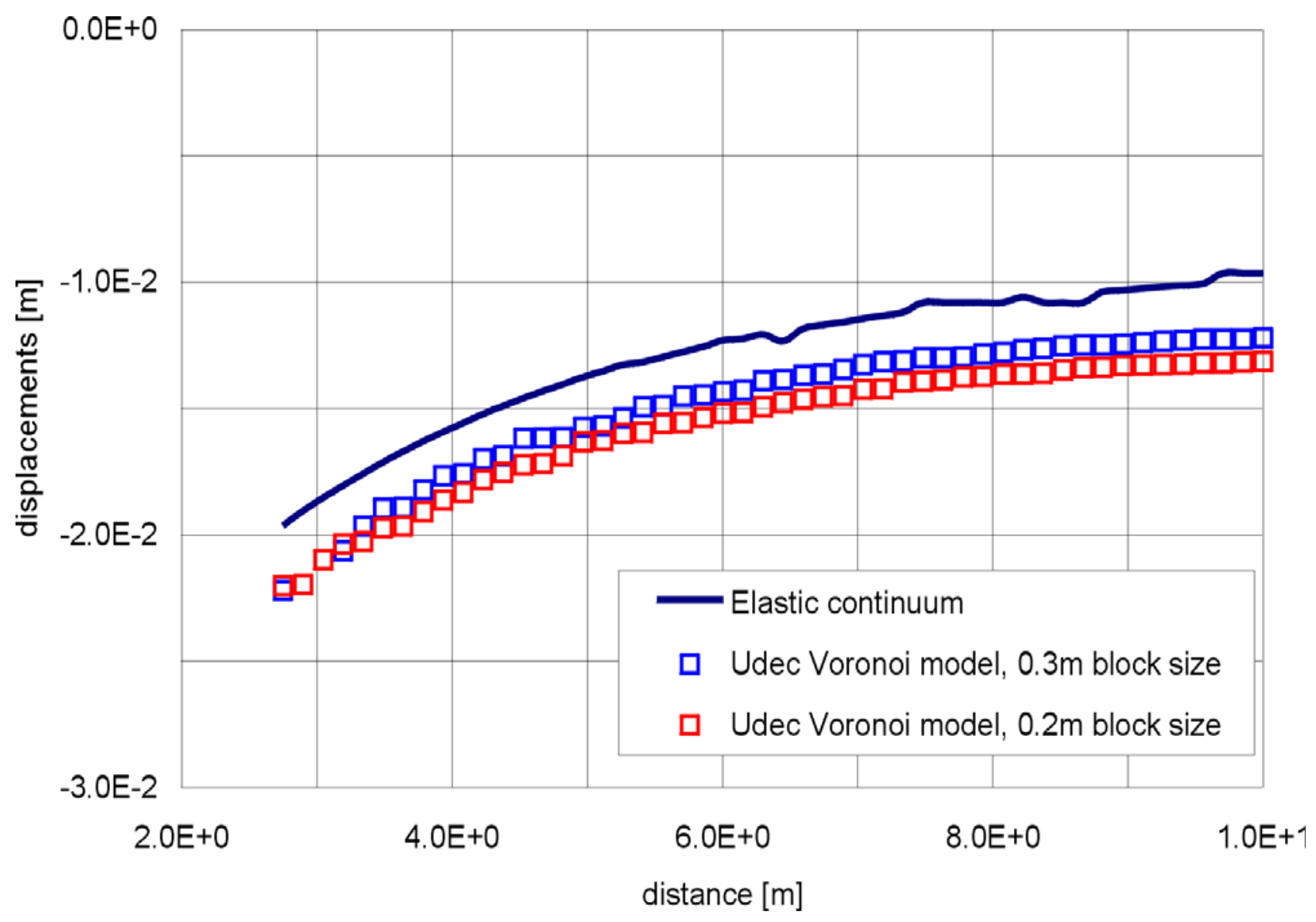

Figure 7-42. Elastic Models of Drift Excavation: Vertical Displacement Along the Vertical Profile Through the Center of Tunnel (Distance is measured from the tunnel center)

Inelastic Models of the Emplacement Drift-The results of damage, stress redistribution and deformation around the emplacement drift predicted using the UDEC Voronoi block model are compared with results obtained using the continuum approach and different considerations of constitutive behavior of the lithophysal rock mass. The micro properties of the joints and blocks in the UDEC model are calibrated to the stiffness and strength of lithophysal rock mass, Category 1, as determined from unconfined compression tests. The resulting constitutive behavior of the UDEC Voronoi block model is very complex, as illustrated by plots of failure envelope, stress-strain curves for different confinements and volumetric strain as a function of axial strain, shown in Figures 7-20 to 7-22. Unfortunately, the number and types of laboratory and in situ experiments was insufficient to describe the complete constitutive behavior of the lithophysal tuff with a high level of confidence, particularly in the post-peak strain range and for confined conditions. The mechanical behavior exhibited by the synthetic Voronoi block model seems to be quite reasonable and typical for hard, brittle rocks like the Topopah Spring. For unconfined conditions, the UDEC synthetic model softens in a rather brittle manner after reaching the peak stress. As confinement increases, the post-peak behavior becomes mode ductile; for 3-MPa confinement, it is almost perfectly plastic (i.e., there is no strength decrease for a considerable plastic strain). Because of the large uncertainty in the post-peak behavior of the rocks, simple continuum constitutive models are used commonly in engineering practice. The 
following continuum constitutive models were selected for analyzing (using FLAC) stability of emplacement drifts under in situ stresses and thermal loads:

- Associated (dilation angle equal to friction angle), perfectly plastic Mohr-Coulomb model

- Associated Mohr-Coulomb with cohesion at yield softening in a brittle manner to 50 percent of its initial value

- Nonassociated (no dilation) Mohr-Coulomb with cohesion at yield softening in a brittle manner to 50 percent of its initial value

- Associated Mohr-Coulomb with complete loss of cohesion at yield in a brittle manner

- Cohesion softening - friction hardening model. In this model the cohesion softens to 25 percent of its initial value after 0.2 percent of plastic strain, while the friction angle increase from $0^{\circ}$ to $40^{\circ}$ after 0.5 percent of plastic strain.

The selected models certainly bound possible behavior of the lithophysal rock mass. The perfectly plastic Mohr-Coulomb model most likely will represent a lower bound of damage and deformation; perfectly brittle Mohr-Coulomb with complete loss of cohesion at yield is certainly a conservative case, an upper bound of damage and deformation around the emplacement drift.

Stability of the emplacement drift was analyzed for in situ and thermal stresses after 80 years of heating. Damage predicted around the emplacement drifts by different models at two states (after excavation and after 80 years of heating) is illustrated in Figure 7-43. Green and red crosses around the drift in the continuum models indicate locations in the model where plastic deformation took place. Green crosses indicate locations of plastic deformation that occurred sometimes in the past; red crosses indicate locations that currently are deforming plastically. Red lines in the plot from the UDEC model (at the bottom of Figure 7-43) represent the positions of microcracks - i.e., where the bonds between blocks are broken in tension or shear. Both the model with no residual cohesion and the cohesion softening - friction hardening model clearly overestimate the damage and deformation around the emplacement drifts. Conditions predicted by these two models do not exist anywhere inside the ESF or ECRB Cross-Drift. There is very good agreement between the damage predicted by the UDEC Voronoi model and two models with cohesion softening to 50 percent of its initial value. Also, predictions of these three models for Category 1 is consistent with fracturing observed in the boreholes drilled in the walls of the ECRB Cross-Drift in the poorest-quality estimated for the Tptpll. The UDEC model shows a number of fractures randomly scattered throughout the model. Those fractures are a consequence of the discontinuous nature of the model. As long as they are distributed and orientated randomly, they should be considered to be artifacts of the numerical method. The aligned and concentrated fractures in the drift wall represent stress-induced damage.

Stresses and displacements along the different profiles, as calculated by the different models, are shown in Figures 7-44 to 7-49 for the state after excavation of the emplacement drift and in Figures 7-50 to 7-55 for the state after 80 years of heating. Drift stability after excavation was analyzed with the UDEC Voronoi block model using 0.2-m and 0.3-m block sizes. Drift stability 
after 80 years of heating was analyzed with the UDEC Voronoi block model using a 0.3-m block size only. In these cases, the UDEC Voronoi block predictions (for both stress and displacement predictions) fall inside the range of predictions by different continuum models.

excavation
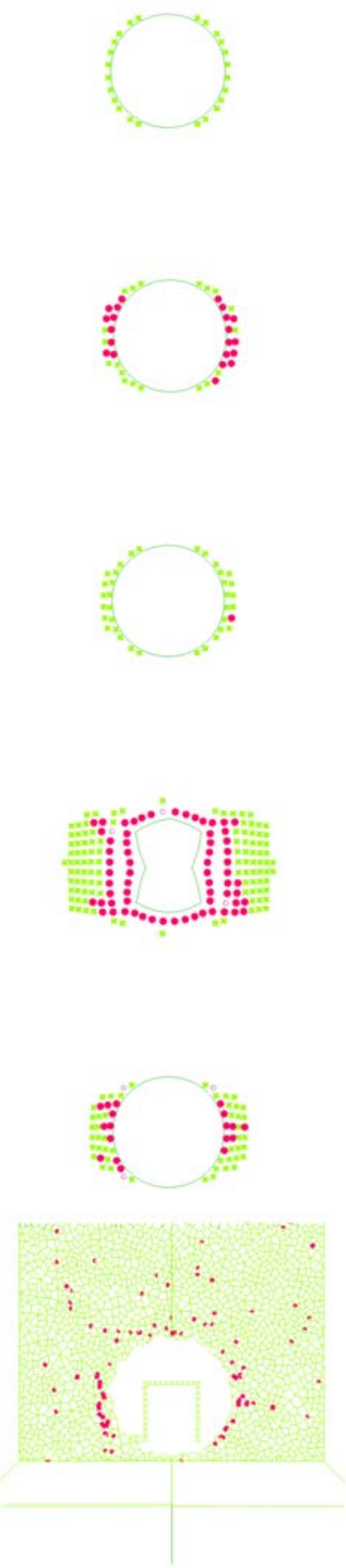

80 years of heating

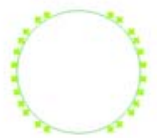

Perfectly plastic Mohr-Coulomb

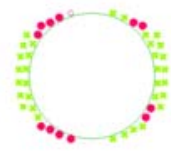

Mohr-Coulomb cohesion softening to 50 percent, associated

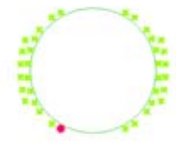

Mohr-Coulomb, cohesion softening

to 50 percent, no dilation

Mohr-Coulomb no residual cohesion, associated

cohesion softening -

friction hardening

UDEC

Figure 7-43. Damage Around the Emplacement Drifts Predicted Using Different Inelastic Models 


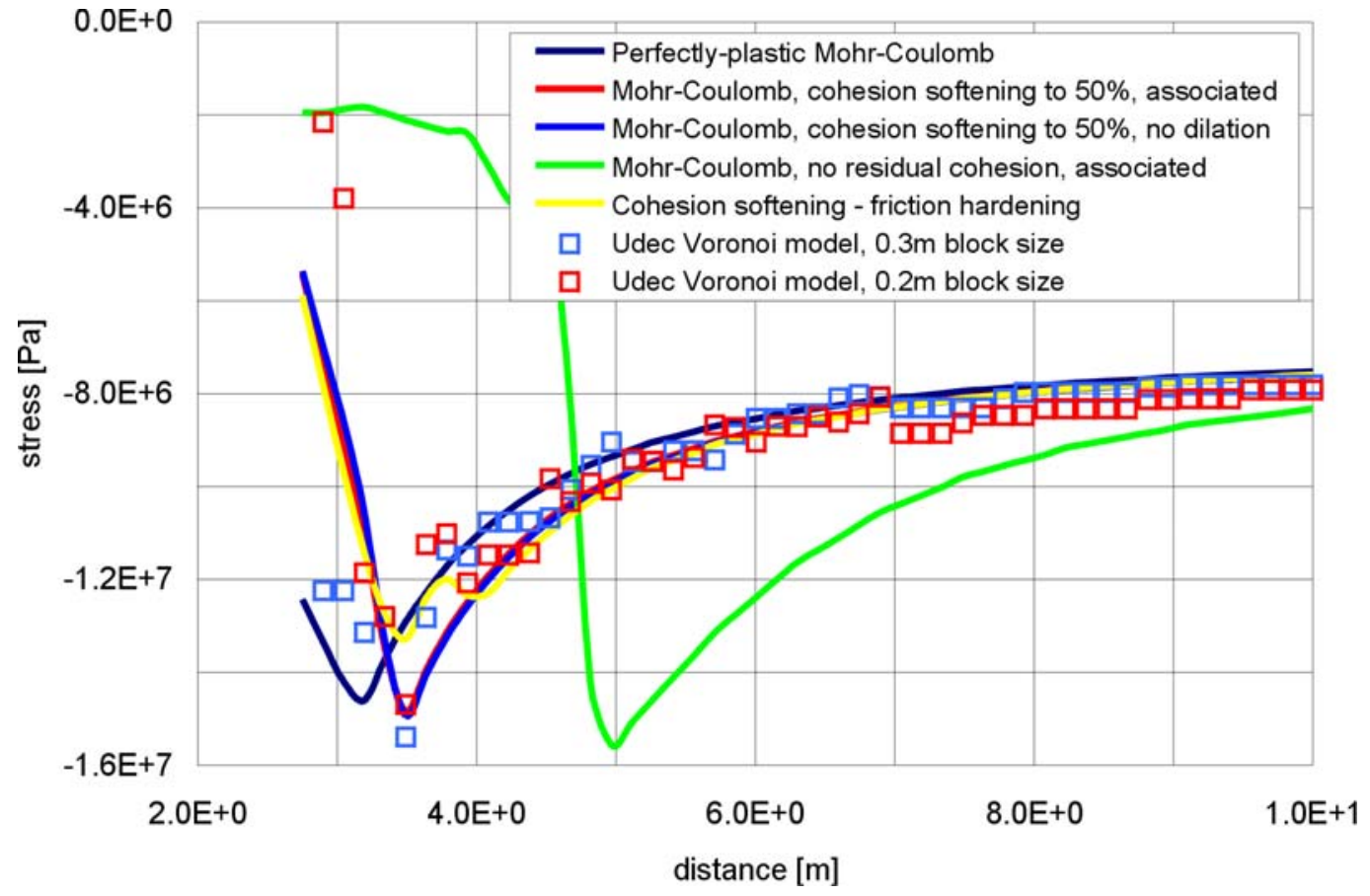

Figure 7-44. Inelastic Models of Drift Excavation: Vertical Normal Stress Along the Horizontal Profile Through the Center of Tunnel (Distance is measured from the tunnel center.)

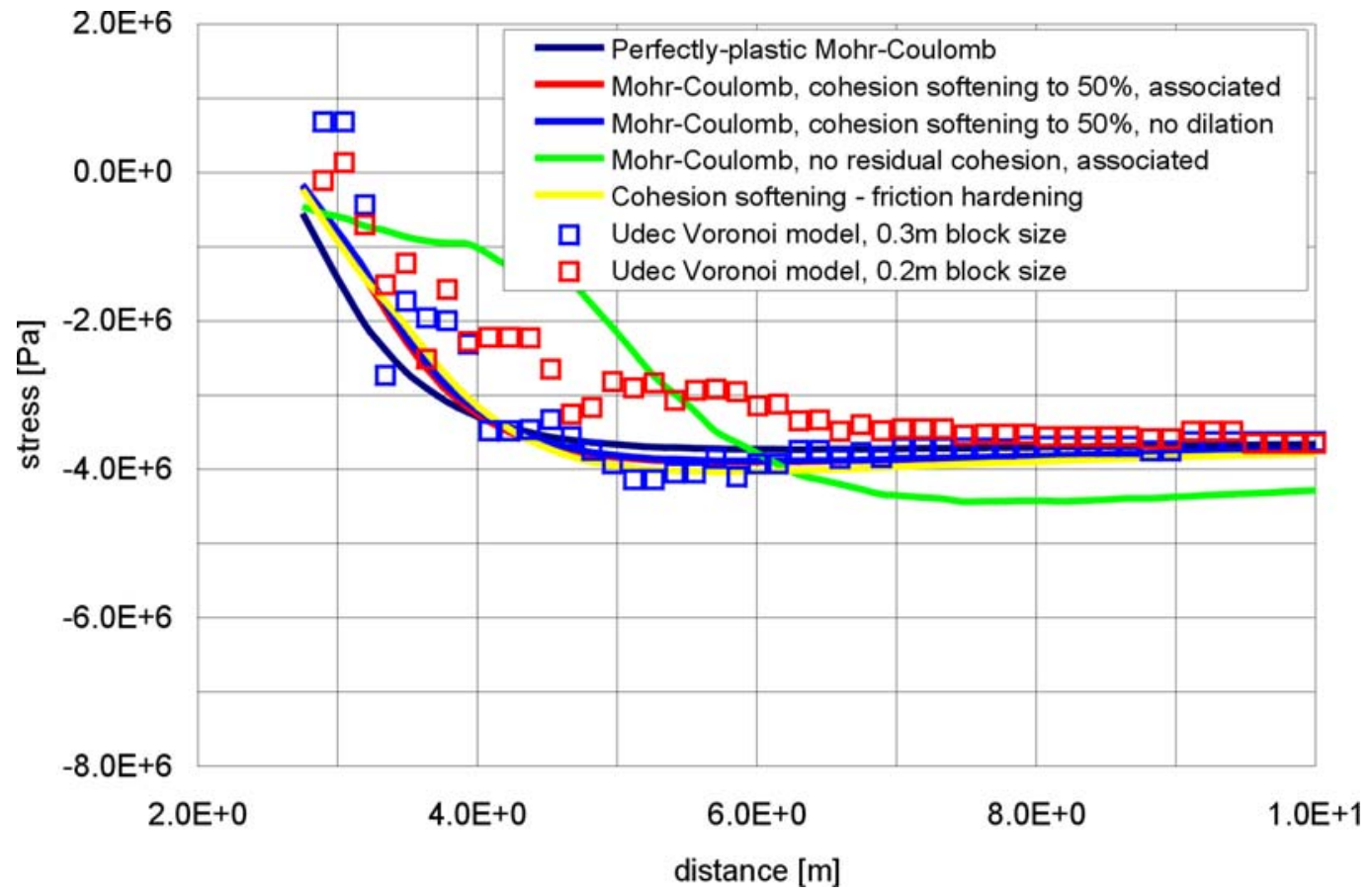

Figure 7-45. Inelastic Models of Drift Excavation: Horizontal Normal Stress Along the Horizontal Profile Through the Center of Tunnel (Distance is measured from the tunnel center) 


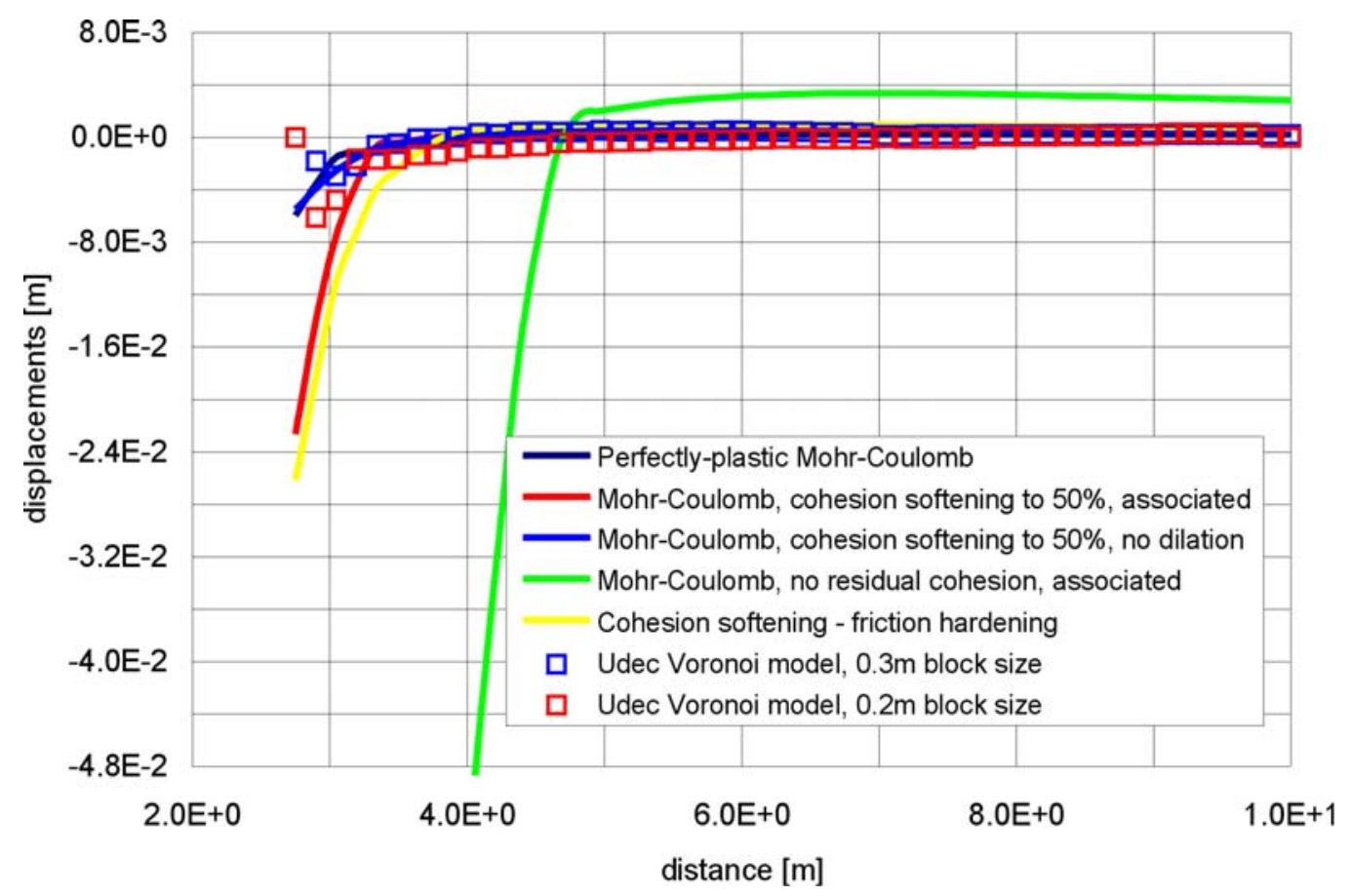

Figure 7-46. Inelastic Models of Drift Excavation: Horizontal Displacement Along the Horizontal Profile Through the Center of Tunnel (Distance is measured from the tunnel center)

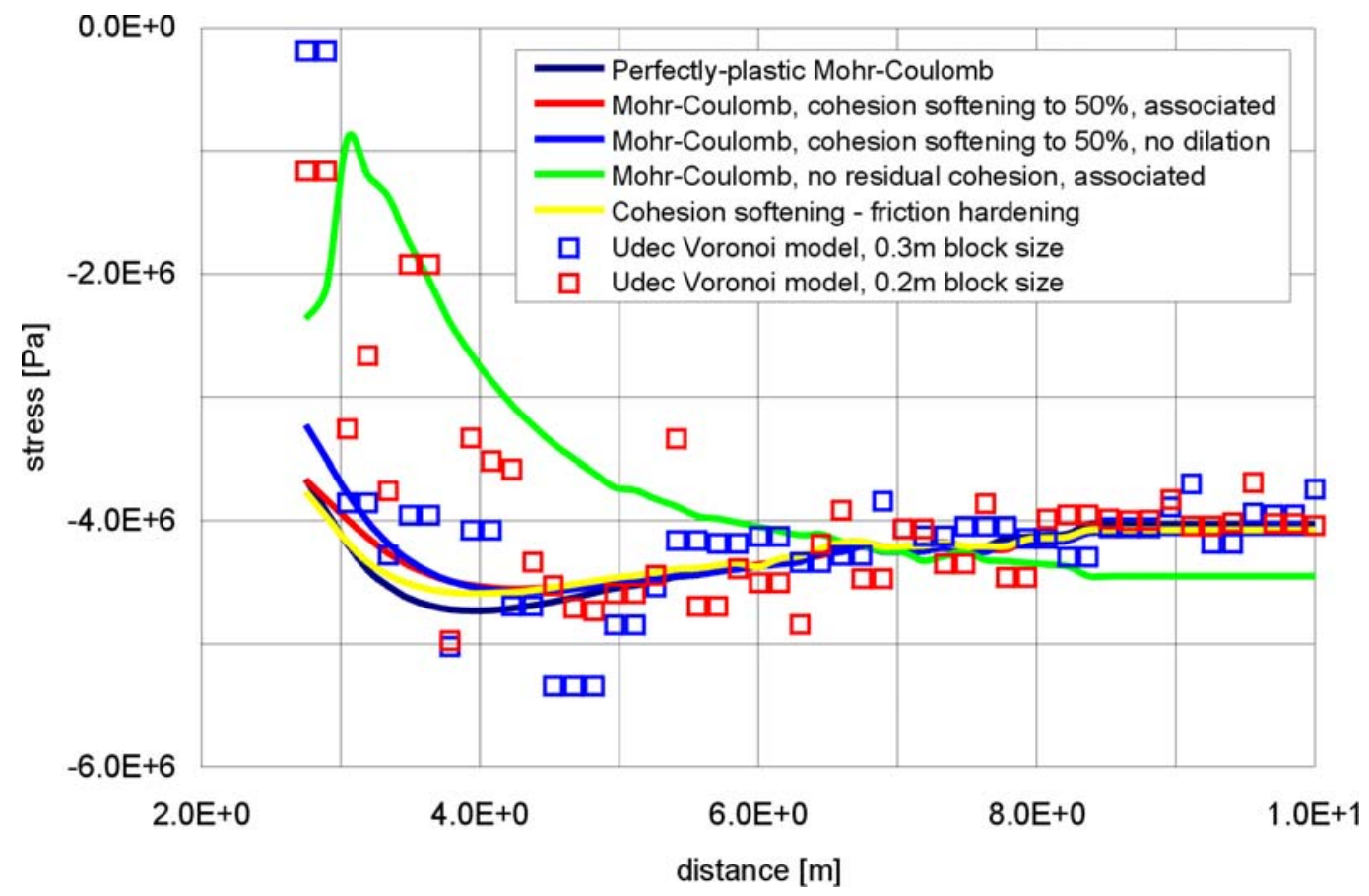

Figure 7-47. Inelastic Models of Drift Excavation: Horizontal Normal Stress Along the Vertical Profile Through the Center of Tunnel (Distance is measured from the tunnel center) 


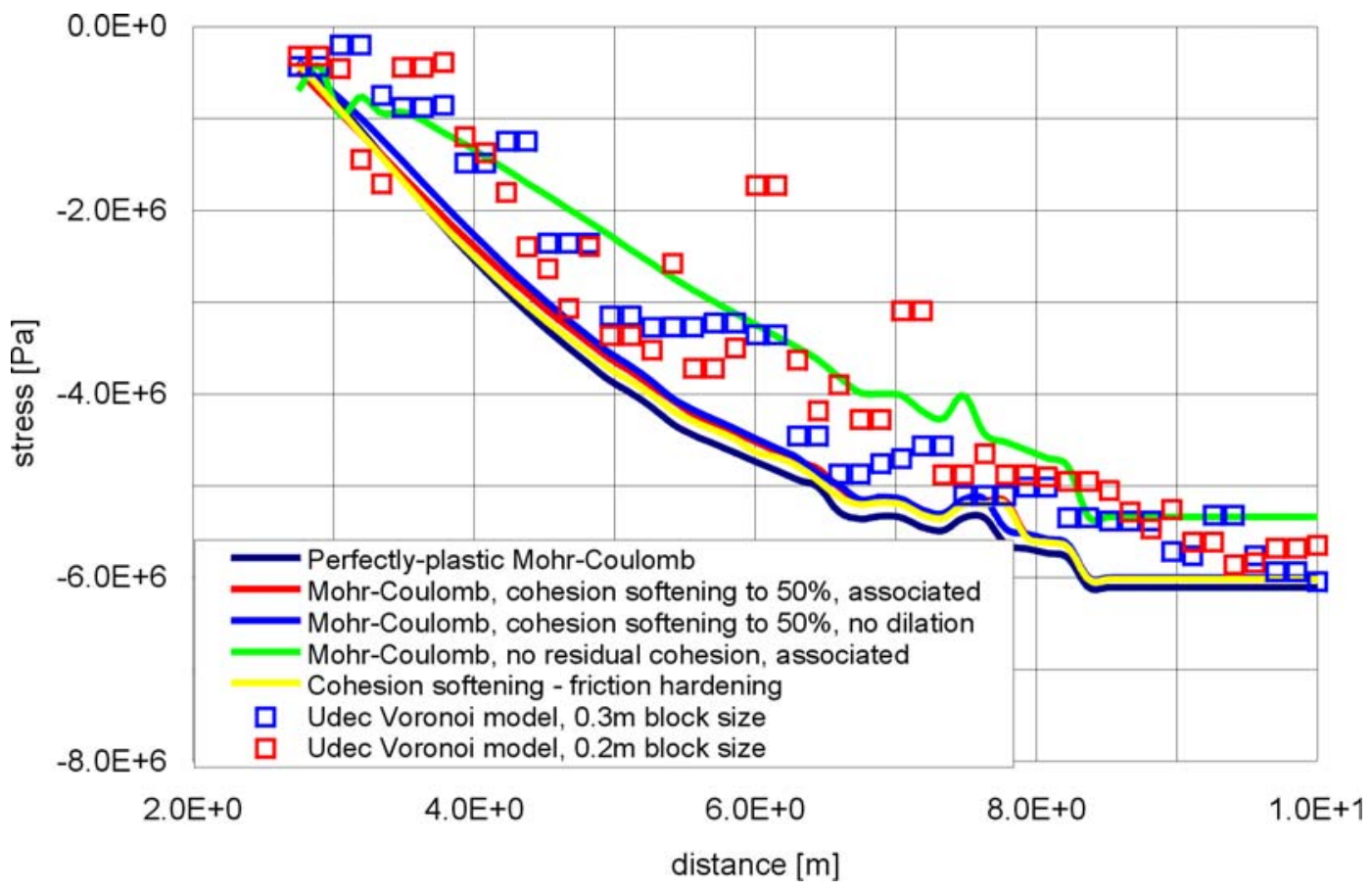

Figure 7-48. Inelastic Models of Drift Excavation: Vertical Normal Stress Along the Vertical Profile Through the Center of Tunnel (Distance is measured from the tunnel center)

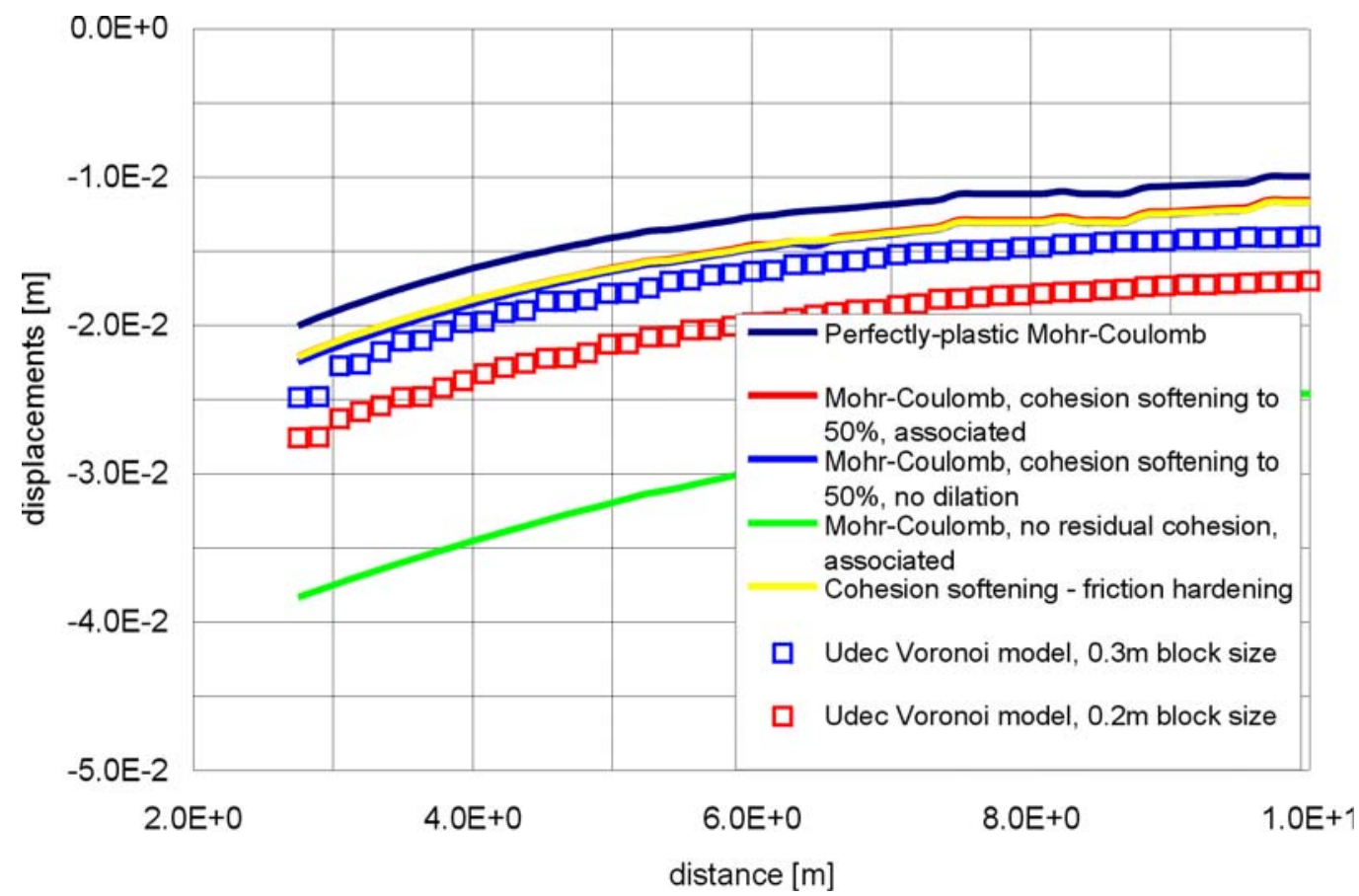

Figure 7-49. Inelastic Models of Drift Excavation: Vertical Displacement Along the Vertical Profile Through the Center of Tunnel (Distance is measured from the tunnel center) 


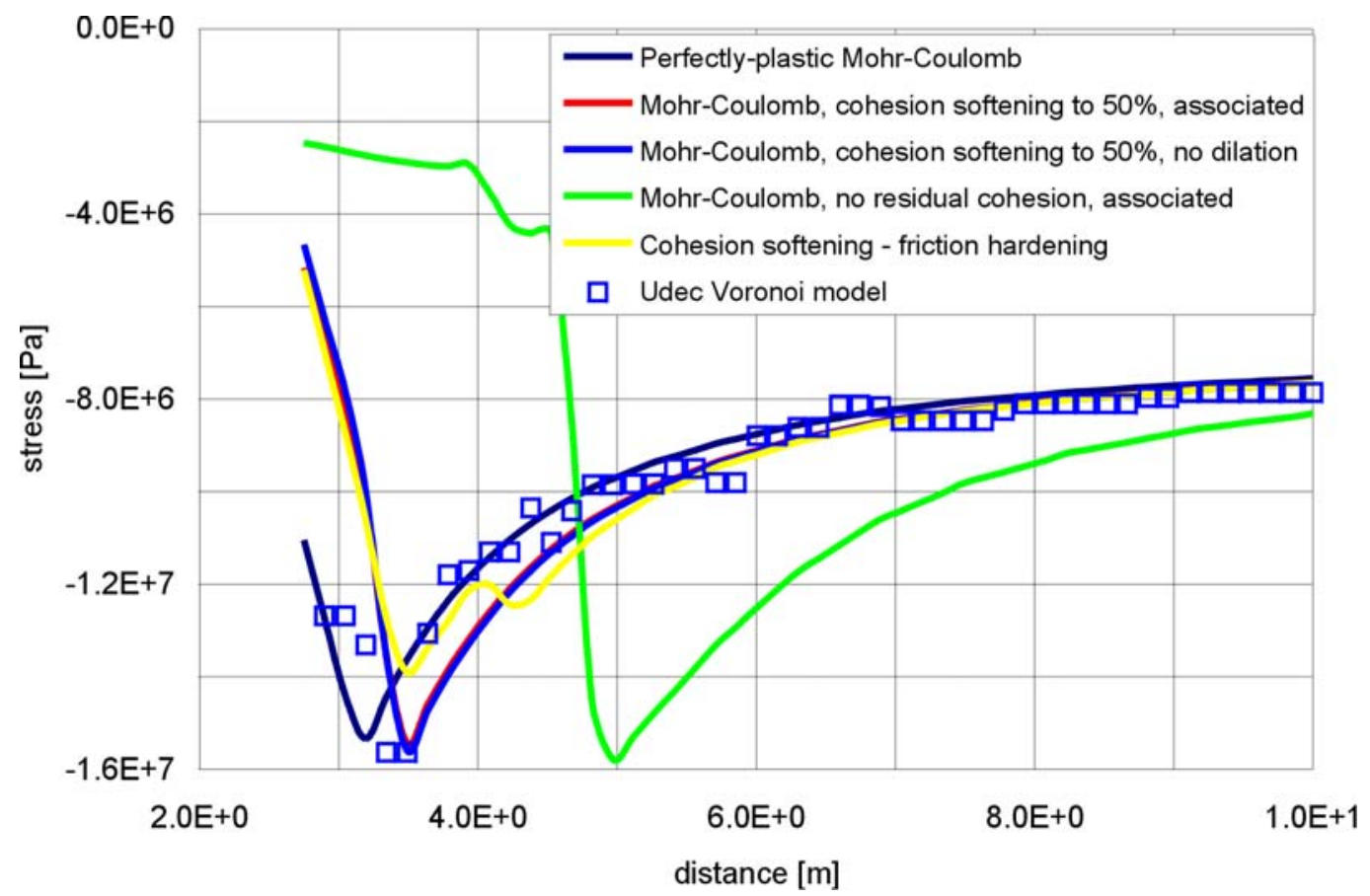

Figure 7-50. Inelastic Models After 80 Years of Heating: Vertical Normal Stress Along the Horizontal Profile Through the Center of Tunnel (Distance is measured from the tunnel center)

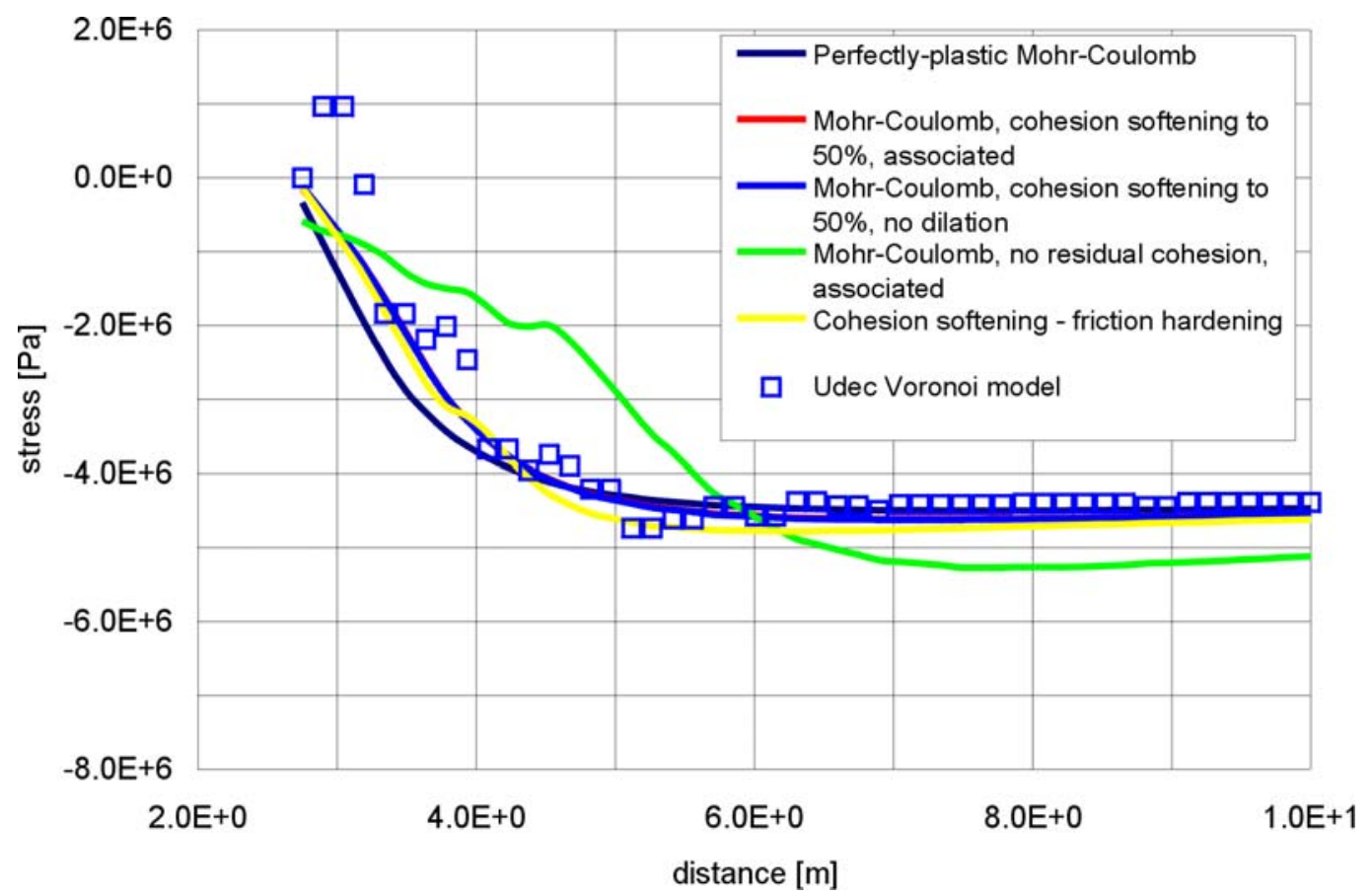

Figure 7-51. Inelastic Models After 80 Years of Heating: Horizontal Normal Stress Along the Horizontal Profile Through the Center of Tunnel (Distance is measured from the tunnel center) 


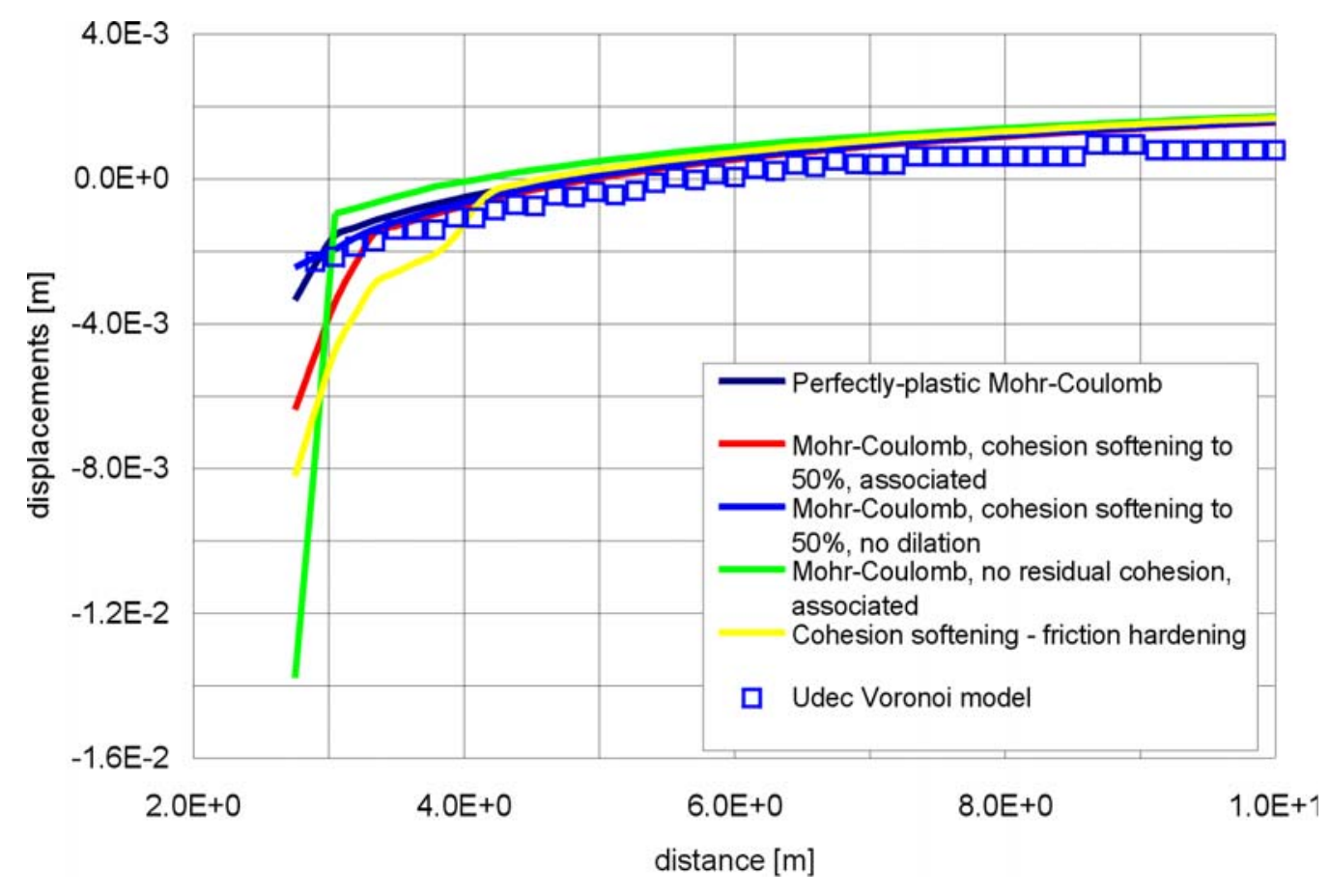

Figure 7-52. Inelastic Models After 80 Years of Heating: Horizontal Displacement Along the Horizontal Profile Through the Center of Tunnel (Distance is measured from the tunnel center)

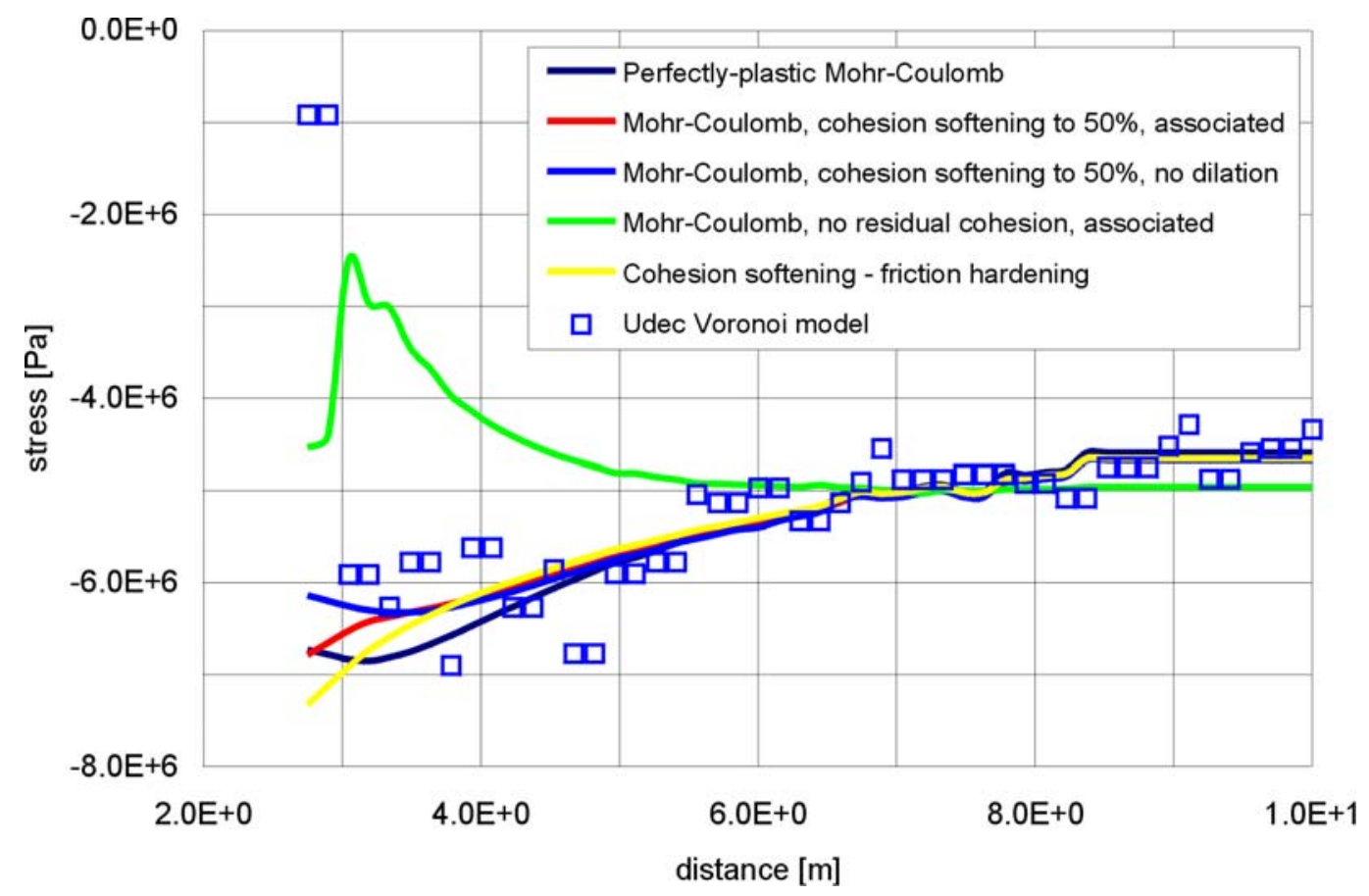

Figure 7-53. Inelastic Models After 80 Years of Heating: Horizontal Normal Stress Along the Vertical Profile Through the Center of Tunnel (Distance is measured from the tunnel center) 


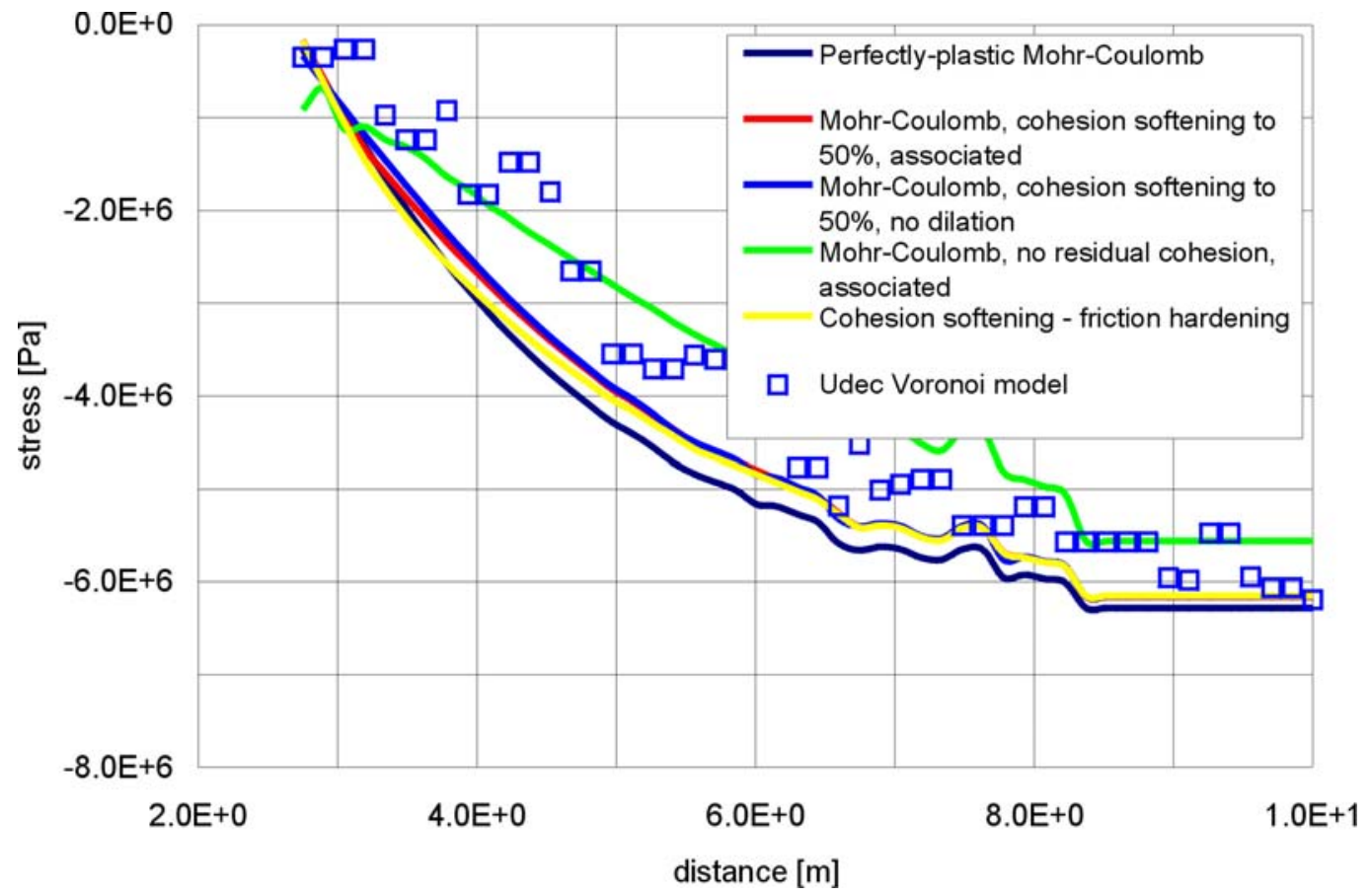

Figure 7-54. Inelastic Models After 80 Years of Heating: Vertical Normal Stress Along the Vertical Profile Through the Center of Tunnel (Distance is measured from the tunnel center)

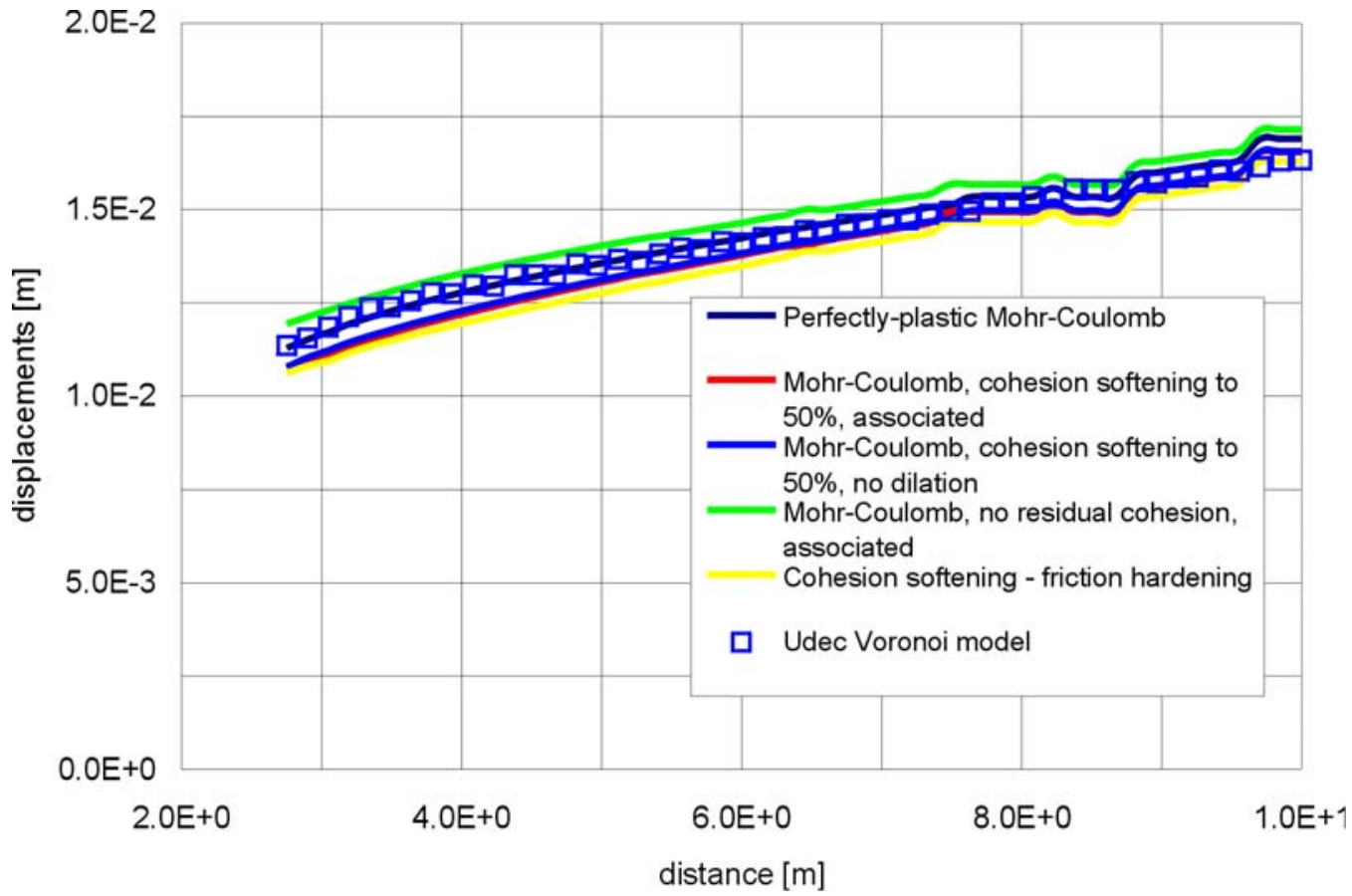

Figure 7-55. Inelastic Models After 80 Years of Heating: Vertical Displacement Along the Vertical Profile Through the Center of Tunnel (Distance is measured from the tunnel center) 
Conclusion-Although stability analysis of underground excavations using the UDEC Voronoi block model is uncommon in engineering practice, it is used to predict rockfall in a lithophysal rock mass because of its clear advantages for this type of analysis (rockfall prediction) compared to standard, continuum-based approaches. However, it is demonstrated in this section that many results (i.e., extent of damage, stress and displacement profiles) of the UDEC Voronoi block model are very comparable to the results of continuum models which are commonly used for modeling of excavation stability in rock.

\subsubsection{UDEC Post-Development Validation Exercise 5 - Comparison of the Mathematical Model Implemented in the UDEC Program to other Numerical Approaches in Solving Dynamic Tunnel Stability Problems in Fractured Rock (Corroboration with Information Published in the Literature)}

The Defense Nuclear Agency conducted a comparison of a number of dynamic numerical modeling approaches for examination of their utility in simulating the effects of dynamic stress wave loading of fractured rock and tunnels in fractured rock (Senseny 1993 [DIRS 162017]). A series of five problems of increasing complexity were posed to five organizations using five distinct computer programs utilizing different assumptions and solution procedures. The input parameters and boundary and initial conditions were given, and the calculators were asked to provide their results to an independent reviewer for analysis and comparison. In other words, this test, termed a "benchmark calculation exercise" provided a blind comparison of various methods for modeling of a complex dynamic problem involving highly non-linear response.

The ultimate problem to be solved was that of a tunnel in explicitly jointed rock subjected to a spherically diverging wave initiated by a blast source (Figure 7-56). The intact rock is treated as a linearly elastic/perfectly plastic material, whereas the slip joint is treated as Coulomb frictional response. Thus, this problem has many aspects in common with the dynamic stability problems of importance for seismically induced rockfall. The principal difference with the present problem is that the dynamic source is different (a spherically diverging wave from a point source rather than shear and compression wave loading), although many of the same mechanical issues are faced in both types of problems.

To solve this overall problem, a series of smaller problems were first posed to test proper solution of fundamental components of the larger problem. These fundamental problems had analytical expressions that could be derived and used for comparison to the model output. The final two problems, which involve determination of the dynamic stressing and yielding of a circular, steel-lined tunnel in a jointed rock mass is complex and has no analytical solution. The problems are reviewed in Table 7-1. 

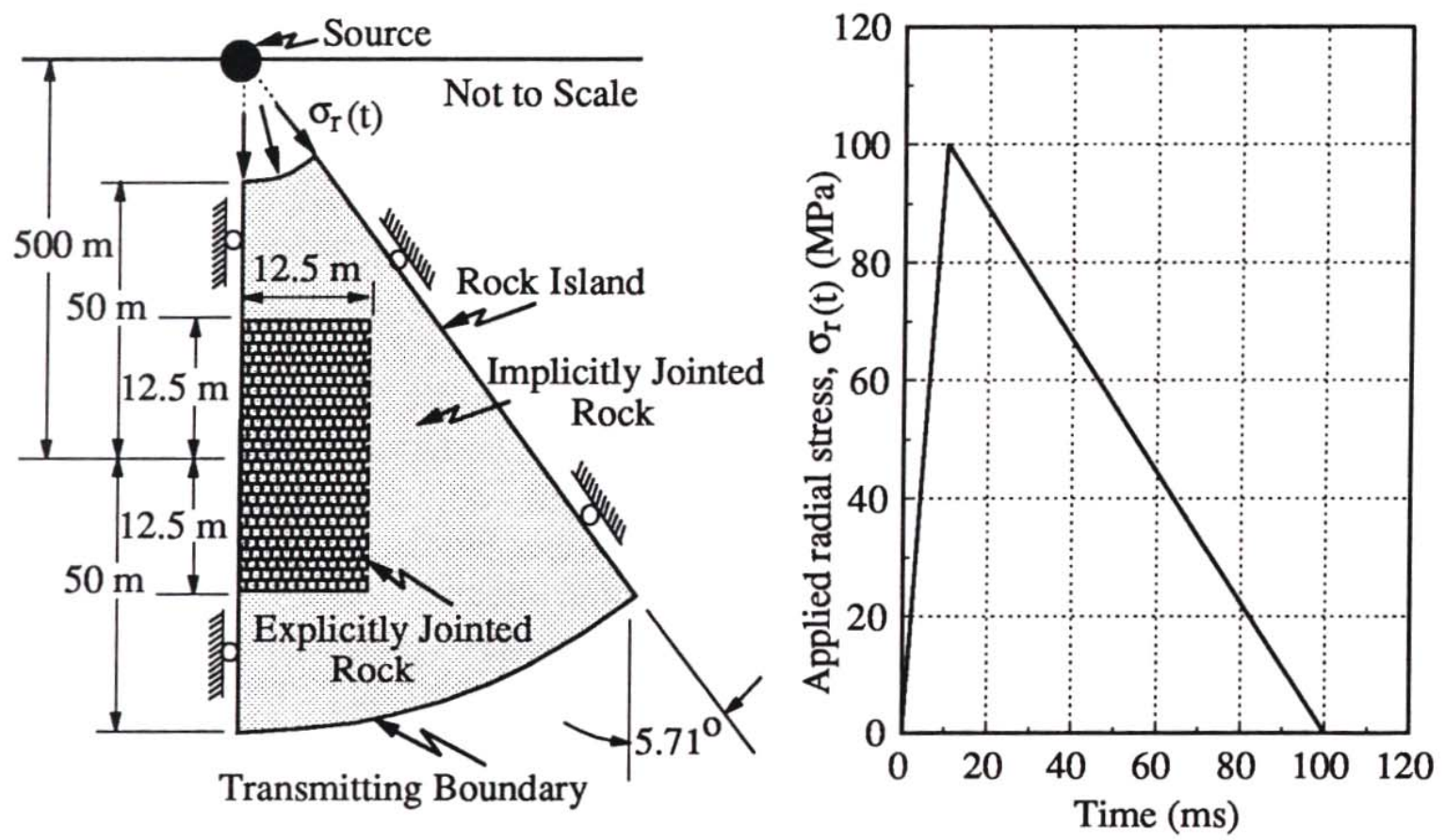

NOTE: The stress characteristics of the source are shown at right (Senseny 1993 [DIRS 162017]).

Figure 7-56. Problem Geometry of the Mechanical Response of a 5-m Diameter Tunnel in Jointed Rock Subjected to a Spherically Expanding Blasting Source

Table 7-1. Code-to-Code Comparison Problems

\begin{tabular}{|c|l|l|}
\hline $\begin{array}{c}\text { Problem } \\
\text { Number }\end{array}$ & \multicolumn{1}{|c|}{ Description } & \multicolumn{1}{c|}{ Comments } \\
\hline 1 & $\begin{array}{l}\text { Testing of intact rock sample to spherically } \\
\text { divergent strain path in intact rock. }\end{array}$ & $\begin{array}{l}\text { Quasi-static strain path that simulates passage of a } \\
\text { shock front in intact rock (i.e., demonstrates the } \\
\text { model accounts properly for propagation in intact } \\
\text { media). }\end{array}$ \\
\hline 2 & $\begin{array}{l}\text { One-dimensional compression of a } 5 \mathrm{~m} \text { by } 4 \mathrm{~m} \\
\text { sample of jointed rock, exercising the joints in } \\
\text { normal deformation. }\end{array}$ & $\begin{array}{l}\text { Tests that the model is able to produce proper } \\
\text { pressure vs. volumetric strain response for jointed } \\
\text { rock and for intact rock components. }\end{array}$ \\
\hline 3 & $\begin{array}{l}\text { Compression of a jointed block, joint in shear } \\
\text { while maintaining a homogenous strain rate in } \\
\text { the intact rock. }\end{array}$ & $\begin{array}{l}\text { Tests ability of model to produce proper } \\
\text { deformations on slipping joint in shear when } \\
\text { subjected to complex deformation path. }\end{array}$ \\
\hline 5 & $\begin{array}{l}\text { Deformation and stress changes in a wedge- } \\
\text { shaped jointed rock mass subjected to } \\
\text { spherically divergent wave (same as } \\
\text { Problem 5, but without tunnel present). }\end{array}$ & $\begin{array}{l}\text { Ability to properly reproduce rock mass strains in the } \\
\text { free field. }\end{array}$ \\
\hline $\begin{array}{l}\text { Deformation and yield of a tunnel in a jointed } \\
\text { rock mass subjected to a spherically divergent } \\
\text { blast wave. Prediction of stress in rock mass } \\
\text { around tunnel. }\end{array}$ & $\begin{array}{l}\text { Complex problem of a jointed rock mass subjected } \\
\text { to a triangular blast wave. Highly non-linear } \\
\text { response of tunnel as joints shear and large } \\
\text { deformations of tunnel occur. No analytic } \\
\text { solution - code to code comparison. }\end{array}$ \\
\hline
\end{tabular}

Source: Senseny 1993 [DIRS 162017]. 
These problems tested a number of aspects of the programs that are used in the current drift degradation work, including:

- Ability to represent wave transmission through intact and jointed rock

- Ability to represent the mechanical response of joints to normal and shear loading

- Ability to represent non-reflecting boundaries

- Ability to represent a non-linear, joint-controlled tunnel deformation mode under dynamic loading.

The numerical programs used to conduct the calculations covered a wide range of techniques and methodologies (Table 7-2). With the exception of the PRONTO code, the simulations were conducted by the organization that developed the programs, and thus, the issue of having ill-informed users was removed from the benchmark study. For each problem, the boundary and initial conditions and rock properties were provided and fully specified. The calculator then used their particular model to solve the problem and submit the solutions in a "blind" fashion.

Table 7-2. Programs and Modeling Participants in the Benchmark Study

\begin{tabular}{|l|l|l|}
\hline \multicolumn{1}{|c|}{ Organization } & \multicolumn{1}{c|}{ Abbreviation } & \multicolumn{1}{c|}{ Code } \\
\hline $\begin{array}{l}\text { California Research and Technology } \\
\text { Division, the Titan Corporation }\end{array}$ & CRT & $\begin{array}{l}\text { EXCALIBUR } \\
\text { (Finite Element, Joints modeled explicitly or } \\
\text { via constitutive model) }\end{array}$ \\
\hline Itasca Consulting Group & Itasca & $\begin{array}{l}\text { UDEC } \\
\text { (Distinct Element/Finite Difference, joints } \\
\text { modeled explicitly) }\end{array}$ \\
\hline $\begin{array}{l}\text { Lawrence Livermore National } \\
\text { Laboratory }\end{array}$ & LLNL & $\begin{array}{l}\text { DIBS } \\
\text { (Distinct Element, Rigid Block Formulation) }\end{array}$ \\
\hline & RE/SPEC & $\begin{array}{l}\text { PRONTO } \\
\text { (From Sandia National Laboratory, Finite } \\
\text { Difference) }\end{array}$ \\
\hline RE/SPEC, Inc. & & $\begin{array}{l}\text { FLEX } \\
\text { (Finite Element, Joints modeled explicitly or } \\
\text { via constitutive model) }\end{array}$ \\
\hline
\end{tabular}

Source: Senseny 1993 [DIRS 162017].

LLNL = Lawrence Livermore National Laboratory

Results-The UDEC program, as described in detail in Senseny (1993 [DIRS 162017]), provided good agreement to analytic solutions for problems 1 to 3. Only the results of Problems 4 and 5 are discussed in greater detail here. Figure 7-57 shows the comparative results of radial stress and radial velocity at the centroid of the tunnel (not yet excavated) in problem 4 . As seen in Figure 7-57, the overall solution of the stress and velocity predictions are quite similar for the various methods, primarily because there is little variation in the stresses or velocities over the computational grid with the exception of temporal offsets in the input function which is consistent with the wavespeed. The distortion, evident in at least one of the models is a result of boundary reflection due to ineffective non-reflecting boundaries. The Lawrence Livermore National Laboratory modeling approach, which has no deformability of the intact material, was 
found to perform poorly for the given source wavelength characteristics. UDEC was found to compare favorably with the finite element approaches, which appear to account properly for both non-reflecting boundaries, and free field straining and energy dissipation due to plastic yield.

The final problem of tunnel stability under the divergent wave loading provides a significant numerical test. As stated in Senseny (1993 [DIRS 162017]), the conventional wisdom assumes that after peak stressing, the radial outward motion causes a rapid tangential loading while resulting in a loss of radial confinement and a reduced failure strength than would be assumed for uniaxial loading of the tunnel. The UDEC program was found to provide a reasonable match to crown and invert tunnel closures with other numerical approaches (Figure 7-58) with the exception of the RE/SPEC and Lawrence Livermore National Laboratory models, which provided contrary results (and were later determined to not have provided credible solutions). The tangential and radial stresses for various radial lines around the tunnel at peak free field stress arrival time are given in Figures 7-59 and 7-60. The calculations are compared to the static analytic solution for an orthotropic elastic material. All of the programs show a relatively close agreement to one another, and demonstrate that the effect of the tunnel is to relieve the radial stress component and greatly increase the tangential stresses in comparison to the equivalent free field values. Radial stresses approaching about $8 \mathrm{MPa}$ at the tunnel wall is the result of confinement provided by the steel tunnel liner. Comparison of tunnel deformation modes indicate that significant springline yield and closure (displacements exaggerated by a factor of 10), resulting from slip on joints and intact rock plastic failure occurs in the models with the exception of the Lawrence Livermore National Laboratory rigid block model, again illustrating the importance of internal block deformability and yield.

As concluded by Senseny (1993 [DIRS 162017]), “Three of the five participants (CRT, WA, Itasca) obtained numerical solutions which-where comparisons were possible-agree with each other in most practical respects. All of these solutions appear credible, based on the significant body of evidence available:

1. Use of rational continuum models to represent the rock

2. Use of physically based models for the joints

3. Compatibility of results with basic understanding of wave propagation processes

4. Absence of obvious numerical artifacts such as spurious reflections

5. Comparison of stresses and strains with complete and partial analytic solutions in all the benchmark problems." 

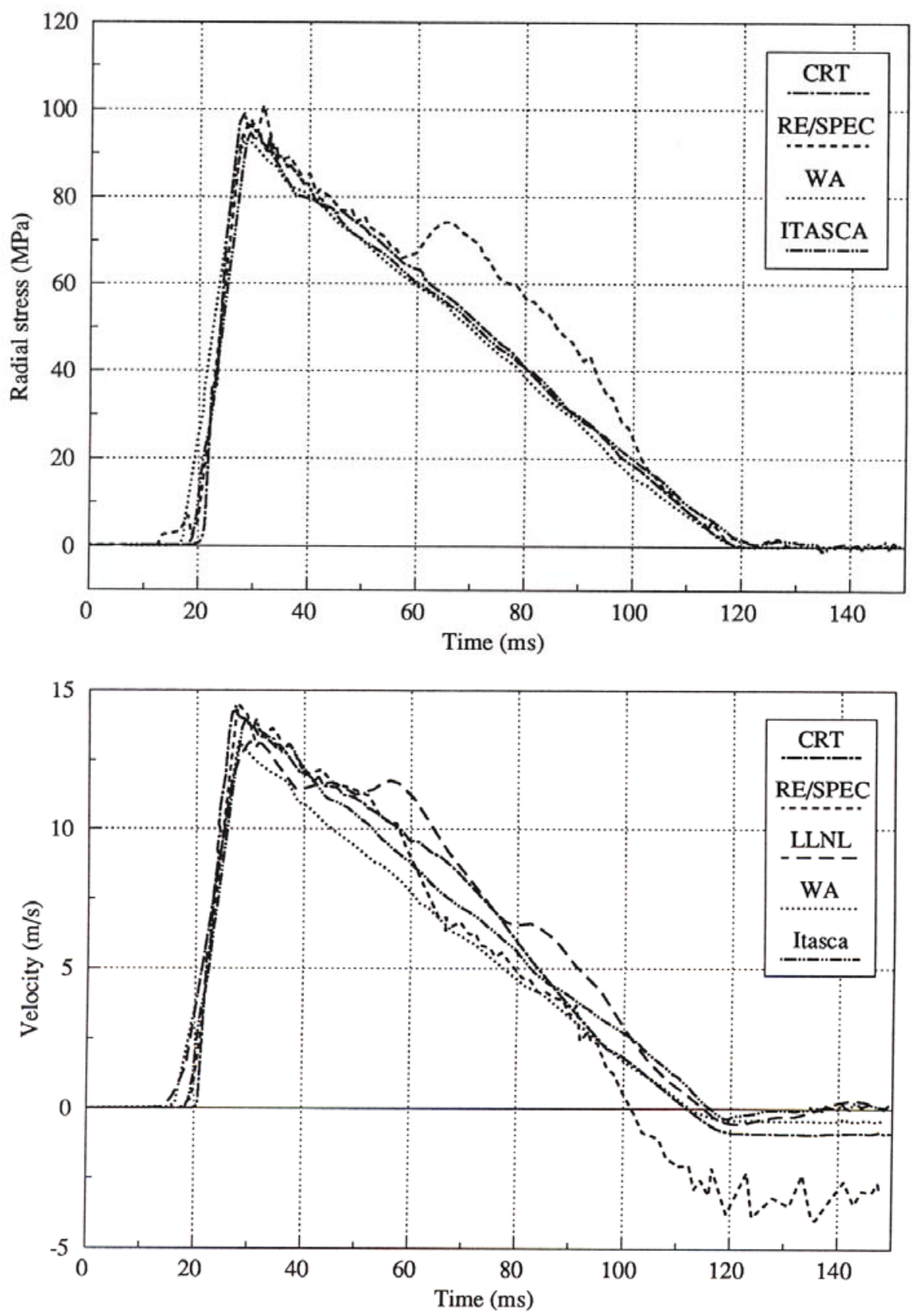

Source: Senseny 1993 [DIRS 162017].

Figure 7-57. Radial Stress (Top) and Radial Velocity (Bottom) at the Centroid of the Future Tunnel Location in Problem 4 

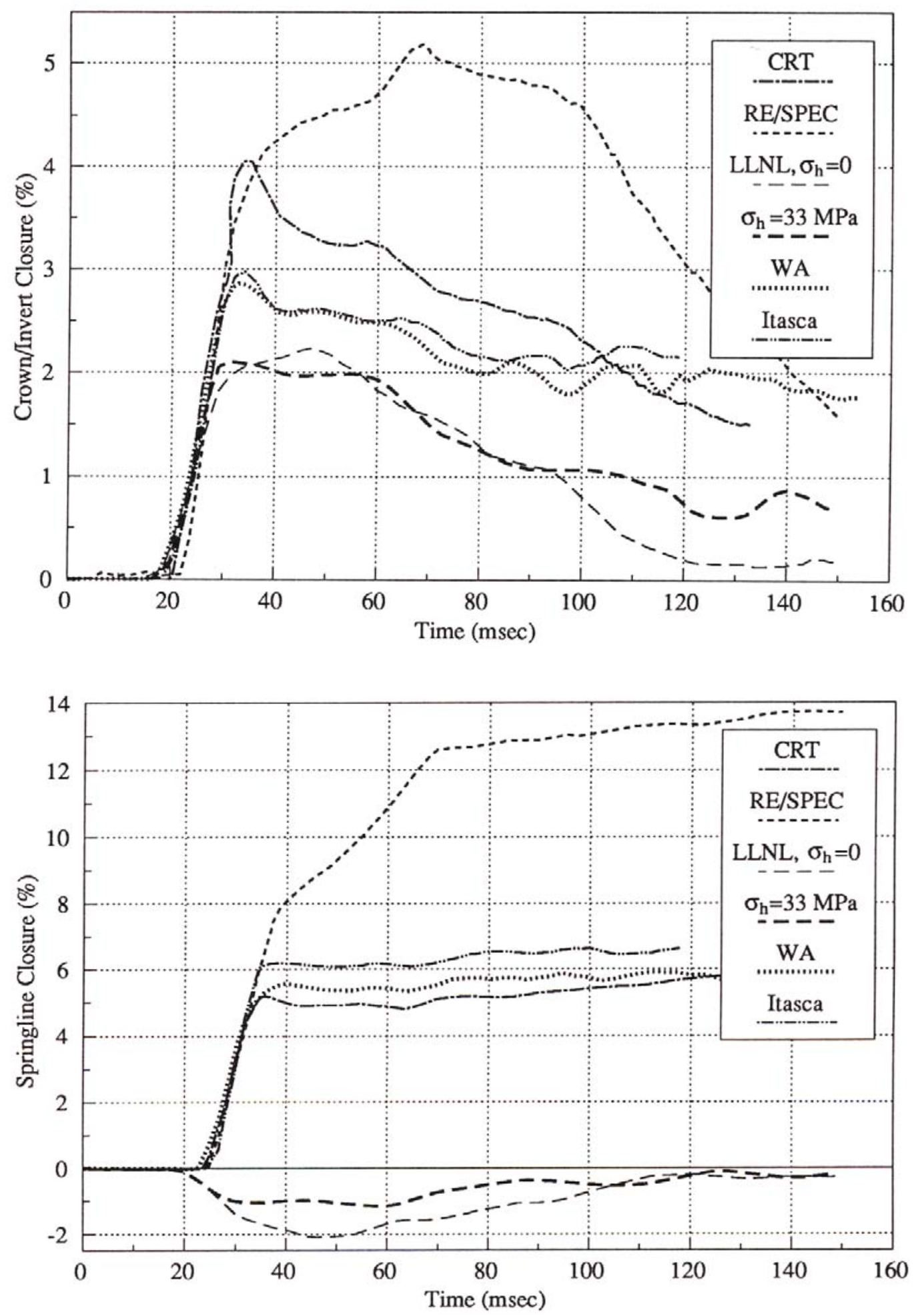

Source: Senseny 1993 [DIRS 162017].

Figure 7-58. Comparison of Predicted Tunnel Invert-Crown (Top) and Springline (Bottom) Closure for Problem 5 


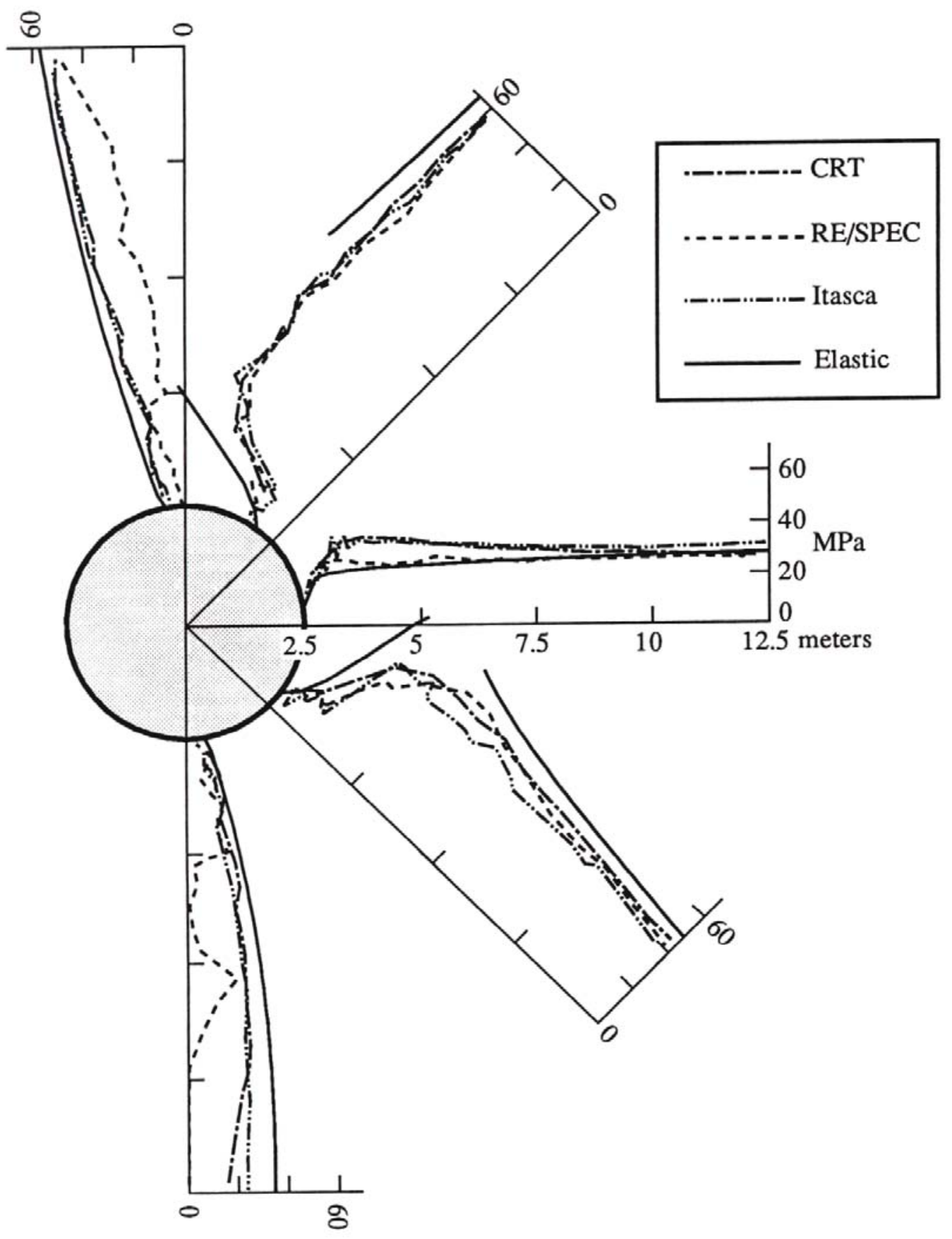

Source: Senseny 1993 [DIRS 162017].

Figure 7-59. Comparison of Radial Stress Along Radial Lines at Peak Free Field Stress Arrival Time, Problem 5 


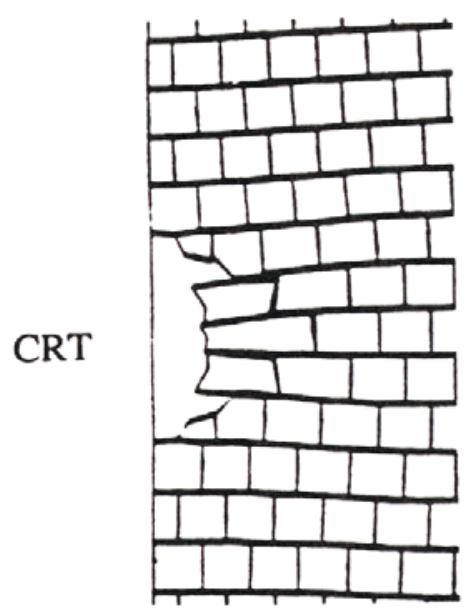

Itasca
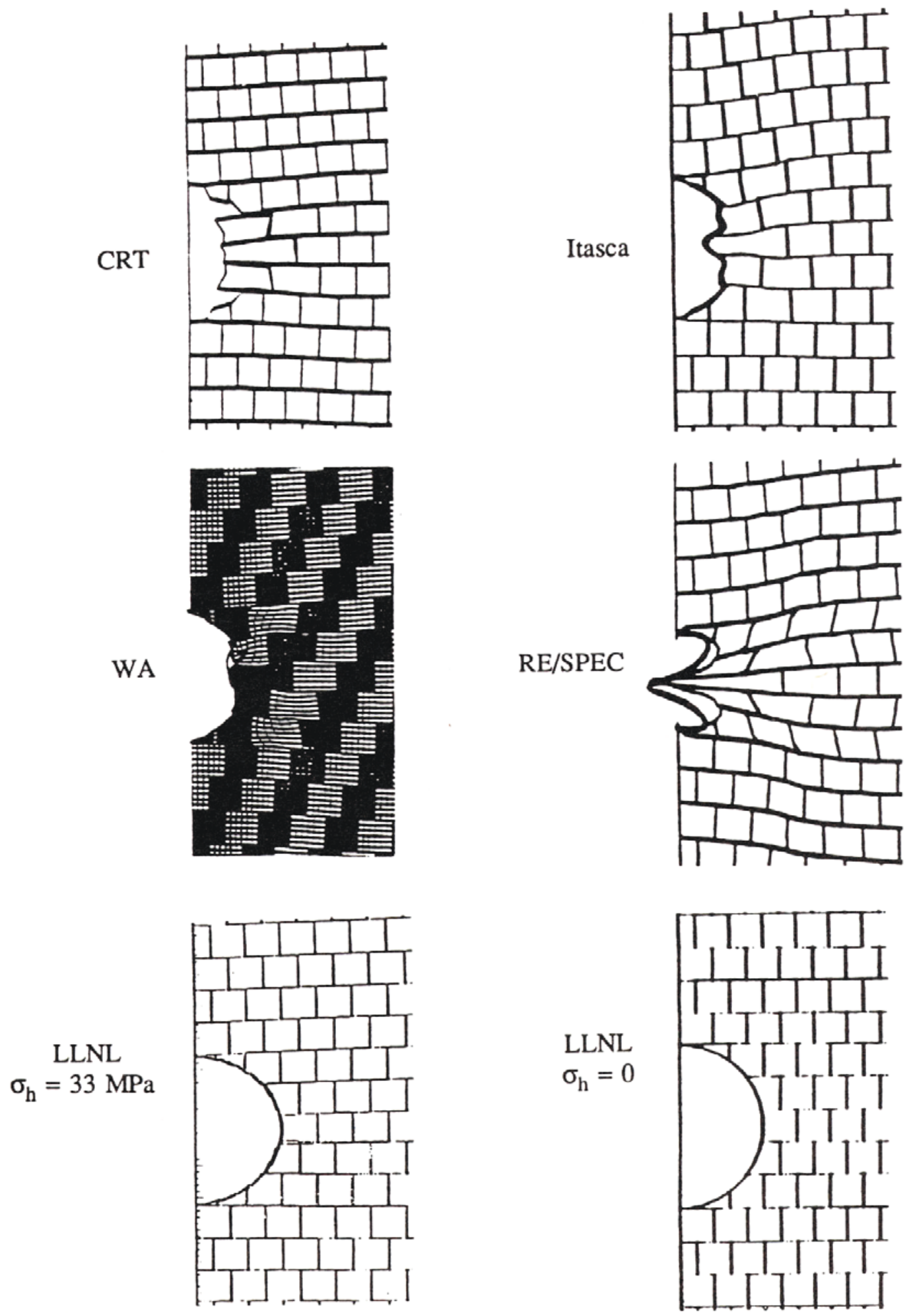

Source: Senseny 1993 [DIRS 162017].

Figure 7-60. Comparisons of Exaggerated Tunnel Shapes $(\times 10)$ at Equilibrium, Problem 5 


\subsubsection{Conclusions from UDEC Lithophysal Rockfall Model Validation-Comparison to Criteria}

Consistent with the stated level of confidence required for the model, the above validation problems satisfy the criteria for mechanical models of lithophysal rock (Section 7.2.3) and demonstrate the following:

A. The mechanical model, implemented within the UDEC program has been calibrated against laboratory compression tests to reproduce the basic deformability and strength properties of the lithophysal rock. To account for variability introduced by lithophysal porosity, the rock properties range has been subdivided into a number of categories that cover the entire deformability/strength range. This is done in lieu of a statistical treatment of the test data due to the relatively small number of large-core tests. The base model was calibrated to reproduce the moduli and strength for each of these categories.

B. The resulting model was applied to several boundary value problems to demonstrate reasonable ability to predict failure mode and failure extent. The first problem was use of the model to represent laboratory testing. The results show an ability to reproduce the basic failure mechanisms observed in the laboratory testing, which includes axial fracture development in uniaxial compression and localization of a single fracture plane normal to the core axis in uniaxial tension. The model was then applied to represent tunnel response of the ECRB Cross-Drift at various depths. Sidewall springline fracturing and yield occur in the model for the lower end of the calibrated strength range for depths of around 300 to $350 \mathrm{~m}$. The model predicts sidewall fracturing, parallel to the tunnel surface developing at the springline region and extending less than $1 \mathrm{~m}$ into the sidewall. This agrees qualitatively to observations of springline fracturing in boreholes and alcoves observed in the lower lithophysal exposures in the ECRB Cross-Drift and ESF main loop, in the mid- to lower-portions of the tunnel. Observations show that wall-parallel fractures in the springline extend approximately $0.5 \mathrm{~m}$ in depth. The model and observation agree that no fracturing should exist in the Tptpul which, although of the same general strength range as the Tptpll, the shallower depth of burial results in stresses insufficient to fail the rock mass. Finally, a qualitative comparison of the modeling approach to predict thermally induced rock fracture was demonstrated through comparison of the model to field observation of the Drift Scale Heater Test in the Tptpmn. This validation showed that the general technique is able to reproduce, qualitatively, the development of roof-parallel spalling fractures induced by the thermally overdriven horizontal stresses in the immediate crown of the drift. The model is able to reproduce the timing (i.e., the stress level), extent and general mechanism of the failure (i.e., splitting parallel to the free surface).

C. The UDEC model has been shown to produce rock mass stress, displacement and yield around a heated emplacement drift that are quite similar to those produced from an alternative, continuum-based modeling approach for both elastic and inelastic rock mass constitutive models. 
D. The ability of the model to properly represent complex dynamic boundary conditions is demonstrated in the UDEC User's Manual, but was further demonstrated in the validation exercise in which comparisons were made between UDEC and other numerical methods (Senseny 1993 [DIRS 162017]). In this work, conducted for the Defense Nuclear Agency, a rigorous code-to-code comparison was conducted in which test problems of increasing complexity were analyzed in a "blind" calculation and comparison exercise. The simplest of the problems involved problems that tested the code's ability to properly reproduce the mechanical response of the basic building blocks of the model (i.e., the fractures, the intact blocks, and the ability to properly account for boundary conditions and complex load paths). The final test was a full comparison of the models to a large scale field experiment of a lined tunnel in a fractured rock mass subjected to dynamic loading sufficient to fail the material and deform the tunnel lining. Of interest was that the "answer" was not known in advance; the predictions made were "blind" and the comparison of the results with various models was performed by an outside agency. The UDEC lithophysal rockfall model, as shown, compared very favorably with the problems and demonstrated the ability of the program to reasonably represent the dynamic response of a fractured media.

\subsubsection{UDEC Lithophysal Rockfall Model Limitations}

\subsubsection{Impact of Block Discretization Level}

As was discussed previously, the discretization of the UDEC lithophysal rockfall model into Voronoi blocks does not represent actual internal structure of the lithophysal material. The block structure is merely a device that allows the formation of potential fractures within the rock mass, thus allowing it to fail and form independent blocks when stressed. There are two important points regarding the level of discretization of the blocks:

- The block dimensions must be small enough that they do not have an overriding influence on the failure extent or mechanical behavior

- The block dimensions should be commensurate to or smaller than the size of the expected rock particles to be formed (see Section 6.4.1).

Therefore, it is necessary to show that the mechanical behavior of the synthetic material is independent of the block size. Selection of the block size for simulation is an optimization process. Very small block size (e.g., 100 times smaller than the drift diameter, the characteristic dimension of the problem) will certainly ensure that the problem solution would be practically independent of the block size, but would lead to very long calculation times. The block size was selected based on the criteria of small differences in rockfall prediction as the block size is reduced, and reasonable calculation time for problem solution. A comparison of the fracturing predictions due to drift excavation in rock mass Category 1 for $300 \mathrm{~m}$ overburden from two models considering average block edges of $0.3 \mathrm{~m}$ (5.4 percent of the drift diameter, or roughly 18 blocks across a drift diameter) and $0.2 \mathrm{~m}$ (3.6 percent) is shown in Figure 7-61. The in situ stress state is characterized with a vertical to horizontal stress ratio of 2:1. The results, shown in Figure 7-61, compare the failure (i.e., sidewall fracturing, for two different cases). As seen, the overall end-result of the calculation shows that mechanism of sidewall spalling is 
roughly the same for both cases. There is some small difference in the amount and location of fracturing, depending on the block geometry. However, the cases show the same general behavior and the same general depth of damage in the sidewalls. Also, the effect of three different realizations of geometry of blocks (maintaining the same average block size of $0.3 \mathrm{~m}$ ) was investigated and results (for Category 1 rock mass an $350 \mathrm{~m}$ overburden) are shown in Figure 7-62. Clearly, the realization of block geometry effects a particular realization of cracking. But more importantly, the general characterization of cracking (density, depth) is not affected by the particular geometry of blocks. If the block size is too large, the effect of a particular geometry of Voronoi blocks on the model results would be more pronounced. From parametric analyses of block size, a block size of $0.3 \mathrm{~m}$ produced satisfactory results while optimizing model run time.
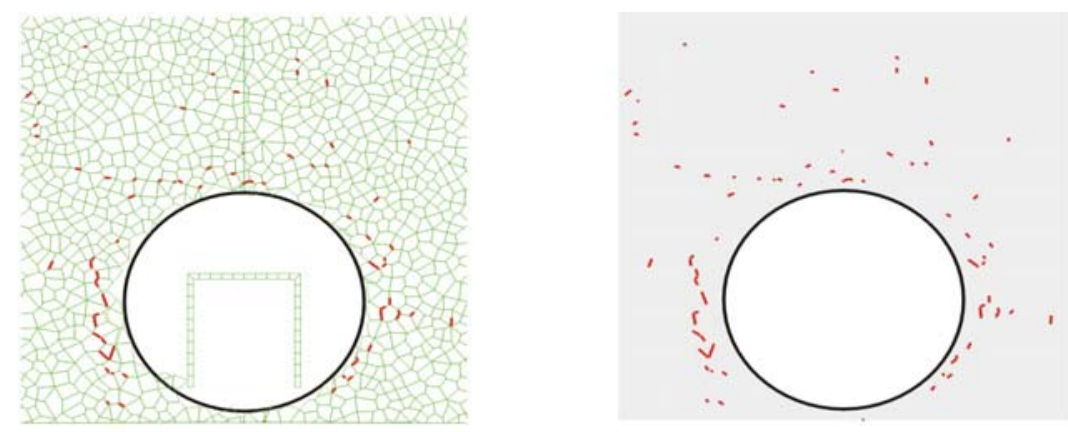

a) block size $0.3 \mathrm{~m}$
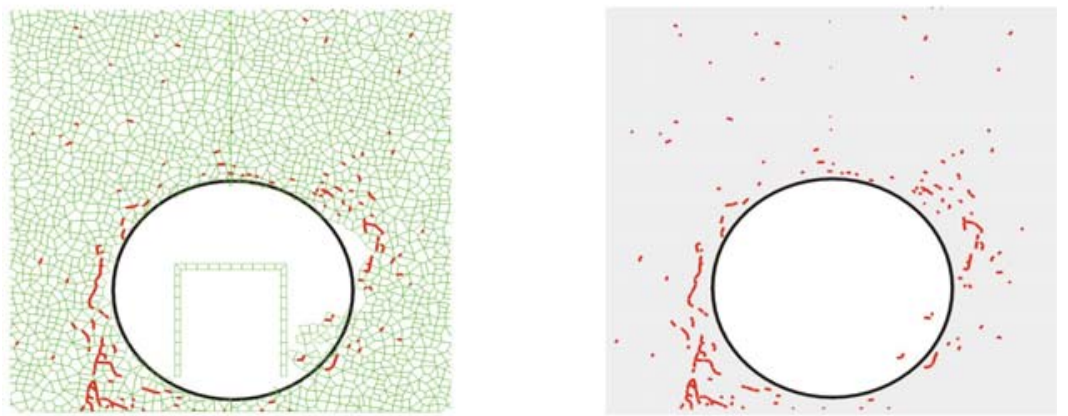

b) block size $0.2 \mathrm{~m}$

NOTE: The general behavior of the drift is similar in each case. A small portion of the sidewalls fails to a depth of approximately $0.5 \mathrm{~m}$, while the depth of fracturing is similar. Note that the failure response is not symmetric due to the random block patterns.

Figure 7-61. Block Size Effect: Behavior of the Rock Mass (Rock Mass Category 1, 300-m Overburden) Under Vertical and Horizontal Stress at Ratio of 2:1 

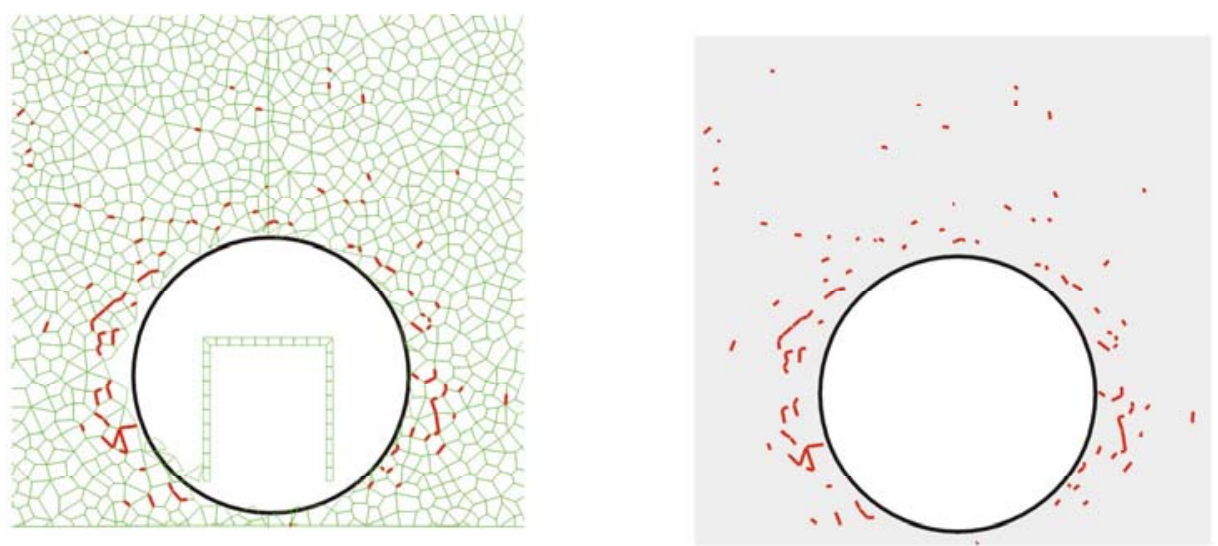

a) realization 1
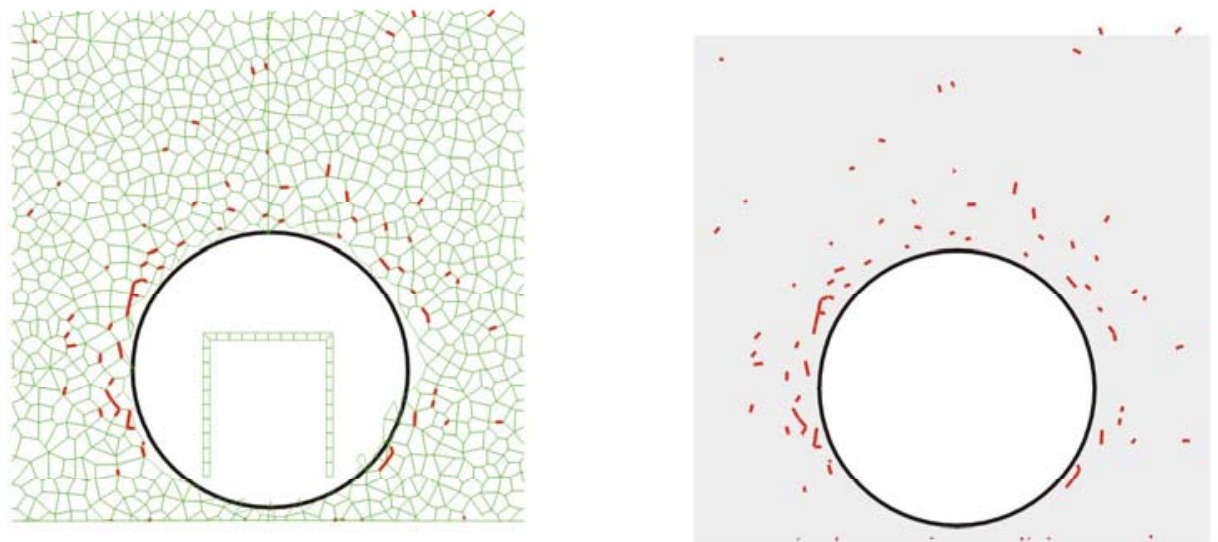

b) realization 2
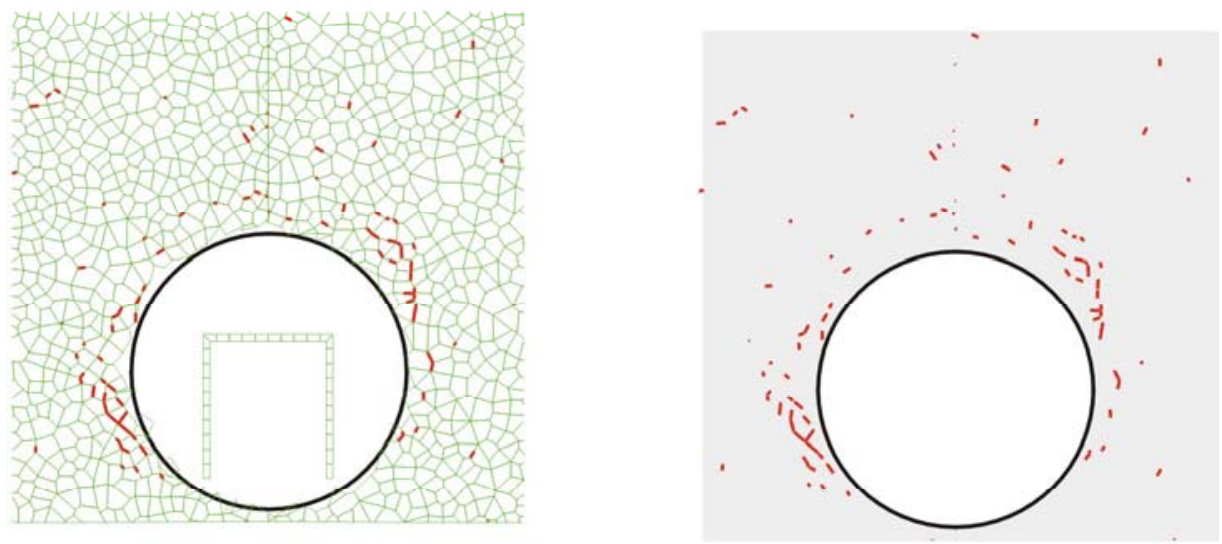

c) realization 3

Figure 7-62. Effect of Voronoi Block Realization: Behavior of the Rock Mass (Rock Mass Category 1, 350-m Overburden) Under Vertical and Horizontal Stress at Ratio of 2:1 


\subsubsection{Impact of Inertial Forces in Quasi-Static Loading}

The UDEC program uses an explicit finite difference method for solving Newton's Laws of Motion utilizing a fully dynamic formulation. A viscous damping scheme is used to remove energy from the model to achieve quasi-static equilibrium. When modeling quasi-static problems, such as thermal loading, it is important not to apply temperatures in too large an increment to avoid dynamic effects. In the modeling conducted in this study for the lithophysal rocks, temperatures are input from the NUFT program (see Section 3) to UDEC, which, in turn, calculates thermally induced expansions and stresses. Sensitivity studies indicated that the change in temperature applied to the UDEC program should be kept to less than $5^{\circ} \mathrm{C}$ to avoid dynamic effects.

\subsubsection{Consideration of Homogenous and Isotropic Response of the Lithophysal Rock Mass}

The modeling method employed for representing lithophysal rock considers that the rock mass is homogeneous and isotropic, and thus a two-dimensional, cross-sectional analysis is sufficient for model tunnel response to heating and dynamic stressing. Essentially, this consideration means that the region around the tunnel that could contribute to yielding has lithophysal porosity that is uniformly distributed. In other words, at any given location, a tunnel driven at any azimuth would encounter roughly the same lithophysal porosity variation. Data on lithophysal porosity variation from Section 6.1.4.2 and Appendix O indicate that lithophysal porosity varies over a range of perhaps $10 \mathrm{~m}$.

\subsubsection{Lack of Confined Compression Tests in the Lithophysal Rock}

No experimental data are available for large diameter lithophysal rock under confined conditions. This is because it is very difficult to carry out triaxial tests on samples from the lithophysal rock mass, since the membrane used for application of the confinement on the sample would deform into the lithophysae exposed on the circumference of the cylinder and most likely be punctured. Additionally, very large triaxial pressure vessels are rare. To overcome this potential issue, the PFC and UDEC lithophysal rockfall models were used to model the lithophysal rock as a solid matrix with internal holes. These models were calibrated against laboratory data on large core unconfined compression tests to verify that that relationship of strength and modulus to lithophysal porosity, and failure mechanisms was reasonably reproduced.

As discussed in Section 9.2.3.2 of the Subsurface Geotechnical Parameters Report (BSC 2003 [DIRS 166660]), the calibrated PFC and UDEC lithophysal rockfall models were used to simulate triaxial compression tests on lithophysal rock "samples" of various porosity. The results of these numerical experiments were then used to construct expected failure envelopes for the lithophysal rock mass. Figure 7-63 and Table 7-3 provide a summary of the results of these analyses.

Model results show that damage (due to excavation, thermally induced stresses, seismically induced preclosure ground motion, or time-dependent effect) is mostly confined to the drift boundary, and takes place under almost uniaxial loading conditions. For these conditions, 
correct behavior of the rock mass under confinement is not essential for proper simulation of damage and rockfall.
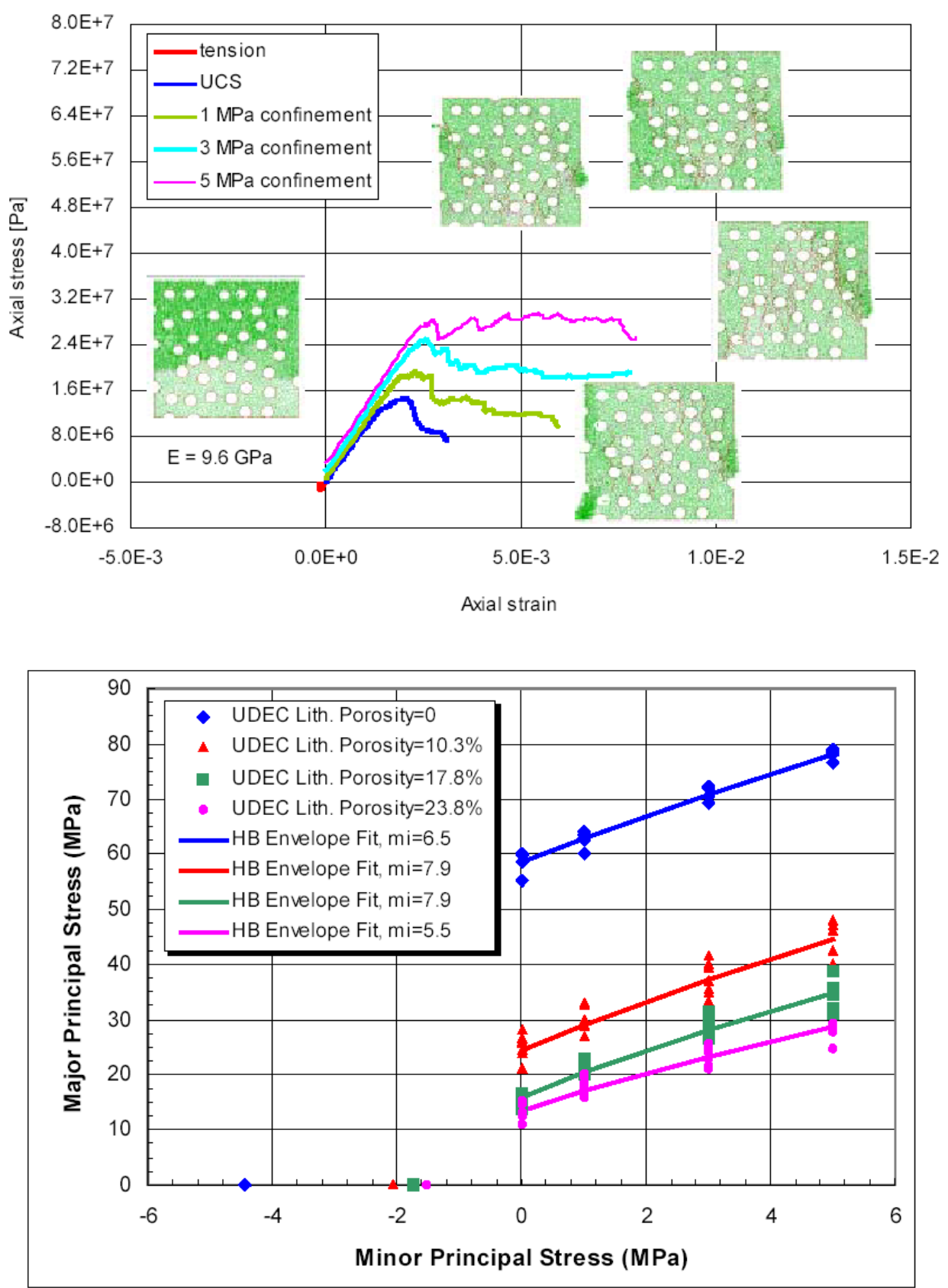

NOTE: Several realizations of UDEC analyses were conducted at each minor principal (confining) stress level. Non-linear Hoek-Brown failure envelopes have been fit to each dataset.

Figure 7-63. Sample UDEC Simulation of Triaxial Response for 23.8\% Lithophysal Porosity (top) and Hoek-Brown Failure Criteria Fits for Lithophysal Rocks Determined from UDEC Lithophysal Rockfall model Triaxial Numerical Test Analysis 
Table 7-3. Estimated Lithophysal Rock Mass Properties as Estimated from UDEC Triaxial Test Simulations

\begin{tabular}{|c|c|c|c|c|c|c|c|}
\hline $\begin{array}{c}\text { Lithophysa } \\
\text { I Porosity } \\
(\%)\end{array}$ & $\begin{array}{c}\text { UCS } \\
(\mathbf{M P a})\end{array}$ & $\begin{array}{c}\text { Young's } \\
\text { Modulus } \\
(\mathbf{G P a})\end{array}$ & $\begin{array}{c}\text { Friction } \\
\text { Angle } \\
\text { (degree) }\end{array}$ & $\begin{array}{c}\text { Cohesion } \\
(\mathbf{M P a})\end{array}$ & $\begin{array}{c}\text { Tensile } \\
\text { Strength } \\
(\mathbf{M P a})\end{array}$ & $\begin{array}{c}\text { Hoek- } \\
\text { Brown } \sigma_{\mathrm{ci}} \\
(\mathrm{MPa})\end{array}$ & $\begin{array}{c}\text { Hoek- } \\
\text { Brown } \mathbf{m}_{\mathbf{i}}\end{array}$ \\
\hline 0 & 58.7 & 19.8 & 36 & 14.9 & 4.4 & 58.5 & 6.6 \\
\hline 10 & 25.1 & 14.2 & 36 & 6.4 & 2.1 & 25.1 & 7.7 \\
\hline 17 & 15.5 & 11.2 & 35 & 4.1 & 1.7 & 16.5 & 7.3 \\
\hline 24 & 13.2 & 9.3 & 29 & 3.9 & 1.5 & 14 & 5.0 \\
\hline
\end{tabular}

Source: Table 9-3, Subsurface Geotechnical Parameters Report (BSC 2003 [DIRS 166660], Table 9-3).

UCS = uniaxial compressive strength

The derived rock mass friction angles from the UDEC lithophysal rockfall models in this table can be compared to laboratory measurements of friction angles measured on small samples of nonlithophysal rock are more than $40^{\circ}$ (Appendix E, Section E.3).

\subsection{MODEL VALIDATION FOR REPRESENTATION OF NONLITHOPHYSAL ROCK}

\subsubsection{Introduction}

As stated in Section 7.1, modeling of the nonlithophysal rock requires use of a three-dimensional, discontinuum modeling approach. A validation strategy was adopted based on demonstrating that the mechanical response of the fractures, which control the stability of the tunnel under shaking, function properly by corroboration with laboratory data. The rockfall component results from 3DEC are compared to an explosively loaded, scaled tunnel stability experiment in jointed rock. Additionally, results from the nonlithophysal rockfall model are compared to an alternative numerical model. Finally, an external expert technical review is used as a method for validation of the overall modeling approach for representation of nonlithophysal rock.

\subsubsection{Verification of Initial Conditions and Dynamic Boundary Conditions (Confidence Building During Model Development)}

Section 6.3.1.2 provides verification that the initial stress conditions and the dynamic boundary conditions were modeled properly within the 3DEC program. A test case was run in which the ground motion is applied at the base of the model and monitored at the mid-point of the model to ascertain that the method of ground motion application at the boundary (by applying equivalent stresses) properly converts the stress history to the velocity history. The test case also verified that no distortion of the waveform (which could result from insufficient model element discretization) occurred. 


\subsubsection{DEC Post-Development Validation Exercise 1 - Validation of the Fracture Mechanical Representation - Comparison to Laboratory Direct Shear Testing (Corroboration with Laboratory Data)}

\subsubsection{Introduction}

This validation example is given to demonstrate the ability of the 3DEC program, and the joint constitutive model used to reproduce the joint direct shear test data from large-scale testing of Tptpmn samples (DTN: GS030283114222.001 [DIRS 161913]).

\subsubsection{Direct Shear Data}

A number of direct shear tests were run on joints obtained from 11.5-in diameter core samples that were drilled at a low angle to either the smooth, sub-vertical cooling joints, or the rough, sub-horizontal vapor-phase alterations. The cores were obtained from the Tptpmn unit. The tests were run by setting (in hydrostone) the two halves of the core sample containing the fracture in opposing halves of a steel direct shear box. The opposing halves of the fracture are then reconstructed and placed in a large direct shear machine. A sequence of direct shear tests were then run by first applying a normal stress of $1 \mathrm{MPa}$ to the sample which is then slowly sheared by applying a lateral stress to the upper half of the sample. The sample fracture surface is then cleaned by compressed air, reconstructed and the test run again with normal stresses of $4 \mathrm{MPa}$ and $7 \mathrm{MPa}$ (approximate) normal stresses. A final re-test at the initial $1 \mathrm{MPa}$ normal stress level is run to document damage to the joint. One possible limitation of these tests is that successive damage is done to the joint surfaces by re-running the tests at increasing normal loads. However, with limited large sample availability, it was decided to get the greatest amount of information from each sample. From these tests, it is possible to plot the shear stress-shear displacement and normal stress-normal displacement behavior as well as the Coulomb slip envelope, from which the cohesion and friction angle can be calculated. The joint shear stiffness and dilation angle can be determined from the shear stress-shear displacement and normal displacement-shear displacement data, respectively. The test data for two representative tests are given in Figures 7-64 and 7-65 (DTN: GS030283114222.001 [DIRS 161913]). Figure 7-64 shows the test results for a typical sub-horizontal vapor-phase parting, and Figure 7-65 shows the test results for the sub-vertical cooling fracture. The plots superimpose the results from the normal stresses as well as the re-test at the $1 \mathrm{MPa}$ stress level. 
Shear Stress versus Horizontal Displacement

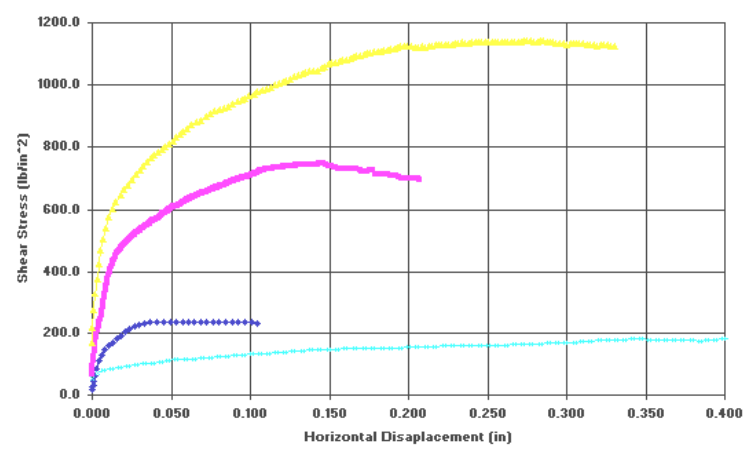

Vertical Displacenent versus Horizontal Displacement

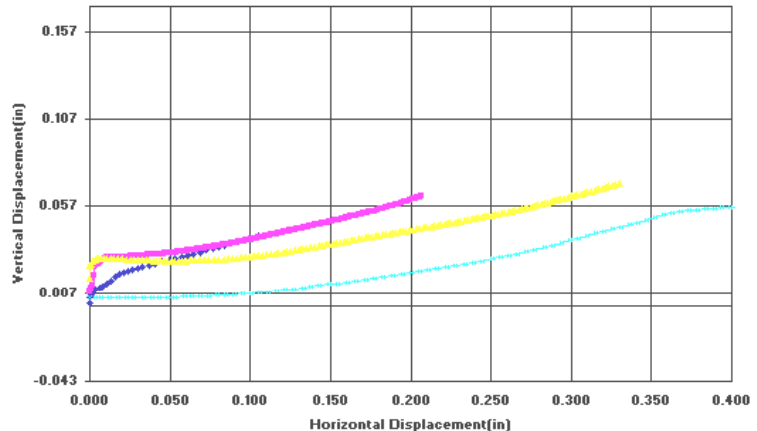

Frictional Strength Plodel
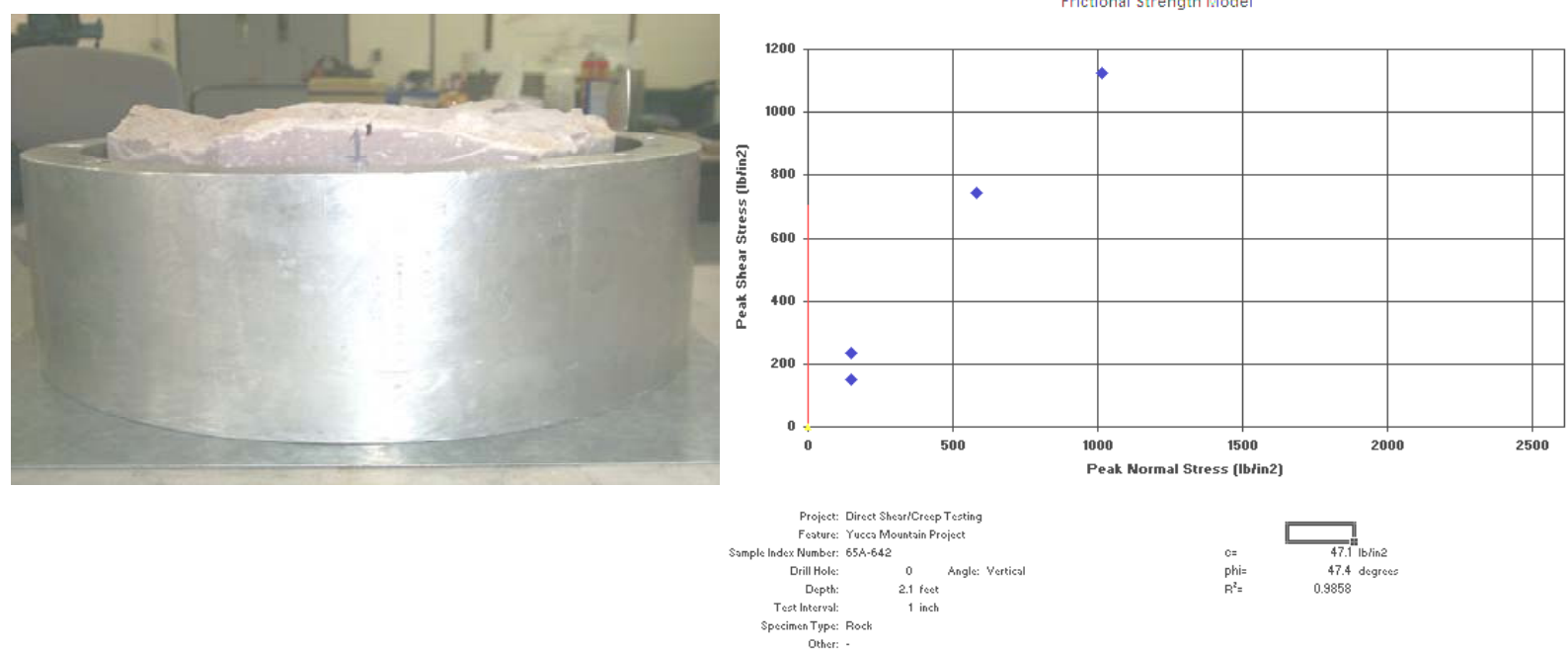

Other: -

Source: DTN: GS030283114222.001 [DIRS 161913].

NOTES: Cohesion is $0.3 \mathrm{MPa}$, and friction angle of the surface is $47.4^{\circ}$. Legend shows normal stress $\left(\mathrm{lbs} / \mathrm{in}^{2}\right)$. The data can be accessed through the Records Processing Center Package \# MOY-030226-41-01

(MOL.20030226.0038, pp. 2-5) associated with the source DTN.

Figure 7-64. Direct Shear Test Results for a Rough, Sub-Horizontal Vapor-Phase Parting 

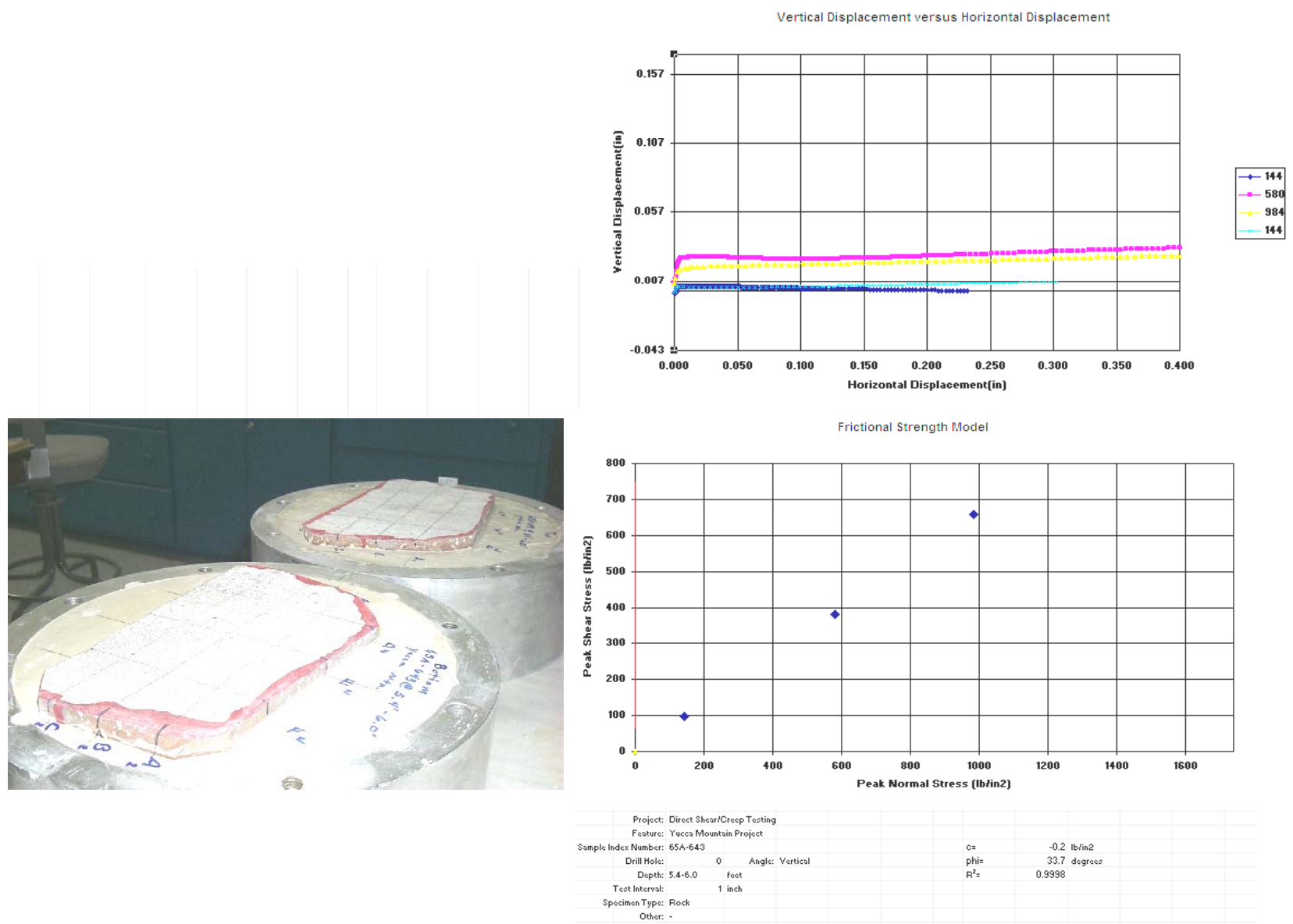

Source: DTN: GS030283114222.001 [DIRS 161913].

NOTES: Cohesion is zero and friction angle of the surface is $33.6^{\circ}$. Legend shows normal stress (lbs/in2). The data can be accessed through the Records Processing Center Package \# MOY-030226-41-01 (MOL.20030226.0039, pp. 2-6) associated with the source DTN.

Figure 7-65. Direct Shear Test Results for a Smooth, Sub-Vertical Cooling Joint

\subsubsection{Analysis}

In this validation, the 3DEC program is used to recreate the direct shear test numerically. The results of the model and test for the calculated surface friction angle and cohesion are compared. Figure 7-66 shows the 3DEC model with a horizontal fracture plane. The bottom block is fixed along its vertical and lower horizontal surfaces to represent the shear box. A vertical pressure is applied to the top of the upper block, while the lateral expansion is held fixed. A velocity is then applied to one of the vertical faces, forcing the top block to shear over the lower block. Figure 7-67 shows a cross-section through the block with superimposed shear slip vectors after it has begun slipping. 
VPP, $1 \mathrm{MPa}$ normal stress, $\mathrm{ks}=2 \mathrm{e} 9$, fric $=45.7, \mathrm{coh}=0.72 \mathrm{MPa}, \mathrm{dil}=7.1$

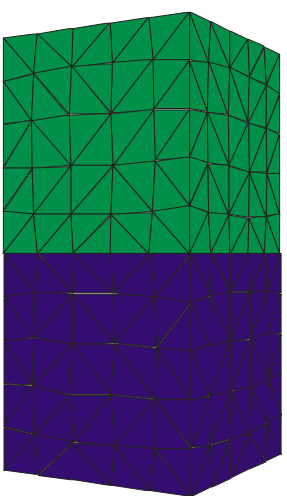

3DEC (Version 2.01)

BSC

NOTE: Lower (blue) block has surface displacements fixed on the vertical and bottom faces to represent the fixed block of the direct shear test. The upper (green) block has two vertical faces fixed, one vertical face free and one vertical face with a prescribed horizontal velocity representing the shear displacement of the test machine. A constant stress is applied to the upper surface to provide the normal stress to the joint surface.

Figure 7-66. Perspective View of 3DEC Model of Direct Shear Test of Joint 


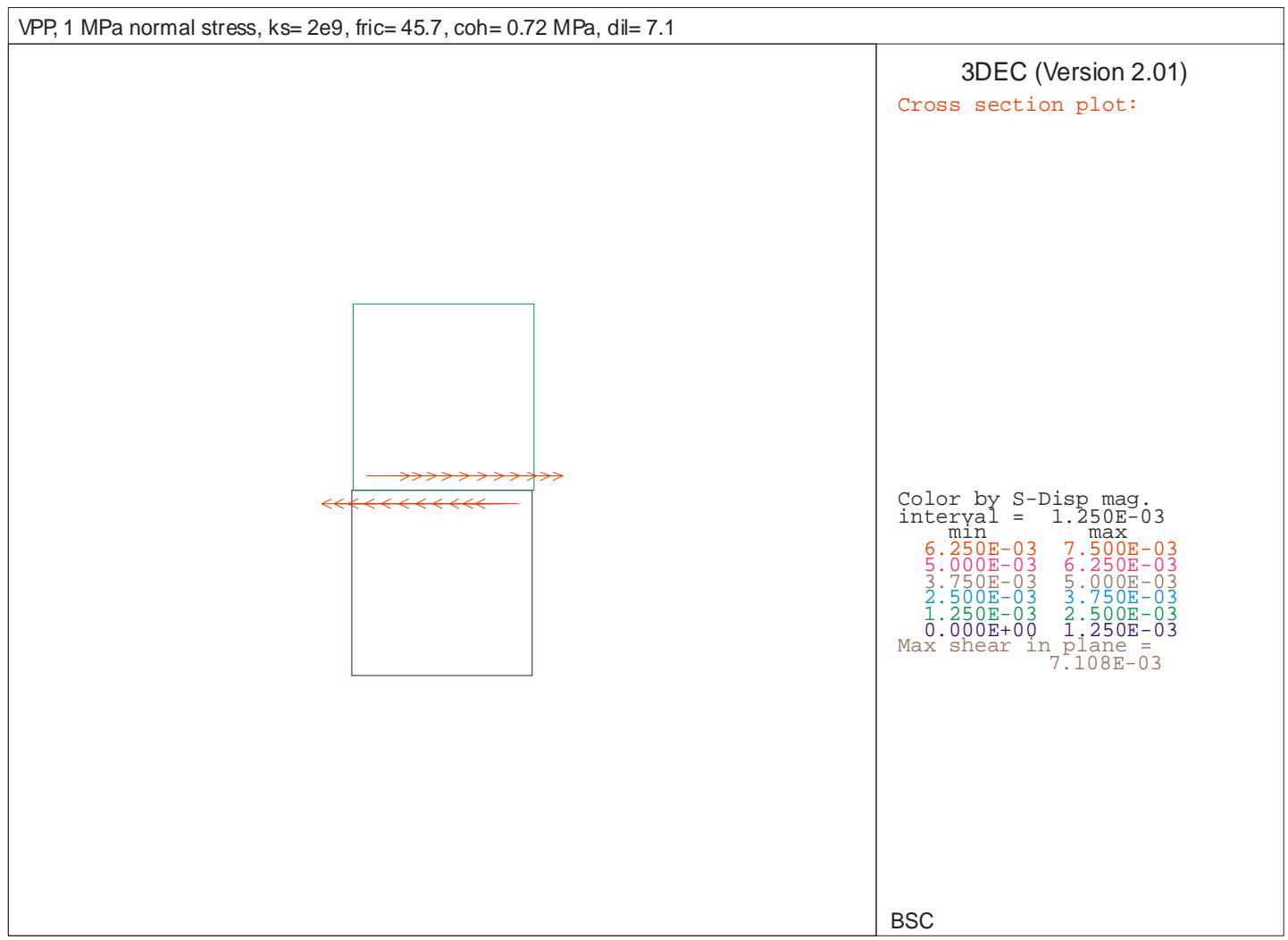

NOTE: Cross-section is taken parallel to shear movement applied by machine.

Figure 7-67. Cross-Sectional View Through Model Showing Relative Shear Displacement of Joint Surfaces

Analyses were performed for two cases: the sub-vertical, smooth cooling joint shown in Figure 7-65, and the sub-horizontal vapor-phase parting illustrated in Figure 7-64. Two basic types of joint shear constitutive models based on a standard Coulomb slip condition are available in the 3DEC program. The first model, the default in 3DEC (JCONS=1), considers that once slip is initiated, the cohesive strength of the joint is broken, and drops to zero. From that point, the joint reaches a residual strength based only on the friction and dilation angles of the surfaces. The second model (JCONS=2) considers that the cohesion of the surfaces remains constant, resulting in a typical elastic-perfectly plastic response. The seismic and thermal analyses discussed in Section 6.3 of this report use the default constitutive model.

The JCONS=1, or default, model is applicable to both the vapor-phase partings and the cooling fractures. First, the rough, vapor-phase partings (which are anastomosing structures) are cohesive structures that have surfaces weakly bonded in situ by minerals such as cristobalite and tridymite. Once this bond is broken, it is sensible that the surfaces reach a residual state of strength based primarily on friction. The cooling joints, however, have smooth surfaces with no apparent cohesion or tensile resistance. Therefore, there is no difference in JCONS 1 or 2. Figures 7-68 and 7-69 show a comparison of the 3DEC direct shear simulations to the laboratory tests. As seen in Figure 7-68, the comparison of model to laboratory is qualitatively quite reasonable, particularly for the first test conducted at $1 \mathrm{MPa}$ normal stress, in which the joint is in an undamaged state. The comparison is still reasonable for the higher confinements, 
but it must be realized that the model is using the average friction angle and dilation angle determined for the tests. The re-test at $1 \mathrm{MPa}$ normal load shows virtually the same results as for the initial test, indicating that there is little surface damage from the previous testing. This makes sense since the joint has less than $2^{\circ}$ dilation angle, and thus very little surface irregularity (roughness) that can be permanently damaged. The shear stiffness used in this simulation is determined from the tangent value (the initial loading slope). The stiffness departs from this approach only near its peak strength.

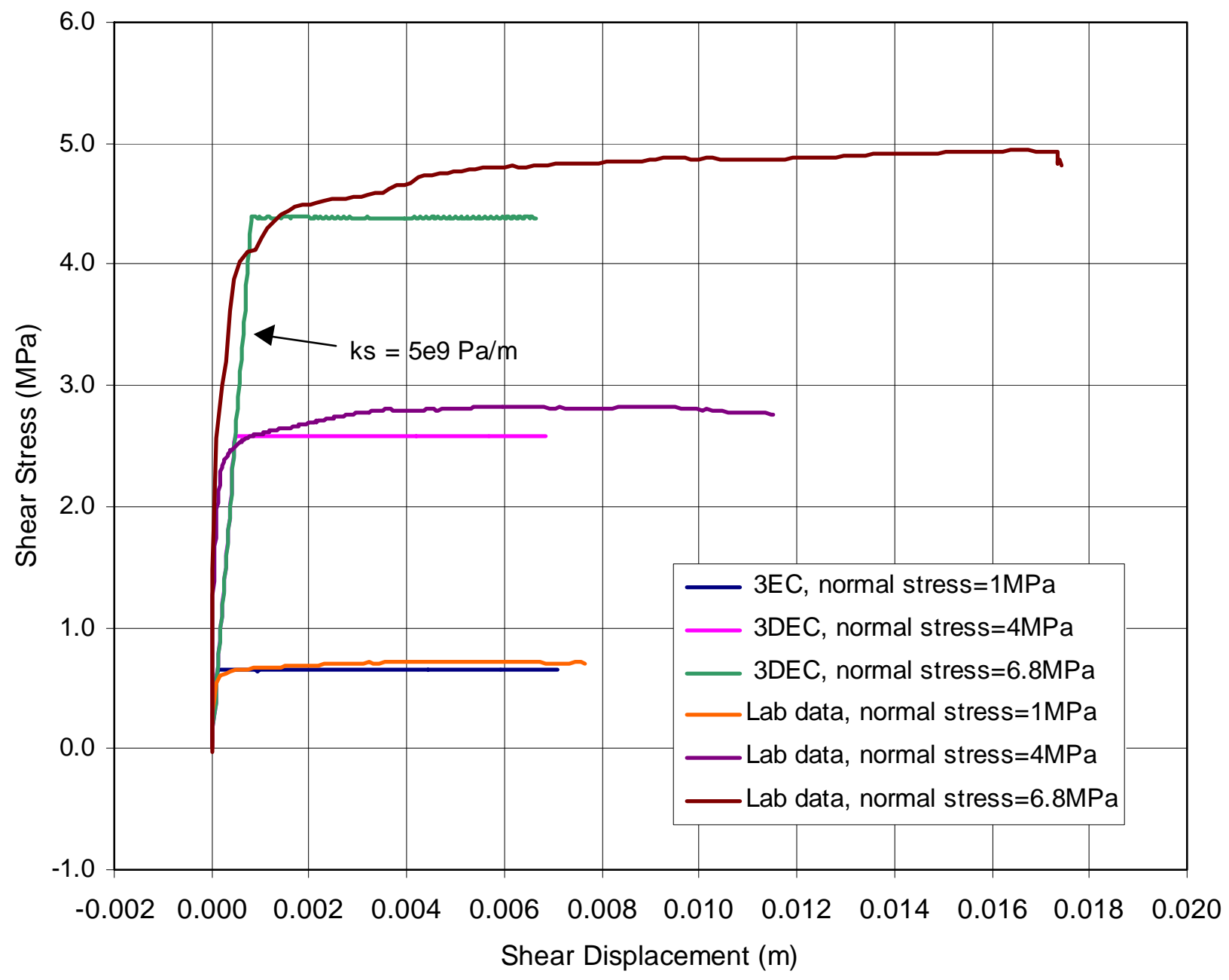

NOTE: Joint sample is a subvertical, smooth cooling joint (see Figure 7-65).

Figure 7-68. Comparison of 3DEC Mohr-Coulomb Joint Constitutive Model to Laboratory Direct Shear Testing for Sample 643, Hole ERCB-GTEC-CS1250-13 


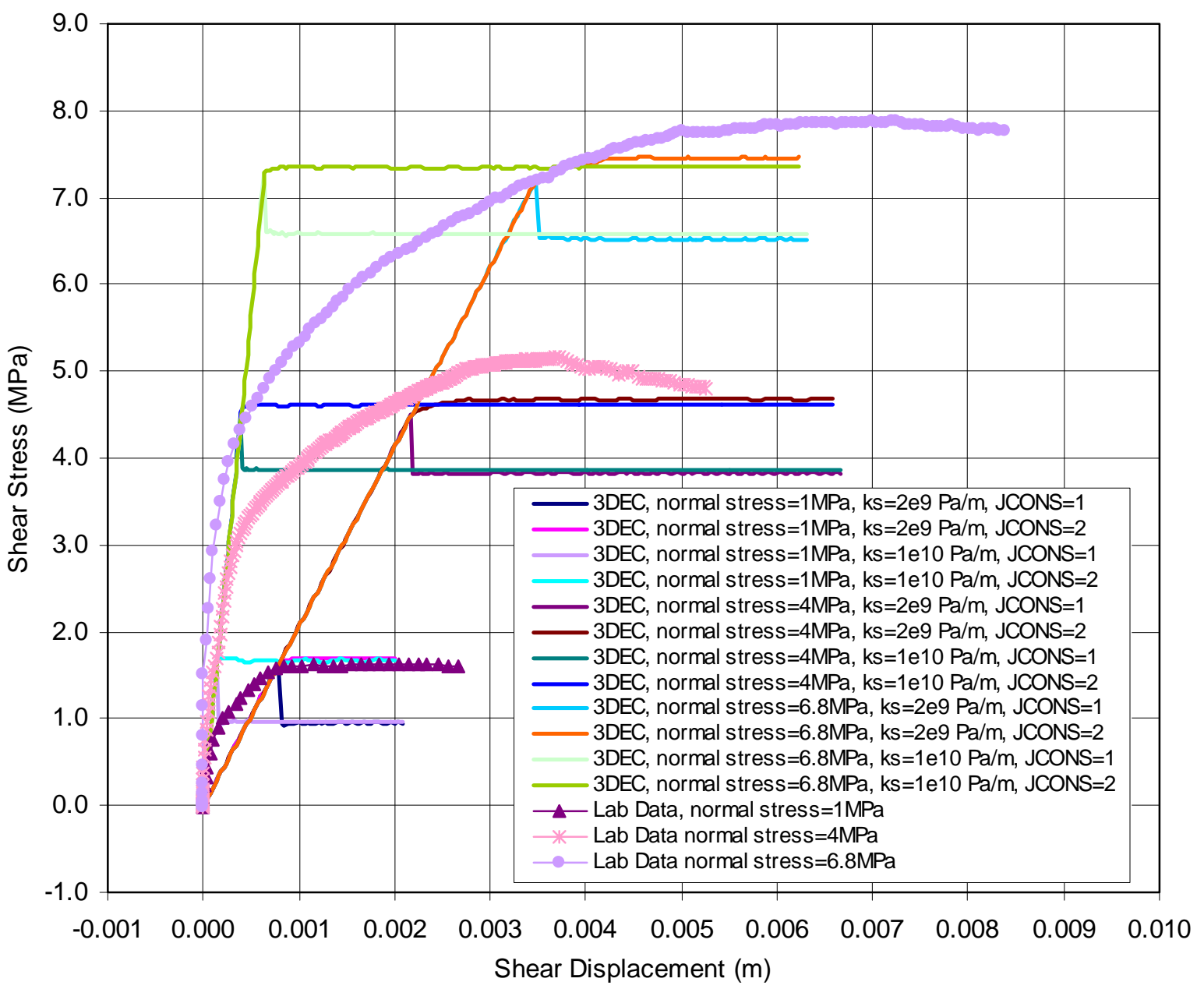

NOTE: The laboratory data are the plots displayed with symbols and the 3DEC results are shown as lines. Three tests are shown for three different normal stress levels. Each of these tests is compared to four different 3DEC results that use the same friction and dilation angles as calculated from laboratory test results. Since 3DEC uses a linear shear stiffness consideration, two different shear stiffness values have been used to bound the laboratory data: a tangent value $(\mathrm{Ks}=1 \mathrm{e} 10 \mathrm{~Pa} / \mathrm{m})$ that represents the initial loading, and a secant value $(\mathrm{Ks}=2 \mathrm{e} 9 \mathrm{~Pa} / \mathrm{m})$ that represents the shear displacement at peak strength.

Figure 7-69. Comparison of 3DEC Simulation of Direction Shear Testing of a Vapor-Phase Parting (see Figure 7-64)

In Figure 7-69, the comparison of the 3DEC results for both JCONS 1 and 2 shows the laboratory data. The vapor-phase partings, being very rough joints with high dilation angle (approximately $13^{\circ}$ ), show a non-linear shear stiffness that is seen as the curvature in the loading portion of the curve. This is contrasted to the largely linear loading slope for the previous smooth cooling joint case. The 3DEC joint model considers a simple, linear loading slope characterized by a constant shear stiffness. Therefore, the approach taken in the tunnel modeling discussed in Section 6.3 of this report is to examine the effect of variable shear (and normal) stiffness on the global response. The validation of the 3DEC model examines two shear stiffness values: the tangential slope defined by the initial loading prior to its departure from linearity, and the secant slope determined from the displacement at peak shear strength. For each of these shear stiffness values, simulations are run for the JCONS $=1$ (softening model) and for 
JCONS=2 (elastic-perfectly plastic model with no strength loss). Thus, for each level of normal stress $(1,4$, and $7 \mathrm{MPa})$, four simulations are conducted. Each of the simulations considers a constant friction angle and dilation angle derived from the laboratory test data.

As seen in Figure 7-69, the laboratory data are fit reasonably well with the selection of a secant shear stiffness and no post-peak softening of the material response. The tangent stiffness consideration, coupled with the post-peak softening model (JCONS $=1$ ) is conservative in that peak strength is reached after a smaller level of shear displacement, and that the strength drops to a slightly smaller residual value when cohesion of the surface is considered to be destroyed. The tunnel scale modeling is conducted with values of shear stiffness (1e10 $\mathrm{Pa} / \mathrm{m}$ - default, and $2 \mathrm{e} 9 \mathrm{~Pa} / \mathrm{m}$ ) that bound the prospective range. It was shown in Section 6.3.1.6.2 that sensitivity studies of shear stiffness have a minor effect on the calculation of rockfall.

\subsubsection{DEC Post-Development Validation Exercise 2 - Validation of the Nonlithophysal Rockfall Model Implemented in 3DEC by Comparison to an Explosively Loaded, Scaled Tunnel Stability Experiment in Jointed Rock (Corroboration with Information Published in the Literature)}

In this example, data from a Defense Nuclear Agency-sponsored explosive tunnel stability field experiment conducted in a simulated jointed rock mass is used as a validation test for the 3DEC program. This problem tests a number of aspects of 3DEC that are used in the current drift degradation model, including:

- The ability of 3DEC for representation of wave transmission through intact and jointed rock

- The ability of 3DEC for representation of the mechanical response of joints to dynamic normal and shear loading

- The ability of 3DEC for representation of a non-linear, joint controlled tunnel deformation under dynamic loading.

Details of the physical experiment are described in detail in Senseny and Pucik (1999 [DIRS 168479]), and summarized here. The test involved blast-induced dynamic loading of a scaled, lined cylindrical tunnel in a simulated jointed rock, and was described in Section 7.6.5.5. The purpose of the test was to provide a realistic experiment at a relatively large scale for validation of and comparison of a number of numerical modeling programs capable of representing tunnel failure under dynamic loading.

The experiment consisted of a simulated rock mass composed of over 4000 limestone blocks, each being $51 \mathrm{~mm}$ square by $0.6 \mathrm{~m}$ or $1.2 \mathrm{~m}$ in length (Figure 7-70). The bricks were stacked into a nearly cubical specimen measuring $2.1 \mathrm{~m}$ square and $2.4 \mathrm{~m}$ in length with a central $0.4 \mathrm{~m}$ diameter cylindrical hole (the tunnel) that was lined with a thin aluminum tube. Instrumentation included 46 gauges for monitoring velocity, stress, joint slip and tunnel closure.

The entire "sample" was placed in a pit and covered with concrete. The midline of the concrete surface was formed in a half-cylinder to allow application of a cylindrically-diverging blast wave 
generated by explosives. The resulting stress wave had a radius of $4.4 \mathrm{~m}$, a rise time of about $500 \mu \mathrm{m}$, a peak stress of about $100 \mathrm{MPa}$ and peak particle velocity of about $14 \mathrm{~m} / \mathrm{sec}$, a total radial displacement of about $25 \mathrm{~mm}$, and peak circumferential strain of about 0.6 percent. This divergent dynamic environment was sufficient to cause joint slip, intact rock fracture and permanent deformation of the lined opening.

A number of calculators were presented with the model boundary and initial conditions, the block geometry and laboratory-measured rock and joint properties. A "blind" validation of a number of two-dimensional numerical models (including the UDEC program), which used different methods for simulating joint surfaces, was then conducted as discussed in Section 7.6.5.5. The term "blind" here refers to fact that the numerical analysts were asked to produce model predictions of the system response without knowledge of the experiment outcome. Analysts were provided the basic intact and joint material testing data, test geometry and boundary and initial conditions. They subsequently formulated the analysis methodology, conducted the numerical analyses and submitted the results to a separate group whose purpose was to perform code-to-experiment and code-to-code comparisons. Senseny and Pucik (1999 [DIRS 168479]) gathered the results of the simulations and performed code-to-experiment and code-to-code comparisons from the various calculators. Here, the results of the same experiment are compared to numerical predictions made by the 3DEC program.

\subsubsection{Rock Properties Data}

The rock chosen for this test was a porous limestone from the Salem formation. Intact specimens were tested in triaxial compression and triaxial extension. The reported data shown in Figure 7-71 indicate very little variation between tests, and the results were consistent between three different testing laboratories.

Seen in Figure 7-72, failure envelopes developed from the triaxial compression and triaxial extension tests. Tests also were conducted on joints to determine their shear strength and stiffness. Special specimen preparation procedures were employed to ensure that the joint surfaces in the laboratory tests were similar to those in the jointed-rock tests. The normal compressibility of the joint surfaces was determined by unconfined compression tests on specimens with a single joint oriented at $90^{\circ}$ to the specimen axis. Each specimen was loaded to approximately 75 percent of its unconfined strength and then unloaded. Figure 7-73(a) shows typical joint normal-direction compressibility data. Under normal loading, the joints are fully closed after approximately $0.05 \mathrm{~mm}$ displacement.

The shear strength of the joints was determined by a series of triaxial compression tests on cylindrical specimens, each containing a single joint oriented at $30^{\circ}$ to the specimen axis. The confining pressure in these tests ranged from $1 \mathrm{MPa}$ to $35 \mathrm{MPa}$. At confining pressures up to $30 \mathrm{MPa}$, the specimens failed by sliding of the joints at approximately constant stress. When loaded at a confining pressure of $35 \mathrm{MPa}$, the intact portion of the test specimen failed without sliding along the joint. Figure 7-73(b) plots peak shear stress on the joint as a function of normal stress on the joint for tests performed at confining pressures up to $30 \mathrm{MPa}$. The joint strength data are well represented by a straight line passing through the origin with a $38.3^{\circ}$ friction angle. 


\subsubsection{Constitutive Models}

Limestone Intact and Joint Constitutive Models-The constitutive model used for intact limestone in the 3DEC program is an elastic-plastic, strain-softening model (no cap on the yield surface) using a Mohr-Coulomb shear failure surface with tension cutoff. Greater detail on the Mohr-Coulomb strain-softening plasticity model can be found in the 3DEC User's Manual (Itasca Consulting Group 2002 [DIRS 160331]). The strains are subject to a non-associated flow with zero dilatancy in shear and associated flow in tension. The strain softening is controlled via isotropic softening of the intact material cohesion and tensile strength. No rate dependence of material properties is considered. The joint model used considered Coulomb slip with constant shear and normal stiffness based on the data shown in Figure 7-73, and given in Table 7-4. The constitutive model for the aluminum liner was an isotropic-hardening Tresca model with properties given in Table 7-4.

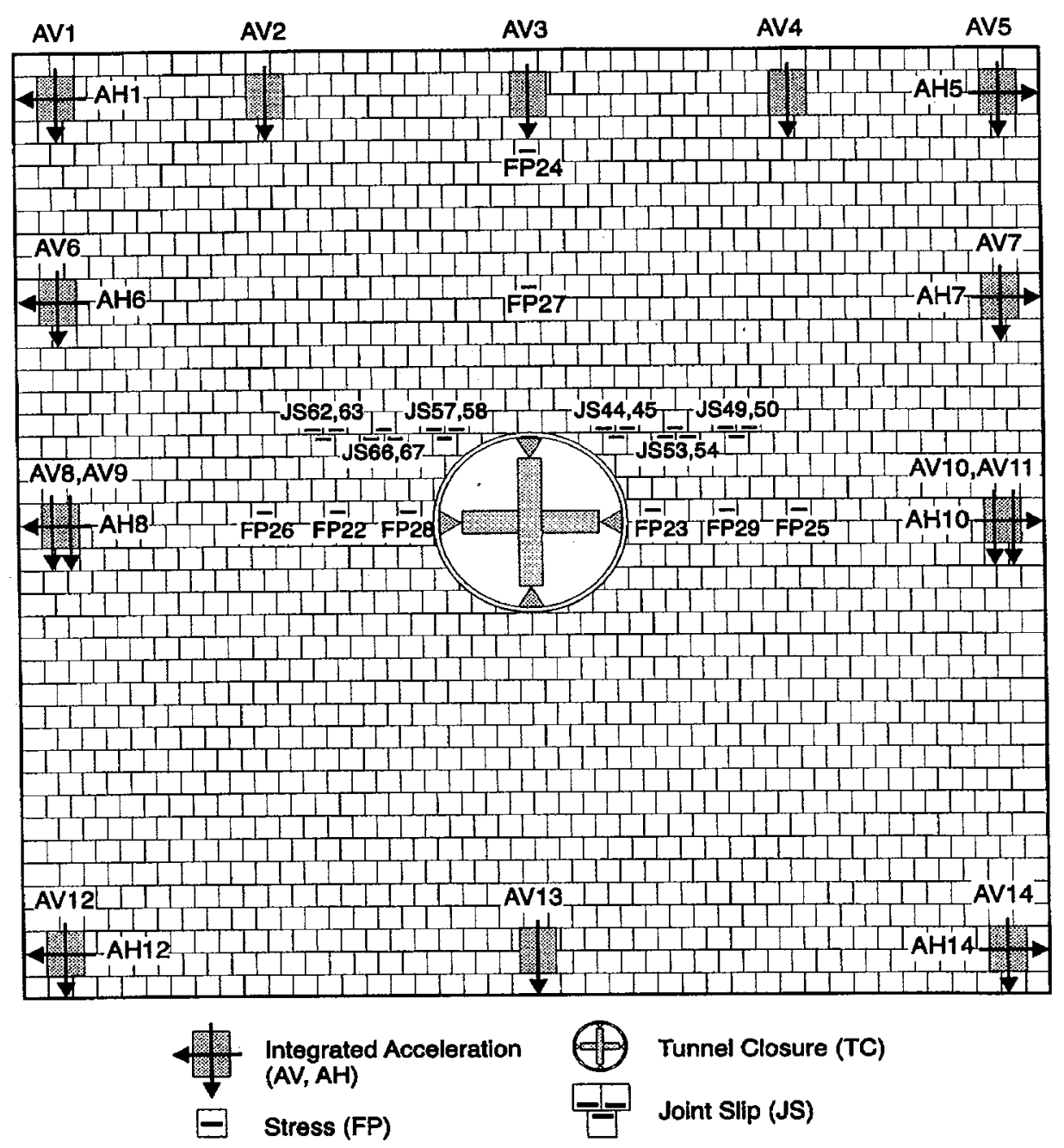

Source: Senseny and Pucik 1999 [DIRS 168479].

Figure 7-70. Geometry of the 2.1-m Square (2.4 m Long) Joint Rock Experiment Showing Internal Tunnel and Instrument Locations 
Confining Pressure $=0$

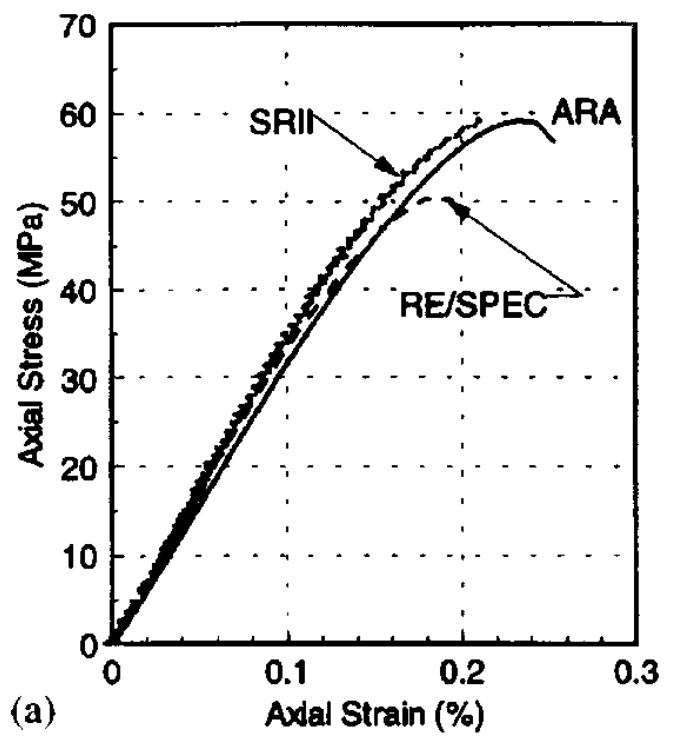

Confining Pressure = $50 \mathrm{MPa}$

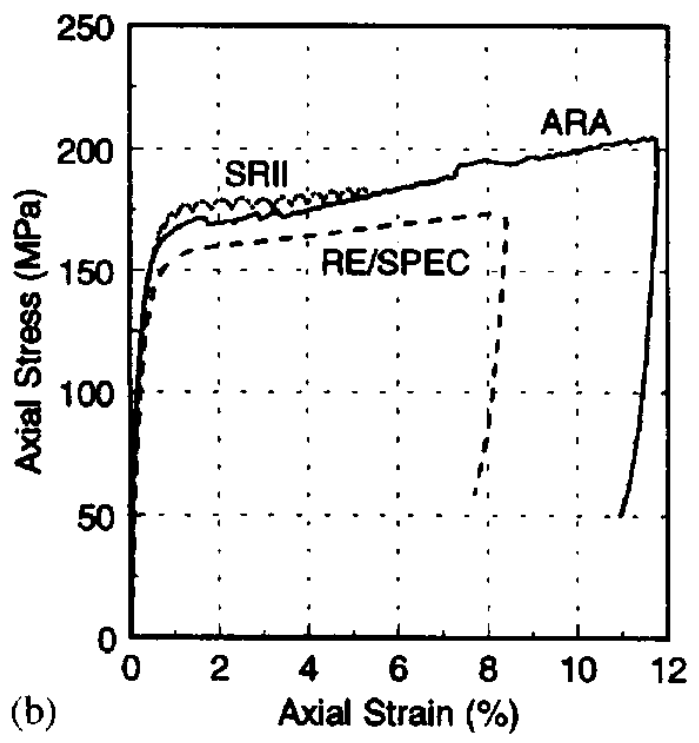

Source: Senseny and Pucik 1999 [DIRS 168479].

Figure 7-71. Stress Strain Curves for Salem Limestone: (a) Unconfined Compression and (b) Triaxial Compression

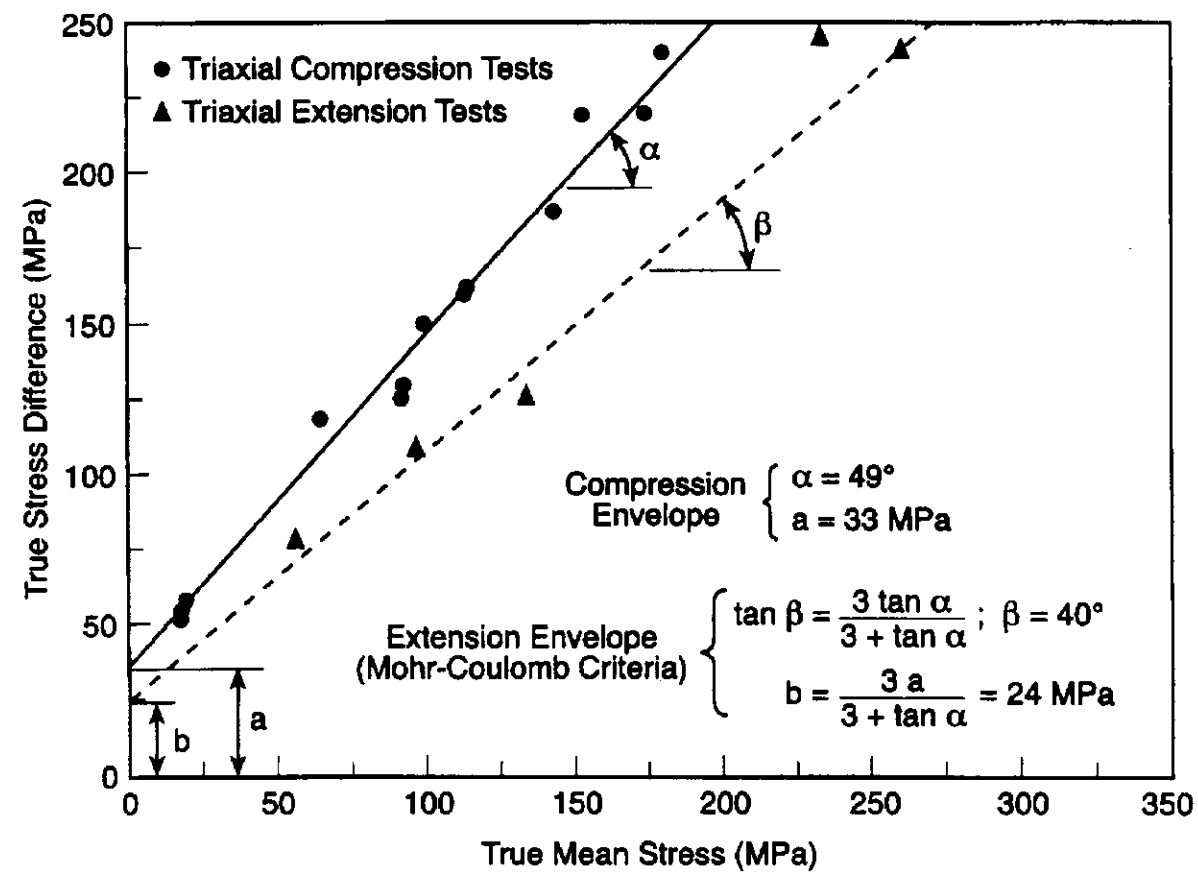

Source: Senseny and Pucik 1999 [DIRS 168479].

Figure 7-72. Comparison of Extension and Compression Strength Envelopes for Salem Limestone 


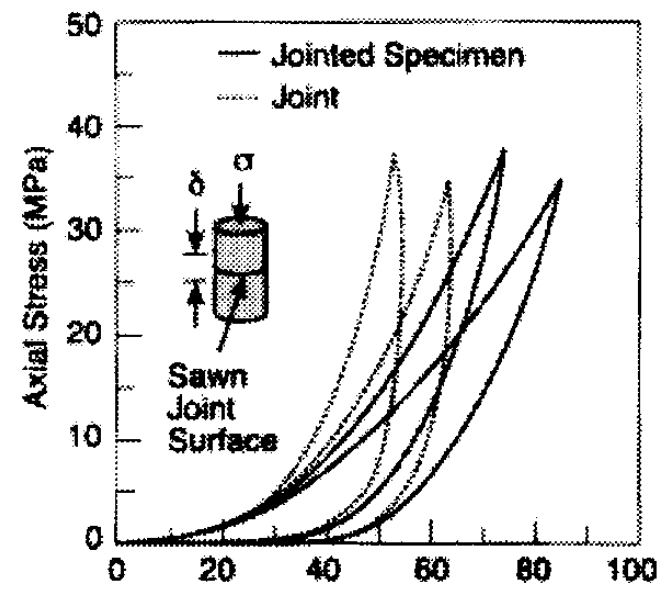

(a)

Axita Displacement (um)

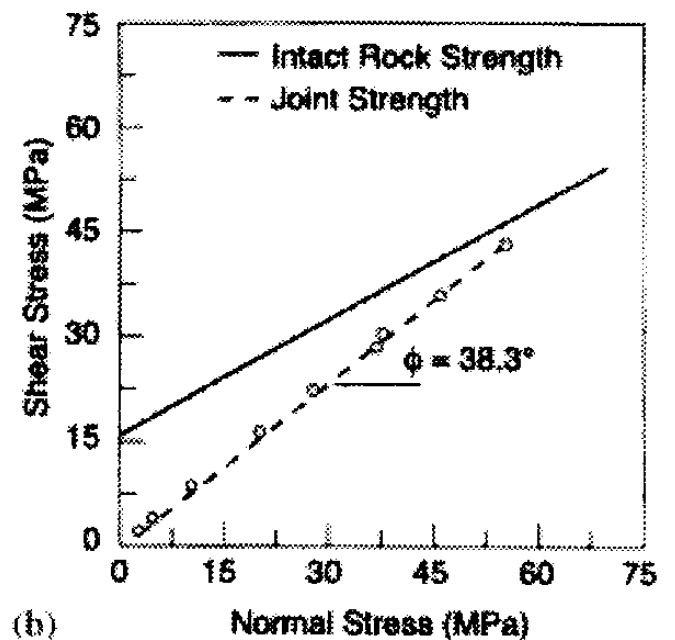

Source: Senseny and Pucik 1999 [DIRS 168479].

Figure 7-73. Compressibility and Strength in Salem Limestone: (a) Normal-Load Compressibility and (b) Shear Strength Envelope

Table 7-4. Properties of the Limestone Rock Mass and Aluminum Liner

\begin{tabular}{|c|c|c|c|c|c|c|}
\hline & $\begin{array}{c}\text { Bulk } \\
\text { Modulus } \\
\text { Component }\end{array}$ & $\begin{array}{c}\text { Shear } \\
\text { Modulus } \\
(\mathbf{G P a})\end{array}$ & $\begin{array}{c}\text { Internal } \\
\text { Angle of } \\
\text { Friction } \\
\text { (degrees) }\end{array}$ & $\begin{array}{c}\text { Cohesion } \\
\text { (MPa) }\end{array}$ & $\begin{array}{c}\text { Tension } \\
\text { Strength } \\
(\mathbf{M P a})\end{array}$ & $\begin{array}{c}\text { Density } \\
\left(\mathbf{k g} / \mathbf{m}^{3}\right)\end{array}$ \\
\hline $\begin{array}{c}\text { Limestone Intact Rock } \\
\text { Properties }\end{array}$ & 21.5 & 12.3 & 56.7 & 8 & 5.4 & 2340 \\
\hline Limestone Joint Properties & 500 & 100 & 38.3 & 0 & 0 & N/A \\
\hline Aluminum Liner & 69.4 & 25.9 & 0 & 27.5 & 55 & 2700 \\
\hline
\end{tabular}

Source: Senseny and Pucik 1999 [DIRS 168479].

NOTE: Limestone is considered to strain-soften via a post-peak reduction in cohesion and tensile strength. Cohesion is reduced linearly from $8 \mathrm{MPa}$ to $3 \mathrm{MPa}$ over 0.2 percent plastic strain. Tensile strength is reduced linearly from $5.4 \mathrm{MPa}$ to 0 over 0.2 percent plastic strain. Aluminum is considered to behave as a strain-hardening material via a post-yield linear in cohesion and tensile strength. Cohesion increases linearly from 27.5 to $60 \mathrm{MPa}$ over 2.9 percent plastic strain. Tensile strength increases linearly from 55 to $120 \mathrm{MPa}$ over 2.9 percent plastic strain.

Block Model-The 3DEC model incorporated information about the effective vertical and horizontal gaps between the limestone bricks as measured in the actual experiment. The width of these gaps was determined using an indirect technique that relied on careful measurements of the overall dimensions of the stack of blocks in both directions. The contribution of the solid material to these measurements (i.e., the values that would be expected in the absence of gaps) was estimated by multiplying the number of bricks by the average brick thickness. The differences between these numbers and the actual measurements then provided an estimate of the total effective gap width. Dividing these differences by the number of joints then provides an estimate of the average effective gap thickness in each direction. 
Since post-test measurements of the test specimen showed that the deformation was symmetric about a vertical plane through the tunnel mid-length and was nearly constant in the middle half of the specimen (Senseny and Pucik 1999 [DIRS 168479]), the problem can reasonably be represented using a two-dimensional, plane strain simulation. Therefore the 3DEC model (Figure 7-74) can be simplified to represent a thin slice parallel to the tunnel axis. The tunnel lies in the z-direction, with Figure 7-74 depicting the $x-y$ plane. The boundary conditions applied include:

- Fixed displacements on the $x-y$ plane outer surfaces to represent the plane-strain condition perpendicular to the tunnel axis

- A roller boundary along the left hand y-z surface to represent a symmetry plane

- Fixed displacements on the lower x-z and outer y-z surfaces

- Free upper surface with application of the input waveform above the symmetry line.

Point of particle velocity history application

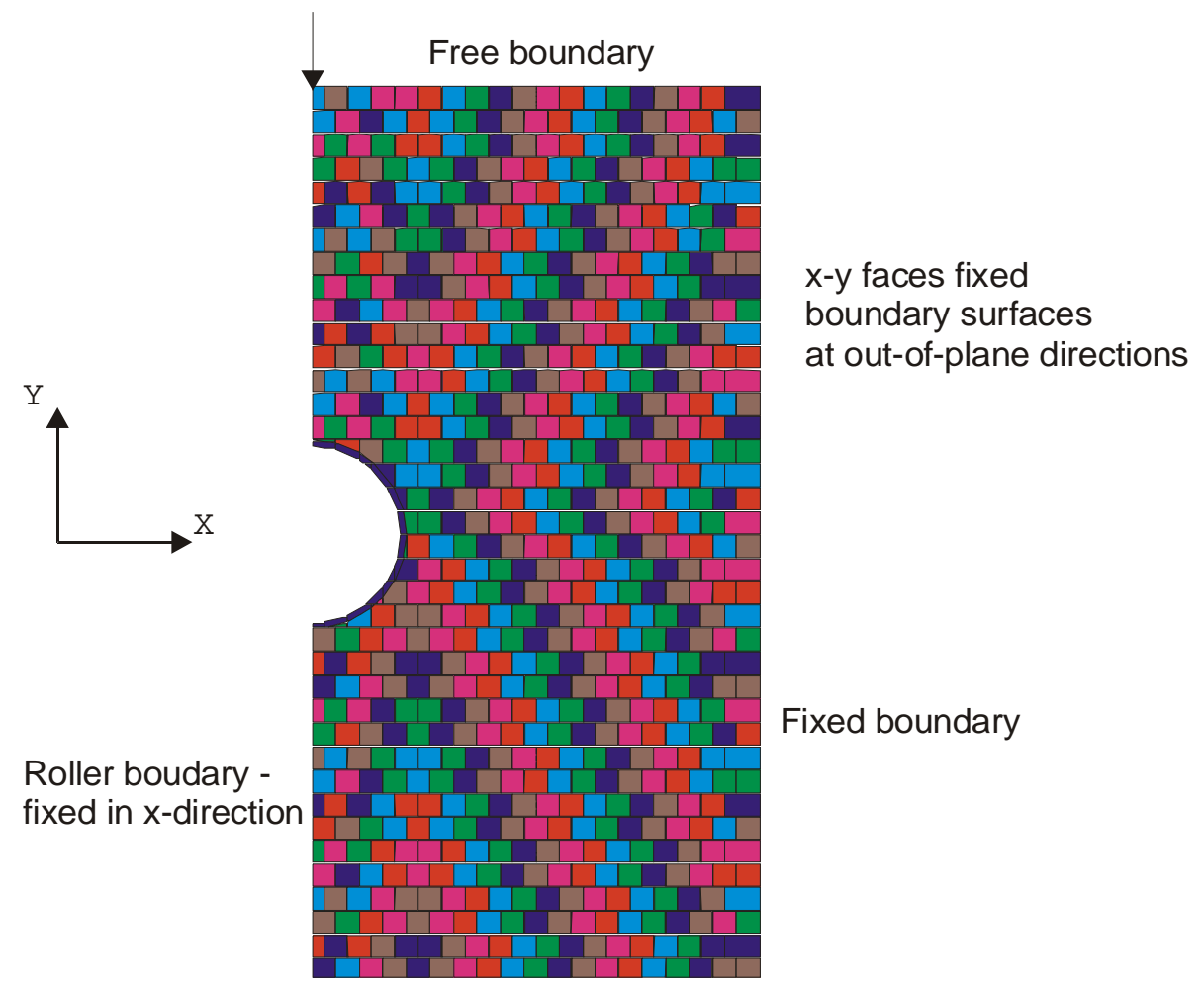

Fixed boundary

Figure 7-74. 3DEC Half-Symmetry Model Used in the Simulation Showing Boundary Conditions 
The measured particle velocity time histories induced by the input blast at its application point were used as a time-dependent boundary condition at the symmetry line at the top of the model above the tunnel. The subsequent stress and deformation induced in the stack of blocks were monitored during the test at the gauge locations shown in Figure 7-70: the stress history measured at two locations above the crown and at three locations laterally from the springlines; deformation of the tunnel crown-invert; and springline diameters. The 3DEC model output is compared to the time histories of these measurements. 3DEC output is also compared to the deformed shape of the aluminum tunnel liner as determined by measurement after the test was completed. Data concerning slip at the joint slip meter gauges were not recorded in 3DEC, as the movements in the actual test were outside the resolution of the installed instrumentation.

Seen in Figure 7-75, the predicted deformation of the thin tunnel liner. In the experiment, the closure instrumentation that was to be used to measure the tunnel liner movements failed, and thus there is no time history of tunnel deformation available for model-test comparison. Therefore, Figure 7-75 shows only the final roof-to-floor and wall-to-wall closures of the liner (on the right edge of the figure) as measured after the test. The predicted and actual final displacements of the crown and springline displacements show close agreement.

Seen in Figure 7-76, the predicted and measured stresses at the two gauges located on the specimen centerline above the tunnel crown (FP 24 and 27). The 3DEC stresses were monitored in the blocks adjacent to the actual stress measurement locations, which were directly on the symmetry line. The adjacent block, was chosen for comparison purposes as the symmetry line boundary conditions in 3DEC impose a condition of no rotation of the half-blocks along this line. The symmetry condition simplifies the model and the associated computing time, but locally results in solution inaccuracy. Since this consideration will affect the modeled stresses at this location, the adjacent block, which is free to translate or rotate provides a better comparison point. As seen in Figure 7-76, the stresses in the blocks directly adjacent to the measurement show good correlation to the measured values.

As seen in Figure 7-77, the predicted and measured stresses at the six gauges are located adjacent to the springlines (FP 23, 25, 26, 28 and 29). Because of symmetry in the experiment, the gauges on each side of the tunnel measure similar stress histories and, therefore, provide a measure of precision. As the figure shows, the precision in these stress measurements is very good. 3DEC predicts the wave arrival time accurately. The magnitude of the 3DEC prediction at stress points FP23/28 and FP25/26 are lower than those measured in the experiment. At stress point FP29/22, the magnitude is similar to the measured stresses. In each case along the springline, there is a dip in the stresses after approximately $1.8 \mathrm{~ms}$. This is a result of a wave reflection from the bottom of the model and could be avoided by using non-reflecting boundaries. However, this simulation was done using the same conditions as were prescribed for the numerical experiments as outlined in Senseny and Pucik (1999 [DIRS 168479]).

After the test, the tunnel liner was recovered and measured to determine more information than was obtained from the crown-invert and springline diameter changes alone. The shape of the liner was measure at three different locations.

As seen in Figure 7-78, the magnified, measured, and predicted shape shows the deformed aluminum liner. Over the entire perimeter, the liner displacements as predicted by 3DEC lie 
within the variability of the actual measurements. 3DEC accurately predicts the diametral closure along the centerline and the diametric expansion along the springline.
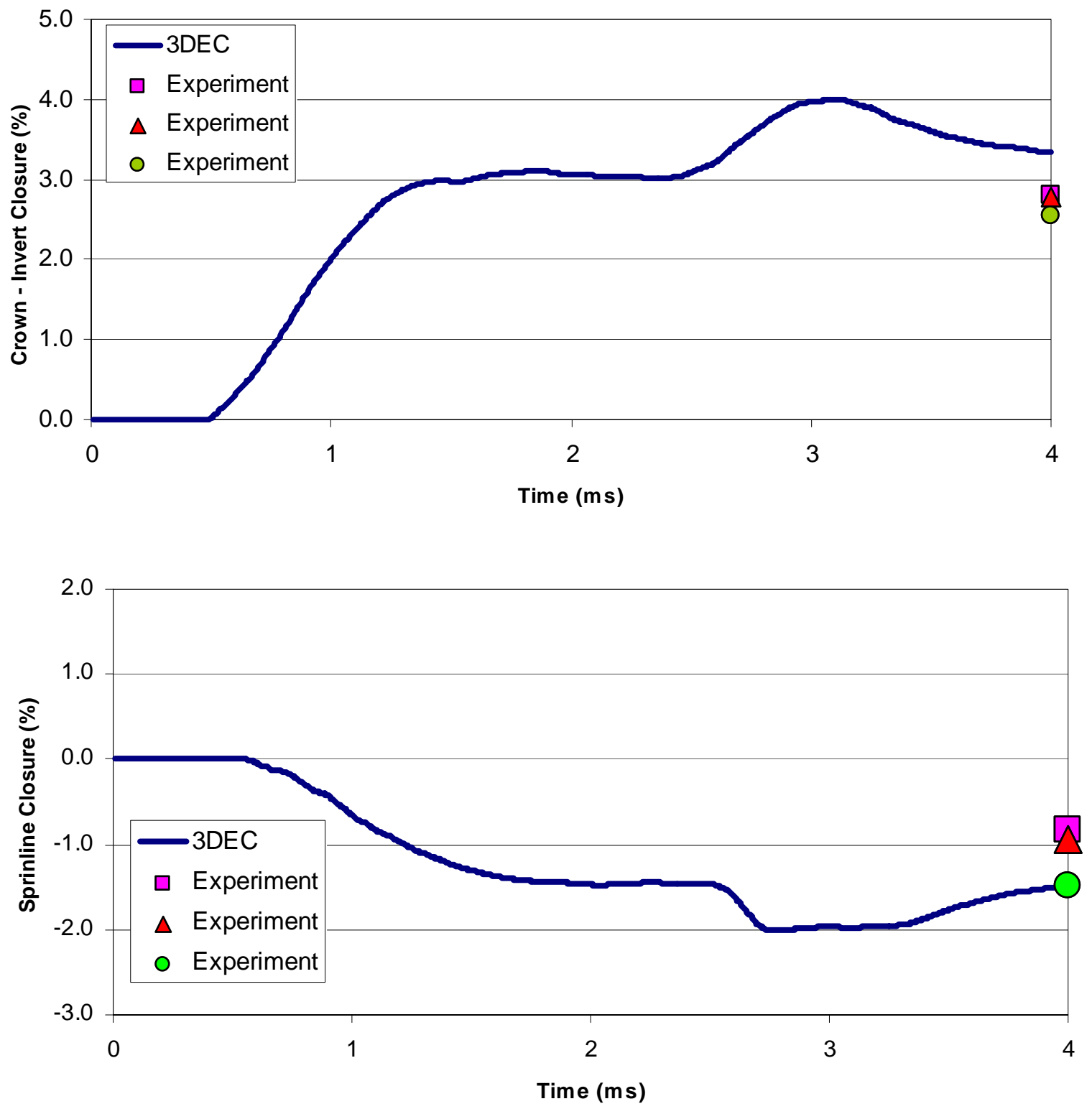

Source: DTN: MO0408MWDDDMIO.002, file mighty_north_2.xIs.

Figure 7-75. Predicted (3DEC) and Measured Final Deformation (Exp) of the Crown-Invert and Springline Tunnel Diameters at Three Locations Along the Tunnel Length 

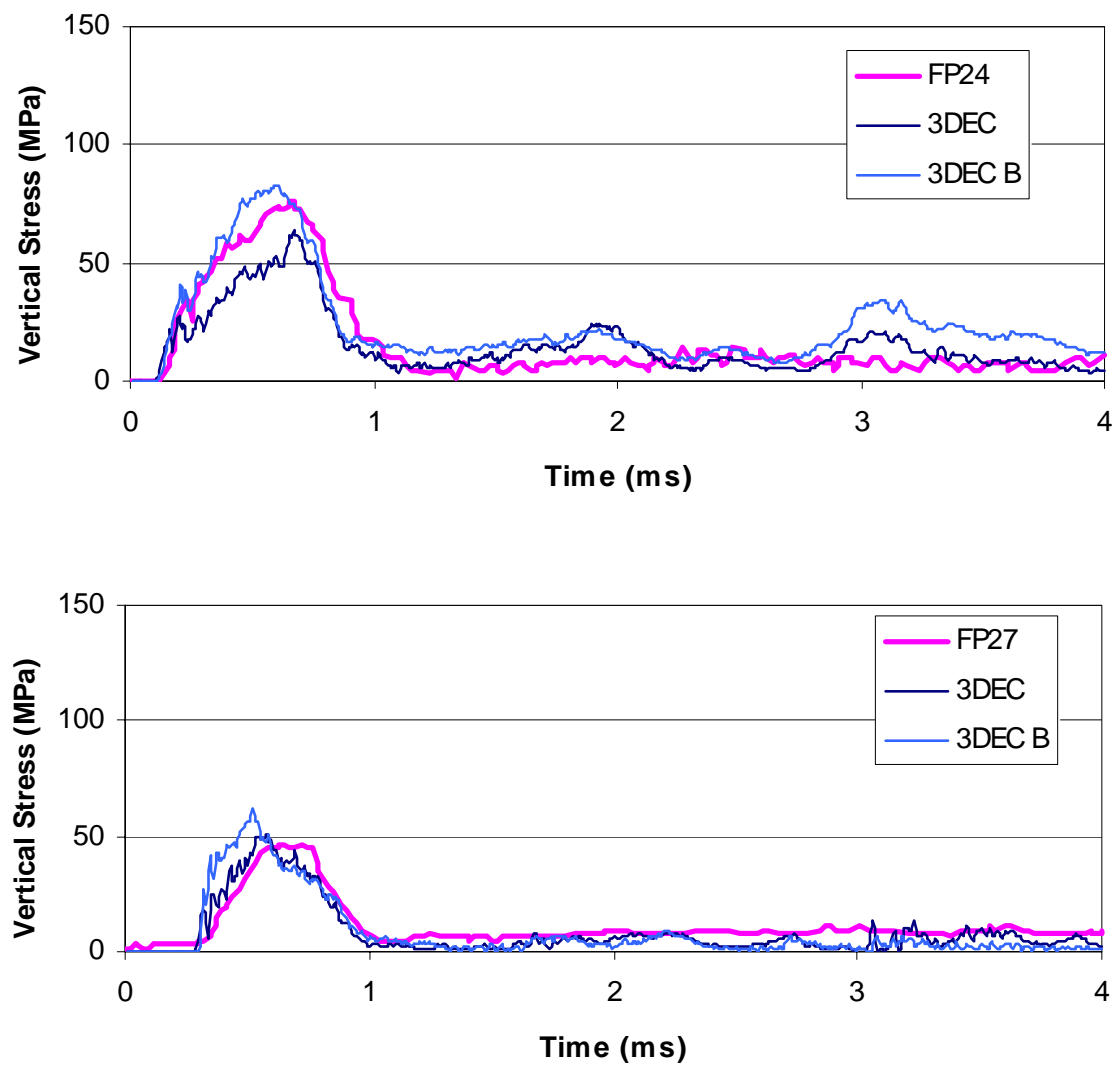

Source: DTN: MO0408MWDDDMIO.002, file mighty_north_2.xIs.

NOTE: The points labeled "3DEC" are taken from the model at the exact reported stress gauge location, and "3DEC A" and "3DEC B" in the 3DEC blocks immediately to the left and right of the reported location, respectively.

Figure 7-76. Predicted Stresses in Block Adjacent to Measured Stresses (Gauges FP24 and FP27) Above the Tunnel Crown 

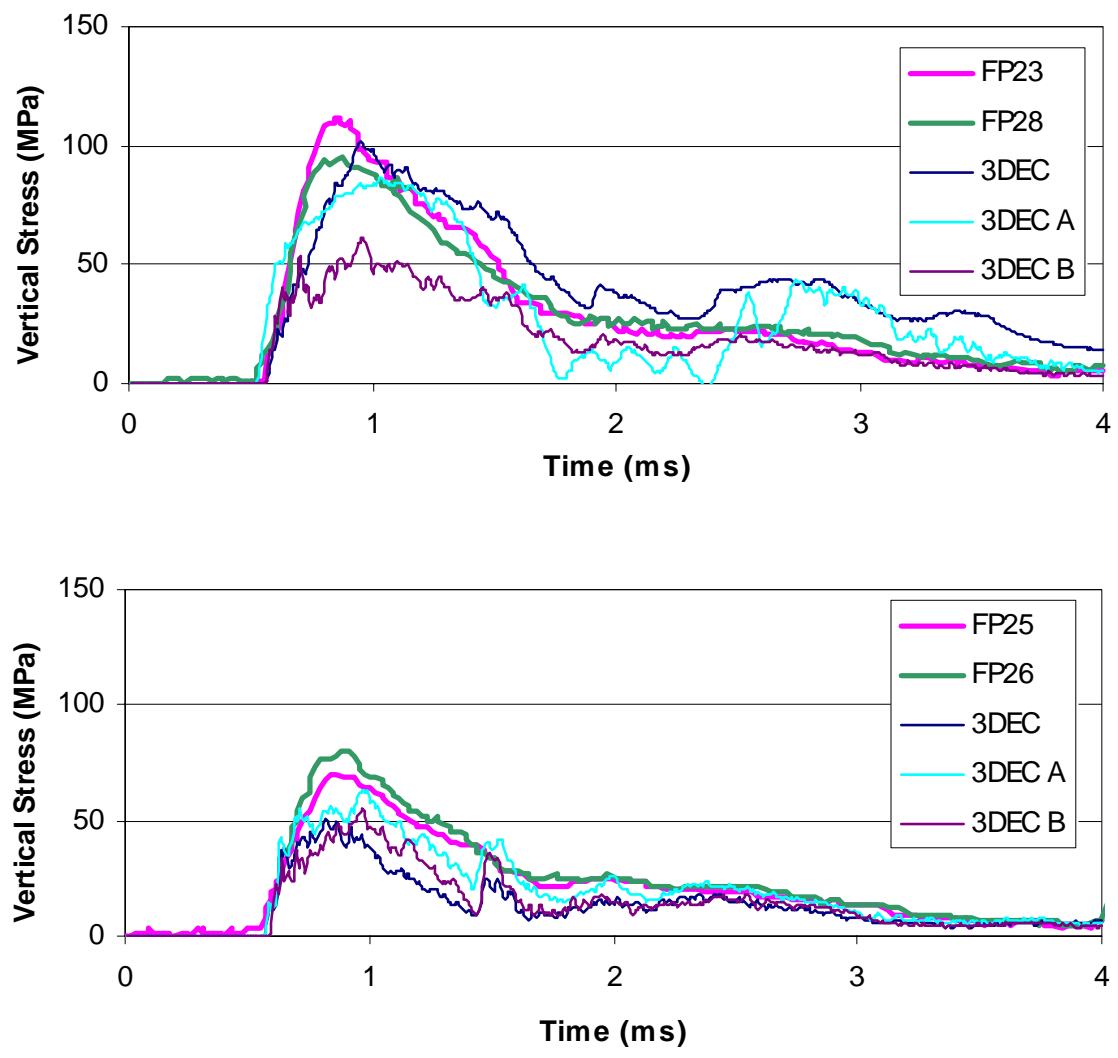

Source: DTN: MO0408MWDDDMIO.002, file mighty_north_2.xls.

NOTE: The points labeled "3DEC" are taken from the model at the exact reported stress gauge location, and "3DEC A" and "3DEC B" in the 3DEC blocks immediately to the left and right of the reported location, respectively.

Figure 7-77. Predicted and Measured Stresses Adjacent to the Tunnel Springline

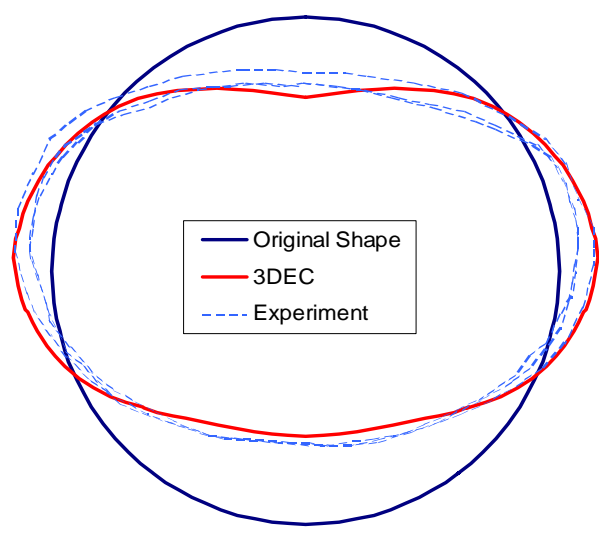

Source: DTN: MO0408MWDDDMIO.002, file mighty_north_2.xIs.

Figure 7-78. Measured and Predicted Shape of the Deformed Aluminum Liner (Displacements are Magnified by 10) 


\subsubsection{DEC Post-Development Validation Exercise 3 - Nonlithophysal Rockfall Model Validation by Corroboration with Alternative Numerical Model}

The probabilistic key-block software DRKBA is used as an alternative numerical model to validate the 3DEC model results on block size distribution and rockfall frequency. The DRKBA code employs a numerical technique with Monte-Carlo simulation to account for the statistical variation of the joint system. A description of DRKBA approach and the input data for the probabilistic key-block analysis are provided in Appendix D.

The results of DRKBA analyses for the $1 \times 10^{-4}$ seismic hazard are presented in Figure 7-79. Size distributions are compared with the 3DEC results, including both $1 \times 10^{-4}$ and $1 \times 10^{-7}$ seismic hazards. The frequency of blocks for both DRKBA and 3DEC is also provided in Figure 7-79. The size distribution curves show that the 3DEC results predict smaller size blocks for the same level of cumulative percentiles compared to the DRKBA results. The frequency of rockfall from the 3DEC results is much higher compared to the DRKBA results.

While both the DRKBA and 3DEC approaches have used the same fracture data inputs based on tunnel mapping in the ESF and ECRB Cross-Drift, the respective methods for developing synthetic fracture geometries are different. The DRKBA joint geometry generator produces larger joint planes concentrated about the center of the three-dimensional model space. The 3DEC joint generator (i.e., FracMan) develops a more realistic sizing of joint planes with an improved distribution throughout the model space, resulting in a higher frequency of smaller blocks compared to DRKBA.

The shape and range of the DRKBA and 3DEC rockfall distributions are generally similar. The DRKBA method resulted in a maximum block size of 34 tons, which is similar the 29 ton maximum block from the 3DEC results for the $1 \times 10^{-7}$ seismic hazard.

\subsubsection{DEC Post-Development Validation Exercise 4 - Model Validation by Expert Technical Review}

An outside expert technical review was conducted as a means of validation, as discussed in procedure AP-SIII.10Q, Models. Dr. John Tinucci of the PanTechnica Corporation in Minneapolis, Minnesota, was contracted for this purpose. Dr. Tinucci is a Professional Engineer and has a Ph.D. from the University of California, Berkeley, where his thesis research was in the area of analysis of the stability of blocky rock masses, and, in particular, in the development of key-block methods for tunnel stability assessment. He has extensive experience in the use of the 3DEC program for surface and underground stability assessment. Particularly valuable experience for the present application is his use of 3DEC to model dynamic stability of deep underground mine openings.

Dr. Tinucci was provided with a number of reports and presentations detailing the geology, laboratory properties, modeling methodology and preliminary results of the FracMan and 3DEC modeling work prior to visiting the site. A site visit of three days was then conducted in which discussions were held with YMP engineers and geologists regarding the FracMan and 3DEC work. A visit to the ESF main loop and ECRB Cross-Drift was conducted to view the rock mass conditions in situ. 
Dr. Tinucci's review report is provided in Appendix N. In general, the technical review finds the 3DEC and FracMan approaches to be adequate for simulation of the rockfall problem in the nonlithophysal rocks. The model approach, data selection and ranges were found to be adequate. The model boundary conditions and methodology for application of the ground motions were also felt to be proper.

\subsubsection{Conclusions and Comparison to Validation Criteria}

The following discussion of comparison of validation criteria is given.

A. Analyses presented in Sections 6.3 and 7.7.4 indicate that the 3DEC program is able to represent dynamic boundary conditions and wave transmission through the material in an accurate fashion.

B. The comparison of the 3DEC program to the results of direct shear testing on fractures from the Tptpmn shows that 3DEC is able to adequately reproduce the shear constitutive response of the cooling and vapor-phase altered fractures. Use of sensitivity analyses to bound fracture shear stiffnesses in the vapor-phase altered fractures is warranted, although the analysis shown here indicates that the use of tangent stiffnesses and a softening joint mechanical model (the default used in Section 6.3 analyses) appears to be conservative in nature, resulting in more rockfall.

C. The ability of 3DEC to represent the complex problem of an explosively-loaded tunnel in jointed rock was tested via comparison to a scaled field experiment in limestone. The field experiment tested several capabilities of the program, including:

- The predictive capability of the nonlithophysal rockfall model as implemented in 3DEC for structures in jointed rock was demonstrated by comparing predictions with the results of a large jointed-rock precision test specimen that that involved dynamic loading and large strain of a lined cylindrical opening. Based on this validation case, 3DEC can reasonably simulate the wave transmission through the jointed rock, the stress change in the rock mass resulting from the dynamic excitation, and the large strain and permanent deformation of a tunnel in jointed rock and its internal support.

- 3DEC demonstrated the ability to represent complex dynamic boundary conditions.

- $3 D E C$ accurately predicted the final shape of the deformed liner.

- 3DEC accurately predicted the arrival time of the stress waves, thus validating the wave transmission simulation through the jointed rock.

- 3DEC accurately predicted the stress magnitudes and wave shape at several of the monitoring points. Wave reflections disturbed this prediction in some locations. Note that the inclusion of random gaps in the model adds difficulty in matching the stresses at specific locations. 


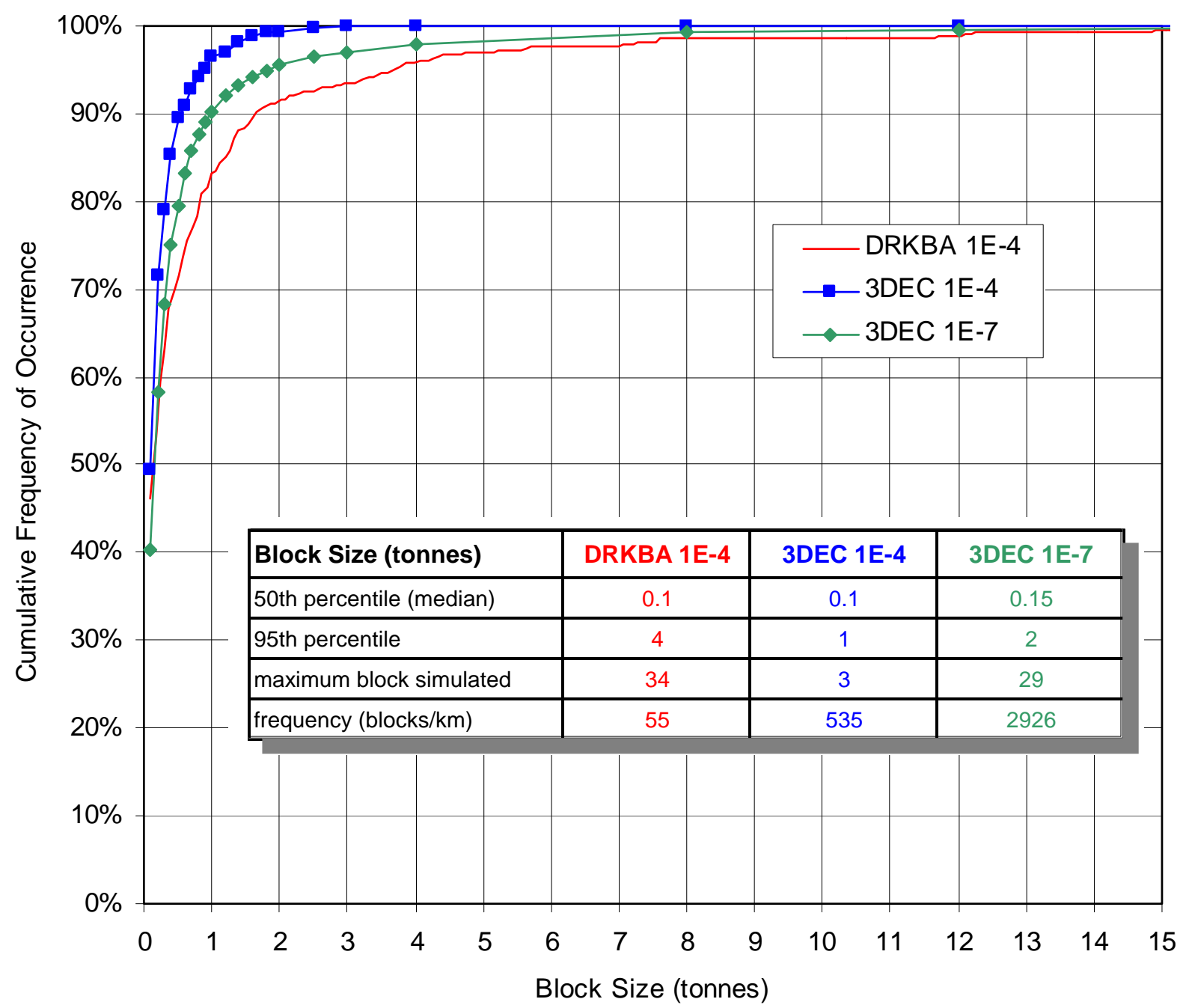

Figure 7-79. Comparison of Rockfall Results from 3DEC and DRKBA

- The 3DEC model as shown compared very favorably with the physical experiment and demonstrated the ability to represent reasonably the dynamic response of a fractured media.

D. The overall adequacy of the modeling approach and the specification of property ranges have been validated by corroboration with the results of an alternative numerical model and by external technical review.

\subsection{VALIDATION SUMMARY}

The drift degradation models for lithophysal and nonlithophysal rocks have been validated by applying acceptance criteria based on an evaluation of the model's relative importance to the potential performance of the repository system. The validation requirements defined in the Technical Work Plan for: Regulatory Integration Modeling of Drift Degradation, Waste Package 
and Drip Shield Vibratory Motion and Seismic Consequences (BSC 2004 [DIRS 171520], Section 2.2.1) have been fulfilled. This includes:

- Corroboration with laboratory measurements or relevant observations not previously used to develop or calibrate the models

- Corroboration of results with alternative mathematical models

- Corroboration with data published in referred journals or literature

- Technical review by reviewers independent of the model development, checking, and interdisciplinary review.

Requirements for confidence building during model development have also been satisfied. The model development activities and post-development validation activities described establish the scientific bases for the drift degradation models. Based on this, the drift degradation models are considered to be sufficiently accurate and adequate for the intended purpose and to the level of confidence required by the models' relative importance to the potential performance of the repository system. 


\section{INTENTIONALLY LEFT BLANK}




\section{CONCLUSIONS}

\subsection{SUMMARY}

This report was developed to document the degradation of the rock mass surrounding the emplacement drifts of a geologic repository at Yucca Mountain. The factors leading to drift degradation include the stresses induced by the heat released by the emplaced waste, the stresses due to seismically related ground motions, and the strength loss of the rock mass due to time-dependent strength degradation. These factors have been modeled and analyzed, resulting in the prediction of the amount and size distribution of rockfall in the repository drifts during both the preclosure and postclosure regulatory periods. The data developed and documented in this model report have been entered into the Technical Data Management System (DTNs: MO0408MWDDDMIO.002, MO0408MWDRNLRA.002, MO0306MWDDPPDR.000, MO0404MWD3DRFA.000, MO0407MWDDSLCR.000, MO0407SPAMTSHR.000, and MO0403MWDRPNLR.000).

The following statements summarize the results from this drift degradation modeling and analysis activity and present the key conclusions:

- The rock mass at the repository host horizon has been geologically characterized to support the rockfall modeling activities presented in this report. Drift degradation models have been developed for both nonlithophysal and lithophysal rock. A detailed description of the rock mass characteristics of the repository host horizon is provided in Section 6.1. The available rock mass geotechnical data, including fracture geometry (Section 6.1.4.1, Section 6.1.6, and Appendix B), lithophysal abundance and geometric characteristics (Section 6.1.4.2 and Appendix O), and geotechnical rock properties (Section 6.1.3 and Appendix E), are sufficient to support detailed drift degradation analyses using both continuum and discontinuum approaches.

- The drift-scale temperature history was calculated throughout the preclosure and postclosure periods of the repository as documented in Section 6.2. The temperature history was used to calculate the thermal stress state that develops within the rock mass due to the heat energy released from the stored nuclear waste, and appropriate boundary conditions for thermal loading have been applied (Sections 6.2, 6.3.1.3, and 6.4.2.3). Appropriate thermal properties have been used in the thermal-mechanical calculation as provided in Section 4.1 and Appendix E (Section E5).

- A nonlithophysal rockfall model was developed using the three-dimensional discontinuum code, 3DEC, with the following features:

- Appropriate boundary conditions are provided for thermal and seismic loading (Sections 6.3.1.2 and 6.3.1.3).

- Critical fracture patterns are included from multiple sampling from a synthetic rock mass volume that contains a realistic fracture population based on field mapping data (Section 6.1.6). 
- Appropriate thermal and mechanical properties of rock blocks and joints are used (Appendix E).

- Long-term degradation of joint strength parameters is considered (Section 6.3.1.5).

- Site-specific ground motion time histories appropriate for both the preclosure ( $5 \times 10^{-4}$ and $1 \times 10^{-4}$ hazard levels) and postclosure $\left(1 \times 10^{-5}, 1 \times 10^{-6}\right.$, and $1 \times 10^{-7}$ hazard levels) time periods are included in the model (Section 4.1.5).

- A lithophysal rockfall model was developed using the two-dimensional discontinuum code, UDEC, with the following features:

- Appropriate boundary conditions are provided for thermal and seismic loading (Sections 6.4.2.1 and 6.4.2.2).

- The rock mass is represented as an assembly of polygonal, elastic blocks in which the bond strength of the blocks is calibrated such that the overall mechanical behavior of the mass is consistent with the material model developed for the lithophysal rock (Section 7.6.4).

- The lithophysal rockfall model allows for the formation of stress-induced fractures between blocks (i.e., the formation of internal fracturing), separation and instability (under the action of gravity or seismic shaking) of the rock mass around the drift (Section 6.4.2).

- Appropriate thermal and mechanical properties of rock blocks and joints are used (Appendix E).

- Long-term degradation of rock mass strength is considered (Section 6.4.2.4).

- Site-specific ground motion time histories appropriate for both the preclosure ( $5 \times 10^{-4}$ and $1 \times 10^{-4}$ hazard levels) and postclosure $\left(1 \times 10^{-5}\right.$ and $1 \times 10^{-6}$ hazard levels) time periods are included in the model (Section 4.1.5).

- Model validation activities include (1) validating the mechanical material models or representations for the two specific repository host rock types (i.e., lithophysal and nonlithophysal rocks), and (2) validating the implementation of these material models in general numerical modeling schemes (Section 7).

- The results for the nonlithophysal units are summarized as follows:

- Preclosure ground motion results in minor drift damage due to rockfall.

- Postclosure ground motion results in varying extent of drift damage due to rockfall, with localized areas of rock failure sufficient to cover the drip shield. 
- Thermal effects have a minor impact on rockfall.

- Time-dependent strength degradation has a minor impact on rockfall.

- The results for the lithophysal units are summarized as follows:

- Degradation is primarily controlled by stress conditions.

- Preclosure ground motion results in minor drift damage due to rock failure.

- Damage to the host rock is not significantly accumulating from multiple preclosure ground motions (Section S3.4.3). That is, a preclosure seismic event is shaking loose rock fragments that have already failed by strength degradation and thermal stress; no new fractures and failures are caused by this low amplitude ground motion.

- Postclosure ground motion results in collapse of the drift, with fragmented rock particle sizes on the order of centimeters to decimeters.

- Thermal and time-dependent effects can result in localized to significant areas of rock failure, depending on the selection of the degree of strength loss of the rock mass with time. The analyses of the available static-fatigue test data indicate that an approximate 40 percent reduction in cohesive strength occurs over a 20,000 year period. The nominal case for drift degradation (i.e., considering thermal and time-dependent effects, but excluding seismic effects) results in only partial collapse of the drift at 20,000 years, as depicted by Figures S-41 through S-44. The analyses of the available static-fatigue test data indicate that the lower bound quality rock mass can be represented as rock mass Category 2, which represents only about 10 percent of the total lithophysal rock mass in the emplacement drifts. A combination of the thermally induced stresses with time-dependent strength degradation results in a deterioration of the walls for Category 2. As rock mass quality increases, there is less rockfall from the walls and more rockfall from the drift roof. Preclosure seismic ground motion causes additional, but not significant, rockfall as a result of shaking down already loose, broken ground.

- The drift degradation models and analyses documented in this report address the requirements of NRC/DOE agreements items regarding rockfall and related issues to support the resolution of NRC's KTI on Repository Design and Thermal-Mechanical Effects (Section 6.8).

\subsection{ASSESSMENT}

The drift degradation and modeling activities presented in this report address the criteria identified in Section 4.2 as summarized in Table 8-1. The rockfall models have adequately captured the physical phenomena associated with the various components of rock mass behavior anticipated within the repository horizon. Appropriate boundary and initial conditions have been 
applied, and the technical bases for the development of these rockfall models have been adequately documented. Sufficient data have been collected to adequately model the drift degradation processes. The technical bases and ranges of data used in the rockfall models are documented. Data uncertainty (Section 6.5) has been characterized through parameter sensitivity studies in the rockfall models. Model uncertainty has been characterized through an evaluation of alternative conceptual models, and the model results have been validated by comparison to field and laboratory data, alternative numerical approaches, and industry experience through external technical review. The most significant uncertainties impacting the results of the rockfall models are the uncertainties associated with the postclosure ground motion and time-dependent strength degradation. Some of the ground motions provided are larger than the largest ground motions observed and may not be physically realizable. Therefore, predictions of complete drift collapse with postclosure ground motion may be unrealistic. Without a technical basis to limit such ground motions to smaller values, these inputs represent the best available information to support this work. Prediction of time-dependent strength degradation for the duration of the regulatory period of 10,000 years is a highly approximate task. A significant program of static-fatigue testing of Tptpmn core specimens is currently being conducted. A part of this static-fatigue data has been included in this document (Section 6.4.2.4.2). This present work will be updated as additional long-term testing data are developed.

\subsection{RECOMMENDATIONS}

The drift degradation and modeling activities presented in this report are sufficient to support a license application. Specifically, the drift degradation results presented in Sections 6.3 and 6.4 are sufficient to provide input to drip shield and waste package design calculations, consequence models for the seismic scenario for TSPA-LA, and seepage abstraction models for TSPA-LA. 
Table 8-1. Mapping of Yucca Mountain Review Plan Acceptance Criteria and Drift Degradation Analysis

\begin{tabular}{|c|c|c|c|}
\hline $\begin{array}{c}\text { Acceptance } \\
\text { Criteria }\end{array}$ & Subcriteria & Paraphrase of Subcriteria & Sections Where Addressed \\
\hline \multirow{6}{*}{$\begin{array}{l}\text { AC1: } \\
\text { System } \\
\text { description and } \\
\text { model } \\
\text { integration are } \\
\text { adequate }\end{array}$} & 1 & $\begin{array}{l}\text { Total system performance } \\
\text { incorporates important aspects of } \\
\text { model }\end{array}$ & $\begin{array}{l}\text { 1.1 - Background } \\
\text { 6.3.1.2 - Rockfall in nonlithophysal units } \\
\text { feed to SCA } \\
\text { 6.4.2 - Rockfall in lithophysal units and } \\
\text { quasi-static drip shield loads - feed to SCA } \\
\text { 6.4.2.2.4 - Drift profile change to DSA } \\
\text { 7.2 - Level of importance to TSPA for } \\
\text { model validation } \\
\text { 8-Conclusions }\end{array}$ \\
\hline & 2 & $\begin{array}{l}\text { Description of geological and } \\
\text { engineering aspects that may affect } \\
\text { design, couplings, of mechanical } \\
\text { disruption }\end{array}$ & $\begin{array}{l}\text { 1.1 - Background } \\
6.1 \text { - Rock mass characteristics and } \\
\text { discussion of geologic parameters of } \\
\text { importance } \\
6.2 \text { - Thermal mechanical calculations that } \\
\text { provide thermal environment } \\
6.3 .1 .2,6.4 .2 \text { - Rockfall parameters for } \\
\text { drip shield evaluation } \\
\text { 6.4.2 - Drip shield loading parameters and } \\
\text { drift profile change parameters for SCA }{ }^{a} \\
\text { and DSA }\end{array}$ \\
\hline & 3 & $\begin{array}{l}\text { Description of assumptions and } \\
\text { technical bases consistent with } \\
\text { other abstractions }\end{array}$ & $\begin{array}{l}4-\text { Inputs, includes data and parameters, } \\
\text { criteria and codes and standards } \\
5-\text { Assumptions } \\
6.1 \text { - Geology and rock mass } \\
\text { characterization consistent with other } \\
\text { abstractions }\end{array}$ \\
\hline & 4 & $\begin{array}{l}\text { Boundary and initial conditions } \\
\text { propagated through abstractions }\end{array}$ & $\begin{array}{l}4-\text { Input - In situ stress, thermal loading } \\
\text { and ground motion data } \\
6.3,6.4 \text { - Boundary conditions specific to } \\
\text { model described } \\
\text { Appendix } W \text { - Thermal and mechanical } \\
\text { boundary condition verification }\end{array}$ \\
\hline & 5 & $\begin{array}{l}\text { Sufficient data for assessment of } \\
\text { FEPs }\end{array}$ & $\begin{array}{l}4 \text { - Input data } \\
5 \text { - Assumptions } \\
6.5 \text { - Uncertainties and limitations } \\
6.6 \text { - FEPs discussion }\end{array}$ \\
\hline & 6 & Criticality & Not relevant to this document \\
\hline $\begin{array}{l}\text { AC2: } \\
\text { Data are } \\
\text { sufficient for } \\
\text { model } \\
\text { justification }\end{array}$ & 1 & $\begin{array}{l}\text { Geological and engineering values } \\
\text { used are adequately justified }\end{array}$ & $\begin{array}{l}4 \text { - Input data } \\
5 \text { - Assumptions } \\
6.5 \text { - Uncertainties and limitations } \\
7.4,7.5,7.6 \text { - Development and validation } \\
\text { of material model and numerical model for } \\
\text { lithophysal rock } \\
\text { Appendix E - Rock properties }\end{array}$ \\
\hline
\end{tabular}


Table 8-1. Mapping of Yucca Mountain Review Plan Acceptance Criteria and Drift Degradation Analysis (Continued)

\begin{tabular}{|c|c|c|c|}
\hline $\begin{array}{c}\text { Acceptance } \\
\text { Criteria }\end{array}$ & Subcriteria & Paraphrase of Subcriteria & Sections Where Addressed \\
\hline \multirow{3}{*}{$\begin{array}{l}\text { AC2: } \\
\text { Data are } \\
\text { sufficient for } \\
\text { model } \\
\text { justification }\end{array}$} & 2 & $\begin{array}{l}\text { Sufficient data has been collected } \\
\text { to establish boundary conditions }\end{array}$ & $\begin{array}{l}4 \text { - Input data } \\
\text { Appendix C - Verification of topographic } \\
\text { effects on thermal and stress initial and } \\
\text { boundary conditions } \\
\text { Appendix W - Thermal and mechanical } \\
\text { boundary conditions verification }\end{array}$ \\
\hline & 3 & $\begin{array}{l}\text { Data on geology based on } \\
\text { appropriate techniques }\end{array}$ & $\begin{array}{l}4-\text { Input } \\
6.1 \text { - Rock mass characteristics of the } \\
\text { repository } \\
6.3 .1,6.4 .2,7.3,7.4,7.5,7.6 \text { - Methods } \\
\text { for incorporation of geology into } \\
\text { degradation models } \\
6.5 \text { - Uncertainties and limitations } \\
\text { Appendix E - Rock properties } \\
\text { Appendix O - Lithophysal characterization }\end{array}$ \\
\hline & 4 & $\begin{array}{l}\text { Engineered barrier mechanical } \\
\text { failure models appropriate }\end{array}$ & $\begin{array}{l}\text { 6.3.1, } 6.4 .2 \text { - Rockfall parameters for feed } \\
\text { to drip shield stability modeling }\end{array}$ \\
\hline \multirow{4}{*}{$\begin{array}{l}\text { AC3: } \\
\text { Data } \\
\text { uncertainty is } \\
\text { characterized } \\
\text { and } \\
\text { propagated } \\
\text { through the } \\
\text { model } \\
\text { abstraction }\end{array}$} & 1 & $\begin{array}{l}\text { Models use parameter values, } \\
\text { ranges, bounding assumptions that } \\
\text { are technically defensible }\end{array}$ & $\begin{array}{l}4 \text { - Input } \\
6.1 \text { - Describes variability of fractures and } \\
\text { lithophysae upon which models are based } \\
6.2 \text { - Thermal analysis and range of } \\
\text { thermal properties on temperature } \\
\text { prediction } \\
6.3 \text { and } 6.2 \text { - Provide implementation of } \\
\text { geologic variability into models via } \\
\text { stochastic representation of fractures and } \\
\text { bounding ranges for lithophysal rock } \\
\text { properties } \\
\text { Appendix E - Rock properties - Ranges of } \\
\text { rock properties used in analyses }\end{array}$ \\
\hline & 2 & $\begin{array}{l}\text { Process models represent and do } \\
\text { not underestimate mechanically } \\
\text { disruptive events }\end{array}$ & $\begin{array}{l}6.2 \text { - Thermal modeling - Determines } \\
\text { thermal stress for range of thermal } \\
\text { properties } \\
6.3,6.4 \text { - Provides rockfall and drift } \\
\text { degradation for seismic events derived from } \\
\text { conservative PSHA }{ }^{c} \text { process; time- } \\
\text { dependent drift degradation based on } \\
\text { bounding of static fatigue behavior of } \\
\text { welded tuff }\end{array}$ \\
\hline & 3 & $\begin{array}{l}\text { Uncertainty is adequately } \\
\text { represented via sensitivity analyses } \\
\text { or conservative limits }\end{array}$ & $\begin{array}{l}6.3,6.4 \text { - Rockfall in nonlithophysal units } \\
\text { represented conducting many analyses of } \\
\text { stochastically defined fracture conditions, } \\
\text { rockfall in lithophysal units determined from } \\
\text { bounding ranges of rock properties } \\
6.5 \text { - Uncertainties and limitations } \\
\text { Appendix E - Development of rock } \\
\text { properties ranges }\end{array}$ \\
\hline & 4 & Use of expert elicitation & $\begin{array}{l}6.3,6.4-\text { Ground motion inputs based on } \\
\text { expert elicitation via PSHA }{ }^{\mathrm{c}} \text { process }\end{array}$ \\
\hline
\end{tabular}


Table 8-1. Mapping of Yucca Mountain Review Plan Acceptance Criteria and Drift Degradation Analysis (Continued)

\begin{tabular}{|c|c|c|c|}
\hline $\begin{array}{c}\text { Acceptance } \\
\text { Criteria }\end{array}$ & Subcriteria & Paraphrase of Subcriteria & Sections Where Addressed \\
\hline \multirow{3}{*}{$\begin{array}{l}\text { AC4: } \\
\text { Model } \\
\text { uncertainty is } \\
\text { characterized } \\
\text { and } \\
\text { propagated } \\
\text { through the } \\
\text { model } \\
\text { abstraction }\end{array}$} & 1 & $\begin{array}{l}\text { Alternative modeling approaches } \\
\text { considered as well as uncertainties } \\
\text { and limitations }\end{array}$ & $\begin{array}{l}6.3 \text { - Alternative, conservative approach to } \\
\text { defining fracture bridges used for rockfall in } \\
\text { nonlithophysal } \\
6.4 \text { - Alternative numerical and analytical } \\
\text { approaches used for estimation of drip } \\
\text { shield static loading } \\
6.5 \text { - Uncertainties and limitations } \\
7.7 .5 \text { - Alternative modeling approach } \\
\text { (DRKBA) considered for rockfall in } \\
\text { nonlithophysal units }\end{array}$ \\
\hline & 2 & $\begin{array}{l}\text { Conceptual model is consistent } \\
\text { with available site characterization } \\
\text { data including lab experiments and } \\
\text { field measurements }\end{array}$ & $\begin{array}{l}1.1 \text { - Background describes } \\
\text { interrelationships between data, model } \\
\text { development and validation } \\
6.1 \text { - Fracture and lithophysae field } \\
\text { mapping consistent with model } \\
6.3,7.7 \text {, Appendix } E \text { - Nonlithophysal } \\
\text { model development based on field geologic } \\
\text { mapping } \\
6.4,7.3,7.4,7.5,7.6 \text {, Appendix E, } \\
\text { Appendix O - Lithophysal model is } \\
\text { consistent with field mapping, laboratory } \\
\text { data and field observations } \\
6.5 \text { - Uncertainties and limitations }\end{array}$ \\
\hline & 3 & $\begin{array}{l}\text { Alternative models used to assess } \\
\text { uncertainties and limitations }\end{array}$ & $\begin{array}{l}\text { 6.4 - Alternative approaches for rock } \\
\text { loading to drip shield in lithophysal rock } \\
6.5 \text { - Uncertainties and limitations } \\
7.7 .5 \text { - DRKBA model used as alternative } \\
\text { for rockfall in nonlithophysal rock }\end{array}$ \\
\hline \multirow{2}{*}{$\begin{array}{l}\text { AC5: } \\
\text { Model } \\
\text { abstraction } \\
\text { output is } \\
\text { supported by } \\
\text { objective } \\
\text { comparison }\end{array}$} & 1 & $\begin{array}{l}\text { Models used in TSPA are } \\
\text { consistent with abstractions in } \\
\text { current model }\end{array}$ & $\begin{array}{l}\text { 1.1- Background - Describes approach to } \\
\text { providing information to TSPA } \\
\text { 6.3.1.2 - Rockfall in nonlithophysal units } \\
\text { feed to SCA } \\
\text { 6.4.2 - Rockfall in lithophysal units and } \\
\text { quasi-static drip shield loads - Feed to } \\
\text { SCA }^{\mathrm{a}} \\
\text { 6.4.2.2.4 - Drift profile change to DSA } \\
\text { 7.2- Level of importance to TSPA for } \\
\text { model validation } \\
8 \text { - Conclusions }\end{array}$ \\
\hline & 2 & $\begin{array}{l}\text { Outputs of mechanical disruption of } \\
\text { engineered barrier abstractions } \\
\text { reasonably produce bound of } \\
\text { process model abstractions }\end{array}$ & $\begin{array}{l}\text { 6.3.1.2 - Rockfall in nonlithophysal units } \\
\text { feed to SCA } \\
\text { 6.4.2 - Rockfall in lithophysal units and } \\
\text { quasi-static drip shield loads - Feed to } \\
\text { SCA }^{\mathrm{a}} \\
\text { 6.4.2.2.4 - Drift profile change to DSA } \\
\text { 7.2 - Level of importance to TSPA for } \\
\text { model validation } \\
\text { 8- Conclusions }\end{array}$ \\
\hline
\end{tabular}


Table 8-1. Mapping of Yucca Mountain Review Plan Acceptance Criteria and Drift Degradation Analysis (Continued)

\begin{tabular}{|c|c|c|c|}
\hline $\begin{array}{c}\text { Acceptance } \\
\text { Criteria }\end{array}$ & Subcriteria & Paraphrase of Subcriteria & Sections Where Addressed \\
\hline \multirow[b]{2}{*}{$\begin{array}{l}\text { AC5: } \\
\text { Model } \\
\text { abstraction } \\
\text { output is } \\
\text { supported by } \\
\text { objective } \\
\text { comparison }\end{array}$} & 3 & $\begin{array}{l}\text { Well-documented, accepted } \\
\text { procedures are provided to support } \\
\text { TSPA abstractions }\end{array}$ & $\begin{array}{l}6.2,6.3 \text { and } 6.4-\text { Use of industry standard } \\
\text { acquired software in modeling analyses } \\
7-\text { Validation of models includes } \\
\text { documentation as per validation } \\
\text { procedures, including outside expert } \\
\text { technical review } \\
9.2 \text { - Describes codes, standards and } \\
\text { procedures followed in development of this } \\
\text { report }\end{array}$ \\
\hline & 4 & $\begin{array}{l}\text { Sensitivity analyses are used to } \\
\text { support the TSPA abstraction that } \\
\text { covers ranges of data obtained } \\
\text { from field and laboratory } \\
\text { measurements }\end{array}$ & $\begin{array}{l}1.1 \text { - Background describes } \\
\text { interrelationships between data, model } \\
\text { development and validation } \\
6.1 \text { - Fracture and lithophysae field } \\
\text { mapping consistent with model } \\
6.3,7.7 \text {, Appendix } \mathrm{E} \text { - Nonlithophysal } \\
\text { model development based on field geologic } \\
\text { mapping } \\
6.4,7.3,7.4,7.5,7.6 \text {, Appendix } \mathrm{E} \text {, } \\
\text { Appendix O - Lithophysal model is } \\
\text { consistent with field mapping, laboratory } \\
\text { data and field observations } \\
6.5-\text { Uncertainties and limitations }\end{array}$ \\
\hline
\end{tabular}

a SCA = Seismic Consequence Abstraction

${ }^{b}$ DSA = Drift Seepage Abstraction

c $\mathrm{PSHA}=$ Probabilistic Seismic Hazard Assessment 


\section{INPUTS AND REFERENCES}

\subsection{DOCUMENTS CITED}

Albin, A.L.; Singleton, W.L.; Moyer, T.C.; Lee, A.C.; Lung, R.C.; Eatman, G.L.W.;

101367

and Barr, D.L. 1997. Geology of the Main Drift - Station 28+00 to 55+00, Exploratory Studies Facility, Yucca Mountain Project, Yucca Mountain, Nevada. Milestone SPG42AM3. Denver, Colorado: Bureau of Reclamation and U.S. Geological Survey. ACC: MOL.19970625.0096.

Anna, L.O. 1998. Preliminary Three-Dimensional Discrete Fracture Model of the 138501 Topopah Spring Tuff in the Exploratory Studies Facility, Yucca Mountain Area, Nye County, Nevada. Open-File Report 97-834. Denver, Colorado: U.S. Geological Survey. TIC: 236829.

Anna, L.O. 1998. Preliminary Three-Dimensional Discrete Fracture Model, Tiva 144421 Canyon Tuff, Yucca Mountain Area, Nye County, Nevada. Open-File Report 97-833. Denver, Colorado: U.S. Geological Survey. TIC: 236723.

Barr, D.L.; Moyer, T.C.; Singleton, W.L.; Albin, A.L.; Lung, R.C.; Lee, A.C.; Beason, S.C.; and Eatman, G.L.W. 1996. Geology of the North Ramp - Stations 4+00 to 28+00, Exploratory Studies Facility, Yucca Mountain Project, Yucca Mountain, Nevada. Denver, Colorado: U.S. Geological Survey. ACC: MOL.19970106.0496.

Barton, N.; Lien, R.; and Lunde, J. 1974. "Engineering Classification of Rock Masses for the Design of Tunnel Support.” Rock Mechanics, 6, (4), 189-236. New York, New York: Springer-Verlag. TIC: 219995.

Bauer, R.A.; Curry, B.B.; Graese, A.M.; Vaiden, R.C.; Su, W.J.; and Hasek, M.J. 161775 1991. Geotechnical Properties of Selected Pleistocene, Silurian, and Ordovician Deposits of Northeastern Illinois. Environmental Geology 139. Champaign, Illinois: Illinois State Geological Survey. TIC: 253871.

Bauer, S.J.; Hardy, M.P.; Goodrich R.; and Lin, M. 1992. "Fault Stress Analysis for 162227 the Yucca Mountain Site Characterization Project." High Level Radioactive Waste Management, Proceedings of the Third International Conference, Las Vegas, Nevada, April 12-16, 1992. 2, 2267-2277. La Grange Park, Illinois: American Nuclear Society. TIC: 204231.

Beason, S.C.; Turlington, G.A.; Lung, R.C.; Eatman, G.L.W.; Ryter, D.; and Barr, D.L. 101191 1996. Geology of the North Ramp - Station 0+60 to 4+00, Exploratory Studies Facility, Yucca Mountain Project, Yucca Mountain, Nevada. Denver, Colorado: U.S. Geological Survey. ACC: MOL.19970106.0449.

Bieniawski, Z.T. 1989. Engineering Rock Mass Classifications. New York, 101715 New York: John Wiley \& Sons. TIC: 226350. 
Board, M. 2003. Resolution Strategy for Geomechanically-Related Repository Design 165036 and Thermal-Mechanical Effects (RDTME). REV 00. Las Vegas, Nevada:

Bechtel SAIC Company. ACC: MOL.20030708.0153.

Bolt, B.A. 1997. "World Earthquakes and Seismicity Rates.” Appendix A of

167798

Earthquakes. Pages 270-274. New York, New York: W.H. Freeman and Company.

TIC: 255644.

Brace, W.F.; Paulding, B.W., Jr.; and Scholz, C.H. 1966. "Dilatancy in the Fracture of

101990

Crystalline Rocks.” Journal of Geophysical Research, 71, (16), 3939-3953.

Washington, D.C.: American Geophysical Union. TIC: 226778.

Brady, B.H.G. and Brown, E.T. 1985. Rock Mechanics for Underground Mining.

126811

London, United Kingdom: George Allen and Unwin. TIC: 226226.

Brekke, T.L.; Cording, E.J.; Daemen, J.; Hart, R.D.; Hudson, J.A.; Kaiser, P.K.; and

Pelizza, S. 1999. Panel Report on the Drift Stability Workshop, Las Vegas, Nevada, December 9-11, 1998. Las Vegas, Nevada: Management and Technical Support Services. ACC: MOL.19990331.0102.

Brodsky, N.S.; Riggins, M.; Connolly, J.; and Ricci, P. 1997. Thermal Expansion, 100653 Thermal Conductivity, and Heat Capacity Measurements for Boreholes UE25 NRG-4, UE25 NRG-5, USW NRG-6, and USW NRG-7/7A. SAND95-1955. Albuquerque, New Mexico: Sandia National Laboratories. ACC: MOL.19980311.0316.

Brown, E.T. 2003. Block Caving Geomechanics. JKMRC Monograph Series in 169527 Mining and Mineral Processing 3. Indooroopilly, Queensland, Australia: Julius Kruttschnitt Mineral Research Centre. TIC: 256115.

Broxton, D.E.; Chipera, S.J.; Byers, F.M., Jr.; and Rautman, C.A. 1993. Geologic 107386 Evaluation of Six Nonwelded Tuff Sites in the Vicinity of Yucca Mountain, Nevada for a Surface-Based Test Facility for the Yucca Mountain Project. LA-12542-MS. Los Alamos, New Mexico: Los Alamos National Laboratory.

ACC: NNA.19940224.0128.

BSC (Bechtel SAIC Company) 2001. Drift Degradation Analysis. ANL-EBS-MD156304 000027 REV 01 ICN 01. Las Vegas, Nevada: Bechtel SAIC Company. ACC: MOL.20011029.0311.

BSC 2001. Ground Control for Emplacement Drifts for SR. ANL-EBS-GE-000002 REV 00 ICN 01. Las Vegas, Nevada: Bechtel SAIC Company. ACC: MOL.20010627.0028.

BSC 2002. Subsurface General Construction, Specification Section 01501. BAB000000-01717-6300-01501 REV 07. Las Vegas, Nevada: Bechtel SAIC Company. ACC: MOL.20021209.0164. 
BSC 2003. Heat Capacity and Thermal Expansion Coefficients Analysis Report. ANL-NBS-GS-000013 REV 00. Las Vegas, Nevada: Bechtel SAIC Company. ACC: DOC.20030820.0002.

BSC 2003. Scoping Analysis on Sensitivity and Uncertainty of Emplacement Drift 166183 Stability. 800-K0C-TEG0-00600-000-000. Las Vegas, Nevada: Bechtel SAIC Company. ACC: ENG.20031125.0002.

BSC 2003. Subsurface Geotechnical Parameters Report. 166660 800-K0C-WIS0-00400-000-00A. Las Vegas, Nevada: Bechtel SAIC Company. ACC: ENG.20040108.0001.

BSC 2003. Underground Layout Configuration. 800-P0C-MGR0-00100-000-00E 165572 Las Vegas, Nevada: Bechtel SAIC Company. ACC: ENG.20031002.0007.

BSC 2004. Abstraction of Drift Seepage. MDL-NBS-HS-000019 REV 01. 169131 Las Vegas, Nevada: Bechtel SAIC Company.

BSC 2004. D\&E / PA/C IED Emplacement Drift Configuration and Environment. 168489 800-IED-MGR0-00201-000-00B. Las Vegas, Nevada: Bechtel SAIC Company. ACC: ENG.20040326.0001

BSC 2004. D\&E / PA/C IED Interlocking Drip Shield and Emplacement Pallet. 800-IED-WIS0-00401-000-00D. Las Vegas, Nevada: Bechtel SAIC Company. ACC: ENG.20040503.0018.

BSC 2004. D\&E / PA/C IED Subsurface Facilities. 800-IED-WIS0-00101-000-00A. 164519 Las Vegas, Nevada: Bechtel SAIC Company. ACC: ENG.20040309.0026.

BSC 2004. D\&E / PA/C IED Typical Waste Package Components Assembly. 167369 800-IED-WIS0-00204-000-00B. Las Vegas, Nevada: Bechtel SAIC Company. ACC: ENG.20040202.0012.

BSC 2004. D\&E/PA/C IED Typical Waste Package Components Assembly. 800-IED-WIS0-00202-000-00C. Las Vegas, Nevada: Bechtel SAIC Company. ACC: ENG.20040517.0008.

BSC 2004. Development of Earthquake Ground Motion Input for Preclosure Seismic 170027 Design and Postclosure Performance Assessment of a Geologic Repository at Yucca Mountain, NV. MDL-MGR-GS-000003 REV 01. Las Vegas, Nevada: Bechtel SAIC Company.

BSC 2004. Drip Shield Structural Response to Rock Fall. 168993 000-00C-SSE0-00300-000-00A. Las Vegas, Nevada: Bechtel SAIC Company. ACC: ENG.20040405.0019. 
BSC 2004. Geologic Framework Model (GFM2000). MDL-NBS-GS-000002

170029

REV 02. Las Vegas, Nevada: Bechtel SAIC Company. ACC: DOC.20040827.0008.

BSC 2004. Ground Control for Emplacement Drifts for LA.

170292

800-K0C-SSE0-00100-000-00A. Las Vegas, Nevada: Bechtel SAIC Company.

ACC: ENG.20040712.0019.

BSC 2004. Lithophysal Rock Mass Mechanical Properties of the Repository Host

168970

Horizon. 800-K0C-SS00-00200-000-00Aa. Las Vegas, Nevada: Bechtel SAIC

Company. ACC: MOL.20040510.0200. TBV-5811.

BSC 2004. Multiscale Thermohydrologic Model. ANL-EBS-MD-000049 REV 02.

169565

Las Vegas, Nevada: Bechtel SAIC Company.

BSC 2004. Peak Ground Velocities for Seismic Events at Yucca Mountain, Nevada.

170137

ANL-MGR-GS-000004 REV 00. Las Vegas, Nevada: Bechtel SAIC Company.

BSC 2004. Q-List. 000-30R-MGR0-00500-000-000 REV 00. Las Vegas, Nevada:

168361

Bechtel SAIC Company. ACC: ENG.20040721.0007.

BSC 2004. Repository Subsurface Emplacement Drifts Steel Invert Structure Plan \&

169503

Elevation. 800-SS0-SSE0-00101-000-00B. Las Vegas, Nevada: Bechtel SAIC

Company. ACC: ENG.20040520.0004.

BSC 2004. Sampling of Stochastic Input Parameters for Rockfall Calculations and for

169999 Structural Response Calculations Under Vibratory Ground Motion.

ANL-EBS-PA-000009 REV 01. Las Vegas, Nevada: Bechtel SAIC Company.

ACC: DOC.20040901.0004.

BSC 2004. Seismic Consequence Abstraction. MDL-WIS-PA-000003 REV 01.

169183

Las Vegas, Nevada: Bechtel SAIC Company.

BSC 2004. Structural Calculations of Waste Package Exposed to Vibratory Ground Motion. 000-00C-WIS0-01400-000-00A. Las Vegas, Nevada: Bechtel SAIC Company. ACC: ENG.20040217.0008.

BSC 2004. Technical Work Plan for: Regulatory Integration Modeling of Drift 171520 Degradation, Waste Package and Drip Shield Vibratory Motion and Seismic Consequences. TWP-MGR-GS-000003 REV 00 ICN 01. Las Vegas, Nevada: Bechtel SAIC Company. ACC: DOC.20040810.0003.

BSC 2004. Thermal Conductivity of Non-Repository Lithostratigraphic Layers.

170033

MDL-NBS-GS-000006 REV 01. Las Vegas, Nevada: Bechtel SAIC Company.

BSC 2004. Thermal Conductivity of the Potential Repository Horizon.

169854

MDL-NBS-GS-000005 REV 01. Las Vegas, Nevada: Bechtel SAIC Company. 
BSC 2004. UZ Flow Models and Submodels. MDL-NBS-HS-000006 REV 02.

169861 Las Vegas, Nevada: Bechtel SAIC Company.

BSC 2004. Ventilation Model and Analysis Report. ANL-EBS-MD-000030 REV 04.

169862 Las Vegas, Nevada: Bechtel SAIC Company.

Buesch, D. 2003. "Fractures in Thin Sections with Rims as Cooling Joints in Tptpmn 163729 and Tptpll for AMR.” E-mail from D. Buesch to D. Kicker, June 2, 2003.

ACC: MOL.20030610.0067.

Buesch, D. 2003. "Hydrogeologic Properties of Features in Crystallized Topopah Spring Tuff.” E-mail from D. Buesch to D. Kicker and D. Rigby, March 10, 2003, with attachment. ACC: MOL.20030314.0188.

Buesch, D.C. and Lung, R.C. 2003. “Tephrostratigraphic Relations and the Timing 170297 and Locations of Faulting Near Exile Hill at Yucca Mountain, Nevada.” Proceedings of the 10th International High-Level Radioactive Waste Management Conference (IHLRWM), March 30-April 2, 2003, Las Vegas, Nevada. Pages 388-397. La Grange Park, Illinois: American Nuclear Society. TIC: 254559.

Buesch, D.C. and Spengler, R.W. 1998. "Character of the Middle Nonlithophysal 101433 Zone of the Topopah Spring Tuff at Yucca Mountain.” High-Level Radioactive Waste Management, Proceedings of the Eighth International Conference, Las Vegas, Nevada, May 11-14, 1998. Pages 16-23. La Grange Park, Illinois: American Nuclear Society. TIC: 237082.

Buesch, D.C.; Beason, S.C.; and Spengler, R.W. 1999. "Relations Among Welding, 165483 Vapor-Phase Activity, Crystallization, and Fractures in the Tiva Canyon and Topopah Spring Tuffs, at Yucca Mountain, Nevada.” Abstracts with Programs - Geological Society of America, 31, (7), A-476 - A-477. Boulder, Colorado: Geological Society of America. TIC: 254857.

Buesch, D.C.; Nelson, J.E.; Dickerson, R.P.; Drake, R.M., II; Spengler, R.W.; Geslin, 101202 J.K.; Moyer, T.C.; and San Juan, C.A. 1996. Distribution of Lithostratigraphic Units Within the Central Block of Yucca Mountain, Nevada: A Three-Dimensional Computer-Based Model, Version YMP.R2.0. Open-File Report 95-124.

Denver, Colorado: U.S. Geological Survey. ACC: MOL.19970618.0573.

Buesch, D.C.; Spengler, R.W.; Moyer, T.C.; and Geslin, J.K. 1996. Proposed 100106 Stratigraphic Nomenclature and Macroscopic Identification of Lithostratigraphic Units of the Paintbrush Group Exposed at Yucca Mountain, Nevada. Open-File Report 94-469. Denver, Colorado: U.S. Geological Survey. ACC: MOL.19970205.0061.

Byers, F.M., Jr.; Carr, W.J.; Orkild, P.P.; Quinlivan, W.D.; and Sargent, K.A. 1976. 104639 Volcanic Suites and Related Cauldrons of Timber Mountain-Oasis Valley Caldera Complex, Southern Nevada. Professional Paper 919. Washington, D.C.: U.S. Geological Survey. TIC: 201146. 
Byrne, P.M.; Srithar, T.; and Kern, C.B. 1990. "Field Measurements and Analysis of

a Large Diameter Flexible Culvert." Structural Performance of Flexible Pipes,

Proceedings of the First National Conference on Flexible Pipes, Columbus, Ohio,

21-23 October, 1990. Sargand, S.M; Mitchell, G.F.; and Hurd, J.O., eds. Pages 27-37.

Brookfield, Vermont: A.A. Balkema. TIC: 255970.

Canori, G.F. and Leitner, M.M. 2003. Project Requirements Document.

166275

TER-MGR-MD-000001 REV 02. Las Vegas, Nevada: Bechtel SAIC Company.

ACC: DOC.20031222.0006.

Carlos, B.A.; Chipera, S.J.; and Bish, D.L. 1995. Distribution and Chemistry of

101326

Fracture-Lining Minerals at Yucca Mountain, Nevada. LA-12977-MS. Los Alamos,

New Mexico: Los Alamos National Laboratory. ACC: MOL.19960306.0564.

Charles, R.J. 1959. "The Strength of Silicate Glasses and Some Crystalline Oxides.”

170308

Fracture, Proceedings of an International Conference on the Atomic Mechanisms of

Fracture held in Swampscott, Massachusetts, April 12-16, 1959. Averback, B.L.;

Felbeck, D.K.; Hahn, G.T.; and Thomas, D.A., eds. Chapter 12, 225-249. New York,

New York: John Wiley \& Sons. TIC: 236240.

Chen, E.P. 1987. A Computational Model for Jointed Media with Orthogonal Sets of

Joints. SAND86-1122. Albuquerque, New Mexico: Sandia National Laboratories.

ACC: MOL.19991116.0419.

Christiansen, R.L.; Lipman, P.W.; Carr, W.J.; Byers, F.M., Jr.; Orkild, P.P.; and

157236

Sargent, K.A. 1977. “The Timber Mountain-Oasis Valley Caldera Complex of

Southern Nevada.” Geological Society of America Bulletin, 88, (7), 943-959.

[Boulder, Colorado]: Geological Society of America. TIC: 201802.

CRWMS M\&O 1997. Data Transmittal Package (DTP) for "Hydraulic Fracturing

147458

Stress Measurements in Test Hole: ESF-AOD-HDFR\#1, Thermal Test Facility, Exploratory Studies Facility at Yucca Mountain. DTN: SNF37100195002.001, TDIF 305878. Las Vegas, Nevada: CRWMS M\&O. ACC: MOL.19970717.0005; MOL.19970717.0006; MOL.19970717.0007; MOL.19970717.0008.

CRWMS M\&O 1997. Yucca Mountain Site Geotechnical Report. B00000000-01717-

103564 5705-00043 REV 01. Two volumes. Las Vegas, Nevada: CRWMS M\&O.

ACC: MOL.19971017.0736; MOL.19971017.0737.

CRWMS M\&O 1998. Geology of the Exploratory Studies Facility Topopah Spring

102679 Loop. BAB000000-01717-0200-00002 REV 01. Las Vegas, Nevada: CRWMS

M\&O. ACC: MOL.19980415.0283.

CRWMS M\&O 1998. Preliminary Block Size Calculation.

102723 BCAA00000-01717-0210-00001 REV 00. Las Vegas, Nevada: CRWMS M\&O. ACC: MOL.19981106.0282. 
CRWMS M\&O 1999. South Ramp 3.01.X Area Ground Support Analysis.

108441

BABEE0000-01717-0200-00023 REV 00. Las Vegas, Nevada: CRWMS M\&O.

ACC: MOL.19990908.0318.

CRWMS M\&O 2000. Fracture Geometry Analysis for the Stratigraphic Units of the

152286 Repository Host Horizon. ANL-EBS-GE-000006 REV 00. Las Vegas, Nevada: CRWMS M\&O. ACC: MOL.20000918.0286.

Cundall, P.A. and Strack, O.D.L. 1979. “A Discrete Numerical Model for Granular 162194 Assemblies.” Geotechnique, 29, (1), 47-65. [London, England: Thomas Telford]. TIC: 253962.

Day, W.C.; Dickerson, R.P.; Potter, C.J.; Sweetkind, D.S.; San Juan, C.A.; Drake, 100027 R.M., II; and Fridrich, C.J. 1998. Bedrock Geologic Map of the Yucca Mountain Area, Nye County, Nevada. Geologic Investigations Series I-2627. Denver, Colorado: U.S. Geological Survey. ACC: MOL.19981014.0301.

Derman, C.; Gleser, L.J.; and Olkin, I. 1973. A Guide to Probability Theory and 108444 Application. New York, New York: Holt, Rinehart and Winston. TIC: 242445.

Dershowitz, W.S. and Herda, H.H. 1992. "Interpretation of Fracture Spacing and 104893 Intensity.” Rock Mechanics, Proceedings of the 33rd U.S. Symposium, Santa Fe, New Mexico, 3-5 June, 1992. Tillerson, J.R. and Wawersik, W.R., eds. Pages 757-766. Rotterdam, The Netherlands: A.A. Balkema. TIC: 245647.

DOE 2004. Software Management Report for: CLUSTRAN V1.1, SMR REV. NO.: 170474 00. 11162-SMR-1.1-00. Las Vegas, Nevada: Bechtel SAIC Company. ACC: MOL.20040426.0368.

Dowding, C.H. 1979. “Earthquake Stability of Rock Tunnels.” Tunnels \& Tunnelling, 11, 15-20. London, England: Morgan-Grampian Publishing. TIC: 242115.

Duan, F. 2003. “A White Paper by Nick Barton.” E-mail from F. Duan to D. Kicker, 163586 May 28, 2003, with attachment. ACC: MOL.20030603.0132; MOL.20030219.0058.

Duncan, J.M.; Byrne, P.; Wong, K.S.; and Mabry, P. 1980. Strength, Stress-Strain 161776 and Bulk Modulus Parameters for Finite Element Analyses of Stresses and Movements in Soil Masses. UCB/GT/80-01. Berkeley, California: University of California, College of Engineering, Office of Research Services. TIC: 253873.

Eatman, G.L.W.; Singleton, W.L.; Moyer, T.C.; Barr, D.L.; Albin, A.L.; Lung, R.C.; 101219 and Beason, S.C. 1997. Geology of the South Ramp - Station 55+00 to 78+77, Exploratory Studies Facility, Yucca Mountain Project, Yucca Mountain, Nevada. Milestone SPG42CM3. Denver, Colorado: U.S. Geological Survey. ACC: MOL.19980216.0328. 
Eckel, E.B. 1970. The Alaska Earthquake, March 27, 1964: Lessons and

Fisher, N.I.; Lewis, T.; and Embleton, B.J.J. 1987. Statistical Analysis of Spherical

108447

Data. New York, New York: Cambridge University Press. TIC: 208442.

Flint, L.E. 1998. Characterization of Hydrogeologic Units Using Matrix Properties,

100033

Yucca Mountain, Nevada. Water-Resources Investigations Report 97-4243. Denver,

Colorado: U.S. Geological Survey. ACC: MOL.19980429.0512.

Freeze, G.A.; Brodsky, N.S.; and Swift, P.N. 2001. The Development of Information

154365

Catalogued in REV00 of the YMP FEP Database. TDR-WIS-MD-000003 REV 00

ICN 01. Las Vegas, Nevada: Bechtel SAIC Company. ACC: MOL.20010301.0237.

Fruchtbaum, J. 1988. "Handling Special Materials.” Bulk Materials Handling

161774

Handbook. Pages 327-375. New York, New York: Van Nostrand Reinhold.

TIC: 253872.

Gibson, J.D.; Shephard, L.E.; Swan, F.H.; Wesling, J.R.; and Kerl, F.A. 1990.

157245

"Synthesis of Studies for the Potential of Fault Rupture at the Proposed Surface

Facilities, Yucca Mountain, Nevada.” High Level Radioactive Waste Management,

Proceedings of the International Topical Meeting, Las Vegas, Nevada, April 8-12,

1990. 1, 109-116. La Grange Park, Illinois: American Nuclear Society.

TIC: 202058.

Goodman, R.E. 1980. Introduction to Rock Mechanics. New York, New York: John 101966 Wiley \& Sons. TIC: 218828.

Goodman, R.E. and Shi, G-H. 1985. Block Theory and Its Application to Rock

150094

Engineering. Englewood Cliffs, New Jersey: Prentice-Hall. TIC: 241514.

Hoek, E. 2000. [Practical] Rock Engineering, [2000 Edition]. Toronto, Ontario,

160705

Canada: RocScience. TIC: 253544.

Hoek, E. and Brown, E.T. 1982. Underground Excavations in Rock.

120981

London, England: The Institution of Mining and Metallurgy. TIC: 217577.

Hoek, E.; Carranza-Torres, C.; and Corkum, B. 2002. "Hoek-Brown Failure Criterion

162204

- 2002 Edition.” 5th North American Rock Mechanics Symposium and 17th

Tunnelling Association of Canada Conference: NARMS-TAC 2002, July 7-10,

University of Toronto. Toronto, Ontario, Canada: Rocscience. Accessed March 17, 2003. TIC: 253954. http://www.rocscience.com/Anon/ResearchPapers/NARMS.pdf

Hoek, E.; Kaiser, P.K.; and Bawden, W.F. 2000. Support of Underground

160539

Excavations in Hard Rock. Rotterdam, The Netherlands: A.A. Balkema.

TIC: 252991. 
Hoerger, S.F. and Young, D.S. 1990. "Probabilistic Prediction of Keyblock Occurrences.” Rock Mechanics Contributions and Challenges: Proceedings of the 31st U.S. Symposium, Golden, [Colorado], 18-20 June, 1990. Hustrulid, W.A. and Johnson, G.A., eds. Pages 229-236. Brookfield, Vermont: A.A. Balkema. TIC: 245123.

Hudson, J.A. and Priest, S.D. 1979. "Discontinuities and Rock Mass Geometry.” 104915 International Journal of Rock Mechanics and Mining Science \& Geomechanics Abstracts, 16, ([6]), 339-362. [New York, New York]: Pergamon. TIC: 240802.

Itasca Consulting Group 2002. Itasca Software-Cutting Edge Tools for Computational

160331 Mechanics. Minneapolis, Minnesota: Itasca Consulting Group. TIC: 252592.

Jackson, J.A., ed. 1997. Glossary of Geology. 4th Edition. Alexandria, Virginia: American Geological Institute. TIC: 236393.

Jaeger, J.C. and Cook, N.G.W. 1979. Fundamentals of Rock Mechanics. 3rd Edition. New York, New York: Chapman and Hall. TIC: 218325.

Kaiser, P.K.; McCreath, D.R.; and Tannant, D.D. 1996. Canadian Rockburst Support Handbook. Ontario, Canada: Geomechanics Research Centre. TIC: 233844.

Kanamori, H. 1977. “The Energy Release in Great Earthquakes.” Journal of Geophysical Research, 82, (20), 2981-2987. Washington, D.C.: American Geophysical Union. TIC: 255672.

Kemeny, J.M. 1991. “A Model for Non-Linear Rock Deformation Under 108455 Compression Due to Sub-Critical Crack Growth.” International Journal of Rock Mechanics and Mining Science \& Geomechanics Abstracts, 28, (6), 459-467. [New York, New York]: Pergamon. TIC: 245750.

Kemeny, J.M. and Cook, N.G.W. 1986. "Effective Moduli, Non-Linear Deformation 108454 and Strength of a Cracked Elastic Solid.” International Journal of Rock Mechanics and Mining Science \& Geomechanics Abstracts, 23, (2), 107-118.

[New York, New York]: Pergamon. TIC: 245751.

Kessler, J.; McGuire, R.; Vlasity, J.; Long, A.; Childs, S.; Ross, B.; Schwartz, F.; 100558 Bullen, D.; Apted, M.; Zhou, W.; Sudicky, E.; Smith, G.; Coppersmith, K.; Kemeny, J.; and Sheridan, M. 1996. Yucca Mountain Total System Performance Assessment, Phase 3. EPRI TR-107191. Palo Alto, California: Electric Power Research Institute. TIC: 238085.

Konietzky, H. 2003. “Preface.” Numerical Modeling in Micromechanics via Particle 162198 Methods, Proceedings of the 1st International PFC Symposium, Gelsenkirchen, Germany, 6-8 November 2002. Konietzky, H., ed. Page ix. Exton, Pennsylvania: A.A. Balkema. TIC: 253950. 
Kuszmaul, J.S. and Goodman, R.E. 1995. “An Analytical Model for Estimating 151816 Keyblock Sizes in Excavations in Jointed Rock Masses.” Fractured and Jointed Rock Masses, [Conference held at Lake Tahoe, California, June 3-5, 1992]. Pages 19-26. Rotterdam, The Netherlands: A.A. Balkema. TIC: 240658.

Lau, J.S.O.; Gorski, B.; Conlon, B.; and Anderson, T. 2000. Long-Term Loading 164769 Tests on Saturated Granite and Granodiorite. Report No. 06819-REP-01300-10016 R00. Toronto, Ontario, Canada: Ontario Power Generation, Nuclear Waste Management Division. TIC: 254970.

Lefebvre, G.; Laliberté, M.; Lefebvre, L.M.; LaFleur, J.; and Fisher, C.L. 1976. "Measurement of Soil Arching Above a Large Diameter Flexible Culvert." Canadian Geotechnical Journal, 13, 58-71. [Toronto, Ontario, Canada: National Research Council of Canada]. TIC: 255968.

Lemos, J. and Damjanac, B. 2002. New Developments in 3DEC Version 2.01. Minneapolis, Minnesota: Itasca Consulting Group. TIC: 252778.

Lipman, P.W.; Christiansen, R.L.; and O’Connor, J.T. 1966. A Compositionally 100773 Zoned Ash-Flow Sheet in Southern Nevada. Professional Paper 524-F. Washington, D.C.: U.S. Geological Survey. TIC: 219972.

Martin, R.J., III 1972. “Time-Dependent Crack Growth in Quartz and its Application to the Creep of Rocks.” Journal of Geophysical Research, 77, (8), 1406-1419. [Washington, D.C.]: American Geophysical Union. TIC: 224770.

Martin, R.J., III and Durham, W.B. 1975. "Mechanisms of Crack Growth in Quartz.” 170301 Journal of Geophysical Research, 80, (35), 4837-4844. Washington, D.C.: American Geophysical Union. TIC: 224771.

Martin, R.J., III.; Price, R.H.; Boyd, P.J.; and Noel, J.S. 1993. “The Influence of Strain Rate and Sample Inhomogeneity on the Moduli and Strength of Welded Tuff.” International Journal of Rock Mechanics and Mining Science \& Geomechanics Abstracts, 30, (7), 1507-1510. [New York, New York]: Pergamon. TIC: 254873.

Martin, R.J., III; Price, R.H.; Boyd, P.J.; and Noel, J.S. 1995. Creep in Topopah Spring Member Welded Tuff. SAND94-2585. Albuquerque, New Mexico: Sandia National Laboratories. ACC: MOL.19950502.0006.

Martin, R.J.; Noel, J.S.; Boyd, P.J.; and Price, R.H. 1997. "Creep and Static Fatigue 165960 of Welded Tuff from Yucca Mountain, Nevada.” International Journal of Rock Mechanics and Mining Sciences, 34, (3-4), Paper No. 190. [New York, New York]: Pergamon. TIC: 255298. 
Martin, R.J.; Noel, J.S.; Boyd, P.J.; and Price, R.H. 1997. Creep Properties of the 148875 Paintbrush Tuff Recovered from Borehole USW NRG-7/7A: Data Report.

SAND95-1759. Albuquerque, New Mexico: Sandia National Laboratories. ACC: MOL.19971017.0661.

Mongano, G.S.; Singleton, W.L.; Moyer, T.C.; Beason, S.C.; Eatman, G.L.W.; Albin, 149850 A.L.; and Lung, R.C. 1999. Geology of the ECRB Cross Drift - Exploratory Studies Facility, Yucca Mountain Project, Yucca Mountain, Nevada. [Deliverable SPG42GM3]. Denver, Colorado: U.S. Geological Survey. ACC: MOL.20000324.0614.

MRD (Mining Research Directorate) 1995. Rockburst Research Handbook, Canadian 169719 Rockburst Research Program 1990-1995. Six volumes. Sudbury, Canada: Canadian Mining Industry Research Organization, Mining Division. TIC: 256095.

Munsell Color Company 1994. Munsell Soil Color Charts. 1994 Revised Edition. 106399 New Windsor, New York: GretagMacbeth. TIC: 238646.

Newmark, N.M. 1965. "Effects of Earthquakes on Dams and Embankments." 169515 Geotechnique, XV, (2), 139-160. London, England: Institution of Civil Engineers. TIC: 255743.

Nimick, F.B. and Connolly, J.R. 1991. Calculation of Heat Capacities for Tuffaceous 100690 Units from the Unsaturated Zone at Yucca Mountain, Nevada. SAND88-3050.

Albuquerque, New Mexico: Sandia National Laboratories.

ACC: NNA.19910308.0017.

NRC (U.S. Nuclear Regulatory Commission) 2002. Integrated Issue Resolution Status 159538 Report. NUREG-1762. Washington, D.C.: U.S. Nuclear Regulatory Commission, Office of Nuclear Material Safety and Safeguards. TIC: 253064.

NRC (U.S. Nuclear Regulatory Commission) 2003. Yucca Mountain Review Plan, 163274 Final Report. NUREG-1804, Rev. 2. Washington, D.C.: U.S. Nuclear Regulatory Commission, Office of Nuclear Material Safety and Safeguards. TIC: 254568.

Olsson, W.A. and Brown, S.R. 1997. Mechanical Properties of Fractures from Drillholes UE25-NRG-4, USW-NRG-6, USW-NRG-7, USW-SD-9 at Yucca Mountain, Nevada. SAND95-1736. Albuquerque, New Mexico: Sandia National Laboratories. ACC: MOL.19970224.0064.

Ortiz, T.S.; Williams, R.L.; Nimick, F.B.; Whittet, B.C.; and South, D.L. 1985. A 101280 Three-Dimensional Model of Reference Thermal/Mechanical and Hydrological Stratigraphy at Yucca Mountain, Southern Nevada. SAND84-1076. Albuquerque, New Mexico: Sandia National Laboratories. ACC: MOL.19980602.0331. 
Otto, S.J. and Buesch, D.C. 2003. "Porosity, Bulk Density, and Rock-Particle Density 170727 of Lithostratigraphic Components in Lithophysal Rocks of the Topopah Spring Tuff at Yucca Mountain, Nevada.” Abstracts with Programs - Geological Society of America, 35, (6), 434-435. Boulder, Colorado: Geological Society of America. TIC: 254862.

Peterman, Z.E. and Cloke, P.L. 2002. "Geochemistry of Rock Units at the Potential 162576 Repository Level, Yucca Mountain, Nevada (includes Erratum).” Applied Geochemistry, 17, (6, 7), 683-698, 955-958. New York, New York: Pergamon. TIC: 252516; 252517.

Potyondy, D. and Cundall, P. 2001. The PFC Model for Rock: Predicting Rock-Mass 156895 Damage at the Underground Research Laboratory.

Report No. 06819-REP-01200-10061-R00. Toronto, Ontario, Canada: Ontario Power Generation, Nuclear Waste Management Division. TIC: 253569.

Potyondy, D.O. 2003. “PFC Stress Corrosion Model.” Annex 11.4 of Seismic 165550 Validation of 3-D Thermo-Mechanical Models for the Prediction of the Rock Damage Around Radioactive Spent Fuel Waste. Project No. FIKW-2001-00200. Liverpool, England: University of Liverpool. TIC: 254978.

Pratt, H.R.; Hustrulid, W.A.; and Stephenson, D.E. 1978. Earthquake Damage to 151817 Underground Facilities. DP-1513. Aiken, South Carolina: E.I. du Pont de Nemours and Company, Savannah River Laboratory. TIC: 210276.

Price, R.H. 1986. Effects of Sample Size on the Mechanical Behavior of Topopah Spring Tuff. SAND85-0709. Albuquerque, New Mexico: Sandia National Laboratories. ACC: NNA.19891106.0125.

Price, R.H.; Nimick, F.B.; Connolly, J.R.; Keil, K.; Schwartz, B.M.; and Spence, S.J. 1985. Preliminary Characterization of the Petrologic, Bulk, and Mechanical Properties of a Lithophysal Zone Within the Topopah Spring Member of the Paintbrush Tuff. SAND84-0860. Albuquerque, New Mexico: Sandia National Laboratories. ACC: NNA.19870406.0156.

Raney, R.G. 1988. Reported Effects of Selected Earthquakes in the Western North 147173 America Intermontane Region, 1852-1983, on Underground Workings and Local and Regional Hydrology: A Summary. NRC FIN D1018. Spokane, Washington: U.S. Department of the Interior, Bureau of Mines. TIC: 217278.

Reamer, C.W. and Williams, D.R. 2001. Summary Highlights of NRC/DOE Technical 154348 Exchange and Management Meeting on Repository Design and Thermal-Mechanical Effects. Meeting held February 6-8, 2001, Las Vegas, Nevada. Washington, D.C.: U.S. Nuclear Regulatory Commission. ACC: MOL.20010307.0511; MOL.20010307.0512; MOL.20010307.0513; MOL.20010307.0514; MOL.20010307.0515; MOL.20010307.0516; MOL.20010307.0517; MOL.20010307.0518; MOL.20010307.0519; MOL.20010307.0520; MOL.20010307.0521. 
Rowe, R. 1992. “Tunnelling in Seismic Zones.” Tunnels \& Tunnelling, 24, (12), 41-44. London, England: Morgan-Grampian. TIC: 252094.

Savino, J.M.; Smith, K.D.; Biasi, G.; Sullivan, T.; and Cline, M. 1999. "Earthquake 148612 Ground Motion Effects on Underground Structures/Tunnels.” Eos, Transactions (Supplement), 80, (17), S10. Washington, D.C.: American Geophysical Union. TIC: 247757.

Sawyer, D.A.; Fleck, R.J.; Lanphere, M.A.; Warren, R.G.; Broxton, D.E.; and Hudson, 100075 M.R. 1994. "Episodic Caldera Volcanism in the Miocene Southwestern Nevada Volcanic Field: Revised Stratigraphic Framework, ${ }^{40} \mathrm{Ar} /{ }^{39} \mathrm{Ar}$ Geochronology, and Implications for Magmatism and Extension.” Geological Society of America Bulletin, 106, (10), 1304-1318. Boulder, Colorado: Geological Society of America.

TIC: 222523.

Schmidtke, R.H. and Lajtai, E.Z. 1985. “The Long-Term Strength of Lac du Bonnet Granite.” International Journal of Rock Mechanics and Mining Science \& Geomechanics Abstracts, 22, (6), 461-465. [New York, New York]: Pergamon. TIC: 254874.

Scholz, C.H. 1972. “Static Fatigue of Quartz.” Journal of Geophysical Research, 77, (11), 2104-2114. [Washington, D.C.]: American Geophysical Union. TIC: 224772.

169724

Schuraytz, B.C.; Vogel, T.A.; and Younker, L.W. 1989. "Evidence for Dynamic 107248 Withdrawal from a Layered Magma Body: The Topopah Spring Tuff, Southwestern Nevada.” Journal of Geophysical Research, 94, (B5), 5925-5942. Washington, D.C.: American Geophysical Union. TIC: 225936.

Scott, R.B. 1990. “Tectonic Setting of Yucca Mountain, Southwest Nevada.” Chapter 12 of Basin and Range Extensional Tectonics Near the Latitude of Las Vegas, Nevada. Wernicke, B.P., ed. Memoir 176. Boulder, Colorado: Geological Society of America. TIC: 222540.

Scott, R.B. and Bonk, J. 1984. Preliminary Geologic Map of Yucca Mountain, Nye 104181 County, Nevada, with Geologic Sections. Open-File Report 84-494. Denver, Colorado: U.S. Geological Survey. ACC: HQS.19880517.1443.

Senseny, P.E. 1993. “Stress Wave Loading of a Tunnel: A Benchmark Study.” 162017 Dynamic Analysis and Design Considerations for High-Level Nuclear Waste Repositories, Proceedings of the Symposium Sponsored by the Nuclear Dynamic Analysis Committee of the Structural Division of the American Society of Civil Engineers and Co-sponsored by the U.S. Department of Energy, Office of Civilian Radioactive Waste Management, San Francisco, California, August 19-20, 1992. Hossain, Q.A., ed. Pages 311-338. New York, New York: American Society of Civil Engineers. TIC: 206451. 
Senseny, P.E. and Pucik, T.A. 1999. "Development and Validation of Computer Models for Structures in Jointed Rock.” International Journal for Numerical and Analytical Methods in Geomechanics, 23, ([8]), 751-778. [New York, New York]: John Wiley \& Sons. TIC: 253795.

Shanley, R.J. and Mahtab, M.A. [1974]. A Computer Program for Clustering Data 169199 Points on the Sphere. Information Circular 8624. Washington, D.C.: U.S. Department of the Interior, Bureau of Mines. ACC: MOL.20040413.0435.

Sharma, S. and Judd, W.R. 1991. "Underground Opening Damage from 154505 Earthquakes.” Engineering Geology, 30, (3/4), 263-276. Amsterdam, [The Netherlands]: Elsevier. TIC: 226268.

Singleton, B. 1995. "Data Report Package, Supporting Information.” Memorandum 107044 from B. Singleton (U.S. Bureau of Reclamation) to C. Miller-Corbett (U.S.Geological Survey), July 20, 1995, with attachments. ACC: MOL.19960731.0235.

SNL (Sandia National Laboratories) 1996. Mechanical Properties of Fractures in 165408 Specimens from Drillhole USW SD-9. Albuquerque, New Mexico: Sandia National Laboratories. ACC: MOL.19961220.0133.

SNL (Sandia National Laboratories) 1996. Mechanical Properties of Fractures in Specimens from Drillholes USW NRG-7/7A and USW SD-12. Albuquerque, New Mexico: Sandia National Laboratories. ACC: MOL.19961029.0087.

Stevens, P.R. 1977. A Review of the Effects of Earthquakes on Underground Mines. Open-File Report 77-313. Reston, Virginia: U.S. Geological Survey. TIC: 211779.

Stone, C.A.; Kuszmaul, J.S.; Boontun, A.; and Young, D. 1996. “Comparison of an Analytical and a Numerical Approach to Probabilistic Keyblock Analysis.” Rock Mechanics, 2, 1769-1775. Rotterdam, The Netherlands: [A.A.] Balkema.

TIC: 240659.

Terzaghi, K. 1943. Theoretical Soil Mechanics. New York, New York: John Wiley 162180 \& Sons. TIC: 223837.

Terzaghi, R.D. 1966. "Sources of Error in Joint Surveys.” Geotechnique, 11 to 15, 287-304. London, England: [Thomas Telford]. TIC: 239078.

Tyler, D.B.; Trueman, R.; and Pine, R.J. 1991. "Rockbolt Support Design Using a 151818 Probabilistic Method of Key Block Analysis.” Rock Mechanics as a Multidisciplinary Science, Proceedings of the 32nd U.S. Symposium, the University of Oklahoma/Norman, July 10-12, 1991. Roegiers, J-C., ed. Pages 1037-1046. Brookfield, Vermont: A.A. Balkema Publishers. TIC: 103533. 
USGS (U.S. Geological Survey) 1996. Geotechnical Report for Station 4+00 to 8+00,

169024

North Ramp of the Exploratory Studies Facility (ESF) Rock Mass Quality Ratings.

Denver, Colorado: U.S. Geological Survey. ACC: MOL.19970610.0620.

USGS 1996. Geotechnical Report for Station 8+00 to 10+00, North Ramp of the

169025

Exploratory Studies Facility (ESF), Rock Mass Quality Ratings. Denver, Colorado:

U.S. Geological Survey. ACC: MOL.19970610.0598.

USGS 1996. Supplemental and Supporting Information for Rock Mass Quality

169030

Ratings, Main Drift of the Exploratory Studies Facility (ESF), Station 30+00 to 35+00.

Denver, Colorado: U.S. Geological Survey. ACC: MOL.19970106.0347.

USGS 1996. Supplemental and Supporting Information for Rock Mass Quality

169031

Ratings, Main Drift of the Exploratory Studies Facility (ESF), Station 35+00 to 40+00.

Denver, Colorado: U.S. Geological Survey. ACC: MOL.19970106.0348.

USGS 1996. Supplemental and Supporting Information for Rock Mass Quality

169032

Ratings, Main Drift of the Exploratory Studies Facility (ESF), Station 40+00 to 45+00.

Denver, Colorado: U.S. Geological Survey. ACC: MOL.19970106.0392.

USGS 1996. Supplemental and Supporting Information for Rock Mass Quality

169033

Ratings, Main Drift of the Exploratory Studies Facility (ESF), Station 45+00 to 50+00.

Denver, Colorado: U.S. Geological Survey. ACC: MOL.19970106.0393.

USGS 1996. Supplemental and Supporting Information for Rock Mass Quality

169034

Ratings, Main Drift of the Exploratory Studies Facility (ESF), Station 50+00 to 55+00.

Denver, Colorado: U.S. Geological Survey. ACC: MOL.19970106.0422.

USGS 1996. Supplemental and Supporting Information for Rock Mass Quality

169035

Ratings, Main Drift of the Exploratory Studies Facility (ESF), Station 55+00 to 60+00.

Denver, Colorado: U.S. Geological Survey. ACC: MOL.19970804.0153.

USGS 1996. Supplemental and Supporting Information for Rock Mass Quality 169029

Ratings, North Ramp and Main Drift of the Exploratory Studies Facility (ESF), Station 26+00 to 30+00. Denver, Colorado: U.S. Geological Survey.

ACC: MOL.19970106.0299.

USGS 1996. Supplemental and Supporting Information for Rock Mass Quality 169026 Ratings, North Ramp of the Exploratory Studies Facility (ESF), Station 10+00 to 18+00. Denver, Colorado: U.S. Geological Survey. ACC: MOL.19970618.0552.

USGS 1996. Supplemental and Supporting Information for Rock Mass Quality 169027 Ratings, North Ramp of the Exploratory Studies Facility (ESF), Station 18+00 to 26+00. Denver, Colorado: U.S. Geological Survey. ACC: MOL.19970106.0276. 
USGS 1997. Supplemental and Supporting Information for Rock Mass Quality 169040 Ratings, Alcove \#5, Cross Drift \& Heated Drift of the Exploratory Studies Facility (ESF). Denver, Colorado: U.S. Geological Survey. ACC: MOL.19980203.0461.

USGS 1997. Supplemental and Supporting Information for Rock Mass Quality 169036 Ratings, South Ramp of the Exploratory Studies Facility (ESF), Station 60+00 to 65+00. Denver, Colorado: U.S. Geological Survey. ACC: MOL.19970804.0164

USGS 1997. Supplemental and Supporting Information for Rock Mass Quality Ratings, South Ramp of the Exploratory Studies Facility (ESF), Station 65+00 to 70+00. Denver, Colorado: U.S. Geological Survey. ACC: MOL.19980216.0348.

USGS 1997. Supplemental and Supporting Information for Rock Mass Quality 169038 Ratings, South Ramp of the Exploratory Studies Facility (ESF), Station 70+00 to 75+00. Denver, Colorado: U.S. Geological Survey. ACC: MOL.19980216.0359.

USGS 1997. Supplemental and Supporting Information for Rock Mass Quality Ratings, South Ramp of the Exploratory Studies Facility (ESF), Station 75+00 to 78+77. Denver, Colorado: U.S. Geological Survey. ACC: MOL.19980216.0299.

USGS 1999. Supplemental and Supporting Information for Rock Mass Quality Ratings, ECRB Cross Block Drift, Station 00+00 to 10+00. Denver, Colorado: U.S. Geological Survey. ACC: MOL.20000209.0203.

USGS 1999. Supplemental and Supporting Information for Rock Mass Quality Ratings, ECRB Cross Block Drift, Station 10+00 to 15+00. Denver, Colorado: U.S. Geological Survey. ACC: MOL.20000209.0212.

USGS 1999. Supplemental and Supporting Information for Rock Mass Quality Ratings, ECRB Cross Block Drift, Station 15+00 to 20+00. Denver, Colorado: U.S. Geological Survey. ACC: MOL.20000209.0221.

USGS 1999. Supplemental and Supporting Information for Rock Mass Quality Ratings, ECRB Cross Block Drift, Station 20+00 to 26+65. Denver, Colorado: U.S. Geological Survey. ACC: MOL.20000209.0231.

Wang, J-M. 1985. "The Distribution of Earthquake Damage to Underground Facilities 151821 During the 1976 Tang-Shan Earthquake.” Earthquake Spectra, 1, (4), 741-757. [Berkeley, California]: Earthquake Engineering Research Institute. TIC: 226272.

Warburton, P.M. 1981. "Vector Stability Analysis of an Arbitrary Polyhedral Rock 150093 Block with Any Number of Free Faces.” International Journal of Rock Mechanics and Mining Science \& Geomechanics Abstracts, 18, (5), 415-427. New York, New York: Pergamon. TIC: 241134. 
Wiederhorn, S.M. 1968. "Moisture Assisted Crack Growth in Ceramics."

170309

International Journal of Fracture Mechanics, 4, (2), 171-177. Groningen,

The Netherlands: Wolters-Noordhoff Publishing. TIC: 256161.

Williams, N.H. 2001. “Contract \#: DE-AC08-01NV12101 - Drift Scale Test (DST)

159516

White Paper: Scaling Along the Roof of the Heated Drift.” Letter from N.H. Williams

(BSC) to S.P. Mellington (DOE/YMSCO), May 15, 2001, PROJ.05/01.033, with

enclosure. ACC: MOL.20010622.0252.

Williams, N.H. 2002. “Thermal Inputs for Evaluations Supporting TSPA-LA.”

159916

Interoffice memorandum from N.H. Williams (BSC) to Distribution,

September 16, 2002, 0911024159, with enclosures. ACC: MOL.20021008.0141.

\subsection{CODES, STANDARDS, REGULATIONS, AND PROCEDURES}

10 CFR 63. Energy: Disposal of High-Level Radioactive Wastes in a Geologic

Repository at Yucca Mountain, Nevada. Readily available.

AP-2.22Q, Rev. 1, ICN 1. Classification Analyses and Maintenance of the Q-List. Washington, D.C.: U.S. Department of Energy, Office of Civilian Radioactive Waste Management.

ACC: DOC.20040714.0002.

AP-3.15Q, Rev. 4, ICN 5. Managing Technical Product Inputs. Washington, D.C.: U.S. Department of Energy, Office of Civilian Radioactive Waste Management.

ACC: DOC.20040812.0004.

AP-SIII.9Q, Rev. 1, ICN 6. Scientific Analyses. Washington, D.C.: U.S. Department of Energy, Office of Civilian Radioactive Waste Management. ACC: DOC.20040805.0003.

AP-SIII.10Q, Rev. 2, ICN 6. Models. Washington, D.C.: U.S. Department of Energy, Office of Civilian Radioactive Waste Management. ACC: DOC.20040805.0005.

AP-SIII.2Q, Rev. 1, ICN 2. Qualification of Unqualified Data. Washington, D.C.: U.S. Department of Energy, Office of Civilian Radioactive Waste Management.

ACC: DOC.20040127.0008.

AP-SIII.3Q, Rev. 2, ICN 1. Submittal and Incorporation of Data to the Technical Data Management System. Washington, D.C.: U.S. Department of Energy, Office of Civilian Radioactive Waste Management. ACC: DOC.20040226.0001.

LP-SI.11Q-BSC, Rev. 0. Software Management. Washington, D.C.: U.S. Department of Energy, Office of Civilian Radioactive Waste Management. ACC: DOC.20040225.0007.

YMP-USGS-GP-20, Rev. 1. Estimating Abundance of Fractures in Core and in Outcrops, Including Lithophysae, Spots, Clasts, and Fractures. Denver, Colorado: U.S. Geological Survey. ACC: MOL.19960129.0372. 


\subsection{SOFTWARE}

BSC 2002. Software Code: 3DEC. V2.01. PC WINDOWS 2000/NT 4.0.

161930 10025-2.01-00.

BSC 2002. Software Code: DRKBA. V3.31. PC WINDOWS 2000/NT 4.0.

161946 10071-3.31-00.

BSC 2002. Software Code: F LAC. V4.0. PC WINDOWS 2000/NT 4.0

161953 10167-4.0-00.

BSC 2002. Software Code: FLAC3D. V2.1. PC WINDOWS 2000/NT 4.0. 10502-2.1-00.

BSC 2002. Software Code: PFC2D. V2.0. PC WINDOWS 2000/NT 4.0.

161950 10828-2.0-00.

BSC 2002. Software Code: PFC3D. V.2.0. PC. 10830-2.0-00.

160612

BSC 2002. Software Code: UDEC. V3.1. PC WINDOWS 2000/NT 4.0. 10173-3.1-00. 161949

BSC 2004. Software Code: Clustran. V. 1.1. PC, Windows 2000. 11162-1.1-00. 169203

BSC 2004. Software Code: PFC2D. V 2.0. PC, Windows 2000. 10828-2.0-01. 169930

BSC 2004. Software Code: PFC3D. V 2.0. PC, Windows 2000. 10830-2.0-01. 169931

BSC 2004. Software Code: Read DXF. V. 1.0. PC, Windows 2000. 11159-1.0-00. 169204

CRWMS M\&O 1997. Software Code: DIPS. V4.03. 30017 V4.03. 149839

CRWMS M\&O 1998. Software Code: UNWEDGE V2.3. V2.3. 30053 V2.3. 145366

Dynamic Graphics 2000. Software Code: EARTHVISION. 5.1. SGI/IRIX 6.5. 167994 10174-5.1-00.

LLNL (Lawrence Livermore National Laboratory) 2002. Software Code: NUFT. 157280 V3.0s. Sun, SunO.S. 5.6 \& 5.7. 10088-3.0s-01.

USGS 1999. Software Code: FracMAN. V.2.512. PC, Windows NT. 10114-2.511-00. 160577

\subsection{SOURCE DATA, LISTED BY DATA TRACKING NUMBER}

GS000608314224.004. Provisional Results: Geotechnical Data for Station 35+00 to 152573 Station 40+00, Main Drift of the ESF. Submittal date: 06/20/2000. 
GS000608314224.005. Provisional Results: Geotechnical Data - Full Periphery Maps 166002 for the North Ramp of the Exploratory Studies Facility, Stations 4+00 to 8+00.

Submittal date: 06/28/2000.

GS000608314224.006. Provisional Results: Geotechnical Data for Station 26+00 to 152572 30+00, North Ramp and Main Drift of the ESF, Full-Periphery Geotechnical Maps (Drawings OA-46-222 through OA-46-226) and Rock Mass Quality Ratings Report. Submittal date: 06/28/2000.

GS020908314224.001. Supplemental Fracture Study Traverses 1 through 16 at WT-11 Wash and Solitario Canyon Starting in WT-11 Wash along Iron Ridge. Submittal date: 10/23/2002.

GS021008314224.002. Lithophysal Data Study from the Tptpll in the ECRB from Stations $14+44$ to $23+26$. Submittal date: 01/28/2003.

GS030283114222.001. Direct Shear Data from Selected Samples of the Topopah 161913 Spring Tuff. Submittal date: 02/20/2003.

GS030483351030.001. Bulk Density, Rock-Particle Density, Porosity Properties of 163440 Core Samples of Spot, Rim \& Matrix-Groundmass from 17 Boreholes in the Upper \& Lower Lithophysal Zones of the Topopah Spring Tuff from the ESF \& ECRB Cross Drift. Submittal date: 04/24/2003.

GS040108314224.001. Detailed Line Survey Data for Horizontal and Vertical 169591 Traverses, ECRB. Submittal date: 02/27/2004.

GS040308314224.002. Supplemental Fracture Study Traverses 17 through 23 at Prow Pass in the Yucca and Windy Washes. Submittal date: 05/05/2004.

GS040608314224.001. Large-Lithophysal Inventory Data from the Tptpll and Tptpln in the ECRB from Stations 14+44 to 25+35. Submittal date: 08/19/2004.

GS950508314224.003. Provisional Results: Geotechnical Data - Full Periphery Map Data from North Ramp of the Exploratory Studies Facility, Stations 0+60 to 4+00. Submittal date: 05/24/1995.

GS960408314224.001. Provisional Results: Geotechnical Data - Full Periphery 168135 Geotechnical Maps of the North Ramp, Exploratory Studies Facility, Station 8+00 to 10+00, Plots OA-46-201, -202, -203; Geotechnical Report - Rock Mass Quality Ratings. Submittal date: 06/24/1996.

GS960408314224.003. Provisional Results: Geotechnical Data - Full-Periphery 168136 Geotechnical Maps (Drawing OA-46-204 through -212) and Rock Mass Quality Ratings from North Ramp of the Exploratory Studies Facility, Stations 10+00 to 18+00. Submittal date: 08/29/1996. 
GS960708314224.008. Provisional Results: Geotechnical Data for Station $30+00$ to

Station 35 + 00, Main Drift of the ESF. Submittal date: 08/05/1996.

GS960708314224.009. Provisional Results: Geotechnical Data for Station 18+00 to

168137 26+00, North Ramp of the ESF, Full-Periphery Geotechnical Maps and Rock Mass Quality Ratings Report. Submittal date: 09/09/1996.

GS960708314224.010. Provisional Results: Geotechnical Data for Station 40+00 to Station 45+00, Main Drift of the ESF. Submittal date: 08/05/1996.

GS960908314224.014. Provisional Results - ESF Main Drift, Station 50+00 to Station 106033 55+00. Submittal date: 09/09/1996.

GS960908314224.015. Provisional Results: Geotechnical Data for Stations 30+00 to 40+00, Main Drift of the ESF, Full-Periphery Geotechnical Maps and Rock Mass Quality Ratings Report. Submittal date: 09/09/1996.

GS960908314224.016. Provisional Results: Geotechnical Data for Station 40+00 to 50+00, Main Drift of the ESF, Full-Periphery Geotechnical Maps and Rock Mass Quality Ratings Report. Submittal date: 09/09/1996.

GS960908314224.017. Provisional Results: Geotechnical Data for Stations 50+00 to 108376 55+00, Main Drift of the ESF, Full-Periphery Geotechnical Maps and Rock Mass Quality Ratings Report. Submittal date: 09/09/1996.

GS960908314224.020. Analysis Report: Geology of the North Ramp - Stations 4+00 to 28+00 and Data: Detailed Line Survey and Full-Periphery Geotechnical Map Alcoves 3 (UPCA) and 4 (LPCA), and Comparative Geologic Cross Section - Stations 0+60 to 28+00. Submittal date: 09/09/1996.

GS970108314224.002. Geotechnical Data for Station 55+00 to Station 60+00, Main Drift of the ESF, Full Periphery Geotechnical Maps. Submittal date: 01/31/1997.

GS970208314224.003. Geotechnical Data for Station 60+00 to Station 65+00, South Ramp of the ESF. Submittal date: 02/12/1997. Periphery Geotechnical Map (Drawing OA-46-300) and Rock Mass Quality Ratings Report. Submittal date: 06/24/1997. 
GS970808314224.009. Provisional Results: Geotechnical Data for Station 65+00 to 107494 Station 70+00, South Ramp of the ESF; Full-Periphery Geotechnical Maps (Drawings 0A-46-269 through 0A-46-274) and Rock Mass Quality Ratings Report. Submittal date: $08 / 18 / 1997$.

GS970808314224.010. Provisional Results: Geotechnical Data for Station 70+00 to Station 75+00, South Ramp of the ESF. Submittal date: 08/25/1997.

GS970808314224.011. Provisional Results: Geotechnical Data for Station 70+00 to Station 75+00, South Ramp of the ESF. Submittal date: 08/25/1997.

GS970808314224.013. Provisional Results: Geotechnical Data for Station 75+00 to Station 78+77, South Ramp of the ESF. Submittal date: 08/25/1997.

GS971108314224.025. Revision 1 of Detailed Line Survey Data, Station 26+00 to 106025 Station 30+00, North Ramp and Main Drift, Exploratory Studies Facility. Submittal date: $12 / 03 / 1997$.

GS971108314224.028. Revision 1 of Detailed Line Survey Data, Station 55+00 to 106047 Station 60+00, Main Drift and South Ramp, Exploratory Studies Facility. Submittal date: 12/03/1997.

GS990408314224.001. Detailed Line Survey Data for Stations 00+00.89 to 14+95.18, 108396 ECRB Cross Drift. Submittal date: 09/09/1999.

GS990408314224.002. Detailed Line Survey Data for Stations 15+00.85 to 26+63.85， 105625 ECRB Cross Drift. Submittal date: 09/09/1999.

GS990408314224.003. Full-Periphery Geologic Maps for Station -0+10 to 10+00, 108404 ECRB Cross Drift. Submittal date: 09/09/1999.

GS990408314224.004. Full-Periphery Geologic Maps for Station 10+00 to 15+00, ECRB Cross Drift. Submittal date: 09/09/1999.

108405

GS990408314224.005. Full-Periphery Geologic Maps for Station 15+00 to 20+00, 108408 ECRB Cross Drift. Submittal date: 09/09/1999.

GS990408314224.006. Full-Periphery Geologic Maps for Station 20+00 to 26+81, 108409 ECRB Cross Drift. Submittal date: 09/09/1999.

LA000000000086.002. Mineralogic Variation in Drill Core UE-25 UZ\#16 Yucca 107144 Mountain, Nevada. Submittal date: 03/28/1995. 
LADB831321AN98.002. Revised Mineralogic Summary of Yucca Mountain, Nevada. 109003 Submittal date: 05/26/1998.

LADV831321AQ97.001. Mineralogic Variation in Drill Holes. Submittal date:

107142 05/28/1997.

LADV831321AQ99.001. Quantitative XRD Results for the USW SD-6 and USW 109044 WT-24 Drill Core Samples. Submittal date: 04/16/1999.

LB0205REVUZPRP.001. Fracture Properties for UZ Model Layers Developed from Field Data. Submittal date: 05/14/2002.

159525

LB0208UZDSCPMI.002. Drift-Scale Calibrated Property Sets: Mean Infiltration Data 161243 Summary. Submittal date: 08/26/2002.

LL030808623122.036. Input and Output Files for NUFT MSTHM Sub-Models 165790 Supporting LA Multi-Scale Analyses. Submittal date: 09/11/2003.

MO0001SEPDSTPC.000. Drift Scale Test (DST) Temperature, Power, Current, and 153836 Voltage Data for June 1, 1999 through October 31, 1999. Submittal date: 01/12/2000.

MO0002ABBLSLDS.000. As-Built Borehole Locations and Sensor Locations for the 147304 Drift Scale Test Given in Local (DST) Coordinates. Submittal date: 02/01/2000.

MO0004QGFMPICK.000. Lithostratigraphic Contacts from 152554 MO9811MWDGFM03.000 to be Qualified Under the Data Qualification Plan, TDP-NBS-GS-000001. Submittal date: 04/04/2000.

MO0007SEPDSTPC.001. Drift Scale Test (DST) Temperature, Power, Current, and 153707 Voltage Data for November 1, 1999 through May 31, 2000. Submittal date: 07/13/2000.

MO0012MWDGFM02.002. Geologic Framework Model (GFM2000). Submittal date: $12 / 18 / 2000$

MO0107SEPDSTPC.003. Drift Scale Test (DST) Temperature, Power, Current, and 158321 Voltage Data for December 1, 2000 through May 31, 2001. Submittal date: 07/06/2001.

MO0202SEPDSTTV.001. Drift Scale Test (DST) Temperature, Power, Current, and 158320 Voltage Data for June 1, 2001 through January 14, 2002. Submittal date: 02/28/2002.

MO0301SPASIP27.004. Sampling of Stochastic Input Parameters for Rockfall 161869 Calculations and for Structural Response Calculations Under Vibratory Ground Motions. Submittal date: 01/15/2003. 
MO0301TMHIS106.001. Acceleration, Velocity, and Displacement Time Histories

161868 for the Repository Level at 10-6 Annual Exceedance Frequency.

Submittal date: 01/28/2003.

MO0306MWDALAFV.000. ANSYS-La-Fine Ventilation. Submittal date:

163961

06/23/2003.

MO0306MWDASLCV.001. ANSYS-LA-Coarse Ventilation.

165695

Submittal date: 07/01/2003.

MO0306SDSAVDTH.000. Seismic Design Spectra and Acceleration, Velocity, and Displacement Time Histories for the Emplacement Level at 10-4 Annual Exceedance Frequency. Submittal date: 06/26/2003.

MO0311RCKPRPCS.003. Intact Rock Properties Data on Uniaxial and Triaxial Compressive Strength. Submittal date: 11/04/2003.

MO0401DQRIRPTS.003. Data Summary for Intact Rock Properties Data on Tensile Strength. Submittal date: 01/07/2004.

MO0402AVDTM105.001. Acceleration, Velocity, and Displacement Time Histories for the Repository Level at 10-5 Annual Exceedance Frequency.

Submittal date: 02/09/2004.

MO0402DQRIRPPR.003. Intact Rock Properties Data on Poisson's Ratio and Young's 168901 Modulus. Submittal date: 02/19/2004.

MO0403AVDSC106.001. Acceleration, Velocity, and Displacement Time Histories for the Repository Level at 10-6 Annual Exceedance Frequency. Submittal date: 03/09/2004.

MO0403AVTMH107.003. Acceleration, Velocity, and Displacement Time Histories for the Repository Level at 10-7 Annual Exceedance Frequency. Submittal date:

03/22/2004.

MO0407SEPFEPLA.000. LA FEP List. Submittal date: 07/20/2004.

170760

MO0407TMHIS104.003. Acceleration, Velocity and Displacement Time Histories for 170599 the Emplacement Level (Point B) at 5X10-4 Annual Exceedance Frequency. Submittal date: 07/15/2004.

MO9807DSTSET01.000. Drift Scale Test (DST) Temperature, Power, Current, 113644 Voltage Data for November 7, 1997 through May 31, 1998. Submittal date: 07/09/1998. 
MO9906DSTSET03.000. Drift Scale Test (DST) Temperature, Power, Current, 113673 Voltage Data for September 1, 1998 through May 31, 1999.

Submittal date: 06/08/1999.

SN0108SD821723.001. Uniaxial and Triaxial Compression Test Data on Samples

159959 from USW G-1 (VA Supporting Data). Submittal date: 08/09/2001.

SN0208F4102102.002. Rock Mass Mechanical Properties, Slot Test \#1, Location 57+77 in the ESF. Submittal date: 08/27/2002.

SN0208L0207502.001. Mechanical Properties of Lithophysal Tuff, Batch \#1 (Test Dates: July 31, 2002 through August 16, 2002). Submittal date: 08/20/2002.

SN0211L0207502.002. Mechanical Properties of Lithophysal Tuff, Batch \#2 (Test Dates: October 22, 2002 through October 25, 2002). Submittal date: 11/13/2002.

SN0212F4102102.004. Rock Mass Mechanical Properties, Slot Test \#2, Location 63+83 in the ESF. Submittal date: 12/17/2002.

SN0301F4102102.006. Rock Mass Mechanical Properties, Slot Test \#3, Location 21+25 in the ECRB. Submittal date: 01/14/2003.

SN0302L0207502.003. Mechanical Properties of Lithophysal Tuff, Room

Temperature Batch \#4, Set 1 (Test Dates: 01/21/03 through 01/23/03).

Submittal date: 02/25/2003.

SN0303T0503102.008. Revised Thermal Conductivity of the Non-Repository Layers 162401 of Yucca Mountain. Submittal date: 03/19/2003.

SN0305L0207502.004. Mechanical Properties of Lithophysal Tuff, Batch \#4, Set 2 165013 (Test Dates: March 5, 2003 through March 13, 2003). Submittal date: 05/01/2003.

SN0305L0207502.005. Material Abundances from Point Counts on Laboratory 163373 Mechanical Property Specimens for Batch \#1 and Batch \#2.

Submittal date: 05/20/2003.

SN0306L0207502.008. Revised Mechanical Properties of Welded Tuff from the 165015 Lower Lithophysal Zone of the Topopah Spring Tuff, Batch \#3 (Test Dates: March 6, 2003 through April 18, 2003). Submittal date: 06/20/2003.

SN0307T0510902.003. Updated Heat Capacity of Yucca Mountain Stratigraphic Units. Submittal date: 07/15/2003.

164196

SN0404T0503102.011. Thermal Conductivity of the Potential Repository Horizon 169129 Rev 3. Submittal date: 04/27/2004. 
SN0406L0212303.002. Static Fatigue Data from New England Research (NER)

170289

(Test Dates: 1/2/2004 through 2/25/2004. Submittal date: 06/08/2004.

SNF37100195002.001. Hydraulic Fracturing Stress Measurements in Test

131356

Hole: ESF-AOD-HDFR1, Thermal Test Facility, Exploratory Studies Facility at

Yucca Mountain. Submittal date: 12/18/1996.

SNL01B05059301.006. Laboratory Thermal Expansion Data for Boreholes UE25

129168

NRG-4, NRG-5; USW NRG-6 and NRG-7/7A. Submittal date: 02/07/1996.

SNL02030193001.001. Mechanical Properties Data for Drillhole USW NRG-6

Samples from Depth $22.2 \mathrm{ft}$. to $328.7 \mathrm{ft}$. Submittal date: 05/17/1993.

SNL02030193001.002. Mechanical Properties Data for Drillhole USW NRG-6

Samples from Depth $22.2 \mathrm{ft}$. to $427.0 \mathrm{ft}$. Submittal date: 06/25/1993.

SNL02030193001.003. Mechanical Properties Data for Drillhole UE-25 NRG-2

Samples from Depth $150.5 \mathrm{ft}$. to $200.0 \mathrm{ft}$. Submittal date: 07/07/1993.

SNL02030193001.004. Mechanical Properties Data for Drillhole USW NRG-6

Samples from Depth $462.3 \mathrm{ft}$. to 1085.0 ft. Submittal date: 08/05/1993

SNL02030193001.005. Mechanical Properties Data for Drillhole UE-25 NRG\#3

122545

Samples from Depth $15.4 \mathrm{ft}$. to $297.1 \mathrm{ft}$. Submittal date: 09/23/1993.

SNL02030193001.006. Mechanical Properties Data for Drill Hole UE-25 NRG\#2A

Samples from Depth $90.0 \mathrm{ft}$. to $254.5 \mathrm{ft}$. Submittal date: 10/13/1993.

SNL02030193001.007. Mechanical Properties Data for Drill Hole UE-25 NRG\#3

Samples from Depth $263.3 \mathrm{ft}$. to $265.7 \mathrm{ft}$. Submittal date: 10/20/1993.

SNL02030193001.008. Mechanical Properties Data for Drill Hole USW NRG-6

120572

120575

120578

108415

Sample $416.0 \mathrm{ft}$. Submittal date: 10/20/1993.

SNL02030193001.009. Mechanical Properties Data for Drillhole UE25 NRG-5

Samples from Depth $781.0 \mathrm{ft}$. to $991.9 \mathrm{ft}$. Submittal date: 11/18/1993.

109614

SNL02030193001.012. Mechanical Properties Data for Drillhole UE25 NRG-5

108416

Samples from Depth $847.2 \mathrm{ft}$. to $896.5 \mathrm{ft}$. Submittal date: 12/02/1993.

SNL02030193001.013. Mechanical Properties Data for Drillhole UE25 NRG-2B

120614

Samples from Depth $2.7 \mathrm{ft}$. to $87.6 \mathrm{ft}$. Submittal date: 12/02/1993.

SNL02030193001.014. Mechanical Properties Data for Drillhole UE25 NRG-4

Samples from Depth $378.1 \mathrm{ft}$. to $695.8 \mathrm{ft}$. Submittal date: 01/31/1994.

109609

SNL02030193001.015. Mechanical Properties Data for Drillhole UE25 NRG-4

120617

Samples from Depth 527.0 ft. Submittal date: 02/16/1994. 
SNL02030193001.016. Mechanical Properties Data for Drillhole USW NRG-7/7A

Samples from Depth $18.0 \mathrm{ft}$. to $472.9 \mathrm{ft}$. Submittal date: 03/16/1994.

SNL02030193001.018. Mechanical Properties Data for Drillhole USW NRG-7/7A

109611

Samples from Depth 344.4 ft. Submittal date: 04/11/1994.

SNL02030193001.019. Mechanical Properties Data for Drillhole USW NRG-7/7A

108431

Samples from Depth 507.4 ft. to 881.0 ft. Submittal date: 06/29/1994.

SNL02030193001.020. Mechanical Properties Data for Drillhole USW NRG-7/7A

Samples from Depth $554.7 \mathrm{ft}$. to $1450.1 \mathrm{ft}$. Submittal date: 07/25/1994.

108432

SNL02030193001.021. Mechanical Properties Data (Ultrasonic Velocities, Static

108433 Elastic Properties, Triaxial Strength, Dry Bulk Density \& Porosity) for Drillhole USW NRG-7/7A Samples from Depth 345.0 ft. to 1408.6 ft. Submittal date: 02/16/1995.

SNL02030193001.022. Mechanical Properties Data for Drill Hole USW NRG-6 Samples from Depth $5.7 \mathrm{ft}$. to $1092.3 \mathrm{ft}$. Submittal date: 02/27/1995.

SNL02030193001.023. Mechanical Properties Data (Ultrasonic Velocities, Static 108435 Elastic Properties, Unconfined Strength, Triaxial Strength, Dry Bulk Density \& Porosity) for Drillhole USW SD-12 Samples from Depth $16.1 \mathrm{ft}$. to $1300.3 \mathrm{ft}$. Submittal date: 08/02/1995.

SNL02030193001.026. Mechanical Properties Data (Ultrasonic Velocities, Elastic 108436 Moduli and Fracture Strength) for Borehole USW SD-9. Submittal date: 02/22/1996.

SNL02030193001.027. Summary of Bulk Property Measurements Including Saturated Bulk Density for NRG-2, NRG-2A, NRG-2B, NRG-3, NRG-4, NRG-5, NRG-6, NRG7/7A, SD-9, and SD12. Submittal date: 08/14/1996.

SNL02112293001.003. Results from Shear Stress Experiments on Natural Fractures from NRG-4 \& NRG-6. Submittal date: 03/13/1995. 108413

108412

SNL02112293001.005. Mechanical Properties of Fractures in Specimens from 108413 Drillhole USW SD-9. Submittal date: 07/15/1996.

SNL02112293001.007. Mechanical Properties of Fractures in Specimens from 108414 Drillholes USW NRG-7/7A and USW SD-12. Submittal date: 08/08/1996.

SNSAND83164600.000. Experimental Data of Fully Saturated and Wet Samples; Static Mechanical Properties of GU-3 760.9 Samples; Ultrasonic Velocity Data; and Dynamic Elastic Model of GU-3 760.9 Samples Compression Test. Submittal date: 04/24/1992.

SNSAND84110100.000. Uniaxial and Triaxial Compression Test Series on Topopah 160016 Spring Tuff from USW G-4, Yucca Mountain, Nevada. Submittal date: 02/01/1986. 
SNSAND85070300.000. Uniaxial and Triaxial Compression Test Series on the 160020 Topopah Spring Member from USW G-2, Yucca Mountain, Nevada. Submittal date: 09/24/1987.

SNSAND85070900.000. Effects of Sample Size on the Mechanical Behavior of the

160022 Topopah Spring Tuff. Submittal date: 12/16/1998.

SNSAND85076200.000. Bulk, Thermal, and Mechanical Properties of the Topopah 160024 Spring Member of the Paintbrush Tuff, Yucca Mountain, Nevada. Submittal date: 10/17/1987.

SNSAND86113100.000. Petrologic and Mechanical Properties of Outcrop Samples of the Welded, Devitrified Topopah Spring Member of the Paintbrush Tuff. Submittal date: 06/11/1987.

\subsection{DEVELOPED DATA, LISTED BY DATA TRACKING NUMBER}

MO0306MWDDPPDR.000. Drift Profile Prediction and Degraded Rock Mass Characteristics in Lithophysal Units. Submittal date: 06/18/2003.

MO0403MWDRPNLR.000. Rock Properties for Nonlithophysal Rock.

Submittal date: 03/31/2004.

MO0404MWD3DRFA.000. Input and Output file for 3DEC Rockfall Analyses with 1E-4 Ground Motion. Submittal date: 04/08/2004.

MO0407MWDDSLCR.000. Drip Shield Load in Collapsed Lithophysal Rock.

Submittal date: 07/21/2004.

MO0407SPAMTSHR.000. Modeled Thermal Stresses Within the Host Rock at Three Graduated Points in Time. Submittal date: 07/20/2004.

MO0408MWDRNLRA.002. Results from Nonlithophysal Rockfall Analyses for Emplacement Drifts with 1E-4 Ground Motion. Submittal date: 08/19/2004.

MO0408MWDDDMIO.002. Drift Degradation Model Inputs and Outputs. Submittal date: 08/31/2004. 


\section{INTENTIONALLY LEFT BLANK}


APPENDIX A

DRIFT DEGRADATION ANALYSIS COMPUTER FILES 


\section{DRIFT DEGRADATION ANALYSIS COMPUTER FILES}

The computer files developed for this model report can be accessed through the Technical Data Management System (TDMS) (DTN: MO0408MWDDDMIO.002), and include the inputs and outputs for the following computer rendered simulations:

- $\quad 3$ DEC Inputs \& Outputs

- $\quad$ DRKBA Inputs \& Outputs

- $\quad$ EarthVision Inputs \& Outputs

- $\quad$ FLAC 3D Inputs \& Outputs

- $\quad$ FLAC Inputs \& Outputs

- $\quad$ FracMan Inputs \& Outputs

- $\quad$ NUFT Inputs \& Outputs

- $\quad$ PFC Inputs \& Outputs

- $\quad$ UDEC Inputs \& Outputs.

Archive file descriptions are provided in DTN: MO0408MWDDDMIO.002 for each software item to explain the format of the input and output sub-directories within the DTN.

Calculation files were developed in this model report to perform support calculation activities as described in Section 6.2, Section 6.3, Section 6.4, and associated appendices. These calculations use the standard functions of commercial off-the-shelf software, including both Microsoft Excel 97 SR-2 and Mathcad 2001i Professional. Additionally, DIPS Version 4.03 (see Section 3.2) was used for graphical presentation of fracture data. Table A-1 provides a listing of the calculation files, including the location in this report where specific details of the calculation can be found. The calculation files listed in Table A-1 can be accessed through the TDMS (DTN: MO0408MWDDDMIO.002).

Microsoft Excel 97 SR-2 and Mathcad 2001i Professional were used to perform support calculations to process the nonlithophysal rockfall output from 3DEC for preclosure ground motion $\left(1 \times 10^{-4}\right.$ annual probability of exceedance). Excel was used to tabulate the rockfall results, including rock block velocity and impact location. Mathcad was used to calculate the impact bounding velocity for preclosure rockfall. The results from nonlithophysal rockfall analyses with $1 \times 10^{-4}$ ground motion can be accessed through the TDMS (DTN: MO0408MWDRNLRA.002). Excel was also used to perform support calculations to process the nonlithophysal rockfall output from 3DEC for postclosure ground motions, including $1 \times 10^{-5}, 1 \times 10^{-6}$, and $1 \times 10^{-7}$ annual probabilities of exceedance. Excel was used to tabulate the rockfall results, calculate the rockfall mass, velocity, impact angle, impact momentum, and impact energy associated with each rock block. These files can be accessed through the TDMS (DTN: MO0408MWDDDMIO.002). 
Output files for drift profile prediction and degraded rock mass characteristics in lithophysal units can be accessed through the TDMS (DTN: MO0306MWDDPPDR.000). Input and output files for 3DEC rockfall analyses using $1 \times 10^{-4}$ ground motion are provided in DTN: MO0404MWD3DRFA.000. Drip shield load results are provided in DTN: MO0407MWDDSLCR.000. The profile of thermal stresses at different times after waste emplacement (extracted from FLAC 3D) is provided in DTN: MO0407SPAMTSHR.000. Intact rock properties used in parts of the drift degradation analyses are summarized in DTN: MO0403MWDRPNLR.000. 
Table A-1. List of Drift Degradation Calculation Files

\begin{tabular}{|c|c|c|c|}
\hline File Name & File Type & Brief Description & References \\
\hline $\begin{array}{l}3 D E C \text { lith analysis } \\
\text { results.xls }\end{array}$ & Microsoft Excel 97 SR-2 & $\begin{array}{l}\text { Calculation file to tabulate the } \\
\text { rockfall results for the 3DEC } \\
\text { lithophysal rockfall analysis } \\
\text { (Section } 6.4 .3 \text { ) }\end{array}$ & $\mathrm{N} / \mathrm{A}$ \\
\hline $\begin{array}{l}\text { impact velocity } \\
\text { bounding cal for } \\
\text { preclosure rockfall } \\
\text { rev1.mcd }\end{array}$ & $\begin{array}{l}\text { Mathcad 2001i } \\
\text { Professional }\end{array}$ & $\begin{array}{l}\text { Calculation file to determine the } \\
\text { bounding impact velocity for } \\
\text { preclosure rockfall } \\
\text { (Section } 6.3 .1 .2 .6 \text { ) }\end{array}$ & $\begin{array}{l}\text { BSC } 2004 \text { [DIRS 168489], BSC } 2004 \text { [DIRS 169503], BSC } 2004 \\
\text { [DIRS 169472], Dowding 1979 [DIRS 101977] }\end{array}$ \\
\hline $\begin{array}{l}\text { nonlith 1e-4 motion } \\
\text { sufficiency } \\
\text { study.xls }\end{array}$ & Microsoft Excel 97 SR-2 & $\begin{array}{l}\text { Calculation file to determine the } \\
\text { number of simulation sufficient for } \\
\text { rockfall analyses (Appendix K) }\end{array}$ & $\mathrm{N} / \mathrm{A}$ \\
\hline $\begin{array}{l}\text { nonlith } 1 e-5 \text { motion } \\
\text { sufficiency } \\
\text { study.xIs }\end{array}$ & Microsoft Excel 97 SR-2 & $\begin{array}{l}\text { Calculation file to determine the } \\
\text { number of simulation sufficient for } \\
\text { rockfall analyses (Appendix K) }\end{array}$ & $\mathrm{N} / \mathrm{A}$ \\
\hline $\begin{array}{l}\text { nonlith 1e-6 motion } \\
\text { sufficiency } \\
\text { study.xls }\end{array}$ & Microsoft Excel 97 SR-2 & $\begin{array}{l}\text { Calculation file to determine the } \\
\text { number of simulation sufficient for } \\
\text { rockfall analyses (Appendix K) }\end{array}$ & $\mathrm{N} / \mathrm{A}$ \\
\hline $\begin{array}{l}\text { nonlith } 1 e-7 \text { motion } \\
\text { sufficiency } \\
\text { study.xls }\end{array}$ & Microsoft Excel 97 SR-2 & $\begin{array}{l}\text { Calculation file to determine the } \\
\text { number of simulation sufficient for } \\
\text { rockfall analyses (Appendix K) }\end{array}$ & $\mathrm{N} / \mathrm{A}$ \\
\hline $\begin{array}{l}\text { nonlith rockfall } \\
\text { characteristics in } \\
\text { emplacement drifts } \\
\text { with } 1 \text { e-4 gm.xls }\end{array}$ & Microsoft Excel 97 SR-2 & $\begin{array}{l}\text { Calculation file to tabulate the } \\
\text { rockfall results, calculate the } \\
\text { rockfall mass, velocity, impact } \\
\text { angle, impact momentum, and } \\
\text { impact energy associated with } \\
\text { each rock block. These data are } \\
\text { for preclosure ground motion with } \\
\text { an annual probability of } \\
\text { exceedance of } 1 \times 10^{-4} \\
\text { (Section } 6.3 .1 .2 .6)\end{array}$ & $\mathrm{N} / \mathrm{A}$ \\
\hline
\end{tabular}


Table A-1. List of Drift Degradation Calculation Files (Continued)

\begin{tabular}{|c|c|c|c|}
\hline File Name & File Type & Brief Description & References \\
\hline $\begin{array}{l}\text { nonlith rockfall } \\
\text { characteristics in } \\
\text { emplacement drifts } \\
\text { with 1e-5 gm.xls }\end{array}$ & Microsoft Excel 97 SR-2 & $\begin{array}{l}\text { Calculation file to tabulate the } \\
\text { rockfall results, calculate the } \\
\text { rockfall mass, velocity, impact } \\
\text { angle, impact momentum, and } \\
\text { impact energy associated with } \\
\text { each rock block. These data are } \\
\text { for preclosure ground motion with } \\
\text { an annual probability of } \\
\text { exceedance of } 1 \times 10^{-5} \\
\text { (Section } 6.3 .1 .2 .3 \text { ) }\end{array}$ & N/A \\
\hline $\begin{array}{l}\text { nonlith rockfall } \\
\text { characteristics in } \\
\text { emplacement drifts } \\
\text { with 1e-6 gm.xls }\end{array}$ & Microsoft Excel 97 SR-2 & $\begin{array}{l}\text { Calculation file to tabulate the } \\
\text { rockfall results, calculate the } \\
\text { rockfall mass, velocity, impact } \\
\text { angle, impact momentum, and } \\
\text { impact energy associated with } \\
\text { each rock block. These data are } \\
\text { for preclosure ground motion with } \\
\text { an annual probability of } \\
\text { exceedance of } 1 \times 10^{-6} \\
\text { (Section } 6.3 .1 .2 .4 \text { ) }\end{array}$ & $\mathrm{N} / \mathrm{A}$ \\
\hline $\begin{array}{l}\text { nonlith rockfall } \\
\text { characteristics in } \\
\text { emplacement drifts } \\
\text { with 1e-7 gm.xls }\end{array}$ & Microsoft Excel 97 SR-2 & $\begin{array}{l}\text { Calculation file to tabulate the } \\
\text { rockfall results, calculate the } \\
\text { rockfall mass, velocity, impact } \\
\text { angle, impact momentum, and } \\
\text { impact energy associated with } \\
\text { each rock block. These data are } \\
\text { for preclosure ground motion with } \\
\text { an annual probability of } \\
\text { exceedance of } 1 \times 10^{-7} \\
\text { (Section } 6.3 .1 .2 .5 \text { ) }\end{array}$ & N/A \\
\hline Cavingnew.mcd & $\begin{array}{l}\text { Mathcad 2001i } \\
\text { Professional }\end{array}$ & $\begin{array}{l}\text { Calculation file for analytical } \\
\text { solution for lithophysal rock mass } \\
\text { degradation (Section 6.4.2.5). }\end{array}$ & $N / A$ \\
\hline $\begin{array}{l}\text { drift degradation- } \\
\text { V1.xls }\end{array}$ & Microsoft Excel 97 SR-2 & $\begin{array}{l}\text { Calculation file for summarizing } \\
\text { drip shield pressure including both } \\
\text { analytical and numerical solutions } \\
\text { (Section 6.4.2). }\end{array}$ & $\mathrm{N} / \mathrm{A}$ \\
\hline
\end{tabular}


Table A-1. List of Drift Degradation Calculation Files (Continued)

\begin{tabular}{|c|c|c|c|}
\hline File Name & File Type & Brief Description & References \\
\hline $\begin{array}{l}\text { FLAC drip shield } \\
\text { pressures.xls }\end{array}$ & Microsoft Excel 97 SR-2 & $\begin{array}{l}\text { Summary drip shield pressures } \\
\text { calculated using FLAC } \\
\text { (Section } 6.4 .2 .5 \text { ) }\end{array}$ & $\mathrm{N} / \mathrm{A}$ \\
\hline $\begin{array}{l}\text { UDEC drip shield } \\
\text { pressures.xls }\end{array}$ & Microsoft Excel 97 SR-2 & $\begin{array}{l}\text { Summary drip shield pressures } \\
\text { calculated using UDEC } \\
\text { (Section } 6.4 .2 .5 \text { ) }\end{array}$ & N/A \\
\hline $\begin{array}{l}\text { Cohesion } \\
\text { Degradation V1.xIs }\end{array}$ & Microsoft Excel 97 SR-2 & $\begin{array}{l}\text { Calculation file for cohesion } \\
\text { degradation due to time and } \\
\text { thermal effects. Application: } \\
\text { DRKBA analyses of } \\
\text { nonlithophysal rock. Calculation } \\
\text { details provided in Appendix D } \\
\text { (Section D5). }\end{array}$ & $\mathrm{N} / \mathrm{A}$ \\
\hline exca vectors V2.xIs & Microsoft Excel 97 SR-2 & $\begin{array}{l}\text { Calculation file for plane equations } \\
\text { to describe the } 5.5-m \text {-diameter } \\
\text { excavation opening. Application: } \\
\text { DRKBA analyses of } \\
\text { nonlithophysal rock. Calculation } \\
\text { details provided in Appendix D } \\
\text { (Section D10). }\end{array}$ & N/A \\
\hline $\begin{array}{l}\text { mcs sensitivity } \\
\text { study Tptpmn } \\
\text { v1.xls }\end{array}$ & Microsoft Excel 97 SR-2 & $\begin{array}{l}\text { Calculation file for rock blocks } \\
\text { cumulative frequency of } \\
\text { occurrence, Monte Carlo } \\
\text { simulations varied. Application: } \\
\text { DRKBA analyses of } \\
\text { nonlithophysal rock. Calculation } \\
\text { details provided in Appendix D } \\
\text { (Section D8). }\end{array}$ & $\mathrm{N} / \mathrm{A}$ \\
\hline $\begin{array}{l}\text { New_Beta_Tptpmn } \\
\text { V1.xls }\end{array}$ & Microsoft Excel 97 SR-2 & $\begin{array}{l}\text { Calculation file for beta distribution } \\
\text { parameters ( } a, b, p, q) \text { for joint } \\
\text { spacing, trace length, and } \\
\text { location. Application: DRKBA } \\
\text { analyses of nonlithophysal rock. } \\
\text { Calculation details provided in } \\
\text { Appendix D (Section D7). }\end{array}$ & Derman, et al. 1973 [DIRS 108444] \\
\hline
\end{tabular}


Table A-1. List of Drift Degradation Calculation Files (Continued)

\begin{tabular}{|c|c|c|c|}
\hline File Name & File Type & Brief Description & References \\
\hline $\begin{array}{l}\text { New-K-Tptpmn } \\
\text { V2.mcd }\end{array}$ & $\begin{array}{l}\text { Mathcad 2001i } \\
\text { Professional }\end{array}$ & $\begin{array}{l}\text { Calculation file for } \mathrm{K} \text { factor of joint } \\
\text { orientation. Application: DRKBA } \\
\text { analyses of nonlithophysal rock. } \\
\text { Calculation details provided in } \\
\text { Appendix D (Section D7). }\end{array}$ & $\mathrm{N} / \mathrm{A}$ \\
\hline Orient-Tptpmn .xIs & Microsoft Excel 97 SR-2 & $\begin{array}{l}\text { Calculation file for components for } \\
\text { the orientation matrix. } \\
\text { Application: DRKBA analyses of } \\
\text { nonlithophysal rock. Calculation } \\
\text { details provided in Appendix D } \\
\text { (Section D7). }\end{array}$ & $\mathrm{N} / \mathrm{A}$ \\
\hline $\begin{array}{l}\text { Thermal curve } \\
\text { V1.xls }\end{array}$ & Microsoft Excel 97 SR-2 & $\begin{array}{l}\text { Calculation file for ratio of effective } \\
\text { shear stress for thermal effect. } \\
\text { Application: DRKBA analyses of } \\
\text { nonlithophysal rock. Calculation } \\
\text { details provided in Appendix D } \\
\text { (Section D5). }\end{array}$ & $\mathrm{N} / \mathrm{A}$ \\
\hline $\begin{array}{l}\text { Time thermal } \\
\text { cohesion } \\
\text { degradation } \\
\text { V1.mcd }\end{array}$ & $\begin{array}{l}\text { Mathcad 2001i } \\
\text { Professional }\end{array}$ & $\begin{array}{l}\text { Calculation file for cohesion } \\
\text { degradation due to time and } \\
\text { thermal effects. Application: } \\
\text { DRKBA analyses of } \\
\text { nonlithophysal rock. Calculation } \\
\text { details provided in Appendix D } \\
\text { (Section D5). }\end{array}$ & $\mathrm{N} / \mathrm{A}$ \\
\hline $\begin{array}{l}\text { tpmn seismic } 75 \\
\text { res } v 2 . x 1 s\end{array}$ & Microsoft Excel 97 SR-2 & $\begin{array}{l}\text { Calculation file for rock blocks } \\
\text { cumulative percentage of } \\
\text { occurrence. Application: DRKBA } \\
\text { analyses of nonlithophysal rock. } \\
\text { Calculation details provided in } \\
\text { Appendix D (Section D6). }\end{array}$ & $\mathrm{N} / \mathrm{A}$ \\
\hline $\begin{array}{l}\text { Tptpll- FracMan } \\
\text { Generated Fracture } \\
\text { Data.xls }\end{array}$ & Microsoft Excel 97 SR-2 & $\begin{array}{l}\text { Calculation file for converting } \\
\text { FracMan fracture output to 3DEC } \\
\text { input. Application: rockfall } \\
\text { models. Calculation details } \\
\text { provided in Appendix L. }\end{array}$ & $\mathrm{N} / \mathrm{A}$ \\
\hline
\end{tabular}


Table A-1. List of Drift Degradation Calculation Files (Continued)

\begin{tabular}{|c|c|c|c|}
\hline File Name & File Type & Brief Description & References \\
\hline $\begin{array}{l}\text { 3DEC- } \\
\text { S1shtA_TPO.xIs }\end{array}$ & Microsoft Excel 97 SR-2 & $\begin{array}{l}\text { Calculation file for converting } \\
\text { FracMan fracture output to 3DEC } \\
\text { input. Application: rockfall } \\
\text { models. Calculation details } \\
\text { provided in Appendix L. }\end{array}$ & $\mathrm{N} / \mathrm{A}$ \\
\hline $\begin{array}{l}\text { 3DEC- } \\
\text { S1shtB_TPO.xls }\end{array}$ & Microsoft Excel 97 SR-2 & $\begin{array}{l}\text { Calculation file for converting } \\
\text { FracMan fracture output to 3DEC } \\
\text { input. Application: rockfall } \\
\text { models. Calculation details } \\
\text { provided in Appendix L. }\end{array}$ & $\mathrm{N} / \mathrm{A}$ \\
\hline $\begin{array}{l}\text { 3DEC- } \\
\text { s2sht_TPO.xIs }\end{array}$ & Microsoft Excel 97 SR-2 & $\begin{array}{l}\text { Calculation file for converting } \\
\text { FracMan fracture output to 3DEC } \\
\text { input. Application: rockfall } \\
\text { models. Calculation details } \\
\text { provided in Appendix L. }\end{array}$ & N/A \\
\hline $\begin{array}{l}\text { 3DEC- } \\
\text { s3_sht_TPO.xls }\end{array}$ & Microsoft Excel 97 SR-2 & $\begin{array}{l}\text { Calculation file for converting } \\
\text { FracMan fracture output to 3DEC } \\
\text { input. Application: rockfall } \\
\text { models. Calculation details } \\
\text { provided in Appendix L. }\end{array}$ & N/A \\
\hline $\begin{array}{l}\text { 3DEC-VPPLONG } \\
\text { TPO.xls }\end{array}$ & Microsoft Excel 97 SR-2 & $\begin{array}{l}\text { Calculation file for converting } \\
\text { FracMan fracture output to 3DEC } \\
\text { input. Application: rockfall } \\
\text { models. Calculation details } \\
\text { provided in Appendix L. }\end{array}$ & N/A \\
\hline $\begin{array}{l}\text { Drift Deg AMR AA } \\
\text { PMap.xls }\end{array}$ & Microsoft Excel 97 SR-2 & $\begin{array}{l}\text { Calculation file for descriptive } \\
\text { statistics for lithophysal } \\
\text { abundance and lithophysal } \\
\text { characteristics in the ECRB } \\
\text { (Enhanced Characterization of the } \\
\text { Repository Block) Cross-Drift. } \\
\text { Application: lithophysal rockfall } \\
\text { model. Calculation details } \\
\text { provided in Appendix O } \\
\text { (Section 06). }\end{array}$ & $N / A$ \\
\hline
\end{tabular}


Table A-1. List of Drift Degradation Calculation Files (Continued)

\begin{tabular}{|c|c|c|c|}
\hline File Name & File Type & Brief Description & References \\
\hline $\begin{array}{l}\text { Drift Deg AMR AB } \\
\text { A-Trav.xls }\end{array}$ & Microsoft Excel 97 SR-2 & $\begin{array}{l}\text { Calculation file for descriptive } \\
\text { statistics for lithophysal } \\
\text { abundance and lithophysal } \\
\text { characteristics in the ECRB } \\
\text { Cross-Drift. Application: } \\
\text { lithophysal rockfall model. } \\
\text { Calculation details provided in } \\
\text { Appendix O (Section O6). }\end{array}$ & GS021008314224.002 [DIRS 161910] \\
\hline $\begin{array}{l}\text { Drift Deg AMR AC } \\
\text { T-Trav.xls }\end{array}$ & Microsoft Excel 97 SR-2 & $\begin{array}{l}\text { Calculation file for descriptive } \\
\text { statistics for lithophysal } \\
\text { abundance and lithophysal } \\
\text { characteristics in the ECRB } \\
\text { Cross-Drift. Application: } \\
\text { lithophysal rockfall model. } \\
\text { Calculation details provided in } \\
\text { Appendix O (Section O6). }\end{array}$ & GS021008314224.002 [DIRS 161910] \\
\hline $\begin{array}{l}\text { Drift Deg AMR AD } \\
\text { L-Litho V1.xls }\end{array}$ & Microsoft Excel 97 SR-2 & $\begin{array}{l}\text { Calculation file for descriptive } \\
\text { statistics for lithophysal } \\
\text { abundance and lithophysal } \\
\text { characteristics in the ECRB } \\
\text { Cross-Drift. Application: } \\
\text { lithophysal rockfall model. } \\
\text { Calculation details provided in } \\
\text { Appendix O (Section O6). }\end{array}$ & GS021008314224.002 [DIRS 161910] \\
\hline $\begin{array}{l}\text { Drift Deg AMR AE } \\
\text { Mongano.xIs }\end{array}$ & Microsoft Excel 97 SR-2 & $\begin{array}{l}\text { Calculation file for descriptive } \\
\text { statistics for lithophysal } \\
\text { abundance and lithophysal } \\
\text { characteristics in the ECRB } \\
\text { Cross-Drift. Application: } \\
\text { lithophysal rockfall model. } \\
\text { Calculation details provided in } \\
\text { Appendix O (Section O6). }\end{array}$ & Mongano et al 1999 [DIRS 149850] \\
\hline
\end{tabular}


Table A-1. List of Drift Degradation Calculation Files (Continued)

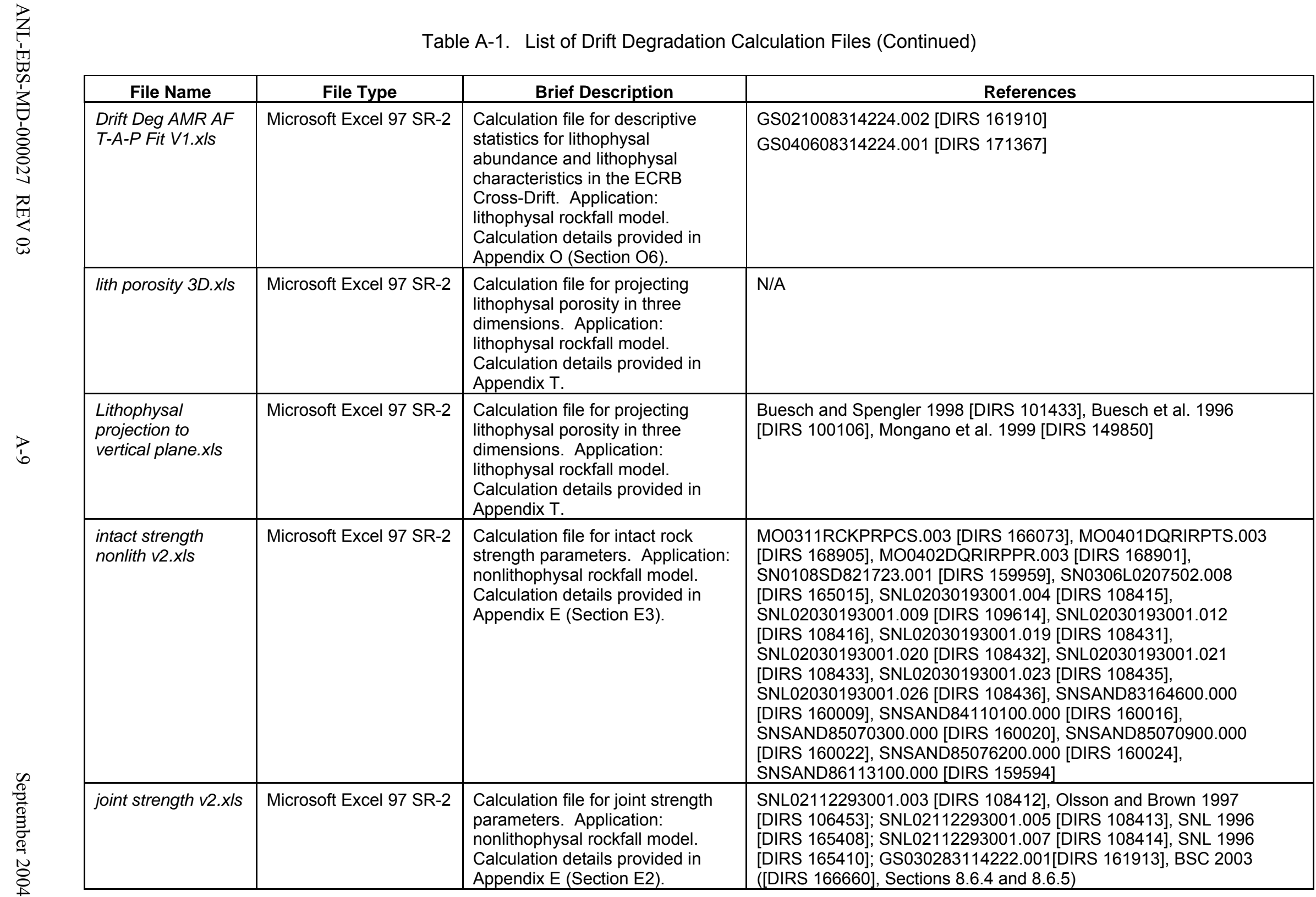




\begin{tabular}{|c|c|c|c|}
\hline File Name & File Type & Brief Description & References \\
\hline $\begin{array}{l}\text { rock mass strength } \\
\text { v2.xls }\end{array}$ & Microsoft Excel 97 SR-2 & $\begin{array}{l}\text { Calculation file for rock mass } \\
\text { strength properties. Application: } \\
\text { thermal-mechanical calculation } \\
\text { and rockfall models. Calculation } \\
\text { details provided in Appendix E } \\
\text { (Section E4). }\end{array}$ & 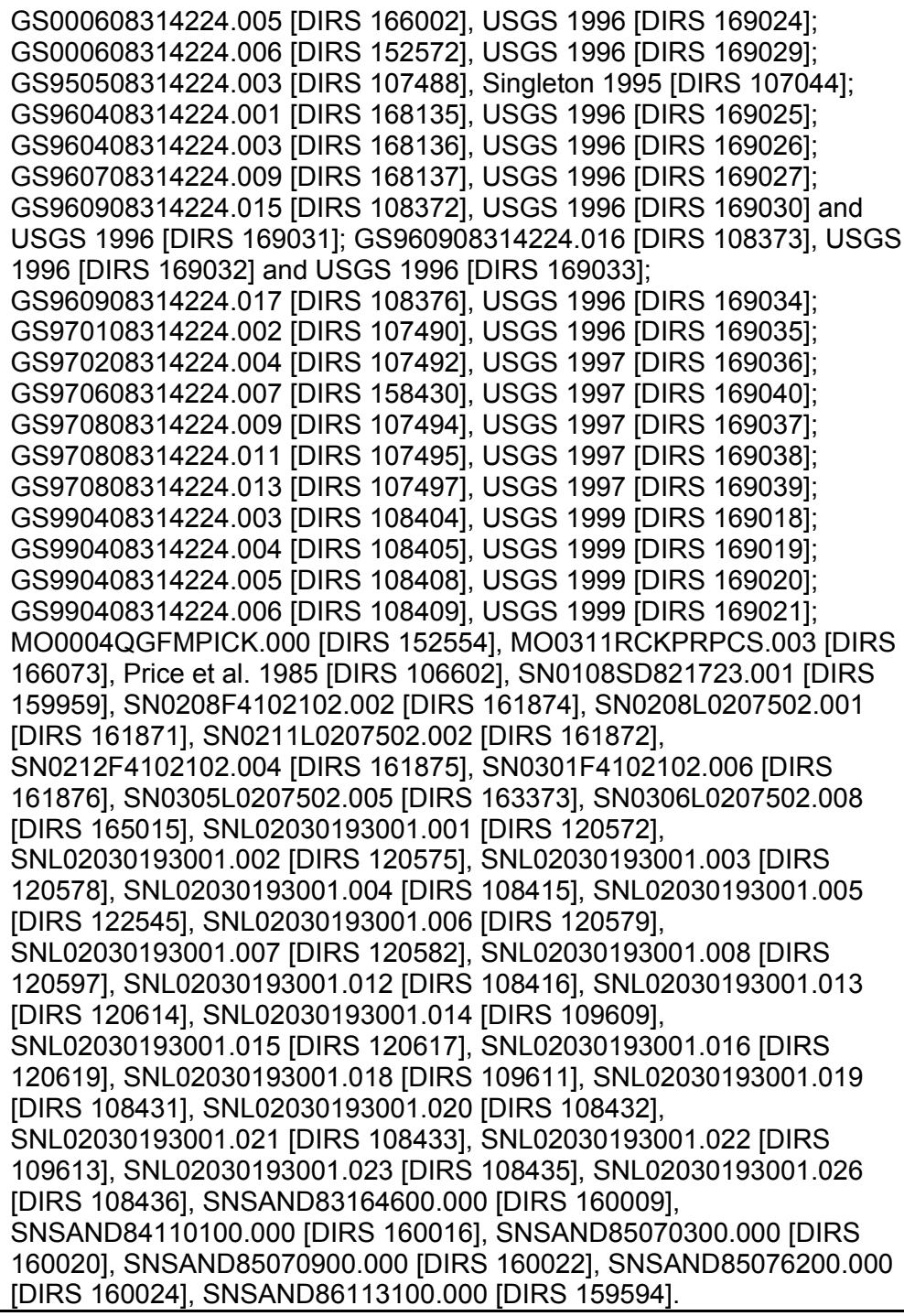 \\
\hline thermal properties & Microsoft Excel 97 SR-2 & Calculation file for thermal & SN0307T0510902.003 [DIRS 164196], SN0303T0503102.008 [DIRS \\
\hline
\end{tabular}


Table A-1. List of Drift Degradation Calculation Files (Continued)

\begin{tabular}{|c|c|c|c|}
\hline File Name & File Type & Brief Description & $\begin{array}{c}\text { References } \\
\end{array}$ \\
\hline TM units v2.xIs & & $\begin{array}{l}\text { properties. Application: thermal- } \\
\text { mechanical calculation and } \\
\text { rockfall models. Calculation } \\
\text { details provided in Appendix D } \\
\text { (Sections D1 and D5). }\end{array}$ & $\begin{array}{l}\text { 162401], SN0404T0503102.11 [DIRS 169129], SNL01B05059301.006, } \\
\text { Brodsky et al. 1997.([DIRS 100653], Table 4-4). }\end{array}$ \\
\hline $\begin{array}{l}\text { lith-summary- } \\
\text { 062104.xls }\end{array}$ & Microsoft Excel 97 SR-2 & $\begin{array}{l}\text { Summary of lithophysal rock } \\
\text { properties. Application: } \\
\text { lithophysal rockfall model. } \\
\text { Calculation details provided in } \\
\text { Appendix S. }\end{array}$ & $\begin{array}{l}\text { Price et al. } 1985 \text { [DIRS 106602], SN0208L0207502.001 [DIRS 161871], } \\
\text { SN0211L0207502.002 [DIRS 161872] }\end{array}$ \\
\hline $\begin{array}{l}\text { modified lith- } \\
\text { current.xls }\end{array}$ & Microsoft Excel 97 SR-2 & $\begin{array}{l}\text { Summary of lithophysal rock } \\
\text { properties. Application: } \\
\text { lithophysal rockfall model. } \\
\text { Calculation details provided in } \\
\text { Appendix S. }\end{array}$ & $\begin{array}{l}\text { Price et al. } 1985 \text { [DIRS 106602], SN0208L0207502.001 [DIRS 161871], } \\
\text { SN0211L0207502.002 [DIRS 161872] }\end{array}$ \\
\hline $\begin{array}{l}\text { Beta-small } \\
\text { scale.xls }\end{array}$ & Microsoft Excel 97.SR-2 & $\begin{array}{l}\text { Calculation file for beta distribution } \\
\text { parameters }(a, b, p, q) \text { for joint } \\
\text { spacing, trace length, and } \\
\text { location. Application: DRKBA } \\
\text { analysis of nonlithophysal rock. } \\
\text { Calculation details provided in } \\
\text { Appendix D (Section D7 }\end{array}$ & Derman, et al. 1973 [DIRS 108444] \\
\hline K-small scale.mcd & $\begin{array}{l}\text { Mathcad } 2001 \mathrm{i} \\
\text { Professional }\end{array}$ & $\begin{array}{l}\text { Calculation file for } \mathrm{K} \text { factor of joint } \\
\text { orientation. Application: DRKBA } \\
\text { analyses of nonlithophysal rock. } \\
\text { Calculation details provided in } \\
\text { Appendix D (Section D7). }\end{array}$ & N/A \\
\hline $\begin{array}{l}\text { small scale } \\
\text { fractures results } \\
\text { rev1.xls }\end{array}$ & Microsoft Excel 97 SR-2 & $\begin{array}{l}\text { Calculation file for rock blocks } \\
\text { cumulative percentage of } \\
\text { occurrence. Application: DRKBA } \\
\text { analyses of nonlithophysal rock. } \\
\text { Calculation details provided in } \\
\text { Appendix D. }\end{array}$ & N/A \\
\hline
\end{tabular}


Table A-1. List of Drift Degradation Calculation Files (Continued)

\begin{tabular}{|c|c|c|c|}
\hline File Name & File Type & Brief Description & References \\
\hline $\begin{array}{l}\text { small trace } \\
\text { filtering.xIs }\end{array}$ & Microsoft Excel 97 SR-2 & $\begin{array}{l}\text { Calculation file for small-scale } \\
\text { joint orientation data. Application: } \\
\text { DRKBA analyses of } \\
\text { nonlithophysal rock. Calculation } \\
\text { details provided in Appendix D } \\
\text { (Section D7). }\end{array}$ & $\mathrm{N} / \mathrm{A}$ \\
\hline small.dip & DIPS Version 4.03 & $\begin{array}{l}\text { Calculation file for the graphical } \\
\text { presentation of fracture data. } \\
\text { Application: DRKBA analyses of } \\
\text { small trace length fracture data. } \\
\text { Calculation details provided in } \\
\text { Section 6.3.3 and Appendix D. }\end{array}$ & $\mathrm{N} / \mathrm{A}$ \\
\hline $\begin{array}{l}\text { Heat_Decay_Cal_L } \\
\text { A1450.xIs }\end{array}$ & Microsoft Excel 97 SR-2 & $\begin{array}{l}\text { Calculation file for heat decay } \\
\text { curves. Application: thermal- } \\
\text { mechanical calculation. } \\
\text { Calculation details provided in } \\
\text { Section } 6.2 \text {. }\end{array}$ & $\mathrm{N} / \mathrm{A}$ \\
\hline $\begin{array}{l}\text { LA1450_NUFT_Te } \\
\text { mp_crss-sctn3.xIs }\end{array}$ & Microsoft Excel 97 SR-2 & $\begin{array}{l}\text { Calculation file for temperature } \\
\text { histories at the drift crown. } \\
\text { Application: thermal-mechanical } \\
\text { calculation. Calculation details } \\
\text { provided in Section } 6.2 \text {. }\end{array}$ & $\mathrm{N} / \mathrm{A}$ \\
\hline $\begin{array}{l}\text { LA1450_R5C10_N } \\
\text { UFT_Temp_crss- } \\
\text { sctn.xls }\end{array}$ & Microsoft Excel 97 SR-2 & $\begin{array}{l}\text { Calculation file for temperature } \\
\text { histories at the drift crown. } \\
\text { Application: impact analyses on } \\
\text { LDTH sub-model. Calculation } \\
\text { details provided in Appendix Q } \\
\text { (Section Q1). }\end{array}$ & $\mathrm{N} / \mathrm{A}$ \\
\hline $\begin{array}{l}\text { ground motion } \\
\text { parameters.xls }\end{array}$ & Microsoft Excel 97 SR-2 & $\begin{array}{l}\text { Summary of ground motion } \\
\text { parameters (Sections 6.3.1.2.1, } \\
6.4 .2 .2 \text {, and Appendix X) }\end{array}$ & $\begin{array}{l}\text { MO0407TMHIS104.003 [DIRS 170599]; MO0306SDSAVDTH.000 } \\
\text { [DIRS 164033]; MO0402AVDTM105.001 [DIRS 168890]; } \\
\text { MO0403AVDSC106.001 [DIRS 168891]; MO0403AVTMH107.003 } \\
\text { [DIRS 168892]; MO0301TMHIS106.001 [DIRS 161868] }\end{array}$ \\
\hline $\begin{array}{l}{ }^{*} \text { power cal.mcd } \\
\left({ }^{*} \text { represents }\right. \\
\text { multiple files with } \\
\text { the ground motion } \\
\text { set indicated) }\end{array}$ & $\begin{array}{l}\text { Mathcad 2001i } \\
\text { Professional }\end{array}$ & $\begin{array}{l}\text { Calculation file for power spectral } \\
\text { density using the fast Fourier } \\
\text { transform function in Mathcad. } \\
\text { Application: ground motion } \\
\text { sensitivity (Section 6.4.2.2). }\end{array}$ & $\mathrm{N} / \mathrm{A}$ \\
\hline
\end{tabular}




\section{APPENDIX B}

DEVELOPMENT OF JOINT DATA FOR THE TPTPLL ZONE 


\section{DEVELOPMENT OF JOINT DATA FOR THE Tptpll ZONE}

A description of the generation of representative rock volume using FracMan is presented in Section 6.1.6. This appendix provides details for the development of FracMan rock volume for the Tptpll (lithophysal rock) zone. The FracMan output data for this zone is provided in the file Tptpll-Fracman Generated Fracture Data.xls (Table A-1).

To begin the analysis of the Tptpll, the observed vapor-phase partings are identified in the detailed line survey data. This is done by sorting the observed data with respect to dip and identifying those fractures that have a dip of less than 45 degrees. For the Tptpll there are 20 vapor-phase partings. The mean pole orientation is 239/76. Figure B-1 shows the Great Circle for the mean orientation of the vapor-phase partings. The poles for the other sets are also plotted.

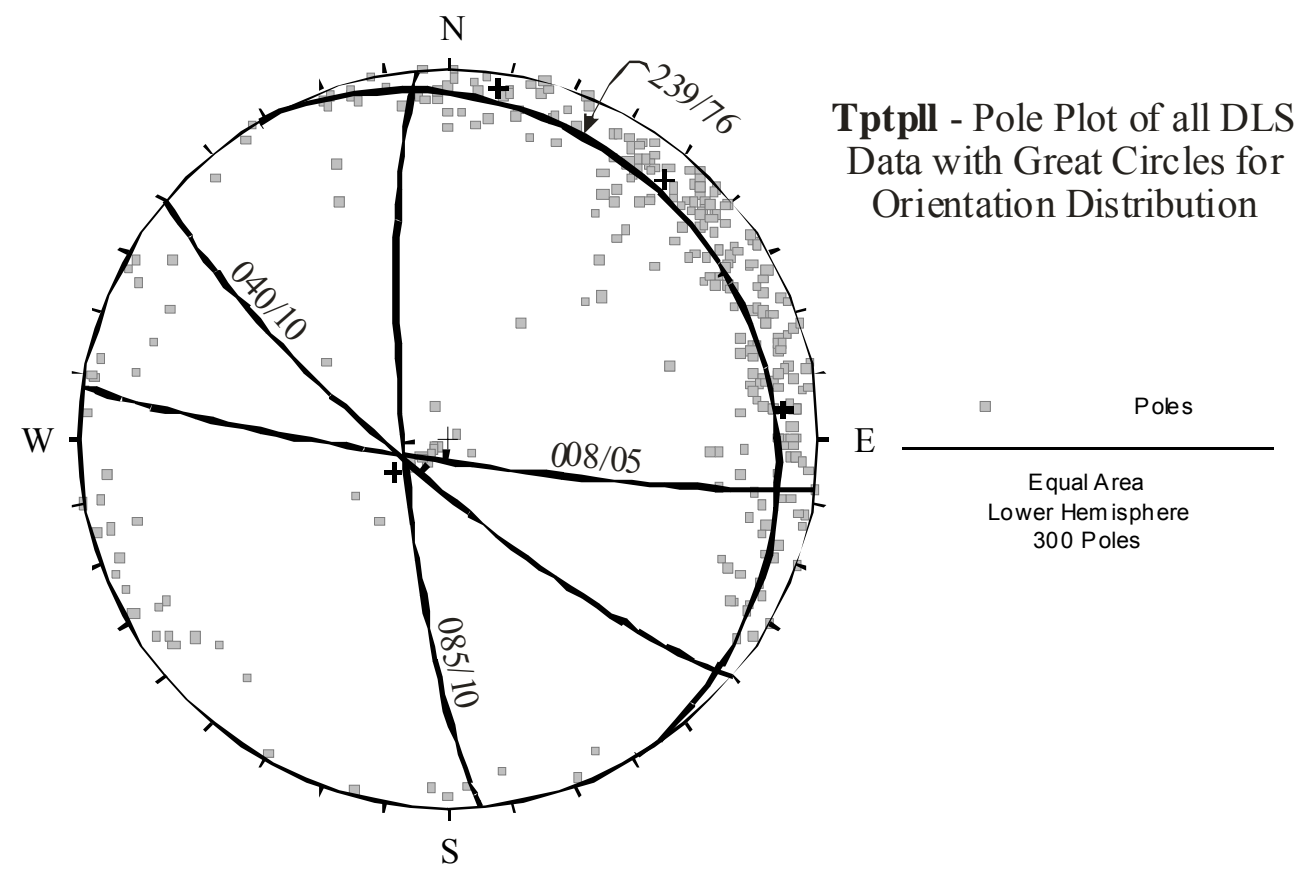

Source: DTN: GS990408314224.001 [DIRS 108396]; GS990408314224.002 [DIRS 105625].

Figure B-1. Tptpll Pole Plot Showing Great Circles for the Tptpll Fractures

The remaining fracture trace lengths are plotted on a histogram and the trace length distribution is evaluated. The distribution is polymodal. A break is defined to separate the long fractures from the short fractures. For the Tptpll, this break occurs at approximately $3 \mathrm{~m}$ (Figure B-2). The distribution of poles for both the cooling and later cooling/tectonic fractures is shown in Figure B-1. The set attributes developed from the detailed line survey are provided in Table B-1. 
In Figure B-3, the values used as input to the FracMan simulation are shown. Table B-2 is a direct comparison of the observed detailed line survey data with the FracMan output with respect to the number of fractures in each set as well as the proportions of the total in each set. The proportions of fracture types are very important to establish a representative FracMan network. The actual number of fractures is not relevant because the sampling areas are not comparable.

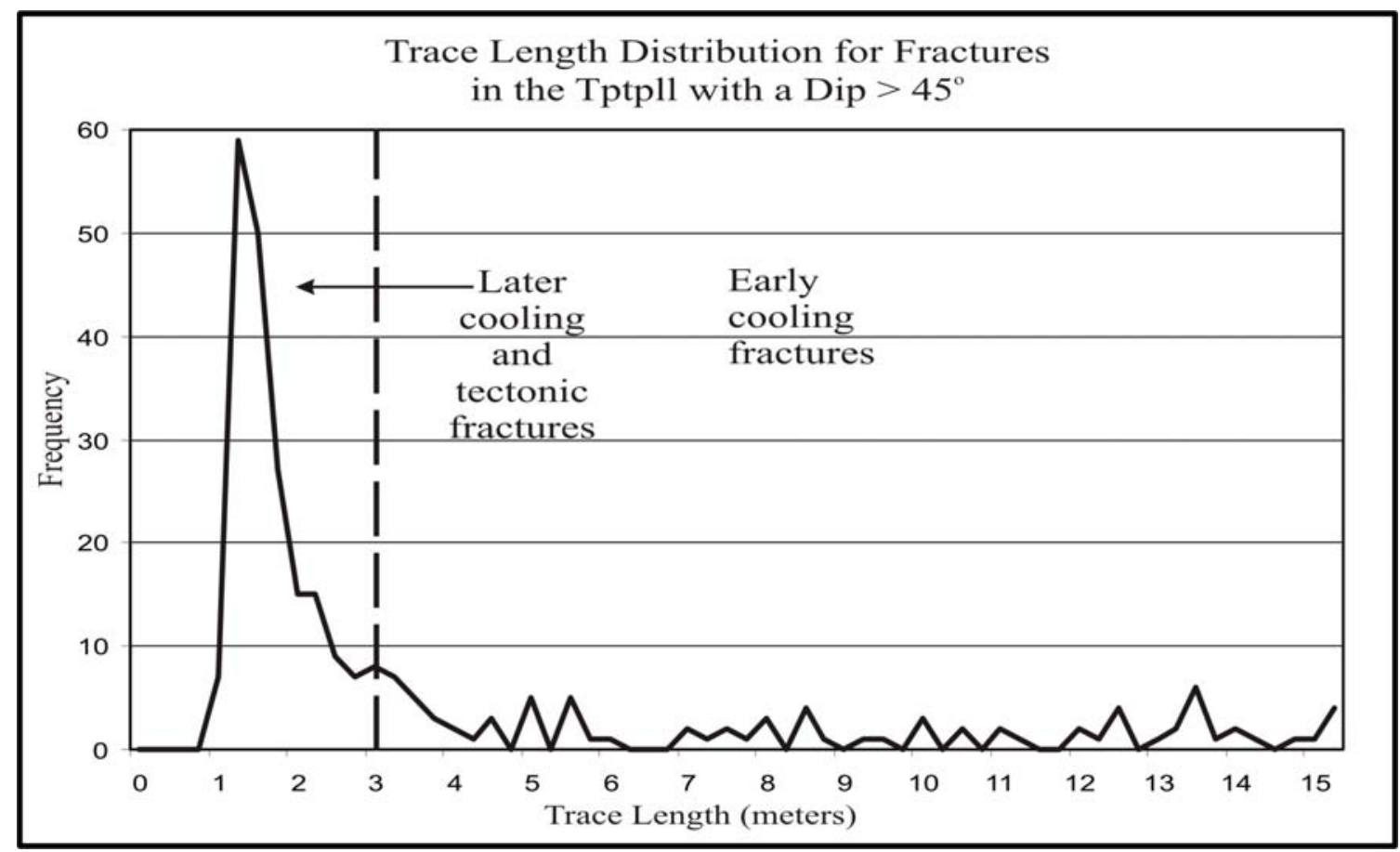

Source: DTN: GS990408314224.001 [DIRS 108396]; GS990408314224.002 [DIRS 105625].

Figure B-2. Trace Length Distribution of the Tptpll Fractures $\left(>45^{\circ}\right)$

Table B-1. Summary Statistics of the Tptpll Detailed Line Survey Data

\begin{tabular}{|l|l|c|c|}
\hline \multicolumn{1}{|c|}{ Set } & \multicolumn{1}{|c|}{$\begin{array}{c}\text { Strike \& Dip } \\
\text { (Trend \& Plunge) }\end{array}$} & $\begin{array}{c}\text { Trace Length } \\
\text { (mean) }\end{array}$ & Number of Fractures \\
\hline Vapor-Phase Partings & $\begin{array}{l}329 / 14 \\
(239 / 76)\end{array}$ & $7.2 \mathrm{~m}$ & 20 \\
\hline $1^{\text {st }}$ Generation Cooling Joints & $\begin{array}{l}130 / 80 \& 175 / 80 \\
(040 / 10 \& 085 / 10)\end{array}$ & $9.5 \mathrm{~m}$ & 71 \\
\hline $\begin{array}{l}2^{\text {nd }} \text { Generation Cooling and Tectonic } \\
\text { Joints }\end{array}$ & $\begin{array}{l}130 / 80,175 / 80,278 / 85 \\
(040 / 10,085 / 10,008 / 05)\end{array}$ & $1.6 \mathrm{~m}$ & 209 \\
\hline
\end{tabular}

Source: DTNs: GS990408314224.001 [DIRS 108396]; GS990408314224.002 [DIRS 105625].

NOTE: Strike and dip values were determined graphically using the stereonet shown in Figure B-1.

The most critical comparison is presented in Figure B-4. This is the direct comparison between actual full periphery geologic maps from the ECRB Cross-Drift to synthetic full periphery geologic maps from FracMan. The synthetic full periphery geologic maps are not a replicate, but based on professional expertise and judgment, the FracMan full periphery geologic maps are adequately similar to the observed full periphery geologic maps both for intensity and lengths. 


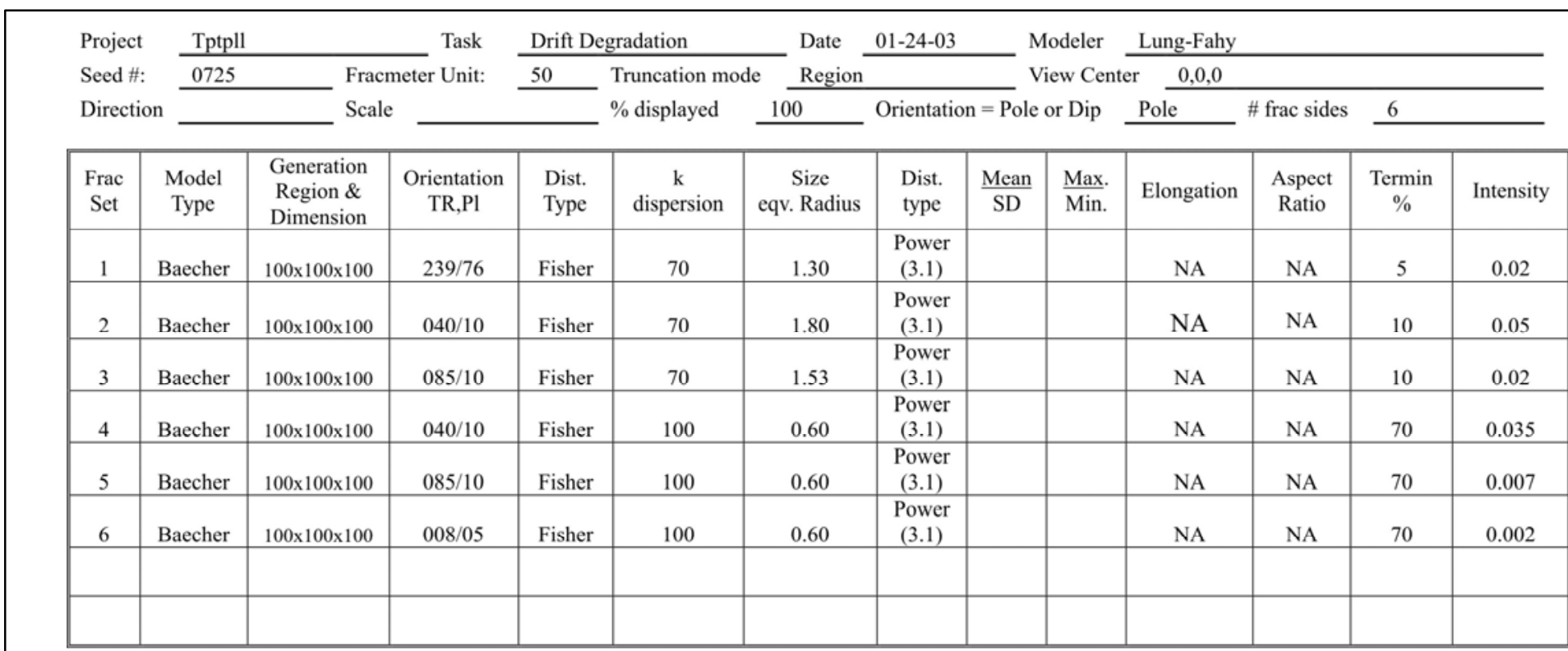

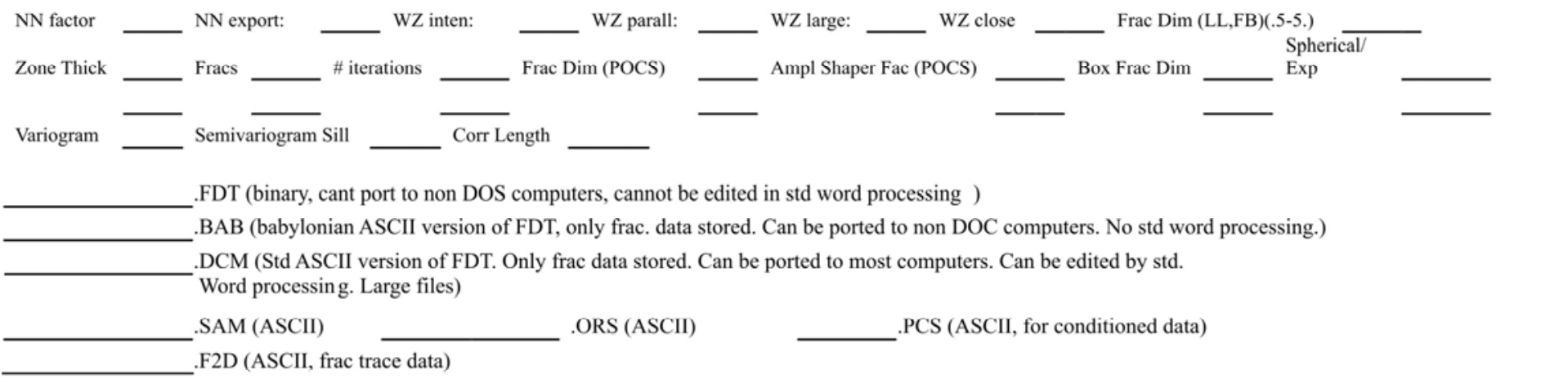

Source: DTN: GS990408314224.001 [DIRS 108396]; GS990408314224.002 [DIRS 105625].

NOTE: The parameter, "k dispersion" is determined visually by comparing simulated stereonets to observed stereonets. The parameter, "size eqv. radius" is the mean radius $(\mathrm{m})$. The power law distribution is used for the parameter, "dist. type." The power law is selected because the fracture process generally follows power law physics, such that the number of fractures greater than a given length $(x)$ is proportional to $1 / x$ raised to the power law exponent. The parameter, "intensity" is selected to maintain the proportion of fractures in each set.

Figure B-3. FracMan Input Sheet for the Tptpll 
Table B-2. Relative Proportions of Fractures from the Detailed Line Survey Versus FracMan Output for the Tptpll

\begin{tabular}{|l|l|l|l|l|l|}
\hline \multicolumn{1}{|c|}{ Detailed Line Survey } & \multicolumn{3}{c|}{ FracMan } \\
\hline \multicolumn{1}{|c|}{ Feature } & $\begin{array}{c}\text { Number of } \\
\text { fractures }\end{array}$ & Proportion & \multicolumn{1}{c|}{ Feature } & $\begin{array}{c}\text { Number of } \\
\text { Fractures }\end{array}$ & Proportion \\
\hline Vapor-Phase Partings & 20 & $6 \%$ & Vapor-Phase Partings & 647 & $7 \%$ \\
\hline $\begin{array}{l}1^{\text {st }} \text { Generation } \\
\text { Cooling Joints }\end{array}$ & 71 & $24 \%$ & $1^{\text {st }}$ Generation Cooling Joints & 2494 & $25 \%$ \\
\hline $\begin{array}{l}2^{\text {nd }} \text { Generation } \\
\text { Jooling and Tectonic }\end{array}$ & 209 & $70 \%$ & $\begin{array}{l}2^{\text {nd }} \text { Generation Cooling and } \\
\text { Tectonic Joints }\end{array}$ & 6738 & $68 \%$ \\
\hline Total & 300 & $100 \%$ & Total & 9879 & $100 \%$ \\
\hline
\end{tabular}

Source: DTNs: GS990408314224.001 [DIRS 108396]; GS990408314224.002 [DIRS 105625].

The orientation comparison is presented in Figure B-5. Pole plots for the detailed line survey data and the FracMan output are compared to ensure that the clusters from the detailed line survey are correctly simulated in FracMan. For the Tptpll this comparison demonstrates that the FracMan output is adequately similar to the observed data. The means are similar and the spread of the data about the mean is similar. Not all observed fractures are simulated because the FracMan output has less scatter and is not a replicate.

Figure B-6 provides confirmation that the radius distribution of fractures from FracMan matches reasonably well with the observed trace lengths. Figure B-7 shows that fracture intensity, that is the slope, is nearly constant until approximately Station $21+50$. At this point a sequence of small offset faults occurs causing the intensity to increase. 
(a)
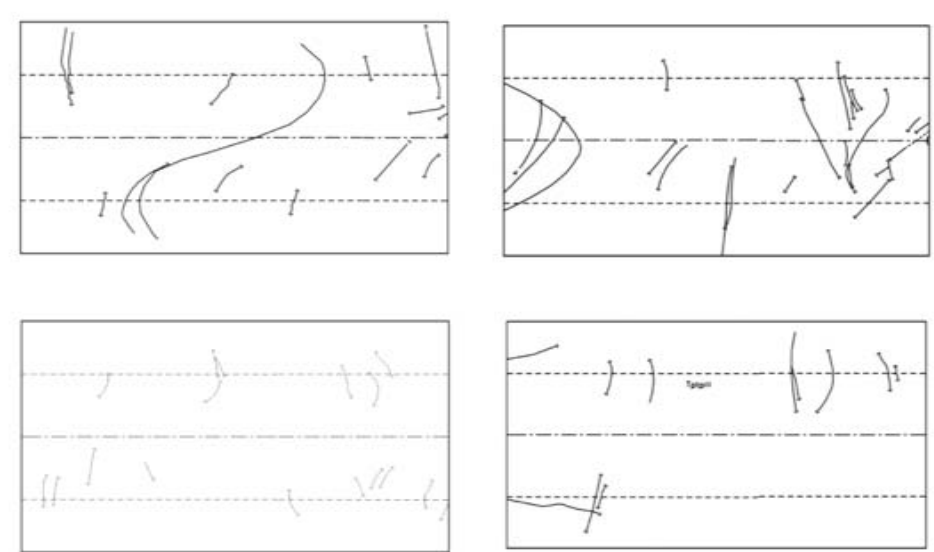

(b)
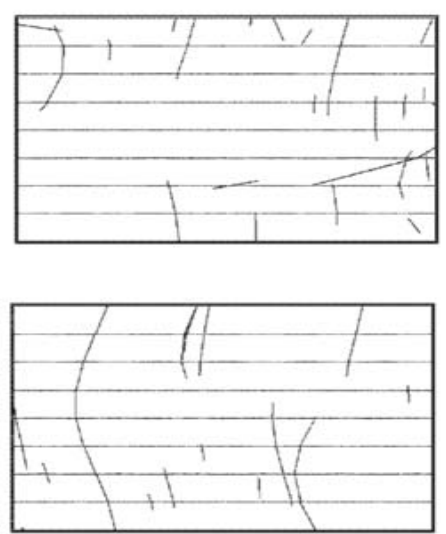
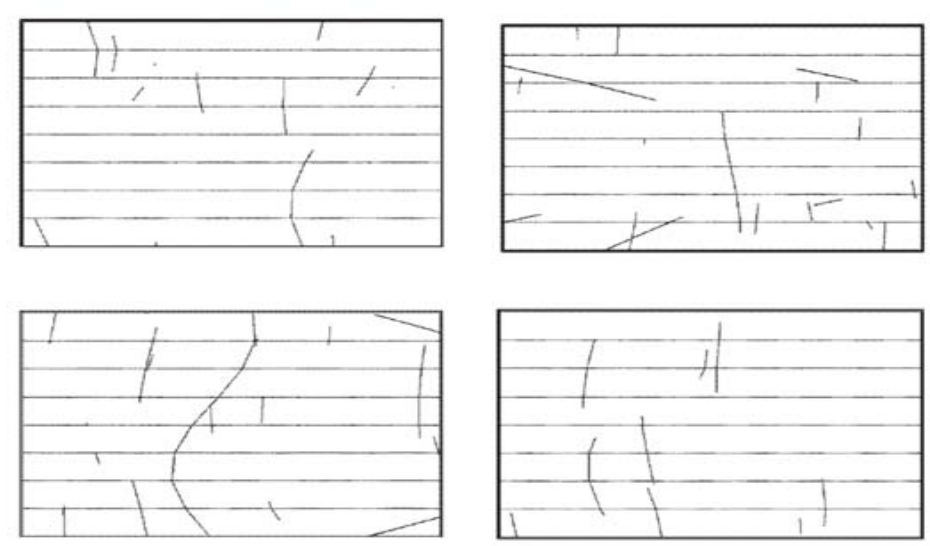
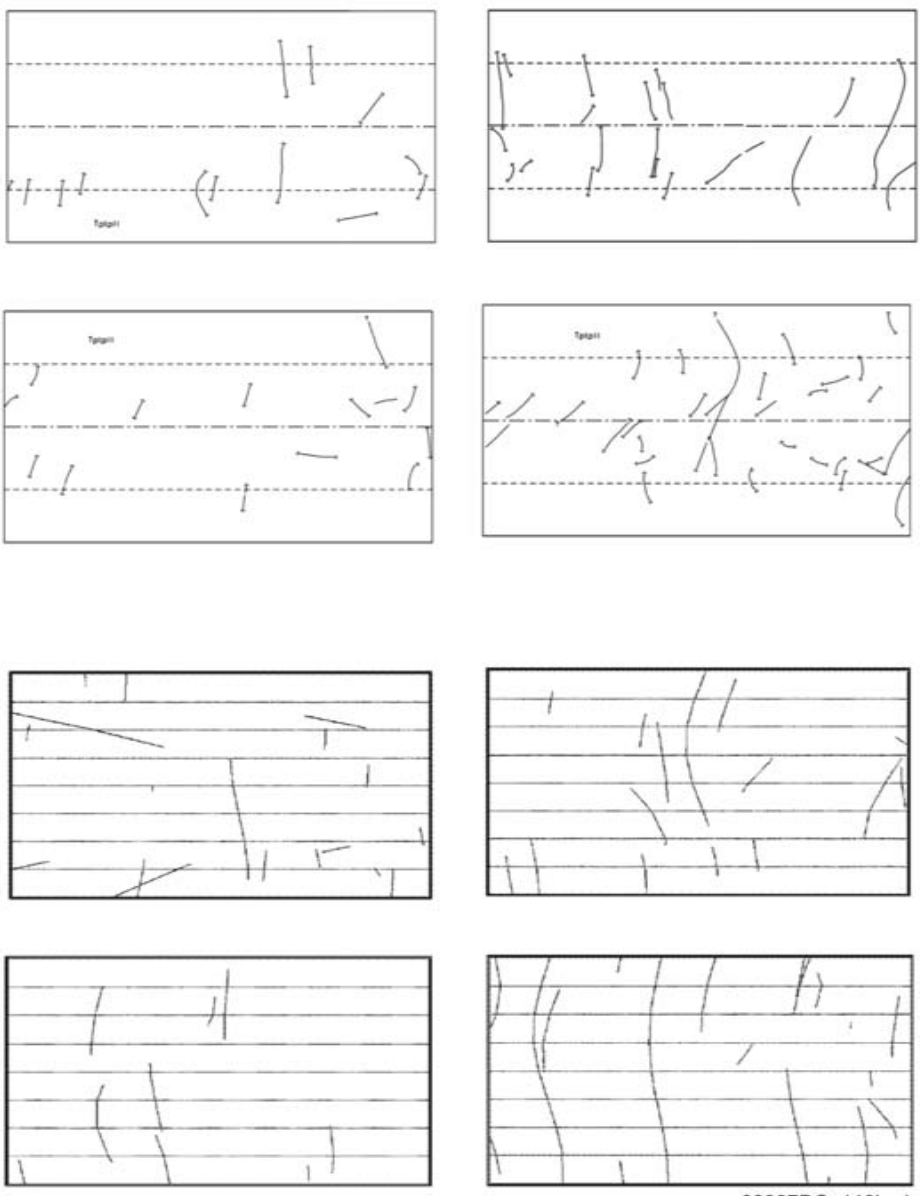

00387DC_113b.ai

Source: DTN: GS990408314224.004 [DIRS 108405]; GS990408314224.005 [DIRS 108408]; GS990408314224.006 [DIRS 108409].

NOTE: The purpose of this figure is to illustrate the geologic structure contained on a full periphery geologic map. The annotated information on this figure is not intended to be legible. (a) from the Tptpll in the ECRB Cross-Drift; (b) with Simulated Full Periphery Geologic Maps from the FracMan Cube.

Figure B-4. Comparison of Full Periphery Geologic Maps 


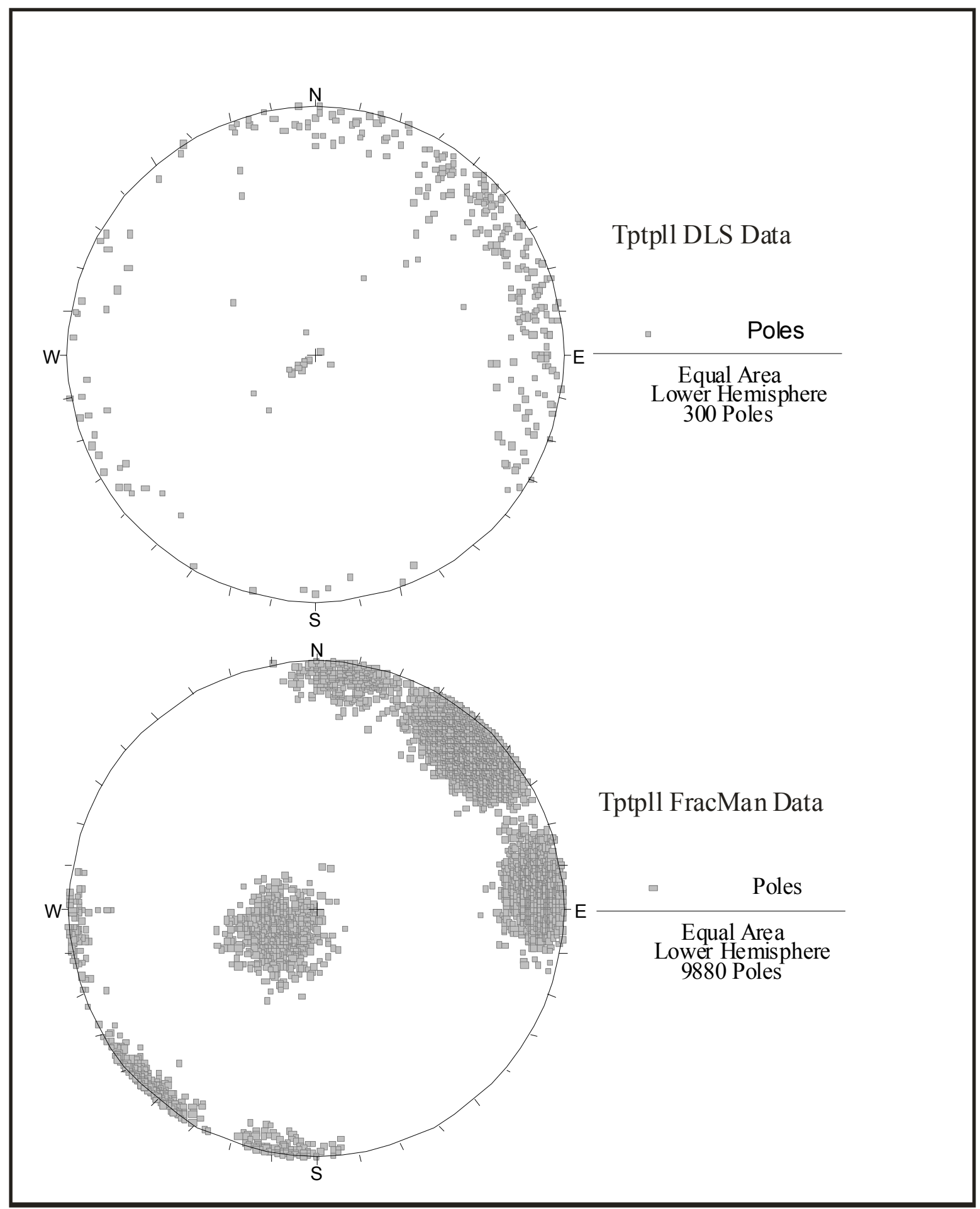

Source: DTN: GS990408314224.001 [DIRS 108396]; GS990408314224.002 [DIRS 105625].

NOTE: The FracMan data is representative of the entire rock mass, and is not a replicate of the detailed line survey data. Therefore, the number of poles in FracMan is expected to be much greater than the detailed line survey data. The location of the poles should agree, which is shown by this figure.

Figure B-5. Comparison of the Observed Tptpll Fracture Poles to the FracMan Fracture Poles 


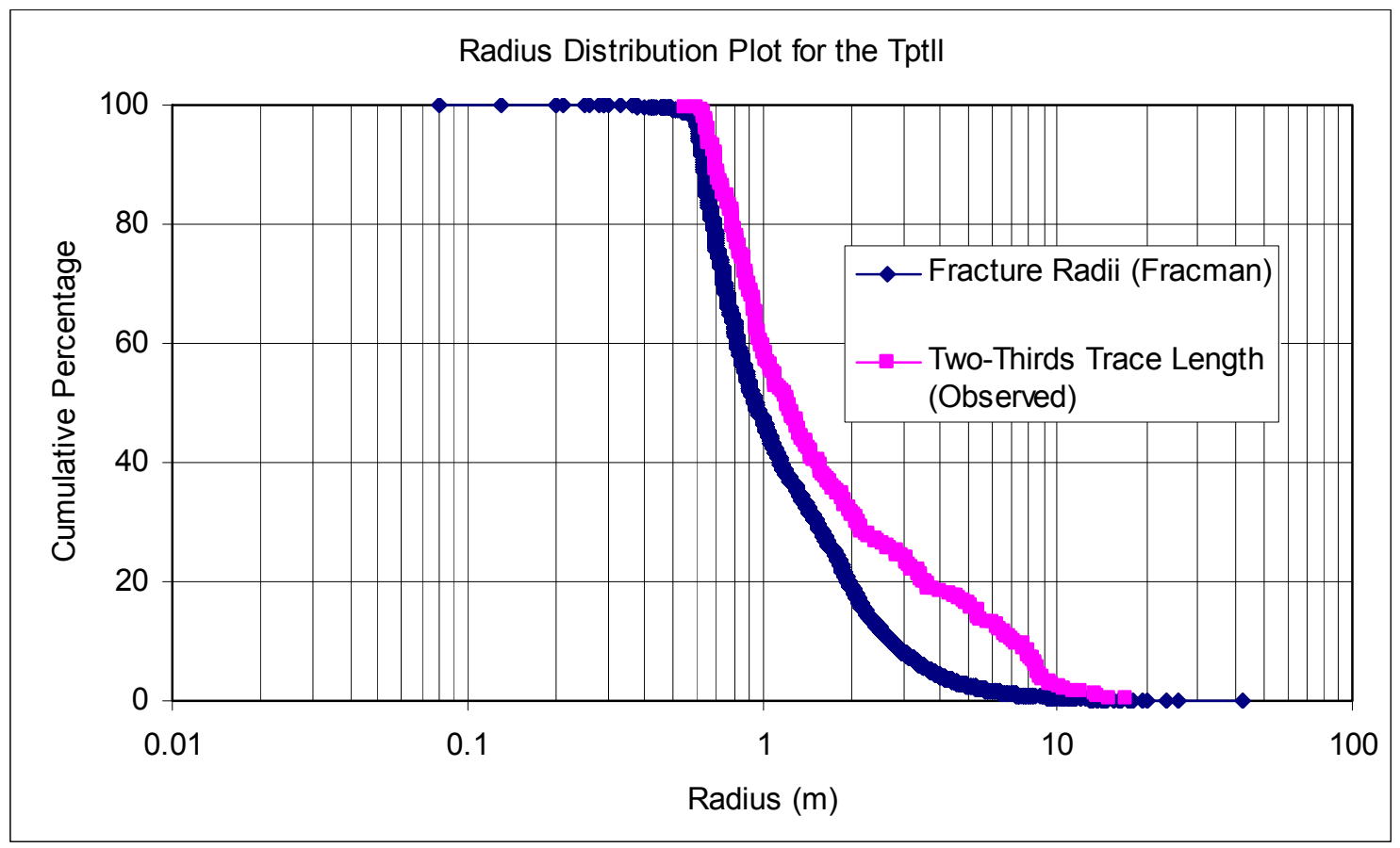

Source: DTN: GS990408314224.001 [DIRS 108396]; GS990408314224.002 [DIRS 105652].

NOTE: This figure compares fracture radii from FracMan to observed trace length data scaled by two-thirds. This is based on the relationship between fracture trace length and radius (see Figure D-11 and Equation 6-3). The mean fracture radius should be about two thirds of the mean trace length observed.

Figure B-6. Comparison of the Observed Trace Length Distribution (Scaled by Two Thirds) to the FracMan Radii Distribution for Tptpll

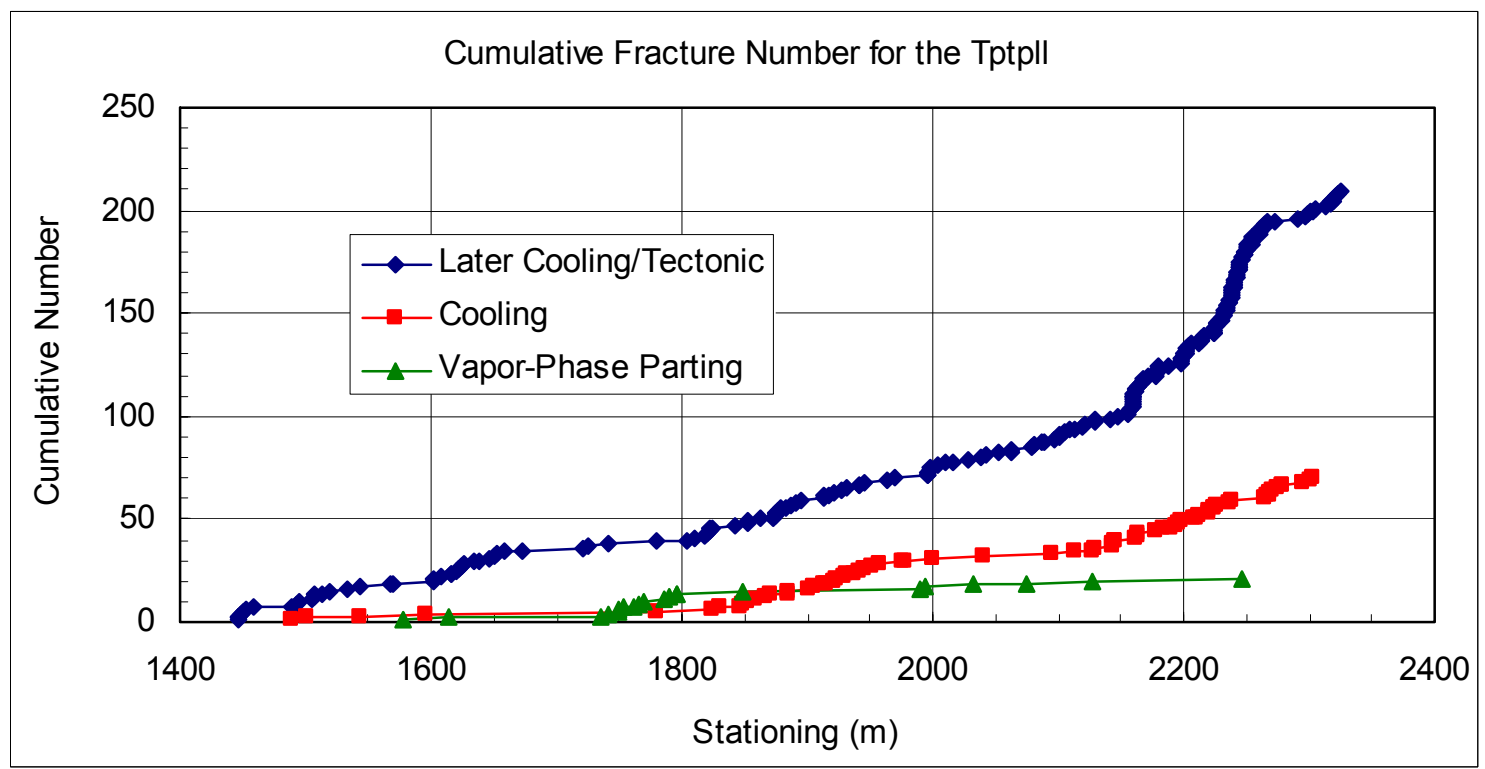

Source: DTN: GS990408314224.001 [DIRS 108396]; GS990408314224.002 [DIRS 105625].

NOTE: Constant slope indicates constant intensity.

Figure B-7. Evaluation of Constant Intensity for Tptpll 
INTENTIONALLY LEFT BLANK 


\section{APPENDIX C \\ REGIONAL AND LOCAL SCALE THERMAL-MECHANICAL ANALYSIS OF THE ROCK MASS SURROUNDING WASTE EMPLACEMENT DRIFTS AT YUCCA MOUNTAIN}




\section{REGIONAL AND LOCAL SCALE THERMAL-MECHANICAL ANALYSIS OF THE ROCK MASS SURROUNDING WASTE EMPLACEMENT DRIFTS AT YUCCA MOUNTAIN}

\section{C1. INTRODUCTION}

This appendix summarizes the results of a three-dimensional thermal-mechanical analysis of the repository site at Yucca Mountain using the finite difference code FLAC3D.

The analysis supports the NUFT drift-scale thermal calculation and to evaluate the edge effect described in Section 6.2 by defining the distribution of stresses around drifts due to progressive heating of the repository area. Unlike the NUFT calculation that simulated complex heat transfer physics (Section 6.2), only the thermal conduction into the rock mass was considered in the analysis in order to compute the thermal stresses around the drifts. Simulation of the rock mass behavior due to excavation and heating of the drifts has been carried out in two steps.

First, a regional scale (small-scale, for instance 1/10,000) calculation of the Yucca Mountain site was constructed. This calculation includes details of topography, stratigraphy and two structural faults. Figure C-1a shows an aerial view of Yucca Mountain, together with a digital elevation calculation generated for the purposes of this calculation. Figure C-1b shows the FLAC3D mesh constructed from the digital elevation calculation and available geological information. In the regional calculation, the heat sources act uniformly distributed over the area delimited by the repository boundaries (see Figure $\mathrm{C}-1$ ).

Second, a detailed local scale (large-scale, for instance 1/100) calculation has been constructed at the specified locations at the center (considered to be the hottest) and edge within the proposed repository area (see Figure C-2). This local scale calculation allows the study of induced stresses and displacements on the rock mass surrounding a central drift due to simultaneous application of heat sources in this drift and in neighboring ones.

\section{C2. DESCRIPTION OF THE REGIONAL (SMALL) SCALE CALCULATION}

A topographical plan shown of the Yucca Mountain site (the coordinates in the plan view correspond to N-S and W-E geographical system in meters) is seen in Figure C-3. The figure indicates the location of the proposed repository area (red lines), access tunnels (blue lines) and location of available geological cross-sections (black lines). The location of boreholes from where thickness of the strata and in situ stresses have been measured is also shown on this figure.

In the regional scale calculation, the repository area is considered to lie on a horizontal plane at an elevation of 1073 meters (averaged from BSC 2003 [DIRS 164519]). From the available geological information, the two faults, the Solitario Canyon fault in the west and the Ghost Dance fault in the east, have been outlined (the green lines in Figure C-3 represent the traces of the faults on the horizontal plane containing the repository at the 1,073 meter elevation). The spatial location of the faults, as measured and interpreted from the available geological maps (BSC 2004 [DIRS 170029]) and cross-sections extracted from DTN: MO0012MWDGFM02.002 [DIRS 153777] (i.e., Figures M-1, M-2 and M-3), is defined in Table C-1 and depicted in Figure $\mathrm{C}-4$. The details of the cross-section extraction are provided in Appendix M. 
a)

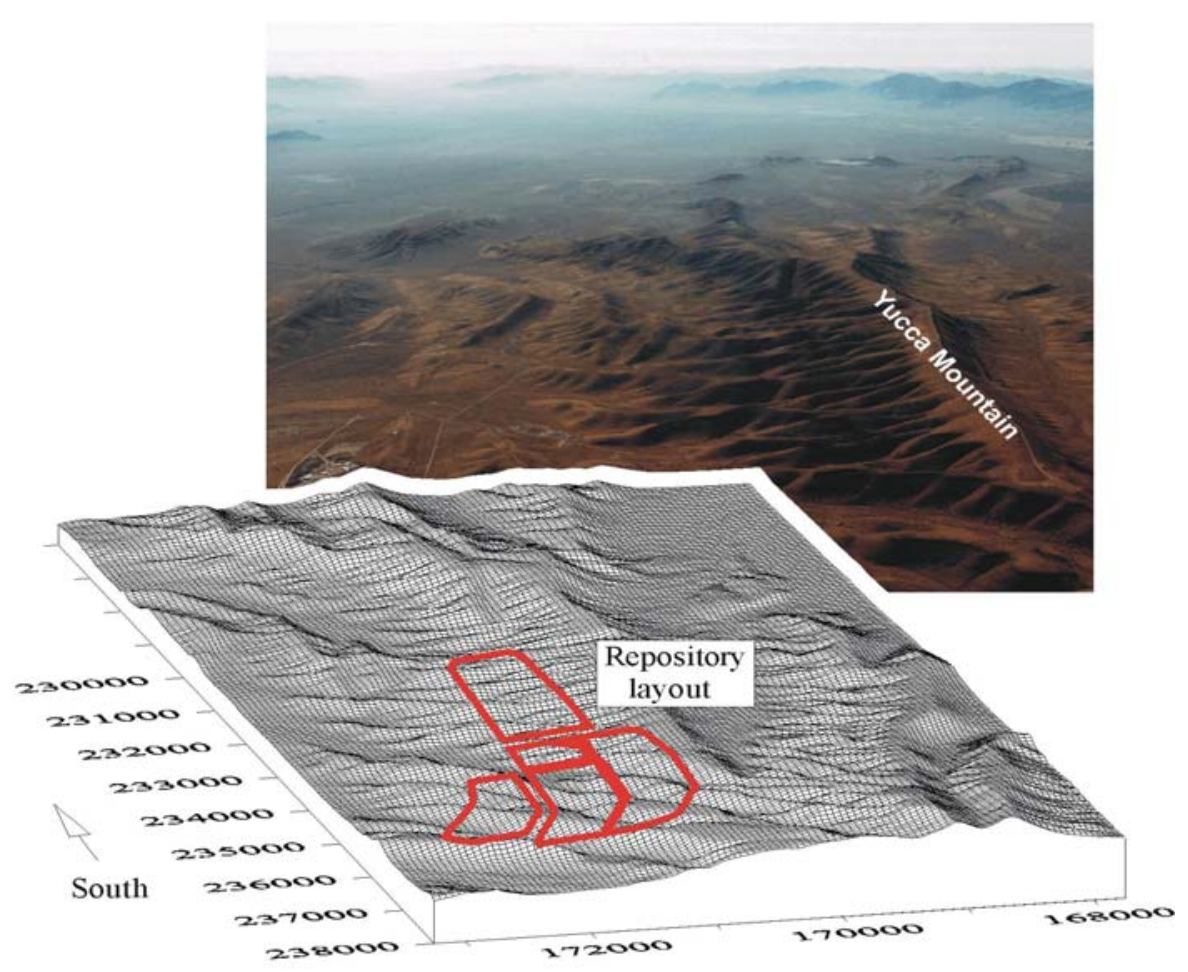

b)

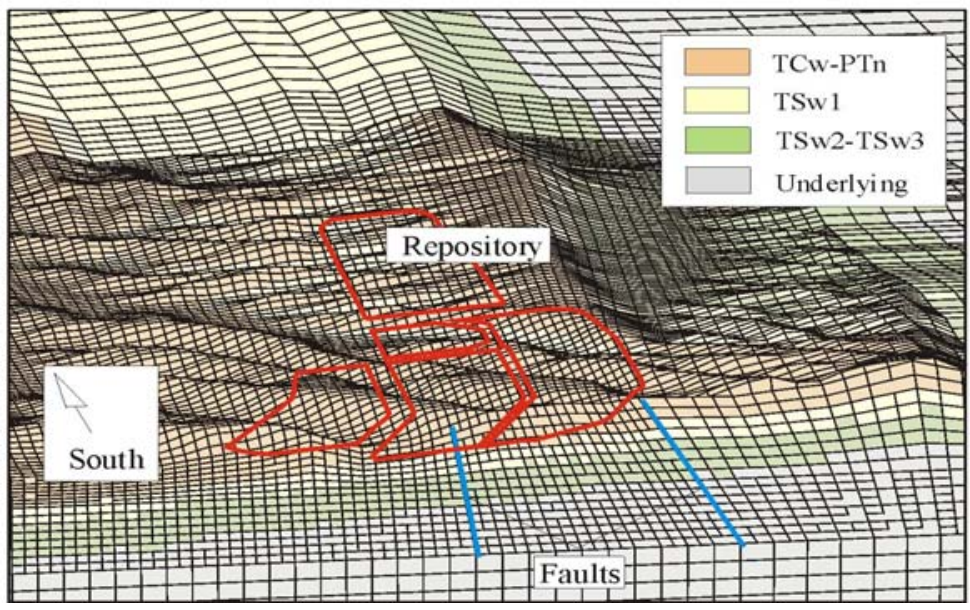

NOTE: a) Aerial View of the Yucca Mountain Site and Digital Elevation Calculation Created from Topographic Information.

b) View of the Regional Scale FLAC3D Calculation Constructed from the Digital Elevation Calculation and Available Geological Information.

Figure C-1. Yucca Mountain Repository Site 


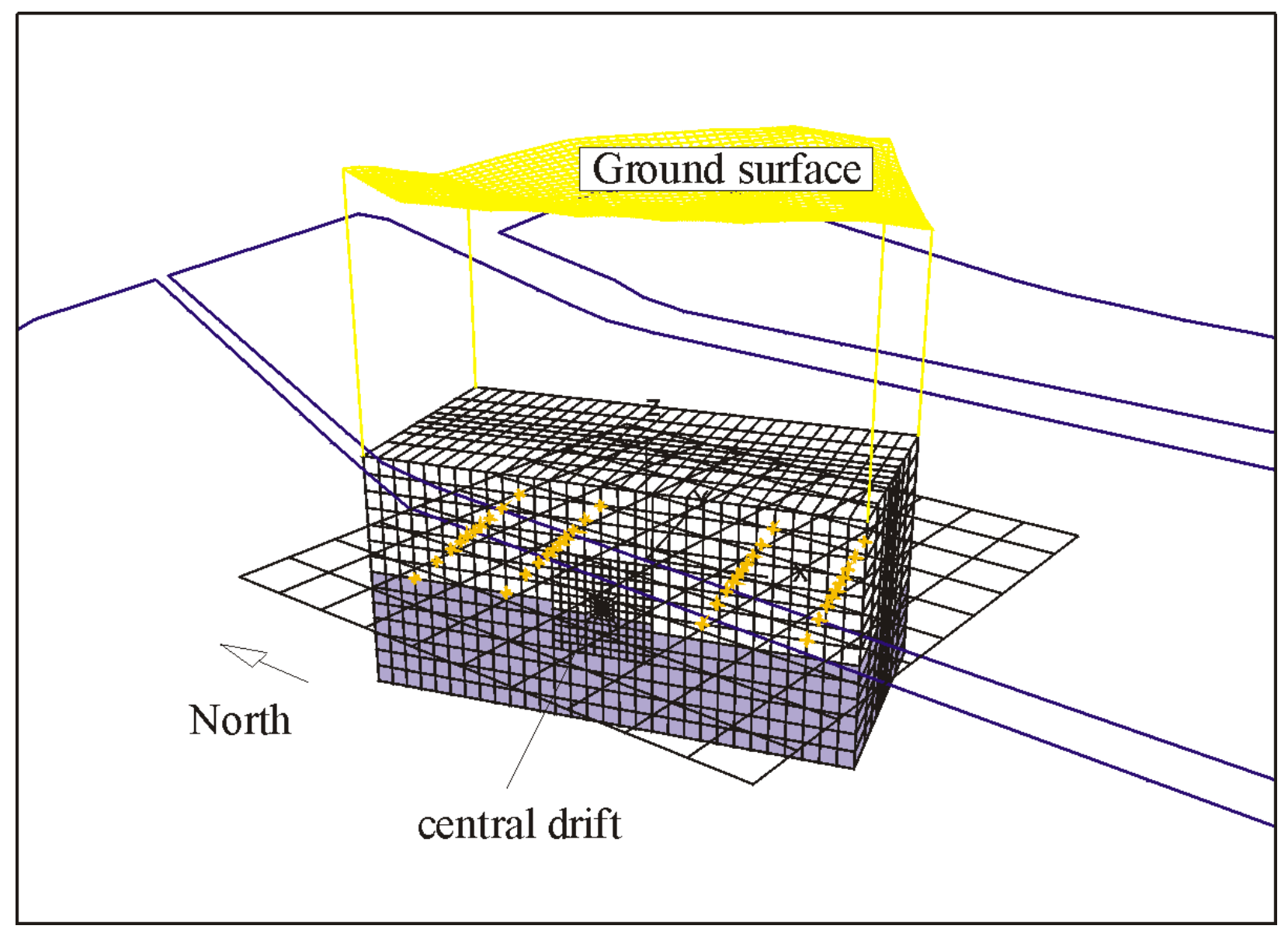

Figure C-2. Local (Large) Scale Calculation in the Central Part of the Repository 


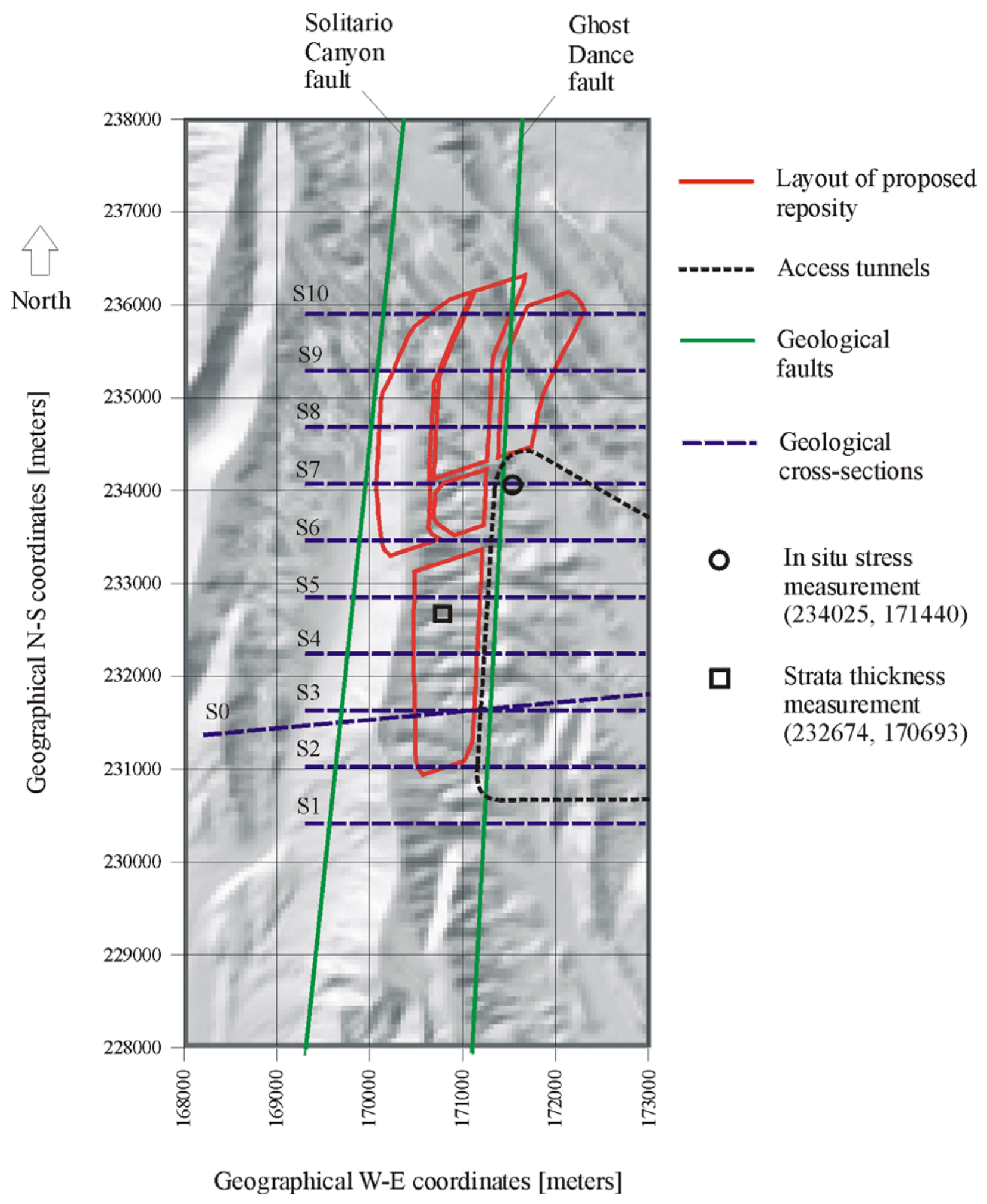

Figure C-3. Topographical Plan View of the Yucca Mountain Site and Main Elements Considered in the Regional Scale Calculation 
Table C-1. Spatial Location of the Tectonic Faults Considered in the Analysis

\begin{tabular}{|l|c|c|}
\hline Name of the fault & $\begin{array}{c}\text { Dip direction/Dip angle [degrees] } \\
\text { (Direction measured from the North) }\end{array}$ & $\begin{array}{c}\text { Coordinates of a point on the fault } \\
\text { [meters] } \\
\text { (coordinates are N-S, W-E and altitude) }\end{array}$ \\
\hline Solitario Canyon & $276 / 60$ & $(232000,169730,1084)$ \\
Ghost Dance & $273 / 85$ & $(232000,171324,1084)$ \\
\hline
\end{tabular}

Four mechanical units have been identified and used based on Ortiz et al. (1985 [DIRS 101280]). The units at the cross-sections S3, S7 and S10 in Figure C-3 are represented in Figures $\mathrm{C}-4 \mathrm{a}, \mathrm{C}-4 \mathrm{~b}$, and $\mathrm{C}-4 \mathrm{c}$, respectively. The spatial location of the geological units, as interpreted from geological maps, is indicated in Table C-2.

Table C-2. Spatial Location of the Stratigraphic Units Contracts Considered in the Calculation

\begin{tabular}{|l|c|c|}
\hline \multicolumn{1}{|c|}{ Contact between units } & $\begin{array}{c}\text { Dip direction/Dip angle [degrees] } \\
\text { (Direction from North) }\end{array}$ & $\begin{array}{c}\text { Coordinates of a point on the contact } \\
{[\mathrm{m}]} \\
\text { (coordinates are N-S, W-E and altitude) }\end{array}$ \\
\hline TCw-PTn \& TSw1 & $090 / 06$ & $(232674,170693,1372)$ \\
TSw1 \& TSw2-TSw3 & $090 / 06$ & $(232674,170693,1260)$ \\
TSw2-TSw3 \& Underlying & $090 / 06$ & $(232674,170693,1060)$ \\
Strata & & \\
\hline
\end{tabular}

The cross-sections in Figure $\mathrm{C}-4$ indicate that the repository level (i.e., at the elevation 1073 meters) lies mostly in the TSw2-TSw3 unit.

Figure C-5 shows the FLAC3D regional scale calculation constructed based on the basis of the information described above. Figures C-5a and C-5b correspond to the sections S3 and S10 in Figures C-4a and C-4c. Figure C-5c is a N-S cross-section along the E-W coordinate 170500 in Figure C-3.

Figure C-6, shows a vertical cross-section at the N-S coordinate 232000 meters and a plan view of the FLAC3D calculation at the repository level (i.e., at the elevation 1073 meters). The calculation consists of three regions of decreasing zone density. A "near" region where the repository is located is made up of zones of characteristic length 75 meters in both the North-South and East-West directions and 50 meters in the vertical direction (the near region has 110,592 zones). The "middle" region is made up of zones that have twice the characteristic length as those in the near region and the "far" region has zones that are twice the characteristic length of those in the "middle" region (the middle region has 51,840 zones and the far region has 72,912 zones; the regional scale calculation has 235,344 zones). The two faults (Solitario Canyon fault on the west and Ghost Dance fault on the east) are represented as interfaces.

The mechanical properties considered for the four units (TCw-PTn, TSw1, TSw2-TSw3, and underlying strata indicated in Figure C-4) were computed based on Ground Control for Emplacement Drifts for SR (BSC 2001 [DIRS 155187], Section 4.1). The original mechanical properties (available for every stratigraphic unit at Yucca Mountain) have been averaged based on the thickness of the different units included in each of the four units considered in this calculation (Figure C-4). The properties are summarized in Table C-3. 
a)

Cross-section S3 (NS 231637 m)

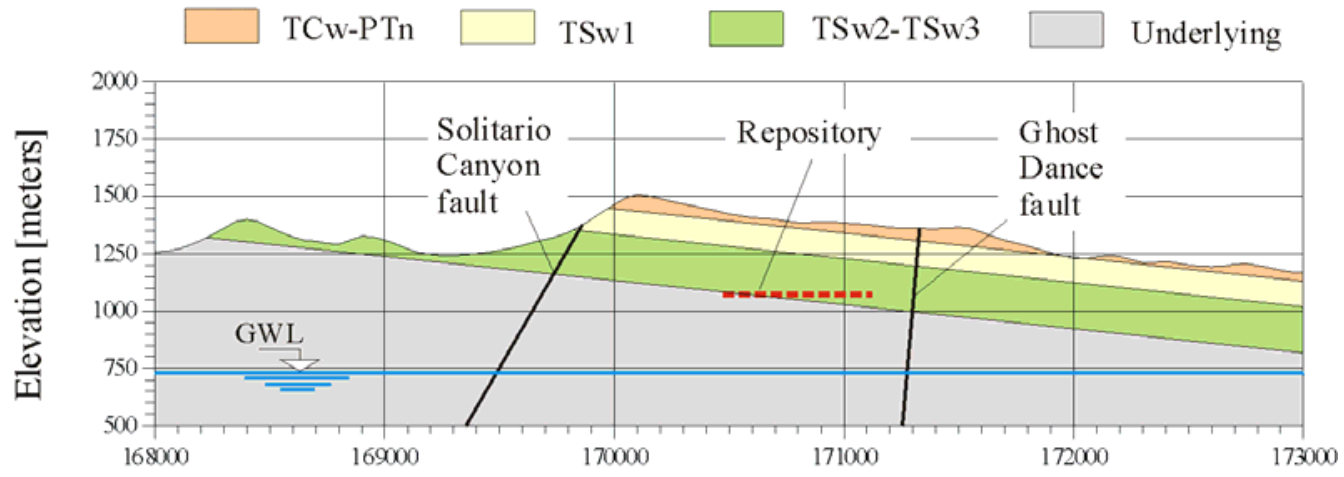

Geographical W-E coordinates [m]

b)

\section{Cross-section S7 (NS $234075 \mathrm{~m})$}

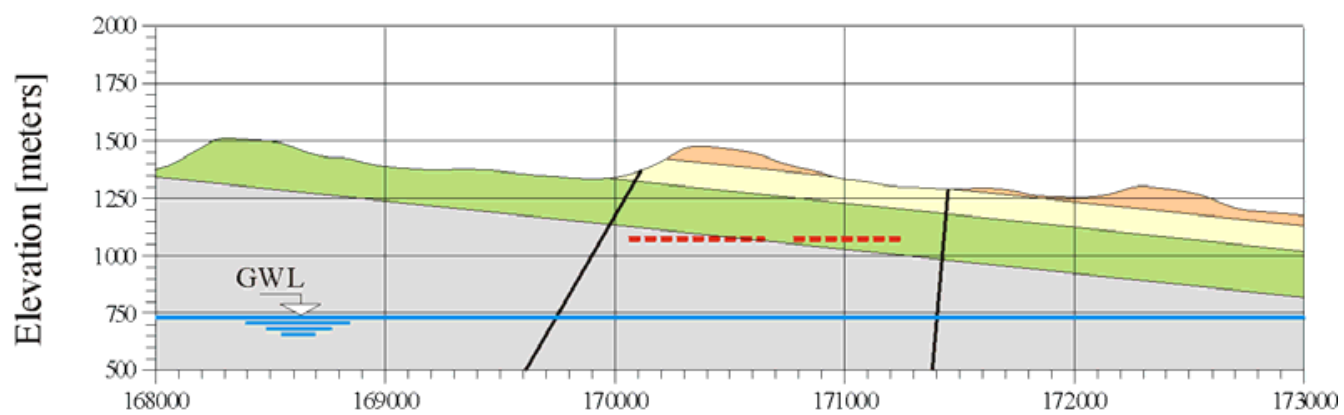

Geographical W-E coordinates [m]

c)

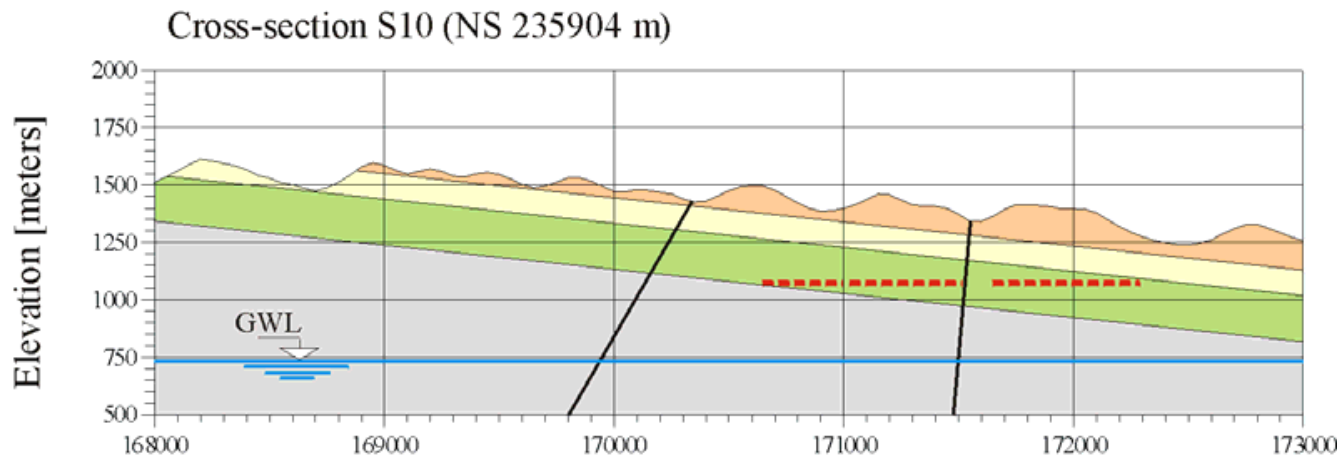

Geographical W-E coordinates [m]

NOTE: Fault displacements are not shown on the simplified cross-sections depicted in this figure. Detailed cross-sections including fault displacements are provided in Appendix M.

Figure C-4. Cross-Sections Showing the Four Thermal-Mechanical Units and Faults at the Locations Indicated as S3, S7, and S10 in Figure C-3 
a)

Cross-section S3 (NS 231637 m)

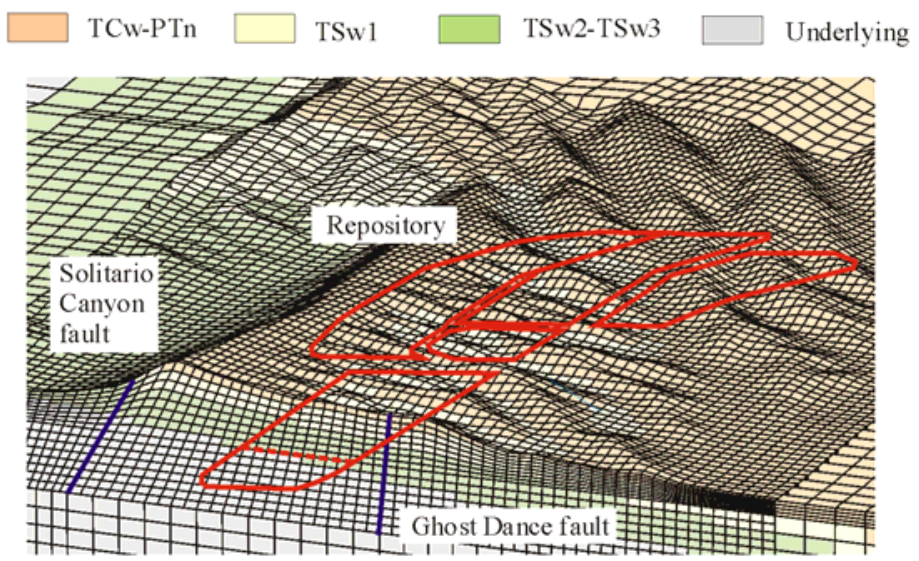

b)

Cross-section S10 (NS $235904 \mathrm{~m}$ )

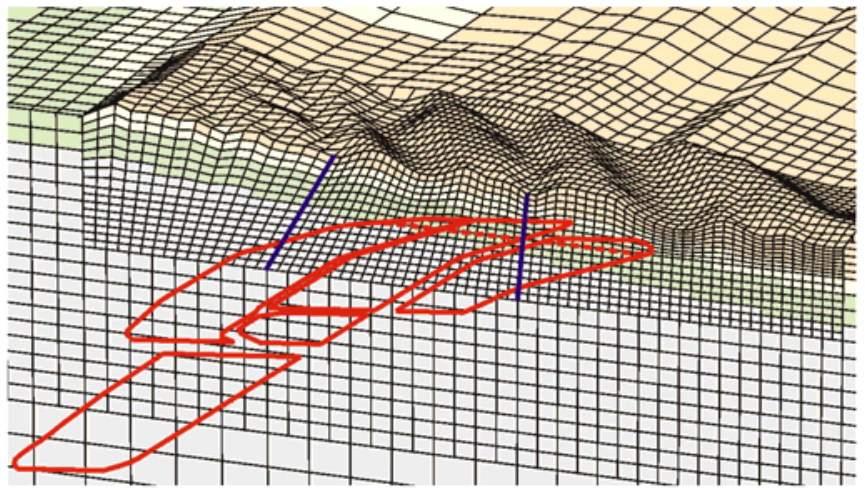

c)

North-South cross section (EW $171000 \mathrm{~m}$ )

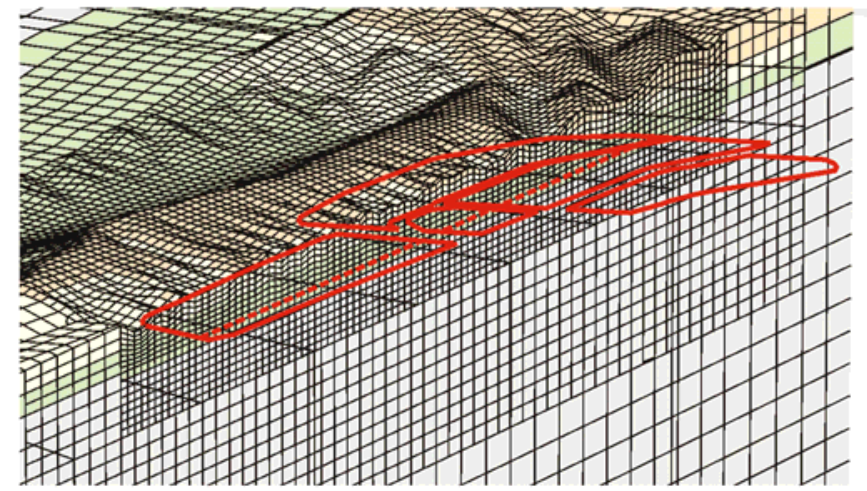

Figure C-5. E-W Cross-Sections S3 and S10 of Figures C-3 and C-4 and N-S Cross-Section Through the FLAC3D Calculation 
a)

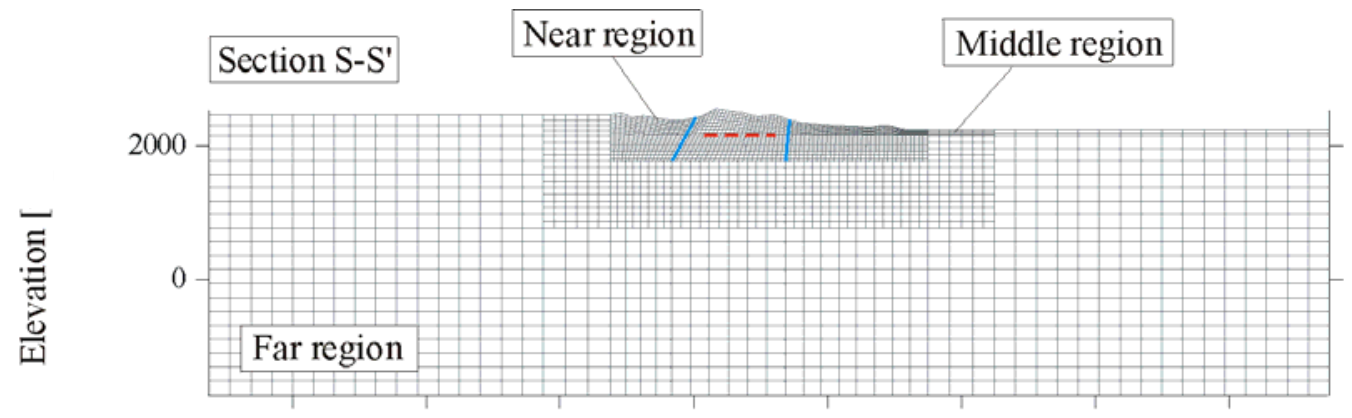

b)

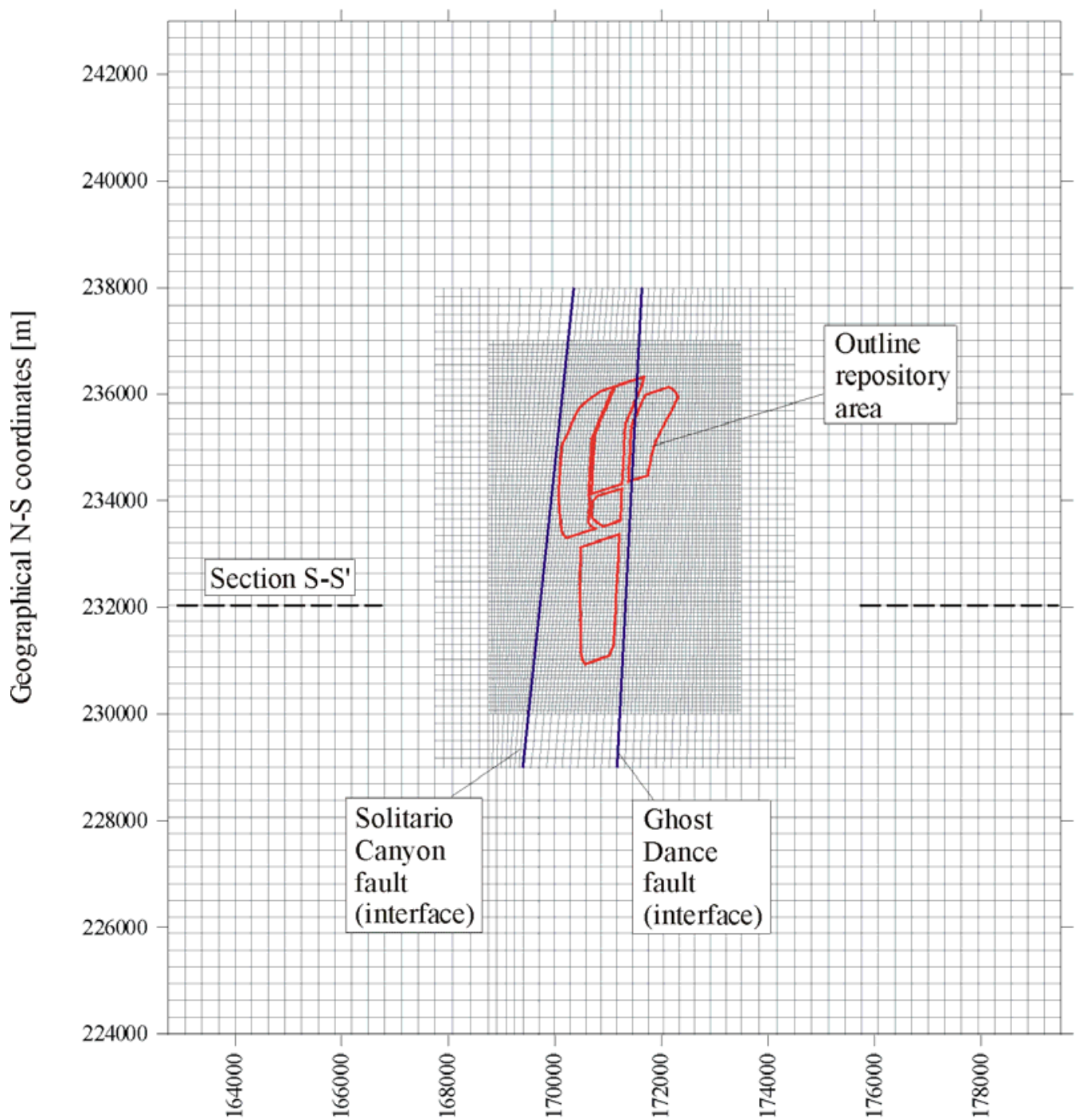

Geographical E-W coordinates [m]

NOTE: a) Cross-Section at the North Coordinate 232,000 Meters.

b) Plan View of the FLAC3D Calculation at the Elevation 1073 Meters.

Figure C-6. Repository Grid 
Table C-3. Mechanical Properties Considered for the Rock Mass in the Regional and Local Scale Calculations

\begin{tabular}{|l|c|c|c|c|}
\hline \multicolumn{1}{|c|}{ Property } & TCw-PTn & TSw1 & TSw2-TSw3 & Underlying \\
\hline Young Modulus $[\mathrm{MPa}]$ & 2540 & 15210 & 15840 & 15840 \\
Poisson's ratio & 0.2 & 0.2 & 0.2 & 0.2 \\
Density $\left[\mathrm{kg} / \mathrm{m}^{3}\right]$ & 1613 & 1983 & 2086 & 1545 \\
\hline
\end{tabular}

NOTE: These data are based on preliminary results that are similar to the information provided in Appendix $E$ (Tables E-1 and E-16). The results from the thermal-mechanical calculation presented in this appendix are not sensitive to minor changes in mechanical properties.

The fault interfaces are calculated as cohesion-less Coulomb contacts. The friction angle is considered to be $34^{\circ}$ (Bauer et al. 1992 [DIRS 162227]) and the stiffness (in both normal and shear directions) is computed, based on the characteristic size of the surrounding zones, so as to simulate the effect of a highly "stiff" contact. Values of $275 \mathrm{MN} / \mathrm{m}$ have been considered for the "stiff" contact based on Equation 3.4 of Theoretical Background Manual of the FLAC3D (Itasca Consulting Group 2002 [DIRS 160331]).

The thermal properties considered for the four units (TCw-PTn, TSw1, TSw2-TSw3, and underlying strata indicated in Figures C-4 and C-5) were also computed by taking averages from the detailed stratigraphic unit information (Appendix E, Section E5). The thermal properties are listed in Table C-4. The specific heat values between $95^{\circ} \mathrm{C}$ and $114^{\circ} \mathrm{C}$ are exceptionally high compared to the values of other temperature ranges (Table $\mathrm{C}-4)$. The high specific heat values are based on the analytical solutions presented by Nimick and Connolly (1991 [DIRS 100690]). The primary NUFT thermal calculation that is used to support the drift degradation analyses (presented in Section 6.2) does not use the high specific heat values, since consideration of latent heat effects above the boiling point is built into the NUFT code.

Table C-4. Thermal Properties Considered for the Rock Mass in the Regional and Local Scale Calculations

\begin{tabular}{|c|c|c|c|c|c|}
\hline Property & Condition & TCw-PTn & TSw1 & TSw2-TSw3 & Underlying \\
\hline \multirow{2}{*}{$\begin{array}{l}\text { Conductivity } k \\
{\left[\mathrm{~W} / \mathrm{m}^{\circ} \mathrm{C}\right]}\end{array}$} & $<100^{\circ} \mathrm{C}$ & 1.015 & 1.771 & 1.925 & 1.201 \\
\hline & $\geq 100^{\circ} \mathrm{C}$ & 0.525 & 1.220 & 1.328 & 0.581 \\
\hline \multirow{3}{*}{$\begin{array}{l}\text { Specific heat } C_{v} \\
{\left[\mathrm{~J} / \mathrm{kg}^{\circ} \mathrm{C}\right]}\end{array}$} & $<95^{\circ} \mathrm{C}$ & 1,158 & 939 & 937 & 1,304 \\
\hline & $95^{\circ} \mathrm{C} \leq \mathrm{C}_{\mathrm{v}}<114^{\circ} \mathrm{C}$ & 11,135 & 5,791 & 5,714 & 15,775 \\
\hline & $\geq 114^{\circ} \mathrm{C}$ & 1,010 & 991 & 990 & 1,016 \\
\hline \multirow{4}{*}{$\begin{array}{l}\text { Thermal expansion } \alpha_{t} \\
{\left[/^{\circ} \mathrm{C}\right]}\end{array}$} & $<50^{\circ} \mathrm{C}$ & $4.46 \times 10^{-6}$ & $6.56 \times 10^{-6}$ & $7.14 \times 10^{-6}$ & $7.14 \times 10^{-6}$ \\
\hline & $50^{\circ} \mathrm{C} \leq \alpha_{t}<75^{\circ} \mathrm{C}$ & $4.46 \times 10^{-6}$ & $6.56 \times 10^{-6}$ & $7.47 \times 10^{-6}$ & $7.47 \times 10^{-6}$ \\
\hline & $75^{\circ} \mathrm{C} \leq \alpha_{t}<100^{\circ} \mathrm{C}$ & $4.46 \times 10^{-6}$ & $6.56 \times 10^{-6}$ & $7.46 \times 10^{-6}$ & $7.46 \times 10^{-6}$ \\
\hline & $\geq 100^{\circ} \mathrm{C}$ & $4.46 \times 10^{-6}$ & $6.56 \times 10^{-6}$ & $9.07 \times 10^{-6}$ & $9.07 \times 10^{-6}$ \\
\hline
\end{tabular}

The heat capacity data used in the thermal property calculation (Table C-4) were preliminary data superseded by DTN: SN0307T0510902.003 [DIRS 164196] (Table E-19). Therefore, an impact analyses was conducted regarding the preliminary data and presented in Appendix Q2. The impact analyses indicates there are insignificant impacts on the below $95^{\circ} \mathrm{C}$ and over $114^{\circ} \mathrm{C}$ ranges, and only minor impact on the 95 to $114^{\circ} \mathrm{C}$ range for the local scale thermal-mechanical calculation (Section C3). An additional local scale calculation is not necessary since the local 
scale calculation was only used to support the main thermal-mechanical calculation in Section 6.2. Both an initial state of stress and an initial state of temperature are considered for the regional scale calculation. The initial temperature in the rock mass is needed to compute the temperature-dependent thermal properties listed earlier.

The vertical component of in situ stress is considered to be a major principal stress, $\sigma_{1}$ (see Section 6.3.1.1). It is considered to be lithostatic (i.e., computed as the weight of the overburden from the topography and density values described earlier). Figure C-7 shows contours of vertical stress in a cross-section of NS coordinate 232000 meters. The intermediate and minor principal stresses ( $\sigma_{2}$ and $\sigma_{3}$ respectively) are horizontal (see Section 4, Table 4-1). The direction of the intermediate principal stress $\sigma_{2}$ is $N 15^{\circ} \mathrm{E}$. The ratio of intermediate to major principal stress is taken to be $\sigma_{2} / \sigma_{1}=0.617$ based on the data developed in Section 6.3.1.1. This is based on values of the in situ stresses measured at the location shown in Figure C-3 (see Section 6.3.1.1). The direction of the minor principal stress $\sigma_{3}$ is $\mathrm{N} 105^{\circ} \mathrm{E}$ (or $\mathrm{E} 15^{\circ} \mathrm{S}$ ). The ratio of minor to major principal stress is taken $\sigma_{3} / \sigma_{1}=0.361$ (also from the values of measured in situ stresses provided in Section 4, Table 4-1, and developed in Section 6.3.1.1).

The initial state of temperature is considered to vary linearly with depth below the surface (i.e., as defined by the topography shown in Figure $\mathrm{C}-1$ ). The initial temperature is considered to be fixed and equal to $18^{\circ} \mathrm{C}$ at ground surface and equal to $34^{\circ} \mathrm{C}$ at the level of the permanent groundwater table. At the elevations of 1231 and 730 meters, time-averaged temperatures based on UZ Flow Models and Submodels [BSC 2004 [DIRS 169861], Section 6.3]) were considered. Note the temperature values are different from the boundary temperatures of the NUFT thermal calculation in the Section $6.2\left(16.9^{\circ} \mathrm{C}\right.$ for the ground surface and $29.2^{\circ} \mathrm{C}$ for the water table temperature), since the initial temperature is considered for the entire repository layout (BSC 2004 [DIRS 169861], Section 6.3). For points above the water table, the initial temperature is linearly interpolated from the fixed values at the ground surface and water table level. For points below the water table, the initial temperature is considered to be constant and equal to $34^{\circ} \mathrm{C}$.

Thermal loading of the repository area is considered to be the only source of stress redistribution and induced displacement within the rock mass (the regional scale calculation does not take into account the excavation of drifts within the repository area). This thermal load is considered to be uniformly distributed within the boundary limits of the repository. In the present calculation, all panels comprising the repository (see Figure C-3) are considered to be activated at once (i.e., the calculation assumes an "instantaneous" emplacement of the waste in all panels of the repository; see Section 5.1).

The thermal load is computed considering a linear heat power source equal to $1450 \mathrm{~W} / \mathrm{m}$ that acts along each drift and a separation between the axes of adjacent drifts of 81 meters (i.e., the value of distributed heat power, before any correction is made due to radioactive decay and ventilation, is equal to $\mathrm{q}_{o}=1450 / 81=17.9 \mathrm{~W} / \mathrm{m}^{2}$ ). 
The heat output is considered to vary in time according to the following equation, which is derived directly from fundamental physics:

$$
q(t)=\delta(t) \times\left[1-\varphi_{v e}(t)\right] q_{0}
$$

where $t$ is the time in years, $\delta(t)$ is a radioactive decay correction factor, and $\varphi_{v e}(t)$ is a correction factor for ventilation.

The graphical representation of the function $\delta(t)$, calculated from $D \& E$ / PA/C IED Typical Waste Package Components Assembly (BSC 2004 [DIRS 167369]), is shown in Figure C-8a.

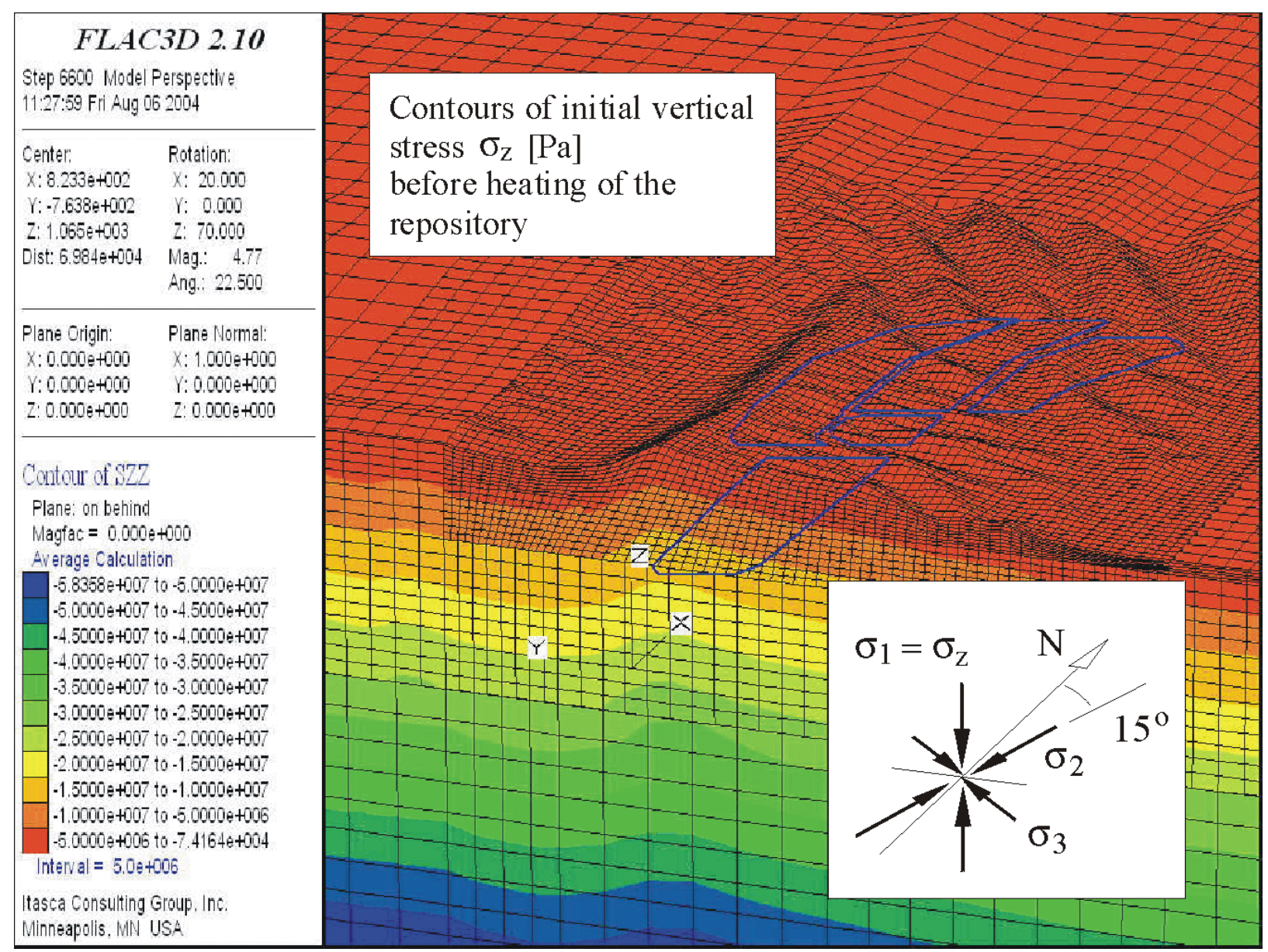

Figure C-7. Contours of the In Situ Vertical Stress $\sigma_{2}=\sigma_{1}$ and Direction of the Horizontal (Principal) Stresses $\sigma_{2}$ and $\sigma_{3}$ 
a)

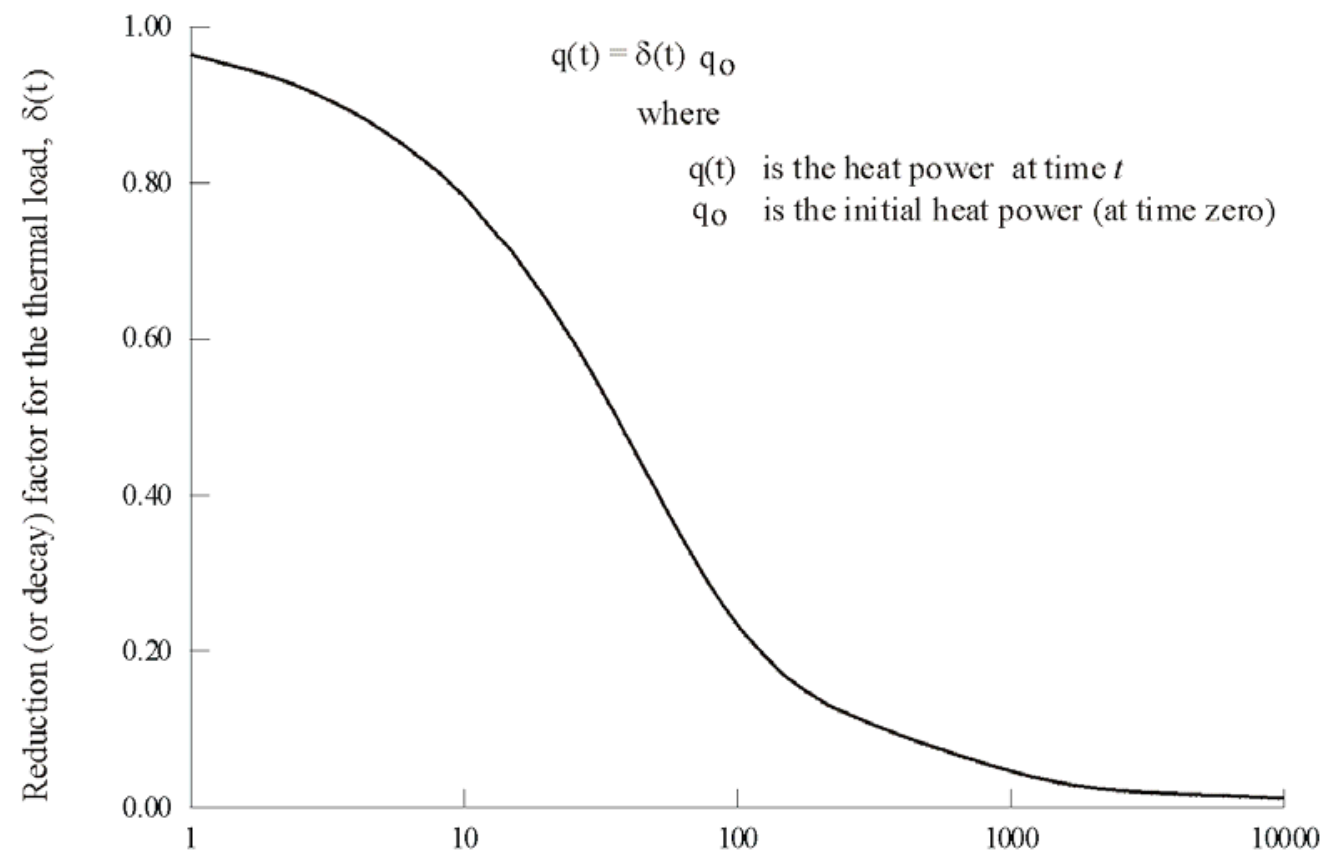

Time [years]

b)

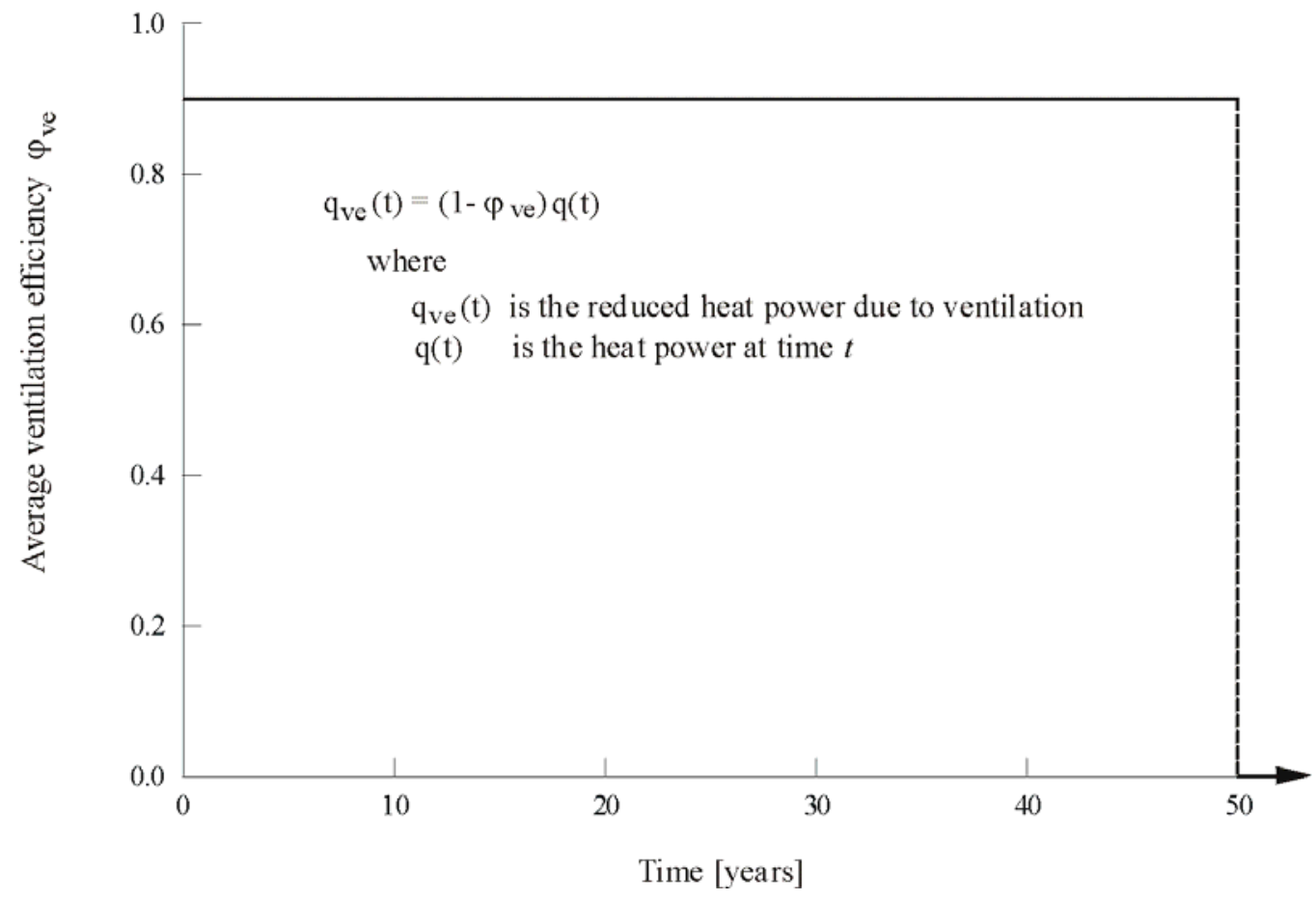

Figure C-8. Heat Source Correction Functions for a) Radioactive Decay and b) Ventilation 
The graphical representation of the function $\varphi_{v e}(t)$ is shown in Figure C-8b. Note that forced ventilation is considered for a pre-closure period of 50 years. Throughout this period of time, ventilation efficiency is constant and equal to 90 percent.

Values of temperature change at specific points within thermal sectors have been determined (the points are indicated by the small circles 'g1' through ' $\mathrm{g} 5$ ' in Figure C-9). Figure C-10 shows the evolution of temperature at these points after 10,000 years of heating. Figure C-10a shows temperature as a function of time, and Figure $\mathrm{C}-10 \mathrm{~b}$ presents the same results using a logarithmic time scale.

Heating of the repository area induces changes in stresses (with respect to the initial stresses described earlier) and displacements. Changes in stresses and displacements have been recorded for different stages of heating in the regional calculation (information is available for the sequence $1,10,20,50,100,200,300,400,500,750,1000,2000,3000,4000,5000,7500$, and 10,000 years).

For example, Figures C-11 and C-12 show the change in temperature along a cross-section of the calculation after 10,100, 1000 and 10,000 years.

Figures C-13a and C-13b show contours of magnitude of induced displacement after 100 and 1000 years of heating.

\section{C3. DESCRIPTION OF THE LOCAL (LARGE) SCALE CALCULATIONS}

The purpose of the local-scale calculation is to analyze the effect of heating at a drift scale.

The locations of the local-scale calculation seen in Figure C-14 are with respect to the regional calculation. The center of the calculation is located at coordinates 170730, 234913, 1073 (W-E, N-S, and altitude in meters), while the edge of the calculation is at coordinates 170126, 233439, 1073 (W-E, N-S, and altitude in meters). The axes of the drifts in Figure C-14 are oriented $\mathrm{N} 72^{\circ} \mathrm{E}$ with respect to the North. The center location is considered to be the hottest location of the calculation.

A plan view of the local-scale seen in Figure C-15 "center" calculation is at the repository level. The figure also shows two vertical cross-sections taken parallel and perpendicular to the axis of the drift. From Figure C-15, it is seen that the local scale calculation extends 200 meters vertically, 200 meters horizontally along the axes of the drifts, and 404 meters horizontally perpendicular to the axes of the drifts. From the vertical cross-sections, it is seen that the central drift (radius 2.75 meters) is simulated explicitly as a tunnel of this dimension. The surrounding drifts, separated a distance of 81 meters from the central drift and from each other, are not represented as voids, but rather as linear sources subject to thermal load. The local-scale "edge" calculation is similar to the center calculation except consideration of the repository edge location.

The local-scale calculation shown in Figures C-15 works in "coordination" with the regional-scale calculation described earlier. Thermal-mechanical properties, in situ temperatures and stresses, thermal loads, decay and ventilation functions are considered to be the same as those used in the regional scale calculations. 


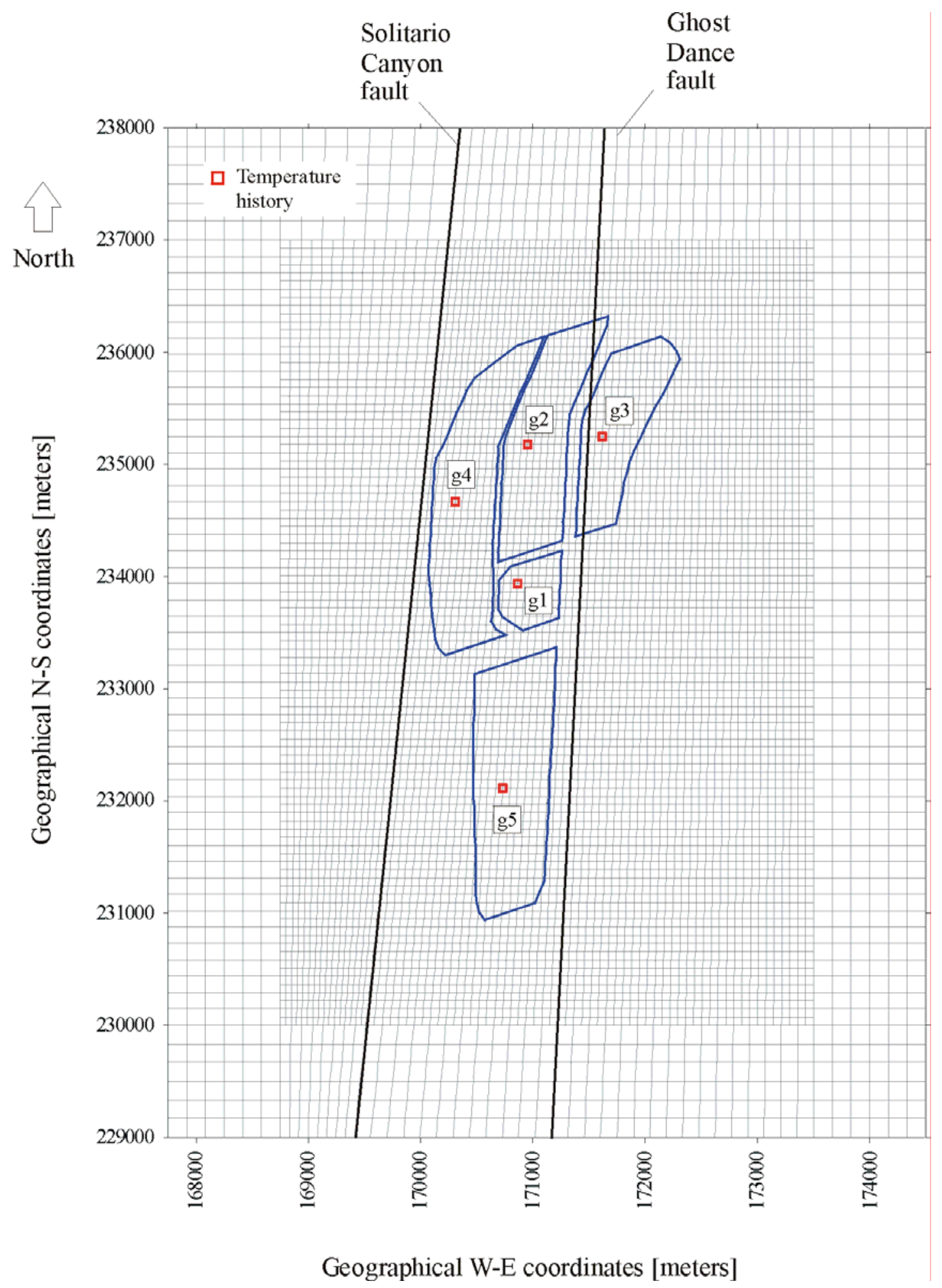

NOTE: Points ' $g 1$ ' through 'g5' indicate the location where temperatures have been recorded in the calculation. These points do not relate to repository emplacement panel nomenclature.

Figure C-9. Plan View of the Repository Area Showing Boundaries of Uniformly Distributed Heating Sections 
a)

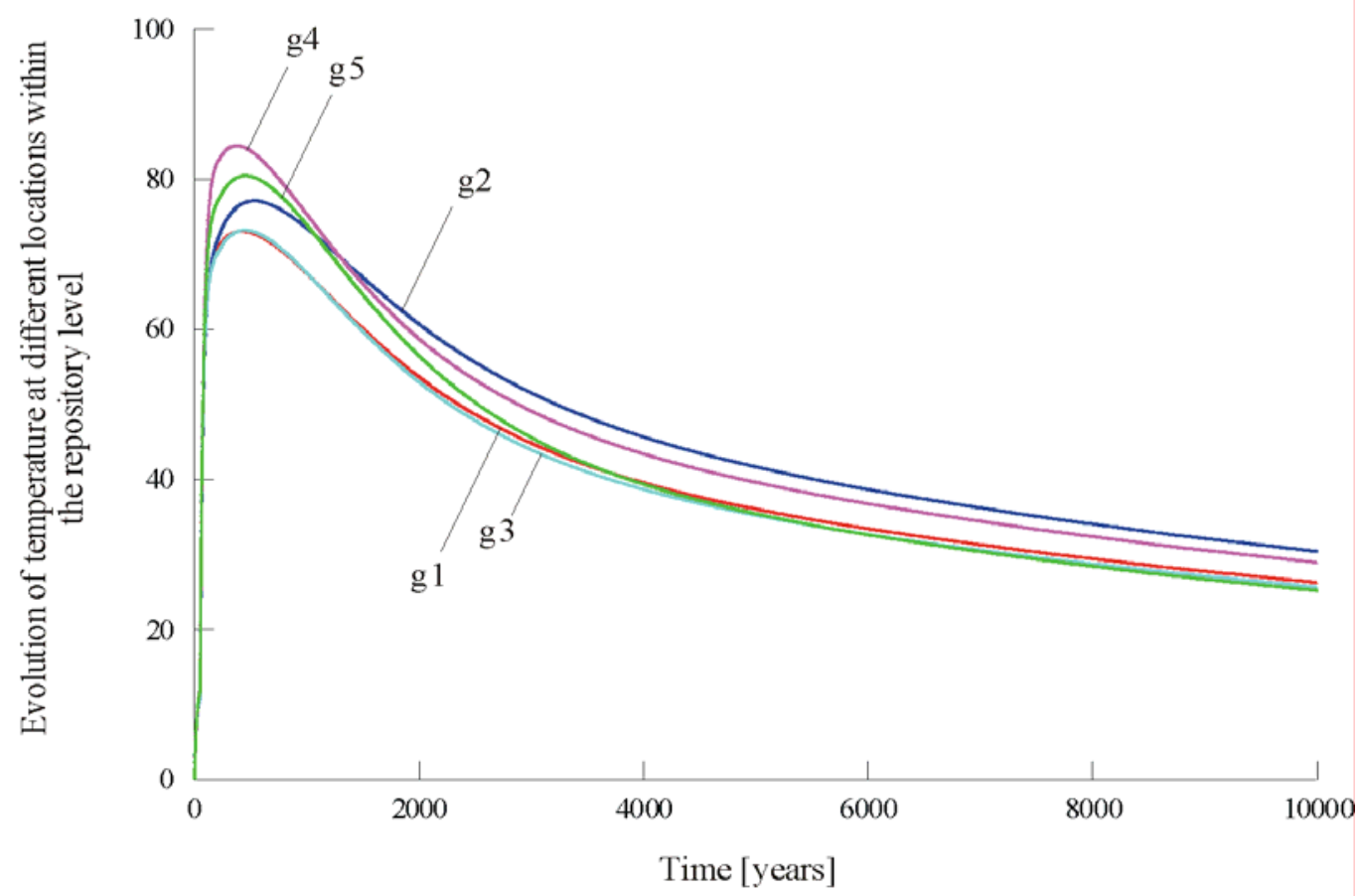

b)

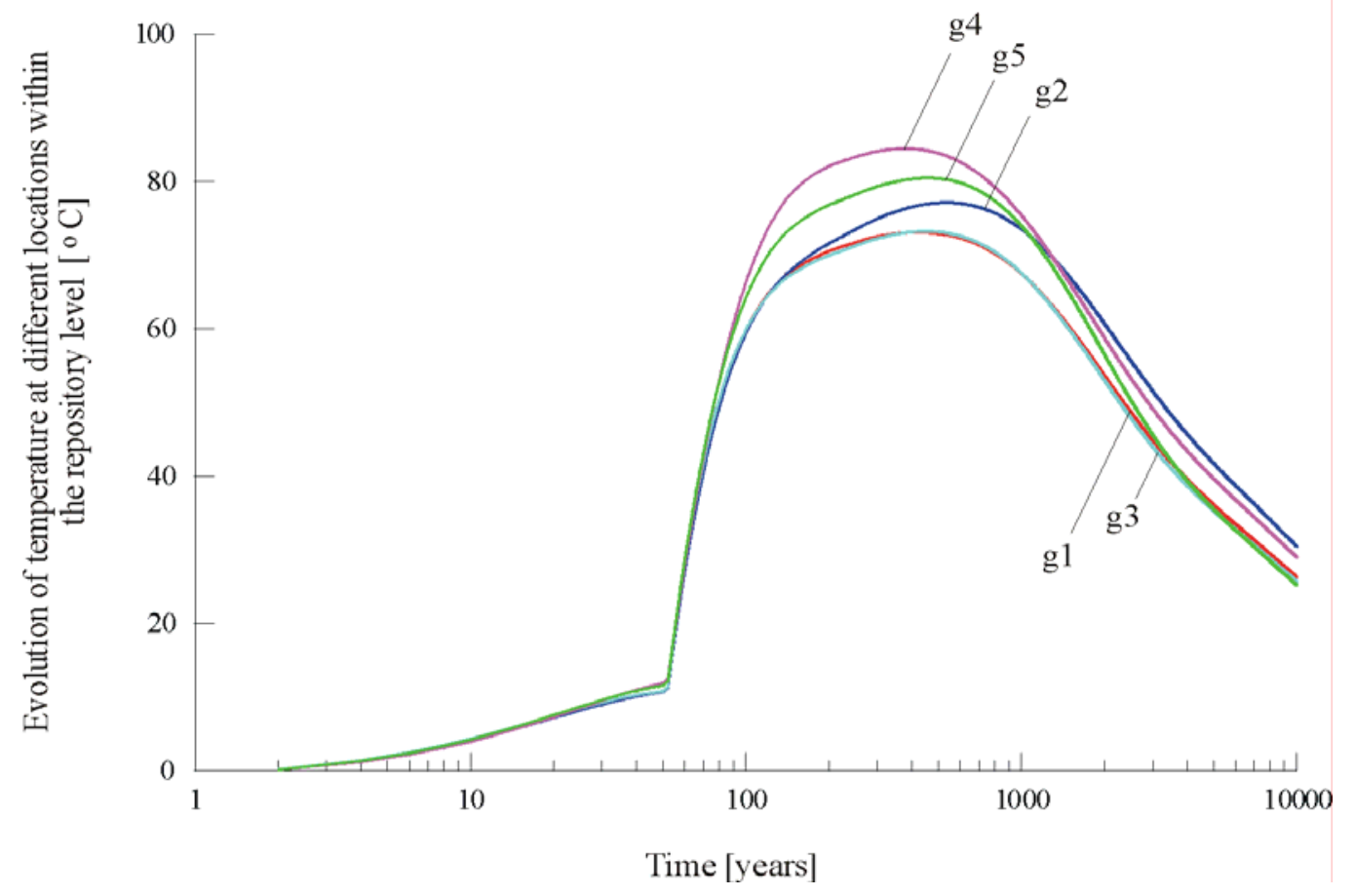

NOTE: a) Time in Years; b) Logarithm of Time in Years, for the Locations ' $g 1$ ' through 'g5' Indicated in Figure C-9.

Figure C-10. Evolution of Temperature Increase as a Function 
a)

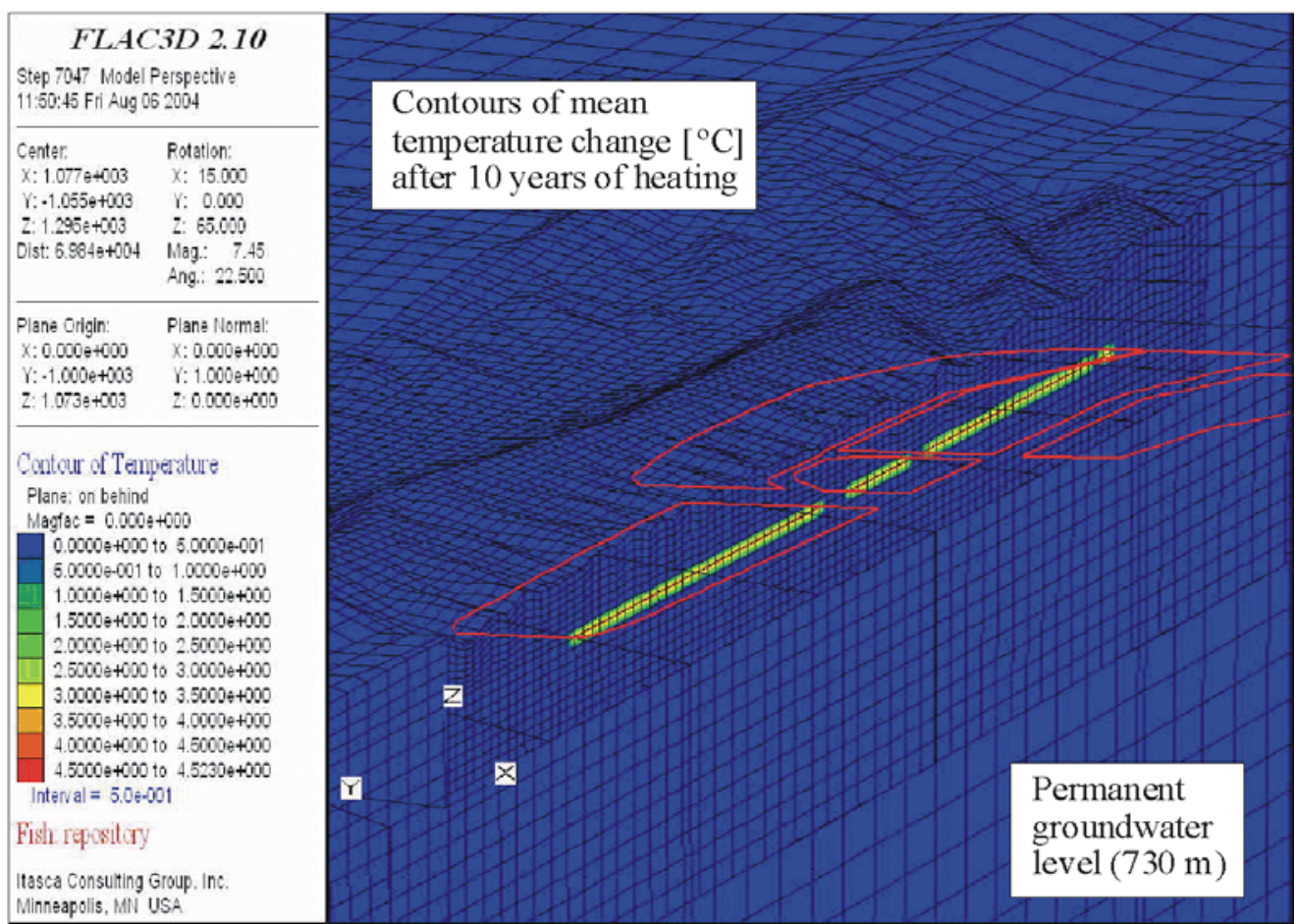

b)

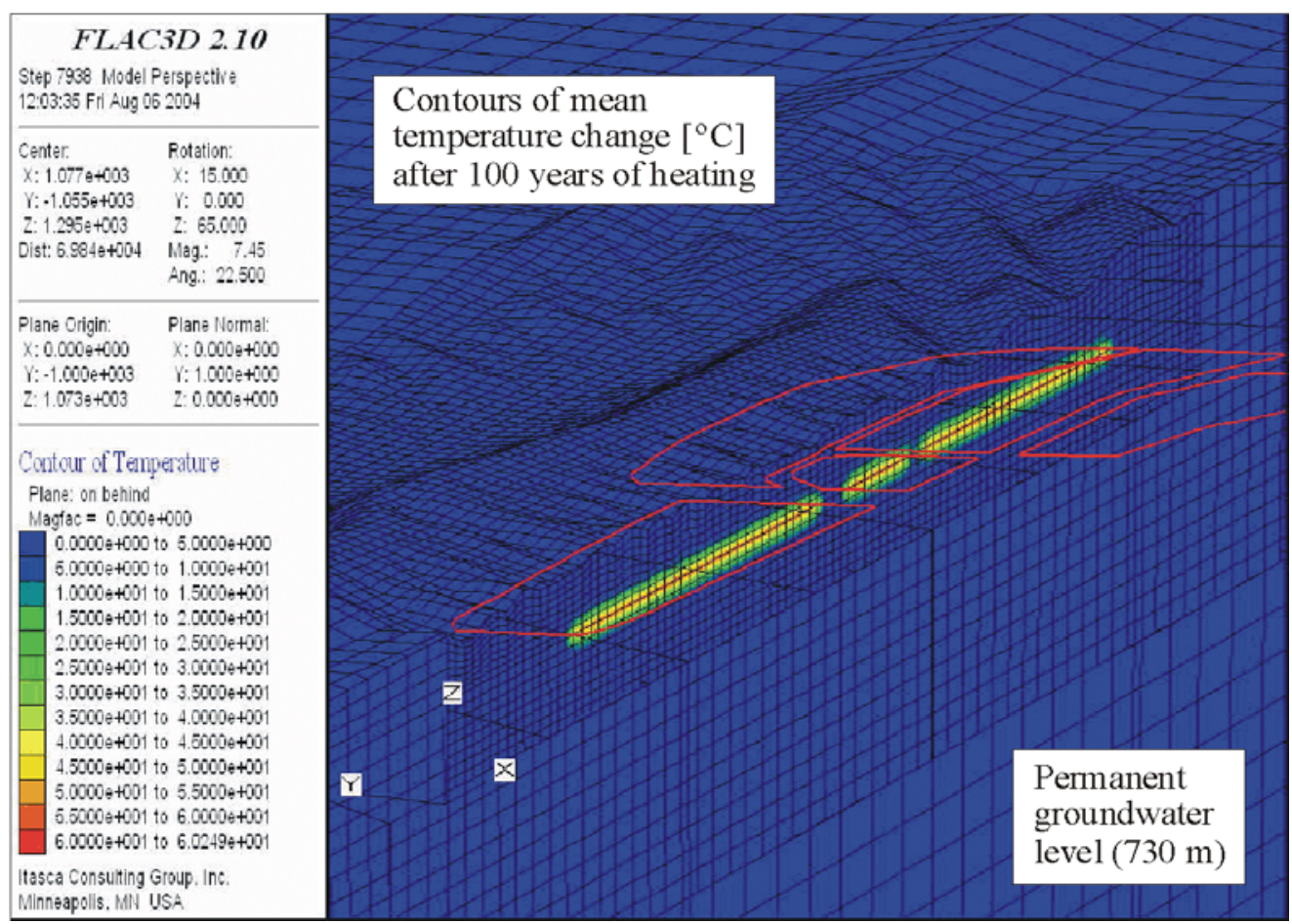

NOTE: a) after 10 years of heating; b) after 100 years of heating.

Figure C-11. Contours of Mean Temperature Change ( $\leq 100$ Years) 
a)

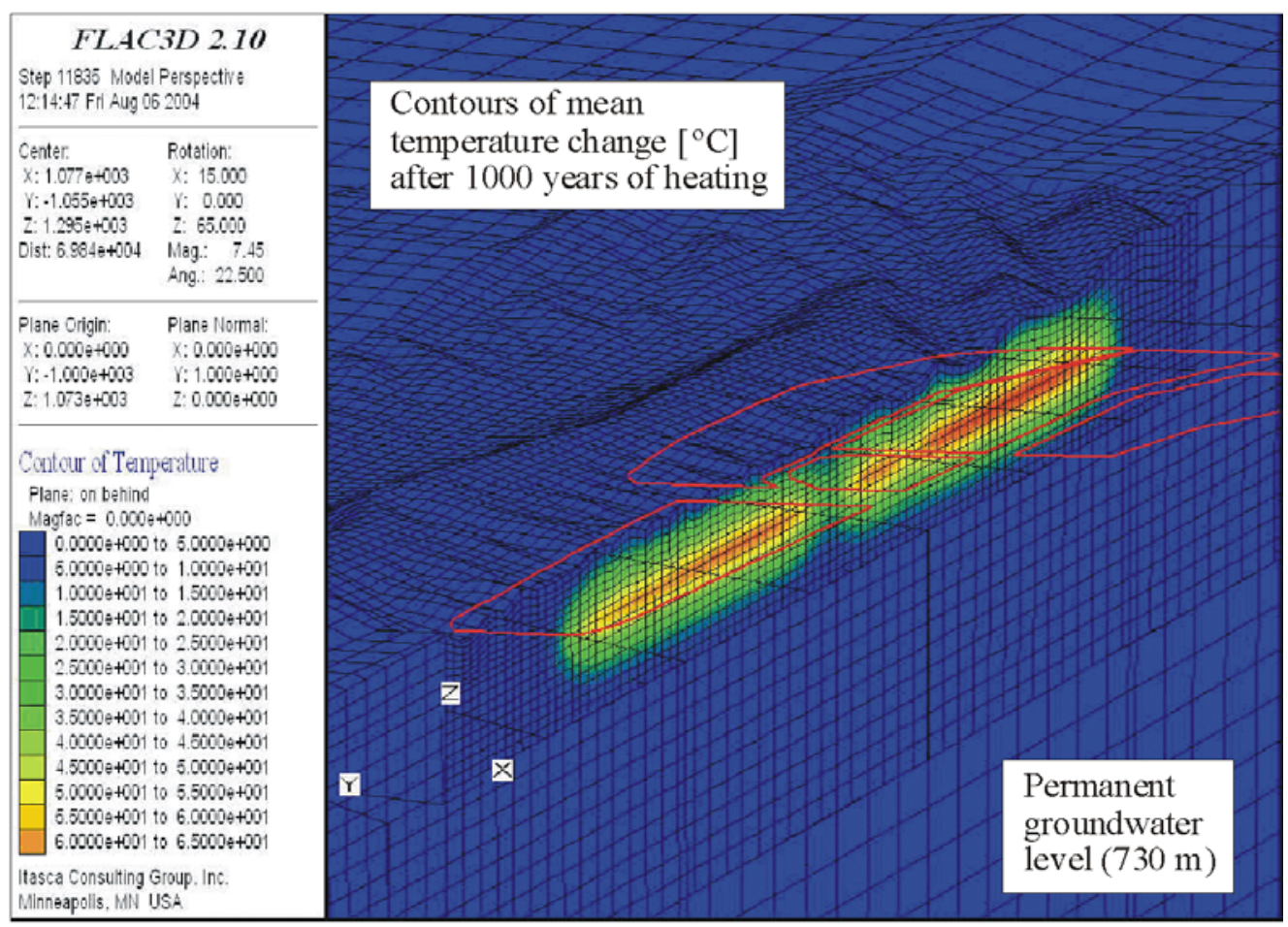

b)

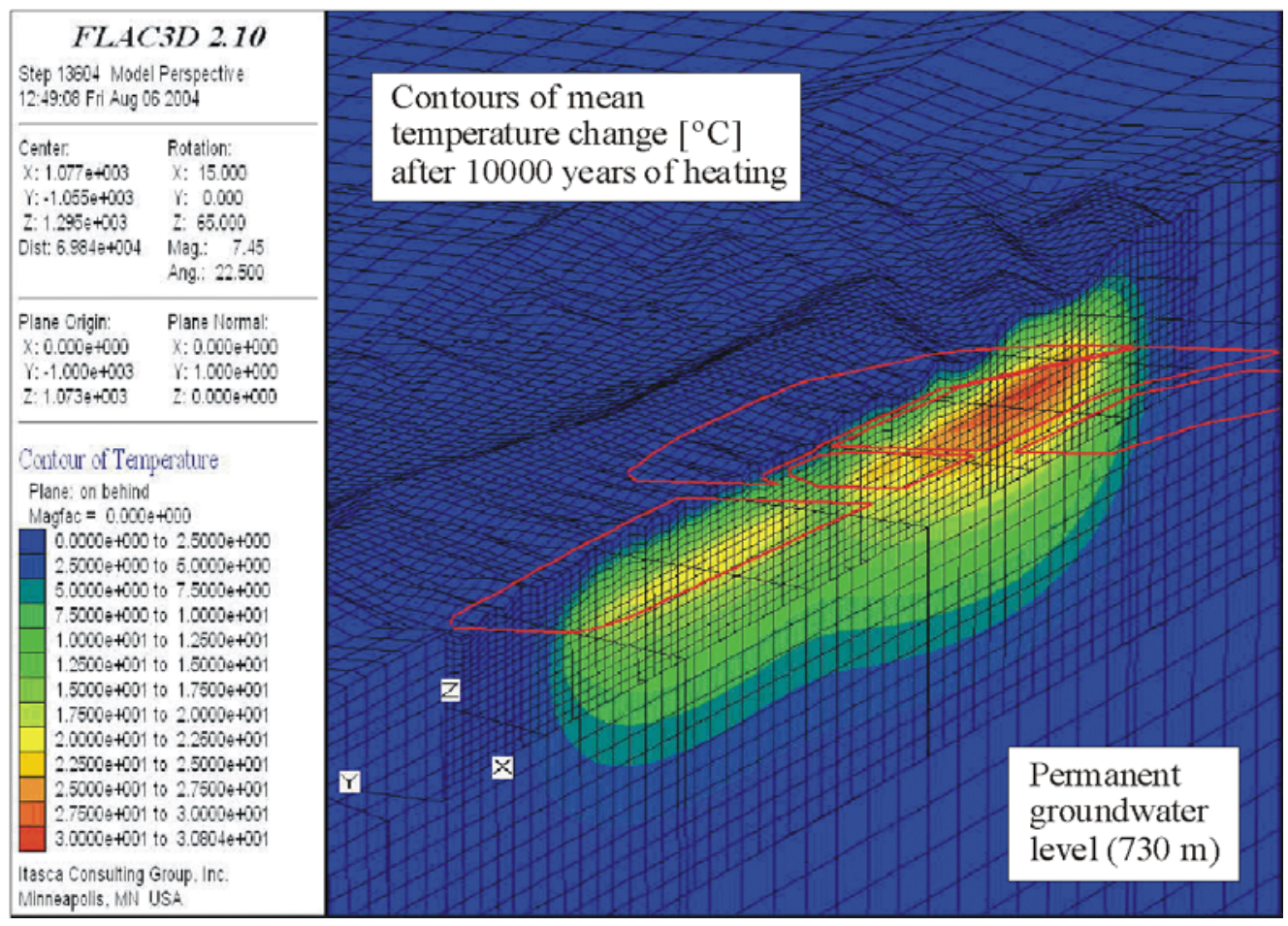

NOTE: a) after 1,000 years of heating; $b$ ) after 10,000 years of heating.

Figure C-12. Contours of Mean Temperature Change ( $\geq 1,000$ Years) 
a)

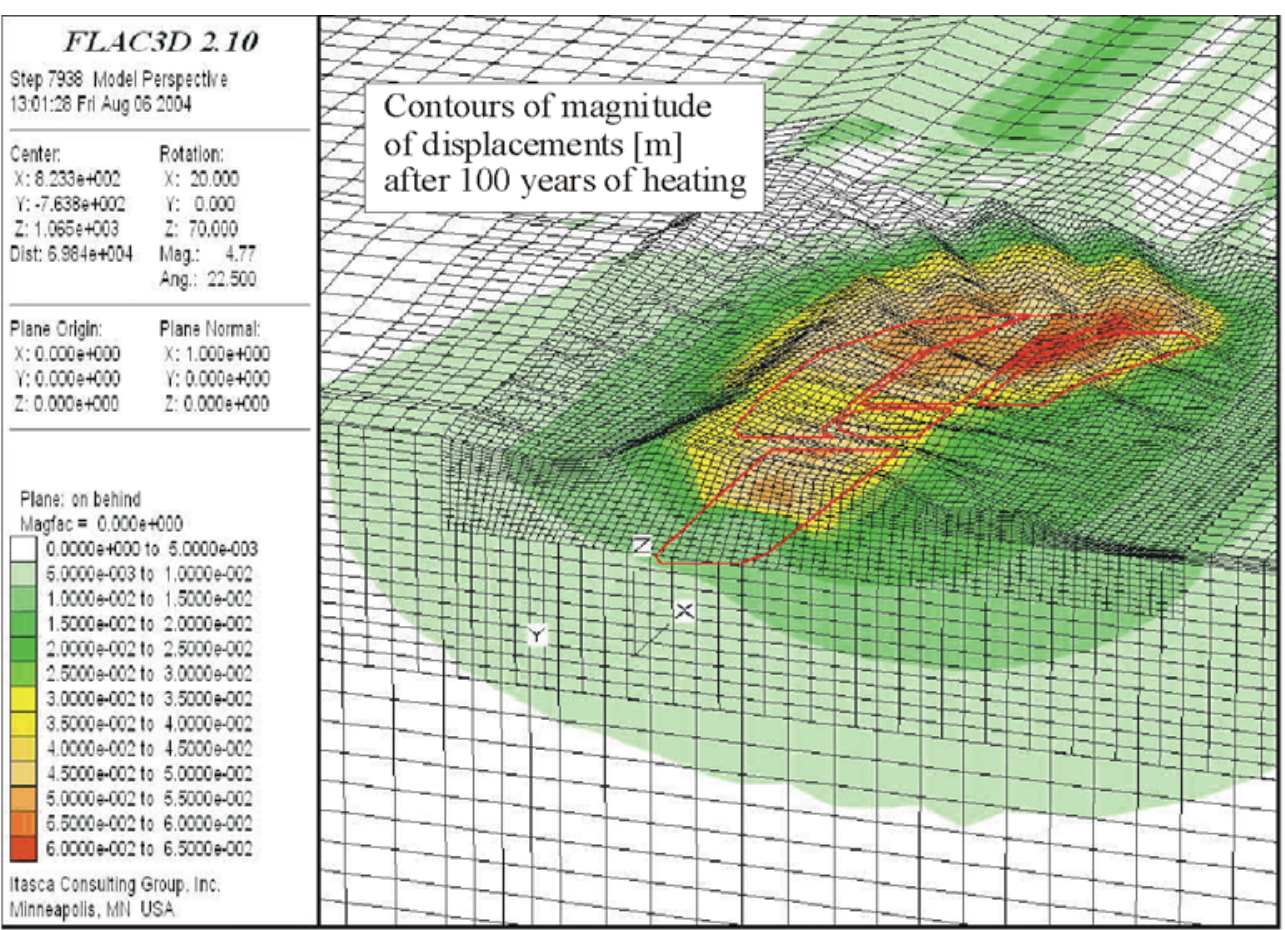

b)

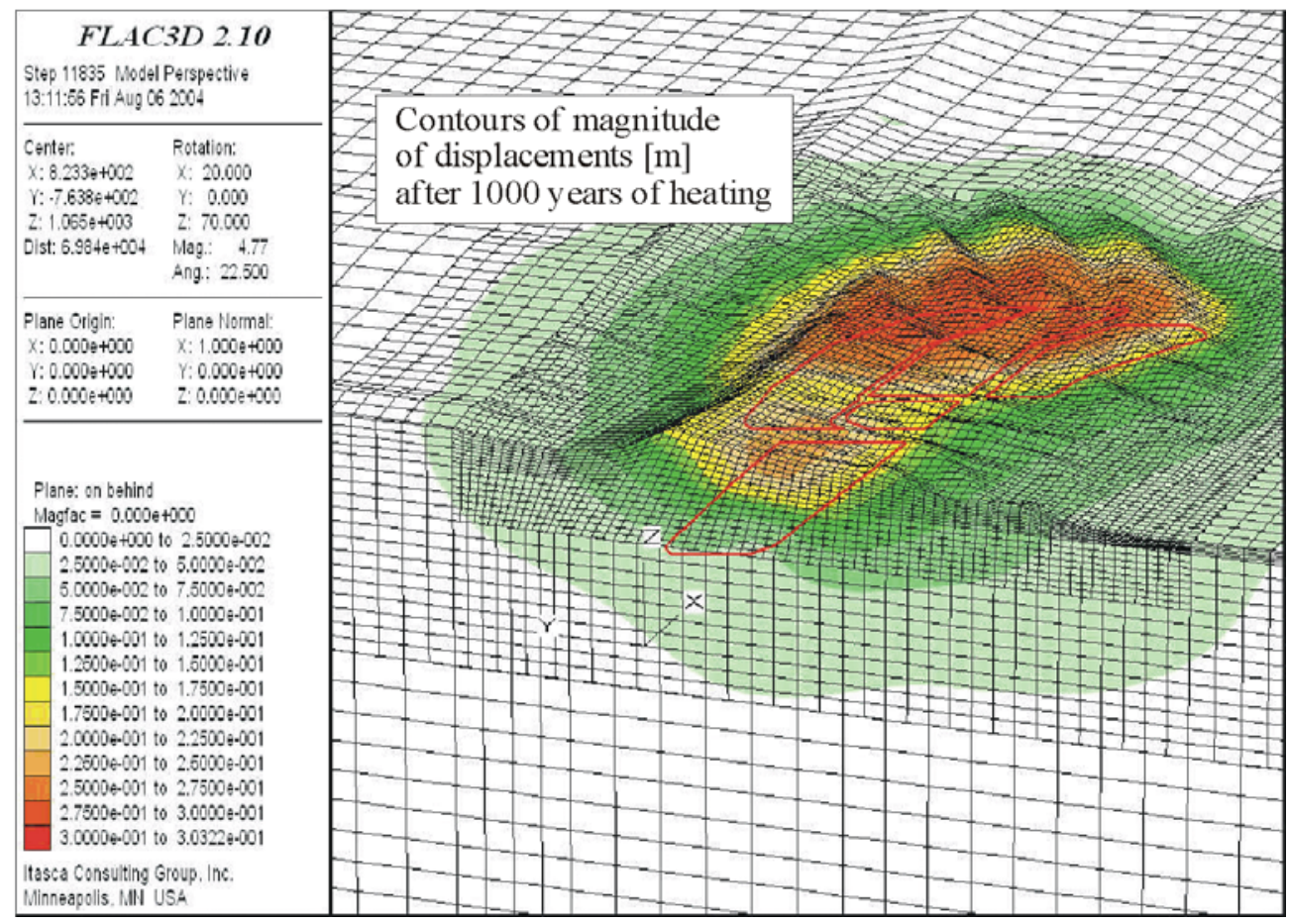

NOTE: a) after 100 years of heating; b) after 1000 years of heating.

Figure C-13. Contours of Magnitude of Induced Displacements ( $\geq 100$ Years) 


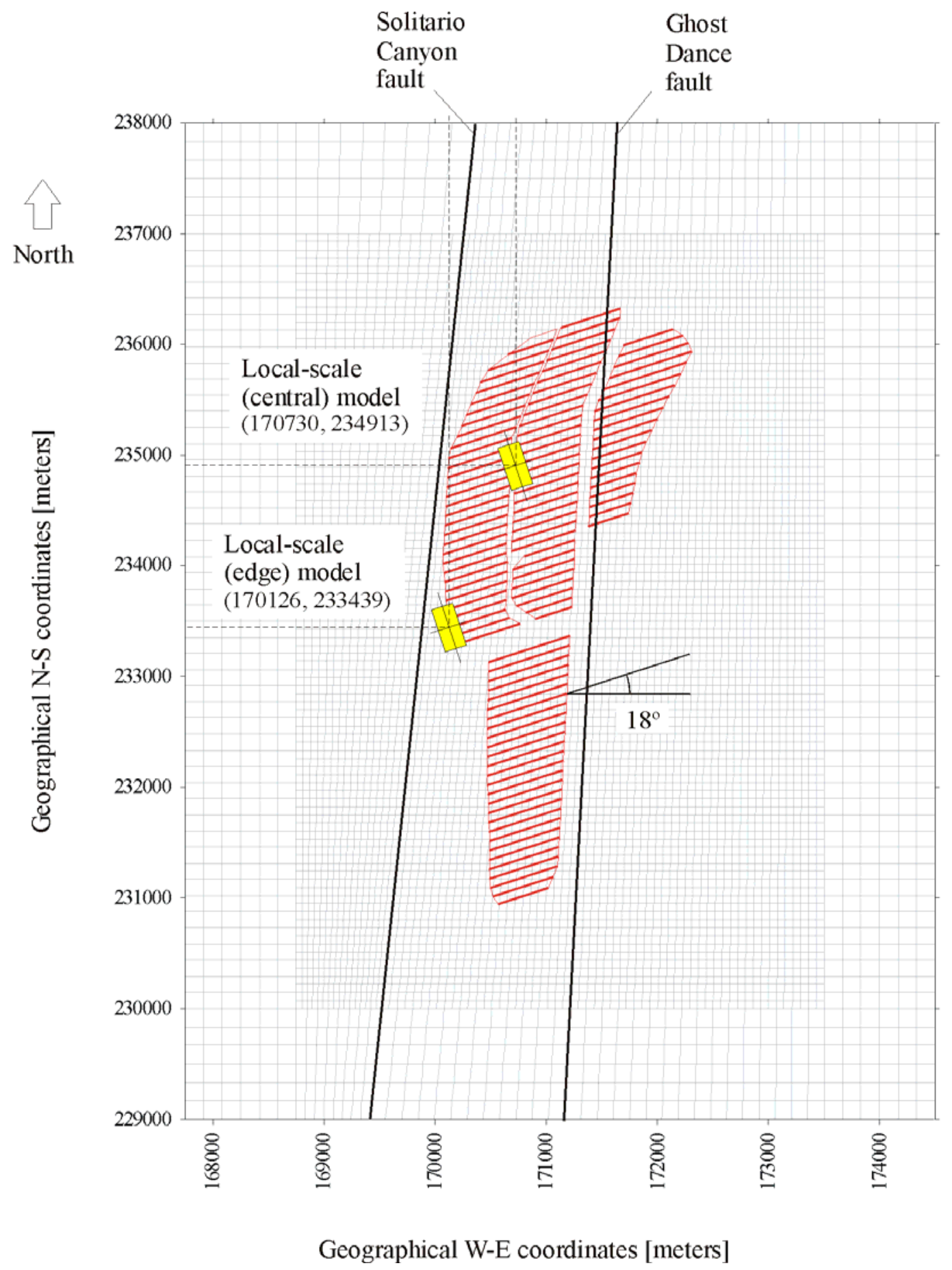

Figure C-14. Geographical Location of the Local Scale Calculation 


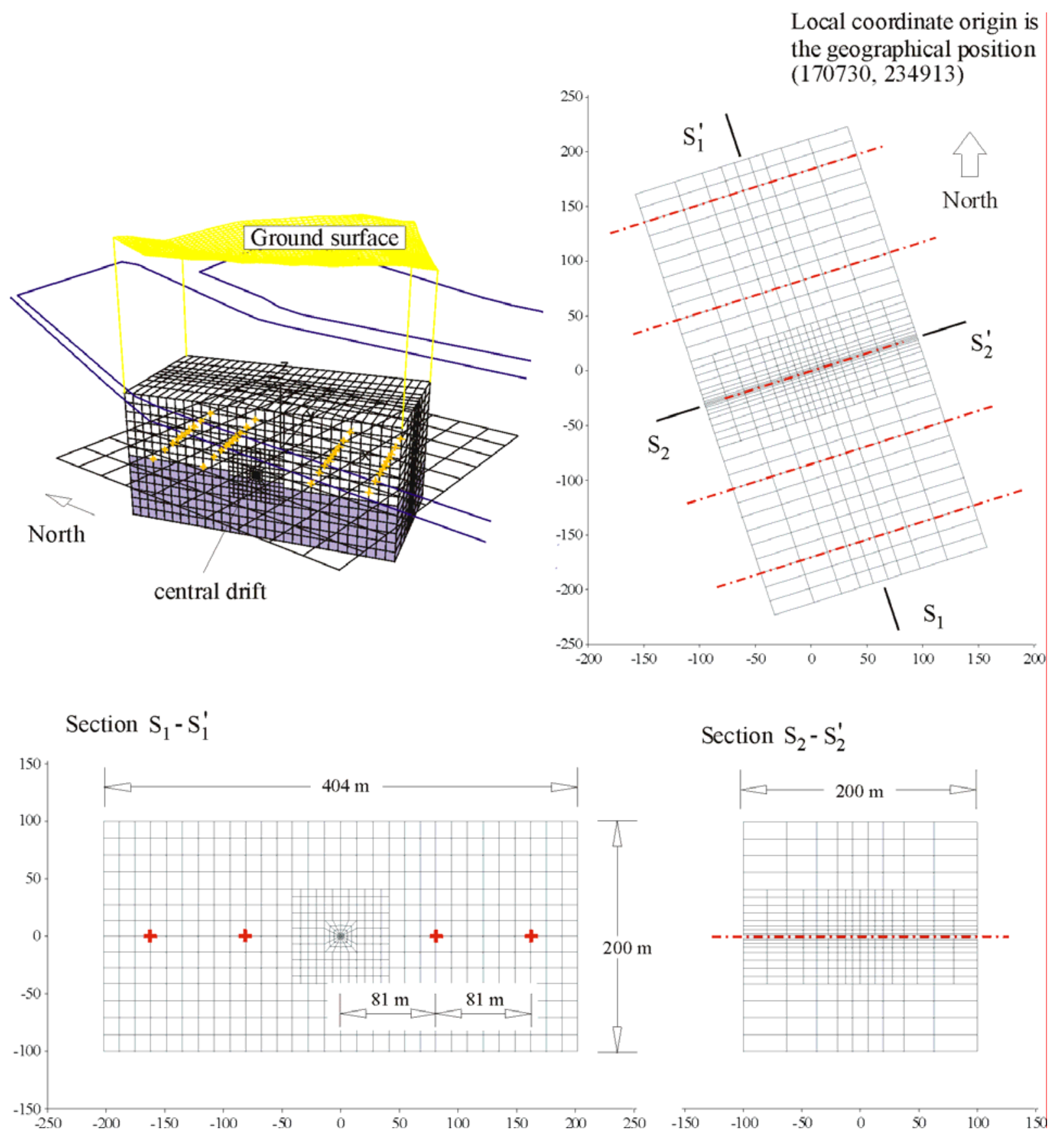

Figure C-15. Isometric and Plan View, and Cross-Sections of the Local Scale Center Calculation

The regional scale calculations provide the boundary conditions (i.e., temperature and stresses at the boundaries) needed to run the thermal-mechanical simulation. Transfer of temperatures and stresses from the regional-scale calculation to the local-scale calculations are performed by a series of interpolation functions. These functions compute the values of temperatures and stresses at the grid points and the zones of the regional scale calculation at specified times in the simulation (e.g., 1, 10, 100, 200, 300 . . 10,000 years) and interpolate these to the grid points and zones of the local scale calculations. 
The thermal-mechanical simulation at the local-scale is intended to determine the distribution of temperatures and stresses around the central drift (see Figure C-15). A linear thermal load of $1450 \mathrm{~W} / \mathrm{m}$ (the same as used in the regional scale calculation) with the decay and ventilation functions shown in Figure C-8 is applied along the drifts represented in the calculations.

Results for the local-scale center calculation are represented in Figures C-16 through C-18. Figure C-16 represents the evolution of temperature at points surrounding the drifts on a vertical plane that passes through the center of the calculation and runs perpendicular to the axis of the drift (i.e., it has a direction of $162^{\circ}$ from the North). Figure C- 17 shows contours of temperature on this plane after 50 and 500 years of heating. Figure C-18 shows contours of the vertical stress $\sigma_{\mathrm{z}}$ after 50 and 500 years of heating.

Results for the local-scale edge calculation are also represented in Figures C-19 through C-21. Figure C-19 represents the evolution of temperature at points surrounding the drifts on a vertical plane that passes through the center of the calculation and runs perpendicular to the axis of the drift. Figure C-20 shows contours of temperature on this plane after 50 and 500 years of heating. Figure C-21 shows contours of the vertical stress $\sigma_{\mathrm{z}}$ after 50 and 500 years of heating. 


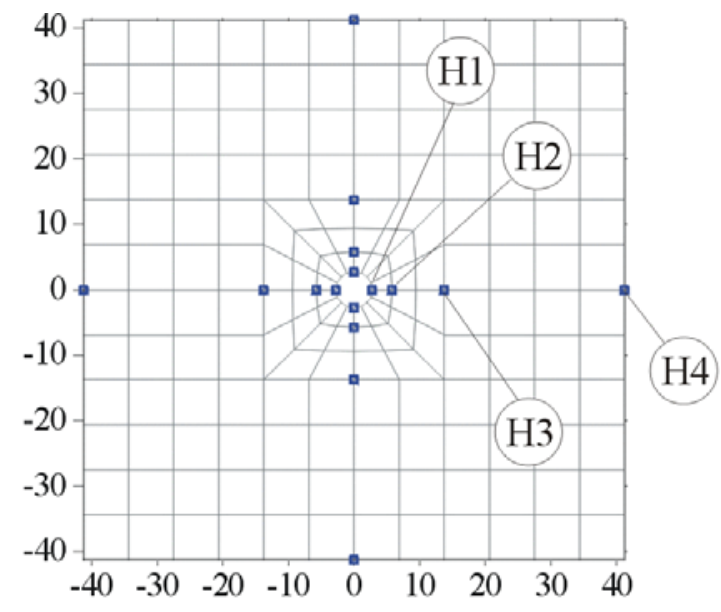

\section{Local-scale model}

History Distance Insitu point to drift temperature axis $[\mathrm{m}] \quad\left[{ }^{\circ} \mathrm{C}\right]$

$\begin{array}{lll}\text { H1 } & 2.75 & 25.46 \\ \text { H2 } & 5.77 & 25.46 \\ \text { H3 } & 13.75 & 25.47 \\ \text { H4 } & 41.25 & 25.51\end{array}$

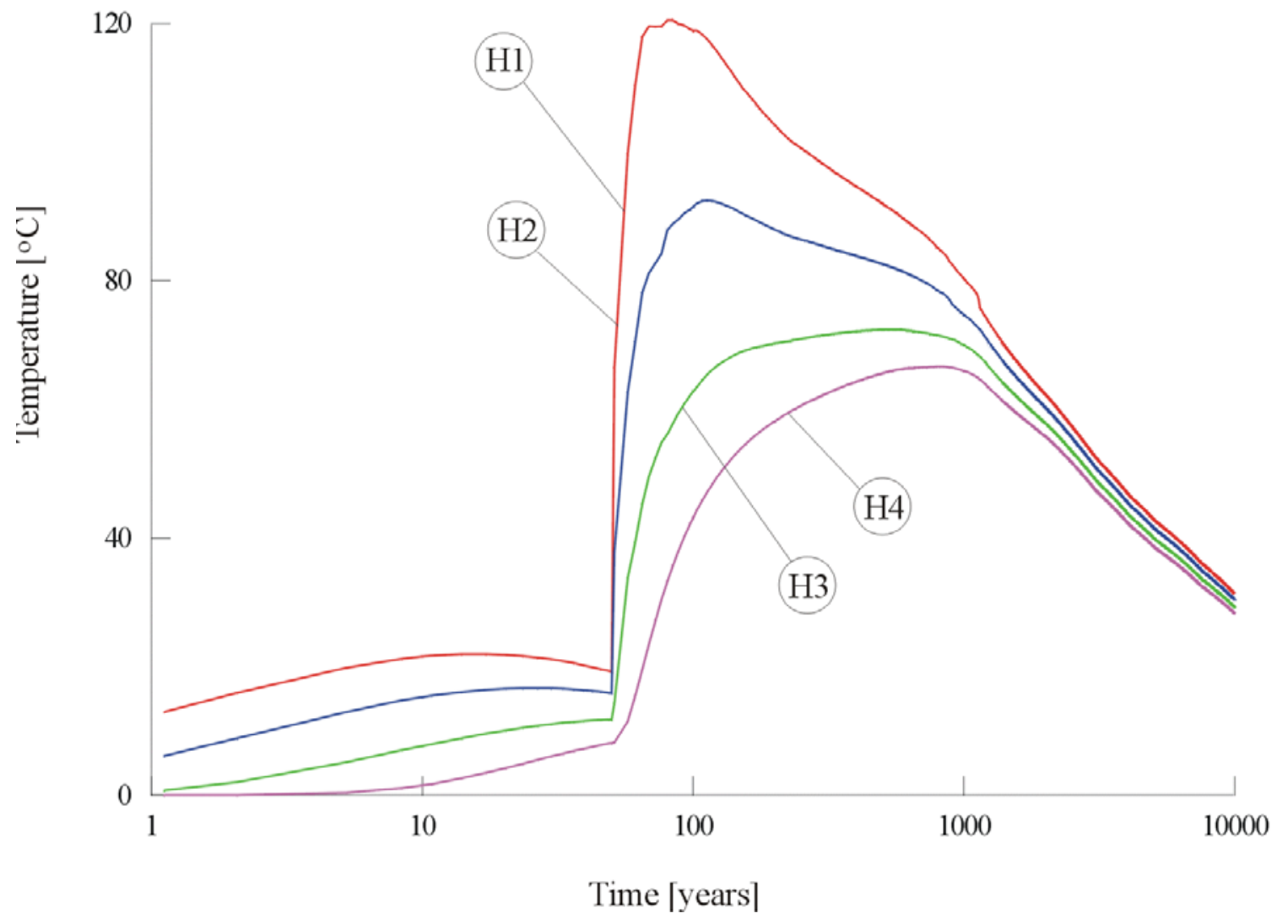

Figure C-16. Evolution of (Induced) Temperatures at Different Locations Around the Central Drift in the Local Scale Center Calculation 
a)

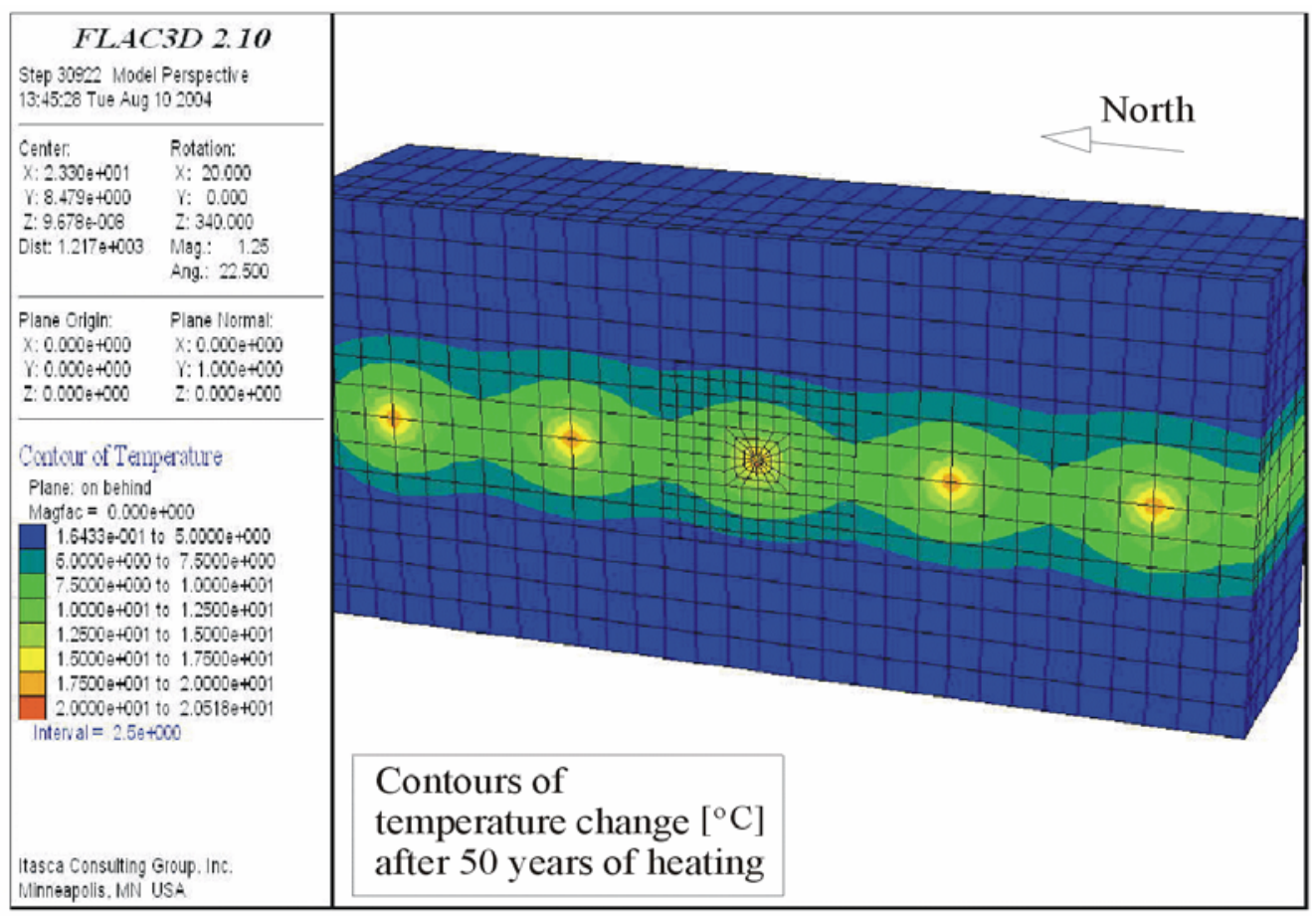

b)

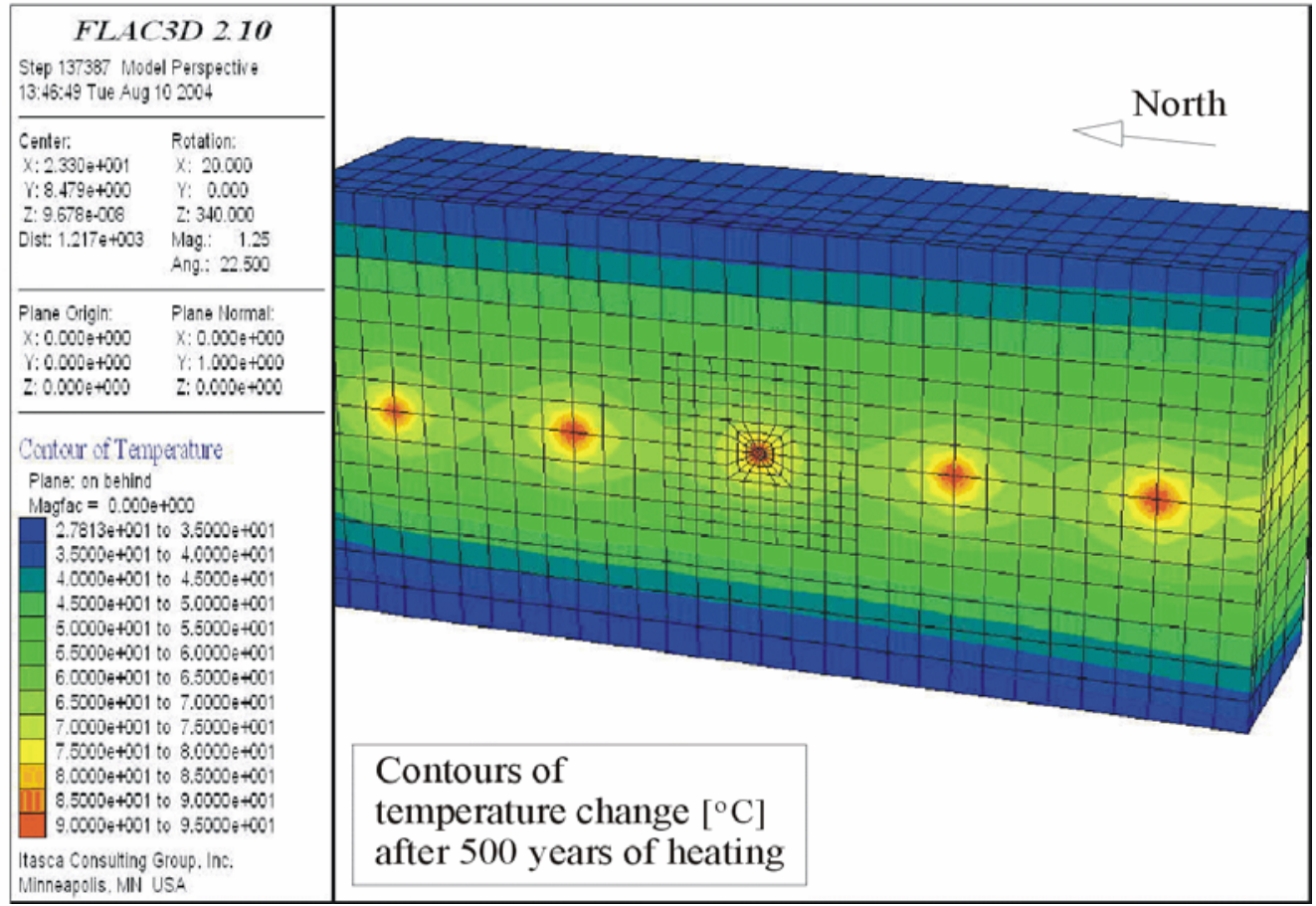

NOTE: Years of heating: a) 50 years; b) 500 years.

Figure C-17. Contours of Induced Temperatures in the Local Scale Center Calculation on Heating 
a)

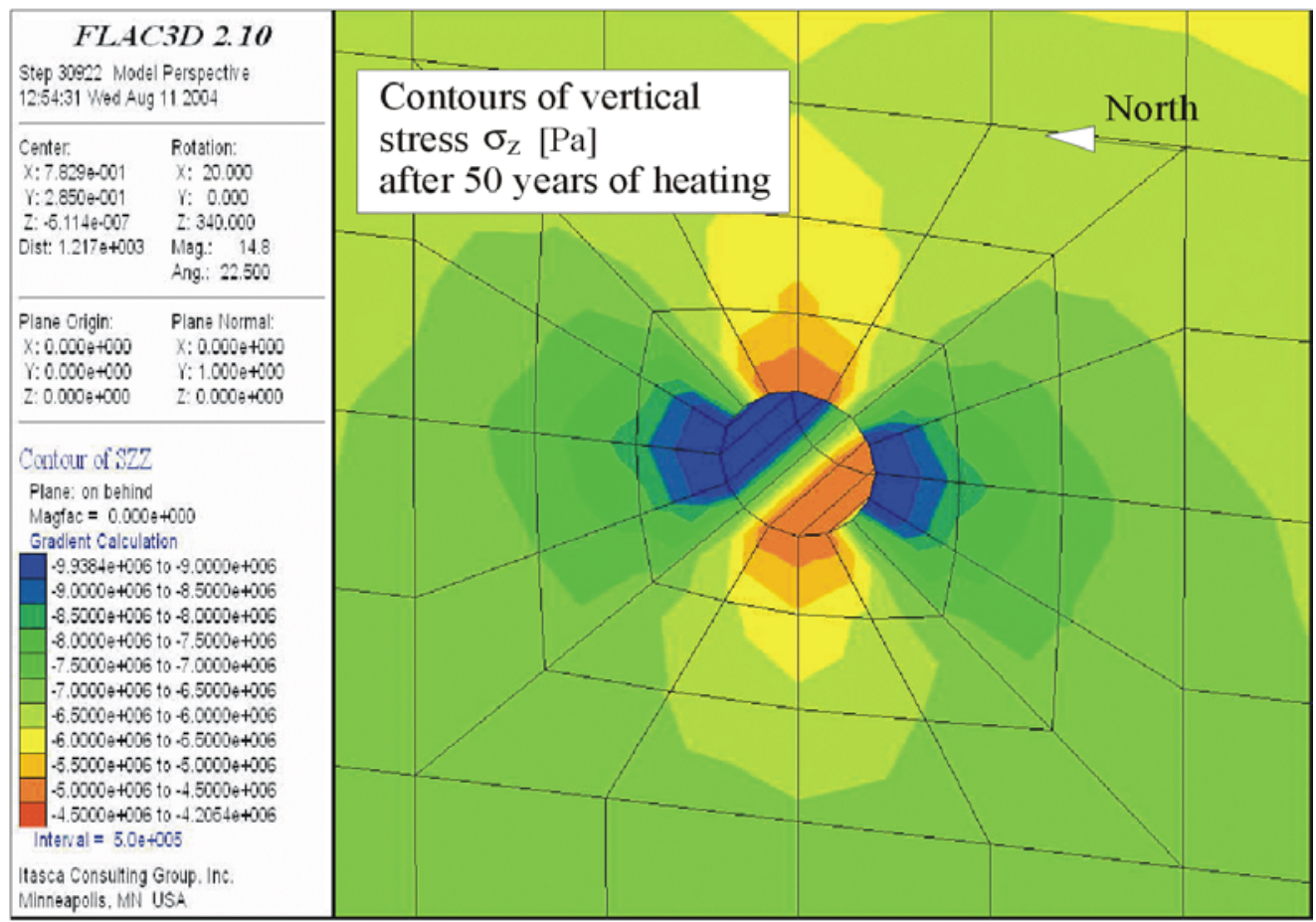

b)

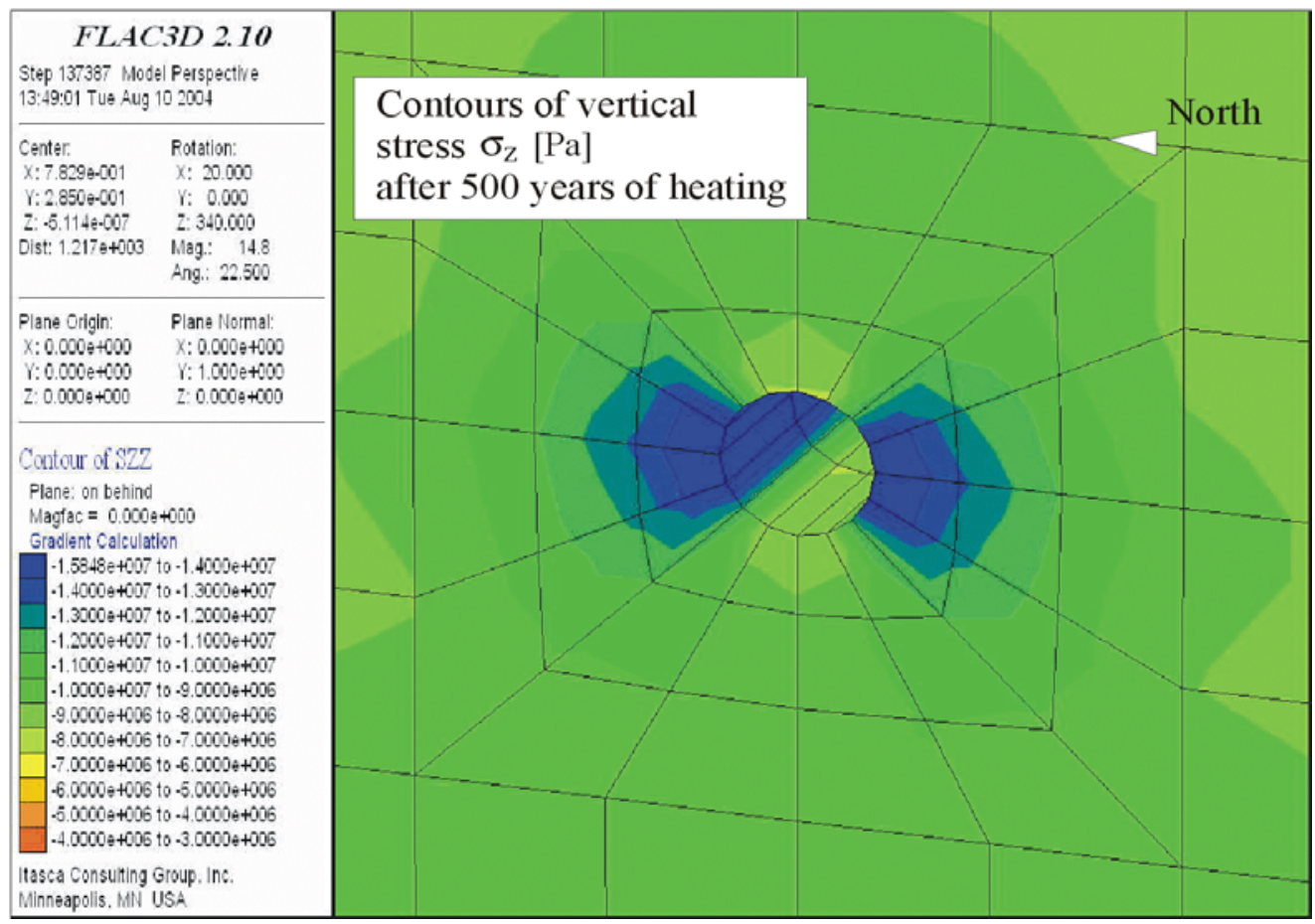

NOTE: Years of heating: a)50 years; b) 500 years.

Figure C-18. Contours of Induced Vertical Stress $\sigma_{z}$ for the Local Scale Center Calculation on Heating 


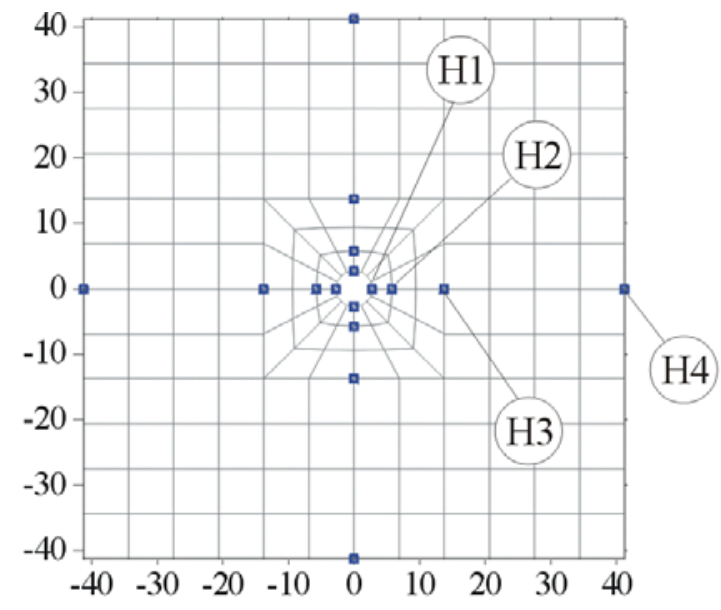

\section{Local-scale model}

History Distance Insitu point to drift temperature axis $[\mathrm{m}] \quad\left[{ }^{\circ} \mathrm{C}\right]$

\begin{tabular}{lll}
\hline $\mathrm{H} 1$ & 2.75 & 25.46 \\
$\mathrm{H} 2$ & 5.77 & 25.46 \\
$\mathrm{H} 3$ & 13.75 & 25.47 \\
$\mathrm{H} 4$ & 41.25 & 25.51
\end{tabular}

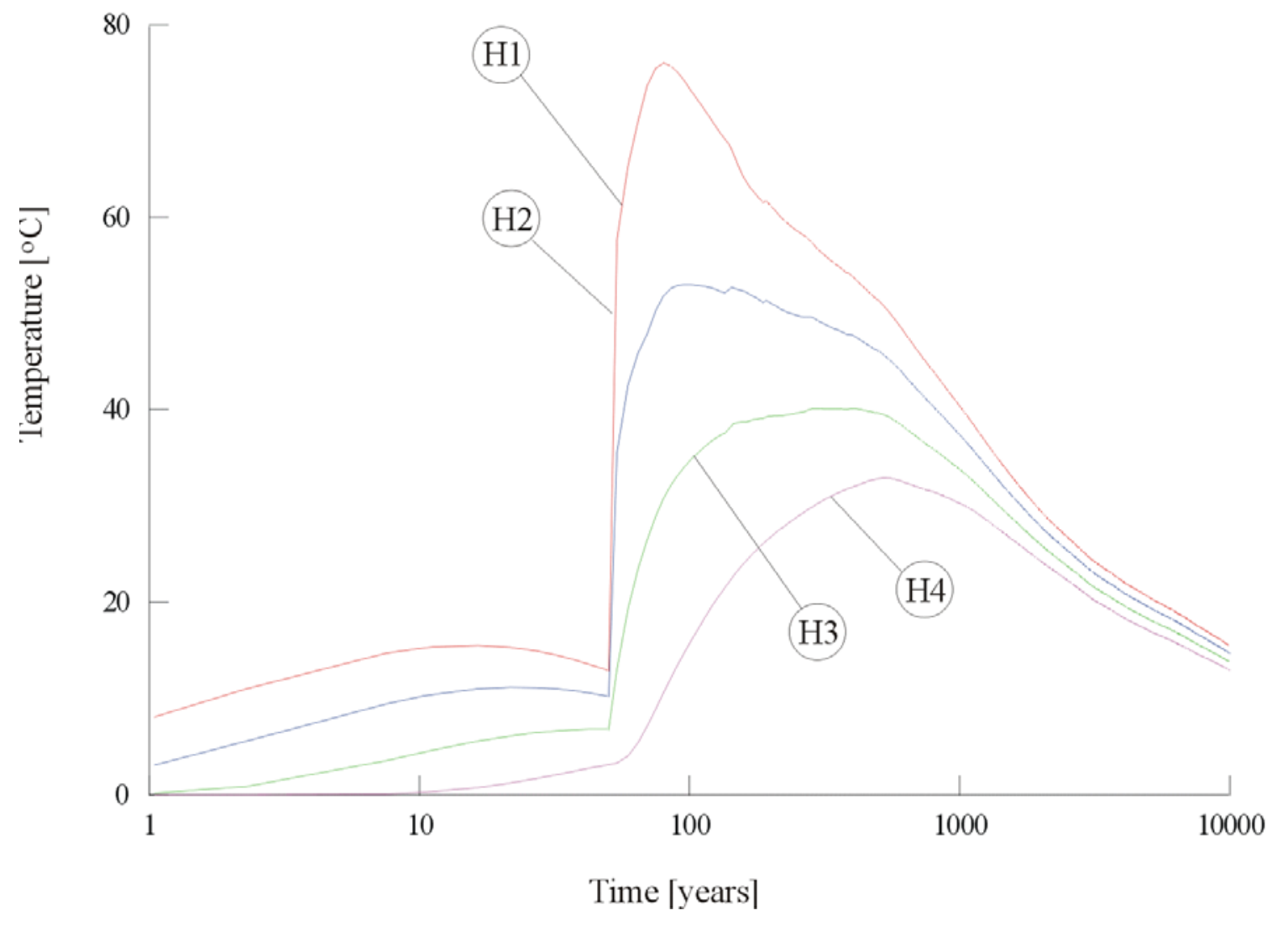

Figure C-19. Evolution of (Induced) Temperatures at Different Locations Around the Drift in the Local Scale Edge Calculation 
a)

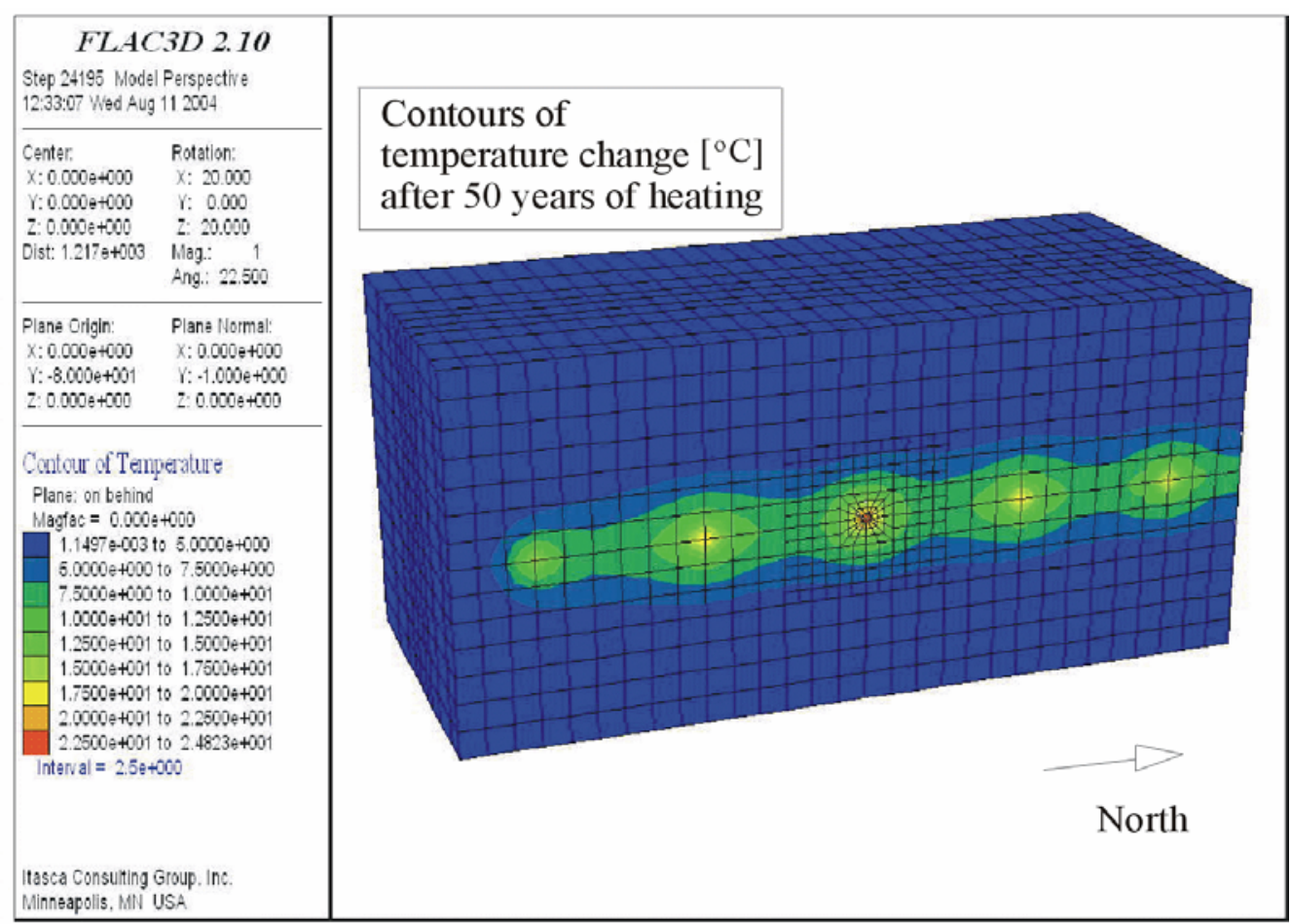

b)

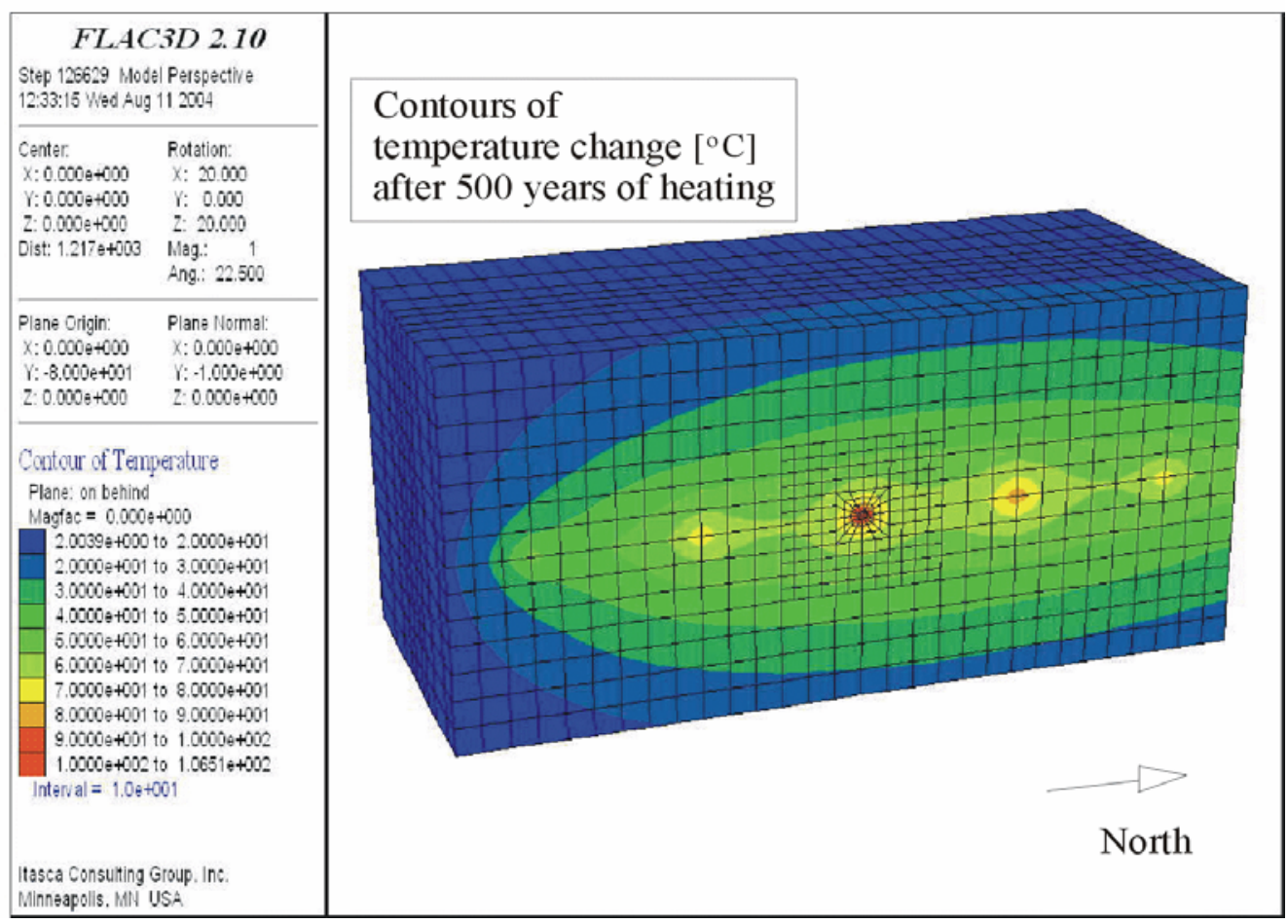

NOTE: After heating: a) 50 years; b) 500 years.

Figure C-20. Contours of Induced Temperatures in the Local Scale Edge Calculation on Heating 
a)

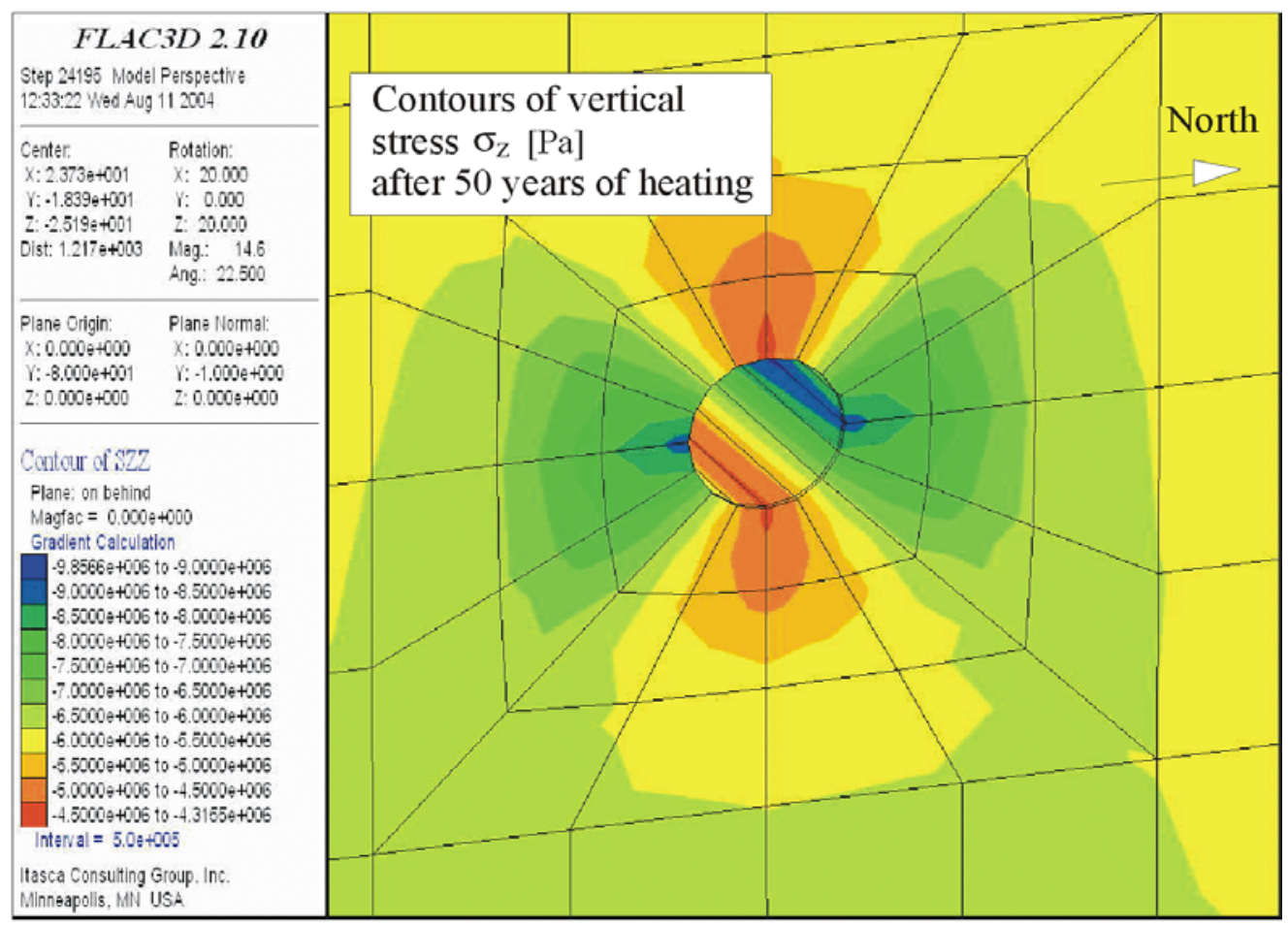

b)

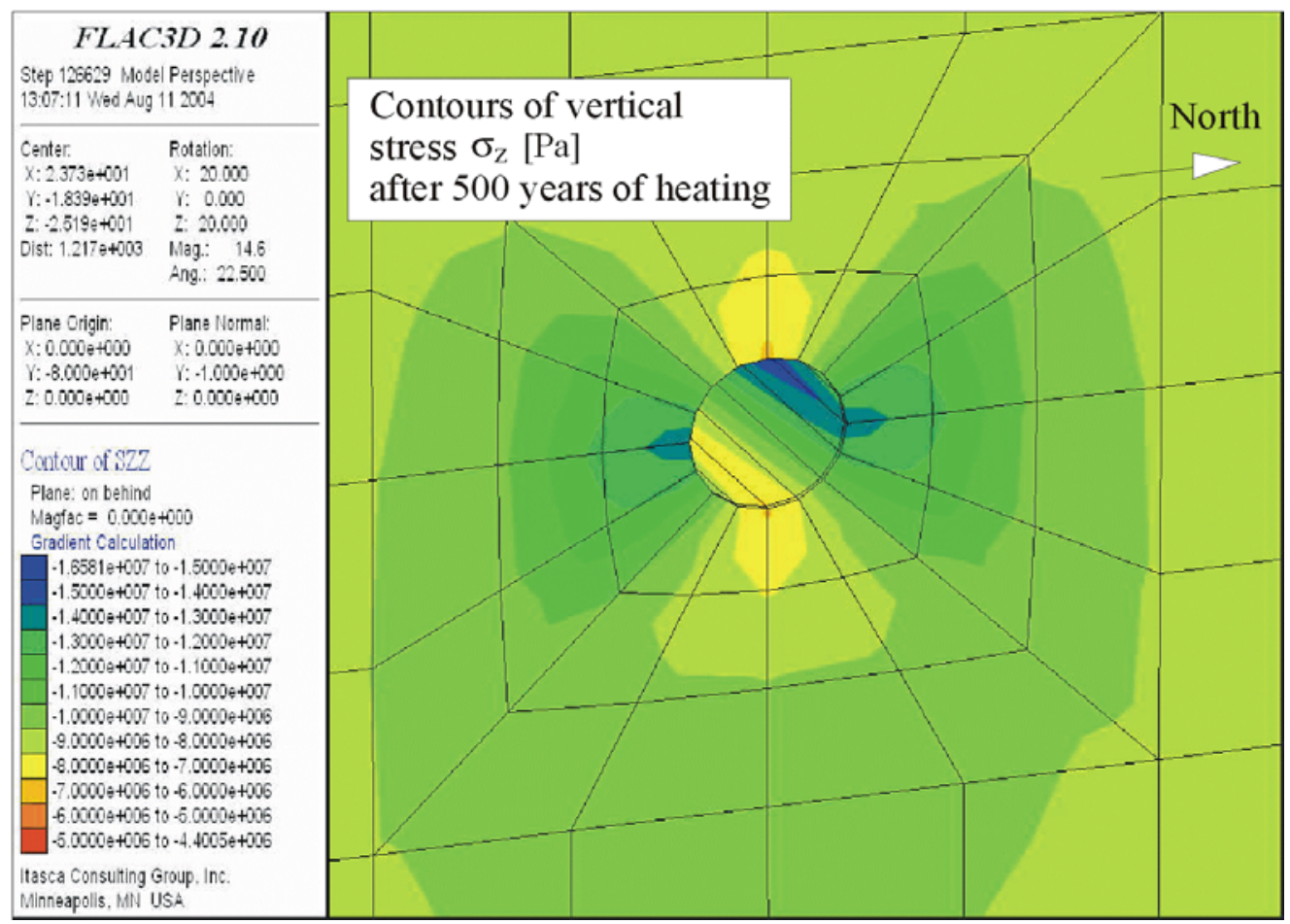

NOTE: After heating: a) 50 years; b) 500 years of heating.

Figure C-21. Contours of Induced Vertical Stress $\sigma_{z}$ for the Local Scale Edge Calculation on Heating 


\section{INTENTIONALLY LEFT BLANK}




\section{APPENDIX D \\ DRKBA ANALYSIS OF NONLITHOPHYSAL ROCK}




\section{DRKBA ANALYSIS OF NONLITHOPHYSAL ROCK}

The DRKBA analysis approach involves the use of probabilistic key-block theory through the numerical code, DRKBA V3.31 (see Section 3.1). This method is based on an industry-accepted approach for analyzing geotechnical problems. Prior to initially purchasing the DRKBA software, technical literature sources were reviewed for the purpose of determining the most appropriate approach to be used in the development of a key-block analysis for the YMP. In summary, the issue of key-block analysis in underground excavations located in jointed rock masses has been considered in a number of design situations. Deterministic methods of block theory in rock engineering were advanced by Warburton (1981 [DIRS 150093]) and Goodman and Shi (1985 [DIRS 150094]). The UNWEDGE software (UNWEDGE V2.3, 30053 V2.3) is an example of a deterministic method that calculates the maximum block size given the spacing and orientation of three joint sets, and the excavation size and orientation. Subsequently Hoerger and Young (1990 [DIRS 151814]), Tyler et al. (1991 [DIRS 151818]), Kuszmaul and Goodman (1995 [DIRS 151816]) and Stone et al. (1996 [DIRS 150437]) have been orientated toward probabilistic risk assessment of key-block failure. Stone et al. (1996 [DIRS 150437]) reports on the use of DRKBA. These latest methods are considered suitable for the analysis of densely jointed and faulted rock masses where planar joint surfaces can reasonably be considered. These conditions typically exist at the YMP.

\section{D1. DRKBA APPROACH}

DRKBA is a commercially available acquired software product (described in Section 3). The software simulates structural discontinuities as circular discs placed in the rock mass according to probabilistic distributions determined from tunnel mapping data. Joint planes are simulated by a Monte Carlo technique from probability distributions representing the orientation, spacing, and trace length of the corresponding joint set. DRKBA determines where joint planes intersect to form blocks, and then analyzes these blocks to determine if they are geometrically feasible (i.e., the shape of the block is such that it is physically possible to slide or fall into the tunnel opening). If the blocks are geometrically feasible, DRKBA then determines if they are mechanically stable (i.e., the gravitational forces that cause the block to move into the tunnel opening are less than the frictional forces on the block sliding surfaces). DRKBA does not include a ground support element.

A probabilistic key-block analysis using DRKBA requires four sets of data. The required data are stored in data files having extensions .mkg, .exc, .den, and .prb, and contain information for the grid, excavation, rock density, and joint sets, respectively. The make grid file (.mkg) includes the information required for building a grid of nodal points for the mesh. The excavation data file (.exc) contains the information for defining an excavation in three-dimensional space. The density file (.den) holds the information for the rock density data. The probabilistic joint data file (.prb) includes the required information for generating fracture space from the given fracture probability distributions.

The DRKBA software employs a bipolar Watson distribution for joint orientation data. The principal axis orientation and a concentration factor $\mathrm{k}$ are the required inputs for the bipolar Watson distribution. The concentration factor $\mathrm{k}$ is an index of the concentration. The larger the value of $\mathrm{k}$, the more the distribution is concentrated towards the principal axis orientation. Joints 
are represented as circular discs in the DRKBA analysis. Joint radii, spacings, and positioning are simulated with beta distributions. The beta distribution is a four-parameter distribution with the parameters $a, b, p$, and $q$. Parameters $a$ and $b$ represent the ends of the closed interval upon which the beta distribution is defined. The parameters $p$ and $q$ determine the shape of the distribution curve, their values were calculated from the mean and standard deviation of the transformed data. The transformed data were obtained by normalizing the data with the maximum value. The cohesion and friction angle of the joints are simulated as a bivariate normal distribution. Inputs for the mean and standard deviation of the joint strength parameters are required.

\section{D2. STATISTICAL REPRESENTATION OF JOINT DATA}

The DRKBA software uses joint geometry inputs provided in Table 4-1, and which are described in Fracture Geometry Analysis for the Stratigraphic Units of the Repository Host Horizon (CRWMS M\&O 2000 [DIRS 152286]). These developed fracture data include joint set orientation, joint spacing, joint trace length, and joint offset from the detailed line survey. Joint sets were identified in Fracture Geometry Analysis for the Stratigraphic Units of the Repository Host Horizon (CRWMS M\&O 2000 [DIRS 152286], Section 6.4.1) based on clustering of the data from joint normal vectors plotted on stereonets as shown in Figure D-1 for the Tptpmn unit. A scatter plot, contour plot, strike rosette, and major planes are included in this figure. The major joint plane is expressed using the strike/dip format in this figure. The joint orientation is expressed in dip direction/dip format in Table D-1. In addition to the primary joint sets listed in Table D-1, a random joint set has also been simulated to account for any joint that is present in the rock mass but not accounted for in the primary sets. The dispersion of the individual joints about their associated joint set axes was modeled by a Watson bipolar distribution for axial data. This probability distribution is characterized by a unit normal vector representing the mean direction about which the data is clustered and a concentration factor $\mathrm{k}$ representing the degree to which the data is clustered about the mean direction. The concentration factors were calculated based on the eigenvalues and eigenvectors of the orientation matrix (Fisher et al. 1987 [DIRS 108447]). The calculated concentration factors are also listed in Table D-1. The process to calculate the concentration factors is included in the electronic files, New-K-Tptpmn V1.mcd and K-small scale.mcd (DTN: MO0408MWDDDMIO.002).

Joint radii, spacings, and positioning (see Section 5.2.1) are simulated with beta distributions. The offset measured from the center of the trace length to the scan line was used as the positioning parameter. The parameters $\mathrm{a}, \mathrm{b}, \mathrm{p}$ and $\mathrm{q}$ for the Tptpmn unit are listed in Table D-2, with the details for the calculation of each parameter provided in the electronic files, New-Beta-Tptpmn V1.xls and Beta-small scale.xls (DTN: MO0408MWDDDMIO.002). An example for calculating the distribution parameters with the fracture data of the first joint set for Tptpmn unit is provided in Section D6.

Cohesion and friction angle of the joints are simulated with the bivariate normal distribution. The laboratory shear strength tests indicate the mean cohesion value of $0.6 \mathrm{MPa}$ with a range of 0.2 to $0.9 \mathrm{MPa}$ (Appendix E, Section E2). Due to the wide range of values, the joint cohesion used in the nonlithophysal rockfall models is conservatively initialized as $0.1 \mathrm{MPa}$, resulting in increased rockfall. 


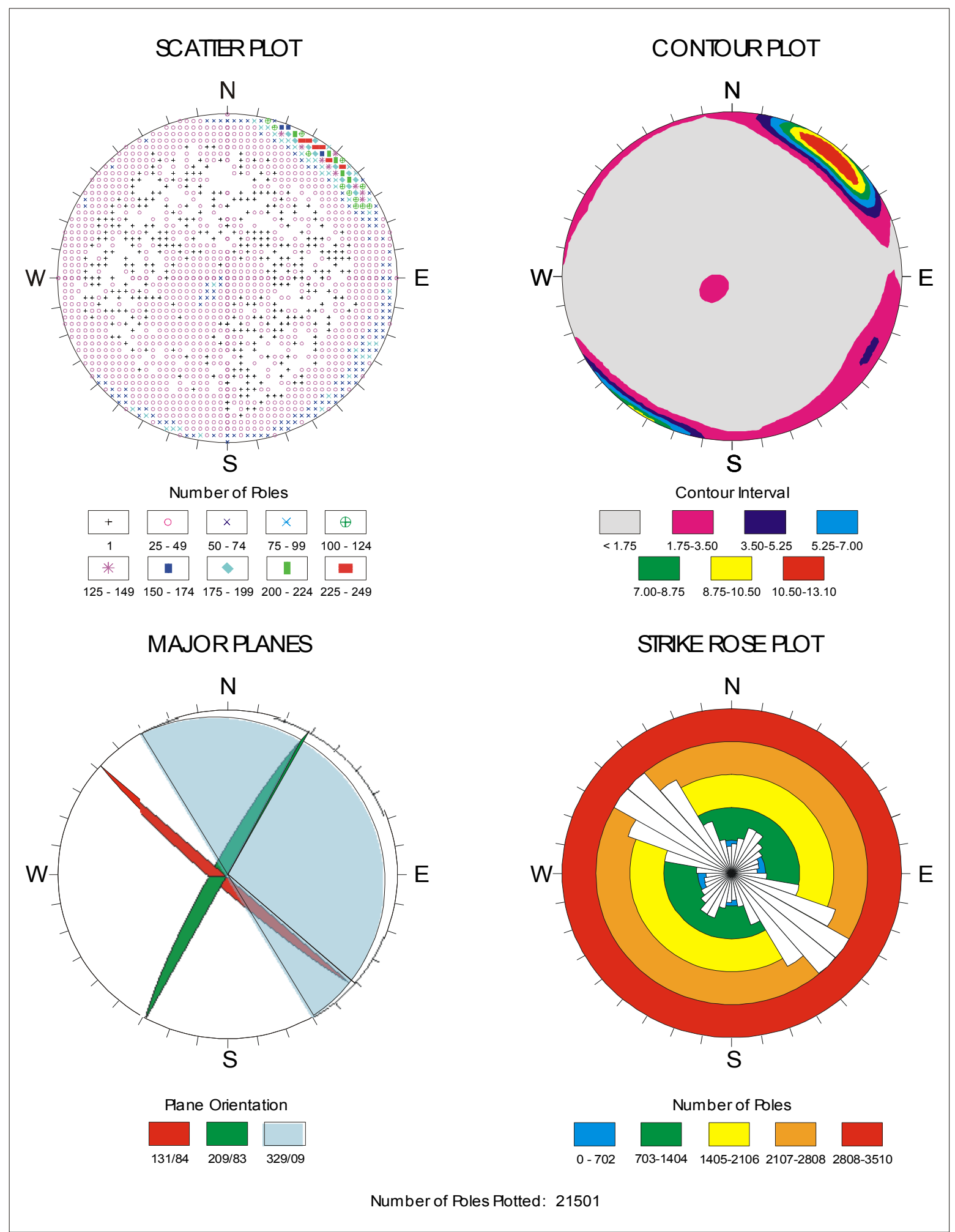

Source: CRWMS M\&O 2000 [DIRS 152286], Figure III-2.

Figure D-1. Determination of Primary Joint Sets, Tptpmn 
Table D-1. Joint Set Orientation Data and Concentration Factors ${ }^{a}$

\begin{tabular}{|c|c|c|c|c|}
\hline \multirow{4}{*}{ Lithologic Unit } & Joint Set Number & $\begin{array}{c}\text { Mean Dip } \\
\text { Direction } \\
\text { (degrees) }^{\mathbf{b}}\end{array}$ & $\begin{array}{c}\text { Mean Dip } \\
\text { (degrees) }^{\mathbf{b}}\end{array}$ & $\begin{array}{c}\text { Concentration } \\
\text { Factor } \mathbf{k}\end{array}$ \\
\hline \multirow{4}{*}{ Tptpmn } & 1 & 221 & 84 & 31.586 \\
\cline { 2 - 5 } & 2 & 299 & 83 & 26.143 \\
\cline { 2 - 5 } & 3 & 59 & 9 & 18.210 \\
\cline { 2 - 5 } & Random (>1-m trace) & 267 & 79 & 2.896 \\
\cline { 2 - 5 } & Random (<1-m trace) & 293 & 64 & 1.833 \\
\hline
\end{tabular}

a Calculation details provided in DTN: MO0408MWDDDMIO.002, files New-K-Tptpmn V1.mcd and K-small scale.mcd and described in Section D7.

$\mathrm{b}$ The derivation of the joint set orientation data is shown in Figure D-1. The joint set orientation data for small trace length fractures (i.e., $<1 \mathrm{~m}$ trace) is documented in the file, small scale filtering.xls (DTN: MO0408MWDDDMIO.002) as the mean of the azimuth and dip data.

Table D-2. Beta Distribution Parameters for Tptpmn Unit ${ }^{\mathrm{a}}$

\begin{tabular}{|c|c|c|c|c|c|}
\hline $\begin{array}{c}\text { Joint Set } \\
\text { Number }\end{array}$ & Parameters & $\begin{array}{c}a \\
(\mathrm{~m})\end{array}$ & $\begin{array}{c}\text { b } \\
(\mathrm{m})\end{array}$ & $p$ & $q$ \\
\hline \multirow{3}{*}{1} & Spacing & 0.0008 & 13.9199 & 0.2322 & 5.1372 \\
\hline & Radius & 1.8200 & 108.0000 & 0.6554 & 20.7171 \\
\hline & Positioning & 0.0000 & 9.1500 & 0.7569 & 10.2825 \\
\hline \multirow{3}{*}{2} & Spacing & 0.0033 & 16.5306 & 0.4098 & 3.0879 \\
\hline & Radius & 1.6400 & 141.0600 & 0.2024 & 7.2515 \\
\hline & Positioning & 0.0000 & 9.1500 & 0.3292 & 4.0327 \\
\hline \multirow{3}{*}{3} & Spacing & 0.0018 & 15.2606 & 0.2010 & 5.2988 \\
\hline & Radius & 0.3200 & 101.6000 & 0.5503 & 8.5360 \\
\hline & Positioning & 0.0150 & 9.1500 & 0.6369 & 4.6763 \\
\hline \multirow{3}{*}{$\begin{array}{c}\text { Random } \\
\text { (> } 1 \mathrm{~m} \text { trace) }\end{array}$} & Spacing & 0.0100 & 15.1900 & 0.5279 & 7.6008 \\
\hline & Radius & 1.3000 & 60.6000 & 0.6333 & 9.2812 \\
\hline & Positioning & 0.0000 & 9.1500 & 0.5735 & 7.6186 \\
\hline \multirow{3}{*}{$\begin{array}{c}\text { Random } \\
(<1 \mathrm{~m} \text { trace })\end{array}$} & Spacing & 0.0100 & 0.9900 & 0.5119 & 3.9947 \\
\hline & Radius & 0.3000 & 1.9400 & 0.3850 & 1.3472 \\
\hline & Positioning & 0.0050 & 0.4550 & 0.8316 & 3.0687 \\
\hline
\end{tabular}

${ }^{a}$ Calculation details provided in DTN: MO0408MWDDDMIO.002, files New-Beta-Tptpmn V1.xls and Beta-small scale.xls are described in Section D7.

\section{D3. EXCAVATION MODELING}

The excavation in this analysis is a horizontal $5.5 \mathrm{~m}$ diameter emplacement drift trending $75^{\circ}$ in accordance with the repository design description (BSC 2003 [DIRS 165572], Sections 5.1.4 and 8.7). It should be noted that the actual emplacement drift azimuth is $72^{\circ}$. This $3^{\circ}$ difference between the modeled and actual drift alignment is acceptable since given the variability of joint set orientations captured in the model, the alignment difference does not significantly affect the results from this analysis. 
For each Monte Carlo simulation, a $24.4 \mathrm{~m}$ long $(80-\mathrm{ft})$ tunnel has been modeled in a three-dimensional space. A circular tunnel opening without backfill was modeled using 18 plane equations to describe the circumference of the circular tunnel, and 2 plane equations were used to describe each end of the tunnel. The selection for the length of the tunnel modeled and the number of planes for simulation of the circular opening were based on the computer run time and the accuracy of the simulation. Calculations for the plane equations are included in the electronic file, exca vectors V2.xls (DTN: MO0408MWDDDMIO.002). The region around the excavation has been modeled with a grid consisting of 681,472 nodes. The nodes are spaced $0.3 \mathrm{~m}$ ( $1 \mathrm{ft}$ ) apart, with each node representing 0.028 cubic meters ( 1 cubic foot) of the rock mass.

\section{D4. SEISMIC CONSIDERATION}

Natural analogues for the effect of seismic events on rockfall are provided in Appendix G. Underground openings are constrained by the surrounding medium, and it is unlikely that underground openings could move to any significant extent independently of the medium or be subjected to vibration amplification. Two potential causes of block movement during seismic events were observed. The first is related to the differential acceleration in the rock blocks surrounding the tunnel due to seismic excitation (Dowding 1979 [DIRS 101977], p. 19). The second cause is the increase of the tangential force from seismic loading along the sliding surfaces of the rock block (Kaiser et al. 1996 [DIRS 108453], p. 8-3).

A high-frequency seismic wave is required for the possibility of block movement due to differential acceleration (Dowding 1979 [DIRS 101977], p. 19). For a case with shear wave velocity of $2000 \mathrm{~m} / \mathrm{sec}$ intersecting a $5.5 \mathrm{~m}$ diameter drift in the repository host rock, the frequency that would produce the differential acceleration was calculated to be approximately $90 \mathrm{~Hz}$. This frequency of concern is very high compared to the principal frequencies ( 1 to $10 \mathrm{~Hz}$ ) with major earthquakes. Block movement due to differential acceleration is therefore not considered in this analysis.

With a relatively high ratio of wavelength to opening diameter, the surrounding rock mass and the opening itself move nearly as a rigid body with free-field acceleration. A simplified quasi-static approach was used in this analysis to account for the increase of the force along the sliding surfaces. Due to the limitation of DRKBA, seismic loads cannot be directly applied to the opening in the numerical simulation. An alternative method with reduction of joint strength parameters was used to account for the seismic effect. The reduced joint strength parameters are listed in Table D-3.

The following equation was derived using basic laws of motion for a sliding block (Figure D-2), and used to calculate the reduced friction angle in the alternative method:

$$
\Delta \phi=\operatorname{atan}(P G A / 1 g)
$$

where PGA is the peak ground acceleration of the shear wave with unit in $g$. The tangential forces ( $T 1$ and $T 2)$ and normal forces $(N 1$ and $N 2)$ in Figure D-2 are defined as follows:

$$
T 1=M g \times \sin \theta
$$


Table D-3. Reduced Joint Strength Parameters to Account for Seismic Effect

\begin{tabular}{|l|c|c|c|}
\hline \multicolumn{1}{|c|}{ Loading Case } & $\begin{array}{c}\text { Peak Ground } \\
\text { Acceleration (g) }\end{array}$ & Joint Cohesion (Pa) & Joint Friction Angle (degree) \\
\hline Static & - & 99,873 & 41 \\
\hline Seismic $1 \times 10^{-3}$ & 0.14 & 21,282 & 34 \\
\hline Seismic $1 \times 10^{-4}$ & 0.47 & 10,776 & 18 \\
\hline
\end{tabular}

NOTE: Peak ground acceleration for $1 \times 10^{-4}$ ground motion was selected based on DTN: MO0306SDSAVDTH.000 [DIRS 164033] (see Table 6-5). Peak ground acceleration for $1 \times 10^{-3}$ ground motion was selected based on preliminary data and is used for comparison only. Static joint cohesion and friction angle values are provided in Appendix E (Section E2). Seismic joint cohesion and friction angle values are calculated as described in this section. Note that static joint cohesion is conservatively scaled down to $0.1 \mathrm{MPa}$ from 0.6 $\mathrm{MPa}$ (see Section D2).

$$
\begin{aligned}
T 2 & =M a \times \cos \theta \\
N 1 & =M g \times \cos \theta \\
N 2 & =-M a \times \sin \theta
\end{aligned}
$$

where $M, a, g$, and $\theta$ are defined in Figure D-2. At the incipience of block sliding, the tangential force is equal to the resisting frictional force:

$$
T 1+T 2=(N 1+N 2) \times \tan \phi
$$

where $\phi$ is defined in Figure D-2. Substituting Equations D-2 through D-5 into Equation D-6 yields

$$
M g \times \sin \theta+M a \times \cos \theta=(M g \times \cos \theta-M a \times \sin \theta) \times \tan \phi
$$

Equation D-7 can be arranged to the following form:

$$
\frac{a}{g}=\frac{\cos \theta \times \tan \phi-\sin \theta}{\cos \theta+\sin \theta \times \tan \phi}=\frac{\tan \phi-\tan \theta}{1+\tan \theta \times \tan \phi}
$$

Equation D-8 can be rewritten based on the trigonometric relationship for the tangent function:

$$
\frac{a}{g}=\tan (\phi-\theta)=\tan (\Delta \phi)
$$

Equation D-1 is therefore derived as:

$$
\Delta \phi=\operatorname{atan}\left(\frac{a}{g}\right)
$$




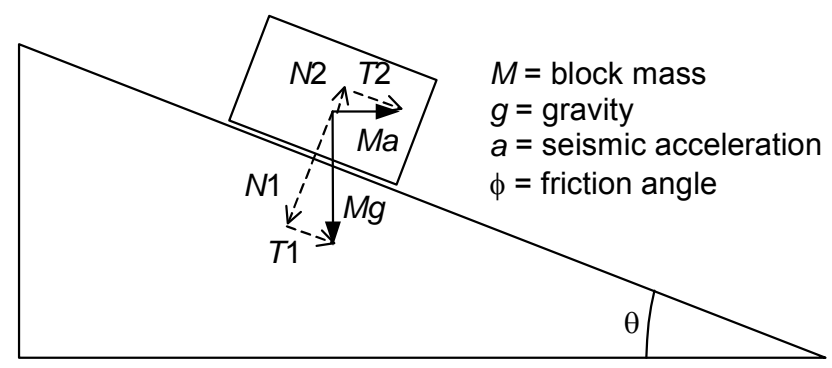

Figure D-2. Illustrative Example of Derivation of Equation D-1

where $a=$ PGA in Equation D-1. Note that this approach is not applicable for large ground motions in which the PGA exceeds $0.86 \mathrm{~g}$, since with an initial static friction angle of $41^{\circ}$, Equation D-1 would produce negative friction angles.

This method is illustrated by the simple examples presented in Figure D-3. The stable joint plane example is presented in Figure D-3a. In this example, the alternative method (i.e., a reduced friction angle) predicts a stable condition, which is the same as the approach with the seismic load included. The unstable joint plane example is presented in Figure D-3b. The alternative reduced friction angle method is capable of predicting the unstable joint condition as shown.

\section{D5. THERMAL AND FRACTURE - DEGRADATION CONSIDERATION}

The induced thermal stress and the potential degradation of joint mechanical properties are the concerns for the thermal effect to the block movement. Due to the lateral confinement of the rock, the predicted thermal stress is highest in the horizontal direction. The high horizontal thermal stress provides a locking effect for the blocks formed by the predominant vertical joint sets during the heating period, thus preventing rockfall. Due to the limitation of the applying external loads using DRKBA, this locking effect, which reduces rockfall, was conservatively ignored in this analysis.

The site-specific time-dependent behavior of joint strength parameters for the host rock is not available at this time. An approach based on the time-dependent degradation work by Kemeny (1991 [DIRS 108455]) is used in this study. The approach considers that the degradation occurs mainly due to the reduction of joint cohesion. Joint cohesion exists due to the asperities along the joint surface. These asperities may shear off with time and they may shear off due to the increased shear stress caused by the thermal effect. By using the numerical analysis results for the thermally induced shear stress and some site-specific data, the joint cohesion degradation with time can be quantified based on the approach reported by Kemeny and Cook (1986 [DIRS 108454]).

The equation for the mode II stress intensity factor $\left(K_{I I}\right)$ for a single asperity under shear and normal stresses can be expressed in the following (Kemeny and Cook 1986 [DIRS 108454]):

$$
K_{I I}=\frac{\left(\tau-\sigma_{n} \tan (\phi)\right) 2 w}{\sqrt{\pi a(t)}}
$$




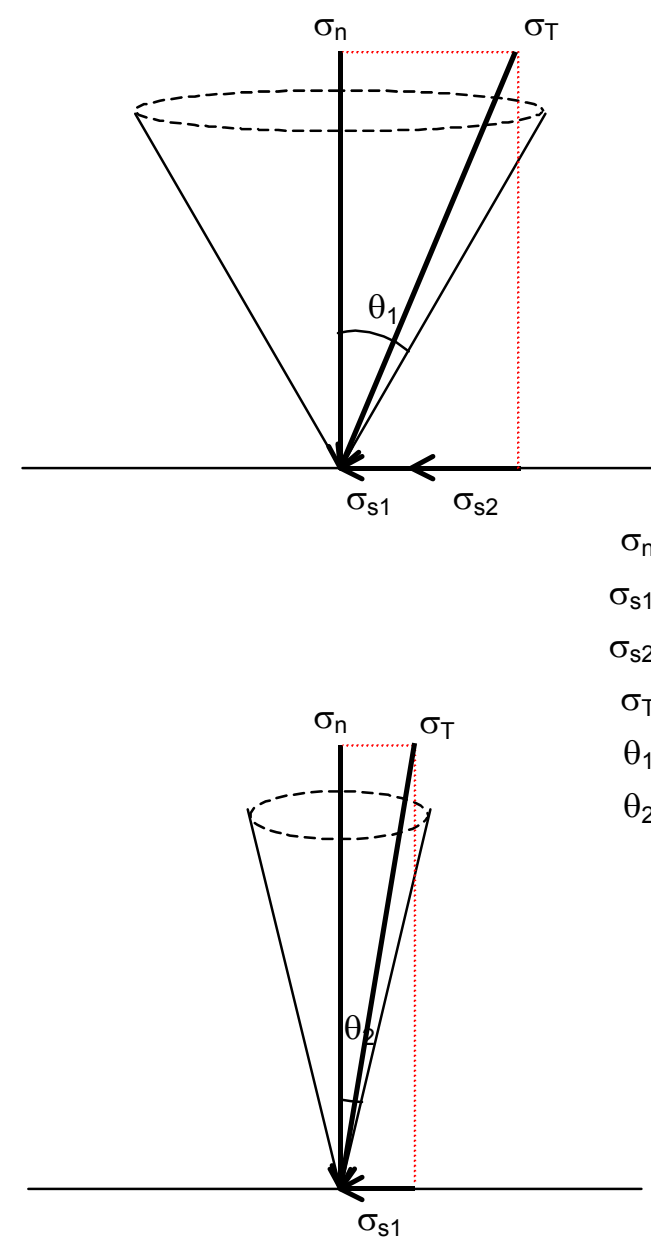

a. Stable Condition

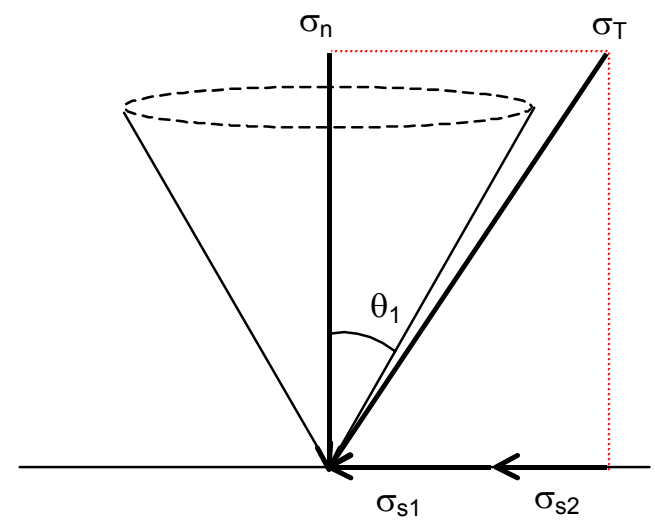

$\sigma_{\mathrm{n}}=$ normal stress

$\sigma_{\mathrm{s} 1}=$ shear stress

$\sigma_{\mathrm{s} 2}=$ seismic induced shear stress

$\sigma_{\mathrm{T}}=$ combined stress

$\theta_{1}=$ joint friction angle

$\theta_{2}=$ reduced joint friction angle

$\left(\theta_{2}=\theta_{1}-\operatorname{atan}\left(\sigma_{\mathrm{s} 2} / \sigma_{\mathrm{n}}\right)\right)$

Figure D-3. Illustrative Examples for the Alternative Method to Account for Seismic Effect

where $\tau$ is the shear stress, $\sigma_{\mathrm{n}}$ is the normal stress, and $\phi$ is the friction angle. The geometrical parameters $w$ and $a$ are shown in Figure D-4.

Critical stress intensity factor of the mode II fracture, $\mathrm{K}_{\mathrm{IIC}}$, of $0.5 \mathrm{MPa} \mathrm{m}^{1 / 2}$ is selected based on data from the direct shear tests (Table E-3) and the Linear Elastic Fracture Mechanics (LEFM) theory. In the LEFM, the $\mathrm{K}_{\mathrm{IIC}}$ is (Jaeger and Cook 1979 [DIRS 106219]):

$$
K_{I I C}=\sqrt{G_{c} E}
$$

where $G_{C}$ is the strain energy release rate $\left(\mathrm{J} \mathrm{m}^{-2}\right)$ and $\mathrm{E}$ is the Young's modulus (GPa). The strain 
energy release rate, $\mathrm{G}_{\mathrm{C}}$, could be estimated from the energy stored during the direct shear tests:

$$
G_{c}=\frac{1}{2} C_{0} d_{c}
$$

where $\mathrm{C}_{0}$ is the cohesion (peak shear strength at zero normal stress), and $\mathrm{d}_{\mathrm{c}}$ is the displacement at the peak shear strength. While $d_{c}$ is considered as $0.5 \mathrm{~mm}$ from the displacement at the peak shear strength of the lowest normal stress, $2.5 \mathrm{MPa}$ (see the first row of Table E-3 and Figure 6 of Olsson and Brown 1997 [DIRS 106453]), cohesion and Young's modulus are utilized as $0.1 \mathrm{MPa}$ (Section D.2) and 33.6 GPa (Table E-6), respectively. The resulting $\mathrm{K}_{\mathrm{IIC}}$ value is $0.92 \mathrm{MPa} \mathrm{m}^{1 / 2}$. However, a value of $0.5 \mathrm{MPa} \mathrm{m}^{1 / 2}$ is selected for this analysis, since the Young's modulus varies from 13.4 to $47.3 \mathrm{GPa}$ (Table E-6) and the resulting $\mathrm{K}_{\mathrm{IIC}}$ varies from 0.58 to $1.09 \mathrm{MPa} \mathrm{m}^{1 / 2}$. The selected value is conservative, since the input cohesion and Young's modulus values are conservative.

It is considered that shear crack growth will occur when the mode II stress intensity factor, $\mathrm{K}_{\mathrm{II}}$ reaches the $\mathrm{K}_{\mathrm{IIC}}$. Setting $\mathrm{K}_{\mathrm{II}}=\mathrm{K}_{\mathrm{IIC}}$ and rearranging Equation D-11 for $\tau$ gives the following:

$$
\tau=\frac{K_{I I C} \sqrt{\pi a}}{2 w}+\sigma_{n} \tan \phi
$$

Equation D-14 is the failure criterion for the discontinuity, and is made up of two terms, a cohesion term and a frictional term. The first term on the right hand side of the equation is the joint cohesion due to the asperity:

where $C_{0}$ is the joint cohesion.

$$
C_{0}=\frac{K_{I I C} \sqrt{\pi a(t)}}{2 w}
$$

The cohesion of $0.1 \mathrm{MPa}$ is predicted using the parameters $K_{I I C}=0.5 \mathrm{MPa} \mathrm{m}^{1 / 2}, w=0.5 \mathrm{~m}$, and $\mathrm{a}_{0}$ is equal to $0.0127 \mathrm{~m}$. These parameters are therefore used as the initial parameters before time-dependent crack growth occurs. As the asperity size decreases due to time-dependent crack growth, the cohesion will decrease as given by Equation D-15.

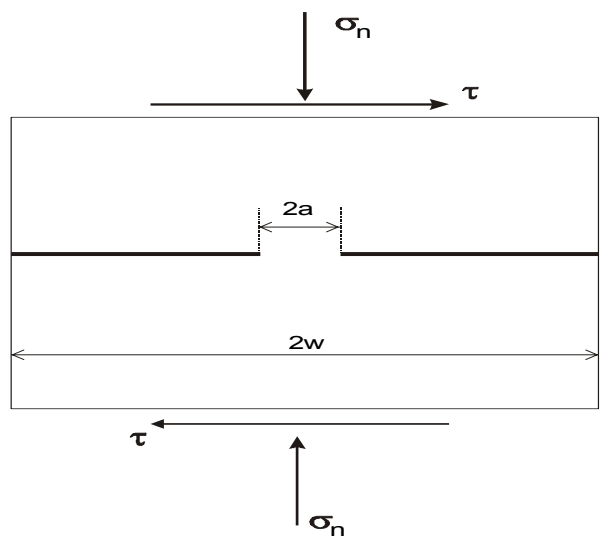

Figure D-4. Parameters Used for Calculation of Mode II Stress Intensity Factor 
The time-dependent crack growth can be expressed using the following equation (Kemeny 1991 [DIRS 108455]):

$$
\frac{d(a(t))}{d t}=A\left[\frac{K_{I I}}{K_{I I C}}\right]^{n}
$$

where $A$ and $n$ are subcritical crack growth parameters.

Combining Equations D-11 and D-16, the time-dependent crack growth can be written as:

$$
\frac{d(a(t))}{d t}=2^{n} A \pi^{-n / 2}\left[\frac{w\left(\tau-\sigma_{n} \tan (\phi)\right)}{\sqrt{a(t)} K_{I I C}}\right]^{n}
$$

Previous studies of the Yucca Mountain area have used $n=25$ and $A$ ranging from $10^{-6}$ to $10^{-4} \mathrm{~m} / \mathrm{sec}$ (Kessler et al. 1996 [DIRS 100558]). A value for $A$ of $10^{-5} \mathrm{~m} / \mathrm{sec}$ is used in this analysis.

The effective shear stress, $\left(\tau-\sigma_{\mathrm{n}} \tan \phi\right)$, is time-dependent due to the thermal loading by the canisters. The thermal loading can cause horizontal stresses as high as $50 \mathrm{MPa}$ in the backs of the underground drifts, decreasing the stability of some joints and increasing the stability of others. On average, it is found that the effective shear stress along the joints $\left(\tau-\sigma_{\mathrm{n}} \tan \phi\right)$ increases by as much as 16 percent in the time period where heating of the rock occurs. The curve-fit function used to describe the additional effective shear stress due to thermal heating is as follows:

$$
f(t)=1+0.00001044556 * e^{(120-t) / 50} t^{2}
$$

This function is presented graphically in Figure D-5. The figure shows that the shear stresses are increased by approximately 10 percent in the period between 50 and 200 years. Adding this function to Equation D-17, the time-dependent crack growth expression is now:

$$
\frac{d(a(t))}{d t}=31536000 * 2^{n} A \pi^{-n / 2}\left[\frac{w\left(\tau-\sigma_{n} \tan (\phi)\right)\left(1+0.00001044556 * e^{(120-t) / 50} t^{2}\right)}{\sqrt{a(t)} K_{\text {IIC }}}\right]^{n}
$$

The nonlinear differential equation was solved numerically using the fourth order Runge-Kutta method in Mathcad (file: Time thermal cohesion degradation V1.mcd). The calculation results in an asperity versus time relationship. This relationship is then used in conjunction with Equation D-15 to obtain the cohesion values for various times (Table A-1, file: Time thermal cohesion degradation V1.mcd). 


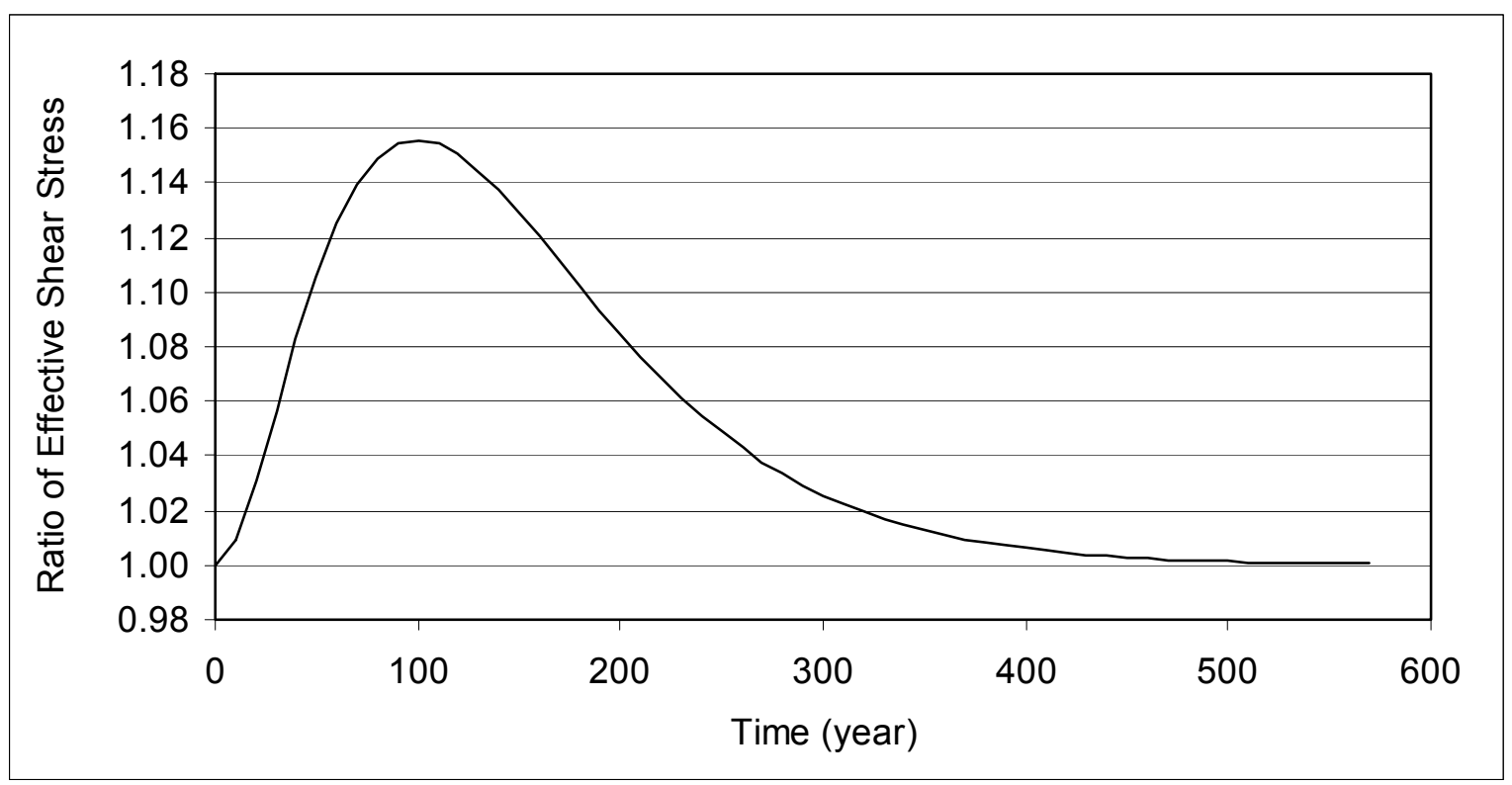

Appendix A-1, file Thermal curve V1.xls

Figure D-5. Function of the Additional Shear Stress Due to Thermal Loading

Numerical analysis made for the in situ stress state give a range of effective shear stresses $\left(\tau-\sigma_{\mathrm{n}} \tan \phi\right)$ that range from 0.04 to $0.06 \mathrm{MPa}$. Calculations were made with effective shear stresses of $0.04,0.0425,0.045,0.0475,0.05,0.0525,0.055,0.0575$, and $0.06 \mathrm{MPa}$, and the results were averaged. This approach results in a stepped cohesion reduction over time as shown in Figure D-6.

\section{D6. ANALYSIS RESULTS}

The prediction of key blocks forming at the emplacement drifts located in the Tptpmn unit is presented in this section. The results are presented for both a static key-block assessment and a quasi-static key-block assessment to account for seismic, thermal, and time effects on key-block development.

In the DRKBA analysis, random joint patterns are generated with joint centers positioned in three-dimensional space, considering each joint set in sequence for each Monte Carlo simulation. The forming of key blocks is therefore different in each Monte Carlo simulation. Test runs were conducted to determine an adequate number of Monte Carlo simulations for the analyses as described in Section D8. Based on the test run results, 400 Monte Carlo simulations are adequate for the Tptpmn unit.

The method used for the quasi-static analysis to simulate the seismic effect is described in Section D4. Two levels of earthquake representing a 1,000-year event $\left(1 \times 10^{-3}\right)$ and a 10,000 year event $\left(1 \times 10^{-4}\right)$ are considered. An emplacement drift orientation with an azimuth of $75^{\circ}$ is the primary orientation for the quasi-static analysis. The inputs and outputs related to the quasi-static analysis are listed in Table A-1. 


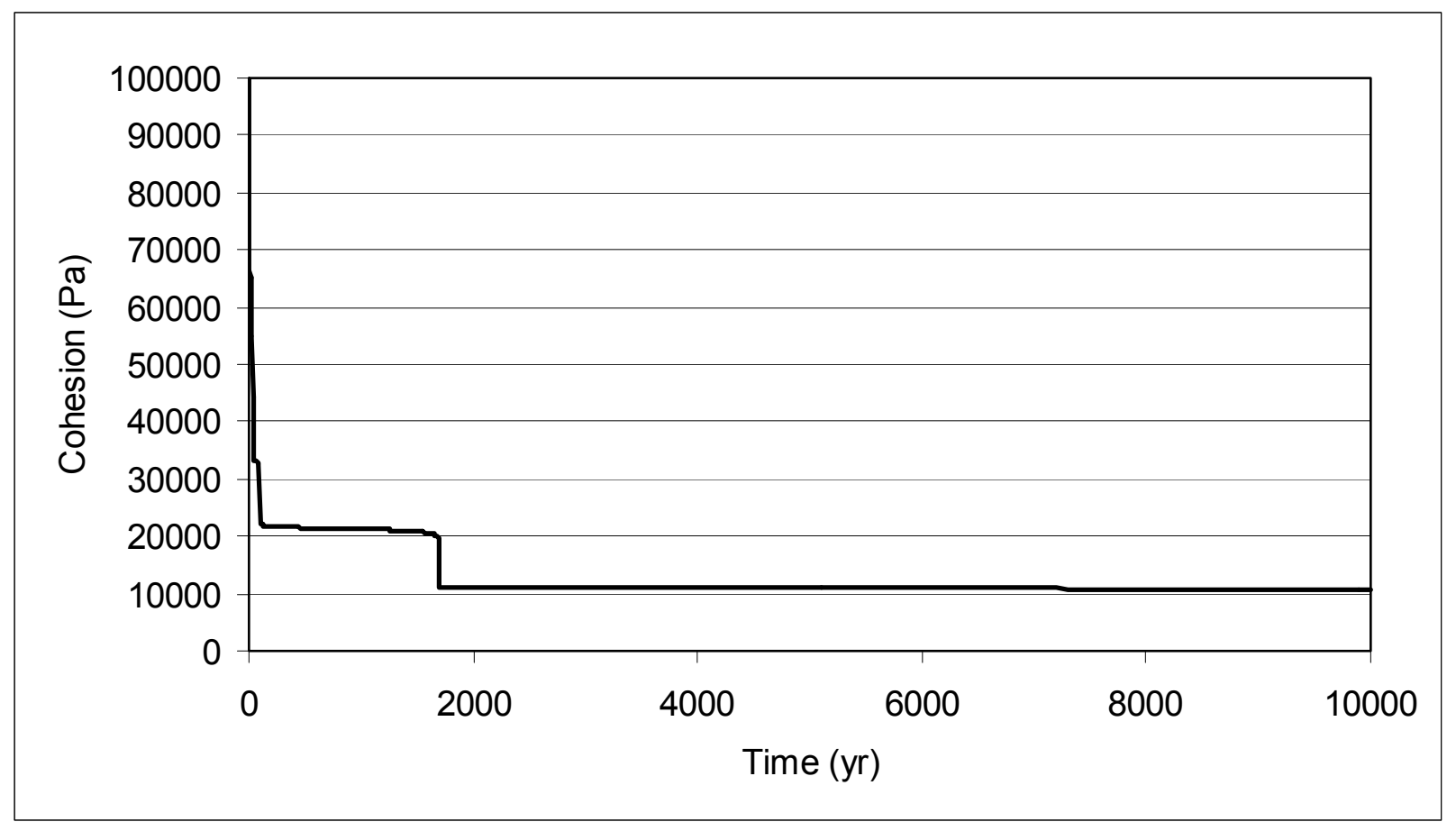

Source: Table A-1, file Cohesion Degradation V1.xls.

Figure D-6. Degradation of Joint Cohesion with Respect to Time

Figure D-7 presents the key-block size distribution for a $5.5 \mathrm{~m}$ diameter emplacement drift with a $75^{\circ}$-drift orientation. The cumulative frequency of occurrence corresponding to $50,75,90,95$, and 98 percentile block volume for each unit is listed in Table D-4. The maximum block size predicted from the analyses is included in this table. Additional details for the calculation of block size distribution data based on DRKBA output data are provided in Section D11.

The predicted number of key blocks per unit length of drift is listed in Table D-5. The results show that there is an insignificant impact for a 1,000-year event earthquake $\left(1 \times 10^{-3}\right)$ on the number of rockfalls, and only a minor impact for a 10,000-year event $\left(1 \times 10^{-4}\right)$.

Table D-4. Block Volume Corresponding to Various Levels of Predicted Cumulative Frequency of Occurrence, $75^{\circ}$-Azimuth Emplacement Drift in Tptpmn Unit, with Seismic Consideration

\begin{tabular}{|c|c|c|c|}
\hline \multirow{2}{*}{$\begin{array}{c}\text { Cumulative Frequency of } \\
\text { Occurrence (\%) }\end{array}$} & Static & \multicolumn{2}{|c|}{ Static Plus Seismic $\left(\mathbf{m}^{\mathbf{3}}\right)$} \\
\cline { 2 - 4 } & 0.04 & $\mathbf{1 0 0 0}-$ Year $\left(\mathbf{1} \times \mathbf{1 \mathbf { 1 } ^ { - 3 }}\right)$ & $\mathbf{1 0 , 0 0 0}-$ Year $\left(\mathbf{1} \times \mathbf{1 \mathbf { 1 } ^ { - 4 }}\right)$ \\
\hline $50 \%$ & 0.21 & 0.04 & 0.04 \\
\hline $75 \%$ & 0.55 & 0.21 & 0.24 \\
\hline $90 \%$ & 1.06 & 0.55 & 0.67 \\
\hline $95 \%$ & 1.85 & 1.35 & 1.51 \\
\hline $98 \%$ & 14.29 & 2.31 & 2.99 \\
\hline maximum & 14.29 & 14.29 \\
\hline
\end{tabular}

Source: Table A-1, file: tpmn seismic 75 res v2.xIs.

NOTE: in cubic meters. 


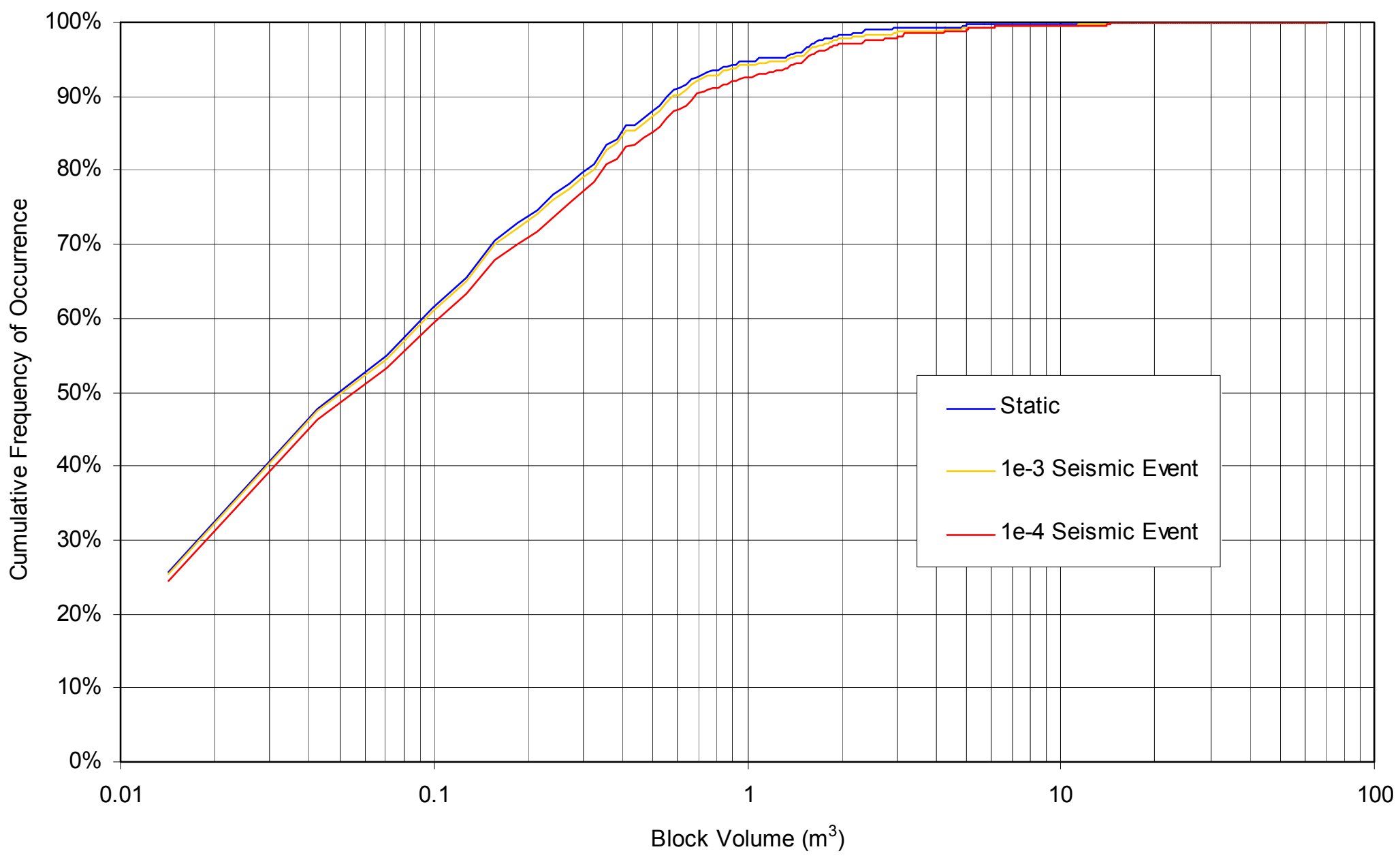

Source: Table A-1, file: tpmn seismic 75 res v2.xls.

Figure D-7. Cumulative Key-block Size Distribution for Seismic Consideration in the Tptpmn Unit, $75^{\circ}$-Azimuth 
Table D-5. Predicted Number of Key Blocks per Unit Length $(\mathrm{km})$ Along $75^{\circ}$-Azimuth Emplacement Drift, with Seismic Consideration

\begin{tabular}{|l|c|c|c|}
\hline \multirow{2}{*}{ Lithologic Unit } & \multirow{2}{*}{ Static } & $\mathbf{2}$ Static Plus Seismic \\
\cline { 3 - 4 } & 50 & 51 & $\mathbf{1 0 0 0}$-Year $\left(\mathbf{1} \times \mathbf{1 0 ^ { - 3 } )}\right.$ \\
\hline Tptpmn & $50 a r\left(\mathbf{1} \times \mathbf{1 0 ^ { - 4 }}\right)$ \\
\hline
\end{tabular}

Source: Table A-1, file: tpmn seismic 75 res v2.xls.

\section{D7. CALCULATION EXAMPLE FOR JOINT PARAMETERS USED IN DRKBA ANALYSIS (TPTPMN, JOINT SET 1)}

An example is provided in this appendix to describe the process of calculating the required joint geometrical parameters. These parameters include the concentration factor $\mathrm{k}$ of a bipolar Watson distribution for joint set orientation and $a, b, p$, and $q$ parameters of the beta distribution for joint radii, spacings, and positioning. The first joint set identified in the Tptpmn unit is used as the example.

The joint spacing, radii (two times the mapped trace lengths), and positioning (offset) were first sorted in the fracture database. Parameters $a$ and $b$ represent the ends of the closed interval upon which the beta distribution is defined. The smallest and largest joint parameters observed were assigned as $\mathrm{a}$ and $\mathrm{b}$ parameters. The values of $\mathrm{p}$ and $\mathrm{q}$ were calculated based on the technique presented by Derman et al. (1973 [DIRS 108444], pp. 398 to 403). In order to determine p and $\mathrm{q}$, the joint data were transformed to the unit interval $[0,1]$ by interpolation between the smallest and largest values encountered. The parameters $\mathrm{p}$ and $\mathrm{q}$ were then calculated from the mean and standard deviation of the transformed data by means of the following equations:

$$
\begin{gathered}
\mathrm{p}=\mu\left[\mu(1-\mu) / \sigma^{2}-1\right] \\
\mathrm{q}=(1-\mu)\left[\mu(1-\mu) / \sigma^{2}-1\right]
\end{gathered}
$$

where $\mu$ is the mean of the transformed data and $\sigma^{2}$ is the variance of the transformed data. The calculations are included in Table D-6.

To calculate the concentration factor, the orientation matrix of the joint data has to be first determined (Fisher et al. 1987 [DIRS 108447], pp. 33, 175, and 176). The orientation matrix T is defined in the following:

$$
T=\left[\begin{array}{ccc}
\sum x_{i}{ }^{2} & \sum x_{i} y_{i} & \sum x_{i} z_{i} \\
\sum x_{i} y_{i} & \sum y_{i}{ }^{2} & \sum y_{i} z_{i} \\
\sum x_{i} z_{i} & \sum y_{i} z_{i} & \sum z_{i}^{2}
\end{array}\right]
$$

where $\left(\mathrm{x}_{\mathrm{i}}, \mathrm{y}_{\mathrm{i}}, \mathrm{z}_{\mathrm{i}}\right)$ is the unit normal vector of a joint plane and $\mathrm{i}$ ranges from 1 to $\mathrm{n}$ (the number of fractures collected in the joint sets). The components of the orientation matrix are calculated in Table D-7. 
Table D-6. Calculation of the a, b, p, and q Parameters for Joint Spacing, Radii, and Positioning

\begin{tabular}{|c|c|c|c|c|c|c|c|c|c|}
\hline \multicolumn{2}{|l|}{ Joint Set \#1 } & Dip= & \multirow[b]{2}{*}{ 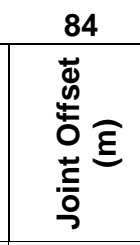 } & \multicolumn{2}{|c|}{ Dip Direction = } & \multicolumn{4}{|c|}{221} \\
\hline & 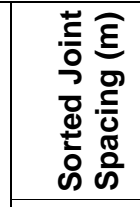 & 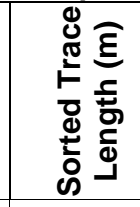 & & 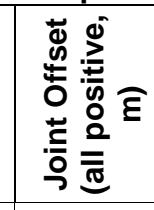 & 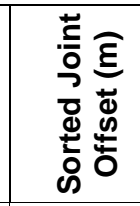 & 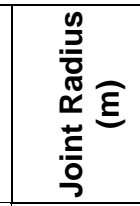 & 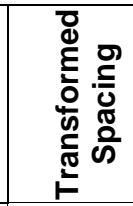 & 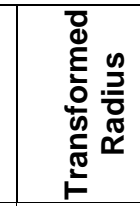 & 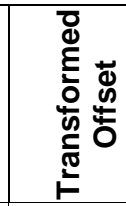 \\
\hline & 13.92 & 54.00 & -0.65 & 0.65 & 9.15 & 108.00 & 1.0000 & 1.0000 & 1.0000 \\
\hline & 13.60 & 25.54 & -0.04 & 0.04 & 9.15 & 51.08 & 0.9773 & 0.4639 & 1.0000 \\
\hline & 12.44 & 23.16 & -1.30 & 1.30 & 9.15 & 46.32 & 0.8938 & 0.4191 & 1.0000 \\
\hline & 12.40 & 22.85 & 0.11 & 0.11 & 9.15 & 45.70 & 0.8910 & 0.4133 & 1.0000 \\
\hline & 11.22 & 20.74 & 0.02 & 0.02 & 8.87 & 41.48 & 0.8063 & 0.3735 & 0.9694 \\
\hline & 11.02 & 17.90 & 0.21 & 0.21 & 8.34 & 35.80 & 0.7915 & 0.3200 & 0.9115 \\
\hline & 10.73 & 17.70 & 0.11 & 0.11 & 8.05 & 35.40 & 0.7707 & 0.3163 & 0.8798 \\
\hline & 10.14 & 17.32 & 0.78 & 0.78 & 7.49 & 34.64 & 0.7284 & 0.3091 & 0.8186 \\
\hline & 9.97 & 17.17 & -0.37 & 0.37 & 7.38 & 34.34 & 0.7163 & 0.3063 & 0.8060 \\
\hline & 9.81 & 17.02 & 0.41 & 0.41 & 6.90 & 34.04 & 0.7046 & 0.3034 & 0.7536 \\
\hline & 9.79 & 17.00 & -0.85 & 0.85 & 6.50 & 34.00 & 0.7035 & 0.3031 & 0.7104 \\
\hline & 9.71 & 16.71 & -0.72 & 0.72 & 6.48 & 33.42 & 0.6979 & 0.2976 & 0.7077 \\
\hline & 9.43 & 15.60 & -0.01 & 0.01 & 6.42 & 31.20 & 0.6776 & 0.2767 & 0.7011 \\
\hline & 9.10 & 15.60 & 0.36 & 0.36 & 6.15 & 31.20 & 0.6538 & 0.2767 & 0.6721 \\
\hline & 8.97 & 15.25 & -0.16 & 0.16 & 5.98 & 30.50 & 0.6442 & 0.2701 & 0.6530 \\
\hline & 8.93 & 14.90 & -0.69 & 0.69 & 5.65 & 29.80 & 0.6416 & 0.2635 & 0.6169 \\
\hline & 8.87 & 14.60 & -0.64 & 0.64 & 5.15 & 29.20 & 0.6374 & 0.2579 & 0.5628 \\
\hline & 8.75 & 14.21 & 0.60 & 0.60 & 5.00 & 28.42 & 0.6283 & 0.2505 & 0.5464 \\
\hline & 8.64 & 14.20 & -0.26 & 0.26 & 4.90 & 28.40 & 0.6204 & 0.2503 & 0.5355 \\
\hline & 8.54 & 13.42 & -0.09 & 0.09 & 4.73 & 26.84 & 0.6135 & 0.2356 & 0.5164 \\
\hline & 8.53 & 13.31 & 0.12 & 0.12 & 4.64 & 26.62 & 0.6126 & 0.2336 & 0.5071 \\
\hline & 8.46 & 13.05 & -0.75 & 0.75 & 4.63 & 26.10 & 0.6075 & 0.2287 & 0.5060 \\
\hline & 8.37 & 12.05 & -0.34 & 0.34 & 4.60 & 24.10 & 0.6013 & 0.2098 & 0.5027 \\
\hline & 7.99 & 11.56 & -0.73 & 0.73 & 4.20 & 23.12 & 0.5742 & 0.2006 & 0.4590 \\
\hline & 7.96 & 11.52 & -0.64 & 0.64 & 4.20 & 23.04 & 0.5719 & 0.1998 & 0.4590 \\
\hline & 7.90 & 10.99 & 0.36 & 0.36 & 4.15 & 21.98 & 0.5674 & 0.1899 & 0.4530 \\
\hline & 7.70 & 10.91 & 0.32 & 0.32 & 4.06 & 21.82 & 0.5533 & 0.1884 & 0.4437 \\
\hline & \multicolumn{9}{|c|}{$\begin{array}{l}\text { Data truncated — see DTN MO0408MWDDDMIO.002, file: "New-Beta-Tptpmn V1.xIs", for } \\
\text { complete data set }\end{array}$} \\
\hline & 0.00 & 1.00 & 4.15 & 4.15 & 0.00 & 2.00 & 0.0000 & 0.0017 & 0.0000 \\
\hline & 0.00 & 1.00 & 0.02 & 0.02 & 0.00 & 2.00 & 0.0000 & 0.0017 & 0.0000 \\
\hline & 0.00 & 0.94 & 0.54 & 0.54 & 0.00 & 1.88 & 0.0000 & 0.0006 & 0.0000 \\
\hline & & 0.91 & 1.53 & 1.53 & 0.00 & 1.82 & & 0.0000 & 0.0000 \\
\hline Mean & 0.60 & 2.54 & - & - & 0.63 & 5.08 & 0.0433 & 0.0307 & 0.0686 \\
\hline $\begin{array}{l}\text { Standard } \\
\text { Deviation }\end{array}$ & 1.12 & 1.94 & - & - & 0.67 & 3.87 & 0.0806 & 0.0365 & 0.0728 \\
\hline Minimum (a) & 0.00 & 0.91 & - & - & 0.00 & 1.82 & - & - & - \\
\hline Maximum (b) & 13.92 & 54.00 & - & - & 9.15 & 108.00 & - & - & - \\
\hline $\mathrm{p}$ & - & & & & & & 0.2322 & 0.6554 & 0.7569 \\
\hline q & - & & & & & & 5.1372 & 20.7171 & 10.2825 \\
\hline
\end{tabular}


Table D-7. Calculation of the Components for the Orientation Matrix

\begin{tabular}{|c|c|c|c|c|c|c|c|c|c|c|c|c|c|c|c|c|c|}
\hline \multirow{2}{*}{ 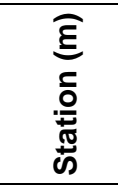 } & \multirow{2}{*}{ 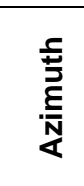 } & \multirow{2}{*}{$\because \frac{2}{0}$} & \multicolumn{3}{|c|}{$\begin{array}{l}\text { Dip Vector } \\
\text { Component }\end{array}$} & \multicolumn{3}{|c|}{$\begin{array}{c}\text { Strike Vector } \\
\text { Component }\end{array}$} & \multicolumn{3}{|c|}{$\begin{array}{l}\text { Pole Vector } \\
\text { Component }\end{array}$} & \multirow[b]{2}{*}{$x_{i} x_{i}$} & \multirow[b]{2}{*}{$x_{i} y_{i}$} & \multirow[b]{2}{*}{$x_{i} z_{i}$} & \multirow[b]{2}{*}{$y_{i} y_{i}$} & \multirow[b]{2}{*}{$y_{i} z_{i}$} & \multirow[b]{2}{*}{$z_{i} z_{i}$} \\
\hline & & & $x d$ & yd & $z d$ & xs & ys & zs & $x_{i}$ & $y_{i}$ & $z_{i}$ & & & & & & \\
\hline 2723.27 & 129 & 85 & -0.055 & -0.068 & -0.996 & -0.777 & 0.629 & 0.000 & 0.627 & 0.774 & -0.087 & 0.3930 & 0.4854 & -0.0546 & 0.5994 & -0.0675 & 0.0076 \\
\hline 2723.85 & 142 & 81 & -0.123 & -0.096 & -0.988 & -0.616 & .788 & 0.000 & 0.778 & 0.608 & -0.156 & .6058 & 0.4733 & -0.1218 & 0.3698 & -0.0951 & 0.0245 \\
\hline 2730.01 & 116 & 81 & -0.069 & -0.141 & -0.988 & -0.899 & 0.438 & 0.000 & 0.433 & 0.888 & -0.156 & 0.1875 & 0.3844 & -0.0677 & 0.7881 & -0.1389 & 0.0245 \\
\hline 2733.73 & 124 & 72 & -0.173 & -0.256 & -0.951 & -0.829 & 0.559 & 0.000 & 0.532 & 0.788 & -0.309 & 0.2828 & 0.4193 & -0.1643 & 0.6217 & -0.2436 & 0.0955 \\
\hline 2735.12 & 129 & 86 & -0.044 & -0.054 & -0.998 & -0.777 & 0.629 & 0.000 & 0.628 & 0.775 & -0.070 & 0.3941 & 0.4867 & -0.0438 & 0.6010 & -0.0541 & 0.0049 \\
\hline 2735.56 & 299 & 84 & 0.051 & 0.091 & -0.995 & 0.875 & -0.485 & 0.000 & -0.482 & -0.870 & -0.105 & 0.2325 & 0.4194 & 0.0504 & 0.7566 & 0.0909 & 0.0109 \\
\hline 2736.15 & 148 & 83 & -0.103 & -0.065 & -0.993 & -0.530 & 0.848 & 0.000 & 0.842 & 0.526 & -0.122 & 0.7085 & 0.4427 & -0.1026 & 0.2766 & -0.0641 & 0.0149 \\
\hline 2738.56 & 141 & 87 & -0.041 & -0.033 & -0.999 & -0.629 & 0.777 & 0.000 & 0.776 & 0.628 & -0.052 & 0.6023 & 0.4877 & -0.0406 & 0.3950 & -0.0329 & 0.0027 \\
\hline 2742.16 & 124 & 76 & -0.135 & -0.201 & -0.970 & -0.829 & 0.559 & 0.000 & 0.543 & 0.804 & -0.242 & 0.2944 & 0.4365 & -0.1313 & 0.6471 & -0.1946 & 0.0585 \\
\hline 2742.34 & 137 & 79 & -0.140 & -0.130 & -0.982 & -0.682 & 0.731 & 0.000 & 0.718 & 0.669 & -0.191 & 0.5154 & 0.4806 & -0.1370 & 0.4482 & -0.1277 & 0.0364 \\
\hline 2743.08 & 119 & 87 & -0.025 & -0.046 & -0.999 & -0.875 & 0.485 & 0.000 & 0.484 & 0.873 & -0.052 & 0.2344 & 0.4229 & -0.0253 & 0.7629 & -0.0457 & 0.0027 \\
\hline 2753 & 115 & 88 & -0.015 & -0.032 & -0.999 & -0.906 & 0.423 & 0.000 & 0.422 & 0.906 & -0.035 & 0.1784 & 0.3826 & -0.0147 & 0.8204 & -0.0316 & 0.0012 \\
\hline 2756.75 & 117 & 83 & -0.055 & -0.109 & -0.993 & -0.891 & 0.454 & 0.000 & 0.451 & 0.884 & -0.122 & 0.2030 & 0.3985 & -0.0549 & 0.7821 & -0.1078 & 0.0149 \\
\hline 2759.11 & 295 & 75 & 0.109 & 0.235 & -0.966 & 0.906 & -0.423 & 0.000 & -0.408 & -0.875 & -0.259 & 0.1666 & 0.3574 & 0.1057 & 0.7664 & 0.2266 & 0.0670 \\
\hline 2762.21 & 138 & 90 & 0.000 & 0.000 & -1.000 & -0.669 & 0.743 & 0.000 & 0.743 & 0.669 & 0.000 & 0.5523 & 0.4973 & 0.0000 & 0.4477 & 0.0000 & 0.0000 \\
\hline 2767.3 & 138 & 72 & -0.230 & -0.207 & -0.951 & -0.669 & 0.743 & 0.000 & 0.707 & 0.636 & -0.309 & 0.4995 & 0.4498 & -0.2184 & 0.4050 & -0.1967 & 0.0955 \\
\hline 2768.07 & 118 & 77 & -0.106 & -0.199 & -0.974 & -0.883 & 0.469 & 0.000 & 0.457 & 0.860 & -0.225 & 0.2093 & 0.3935 & -0.1029 & 0.7401 & -0.1935 & 0.0506 \\
\hline 2772.04 & 145 & 84 & -0.086 & -0.060 & -0.995 & -0.574 & 0.819 & 0.000 & 0.815 & 0.570 & -0.105 & 0.6637 & 0.4647 & -0.0852 & 0.3254 & -0.0596 & 0.0109 \\
\hline 2774.87 & 127 & 76 & -0.146 & -0.193 & -0.970 & -0.799 & 0.602 & 0.000 & 0.584 & 0.775 & -0.242 & 3410 & 0.4525 & -0.1413 & 0.6005 & -0.1875 & 0.0585 \\
\hline 2775.37 & 138 & 88 & -0.026 & -0.023 & -0.999 & -0.669 & 0.743 & 0.000 & & 0.669 & & 5516 & 0.4967 & -0.0259 & 4472 & -0.0233 & 0.0012 \\
\hline 2777.34 & 124 & 76 & & -0.201 & & -0.829 & & & & & & 0.2944 & & & 0.6471 & -0.1946 & 0.0585 \\
\hline 2777.59 & 119 & 82 & -0.067 & -0.122 & -0.990 & -0.875 & 0.485 & 0.000 & 0.480 & 0.866 & -0.139 & 0.2305 & 0.4158 & -0.0668 & 0.7501 & -0.1205 & 0.0194 \\
\hline
\end{tabular}

Data truncated - see DTN MO0408MWDDDMIO.002, file: Orient-Tptpmn V1.xls, for complete data set

\begin{tabular}{|l|l|l|l|l|l|l|l|l|l|l|l|l|l|l|l|l|l|}
\hline 1437.69 & 115 & 86 & -0.029 & -0.063 & -0.998 & -0.906 & 0.423 & 0.000 & 0.422 & 0.904 & -0.070 & 0.1777 & 0.3812 & -0.0294 & 0.8174 & -0.0631 & 0.0049 \\
\hline 1440.02 & 125 & 86 & -0.040 & -0.057 & -0.998 & -0.819 & 0.574 & 0.000 & 0.572 & 0.817 & -0.070 & 0.3274 & 0.4676 & -0.0399 & 0.6677 & -0.0570 & 0.0049 \\
\hline 1441.27 & 128 & 73 & -0.180 & -0.230 & -0.956 & -0.788 & 0.616 & 0.000 & 0.589 & 0.754 & -0.292 & 0.3466 & 0.4437 & -0.1721 & 0.5679 & -0.2203 & 0.0855 \\
\hline 1442.28 & 123 & 80 & -0.095 & -0.146 & -0.985 & -0.839 & 0.545 & 0.000 & 0.536 & 0.826 & -0.174 & 0.2877 & 0.4430 & -0.0931 & 0.6822 & -0.1434 & 0.0302 \\
\hline \multicolumn{10}{|c|}{ SUM } & 2075.5 & 2290.83 & -360.26 & 2803.2 & -402.52 & 103.36 \\
\hline
\end{tabular}


The solution for the concentration factor $\mathrm{k}$ can be approximated based on the largest eigenvalue $\left(\tau_{3}\right)$ of the orientation matrix T (Fisher et al. 1987 [DIRS 108447], pp. 175 and 176). The solution is:

$$
\mathrm{k}=\left\{\begin{array}{lll}
3.75 \times\left(3 \tau_{3}-1\right) & \text { if } & 0.333<\tau_{3} \leq 0.38 \\
3.34 \times\left(3 \tau_{3}-1\right) & \text { if } & 0.38<\tau_{3} \leq 0.65 \\
0.7+1 /\left(1-\tau_{3}\right) & \text { if } & 0.65<\tau_{3} \leq 0.99 \\
1 /\left(1-\tau_{3}\right) & \text { if } & \tau_{3} \geq 0.99
\end{array}\right.
$$

Calculations of the eigenvalues and $\mathrm{k}$ factor were conducted using Mathcad and are presented in Table D-8.

\section{D8. DETERMINATION OF THE NUMBER OF DRKBA MONTE CARLO SIMULATIONS}

In the DRKBA analysis, random joint patterns are generated with joint centers positioned in three-dimensional space, considering each joint set in sequence for each Monte Carlo simulation. The forming of key blocks is therefore different in each Monte Carlo simulation. To determine the adequate number of Monte Carlo simulations for the analyses, test runs were first conducted. The criteria used to determine the adequate number of Monte Carlo simulations include: (1) consistent prediction of the block size distribution, (2) consistent prediction of the number of blocks per 10 simulations, and (3) consistent prediction of the maximum block size.

For the Tptpmn unit, test runs with 100, 200, 400, 600, and 800 Monte Carlo simulations were conducted. Figure D-8 shows the block size distribution curves for the five cases. The prediction of block size distribution for 200 simulations is similar to the results from 400 simulations. The predicted numbers of blocks per 10 simulations for the five cases are presented in Figure D-9. The results show that the number of blocks increases with the number of simulations until 400 simulations is reached. For 400 simulations or higher, the predicted numbers of blocks per 10 simulations converges to about 12 and remains fairly constant. The maximum block sizes predicted for the five cases are shown in Figure D-10. The maximum blocks predicted for 400,600 , and 800 simulations are identical. It was determined that 400 simulations are adequate for the DRKBA analyses for Tptpmn unit. 
Table D-8. Calculation of the Concentration Factor $\mathrm{k}$ for Joint Orientation

Concentration Factor (k) Calculation for Watson Bipolar Distribution:

$(x x, x y, x z, y y, y z, z z$ calculated in EXCEL worksheet

Orient-Tptpmn V1.xls)

\section{Tptpmn, Joint Set 1}

$\mathrm{xx}:=2075.455$

$x y:=2290.832$

$\mathrm{xz}:=-360.263$

yy $:=2803.184$

$\mathrm{yz}:=-402.518$

$\mathrm{zz}:=103.3607$

$\underset{w}{T}:=\left(\begin{array}{ccc}x x & x y & x z \\ x y & y y & y z \\ x z & y z & z z\end{array}\right)$

$\mathrm{c}:=$ eigenvals $(\mathrm{T}) \quad \mathrm{c}=\left(\begin{array}{c}121.739 \\ 39.566 \\ 4.821 \times 10^{3}\end{array}\right)$

$\mathrm{n}:=\mathrm{c}_{0}+\mathrm{c}_{1}+\mathrm{c}_{2}$

$\mathrm{cn}:=\frac{\mathrm{c}}{\mathrm{n}} \quad \mathrm{cn}=\left(\begin{array}{c}0.024 \\ 7.942 \times 10^{-3} \\ 0.968\end{array}\right) \quad \tau_{3}:=\max (\mathrm{cn})$

$\mathrm{k} 1:=3.75 \cdot\left(3 \tau_{3}-1\right) \quad \mathrm{k} 2:=3.34\left(3 \tau_{3}-1\right)$

$\mathrm{k} 3:=0.7+\frac{1}{\left(1-\tau_{3}\right)} \quad \mathrm{k} 4:=\frac{1}{\left(1-\tau_{3}\right)}$

$\mathrm{k}:=\mid \mathrm{k} 1$ if $0.333<\tau_{3} \leq 0.38$

$\mathrm{k} 2$ if $0.38<\tau_{3} \leq 0.65$

$\mathrm{k} 3$ if $0.65<\tau_{3} \leq 0.99$

$\mathrm{k} 4$ if $\tau_{3} \geq 0.99$

$\mathrm{k}=31.586$

NOTE: New-K-Tptpmn V2.mcd. 


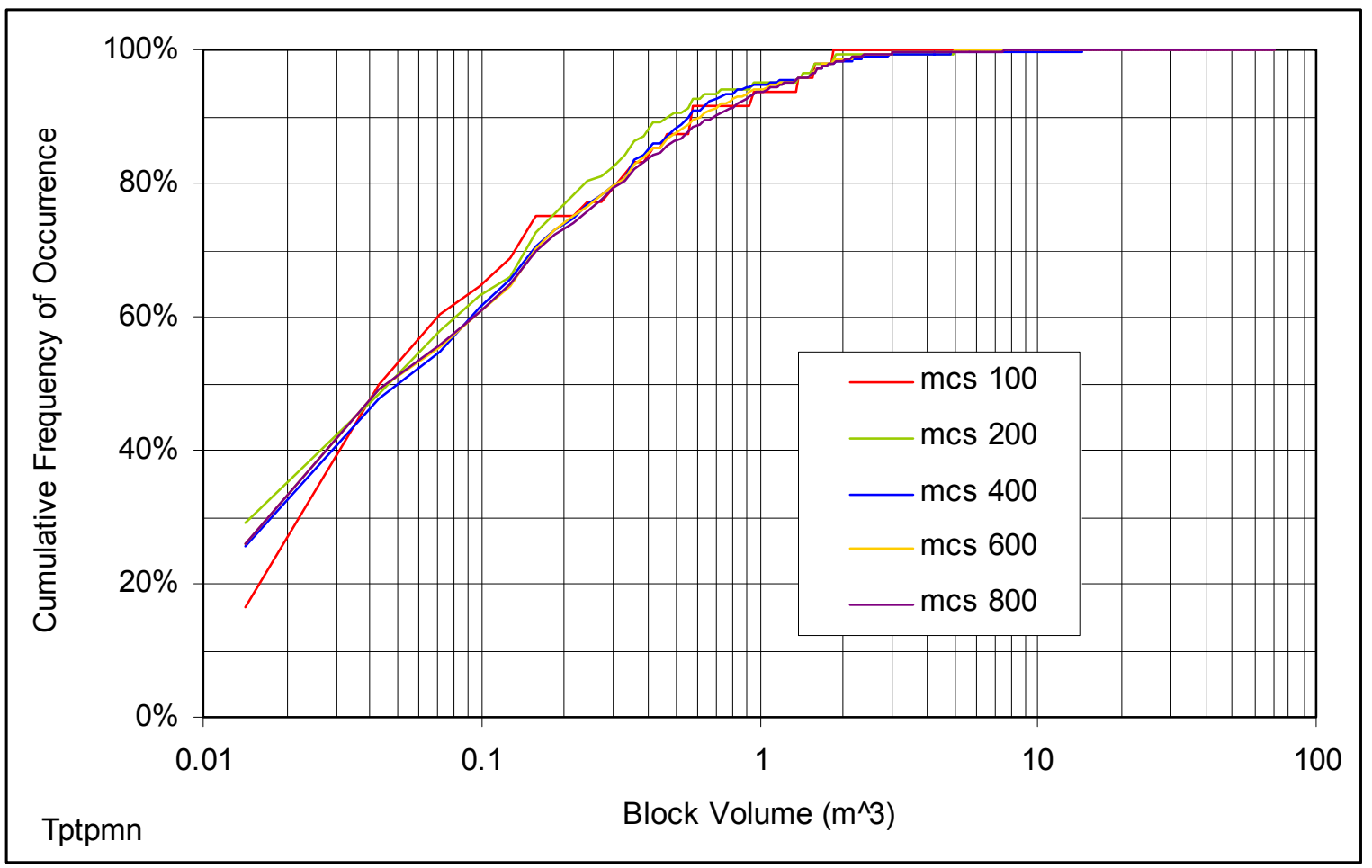

Figure D-8. Block Size Distributions for the Test Runs, Tptpmn Unit

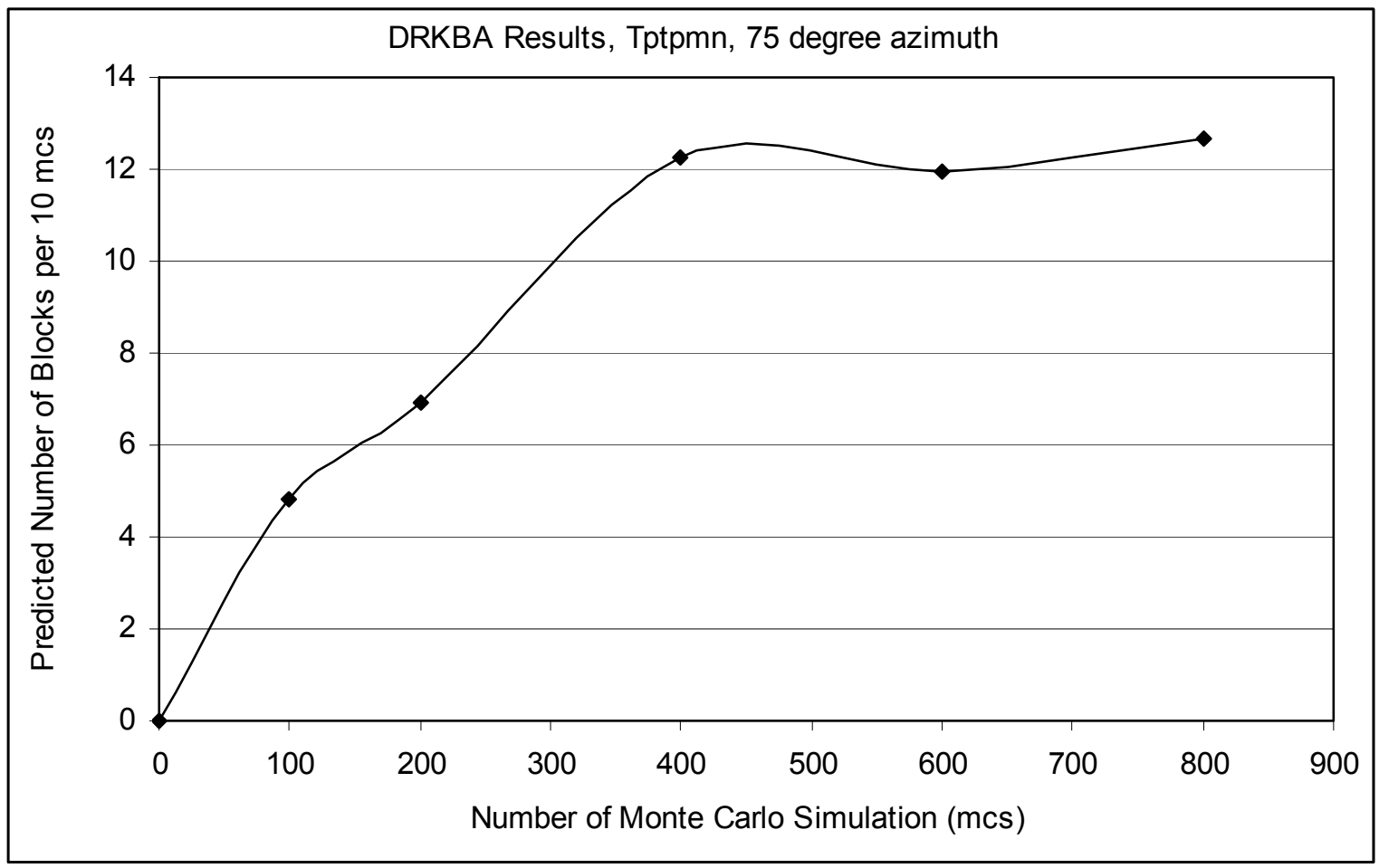

Figure D-9. Predicted Number of Key Blocks Per 10 Monte Carlo Simulations, Tptpmn Unit 


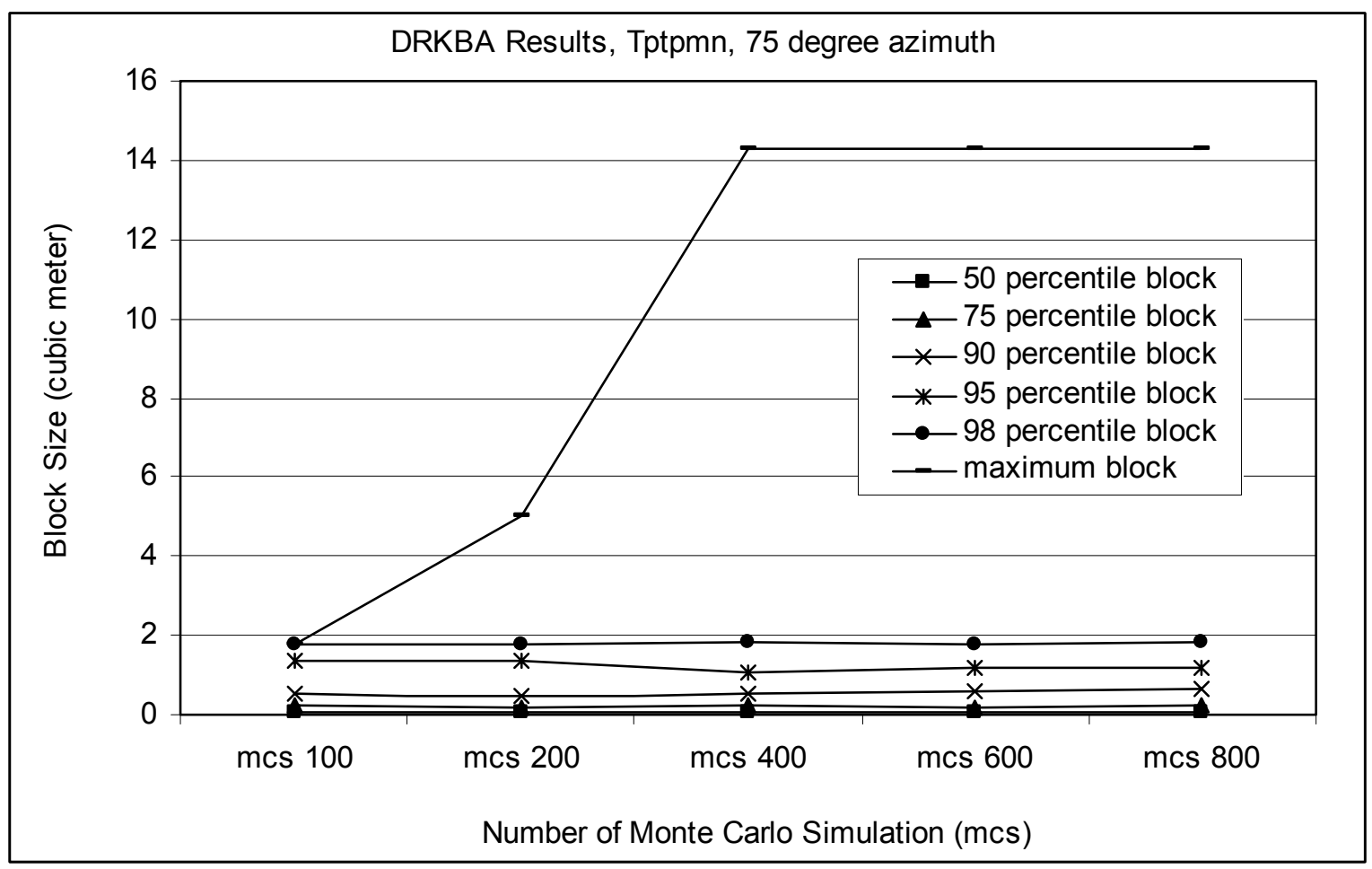

Figure D-10. Predicted Number of Maximum Block Size, Tptpmn Unit

\section{D9. ASSESSMENT OF JOINT PLANE REPRESENTATION IN THE DRKBA ROCKFALL MODEL}

This section presents the results of a sensitivity calculation for the extent of the modeled joint plane based on the mapped joint trace length. It is recognized that the actual extent of a joint plane cannot be fully known based on field mapping data. The mapped trace length of a joint represents some portion of the overall joint plane. Under representing the extent of the joint plane would not be conservative in a key-block analysis. Since the underrepresented joint planes may not extent or connect to adjacent joint planes, under representation would limit the number of blocks otherwise generated in the model. Conversely, overstating the extent of the joint plane would increase connectivity among joint planes, thus creating more blocks in the model and resulting in an increased, or conservative, estimate of block development. However, infinite joint planes would not be an accurate representation of the jointed rock mass. This appendix develops the basis to sufficiently model the extent of the joint plane based on the available field data.

Joint planes are represented as circular discs in the DRKBA rockfall model with the radius of the joint plane equal to twice the mapped trace length. Figure D-11 shows a top view of a circular fracture disc intersecting an opening. Figure D-11 depicts three parameters used for the sensitivity calculation, including joint trace length $(T)$, joint radius $(R)$, and the shortest distance $(Z)$ from the center of the joint disc to the fracture trace. 


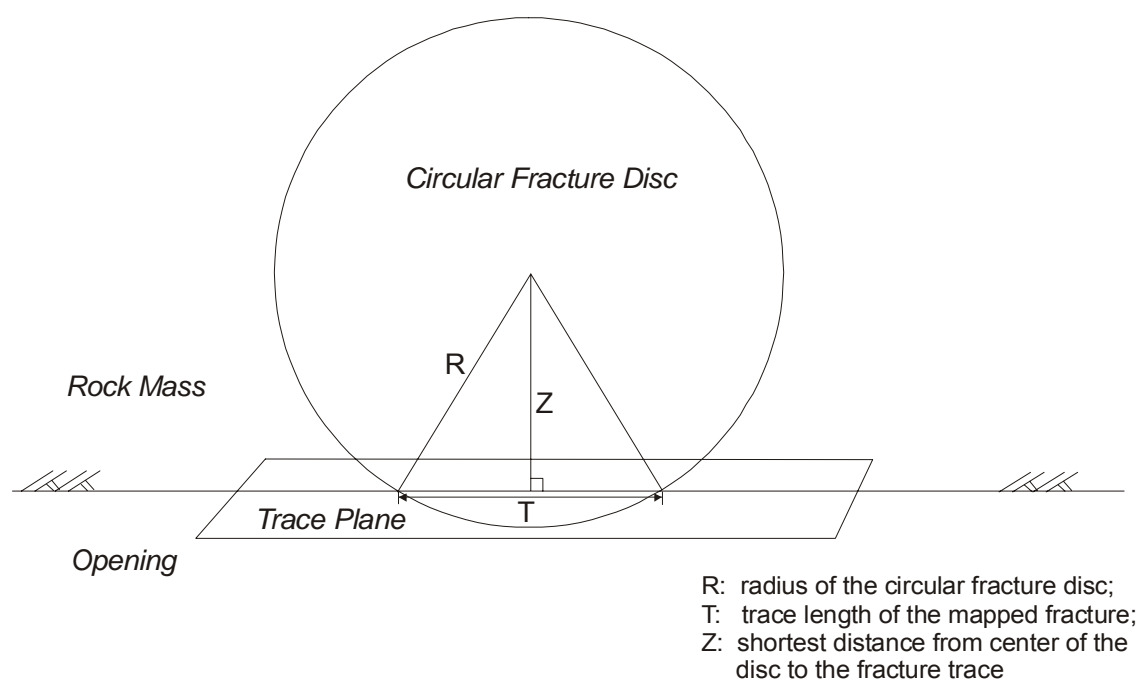

Figure D-11. Top View of a Circular Fracture Disc Intersecting an Opening

The multiplier, $M$, is used to obtain the radius of the circular fracture disc from the trace length, such that the radius parameter, $R$, as depicted in Figure D-11, is defined as:

$$
R=M * T
$$

Based on standard trigonometric relationships for triangles, the shortest distance from the center of the disc to the fracture trace can be derived as follows:

$$
Z=\left(R^{2}-(T / 2)^{2}\right)^{1 / 2}=\left(M^{2}-1 / 4\right)^{1 / 2} * T
$$

It is reasoned that the location where the circular disc intersects the opening (i.e., the intersection point of line $Z$ and trace $T$ ) is uniformly distributed at any point from the center of disc to the periphery of the disc. In other words, the opening can be located with equal probability to intersect any points of the disc. Therefore, the probability for the radius of the disc to be larger than the value derived from Equation D-14 can be simply expressed as a function of $Z / R$, such that:

$$
P=100 \%-Z / R=100 \%-\left(M^{2}-1 / 4\right)^{1 / 2} / M
$$

where $P$ is the probability that $R>M \times T$.

The probabilities for various multipliers, $M$, are listed in Table D-9. For a circular joint plane described using a radius equal to twice the mapped trace length (i.e., $M=2$ ) as used in this analysis, there is an approximate 3 percent probability that the actual joint radius is greater than the modeled value. Therefore, the use of a multiplier, $M$, of 2 in this analysis is conservative.

Table D-9. Probability of $\mathrm{R}>\mathrm{M} \times \mathrm{T}$ for Various Multipliers

\begin{tabular}{|c|c|c|c|c|c|c|c|c|c|}
\hline Multiplier (M) & $\mathbf{0 . 5}$ & $\mathbf{0 . 6}$ & $\mathbf{0 . 7}$ & $\mathbf{0 . 8}$ & $\mathbf{1}$ & $\mathbf{1 . 5}$ & $\mathbf{2}$ & $\mathbf{3}$ & $\mathbf{5}$ \\
\hline $\begin{array}{l}\text { Probability of } \\
\text { R>MxT }\end{array}$ & $100.0 \%$ & $44.7 \%$ & $30.0 \%$ & $21.9 \%$ & $13.4 \%$ & $5.7 \%$ & $3.2 \%$ & $1.4 \%$ & $0.5 \%$ \\
\hline
\end{tabular}




\section{D10. CALCULATION OF THE PLANE EQUATIONS TO DESCRIBE THE EXCAVATION OPENING AS INPUT TO DRKBA}

The method employed by the DRKBA code to represent excavation openings involves specification of sets of infinite planes that approximate the opening geometry. The infinite planes are defined using unit normal vectors and the shortest distance from the origin. For a circular opening without backfill (exca vectors V2.xls), a total of 20 planes were used to represent an 80-ft long cylinder as shown in Figure D-12.

Inputs for the calculation include the azimuth of tunnel axis (Cell D1, exca vectors V2.xls) and angle measured from horizontal axis for each plane (Cells P5 to P22, exca vectors V2.xls).

The equations for the rotation of unit vectors and axes presented in Fisher et al. (1987 [DIRS 108447], p. 32) were used to calculate the unit normal vector for each plane. The rotation matrix A is shown below:

$$
A(\theta, \phi)=\left(\begin{array}{lll}
a 11 & a 12 & a 13 \\
a 21 & a 22 & a 23 \\
a 31 & a 32 & a 33
\end{array}\right)=\left(\begin{array}{ccc}
\cos \theta \cos \phi & \cos \theta \sin \phi & -\sin \theta \\
-\sin \phi & \cos \phi & 0 \\
\sin \theta \cos \phi & \sin \theta \sin \phi & \cos \theta
\end{array}\right)
$$

where $(\theta, \phi)$ are the polar coordinates of a unit vector measured relative to a pole in the direction $(0,0)$. The rotation of the tunnel axis sets $\phi$ equal to the azimuth and $\theta$ as 0 . Cells contained in Columns $\mathrm{F}$ to $\mathrm{N}$ are the elements of the rotation matrix. Calculation of the unit vector of the infinite plane on the local coordinate (coordinate axes shown in Figure D-12) is based on the following equation:

$$
u_{i}=\left(\begin{array}{l}
x \\
y \\
z
\end{array}\right)=\left(\begin{array}{c}
\sin \alpha_{i} \\
0 \\
\cos \alpha_{i}
\end{array}\right)
$$

The $\mathrm{x}, \mathrm{y}$, and $\mathrm{z}$ components of the unit vector are calculated in Columns $\mathrm{Q}$ to $\mathrm{S}$. Finally, the rotated unit normal vector on the global coordinate (East as x' axis and North as y' axis) are computed using the equation

$$
\left(\begin{array}{l}
x^{\prime} \\
y^{\prime} \\
z^{\prime}
\end{array}\right)=A(\theta, \phi)\left(\begin{array}{l}
x \\
y \\
z
\end{array}\right)
$$

The x', y', and z' components are calculated in Columns $U$ to W. The last two rows in Columns $\mathrm{U}$ to $\mathrm{W}$ are for the end plane (shown in Figure D-12). The end plane normal vector is in the horizontal direction with $x^{\prime}$ equal to $\sin \phi$ and $y^{\prime}$ equal to $\cos \phi$. 

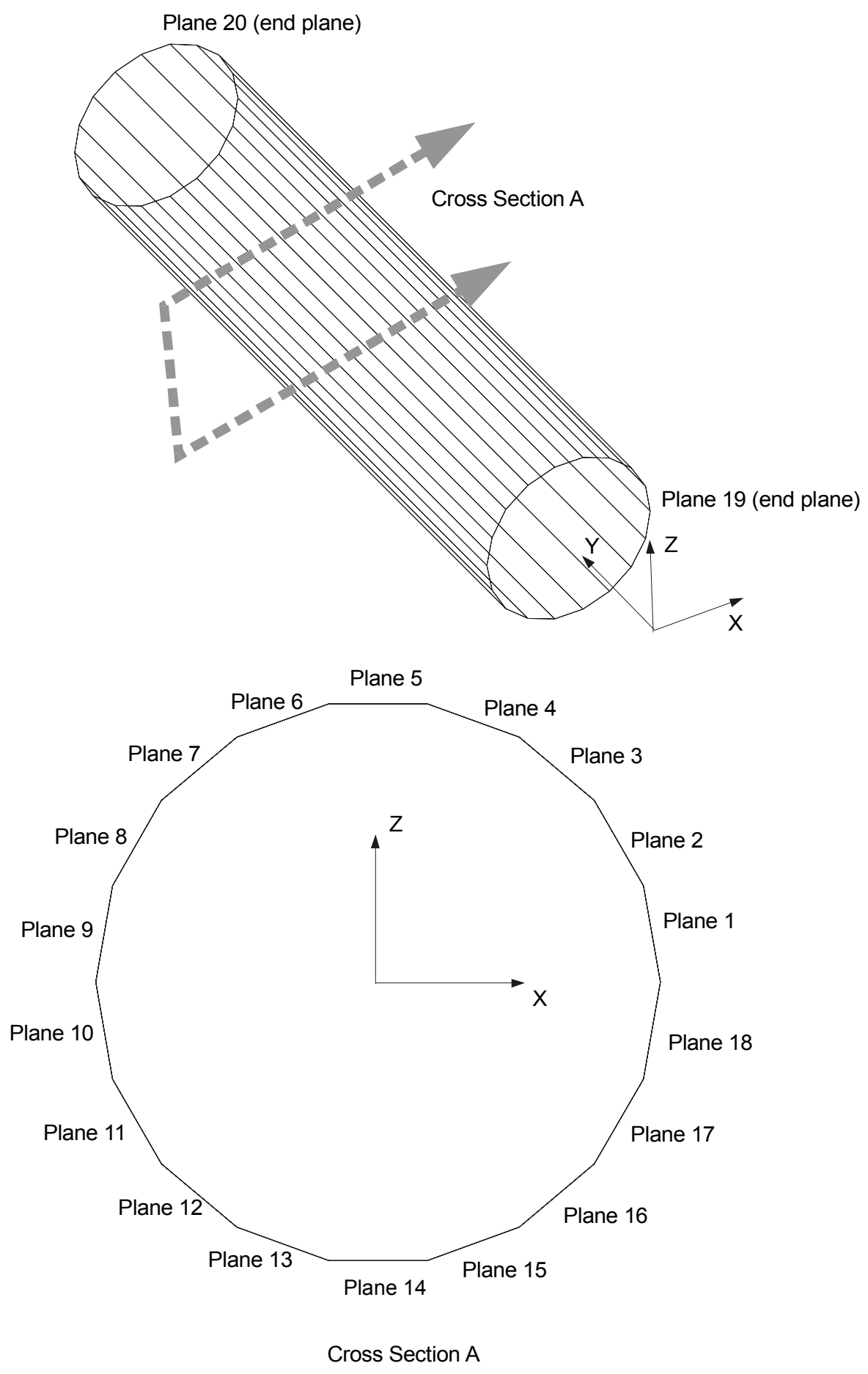

Figure D-12. Opening Representation - No Backfill 


\section{D11. CALCULATION OF KEY-BLOCK SIZE DISTRIBUTION}

The key-block output files *.bsd (DTN: MO0408MWDDDMIO.002) from DRKBA contain the information on key-block size distribution in a histogram format which provides the number of blocks in each bin the user specified in the DRKBA input files. Two spreadsheet files (files tpmn seismic 75 res v2.xls and small scale fractures results.xls, DTN: MO0408MWDDDMIO.002) were generated to provide the key-block distribution in cumulative frequency of occurrence format presented in Sections D6 and 6.3.3.

There are three calculation worksheets contained in each of the two spreadsheet files. The worksheets are entitled "results", "cum", and "percentile". The first worksheet "results" includes the imported block size data from DRKBA output files and the calculated percentage results within each block size bin. The second worksheet "cum" calculates the cumulative percentage corresponding to the various block sizes. The third worksheet "percentile" provides the results for the 50 percentile, 75 percentile, 90 percentile, 95 percentile, 98 percentile, and maximum size blocks.

Column A of the "results" worksheet lists the bin value for the block volume in cubic meters. These values are the converted values from the English unit outputs of DRKBA. The number of blocks predicted in DRKBA for each block volume bin is listed in the columns of the "results" worksheet identified in Table D-10. The values are imported from the *.bsd output files of the DRKBA analysis. The total number of blocks was calculated in Row 6 using the Microsoft Excel sum function for each case. The percentage columns adjacent to the input block number columns listed in Table D-10 were then calculated using the individual block number in each bin and the total number of blocks. The values in the percentage columns represent the probabilistic density of rockfall within each block size bin.

Table D-10. Structure of Spreadsheet Files for Key-Block Size Distribution

\begin{tabular}{|c|l|l|l|}
\hline \multirow{2}{*}{ File } & \multicolumn{3}{|c|}{ Column } \\
\cline { 2 - 4 } & \multicolumn{1}{|c|}{ B } & \multicolumn{1}{|c|}{ D } & \multicolumn{1}{c|}{ F } \\
\hline tpmn seismic 75 res v2.xls & Static & Seismic Level $1 \times 10^{-3}$ & Seismic Level $1 \times 10^{-4}$ \\
\hline small scale fractures results.xls & Without Small-Scale & With Small-Scale & Not applicable \\
\hline
\end{tabular}

Worksheet "cum" was constructed from worksheet "results" by changing the columns identified in Table D-10 from number of blocks to cumulative number of blocks. The iterative formula to calculate the cumulative number of block is given below:

$$
\mathrm{CNB}_{\mathrm{i}}=\mathrm{CNB}_{\mathrm{i}-1}+\mathrm{NB}_{\mathrm{I}}
$$

where $\quad \mathrm{CNB}_{\mathrm{i}}=$ the cumulative number of block at block size bin $\mathrm{i}$

$\mathrm{CNB}_{\mathrm{i}-1}=$ the cumulative number of block at block size bin $\mathrm{i}-1$

$\mathrm{NB}_{\mathrm{i}}=$ the number of block at block size bin $\mathrm{i}$. 
The cumulative percentage was then obtained from the cumulative number of blocks and the total number of blocks. Same as in worksheet "results", the total number of blocks is recorded in Row 6.

In order to locate the 50 percentile, 75 percentile, 90 percentile, 95 percentile, 98 percentile, and maximum size blocks efficiently, the Microsoft Excel vlookup function was used in worksheet "percentile". Cells C8 to G2509 for file tpmn seismic 75 res v2.xls and cells C8 to E2509 for small scale fractures results.xls were set up as the table_array for the vlookup function. The cumulative percentage values in these cells are the replicate of cells in the worksheet "cum". The block sizes are expressed in cubic feet in the table_array. The blocks for the cumulative frequency of occurrence at 50, 75, 90, 95, and 98 percent, and the maximum blocks (in cubic feet) are calculated in Cells C2517 to E2522 for file tpmn seismic 75 res v2.xls and Cells L5 to $\mathrm{O} 10$ for file small scale fractures results.xls. The block sizes were converted to cubic meter in Cells C2526 to E2531 for file tpmn seismic 75 res v2.xls and Cells Q5 to T10 for file small scale fractures results.xls.

The number of blocks per kilometer is calculated by dividing the total number of key blocks by the total simulated length. The total simulated length is determined as the number of simulations (i.e., 400 simulations) times the length of simulation (e.g., $80 \mathrm{ft} /$ simulation $\times 0.0348 \mathrm{~m} / \mathrm{ft} \times$ $0.001 \mathrm{~km} / \mathrm{m})$. 


\section{INTENTIONALLY LEFT BLANK}


APPENDIX E

CALCULATION OF ROCK PROPERTIES 


\section{CALCULATION OF ROCK PROPERTIES}

This appendix documents the calculation of rock property values based on source data provided in the TDMS. The rock properties include density, joint strength properties, intact rock properties, rock mass strength properties, and thermal properties. The use of these properties in this analysis is described in Section 4.1.

\section{E1. ROCK DENSITY}

The rock densities used in the thermal mechanical calculation of stresses at Yucca Mountain due to heating and cooling of the repository (Section 6.2) are provided in Table E-1. These data include dry bulk density values for the various lithostratigraphic and thermal-mechanical units of the Yucca Mountain rock strata. The mean values for thermal-mechanical units are determined by averaging the densities of the lithostratigraphic units within each thermal-mechanical unit, weighted according to the thickness of each lithostratigraphic unit. Additional details are provided in the Microsoft Excel file "thermal properties TM units v2.xls" (Table A-1).

For conservatism, saturated bulk density data from the Tptpln unit have been used in rockfall modeling (see Section 4.1.3). The saturated bulk density data are provided in Table E-2. The mean density value for these data is $2410 \mathrm{~kg} / \mathrm{m}^{3}$.

\section{E2. JOINT STRENGTH PROPERTIES}

Data from rotary shear stress experiments using core from the nonlithophysal units (i.e., Tptpmn and Tptpln) are provided in Table E-3. These data include pairs of normal stress $(\sigma)$ and shear stress $\left(\tau_{p}\right)$ values determined from shear testing of various core specimens. The data pairs were plotted (Figure E-1) and a linear fit of the data was determined. The calculation of the linear fit is documented in Microsoft Excel file "joint strength v2.xls" (Table A-1). The equation for the linear fit is:

$$
\tau_{\mathrm{p}}=\tan \phi_{\mathrm{j}} \sigma+C_{\mathrm{j}}
$$

where

$$
\begin{array}{ll}
\tau_{\mathrm{p}} & =\text { peak shear stress (MPa), } \\
\tan \phi_{\mathrm{j}} & =\text { coefficient of friction, } \\
\phi_{\mathrm{j}} & =\text { joint friction angle (degree), } \\
\sigma & =\text { normal stress (MPa), and } \\
C_{\mathrm{j}} & =\text { joint cohesion (MPa). }
\end{array}
$$

Based on this linear fit, the following joint strength parameters were determined:

- Joint cohesion $=0.6 \mathrm{MPa}$

- Coefficient of friction $=0.90$

- Joint friction angle $=42^{\circ}$. 
Table E-1. Density Data for Various Thermal Mechanical Units and Associated Lithostratigraphic Units

\begin{tabular}{|c|c|c|c|c|}
\hline $\begin{array}{c}\text { Thermal Mechanical } \\
\text { Unit }\end{array}$ & Stratigraphic Unit & Thickness $^{\mathrm{a}}(\mathrm{m})$ & $\begin{array}{c}\text { Dry Bulk Density } \\
\left(\mathrm{kg} / \mathrm{m}^{3}\right)\end{array}$ & DTN $^{b}$ \\
\hline \multirow{11}{*}{ TCw / PTn } & Tpcpv3 & 0.0 & 2310 & \multirow{14}{*}{$\begin{array}{c}\text { SN0303T0503102.008 } \\
\text { [DIRS 162401] }\end{array}$} \\
\hline & Tpcpv2 & 5.1 & 1460 & \\
\hline & Tpcpv1 & 2.4 & 1460 & \\
\hline & Tpbt4 & 0.5 & 1460 & \\
\hline & Tpy & 3.8 & 1460 & \\
\hline & Tpbt3 & 3.8 & 1460 & \\
\hline & Tpp & 5.1 & 1460 & \\
\hline & Tpbt2 & 8.3 & 1460 & \\
\hline & Tptrv3 & 1.9 & 1460 & \\
\hline & Tptrv2 & 1.2 & 1460 & \\
\hline & Mean (weighted by & nit thickness) & 1460 & \\
\hline \multirow{5}{*}{ TSw1 } & \begin{tabular}{|l} 
Tptrv1 \\
\end{tabular} & 1.2 & 2310 & \\
\hline & Tptrn & 35.6 & 2190 & \\
\hline & Tptrl & 6.1 & 2190 & \\
\hline & Tptpul & 66.8 & 1834 & \multirow{5}{*}{$\begin{array}{c}\text { SN0404T0503102.011 } \\
\text { [DIRS 169129] }\end{array}$} \\
\hline & Mean (weighted by & it thickness) & 1974 & \\
\hline \multirow{5}{*}{ TSw2 / TSw3 } & Tptpmn & 38.3 & 2148 & \\
\hline & Tptpll & 95.6 & 1979 & \\
\hline & Tptpln & 55.1 & 2211 & \\
\hline & Tptpv3 & 12.0 & 2310 & \multirow{8}{*}{$\begin{array}{l}\text { SN0303T0503102.008 } \\
\text { [DIRS 162401] }\end{array}$} \\
\hline & Mean (weighted by & nit thickness) & 2095 & \\
\hline \multirow{6}{*}{$\mathrm{CHn} 1 / \mathrm{CHn} 2$} & Tptpv2 & 4.7 & 1460 & \\
\hline & Tptpv1 & 15.4 & 1460 & \\
\hline & Tpbt1 & 2.0 & 1460 & \\
\hline & Calico & 45.5 & 1670 & \\
\hline & Calicobt & 15.9 & 1670 & \\
\hline & Mean (weighted by & it thickness) & 1614 & \\
\hline
\end{tabular}

${ }^{a}$ Thickness of units extracted from DTN: MO0012MWDGFM02.002 [DIRS 153777]. The details of this extraction are provided in Appendix M.

b Mean values are calculated in this report and not provided by the DTNs listed in this table. Data extracted from DTN: SN0404T0503102.11 [DIRS 169129] are summarized in BSC 2004 [DIRS 169854], Table 7-10. Data extracted from DTN: SN0303T0503102.008 [DIRS 162401] are summarized in BSC 2004 [DIRS 170033], Table 6-13. 
Table E-2. Density Data from the Tptpln Unit

\begin{tabular}{|c|c|c|}
\hline Borehole & Sample Number & Saturated Bulk Density $\left(\mathrm{kg} / \mathrm{m}^{3}\right)$ \\
\hline NRG-7a & NRG-7a-1230.2-SNL & 2395 \\
\hline NRG-7a & NRG-7a-1236.7-SNL & 2393 \\
\hline NRG-7a & NRG-7a-1252.3-SNL & 2369 \\
\hline NRG-7a & NRG-7a-1257.8-SNL & 2421 \\
\hline NRG-7a & NRG-7a-1259.1-SNL & 2420 \\
\hline NRG-7a & NRG-7a-1265.2-SNL & 2426 \\
\hline NRG-7a & NRG-7a-1314.8-SNL & 2418 \\
\hline NRG-7a & NRG-7a-1399.1-A-SNL & 2409 \\
\hline NRG-7a & NRG-7a-1400.5-B-SNL & 2428 \\
\hline NRG-7a & NRG-7a-1230.2-SNL & 2339 \\
\hline NRG-7a & NRG-7a-1263.7-SNL & 2416 \\
\hline NRG-7a & NRG-7a-1263.7-SNL & 2396 \\
\hline NRG-7a & NRG-7a-1263.7-SNL & 2421 \\
\hline NRG-7a & NRG-7a-1307.0-SNL & 2414 \\
\hline NRG-7a & NRG-7a-1307.0-SNL & 2411 \\
\hline NRG-7a & NRG-7a-1348.8-SNL & 2440 \\
\hline NRG-7a & NRG-7a-1348.8-SNL & 2424 \\
\hline NRG-7a & NRG-7a-1353.7-SNL & 2388 \\
\hline NRG-7a & NRG-7a-1363.5-SNL & 2442 \\
\hline NRG-7a & NRG-7a-1385.0-SNL & 2424 \\
\hline NRG-7a & NRG-7a-1385.0-SNL & 2419 \\
\hline NRG-7a & NRG-7a-1402.7-SNL & 2358 \\
\hline NRG-7a & NRG-7a-1409.0-SNL & 2450 \\
\hline SD-12 & SD-12-1073.3-SNL & 2415 \\
\hline SD-12 & SD-12-1077.1-SNL & 2426 \\
\hline SD-12 & SD-12-1107.1-SNL & 2416 \\
\hline SD-12 & SD-12-1112.1-SNL & 2400 \\
\hline SD-12 & SD-12-1118.9-SNL & 2372 \\
\hline SD-12 & SD-12-1209.0-SNL & 2423 \\
\hline SD-9 & NRG-SD-9-1243-SNL & 2418 \\
\hline SD-9 & NRG-SD-9-1298-SNL & 2439 \\
\hline SD-9 & NRG-SD-9-1346.5-SNL & 2419 \\
\hline \multicolumn{2}{|c|}{ Mean Density Value } & 2411 \\
\hline
\end{tabular}

Source: DTN: SNL02030193001.027 [DIRS 108410]. 
Table E-3. Data from Shear Stress Experiments on Natural Fractures from the Nonlithophysal Units of the Repository Horizon

\begin{tabular}{|c|c|c|c|c|c|c|}
\hline Source DTN & 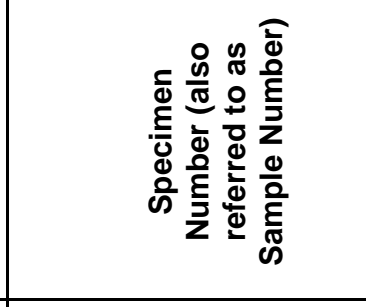 & 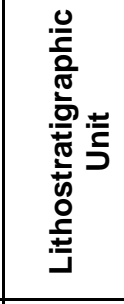 & 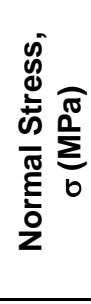 & 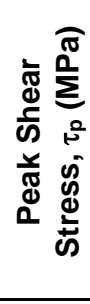 & 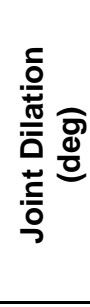 & Source Reports $^{a}$ \\
\hline $\begin{array}{l}\text { SNL02112293001.003 } \\
\text { [DIRS 108412] }\end{array}$ & NRG-6-782.3-782.6-SNL & Tptpmn & 2.5 & 1.9 & 1.1 & $\begin{array}{l}\text { Olsson and Brown } 1997 \\
\text { [DIRS 106453] (Table 1) }\end{array}$ \\
\hline \multirow{3}{*}{$\begin{array}{l}\text { SNL02112293001.005 } \\
\text { [DIRS 108413] }\end{array}$} & SD-9-1254.7-1255.2-A & Tptpln & 10.0 & 7.7 & 33.4 & \multirow{3}{*}{$\begin{array}{l}\text { SNL1996 [DIRS 165408] } \\
\text { (Tables } 1 \text { and 3) }\end{array}$} \\
\hline & SD-9-1255.9-1256.3 & Tptpln & 2.5 & 2.4 & 8.5 & \\
\hline & SD-9-1254.7-1255.2-B & Tptpln & 10.0 & 9.0 & 18.4 & \\
\hline \multirow{4}{*}{$\begin{array}{l}\text { SNL02112293001.007 } \\
\text { [DIRS 108414] }\end{array}$} & SD-12-688.4-688.7 & Tptpmn & 2.5 & 3.6 & 14.2 & \multirow{4}{*}{$\begin{array}{l}\text { SNL } 1996 \\
\text { [DIRS 165410] (Tables } 1 \\
\text { and 3) }\end{array}$} \\
\hline & SD-12-1072.5-1073.0-A & Tptpln & 2.5 & 3.3 & 13.7 & \\
\hline & SD-12-1072.5-1073.0-B & Tptpln & 5.0 & 6.6 & 15.1 & \\
\hline & SD-12-778.1-780.0 & Tptpmn & 10.0 & 12.0 & 17.7 & \\
\hline
\end{tabular}

${ }^{a}$ Data can be accessed through the source reports available via Records Processing Center Packages linked to the Source DTN.

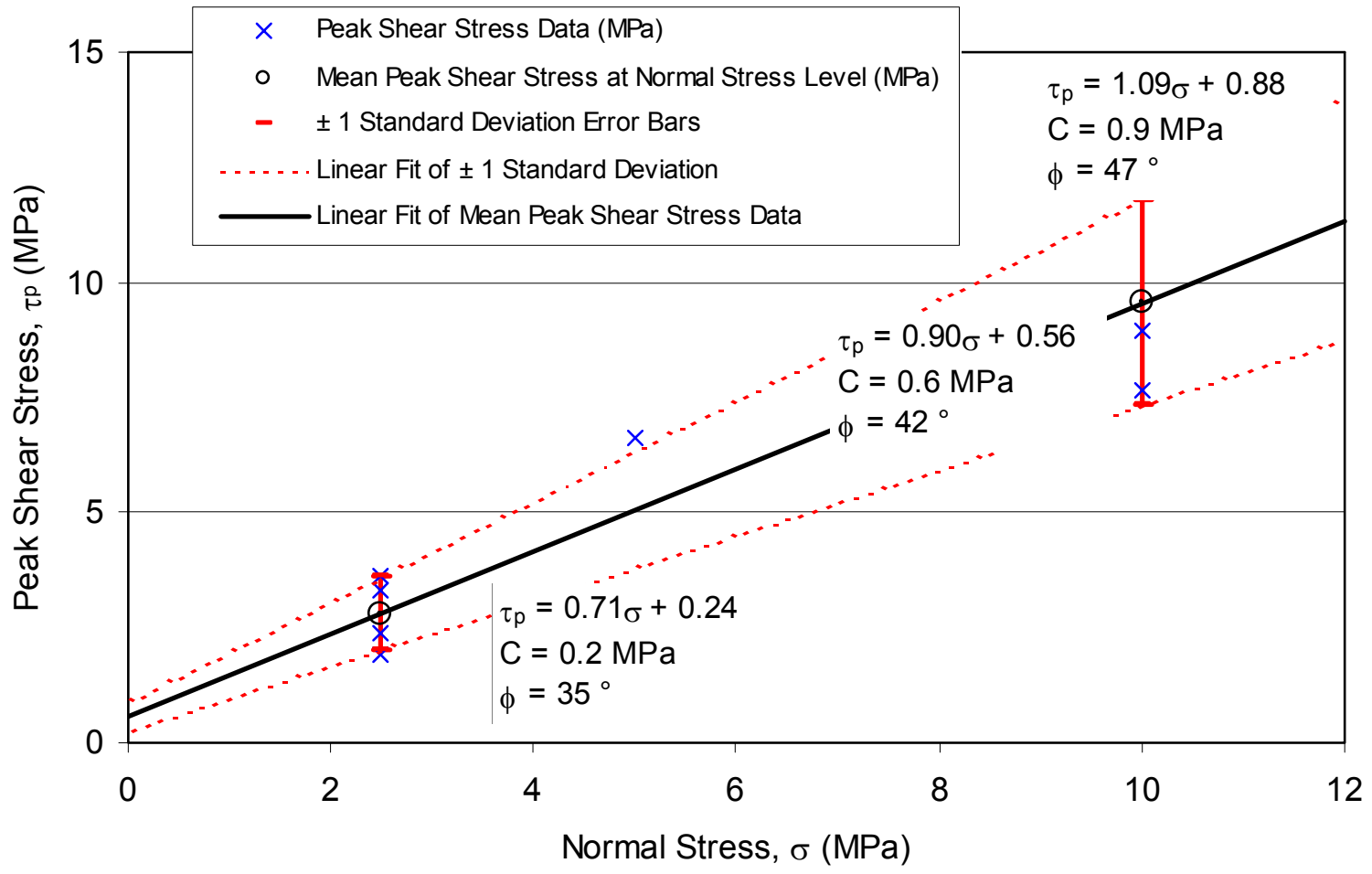

Source: Data provided in Table E-3.

Figure E-1. Plot of Shear Strength Test Data from the TSw2 Thermal Mechanical Unit 
To determine the range of the joint strength parameters (cohesion and friction angle), a statistical analysis was conducted as documented in file "joint strength v2.xls" (Table A-1). The mean shear stress was calculated at each normal stress level. A linear fit of the \pm one standard deviation about the mean data was used to determine the range of cohesion and friction angle (Figure E-1). Cohesion ranges from 0.2 to $0.9 \mathrm{MPa}$, while friction angle varies from $35^{\circ}$ to $47^{\circ}$.

Joint dilation data from rotary shear tests for the nonlithophysal units are presented in Table E-3. The mean joint dilation is $15.3^{\circ}$, with a standard deviation of $9.2^{\circ}$. The range of joint stiffness data from rotary shear tests is presented in Table E-4 together with the mean values. The joint stiffness data presented are consistent with Subsurface Geotechnical Parameters Report (BSC 2003 [DIRS 166660], Tables 8-50 and 8-51).

Direct shear test data have recently been collected as documented in the Subsurface Geotechnical Parameters Report (BSC 2003 [DIRS 166660], Tables 8-47 and 8-52). For these tests, cooling joints have been distinguished from vapor phase partings. Results for cohesion, friction angle, dilation, and shear stiffness are shown in Table E-5. With the exception of the shear stiffness, the direct shear results (Table E-5) are similar to the rotary shear results (Tables E-3, E-4, and Figure E-1). Shear stiffness values determined from the direct shear tests are similar to the empirical estimations of joint shear stiffness (Duan 2003 [DIRS 163586], Tables 5.2 and 5.3). Normal joint stiffness values from direct shear tests were not available.

\section{E3. INTACT ROCK PROPERTIES FOR NONLITHOPHYSAL ROCK}

Elastic rock properties data for nonlithophysal rock (i.e., the Tptpmn and Tptpln units), including Young's modulus, E, and Poisson's ratio, v, from laboratory tests on core specimens are shown in Table E-6. The mean Young's modulus from this data is $33.6 \mathrm{GPa}$, and the mean Poisson's ratio is 0.20 . Bulk modulus, $K$, and shear modulus, $G$, are calculated as follows (Jaeger and Cook 1979 [DIRS 106219], p. 111):

$$
\begin{aligned}
& K=\frac{E}{3 \cdot(1-2 v)} \\
& G=\frac{E}{2 \cdot(1+v)}
\end{aligned}
$$

Plugging the mean values of $E$ and $v$ into Equations E-2 and E-3 results in a bulk modulus value of $18.7 \mathrm{GPa}$, and a shear modulus value of $14.0 \mathrm{GPa}$.

Tensile strength data for the TSw2 unit were obtained from indirect tensile strength tests performed by the Brazilian Test method using core specimens as shown in Table E-7. The mean tensile strength from this data for the nonlithophysal units is $10.9 \mathrm{MPa}$ for the Tptpmn and 7.9 MPa for the Tptpln. The lower lithophysal unit (i.e., Tptpll) has a mean tensile strength of 8.3 $\mathrm{MPa}$. For the small Brazilian test samples, lithophysal cavities are not represented. The matrix rock material for the Tptpmn, Tptpll, and Tptpln Brazilian samples is therefore the same, and has a mean tensile strength of $8.9 \mathrm{MPa}$ (Table E-7). 
Table E-4. Normal and Shear Stiffness Data from Shear Stress Experiments on Natural Fractures from the Nonlithophysal Units of the Repository Horizon ${ }^{a}$

\begin{tabular}{|c|c|c|c|c|c|c|}
\hline Source DTN & 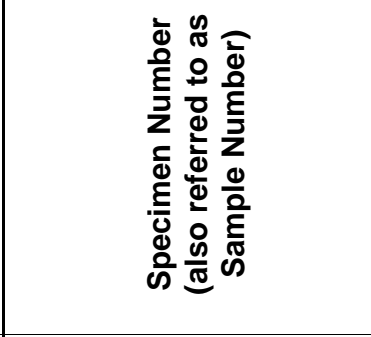 & 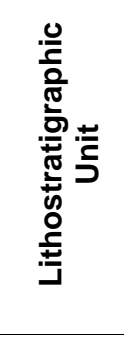 & $\stackrel{9}{\stackrel{0}{0}}$ & 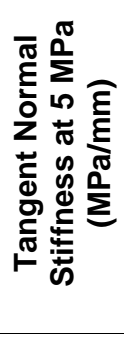 & 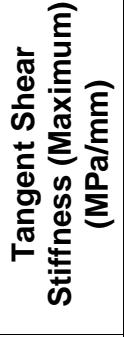 & Source Reports ${ }^{a}$ \\
\hline $\begin{array}{l}\text { SNL02112293001.003 } \\
\text { [DIRS 108412] }\end{array}$ & NRG-6-782.3-782.6-SNL & Tptpmn & YM9 & NA & 45 & $\begin{array}{l}\text { Olsson and Brown } \\
1997 \text { [DIRS 106453], } \\
\text { Figure } 6\end{array}$ \\
\hline \multirow{3}{*}{$\begin{array}{l}\text { SNL02112293001.005 } \\
\text { [DIRS 108413] }\end{array}$} & SD-9-1254.7-1255.2-A & Tptpln & YM23 & 105 & 100 & $\begin{array}{l}\text { SNL1996 [DIRS } \\
\text { 165408], p. A-2 }\end{array}$ \\
\hline & SD-9-1255.9-1256.3 & Tptpln & YM24 & NA & 145 & $\begin{array}{l}\text { SNL1996 [DIRS } \\
\text { 165408], p. A-5 }\end{array}$ \\
\hline & SD-9-1254.7-1255.2-B & Tptpln & YM25 & 115 & 180 & $\begin{array}{l}\text { SNL1996 [DIRS } \\
\text { 165408], p. A-8 }\end{array}$ \\
\hline \multirow{4}{*}{$\begin{array}{l}\text { SNL02112293001.007 } \\
\text { [DIRS 108414] }\end{array}$} & SD-12-688.4-688.7 & Tptpmn & YM33 & NA & 45 & $\begin{array}{l}\text { SNL 1996 [DIRS } \\
\text { 165410], p. A-2 }\end{array}$ \\
\hline & SD-12-1072.5-1073.0-A & Tptpln & YM34 & NA & 23 & $\begin{array}{l}\text { SNL 1996 [DIRS } \\
\text { 165410], p. A-4 }\end{array}$ \\
\hline & SD-12-1072.5-1073.0-B & Tptpln & YM35 & 90 & 115 & $\begin{array}{l}\text { SNL 1996 [DIRS } \\
\text { 165410], p. A-6 }\end{array}$ \\
\hline & SD-12-778.1-780.0 & Tptpmn & YM36 & 65 & 120 & $\begin{array}{l}\text { SNL 1996 [DIRS } \\
\text { 165410], p. A-8 }\end{array}$ \\
\hline \multicolumn{4}{|l|}{ Mean } & 94 & 97 & \multirow{2}{*}{-} \\
\hline \multicolumn{4}{|l|}{ Standard Deviation } & 22 & 55 & \\
\hline
\end{tabular}

a Data can be accessed through the source reports available via Records Processing Center Packages linked to the source DTN. 
Table E-5. Summary Statistics of Direct Joint Shear Test Results

\begin{tabular}{|c|c|c|c|}
\hline Property & Statistic & Vapor Phase Parting & Cooling Joint \\
\hline \multirow{5}{*}{ Joint Cohesion (MPa) } & Mean & 0.7 & 0.0 \\
\hline & Standard Deviation & 0.1 & 0.1 \\
\hline & Minimum & 0.7 & -0.0 \\
\hline & Maximum & 0.8 & 0.1 \\
\hline & Count & 3 & 2 \\
\hline \multirow{5}{*}{$\begin{array}{l}\text { Joint Friction Angle } \\
\text { (degree) }\end{array}$} & Mean & 44 & 33 \\
\hline & Standard Deviation & 2 & 0 \\
\hline & Minimum & 42 & 33 \\
\hline & Maximum & 46 & 34 \\
\hline & Count & 3 & 2 \\
\hline \multirow{5}{*}{ Joint Dilation (degree) } & Mean & 14 & 2 \\
\hline & Standard Deviation & 2 & 4 \\
\hline & Minimum & 12 & -1 \\
\hline & Maximum & 16 & 4 \\
\hline & Count & 3 & 2 \\
\hline \multirow{5}{*}{$\begin{array}{l}\text { Joint Shear Stiffness } \\
(\mathrm{MPa} / \mathrm{mm})\end{array}$} & Mean & 13 & 11 \\
\hline & Standard Deviation & 6 & 6 \\
\hline & Minimum & 8 & 7 \\
\hline & Maximum & 20 & 15 \\
\hline & Count & 3 & 2 \\
\hline
\end{tabular}

Source: BSC 2003 [DIRS 166660], Tables 8-47 and 8-52. 
Table E-6. Elastic Properties Data from the Nonlithophysal Units of the Repository Horizon ${ }^{\text {a }}$

\begin{tabular}{|c|c|c|c|c|c|}
\hline $\begin{array}{l}\text { Litho- } \\
\text { stratigraphic } \\
\text { Unit }\end{array}$ & Location & $\begin{array}{c}\text { Specimen Number (also } \\
\text { referred to as Sample } \\
\text { Number) }\end{array}$ & $\begin{array}{c}\text { Young's } \\
\text { Modulus } \\
\text { (GPa) }\end{array}$ & $\begin{array}{c}\text { Poisson's } \\
\text { Ratio }\end{array}$ & Original Source DTN \\
\hline \multirow{32}{*}{ Tptpmn } & \multirow{18}{*}{ Busted Butte } & $10 / \mathrm{AE} / 2 / \mathrm{Z}$ & 28.7 & 0.17 & \multirow{6}{*}{$\begin{array}{l}\text { SNSAND85076200.000 } \\
\text { [DIRS 160024] }\end{array}$} \\
\hline & & 10/AE/46/Z & 34.2 & 0.18 & \\
\hline & & 10/AE/9/Z & 31.5 & 0.20 & \\
\hline & & 10-AE-3Y & 18.6 & 0.07 & \\
\hline & & $10-A E-6 X$ & 28.6 & 0.14 & \\
\hline & & $10-A E-8 X$ & 21.7 & 0.11 & \\
\hline & & $10 \times 12$ & 34.6 & 0.21 & \multirow{12}{*}{$\begin{array}{l}\text { SNSAND85070900.000 } \\
\text { [DIRS 160022] }\end{array}$} \\
\hline & & $10 Y 47$ & 35.9 & 0.20 & \\
\hline & & $10 Z 15$ & 37.4 & 0.20 & \\
\hline & & $12 \mathrm{~A} 2$ & 45.8 & 0.22 & \\
\hline & & $12 \mathrm{~A} 3$ & 44.2 & 0.21 & \\
\hline & & $13 \mathrm{~A} 2$ & 34.9 & 0.21 & \\
\hline & & $26 \mathrm{~A} 1$ & 45.7 & 0.20 & \\
\hline & & 26B1 & 34.6 & 0.21 & \\
\hline & & $26 \mathrm{C} 1$ & 47.3 & 0.19 & \\
\hline & & 26D1 & 42.5 & 0.14 & \\
\hline & & 26E1 & 47.2 & 0.19 & \\
\hline & & $28 \mathrm{~A} 2$ & 34.6 & 0.20 & \\
\hline & \multirow{10}{*}{ USW G-4 } & G4-686.6-A & 36.2 & 0.18 & \multirow{10}{*}{$\begin{array}{l}\text { SNSAND84110100.000 } \\
\text { [DIRS 160016] }\end{array}$} \\
\hline & & G4-686.6-D & 40.7 & 0.17 & \\
\hline & & G4-686.6-G & 33.1 & 0.21 & \\
\hline & & G4-742.75-E & 35.6 & 0.21 & \\
\hline & & G4-742.75-F & 36.8 & 0.21 & \\
\hline & & G4-742.75-G & 34.6 & 0.21 & \\
\hline & & G4-748.6-A & 32.2 & 0.16 & \\
\hline & & G4-748.6-B & 32.3 & 0.21 & \\
\hline & & G4-749.0-A & 33.5 & 0.29 & \\
\hline & & G4-749.0-B & 34.1 & 0.27 & \\
\hline & \multirow{4}{*}{ USW GU-3 } & GU-3 760.9/1A & 30.2 & 0.19 & \multirow{4}{*}{$\begin{array}{l}\text { SNSAND83164600.000 } \\
\text { [DIRS 160009] }\end{array}$} \\
\hline & & GU-3 760.9/1B & 28.6 & 0.29 & \\
\hline & & GU-3 760.9/2A & 29.0 & 0.22 & \\
\hline & & GU-3 760.9/2B & 30.2 & 0.22 & \\
\hline
\end{tabular}


Table E-6. Elastic Properties Data from the Nonlithophysal Units of the Repository Horizon (Continued) ${ }^{\mathrm{a}}$

\begin{tabular}{|c|c|c|c|c|c|}
\hline $\begin{array}{c}\text { Litho- } \\
\text { stratigraphic } \\
\text { Unit }\end{array}$ & Location & $\begin{array}{c}\text { Specimen Number (also } \\
\text { referred to as Sample } \\
\text { Number) }\end{array}$ & $\begin{array}{l}\text { Young's } \\
\text { Modulus } \\
\text { (GPa) }\end{array}$ & $\begin{array}{l}\text { Poisson's } \\
\text { Ratio }\end{array}$ & Original Source DTN \\
\hline \multirow{39}{*}{ Tptpmn } & \multirow{6}{*}{ USW GU-3 } & GU-3 760.9/3A & 30.6 & 0.23 & \multirow{6}{*}{$\begin{array}{l}\text { SNSAND83164600.000 } \\
\text { [DIRS 160009] }\end{array}$} \\
\hline & & GU-3 760.9/3B & 30.8 & 0.21 & \\
\hline & & GU-3 760.9/4A & 29.3 & 0.19 & \\
\hline & & GU-3 760.9/4B & 28.1 & 0.16 & \\
\hline & & GU-3 760.9/5A & 30.7 & 0.22 & \\
\hline & & GU-3 760.9/5B & 30.0 & 0.21 & \\
\hline & \multirow{8}{*}{ UE-25 NRG \#5 } & NRG-5-847.2-SNL-A & 35.2 & 0.21 & \multirow{8}{*}{$\begin{array}{l}\text { SNL02030193001.012 } \\
\text { [DIRS 108416] }\end{array}$} \\
\hline & & NRG-5-849.4-SNL-A & 37.0 & 0.19 & \\
\hline & & NRG-5-861.2-SNL-A & 17.1 & 0.23 & \\
\hline & & NRG-5-873.4-SNL-A & 13.4 & 0.30 & \\
\hline & & NRG-5-887.2-SNL-A & 40.5 & 0.20 & \\
\hline & & NRG-5-888.8-SNL-A & 39.4 & 0.19 & \\
\hline & & NRG-5-891.9-SNL-A & 38.3 & 0.15 & \\
\hline & & NRG-5-896.5-SNL-A & 39.1 & 0.10 & \\
\hline & \multirow{8}{*}{ USW NRG-6 } & NRG-6-720.7-SNL-A & 37.1 & 0.19 & \multirow{8}{*}{$\begin{array}{l}\text { SNL02030193001.004 } \\
\text { [DIRS 108415] }\end{array}$} \\
\hline & & NRG-6-742.3-SNL-A & 30.6 & 0.20 & \\
\hline & & NRG-6-742.9-SNL-A & 32.4 & 0.22 & \\
\hline & & NRG-6-762.9-SNL-A & 29.2 & 0.18 & \\
\hline & & NRG-6-773.5-SNL-A & 36.2 & 0.23 & \\
\hline & & NRG-6-784.8-SNL-A & 29.7 & 0.17 & \\
\hline & & NRG-6-785.6-SNL-A & 30.1 & 0.16 & \\
\hline & & NRG-6-806.8-SNL-A & 31.7 & 0.16 & \\
\hline & \multirow{8}{*}{ USW NRG-7a } & NRG-7/7A-777.0-SNL-A & 32.9 & 0.22 & \multirow{8}{*}{$\begin{array}{l}\text { SNL02030193001.019 } \\
\text { [DIRS 108431] }\end{array}$} \\
\hline & & NRG-7/7A-806.3-SNL-A & 36.7 & 0.19 & \\
\hline & & NRG-7/7A-818.5-SNL-A & 33.1 & 0.20 & \\
\hline & & NRG-7/7A-859.2-SNL-A & 38.8 & 0.20 & \\
\hline & & NRG-7/7A-865.4-SNL-I & 34.3 & 0.20 & \\
\hline & & NRG-7/7A-865.4-SNL-J & 33.5 & 0.19 & \\
\hline & & NRG-7/7A-865.4-SNL-K & 34.9 & 0.22 & \\
\hline & & NRG-7/7A-865.4-SNL-L & 35.7 & 0.21 & \\
\hline & \multirow{2}{*}{ USW SD-12 } & SD-12-734.7-SNL-B & 31.9 & 0.18 & \multirow{2}{*}{$\begin{array}{l}\text { SNL02030193001.023 } \\
\text { [DIRS 108435] }\end{array}$} \\
\hline & & SD-12-781.1-SNL-B & 36.7 & 0.21 & \\
\hline & \multirow{7}{*}{ USW SD-9 } & SD-9-761.5-SNL-A & 33.9 & 0.21 & \multirow{7}{*}{$\begin{array}{l}\text { SNL02030193001.026 } \\
\text { [DIRS 108436] }\end{array}$} \\
\hline & & SD-9-768.7-SNL-A & 36.9 & 0.20 & \\
\hline & & SD-9-771.7-SNL-A & 34.8 & 0.19 & \\
\hline & & SD-9-774.6-SNL-B & 16.8 & 0.19 & \\
\hline & & SD-9-826.7-SNL-A & 31.9 & 0.21 & \\
\hline & & SD-9-832.8-SNL-C & 29.8 & 0.19 & \\
\hline & & SD-9-842.1-SNL-E-1 & 36.3 & 0.20 & \\
\hline \multirow{2}{*}{ Tptpln } & \multirow{2}{*}{ USW G-4 } & G4-1307.2-A & 30.2 & 0.23 & \multirow{2}{*}{$\begin{array}{l}\text { SNSAND84110100.000 } \\
\text { [DIRS 160016] }\end{array}$} \\
\hline & & G4-1307.2-C & 22.8 & 0.20 & \\
\hline
\end{tabular}


Table E-6. Elastic Properties Data from the Nonlithophysal Units of the Repository Horizon (Continued) ${ }^{\text {a }}$

\begin{tabular}{|c|c|c|c|c|c|}
\hline $\begin{array}{l}\text { Litho- } \\
\text { stratigraphic } \\
\text { Unit }\end{array}$ & Location & $\begin{array}{c}\text { Specimen Number (also } \\
\text { referred to as Sample } \\
\text { Number) }\end{array}$ & $\begin{array}{c}\text { Young's } \\
\text { Modulus } \\
\text { (GPa) }\end{array}$ & $\begin{array}{c}\text { Poisson's } \\
\text { Ratio } \\
\end{array}$ & Original Source DTN \\
\hline \multirow{18}{*}{ Tptpln } & \multirow{3}{*}{ USW G-4 } & G4-1307.2-D & 20.0 & 0.30 & \multirow{3}{*}{$\begin{array}{l}\text { SNSAND84110100.000 } \\
\text { [DIRS 160016] }\end{array}$} \\
\hline & & G4-1307.2-E & 16.6 & 0.24 & \\
\hline & & G4-1307.2-F & 34.9 & 0.20 & \\
\hline & \multirow{5}{*}{ USW GU-3 } & GU-3 1050.4/1 & 35.5 & 0.18 & \multirow{5}{*}{$\begin{array}{l}\text { SNSAND83164600.000 } \\
\text { [DIRS 160009] }\end{array}$} \\
\hline & & GU-3 1050.4/2 & 36.1 & 0.19 & \\
\hline & & GU-3 1050.4/3 & 36.3 & 0.19 & \\
\hline & & GU-3 1067.8/3 & 32.7 & 0.24 & \\
\hline & & GU-3 1067.8/4 & 32.1 & 0.24 & \\
\hline & \multirow{5}{*}{ USW NRG-7a } & NRG-7/7A-1265.2-SNL-A & 40.7 & 0.21 & \multirow{5}{*}{$\begin{array}{l}\text { SNL02030193001.020 } \\
\text { [DIRS 108432] }\end{array}$} \\
\hline & & NRG-7/7A-1257.8-SNL-A & 41.8 & 0.20 & \\
\hline & & NRG-7/7A-1259.1-SNL-A & 40.6 & 0.21 & \\
\hline & & NRG-7/7A-1314.8-SNL-A & 37.7 & 0.21 & \\
\hline & & NRG-7/7A-1252.3-SNL-A & 30.4 & 0.14 & \\
\hline & \multirow{2}{*}{ USW SD-12 } & SD-12-1107.1-SNL-B & 34.5 & 0.23 & \multirow{2}{*}{$\begin{array}{l}\text { SNL02030193001.023 } \\
\text { [DIRS 108435] }\end{array}$} \\
\hline & & SD-12-1209.0-SNL-B & 31.9 & 0.28 & \\
\hline & \multirow{3}{*}{ USW SD-9 } & SD-9-1243.0-SNL-A & 35.9 & 0.19 & \multirow{3}{*}{$\begin{array}{l}\text { SNL02030193001.026 } \\
\text { [DIRS 108436] }\end{array}$} \\
\hline & & SD-9-1298.0-SNL-A & 39.9 & 0.25 & \\
\hline & & SD-9-1346.5-SNL-A & 44.4 & 0.25 & \\
\hline \multicolumn{3}{|c|}{ Mean property values } & 33.6 & 0.20 & - \\
\hline
\end{tabular}

${ }^{\text {a }}$ Elastic properties data are qualified and summarized in DTN: MO0402DQRIRPPR.003 [DIRS 168901]. The data can be found by downloading the data file from this DTN, and searching for the data using the Specimen Number. The elastic properties data have been selected according to test conditions to provide a consistent data set. Data with the following test conditions were selected: ambient temperature conditions, saturated samples, unconfined (confining pressure $=0$ or $0.1 \mathrm{MPa}$ ), nominal strain rate of $10^{-5} \mathrm{~s}^{-1}$, with sample diameters ranging from 25.4 to $50.8 \mathrm{~mm}$.

Table E-7. Tensile Strength Data from the TSw2 Thermal Mechanical Unit ${ }^{a}$

\begin{tabular}{|c|c|c|c|c|}
\hline \multirow{4}{*}{ Borehole } & $\begin{array}{c}\text { Specimen Number (also } \\
\text { referred to as Sample } \\
\text { Number) }\end{array}$ & $\begin{array}{c}\text { Tensile Strength } \\
\text { (MPa) }\end{array}$ & Original Source DTN & Lithostratigraphic Unit \\
\hline \multirow{4}{*}{ NRG-5 } & NRG-5-788.6-SNL-A & 4.3 & & \\
\cline { 2 - 3 } & NRG-5-832.9-SNL-A & 7.7 & \\
& NRG-5-847.2-SNL-B & 5.7 & \multirow{4}{*}{$\begin{array}{c}\text { SNL02030193001.009 } \\
\text { [DIRS 109614] }\end{array}$} & \\
\cline { 2 - 3 } & NRG-5-887.2-SNL-B & 16.8 & & \\
\cline { 2 - 3 } & NRG-5-888.8-SNL-B & 15.9 & & \multirow{2}{*}{ Tptpmn } \\
\cline { 2 - 3 } & NRG-5-891.9-SNL-B & 12.9 & & \\
\hline \multirow{4}{*}{ NRG-6 } & NRG-6-742.3-SNL-B & 14.5 & & \\
\cline { 2 - 3 } & NRG-6-742.9-SNL-B & 13.0 & \multirow{2}{*}{ SNL02030193001.004 } & \\
\cline { 2 - 3 } & NRG-6-773.5-SNL-B & 7.9 & & \\
\cline { 2 - 3 } & NRG-6-784.8-SNL-B & 12.5 & & \\
\cline { 2 - 3 } & NRG-6-785.6-SNL-B & 14.1 & & \\
\hline
\end{tabular}


Table E-7. Tensile Strength Data from the TSw2 Thermal Mechanical Unit (Continued) ${ }^{\text {a }}$

\begin{tabular}{|c|c|c|c|c|}
\hline Borehole & $\begin{array}{c}\text { Specimen Number (also } \\
\text { referred to as Sample } \\
\text { Number) }\end{array}$ & $\begin{array}{c}\text { Tensile } \\
\text { Strength (MPa) }\end{array}$ & Original Source DTN & Lithostratigraphic Unit \\
\hline \multirow{3}{*}{ NRG-7a } & NRG-7/7A-762.1-SNL-A & 9.3 & \multirow{3}{*}{$\begin{array}{c}\text { SNL02030193001.019 } \\
\text { [DIRS 108431] }\end{array}$} & \multirow[b]{3}{*}{ Tptpmn } \\
\hline & NRG-7/7A-828.4-SNL-A & 6.1 & & \\
\hline & NRG-7/7A-855.0-SNL-A & 11.6 & & \\
\hline & Mean & 10.9 & \multirow{5}{*}{\multicolumn{2}{|c|}{ Summary Statistics for Tptpmn }} \\
\hline & Count & 14 & & \\
\hline & Standard Deviation & 4.0 & & \\
\hline & Minimum & 4.3 & & \\
\hline & Maximum & 16.8 & & \\
\hline \multirow{8}{*}{ NRG-6 } & NRG-6-848.0-SNL-B & 7.9 & \multirow{8}{*}{$\begin{array}{l}\text { SNL02030193001.004 } \\
\text { [DIRS 108415] }\end{array}$} & \multirow{24}{*}{ Tptpll } \\
\hline & NRG-6-908.2-SNL-A & 8.8 & & \\
\hline & NRG-6-934.0-SNL-A & 10.8 & & \\
\hline & NRG-6-934.0-SNL-B & 4.0 & & \\
\hline & NRG-6-956.8-SNL-A & 5.3 & & \\
\hline & NRG-6-963.3-SNL-B & 3.2 & & \\
\hline & NRG-6-969.3-SNL-A & 7.5 & & \\
\hline & NRG-6-971.4-SNL-B & 11.7 & & \\
\hline \multirow{16}{*}{ NRG-7a } & NRG-7/7A-879.2-SNL-A & 14.3 & \multirow{3}{*}{$\begin{array}{l}\text { SNL02030193001.019 } \\
\text { [DIRS 108431] }\end{array}$} & \\
\hline & NRG-7/7A-879.2-SNL-B & 11.0 & & \\
\hline & NRG-7/7A-881.0-SNL-A & 12.1 & & \\
\hline & NRG-7/7A-958.7-SNL-A & 11.2 & \multirow{13}{*}{$\begin{array}{l}\text { SNL02030193001.020 } \\
\text { [DIRS 108432] }\end{array}$} & \\
\hline & NRG-7/7A-958.7-SNL-B & 11.5 & & \\
\hline & NRG-7/7A-976.4-SNL-A & 5.5 & & \\
\hline & NRG-7/7A-976.4-SNL-B & 6.3 & & \\
\hline & NRG-7/7A-979.6-SNL-A & 5.2 & & \\
\hline & NRG-7/7A-1046.8-SNL-A & 6.2 & & \\
\hline & NRG-7/7A-1090.3-SNL-A & 10.4 & & \\
\hline & NRG-7/7A-1090.3-SNL-B & 10.2 & & \\
\hline & NRG-7/7A-1098.3-SNL-A & 6.6 & & \\
\hline & NRG-7/7A-1129.3-SNL-A & 7.0 & & \\
\hline & NRG-7/7A-1180.0-SNL-A & 5.3 & & \\
\hline & NRG-7/7A-1188.7-SNL-A & 8.6 & & \\
\hline & NRG-7/7A-1230.2-SNL-B & 9.2 & & \\
\hline & Mean & 8.3 & \multirow{5}{*}{\multicolumn{2}{|c|}{ Summary Statistics for Tptpll }} \\
\hline & Count & 24 & & \\
\hline & Standard Deviation & 2.9 & & \\
\hline & Minimum & 3.2 & & \\
\hline & Maximum & 14.3 & & \\
\hline \multirow{3}{*}{ NRG-7a } & NRG-7/7A-1263.7-SNL-A & 13.7 & \multirow{3}{*}{$\begin{array}{l}\text { SNL02030193001.020 } \\
\text { [DIRS 108432] }\end{array}$} & \multirow{3}{*}{ Tptpln } \\
\hline & NRG-7/7A-1263.7-SNL-B & 9.9 & & \\
\hline & NRG-7/7A-1263.7-SNL-C & 9.0 & & \\
\hline
\end{tabular}


Table E-7. Tensile Strength Data from the TSw2 Thermal Mechanical Unit (Continued) ${ }^{\text {a }}$

\begin{tabular}{|c|c|c|c|c|}
\hline Borehole & $\begin{array}{c}\text { Specimen Number (also } \\
\text { referred to as Sample } \\
\text { Number) }\end{array}$ & $\begin{array}{c}\text { Tensile } \\
\text { Strength (MPa) }\end{array}$ & Original Source DTN & Lithostratigraphic Unit \\
\hline \multirow{10}{*}{ NRG-7a } & NRG-7/7A-1307.0-SNL-A & 10.9 & \multirow{10}{*}{$\begin{array}{l}\text { SNL02030193001.020 } \\
\text { [DIRS 108432] }\end{array}$} & \multirow{10}{*}{ Tptpln } \\
\hline & NRG-7/7A-1307.0-SNL-B & 8.8 & & \\
\hline & NRG-7/7A-1348.8-SNL-A & 4.8 & & \\
\hline & NRG-7/7A-1348.8-SNL-B & 5.9 & & \\
\hline & NRG-7/7A-1353.7-SNL-A & 7.6 & & \\
\hline & NRG-7/7A-1363.5-SNL-A & 7.6 & & \\
\hline & NRG-7/7A-1385.0-SNL-A & 6.1 & & \\
\hline & NRG-7/7A-1385.0-SNL-B & 6.3 & & \\
\hline & NRG-7/7A-1402.7-SNL-A & 4.8 & & \\
\hline & NRG-7/7A-1409.0-SNL-A & 7.6 & & \\
\hline & Mean & 7.9 & \multirow{5}{*}{\multicolumn{2}{|c|}{ Summary Statistics for Tptpll }} \\
\hline & Count & 13 & & \\
\hline & Standard Deviation & 2.5 & & \\
\hline & Minimum & 4.8 & & \\
\hline & Maximum & 13.7 & & \\
\hline & Mean & 8.9 & \multirow{5}{*}{\multicolumn{2}{|c|}{ Summary Statistics for TSW2 }} \\
\hline & Count & 51 & & \\
\hline & Standard Deviation & 3.3 & & \\
\hline & Minimum & 3.2 & & \\
\hline & Maximum & 16.8 & & \\
\hline
\end{tabular}

${ }^{\text {a }}$ Tensile strength data are qualified and summarized in DTN: MO0401DQRIRPTS.003 [DIRS 168905].

The tensile strength of intact rock material is typically an order of magnitude lower than its compressive strength (compare the mean tensile strength of $10.9 \mathrm{MPa}$ for the Tptpmn unit [Table E-7] to the mean compressive strength of $188.8 \mathrm{MPa}$ for the Tptpmn unit [see Section E4.2, Table E-14]). The tensile strength of a rock mass is often considered to be zero since discontinuities offer little or no resistance to tensile stresses. However, compressive stresses are most prevalent in geotechnical problems, so the emphasis in geotechnical design is typically placed on the compressive and shear strength of rock (Brady and Brown 1985 [DIRS 126811], pp. 86-87).

Triaxial strength data (Table E-8) are used to calculate intact cohesion and friction angle of the nonlithophysal rocks. The triaxial data includes sets of confining pressure data paired with the corresponding axial stress at failure, as plotted in Figures E-2 and E-3. The Mohr-Coulomb approach for calculating cohesion and friction angle is used (Jaeger and Cook 1979 [DIRS 106219], pp. 87 to 93). A least-square linear fit of the axial stress $\left(\sigma_{1}\right)$ and the confining 
pressure $\left(\sigma_{3}\right)$ data sets was performed (Figure E-2) and plotted in the form:

$$
\sigma_{1}=\mathrm{N} \sigma_{3}+\sigma_{\mathrm{C}}
$$

where $\sigma_{1}=$ axial stress, or the strength of the rock at failure,

$\sigma_{3}=$ confining pressure,

$\sigma_{\mathrm{C}}=$ unconfined compressive strength,

$\mathrm{N}=$ confinement factor.

The relationship between the linear equation above and the Mohr-Coulomb parameters, cohesion (C) and friction angle $(\phi)$, is given by the following (Jaeger and Cook 1979 [DIRS 106219], p. 93):

$$
\tau=\mathrm{C}+\sigma_{\mathrm{n}} \tan \phi
$$

$$
\text { where } \begin{array}{lll}
\tau & =\text { sheer stress, } \\
\mathrm{C} & =\text { cohesion, } \\
\sigma_{\mathrm{n}} & =\text { normal stress } \\
\phi & =\text { friction angle. }
\end{array}
$$

Cohesion and friction angle are calculated based on their relationship to $N$ and $\sigma_{\mathrm{c}}$ as follows (Jaeger and Cook 1979 [DIRS 106219], pp. 88 to 91):

$$
\begin{gathered}
\mathrm{C}=\frac{\sigma_{c}}{2 \cdot \sqrt{N}} \\
\phi=2\left(\tan ^{-1} \sqrt{N}-45^{\circ}\right) .
\end{gathered}
$$

The calculation of cohesion and friction angle using the approach described above is documented in Microsoft Excel file, intact strength nonlith v2.xls (Table A-1), resulting in a mean cohesion of $36 \mathrm{MPa}$ and a friction angle of $50^{\circ}$ for the Tptpmn unit from borehole samples located near the ESF (Table E-8). The mean value of cohesion and friction angle is within the range of the values provided in the Subsurface Geotechnical Parameters Report (BSC 2003 [DIRS 166660], Table 8-40).

To evaluate the range of the intact strength parameters, cohesion and friction angle, using the data from Table E-8, a statistical analysis was conducted as documented in Table A-1, file: intact strength nonlith v2.xls. The mean axial stress was calculated at each confining stress level. A linear fit of the \pm one standard deviation about the mean data was used to determine the range of cohesion and friction angle. Cohesion ranges from 32 to $40 \mathrm{MPa}$, while friction angle varies from $41^{\circ}$ to $56^{\circ}$ (Figure E-2). 
Table E-8. Uniaxial and Triaxial Test Data from the Tptpmn Lithostratigraphic Unit ${ }^{a}$

\begin{tabular}{|c|c|c|c|c|c|}
\hline Location & $\begin{array}{c}\text { Specimen Number (also } \\
\text { referred to as Sample } \\
\text { Number) }\end{array}$ & 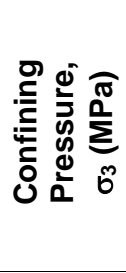 & 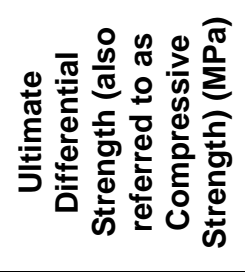 & 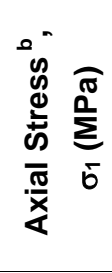 & Original Source DTN \\
\hline \multirow{10}{*}{ USW GU-3 } & GU-3 760.9-1A & 0 & 210.3 & 210.3 & \multirow{10}{*}{$\begin{array}{l}\text { SNSAND83164600.000 } \\
\text { [DIRS 160009] }\end{array}$} \\
\hline & GU-3 760.9-1B & 0 & 234.4 & 234.4 & \\
\hline & GU-3 760.9-2A & 0 & 215.5 & 215.5 & \\
\hline & GU-3 760.9-3A & 0 & 245.2 & 245.2 & \\
\hline & GU-3 760.9-5A & 0 & 229.7 & 229.7 & \\
\hline & GU-3 760.9-5B & 0 & 226.4 & 226.4 & \\
\hline & GU-3 760.9-2B & 0 & 221.4 & 221.4 & \\
\hline & GU-3 760.9-3B & 0 & 222.2 & 222.2 & \\
\hline & GU-3 760.9-4A & 0 & 205.2 & 205.2 & \\
\hline & GU-3 760.9-4B & 0 & 183.5 & 183.5 & \\
\hline \multirow{8}{*}{ UE-25 NRG \#5 } & NRG-5-847.2-SNL-A & 0 & 84.2 & 84.2 & \multirow{8}{*}{$\begin{array}{l}\text { SNL02030193001.012 } \\
\text { [DIRS 108416] }\end{array}$} \\
\hline & NRG-5-849.4-SNL-A & 0 & 240.8 & 240.8 & \\
\hline & NRG-5-861.2-SNL-A & 0 & 55.3 & 55.3 & \\
\hline & NRG-5-873.4-SNL-A & 0 & 38.4 & 38.4 & \\
\hline & NRG-5-887.2-SNL-A & 0 & 240.9 & 240.9 & \\
\hline & NRG-5-888.8-SNL-A & 0 & 288.9 & 288.9 & \\
\hline & NRG-5-891.9-SNL-A & 0 & 253.5 & 253.5 & \\
\hline & NRG-5-896.5-SNL-A & 0 & 184.7 & 184.7 & \\
\hline \multirow{8}{*}{ USW NRG-6 } & NRG-6-720.7-SNL-A & 0 & 235.5 & 235.5 & \multirow{8}{*}{$\begin{array}{l}\text { SNL02030193001.004 } \\
\text { [DIRS 108415] }\end{array}$} \\
\hline & NRG-6-742.3-SNL-A & 0 & 162.3 & 162.3 & \\
\hline & NRG-6-742.9-SNL-A & 0 & 212.8 & 212.8 & \\
\hline & NRG-6-762.9-SNL-A & 0 & 112.1 & 112.1 & \\
\hline & NRG-6-773.5-SNL-A & 0 & 117.4 & 117.4 & \\
\hline & NRG-6-784.8-SNL-A & 0 & 223.0 & 223.0 & \\
\hline & NRG-6-785.6-SNL-A & 0 & 218.6 & 218.6 & \\
\hline & NRG-6-806.8-SNL-A & 0 & 261.9 & 261.9 & \\
\hline \multirow{9}{*}{ USW NRG-7a } & NRG-7/7A-777.0-SNL-A & 0 & 143.8 & 143.8 & \multirow{9}{*}{$\begin{array}{l}\text { SNL02030193001.019 } \\
\text { [DIRS 108431] }\end{array}$} \\
\hline & NRG-7/7A-800.2-SNL-A & 0 & 179.2 & 179.2 & \\
\hline & NRG-7/7A-806.3-SNL-A & 0 & 225.4 & 225.4 & \\
\hline & NRG-7/7A-818.5-SNL-A & 0 & 126.3 & 126.3 & \\
\hline & NRG-7/7A-859.2-SNL-A & 0 & 118.8 & 118.8 & \\
\hline & NRG-7/7A-865.4-SNL-I & 0 & 215.8 & 215.8 & \\
\hline & NRG-7/7A-865.4-SNL-J & 0 & 232.0 & 232.0 & \\
\hline & NRG-7/7A-865.4-SNL-K & 0 & 239.1 & 239.1 & \\
\hline & NRG-7/7A-865.4-SNL-L & 0 & 248.5 & 248.5 & \\
\hline \multirow{2}{*}{ USW SD-12 } & SD-12-734.7-SNL-B & 0 & 193.3 & 193.3 & \multirow{2}{*}{$\begin{array}{l}\text { SNL02030193001.023 } \\
\text { [DIRS 108435] }\end{array}$} \\
\hline & SD-12-781.1-SNL-B & 0 & 198.2 & 198.2 & \\
\hline \multirow{4}{*}{ USW SD-9 } & SD-9-761.5-SNL-A & 0 & 231.5 & 231.5 & \multirow{4}{*}{$\begin{array}{l}\text { SNL02030193001.026 } \\
\text { [DIRS 108436] }\end{array}$} \\
\hline & SD-9-768.7-SNL-A & 0 & 254.5 & 254.5 & \\
\hline & SD-9-771.7-SNL-A & 0 & 160.8 & 160.8 & \\
\hline & SD-9-774.6-SNL-B & 0 & 60.1 & 60.1 & \\
\hline
\end{tabular}


Table E-8. Uniaxial and Triaxial Test Data from the Tptpmn Lithostratigraphic Unit (Continued) ${ }^{\text {a }}$

\begin{tabular}{|c|c|c|c|c|c|}
\hline Location & $\begin{array}{c}\text { Specimen Number (also } \\
\text { referred to as Sample } \\
\text { Number) }\end{array}$ & 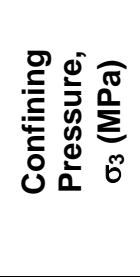 & 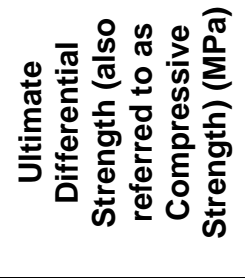 & 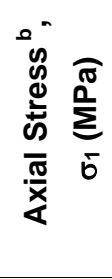 & Original Source DTN \\
\hline \multirow{3}{*}{ USW SD-9 } & SD-9-826.7-SNL-A & 0 & 224.9 & 224.9 & \multirow{3}{*}{$\begin{array}{l}\text { SNL02030193001.026 } \\
\text { [DIRS 108436] }\end{array}$} \\
\hline & SD-9-832.8-SNL-C & 0 & 183.3 & 183.3 & \\
\hline & SD-9-842.1-SNL-E-1 & 0 & 208.9 & 208.9 & \\
\hline \multirow{12}{*}{ USW G-4 } & G4-686.6-G & 0.1 & 180.0 & 180.1 & \multirow{12}{*}{$\begin{array}{l}\text { SNSAND84110100.000 } \\
\text { [DIRS 160016] }\end{array}$} \\
\hline & G4-749.0-A & 0.1 & 268.0 & 268.1 & \\
\hline & G4-749.0-B & 0.1 & 188.0 & 188.1 & \\
\hline & G4-686.6-A & 0.1 & 270.0 & 270.1 & \\
\hline & G4-686.6-D & 0.1 & 326.0 & 326.1 & \\
\hline & G4-742.75-E & 0.1 & 235.0 & 235.1 & \\
\hline & G4-742.75-F & 0.1 & 256.0 & 256.1 & \\
\hline & G4-742.75-G & 0.1 & 279.0 & 279.1 & \\
\hline & G4-748.6-B & 0.1 & 190.0 & 190.1 & \\
\hline & G4-748.6-A & 0.1 & 196.0 & 196.1 & \\
\hline & G4-686.6-B & 5 & 156.0 & 161.0 & \\
\hline & G4-686.6-E & 5 & 87.0 & 92.0 & \\
\hline \multirow{5}{*}{ USW NRG-7a } & NRG-7/7A-865.4-SNL-C & 5 & 254.8 & 259.8 & \multirow{4}{*}{$\begin{array}{l}\text { SNL02030193001.019 } \\
\text { [DIRS 108431] }\end{array}$} \\
\hline & NRG-7/7A-865.4-SNL-F & 5 & 317.3 & 322.3 & \\
\hline & NRG-7/7A-865.4-SNL-G & 5 & 250.1 & 255.1 & \\
\hline & NRG-7/7A-865.4-SNL-H & 5 & 226.6 & 231.6 & \\
\hline & NRG-7/7A-861.7-SNL-A & 5 & 245.8 & 250.8 & $\begin{array}{l}\text { SNL02030193001.021 } \\
\text { [DIRS 108433] }\end{array}$ \\
\hline USW SD-12 & SD-12-745.6-SNL-B & 5 & 330.7 & 335.7 & $\begin{array}{l}\text { SNL02030193001.023 } \\
\text { [DIRS 108435] }\end{array}$ \\
\hline \multirow{2}{*}{ USW G-4 } & G4-686.6-C & 10 & 344.0 & 354.0 & \multirow{2}{*}{$\begin{array}{l}\text { SNSAND84110100.000 } \\
\text { [DIRS 160016] }\end{array}$} \\
\hline & G4-686.6-F & 10 & 360.0 & 370.0 & \\
\hline \multirow{6}{*}{ USW NRG-7a } & NRG-7/7A-865.4-SNL-A & 10 & 315.2 & 325.2 & \multirow{4}{*}{$\begin{array}{l}\text { SNL02030193001.019 } \\
\text { [DIRS 108431] }\end{array}$} \\
\hline & NRG-7/7A-865.4-SNL-B & 10 & 344.0 & 354.0 & \\
\hline & NRG-7/7A-865.4-SNL-D & 10 & 225.5 & 235.5 & \\
\hline & NRG-7/7A-865.4-SNL-E & 10 & 306.7 & 316.7 & \\
\hline & NRG-7/7A-805.6-SNL-A & 10 & 137.1 & 147.1 & \multirow{2}{*}{$\begin{array}{l}\text { SNL02030193001.021 } \\
\text { DIRS 108433] }\end{array}$} \\
\hline & NRG-7/7A-827.4-SNL-A & 10 & 125.3 & 135.3 & \\
\hline USW SD-12 & SD-12-762.6-SNL-B & 10 & 272.8 & 282.8 & $\begin{array}{l}\text { SNL02030193001.023 } \\
\text { [DIRS 108435] }\end{array}$ \\
\hline
\end{tabular}

${ }^{a}$ Uniaxial and triaxial test data are qualified and summarized in DTN: MO0311RCKPRPCS.003 [DIRS 166073]. The data can be found by downloading the data file from this DTN, and searching for the data using the Specimen Number. The uniaxial and triaxial test data have been selected according to test conditions to provide a consistent data set. Borehole data with the following test conditions were selected: ambient temperature conditions, saturated samples, nominal strain rate of $10^{-5} \mathrm{~s}^{-1}$, with sample diameters ranging from 25.4 to $50.8 \mathrm{~mm}$.

${ }^{\mathrm{b}}$ Axial Stress $\left(\sigma_{1}\right)$ is not provided in the DTN. Axial Stress $=\sigma_{1}=\sigma_{3}+$ Ultimate Differential Strength. 


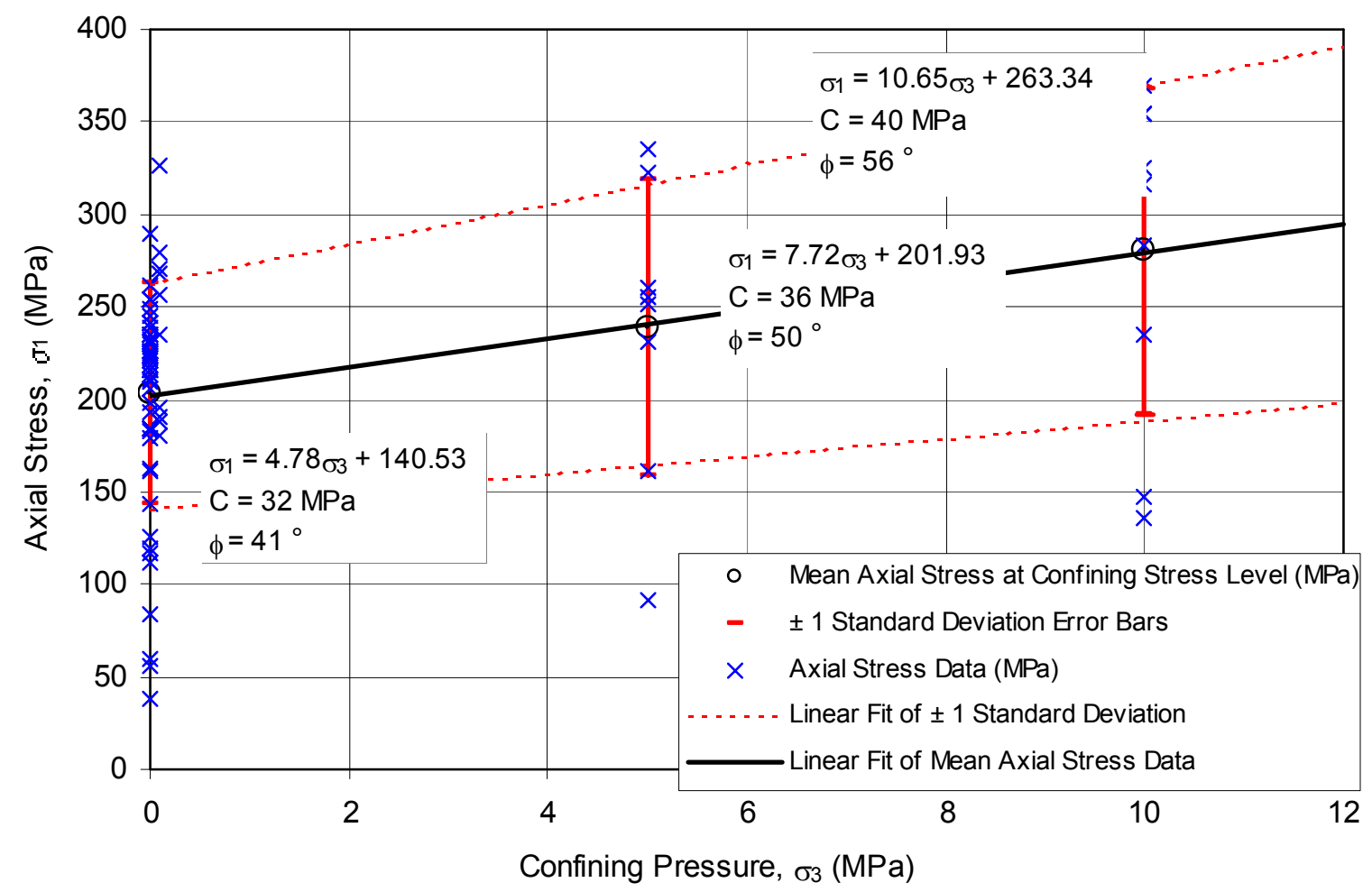

Figure E-2. Uniaxial and Triaxial Test Data from Borehole Samples Near the ESF for the Tptpmn Lithostratigraphic Unit

\section{E4. ROCK MASS PROPERTIES}

\section{E4.1 ASSESSMENT OF LITHOPHYSAL ROCK STRENGTH}

\section{E4.1.1 Introduction}

The following section provides a discussion of the development of estimates of the rock mass mechanical properties of the lithophysal units of the Topopah Spring tuff. A description of the small and large core laboratory testing database is provided. The large core mechanical testing (including room dry and saturated conditions) was used to relate strength and modulus to lithophysal porosity, which is the primary factor in control of variability of mechanical properties in this rock. An initial set of base case strength and modulus values (termed rock strength "categories") are developed as from the most-recent large core testing that span the entire range of lithophysal porosity conditions observed in the ECRB Cross-Drift. These base case values are used as a basis for a series of parametric analyses of emplacement drift stability under in situ, thermal and seismic loading described in Section 6.4. These analyses consider homogenous rock properties for each rock strength category with the lower strength categories leading to conservative results. Additional discussion on lithophysal rock strength is provided in Lithophysal Rock Mass Mechanical Properties of the Repository Host Horizon (BSC 2004 [DIRS 168970]). 
The large core laboratory data set is necessarily limited in scope due to the variability and difficulty in sampling and testing large volume samples of the lithophysal rock mass. Therefore, discontinuum numerical models (PFC and UDEC), calibrated to reproduce the basic mechanical response of the laboratory test results, are used here to supplement the data base and clarify understanding of the mechanical response of lithophysal rock. The PFC model is used to explore the impact of lithophysal porosity, size, shape and distribution on the variability of mechanical properties, and thus establish upper and lower property bounds. The UDEC model is used to conduct drift-scale simulated compression analyses to examine the effect of spatial variability of in situ lithophysal porosity on rock mass strength variability. Conclusions are given as to the base case mechanical properties data set and the variability of the rock mass mechanical properties for use in performance analyses.

\section{E4.1.2 Small Core Mechanical Properties Data Base}

A large number of compression and tension tests have been conducted on small diameter (1-in to 2-in [25 $\mathrm{mm}$ to $50 \mathrm{~mm}]$ ) cores from the Tptpul and Tptpll. This data is described in detail in the Subsurface Geotechnical Parameters Report (BSC 2003 [DIRS 166660]), and the results reviewed here.

Testing on small cores from the Topopah Spring subunits indicates a distinct control of both compressive strength and elastic modulus based on the total porosity of the sample (Figure E-3). The total porosity of these samples, due to their small size, is primarily composed of matrix ground mass porosity ${ }^{1}$. On the scale of the emplacement drifts, the total porosity is the sum of the matrix porosity (approximately 10 percent) plus lithophysal void porosity (approximately 10 to 25 percent). The additional porosity of vapor phase altered material may form rims or fill lithophysal voids (generally less than 5 percent). Estimates of the component porosity within the Tptpll derived from field mapping in the ECRB Cross-Drift are discussed in Appendix O. The impact of lithophysal voids (and the inability to sample them) with small core samples is evident as the maximum total lithophysal porosities are typically less than 20 percent (see Figure O-15).

\section{E4.1.3 Large Core Unconfined Compression Testing}

\section{E4.1.3.1 Sample Gathering}

The small diameter cores (e.g., 1-in or 2-in diameter) do not accurately reflect the true strength or elastic properties of the lithophysal rock since the diameter precludes a reasonable sampling of the lithophysal voids. Therefore, reliance is placed on measurements from large diameter core samples that contain multiple lithophysal cavities in a given sample. To this end, an extensive drilling program was undertaken in the ESF main loop and ECRB Cross-Drift in 2002 to provide large-diameter (11.5-in.) core samples of lithophysal rock from the Tptpul and Tptpll that contain a reasonable lithophysal sampling.

\footnotetext{
${ }^{1}$ Matrix groundmass porosity is that pore space generally less than $2 \mu \mathrm{m}$ in size, and totaling approximately 10 percent of volume in densely welded tuffs (BSC 2003 [DIRS 166660], Section 8.2.3.2, p. 8-9). This porosity is considered to be an intrinsic property of the matrix groundmass for the subunits of the Topopah Spring, and is distinguished from lithophysal porosity, which is formed from gas collection in the matrix during the cooling process.
} 


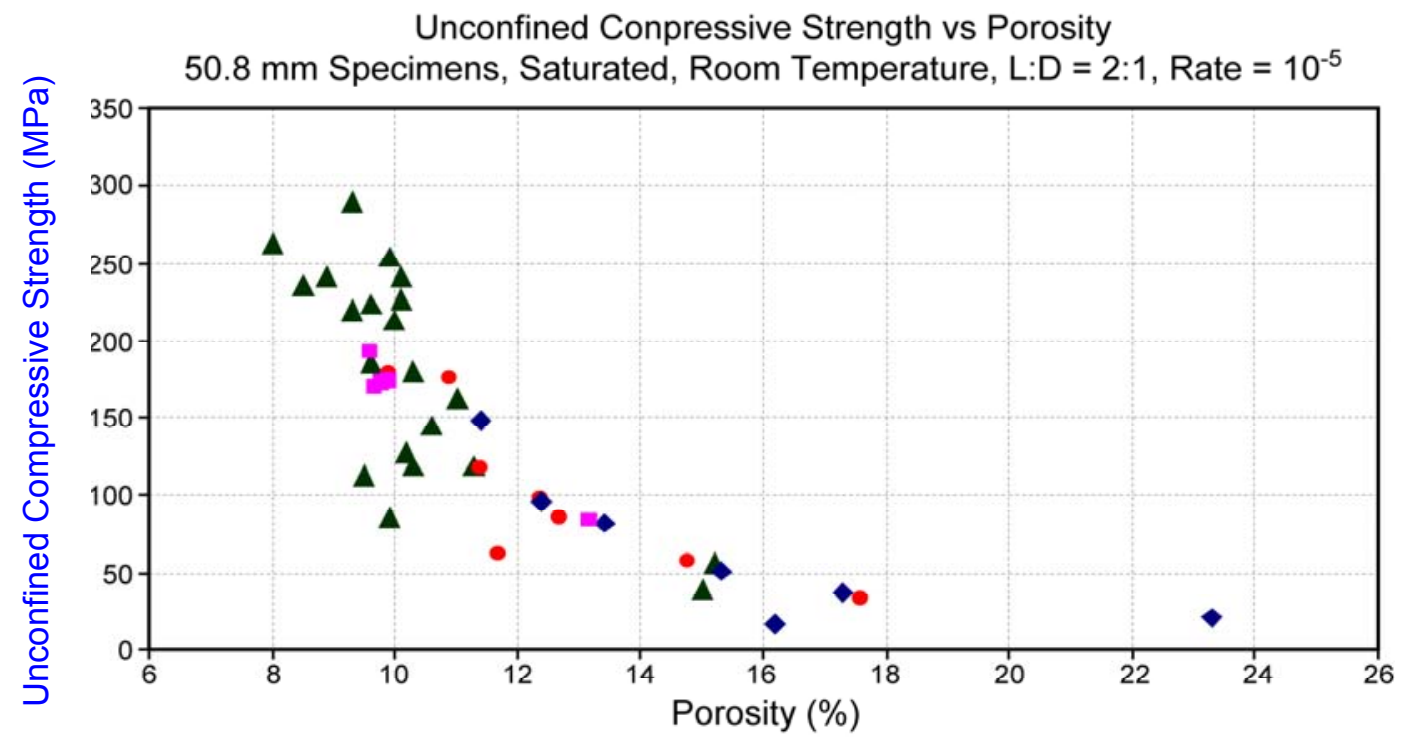

Upper Lithophysal

A Middle Non-Lithophysal

- Lower Lithophysal

- Lower Non-Lithophysal

Young's Modulus vs Porosity

$50.8 \mathrm{~mm}$ Specimens, Saturated, Room Temperature, L:D $=2: 1$, Rate $=10^{-5}$

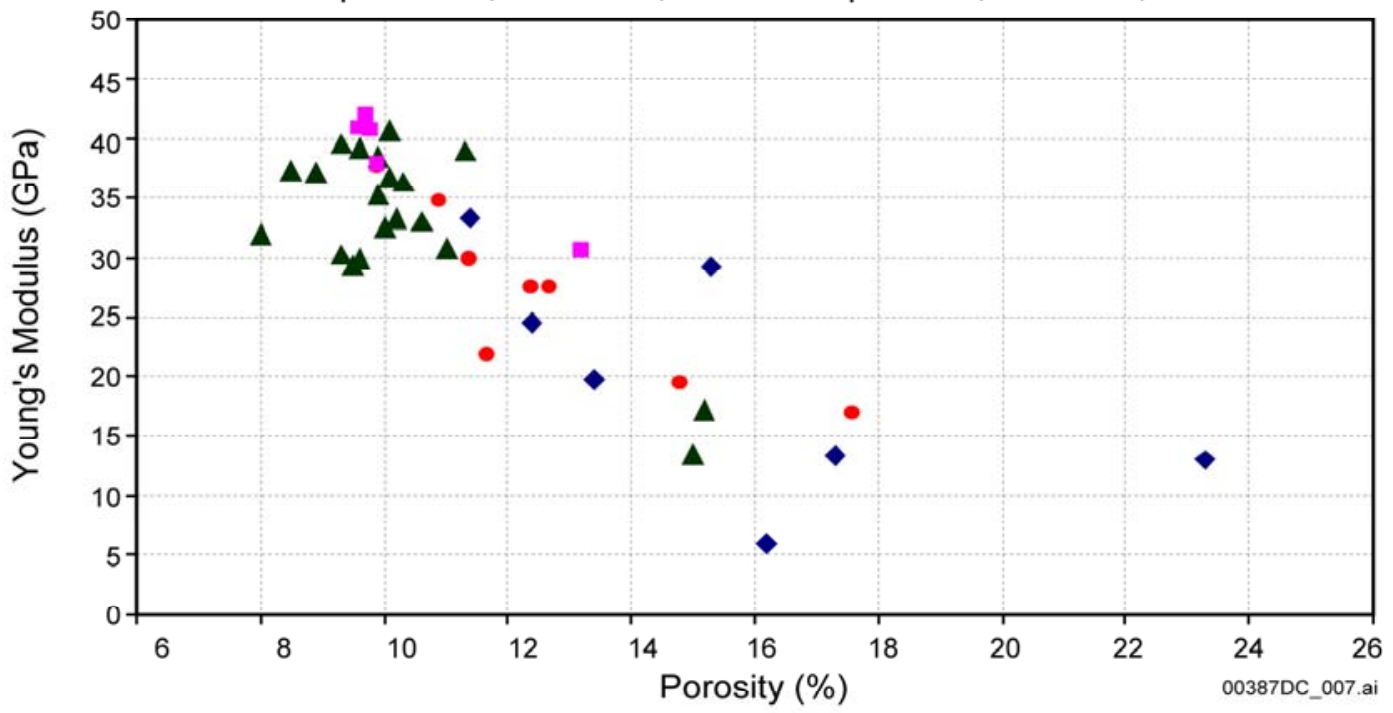

Upper Lithophysal $\mathbf{\Delta}$ Middle Non-Lithophysal $\quad$ Lower Lithophysal $\quad$ Lower Non-Lithophysal

Source: BSC 2003 [DIRS 166660] (Figures 8-22 and 8-11).

NOTE: Porosity is composed of matrix and lithophysal porosity. The measurements are from a $50.8 \mathrm{~mm}$ diameter core. Note that small cores from lithophysal zones generally contain only small amounts of lithophysal porosity, and thus the above tests are not indicative, in general, of properties of the lower and upper lithophysal units.

Figure E-3. Intact Uniaxial Compressive Strength and Young's Modulus for Topopah Spring Subunits as a Function of Effective Porosity for $50.8 \mathrm{~mm}$ Diameter Samples 
Figure E-4 shows a plan view of the ESF main loop and ECRB Cross-Drift and the locations from which core samples were retrieved (see Figure 7-1 for a photograph of one of the core lengths obtained from the Tptpll in the ECRB Cross-Drift). A total of nineteen 11.5-in. $(290 \mathrm{~mm})$ cores at least $12 \mathrm{in.}(304 \mathrm{~mm})$ in length was obtained. Of these, $13 \mathrm{had}$ a length to diameter (L:D) ratio of 1.7 or greater, with one additional sample with $L: D$ of 1.5 . These were felt to be sufficiently close to the recommended 2:1 length-to-diameter ratio to allow for unconfined compression testing. Figure E-5 shows a photograph of some of the large cores and an unconfined compression test in progress. The remaining core sections were under-cored to provide sixteen additional 5.7-in. (146 mm) test samples. Although these samples are not judged to be sufficiently large to represent in situ properties, the data is, nonetheless useful as additional information for establishing the impact of porosity on strength and modulus and for estimating sample size effects. This data was supplemented by previous testing by Price et al. (1985 [DIRS 106602]) on 10.5-in. (267 mm) diameter cores taken from an outcrop of the Tptpul at Busted Butte (directly adjacent to and south of Yucca Mountain).

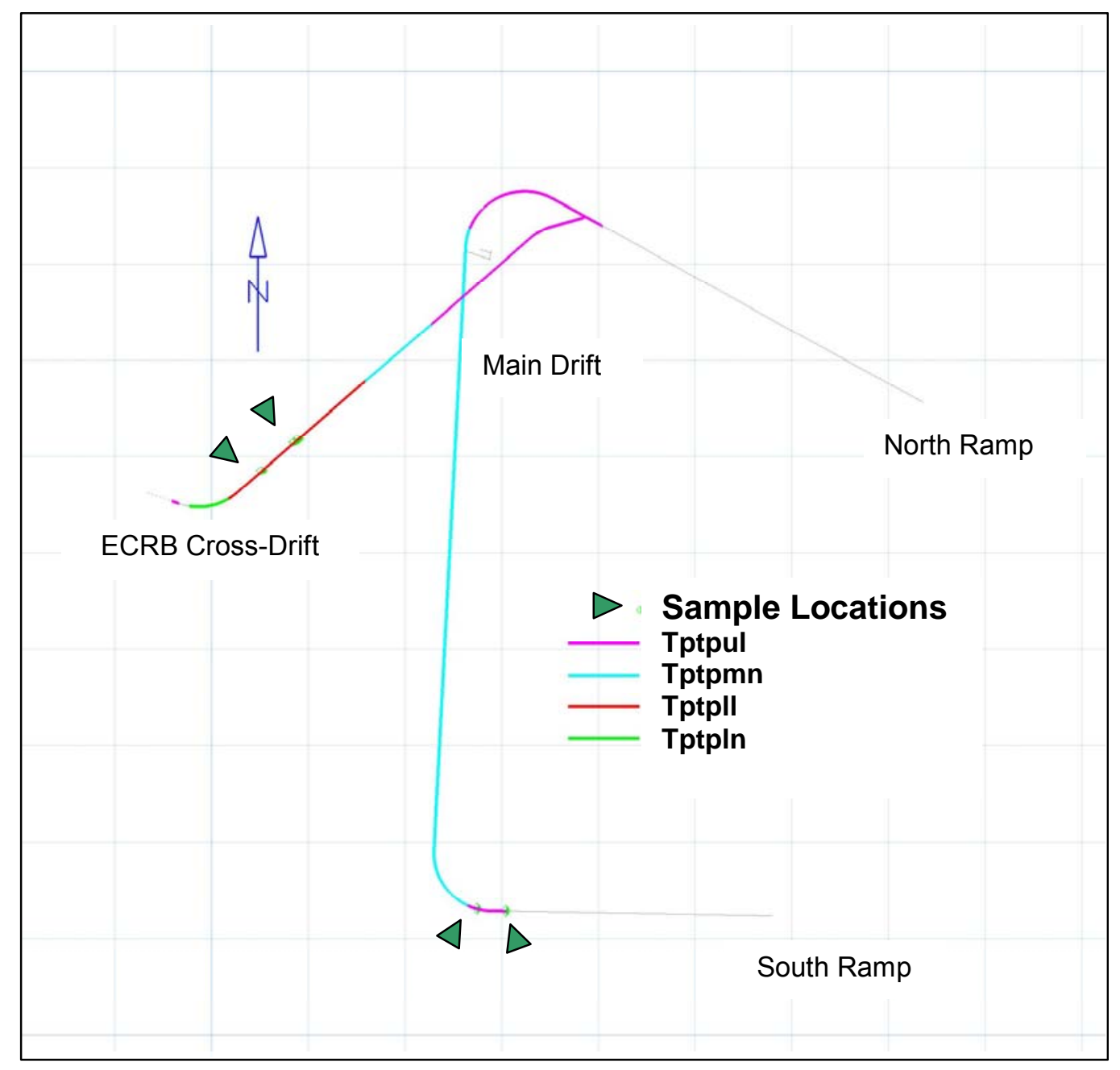

Figure E-4. Plan View of the ESF Main Loop and ECRB Cross-Drift Showing the Topopah Spring Rock Units and Location of 11.5-in Core Samples Taken in the Tptpul and Tptpll 
(a)

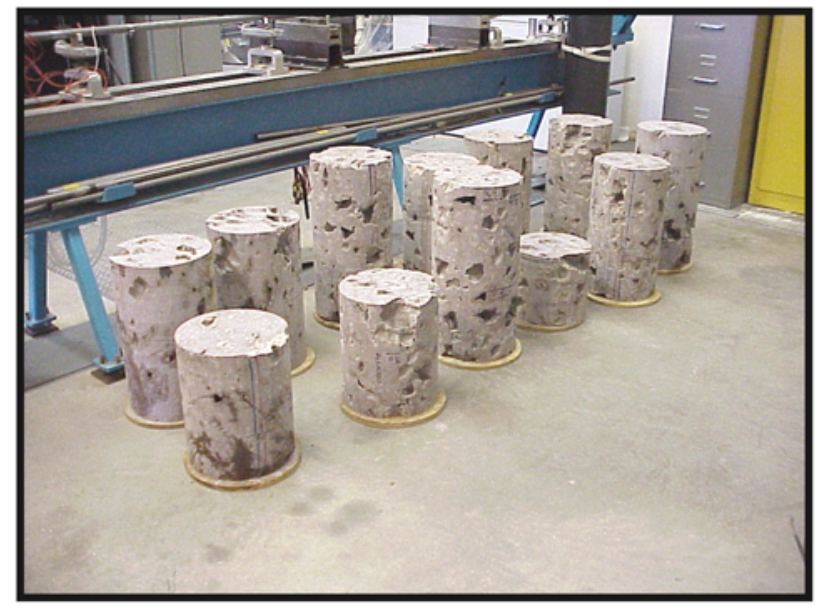

(b)

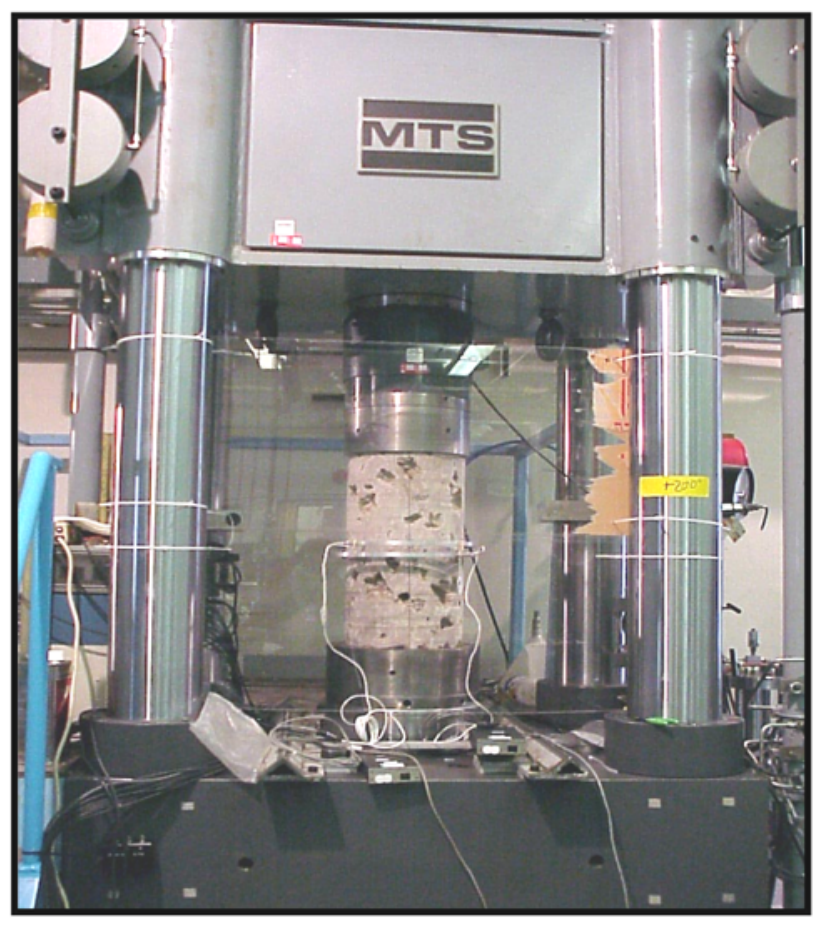

00387DC_012.ai

NOTE: a) from the Tptpll and Tptpul; b) a sample in unconfined compression.

Figure E-5. Photographs of Large Lithophysal Core Samples (290-mm/11.5-in. Diameter)

A program of laboratory compression testing to examine the matrix properties of the Tptpll (and comparison to previous testing in the Tptpmn) was undertaken as well. A large boulder from the lower portion of the Tptpll, containing few lithophysae, was collected and cut into samples of varying size (see Section E4.1.4.3). These samples were used for size effect and anisotropy examination in the Tptpll matrix material. 
A primary source document that compiles the testing data on Topopah Spring tuff is the Subsurface Geotechnical Parameters Report (BSC 2003 [DIRS 166660]). Some of the specific data sources used here on lithophysal rock include:

- Uniaxial compression and Brazilian tensile strength tests on 2-in (50 mm) cores from North Ramp geotechnical boreholes (DTNs: SNL02030193001.004 [DIRS 108415]; SNL02030193001.019 [DIRS 108431]; SNL02030193001.020 [DIRS 108432])

- Uniaxial compression tests on 10.5-in (267-mm) diameter core samples of Tptpul from Busted Butte (Price et al. 1985 [DIRS 106602]) (DTN: MO0311RCKPRPCS.003 [DIRS 166073])

- Uniaxial compression tests on 11.5-in (290 mm) and 5.7-in. (146 mm) diameter core samples from the Tptpul and Tptpll drilled from exposures in the ESF main loop and ECRB Cross-Drift (Table E-9) (DTNs: SN0208L0207502.001 [DIRS 161871]; SN0211L0207502.002 [DIRS 161872]; SN0302L0207502.003 [DIRS 165014]; SN0305L0207502.004 [DIRS 165013])

- Uniaxial compression tests on 1, 2, 3.2 and 4.7-in $(26,51,82$, and $121 \mathrm{~mm})$ diameter samples of the Tptpll from a Busted Butte outcrop boulder (DTN: SN0306L0207502.008 [DIRS 165015])

- Uniaxial compression experiments on wire-sawed samples (8-in square [200 mm] parallelpipeds) from a non-lithophysal boulder of Tptpll obtained from Busted Butte (DTN: SN0306L0207502.008 [DIRS 165015]).

\section{E4.1.3.2 Large Core Test Results and Analysis of Data}

The results of compression testing on 11.5-in. samples from the Tptpul and Tptpll from the ESF main loop and ECRB Cross-Drift (described above) and 10.5-in. samples from the Tptpul at Busted Butte form the basis for the development of mechanical property ranges. The data from these tests are provided in Table E-9.

Unconfined compression strength and Young's modulus as functions of approximate lithophysal porosity for the 10.5 and 11.5-in. samples of the Tptpll and Tptpul are shown in Figure E-6. Although significant scatter exists in the data, a best-fit exponential function has been superimposed on the data for room dry and saturated sample conditions. The data shows little average impact of saturation level on Young's Modulus, but results in a general reduction in unconfined compressive strength (UCS) as would be expected. Histograms of the distribution of UCS and Young's Modulus, given in Figure E-7, show a mean strength of 18.0 MPa and a mean modulus of $12.3 \mathrm{GPa}$ for the samples.

It is useful to define the relationship of the UCS and Young's Modulus in a fashion that is independent of the lithophysal porosity. The UCS and Young's Modulus are the primary mechanical input properties, and representing their interrelationship on a single diagram allows one to more easily develop a base set of input properties that will define the pairing of these parameters across the entire range of potential in situ porosity conditions. Each of the mechanical properties pairs (UCS and Young's Modulus) can be related to an approximate 
lithophysal porosity range, which can, in turn, be related to field mapping in the ESF main loop and ECRB Cross-Drift.

Table E-9. Mechanical Properties of Lithophysal Tuff from Large-Diameter Samples

\begin{tabular}{|c|c|c|c|c|c|c|c|c|c|}
\hline 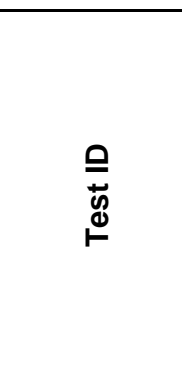 & 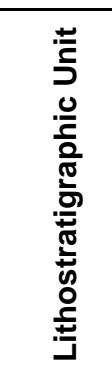 & 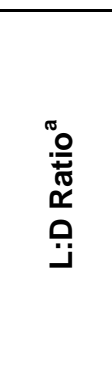 & 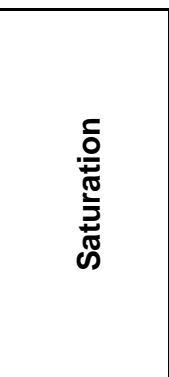 & 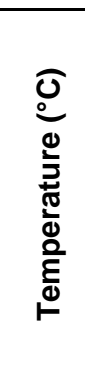 & 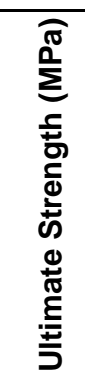 & 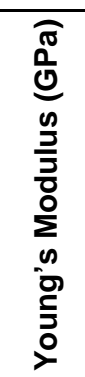 & 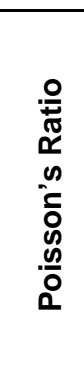 & 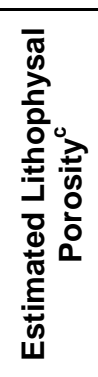 & $\stackrel{2}{z}$ \\
\hline YMPLL49A & Tptpll & $1.1: 1$ & Dry & 195 & 32.2 & 7.1 & - & 11.7 & $\begin{array}{l}\text { SN0211L0207502.002 } \\
\text { [DIRS 161872] }\end{array}$ \\
\hline YMPLL43A & Tptpll & $1.1: 1$ & Dry & 200 & 31.1 & 6.5 & - & 20.3 & $\begin{array}{l}\text { SN0211L0207502.002 } \\
\text { [DIRS 161872] }\end{array}$ \\
\hline YMPLL23A & Tptpll & $1.8: 1$ & Room Dry & 24 & 28.7 & 9.2 & - & 19.2 & $\begin{array}{l}\text { SN0211L0207502.002 } \\
\text { [DIRS 161872] }\end{array}$ \\
\hline YMPLL24A & Tptpll & $1.8: 1$ & Room Dry & 24 & 13.3 & 5.0 & - & 22.2 & $\begin{array}{l}\text { SN0211L0207502.002 } \\
\text { [DIRS 161872] }\end{array}$ \\
\hline YMPLL46A & Tptpll & $1.8: 1$ & Room Dry & 24 & 21.7 & 8.5 & - & 28.4 & $\begin{array}{l}\text { SN0211L0207502.002 } \\
\text { [DIRS 161872] }\end{array}$ \\
\hline YMPLL87A & Tptpll & $1.9: 1$ & Saturated & 24 & 15.7 & 5.3 & - & 14.5 & $\begin{array}{l}\text { SN0211L0207502.002 } \\
\text { [DIRS 161872] } \\
\end{array}$ \\
\hline YMPUL59B & Tptpul & $1.2: 1$ & Dry & 190 & 19.6 & 7.3 & - & 39.4 & $\begin{array}{l}\text { SN0208L0207502.001 } \\
\text { [DIRS 161871] }\end{array}$ \\
\hline YMPUL67A & Tptpul & $1.3: 1$ & Dry & 190 & 34.8 & 9.9 & - & 6.2 & $\begin{array}{l}\text { SN0208L0207502.001 } \\
\text { [DIRS 161871] } \\
\end{array}$ \\
\hline YMPUL62B & Tptpul & $1.0: 1$ & Dry & 200 & 37.0 & 13.7 & - & 19.3 & $\begin{array}{l}\text { SN0208L0207502.001 } \\
\text { [DIRS 161871] }\end{array}$ \\
\hline YMPUL50A & Tptpul & $1.5: 1$ & Room Dry & 24 & 22.1 & 14.9 & 0.21 & 28.5 & $\begin{array}{l}\text { SN0211L0207502.002 } \\
\text { [DIRS 161872] }\end{array}$ \\
\hline YMPUL59A & Tptpul & $2.0: 1$ & Room Dry & 24 & 13.5 & 5.8 & 0.39 & 30.3 & $\begin{array}{l}\text { SN0208L0207502.001 } \\
\text { [DIRS 161871] }\end{array}$ \\
\hline YMPUL61A & Tptpul & $1.9: 1$ & Room Dry & 24 & 17.7 & 8.8 & - & 23.9 & $\begin{array}{l}\text { SN0208L0207502.001 } \\
\text { [DIRS 161871] }\end{array}$ \\
\hline YMPUL62A & Tptpul & $1.8: 1$ & Room Dry & 24 & 25.9 & 13.7 & - & 12.7 & $\begin{array}{l}\text { SN0208L0207502.001 } \\
\text { [DIRS 161871] }\end{array}$ \\
\hline YMPUL64A & Tptpul & $1.7: 1$ & Room Dry & 24 & 33.5 & 20.5 & - & 12.8 & $\begin{array}{l}\text { SN0208L0207502.001 } \\
\text { [DIRS 161871] }\end{array}$ \\
\hline YMPUL65A & Tptpul & $2.0: 1$ & Room Dry & 24 & 26.2 & 19.5 & - & 11.9 & $\begin{array}{l}\text { SN0208L0207502.001 } \\
\text { [DIRS 161871] }\end{array}$ \\
\hline YMPUL66A & Tptpul & $1.7: 1$ & Room Dry & 24 & 16.5 & 12.4 & - & 16.7 & $\begin{array}{l}\text { SN0208L0207502.001 } \\
\text { [DIRS 161871] }\end{array}$ \\
\hline YMPUL60A & Tptpul & $1.8: 1$ & Saturated & 24 & 12.7 & 6.7 & - & 18.6 & $\begin{array}{l}\text { SN0208L0207502.001 } \\
\text { [DIRS 161871] }\end{array}$ \\
\hline YMPUL63A & Tptpul & $1.9: 1$ & Saturated & 24 & 9.4 & 5.0 & 0.24 & 20.0 & $\begin{array}{l}\text { SN0208L0207502.001 } \\
\text { [DIRS 161871] }\end{array}$ \\
\hline
\end{tabular}


Table E-9. Mechanical Properties of Lithophysal Tuff from Large-Diameter Samples (Continued)

\begin{tabular}{|c|c|c|c|c|c|c|c|c|c|}
\hline$\frac{O}{\stackrel{0}{\mathscr{g}}}$ & 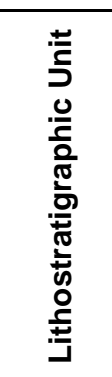 & 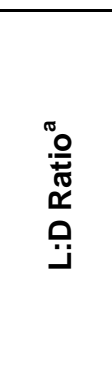 & 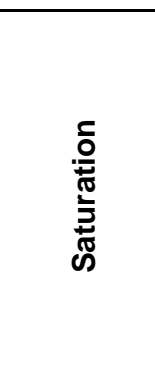 & 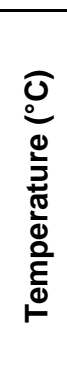 & 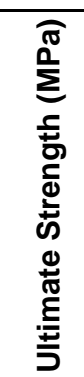 & 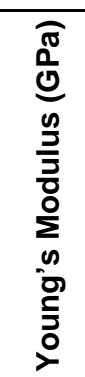 & 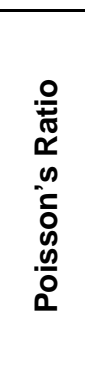 & 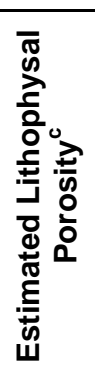 & $\stackrel{2}{z}$ \\
\hline YMPUL68A & Tptpul & $2.1: 1$ & Saturated & 24 & 11.6 & 5.9 & 0.03 & 25.8 & $\begin{array}{l}\text { SN0208L0207502.001 } \\
\text { [DIRS 161871] }\end{array}$ \\
\hline 1B & Tptpul & $2.0: 1$ & Saturated & 22 & 14.5 & 14.2 & - & 17.3 & $\begin{array}{l}\text { MO0311RCKPRPCS.003 } \\
\text { [DIRS 166073] }\end{array}$ \\
\hline $1 \mathrm{D}$ & Tptpul & $2.0: 1$ & Saturated & 22 & 10.3 & 10.9 & - & 22.2 & $\begin{array}{l}\text { MO0311RCKPRPCS.003 } \\
\text { [DIRS 166073] }\end{array}$ \\
\hline $2 A$ & Tptpul & $2.0: 1$ & Saturated & 22 & 12.4 & 11.9 & - & 14.1 & $\begin{array}{l}\text { MO0311RCKPRPCS.003 } \\
\text { [DIRS 166073] }\end{array}$ \\
\hline $3 A$ & Tptpul & $2.0: 1$ & Saturated & 22 & 12.0 & 12.9 & - & 14.0 & $\begin{array}{l}\text { MO0311RCKPRPCS.003 } \\
\text { [DIRS 166073] }\end{array}$ \\
\hline $8 \mathrm{~A}$ & Tptpul & $2.0: 1$ & Saturated & 22 & 18.2 & 16.6 & - & 13.5 & $\begin{array}{l}\text { MO0311RCKPRPCS.003 } \\
\text { [DIRS 166073] }\end{array}$ \\
\hline $8 B$ & Tptpul & $2.0: 1$ & Saturated & 22 & 17.4 & 16.8 & - & 14.2 & $\begin{array}{l}\text { MO0311RCKPRPCS.003 } \\
\text { [DIRS 166073] }\end{array}$ \\
\hline $8 \mathrm{C}$ & Tptpul & $2.0: 1$ & Saturated & 22 & 18.5 & 15.8 & - & 17.9 & $\begin{array}{l}\text { MO0311RCKPRPCS.003 } \\
\text { [DIRS 166073] }\end{array}$ \\
\hline $8 D$ & Tptpul & $2.0: 1$ & Saturated & 22 & 17.5 & 18.3 & - & 21.4 & $\begin{array}{l}\text { MO0311RCKPRPCS.003 } \\
\text { [DIRS 166073] }\end{array}$ \\
\hline $8 \mathrm{E}$ & Tptpul & $2.0: 1$ & Saturated & 22 & 13.8 & 15.8 & - & 19.3 & $\begin{array}{l}\text { MO0311RCKPRPCS.003 } \\
\text { [DIRS 166073] }\end{array}$ \\
\hline $8 \mathrm{~F}$ & Tptpul & $2.0: 1$ & Saturated & 22 & 27.8 & 21.5 & - & 12.6 & $\begin{array}{l}\text { MO0311RCKPRPCS.003 } \\
\text { [DIRS 166073] }\end{array}$ \\
\hline
\end{tabular}

a Specimen length-to-diameter ratio.

b Specific data are located in rows 737 to 746 from DTN: MO0311RCKPRPCS.003 [DIRS 166073]. Additional test descriptions for the data in DTN: MO0311RCKPRPCS.003 [DIRS 166073] are provided by Price et al. (1985 [DIRS 106602]).

c Lithophysal porosity data for tests documented in DTNs SN0208L0207502.001 [DIRS 161871] and SN0211L0207502.002 [DIRS 161872] are provided by DTN: SN0305L0207502.005 [DIRS 163373]. Lithophysal property data for tests documented in DTN: MO0311RCKPRPCS.003 [DIRS 166073] are provided by Price et al. (1985 [DIRS 106602], Table 4). 


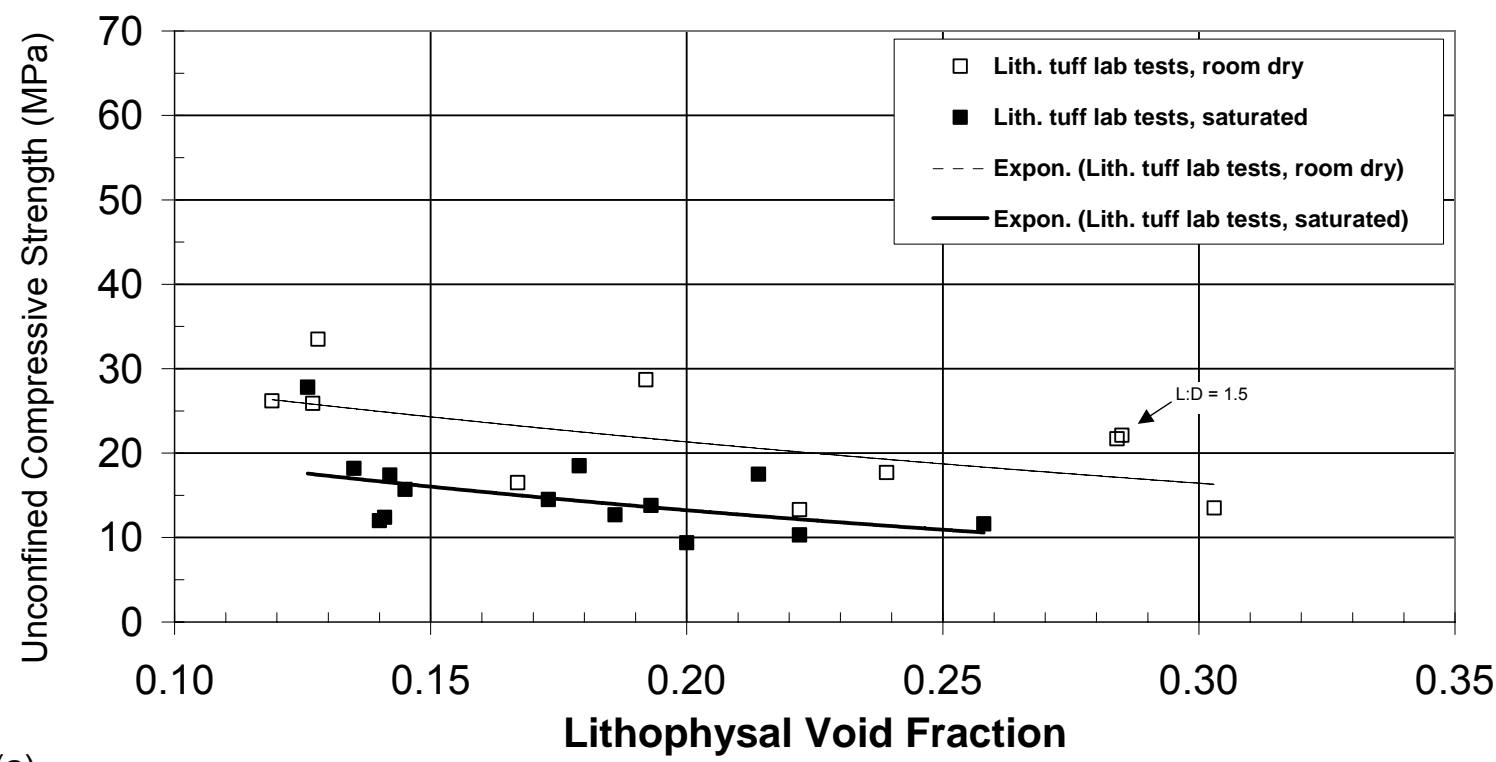

(a)

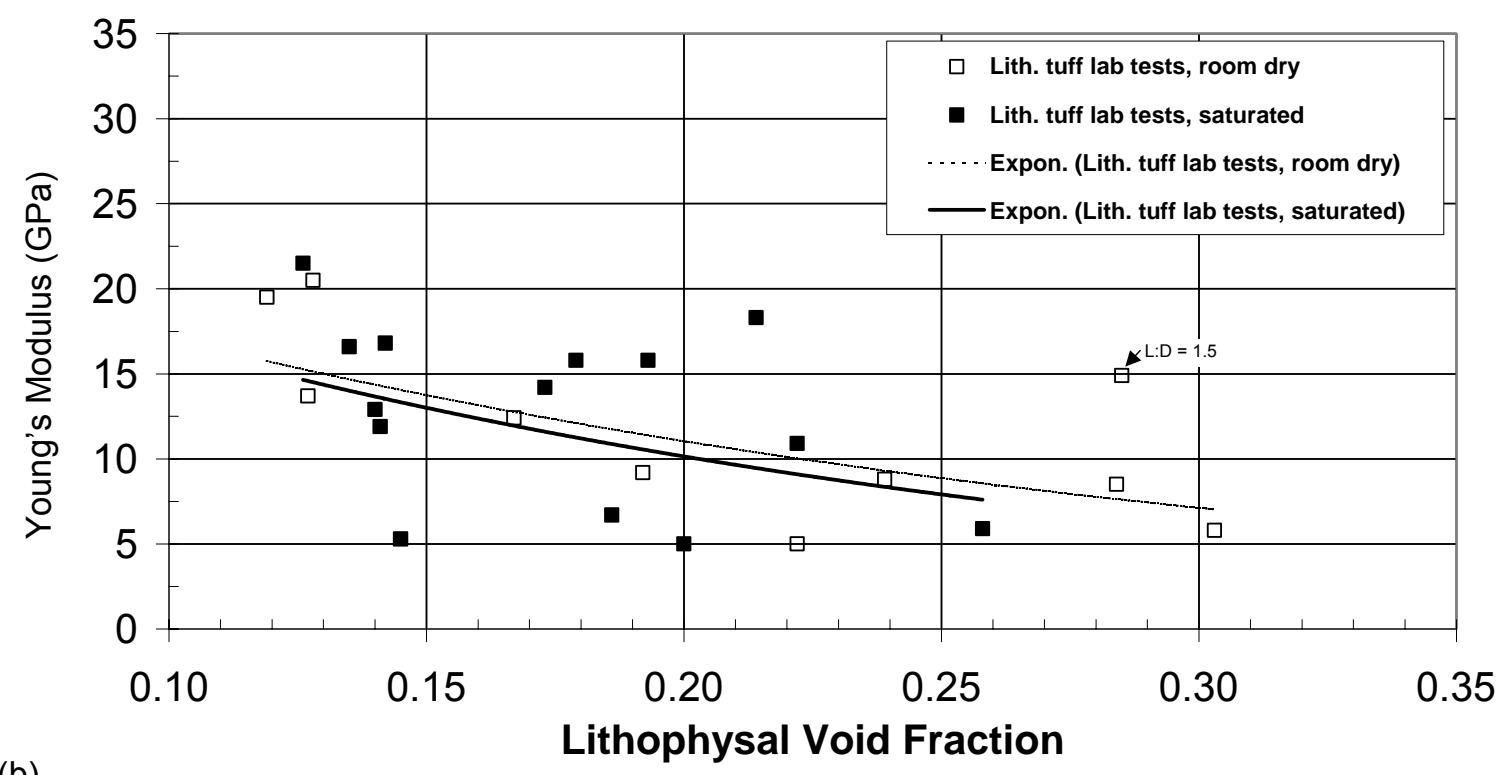

NOTE: (a) Unconfined Compressive Strength; (b) Young's Modulus as a Function of the Lithophysal Void Fraction and Saturation Level for 10.5-in. and 11.5-in.

Figure E-6. Variation in Diameter Cores from the Tptpul and Tptpll 


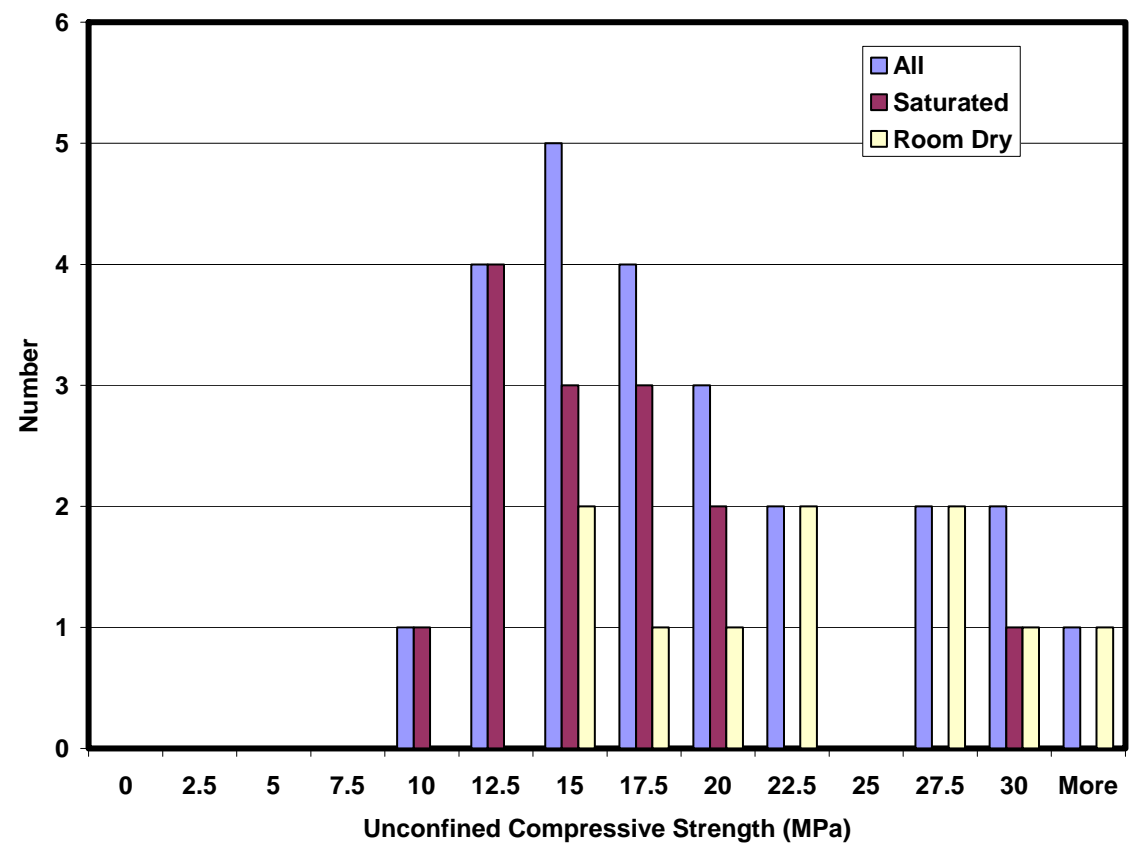

(a)

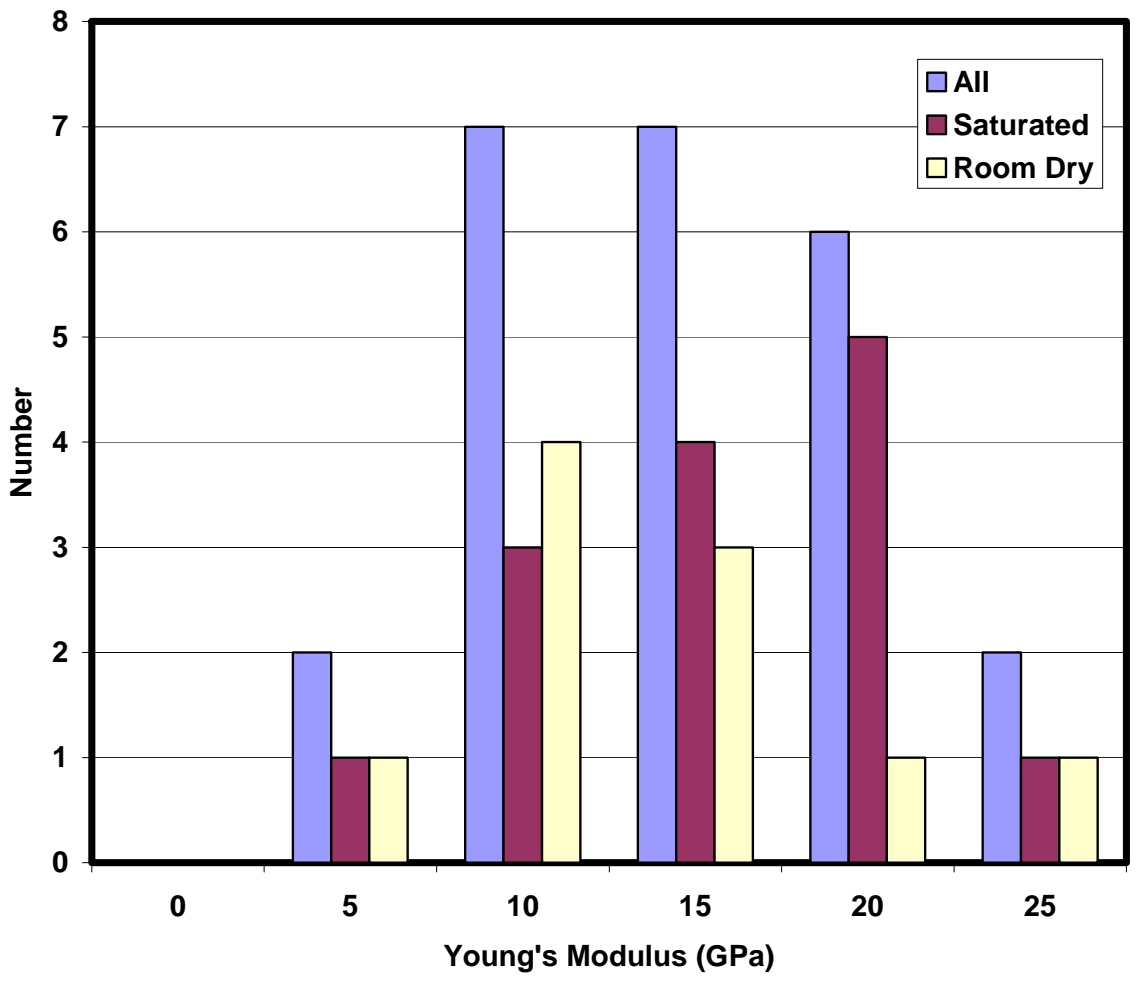

(b)

NOTE: (a) Unconfined Compressive Strength; (b) Young's Modulus for the 10.5-in. and 11.5-in.

Figure E-7. Histograms of Diameter Core Samples of Lithophysal Tuff 
The UCS and modulus data for each large core test, presented in Figure E-6, is plotted in the form of UCS versus Young's modulus in Figure E-8. The data shows that a reasonably linear relationship exists between these mechanical properties. The large core data has been subdivided into two sets - the 11.5-in. data (room-dry and saturated) collected in 2002 and the 10.5-in. saturated samples from Busted Butte - and linear relations fit to each set. As seen in this plot, the saturated samples tend to form a lower bound to the room dry strengths.

A parametric bounding analysis approach is developed initially in which the base case set of the 11.5-in. values of UCS and Young's modulus are defined from the linear fit to the data as shown in Figure E-8. The entire range of UCS is subdivided into a series of five evenly-distributed rock mass strength "categories" that reflect the approximate range of lithophysal porosity as observed in the field mapping (Table E-10 and Figure E-9). The categories encompass the range in UCS values from $10 \mathrm{MPa}$ (lowest) to $30 \mathrm{MPa}$ (highest). The modulus corresponding to each strength value is determined from the linear fit of the 11.5-in. data as shown. The initial or base case analysis of emplacement drift stability in lithophysal rock, as discussed in Section 6.4 of this document, use these rock strength categories and the consideration of a homogeneous rock mass for the parametric analyses. As discussed later, analyses are presented in which the impact of estimated in situ lithophysal porosity spatial variability on rock mass properties and drift stability is examined. The results are used to verify the conservative nature of the homogeneous rock mass consideration and the bounding calculation approach.

An estimate of the overall distribution of these rock mass strength categories within the Tptpll can be obtained from the lithophysal porosity mapping studies conducted in the ECRB Cross-Drift (see Appendix O, Figure O-15). The histogram given in Figure E-10 shows the abundance (frequency) and cumulative frequency distributions of lithophysal porosity, averaged over $5 \mathrm{~m}$ intervals in the ECRB Cross-Drift from stations $14+44$ to $23+26$ (essentially the top to bottom of the Tptpll). This plot subdivides the abundance of lithophysal porosity into 5-percent intervals that roughly correspond to those lithophysal porosity ranges for the various rock mass categories given in Table E-10. It is seen that the most abundant rock mass lithophysal porosity ranges found in situ are 10 to 20 percent, or corresponding roughly to rock mass strength Categories 3 and 4 . Observations in the range of 10 to 15 percent lithophysal porosity are most common, and correspond to the Category 4 range. Observations of lithophysal porosity above 20 percent (Categories 1 and 2) are uncommon, representing about 10 percent of the entire Tptpll. Observations of lithophysal porosities greater than 20 percent are most common near the top of the Tptpll, around stations $15+50$ to $16+00$ (Figure 6-12).

Using the calculated Young's modulus values in Table E-10, corresponding values of bulk modulus, $K$, and shear modulus, $G$, were calculated according to Equations E-2 and E-3. A Poisson's ratio value of 0.2 was used for these calculations, which is based on both the laboratory test data (Table E-9) and data from the in situ slot tests (DTNs: SN0208F4102102.002 [DIRS 161874]; SN0212F4102102.004 [DIRS 161875]; SN0301F4102102.006 [DIRS 161876]). Cohesion (Table E-10) was calculated for a range of 
friction angles using Equations E-6 and E-7, such that

$$
C=\frac{0.5 \cdot \sigma_{c}}{\tan \left(\frac{\phi}{2}+45^{\circ}\right)}
$$

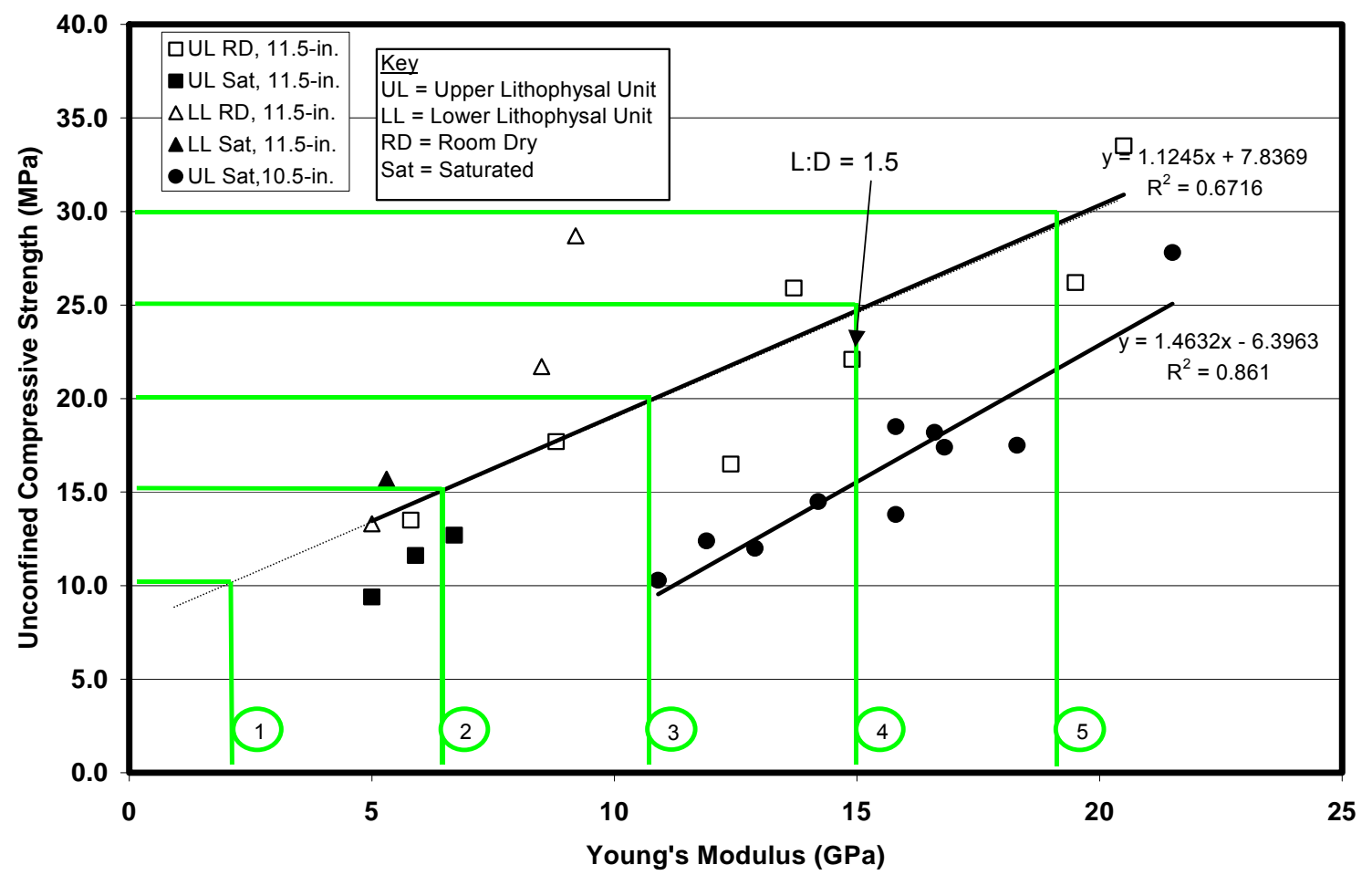

NOTE: Source DTNs are provided in Table E-9. The 11.5-in. room-dry sample data has been subdivided into a series of categories for base-case calculations.

Figure E-8. Relationship of Unconfined Compressive Strength to Young's Modulus for Room-Dry and Saturated 10.5-in. and 11.5-in. Core Samples from the Tptpul and Tptpll 
Table E-10. Suggested Range of Mechanical Properties Developed from 11.5-in. Core Testing, Selected for Base-Case Design and Performance Analyses

\begin{tabular}{|c|c|c|c|c|c|c|c|c|}
\hline \multirow[b]{2}{*}{$\begin{array}{c}\text { Rock } \\
\text { Mass } \\
\text { Category } \\
\end{array}$} & \multirow{2}{*}{$\begin{array}{l}\text { Unconfined } \\
\text { Compressive } \\
\text { Strength } \\
\text { (MPa) }\end{array}$} & \multirow{2}{*}{$\begin{array}{c}\text { Estimated } \\
\text { Young's } \\
\text { Modulus }^{\mathrm{a}} \\
(\mathrm{GPa})\end{array}$} & \multicolumn{3}{|c|}{ Cohesion $^{\mathrm{c}}$ (MPa) } & \multirow[b]{2}{*}{$\begin{array}{c}\text { Bulk } \\
\text { Modulus } \\
\text { K (GPa) }\end{array}$} & \multirow[b]{2}{*}{$\begin{array}{c}\text { Shear } \\
\text { Modulus }^{c} \text {, } \\
\text { G (GPa) }\end{array}$} & \multirow{2}{*}{$\begin{array}{l}\text { Approximate } \\
\text { Lithophysal } \\
\text { Porosity From } \\
\text { Laboratory } \\
\text { Tests }^{\text {b }} \\
(\%)\end{array}$} \\
\hline & & & $\phi=50$ & $\phi=45$ & $\phi=40$ & & & \\
\hline 1 & 10 & 1.9 & 1.82 & 2.07 & 2.33 & 1.07 & 0.80 & $35 \pm 8$ \\
\hline 2 & 15 & 6.4 & 2.73 & 3.11 & 3.50 & 3.54 & 2.65 & $28 \pm 6$ \\
\hline 3 & 20 & 10.8 & 3.64 & 4.14 & 4.66 & 6.01 & 4.51 & $21 \pm 4$ \\
\hline 4 & 25 & 15.3 & 4.55 & 5.18 & 5.83 & 8.48 & 6.36 & $13 \pm 5$ \\
\hline 5 & 30 & 19.7 & 5.46 & 6.21 & 7.00 & 10.95 & 8.21 & $7 \pm 7$ \\
\hline
\end{tabular}

Source: DTNs provided in Table E-9.

a Young's Modulus estimated from linear fit to 11.5-in. core data given in Figure E-8.

${ }^{b}$ Approximated lithophysal porosity and ranges are from BSC 2004 [DIRS 168970], Table 6.6-1.

${ }^{\mathrm{C}}$ Cohesion is calculated using Equation E-8. Bulk and shear modulus values are calculated based on Equations E-2 and E-3. 

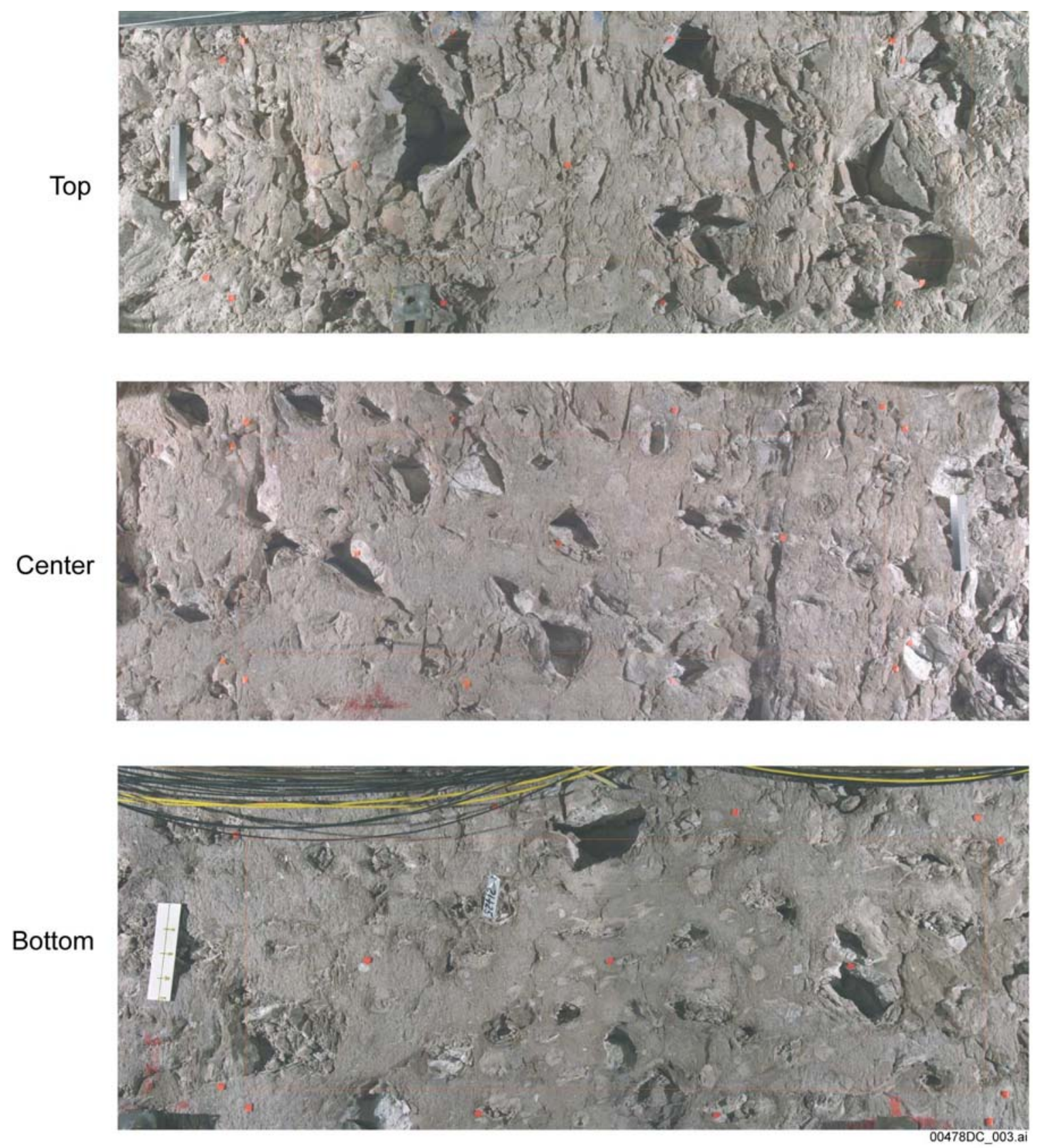

NOTE: Section 16+41 (top), Section 14+93 (center) and Section 21+24 (bottom). (see Appendix O): Category 3 (Top) With Lithophysal Porosity of Approximately 19 Percent, Category 4 (Center) With Lithophysal Porosity of 13.3 Percent, and Category 5 (Bottom) With Lithophysal Porosity of 8.5 Percent.

Figure E-9. Examples of Approximate Rock Strength Category Levels Taken from 1x3-m Panel Maps 


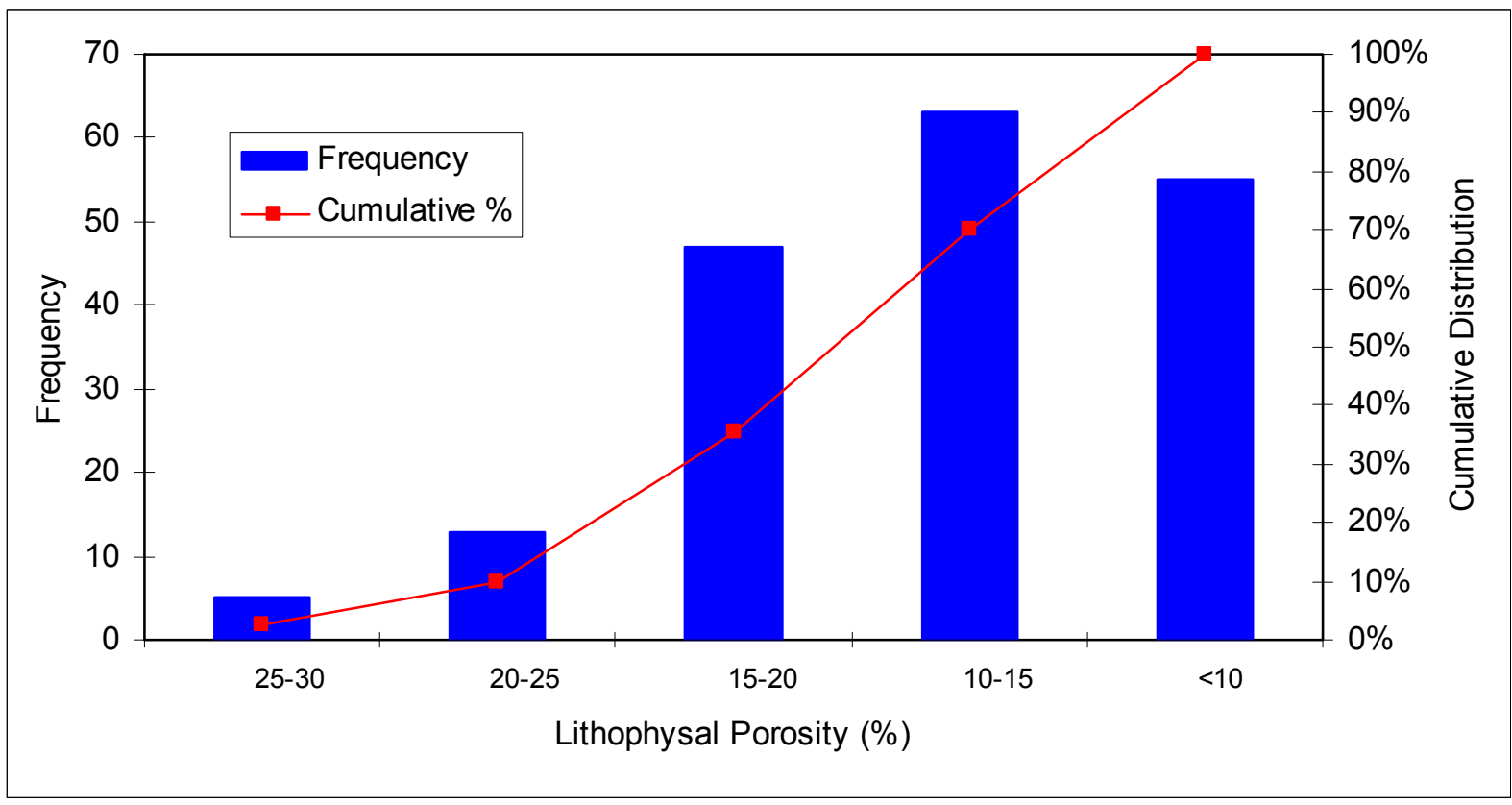

NOTE: Lithophysal porosity data are from ECRB Cross-Drift station 14+44 to 23+26 (Appendix O, Section O6.6; see Microsoft Excel file, Drift Deg AMR AF T-A-P Fit.xIs, worksheet "Volume Percent - Stats", which can be accessed through the TDMS using DTN: MO0408MWDDDMIO.002).

Figure E-10. Distribution of Lithophysal Porosity Abundance (Frequency) for the Tptpll in the Enhanced Characterization of the Repository Block Cross-Drift

\section{E4.1.4 Investigation of Impact of Lithophysal Variability on Rock Mass Properties}

The Tptpll rock mass is characterized by lithophysal porosity that varies with position in the rock mass. The Topopah Spring unit was laid down rapidly in thin, but laterally-extensive sheets. The formation of lithophysae, which is a phenomenon resulting from movement of vapor within the rock mass during the cooling process, results in a similar layering effect of lithophysal porosity. The mapping presented in Appendix $\mathrm{O}$ and analysis of spatial variability presented in Appendix $\mathrm{T}$ shows that the lithophysal porosity occurs in thin, laterally-extensive sheets with variability occurring primarily within the plane perpendicular to dip of the units. The approach to assessment of drift stability described in Section 6.4.2 uses parametric analyses based on the consideration of a homogenous rock mass characterized by constant rock properties. To represent the inherent variability of the rock mass, a series of discrete constant property levels, linked to lithophysal porosity, are used to represent (approximately) the lowest, highest and median in situ conditions. The likelihood of occurrence of these particular conditions is based on the percentage of a given strength category to exist in the Tptpll. This simplistic approach (as opposed to attempting to model spatial variability directly) was taken to facilitate modeling.

The rock mass porosity is, in reality, spatially-variable over a relatively small length scale (on the order of meters - see Appendix O). Therefore, the rock mass rarely consists of uniformly weak or strong material, but consists of small regions of varying strength and modulus. Appendix $T$ presents a model that produces a synthetic representation of the spatial variability of the lithophysal porosity in the Tptpll, based on field mapping as described in Appendix O. Therefore, the consideration of a homogenous rock mass will tend to over predict the failure 
potential of drifts in the weakest rock mass classifications and will under predict the yield in the highest rock mass classifications. The impact of actual lithophysae geometry and spatial variability on the rock mass properties and the relation to conservatism in the strength category bounding methodology is discussed below.

\section{E4.1.4.1 Effect of Variability of Lithophysal Porosity, Size and Shape on Mechanical Properties - Estimation of Upper and Lower Bounds for Lithophysal Mechanical Properties}

The large core laboratory testing is a relatively small sampling of the lithophysae conditions that exist in the field, although the approximate porosities of the cores encompass the range of most field-measured conditions. To extend the laboratory data base to account for the in situ variability in lithophysal porosity (i.e., shape, size, and distribution) a numerical study was conducted using the calibrated Particle Flow Code (PFC) model. The basic calibration and validation of the PFC model is described in Section 7.5 of this document. In this calibration, lithophysae were represented in simulated tuff samples as circular holes that were randomly distributed to produce a given porosity. It was shown that the numerical model was able to reasonably account for the failure mechanisms of lithophysal and nonlithophysal rock specimens as observed in the laboratory, and could reproduce the general effect of lithophysal porosity on UCS and Young's Modulus.

The same calibrated model is used here to conduct a "shape study" in which the impacts of lithophysal porosity, shape, size and distribution on rock property variability were examined. ${ }^{2}$ In this study, simulated samples of the lithophysal rock mass were developed directly from field panel map lithophysae distributions (Appendix O) by overlaying (stenciling) the panel map directly onto the PFC model to create the void geometry. Figure E-11 shows an example of the result of simulated UCS tests on two "samples" of PFC models with stenciled lithophysae distributions. The figures show the tensile cracking between lithophysae at failure, and the impact of the specific distribution on failure mechanism and the associated stress-strain behavior.

Approximately 80 simulated unconfined compression cases of actual lithophysae distributions were modeled, and the results in terms of UCS and Young's Modulus as functions of the lithophysal porosity given in Figure E-12. The results are compared to the 11.5-in. laboratory test data as well as the previous PFC modeling using idealized circular lithophysae. The introduction of actual lithophysae shapes and distributions has two distinct effects with regard to the use of circular voids.

- The actual lithophysae shapes and distributions introduce significant variability into the strength or modulus for a given porosity. This variability is a function of the distribution of solid bridge length between lithophysae, which are, in turn, a function of the porosity and nature of the distribution of that porosity.

- The actual lithophysae shapes and distributions provide a lower bound to the strength and modulus to that given by the circular lithophysae shapes and to the laboratory data.

\footnotetext{
${ }^{2}$ This study is documented in detail in the Subsurface Geotechnical Parameters Report (BSC 2003 [DIRS 166660], Section 9.1).
} 
The PFC shape study extrapolations are superimposed on the previous figure (Figure E-8) of UCS vs. Young's Modulus to estimate bounding values (Figure E-13). Upper and lower bounds to the data are estimated, and a mean value between these bounds shown which falls approximately along the original base case linear extrapolation for the 11.5 -in. test results. The portion of the bounding curves that fall outside (below) the laboratory measurement range is dashed indicating that this extrapolation is not based on measurements. The base case rock mass property categories are shown in Figure E-13, illustrating the estimated upper and lower bounding values of UCS associated with each value of Young's Modulus.

The impact of the bounding values on yield and performance are discussed in Section 6.4. In these studies, the rock mass was considered to be homogeneous with constant rock mass mechanical properties consisting of the lower bound of strength at the respective values of Young's Modulus (i.e., the intersection of the vertical category bar and the lower bound line in Figure E-13). The analyses involved examine stability of the emplacement drifts under in situ and thermal loading for the lower bound values for the categories. This modeling showed that UCS values less than approximately $10 \mathrm{MPa}$ (i.e., the lower bound of Categories 1 and 2) result in predicted extensive sidewall failure of emplacement tunnels under in situ stresses only (Figure E-14). This is obviously not observed in the ECRB Cross-Drift or ESF main loop where tunnels are in stable and excellent condition with minimal ground support in the crown and generally no ground support in the sidewalls. The laboratory database shows that minimum UCS values, even for lithophysal porosities in excess of 30 percent, are approximately $10 \mathrm{MPa}$.

An explanation of why the rock mass UCS may have a lower bound of approximately $10 \mathrm{MPa}$ is the inherent spatial variability of lithophysal porosity, and thus local variability in rock mass mechanical properties. The consideration of a homogeneous, high porosity rock mass, as used in the Category 1 and 2 cases, is conservative since spatial variability of porosity will result in a higher rock mass strength. 


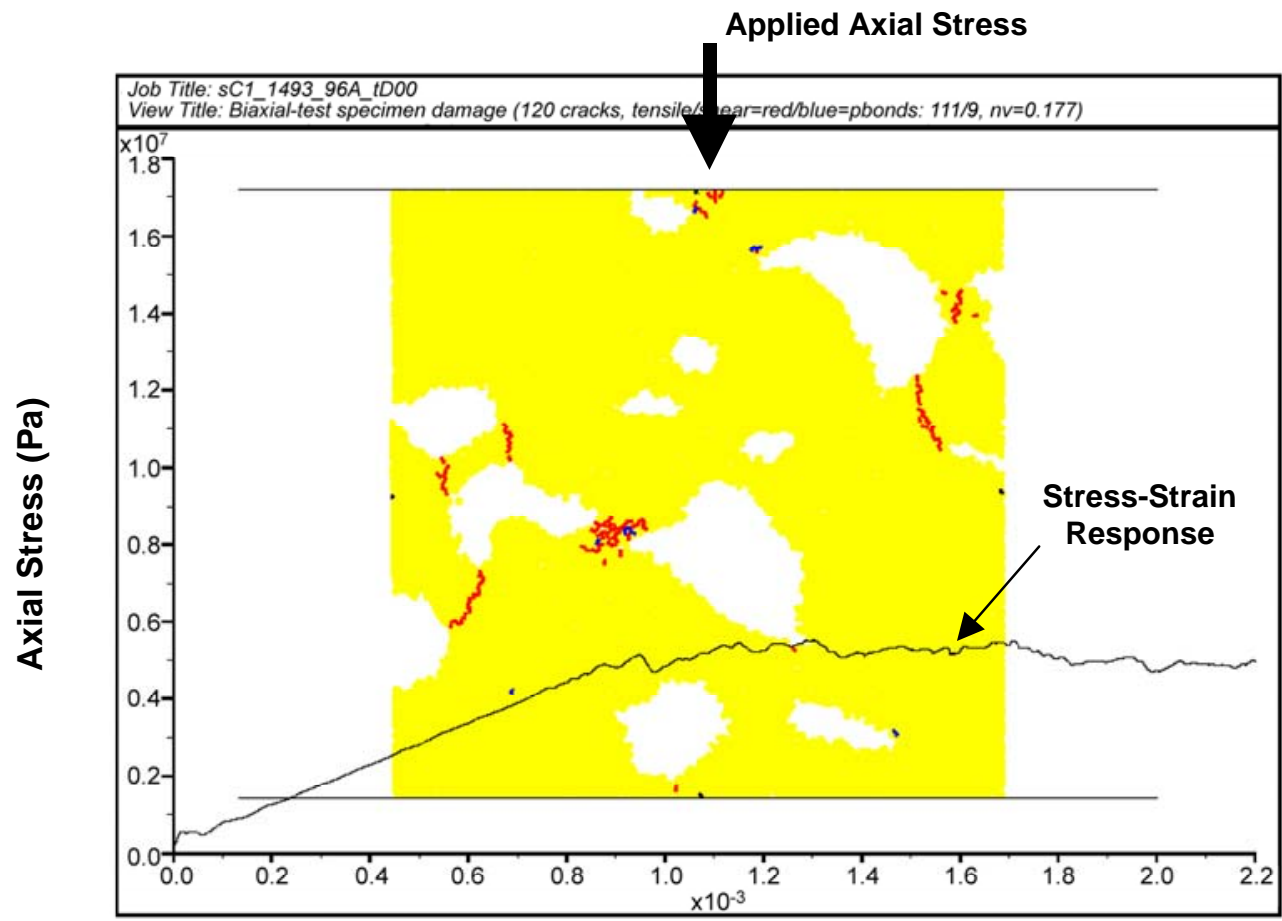

Strain $(\mathrm{m} / \mathrm{m})$

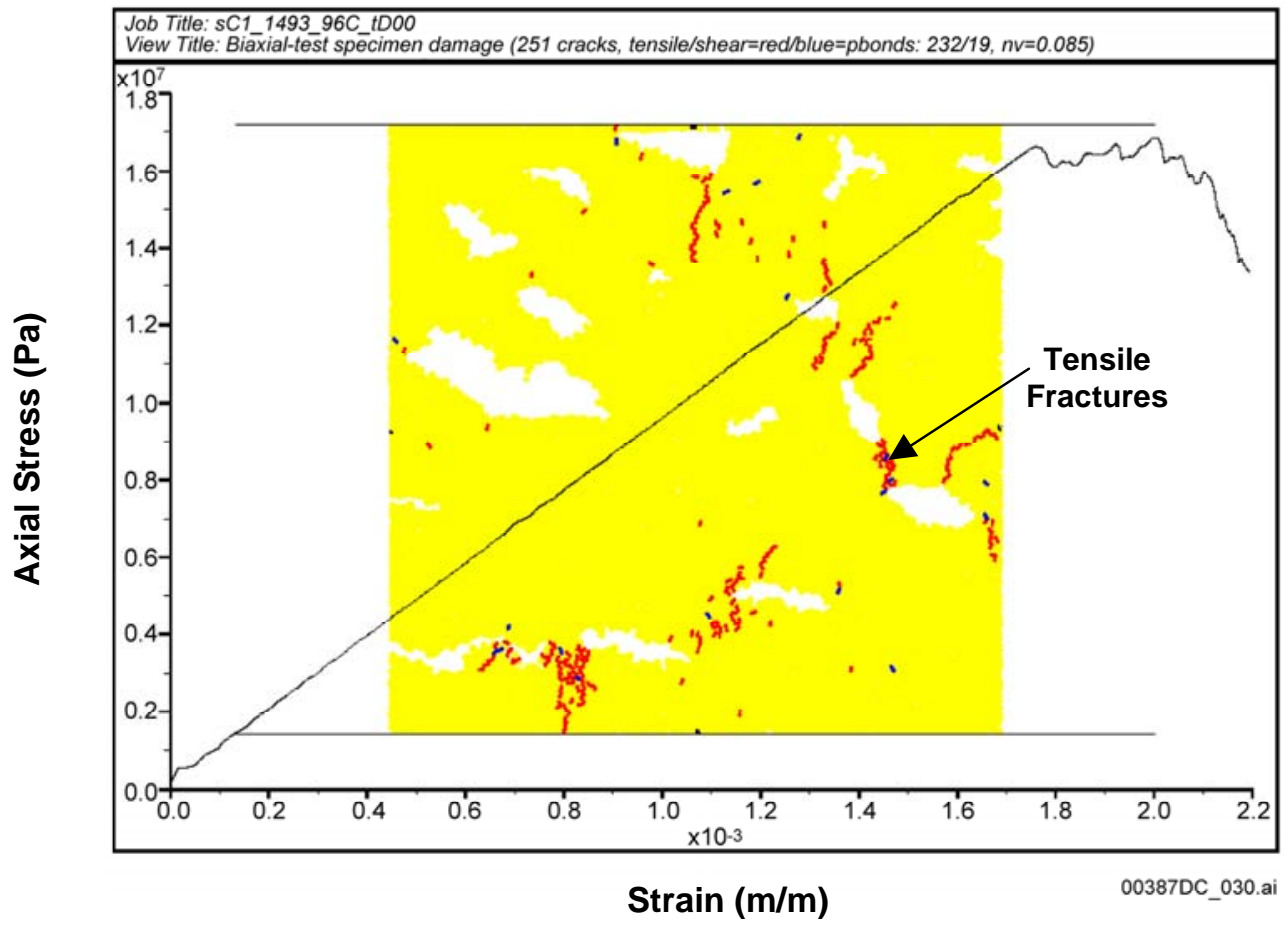

NOTE: Specimen is composed of several thousand bonded particles. Red lines are tensile fractures that have propagated between lithophysae to ultimately form a failure mechanism. Superimposed stress-strain curve illustrates impact of lithophysae distribution on strength, modulus and post-peak failure mechanism. Vertical axis is axial stress in $\mathrm{Pa}$; horizontal axis is strain in $\mathrm{m} / \mathrm{m}$.

Figure E-11. Examples of Particle Flow Code Compression Tests Using Simulated Rock Specimens Developed by "Stenciling" Field Panel Maps in the Enhanced Characterization of the Repository Block 

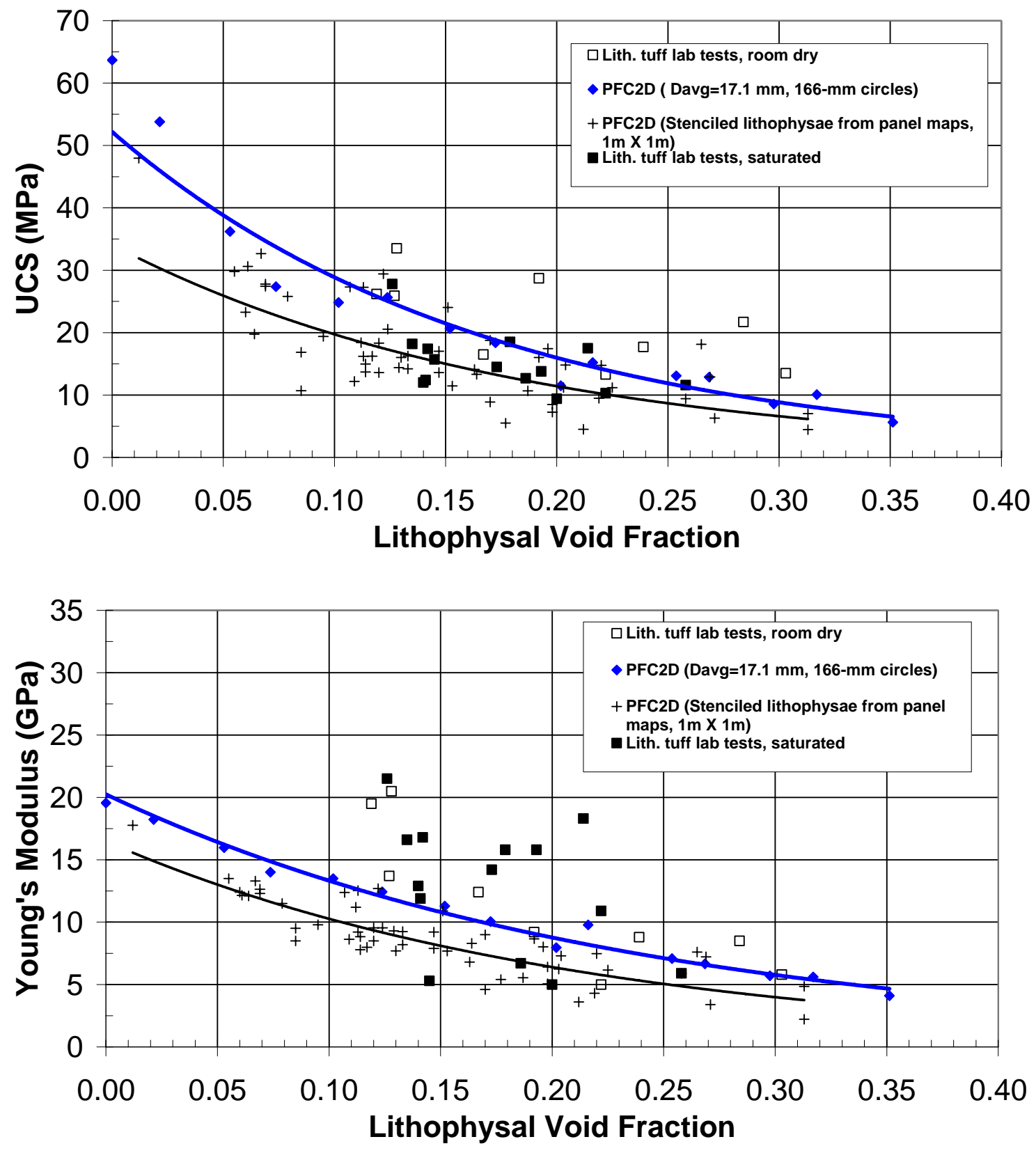

NOTE: Test data from large-core lithophysal tests -Table E-9.

Figure E-12. Plots Showing Data from Large Core Compression Testing of Tptpul and Tptpll Compared to Particle Flow Code Simulations Using Circular and Triangular Shaped Lithophysae as Well as Actual "Stenciled" Shapes from Enhanced Characterization of the Repository Block Panel Maps 


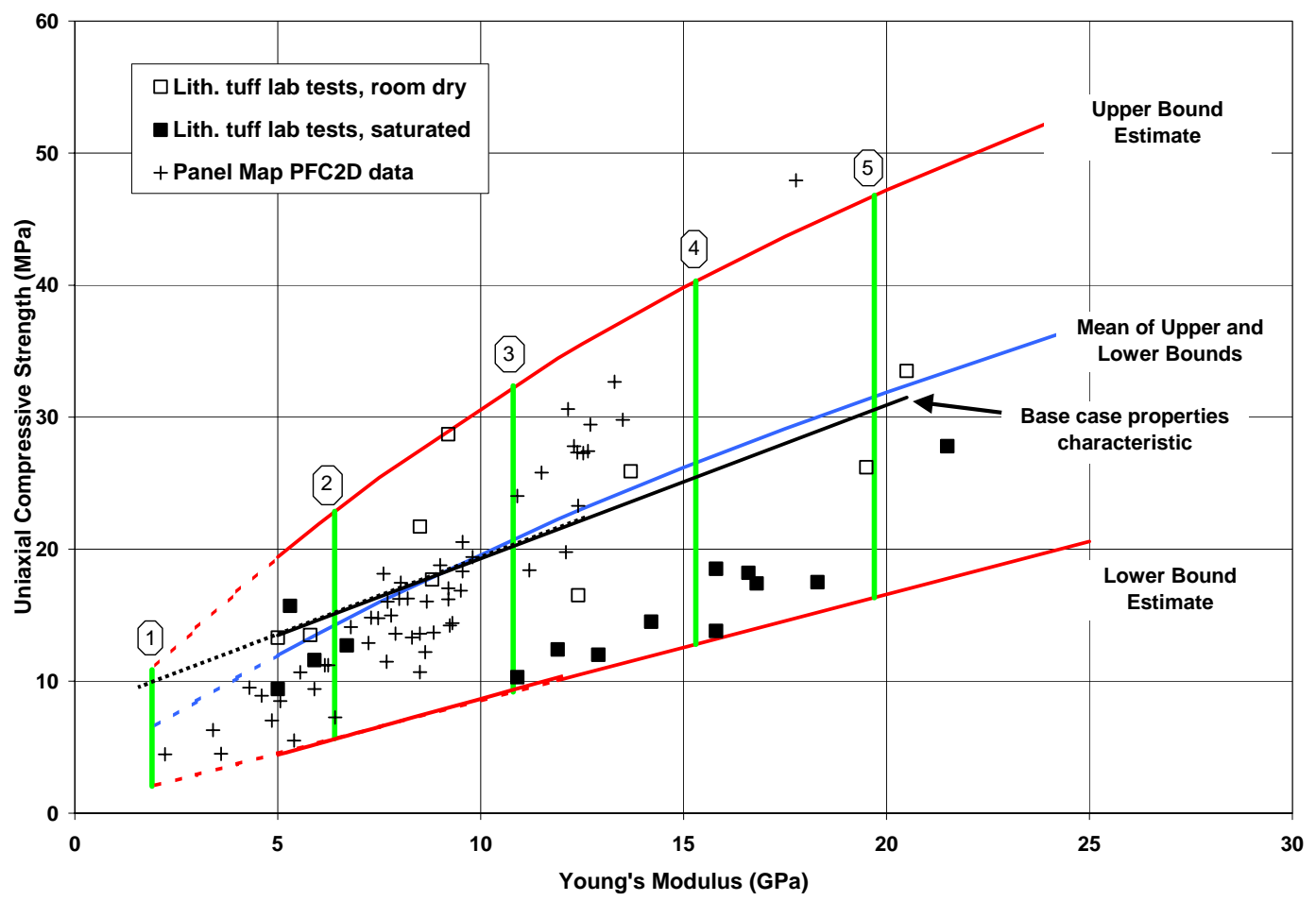

NOTE: Approximate upper and lower bounds are shown.

Figure E-13. Unconfined Compressive Strength Versus Young's Modulus Showing Large Core Data and Results from PFC Panel Map Lithophysae Shape Study 


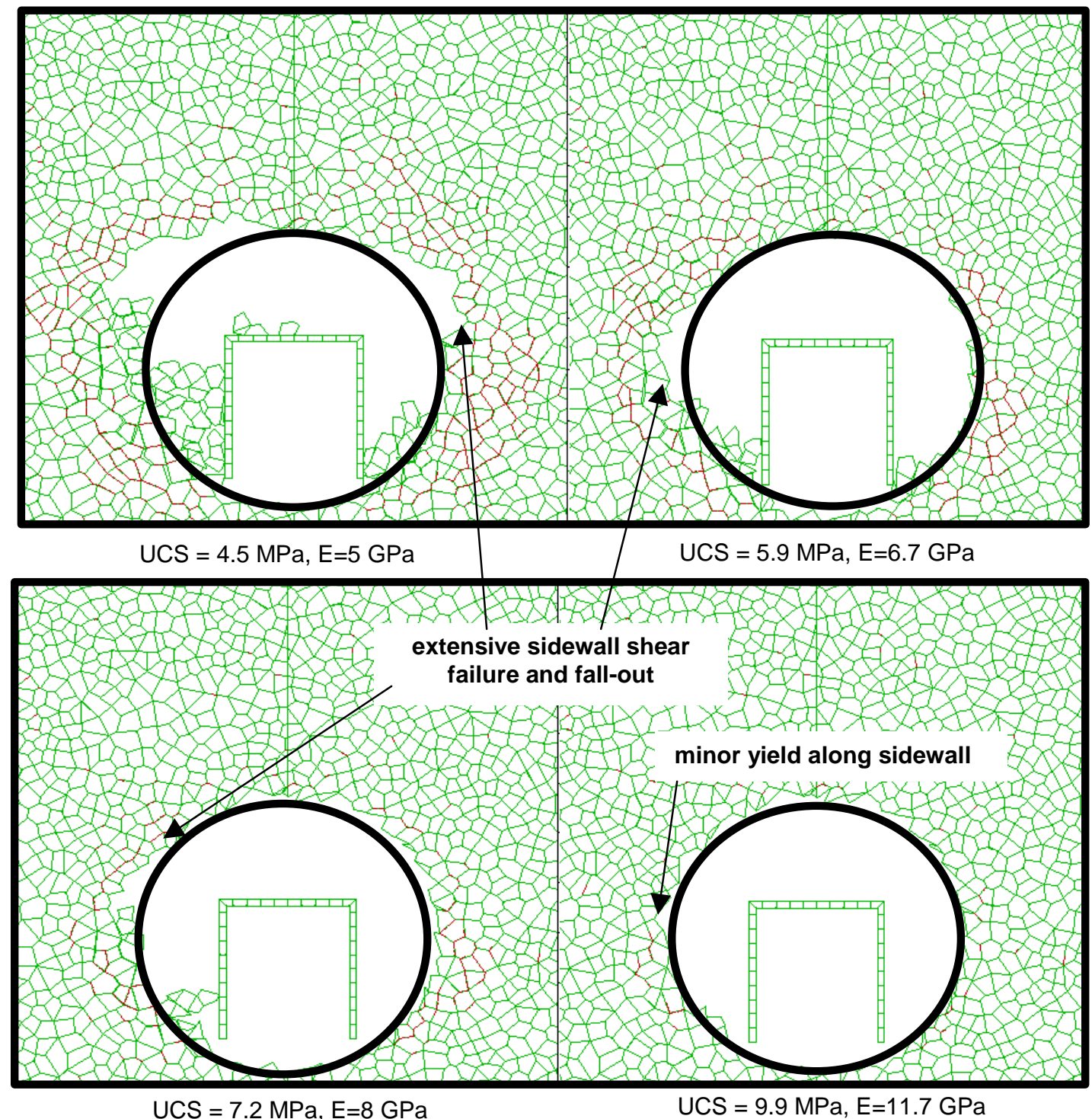

NOTE: Drift exhibits extensive sidewall failure under in situ load only for UCS values less than approximately $10 \mathrm{MPa}$. This behavior is not observed in the ESF main loop or ECRB Cross-Drift and lower bound properties (UCS < approximately $10 \mathrm{MPa}$ ) under predict in situ strength values. See Figure E-13.

Figure E-14. Emplacement Drift Stability Analysis Under In Situ Loading for Combinations of UCS and Young's Modulus Along the Lower Bound Properties Line

\section{E4.1.4.2 Investigation of Lithophysal Porosity Spatial Variability on Rock Mass Properties}

To investigate the impact of spatial variability of porosity on the lower bound and mean rock mass properties, a numerical investigation was carried out using the calibrated UDEC Voronoi drift scale model ${ }^{1}$. The purpose of the analyses is to determine the rock mass stress-strain response for an inhomogeneous rock mass composed of spatially-varying lithophysal porosity,

\footnotetext{
${ }^{1}$ See Section 7.6.4 for details of UDEC model calibration methodology and Section 6.4.1 for resulting calibrated rock mass properties by strength category.
} 
and thus spatially-varying rock mass UCS and Young's Modulus. The goal of the modeling is to conduct numerical compression tests on simulated rock mass "samples" that are sufficiently large to contain the variability of lithophysal porosity that will affect the emplacement drift scale. This requires a geometric model of the spatial variability of lithophysal porosity as a function of position within the Tptpll as well as the UDEC model.

Appendix $\mathrm{T}$ of this document presents a methodology for simulating the spatial variability of lithophysal porosity based on field measurements in the Tptpll in the ECRB Cross-Drift. The model is used to statistically represent lithophysal porosity in a series of $40 \mathrm{~m}$ long (along the axis of the ECRB Cross-Drift) by $50 \mathrm{~m}$ high (vertical) by $200 \mathrm{~m}$ wide parallelepipeds along the ECRB Cross-Drift axis from top to bottom of the Tptpll. The parallelepipeds are subdivided into a number of small (meter-scale) cubical grids within which the lithophysal porosity is estimated as a function of vertical and horizontal position. Figure T-5 (reproduced below in Figure E-15) presents examples of two vertical planes perpendicular to the drift axis centered at locations in the upper and lower portions of the Tptpll. These two planes correspond to the higher porosity zones at the top of the Tptpll and the lower porosity material near the contact with the Tptpln. Thirty rock mass "samples" measuring $10 \mathrm{~m}$ high by $5 \mathrm{~m}$ wide (drift scale) were randomly selected both vertically and horizontally within each of the parallelepipeds. Each of the porosity grids of the parallelepiped that are found within the boundaries of each of these $10 \mathrm{~m} \times 5 \mathrm{~m}$ rock mass samples have a value of lithophysal porosity associated with them. This porosity is used to assign the associated rock mass category and, in turn, its associated UCS and modulus (and the calibrated cohesion ${ }^{2}$, friction angle and stiffness representing the strength and modulus) to the elements within that particular grid. The resulting sample thus contains spatially variable UCS and modulus that represents the in situ variability of lithophysal porosity. Figure E-15 shows an example of the geometry of one of the $10 \mathrm{~m} \times 5 \mathrm{~m}$ UDEC "samples" composed of Voronoi blocks and the contours of the resulting lithophysal porosity captured from the simulated Tptpll parallelepipeds. The mean, maximum and minimum lithophysal porosities in each of the samples are plotted in Figure E-16, showing that the samples from the upper block, as expected, contain a greater proportion of lithophysal material with porosities in excess of 25 percent. The means of the samples show and average lithophysal porosity for the upper block of 15.3 percent and 12.8 percent for the lower block. These are consistent with the field measurements presented in Appendix $\mathrm{O}$.

\footnotetext{
${ }^{2}$ See Table E-11 for relationship of approximate lithophysal porosity to rock mass category and Table 6-43 for calibrated rock mass Mohr-Coulomb properties for each rock mass category.
} 

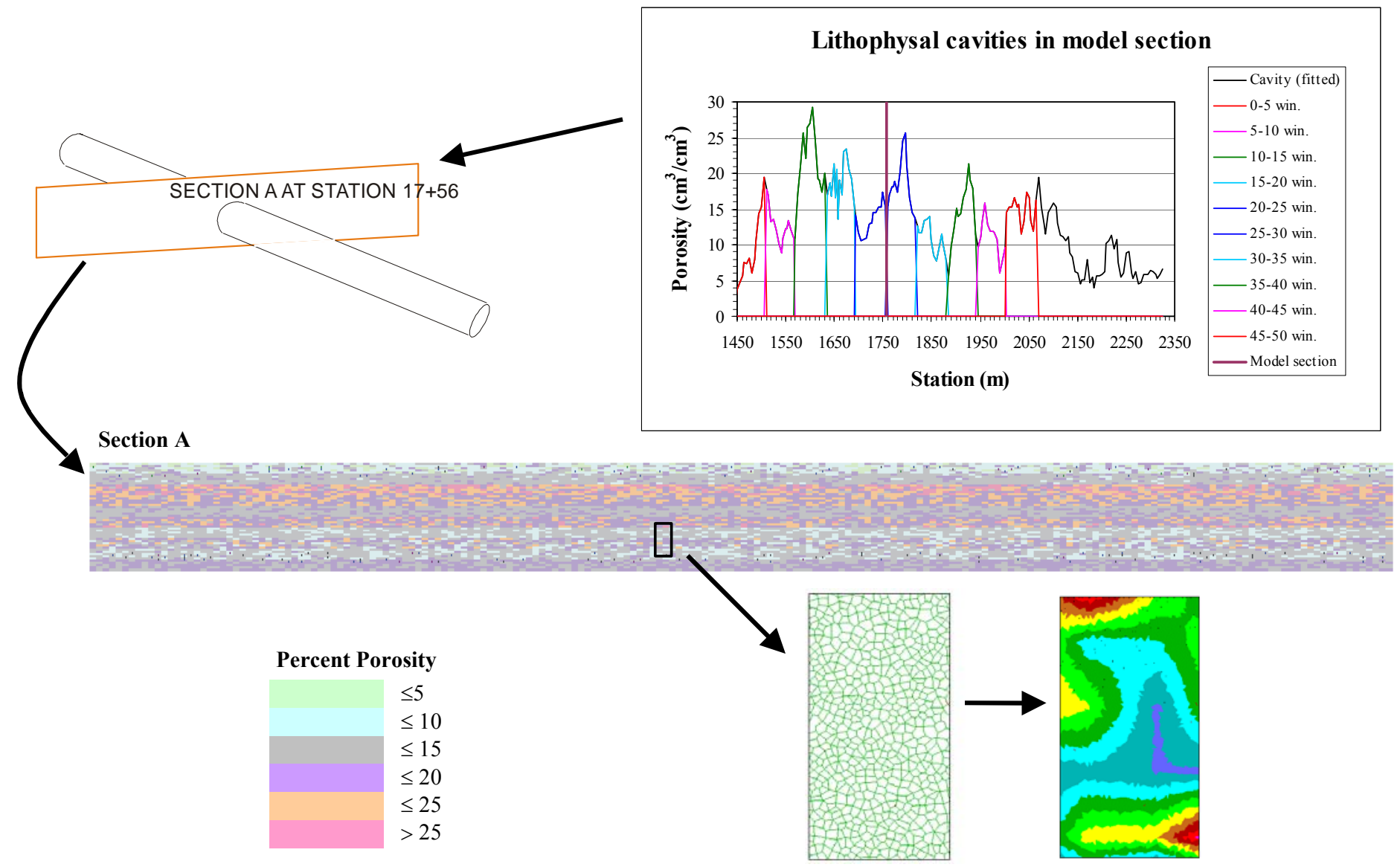

NOTE: A series of $10 \mathrm{~m} \times 5 \mathrm{~m}$ test "sample" locations are chosen randomly in three-dimensional space. Spatial variability of porosity within the sample is overlaid onto the UDEC Voronoi test specimen and material properties associated with porosities are assigned to model elements to represent spatial variability of properties. Compression testing is performed to estimate the impact of spatial variability on UCS and Young's modulus. See Appendix T for details of the porosity model. Presented in Appendix T.

Figure E-15. Schematic Illustration of the Process of Sampling and Modeling Spatial Variability Using Lithophysal Porosity Simulation Model 
UDEC simulations of compression tests were conducted for 30 samples from each of the upper and lower cross sections. For each sample, for rock mass strengths for each strength category were defined by two sets of values - the base case properties, and the lower bound rock mass properties, both illustrated in Figure E-16 and summarized in Table E-11. The upper bound values are not examined as they are irrelevant since the base case analyses of drift stability presented in Section 6.4 are conservative - higher strengths will only result in greater stability.

Table E-11. Base Case and Lower Bound Strength Values for Rock Categories Used in UDEC Analyses of Spatial Variability

\begin{tabular}{|c|c|c|c|c|}
\hline \multirow{2}{*}{$\begin{array}{c}\text { Rock Mass } \\
\text { Category }\end{array}$} & Base Case & $\begin{array}{c}\text { Unconfined Compressive } \\
\text { Strength (MPa) }\end{array}$ & $\begin{array}{c}\text { Estimated } \\
\text { Young's } \\
\text { Modulus } \\
\text { (GPa) }\end{array}$ & $\begin{array}{c}\text { Approximate Lithophysal } \\
\text { Porosity From } \\
\text { Laboratory Tests } \\
\text { (\%) }\end{array}$ \\
\hline 1 & 10 & 2.0 & 1.9 & $35 \pm 8$ \\
\hline 2 & 15 & 5.6 & 6.4 & $28 \pm 6$ \\
\hline 3 & 20 & 9.2 & 10.8 & $21 \pm 4$ \\
\hline 4 & 25 & 12.8 & 15.3 & $13 \pm 5$ \\
\hline 5 & 30 & 16.3 & 19.7 & $7 \pm 7$ \\
\hline
\end{tabular}

Source: DTNs provided in Table E-9.

a Young's Modulus estimated from linear fit to 11.5-in. core data given in Figure E-8

b Estimated from correlations of strength and modulus to lithophysal porosity in Figure E-6. Porosity ranges are based on BSC 2004 [DIRS 168970], Table 6.6-1.

The numerical compression tests typically show that the samples fail as expected in an axial splitting mode (Figure E-17). The results of these analyses are summarized in Figure E-18 in terms of the relationship of UCS and Young's Modulus. Here, the laboratory and PFC shape study analyses are plotted along with the results of the numerical compression experiments for base case and lower bound properties. Several conclusions from this work can be made, including:

1. The variability in porosity distribution inherent in the samples results in UCS values that roughly equal or exceed $10 \mathrm{MPa}$. As seen in Figure E-18, the spatial variability in rock mass strength naturally results in sample strengths that gravitate toward that of the average porosity (i.e., around 15 percent). It is difficult, considering variable rock mass porosity, to produce average rock mass strength values that are at the low end of the category range. This agrees with observations in the ESF main loop and ECRB Cross-Drift of stable, lightly supported excavations in the lithophysal units that show little or no signs of instability. 
a)

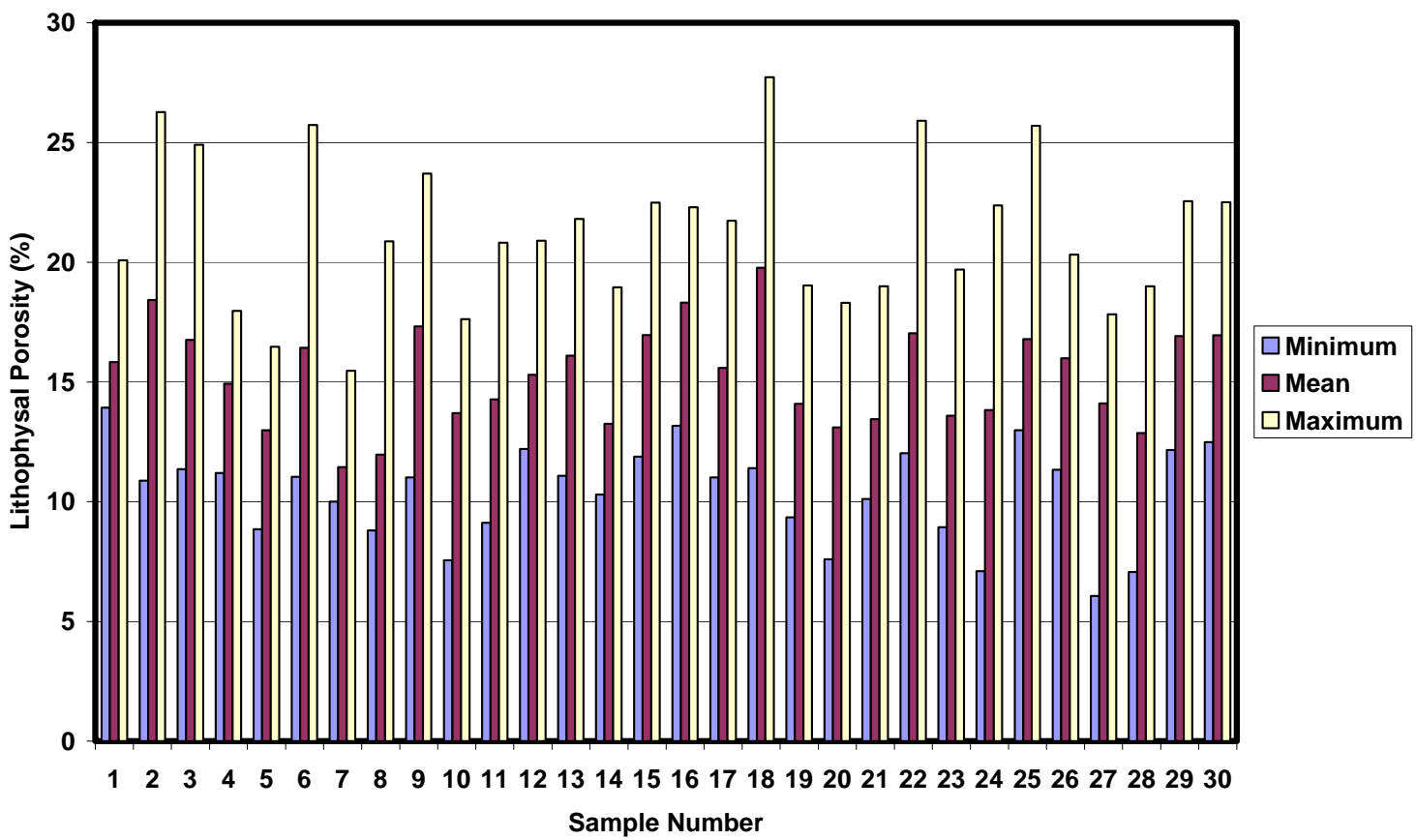

b)

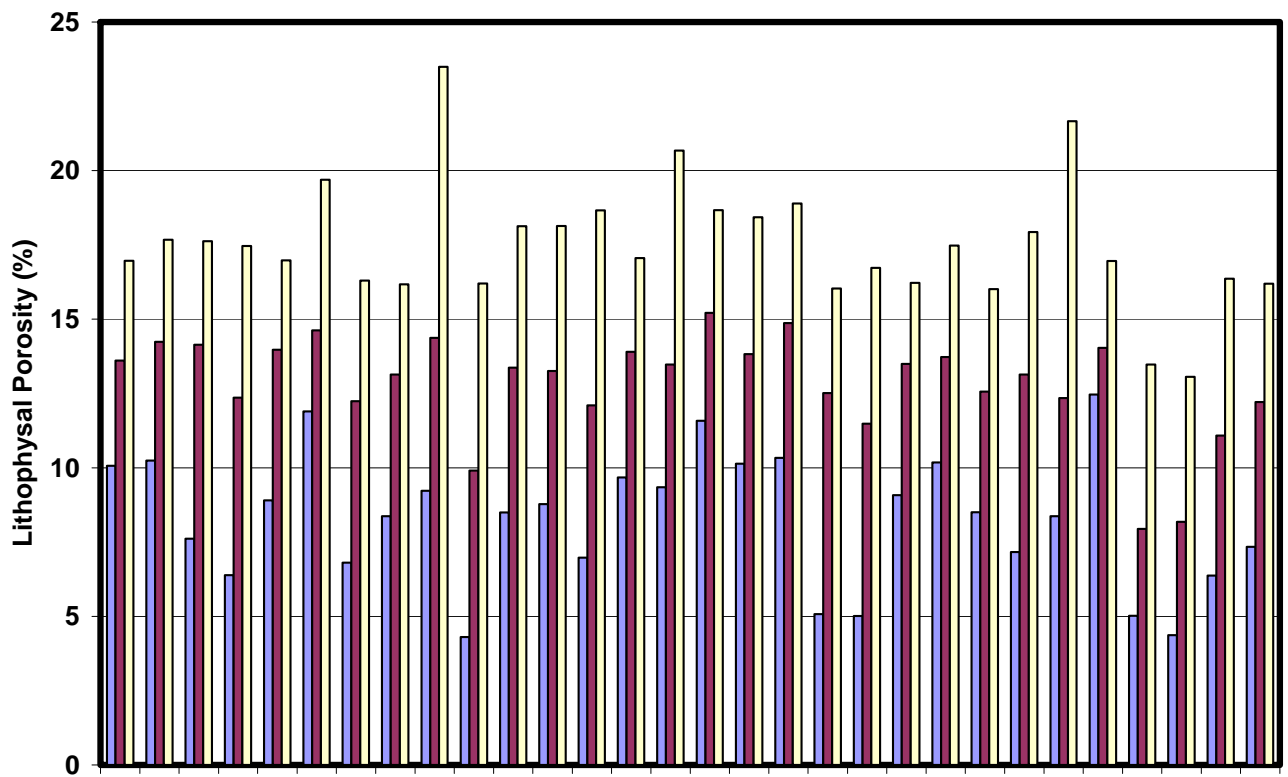

$\square$ Minimum

$\square$ Mean

$\square$ Maximum

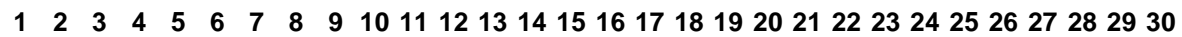

Sample Number

NOTE: Mean, minimum, and maximum refer to those values of lithophysal porosity in the particular sample. (a) the upper cross-section; (b) the lower cross-section of the Tptpll.

Figure E-16. Spatial Variability in Lithophysal Porosity in Each of 30 Samples Taken 

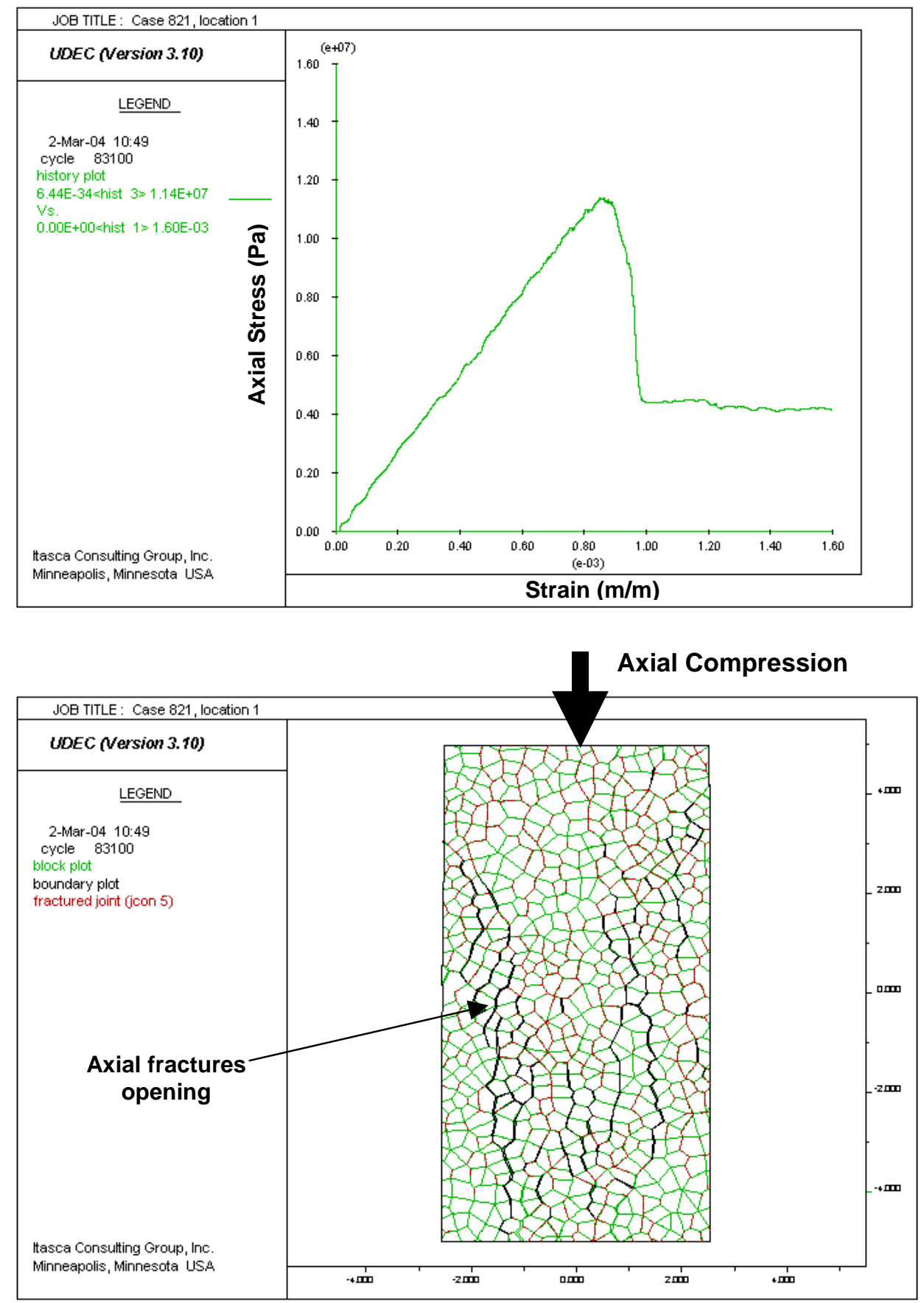

NOTE: Estimated modulus and peak strength are determined from stress-strain curve. Sample is same as shown in Figure E-18. Sample fails in axial splitting mode as seen by black, axially oriented macro-fractures. Red block contacts indicate yield in either tension or shear.

Figure E-17. Example of Unconfined Compression Test Results on $10 \mathrm{~m} \times 5 \mathrm{~m}$ Rock Mass Sample Containing Spatially Variable Lithophysal Porosity 


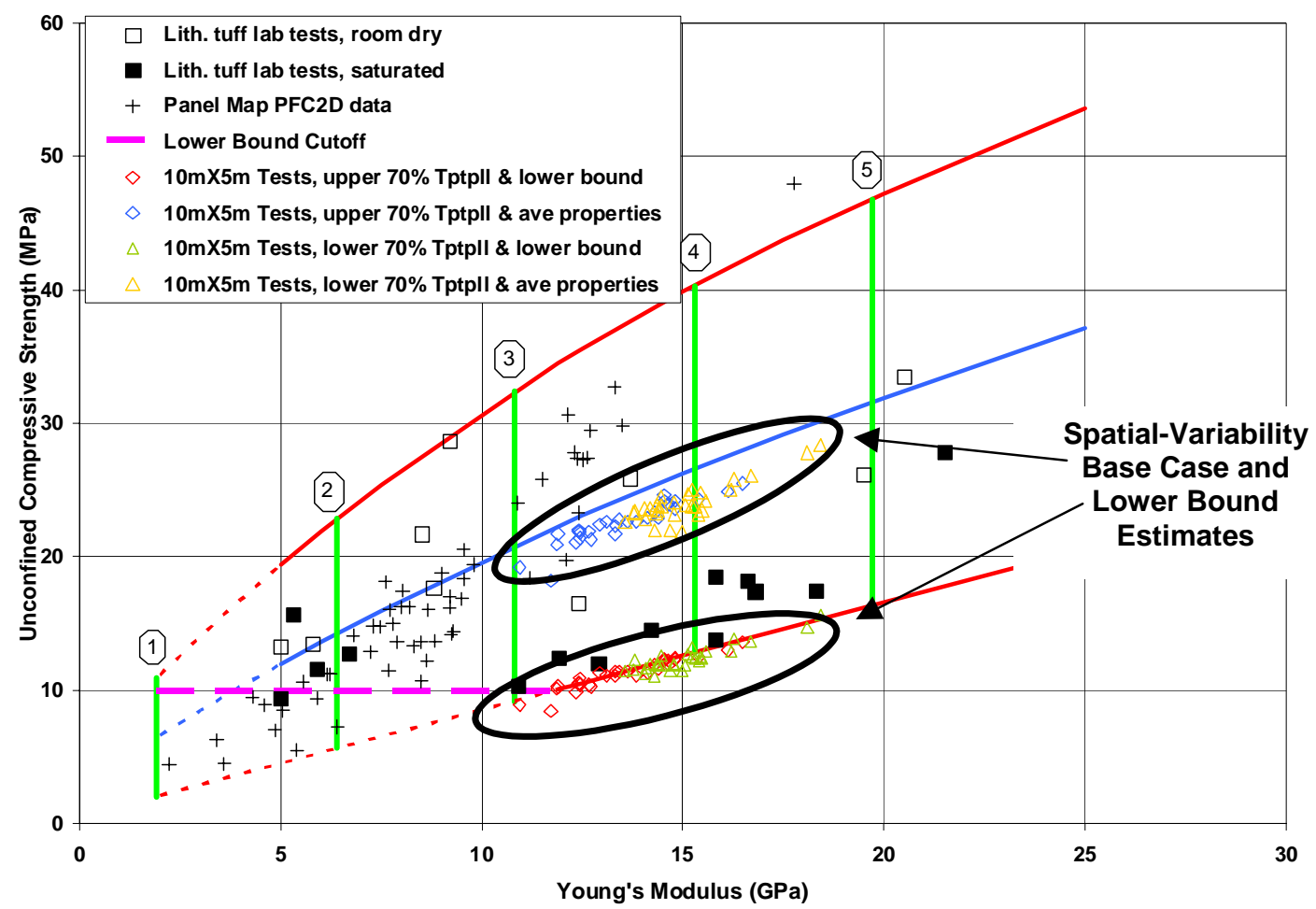

NOTE: The results derived from base case and lower bound rock properties estimates. Note that a lower bound strength cut-off exists at approximately $10 \mathrm{MPa}$ as a result of spatial variability of porosity.

Figure E-18. Relationship of UCS to Young's Modulus Showing the Results of Modeling Estimates of Properties for Spatially-Variable Lithophysal Rock Mass

2. The distribution of sample UCS and moduli for both base case and lower bound properties naturally fall within the range of rock mass strength categories 3 to 4 . This is in agreement with the in situ distribution of lithophysal porosities (e.g., Figure O-15) that show the most common values lie in the Category 3 to 4 range. This confirms the consideration that the typical rock mass properties for the lithophysal units lie in the Category 3 to 4 range, and that the occurrence of Category 1 or 2 rocks is typically as localized regions of high porosity, potentially accompanied by large lithophysae.

3. The results verify that the consideration of homogenous rock mass properties used in the base case rock strength categories is conservative in nature.

Based on these calculations, the range of lithophysal rock mass properties are considered to have a lower bound strength of $10 \mathrm{MPa}$, with the lower bound following the saturated rock strength estimate for strengths greater than $10 \mathrm{MPa}$.

\section{E4.1.4.3 Size Effect and Anisotropy of the Matrix of the Lithophysal Rock}

To further explore the effect of sample size for nonlithophysal material, a single large block of material from the nonlithophysal section of the Tptpll near its lower boundary with the Tptpln was obtained from Busted Butte (Figure E-19). 
A total of 110 samples with sizes ranging from 1-in to 8.8 -in. (26 $\mathrm{mm}$ to $223 \mathrm{~mm}$ ) diameter were cut and tested to examine both size effect and mechanical anisotropy. The mechanical anisotropy studies included testing of 2-in to 2.4-in. (51 $\mathrm{mm}$ to $62 \mathrm{~mm}$ ) samples drilled at three mutually perpendicular directions from the same block of material. The results of the sample size on UCS are shown in Figure E-20. In this figure, the UCS is plotted as a function of the sample volume (as a log-log plot), and is compared to the test data for the Tptpmn given in Price 1986 [DIRS 106589]. The vertical offset of the two lines is indicative of the slightly different average strength of the Tptpll and Tptpmn matrix material, although the size effect is virtually identical. The mechanical anisotropy is demonstrated in terms of the average values for the Young's moduli from each of the perpendicular orientations. As seen in Figure E-21, there is a maximum anisotropy of approximately 10.6 percent in the average matrix moduli, which is considered to be a second order effect in comparison to lithophysal and fracturing effects.

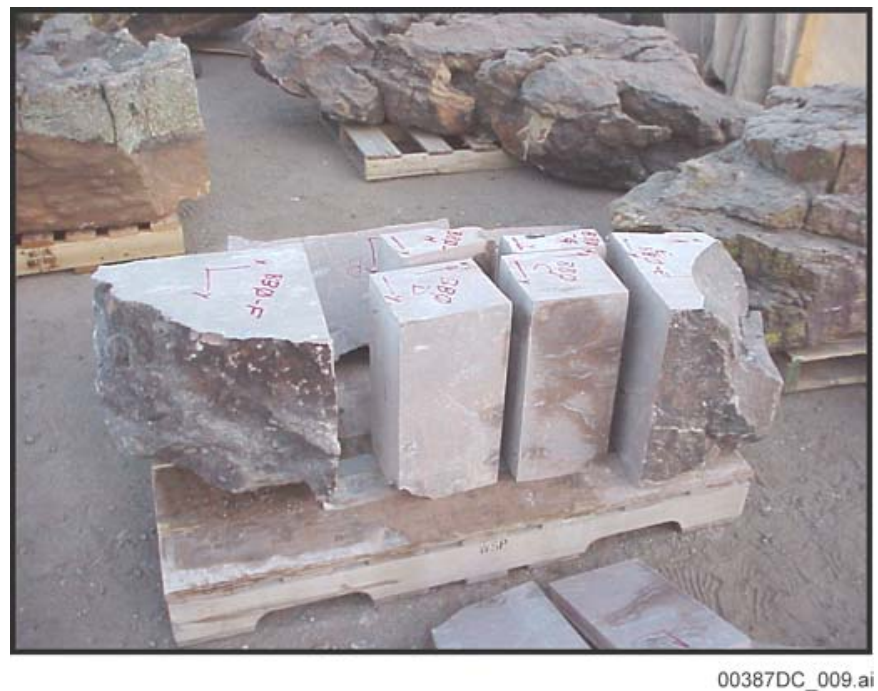

NOTE: Block from nonlithophysal portion of the Tptpll near its lower boundary with the Tptpln, Busted Butte.

Figure E-19. Development of Rectangular Specimens for Matrix Size Effect and Anisotropy Study

A series of tests were run on 2-in. $(51 \mathrm{~mm})$ nonlithophysal Tptpll samples from the same outcrop boulder to examine the impact of saturation level on uniaxial compressive strength. It is impossible to accurately control moisture content at specific levels of saturation for a rock sample, so a number of tests aimed at fully drying and saturating and allowing the samples to equilibrate at room humidity conditions were run as shown in Table E-12. As seen in this table, the presence of moisture has a significant effect on compressive strength, particularly whether the samples are under heated-dry or exposed to humid air conditions. Complete drying of samples increases the mean strength of the samples tested by approximately 20 percent. This strength decrease in the presence of moisture is consistent with other testing of silicic rocks and is typical stress-corrosion mechanism involving chemical alterations due to moisture in flaws within the samples. The compression test data reported here is, unless otherwise noted, at room humidity conditions. Following a conservative design approach, performance calculations performed for ground support or postclosure effects consider average strength conditions from room temperature testing, with data ranges to cover fully saturated conditions. 
Table E-12. Impact of Moisture Conditions on Uniaxial Compressive Strength of Nonlithophysal Tptpll Samples

\begin{tabular}{|c|l|c|}
\hline Test Condition & \multicolumn{1}{|c|}{ Moisture Condition } & Mean Strength (MPa) \\
\hline 1 & Samples dried by slow heating to $200^{\circ} \mathrm{C}$, tested at $200^{\circ} \mathrm{C}$ & 213 \\
\hline 2 & $\begin{array}{l}\text { Samples dried by slow heating to } 200^{\circ} \mathrm{C} \text {, then slowly cooled } \\
\text { in dry environment, exposed to room humidity for about } 30 \\
\text { minutes and tested at room temperature }\end{array}$ & 176 \\
\hline 3 & $\begin{array}{l}\text { Samples allowed to equilibrate with room humidity, tested at } \\
\text { room temperature }\end{array}$ & 158 \\
\hline 4 & Samples water saturated, tested at room temperature & 149 \\
\hline
\end{tabular}

NOTE: Strengths are mean values from testing of $51 \mathrm{~mm}$ diameter samples at each moisture condition.

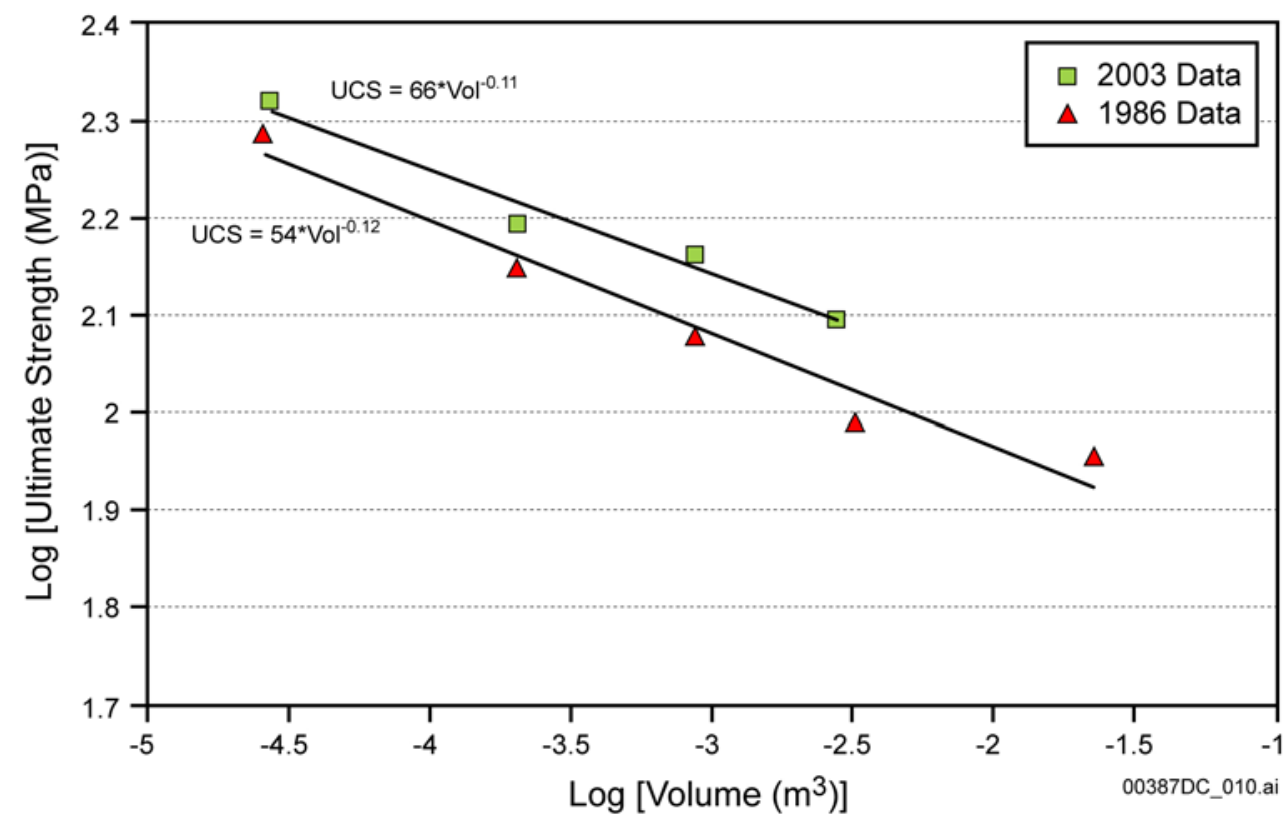

NOTE: Results from the 2003 testing of Tptpln/Tptpll samples (DTN: SN0306L0207502.008 [DIRS 165015]) are compared to previous testing of samples from the Tptpmn (Price 1986 [DIRS 106589]).

Figure E-20. Results of Size Effect Study Showing Variation in Sample Uniaxial Compressive Strength as a Function of Sample Volume 


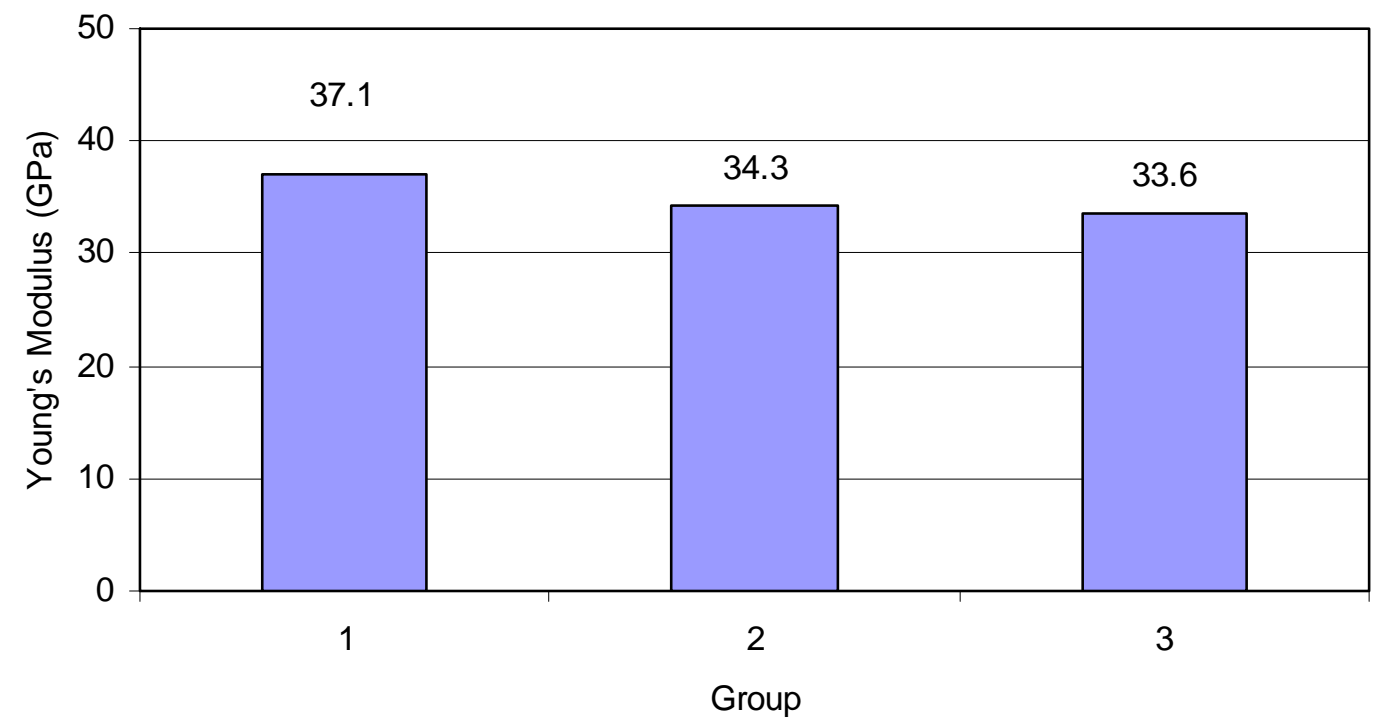

Source: Developed from source data provided by DTN: SN0306L0207502.008.

NOTE: Four block samples were used in the mechanical anisotropy study (see Figure E-19), including a total of 57 specimens cored from these samples in three mutually perpendicular directions. For each of the four blocks, an average Young's modulus was determined for each direction. This provides the orientation with the largest, medium, and smallest Young's modulus value for each block. Group 1 is the average of the largest values from each block, Group 2 is the average of the medium values from each block, and Group 3 is the average of the smallest values from each block. The averages of the 57 specimens show a maximum of 10.6 percent anisotropy in the average Young's modulus.

Figure E-21. Anisotropy in Young's Modulus of Nonlithophysal Tptpll Matrix for Three Mutually Perpendicular Coring Directions

\section{E4.2 ASSESSMENT OF ROCK MASS PROPERTIES FOR THE HEATED DRIFT}

The calculation of rock mass properties for the Heated Drift in the ESF is described in this section, and also documented in the Microsoft Excel file, rock mass strength v2.xls, worksheet "Heated Drift" (Table A-1). Rock mass properties are calculated using the Hoek-Brown failure criterion (Hoek et al. 2002 [DIRS 162204], Section 2), which is expressed as

$$
\sigma_{1}=\sigma_{3}+\sigma_{c i}\left(m_{b} \frac{\sigma_{3}}{\sigma_{c i}}+s\right)^{a}
$$

where $\quad \sigma_{1}$ and $\sigma_{3}$ are the major and minor effective principle stresses at failure

$\sigma_{c i}$ is the uniaxial compressive strength of the intact rock material

$m_{b}, s$, and $a$ are material constants.

This approach uses the Geological Strength Index (GSI) to characterize rock mass strength (Hoek et al. 2000 [DIRS 160539], pp. 91 to 97). Rock mass classification data using the Q system has been collected in the Heated Drift (Table E-13). To apply Q system data to estimate the strength of jointed rock masses, the Q system parameters related to stress (i.e., $J_{w}$ and $S R F$ ) 
should be set equal to 1 , which is equivalent to a dry rock mass subjected to medium stress conditions (Hoek et al. 2000 [DIRS 160539], pp. 96 to 97), such that:

$$
\begin{gathered}
\mathrm{GSI}=9 \ln \mathrm{Q}^{\prime}+44 \\
\mathrm{Q}^{\prime}=\left(\frac{R Q D}{J_{n}}\right) \times\left(\frac{J_{r}}{J_{a}}\right)
\end{gathered}
$$

where

$$
\begin{array}{lll}
R Q D & = & \text { rock quality designation } \\
J_{n} & = & \text { joint set number } \\
J_{r} & = & \text { joint roughness number } \\
J_{a} & = & \text { joint alteration number. }
\end{array}
$$

The material constants $m_{b}, s$, and $a$ are given by

$$
\begin{gathered}
m_{b}=m_{i} \exp \left(\frac{G S I-100}{28-14 D}\right) \\
s=\exp \left(\frac{G S I-100}{9-3 D}\right) \\
a=\frac{1}{2}+\frac{1}{6}\left(e^{-G S I / 15}-e^{-20 / 3}\right)
\end{gathered}
$$

where $m_{i}$ is the value of $m_{b}$ for intact rock and is determined based on laboratory triaxial test data, and $D$ is a factor that depends on the degree of disturbance to which the rock mass has been subjected by blast damage and stress relaxation. $D$ is 0 for the mechanically excavated tunnels in the ESF.

Following the approach by Hoek et al. (2002 [DIRS 162204], Section 3), the rock mass modulus of deformation is given by

$$
\begin{gathered}
E_{m}=\left(1-\frac{D}{2}\right) \cdot 10^{(G S I-10) / 40} \text { for } \sigma_{c i}>100 \mathrm{MPa} \\
E_{m}=\left(1-\frac{D}{2}\right) \sqrt{\frac{\sigma_{c i}}{100}} \cdot 10^{(G S I-10) / 40} \text { for } \sigma_{c i} \leq 100 \mathrm{MPa}
\end{gathered}
$$

where $E_{m}$ is the rock mass modulus of deformation in GPa. 
The global rock mass strength is determined as

$$
\sigma_{c m}=\sigma_{c i} \cdot \frac{\left(m_{b}+4 s-a\left(m_{b}-8 s\right)\right)\left(m_{b} / 4+s\right)^{a-1}}{2(1+a)(2+a)} .
$$

Table E-13. Q System Rock Mass Classification Data from the Heated Drift

\begin{tabular}{|c|c|c|c|c|c|c|c|}
\hline \multirow{2}{*}{\multicolumn{2}{|c|}{$\begin{array}{c}\text { Tunnel } \\
\text { Station } \\
\text { Interval } \\
(\mathbf{m}) \\
\end{array}$}} & \multirow{3}{*}{$\begin{array}{c}\begin{array}{c}\text { Lithostratigraphic } \\
\text { Unit }\end{array} \\
\text { Tptpmn } \\
\end{array}$} & \multirow{3}{*}{$\begin{array}{c}\begin{array}{c}\text { Thermal- } \\
\text { Mechanical Unit }\end{array} \\
\text { TSw2 } \\
\end{array}$} & \multicolumn{4}{|c|}{ Q System Parameters } \\
\hline & & & & \multirow{2}{*}{$\begin{array}{c}\text { RQD } \\
80\end{array}$} & \multirow{2}{*}{$\frac{\mathrm{Jn}}{12}$} & \multirow{2}{*}{$\frac{\mathrm{Jr}}{3}$} & \multirow{2}{*}{$\begin{array}{r}\mathrm{Ja} \\
2\end{array}$} \\
\hline 0 & 5 & & & & & & \\
\hline 5 & 10 & Tptpmn & TSw2 & \multicolumn{4}{|c|}{ Not rated due to plate loading niche. } \\
\hline 10 & 15 & Tptpmn & TSw2 & 78 & 9 & 1 & 2 \\
\hline 15 & 20 & Tptpmn & TSw2 & 69 & 12 & 1 & 2 \\
\hline 20 & 25 & Tptpmn & TSw2 & 90 & 12 & 3 & 2 \\
\hline 25 & 30 & Tptpmn & TSw2 & 76 & 9 & 3 & 2 \\
\hline 30 & 35 & Tptpmn & TSw2 & 77 & 9 & 3 & 2 \\
\hline 35 & 40 & Tptpmn & TSw2 & 67 & 9 & 3 & 2 \\
\hline 40 & 45 & Tptpmn & TSw2 & 83 & 15 & 3 & 2 \\
\hline 45 & 50 & Tptpmn & TSw2 & 58 & 15 & 3 & 2 \\
\hline 50 & 55 & Tptpmn & TSw2 & 59 & 15 & 2 & 2 \\
\hline 55 & 60 & Tptpmn & TSw2 & 54 & 15 & 2 & 2 \\
\hline
\end{tabular}

Source: DTN: GS970608314224.007 [DIRS 158430].

NOTE: Q system parameters can be accessed through USGS 1997 [DIRS 169040], which is linked to the Source DTN.

The calculation of the mean intact rock strength, $\sigma_{c i}$, is documented in Table E-14. The value of the material constant for intact rock, $m_{i}$, is 33.87, which is documented in the Subsurface Geotechnical Parameters Report (BSC 2003 [DIRS 166660], Table 8-39).

The results of the calculation of rock mass properties for the Heated Drift using the approach described above are provided in Table E-15, with additional documentation provided in the Microsoft Excel file, rock mass strength v2.xls (Table A-1).

Table E-14. Intact Compressive Strength Data for the Tptpmn Unit ${ }^{\text {a }}$

\begin{tabular}{|c|c|c|c|}
\hline Number & $\begin{array}{c}\text { Specimen Number } \\
\text { (also referred to as Sample } \\
\text { Number) }\end{array}$ & $\begin{array}{c}\text { Ultimate Differential Strength } \\
\text { (also referred to as } \\
\text { Compressive Strength) (MPa) }\end{array}$ & \multirow{2}{*}{ Original Source DTN } \\
\hline 1 & NRG-6-720.7-SNL-A & 235.5 & \multirow{2}{*}{ SNL02030193001.004 } \\
\hline 2 & NRG-6-742.3-SNL-A & 162.3 & \\
\hline 3 & NRG-6-742.9-SNL-A & 212.8 & \\
\hline 4 & NRG-6-762.9-SNL-A & 112.1 & \\
\hline 5 & NRG-6-773.5-SNL-A & 117.4 & \\
\hline
\end{tabular}


Table E-14. Intact Compressive Strength Data for the Tptpmn Unit ${ }^{a}$ (Continued)

\begin{tabular}{|c|c|c|c|}
\hline Number & $\begin{array}{c}\text { Specimen Number } \\
\text { (also referred to as Sample } \\
\text { Number) }\end{array}$ & $\begin{array}{l}\text { Ultimate Differential Strength } \\
\text { (also referred to as } \\
\text { Compressive Strength) (MPa) }\end{array}$ & Original Source DTN \\
\hline 6 & NRG-6-784.8-SNL-A & 223.0 & \multirow{3}{*}{$\begin{array}{l}\text { SNL02030193001.004 } \\
\text { [DIRS 108415] }\end{array}$} \\
\hline 7 & NRG-6-785.6-SNL-A & 218.6 & \\
\hline 8 & NRG-6-806.8-SNL-A & 261.9 & \\
\hline 9 & NRG-5-847.2-SNL-A & 84.2 & \multirow{4}{*}{$\begin{array}{l}\text { SNL02030193001.012 } \\
\text { [DIRS 108416] }\end{array}$} \\
\hline 10 & NRG-5-849.4-SNL-A & 240.8 & \\
\hline 11 & NRG-5-861.2-SNL-A & 55.3 & \\
\hline 12 & NRG-5-873.4-SNL-A & 38.4 & \\
\hline 13 & NRG-5-887.2-SNL-A & 240.9 & \multirow{4}{*}{$\begin{array}{l}\text { SNL02030193001.012 } \\
\text { [DIRS 108416] }\end{array}$} \\
\hline 14 & NRG-5-888.8-SNL-A & 288.9 & \\
\hline 15 & NRG-5-891.9-SNL-A & 253.5 & \\
\hline 16 & NRG-5-896.5-SNL-A & 184.7 & \\
\hline 17 & NRG-7/7A-777.0-SNL-A & 143.8 & \multirow{9}{*}{$\begin{array}{l}\text { SNL02030193001.019 } \\
\text { [DIRS 108431] }\end{array}$} \\
\hline 18 & NRG-7/7A-800.2-SNL-A & 179.2 & \\
\hline 19 & NRG-7/7A-806.3-SNL-A & 225.4 & \\
\hline 20 & NRG-7/7A-818.5-SNL-A & 126.3 & \\
\hline 21 & NRG-7/7A-859.2-SNL-A & 118.8 & \\
\hline 22 & NRG-7/7A-865.4-SNL-I & 215.8 & \\
\hline 23 & NRG-7/7A-865.4-SNL-J & 232.0 & \\
\hline 24 & NRG-7/7A-865.4-SNL-K & 239.1 & \\
\hline 25 & NRG-7/7A-865.4-SNL-L & 248.5 & \\
\hline 26 & SD-12-734.7-SNL-B & 193.3 & \multirow{2}{*}{$\begin{array}{c}\text { SNL02030193001.023 } \\
\text { [DIRS 108435] }\end{array}$} \\
\hline 27 & SD-12-781.1-SNL-B & 198.2 & \\
\hline 28 & SD-9-761.5-SNL-A & 231.5 & \multirow{7}{*}{$\begin{array}{l}\text { SNL02030193001.026 } \\
\text { [DIRS 108436] }\end{array}$} \\
\hline 29 & SD-9-768.7-SNL-A & 254.5 & \\
\hline 30 & SD-9-771.7-SNL-A & 160.8 & \\
\hline 31 & SD-9-774.6-SNL-B & 60.1 & \\
\hline 32 & SD-9-826.7-SNL-A & 224.9 & \\
\hline 33 & SD-9-832.8-SNL-C & 183.3 & \\
\hline 34 & SD-9-842.1-SNL-E-1 & 208.9 & \\
\hline 35 & GU-3 760.9/1A & 210.3 & \multirow{5}{*}{$\begin{array}{l}\text { SNSAND83164600.000 } \\
\text { [DIRS 160009] }\end{array}$} \\
\hline 36 & GU-3 760.9/1B & 234.4 & \\
\hline 37 & GU-3 760.9/2A & 215.5 & \\
\hline 38 & GU-3 760.9/2B & 221.4 & \\
\hline 39 & GU-3 760.9/3A & 245.2 & \\
\hline 40 & GU-3 760.9/3B & 222.2 & \\
\hline 41 & GU-3 760.9/4A & 205.2 & \\
\hline 42 & GU-3 760.9/4B & 183.5 & \\
\hline 43 & GU-3 760.9/5A & 229.7 & \\
\hline 44 & GU-3 760.9/5B & 226.4 & \\
\hline 45 & 10/AE/2/Z & 109.0 & SNSAND85076200.000 \\
\hline
\end{tabular}


Table E-14. Intact Compressive Strength Data for the Tptpmn Unit ${ }^{\text {a }}$ (Continued)

\begin{tabular}{|c|c|c|c|}
\hline Number & $\begin{array}{c}\text { Specimen Number } \\
\text { (also referred to as Sample } \\
\text { Number) }\end{array}$ & $\begin{array}{l}\text { Ultimate Differential Strength } \\
\text { (also referred to as } \\
\text { Compressive Strength) (MPa) }\end{array}$ & Original Source DTN \\
\hline 46 & 10/AE/46/Z & 143.0 & \multirow[t]{5}{*}{ [DIRS 160024] } \\
\hline 47 & 10/AE/9/Z & 153.0 & \\
\hline 48 & 10-AE-3Y & 53.7 & \\
\hline 49 & 10-AE-6X & 107.0 & \\
\hline 50 & $10-A E-8 X$ & 62.4 & \\
\hline 51 & G4-686.6-A & 270.0 & \multirow{2}{*}{$\begin{array}{c}\text { SNSAND84110100.000 } \\
\text { [DIRS 160016] }\end{array}$} \\
\hline 52 & G4-686.6-D & 326.0 & \\
\hline 53 & G4-686.6-G & 180.0 & \multirow{8}{*}{$\begin{array}{l}\text { SNSAND84110100.000 } \\
\text { [DIRS 160016] }\end{array}$} \\
\hline 54 & G4-742.75-E & 235.0 & \\
\hline 55 & G4-742.75-F & 256.0 & \\
\hline 56 & G4-742.75-G & 279.0 & \\
\hline 57 & G4-748.6-A & 196.0 & \\
\hline 58 & G4-748.6-B & 190.0 & \\
\hline 59 & G4-749.0-A & 268.0 & \\
\hline 60 & G4-749.0-B & 188.0 & \\
\hline 61 & $10 \times 12$ & 126.8 & \multirow{12}{*}{$\begin{array}{c}\text { SNSAND85070900.000 } \\
\text { [DIRS 160022] }\end{array}$} \\
\hline 62 & $10 Y 47$ & 143.2 & \\
\hline 63 & $10 Z 15$ & 158.4 & \\
\hline 64 & $12 \mathrm{~A} 2$ & 203.2 & \\
\hline 65 & $12 \mathrm{~A} 3$ & 132.2 & \\
\hline 66 & $13 \mathrm{~A} 2$ & 113.3 & \\
\hline 67 & $26 \mathrm{~A} 1$ & 200.5 & \\
\hline 68 & 26B1 & 111.7 & \\
\hline 69 & $26 \mathrm{C} 1$ & 274.3 & \\
\hline 70 & 26D1 & 198.6 & \\
\hline 71 & 26E1 & 241.3 & \\
\hline 72 & $28 \mathrm{~A} 2$ & 104.3 & \\
\hline \multicolumn{2}{|r|}{ Mean } & 188.8 & \multirow{2}{*}{ - } \\
\hline \multicolumn{2}{|r|}{ Standard Deviation } & 63.7 & \\
\hline
\end{tabular}

${ }^{\text {a }}$ Intact compressive strength data are qualified and summarized in DTN: MO0311RCKPRPCS.003 [DIRS 166073]. The data can be found by downloading the data file from this DTN, and searching for the data using the Specimen Number. The intact compressive strength data from the Tptpmn unit have been selected according to test conditions to provide a consistent data set. Data with the following test conditions were selected: ambient temperature conditions, saturated samples, nominal strain rate of $10^{-5} \mathrm{~S}^{-1}$, with sample diameters ranging from about $25.4 \mathrm{~mm}$ to $50.8 \mathrm{~mm}$. 
Table E-15. Calculated Rock Mass Properties for the Heated Drift

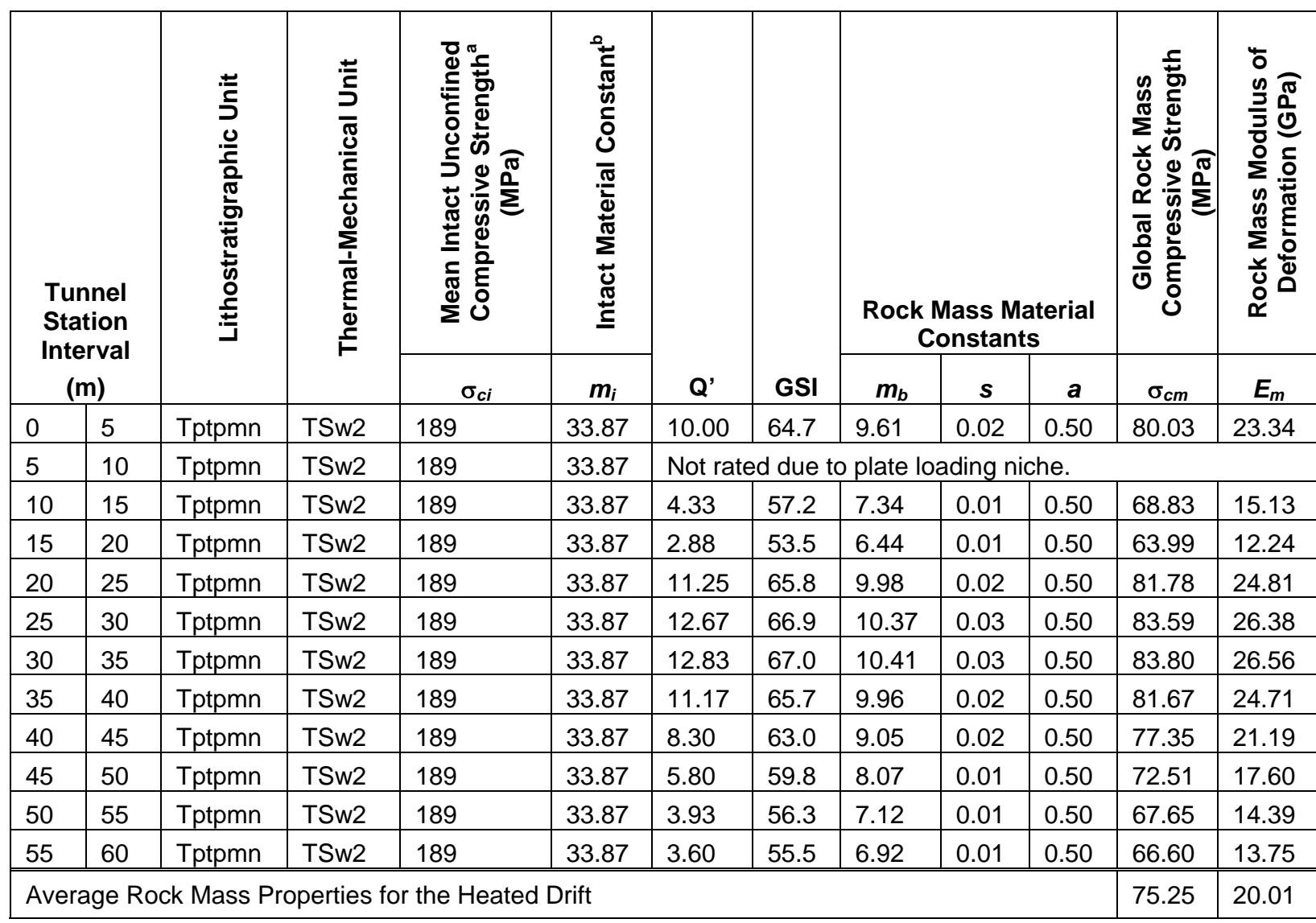

${ }^{a}$ Mean intact compressive strength is from Table E-14.

b The intact material constant, $m_{i}$, is from the Subsurface Geotechnical Parameters Report (BSC 2003 [DIRS 166660], Table 8-39).

\section{E4.3 ASSESSMENT OF ROCK MASS ELASTIC PROPERTIES FOR THERMAL MECHANICAL UNITS}

Rock mass modulus of deformation was calculated using the approach described above (Section E4.2), with the rock mass modulus calculated using either Equation E-15 or E-16, depending on the intact rock strength. The thermal-mechanical units evaluated include the TCw, PTn, TSw1, and TSw2. The required input data include Q system input parameters $R Q D, J_{n}, J_{r}$, and $J_{a}$. These data were collected in five-meter intervals throughout the ESF, and are documented in the Microsoft Excel file, rock mass strength v2.xls, in worksheet "Spatial Data" (Table A-1). The mean intact unconfined compressive strength $\sigma_{c i}$ is used to determine the appropriate equation for rock mass modulus (see Equations E-15 and E-16). The calculation of mean intact unconfined compressive strength values for each thermal-mechanical unit is documented in the Microsoft Excel file, rock mass strength v2.xls, in worksheet "Intact Strength" (Table A-1). The calculation of rock mass modulus of deformation for each five-meter tunnel interval throughout the ESF is documented in the Microsoft Excel file, rock mass strength v2.xls, in worksheet "Spatial Data" (Table A-1). Using the standard data functions of Microsoft Excel, these data were sorted by thermal-mechanical unit, rank-ordered by rock mass modulus, and placed in the worksheet, "Sorted by TM Unit". The cumulative frequency of occurrence was 
calculated in this worksheet, and five rock mass quality categories were identified for each thermal-mechanical unit to represent the range of property values, corresponding to cumulative frequencies of occurrence of 5, 20,40, 70, and 90 percent. The calculated rock mass modulus values for each thermal-mechanical unit are summarized in Table E-16. The rock mass modulus data in Table E-16 were adjusted so that the upper bound limit did not exceed the mean intact Young's modulus. Mean intact Young's modulus values for thermal-mechanical units are calculated in the Microsoft Excel file, rock mass strength v2.xls, in worksheet "Intact Strength" (Table A-1). Rock mass modulus values corresponding to rock mass category 3 were selected for use in the thermal-mechanical assessment of stress within the rock mass (Section 6.2).

Empirical relationships to estimate rock mass Poisson's ratio from rock mass classification data are not available, and in situ test Poisson's ratio data are limited. It is considered that the mean values for intact rock from each thermal-mechanical unit are representative of the rock mass Poisson's ratio (Table E-16).

\section{E4.4 ASSESSMENT OF BLOCK STRENGTH FOR NONLITHOPHYSAL ROCK}

The strength of large-scale intact rock block material (i.e., between joints) for nonlithophysal rock is calculated based on available size-effect laboratory compression test data from Price (1986 [DIRS 106589]). The size-effect data are presented in Table E-17, and plotted in Figure E-22. Figure E-22 also shows a best-fit curve of the size effect data developed by Price (1986 [DIRS 106589], p. 7) together with the Hoek and Brown (1982 [DIRS 120981], p. 156) relationship between unconfined compressive strength and specimen diameter. The equation by Price (1986 [DIRS 106589]) for the best-fit curve was used to extrapolate the size-effect data to a sample size of $3 \mathrm{~m}$ (Figure E-22). Based on this extrapolation, a strength of $70 \mathrm{MPa}$ was selected as representative of the large-scale intact rock block material for nonlithophysal rock.

Table E-16. Rock Mass Poisson's Ratio and Modulus of Deformation Values for Thermal Mechanical Units

\begin{tabular}{|c|c|c|c|c|}
\hline \multirow[b]{2}{*}{$\begin{array}{l}\text { Thermal-Mechanical } \\
\text { Unit }\end{array}$} & \multirow[b]{2}{*}{$\begin{array}{c}\text { Rock Mass Poisson's } \\
\text { Ratio }^{\mathrm{a}}\end{array}$} & \multirow[b]{2}{*}{$\begin{array}{l}\text { Rock Mass Modulus of } \\
\text { Deformation (GPa) }\end{array}$} & \multicolumn{2}{|c|}{ Data Range } \\
\hline & & & $\begin{array}{c}\text { Rock Mass } \\
\text { Modulus of } \\
\begin{array}{c}\text { Deformation, Em } \\
(\mathrm{GPa})\end{array} \\
\end{array}$ & $\begin{array}{c}\text { Rock Mass } \\
\text { Quality } \\
\text { Category }\end{array}$ \\
\hline \multirow{5}{*}{ TCw } & \multirow{5}{*}{0.22} & \multirow{5}{*}{16.1} & 7.3 & 1 \\
\hline & & & 12.9 & 2 \\
\hline & & & 16.1 & 3 \\
\hline & & & 23.2 & 4 \\
\hline & & & 27.8 & 5 \\
\hline \multirow{5}{*}{ PTn } & \multirow{5}{*}{0.23} & \multirow{5}{*}{2.2} & 2.2 & 1 \\
\hline & & & 2.2 & 2 \\
\hline & & & 2.2 & 3 \\
\hline & & & 2.2 & 4 \\
\hline & & & 2.2 & 5 \\
\hline
\end{tabular}


Table E-16. Rock Mass Poisson's Ratio and Modulus of Deformation Values for Thermal Mechanical Units (Continued)

\begin{tabular}{|c|c|c|c|c|}
\hline \multirow[b]{2}{*}{$\begin{array}{c}\text { Thermal-Mechanical } \\
\text { Unit }\end{array}$} & \multirow[b]{2}{*}{$\begin{array}{c}\text { Rock Mass Poisson's } \\
\text { Ratio }^{\mathrm{a}}\end{array}$} & \multirow[b]{2}{*}{$\begin{array}{c}\text { Rock Mass Modulus of } \\
\text { Deformation (GPa) }\end{array}$} & \multicolumn{2}{|c|}{ Data Range } \\
\hline & & & $\begin{array}{c}\text { Rock Mass } \\
\begin{array}{c}\text { Modulus of } \\
\text { Deformation, Em } \\
(\mathrm{GPa})\end{array} \\
\end{array}$ & $\begin{array}{c}\text { Rock Mass } \\
\text { Quality } \\
\text { Category }\end{array}$ \\
\hline \multirow{5}{*}{ TSw1 } & \multirow{5}{*}{0.25} & \multirow{5}{*}{17.3} & 8.6 & 1 \\
\hline & & & 12.8 & 2 \\
\hline & & & 17.3 & 3 \\
\hline & & & 23.5 & 4 \\
\hline & & & 23.5 & 5 \\
\hline \multirow{5}{*}{ TSw2 } & \multirow{5}{*}{0.21} & \multirow{5}{*}{15.8} & 9.4 & 1 \\
\hline & & & 12.9 & 2 \\
\hline & & & 15.8 & 3 \\
\hline & & & 21.5 & 4 \\
\hline & & & 28.0 & 5 \\
\hline
\end{tabular}

${ }^{\text {a }}$ Recent field test data in the Tptpll that indicate a mean rock mass Poisson's ratio of 0.2

(DTN: SN0208F4102102.002 [DIRS 161874]) compared to a mean intact Poisson's ratio of 0.21 (CRWMS M\&O 1997 [DIRS 103564], Table 5-27). Therefore, rock mass Poisson's ratio values in this table are based on laboratory test data. The calculation of mean Poisson's ratio values is documented in the Microsoft Excel file, rock mass strength v2.xls, in worksheet "Intact Strength" (Table A-1).

Table E-17. Size-Effect Laboratory Compression Test Data for Nonlithophysal Rock

\begin{tabular}{|c|c|c|c|c|}
\hline Row \# & Test & Specimen Number & $\begin{array}{c}\text { Specimen Diameter } \\
(\mathrm{mm})\end{array}$ & $\begin{array}{l}\text { Uniaxial Compressive } \\
\text { Strength, }\left(\sigma_{\mathrm{ax}}\right)_{\mathrm{u}}(\mathrm{MPa})\end{array}$ \\
\hline 1 & 1 & $12 \mathrm{~A} 2$ & 25.4 & 203.2 \\
\hline 2 & 1 & $12 \mathrm{~A} 3$ & 25.4 & 132.2 \\
\hline 3 & 1 & $13 \mathrm{~A} 2$ & 25.4 & 113.3 \\
\hline 4 & 2 & $26 \mathrm{C} 1$ & 25.4 & 274.3 \\
\hline 5 & 2 & $26 \mathrm{D} 1$ & 25.4 & 198.6 \\
\hline 6 & 2 & 26E1 & 25.4 & 241.3 \\
\hline \multicolumn{4}{|l|}{ Mean value } & 193.82 \\
\hline 7 & 1 & $10 \times 12$ & 50.8 & 126.8 \\
\hline 8 & 1 & $10 Y 47$ & 50.8 & 143.2 \\
\hline 9 & 1 & $10 Z 15$ & 50.8 & 158.4 \\
\hline 10 & 2 & $26 \mathrm{~A} 1$ & 50.8 & 200.5 \\
\hline 11 & 2 & 26B1 & 50.8 & 111.7 \\
\hline 12 & 2 & $28 \mathrm{~A} 2$ & 50.8 & 104.3 \\
\hline \multicolumn{4}{|l|}{ Mean value } & 140.82 \\
\hline \begin{tabular}{|l|}
13 \\
\end{tabular} & 1 & 10E3 & 82.6 & 141.7 \\
\hline 14 & 1 & 10E4 & 82.6 & 99.8 \\
\hline 15 & 1 & $11 \mathrm{~A} 1$ & 82.6 & 130.6 \\
\hline 16 & 1 & $11 \mathrm{~A} 2$ & 82.6 & 87.7 \\
\hline
\end{tabular}


Table E-17. Size-Effect Laboratory Compression Test Data for Nonlithophysal Rock (Continued)

\begin{tabular}{|c|c|c|c|c|}
\hline Row \# & Test & Specimen Number & $\begin{array}{c}\text { Specimen Diameter } \\
(\mathrm{mm})\end{array}$ & $\begin{array}{l}\text { Uniaxial Compressive } \\
\text { Strength, }\left(\sigma_{\mathrm{ax}}\right)_{\mathrm{u}}(\mathrm{MPa})\end{array}$ \\
\hline 17 & 1 & $11 \mathrm{C1}$ & 82.6 & 124.3 \\
\hline 18 & 1 & 11D1 & 82.6 & 131.8 \\
\hline 19 & 2 & 211 & 82.6 & 160.7 \\
\hline 20 & 2 & 231 & 82.6 & 140.7 \\
\hline 21 & 2 & 271 & 82.6 & 58.9 \\
\hline \multicolumn{4}{|l|}{ Mean value } & 119.57 \\
\hline 22 & 1 & 10A1 & 127.0 & 59.9 \\
\hline 23 & 1 & 10A2 & 127.0 & 84.3 \\
\hline 24 & 1 & $10 \mathrm{C} 1$ & 127.0 & 92.4 \\
\hline 25 & 1 & $10 \mathrm{C} 2$ & 127.0 & 98.2 \\
\hline 26 & 1 & 10D1 & 127.0 & 89.8 \\
\hline 27 & 1 & 10D2 & 127.0 & 69.7 \\
\hline 28 & 2 & 221 & 127.0 & 134.3 \\
\hline 29 & 2 & 234 & 127.0 & 85.8 \\
\hline 30 & 2 & 261 & 127.0 & 170.8 \\
\hline 31 & 2 & 281 & 127.0 & 90.4 \\
\hline 32 & 2 & 282 & 127.0 & 98.8 \\
\hline \multicolumn{4}{|l|}{ Mean value } & 97.67 \\
\hline 33 & 2 & 222 & 228.6 & 86.9 \\
\hline 34 & 2 & 282 & 228.6 & 93.4 \\
\hline \multicolumn{4}{|l|}{ Mean value } & 90.14 \\
\hline
\end{tabular}

Source: DTN: MO0311RCKPRPCS.003 [DIRS 166073] (see native data file, DTN SEP data file revised2.xIs, rows 519-528, 532-533, and 542-563, from worksheet "basic data DTN"). 


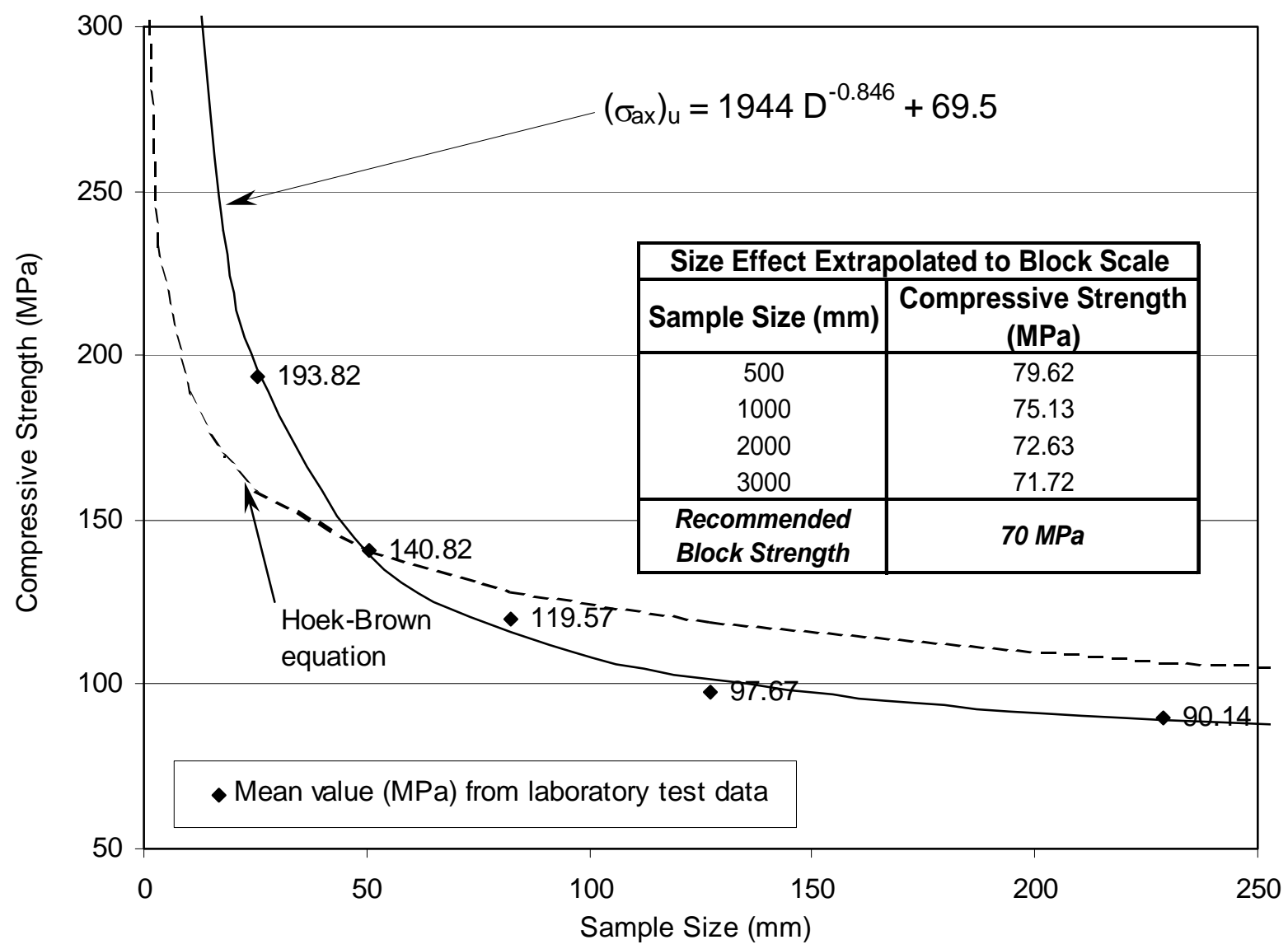

Source: Laboratory test data provided in Table E-17. Hoek-Brown equation based on Hoek and Brown (1982 [DIRS 120981], p. 156).

Figure E-22. Sample Size Effect on Compressive Strength Based on Laboratory Test Data for Nonlithophysal Rock

\section{E5. THERMAL PROPERTIES}

The thermal properties used in the thermal mechanical calculation of stresses at Yucca Mountain due to heating and cooling of the repository (Section 6.2), are provided in this section. These data include thermal conductivity (Table E-18), specific heat (Table E-19), and thermal expansion for saturated rock (Table E-20) for the various lithostratigraphic and thermal-mechanical units of the Yucca Mountain rock strata. The mean values for thermal-mechanical units are determined by averaging the thermal properties of the lithostratigraphic units within each thermal-mechanical unit, weighted according to the thickness of each lithostratigraphic unit. Additional details are provided in the Microsoft Excel file, thermal properties TM units v2.xls (Table A-1). 
Table E-18. Thermal Conductivity for Various Thermal Mechanical Units and Associated Lithostratigraphic Units

\begin{tabular}{|c|c|c|c|c|c|}
\hline \multirow{2}{*}{$\begin{array}{c}\text { Thermal Mechanical } \\
\text { Unit }\end{array}$} & \multirow{2}{*}{ Stratigraphic Unit } & \multirow[b]{2}{*}{ Thickness $^{\mathrm{a}}(\mathrm{m})$} & \multicolumn{2}{|c|}{$\begin{array}{c}\text { Thermal Conductivity } \\
\left(\mathrm{W} / \mathrm{m}^{\circ} \mathrm{K}\right)\end{array}$} & \multirow[b]{2}{*}{ DTN $^{c}$} \\
\hline & & & $\mathrm{T} \leq 100^{\circ} \mathrm{C}$ & $\mathrm{T}>100^{\circ} \mathrm{C}$ & \\
\hline \multirow{11}{*}{ TCw / PTn } & Tpcpv3 & 0.0 & 0.80 & 0.69 & \multirow{14}{*}{$\begin{array}{c}\text { SN0303T0503102.008 } \\
\text { [DIRS 162401] }\end{array}$} \\
\hline & Tpcpv2 & 5.1 & 1.06 & 0.49 & \\
\hline & Tpcpv1 & 2.4 & 1.06 & 0.49 & \\
\hline & Tpbt4 & 0.5 & 1.06 & 0.49 & \\
\hline & Tpy & 3.8 & 1.06 & 0.49 & \\
\hline & Tpbt3 & 3.8 & 1.06 & 0.49 & \\
\hline & Tpp & 5.1 & 1.06 & 0.49 & \\
\hline & Tpbt2 & 8.3 & 1.06 & 0.49 & \\
\hline & Tptrv3 & 1.9 & 1.06 & 0.49 & \\
\hline & Tptrv2 & 1.2 & 1.06 & 0.49 & \\
\hline & \multicolumn{2}{|c|}{ Mean (weighted by unit thickness) } & 1.06 & 0.49 & \\
\hline \multirow{5}{*}{ TSw1 } & Tptrv1 & 1.2 & 0.80 & 0.69 & \\
\hline & Tptrn & 35.6 & 1.81 & 1.30 & \\
\hline & Tptrl & 6.1 & 1.81 & 1.30 & \\
\hline & Tptpul & 66.8 & 1.77 & 1.18 & \multirow{5}{*}{$\begin{array}{l}\text { SN0404T0503102.011 } \\
\text { [DIRS 169129] }\end{array}$} \\
\hline & Mean (weighted $b$ & v unit thickness) & 1.77 & 1.22 & \\
\hline \multirow{5}{*}{ TSw2 / TSw3 } & Tptpmn & 38.3 & 2.07 & 1.42 & \\
\hline & Tptpll & 95.6 & 1.89 & 1.28 & \\
\hline & Tptpln & 55.1 & 2.13 & 1.49 & \\
\hline & Tptpv3 & 12.0 & 0.80 & 0.69 & \multirow{8}{*}{$\begin{array}{l}\text { SN0303T0503102.008 } \\
\text { [DIRS 162401] }\end{array}$} \\
\hline & \multicolumn{2}{|c|}{ Mean (weighted by unit thickness) } & 1.92 & 1.33 & \\
\hline \multirow{6}{*}{$\mathrm{CHn} 1 / \mathrm{CHn} 2$} & Tptpv2 & 4.7 & 1.06 & 0.49 & \\
\hline & Tptpv1 & 15.4 & 1.06 & 0.49 & \\
\hline & Tpbt1 & 2.0 & 1.06 & 0.49 & \\
\hline & Calico & 45.5 & 1.26 & 0.60 & \\
\hline & Calicobt & 15.9 & 1.26 & 0.60 & \\
\hline & Mean (weighted b) & v unit thickness) & 1.21 & 0.57 & \\
\hline
\end{tabular}

${ }^{a}$ Thickness of units extracted from DTN: MO0012MWDGFM02.002 [DIRS 153777]. The details of this extraction are provided in Appendix M.

${ }^{\mathrm{b}} \mathrm{T}=$ temperature.

${ }^{\mathrm{C}}$ Mean values are calculated in this report and not provided by the DTNs listed in this table. Data extracted from DTN: SN0404T0503102.11 [DIRS 169129] are summarized in BSC 2004 [DIRS 169854] , Table 7-10. Data extracted from DTN: SN0303T0503102.008 [DIRS 162401] are summarized in BSC 2004 [DIRS 170033], Table 6-13. 
Table E-19. Specific Heat for Various Thermal Mechanical Units and Associated Lithostratigraphic Units

\begin{tabular}{|c|c|c|c|c|c|c|}
\hline \multirow{2}{*}{$\begin{array}{c}\text { Thermal } \\
\text { Mechanical } \\
\text { Unit }\end{array}$} & \multirow{2}{*}{$\underset{\text { Unit }}{\text { Stratigraphic }}$} & \multirow[b]{2}{*}{ Thickness $^{\mathrm{a}}(\mathrm{m})$} & \multicolumn{3}{|c|}{ Specific Heat ${ }^{\mathrm{b}}\left(\mathrm{J} / \mathrm{kg}^{\circ} \mathrm{K}\right)$} & \multirow[b]{2}{*}{ DTN $^{c}$} \\
\hline & & & $\mathrm{T} \leq 95^{\circ} \mathrm{C}$ & $95^{\circ} \mathrm{C}<\mathrm{T}<114^{\circ} \mathrm{C}$ & $\mathrm{T}>114^{\circ} \mathrm{C}$ & \\
\hline \multirow{11}{*}{$\mathrm{TCw} / \mathrm{PTn}$} & Tpcpv3 & 0.0 & $1.2 \mathrm{E}+03$ & $8.4 \mathrm{E}+03$ & $1.0 \mathrm{E}+03$ & \multirow{27}{*}{$\begin{array}{c}\text { SN0307T0510902.003 } \\
\text { [DIRS 164196] }\end{array}$} \\
\hline & Tpcpv2 & 5.1 & $1.2 \mathrm{E}+03$ & $8.4 \mathrm{E}+03$ & $1.0 \mathrm{E}+03$ & \\
\hline & Tpcpv1 & 2.4 & $1.3 \mathrm{E}+03$ & $9.1 \mathrm{E}+03$ & $1.0 \mathrm{E}+03$ & \\
\hline & Tpbt4 & 0.5 & $1.3 \mathrm{E}+03$ & $9.1 \mathrm{E}+03$ & $1.0 \mathrm{E}+03$ & \\
\hline & Tpy & 3.8 & $1.3 \mathrm{E}+03$ & $9.1 \mathrm{E}+03$ & $1.0 \mathrm{E}+03$ & \\
\hline & Tpbt3 & 3.8 & $1.3 \mathrm{E}+03$ & $9.1 \mathrm{E}+03$ & $1.0 \mathrm{E}+03$ & \\
\hline & Tpp & 5.1 & $1.3 \mathrm{E}+03$ & $9.1 \mathrm{E}+03$ & $1.0 \mathrm{E}+03$ & \\
\hline & Tpbt2 & 8.3 & $1.3 \mathrm{E}+03$ & $9.1 \mathrm{E}+03$ & $1.0 \mathrm{E}+03$ & \\
\hline & Tptrv3 & 1.9 & $1.3 \mathrm{E}+03$ & $9.1 \mathrm{E}+03$ & $1.0 \mathrm{E}+03$ & \\
\hline & Tptrv2 & 1.2 & $1.3 \mathrm{E}+03$ & $9.1 \mathrm{E}+03$ & $1.0 \mathrm{E}+03$ & \\
\hline & \multicolumn{2}{|c|}{ Mean (weighted by unit thickness) } & 1.3E+03 & $9.0 E+03$ & $1.0 E+03$ & \\
\hline \multirow{5}{*}{ TSw1 } & Tptrv1 & \begin{tabular}{|l|}
1.2 \\
\end{tabular} & $8.9 \mathrm{E}+02$ & $1.8 \mathrm{E}+03$ & $9.9 \mathrm{E}+02$ & \\
\hline & Tptrn & 35.6 & $8.9 \mathrm{E}+02$ & $2.7 \mathrm{E}+03$ & $9.9 \mathrm{E}+02$ & \\
\hline & Tptrl & 6.1 & $8.9 \mathrm{E}+02$ & $2.7 \mathrm{E}+03$ & $9.9 \mathrm{E}+02$ & \\
\hline & Tptpul & 66.8 & $9.4 \mathrm{E}+02$ & $3.6 \mathrm{E}+03$ & $9.9 \mathrm{E}+02$ & \\
\hline & \multicolumn{2}{|c|}{ Mean (weighted by unit thickness) } & $9.2 E+02$ & $3.2 E+03$ & $9.9 E+02$ & \\
\hline \multirow{5}{*}{ TSw2 / TSw3 } & Tptpmn & 38.3 & $9.1 \mathrm{E}+02$ & $3.0 \mathrm{E}+03$ & $9.9 \mathrm{E}+02$ & \\
\hline & Tptpll & 95.6 & $9.3 \mathrm{E}+02$ & $3.3 \mathrm{E}+03$ & $9.9 \mathrm{E}+02$ & \\
\hline & Tptpln & 55.1 & $9.0 \mathrm{E}+02$ & $2.8 \mathrm{E}+03$ & $9.9 \mathrm{E}+02$ & \\
\hline & Tptpv3 & 12.0 & $9.1 \mathrm{E}+02$ & 1.7E+03 & $1.0 \mathrm{E}+03$ & \\
\hline & \multicolumn{2}{|c|}{ Mean (weighted by unit thickness) } & $9.1 E+02$ & $3.0 E+03$ & $9.9 E+02$ & \\
\hline \multirow{6}{*}{$\mathrm{CHn} 1 / \mathrm{CHn} 2$} & Tptpv2 & \begin{tabular}{|l|}
4.7 \\
\end{tabular} & $1.1 \mathrm{E}+03$ & $5.1 \mathrm{E}+03$ & $1.0 \mathrm{E}+03$ & \\
\hline & Tptpv1 & 15.4 & $1.2 \mathrm{E}+03$ & $6.4 \mathrm{E}+03$ & $1.1 \mathrm{E}+03$ & \\
\hline & Tpbt1 & 2.0 & $1.2 \mathrm{E}+03$ & $6.4 \mathrm{E}+03$ & $1.1 \mathrm{E}+03$ & \\
\hline & Calico & 45.5 & $1.4 \mathrm{E}+03$ & $9.8 \mathrm{E}+03$ & $1.1 \mathrm{E}+03$ & \\
\hline & Calicobt & 15.9 & $1.2 \mathrm{E}+03$ & $7.6 \mathrm{E}+03$ & $1.1 \mathrm{E}+03$ & \\
\hline & \multicolumn{2}{|c|}{ Mean (weighted by unit thickness) } & $1.3 E+03$ & $8.4 E+03$ & $1.1 E+03$ & \\
\hline
\end{tabular}

${ }^{\mathrm{a}}$ Thickness of units provided in Appendix $\mathrm{M}$.

${ }^{\mathrm{b}} \mathrm{T}=$ temperature.

${ }^{\mathrm{c}}$ Mean values are calculated in this report and not provided by the DTNs listed in this table.

Table E-20. Thermal Expansion for Various Thermal Mechanical Units

\begin{tabular}{|c|c|c|c|c|}
\hline \multirow{2}{*}{$\begin{array}{c}\text { Thermal } \\
\text { Mechanical Unit }\end{array}$} & \multicolumn{4}{|c|}{ Thermal Expansion Coefficient $\left({ }^{\circ} \mathbf{C}\right)$} \\
\cline { 2 - 5 } & $\mathbf{2 5}^{\circ} \mathbf{C}<\mathbf{T} \leq \mathbf{5 0}^{\circ} \mathbf{C}$ & $\mathbf{5 0}^{\circ} \mathbf{C}<\mathbf{T} \leq \mathbf{7 5 ^ { \circ }} \mathbf{C}$ & $\mathbf{7 5}^{\circ} \mathbf{C}<\mathbf{T} \leq \mathbf{1 0 0 ^ { \circ } \mathbf { C }}$ & $\mathbf{1 0 0}^{\circ} \mathbf{C}<\mathbf{T} \leq \mathbf{1 2 5}^{\circ} \mathbf{C}$ \\
\hline TCW & $7.09 \times 10^{-6}$ & $7.62 \times 10^{-6}$ & $8.08 \times 10^{-6}$ & $10.34 \times 10^{-6}$ \\
\hline PTn & $4.46 \times 10^{-6}$ & $4.28 \times 10^{-6}$ & $-1.45 \times 10^{-6}$ & $-30.42 \times 10^{-6}$ \\
\hline TSw1 & $6.56 \times 10^{-6}$ & $7.32 \times 10^{-6}$ & $6.83 \times 10^{-6}$ & $6.92 \times 10^{-6}$ \\
\hline TSw2 & $7.14 \times 10^{-6}$ & $7.47 \times 10^{-6}$ & $7.46 \times 10^{-6}$ & $9.07 \times 10^{-6}$ \\
\hline
\end{tabular}

$T=$ temperature

NOTE: Source data provided by DTN: SNL01B05059301.006 [DIRS 129168]. Thermal expansion data are for saturated rock. The calculation of mean data is documented in Brodsky et al. (1997 [DIRS 100653], Table 4-4). 


\section{APPENDIX F}

FIELD OBSERVATION OF KEY BLOCKS IN THE ECRB CROSS-DRIFT 


\section{FIELD OBSERVATION OF KEY BLOCKS IN THE ECRB CROSS-DRIFT}

This appendix documents the observation of key blocks in the ECRB Cross-Drift, including the Tptpul unit (Stations $0+00$ to $10+15$ ), the Tptpmn unit (Stations $10+15$ to $14+44$ ), the Tptpll unit (Stations 14+44 to 23+26), and the Tptpln unit (Stations 23+26 to 25+85) (Mongano et al. 1999 [DIRS 149850], pp. 105 and 106). Additional descriptions of key blocks in the ECRB Cross-Drift are provided in Section 6.1.5. Portions of the full periphery geologic maps containing key blocks are presented in Figures F-1 through F-14. An explanation of symbols on the full periphery geologic maps is provided in Figure F-1. The potential key blocks are identified on these maps as exposed fracture faces bounded by joints. The number of blocks per kilometer observed in the ECRB Cross-Drift (Table F-1) was determined by identifying the number of key blocks in each lithologic unit as indicated in Figures F-2 through F-14 over the total length of drift in the unit.

Table F-1. Number of Key Blocks Observed in the ECRB Cross-Drift

\begin{tabular}{|c|c|c|c|c|}
\hline Lithologic Unit & $\begin{array}{c}\text { Metric Stationing }{ }^{a} \\
(\mathrm{~m})\end{array}$ & $\begin{array}{l}\text { Length of Drift } \\
(\mathrm{km})\end{array}$ & Number of Blocks ${ }^{c}$ & $\begin{array}{l}\text { Blocks per } \\
\text { Kilometer }\end{array}$ \\
\hline Tptpul & $0+00$ to $10+15$ & 1.02 & 3 & 3 \\
\hline Tptpmn & $10+15$ to $14+44$ & 0.43 & 17 & 40 \\
\hline Tptpll & $14+44$ to $23+26$ & 0.88 & 0 & 0 \\
\hline Tptpln & $23+26$ to $25+85$ & 0.26 & 2 & 8 \\
\hline
\end{tabular}

${ }^{a}$ Mongano et al. (1999 [DIRS 149850], pp. 105 and 106).

b Based on metric stationing (e.g., for the Tptpmn unit, length $=(1444 \mathrm{~m}-1015 \mathrm{~m}) / 1000=0.43 \mathrm{~km})$.

c The observation of key blocks is documented in Figures F-2 through F-14. 


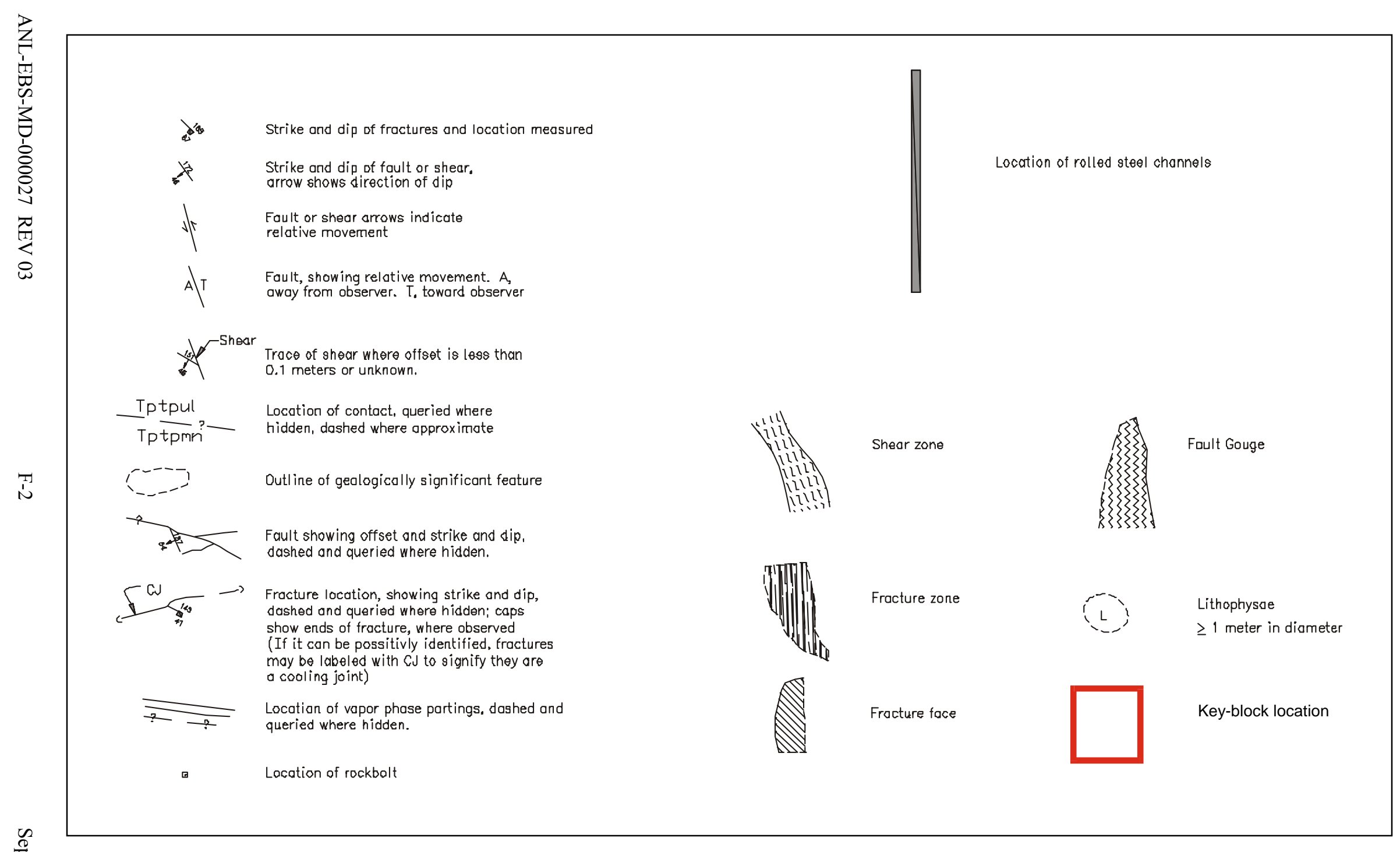

Figure F-1. Explanation of Symbols on Full Periphery Geologic Maps 


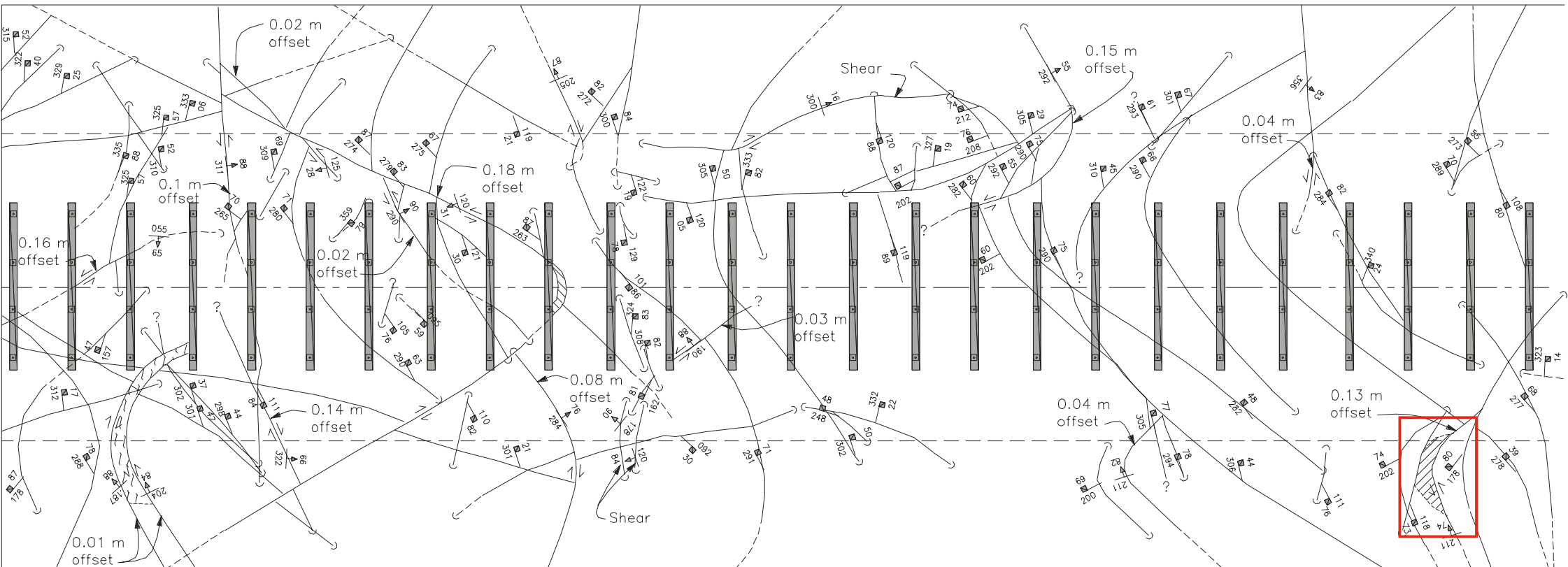

Source: GS990408314224.003 [DIRS 108404].

Figure F-2. Key-Block Location, Tptpul Unit, ECRB Cross-Drift Stations 8+60 to 9+00 


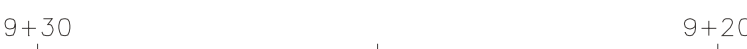

Source: GS990408314224.003 [DIRS 108404].

Figure F-3. Key-Block Location, Tptpul Unit, ECRB Cross-Drift Stations 9+00 to 9+30 


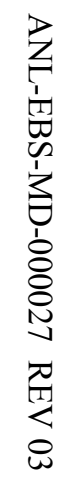

茫

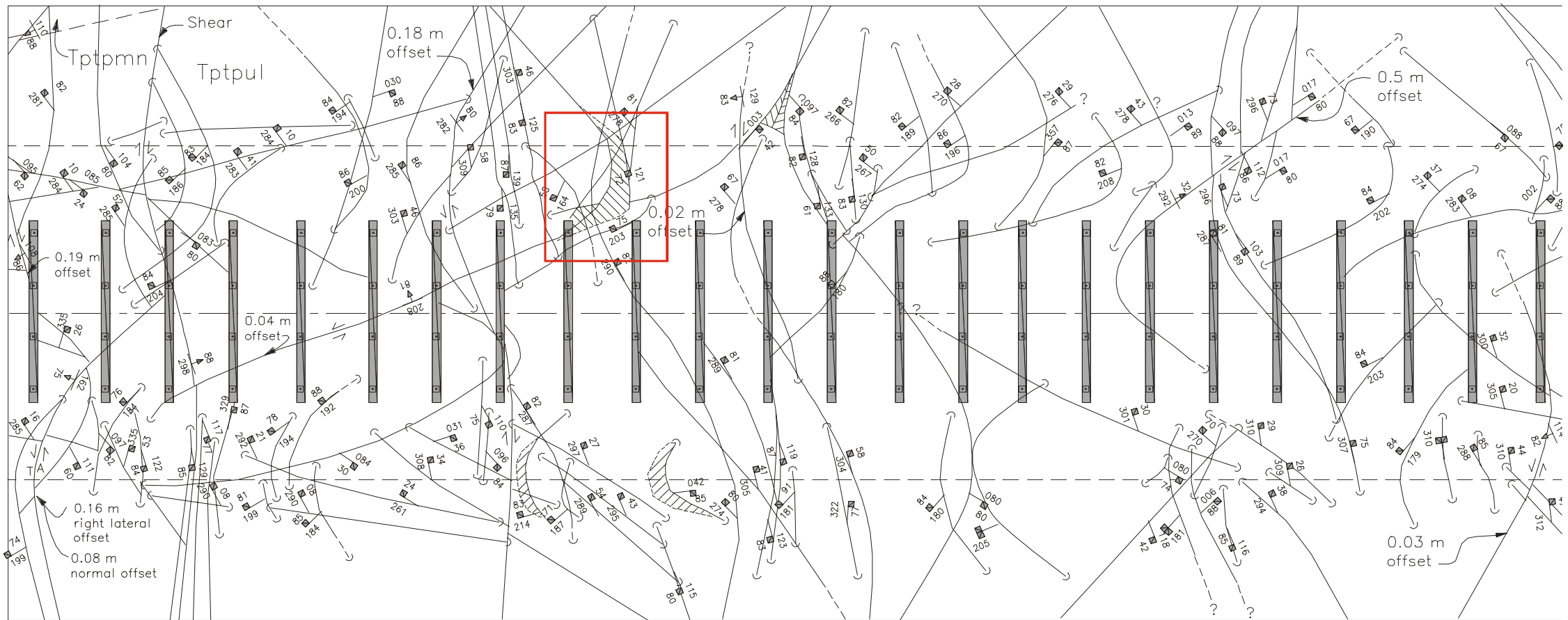

$0+00$

$9+90$

Source: GS990408314224.003 [DIRS 108404].

Figure F-4. Key-Block Location, Tptpul Unit, ECRB Cross-Drift Stations 9+64 to 10+00 


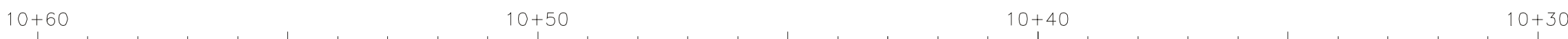

Source: GS990408314224.004 [DIRS 108405].

Figure F-5. Key-Block Location, Tptpmn Unit, ECRB Cross-Drift Stations $10+30$ to 10+60 
Source: GS990408314224.004 [DIRS 108405].

Figure F-6. Key-Block Location, Tptpmn Unit, ECRB Cross-Drift Stations 10+60 to 11+00 
$12+00$

$+90$

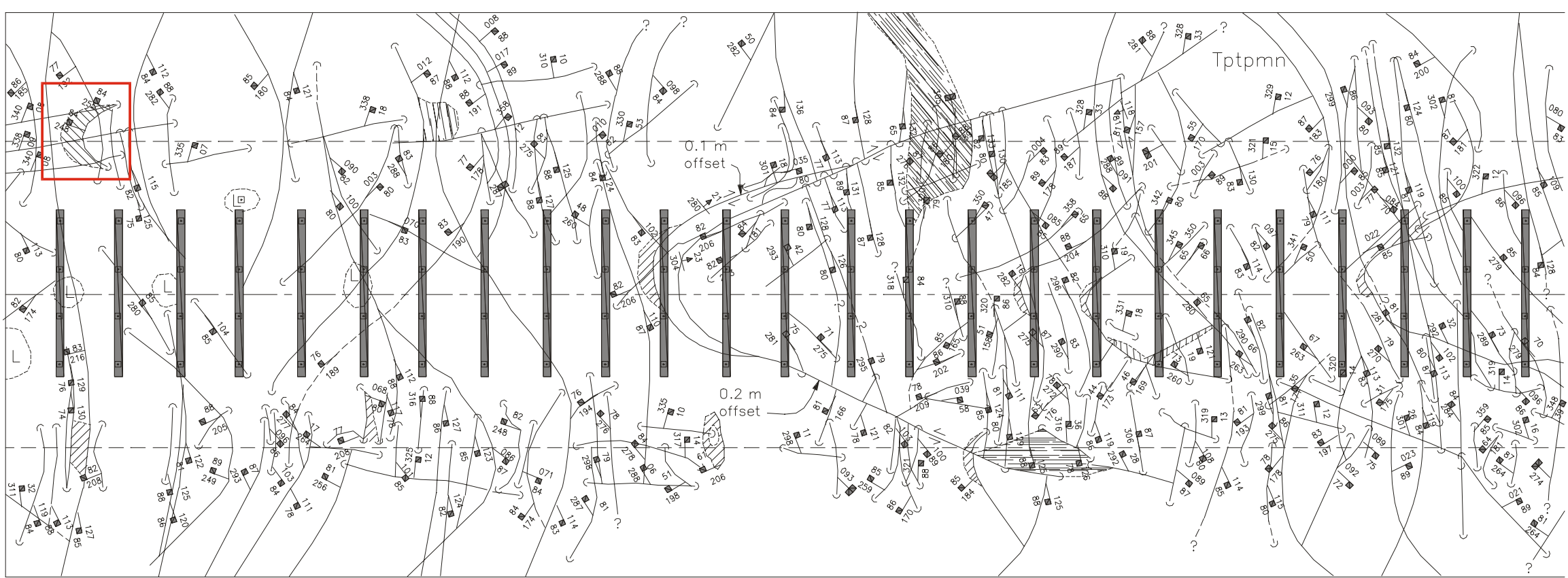

Source: GS990408314224.004 [DIRS 108405].

Figure F-9. Key-Block Location, Tptpmn Unit, ECRB Cross-Drift Stations $11+60$ to 12+00 


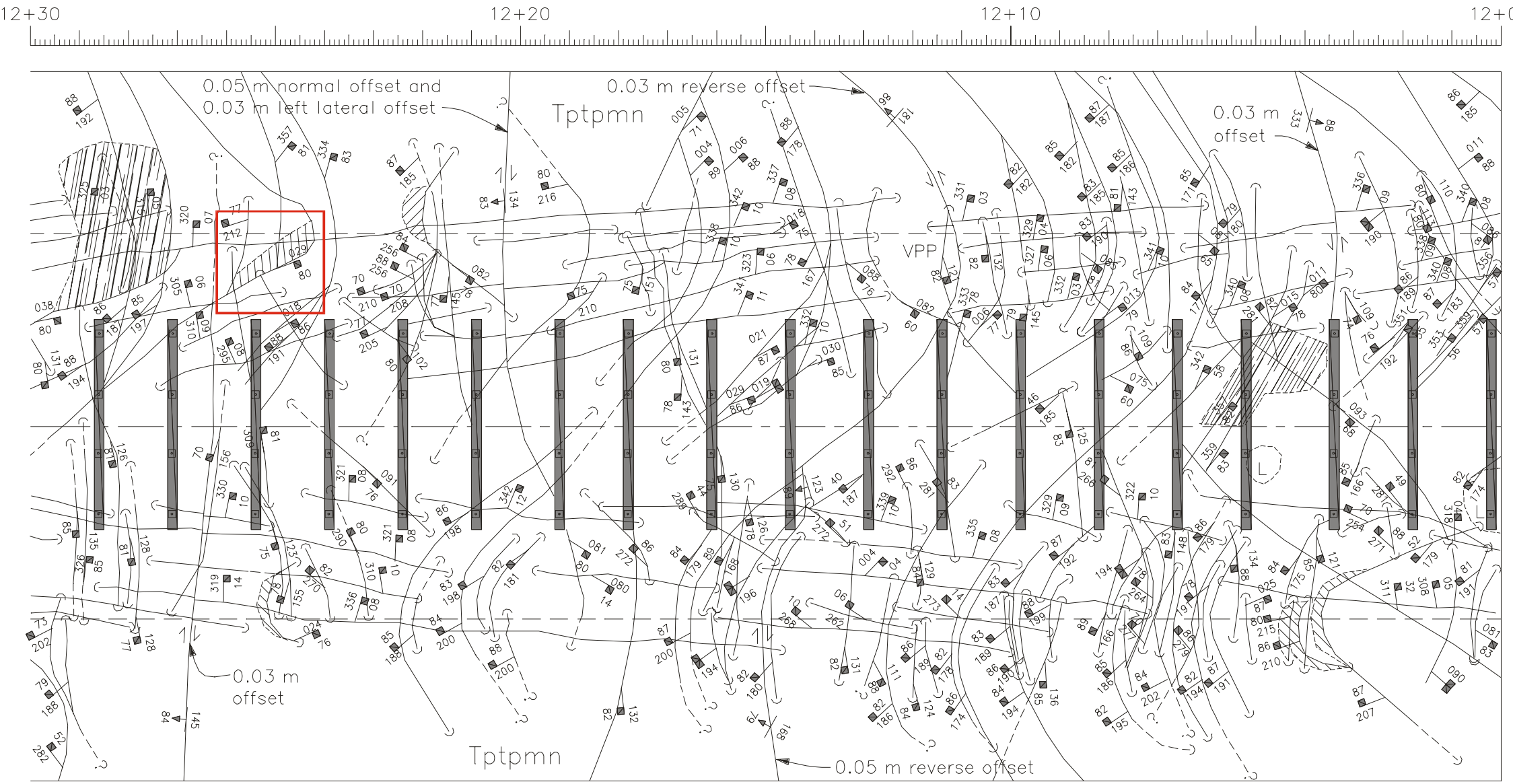


$3+80-13-70$

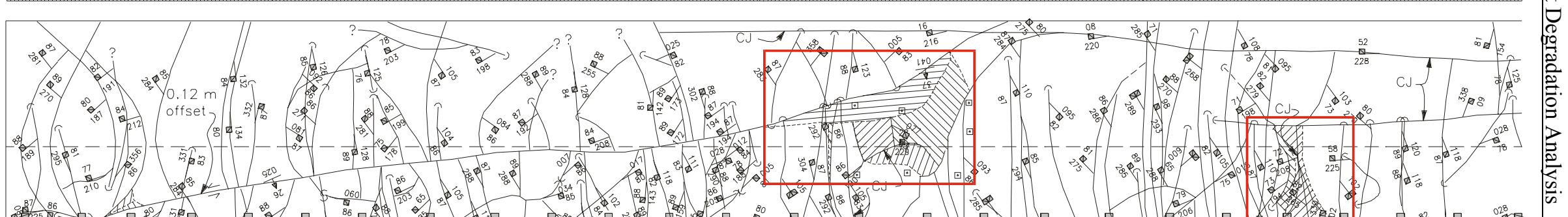

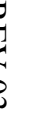
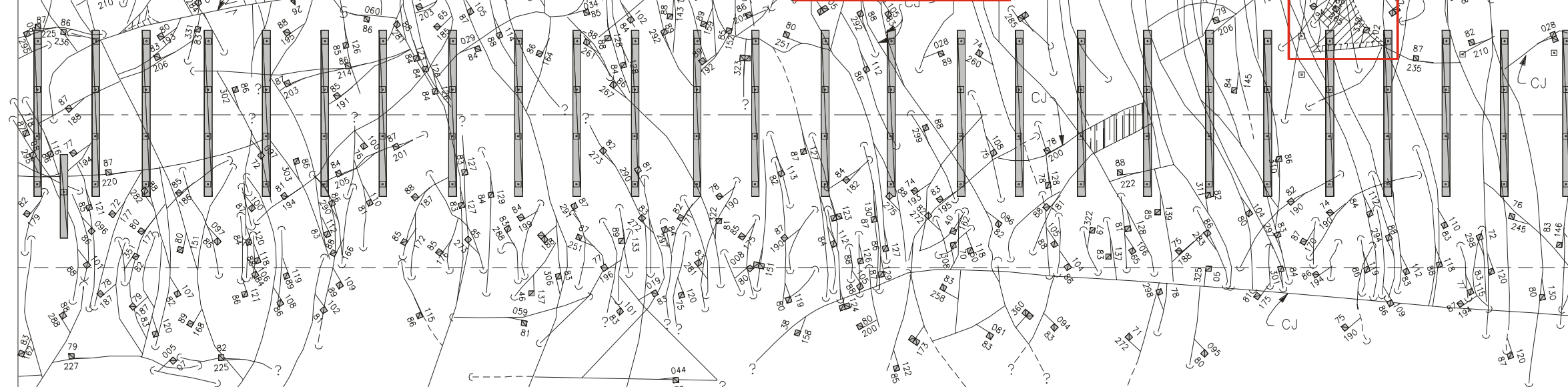

$14+00$

$13+90$

$13+80$

Source: GS990408314224.004 [DIRS 108405].

Figure F-12. Key-Block Location, Tptpmn Unit, ECRB Cross-Drift Stations $13+60$ to $14+00$ 


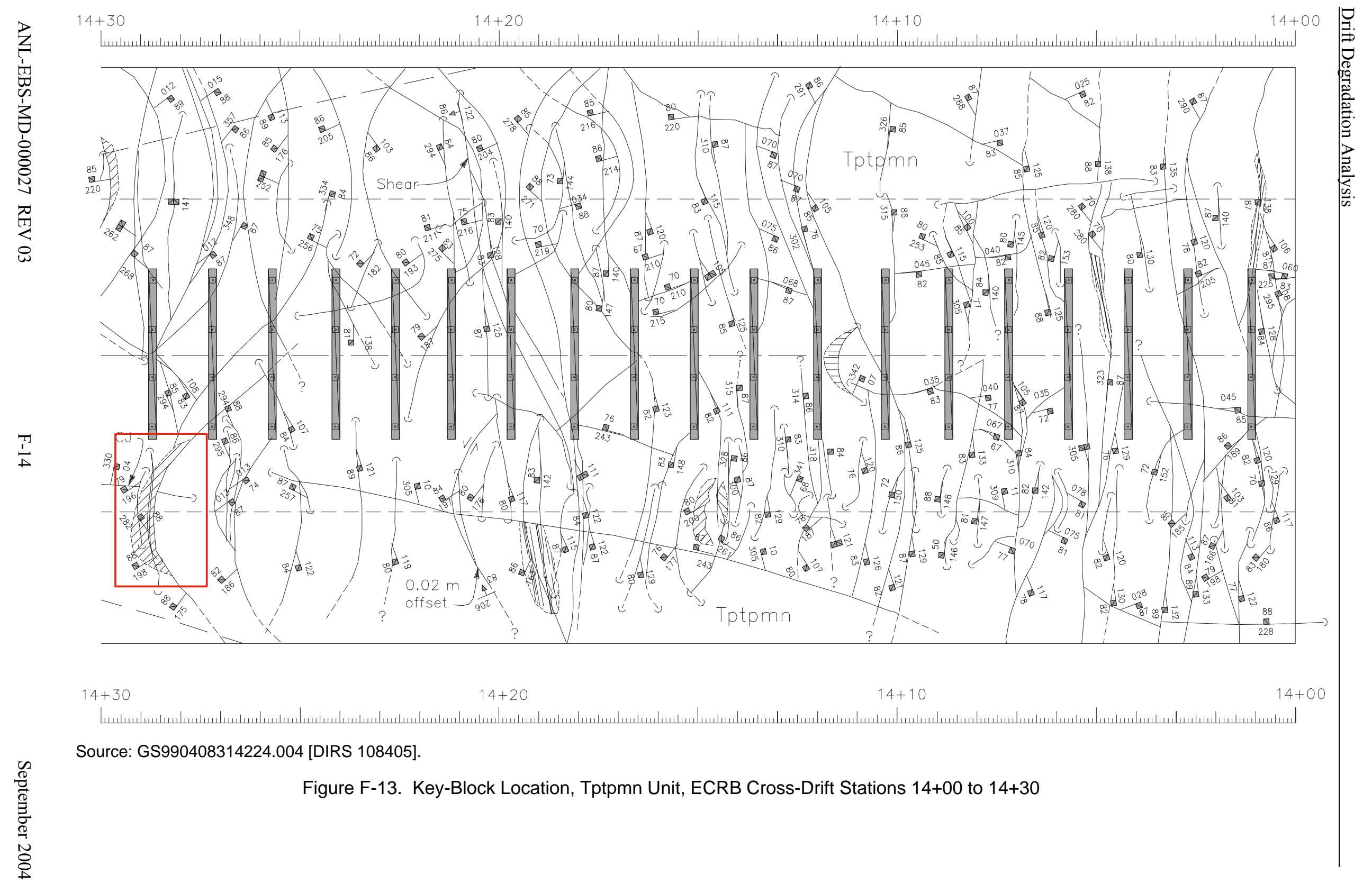




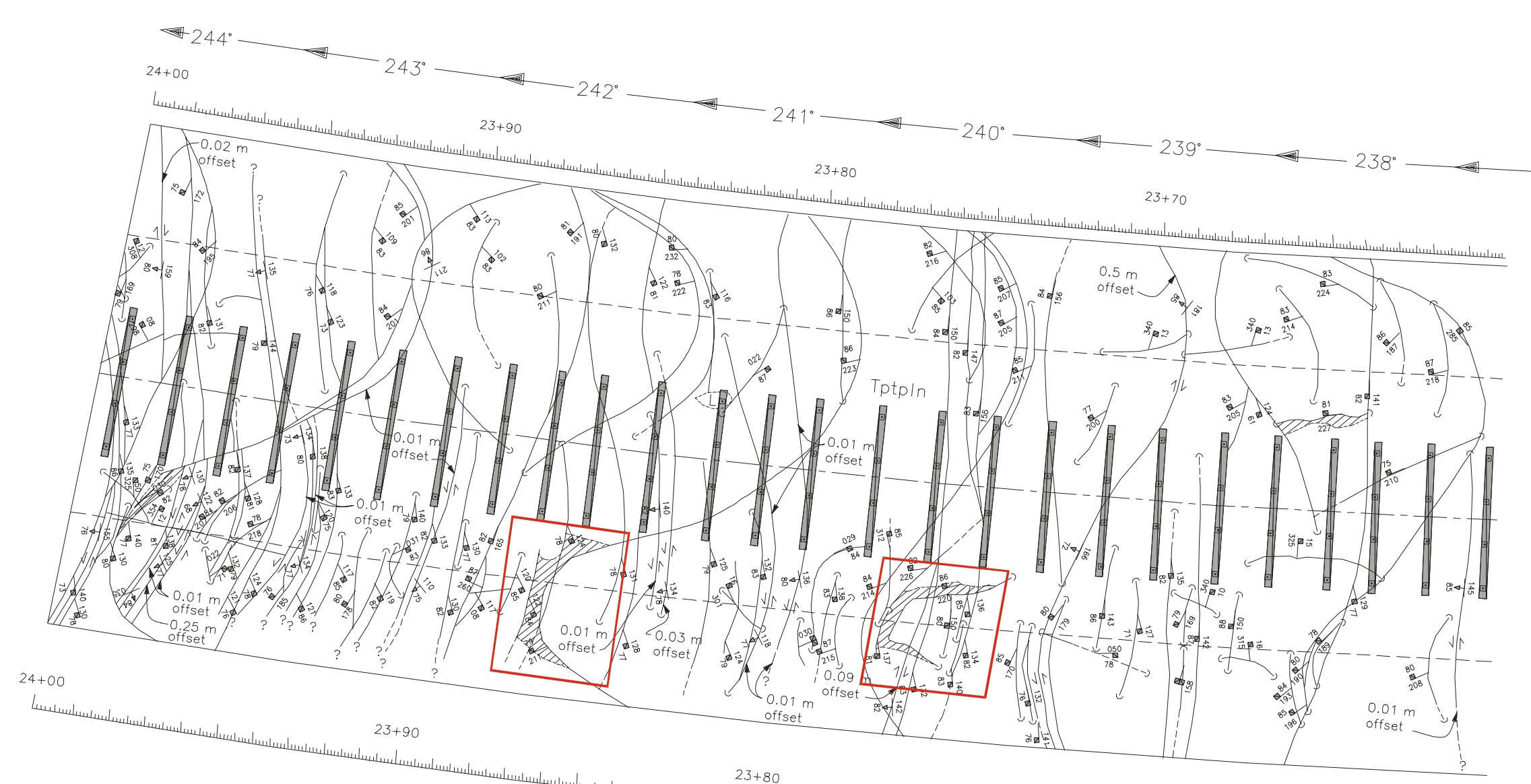

Source: GS990408314224.006 [DIRS 108409].

Figure F-14. Key-Block Location, Tptpln Unit, ECRB Cross-Drift Stations $23+65$ to 24+00 


\section{INTENTIONALLY LEFT BLANK}


APPENDIX G

NATURAL ANALOGUES OF THE EFFECT OF SEISMIC EVENTS ON THE DEGRADATION OF UNDERGROUND STRUCTURES 


\section{NATURAL ANALOGUES OF THE EFFECT OF SEISMIC EVENTS ON THE DEGRADATION OF UNDERGROUND STRUCTURES}

\section{G1. ANALOGUES OF MAJOR EARTHQUAKES}

On July 28, 1976, a magnitude 7.8 earthquake occurred in Tang-Shan, China, a city with both substantial mining and industrial facilities. Surface shaking intensities at Tang-Shan were such that in the area where the strongest shaking occurred, 80 to 90 percent of the surface structures collapsed. However, for important engineered structures immediately below the surface, there was generally no serious damage regardless of the depth or size of the structure (Wang 1985 [DIRS 151821], p. 741).

The USGS reported in the lessons and conclusions of the Alaskan earthquake on March 28, 1964 that no significant damage was reported to underground facilities, including mines and tunnels, as a result of the earthquake, although some rocks were shaken loose in places. The epicenter of the earthquake is shown in Figure G-1. Included in this analysis were studies of the coal mines in the Matanuska Valley, which were undamaged; the railroad tunnels near Whittie; the tunnel and penstocks at the Eklutna Hydroelectric Project; and the Chugach Electric Association tunnel between Cooper Lake and Kenai Lake. There were also no reports of damage to the oil and gas wells in and along Cook Inlet. The reports of no damage from the Alaskan earthquake are significant. With a moment magnitude is 9.2 (Kanamori 1977 [DIRS 167797], p. 2982), this earthquake was one of the largest to occur in this country, and surface damage was extreme (Pratt et al. 1978 [DIRS 151817], p. 32).

\section{G2. ANALOGUE OF A RECENT EARTHQUAKE}

An example of a more recent earthquake can be found in the January 16, 1995, earthquake in Kobe, Japan, which had a magnitude of 6.9 (Bolt 1997 [DIRS 167798], p. 273). In this earthquake, tunnels in the epicentral region experienced no major damage (partial or total collapse) for peak ground accelerations measured at the surface of approximately $0.6 \mathrm{~g}$ (Savino et al. 1999 [DIRS 148612]).

\section{G3. ANALOGUE OF A SITE-SPECIFIC EARTHQUAKE}

On June 29, 1992, a magnitude 5.6 earthquake occurred at Little Skull Mountain about $20 \mathrm{~km}$ from Yucca Mountain. Within days of the earthquake, a team of scientists examined the interior of the tunnel 125 meters deep in the epicentral region of the earthquake. The team reported no evidence of damage in the tunnel that could be associated with the earthquake (Savino et al. 1999 [DIRS 148612]). 


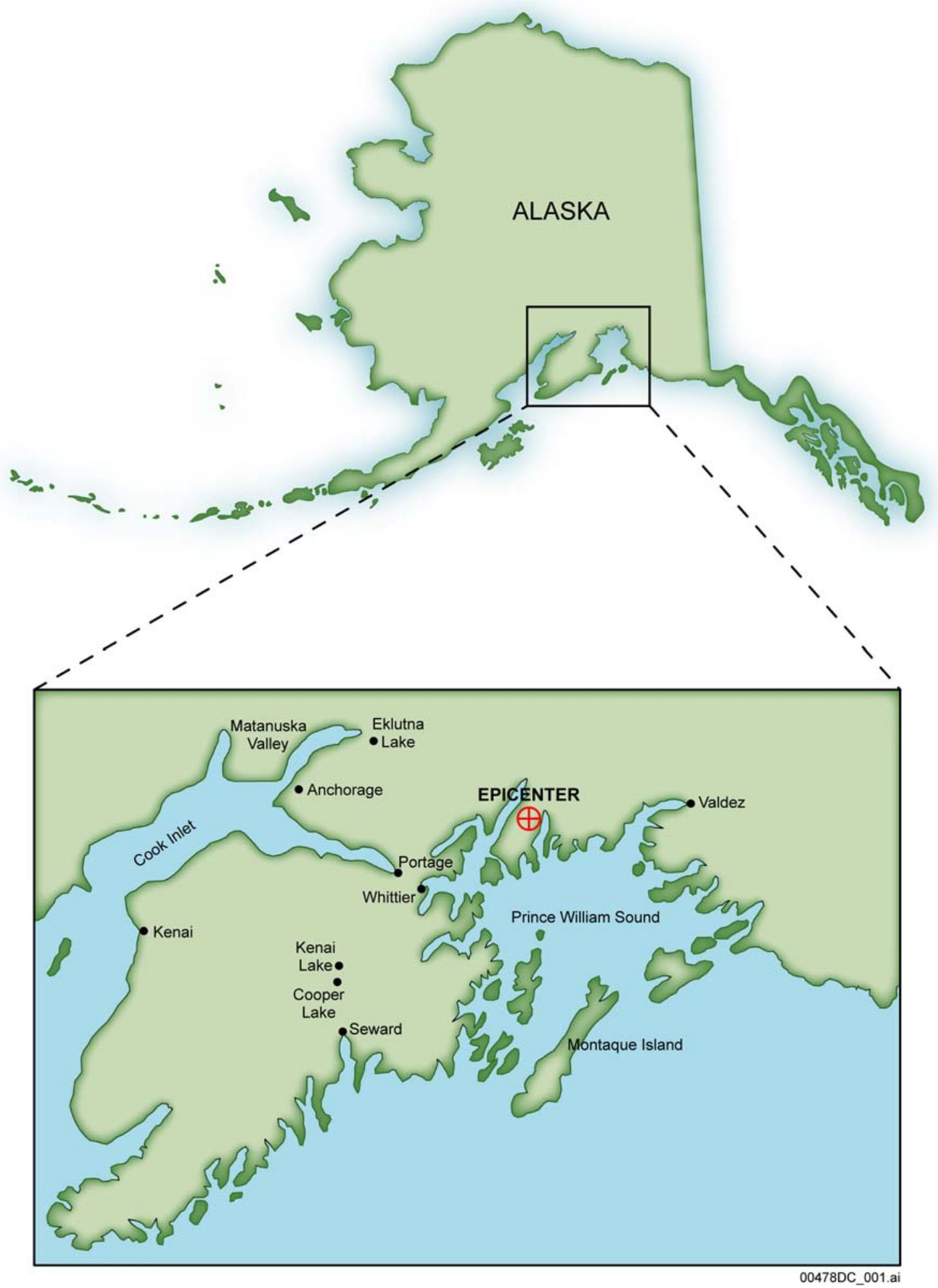

Source: Eckel 1970 [DIRS 157493].

Figure G-1. Epicenter of the 1964 Alaskan Earthquake 


\section{G4. DISCUSSION}

Underground facilities in general are less prone to seismic damage than surface facilities. In fact, earthquake design features are low on the list of design priorities for underground construction projects (Rowe 1992 [DIRS 156898]). Nevertheless, case studies where underground facilities subjected to earthquake received significant damage have been reported (Sharma and Judd 1991 [DIRS 154505]; Rowe 1992 [DIRS 156898]; Raney 1988 [DIRS 147173]). These cases are in general characterized by either shallow overburden (Sharma and Judd 1991 [DIRS 154505]), poor ground condition (Rowe 1992 [DIRS 156898]), fault intersection (Stevens 1977 [DIRS 154501]; Rowe 1992 [DIRS 156898]), or are near the epicenter (Stevens 1977 [DIRS 154501]; Raney 1988 [DIRS 147173]). Sharma and Judd (1991 [DIRS 154505]) generated an extensive database of seismic damage to underground structures using 192 case histories. They reported that there is considerably less damage at depths greater than $50 \mathrm{~m}$, and no heavy damage below $300 \mathrm{~m}$. Rowe (1992 [DIRS 156898]) stated that total collapse of a civil engineering tunnel is invariably associated with the movement of an intersecting fault, and tunneling in soft, poor-quality ground is more susceptible to damage from earthquakes than those constructed in hard, competent rock. Stevens (1977 [DIRS 154501]) concluded that severe damage is inevitable when a mine or tunnel intersects a fault along which movement occurs and mines in the epicentral region of strong motions may suffer severe damage by shaking. Raney (1988 [DIRS 147173]) reported the effects of selected earthquakes in the western North American intermontane region and provided the observation of subsurface damages for 28 earthquakes. No damage was reported in 22 earthquakes and minor damage with spalling reported for 3 earthquakes. For the 3 cases with reporting damage, a "considerable portion of mine tunnels" was caved at Kennedy, Nevada near the epicenter for the 1915 Pleasant Valley, Nevada earthquake. No details were provided for the other 2 cases: the Quality Mine after the 1934 Excelsior Mountains earthquake (southeast of Hawthorne, Nevada) and Kraken Hill Mine after the 1983 Borah Peak, Idaho earthquake. 


\section{INTENTIONALLY LEFT BLANK}




\section{APPENDIX H \\ 3DEC PROGRAM MODIFICATION AND MODEL OPTIMIZATION FOR ROCKFALL ANALYSIS}




\section{DEC PROGRAM MODIFICATION AND MODEL OPTIMIZATION FOR ROCKFALL ANALYSIS}

\section{H1. INTRODUCTION}

Although 3DEC is fully capable for dynamic rockfall calculations, program modifications and optimization of the computer model are required in order to solve complex rockfall problems within a reasonable time frame. The complexity of the rockfall problems includes:

- Incorporating field fracture geometries with relatively short trace length

- Subjecting the rock mass to postclosure ground motion time histories

- Subjecting the rock mass to thermal stresses induced from emplaced waste

- Conducting a large number of analyses to obtain a statistically meaningful rockfall frequency and size distribution.

\section{H2. 3DEC PROGRAM MODIFICATION}

Modifications of the 3DEC program for rockfall analyses include: (1) free-field boundaries, (2) partial density scaling for dynamic analysis, and (3) variable mechanical properties within a contact. A detailed description of the implementation and verification of these enhancements is provided by Lemos and Damjanac (2002 [DIRS 162058]). These modifications are included in the qualified version of $3 \mathrm{DEC}$ (Version 2.01). The areas of modification were validated during software qualification process. This appendix provides a brief description of these modifications and their relevance to rockfall analyses.

\section{H2.1 FREE-FIELD BOUNDARIES}

The free-field boundaries ensure that plane waves propagating upward suffer no distortion at the boundary because the free-field grid supplies conditions that are identical to those in an infinite model. In order to apply a free-field boundary in 3DEC, the model must be oriented such that the base is horizontal and its normal is in the direction of the y-axis, and the sides are vertical and their normals are in the direction of either the $\mathrm{x}$-axis or $\mathrm{z}$-axis.

The free-field model consists of four plane free-field grids on the side boundaries of the model and four column free-field grids at the corners. The four corner free-field columns act as free-field boundaries for the plane free-field grids. The plane free-field grids are two-dimensional models that consider infinite extension in the direction normal to the plane. The column free-field grids are one-dimensional models that consider infinite extension in both horizontal directions. Both the plane and column grids consist of standard 3DEC zones, which have gridpoints constrained in such a way to achieve the infinite extension consideration. The zoning of free-field blocks is similar to the model side faces. The side free-field blocks have two gridpoints across the thickness that are linked to move together. The corner free-field meshes have four gridpoints at each elevation, also linked to move together. 


\section{H2.2 PARTIAL DENSITY SCALING FOR DYNAMIC ANALYSIS}

Density scaling is a technique used in 3DEC in quasi-static calculations that substantially improves the efficiency of obtaining solutions. For the case of complex jointing models, zones with edge lengths much smaller than the average zone edge length are created during the automatic meshing procedure. These zones require very small time steps for numerical stability of the explicit algorithm. The critical time step is proportional to the smallest zone edge length. This makes the dynamic solution extremely time consuming. Density scaling only for those very small zones (a couple of orders of magnitude smaller than the average zone size) for dynamic analysis eliminates the very small time steps. The accuracy of the solution is preserved by keeping the change of the system inertia negligible. This scheme of partial density scaling is implemented in 3DEC in such a way that the user controls the amount of scaling to be introduced.

\section{H2.3 VARIABLE MECHANICAL PROPERTIES WITHIN A CONTACT}

A contact between two blocks in 3DEC is subdivided into a number of sub-contacts if the blocks involved in the contact are deformable. The sub-contacts are determined based on discretization of the block faces that create the contact. Discretization of contact into sub-contacts allows representation of variation of contact forces and deformation in the plane. In earlier versions of 3DEC, mechanical properties (e.g., normal and shear stiffness, shear strength) of sub-contacts were assigned based on material properties of the contact they belong to. A modification of the code allows assignment of material properties to the sub-contacts independent of the material properties of the contact (to which sub-contact belongs to). This capability allows the program to model the finite trace length fractures from FracMan. Figure H-1 shows an example of the finite trace length fractures with extension of the rock bridges (i.e., the dashed lines in Figure $\mathrm{H}-1$ ) to form the distinct blocks in 3DEC.

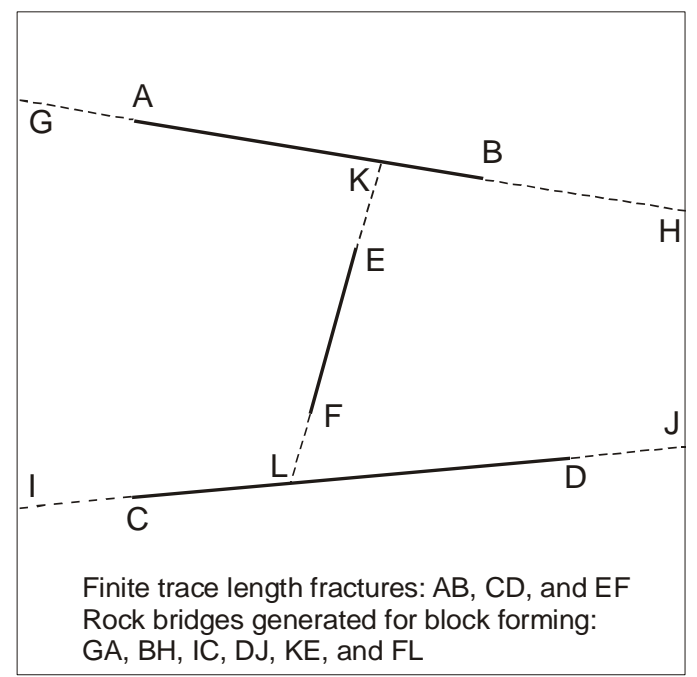

Figure H-1. Block Forming with Finite Trace Length Fractures and Rock Bridges in 3DEC 


\section{H3. 3DEC MODEL OPTIMIZATION}

Model optimization involves two aspects: reducing the model size and increasing the time step. 3DEC is based on a dynamic (time domain) algorithm that solves the equations of motion of the block system by an explicit finite difference method. A time step must be chosen that is smaller than some critical time step but is reasonable for solution time.

\section{H3.1 REDUCING THE MODEL SIZE}

The following methods are used to reduce the model size:

A. Joints are generated within a limited domain as a representative volume around the drift. The representative volume extends one diameter at the side and two diameters on the top of the opening as shown in Figure 6-34 in Section 6.3.1.1. A sensitivity study of the size of the representative volume to rockfall prediction is presented in Section 6.3.1.6.5.

B. Only blocks intersected by circular joints are cut during joint generation. Joints are sorted based on their trace length in a descending order. An algorithm is placed in the block cutting process to hide the blocks that are not intersected by the joint considered.

C. Blocks that have face-face contact and their contact properties are completely solid are joined. That is, several blocks are merged to one if their contacts are solid. Blocks that have partial cracks between them are not joined. This approach allows for an analysis of the potential for crack extension.

\section{H3.2 INCREASING THE TIME STEP}

3DEC is based on a dynamic (time domain) algorithm that solves the equations of motion of the block system by an explicit finite difference method. The solution scheme used for the distinct element method is conditionally stable if the selected limiting time step satisfies both the stability criterion for calculation of internal block deformation as well as that for inter-block relative displacement. Even though explicit calculations execute very rapidly per time step, some way of increasing the time step is desirable in order to reduce computer time.

The following methods are used to increase the time step:

A. Calculation of the time steps is a function of the minimum length (zone edge length) and stiffness (Itasca Consulting Group 2002 [DIRS 160331], Manual/3DEC). Cutting blocks with random joints results in very small block edge lengths. Blocks with a small volume (i.e., less than $0.01 \mathrm{~m}^{3}$ ) are deleted in the model to eliminate part of the blocks with small zone edge lengths. However, blocks of large volume may contain one or two small edges. An algorithm was developed that alters the geometry of these blocks and removes small edges less than $10 \mathrm{~cm}$ in length. The blocks were first detected and their geometry is stored in a data structure before they were deleted. New blocks are constructed within the bounds of the original blocks. In most cases, two close vertices are contracted into a single vertex. Faces that have both vertices lose one vertex. If the face already has only three vertices, then the entire face is 
deleted. On faces that have only one of two vertices, a new face with co-planarity of vertices is created. The flow chart for the algorithm is shown in Figure H-2.

B. The method of partial density scaling was adopted for dynamic analysis. Partial density scaling was implemented for dynamic analysis in 3DEC as described in Section H2.2. A time step of $3 \times 10^{-5}$ seconds is set for the analysis, which satisfies the stability criteria for calculation and provides a solution in a reasonable time. This results in an increase of system mass ranging from 1 to 4 percent. The amount of increase is consistent with the verification problem provided by Lemos and Damjanac (2002 [DIRS 162058]). The accuracy of the solution is therefore preserved by keeping the change of the system inertia negligible. 


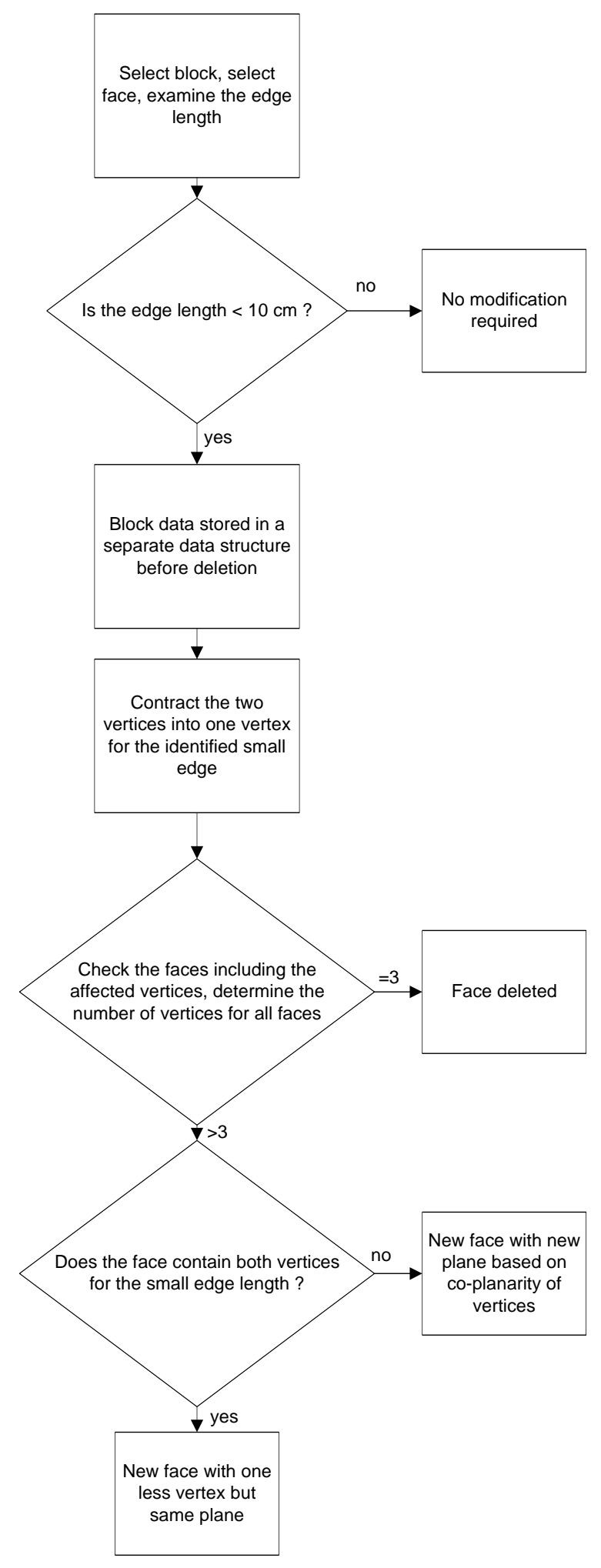

Figure H-2. Flow Chart for Treating the Small Edge Length Block 


\section{INTENTIONALLY LEFT BLANK}




\section{APPENDIX I}

\section{BLOCK SIZE GEOMETRY}




\section{BLOCK SIZE GEOMETRY}

The predicted rock blocks impacting the drip shield have many different sizes and shapes. Since the block geometry information is mainly used for drip shield impact calculations, the geometry of large blocks is provided in this appendix. A total of 7 blocks with volume greater than $2.5 \mathrm{~m}^{3}$ (6 metric tons) was selected for presentation. Blocks with high impact energy were considered during the selection process. The block geometric information for each individual block is presented in Figures I-1 to I-7 respectively. Six different views are provided for each block to illustrate the complex geometry observed for most large blocks. Most of the blocks consist of many surfaces and some of them have highly irregular shapes that are the end result of a non-persistent fracture network. 


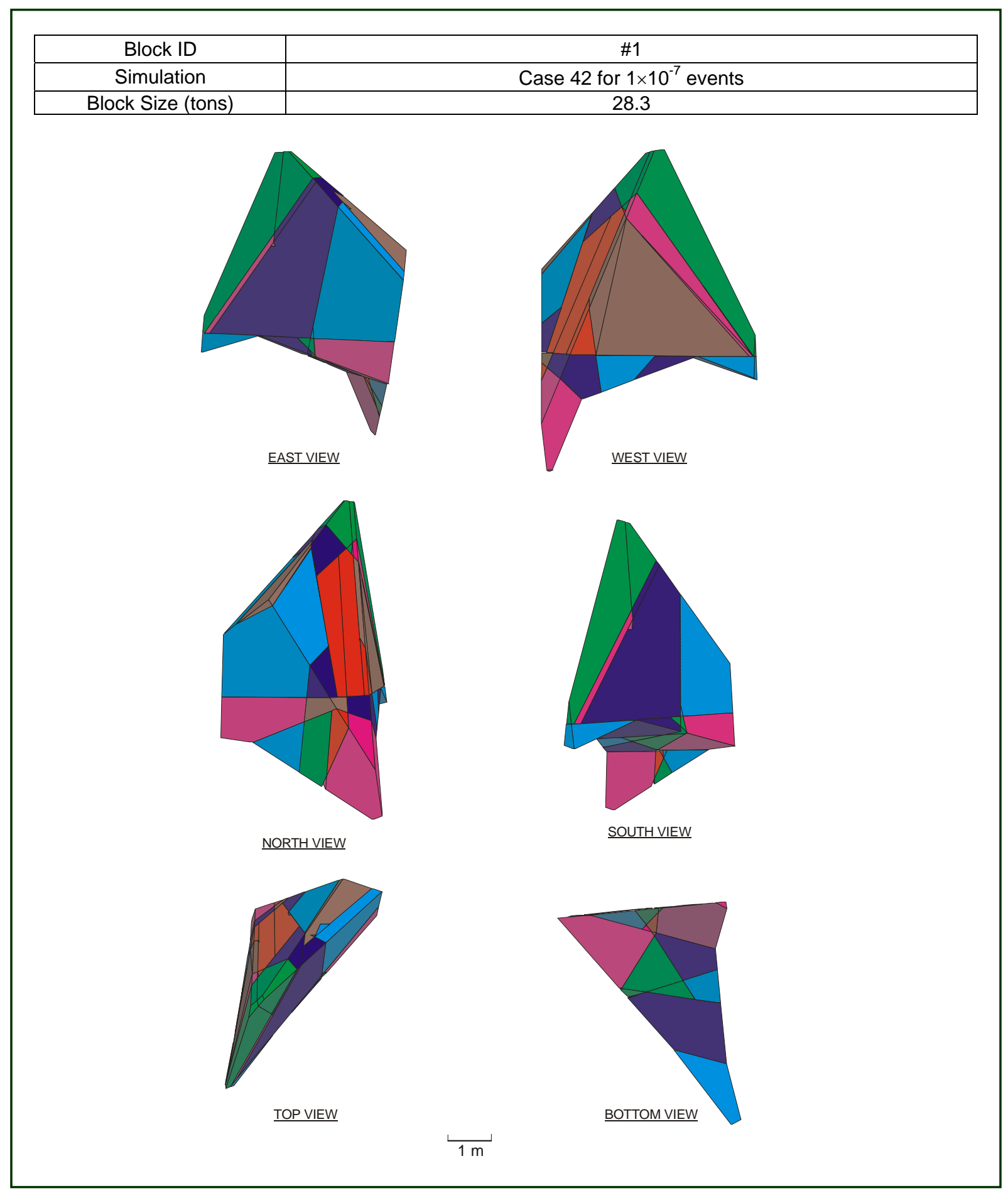

Figure I-1. Block Geometry Information for Block \#1 


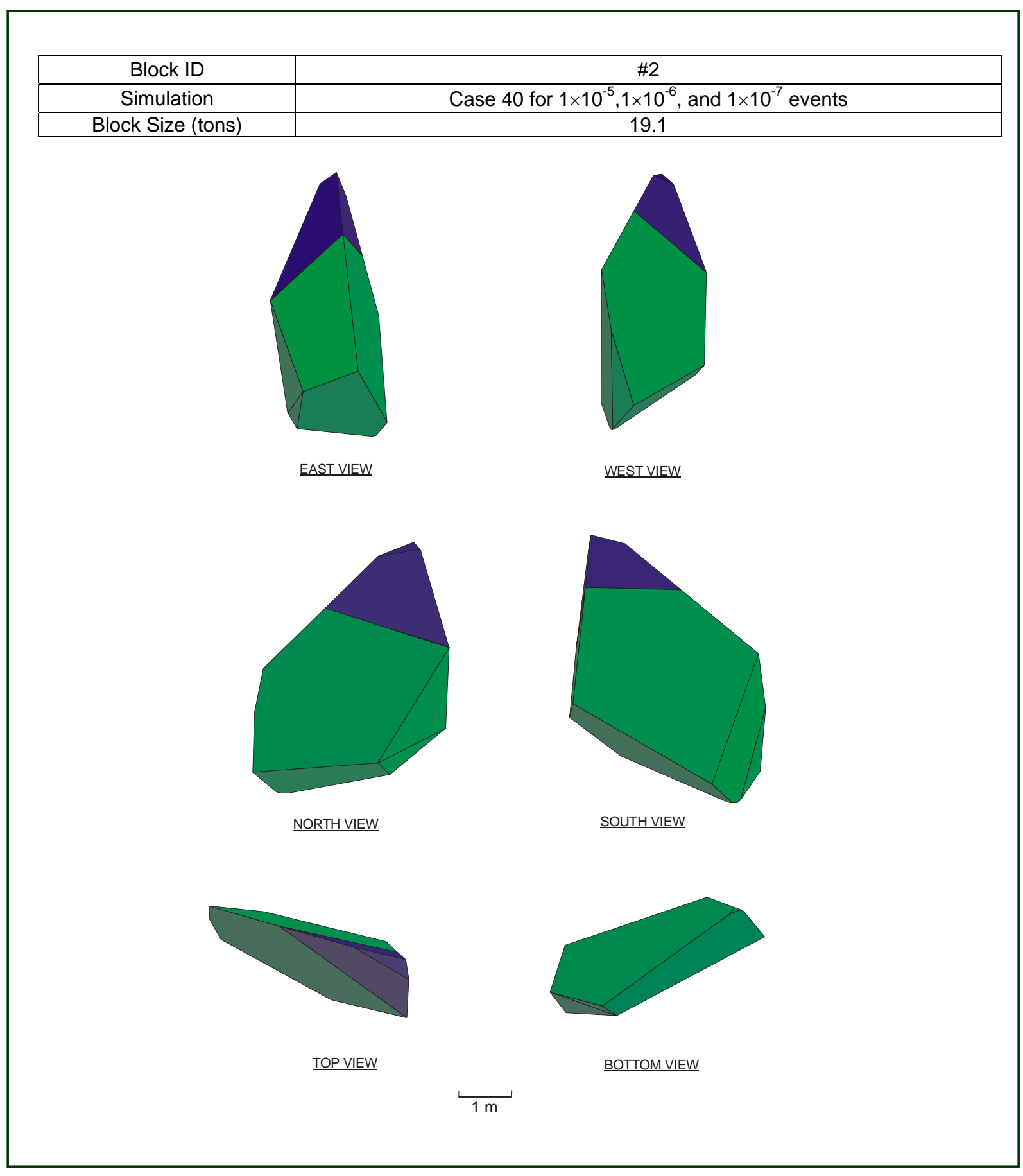

Figure I-2. Block Geometry Information for Block \#2 


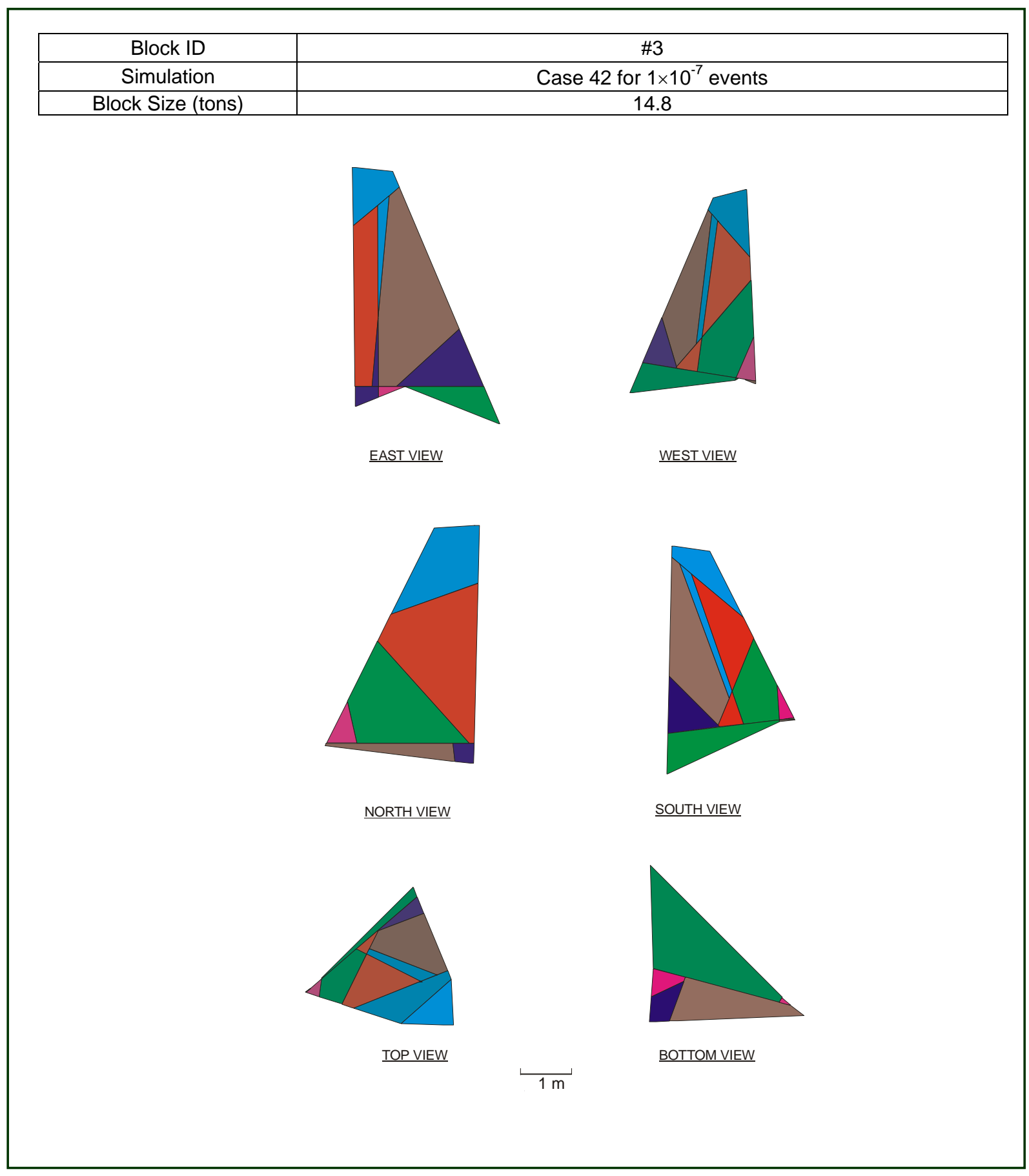

Figure I-3. Block Geometry Information for Block \#3 


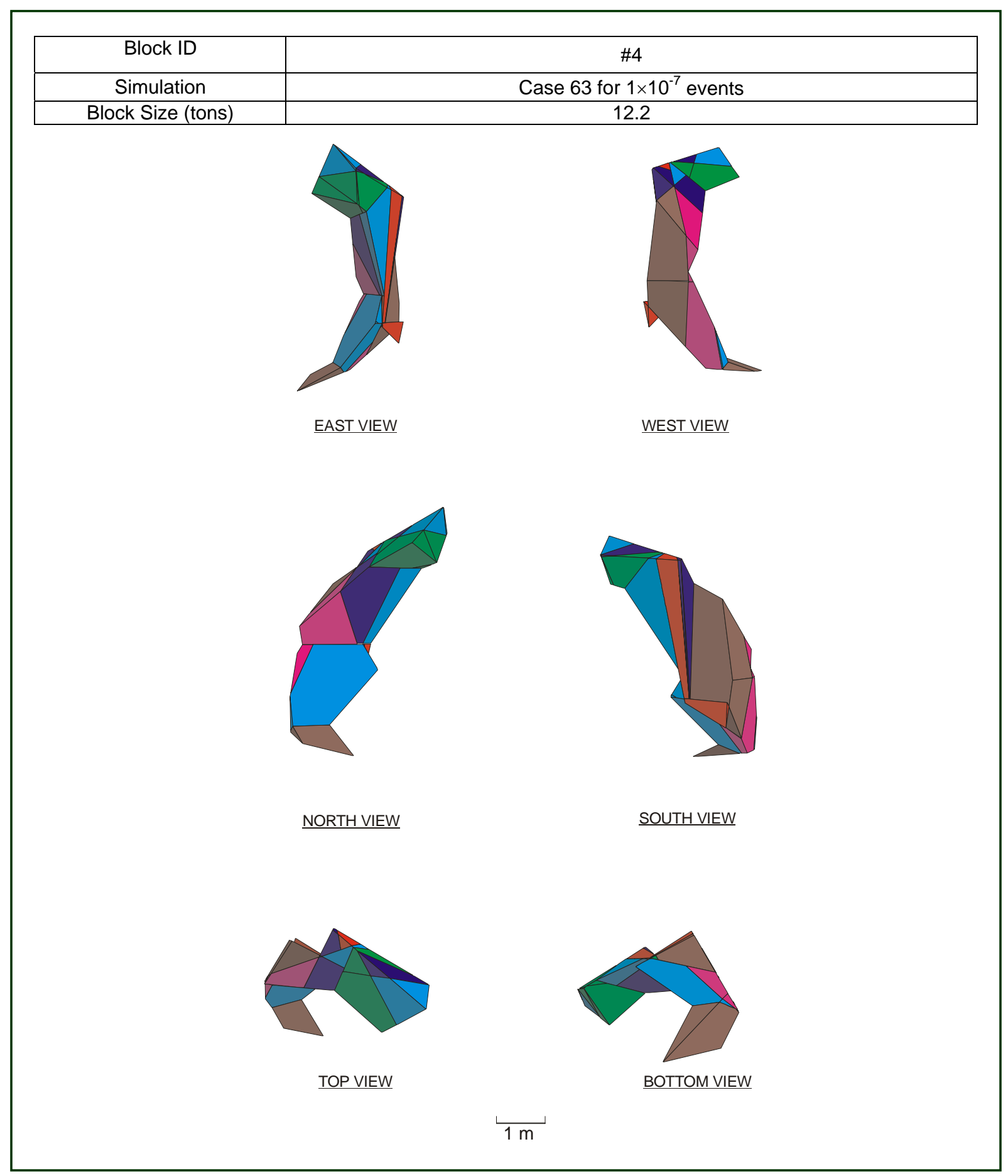

Figure I-4. Block Geometry Information for Block \#4 


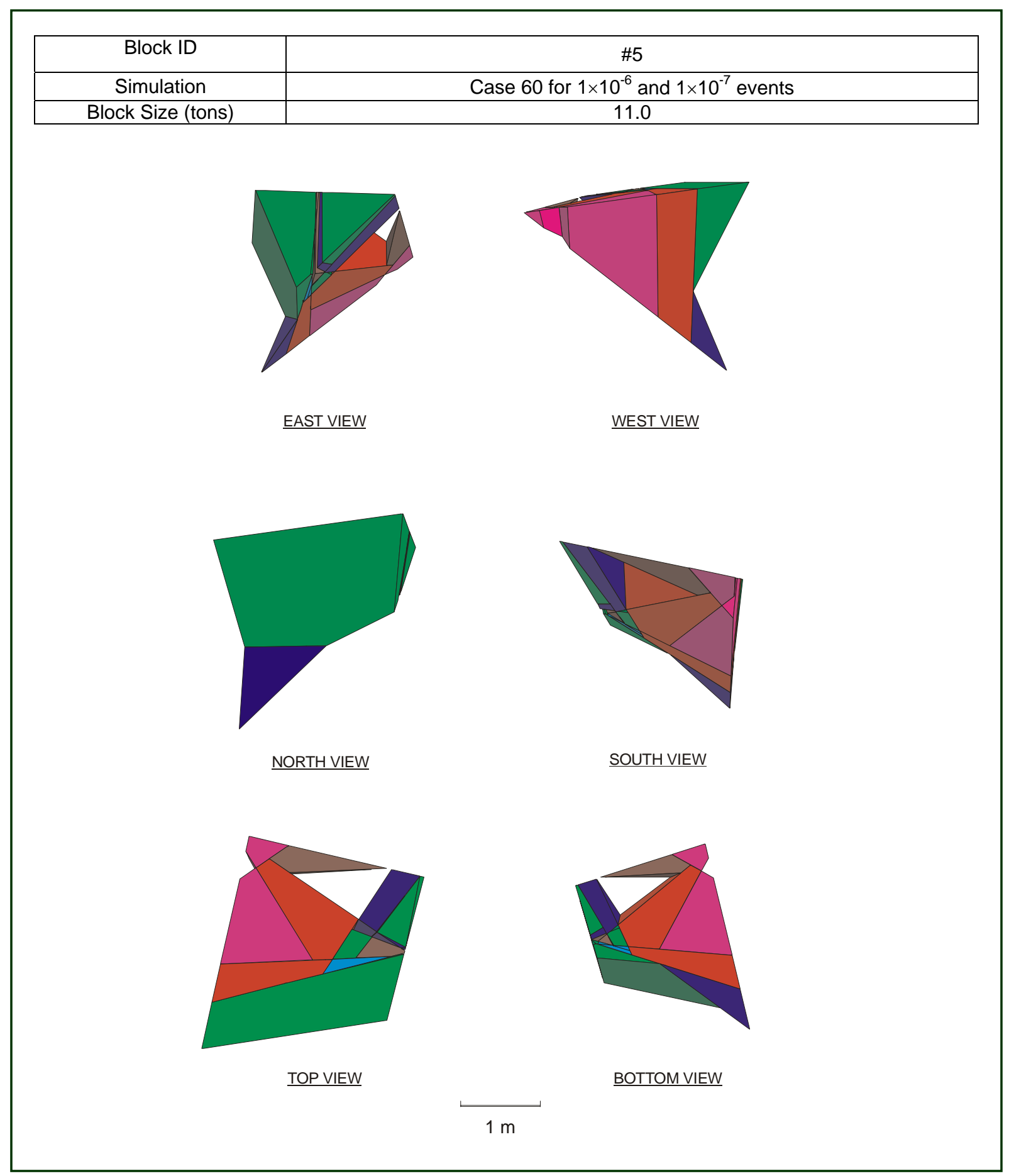

Figure 1-5. Block Geometry Information for Block \#5 


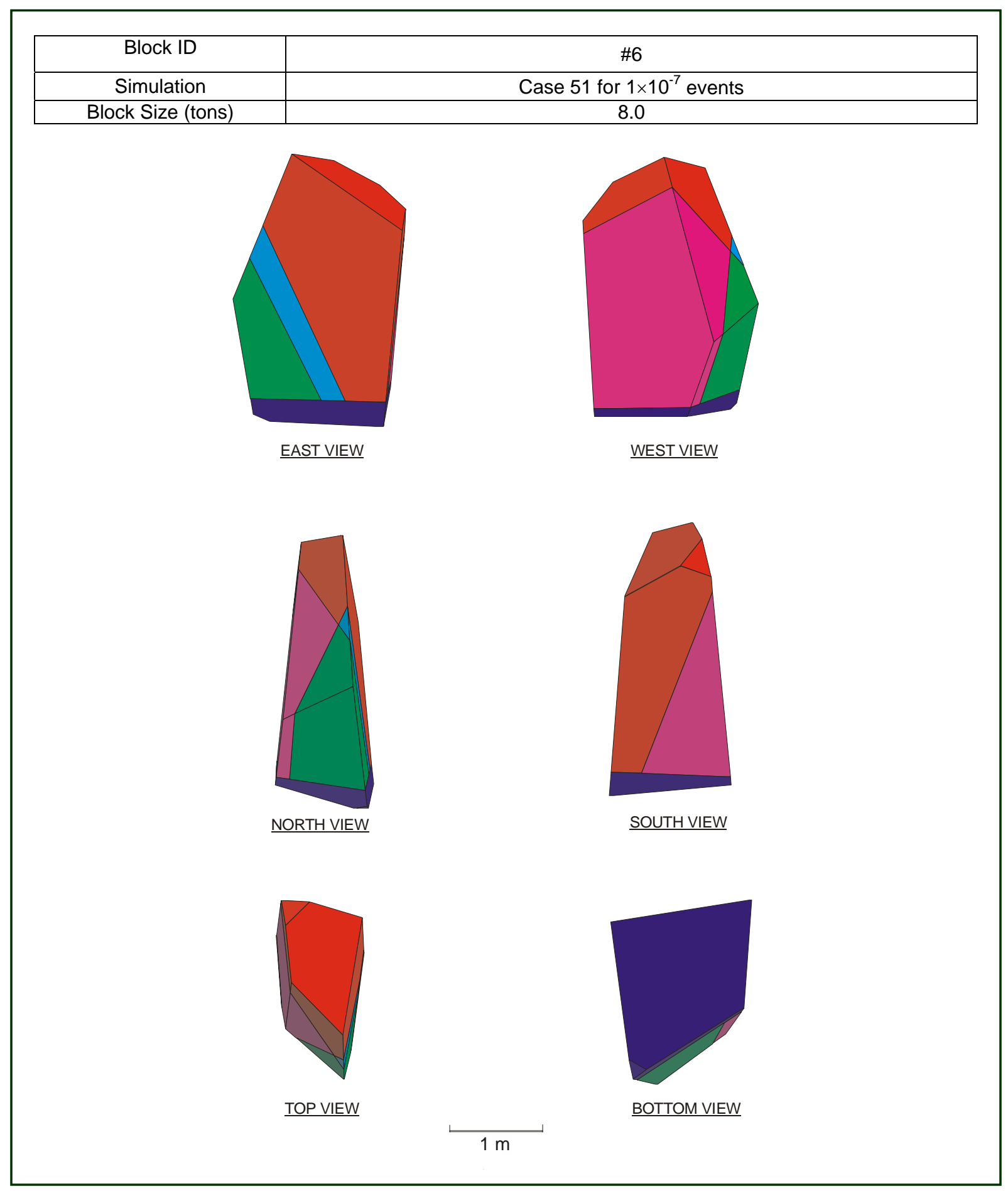

Figure I-6. Block Geometry Information for Block \#6 


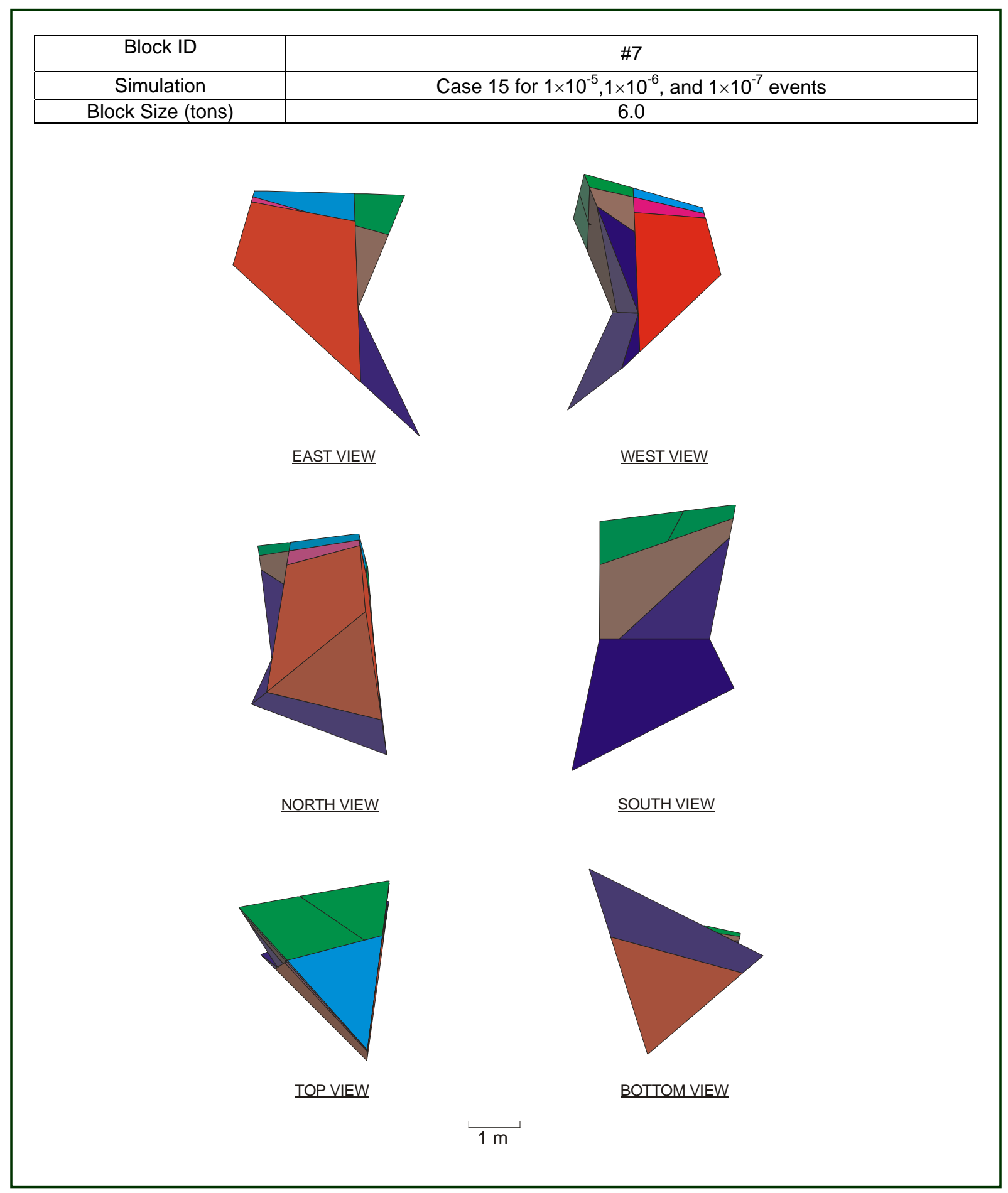

Figure I-7. Block Geometry Information for Block \#7 
APPENDIX J

RANDOM SELECTION OF 3DEC MODELING REGION IN A 100-M CUBE FRACTURE NETWORK GENERATED BY FRACMAN 


\section{RANDOM SELECTION OF 3DEC MODELING REGION IN A 100-M CUBE FRACTURE NETWORK GENERATED BY FRACMAN}

A random selection of the 3 DEC modeling region within a $100 \mathrm{~m}$ FracMan fracture network cube was conducted using the random number generation function provided in Microsoft Excel's spreadsheet analysis tools. Each 3DEC modeling region was uniquely determined by choosing the centroid of the modeling block. A random number generator with a uniform distribution in the range of -32.5 to 32.5 was used to generate the $\mathrm{x}-, \mathrm{y}-$, and $\mathrm{z}$-coordinates. The range was selected so that the selected region was free of edge effects. The Microsoft Excel inputs for random number generation are shown in Figure $\mathrm{J}-1$.

Table J-1 lists the 105 selected centroid locations. The centroids are projected to the X-Y, X-Z, and $\mathrm{Y}-\mathrm{Z}$ planes as shown in Figures $\mathrm{J}-2$ to $\mathrm{J}-4$.

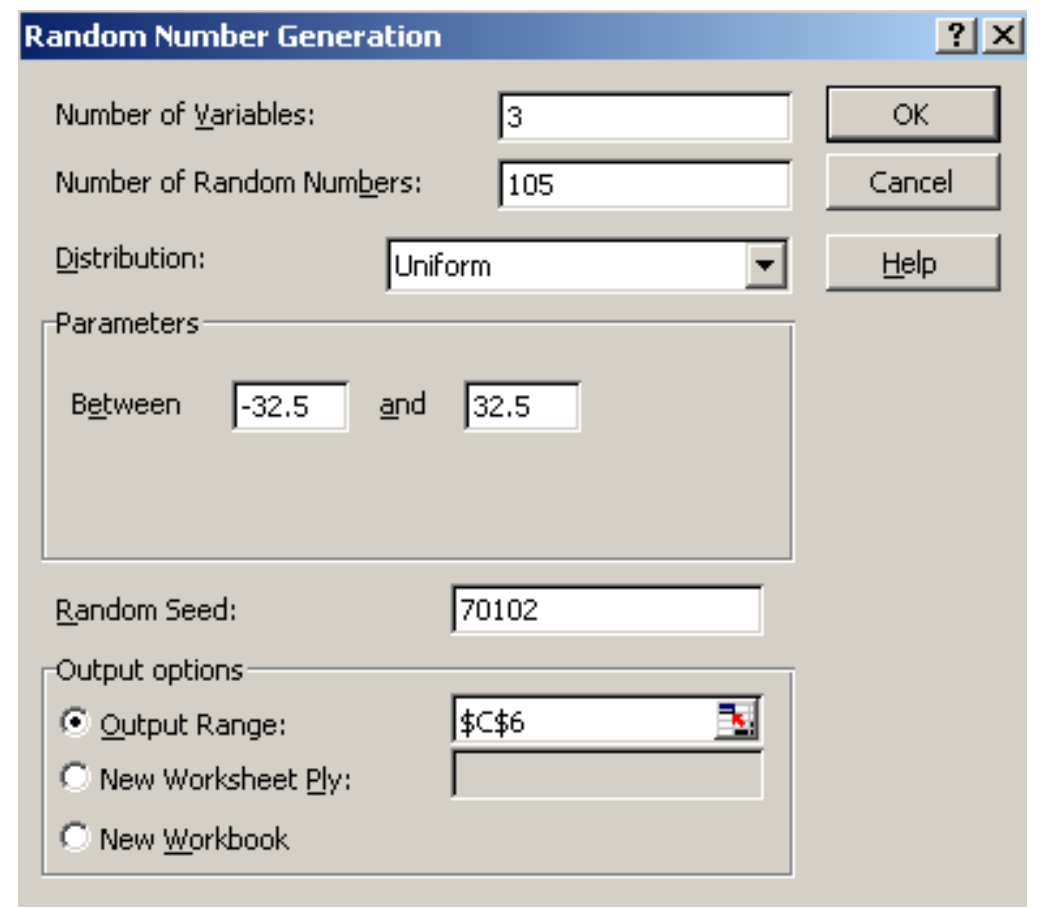

Figure J-1. Microsoft Excel Inputs for Random Number Generation 


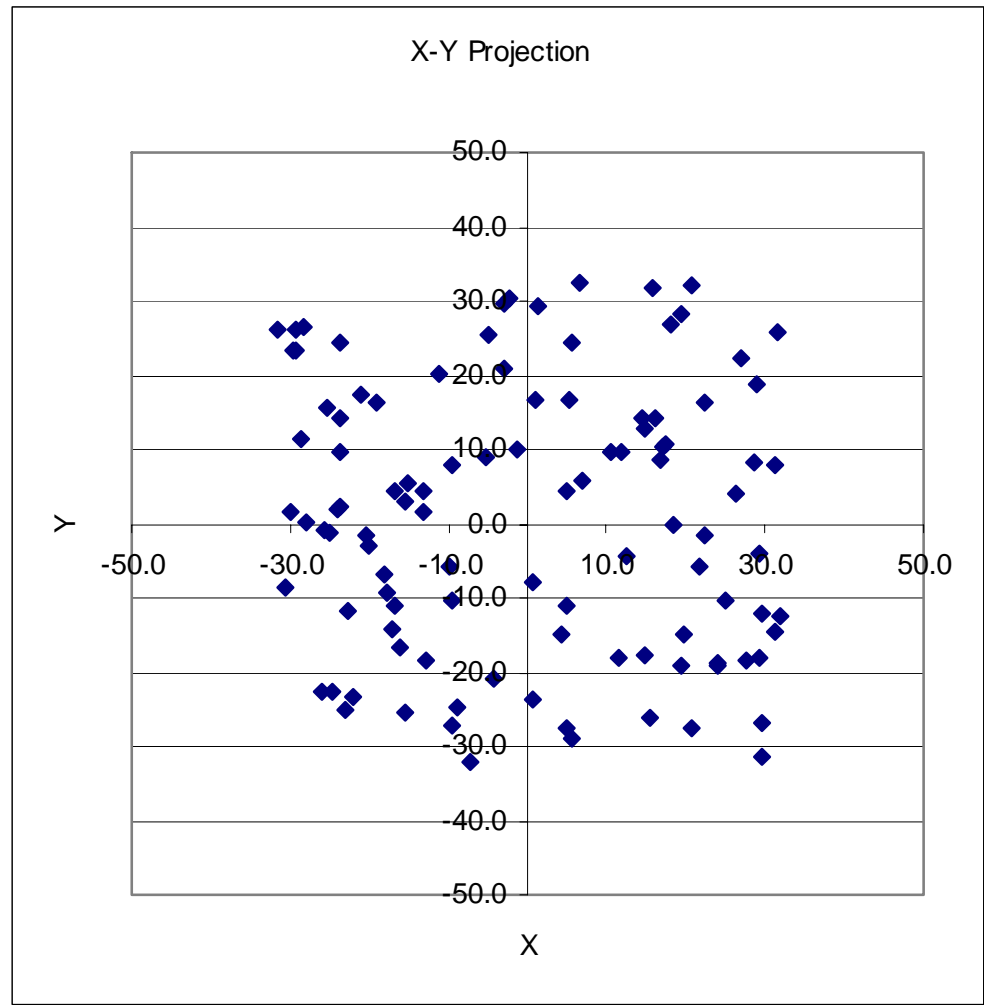

Figure J-2. Centroid Locations Projected to X-Y Plane

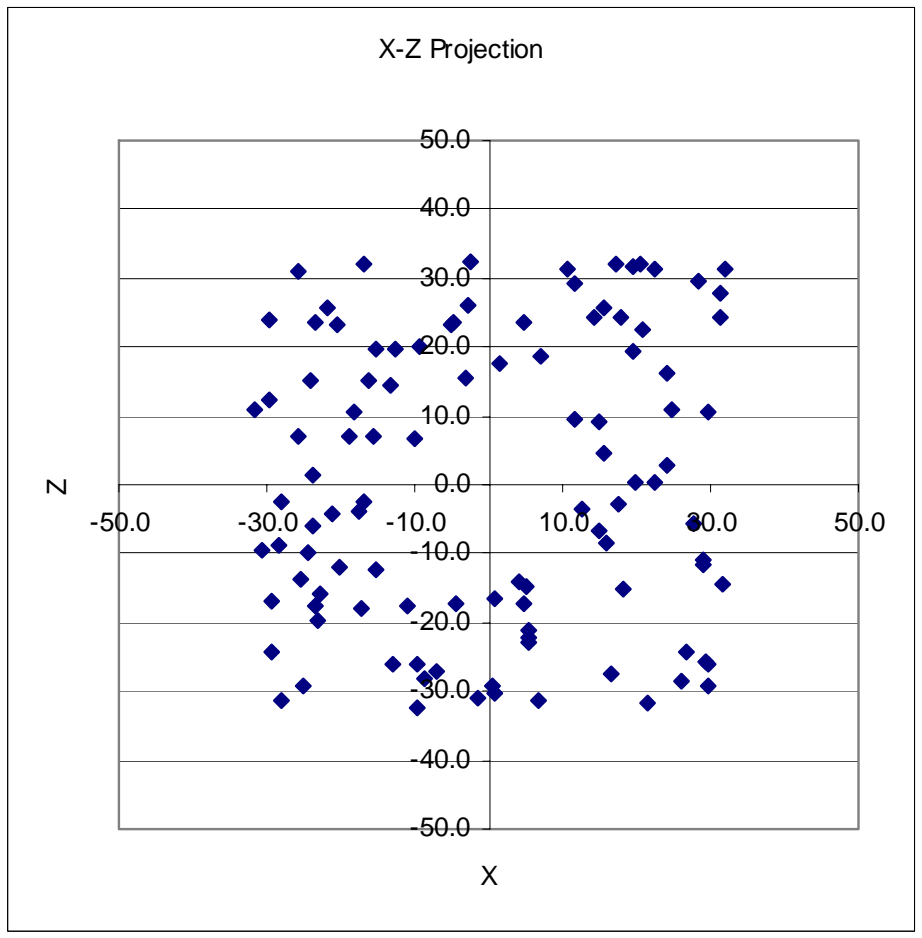

Figure J-3. Centroid Locations Projected to X-Z Plane 


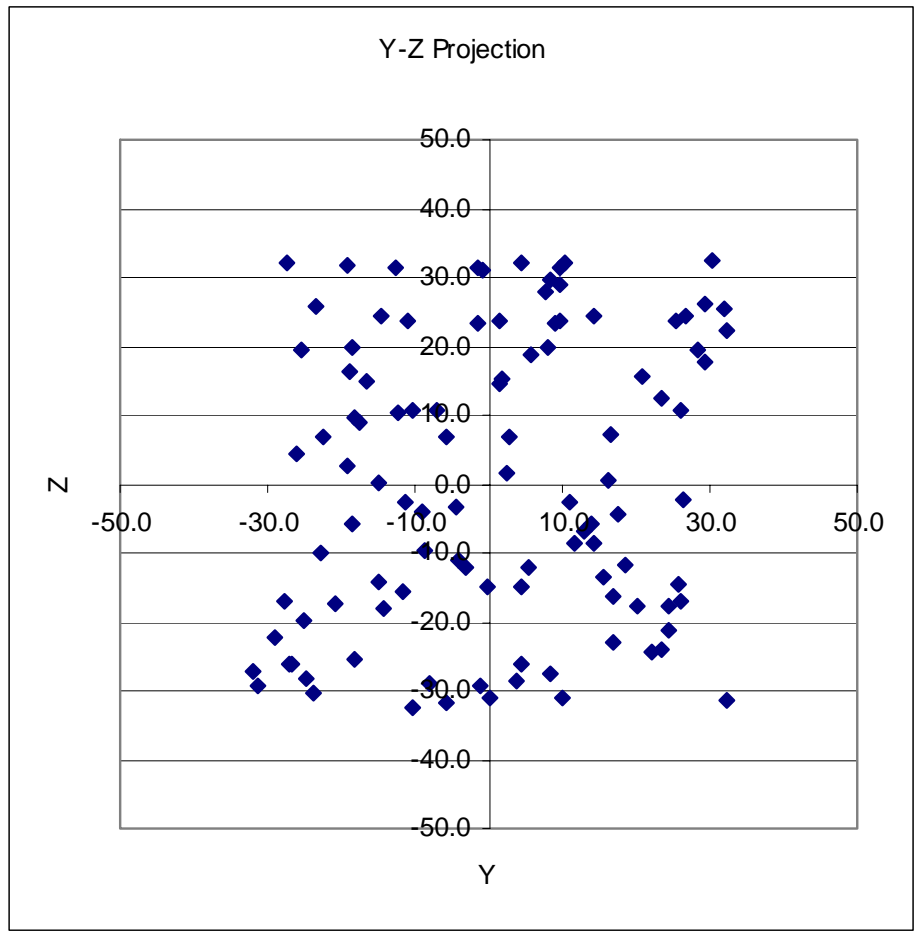

Figure J-4. Centroid Locations Projected to Y-Z Plane

Table J-1. Listing of Fracture Model Region Centroid Coordinates

\begin{tabular}{|c|c|c|c|}
\hline \multirow{2}{*}{ Model Region } & \multicolumn{3}{|c|}{ Centroid of Fracture Model Region } \\
\cline { 2 - 4 } & $\mathbf{X c}$ & Yc & Zc \\
\hline 1 & -2.8 & 29.5 & 26.0 \\
\hline 2 & -23.7 & 2.4 & -26.1 \\
\hline 3 & 29.5 & -26.7 & 32.2 \\
\hline 4 & -16.7 & 4.5 & 29.6 \\
\hline 5 & 28.5 & 8.3 & -17.4 \\
\hline 6 & -4.4 & -20.8 & -12.1 \\
\hline 7 & -20.2 & -3.1 & -17.7 \\
\hline 8 & -23.6 & 24.4 & -27.0 \\
\hline 9 & -7.2 & -32.0 & 0.4 \\
\hline 10 & 22.4 & 16.2 & -18.1 \\
\hline 11 & -17.2 & -14.2 & -26.0 \\
\hline 12 & -9.7 & -27.1 & -4.2 \\
\hline 13 & -21.1 & 17.5 & 10.8 \\
\hline 14 & 24.9 & -10.4 & 19.4 \\
\hline 15 & 19.5 & 28.3 & -12.3 \\
\hline 16 & -15.3 & 5.5 & -31.2 \\
\hline 17 & -28.1 & 0.3 & 31.5 \\
\hline 18 & 10.6 & 9.8 & 32.4 \\
\hline 19 & -2.3 & 30.2 & \\
\hline
\end{tabular}


Table J-1. Listing of Fracture Model Region Centroid Coordinates (Continued)

\begin{tabular}{|c|c|c|c|}
\hline \multirow[b]{2}{*}{ Model Region } & \multicolumn{3}{|c|}{ Centroid of Fracture Model Region } \\
\hline & Xc & Yc & Zc \\
\hline 20 & 14.8 & -17.7 & 9.0 \\
\hline 21 & -15.6 & 2.9 & 6.9 \\
\hline 22 & -25.3 & 15.5 & -13.6 \\
\hline 23 & -16.8 & -11.2 & -2.6 \\
\hline 24 & 18.3 & 0.0 & -15.0 \\
\hline 25 & 17.1 & 10.3 & 32.0 \\
\hline 26 & 31.9 & -12.6 & 31.3 \\
\hline 27 & 27.6 & -18.6 & -5.8 \\
\hline 28 & 21.6 & -5.8 & -31.9 \\
\hline 29 & -23.6 & 14.0 & -5.9 \\
\hline 30 & 6.6 & 32.3 & -31.4 \\
\hline 31 & -3.1 & 20.7 & 15.4 \\
\hline 32 & -11.1 & 20.0 & -17.7 \\
\hline 33 & -29.4 & 26.2 & -16.9 \\
\hline 34 & -1.4 & 10.0 & -31.0 \\
\hline 35 & -31.5 & 26.1 & 10.7 \\
\hline 36 & 4.8 & -11.1 & 23.7 \\
\hline 37 & 6.9 & 5.7 & 18.8 \\
\hline 38 & 29.6 & -31.4 & -29.3 \\
\hline 39 & -25.1 & -1.1 & -29.3 \\
\hline 40 & 16.0 & 14.2 & -8.6 \\
\hline 41 & 29.2 & -4.1 & -11.0 \\
\hline 42 & 26.8 & 22.2 & -24.3 \\
\hline 43 & -13.3 & 1.5 & 14.4 \\
\hline 44 & 14.4 & 14.2 & 24.3 \\
\hline 45 & -29.2 & 23.4 & -24.2 \\
\hline 46 & 5.5 & 24.4 & -21.1 \\
\hline 47 & 18.0 & 26.9 & 24.4 \\
\hline 48 & 19.8 & -14.9 & 0.3 \\
\hline 49 & -18.1 & -6.9 & 10.6 \\
\hline 50 & 14.9 & 12.9 & -6.8 \\
\hline 51 & 11.7 & 9.5 & 29.1 \\
\hline 52 & 29.3 & -18.2 & -25.5 \\
\hline 53 & -15.3 & -25.5 & 19.6 \\
\hline 54 & -29.5 & 23.5 & 12.3 \\
\hline 55 & -25.6 & -1.0 & 30.9 \\
\hline 56 & 4.3 & -15.1 & -14.1 \\
\hline 57 & 16.7 & 8.5 & -27.5 \\
\hline 58 & -22.7 & -11.6 & -15.7 \\
\hline 59 & 15.7 & 31.8 & 25.6 \\
\hline 60 & 0.6 & -8.0 & -29.1 \\
\hline 61 & -4.8 & 25.4 & 23.7 \\
\hline
\end{tabular}


Table J-1. Listing of Fracture Model Region Centroid Coordinates (Continued)

\begin{tabular}{|c|c|c|c|}
\hline \multirow[b]{2}{*}{ Model Region } & \multicolumn{3}{|c|}{ Centroid of Fracture Model Region } \\
\hline & $\mathrm{Xc}$ & Yc & Zc \\
\hline 62 & 31.2 & 7.7 & 27.9 \\
\hline 63 & -16.1 & -16.7 & 15.0 \\
\hline 64 & -9.6 & -10.4 & -32.4 \\
\hline 65 & -25.9 & -22.5 & 6.9 \\
\hline 66 & 29.0 & 18.6 & -11.7 \\
\hline 67 & -23.0 & -25.1 & -19.7 \\
\hline 68 & 1.0 & 16.8 & -16.4 \\
\hline 69 & -20.6 & -1.4 & 23.4 \\
\hline 70 & 12.7 & -4.4 & -3.4 \\
\hline 71 & -9.8 & -5.8 & 6.8 \\
\hline 72 & -8.8 & -24.7 & -28.2 \\
\hline 73 & -24.6 & -22.7 & -9.9 \\
\hline 74 & 20.7 & 32.2 & 22.4 \\
\hline 75 & -19.0 & 16.4 & 7.1 \\
\hline 76 & 23.9 & -19.0 & 2.8 \\
\hline 77 & 24.1 & -18.8 & 16.3 \\
\hline 78 & -9.4 & 7.9 & 20.0 \\
\hline 79 & -24.1 & 1.9 & 15.2 \\
\hline 80 & 26.2 & 3.9 & -28.7 \\
\hline 81 & 17.5 & 10.8 & -2.7 \\
\hline 82 & -5.2 & 8.9 & 23.2 \\
\hline 83 & 5.3 & 16.8 & -23.1 \\
\hline 84 & 19.4 & -19.3 & 31.9 \\
\hline 85 & 22.4 & -1.6 & 31.4 \\
\hline 86 & 20.6 & -27.4 & 32.1 \\
\hline 87 & 11.6 & -18.2 & 9.5 \\
\hline 88 & -17.6 & -9.2 & -4.0 \\
\hline 89 & 31.6 & 25.8 & -14.4 \\
\hline 90 & 31.2 & -14.7 & 24.5 \\
\hline 91 & -28.5 & 11.6 & -8.8 \\
\hline 92 & -30.6 & -8.7 & -9.7 \\
\hline 93 & 29.7 & -12.2 & 10.5 \\
\hline 94 & -28.2 & 26.5 & -2.4 \\
\hline 95 & -13.0 & 4.3 & -26.2 \\
\hline 96 & -29.8 & 1.6 & 23.9 \\
\hline 97 & 15.5 & -26.1 & 4.6 \\
\hline 98 & 4.9 & 4.3 & -14.7 \\
\hline 99 & 1.4 & 29.3 & 17.8 \\
\hline 100 & 4.8 & -27.6 & -17.1 \\
\hline 101 & -23.6 & 9.7 & 23.7 \\
\hline 102 & -12.7 & -18.5 & 19.9 \\
\hline 103 & 0.8 & -23.8 & -30.4 \\
\hline
\end{tabular}


Table J-1. Listing of Fracture Model Region Centroid Coordinates (Continued)

\begin{tabular}{|c|c|c|c|}
\hline \multirow{2}{*}{ Model Region } & \multicolumn{3}{|c|}{ Centroid of Fracture Model Region } \\
\cline { 2 - 4 } & Xc & Yc & Zc \\
\hline 104 & 5.5 & -29.0 & -22.3 \\
\hline 105 & -22.0 & -23.3 & 25.8 \\
\hline
\end{tabular}


APPENDIX K

SUFFICENCY OF THE NUMBER OF 3DEC SIMULATIONS TO REPRESENT THE ROCKFALL CHARACTERISTICS 


\section{SUFFICENCY OF THE NUMBER OF 3DEC SIMULATIONS TO REPRESENT THE ROCKFALL CHARACTERISTICS}

This appendix addresses the issue on the sufficiency of the number of 3DEC simulations to represent the likely rockfall characteristics, such as block size, relative impact velocity, and impact energy of the rock to the drip shield. Summary statistics of the rockfall characteristics was compiled after each 5-run increment. The statistics, such as mean, median, maximum, and standard deviation, was then observed for the trend. The block size distribution was also observed to ensure the analyses results capture the proper rockfall size distribution.

Figures K-1 to K-3 shows the trend of the statistics for the analyses considering the $1 \times 10^{-4}$ annual probability of exceedance ground motion with a total of 32 3DEC simulations. The corresponding numeric values for the statistics are tabulated in Tables K-1 to K-3. The maximum values of the block size, impact velocity, and impact energy occur between the $11^{\text {th }}$ and $15^{\text {th }}$ simulation. The trend shows that the statistics of rockfall characteristics approaches to asymptotic value approximately 15 to 20 runs of 3DEC simulation. Figure K-4 presents the block size cumulative distribution for the evolution of the analyses, the distribution also shows that approximately 15 to 20 runs of 3DEC simulation provide adequate representation of the size distribution.

Table K-1. Summary Statistics of Block Size (metric ton) for $1 \times 10^{-4}$ Preclosure Ground Motion

\begin{tabular}{|c|c|c|c|c|c|c|}
\hline Summary Statistics & $\mathbf{1}^{\text {st }} \mathbf{5}$ runs & $\mathbf{1}^{\text {st }} \mathbf{1 0}$ runs & $\mathbf{1}^{\text {st }} \mathbf{1 5}$ runs & $\mathbf{1}^{\text {st }} \mathbf{2 0}$ runs & $\mathbf{1}^{\text {st }} \mathbf{2 5}$ runs & All $\mathbf{3 2}$ runs \\
\hline Median & 0.09 & 0.09 & 0.10 & 0.10 & 0.11 & 0.10 \\
\hline Mean & 0.14 & 0.20 & 0.22 & 0.21 & 0.23 & 0.22 \\
\hline Maximum & 0.69 & 2.04 & 2.72 & 2.72 & 2.72 & 2.72 \\
\hline Standard Deviation & 0.14 & 0.29 & 0.35 & 0.33 & 0.35 & 0.33 \\
\hline
\end{tabular}

Table K-2. Summary Statistics of Impact Velocity $(\mathrm{m} / \mathrm{sec})$ for $1 \times 10^{-4}$ Preclosure Ground Motion

\begin{tabular}{|c|c|c|c|c|c|c|}
\hline Summary Statistics & $\mathbf{1}^{\text {st }} \mathbf{5}$ runs & $\mathbf{1}^{\text {st }} \mathbf{1 0}$ runs & $\mathbf{1}^{\text {st }} \mathbf{1 5}$ runs & $\mathbf{1}^{\text {st }} \mathbf{2 0}$ runs & $\mathbf{1}^{\text {st }} \mathbf{2 5}$ runs & All $\mathbf{3 2}$ runs \\
\hline Median & 2.40 & 2.30 & 2.36 & 2.22 & 2.36 & 2.25 \\
\hline Mean & 2.51 & 2.47 & 2.58 & 2.47 & 2.57 & 2.43 \\
\hline Maximum & 6.38 & 6.38 & 7.20 & 7.20 & 7.20 & 7.20 \\
\hline Standard Deviation & 1.36 & 1.38 & 1.54 & 1.46 & 1.40 & 1.38 \\
\hline
\end{tabular}

Table K-3. Summary Statistics of Impact Energy (J) for $1 \times 10^{-4}$ Preclosure Ground Motion

\begin{tabular}{|c|c|c|c|c|c|c|}
\hline Summary Statistics & $\mathbf{1}^{\text {st }} \mathbf{5}$ runs & $\mathbf{1}^{\text {st }} \mathbf{1 0}$ runs & $\mathbf{1}^{\text {st }} \mathbf{1 5}$ runs & $\mathbf{1}^{\text {st }} \mathbf{2 0}$ runs & $\mathbf{1}^{\text {st }} \mathbf{2 5}$ runs & All $\mathbf{3 2}$ runs \\
\hline Median & 303 & 290 & 316 & 249 & 310 & 232 \\
\hline Mean & 676 & 933 & 1196 & 1030 & 1161 & 1022 \\
\hline Maximum & 6127 & 10304 & 20358 & 20358 & 20358 & 20358 \\
\hline Standard Deviation & 1113 & 1828 & 2664 & 2424 & 2430 & 2224 \\
\hline
\end{tabular}




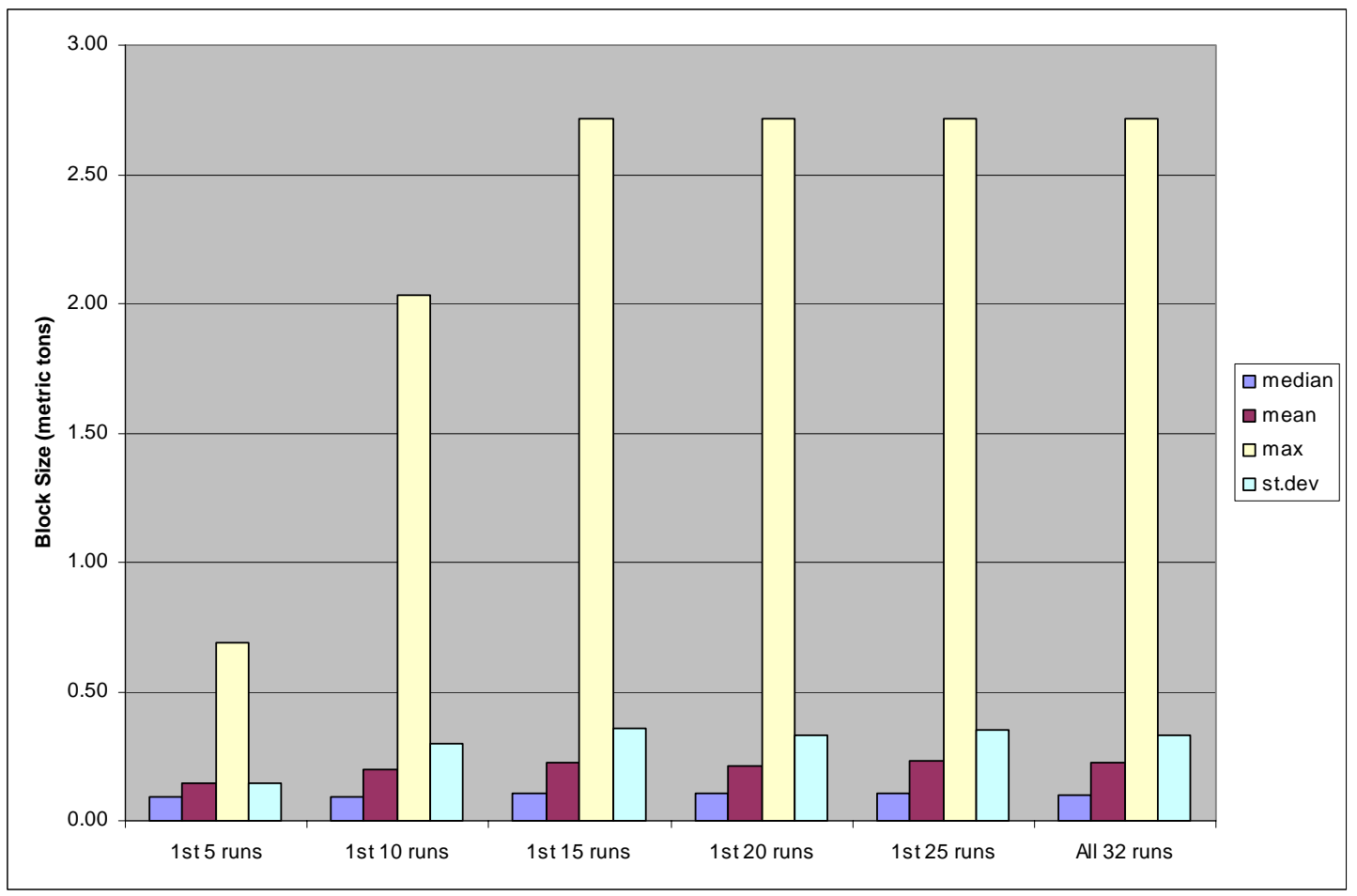

Figure K-1. Summary Statistics of Block Size (metric ton) for $1 \times 10^{-4}$ Preclosure Ground Motion

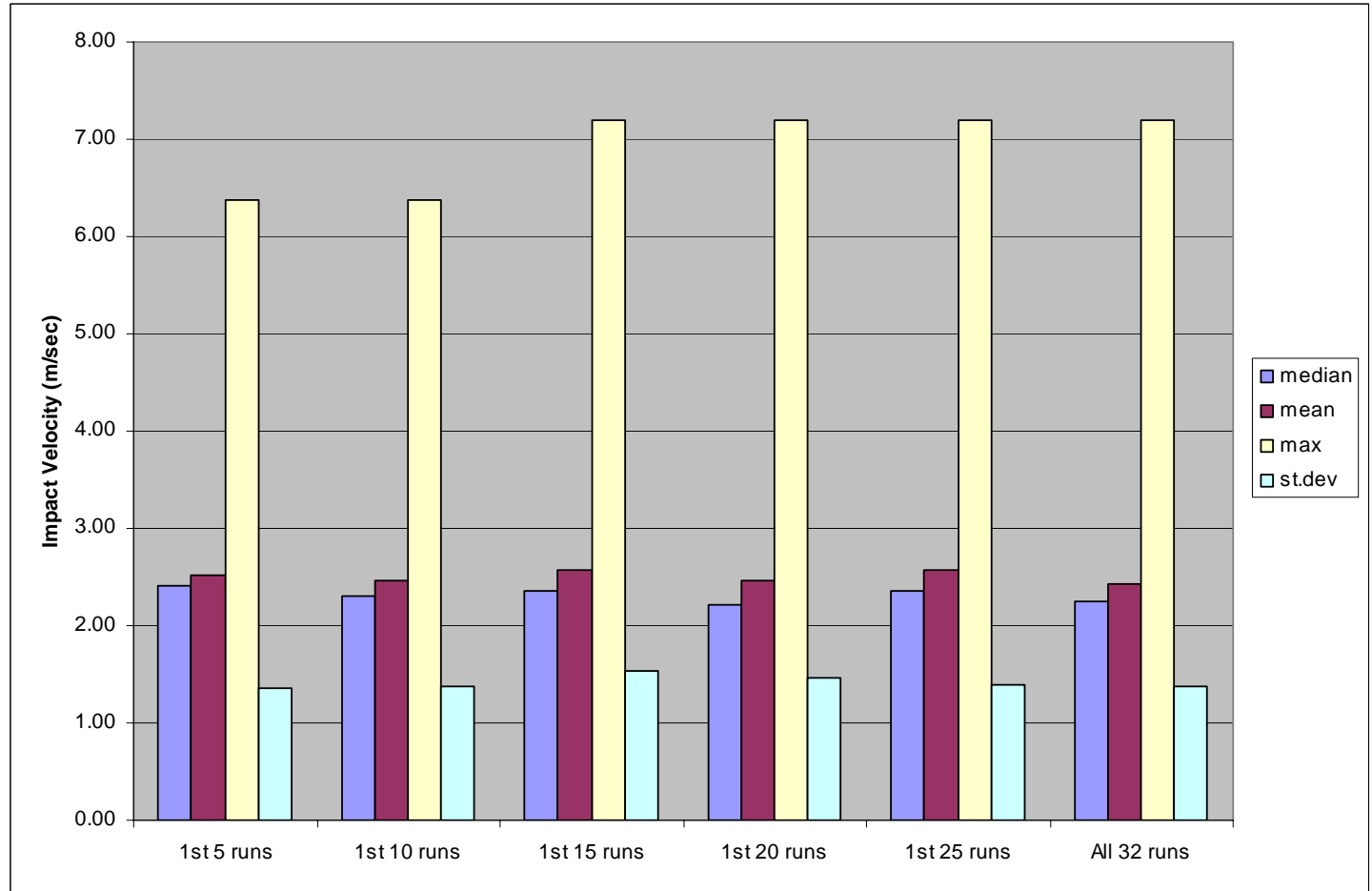

Figure K-2. Summary Statistics of Impact Velocity $(\mathrm{m} / \mathrm{sec})$ for $1 \times 10^{-4}$ Preclosure Ground Motion 


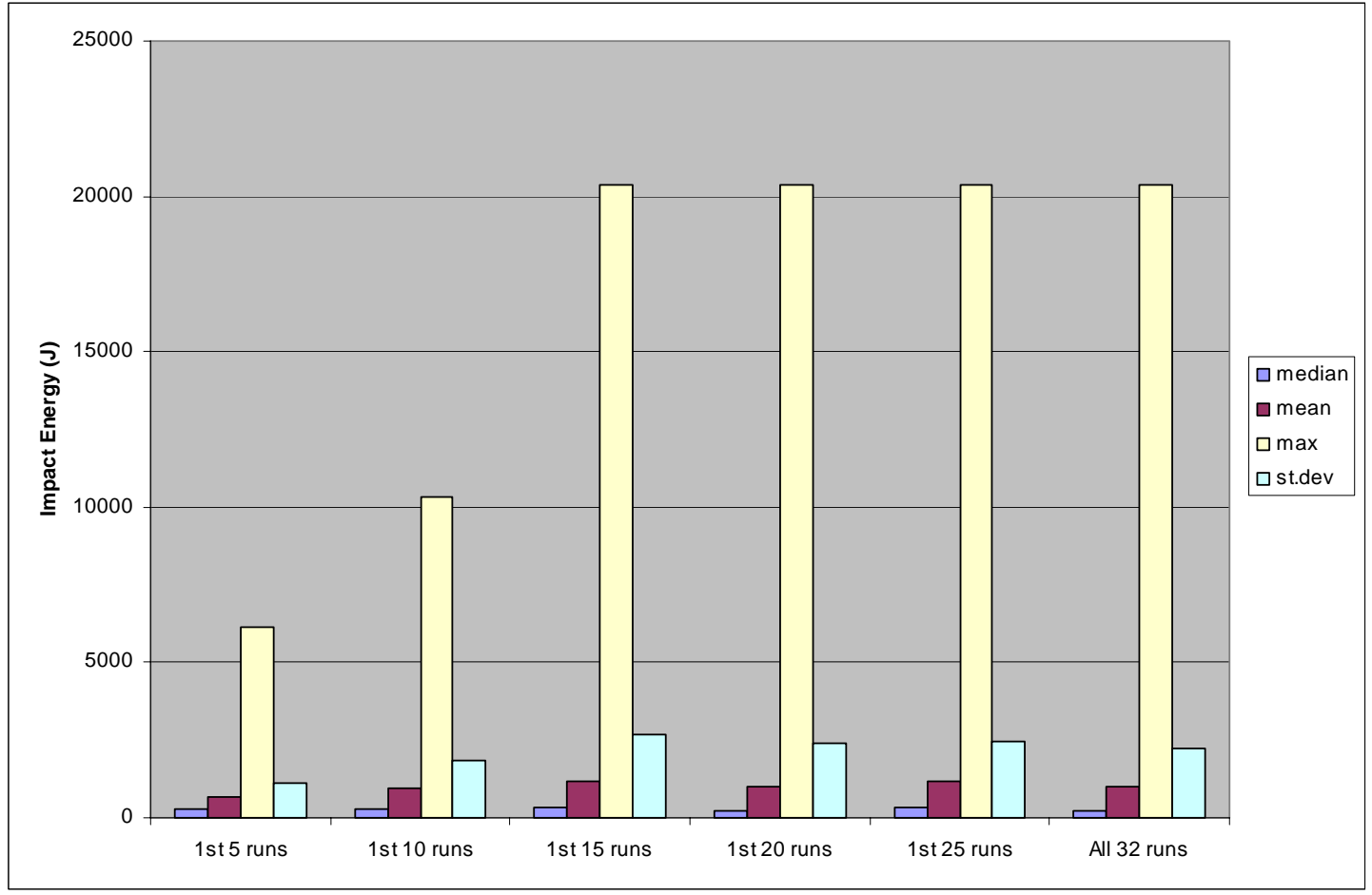

Figure K-3. Summary Statistics of Impact Energy (J) for $1 \times 10^{-4}$ Preclosure Ground Motion

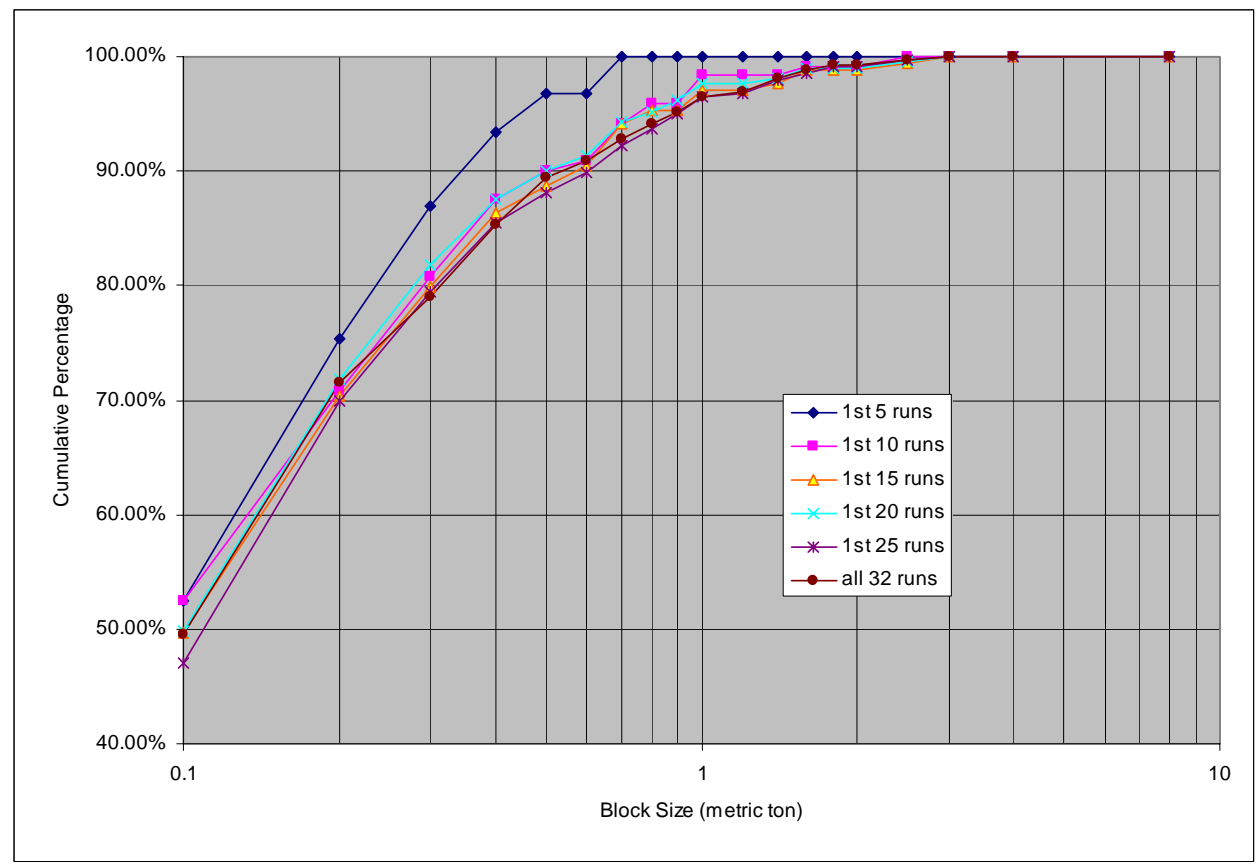

Figure K-4. Block Size Distribution for $1 \times 10^{-4}$ Preclosure Ground Motion 
Figures K-5 to K-7 shows the trend of the statistics for the analyses considering the $1 \times 10^{-5}$ annual probability of exceedance ground motion with a total of 50 3DEC simulations. The corresponding numeric values for the statistics are tabulated in Tables K-4 to K-6. The maximum values of the block size, impact velocity, and impact energy occur between the $20^{\text {th }}$ and $25^{\text {th }}$ simulation. The trend shows that the statistics of rockfall characteristics approaches to asymptotic value approximately 25 to 30 runs of 3DEC simulation. Figure K-8 present the block size cumulative distribution for the evolution of the analyses, the distribution also shows that approximately 25 to 30 runs of $3 \mathrm{DEC}$ simulation provide adequate representation of the size distribution.

Table K-4. Summary Statistics of Block Size (metric ton) for $1 \times 10^{-5}$ Ground Motion

\begin{tabular}{|c|c|c|c|c|c|c|c|c|c|c|}
\hline $\begin{array}{c}\text { Summary } \\
\text { Statistics }\end{array}$ & $\begin{array}{c}\mathbf{1}^{\text {st }} \mathbf{5} \\
\text { runs }\end{array}$ & $\begin{array}{c}\mathbf{1}^{\text {st }} \mathbf{1 0} \\
\text { runs }\end{array}$ & $\begin{array}{c}\mathbf{1}^{\text {st }} \mathbf{1 5} \\
\text { runs }\end{array}$ & $\begin{array}{c}\mathbf{1}^{\text {st }} \mathbf{2 0} \\
\text { runs }\end{array}$ & $\begin{array}{c}\mathbf{1}^{\text {st }} \mathbf{2 5} \\
\text { runs }\end{array}$ & $\begin{array}{c}\mathbf{1}^{\text {st }} \mathbf{3 0} \\
\text { runs }\end{array}$ & $\begin{array}{c}\mathbf{1}^{\text {st }} \mathbf{3 5} \\
\text { runs }\end{array}$ & $\begin{array}{c}\mathbf{1}^{\text {st }} \mathbf{4 0} \\
\text { runs }\end{array}$ & $\begin{array}{c}\mathbf{1}^{\text {st }} \mathbf{4 5} \\
\text { runs }\end{array}$ & $\begin{array}{c}\text { All } \mathbf{5 0} \\
\text { runs }\end{array}$ \\
\hline Median & 0.09 & 0.10 & 0.12 & 0.11 & 0.13 & 0.12 & 0.12 & 0.12 & 0.12 & 0.12 \\
\hline Mean & 0.26 & 0.26 & 0.31 & 0.30 & 0.40 & 0.37 & 0.37 & 0.36 & 0.35 & 0.35 \\
\hline Maximum & 6.01 & 6.01 & 8.94 & 8.94 & 19.07 & 19.07 & 19.07 & 19.07 & 19.07 & 19.07 \\
\hline $\begin{array}{c}\text { Standard } \\
\text { Deviation }\end{array}$ & 0.59 & 0.51 & 0.73 & 0.69 & 1.08 & 0.99 & 0.98 & 0.96 & 0.95 & 0.93 \\
\hline
\end{tabular}

Table K-5. Summary Statistics of Impact Velocity $(\mathrm{m} / \mathrm{sec})$ for $1 \times 10^{-5}$ Ground Motion

\begin{tabular}{|c|c|c|c|c|c|c|c|c|c|c|}
\hline $\begin{array}{c}\text { Summary } \\
\text { Statistics }\end{array}$ & $\begin{array}{c}\mathbf{1}^{\text {st }} \mathbf{5} \\
\text { runs }\end{array}$ & $\begin{array}{c}\mathbf{1}^{\text {st }} \mathbf{1 0} \\
\text { runs }\end{array}$ & $\begin{array}{c}\mathbf{1}^{\text {st }} \mathbf{1 5} \\
\text { runs }\end{array}$ & $\begin{array}{c}\mathbf{1}^{\text {st }} \mathbf{2 0} \\
\text { runs }\end{array}$ & $\begin{array}{c}\mathbf{1}^{\text {st }} \mathbf{2 5} \\
\text { runs }\end{array}$ & $\begin{array}{c}\mathbf{1}^{\text {st }} \mathbf{3 0} \\
\text { runs }\end{array}$ & $\begin{array}{c}\mathbf{1}^{\text {st }} \mathbf{3 5} \\
\text { runs }\end{array}$ & $\begin{array}{c}\mathbf{1}^{\text {st }} \mathbf{4 0} \\
\text { runs }\end{array}$ & $\begin{array}{c}\mathbf{1}^{\text {st }} \mathbf{4 5} \\
\text { runs }\end{array}$ & $\begin{array}{c}\text { All } \mathbf{5 0} \\
\text { runs }\end{array}$ \\
\hline Median & 2.58 & 2.55 & 2.52 & 2.51 & 2.60 & 2.53 & 2.60 & 2.60 & 2.55 & 2.57 \\
\hline Mean & 2.48 & 2.51 & 2.59 & 2.58 & 2.70 & 2.62 & 2.67 & 2.69 & 2.66 & 2.69 \\
\hline Maximum & 5.35 & 5.81 & 9.05 & 9.05 & 9.42 & 9.42 & 9.42 & 9.42 & 9.42 & 9.42 \\
\hline $\begin{array}{l}\text { Standard } \\
\text { Deviation }\end{array}$ & 1.22 & 1.22 & 1.48 & 1.43 & 1.50 & 1.50 & 1.43 & 1.45 & 1.44 & 1.48 \\
\hline
\end{tabular}

Table K-6. Summary Statistics of Impact Energy (J) for $1 \times 10^{-5}$ Preclosure Ground Motion

\begin{tabular}{|c|c|c|c|c|c|c|c|c|c|c|}
\hline $\begin{array}{c}\text { Summary } \\
\text { Statistics }\end{array}$ & $\begin{array}{c}\mathbf{1}^{\text {st }} \mathbf{5} \\
\text { runs }\end{array}$ & $\begin{array}{c}\mathbf{1}^{\text {st }} \mathbf{1 0} \\
\text { runs }\end{array}$ & $\begin{array}{c}\mathbf{1}^{\text {st }} \mathbf{1 5} \\
\text { runs }\end{array}$ & $\begin{array}{c}\mathbf{1}^{\text {st }} \mathbf{2 0} \\
\text { runs }\end{array}$ & $\begin{array}{c}\mathbf{1}^{\text {st }} \mathbf{2 5} \\
\text { runs }\end{array}$ & $\begin{array}{c}\mathbf{1}^{\text {st }} \mathbf{3 0} \\
\text { runs }\end{array}$ & $\begin{array}{c}\mathbf{1}^{\text {st }} \mathbf{3 5} \\
\text { runs }\end{array}$ & $\begin{array}{c}\mathbf{1}^{\text {st }} \mathbf{4 0} \\
\text { runs }\end{array}$ & $\begin{array}{c}\mathbf{1}^{\text {st }} \mathbf{4 5} \\
\text { runs }\end{array}$ & $\begin{array}{c}\text { All } \mathbf{5 0} \\
\text { runs }\end{array}$ \\
\hline Median & 288 & 271 & 318 & 326 & 391 & 355 & 364 & 358 & 343 & 357 \\
\hline Mean & 1005 & 1020 & 1190 & 1141 & 2260 & 2055 & 1899 & 1903 & 1839 & 1814 \\
\hline Maximum & 17557 & 19410 & 20913 & 20913 & 435077 & 435077 & 435077 & 435077 & 435077 & 435077 \\
\hline $\begin{array}{l}\text { Standard } \\
\text { Deviation }\end{array}$ & 2443 & 2356 & 2518 & 2414 & 16028 & 14585 & 12752 & 12346 & 12081 & 11430 \\
\hline
\end{tabular}




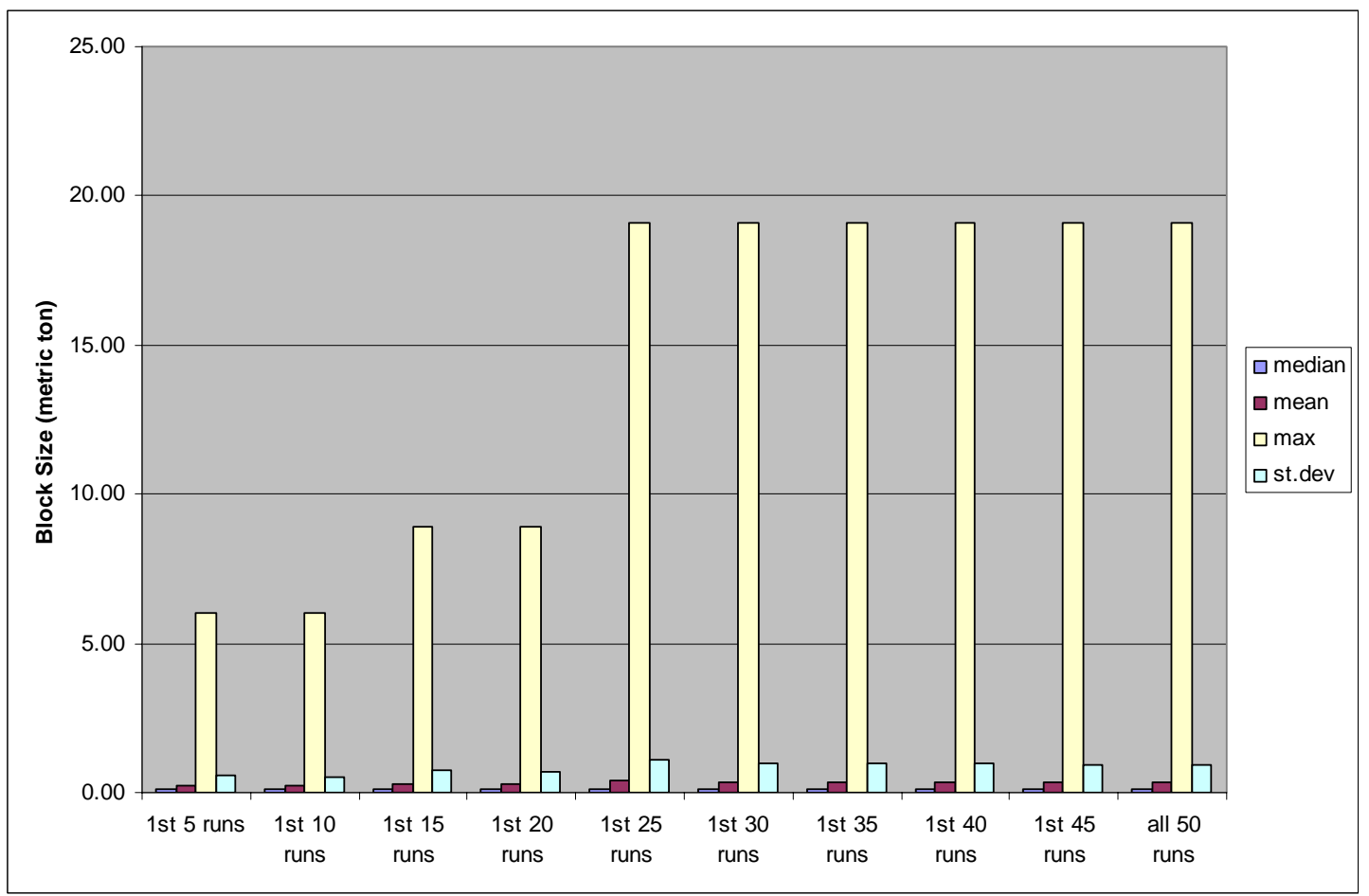

Figure K-5. Summary Statistics of Block Size (metric ton) for $1 \times 10^{-5}$ Ground Motion

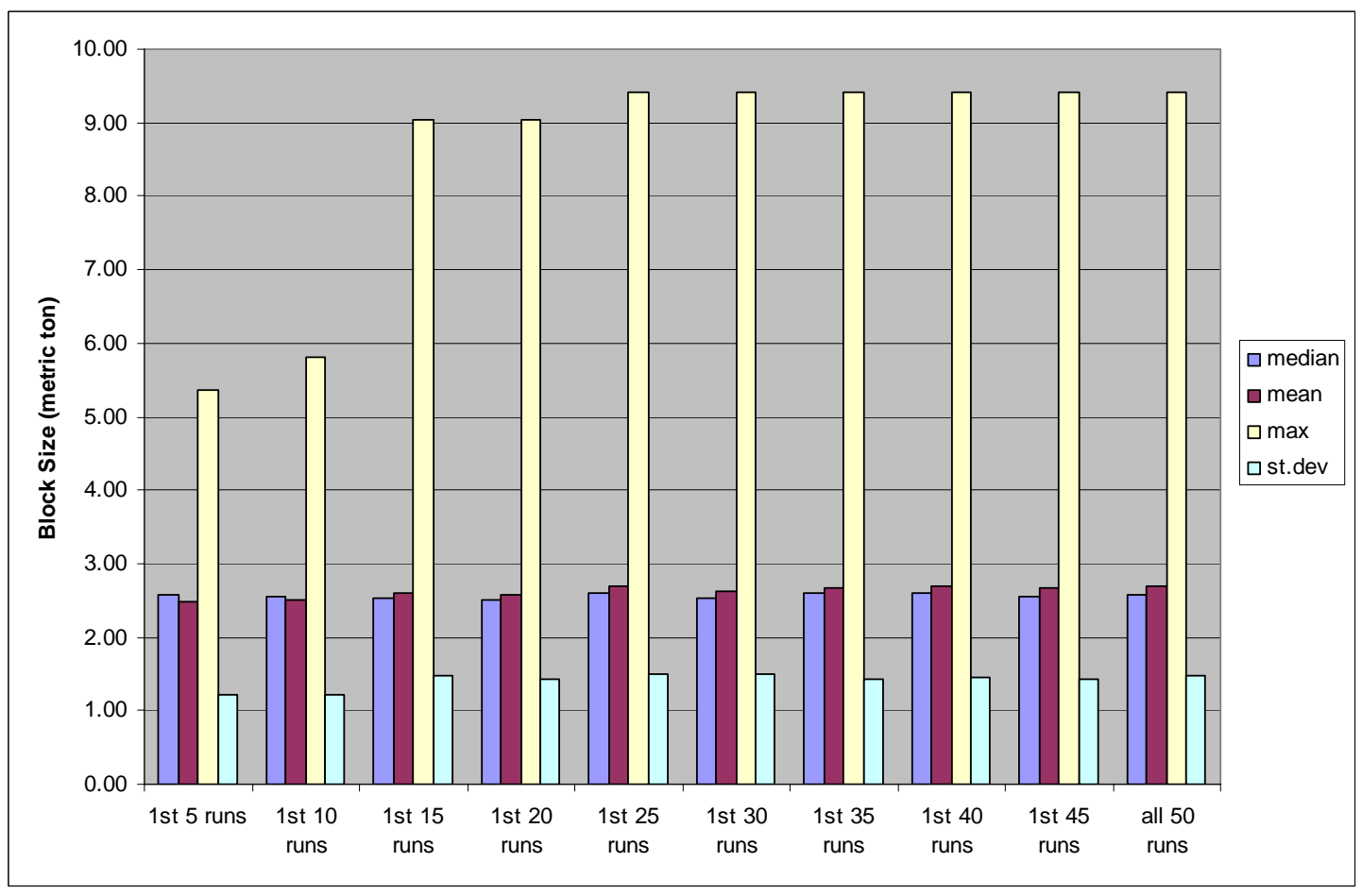

Figure K-6. Summary Statistics of Impact Velocity $(\mathrm{m} / \mathrm{sec})$ for $1 \times 10^{-5}$ Ground Motion 


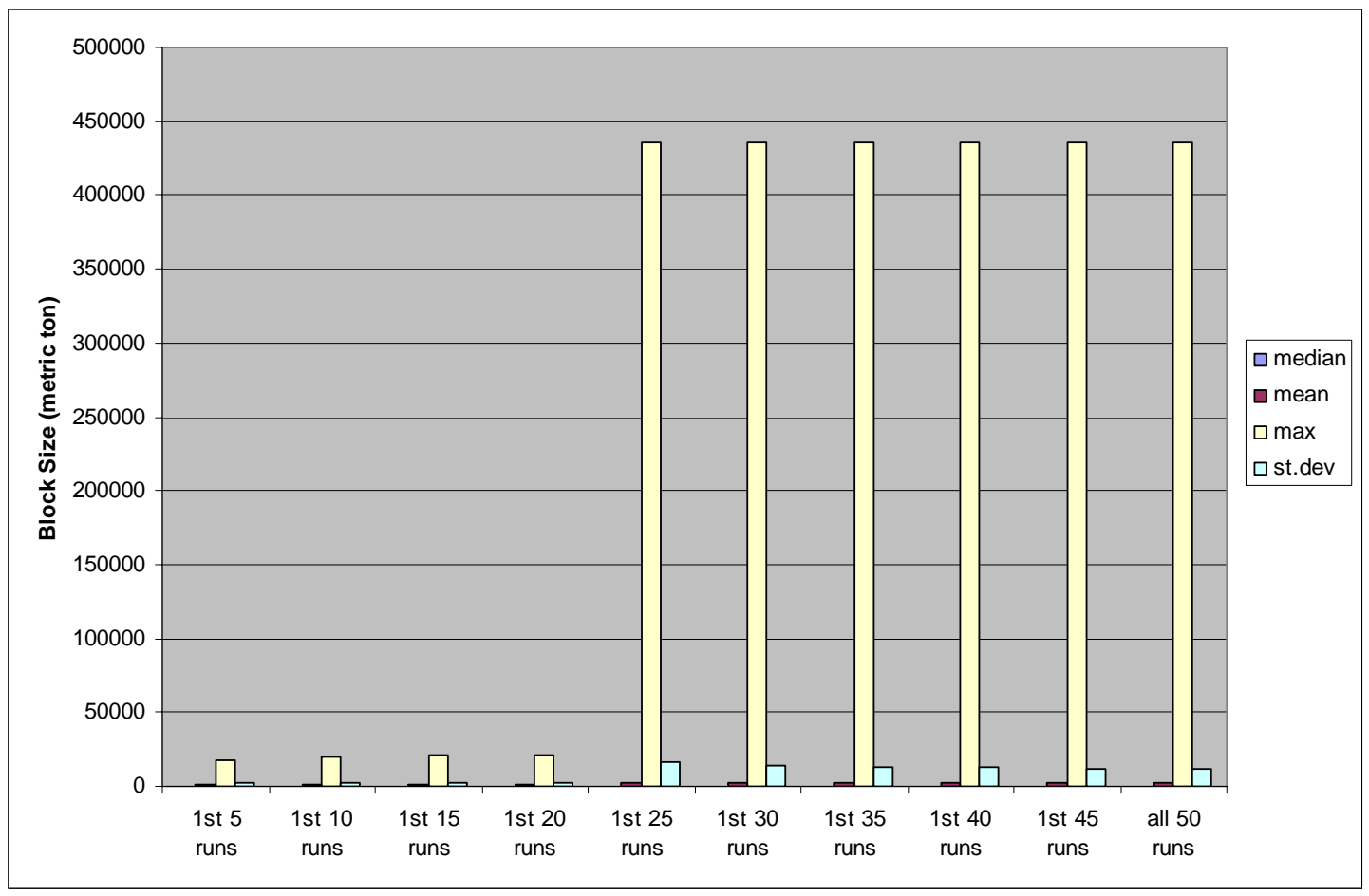

Figure K-7. Summary Statistics of Impact Energy (J) for $1 \times 10^{-5}$ Ground Motion

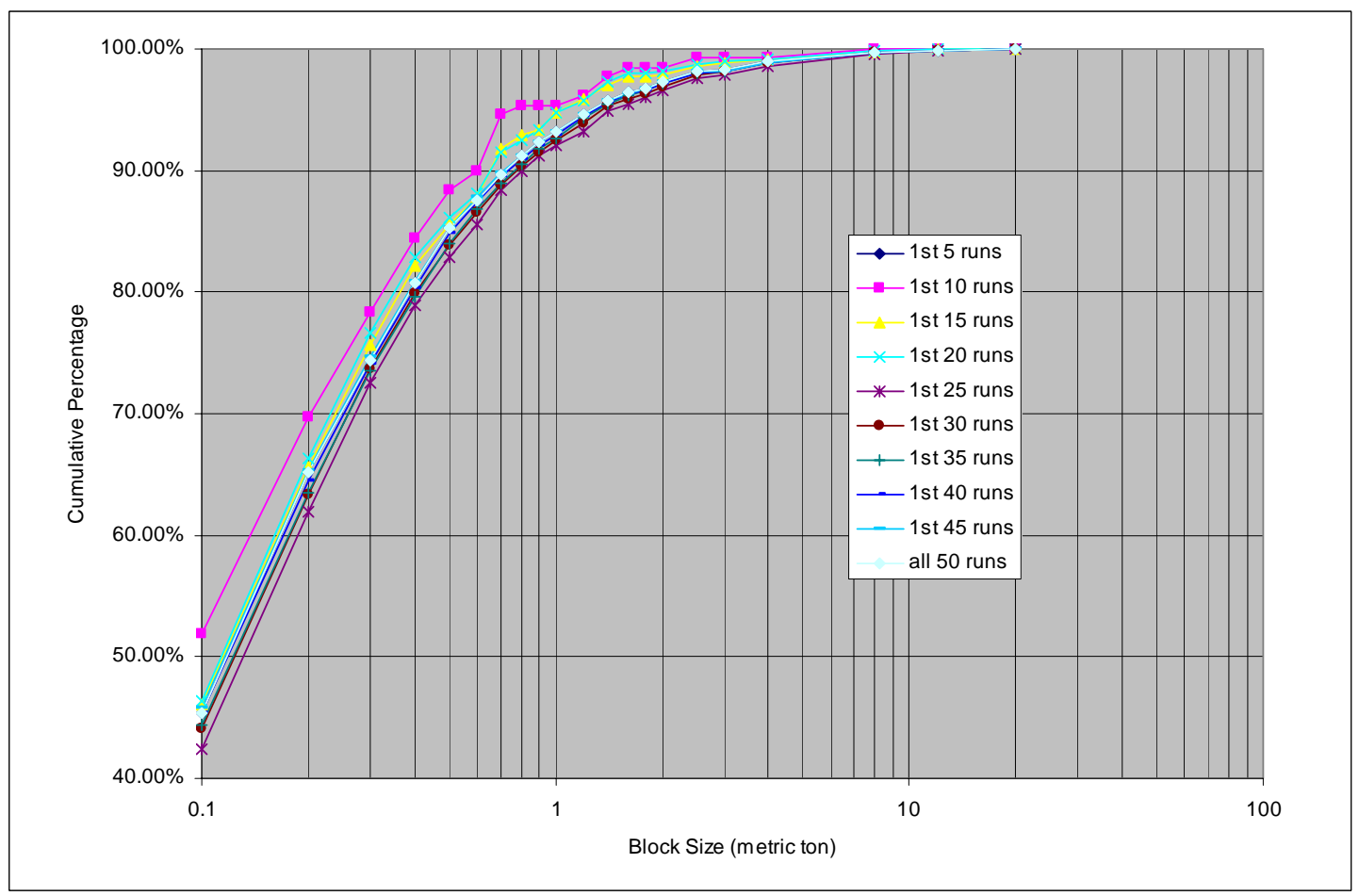

Figure K-8. Block Size Distribution for $1 \times 10^{-5}$ Ground Motion 
Figures K-9 to K-11 shows the trend of the statistics for the analyses considering the $1 \times 10^{-6}$ annual probability of exceedance ground motion with a total of 50 3DEC simulations. The corresponding numeric values for the statistics are tabulated in Tables K-7 to K-9. The maximum block size occurs in between the $30^{\text {th }}$ and $35^{\text {th }}$ simulation, whereas the maximum impact velocity and impact energy occurs in between the $20^{\text {th }}$ and $25^{\text {th }}$ simulation. The trend shows that the statistics of rockfall characteristics approaches to asymptotic value approximately 30 to 35 runs of 3DEC simulation. Figure K-12 present the block size cumulative distribution for the evolution of the analyses, the distribution shows that approximately 25 to 30 runs of 3DEC simulation provide adequate representation of the size distribution.

Table K-7. Summary Statistics of Block Size (metric ton) for $1 \times 10^{-6}$ Ground Motion

\begin{tabular}{|c|c|c|c|c|c|c|c|c|c|c|}
\hline $\begin{array}{c}\text { Summary } \\
\text { Statistics }\end{array}$ & $\begin{array}{c}\mathbf{1}^{\text {st }} \mathbf{5} \\
\text { runs }\end{array}$ & $\begin{array}{c}\mathbf{1} \text { st } \mathbf{1 0} \\
\text { runs }\end{array}$ & $\begin{array}{c}\mathbf{1}^{\text {st }} \mathbf{1 5} \\
\text { runs }\end{array}$ & $\begin{array}{c}\mathbf{1}^{\text {st }} \mathbf{2 0} \\
\text { runs }\end{array}$ & $\begin{array}{c}\mathbf{1}^{\text {st }} \mathbf{2 5} \\
\text { runs }\end{array}$ & $\begin{array}{c}\mathbf{1} \text { st } \mathbf{3 0} \\
\text { runs }\end{array}$ & $\begin{array}{c}\mathbf{1}^{\text {st }} \mathbf{3 5} \\
\text { runs }\end{array}$ & $\begin{array}{c}\mathbf{1}^{\text {st }} \mathbf{4 0} \\
\text { runs }\end{array}$ & $\begin{array}{c}\mathbf{1}^{\text {st }} \mathbf{4 5} \\
\text { runs }\end{array}$ & $\begin{array}{c}\text { All } \mathbf{5 0} \\
\text { runs }\end{array}$ \\
\hline Median & 0.09 & 0.10 & 0.12 & 0.12 & 0.13 & 0.13 & 0.13 & 0.12 & 0.12 & 0.13 \\
\hline Mean & 0.35 & 0.34 & 0.35 & 0.36 & 0.44 & 0.41 & 0.43 & 0.43 & 0.43 & 0.43 \\
\hline Maximum & 10.75 & 10.75 & 10.75 & 11.50 & 19.07 & 19.07 & 28.22 & 28.22 & 28.22 & 28.22 \\
\hline $\begin{array}{c}\text { Standard } \\
\text { Deviation }\end{array}$ & 1.01 & 0.85 & 0.85 & 0.91 & 1.16 & 1.06 & 1.37 & 1.35 & 1.35 & 1.30 \\
\hline
\end{tabular}

Table K-8. Summary Statistics of Impact Velocity $(\mathrm{m} / \mathrm{sec})$ for $1 \times 10^{-6}$ Ground Motion

\begin{tabular}{|c|c|c|c|c|c|c|c|c|c|c|}
\hline $\begin{array}{c}\text { Summary } \\
\text { Statistics }\end{array}$ & $\begin{array}{c}\mathbf{1}^{\text {st }} \mathbf{5} \\
\text { runs }\end{array}$ & $\begin{array}{c}\mathbf{1}^{\text {st }} \mathbf{1 0} \\
\text { runs }\end{array}$ & $\begin{array}{c}\mathbf{1}^{\text {st }} \mathbf{1 5} \\
\text { runs }\end{array}$ & $\begin{array}{c}\mathbf{1}^{\text {st }} \mathbf{2 0} \\
\text { runs }\end{array}$ & $\begin{array}{c}\mathbf{1}^{\text {st }} \mathbf{2 5} \\
\text { runs }\end{array}$ & $\begin{array}{c}\mathbf{1}^{\text {st }} \\
\mathbf{3 0} \\
\text { runs }\end{array}$ & $\begin{array}{c}\mathbf{1}^{\text {st }} \\
\text { runs }\end{array}$ & $\begin{array}{c}\mathbf{1}^{\text {st }} \\
\mathbf{4 0} \\
\text { runs }\end{array}$ & $\begin{array}{c}\mathbf{1}^{\text {st }} \mathbf{4 5} \\
\text { runs }\end{array}$ & $\begin{array}{c}\text { All } \mathbf{5 0} \\
\text { runs }\end{array}$ \\
\hline Median & 2.97 & 3.01 & 3.10 & 3.06 & 3.11 & 3.02 & 2.97 & 2.98 & 2.98 & 2.97 \\
\hline Mean & 3.08 & 3.17 & 3.30 & 3.27 & 3.36 & 3.26 & 3.23 & 3.22 & 3.21 & 3.23 \\
\hline Maximum & 7.09 & 8.08 & 8.77 & 8.77 & 12.09 & 12.09 & 12.10 & 12.10 & 12.10 & 12.10 \\
\hline $\begin{array}{c}\text { Standard } \\
\text { Deviation }\end{array}$ & 1.32 & 1.44 & 1.64 & 1.59 & 1.69 & 1.69 & 1.71 & 1.72 & 1.70 & 1.74 \\
\hline
\end{tabular}

Table K-9. Summary Statistics of Impact Energy (J) for $1 \times 10^{-6}$ Ground Motion

\begin{tabular}{|c|c|c|c|c|c|c|c|c|c|c|}
\hline $\begin{array}{c}\text { Summary } \\
\text { Statistics }\end{array}$ & $\begin{array}{c}\mathbf{1}^{\text {st }} \mathbf{5} \\
\text { runs }\end{array}$ & $\begin{array}{c}\mathbf{1}^{\text {st }} \mathbf{1 0} \\
\text { runs }\end{array}$ & $\begin{array}{c}\mathbf{1}^{\text {st }} \mathbf{1 5} \\
\text { runs }\end{array}$ & $\begin{array}{c}\mathbf{1}^{\text {st }} \mathbf{2 0} \\
\text { runs }\end{array}$ & $\begin{array}{c}\mathbf{1}^{\text {st }} \mathbf{2 5} \\
\text { runs }\end{array}$ & $\begin{array}{c}\mathbf{1}^{\text {st }} \mathbf{3 0} \\
\text { runs }\end{array}$ & $\begin{array}{c}\mathbf{1}^{\text {st }} \mathbf{3 5} \\
\text { runs }\end{array}$ & $\begin{array}{c}\mathbf{1}^{\text {st }} \mathbf{4 0} \\
\text { runs }\end{array}$ & $\begin{array}{c}\mathbf{1}^{\text {st }} \mathbf{4 5} \\
\text { runs }\end{array}$ & $\begin{array}{c}\text { All } \mathbf{5 0} \\
\text { runs }\end{array}$ \\
\hline Median & 407 & 475 & 582 & 563 & 678 & 574 & 556 & 550 & 548 & 576 \\
\hline Mean & 1455 & 1625 & 1868 & 1974 & 2521 & 2368 & 2296 & 2275 & 2288 & 2350 \\
\hline Maximum & 36584 & 36584 & 60585 & 60585 & 163657 & 163657 & 163657 & 163657 & 163657 & 163657 \\
\hline $\begin{array}{l}\text { Standard } \\
\text { Deviation }\end{array}$ & 3428 & 3743 & 4277 & 4794 & 7788 & 7868 & 7600 & 7349 & 7786 & 7704 \\
\hline
\end{tabular}




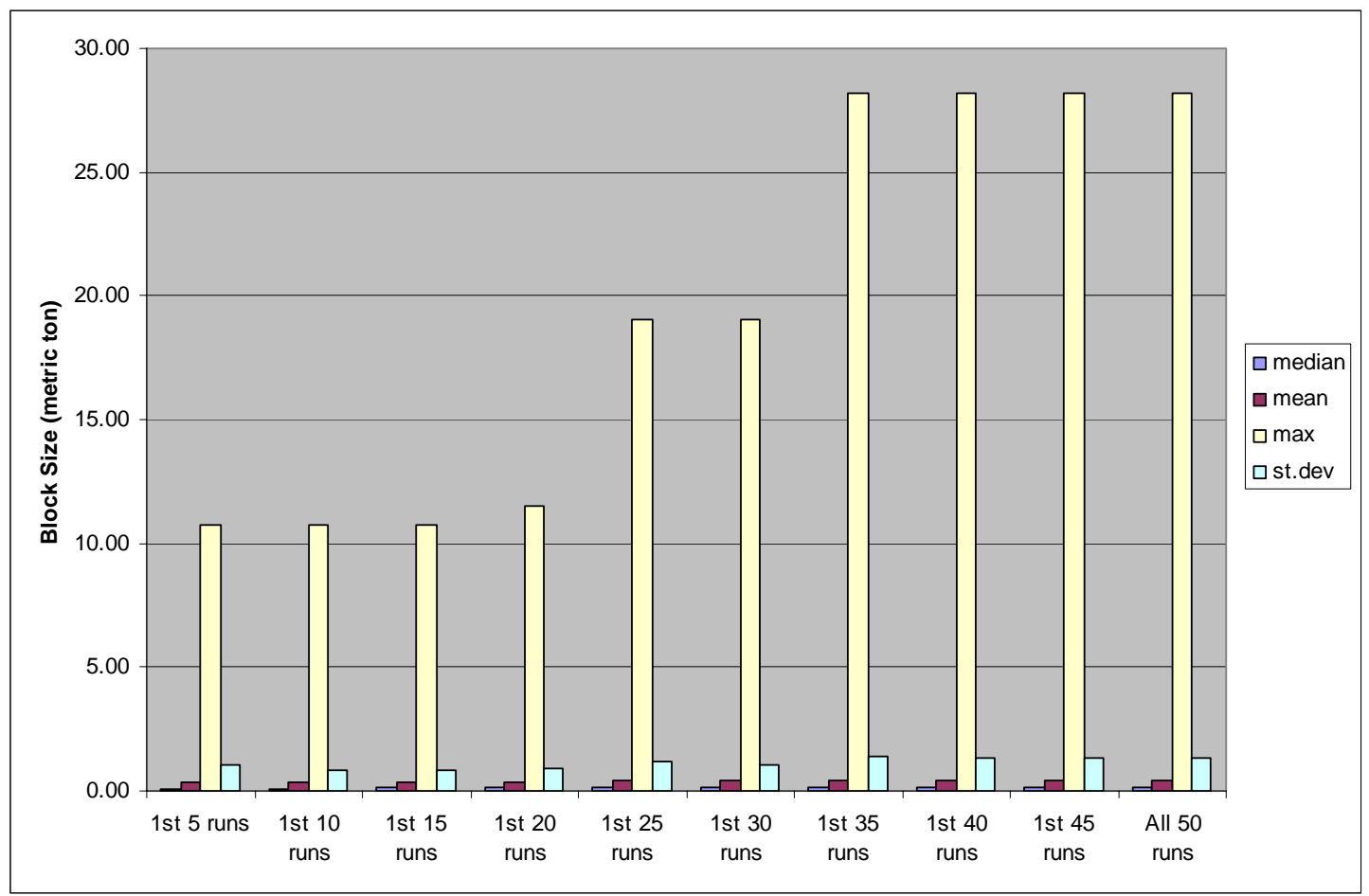

Figure K-9. Summary Statistics of Block Size (metric ton) for $1 \times 10^{-6}$ Ground Motion

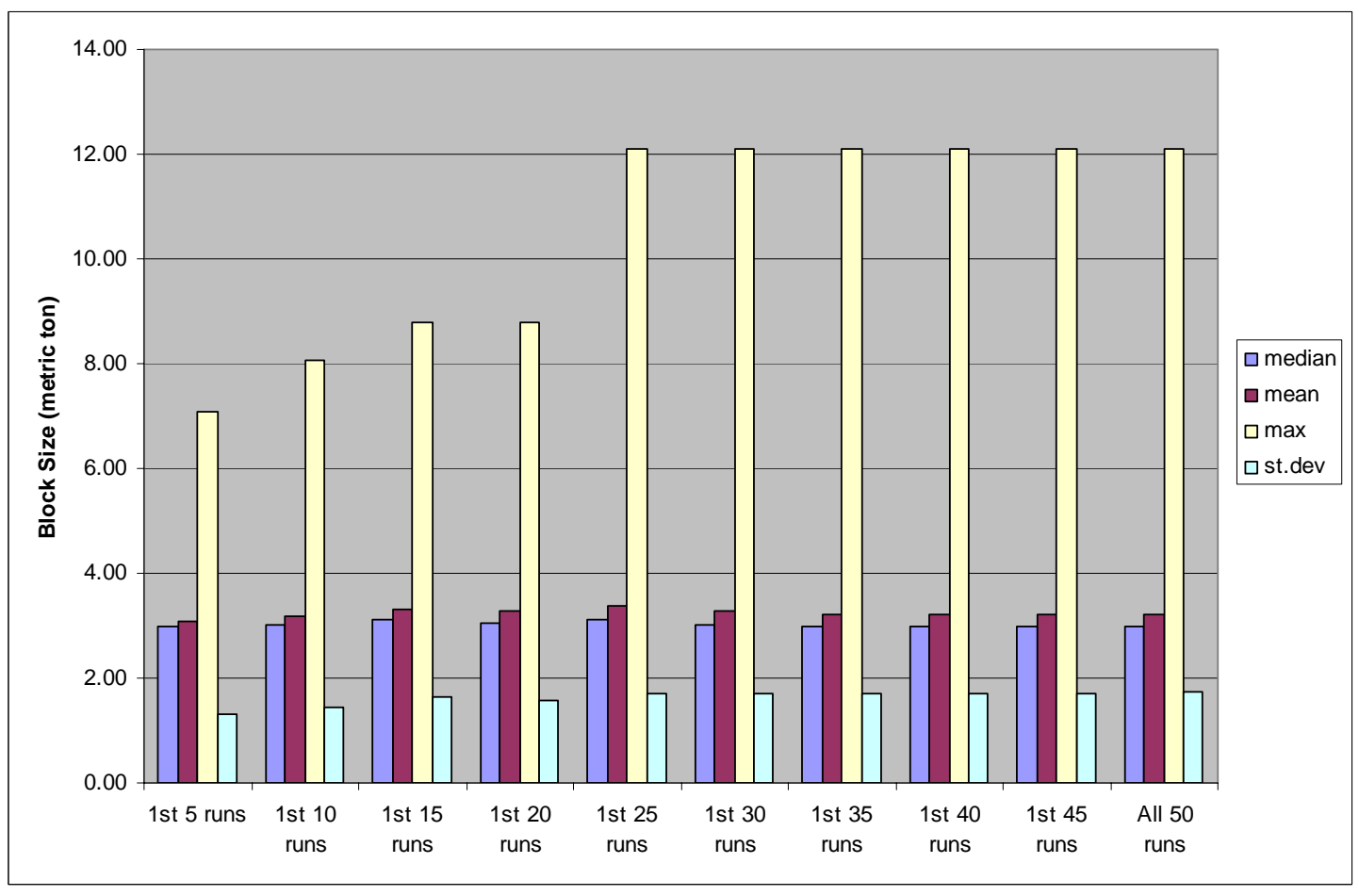

Figure K-10. Summary Statistics of Impact Velocity $(\mathrm{m} / \mathrm{sec})$ for $1 \times 10^{-6}$ Ground Motion 


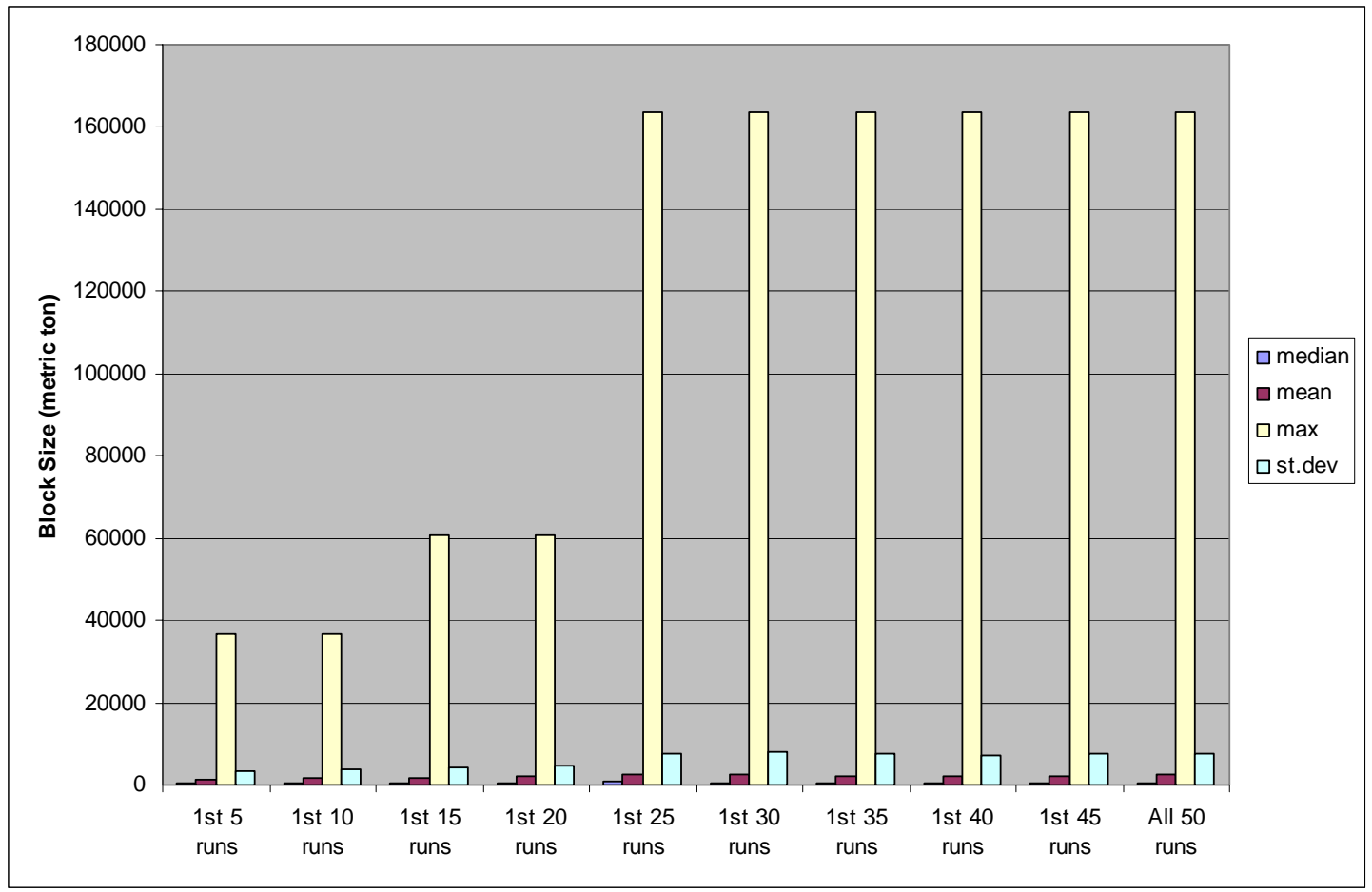

NOTE: $\mathrm{J}=$ Joule.

Figure K-11. Summary Statistics of Impact Energy (J) for $1 \times 10^{-6}$ Ground Motion

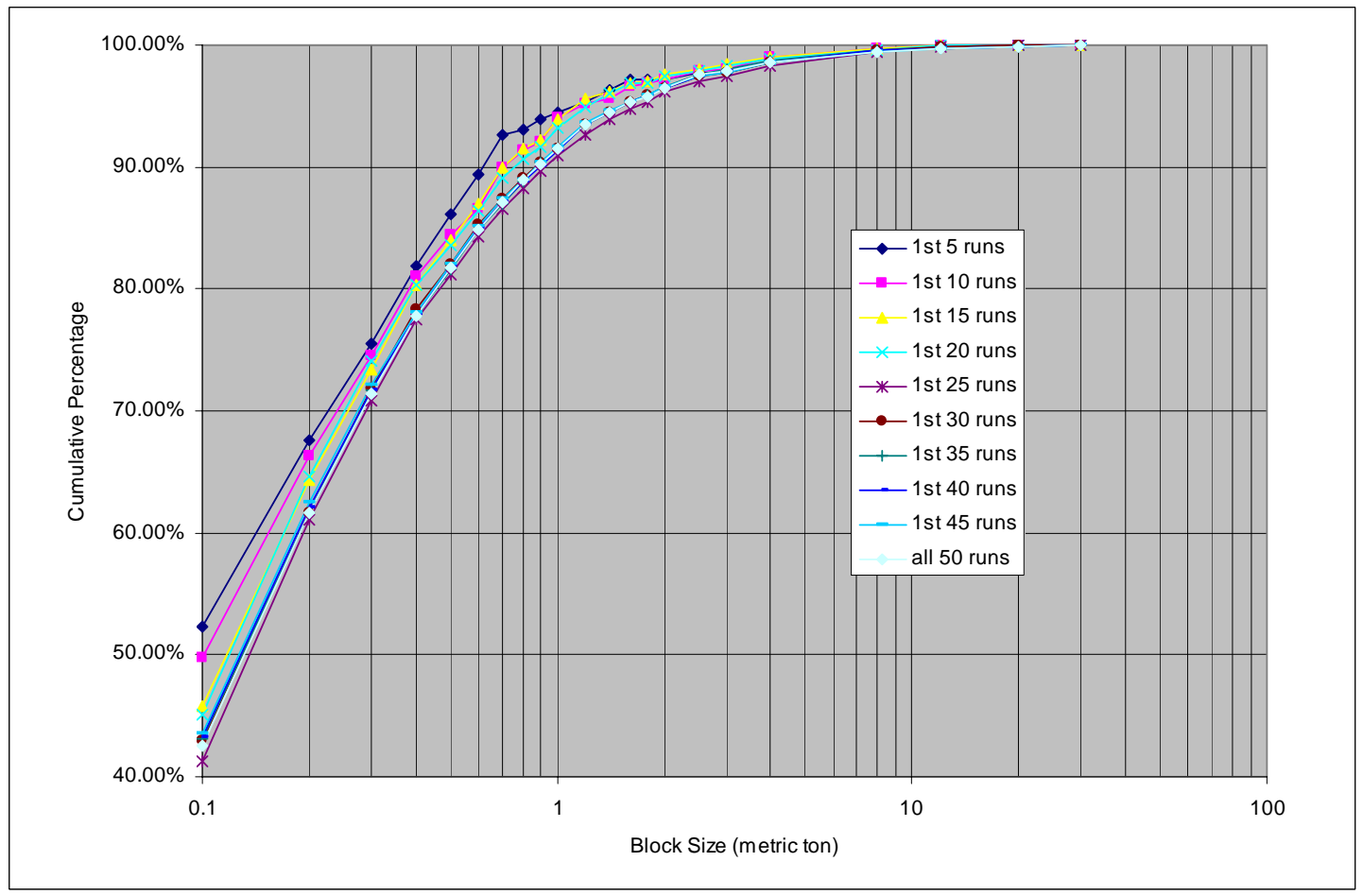

Figure K-12. Block Size Distribution for $1 \times 10^{-6}$ Ground Motion 
Figures K-13 to K-15 shows the trend of the statistics for the analyses considering the $1 \times 10^{-7}$ annual probability of exceedance ground motion with a total of 44 3DEC simulations. The corresponding numeric values for the statistics are tabulated in Tables K-10 to K-12. The maximum block size and impact energy occurs in between the $20^{\text {th }}$ and $25^{\text {th }}$ simulation, whereas the maximum impact velocity occurs in between the $40^{\text {th }}$ and $44^{\text {th }}$ simulation. The trend shows that the statistics of rockfall characteristics approaches to asymptotic value approximately 30 to 35 runs of 3DEC simulation. Figure K-16 present the block size cumulative distribution for the evolution of the analyses, the distribution shows that approximately 20 to 25 runs of 3DEC simulation provide adequate representation of the size distribution.

Table K-10. Summary Statistics of Block Size (metric ton) for $1 \times 10^{-7}$ Ground Motion

\begin{tabular}{|l|l|l|l|l|l|l|l|l|l|}
\hline $\begin{array}{c}\text { Summary } \\
\text { Statistics }\end{array}$ & $\begin{array}{c}\mathbf{1}^{\text {st }} \mathbf{5} \\
\text { runs }\end{array}$ & $\begin{array}{c}\mathbf{1}^{\text {st }} \mathbf{1 0} \\
\text { runs }\end{array}$ & $\begin{array}{c}\mathbf{1}^{\text {st }} \mathbf{1 5} \\
\text { runs }\end{array}$ & $\begin{array}{c}\mathbf{1}^{\text {st }} \mathbf{2 0} \\
\text { runs }\end{array}$ & $\begin{array}{l}\mathbf{1}^{\text {st }} \mathbf{2 5} \\
\text { runs }\end{array}$ & $\begin{array}{l}\mathbf{1}^{\text {st }} \mathbf{3 0} \\
\text { runs }\end{array}$ & $\begin{array}{l}\mathbf{1}^{\text {st }} \mathbf{3 5} \\
\text { runs }\end{array}$ & $\begin{array}{l}\mathbf{1}^{\text {st }} \mathbf{4 0} \\
\text { runs }\end{array}$ & $\begin{array}{c}\text { All } \mathbf{4 4} \\
\text { runs }\end{array}$ \\
\hline Median & 0.12 & 0.12 & 0.13 & 0.14 & 0.14 & 0.14 & 0.14 & 0.14 & 0.15 \\
\hline Mean & 0.47 & 0.49 & 0.50 & 0.53 & 0.52 & 0.51 & 0.50 & 0.50 & 0.50 \\
\hline Maximum & 14.58 & 14.58 & 14.58 & 19.05 & 28.29 & 28.29 & 28.29 & 28.29 & 28.29 \\
\hline $\begin{array}{l}\text { Standard } \\
\text { Deviation }\end{array}$ & 1.29 & 1.25 & 1.29 & 1.39 & 1.57 & 1.50 & 1.44 & 1.44 & 1.43 \\
\hline
\end{tabular}

Table K-11. Summary Statistics of Impact Velocity $(\mathrm{m} / \mathrm{sec})$ for $1 \times 10^{-7}$ Ground Motion

\begin{tabular}{|l|l|l|l|l|l|l|l|l|l|}
\hline $\begin{array}{c}\text { Summary } \\
\text { Statistics }\end{array}$ & $\begin{array}{c}\mathbf{1}^{\text {st }} \mathbf{5} \\
\text { runs }\end{array}$ & $\begin{array}{c}\mathbf{1}^{\text {st }} \mathbf{1 0} \\
\text { runs }\end{array}$ & $\begin{array}{c}\mathbf{1}^{\text {st }} \mathbf{1 5} \\
\text { runs }\end{array}$ & $\begin{array}{c}\mathbf{1}^{\text {st }} \mathbf{2 0} \\
\text { runs }\end{array}$ & $\begin{array}{c}\mathbf{1}^{\text {st }} \mathbf{2 5} \\
\text { runs }\end{array}$ & $\begin{array}{c}\mathbf{1}^{\text {st }} \\
\mathbf{3 0} \\
\text { runs }\end{array}$ & $\begin{array}{c}\mathbf{1}^{\text {st }} \\
\mathbf{3 5} \\
\text { runs }\end{array}$ & $\begin{array}{c}\mathbf{1}^{\text {st }} \\
\mathbf{4 0} \\
\text { runs }\end{array}$ & $\begin{array}{c}\text { All 44 } \\
\text { runs }\end{array}$ \\
\hline Median & 4.35 & 4.16 & 4.11 & 3.75 & 3.97 & 3.85 & 3.82 & 3.83 & 3.78 \\
\hline Mean & 4.38 & 4.25 & 4.31 & 4.04 & 4.26 & 4.18 & 4.19 & 4.17 & 4.17 \\
\hline Maximum & 11.67 & 11.67 & 13.58 & 13.58 & 20.53 & 20.53 & 20.53 & 20.53 & 20.94 \\
\hline $\begin{array}{l}\text { Standard } \\
\text { Deviation }\end{array}$ & 2.20 & 2.07 & 2.22 & 2.16 & 2.42 & 2.35 & 2.40 & 2.37 & 2.47 \\
\hline
\end{tabular}

Table K-12. Summary Statistics of Impact Energy (J) for $1 \times 10^{-7}$ Ground Motion

\begin{tabular}{|l|c|l|l|l|l|l|l|l|l|}
\hline $\begin{array}{l}\text { Summary } \\
\text { Statistics }\end{array}$ & $\begin{array}{c}\mathbf{1}^{\text {st }} \mathbf{5} \\
\text { runs }\end{array}$ & $\begin{array}{c}\mathbf{1}^{\text {st }} \mathbf{1 0} \\
\text { runs }\end{array}$ & $\begin{array}{c}\mathbf{1}^{\text {st }} \mathbf{1 5} \\
\text { runs }\end{array}$ & $\begin{array}{c}\mathbf{1}^{\text {st }} \mathbf{2 0} \\
\text { runs }\end{array}$ & $\begin{array}{c}\mathbf{1}^{\text {st }} \mathbf{2 5} \\
\text { runs }\end{array}$ & $\begin{array}{c}\mathbf{1}^{\text {st }} \mathbf{3 0} \\
\text { runs }\end{array}$ & $\begin{array}{c}\mathbf{1}^{\text {st }} \mathbf{3 5} \\
\text { runs }\end{array}$ & $\begin{array}{c}\mathbf{1}^{\text {st }} \mathbf{4 0} \\
\text { runs }\end{array}$ & $\begin{array}{c}\text { All } \mathbf{4 4} \\
\text { runs }\end{array}$ \\
\hline Median & 1163 & 1127 & 1176 & 981 & 1077 & 1020 & 1005 & 1004 & 1022 \\
\hline Mean & 3786 & 3890 & 4005 & 3666 & 4301 & 4240 & 4099 & 4069 & 4146 \\
\hline Maximum & 80283 & 80283 & 80283 & 80283 & 706914 & 706914 & 706914 & 706914 & 706914 \\
\hline $\begin{array}{l}\text { Standard } \\
\text { Deviation }\end{array}$ & 8419 & 8294 & 8457 & 8003 & 20139 & 18558 & 17649 & 17526 & 16749 \\
\hline
\end{tabular}




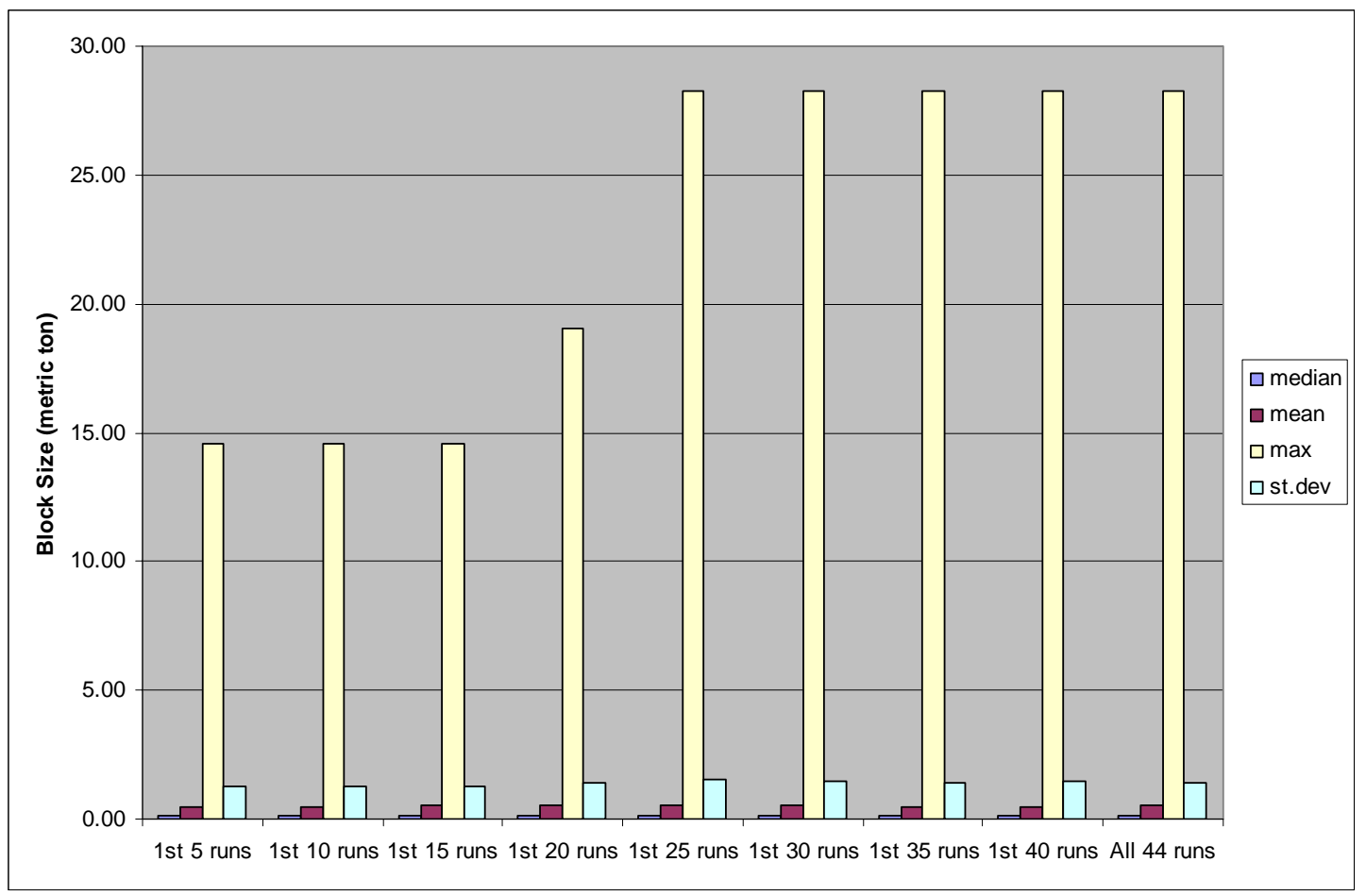

Figure K-13. Summary Statistics of Block Size (metric ton) for $1 \times 10^{-7}$ Ground Motion

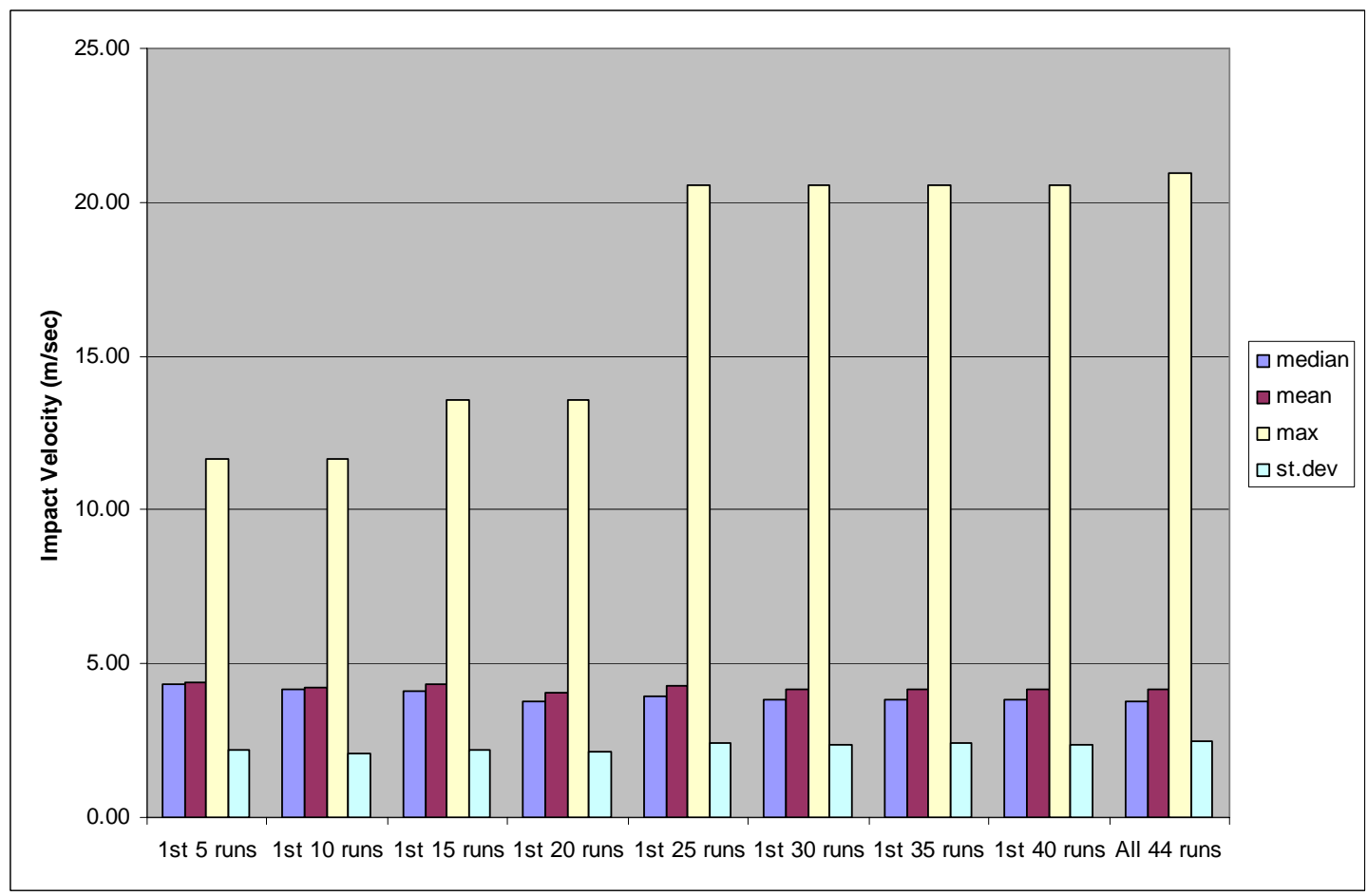

Figure K-14. Summary Statistics of Impact Velocity $(\mathrm{m} / \mathrm{sec})$ for $1 \times 10^{-7}$ Ground Motion 


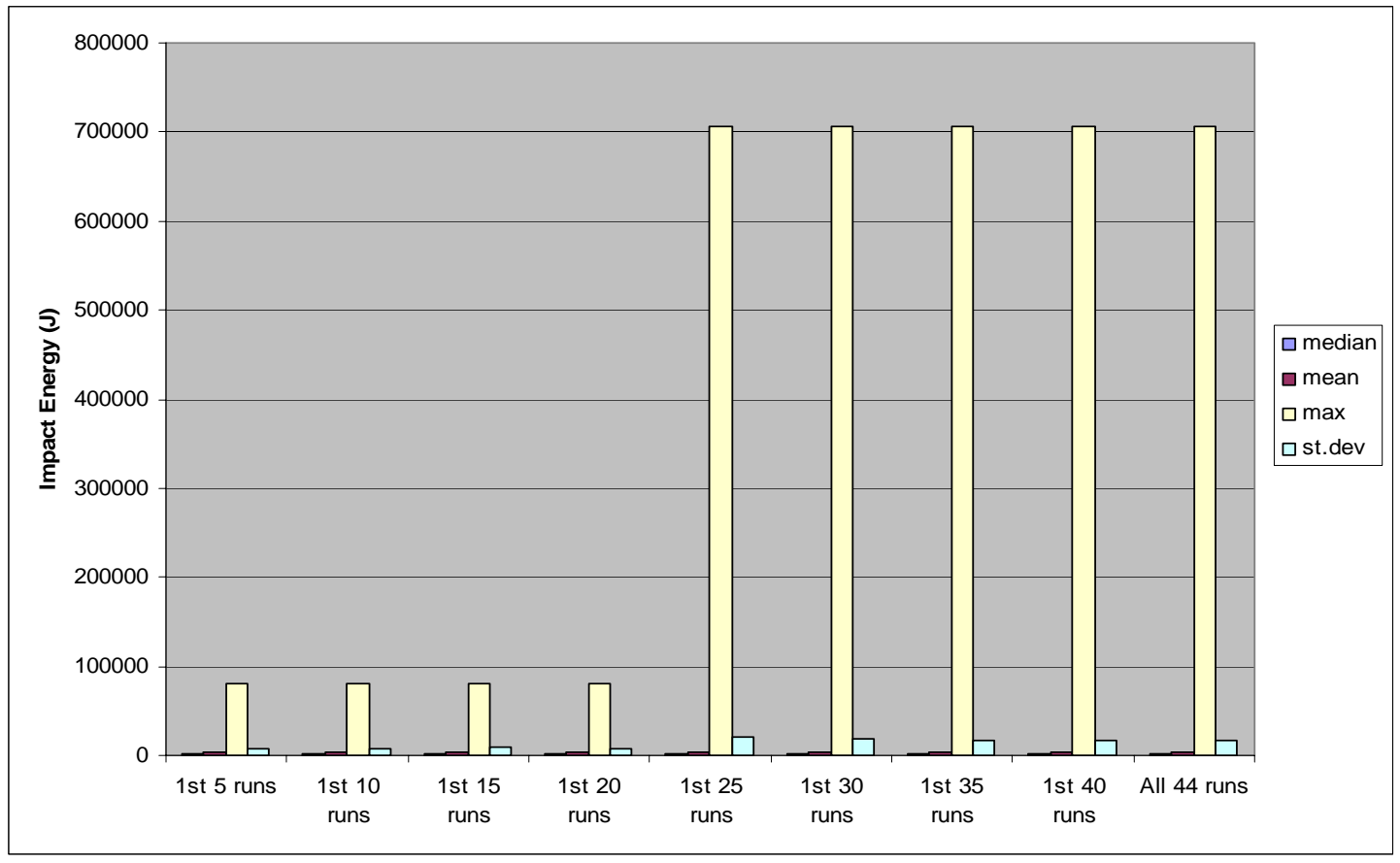

NOTE: $\mathrm{J}=$ Joule.

Figure K-15. Summary Statistics of Impact Energy (J) for $1 \times 10^{-7}$ Ground Motion

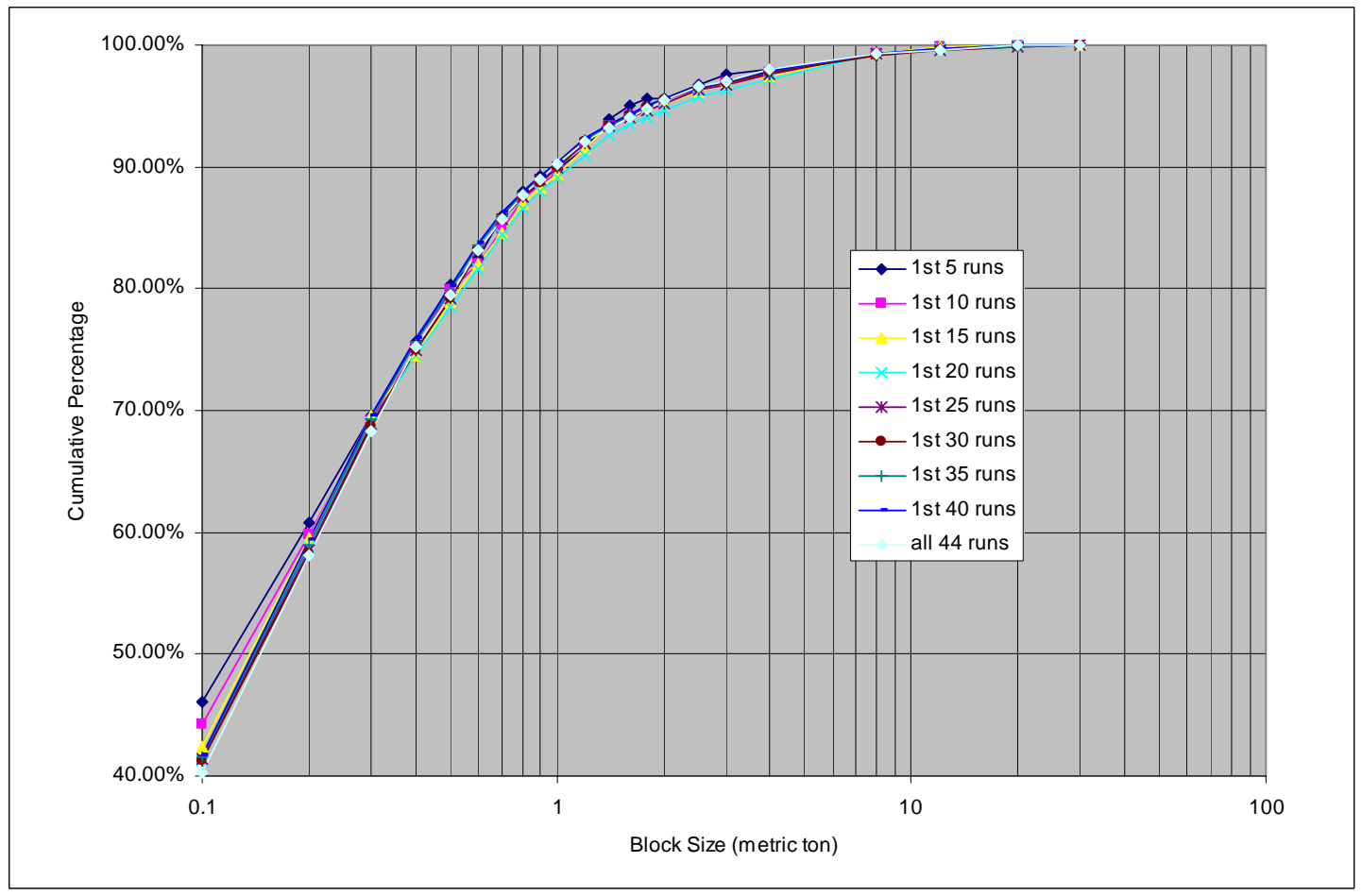

Figure K-16. Block Size Distribution for $1 \times 10^{-7}$ Ground Motion 
APPENDIX L

CONVERSION OF FRACMAN FRACTURE OUTPUT TO 3DEC INPUT 


\section{CONVERSION OF FRACMAN FRACTURE OUTPUT TO 3DEC INPUT}

The coordinate systems used for FracMan and 3DEC are shown in Figure L-1. The FracMan system is a right-hand system with North pointing to the negative x-axis, whereas the 3DEC system uses a left-hand system with North parallel to the z-axis. The conversion is accomplished by using the following equations:

$$
\begin{aligned}
& \mathrm{x}_{3 \mathrm{DEC}}=\mathrm{y}_{\text {FracMan }} \\
& \mathrm{z}_{3 \mathrm{DEC}}=-\mathrm{x}_{\text {FracMan }} \\
& \mathrm{y}_{3 \mathrm{DEC}}=\mathrm{z}_{\text {FracMan }}
\end{aligned}
$$

This conversion was done in the Microsoft Excel spreadsheet files 3DEC-S1shtA_TPO.xls, 3DEC-S1shtB_TPO.xls, 3DEC-s2sht_TPO.xls, 3DEC-s3_sht_TPO.xls, 3DECVPPLONG_TPO.xls, and Tptpll-Fracman Generated Fracture Data.xls (Table A-1). The x-, y-, and z-coordinates in worksheet "3DEC input" were obtained based on the original coordinate values in worksheet "Fracman output" and Equations L-1 to L-3. The dip, dip direction, and radius inputs in 3DEC were a direct copy from FracMan outputs. Additional worksheets, which sort the fracture data listing based on the descending order for radius, are included in the spreadsheet files. This sorted fracture data is used for 3DEC model optimization as described in Appendix H.

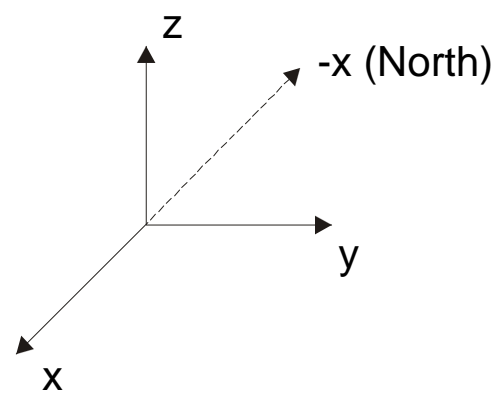

FracMan Coordinate System

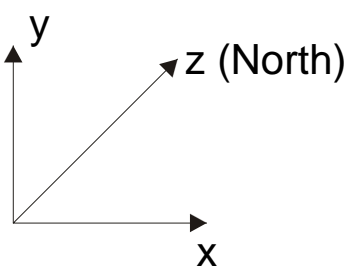

3DEC Coordinate

Figure L-1. Coordinate System Adopted in FracMan and 3DEC 


\section{INTENTIONALLY LEFT BLANK}




\section{APPENDIX M}

GFM2000 INPUT AND OUTPUT FILES FOR STRATIGRAPHIC UNIT THICKNESS DATA AND CROSS-SECTIONS 


\section{GFM2000 INPUT AND OUTPUT FILES FOR STRATIGRAPHIC UNIT THICKNESS DATA AND CROSS-SECTIONS}

\section{M1. INTRODUCTION}

Stratigraphic unit thickness and cross-sections for the thermal-mechanical calculation were extracted from DTN: MO0012MWDGFM02.002 [DIRS 153777]. The extracted stratigraphic unit thickness was used in calculating mean rock properties for the thermal-mechanical units, while the cross-sections were utilized to create three-dimensional mesh used in the thermal-mechanical calculation. The detailed calculation, data, and mesh description are presented in Appendices $\mathrm{C}$ and $\mathrm{E}$.

The extraction of the unit thickness and cross-sections was conducted on the geologic data from the TDMS (DTN: MO0012MWDGFM02.002 [DIRS 153777]), using EarthVision V.5.1 software (see Section 3). The EarthVision V.5.1 software was qualified for three-dimensional geologic modeling and was used within its range of validation. The stratigraphic unit thickness was extracted at the location of NS $232674 \mathrm{~m}$ and WE $170693 \mathrm{~m}$, which is approximately the center of the repository (Appendix C, Figure C-3), while the three cross-sections were extracted at the locations of NS $231637 \mathrm{~m}$, NS $234075 \mathrm{~m}$, and NS $235904 \mathrm{~m}$ (Appendix C, Figure C-3). An additional stratigraphic unit thickness was extracted at the location of NS $234025 \mathrm{~m}$ and WE $171440 \mathrm{~m}$, which is the location of the in situ stress measurements (DTN: SNF37100195002.001 [DIRS 131356]) at borehole ESF-AOD-HDRFR\#1 (Section 6.3.1.1 and Figure C-3). The unit thickness data were used to calculate the overburden stress at the depth of the in situ measurement from the surface.

All the input and output files from the EarthVision software for the extraction of the unit thickness and the cross-section are presented in the following sections.

\section{M2. EARTHVISON INPUT AND OUTPUT FILES}

The input files (central.dat, hope_01.sh, and combine.sh) and output file (alldata_01_2.dat) for the extraction of the unit thickness at the location of WE $170693 \mathrm{~m}$ and NS $232674 \mathrm{~m}$ are available in the TDMS (DTN: MO0408MWDDDMIO.002).

The input files for the extraction of the three cross-sections at the locations of NS $231637 \mathrm{~m}$ (S3), NS $234075 \mathrm{~m}$ (S7), and NS $235904 \mathrm{~m}$ (S10) are also available in the TDMS (DTN: MO0408MWDDDMIO.002). The resulting cross-sections (output files s3.dxf, s7.dxf, and s10.dxf) are shown in Figures M-1 to M-3.

The input files (hfdr1.dat, hope_02.sh, and combine.sh) and output file (alldata.dat) for the extraction of the unit thickness at the location of NS $234025 \mathrm{~m}$ and WE $171440 \mathrm{~m}$ are available in the TDMS (DTN: MO0408MWDDDMIO.002). 


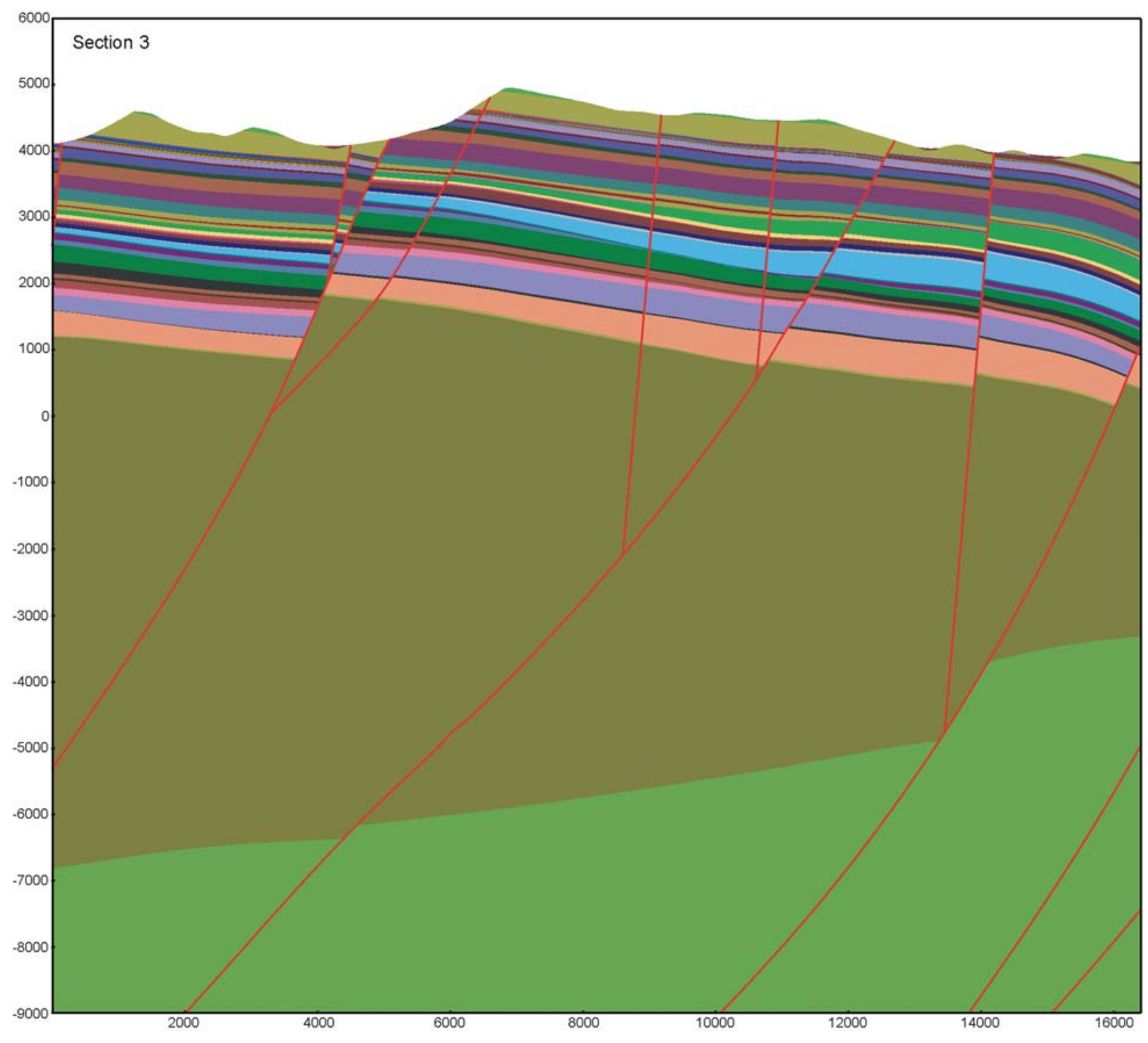

Figure M-1. Cross-Section Extracted at the Location of S3 (NS $231637 \mathrm{~m}$ ), Using the EarthVision Software 


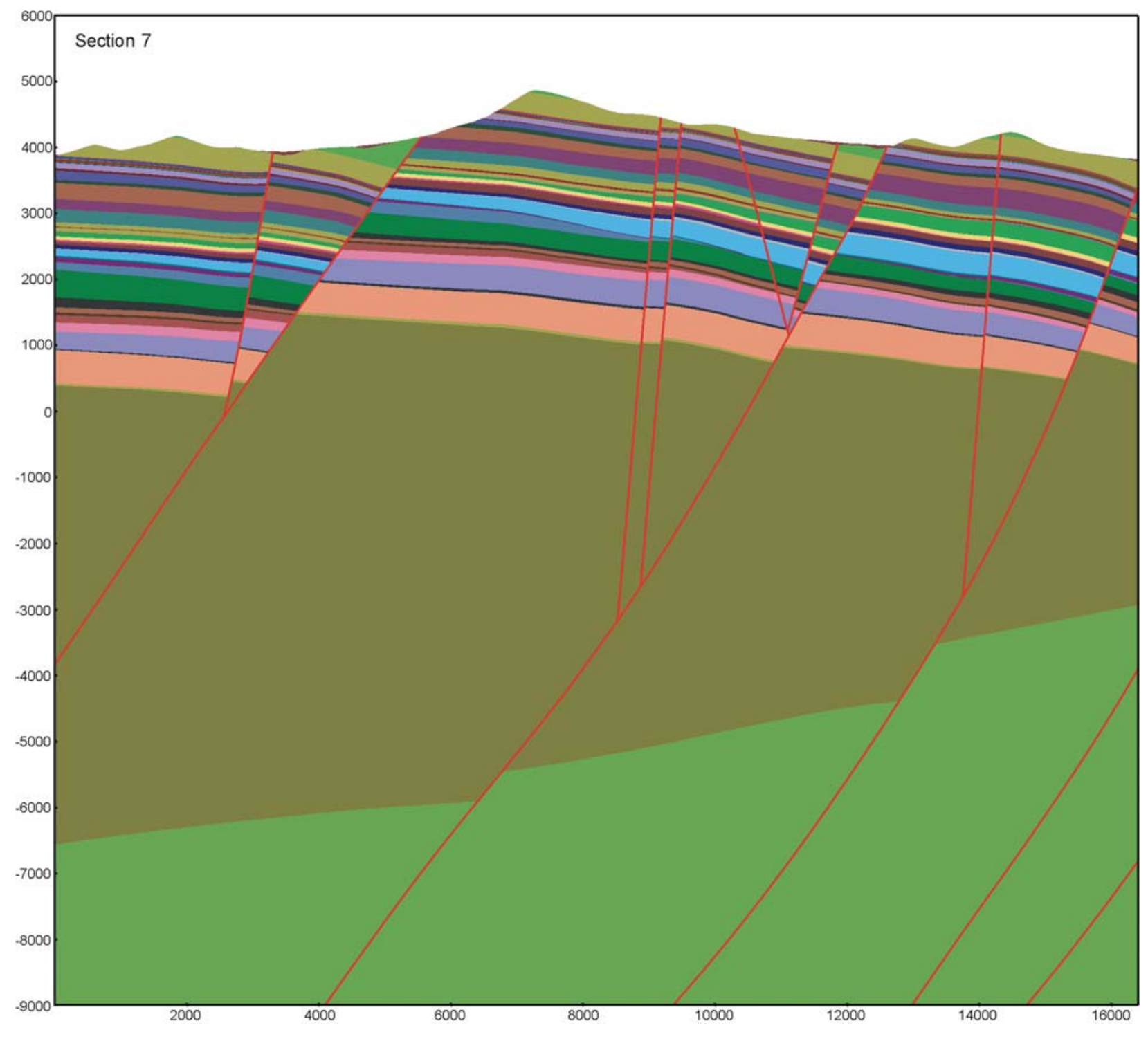

Figure M-2. Cross-Section Extracted at the Location of S7 (NS $234075 \mathrm{~m}$ ), Using the EarthVision Software 


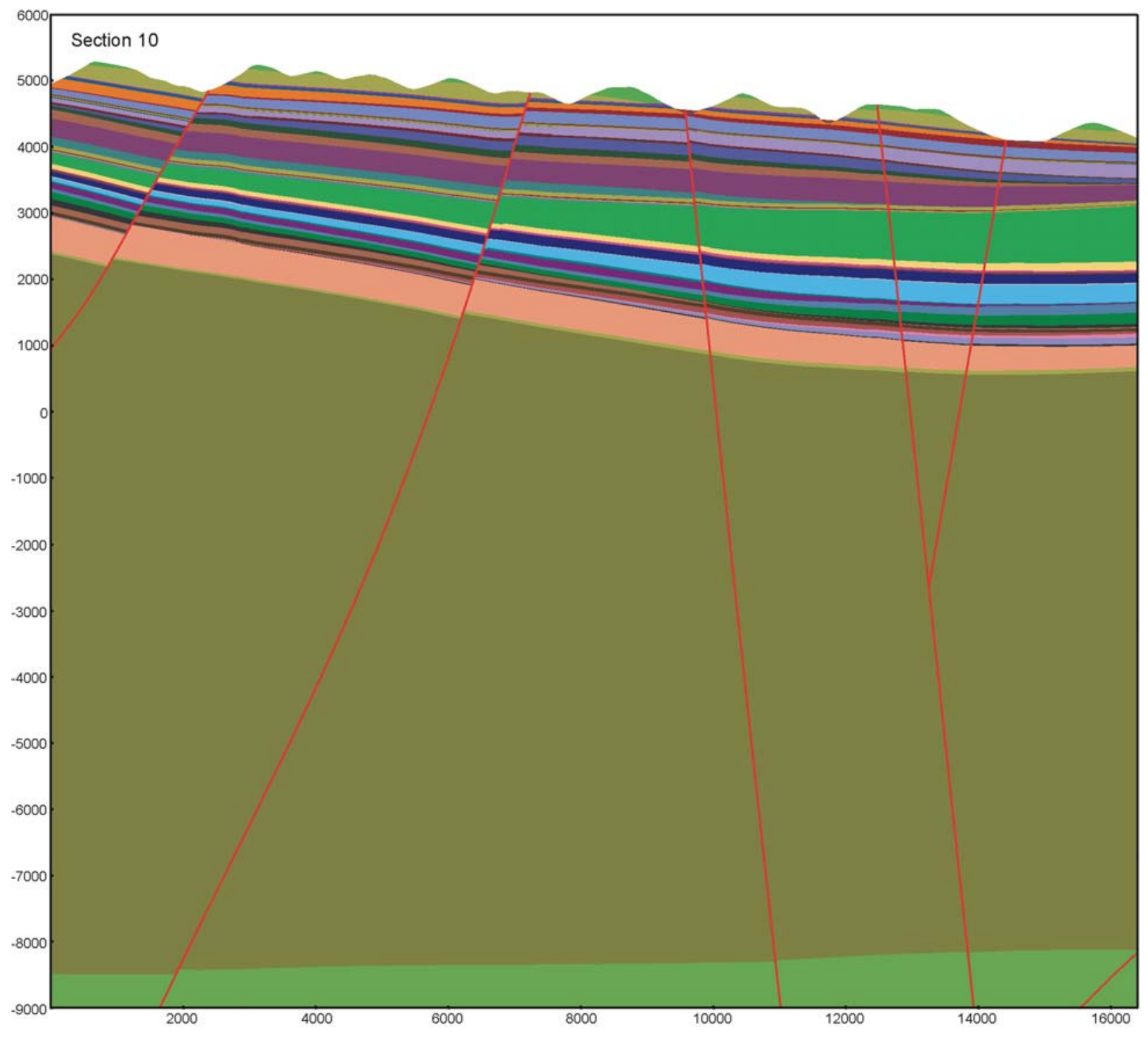

Figure M-3. Cross-Section Extracted at the Location of S10 (NS 235904 m), Using the EarthVision Software

\section{M3. OVERBURDEN STRESS AT THE DEPTH OF THE IN SITU TEST}

The vertical stress due to the weight of overburden at the depth of the in situ test from the surface was calculated from the stratigraphic unit thickness at the in situ test location and the mean stratigraphic unit density presented in Table E-1 (i.e., vertical stress = overburden thickness [m] $\times 9.81 \mathrm{~m} / \mathrm{sec}^{2} \times$ density $\left.\left[\mathrm{kg} / \mathrm{m}^{3}\right]\right)$. Based on the supporting information for DTN: SNF37100195002.001 [DIRS 131356], the elevation of the in situ measurement is 1033.3 m (CRWMS M\&O 1997 [DIRS 147458], MOL.19970717.0008, Table 5). Details of the calculation and the resulting overburden load of $4.7 \mathrm{MPa}$ are presented in Table M-1. 
Table M-1. Overburden Load at the Depth of the In Situ Test

\begin{tabular}{|c|c|c|c|c|c|c|}
\hline Unit & $\begin{array}{c}\text { Thickness } \\
\text { (m) }\end{array}$ & $\begin{array}{c}\text { Elevation at } \\
\text { Top } \\
\text { (m) }\end{array}$ & $\begin{array}{c}\text { Elevation at } \\
\text { Bottom } \\
(\mathrm{m})\end{array}$ & $\begin{array}{l}\text { Density }^{a} \\
\left(\mathrm{~kg} / \mathrm{m}^{3}\right)\end{array}$ & $\begin{array}{c}\text { Overburden } \\
\text { Thickness }^{\mathrm{b}} \\
\text { (m) }\end{array}$ & $\begin{array}{c}\text { Overburden } \\
\text { Load } \\
\text { (MPa) }\end{array}$ \\
\hline Tpcpv3 & 0.0 & 1285.1 & 1285.1 & 2310 & 0.0 & 0.0 \\
\hline Tpcpv2 & 4.9 & 1285.1 & 1280.2 & 1460 & 4.9 & 0.1 \\
\hline Tpcpv1 & 4.2 & 1280.2 & 1275.9 & 1460 & 4.2 & 0.1 \\
\hline Tpbt4 & 1.4 & 1275.9 & 1274.6 & 1460 & 1.4 & 0.0 \\
\hline Tpy & 10.4 & 1274.6 & 1264.1 & 1460 & 10.4 & 0.1 \\
\hline Tpbt3 & 4.3 & 1264.1 & 1259.8 & 1460 & 4.3 & 0.1 \\
\hline Tpp & 20.8 & 1259.8 & 1239.0 & 1460 & 20.8 & 0.3 \\
\hline Tpbt2 & 8.2 & 1239.0 & 1230.8 & 1460 & 8.2 & 0.1 \\
\hline Tptrv3 & 2.8 & 1230.8 & 1227.9 & 1460 & 2.8 & 0.0 \\
\hline Tptrv2 & 0.8 & 1227.9 & 1227.2 & 1460 & 0.8 & 0.0 \\
\hline Tptrv1 & 1.0 & 1227.2 & 1226.2 & 2310 & 1.0 & 0.0 \\
\hline Tptrn & 54.4 & 1226.2 & 1171.8 & 2190 & 54.4 & 1.2 \\
\hline Tptrl & 9.1 & 1171.8 & 1162.7 & 2190 & 9.1 & 0.2 \\
\hline Tptpul & 74.8 & 1162.7 & 1087.9 & 1834 & 74.8 & 1.3 \\
\hline Tptpmn & 36.8 & 1087.9 & 1051.1 & 2148 & 36.8 & 0.8 \\
\hline Tptpll & 102.6 & 1051.1 & 948.5 & 1979 & 17.8 & 0.3 \\
\hline \multicolumn{6}{|c|}{ In Situ Vertical Stress } & 4.7 \\
\hline
\end{tabular}

a The mean stratigraphic unit density is from Table E-1.

b The overburden thickness is from the elevation of the in situ test, which is $1033.3 \mathrm{~m}$ (CRWMS M\&O 1997 [DIRS 147458], MOL.19970717.0008, Table 5). 


\section{INTENTIONALLY LEFT BLANK}




\section{APPENDIX N}

MODEL VALIDATION REVIEW - 3DEC MODELING OF SEISMIC GROUND MOTION-INDUCED ROCKFALL 


\section{MODEL VALIDATION REVIEW - 3DEC MODELING OF SEISMIC GROUND MOTION-INDUCED ROCKFALL}

An outside expert technical review was conducted as a means of validating the 3DEC model for representation of nonlithophysal rock (see Section 7.7.6). Dr. John Tinucci of the PanTechnica Corporation in Minneapolis, Minnesota, was contracted for this purpose. Dr. Tinucci is a Professional Engineer and has a Ph.D. from the University of California, Berkeley, where his thesis research was in the area of analysis of the stability of blocky rock masses, and, in particular, in the development of key-block methods for tunnel stability assessment. He has extensive experience in the use of the 3DEC program for surface and underground stability assessment. Particularly valuable experience for the present application is his use of 3DEC to model dynamic stability of deep underground mine openings. Dr. Tinucci's review report is provided in this appendix.

Dr. Tinucci provides a summary of specific 3DEC model assumptions and abstractions, including recommendations for changes or other issues that should be considered (see "Recommendations" on p. 19/20 and Table 1, pp. 7/20 through 9/20, of the review report in this appendix). A response to Dr. Tinucci's recommendations is provided as follows:

- Recommendation \#1 (from Table 1, p. 7/20): Reexamine the magnitude of input ground motions.

- Response: A limitation study of ground motions is ongoing, which reexamines ground motion magnitudes. Any impacts to this report due to changes to ground motion data as a result of the limitation study would be documented in a future revision. The current input ground motions (see Section 4.1) are the best available source of site-specific ground motion data.

- Recommendation \#2 (from Table 1, p. 7/20): Values of joint cohesion, joint friction, and joint dilation should depend on other joint strength parameters.

- Response: Sensitivity analyses were conducted using three additional joint categories that consider a range of joint strength parameters (Section 6.3.1.6.2).

- Recommendation \#3: Due to the complexity of the FISH functions within 3DEC model, it is highly recommended that the functions be independently checked by another engineer to ensure accuracy.

- Response: FISH functions have been independently checked (by the technical checker) as part of the checking of the 3DEC input files.

- Recommendation \#4 (from Table 1, p. 8/20): Compute blocks based on local spacing (approximately $0.5 \mathrm{~m}$ ) to determine block volume change.

- Response: The recommendation was provided for the original FracMan results. The synthetic fracture network from FracMan has since been revised to provide a better quantitative comparison with mapped fracture data (based on joint spacing, trace length, and orientation). The current synthetic FracMan fracture geometry provides a 
relatively good fit of the underground mapping fracture geometry data, as shown in Table 6-2.

- Recommendation \#5 (from Table 1, p. 8/20): Include references for other known studies that employ similar approaches.

- Response: Additional validation based on data from a Defensive Nuclear Agency-sponsored explosive tunnel stability field experiment has been included, which builds confidence in the simulation of dynamic blocky systems (Section 7.7.4). Reference for other Yucca Mountain applications using FracMan have been added in Section 6.1.6.2.

- Recommendation \#6 (from Table 1, p. 8/20): Include sensitivity runs for natural damping of the rock mass.

- Response: Although damping is not explicitly specified in the 3DEC input, it is considered with the simulation of joint slip, joint separation, and bridge damage during seismic shaking. The current approach is considered reasonable and yet not overly conservative.

- Recommendation \#7 (from Table 1, p. 8/20): Check sub-contacts for several cases for failure along bridges, and then re-assess the need for using finer discretization.

- Response: Bridge damage during seismic shaking is discussed in Section 6.3.1. In general, less than 1 percent bridge area is damaged when subjected to $1 \times 10^{-5}$ ground motions. Bridge area damage increases to about 4 percent with $1 \times 10^{-6}$ ground motions, and 30 percent for $1 \times 10^{-7}$ ground motions. Since only a relatively small portion of the surface area of the unstable blocks was formed by the damaged bridge, it was not necessary to conduct additional sensitivity studies using a more refined grid.

- Recommendation \#8 (from Table 1, p. 8/20): Run one case with a much larger fractured volume including the floor.

- Response: The sensitivity of model sizes is provided in Section 6.3.1.6.5. The base-case model $(25 \mathrm{~m} \times 25 \mathrm{~m} \times 25 \mathrm{~m})$ was determined to be adequate for rockfall prediction.

- Recommendation \#9 (from Table 1, p. 9/20): Should qualitatively compare blocks formed with those formed from simulated fractures.

- Response: The identification of blocks observed in the ECRB Cross-Drift is provided in Appendix F. For simulating an actual joint geometry using 3DEC, the difficulty of generating joints in the rock mass not exposed at the tunnel surface prevents a solution with credible geometry. The quantitative comparison of the joint geometrical parameters from mapping data and from FracMan as discussed in Section 6.1.6 provides a similar confirmation for the adequacy of the fracture system. 
- Recommendation \#10 (from Table 1, p. 9/20): De-emphasize DRKBA results in the final report.

- Response: The DRKBA results have been de-emphasized, appearing primarily in Appendix D. This report focuses on the use of 3DEC and UDEC as documented in Sections 6.3 and 6.4. The DRKBA results are primarily used as confirmation for the 3DEC results (Section 7.7.5).

The following errata are provided for Dr. Tinucci's report:

- Page 1/20: The report was submitted to the "Engineered Barrier System Department."

- Page 2/20: “G. Neider-Westerman, 2000" refers to CRWMS M\&O 2000 [DIRS 152286].

- Page 2/20: “N. Barton, 2002” refers to Duan 2003 [DIRS 163586].

- Page 7/20: In Table 1, “Small Joints" are discussed on p. 11/20.

- Page 8/20: In Table 1, "Sub-horizontal Joint Spacing” is discussed on p. 12/20.

- Page 8/20: In Table 1, “Joint Strength Degradation” is discussed on p. 13/20.

- Page 8/20: In Table 1, "Fractured Rock Boundaries" are discussed on p. 14/20.

- Page 8/20: In Table 1, "Fractures in Floor" are discussed on p. 14/20.

- Page 9/20: In Table 1, "Event Orientation” is discussed on p. 15/20.

- Page 9/20: In Table 1, "Removing Unstable Blocks" is discussed on p. 15/20.

- Page 9/20: In Table 1, "Support System” is discussed on p. 17/20.

- Page 11/20: In the "Ground Motion" discussion, the three probable events are the 1 in 2000 year event, the 1 in 1 million year event, and the 1 in 10 million year event. 


\section{(18 PANECGNINCA \\ MODEL VALIDATION REVIEW \\ 3DEC MODELING OF SEISMIC GROUND MOTION-INDUCED ROCKFALL}

\section{Submitted to}

Engineers Barrier Group

Bechtel/SAIC

\section{Review by}

John P. Tinucci, PE, PhD

PanTechnica Corporation

\section{INTRODUCTION}

The 3DEC program is currently being used for simulation of mechanical response of the Middle Non-Lithophysal unit to seismic shaking induced by seismic ground motions. The objective of this modeling is to provide estimates of the size, shape and number of rocks that may be dislodged and fall into the emplacement drifts as a function of the level of the estimated ground motions. The ground motions (for various annual exceedence probability levels) are supplied by others within the project. This review is to be used as a portion of the validation requirements for model analysis given in procedure AP-SIII.10Q

Review Criteria-The documentation regarding the use of the 3DEC program for representing rockfall work has been reviewed using the following criteria:

1. Is this information presented accurately using applicable methods, assumptions, and recognized techniques?

2. Does existing model documentation provide adequate confidence required by the model's relative importance to the potential performance of the repository system to support model validation for its intended purpose and stated limitations?

Associated Documentation for Review-The following documents have been provided for review. It is understood that several of these documents are work-in-progress whose final content will be different upon submittal.

1. 3DEC V2.01 software qualification reports and Itasca 3DEC V2.01 addendum.

2. PowerPoint presentations of rockfall analyses. 


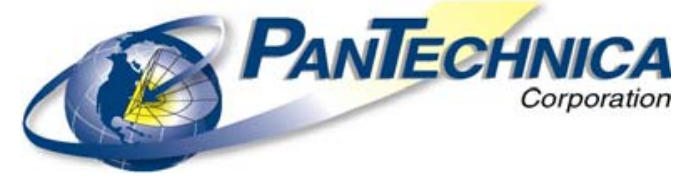

3. Geology of the ECRB Cross Drift-Exploratory Studies Facility, Yucca Mountain Project, Yucca Mountain, Nevada, Mongano, et al, 1999.

4. Fracture Geometry Analysis for the Stratigraphic Units of the Repository Host Horizon, G. Neider-Westerman, 2000.

5. Draft of preliminary work (draft report to date, Excel Spreadsheets for results summary, input files).

6. An Application of Rock Mass Characterization and Rock Joint Empirical Models at Yucca Mountain, To Assist in the Disposal Tunnel Design Studies, N. Barton, 2002

Modeling Objectives-The original Drift Degradation Analysis documentation for these analyses was reviewed by NRC in 2001. The NRC identified four items related to rockfall analysis that must be resolved to close the Repository Design and Thermal-Mechanical Effects key technical issue. The four items, in annotated form, are:

- Provide clarification for how reduction in cohesion adequately accounts for thermal effects.

- Analyze small trace-length fracture data from the ESF and ECRB to assess their effect on block development.

- Provide basis for effective maximum rock size including consideration of the effect of variation of the joint dip angle.

- 1) Revise DRKBA analyses using appropriate joints strengths accounting for their long-term degradation. 2) Analyze block sizes based on joint trace length data supplemented by available small joint trace length data. 3) Verify DRKBA analyses using (a) thermal and seismic boundary conditions, (b) fracture patterns simulations, (c) thermal and mechanical properties for rock blocks and joints, (d) long-term degradation of joint strength, and (e) site-specific ground motion.

The 3DEC analyses are intended to address several of these items and this review includes comments on the applicable portions. The stated objectives of the drift degradation analysis, in annotated form are to:

- model jointing around the drifts,

- provide a statistical description of block sizes around the drifts,

- estimate changes in drift profile resulting from deterioration of the drifts, and

- provide an estimate of the time required for significant drift deterioration to occur.

Site Visit-On January 28 -30, 2003, a site visit was made to both the Bechtel/SAIC facilities and ESF facilities. Time spent at the Bechtel/SAIC facilities was to review the input data, model setup and analysis results which had been performed to date. Engineers Mark Board, Ming Lin, Dwayne

(a)




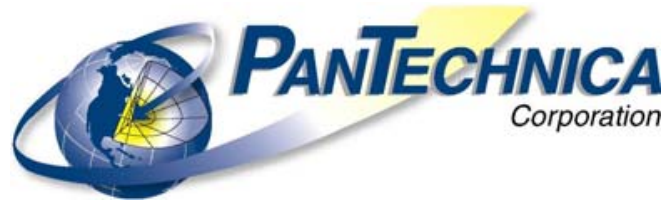

Kicker and Rob Lung were involved in discussions. Part of one day involved an underground tour of the ESF facilities. The purpose of this trip was to examine actual rock conditions for which the 3DEC analyses were to represent. Both ESF and ECRB drifts were examined in the Lithophysal and Non-Lithophysal zones.

\section{GENERAL OBSERVATIONS ON MODELING APPROACH}

The conceptual model that is used for these analyses is that a finite volume of rock containing the emplacement drift starts in an unsupported, equilibrium condition. Then a seismic event is applied to the model and blocks are shaken loose falling on the drip shield. Simulated fractures are used to compute blocks formed by their intersection and the rockmass is descretized in the numerical model. The program 3DEC is used to solve the system of equations. 3DEC uses a distinct element method to solve for the interaction between blocks. An explicit finite difference solution scheme is use to solve the equations of motion and deformability of the rock.

Conceptual Model Components-There are three key components of this conceptual model that have been included to represent realistic conditions. First the represented rock contains simulated fractures to capture the discontinuum behavior of the expected blocky rockmass. Second, the fractures have been generated using statistical data from mapped fractures, which produce realistic trace maps similar to traces mapped by the geologists underground. Finally, the in situ conditions of gravitational stresses, excavation-induced stresses and thermally-induced stresses have been included to represent static loading conditions, plus a stress wave is propagated through the model to represent dynamic loading conditions. These essential components define a model that is appropriate for the described purposes.

Representation Accuracy-As with any modeling analysis, the model is an accurate representation of actual expected rock behavior only when it represents conditions that lie within the known limitations. The mathematical tools employed (FRACMAN and 3DEC) are known to have limitations. However, upon review of the model, it does not appear that the conceptual model lies beyond the applicable mathematical representations of underground conditions and rock behavior. What has been implemented in these analyses is consistent with state-of-the-art numerical modeling techniques in the geomechanics industry.

Judging the accuracy of the model is very difficult because of the lack of measured data. The mathematical model only generally represents the underlying conceptual model. That is - there are no real underground drifts oriented the same as what was modeled to compare static results to. The fractures were only simulated since there is no way to map joints until the excavations are made. Rock and joint properties were only estimated from conditions with sufficient accuracy required to estimate the four objectives of the analysis: effects of jointing, statistical representation of block sizes, changes in drift profile, and time required for drift deterioration to occur. We may never know how accurate the model results are, however, we do know that the approach adopted has been known to produce reasonably accurate results for analyses for which accuracy is known.

Prepared for
Bechtel/SAIC on behalf of
U.S. Department of Energy

ANL-EBS-MD-000027 REV 03
$3 / 20$

19 February 2003 


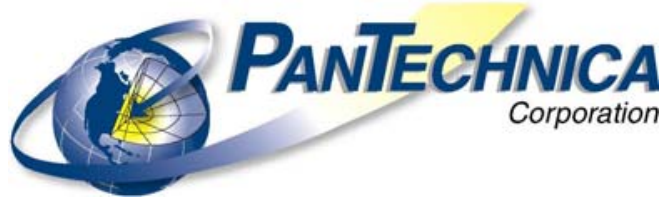

The analyses have done a reasonable job of quantifying where accuracy is required when additional, more accurate, analyses are preformed. The sensitivity study has identified that joint strength (especially dilation and cohesion), and joint frequency and orientation are critical parameters for predicting unstable block volumes. By identifying the sources of uncertainties and impacts of uncertainties on model output, the authors of this study are able to defend their current estimates and are knowledgeable about improving the model to reduce the uncertainties. More importantly, this study provides a basis for collecting additional field and laboratory data for resolving an important NRC key technical issue.

Mathematical Model Confidence-Due to the complexity of the analysis, the process used to establish confidence that the mathematical model produces reasonable results was broken down in parts. First the inputs, or initial conditions, were checked prior to simulating the seismic event. The volume of unstable blocks under 'static' conditions was examined for reasonableness. Since the analysis did not examine actual ESF or ECRB drift block geometries, it was not possible to compare the model results to unstable blocks observed underground. The next confidence check of the model was to pass a simple undamped wave to the model, applied at the bottom of the model. The output response at the top of the model was examined for reasonableness. This confirmed that the model was capable of passing waves without energy loss at boundaries and internally to the model. The model was then checked for result reasonableness by applying sequentially larger seismic events. This confirmed that larger seismic loading produced larger volumes of unstable blocks. Finally the sensitivity study was used to confirm the parameters having the greatest influence on the results. This was done to demonstrate the reasonableness of the base case conditions.

Alternative Algorithms-The overall approach of using FRACMAN to generate fracture, and 3DEC to compute the block and solve the equations of motions is not the only approach available for assessing block stability. There are alternative algorithms of simulating fractures, but none are known to so robustly address stochastic simulation, plus FRACMAN is the most widely used fracture simulation program in the petroleum, mining and nuclear waste industries. An alternative approach to simulating fractures was examined through the DRKBA rockfall analyses performed prior to this work. The simulation algorithm is not considered as robust as that implemented by FRACMAN. Similarly there are alternative block stability analysis methods available besides using the 3DEC program. The DRKBA program was used which makes use of limit equilibrium solution to stability. It is considered not as accurate as 3DEC since in situ stress, thermal stress, and seismic loading are not explicitly represented. An alternative numerical approach to 3DEC program is the 3-D DDA program. 3-D DDA is a distinct element method that solves the equations of motion and can account for in situ stress, thermal stress and seismic loading. Its limitation, as currently implemented is that blocks are simply deformable and the program has not been 'qualified' for use in the quality assurance aspects of nuclear waste program. Therefore, the overall approach to solving the mathematical models (i.e. FRACMAN and 3DEC combination) is the best that the geomechanics industry has to offer. The $3 \mathrm{DEC}$ program has been through the process of being 'qualified' for use from the quality assurance point of view.

Prepared for

Bechtel/SAIC on behalf of

U.S. Department of Energy

$4 / 20$

N-7

September 2004

19 February 2003

ANL-EBS-MD-00027 REV 03 


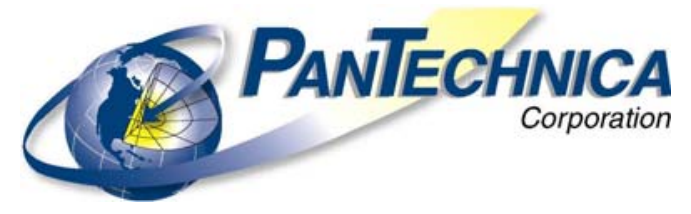

Input Data Reasonableness-There are two classes of information used to develop the mathematical models: input data for assigning values to parameters and professional judgment for assembling the model. Great effort has been focused on using representative laboratory and field data to assign to parameters. A table in the report has been developed which identifies the source of inputs and how the magnitudes were determined. The only data that is unsubstantiated is the low probability seismic events (i.e. 1e-6, 1). In the absence of historic data, it is my opinion that these motions are too large and it needs to be demonstrated that the ground can geologically store and release such energy.

Model Abstractions-There is no doubt that some of the professional judgments used to develop the model have influence on the results. These judgments are treated differently because they are not a statement that is taken to be true in the absence of confirming data, as an assumption would do. Rather, these judgments are made to simplify the mathematical model, and thus are abstractions. There are trade- offs between accuracy and simplifications in order to compute results. The central constraint on these analyses is that the numerical model required to accurately represent the conceptual model can be excessively large and computationally intensive. Significant effort has been placed on reducing the mathematical model to a manageable size while having minimal impact on the accuracy of results. Judgments were necessary to optimize the number of blocks, the number of finite different zones, the boundary distance from the tunnel, constitutive behavior of intact rock and joints, time-step for dynamic loading, etc. The professional judgments used to simplify the model to a manageable size are logical and not inconsistent with what is commonly practiced in modeling underground tunnels in blocky ground conditions. Several of the simplifications can be argued as to their impact on results accuracy. However, their impact is minimal compared to the impact of the assumptions, especially in regards to the assumed seismic ground motions.

Intended Use of Results-It is understood that the output data is intended to be used for two general purposes: to estimate the force magnitude and location of blocks impacting the drip shield, and the profile of the degraded drift. These results could only represent 'typical best estimates' given that none of the real drifts currently exist and the fractures have not been mapped. Collectively, the assumptions and simplifications serve to provide results that are thought to be conservative; that is one would expect that fewer blocks than are predicted by the model results would become unstable and fall when subjected to these conditions. However, these results are not considered to be 'upper bound' estimates because even more conservative assumptions and simplifications could be made and yet they would not be considered unreasonable. For example, it would have been reasonable to use 2-D UDEC models to provide estimates of unstable blocks. Therefore, the modeling approach adopted is reasonable (and rather novel) when compared to the intended use of the results.

Appropriate Confidence Level-Criteria for ensuring the appropriate level of confidence in the model results has been obtained is governed by two sets of criteria: appropriateness of the seismic events and appropriateness of the drift degradation analysis.

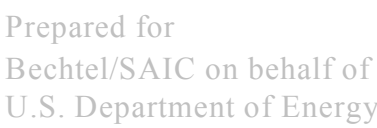

Prepared for

U.S. Department of Energy
$5 / 20$

N-8
19 February 2003 


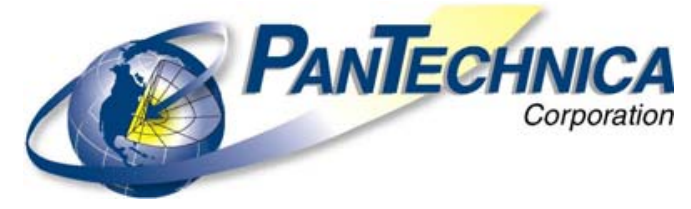

As mentioned before, I have serious concerns about the applicability of the low probability seismic records (i.e. 1e-6 and 1e-7 probability events) supplied as input to appropriately represent the expected ground motion. It has not been shown that such motions are sustainable by the geology, although the mathematical modeling techniques used to estimate the motion are consistent with common practice. Those techniques have not been shown to be applicable to low probability events. Other aspects of the seismic portion of the analysis (i.e. motion application, free field boundaries, event duration, etc.) appear to be appropriate. In order not to bias the results to an extreme type of seismic event, 17 real records were scaled to 3 expected magnitudes (i.e. 15 events implemented in combinations of various fracture realizations for a total of 105 simulations). This approach to examining various scenarios is appropriate given the lack of information on extremely infrequent historic seismic events.

Confidence in the other parts of the model related to simulating ground conditions (i.e. fracture simulation, application of various stress conditions, model discretization, removal of fallen blocks, etc.) are adequate given the intended use of the results. The criterion that data uncertainty be characterized and propagated through the model abstraction appears to be adequately addressed by the sensitivity studies. The need for the model to be compared to known conditions also appears to be adequately addressed by the fracture map comparisons, the pre-event conditions comparisons, and 3DEC results comparisons to DRKBA results. It is important to note that confidence in the model is based only on visual examination of expected conditions since no measurements or recordings were made as part of this analysis.

\section{SPECIFIC OBSERVATIONS ON MODEL ASSUMPTIONS AND ABSTRACTIONS}

Given the above general discussion on the adequacy of the overall model results, there are aspects of the analysis that deserve specific comments. The purpose of this section is to address specific assumptions and abstractions that were necessary to assemble the conceptual and mathematical models.

Table 1 is a summary of each modeling issue. The table includes a summary of what aspect of that issue is important and the approach that was adopted in the analysis. Also tabulated is a summary of whether the approach is reasonable and any recommendations for changes or other issues that need to be considered. 


\section{PANIECHNICA}

Table 1. Summary Model Assumption and Abstraction Issues

\begin{tabular}{|c|c|c|c|c|c|}
\hline Issue & Aspect & Approach & $\begin{array}{c}\text { Approach } \\
\text { Reasonableness }\end{array}$ & Recommendation & $\begin{array}{c}\text { Page } \\
\text { Discussed }\end{array}$ \\
\hline $\begin{array}{l}\text { Joint } \\
\text { Cohesion }\end{array}$ & $\begin{array}{l}\text { Assumption - } \\
\text { Magnitude of } \\
\text { values }\end{array}$ & $\begin{array}{l}\text { Mean minus } 1 \text { std } \\
\text { dev, Zero in } \\
\text { sensitivity }\end{array}$ & $\begin{array}{l}\text { Reasonable, } \\
\text { sensitivity will likely } \\
\text { over-predict } \\
\text { unstable blocks }\end{array}$ & $\begin{array}{l}\text { Values should depend on } \\
\text { other joint strength } \\
\text { parameters. }\end{array}$ & 10 \\
\hline Joint Friction & $\begin{array}{l}\text { Assumption - } \\
\text { Peak vs. } \\
\text { Residual } \\
\text { values }\end{array}$ & $\begin{array}{l}\text { Mean peak, Residual } \\
\text { in sensitivity }\end{array}$ & $\begin{array}{l}\text { Slightly } \\
\text { conservative/slightly } \\
\text { conservative }\end{array}$ & See above. & 10 \\
\hline Joint Dilation & $\begin{array}{l}\text { Assumption - } \\
\text { not coupled w/ } \\
\text { Friction }\end{array}$ & $\begin{array}{l}\text { Zero, mean in } \\
\text { sensitivity }\end{array}$ & $\begin{array}{l}\text { Base case of zero } \\
\text { combined with peak } \\
\text { friction values is not } \\
\text { reasonable }\end{array}$ & See above. & 10 \\
\hline $\begin{array}{l}\text { Joint } \\
\text { Stiffness }\end{array}$ & $\begin{array}{l}\text { Assumption - } \\
\text { low normal \& } \\
\text { shear } \\
\text { magnitudes }\end{array}$ & $\begin{array}{l}\text { Similar normal \& } \\
\text { shear stiffness }\end{array}$ & $\begin{array}{l}\text { Low values but } \\
\text { acceptable since } \\
\text { magnitude has } \\
\text { minor impact on } \\
\text { results }\end{array}$ & & 10 \\
\hline $\begin{array}{l}\text { Intact Blocks } \\
\text { Behavior }\end{array}$ & $\begin{array}{l}\text { Abstraction - } \\
\text { No rockmass } \\
\text { failure }\end{array}$ & $\begin{array}{l}\text { All elastic except } \\
\text { 'glued' joints with high } \\
\text { strength }\end{array}$ & $\begin{array}{l}\text { Reasonable since } \\
\text { inelastic blocks } \\
\text { would not change } \\
\text { results }\end{array}$ & & 11 \\
\hline $\begin{array}{l}\text { Ground } \\
\text { Motion }\end{array}$ & $\begin{array}{l}\text { Assumption - } \\
\text { extreme } \\
\text { probabilities }\end{array}$ & $\begin{array}{l}\text { Extrapolate using } \\
\text { standard methods }\end{array}$ & $\begin{array}{l}1 \mathrm{e}^{-6} \text { and } 1 \mathrm{e}^{-7} \text { events } \\
\text { appear } \\
\text { unreasonably large, } \\
\text { not completely } \\
\text { rational }\end{array}$ & $\begin{array}{l}\text { Reexamine the } \\
\text { magnitude of input } \\
\text { ground motions }\end{array}$ & 11 \\
\hline $\begin{array}{l}\text { Simulated } \\
\text { Fracture } \\
\text { Volume }\end{array}$ & $\begin{array}{l}\text { Abstraction - } \\
\text { Single } \\
\text { realization in } \\
\text { large volume }\end{array}$ & $\begin{array}{l}\text { Random tunnel } \\
\text { location within volume } \\
\text { for different } \\
\text { realizations }\end{array}$ & $\begin{array}{l}\text { Reasonable given } \\
\text { the limited of } \\
\text { mapped data }\end{array}$ & & 11 \\
\hline Small Joints & $\begin{array}{l}\text { Abstraction - } \\
\text { small joints } \\
\text { pulled from } \\
\text { analysis } \\
\text { database } \\
\end{array}$ & $\begin{array}{l}\text { Less than } 1 \mathrm{~m} \text { length } \\
\text { not included in } \\
\text { statistics }\end{array}$ & $\begin{array}{l}\text { Reasonable since } \\
\text { they have low } \\
\text { probability of } \\
\text { forming blocks. }\end{array}$ & & 11 \\
\hline $\begin{array}{l}\text { Non- } \\
\text { Concave } \\
\text { Blocks }\end{array}$ & $\begin{array}{l}\text { Abstraction - } \\
\text { Cutting non- } \\
\text { joint area }\end{array}$ & $\begin{array}{l}\text { Convex-blocks glued } \\
\text { \& given intact } \\
\text { strength }\end{array}$ & $\begin{array}{l}\text { Reasonable given } \\
\text { that intact strength } \\
\text { is much greater } \\
\text { than joint strengths. }\end{array}$ & & 12 \\
\hline Fracture Size & $\begin{array}{l}\text { Abstraction - } \\
\text { Realness of } \\
\text { simulation }\end{array}$ & $\begin{array}{l}\text { Simulation based on } \\
\text { area of joints per unit } \\
\text { volume instead of } \\
\text { length \& spacing }\end{array}$ & $\begin{array}{l}\text { Reasonable since } \\
\text { samples from } \\
\text { simulation } \\
\text { compared well to } \\
\text { maps. }\end{array}$ & & 12 \\
\hline $\begin{array}{l}\text { Terezaghi } \\
\text { Correction }\end{array}$ & $\begin{array}{l}\text { Abstraction - } \\
\text { Correct for } \\
\text { joints sub- } \\
\text { parallel to } \\
\text { tunnel }\end{array}$ & Neglect correction & $\begin{array}{l}\text { Reasonable given } \\
\text { data collected from } \\
\text { variable tunnel } \\
\text { orientations \& large } \\
\text { tunnel size } \\
\text { compared to joint } \\
\text { spacing. }\end{array}$ & & 12 \\
\hline
\end{tabular}




\begin{tabular}{|c|c|c|c|c|c|}
\hline Issue & Aspect & Approach & $\begin{array}{c}\text { Approach } \\
\text { Reasonableness } \\
\end{array}$ & Recommendation & $\begin{array}{c}\text { Page } \\
\text { Discussed }\end{array}$ \\
\hline $\begin{array}{l}\text { Sub-horizontal. } \\
\text { Joint Spacing }\end{array}$ & $\begin{array}{l}\text { Abstraction - } \\
\text { Localized } \\
\text { variations }\end{array}$ & $\begin{array}{l}\text { Include all data to } \\
\text { determine average }\end{array}$ & $\begin{array}{l}\text { Locally not very } \\
\text { conservative, but } \\
\text { quite reasonable on } \\
\text { overall repository } \\
\text { scale. }\end{array}$ & $\begin{array}{l}\text { Compute blocks on local } \\
\text { spacing }(\sim 0.5 \mathrm{~m}) \text { to see } \\
\text { block volume change - } \\
\text { dynamic runs not } \\
\text { necessary. }\end{array}$ & 12 \\
\hline Damping & $\begin{array}{l}\text { Abstraction - } \\
\text { natural damping } \\
\text { of rock mass }\end{array}$ & $\begin{array}{l}\text { None, } 5 \% \text { in } \\
\text { sensitivity study }\end{array}$ & $\begin{array}{l}\text { Reasonable given } \\
\text { real value is not } \\
\text { known and jointing } \\
\text { provides some } \\
\text { motion damping } \\
\end{array}$ & $\begin{array}{l}\text { Include a couple } \\
\text { sensitivity runs }\end{array}$ & 13 \\
\hline Bridge Failure & $\begin{array}{l}\text { Abstraction - } \\
\text { Bridge is only } \\
\text { inelastic portion } \\
\text { of block }\end{array}$ & $\begin{array}{l}\text { Joints used intact } \\
\text { rock strengths }\end{array}$ & $\begin{array}{l}\text { Reasonable given } \\
\text { rock strength is } \\
\text { much greater than } \\
\text { induced stress field }\end{array}$ & $\begin{array}{l}\text { Check sub-contacts for } \\
\text { several cases for failure } \\
\text { along bridge and then } \\
\text { re-assess need for using } \\
\text { finer discretization. }\end{array}$ & 13 \\
\hline $\begin{array}{l}\text { Joint Strength } \\
\text { Degradation }\end{array}$ & $\begin{array}{l}\text { Assumption - } \\
\text { Previous seismic } \\
\text { loading of joint } \\
\text { system }\end{array}$ & $\begin{array}{l}\text { No degradation, } \\
\text { Residual friction. in } \\
\text { sensitivity study }\end{array}$ & $\begin{array}{l}\text { Unknown influence, } \\
\text { but reasonable } \\
\text { approach given } \\
\text { sensitivity analysis } \\
\text { is lower bound } \\
\text { condition. }\end{array}$ & & 13 \\
\hline $\begin{array}{l}\text { Similar Analysis } \\
\text { Approach }\end{array}$ & $\begin{array}{l}\text { Abstraction - } \\
\text { Acceptableness } \\
\text { of approach }\end{array}$ & $\begin{array}{l}\text { None globally, } \\
\text { Portions have been } \\
\text { performed before }\end{array}$ & $\begin{array}{l}\text { Collectively the } \\
\text { approach is novel, } \\
\text { but various parts } \\
\text { are common to that } \\
\text { done by others and } \\
\text { thus overall } \\
\text { approach is } \\
\text { reasonable. }\end{array}$ & $\begin{array}{l}\text { Include references for } \\
\text { other known studies that } \\
\text { employ similar } \\
\text { approaches. }\end{array}$ & 14 \\
\hline $\begin{array}{l}\text { Fractured Rock } \\
\text { Boundaries }\end{array}$ & $\begin{array}{l}\text { Abstraction - } \\
\text { Sufficient Block } \\
\text { Volume }\end{array}$ & $\begin{array}{l}\text { Identify blocks } \\
\text { along tunnel } \\
\text { surface } \\
25 \mathrm{~m}, 35, \& 45 \mathrm{~m} \text { in } \\
\text { sensitivity study }\end{array}$ & $\begin{array}{l}\text { Unknown impact, } \\
\text { but issue with low } \\
\text { probability seismic } \\
\text { events, which are } \\
\text { already suspect. }\end{array}$ & $\begin{array}{l}\text { Run one case with a } \\
\text { much larger fractured } \\
\text { volume including floor }\end{array}$ & 14 \\
\hline $\begin{array}{l}\text { Fractures in } \\
\text { Floor }\end{array}$ & $\begin{array}{l}\text { Abstraction - } \\
\text { Tunnel } \\
\text { Deformability }\end{array}$ & $\begin{array}{l}\text { Neglect blocks in } \\
\text { floor }\end{array}$ & $\begin{array}{l}\text { Reasonable given } \\
\text { size of model and } \\
\text { interest focused on } \\
\text { falling rocks. }\end{array}$ & See above. & 15 \\
\hline In Situ Stress & $\begin{array}{l}\text { Assumption - } \\
\text { Lithostatic stress } \\
\text { field }\end{array}$ & $\begin{array}{l}\text { Mean values, } \\
\text { high stress ratio in } \\
\text { sensitivity study }\end{array}$ & $\begin{array}{l}\text { Reasonable, little } \\
\text { impact on results } \\
\text { since stresses } \\
\text { would need to be } \\
\text { much lower. }\end{array}$ & & 15 \\
\hline Event Duration & $\begin{array}{l}\text { Abstraction - } \\
\text { Length of } \\
\text { shaking motion }\end{array}$ & $\begin{array}{l}5 \% / 95 \% \text { energy cut } \\
\text { off by time }\end{array}$ & $\begin{array}{l}\text { Reasonable, little } \\
\text { impact on results } \\
\text { since significant } \\
\text { energy would need } \\
\text { to be excluded. }\end{array}$ & & 15 \\
\hline
\end{tabular}




\section{(18) PANTECHNICA}

Table 1. Summary Model Assumption and Abstraction Issues (Continued)

\begin{tabular}{|c|c|c|c|c|c|}
\hline Issue & Aspect & Approach & $\begin{array}{c}\text { Approach } \\
\text { Reasonableness }\end{array}$ & Recommendation & $\begin{array}{c}\text { Page } \\
\text { Discussed }\end{array}$ \\
\hline $\begin{array}{l}\text { Event } \\
\text { Orientation }\end{array}$ & $\begin{array}{l}\text { Abstraction - } \\
\text { Compare to least } \\
\text { stable block } \\
\text { forces }\end{array}$ & $\begin{array}{l}\text { Flip } \mathrm{H} 1 \text { \& } \mathrm{H} 2 \text { along } \\
\text { X\&Y axes in } \\
\text { sensitivity }\end{array}$ & $\begin{array}{l}\text { Reasonable, little } \\
\text { impact since } \\
\text { horizontal } \\
\text { components are } \\
\text { similar in } \\
\text { magnitude. }\end{array}$ & & 15 \\
\hline $\begin{array}{l}\text { Removing } \\
\text { Unstable blocks }\end{array}$ & $\begin{array}{l}\text { Abstraction - } \\
\text { Bulking } \\
\text { stabilizes chain } \\
\text { blocks }\end{array}$ & $\begin{array}{l}\text { Deleted on contact, } \\
\text { left in contact with } \\
\text { drip shield in } \\
\text { sensitivity study }\end{array}$ & $\begin{array}{l}\text { Over predicts } \\
\text { volume of unstable } \\
\text { blocks, but provides } \\
\text { a broader } \\
\text { simulation of } \\
\text { rockfall on drip } \\
\text { shield }\end{array}$ & & 16 \\
\hline $\begin{array}{l}\text { Comparison to } \\
\text { Real Blocks }\end{array}$ & $\begin{array}{l}\text { Abstraction - } \\
\text { Observable } \\
\text { validation }\end{array}$ & $\begin{array}{l}\text { No comparisons } \\
\text { made }\end{array}$ & $\begin{array}{l}\text { Unknown impact } \\
\text { since no real } \\
\text { seismic response } \\
\text { data exists }\end{array}$ & $\begin{array}{l}\text { Should qualitatively } \\
\text { compare blocks formed } \\
\text { with those formed from } \\
\text { simulated fractures. }\end{array}$ & 16 \\
\hline $\begin{array}{l}\text { DRKBA } \\
\text { Analyses }\end{array}$ & $\begin{array}{l}\text { Abstraction - } \\
\text { Comparison to } \\
\text { another } \\
\text { approach }\end{array}$ & $\begin{array}{l}\text { Of minor } \\
\text { importance since } \\
\text { analysis had major } \\
\text { limitations }\end{array}$ & $\begin{array}{l}\text { Stability part does } \\
\text { not provide reliable } \\
\text { comparison } \\
\text { because no stress } \\
\text { \& no motion }\end{array}$ & $\begin{array}{l}\text { De-emphasize DRKBA } \\
\text { results in final report }\end{array}$ & 16 \\
\hline Pore Pressures & $\begin{array}{l}\text { Abstraction - } \\
\text { Strength } \\
\text { reduction during } \\
\text { shaking } \\
\end{array}$ & Neglect & $\begin{array}{l}\text { Reasonable since } \\
\text { not saturated }\end{array}$ & & 17 \\
\hline $\begin{array}{l}\text { Thermal } \\
\text { Stresses }\end{array}$ & $\begin{array}{l}\text { Abstraction - } \\
\text { Additional forces } \\
\text { on blocks }\end{array}$ & $\begin{array}{l}\text { Decoupled thermal } \\
\text { and mechanical }\end{array}$ & $\begin{array}{l}\text { Reasonable since } \\
\text { boundary conditions } \\
\text { for cooling are } \\
\text { unknown }\end{array}$ & & 17 \\
\hline $\begin{array}{l}\text { Reflecting } \\
\text { Boundaries }\end{array}$ & $\begin{array}{l}\text { Abstraction - } \\
\text { Wave } \\
\text { interference due } \\
\text { to close } \\
\text { boundaries }\end{array}$ & $\begin{array}{l}\text { Implemented free- } \\
\text { field non-reflecting } \\
\text { boundaries }\end{array}$ & Reasonable & & 17 \\
\hline Support System & $\begin{array}{l}\text { Abstraction - } \\
\text { Effectiveness for } \\
\text { additional } \\
\text { support }\end{array}$ & Neglected & $\begin{array}{l}\text { Reasonable since } \\
\text { nobody knows how } \\
\text { effective they will be } \\
\text { in long-term }\end{array}$ & & 17 \\
\hline
\end{tabular}

Prepared for

Bechtel/SAIC on behalf of

$9 / 20$

19 February 2003

U.S. Department of Energy 


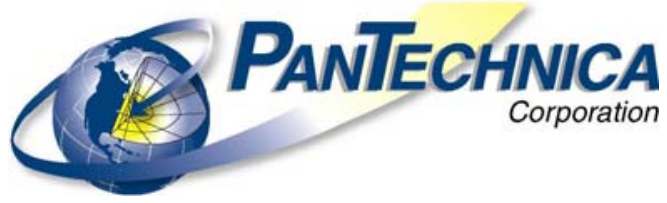

Joint Cohesion-The approach adopted for joint cohesive strength was to use the mean value minus one standard deviation from laboratory data. It is not clear for these calculations how much of the cohesion can be relied on in the long-term. For most dam stability analyses (USACOE \& USBR) the designers would assume no long-term cohesion. However, during trip underground the joints were observed to be very tight, with the only observable open joints at the springline, most likely associated with tunnel excavation disturbance. Overall, this approach to cohesion is reasonable and yet not overly conservative. It is recommended that joint cohesion be considered in conjunction with the other joint strength parameters, per Barton's recommendation. See Table 1.

Joint Friction-Friction angle values have been taken as mean peak total friction for the base calculations (while assuming dilation is zero). Residual friction values were used in the sensitivity studies. The combinations of cohesion, friction and dilation for estimating rock strength should all be inter-connected and not be treated as independent cases. The base case (i.e. fri. = peak fri. \& dil. $=0$ ) is not logical since laboratory tests did not show zero dilation when peak friction is attained. The case with residual friction and no dilation makes physical sense as a state that could exist after disturbance has occurred. It is recommended that joint friction be considered in conjunction with the other joint strength parameters. See Table 1.

Joint Dilation-Dilation angles other than zero were run in the sensitivity study. Results suggest dilation has a large influence on the stability of blocks. The laboratory values used for dilation are probably on the low side given the tightness of joints observed during the underground visit. Dilation plays an important role in these analyses partly because of the presence of low apex angle blocks formed by the intersection of the high angle joints. That is, the dominant joints intersect to form large sliver-shaped blocks whose apex angle is between $10^{\circ}-20^{\circ}$. Removable blocks require roughness (or dilation) angle if less than $1 / 2$ the apex angle - in the range of $5^{\circ}-10^{\circ}$ in order to be removable. This range is close to values reported for the laboratory tests. Therefore, by assuming dilation angle of zero would conservatively predict the number of removable blocks as well as a lower composite joint strength. It is recommended that joint dilation be considered in conjunction with the other joint strength parameters. See Table 1.

Joint Stiffness-Joint stiffness were taken as mean values from laboratory data. Shear stiffness normally is expected to be less than normal stiffness, by about 1-2 orders of magnitude. However, joint normal and shear stiffness were the same value in the analysis, which were 6 orders of magnitude less than the stiffness of the intact blocks. Their magnitude seems low given the tightness of joints. The implication of this is that most of the deformation around the tunnel will be taken up by the joint system. When combined with the low cohesion and medium friction angles used for joint strengths, much of the block deformation will be in the form of joint slip. Stiffer joints would mean more of the deformation would be from joint slip instead of slip. Stiffer joints would mean more of the deformation would be from joint slip instead of compression. The approach adopted to assign joint stiffness is not expected to have significant influence on the number of unstable blocks. Thus, the approach to adopting joint stiffness is reasonable and yet not overly conservative. See Table 1. 


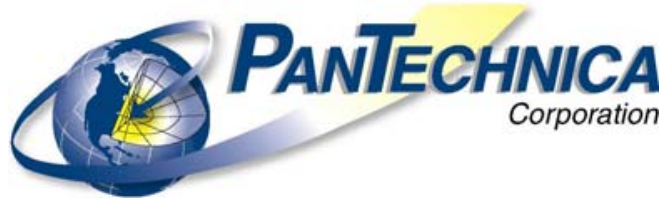

Intact Blocks Behavior-Elastic blocks have been assumed in this analysis. This implies that the intact rock in infinitely strong. Sidewall fractures near springline in the tunnel were observed in the lower non-lithophysal unit during the underground visit. However, beyond a distance of about $1 / 2 \mathrm{~m}$ the rock showed minimal observable damage, even in the jointing. The strength of the nonlithophysal rocks is estimated at about $70 \mathrm{MPa}$, yet the maximum stresses around the tunnel are about $21 \mathrm{MPa}$ (i.e. 3 times $\sigma 1$ ). During dynamic loading some localized sidewall spalling could be expected. By ignoring the energy loss associated with minor spalling more energy is transmitted to the joint system. This might slightly over estimate the number of unstable blocks. This approach to intact rock strength is quite reasonable, but might result in conservative results (i.e. too large unstable block volumes). It is recommended that a sensitivity case be run with inelastic blocks to see if the low probability seismic events produce stress spikes sufficient to local sidewall spalling. See Table 1.

Ground Motion-Ground motion input data represents three probable events: the 1 in 10,000 year event, the 1 in 1 million year event and the 1 in 10 million year event. Peak motions are reasonable for the $5 \mathrm{e}-4$ event $(\mathrm{PPV}=19 \mathrm{~cm} / \mathrm{s}, \mathrm{PPA}=0.19 \mathrm{~g})$. However, they appear high for the other 2 events $(1 \mathrm{e}-6: \mathrm{PPV}=2.44 \mathrm{~m} / \mathrm{s}, \mathrm{PPA}=10.46 \mathrm{~g}$ and $1 \mathrm{e}-7: \mathrm{PPV}=5.35 \mathrm{~m} / \mathrm{s}, \mathrm{PPA}=16.28 \mathrm{~g})$. If such ground motions had been experienced underground, there is expected to be geologic evidence of damage, especially in the weaker lithophysal zone. Yet nothing has been reported by site geologists. When these large ground motions are input to the 3DEC model, the results indicate that all removable blocks become unstable. The results appear excessively conservative. See Table 1.

Simulated Fracture Volume-Simulated joints have been used to generate the jointing geometry that the blocks are computed from. Statistical parameters from scanline mapping data were computed and input to FRACMAN program to simulate a single realization of the 3-D joint system. The volume of rocks simulated was a $100 \mathrm{~m}$ x $100 \mathrm{~m} \times 100 \mathrm{~m}$ cube oriented parallel the emplacement drifts (00/073 as X axis,). A $25 \mathrm{~m} \times 25 \mathrm{~m}$ x $25 \mathrm{~m}$ of rock surrounding the tunnel was then randomly located within the cube. The 3DEC model was "cut" depending on the relative location of joints within the volume. Given the lack of real data in the emplacement drifts (as they are unmined to date) this is a very reasonable approach to estimate the jointing that might be there when the tunnels are excavated. See Table 1.

Small Joints-It is understood that statistics were computed (length, spacing, dip, dip direction, termination, etc.) with only mapped joints longer than $1 \mathrm{~m}$. Ignoring small joints will have minimal impact on the stability results because 1) it can be shown thatsmall joints have a low probability of intersecting to form blocks and 2) such small blocks have a high probability of being "nested" in larger removable blocks. Thus, the approach to neglecting short joints in the FRACMAN simulation is reasonable and does not produce overly conservative results. In fact the inclusion of such short joints is expected to produce a large number of "isolated" joints whose impact would be to soften the overall rockmass, likely reducing the number of unstable blocks for a given ground motion. This could be verified by making a sensitivity run but is not necessarily recommended at this time given the purpose of the analyses. See Table 1 . 


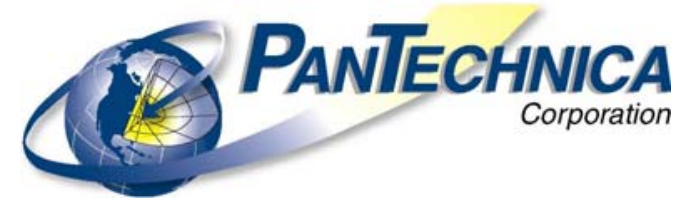

Non-concave Blocks-3DEC is limited to using non-concave blocks. When fractures are input they must "cut" completely through a given block. The approach adopted was to overcome this limitation by "gluing" joints back together for the portion of the joint beyond the radius of the simulated joint. Complex FISH functions were written to allow this on a block by block basis. Although this approach is quite clever, it is recommended that these functions be carefully checked for errors due to their complexity. This approach has been used by others in programs like UDEC; however, I am not aware of it being used in 3-D. Although "gluing" cut blocks using intact rock properties is a common practice in 3DEC analyses, this application of "gluing partially cut" blocks in novel. This approach is a very reasonable and is capable of producing realistic block geometries and fractured rockmass geometries. See Table 1.

Fracture Size-Fracture size is handled in FRACMAN by using trace length and spacing data to compute a statistical area of fractures required in the given volume of rock. The simulation generates a fracture radius and location for a given set while checking the area-to-volume ratio. Each set is simulated separately and then superimposed to compute truncations. The reasonableness of this approach is checked by generating unrolled simulated fracture maps of fractures as they intersect the tunnel walls. These maps were compared to actual unrolled fracture maps recorded underground. The FRACMAN results produce reasonable maps that look realistic when compared to recorded unrolled maps. See Table 1.

Terezaghi Correction-The FRACMAN analysis has made no adjustments in the data for fractures oriented sub-parallel to the tunnel. It is common for fractures mapped in smaller diameter openings, such as boreholes, to be biased in the number of fractures recorded sub-parallel to the opening. A Terezaghi correction would normally be applied to the data to correct for this. In the case of the ESF, there is a sub-horizontal joint set sub-parallel to the plunge of the tunnel. However, the project geologists that did the mapping felt that due to a) the large diameter of the tunnel when compared to the observed spacing of the sub-horizontal set and b) the mapped tunnels traversed a range of orientations, it is not likely that a significant number of sub-horizontal fractures were not accounted for in the overall database of joints. Thus, the approach of not applying a Terezaghi correction to the sub-horizontal joint set data is reasonable. See Table 1.

Sub-Horizontal Joint Spacing-The spacing of sub-horizontal jointing was observed to vary along the length of the tunnel in the non-lithophysal zone. In some locations it appeared to be on the order of $1 / 2 \mathrm{~m}$ spacing (longer joints) while in other areas it was in excess of $4 \mathrm{~m}$ spacing (shorter joints).

19 February 2003




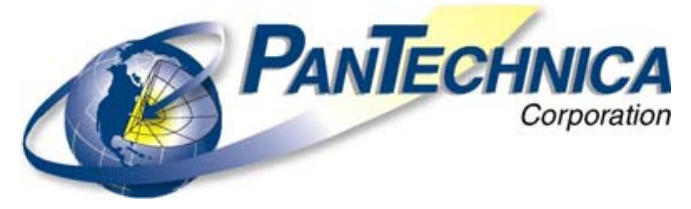

Results from the joint statistics report an average spacing of $4.2 \mathrm{~m}$. It is likely that the statistics "smear" the spacing to this larger value. It is this sub-horizontal plane that typically forms the release plane on blocks formed by the intersection on the other 3 joint sets. By not directly accounting for the $1 / 2 \mathrm{~m}$ spacing long sub-horizontal joints, only very large blocks become removable. It is these large blocks where de-stressing around the tunnel has little impact on their stability. Had this closer spacing been used, more blocks nearer the tunnel surface would have been formed and thus a larger unstable volume predicted in certain areas of the tunnel. The approach adopted is reasonable on the scale of the repository, but might under predict unstable blocks locally. It is recommended that other FRACMAN simulations be performed to check the effect on the distribution of removable blocks. It is probably not necessary to perform additional dynamic analyses unless block size distributions are vastly different. See Table 1.

Damping-All of the dynamic analyses have been performed with a motion damping coefficient of zero. This implies that the only damping in the system is the energy loss due to interaction between blocks brought about by the open/close shaking of joints. It is common practice to use some minor amount of damping $(2 \%-5 \%)$ to account for natural damping of the rock mass. The impact of not damping the motion is expected to be more high-frequency energy being available at block boundaries and more "vibration" of the joints. This would lead to more joint slip and, thus, more unstable blocks. To neglect damping is reasonable and yet not overly conservative. It is recommended that a couple sensitivity runs be made to verify how conservative this assumption is. See Table 1.

Bridge Failure-The way blocks are formed in the model required that the joint extend beyond the simulated radius, but the "non-real" area of the joint was "glued" back using intact rock strengths (see item Non-Concave Blocks above). This glued area simulates an intact "bridge" of rock. When combined with the elastic blocks, any differential motion across the "isolated" joint will result in significant stress concentrations in the "glued" portion nearest the joint. Since the intact rock strength was used for simulate the gluing, this is the only place in the model where the intact rock could fail. Given a) the large strength difference between the joints and the intact rock, b) the rapid load change of the applied seismic event, and c) no applied damping in the system, there could be artificially high stresses generated at the glued contacts nearest the joint contacts. It is not known what percent of the reported unstable blocks had originally glued joints that had broken during the seismic event. The percentage of "unstable blocks with partially glued faces" might be sensitive to the number of sub-contacts along the glued joints. If this is the case, the reported volume of unstable blocks could be over estimated for a modeling discretization reasons. It is recommended that the unstable blocks from a few runs be checked to see if a large portion of their face area were from glued sub-contacts. If this is true, a sensitivity run should be made with a more finely descretized grid. See Table 1.

Prepared for

Bechtel/SAIC on behalf of

U.S. Department of Energy
$13 / 20$

19 February 2003 


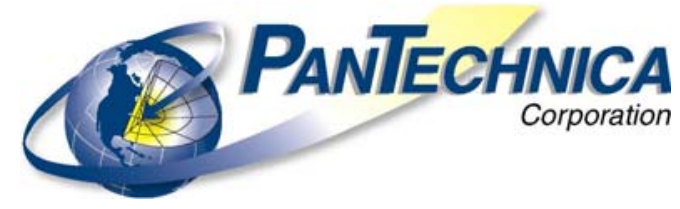

Joint Strength Degradation-The strength of joints were held constant for all seismic events. However, blocks exposed to low probability events will also have experienced higher probability events. This repetitive loading will result in shaking damage to the joint system (e.g., on average for every 10-7 event the rock will have experienced 10 of the 10-6 events). This shaking damage should manifest itself as a reduction in strength. This behavior was not simulated in the base case analysis. The sensitivity study includes a case with residual joint strengths, which would represent a lower bound condition for this behavior. It is unlikely that accounting for this behavior would improve the reliability of the results since no laboratory data is available to estimate the magnitude of joint strength degradation. Thus, the approach adopted of examining results from residual strength runs is reasonable. See Table 1.

Similar Analysis Approach-The entire analysis approach adopted for this study is thought to be unique. The reviewer knows of no other complete set of analyses that have been published in the literature that approach the magnitude or complexity of this study. However, others have adopted aspects of the analyses. For example, the use of FRACMAN to simulate a volume of fractures based on line mapping data has been documented. The same is true of the use of 3DEC to simulate seismic ground motion. The novel portions of the model development (i.e. gluing blocks in non-joint regions, selectively cutting blocks to minimize the numbers of blocks, etc.) is not unique and has been documented. However, it is their automation via FISH functions that has not been published else where to the reviewer's knowledge. Rockfall analyses of waste repository drifts have been studied in the Finish waste program, although the approach was to analyze block stability using static loading and limit equilibrium solutions. Dynamic analyses of rockfall conditions have been performed for South African deep-mining rockburst problems. Given the uniqueness of these analysis requirements, it is the reviewer's opinion, sufficient aspects of the adopted modeling techniques have been documented by other researchers that the overall approach to estimating seismic rockfall volumes is reasonable. All other known similar analyses would be sufficiently more conservative than those presented here. It is recommended that the final report contain references to known published analyses. See Table 1.

Fractured Rockmass Boundaries-A $25 \mathrm{~m}$ x $25 \mathrm{~m}$ x $25 \mathrm{~m}$ volume of rock was used to compute discrete blocks in 3DEC, even though $100 \mathrm{~m} \times 100 \mathrm{~m} \times 100 \mathrm{~m}$ was simulated in FRACMAN. The sensitivity of results to this volume has been examined by computing blocks in $35 \mathrm{~m} \times 35 \mathrm{~m} \times 35 \mathrm{~m}$ volume and $45 \mathrm{~m} \times 45 \mathrm{~m} \times 45 \mathrm{~m}$ volume. Results indicate less unstable blocks at $35 \mathrm{~m}$ and more at $45 \mathrm{~m}$. The reason for this is not explained. The reason for using the original $25 \mathrm{~m}$ was to keep the computations to a manageable size. In the reviewers opinion the sensitivity study does not address whether the $25 \mathrm{~m}$ volume is adequate. It is recommended that one large block model $(60 \mathrm{~m} \mathrm{x} 60 \mathrm{~m} \mathrm{x}$ $60 \mathrm{~m}$ of fractured rocks) with the tunnel centered in the volume be computed with fine zone discretization. This model would simulate blocks more than 10 tunnel diameters extending beyond the major zone of excavation-induced stress region. See Table 1. 


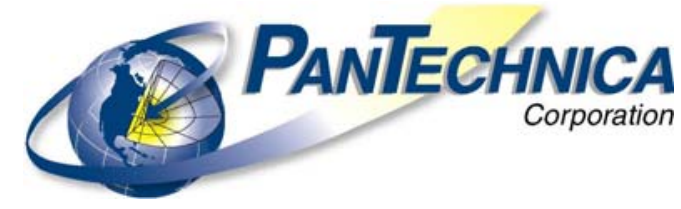

Fractures in Floor-The model did not simulate any blocks in the floor of the tunnel, yet fractures are known to exist there. The reason was that the analysis focuses on gravitational rockfall after being dislodged. The impact of neglecting fractures in the floor is less deformability of the tunnel and more motion-energy is likely transmitted to the joint system. This approach allows a reduction in the computational size of the model. The approach is reasonable, yet would produce a larger volume of unstable blocks than had the floor been represented as fractured. It is recommended one large block model be computed that includes fractures in the floor (see Fractured Rockmass Boundaries). See Table 1.

In Situ Stress-Pre-excavation in situ stresses used in the analyses were taken from mean measurement values. A sensitivity run was made with a higher stress ratio $(\tau \mathrm{h}: \tau \mathrm{v})$. Given the small expected variations in the stress field, there is little influence on the results. In situ stress is considered a minor variable in the analyses and thus the approach adopted is reasonable. See Table 1.

Event Duration-The decision was made to truncate the duration of the seismic record due to excessive computational time required to complete the analysis. The approach was to compute the applied energy over time and cut the record duration so that the first $5 \%$ and last $5 \%$ of the energy was neglected. This is a common practice in numerical modeling of seismic events in such high strength materials because only small changes occur in the model with late-time motion. This would not be the case if pore pressure dissipation was thought to be an issue for block stability. An alternative approach that is used in similar analyses is to perform frequency filtering where high frequencies are filtered since they contain little energy. This was not necessary for these analyses for two reasons: a) the critical time-step is governed by the minimum block and zone sizes capable of transmitting the wave motion, and b) automatic inertial mass scaling was implemented into 3DEC. Additionally, the peak energy is applied early in the record so loose blocks will have had sufficient time to fall, and thus the length of the event is expected to have little impact on the final rockfall volume results. This approach to shorting the record duration is reasonable. See Table 1.

Event Orientation-Ground motion was applied to the model parallel the model boundaries with $v v$ vertically in $\mathrm{Z}$ axis, $\mathrm{vH} 1$ horizontally in $\mathrm{X}$ axis and $\mathrm{vH} 2$ horizontally in $\mathrm{Y}$ axis. In the sensitivity study $\mathrm{H} 1$ and $\mathrm{H} 2$ motion components were reversed. This method does not necessarily produce the worst case motion on individual blocks. However, the combination of forces critical for block stability will be different for each block since each block is comprised of joints of different orientations. Given the near random shape of blocks (and thus their critical force vector orientation) and the fact that $\mathrm{H} 1$ and $\mathrm{H} 2$ components are of similar magnitude, the net impact on the predicted volume of unstable blocks is expected to be minimal. Therefore the approach of performing a sensitivity computation where the $\mathrm{H} 1$ and $\mathrm{H} 2$ components are reversed is reasonable. See Table 1. 


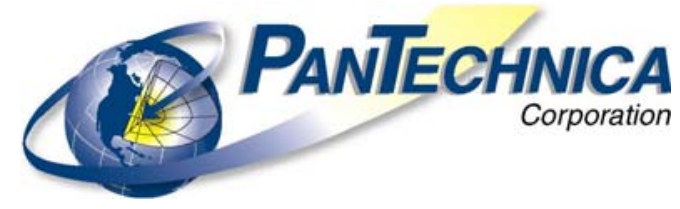

Removing Unstable Blocks-The base case analysis adopted the approach of removing blocks from the analysis after they had made contact with the simulated drip shield. This was done to estimate potential impact of subsequently unstable blocks that might hit the drip shield. In actuality, large blocks would likely stay in contact with the drip shield preventing other blocks from impacting it.

For large collapse zones, large blocks might even prevent other blocks from falling. The other blocks would loosen but not have space to fall freely. In the sensitivity analysis a case was run where no unstable blocks were deleted in order to check this approach. The approach of removing the blocks by deleting them after they contact the drip shield is reasonable. See Table 1.

Comparison to Real Blocks-All of the analyses were performed with block geometries determined from the FRACMAN-simulated joint volume. No real blocks in the underground tunnels were analyzed. Although the actual geometry is not known because they extend back into the Rockmass, fewer modeling assumptions are required to generate the blocks (i.e. their location, orientation and tunnel trace length are known). Such an analysis would provide a comparison between the volume of unstable simulated-blocks and the volume of unstable real-blocks. Comparisons of unstable blocks from real and simulated fracture sections are not expected to be the same; however, the ratio of stable to unstable volume of blocks should be similar. It is recommended for purposes of model calibration that 3DEC blocks be generated from the FRACMAN volume for comparison to specific sections of tunnel. If the block volumes are similar then there will be more confidence in the approach used to simulate blocks for emplacement drift orientations. There would be no need at this time to compute the seismic response unless the block volumes were vastly different. See Table 1.

DRKBA Analyses-The original rockfall study was comprised exclusively of results from DRKBA limit equilibrium analyses. Those analyses were limited by the following assumptions:

- In situ stresses were neglected.

- The seismic motion was represented by changing joint cohesive strengths.

- Thermal stresses were neglected.

- Fracture simulation was based on joint length and spacing only along tunnel surface and assumed infinite into the Rockmass.

- Small trace length data was included producing significantly more volume of small blocks

The first 3 of these are considered major limitations (the 2 nd is considered not completely rational as it applies to resisting forces instead of driving forces). Although there are these limitations, the analyses results provide an alternative approach to the 3DEC numerical model results. It is recommended that the DRKBA results discussion in the original report on be moved to an attachment and they be de-emphasized. See Table 1.

Prepared for

19 February 2003

(19 February 2003




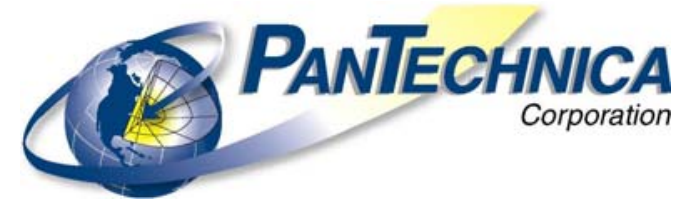

Pore Pressures-Pore pressure in the rockmass generated as a result of the seismic shaking were neglected in these analyses. This is reasonable since the rock mass is only partly saturated and the build up of pore pressures is unlikely. See Table 1.

Thermal Stresses-Thermal strains induced by the waste heating the drifts will generally serve to increase the stresses on the blocks. As the repository cools over time, these stresses will dissipate. The cooling impact on the local joint system is unknown as joints may either stay closed in compression or open due to tension. Either way, this effect is expected to extend only locally around the peripheral of the drift where the radial stresses are low. Larger blocks would remain clamped by the thermal stresses. The approach adopted in the analysis was to decouple the thermal calculations from the mechanical calculations. This is reasonable since the rock is treated as elastic and all the strains (including thermally induced) are fully recoverable. The only irrecoverable deformations occur as joints slip. Thermal calculations were sequenced by computing: thermal equilibrium, static mechanical equilibrium, and then dynamic loading. This approach is reasonable because it allows the blocks to come to static equilibrium prior to seismic loading. See Table 1.

Non-Reflecting Boundaries-One of the problems in modeling seismic events is that the applied wave reaches the boundary of the model and is reflected back into the area of interest before the complete wave has passed through the area of interest. This would result in an amplification of the motion. The 3DEC program was modified specifically for these analyses to include non-reflecting boundaries. This prevents reflected motion from propagating back through the grid. It is reasonable that an equivalent dynamic stress was applied to the base of the model propagating upwards to simulate the seismic event. Vertical free-field boundaries were applied consisting of a row of zones that simulate non-reflecting boundaries. This approach is common for dynamic analyses. See Table 1.

Support System-No ground support was included in the model. Although support is expected to be installed in the drifts, it is reasonable to assume that they will not contribute significant support in the long-term. See Table 1.

\section{CONCLUSIONS}

The modeling effort represented by this work is some of the most extensive rockfall analyses in blocky rockmass known to be performed to date. The mathematical model makes use of several novel techniques for representing fractures and then creating a blocky rockmass.

The simulation work done with FRACMAN is theoretically sound and produces a realistic fracture pattern similar to trace maps recorded by the geologists. Although local fracturing (i.e. lengths, spacing, orientation relative to the drift, etc.) might be different than average values computed from the entire database, the simulated fractures appear very reasonable. Even the technique of simulating one set of fractures in a large volume and then sampling from random locations within the volume to create the $3 \mathrm{DEC}$ block model is a rational approach, 


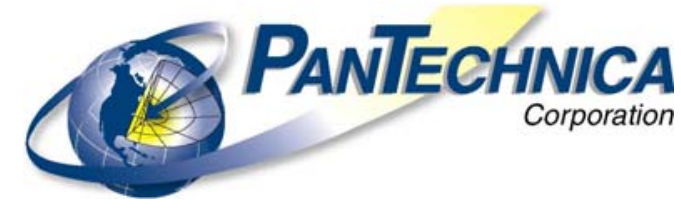

The combination of joint strength properties (i.e. cohesion, friction angle and dilation angle) for the base case has not been considered collectively. Rather, as independent parameters they represent conditions that do not make sense (i.e. peak friction and no dilation).

Joint stiffness values are low but, since their magnitude has minor impact on results, the approach is acceptable. In agreeing with Dr. Barton (Introduction: Reference \#6, above), the normal stiffness should be stiffer than the shear stiffness, although I am not sure I agree with Dr Barton on the orders of magnitude.

The low probability seismic events (i.e. 1e-6 and 1e-7) appear unreasonably large as input ground motion. It should be demonstrated that the geology can store such energy before such events are used in analysis. No geologic evidence, to the reviewer's knowledge, has been presented which suggests that such large events have occurred in the geologic past. There is no doubt that this is the single most influential parameter in the analysis due to the large range of acceleration and velocity variations.

The manner in which sub-horizontal fracture spacing was treated results in predications not very conservative on a local level where average spacing of long fractures is significantly less. However, on an overall repository scale the approach is reasonable because there are other local areas where the sub-horizontal fracture spacing is significantly more than average. This is another reason that the study results apply overall conditions and not locally.

The DRKBA stability analysis performed for the original rockfall study does not provide reliable comparison to these analyses because no stress was included nor was ground motion properly represented. However since there are not many other discontinuum block analyses techniques that can be use to compare the FRACMAN/3DEC analyses to, a summary of the DRKBA results should be left in the report because they are of comparison value.

Finally, it is important to note that the analyses presented in this study have been well conceived. Given the complexity of mathematical models and the limited data available, the team has developed an analysis procedure which is state-of-the-art. They have combined techniques in a way that provides realistic estimates of rockfall volumes and impact on the drip shield. Undoubtedly, as more data become available this approach can be refined to provide more accurate estimates. I do not believe it is worthwhile spending the effort to provide more accurate estimates at this time since data uncertainty is still large. 


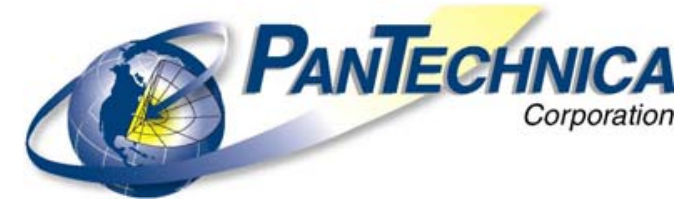

\section{Recommendations}

There are several techniques that can be used to improve the accuracy of these analyses with the current uncertainty in data. The following recommendations should be considered as part of the work scope for producing a final document for this work. The recommendations are in order of decreasing importance.

1. As mentioned throughout this review the large seismic events are suspect. It is recommended that the input motions be reexamined. Although review of the seismology work was not part of this review scope, more convincing arguments need to be presented which demonstrates that the geology can actually store this energy and sustain such motion.

2. The base case values for joint strength parameters should be examined through a sensitivity study to be consistent with each of cohesion, fraction angle and dilation angle.

3. Due to the complexity of the FISH functions within 3DEC model, it is highly recommended that all the functions be independently checked by another engineer to ensure accuracy. This might include more detailed comments/documentation of those functions.

4. A sensitivity case should be included where a block system is compute on local spacing $(\sim 0.5 \mathrm{~m})$ of sub-horizontal joints to see block volume change. It would not be necessary to perform the dynamic runs. This will provide a feel for variations in the unstable block volumes.

5. The documentation of these analyses should include references for other known studies that employ similar approaches to solving this type problem. This will significantly boost the reader's confidence that the adopted approach has been published elsewhere.

6. A sensitivity case should be included were several damping values are used to estimate the uncertainty in neglecting damping in the model.

7. Unstable blocks should be checked for sub-contacts to have been broken along the "bridge" portion of the block. The results should then be reassessed to see if a sensitivity case is needed with finer discretization provides the same results.

8. A sensitivity case should be developed that uses a much larger fractured volume which includes the floor. This will provide confidence that block stability is not biased by the limited number of blocks simulated in the model. 


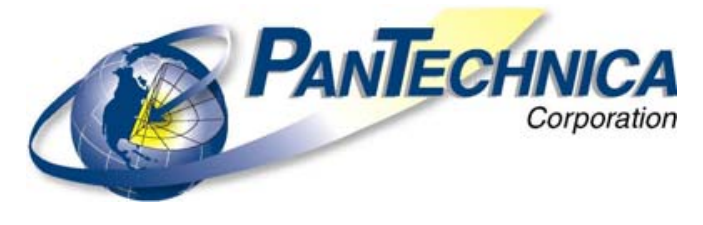

9. To provide confidence that the simulated fracture set provides stability results similar to that obtained from real mapped fractures, a sensitivity case should be run using specific jointing mapped in the ESF or ECRB drifts. This will qualitatively compare the volume of blocks formed with those formed from simulated fractures and provide confidence that the analyses are not excessively conservative in predicting unstable blocks.

10. The final documentation should de-emphasize DRKBA results by moving them to an attachment and provide a succinct summary of their results.

I hope that BSC finds this 3DEC modeling review to be beneficial. If you have questions on the findings I can be reached at 952-368-3079 or jtinucci@pantechnica.com.

Respectfully submitted

John P. Tinucci, PE, PhD

President PanTechnica Corporation 


\section{INTENTIONALLY LEFT BLANK}


APPENDIX O

DESCRIPTION OF LITHOPHYSAL ABUNDANCE AND LITHOPHYSAL CHARACTERISTICS IN THE ECRB CROSS-DRIFT 


\section{DESCRIPTION OF LITHOPHYSAL ABUNDANCE AND LITHOPHYSAL CHARACTERISTICS IN THE ECRB CROSS-DRIFT}

With the large volume of the proposed repository located in the lower lithophysal zone, a detailed study of the lithostratigraphic features in the lower lithophysal zone exposed in the ECRB Cross-Drift has been completed (DTNs: GS021008314224.002 [DIRS 161910] and GS040608314224.001 [DIRS 171367]). The data package documents the distributions of size, shape, and abundance of lithophysal cavities, rims, spots, and lithic clasts, and these data can be displayed and analyzed as (1) local variations, (2) along the tunnel (a critical type of variation), and (3) as values for the total zone. The percent of lengths and areas of features on the tunnel wall are typically referred as "abundance". Because of the variations in scale of the features from lengths measured in millimeters to meters and variations in similar rock characteristics from tens to hundreds of meters, a variety of methods have been used to document the features in the rocks (Table O-1). Full Peripheral Maps, Detailed Line Surveys, and Small-Scale Fracture Surveys are primarily to document fractures, although lithophysae are described or annotated in some of these products.

Table O-1. Methods Used to Document the Distribution of Lithostratigraphic Features in the Lower Lithophysal Zone of the Topopah Spring Tuff in the ECRB Cross-Drift

\begin{tabular}{|c|c|c|c|}
\hline Method & Location & Procedure/Configuration & Data Collected \\
\hline $\begin{array}{l}\text { Full peripheral } \\
\text { mapping }\end{array}$ & $\begin{array}{l}\text { ECRB Cross-Drift, } \\
\text { continuous }(14+44 \text { to } \\
23+26)\end{array}$ & Map visible tunnel surfaces & $\begin{array}{l}\text { Discontinuities }>1 \mathrm{~m} \text {, } \\
\text { contacts, tunnel supports }\end{array}$ \\
\hline Detailed line surveys & $\begin{array}{l}\text { ECRB Cross-Drift, } \\
\text { continuous }(14+44 \text { to } \\
23+26)\end{array}$ & $\begin{array}{l}\text { Tape line along one side of } \\
\text { tunnel }\end{array}$ & Discontinuities $>1 \mathrm{~m}$ \\
\hline $\begin{array}{l}\text { Small-scale fracture } \\
\text { surveys }\end{array}$ & $\begin{array}{l}\text { ECRB Cross-Drift, } 6 \\
\text { selected locations } \\
(11+15 \text { to } 24+30)\end{array}$ & $\begin{array}{l}\text { Each } 6 \text { meter long horizontal } \\
\text { traverse intersects three } 2 \\
\text { meter long vertical traverses }\end{array}$ & Discontinuities $<1 \mathrm{~m}$ \\
\hline Panel maps & $\begin{array}{l}\text { ECRB Cross-Drift, } 18 \\
\text { selected locations } \\
(14+93 \text { to } 22+94)\end{array}$ & $\begin{array}{l}1 \times 3 \text { meter maps, } 1: 10 \text { scale, } \\
\text { overlays on photographs }\end{array}$ & $\begin{array}{l}\text { Lithophysae, rims, spots, } \\
\text { lithic clasts }\end{array}$ \\
\hline Tape traverses & $\begin{array}{l}\text { ECRB Cross-Drift, } 187 \\
\text { selected locations at } 5 \\
\text { meter intervals }(14+05 \\
\text { to } 23+35) \\
\end{array}$ & $\begin{array}{l}\text { Traverses across tunnel, } \\
\text { measured with tape attached } \\
\text { to pole }\end{array}$ & Lithophysae cavities only \\
\hline Angular traverses & $\begin{array}{l}\text { ECRB Cross-Drift, } 22 \\
\text { selected locations } \\
(14+60 \text { to } 22+00)\end{array}$ & $\begin{array}{l}\text { Traverses across tunnel, laser- } \\
\text { prism measurements with } \\
\text { geometric solutions }\end{array}$ & $\begin{array}{l}\text { Length of lithophysal cavities, } \\
\text { rims, spots, stringers, lithic } \\
\text { clasts, and matrix- } \\
\text { groundmass }\end{array}$ \\
\hline $\begin{array}{l}\text { Large-lithophysae } \\
\text { inventory }\end{array}$ & $\begin{array}{l}\text { ECRB Cross-Drift, } \\
\text { continuous ( } 14+40 \text { to } \\
17+55)\end{array}$ & $\begin{array}{l}528 \text { Lithophysae with long axis } \\
0.5 \mathrm{~m} \text { and greater }\end{array}$ & $\begin{array}{l}\text { Long axis, short axis, station, } \\
\text { wall position }\end{array}$ \\
\hline
\end{tabular}

\section{O1. TAPE AND ANGULAR TRAVERSE DATA}

Tape and angular traverses, which are variations in linear or one-dimensional measurement techniques, include data from the upper half of the tunnel (typically from the compressed air pipe on one side to the top of the conveyor belt on the other side, Figure O-1). In linear traverses, 
total abundance (percent) of a type of feature is the sum of lengths of the features divided by the total length of the traverse. Tape traverses include the measured length of lithophysal cavities along the traverse, length of the traverse, and a visual estimate of the abundance of rims and spots; therefore, tape data are discontinuous data (not all features are mapped). The advantage of tape traverses is that these data are every $5 \mathrm{~m}$ along the tunnel and indicate variations in the lithophysal cavity abundance along the tunnel (Figure O-2; see Section O6.3), but abundance values are typically greater than those documented with angular traverses and panel maps. There are 22 angular traverses, but they consist of continuous data (specific lengths of each lithophysal cavity, rim, spot, lithic clast, and matrix-groundmass), and measurements are to the nearest 5 to $10 \mathrm{~mm}$. Angular traverses consist of continuous data (all features are mapped) and provide a similar resolution of data to that of panel maps. Abundance of lithophysal cavities determined in angular traverses is similar to, or slightly less than, the abundance determined with tape traverses (Figure O-2). Angular traverse data (Table O-2; see Section O6.2) can be used to adjust the lithophysal cavity, rim, and spot data from tape traverses (Section O6.6).
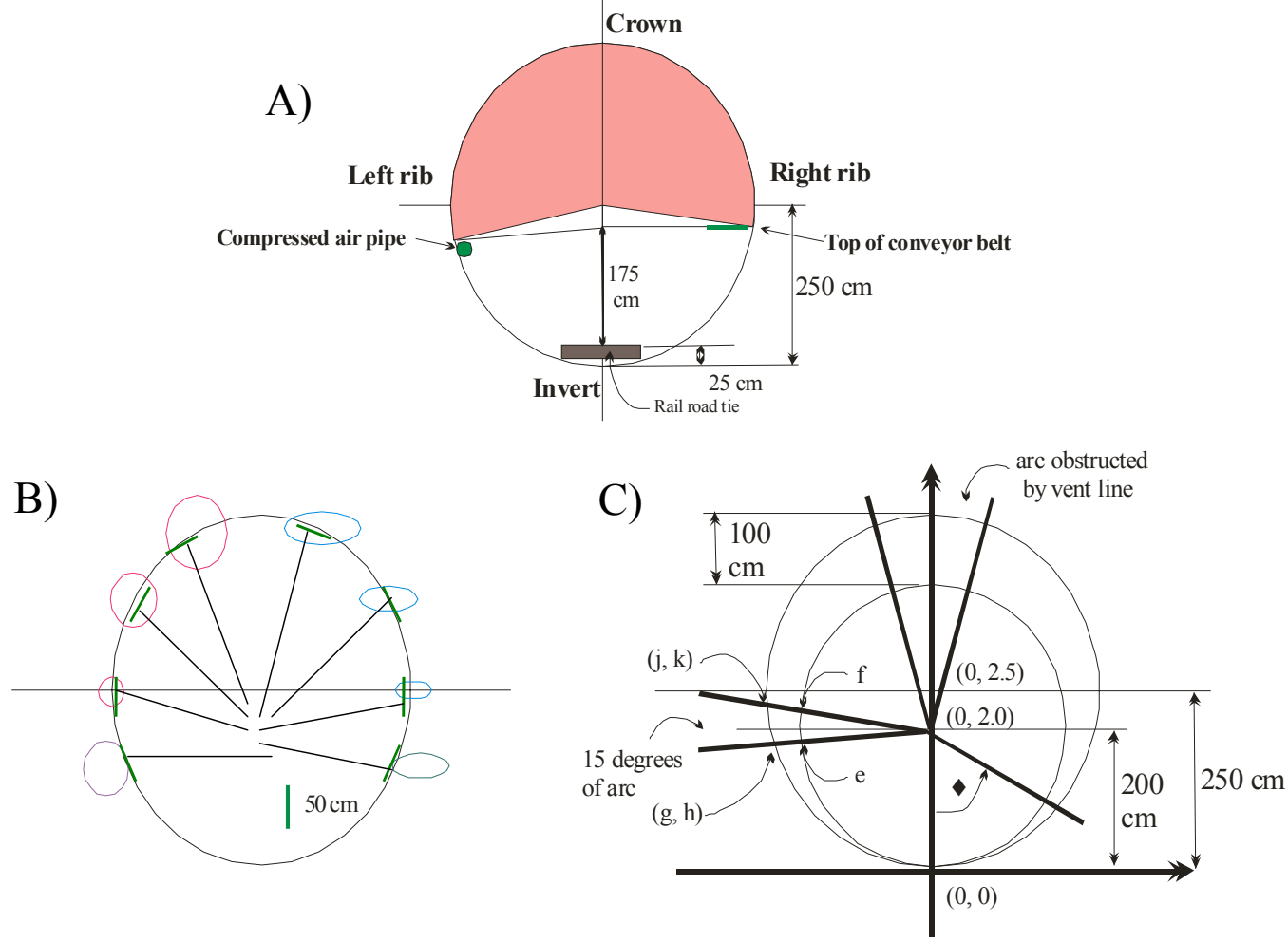

NOTE:

A) Cross-section view of tunnel (looking toward the heading) showing parts of the tunnel (crown, ribs, and invert), positions of the compressed air pipe, conveyor belt, railroad ties, and position of the laser-prism (175 $\mathrm{cm}$ above railroad tie). The shaded area is the most typically measured part of the tunnel.

B) Tape traverse data are discontinuous in that only the length of the lithophysal cavities is measured.

C) Angular traverse data are continuous in that the edges of the features are measured and lengths are calculated with analytical geometric relations.

Figure O-1. Geometric Relations of Tape and Angular Traverse Data from the Tptpll 


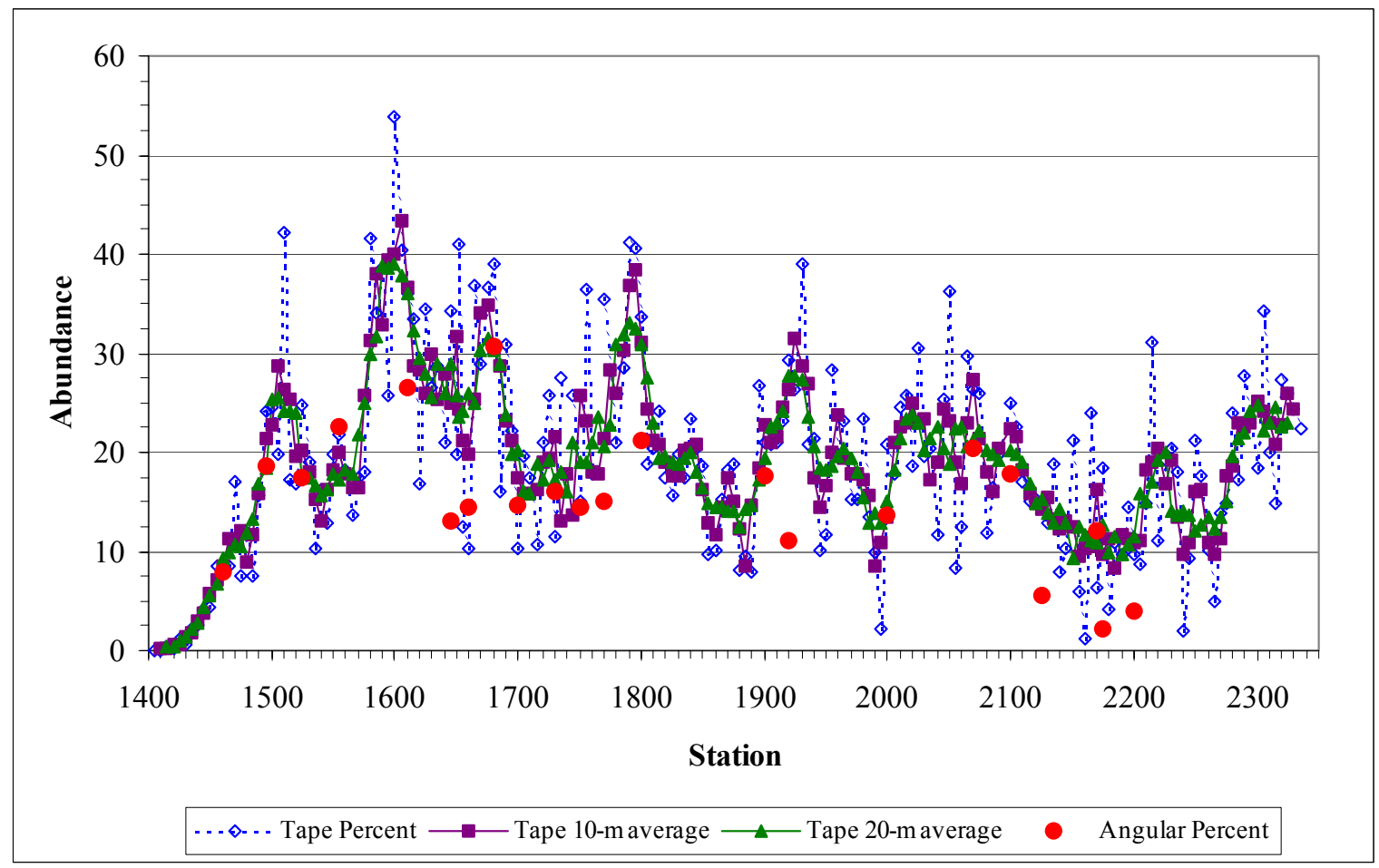

NOTE: Abundance (percent of traverse length) of cavities are from tape and angular traverse data. These data are from DTN: GS021008314224.002 [DIRS 161910] and have not been adjusted as they are in Figure 0-9.

Figure O-2. Abundance of Lithophysal Cavities from Angular Traverse data and Tape Traverse Data Collected at $5 \mathrm{~m}$ Intervals from the Tptpll in the ECRB Cross-Drift with $10 \mathrm{~m}$ and $20 \mathrm{~m}$ Moving Averages

\section{O2. PANEL MAP DATA}

In addition to the along-the-tunnel variation in the abundance of features such as lithophysae, there are variations in the sizes, shapes, and distances between features. These types of variations are most easily observed with the panel map data (Figures O-3 to O-8). Locations of the panel maps were positioned to capture representative variations in the rocks along the tunnel, and they were not positioned to capture a specific feature such as the largest lithophysae. The tunnel walls at panel map locations were washed prior to photographing and mapping the site. At each panel map location, three photographs were taken at $90^{\circ}$ to the wall and with low-angle illumination to accentuate the relief of the wall caused by cavities (and fractures). The three photographs are merged (to form a mosaic) of an area about $1.6 \times 4.3 \mathrm{~m}$ and the $1 \times 3 \mathrm{~m}$ map area is positioned to minimize the number and amount of partially included features. The panel maps, which have a 1:10 scale, are two-dimensional, continuous data because the features are mapped and documented. Boundaries of the features were drawn on the photographs in the field. During the mapping, the mapper attempted to represent the projected intersection of the feature with the tunnel wall, so there might be a slight difference in the mapped shape of the feature compare to the perceived shape in the photograph. On the panel maps, the boundaries of lithophysal cavities, rims, spots, and lithic clasts are depicted with different colors (red, green, blue, and gold respectively) and the alphanumeric labels of the features are L (lithophysal cavities and rims), $\mathrm{S}$ (spots), and $\mathrm{C}$ (clasts). 
Table O-2. Summary of Traverse Lengths and Abundance (Percentage) of Lithophysal Cavities, Rims, Spots, Lithic Clasts and Matrix-Groundmass Based on Angular Traverses from Stations $14+60$ to $22+00$ in the ECRB Cross-Drift

\begin{tabular}{|c|c|c|c|c|c|c|c|c|c|}
\hline 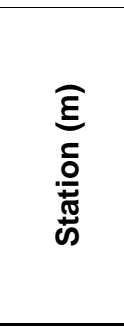 & 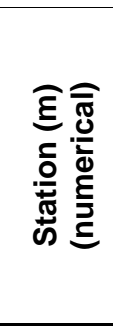 & 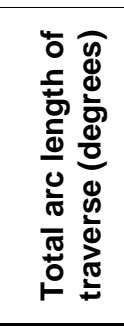 & 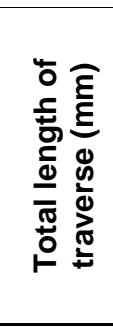 & 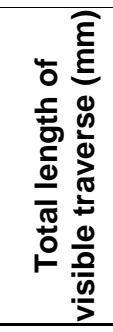 & 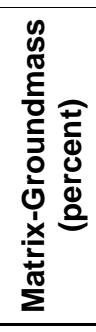 & 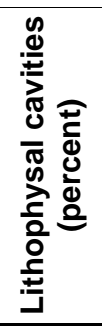 & 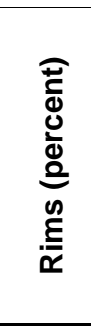 & 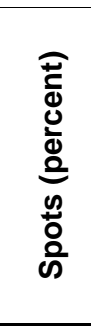 & 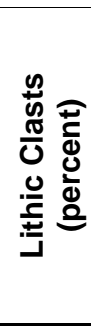 \\
\hline $14+60$ & 1460 & 228.50 & 10851 & 7829 & 64.2 & 7.9 & 11.0 & 16.8 & 0.2 \\
\hline $14+95$ & 1495 & 232.33 & 11003 & 8967 & 62.0 & 18.7 & 7.2 & 12.1 & 0.0 \\
\hline $15+25$ & 1525 & 202.00 & 9784 & 7457 & 59.1 & 17.4 & 7.2 & 15.8 & 0.5 \\
\hline $15+53$ & 1553 & 202.08 & 9786 & 7759 & 59.9 & 22.5 & 8.0 & 9.6 & 0.0 \\
\hline $16+10$ & 1610 & 209.58 & 10095 & 7393 & 53.5 & 26.5 & 7.0 & 13.0 & 0.0 \\
\hline $16+42$ & 1642 & 360.00 & 15081 & 11614 & 70.7 & 13.1 & 6.3 & 8.8 & 1.1 \\
\hline $16+58$ & 1658 & 206.25 & 9960 & 7932 & 68.0 & 14.4 & 8.1 & 9.5 & 0.0 \\
\hline $16+75$ & 1675 & 192.25 & 9369 & 7316 & 49.6 & 30.7 & 13.7 & 6.0 & 0.0 \\
\hline $17+00$ & 1700 & 196.92 & 9569 & 7281 & 63.0 & 14.6 & 11.0 & 11.4 & 0.0 \\
\hline $17+27$ & 1727 & 208.33 & 10044 & 7958 & 68.2 & 16.1 & 8.0 & 7.7 & 0.0 \\
\hline $17+50$ & 1750 & 184.17 & 9016 & 6916 & 69.8 & 14.4 & 10.6 & 4.0 & 1.2 \\
\hline $17+70$ & 1770 & 233.67 & 10980 & 8989 & 74.9 & 15.0 & 6.9 & 3.2 & 0.0 \\
\hline $18+00$ & 1800 & 191.50 & 9292 & 7111 & 64.0 & 21.1 & 10.2 & 4.8 & 0.0 \\
\hline $19+00$ & 1900 & 195.08 & 9450 & 7046 & 60.8 & 17.7 & 13.9 & 6.6 & 1.0 \\
\hline $19+20$ & 1920 & 194.08 & 9404 & 7424 & 67.0 & 11.1 & 19.6 & 2.3 & 0.0 \\
\hline $20+00$ & 2000 & 192.25 & 9314 & 7353 & 70.3 & 13.7 & 6.4 & 7.2 & 7.2 \\
\hline $20+70$ & 2070 & 193.83 & 9387 & 7049 & 68.6 & 20.4 & 7.5 & 3.1 & 0.5 \\
\hline $21+00$ & 2100 & 180.08 & 9513 & 7367 & 66.1 & 17.8 & 10.5 & 5.5 & 5.5 \\
\hline $21+25$ & 2125 & 193.67 & 9372 & 7396 & 78.6 & 5.6 & 8.8 & 7.0 & 0.0 \\
\hline $21+70^{a}$ & $2170^{a}$ & 176.67 & 8826 & 5731 & 57.9 & 12.0 & 5.7 & 24.3 & 0.0 \\
\hline $21+75^{a}$ & $2175^{a}$ & 171.58 & 8532 & 6470 & 68.0 & 2.2 & 8.3 & 20.9 & 0.0 \\
\hline $22+00$ & 2200 & 198.00 & 9628 & 9196 & 67.2 & 3.9 & 4.8 & 23.5 & 0.6 \\
\hline
\end{tabular}

Source: DTN: GS021008314224.002 [DIRS 161910] (Table from file Tptpll Lithop SEP Data File.xIs, worksheet "SEP-Angular Trav. Data".)

a Only cavity data was collected in the angular traverse; however, the amounts of rims and spots were estimated in the field and the values were recalculated to 100 percent. 

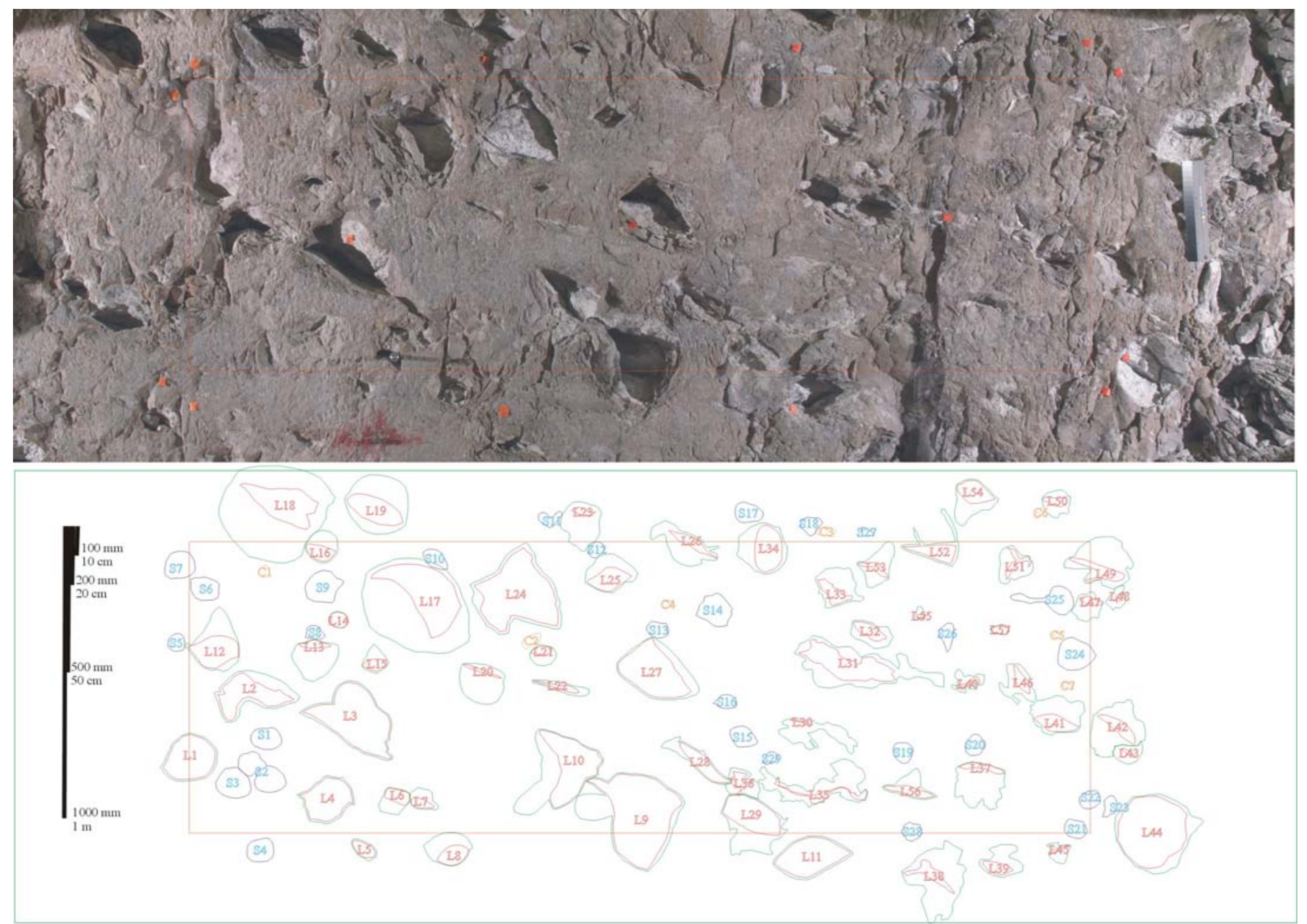

Source: Photograph and map are from DTN: GS021008314224.002 [DIRS 161910].

NOTE: Meter scale is on the left. Red rectangle is the $1 \times 3 \mathrm{~m}$ panel map area. Lithophysae have red "L" identifiers with cavities outlined in red and rims in green. Spots have blue " $\mathrm{S}$ " identifiers with cyan outlines. Lithic clasts have orange "C" identifiers with gold outlines.

Figure O-3. Lithophysae, Spots, and Clasts of Tptpll in Panel Map 1493 Located on the Right Rib from Station 14+93 to 14+96 


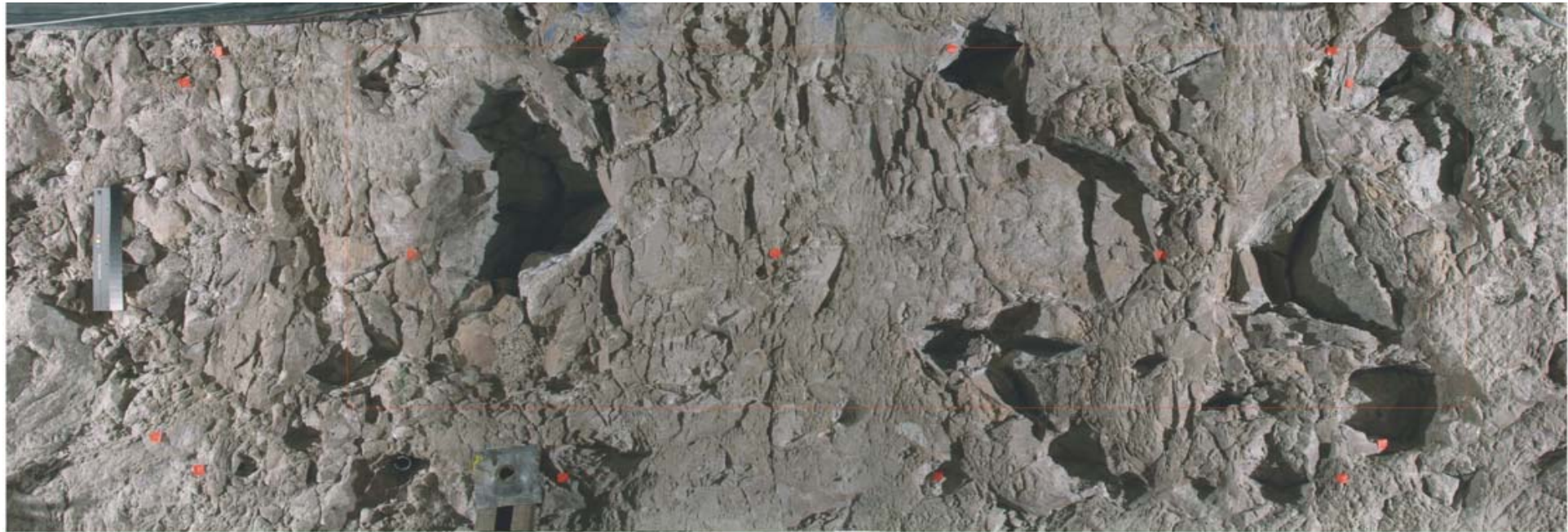

Source: Photograph and Map are from DTN: GS021008314224.002 [DIRS 161910].

NOTE: Meter scale is on the left. Red rectangle is the $1 \times 3 \mathrm{~m}$ panel map area. Lithophysae have red "L" identifiers with cavities outlined in red and rims in green. Spots have blue "S" identifiers with cyan outlines. Lithic clasts have orange "C" identifiers with gold outlines.

Figure O-4. Lithophysae, Spots, and Clasts of Tptpll in Panel Map 1641 Located on the Left rib from Station 16+41 to 16+44 

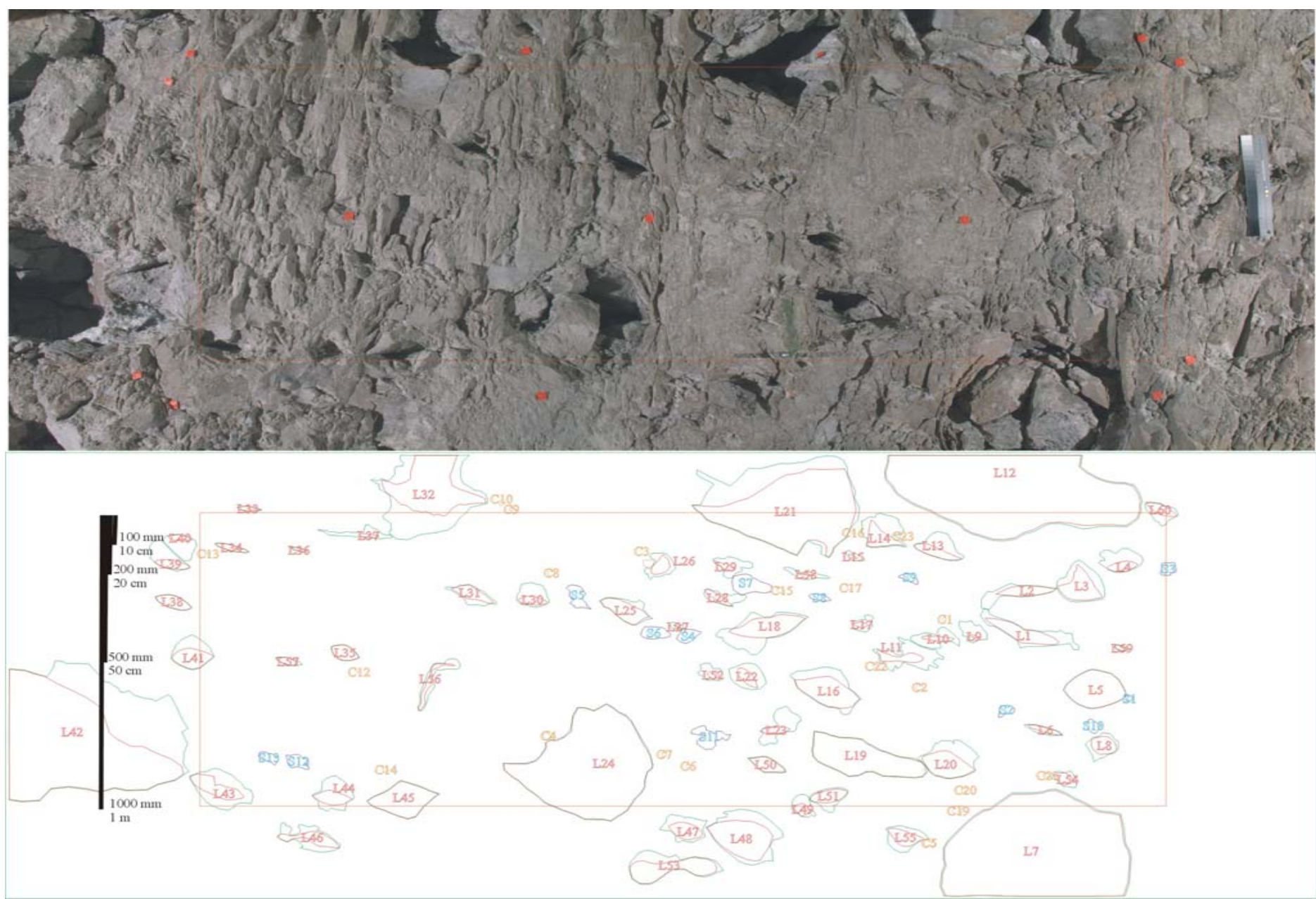

Source: Photograph and map are from DTN: GS021008314224.002 [DIRS 161910].

NOTE: Meter scale is on the left. Red rectangle is the $1 \times 3 \mathrm{~m}$ panel map area. Lithophysae have red "L" identifiers with cavities outlined in red and rims in green. Spots have blue "S" identifiers with cyan outlines. Lithic clasts have orange "C" identifiers with gold outlines.

Figure 0-5. Lithophysae, Spots, and Clasts of Tptpll in Panel Map 1641 Located on the Right Rib from Station 16+41 to 16+44 


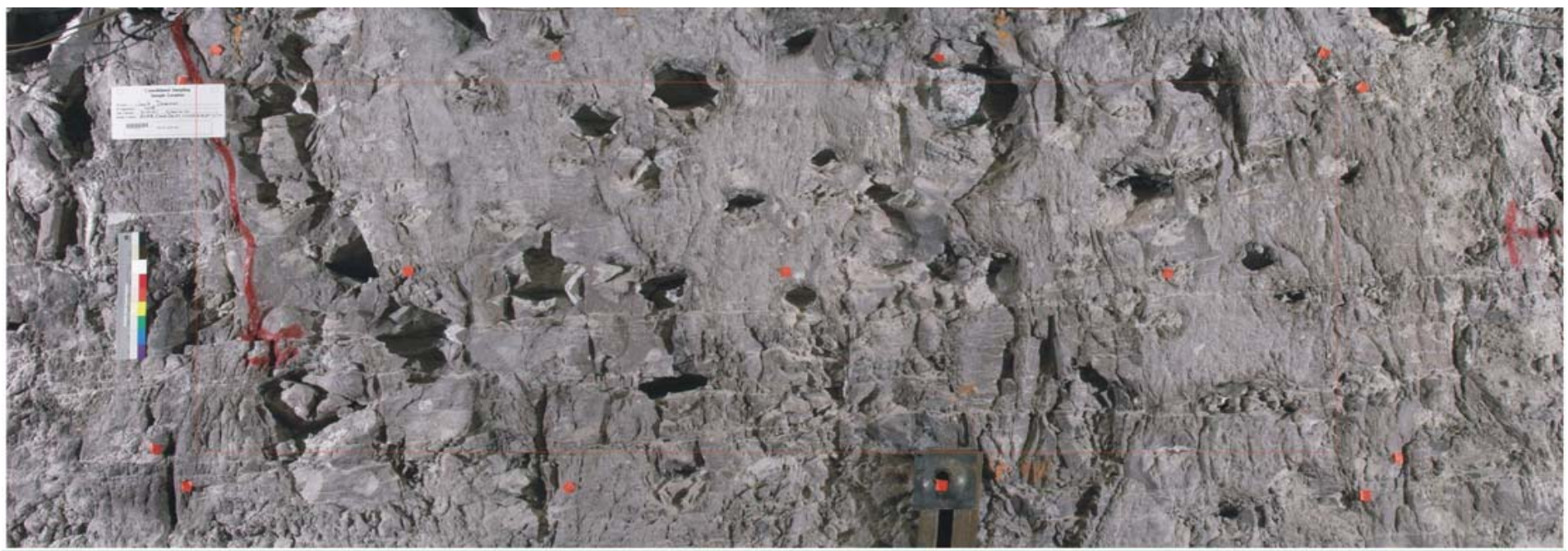

Source: Photograph and map are from DTN: GS021008314224.002 [DIRS 161910].

NOTE: Meter scale is on the left. Red rectangle is the $1 \times 3 \mathrm{~m}$ panel map area. Lithophysae have red "L" identifiers with cavities outlined in red and rims in green. Spots have blue " $\mathrm{S}$ " identifiers with cyan outlines. Lithic clasts have orange " $\mathrm{C}$ " identifiers with gold outlines.

Figure O-6. Lithophysae, Spots, and Clasts of Tptpll in Panel Map 1726 Located on the Left Rib from Station 17+26 to 17+29 

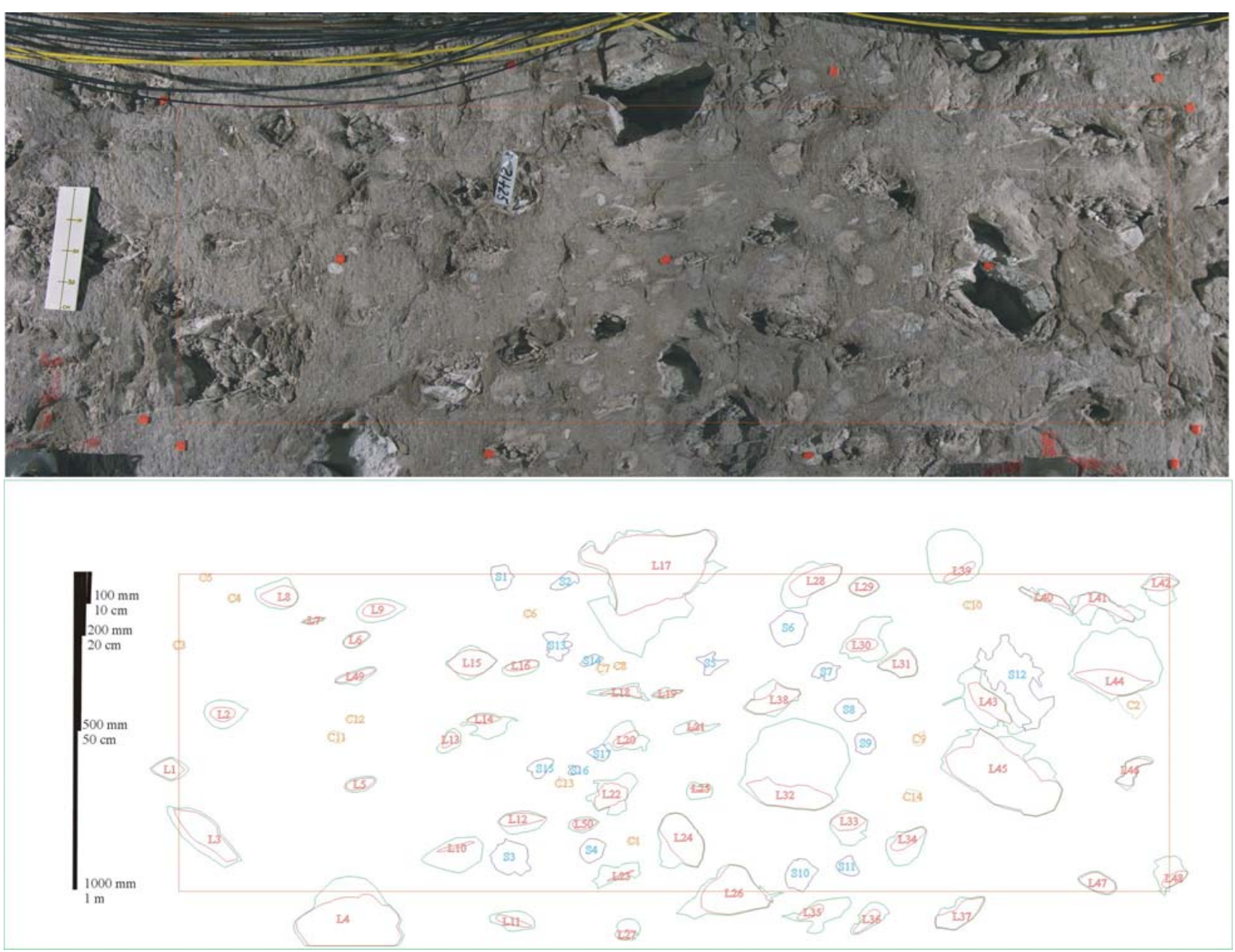

Source: Photograph and map are from DTN: GS021008314224.002 [DIRS 161910].

NOTE: Meter scale is on the left. Red rectangle is the $1 \times 3 \mathrm{~m}$ panel map area. Lithophysae have red "L" identifiers with cavities outlined in red and rims in green. Spots have blue " $\mathrm{S}$ " identifiers with cyan outlines. Lithic clasts have orange " $\mathrm{C}$ " identifiers with gold outlines.

Figure O-7. Lithophysae, Spots, and Clasts of Tptpll in Panel Map 2124 Located on the Left Rib from Station 21+24 to 21+27 


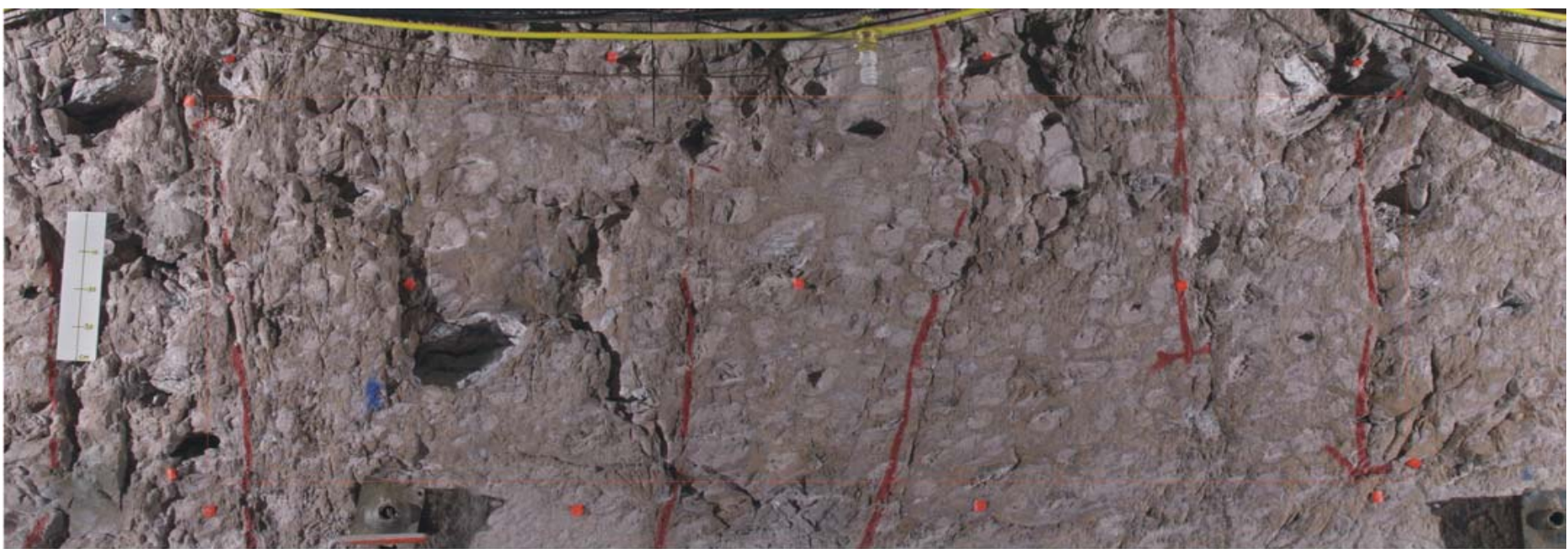

웅

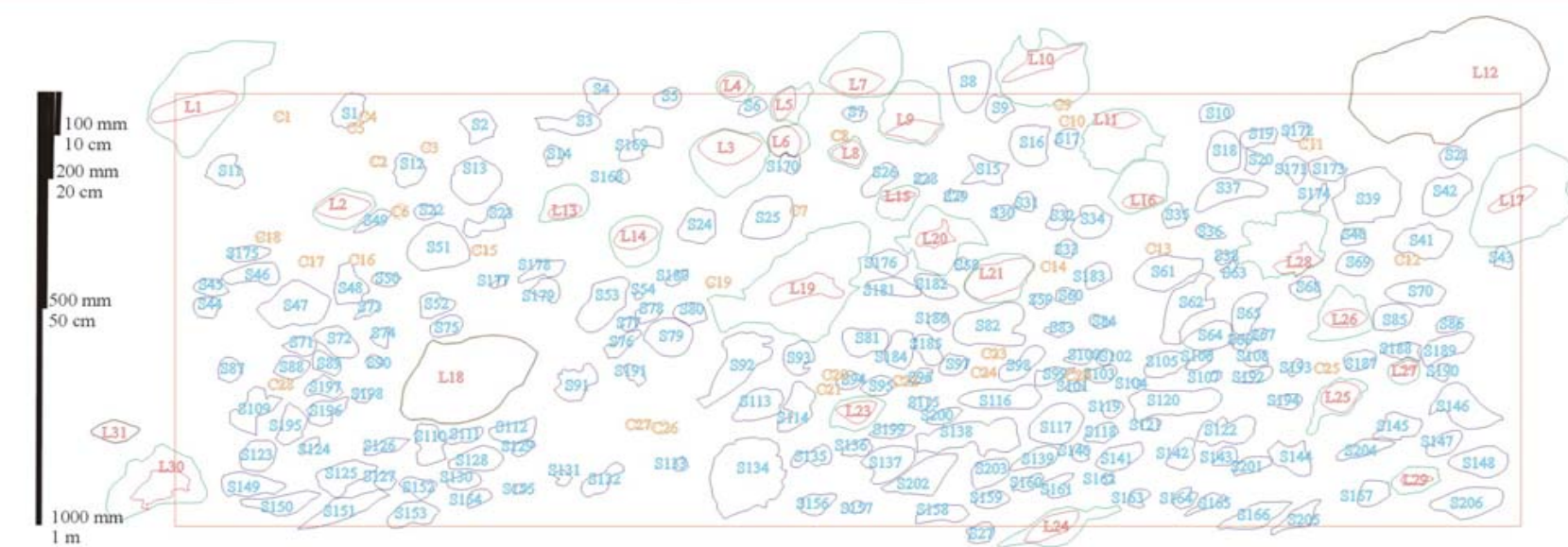

Source: Photograph and map are from DTN: GS021008314224.002 [DIRS 161910].

NOTE: Meter scale is on the left. Red rectangle is the $1 \times 3 \mathrm{~m}$ panel map area. Lithophysae have red "L" identifiers with cavities outlined in red and rims in green. Spots have blue "S" identifiers with cyan outlines. Lithic clasts have orange "C" identifiers with gold outlines.

Figure O-8. Lithophysae, Spots, and Clasts of Tptpll in Panel Map 2232 Located on the Left Rib from Station 22+32 to 22+35 
The selected panel maps (Figures O-3 to O-8) display good examples of many of the lithostratigraphic features. Some of these features are listed below.

- "Simple" lithophysae: L25, L26, and L34 on Figure O-3; L34 on Figure O-4; L4 and L41 on Figure O-6

- $\quad$ Merged lithophysae: L2 on Figure O-4

- Lithophysae with extension cracks where small cracks occur along the cavity wall: L44 on Figure O-3

- Extension-crack lithophysae where the expansion cracks dominate the geometry of the cavity wall: L17 and L25 on Figure O-4; L7, L12, L21, and L24 on Figure O-5

- $\quad$ Backfilled lithophysae (some partial): L26 on Figure O-4; L2 on Figure O-7

- Large-lithophysae (> $50 \mathrm{~cm}$ diameter): L2, L25, and L26 on Figure O-4; L7, L12, L21, L24, and L42 on Figure O-5

- Vapor-phase partings (and stringers): Figure O-6 (lower half)

- Spots: Any map, but especially Figure O-7 and Figure O-8

- Fractures mapped with detailed line survey: Red lines in Figure O-8

- Small-scale fractures: Any map, especially the left side of Figure O-5 and the right side of Figure O-6.

Panel maps provide 2-dimensional (area) data for specific features or as the total of the map area (DTN: GS021008314224.002 [DIRS 161910], Table O-3). Additionally, the "Data" files for the panel maps in the data package include 3-dimensional measurements (height, width, and depth) from which an equivalent ellipsoid can be calculated. The methods used in making panel maps and point-counting the areas of features result in values accurate to about 2 to 5 percent of the listed value (DTN: GS021008314224.002 [DIRS 161910]). To test the influence of positioning the map area, the panel map for $16+41$ on the left wall was used to compare the reported values with values from four alternative positions. The descriptive statistics on the area percent determined from the five map positions indicate the matrix-groundmass and lithophysal cavities have 95 percent confidence levels of less than 4 percent and the rims, spots, and lithic clasts have 95 percent confidence levels of less than 0.5 percent (DTN: GS021008314224.002 [DIRS 161910], see data summary documentation in the records package). 
Table O-3. Summary of Abundance (Percentage) of Lithophysal Cavities, Rims, Spots, and Matrix-Groundmass Based on Panel Maps in the ECRB CROSS-DRIFT from Stations 14+93 to $22+94$

\begin{tabular}{|c|c|c|c|c|c|c|c|}
\hline $\begin{array}{c}\text { Station } \\
(\mathbf{m})\end{array}$ & $\begin{array}{c}\text { Station }(\mathbf{m}) \\
\text { (numerical) }\end{array}$ & $\begin{array}{c}\text { Panel } \\
\text { Maps }\end{array}$ & $\begin{array}{c}\text { Matrix I } \\
\text { Groundmass } \\
\text { (percent) }\end{array}$ & $\begin{array}{c}\text { Lithophysal } \\
\text { Cavities } \\
\text { (percent) }\end{array}$ & $\begin{array}{c}\text { Rims } \\
\text { (percent) }\end{array}$ & $\begin{array}{c}\text { Spots } \\
\text { (percent) }\end{array}$ & $\begin{array}{c}\text { Lithic Clasts } \\
\text { (percent) }\end{array}$ \\
\hline $14+93$ & 1493 & $14+93 \mathrm{~L}$ & 69.5 & 13.3 & 13.3 & 3.7 & 0.2 \\
\hline $15+51$ & 1551 & $15+51 \mathrm{~L}$ & 77.3 & 15.8 & 3.6 & 2.0 & 1.3 \\
\hline $16+10$ & 1610 & $16+10 \mathrm{R}$ & 78.2 & 15.3 & 3.6 & 2.8 & 0.1 \\
\hline $16+24$ & 1624 & $16+24 \mathrm{R}$ & 72.6 & 13.4 & 11.3 & 2.6 & 0.1 \\
\hline $16+41$ & 1641 & $16+41 \mathrm{~L}$ & 71.6 & 19.0 & 5.7 & 3.5 & 0.1 \\
\hline $16+41$ & 1641 & $16+41 \mathrm{R}$ & 80.4 & 12.6 & 5.9 & 1.0 & 0.1 \\
\hline $16+56$ & 1656 & $16+56 \mathrm{~L}$ & 75.6 & 13.2 & 7.3 & 3.7 & 0.1 \\
\hline $17+26$ & 1726 & $17+26 \mathrm{~L}$ & 81.9 & 16.4 & 0.9 & 0.7 & 0.0 \\
\hline $17+68$ & 1768 & $17+68 \mathrm{~L}$ & 83.2 & 13.6 & 2.1 & 0.9 & 0.1 \\
\hline $17+68$ & 1768 & $17+68 \mathrm{R}$ & 84.5 & 10.1 & 4.6 & 0.6 & 0.1 \\
\hline $18+05$ & 1805 & $18+05 \mathrm{~L}$ & 76.7 & 14.0 & 5.6 & 3.5 & 0.2 \\
\hline $18+86$ & 1886 & $18+86 \mathrm{~L}$ & 73.8 & 17.4 & 5.4 & 3.0 & 0.3 \\
\hline $19+19$ & 1919 & $19+19 \mathrm{~L}$ & 83.6 & 12.8 & 2.1 & 1.3 & 0.3 \\
\hline $20+18$ & 2018 & $20+18 \mathrm{~L}$ & 77.5 & 15.3 & 4.9 & 2.1 & 0.2 \\
\hline $20+69$ & 2069 & $20+69 \mathrm{~L}$ & 83.8 & 9.2 & 3.9 & 3.0 & 0.2 \\
\hline $21+24$ & 2124 & $21+24 \mathrm{~L}$ & 78.2 & 8.5 & 9.7 & 3.2 & 0.5 \\
\hline $22+32$ & 2232 & $22+32 \mathrm{~L}$ & 62.4 & 5.3 & 7.4 & 24.6 & 0.2 \\
\hline $22+94$ & 2294 & $22+94 \mathrm{~L}$ & 86.1 & 7.5 & 0.3 & 5.7 & 0.4 \\
\hline
\end{tabular}

Source: DTN: GS021008314224.002 [DIRS 161910].

NOTE: Table is from file Tptpll Lithop SEP Data File.xls, worksheet "SEP - Panel Map Data".

\section{O3. VARIATION IN ABUNDANCE IN LITHOPHYSAL CAVITIES, RIMS, AND SPOTS ALONG THE TUNNEL}

The abundance of lithophysal cavities varies along the Cross-Drift partially from actual variations in the rocks and in part resulting from the methods used to collect the data (i.e., tape or angular traverses or panel maps) (Figure O-9). The abundance of cavities determined from the panel maps and angular traverses have not been adjusted. However, the original abundance values for lithophysal cavities from tape data (Figure O-2) have been corrected using a "typical" traverse length, a $15 \mathrm{~m}$ moving average, and a linear equation of correlation for collocated tape and angular traverse data (Sections O6.3 and O6.6). Numerous correlation equations were examined (Section O6.6), and a linear equation fitted to the collocated data and having an intercept at 0 , with an $\mathrm{R}^{2}$ of 0.6204 was the best correlation and resulted in the corrected curve "Ct" in Figure O-9. A set of cavity values was calculated for each location with two or more types of data using the ratios 60:30:10 (panel:angular:tape) where the three data occur and 60:40 (panel:tape or angular:tape) where there are only two types of data ("Cpat fit" in Figure O-9). These weighting ratios are empirically determined based on the relative detail of each type of data. The tape data was corrected one last time using an empirically determined proportional adjustment (i.e., corrected value [Ctc] equals tape value $[\mathrm{Ct}]$ plus the tape value $[\mathrm{Ct}]$ times a percent) (Section O6.6). The percents used include -0.05 from $14+05$ to $21+40,-0.35$ from $21+45$ to $22+70$, and -0.70 from $22+75$ to $23+35$. These percents, especially the larger 
amounts from $21+45$ to $23+35$, were used to correct large cavity abundance values inherited from the original tape data that resulted from initially identifying the abundant spots (some with thin veinlets in them) as lithophysal cavities. This correction of the tape data is warranted on the basis of comparisons with the angular traverse and panel map data (there are no angular traverse data from $22+00$ to $23+35$ ) and estimates of lithophysae described in Mongano et al. (1999 [DIRS 149850]) (Figure O-9; see Section O6.5).

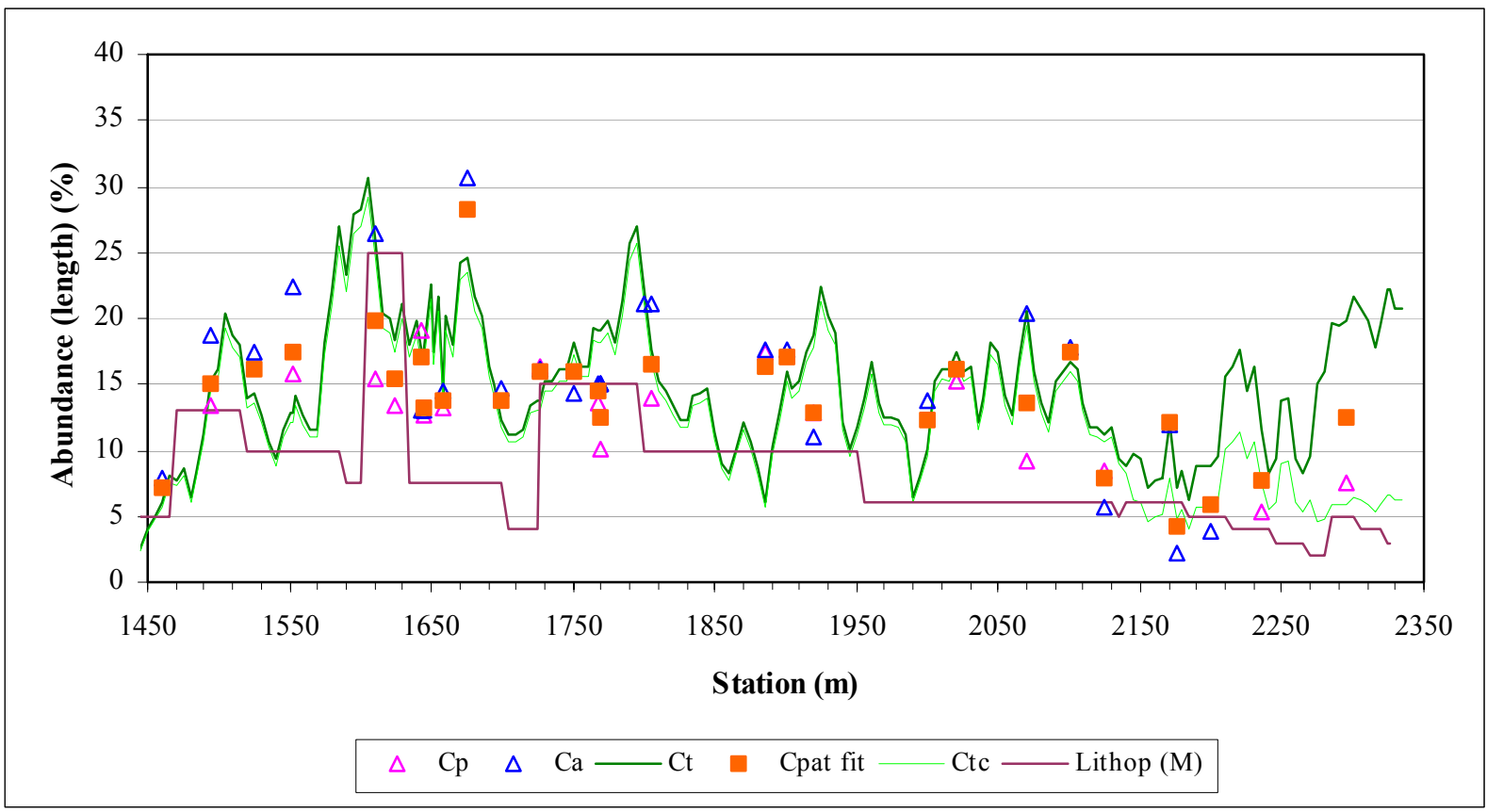

Source: DTN: GS021008314224.002 [DIRS 161910].

NOTE: "Ct" data has been corrected based on an equation for correlation of tape and angular data. "Cpat fit" is the calculated value where two or more types of data occur together (map, angular, or tape data). "Ctc" has been corrected, especially from Station $21+25$ to $23+35$, to emulate the smaller amounts of lithophysal cavities determined from panel maps and angular traverses. Correlations and calculations for $\mathrm{Ct}$, Cpat fit, and Ctc are described in Section O6.6. The results are compared to the cavity values (Lithop M) from Mongano et al. (1999 [DIRS 149850]). The data and curves are presented in file Drift Deg AMR AF T-A-P fit V1.xls, worksheet "Length - Fit and Stats" (See Table A-1).

Figure O-9. Abundance of Lithophysal Cavities from Panel Maps (Cp) and Angular and Tape Traverses (Ca and Ct, Respectively)

Similar to the lithophysal cavity data, the abundance of rims and spots varies along the ECRB Cross-Drift partially from actual variations in the rocks and in part resulting from the methods used to collect the data (i.e., tape or angular traverses or panel maps) (Figure O-10). The abundance of rims and spots determined from the panel maps and angular traverses have not been adjusted. However, the original visual estimates of "rims plus spots" in the tape traverses (see Section O6.3 and "RSt" in Figure O-10) have been corrected using 5-m and a $2^{\text {nd }}$-order polynomial equation of correlation for collocated tape and angular traverse data (Section O6.6). Numerous correlation equations were examined, but in the end, a $2^{\text {nd }}$-order polynomial equation (which because of the very small $\mathrm{x}^{2}$ value approximates a linear equation) was fitted to the collocated data from $17+60$ to $22+00$, and although the $\mathrm{Y}$-axis intercept is +11.086 , the $\mathrm{R}^{2}$ is 0.7973 (Section O6.6). As with the lithophysal cavity data, a set of "rim+spot" values were 
calculated for each location with two or more types of data using the empirically determined ratios of 60:30:10 (panel:angular:tape) where the three data occur and 60:40 (panel:tape or angular:tape) where there are only two types of data. These values were used during curve fitting, but are not displayed in Figure O-10. The totals of "rims plus spots" from the panel and angular data have been calculated and compare well to the corrected "rim plus spot:" tape values $(\mathrm{R}+\mathrm{Sp}, \mathrm{R}+\mathrm{Sa}$, and $\mathrm{RStc}$, respectively in Figure $\mathrm{O}-10)$. There are no visual estimates of rims plus spots in the tape traverse data from $22+00$ to $23+35$, so these values are estimated from the panel map data and descriptions from Mongano et al. (1999 [DIRS 149850]) (Sections O6.3, O6.5, and O6.6). The sharp decrease in spots depicted in curves "RStc" and "Spot (M)" (Figures O-10 and $\mathrm{O}-11$ ) result from changes in the abundance of spots across a fault at 22+38 (Mongano et al. 1999 [DIRS 149850]).

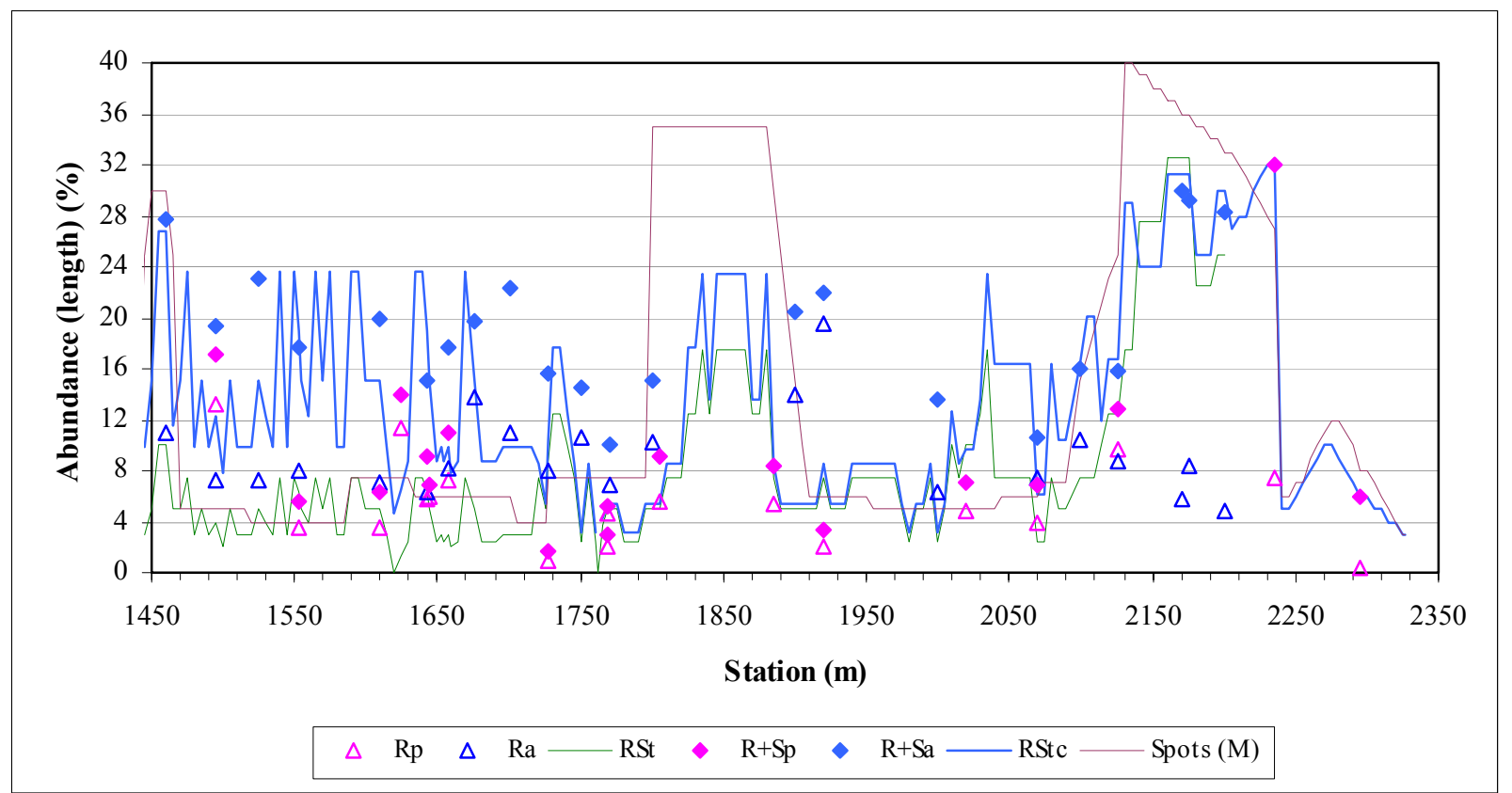

Source: DTN: GS021008314224.002 [DIRS 161910].

NOTES: "R+Sp" is rims plus spot values in panel maps. "R+Sa" is rims plus spot values in angular traverses. "RStc" is the corrected tape values based on an equation for correlation of tape and angular data. Correlations and calculations for R+Sp, R+Sa, and RStc are described in Section O6.6. Spot values from Mongano et al. (1999 [DIRS 149850]) are described in Section O6.5. The data and curves are presented in file Drift Deg AMR AF T-A-P fit V1.xls, worksheet "Length - Fit and Stats" (See Table A-1).

Figure O-10. Abundance of Rims From Panel Maps (Rp) and Angular (Ra) and the Combined Rim and Spot Values from Tape Traverses (Rt)

The "rim plus spot" values from the corrected tape data was separated into rim and spot values based on the general ratios of each feature in the panel and angular traverse data respectively. These proportions are not the same along the tunnel, so a series of proportions were empirically determined. The ratios of rims to spots include 0.50 from $14+45$ to $15+35,0.40$ from $15+40$ to $16+52,0.53$ from $16+55$ to $17+35,0.55$ from $17+40$ to $21+25$, and 0.22 from $21+30$ to $23+35$. The total corrected "rim plus spot" (RStc) was multiplied by these ratios to calculate the amount of rims, and the amount of spots was determined by difference (Rtc and Stc, respectively in Figure O-11). 


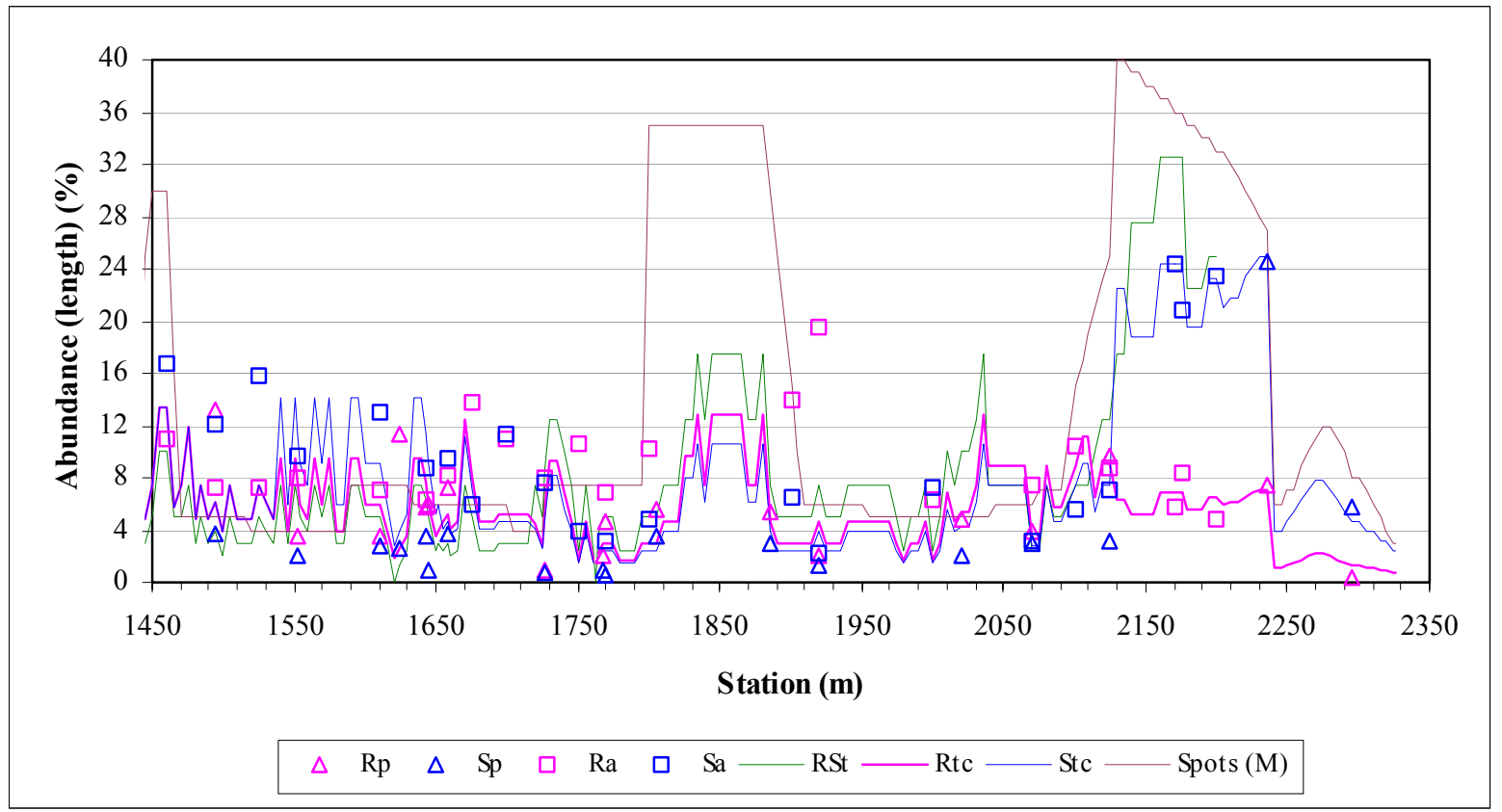

Source: DTN: GS021008314224.002 [DIRS 161910].

NOTE: "Rtc" represents fitted rim values from the corrected "RStc" (Figure O-10) based on the ratio of rim and spot values in panels and angular data. "Stc" represents fitted spot values from the corrected "RStc" (Figure 0-10) based on the ratio of rim and spot values in panels and angular data. Correlations and calculations for Rtc and Stc are described in Section 06.6. Spot values from Mongano et al. (1999 [DIRS 149850]) are described in Section 06.5. The data and curves are presented in file Drift Deg AMR AF T-A-P fit V1.xls, worksheet "Length - Fit and Stats" (See Table A-1).

Figure O-11. Abundance of Rims and Spots from Panel Maps (Rp and Sp), Angular (Ra and Sa), and the Original Estimated Combined Rim and Spot Values from Tape Traverses (RSt)

\section{O4. LARGE LITHOPHYSAE}

The large-lithophysae inventory was designed to document the large lithophysae (those with a minimum diameter of $50 \mathrm{~cm}$ ) in the ECRB Cross-Drift from Station $14+00$ to $17+56$. The initial phase of the inventory stopped at $17+56$ because of a closed bulkhead (DTNs: GS021008314224.002 [DIRS 161910]), and the second phase of the inventory was completed from $17+60$ to $25+35$ after the bulkhead was opened (GS040608314224.001 [DIRS 171367]). A few large lithophysae were documented (entirely or partially) in the tape and angular traverses and panel maps, but most were not included in these other techniques because of the scales and locations at which the other measurements were made. The long and short axis exposed on the wall of the tunnel was measured (with the same tape on a pole technique used in the tape traverses), and the station and position on the tunnel wall was recorded (DTNs: GS021008314224.002 [DIRS 161910]; GS040608314224.001 [DIRS 171367]). There are accurately surveyed station, northing, easting, and elevation values for the large lithophysae (DTNs: GS021008314224.002 [DIRS 161910]; GS040608314224.001 [DIRS 171367]). The large-lithophysae data can be displayed by station along the tunnel as discrete features and $5 \mathrm{~m}$ abundance (simply the number count) (Figure O-12), or a cumulative frequency and frequency plots of axis length and area (Figure O-13). 


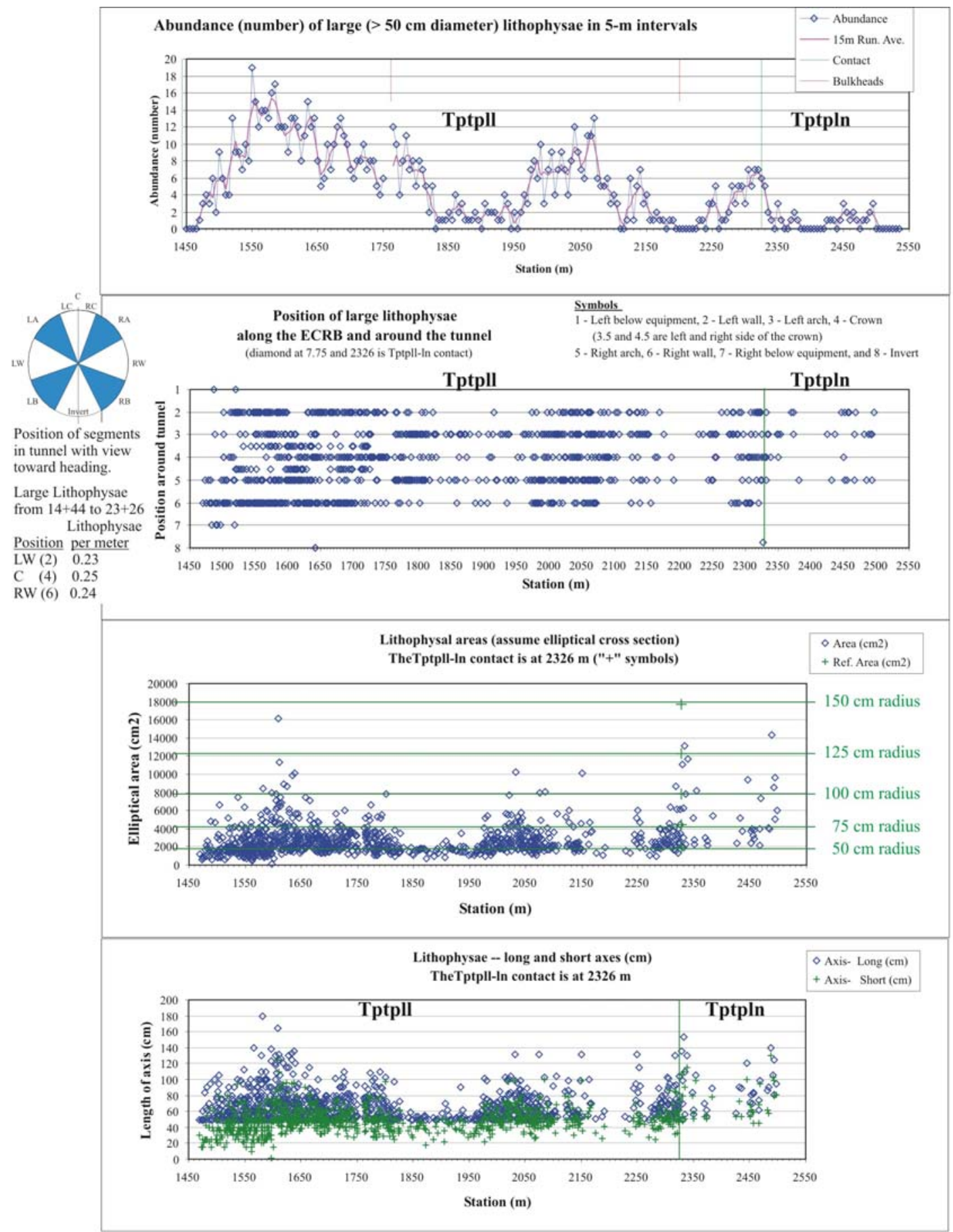

Source: DTNs: GS021008314224.002 [DIRS 161910]; GS040608314224.001 [DIRS 171367].

NOTE: Diagram of tunnel cross-section shows the nomenclature used to identify the position of large lithophysae. The small inserted table lists the average number of large lithophysae per meter of tunnel for the left and right walls (LW and RW, positions 2 and 6, respectively) and the crown (C, position 4) from Stations 14+70 to $17+56$.

Figure 0-12. Abundance (Number of Large Lithophysae) per $5 \mathrm{~m}$ Intervals, Locations, Areas, and Long and Short Axes of Large Lithophysae in the Tptpll and Tptpln from ECRB Cross-Drift Station $14+50$ to $25+00$ 


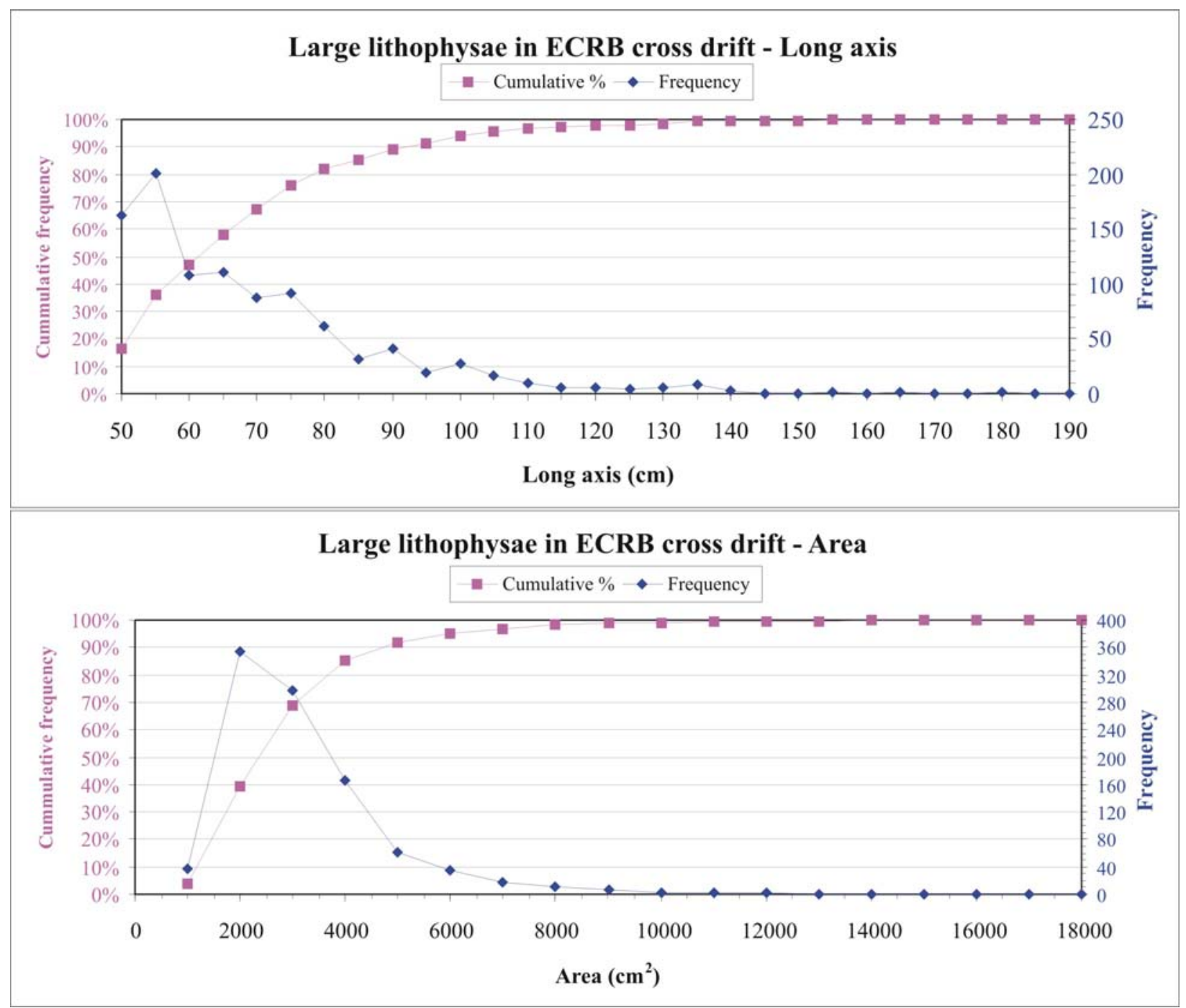

Source: DTNs: GS021008314224.002 [DIRS 161910]; GS040608314224.001 [DIRS 171367].

NOTE: The data and curves are presented in file Drift Deg AMR AD L-Litho V1.xls, worksheet "Tptpll Large-Litho Sum Graphs" (See Table A-1).

Figure 0-13. Frequency and Cumulative Frequency of the Long Axes and Areas of Large Lithophysae in the Tptpll in the Cross-Drift

\section{O5. CALCULATED POROSITY OF LITHOPHYSAL CAVITIES, RIMS, SPOTS AND TOTAL POROSITY ALONG THE TUNNEL}

The corrected tape traverse data for lithophysal cavities, rims, and spots results in "fitted" abundance curves and indicates substantial variations along the tunnel in these features (Figure O-14). Using these "fitted" abundance curves for lithophysal cavities, rims, and spots, and (by difference) the matrix-groundmass (and ignoring the trace amount of lithic clasts), the porosity of these features and the total porosity along the tunnel can be calculated (Figure O-15). The porosities of each of the component features are variably constrained. Lithophysal cavities have a porosity of $1.00 \mathrm{~cm}^{3} / \mathrm{cm}^{3}$. Samples from the upper and lower lithophysal zone in the ECRB Cross-Drift have been used to determine the porosities of the matrix-groundmass, rim, and spot features (DTN: GS030483351030.001 [DIRS 163440]). Measured porosity values of 
the matrix-groundmass in samples from the lower lithophysal zone in the ECRB Cross-Drift range from 0.09 to $0.14 \mathrm{~cm}^{3} / \mathrm{cm}^{3}$, and rims and spots in these same samples range from 0.23 to $0.37 \mathrm{~cm}^{3} / \mathrm{cm}^{3}$, so calculations of porosity in this report use a mean porosity of $0.104 \mathrm{~cm}^{3} / \mathrm{cm}^{3}$ for matrix-groundmass and $0.30 \mathrm{~cm}^{3} / \mathrm{cm}^{3}$ for rims and spots (Otto and Buesch 2003 [DIRS 170727]; DTN: GS030483351030.001 [DIRS 163440]). Additionally, inclusion of the large lithophysae can locally contribute as much as 9.4 percent to the total porosity (see station $16+10$ in Figure $\mathrm{O}-15 \mathrm{~b}$ ). In several other sections of the tunnel, the large lithophysae contribute from 3 to 6 percent, with other sections having 0 to 2 percent (Figure O-15b). Although for many purposes it is appropriate to describe the distributions and porosities of each type of feature (lithophysal cavities, large-lithophysal cavities, rims, spots, and matrix-groundmass), these features can be combined into similar associations (small and large lithophysal cavities, rims plus spots, and matrix-groundmass) (Figure O-16). 


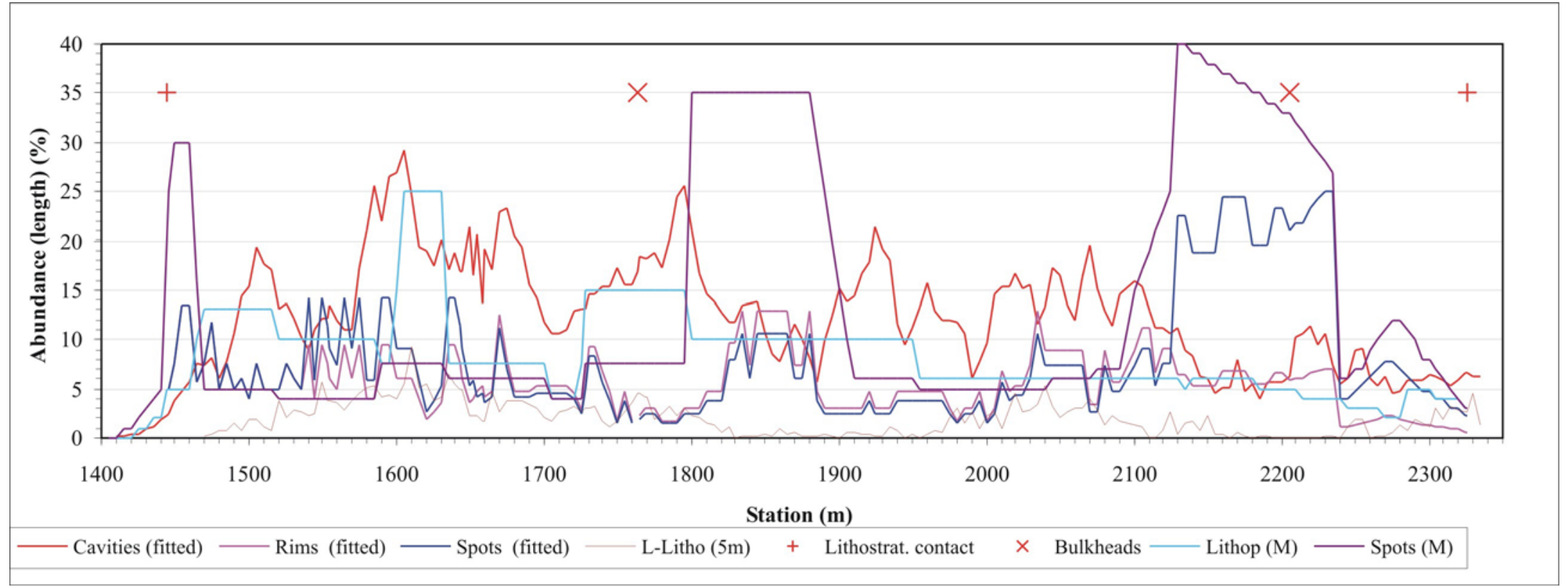

$\frac{1}{6}$

Source: DTNs: GS021008314224.002 [DIRS 161910]; GS040608314224.001 [DIRS 171367].

NOTE: Additional details provided in Section 06.6 and file Drift Deg AMR AF T-A-P fit V1.xls, worksheet "Length - Fit and Stats" (See Table A-1). Estimates of lithophysae (Lithop M) and spots (Spots M) are from Mongano et al. (1999 [DIRS 149850]).

Figure 0-14. Abundance Curves of Lithophysal Cavities, Rims, and Spots (Determined by Combining Panel Map and Tape and Angular Traverse Data), Large-Lithophysae Based on $5 \mathrm{~m}$ Segments of the Tunnel, and Estimates of Lithophysae and Spots 


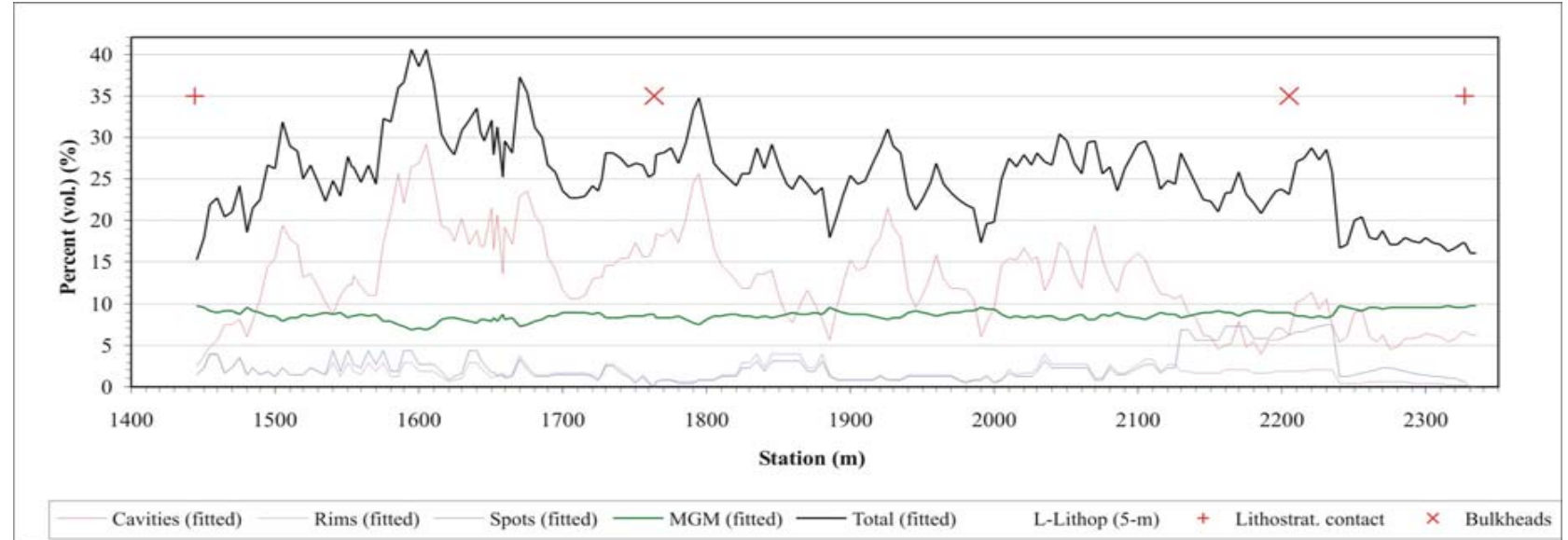

a)

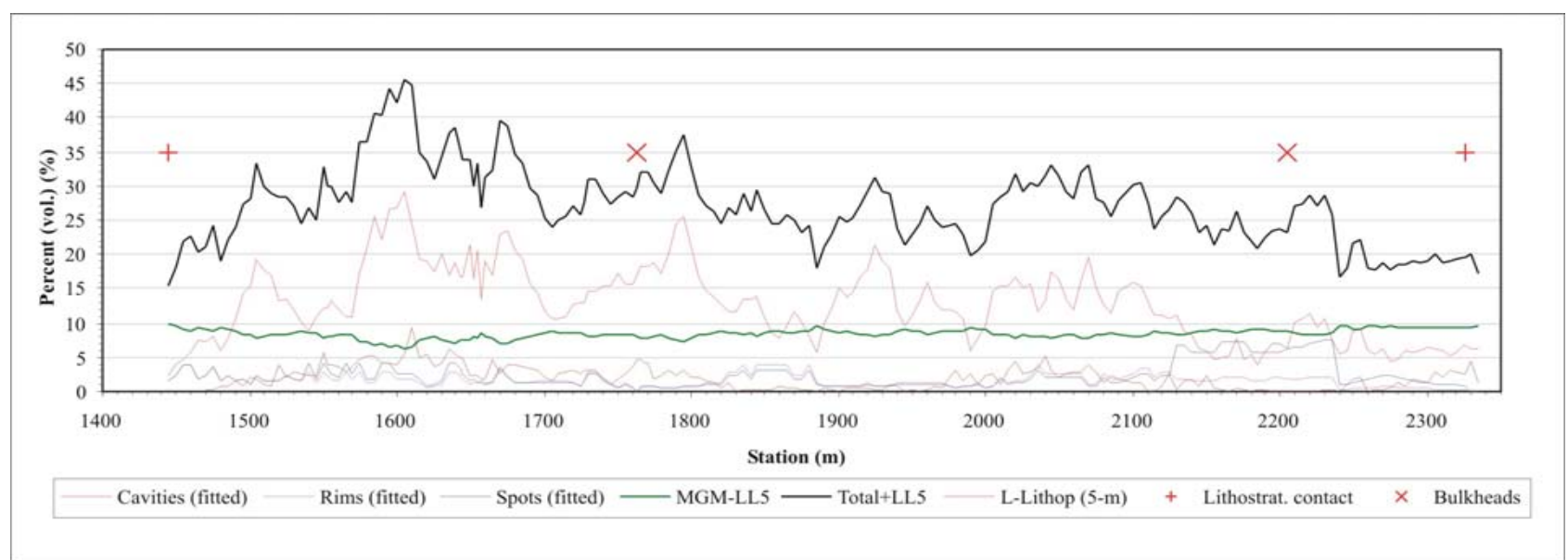

b)

Source: DTNs: GS021008314224.002 [DIRS 161910]; GS040608314224.001 [DIRS 171367].

NOTES: Porosity of the $5 \mathrm{~m}$ averaged large-lithophysae inventory is not included in the total in the upper graph (a). The large-lithophysae values are included in the lower graph (b). Additional details provided in Section O6.6 and file Drift Deg AMR AF T-A-P fit V1.xIs (See Table A-1).

Figure O-15. Calculated Porosity of Lithophysal Cavities, Rims, Spots, Matrix-Groundmass, and the Total Porosity in the Tptpll Exposed Along the ECRB Cross-Drift 


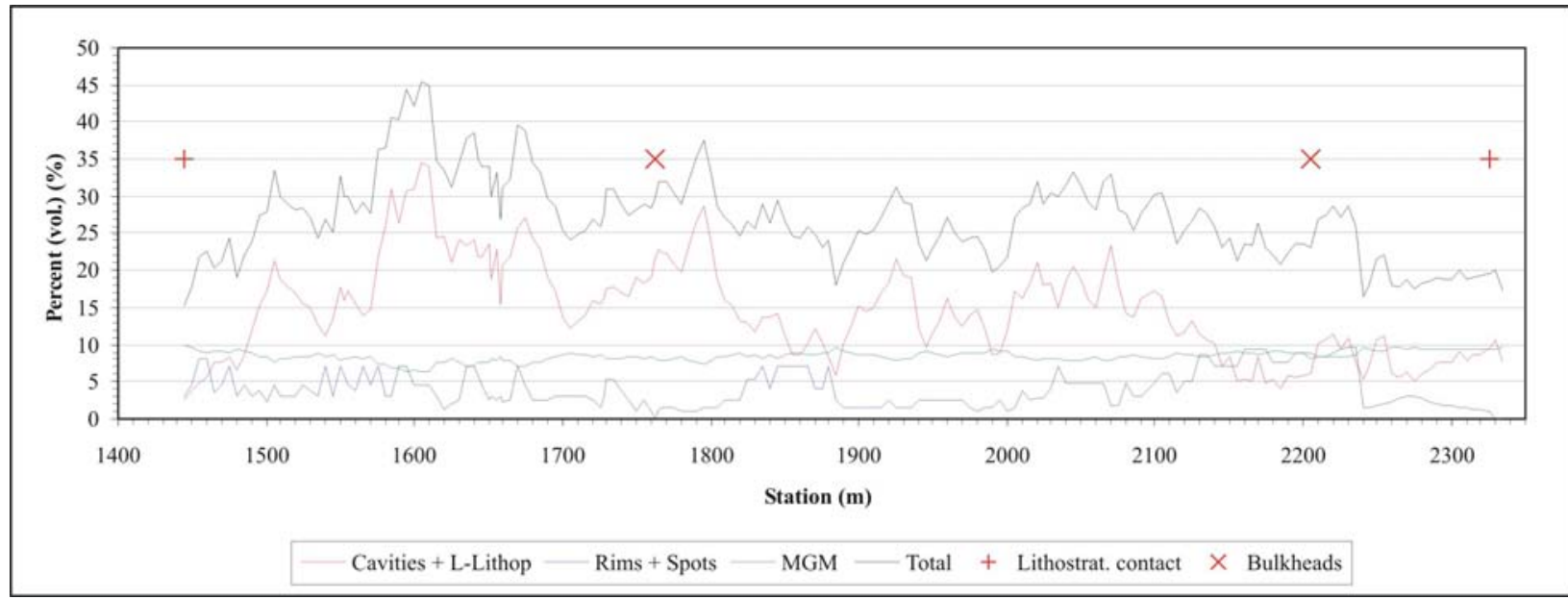

Source: DTNs: GS021008314224.002 [DIRS 161910]; GS040608314224.001 [DIRS 171367].

NOTE: Additional details provided in Section 06.6 and file Drift Deg AMR AF T-A-P fit V1.xls, worksheet "Volume Percent - Stats" (See Table A-1).

Figure O-16. Calculated Porosity of Lithophysal Cavities (Including Large Lithophysae), the Combination of Rims and Spots, Matrix-Groundmass (MGM), and the Total Porosity in the Tptpll Exposed in the ECRB Cross-Drift from Station 14+44 to $23+30$

\section{O6. DESCRIPTIVE STATISTICS FOR THE TOTAL LOWER LITHOPHYSAL ZONE}

In addition to the along-the-tunnel variations in abundance, size, and shape of lithophysal cavities, rims, and spots, the distributions of these features can be summarized for the total lower lithophysal zone. For example, using the tape traverse data, the abundance of cavities in each traverse has a mean of 18 to 19 percent depending on the length of tunnel used in the calculation (Table O-4, Figure O-17, and Section O6.3). The tape data used in this figure has been adjusted to the "typical traverse length" but has not been "corrected" with the several "correlation functions" described previously and in Section 06.6. Similarly, the abundance (percent) of individual lithophysal cavities within a traverse indicates most lithophysal cavities form about 2 percent of a traverse length (Table O-5, Figure O-18, and Section O6.3), and the typical length of lithophysal cavities along the traverses is about $150 \mathrm{~mm}$ (Table O-6, Figure O-19, and Section O6.3). Descriptive statistics comparing the $5 \mathrm{~m}$ traverse data with $10 \mathrm{~m}, 15 \mathrm{~m}, 20 \mathrm{~m}$, $25 \mathrm{~m}$, and $30 \mathrm{~m}$ "moving averages" indicates no effective change in the mean of 18.9 percent lithophysal cavities, but many of the statistics decrease with increasing length of the "moving average" (Table O-7 and Section O6.3). However, the most significant change in the statistics for the abundance of lithophysal cavities, especially in the standard deviation and sample variance, occurs from the $5 \mathrm{~m}$ to $10 \mathrm{~m}$ or $15 \mathrm{~m}$ data (Table O-7 and Section O6.3). The typical abundance of "rims plus spots" from the tape traverse data is about 8 percent depending on the length of tunnel used in the calculation (Table O-8 and Section O6.3). 
Table O-4. Descriptive Statistics for the Abundance of Lithophysal Cavities in Individual Tape Traverses for Various Lengths of Tunnel in the Tptpll in the Cross-Drift

\begin{tabular}{|l|r|r|r|r|r|}
\hline \multicolumn{1}{|c|}{ Statistic } & Data Package & \multicolumn{5}{|c|}{ Revised } \\
\hline Stations & 2335 to 1405 & 2335 to 1405 & 2326 to 1444 & 2320 to 1460 & 2200 to 1460 \\
\hline Length along tunnel $(\mathrm{m})$ & 930 & 930 & 882 & 860 & 740 \\
\hline Mean & 19.4 & 18.0 & 18.7 & 18.9 & 18.9 \\
\hline Standard Error & 0.7 & 0.7 & 0.7 & 0.7 & 0.7 \\
\hline Median & 18.8 & 17.6 & 17.8 & 17.8 & 17.8 \\
\hline Mode & 15.2 & 16.2 & 16.2 & 16.2 & 16.6 \\
\hline Standard Deviation & 10.2 & 9.3 & 8.8 & 8.7 & 8.7 \\
\hline Sample Variance & 103.3 & 86.7 & 76.9 & 74.8 & 75.4 \\
\hline Kurtosis & 0.1 & -0.1 & 0.0 & 0.1 & 0.2 \\
\hline Skewness & 0.4 & 0.3 & 0.5 & 0.6 & 0.6 \\
\hline Range & 53.9 & 48.4 & 47.2 & 47.2 & 47.2 \\
\hline Minimum & 0.0 & 0.0 & 1.2 & 1.2 & 1.2 \\
\hline Maximum & 53.9 & 48.4 & 48.4 & 48.4 & 48.4 \\
\hline Sum & 3,608 & 3,355 & 3,298 & 3,254 & 2,793 \\
\hline Count & 186 & 186 & 176 & 172 & 148 \\
\hline Confidence Level (95.0\%) & 1.5 & 1.3 & 1.3 & 1.3 & 1.4 \\
\hline
\end{tabular}

NOTE: Data in "Data Package" column from DTN: GS021008314224.002 [DIRS 161910]. The Revised data are in Drift Deg AMR AC T-Trav.xls, worksheet "Tape data (mm)" (see Table A-1).

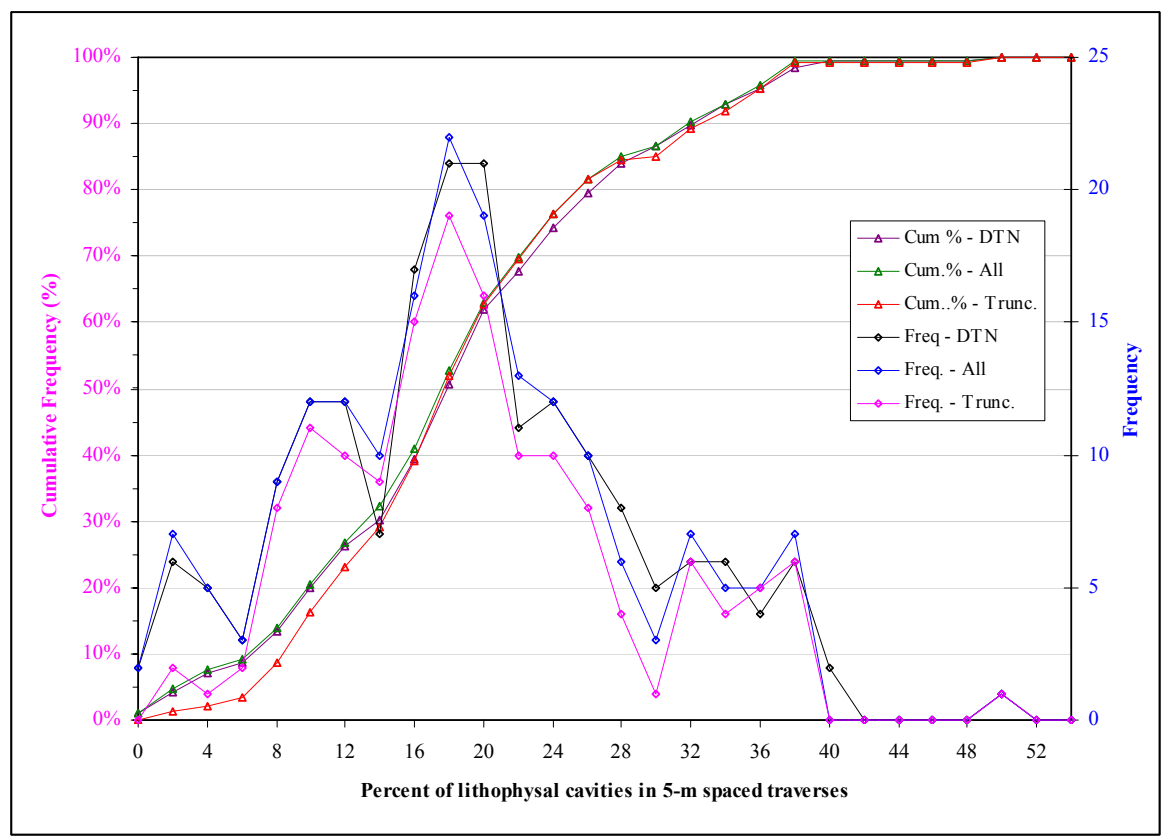

NOTE: Data submitted in the original data package (DTN: GS021008314224.002 [DIRS 161910]) is indicated by "DTN". The "All" and "trunc." data are from the adjusted length traverses (see Section O6.3 and file Drift Deg AMR AC T-Trav.xls, worksheet "Tape data (percent)" [Table A-1]). Truncated data designated as "Trunc."

Figure O-17. Frequency (Number) and Cumulative Frequency of the Abundance (Percent) Lithophysal Cavities from Tape Traverses in the Tptpll of the ECRB Cross-Drift from 14+05 to 23+35 (All) and $14+60$ to $22+00$ (Truncated Data) 
Table 0-5. Descriptive Statistics for the Abundance of Individual Lithophysal Cavities in Individual Tape Traverses for Various Lengths of Tunnel in the Tptpll in the Cross-Drift

\begin{tabular}{|l|r|r|r|r|r|}
\hline \multicolumn{1}{|c|}{ Statistic } & Data Package & \multicolumn{5}{|c|}{ Revised } \\
\hline Stations & 2335 to 1405 & 2335 to 1405 & 2326 to 1444 & 2320 to 1460 & 2200 to 1460 \\
\hline Length along tunnel $(\mathrm{m})$ & 930 & 930 & 882 & 860 & 740 \\
\hline Mean & 2.17 & 2.02 & 2.02 & 2.06 & 2.00 \\
\hline Standard Error & 0.05 & 0.05 & 0.05 & 0.05 & 0.05 \\
\hline Median & 1.49 & 1.34 & 1.34 & 1.46 & 1.34 \\
\hline Mode & 1.49 & 1.33 & 1.33 & 1.33 & 1.33 \\
\hline Standard Deviation & 1.99 & 1.85 & 1.83 & 1.82 & 1.84 \\
\hline Sample Variance & 3.96 & 3.43 & 3.35 & 3.32 & 3.38 \\
\hline Kurtosis & 6.32 & 6.05 & 6.13 & 6.16 & 6.34 \\
\hline Skewness & 2.03 & 2.01 & 2.00 & 2.00 & 2.03 \\
\hline Range & 17.91 & 16.09 & 16.09 & 16.09 & 16.09 \\
\hline Minimum & 0.00 & 0.00 & 0.00 & 0.00 & 0.00 \\
\hline Maximum & 17.91 & 16.09 & 16.09 & 16.09 & 16.09 \\
\hline Sum & 3607.71 & 3355.24 & 3297.95 & 3254.38 & 2792.89 \\
\hline Count & 1664 & 1664 & 1630 & 1583 & 1393 \\
\hline Confidence Level (95.0\%) & 0.10 & 0.09 & 0.09 & 0.09 & 0.10 \\
\hline
\end{tabular}

NOTE: Data in "Data Package" column from DTN: GS021008314224.002 [DIRS 161910]. The Revised data are in Drift Deg AMR AC T-Trav.Xls, worksheet "Tape data (percent)" (see Table A-1).

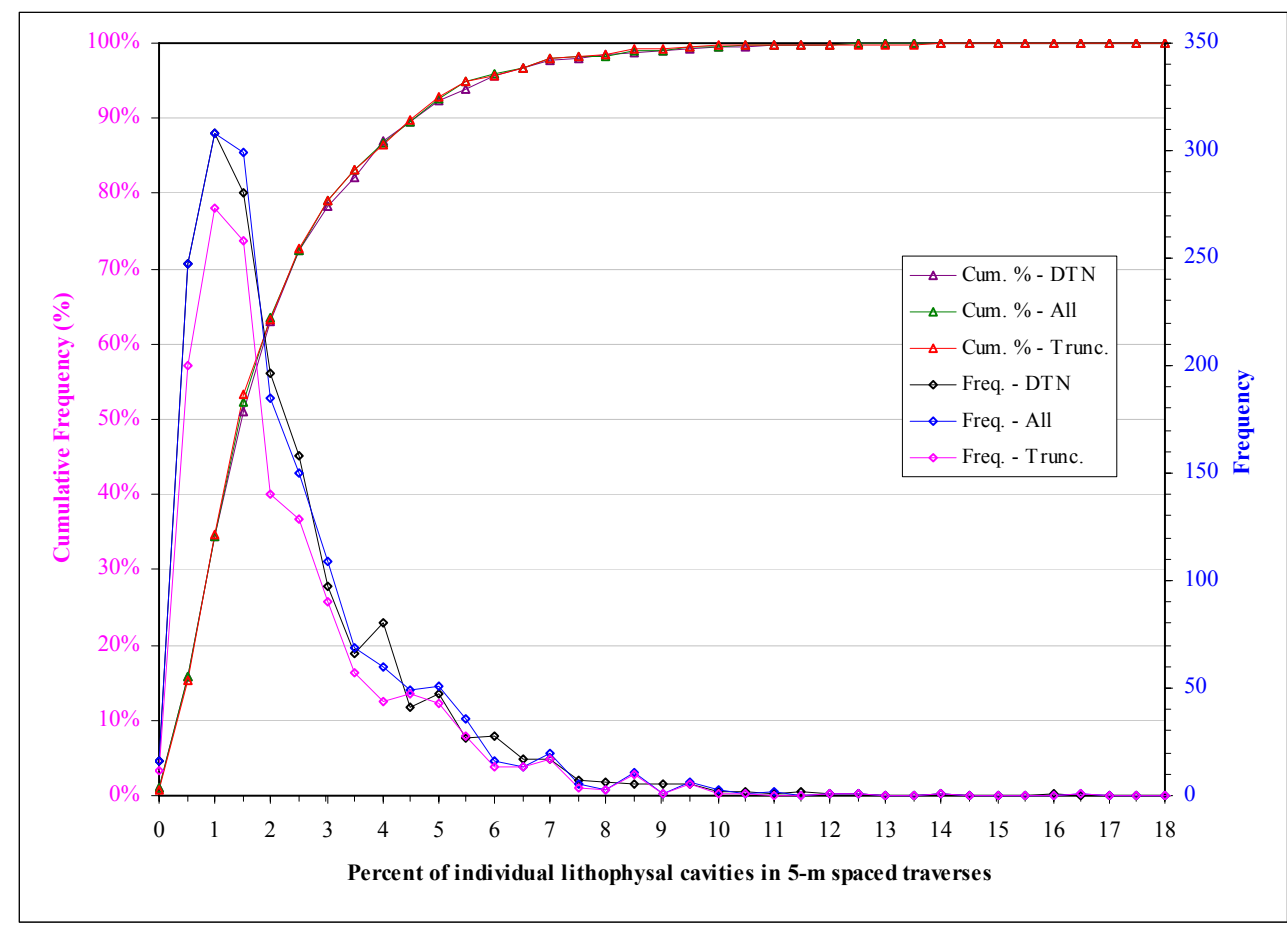

NOTE: Data submitted in the original data package (DTN: GS021008314224.002 [DIRS 161910]) is indicated by "DTN". The "All" and "Trunc." data are from the adjusted length traverses (see Section O6.3 and file Drift Deg AMR AC T-Trav.xls, worksheet "Tape data (percent)" [Table A-1]). Truncated data designated as "Trunc."

Figure 0-18. Frequency (Number) and Cumulative Frequency of the Abundance (Percent) of Individual Lithophysal Cavities from Tape Traverses in the Tptpll in the Cross-Drift from 14+05 to 23+35 (All) and 14+60 to 22+00 (Truncated Data) 
Table O-6. Descriptive Statistics for the Lengths $(\mathrm{mm})$ of Individual Lithophysal Cavities in Individual Tape Traverses for Various Lengths of Tunnel in the Tptpll zone in the Cross-Drift

\begin{tabular}{|l|l|l|l|l|l|}
\hline \multicolumn{1}{|c|}{ Statistic } & Data Package & \multicolumn{5}{c|}{ Revised } \\
\hline Stations & 2335 to 1405 & 2335 to 1405 & 2326 to 1444 & 2320 to 1460 & 2200 to 1460 \\
\hline Length along tunnel $(\mathrm{m})$ & 930 & 930 & 882 & 860 & 740 \\
\hline Mean & 152.6 & 152.6 & 152.9 & 155.4 & 151.6 \\
\hline Standard Error & 3.4 & 3.4 & 3.4 & 3.4 & 3.7 \\
\hline Median & 100 & 100 & 110 & 110 & 100 \\
\hline Mode & 100 & 100 & 100 & 100 & 100 \\
\hline Standard Deviation & 138.6 & 138.6 & 137.0 & 136.3 & 137.6 \\
\hline Sample Variance & 19208.3 & 19208.3 & 18757.0 & 18586.5 & 18926.2 \\
\hline Kurtosis & 6.0 & 6.0 & 6.1 & 6.1 & 6.3 \\
\hline Skewness & 2.0 & 2.0 & 2.0 & 2.0 & 2.0 \\
\hline Range & 1200 & 1200 & 1190 & 1190 & 1190 \\
\hline Minimum & 0 & 0 & 10 & 10 & 10 \\
\hline Maximum & 1200 & 1200 & 1200 & 1200 & 1200 \\
\hline Sum & 251723 & 251723 & 247413 & 244143 & 209393 \\
\hline Count & 1650 & 1650 & 1618 & 1571 & 1381 \\
\hline Confidence Level (95.0\%) & 6.69 & 6.69 & 6.67 & 6.74 & 7.26 \\
\hline
\end{tabular}

NOTE: Data in "Data Package" column from DTN: GS021008314224.002 [DIRS 161910]. The Revised data are in Drift Deg AMR AC T-Trav.xls, worksheet "Tape data (mm)" (see Table A-1).

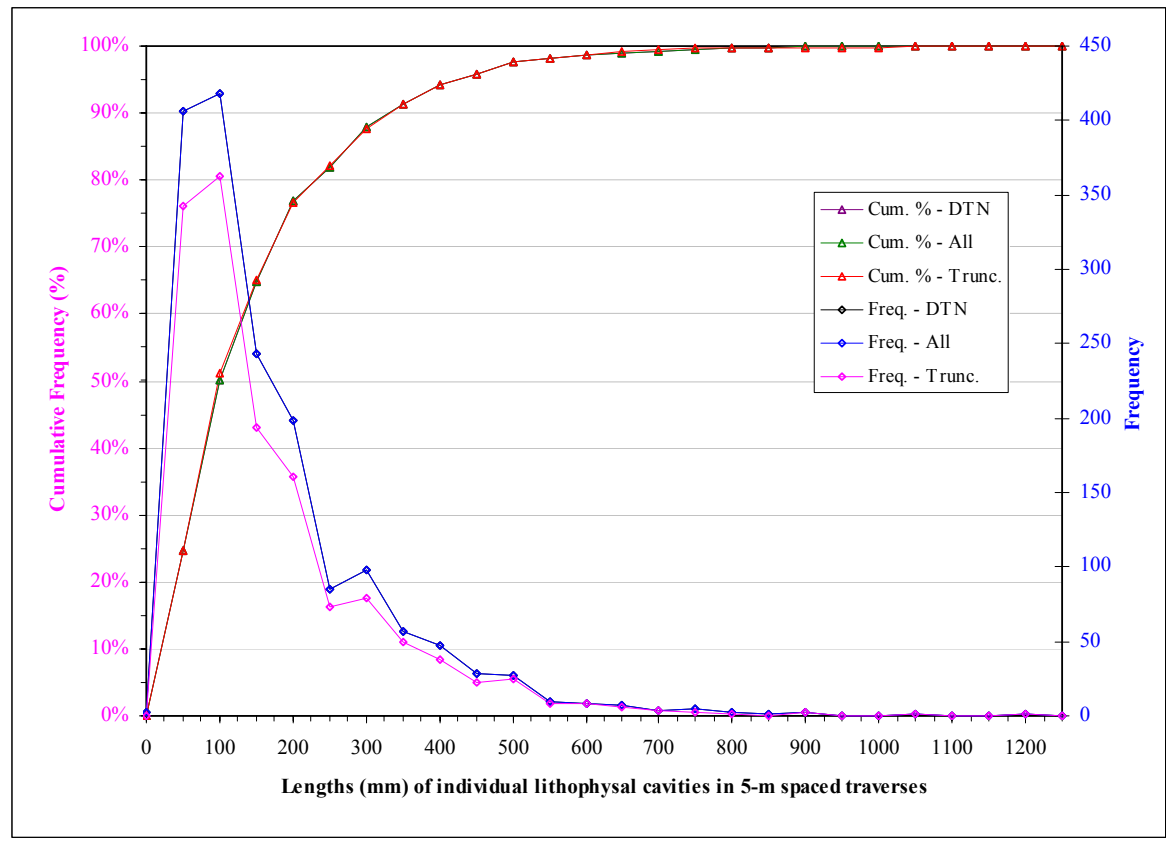

NOTE: Data submitted in the original data package (DTN: GS021008314224.002 [DIRS 161910]) is indicated by "DTN" The "All" and "Trunc." data are from the adjusted length traverses (see Section O6.3 and file Drift Deg AMR AC T-Trav.xls, worksheet "Tape data (mm)" [Table A-1]). Truncated data designated as "Trunc."

Figure O-19. Frequency (Number) and Cumulative Frequency of the Lengths ( $\mathrm{mm}$ ) of Individual Lithophysal Cavities from Tape Traverses in the Tptpll of the ECRB Cross-Drift from 14+05 to $23+35$ (All) and $14+60$ to $22+00$ (Truncated Data) 
Drift Degradation Analysis

Table O-7. Descriptive Statistics for the Abundance of Lithophysal Cavities in Tape Traverses Calculated with $10 \mathrm{~m}, 15 \mathrm{~m}, 20 \mathrm{~m}, 25 \mathrm{~m}$, and $30 \mathrm{~m}$ "moving averages" for the Total Tptpll in the ECRB Cross-Drift

\begin{tabular}{|c|c|c|c|c|c|c|}
\hline \multirow{3}{*}{\begin{tabular}{|l}
\multicolumn{1}{c}{ Statistic } \\
Stations \\
Length along tunnel $(\mathrm{m})$
\end{tabular}} & \multicolumn{6}{|c|}{ Value } \\
\hline & \multicolumn{6}{|c|}{2200 to 1460} \\
\hline & $\begin{array}{l}5-\mathrm{m} \\
\text { traverses }\end{array}$ & $\begin{array}{l}10-\mathrm{m} \\
\text { average }\end{array}$ & $\begin{array}{l}15-\mathrm{m} \\
\text { average }\end{array}$ & $\begin{array}{l}20-\mathrm{m} \\
\text { average }\end{array}$ & $\begin{array}{l}25-\mathrm{m} \\
\text { average }\end{array}$ & $\begin{array}{l}30-\mathrm{m} \\
\text { average }\end{array}$ \\
\hline Mean & 18.9 & 18.9 & 18.9 & 18.9 & 18.9 & 18.9 \\
\hline Standard Error & 0.7 & 0.6 & 0.5 & 0.5 & 0.5 & 0.5 \\
\hline Median & 17.8 & 18.3 & 18.1 & 18.3 & 18.1 & 18.3 \\
\hline Mode & 16.6 & 16.7 & 15.5 & 23.3 & 11.8 & 22.0 \\
\hline Standard Deviation & 8.7 & 7.0 & 6.5 & 6.1 & 5.9 & 5.7 \\
\hline Sample Variance & 75.4 & 48.6 & 41.8 & 37.6 & 35.3 & 33.0 \\
\hline Kurtosis & 0.2 & 0.29 & 0.20 & 0.00 & -0.15 & -0.14 \\
\hline Skewness & 0.6 & 0.55 & 0.59 & 0.56 & 0.49 & 0.48 \\
\hline Range & 47.2 & 39.0 & 31.4 & 27.9 & 26.6 & 27.0 \\
\hline Minimum & 1.2 & 3.4 & 7.6 & 8.9 & 8.4 & 8.1 \\
\hline Maximum & 48.4 & 42.4 & 39.0 & 36.8 & 35.0 & 35.1 \\
\hline Sum & 2,793 & $2,890.5$ & $2,887.6$ & $2,890.4$ & $2,897.1$ & $2,897.0$ \\
\hline Count & 148 & 153 & 153 & 153 & 153 & 153 \\
\hline Confidence Level (95.0\%) & 1.4 & 1.10 & 1.02 & 0.97 & 0.94 & 0.91 \\
\hline
\end{tabular}

NOTE: Data in Drift Deg AMR AC T-Trav.xls, worksheet "Tape data (percent)" (see Table A-1).

Table O-8. Descriptive Statistics for the Abundance of "Rims Plus Spots" in Individual Tape Traverses for Various Lengths of Tunnel in the Tptpll of the ECRB Cross-Drift

\begin{tabular}{|l|r|r|r|}
\hline \multicolumn{1}{|c|}{ Statistic } & Data Package & \multicolumn{2}{|c|}{ Revised } \\
\hline Stations & 2200 to 1405 & 2200 to 1405 & 2200 to 1460 \\
\hline Length along tunnel $(\mathrm{m})$ & 795 & 795 & 740 \\
\hline Mean & 8.0 & 8.0 & 8.4 \\
\hline Standard Error & 0.6 & 0.6 & 0.6 \\
\hline Median & 5.0 & 5.0 & 7.5 \\
\hline Mode & 7.5 & 7.5 & 7.5 \\
\hline Standard Deviation & 7.1 & 7.1 & 7.1 \\
\hline Sample Variance & 50.1 & 50.1 & 50.5 \\
\hline Kurtosis & 3.3 & 3.3 & 3.1 \\
\hline Skewness & 1.9 & 1.9 & 1.9 \\
\hline Range & 32.0 & 32.0 & 31.5 \\
\hline Minimum & 0.5 & 0.5 & 1.0 \\
\hline Maximum & 32.5 & 32.5 & 32.5 \\
\hline Sum & 1257 & 1257 & 1233 \\
\hline Count & 157 & 157 & 146 \\
\hline Confidence Level (95.0\%) & 1.1 & 1.1 & 1.2 \\
\hline
\end{tabular}

NOTE: Data in "Data Package" column from DTN: GS021008314224.002 [DIRS 161910]. The Revised data are in Drift Deg AMR AC T-Trav.xls, worksheet "Tape data (percent)" (see Table A-1). 
Comparison of the descriptive statistics for abundance of lithophysal cavities, rims, and spots in panel maps, angular traverses, and corrected tape traverses in the lower lithophysal zone indicate the corrected tape values are consistent with the values determined from the other methods (Table O-9 and Section O6.6). These relations are also consistent for various lengths of the tunnel such as comparing the segments from $14+60$ to $23+20$ and $14+60$ to $22+00$ (Table O-9; Section O6.6). The "prime" section of the tunnel for the lower lithophysal zone is from 14+60 to $23+20$ where the tunnel is entirely within the lower lithophysal zone (i.e., there is no "mixing" from the adjacent rock units). The more restricted section from $14+60$ to $22+00$ is better to use for many detailed descriptions and comparative statistics because there is good overlap of the various types of data (panel maps and angular and tape traverses) and there is minimal need to extrapolate and convert some of the data. The abundance values for each of the lithostratigraphic features can be converted into rock-mass porosity values (using the porosity values of each component). Using the porosities of $1.00 \mathrm{~cm}^{3} / \mathrm{cm}^{3}$ for lithophysal cavities, $0.25 \mathrm{~cm}^{3} / \mathrm{cm}^{3}$ for rims and spots, and $0.13 \mathrm{~cm}^{3} / \mathrm{cm}^{3}$ for the matrix-groundmass (Flint 1998 [DIRS 100033], Table 7), the lower lithophysal zone (as a whole and not including the large lithophysae) averages 13.1 percent lithophysal cavities, 1.4 percent rims, 1.9 percent spots, and 10.9 percent matrix-groundmass for a total porosity of 27.3 percent (Table O-10). Alternatively, using the porosities of $1.00 \mathrm{~cm}^{3} / \mathrm{cm}^{3}$ for lithophysal cavities, $0.30 \mathrm{~cm}^{3} / \mathrm{cm}^{3}$ for rims and spots, $0.104 \mathrm{~cm}^{3} / \mathrm{cm}^{3}$ for the matrix-groundmass (Otto and Buesch 2003 [DIRS 170727]), and including the large-lithophysal cavities, the lower lithophysal zone averages 13.1 percent lithophysal cavities, 2.0 percent large-lithophysal cavities, 1.7 percent rims, 2.3 percent spots, and 8.4 percent matrix-groundmass for a total porosity of 27.5 percent (Table O-11).

\section{O6.1 DESCRIPTIVE STATISTICS FOR LITHOPHYSAL CAVITIES, RIMS, SPOTS, AND LITHIC CLASTS IN PANEL MAPS IN THE Tptpll OF THE ECRB CROSS-DRIFT FROM STATIONS 14+93 TO 22+97}

The descriptive statistics for lithophysal cavities, rims, spots, and lithic clasts in panel maps in the Tptpll of the ECRB Cross-Drift from Stations 14+93 to 22+97 were determined to support the distribution of size and abundance of lithostratigraphic features as described in Sections O2 and O6.6. Descriptive statistics were determined using data provided in DTN: GS021008314224.002 [DIRS 161910] and are reproduced in Table A-1. Descriptive statistics are provided for the sizes (actually areas in $\mathrm{mm}^{2}$ ) and percent of the total area for lithostratigraphic features including lithophysal cavities, rims, spots, and lithic clasts. The descriptive statistics were determined with the standard functions of commercial off-the-shelf software Microsoft Excel 97 SR-2, and are documented in the Microsoft Excel file, Drift Deg AMR AA PMap.xls (Table A-1), which can be accessed through the TDMS (DTN: MO0408MWDDDMIO.002).

\section{O6.2 DESCRIPTIVE STATISTICS FOR LITHOPHYSAL CAVITIES, RIMS, SPOTS, AND LITHIC CLASTS IN ANGULAR TRAVERSES IN THE Tptpll OF THE ECRB CROSS-DRIFT FROM STATIONS 14+60 TO 22+00}

The descriptive statistics for lithophysal cavities, rims, spots, lithic clasts, and matrix-groundmass in angular traverses in the Tptpll of the ECRB Cross-Drift from Stations $14+60$ to $22+00$ were determined to support the distribution of size and abundance of lithostratigraphic features as described in Sections $\mathrm{O} 1$ and O6.6. Descriptive statistics were 
determined on data provided in DTN: GS021008314224.002 [DIRS 161910], and were determined in support of this report. Descriptive statistics are provided for the sizes (actually lengths in $\mathrm{mm}$ ) and percent of the total lengths for lithostratigraphic features including lithophysal cavities, rims, spots, lithic clasts, and the matrix-groundmass. The descriptive statistics were determined with the standard functions of commercial off-the-shelf software Microsoft Excel 97 SR-2, and are documented in the Microsoft Excel file,Drift Deg AMR AB A-Trav.xls (Table A-1), which can be accessed through the TDMS (DTN: MO0408MWDDDMIO.002). 
Table O-9. Descriptive Statistics for Abundance of Lithophysal Cavities, Rims, and Spots in Panel Maps, Angular Traverses, and Corrected Tape Traverses in the Tptpll Exposed in the ECRB Cross-Drift from Stations $14+60$ to $23+20$ and $14+60$ to $22+00$

\begin{tabular}{|c|c|c|c|c|c|c|c|c|c|c|c|c|c|c|}
\hline \multirow{2}{*}{$\begin{array}{l}\text { Descriptive } \\
\text { Statistics }\end{array}$} & \multicolumn{5}{|c|}{1460 to $2320 \mathrm{~m}$} & \multirow{2}{*}{$\begin{array}{c}1460 \text { to } \\
2200 \mathrm{~m} \\
\text { Ctc-m } \\
\end{array}$} & \multicolumn{3}{|c|}{1460 to $2320 \mathrm{~m}$} & \multirow{2}{*}{$\begin{array}{c}1460 \text { to } \\
2200 \mathrm{~m} \\
\text { Rtc-m } \\
\end{array}$} & \multicolumn{3}{|c|}{1460 to $2320 \mathrm{~m}$} & \multirow{2}{*}{$\begin{array}{c}1460 \text { to } \\
2200 \mathrm{~m} \\
\text { Stc-m } \\
\end{array}$} \\
\hline & $\mathrm{Cp}$ & $\mathrm{Ca}$ & $\mathrm{Ct}$ & Ctc & LLm5 & & $\mathbf{R p}$ & $\mathbf{R a}$ & Rtc & & Sp & Sa & Stc & \\
\hline Mean & 12.9 & 15.5 & 15.0 & 13.1 & 1.9 & 14.0 & 5.4 & 9.1 & 5.6 & 6.0 & 3.8 & 10.1 & 7.8 & 7.4 \\
\hline Standard Error & 0.8 & 1.2 & 0.4 & 0.4 & 0.1 & 0.4 & 0.8 & 0.7 & 0.2 & 0.2 & 1.3 & 1.4 & 0.5 & 0.5 \\
\hline Median & 13.4 & 15.0 & 14.6 & 12.9 & 1.8 & 13.6 & 5.2 & 8.1 & 5.2 & 5.3 & 2.9 & 8.3 & 5.7 & 5.7 \\
\hline Mode & $\mathrm{N} / \mathrm{A}$ & 15.0 & 17.9 & 17.0 & 0.0 & 17.0 & 2.1 & 11.0 & 3.0 & 3.0 & 3.5 & N/A & 2.4 & 2.4 \\
\hline Standard Deviation & 3.6 & 6.3 & 5.0 & 5.3 & 1.7 & 5.1 & 3.4 & 3.3 & 3.0 & 2.9 & 5.4 & 6.5 & 6.2 & 5.7 \\
\hline Sample Variance & 12.9 & 39.8 & 24.7 & 28.6 & 2.8 & 26.0 & 11.9 & 11.2 & 9.2 & 8.5 & 28.7 & 42.3 & 38.4 & 32.4 \\
\hline Kurtosis & -0.1 & 0.8 & 0.1 & -0.2 & 1.2 & 0.1 & 0.4 & 3.5 & 0.0 & 0.0 & 15.5 & 0.1 & 1.3 & 1.7 \\
\hline Skewness & -0.5 & 0.0 & 0.5 & 0.4 & 1.0 & 0.3 & 0.8 & 1.6 & 0.7 & 0.8 & 3.8 & 1.0 & 1.5 & 1.5 \\
\hline Range & 13.7 & 28.5 & 24.7 & 25.2 & 9.4 & 25.2 & 13.0 & 14.8 & 12.5 & 11.7 & 24.0 & 22.0 & 23.5 & 23.0 \\
\hline Minimum & 5.3 & 2.2 & 6.0 & 4.0 & 0.0 & 4.0 & 0.3 & 4.8 & 0.9 & 1.7 & 0.6 & 2.3 & 1.4 & 1.4 \\
\hline Maximum & 19.0 & 30.7 & 30.7 & 29.2 & 9.4 & 29.2 & 13.3 & 19.6 & 13.4 & 13.4 & 24.6 & 24.3 & 25.0 & 24.4 \\
\hline Sum & 232.7 & 418.7 & 2693.3 & 2352.8 & 329.8 & 2182.9 & 97.5 & 200.8 & 1005.7 & 934.8 & 68.1 & 223.1 & 1402.7 & 1151.6 \\
\hline Count & 18 & 27 & 180 & 180 & 170 & 156 & 18 & 22 & 179 & 155 & 18 & 22 & 179 & 155 \\
\hline $\begin{array}{l}\text { Confidence Level } \\
(95.0 \%)\end{array}$ & 1.7 & 2.4 & 0.7 & 0.8 & 0.3 & 0.8 & 1.6 & 1.4 & 0.4 & 0.5 & 2.5 & 2.7 & 0.9 & 0.9 \\
\hline
\end{tabular}

"N/A" indicates "Not Applicable".

Source: DTNS: GS021008314224.002 [DIRS 161910]; GS040608314224.001 [DIRS 171367].

NOTE: $\quad$ Symbols $\mathrm{Cp}, \mathrm{Ca}, \mathrm{Ct}$, Ctc are defined in the caption for Figure O-9. LLm5 is Large Lithophysae in 5-m intervals and Ctc-m is Cavities in the converted tape data in the main (or prime) part of the tunnel from 1460 to $2200 \mathrm{~m}$. Symbols Rp, Ra, Rt, Rtc are defined in the caption for

Figure O-11, and Rtc-m are the Rims in the converted tape data in the main (or prime) part of the tunnel from 1460 to $2200 \mathrm{~m}$. Symbols Sp, Sa,

St, Stc are defined in the caption for Figure 0-11, and Stc-m are the Spots in the converted tape data in the main (or prime) part of the tunnel

from 1460 to $2200 \mathrm{~m}$. The data are presented in Drift Deg AMR AF T-A-P fit V1.xls (See Table A-1). 
Table O-10. Descriptive Statistics for Porosity of Lithophysal Cavities, Rims, and Spots in Panel Maps, Angular Traverses and Corrected Tape Traverses in the Tptpll Exposed in the ECRB Cross-Drift from Stations 14+60 to 23+20 (without Large Lithophysae)

\begin{tabular}{|c|c|c|c|c|c|c|c|c|c|c|c|c|c|}
\hline Descriptive Statistic & $\begin{array}{c}\text { Cavities } \\
\text { (panel) }\end{array}$ & $\begin{array}{c}\text { Rims } \\
\text { (panel) }\end{array}$ & $\begin{array}{c}\text { Spots } \\
\text { (panel) }\end{array}$ & $\begin{array}{l}\text { Cavities } \\
\text { (angular) }\end{array}$ & $\begin{array}{c}\text { Rims } \\
\text { (angular) }\end{array}$ & $\begin{array}{c}\text { Spots } \\
\text { (angular) }\end{array}$ & $\begin{array}{c}\text { Cavities } \\
\text { (tape) }\end{array}$ & $\begin{array}{l}\text { Rim- } \\
\text { Spot } \\
\text { (tape) }\end{array}$ & $\begin{array}{c}\text { MGM } \\
\text { (fitted) }\end{array}$ & $\begin{array}{c}\text { Cavities } \\
\text { (fitted) }\end{array}$ & $\begin{array}{c}\text { Rims } \\
\text { (fitted) }\end{array}$ & $\begin{array}{c}\text { Spots } \\
\text { (fitted) }\end{array}$ & $\begin{array}{r}\text { Total } \\
\text { (fitted) }\end{array}$ \\
\hline Mean & 12.9 & 1.4 & 0.9 & 15.3 & 2.3 & 2.5 & 16.4 & 2.1 & 10.9 & 13.1 & 1.4 & 1.9 & 27.3 \\
\hline Standard Error & 0.8 & 0.2 & 0.3 & 1.5 & 0.2 & 0.3 & 0.4 & 0.1 & 0.1 & 0.4 & 0.1 & 0.1 & 0.3 \\
\hline Median & 13.4 & 1.3 & 0.7 & 14.8 & 2.0 & 2.1 & 16.0 & 1.6 & 10.8 & 12.9 & 1.3 & 1.4 & 27.4 \\
\hline Mode & $\mathrm{N} / \mathrm{A}$ & 0.5 & 0.9 & $\mathrm{~N} / \mathrm{A}$ & 2.8 & $\mathrm{~N} / \mathrm{A}$ & 16.2 & 1.3 & 10.5 & 17.0 & 0.7 & 0.6 & 30.0 \\
\hline Standard Deviation & 3.6 & 0.9 & 1.3 & 6.9 & 0.8 & 1.6 & 4.8 & 1.7 & 0.7 & 5.3 & 0.8 & 1.6 & 4.5 \\
\hline Sample Variance & 12.9 & 0.7 & 1.8 & 47.2 & 0.7 & 2.6 & 22.9 & 2.9 & 0.5 & 28.6 & 0.6 & 2.4 & 20.2 \\
\hline Kurtosis & -0.14 & 0.42 & 15.49 & 0.37 & 3.45 & 0.08 & 0.14 & 3.58 & 0.66 & -0.17 & 0.00 & 1.26 & 0.66 \\
\hline Skewness & -0.51 & 0.76 & 3.82 & 0.10 & 1.63 & 0.98 & 0.44 & 1.99 & -0.42 & 0.42 & 0.67 & 1.48 & 0.42 \\
\hline Range & 13.7 & 3.2 & 6.0 & 28.5 & 3.7 & 5.5 & 27.0 & 7.8 & 3.5 & 25.2 & 3.3 & 6.2 & 23.2 \\
\hline Minimum & 5.3 & 0.1 & 0.2 & 2.2 & 1.2 & 0.6 & 5.5 & 0.3 & 8.7 & 4.0 & 0.0 & 0.0 & 18.5 \\
\hline Maximum & 19.0 & 3.3 & 6.2 & 30.7 & 4.9 & 6.1 & 32.5 & 8.1 & 12.2 & 29.2 & 3.3 & 6.2 & 41.7 \\
\hline Sum & 232.7 & 24.4 & 17.0 & 336.8 & 50.2 & 55.8 & 2894.3 & 311.4 & 1955.9 & 2352.8 & 251.4 & 350.7 & 4910.7 \\
\hline Count & 18 & 18 & 18 & 22 & 22 & 22 & 177 & 150 & 180 & 180 & 180 & 180 & 180 \\
\hline Confidence Level (95.0\%) & 1.7 & 0.4 & 0.6 & 2.9 & 0.3 & 0.7 & 0.7 & 0.3 & 0.1 & 0.8 & 0.1 & 0.2 & 0.7 \\
\hline
\end{tabular}

"N/A" indicates "Not Applicable".

Source: DTN: GS021008314224.002 [DIRS 161910].

NOTE: Porosity of the Rim and Spot material was calculated with a mean values of $0.25 \mathrm{~cm}^{3} / \mathrm{cm}^{3}$ and matrix-groundmass (MGM) was calculated with a mean value of $0.13 \mathrm{~cm}^{3} / \mathrm{cm}^{3}$, and Rim-Spot (tape data) is only from 14+60 to 22+00. The data are presented in file Drift Deg AMR AF T-A-P fit V1.xIs, worksheet "Volume Percent - Stats" (See Table A-1). 
Table O-11. Descriptive Statistics for Porosity of Lithophysal Cavities, Rims, and Spots in Panel Maps, Angular Traverses and Corrected Tape Traverses and the Large Lithophysae Inventory in the Tptpll Exposed in the ECRB Cross-Drift from Stations $14+60$ to $23+20$

\begin{tabular}{|c|c|c|c|c|c|c|c|c|c|c|c|c|c|c|}
\hline $\begin{array}{c}\text { Descriptive } \\
\text { Statistic } \\
\end{array}$ & $\begin{array}{c}\text { Cavities } \\
\text { (panel) }\end{array}$ & \begin{tabular}{|c|} 
Rims \\
(panel)
\end{tabular} & $\begin{array}{c}\text { Spots } \\
\text { (panel) }\end{array}$ & $\begin{array}{l}\text { Cavities } \\
\text { (angular) }\end{array}$ & $\begin{array}{c}\text { Rims } \\
\text { (angular) }\end{array}$ & $\begin{array}{c}\text { Spots } \\
\text { (angular) }\end{array}$ & $\begin{array}{c}\text { Cavities } \\
\text { (tape) }\end{array}$ & $\begin{array}{l}\text { Rim- } \\
\text { Spot } \\
\text { (tape) }\end{array}$ & $\begin{array}{c}\text { MGM } \\
\text { (fitted) }\end{array}$ & $\begin{array}{c}\text { Cavities } \\
\text { (fitted) }\end{array}$ & $\begin{array}{c}\text { Rims } \\
\text { (fitted) }\end{array}$ & $\begin{array}{l}\text { Spots } \\
\text { (fitted) }\end{array}$ & $\begin{array}{c}\text { L-Litho } \\
(5 \mathrm{~m})\end{array}$ & $\begin{array}{c}\begin{array}{c}\text { Total } \\
\text { (fitted) }\end{array} \\
\end{array}$ \\
\hline Mean & 12.9 & 1.6 & 1.1 & 15.3 & 2.7 & 3.0 & 15.0 & 4.0 & 8.4 & 13.1 & 1.7 & 2.3 & 2.0 & 27.5 \\
\hline Standard Error & 0.8 & 0.2 & 0.4 & 1.5 & 0.2 & 0.4 & 0.4 & 0.2 & 0.0 & 0.4 & 0.1 & 0.1 & 0.1 & 0.4 \\
\hline Median & 13.4 & 1.5 & 0.9 & 14.8 & 2.4 & 2.5 & 14.6 & 3.0 & 8.4 & 12.9 & 1.6 & 1.7 & 1.8 & 27.3 \\
\hline Mode & $\mathrm{N} / \mathrm{A}$ & 0.6 & 1.1 & $\mathrm{~N} / \mathrm{A}$ & 3.3 & $\mathrm{~N} / \mathrm{A}$ & 17.9 & 1.6 & 7.9 & 17.0 & 0.9 & 0.7 & 0.0 & 31.9 \\
\hline Standard Deviation & 3.6 & 1.0 & 1.6 & 6.9 & 1.0 & 2.0 & 5.0 & 2.3 & 0.6 & 5.3 & 0.9 & 1.9 & 1.7 & 5.6 \\
\hline Sample Variance & 12.9 & 1.1 & 2.6 & 47.2 & 1.0 & 3.8 & 24.7 & 5.2 & 0.4 & 28.6 & 0.8 & 3.5 & 2.9 & 31.3 \\
\hline Kurtosis & -0.14 & 0.4 & 15.5 & 0.37 & 3.5 & 0.1 & 0.1 & -0.6 & 0.7 & -0.2 & 0.0 & 1.3 & 0.9 & 0.7 \\
\hline Skewness & -0.51 & 0.8 & 3.8 & 0.10 & 1.6 & 1.0 & 0.5 & 0.7 & -0.6 & 0.4 & 0.7 & 1.5 & 0.9 & 0.6 \\
\hline Range & 13.7 & 3.9 & 7.2 & 28.5 & 4.4 & 6.6 & 24.7 & 9.4 & 3.3 & 25.2 & 4.0 & 7.5 & 9.4 & 28.9 \\
\hline Minimum & 5.3 & 0.1 & 0.2 & 2.2 & 1.4 & 0.7 & 6.0 & 0.0 & 6.3 & 4.0 & 0.0 & 0.0 & 0.0 & 16.6 \\
\hline Maximum & 19.0 & 4.0 & 7.4 & 30.7 & 5.9 & 7.3 & 30.7 & 9.4 & 9.7 & 29.2 & 4.0 & 7.5 & 9.4 & 45.4 \\
\hline Sum & 232.7 & 29.2 & 20.4 & 336.8 & 60.2 & 66.9 & 2693.3 & 625.9 & 1514.8 & 2352.8 & 301.7 & 420.8 & 359.0 & 4949.1 \\
\hline Count & 18 & 18 & 18 & 22 & 22 & 22 & 180 & 156 & 180 & 180 & 180 & 180 & 178.0 & 180.0 \\
\hline $\begin{array}{l}\text { Confidence Level } \\
(95.0 \%)\end{array}$ & 1.7 & 0.5 & 0.7 & 2.9 & 0.4 & 0.8 & 0.7 & 0.4 & 0.1 & 0.8 & 0.1 & 0.3 & 0.3 & 0.8 \\
\hline
\end{tabular}

N/A indicates "Not Applicable".

Source: DTN: GS021008314224.002 [DIRS 161910]; GS040608314224.001 [DIRS 171367].

NOTE: $\quad$ Porosity of the Rim and Spot material was calculated with a mean values of $0.30 \mathrm{~cm} 3 / \mathrm{cm} 3$ and matrix-groundmass (MGM) was calculated with a mean value of $0.104 \mathrm{~cm} 3 / \mathrm{cm} 3$ (Section 05 and 06.6), and Rim-Spot (tape data) is only from 14+60 to 22+00. The data are presented in file Drift Deg AMR AF T-A-P fit V1.xls, worksheet "Volume Percent - Stats" (See Table A-1) 


\section{O6.3 DESCRIPTIVE STATISTICS FOR LITHOPHYSAL CAVITIES, RIMS, SPOTS, AND LITHIC CLASTS IN TAPE TRAVERSES IN THE Tptpll OF THE ECRB CROSS-DRIFT FROM STATIONS 14+05 TO 23+35}

The descriptive statistics for lithophysal cavities, rims, spots, and lithic clasts in tape traverses in the Tptpll of the ECRB Cross-Drift from Stations 14+05 to $23+35$ were determined to support the distribution of size and abundance of lithostratigraphic features as described in Sections O1 and O6.6. Descriptive statistics were determined on data provided in DTN: GS021008314224.002 [DIRS 161910], and were determined in support of this report. The lengths of the tape traverses in the original data package (DTN: GS021008314224.002 [DIRS 161910]) were longer or shorter than those determined at the same locations with the angular traverses, so the tape traverse lengths were corrected using the angular traverse lengths and resulted in "typical traverse lengths". The "typical traverse lengths" used to determine the abundance of lithophysal cavities are $7.46 \mathrm{~m}$ from $14+20$ to $17+55$ (double vent line), and $7.53 \mathrm{~m}$ from $17+65$ to $23+35$ (single vent line). Descriptive statistics and histograms are provided for the sizes (actually lengths in $\mathrm{mm}$ ) and percent of the individual and total lengths for lithophysal cavities and the total percent of the visually estimated amounts of rims plus spots. Descriptive statistics were determined for individual traverses, $10 \mathrm{~m}, 15 \mathrm{~m}, 20 \mathrm{~m}, 25 \mathrm{~m}$, and $30 \mathrm{~m}$ "running averages" and for total lithophysal cavities. The descriptive statistics and histograms were determined with the standard functions of commercial off-the-shelf software Microsoft Excel 97 SR-2, and are documented in the Microsoft Excel file, Drift Deg AMR AC T-Trav.xls (Table A-1), which can be accessed through the TDMS (DTN: MO0408MWDDDMIO.002).

Adjustments were made to the tape data in the Microsoft Excel file, Drift Deg AMR AC T-Trav.xls (Table A-1), for the calculation of "moving averages" where there is a "gap" in the data. A gap occurs where a tape traverse was not made including the locations of a few panel maps. A description of the calculation of "moving averages" includes the following:

A. Running averages of tape traverse data were made for 10, 15, 20, 25, and 30 meters. These cells (Microsoft Excel file, Drift Deg AMR AC T-Trav.xls [Table A-1]) have no color fill.

B. The standard averaging practice includes:

- $10 \mathrm{~m}$ : value averaged with next value below ("down" tunnel to next station)

- $15 \mathrm{~m}$ : value averaged with value above and value below

- $20 \mathrm{~m}$ : value averaged with value above and next 2 values below

- $25 \mathrm{~m}$ : value averaged with 2 values above and 2 values below

- 30 m: value averaged with 2 values above and next 3 values below.

C. Where a gap in data occurs, the affected cell contains a comment, and may be color-coded. A gray color-coded cell indicates a null value was adjusted by averaging values of adjacent cells. Gray cells may indicate adjustments of null values on $5 \mathrm{~m}$ increments or on less than $5 \mathrm{~m}$ increments. 
D. In some cases where a gap in data occurs in an adjacent cell on an increment less than $5 \mathrm{~m}$, the affected cell was not color coded, but a comment was included indicating a default to standard averaging practice using the next $5 \mathrm{~m}$ increment. Where a gap in data occurs on a $5 \mathrm{~m}$ increment, adjustments were made, and affected cells were colored light turquoise.

E. The standard adjustment (rule 1) for data gaps consists of:

- $10 \mathrm{~m}$ : two values below null value averaged

- $15 \mathrm{~m}$ : one value above and 2 values below null value are averaged

- $20 \mathrm{~m}$ : one value above and 3 values below null value are averaged

- $25 \mathrm{~m}$ : two values above and 3 values below null value are averaged

- $30 \mathrm{~m}$ : two values above and 4 values below null value are averaged.

F. A light yellow cell located in the first 12 rows indicates a gap in the data. A light yellow cell located in the running average section indicates a situation where rule 1 was altered to avoid using null values in adjacent cells. In an effort to lessen the effect of data spikes in the tape traverse data, the above procedure (rule 1) for adjustments was departed to capture a smaller value in place of a larger value where the choice was available. (light green cells).

Sample variance of the summed lengths of lithophysal cavities in the $5 \mathrm{~m}$ data and the $10 \mathrm{~m}$ to $30 \mathrm{~m}$ moving average data indicates (1) variations along the tunnel and (2) the most significant minimization in variance in the $10 \mathrm{~m}$ and $15 \mathrm{~m}$ moving average data. Sample variance is a measure of the variability of the values relative to the mean value, so variations in the variance provide insight into the internal lithostratigraphic features of the lower lithophysal zone. Sample variance along the tunnel indicates there are segments (from Stations $15+00$ to $18+05$ and 19+90 to $21+80$ ) that have significantly greater amounts of cavities than is typical for the lithostratigraphic unit as a whole (Figure O-20). As discussed in Section O3, the amounts of lithophysal cavities measured behind the bulkhead at $22+01$ are probably over estimates, so the larger variances from $22+45$ to $23+35$ must be viewed with caution. Comparison of the variance in the $5 \mathrm{~m}$ data and $10 \mathrm{~m}$ to $30 \mathrm{~m}$ moving average data provides a measure of length scales across which the data have large or small variations. The $5 \mathrm{~m}$ data has the largest variation in values and progressively longer moving average values have smaller variations, but regardless of moving average or not, the data maintain the along-the-tunnel variations in the abundance of lithophysal cavities (Figure O-20). Differences in sample variance pairs of data at each station indicate the greatest step in minimizing the variance is with the $10 \mathrm{~m}$ or $15 \mathrm{~m}$ moving averages (Figure O-21). For example, subtracting the $10 \mathrm{~m}$ moving average value from the $5 \mathrm{~m}$ data results in numerous values larger or small than $\pm 4,000$, and subtracting the $15 \mathrm{~m}$ moving average value from the $10 \mathrm{~m}$ moving average value results in only a few values larger or smaller than $\pm 2,000$. 


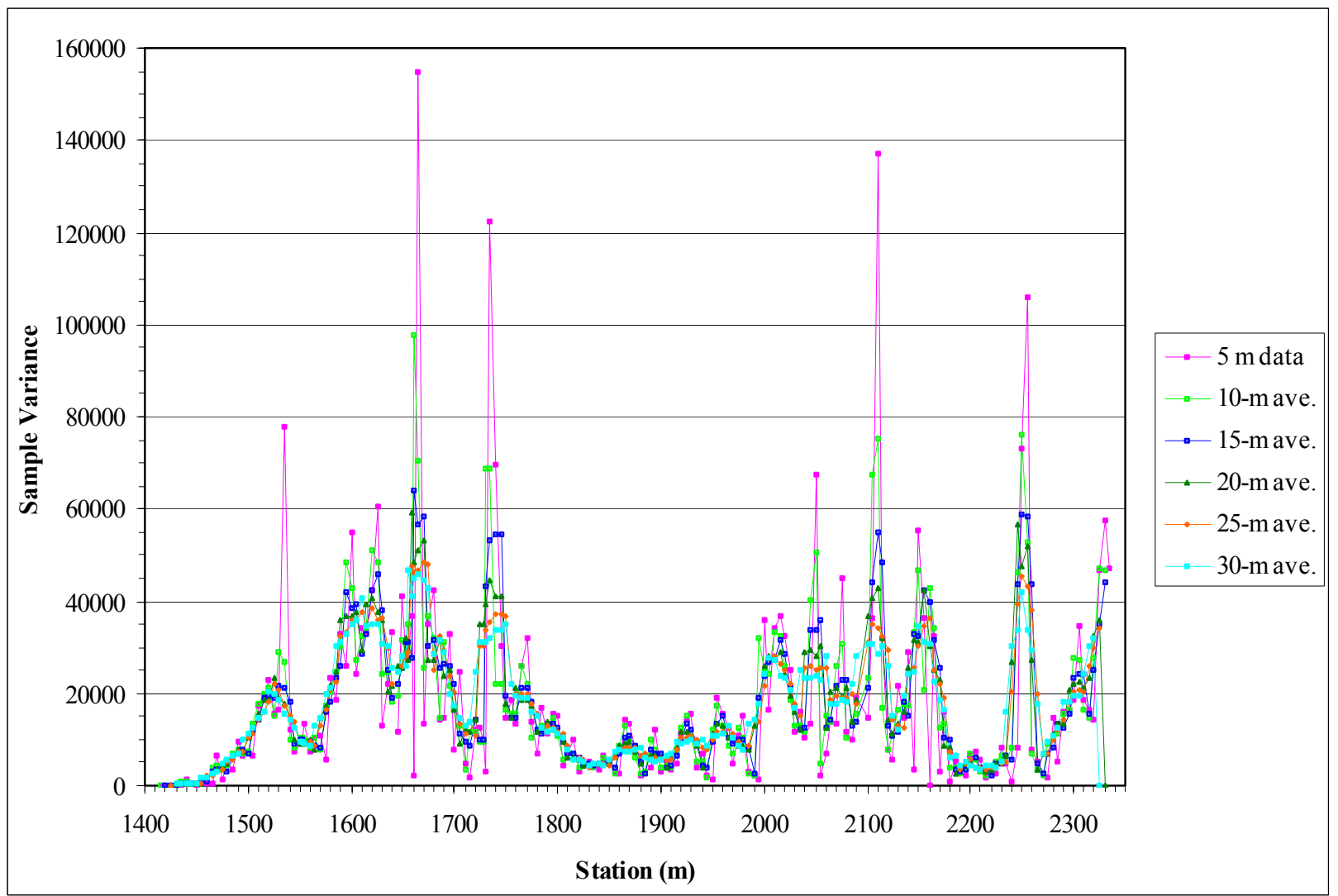

NOTE: Data and graph are from the adjusted length traverses (see Table A-1, Drift Deg AMR AC T-Trav.xls, worksheet “Tape data $(\mathrm{mm})$ ").

Figure 0-20. Sample Variance in the Summed Length of Lithophysal Cavities Based on $5 \mathrm{~m}$ Data and $10 \mathrm{~m}$ to $30 \mathrm{~m}$ Moving Average Data from Tape Traverses in the Tptpll of the ECRB Cross-Drift from $14+05$ to $23+35$ 


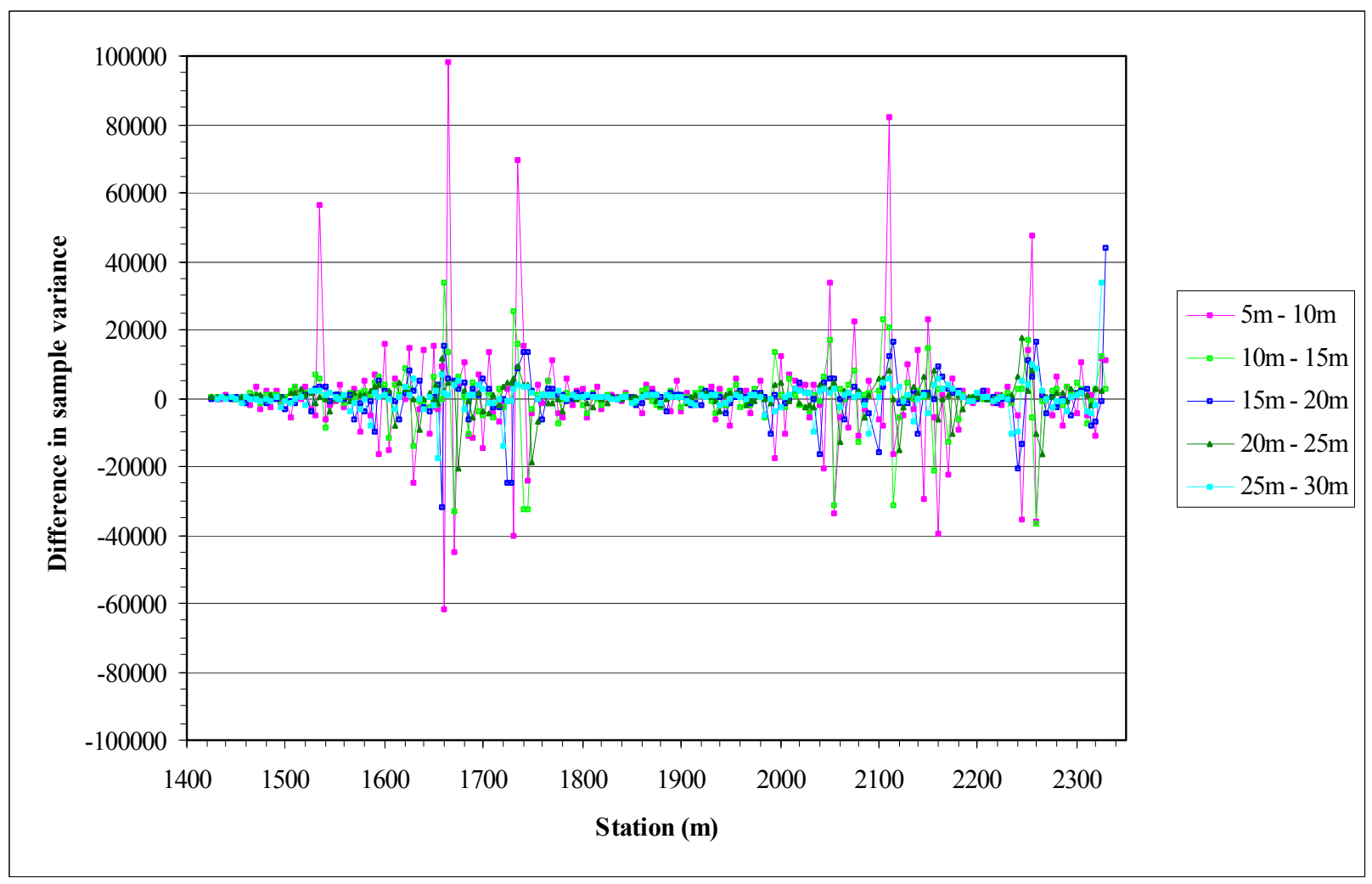

NOTE: Data and graph are from the adjusted length traverses (see Table A-1, Drift Deg AMR AC T-Trav.xIs, worksheet "Tape data ( $\mathrm{mm})$ "). " $5 \mathrm{~m}$ to10 $\mathrm{m}$ " is the difference in sample variance at each station of the $5 \mathrm{~m}$ data minus the variance of $10 \mathrm{~m}$ data.

Figure O-21. Differences in Sample Variance in the Summed Length of Lithophysal Cavities with Pairs of Various Moving Average Data from Tape Traverses in the Tptpll of the ECRB Cross-Drift from $14+05$ to $23+35$

\section{O6.4 DESCRIPTIVE STATISTICS FOR LARGE LITHOPHYSAE FROM THE LARGE-LITHOPHYSAL INVENTORY IN THE Tptpll OF THE ECRB CROSS- DRIFT FROM STATIONS 14+50 TO 17+56}

The descriptive statistics for lithophysal cavities, rims, spots, and lithic clasts in large-lithophysal inventory in the Tptpll of the ECRB Cross-Drift from Stations 14+50 to 17+56 were determined to support the distribution of size and abundance of lithostratigraphic features as described in Sections O5 and O6.6. Descriptive statistics were determined on data provided in DTN: GS021008314224.002 [DIRS 161910], and were determined in support of this report. Descriptive statistics are provided for the sizes (actually areas in $\mathrm{mm}^{2}$ ) and percent of the individual and total area for lithophysal cavities for $5 \mathrm{~m}$ long and $10 \mathrm{~m}$ long tunnel segments. The descriptive statistics were determined with the standard functions of commercial off-the-shelf software Microsoft Excel 97 SR-2, and are documented in the Microsoft Excel file, Drift Deg AMR AD L-Litho V1.xls (Table A-1), which can be accessed through the TDMS (DTN: MO0408MWDDDMIO.002). 


\section{O6.5 DESCRIPTIVE STATISTICS FOR ABUNDANCE OF LITHOPHYSAE AND SPOTS IN THE Tptpll ALONG THE ECRB CROSS-DRIFT FROM STATIONS 14+05 TO 23+35}

The descriptive statistics for the abundance of lithophysae and spots in the Tptpll of the ECRB Cross-Drift from Stations $14+05$ to $23+25$ were compiled in support of the calculation of the distribution of the abundance of lithostratigraphic features as described in Sections O4 and O6.6. Descriptive statistics were determined from (and are consistent with) values described in Mongano et al. (1999 [DIRS 149850], Tables 3 and 4). The descriptions presented in Mongano et al. (1999 [DIRS 149850], Tables 3 and 4) are summarized in the Microsoft Excel file, Drift Deg AMR AE Mongano.xls (Table A-1), and specific values for drift segments presented in Tables 3 and 4 (Mongano et al. 1999 [DIRS 149850]) are listed in $5 \mathrm{~m}$ station increments to facilitate plotting of and determining descriptive statistics for the data. The estimated "median" and "maximum" values are summarized in Table O-12 where the "median" values do not include local maximum values and the "maximum" values include only the maximum values. The descriptive statistics were determined with the standard functions of commercial off-the-shelf software Microsoft Excel 97 SR-2. The Microsoft Excel file, Drift Deg AMR AE Mongano.xls (Table A-1), can be accessed through the TDMS (DTN: MO0408MWDDDMIO.002).

\section{O6.6 CORRELATIONS AND CORRECTIONS TO TAPE TRAVERSE DATA AND DETERMINATION OF “BEST FIT" VALUES OF LITHOPHYSAL CAVITIES, RIMS, SPOTS, AND MATRIX-GROUNDMASS IN THE Tptpll ALONG THE ECRB CROSS-DRIFT}

To produce the "best fit" values for lithophysal cavities, rims, spots, and matrix-groundmass located every $5 \mathrm{~m}$ along the ECRB Cross-Drift, the tape traverse data output for cavities and "rims plus spots" were initially corrected to the angular traverse data, then panel map data, and finally with one more set of empirical correction factors. The panel map and angular traverse data are not corrected and are from the original lithophysal study data package (DTN: GS021008314224.002 [DIRS 161910]) and the tape traverse data are from the file Drift Deg AMR AC T-Trav.xls (Table A-1). The basic data including $10 \mathrm{~m}$ to $30 \mathrm{~m}$ moving averages of tape data, correlation equations, and empirical corrections are included in the Microsoft Excel file, Drift Deg AMR AF T-A-P Fit V1.xls (Table A-1), and can be accessed through the TDMS (DTN: MO0408MWDDDMIO.002). The descriptive statistics in the "Length - Fit and Stats" and "Volume Percent - Stats" worksheets were determined with the standard functions of commercial off-the-shelf software Microsoft Excel 97 SR-2. A description of the worksheets contained in Drift Deg AMR AF T-A-P Fit V1.xls (Table A-1) is provided as follows:

A. The "T-A-P Cav Fit" worksheet contains lithophysal cavity data from the tape and angular traverses and panel maps, and compares and correlates the tape and angular traverse data using equations of correlation. The abundance of cavities is calculated using the tape data and correlation equation and results in values every $5 \mathrm{~m}$ along the tunnel (symbol "Ct"). The "Ct" values are used in the "Length - Fit and Stats" worksheet. 
Table 0-12. Descriptive Statistics for "Median" and "Maximum" Abundance (Percent) of Lithophysal Cavities and Spots in the Tptpll Exposed in the ECRB Cross-Drift from Stations 14+44 to $23+26$

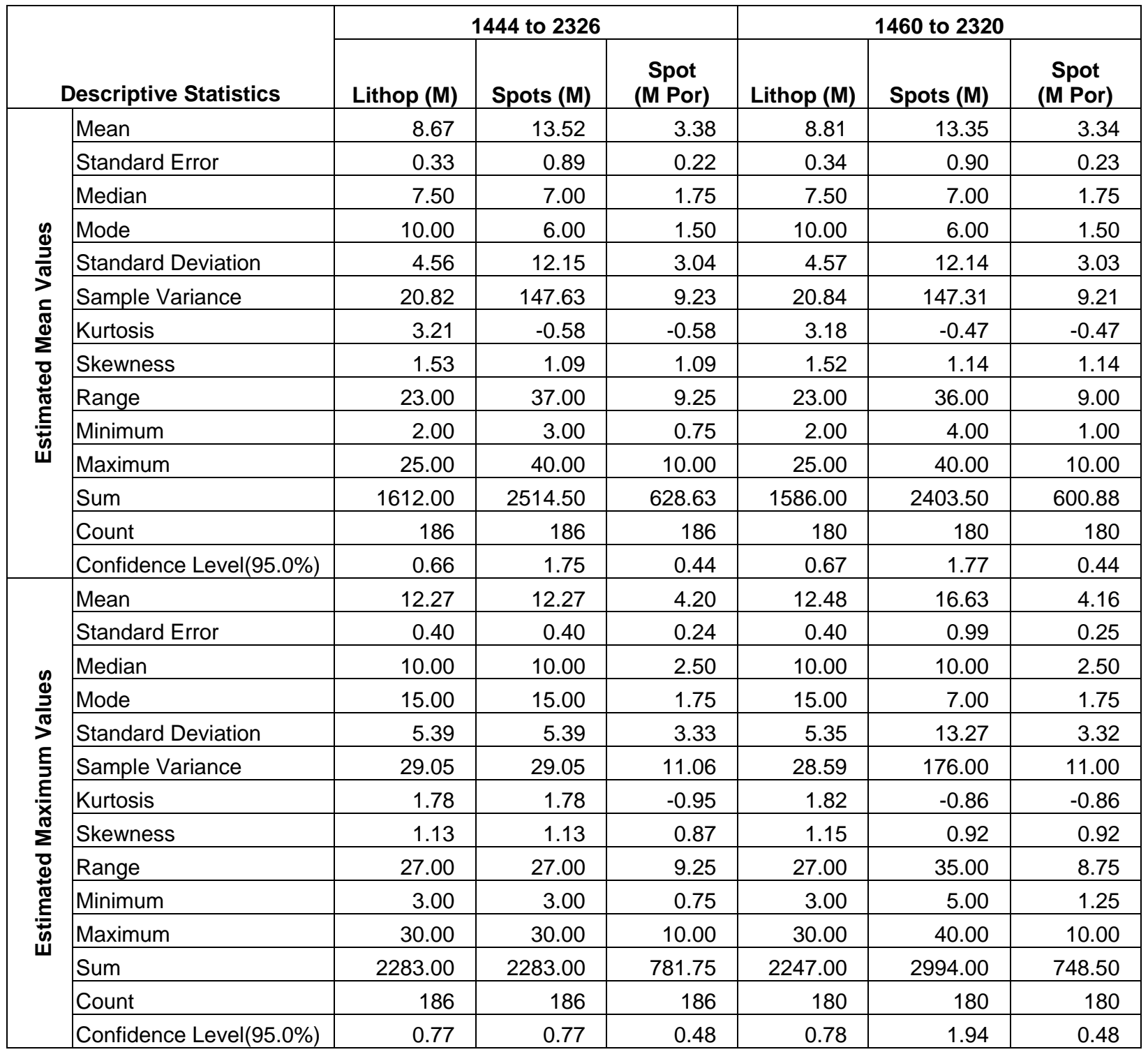

Source: Mongano et al. 1999 [DIRS 149850], Tables 3 and 4.

NOTE: Data from Mongano et al. 1999 [DIRS 149850] (Tables 3 and 4) utilized for $5 \mathrm{~m}$ station increments. See Drift Deg AMR AE Mongano.xls (Table A-1).

B. The "T-A-P R-S Fit" worksheet contains estimated "rims plus spot" data from the tape traverses and angular traverse and panel map data, and compares and correlates the tape and angular traverse data using equations of correlation. The abundance of "rims plus spots" is calculated using the tape data and correlation equation and results in values every $5 \mathrm{~m}$ along the tunnel. These calculated tape values are adjusted to the angular traverse and panel map values by empirically determined correction factors and result in "best fit" values "Rims+Spots (tape-cor)". The "Rims+Spots (tape-cor)" values are used in the "Length - Fit and Stats" worksheet. 
C. The "Length - Fit and Stats" worksheet summarize lithophysal cavity, rim, and spot data from the corrected tape traverses and the angular traverses and panel maps, and is used to develop "fitted" abundance along the tunnel. The "Ct" values are from the "T-A-P Cav Fit" worksheet, and the "Rims+Spots (tape-cor)" values are from the "T-A-P R-S Fit" worksheet. "Fitted" cavity, rim, and spot curves are developed using corrected tape values that are adjusted by to the angular traverse and panel map values with empirically determined correction factors. Descriptive statistics for abundance of cavities, rims, and spots are determined for data along the tunnel from Stations $14+60$ to $23+20$, the "best" technical data from $14+60$ to $22+00$, and as a "average" for the entire Tptpll zone.

D. The "Volume Percent - Stats" worksheet replicates the "Length - Fit and Stats" worksheet, but the porosity is calculated every $5 \mathrm{~m}$ along the tunnel and is "averaged" for the total length of the Tptpll zone. The amount of matrix-groundmass is determined by difference (100 minus the sum of cavities, rims, and spots). Based on the description of lithostragraphic features related to lithophysae (Figure 6-3), the porosity of lithophysal cavities is considered to be $1.00\left(\mathrm{~cm}^{3} / \mathrm{cm}^{3}\right)$, rims and spots are $0.30\left(\mathrm{~cm}^{3} / \mathrm{cm}^{3}\right)$, and the matrix-groundmass is $0.104\left(\mathrm{~cm}^{3} / \mathrm{cm}^{3}\right)$. Descriptive statistics for the porosity of cavities, rims, and spots are determined for data along the tunnel from Stations $14+60$ to $23+20$, the "best" technical data from $14+60$ to $22+00$, and as an "average" for the entire Tptpll zone.

This report provides alternative methods for both the calculation of the porosity of features and the inclusion of the large lithophysal inventory data, and the differences in these approaches is shown by the "fitted" mean porosity values in Table O-13. Relative to Method A in Table O-13, an increase in mean porosity of the rims and spot material results in slight increases in the "fitted" rims and spots, and the decrease in the mean porosity of the matrix-groundmass material results in a decrease in the "fitted" matrix-groundmass. A cumulative effect of these changes in the mean porosity of the rim, spot, and matrix-groundmass materials is that the total "fitted" porosity decreased by 1.6 percent resulting primarily from the larger amount of matrix-groundmass than rim and spot materials (see Method B in Table O-13). The inclusion of the large lithophysal cavities slightly reduced the "fitted" matrix-groundmass to 8.4 percent because the large lithophysal cavity porosity is subtracted at each station and increased the total "fitted" porosity to 27.5 percent (see Method C in Table O-13). 
Table O-13. Mean Porosity of Lithophysal Cavities, Large-Lithophysal Cavities, Rims, Spots, Matrixgroundmass, and Total Porosity in the Tptpll Exposed in the ECRB Cross-Drift from Stations $14+60$ to $23+20$ Using Three Methods

\begin{tabular}{|l|l|l|l|}
\hline \multicolumn{1}{|c|}{ "Fitted" Features } & $\begin{array}{c}\text { Method A: Excluding } \\
\text { Large Lithophysae } \\
\text { ffrom Table O-10) }^{\mathbf{a}}\end{array}$ & $\begin{array}{c}\text { Method B: Excluding } \\
\text { Large Lithophysae with } \\
\text { Modified Calculation of } \\
\text { Porosity Features }^{\text {b }}\end{array}$ & $\begin{array}{c}\text { Method C: Including } \\
\text { Large Lithophysae with } \\
\text { Modified Calculation of } \\
\text { Porosity Features (from } \\
\text { Table O-11) }^{\mathbf{c}}\end{array}$ \\
\hline Cavities & 13.1 & 13.1 & 13.1 \\
\hline Large-lithophysae & N/A & N/A & 2.0 \\
\hline Rims & 1.4 & 1.7 & 1.7 \\
\hline Spots & 1.9 & 2.3 & 2.3 \\
\hline Matrix-groundmass & 10.9 & 8.6 & 8.4 \\
\hline Total & 27.3 & 25.7 & 27.5 \\
\hline
\end{tabular}

"N/A" indicates "Not Applicable".

a Mean porosity of the matrix-groundmass is $0.13 \mathrm{~cm}^{3} / \mathrm{cm}$. The mean porosity of the rims and spots is estimated to range from 0.20 to $0.30 \mathrm{~cm}^{3} / \mathrm{cm}^{3}$ (with a mean porosity of $0.25 \mathrm{~cm}^{3} / \mathrm{cm}^{3}$ ). The large lithophysae data are not included. The full table of descriptive statistics is provided in Table 0-10.

b Mean porosity of the matrix-groundmass is $0.104 \mathrm{~cm}^{3} / \mathrm{cm}^{3}$. The mean porosity of the rims and spots is 0.30 $\mathrm{cm}^{3} / \mathrm{cm}^{3}$, and the large lithophysae data are included (DTN: MO0408MWDDDMIO.002, file Drift Deg AMR AF T-A-P V1.xls, worksheet "Volume Percent - Stats" (see Table A-1).

c Mean porosity of the matrix-groundmass is $0.104\left(\mathrm{~cm}^{3} / \mathrm{cm}^{3}\right)$. The mean porosity of the rims and spots is 0.30 $\mathrm{cm}^{3} / \mathrm{cm}^{3}$. The large lithophysae data are included. The full table of descriptive statistics is provided in Table 0-11.

\section{O6.7 ACCURACY OF MEASURED AND CALCULATED VALUES}

The accuracy of measured values must be understood in the context of three conditions: (1) the specific measurements made on features, (2) conditions that affect the measurements, and (3) how well the measurements and the summed and calculated values represent the three-dimensional distributions of the features.

Accuracy of Measured Data for Each of the Four Data Collection Methods-The panel maps are at a 1:10 scale and measurements are recorded to the nearest millimeter. Individual measurements in the panel maps can be accurate to 1 or $2 \mathrm{~mm}$ for small or narrow features; however, large, irregularly shaped objects (those with dimensions of several decimeters) can be accurate to 10 to $50 \mathrm{~mm}$ depending on how the data collector identifies the long and short axes.

Angular traverses are measured in degrees and minutes, and the recorded values are rounded to the nearest 5 minutes. In the ECRB Cross-Drift, an arc of 5 minutes calculates to about $4 \mathrm{~mm}$ on the tunnel wall, and this is also about the diameter of the laser beam. Pragmatically, the identification of the edge of a feature is a function of how sharp (or gradational) is the edge and the conditions in the tunnel. The edges of most features including lithophysal cavities, rims, and spots are relatively sharp (can be identified to less than $2 \mathrm{~mm}$ in width) with close examination. However for most features, the distance from the data collector to the tunnel wall was 1 to $3.5 \mathrm{~m}$, so even with binoculars, the accuracy of the measurement is about 15 minutes (about $10 \mathrm{~mm}$ ). The conditions in the tunnel during collection of the angular traverse data included the need to wear safety glasses (and at times a respirator), irregular distribution of tunnel illumination, dust cover on the tunnel walls, irregularities (breakouts) along the tunnel walls, and obstructions to 
the line of sight and the need to estimate positions of features. With these various conditions, a practical accuracy is probably 5 to 40 minutes (about 4 to $30 \mathrm{~mm}$ ) for any given measurement.

The tape (stadia rod) used for the tape traverses is divided into decimeters and centimeters, and the data can be recorded to the nearest $1 \mathrm{~cm}$. However, based on the projection of the cavity walls to the tape, the difficulties in positioning the tape along the wall result in a practical accuracy of probably 2 to $10 \mathrm{~cm}$ for any given measurement.

Similar to the tape traverse measurements, the tape (stadia rod) used in the large-lithophysae inventory is divided into decimeters and centimeters, and the data can be recorded to the nearest $1 \mathrm{~cm}$. However, based on the projection of the cavity walls to the tape, the difficulties in positioning the tape along the wall result in a practical accuracy probably 2 to $10 \mathrm{~cm}$ for any given measurement.

Conditions that Affect the Accuracy and Use of Measurements-In the panel maps there are three main conditions that can affect the accuracy of the values (others are described in the data package for DTN: GS021008314224.002 [DIRS 161910]):

1. The boundaries of features in the panel maps are based on photographic interpretation, hand-drawn maps compiled in the tunnel, and values measured in the tunnel and recorded in the Excel workbooks. Boundaries of features are typically sharp (as described above); however, the portrayal of the boundaries, regardless of being observations in the tunnel or as photographic interpretation, is a bit subjective; therefore, it can affect the accuracy of the feature boundaries. The subjective aspects typically arise where the edge of a feature does not occur on the tunnel wall (i.e., in a broken out lithophysal cavity or block bounded by fractures). The attempted balance used by the mapper is to project the contact to the plane of the tunnel wall, which is the plane on which the map is made, but also depict the contact where it "appears" to be on the photograph and would be viewed by other users. In part, this is an issue of perspective, but it does not affect the total percent of features by more than 1 to 3 percent.

2. A few of the panels from $17+63$ to $23+00$ were not washed as well as the ones from $14+90$ to $17+63$; therefore, the photographs of the tunnel walls were not as helpful for mapping the features. One result of the incomplete washing was that some of the features were more difficult to identify in the photograph than in other locations. A second result was that some of the lithophysal cavities that had been backfilled with rock flour from the tunnel boring machine were not cleaned out; therefore, they were excavated by hand and hammer. Because the photographs were taken before this additional excavation, the edges of the lithophysae were approximated and drawn on the photograph.

3. Rocks in the panel maps have distributions in the sizes and spatial positions of lithostratigraphic features; therefore, the position of the map-area $(1 \times 3 \mathrm{~m})$ box can result in variations in areas. Panel map 1641-44L was used to compare the original position of the map area (that which is included in the data package) and four other alternative positions. The alternative positions were selected such that one position is 
to the upper left of the original position, and the other alternative positions are to the upper right, lower right, and lower left (respectively) of the original position. Descriptive statistics on the percent areas determined from the five map positions indicate the matrix-groundmass and lithophysal cavities have 95 percent confidence levels of less than 4 percent and the rims, spots, and lithic clasts have 95 percent confidence levels of less than 0.5 percent (Table O-14).

Table O-14. Comparative Values from the Original Position of the Panel Map and Four Alternative-Position Maps

\begin{tabular}{|l|l|l|l|l|l|l|}
\hline \multicolumn{1}{|c|}{ Map positions } & No. of Objects & MGM \% & L-cavities \% & L-rims \% & Spots \% & C-Lithic \% \\
\hline OP & 117 & 71.61 & 19.01 & 5.75 & 3.49 & 0.14 \\
\hline AP1 & 90 & 70.35 & 21.70 & 5.13 & 2.77 & 0.05 \\
\hline AP2 & 110 & 75.69 & 15.52 & 5.01 & 3.54 & 0.24 \\
\hline AP3 & 106 & 76.75 & 14.45 & 4.91 & 3.65 & 0.24 \\
\hline AP4 & 99 & 75.77 & 15.89 & 5.20 & 3.08 & 0.05 \\
\hline Descriptive statistics & No. of Objects & MGM \% & L-cavities \% & L-rims \% & Spots \% & C-Lithic \% \\
\hline Mean & 104.40 & 74.03 & 17.31 & 5.20 & 3.31 & 0.15 \\
\hline Standard Error & 4.63 & 1.28 & 1.33 & 0.15 & 0.17 & 0.04 \\
\hline Median & 106.00 & 75.69 & 15.89 & 5.13 & 3.49 & 0.14 \\
\hline Standard Deviation & 10.36 & 2.85 & 2.98 & 0.33 & 0.37 & 0.09 \\
\hline Sample Variance & 107.30 & 8.15 & 8.89 & 0.11 & 0.14 & 0.01 \\
\hline Range & 27.00 & 6.40 & 7.25 & 0.84 & 0.88 & 0.19 \\
\hline Minimum & 90.00 & 70.35 & 14.45 & 4.91 & 2.77 & 0.05 \\
\hline Maximum & 117.00 & 76.75 & 21.70 & 5.75 & 3.65 & 0.24 \\
\hline Confidence Level(95.0\%) & 12.86 & 3.54 & 3.70 & 0.40 & 0.46 & 0.12 \\
\hline
\end{tabular}

Source: DTN: GS021008314224.002 [DIRS 161910], Table S03045_001, file Tptpll Lithop Data Sum Sheet 15Nov02.doc.

NOTE: $\mathrm{OP}=$ original position, $\mathrm{AP}=$ alternative position, $\mathrm{MGM}=$ matrix-groundmass, L-cavities $=$ lithophysal cavities, L-rims $=$ rims on lithophysae, C-Lithic $=$ lithic clasts.

In the tape traverse data there are three main conditions that can affect the accuracy of the values (others are described in the data package for DTN: GS021008314224.002 [DIRS 161910]):

1. In the data package, the amounts of lithophysal cavities in the tape traverses from $21+25$ to $23+35$ are greater than (and from $22+01$ to $23+35$ much greater than) those documented in panel maps and angular traverses. This segment of the tunnel was the first to have data collected and it contains abundant spots. Re-examination of the exposures from $21+25$ to $22+01$ indicates many of the initially identified lithophysae are spots, although some spots have a thin stringer or veinlet inside, and this appears to have lead to the identification as lithophysae.

2. Tape traverse data were collected by three collectors, and there appears to be a slight variation in the estimated amounts of rims and spots depending on the different collectors. There are slightly smaller estimates in the section from $14+00$ to $17+63$ compared to the section from $17+63$ to 22+01. Additionally, some of the measurements of rims and spots from the panel maps and angular traverses in these 
sections of the tunnel appear to confirm the smaller visual estimates determined in the tape traverse. However, other panel map and angular traverse data appears to indicate the visual estimates determined in the tape traverse are underestimated. Adjustments of the tape data are described in Sections O4 and O6.

3. In the tape traverse data, one component used in calculating the abundance of lithophysal cavities is the total length of the traverse. The length of the traverse results from the amount of construction materials in the tunnel and the height of the laser-prism above the invert (see Figure O-1 and the data package for DTN: GS021008314224.002 [DIRS 161910] for a detailed discussion). The traverses began at the top of the compressed air pipe and ended at the top of the conveyor belt, and the construction materials that affected the length include pipes, electrical lines, steel sets, vent lines, the conveyor belt and frame, and other equipment. Although the influence of the laser-prism height on the length was discussed by investigators, it was never specified and not explicitly recorded. Initially (from Station $22+00$ to $19+80$ ), the total and visible lengths were measured for each traverse with a wheel on the end of the extension rod/handle. At Station 19+80 the compiler determined that most measured lengths and tunnel conditions were similar enough that the visible length of $6.7 \mathrm{~m}$ was used as the standard value for the remainder of the traverses to Station $14+05$. Some of the angular traverses were measured at the same locations as the tape traverses, and the calculated visible lengths vary from 7.0 to $7.8 \mathrm{~m}$ (these values do not include the traverses where there is no vent line or conveyor). This comparison indicates the $6.7 \mathrm{~m}$ visible length is probably too short for most of the tape traverses. The amount of difference in the calculated percent based on the total length of the traverse is proportional to the amount of cavities measured such that a traverse with only a few percent cavities is barely affected whereas the traverse with the most cavities is affected the most. For example, the greatest effect occurs in the traverse at $16+00$ with $3.6 \mathrm{~m}$ length of cavities, so with a $6.7 \mathrm{~m}$ length, the cavities form 53.9 percent of the tunnel wall. If the visible length of the tape traverse is adjusted to $7.2 \mathrm{~m}$, the calculated abundance of lithophysal cavities locally decreases by much as 3.7 percent (a 6.9 percent decrease). Additionally, and if the adjusted visible length is $7.4 \mathrm{~m}$, the cavity value decreases by as much as 5.8 percent (a 10.7 percent decrease). The correction of tape data is described more in Sections O4 and O6.

Qualitatively, there are reasonably good comparisons of values measured with different techniques, and some data can be compared quantitatively. Differences in the values measured by the three methods (panel maps, angular traverses, and tape traverses) are expected because of how the data are collected, and these relations are implicit in the need to design three methods of data collection. The lithophysal cavity values from the tape traverses tend to be 1 to 3 times greater than in adjacent or collocated panel map and/or angular traverse values. The angular traverse values (for lithophysal cavities, rims, spots, and clasts) tend to be slightly greater than those for the panel maps; however, locally the panel map values can be greater. The average lithophysal-cavity value that is fully within the lower lithophysal zone (from Station 14+60 to $23+20$ ) is 18.9 percent from tape traverses (nonadjusted values from Table O-4) compared to 15.5 percent from angular traverses and 12.9 percent from panel maps (Table O-9). 
How Well Measurements Represent the Three-Dimensional Distributions of the FeaturesDetermining the 3-dimensional size, shape, and distribution of features and objects is one of the ultimate results of the measurements described in this appendix. Most measurements in solid objects that cannot be disaggregated (such as rocks) are made with 2-dimensional cross sections and 1-dimensional traverses, so it is important to appreciate the geometric relations of the three-dimensional objects with respect to how they are measured. For example, an ellipsoid consisting of three axes ( $\mathrm{A}$ is the longest, $\mathrm{B}$ is intermediate in length, and $\mathrm{C}$ is the shortest) can be cut along many planes to create various two dimensional cross-sections (Figure O-22). The smallest cross sectional area is for a plane through the B-C axes, an intermediate cross sectional area is through the A-C axes, and the maximum cross sectional area is through the A-B axes. An ellipsoid is a simplified rendition of many lithostratigraphic features, especially where a foliation is well developed such as rocks in the lower lithophysal zone exposed in the ECRB Cross-Drift. With respect to the lower lithophysal zone in the tunnel, the left and right ribs approximate cuts along planes parallel to the one that contains the A-C axes, and the crown and invert approximate cuts along planes parallel to the one that contain the A-B axes. Cross sections that contain the primary axes and transect the center of the ellipsoid have the maximum area (for example, a and $\mathrm{c}$ in Figure O-22). However, any plane cut parallel to the primary plane (for example A-C) that does not transect the center of the ellipsoid has the same cross sectional shape, but the axes are shorter ( $\mathrm{a} 2$ and $\mathrm{c} 2$ ) and the area is smaller. If a 1-dimensional linear traverse transects an object, then the maximum length of the intercept occurs only if the transect is along the primary axis (for example, $\mathrm{c}$ in Figure $\mathrm{O}-22$ ). However, if the transect is parallel to the $\mathrm{C}$ axis, but does not intersect the center of the ellipsoid, then the length of the intercept is less than the length of the axis (for example, c' and c'2 in Figure O-22). These relations are the basis of the observation in technical procedure, YMP-USGS-GP-20, R1 (Estimating Abundance of Features in Core and in Outcrop, Including Lithophysae, Spots, Clasts, and Fractures) that 2- and 1-dimensional measurements typically result in under estimates of the true measurements of a feature. This review of geometric relations of measurements indicates that even with the methods used and documentation of measurements and correlations of values between the various techniques, the actual values at a specific location or the descriptive statistics are judged to represent minimum values. 


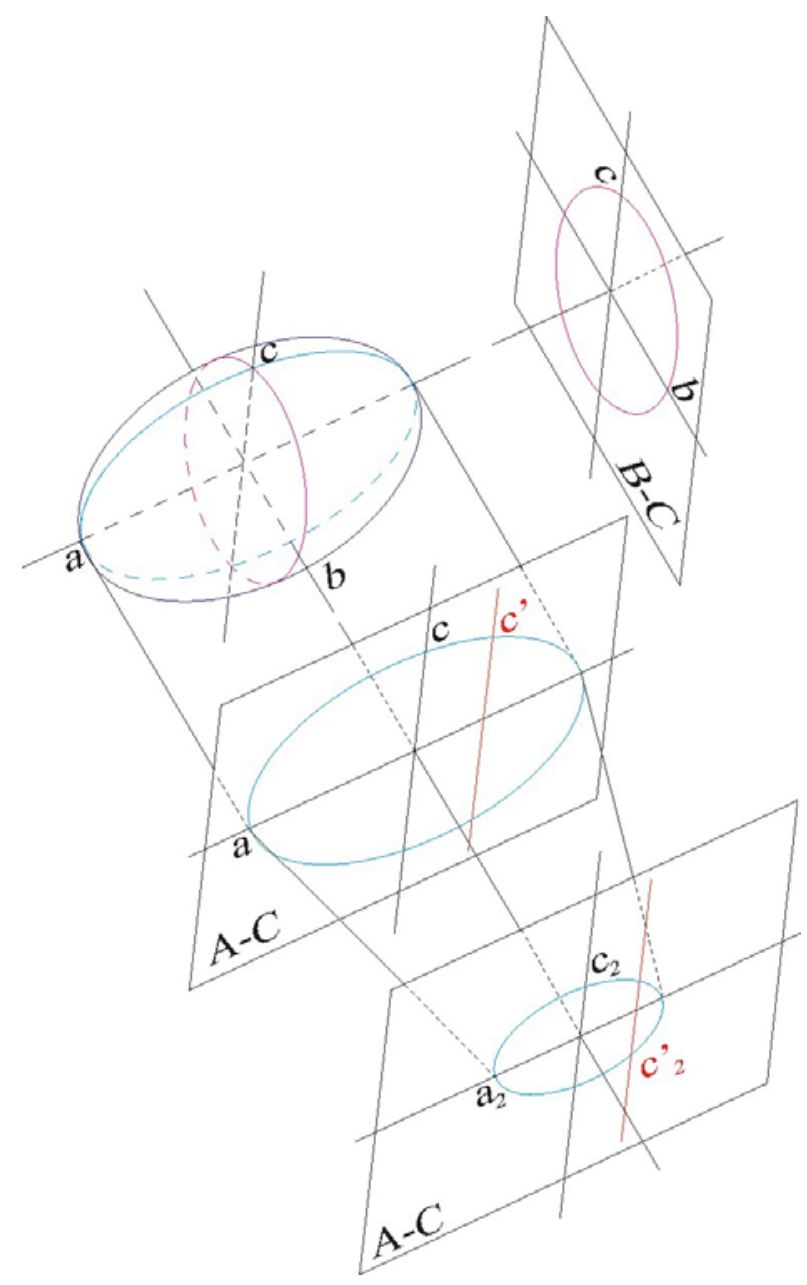

NOTE: The $a$ axis is the longest axis, the $b$ axis is the intermediate length, and the $c$ axis is the shortest.

Figure O-22. Geometric Relations of Three-Dimensional Ellipsoid with Two-Dimensional Cross Sections and One-Dimensional Transects 


\section{INTENTIONALLY LEFT BLANK}




\section{APPENDIX P \\ PRESSURES ON THE DRIP SHIELD \\ CALCULATED FROM THE DISCONTINUUM MODEL}




\section{PRESSURES ON THE DRIP SHIELD CALCULATED FROM THE DISCONTINUUM MODEL}

\section{P1. INTRODUCTION}

The drip shield loads (i.e., impact and static loads of the caved rock) in the lithophysal rock mass were first assessed considering that the drip shield is rectangular (with geometry approximately corresponding to the outline of the actual shape), rigid, and slaved to the free-field ground motion (i.e., the motion unaffected by interaction of the seismic waves with the drift). Those considerations were used in the initial analysis because they are conservative, resulting in overprediction of the caved rock-mass loads on the drip shield. The rectangular drip-shield shape reduces the potential for stress arching through the caved rock mass above the drip shield. Stress redistribution through the multi-component system is a function of ratios between stiffnesses of different components. If the drip shield is considered to be infinitely stiff, it certainly will reduce the positive stress arching in the caved rock mass, resulting in increased loads on the drip shield. In order to demonstrate the level of conservatism in those results and to obtain more realistic estimates of the drip shield loads, an improved model of the drip shield has been developed that includes better representation of geometry and has stiffness that approximates the actual drip-shield stiffness. (The model used in the UDEC drift collapse analysis is two-dimensional. The geometry of the drip shield is three-dimensional.) Development and validation of the drip-shield model is discussed in Appendix Y.

In Section P2, the effects of the shape and stiffness of the drip shield on the drip shield loads are analyzed for different loading conditions (i.e., seismic shaking and quasi-static drift collapse). Detailed analysis of the drip shield loads (using the new model) and the results are presented in Sections P3 to P5.

\section{P2. EFFECT OF DRIP-SHIELD SHAPE AND STIFFNESS}

The effect of drip-shield stiffness and shape on the drip shield loads, both impact and static, due to rockfall is analyzed for seismic shaking with probability of annual recurrence of $1 \times 10^{-5}$ and for quasi-static drift degradation. None of the actual static loads (e.g., in situ or thermal stresses) are expected to cause total drift collapse even for the long-term strength of the rock mass (i.e., accounting for time-dependent strength degradation). The quasi-static drift degradation is considered here to represent an extreme case of the static load on the drip shield. It is considered that the rock mass completely losses its cohesive strength and that total drift collapse takes place under the action of in situ stresses and gravitational forces.

\section{P2.1 SEISMIC SHAKING}

Case 11 (i.e., ground motion 9 and rock mass category 1, see Table 6-44) with $1 \times 10^{-5}$ ground motion was used in this analysis since this case couples a high-energy ground motion (see Table 6-6) with the lowest strength rock category. The initial analyses were performed using the original drip-shield model (rectangular and rigid drip shield) shown in Figure P-1 and the model shown in Figure P-2, in which the drip shield has an arched top and is deformable, but pinned

(i.e., free rotation, fixed translation) at the bottom of both sides. The pinned points are slaved to 
the free-field motion in a similar way the entire drip shield was slaved in the original model. (The invert, the pallet, and the waste canisters are not represented in these two models.)

Figures P-1 and P-2 show the segment ID and the final configuration of the models when equilibrium is achieved after the shaking. This ground motion does not result in total drift collapse. The calculated loads on the drip shield, shown in Figure P-3, and the average pressures (for the sides and the top), listed in Table P-1, are fairly similar for these two cases and are insignificant with regard to the stability of the drip shield.
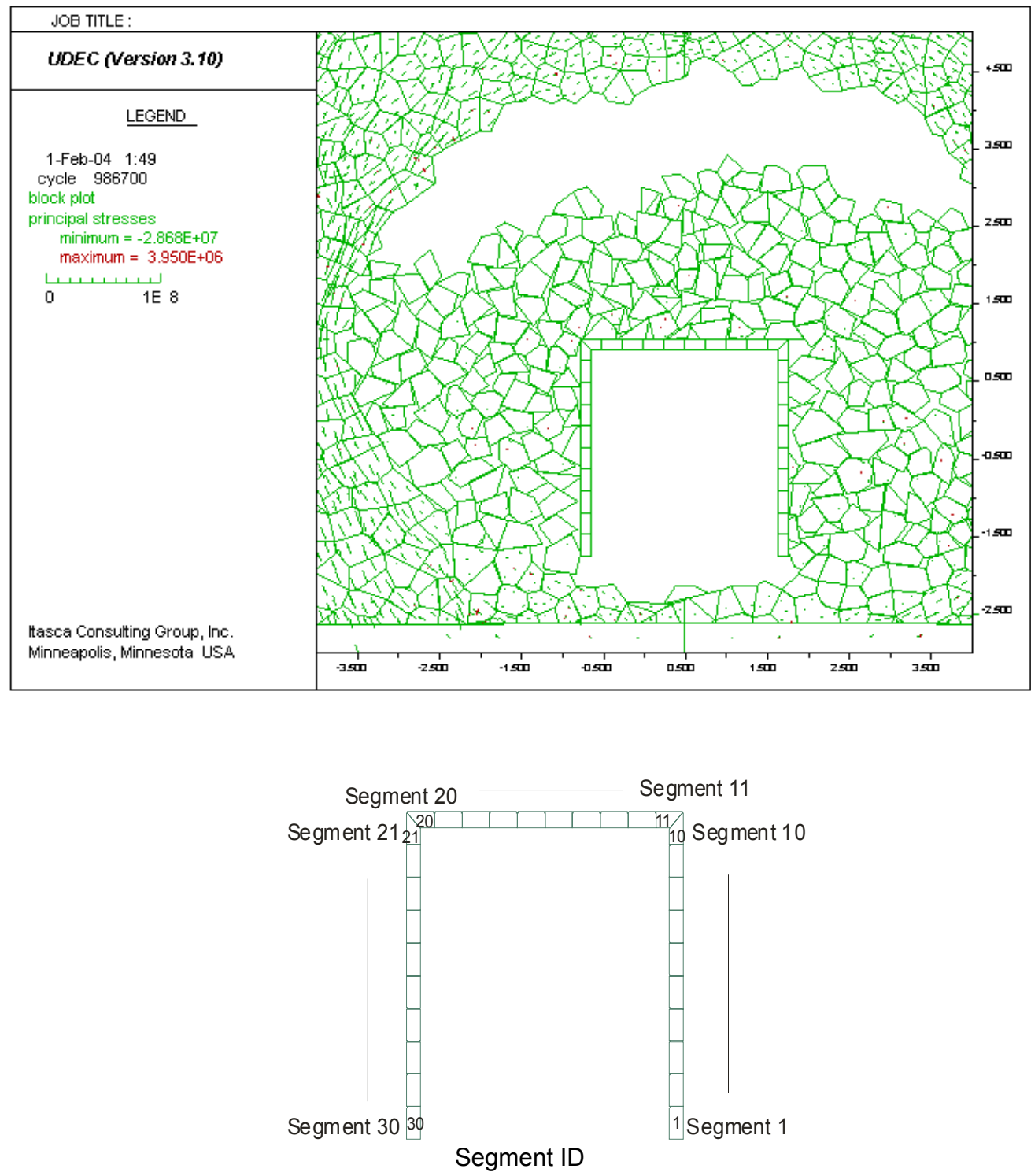

Figure P-1. Ground Motion $10^{-5}$, Case 11: Equilibrium State for Rigid, Rectangular Drip Shield 

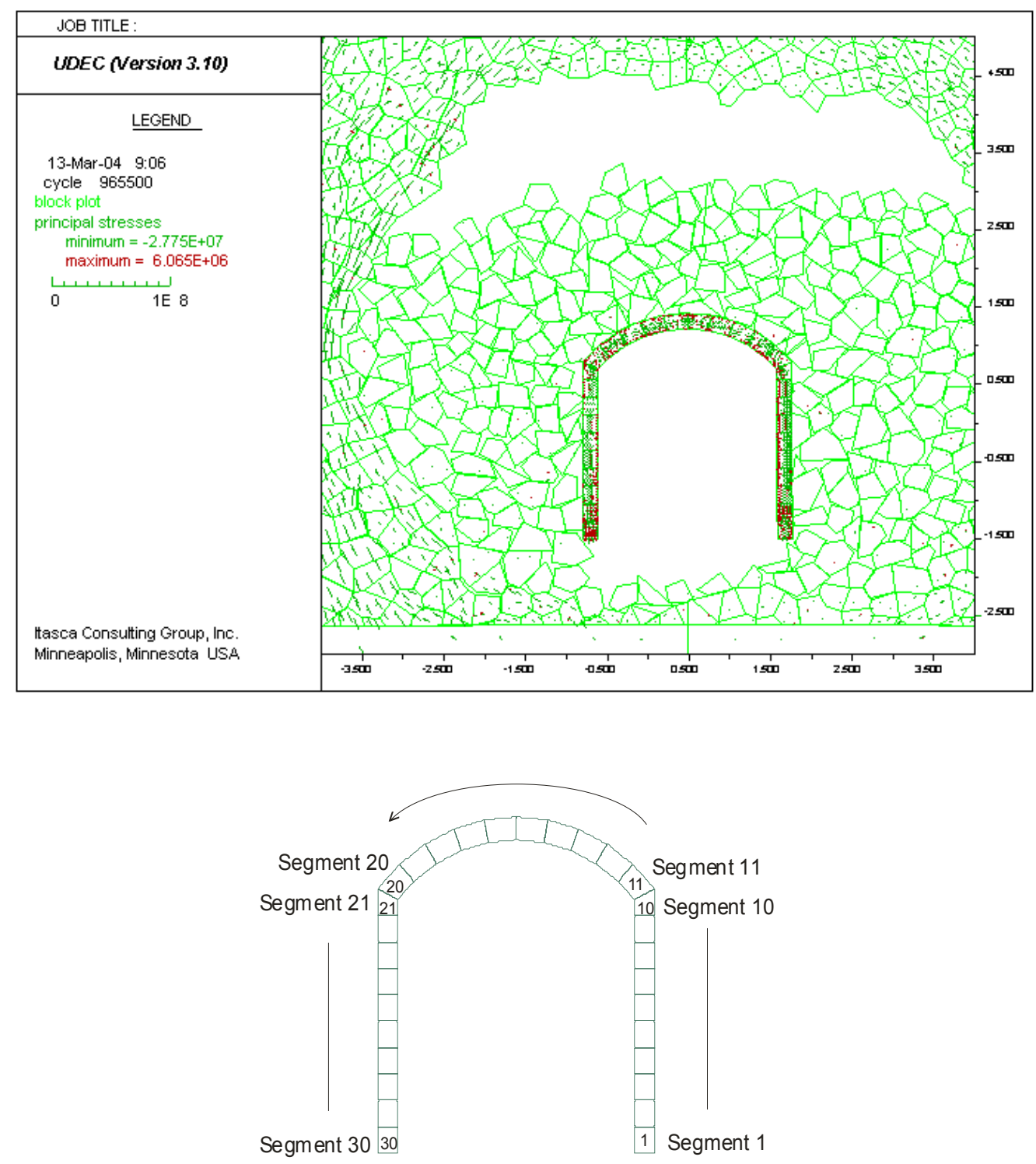

Segment ID

Figure P-2. Ground Motion $10^{-5}$, Case 11: Equilibrium State for Deformable Drip Shield With Arched Top, Pinned Bottom, No Invert 


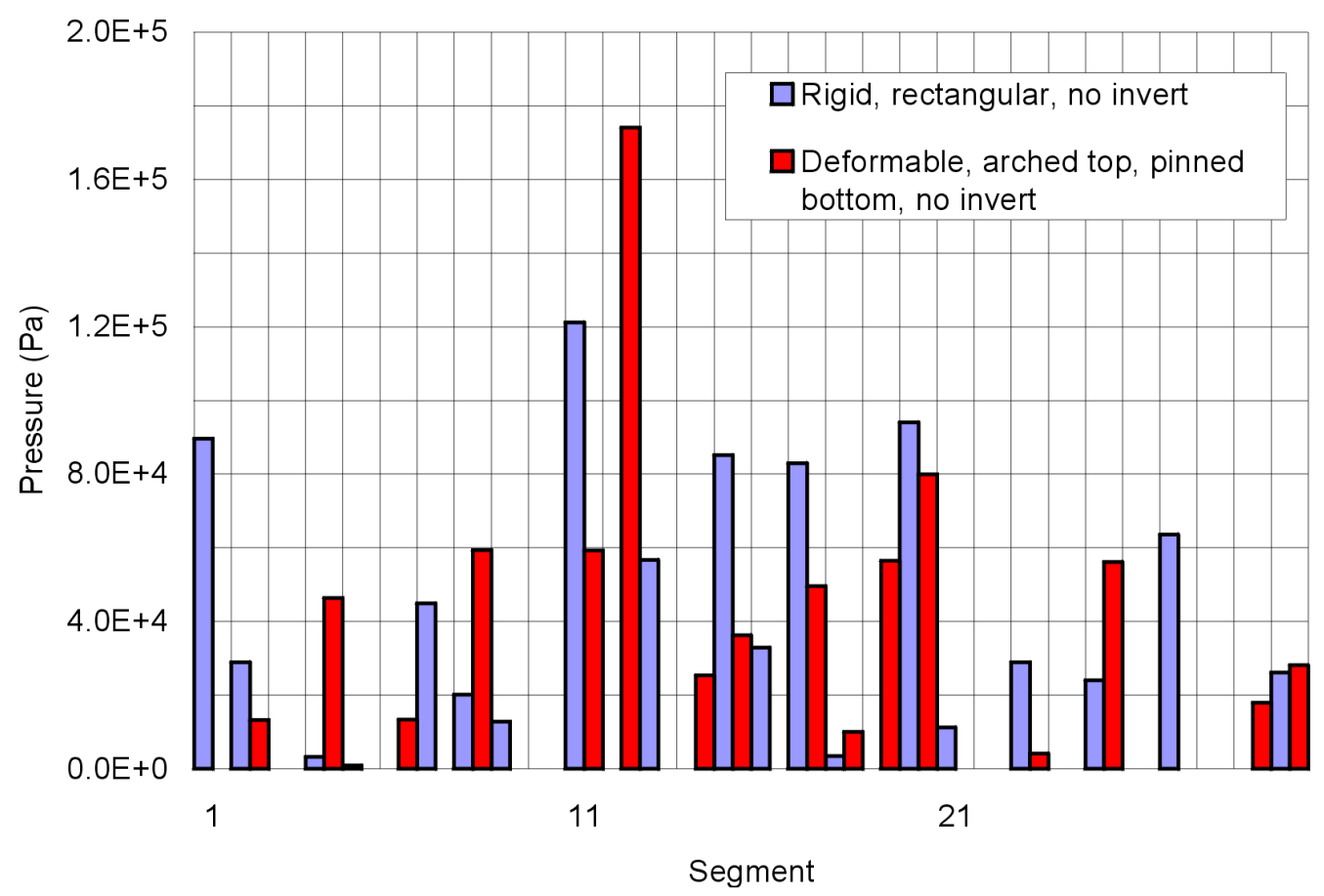

Figure P-3. Ground Motion 10 $0^{-5}$, Case 11: Loads On the Drip Shield For Cases Without the Invert

Table P-1. Ground motion 10-5, Case 11: Average Loads On the Drip Shield For Cases Without the Invert

\begin{tabular}{|l|c|c|c|}
\hline \multicolumn{1}{|c|}{ Case } & Left & Top & Right \\
\hline & $\mathbf{k N} / \mathbf{m}^{\mathbf{2}}$ & $\mathbf{k N / \mathbf { m } ^ { 2 }}$ & $\mathbf{k N} / \mathbf{m}^{\mathbf{2}}$ \\
\hline rigid, rectangular & 15.4 & 47.63 & 20.03 \\
\hline $\begin{array}{l}\text { deformable, arched top, pinned } \\
\text { sides }\end{array}$ & 10.62 & 49.13 & 13.25 \\
\hline
\end{tabular}

The drip shield will rest on the invert under its own weight. The load by the rockfall, in addition to deforming it, may also move the entire drip shield by sliding it along the invert and by lifting it from the invert. Also, the inertial forces during seismic shaking can cause movement of the drip shield. It is expected that movement of the drip shield will have an effect on the load of the caved rock on the drip shield. For example, it is observed in the case of the rigid drip shield that there is often a significant imbalance between the horizontal forces acting on the drip shield. If the drip shield is free to move horizontally, the imbalance should be relatively small, less than the frictional force between the drip shield and the invert.

Case 11 was then run with the invert presented as a horizontal slab (shown in Figure P-4). It was considered in the simulations that the invert is rigid, slaved to the free-field motion of the rock mass. The friction angle between the drip shield and the invert is 22 degrees, which corresponds to the friction coefficient of 0.4 . The pallet and the waste package also are included in the model and are modeled as rigid, slaved to the free-field motion of the rock mass. The presence of the invert affects the rockfall. The invert provides horizontal support at its elevation and affects the volume of the initial drift cross-section that can be filled with the caved rock, resulting in earlier build-up of the back-pressure by the caved rock, compared to the cases in which the caved rock 
also fills the space below the invert (as shown in Figure P-2). Consequently, the results of the models with the invert cannot be compared with the results of the models without the invert. Three cases (all of which include the invert) are considered. The model shown in Figure P-4 (The model configuration in the equilibrium state after seismic shaking is shown.) is for a rigid drip shield slaved to the invert (i.e., the drip shield has the same motion as the free-field). In the model shown in Figure P-5, the drip shield can slide freely on the invert, but it cannot separate from the invert. The most realistic conditions of interaction between the drip shield and the invert are represented in the case shown in Figure P-6. In this case, the drip shield can slide, but it also can detach from the invert. (It is shown in Figure P-6 that the left side of the drip shield has lifted off the invert.)

The amount of the rockfall in the three cases is less than in the cases without the invert. The drip shield is not completely covered with caved rock. Therefore, the example is not good for assessing the effect of the deformability of the drip shield on the stress arching in the caved rock mass above the drip shield. The static loads on the drip shield (shown in Figure P-7 and summarized in Table P-2) are relatively small. However, the effect of the drip shield sliding on the invert on the horizontal forces acting on the drip shield can be noticed. The imbalance between the forces on the left and right sides of the drip shield is much smaller for the cases in which the drip shield is allowed to slide (Some imbalance still exists even for those two cases because of the frictional forces and the reaction between the drip shield and the pallet when the drip shield comes in the contact with the pallet, as shown in Figure P-6.). The histories of the impact loads during the rockfall for the case shown in Figure P-6 are shown in Figures P-8, P-9, and P-10 for the left side, the top, and the right side of the drip shield, respectively. Relatively large impact loads are recorded; in this case, the maximum impact pressures are of the order of $5 \mathrm{MPa}$.

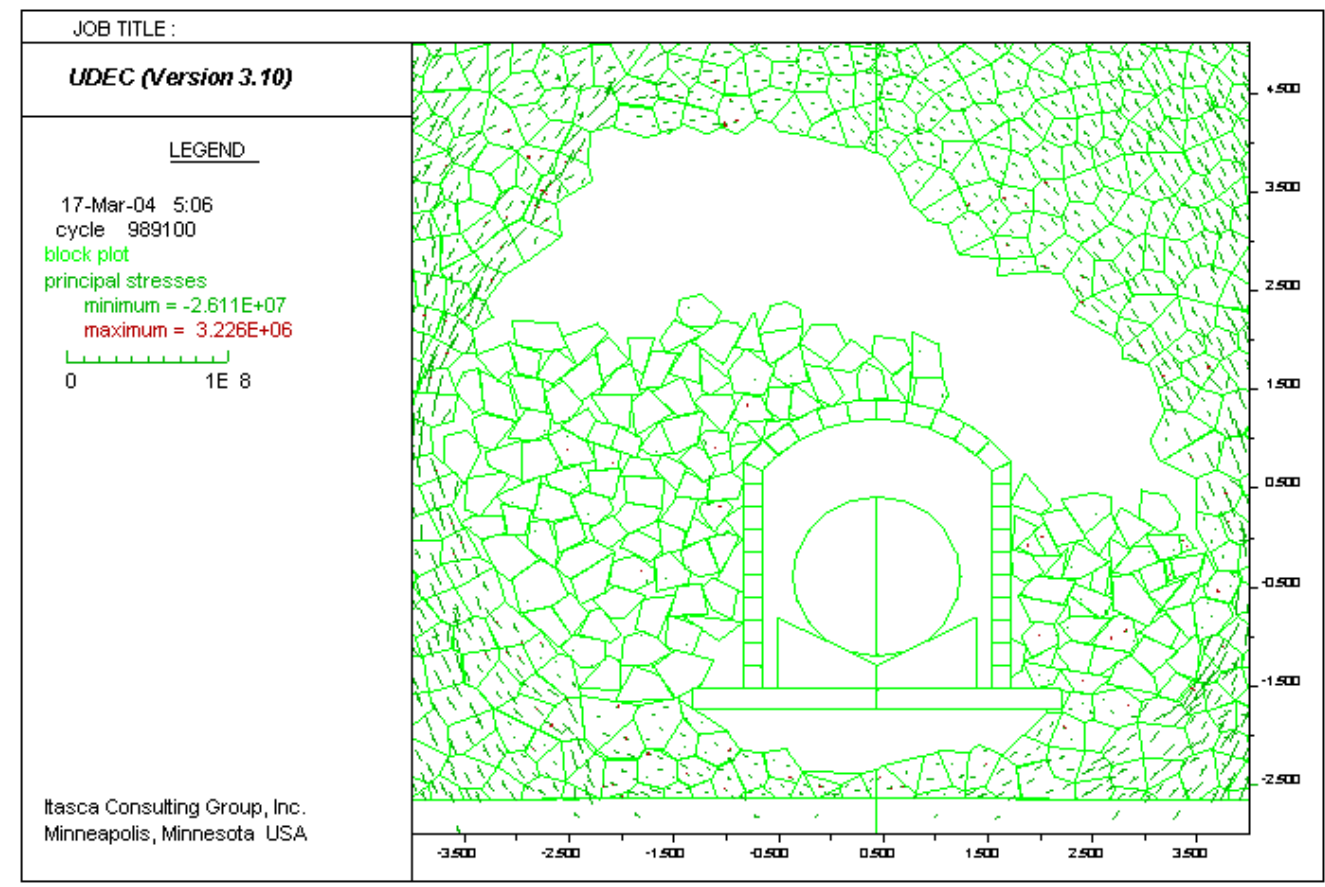

Figure P-4. Ground Motion 10-5, Case 11: Equilibrium State for Rigid Drip Shield With Arched Top, Bottom Fixed to the Invert 


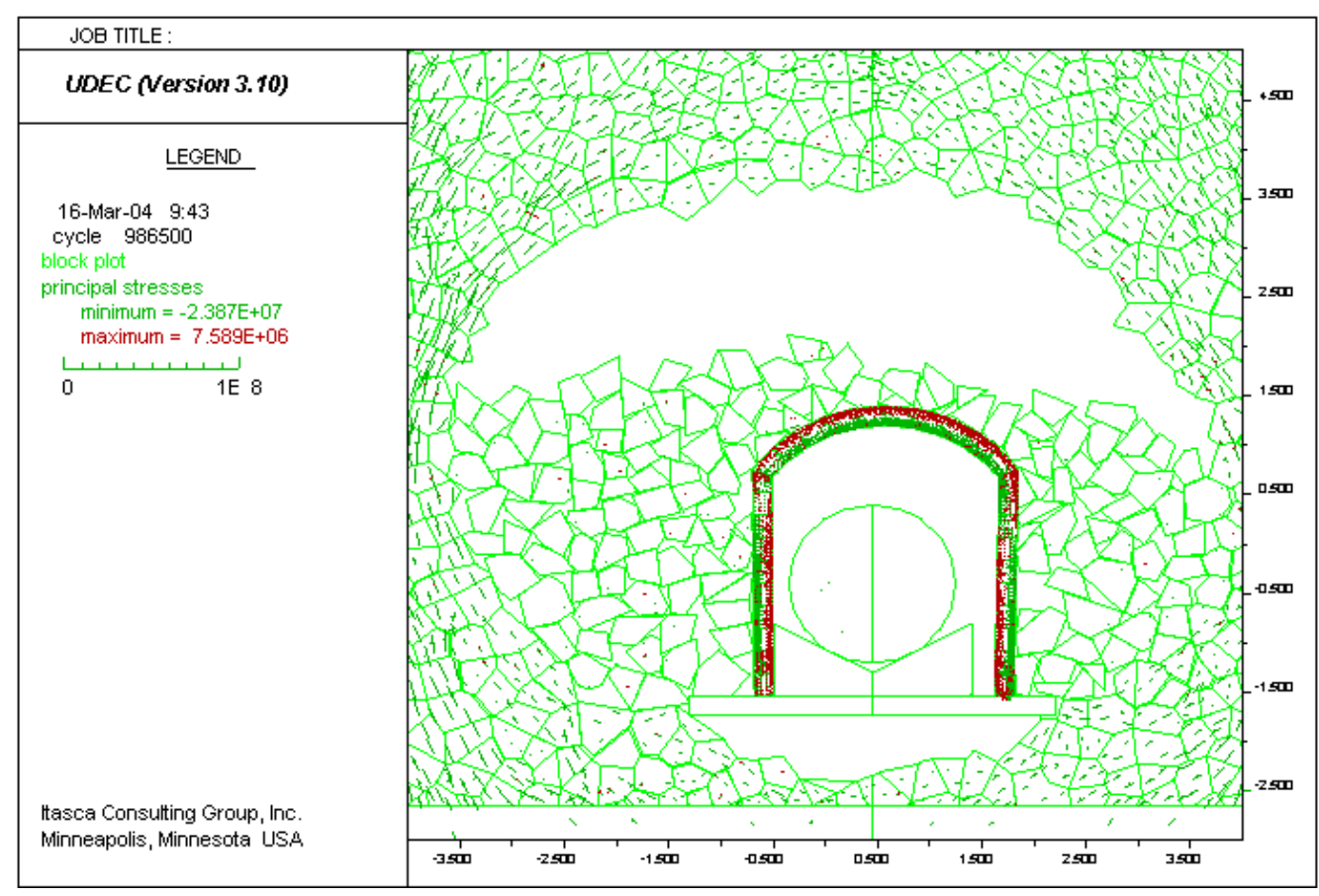

Figure P-5. Ground Motion $10^{-5}$, Case 11: Equilibrium State for Deformable Drip Shield With Arched Top, Bottom Slides On the Invert

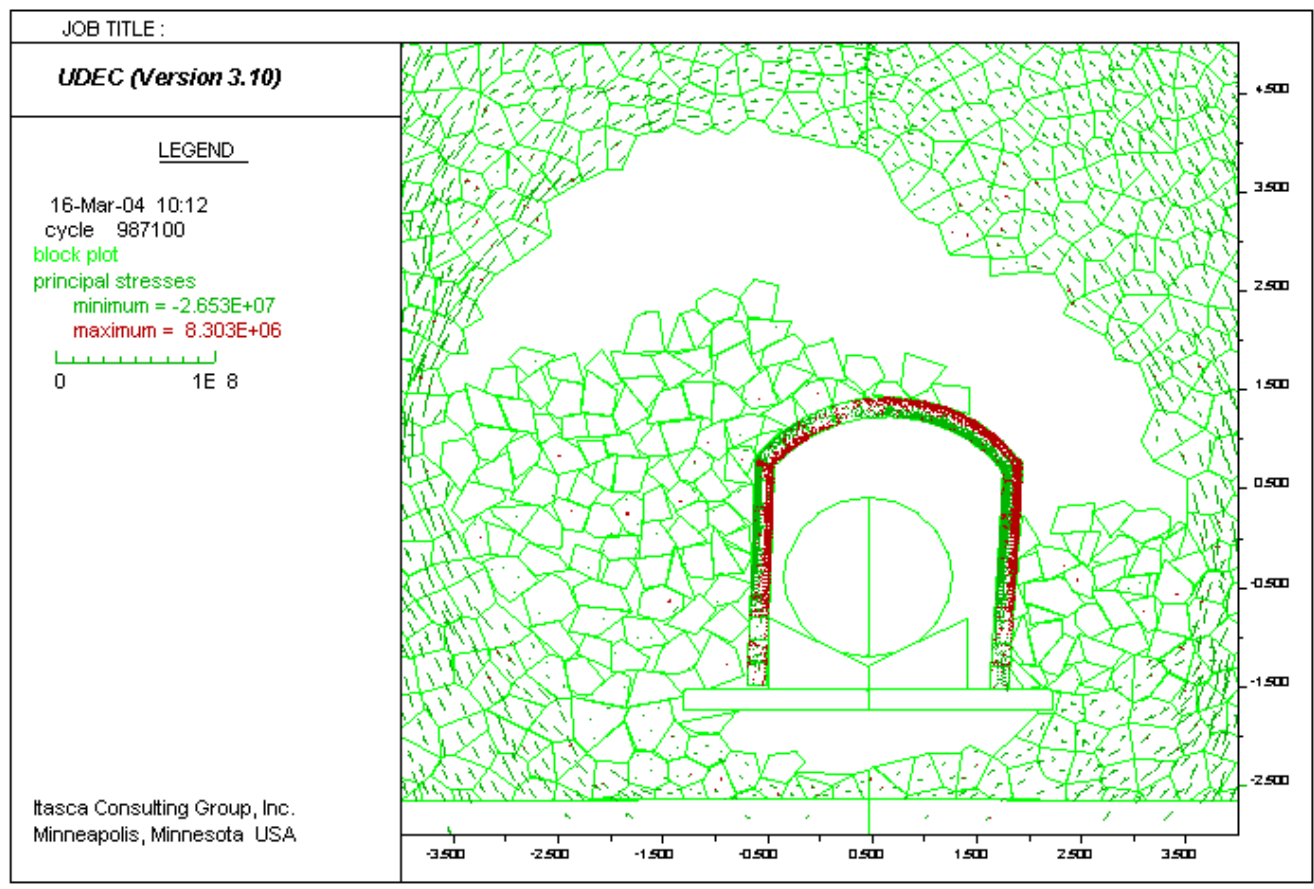

Figure P-6. Ground Motion $10^{-5}$, Case 11: Equilibrium State for Deformable Drip Shield With Arched Top, Bottom Rests On the Invert 


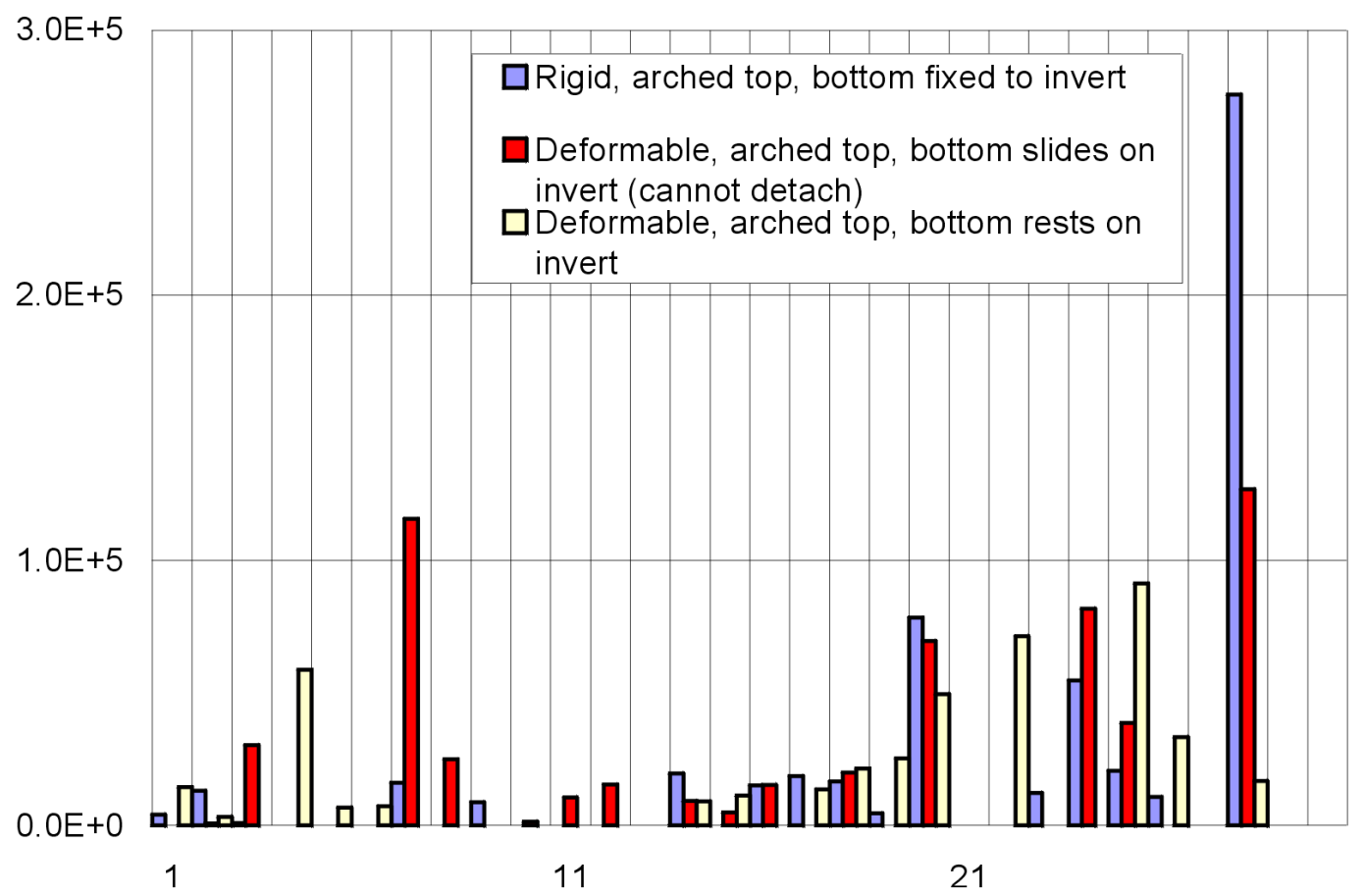

Figure P-7. Ground Motion $10^{-5}$, Case 11: Loads On The Drip Shield for Cases With the Invert

Table P-2. Ground Motion 10-5 , Case 11: Average Loads On the Drip Shield for Cases With Invert

\begin{tabular}{|c|c|c|c|}
\hline Case & Left & Top & Right \\
\hline & $\mathrm{kN} / \mathrm{m}^{2}$ & $\mathrm{kN} / \mathrm{m}^{2}$ & $\mathrm{kN} / \mathrm{m}^{2}$ \\
\hline $\begin{array}{l}\text { rigid, arched top, bottom fixed to } \\
\text { invert }\end{array}$ & 37.40 & 15.25 & 4.28 \\
\hline $\begin{array}{l}\text { deformable, arched top, bottom } \\
\text { slides on invert }\end{array}$ & 24.72 & 14.46 & 17.28 \\
\hline $\begin{array}{l}\text { deformable, arched top, bottom } \\
\text { rests on invert }\end{array}$ & 21.26 & 12.99 & 9.00 \\
\hline
\end{tabular}




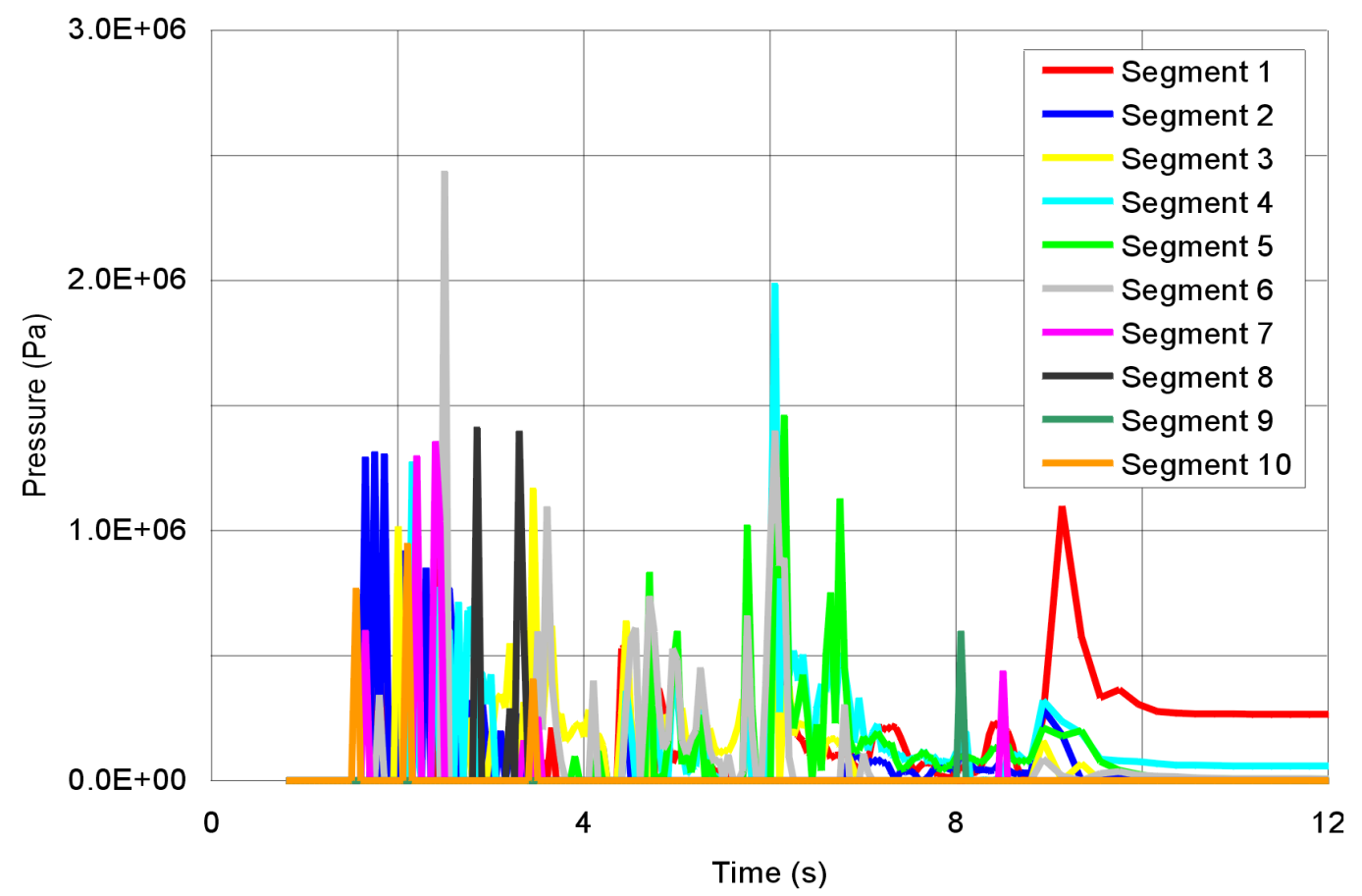

Figure P-8. Ground Motion 10 ${ }^{-5}$, Case 11: Dynamic Loads On the Right Side for Deformable Drip Shield With Arched Top, Bottom Rests On the Invert

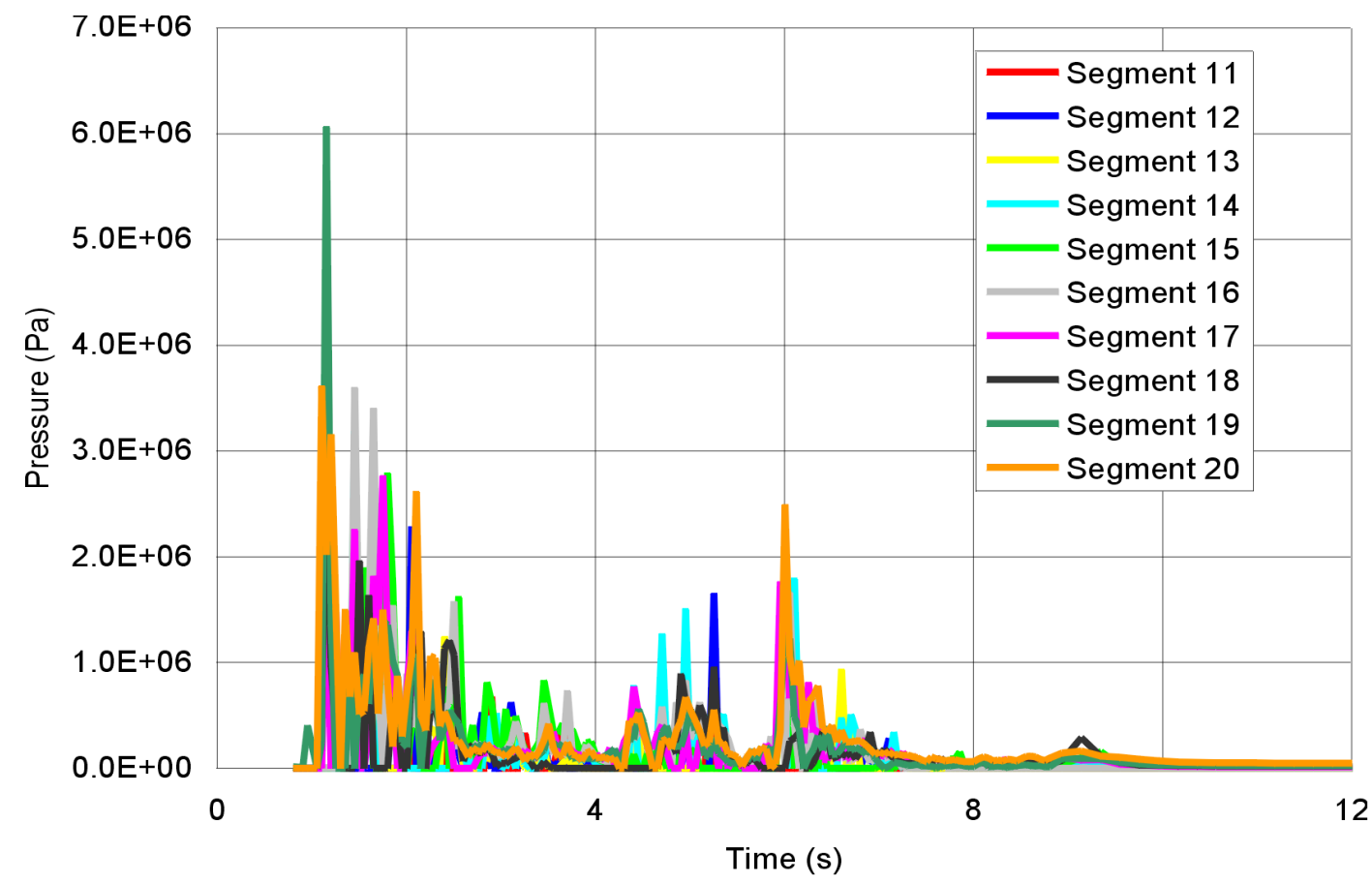

Figure P-9. Ground Motion $10^{-5}$, Case 11: Dynamic Loads On The Top for Deformable Drip Shield With Arched Top, Bottom Rests On the Invert 


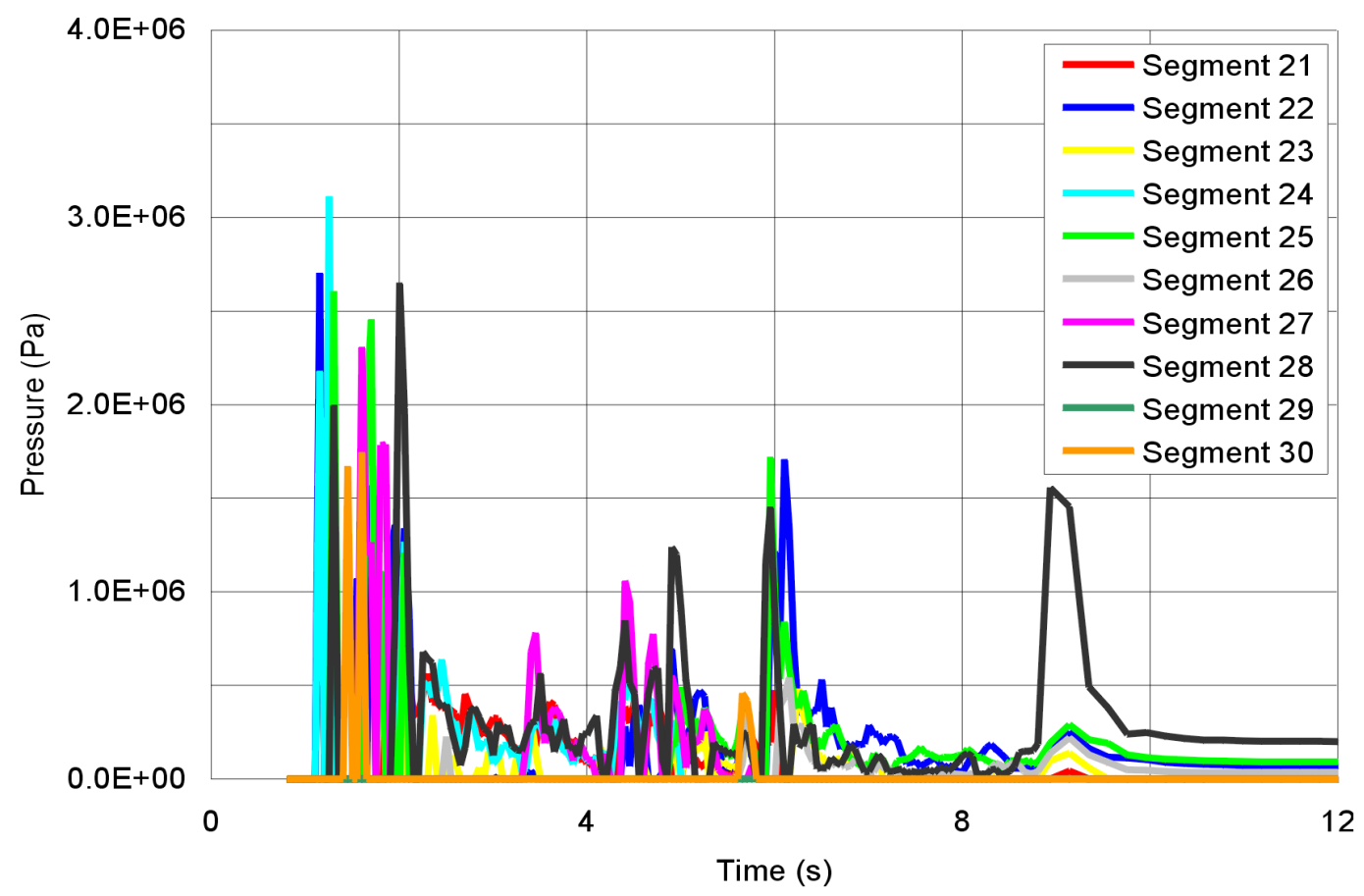

Figure P-10. Ground Motion $10^{-5}$, Case 11: Dynamic Loads On the Left Side for Deformable Drip Shield With Arched Top, Bottom Rests On the Invert

\section{P2.2 QUASI-STATIC DEGRADATION}

The quasi-static drift degradation was analyzed for both $0.2-\mathrm{m}$ and $0.3-\mathrm{m}$ sizes of the Voronoi blocks.

\section{P2.2.1 Block Size $0.3 \mathrm{~m}$}

The final geometries of the models without the invert are shown for the rectangular, rigid drip shield in Figure P-11 and for the deformable drip shield pinned at the bottom of two sides in Figure P-12. The summary of the drip shield loads is provided in Figure P-13 and Table P-3. In this particular case deformability of the drip shield does not seem to have a significant effect on the vertical load on the drip shield. In fact, the load on the deformable drip shield is approximately 10 percent larger than on the rigid, rectangular drip shield (The increase in the load on the top is probably due to randomness in the response of this system.). However, the horizontal loads on the sides of the drip shield in the model with the deformable drip shield are much less than in the model with the rigid drip shield. The imbalance between the horizontal forces in the case of the deformable drip shield is because the bottom on both sides of the deformable drip shield is pinned. That boundary condition resulted in very large force at the lower left end (i.e., segment 30 in Figure P-13) of the drip shield. 


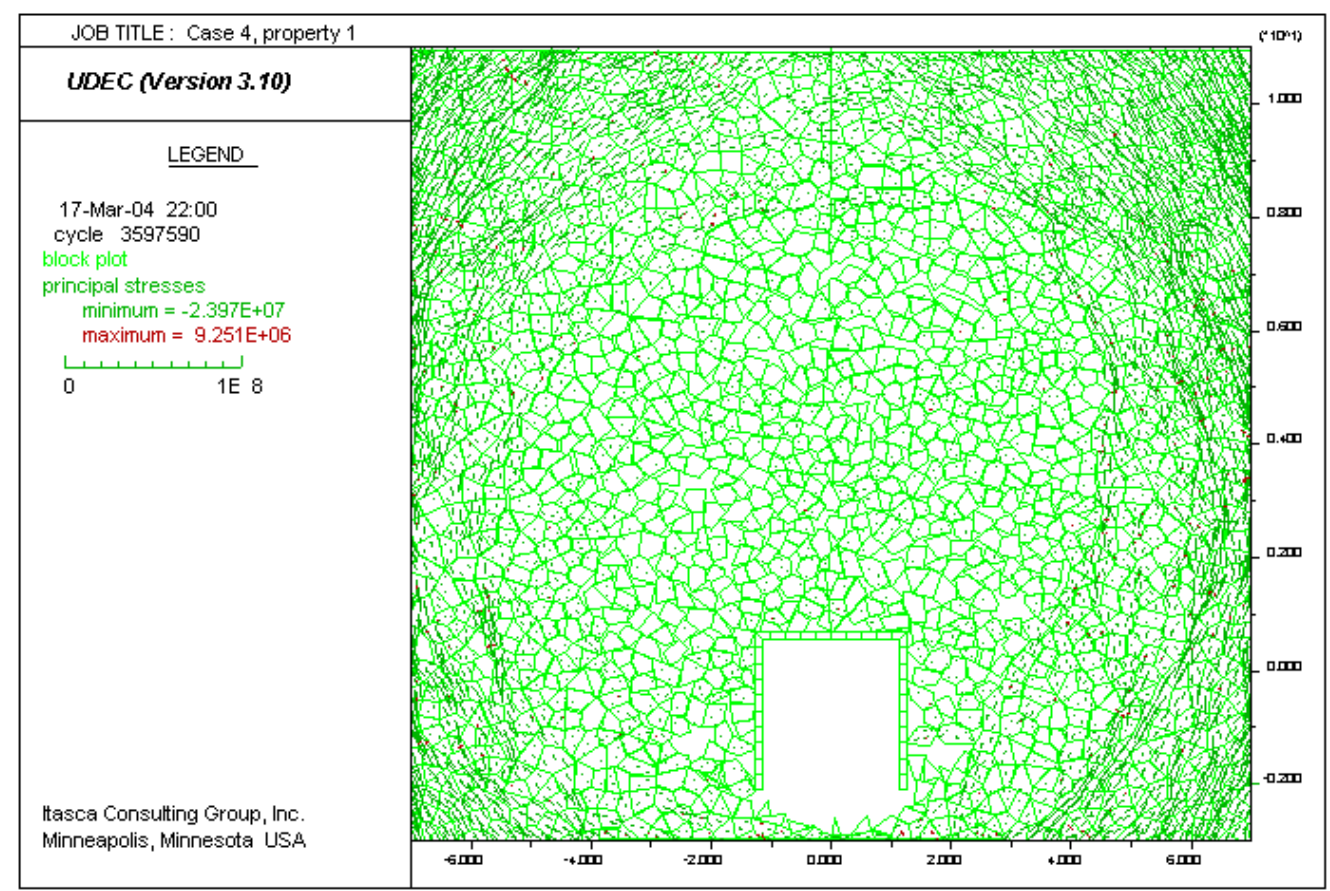

Figure P-11. Quasi-Static Drift Degradation, $0.3 \mathrm{~m}$ Block Size: Equilibrium State for Rigid, Rectangular Drip Shield

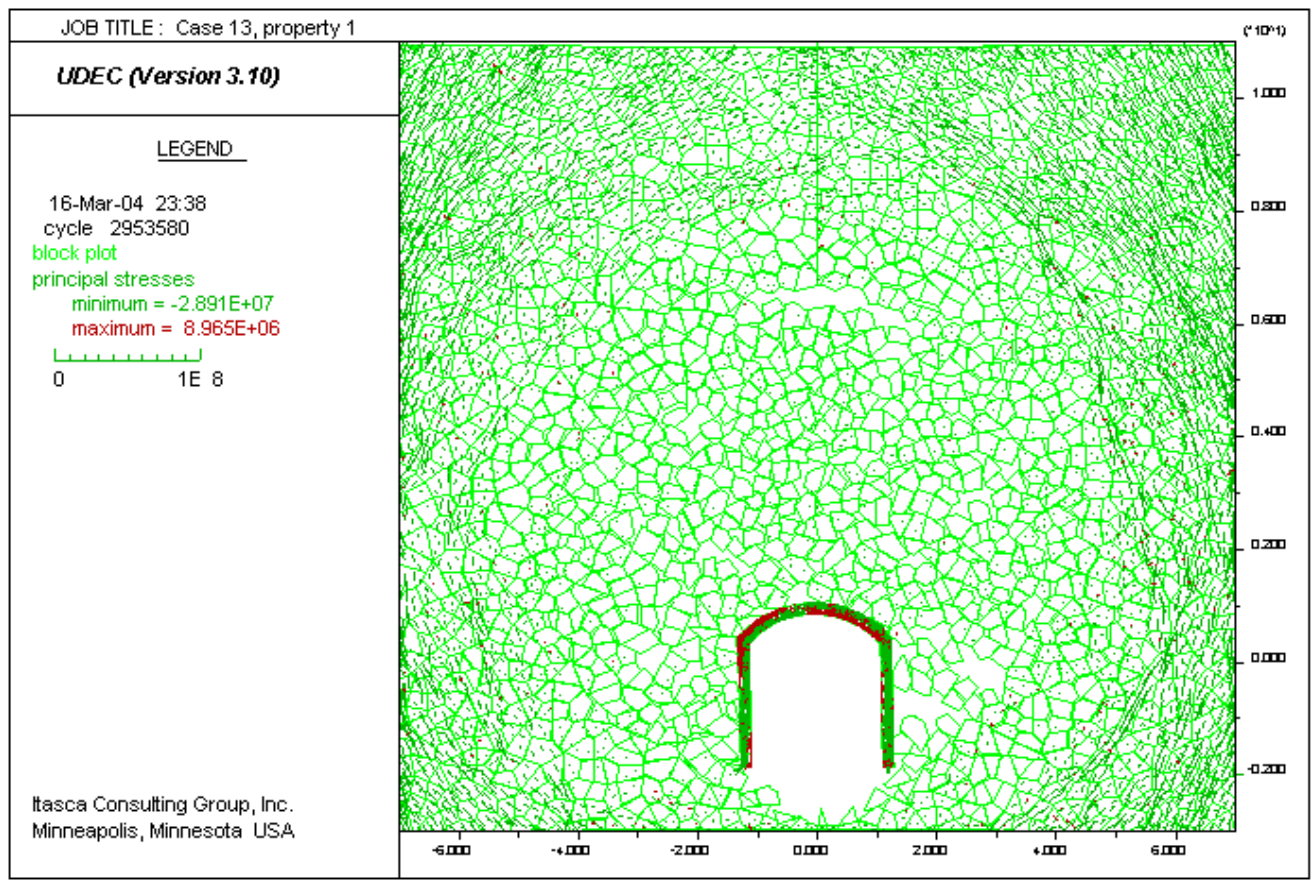

Figure P-12. Quasi-Static Drift Degradation, 0.3-m Block Size: Equilibrium State for Deformable Drip Shield With Arched Top, Pinned Bottom, No Invert 


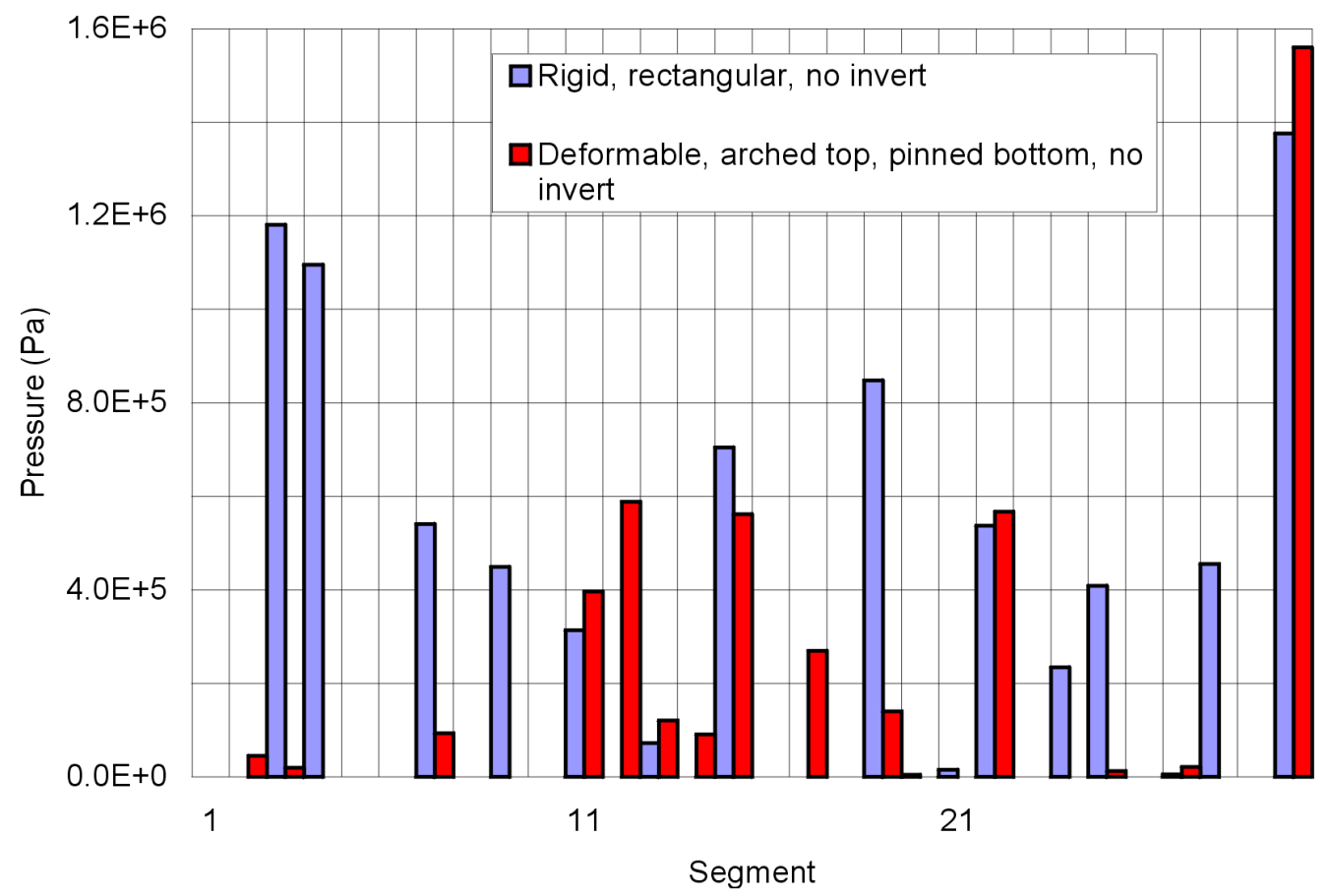

Figure P-13. Quasi-Static Drift Degradation, $0.3 \mathrm{~m}$ Block Size: Loads On the Drip Shield for Cases Without Invert

Table P-3. Quasi-Static Drift Degradation, $0.3 \mathrm{~m}$ Block Size: Average Loads On the Drip Shield For Cases Without the Invert

\begin{tabular}{|l|c|c|c|}
\hline \multicolumn{1}{|c|}{ Case } & Left & Top & Right \\
\hline & $\mathbf{k N} / \mathbf{m}^{\mathbf{2}}$ & $\mathbf{k N} / \mathbf{m}^{\mathbf{2}}$ & $\mathbf{k N} / \mathbf{m}^{\mathbf{2}}$ \\
\hline rigid, rectangular & 303.18 & 194.18 & 326.70 \\
\hline $\begin{array}{l}\text { deformable, arched top, pinned } \\
\text { sides }\end{array}$ & 216.06 & 216.65 & 15.82 \\
\hline
\end{tabular}

If the invert, the pallet, and the waste package are included in the model, the extent of the caved region is reduced as shown in Figures P-14 and P-15. Stable arches are formed, with a gap between the caved rubble and the stable rock mass, due to the finite size of the rock blocks considered here despite the fact that the cohesive strength of the joints (contacts between the blocks) is reduced to zero. Two cases are considered here. The case with the rigid drip shield is shown in Figure P-14; the case with the drip shield resting under gravity on the invert is shown in Figure P-15 (When resting under gravity, the drip shield is allowed to slide and detach from the invert.). The results for the drip shield loads (shown in Figure P-16 and Table P-4) are completely dominated by the reduced size of the cave above the emplacement drift. The pressures are relatively small, and the effect of deformability of the drip shield is not apparent. 


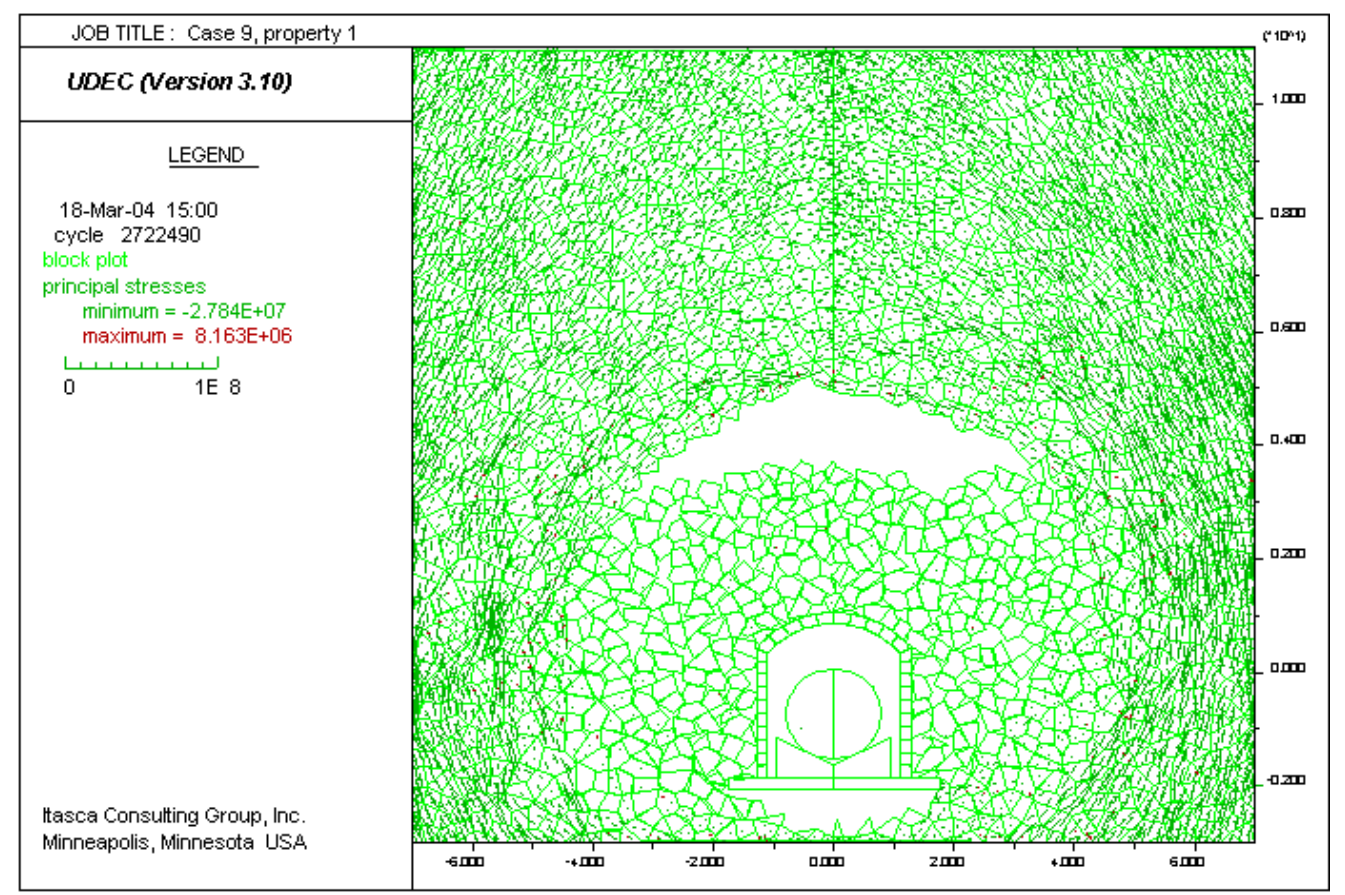

Figure P-14. Quasi-Static Drift Degradation, $0.3 \mathrm{~m}$ Block Size: Equilibrium State for Rigid Drip Shield With Arched Top, Bottom Fixed To the Invert

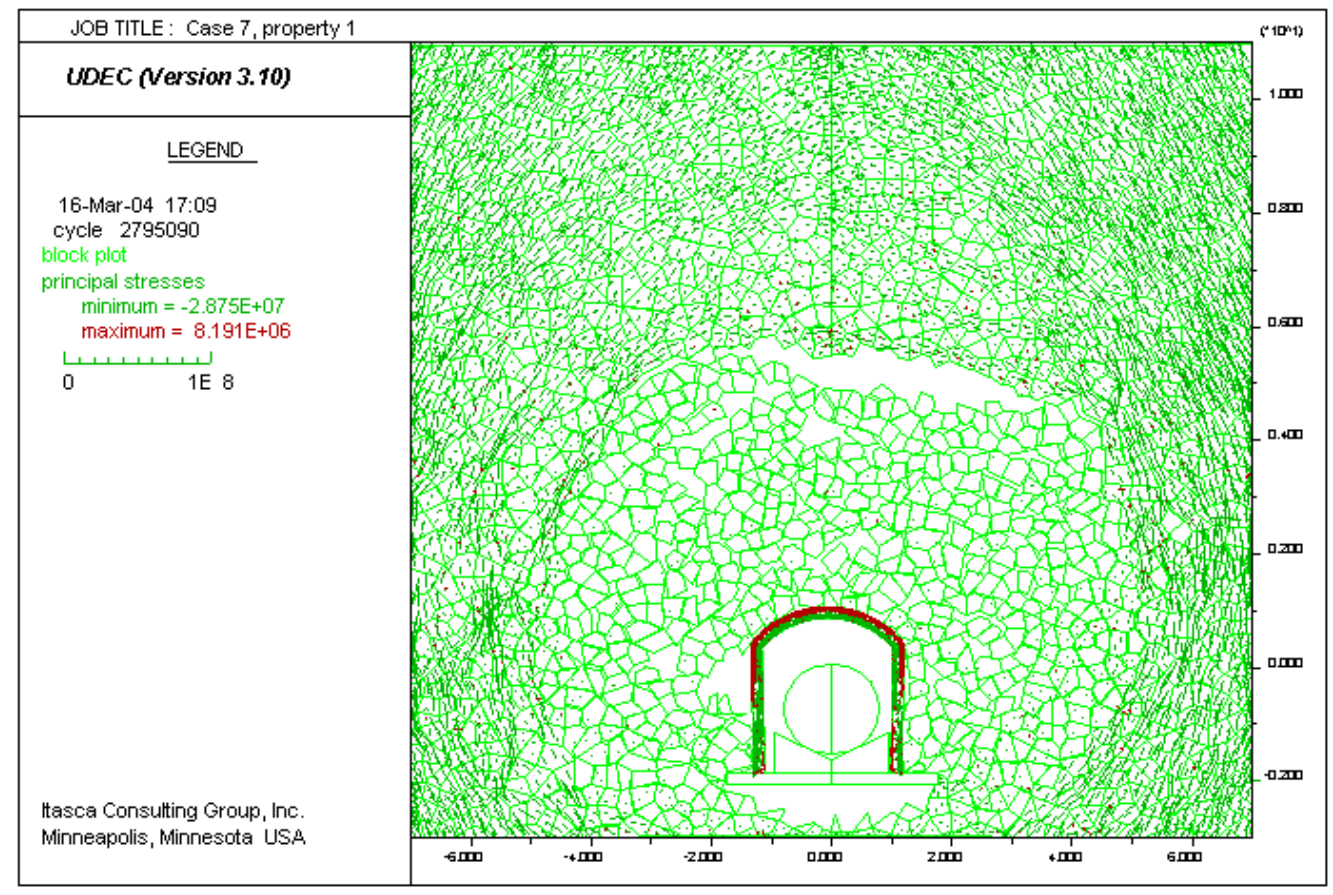

Figure P-15. Quasi-static Drift Degradation, $0.3 \mathrm{~m}$ Block Size: Equilibrium State for Deformable Drip Shield With Arched Top, Bottom Rests On the Invert 


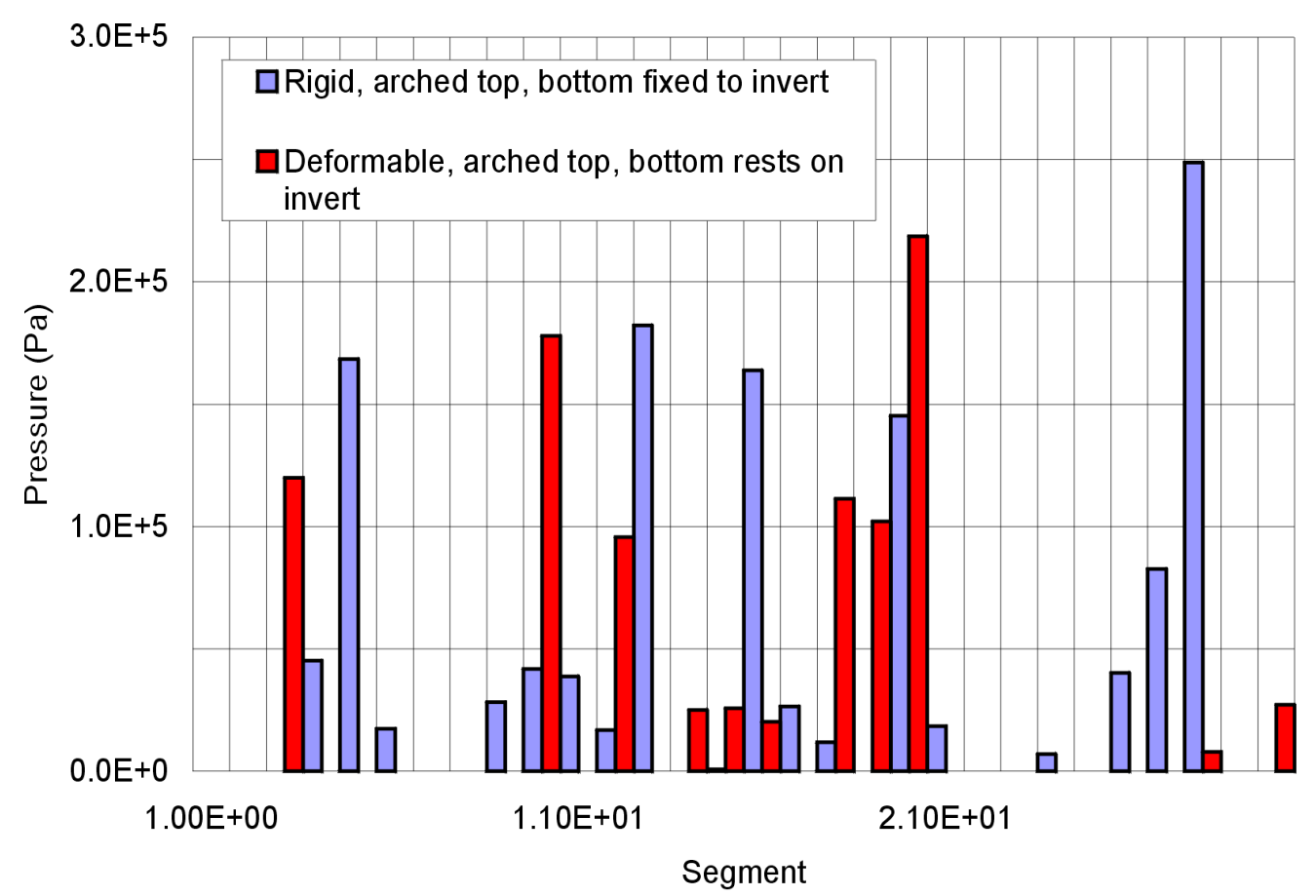

Figure P-16. Quasi-Static Drift Degradation, $0.3 \mathrm{~m}$ Block Size: Loads On the Drip Shield for Cases With the Invert

Table P-4 Quasi-Static Drift Degradation, $0.3 \mathrm{~m}$ Block Size: Average Loads On the Drip Shield For Cases With Invert

\begin{tabular}{|l|c|c|c|}
\hline \multicolumn{1}{|c|}{ Case } & Left & Top & Right \\
\hline & $\mathbf{k N} / \mathbf{m}^{2}$ & $\mathbf{k N} / \mathbf{m}^{2}$ & $\mathbf{k N} / \mathbf{m}^{2}$ \\
\hline rigid, arched top, bottom fixed to invert & 39.70 & 58.56 & 30.09 \\
\hline $\begin{array}{l}\text { deformable, arched top, bottom rests on } \\
\text { invert }\end{array}$ & 35.04 & 59.85 & 29.79 \\
\hline
\end{tabular}

\section{P2.2.2 Block Size $0.2 \mathrm{~m}$}

Quasi-static drift degradation using the smaller, $0.2 \mathrm{~m}$ Voronoi block size, generally results in more conservative predictions of the load on the drip shield. The smaller block size yields better packing and smaller bulking of the caved rock. Also, the potential for formation of stable arches when the cohesive strength of the joints between the blocks is reduced to zero becomes smaller as the block size is decreased.

The equilibrium model configurations for the cases without the invert are shown for the rigid, rectangular drip shield in Figure P-17 and for the deformable drip shield pinned at the bottom in Figure P-18. The contours of displacement magnitudes, which indicate the extent of the caved rock, are shown in Figure P-19 for the model with deformable drip shield. The stress tensor field, shown in Figure P-20 for the same model, illustrates how the stress arches are formed in the caved rock above the drip shield. There is a significant component of randomness in the response of such systems. The correlation between the stress trajectories (shown in Figure P-20) and the static loads on the drip shield (shown in Figure P-21) can be established easily. The large drip shield loads for segments 3 and 13 are consequences of the localized stress trajectories 
of large stress magnitudes directed toward segments 3 and 13. (The segments are numbered from the lower right corner of the drip shield in the counter-clockwise direction.)

The summary of the drip shield loads in Figure P-21 and Table P-5 indicates that the vertical load on the drip shield is reduced for the deformable drip shield. However, there is a significant component of the imbalance in the horizontal forces acting on the deformable drip shield because of the boundary condition used at the bottom of the drip shield.

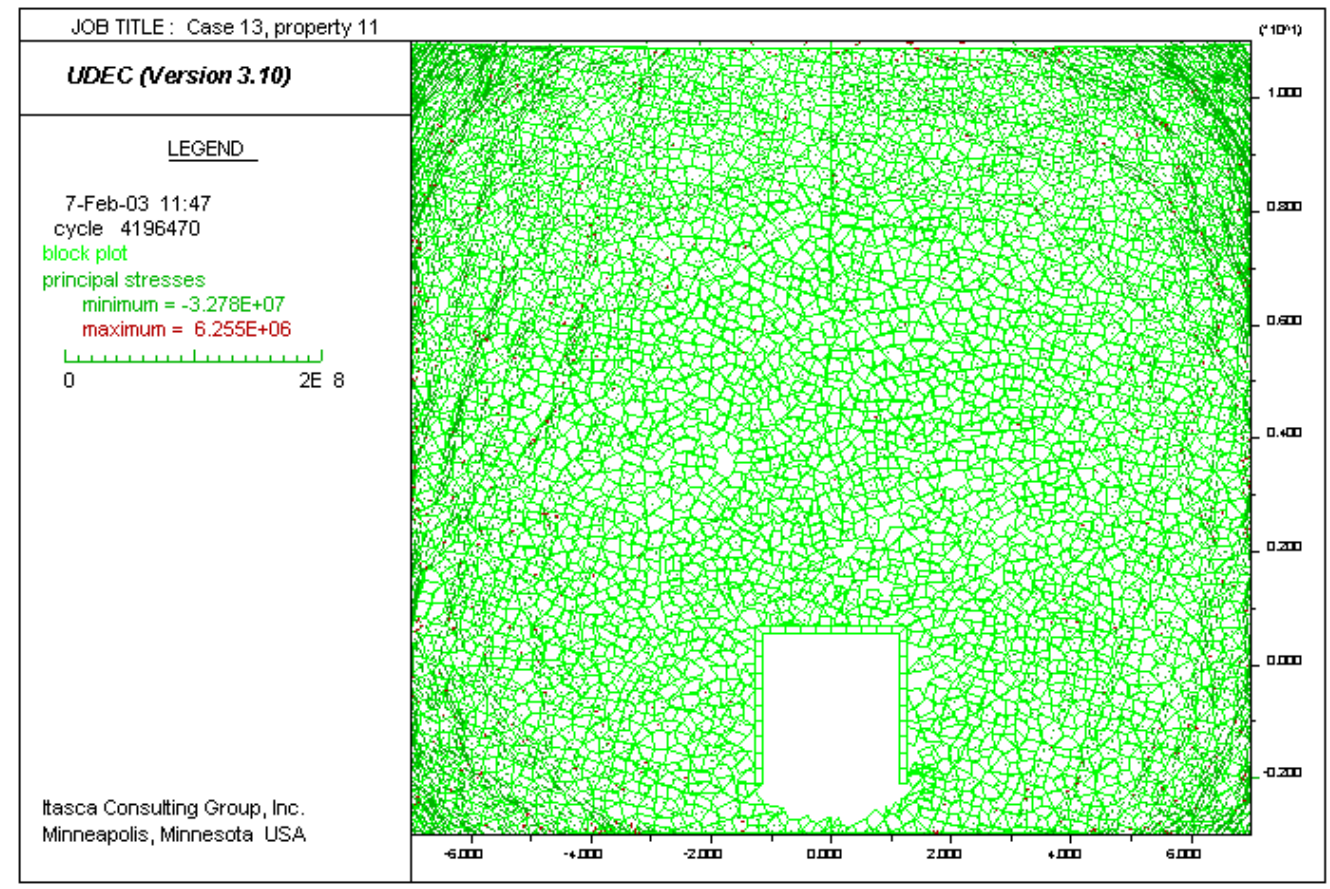

Figure P-17. Quasi-Static Drift Degradation, 0.2-m Block Size: Equilibrium State for Rigid, Rectangular Drip Shield 


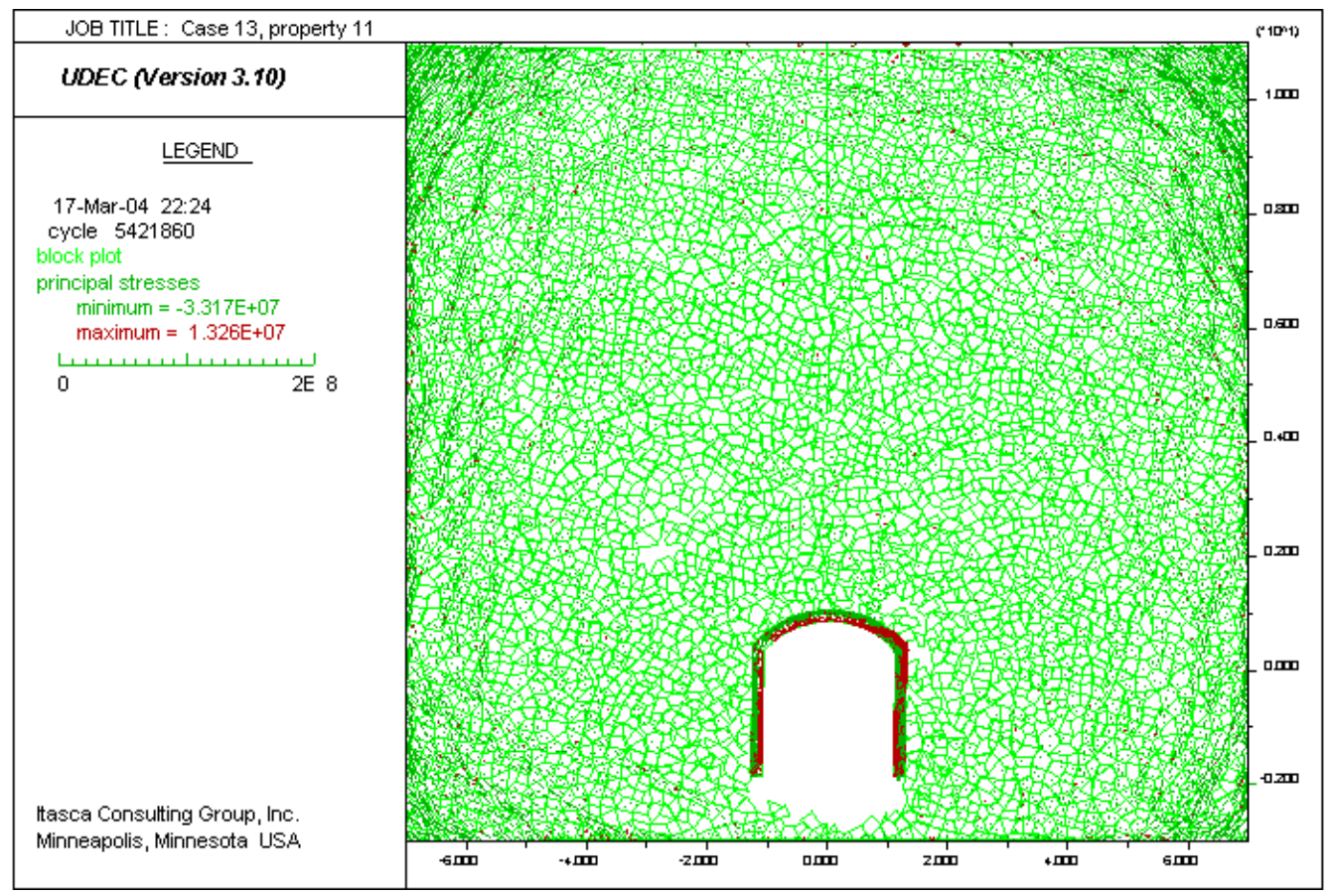

Figure P-18. Quasi-Static Drift Degradation, $0.2 \mathrm{~m}$ Block Size: Equilibrium State for Deformable Drip Shield With Arched Top, Pinned Bottom, No Invert

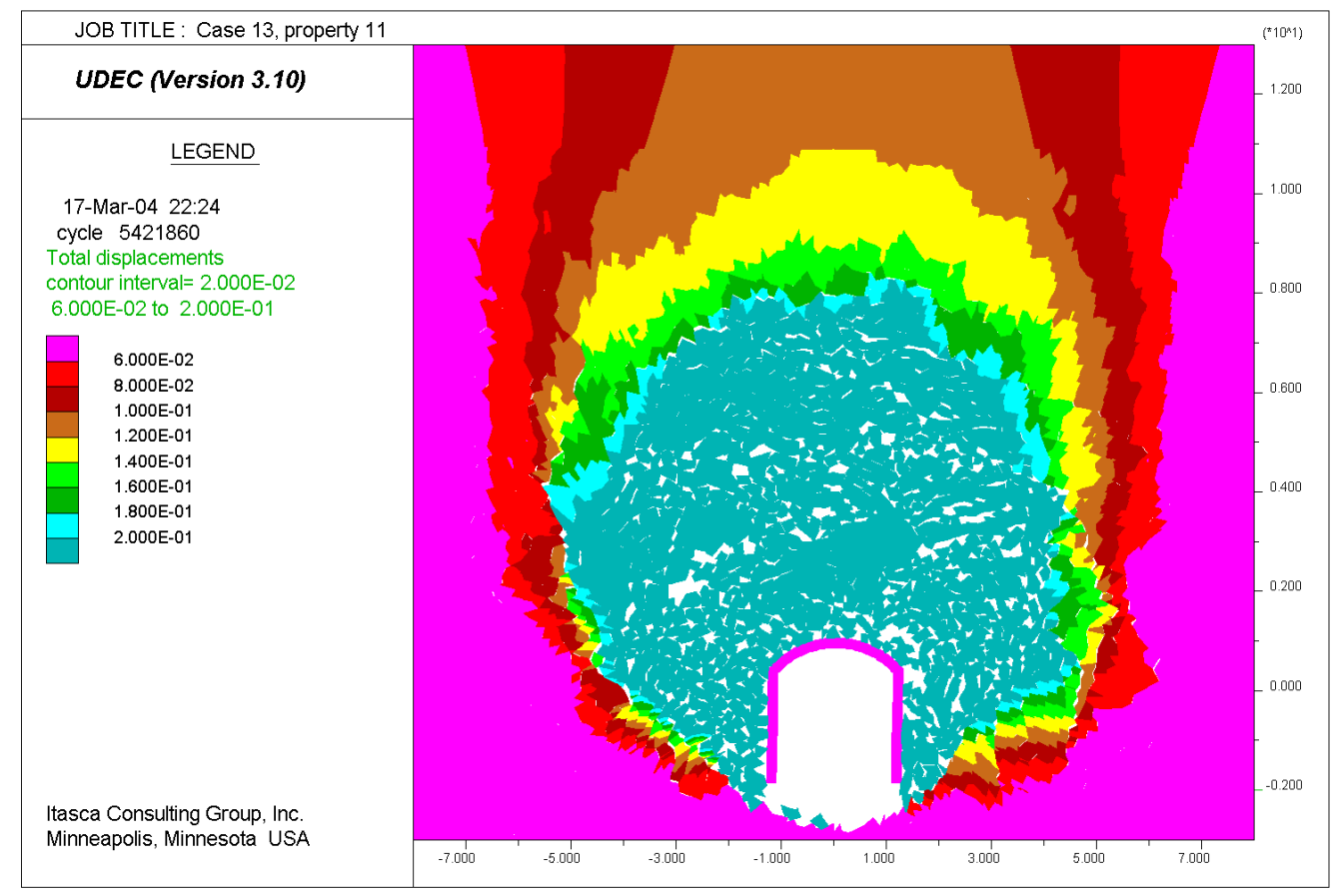

Figure P-19. Quasi-Static Drift Degradation, $0.2 \mathrm{~m}$ Block Size: Contours of Displacement $(\mathrm{m})$ Magnitude for Deformable Drip Shield With Arched Top, Pinned Bottom, No Invert 


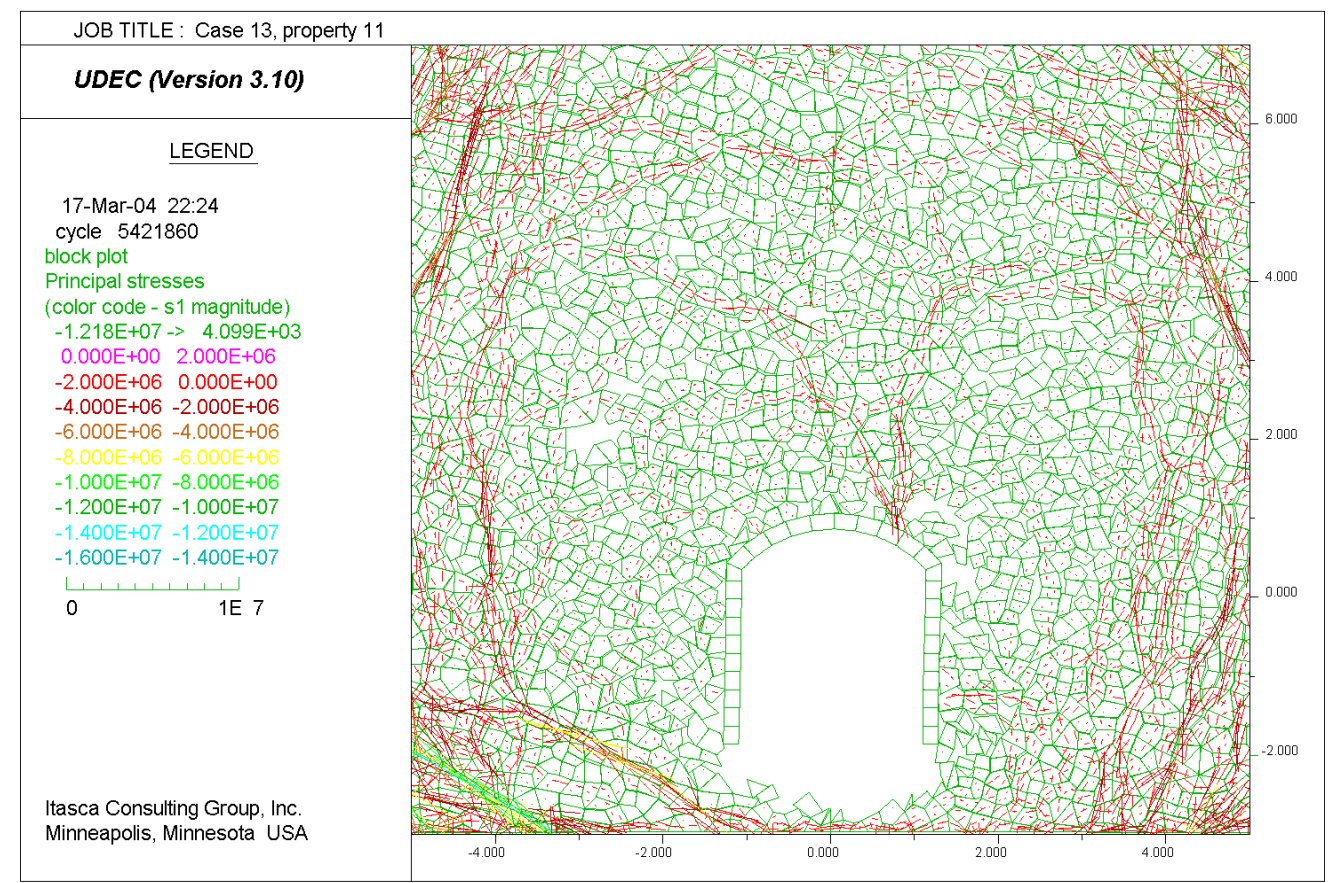

NOTE: $\mathrm{Pa}=$ Pascal.

Figure P-20. Quasi-Static Drift Degradation, $0.2 \mathrm{~m}$ Block Size: Stress Tensor Field (Pa) for Deformable Drip Shield With Arched Top, Pinned Bottom, No Invert

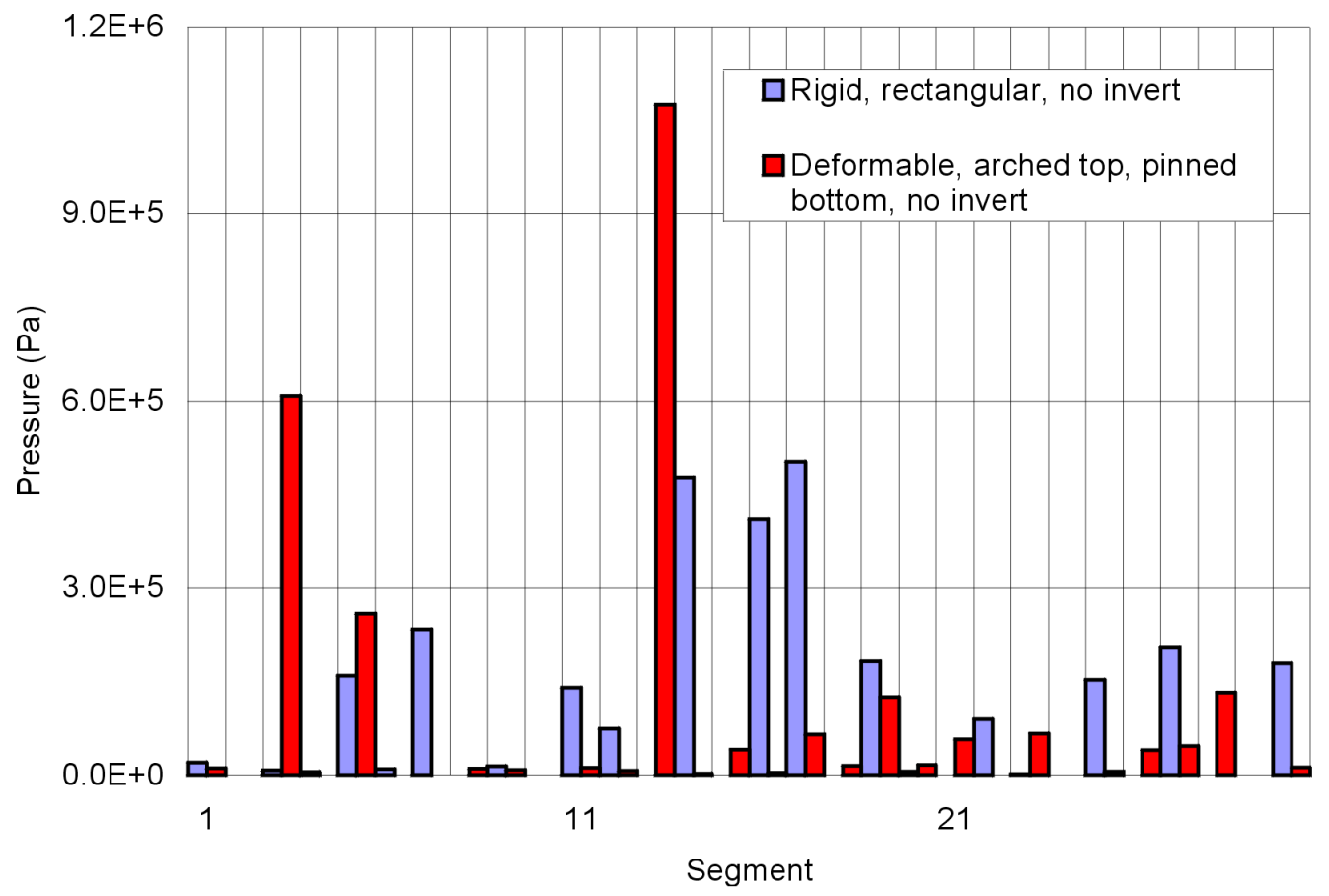

Figure P-21. Quasi-Static Drift Degradation, $0.2 \mathrm{~m}$ Block Size: Loads on the Drip Shield for Cases Without the Invert 
Table P-5. Quasi-Static Drift Degradation, $0.2 \mathrm{~m}$ Block Size: Average Loads On the Drip Shield For Cases Without the Invert

\begin{tabular}{|l|c|c|c|}
\hline \multirow{2}{*}{ Case } & Left & Top & Right \\
\cline { 2 - 4 } & $\mathbf{k N} / \mathbf{m}^{\mathbf{2}}$ & $\mathbf{k N} / \mathbf{m}^{\mathbf{2}}$ & $\mathbf{k N} / \mathbf{m}^{\mathbf{2}}$ \\
\hline rigid, rectangular & 62.61 & 179.16 & 44.78 \\
\hline deformable, arched top, pinned sides & 35.75 & 136.04 & 89.52 \\
\hline
\end{tabular}

The results for the cases with the invert, the pallet, and the waste packages included in the model are shown in Figures P-22 through P-26, and Table P-6. Two cases are considered: the rigid drip shield; and the deformable drip shield, free to slide and detach from the invert. The more realistic model of the drip shield results in reduction (approximately 25 percent) of the vertical load on the drip shield and more balanced horizontal loads (see Table P-6).

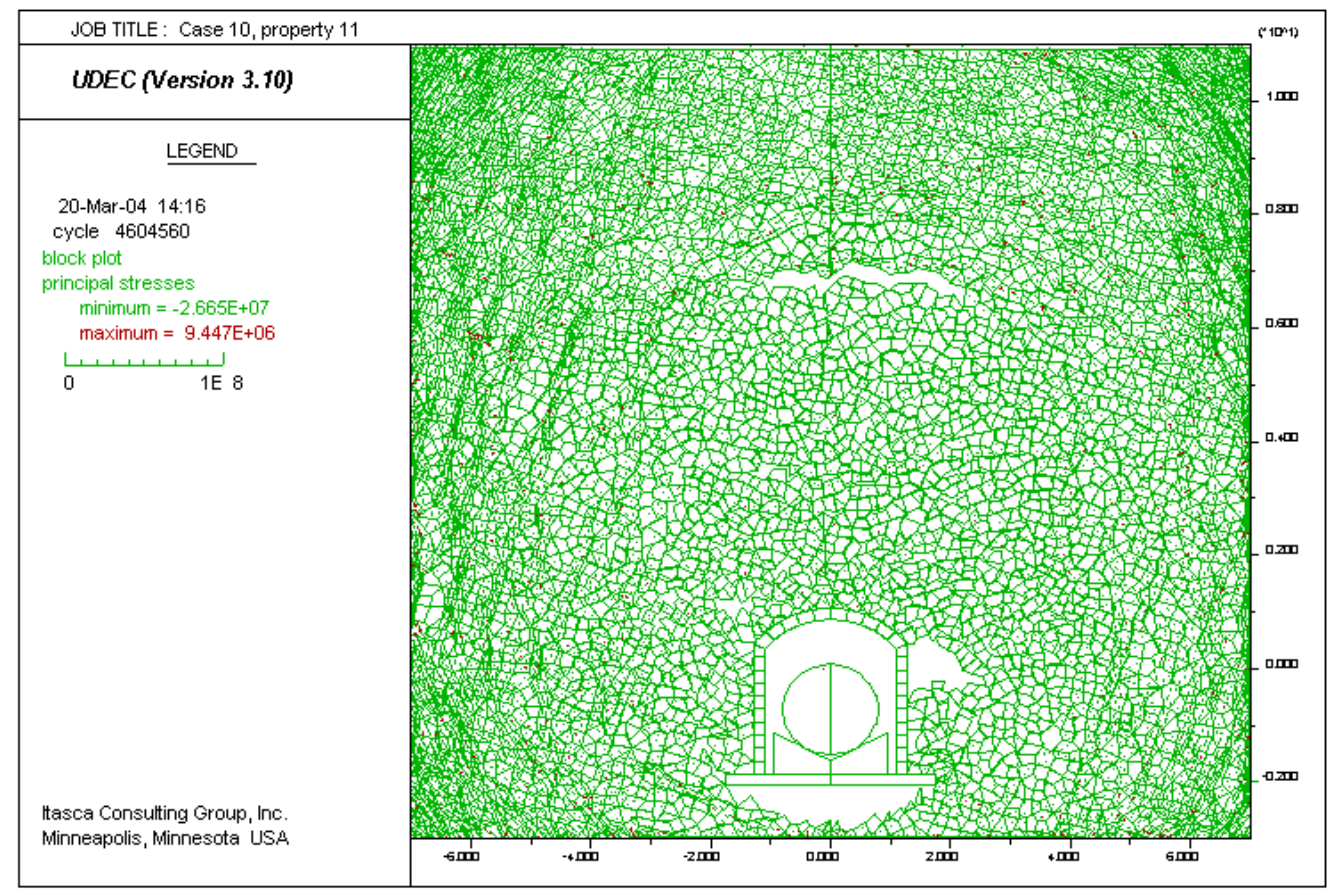

Figure P-22. Quasi-Static Drift Degradation, $0.2 \mathrm{~m}$ Block Size: Equilibrium State for Rigid Drip Shield With Arched Top, Bottom Fixed to the Invert 


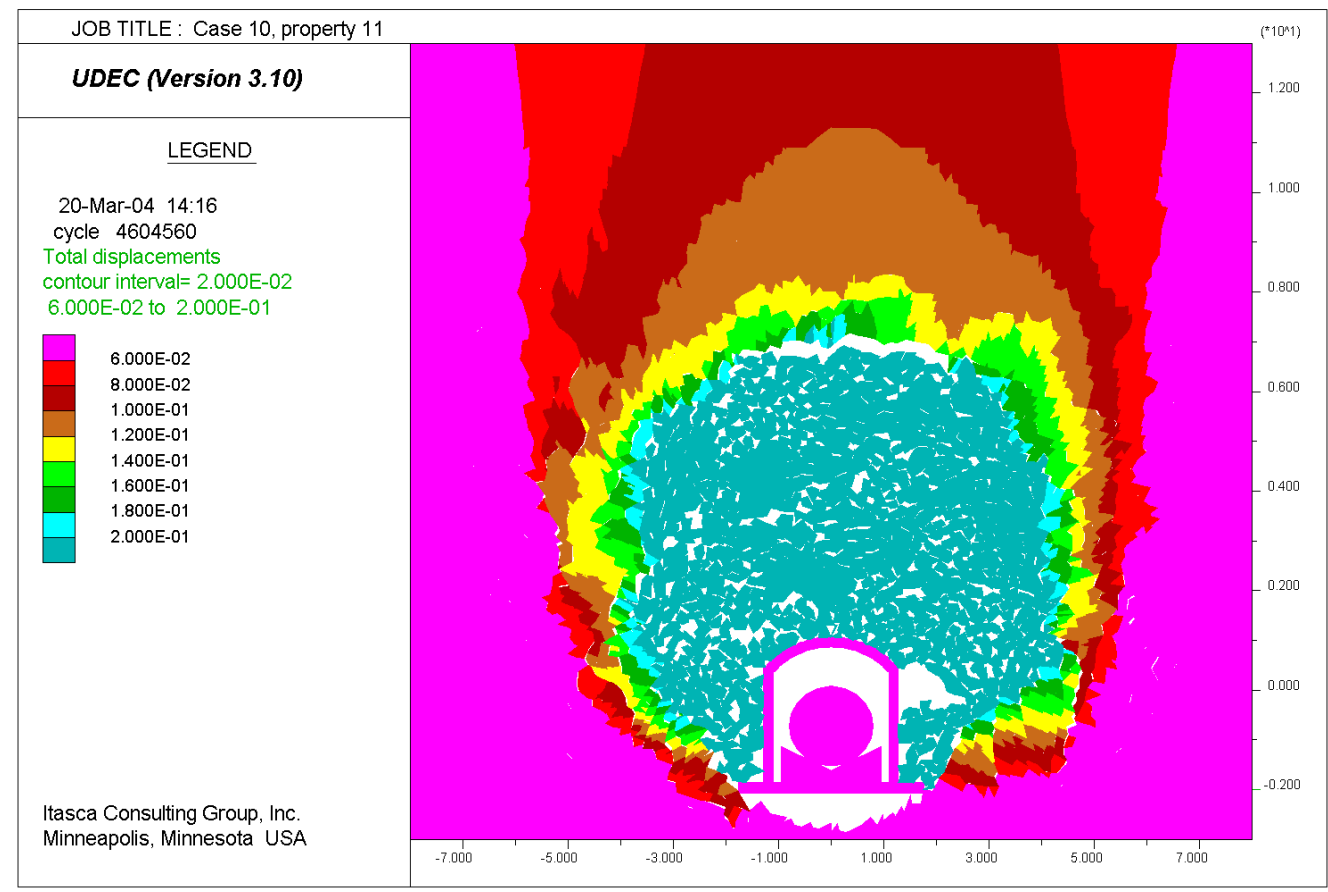

Figure P-23. Quasi-Static Drift Degradation, $0.2 \mathrm{~m}$ Block Size: Contours of Displacement $(\mathrm{m})$ Magnitude for Rigid Drip Shield With Arched Top, Bottom Fixed to the Invert

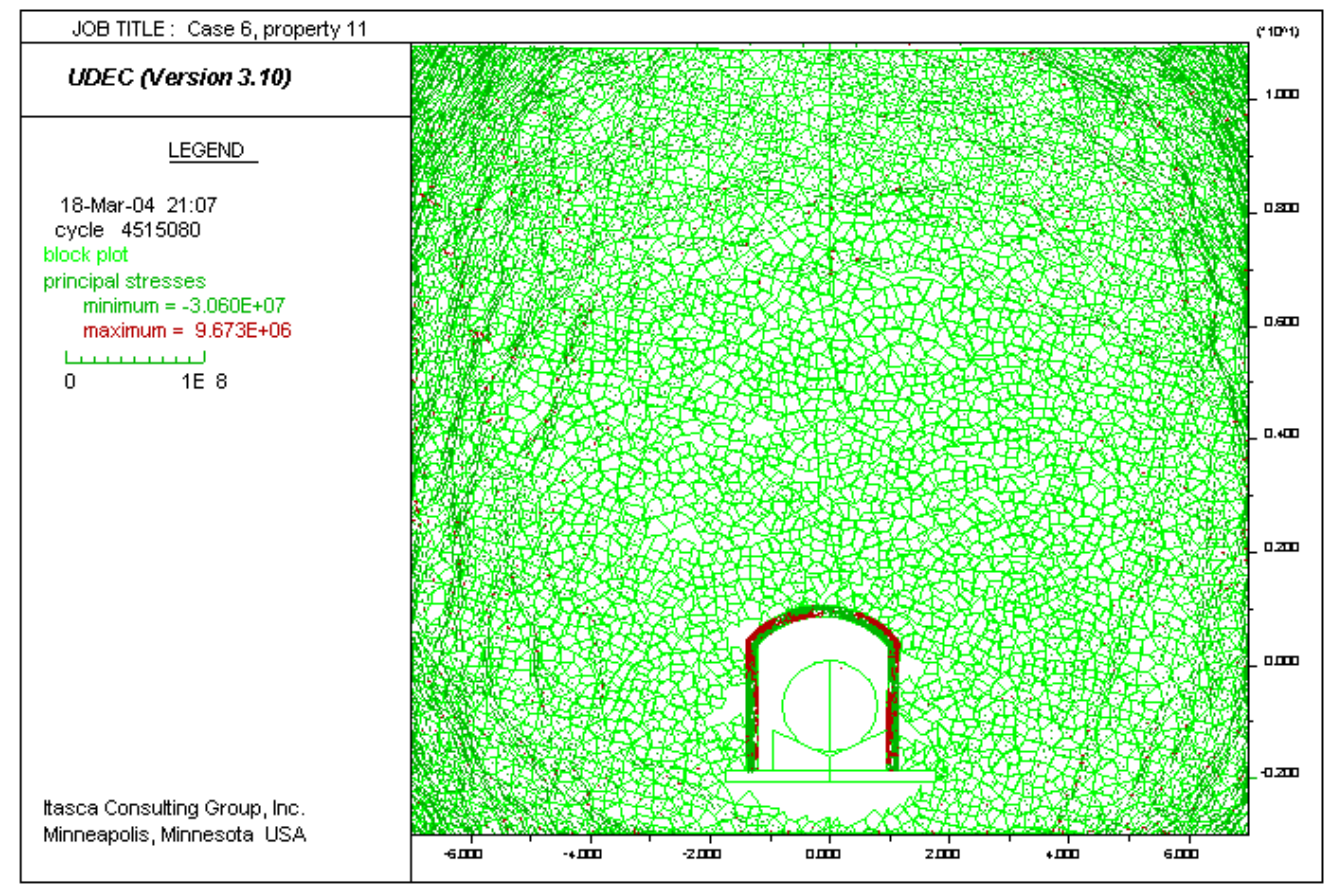

Figure P-24. Quasi-Static Drift Degradation, $0.2 \mathrm{~m}$ Block Size: Equilibrium State for Deformable Drip Shield With Arched Top, Bottom Rests On the Invert 


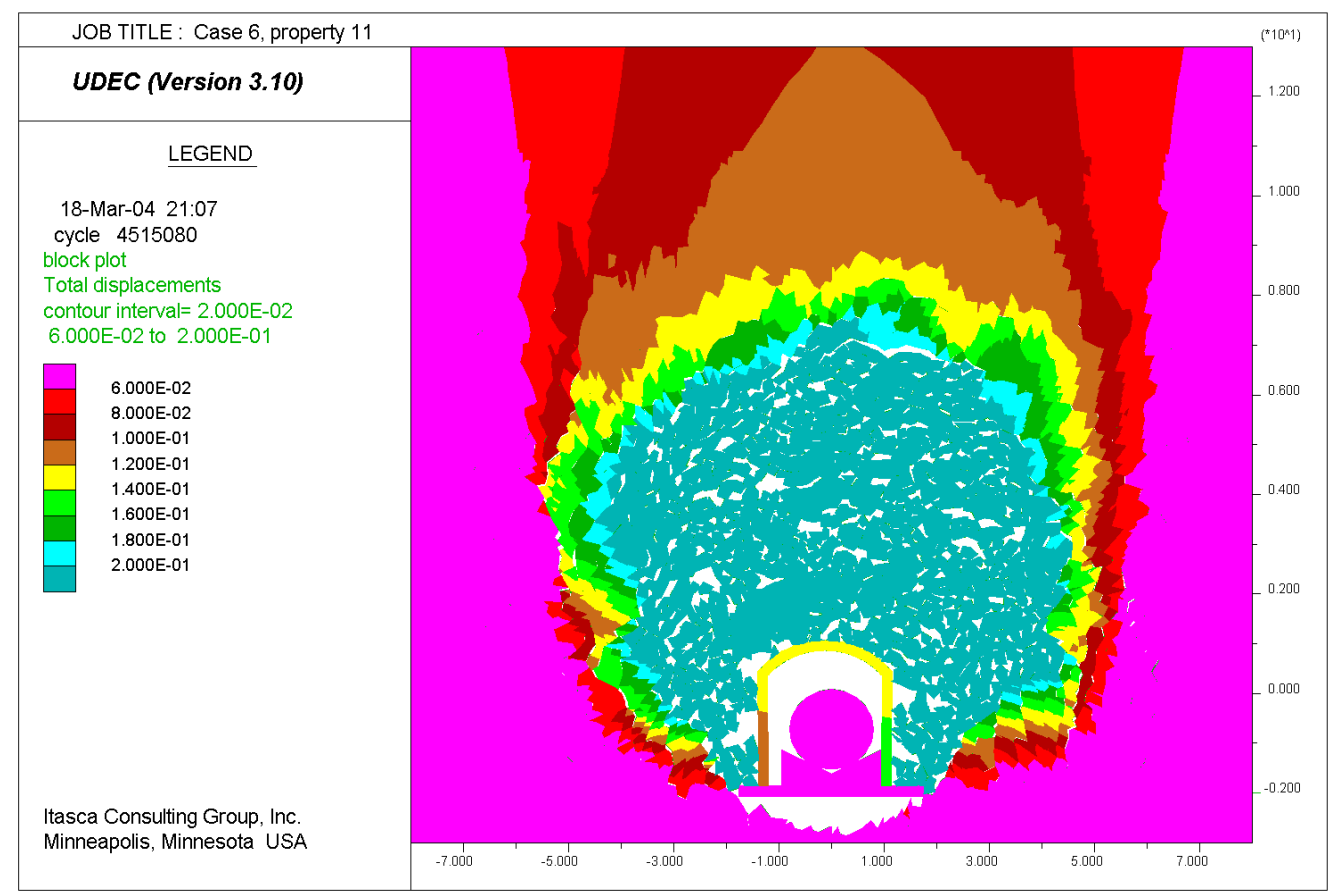

Figure P-25. Quasi-Static Drift Degradation, $0.2 \mathrm{~m}$ Block Size: Contours of Displacement $(\mathrm{m})$ Magnitude for Deformable Drip Shield With Arched Top, Bottom Rests On the Invert

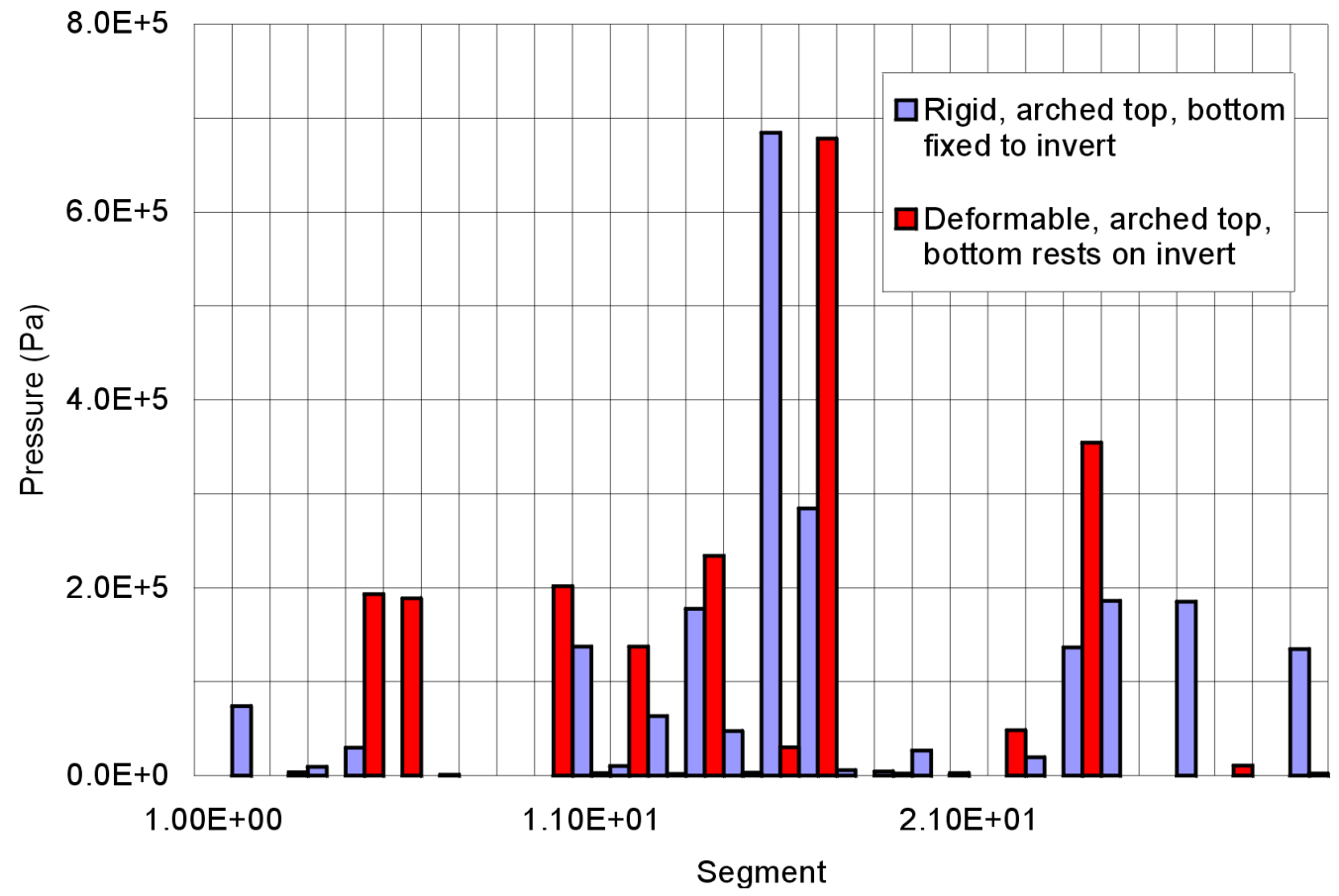

Figure P-26. Quasi-static Drift Degradation, $0.2 \mathrm{~m}$ Block Size: Loads On the Drip Shield for Cases With the Invert 
Table P-6. Quasi-Static Drift Degradation, $0.2 \mathrm{~m}$ Block Size: Average Loads On the Drip Shield For Cases With Invert

\begin{tabular}{|l|c|c|c|}
\hline \multicolumn{1}{|c|}{ Case } & Left & Top & Right \\
\cline { 2 - 4 } & $\mathbf{k N} / \mathbf{m}^{\mathbf{2}}$ & $\mathbf{k N / \mathbf { m } ^ { \mathbf { 2 } }}$ & $\mathbf{k N / \mathbf { m } ^ { \mathbf { 2 } }}$ \\
\hline rigid, arched top, bottom fixed to invert & 66.45 & 144.15 & 11.28 \\
\hline $\begin{array}{l}\text { deformable, arched top, bottom rests on } \\
\text { invert }\end{array}$ & 41.54 & 108.92 & 58.76 \\
\hline
\end{tabular}

\section{P3. IMPACT AND STATIC LOADS DUE TO STRONG GROUND MOTION SEISMIC SHAKING}

Impact and static loads on the drip shield are assessed for ground motions with $1 \times 10^{-6}$ and $1 \times 10^{-7}$ probability of annual recurrence. Another objective of these simulations was to investigate if the drip shield could be overturned during strong ground motions. Ground motions 3, 7, 9, and 13 were analyzed for both levels of probability. Those particular ground motions were selected based on different criteria (i.e., peak ground velocity, total power in the velocity spectrum, Arias intensity) for intensity of ground motion, as the four strongest ground motions from the sets of 15 ground motions for both $1 \times 10^{-6}$ and $1 \times 10^{-7}$ levels of probability. Category 3 lithophysal rock mass was considered in the simulations.

Although the seismic shaking for 8 simulated ground motions causes large displacements of the entire model, and large displacement of the drip shield relative to its original position inside the emplacement drift (as shown in Figure P-27), the drip shield does not get overturned at the end of the simulations. The model equilibrium configurations for ground motion 3 from $1 \times 10^{-6}$ and $1 \times 10^{-7}$ sets are shown in Figures P-28 and P-33, respectively. The model reached the equilibrium configuration with drip shield in an upright position in both cases. For these strong ground motions, the collapse of the drift occurs very quickly - in some cases backfilling the drip shield within a second after the onset of strong ground motion (The strong ground motion for the model shown in Figure P-27 started at $1.75 \mathrm{~s}$. At the state shown in Figure P-27, which is at $2.74 \mathrm{~s}$, the drift is already backfilled.). Once the drip shield is backfilled, it is difficult to overturn it, because the caved rock provides the back-pressure and constrains the motion of the drip shield.

The pressure histories for the segments of the drip shield are shown in Figures P-29 through P-31 for $1 \times 10^{-6}$ ground motion, and in Figures P-34 through P-36 for $1 \times 10^{-7}$ ground motion. The maximum transient pressures are relatively large, up to $10 \mathrm{MPa}$ for $10^{-6}$ ground motion and up to $40 \mathrm{MPa}$ for $1 \times 10^{-7}$ ground motion. The average block mass in these simulations is approximately $200 \mathrm{~kg}$. (The characteristic block size in the plane of the model is $0.3 \mathrm{~m}$.) If the maximum impact velocity in the case of $1 \times 10^{-6}$ ground motion is approximately $8 \mathrm{~m} / \mathrm{s}$, the maximum impact energy for a single block is $6.4 \mathrm{~kJ} / \mathrm{m}$. During these strong ground motions, the rock mass shatters before reaching the drip shield. Consequently, the drip shield is subjected to series of small energy impacts by small blocks, instead of impacts by large blocks (as is the case in the model of drift stability in the non-lithophysal rock mass). Duration of the impact by a single block in the case of $1 \times 10^{-6}$ ground motion is of the order of one millisecond. 
The static pressures on the drip shield are summarized in Figure P-32 and Table P-7 for $1 \times 10^{-6}$ ground motion and in Figure P-37 and Table P-8 for $1 \times 10^{-7}$ ground motion.

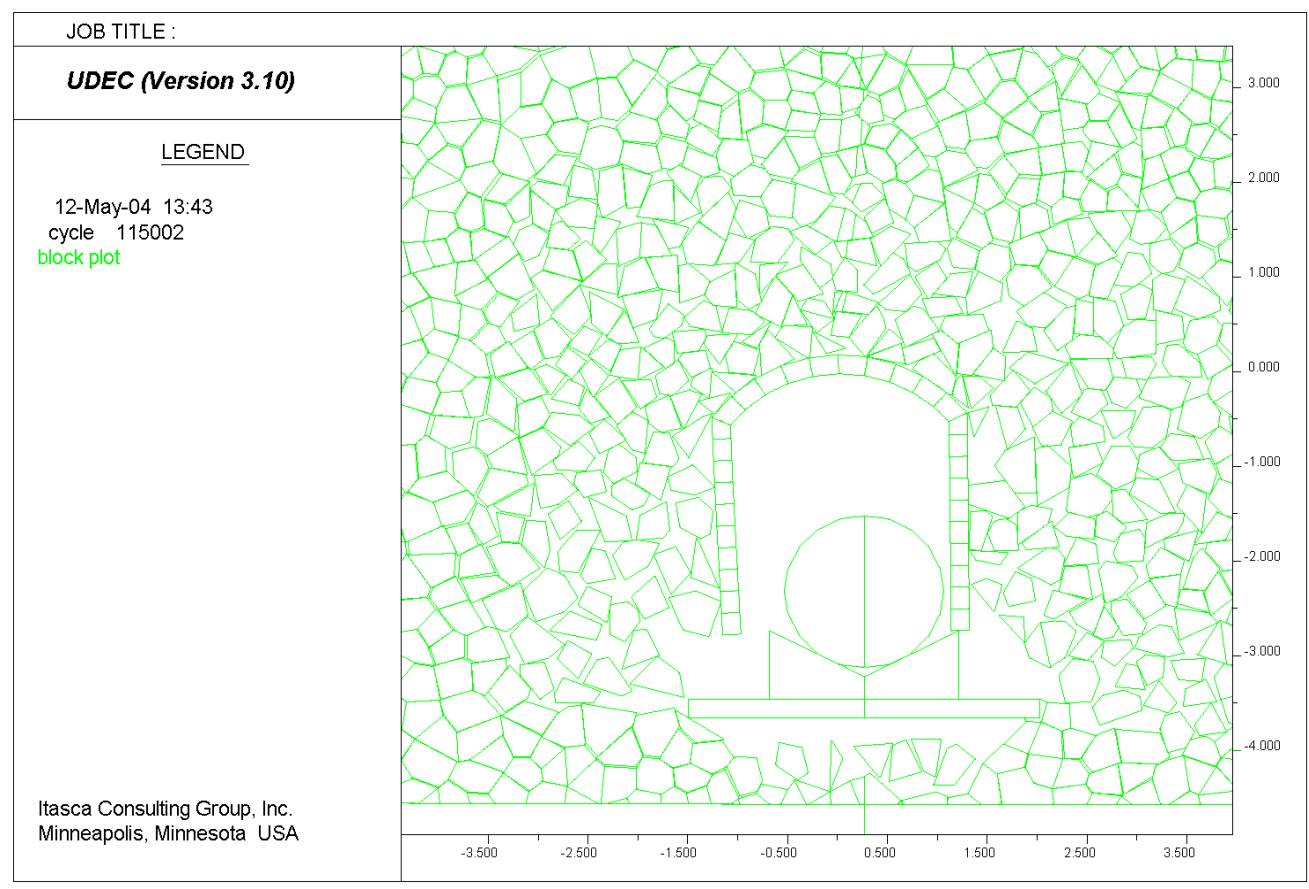

Figure P-27. Ground Motion $10^{-6}$ Number 3: Model Configuration After $2.75 \mathrm{~s}$ of Shaking

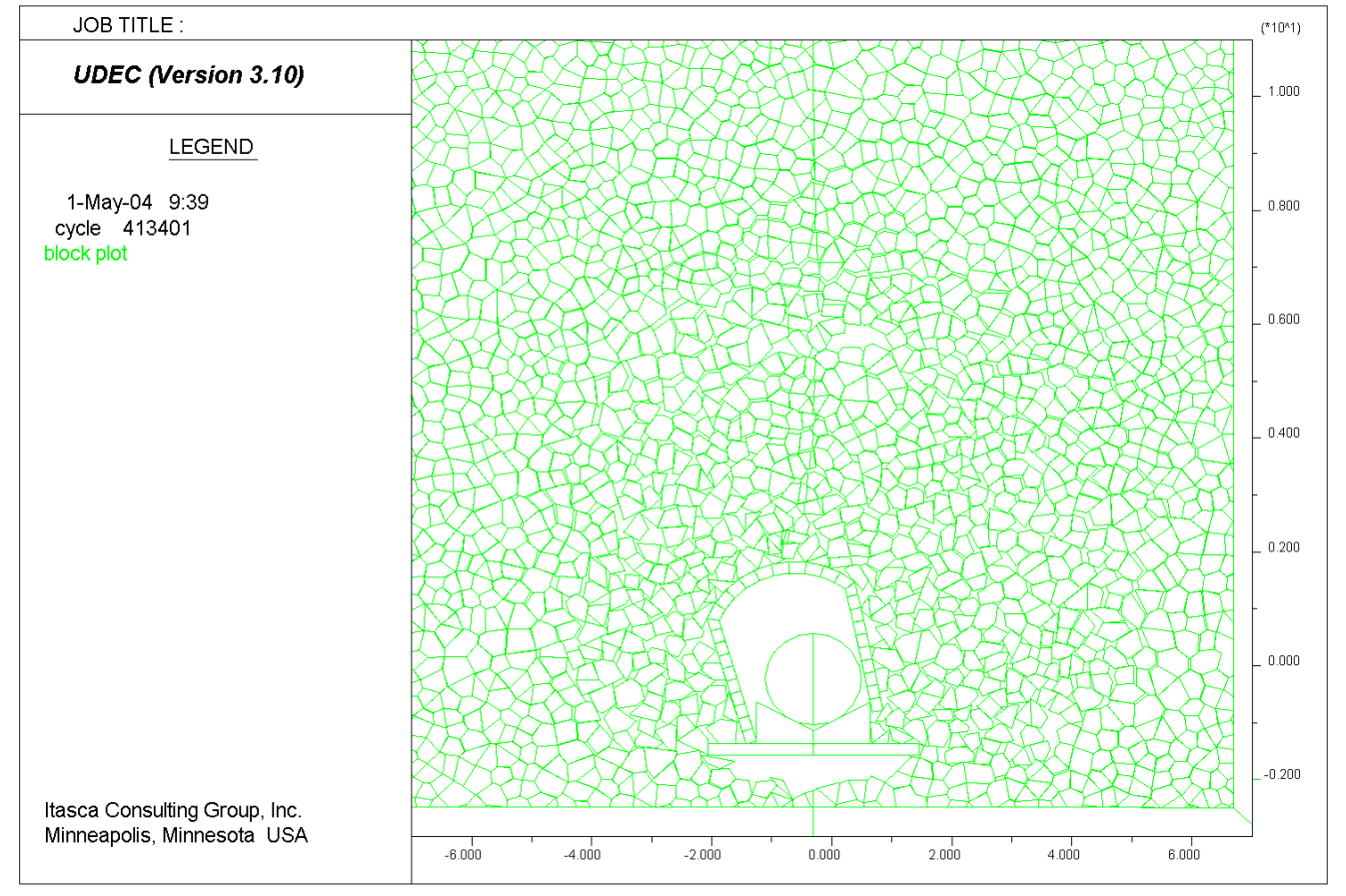

Figure P-28. Ground Motion $10^{-6}$ Number 3: Model Configuration in the Equilibrium State After Shaking 


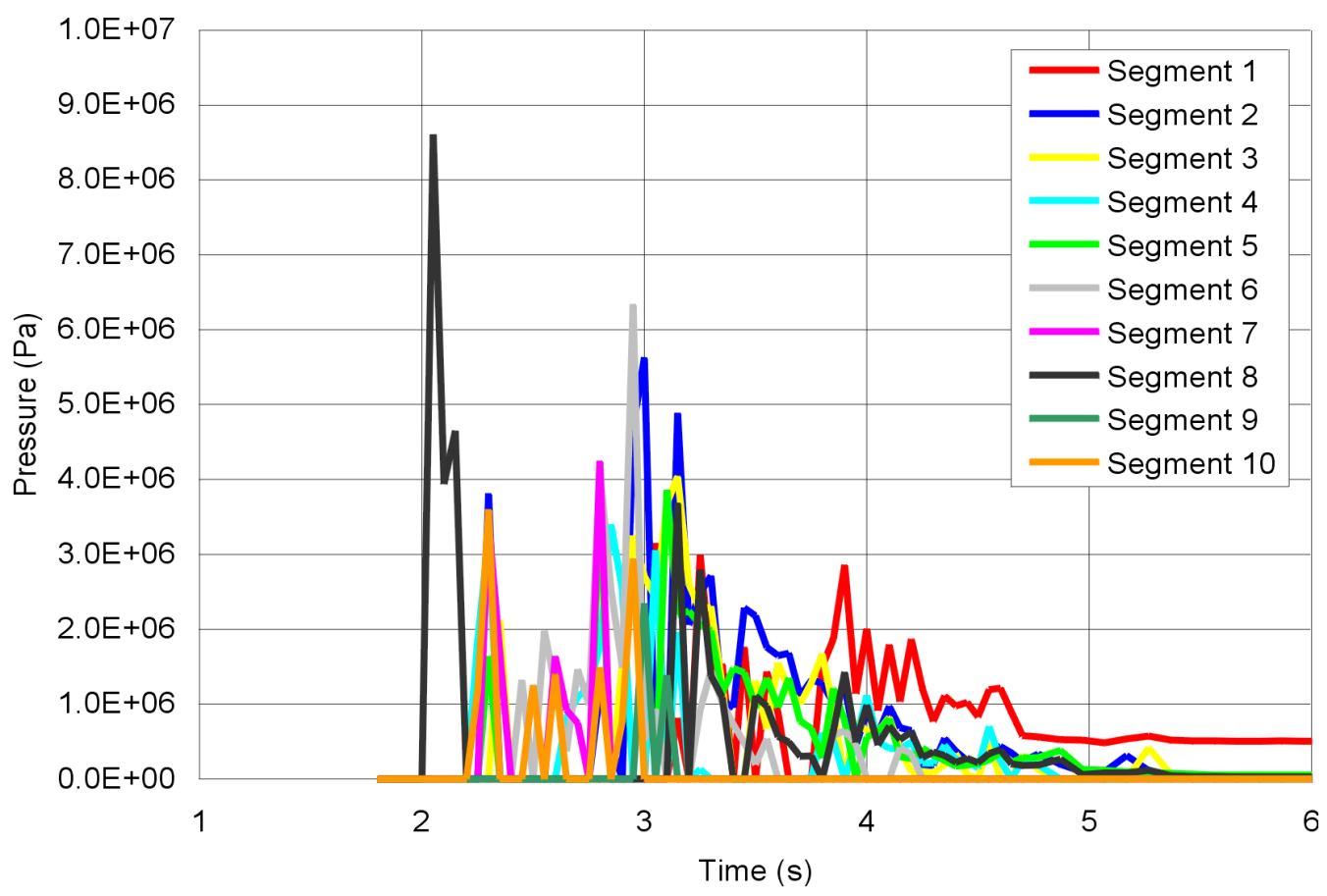

Figure P-29. Ground Motion $10^{-6}$ Number 3: Dynamic Loads On the Right Side

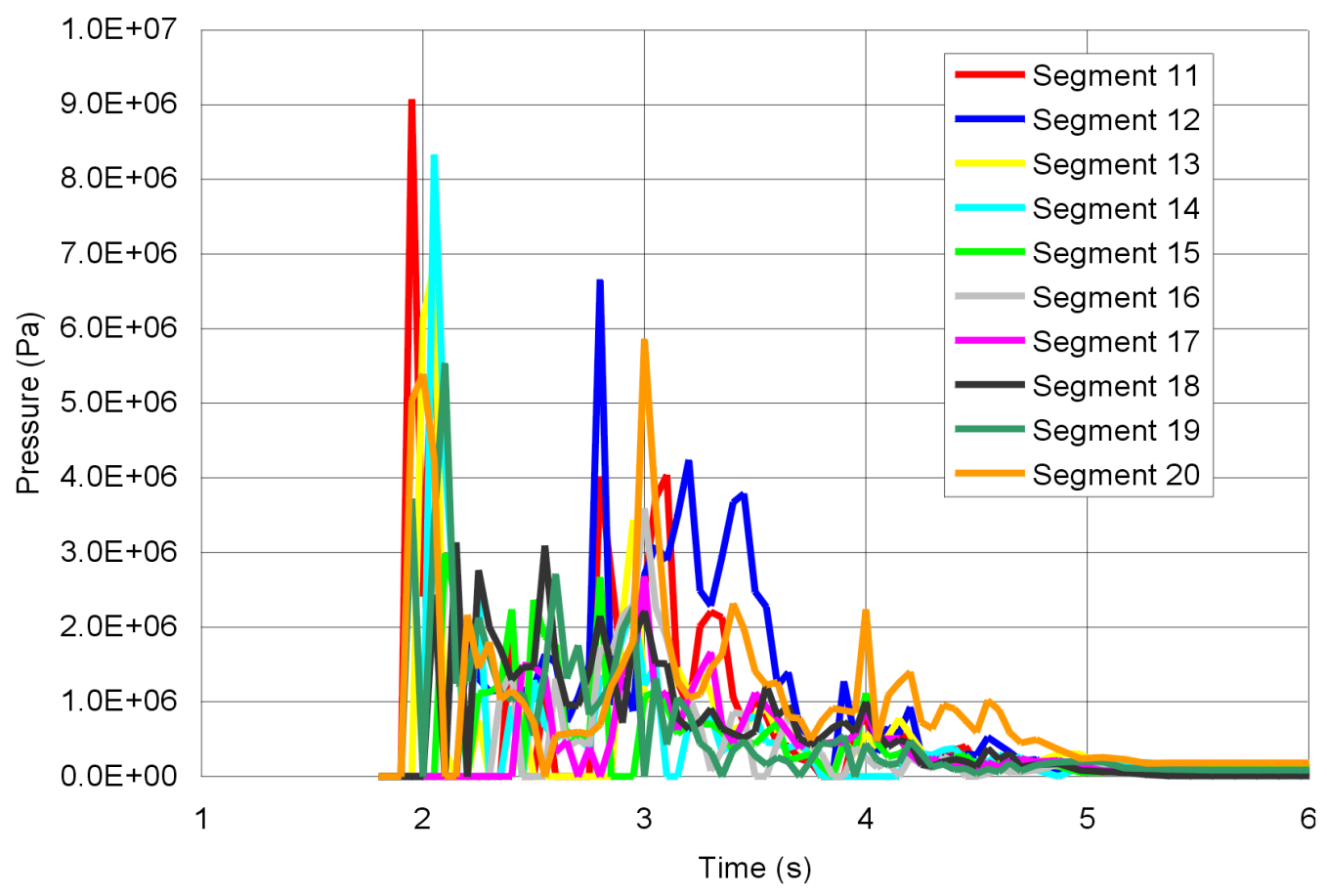

Figure P-30. Ground Motion $10^{-6}$ Number 3: Dynamic Loads On the Top 


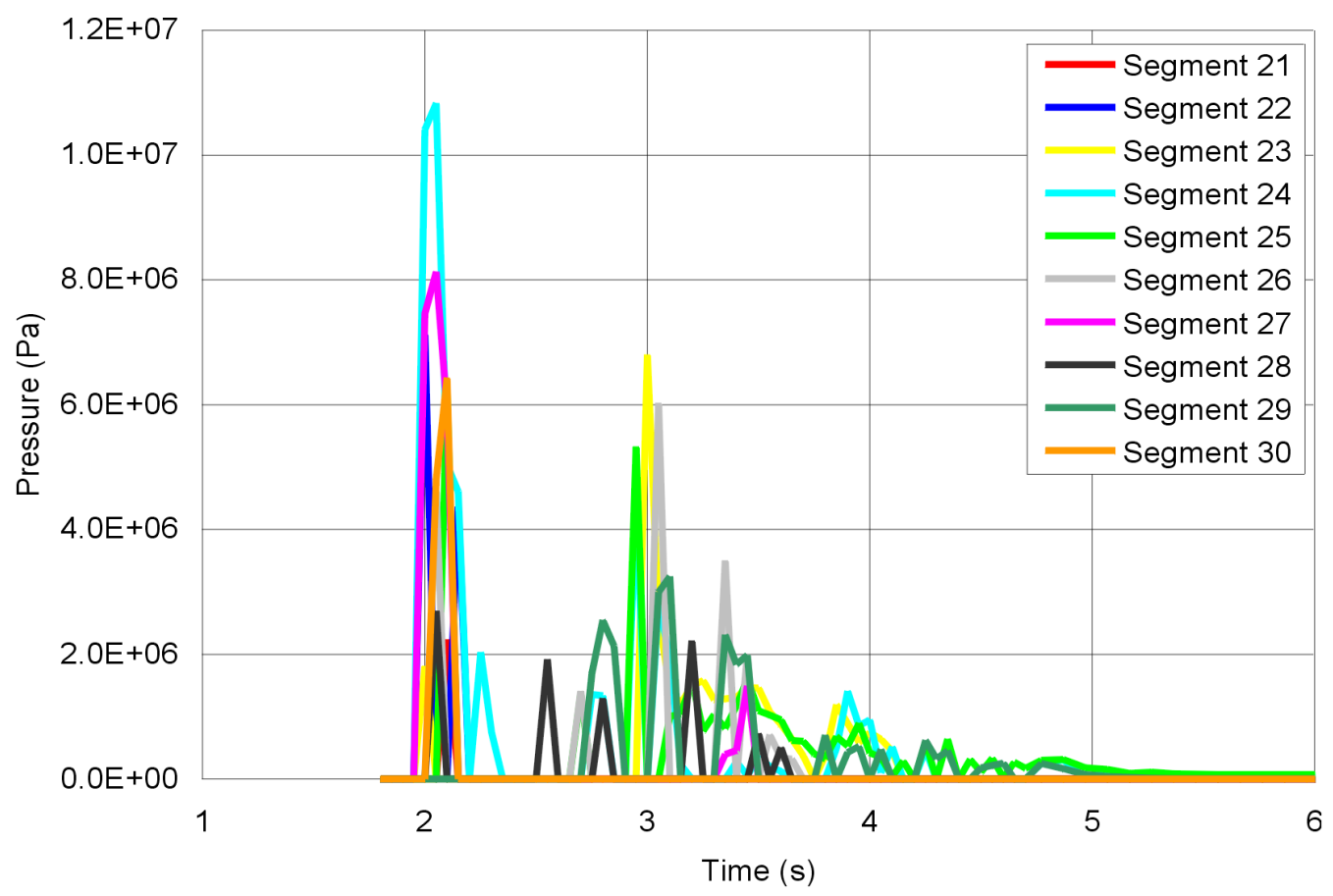

Figure P-31. Ground Motion $10^{-6}$ Number 3: Dynamic Loads On the Left Side

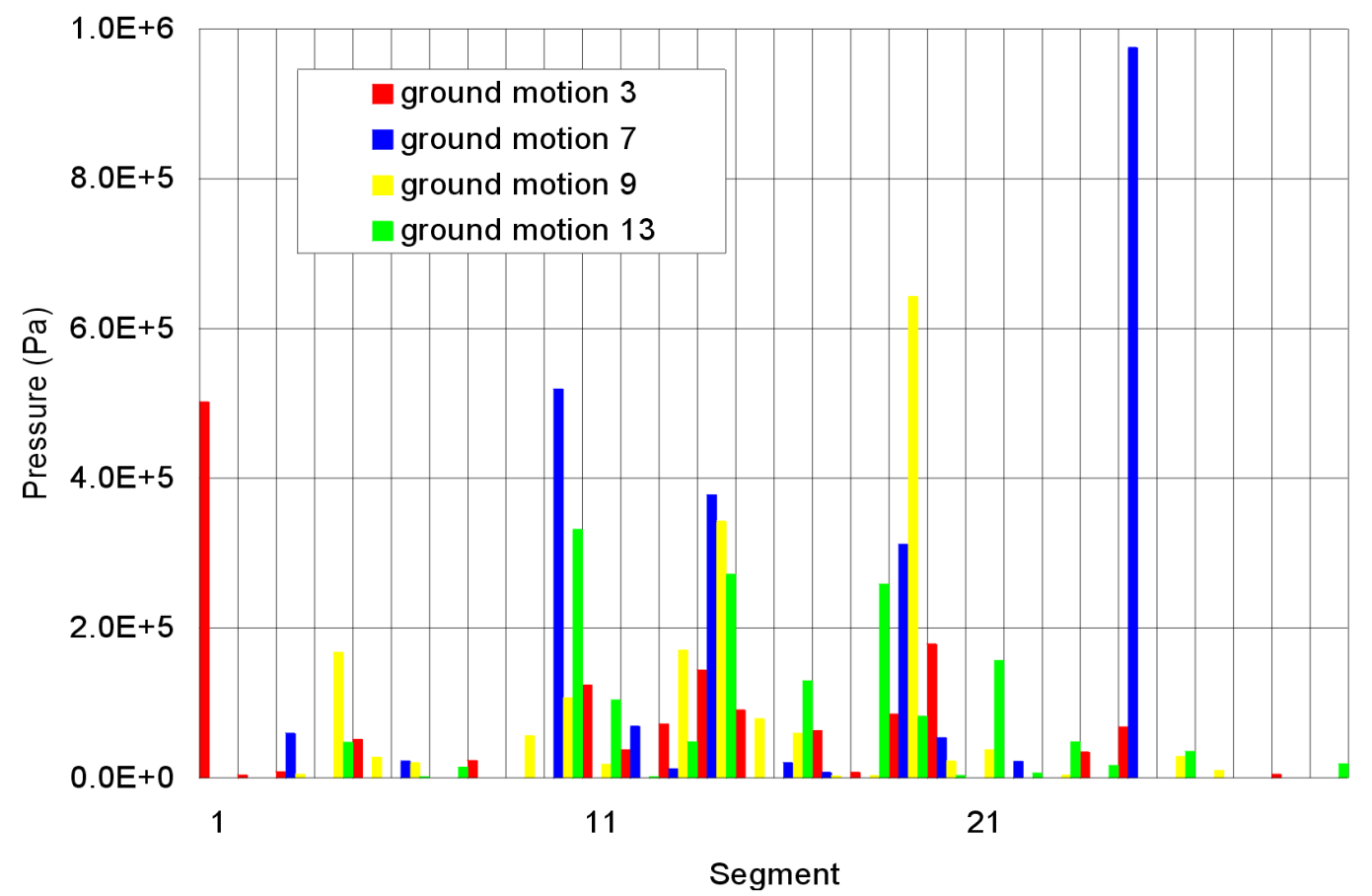

Figure P-32. Static Loads On The Drip Shield After Shaking With Four Different $10^{-6}$ Ground Motions 
Table P-7. Four Different $10^{-6}$ Ground Motions: Average Loads On the Drip Shield

\begin{tabular}{|c|c|c|c|}
\hline \multirow{2}{*}{ Ground motion } & Left & Top & Right \\
\cline { 2 - 4 } & $\mathbf{k N} / \mathbf{m}^{\mathbf{2}}$ & $\mathbf{k N} / \mathbf{m}^{\mathbf{2}}$ & $\mathbf{k N} / \mathbf{m}^{\mathbf{2}}$ \\
\hline 3 & 10.77 & 80.44 & 58.92 \\
\hline 7 & 99.78 & 85.42 & 60.19 \\
\hline 9 & 8.03 & 134.34 & 38.46 \\
\hline 13 & 28.29 & 90.15 & 39.57 \\
\hline
\end{tabular}

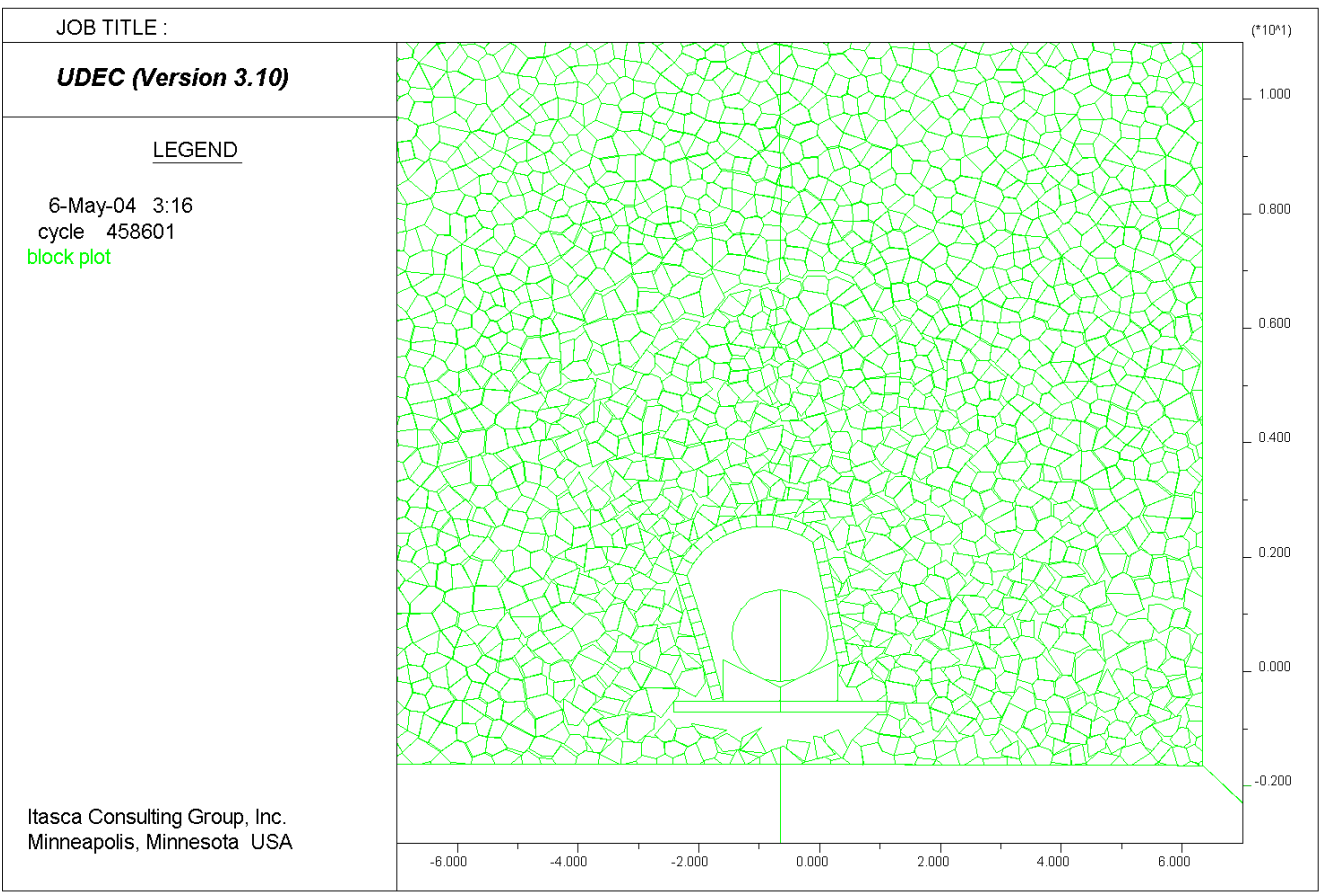

Figure P-33. Ground Motion $10^{-7}$ Number 3: Model Configuration in the Equilibrium State After Shaking 


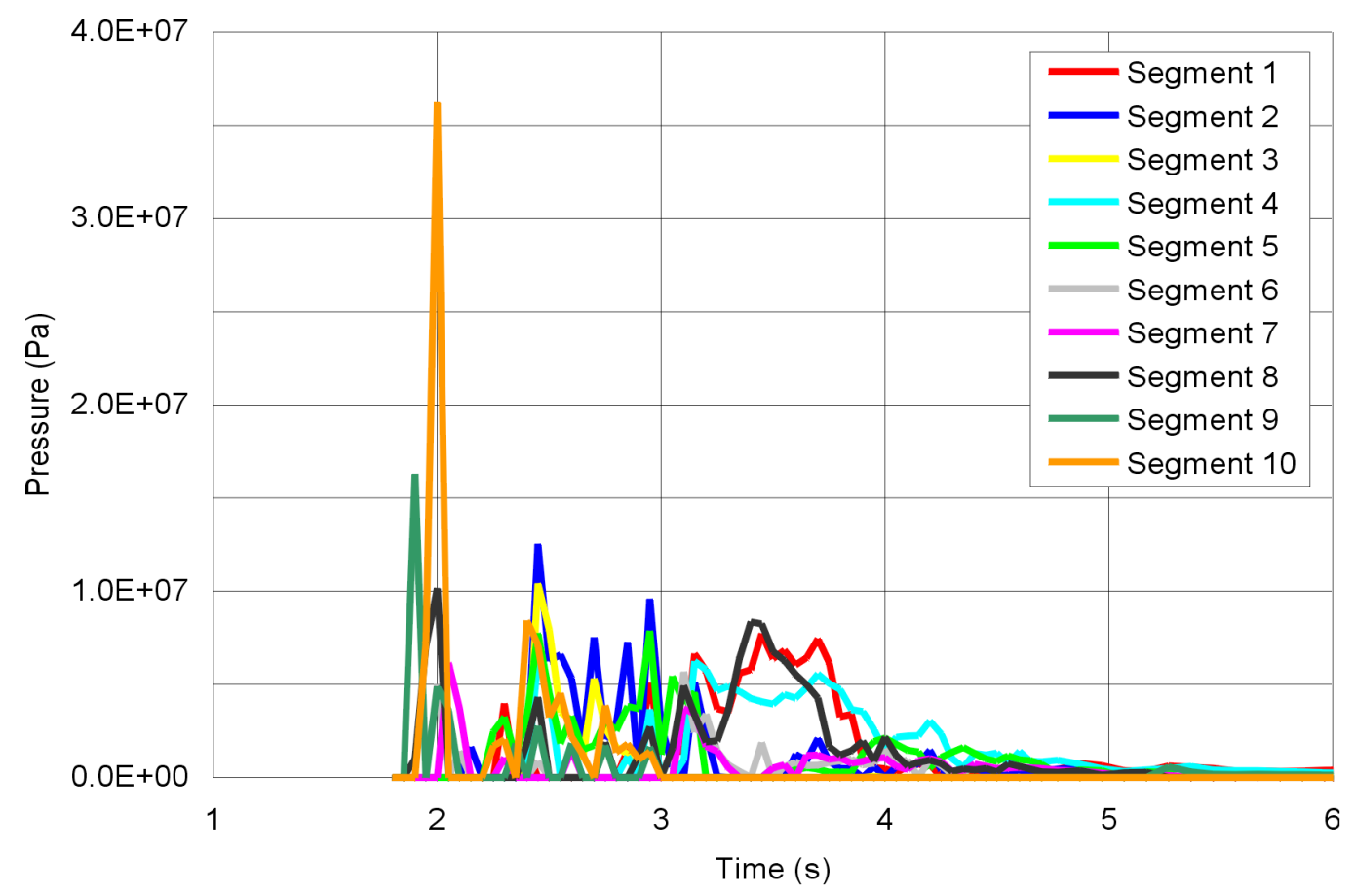

Figure P-34. Ground Motion $10^{-7}$ Number 3: Dynamic Loads On the Right Side

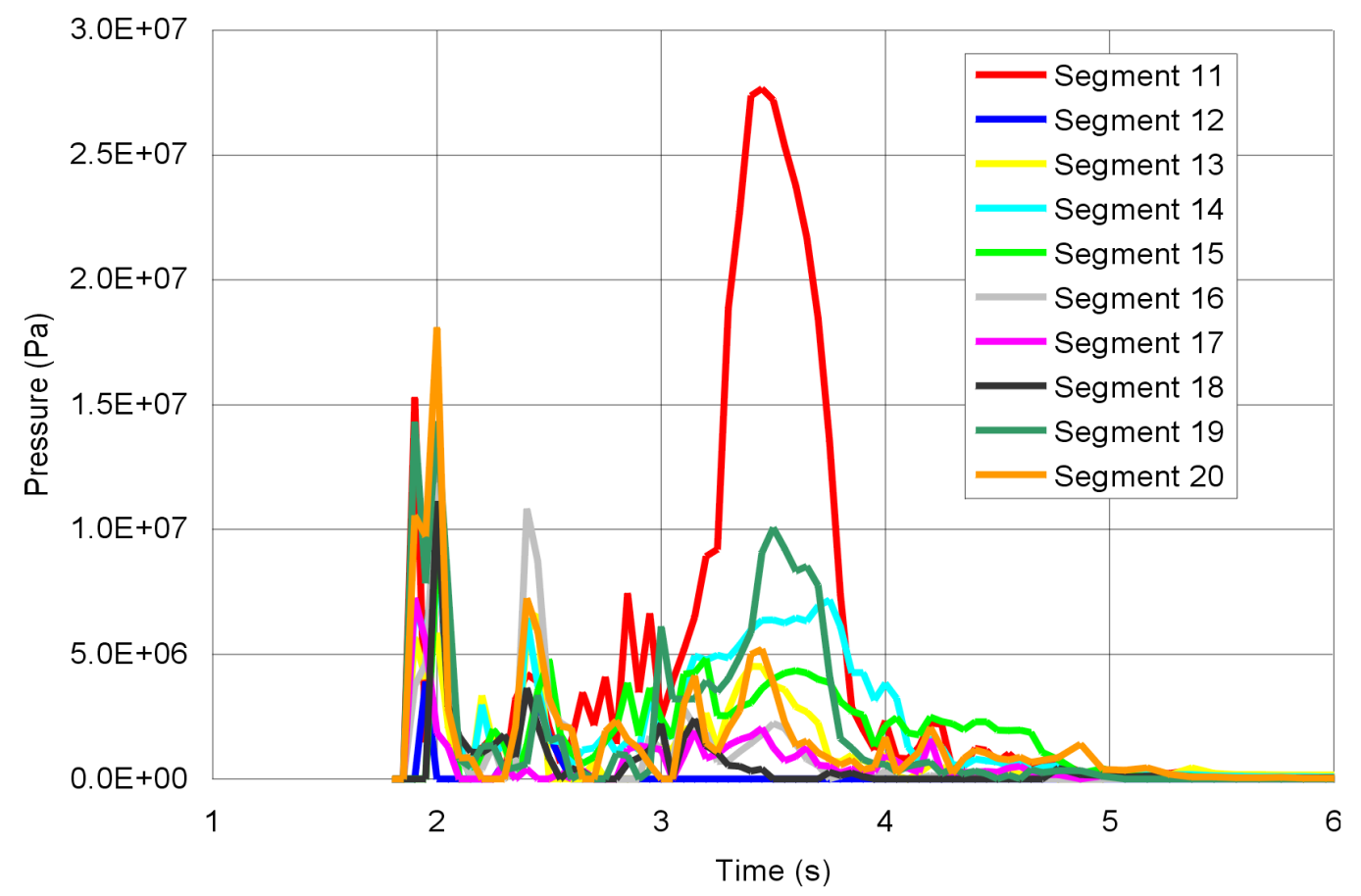

Figure P-35. Ground Motion $10^{-7}$ Number 3: Dynamic Loads On the Top 


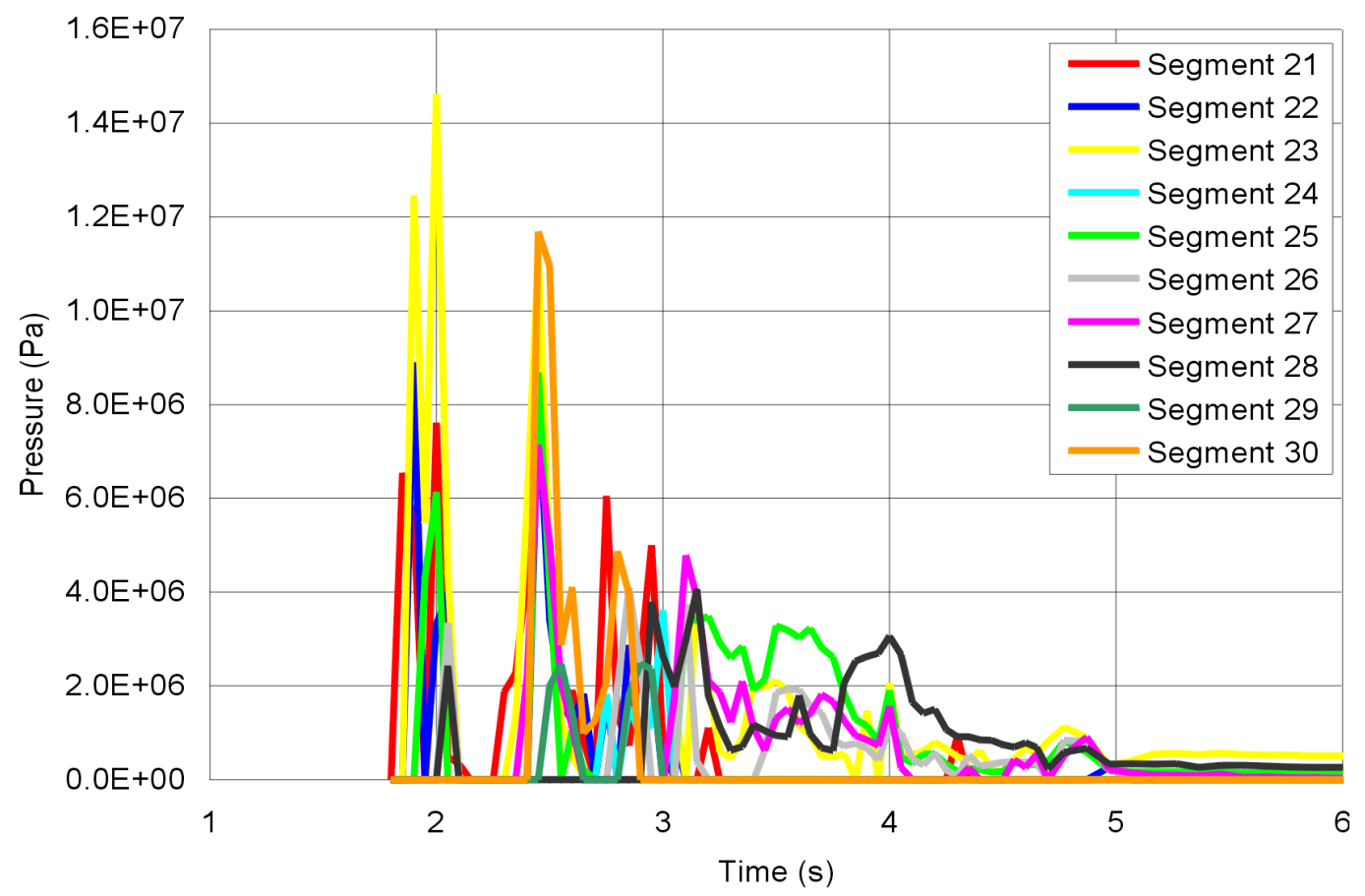

Figure P-36. Ground Motion $10^{-7}$ Number 3: Dynamic Loads On the Left Side

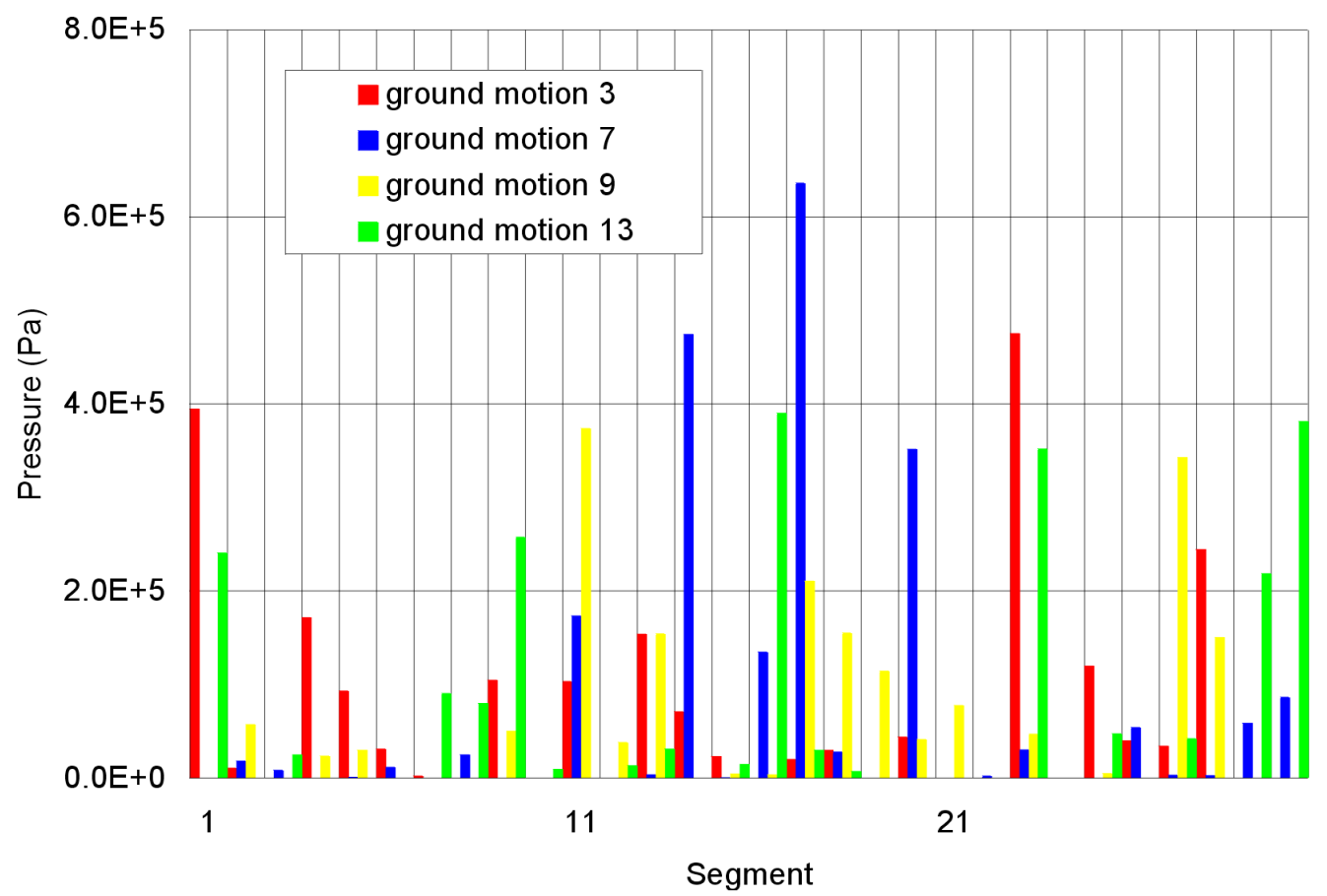

Figure P-37. Static Loads On the Drip Shield After Shaking With Four Different $10^{-7}$ Ground Motions 
Table P-8. Four Different $10^{-7}$ Ground Motions: Average Loads On the Drip Shield

\begin{tabular}{|c|c|c|c|}
\hline \multirow{2}{*}{ Ground motion } & Left & Top & Right \\
\cline { 2 - 4 } & $\mathbf{k N} / \mathbf{m}^{\mathbf{2}}$ & $\mathbf{k N} / \mathbf{m}^{\mathbf{2}}$ & $\mathbf{k N} / \mathbf{m}^{\mathbf{2}}$ \\
\hline 3 & 91.32 & 44.50 & 80.78 \\
\hline 7 & 23.71 & 180.27 & 6.39 \\
\hline 9 & 62.27 & 109.59 & 16.07 \\
\hline 13 & 104.16 & 48.63 & 70.31 \\
\hline
\end{tabular}

\section{P4. MULTIPLE REALIZATIONS OF QUASI-STATIC DRIFT DEGRADATION}

The drift collapse and the drip shield loads are expected to be random. The rockfall will vary considerably along the drifts, even within the same units, mostly because of variability in mechanical properties throughout the repository horizon. Even in the sections in which the emplacement drifts collapsed in a similar way, the load on the drip shield can vary significantly from one cross-section to another. The reason for this variability is the stochastic nature of rockfall, which involves formation of the blocks of irregular shapes and different sizes and their rockfall, during which the blocks undergo large translations and rotations. In such systems, a small change in the initial conditions or block geometry can result in a very different outcome of the rockfall in terms of position and orientation of the block. Consequently, the load on the drip shield will vary significantly (along the drip shield, but also in the cross-section). The UDEC model of drift stability mimics this variability in the rockfall and in loads on the drip shield. To assess dependence of the drip shield loads on the different realizations of Voronoi block geometry, the problem of quasi-static drift collapse was solved for five additional realizations. The base case, realization 1, is the model of the deformable drip shield resting on the invert and the particular realization of the Voronoi block geometry discussed in Section P2.2.2. The results for the six cases are summarized in Table P-9 and Figure P-38. The bulking factors for the caved rock mass are also calculated and listed in Table P-9. The variability of the load in the cross-section (for each realization and from one realization to another) is very large. The average pressure distribution is calculated for the six realizations and included as the solid line in Figure P-38. After averaging, the pressure variability in the cross-section is reduced. The average pressures on the top of the drip shield vary in the range between $110 \mathrm{kN} / \mathrm{m}^{2}$ and $155 \mathrm{kN} / \mathrm{m}^{2}$ (Table P-9).

Table P-9. Quasi-Static Drift Degradation, $0.2 \mathrm{~m}$ Block Size, Multiple Realizations of Voronoi Block Geometry: Average Loads On the Drip Shield

\begin{tabular}{|c|c|c|c|c|}
\hline & Left & Top & Right & \\
\cline { 2 - 4 } Realization & $\mathbf{k N / \mathbf { m } ^ { 2 }}$ & $\mathbf{k N} / \mathbf{m}^{\mathbf{2}}$ & $\mathbf{k N / \mathbf { m } ^ { 2 }}$ & $\begin{array}{c}\text { Bulking } \\
\text { factor }\end{array}$ \\
\hline 1 & 41.54 & 108.92 & 58.76 & 0.24 \\
\hline 2 & 19.15 & 147.07 & 19.33 & 0.19 \\
\hline 3 & 31.35 & 154.80 & 6.69 & 0.25 \\
\hline 4 & 57.23 & 129.76 & 128.82 & 0.20 \\
\hline 5 & 69.69 & 112.73 & 105.43 & 0.22 \\
\hline 6 & 32.97 & 113.87 & 52.19 & 0.21 \\
\hline
\end{tabular}




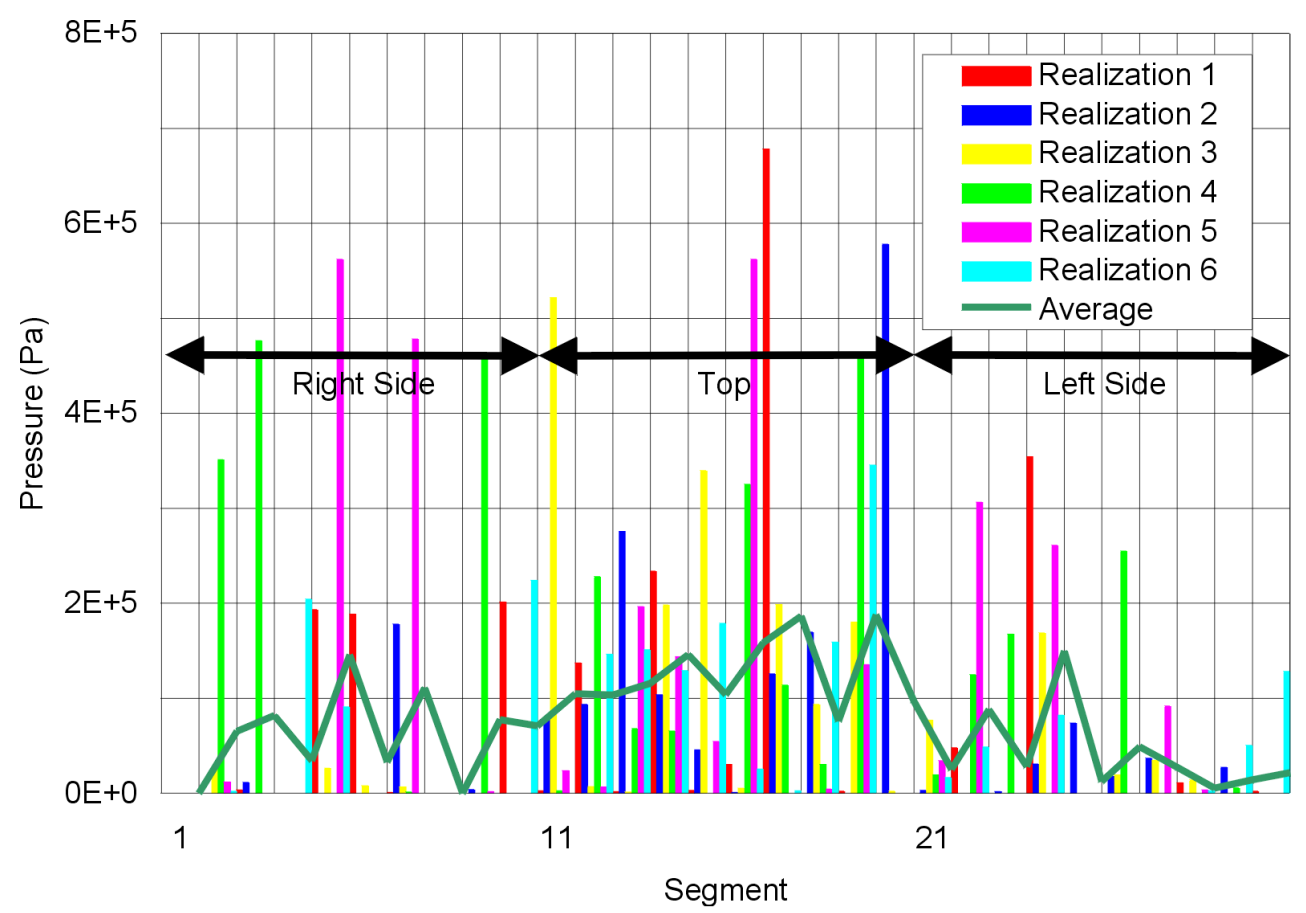

Figure P-38. Static Loads On The Drip Shield After Quasi-Static Drift Degradation For Six Realizations Of Voronoi Block Geometry

\section{P5. EFFECT OF SEISMIC SHAKING OF COLLAPSED DRIFT}

The effect of seismic shaking of the collapsed drift on the drip shield loads in the case of the rigid, rectangular drip shield is presented in Appendix V. The same analysis is carried out again for the more realistic drip shield model described in Section P2, and for a wider range of ground motions-i.e., ground motions with $1 \times 10^{-4}, 1 \times 10^{-5}$ and $1 \times 10^{-6}$ probability of annual recurrence. Ground motions number 9 , from the set of $1 \times 10^{-5}$ ground motions, and number 1 , from the set of $1 \times 10^{-6}$ ground motions, were used in these simulations. The pressure (of the caved rock on the drip shield) histories for the segments during $1 \times 10^{-4}$ and $1 \times 10^{-6}$ ground shaking are shown in Figures P-39 through P-44. The static pressures on the drip shield after the models are equilibrated are summarized in Figure P-45 and Table P-10. The pressures on the drip shield vary during the shaking, sometimes resulting in transient pressures that are up to an order of magnitude larger than the original static pressures. For example, the static pressure for segment 10 in Figure P-42 is approximately $0.5 \mathrm{MPa}$, but it increases to approximately $5 \mathrm{MPa}$ at $2.4 \mathrm{~s}$ of $1 \times 10^{-6}$ ground motion. The static pressure in the equilibrium state after shaking increases compared to the static pressures in the equilibrium state before shaking. In Table P-10, the trend is apparent from the average pressures on the top of the drip shield. The average pressure increases for each level of ground motion, and the increase becomes larger for stronger ground motions. Associated with pressure increase is reduction in the bulking factor. The shaking results in compaction (i.e., irreversible volume reduction) of the caved rock. The bulking factor decreases more for stronger ground motions. 


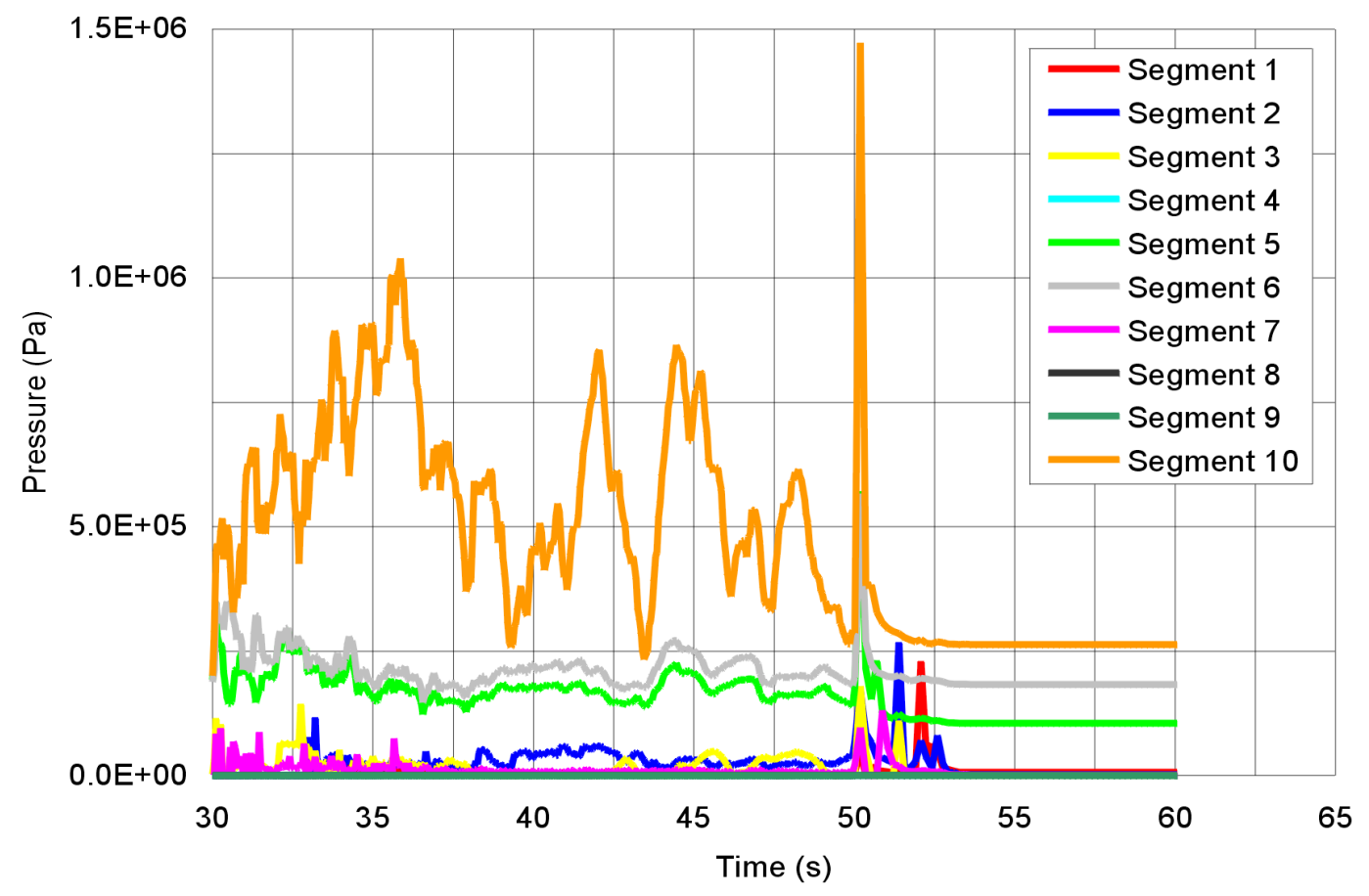

Figure P-39. Already Collapsed Drift, Ground Motion $10^{-4}$ : Dynamic Loads On the Right Side

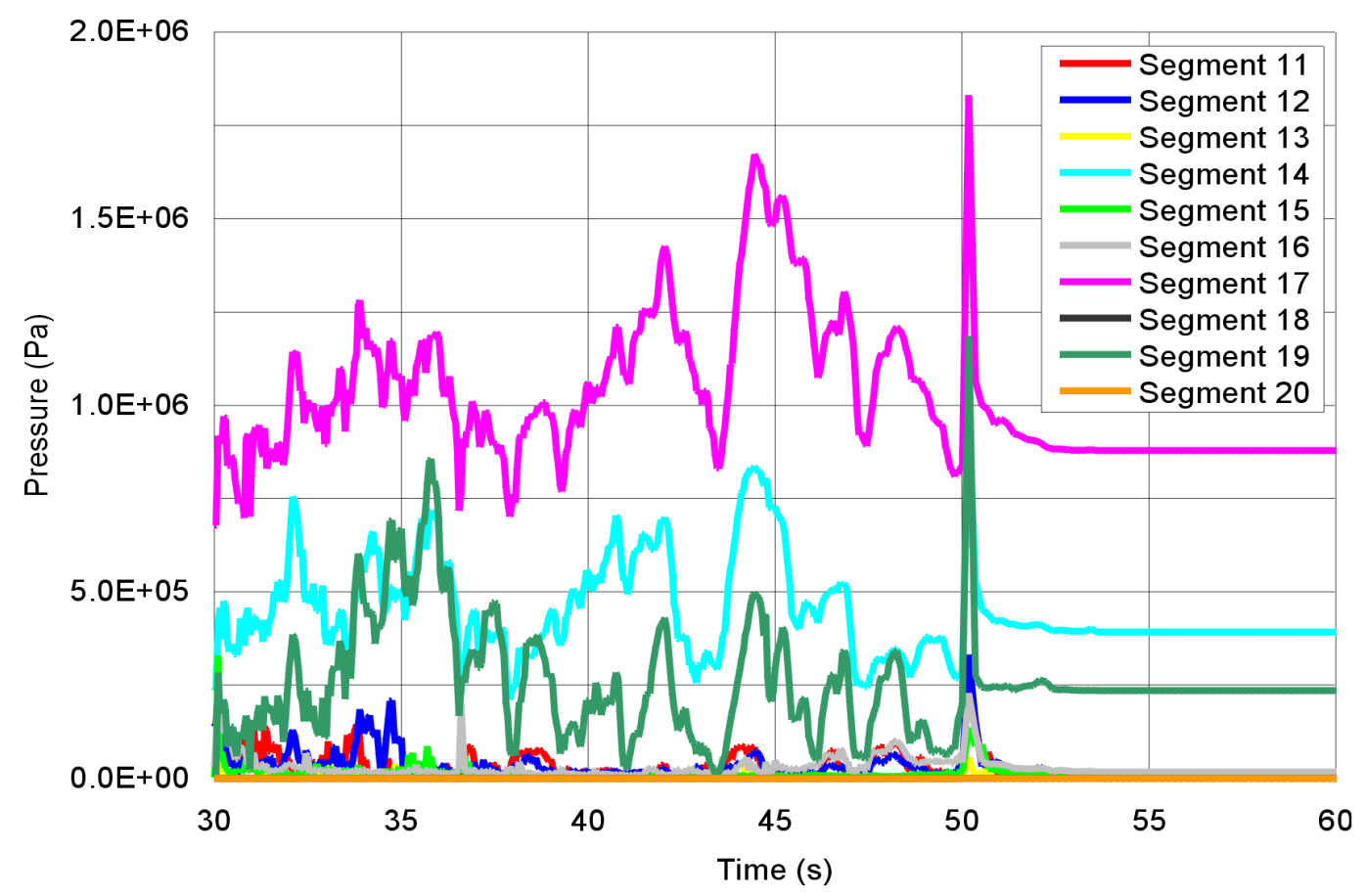

Figure P-40. Already Collapsed Drift, Ground Motion $10^{-4}$ : Dynamic Loads On the Top 


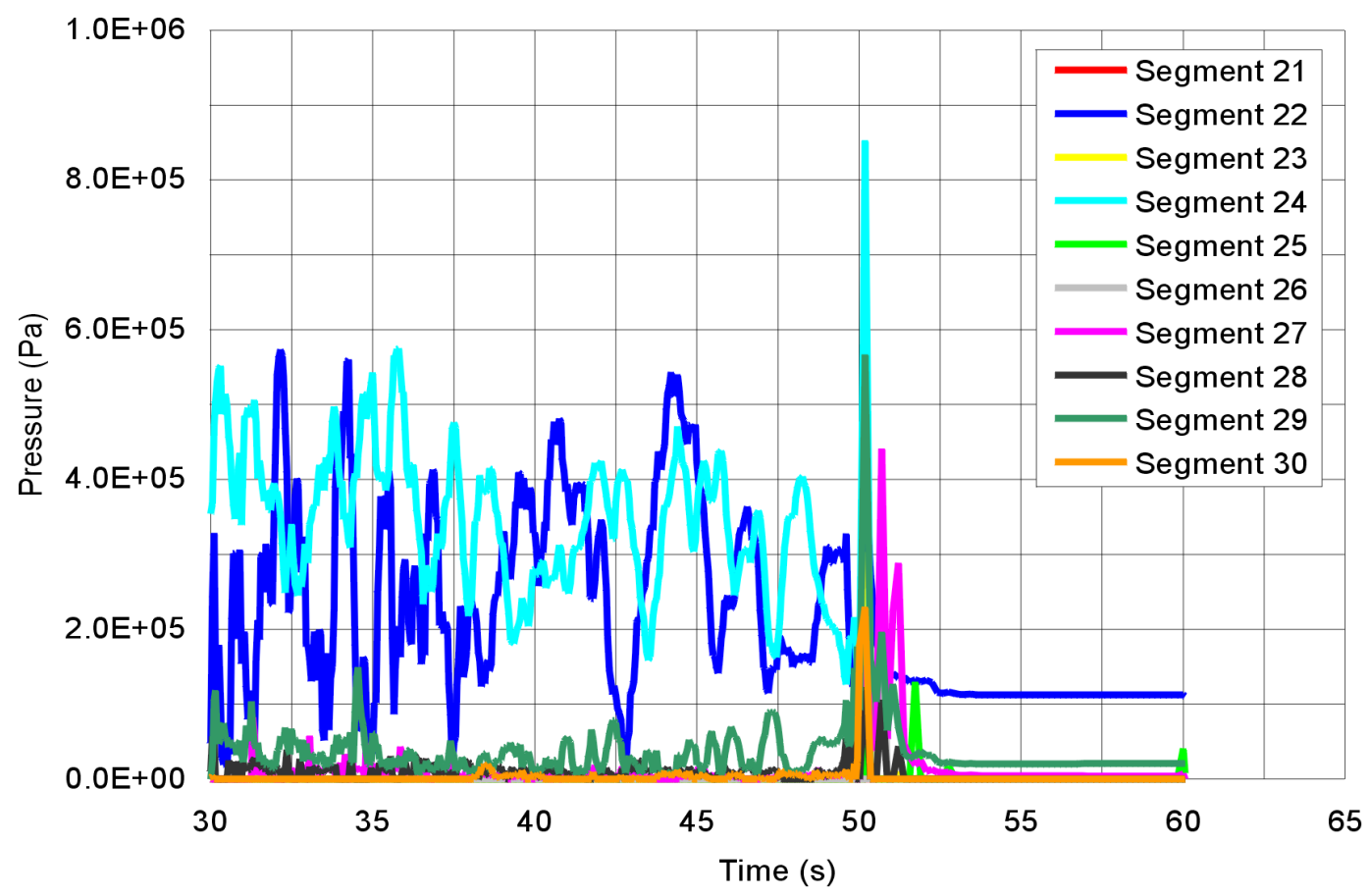

Figure P-41. Already Collapsed Drift, Ground Motion $10^{-4}$ : Dynamic Loads On the Left Side

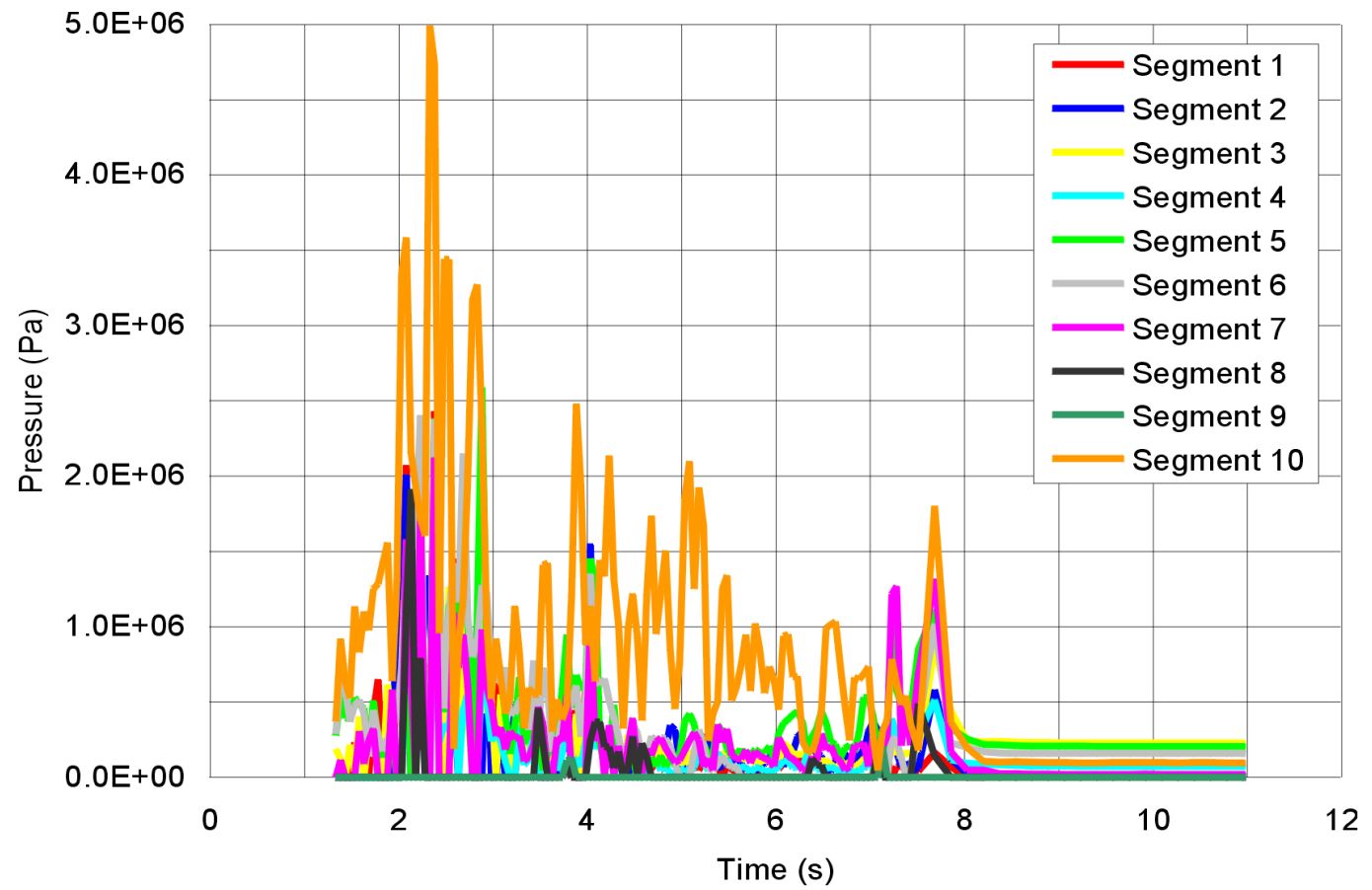

Figure P-42. Already Collapsed Drift, Ground Motion $10^{-6}$ Number 1: Dynamic Loads On the Right Side 


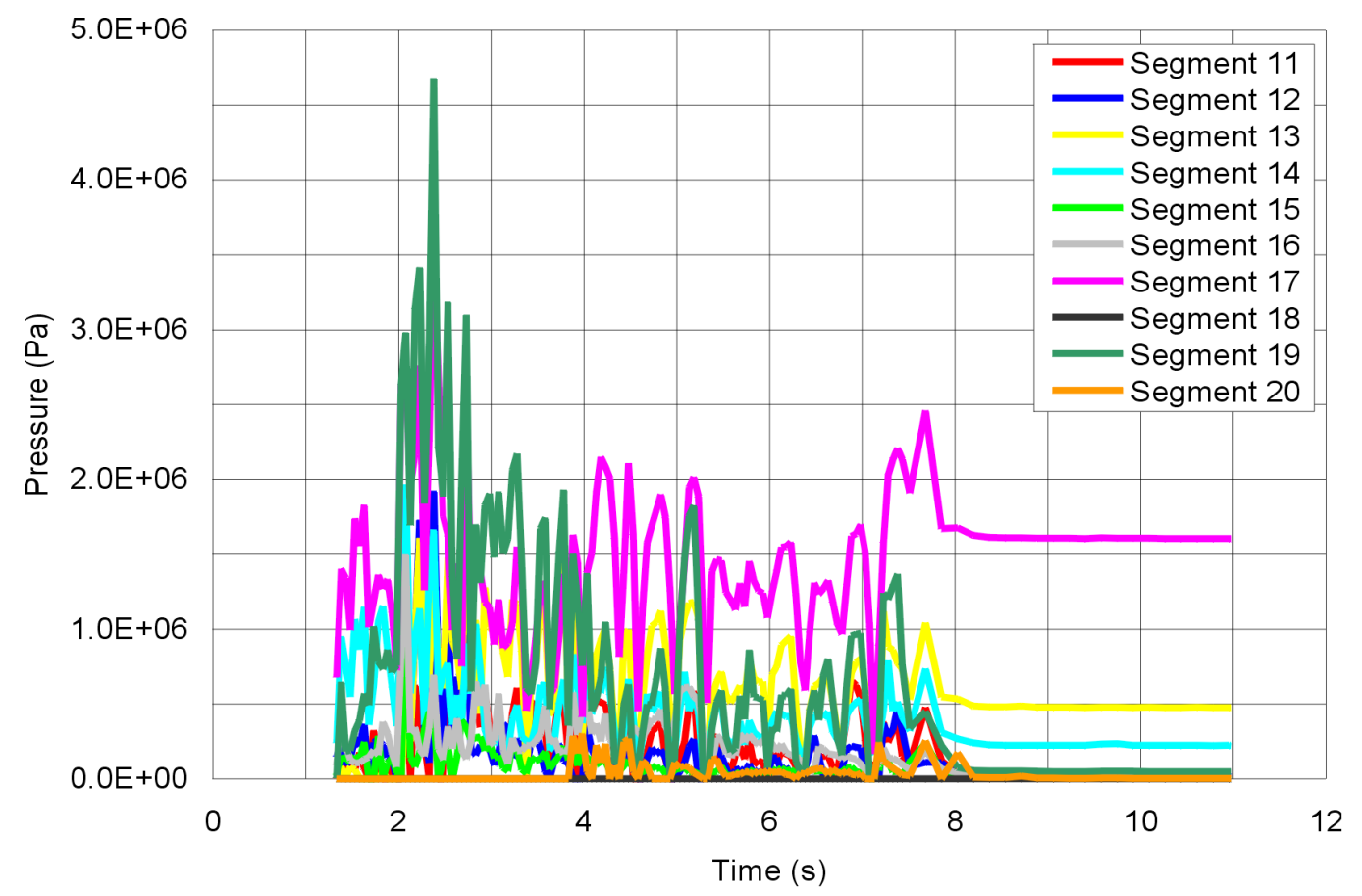

Figure P-43. Already Collapsed Drift, Ground Motion $10^{-6}$ Number 1: Dynamic Loads On the Top

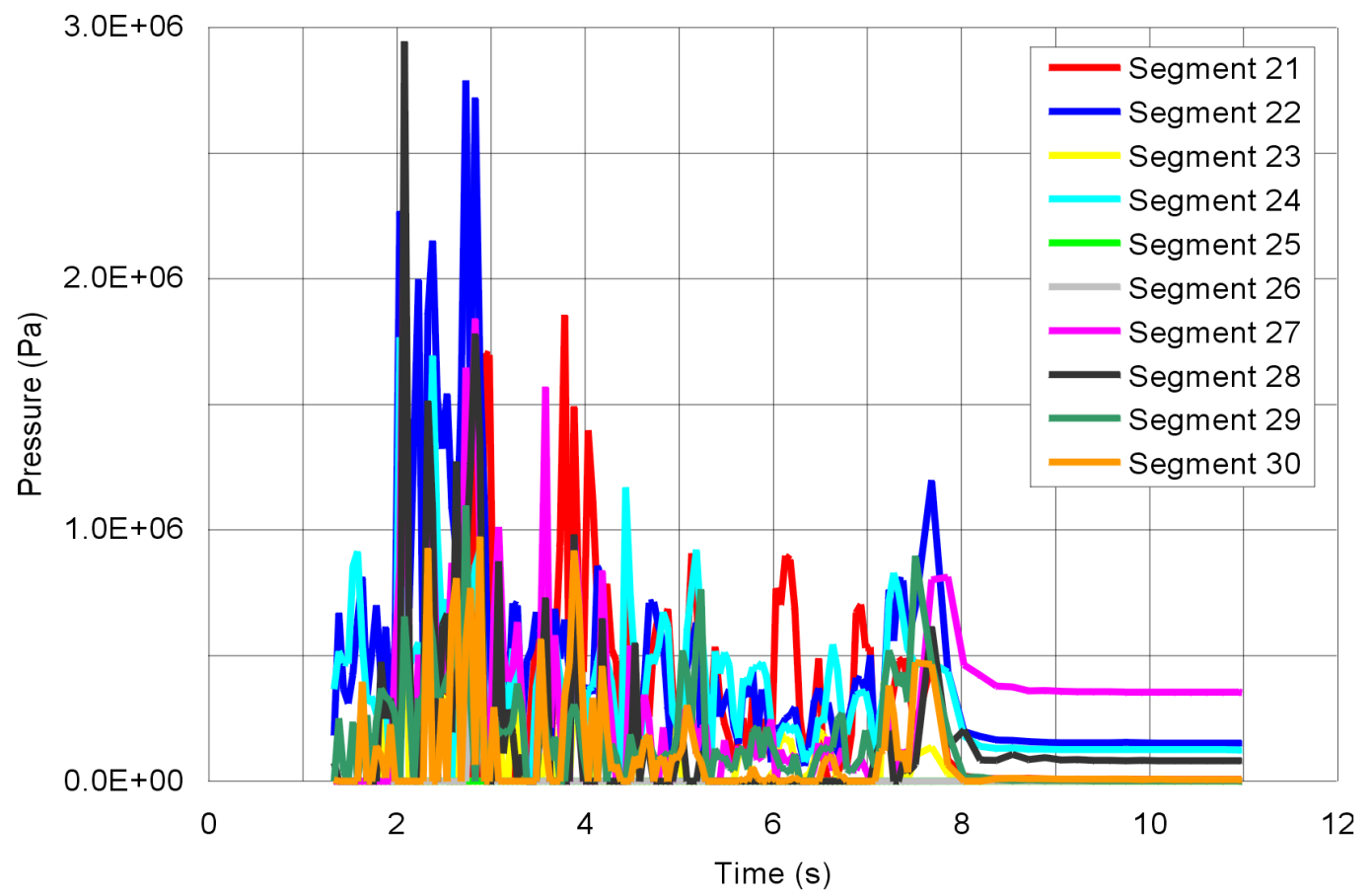

NOTE: $\mathrm{Pa}=$ Pascal .

Figure P-44. Already Collapsed Drift, Ground Motion $10^{-6}$ Number 1: Dynamic Loads On The Left Side 


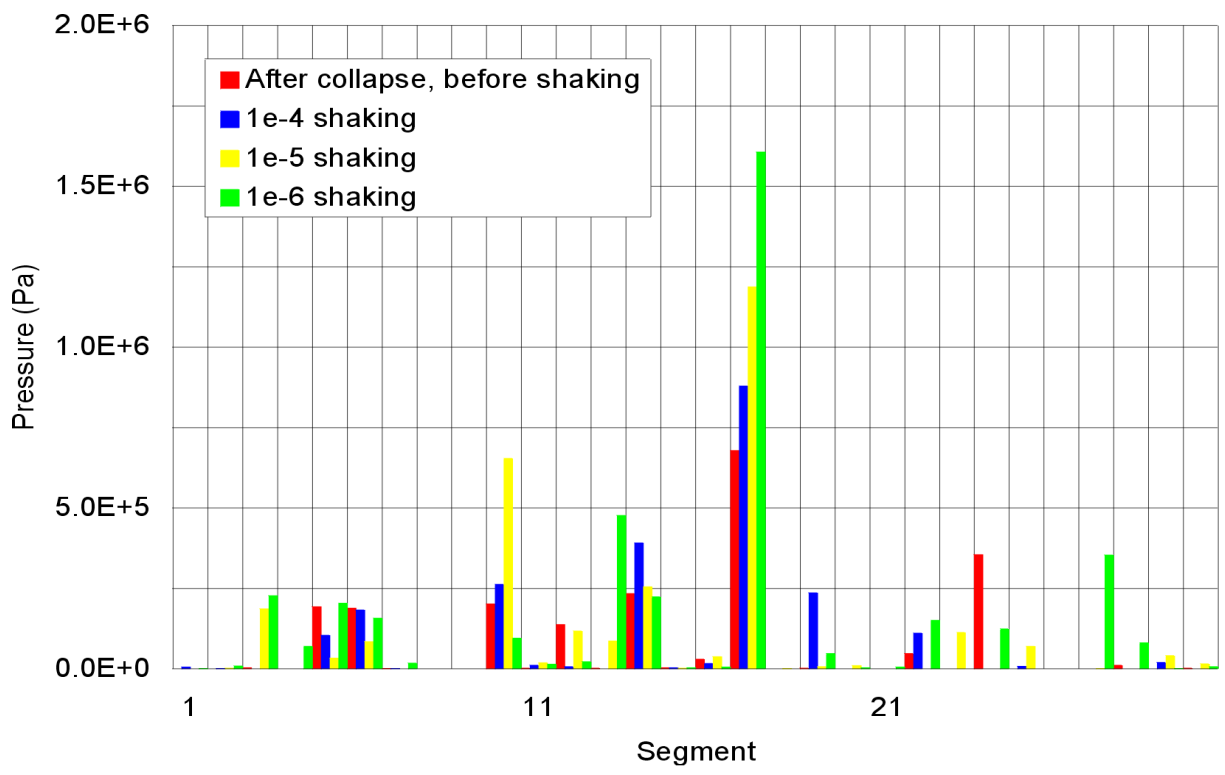

NOTE: $\mathrm{Pa}=$ Pascal.

Figure P-45. Effect Of Seismic Shaking After Quasi-Static Collapse On Drip Shield Loads

Table P-10. Effect of Seismic Shaking After Quasi-Static Collapse: Average Loads On the Drip Shield

\begin{tabular}{|l|c|c|c|c|}
\hline \multirow{2}{*}{\multicolumn{1}{|c|}{ Case }} & Left & Top & Right & \multirow{2}{*}{$\begin{array}{c}\text { Bulking } \\
\text { Factor }\end{array}$} \\
\cline { 2 - 4 } & $\mathbf{k N / \mathbf { m } ^ { 2 }}$ & $\mathbf{k N / \mathbf { m } ^ { 2 }}$ & $\mathbf{k N / \mathbf { m } ^ { 2 }}$ & 0.24 \\
\hline quasi-static collapse & 41.54 & 108.92 & 58.76 & 0.20 \\
\hline $10^{-4}$ shaking & 13.94 & 154.39 & 55.90 & 0.14 \\
\hline $10^{-5}$ shaking & 24.08 & 172.32 & 96.08 & 0.14 \\
\hline $10^{-6}$ shaking & 72.18 & 240.05 & 78.14 & 0.10 \\
\hline
\end{tabular}

\section{P6. CONCLUSION}

The drip shield loads are estimated and compared using different models. The most realistic drip-shield model, which generally resulted in the smallest loads, is used for further investigations of drip shield loads for different conditions of drift collapse and seismic loading subsequent to the collapse. Strong ground motions with $1 \times 10^{-6}$ and $1 \times 10^{-7}$ probability of annual recurrence, cause drift collapse within a second after onset of strong ground motion. The caved rock backfills the drift, providing a constraint to the motion of the drip shield and preventing the drip shield from being overturned. The rock mass is fragmented into small pieces (The model predicts disintegration of the rock mass into the original Voronoi blocks.) before they impact the drip shield. Large blocks, of the size similar to the size of the block created in the non-lithophysal rock mass, are not expected to impact the drip shield located in lithophysal rock mass. However, the transient impact pressures can be quite large, of the order of tens of megapascals. The drip shield load after quasi-static drift collapse was estimated for six different realization of the Voronoi block geometry. The average pressures on the top of the drip shield vary in the range $110 \mathrm{kN} / \mathrm{m}^{2}$ and $155 \mathrm{kN} / \mathrm{m}^{2}$. The seismic shaking subsequent to the drift collapse results in an increase of the load on the drip shield. For strong ground motions, that increase can be more than 100 percent. 
APPENDIX Q

IMPACT ANALYSES 


\section{IMPACT ANALYSES}

\section{Q1. IMPACT ANALYSES ON LDTH (LINE-AVERAGED HEAT SOURCE, DRIFT-SCALE, THERMOHYDROLOGIC) SUB-MODEL}

An impact analysis was conducted for the drift-scale thermal calculation performed by the NUFT thermohydrology software employing a two-dimensional, line-averaged heat source, drift-scale, thermohydrologic (LDTH) sub-model. The LDTH sub-model is a part of the multiscale thermohydrologic model created by the NUFT software, which is described in Multiscale Thermohydrologic Model (BSC 2004 [DIRS 163056]). An LDTH sub-model, P2WR5C10 (coordinates: E 170730, N 234913), was selected from the new 108 LDTH sub-models (DTN: LL030808623122.036 [DIRS 165790]) for this impact review. The P2WR5C10 LDTH sub-model location selected has the following characteristics of interest compared to the L2C3 LDTH sub-model (Section 6.2):

- Approximately the geometric center of the license application reference repository layout (BSC 2003 [DIRS 164519]).

- The repository horizon is located approximately $310 \mathrm{~m}$ below the ground surface and $279 \mathrm{~m}$ above the water table. This elevation puts the repository horizon at approximately $1053 \mathrm{~m}$ above sea level (DTN: LL030808623122.036 [DIRS 165790]).

- The repository horizon is located in the Tptpll with approximately $45 \mathrm{~m}$ of Tptpll above the repository horizon and $59 \mathrm{~m}$ of Tptpll below the repository horizon (DTN: LL030808623122.036 [DIRS 165790]).

- The mean infiltration conditions have surface infiltration rates of $4.7 \mathrm{~mm} /$ year during the first 600 years of emplacement (present day climate), $14.6 \mathrm{~mm} /$ year from 600 years to 2000 years (monsoonal climate), and $22.1 \mathrm{~mm} /$ year from 2000 years on (glacial transition climate) (DTN: LL030808623122.036 [DIRS 165790]).

- The ground surface temperature is fixed at $16.9^{\circ} \mathrm{C}$, and the water table temperature is fixed at $28.3^{\circ} \mathrm{C}$ (DTN: LL030808623122.036 [DIRS 165790]).

The preclosure forced ventilation has a varying heat removal capacity from the air inlet to exit of an emplacement drift due to temperature change of the airflow. The heat removal ratio is also a function of time as the waste package power output and rock mass temperature changes (BSC 2004 [DIRS 169862]). The heat removal ratio at $600 \mathrm{~m}$ from inlet ${ }^{1}$, as shown in Table Q-1, was obtained from DTN: MO0306MWDALAFV.000 [DIRS 163961] and was used for calculating temperature during the preclosure period.

${ }^{1}$ Emplacement drifts in the repository average approximately $600 \mathrm{~m}$ in length (BSC 2003 [DIRS 165572]). 
Table Q-1. Preclosure Ventilation Heat Removal Ratio at $600 \mathrm{~m}$ from Inlet

\begin{tabular}{|c|c|}
\hline Time (year) & Heat Removal Ratio (\%) \\
\hline 0.00 & 0.0 \\
\hline 0.01 & 38.4 \\
\hline 0.02 & 39.1 \\
\hline 0.05 & 36.4 \\
\hline 0.1 & 35.8 \\
\hline 0.167 & 59.7 \\
\hline 0.5 & 67.7 \\
\hline 1 & 70.1 \\
\hline 2 & 74.0 \\
\hline 5 & 78.2 \\
\hline 7 & 79.3 \\
\hline 10 & 80.7 \\
\hline 20 & 84.3 \\
\hline 30 & 86.0 \\
\hline 50 & 90.2 \\
\hline
\end{tabular}

Source: DTN MO0306MWDALAFV.000 [DIRS 163961].

The temperature history at the drift crown from this thermal calculation based on the revised LDTH sub-model is presented in Figure Q-1, and is compared to the three cases of thermal calculations (Section 6.2) previously reported in this document. The new thermal calculation results (termed "Case 1 impact") vary from the previous Case 1 base-case calculation, primarily in the preclosure period. Maximum temperature differences are about $35^{\circ} \mathrm{C}$ and $9{ }^{\circ} \mathrm{C}$ for the preclosure and postclosure periods, respectively. The temperature increase during the preclosure period is caused by the time-dependent ventilation heat removal ratio (Table Q-1) that is lower than 90 percent (Section 5.1.2) used in the previous preclosure calculations. Note that the temperature from the revised thermal calculation is slightly higher than the three previous cases after 2000 years. The temperature increase is due to a lower seepage infiltration ratio of the new LDTH sub-model (see Section 6.2 and this appendix).

The primary impact of this change in temperature on drift degradation is the impact on thermally induced stresses in the near-field of the emplacement drift. A simple, yet conservative, estimate of the impact on thermal stresses can be made based on the maximum additional postclosure temperature in the revised analyses, the rock mass thermal expansion coefficient and the bulk modulus. The results of these calculations are presented in Table Q-2. The approximate thermal stress increase due to the revised thermal calculation is based on Equation 6-6 (Section 6.2) and on the maximum temperature increase of $9^{\circ} \mathrm{C}$ during the postclosure period (Figure Q-1). The bulk modulus, $\mathrm{K}$, is calculated from rock mass Young's modulus and Poisson's ratio of the TSw2 thermal-mechanical unit based on Equation E-2 (Appendix E). The increase of thermal stress is about $1.5 \mathrm{MPa}$ for the Tptpll Category 3 (Table E-10) that has a representative rock mass Young's modulus and Poisson's ratio, while the Tptpmn from the Heated Drift (Table E-15) has a thermal stress increase of $2.8 \mathrm{MPa}$. The thermal stress increase of the Tptpll is less than 10 percent of the rock mass strength of the Tptpll Category 3 (20 MPa, Table E-10). Also, the thermal stress increase of the Tptpmn is less than 10 percent of the rock mass strength of the Tptpmn (75.25 MPa, Table E-15), which has a higher rock quality than the Tptpll. 


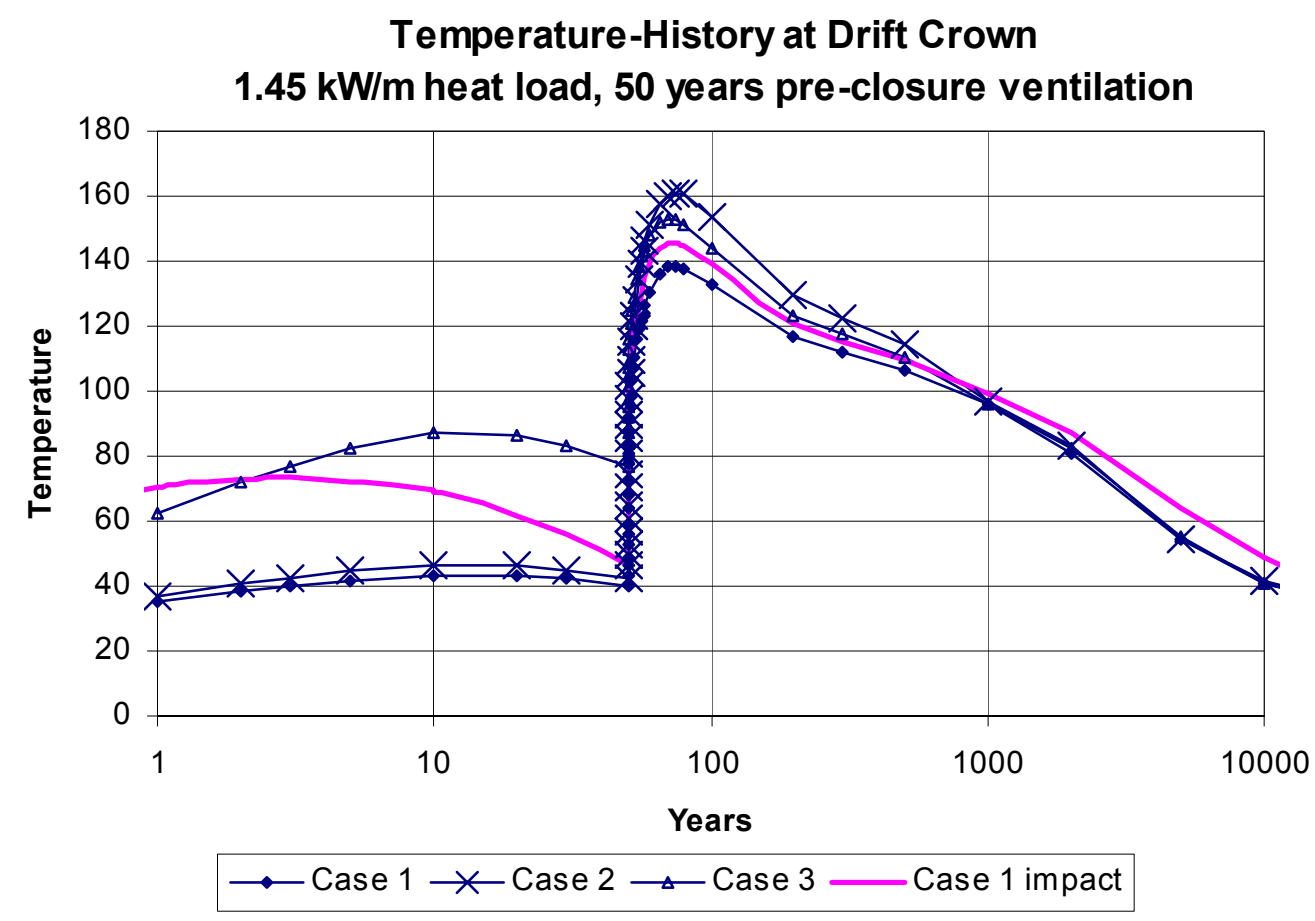

File source: DTN: MO0408MWDDDMIO.002, file LA1450_R5C10_NUFT_Temp_crss-sctn.xls.

Figure Q-1. Temperature History at the Drift Crown up to 10000 Years

Table Q-2. Maximum Increase of Thermal Stress during the Postclosure

\begin{tabular}{|c|c|c|c|c|c|c|}
\hline Rock Mass & $\begin{array}{c}\text { Young's } \\
\text { Modulus } \\
(\mathrm{Pa}) \\
\end{array}$ & $\begin{array}{c}\text { Poisson's } \\
\text { Ratioc }^{c}\end{array}$ & $\begin{array}{c}\text { Thermal } \\
\text { Expansion }^{\mathrm{d}} \\
\text { Coefficient }^{\mathrm{d}} \\
\left(/^{\circ} \mathrm{C}\right)\end{array}$ & $\begin{array}{c}\text { Bulk } \\
\text { Modulus } \\
(\mathrm{Pa}) \\
\end{array}$ & $\begin{array}{c}\text { Maximum } \\
\text { Temperature } \\
\text { Increase }\left({ }^{\circ} \mathrm{C}\right) \\
\end{array}$ & $\begin{array}{c}\text { Increase of } \\
\text { Thermal } \\
\text { Stress }(\mathrm{Pa}) \\
\end{array}$ \\
\hline $\begin{array}{l}\text { Tptpll } \\
\text { Category } 3^{\mathrm{a}} \\
\end{array}$ & $1.08 \mathrm{E}+10$ & 0.21 & 9.07E-06 & $6.21 \mathrm{E}+09$ & 9 & $1.52 \mathrm{E}+06$ \\
\hline $\begin{array}{l}\text { TSw2 } \\
\text { Category } 5^{\mathrm{b}}\end{array}$ & $2.01 \mathrm{E}+10$ & 0.21 & 9.07E-06 & $1.16 \mathrm{E}+10$ & 9 & $2.83 \mathrm{E}+06$ \\
\hline
\end{tabular}

a Obtained from Table E-10.

${ }^{b}$ Obtained from Table E-15.

c Obtained from Table E-16.

${ }^{d}$ Obtained from Table E-20; TSw2 and $100^{\circ} \mathrm{C}<\mathrm{T} \leq 125^{\circ} \mathrm{C}$.

The thermal stress increase from the revised LDTH sub-model (Table Q-2), although it is less than 10 percent of the rock mass strength, could potentially have some impact on thermal degradation and thermal/seismic combined degradation. However, the revised thermal calculation for the postclosure period is bounded by the Case 2 and Case 3 sensitivity calculation (Figure Q-1). Based on the rockfall analysis for the nonlithophysal rock (Sections 6.3.1.3 and 6.3.1.4) and the lithophysal rock (Section 6.4.2.3), the Case 2 and Case 3 sensitivity calculation demonstrated that the temperature increase from the Case 1 base case did not induce any significant additional rockfall (Section 6.3.1.3 and Section 6.4.2.3), and even generated less rockfall for Tptpmn (Table 6-24). Therefore, the temperature increase from the revised LDTH sub-model during the postclosure period is already covered by the previous rockfall analysis, 
and it is concluded that there is no impact to the rockfall prediction by using the new thermal calculation for the postclosure period. An additional analysis with thermal consideration, and combined thermal and seismic consideration for the drift degradation is not necessary for the postclosure period.

The temperature increase due to the revised LDTH sub-model during the preclosure period is much more significant than the postclosure period (Figure Q-2). However, the temperature itself is much lower compared to the postclosure period (below $75^{\circ} \mathrm{C}$ ), and it is still bounded by the Case 3 sensitivity calculation. The rockfall analysis for the lithophysal rock (Section 6.4.2.3) considered the Case 3 sensitivity case, and concluded temperature increase from the Case 1 base case did not induce any significant additional rockfall (Section 6.4.2.3). Therefore, it is also concluded that the temperature increase from the new LDTH sub-model during the preclosure period has no impact on the rockfall prediction by using the new thermal calculation for the preclosure period.

Drift deterioration analysis due to the time-dependent rock mass degradation is presented in Section 6.4.2.4 and Appendix S. Combined effects of the thermal and time-dependent degradation are presented in Appendix S3.4.2 based on the Case 1 base-case calculation. The results show minor spalling around the drift (Figures S-42, S-43, and S-44) and only a small increase in spalling compared to the time-dependent consideration case (Figure S-38, S-39, and S-40). While the temperature effects combined with the time-dependant degradation accelerated and increased drift degradation especially after the emplacement drift closure (see 80 years plots in Figure S-42, S-43, and S-44), the amount of rockfall is still small and the damage is limited to vicinity of the emplacement drift. The increase of temperature due to the revised thermal calculation (Case 1 impact) could potentially result in some additional deterioration of emplacement drift.

Time-dependent strength degradation combined with revised thermal load was evaluated for the Category 2 and 5 lithophysal rocks (Figures Q-3 and Q-4). The impact runs considered the higher temperatures of the revised LDTH NUFT model (Figure Q-1) for both the preclosure and postclosure periods. The spalling and damage due to the revised thermal and time-dependent degradation were slightly different from the previous coupled thermal and time-dependent damage analysis (Figures S-42 and S-44). However, the amount of spalling and damage was generally remained same for the Category 2 and 5 rocks compared to the previous coupled thermal and time-dependent damage. Therefore, it is concluded that the temperature increase from the revised LDTH sub-model has no significant impact on the rockfall prediction of combined thermal and time-dependent effects.

Based on the previous observation, the same conclusion that there is no significant impact could be attained for the coupled seismic, thermal, and time-dependent damage analysis (Appendix S3.4.3), and an additional analysis for the coupled seismic, thermal, and time-dependent damage is not necessary. 


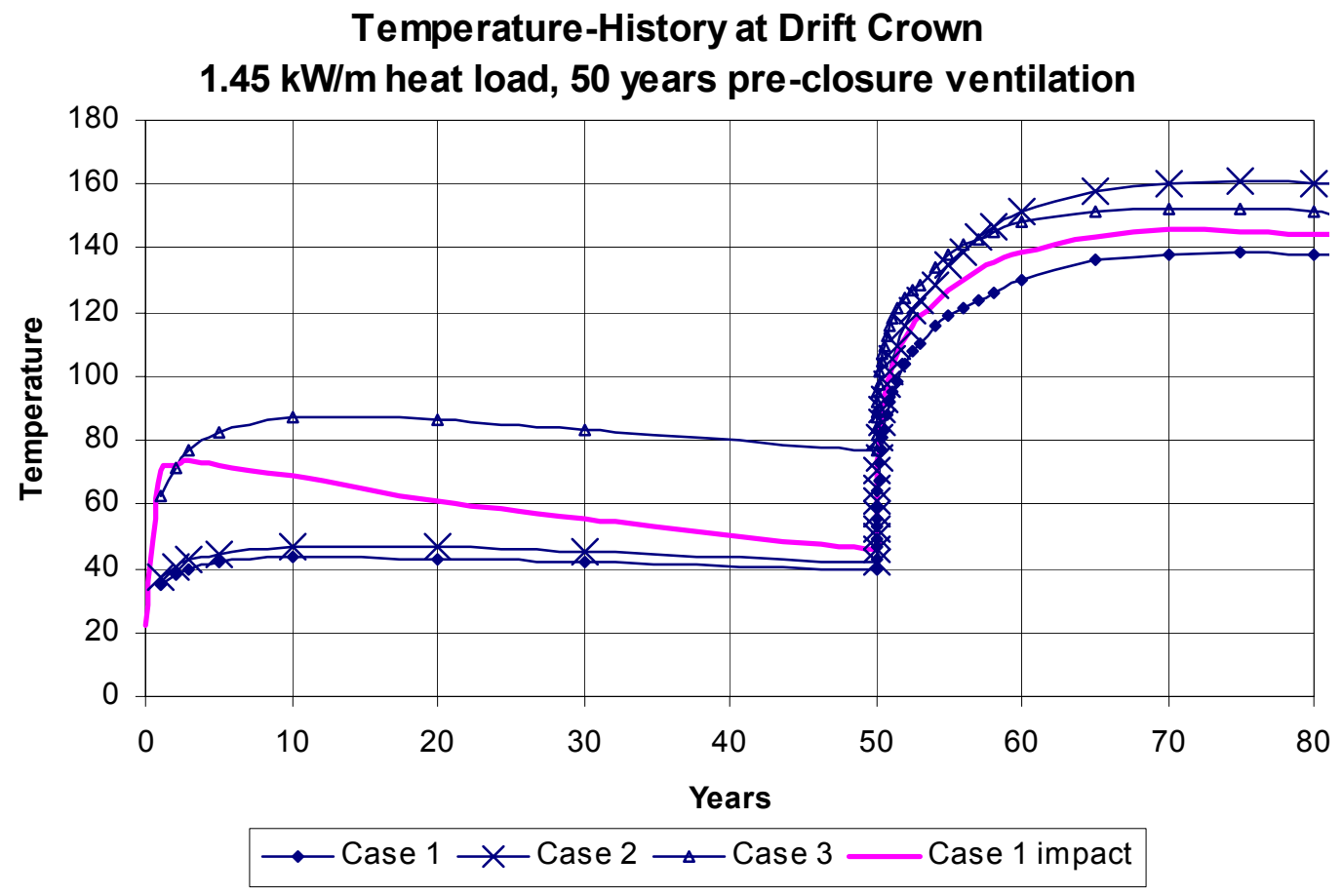

Source: DTN: MO0408MWDDDMIO.002, file LA1450_R5C10_NUFT_Temp_crss-sctn.xIs.

Figure Q-2. Temperature History at the Drift Crown up to 80 Years 

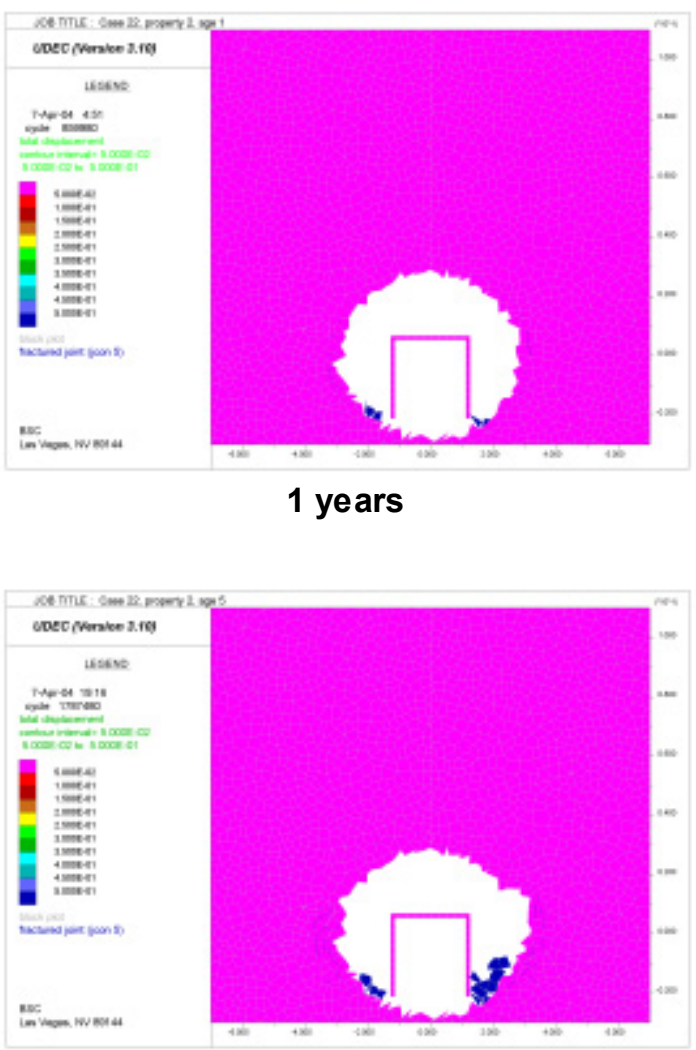

5 years

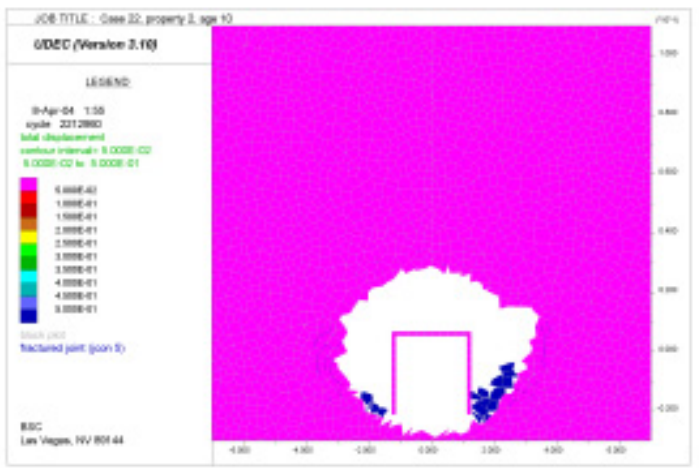

10 years

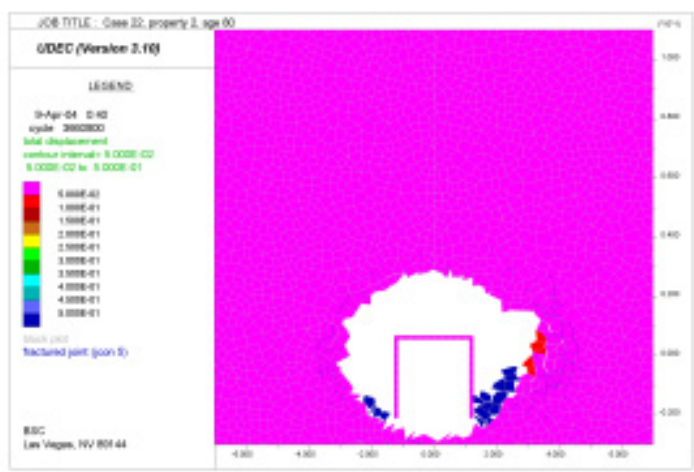

80 years

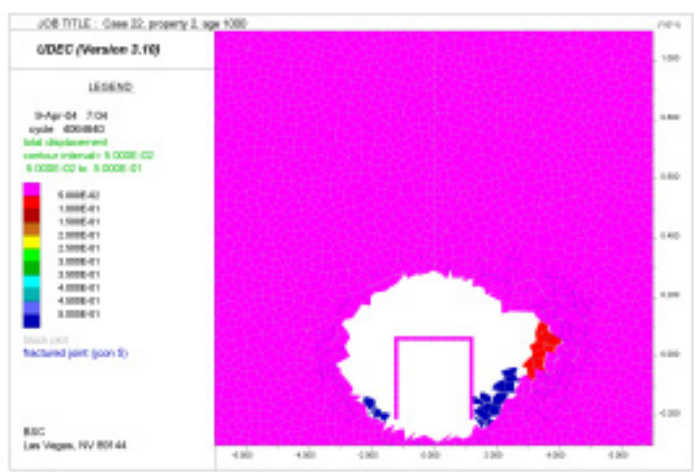

1000 years

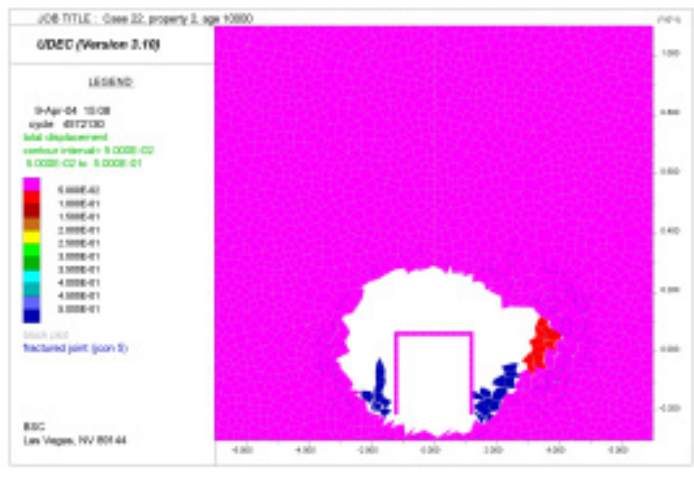

10000 years

Figure Q-3. Evolution of Damage Due to Strength Degradation and with Revised Thermal Load for Category 2 - Tuff Best-fit Static-Fatigue Curve 


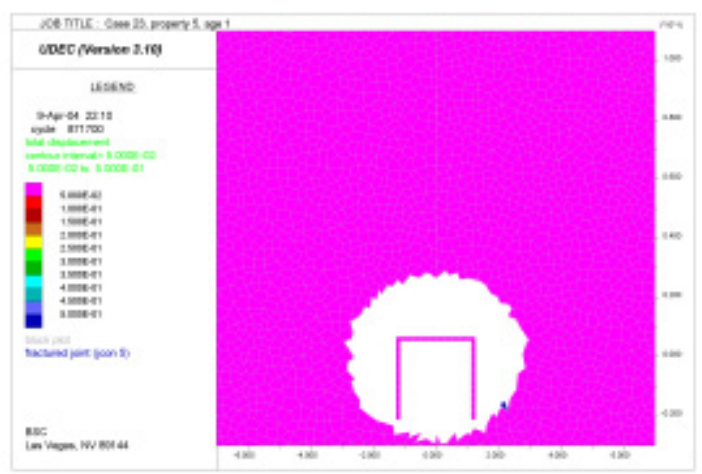

1 years

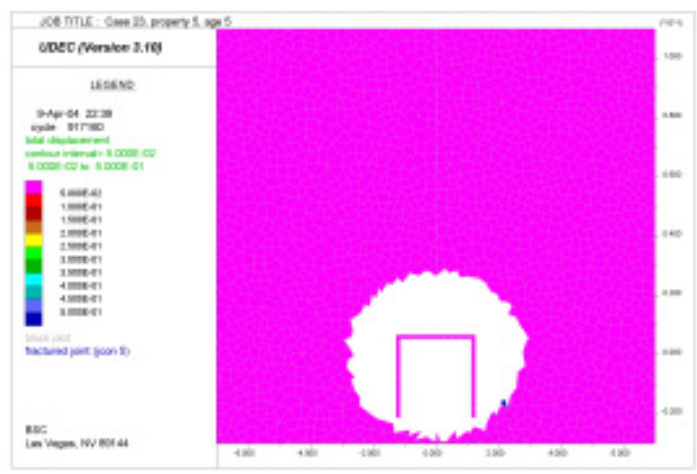

5 years

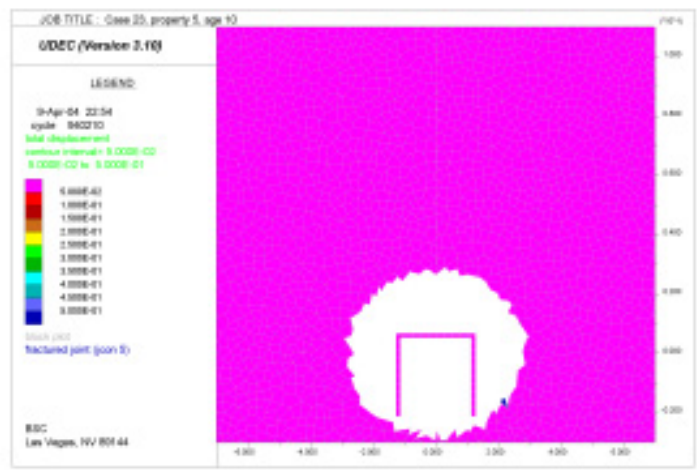

10 years

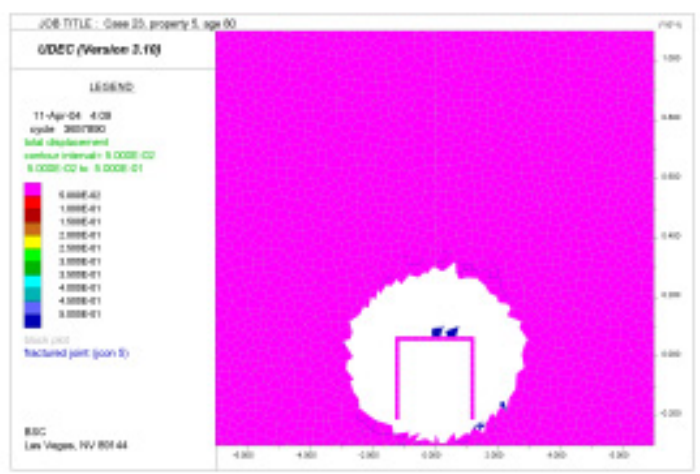

80 years

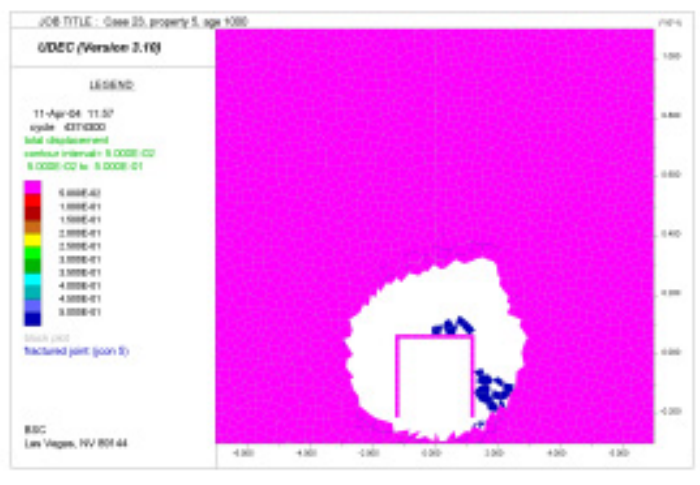

1000 years

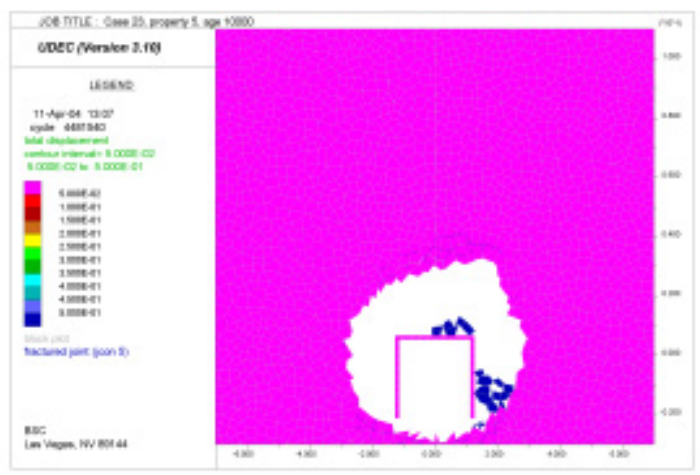

10000 years

Figure Q-4. Evolution of Damage Due to Strength Degradation and with Revised Thermal Load for Category 5 - Tuff Best-fit Static-Fatigue Curve 


\section{Q2. IMPACT ANALYSES ON HEAT CAPACIY}

The regional and local scale thermal-mechanical calculations used the weight-averaged thermal property values for the four thermal-mechanical units (Table C-4). The heat capacity data used in the thermal property calculation were preliminary data superseded by DTN: SN0307T0510902.003 [DIR 164196] (Table E-19). The revised specific heat values for the thermal-mechanical units are presented in Table Q-3. Only small changes of the values occur in the below $95^{\circ} \mathrm{C}$ range, especially in the repository units $(2$ percent decrease in TSw1 and 3 percent decrease in TSw2-TSw3). The impacts of the thermal properties for the below $95^{\circ} \mathrm{C}$ range are estimated as minor for the FLAC3D thermal-mechanical calculation, since the value changes in the repository units (TSw1 and TSw2-TSw3) are less than 3 percent. Based on the equation defined heat capacity at constant pressure (Brodsky et al. 1997 [DIRS 100653], p. 20):

$$
C_{p}=\frac{1}{m} \frac{\Delta Q}{\Delta T}
$$

where $m$ is the mass of the specimen $(\mathrm{kg}), \Delta Q$ is the increment of heat added to the subject $(\mathrm{J})$, and $\Delta T$ is the change of specimen temperature $(\mathrm{K})$, the change of the temperature is also estimated to be about 3 percent.

The impact of the revised heat capacity for the over $114^{\circ} \mathrm{C}$ range is also considered insignificant since change of the heat capacity value is irrelevant (less than 0.2 percent) for the TSw2-TSw3 repository unit.

Large heat capacity value changes occur in the $95^{\circ} \mathrm{C}$ to $114^{\circ} \mathrm{C}$ range (almost 50 percent decrease in the TSw2-TSw3 unit, as shown in Table Q-3). The $95^{\circ} \mathrm{C}$ to $114^{\circ} \mathrm{C}$ range is not substantial for the regional scale FLAC3D thermal-mechanical calculation, since the calculated temperatures in Appendix $\mathrm{C}$ were well below $95^{\circ} \mathrm{C}$ (Figure $\mathrm{C}-10$ ). For the local scale calculation, the resulting temperature and thermally induced stress using the revised specific heat should be under some impact as a result of the its low heat capacity value, especially for the central drift (Figure C-16). However, the rock volume for temperatures over $95^{\circ} \mathrm{C}$ is localized adjacent to the drift wall, and the time duration over $95^{\circ} \mathrm{C}$ is also limited to several hundred years. Also, the local scale thermal-mechanical calculation was only served to support and add confidence to the main thermal-mechanical calculation presented in Section 6.2. The resulting data from Section 6.2 (not from Appendix C) were used in the subsequent analyses of this document. Therefore, an additional local scale thermal-mechanical calculation is not necessary.

Table Q-3. Specific Heat Considered for the Rock Mass in the Regional and Local Scale Thermal-Mechanical Calculations (Appendix C)

\begin{tabular}{|l|c|r|r|r|r|}
\hline \multicolumn{1}{|c|}{ Property } & Condition & TCw-PTn & \multicolumn{1}{c|}{ TSw1 } & TSw2-TSw3 & Underlying \\
\hline Preliminary & $<95^{\circ} \mathrm{C}$ & 1,158 & 939 & 937 & 1,304 \\
specific heat $\mathrm{C}_{\mathrm{v}}$ & $95^{\circ} \mathrm{C} \leq \mathrm{C}_{\mathrm{v}}<114^{\circ} \mathrm{C}$ & 11,135 & 5,791 & 5,714 & 15,775 \\
{$\left[\mathrm{~J} / \mathrm{kg}{ }^{\circ} \mathrm{C}\right]$} & $\geq 114^{\circ} \mathrm{C}$ & 1,010 & 991 & 990 & 1,016 \\
\hline & $<95^{\circ} \mathrm{C}$ & 1,300 & 920 & 910 & 1,300 \\
Updated specific & $95^{\circ} \mathrm{C} \leq \mathrm{C}_{\mathrm{v}}<114^{\circ} \mathrm{C}$ & 9,000 & 3,200 & 3,000 & 8,400 \\
heat $^{\mathrm{a}} \mathrm{C}_{\mathrm{v}}\left[\mathrm{J} / \mathrm{kg}^{\circ} \mathrm{C}\right]$ & $\geq 114^{\circ} \mathrm{C}$ & 1,000 & 990 & 990 & 1,100 \\
\hline
\end{tabular}

${ }^{a}$ The mean values are calculated from DTN: SN0307T0510902.003 [DIRS 164196]. 


\section{Q3. IMPACT ANALYSES FOR USE OF PFC2D AND PFC3D FISHTANK}

PFC2D V.2.0 and PFC3D V.2.0 (Section 3.1) were used for the study of rock mass strength and long-term strength degradation in Section 7.6 and Appendix S.

The PFC models of rock mass strength and long-term strength degradation used FishTank 04lb. FishTank is a library of Fish functions that is technically supported and updated by the PFC software vendor, Itasca. FishTank can be downloaded from the Itasca website (www.itascacg.com). PFC2D V.2.0 and PFC3D V.2.0 install FishTank 03a and 04c automatically during the software installation, respectively. Since qualification of PFC2D and PFC3D did not specifically identify FishTank in their qualification processes, the usage of FishTank 04lb is outside of the range of PFC2D and PFC3D software validation.

PFC2D V.2.0 and PFC3D V.2.0 with FishTank 04lb (STN: 10828-2.0-01 and 10830-2.0-01 respectively) were qualified in accordance with LP-SI.11Q-BSC, Software Management, and LP-SI-12Q-BSC, Qualification of Level A Software. An impact review was conducted on the PFC models in the Section 7.6 and Appendix Q using the newly qualified PFC2D and PFC3D software.

A typical static fatigue model, sA_mS50eXu_tC0p1-sf, was re-run for exploring impacts of PFC2D V.2.0 with FishTank 04lb. The model is a representative case of the static fatigue test simulation in Appendix $\mathrm{S}$, which has $0.1 \mathrm{MPa}$ of confining stress and 10 percent of void (lithophysal) porosity. Results of the re-run were identical with the previous run calculated from the previous version of PFC2D. Figure Q-5 presents the strain energy stored during the static fatigue simulations for both runs, which shows identical results for the runs. In addition to the results, their log files, sA_mS50e10u_tC0p1_n-sf.log, that contained the information regarding numerical calculation were identical, with the exception of header, dates, and times (Figure Q-6).

A PFC3D biaxial model, sB1_mKvbX_tA, was re-run in order to investigate impacts of PFC3D V.2.0 with FishTank 04lb. Figure Q-7 shows the axial and confining stresses during the biaxial simulation, which have identical values. Also, Figure Q-8 shows that their log files, $s B 1 \_m K v B 2 \_t A y \cdot \log$, that contain the information regarding numerical calculation are identical except for header, dates, and times.

Based on the impact evaluation, it is concluded there is no impact to the re-qualification of PFC2D and PFC3D. 


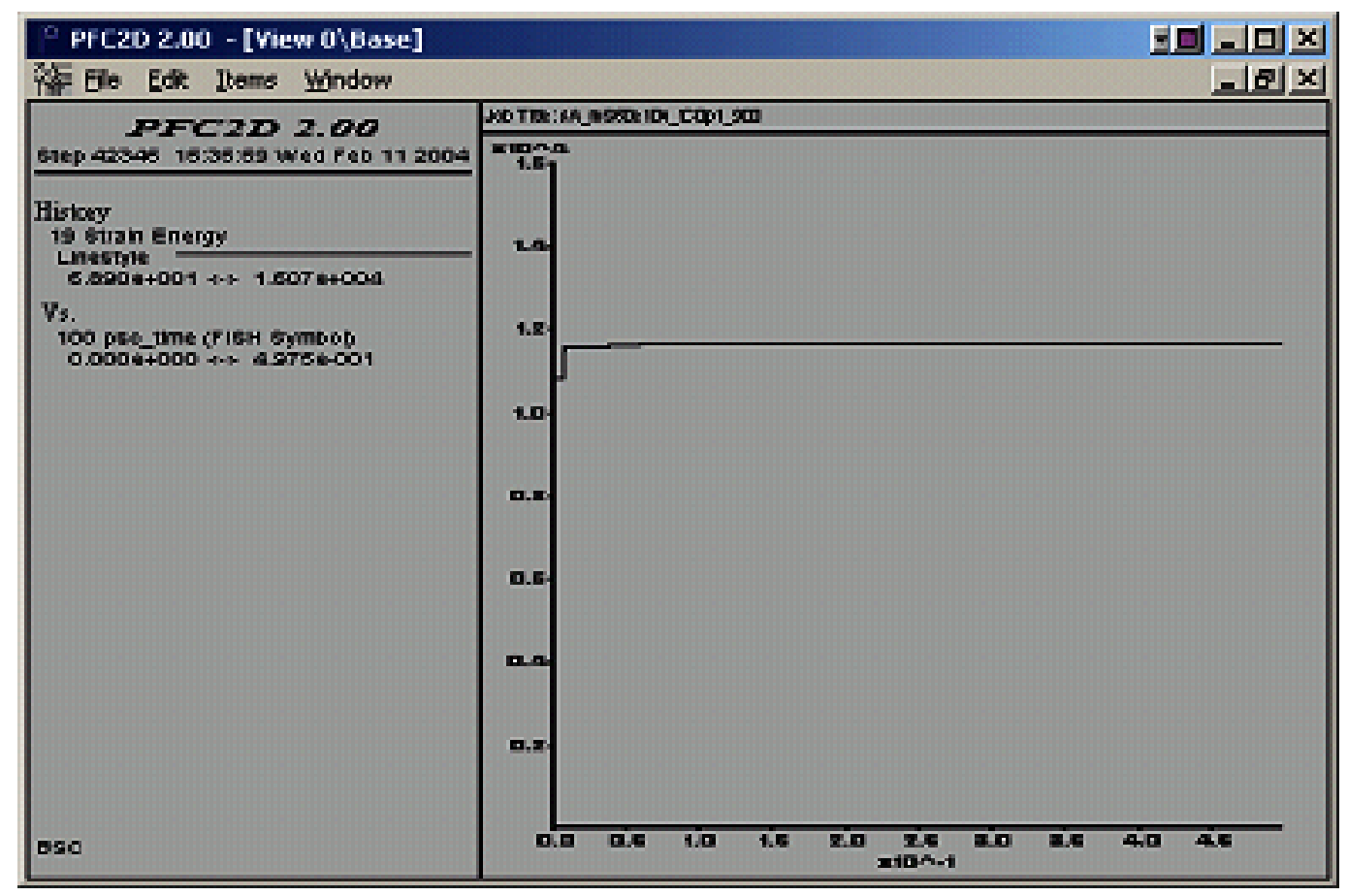

a)

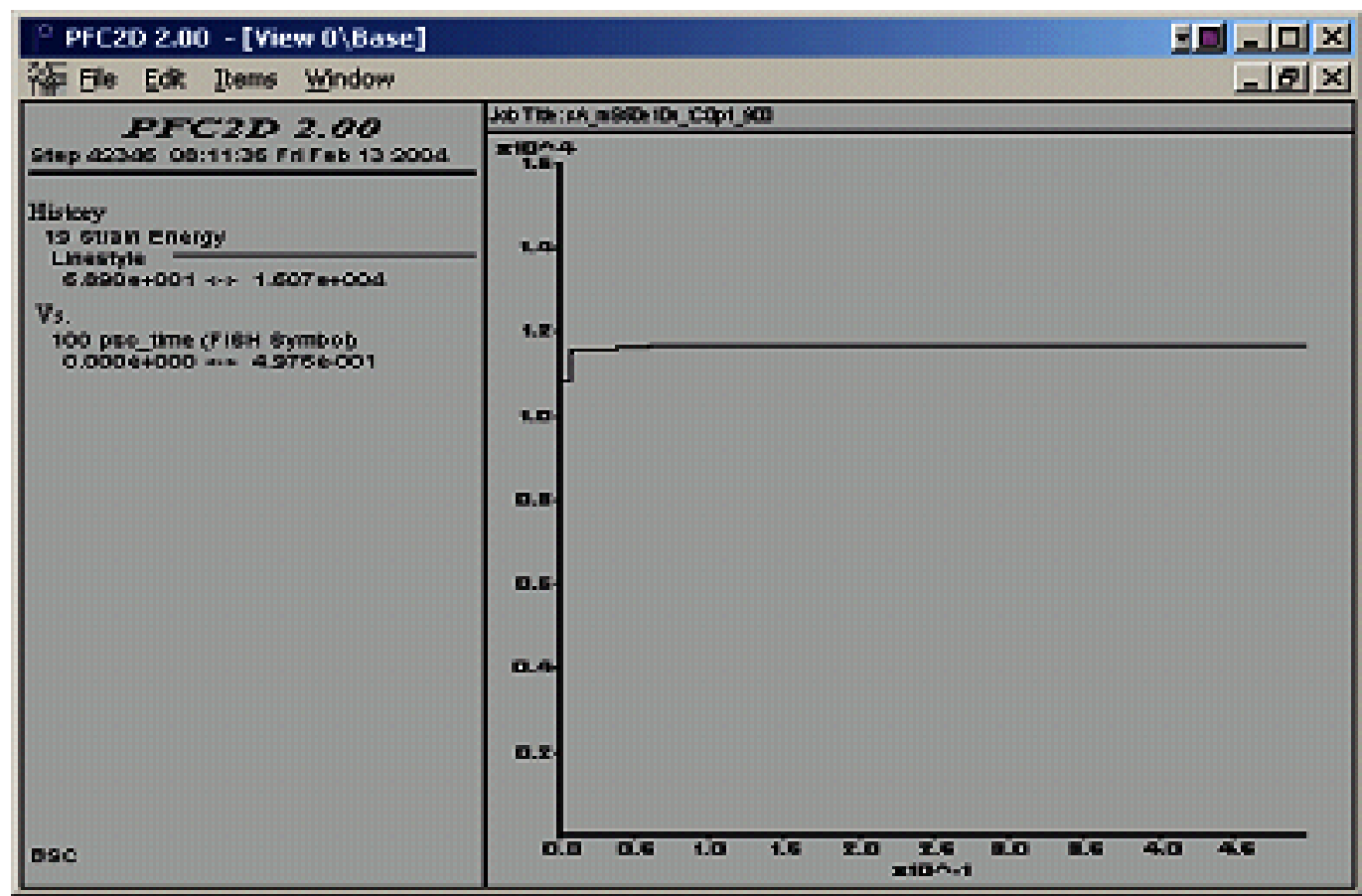

b)

NOTE: a) previous run and b) impact run using re-qualified PFC2D.

Figure Q-5. Strain Energy Stored During the Static Fatigue Simulations 


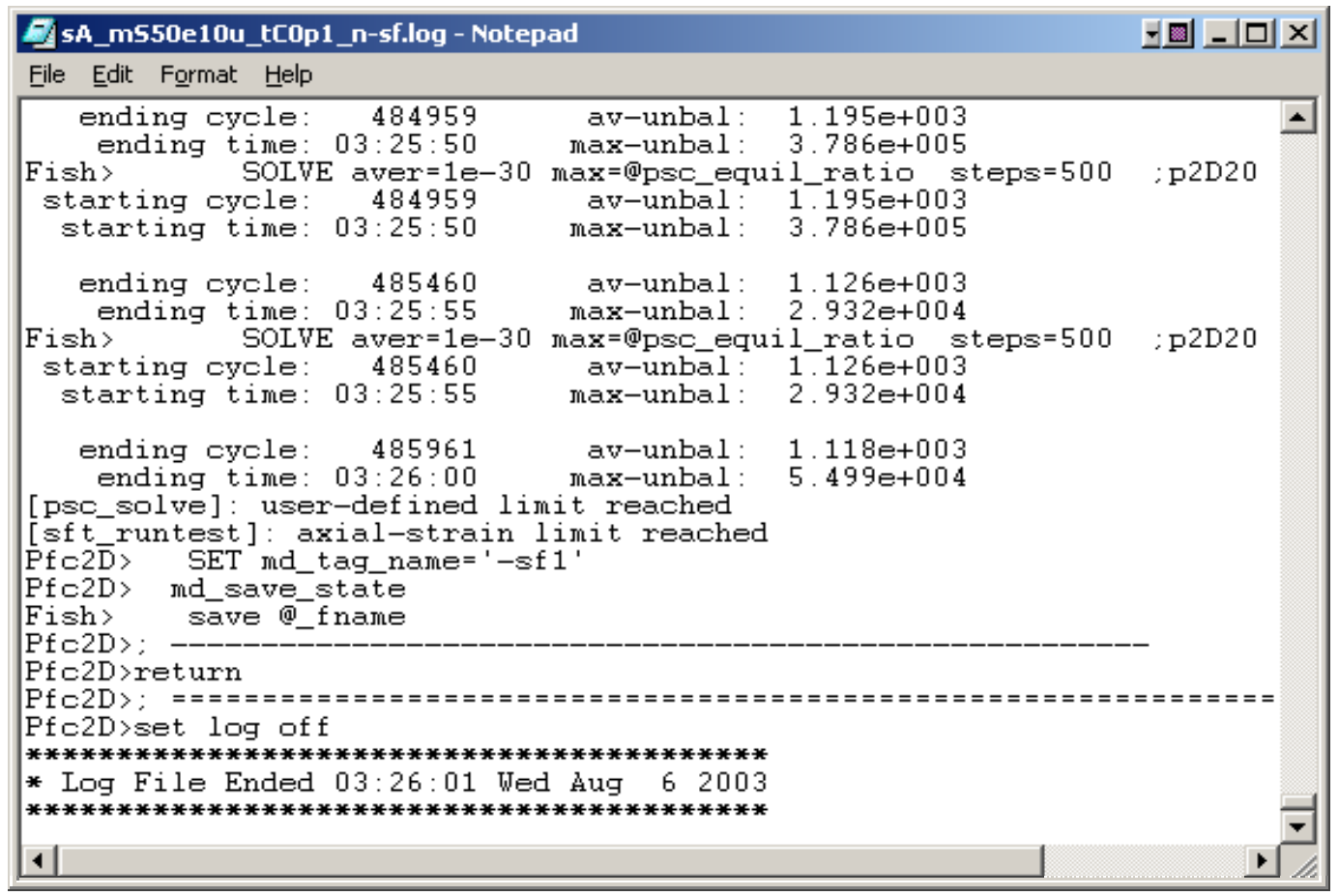

a)

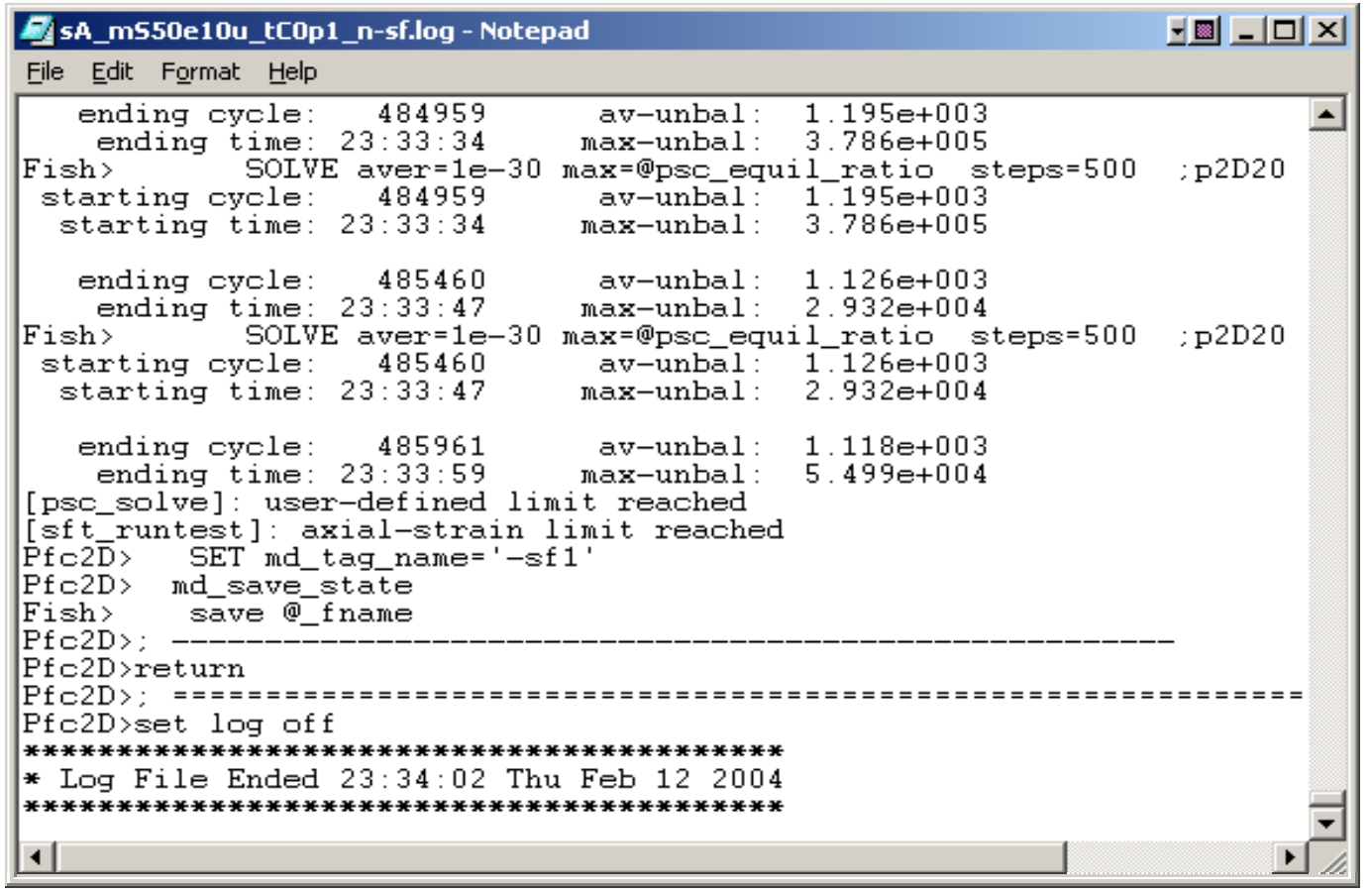

b)

NOTE: a) previous run; b) impact run using re-qualified PFC2D.

Figure Q-6. Log Files from PFC2D 


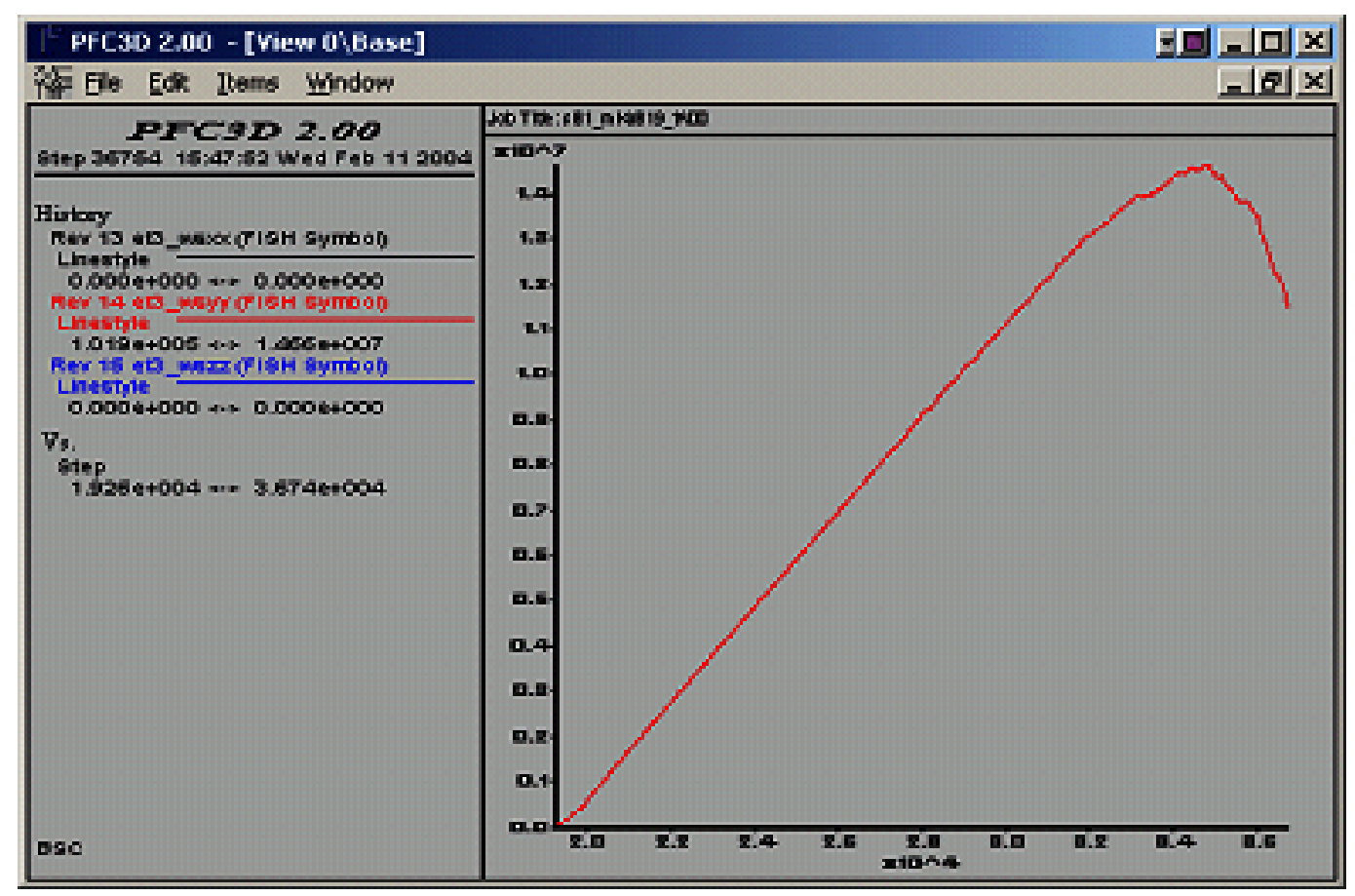

a)

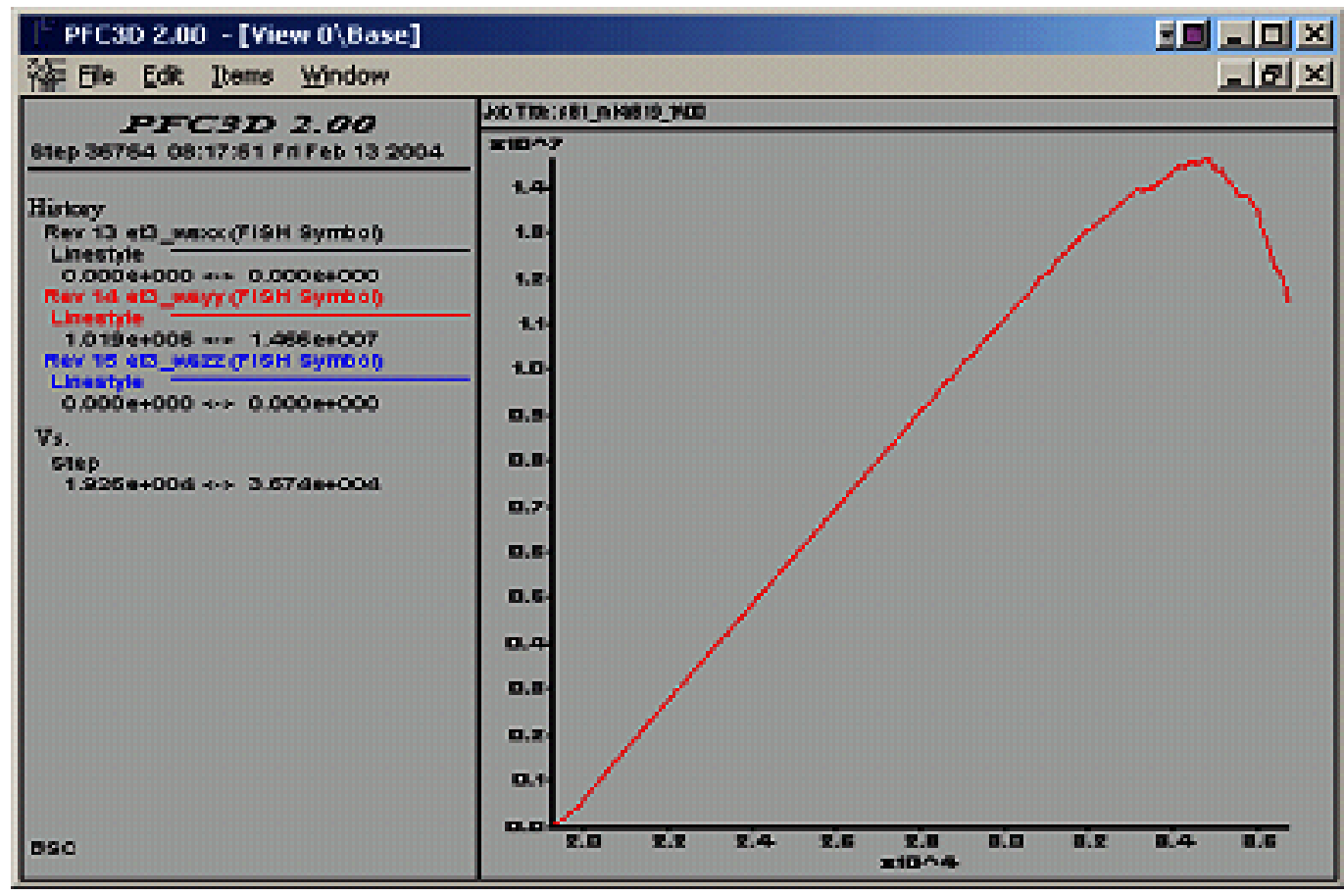

b)

NOTE: a) previous run; b) impact run using re-qualified PFC3D.

Figure Q-7. Axial (wsyy) and Confining Stresses (wsxx and wszz) During the Biaxial Simulations 


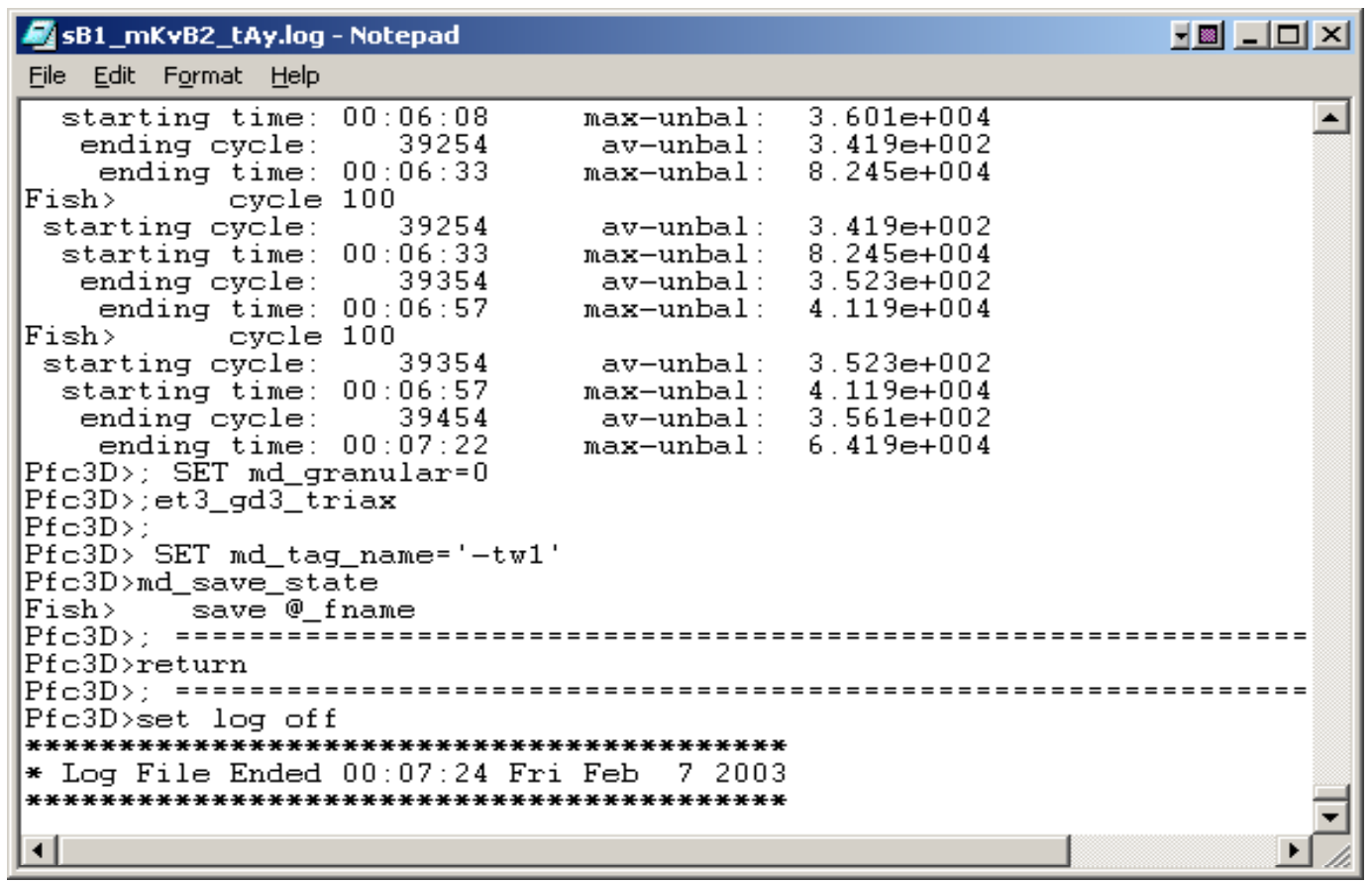

a)

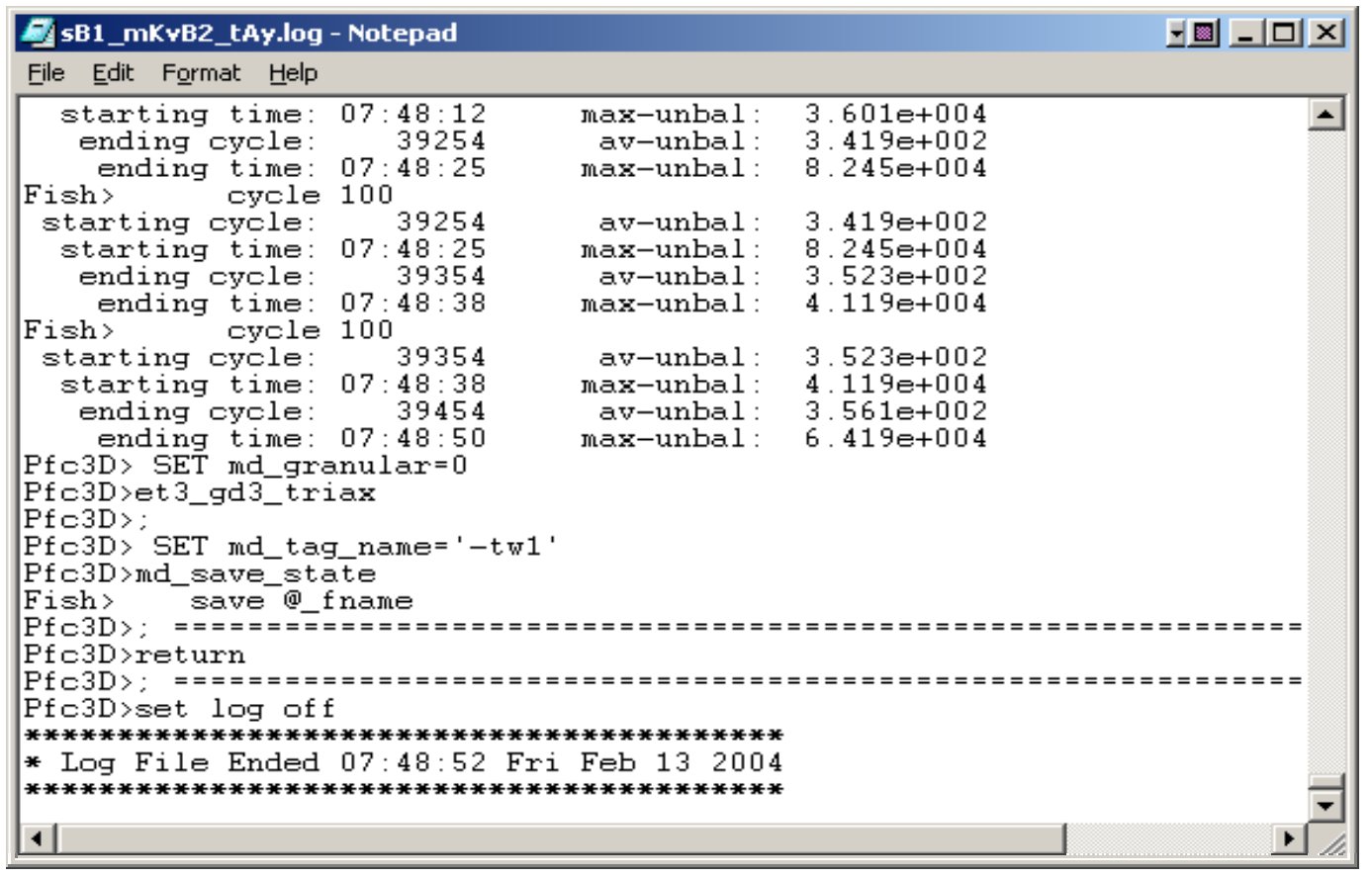

b)

NOTE: a) previous run; b) impact run using re-qualified PFC3D.

Figure Q-8. Log Files from PFC3D 


\section{INTENTIONALLY LEFT BLANK}


APPENDIX R

DRIFT PROFILE PREDICTION AND DEGRADED ROCK MASS

CHARACTERISTICS IN LITHOPHYSAL UNITS 


\section{DRIFT PROFILE PREDICTION AND DEGRADED ROCK MASS CHARACTERISTICS IN LITHOPHYSAL UNITS}

To a large extent, deformation of the rock mass occurs as a result of deformation of pre-existing joints or creation and deformation of new fractures, resulting in a change in rock mass permeability. It is observed that both normal (opening and closure) and shear (slip) deformation of joints affect joint permeability. However, because joint slip results in joint opening (due to dilatancy), joint permeability can be considered to be a function of joint opening only. If rockfall occurs, which is a consequence of rock mass deformation, the size and the shape of the emplacement drifts will change. Changes in permeability and drift geometry will affect percolation of groundwater around the drifts and potential for water seepage into the drifts.

The results for drift degradation and rock mass deformation from seismic loading (for preclosure and postclosure ground motions), thermal loading, and time-dependent drift degradation are generated as input data for seepage analysis. Results for a total of 30 scenarios of UDEC lithophysal modeling cases are provided. The blocks used in the UDEC Voronoi block model do not represent the actual internal structure of the lithophysal rock mass. The blocks are a tool in the numerical model used to simulate damage and fracturing of the rock mass (i.e., the potential fractures in this model do not correspond to actual features observed in the lithophysal units) as documented in Section 7.6.4. The joint data from the Voronoi block model presented in this appendix are provided to assess the overall degraded rock mass response. A description of each scenario is provided Table R-1. For each scenario, the following results are generated and included:

1. Plot of the geometry of the model (see Figures R-1 through R-30). The drift profile is generated deleting blocks that moved more than $0.15 \mathrm{~m}$.

2. ASCII text with values of stress tensor components $\left(\sigma_{\mathrm{xx}}, \sigma_{\mathrm{xy}}, \sigma_{\mathrm{yy}}\right.$, and $\left.\sigma_{\mathrm{zz}}\right)$ at UDEC grid points (provided by coordinates $x$ and $y$ ).

3. ASCII text with Voronoi block model joint data (coordinates of center, $x$ and $y$, normal displacement, length and orientation; i.e., a unit vector, $n$, normal to the joint) for the joints in the UDEC Voronoi block model.

4. ASCII text with averaged volumetric strain from fracture deformation as calculated in the UDEC Voronoi block model.

The UDEC model keeps track of all joints (i.e., contacts between the blocks) with joint aperture smaller than a predefined tolerance. In the simulations carried out for this report the contact tolerance is $0.0055 \mathrm{~m}$. When the contact aperture becomes larger than the tolerance, the contact is deleted because the blocks involved in the contact are no longer interacting with each other. However, the joints with large openings (i.e., larger than $0.0055 \mathrm{~m}$ ) are relevant for the seepage analysis and needs to be included in the list of joints created in the model due to deformation, and taken into account in calculation of the volumetric strain. An algorithm is developed which detects large-opening joints based on distance and co-linearity of block edges. The blocks in the vicinity of block edges (within a distance of $0.5 \mathrm{~m}$ and $0.7 \mathrm{~m}$ for block size of $0.2 \mathrm{~m}$ and $0.3 \mathrm{~m}$, respectively) are checked for large apertures. Edges around the blocks are treated as co-linear if 
the angle between them is smaller than $10^{\circ}$. The list of joints based on the UDEC contact list is supplemented with the list of joints with large apertures.

In the simulations carried out for this report, contact deformation in the UDEC model includes deformation due to the in situ stress state prior to excavation of the drift and any other subsequent loading. However, for the seepage analysis, it is of interest to have joint deformation and volumetric strain due to drift excavation and subsequent loading only. Therefore, in situ joint deformation is calculated analytically and subtracted from cumulative joint deformation. The in situ stress is characterized by the horizontal $\left(\stackrel{o}{\sigma}_{x x}=3.5 \mathrm{MPa}\right)$ and the vertical principal stresses $\left(\stackrel{o}{\sigma}_{y y}=7.0 \mathrm{MPa}\right)$ acting in the plane of the model. The normal traction acting on a joint with a unit normal vector, $n$, is:

$$
\stackrel{o}{\sigma}_{n}=\stackrel{o}{\sigma_{x x}} n_{x}^{2}+\stackrel{o}{\sigma_{y y}} n_{y}^{2}
$$

where $n_{x}$ is the x-component of $n$, and $n_{y}$ is the y-component of $n$. Consequently, the in situ joint deformation is (Itasca Consulting Group 2002 [DIRS 160331])

$$
\Delta \stackrel{o}{u_{n}}=k_{n} \stackrel{o}{n}_{n}
$$

where $k_{n}$ is the joint normal stiffness.

The volumetric strain is calculated on a rectangular grid with horizontal and vertical spacing of $0.25 \mathrm{~m}$ based on joint deformation and area of the blocks. At each point of the grid, the joints within a predefined distance (i.e., a circle with a radius of $0.5 \mathrm{~m}$ and $0.75 \mathrm{~m}$ for block size of $0.2 \mathrm{~m}$ and $0.3 \mathrm{~m}$, respectively) are detected. Areas of the joints within the circle, $\sum_{j=1}^{N} A_{j}$, and area of the blocks that form those joints, $\sum_{b=1}^{M} A_{b}$, are calculated. Thus, the volumetric strain is

$$
\varepsilon_{v}=\frac{\sum_{j=1}^{N} A_{j}}{\sum_{b=1}^{M} A_{b}} .
$$

The information presented in this appendix, which is obtained as direct output from UDEC, is provided in DTN: MO0306MWDDPPDR.000. 
Table R-1. Considered Scenarios for Drift Profile and Degraded Rock Mass Characteristics

\begin{tabular}{|c|c|}
\hline Scenario & Brief Description of the Scenario \\
\hline 1 & $\begin{array}{l}\text { seismic with } 5 \times 10^{-4} \text { probability of exceedance ground motion, rock mass category } 1 \text {, Voronoi block size } \\
0.3 \mathrm{~m}\end{array}$ \\
\hline 2 & $\begin{array}{l}\text { seismic with } 1 \times 10^{-6} \text { probability of exceedance ground motion, rock mass category } 1 \text {, ground motion \#12, } \\
\text { Voronoi block size } 0.3 \mathrm{~m} \text { (Table } 6-44 \text {, realization number } 4 \text { ) }\end{array}$ \\
\hline 3 & $\begin{array}{l}\text { seismic with } 1 \times 10^{-6} \text { probability of exceedance ground motion, rock mass category } 1 \text {, ground motion \#8, } \\
\text { Voronoi block size } 0.3 \mathrm{~m} \text { (Table } 6-44 \text {, realization number } 6 \text { ) }\end{array}$ \\
\hline 4 & $\begin{array}{l}\text { seismic with } 1 \times 10^{-6} \text { probability of exceedance ground motion, rock mass category } 1 \text {, ground motion } \# 9 \text {, } \\
\text { Voronoi block size } 0.3 \mathrm{~m} \text { (Table } 6-44 \text {, realization number } 11)\end{array}$ \\
\hline 5 & $\begin{array}{l}\text { seismic with } 1 \times 10^{-6} \text { probability of exceedance ground motion, rock mass category } 1 \text {, ground motion \#1, } \\
\text { Voronoi block size } 0.3 \mathrm{~m} \text { (Table } 6-44 \text {, realization number } 12 \text { ) }\end{array}$ \\
\hline 6 & thermal at 10,000 years, rock mass category 1 , Voronoi block size $0.3 \mathrm{~m}$ \\
\hline 7 & $\begin{array}{l}\text { degradation consideration, } 0 \% \text { cohesion reduction, Voronoi block size } 0.3 \mathrm{~m} \text {, and random block } \\
\text { generation seed \#1 }\end{array}$ \\
\hline 8 & $\begin{array}{l}\text { degradation consideration, } 20 \% \text { cohesion reduction, Voronoi block size } 0.3 \mathrm{~m} \text {, and random block } \\
\text { generation seed } \# 1\end{array}$ \\
\hline 9 & $\begin{array}{l}\text { degradation consideration, } 40 \% \text { cohesion reduction, Voronoi block size } 0.3 \mathrm{~m} \text {, and random block } \\
\text { generation seed } \# 1\end{array}$ \\
\hline 10 & $\begin{array}{l}\text { degradation consideration, } 60 \% \text { cohesion reduction, Voronoi block size } 0.3 \mathrm{~m} \text {, and random block } \\
\text { generation seed } \# 1\end{array}$ \\
\hline 11 & $\begin{array}{l}\text { degradation consideration, } 80 \% \text { cohesion reduction, Voronoi block size } 0.3 \mathrm{~m} \text {, and random block } \\
\text { generation seed } \# 1\end{array}$ \\
\hline 12 & $\begin{array}{l}\text { degradation consideration, } 100 \% \text { cohesion reduction, Voronoi block size } 0.3 \mathrm{~m} \text {, and random block } \\
\text { generation seed \#1 }\end{array}$ \\
\hline 13 & $\begin{array}{l}\text { degradation consideration, } 0 \% \text { cohesion reduction, Voronoi block size } 0.3 \mathrm{~m} \text {, and random block } \\
\text { generation seed \#2 }\end{array}$ \\
\hline 14 & $\begin{array}{l}\text { degradation consideration, } 20 \% \text { cohesion reduction, Voronoi block size } 0.3 \mathrm{~m} \text {, and random block } \\
\text { generation seed } \# 2\end{array}$ \\
\hline 15 & $\begin{array}{l}\text { degradation consideration, } 40 \% \text { cohesion reduction, Voronoi block size } 0.3 \mathrm{~m} \text {, and random block } \\
\text { generation seed \#2 }\end{array}$ \\
\hline 16 & $\begin{array}{l}\text { degradation consideration, } 60 \% \text { cohesion reduction, Voronoi block size } 0.3 \mathrm{~m} \text {, and random block } \\
\text { generation seed \#2 }\end{array}$ \\
\hline 17 & $\begin{array}{l}\text { degradation consideration, } 80 \% \text { cohesion reduction, Voronoi block size } 0.3 \mathrm{~m} \text {, and random block } \\
\text { generation seed \#2 }\end{array}$ \\
\hline 18 & $\begin{array}{l}\text { degradation consideration, } 100 \% \text { cohesion reduction, Voronoi block size } 0.3 \mathrm{~m} \text {, and random block } \\
\text { generation seed \#2 }\end{array}$ \\
\hline 19 & $\begin{array}{l}\text { degradation consideration, } 0 \% \text { cohesion reduction, Voronoi block size } 0.2 \mathrm{~m} \text {, and random block } \\
\text { generation seed \#1 }\end{array}$ \\
\hline 20 & $\begin{array}{l}\text { degradation consideration, } 20 \% \text { cohesion reduction, Voronoi block size } 0.2 \mathrm{~m} \text {, and random block } \\
\text { generation seed } \# 1\end{array}$ \\
\hline 21 & $\begin{array}{l}\text { degradation consideration, } 40 \% \text { cohesion reduction, Voronoi block size } 0.2 \mathrm{~m} \text {, and random block } \\
\text { generation seed } \# 1\end{array}$ \\
\hline 22 & $\begin{array}{l}\text { degradation consideration, } 60 \% \text { cohesion reduction, Voronoi block size } 0.2 \mathrm{~m} \text {, and random block } \\
\text { generation seed } \# 1\end{array}$ \\
\hline 23 & $\begin{array}{l}\text { degradation consideration, } 80 \% \text { cohesion reduction, Voronoi block size } 0.2 \mathrm{~m} \text {, and random block } \\
\text { generation seed } \# 1\end{array}$ \\
\hline 24 & $\begin{array}{l}\text { degradation consideration, } 100 \% \text { cohesion reduction, Voronoi block size } 0.2 \mathrm{~m} \text {, and random block } \\
\text { generation seed } \# 1\end{array}$ \\
\hline
\end{tabular}


Table R-1. Considered Scenarios for Drift Profile and Degraded Rock Mass Characteristics (Continued)

\begin{tabular}{|c|l|}
\hline Scenario & \multicolumn{1}{|c|}{ Brief Description of the Scenario } \\
\hline 25 & $\begin{array}{l}\text { degradation consideration, 0\% cohesion reduction, Voronoi block size 0.2 m, and random block } \\
\text { generation seed \#2 }\end{array}$ \\
\hline 26 & $\begin{array}{l}\text { degradation consideration, 20\% cohesion reduction, Voronoi block size 0.2 m, and random block } \\
\text { generation seed \#2 }\end{array}$ \\
\hline 27 & $\begin{array}{l}\text { degradation consideration, 40\% cohesion reduction, Voronoi block size 0.2 m, and random block } \\
\text { generation seed \#2 }\end{array}$ \\
\hline 28 & $\begin{array}{l}\text { degradation consideration, 60\% cohesion reduction, Voronoi block size 0.2 m, and random block } \\
\text { generation seed \#2 }\end{array}$ \\
\hline 29 & $\begin{array}{l}\text { degradation consideration, 80\% cohesion reduction, Voronoi block size 0.2 m, and random block } \\
\text { generation seed \#2 }\end{array}$ \\
\hline 30 & $\begin{array}{l}\text { degradation consideration, 100\% cohesion reduction, Voronoi block size 0.2 m, and random block } \\
\text { generation seed \#2 }\end{array}$ \\
\hline
\end{tabular}

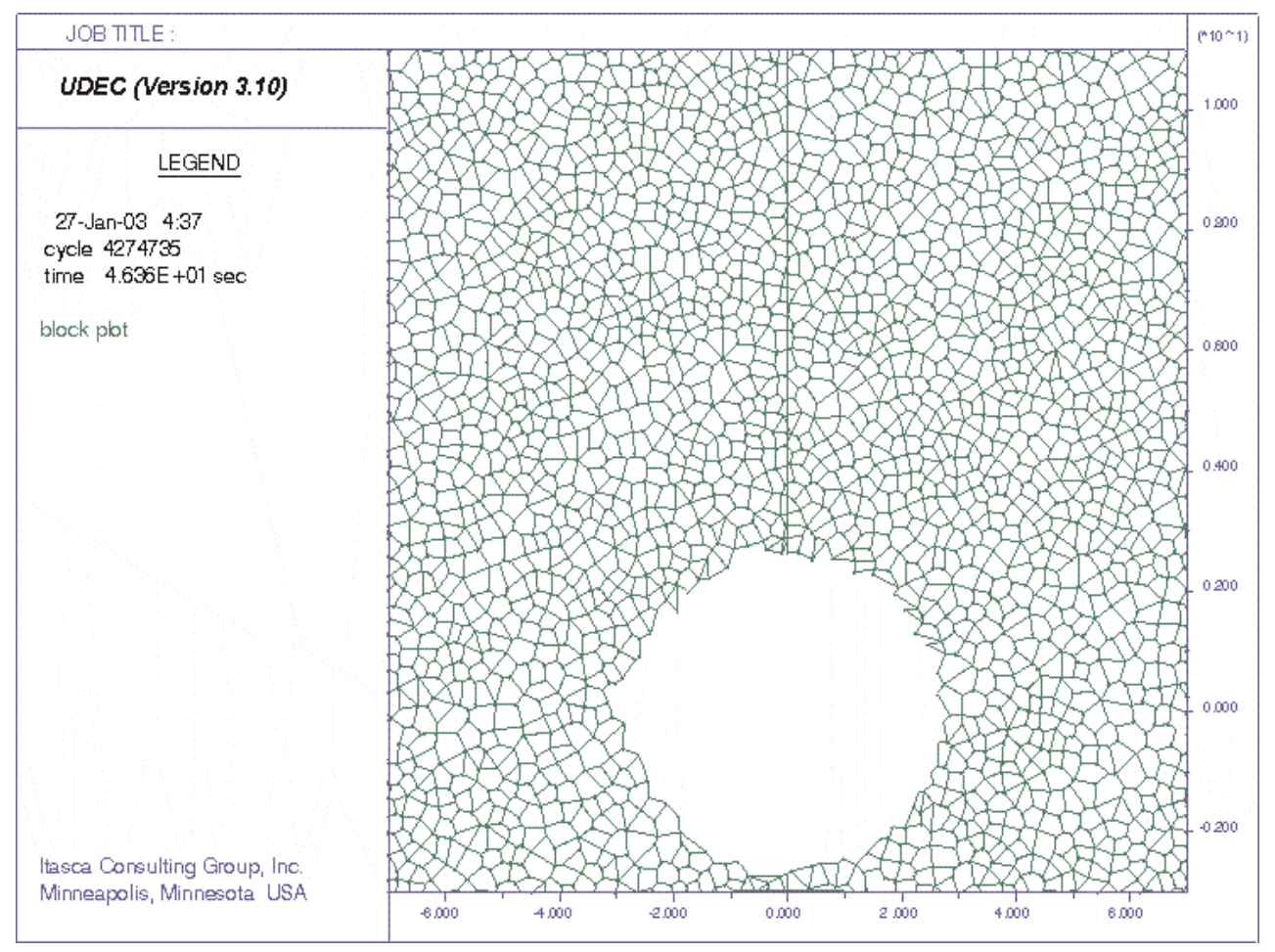

Figure R-1. Drift Profile for Scenario 1: Seismic with $5 \times 10^{-4}$ Probability of Exceedance Ground Motion, Rock Mass Category 1, Voronoi Block Size $0.3 \mathrm{~m}$ 


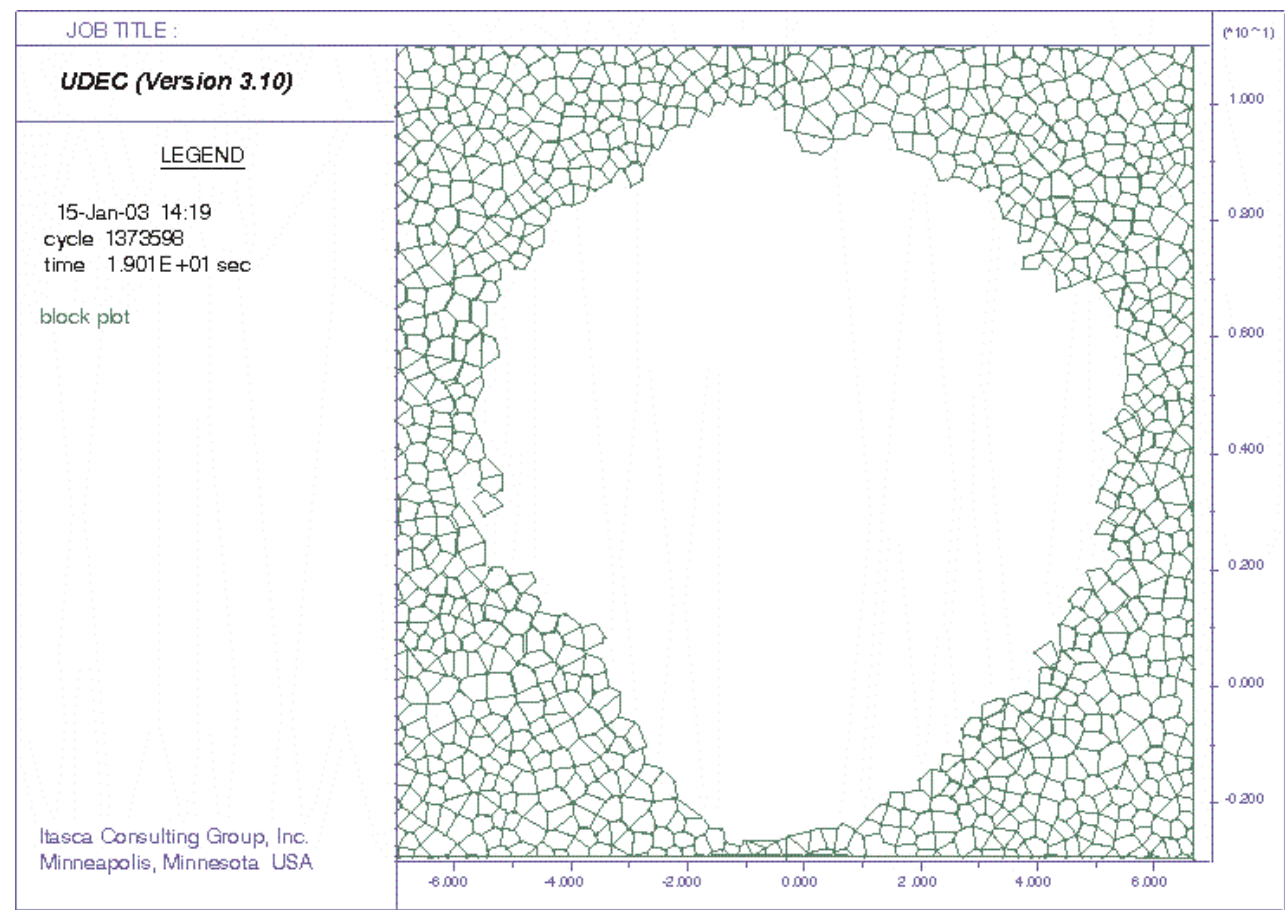

Figure R-2. Drift Profile for Scenario 2: Seismic with $1 \times 10^{-6}$ Probability of Exceedance Ground Motion, Rock Mass Category 1, Ground Motion \#12, Voronoi Block Size $0.3 \mathrm{~m}$

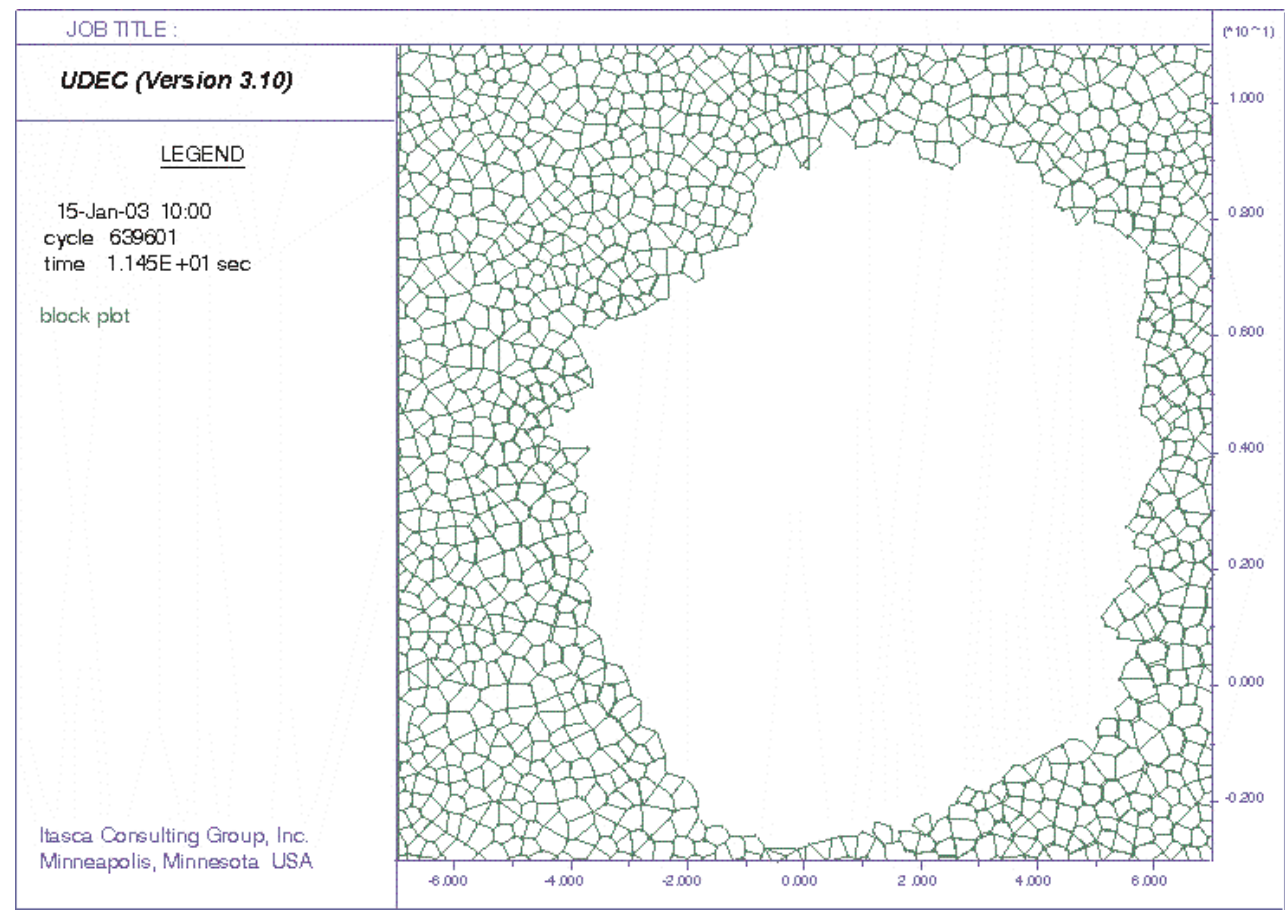

Figure R-3. Drift Profile for Scenario 3: Seismic with $1 \times 10^{-6}$ Probability of Exceedance Ground Motion, Rock Mass Category 1, Ground Motion \#8, Voronoi Block Size $0.3 \mathrm{~m}$ 


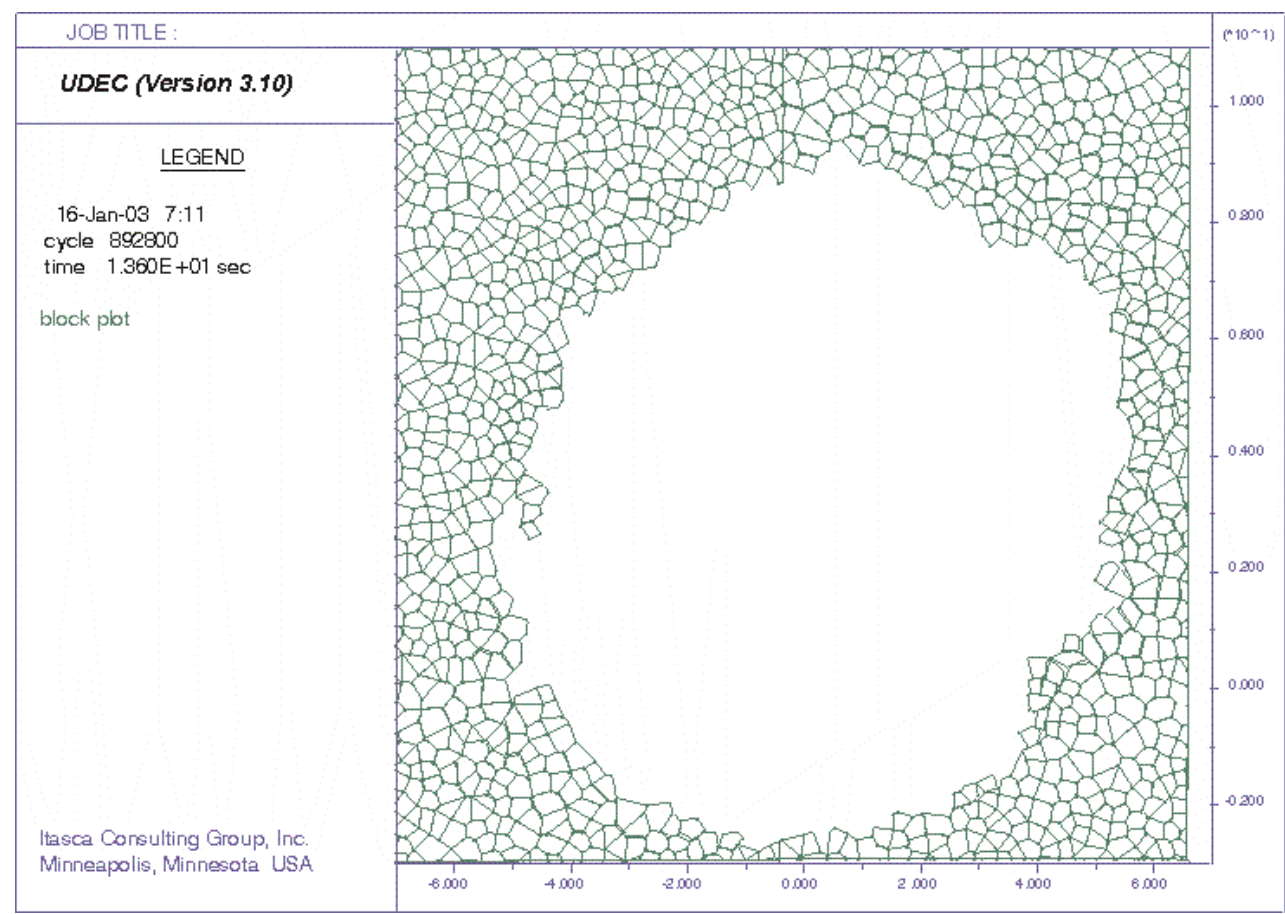

Figure R-4. Drift Profile for Scenario 4: Seismic with $1 \times 10^{-6}$ Probability of Exceedance Ground Motion, Rock Mass Category 1, Ground Motion \#9, Voronoi Block Size $0.3 \mathrm{~m}$

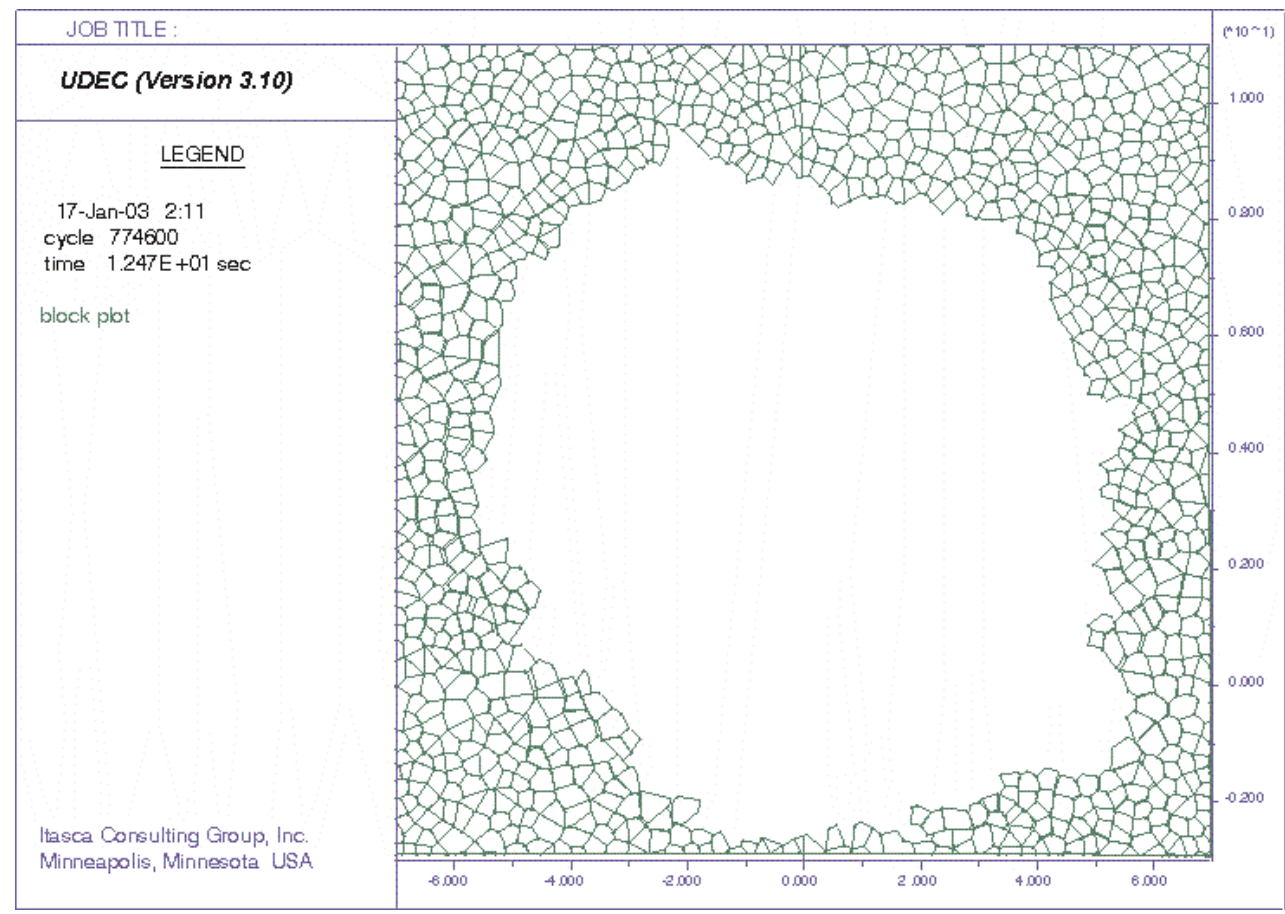

Figure R-5. Drift Profile for Scenario 5: Seismic with $1 \times 10^{-6}$ Probability of Exceedance Ground Motion, Rock Mass Category 1, Ground Motion \#1, Voronoi Block Size $0.3 \mathrm{~m}$ 


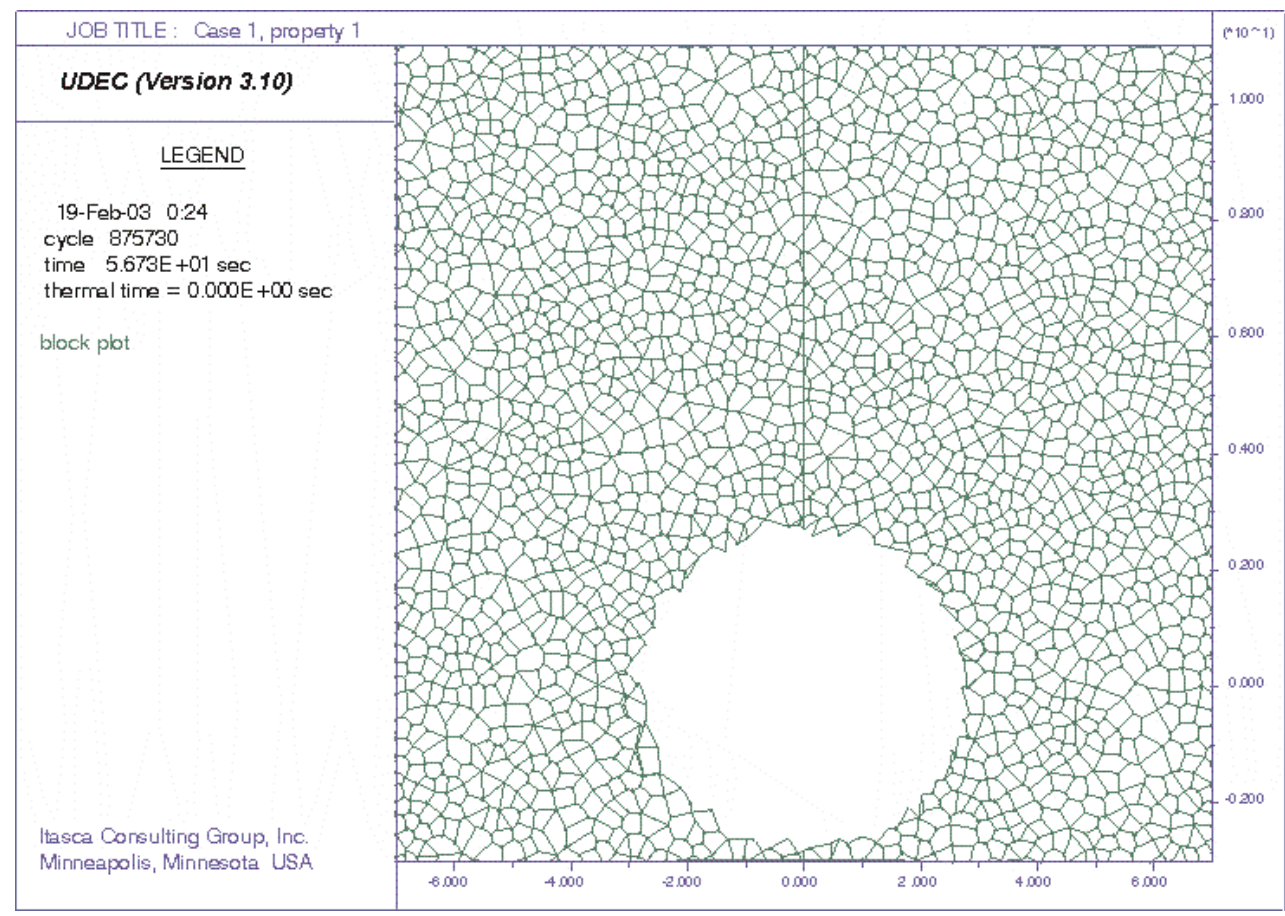

Figure R-6. Drift Profile for Scenario 6: Thermal at 10,000 Years, Rock Mass Category 1, Voronoi Block Size $0.3 \mathrm{~m}$

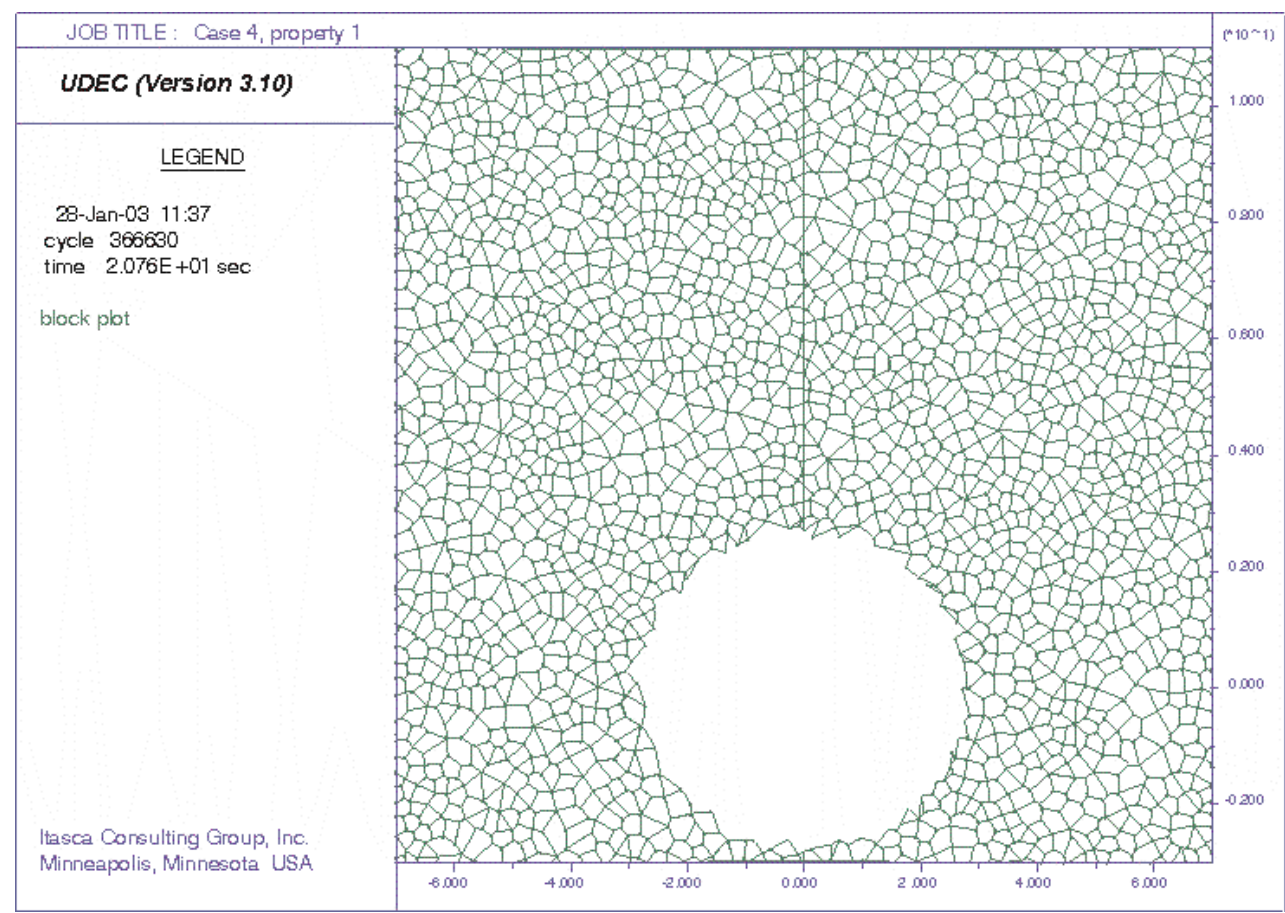

Figure R-7. Drift Profile for Scenario 7: Degradation Consideration, 0\% Cohesion Reduction, Voronoi Block Size $0.3 \mathrm{~m}$, and Random Block Generation Seed \#1 
$\underline{\text { Drift Degradation Analysis }}$

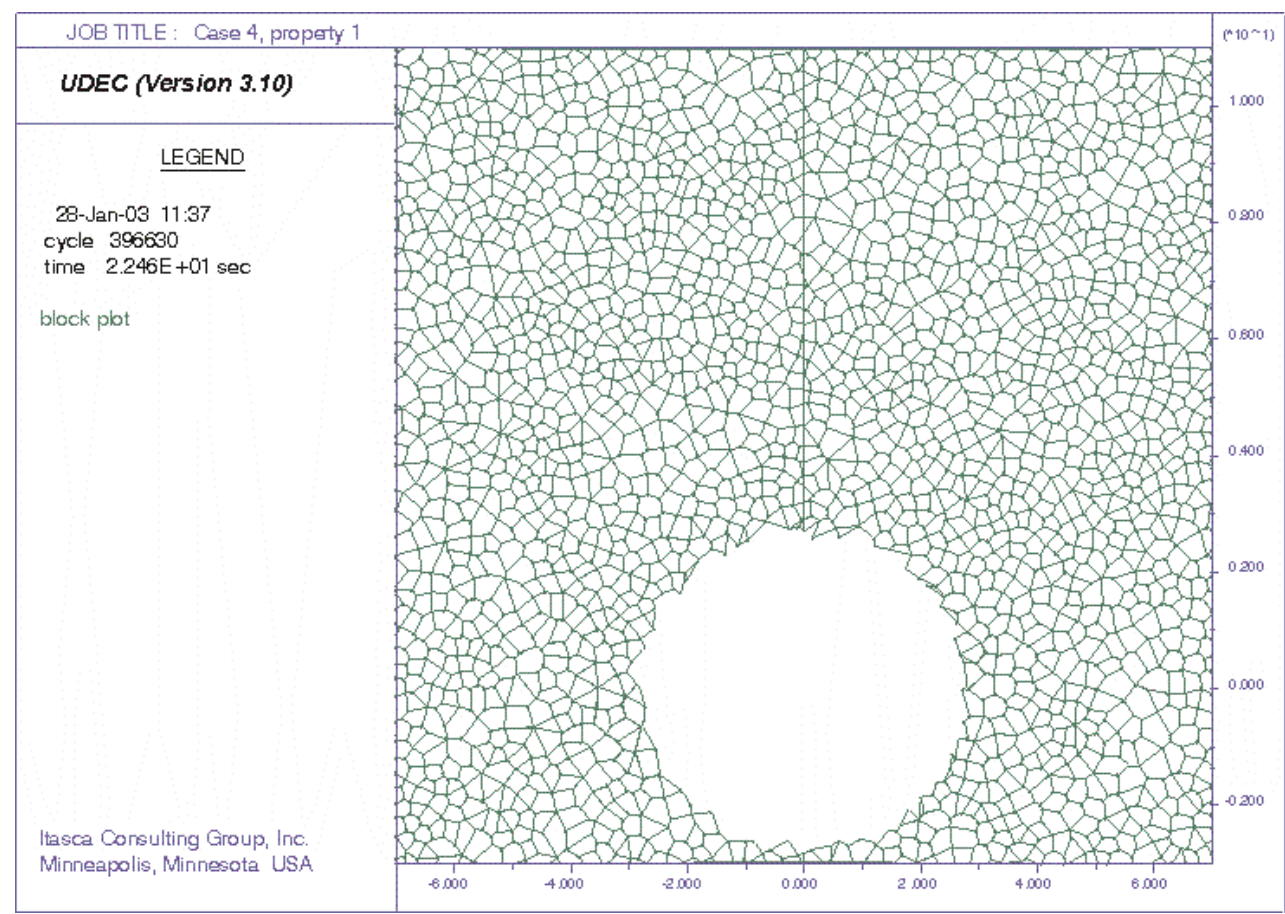

Figure R-8. Drift Profile for Scenario 8: Degradation Consideration, 20\% Cohesion Reduction, Voronoi Block Size $0.3 \mathrm{~m}$, and Random Block Generation Seed \#1

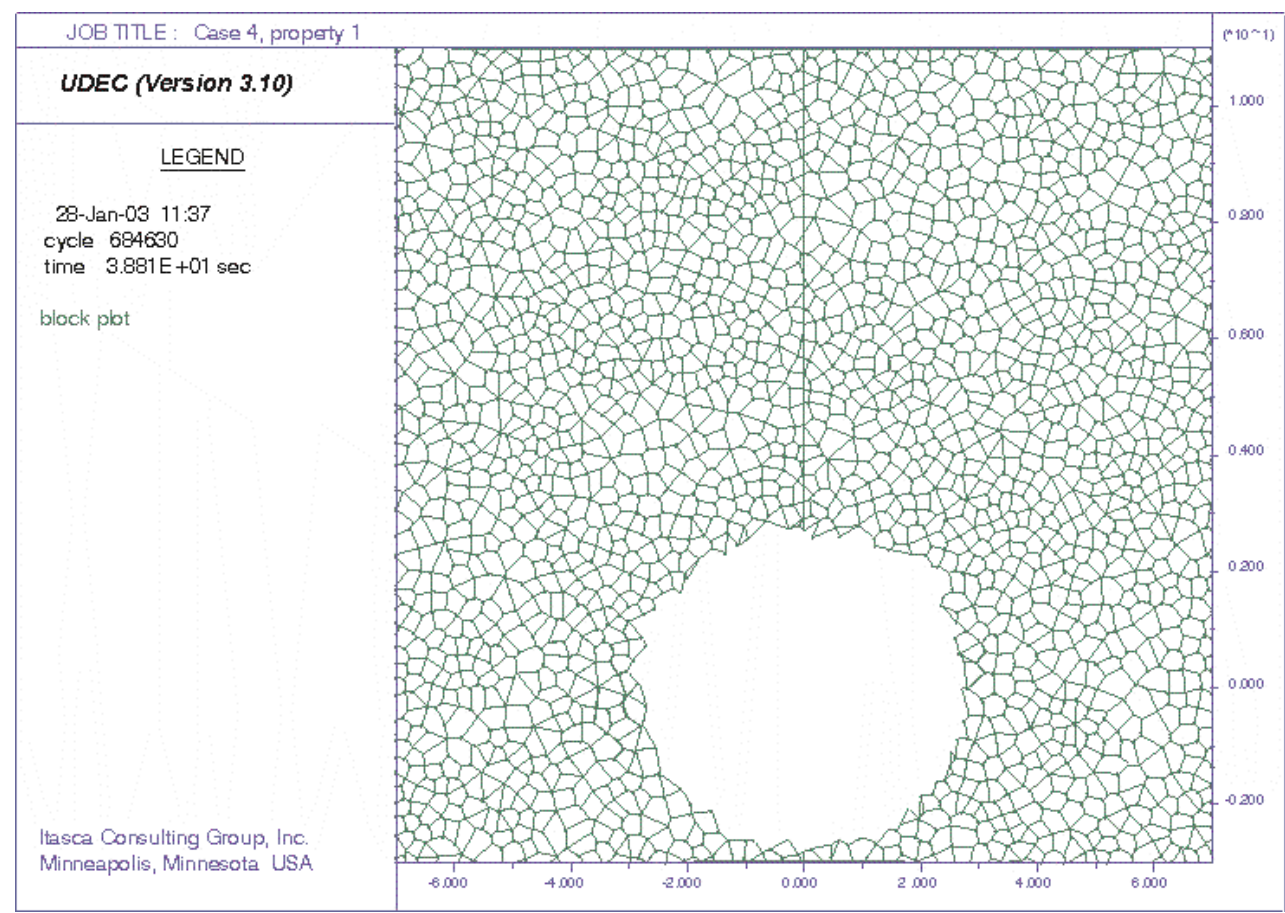

Figure R-9. Drift Profile for Scenario 9: Degradation Consideration, 40\% Cohesion Reduction, Voronoi Block Size $0.3 \mathrm{~m}$, and Random Block Generation Seed \#1 
$\underline{\text { Drift Degradation Analysis }}$

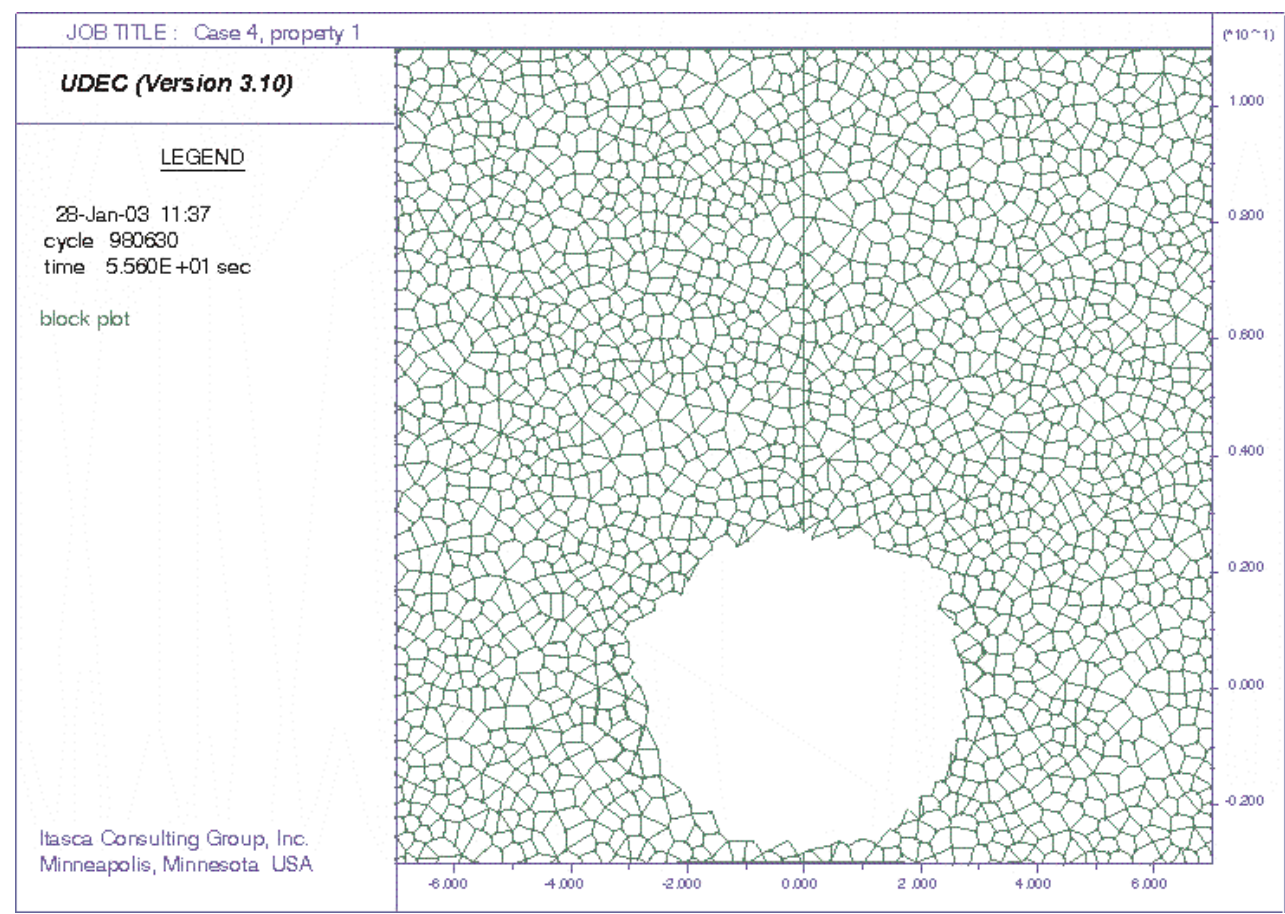

Figure R-10. Drift Profile for Scenario 10: Degradation Consideration, 60\% Cohesion Reduction, Voronoi Block Size $0.3 \mathrm{~m}$, and Random Block Generation Seed \#1

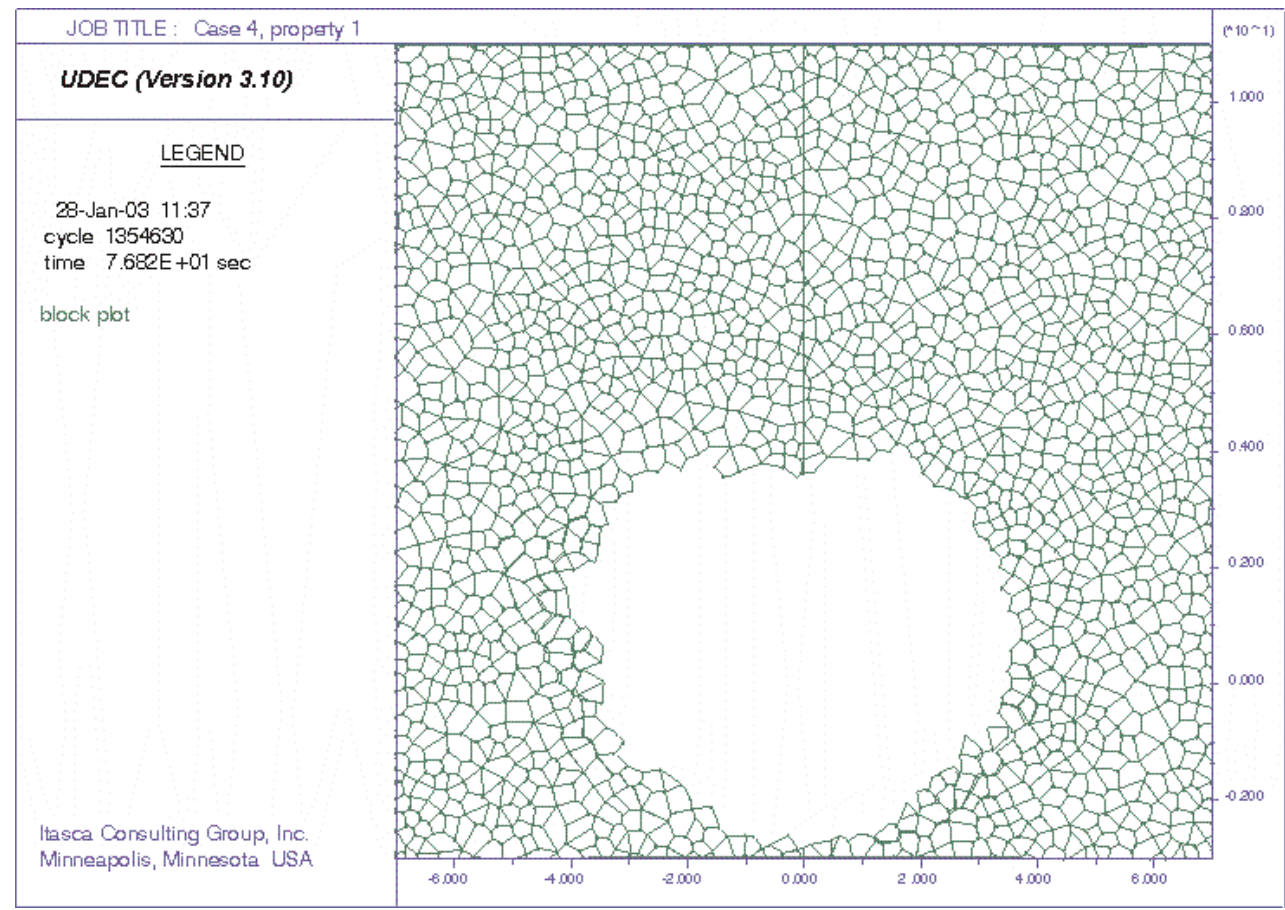

Figure R-11. Drift Profile for Scenario 11: Degradation Consideration, 80\% Cohesion Reduction, Voronoi Block Size 0.3 m, and Random Block Generation Seed \#1 
$\underline{\text { Drift Degradation Analysis }}$

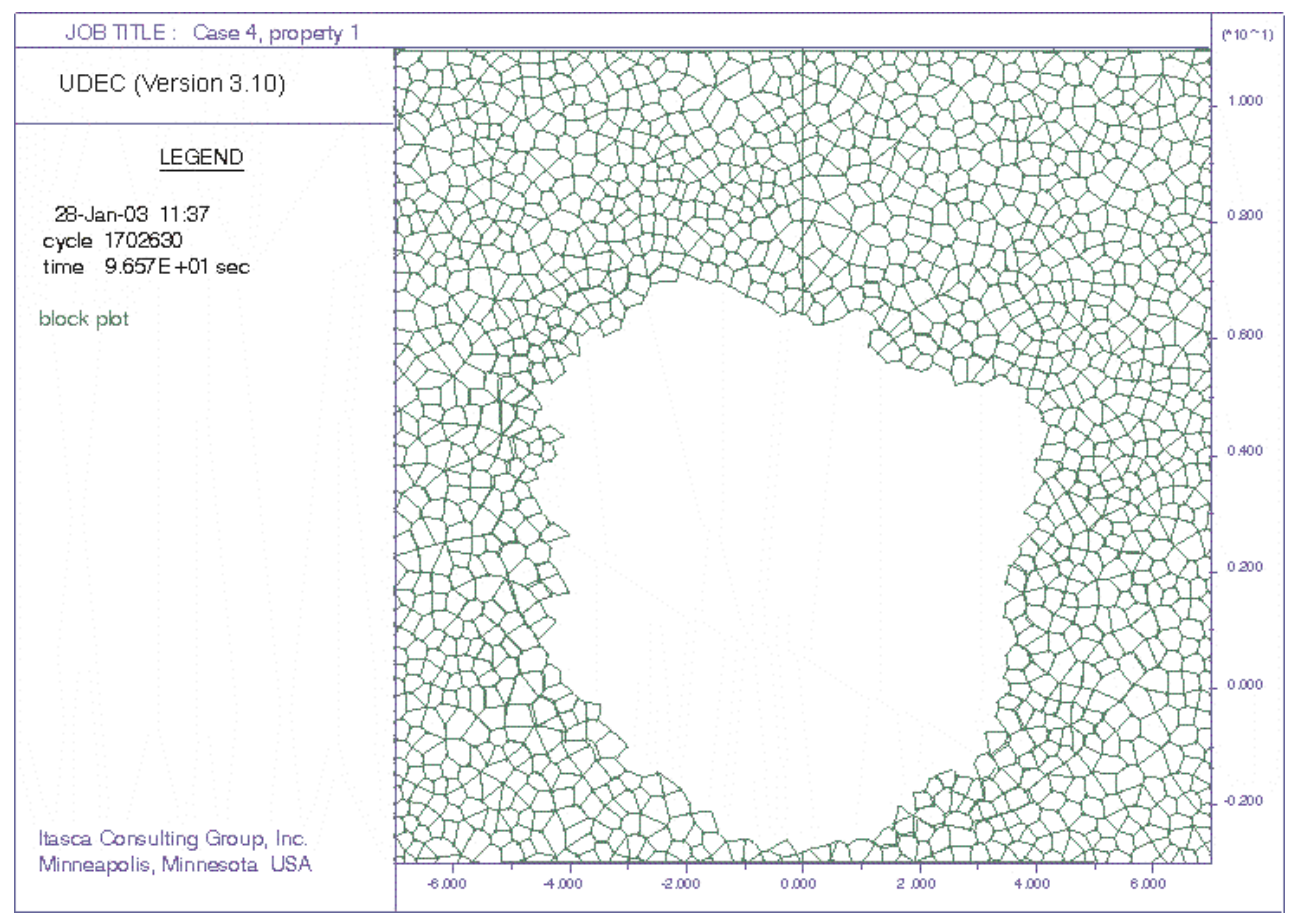

Figure R-12. Drift Profile for Scenario 12: Degradation Consideration, 100\% Cohesion Reduction, Voronoi Block Size 0.3 m, and Random Block Generation Seed \#1

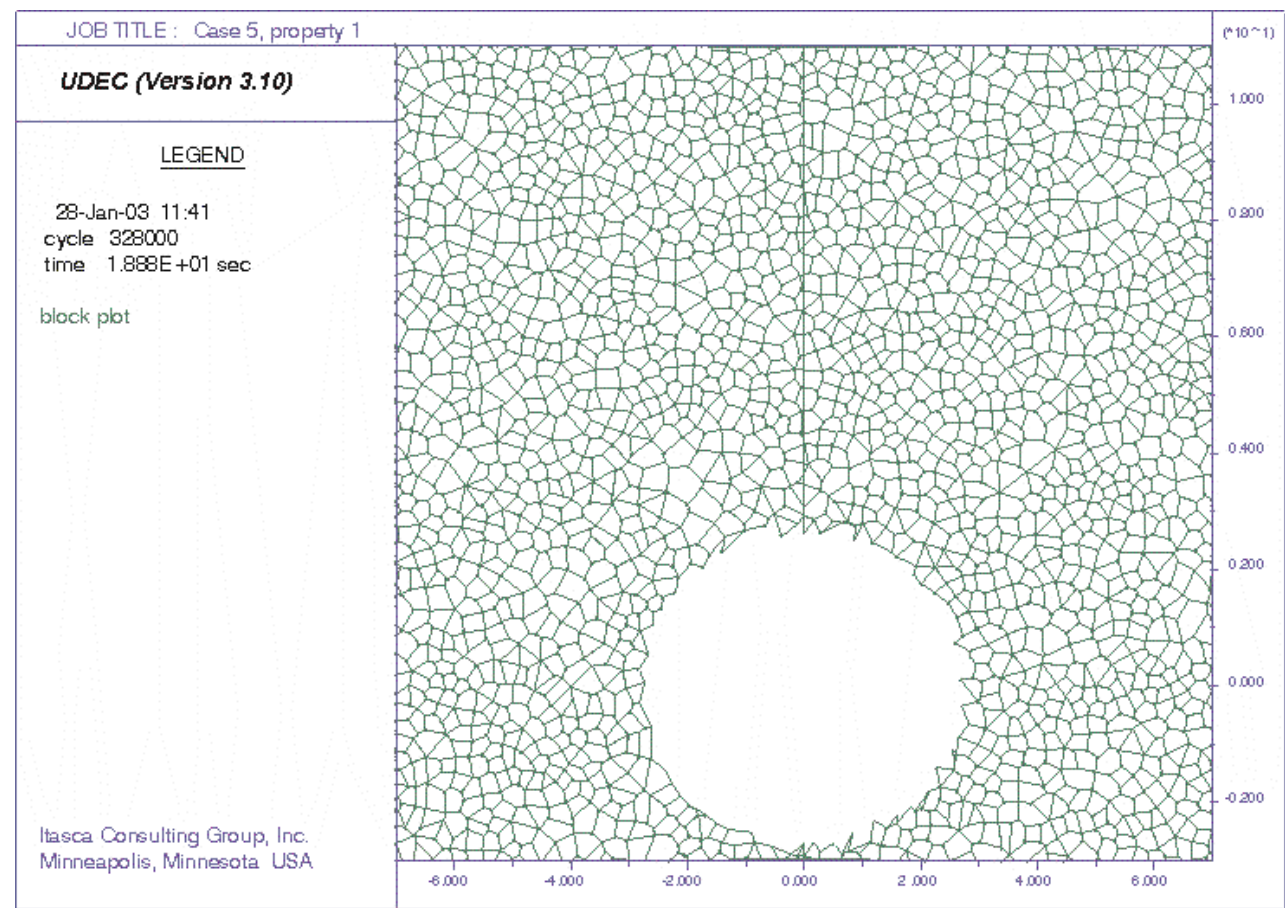

Figure R-13. Drift Profile for Scenario 13: Degradation Consideration, 0\% Cohesion Reduction, Voronoi Block Size $0.3 \mathrm{~m}$, and Random Block Generation Seed \#2 
$\underline{\text { Drift Degradation Analysis }}$

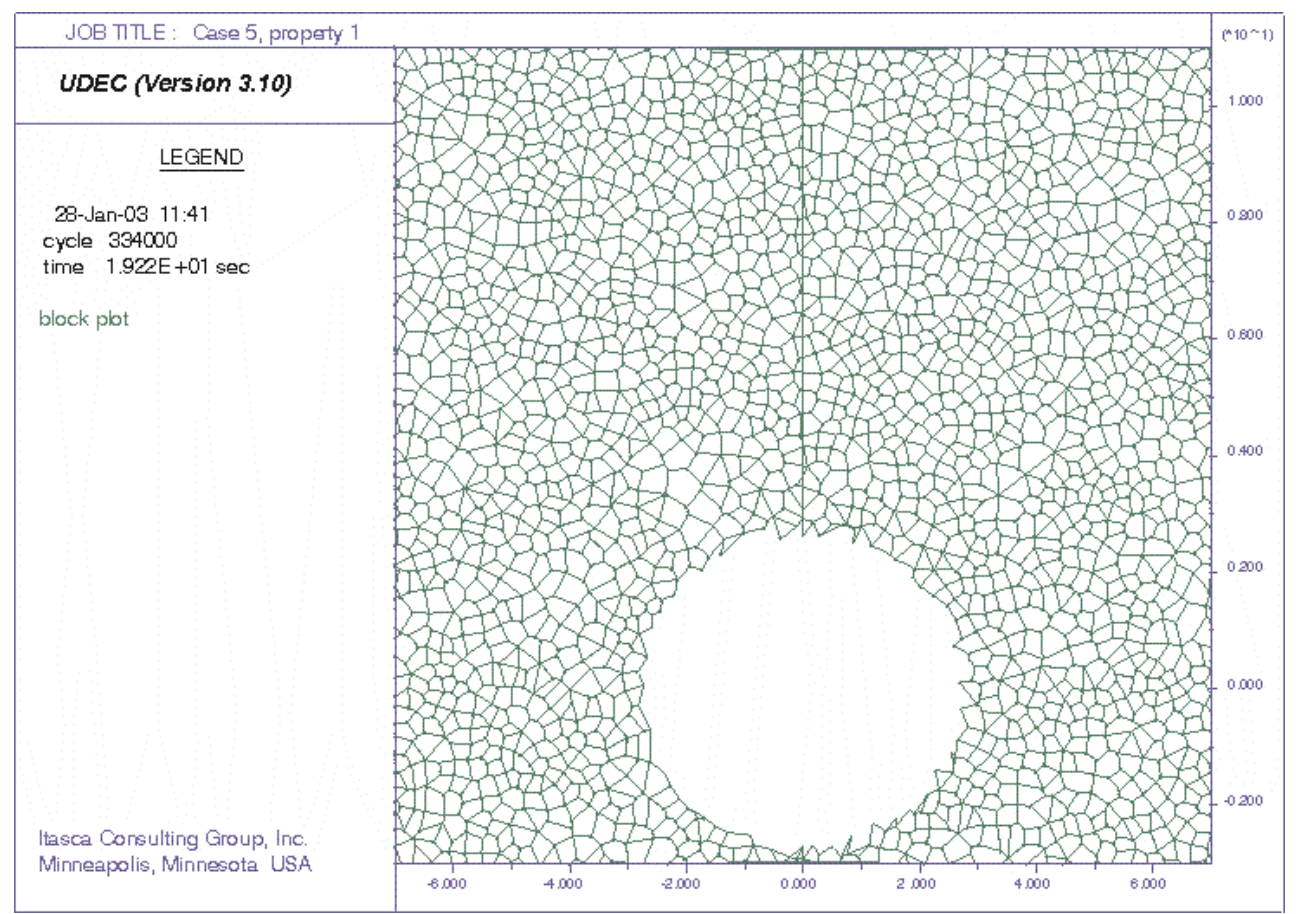

Figure R-14. Drift Profile for Scenario 14: Degradation Consideration, 20\% Cohesion Reduction, Voronoi Block Size 0.3 m, and Random Block Generation Seed \#2

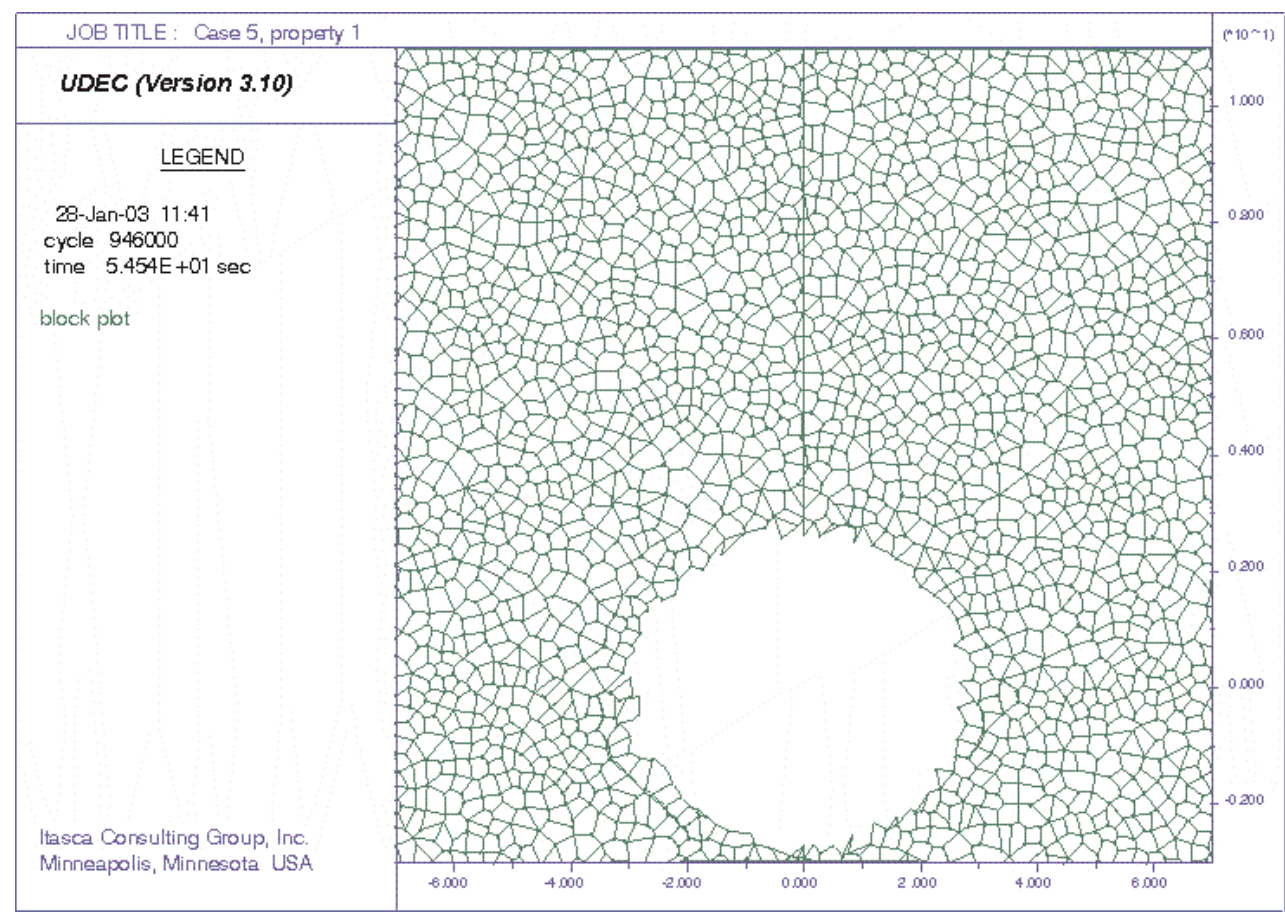

Figure R-15. Drift Profile for Scenario 15: Degradation Consideration, 40\% Cohesion Reduction, Voronoi Block Size 0.3 m, and Random Block Generation Seed \#2 


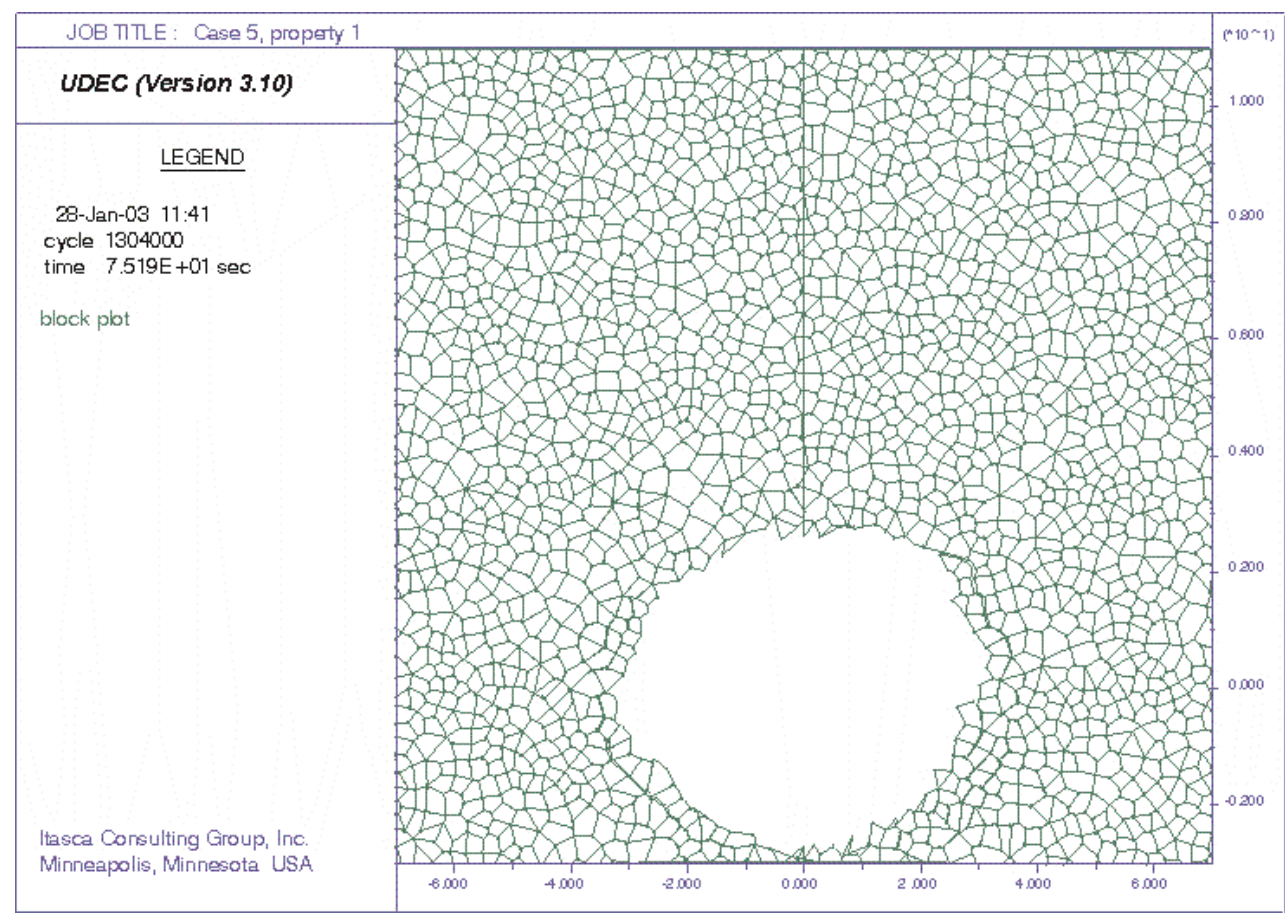

Figure R-16. Drift Profile for Scenario 16: Degradation Consideration, 60\% Cohesion Reduction, Voronoi Block Size 0.3 m, and Random Block Generation Seed \#2

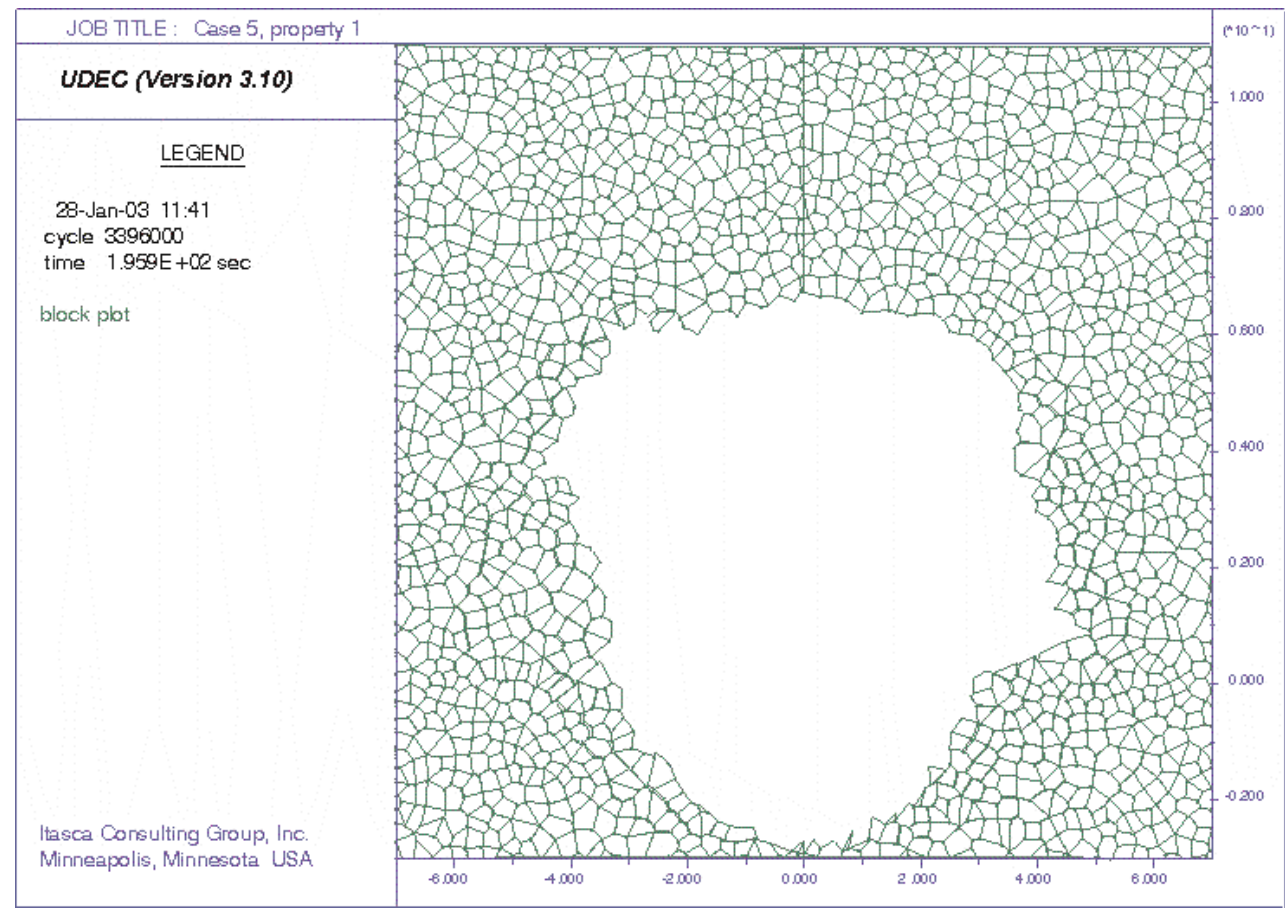

Figure R-17. Drift Profile for Scenario 17: Degradation Consideration, 80\% Cohesion Reduction, Voronoi Block Size 0.3 m, and Random Block Generation Seed \#2 
$\underline{\text { Drift Degradation Analysis }}$

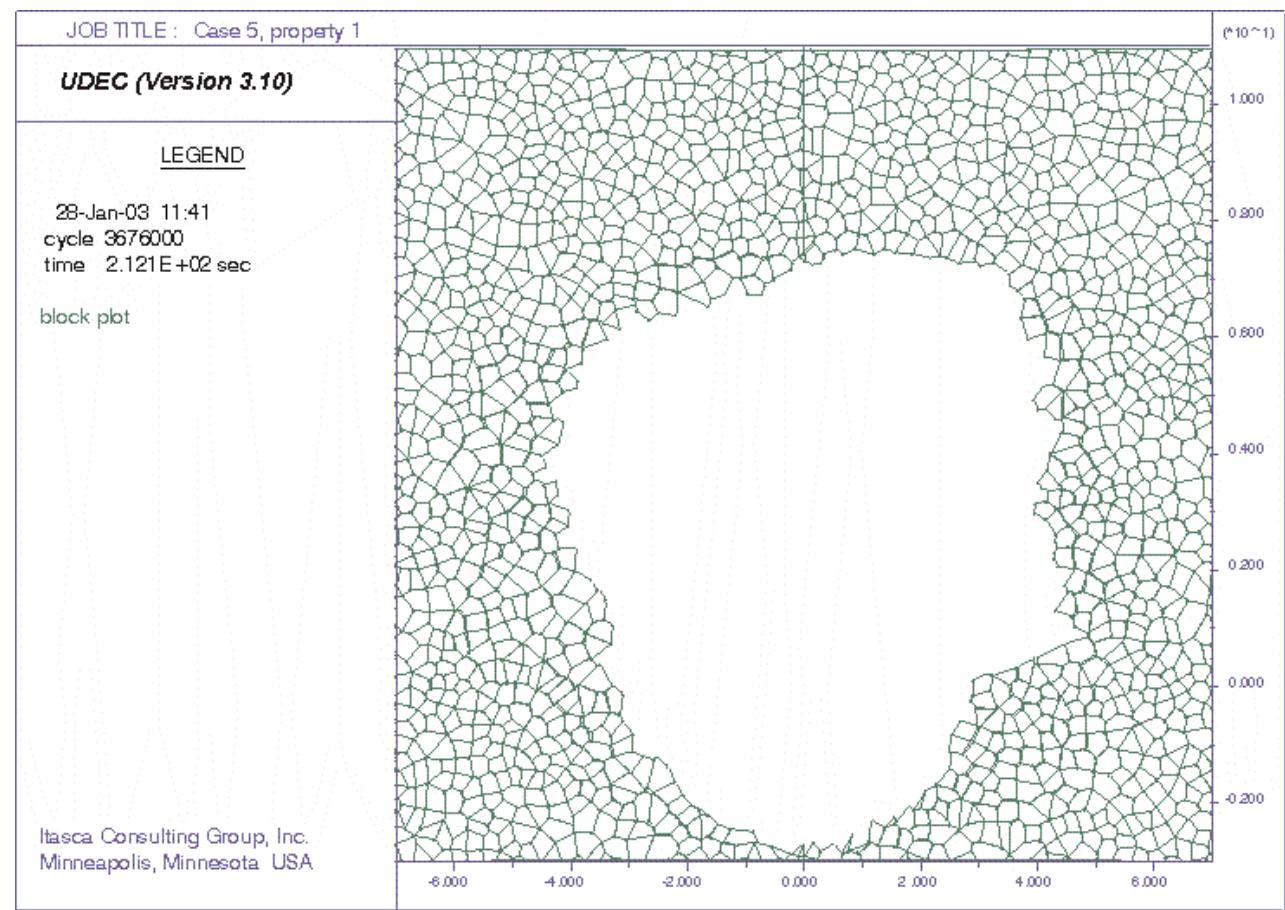

Figure R-18. Drift Profile for Scenario 18: Degradation Consideration, 100\% Cohesion Reduction, Voronoi Block Size $0.3 \mathrm{~m}$, and Random Block Generation Seed \#2

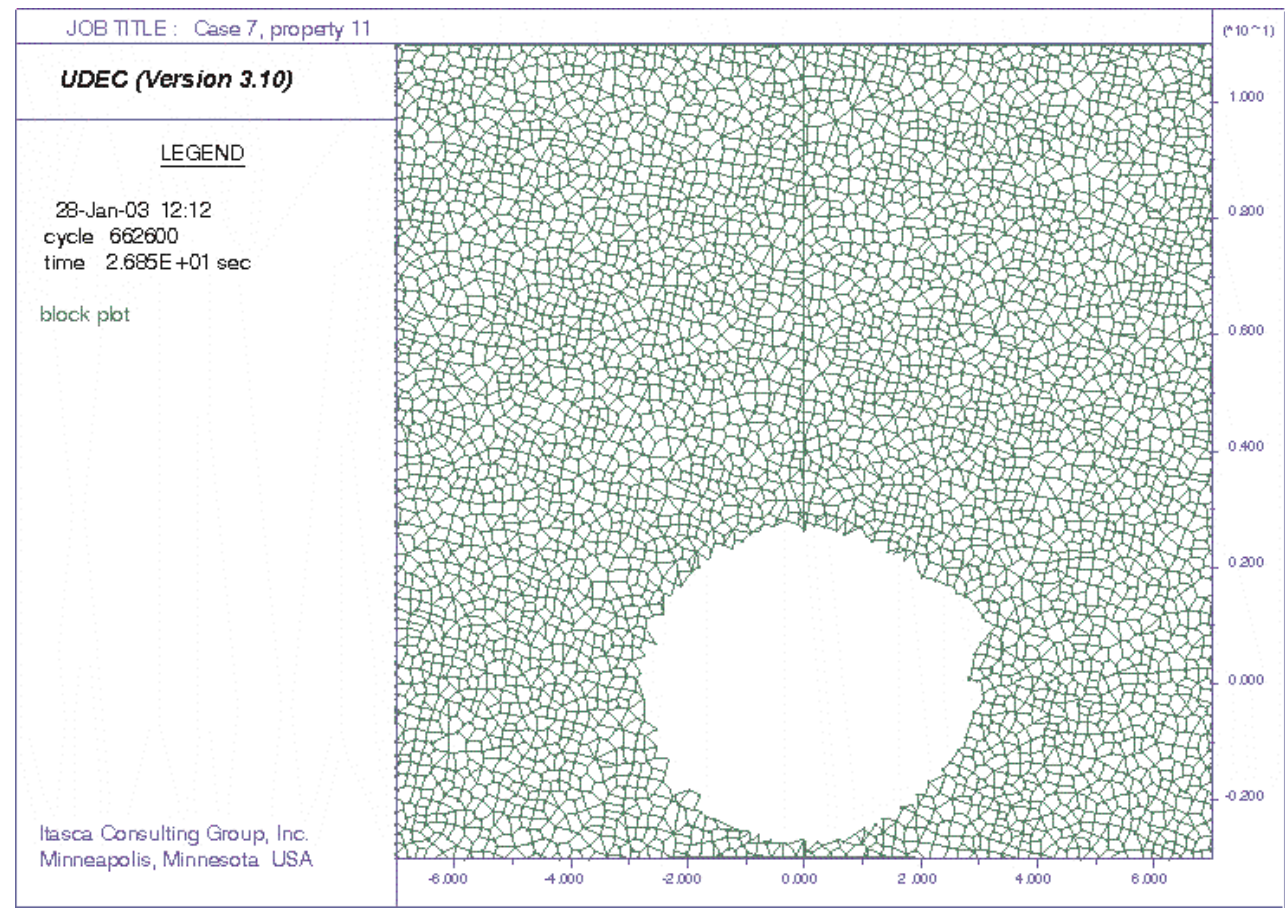

Figure R-19. Drift Profile for Scenario 19: Degradation Consideration, 0\% Cohesion Reduction, Voronoi Block Size $0.2 \mathrm{~m}$, and Random Block Generation Seed \#1 
Drift Degradation Analysis

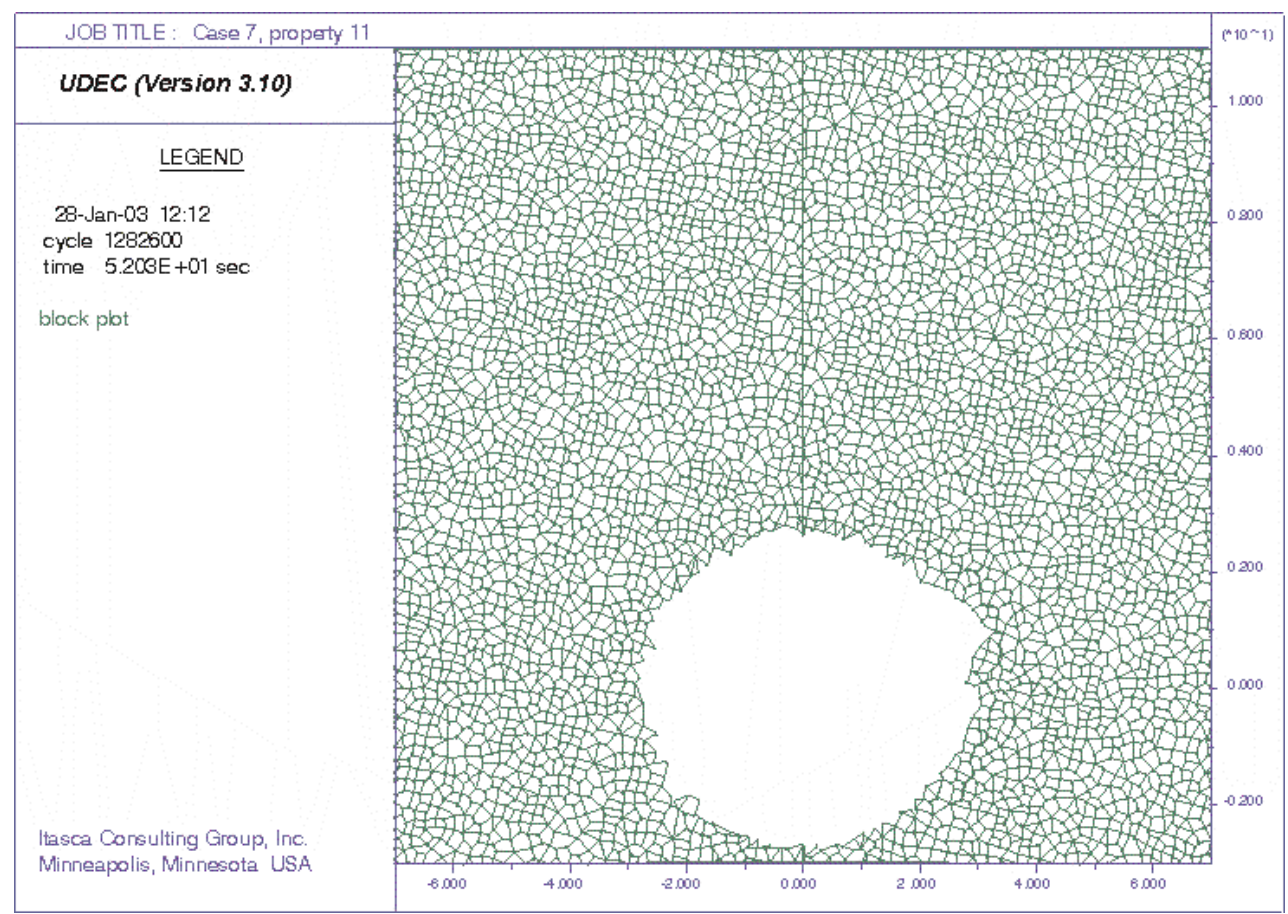

Figure R-20. Drift Profile for Scenario 20: Degradation Consideration, 20\% Cohesion Reduction, Voronoi Block Size 0.2 m, and Random Block Generation Seed \#1

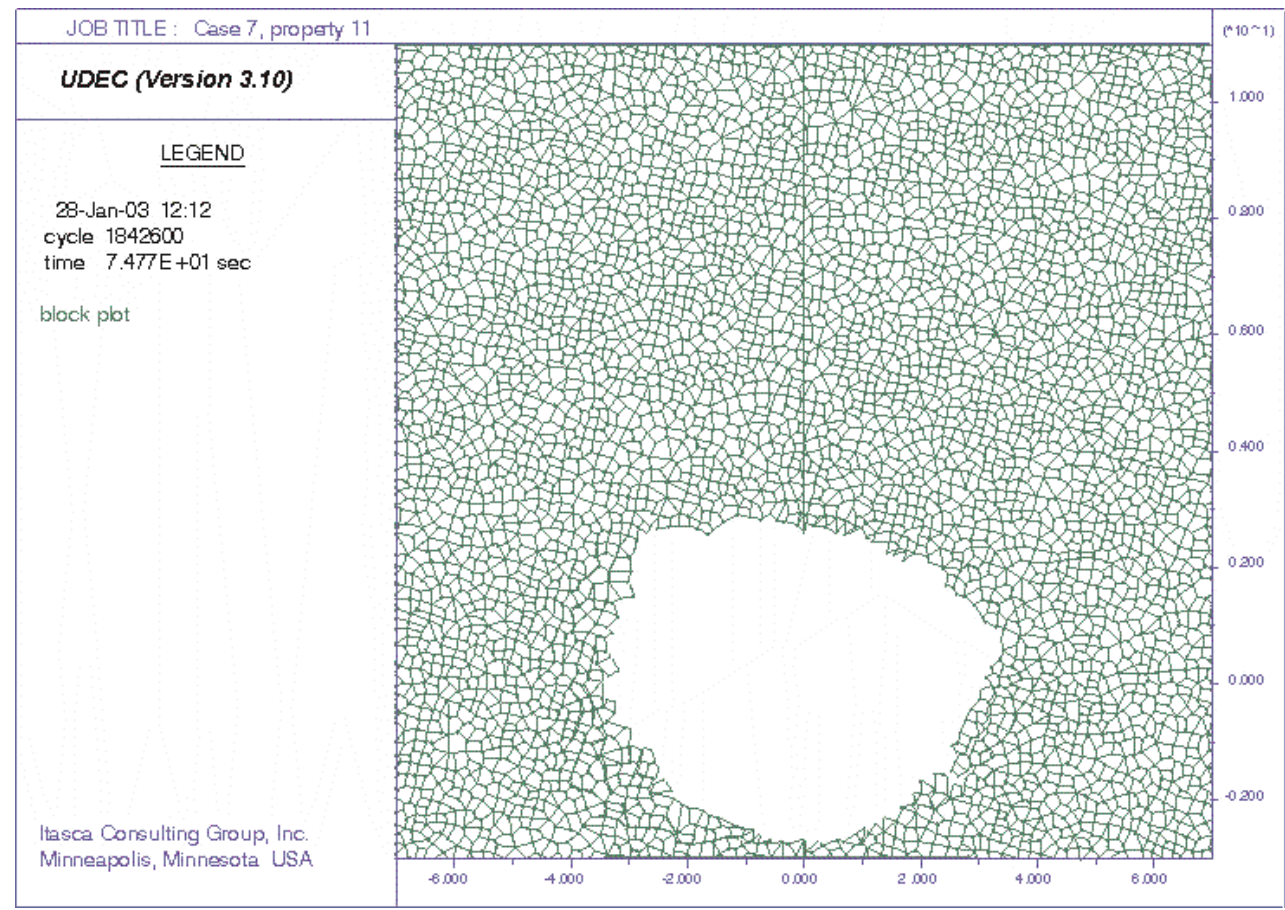

Figure R-21. Drift Profile for Scenario 21: Degradation Consideration, 40\% Cohesion Reduction, Voronoi Block Size 0.2 m, and Random Block Generation Seed \#1 
$\underline{\text { Drift Degradation Analysis }}$

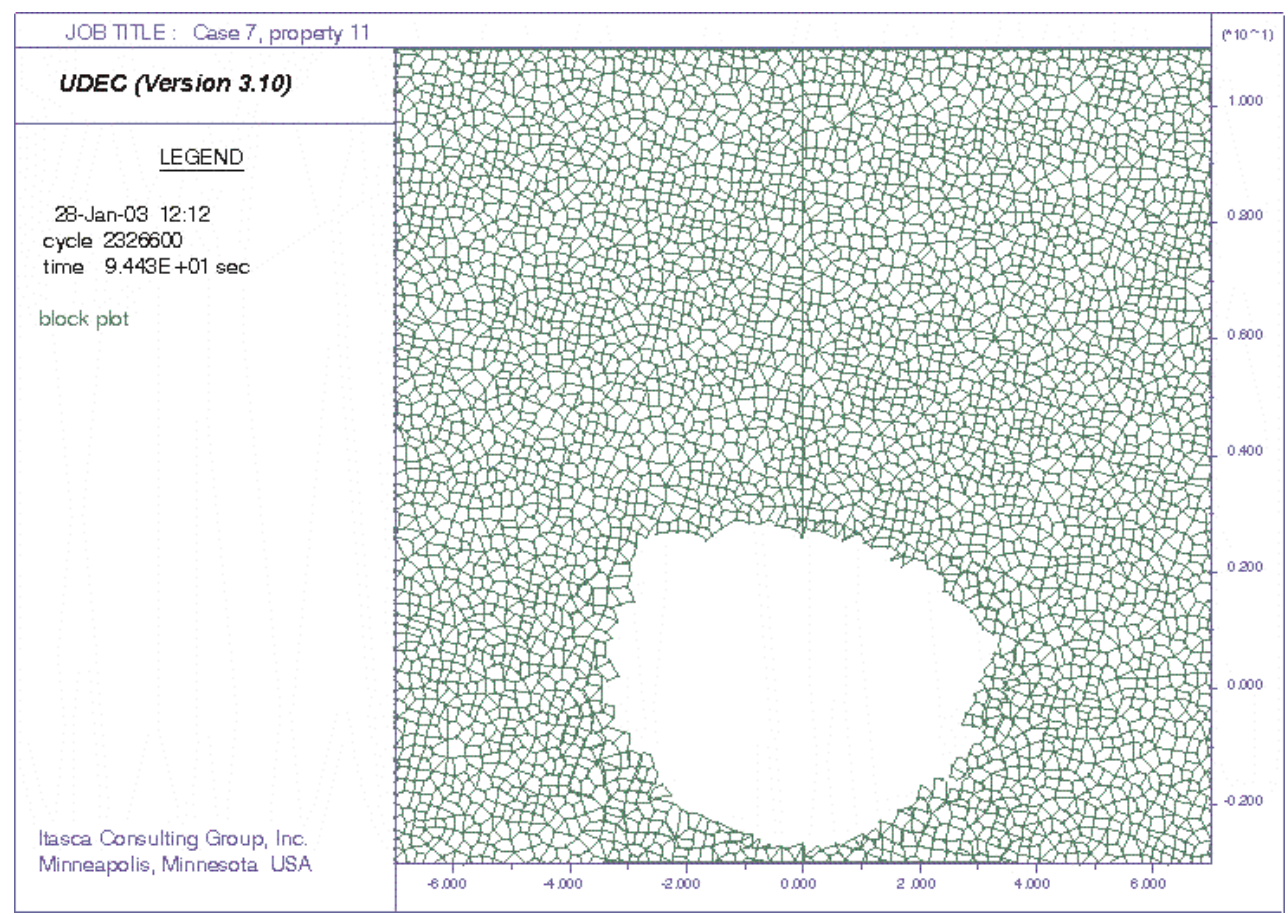

Figure R-22. Drift Profile for Scenario 22: Degradation Consideration, 60\% Cohesion Reduction, Voronoi Block Size 0.2 m, and Random Block Generation Seed \#1

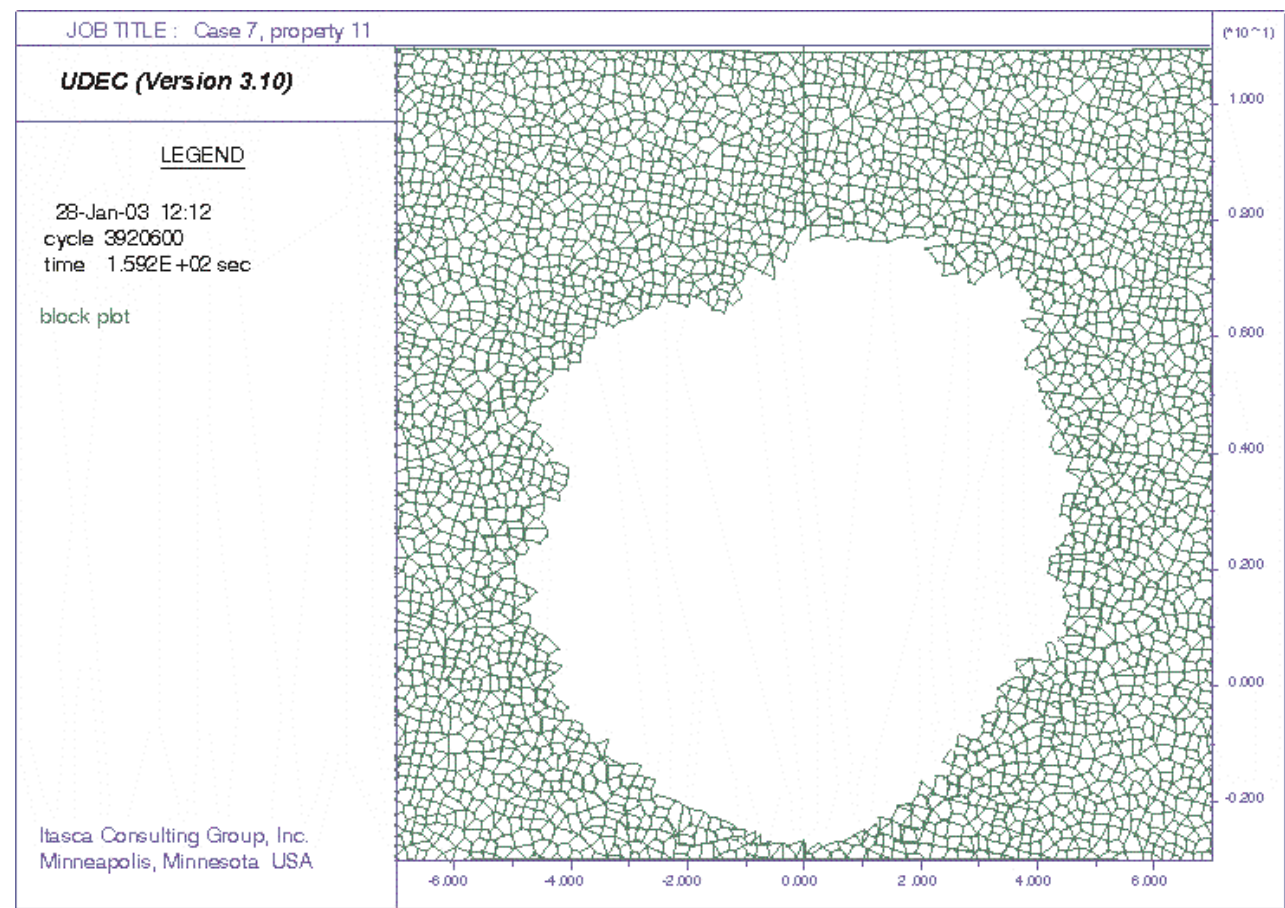

Figure R-23. Drift Profile for Scenario 23: Degradation Consideration, 80\% Cohesion Reduction, Voronoi Block Size 0.2 m, and Random Block Generation Seed \#1 
$\underline{\text { Drift Degradation Analysis }}$

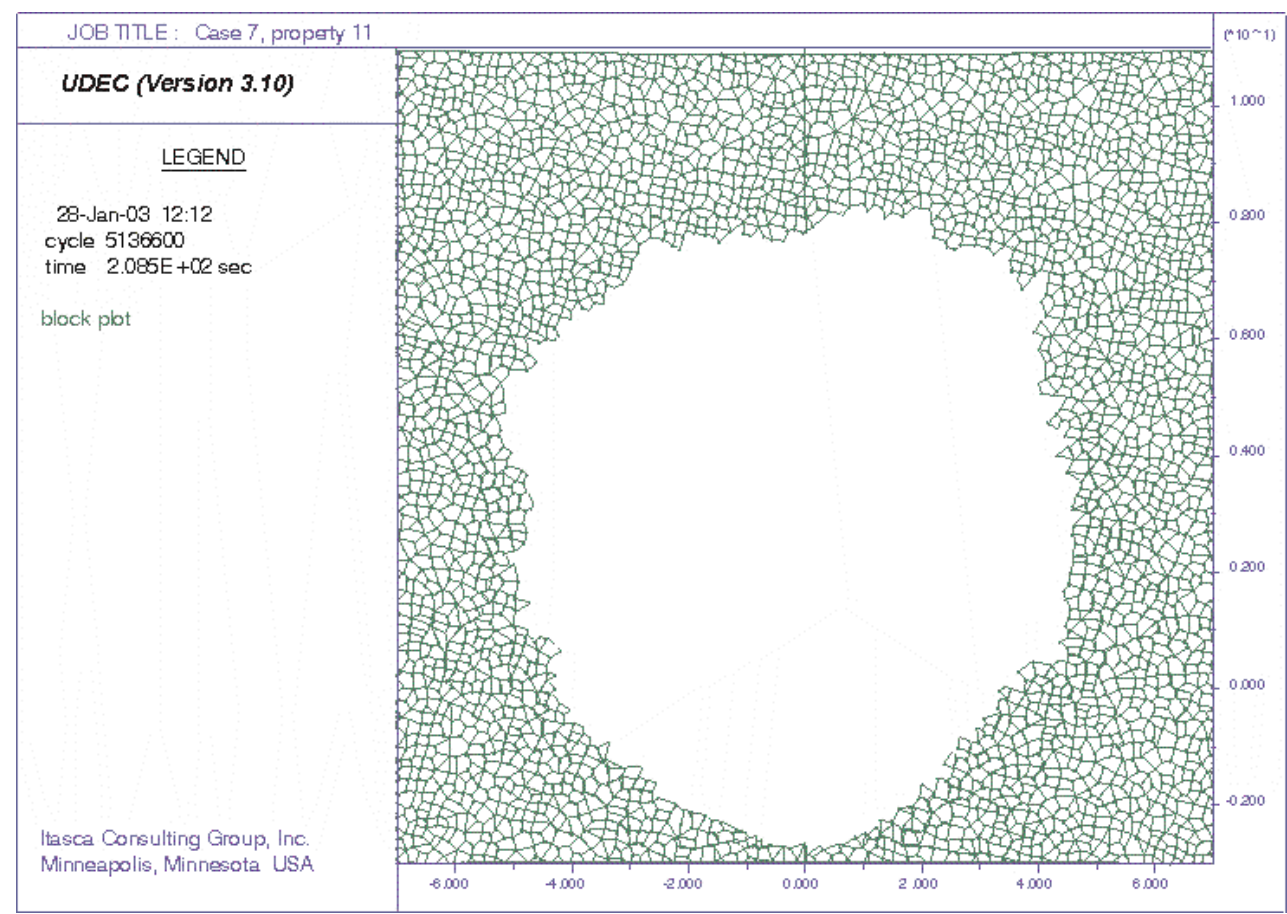

Figure R-24. Drift Profile for Scenario 24: Degradation Consideration, 100\% Cohesion Reduction, Voronoi Block Size 0.2 m, and Random Block Generation Seed \#1

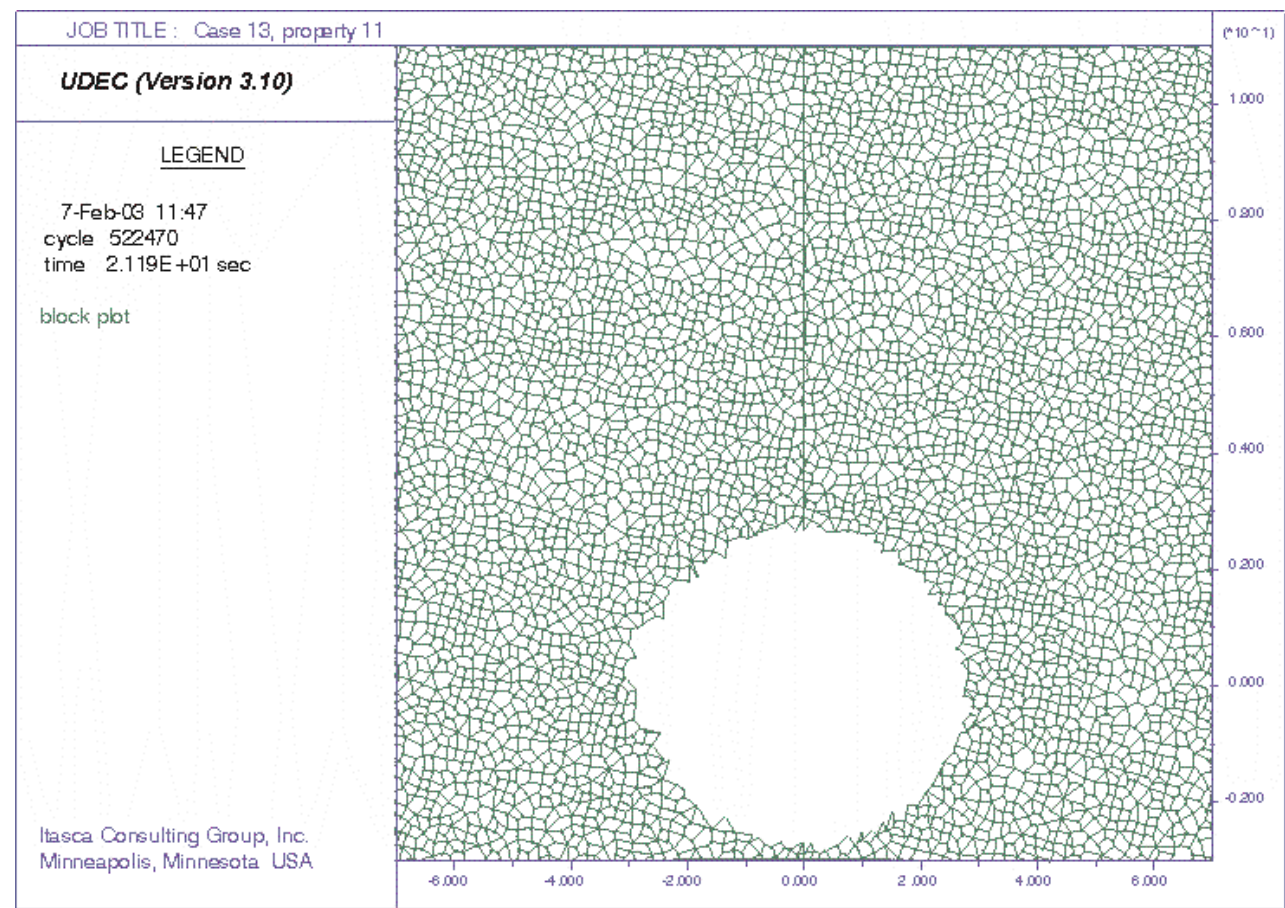

Figure R-25. Drift Profile for Scenario 25: Degradation Consideration, 0\% Cohesion Reduction, Voronoi Block Size $0.2 \mathrm{~m}$, and Random Block Generation Seed \#2 
Drift Degradation Analysis

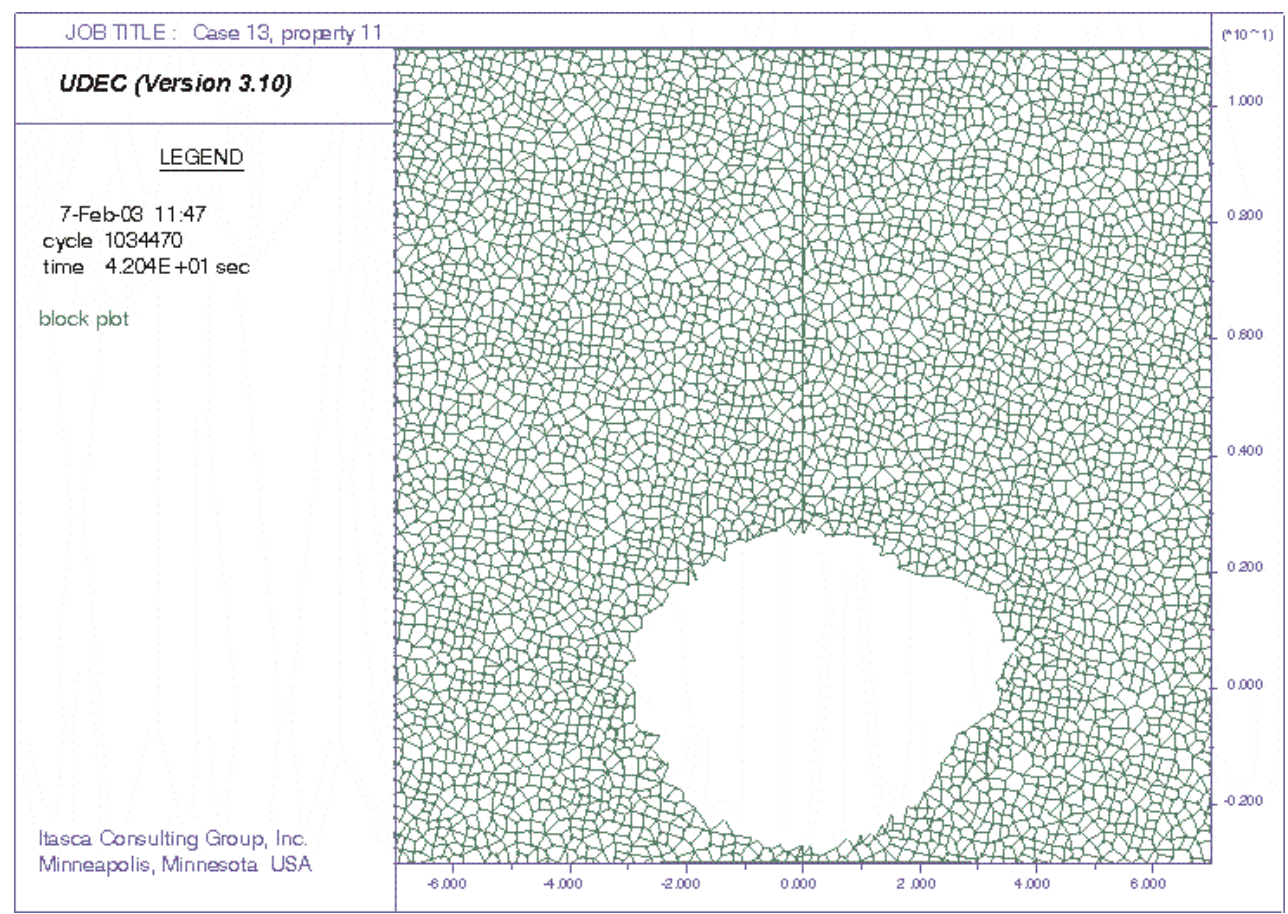

Figure R-26. Drift Profile for Scenario 26: Degradation Consideration, 20\% Cohesion Reduction, Voronoi Block Size 0.2 m, and Random Block Generation Seed \#2

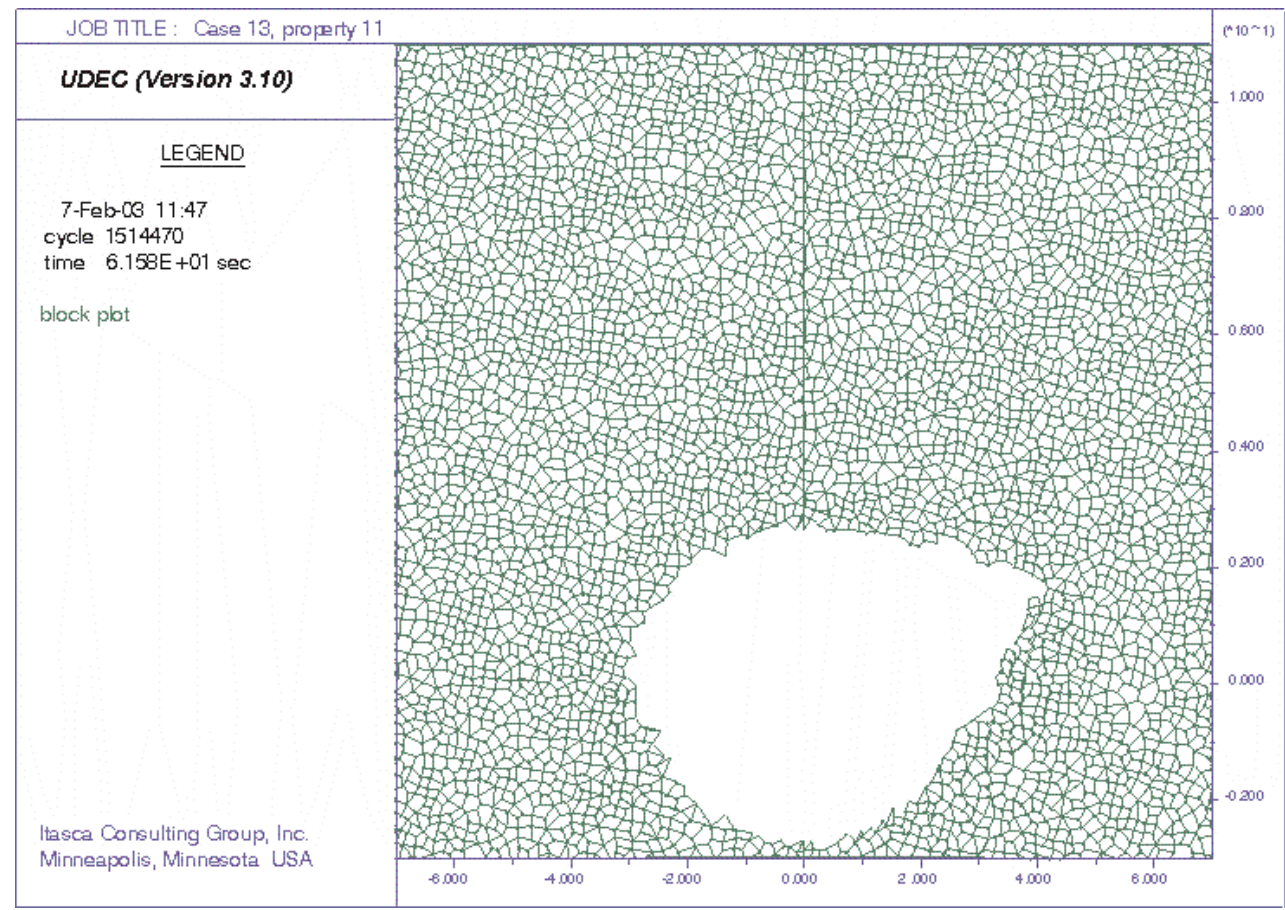

Figure R-27. Drift Profile for Scenario 27: Degradation Consideration, 40\% Cohesion Reduction, Voronoi Block Size 0.2 m, and Random Block Generation Seed \#2 
$\underline{\text { Drift Degradation Analysis }}$

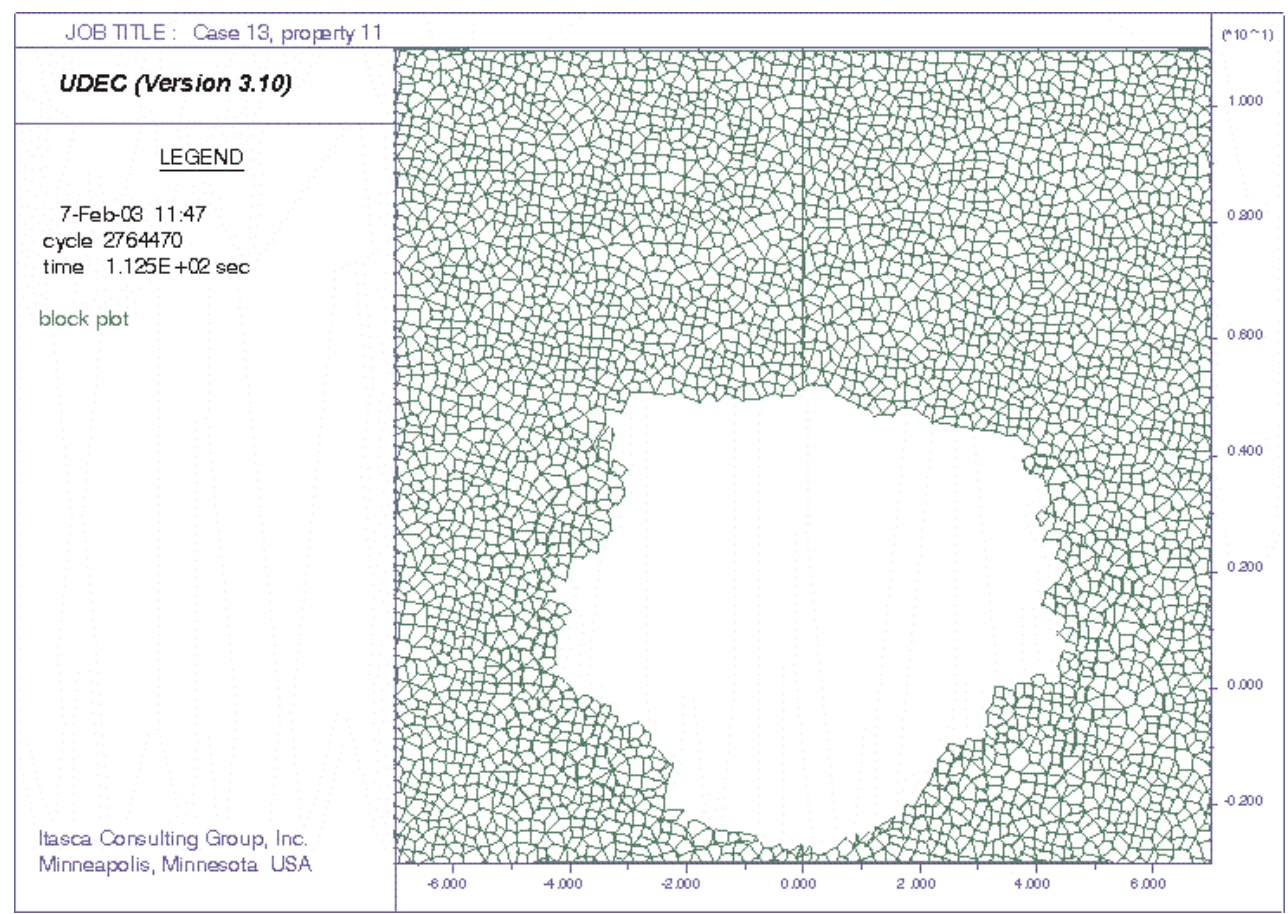

Figure R-28. Drift Profile for Scenario 28: Degradation Consideration, 60\% Cohesion Reduction, Voronoi Block Size 0.2 m, and Random Block Generation Seed \#2

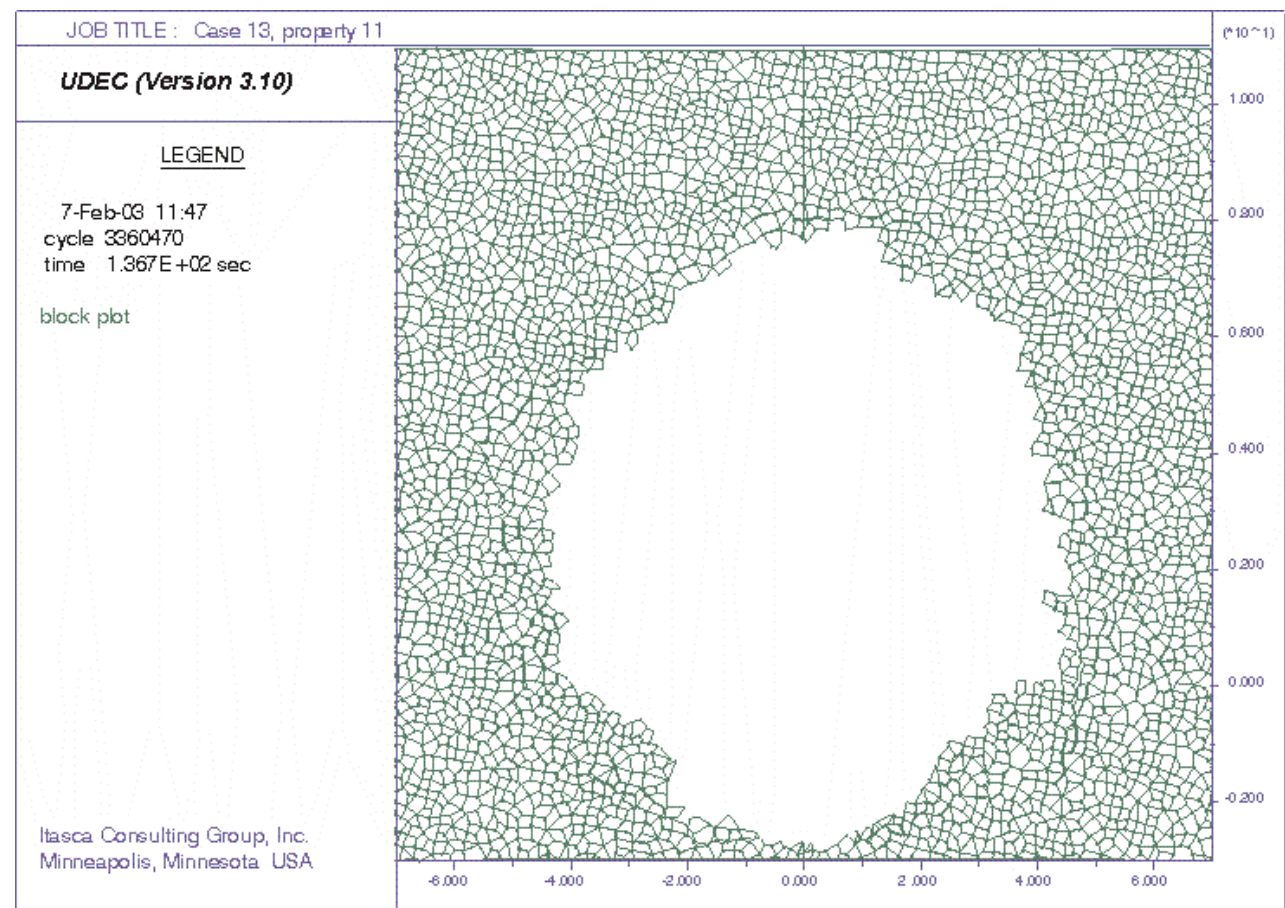

Figure R-29. Drift Profile for Scenario 29: Degradation Consideration, 80\% Cohesion Reduction, Voronoi Block Size $0.2 \mathrm{~m}$, and Random Block Generation Seed \#2 
$\underline{\text { Drift Degradation Analysis }}$

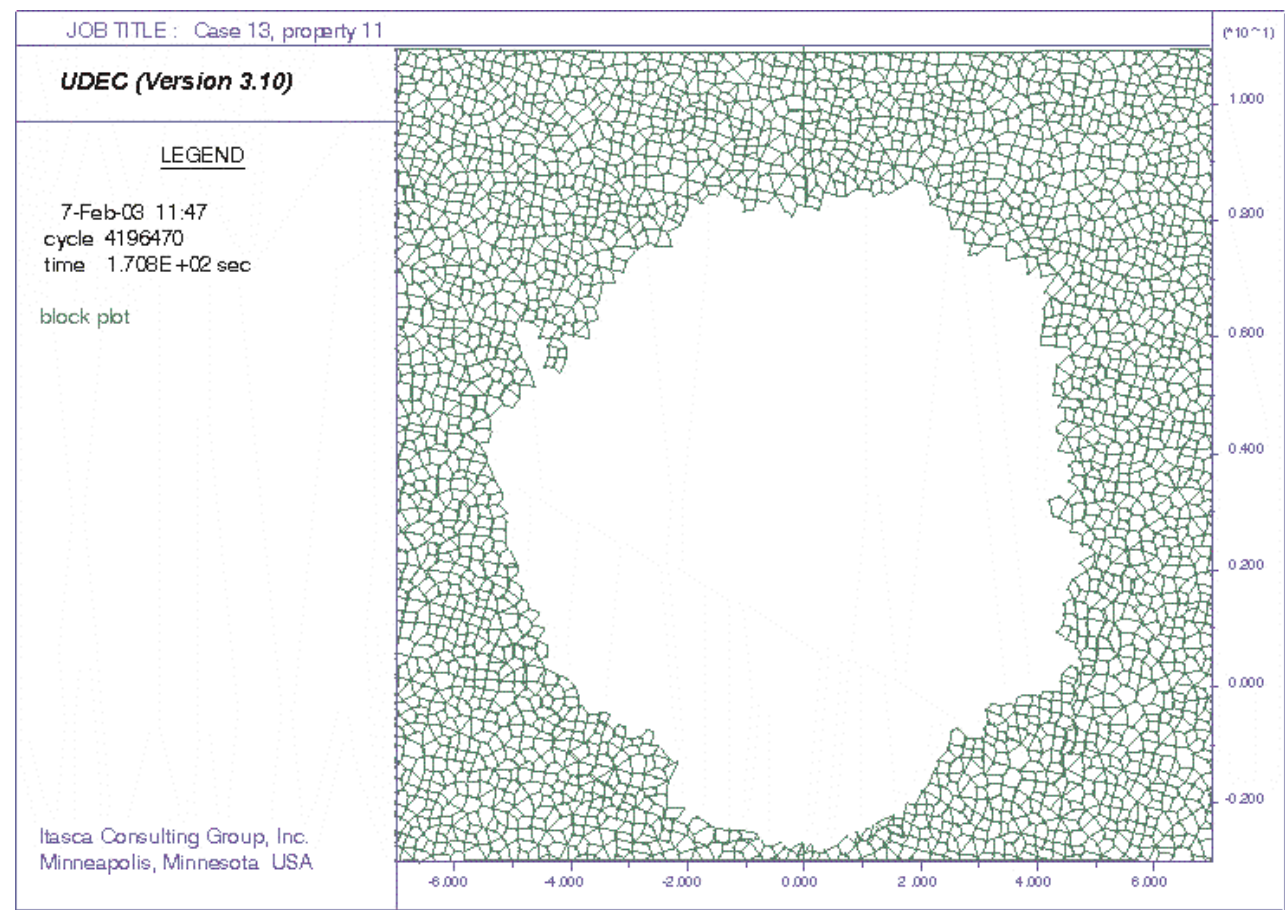

Figure R-30. Drift Profile for Scenario 30: Degradation Consideration, 100\% Cohesion Reduction, Voronoi Block Size 0.2 m, and Random Block Generation Seed \#2 


\section{INTENTIONALLY LEFT BLANK}




\section{APPENDIX S}

\section{ESTIMATING LONG-TERM DAMAGE FORMATION SURROUNDING}

EMPLACEMENT DRIFTS 


\section{ESTIMATING LONG-TERM DAMAGE FORMATION SURROUNDING EMPLACEMENT DRIFTS}

\section{S1. INTRODUCTION}

Predicting the time evolution of the drift profile and damage (fracturing) of the rock mass are necessary for assessing repository performance. The analysis of time-dependent drift degradation described in Section 6.4.2.4 is simplified and does not relate damage and deformation to time after drift excavation. Instead, rockfall and damage of the rock mass are calculated as functions of the level of cohesive strength reduction with no time scale being associated with this strength reduction. In the analysis presented in this appendix, the limited existing data (for Lac du Bonnet granite and nonlithophysal tuff) on time-dependent rock mass strength is used to predict the evolution of the drift profile as a function of time. The PFC stress corrosion model (Potyondy 2003 [DIRS 165550]) is used to assess the influence of confinement and lithophysal void porosity on the static-fatigue curves of lithophysal rock, and to generate curves of damage increase as a function of time for static-fatigue tests performed at different load levels. These curves are then used in the UDEC models of the drift for predictions of time-dependent damage and rockfall.

Additional time-dependent testing is currently underway. New data from this testing has been included in the analysis of time-dependent drift degradation (Section 6.4.2.4.2). The uncertainties and limitations associated with the static-fatigue test data and the modeling of time-dependent drift degradation are discussed in Section 6.5.

\section{S2. LONG-TERM BEHAVIOR OF ROCK AND PFC MATERIAL}

\section{S2.1 STATIC-FATIGUE BEHAVIOR OF GRANITE AND TUFF}

\section{S2.1.1 Summary of Test Data}

Static-fatigue data for $\mathrm{Lac}$ du Bonnet granite $(\mathrm{LdB})$ is shown in Figure S-1. Potyondy and Cundall (2001 [DIRS 156895]) discuss the assumptions that went into the generation of these curves and provide additional data for Lac du Bonnet granite, Lac du Bonnet granodiorite and Barre granite. During the static-fatigue tests, environmental conditions of moisture and temperature were held constant and direct measurements were made of applied creep stress $\left(\sigma_{l}\right)$, applied confinement $\left(P_{c}\right)$ and time to failure $\left(t_{f}\right){ }^{2}$. Figure S-1 shows four data sets produced by two different investigators; the data set of Schmidtke and Lajtai (1985 [DIRS 164774]) is labeled LdB1, and the data sets of Lau et al. (2000 [DIRS 164769]) are labeled LdB2. The Schmidtke and Lajtai (1985 [DIRS 164774]) specimens (2:1 aspect-ratio right circular cylinders of $31.7 \mathrm{~mm}$ diameter) were saturated before testing and kept submerged during testing at $25^{\circ} \mathrm{C}$. Load

2 The following notation is employed to describe the results of static-fatigue tests. The applied load in the axial direction and the confining pressure are denoted by $\sigma_{l}$ and $P_{c}$, respectively. The axial load at failure during a short-term test is denoted by $\sigma_{f}$. The stress difference maintained during a static-fatigue test conducted at a confining pressure of $P_{c}$ is $\sigma=\sigma_{l}-P_{c}$. The stress difference at failure during a short-term test is $\sigma_{c}=\sigma_{f}-P_{c}$. To facilitate comparison between different data sets, we generate a static-fatigue curve by plotting the logarithm of time-to-failure, $t_{f}$, versus the driving-stress ratio given by $\sigma / \sigma_{c}=\left(\sigma_{l}-P_{c}\right) /\left(\sigma_{f}-P_{c}\right)$. The peak strength, $\sigma_{f}$, is not known for a tested specimen. Different schemes to estimate this value have been employed by the different investigators (Potyondy and Cundall 2001 [DIRS 156895], pp. 114 to 115). 
application was rapid, with full static-fatigue load being reached in about two seconds. The Lau et al. (2000 [DIRS 164769]) specimens (2.5:1 aspect-ratio right circular cylinders of $61 \mathrm{~mm}$ diameter) were saturated before testing and tested in a triaxial cell under drained conditions (i.e., water from a saturated sample is allowed to freely flow in or out of the sample during loading) at $25^{\circ} \mathrm{C}$. Load application was slow, with full load being reached at a constant rate of $0.75 \mathrm{MPa} / \mathrm{sec}$. For unconfined conditions, both data sets have a similar slope when fit with a straight line. While confined static-fatigue tests are limited, confinements of $5 \mathrm{MPa}$ and $10 \mathrm{MPa}$ increase the slope, and also increase the time-to-failure for $\sigma / \sigma_{c}<0.8$.

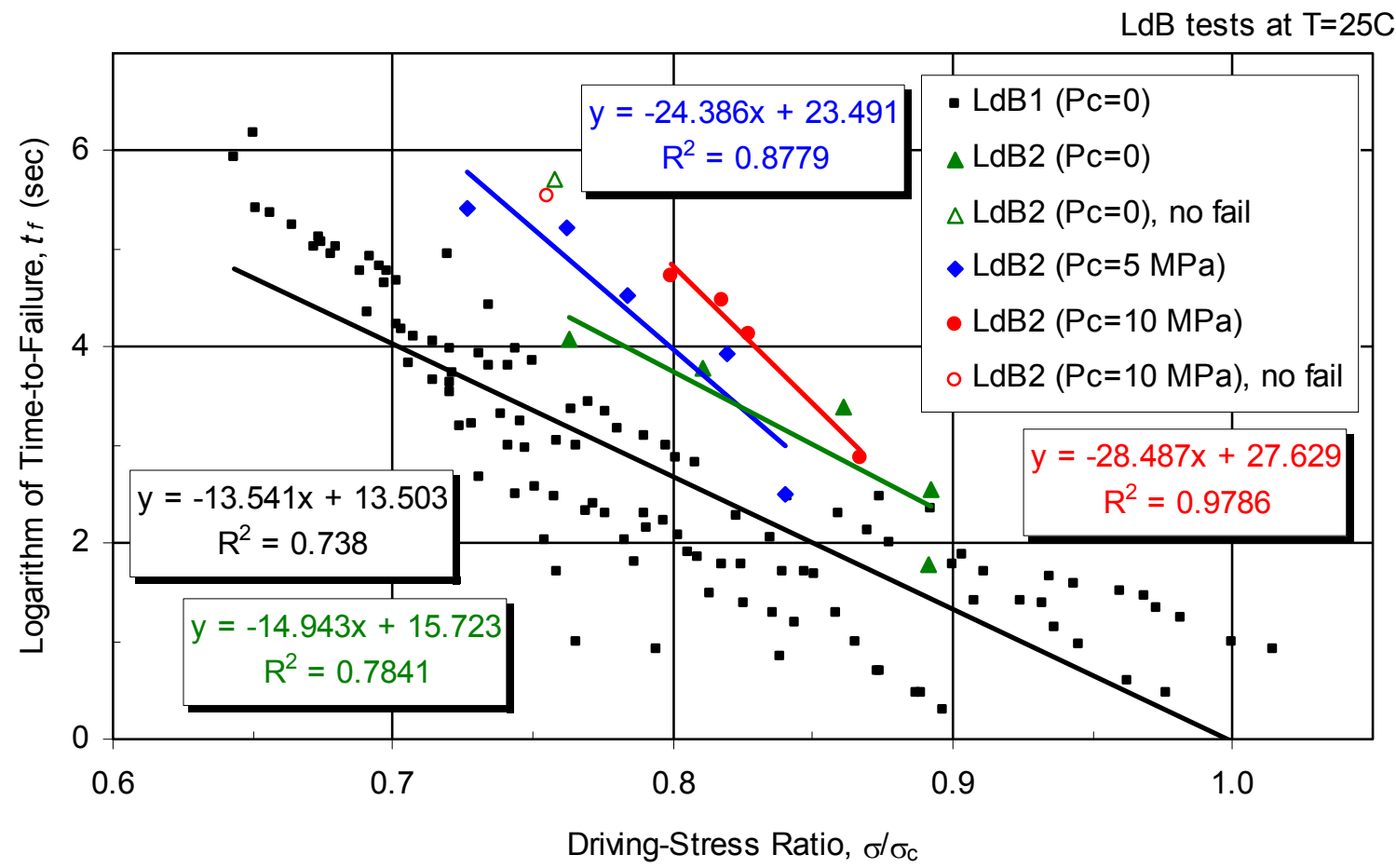

Source: LdB1 data from Schmidtke and Lajtai (1985 [DIRS 164774]); LdB2 data from Lau et al. (2000 [DIRS 164769]).

Figure S-1. Static-Fatigue Data for Lac du Bonnet Granite (Confinements of 0, 5, and $10 \mathrm{MPa}$ )

Martin et al. (1997 [DIRS 165960] and 1997 [DIRS 148875]) present static-fatigue results for a total of 16 specimens of welded (lithophysae poor) tuff from borehole NRG-7/7A at Yucca Mountain and from Busted Butte boulders taken from the same block of rock. ${ }^{3}$ The specimens were 2:1 aspect-ratio right circular cylinders of $50.8 \mathrm{~mm}$ diameter. Load application was rapid, with full load being reached in less than 10 seconds. The 7 borehole specimens drained and vented to the atmosphere were tested at a temperature of $225^{\circ} \mathrm{C}$ and a confining pressure of $10 \mathrm{MPa}$ at differential stresses ranging from $40 \mathrm{MPa}$ to $130 \mathrm{MPa}$. None of these specimens had failed after loading for times ranging from $2.5 \times 10^{6}$ to $5.9 \times 10^{6}$ seconds. The nine (9) Busted Butte specimens were tested at a pore water pressure $\left(\mathrm{P}_{\mathrm{p}}\right)$ of $4.5 \mathrm{MPa}$, a temperature of $150^{\circ} \mathrm{C}$ and a confining pressure of $5 \mathrm{MPa}$ at differential stresses ranging from $115 \mathrm{MPa}$ to $150 \mathrm{MPa}$, and

\footnotetext{
${ }^{3}$ Martin et al. (1997 [DIRS 148875]) is the Sandia report describing the tests on the borehole specimens, and additional scoping studies are reported in Martin et al. (1995 [DIRS 100159]).
} 
the test results are summarized in Table S-1. Six of these specimens failed at times less than $2 \times 10^{6}$ seconds, while the remaining three specimens (BB-9392-H, -G, and -J) did not fail during the testing period. The times-to-failure for these six tests can be plotted versus applied load; however, the peak strength must be estimated in order to plot them versus driving-stress ratio for comparison with the Lac du Bonnet granite data in Figure S-2. For these purposes, the peak strength at a effective confinement of $0.5 \mathrm{MPa}\left(\mathrm{P}_{\mathrm{c}}-\mathrm{P}_{\mathrm{p}}\right)$ is estimated to be $151 \mathrm{MPa}$ to give a failure time of one second for a driving-stress ratio of unity.

Table S-1. Static-Fatigue Data for Busted Butte Specimens

\begin{tabular}{|c|c|c|c|c|c|c|}
\hline Specimen & $\begin{array}{c}\text { Confining } \\
\text { Pressure, } \\
\text { P }_{c}(\mathrm{MPa})\end{array}$ & $\begin{array}{c}\text { Stress Difference } \\
\text { Maintained } \\
\text { During Test, } \\
\sigma(\mathrm{MPa}) \\
\end{array}$ & $\begin{array}{l}\text { Time-to- } \\
\text { Failure, } \mathbf{t}_{\mathrm{f}} \\
\text { (sec) }\end{array}$ & $\begin{array}{c}\text { Logarithm of } \\
\text { Time-to- } \\
\text { Failure, } \log \left(t_{f}\right) \\
(\mathrm{sec})\end{array}$ & $\begin{array}{c}\text { Peak } \\
\text { Strength, } \sigma_{\mathrm{f}} \\
\text { (MPa) }\end{array}$ & $\begin{array}{c}\text { Driving- } \\
\text { Stress } \\
\text { Ratio, } \sigma / \sigma_{\mathrm{c}}\end{array}$ \\
\hline BB-9392-K & 5 & 149.0 & 1.2 & 0.08 & 151 & 0.99 \\
\hline BB-9392-N & 5 & 141.0 & 4 & 0.60 & 151 & 0.94 \\
\hline BB-9392-E & 5 & 134.6 & 250 & 2.40 & 151 & 0.89 \\
\hline BB-9392-C & 5 & 134.2 & 636 & 2.80 & 151 & 0.89 \\
\hline BB-9392-F & 5 & 132.8 & 5848 & 3.77 & 151 & 0.88 \\
\hline BB-9392-B & 5 & 127.8 & 1960000 & 6.29 & 151 & 0.85 \\
\hline BB-9392-H & 5 & 131.4 & 1180000 & 6.07 & 151 & 0.87 \\
\hline BB-9392-G & 5 & 131.3 & 732000 & 5.86 & 151 & 0.87 \\
\hline BB-9392-J & 5 & 115.0 & 2000000 & 6.30 & 151 & 0.76 \\
\hline
\end{tabular}

NOTE: See footnote 1 in this Appendix for a discussion of the notation used in this table. Specimens were saturated and tested at a pore water pressure of $4.5 \mathrm{~Pa}$ and temperature of $150^{\circ} \mathrm{C}$. Specimens were loaded directly to creep stress $\left(\sigma_{1}\right)$ in less than 10 seconds. Specimen diameter is $50.8 \mathrm{~mm}$. Specimens BB-9392-H, BB-9392-G, and BB-9392-J did not fail during the test. Confining pressure is the effective value from the applied confining stress $(5 \mathrm{MPa})$ and pore pressure $(4.5 \mathrm{MPa})$. See Martin et al. 1997 [DIRS 165960].

It is noted that there is a difference in test temperature for the granite and tuff data (i.e., $25^{\circ} \mathrm{C}$ and $150^{\circ} \mathrm{C}$, respectively). Based on a postulated physical mechanism for stress corrosion, which is a chemical reaction that increases its rate with increased temperature, it is determined that increasing temperature should decrease the time-to-failure for a fixed driving-stress ratio $\left(\sigma / \sigma_{c}\right)$.

\section{S2.1.2 Suitability of Static-Fatigue Data for Estimating the Long-Term Behavior of the Rock Mass Surrounding the Emplacement Drifts}

The static-fatigue test data for granite (Schmidtke and Lajtai 1985 [DIRS 164774]; Lau et al. 2000 [DIRS 164769]) and tuff (Martin et al. 1997 [DIRS 165960]) were obtained from outside sources. In accordance with AP-SIII.10Q (Section 5.2), these data are considered qualified for use within this analysis and model report based on the reliability of the data sources, the qualifications of the organizations generating the data, and the availability of corroborating data, as documented in this section.

\footnotetext{
${ }^{4}$ The unconfined compressive strength values from Martin et al. (1993) for six saturated 50.8 mm diameter Busted Butte specimens tested at a strain rate of $10^{-5} \mathrm{~s}^{-1}$ ranged from approximately $105 \mathrm{MPa}$ to $200 \mathrm{MPa}$, with a mean of approximately $128 \mathrm{MPa}$ for the five weakest specimens.
} 
Extent to Which the Data Demonstrate Properties of Interest-These data have been collected as part of thermal-mechanical stability studies in both the United States and Canada with the purpose of improving the fundamental understanding of long-term rock mass behavior around underground openings. This information represents the best available data for assessing long-term strength of tuff at Yucca Mountain. The granite data from the Canadian thermal-mechanical studies (i.e., Schmidtke and Lajtai 1985 [DIRS 164774) and Lau et al. 2000 [DIRS 164769]) provide a means of comparing the effects of rock type and demonstrating the similarity of the general nature of the time-to-failure data for different rock types. Additionally, corroborating data (described in this section) confirm the general consistency and similarity of the data sets for providing the long-term strength of rock.

Lau et al. (2000 [DIRS 164769])-Data from long-term loading tests on granite were developed by the CANMET Mining and Mineral Sciences Laboratories within Natural Resources Canada, which is a federal government department specializing in earth sciences. The mining group at CANMET has established a team of specialists in geomechanics, numerical modeling, and mechanical rock property testing. Their laboratories include state-of-the-art rock mechanics testing systems. Specimen preparation, test apparatus, test procedures, data collection, and analysis of data are well documented, providing a reliable source of data from long-term loading tests.

Schmidtke and Lajtai (1985 [DIRS 164774])-Data from long-term loading tests on granite were also developed by the Departments of Civil and Geological Engineering the University of Manitoba under the sponsorship of the Atomic Energy of Canada. This work was conducted by Dr. Emery Lajtai, Professor Emeritus of Civil Engineering at the University of Manitoba. Dr. Lajtai specializes in the fracture and deformation of rocks.

Martin et al. (1997 [DIRS 165960])-Creep and static-fatigue data for welded tuff from Yucca Mountain were developed by the combined efforts of New England Research, Inc. and Sandia National Laboratories. Sandia National Laboratories, with the support of New England Research, Inc., has been a primary developer of rock mechanics testing data within the Office of Civilian Radioactive Waste Management quality assurance program at Yucca Mountain. The collection of the creep and static-fatigue data for tuff, while completed independently from YMP sponsorship, was developed using YMP quality standards. The principal author of the creep and static-fatigue data for tuff, Dr. Randolph Martin, is the President of and Principal Scientist at New England Research, Inc. He has a Ph.D. from MIT, where his thesis research was entitled, "Time-Dependent Crack Growth in Quartz and Its Application to the Creep of Rocks." Dr. Martin has a wide range of experience managing and performing both field and laboratory rock mechanics projects, including designing/building high-pressure equipment, testing rocks at elevated pressures and temperatures, and analyzing data with various (e.g. empirical, analytical, and numerical) techniques. The co-author of this data, Mr. Ronald Price, is a Senior Member of Technical Staff at Sandia National Laboratories. Mr. Price has had a central focus on the mechanical properties of tuffs, with special emphasis on Yucca Mountain tuffs, for over 22 years. His depth of knowledge of tuff rheological properties is particularly valuable for the present application. 
Corroborating Data-New static-fatigue data for tuff (DTN: SN0406L0212303.002 [DIRS 170289], tuff 2004 data) have recently been collected and are used to corroborate the 1997 test data for tuff (Martin et al. 1997 [DIRS 165960]). The static-fatigue data are provided in Section 6.4.2.4 (Figure 6-155). Granite results are included as a means of comparing the effects of rock type and for demonstrating the similarity in the general nature of the time-to-failure data for different rock types. Scatter in the data is due to sample in homogeneity, as well as the fact that the driving stress ratio (the horizontal axis) uses an estimated value for the unconfined compressive strength (adjusted for sample porosity) for normalizing the applied stress level.

Since there is significant variability in the unconfined compressive strength of each sample, there will be a scatter in the resulting plot of time-to-failure versus driving stress ratio. As seen in Figure 6-155, the welded tuff has a significantly slower time static fatigue failure than granite, as evidenced by the steeper slope of the linear fit to the data. This slower time-to-failure is presumably a result of the relatively homogeneous, fine-grained, high silica content nature of the tuff, as opposed to the heterogeneous nature of the grain structure of granite.

Linear fits to the unconfined compression data of Lac du Bonnet granite and to the tuff 1997 data only and to the welded tuff data (including both 1997 and 2004 data) are given (Figure 6-155). Although there is considerably more scatter in the 2004 test results, the linear fits to the data sets show the general consistency of the overall slope of the fits.

\section{S2.2 STATIC-FATIGUE BEHAVIOR OF PFC2D MATERIAL FOR LITHOPHYSAL TUFF}

The PFC stress corrosion model is described in Potyondy (2003 [DIRS 165550]), and only the model behavior when applied to simulating lithophysal tuff is described here. ${ }^{5}$

\section{S2.2.1 PFC2D Base Material and Specimen (Short-Term Behavior)}

The PFC model for lithophysal tuff is described in Section 7.5 and in Subsurface Geotechnical Parameters Report (BSC 2003 [DIRS 166660], Section 9.1). This PFC2D model (consisting of circular voids within a well-connected base material) has the microproperties and void geometry given in Table $\mathrm{S}-2$, and provides the base material for which the stress-corrosion behavior is measured. Determination of the appropriate model conditions requires balancing many factors such as (1) behavior of previous models, (2) appropriate resolution of voids and bridges, and (3) ability to perform a simulation in a reasonable amount of time.

\footnotetext{
${ }^{5}$ Much of the development of the model has been funded by Atomic Energy of Canada Limited and Ontario Power Generation during the years 1995-2001 as part of its Thermal-Mechanical Stability Study, one aim of which has been to improve our fundamental understanding of short- and long-term rock-mass behavior around underground openings at ambient and elevated temperatures. The result of this work has been the development and verification of the Bonded-Particle Model for Rock - a mechanistically based numerical model for predicting excavationinduced rock-mass damage and long-term strength (by incorporating a damage process based on a stress-corrosion mechanism) in Lac du Bonnet granite (Potyondy and Cundall 2001 [DIRS 156895]).
} 


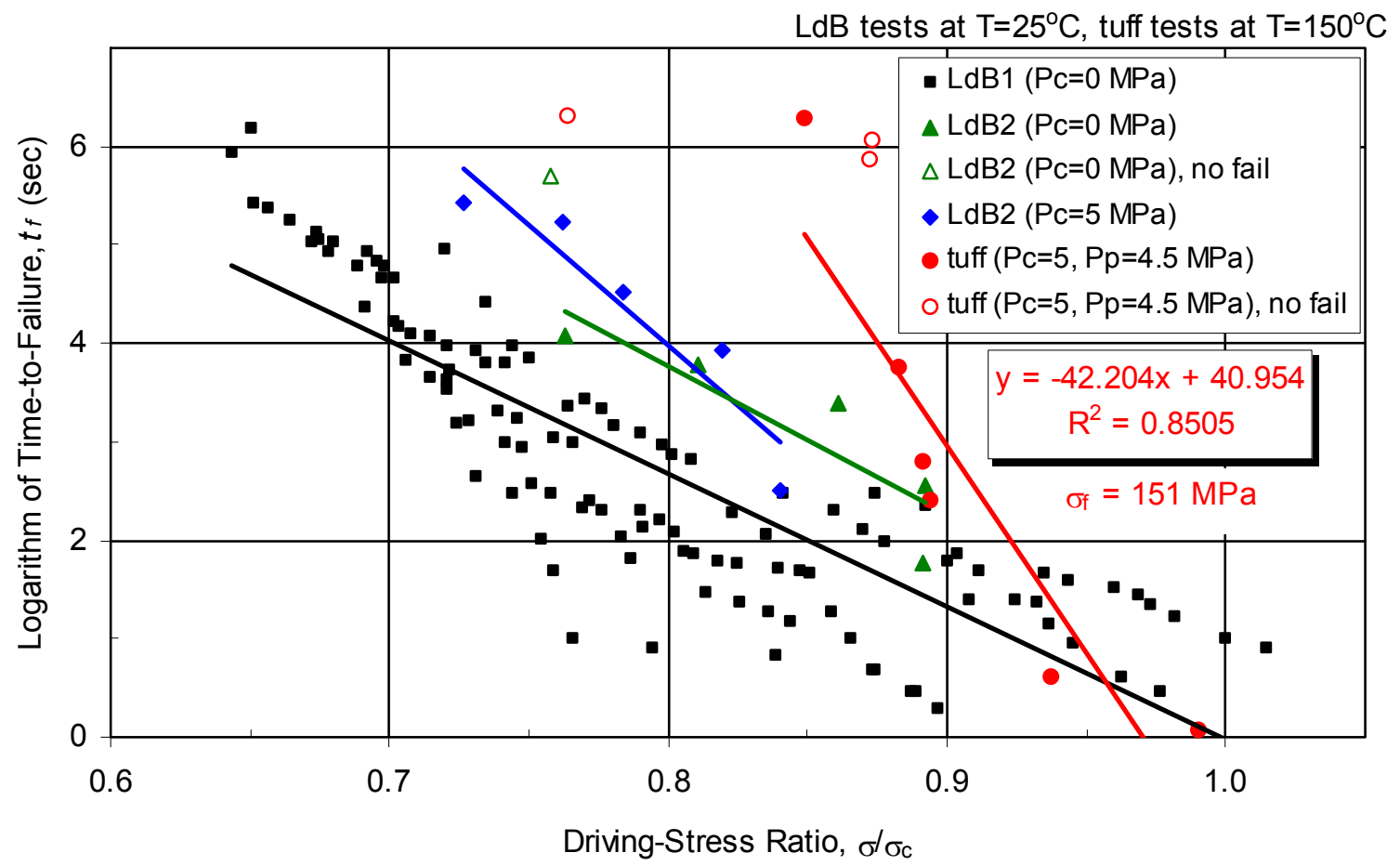

Sources: LdB1 from Schmidtke and Lajtai (1985 [DIRS 164774]); LdB2 from Lau et al. (2000 [DIRS 164769]); tuff from Martin et al. (1997 [DIRS 165960]).

Figure S-2. Static-Fatigue Data for Welded Tuff and Lac du Bonnet Granite

The properties of the PFC2D material are obtained by testing 1:1 aspect-ratio specimens of one-meter diameter, with circular voids of $90 \mathrm{~mm}$ diameter and a $41.5 \mathrm{~mm}$ minimum bridge length. The use of 1:1 aspect-ratio specimens is justified due to frictionless boundary conditions. It is noted that the modulus and strength versus void porosity relations are similar for both $1: 1$ and 2:1 aspect-ratio specimens - the 2:1 aspect-ratio specimens are only slightly weaker than the 1:1 aspect-ratio specimens (see Figures S-3 and S-4).

The resolutions of previous PFC materials are shown in Table S-3. The materials in the first two columns are 2:1 aspect ratio specimens that were used to obtain the initial relations between modulus, strength and void porosity (see Figures 7-12 and 7-13). These 2D and 3D materials have average particle diameters of $17.1 \mathrm{~mm}$ and $52.3 \mathrm{~mm}$, respectively, and the macroproperties of the 2D material are shown in Figures S-3 through S-5. The materials in the third and fourth columns are 1:1 aspect ratio specimens that differ only in the size of the circular voids. This 2D material has an average particle diameter of $9.9 \mathrm{~mm}$, and the macroproperties of these 2D materials are shown in Figures S-3 through S-5. The material in the fourth column is used for the present work. 
Table S-2. PFC2D Material for Lithophysal Tuff (Microproperties and Void Geometry)

\begin{tabular}{|c|c|}
\hline Grains & Cement \\
\hline$\rho=2510 \mathrm{~kg} / \mathrm{m}^{3}$ & $\mathrm{~N} / \mathrm{A}$ \\
\hline $\begin{array}{c}\left(D_{\max } / D_{\min }\right)=1.5 \\
D_{\text {avg }} \text { varies }\end{array}$ & $\bar{\lambda}=1$ \\
\hline$E_{c}=14.8 \mathrm{GPa}$ & $\bar{E}_{c}=14.8 \mathrm{GPa}$ \\
\hline$\left(k_{n} / k_{s}\right)=2.1$ & $\left(\bar{k}^{n} / \bar{k}^{s}\right)=2.1$ \\
\hline$\mu=0.5$ & $\bar{\sigma}_{c}=\bar{\tau}_{c}=$ mean \pm standard deviation $=48.11 \pm 11 \mathrm{MPa}$ \\
\hline \multicolumn{2}{|c|}{ Void Geometry: circular, $D_{V}$ varies, $B_{\min }=41.5 \mathrm{~mm}$} \\
\hline
\end{tabular}

NOTE: The PFC microproperties in this table were obtained by calibration of the PFC model to match the macro-behavior of tuff, as described in Section 7.6.3. $\rho=$ grain density, $D_{\max }=$ maximum particle diameter $(\mathrm{mm}), D_{\min }=$ minimum particle diameter $(\mathrm{mm}), D_{\text {avg }}=$ average particle diameter $(\mathrm{mm})$, $E_{c}=$ Young's modulus of the grains, $\bar{E}_{c}=$ Young's modulus of the cement, $k_{n}=$ particle normal stiffness, $k_{s}=$ particle shear stiffness, $\mu=$ grain friction coefficient, $\bar{\lambda}=$ bond-radius multiplier of cemented contact, $\bar{k}^{n}=$ normal stiffness of cemented contact, $\bar{k}^{s}=$ shear stiffness of cemented contact, $\bar{\sigma}_{\mathrm{c}}=$ tensile strength of cemented contact, $\bar{\tau}_{\mathrm{c}}=$ shear strength of cemented contact, $D_{\mathrm{v}}=$ void diameter $(\mathrm{mm}), B_{\min }=$ minimum bridge length.

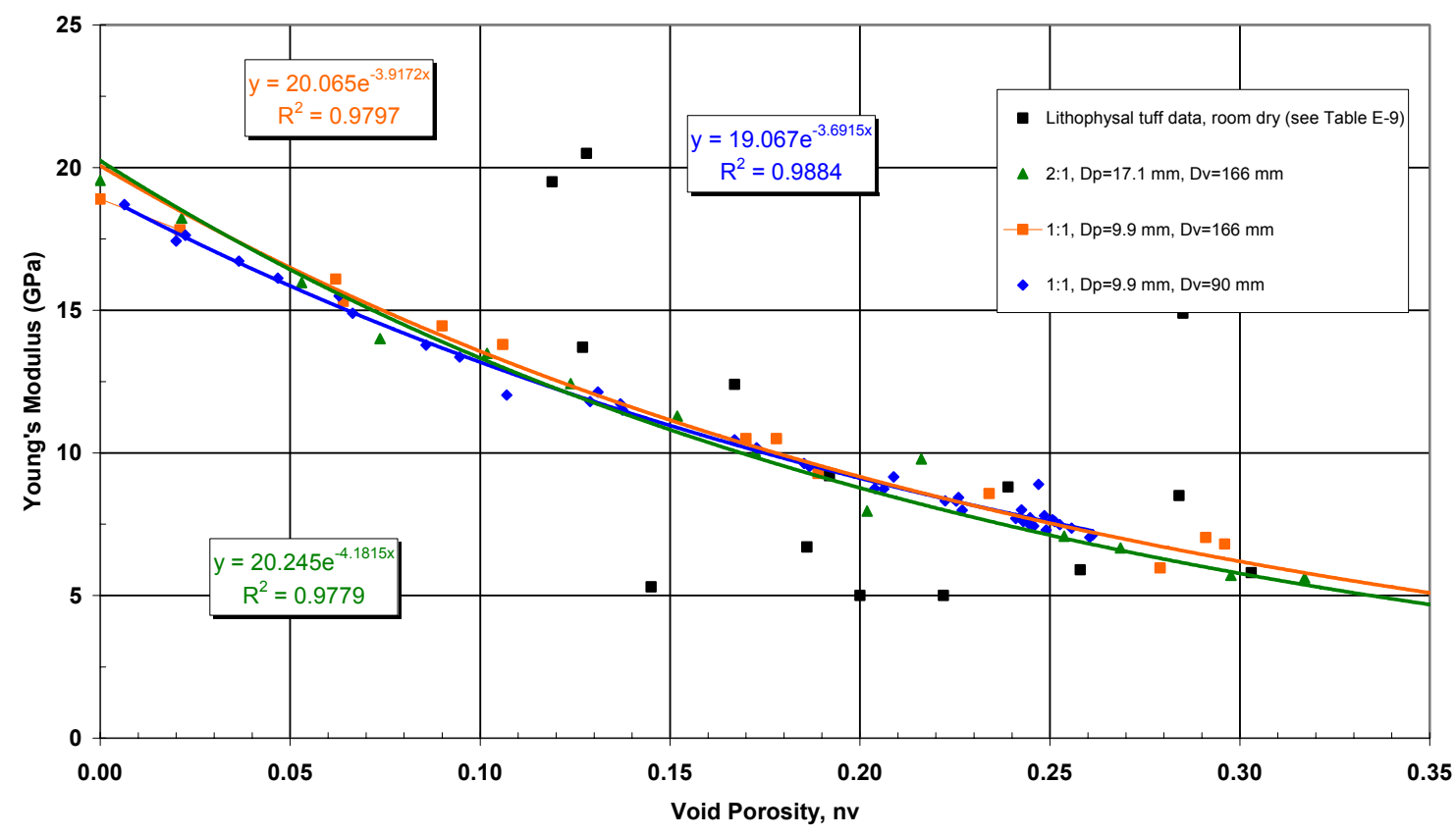

Figure S-3. Young's Modulus Versus Void Porosity for Lithophysal Tuff and PFC2D Models of Randomly Distributed Circular Voids 


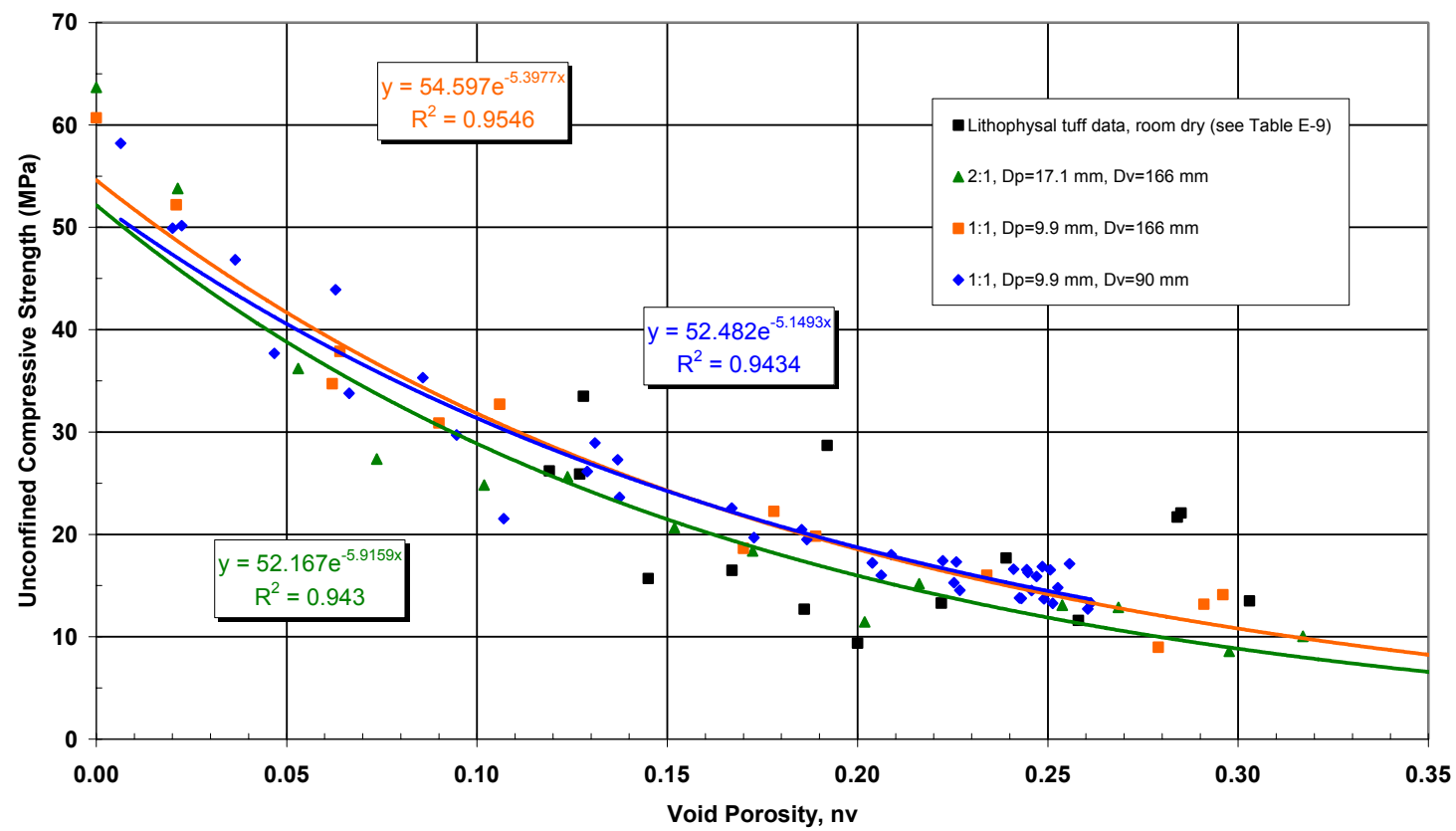

Figure S-4. Unconfined Compressive Strength Versus Void Porosity for Lithophysal Tuff and PFC2D Models of Randomly Distributed Circular Voids

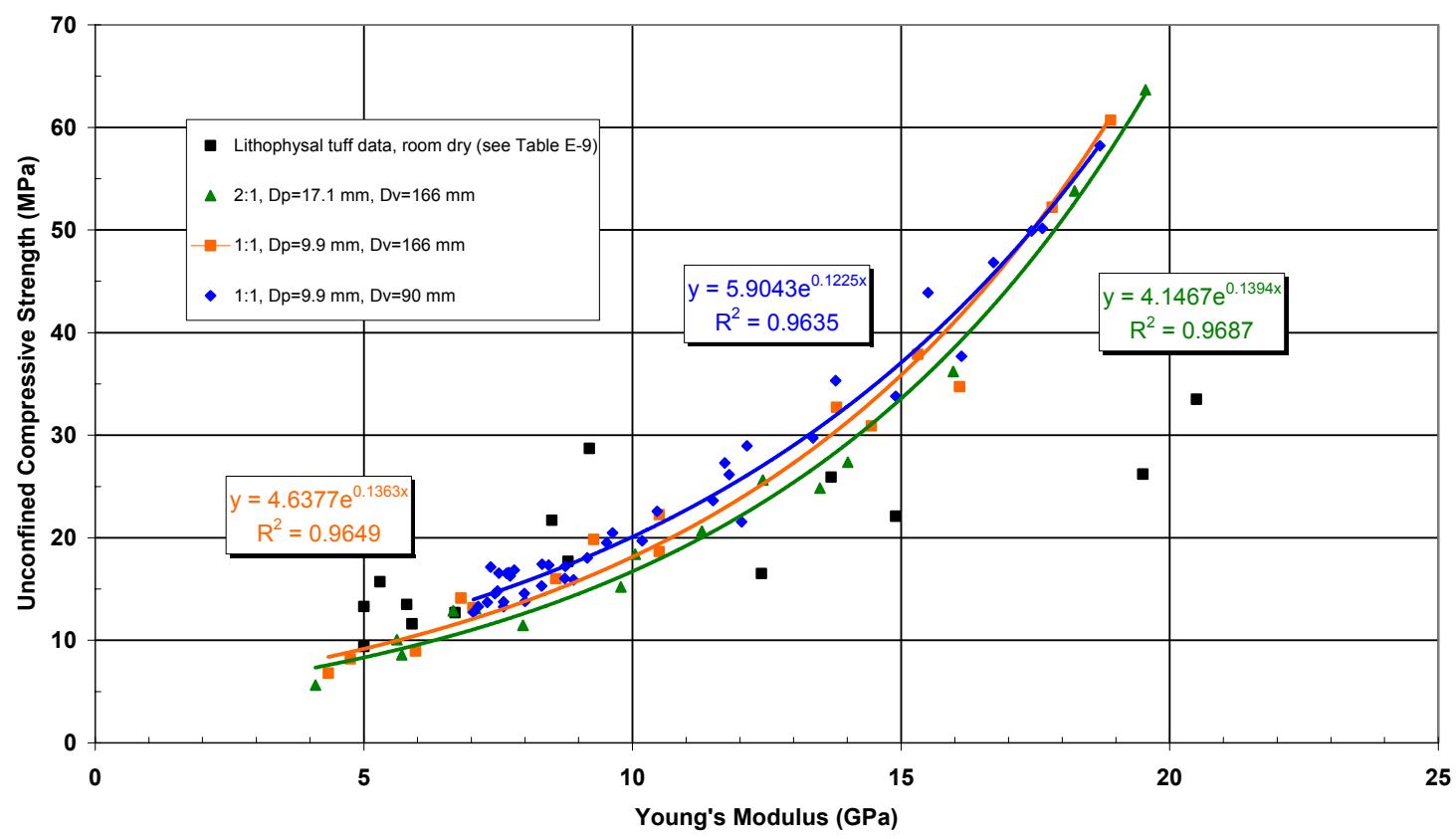

Figure S-5. Young's Modulus Versus Unconfined Compressive Strength for Lithophysal Tuff and PFC2D Models of Randomly Distributed Circular Voids 
Table S-3. PFC Resolutions for Lithophysal Tuff Specimens

\begin{tabular}{|c|c|c|c|c|}
\hline $\begin{array}{c}\text { Resolution } \\
\left(\boldsymbol{D}_{s}=\mathbf{1 0 0 0} \mathbf{m m}\right)\end{array}$ & PFC3D & PFC2D & PFC2D & PFC2D \\
$\mathbf{2 : 1}$ cyl. & $\mathbf{2 : 1}$ & $\mathbf{1 : 1}$ & $\mathbf{1 : 1}$ \\
\hline$D_{\text {avg }}(\mathrm{mm})$ & 52.3 & 17.1 & 9.9 & 9.9 \\
\hline$D_{v}(\mathrm{~mm})$ & 166 & 166 & 166 & 90 \\
\hline specimen, $\psi_{s}=D_{s} / D_{\text {avg }}$ & 19.1 & 58.5 & 101 & 101 \\
\hline void, $\psi_{v}=D_{v} / D_{\text {avg }}$ & 3.2 & 9.7 & 16.8 & 9.1 \\
\hline bridge, $\psi_{B}=B_{\min } / D_{\text {avg }}$ & 0.8 & 2.4 & 4.2 & 4.2 \\
\hline
\end{tabular}

NOTE: $\quad D_{\mathrm{s}}=$ specimen diameter $(\mathrm{mm}), \psi_{\mathrm{s}}=$ specimen resolution, $\psi_{v}=$ void resolution, $\psi_{B}=$ bridge resolution. All other parameters defined in Table S-2. $B_{\min }=41.5 \mathrm{~mm}$.

\section{S2.2.2 PFC2D Base Material and Specimen (Long-Term Behavior)}

The long-term behavior of the PFC2D material is characterized by performing a series of numerical static-fatigue tests on the PFC2D lithophysal-tuff model using the microproperties in Table S-4. The long-term behavior is controlled by the three PFC stress corrosion model parameters of $\beta_{l}, \beta_{2}$, and $\bar{\sigma}_{a}$. These parameters do not affect the short-term behavior. The properties of the PFC2D material are obtained by testing 1:1 aspect-ratio specimens of one-meter diameter with void porosities of $0,0.1$, and 0.2 under static-fatigue conditions at confinements of 0.1 and $5 \mathrm{MPa}$. The PFC2D materials have average particle diameters ranging from $10 \mathrm{~mm}$ to $40 \mathrm{~mm}$, giving the specimen, void, and bridge resolutions shown in Table S-5. The results presented here were produced for the $\mathrm{mS} 50$ specimens (average particle diameter of $20 \mathrm{~mm}$ ), which provide a specimen resolution of 50 particles across a one-meter diameter specimen. The specimens with non-zero void porosities are shown in Figure S-6.

Table S-4. PFC2D Material for Lithophysal Tuff (Short- and Long-Term Microproperties and Void Geometry)

\begin{tabular}{|c|c|}
\hline Grains & Cement \\
\hline$\rho=2510 \mathrm{~kg} / \mathrm{m}^{3}$ & $\mathrm{~N} / \mathrm{A}$ \\
\hline $\begin{array}{c}\left(D_{\max } / D_{\min }\right)=1.5 \\
D_{\text {avg }} \text { varies }(10,20, \text { or } 40 \mathrm{~mm})\end{array}$ & $\bar{\lambda}=1$ \\
\hline$E_{c}=14.8 \mathrm{GPa}$ & \multicolumn{1}{|c|}{$\bar{E}_{c}=14.8 \mathrm{GPa}$} \\
\hline$\left(k_{n} / k_{s}\right)=2.1$ & \multicolumn{1}{c|}{$\left(\bar{k}^{n} / \bar{k}^{s}\right)=2.1$} \\
\hline$\mu=0.5$ & $\bar{\sigma}_{\mathrm{c}}=\bar{\tau}_{\mathrm{c}}=$ mean \pm standard deviation $=48.11 \pm 11 \mathrm{MPa}$ \\
\hline $\mathrm{N} / \mathrm{A}$ & $\begin{array}{l}\beta_{1}=5 \times 10^{-15} \mathrm{~m} / \mathrm{sec} \quad \bar{\sigma}_{\mathrm{a}}=0 \mathrm{MPa} \\
\beta_{2}=30\end{array} \quad f_{r}=1 \times 10^{-4}, n_{s}=4, f_{s}=2$ \\
\hline \multicolumn{2}{r|}{ Void Geometry: circular, $D_{v}=90 \mathrm{~mm}, B_{\min }=41.5 \mathrm{~mm}$} \\
\hline
\end{tabular}

NOTE: $\quad \beta_{1}=$ rate constant $(\mathrm{m} / \mathrm{sec}), \beta_{2}=$ rate constant (dimensionless), $\bar{\sigma}_{\mathrm{a}}=$ micro-activation stress, $f_{r}=$ equilibrium ratio limit, $n_{s}=$ number of steps until the first bond breaks, $f_{s}=$ time step multiplier. All other parameters defined in Table S-2. 
Table S-5. PFC2D Resolutions for Current Lithophysal Tuff Specimens

\begin{tabular}{|c|c|c|c|}
\hline $\begin{array}{c}\text { Resolution } \\
\left(\boldsymbol{D}_{\mathbf{s}}=\mathbf{1 0 0 0} \mathbf{m m}\right)\end{array}$ & $\begin{array}{c}\mathbf{m S 1 0 0} \\
\text { (fine) }\end{array}$ & $\begin{array}{c}\text { mS50 } \\
\text { (medium) }\end{array}$ & $\begin{array}{c}\text { mS25 } \\
\text { (coarse) }\end{array}$ \\
\hline specimen, $\psi_{s}=D_{s} / D_{\text {avg }}$ & 100 & 50 & 25 \\
\hline void, $\psi_{v}=D_{v} / D_{\text {avg }}$ & 9.0 & 4.5 & 2.3 \\
\hline bridge, $\psi_{B}=B_{\min } / D_{\text {avg }}$ & 4.2 & 2.1 & 1.0 \\
\hline
\end{tabular}

NOTE: All parameters defined in Tables S-2 and S-3.
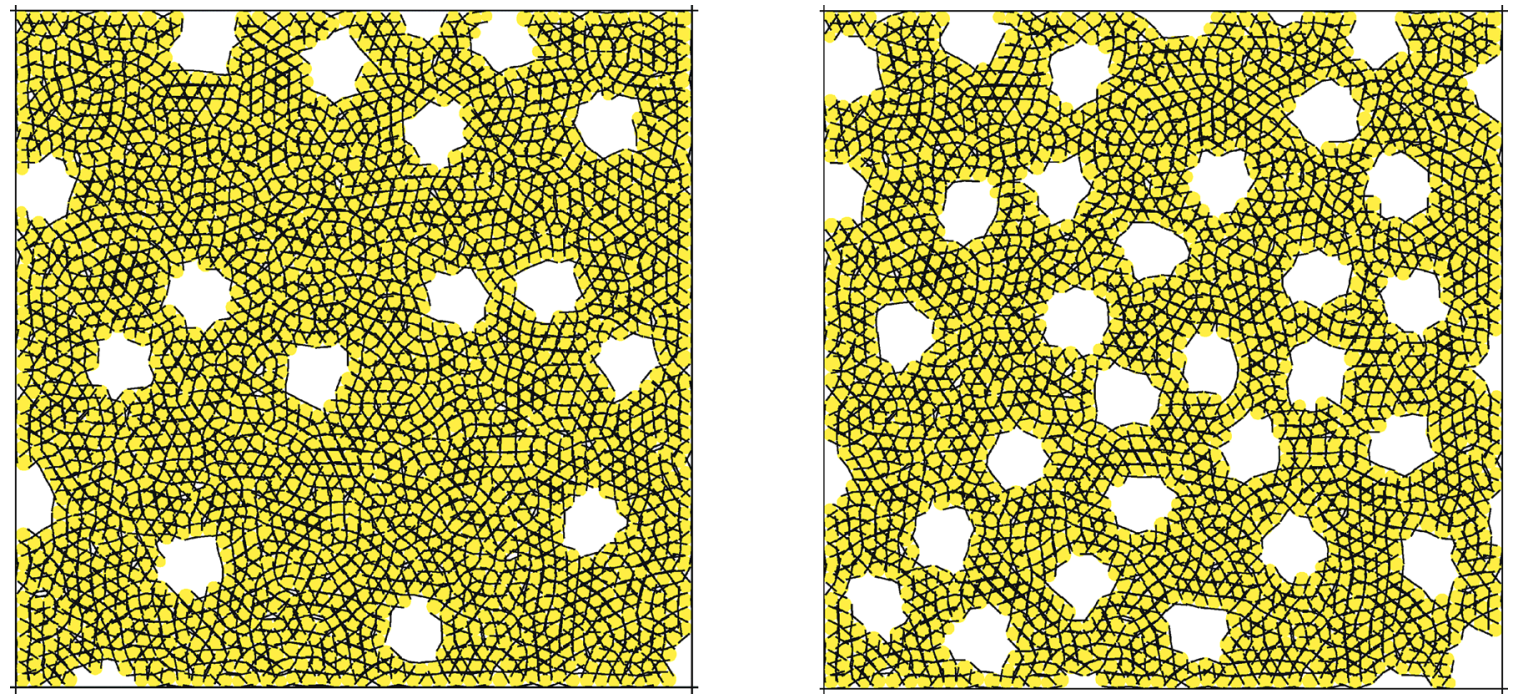

NOTE: Void porosities of 0.107 and 0.204 .

Figure S-6. PFC2D Specimens of mS50 Material

\section{S2.2.3 Selection of Stress Corrosion Algorithm-Control Parameters}

The equilibrium ratio limit, $f_{r}$, defines when the system has returned to static equilibrium after each stress-corrosion step. This study uses PFC2D version 2.0, for which the equilibrium ratio is taken as the ratio of maximum unbalanced force over maximum contact force. Numerical static-fatigue tests were performed on the mS50 material with no holes and with $\bar{\sigma}_{a}=19 \mathrm{MPa}$ at driving-stress ratios ranging from 0.25 to 0.90 . The $f_{r}$ was varied over three orders of magnitude from $1 \times 10^{-3}$ to $1 \times 10^{-6}$ while keeping the other algorithm-control parameters fixed at $n_{s}=2$ and $f_{s}=2.0$. The failure times were $4.91 \times 10^{5}, 3.66 \times 10^{5}, 3.85 \times 10^{5}$, and $3.66 \times 10^{5}$ seconds, respectively. A plot showing the total number of cracks ${ }^{6}$ versus time for a driving-stress ratio of 0.75 is displayed in Figure S-7. These results suggest that the cracking during primary and secondary creep is not affected by the equilibrium ratio limit, but that cracking during the tertiary creep stage and the corresponding failure time is affected by the equilibrium ratio limit. Further study is required to determine what is the equilibrium ratio limit below which the failure time is constant. The results presented here demonstrate that values less than $1 \times 10^{-3}$ produce similar primary and secondary creep. Therefore, to ensure similar primary and secondary creep, the results in this report were produced using an equilibrium ratio of $1 \times 10^{-4}$.

\footnotetext{
${ }^{6}$ The term "crack" is used throughout this appendix to refer to bond breakages in the PFC material.
} 


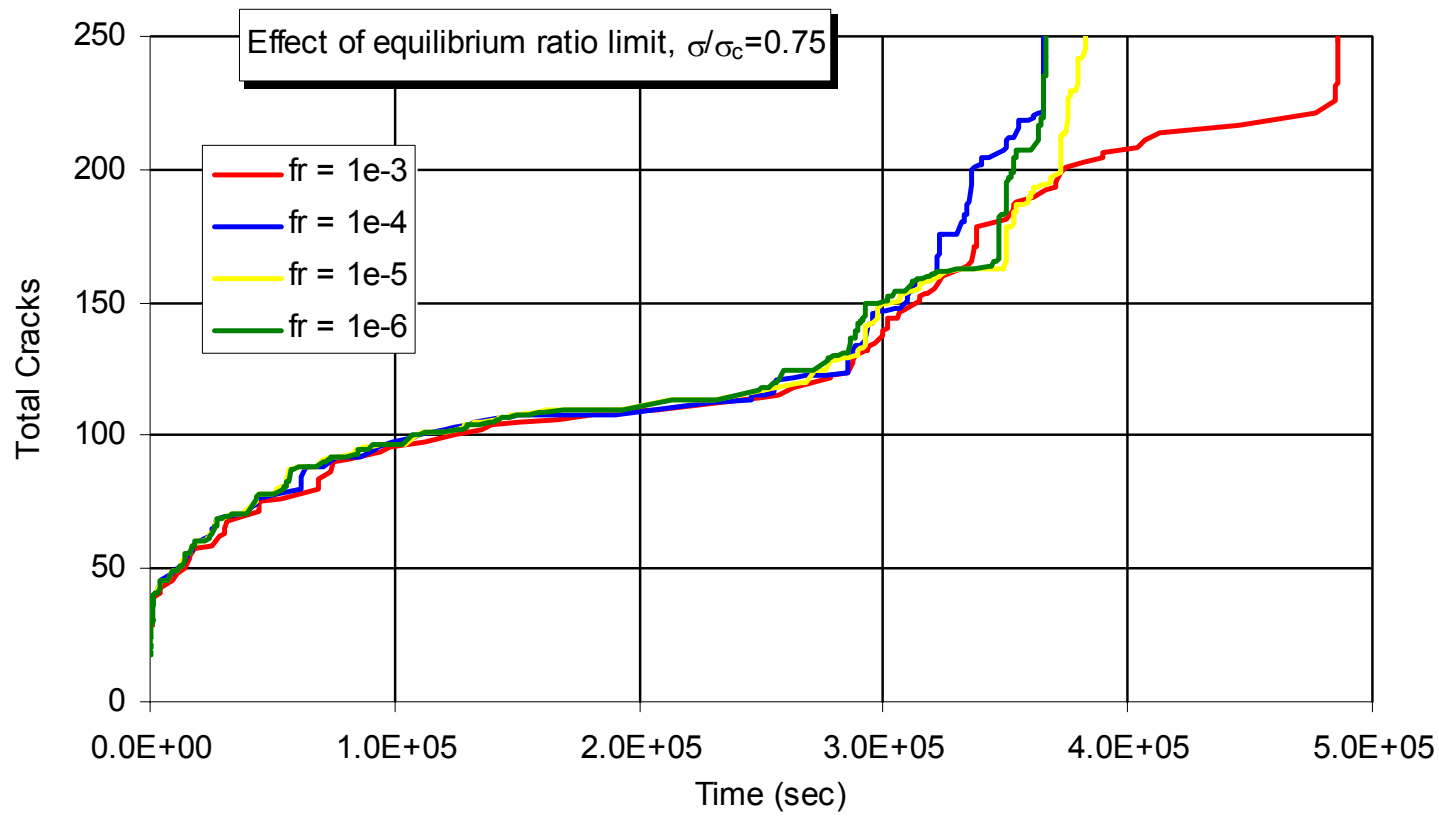

Figure S-7. Number of Cracks Versus Time for Different Equilibrium Ratio Limits

By default, the subinterval factor, $n_{s}$, is set to 2 . The effect of increasing this value (and therefore decreasing the initial size of each stress-corrosion time step) is examined here. Numerical static-fatigue tests were performed on the $\mathrm{mS} 50$ material with no holes at driving-stress ratios of 0.4 and 0.8 , and $n_{s}$ was varied from 2 to 32 while keeping the other algorithm-control parameters fixed at $f_{r}=1 \times 10^{-4}$ and $f_{s}=2.0$. The failure times are normalized by the corresponding failure time for $n_{s}=32$ and plotted versus the subinterval factor in Figure S-8. Increasing the subinterval factor reduces the size of each stress-corrosion time step, which reduces the error associated with considering that the forces remain constant during each step, and is in keeping with the conclusion that as $\Delta \mathrm{t} \rightarrow 0$, the true macroscopic time-to-failure is approached from above. The creep response is similar for different subintervals as seen in Figure S-9. The results in this report were produced using a subinterval factor of 4 . The subinterval factor of 4 results in an error of approximately 5 percent. This error is considered as acceptable with the level of uncertainty in this type of model. 


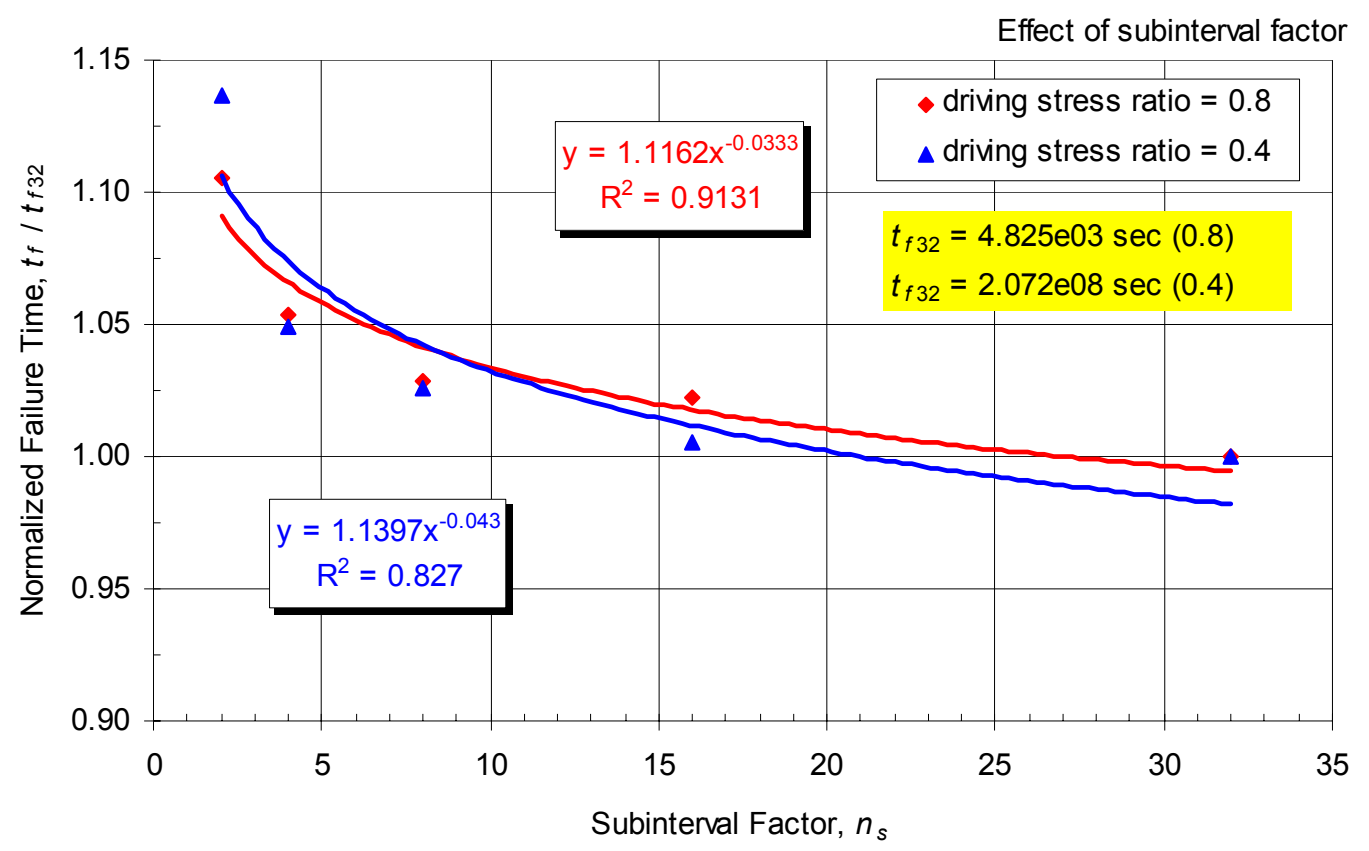

NOTE: Driving-stress ratios of 0.8 and 0.4 .

Figure S-8. Normalized Time-to-Failure Versus Subinterval Factor for mS50 Material for Numerical Static-Fatigue Tests (0.1 MPa Confinement)

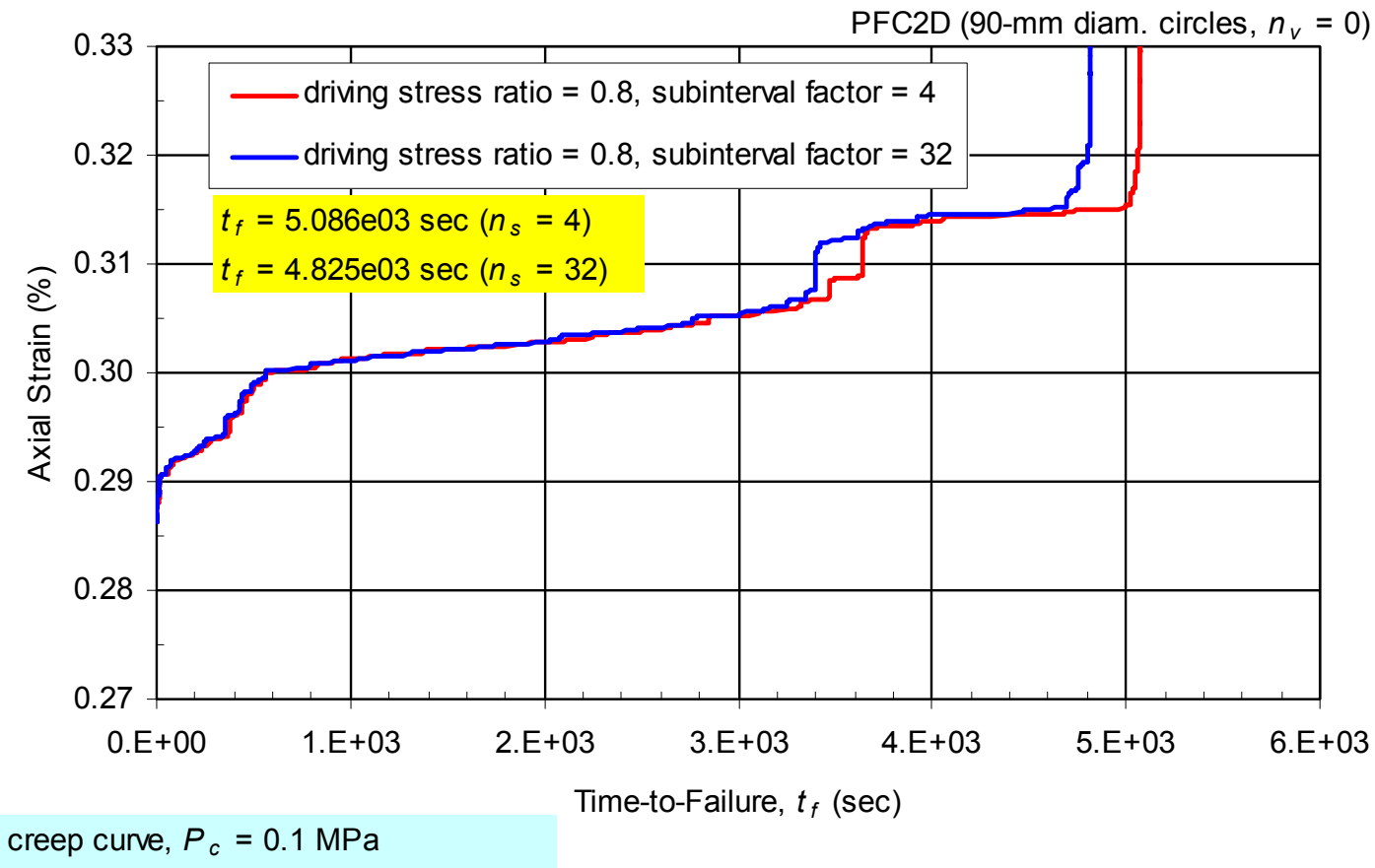

NOTE: Driving-stress ratio of 0.8 .

Figure S-9. Effect of Subinterval Factor on Creep Curves for mS50 Material for Numerical Static-Fatigue Tests (0.1 MPa Confinement) 


\section{S2.2.4 Typical Model Behavior During a Static-Fatigue Test}

Numerical static-fatigue tests at a confinement of $0.1 \mathrm{MPa}$ were performed upon the mS50 material with no voids to produce the static-fatigue curve shown in Figure S-10. The PFC stress corrosion model parameters of $\beta_{1}$ and $\beta_{2}$ were chosen to match the LdB1 data set in the range $0.6 \leq \sigma / \sigma_{c} \leq 1.0$. The bump in the curve for $0.885 \leq \sigma / \sigma_{c} \leq 0.890$ is caused by a change in the failure mode of the specimen as shown in Figure S-10. The micro-activation stress, $\bar{\sigma}_{a}$, controls the minimum driving-stress ratio for which the time-to-failure becomes infinite. This lower limit for time-dependent failure is called the static-fatigue limit. There is, as yet, no scientific consensus on the value of the static-fatigue limit, although exponential extrapolation of the LdB1 data set by Schmidtke and Lajtai (1985 DIRS [164774]) gives a value of 0.45. Because the $\mathrm{mS50}$ material is being used to generate damage curves to serve as input to the UDEC model, the conservative consideration that $\bar{\sigma}_{a}=0$ is used. A zero value of $\bar{\sigma}_{a}$ means that stress corrosion will continue until the micro-tensile forces in the material have been removed. It is found that the time-to-failure is indeed finite for driving-stress ratios larger than 0.2 , and that the static-fatigue curve is nearly linear for small driving-stress ratios (see Figure S-11). ${ }^{1}$

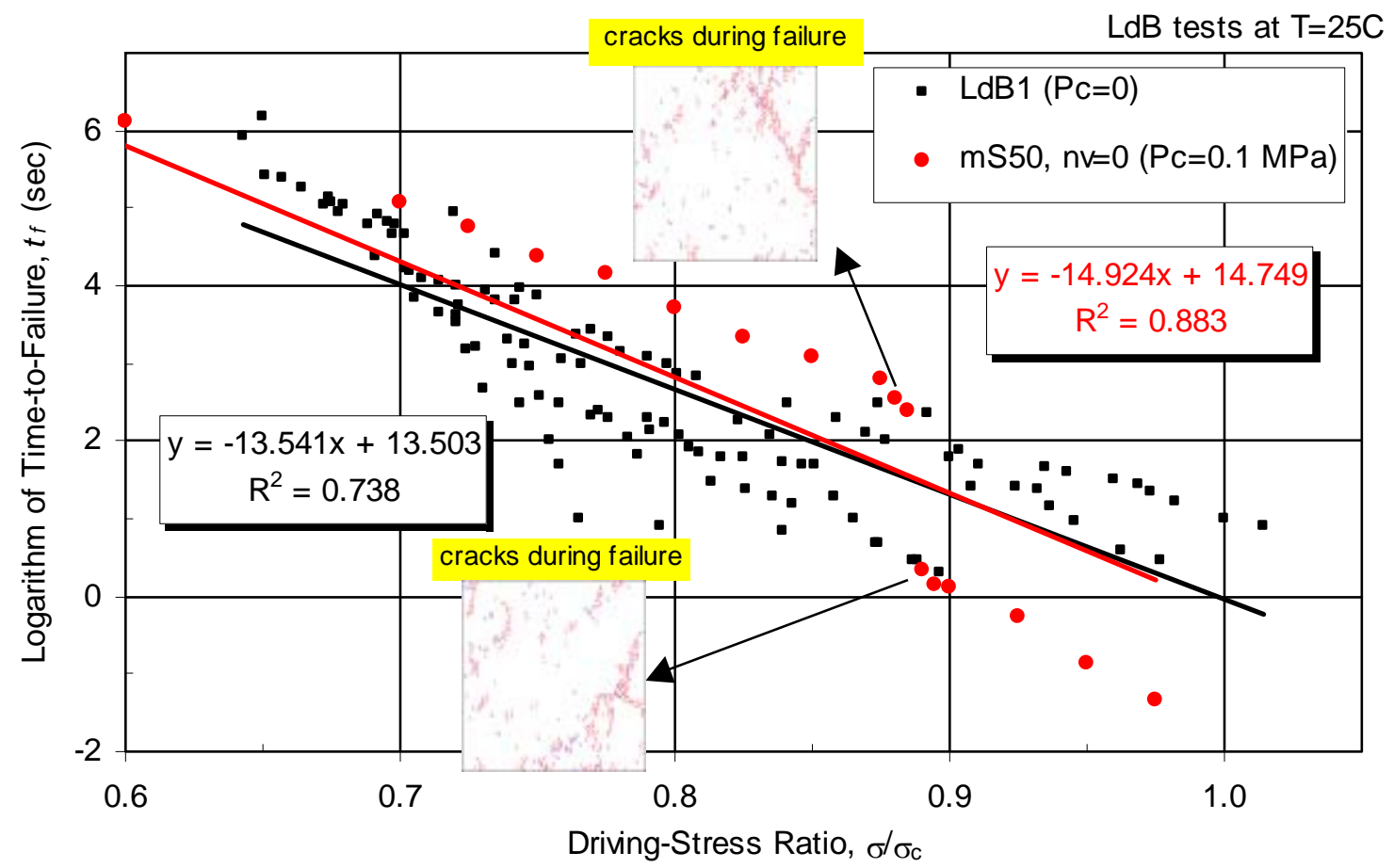

NOTE: Data set LdB1 from Figure S-1.

Figure S-10. Static-Fatigue Curve (0.1 MPa Confinement) for mS50 Material for Numerical Static-Fatigue Tests Compared with the Data and Curve for Lac du Bonnet Granite

\footnotetext{
${ }^{1}$ A better fit to the mS50 data would bend strongly downwards for driving-stress ratios that approach one (because the time-to-failure must approach zero), and would bend slightly downwards for driving-stress ratios that approach zero. Such a fit is used in Appendix S2.2.5.
} 


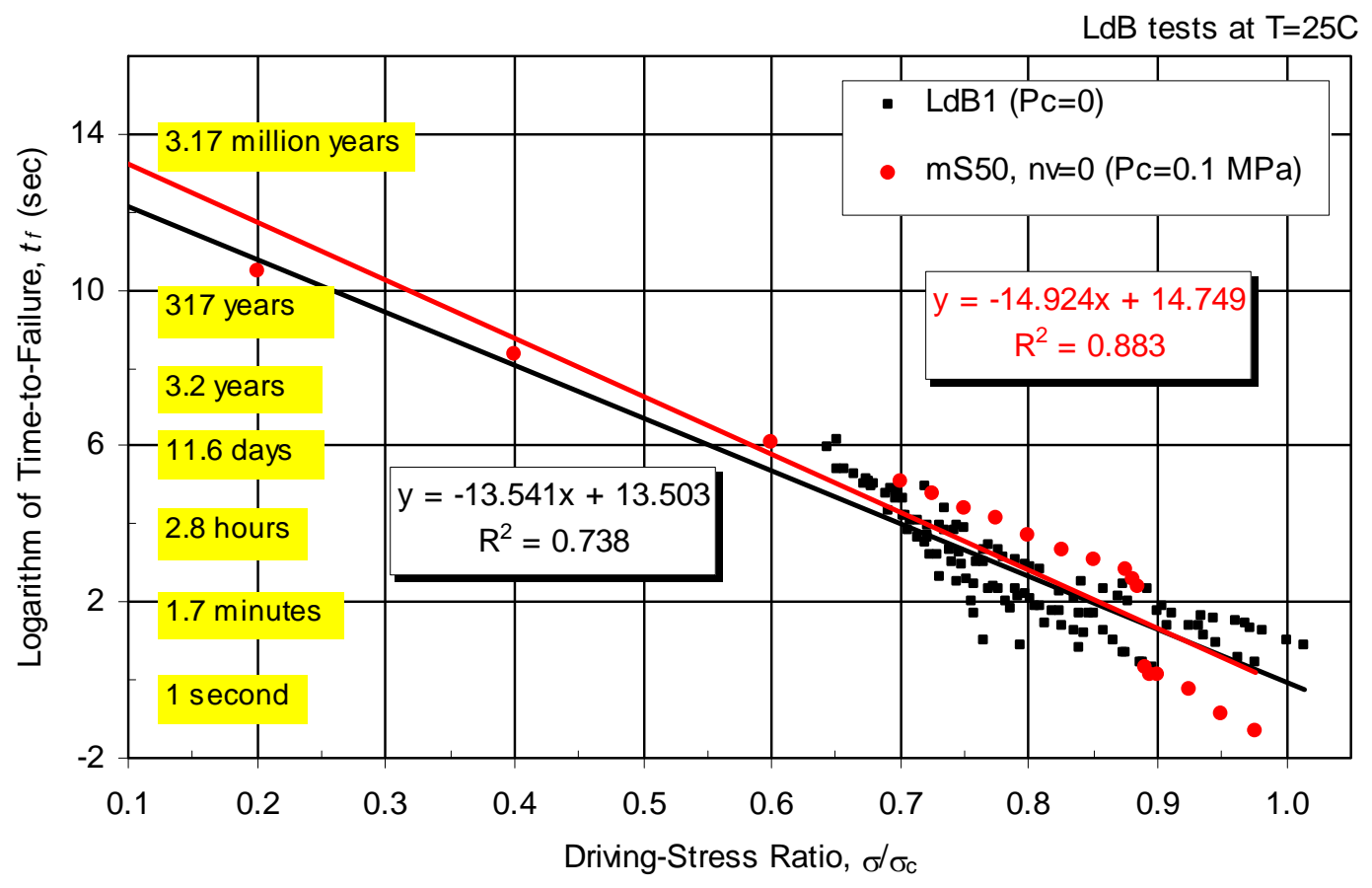

NOTE: Data set LdB1 from Figure S-1.

Figure S-11. Static-Fatigue Curve (0.1 MPa Confinement) for mS50 Material for Numerical Static-Fatigue Tests Compared with the Data and Curve for Lac du Bonnet Granite Expanded Scales

Representative creep curves are shown in Figure S-12, where the axial strain is plotted versus normalized time-to-failure. The general behavior is one of primary, secondary and tertiary creep. The creep response is produced by the reduction of parallel-bond radii and by the formation of microcracks as can be seen in Figure S-13. 


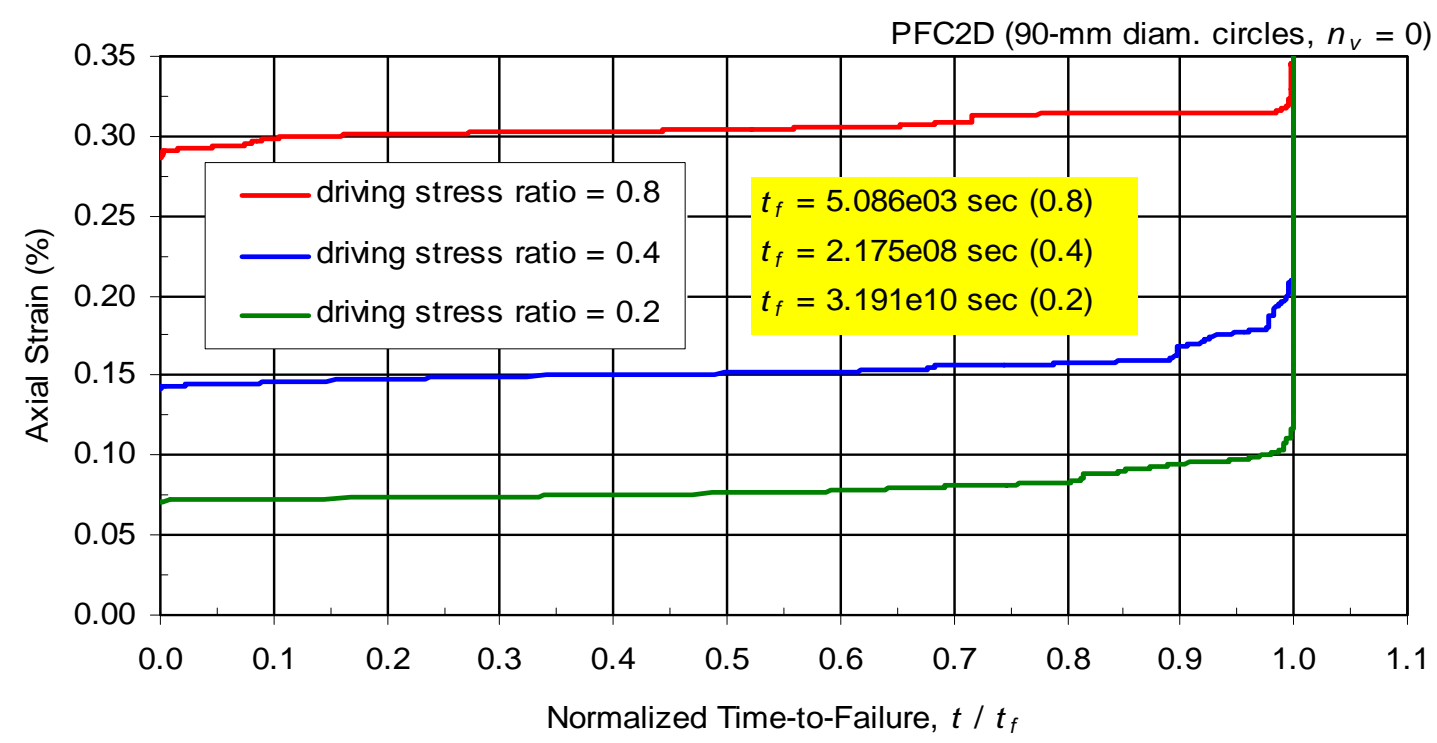

creep curves, $P_{c}=0.1 \mathrm{MPa}$

NOTE: Driving-stress ratios of $0.2,0.4$ and 0.8 .

Figure S-12. Creep Curves for mS50 Material for Numerical Static-Fatigue Tests (0.1 MPa Confinement)

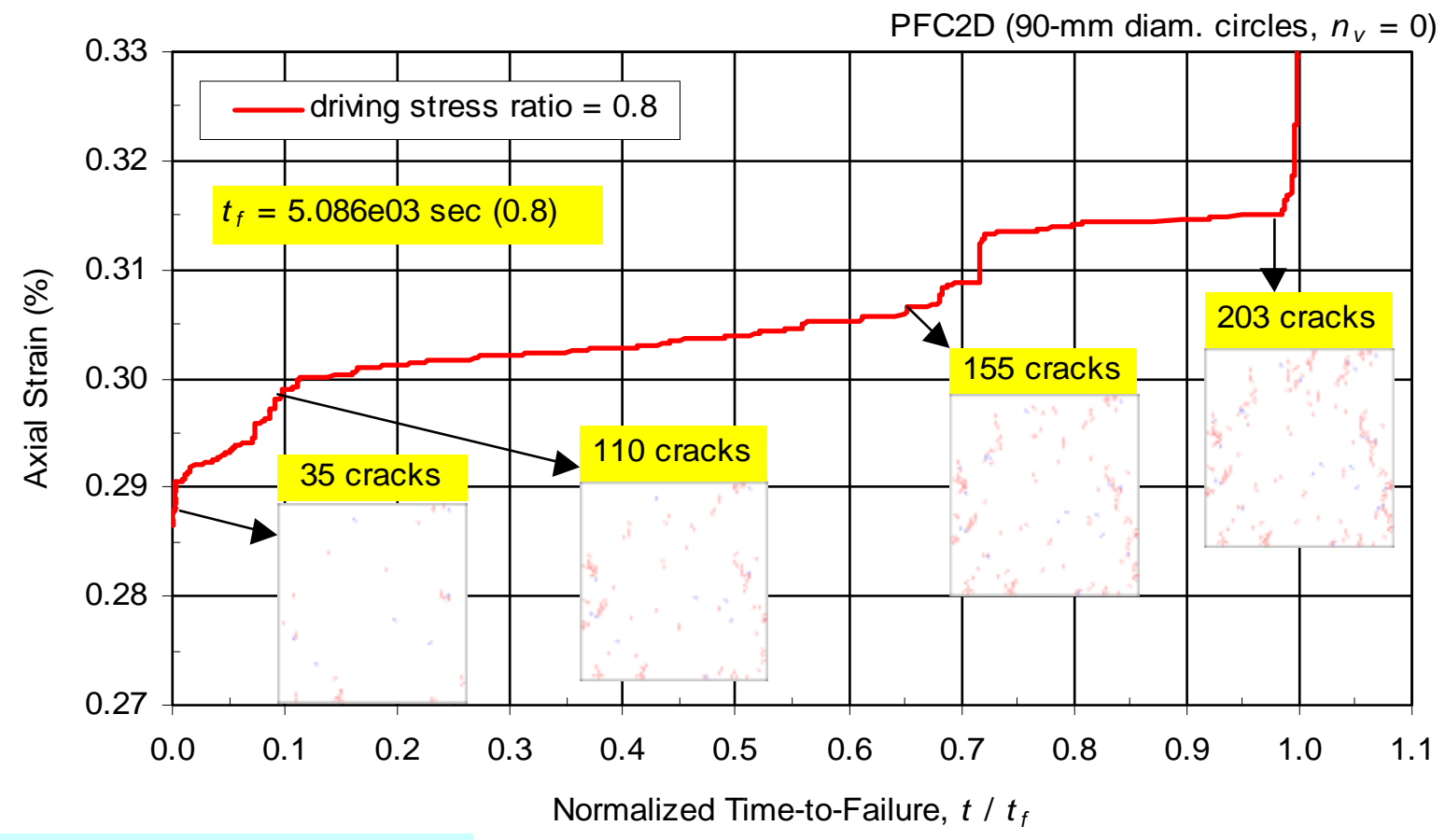

creep curve, $P_{c}=0.1 \mathrm{MPa}$

NOTE: Driving-stress ratios of 0.8 .

Figure S-13. Creep Curve and Damage in mS50 Material for Static-Fatigue Test (0.1 MPa Confinement) 


\section{S2.2.5 Effect of Void Porosity and Confinement on Static-Fatigue Curves}

The effect of void porosity on the static-fatigue curves of the mS50 material is shown in Figures S-14 and S-15. While the slope of the curves varies slightly, it is generally observed that increasing the void porosity reduces the time-to-failure for the same driving-stress ratio, and the static-fatigue curves are similar. It seems that the curves for various void porosities may be converging for very small driving-stress ratios. Note that in these figures, the data is fit with a fourth-order polynomial instead of a straight line (see Figures S-16 and S-17). Based on the definition of a static-fatigue curve, the time to failure should be zero for a driving-stress ratio of one. The polynomial fit approximates this trend, whereas a linear fit does not. The polynomial fit is used for most figures in this section; however, a linear fit has been used in the remainder of the report. The exact form of the static-fatigue curve is not known, because of a lack of laboratory data for driving-stress ratios below 0.65; thus, for extrapolation purposes, a linear fit was deemed acceptable.

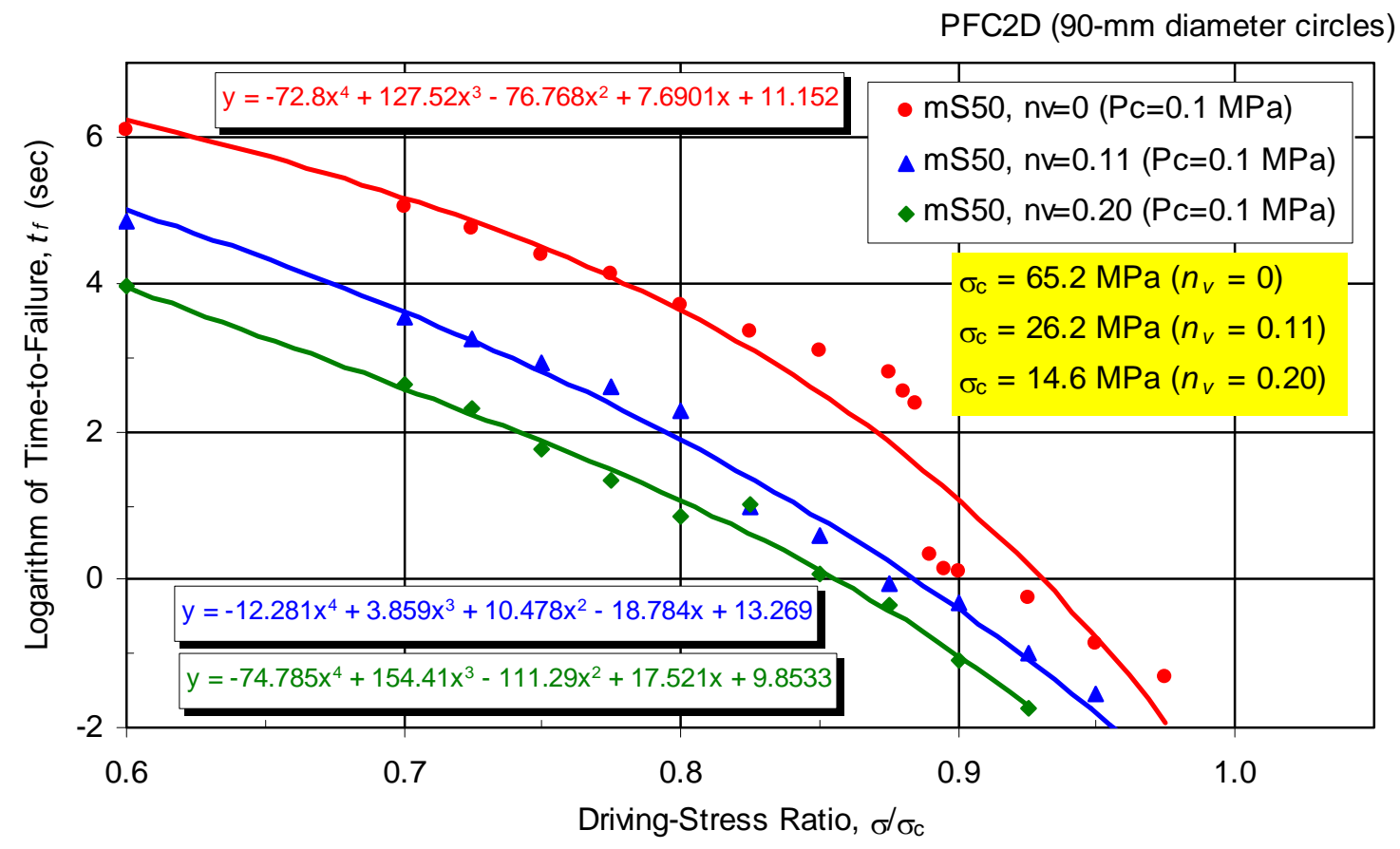

Figure S-14. Effect of Void Porosity on Static-Fatigue Curves (0.1 MPa Confinement) for mS50 Material 
PFC2D (90-mm diameter circles)

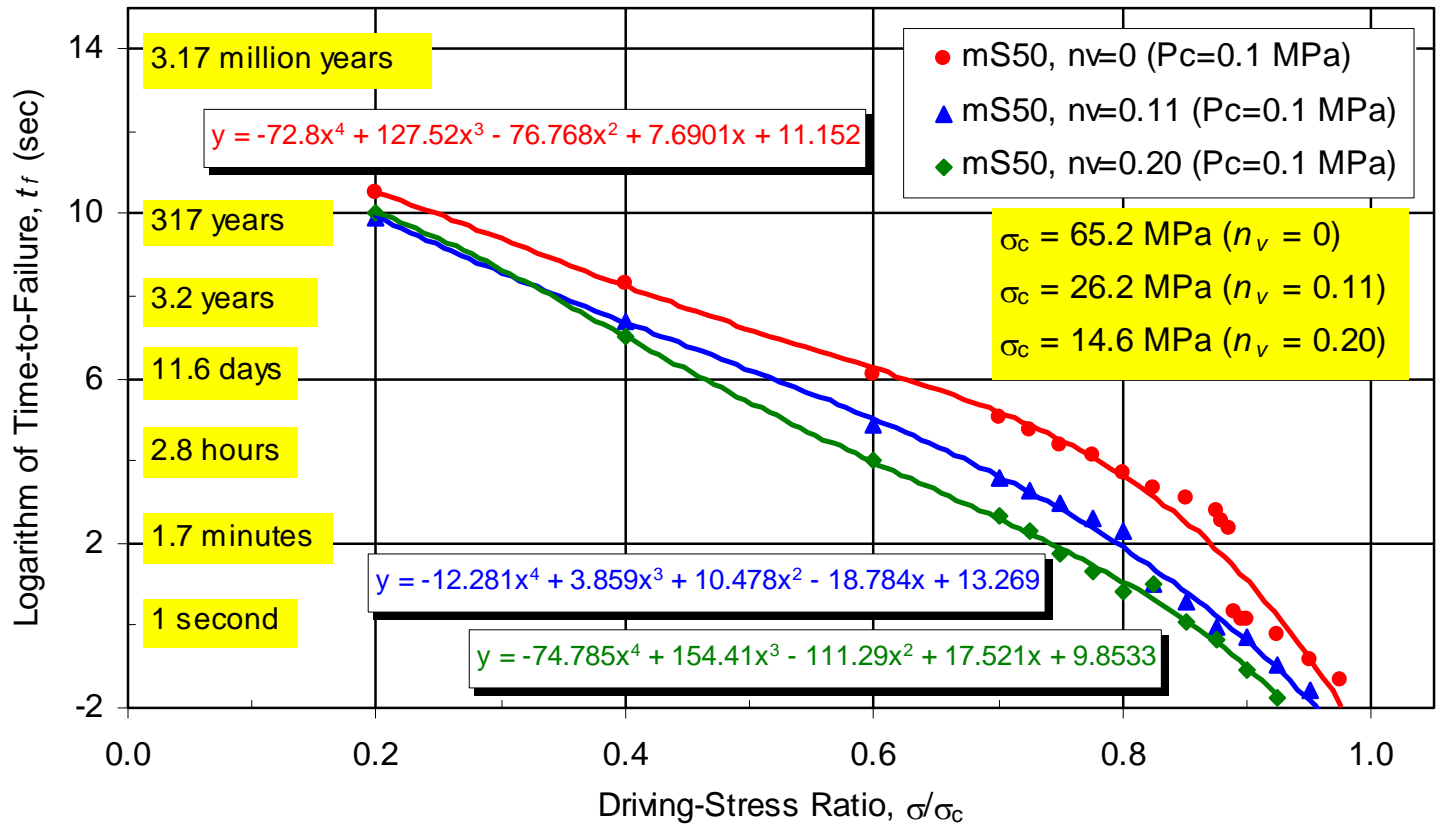

Figure S-15. Effect of Void Porosity on Static-Fatigue Curves (0.1 MPa Confinement) for mS50 Material - Expanded Scales

PFC2D (90-mm diameter circles)

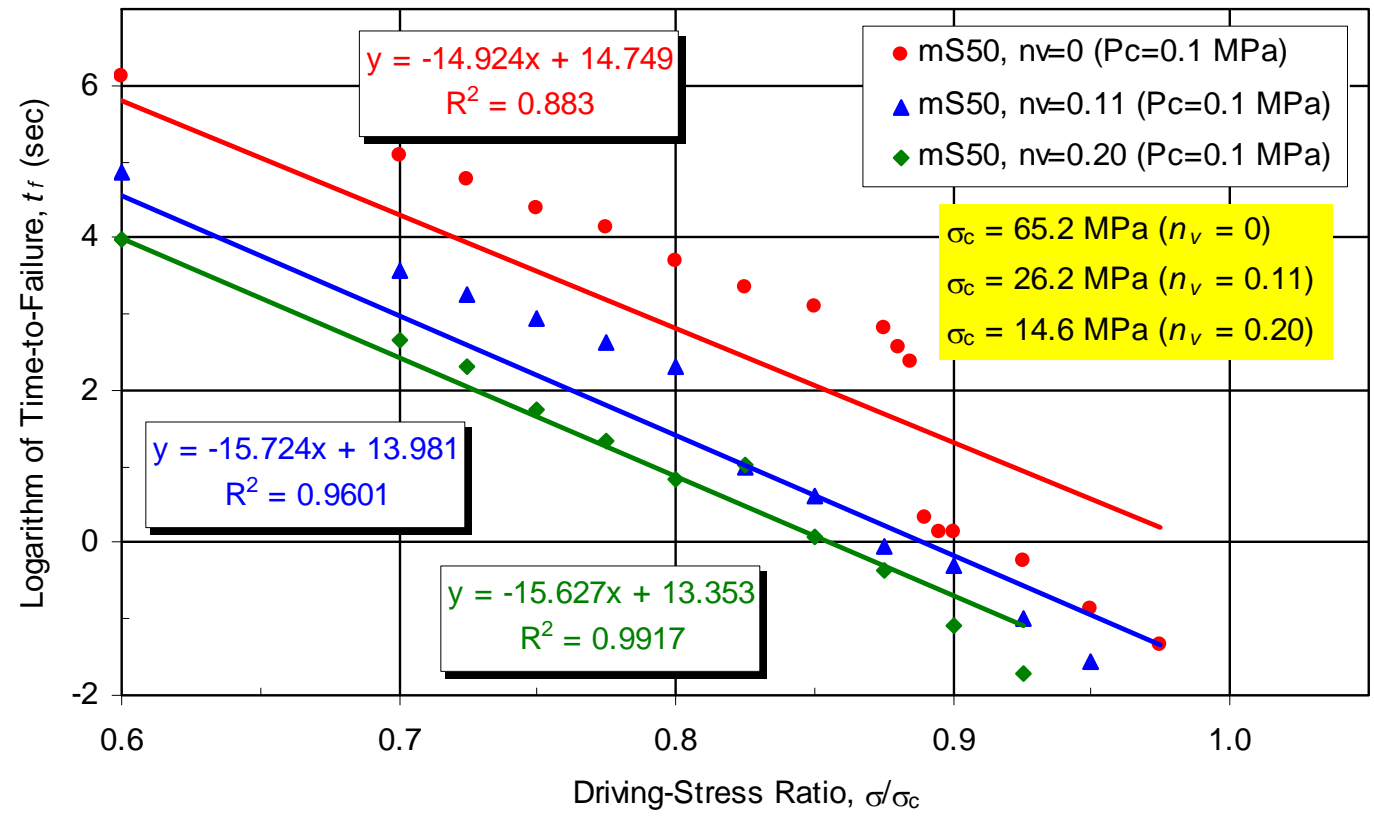

Figure S-16. Effect of Void Porosity on Static-Fatigue Curves (0.1-MPa Confinement) for mS50 Material (Straight-Line Fit) 
PFC2D (90-mm diameter circles)

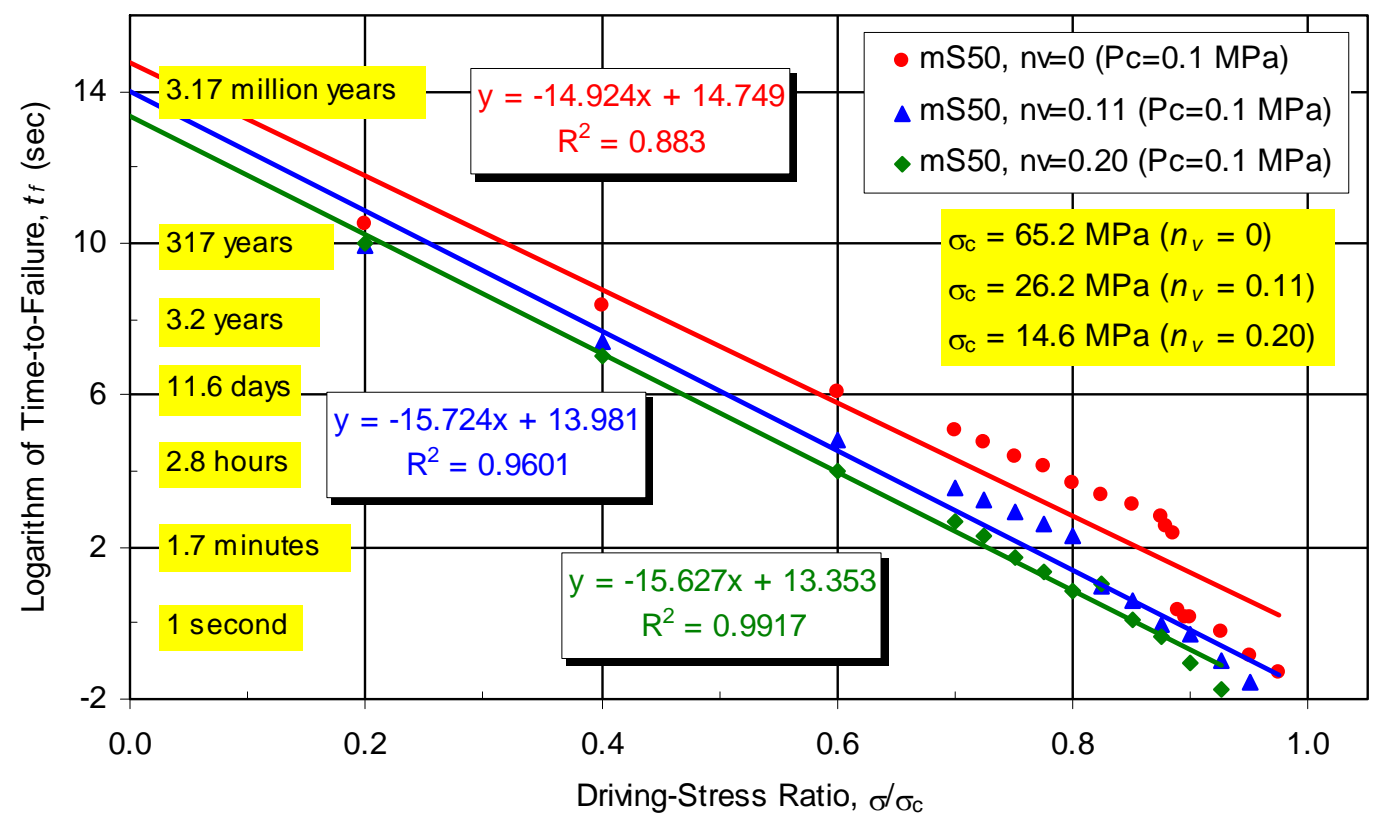

Figure S-17. Effect of Void Porosity on Static-Fatigue Curves (0.1 MPa Confinement) for mS50 Material (Straight-Line Fit) — Expanded Scales

If the linear fit is used for time-to-failure results obtained using PFC for different percentages of lithophysal porosity, the slope of the line is considered independent of the lithophysal porosity. The main effect of lithophysal porosity is translation of the time-to-failure line. Consequently, the line for 20 percent porosity intersects the horizontal line corresponding to $1 \mathrm{~s}$ time-to-failure for driving stress ratio of 0.85 (see Figure S-15). The strength after $1 \mathrm{~s}$ of loading time is considered to represent the short-term strength of a rock. This implies that if the lines in Figure S-15 are scaled with strength of the rock after $1 \mathrm{~s}$ loading time, the lines would coincide with each other. However, the consideration of time-dependent behavior contributes to an additional short-term strength reduction of approximately 15 percent (it is accounted for in the short-term strength reduction because it happens over a time period on the order of a second). In the calculation of time-dependent drift degradation, it is considered that time-to-failure curves are independent of lithophysal porosity. The effect of lithophysal porosity on short-term strength is accounted for because 5 different categories were analyzed. Variation of short-term strength between categories 1 and 5 is from $10 \mathrm{MPa}$ to $30 \mathrm{MPa}$. The effect of time-dependency, within one or a few seconds, on short-term strength (of the order of 15 percent) is taken into account by the consideration of a wide range of strength variation. Although the time-to-failure curves for different lithophysal porosities are the same, the effect of lithophysal porosity on time-dependent drift degradation is significant. For example, uniaxial compressive elastic stress in the drift wall is estimated to be $17.5 \mathrm{MPa}$, which is derived considering that the vertical in situ stress $\left(\sigma_{v}\right)$ is $7 \mathrm{MPa}$ and the horizontal-to-vertical stress ratio $(k)$ is 0.5 (see Section 6.3.1.1), using the relation $\sigma_{1}=\sigma_{v}(3-k)$ (Hoek and Brown 1982 [DIRS 120981], p. 105). Using the time-to-failure curve for tuff (Figure S-2), time to failure in category 2 corresponding to 28 percent porosity (such that $\mathrm{UCS}=20 \mathrm{MPa}$ resulting in a driving stress ratio of 0.875 ) is approximately 3 hours, while 
time-to-failure in category 3 corresponding to 21 percent porosity (such that UCS $=25 \mathrm{MPa}$ resulting in a driving stress ratio of 0.7 ) is approximately 8,200 years.

The effect of confinement on the static-fatigue curves of the mS50 material is shown in Figures S-18 and S-19. Increasing the confinement increases the time-to-failure for the same driving-stress ratio, and the static-fatigue curves are similar. The effect of void porosity on the static-fatigue curves of the mS50 material at $5 \mathrm{MPa}$ confinement, is shown in Figures $\mathrm{S}-20$ and $\mathrm{S}-21$. Increasing the void porosity reduces the time-to-failure for the same driving-stress ratio; however, the effect is not seen for void porosities greater than 0.11. Based on this numerical assessment, it appears that the effect of void porosity on time-to-failure is reduced as confinement increases, and that there is a limiting void porosity above which no further reduction occurs.

The effect of voids on time-to-failure was investigated numerically (e.g., Figure S-20). The increase in porosity results in shorter time-to-failure. However, the slopes of the lines of time-to-failure versus driving stress ratio are practically the same. That implies that if the driving stress ratio is normalized with the strength for one minute of load duration, the lines would be the same. Thus, the time to failure is independent of the lithophysal porosity if plotted versus normalized driving stress ratio. The evolution of damage as a function of driving stress ratio and time normalized with time-to-failure is similar. Particularly for large driving stress ratios (greater than 0.5), which are of interest because they result in failure for time-scales of 10,000 years or less, there is very little damage increase until time-to-failure is reached when damage suddenly increases resulting in the collapse.

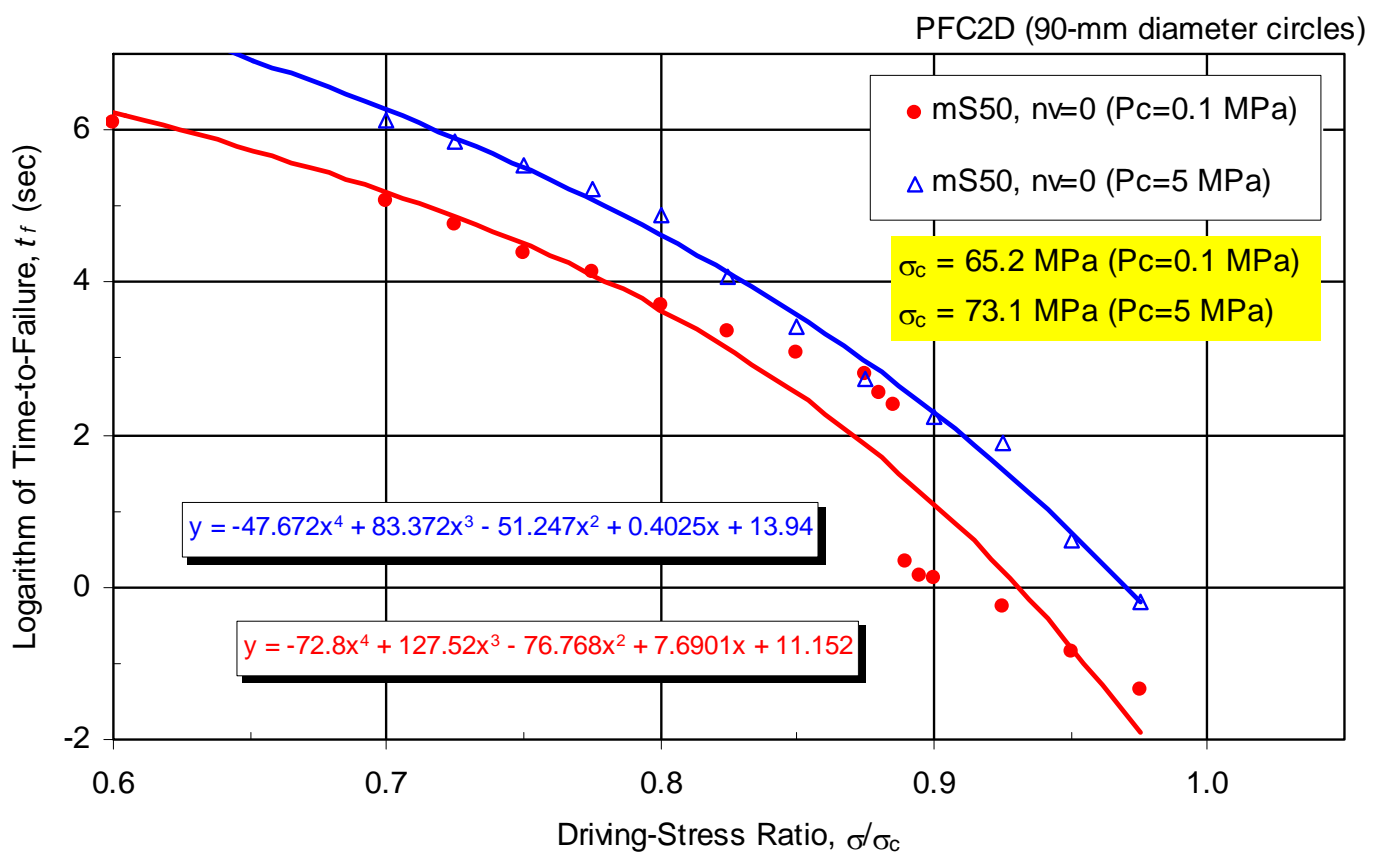

Figure S-18. Effect of Confinement on Static-Fatigue Curves for mS50 Material 


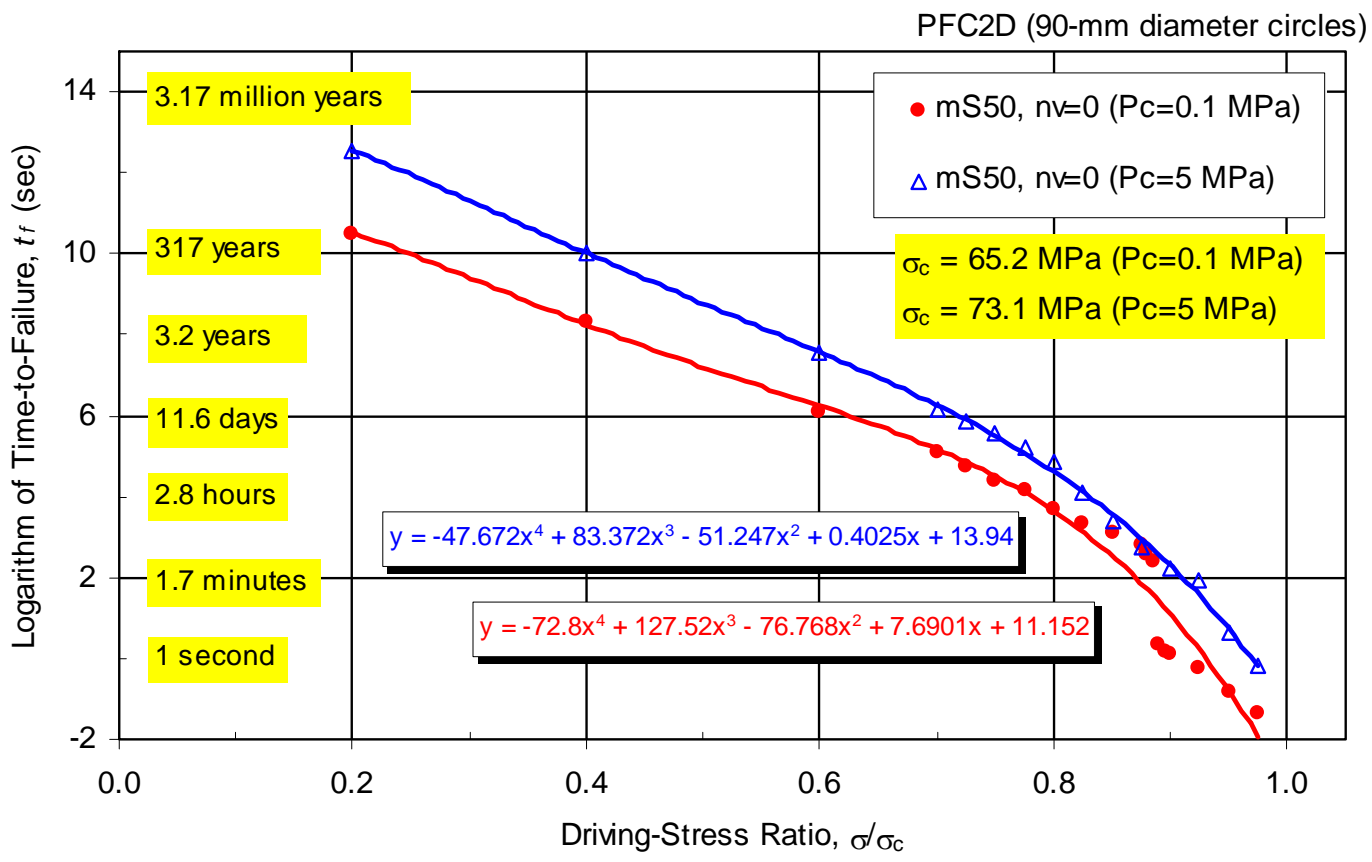

Figure S-19. Effect of Confinement on Static-Fatigue Curves for mS50 Material - Expanded Scales

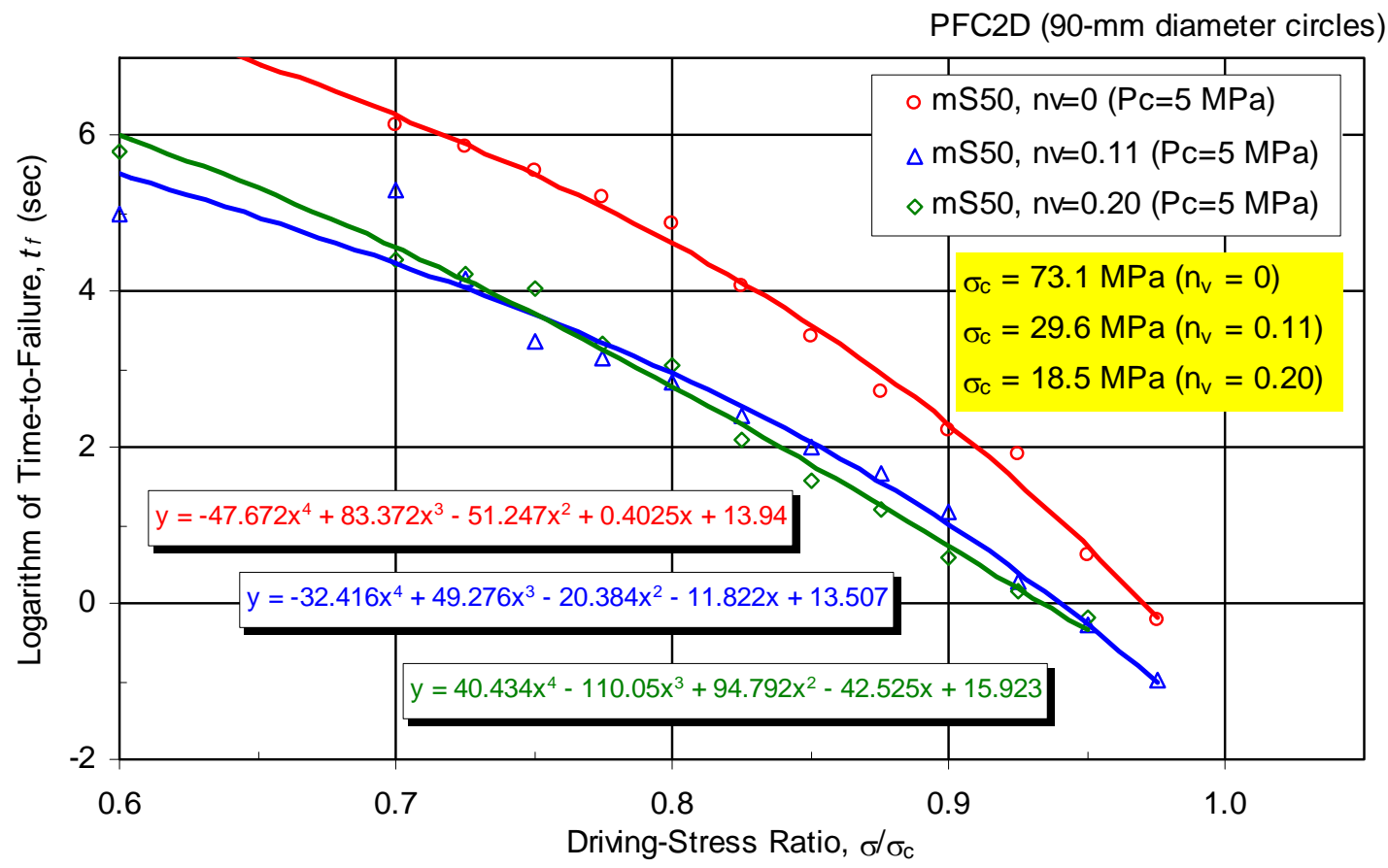

Figure S-20. Effect of Void Porosity on Static-Fatigue Curves (5 MPa Confinement) for mS50 Material 


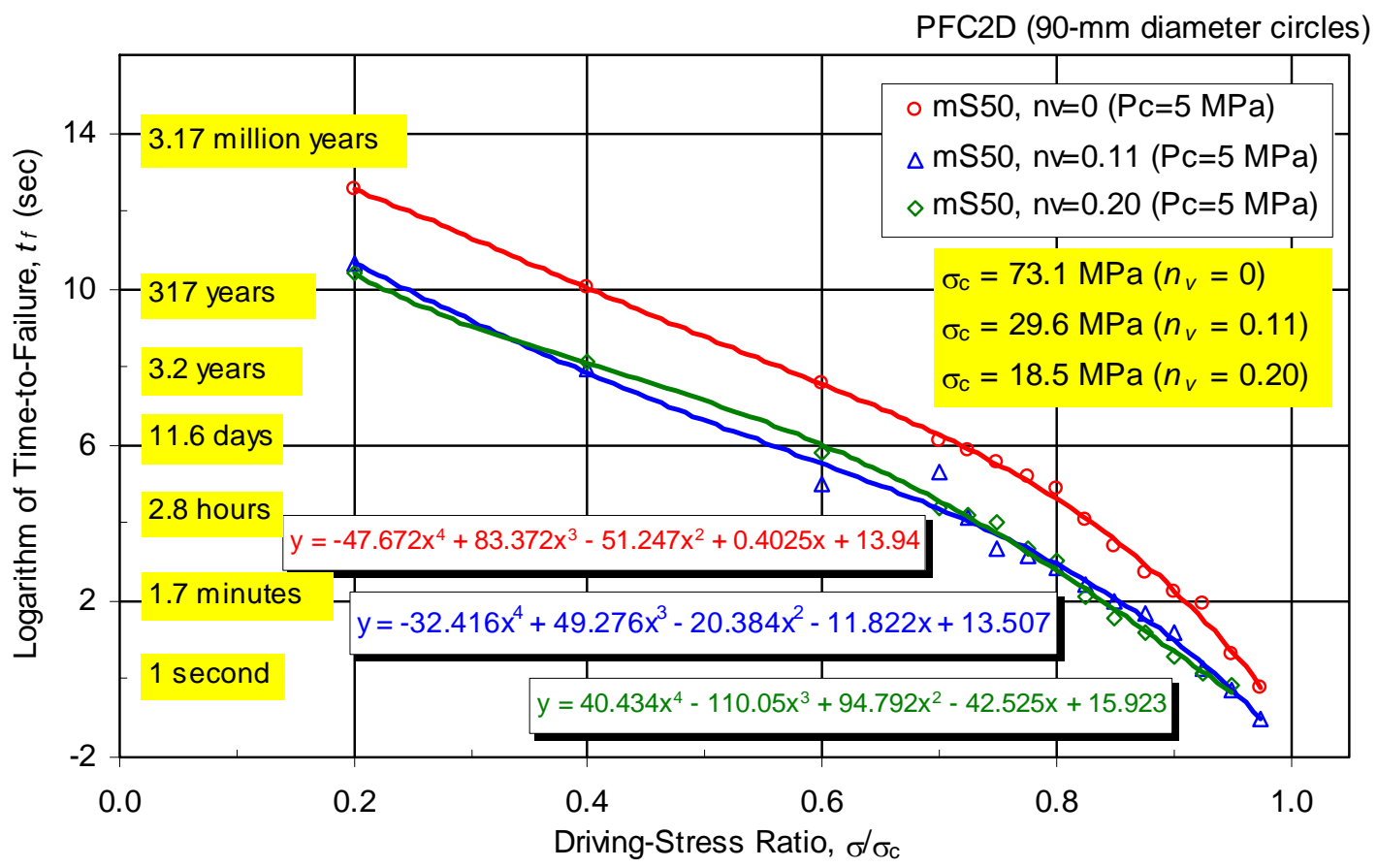

Figure S-21. Effect of Void Porosity on Static-Fatigue Curves (5-MPa Confinement) for mS50 Material - Expanded Scales

\section{S2.3 QUANTIFYING DAMAGE DURING A STATIC-FATIGUE TEST}

The axial load at failure (peak strength) during a short-term test performed at an elapsed time, $t$, since the start of a static-fatigue test is denoted by $\sigma_{f}^{*}=\sigma_{f}^{*}(t)$. The values of $\sigma_{f}^{*}$ are bounded by

$$
\begin{aligned}
& \sigma_{f}^{*}(0)=\sigma_{f} \\
& \sigma_{f}^{*}\left(t_{f}\right)=\left(\sigma / \sigma_{c}\right)\left(\sigma_{f}-P_{c}\right)+P_{c}
\end{aligned}
$$

where the notation is defined in the first footnote of Section S2.1. The values of $\sigma_{f}^{*}$ for times $0<t<t_{f}$ are found by stopping the static-fatigue test at the desired time and measuring the peak strength.

The strength degradation is quantified by means of a damage coefficient

$$
D=1-\sigma_{c}^{*} / \sigma_{c}
$$

where $\sigma_{c}^{*}=\sigma_{f}^{*}-P_{c}$ is the stress difference at failure. Substituting values from Equation S-1 into this expression provides the following bounds for the damage coefficient:

$$
\begin{gathered}
D(0)=0 \\
D\left(t_{f}\right)=1-\left(\sigma / \sigma_{c}\right)
\end{gathered}
$$

The time evolution of the damage coefficient for the mS50 material tested at a confinement of $0.1 \mathrm{MPa}$ is shown in Figure S-22, which was produced by performing 11 compression tests 
during the four numerical static-fatigue tests at driving-stress ratios of $0.8,0.6,0.4$ and 0.2 . Typical model responses during some of the compression tests are shown in Figures S-23 to S-25. It is noted that the curve for $t / t_{f}=0.975$ in Figure S-23 results in a higher axial stress compared to the other curves. This behavior is a result of complex interactions in the model (and in actual rock). The peak strength in an unconfined compressive strength test is a measure of a critical state forming, and if a very slightly different critical state forms, a slightly different strength will be measured. This means that there is no reason why it is not possible that the addition of a few additional cracks (and reduced parallel bond radii in the PFC the stress corrosion model) might not increase the strength. The critical state at peak is very complex, and a minor change in rearrangements of force chains (i.e., trajectories of magnified principal stresses) might lead to a small increase in strength. Most damage occurs during the final stages of a static-fatigue test, and tests performed at lower driving-stress ratios produce an earlier (in terms of normalized times-to-failure) onset of damage.

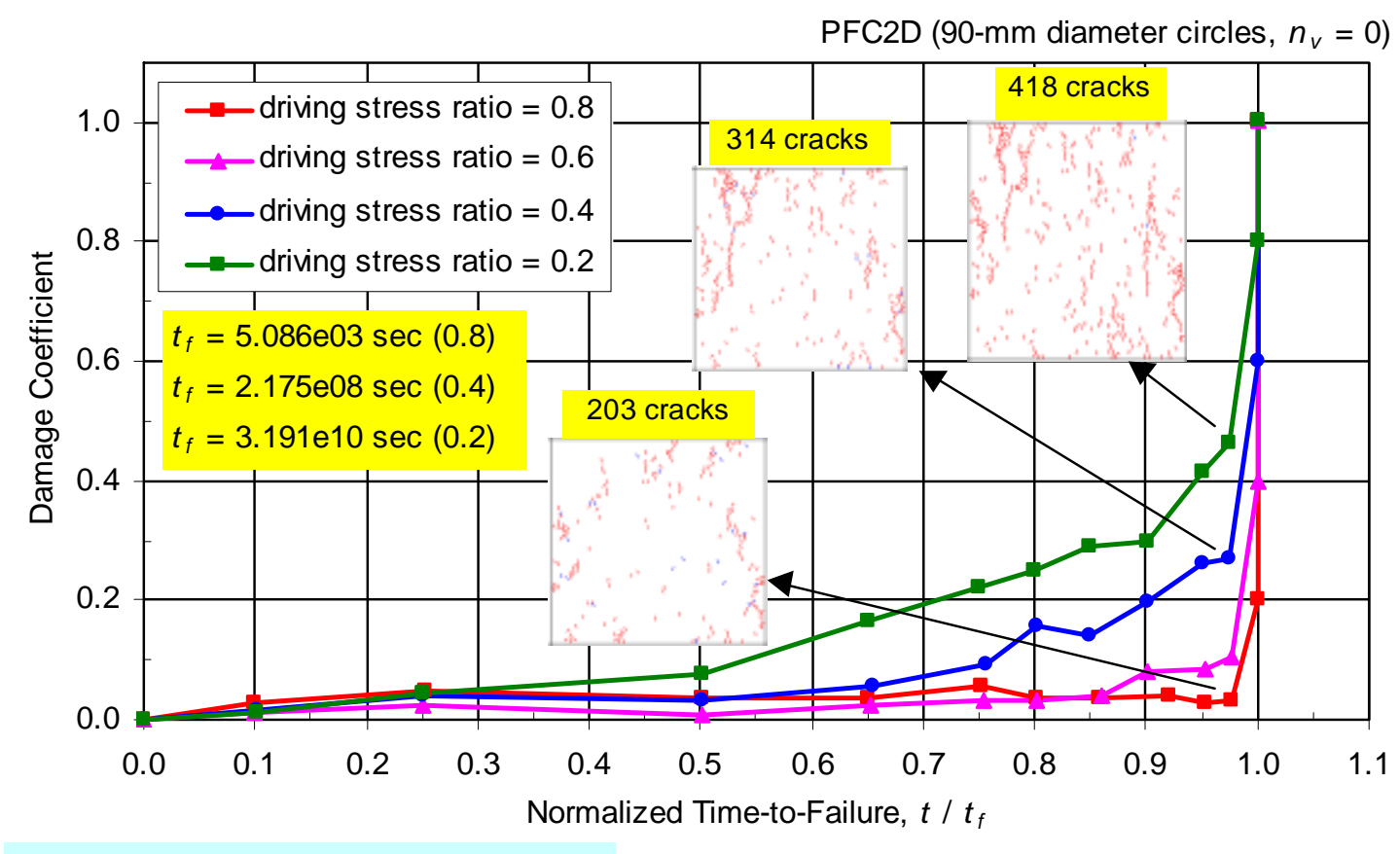

damage curves, $P_{c}=0.1 \mathrm{MPa}$

NOTE: Driving-stress ratios ranging from 0.2 to 0.8 .

Figure S-22. Time Evolution of Damage Coefficient for mS50 Material During Numerical Static-Fatigue Tests (0.1 MPa Confinement) 


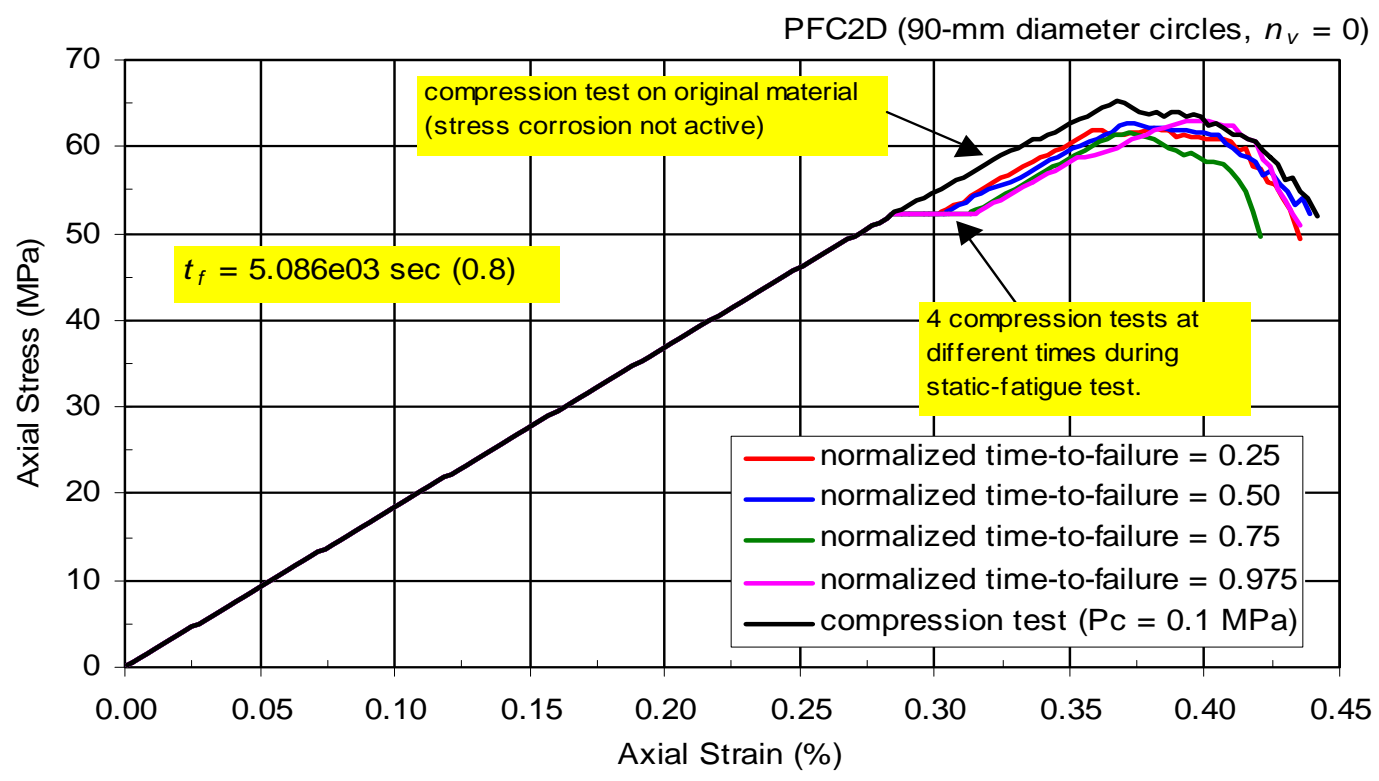

stress-strain curves, $\sigma / \sigma_{c}=0.8$

NOTE: Driving-stress ratio of 0.8 .

Figure S-23. Stress-Strain Curves for mS50 Material at Different Times During Static-Fatigue Test (0.1 MPa Confinement)

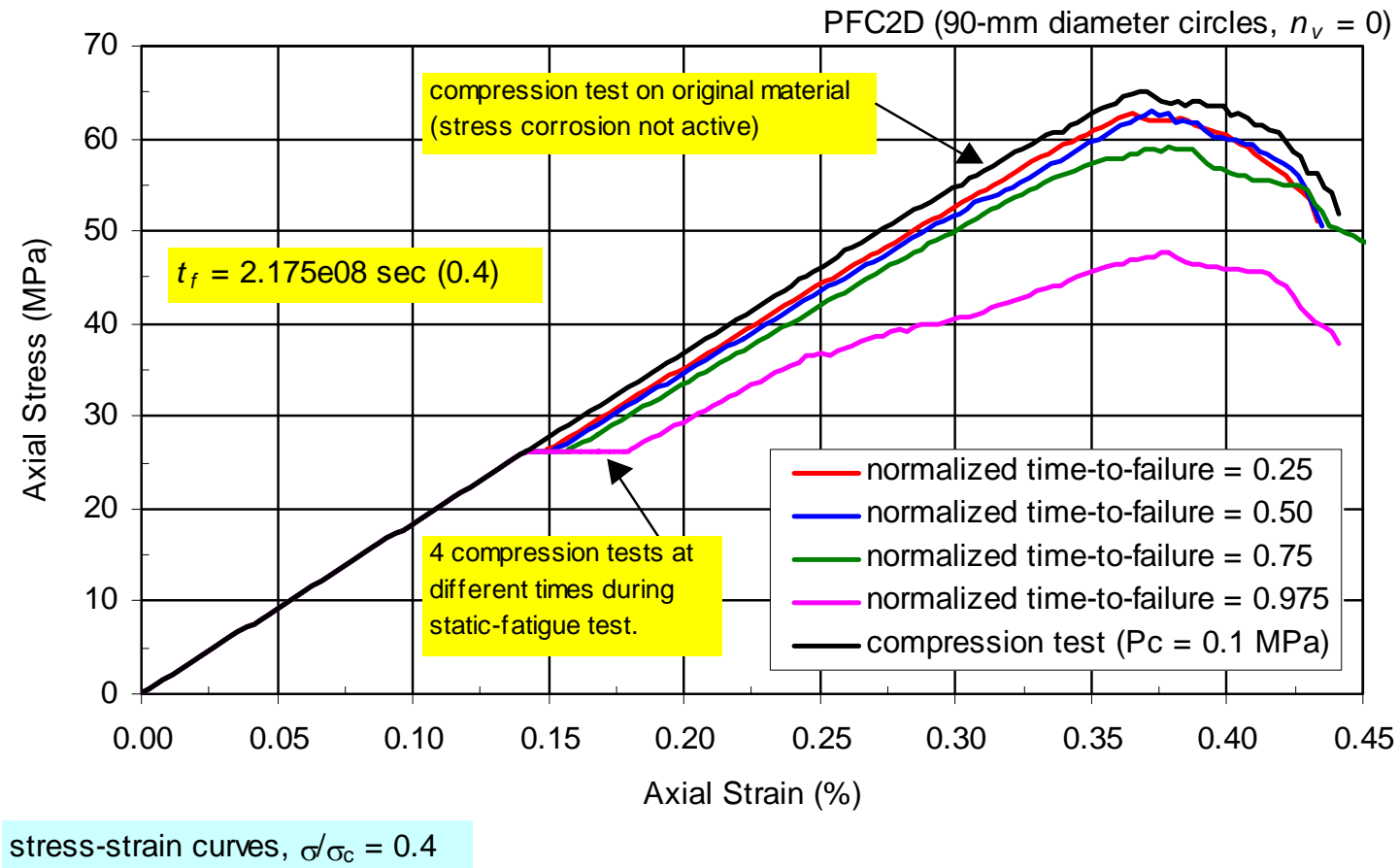

NOTE: Driving-stress ratio of 0.4 .

Figure S-24. Stress-Strain Curves for mS50 Material at Different Times During Static-Fatigue Test (0.1 MPa Confinement) 


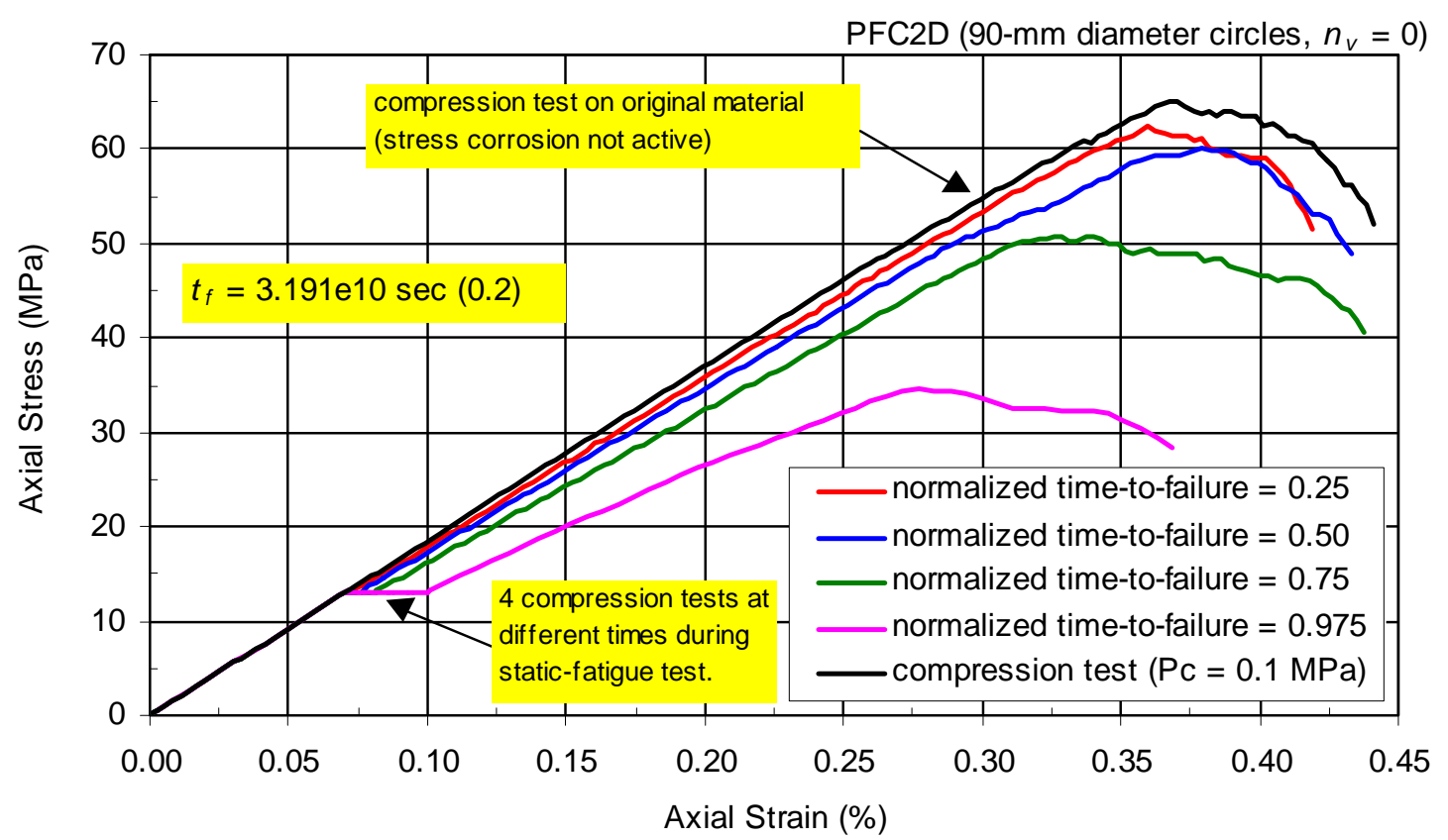

stress-strain curves, $\sigma / \sigma_{\mathrm{c}}=0.2$

NOTE: Driving-Stress Ratio of 0.2 .

Figure S-25. Stress-Strain Curves for mS50 Material at Different Times During Static-Fatigue Test (0.1 MPa Confinement)

\section{S3. MODELING TUNNEL STABILITY WITH UDEC}

The objective of the analysis presented in this section is to predict the amount of rockfall in the emplacement drifts due to long-term (approximately 10,000 years) strength degradation caused by stress corrosion of the lithophysal rock units combined with thermal and seismic loads.

The two-dimensional distinct element code UDEC (Version 3.1) was used to investigate drift degradation based upon the time evolution of damage due to strength degradation for different driving-stress ratios $\left(\sigma / \sigma_{c}\right)$.

\section{S3.1 UDEC MODEL FOR DRIFT DEGRADATION}

The same UDEC model validated and used to predict the amount of rockfall in the emplacement drifts (as documented in Sections 6.4 and 7.6) was used to investigate the long-term degradation caused by stress corrosion of the lithophysal rock units.

In the UDEC model, the rock mass is represented as an assembly of polygonal, elastic blocks. The entire domain is discretized into blocks using Voronoi tessellations (Itasca Consulting Group 2002 [DIRS 160331]). The joints between the blocks are considered to be linearly elastic-brittle. The elastic behavior of the joints is controlled by normal and shear stiffness. The joints can sustain finite tensile stress as prescribed by a tensile strength. The Coulomb slip condition governs the onset of slip as a function of joint cohesion and friction angle. If a joint fails either in tension or shear, tensile strength, friction and cohesion are reset to residual values. The model 
allows for the formation of joints between blocks, separation and instability (under gravity) of portions of the rock mass around the drift. The average size of the Voronoi blocks is $0.3 \mathrm{~m}$. No ground support was considered in the analysis.

The geometry of the UDEC model is shown in Figure 6-116. Only the region around the drift (where inelastic deformation is expected) is discretized into Voronoi blocks. The remainder of the model is composed of a few large elastic blocks.

Four different categories of the lithophysal rock mass were used to investigate the long-term degradation caused by stress corrosion. The categories investigated were 1, 2, 3, and 5. The calibrated UDEC micro-properties for those categories are listed in Table 6-43.

\section{S3.2 STATIC-FATIGUE CURVES AND THE EVOLUTION OF DAMAGE DUE TO STRENGTH DEGRADATION}

The static-fatigue behavior of Lac du Bonnet granite and welded lithophysal tuff forms the basis of the UDEC model for stress corrosion around a drift. The static-fatigue curves provide the time-to-failure $\left(t_{f}\right)$ of the material at a particular driving-stress ratio $\left(\sigma / \sigma_{c}\right)$.

The static-fatigue data for Lac du Bonnet granite at 0 and $5 \mathrm{MPa}$ confinement, tuff at $5 \mathrm{MPa}$ confinement, and 4.5 MPa pore pressure, are shown in Figure S-2. Each data set was fit with a straight line, and the line was extrapolated to encompass driving-stress ratios ranging from zero to one. This is a conservative consideration, because the curves most likely approach infinity at a driving-stress ratio greater than zero (see the discussion in Appendix S2.2.4). Three lines for the tuff data are shown in Figure S-26. The blue line in the figure is the least-square linear fit through the tuff data, while the purple line (labeled "tuff, best fit through origin") is the best fit for the tuff data with the origin (i.e., logarithm of time-to-failure $=0$ ) set at a driving-stress ratio of one. Since the tuff data are limited and are for confined conditions (effective confining stress of $0.5 \mathrm{MPa}$ ) only, the UDEC model has used a simplified best fit (red line) for the tuff best-fit curve.

The two sets of extended curves that were used as input to the UDEC analyses are shown in Figure S-27: one set based on the Lac du Bonnet data and the other set based on tuff data. 


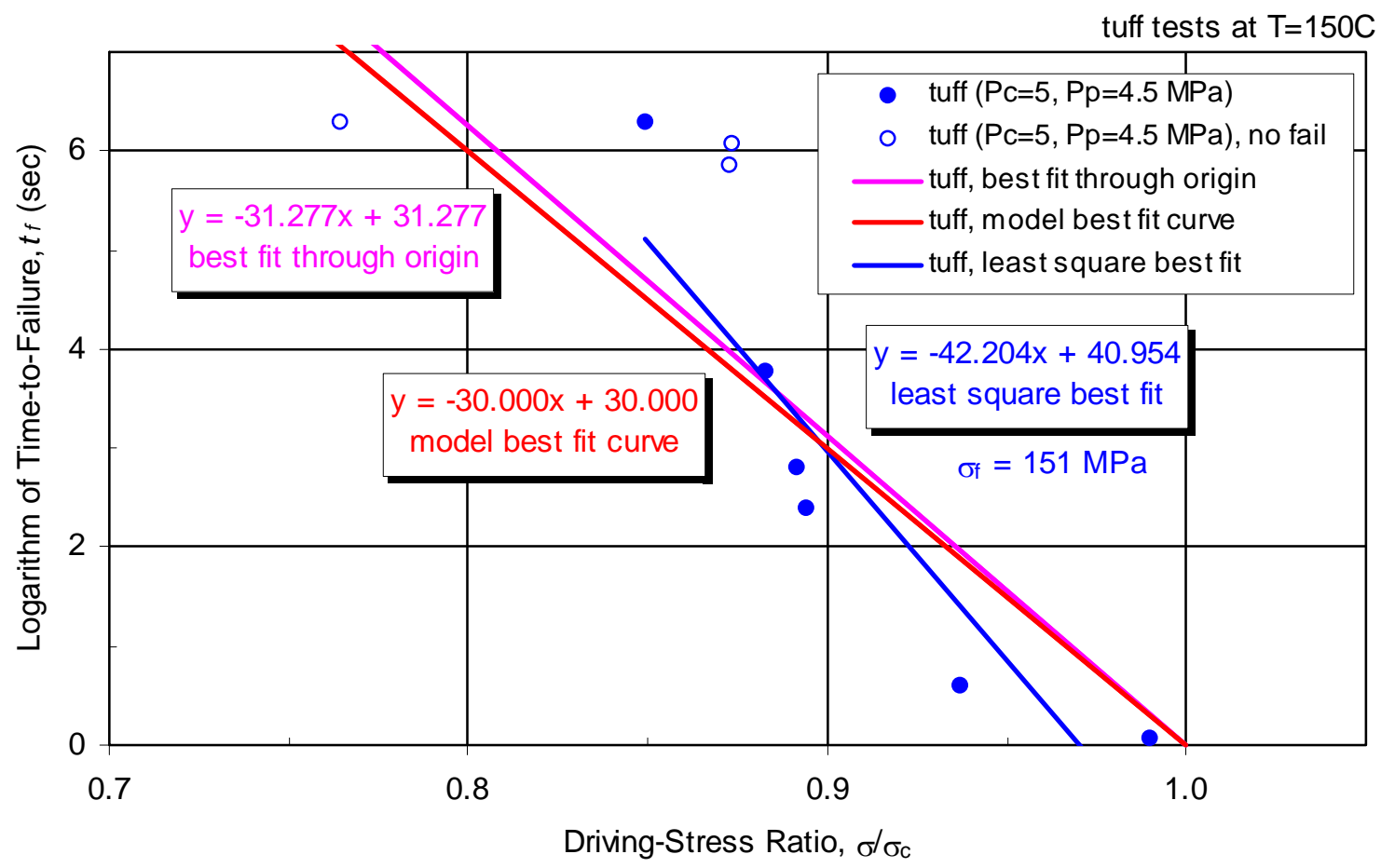

Source: Tuff data from Martin et al. (1997 [DIRS 165960]).

Figure S-26. Static-Fatigue Data for Welded Tuff and Best-Fit Lines

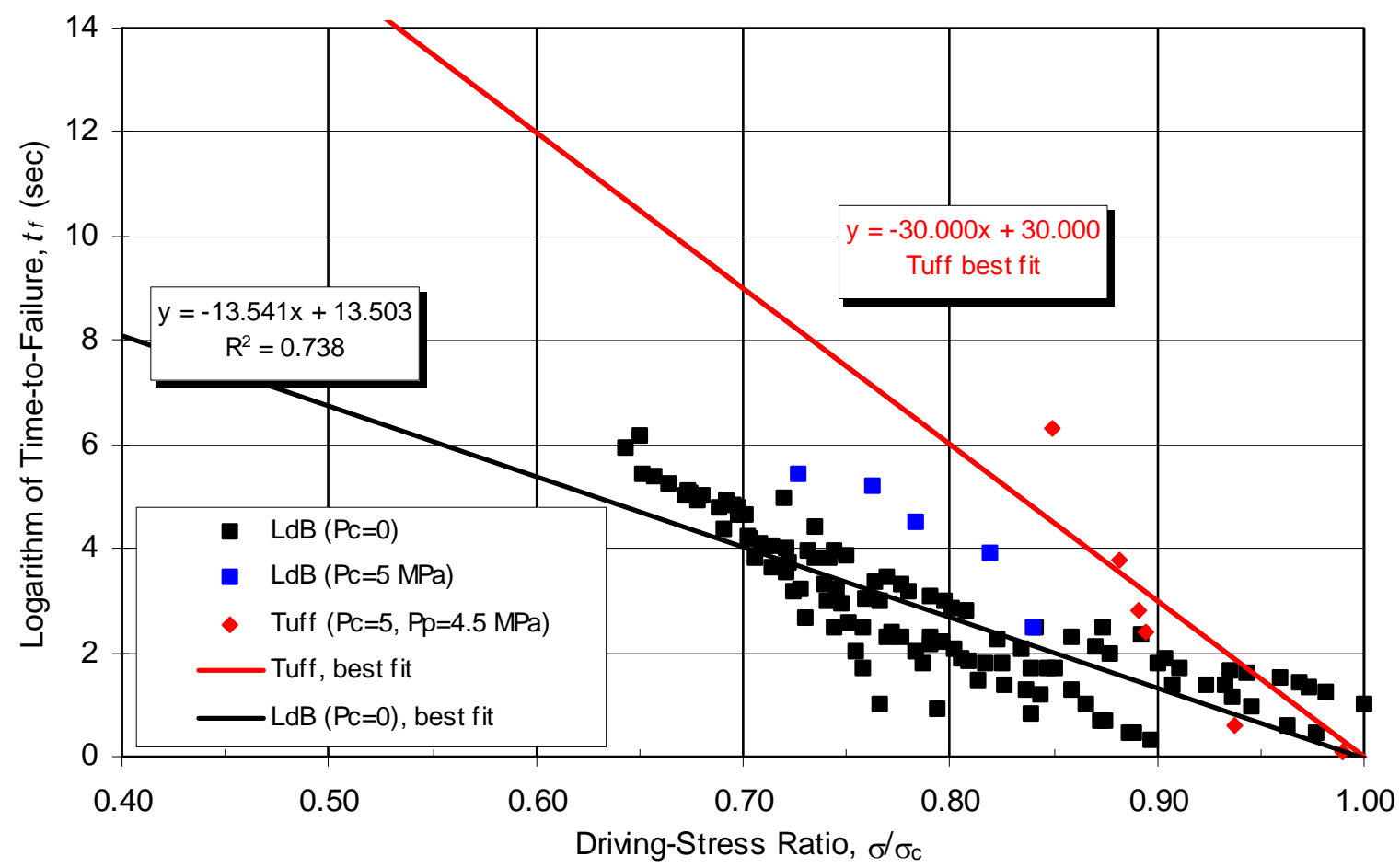

Source: LdB data from Schmidtke and Lajtai (1985 [DIRS 164774]) and Lau et al. (2000 [DIRS 164769]); tuff data from Martin et al. (1997 [DIRS 165960]).

Figure S-27. Static-Fatigue Curves Used as Input to the UDEC Analyses 
An understanding of the evolution of damage due to strength degradation during a static-fatigue test prior to the time-to-failure enables a modeling methodology to be developed whereby the strength of material is degraded with time based upon the local driving-stress ratio. The evolution of damage due to strength degradation for the static-fatigue curve (unconfined Lac du Bonnet granite) was developed using the PFC stress corrosion model and is shown in Figure S-22 for Lac du Bonnet granite. The evolution of damage for tuff (i.e., unconfined best-fit tuff) was not obtained by conducting a PFC simulation, but by changing the time scale of the relation between damage and time for the Lac du Bonnet granite. These damage curves were simplified (as shown in Figures S-28 and S-29), and then used along with the static-fatigue curves in Figure S-27 to provide the degradation input properties used in the UDEC analyses.
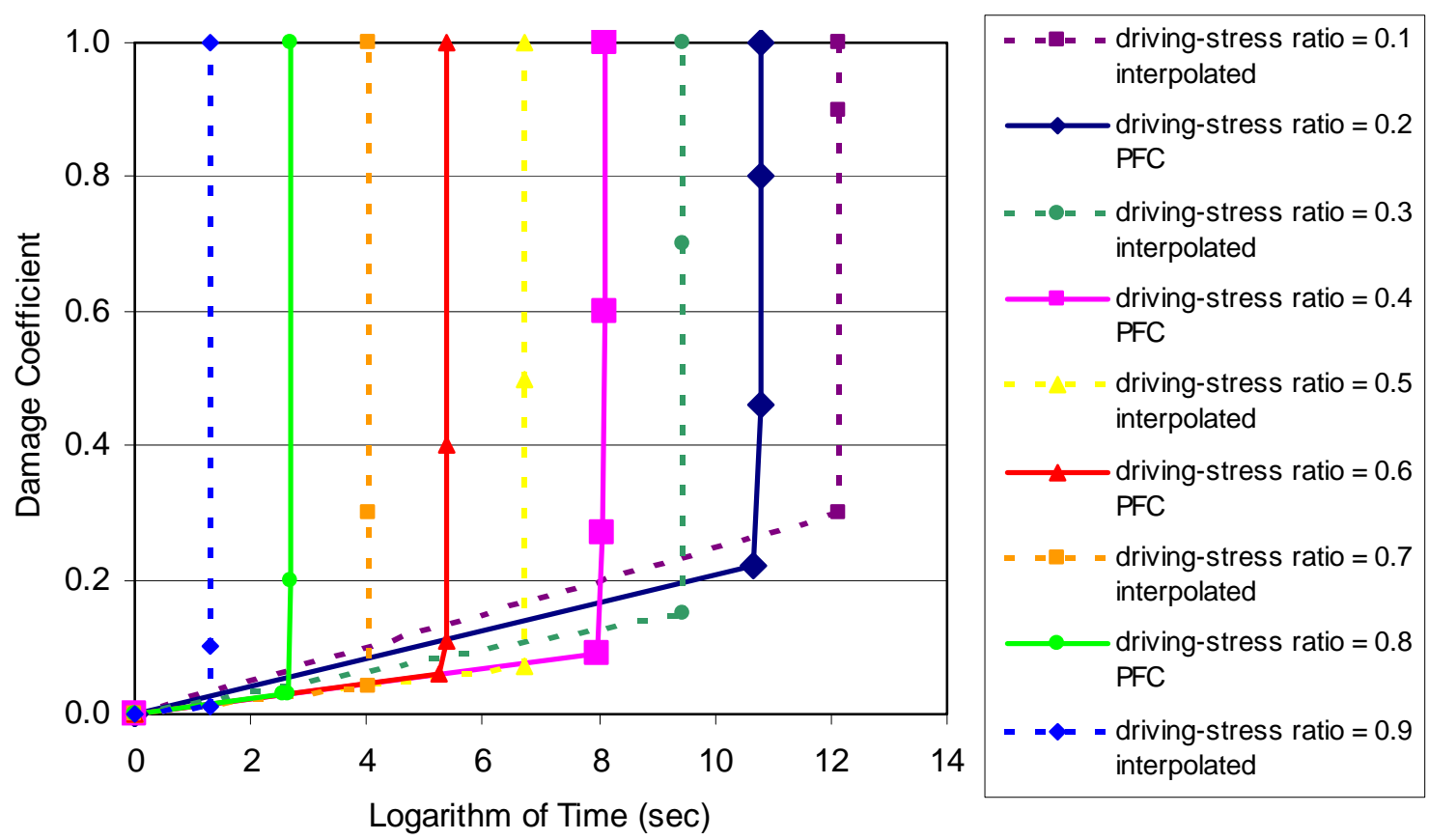

NOTE: Each curve has a vertical asymptote at a time-to-failure for a given driving-stress ratio, which is provided by the LdB $\left(P_{c}=0\right)$ curve from Figure S-27. The evolution of damage up to the vertical asymptote (i.e., the failure time) is provided by the PFC stress corrosion model. $P_{c}=0$.

Figure S-28. Damage Curves Used as Input to the UDEC LdB Analyses 


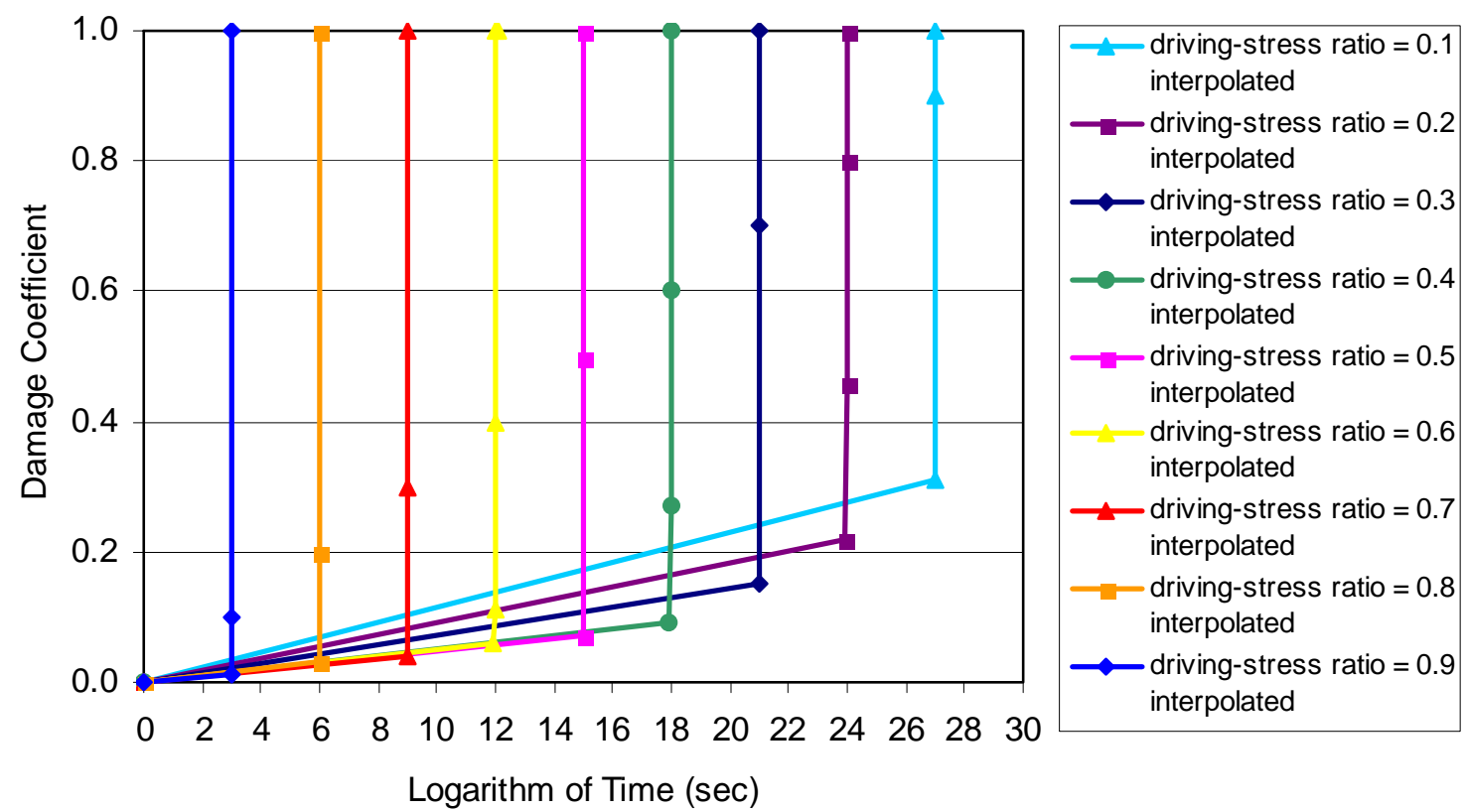

NOTE: Each curve has a vertical asymptote at a time-to-failure for a given driving-stress ratio, which is provided by the tuff best fit $\left(P_{c}=0\right)$ curve from Figure S-27. The evolution of damage up to the vertical asymptote (i.e., the failure time) was not provided by the PFC stress corrosion model, but was obtained by changing time scales for each curve proportional to the relation between damage and time for the Lac du Bonnet granite (Figure S-28). $P_{c}=0$.

Figure S-29. Damage Curves Used as Input to the UDEC Tuff Best-Fit Analyses

Two parameters control the UDEC predictions of time-dependent strength degradation, and eventually the predictions of rockfall: a) time-to-failure, and b) damage rate before time-to-failure. The evolution of damage before failure can be approximated with a constant damage rate. Time-to-failure as a function of the stress state (i.e., the driving stress) is determined from the static-fatigue lines constructed by interpolation and extrapolation of testing results (obtained on tuff and Lac du Bonnet granite). Damage rates at different stress levels are generated using the PFC stress corrosion model. To address the concern about the level of uncertainty in PFC predictions, and how the damage rates affect the final result of the model (i.e., the rockfall induced by time-dependent strength degradation), the sensitivity of the model predictions to the damage rate was investigated. New damage curves are generated for tuff best-fit static-fatigue (shown in Figure S-30), where the damage rates for the driving stress levels are considered to be the same, equal to the maximum rate predicted by PFC.

The rockfall predictions due to time-dependent strength reduction, using damage curves from Figure S-30, are shown in Figure S-31. It is clear that the considered variation of damage rates has no practical effect on predicted rockfall. The time-to-failure is the main factor controlling evolution of the rockfall due to time-dependent strength reduction. Consequently, UDEC predictions are not very sensitive to the input from the PFC stress corrosion model. 


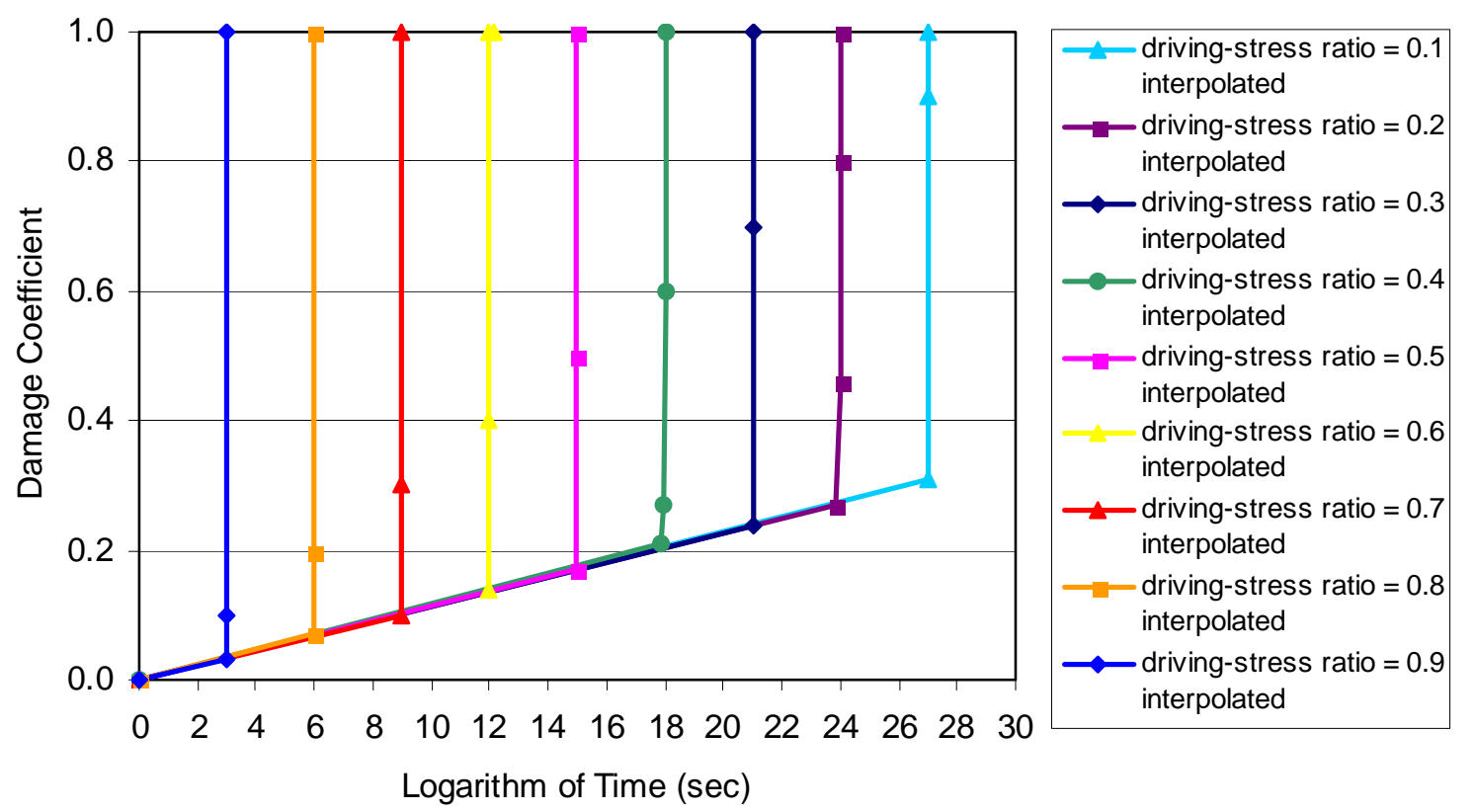

Figure S-30. Damage Curves for Sensitivity Analysis of Damage Rate 

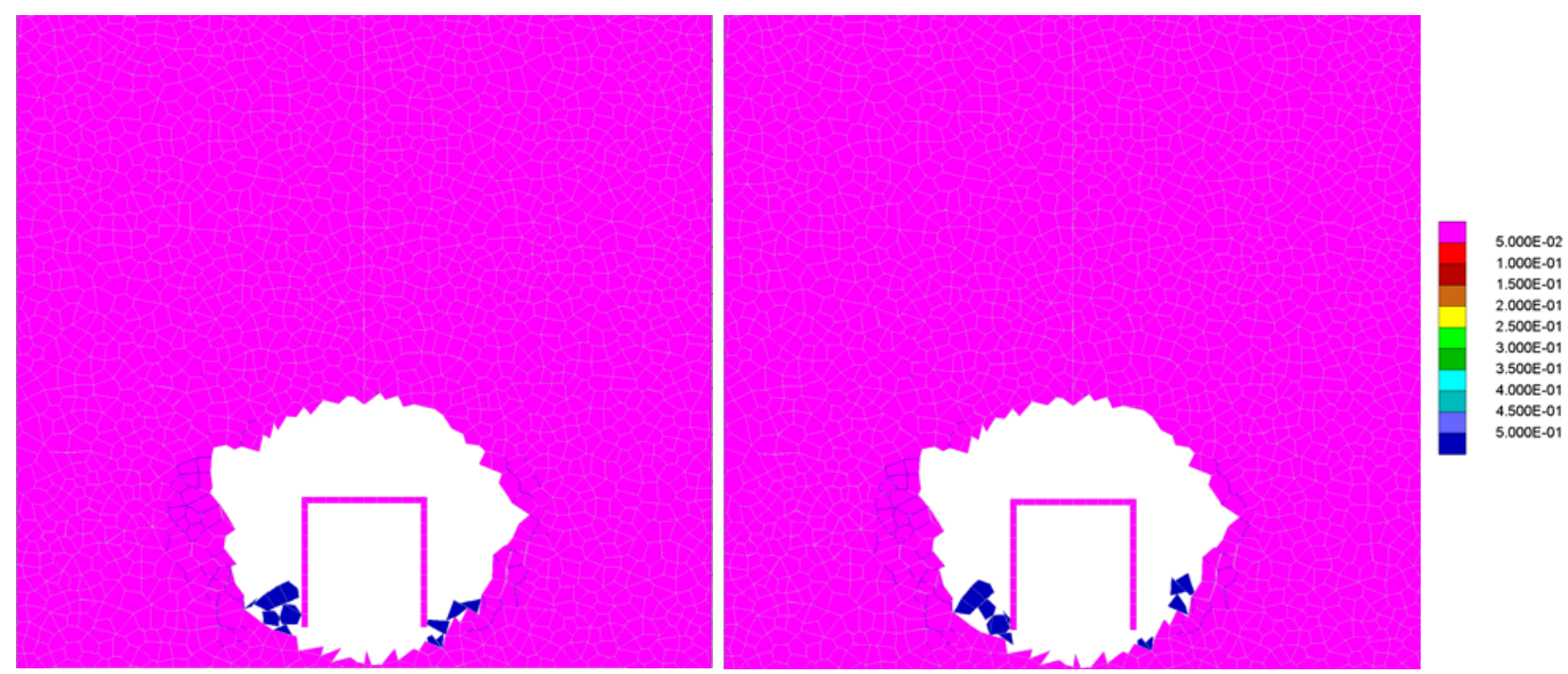

Tuff best fit static fatigue and damage rate sensitivity at 100 years
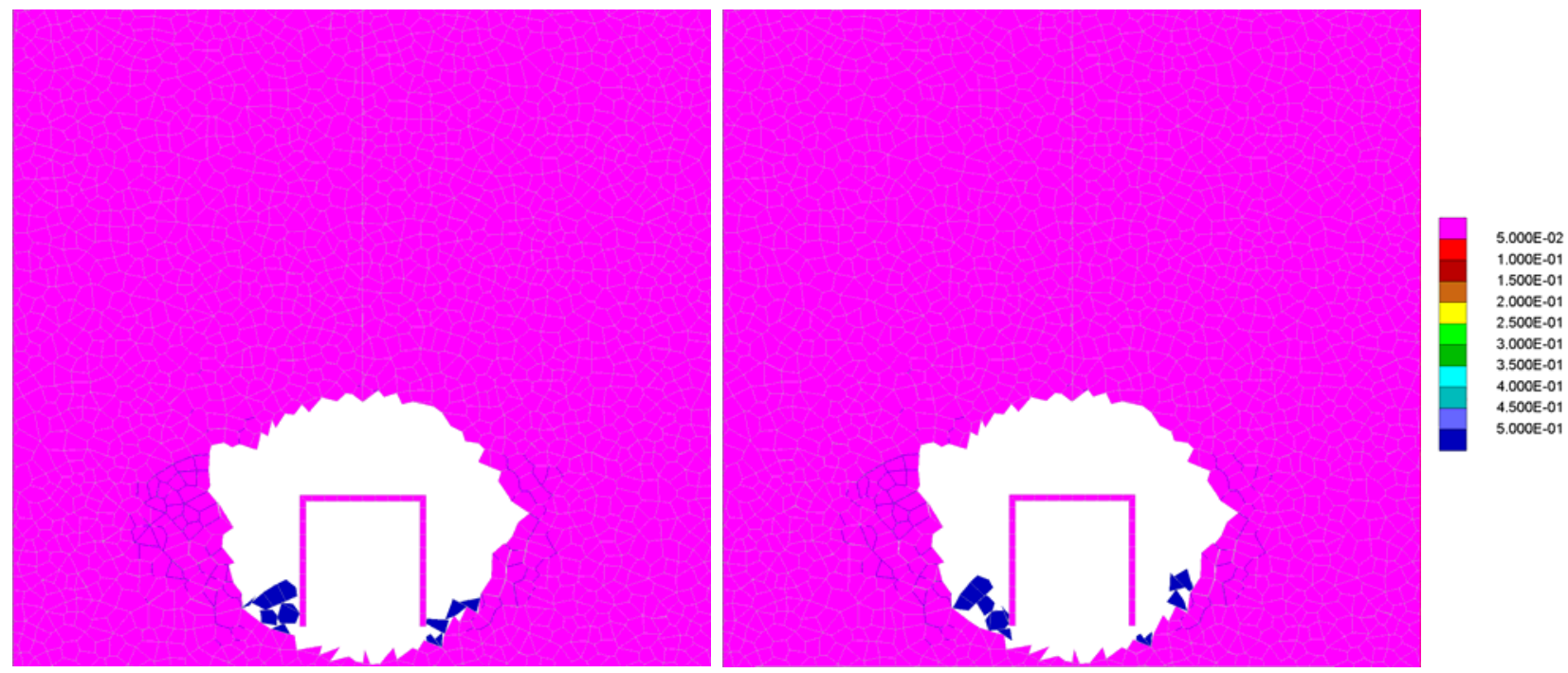

Tuff best fit static fatigue and damage rate sensitivity at 10000 years

Figure S-31. The Effect of the Damage Rate on Rockfall Predictions Due to Time-Dependent Strength Degradation After 100 Years and 10,000 Years

\section{S3.3 UDEC STRESS CORROSION MODELING}

The long-term strength degradation caused by stress corrosion of the lithophysal rock units was implemented in the UDEC model by incrementally referencing a series of evolution of damage due to strength degradation tables from the PFC stress corrosion model (shown in Figures S-28 and S-29). Based upon the local driving-stress ratio at the Voronoi block contacts within the UDEC model, the strength of the contact in the model is degraded as a function of time. The times considered were $1,5,10,50,100,500,1000,5000$ and 10,000 years. 
Time-dependent strength degradation in the UDEC model is generalized by a damage coefficient, $D$, which is, in general, in the range between 0 and 1 . The cohesion and tensile strength of the material are considered to be functions of time:

$$
\begin{aligned}
& c(t)=c_{0} D(t) \\
& T(t)=T_{0} D(t)
\end{aligned}
$$

where $c_{0}$ and $T_{0}$ are the cohesion and tensile strength of joints in the UDEC model. The short-term strength of the UDEC synthetic model of the rock mass (large scale) is proportional to the cohesion and tensile strength of joints, $c_{0}$ and $T_{0}$, respectively. Consequently, the time-dependent strength of the UDEC synthetic model of lithophysal rock mass will decay proportionally to $D(t)$.

It is considered that in the general case:

$$
\frac{d D}{d t}=f(\mathrm{~F}, D)
$$

where $F$, a function of stress state and material strength, defines the load level (driving stress). For unconfined stress conditions (i.e., $P_{c}=0$ ), the function $\mathrm{F}$ must be identical to the ratio of the axial load and the unconfined short-term strength: $\mathrm{F}\left(P_{c}=0\right) \equiv \sigma_{l} / \sigma_{f}$. The load at failure during a short-term test is calculated as follows (Jaeger and Cook 1979 [DIRS 106219], pp. 95 to 97):

$$
\begin{aligned}
& \sigma_{f}=P_{c} N_{\phi}+2 c \sqrt{N_{\phi}} \\
& N_{\phi}=\frac{1+\sin \phi}{1-\sin \phi}
\end{aligned}
$$

where $c$ and $\phi$ are the rock mass cohesion and friction angle, respectively. It is considered that if time-to-failure for two different stress states is the same, then evolution of damage due to strength degradation for both states as a function of time is the same, irrespective of the confinement. Based on the existing data (Lau et al. 2000 [DIRS 146749]; Schmidtke and Lajtai 1985 [DIRS 164774]), it can be concluded that the confinement affects the slope, $k\left(P_{c}\right)=\Delta\left(\sigma / \sigma_{c}\right) / \Delta \log \left(t_{f}\right)$, of the static-fatigue line. For example, the slopes of the static-fatigue lines for LdB granite (Figure S-1) are:

$$
\begin{gathered}
k(0)=0.074 \quad 1 / \log (\mathrm{sec}) \\
k(5 \mathrm{MPa})=0.041 \quad 1 / \log (\mathrm{sec})
\end{gathered}
$$

Because static-fatigue lines are available for only two values of confining stress ( 0 and $5 \mathrm{MPa})$ it was considered that the dependence of slope $k$ on confinement $P_{c}$ is linear. This consideration is not a consequence of limitation of the implementation, but due to limited data. The form of the function F used in the UDEC model is as follows:

$$
\mathrm{F}=1-\frac{k(0)}{k\left(P_{c}\right)}\left(1-\frac{\sigma}{\sigma_{c}}\right)
$$


The damage evolution $D(F ; t)$ was generated using PFC2D for values of function $F$ in the range between 0 and 1 (see Figure S-22), and used as the UDEC input data in a tabular form (see Figure S-28.). Interpolation was carried out for stress states in the model during the simulation for which function $\mathrm{F}$ did not coincide with values for which the tables were provided.

It is realistic for implementation that the damage increment in Equation S-5 depends implicitly on stress history. The damage increment depends on accumulated damage, which is a function of the stress history. Although the stress state at a point can undergo complex history as a function of time (due to stress redistribution), it is sufficient in the simulation to keep track of accumulated damage only.

The calculation of the damage increment in the UDEC simulation was carried out in the following way. For a given time increment, $\Delta t$, it is considered that the stress state and the stress function, $F$, at a given point in the model are constant, $F=F_{i}$. The table of damage evolution $D(F ; t)$ is selected or interpolated based on tables provided. A point on the damage evolution curve corresponding to accumulated damage $D_{j}$ is determined, $D_{j}=D\left(F_{i} ; t_{j}\right)$. The damage increment is calculated as follows:

$$
\Delta D=D\left(\mathrm{~F}_{i} ; t_{j}+\Delta t\right)-D\left(\mathrm{~F}_{i} ; t_{j}\right)
$$

Time increment(s) for the simulation must be selected. The criteria for selection are the accuracy of the simulation (stress state considered to be constant during the time increment) and calculation time. Preliminary investigations showed that initially selected time increments did not significantly affect model results. For example, the results in Figure S-36 are obtained for the same conditions as the results in Figure S-38, but using the following points in time: 1, 2, 3, $5,10,20,30,50,100,200,300,500,1000,2000,3000,5000$ and 10,000 years. The results are not identical. However, the difference is insignificant considering other uncertainties in the model, and the use of the selected time increments is justified.

Damage is calculated and accumulated for joints. The stress state used for calculation of the damage is determined by averaging stresses in the blocks separated by a joint.

\section{S3.4 MODELING RESULTS}

\section{S3.4.1 Time-Dependent Consideration in Lithophysal Units}

The drift degradation results are presented as damage and displacement plots at time increments of 1, 5, 100,1000, 5000 and 10,000 years. A complete set of damage and displacement results for the tuff static-fatigue curves at lithophysal categories 1,2,3, and 5 are presented in this section. Lac du Bonnet granite static-fatigue curves are analyzed for lithophysal categories 1, 2, and 5, only, to show the range of results.

Two sets of static-fatigue curves (for Lac du Bonnet granite and tuff) were selected to bound expected time-dependent behavior of the lithophysal tuff, considering that limited data are available. The validity of the PFC stress corrosion modeling and the selected model parameters can be shown by a comparison with the observed behavior of the existing drifts at Yucca Mountain. The construction of the ESF main loop began in November 1992 and was completed 
in April 1997, while the construction of the ECRB Cross-Drift began in December 1997, and was completed in October 1998. The ESF and ECRB Cross-Drift have been excavated and open for 5 to 12 years. While minor rockfall in the drifts was observed immediately after excavation, there is no indication of increased damage as a function of time, and no indication of rockfall as a consequence of time-dependent drift degradation. The ground support in the lithophysal rock in the ECRB Cross-Drift consists of rock bolts and wire mesh installed in the roof. The walls are not supported, and are comparable to the UDEC model results, which do not include ground support.

Figure S-32 shows the model state 500 years after excavation of the drift in category 2 tuff material considering the tuff best-fit static fatigue line. The damage occurs in the drift walls. Stresses are redistributed away from the drift sidewalls as the drift degrades. The stress redistribution causes the local driving-stress ratio to increase at greater distances from the excavation boundary.
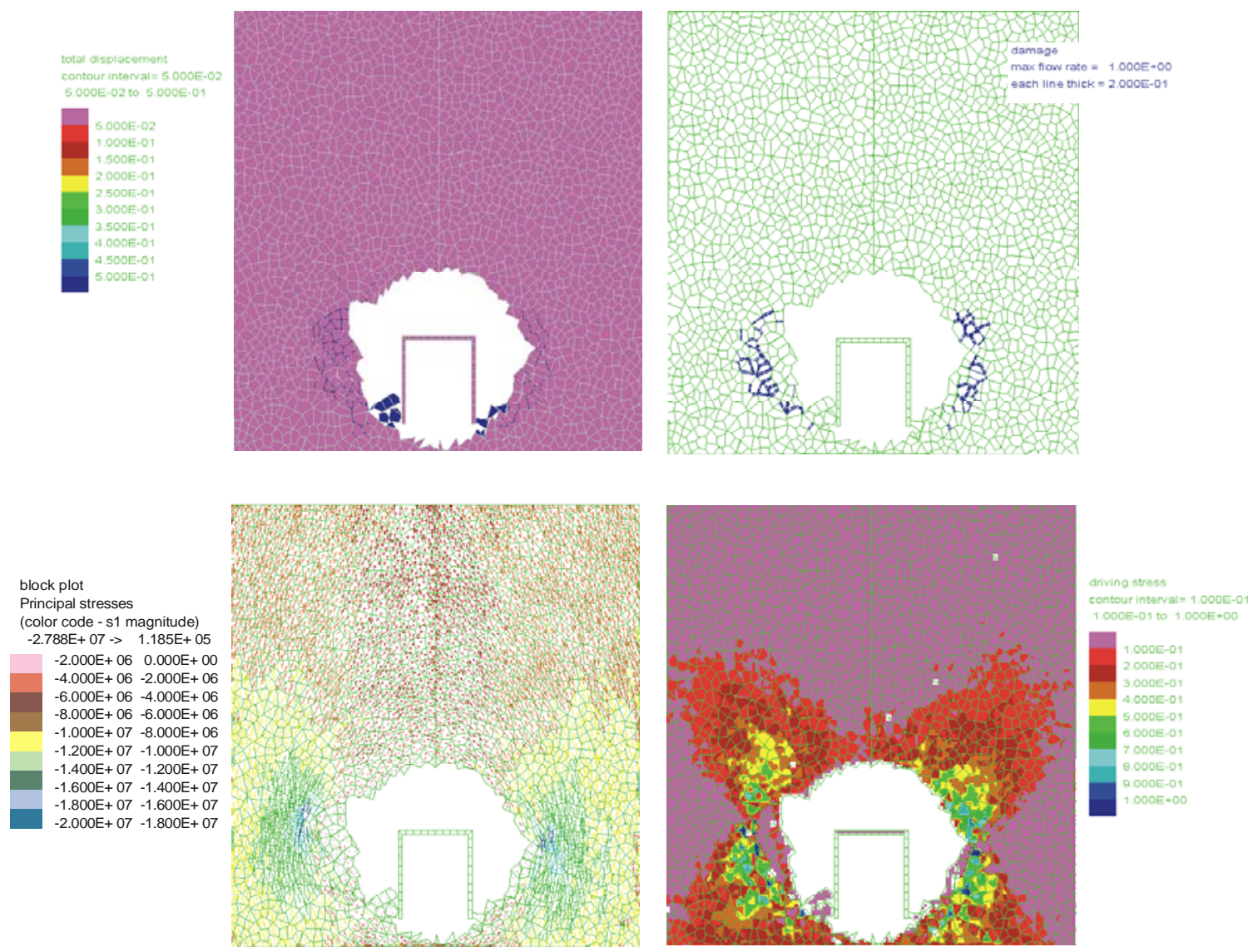

NOTE: The top left figure shows the contours of displacement magnitudes $(\mathrm{m})$ and fractures in the rock mass (blue lines); the top right figure shows accumulated damage, where the thickness of the blue lines are proportional to the accumulated damage (between 0 and 1); the bottom left figure shows the principal stress tensors $(\mathrm{Pa})$ colored by the magnitude of the major principal stress; the bottom right figure shows the contours of the scaled driving stress (between 0 and 1 ).

Figure S-32. Model State for Tuff, Category 2 After 500 Years 
Evolution of damage due to time-dependent strength degradation in the lithophysal rock mass (categories 1, 2, and 5) considering Lac du Bonnet granite static-fatigue, is shown in Figures S-33 through S-35. The stress states in the wall in category 2, and particularly in category 1 , are close to the yield state under in situ stress conditions. There is a relatively large region of the rock mass, a couple of meters from the drift wall, loaded with driving stress, F, equal to, or larger than 0.7. The static-fatigue curve for the Lac du Bonnet granite implies that time-to-failure is 1 year for the driving stress approximately equal to 0.5 . Consequently, there is a significant rockfall from the drift walls 1 year after drift excavation. Damage and rockfall increase with time (for categories 1 and 2), eventually resulting in total drift collapse for category 1 . In the case of category 5, the driving stress around the opening is on the order of 0.3 , resulting in relatively minor rockfall from the drift walls over a period of 10,000 years. Clearly, the model predictions after 5 and 10 years are in disagreement with observations in the ESF and ECRB. The tunnels, which have been open between 5 and 12 years, are stable. There are no observations of their degradation with time. It appears that static-fatigue curves for Lac du Bonnet granite result in too rapid deterioration of the drift, and do not provide a good representation of time-dependent behavior of the lithophysal tuff.

Evolution of damage due to time-dependent strength degradation in the lithophysal rock mass (categories 1, 2, 3 and 5) considering tuff static-fatigue, is shown in Figures S-37 through S-40 for tuff best-fit static-fatigue curves. Time-dependent strength degradation using the best-fit static-fatigue curves for lithophysal tuff has been extended to 20,000 years in Figure S-41 for categories $1,2,3$, and 5 .

It seems that category 1 underestimates the strength of the lithophysal rock mass. The tuff best-fit static-fatigue curve results in significant rockfall from the drift walls at 5 and 10 years after excavation (Figure S-37). The minor rockfall in Figure S-38 predicted by the model at 5 and 10 years after excavation, would have been prevented if the ground support was taken into account in the model (note that the rockfall comes from above the springline). Based on model validation with respect to the conditions in the ESF and ECRB, it seems that category 2 with a tuff best-fit static-fatigue curve is a conservative approximation of the mechanical behavior of the poorest quality lithophysal rock mass.

The best-fit tuff static fatigue line implies that a driving-stress ratio of approximately 0.60 results in approximately 20,000 years time-to-failure (see the tuff $\left(P_{c}=0\right)$ best-fit curve in Figure S-27). The damage coefficient for this case is $D_{20,000} \approx 1-0.60$ (Equation S-3), or 0.40 , indicating there will be an approximate 40 percent cohesive strength reduction in 20,000 years. The drift profile for a 40 percent cohesive strength reduction case (i.e., 60 percent cohesive strength) was initially determined as shown in Figure 6-171c for category 1. Note that Figure 6-171c is similar to the category 1 profile in Figure S-41, indicating that at year 20,000, the rock mass is expected to have about 60 percent of its original cohesive strength due to time-dependent strength degradation. 


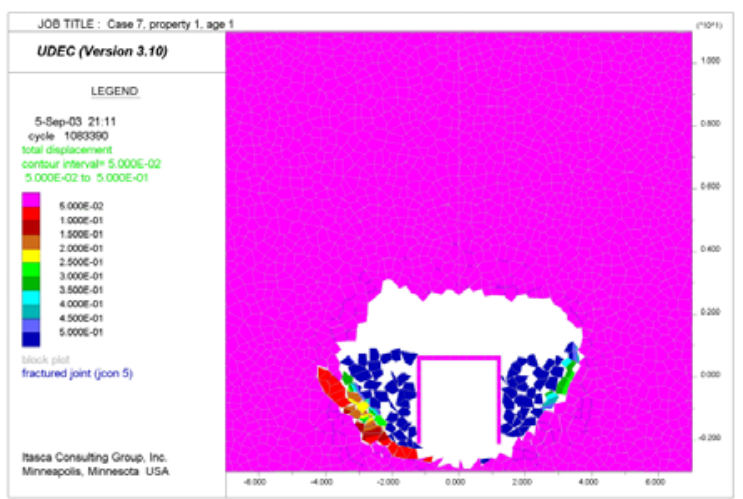

1 year

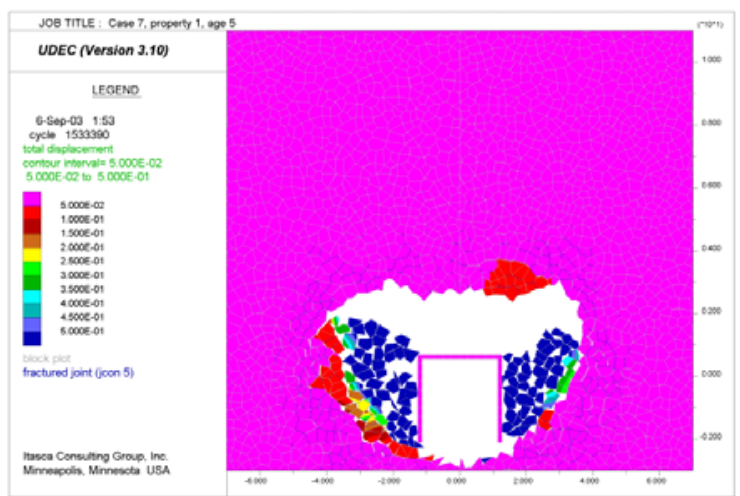

5 years

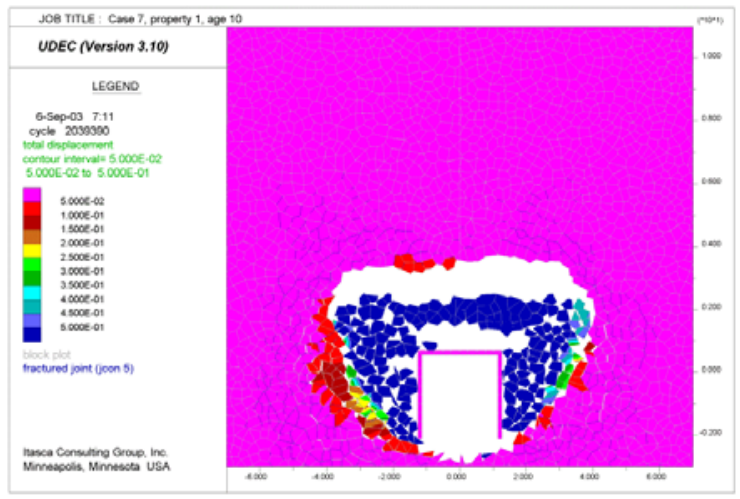

10 years

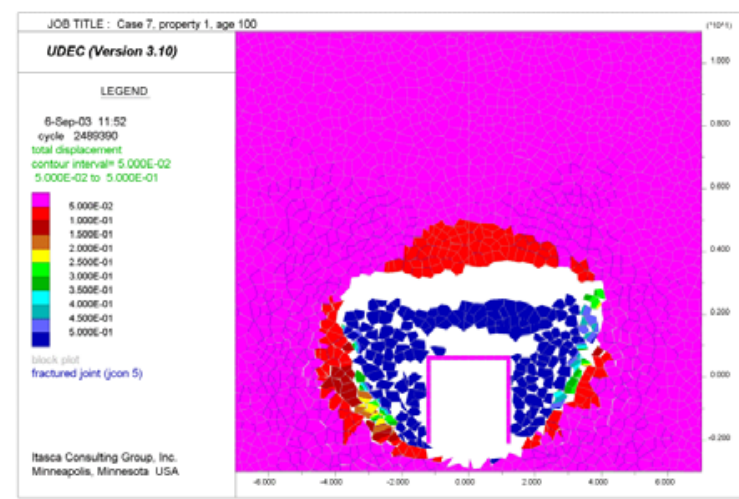

100 years

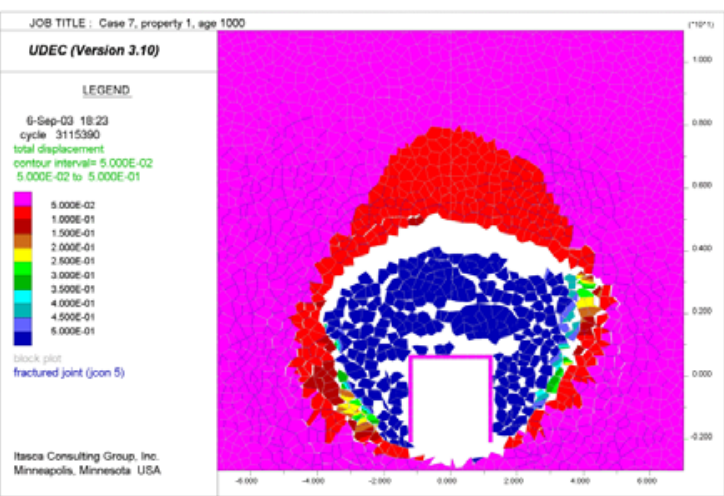

1000 years

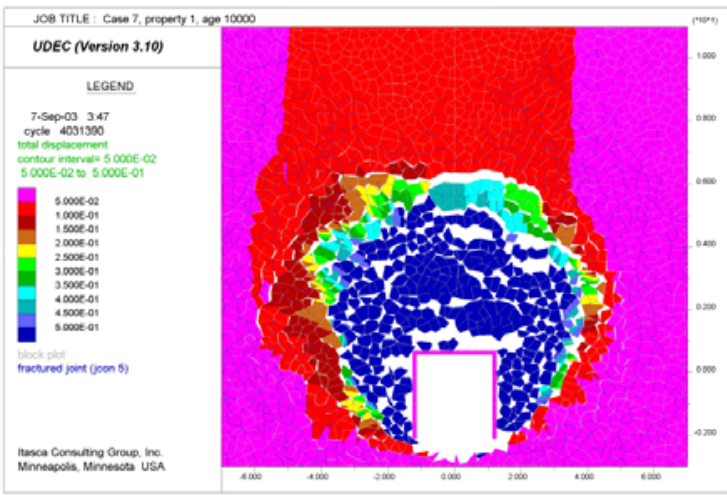

10000 years

Figure S-33. Evolution of Damage Due to Strength Degradation for Category 1 - Lac du Bonnet Granite Static-Fatigue Curve 


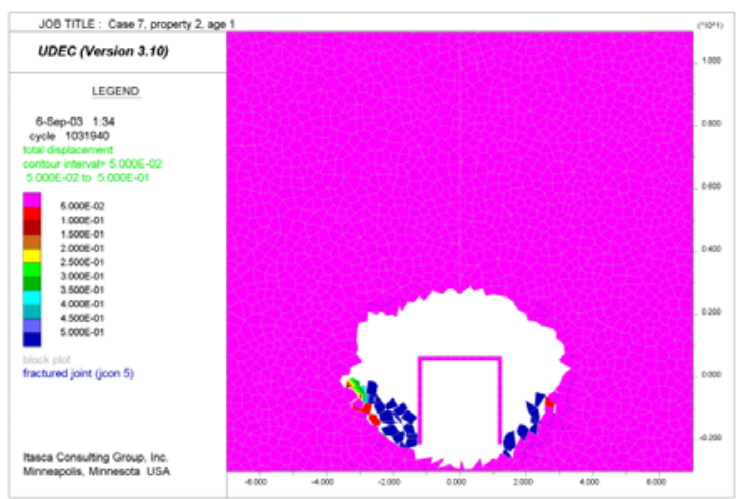

1 year

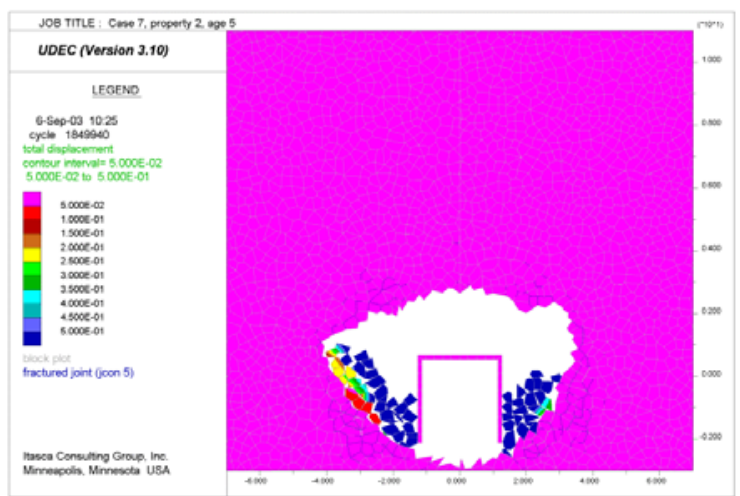

5 years

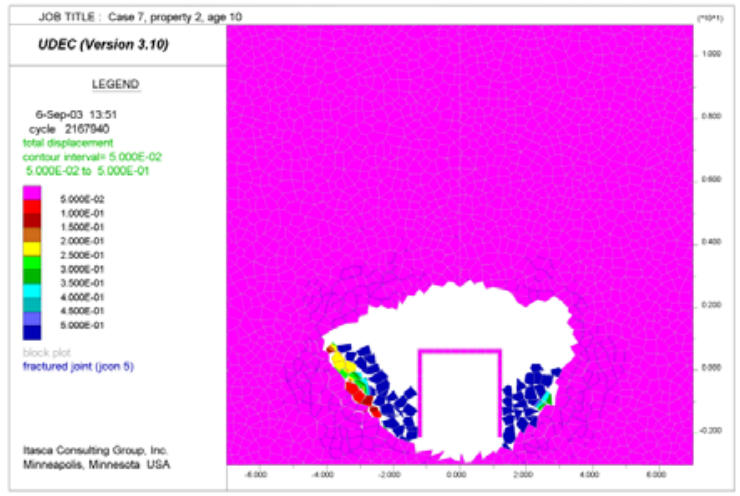

10 years

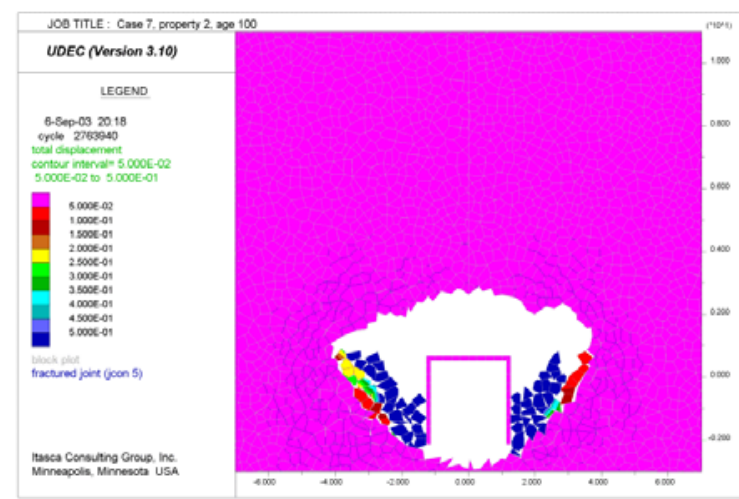

100 years

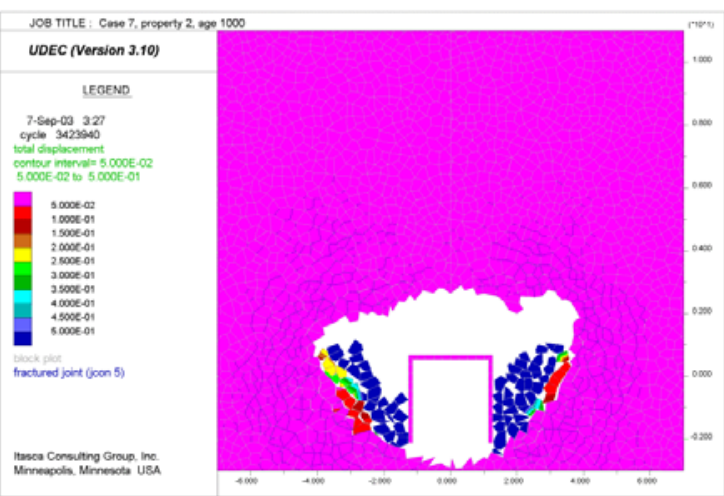

1000 years

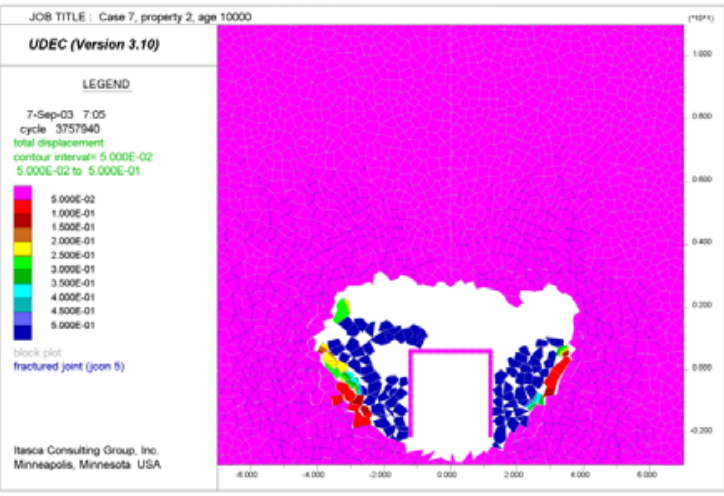

10000 years

Figure S-34. Evolution of Damage Due to Strength Degradation for Category 2 - Lac du Bonnet Granite Static-Fatigue Curve 


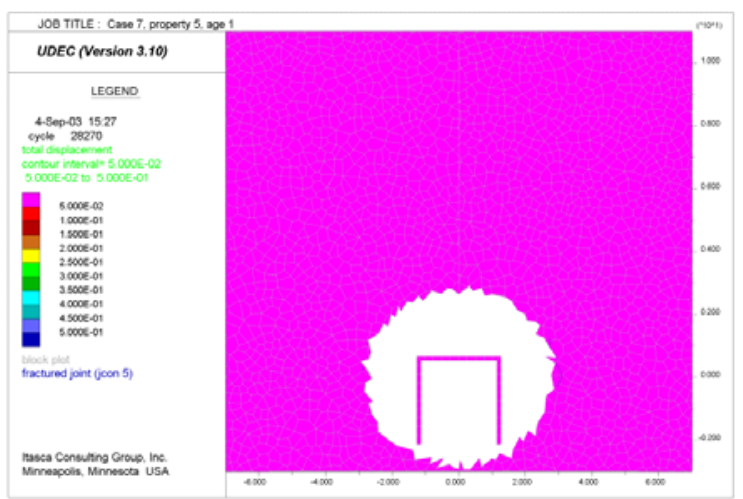

1 year

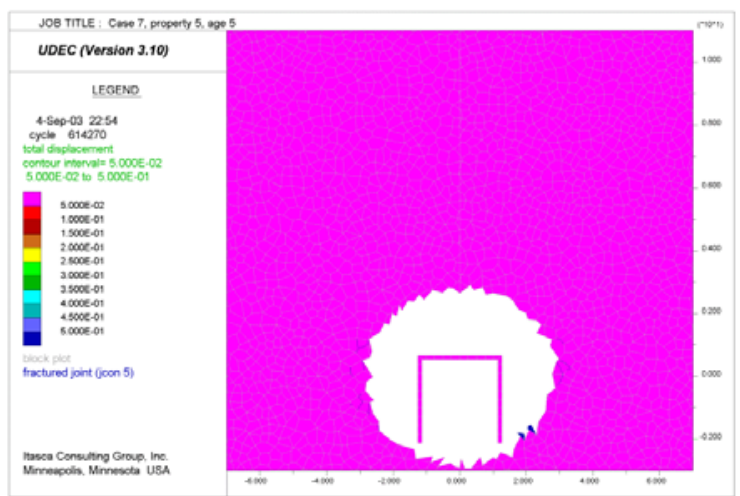

5 years

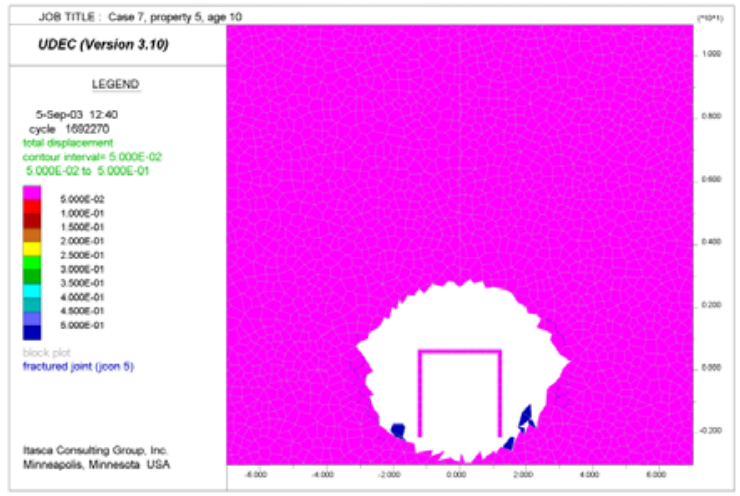

10 years

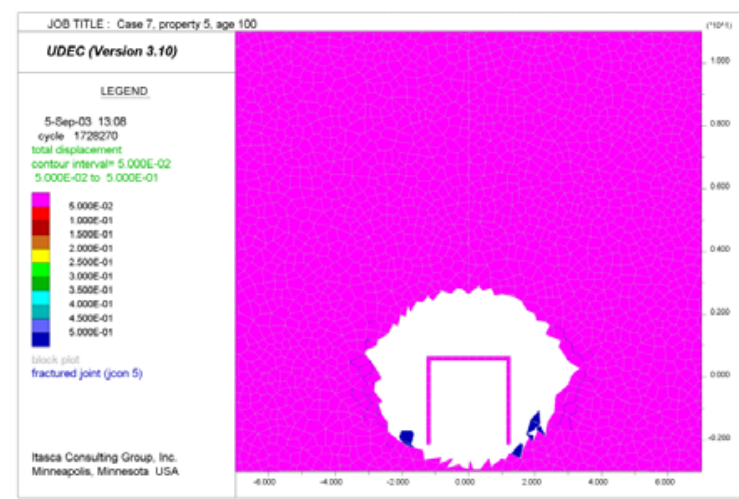

100 years

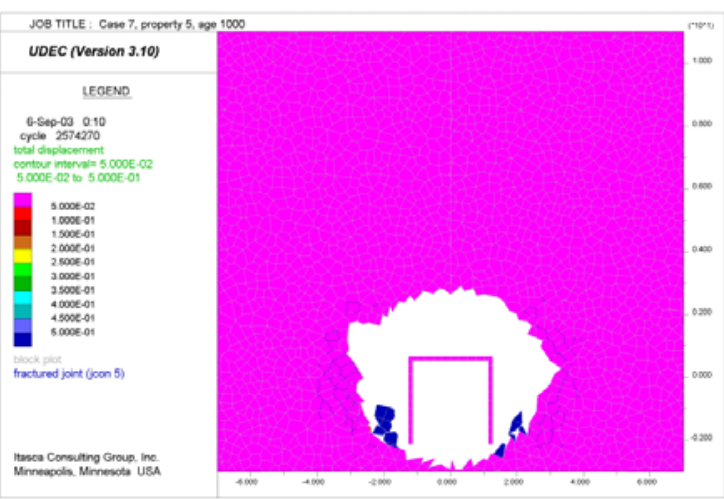

1000 years

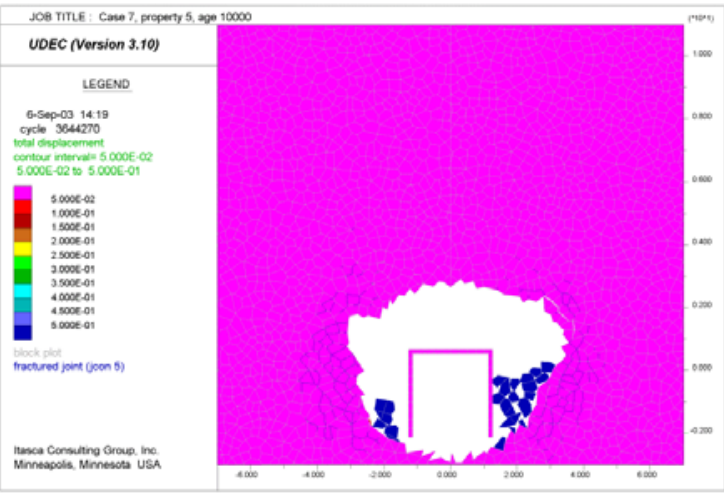

10000 years

Figure S-35. Evolution of Damage Due to Strength Degradation for Category 5 - Lac du Bonnet Granite Static-Fatigue Curve 


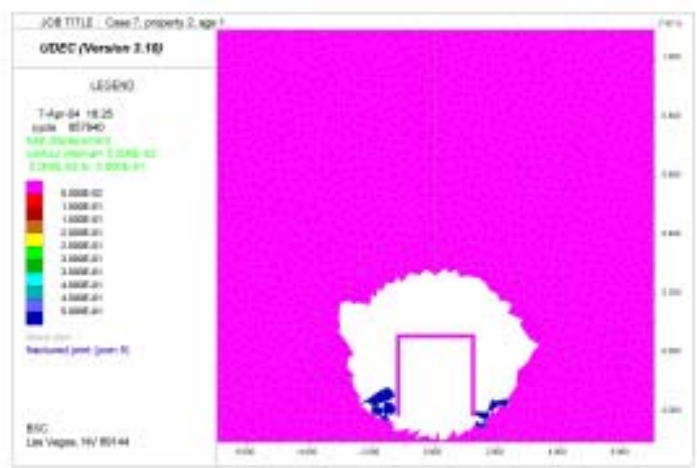

1 years

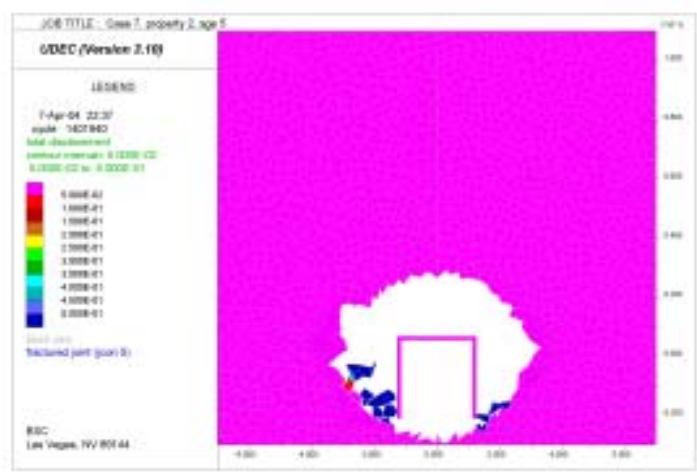

5 years

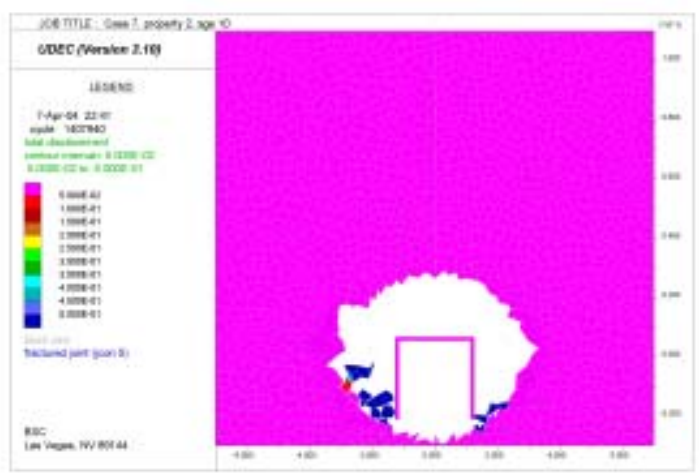

10 years

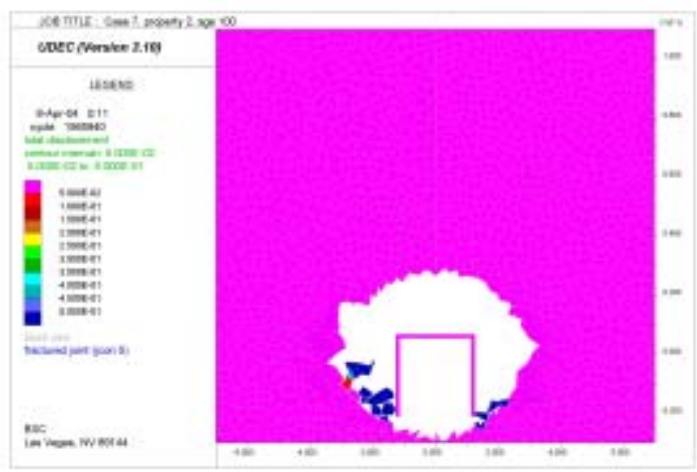

100 years

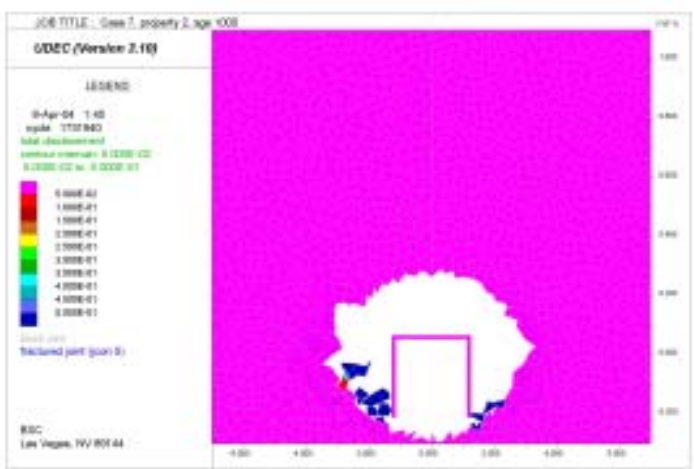

1000 years

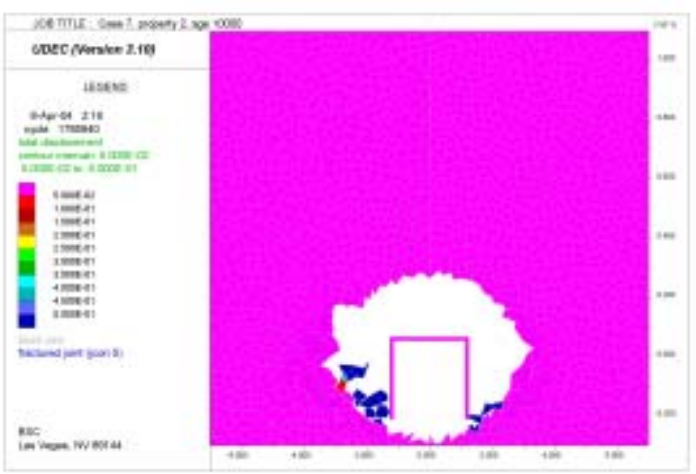

10000 years

Figure S-36. Evolution of Damage Due to Strength Degradation for Category 2 - Tuff Best-Fit Static-Fatigue Curve (Reduced Time Increment) 


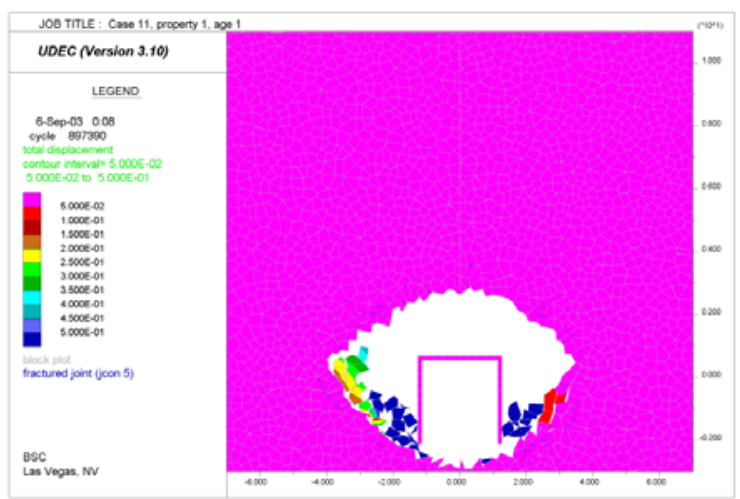

1 year

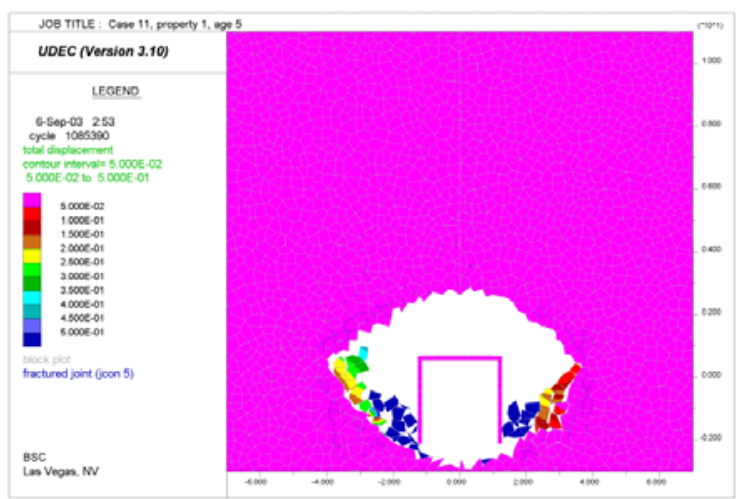

5 years

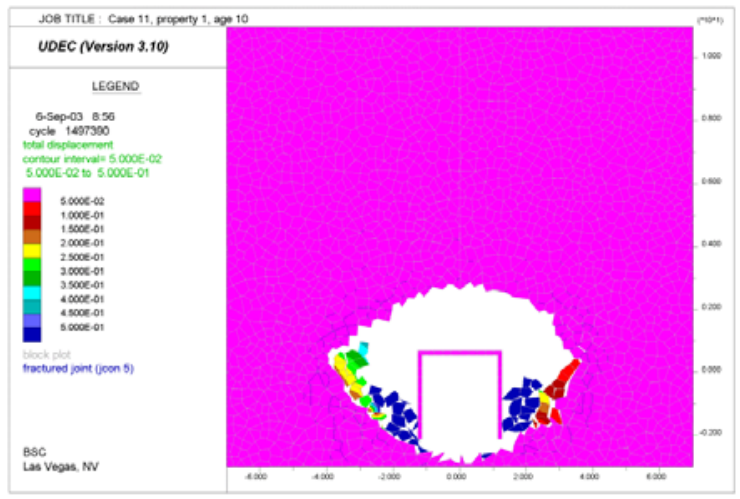

10 years

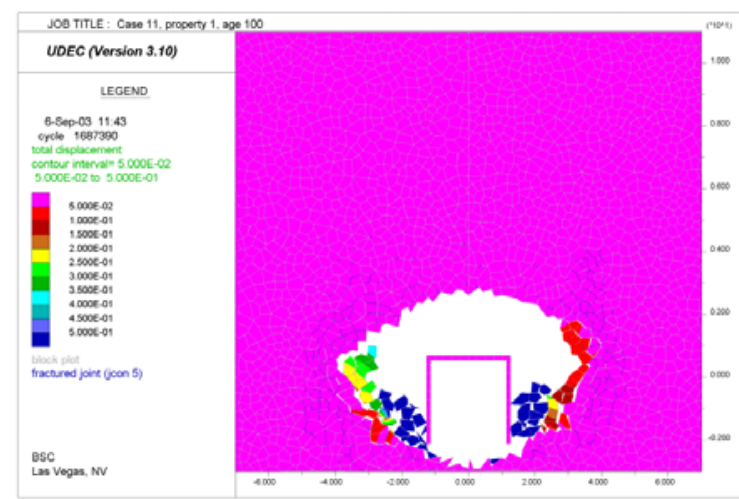

100 years

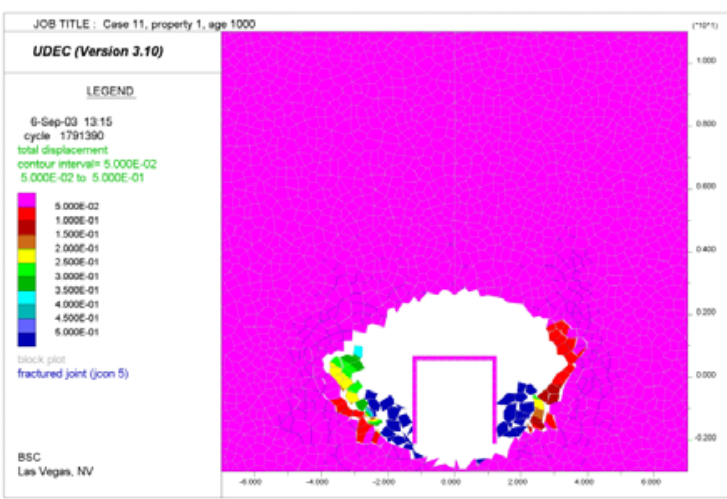

1000 years

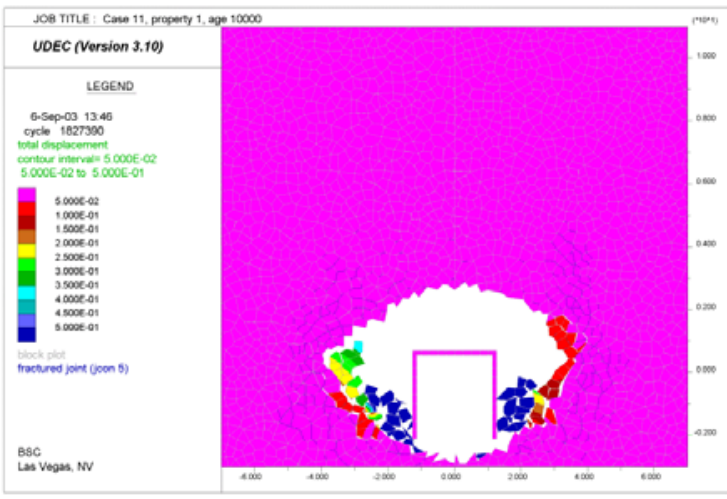

10000 years

Figure S-37. Evolution of Damage Due to Strength Degradation for Category 1 - Tuff Best-Fit Static-Fatigue Curve 


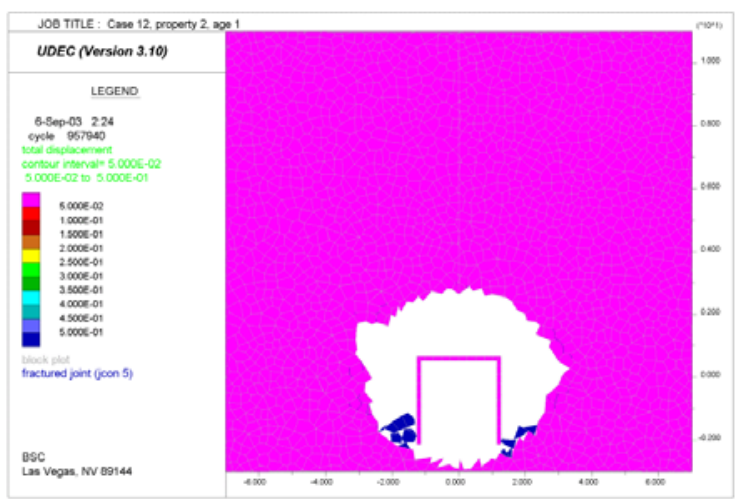

1 year

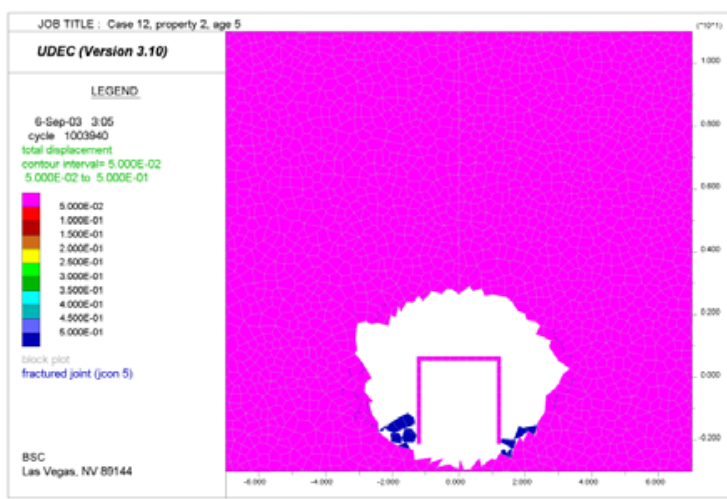

5 years

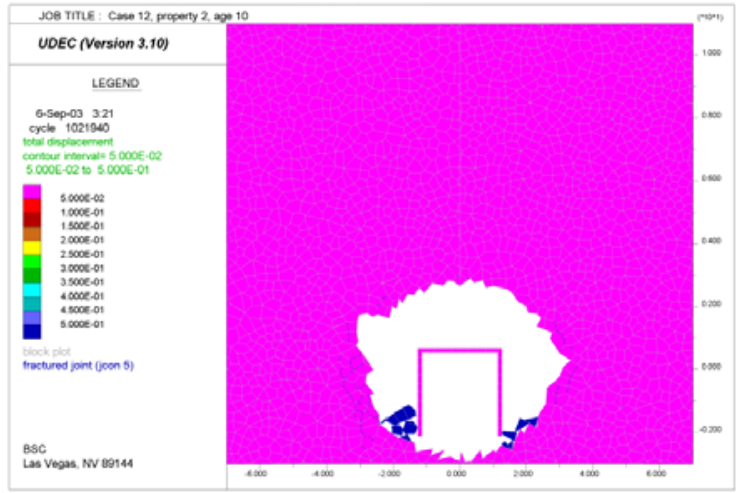

10 years

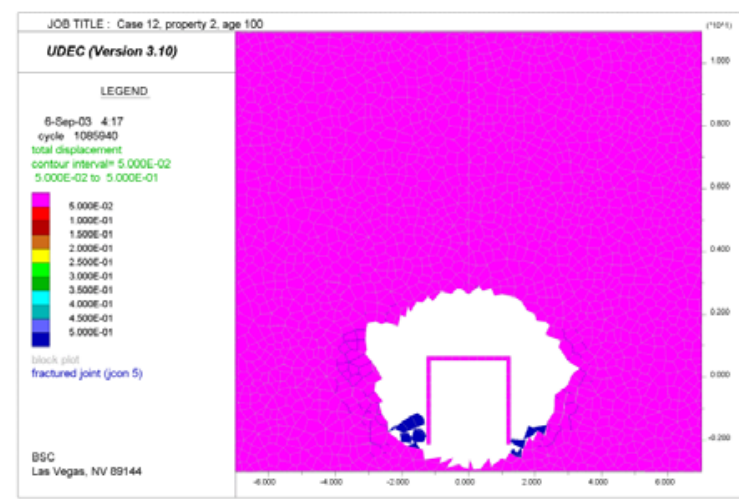

100 years

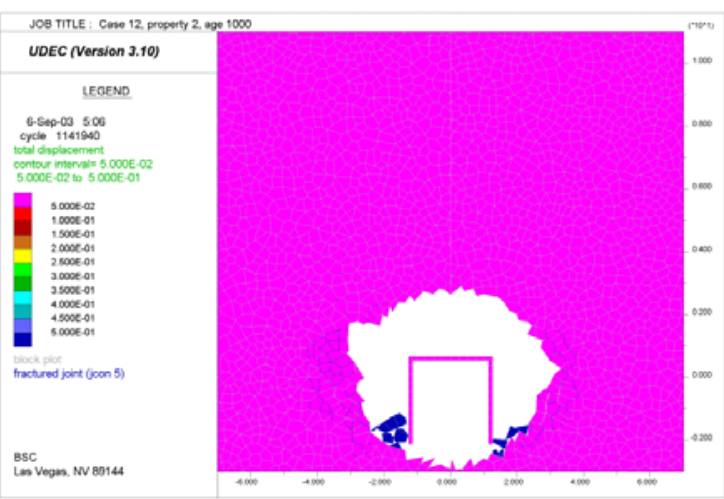

1000 years

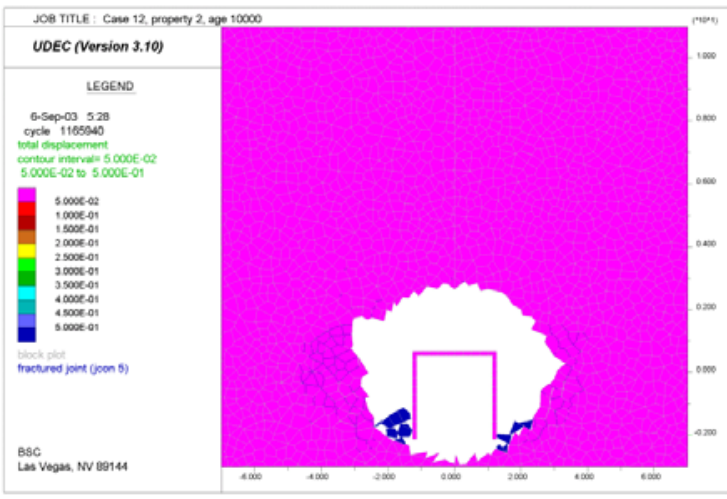

10000 years

Figure S-38. Evolution of Damage Due to Strength Degradation for Category 2 - Tuff Best-Fit Static-Fatigue Curve 


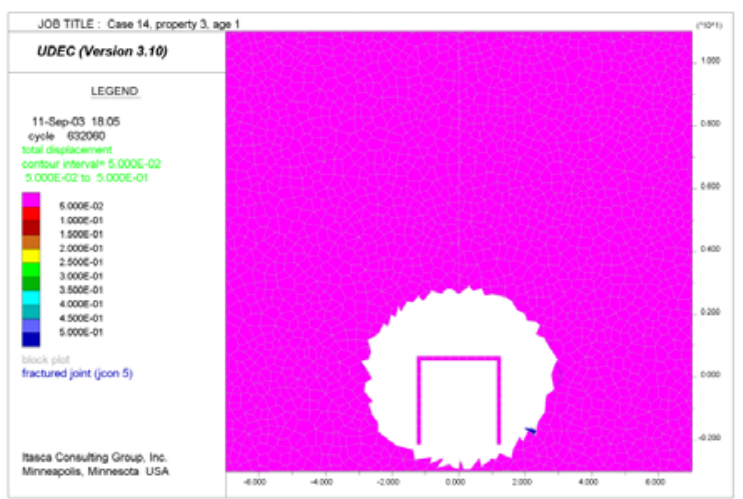

1 year

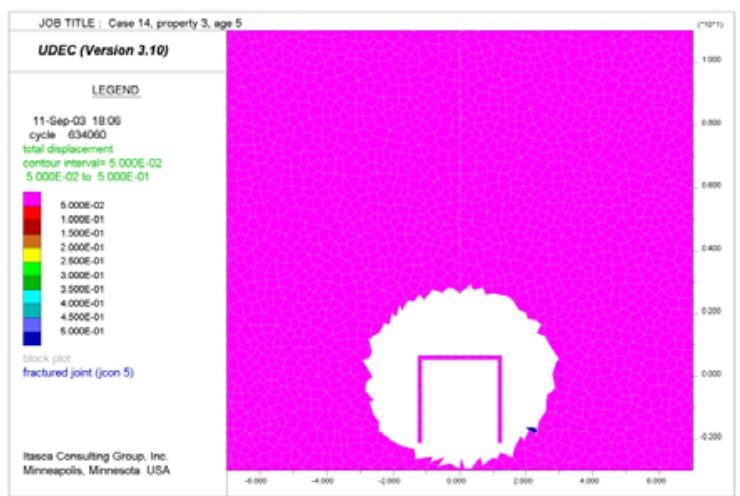

5 years

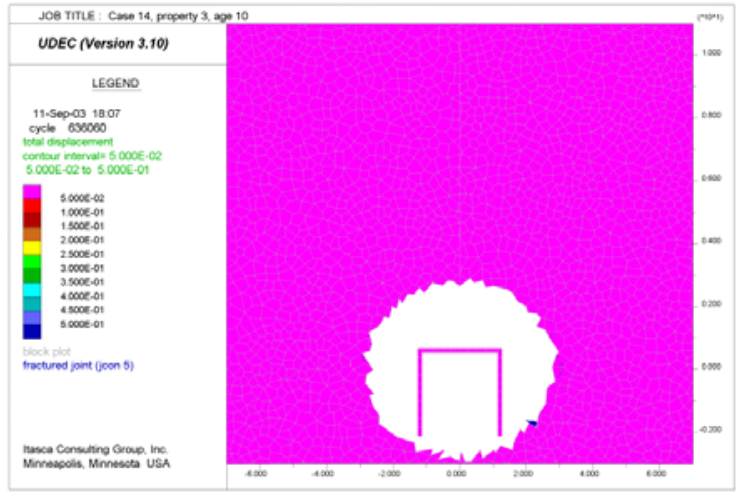

10 years

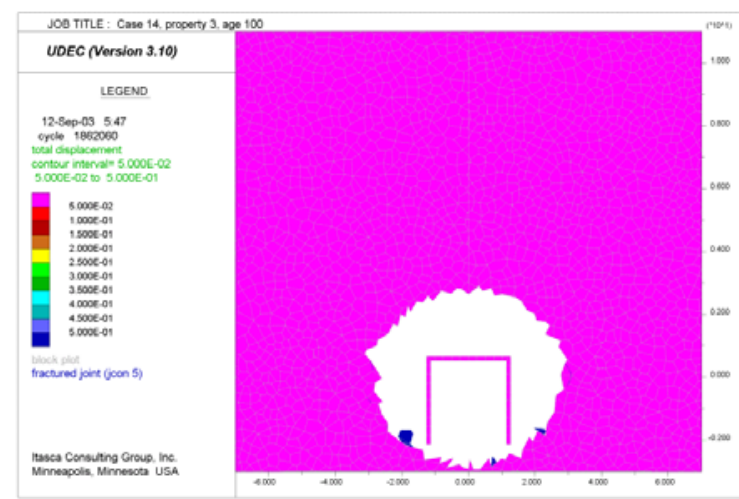

100 years

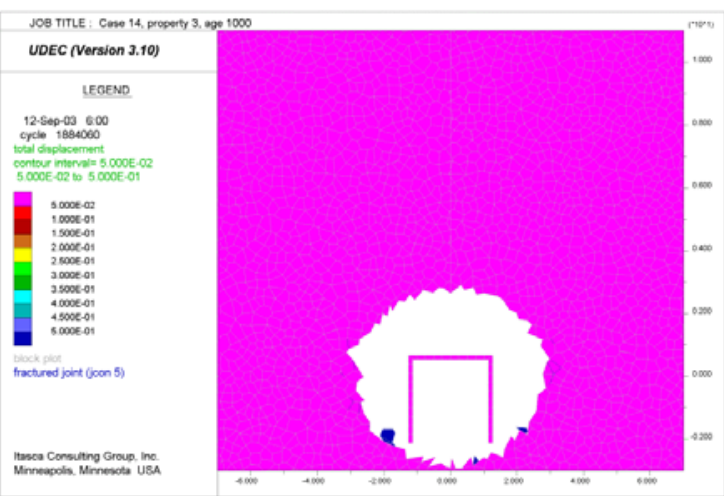

1000 years

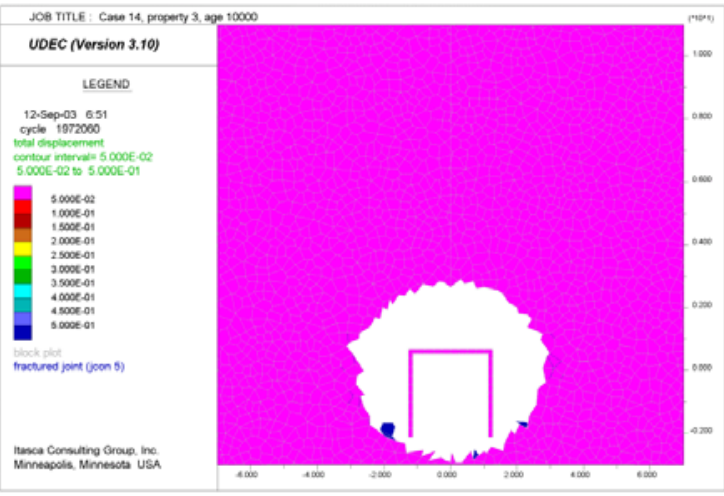

10000 years

Figure S-39. Evolution of Damage Due to Strength Degradation for Category 3 - Tuff Best-Fit Static-Fatigue Curve 


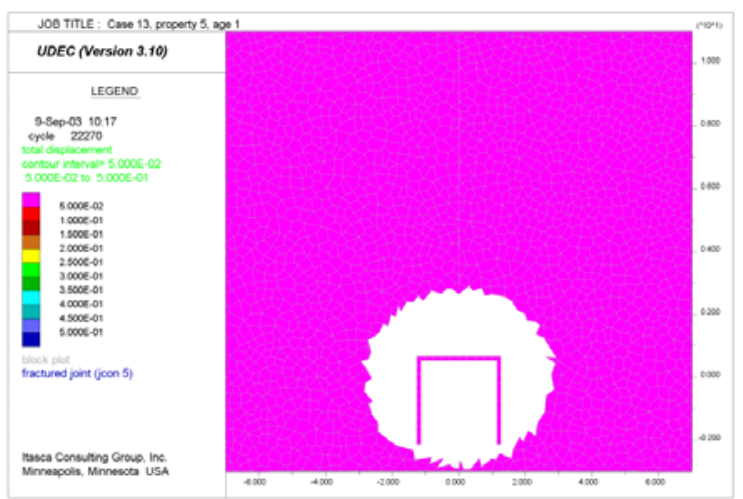

1 year

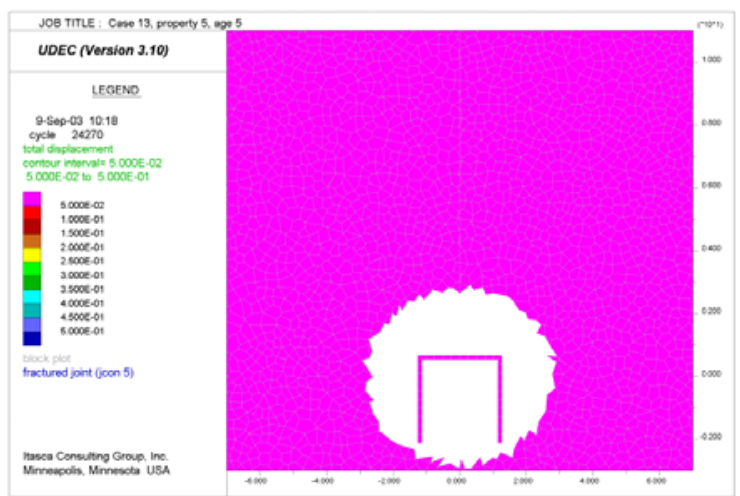

5 years

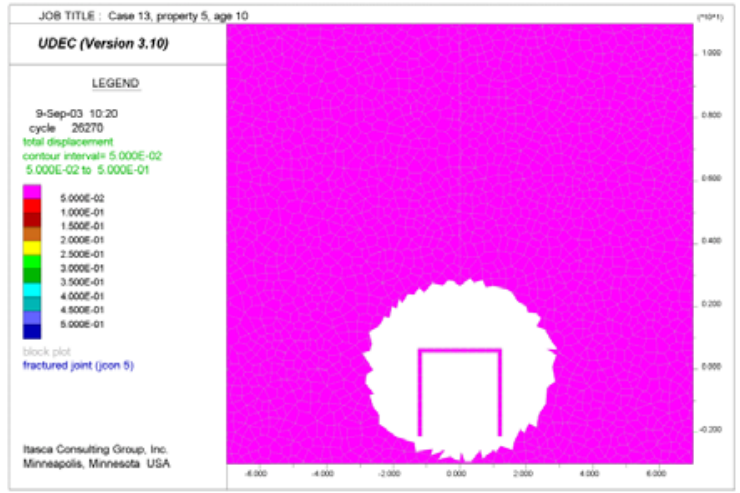

10 years

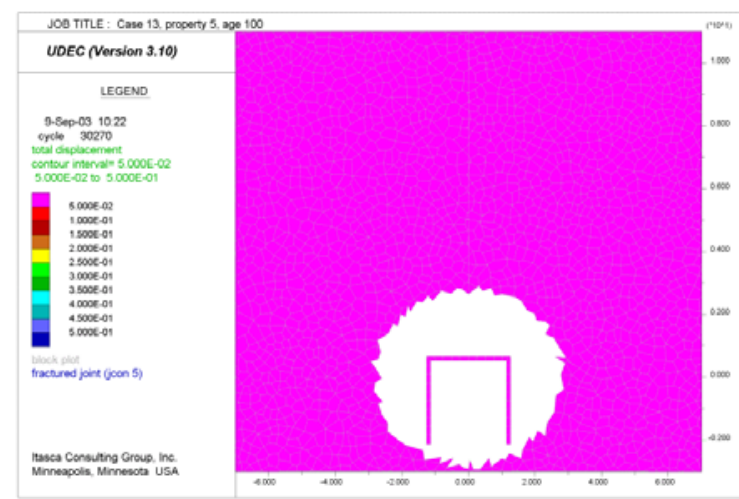

100 years

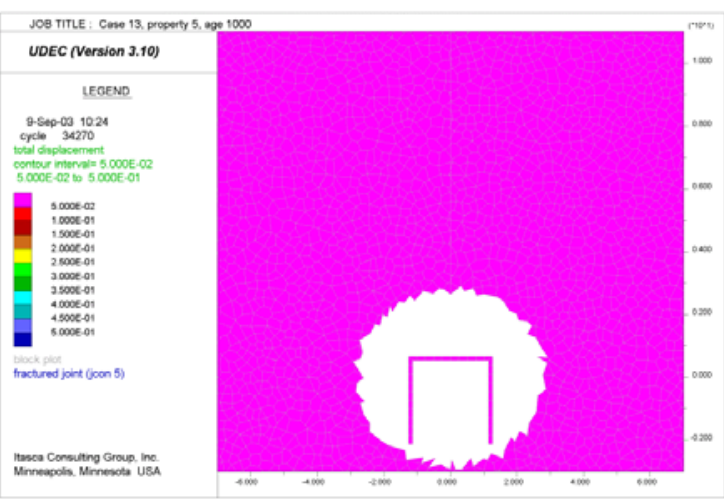

1000 years

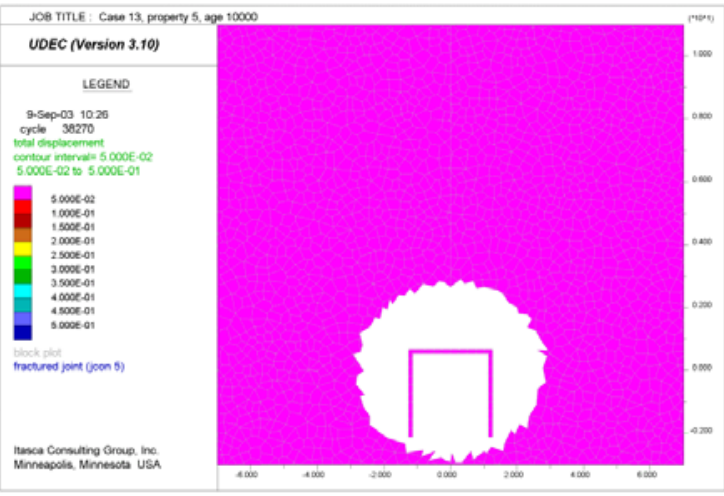

10000 years

Figure S-40. Evolution of Damage Due to Strength Degradation for Category 5 - Tuff Best-Fit Static-Fatigue Curve 


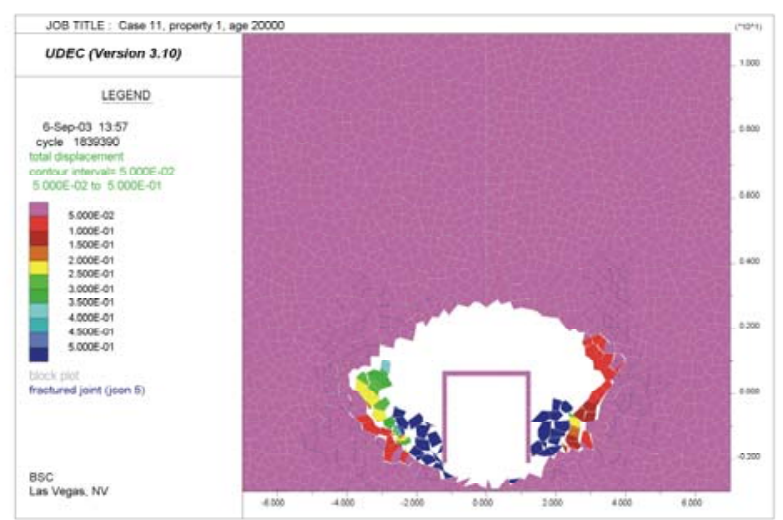

Category 1

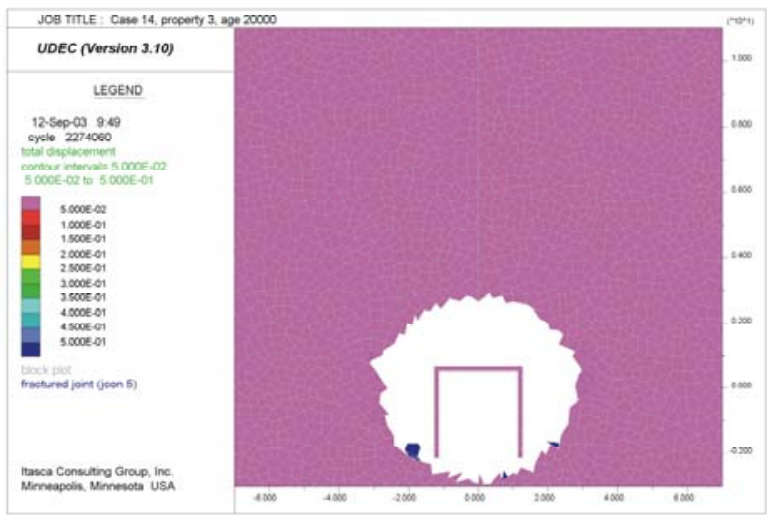

Category 3

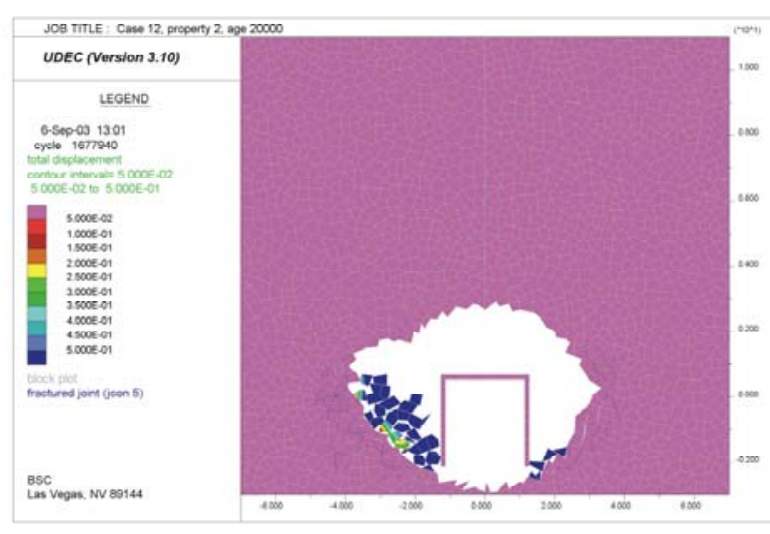

Category 2

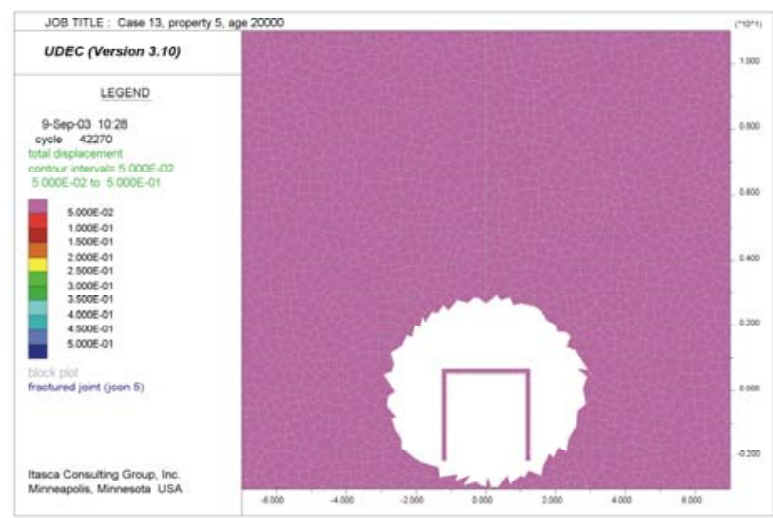

Category 5

NOTE: The drift profiles show the effects of time-dependent strength degradation at 20,000 years. Thermal and seismic effects are not included with these drift profiles. Based on the comparison of model results to field data as described in this section, the category 2 rock mass is considered representative of the poorest quality lithophysal rock.

Figure S-41. Damage Due to Strength Degradation for Categories 1, 2, 3, and 5 - Tuff Best-Fit Static-Fatigue Curve at Year 20,000

\section{S3.4.2 Combined Thermal and Time-Dependent Effect in Lithophysal Units}

Throughout the regulatory period of 10,000 years, the emplacement drifts and surrounding rock mass will be subject to a heating cycle. Time-dependent strength degradation will happen concurrently with transient, thermally induced stress changes. Increased stresses around the excavation will accelerate the process of strength degradation. The results of numerical simulation of drift degradation as a result of these two processes are shown in Figures S-42 through S-44. Time-dependent strength degradation is assessed using the tuff best-fit static-fatigue line. From the discussion in the previous section, it appears that the tuff best-fit static-fatigue line is consistent with the behavior of the excavated drifts at Yucca Mountain and the results of the testing on lithophysal rock mass completed so far. As expected, most rockfall occurs in category 2 rock mass, as shown in Figure S-42. Initially most of rockfall comes from 
the walls, which are loaded almost to a yielding state for this rock mass category under in situ stress conditions. Strength degradation combined with a temperature increase, which at early times increases the hoop stress in the walls (not only in the roof), results in some rockfall from the wall at 5 and 10 years after emplacement of the waste. The large increase in the temperature, and consequently in the stresses, after the forced ventilation stops causes additional rockfall (at 80 years). At this stage, stress increase is predominantly in the roof. Therefore, some rockfall comes from the roof. It is counterintuitive that more rockfall is predicted in category 5 (Figure S-44) than in category 3 (Figure S-43). However, a large stiffness of category 5 lithophysal rock mass causes a large (larger than in category 3 ) increase in the hoop stress and yielding in the roof, even considering the short-term yield strength of the rock mass (Figure 6-144).

It should be noted that static-fatigue curves are temperature dependent. This dependence is not explicitly included in the analysis. However, the tuff data are obtained from tests conducted at $150^{\circ} \mathrm{C}$ (see Section S2.1), which is larger than the maximum temperature of the rock mass anticipated throughout the repository for the base case described in Section 6.2. Consequently, the results obtained in this analysis, although for "isothermal" static-fatigue curves are conservative. 


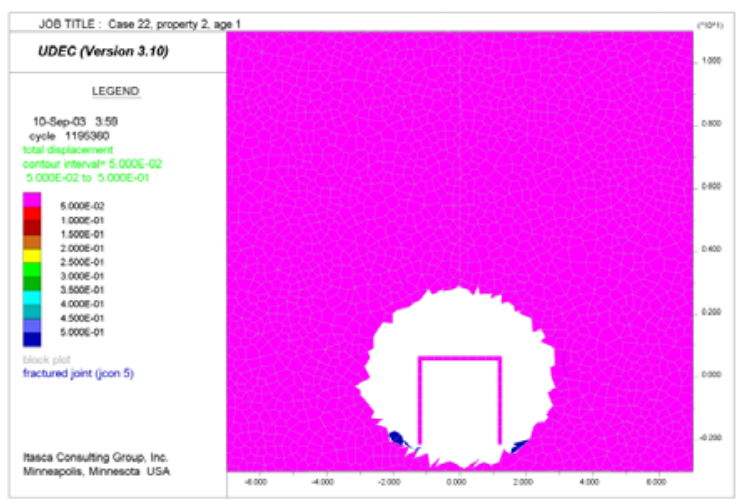

1 year

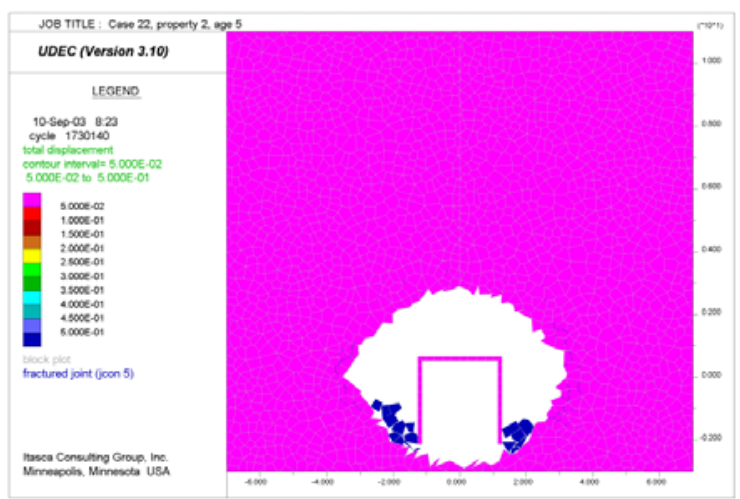

5 years

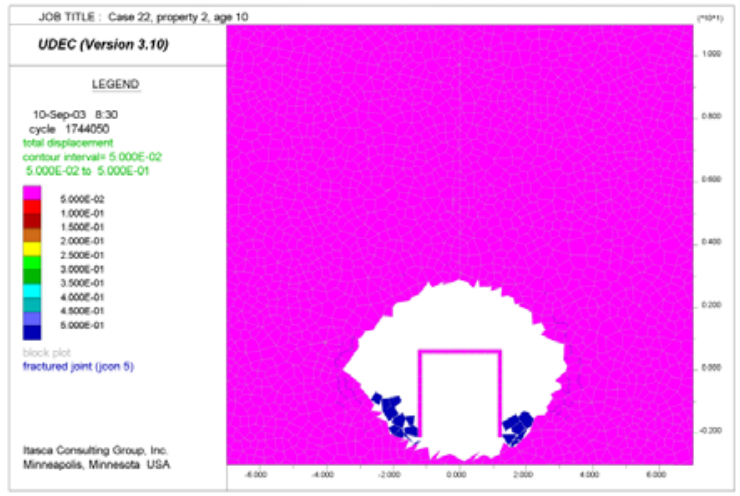

10 years

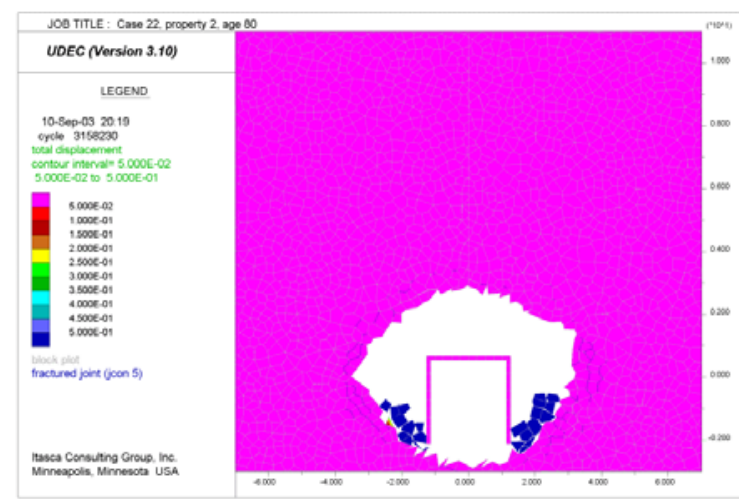

80 years

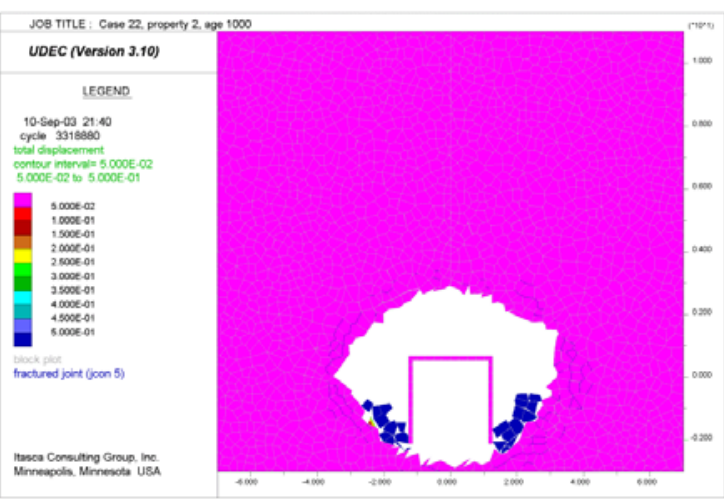

1000 years

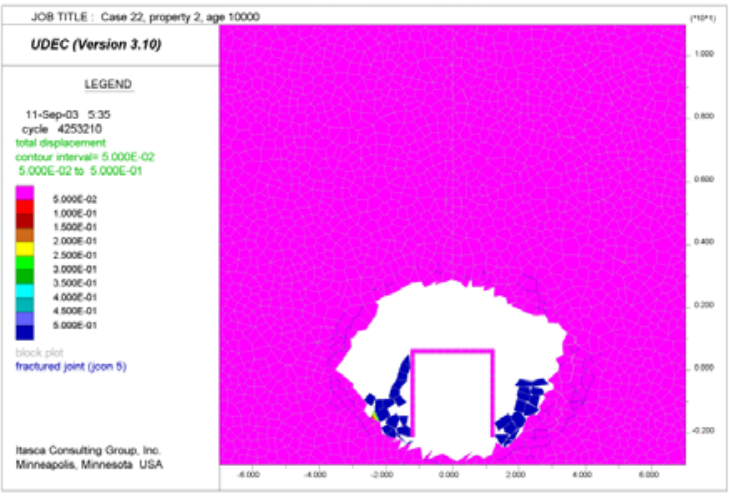

10000 years

Figure S-42. Evolution of Damage Due to Strength Degradation and Thermal Load for Category 2 - Tuff Best-Fit Static-Fatigue Curve 


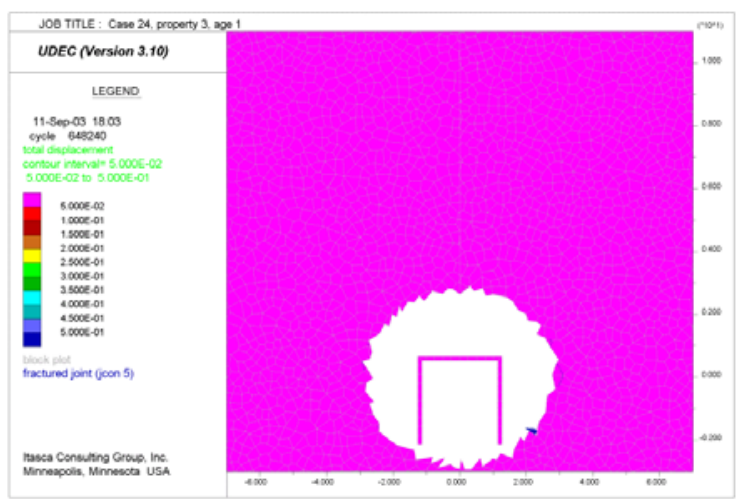

1 year

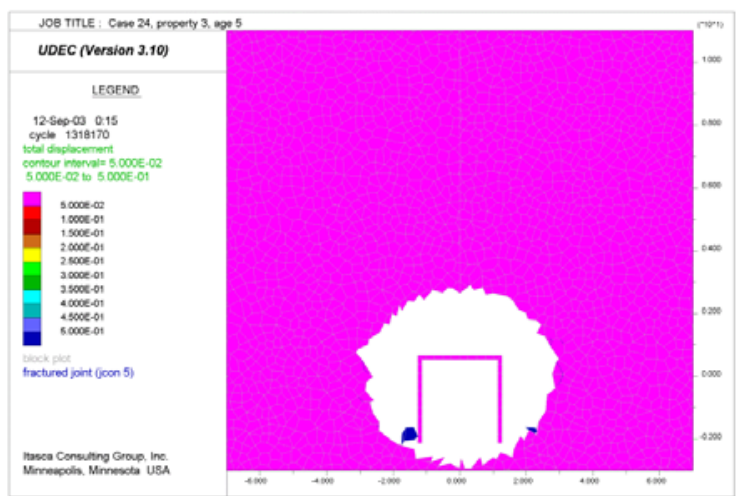

5 years

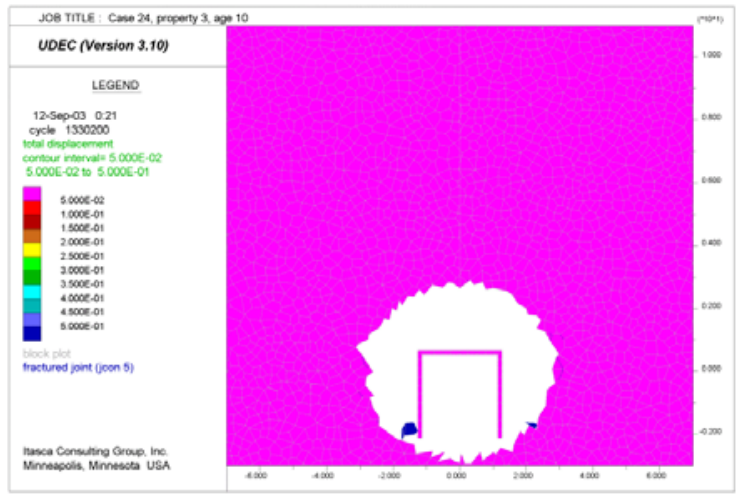

10 years

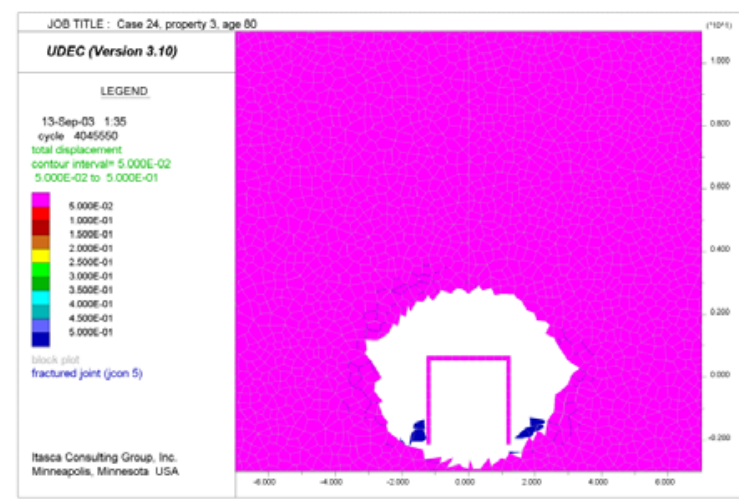

80 years

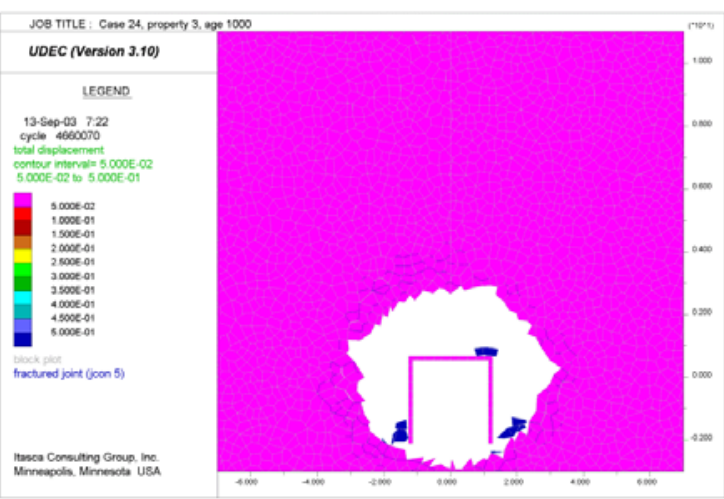

1000 years

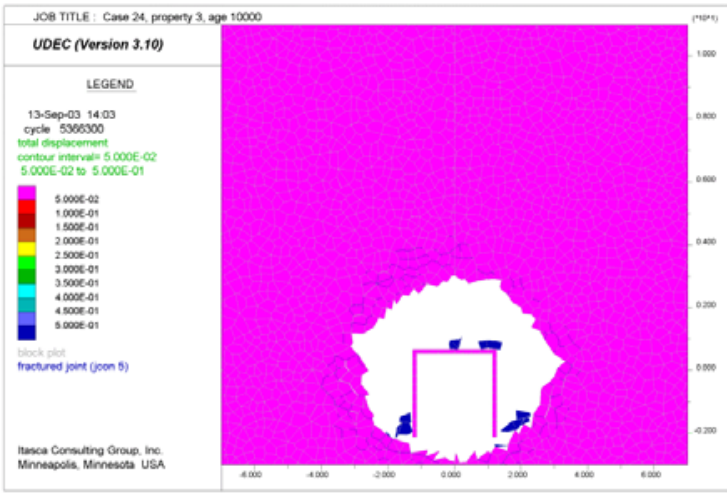

10000 years

Figure S-43. Evolution of Damage Due to Strength Degradation and Thermal Load for Category 3 - Tuff Best-Fit Static-Fatigue Curve 


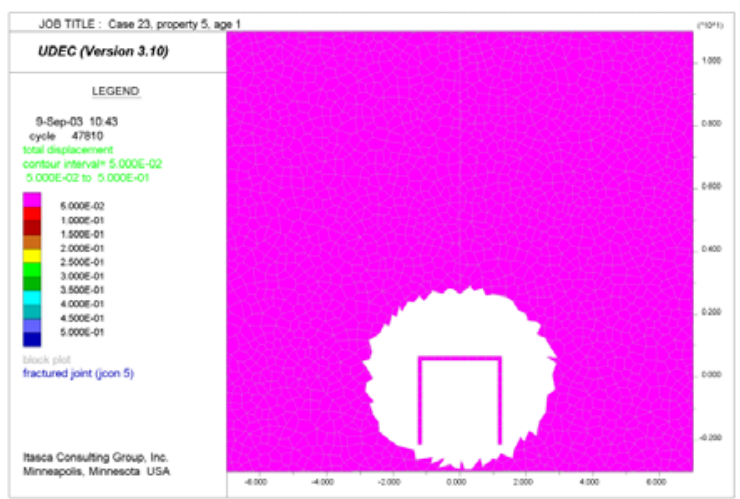

1 year

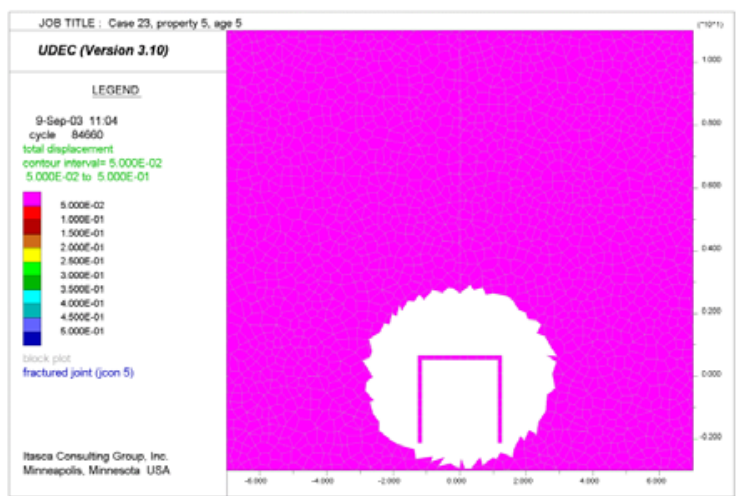

5 years

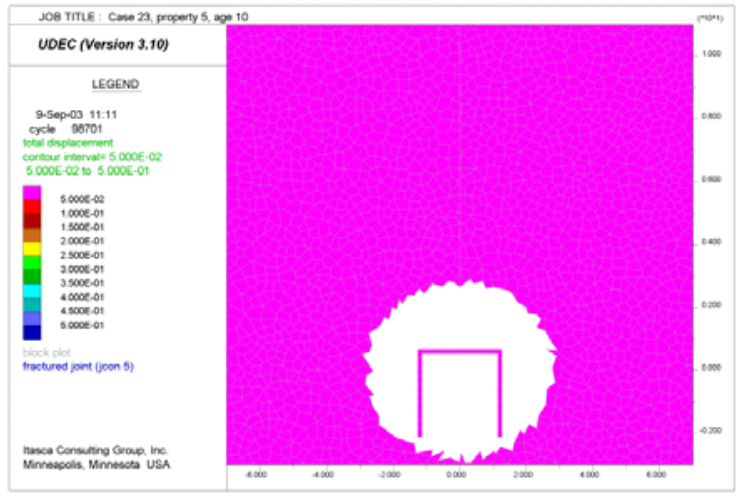

10 years

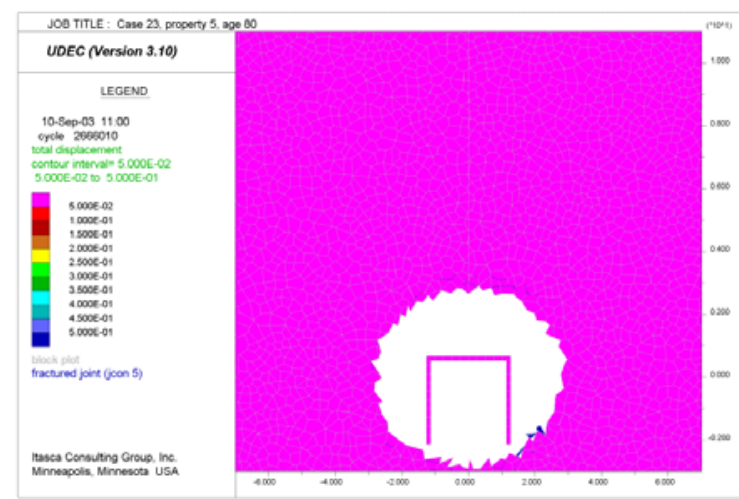

80 years

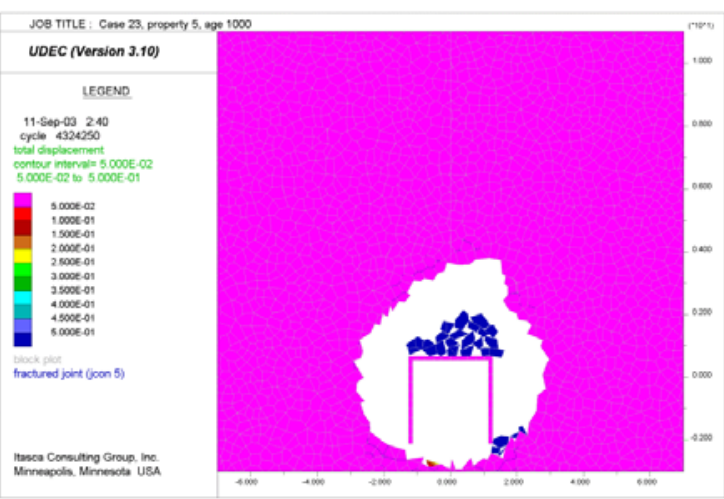

1000 years

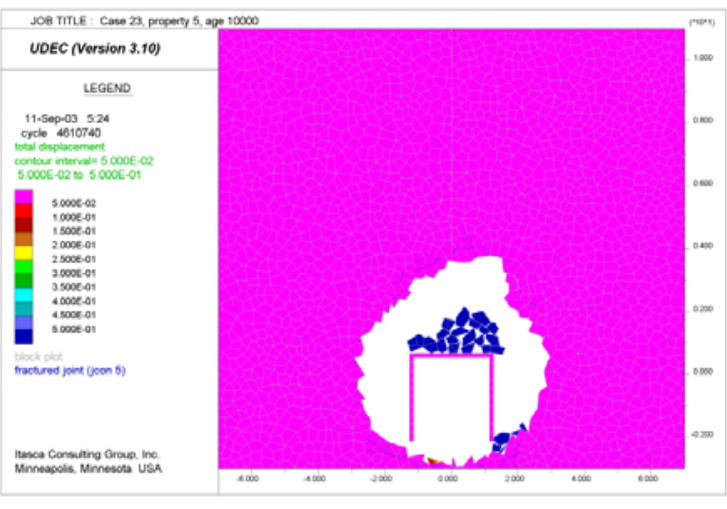

10000 years

Figure S-44. Evolution of Damage Due to Strength Degradation and Thermal Load for Category 5 - Tuff Best-Fit Static-Fatigue Curve

\section{S3.4.3 Combined Seismic, Thermal, and Time-Dependent Effect in Lithophysal Units}

The effect of the preclosure seismic loading $\left(1 \times 10^{-4}\right.$ probability of annual occurrence) was investigated for categories 2 and 5 of the tuff best-fit curve. An analysis of the combined effects of thermal and seismic loading is presented in Section 6.4.2.3. Note that because ground motion with $1 \times 10^{-6}$ probability of annual occurrence results in complete drift collapse in lithophysal rock 
(see Section 6.4.2.2), it was not of particular interest to investigate the effect of that level of ground motion combined with thermally induced initial stresses and time-dependent strength degradation. Instead, a ground motion with $1 \times 10^{-4}$ probability of annual occurrence was considered. The state of the rock mass when the effect of seismic ground motion is most adverse for drift stability was selected based on an elastic stress path with respect to the short-term yield surface. Under such conditions, the critical state was reached 80 years after waste emplacement, when the temperatures and the thermal stresses around the drift reach the maximum. When the time-dependent strength degradation is considered, the state when the maximum stresses are generated around the drift is not necessarily the critical one. The largest stresses occur relatively early during the regulatory period. Subsequently, the stresses decay gradually, returning to the state that existed prior to heating. At the same time, the strength of the rock mass monotonically decreases as a function of time, such that the weakest rock strength occurs at the end of the regulatory period (i.e., at year 10,000). In order to investigate the worst-case effects of seismic ground motion on drift stability, dynamic analyses were carried out for the model states at 80 and 10,000 years after waste emplacement.

The model geometry before and after the dynamic simulation is shown in Figures S-45 and S-46 for seismic ground motion at 80 years after emplacement, and in Figures S-47 and S-48 for seismic ground motion at 10,000 years after emplacement. In each case, an additional rockfall is predicted due to the earthquake, which shakes down already damaged rock mass. This increase in the rockfall due to seismic loading is not significant in any of the cases, although it seems that there is more rockfall in the case of an earthquake at 10,000 years after waste emplacement.

The effect of multiple seismic events on stability of the emplacement drifts in category 2 lithophysal rock mass at different stages during the regulatory period was also investigated. Figure S-49 shows the model geometry after two identical $1 \times 10^{-4}$ seismic events have shaken the emplacement drifts at 80 and 10,000 years of heating. These results should be compared with results shown in Figures S-45 and S-47 for a single seismic event in a rock mass of the same quality and age (80 and 10,000 respectively) after waste emplacement. The second event, although exactly the same ground motion, causes much less additional rockfall. In fact, after 10,000 years of heating, the second event does not produce any additional rockfall. Some relatively small additional rockfall can be observed on the left side of the drip shield for a repetitive seismic event taking place 80 years after waste emplacement. The second earthquake shakes down a small volume of the loose rock that remained in the drift roof after the first earthquake. 


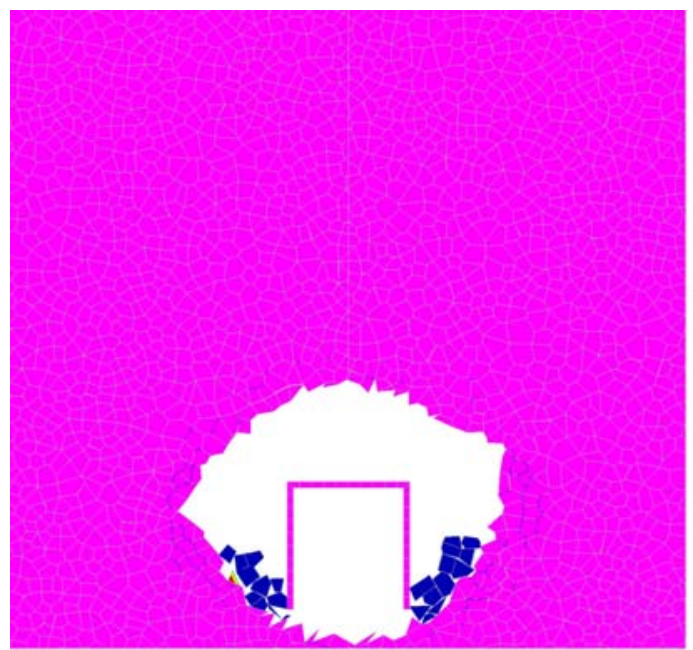

80 years of heating

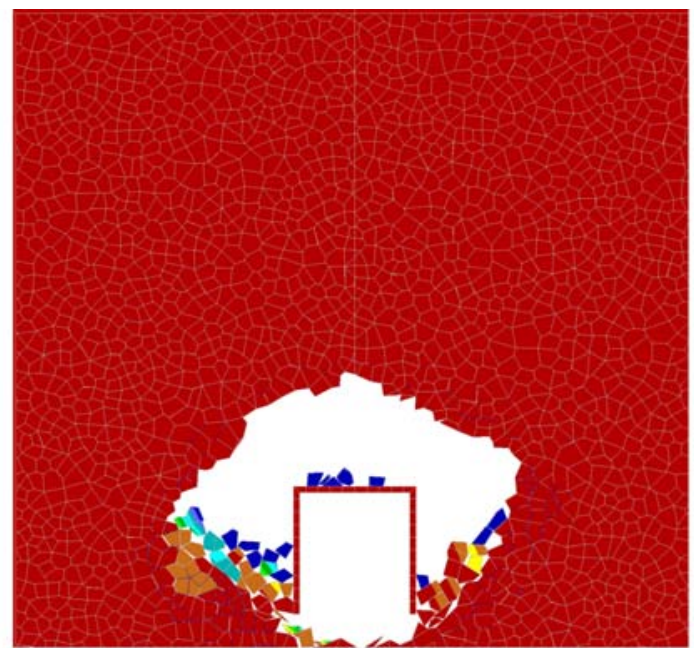

80 years of heating + seismicity

Figure S-45. Effect of $1 \times 10^{-4}$ Ground Motion After 80 Years of Heating in Category 2 Contours of Displacement Magnitude $(\mathrm{m})$

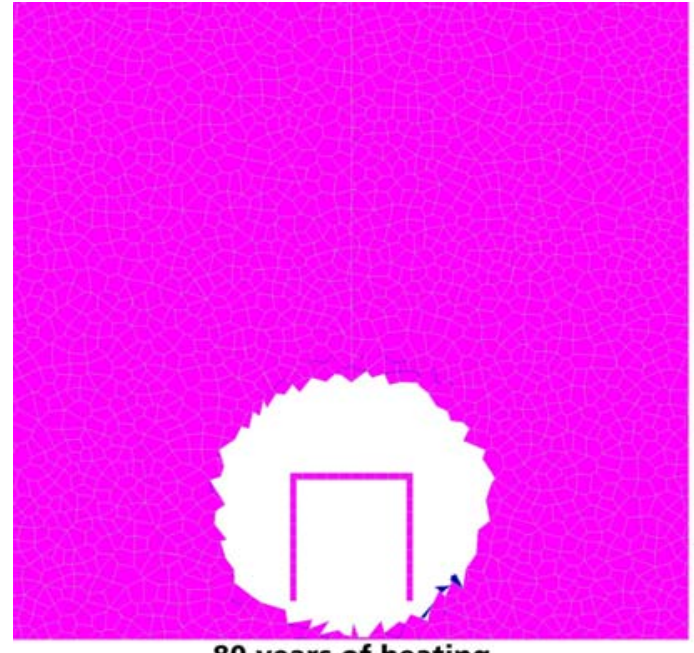

80 years of heating

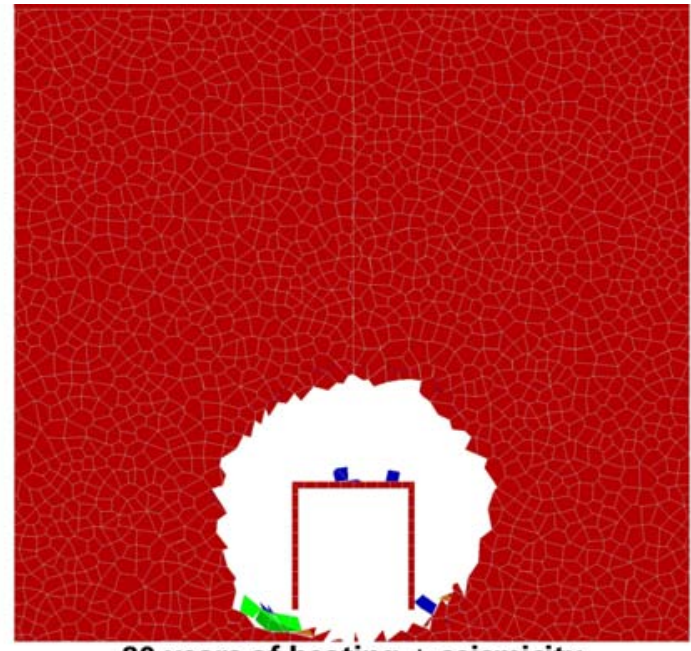

80 years of heating + seismicity

NOTE: There is a residual, rigid body translation of the model at the end of dynamic simulation because the entire seismogram was not simulated.

Figure S-46. Effect of $1 \times 10^{-4}$ Ground Motion After 80 Years of Heating in Category 5: Contours of Displacement Magnitude (m) 


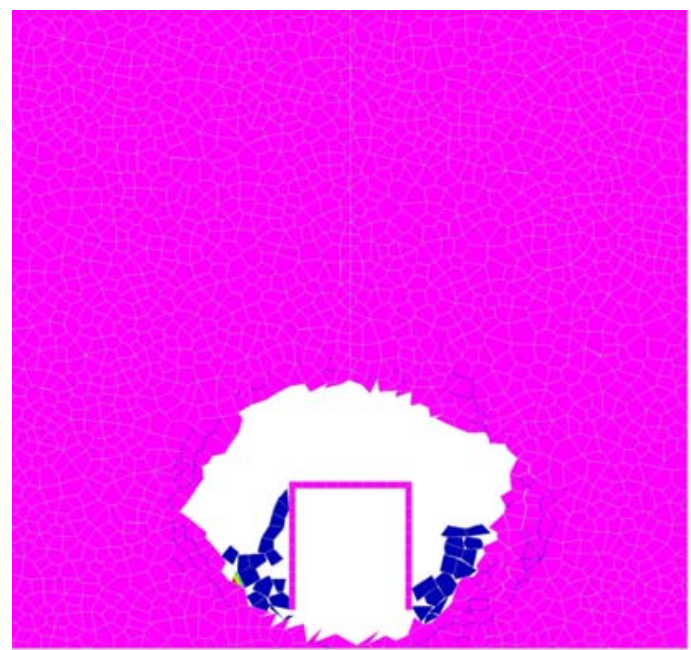

10000 years of heating

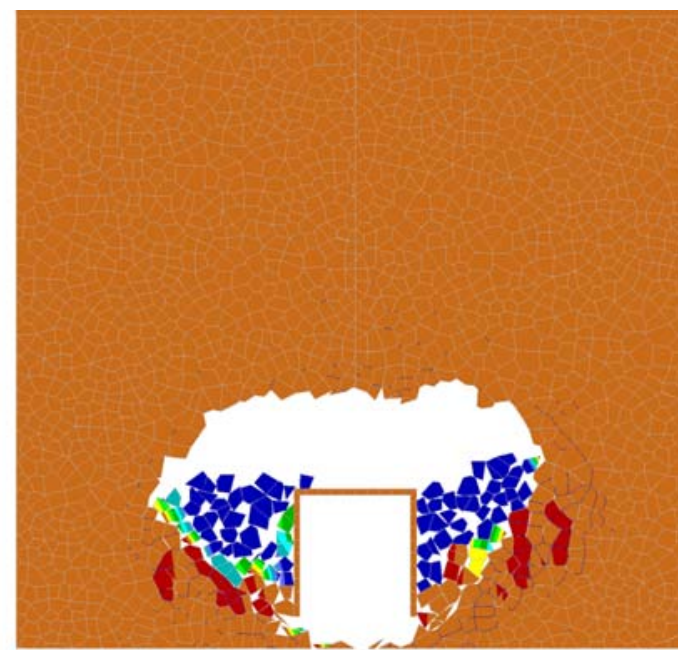

10000 years of heating + seismicity

NOTE: There is a residual, rigid body translation of the model at the end of dynamic simulation because the entire seismogram was not simulated.

Figure S-47. Effect of $1 \times 10^{-4}$ Ground Motion After 10,000 Years of Heating in Category 2: Contours of Displacement Magnitude (m)

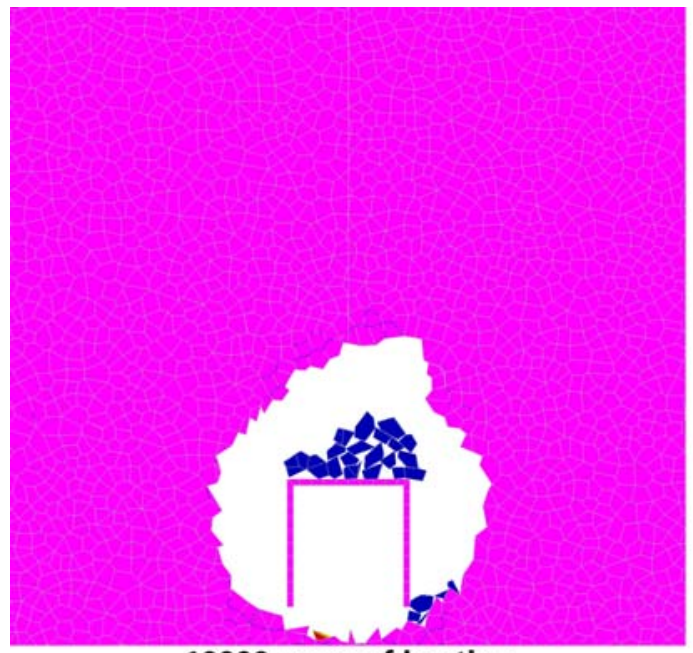

10000 years of heating

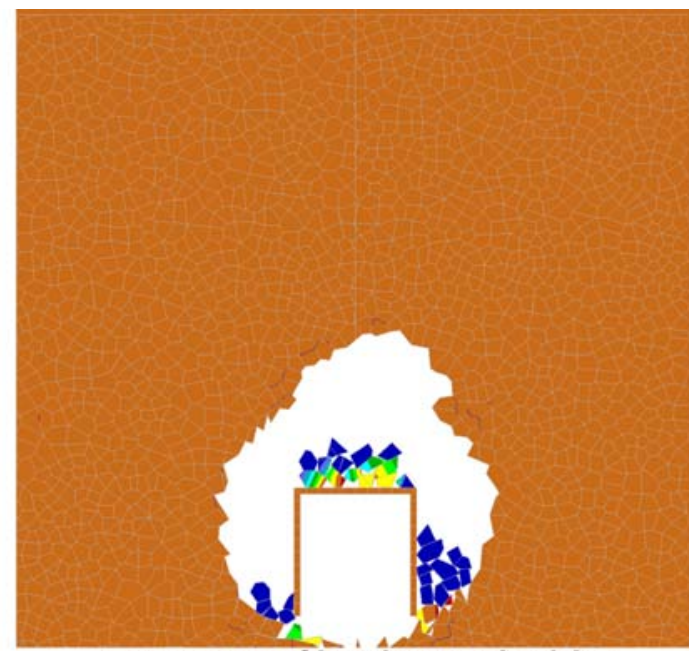

10000 years of heating + seismicity

NOTE: There is a residual, rigid body translation of the model at the end of dynamic simulation because the entire seismogram was not simulated.

Figure S-48. Effect of $1 \times 10^{-4}$ Ground Motion After 10,000 Years of Heating in Category 5: Contours of Displacement Magnitude ( $\mathrm{m}$ ) 


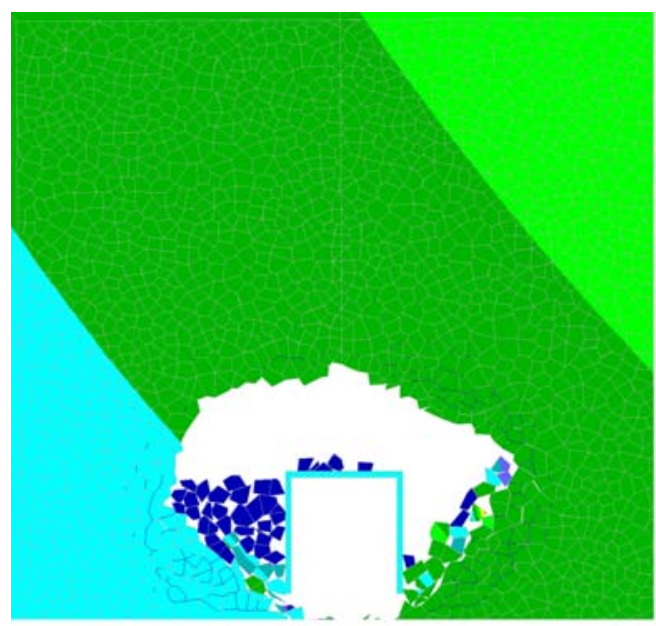

80 years of heating+repetitive seismicity

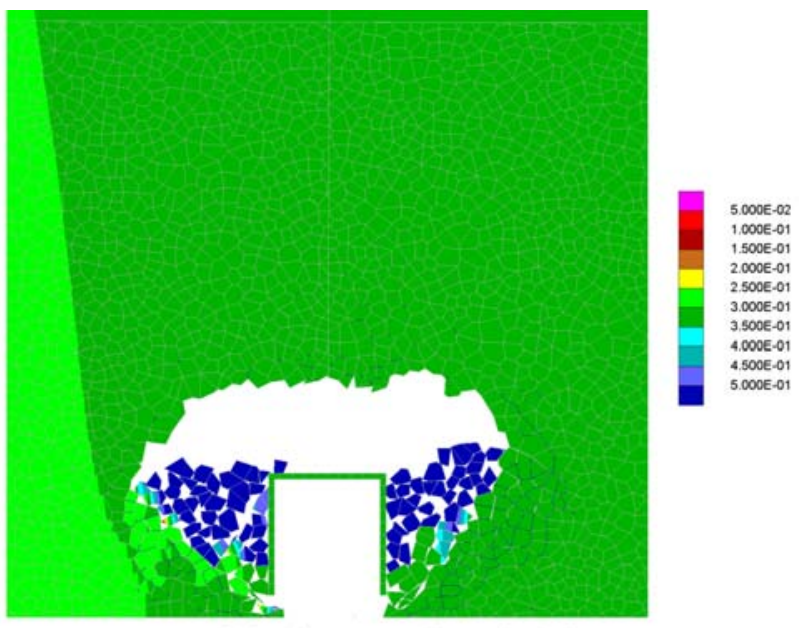

10,000 years of heating+repetitive seismicity

NOTE: There is a residual, rigid body translation of the model at the end of dynamic simulation since the entire seismogram was not simulated.

Figure S-49. Effect of Two Successive $1 \times 10^{-4}$ Ground Motions in Category 2: Contours of Displacement Magnitude (m)

\section{S4. CONSIDERATION OF SPATIAL VARIABILTY OF ROCK MASS STRENGTH}

The lithophysal rockfall modeling presented in Section S3 considers a constant rock property category throughout the model. In reality, the lithophysal rock mass can contain multiple rock property categories within a 5 to 10 meter zone (see Section 7.3.2). The use of a constant rock property category throughout the rockfall model bounds the rockfall response since the poorest quality category (categories 1 and 2) will likely contain areas of higher quality rock, and therefore, the rockfall models for these categories will produce conservative (i.e., higher) predictions of drift damage and rockfall. Conversely, the highest quality category (category 5) will likely contain areas of poorer quality rock, and therefore, the rockfall model for this category may result in less damage and rockfall compared to actual conditions. A more realistic model of lithophysal rock mass conditions is described in this section, allowing for varied rock mass properties throughout the model. The results presented in this section supplement the analyses presented in Section S3 by providing a more realistic case for lithophysal drift degradation.

It is considered that the volume fraction of the lithophysae (referred to as porosity) is the only factor that controls mechanical properties of the lithophysal rock mass. The other factors certainly have an effect (e.g. jointing), but the volume fraction of the lithophysae is the most important. Therefore, the consideration is reasonable, while it considerably simplifies the task of establishing a correlation between the actual conditions of the rock mass and the mechanical properties used in the model. The correlation between the porosity and lithophysal rock mass categories from Table E-10 was used in the analysis.

The distribution of lithophysal porosity in the ECRB Cross-Drift is shown in Figure S-50. Spatial variation of porosity (developed in Appendix $\mathrm{T}$ ) was simulated inside a $50 \mathrm{~m} \times 50 \mathrm{~m} \times 40 \mathrm{~m}$ volume. The simulated porosity, shown in Figure S-51, varies between 5 percent and 30 percent throughout the simulated region. The analysis was conducted using a 
two-dimensional model for three different cross-sections and locations of the drift center within the simulated volume. Normal to the cross-section plane is always in the direction of the $y$-axis. The coordinates of the drift center (relative to the coordinate system shown in Figure S-51) are: a) Section $1, x=25 \mathrm{~m}, \mathrm{y}=5 \mathrm{~m}, \mathrm{z}=37.5 \mathrm{~m}$; b) Section $2, \mathrm{x}=25 \mathrm{~m}, \mathrm{y}=10 \mathrm{~m}, \mathrm{z}=37.5 \mathrm{~m}$; and c) Section $3, x=25 \mathrm{~m}, \mathrm{y}=5 \mathrm{~m}, \mathrm{z}=25 \mathrm{~m}$. Sections 1 and 2 are located in a region of the simulated volume with a large average porosity, while the third section is located in a region with a medium average porosity. The analysis has shown that there is no significant variability of the rockfall for different cross-sections throughout the simulated volume. Consequently, the use of a two-dimensional model is justified for the assessment of rockfall for a drift located in the lithophysal rock mass, accounting for actual variability of porosity and mechanical properties.

The porosity is interpolated in the centers of zones and joints of the UDEC model. Using the relations between porosity and rock mass categories (Table E-10) and between the rock mass categories and UDEC micro-properties (Table 6-43), variable properties of the blocks (bulk and shear moduli) and the joints (normal and shear stiffness, cohesion and tensile strength) are generated. Variability of block bulk modulus for Section 1 is shown in Figure S-52.

The results of the simulation for the thermal load combined with time-dependent strength degradation for Section 1 are shown in Figure S-53. The rockfall is very similar to the rockfall predicted for category 3, considering homogeneous rock mass properties, shown in Figure S-43. This is an expected result because the average properties for Section 1 are similar to category 3 rock mass properties.

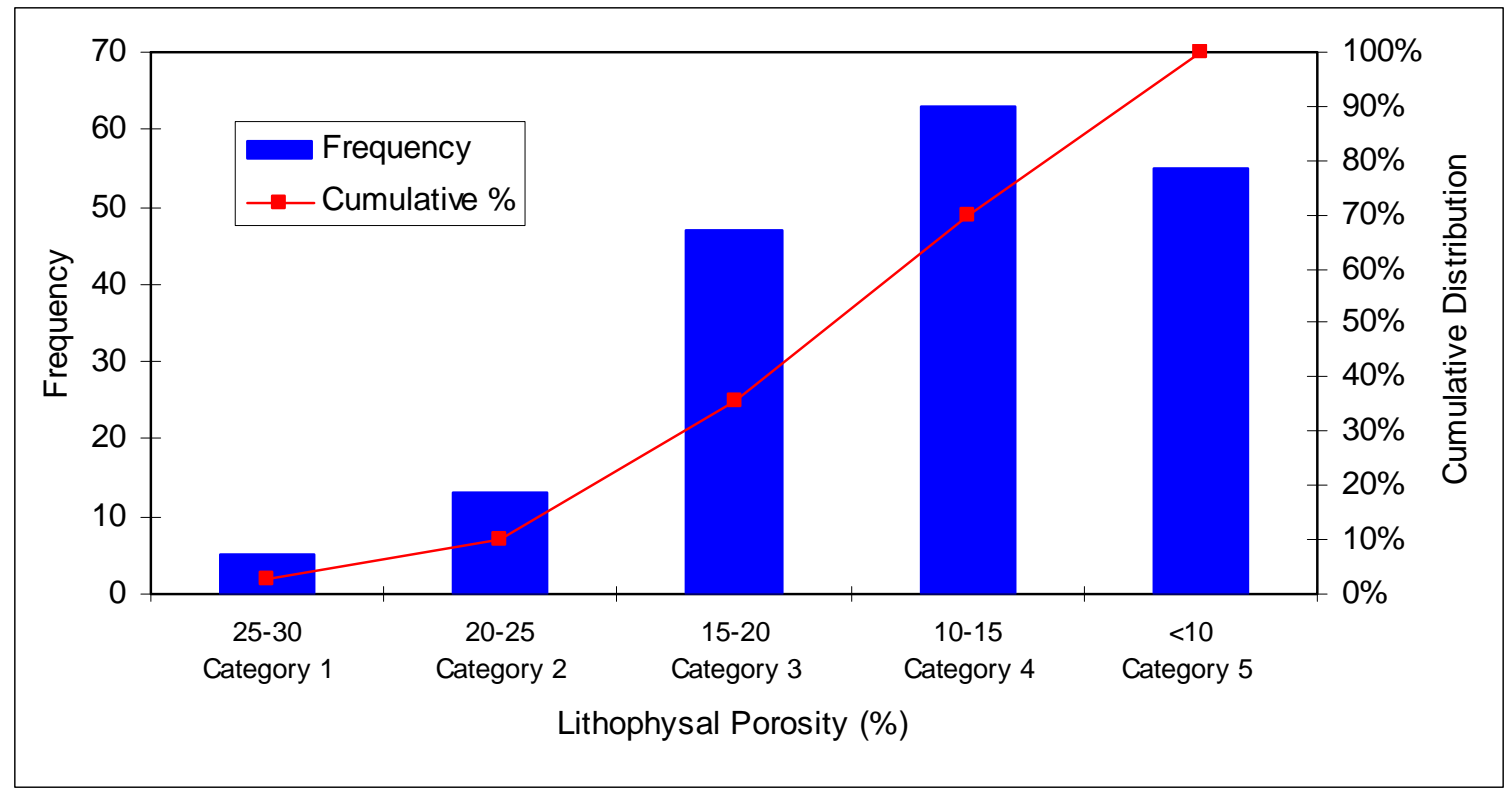

NOTE: Lithophysal porosity data are from ECRB Cross-Drift station 14+44 to 23+26 (Appendix O and Section O6.6; see Microsoft Excel file, Drift Deg AMR AF T-A-P Fit.xls, worksheet "Volume Percent - Stats", which can accessed through the TDMS using DTN: MO0408MWDDDMIO.002).

Figure S-50. Distribution of Lithophysal Porosity in the ECRB Cross-Drift 

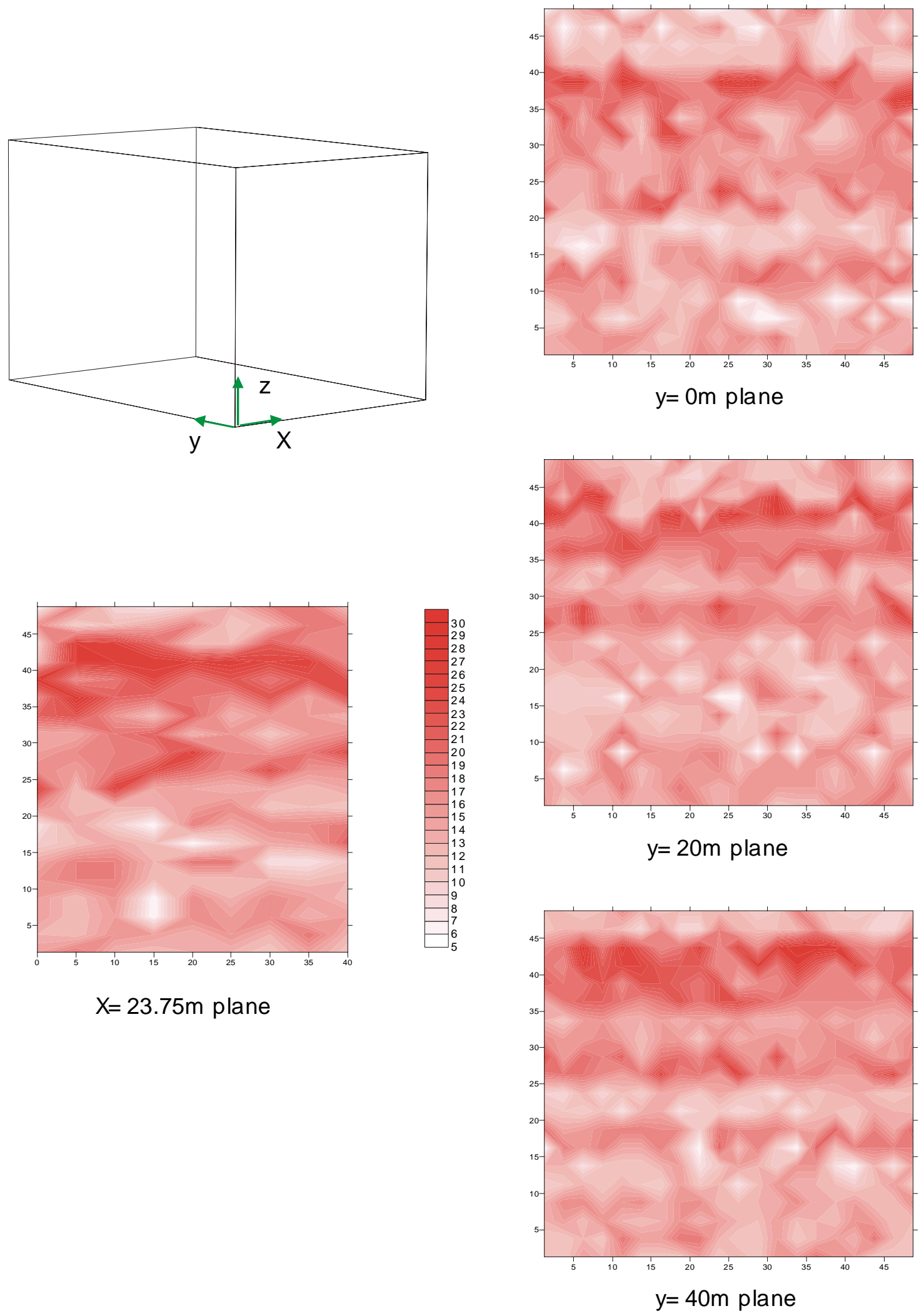

$X=23.75 \mathrm{~m}$ plane

Figure S-51. Porosity Contours in Cross-Sections Through the 3D Simulated Porosity Field 


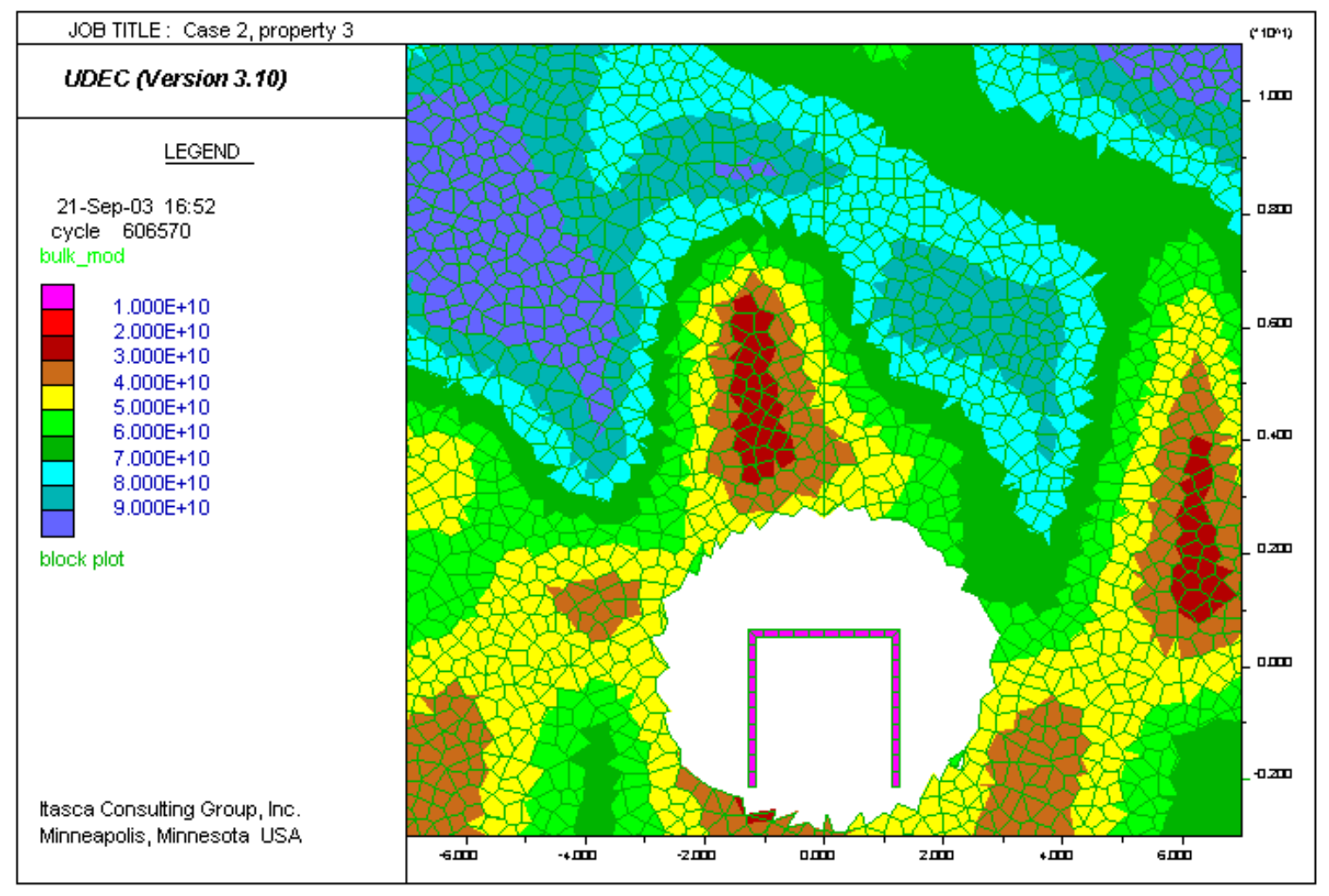

Figure S-52. Distribution of Block Bulk Modulus for Section 1 


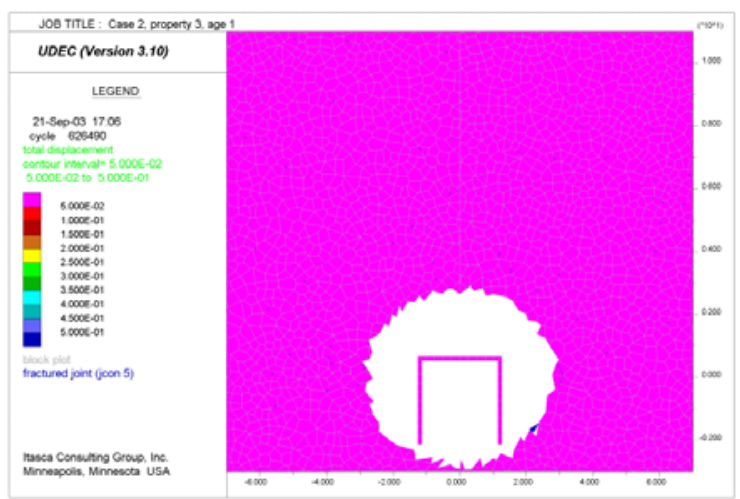

1 year

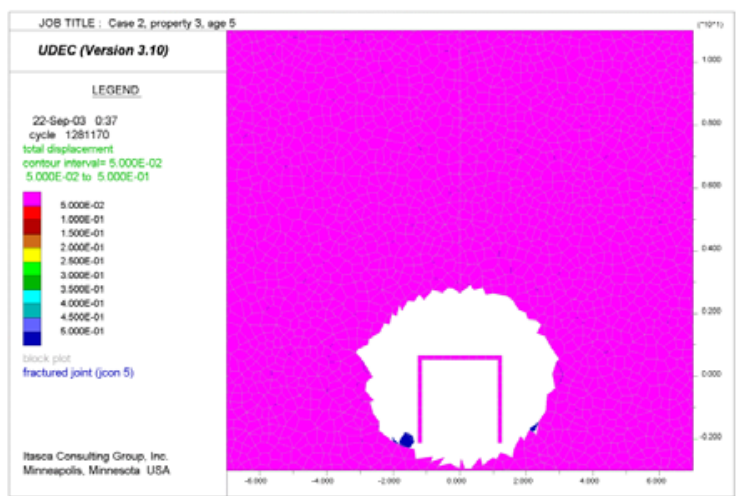

5 years

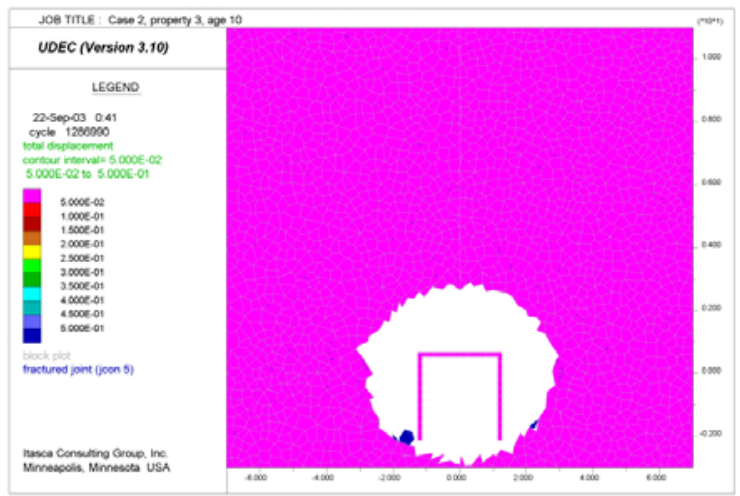

10 years

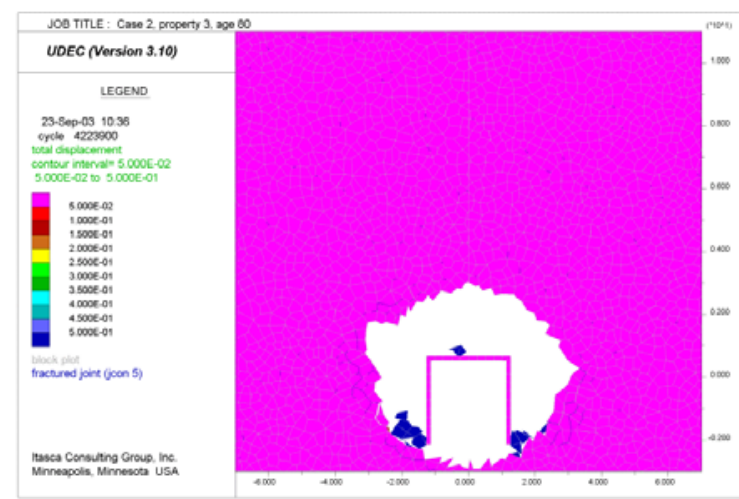

80 years

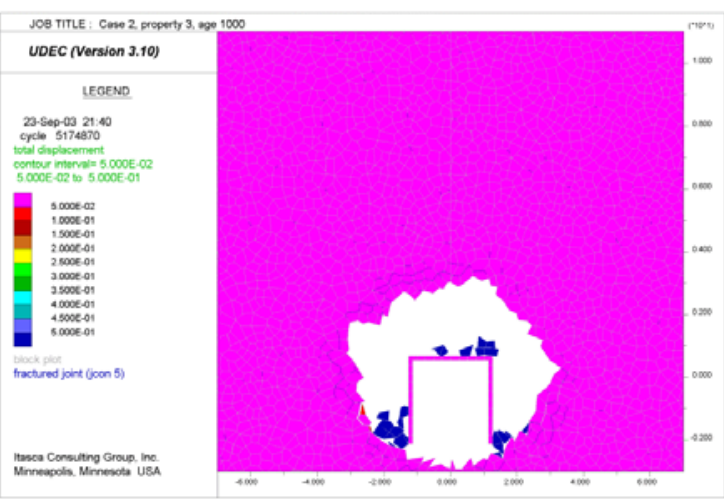

1000 years

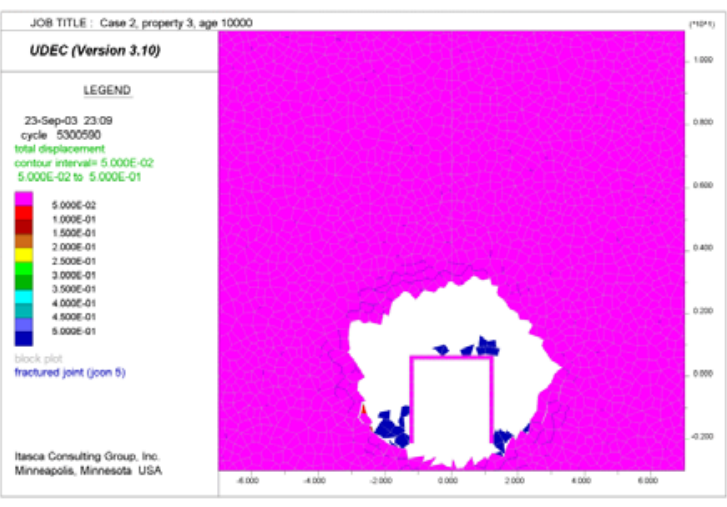

10000 years

Figure S-53. Evolution of Damage Due to Strength Degradation and Thermal Load for Spatially Variable Properties, Section 1 - Tuff Best-Fit Static-Fatigue Curve

\section{S5. VALIDATION OF THE MODELING APPROACH}

As one means of validating the PFC stress corrosion modeling approach for estimating long-term damage formation surrounding the ECRB Cross-Drift, two independent technical reviews were conducted using experts in the field of rock mechanics testing (see Section 7.5.2.3). 
The first independent technical review is provided by Dr. Jaak Daemen, Professor of Mining Engineering and Department Chair at the University of Nevada, Reno. Dr. Daemen received his Ph.D. in Geological Engineering from the University of Minnesota where his research involved development of the analytical and numerical solutions for ground support - rock mass interaction. He worked for DuPont in development of ground support products prior to joining the University of Arizona, Department of Geological Engineering. Dr. Daemen's current research involves time-dependent testing of joints and intact tuff from the Yucca Mountain nuclear waste disposal site.

The second independent technical review is provided by Mr. Ronald Price and Dr. Randolph Martin. Mr. Price is a Senior Member of Technical Staff at Sandia National Laboratories. He has a M.S. in Geology from the Center for Tectonophysics at Texas A\&M University, where his thesis research was entitled, "Effects of Anhydrite and Pressure on the Mechanical Behavior of Synthetic Rocksalt". Since his arrival at Sandia in 1980, Mr. Price has planned, carried out and published results from laboratory studies on many different rock types and for many applications. He has, however, had a central focus on the mechanical properties of tuffs, with special emphasis on Yucca Mountain tuffs, for over 22 years. His depth of knowledge of tuff rheological properties is particularly valuable for the present application. Dr. Martin is the President of and Principal Scientist at New England Research, Inc. in White River Junction, Vermont. He has a Ph.D. from MIT, where his thesis research was entitled, "Time-Dependent Crack Growth in Quartz and Its Application to the Creep of Rocks." Dr. Martin has a wide range of experience managing and performing both field and laboratory rock mechanics projects, including designing/building high-pressure equipment, testing rocks at elevated pressures and temperatures, and analyzing data with various (e.g. empirical, analytical, and numerical) techniques. His seminal work in the area of static fatigue makes him particularly valuable in the review of this material.

\section{S5.1 OBJECTIVE AND SCOPE OF THE INDEPENDENT TECHNICAL REVIEW}

The technical review is limited to documentation on the validity of the PFC stress corrosion modeling approach applied to the rockfall models (i.e., draft documentation of this appendix). While the time of failure presented in the damage curves (Figures S-28 and S-29) is based on laboratory measurements, the shape of the curve as a function of time is determined from the PFC stress corrosion model, and has not been validated by test data. To assess the validity of the PFC stress corrosion model, the technical review addresses the following items:

- Provide an assessment of the bi-linear shapes of these damage curves to determine if they are reasonable and consistent with observations and measurements of static fatigue failure of rock specimens.

- Provide a discussion of the validity of the static-fatigue curves and the damage curves used as input to the UDEC analyses (Figures S-27 through S-29).

- Provide a discussion of the validity of the results (i.e., the predictions of drift degradation as a function of time-dependent strength degradation) produced by the UDEC rockfall model (Section S3.4.1). 


\section{S5.2 REVIEW CRITERIA}

The following criteria are used when reviewing the documentation on the validity of the PFC stress corrosion modeling approach:

- Is this information presented accurately using applicable methods, assumptions, and recognized techniques?

- Does existing model documentation provide adequate confidence required by the model's relative importance to the potential performance of the repository system to support model validation for its intended purpose and stated limitations?

\section{S5.3 INDEPENDENT TECHNICAL REVIEW \#1}

The review from Dr. Jaak Daemen is provided in this section.

This appendix presents a powerful analysis of potential time-dependent drift deterioration. The analysis is based on a convincing fundamental model of rock strength deterioration over time. The results provide considerable insight into what might be expected with regard to time-dependent drift deterioration.

While the strategy developed in this appendix is very convincing, the significance of specific results is less so, because of the lack of experimental input data, as recognized by the authors.

The shape of the bi-linear damage curves is eminently reasonable. However, the presentation of the sensitivity analysis (Section S3.2) and its implementation and results (Figure S-31) is exceedingly brief. It would help if this discussion could be expanded, could provide a bit more detail. The most convincing support for the damage curves is the "calibration" of the results based on the ESF and ECRB observations (Section S3.4.1).

The results are eminently reasonable, and provide significant insight into the likely drift degradation mechanisms and time frame. Although, as the report recognizes, there is considerable input data uncertainty, the sensitivity analyses performed give considerable confidence that the results are good predictors of likely drift degradation.

The information presented appears accurate, and the analysis uses applicable models, assumptions, and recognized techniques.

The model documentation provides adequate confidence about the potential repository system component performance, and will support model validation. Limitations associated with the model, in particular with regard to the paucity of experimental input data, are clearly identified. 


\section{S5.4 INDEPENDENT TECHNICAL REVIEW \#2}

The review from Mr. Ronald Price and Dr. Randolph Martin is provided in this section.

This manuscript contains two sections. First, analysis of the time-dependent behavior of intact rocks on specimens using the PFC and second, a model incorporating the time-dependent strength of tuff into long-term strength of the roof and rock fall in the repository.

In general, the paper presents a good representation of the behavior of intact rock samples and how that might be used to predict long-term rock properties especially strength. The approach used in these models has been developed on other projects. Several modifications were made to the models to accommodate the strong porosity dependence of rock properties measured at the laboratory scale.

The PFC is used to model the time-dependent strain (creep) and the time-dependent strength (static fatigue) observed in laboratory measurements. The flexibility of the PFC model allows incorporation of (1) large-scale porosity in the sample and (2) time-dependent properties in the matrix bonds to adequately represent time-dependent processes in the bulk rock.

The approach used here has been successfully applied in Canada for granitic rocks. The model is calibrated with available rock properties measurements both in situ and in the laboratory. By tying the model to existing data, they were able to represent the behavior of the material and in particular its time-dependent properties reasonably well.

The PFC is a representation of the gross behavior of rock and does not provide insight into the physical processes leading to deformation or failure in the tuffs. However, in most codes this is the case and probably should not be considered as a serious defect in the model. What is needed to fully validate the model is additional in situ and laboratory data to check the predictive capability of the PFC.

The time-dependent deformation and failure results of the particle flow code are incorporated into the analysis of roof collapse. The approach that they used is clearly presented and is a reasonable for the long-term performance of the roof in the repository.

Again, as with the PFC, as additional measurements on time-dependent behavior and in situ strength become available, these data will be incorporated into the model to further refine the predictions.

Another suggestion is that they consider referring to some of the historical data on the long-term performance of existing tunnels. There is sufficient experience over the years on numerous mines in a variety of rocks that have been subjected to elevated temperatures (especially deep mines in South Africa). Sufficient 
measurements have been made in some cases so that time-dependent changes can be used to bound the parameters in the model. No reference has been made as yet to such historical data in the report. It seems prudent that in order to demonstrate the models are valid and that the long-term predictions are defensible, these must be considered.

\section{S6. CONCLUSIONS}

Time-dependent drift stability for unsupported emplacement drifts is predicted. Time-dependent strength degradation under an in-situ stress state was combined with thermal or seismic loading conditions expected during the regulatory period. Predictions are based on two sets of data: a) test results obtained for Lac du Bonnet granite, and b) test results obtained for nonlithophysal tuff.

The effect of lithophysae on time-to-failure is investigated using the PFC stress corrosion model. The time-dependent parameters of the model were selected to match a straight-line fit to the Lac du Bonnet granite static-fatigue curve. Voids (corresponding to lithophysal porosity) were then generated in the synthetic material, which was numerically tested again to generate static-fatigue curves for lithophysal rock with different percentages of lithophysal porosity. The analysis showed that lithophysal porosity does affect the static-fatigue curves. As a function of porosity, the straight-line fits are offset slightly relative to one another, but have the same slope. The variability is not significant and for the purposes of this application, considering uncertainties in the analysis, it was justified to consider that lithophysal porosity does not affect the static-fatigue curve when the driving stress is normalized with the short-term strength of the rock mass. Considering the stress in the absolute form, the lithophysal porosity has a significant effect on the time-to-failure.

The evolution of damage due to strength degradation for different levels of driving-stress ratio was studied using the PFC stress corrosion model. At different stages during the numerical simulation of static-fatigue tests, samples were loaded in compression (at $0.1 \mathrm{MPa}$ confinement) to failure. These numerical tests indicate that damage increases gradually, at a very slow rate, until a relatively short time before time-to-failure for a given driving stress, when damage quickly increases, resulting in the sample failure.

Analysis of drift stability was carried out using the UDEC model in which the rock mass was represented as an assembly of Voronoi blocks. The cohesive strength of the synthetic material decays as a function of time according to the input static-fatigue lines and curves of damage evolution under the different levels of sustained load as a function of time. Predictions of the rockfall are not sensitive to variation of the damage rate (before the time-to-failure) within the range of rates predicted by the PFC stress corrosion model. The most important model parameter for rockfall predictions is time-to-failure as a function of the driving stress.

Model prediction for different categories (1 through 5) of rock mass quality, combined with different static-fatigue lines were compared with observations from the ESF and ECRB. The drifts have been open between 5 and 12 years and no indication of their time-dependent deterioration has been observed yet (note that the drifts are supported with bolts and wire mesh in the roof only). Comparison of the model predictions of drift behavior after 5 and 10 years 
with underground observation led to the following conclusions: a) rock mass category 1 for tuff as a homogeneous medium around the drifts underestimates the strength of the poorest quality lithophysal rock mass, b) Lac du Bonnet static-fatigue lines are inconsistent with tunnel behavior, leading to some rockfall after 10 years for all rock mass categories, and c) the poorest quality rock mass can be represented as rock mass category 2 with the tuff best-fit static-fatigue curve. It appears that the tuff best-fit static-fatigue lines are in the best agreement with both observations of tunnel performance and the results from short-term tests on the lithophysal rock mass. Further analysis was carried out using the tuff best-fit static-fatigue line only.

The best-fit tuff static fatigue line implies that a driving-stress ratio of approximately 0.60 results in approximately 20,000 years time-to-failure (see the tuff $\left[P_{c}=0\right]$ best-fit curve in Figure S-26), indicating there will be an approximate 40 percent cohesive strength reduction in 20,000 years. The drift profile for a 40 percent cohesive strength reduction case (i.e., 60 percent cohesive strength) was initially determined as shown in Figure 6-171c for category 1. Note that Figure 6-171c is similar to the category 1 profile in Figure S-41. Considering only time-dependent strength degradation, it is clear that the 60 percent through 100 percent strength reduction cases (Figures 6-171d, 6-171e, and 6-171f) do not occur within the first 20,000 years of the postclosure period.

A combination of the thermally induced stresses with time-dependent strength degradation results in more rockfall than predicted for each of the loading conditions independently. Most rockfall, which is a result of deterioration of the walls, occurs for category 2 . However, this poor quality rock accounts for only a small percentage (i.e., approximately 10 percent as shown in Figure S-50) of the total lithophysal rock mass in the emplacement drifts. Also, the combination of thermally induced stresses with time-dependent strength degradation does not increase rockfall significantly over a period of 10,000 years, as shown by comparing Figures S-38 and S-42. Note that while thermal stresses were not analyzed for the period from 10,000 years to 20,000 years, it can be inferred that the thermal impacts will be minimal during this period, since the temperature during this period has returned to near ambient, as shown in Section 6.2. Therefore, for the nominal case (i.e., considering thermal and time-dependent effects, but excluding seismic effects), the expected drift profiles after 20,000 years are adequately represented by Figures S-41 through S-44. As rock mass quality increases, there is less rockfall from the walls and more rockfall from the drift roof (Figure S-44). Better quality rock mass is stiffer, resulting in larger thermal stresses in the roof.

Postclosure seismic ground motion with a $1 \times 10^{-6}$ probability of annual occurrence results in complete drift collapse, with the geometry of the collapsed drift unchanged from the previous results (see Section 6.4.2.2). To analyze the coupled effects of seismic load, thermal load, and time-dependent strength degradation, seismic loading by a preclosure ground motion with a $1 \times 10^{-4}$ probability of annual occurrence was considered at two stages during the regulatory period (accounting for damage and rockfall due to thermal load history and time-dependent strength degradation): 80 years after waste emplacement, when thermally-induced stresses are maximum and 10,000 years after waste emplacement, which is the worst-case condition (during the regulatory period) of time-dependent strength degradation. Preclosure seismic ground motion causes an additional, but not significant, rockfall, which comes as a result of shaking down already loose, broken ground. 
Damage to the host rock is not significantly accumulating from multiple $1 \times 10^{-4}$ probability of annual occurrence ground motions. That is, the $1 \times 10^{-4}$ seismic event is shaking loose rock fragments that have already failed by strength degradation and thermal stress; no new fractures and failures are caused by this low amplitude ground motion, either at 80 years when thermal stress is at its peak or at 10,000 years, when long-term strength degradation has occurred. Lack of new damage is also anticipated for more probable seismic events, such as $5 \times 10^{-4}$ or $1 \times 10^{-3}$ probability of annual occurrence ground motions, because they have smaller amplitudes than the $1 \times 10^{-4}$ probability of annual occurrence ground motion.

Most of the analyses were carried out for different rock mass categories, but considering homogeneous properties throughout the model. Mechanical properties of the lithophysal rock mass are variable as a function of the position within the lithophysal unit. There is concern that homogeneous models do not properly represent the mechanical behavior of a heterogeneous rock mass. A mechanical model (with variable properties) of drift stability was generated corresponding to porosity fields obtained from the cross-sections through a three-dimensional model of the lithophysal porosity, which is considered to be the factor controlling the quality of the rock mass. There is no significant variability in rockfall predictions from one cross-section to another. Also, the rockfall predictions are very similar to those obtained for rock mass category 3 .

The presented analysis deals with time-dependent drift degradation explicitly relating the rockfall predictions to a specific time. The analysis uses the existing information about the time-dependent behavior of tuff (static-fatigue tests), and behavior of the existing drifts (ESF and ECRB) over time. However, there is still a significant level of uncertainty in the predictions, because they are obtained by extrapolation of the test results and observations on short time-scales (maximum 10 years) to very long time-scales $(10,000$ years). 


\section{INTENTIONALLY LEFT BLANK}


APPENDIX T

SIMULATION OF LITHOPHYSAL POROSITY SPATIAL VARIATION 


\section{SIMULATION OF LITHOPHYSAL POROSITY SPATIAL VARIATION}

\section{T1. INTRODUCTION}

To assist in modeling the spatial variability of mechanical properties in two and three dimensions for areas and volumes surrounding tunnels, a simple method of projecting the two-dimensional distribution of lithophysal cavity porosity has been developed. The calculation described in this appendix is for rock in the lower lithophysal zone of the Topopah Spring Tuff (Tptpll), and it is based on the data from the ECRB Cross-Drift (see Appendix O). The ECRB Cross-Drift data represents one of the best and detailed distributions of lithophysal cavity porosity available, so these data are projected to a vertical simulated cross section that is perpendicular to the ECRB Cross-Drift. Once the spatial variation of the lithophysal cavity porosity has been determined for areas and volumes surrounding the tunnels, correlation equations for the porosity to unconfined compressive strength and Young's Modulus can be used distribute the elastic properties and material strength (see Appendix E, Table E-10).

Four steps are used for projecting and distributing lithophysal cavity porosity in a tunnel (such as the ECRB Cross-Drift) into a two-dimensional cross section that is perpendicular to the tunnel. A simplified summary of these four steps is described below and in Figure T-1, with a detailed explanation (with specific examples) provided in Section T6.

- Step 1. Lithophysal cavity porosity values are projected along the apparent dip of the lithostratigraphic unit to a vertical line that is perpendicular to the tunnel (Figure T-1a), and this vertical line forms the center of the cross section. For simplicity, only the values that project to the top and bottom of the vertical line are depicted (Figure T-1a), but each point along the tunnel can be projected along the same apparent dip.

- Step 2. The vertical line is divided into a series of sections or horizons, and these sections are projected along the apparent dip to form stratigraphically equivalent "windows" along the tunnel (Figure T-1b).

- Step 3. The distribution of values and descriptive statistics, for example mean and standard deviation, are determined for each "window", and these statistics are imparted to the correlative section on the vertical line (Figure T-1c).

- $\quad$ Step 4. Descriptive statistics for each section on the vertical line are propagated along a horizon across the cross section (Figure T-1d).

\section{T2. INPUT DATA}

The data required for the projection of lithophysal cavity porosity in a vertical cross section include (1) the distribution of the lithophysal cavity porosity along the ECRB Cross-Drift (Appendix O) and (2) the strike and dip of the top of the Tptpll in the ECRB Cross-Drift (Mongano et al. 1999 [DIRS 149850], Table 1). 
(a)

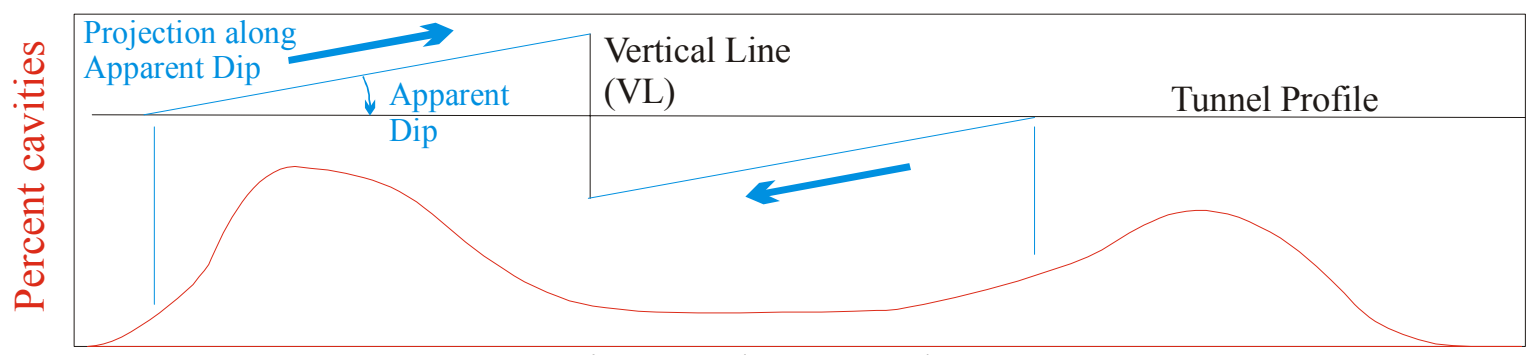

Distance along tunnel

(b)

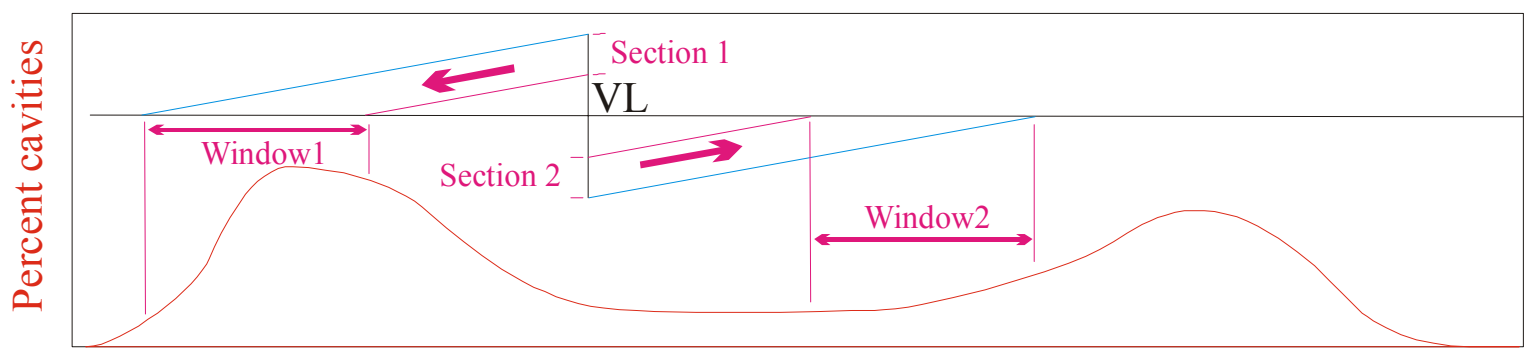

Distance along tunnel

(c)

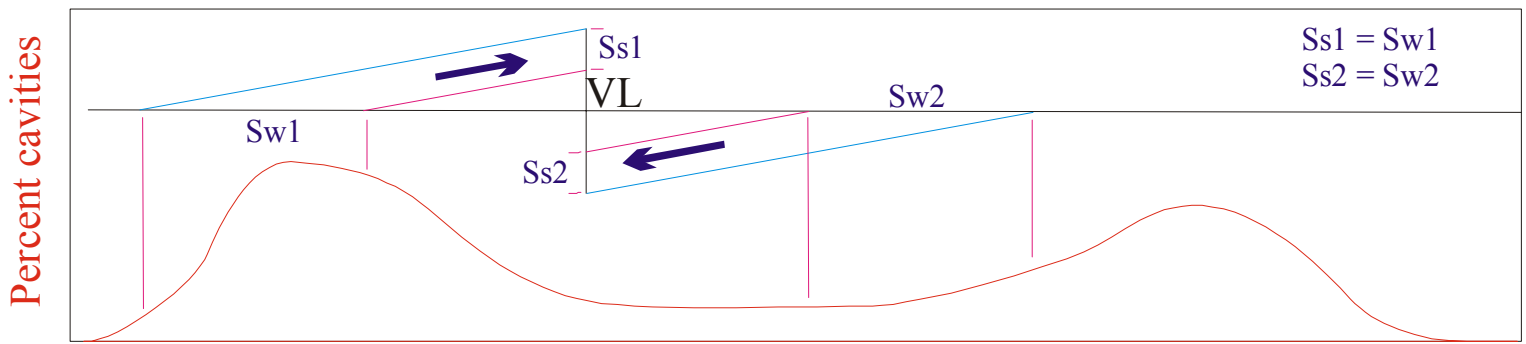

Distance along tunnel

(d)

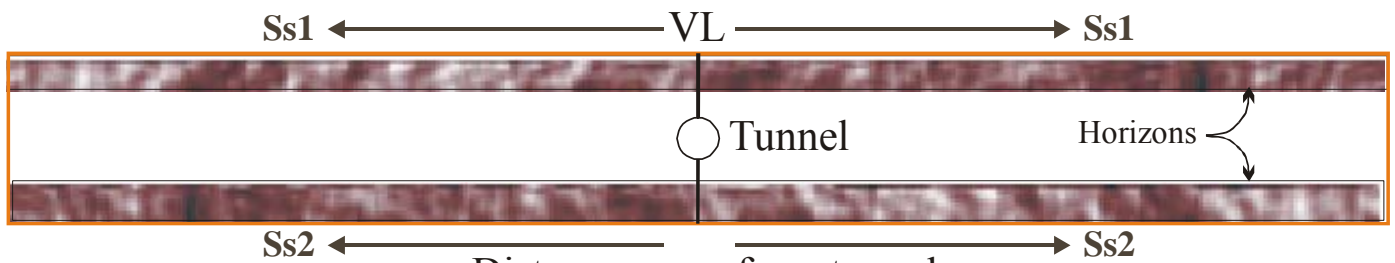

Distance away from tunnel

Figure T-1. Simplified Steps for Projecting and Distributing Lithophysal Cavity Porosity Values in a Tunnel Into a Two-Dimensional Cross Section

\section{T3. SOFTWARE USED IN THE CALCULATIONS}

The input data, intermediate calculations, and results of the assessment of the distribution of lithophysal cavity porosity are stored and implemented in the Microsoft Excel file, Lithophysal projection to vertical plane.xls (DTN: MO0408MWDDDMIO.002). The transfers of values, calculations, logic functions, and descriptive statistics are done with standard functions in Excel. There are three small macros embedded in the Excel file, named "Prop_Distribute," "Contour_Text," and "Contour_Fill." These macros are exempt from the qualification 
requirements of LP-SI.11Q-BSC, Software Management, since they are used solely for visual display of data:

A. The "Prop_Distribute" macro is an automated "copy and paste" function that takes the distributed values in a large $(10 \times 184$ cell) "5 m window" table and makes a small $(10 \times 29$ cell) "compacted" table of the values.

B. The "Contour_Text" and "Contour_Fill" macros are basically the same and they simply change the format of the values or cells (but not the values themselves) in the $50 \times 200$ and $20 \times 80$ cell tables. The difference between these two macros is that one ("Contour_Text") colors the text (i.e., values), and the other ("Contour_Fill") changes the fill color of the cell and the color of the text (i.e., values).

C. Confirmation that the macros are operating correctly can be made with simple visual comparisons of the large and small tables for the "Prop_Distribute" macro, and the input data table with the $50 \times 200$ and $20 \times 80$ cell tables for the "Contour_Text" and "Contour_Fill" macros.

\section{T4. GEOMETRIC RELATIONS AND CONDITIONS IN THE CALCULATION}

Calculations of the distributed lithophysal cavity porosity in a vertical plane are based on six fundamental lithostratigraphic and geometric relations and conditions:

A. Lithostratigraphic zones and subzones of the Topopah Spring Tuff are stratiform and are traceable across the repository area. However, some subzones might not occur across the entire repository area.

B. The ECRB Cross-Drift transects the Tptpll as a shallowly inclined tunnel. Therefore, lithophysal cavity data represents vertical (and to some amount horizontal) variations in the lithostratigraphic features.

C. Lateral continuity of variations in lithophysal cavity porosity in the tunnel is projected along the apparent dip of the Tptpll (and lithostratigraphic features) to a vertical line that is perpendicular to the tunnel.

D. The vertical line is divided into $5 \mathrm{~m}$ tall horizons, and these horizons are projected along the apparent dip to the tunnel to form a series of "windows" along the tunnel.

E. Each $5 \mathrm{~m}$ horizon along the vertical line contains the potential variability in porosity in their respective "window" along the tunnel.

F. The statistical variation in porosity in each $5 \mathrm{~m}$ tall horizon is projected away from the tunnel along a vertical cross section that is perpendicular to the tunnel.

\section{T5. DETERMINATION OF THE APPARENT DIPS FOR INPUT}

The three-dimensional orientation of an inclined plane can be defined by a strike and dip, but an apparent dip is formed where the inclined plane intersects vertical planes along a section that is 
not at a right angle to the strike of the vertical plane. The strike is the angle from north of a horizontal line in the inclined plane, and the dip is the angle from horizontal measured in a vertical plane that is $90^{\circ}$ to the strike of the inclined plane. An apparent dip is the angle from the horizontal in a vertical plane of a line formed by the intersection of an inclined plane with the vertical plane.

An example of these geometric relations is illustrated in Figure T-2 with three planes. The inclined plane is the top contact of the Tptpll in the ECRB Cross-Drift and has a strike of $270^{\circ}$ (Mongano et al. 1999 [DIRS 149850], Table 1). The true dip is measured in a plane perpendicular to the strike of the inclined plane, and is illustrated with the $7^{\circ}$ dip. The ECRB Cross-Drift is contained in a vertical plane that has a strike of $229^{\circ}$. This strike is used because it is in the direction of the heading of the tunnel and in the area of the lithostratigraphic contact is in the direction of the inclination or plunge of the tunnel. A cross section perpendicular to the ECRB Cross-Drift forms a second vertical plane with a strike of $319^{\circ}$. The apparent dip of the lithophysal zone contact is $4.6^{\circ}$ to the northeast (NE) in the plane of the cross drift and $5.3^{\circ}$ to the northwest (NW) in the cross section perpendicular to the ECRB Cross-Drift. If another strike and dip were used, then the apparent dips will differ. For example, the top of the Tptpll in the ECRB Cross-Drift in the Geologic Framework Model (BSC 2004 [DIRS 170029]) has a strike and dip of $345^{\circ}$ and $5.8^{\circ}$, respectively. The apparent dips are $5.2^{\circ} \mathrm{NE}$ in the plane of the ECRB Cross-Drift and $2.5^{\circ} \mathrm{NW}$ in the plane perpendicular to the ECRB Cross-Drift.

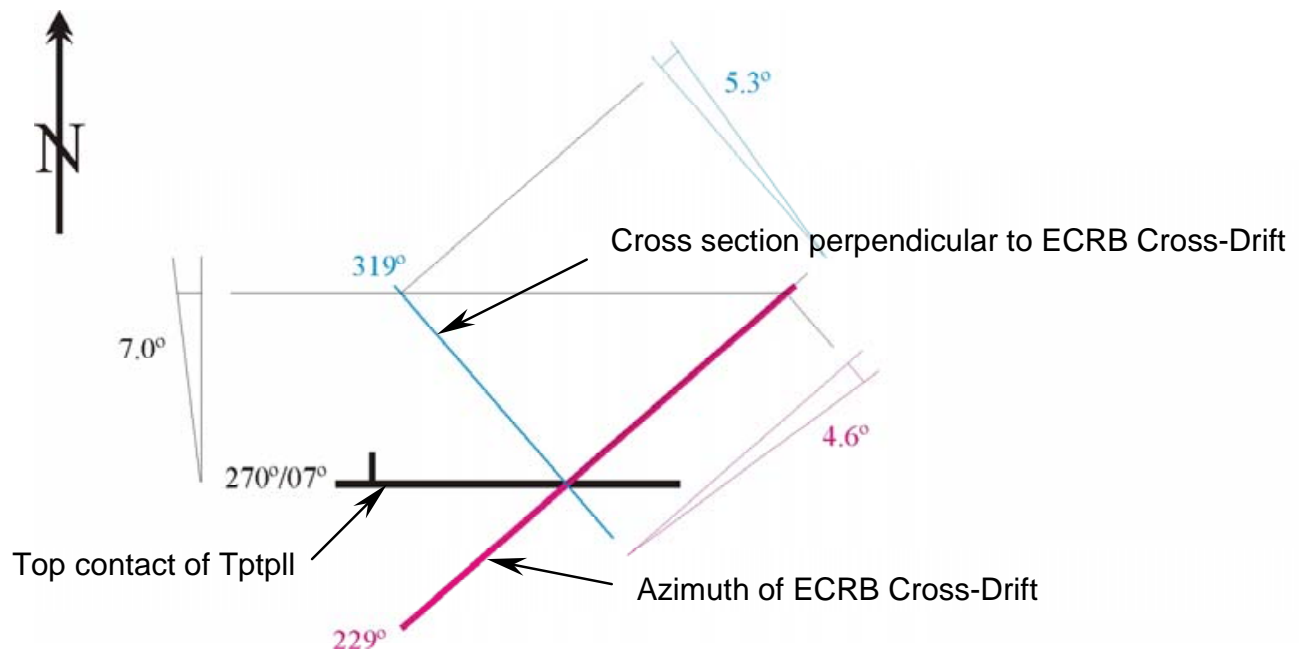

NOTE: The orientation of the Tptpll contact and the ECRB Cross-Drift is based on Mongano et al. (1999 [DIRS 149850]). The ECRB Cross-Drift is considered to be horizontal.

Figure T-2. Geometric Relations of Strike and Dip and the Apparent Dips in Cross Sections Parallel and Perpendicular to the ECRB Cross-Drift

\section{T6. DISTRIBUTION OF LITHOPHYSAL CAVITY POROSITY IN THE ECRB CROSS-DRIFT AND SIMULATED VERTICAL CROSS SECTION}

The stratiform geometry of the zones in the Topopah Spring Tuff occur throughout the repository area (Buesch et al. 1996 [DIRS 100106] and Buesch et al. 1996 [DIRS 101202], BSC 2004 [DIRS 170029]) as do many of the subzones such as the subzones of the Tptpmn (Buesch et al. 1996 [DIRS 100106], Buesch and Spengler 1998 [DIRS 101433]), although some subzones 
might not occur across the entire repository area (Buesch and Spengler 1998 [DIRS 101433]). Variations in the orientation of lithostratigraphic contacts (Mongano et al. 1999 [DIRS 149850]) and the abundance (and percent) of lithostratigraphic features in the lower lithophysal zone, including lithophysal cavity porosity (Appendix O), are consistent with the ECRB Cross-Drift transecting a dipping lithostratigraphic section (Figure T-2). The lower lithophysal zone has not been divided into subzones, but the variations in features including the lithophysal cavity porosity are consistent with identification of 5 to 12 subzones (Figure T-3).

The lateral continuity of lithostratigraphic features, and the projection of these features along the apparent dip in the ECRB Cross-Drift, forms the principal component of creating a geologically informed calculation of the distribution of lithophysal cavity porosity in a vertical plane. Identification of a $50 \mathrm{~m}$ tall, vertical line (section) perpendicular to the tunnel is the first step in creation of the $50 \times 200 \mathrm{~m}$ cross section (Figure T-3). Based on the apparent dip, the top and bottom of the vertical section can represent rocks from several hundred meters away from the centerline of the section. For example, with a $5^{\circ}$ apparent dip, the equivalent rocks at the top and bottom of the vertical section are $286 \mathrm{~m}$ from the section (Figure T-3). With an apparent dip of $4.6^{\circ}$ (Figure T-2), the projection for the top and bottom of vertical section is $311 \mathrm{~m}$. This projection distance is consistent with the overall stratiform characteristics of the lithostratigraphic section.

The second step in creation of a cross section is to divide the vertical section into a series of $5 \mathrm{~m}$ tall sections or horizons. The projection along the apparent dip of the $5 \mathrm{~m}$ horizons result in a series of "windows" along the tunnel, and the position and length of each window results from the apparent dip. For example, with a $5^{\circ}$ apparent dip, the equivalent window for the top $5 \mathrm{~m}$ horizon is $57 \mathrm{~m}$ long (Figure T-3). Each window contains unique variations in the number of measurements and the distribution of lithophysal cavity porosity values (Table T-1 and Figure T-4).

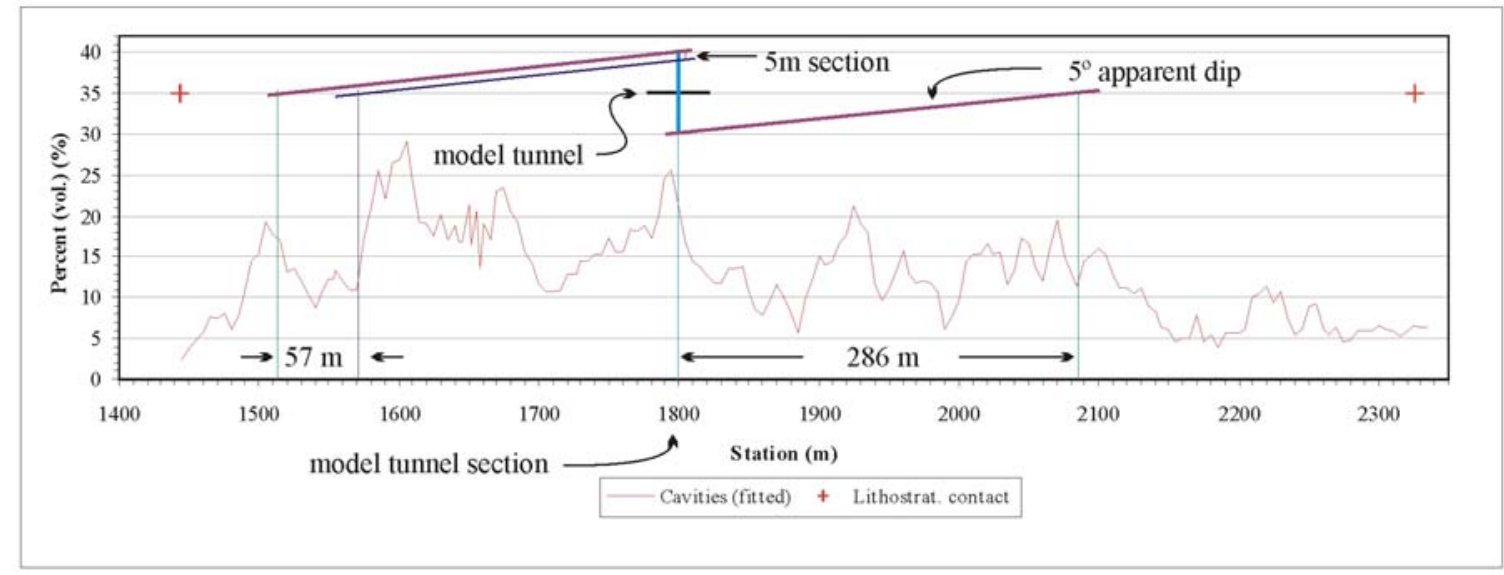

NOTE: The simulated cross section is at $1800 \mathrm{~m}$ with an apparent dip of $5^{\circ}$ for the stratiform features.

Figure T-3. Variation in Lithophysal Cavity Porosity Along the ECRB Cross-Drift and the Geometric Relations of Calculation Components 
Table T-1. Windows Containing Unique Variations of Lithophysal Cavity Porosity Values

\begin{tabular}{|c|c|c|c|c|c|}
\hline Station $(m)$ & Cavity "fitted" & $0-5$ Window & 5-10 Window & 10-15 Window & 15-20 Window \\
\hline 1445 & 2.5 & null & null & null & null \\
\hline 1450 & 3.8 & 3.8 & null & null & null \\
\hline 1455 & 4.7 & 4.7 & null & null & null \\
\hline 1460 & 5.7 & 5.7 & null & null & null \\
\hline 1465 & 7.6 & 7.6 & null & null & null \\
\hline 1470 & 7.4 & 7.4 & null & null & null \\
\hline 1475 & 8.2 & 8.2 & null & null & null \\
\hline 1480 & 6.0 & 6.0 & null & null & null \\
\hline 1485 & 7.9 & 7.9 & null & null & null \\
\hline 1490 & 10.6 & 10.6 & null & null & null \\
\hline 1495 & 14.4 & 14.4 & null & null & null \\
\hline 1500 & 15.3 & 15.3 & null & null & null \\
\hline 1505 & 19.4 & 19.4 & null & null & null \\
\hline 1510 & 17.7 & null & 17.7 & null & null \\
\hline 1515 & 17.0 & null & 17.0 & null & null \\
\hline 1520 & 13.2 & null & 13.2 & null & null \\
\hline 1525 & 13.6 & null & 13.6 & null & null \\
\hline 1530 & 12.1 & null & 12.1 & null & null \\
\hline 1535 & 10.2 & null & 10.2 & null & null \\
\hline 1540 & 8.8 & null & 8.8 & null & null \\
\hline 1545 & 11.0 & null & 11.0 & null & null \\
\hline 1550 & 12.2 & null & 12.2 & null & null \\
\hline 1552.8 & 12.2 & null & 12.2 & null & null \\
\hline 1555 & 13.4 & null & 13.4 & null & null \\
\hline 1560 & 12.0 & null & 12.0 & null & null \\
\hline 1565 & 11.0 & null & 11.0 & null & null \\
\hline 1570 & 11.0 & null & null & 11.0 & null \\
\hline 1575 & 17.2 & null & null & 17.2 & null \\
\hline 1580 & 21.0 & null & null & 21.0 & null \\
\hline 1585 & 25.6 & null & null & 25.6 & null \\
\hline 1590 & 22.1 & null & null & 22.1 & null \\
\hline 1595 & 26.5 & null & null & 26.5 & null \\
\hline 1600 & 26.9 & null & null & 26.9 & null \\
\hline 1605 & 29.2 & null & null & 29.2 & null \\
\hline 1610 & 24.6 & null & null & 24.6 & null \\
\hline 1615 & 19.3 & null & null & 19.3 & null \\
\hline 1620 & 19.0 & null & null & 19.0 & null \\
\hline 1625 & 17.4 & null & null & 17.4 & null \\
\hline
\end{tabular}


Table T-1. Windows Containing Unique Variations of Lithophysal Cavity Porosity Values (Continued)

\begin{tabular}{|c|c|c|c|c|c|}
\hline Station $(\mathbf{m})$ & Cavity "fitted" & $\mathbf{0 - 5}$ Window & $\mathbf{5 - 1 0}$ Window & $\mathbf{1 0 - 1 5}$ Window & $\mathbf{1 5 - 2 0}$ Window \\
\hline 1630 & 20.1 & null & null & 20.1 & null \\
\hline 1635 & 17.0 & null & null & null & 17.0 \\
\hline 1640 & 18.8 & null & null & null & 18.8 \\
\hline
\end{tabular}

NOTE: This table shows a portion of the lithophysal cavity porosity input data that are divided into windows representing $5 \mathrm{~m}$ tall horizons in the simulated cross section. The "Cavity (fitted)" column provides adjusted mapped lithophysal porosity values as described in Appendix O (Section O5). Porosity values for each window are depicted in Figure T-4. Data in the "Station (m)" and "Cavity (fitted)" columns are from Appendix O (Section 06.6; see Microsoft Excel file, Drift Deg AMR AF T-A-P Fit.xIs, worksheet "Volume Percent - Stats", which can accessed through the TDMS using DTN: MO0408MWDDDMIO.002). These data are for a calculation with a centerline of the simulated cross section at $1756 \mathrm{~m}$ and an apparent dip of $4.6^{\circ}$.

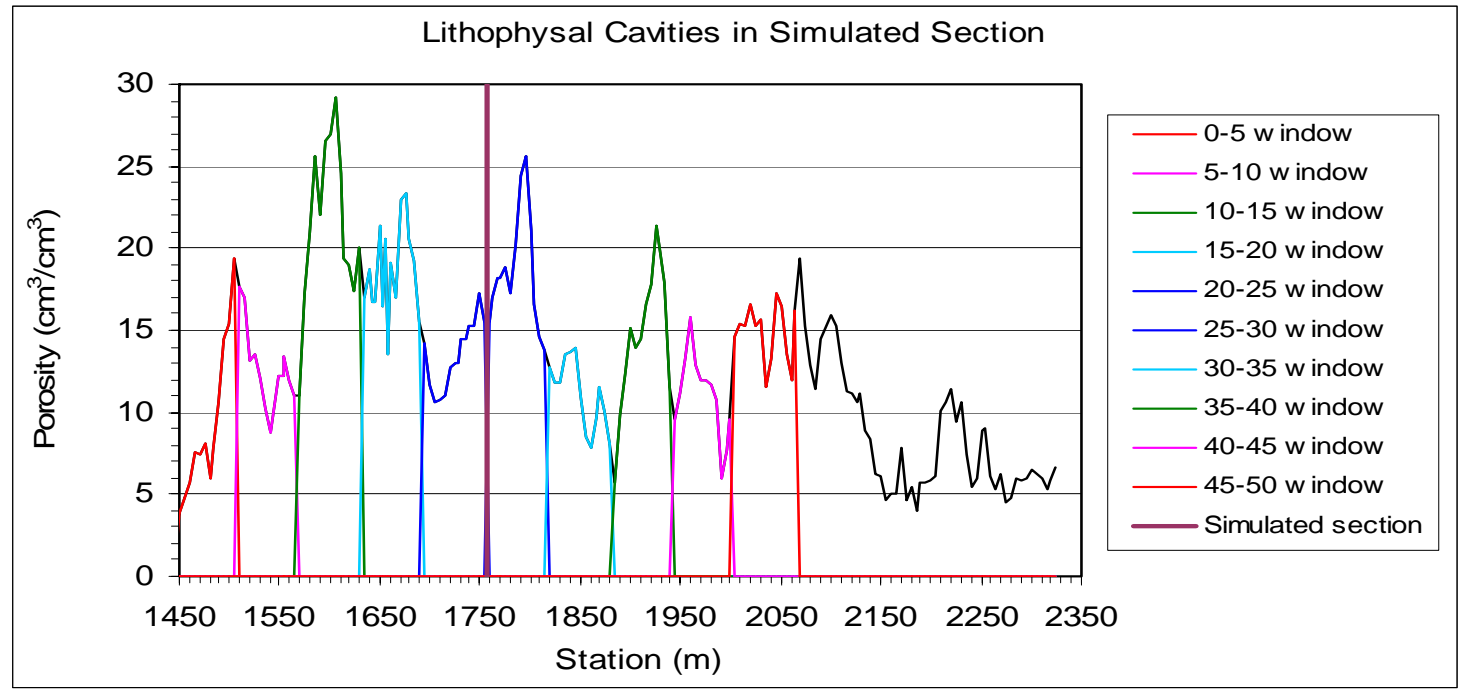

NOTE: Apparent Dip of $4.6^{\circ}$, and 10 "Windows".

Figure T-4. Lithophysal Cavity Porosity in the Lower Lithophysal Zone of the ECRB Cross-Drift with the Centerline of the Simulated Cross Section at $1756 \mathrm{~m}$

The third step in creation of a simulated cross section is to distribute the descriptive statistics of the lithophysal cavity porosity in each window in the associated $5 \mathrm{~m}$ tall horizon. The statistical variation in porosity in each horizon is represented by sampling the actual porosity values in the respective "window". Two methods using standard Excel functions have been used for this distribution; one function is "Choose" where the values in each window are randomly selected, and the other approach uses the random number generator in the analysis tool. For example, the first three $5 \mathrm{~m}$ horizons (0-5, 5-10, and 10-15 windows) in Table T-1 are depicted as Horizons " 0 ", "5", and " 10 " and Y positions 1 to 15, respectively, in Table T-2 and T-3. Comparison of values in Table T-1 and parts of Table T-2 and T-3 indicate the same values occur in the tables. 
Table T-2. Display of Part of the $50 \times 200$ Cell Table with Descriptive Statistics for Calculation of Lithophysal Cavity Porosity in a $50 \times 200 \mathrm{~m}$ Simulated Cross Section with the Centerline Station $17+56$

\begin{tabular}{|c|c|c|c|c|c|c|c|c|c|c|c|}
\hline \multicolumn{12}{|c|}{ Table of porosity values (1x1 m grid) } \\
\hline Horizon & Cell $\left.y\right|^{x}$ & 1 & 2 & 3 & 4 & 5 & 6 & 7 & 8 & 9 & 10 \\
\hline 0 & 1 & 7.6 & 4.7 & 19.4 & 7.6 & 8.2 & 8.2 & 10.6 & 7.6 & 7.9 & 3.8 \\
\hline 0 & 2 & 6.0 & 7.4 & 8.2 & 19.4 & 7.9 & 10.6 & 14.4 & 7.9 & 15.3 & 7.9 \\
\hline 0 & 3 & 6.0 & 15.3 & 15.3 & 7.9 & 7.4 & 6.0 & 4.7 & 3.8 & 15.3 & 7.6 \\
\hline 0 & 4 & 10.6 & 10.6 & 10.6 & 7.9 & 3.8 & 3.8 & 19.4 & 7.9 & 7.6 & 7.6 \\
\hline 0 & 5 & 8.2 & 15.3 & 7.9 & 10.6 & 5.7 & 8.2 & 7.4 & 6.0 & 7.9 & 7.6 \\
\hline 5 & 6 & 13.2 & 11.0 & 17.7 & 11.0 & 17.7 & 10.2 & 12.2 & 12.1 & 12.2 & 12.2 \\
\hline 5 & 7 & 11.0 & 12.1 & 12.2 & 10.2 & 12.2 & 8.8 & 12.2 & 11.0 & 12.2 & 12.0 \\
\hline 5 & 8 & 12.2 & 13.6 & 12.0 & 12.2 & 11.0 & 8.8 & 12.1 & 12.2 & 11.0 & 12.0 \\
\hline 5 & 9 & 17.7 & 13.6 & 10.2 & 17.0 & 10.2 & 17.0 & 8.8 & 11.0 & 12.2 & 10.2 \\
\hline 5 & 10 & 12.2 & 12.2 & 12.1 & 11.0 & 12.2 & 10.2 & 13.4 & 12.2 & 13.2 & 17.7 \\
\hline 10 & 11 & 26.5 & 26.9 & 22.1 & 25.6 & 19.0 & 21.0 & 17.2 & 26.9 & 17.2 & 26.9 \\
\hline 10 & 12 & 11.0 & 26.5 & 24.6 & 26.9 & 19.0 & 29.2 & 19.0 & 21.0 & 17.2 & 19.0 \\
\hline 10 & 13 & 24.6 & 17.4 & 26.9 & 19.0 & 19.0 & 19.0 & 19.3 & 29.2 & 25.6 & 17.4 \\
\hline 10 & 14 & 17.4 & 26.5 & 17.2 & 17.2 & 24.6 & 21.0 & 26.9 & 26.5 & 20.1 & 26.9 \\
\hline 10 & 15 & 22.1 & 17.2 & 19.0 & 17.4 & 26.9 & 26.9 & 21.0 & 11.0 & 17.2 & 21.0 \\
\hline 15 & 16 & 18.8 & 16.5 & 13.6 & 20.5 & 20.5 & 22.9 & 21.4 & 20.6 & 16.5 & 20.6 \\
\hline 15 & 17 & 16.8 & 15.5 & 22.9 & 20.5 & 16.5 & 17.0 & 13.6 & 19.1 & 13.6 & 17.0 \\
\hline 15 & 18 & 20.6 & 19.3 & 15.5 & 17.0 & 17.0 & 19.3 & 20.6 & 19.1 & 16.8 & 17.0 \\
\hline 15 & 19 & 20.5 & 13.6 & 23.4 & 16.8 & 23.4 & 16.8 & 20.6 & 22.9 & 15.5 & 20.5 \\
\hline 15 & 20 & 23.4 & 21.4 & 19.3 & 15.5 & 16.8 & 21.4 & 20.5 & 17.0 & 21.4 & 17.0 \\
\hline 20 & 21 & 10.7 & 15.5 & 13.0 & 15.5 & 11.0 & 15.3 & 15.3 & 15.3 & 12.8 & 15.3 \\
\hline 20 & 22 & 13.0 & 14.5 & 17.3 & 11.0 & 11.7 & 13.0 & 17.3 & 14.5 & 10.6 & 10.6 \\
\hline 20 & 23 & 15.5 & 15.3 & 11.7 & 15.3 & 14.2 & 14.5 & 10.6 & 14.5 & 10.6 & 11.0 \\
\hline 20 & 24 & 15.3 & 14.5 & 15.5 & 13.0 & 15.5 & 15.3 & 11.7 & 14.5 & 13.0 & 10.7 \\
\hline 20 & 25 & 10.7 & 10.6 & 11.0 & 15.5 & 11.0 & 14.5 & 15.3 & 11.0 & 15.3 & 14.5 \\
\hline 25 & 26 & 16.9 & 24.5 & 17.3 & 20.1 & 18.1 & 15.5 & 20.1 & 18.1 & 13.8 & 13.8 \\
\hline 25 & 27 & 18.1 & 25.6 & 14.5 & 17.3 & 18.1 & 20.1 & 21.1 & 17.3 & 14.5 & 14.5 \\
\hline 25 & 28 & 17.3 & 15.5 & 18.8 & 18.1 & 17.3 & 21.1 & 17.3 & 18.8 & 17.3 & 18.1 \\
\hline 25 & 29 & 20.1 & 20.1 & 18.1 & 24.5 & 18.8 & 21.1 & 18.1 & 13.8 & 18.1 & 21.1 \\
\hline 25 & 30 & 18.1 & 18.1 & 15.5 & 18.1 & 13.8 & 18.1 & 14.5 & 24.5 & 18.1 & 21.1 \\
\hline 30 & 31 & 12.7 & 13.5 & 8.5 & 12.7 & 13.5 & 8.5 & 8.5 & 12.7 & 11.6 & 10.0 \\
\hline 30 & 32 & 8.1 & 11.8 & 10.8 & 13.9 & 13.9 & 13.5 & 13.9 & 7.8 & 8.1 & 8.5 \\
\hline 30 & 33 & 9.7 & 12.7 & 9.7 & 9.7 & 10.8 & 10.0 & 11.8 & 13.9 & 9.7 & 11.6 \\
\hline
\end{tabular}


Table T-2. Display of Part of the $50 \times 200$ Cell Table with Descriptive Statistics for Calculation of Lithophysal Cavity Porosity in a 50×200 m Simulated Cross Section with the Centerline Station 17+56 (Continued)

\begin{tabular}{|c|c|c|c|c|c|c|c|c|c|c|c|}
\hline \multicolumn{12}{|c|}{ Table of porosity values (1×1 m grid) } \\
\hline Horizon & Cell ${ }_{Y}{ }^{x}$ & 1 & 2 & 3 & 4 & 5 & 6 & 7 & 8 & 9 & 10 \\
\hline 30 & 34 & 13.5 & 10.0 & 11.8 & 13.6 & 13.6 & 7.8 & 13.6 & 13.9 & 11.6 & 11.8 \\
\hline 30 & 35 & 7.8 & 10.0 & 10.8 & 13.6 & 10.0 & 8.5 & 13.6 & 7.8 & 10.8 & 8.5 \\
\hline 35 & 36 & 12.3 & 19.1 & 21.3 & 12.3 & 17.8 & 12.3 & 13.9 & 15.2 & 5.7 & 21.3 \\
\hline 35 & 37 & 15.2 & 5.7 & 12.3 & 16.6 & 13.9 & 12.3 & 14.4 & 5.7 & 16.6 & 17.8 \\
\hline 35 & 38 & 19.1 & 5.7 & 5.7 & 19.1 & 11.6 & 15.2 & 14.4 & 18.0 & 18.0 & 18.0 \\
\hline 35 & 39 & 21.3 & 13.9 & 12.3 & 19.1 & 12.3 & 13.9 & 17.8 & 16.6 & 18.0 & 15.2 \\
\hline 35 & 40 & 15.2 & 13.9 & 9.8 & 19.1 & 15.2 & 17.8 & 16.6 & 9.8 & 16.6 & 16.6 \\
\hline 40 & 41 & 10.7 & 10.7 & 12.9 & 11.1 & 13.3 & 7.7 & 15.8 & 9.6 & 7.7 & 11.7 \\
\hline 40 & 42 & 7.7 & 13.3 & 10.7 & 13.3 & 10.7 & 10.7 & 11.9 & 15.8 & 6.0 & 11.1 \\
\hline 40 & 43 & 7.7 & 11.9 & 11.7 & 9.6 & 6.0 & 12.9 & 15.8 & 11.7 & 13.3 & 12.9 \\
\hline 40 & 44 & 11.9 & 6.0 & 7.7 & 10.7 & 11.1 & 11.9 & 12.9 & 12.9 & 12.9 & 11.1 \\
\hline 40 & 45 & 15.8 & 9.6 & 12.9 & 9.6 & 6.0 & 12.9 & 11.1 & 11.9 & 7.7 & 7.7 \\
\hline 45 & 46 & 12.0 & 16.5 & 17.3 & 17.3 & 16.3 & 16.3 & 13.2 & 15.3 & 16.3 & 11.6 \\
\hline 45 & 47 & 13.5 & 12.0 & 11.6 & 13.2 & 16.6 & 11.6 & 15.6 & 15.3 & 15.3 & 13.5 \\
\hline 45 & 48 & 15.6 & 12.0 & 15.3 & 15.6 & 16.6 & 15.2 & 16.6 & 13.5 & 15.3 & 15.6 \\
\hline 45 & 49 & 12.0 & 15.3 & 17.3 & 15.3 & 16.3 & 16.3 & 13.2 & 17.3 & 11.6 & 14.5 \\
\hline 45 & 50 & 16.3 & 16.3 & 13.5 & 13.2 & 17.3 & 13.2 & 16.6 & 15.2 & 16.6 & 13.5 \\
\hline \multicolumn{12}{|c|}{ Descriptive Statistics } \\
\hline \multicolumn{2}{|c|}{$\begin{array}{l}\text { Simulated "X" } \\
\text { position }\end{array}$} & 1 & 2 & 3 & 4 & 5 & 6 & 7 & 8 & 9 & 10 \\
\hline \multicolumn{2}{|c|}{ Mean } & 14.4 & 14.6 & 14.5 & 15.2 & 14.2 & 14.5 & 15.2 & 14.5 & 13.8 & 14.3 \\
\hline \multicolumn{2}{|c|}{ Standard Error } & 0.7 & 0.7 & 0.7 & 0.6 & 0.7 & 0.8 & 0.6 & 0.8 & 0.6 & 0.7 \\
\hline \multicolumn{2}{|c|}{ Median } & 13.5 & 13.9 & 13.2 & 15.4 & 13.9 & 14.2 & 14.5 & 14.2 & 13.7 & 13.6 \\
\hline \multicolumn{2}{|l|}{ Mode } & 6.0 & 15.3 & 15.5 & 19.1 & 11.0 & 8.2 & 12.2 & 14.5 & 12.2 & 7.6 \\
\hline \multicolumn{2}{|l|}{$\begin{array}{l}\text { Standard } \\
\text { Deviation }\end{array}$} & 5.0 & 5.3 & 4.8 & 4.5 & 4.9 & 5.3 & 4.2 & 5.5 & 4.1 & 5.0 \\
\hline \multicolumn{2}{|c|}{ Sample Variance } & 24.6 & 28.1 & 22.6 & 20.0 & 23.8 & 28.6 & 17.2 & 30.7 & 17.1 & 25.2 \\
\hline \multicolumn{2}{|l|}{ Kurtosis } & -0.4 & 0.4 & -0.1 & 0.1 & 0.2 & 0.2 & 0.5 & 0.4 & 0.2 & 0.1 \\
\hline \multicolumn{2}{|c|}{ Skewness } & 0.4 & 0.6 & 0.6 & 0.5 & 0.2 & 0.5 & 0.2 & 0.6 & 0.1 & 0.5 \\
\hline \multicolumn{2}{|c|}{ Range } & 20.5 & 22.2 & 21.2 & 19.3 & 23.1 & 25.4 & 22.2 & 25.4 & 19.9 & 23.1 \\
\hline \multicolumn{2}{|l|}{ Minimum } & 6.0 & 4.7 & 5.7 & 7.6 & 3.8 & 3.8 & 4.7 & 3.8 & 5.7 & 3.8 \\
\hline \multicolumn{2}{|l|}{ Maximum } & 26.5 & 26.9 & 26.9 & 26.9 & 26.9 & 29.2 & 26.9 & 29.2 & 25.6 & 26.9 \\
\hline \multicolumn{2}{|l|}{ Sum } & 720.3 & 731.0 & 726.9 & 758.6 & 711.3 & 723.6 & 758.2 & 727.1 & 689.7 & 715.6 \\
\hline \multicolumn{2}{|c|}{ Count } & 50 & 50 & 50 & 50 & 50 & 50 & 50 & 50 & 50 & 50 \\
\hline \multicolumn{2}{|c|}{\begin{tabular}{|l} 
Confidence Level \\
$(95.0 \%)$
\end{tabular}} & 1.4 & 1.5 & 1.3 & 1.2 & 1.4 & 1.5 & 1.2 & 1.5 & 1.1 & 1.4 \\
\hline \multicolumn{12}{|c|}{ Explanation of symbols (percent lithophysal cavity porosity) } \\
\hline
\end{tabular}


Table T-3. Display of Part of the $20 \times 80$ Cell Table with Descriptive Statistics for Calculation of Lithophysal Cavity Porosity in a 50×200 m Simulated Cross Section with the Centerline at Station $17+56$

\begin{tabular}{|c|c|c|c|c|c|c|c|c|c|c|c|}
\hline \multicolumn{12}{|c|}{ Table of porosity values ( $2.5 \times 2.5 \mathrm{~m}$ grid) } \\
\hline Horizon & Cell $y^{x}$ & 2.5 & 5.0 & 7.5 & 10.0 & 12.5 & 15.0 & 17.5 & 20.0 & 22.5 & 25.0 \\
\hline 0 & 2.5 & 15.3 & 7.4 & 7.9 & 5.7 & 8.2 & 6.0 & 5.7 & 7.4 & 5.7 & 15.3 \\
\hline 0 & 5.0 & 7.4 & 8.2 & 8.2 & 10.6 & 8.2 & 8.2 & 3.8 & 6.0 & 14.4 & 10.6 \\
\hline 5 & 7.5 & 12.0 & 12.2 & 11.0 & 17.0 & 12.2 & 10.2 & 10.2 & 12.1 & 8.8 & 12.2 \\
\hline 5 & 10.0 & 13.4 & 10.2 & 13.6 & 12.0 & 11.0 & 17.0 & 10.2 & 12.2 & 11.0 & 17.7 \\
\hline 10 & 12.5 & 29.2 & 21.0 & 19.0 & 26.9 & 17.4 & 17.2 & 29.2 & 19.0 & 17.4 & 19.0 \\
\hline 10 & 15.0 & 24.6 & 29.2 & 25.6 & 25.6 & 11.0 & 19.0 & 19.0 & 17.4 & 21.0 & 17.4 \\
\hline 15 & 17.5 & 18.8 & 17.0 & 13.6 & 18.8 & 20.5 & 21.4 & 19.3 & 17.0 & 23.4 & 15.5 \\
\hline 15 & 20.0 & 19.1 & 20.6 & 20.5 & 16.8 & 15.5 & 16.8 & 16.8 & 15.5 & 19.1 & 22.9 \\
\hline 20 & 22.5 & 13.0 & 15.3 & 13.0 & 14.5 & 10.7 & 14.5 & 11.0 & 13.0 & 11.0 & 14.5 \\
\hline 20 & 25.0 & 15.3 & 14.5 & 15.3 & 17.3 & 11.7 & 11.7 & 10.7 & 10.6 & 15.5 & 17.3 \\
\hline 25 & 27.5 & 15.5 & 13.8 & 18.1 & 16.9 & 25.6 & 16.9 & 18.1 & 25.6 & 18.8 & 20.1 \\
\hline 25 & 30.0 & 14.5 & 16.9 & 25.6 & 18.1 & 18.1 & 21.1 & 17.3 & 18.1 & 25.6 & 16.9 \\
\hline 30 & 32.5 & 7.8 & 10.8 & 9.7 & 7.8 & 11.8 & 12.7 & 11.8 & 10.8 & 11.8 & 11.6 \\
\hline 30 & 35.0 & 9.7 & 11.8 & 12.7 & 13.6 & 8.5 & 9.7 & 9.7 & 10.8 & 12.7 & 7.8 \\
\hline 35 & 37.5 & 9.8 & 9.8 & 11.6 & 19.1 & 5.7 & 21.3 & 16.6 & 17.8 & 17.8 & 5.7 \\
\hline 35 & 40.0 & 21.3 & 15.2 & 9.8 & 19.1 & 9.8 & 12.3 & 14.4 & 15.2 & 21.3 & 17.8 \\
\hline 40 & 42.5 & 9.6 & 12.9 & 9.6 & 11.9 & 9.6 & 11.9 & 6.0 & 12.9 & 11.7 & 13.3 \\
\hline 40 & 45.0 & 9.6 & 11.1 & 11.9 & 10.7 & 9.6 & 9.6 & 10.7 & 6.0 & 11.1 & 11.9 \\
\hline 45 & 47.5 & 14.5 & 17.3 & 15.2 & 17.3 & 15.3 & 13.5 & 16.6 & 15.6 & 16.6 & 15.2 \\
\hline 45 & 50.0 & 15.3 & 16.6 & 14.5 & 16.5 & 12.0 & 16.5 & 15.6 & 13.2 & 16.5 & 16.6 \\
\hline \multicolumn{12}{|c|}{ Descriptive Statistics } \\
\hline \multicolumn{2}{|c|}{$\begin{array}{l}\text { Simulated "X" } \\
\text { position }\end{array}$} & 2.5 & 5.0 & 7.5 & 10.0 & 12.5 & 15.0 & 17.5 & 20.0 & 22.5 & 25.0 \\
\hline \multicolumn{2}{|l|}{ Mean } & 14.8 & 14.6 & 14.3 & 15.8 & 12.6 & 14.4 & 13.6 & 13.8 & 15.6 & 15.0 \\
\hline \multicolumn{2}{|c|}{ Standard Error } & 1.3 & 1.1 & 1.2 & 1.2 & 1.1 & 1.0 & 1.3 & 1.1 & 1.1 & 0.9 \\
\hline \multicolumn{2}{|l|}{ Median } & 14.5 & 14.1 & 13.3 & 16.9 & 11.4 & 14.0 & 13.1 & 13.1 & 16.0 & 15.4 \\
\hline \multicolumn{2}{|l|}{ Mode } & 14.5 & $\# \mathrm{~N} / \mathrm{A}$ & $\# \mathrm{~N} / \mathrm{A}$ & 19.1 & 8.2 & $\# \mathrm{~N} / \mathrm{A}$ & 10.2 & 10.8 & $\# \mathrm{~N} / \mathrm{A}$ & $\# N / A$ \\
\hline \multicolumn{2}{|c|}{$\begin{array}{l}\text { Standard } \\
\text { Deviation }\end{array}$} & 5.6 & 5.1 & 5.2 & 5.2 & 4.8 & 4.5 & 5.9 & 4.8 & 5.1 & 4.2 \\
\hline \multicolumn{2}{|c|}{ Sample Variance } & 31.8 & 25.9 & 26.6 & 27.3 & 23.3 & 20.5 & 34.3 & 22.7 & 26.4 & 17.3 \\
\hline \multicolumn{2}{|l|}{ Kurtosis } & 1.0 & 2.3 & 0.5 & 0.4 & 1.5 & -0.9 & 1.3 & 0.7 & -0.5 & 0.3 \\
\hline \multicolumn{2}{|c|}{ Skewness } & 1.0 & 1.2 & 1.0 & 0.2 & 1.2 & 0.0 & 0.6 & 0.4 & 0.1 & -0.5 \\
\hline \multicolumn{2}{|l|}{ Range } & 21.8 & 21.8 & 17.8 & 21.2 & 19.9 & 15.4 & 25.4 & 19.6 & 20.0 & 17.2 \\
\hline \multicolumn{2}{|c|}{ Minimum } & 7.4 & 7.4 & 7.9 & 5.7 & 5.7 & 6.0 & 3.8 & 6.0 & 5.7 & 5.7 \\
\hline \multicolumn{2}{|c|}{ Maximum } & 29.2 & 29.2 & 25.6 & 26.9 & 25.6 & 21.4 & 29.2 & 25.6 & 25.6 & 22.9 \\
\hline \multicolumn{2}{|l|}{ Sum } & 295.8 & 291.7 & 286.4 & 316.3 & 252.4 & 287.7 & 272.6 & 276.5 & 311.4 & 299.5 \\
\hline \multicolumn{2}{|l|}{ Count } & 20 & 20 & 20 & 20 & 20 & 20 & 20 & 20 & 20 & 20 \\
\hline \multicolumn{2}{|c|}{$\begin{array}{l}\text { Confidence Level } \\
(95.0 \%)\end{array}$} & 2.5 & 2.2 & 2.3 & 2.3 & 2.1 & 2.0 & 2.6 & 2.1 & 2.3 & 1.8 \\
\hline \multicolumn{12}{|c|}{ Explanation of symbols (percent lithophysal cavity porosity) } \\
\hline
\end{tabular}


The fourth step in creation of a simulated vertical cross section is to project the $5 \mathrm{~m}$ horizons in the vertical section away from the vertical section to create the cross section. For a $200 \mathrm{~m}$ wide cross section, the projection away from the central vertical section is $100 \mathrm{~m}$ to either side. In this construct, the maximum "straight line" projection distance for an apparent dip of $4.6^{\circ}$ and an along-the-tunnel projection of $311 \mathrm{~m}$ is only $327 \mathrm{~m}$. This projection distance is consistent with the overall stratiform characteristics of the lithostratigraphic section. Figure T-5 displays two simulations of a $50 \times 200 \mathrm{~m}$ cross section using a $4.6^{\circ}$ apparent dip, one for a center of the section at $1756 \mathrm{~m}$ and a second for a center at $2014 \mathrm{~m}$. In these simulations, there is an overlap of $364 \mathrm{~m}$ along the tunnel and when projected to the vertical plane it represents an overlap of about $30 \mathrm{~m}$ of section (Figure T-5). Each simulation is depicted with a $50 \times 200$ cell table representing a $1 \times 1 \mathrm{~m}$ grid (sections $\mathrm{A}$ and $\mathrm{C}$ ) and a $20 \times 80$ cell table representing a $2.2 \times 2.5 \mathrm{~m}$ grid (sections $\mathrm{B}$ and D). The four sections in Figure T-5 display similar stratiform relations.

Descriptive statistics (from standard Excel functions) for the input data in the various windows (Table T-4) with the selected statistics from $5 \mathrm{~m}$ tall horizons in the $50 \times 200$ cell and $20 \times 80$ cells indicate very good correlations. The descriptive statistics (from standard Excel functions) of the total Tptpll zone in the ECRB Cross-Drift is provided in Table T-4 (first column of values). Descriptive statistics for the total windows in the ECRB Cross-Drift (input) data and the total $50 \times 200$ cell and $20 \times 80$ cell tables indicate very high correlations (Table T-5). These correlations reinforce the technical soundness of this approach to project the distribution of lithophysal cavity porosity from the cross section data to a vertical plane.

\section{T7. LIMITATIONS OF THE CALCULATION}

The calculations of the distribution of lithophysal cavity porosity from the ECRB Cross-Drift to a vertical plane that is perpendicular to the tunnel is based on sound geologic and geometric relations; however, there are a few limitations to the results:

A. The calculations exemplified in this appendix are based on the consideration that the ECRB Cross-Drift is horizontal. The gradient of the tunnel is 1.5 percent $\left(0.86^{\circ}\right)$ from $07+73$ to $16+02$ and is 0.9 percent $\left(0.52^{\circ}\right.$ ) from $16+02$ to $24+67$ (Mongano et al. 1999 [DIRS 149850], pp. 3 to 6). So, although these inclinations are small, they can be factored into the apparent dip of the lithostratigraphic units and features to enhance the geologic and construction conditions.

B. Using a constant apparent dip of $4.6^{\circ}$ from the strike and dip of 270/07 for the top contact of the lower lithophysal zone in the ECRB Cross-Drift (Mongano et al. 1999 [DIRS 149850], Table 1) and the total intercept of the lower lithophysal zone in the ECRB Cross-Drift (from 14+44 to 23+26), the calculated thickness of the lower lithophysal zone is only $71 \mathrm{~m}$. This calculated thickness is less than what is calculated and depicted by a variety of other methods, so the apparent dip of $4.6^{\circ}$ is probably too shallow; therefore, the number and the distribution of values in each window along the tunnel might be over represented.

C. The simulated cross section is constructed perpendicular to the tunnel; however, it does not include the apparent dip in the plane of the cross section. For example, using the features and data depicted in Figure T-2, the apparent dip in the cross section is $5.3^{\circ}$ to the northwest. 
A

B

$-1$

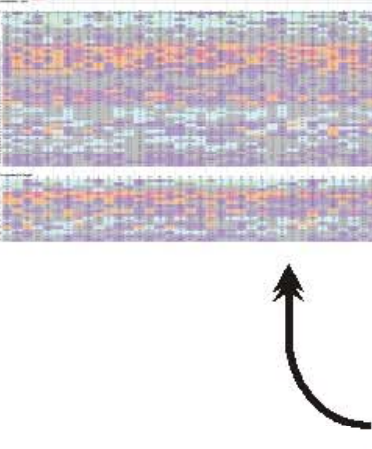

Explanation of symbols

$<=5$

$<=5$
$<=10$

$<=15$

$<=20$

$<=25$

$>25$
Lithophysal cavities in model section at $1756 \mathrm{~m}$

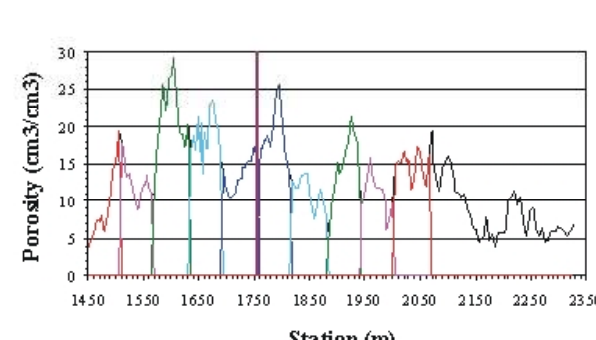

Station (m)
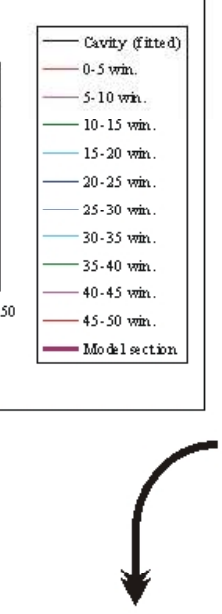

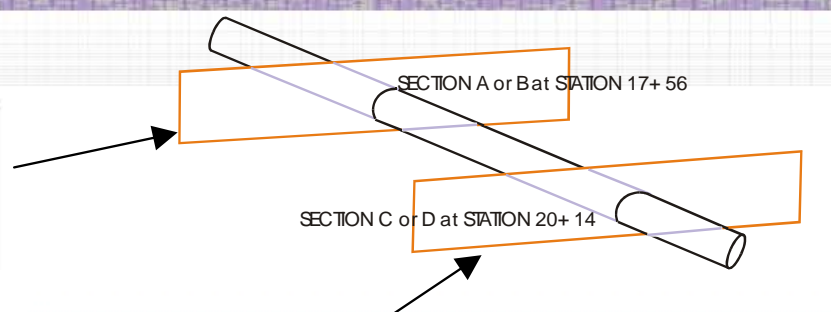

Lithophysal cavities in model section at $2014 \mathrm{~m}$

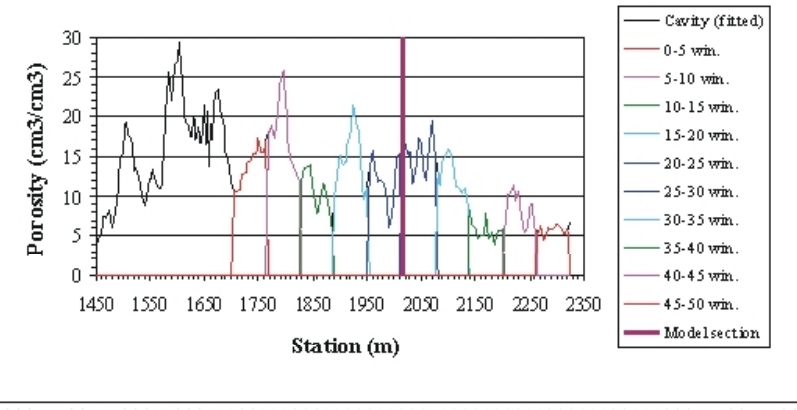

C

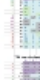

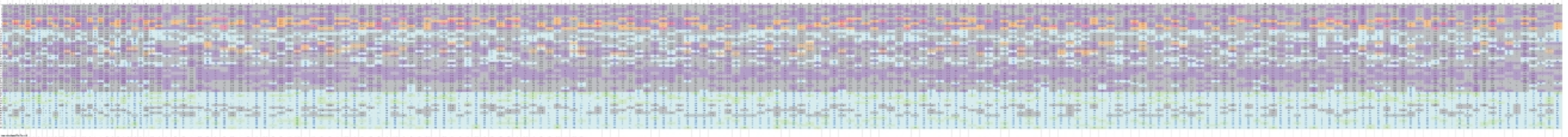

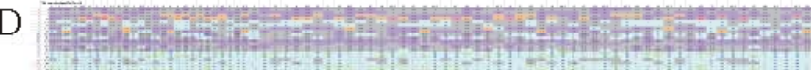

NOTE: Cross section $A$ is a $50 \times 200$ cell table representing a $1 \times 1 \mathrm{~m}$ grid, and cross section $B$ is a $20 \times 80$ cell table representing a $2.2 \times 2.5 \mathrm{~m}$ grid for the simulated section at $17+56$. Cross Section $C$ is a $50 \times 200$ cell table representing a $1 \times 1 \mathrm{~m}$ grid, and cross Section $\mathrm{D}$ is a $20 \times 80$ cell table representing a $2.2 \times 2.5 \mathrm{~m}$ grid for the simulated section at $20+14$.

Figure T-5. Two 50×200 m Simulated Cross Sections of Lithophysal Cavity Porosity at Stations $17+56$ and 20+14 
Because the values in each cell in the $50 \times 200$ and $20 \times 80$ cell tables are independently and randomly allocated, locally there are a few geologically inconsistent results. While this allocation technique results in very high correlations of the descriptive statistics between the input data and resulting cross-section horizons, it is possible that locally, the minimum and maximum values in a window or in adjacent windows can be in adjacent cells. This extreme change in lithophysal cavity porosity has not been observed in the ECRB Cross-Drift as shown by the gradual increase or decrease in values (although sharp changes can occur across distances of 5 to $10 \mathrm{~m}$; Figure T-3). One result of this random allocation of values and the potential juxtaposition of large and small (or mostly values of one end of the distribution or another) is the variation in descriptive statistics in vertical sections (X positions; Table T-2 and T-3). The affect of this juxtaposition of minimum and maximum values is probably greater in the $20 \times 80$-cell table that represents a $2.5 \times 2.5 \mathrm{~m}$ grid than in the $50 \times 200$ cell table that represents a $1 \times 1 \mathrm{~m}$ grid. One way to minimize this affect is to filter the values in the tables and remove (or change) one or both of the juxtaposed values. Development of such a filter needs to focus on diminishing the anomalies, but maintaining the statistical integrity of the resultant calculated values.

Table T-4. Comparison of Descriptive Statistics for the Total Tptpll Zone in the ECRB Cross-Drift, Individual Windows from the Input Data, and Selective Statistics for $5 \mathrm{~m}$ Tall Horizons in a $50 \times 200 \mathrm{~m}$ Simulated Cross Section with $1 \times 1 \mathrm{~m}$ and $2.5 \times 2.5 \mathrm{~m}$ Grids

\begin{tabular}{|c|c|c|c|c|c|c|c|c|c|c|c|c|c|c|c|c|}
\hline \multicolumn{17}{|c|}{ Descriptive Statistics (for Total Input and Windows) } \\
\hline 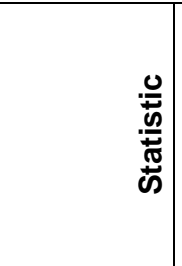 & 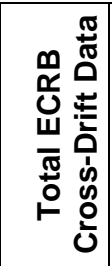 & $\begin{array}{l}3 \\
0 \\
0 \\
\vdots \\
3 \\
3 \\
10 \\
0\end{array}$ & 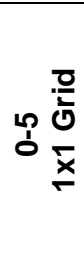 & 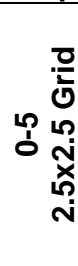 & 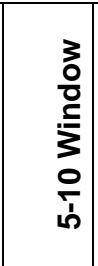 & 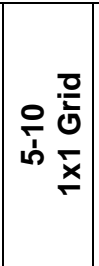 & 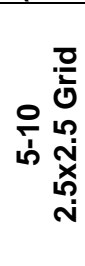 & 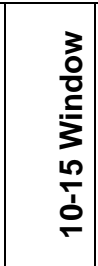 & 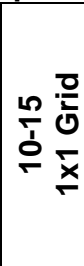 & 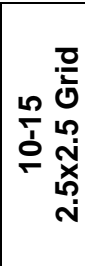 & 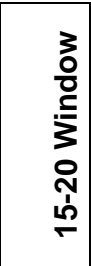 & 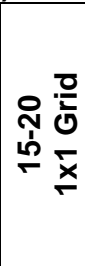 & 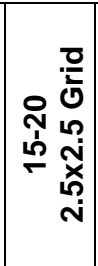 & 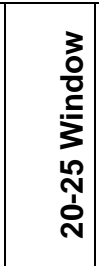 & 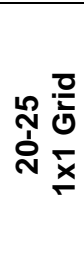 & 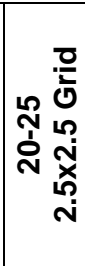 \\
\hline Mean & 12.9 & 9.2 & 9.1 & 9.3 & 12.6 & 12.6 & 12.3 & 21.5 & 21.2 & 22.4 & 18.6 & 18.6 & 18.3 & 13.5 & 13.6 & 13.6 \\
\hline $\begin{array}{l}\text { Standard } \\
\text { Error }\end{array}$ & 0.4 & 1.4 & 0.1 & 0.4 & 0.7 & 0.1 & 0.2 & 1.4 & 0.1 & 0.4 & 0.7 & 0.1 & 0.2 & 0.5 & 0.1 & 0.2 \\
\hline Median & 12.7 & 7.7 & - & - & 12.2 & - & - & 21.0 & - & - & 18.8 & - & - & 13.6 & - & - \\
\hline Mode & 17.0 & $\# \mathrm{~N} / \mathrm{A}$ & - & - & 12.2 & - & - & $\# \mathrm{~N} / \mathrm{A}$ & - & - & 17.0 & - & - & 13.0 & - & - \\
\hline $\begin{array}{l}\text { Standard } \\
\text { Deviation }\end{array}$ & 5.4 & 4.8 & 4.6 & 4.7 & 2.5 & 2.3 & 2.4 & 5.0 & 4.7 & 4.6 & 2.8 & 2.7 & 2.6 & 2.0 & 2.0 & 2.0 \\
\hline $\begin{array}{l}\text { Sample } \\
\text { Variance }\end{array}$ & 29.6 & 22.7 & 21.1 & 21.9 & 6.2 & 5.5 & 5.9 & 24.8 & 22.2 & 20.8 & 7.7 & 7.0 & 7.0 & 4.2 & 3.9 & 3.8 \\
\hline Kurtosis & -0.2 & 0.3 & & & 0.8 & & & 0.1 & & & -0.6 & & & -0.8 & & \\
\hline Skewness & 0.4 & 1.1 & 1.0 & 1.0 & 0.9 & 0.8 & 0.9 & -0.4 & -0.2 & -0.5 & 0.2 & 0.2 & 0.1 & 0.0 & 0.0 & 0.0 \\
\hline Range & 26.7 & 15.5 & - & - & 8.9 & - & - & 18.2 & - & - & 9.8 & - & - & 6.7 & - & - \\
\hline Minimum & 2.5 & 3.8 & - & - & 8.8 & - & - & 11.0 & - & - & 13.6 & - & - & 10.6 & - & - \\
\hline Maximum & 29.2 & 19.4 & - & - & 17.7 & - & - & 29.2 & - & - & 23.4 & - & - & 17.3 & - & - \\
\hline Sum & 2352.1 & 110.9 & - & - & 164.4 & - & - & 279.9 & - & - & 279.2 & - & - & 189.5 & - & - \\
\hline Count & 183 & 12 & - & - & 13 & - & - & 13 & - & - & 15 & - & - & 14 & - & - \\
\hline $\begin{array}{l}\text { Confidence } \\
\text { Level } \\
(95.0 \%)\end{array}$ & 0.8 & 2.7 & - & - & 1.3 & - & - & 2.7 & - & - & 1.4 & - & - & 1.1 & - & - \\
\hline
\end{tabular}


Table T-4. Comparison of Descriptive Statistics for the Total Tptpll Zone in the ECRB Cross-Drift, Individual Windows from the Input Data, and Selective Statistics for $5 \mathrm{~m}$ Tall Horizons in a $50 \times 200 \mathrm{~m}$ Simulated Cross Section with $1 \times 1 \mathrm{~m}$ and $2.5 \times 2.5 \mathrm{~m}$ Grids (Continued)

\begin{tabular}{|c|c|c|c|c|c|c|c|c|c|c|c|c|c|c|c|c|}
\hline \multicolumn{17}{|c|}{ Descriptive Statistics (for Total Input and Windows) } \\
\hline 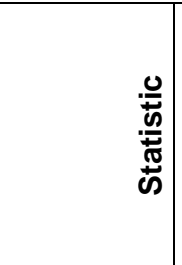 & 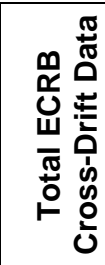 & 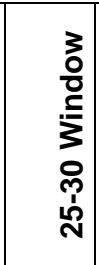 & 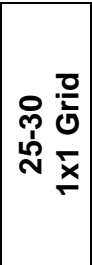 & 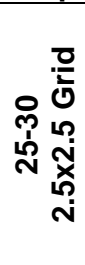 & 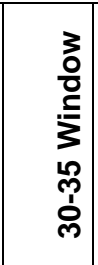 & 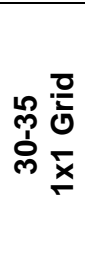 & 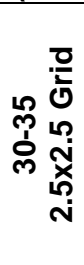 & 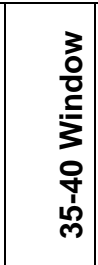 & 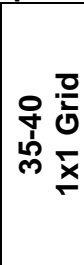 & 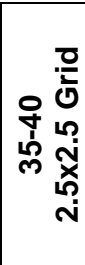 & $\begin{array}{l}3 \\
0 \\
0 \\
\mathbf{3} \\
3 \\
4 \\
\dot{3} \\
\dot{y}\end{array}$ & 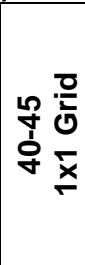 & 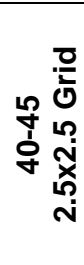 & 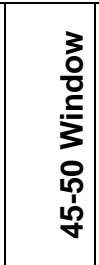 & 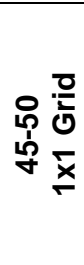 & 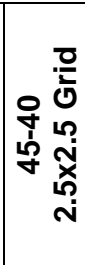 \\
\hline Mean & 12.9 & 18.5 & 18.6 & 18.2 & 11.1 & 11.0 & 11.0 & 14.6 & 14.6 & 14.6 & 11.0 & 11.0 & 10.8 & 14.8 & 14.9 & 14.6 \\
\hline $\begin{array}{l}\text { Standard } \\
\text { Error }\end{array}$ & 0.4 & 0.9 & 0.1 & 0.3 & 0.6 & 0.1 & 0.2 & 1.3 & 0.1 & 0.4 & 0.7 & 0.1 & 0.2 & 0.5 & 0.1 & 0.1 \\
\hline Median & 12.7 & 18.1 & - & - & 11.6 & - & - & 14.8 & - & - & 11.4 & - & - & 15.3 & - & - \\
\hline Mode & 17.0 & 18.1 & - & - & 11.8 & - & - & $\# \mathrm{~N} / \mathrm{A}$ & - & - & $\# \mathrm{~N} / \mathrm{A}$ & - & - & $\# \mathrm{~N} / \mathrm{A}$ & - & - \\
\hline $\begin{array}{l}\text { Standard } \\
\text { Deviation }\end{array}$ & 5.4 & 3.4 & 3.3 & 3.3 & 2.1 & 2.0 & 2.0 & 4.4 & 4.1 & 4.6 & 2.6 & 2.4 & 2.7 & 1.8 & 1.7 & 1.8 \\
\hline $\begin{array}{l}\text { Sample } \\
\text { Variance }\end{array}$ & 29.6 & 11.6 & 10.8 & 10.6 & 4.4 & 4.1 & 4.1 & 19.0 & 17.2 & 20.8 & 6.7 & 5.9 & 7.5 & 3.2 & 2.9 & 3.3 \\
\hline Kurtosis & -0.2 & 0.5 & - & - & -1.2 & - & - & 0.2 & - & - & 0.6 & - & - & -0.6 & - & - \\
\hline Skewness & 0.4 & 0.9 & 0.8 & 0.8 & -0.2 & -0.2 & -0.1 & -0.5 & -0.5 & -0.6 & -0.2 & -0.2 & -0.3 & -0.6 & -0.6 & -0.3 \\
\hline Range & 26.7 & 11.9 & - & - & 6.1 & - & - & 15.6 & - & - & 9.8 & - & - & 5.7 & - & - \\
\hline Minimum & 2.5 & 13.8 & - & - & 7.8 & - & - & 5.7 & - & - & 6.0 & - & - & 11.6 & - & - \\
\hline Maximum & 29.2 & 25.6 & - & - & 13.9 & - & - & 21.3 & - & - & 15.8 & - & - & 17.3 & - & - \\
\hline Sum & 2352.1 & 259.4 & - & - & 143.8 & - & - & 175.8 & - & - & 132.3 & - & - & 192.9 & - & - \\
\hline Count & 183 & 14 & - & - & 13 & - & - & 12 & - & - & 12 & - & - & 13 & - & - \\
\hline $\begin{array}{l}\text { Confidence } \\
\text { Level } \\
(95.0 \%)\end{array}$ & 0.8 & 1.8 & - & - & 1.1 & - & - & 2.5 & - & - & 1.5 & - & - & 1.0 & - & - \\
\hline
\end{tabular}

Table T-5. Comparison of Descriptive Statistics for the Total Windows from ECRB Cross-Drift (Input) Data and the Total $50 \times 200 \mathrm{~m}$ Simulated Cross Section with $1 \times 1 \mathrm{~m}$ and $2.5 \times 2.5 \mathrm{~m}$ Grids

\begin{tabular}{|l|c|c|c|l|c|c|c|}
\hline \multicolumn{1}{|c|}{ Descriptive Statistics for Total Windows } \\
\hline Statistic & $\begin{array}{c}\text { ECRB } \\
\text { Cross-Drift } \\
\text { Data }\end{array}$ & $\mathbf{1 \times 1}$ Grid & $\begin{array}{c}\mathbf{2 . 5 \times 2 . 5} \\
\text { Grid }\end{array}$ & \multicolumn{1}{|c|}{ Statistic } & $\begin{array}{c}\text { ECRB } \\
\text { Cross-Drift } \\
\text { Data }\end{array}$ & $\mathbf{1 \times 1 \text { Grid }}$ & $\begin{array}{c}\mathbf{2 . 5 \times 2 . 5} \\
\text { Grid }\end{array}$ \\
\hline Mean & 14.7 & 14.5 & 14.5 & Skewness & 0.4 & 0.4 & 0.4 \\
\hline Standard Error & 0.4 & 0.0 & 0.1 & Range & 25.4 & 25.4 & 25.4 \\
\hline Median & 14.4 & 13.9 & 13.9 & Minimum & 3.8 & 3.8 & 3.8 \\
\hline Mode & 17.0 & 11.6 & 11.6 & Maximum & 29.2 & 29.2 & 29.2 \\
\hline $\begin{array}{l}\text { Standard } \\
\text { Deviation }\end{array}$ & 4.9 & 4.9 & 5.1 & Sum & 1928.1 & 145404.3 & 23193.6 \\
\hline $\begin{array}{l}\text { Sample } \\
\text { Variance }\end{array}$ & 24.0 & 24.0 & 25.5 & Count & 131.0 & 10000 & 1600 \\
\hline Kurtosis & 0.2 & 0.2 & 0.2 & $\begin{array}{l}\text { Confidence } \\
\text { Level (95.0\%) }\end{array}$ & 0.8 & 0.10 & 0.25 \\
\hline
\end{tabular}




\begin{abstract}
APPENDIX U
METHODOLOGY OF AND VERIFICATION OF THE INTERCHANGE AND APPLICATION OF ROCK MASS PRE- AND POSTCLOSURE TEMPERATURE PREDICTIONS FROM THE NUFT THERMAL CALCULATION TO THE UDEC AND FLAC MODELS
\end{abstract}




\section{METHODOLOGY OF AND VERIFICATION OF THE INTERCHANGE AND APPLICATION OF ROCK MASS PRE- AND POSTCLOSURE TEMPERATURE PREDICTIONS FROM THE NUFT THERMAL CALCULATION TO THE UDEC AND FLAC MODELS}

Stability of the drift in the lithophysal and nonlithophysal rock mass due to thermal loading was analyzed using the UDEC and 3DEC discontinuum models as described in Sections 6.3 and 6.4. For consistency with other thermal calculations performed for performance assessment at Yucca Mountain, the UDEC and 3DEC programs were not used to determine the rock mass temperatures. Instead, the evolution of the temperature field after waste emplacement was obtained using the hydro-thermal code NUFT, which is one of the component submodels of the LDTH model, described in Multiscale Thermohydrologic Model (BSC 2004 [DIRS 169565]). The temperature fields were imported sequentially into UDEC (lithophysal rock) and FLAC (nonlithophysal rock) for a number of times after waste emplacement, making sure that the temperature change between two stages is relatively small (i.e., it does not result in a large stress change). The thermal stresses due to temperature changes were calculated, and the model was solved for equilibrium for the selected thermal times. The purpose of this appendix is to describe the process of application of the NUFT temperature fields to the UDEC and FLAC models, and to verify that this process results in proper NUFT rock mass temperature within the UDEC and FLAC models.

NUFT provides the temperature fields on a rectangular grid, which are stored in a spreadsheet (DTN: MO0408MWDDDMIO.002, file LA1450_NUFT_Temp_crss-sctn3.xls; see example shown in Figure U-1). The temperature fields, corresponding to different thermal times, are extracted and stored in separate ASCII files (see example shown in Figure U-2.), which are read by UDEC. The UDEC model is composed of a large number of irregularly-shaped blocks which are, in turn, discretized into a number of triangular finite difference elements. The temperatures from the NUFT grid must be interpolated at the nearby UDEC grid points. To perform this interpolation, the NUFT elements that contain UDEC grid points must be identified. In order to speed up the search of the NUFT element that contains a UDEC grid point, the coordinates in the ASCII files are sorted by increasing $x$ - and $y$-coordinates. The UDEC geometry is generated using the same coordinate system as the one used in NUFT. The origins of the coordinate systems in both models are at the center of the drift. The NUFT model uses the symmetry condition with respect to the vertical plane through the drift center. The symmetry was not used in the UDEC model for the mechanical simulations, but the temperature field is considered to be symmetrical, i.e., $T(x, y)=T(-x, y)$. 


\begin{tabular}{|c|c|c|c|c|c|c|c|}
\hline Location & & $\begin{array}{l}\text { Temperature } \\
\text { Pre-closure }\end{array}$ & & & & & \\
\hline $\mathrm{x}$ & $\mathrm{z}$ & 1 & 2 & 3 & 5 & 10 & 20 \\
\hline$(\mathrm{m})$ & $(\mathrm{m})$ & $\left({ }^{\circ} \mathrm{C}\right)$ & $\left({ }^{\circ} \mathrm{C}\right)$ & $\left({ }^{\circ} \mathrm{C}\right)$ & $\left({ }^{\circ} \mathrm{C}\right)$ & $\left({ }^{\circ} \mathrm{C}\right)$ & $\left({ }^{\circ} \mathrm{C}\right)$ \\
\hline 0.285 & 278.293 & 16.94 & 16.94 & 16.94 & 16.94 & 16.94 & 16.94 \\
\hline 0.745 & 278.293 & 16.94 & 16.94 & 16.94 & 16.94 & 16.94 & 16.94 \\
\hline 1.0855 & 278.293 & 16.94 & 16.94 & 16.94 & 16.94 & 16.94 & 16.94 \\
\hline 1.43085 & 278.293 & 16.94 & 16.94 & 16.94 & 16.94 & 16.94 & 16.94 \\
\hline 1.80055 & 278.293 & 16.94 & 16.94 & 16.94 & 16.94 & 16.94 & 16.94 \\
\hline 2.2004 & 278.293 & 16.94 & 16.94 & 16.94 & 16.94 & 16.94 & 16.94 \\
\hline 2.5801 & 278.293 & 16.94 & 16.94 & 16.94 & 16.94 & 16.94 & 16.94 \\
\hline 2.9998 & 278.293 & 16.94 & 16.94 & 16.94 & 16.94 & 16.94 & 16.94 \\
\hline 3.6998 & 278.293 & 16.94 & 16.94 & 16.94 & 16.94 & 16.94 & 16.94 \\
\hline 4.8998 & 278.293 & 16.94 & 16.94 & 16.94 & 16.94 & 16.94 & 16.94 \\
\hline 6.8998 & 278.293 & 16.94 & 16.94 & 16.94 & 16.94 & 16.94 & 16.94 \\
\hline 10.1498 & 278.293 & 16.94 & 16.94 & 16.94 & 16.94 & 16.94 & 16.94 \\
\hline 15.1498 & 278.293 & 16.94 & 16.94 & 16.94 & 16.94 & 16.94 & 16.94 \\
\hline 22.6498 & 278.293 & 16.94 & 16.94 & 16.94 & 16.94 & 16.94 & 16.94 \\
\hline 33.8249 & 278.293 & 16.94 & 16.94 & 16.94 & 16.94 & 16.94 & 16.94 \\
\hline 0.285 & 277.385 & 16.96 & 16.96 & 16.96 & 16.96 & 16.96 & 16.96 \\
\hline 0.745 & 277.385 & 16.96 & 16.96 & 16.96 & 16.96 & 16.96 & 16.96 \\
\hline 1.0855 & 277.385 & 16.96 & 16.96 & 16.96 & 16.96 & 16.96 & 16.96 \\
\hline 1.43085 & 277.385 & 16.96 & 16.96 & 16.96 & 16.96 & 16.96 & 16.96 \\
\hline 1.80055 & 277.385 & 16.96 & 16.96 & 16.96 & 16.96 & 16.96 & 16.96 \\
\hline 2.2004 & 277.385 & 16.96 & 16.96 & 16.96 & 16.96 & 16.96 & 16.96 \\
\hline 2.5801 & 277.385 & 16.96 & 16.96 & 16.96 & 16.96 & 16.96 & 16.96 \\
\hline 2.9998 & 277.385 & 16.96 & 16.96 & 16.96 & 16.96 & 16.96 & 16.96 \\
\hline 3.6998 & 277.385 & 16.96 & 16.96 & 16.96 & 16.96 & 16.96 & 16.96 \\
\hline 4.8998 & 277.385 & 16.96 & 16.96 & 16.96 & 16.96 & 16.96 & 16.96 \\
\hline 6.8998 & 277.385 & 16.96 & 16.96 & 16.96 & 16.96 & 16.96 & 16.96 \\
\hline 10.1498 & 277.385 & 16.96 & 16.96 & 16.96 & 16.96 & 16.96 & 16.96 \\
\hline 15.1498 & 277.385 & 16.96 & 16.96 & 16.96 & 16.96 & 16.96 & 16.96 \\
\hline 22.6498 & 277.385 & 16.96 & 16.96 & 16.96 & 16.96 & 16.96 & 16.96 \\
\hline 33.8249 & 277.385 & 16.96 & 16.96 & 16.96 & 16.96 & 16.96 & 16.96 \\
\hline 0.285 & 272.595 & 17.07 & 17.07 & 17.07 & 17.07 & 17.07 & 17.07 \\
\hline 0.745 & 272.595 & 17.07 & 17.07 & 17.07 & 17.07 & 17.07 & 17.07 \\
\hline 1.0855 & 272.595 & 17.07 & 17.07 & 17.07 & 17.07 & 17.07 & 17.07 \\
\hline 1.43085 & 272.595 & 17.07 & 17.07 & 17.07 & 17.07 & 17.07 & 17.07 \\
\hline 1.80055 & 272.595 & 17.07 & 17.07 & 17.07 & 17.07 & 17.07 & 17.07 \\
\hline 2.2004 & 272.595 & 17.07 & 17.07 & 17.07 & 17.07 & 17.07 & 17.07 \\
\hline 2.5801 & 272.595 & 17.07 & 17.07 & 17.07 & 17.07 & 17.07 & 17.07 \\
\hline 2.9998 & 272.595 & 17.07 & 17.07 & 17.07 & 17.07 & 17.07 & 17.07 \\
\hline 3.6998 & 272.595 & 17.07 & 17.07 & 17.07 & 17.07 & 17.07 & 17.07 \\
\hline 4.8998 & 272.595 & 17.07 & 17.07 & 17.07 & 17.07 & 17.07 & 17.07 \\
\hline 6.8998 & 272.595 & 17.07 & 17.07 & 17.07 & 17.07 & 17.07 & 17.07 \\
\hline 10.1498 & 272.595 & 17.07 & 17.07 & 17.07 & 17.07 & 17.07 & 17.07 \\
\hline
\end{tabular}

Source: DTN: MO0408MWDDDMIO.002, file LA1450_NUFT_Temp_crss-sctn3.xIs.

Figure U-1. Portion of the Excel Spreadsheet With the NUFT Output 


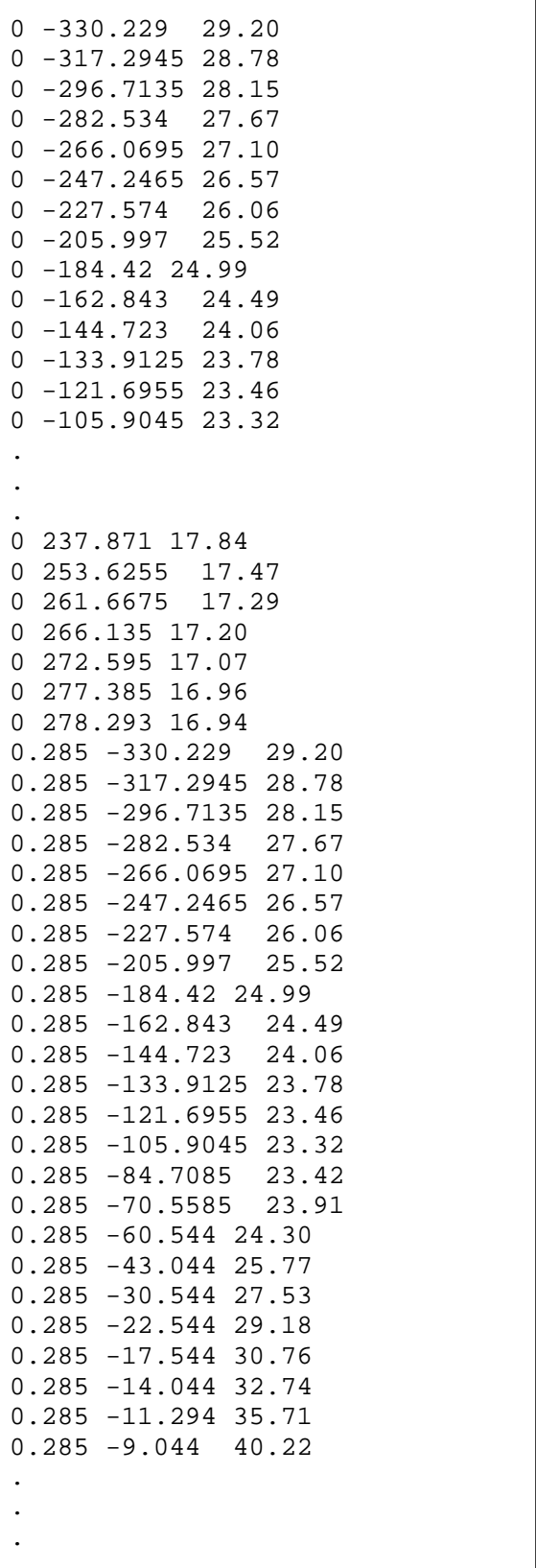

Source: DTN: MO0408MWDDDMIO.002, file temperature_5080.dat.

Figure U-2. Example of ASCII File With Temperature Field for 50.8 Years After Waste Emplacement

After the NUFT temperature field is read into UDEC, interpolation of temperatures was performed for the UDEC grid points. In UDEC, the temperature is a grid point variable. First, a UDEC grid point is located in one of the NUFT rectangular zones (Figure U-3). This operation can be done relatively quickly because the NUFT grid is rectangular. It is carried out by independent searches along $x$ - and $y$-coordinate axes. After local coordinates $\xi, \eta$ (of the UDEC grid point inside the NUFT zone) are determined (Equation U-1), the temperature is calculated using bi-linear interpolation based on temperatures at four NUFT grid points, as shown in Equation U-2. 


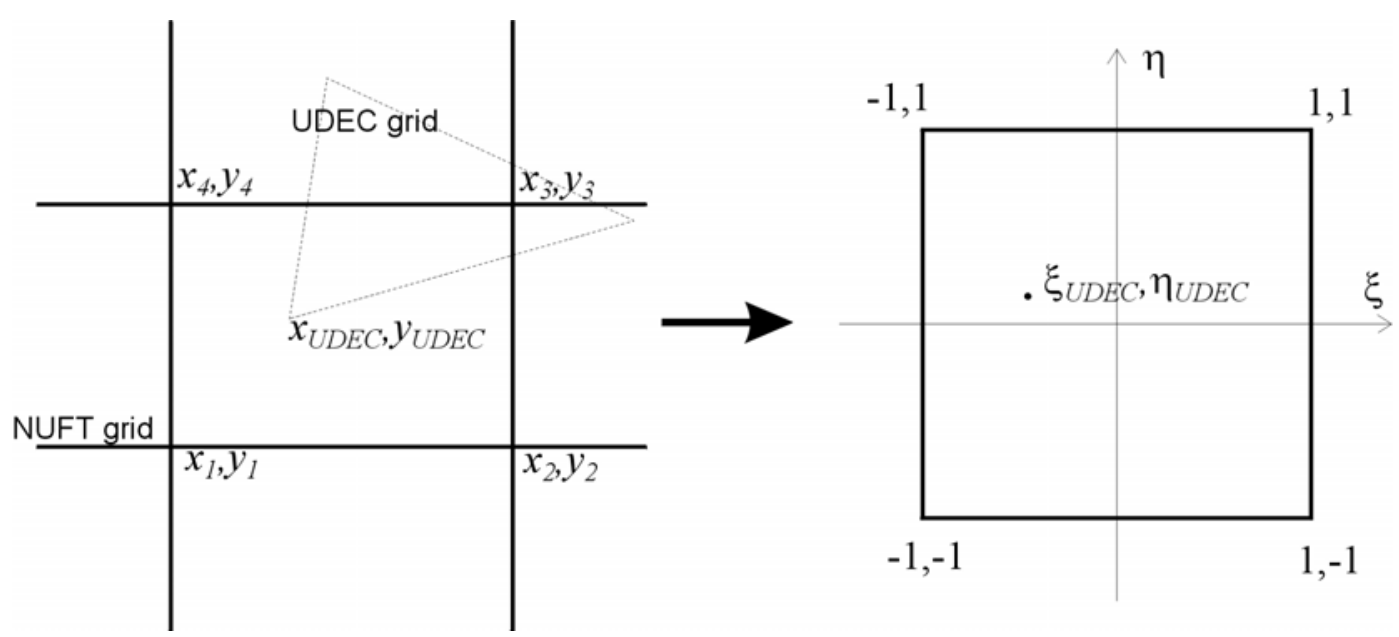

Figure U-3. Interpolation of UDEC Temperatures from the NUFT Grid

$$
\begin{gathered}
\xi_{U D E C}=2 \frac{x_{U D E C}-x_{1}}{x_{3}-x_{1}}-1 \\
\eta_{U D E C}=2 \frac{y_{U D E C}-y_{1}}{y_{3}-y_{1}}-1 \\
f_{1}=\frac{1}{4}(1-\xi)(1-\eta) \\
f_{2}=\frac{1}{4}(1+\xi)(1-\eta) \\
f_{3}=\frac{1}{4}(1+\xi)(1+\eta) \\
f_{4}=\frac{1}{4}(1-\xi)(1+\eta) \\
T_{U D E C}=f_{1} T_{1}+f_{2} T_{2}+f_{3} T_{3}+f_{4} T_{4}
\end{gathered}
$$

The temperature field 50.8 years after emplacement of the waste, as provided by NUFT, is transferred into UDEC using the method described above. The contour lines of the temperature field imported in UDEC are compared with contour lines of the original temperature field in Figure U-4. The temperature profiles along the horizontal section through the drift center obtained from the NUFT data and after importing them into UDEC are compared in Figure U-5. The transfer of temperature field and interpolation are carried out correctly, as the contour lines and the profiles in the horizontal section are almost coincident.

The same algorithm was used for the FLAC model, the verification for UDEC model is therefore applicable to FLAC results. 


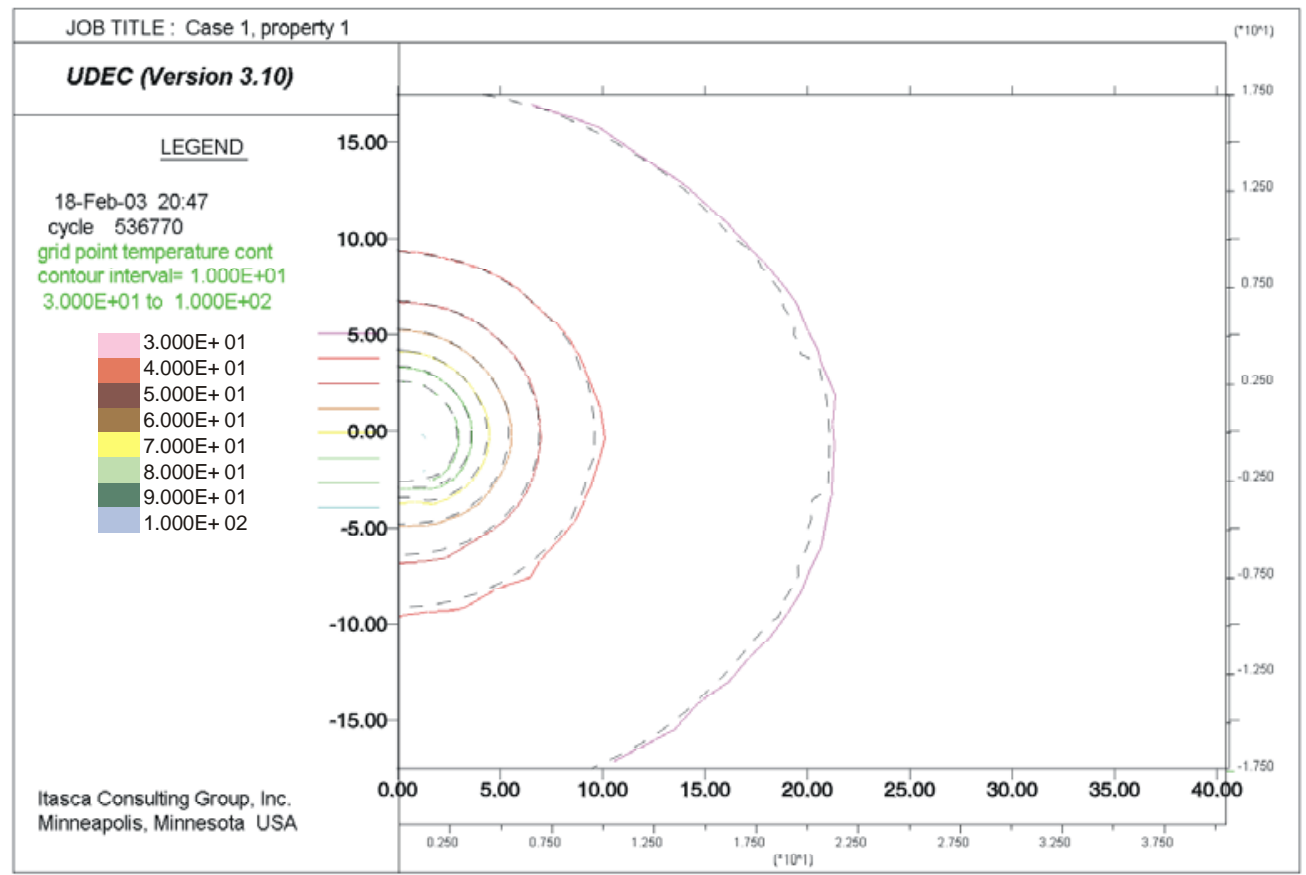

NOTE: Temperature in degrees C; NUFT Results are dashed lines; Data transferred into UDEC solid colored lines.

Figure U-4. Comparison of Temperature Contours 50.8 Years after Waste Emplacement Obtained from the NUFT Results and the Data Transferred into UDEC

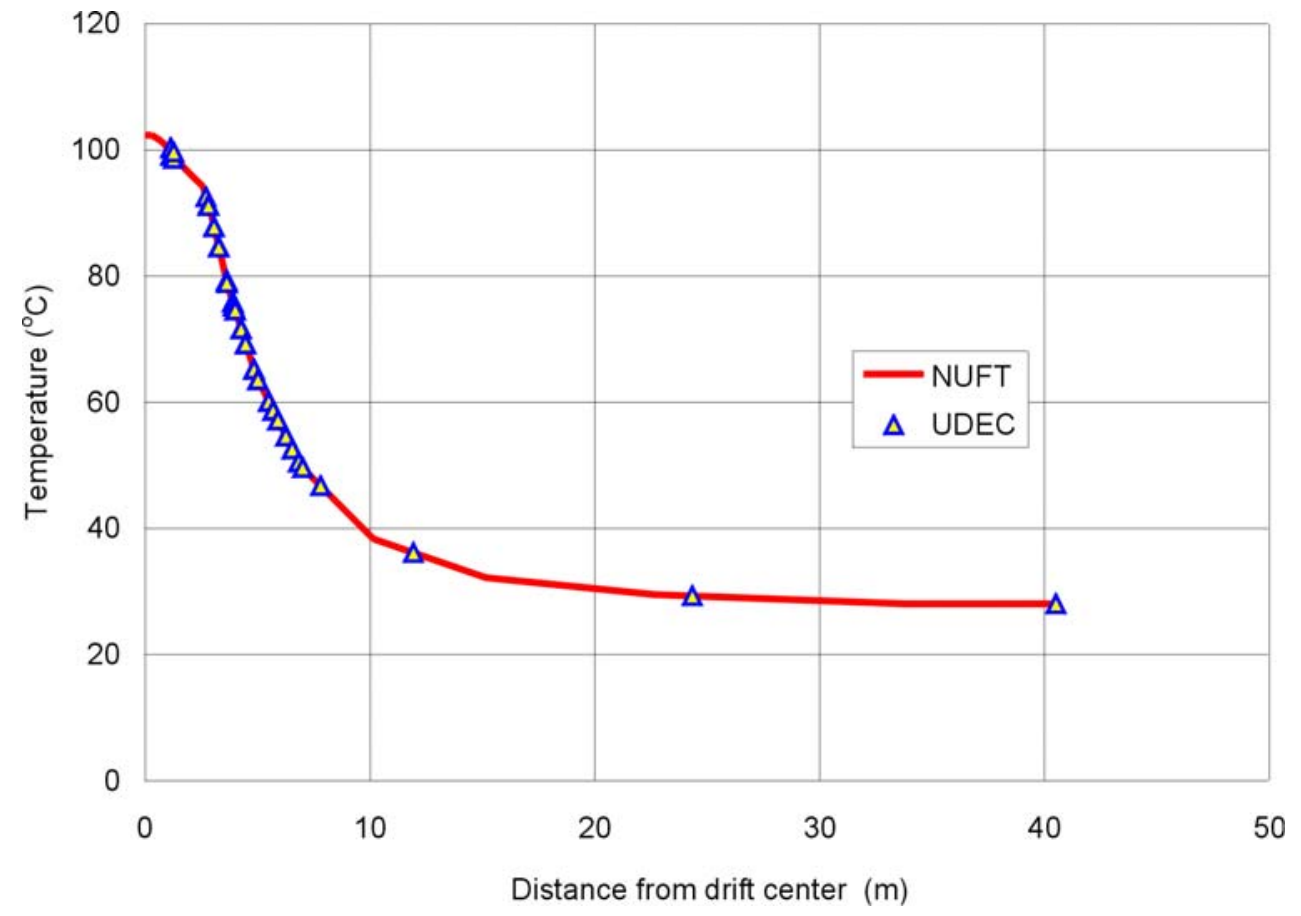

Figure U-5. Comparison of Temperature Profiles Along the Horizontal Section Through the Center of the Drift 50.8 Years After Waste Emplacement Obtained from the NUFT Results and the Data Transferred into UDEC 


\section{INTENTIONALLY LEFT BLANK}




\section{APPENDIX V \\ CALCULATION OF BULKING AND IMPACT OF STRESS ARCHING FROM THE UDEC DISCONTINUUM MODEL}




\section{CALCULATION OF BULKING AND IMPACT OF STRESS ARCHING FROM THE UDEC DISCONTINUUM MODEL}

\section{V1. INTRODUCTION}

It is possible, using the UDEC Voronoi block model, to simulate the entire process of rockfall, including accumulation of the broken rock on the invert of the emplacement drift and on the top of the drip shield. The final configuration of the blocks and effective bulking are results of a simulation. Many approaches for calculating the extent of caving above excavations use bulking factor as an input to the analysis. In the UDEC Voronoi block model, the bulking is a model result, a function of many factors, including size distribution and shape of the blocks, friction angle between the blocks, and sequence of rockfall formation (i.e. if the rockfall first occurs from the crown or from the walls of the drift). However, it is useful to calculate the effective bulking factor of the caved rock resulting from UDEC simulations as a reference for comparison with other methods.

In order to calculate the bulking factor, the region of the rock mass that caved must be identified first. This region is determined based on the displacement magnitudes of the blocks. If the average block displacements are larger than a predefined length threshold, the block is classified to be a part of the rockfall. Considering that the caved rock completely fills the drift, the bulking factor is calculated as the ratio between the area inside the drift (area of the drift in the original configuration before the rockfall minus the area of the outline of the drip shield) and the area of the caved blocks. A larger value of the predefined threshold will result in a smaller region of caved rock and, consequently, a larger bulking factor. The displacement length threshold was selected based on inspection of the displacement contours. Figure V-1 illustrates the contours of the displacement field for Case 4 from Section 6.4.2.5. Although the legend of Figure V-1 indicates $x$-displacements, the figure actually represents contours of total displacement. The contour line corresponding to a displacement of $0.12 \mathrm{~m}$ appears to be a good choice for the outline of the caved rock around the emplacement drift, because there is a large displacement gradient inside that contour line. If the caved rock completely fills the drift, the available volume predefines the increase in volume of the caved rock. The volume of the rock mass (in its original configuration) that caved is calculated by simply adding the areas of the blocks classified to be a part of the rockfall. Note that UDEC's data structure has information about geometry, including area, of every block in a model. The total area, $A_{c o}$, of the blocks in the model that displaced more than $0.12 \mathrm{~m}$, calculated by summing their areas, is $88.71 \mathrm{~m}^{2}$. The calculated bulking factor is:

$$
B=\frac{\pi R^{2}-b_{d} h_{d}}{A_{c o}}=\frac{23.76-7.31}{88.71}=0.19
$$

The area of the outline of the drip shield in the cross-section normal to the drift axis is $7.31 \mathrm{~m}^{2}$ (the drip shield is $2.533 \mathrm{~m}$ wide and $2.886 \mathrm{~m}$ high).

Summation of block areas was also done manually. The blocks with average displacements larger than $0.12 \mathrm{~m}$ are printed out (Figure V-2). UDEC prints out, among the other information, the block masses, which are summed in Excel. The sum of masses of the caved blocks is 
$189,840 \mathrm{~kg} / \mathrm{m}$. The corresponding area for a density of $2,140 \mathrm{~kg} / \mathrm{m}^{3}$ is $88.71 \mathrm{~m}^{2}$ - exactly the same number as obtained using the FISH function.

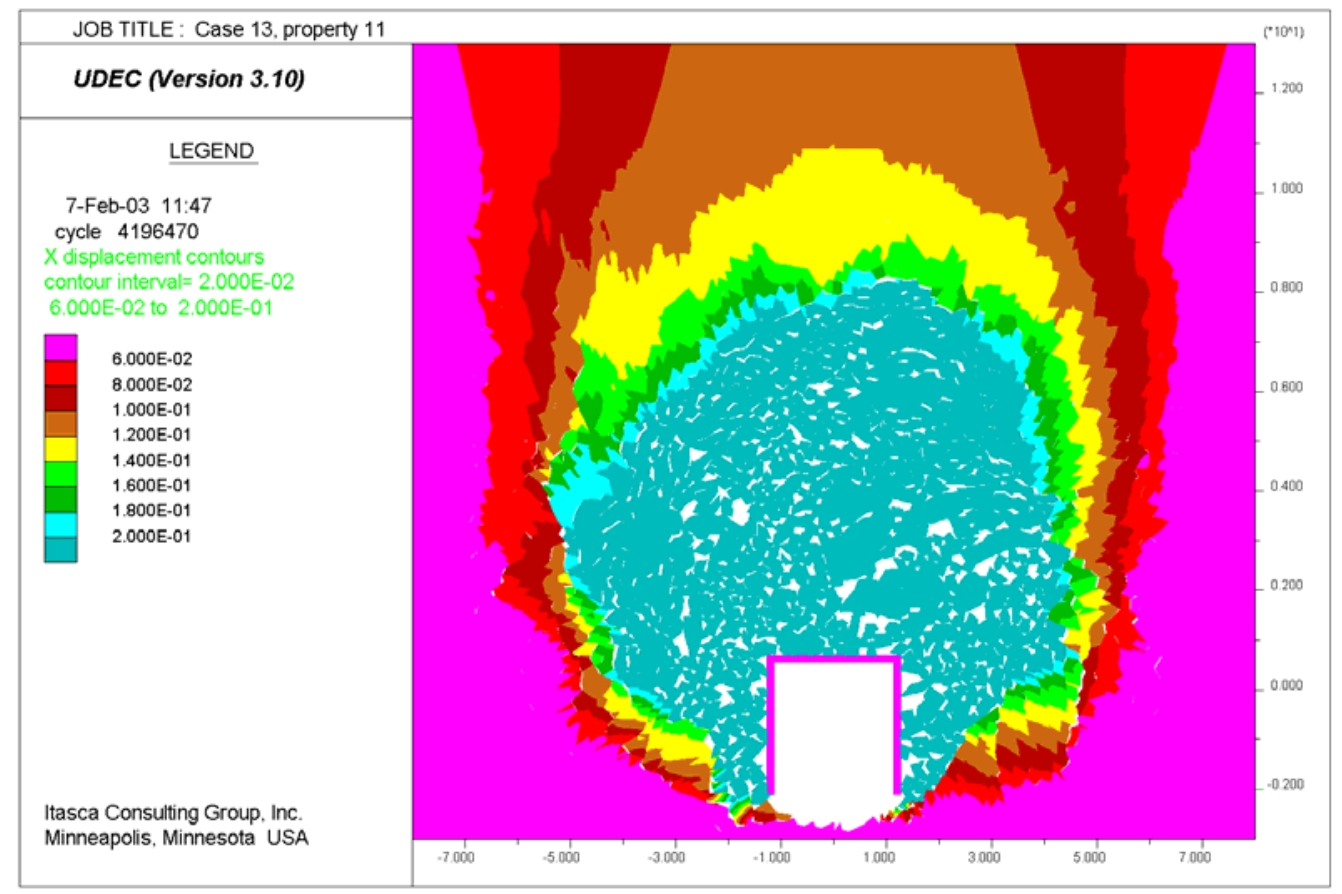

Figure V-1. Contours of Displacement Magnitudes (m): Case 4 of the Drift Degradation Analysis

The area of the rock mass that has caved and the bulking factor are also calculated manually in order to verify the procedure described in the previous paragraph. The outline of the caved rock mass is drawn and measured horizontally at every 1 meter increment of the cave height, which is approximately $14 \mathrm{~m}$ (see Figure V-3). The area of the cross-section of the cave, $A_{c}$, is $111.03 \mathrm{~m}^{2}$, equal to the sum of the widths indicated in Figure V-3 (multiplied by the $1 \mathrm{~m}$ increment height). The other approach is to approximate the cave with an ellipse (as indicated in red in Figure V-3). With a major axis of $14.0 \mathrm{~m}$ and a minor axis of $10.34 \mathrm{~m}$, the area of the ellipse is $113.69 \mathrm{~m}^{2}$. The difference between these two estimates of cave area is very small, of the order of a couple of percent. The total area of the blocks that have caved is equal to the area of the cave minus the increase in volume (i.e. area filled with rubble):

$$
A_{c o}=A_{c}-\pi R^{2}=111.03-23.76=87.27 \mathrm{~m}^{2}
$$

The difference between the area of the caved rock mass calculated by adding areas of blocks in UDEC and manually integrating the area of the cave is less than 2 percent. The bulking factor, based on the manually estimated area of the caved rock mass, is:

$$
B=\frac{\pi R^{2}-b_{d} h_{d}}{A_{c}-\pi R^{2}}=\frac{23.76-7.31}{111.03-23.76}=0.19
$$

Clearly, the bulking factor numerically calculated using UDEC is in agreement with the estimates obtained using simple methods. 


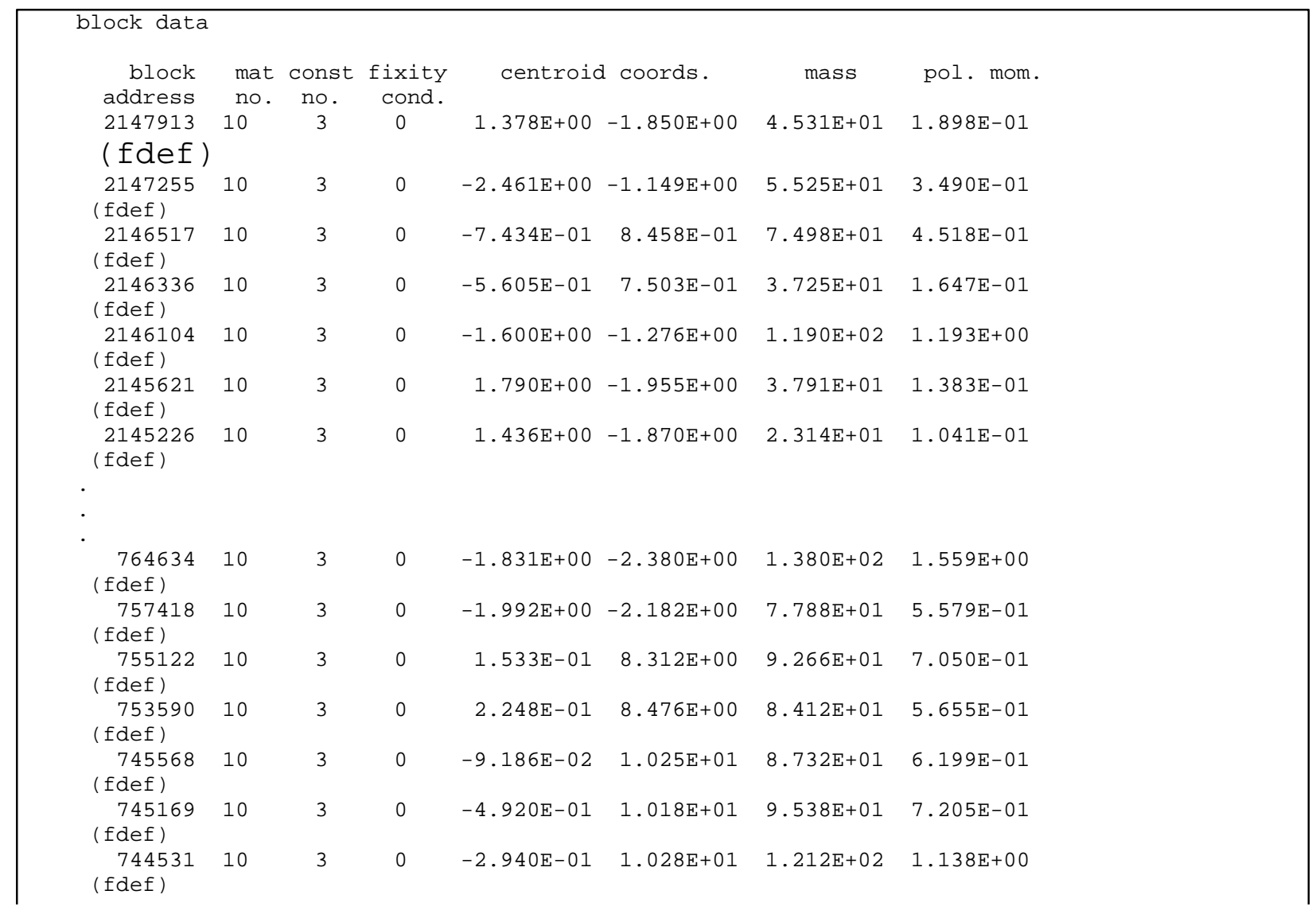

Source: File: loose_blocks.log.

Figure V-2. Printout of Information for the Blocks with Average Displacement Larger than $0.12 \mathrm{~m}$

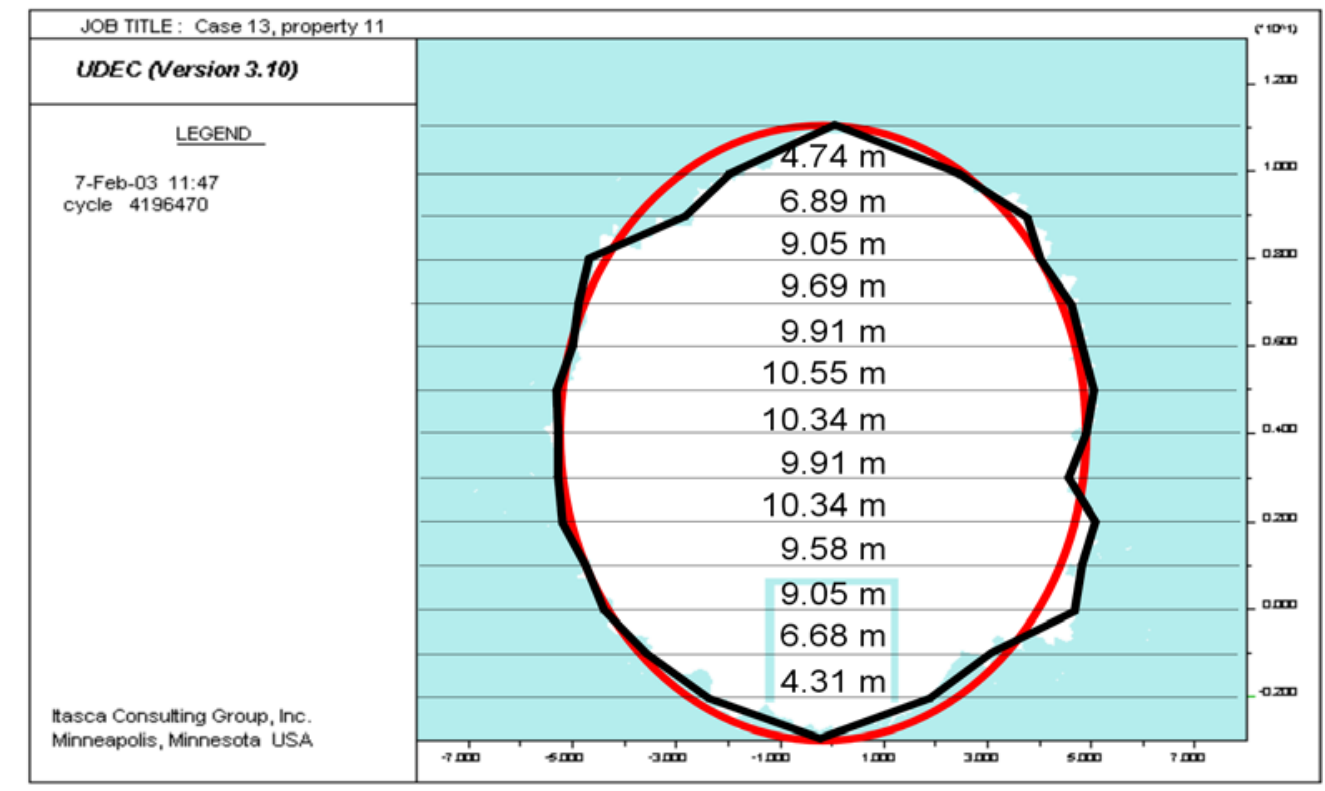

Figure V-3. Outline of the Caved Rock Mass and Its Dimensions Used for Manual Integration 


\section{V2. STRESS ARCHING IN THE BROKEN ROCK ABOVE THE DRIP SHIELD ARCHING EFFECT FOR A RIGID, RECTANGULAR DRIP SHIELD}

A calculation is presented here to demonstrate the impact of stress arching for the case illustrated in Figure V-1. Here, a rigid, rectangular drip shield is considered, which will result in less stress arching effect than would be expected for a deformable drip shield. For the approximate height $(14.0 \mathrm{~m})$ of the cave (measured from the invert of the drift), the dead weight of the broken rock on the drip shield is:

$$
p=h \frac{\rho g}{1+B}=(14.0 \mathrm{~m}-2.75 \mathrm{~m}-0.67 \mathrm{~m}) \times \frac{2400 \mathrm{~kg} / \mathrm{m}^{3} \times 10 \mathrm{~m} / \mathrm{s}^{2}}{(1+0.19)}=213.4 \mathrm{kN} / \mathrm{m}^{2} \quad(\mathrm{Eq} . \mathrm{V}-4)
$$

where $h$ is the height of broken rock above the drip shield, which is determined knowing the cave height $(14.0 \mathrm{~m})$, the drift radius $(2.75 \mathrm{~m})$, and the distance from the drift center to the top of the drip shield $(0.67 \mathrm{~m})$. The average vertical pressure on the drip shield as calculated by using UDEC, which integrates the forces acting between the drip shield and the blocks in the rubble, is $179.2 \mathrm{kN} / \mathrm{m}^{2}$. The arching inside the rubble accounts for only a 16 percent reduction in the load on the drip shield. LeFebvre et al. (1976 [DIRS 168919]) measured pressures of the fill on the corrugated steel arch, $15.5 \mathrm{~m}$ in span. The pressure was measured during backfilling of the arch. The fill consisted mainly of fine silty sand, compacted at 90 percent of the modified Proctor. The measured vertical stress, $2 \mathrm{ft}$ above the top of the structure, shows that positive arching develops when the fill is approximately $3.5 \mathrm{~m}$ above the measurement point. At the end of construction, when the top of the embankment is approximately $12.5 \mathrm{~m}$ above the pressure cell, the measured pressure is only 25 percent of the overburden. Similar results are reported by Byrne et al. (1990 [DIRS 168921]) for an arch metal culvert, $13.4 \mathrm{~m}$ in span. The arch was $7.3 \mathrm{~m}$ high, covered by $9.6 \mathrm{~m}$ of natural sand and gravel compacted to between 95 and 100 percent of standard Proctor. The pressure cell was located $1.2 \mathrm{~m}$ above the crown of the arch. The stresses were measured as a function of the height of fill. Positive arching is observed when the fill was approximately $1.5 \mathrm{~m}$ above the pressure cell. At the end of construction, with $9.6 \mathrm{~m}$ of the cover, the measured vertical stress is 40 percent of the overburden. The pressure cells placed in the fill at the elevation of the springline show the vertical stress larger than the overburden, which is more evidence of the presence of a stress arch.

Stress arching is much more likely to develop in the caved rock, resulting from rockfall, than in sand or gravel, because: a) the average block size in the caved rock is larger than the grain size in sand or gravel, and b) the friction angle in the broken rock fill is larger than the friction angle in sand or gravel. Relatively large load ( 84 percent of overburden) of the broken rock for the rigid, rectangular drip shield predicted by the UDEC model, compared to measured loads on the steel arch culverts, is due to considerations that: a) the drip shield is infinitely stiff, and b) the drip shield is rectangular.

\section{V3. IMPACT OF DEFORMABILITY AND SHAPE OF THE DRIP SHIELD}

The actual finite stiffness of the drip shield will result in deformation and increase load transfer through the broken rock (i.e., a positive arching effect). The top of the drip shield is designed to have an arched shape, which is more favorable for development of a stress arch in the cover (above the drip shield) than the rectangular shape considered in the previous example. The 
arched shape of the top of the drip shield will promote lateral displacements of the blocks above, causing more load to be transferred through the broken rock than to the drip shield. In the following example, taken from Section 6.4, a random geometry of $20 \mathrm{~cm}$ blocks form the rock mass. The cohesion and tensile strength of the rock mass is reduced to force complete collapse and filling of the excavation until equilibrium is achieved. The approximate bulking factor for these simulations is 19 percent.

A comparison of loads to the drip shield is made for two cases: a) rigid drip shield with proper arched geometry, and b) a deformable drip shield with proper arched geometry. The drip shield in both cases is developed from finite difference elements within the UDEC model. The objective here is not to represent the exact geometry of the drip shield, which is a true three-dimensional frame structure, but to provide a two-dimensional model that reproduces the overall stiffness of the actual structure. To ensure that the model adequately represents this stiffness, it was calibrated against the LS-DYNA finite element model that is used for the detailed drip shield vibratory motion and damage assessment modeling (see, for example, Drip Shield Structural Response to Rockfall, BSC 2004 [DIRS 168993]). A sample problem was run with the LS-DYNA program in which the detailed drip shield model was subjected to a uniform vertical pressure over its crown. It was demonstrated that the simplified UDEC model correctly represents deformation of the drip shield (See Appendix Y).

The final collapsed state for the rigid and deformable cases are given in Figures V-4 to V-7. The deformable drip shield footings are allowed to slide on or separate from the invert. A friction coefficient of 0.5 is considered between the footing and the invert, although this value is not important in defining load in the drip shield. The invert, pallet and waste package are rigid and placed only to provide a boundary restraint to the drip shield legs. The displacement contours of the rubble and intact rock are given to help visualize the ultimate height of broken rock, as opposed to yielded or damage rock in the surrounding mass.

The deformation of the drip shield legs and sliding against the pallet due to side pressure of the broken rock on the sides of the drip shield are clearly visible in Figure V-6. The resulting average pressure on the top and sides of the drip shield are given in Table V-1 show that the average pressure on the top of the drip shield is approximately 25 percent lower, in this case, for the deformable drip shield, although the right hand side loading is increased significantly. Although a number of realizations are necessary for a complete comparison of the impact of rigid versus deformable considerations, this example provides an illustration of the methodology employed. The estimates of drip shield loading presented in the main body of the report (Section 6.4) consider a deformable drip shield. 


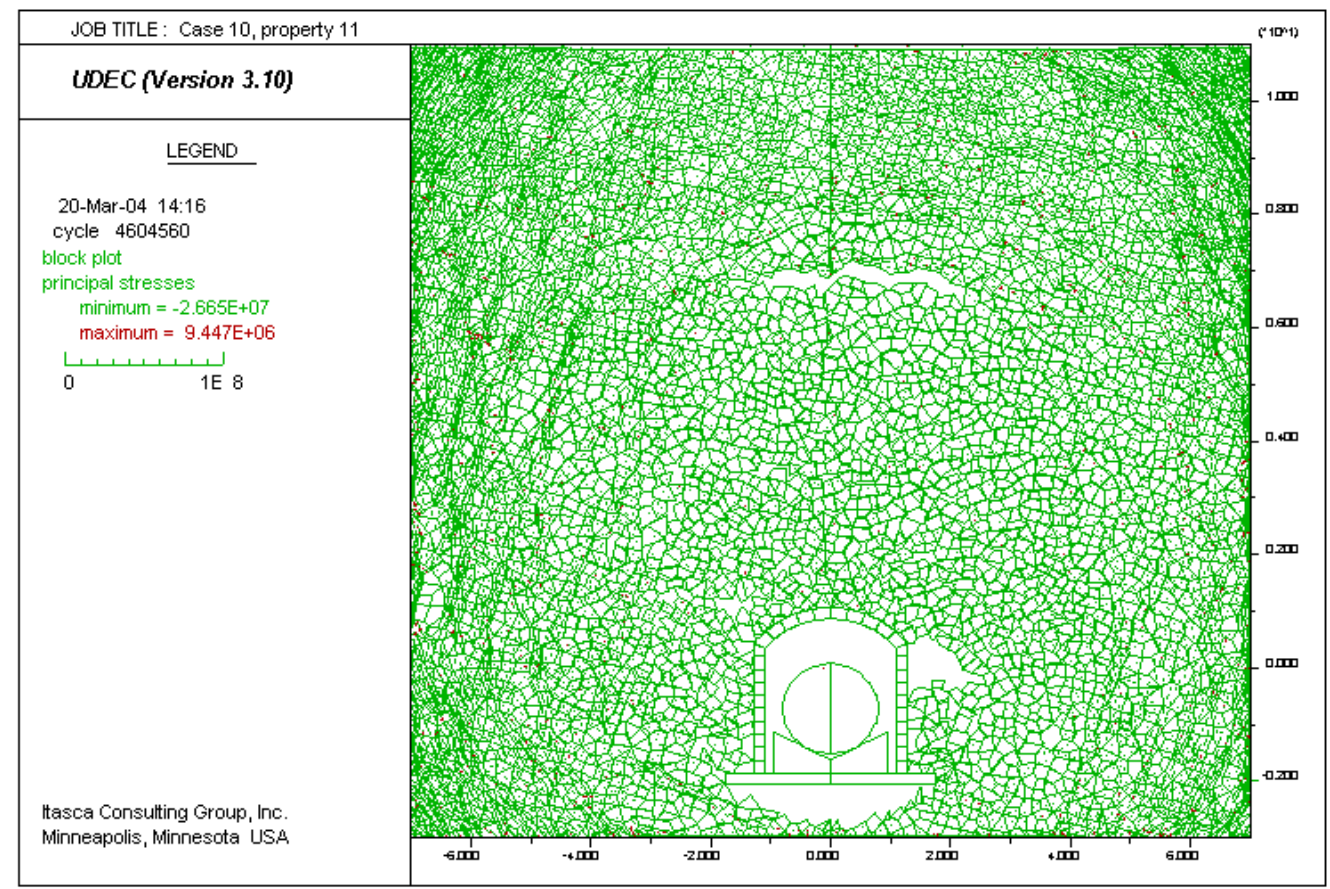

Figure V-4. Quasi-static Drift Degradation, 0.2-m Block Size: Equilibrium State for Rigid Drip Shield with Arched Top, Bottom Fixed to the Invert

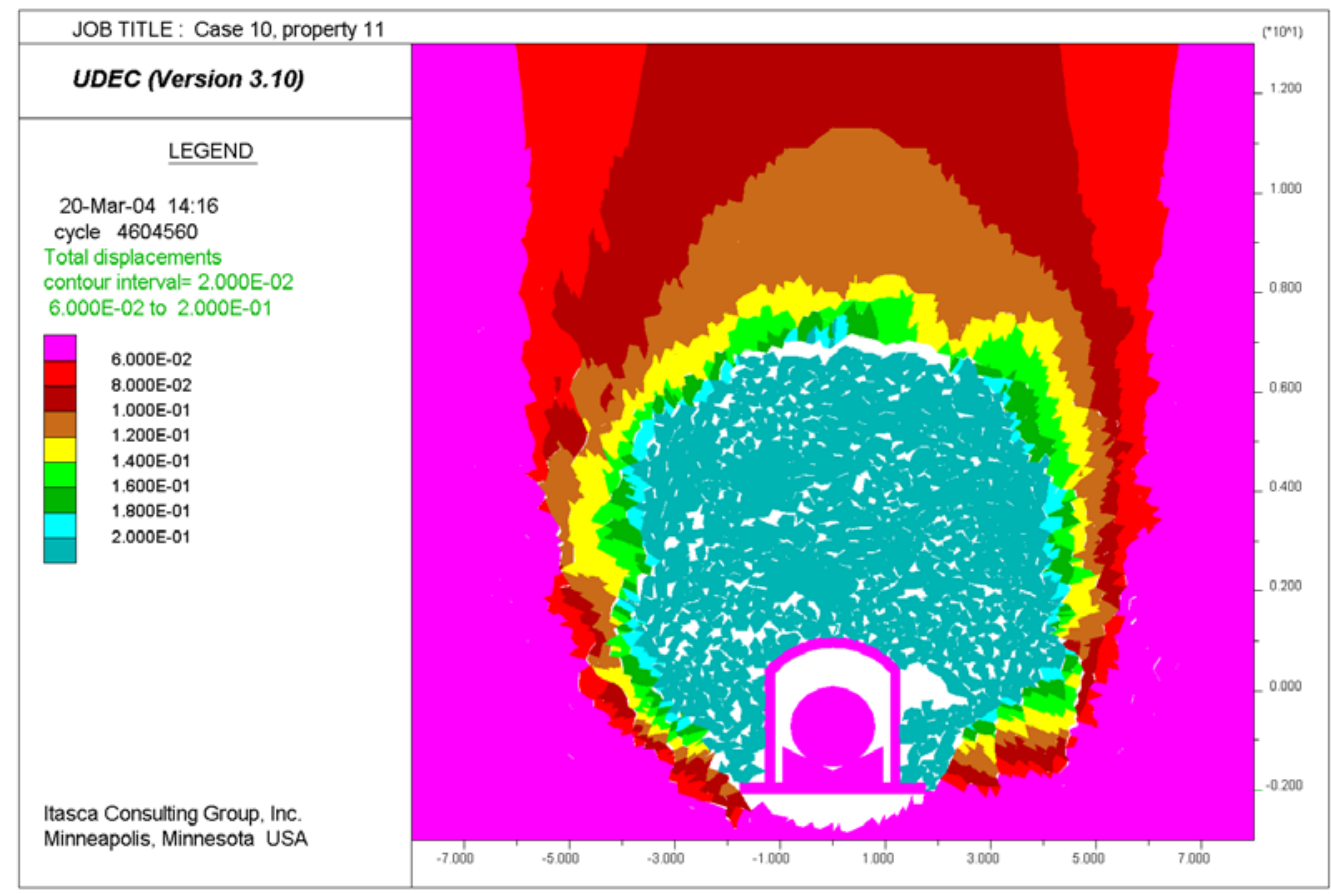

Figure V-5. Quasi-static Drift Degradation, 0.2-m Block Size: Contours of Displacement $(\mathrm{m})$ Magnitude for Rigid Drip Shield with Arched Top, Bottom Fixed to the Invert 


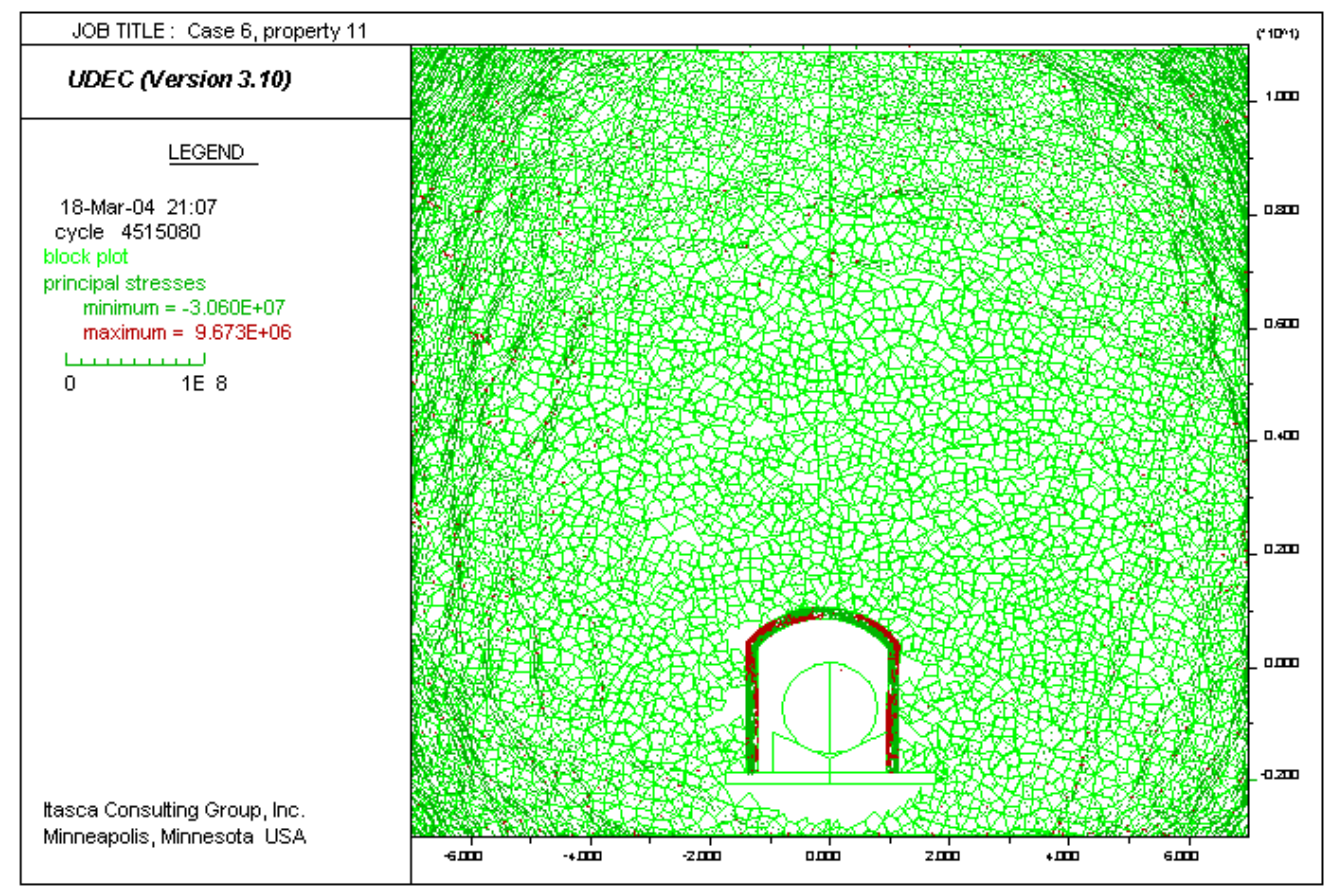

Figure V-6. Quasi-static Drift Degradation, $0.2 \mathrm{~m}$ Block Size: Equilibrium State for Deformable Drip Shield with Arched Top, Bottom Rests on the Invert

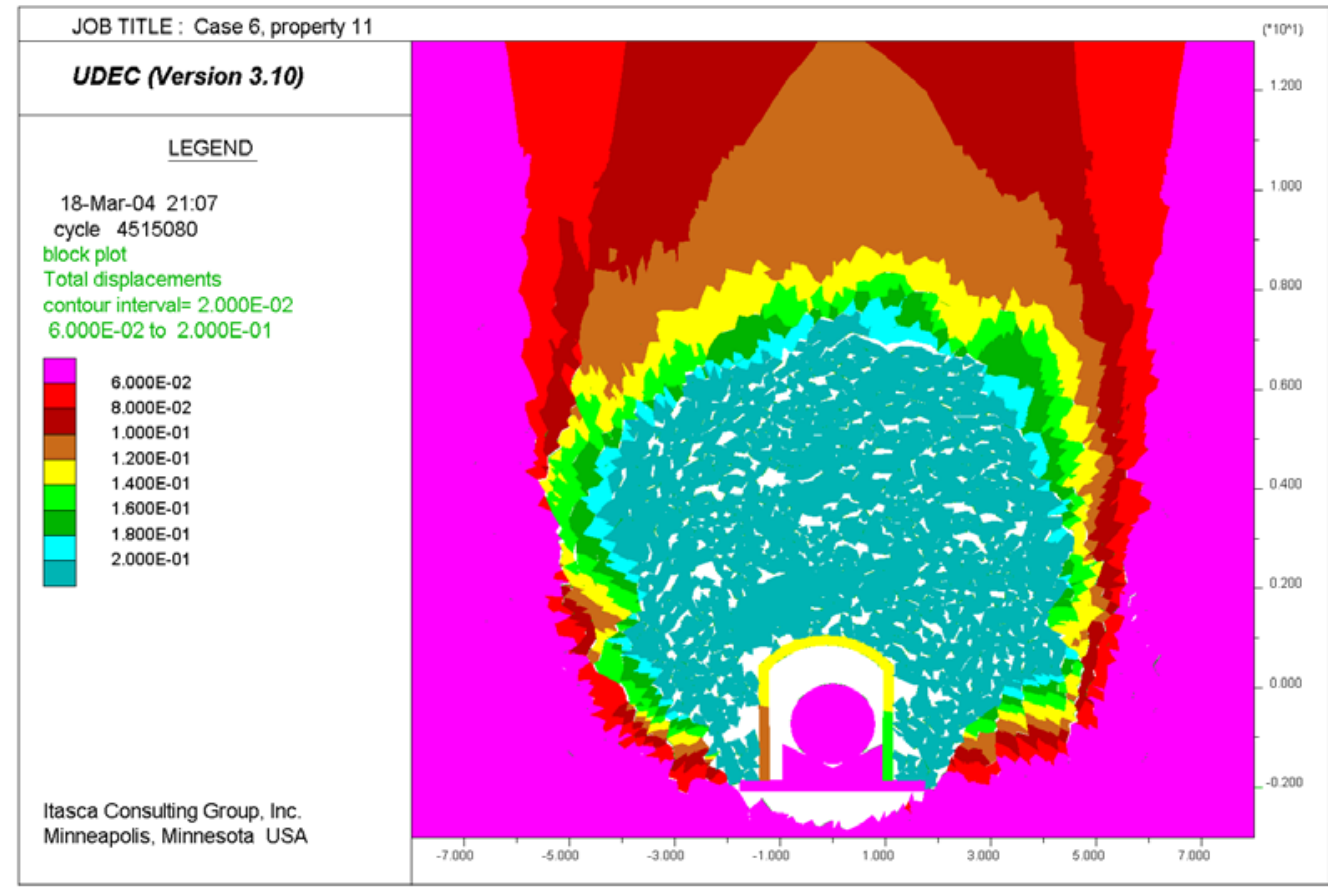

Figure V-7. Quasi-static Drift Degradation, $0.2 \mathrm{~m}$ Block Size: Contours of Displacement $(\mathrm{m})$ Magnitude for Deformable Drip Shield with Arched Top, Bottom Rests on the Invert 
Table V-1. Quasi-static Drift Degradation, 0.2 m Block Size: Average Loads on the Drip Shield for Cases with Invert

\begin{tabular}{|l|c|c|c|}
\hline \multicolumn{1}{|c|}{ Drip Shield } & $\begin{array}{c}\text { Left } \\
\mathbf{k N} / \mathbf{m}^{2}\end{array}$ & $\begin{array}{c}\text { Top } \\
\mathbf{k N} / \mathbf{m}^{2}\end{array}$ & $\begin{array}{c}\text { Right } \\
\mathbf{k N} / \mathbf{m}^{2}\end{array}$ \\
\hline $\begin{array}{l}\text { Rigid, arched top, bottom fixed to } \\
\text { invert }\end{array}$ & 66.45 & 144.15 & 11.28 \\
\hline $\begin{array}{l}\text { Deformable, arched top, bottom } \\
\text { rests on invert }\end{array}$ & 41.54 & 108.92 & 58.76 \\
\hline
\end{tabular}




\section{APPENDIX W}

BOUNDARY CONDITIONS IN THE THERMAL-MECHANICAL MODEL 


\section{BOUNDARY CONDITIONS IN THE THERMAL-MECHANICAL MODEL}

The thermal-mechanical analysis of drift stability in the lithophysal rock was carried out using a two-dimensional model. The vertical model boundaries are placed in the plane half-distance between two drifts. The symmetry conditions of stresses and deformation considered on that plane (i.e., the "roller" boundary condition) are applied on the vertical model boundaries. There are no natural boundaries below the repository. The ground surface is the natural mechanical boundary above the repository. The model size in the vertical direction is considered finite. The horizontal model boundaries are artificial, truncation boundaries, created to limit the model size and calculation time. In the UDEC thermal-mechanical calculations, it was considered that the horizontal model boundaries are $17.5 \mathrm{~m}$ below and above the drift axis. The vertical model size is $35 \mathrm{~m}$. The bottom model boundary was considered to be fixed. The uniform normal stress equal to the weight of the truncated overburden was applied on the top model boundary as a stress boundary condition. It is necessary to demonstrate that the model size and the selected boundary conditions do not affect significantly model results. The stresses around the drift (in the roof and the wall) are predicted (with continuum elastic model in FLAC) using three different model geometries: $30 \mathrm{~m}$ (Figure W-1), $60 \mathrm{~m}$ (Figure W-2) and $120 \mathrm{~m}$ (Figure W-3) vertical model dimensions. The horizontal model size is the same in the three cases. The simulations were carried out for two extreme cases of material properties in the lithophysal rock mass, Categories 1 and 5.

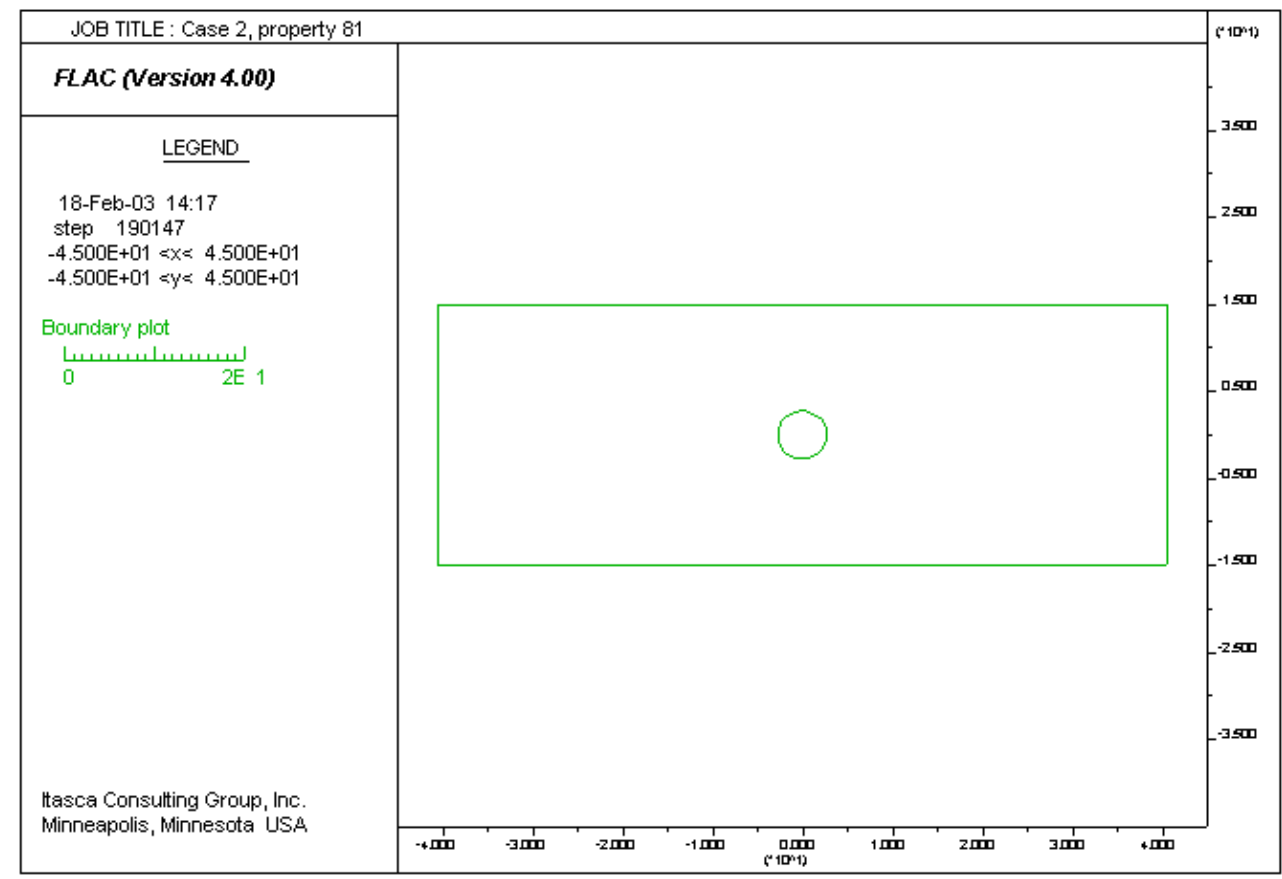

Figure W-1. Geometry of the Model: Vertical Model Dimension $30 \mathrm{~m}$ 


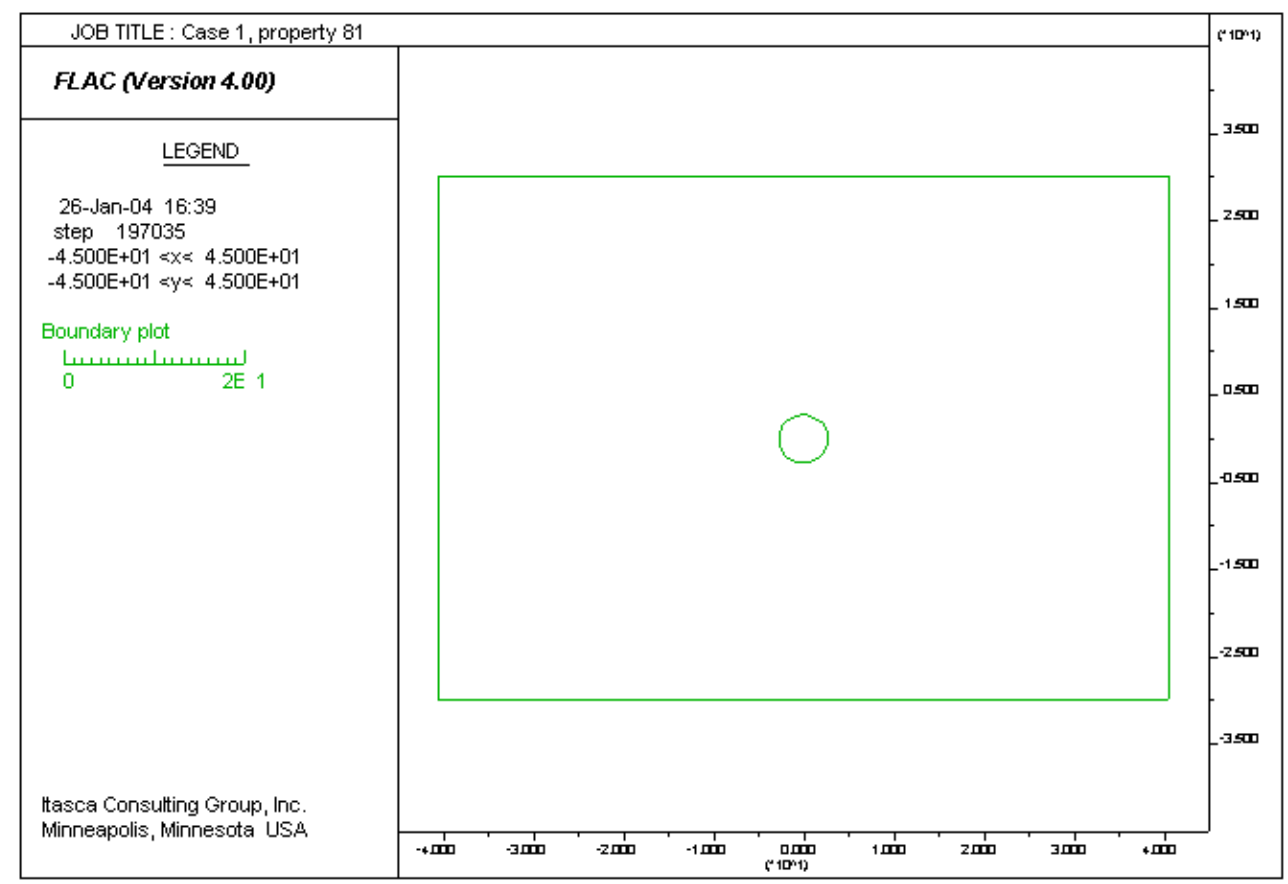

Figure W-2. Geometry of the Model: Vertical Model Dimension $60 \mathrm{~m}$

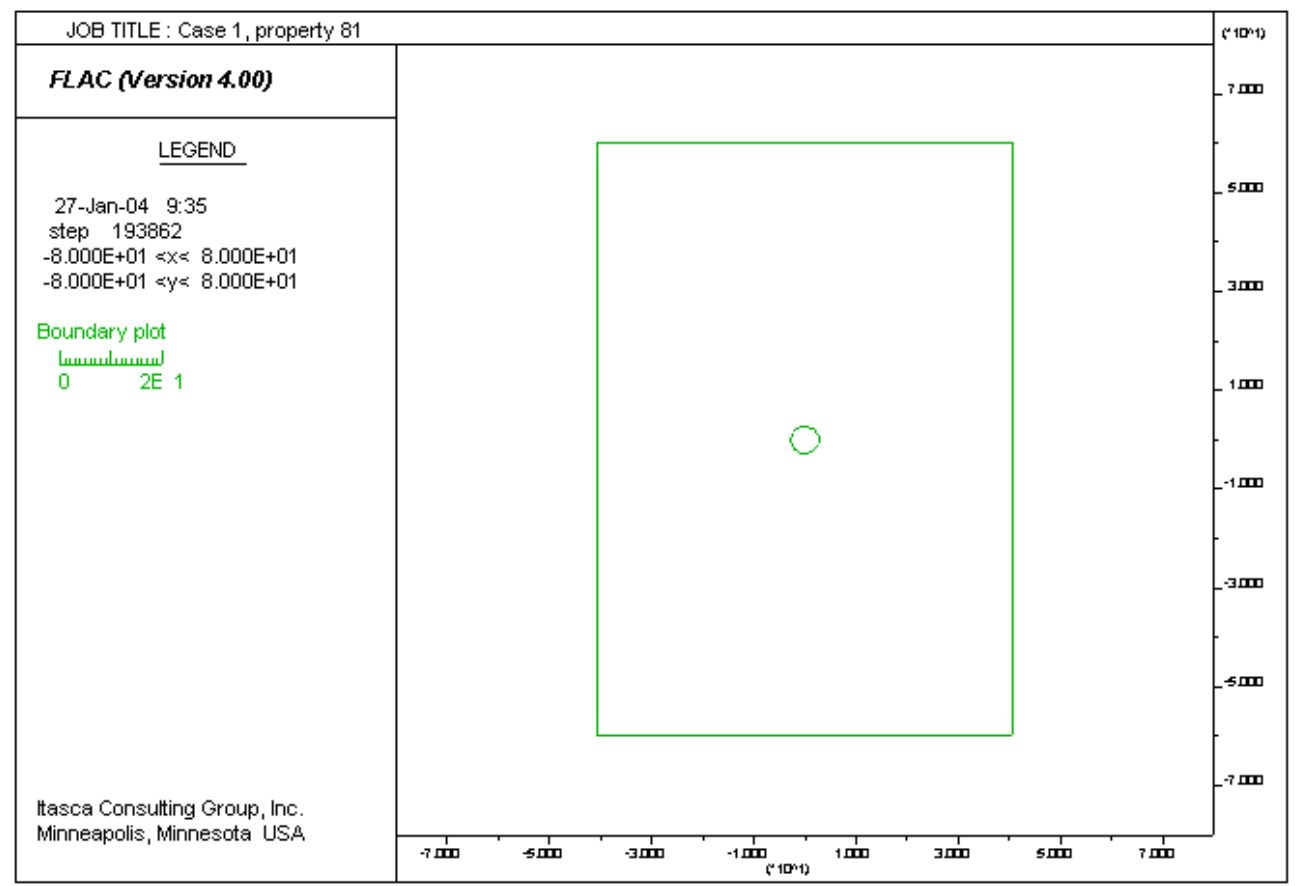

Figure W-3. Geometry of the Model: Vertical Model Dimension $120 \mathrm{~m}$

The stress paths in the principal stress space at five points in the roof and in the wall are generated for the simulated cases. The results for Category 1 are shown in Figures W-4 and $\mathrm{W}-5$. The model size (in the range between $30 \mathrm{~m}$ and $120 \mathrm{~m}$ ) has no effect on predicted stress paths. If the model were extended to the ground surface, the results would not be different. The results for Category 5 are shown in Figures W-6 and W-7. Stresses in the crown are practically 
independent of the model size. The effect of the model size can be observed on stress paths recorded at the points in the wall. The maximum value of the major principal stress during the thermal cycle at the point $0.14 \mathrm{~m}$ from the wall is approximately 20 percent larger in the $60 \mathrm{~m}$ model than in the $30 \mathrm{~m}$ model. The stress difference between the $60 \mathrm{~m}$ and $120 \mathrm{~m}$ models is insignificant. That stress change does not cause yield in the drift wall since it is below the yield surface and consequently does not effect model predictions of rockfall. Also, at the points that are at $0.5 \mathrm{~m}$ from the drift wall or further, the increase in the vertical model size results in increase in the both principal stresses resulting in the stress state moving away from the yield surface, and more favorable stability conditions. With an exception of the point very close to the wall surface, the smaller size model results in more conservative conditions from the perspective of rockfall predictions. The different stress path as a function of model size take place over a relatively short period of time (compared to the duration of the regulatory period), between 50 years and 100 years after waste emplacement, just after ventilation shut down.

The selected vertical model size $(35 \mathrm{~m})$ and the boundary conditions on the bottom and the top model boundaries are satisfactory for the analysis of drift degradation.

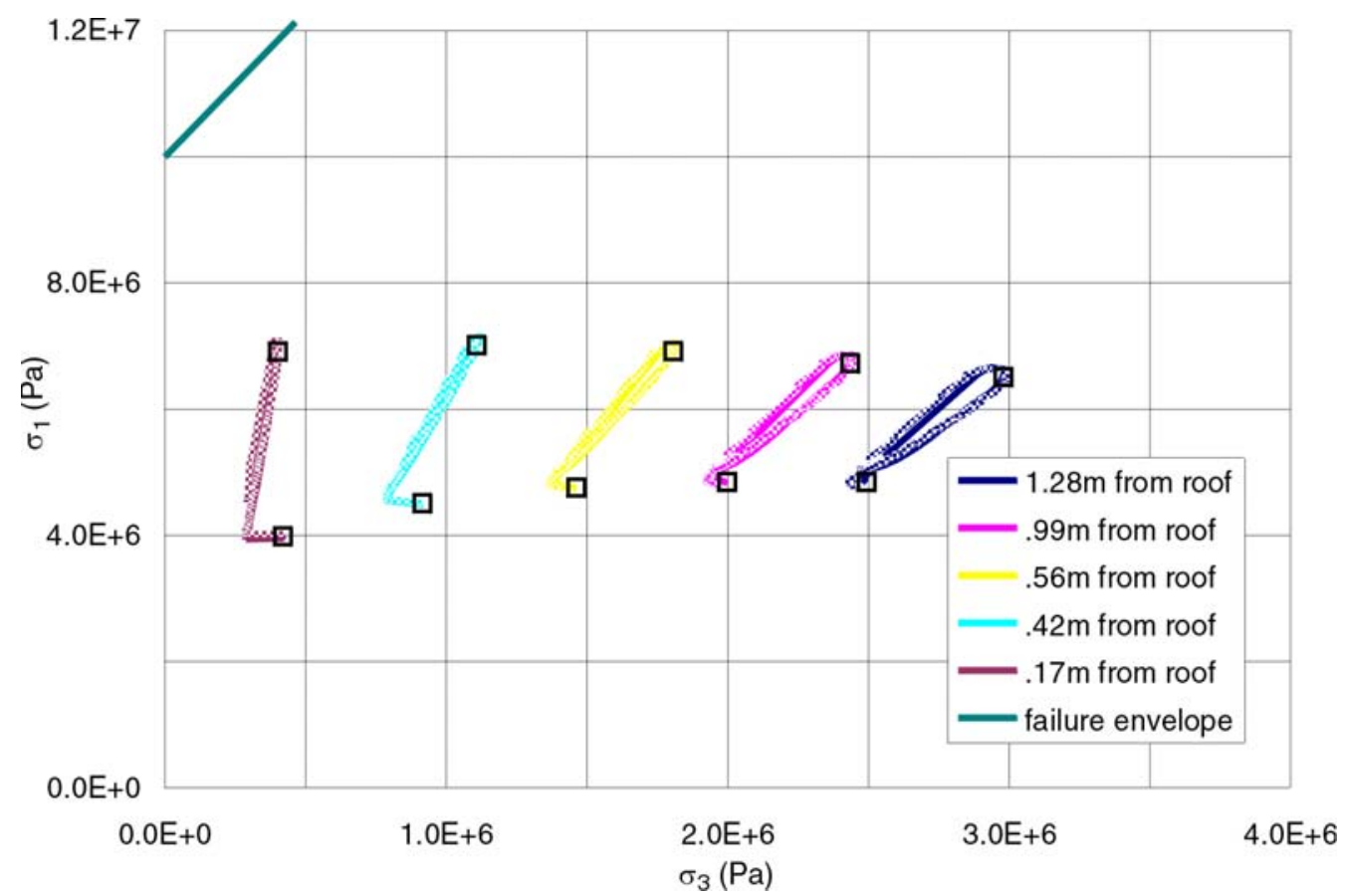

NOTE: 30 m model size - solid line; 60 m model size - dashed line; 120 m model size - pale line.

Figure W-4. Stress Paths in the Drift Crown for Category 1 


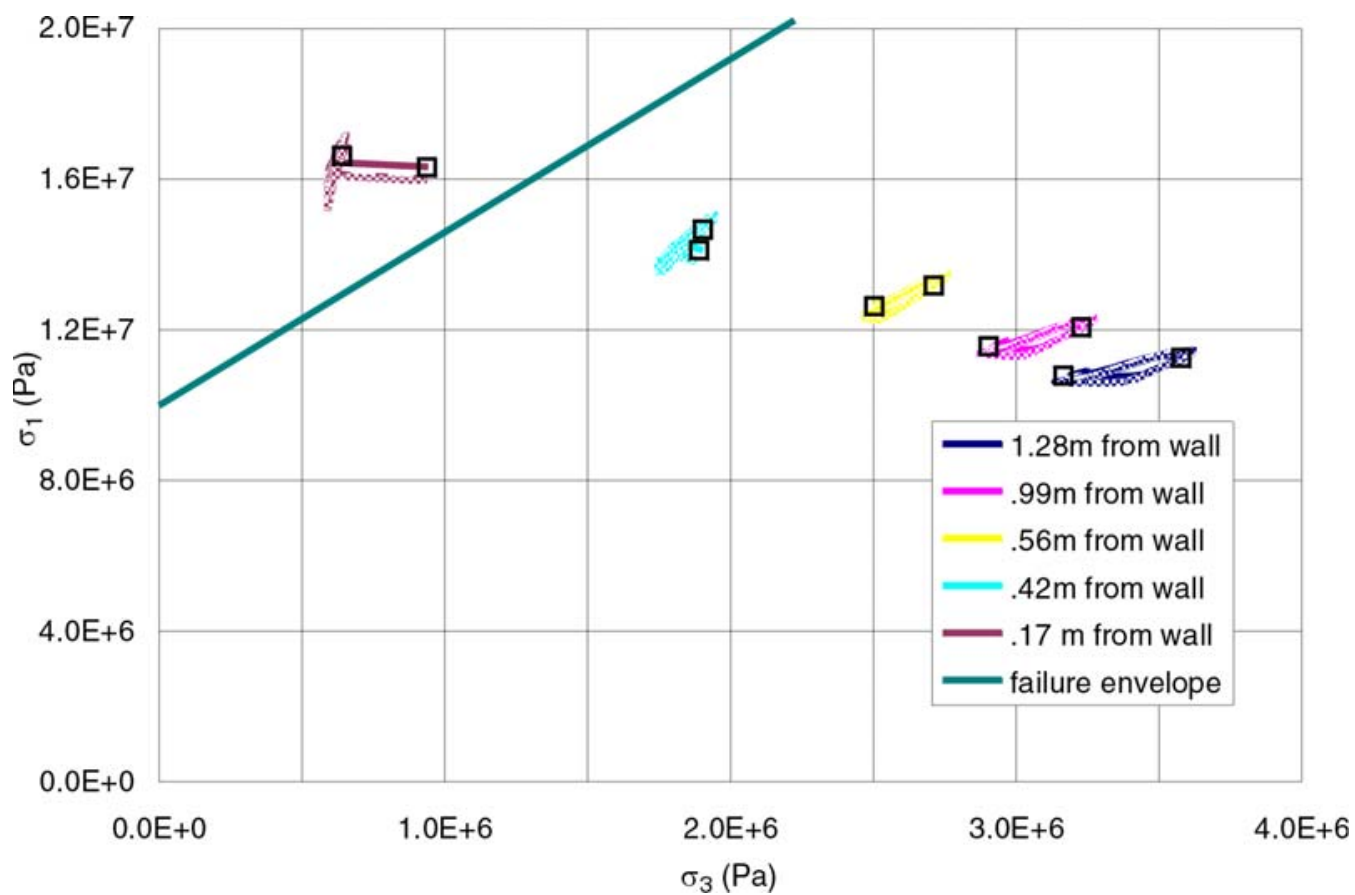

NOTE: $30 \mathrm{~m}$ model size - solid line; $60 \mathrm{~m}$ model size - dashed line; $120 \mathrm{~m}$ model size - pale line.

Figure W-5. Stress Paths in the Drift Wall for Category 1

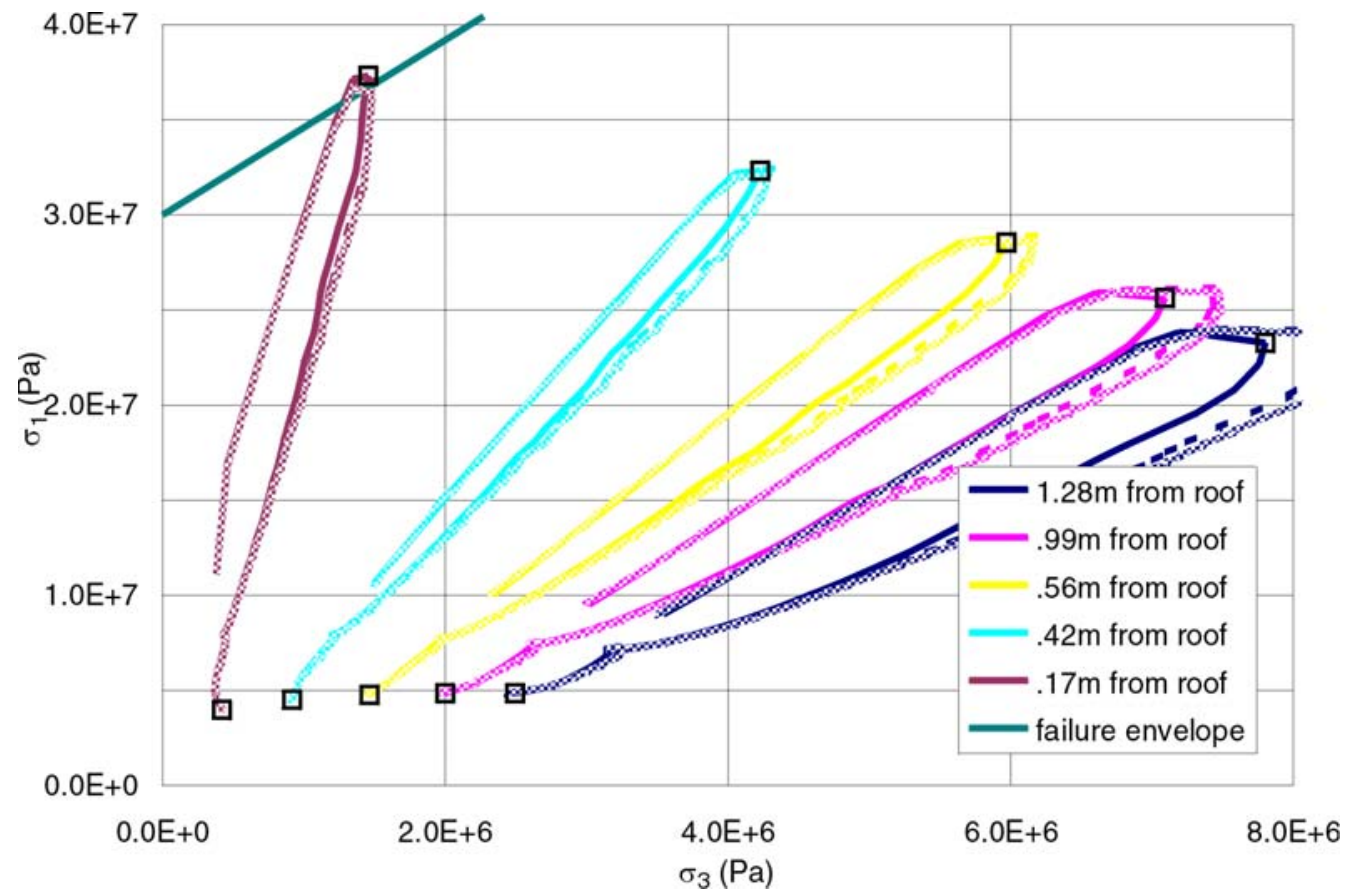

NOTE: 30 m model size - solid line; $60 \mathrm{~m}$ model size - dashed line; $120 \mathrm{~m}$ model size - pale line.

Figure W-6. Stress Paths in the Drift Crown for Category 5 


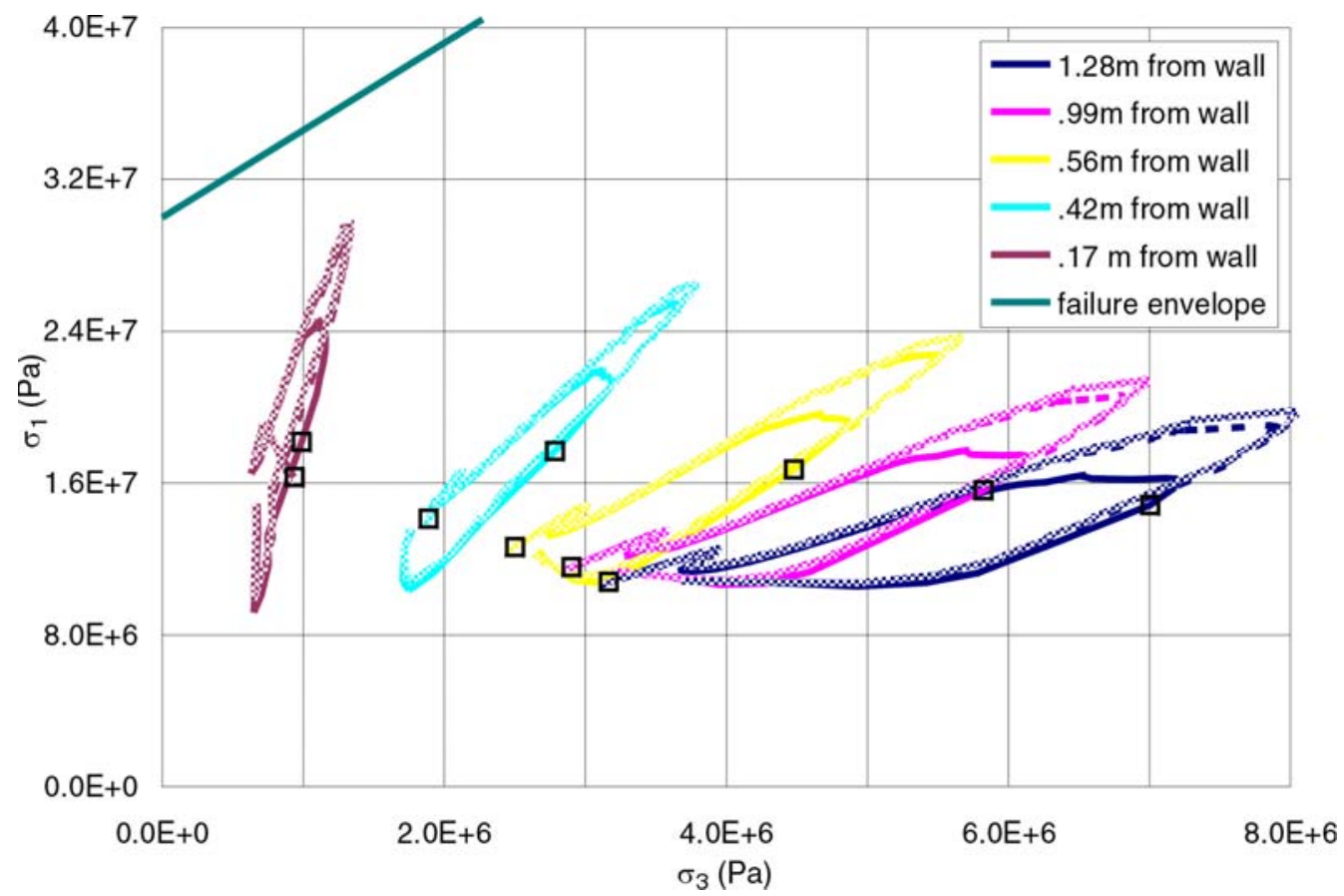

NOTE: $30 \mathrm{~m}$ model size - solid line; $60 \mathrm{~m}$ model size - dashed line; $120 \mathrm{~m}$ model size - pale line.

Figure W-7. Stress Paths in the Drift Wall for Category 5 


\section{INTENTIONALLY LEFT BLANK}




\section{APPENDIX X \\ LISTING OF SITE-SPECIFIC GROUND MOTION PARAMETERS}




\section{LISTING OF SITE-SPECIFIC GROUND MOTION PARAMETERS}

Site-specific ground motions for five levels of annual probability of exceedance, $5 \times 10^{-4}, 1 \times 10^{-4}$, $1 \times 10^{-5}, 1 \times 10^{-6}$, and $1 \times 10^{-7}$, are included in this study. The $5 \times 10^{-4}$ and $1 \times 10^{-4}$ ground motions are for preclosure consideration, while the $1 \times 10^{-5}, 1 \times 10^{-6}$ and $1 \times 10^{-7}$ ground motions are for postclosure. The preclosure level motions are provided for comparison to the postclosure levels. A total of 15 sets of Point B ground motions (i.e., ground motions developed at repository horizon) were selected for each annual postclosure hazard level. The multiple sets ensure a reasonable distribution of spectral shapes and time history durations. For each set of ground motions, two horizontal components (H1 and $\mathrm{H} 2)$ and one vertical component (V) of acceleration, velocity, and displacement are supplied.

Two sets of $1 \times 10^{-6}$ ground motions were used. The difference in these sets is described in DTN: MO0403AVDSC106.001, file 10-6 TH memo.doc. The original set (i.e., DTN: MO0301TMHIS106.001) is used in Section 6.4.2.2. Since this ground motion results in complete drift collapse for lithophysal rock, it was not necessary to repeat the analyses using the revised set (i.e., DTN: MO0403AVDSC106.001).

Only one ground motion was provided for the preclosure hazard levels because of the deterministic-based design approach for preclosure consideration. This appendix provides a complete listing of the peak ground velocity (Tables X-1 to X-5), Arias Intensity (Tables X-6 to X-10), and Power Spectral Density (Tables X-11 to X-15).

Ground velocity time histories are provided for fixed time intervals in the ASCII files contained in the DTNs listed below each table. Files for ground velocity are the ones with extension of vts or vth. Peak ground velocity is obtained by opening the vts or vth files in the Excel program and using the spreadsheet function abs() (absolute value) and $\max ()$ (maximum value). The values for Arias Intensity can be directly extracted from the ASCII files with file extension dur contained in the DTNs. Power Spectral Density is obtained by transforming the velocity time history to the frequency domain using the fast Fourier transform function in Mathcad. Next, the square of the velocities is integrated along the frequency domain. The Mathcad files used to obtain the Power Spectral Density are described in Appendix A (Table A-1, files *.powe cal.mcd).

Table X-1. Peak Ground Velocity (cm/sec) for Preclosure Ground Motions

\begin{tabular}{|c|c|c|c|}
\hline Ground Motion Set & H1 & H2 & V \\
\hline $5 \times 10-4$ & 19.00 & 17.72 & 17.73 \\
\hline $1 \times 10-4$ & 38.38 & 43.78 & 47.51 \\
\hline
\end{tabular}

Source: DTNS: MO0407TMHIS104.003 [DIRS 170599] and MO0306SDSAVDTH.000 [DIRS 164033]. 
Table X-2. Peak Ground Velocity (cm/sec) for $1 \times 10^{-5}$ Ground Motions

\begin{tabular}{|c|c|c|c|}
\hline Ground Motion Set & H1 & H2 & V \\
\hline 1 & 104.58 & 83.31 & 70.88 \\
\hline 2 & 104.58 & 125.02 & 145.25 \\
\hline 3 & 104.58 & 262.05 & 398.11 \\
\hline 4 & 104.59 & 100.41 & 152.27 \\
\hline 5 & 104.58 & 166.71 & 106.52 \\
\hline 6 & 104.54 & 45.61 & 173.88 \\
\hline 7 & 104.51 & 89.33 & 333.16 \\
\hline 8 & 104.56 & 152.20 & 98.16 \\
\hline 9 & 104.59 & 357.76 & 281.76 \\
\hline 10 & 104.60 & 31.81 & 50.16 \\
\hline 11 & 104.60 & 126.04 & 120.31 \\
\hline 12 & 104.54 & 70.34 & 100.60 \\
\hline 13 & 104.58 & 103.75 & 318.01 \\
\hline 14 & 104.62 & 40.87 & 92.78 \\
\hline 16 & 104.56 & 67.43 & 137.53 \\
\hline
\end{tabular}

Source: DTN: MO0402AVDTM105.001 [DIRS 168890], file vts.zip.

Table X-3. Peak Ground Velocity (cm/sec) for $1 \times 10^{-6}$ Ground Motions (Revised Set)

\begin{tabular}{|c|c|c|c|}
\hline Ground Motion Set & H1 & H2 & V \\
\hline 1 & 244.14 & 195.41 & 111.29 \\
\hline 2 & 244.12 & 268.58 & 233.12 \\
\hline 3 & 244.14 & 642.80 & 609.45 \\
\hline 4 & 244.10 & 259.50 & 297.45 \\
\hline 5 & 244.07 & 257.01 & 113.84 \\
\hline 6 & 244.13 & 132.27 & 270.94 \\
\hline 7 & 244.66 & 242.17 & 637.11 \\
\hline 8 & 244.14 & 401.84 & 153.58 \\
\hline 9 & 244.16 & 817.00 & 457.09 \\
\hline 10 & 244.02 & 78.24 & 84.58 \\
\hline 11 & 244.12 & 255.98 & 127.82 \\
\hline 12 & 244.14 & 271.53 & 194.53 \\
\hline 13 & 244.13 & 303.50 & 337.21 \\
\hline 14 & 244.15 & 125.60 & 245.79 \\
\hline 16 & 244.12 & 158.41 & 211.80 \\
\hline
\end{tabular}

Source: DTN: MO0403AVDSC106.001 [DIRS 168891], file Vts.zip. 
Table X-4. Peak Ground Velocity (cm/sec) for $1 \times 10^{-6}$ Ground Motions (Original Set)

\begin{tabular}{|c|c|c|c|}
\hline Ground Motion Set & H1 & H2 & V \\
\hline 1 & 244.00 & 243.35 & 229.79 \\
\hline 2 & 243.79 & 243.90 & 229.34 \\
\hline 3 & 254.63 & 242.69 & 228.36 \\
\hline 4 & 243.61 & 243.28 & 228.37 \\
\hline 5 & 243.35 & 243.39 & 229.59 \\
\hline 6 & 244.11 & 243.05 & 229.92 \\
\hline 7 & 243.86 & 244.08 & 229.78 \\
\hline 8 & 244.21 & 243.93 & 229.62 \\
\hline 9 & 244.01 & 243.98 & 230.00 \\
\hline 10 & 241.90 & 238.07 & 229.73 \\
\hline 11 & 243.76 & 243.82 & 229.76 \\
\hline 12 & 243.27 & 242.83 & 229.77 \\
\hline 13 & 243.95 & 243.95 & 230.13 \\
\hline 14 & 244.13 & 244.27 & 229.80 \\
\hline
\end{tabular}

Source: DTN: MO0301TMHIS106.001 [DIRS 161868], file 10-6THb.zip.

Table X-5. Peak Ground Velocity $(\mathrm{cm} / \mathrm{sec})$ for $1 \times 10^{-7}$ Ground Motions

\begin{tabular}{|c|c|c|c|}
\hline Ground Motion Set & H1 & H2 & V \\
\hline 1 & 535.26 & 428.42 & 298.44 \\
\hline 2 & 535.32 & 588.89 & 625.10 \\
\hline 3 & 535.27 & 1409.30 & 1634.20 \\
\hline 4 & 535.27 & 569.05 & 797.61 \\
\hline 5 & 535.27 & 563.65 & 305.27 \\
\hline 6 & 535.27 & 290.00 & 726.52 \\
\hline 7 & 536.24 & 530.78 & 1708.30 \\
\hline 8 & 535.14 & 880.81 & 411.80 \\
\hline 9 & 535.22 & 1791.10 & 1225.70 \\
\hline 10 & 535.24 & 171.62 & 226.79 \\
\hline 11 & 535.23 & 561.25 & 342.73 \\
\hline 12 & 535.39 & 595.47 & 521.62 \\
\hline 13 & 535.27 & 665.45 & 904.21 \\
\hline 14 & 535.28 & 275.36 & 659.11 \\
\hline 16 & 535.27 & 347.33 & 567.89 \\
\hline
\end{tabular}

Source: DTN: MO0403AVTMH107.003 [DIRS 168892], file Vts.zip. 
Table X-6. Arias Intensity $(\mathrm{m} / \mathrm{sec})$ for Preclosure Ground Motions

\begin{tabular}{|c|c|c|c|c|}
\hline Ground Motion Set & H1 & H2 & V & Sum \\
\hline $5 \times 10^{-4}$ & 0.59 & 0.67 & 0.46 & 1.72 \\
\hline $1 \times 10^{-4}$ & 4.21 & 4.51 & 8.97 & 17.69 \\
\hline
\end{tabular}

Source: DTNs: MO0407TMHIS104.003 [DIRS 170599] and MO0306SDSAVDTH.000 [DIRS 164033].

Table X-7. Arias Intensity (m/sec) for $1 \times 10^{-5}$ Ground Motions

\begin{tabular}{|c|c|c|c|c|}
\hline Ground Motion Set & H1 & H2 & V & Sum \\
\hline 1 & 32.90 & 34.36 & 36.06 & 103.32 \\
\hline 2 & 30.76 & 38.43 & 123.30 & 192.49 \\
\hline 3 & 16.02 & 22.53 & 47.60 & 86.15 \\
\hline 4 & 12.09 & 15.47 & 19.97 & 47.53 \\
\hline 5 & 16.20 & 11.15 & 13.48 & 40.83 \\
\hline 6 & 6.99 & 5.30 & 18.21 & 30.50 \\
\hline 7 & 3.99 & 3.75 & 49.48 & 57.22 \\
\hline 8 & 8.45 & 12.70 & 15.53 & 36.68 \\
\hline 9 & 21.64 & 52.24 & 138.70 & 212.58 \\
\hline 10 & 8.60 & 3.51 & 14.05 & 26.16 \\
\hline 11 & 8.27 & 6.67 & 14.64 & 29.58 \\
\hline 12 & 3.93 & 4.05 & 6.69 & 14.67 \\
\hline 13 & 9.41 & 16.03 & 25.95 & 51.39 \\
\hline 14 & 2.57 & 2.46 & 7.28 & 12.31 \\
\hline 16 & 2.71 & 1.57 & 6.85 & 11.13 \\
\hline
\end{tabular}

Source: DTN: MO0402AVDTM105.001 [DIRS 168890], file dur.zip.

Table X-8. Arias Intensity (m/sec) for $1 \times 10^{-6}$ Ground Motions (Revised Set)

\begin{tabular}{|c|c|c|c|c|}
\hline Ground Motion Set & H1 & H2 & V & Sum \\
\hline 1 & 234.70 & 252.80 & 114.00 & 601.50 \\
\hline 2 & 205.60 & 250.00 & 413.30 & 868.90 \\
\hline 3 & 120.10 & 152.80 & 135.00 & 407.90 \\
\hline 4 & 177.90 & 218.70 & 140.90 & 537.50 \\
\hline 5 & 77.53 & 52.45 & 28.52 & 158.50 \\
\hline 6 & 68.81 & 56.33 & 78.73 & 203.87 \\
\hline 7 & 62.98 & 60.60 & 466.90 & 590.48 \\
\hline 8 & 71.44 & 109.00 & 60.79 & 241.23 \\
\hline 9 & 169.20 & 351.80 & 464.50 & 985.50 \\
\hline 10 & 58.58 & 26.02 & 56.83 & 141.43 \\
\hline 11 & 56.60 & 44.59 & 44.66 & 145.85 \\
\hline 12 & 57.63 & 59.04 & 46.19 & 162.86 \\
\hline 13 & 97.55 & 169.50 & 122.60 & 389.65 \\
\hline
\end{tabular}


Table X-8. Arias Intensity (m/sec) for $1 \times 10^{-6}$ Ground Motions (Revised Set) (Continued)

\begin{tabular}{|c|c|c|c|c|}
\hline Ground Motion Set & H1 & H2 & V & Sum \\
\hline 14 & 62.75 & 73.01 & 118.80 & 254.56 \\
\hline 16 & 23.29 & 14.90 & 33.94 & 72.13 \\
\hline
\end{tabular}

Source: DTN: MO0403AVDSC106.001 [DIRS 168891], file Dur.zip.

Table X-9. Arias Intensity (m/sec) for $1 \times 10^{-6}$ Ground Motions (Original Set)

\begin{tabular}{|c|c|c|c|c|}
\hline Ground Motion Set & H1 & H2 & V & Sum \\
\hline 1 & 246.40 & 303.80 & 481.70 & 1031.90 \\
\hline 2 & 228.60 & 188.10 & 471.20 & 887.90 \\
\hline 3 & 139.00 & 22.53 & 33.45 & 194.98 \\
\hline 4 & 179.10 & 176.30 & 282.30 & 637.70 \\
\hline 5 & 57.90 & 80.54 & 149.50 & 287.94 \\
\hline 6 & 41.90 & 159.70 & 70.89 & 272.49 \\
\hline 7 & 64.79 & 58.10 & 216.60 & 339.49 \\
\hline 8 & 64.55 & 35.10 & 212.60 & 312.25 \\
\hline 9 & 174.00 & 38.51 & 90.62 & 303.13 \\
\hline 10 & 93.55 & 185.50 & 614.60 & 893.65 \\
\hline 11 & 63.25 & 73.79 & 146.10 & 283.14 \\
\hline 12 & 96.98 & 40.30 & 117.10 & 254.38 \\
\hline 13 & 81.51 & 131.00 & 56.29 & 268.80 \\
\hline 14 & 43.49 & 386.10 & 206.20 & 635.79 \\
\hline 16 & 24.26 & 41.52 & 85.64 & 151.42 \\
\hline
\end{tabular}

Source: DTN: MO0301TMHIS106.001 [DIRS 161868], file dur.zip.

Table X-10. Arias Intensity (m/sec) for $1 \times 10^{-7}$ Ground Motions

\begin{tabular}{|c|c|c|c|c|}
\hline Ground Motion Set & H1 & H2 & V & Sum \\
\hline 1 & 1128.00 & 1215.00 & 819.60 & 3162.60 \\
\hline 2 & 988.70 & 1202.00 & 2972.00 & 5162.70 \\
\hline 3 & 577.30 & 734.70 & 970.60 & 2282.60 \\
\hline 4 & 855.60 & 1052.00 & 1013.00 & 2920.60 \\
\hline 5 & 372.90 & 252.20 & 205.10 & 830.20 \\
\hline 6 & 330.80 & 270.80 & 566.10 & 1167.70 \\
\hline 7 & 302.60 & 291.10 & 3357.00 & 3950.70 \\
\hline 8 & 343.30 & 523.60 & 437.00 & 1303.90 \\
\hline 9 & 812.90 & 1691.00 & 3340.00 & 5843.90 \\
\hline 10 & 281.80 & 125.20 & 408.60 & 815.60 \\
\hline 11 & 272.10 & 214.40 & 321.10 & 807.60 \\
\hline 12 & 277.20 & 283.90 & 332.10 & 893.20 \\
\hline 13 & 469.00 & 815.00 & 881.40 & 2165.40 \\
\hline 14 & 301.60 & 350.90 & 854.40 & 1506.90 \\
\hline 16 & 112.00 & 71.63 & 244.00 & 427.63 \\
\hline
\end{tabular}

Source: DTN: MO0403AVTMH107.003 [DIRS 168892], file Dur.zip. 
Table X-11. Power Spectral Density $\left(\mathrm{m}^{2} / \mathrm{sec}\right)$ for Preclosure Ground Motions

\begin{tabular}{|c|c|c|c|c|}
\hline Ground Motion Set & H1 & H2 & V & Sum \\
\hline $5 \times 10^{-4}$ & 1287 & 1427 & 901 & 3615 \\
\hline $1 \times 10^{-4}$ & 8251 & 7359 & 9672 & 25282 \\
\hline
\end{tabular}

Source: DTNS: MO0407TMHIS104.003 [DIRS 170599] and MO0306SDSAVDTH.000 [DIRS 164033].

Table X-12. Power Spectral Density $\left(\mathrm{m}^{2} / \mathrm{sec}\right)$ for $1 \times 10^{-5}$ Ground Motions

\begin{tabular}{|c|c|c|c|c|}
\hline Ground Motion Set & H1 & H2 & V & Sum \\
\hline 1 & 5594 & 3024 & 5896 & 14514 \\
\hline 2 & 8826 & 15622 & 20070 & 44518 \\
\hline 3 & 5708 & 34876 & 175806 & 216390 \\
\hline 4 & 38760 & 31748 & 47600 & 118108 \\
\hline 5 & 18787 & 17025 & 25098 & 60910 \\
\hline 6 & 35838 & 2702 & 68988 & 107528 \\
\hline 7 & 21865 & 15657 & 140657 & 178179 \\
\hline 8 & 9688 & 11694 & 9819 & 31201 \\
\hline 9 & 16553 & 91014 & 88415 & 195982 \\
\hline 10 & 7799 & 929 & 2315 & 11043 \\
\hline 11 & 10747 & 14344 & 29290 & 54381 \\
\hline 12 & 21548 & 10193 & 18214 & 49955 \\
\hline 13 & 39915 & 37122 & 288495 & 365532 \\
\hline 14 & 50317 & 2198 & 27392 & 79907 \\
\hline 16 & 15940 & 5339 & 22348 & 43627 \\
\hline
\end{tabular}

Source: DTN: MO0402AVDTM105.001 [DIRS 168890].

Table X-13. Power Spectral Density ( $\mathrm{m}^{2} / \mathrm{sec}$ ) for $1 \times 10^{-6}$ Ground Motions (Revised Set)

\begin{tabular}{|c|c|c|c|c|}
\hline Ground Motion Set & H1 & H2 & V & Sum \\
\hline 1 & 25137 & 15521 & 13552 & 54210 \\
\hline 2 & 38218 & 56878 & 44828 & 139924 \\
\hline 3 & 21097 & 127952 & 271411 & 420460 \\
\hline 4 & 143472 & 142743 & 162474 & 448689 \\
\hline 5 & 34247 & 32007 & 24550 & 90804 \\
\hline 6 & 92128 & 19052 & 94674 & 205854 \\
\hline 7 & 94514 & 74336 & 309918 & 478768 \\
\hline 8 & 37159 & 69337 & 23214 & 129710 \\
\hline 9 & 62740 & 389694 & 168328 & 620762 \\
\hline 10 & 36474 & 4801 & 6386 & 47661 \\
\hline 11 & 37799 & 46690 & 31106 & 115595 \\
\hline 12 & 108978 & 78619 & 75170 & 262767 \\
\hline 13 & 149590 & 155633 & 324138 & 629361 \\
\hline
\end{tabular}


Table X-13. Power Spectral Density ( $\left.\mathrm{m}^{2} / \mathrm{sec}\right)$ for $1 \times 10^{-6}$ Ground Motions (Revised Set) (Continued)

\begin{tabular}{|c|c|c|c|c|}
\hline Ground Motion Set & H1 & H2 & V & Sum \\
\hline 14 & 180951 & 13466 & 67867 & 262284 \\
\hline 16 & 75416 & 26879 & 46547 & 148842 \\
\hline
\end{tabular}

Source: DTN: MO0403AVDSC106.001 [DIRS 168891].

Table X-14. Power Spectral Density $\left(\mathrm{m}^{2} / \mathrm{sec}\right)$ for $1 \times 10^{-6}$ Ground Motions (Original Set)

\begin{tabular}{|c|c|c|c|c|}
\hline Ground Motion Set & H1 & H2 & V & Sum \\
\hline 1 & 29936 & 21251 & 39224 & 90411 \\
\hline 2 & 46225 & 42946 & 33651 & 122822 \\
\hline 3 & 26398 & 15208 & 30807 & 72413 \\
\hline 4 & 109976 & 90561 & 30803 & 231340 \\
\hline 5 & 23474 & 38142 & 75680 & 137296 \\
\hline 6 & 42567 & 53873 & 37483 & 133923 \\
\hline 7 & 71944 & 48153 & 18740 & 138837 \\
\hline 8 & 29360 & 22606 & 43412 & 95378 \\
\hline 9 & 56045 & 34205 & 22540 & 112790 \\
\hline 10 & 50542 & 34874 & 47166 & 132582 \\
\hline 11 & 33239 & 61177 & 56971 & 151387 \\
\hline 12 & 122679 & 40647 & 85307 & 248633 \\
\hline 13 & 88844 & 89105 & 68762 & 246711 \\
\hline 14 & 103244 & 73012 & 42195 & 218451 \\
\hline 16 & 56962 & 52193 & 58160 & 167315 \\
\hline
\end{tabular}

Source: DTN: MO0301TMHIS106.001 [DIRS 161868].

Table X-15. Power Spectral Density $\left(\mathrm{m}^{2} / \mathrm{sec}\right)$ for $1 \times 10^{-7}$ Ground Motions

\begin{tabular}{|c|c|c|c|c|}
\hline Ground Motion Set & H1 & H2 & V & Sum \\
\hline 1 & 120827 & 74606 & 97450 & 292883 \\
\hline 2 & 183772 & 273453 & 322334 & 779559 \\
\hline 3 & 101411 & 615062 & 1951533 & 2668006 \\
\hline 4 & 689917 & 686412 & 1168272 & 2544601 \\
\hline 5 & 164712 & 153940 & 176528 & 495180 \\
\hline 6 & 442885 & 91587 & 680740 & 1215212 \\
\hline 7 & 454046 & 357113 & 2228184 & 3039343 \\
\hline 8 & 178537 & 333143 & 166899 & 678579 \\
\hline 9 & 301482 & 1872982 & 1210336 & 3384800 \\
\hline 10 & 175483 & 23099 & 45916 & 244498 \\
\hline 11 & 181710 & 224448 & 223650 & 629808 \\
\hline 12 & 524097 & 378094 & 540483 & 1442674 \\
\hline 13 & 719146 & 748201 & 2330664 & 3798011 \\
\hline 14 & 869763 & 64725 & 488013 & 1422501 \\
\hline 16 & 362583 & 129224 & 334650 & 826457 \\
\hline
\end{tabular}

Source: DTN: MO0403AVTMH107.003 [DIRS 168892]. 
INTENTIONALLY LEFT BLANK 
APPENDIX Y

VALIDATION OF THE UDEC DRIP SHIELD MODEL 


\section{VALIDATION OF THE UDEC DRIP SHIELD MODEL}

\section{Y1. INTRODUCTION}

The analysis of the rockfall inside the emplacements drifts at Yucca Mountain under different loading conditions (e.g. in situ stress, thermally induced load and seismic load) has been carried out using the two-dimensional, distinct element code UDEC. The rock mass is represented as an assembly of polygonal (Voronoi) blocks of relatively small size (e.g., $0.2 \mathrm{~m}$ or $0.3 \mathrm{~m}$ ) compared to the drift size. It was considered in the initial calculations that the drip shield was rectangular (with dimensions approximately corresponding to the actual drip shield geometry), infinitely stiff, and slaved to free-field movement of the rock mass (i.e., movement unaffected by interaction of the seismic wave with the drift). One of the objectives of the rockfall analysis is to estimate the drip shield loads, either due to dynamic impact during the rockfall or quasi-static load of the caved rock when it reaches equilibrium. If the drip shield is considered to be infinitely rigid, the predicted loads are conservative and sometimes can be excessively large. In order to access the level of conservatism in predicting loads, the drip shield also is modeled as deformable.

Representation of the deformable drip shield in the two-dimensional model, calculation of the model geometrical and mechanical properties, and model validation are discussed in this appendix.

\section{Y2. CALCULATION OF GEOMETRICAL AND MECHANICAL PROPERTIES}

The complex geometry of the drip shield, as illustrated in Figures Y-1 to Y-4 in different views and sections, is three-dimensional and, as such, was considered in the analysis of its performance under different loads. However, in the UDEC model for rockfall predictions, the drip shield was approximated in two dimensions. A typical longitudinal segment in the middle of the drip shield equal to the spacing of $1071.6 \mathrm{~mm}$ between the stiffeners (Figure Y-2) was considered to be representative of the drip shield geometry. The geometry of the cross-sections in the top and the side-wall of the drip shield, as used to calculate the geometrical characteristics, are shown in Figures Y-4 and Y-5, respectively. The drip shield dimensions used for the calculation are listed in Table Y-1. The height of the sidewall stiffener varies between $86.27 \mathrm{~mm}$ at the top to $27.69 \mathrm{~mm}$ at the base. In the UDEC approximation of the drip shield, it is considered that the height of the stiffener is constant, equal to $86 \mathrm{~mm}$ (Figure Y-5). This consideration is conservative, as it results in a stiffer drip shield and, consequently, larger predicted loads. The calculated geometrical characteristics of the two cross-sections are listed in Table Y-2.

The drip shield was represented using a regular grid and triangular, two-dimensional zones. Consequently, each cross-section is rectangular with a given height, $h$, and unit width, $b$. The heights of the cross-sections were calculated from the moment of inertia, using the following formula:

$$
I=\frac{1}{12} b h^{3}
$$


where $b=1$. The calculated heights of the rectangular cross-sections are $6.2 \mathrm{~cm}$ and $5.7 \mathrm{~cm}$ in the top and the sidewall of the drip shield, respectively. With these dimensions, the UDEC model of the drip shield matches moments of inertia of different cross-sections of the drip shield, but the areas of the cross-sections in the UDEC model are larger. This discrepancy has negligible effect on predicted displacements, because axial deformation of beams can be neglected in bending dominated deformation (as is the case for the drip shield).

In order to correctly model bending of the beams, represented by the two-dimensional, constant-strain, continuum zones, it is necessary to have at least four or five zones per beam thickness. For beam $6.2 \mathrm{~cm}$ or $5.7 \mathrm{~cm}$ thick, the zone size would be of the order of $1 \mathrm{~cm}$. Such a small zone size in the drift stability model would result in a number of numerical problems and very long calculation times (particularly for dynamic simulations). The product $E I$ is the measure of beam stiffness, where $E$ is the Young's modulus. To overcome the problem of small zone size, the heights of the cross-sections and Young's modulus were rescaled, maintaining the product EI constant, according to the following formula:

$$
\bar{E}=E\left(\frac{h}{\bar{h}}\right)^{3}
$$

where $\bar{E}$ and $\bar{h}$ are rescaled values of Young's modulus and height of the cross-section, respectively. Different parts of the drip shield are designed to be constructed from titanium grades 7 (Ti-7) and 24. Young's moduli at $150^{\circ} \mathrm{C}$ for Ti-7 and Ti-24 are E=101 GPa and $E=108 \mathrm{GPa}$, respectively (BSC 2004 [DIRS 168993]). The Poisson's ratio is 0.32. It was considered conservatively (with small overall error) that the entire drip shield was built from Ti-24 (i.e., a Young's modulus of $108 \mathrm{GPa}$ ). After rescaling according to Equation Y-2, a Young's modulus of $3.22 \mathrm{GPa}$ and cross-section heights of $20 \mathrm{~cm}$ and $18.3 \mathrm{~cm}$ in the top and the sidewall, respectively, were used for the drift shield in the UDEC simulations of the emplacement drift stability. Geometry of the drip shield, as idealized in the UDEC model, is shown in Figure Y-6. Because of the relatively large thickness of the drip shield in the UDEC model, compared to its height and span, the neutral axis of the UDEC representation was selected to coincide with the outline of the actual drip shield geometry. (The geometry of the drip shield is such that neutral axis is very close to the outline.) 


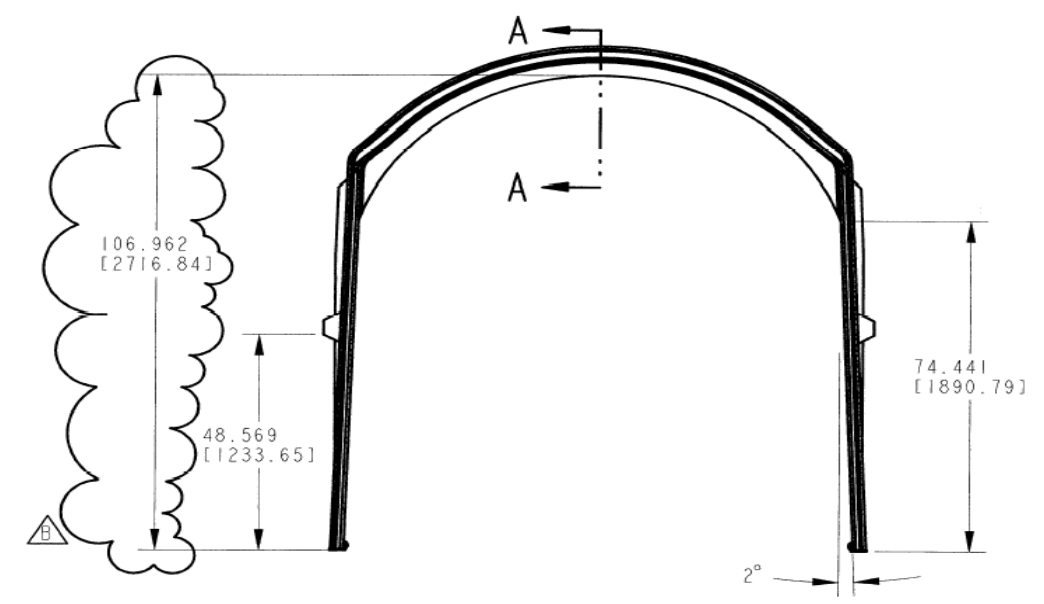

Source: BSC 2004 [DIRS 168993], Attachment I, p. I-2.

NOTE: Dimensions are in inches [millimeters].

Figure Y-1. Geometry of the Drip Shield: Cross-Section

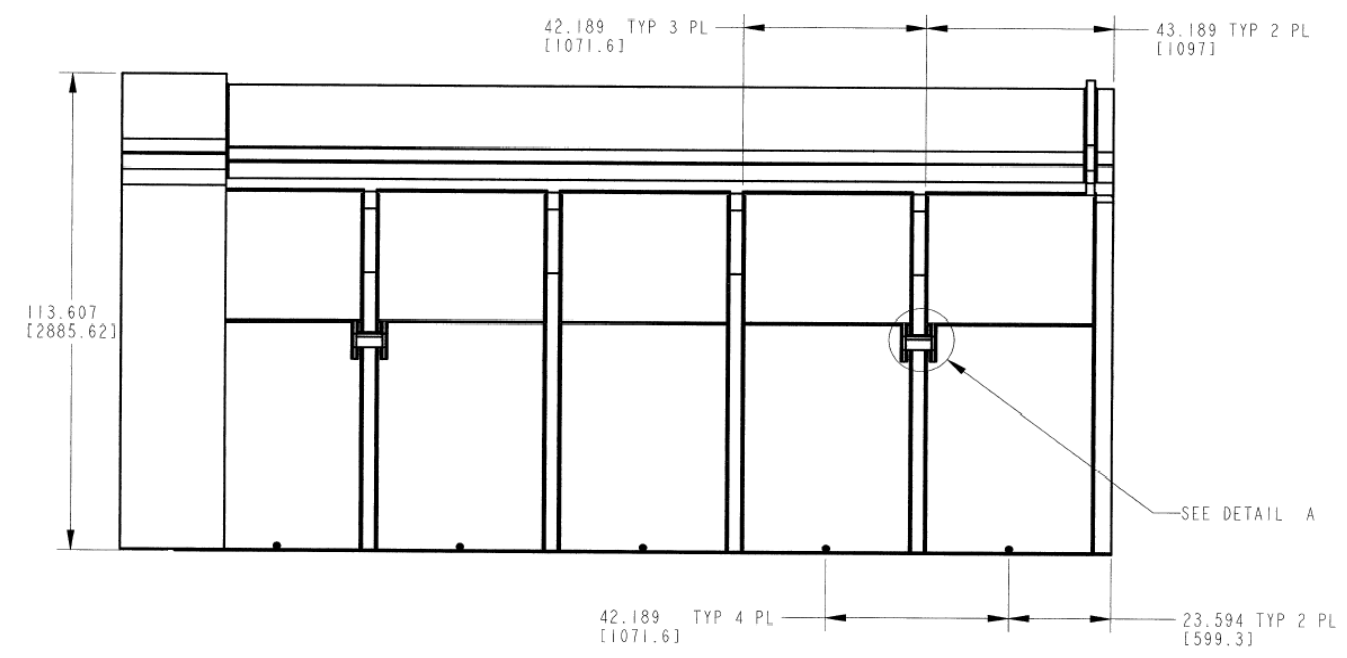

Source: BSC 2004 [DIRS 168993], Attachment I, p. I-2.

NOTE: Dimensions are in inches [millimeters].

Figure Y-2. Geometry of the Drip Shield: Side View 


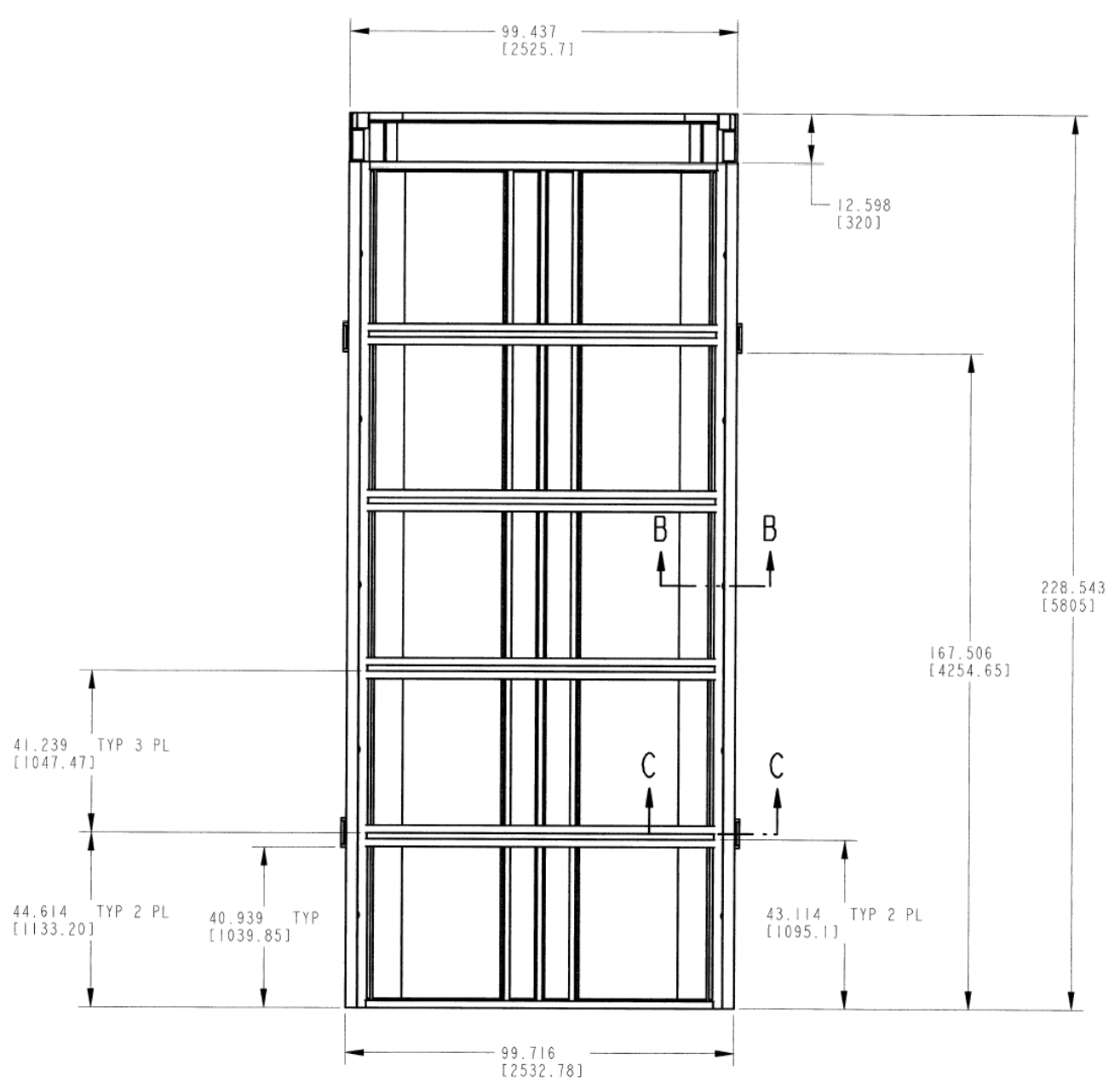

Source: BSC 2004 [DIRS 168993], Attachment I, p. I-2.

NOTE: Dimensions are in inches [millimeters].

Figure Y-3. Geometry of the Drip Shield: Plane View 


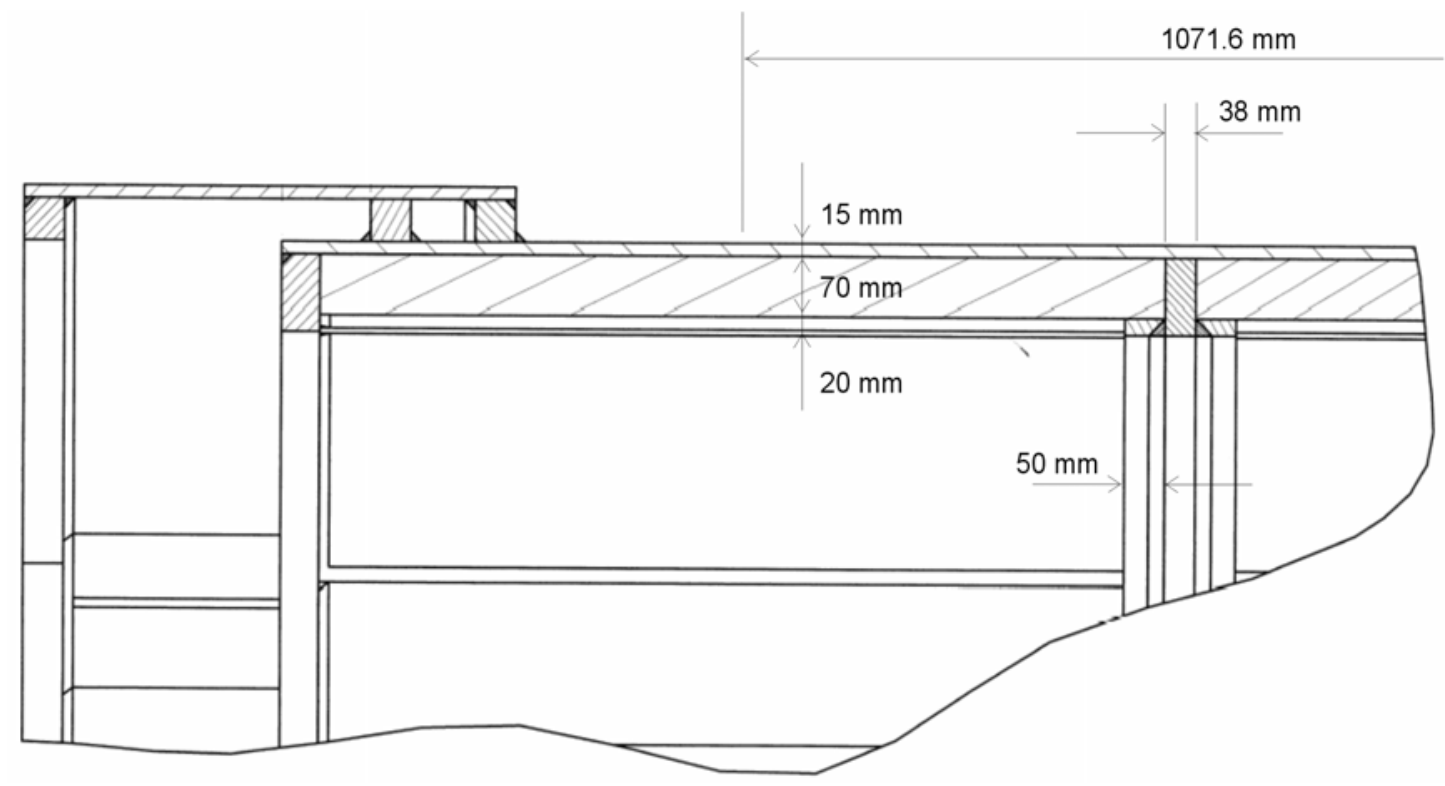

Source: BSC 2004 [DIRS 168993], Attachment I, p. I-2.

Figure Y-4. Section A-A through the Roof of the Drip Shield Indicated in Figure Y-1

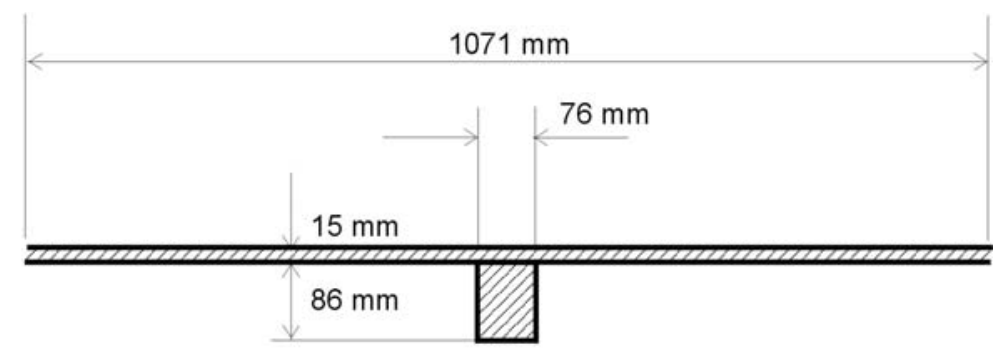

Figure Y-5. Horizontal Section Through the Wall of the Drip Shield

Table Y-1. Drip Shield Dimensions

\begin{tabular}{|c|c|c|}
\hline Nominal Length & Nominal width & Nominal Height \\
\hline $5805 \mathrm{~mm}$ & $2532.78 \mathrm{~mm}$ & $2885.62 \mathrm{~mm}$ \\
\hline $228.543 \mathrm{in}$ & $99.716 \mathrm{in}$ & $113.607 \mathrm{in}$ \\
\hline
\end{tabular}

Source: BSC 2004 [DIRS 169220], Table 1.

Table Y-2. Geometrical Characteristic of Cross-Sections

\begin{tabular}{|c|c|c|}
\hline & Top & Side-wall \\
\hline $\mathrm{I}\left[\mathrm{cm}^{4}\right]$ & 2156.4 & 1617.8 \\
\hline $\mathrm{A}\left[\mathrm{cm}^{2}\right]$ & 214.8 & 226.0 \\
\hline
\end{tabular}




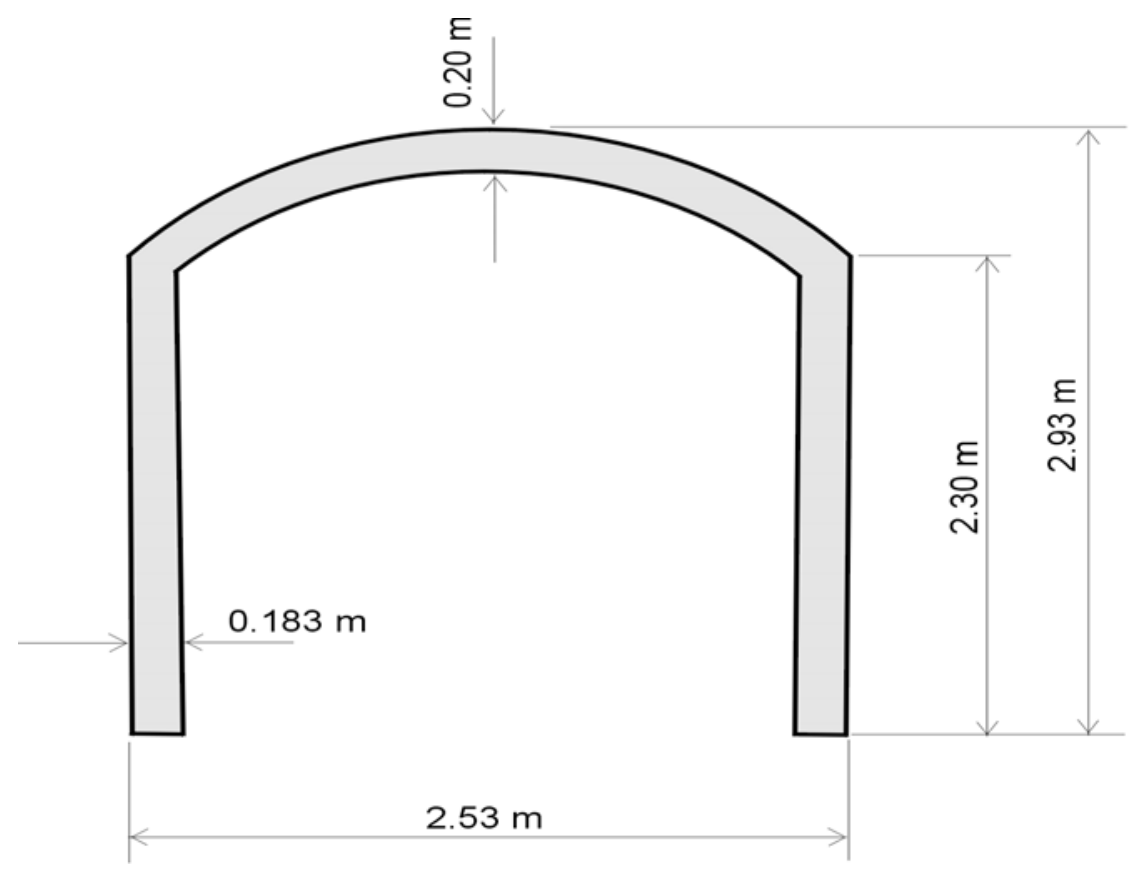

Figure Y-6. Geometry of the Drip Shield as Idealized in the UDEC Model

\section{Y3. VALIDATION OF THE DRIP SHIELD MODEL}

In order to demonstrate that the UDEC model of the drip shield correctly represents its deformation, two tests were carried out. In the first test, the UDEC results were compared with FLAC results obtained using FLAC structural element logic. The actual geometrical properties (shown in Table Y-1) and Young's modulus were used in the FLAC simulations. Because of the plane-strain deformation of the drip shield and the plane-stress formulation of the structural element logic in FLAC, the Young's modulus in the FLAC model was modified according to the following formula:

$$
E^{\prime}=\frac{E}{1-v^{2}}
$$

Two loading cases were considered. The results for loading case 1 (illustrated in Figure Y-7), the vertical concentrated force acting in the middle of the drip shield, are shown in Figures Y-8 to Y-12. The maximum vertical displacement calculated in UDEC is $6.31 \mathrm{~mm}$ (Figure Y-10), compared to $6.05 \mathrm{~mm}$ calculated in FLAC (Figure Y-12). The error is 4 percent. The results for loading case 2 (illustrated in Figure Y-13), the horizontal concentrated force acting at the top of the drip shield sidewall, are shown in Figures Y-14 to Y-18. The horizontal vertical displacement calculated in UDEC is $1.60 \mathrm{~cm}$ (Figure Y-16), compared to $1.67 \mathrm{~cm}$ calculated in FLAC (Figure Y-18). The error is 4 percent in this case as well. In the second test, the UDEC results were compared with results obtained using the code LS-DYNA, in which the drip shield was modeled as a three-dimensional body. For loading case 3 (illustrated in Figure Y-19), the uniformly distributed load on top of the drip shield, LS-DYNA predicts vertical displacement in the middle of the top of the drip shield of $2.4 \mathrm{~cm}$. The UDEC results are shown in Figures Y-20 
to $\mathrm{Y}-22$. The maximum vertical displacement in the middle of the drip shield is $2.4 \mathrm{~cm}$ (Figure Y-22).

\section{Y4. CONCULSIONS}

The deformable drip shield is represented in the two-dimensional UDEC model using continuum, constant-strain zones that form beams of constant thickness. To optimize UDEC simulations, the thickness and Young's modulus of beams were rescaled to maintain their stiffness.

It is demonstrated that the simplified UDEC model correctly represents deformation of the drip shield.

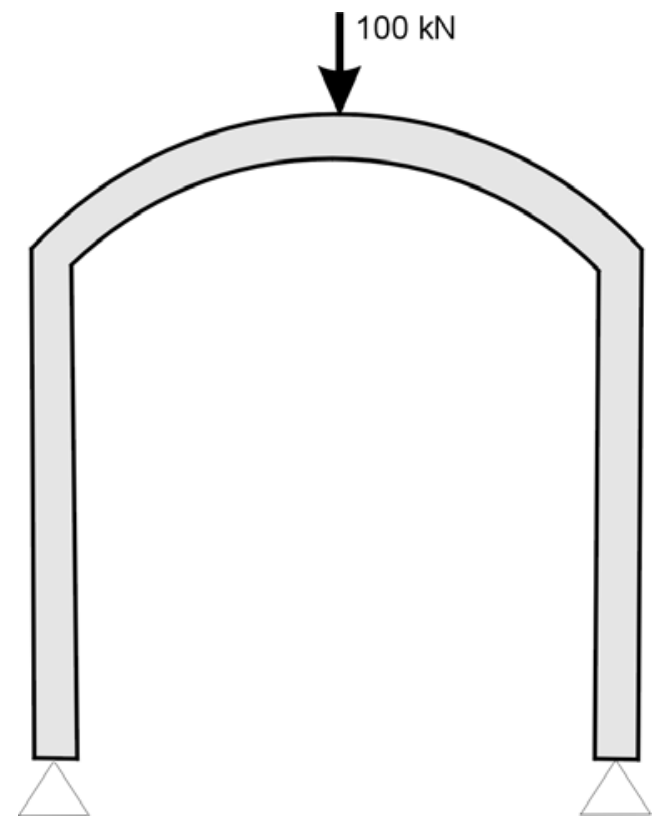

Figure Y-7. Loading Case 1 


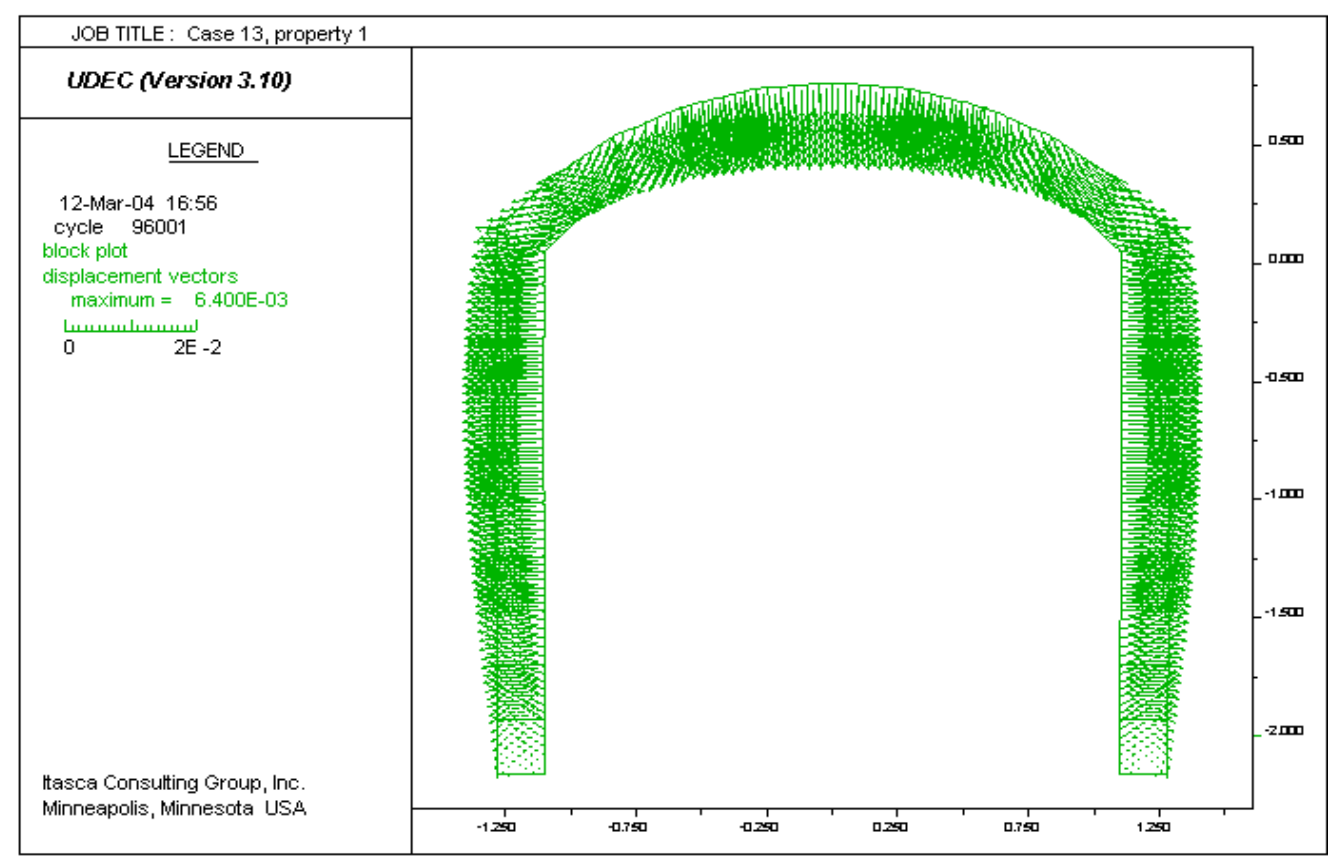

Figure Y-8. Deformation (m) of the Drip Shield for Loading Case 1

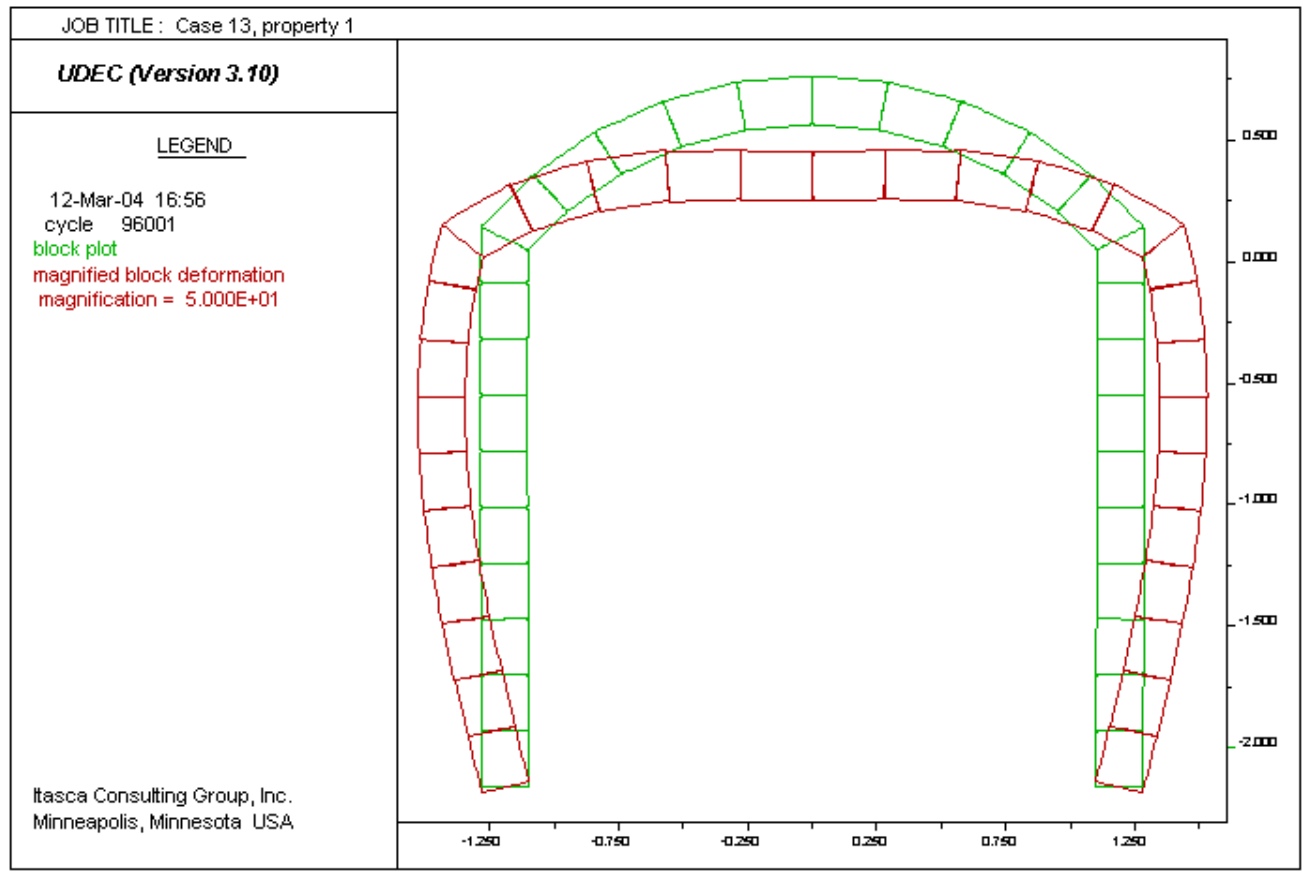

NOTE: Deformation magnified 50 times.

Figure Y-9. Original and Deformed Configuration of the Drip Shield for Loading Case 1 


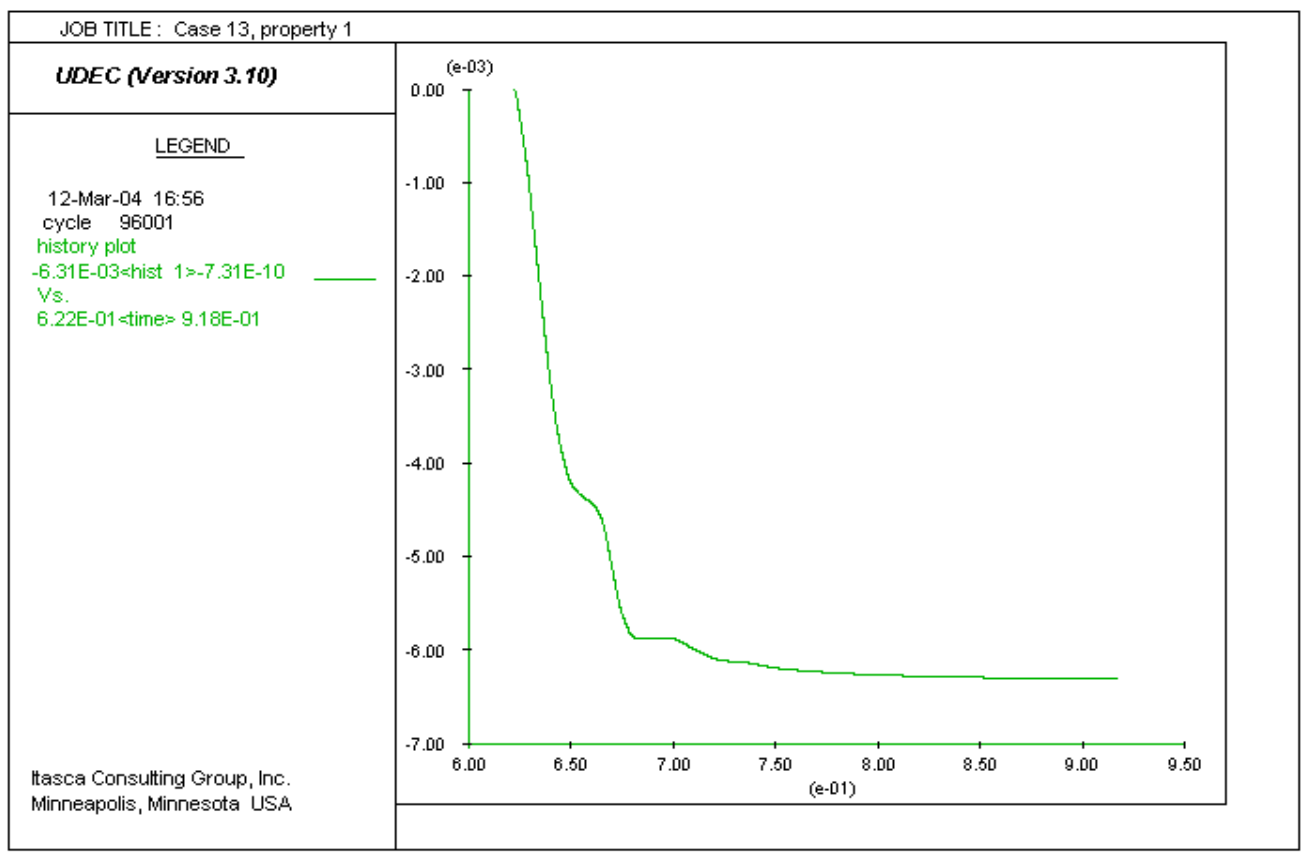

Figure Y-10. History of Vertical Displacement $(\mathrm{m})$ of a Point on the Drip Shield Where Vertical Concentrated Force is Applied for Loading Case 1

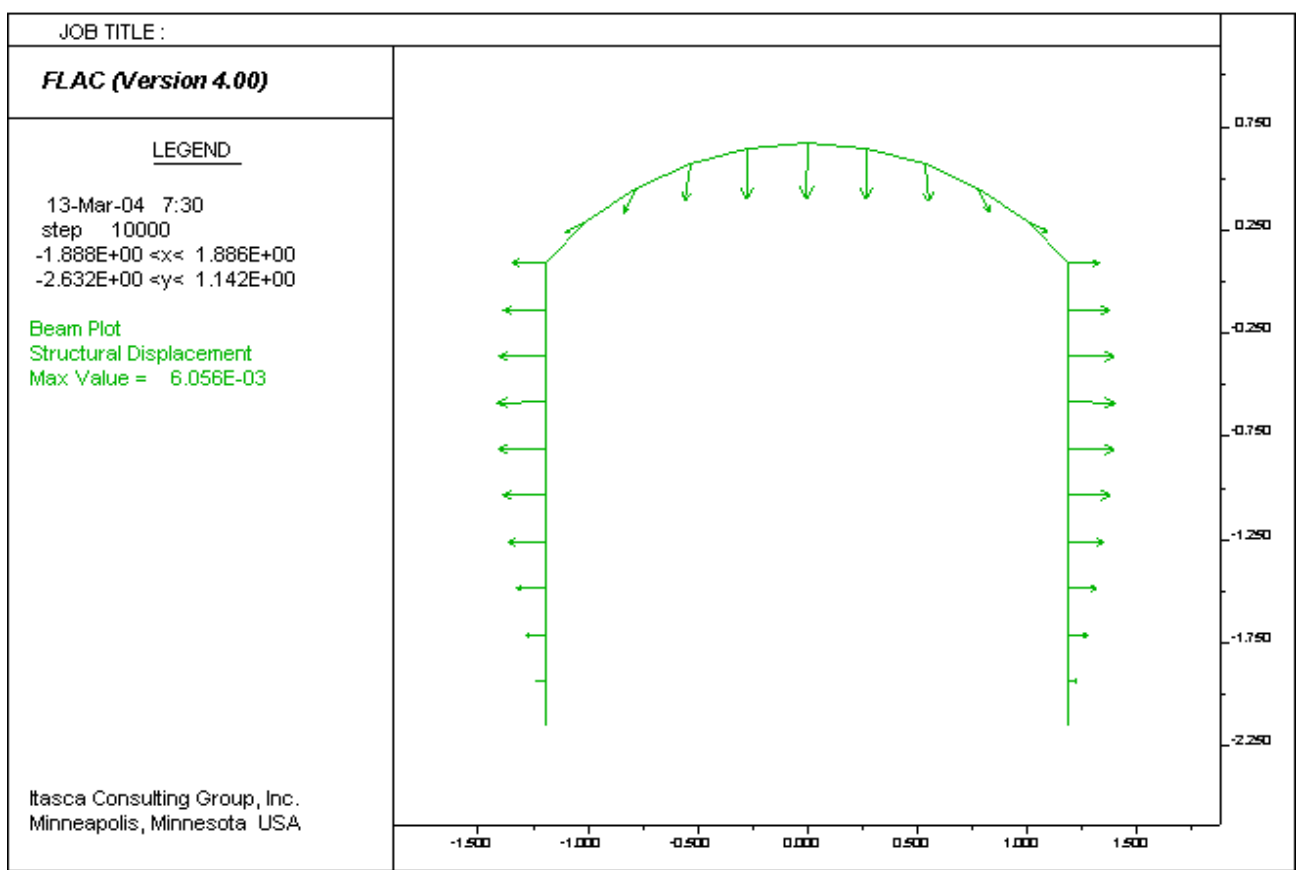

Figure Y-11. Deformation of FLAC Structure Elements for Loading Case 1 


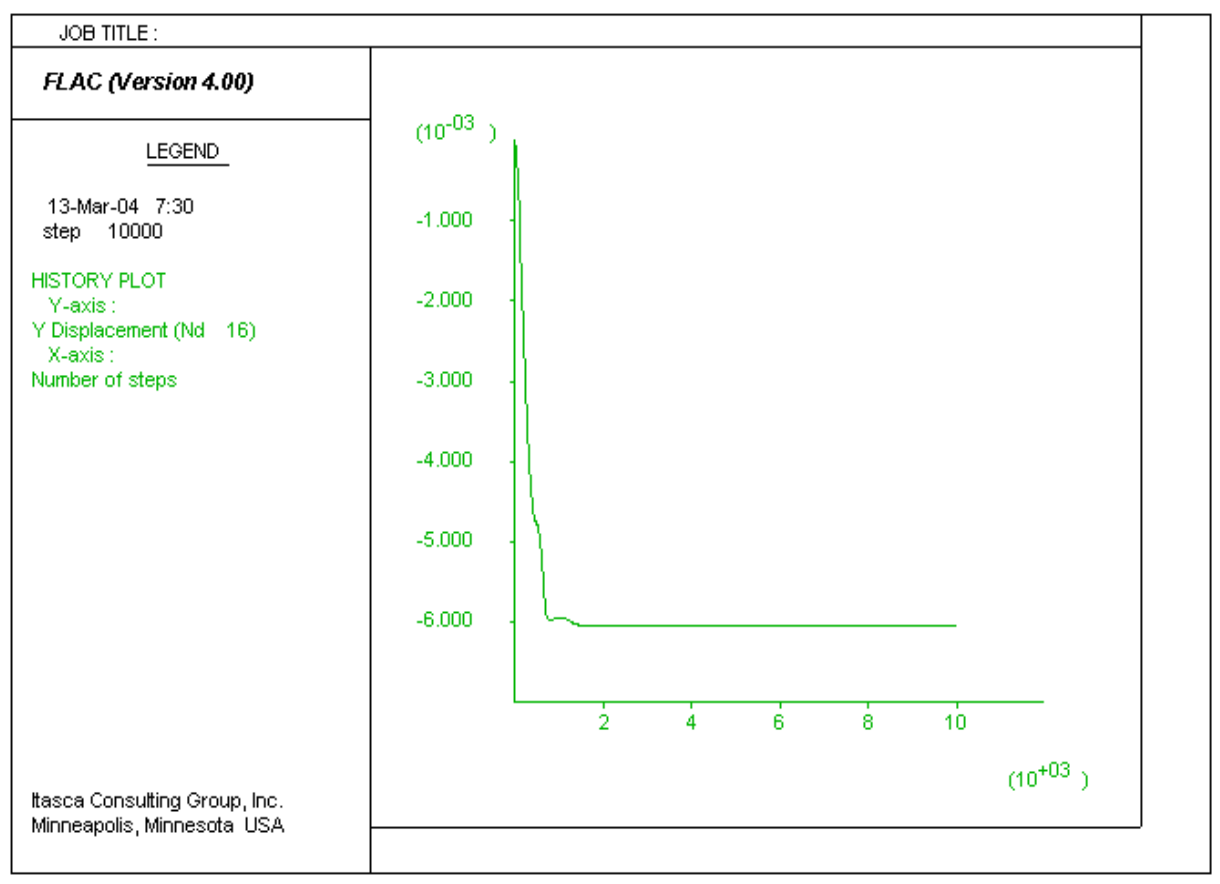

Figure $\mathrm{Y}$-12. History of Vertical Displacement $(\mathrm{m})$ of a Point on the Drip Shield Where Vertical Concentrated Force is Applied for Loading Case 1 Calculated Using FLAC Structural Elements

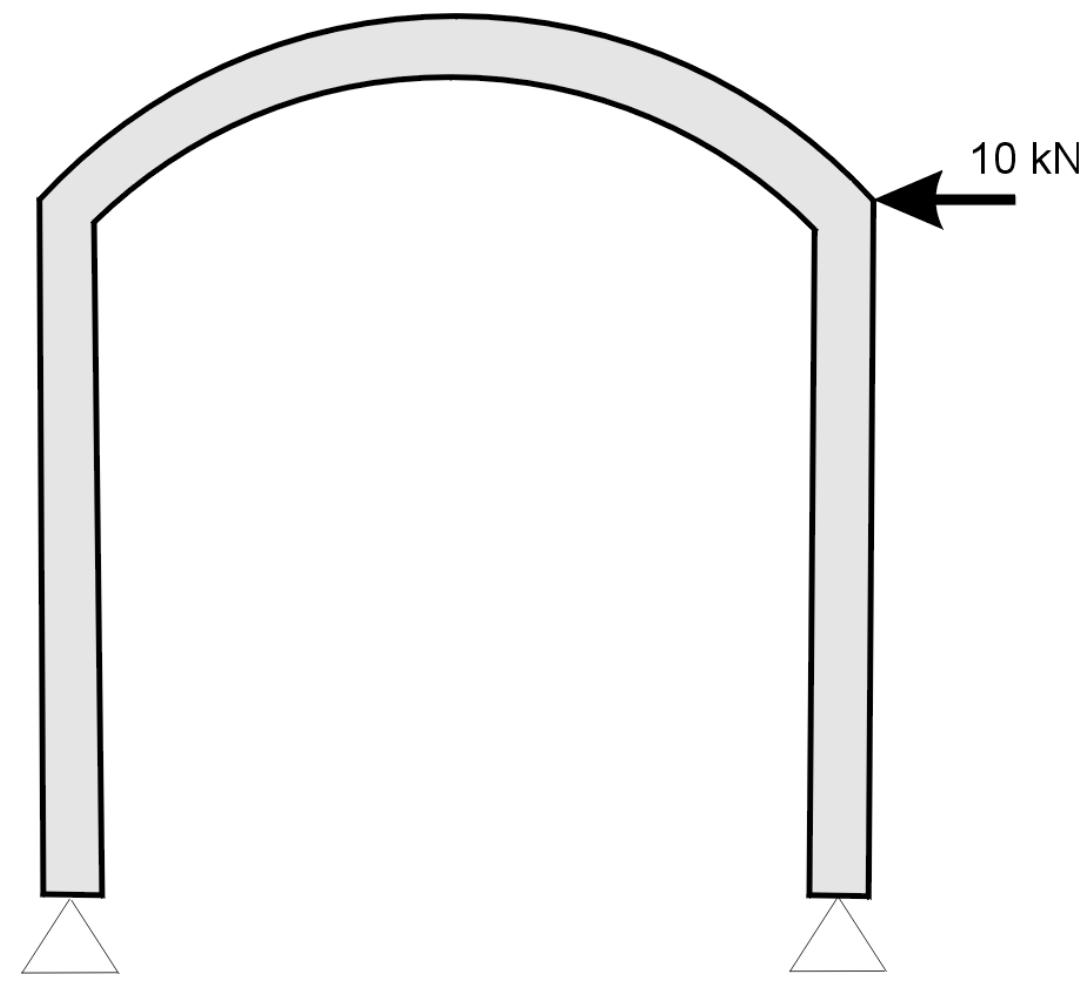

Figure Y-13. Loading Case 2 


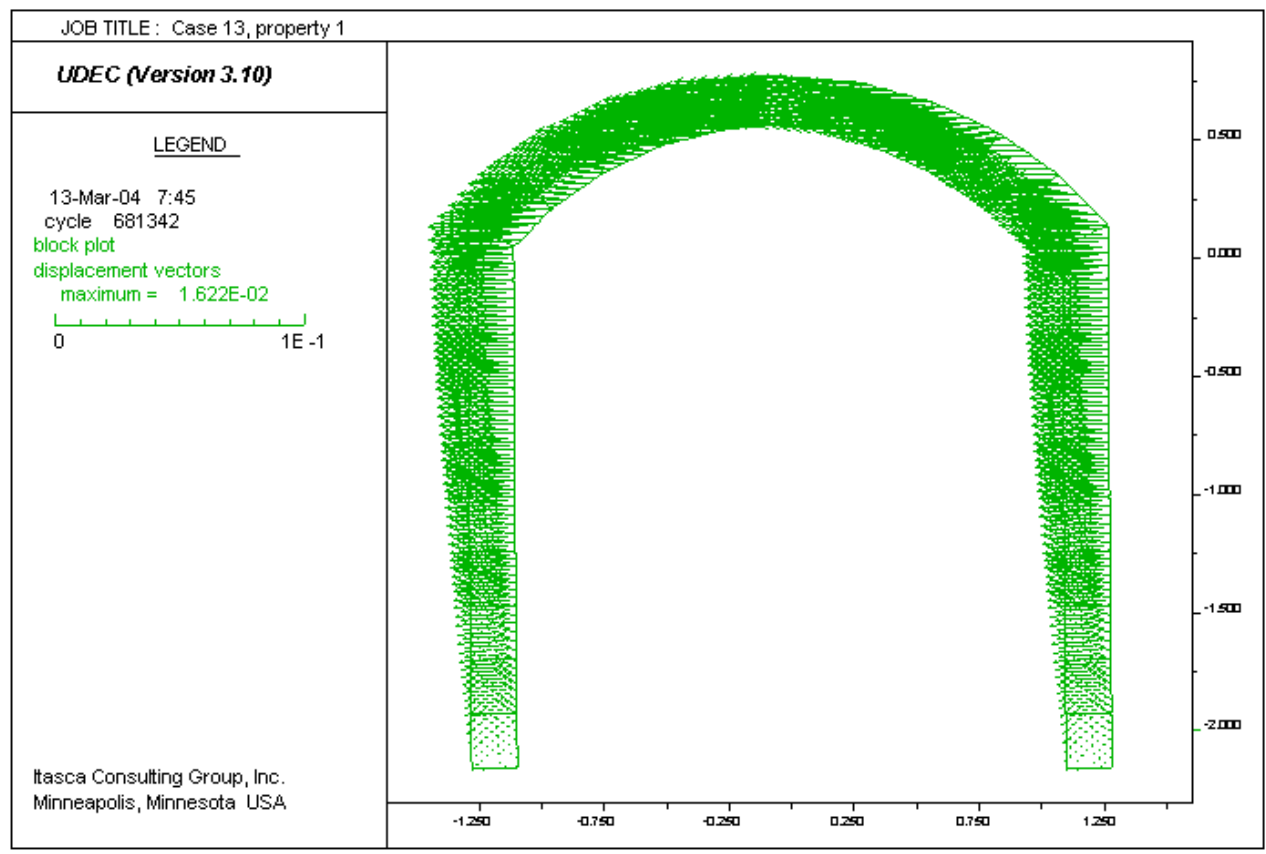

Figure Y-14. Deformation (m) of the Drip Shield for Loading Case 2

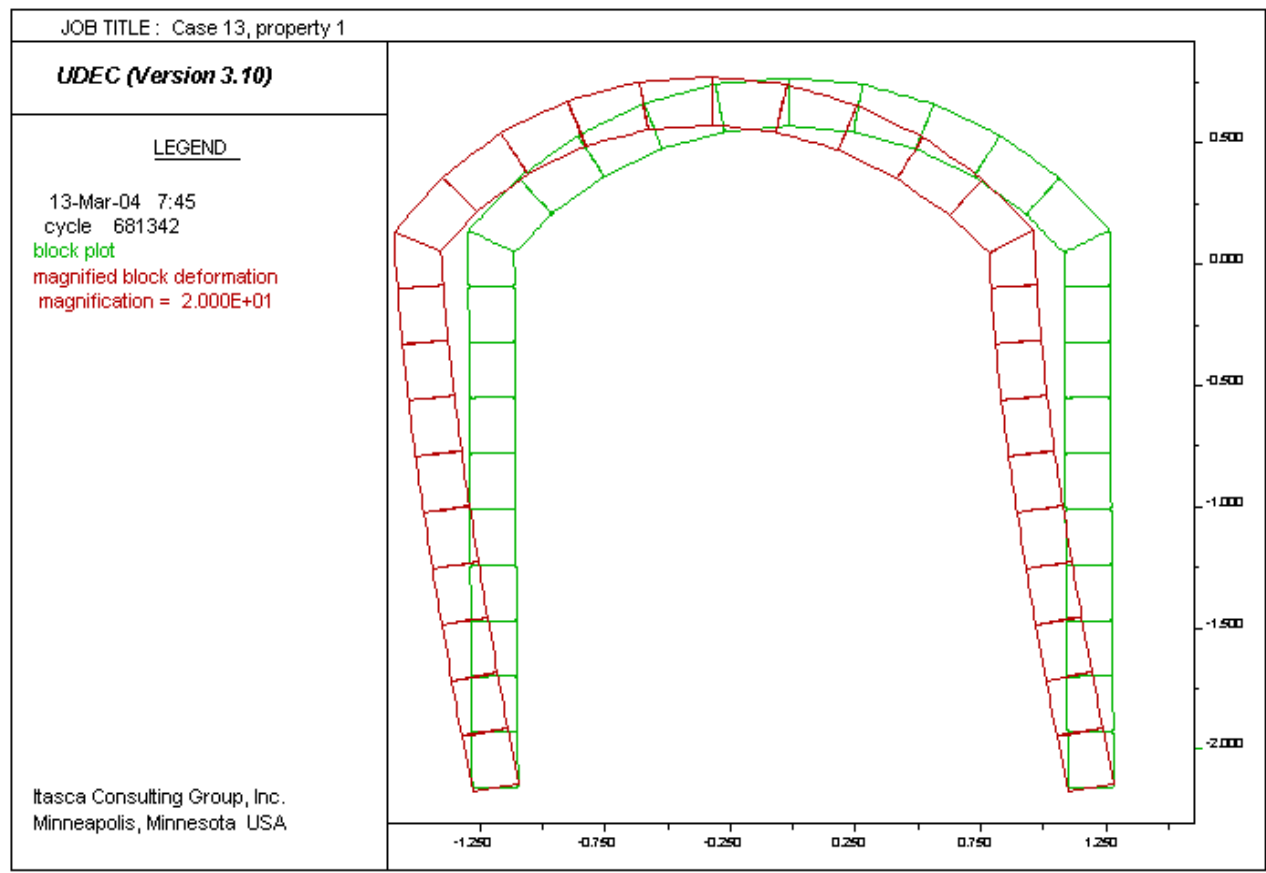

NOTE: Deformation magnified 20 times.

Figure Y-15. Original and Deformed Configuration of the Drip Shield for Loading Case 2 


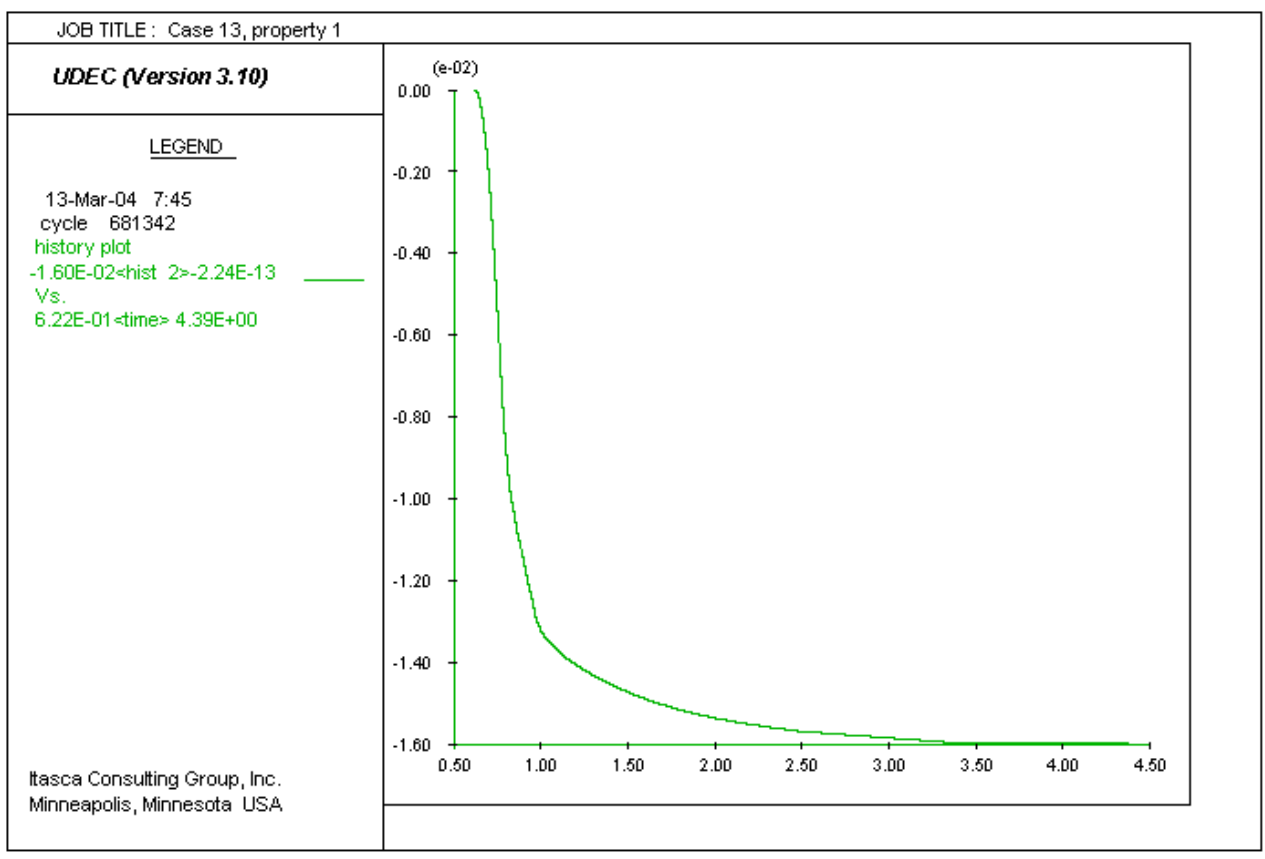

Figure Y-16. History of Vertical Displacement $(\mathrm{m})$ of a Point on the Drip Shield Where Vertical Concentrated Force is Applied for Loading Case 2

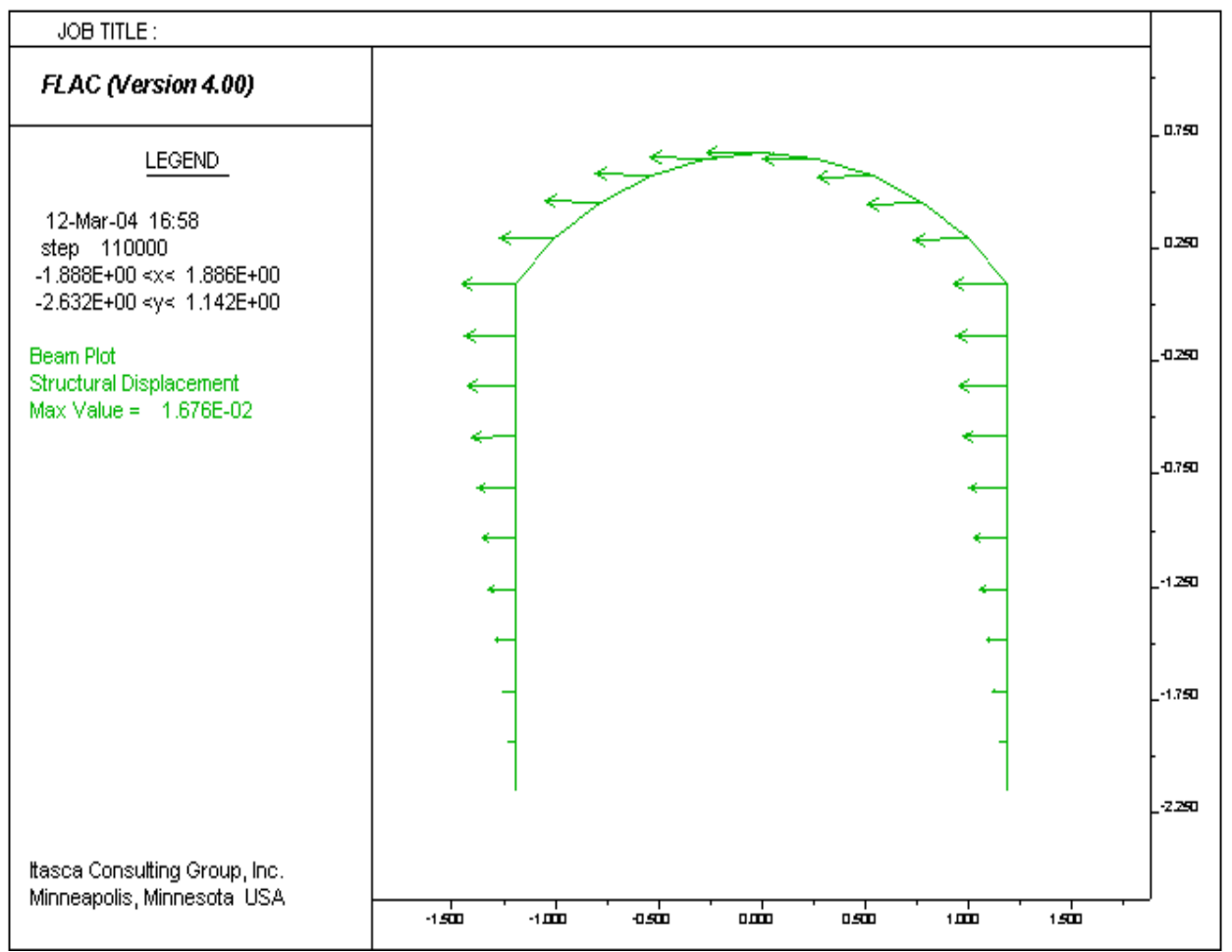

Figure Y-17. Deformation of FLAC Structure Elements for Loading Case 2 


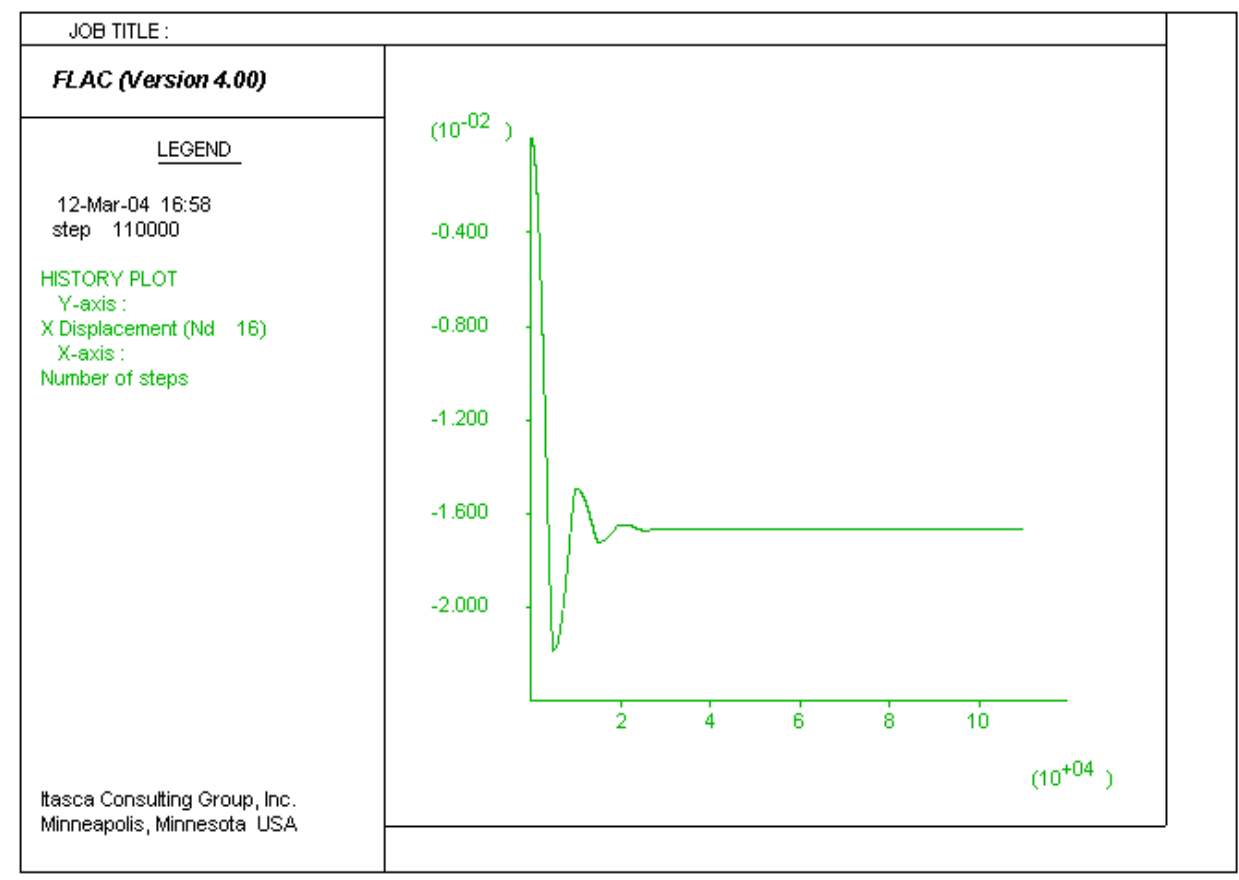

Figure Y-18. History of Vertical Displacement $(\mathrm{m})$ of a Point on the Drip Shield Where Vertical Concentrated Force is Applied for Loading Case 2 Calculated Using FLAC Structural Elements

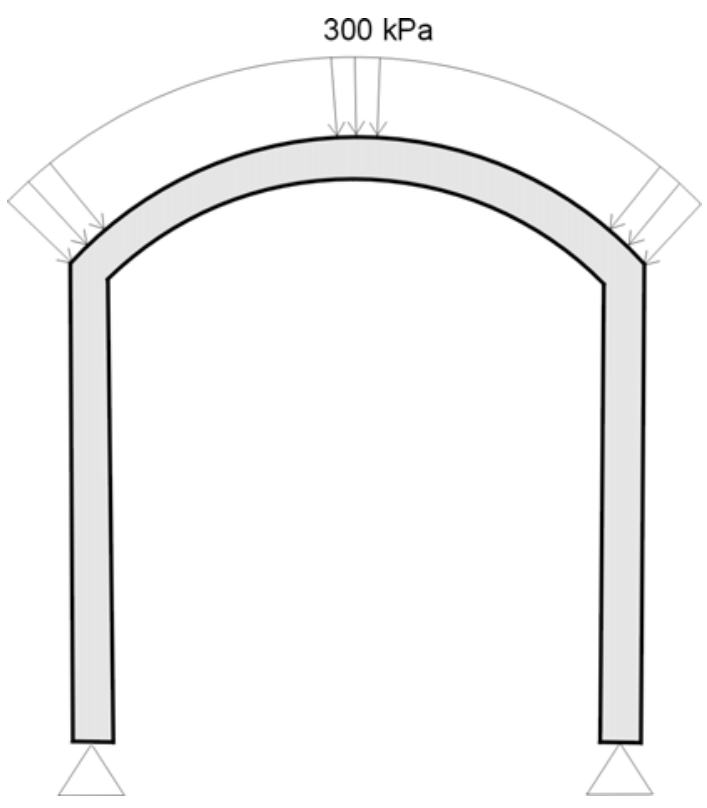

Figure Y-19. Loading Case 3 


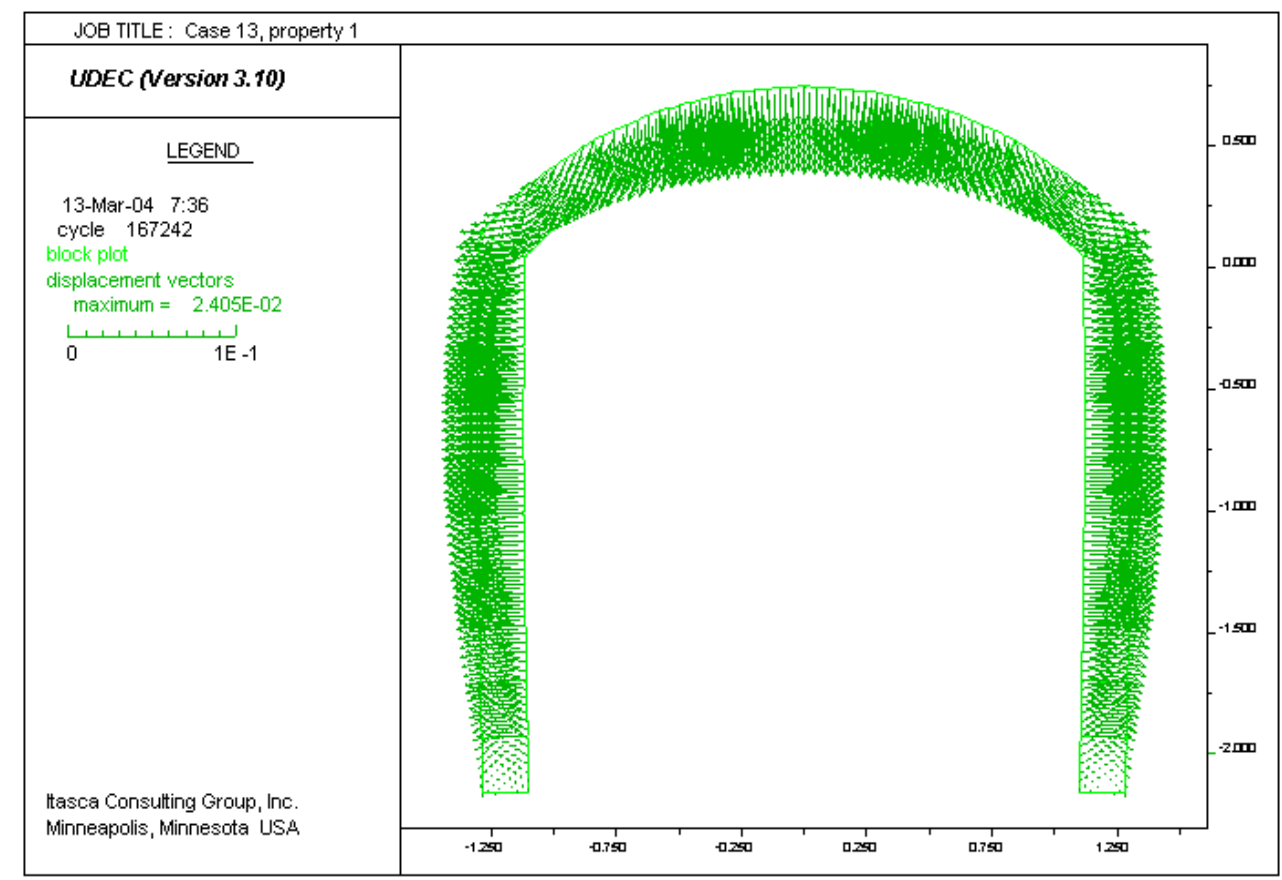

Figure Y-20. Deformation (m) of the Drip Shield for Loading Case 3

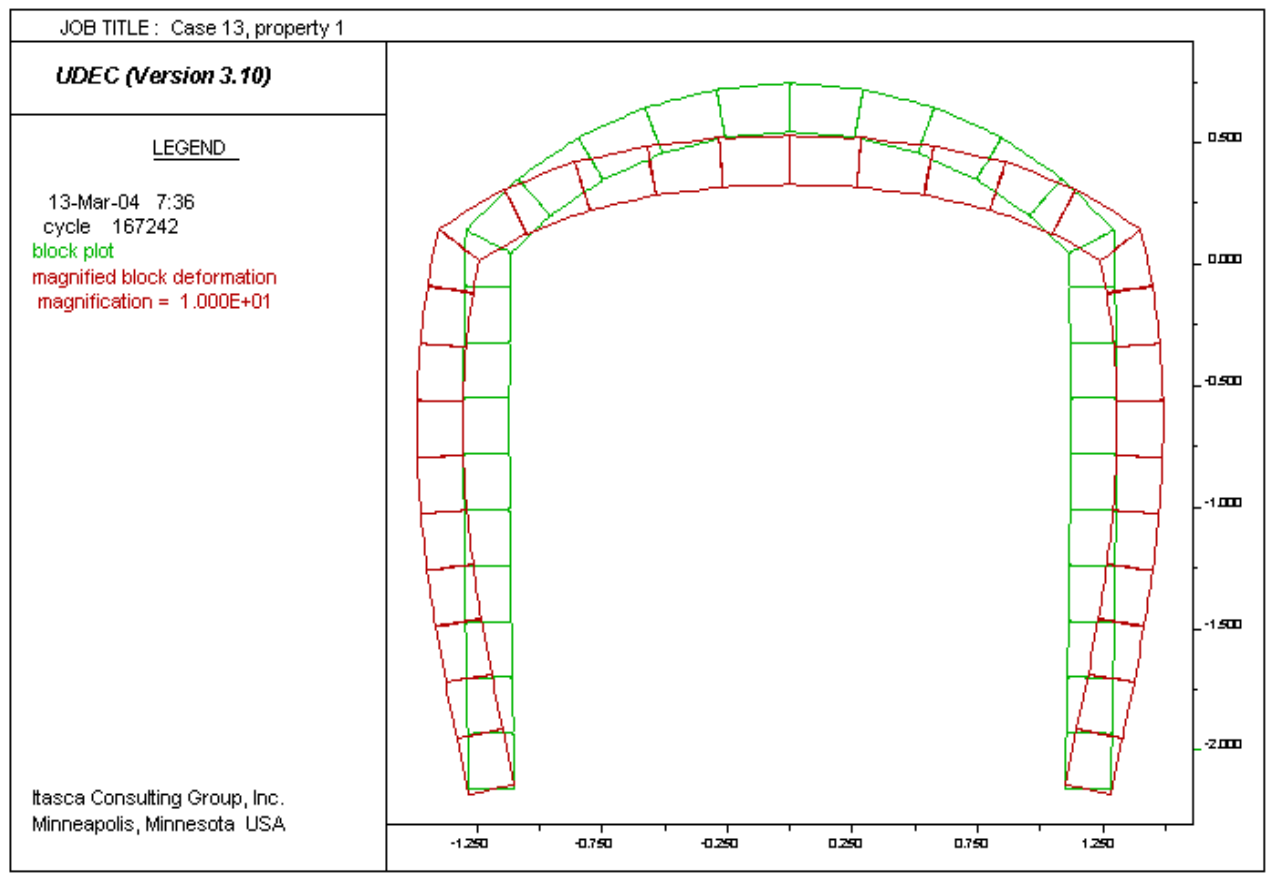

NOTE: Deformation magnified 10 times.

Figure Y-21. Original and Deformed Configuration of the Drip Shield for Loading Case 3 


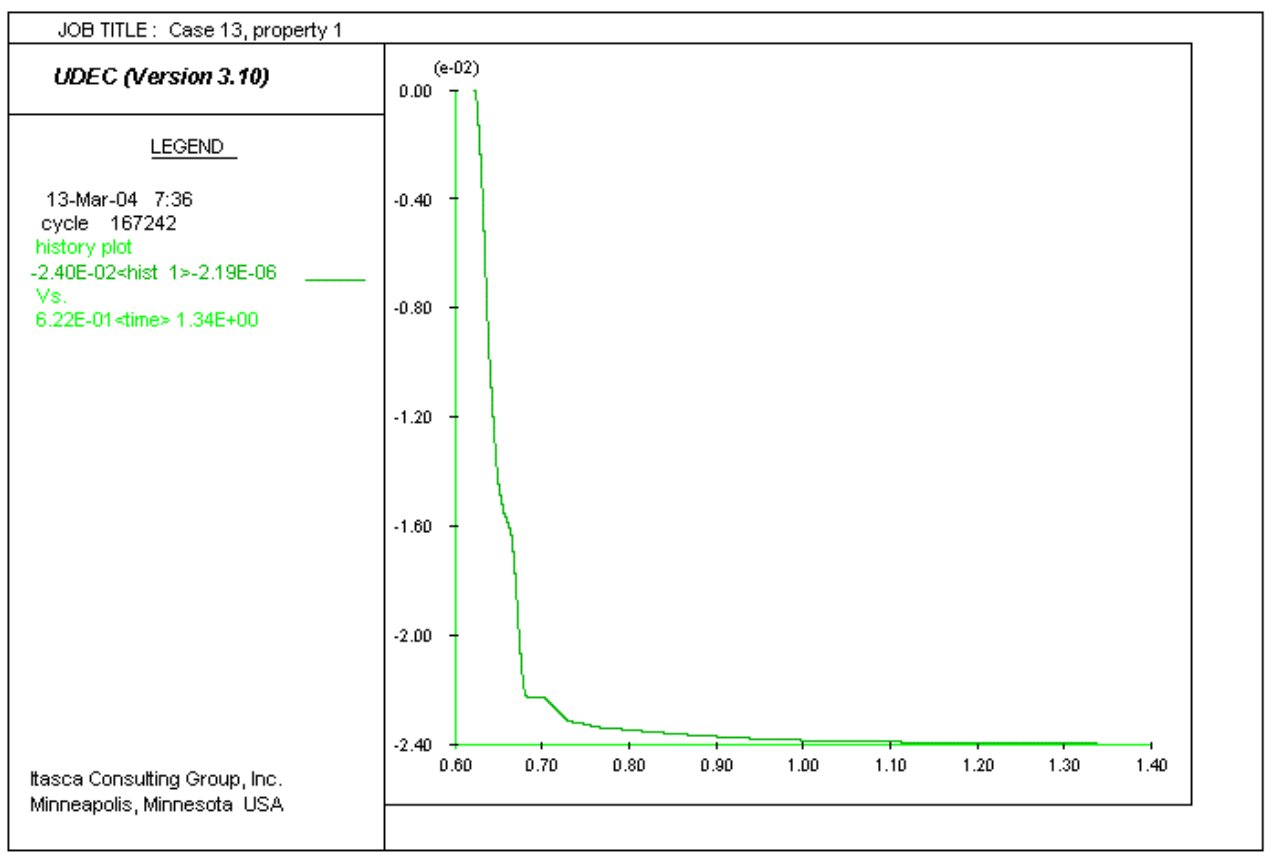

Figure Y-22. History of Vertical Displacement $(\mathrm{m})$ of a Point on the Drip Shield Where Vertical Concentrated Force is Applied for Loading Case 3 


\section{INTENTIONALLY LEFT BLANK}

